\title{
The Copper Age \\ cemetery \\ of Budakalász
}

Mária bondár and Pál Raczky

* Maria Bondár and Pal Raczky Ley

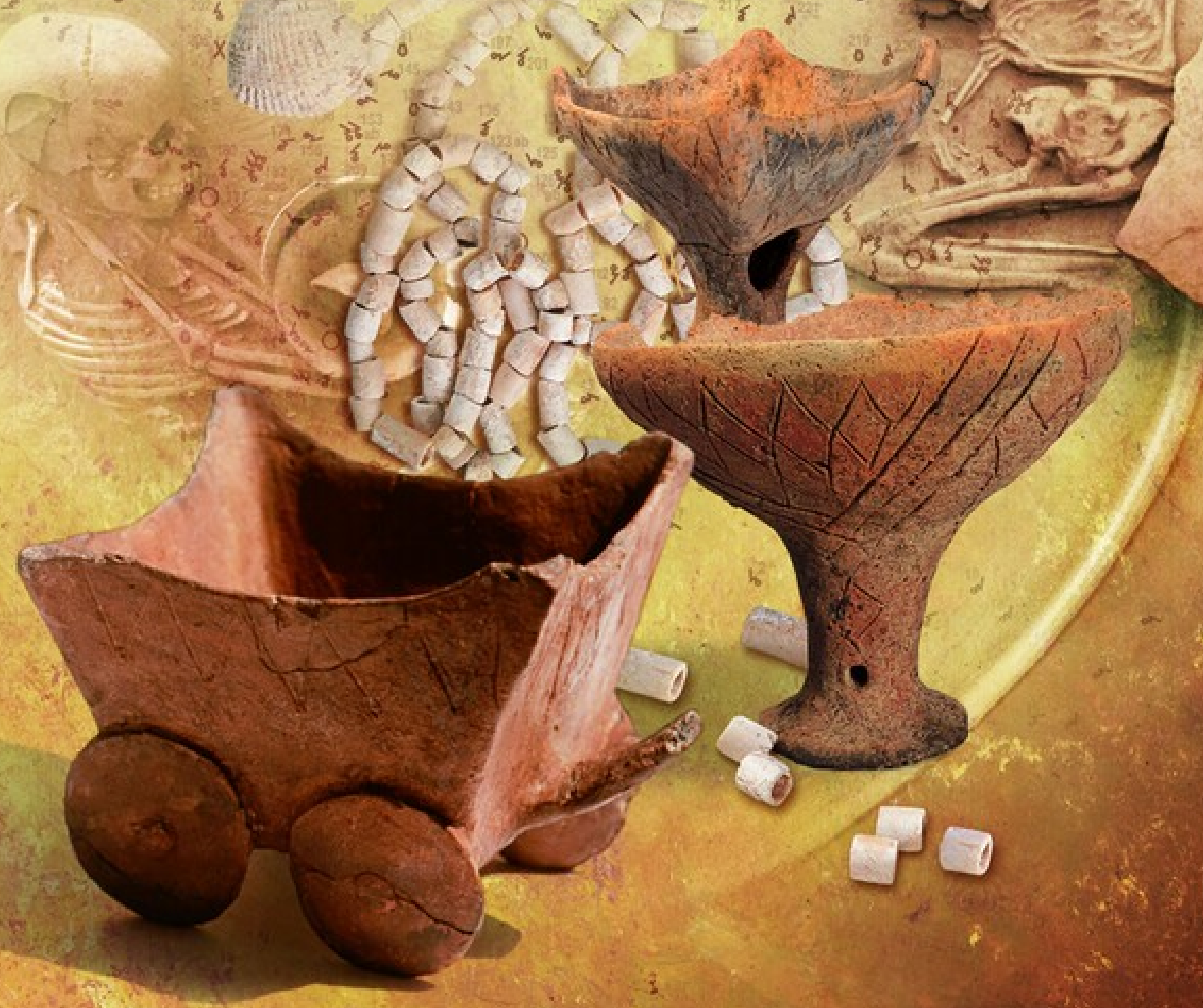


THE COPPER AGE CEMETERY OF BUDAKALÁSZ 
Dedicated to the Memory of Sándor Soproni and Fozsef Korek 


\title{
THE COPPER AGE CEMETERY OF BUDAKALÁSZ
}

\author{
Edited by \\ Mária Bondár and Pál Raczky
}

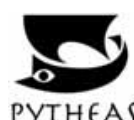

BUDAPEST 2009 
The publication of this volume was made possible by generous grants from the Hungarian Scientific Research Fund (OTKA T 37503, T 62689, PUB 77431)

\author{
Illustrations \\ Zsolt Bényei, Jolán Gajzágó, László Gucsi, Tibor Kádas, Csaba Peterdi and György Szabó \\ Desktop editing and layout \\ György Szabó \\ Cover design \\ Zoltán Jeney \\ English translation \\ Magdaléna Seleanu
}

(C) Archaeological Institute, Hungarian Academy of Sciences (Budapest), 2009

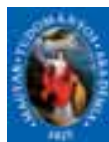

C Institute of Archaeological Sciences, Eötvös Loránd University (Budapest), 2009

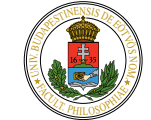

(c) The Authors, 2009

(c) English translation, Magdaléna Seleanu, 2009

All rights reserved. No part of this publication may be reproduced or transmitted in any form or by any means, electronic or mechanical, including photocopy, recording or any other information storage and retrieval system, without prior permission in writing from the publisher.

ISBN 978-963-9746-72-5

Printed in Hungary by Pytheas Printing House 


\section{CONTENS}

PREFACE (Pál Raczky) / 7

ACKNOWLEDGEMENTS (Pál Raczky-Mária Bondár) / 9

THE CEMETERY (Mária Bondár) / 11

THE EXCAVATIONS AT BUDAKALÁSZ / 13

The site / 14

The excavation / 14

Evaluation of the finds / 19

The documentation / 24

The cementery plan / 24

The modern re-assessment and interpretation of the finds / 24

CATALOGUE OF GRAVES / 31

Description of the burials / 32

Stray finds from the area of the cemetery / 194

FUNERARY RITES IN THE BUDAKALÁSZ CEMETERY / 197

Inhumation burials / 200

Single inbumation burials with grave goods / 201

Single inbumation burials without grave goods / 213

Multiple burials / 220

Double inhumation burials / 221

Triple inhumation burials / 230

Skull burials / 231

Cremation burials / 232

Scattered cremation burials / 233

Inurned burials / 239

Double cremation burials / 241

Chronology of the cremation graves / 241

Symbolic burials / 242

GRAVE GOODS / 245

Pottery / 246

Goblets / 246

Ladles / 274

Dippers / 275

Suspension vessels / 276

Mugs / 277

Pitchers / 278

7ugs / 279

Scooping vessels / 280

Handled cups / 280

Beakers / 281

Handled pots / 281

Pots / 282

Amphoras / 282

Bowls / 283

Handled bowls / 284

Bipartite bowls / 285 
Other ceramic finds / 286

Clay spools / 286

Wagon model / 288

Jewellery / 290

Tools and implements / 295

THE ANTHROPOLOGICAL REMAINS FROM THE BUDAKALÁSZ CEMETERY (Kitti Köhler) / 303

ARCHEOGENETIC ANALYSIS OF HUMAN SKELETAL SAMPLES FROM THE BUDAKALÁSZ CEMETERY

(Aranka Csősz) / 365

ANIMAL BONE OFFERINGS FROM THE BADEN CEMETERY AT BUDAKALÁSZ (Erika Gál) / 371

THE LITHIC FINDS FROM BUDAKALÁSZ (Éva Cs. Balogh) / 379

THE ARCHAEOZOOLOGICAL ANALYSIS OF THE BEADS AND MOLLUSCS FROM THE LATE COPPER AGE BADEN CEMETERY AT BUDAKALÁSZ (Pál Sümegi) / 409

STABLE ISOTOPE ANALYSIS OF CARBONATIC ORNAMENTS FROM THE LATE COPPER AGE CEMETERY AT

BUDAKALÁSZ (Attila Demény, Bernadett Bajnóczi, Sándor Kele, István Fórizs, Gabriella Barna and Zoltán Siklósy / 437

THE MANUFACTURING TECHNIQUES OF THE GRAVE POTTERY FROM BUDAKALÁSZ (László Gucsi) / 449

ABSOLUTE AND INTERNAL CHRONOLOGY OF THE LATE COPPER AGE CEMETERY AT BUDAKALÁSZ

(Zsuzsanna Siklósi) / 457

HISTORICAL CONTEXT OF THE LATE COPPER AGE CEMETERY AT BUDAKALÁSZ (Pál Raczky) / 475

ABBREVIATIONS / 485

PLATES / 487

LIST OF CONTRIBUTORS / 667 


\section{PREFACE}

The Copper Age cemetery at Budakalász-Luppa-csárda has, in a sense, become a textbook case of Hungarian prehistoric studies, reflecting the professional, institutional and human problems bedevilling this discipline. This is best illustrated by the very fact that the 436 graves of the Late Copper Age cemetery uncovered between 1952 and 1961 have remained unpublished until now. The find assemblage suffered many hardships during the almost fifty years since the excavation; these are discussed in detail by Mária Bondár in the chapter describing the history of the excavation and previous work in the assessment of the cemetery and its finds. Even though the first 115 graves of the cemetery were presented to the archaeological community in János Banner's seminal monograph on the Baden culture published in 1956, work on the remaining graves seems to have gradually died away. In the early 1980s, there arose the hope that the publication of the cemetery, entrusted by Sándor Soproni to József Korek, would at long last be accomplished (together with contributions by renowned specialists from related disciplines) with the active support of the Hungarian National Museum. Korek's untimely death in 1992 frustrated these hopes: the cemetery and its finds remained unpublished and the documentation became dispersed. Beside his post in the Hungarian National Museum, Soproni became a lecturer at the Institute of Archaeological Sciences of the Eötvös Loránd University, and in early 1995, he proposed a meeting for discussing the fate of the Budakalász cemetery. Perceiving the importance of the finds he had uncovered, he was intent on persuading his colleagues, Tibor Kovács of the Hungarian National Museum, István Ecsedy of the Janus Pannonius Museum in Pécs, and the present author, to complete the cemetery's evaluation, which had come to a standstill with Korek's death. According to the agreement reached at this meeting, the principal supporter of the project would be Gábor Rezi-Kató, vice-director of the Hungarian National Museum. Soproni gave me his personal notes and documents on the Budakalász cemetery. It soon became clear that the original plan of the Budakalász cemetery had been lost and that the grave assemblages housed in the Ferenczy Károly Museum of Szentendre had become mixed up to some extent. Moreover, the graves and their furnishings shown on the grave sheets prepared and drawn by Korek were often at variance with Soproni's original documentation. The assessment of the Budakalász cemetery thus had to be begun almost from scratch, a rather daunting and time consuming task. It seemed that this work held little appeal. Soproni's unexpected death in late 1995 was the next sad milestone in the cemetery's history for it meant that he would see neither the publication of one of his major excavations, nor even the start of renewed research on the cemetery.

In the meantime, the daily schedules, such as the pressing archaeological investigations and salvage excavations necessitated by the motorway construction projects, detracted most of us from the less urgent issue of the Budakalász cemetery. Soproni's still unfulfilled dream, the full assessment of the Budakalász cemetery, haunted us from time to time, filling us with self-remorse, while the number of participants who would be willing to actually work with the material dwindled. Searching for a way out of this deadlock, in early 2002 I turned to Mária Bondár, the renowned specialist of the Baden culture, and requested her to organise and co-ordinate the work on the final report of the Budakalász cemetery. In addition to her expertise, we could also rely on the technical infrastructure and broad interdisciplinary background of the Archaeological Institute of the Hungarian Academy of Sciences. Bondár's enthusiasm brought a fresh impetus to the Budakalász project, whose fruit, the full publication of the Baden cemetery, was finally accomplished after eight years of intense work. The Institute of Archaeological Sciences of the Eötvös Loránd University too made every effort to contribute both funds and technical support, not least because of the moral obligations owed to Soproni. Responsibility for the final presentation of the cemetery and its finds was predominantly borne by the Archaeological Institute and personally by Bondár, who ensured the restoration of the grave finds and the collection of the relevant field reports and other documents. The 
present monograph, offering a full re-assessment of the graves and their finds, is also a tribute to her skills in organising the work and persuading the specialists of related disciplines to participate in this project.

The publication of the Late Copper Age cemetery of Budakalász-Luppa-csárda is both a tribute to the memory of Sándor Soproni and József Korek, and our contribution towards redeeming one of the major debts of Hungarian prehistoric research. One of the special delights in this work was the constant encouragement and inspiration offered by Nándor Kalicz, who read through and commented on draught versions of the manuscript. He was our personal link to the outstanding archaeologists of the previous generation and an earlier age of prehistoric research, as well as to current European Copper Age studies. Our main goal with the publication of this monograph was to make available an important corpus of finds from the Copper Age of the Carpathian Basin.

Budapest, December 17, 2009. 


\section{ACKNOWLEDGEMENTS}

The editors would like to thank the many individuals, who participated in the work and contributed to the preparation and publication of the monograph.

Our greatest debt of gratitude is to Sándor Soproni, who excavated the Budakalász cemetery. Much of the information about this important burial ground would have been lost without his keen observation of the tiniest detail during the careful uncovering of the burials, all meticulously recorded his field diaries.

Another debt of gratitude is due to fozsef Korek, who intended to publish the cemetery and its finds using the most modern analytical techniques available at the time. His untimely death prevented him from completing this work.

Special thanks are due to Nándor Kalicz for his insightful comments and remarks on draught versions of the text, and his constant encouragement.

Thanks are extended to Lászlo Gucsi, who kindly allowed the publication of the finds and prepared the drawings, to Zsolt Bényei, who digitised the grave plans, to Csaba Peterdi, who worked on the computer graphics, and to Tibor Kádas, who took photographs of individual artefacts.

Very special appreciation is given to Éva Maróti, Tamás Repiszky and Folán Gajzágó, our colleagues in the Ferenczy Karoly Museum of Szentendre where the finds are housed, for their help in identifying the grave assemblages and locating the relevant documentation. We are grateful to Lászlo Simon, former director of the Directorate of the County Pest Museums, for his support of our work.

Thanks are due to Eörs Kelemen and his colleagues at Pytheas Studio for their devoted work and seemingly endless patience. We are grateful to György Szabó for the extra efforts in digitising the illustrations and for designing this book.

Finally, we wish to offer our warmest thanks to the board of the Hungarian Scientific Research Fund for providing the necessary funds for the publication of this volume, and, not least, for their goodwill and patience.

The Editors 

THE CEMETERY

Mária Bondár 



\section{The excavations at Budakalász}



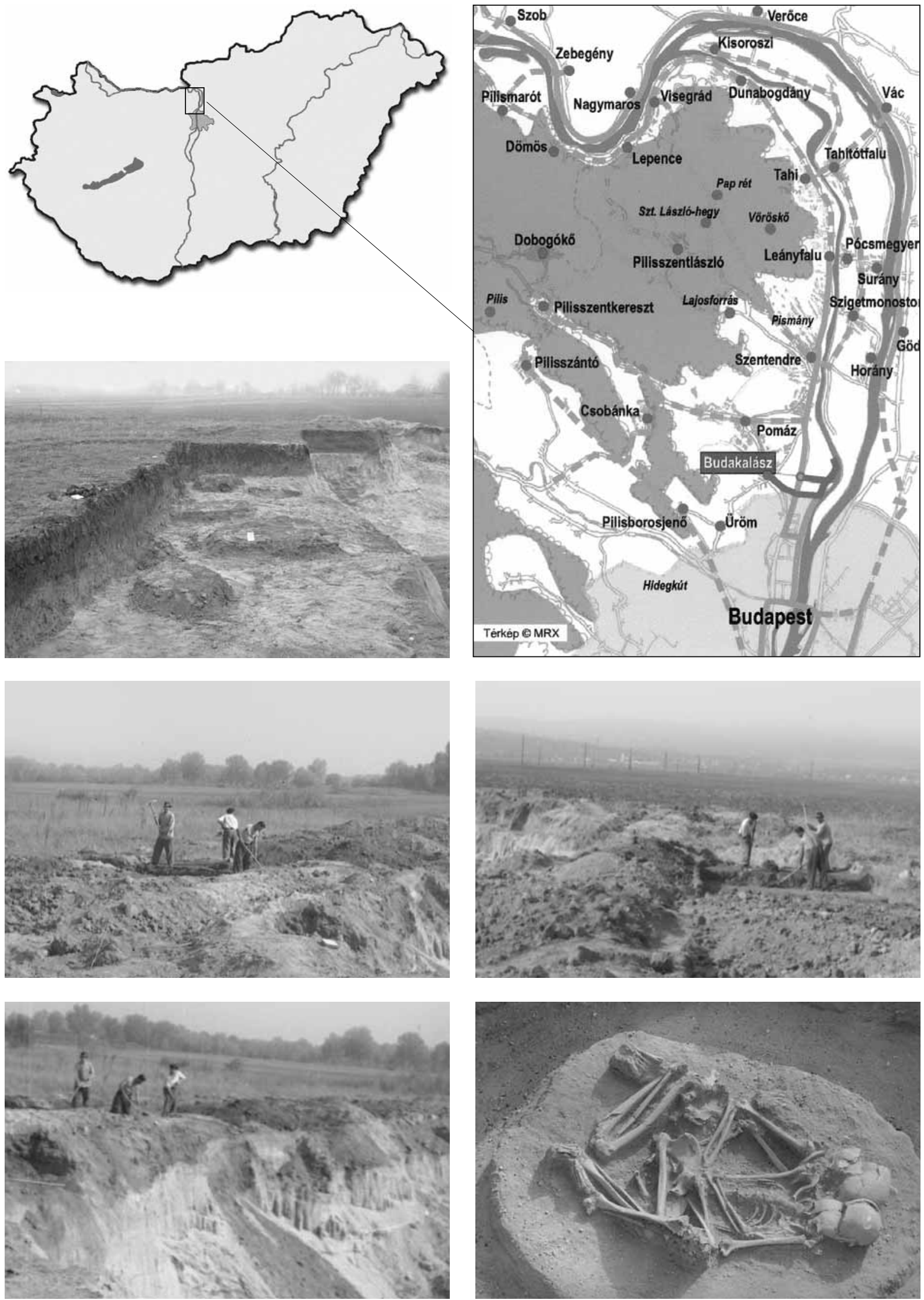

Fig. 1. View of the excavation 
Called the gateway to the Danube Bend, Budakalász is girded by the Pilis Mountains in the north and west, the Danube and the marshland zone along its bank in the east, and the Berdo Mountain and the marshland of Békásmegyer in the south (Fig. 1). Budakalász also lies close to the Buda and Visegrád Mountains. The site's broader area was excellently suited to human occupation at all times.

\section{THE SITE}

Luppa Island (and probably the inn, now an attractive restaurant) was named after Péter Luppa (1838-1904), an engineer and landowner living in Pomáz, who also acted as the town's parliamentary deputy. ${ }^{1}$

The Late Copper Age cemetery was discovered during sand-mining in the sand-pit of the local Szabadság Co-operative. The rescue excavation of the site was undertaken by Sándor Soproni between 1952 and 1960. The investigation of the site conformed to the rhythm of work in the sand-pit.

Soproni did not describe the site at greater length in his excavation reports and field documentation: the site's location was generally specified as Luppa-csárda [Luppa Inn], although he sometime merely gave the sand-pit as the site's location. Only two passages of his hand-written field diary contain information concerning the more exact location of the graves, when he specified distances relative to electricity pylons and recorded the identification tag of the pylons (Fig. 2a). On a sketch of the site, he indicated its location relative to the road leading to the Danube and the Luppa Inn (Fig. 2b). The location of the cemetery is also shown on a map accompanying the publication of the first 115 graves in János Banner's monograph (Fig. 2c). ${ }^{2}$ A sketch of the area showing the location of the cemetery can also be found among Sándor Sashegyi's notes, who continuously monitored the area and collected the stray finds (Fig. 3). ${ }^{3}$

In his academic DSc thesis, Korek described the site as follows: "The Budakalász-Luppa-csárda site lies $15 \mathrm{~km}$ north of Budapest on an alluvial plain beside a smaller islet of Nagysziget Island of Szentendre. The area was shaped by the Danube's one-time channel; a thick sand layer was deposited on the deeper lying gravel during the Alluvium. In 1952, the Szabadság Co-operatve of Budakalász opened a sand-pit in the area and S. Soproni, the then director of the museum in Szentendre, began the excavation of the burials discovered in the area. Located beside the road leading to the one-time Luppa Inn and the ferry, the cemetery extends parallel to the Danube, some 2-3 $\mathrm{m}$ higher than the median water level. A total of $9000 \mathrm{~m}^{2}$ was excavated." ${ }^{4}$ The location of

\footnotetext{
1 Magyar Életrajzi Lexikon 1000-1990 [Hungarian Biographical Encyclopedia]. Budapest 1994.

2 SOPRONI 1956, 113, Abb. 29.

3 Sándor Sashegyi's report, SzFM Archives, inv. no. 752-73

4 KoREK 1983, 9-10.
}

the cemetery (Fig. 4) is also described in the volume detailing the area's archaeological topography: "The currently known largest cemetery of the Baden culture extends parallel to the Danube, some $200-250 \mathrm{~m}$ from the river's bank, in the north-eastern corner of the Budakalász settlement." 5 The area of the site lying between the embankment and the Danube beside the road across Luppa Island is currently unploughed land.

\section{THE EXCAVATION}

On February 20, 1952, Soproni, then working in the Ferenczy Károly Museum in Szentendre, was notified that the Szabadság Co-operative had opened a new sand-pit at Budakalász and that graves had been found during mining operations. During his inspection of the site, the foreman showed him a few broken pottery fragments which had come to light earlier. The workers were unable to provide any detailed information on the finds. According to their account, some eight to ten graves had been destroyed. Soproni believed that a few graves were still at risk and he therefore began the excavation of the site the next day. The excavation begun on February 21 lasted for several years; the site turned out to be the largest burial ground of the Late Copper Age Baden culture.

According to Soproni's report, he continuously monitored the area of the sand-pit from April 23, 1952, and visited the site once a week on the average to excavate the graves that had come to light. ${ }^{6}$ Between September 30 and October 10, he conducted a salvage excavation with four workers in the area scheduled for mining during the winter. He uncovered a total of 115 graves in 1952.7 He observed 5-6 grave clusters in the excavated cemetery section. Conservator Gyôző Baky also participated in the excavation, together with anthropologists György Acsády and Mihály Malán, as well as István Erdélyi, who was a university student at the time.

In February 1953, Soproni requested a sum of $2400 \mathrm{Ft}$ for continuing the excavation ${ }^{8}$ and a further $3000 \mathrm{Ft}$ on August $5 .{ }^{9} \mathrm{He}$ continued the excavation from August 10,10 employing three excavation workers. Together with the additional fifteen graves brought to light during these few days, the number of graves rose to 131. The excavation was finished on August 15 "owing to the lack of funds." In his report, Soproni emphasised that the rate of sand-mining had accelerated and that the mined area almost extended to the boundary of the investigated area. The site was also endangered by the imminent collapse of the sand-pit's

\footnotetext{
${ }^{5}$ MRT 7, 45, Site $3 / 7$

${ }^{6}$ SzFM Archives, inv. no. 204 (dated July 2, 1953).

7 The campaigns of the 1952 season were as follows: February 21-29, March 1, 4-5, 10, 12-13, 18, 29, April 23, May 15, 30, June 2, 4, 17, 19, 24, July 2, 7, 15, August 26, 28, September 11, 15, 26, 30, October 1-3, 6-10, 18. The field diary was deposited in the SzFM Archives (inv. no. 100).

${ }^{8}$ SzFM Archives, inv. no. 56 (dated February 23, 1953).

${ }^{9}$ SzFM Archives, inv. no. 236 (dated August 5, 1953).

${ }^{10}$ SzFM Archives, inv. no. 252 (dated August 17, 1953).
} 


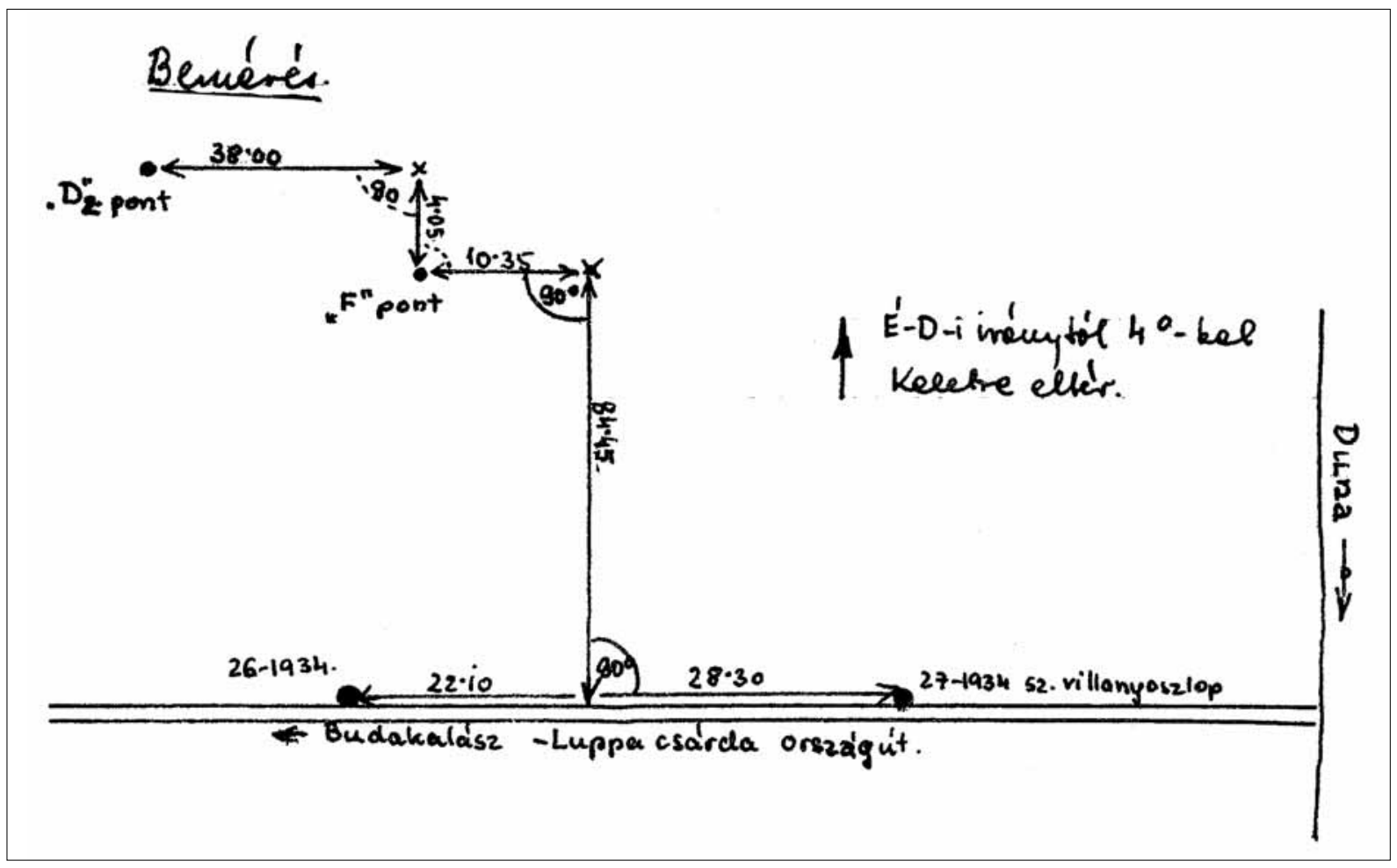

\section{Benuérés.}

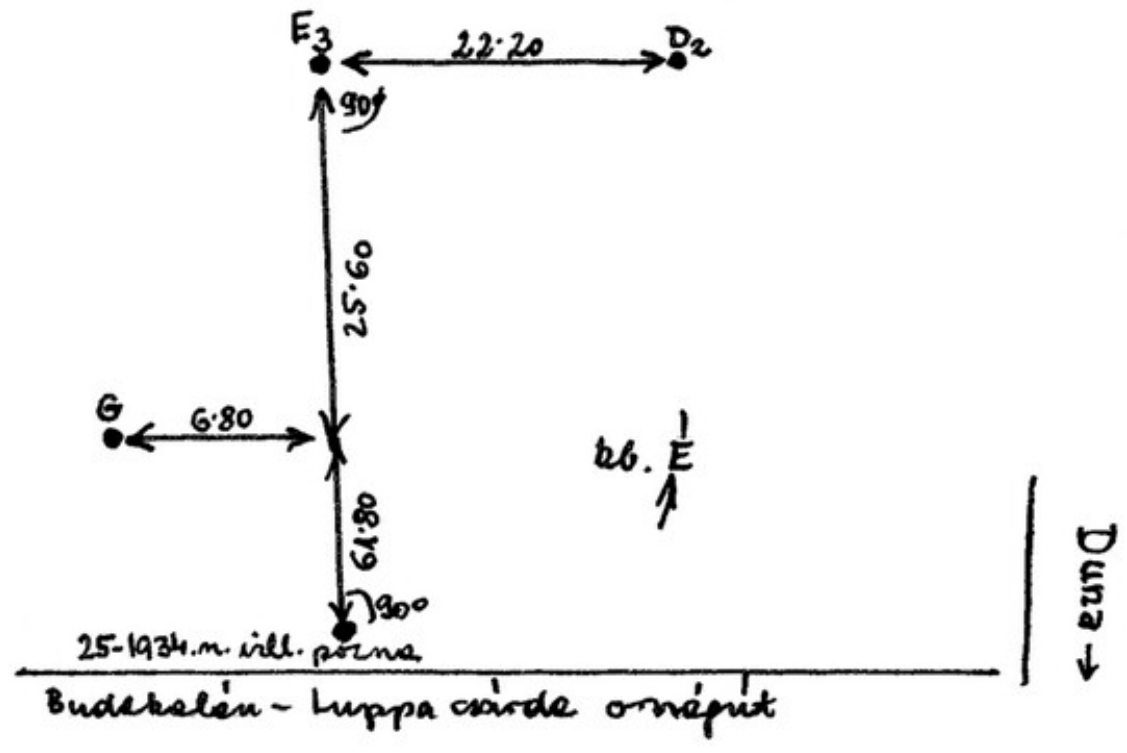

1952. nepteuber 11.

crütostiot

Fig. 2a, b. Plan of the site in Sándor Soproni's field diary

walls and therefore Soproni urgently requested a sum of $2400 \mathrm{Ft}$ in his report dated August 15, 1953. He continued the excavation in August ${ }^{11}$ after receiving the funds. ${ }^{12} \mathrm{He}$ employed four workers during this period and uncovered a further ninety graves. Together with the graves uncovered earlier, the number of graves rose to 221 . The $1500 \mathrm{~m}^{2}$ area investigated in 1953 with $5 \mathrm{~m}$ by $5 \mathrm{~m}$ large trenches lay north and west of the sandpit. Soproni conducted a survey and prepared a contour map of the area together with Erdélyi. Soproni cal- 
culated that sand-mining operations would not endanger the cemetery until later February of the coming year.

Soproni resumed the excavation of the cemetery on March 30, 1954, first with three workers and, later, with five to six excavation workers on the average. ${ }^{13} \mathrm{He}$ finished work on April 24.14 Beside completing the excavation of Trench G, Soproni opened two new trenches, both measuring $5 \mathrm{~m}$ by $5 \mathrm{~m}$. Trench $\mathrm{H}$ was excavated along the sand-pit's entire length, while Trench I along half its length. A narrower trench was opened along the sand-pit's western wall, extending to the cultivated area beside the sand-pit. This trench clarified the cemetery's southern boundary and its western side. Soproni noted that the cemetery continued toward the north and that this section was still at risk. He uncovered thirty-five burials in Spring 1954, and thus the overall number of graves rose to 256. Soproni found larger open areas between the grave clusters. In his report he noted that the investigation of the cemetery would have to be continued in late September and October because sand-mining would by then extend to the investigated area. He had not used up $305.72 \mathrm{Ft}$ of the $6000 \mathrm{Ft}$ received for the excavation, and he returned this money to the Historical Museum of the Hungarian National Museum.

The investigation of the site was continued in Autumn 1954. Employing four workers on the average, Soproni uncovered a total of $730 \mathrm{~m}^{2}$ in the sand-pit's northern and western part. Together with the forty-six graves uncovered at this time, the number of graves rose to $303 .{ }^{15}$ (One burial, Grave 257, was destroyed in summer, when a military exercise was held in the area, and thus the numbering of the graves during the autumn campaign continued from no. 258.) Soproni reported that continued sand mining operations would not endanger any burials and that the next campaign should take place in the spring of the next year.

Another excavation became necessary in 1955 because continued sand mining endangered the still unexplored section of the cemetery. ${ }^{16}$ Soproni's report on the investigations conducted in the sand-pit's eastern half noted that the immediate risk had passed. A 3-6 $\mathrm{m}$ wide zone cutting across the sand-pit's entire length had been cleared, meaning that mining operations could proceed and that there would be no need for an excavation for another one or two months. Soproni employed 3-4 excavation workers for this campaign. ${ }^{17}$ The plan of the cemetery suggested that

\footnotetext{
11 The campaigns of the 1953 season were as follows: August 10-15, August 31-September 22, September 29-October 29. The field diary was deposited in the SzFM Archives (inv. no. 240).

12 SzFM Archives, inv. no. 16 (dated December 28, 1953). The field diary was a supplement to the report filed under no. 392/1953.

13 SzFM Archives, inv. no. 241 (dated June 1, 1954).

14 The campaigns of the 1954 season were as follows: March 30-April 24 September 27-October 22 and October 28-November 3.

15 SzFM Archives, inv. no. 56 (dated November 8, 1954). The field diary was deposited in the SzFM Archives (inv. no. 101).
}

the Copper Age burial ground extended further in the north and west, and that at least another one hundred graves could be expected.

The area selected for mining lay by the cemetery's northern and western boundary, and operations were also begun in the sand-pit's south-western end, which had not been investigated by Soproni because he believed that the cemetery did not extend to that area. Soproni requested a sum of $1500 \mathrm{Ft}$ for the 3-4 weeks long campaign to be conducted in autumn..$^{18}$

Soproni opened a trench in the sand-pit's northern and western part, adjoining the areas investigated in 1954 and 1955. Two Early Iron Age burials came to light in the sand-pit's south-western part (Graves 313 and 327). The area was not investigated further in the lack of funds. ${ }^{19}$ Altogether thirty graves were uncovered in 1955, bringing the total number to 334 .

On June 19, 1956, continued sand mining disturbed the still unexcavated part of the burial ground. ${ }^{20}$ The co-operative notified Soproni, who reported the damage to the Hungarian National Museum. The very same day, József Korek, László Barkóczi and Tihamér Szentléleky inspected the site and drew up a report on what they had seen. It turned out that the datum points of the excavation had been removed and it therefore became necessary to establish new ones before the excavations were resumed. The first campaign was conducted between June 20 and July 11 in the area by the sand-pit's edges. The number of graves rose to 366.21 Another campaign became necessary in October in the sand-pit's northern and western part. Soproni believed that the Copper Age burial ground extended to the area of the old sand-pit and that the number of the graves destroyed in that area could only be estimated after the investigation. Soproni was told that sand mining in the old sand-pit was conducted during World War 1. The cemetery's eastern boundary (toward the Danube) had been reached and no more than a few graves could be expected. The area was strongly disturbed and often inundated by floods. Two main clusters of graves were uncovered in the sand-pit's north-eastern and northwestern corner during the October campaign. Soproni employed between one and seven workers at this time. The number of graves rose to 386.22

In 1957, the area affected by sand mining lay dangerously close to the cemetery section investigated in 1956, and a new campaign became necessary. Work was continued in the sandpit's north-western and

\footnotetext{
16 The campaigns of the 1955 season were as follows: June 13-18, September 26-28 and October 10-21. The field diary was deposited in the SzFM Archives (inv. no. 171)

${ }^{17}$ SzFM Archives, inv. no. 70 (dated June 21, 1955)

${ }^{18}$ SzFM Archives, inv. no. 87 (dated September 1, 1955). Soproni specified the site as Budakalász-Homokbánya [sandpit].

${ }^{19}$ SzFM Archives, inv. no. 88 (dated December 10, 1955)

20 The campaigns of the 1956 season were as follows: June 20-July 11,

October 2-13. The field diary was deposited in the SzFM Archives (inv. no.

171).

${ }^{21}$ SzFM Archives, inv. no. 105 (dated September 27, 1956).

${ }^{22}$ SzFM Archives, inv. no. 397/1956 (dated December 19 1956).
} 


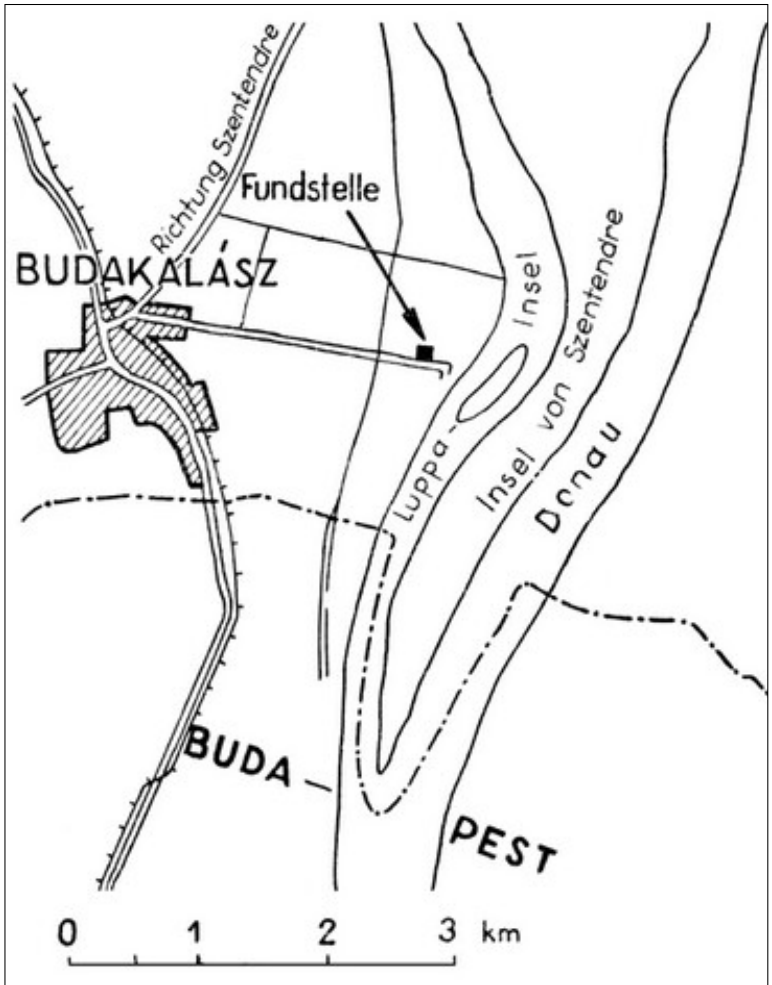

Fig. 2c. Location of the cemetery (after BANNER 1956, 113)

western half. The map of the cemetery indicated that while there were no more burials in the north, the burial ground continued toward the west. The eight graves uncovered during the campaign ${ }^{23}$ all lay in the sand-pit's western corner. ${ }^{24}$ Soproni employed five workers during this excavation season. The number of graves rose to $394 .{ }^{25}$

Work was continued in the sand-pit's western half in $1958,{ }^{26}$ with three excavation workers on the average. The number of graves rose to 407 together with the burials uncovered that year. ${ }^{27}$

In 1959, the excavation was continued in the sandpit's western side. ${ }^{28}$ Soproni employed five workers on the average. The cemetery map indicated that the burial ground had been almost completely excavated with the exception of a small section on the western side. Soproni uncovered one grave before the start of the campaign (Grave 408). ${ }^{29}$

Soproni uncovered nineteen new burials of the Late Copper Age in $1960 .^{30} \mathrm{He}$ employed five workers on the average during this season. Although the graves lay

\footnotetext{
${ }^{23}$ A single campaign was conducted in the 1957 season between June 3 and 7. The field diary was deposited in the SzFM Archives (inv. no. 243).

${ }^{24}$ SzFM Archives, inv. no. 153 (dated June 8, 1957), which is identical with the report filed under no. 122 (a copy). The same report was filed under no. 427.

25 SzFM Archives, inv, no. 122 (dated June 8, 1957).

26 A single campaign was conducted in the 1958 season between April 14 and 24 . The field diary was deposited in the SzFM Archives (inv. no. 243). 27 I did not find a report on the 1958 season in the SzFM Archives.

28 The campaigns of the 1959 season were as follows: March 3, March 23-27, April 15-17. The field diary was deposited in the SzFM Archives (inv. no. 243)

${ }^{29}$ SzFM Archives, inv. no. 158 (dated April 18, 1959).
}

quite far from each other, definite burial clusters could be identified. The excavated graves lay on the edge of the cemetery. ${ }^{31}$

In 1961, mining operations were again conducted near the already investigated area and Soproni therefore continued the excavation there. ${ }^{32}$ The new trench, measuring $33.5 \mathrm{~m}$, by $5.6 \mathrm{~m}$, was opened next to the cemetery section excavated the previous year on the sand-pit's western side. He investigated a 6-10 m wide zone lying beyond the cemetery's outermost burials. He did not find additional graves, confirming his belief that he had excavated the cemetery's entire area. In his report he noted that he had excavated the entire burial ground and requested that the earlier protected status of the site be cancelled. He had used up $1303.80 \mathrm{Ft}$ of the $3000 \mathrm{Ft}$ received for the season, and returned the rest to the Finance Department of the Hungarian National Museum. ${ }^{33}$

Table I shows the number of burials uncovered during the successive campaigns.

Table I

\begin{tabular}{|c|c|c|}
\hline $\begin{array}{c}\text { Excavation } \\
\text { season }\end{array}$ & $\begin{array}{c}\text { Number } \\
\text { of excavated graves }\end{array}$ & $\begin{array}{c}\text { Grave } \\
\text { numbers }\end{array}$ \\
\hline 1952 & 115 & $1-115$ \\
\hline 1953 & 106 & $116-221$ \\
\hline 1954 & 82 & $222-303$ \\
\hline 1955 & 31 & $304-334$ \\
\hline 1956 & 52 & $335-386$ \\
\hline 1957 & 8 & $387-394$ \\
\hline 1958 & 13 & $395-407$ \\
\hline 1959 & 13 & $408-420$ \\
\hline 1960 & 19 & $421-439$ \\
\hline
\end{tabular}

The cemetery contained 436 graves of the Baden culture, one Early Bronze Age burial and two Early Iron Age burials. Copies of the field diaries were deposited in the Archives of the Hungarian National Museum in Budapest, the Ferenczy Károly Museum in Szentendre and the Anthropological Department of the Natural History Museum of the Hungarian National Museum. The photos were inventoried in the Ferenczy Károly Museum. The finds were taken to the Hungarian National Museum for conservation and restoration, and then deposited in the collection of the Ferenczy Károly Museum. The finds were inventoried in two phases: the material from the 1952 campaign was inventoried in $1956,{ }^{34}$ while the material brought to light between 1953 and 1960 in $1961 .{ }^{35}$

\footnotetext{
30 A single campaign was conducted in the 1960 season between April 19-28. The field diary was deposited in the SzFM Archives (inv. no. 243). 31 SzFM Archives, inv. no. 205.

32 A single campaign was conducted in the 1961 season between April 24-27. The field diary was deposited in the SzFM Archives (inv. no. 229). ${ }^{33}$ SzFM Archives, inv. no. 186 (dated April 27, 1961).

${ }^{34} \mathrm{SzFM}$ inv. nos 56.11.1.1-56.11.80.1 and 72.3.1-72.3.3c (the finds from Grave 3, lifted in situ in 1952, after it was dismantled).

${ }^{35}$ SzFM inv. nos 61.2.1.1-61.2.11.4.
} 


\section{EVALUATION OF THE FINDS}

The currently known largest and virtually completely excavated cemetery of the Baden culture engaged the attention of the archaeological community since the publication of the first graves. A report on the first 115 graves uncovered during the first excavation was published in Banner's monograph ${ }^{36}$ and several studies were written on the wagon model from Grave 177, a sensational find. ${ }^{37}$ The wagon model achieved a fame of its own and has been quoted in virtually every study and monograph discussing this period, as well as in the books written for the broader public and in monographs devoted to European prehistory and culture. A list of all the works mentioning the wagon model in brief or at greater length would require a separate bibliography.

Following the reports and studies written concurrently with the excavations, there was a longer lull in the evaluation of the finds. The main publications on the Budakalász cemetery are as follows:

\section{Excavation reports:}

Sándor Soproni: Budakalász-Homokbánya. ArchÉrt 81 (1954) 70 (the 1952 season).

Sándor Soproni: Budakalász. ArcbÉrt 82 (1955) 92 (the 1953 season).

Sándor Soproni: Budakalász-Homokbánya. ArcbÉrt 83 (1956) 94 (the 1954 season).

Sándor Soproni - Mihály Malán: Budakalász-Homokbánya. ArchÉrt 84 (1957) 82 (the 1955 season).

Sándor Soproni: Budakalász-Sandgrube. ArchÉrt 85 (1958) 79-80 (the 1956 season).

Sándor Soproni: Budakalász-Sandgrube. ArchÉrt 86 (1959) 196 (the 1958 season).

Sándor Soproni: Budakalász-Donauufer. ArchÉrt 87 (1960) 227 (the 1959 season).

Sándor Soproni: Budakalász-Donauufer. ArchÉrt 88 (1961) 282 (the 1960 season).

Sándor Soproni: Budakalász-Homokbánya. RégFüz Ser. I. 9 (1958) 4 (the 1956 season).

Sándor Soproni: Budakalász. RégFüz Ser. I. 10 (1958) 3 (the 1957 season).

Sándor Soproni: Budakalász-Homokbánya. RégFüz Ser. I. 11 (1959) 5 (the 1958 season).

Sándor Soproni: Budakalász-Dunapart. RégFüz Ser. I. 13 (1960) 4 (the 1959 season).

Sándor Soproni: Budakalász-Dunapart. RégFüz Ser. I. 14 (1961) 11 (the 1960 season).

Sándor Soproni: Budakalász-Homokbánya. RégFüz Ser. I. 15 (1962) 12 (the 1961 season).

\section{Other:}

Sándor Soproni: A budakalászi kocsi [The wagon model from Budakalász]. FolArch 6 (1954) 29-36.

Sándor Soproni: Budakalász. In: Banner 1956, 111-128.

${ }^{36}$ SOPRONI 1956a.

37 SOPRONI 1954; SOPRONI 1956.
János Nemeskéri: Anthropologische Übersicht des Volkes der Péceler Kultur. In: Banner 1956, 293-311.

Sándor Soproni: A négyezeréves agyagszekér [A four thousand years old clay wagon]. Budapest 1956 (A MNM Történeti Múzeum népszerúsító kiadványai). József Korek: Der älteste Wagenfund Europas. HelmsMuseum. Hamburgische Museum für Vor- und Frühgeschichte 1973.

József Korek: Európa legidôsebb kocsi-leletei [The earliest wagon finds from Europe]. Budapest [1976?] Magyar Nemzeti Múzeum. Kiállítási Lapok 2.

Imre Lengyel: Nem, életkor, vércsoport értékelése a budakalászi bádeni temetốben [Age, sex, and blood groups in the Baden cemetery at Budakalász]. Budapest 1983. (Régészeti Továbbképző Füzetek 2)

József Korek: Budakalász. In: MRT 7, 45-47.

József Korek: The Grave of an Artisan in the Copper Age at Budakalász. In: International conference on prehistoric flint mining and lithic raw material identification in the Carpathian Basin. Ed. by Katalin T. Bíró. Budapest-Sümeg 1986, 317-322.

Soproni granted the right of publication of the graves and their finds to József Korek, who began the comprehensive evaluation of the finds with tremendous enthusiasm. He organised the archaeometric and provenance analyses of samples taken from various categories of finds with specialists from related fields, and together with János Nemeskéri, he worked out a new system for the publication of the graves using grave sheets (see below).

The evaluation of the skeletal remains was begun by Mihály Malán of the Anthropological Department of the Natural History Museum, who analysed the skeletal remains from the first seventy-five graves based on the field documentation. He employed the autopsy technique in the case of the graves in whose excavation he had participated personally. An untimely death intervened and prevented him from completing this work. János Nemeskéri, head of the Anthropological Department, was supposed to continue this work, but owing to his involvement in the research of living populations, he was unable to complete the anthropological analyses and only published the first 115 graves in Banner's monograph. ${ }^{38}$

In the early 1980s, Korek turned to Imre Lengyel to continue the anthropological evaluation of the finds. Lengyel sexed the Budakalász population based on his identification of blood groups, essentially a form of genetic analyses. He performed the serological analyses under extremely difficult laboratory conditions, after his working hours at the Vascular Surgery Clinic. He received only the bone samples and was not permitted to study the excavation documents because Korek was curious to learn to what extent the archaeological evaluation and the findings of the anthropological analyses confirmed or, conversely, contradicted each

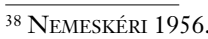




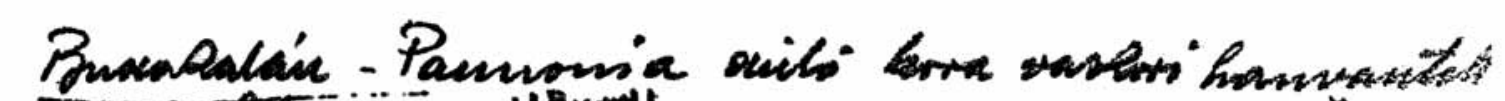

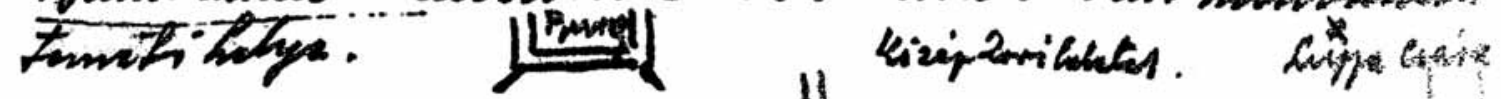

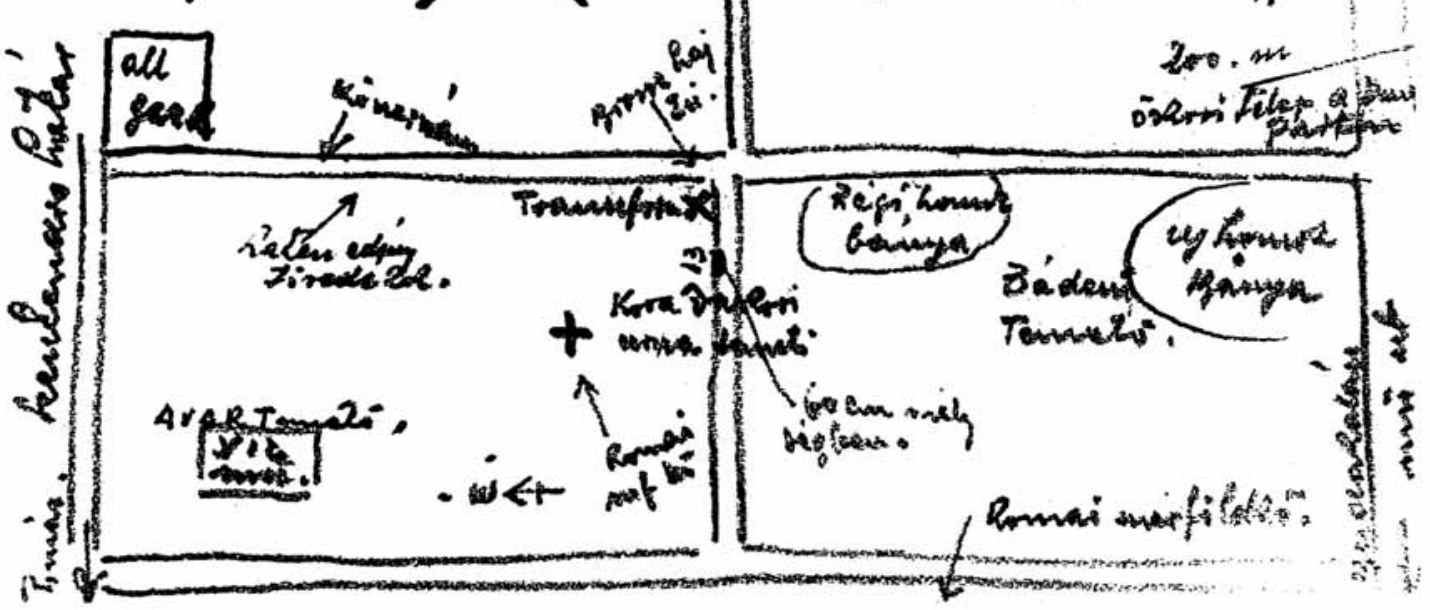

Fig. 3. Plan of the site by Sándor Sashegyi

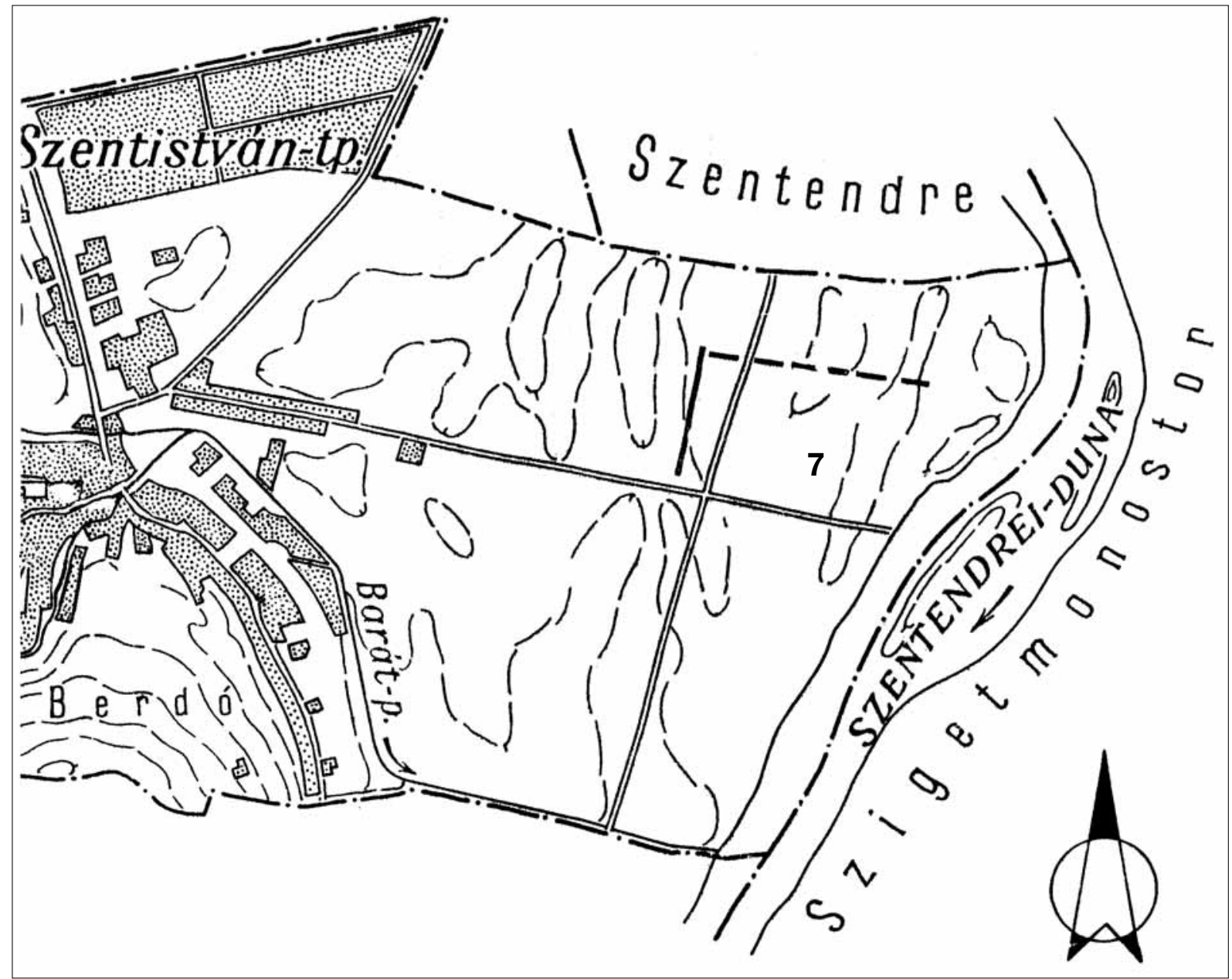

Fig. 4. Plan of the site (after MRT 7, 42) 
other. Korek and Lengyel worked independently of each other when identifying possible groups within the cemetery. Korek based his evaluation on the cemetery plan, while Lengyel's groups were outlined by the findings of the serological analyses, kinship/lineage and genetic aggregates.

Following the completion of the anthropological analyses (age. sex, pathology, blood groups, etc.), Korek and Lengyel compared their findings on February 15, 1979 to see how the anthropological findings compared with the traditional archaeological analysis and the results of Lengyel's new analytical method. Only a few details needed to be modified by mutual agreement which appeared to be at variance with each other, probably owing to minor mix-ups during sampling. ${ }^{39}$ These modifications remained under 2 per cent. Lengyel published a brief article about his anthropological analysis. ${ }^{40}$ His tragic death in a car accident prevented the publication of his truly innovative analysis of the skeletal remains from the Budakalász cemetery.

Owing to the extraordinarily high number of lithic artefacts, the stone artefacts were not all provenanced. Instead, Korek decided to provenance the lithic finds from Grave 91, the burial containing some one hundred stone tools and implements because he believed that the finds from this grave would provide a good cross-section of the rocks and minerals used by the Budakalász community. The lithic finds were analyzed by Mrs Csaba Ravasz of the State Geological Institute, who found that most had been made from chert or some other flint type. She distinguished two main types among the genuine cherts: bluish, dense cherts, probably acquired from Poland, and reddish-brown, opaque cherts which could be procured from Hungarian deposits. The few obsidian pieces came from the same area, probably from the Tokaj Mountains. The raw material of the other stone finds from Grave 91 was procured from Alpine actinolite schist deposits. Korek published the finds from this grave in a separate article. ${ }^{41}$

The beads and shells were analysed by Ilona Meznerich of the Department of Geology and Palaeontology of the Hungarian National Museum. Owing to her unexpected death, she did not publish the results of her work on the beads and Korek had to rely on her notes, according to which the Dentalium shells used

\footnotetext{
${ }^{39}$ MNM Archives, inv. no. VII.61/1984.

40 LENGYEL 1983.

${ }^{41}$ KOREK 1986a. The lithic raw materials listed in Korek's articles, based on Mrs Csaba Ravasz's identification, differ from the ones in the study of the lithic finds in this volume (see pp. 379-408).

42 MeZNeRICS 1951, 102-104.

${ }^{43}$ Dr. Manfred Schröder's report is filed under no. 1170/76 in the SzFM Archives. According to a remark in the report, it was made up of eight pages and four illustrations, and was filed under no. 560 in the inventory book of the Archives. It was re-inventoried in January 1976, when the volume on the area's archaeological topography was assembled.

44 The Archaeometallurgy Database in Stuttgart, created as part of the Studien zu den Anfängen der Metallurgie (SAM) project.

45 The procedure is described in detail in the supplement to Korek's DSc thesis (KOREK 1983, 32-37). The data recording was performed by Dániel Gróh.
}

most often for the manufacture of beads were fossil specimens $s^{42}$ and were thus unsuitable for reconstructing possible trade contacts or other cultural contacts.

The few copper artefacts (jewellery items and tools) were submitted for analyses to the German Archaeological Institute in Frankfurt and the metallurgical laboratory of the Lenin Foundry Works in Diósgyôr. The results of the analyses performed in Germany can be found in the Archives of the Ferenczy Museum in Szentendre, ${ }^{43}$ according to which the metal analysis was conducted by Dr. Siegfried Junghaus of the Landesmuseum Württemberg, although the actual work was done by Dr. Manfred Schröder. The analytical results were entered into the SAM archaeometallurgical database in Stuttgart. ${ }^{44}$ Most of the artefacts sent to Stuttgart were not returned to Hungary. Nothing is known about the analytical results of the artefacts sent to Diósgyôr.

In the early 1980s, Korek began the evaluation of the Budakalász cemetery using the then most advanced technique of recording the most important data on punch cards. ${ }^{45}$ Together with Nemeskéri, he had elaborated an innovative system involving the use of what he called "grave sheets", containing all the relevant information on each grave such as the grave plan, a sketch and a description of the grave goods, the dimensions of the grave pit (length, width and depth), the orientation of the deceased, the metric data of the anthropological analysis and the findings of the major archaeometric analyses (lithics, jewellery, animal bones, metal), as well as any unusual features (Fig. 5). The planned monograph would have included both photos and grave sheets; Korek believed that he would have been unable to find a publisher owing to the length of the manuscript and the printing difficulties. The completed grave sheets and the evaluation of the finds were published in his academic doctoral thesis. ${ }^{46}$ He planned to publish the grave sheets in the Régészeti Füzetek II series, ${ }^{47}$ but this was never realized.

Korek devoted much of his energy to collecting the primary sources on the cemetery and its excavation, namely the surviving documentation, as well as the

\footnotetext{
46 In his DSc thesis, Korek repeatedly referred to the two-volume Budakalász monograph he had written (KOREK 1983). I searched far and wide to locate the manuscript and I tried to find out where it was supposed to have been published. As a university student, I often heard him say that it would be published in Germany. Unfortunately, no-one had any idea about the fate of the two volumes. I had received a copy of the grave sheets made and mimeographed by him, meaning that the volume of illustrations actually existed, but no-one I spoke to knew about a text volume. In his Dsc thesis, Korek covered the Baden culture, and merely quoted various findings of his analyses and his conclusions concerning the Budakalász cemetery. The breakthrough in this respect came when János Makkay heard that I was working on the Budakalász material and unexpectedly handed me a thick type-written volume, telling me that it had been lying on his bookshelf and that he had no need of it. The title page and the inner cover were missing; the bound manuscript began with the contents page. The volume was undoubtedly the missing volume of the "Budakalász monograph". Made up of 238 type-written pages, the manuscript was not a conventional report, but rather an evaluation of the cemetery, with a brief overview of the different artefact types (pottery, tools and implements, jewellery, bone artefacts, etc.) and Korek's analysis of the cemetery. 47 KorEK 1986a, note 3.
} 


\section{S 82}

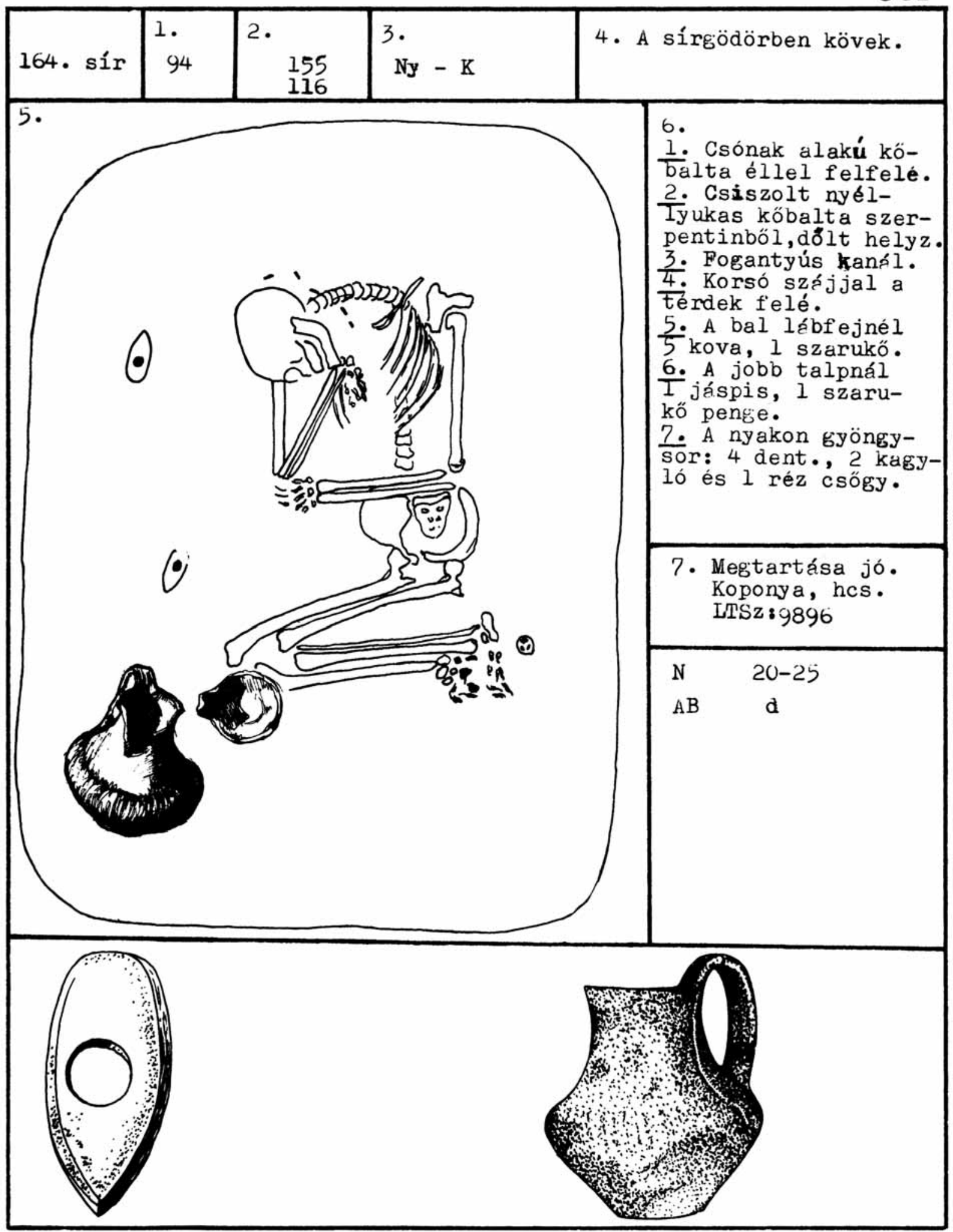

Fig. 5. Grave 164 on Fózsef Korek's grave sheet 
drawings and photos for the planned monograph. His death on May 29, 1992 prevented him from completing his work on the Budakalász cemetery, a part of which appeared in his doctoral thesis.

In his obituary, István Fodor wrote that "the last major accomplishment in [Korek's] archaeological oeuvre was the academic doctoral dissertation, "East-Central Europe at the close of the Copper Age", based on the analysis of the over four hundred burials of the Baden cemetery uncovered at Budakalász and the findings of related disciplines. He was awarded the academic doctoral degree in 1985 for this pioneering work. Unfortunately, his ill health prevented him from preparing the manuscript for printing. The publication of this study is one of the debts owed by the prehistorians of this discipline." 48

$$
\text { *** }
$$

Ten years after Korek's death, I was deeply honoured by a request from Pál Raczky to participate in the assessment of the finds from the Budakalász cemetery. In the following, I shall briefly describe the documentation and the find material, and the conditions under which we began our work.

\section{THE DOCUMENTATION}

When I began work on the Budakalász cemetery, Pál Raczky presented me with the documentation which had been Soproni's own copy. This contained the following documents: the field diaries for the years 1952, 1953, 1954, 1955, 1956, 1957, 1959 and 1960, a hand-written field diary of the first 115 graves (Graves 1-115), a plan of the cemetery (based on the excavations in 1952, 1956 and 1957), photocopies of a few grave plans, black-and-white photos of a few graves, the report on the 1954 campaign and Soproni's letter to Banner. These, then, were the initially available documents. I made every effort to collect the missing documentation from the archives of the Hungarian National Museum in Budapest and the Ferenczy Károly Museum in Szentendre.

I found two relevant documents in the Archives of the Hungarian National Museum: two hand-written lists by Lengyel containing the anthropological analysis of the skeletal remains (grave number, age, sex and blood group), ${ }^{49}$ and the mimeographed cemetery plans on which Lengyel distinguished the grave groups based on his findings. ${ }^{50}$ Sadly, this is all that survived of Lengyel's work. I was unable to locate the complete documentation either in the Archives of the Hungarian National Museum, or in the Archives of his one-time work-place, the Vascular Surgery Clinic. I was unable to find anything else in the Archives of the Hungarian National

\footnotetext{
48 FODOR 1995, 12.

${ }^{49}$ HNM Archives, inv. nos X.262/1963 and VII.61/1984. I would here like to thank Gábor Rezi Kató for providing a copy of these two documents. ${ }^{50}$ These maps formed the basis for the re-drawing of the cemetery plan.
}

Museum aside from a few newspaper cuttings. ${ }^{51} \mathrm{I}$ also contacted Korek's family in the hope that they might know about additional documents relevant to the Budakalász cemetery among his personal papers. ${ }^{52}$

My search for surviving documents took me to Szentendre. The Archives of the Ferenczy Károly Museum contained an almost complete set of records concerning the excavations at Budakalász and I therefore used the field diaries and reports deposited there. The museum kindly loaned me the relevant documents in June 2002. I compared the documents received from the Ferenczy Museum with the ones received from Pál Raczky. As it turned out, Soproni had not retained a copy of the entire documentation. I found some duplicates, for example the hand-written field diary of the first 115 graves, a photocopy of the cemetery plans for the successive excavation seasons and the like.

In June 2004, I returned to the Archives of the Ferenczy Museum in the hope that I would find some of the still missing documents. Together with Éva Maróti, who spared no effort in the search for possible records, I sifted through the inventory books describing the museum's archival material and the twenty-two inventory books of the photo archives. As a result, I found two of the missing reports and the report on the metal analyses. I also found a document containing 277 black-and-white photographs of various artefacts brought to light during the excavations, which the museum had received from Korek. ${ }^{53}$ I was also granted permission by László Simon to loan the negatives of the grave photos made by Soproni. ${ }^{54}$ Sadly, this set of records is also incomplete; according to a note in the inventory book, the missing negatives had been taken to the Department of Anthropology by Nemeskéri. ${ }^{55}$ The inventory book did not mention any other photos of the Budakalász cemetery, even though I had hoped to discover a repro or diapositive of the combined cemetery plan. The grave photos were digitised by the Pytheas Studio and we thus obtained fairly good quality images of the rather worn negatives.

\footnotetext{
${ }^{51}$ I would here like to extend my gratitude to Károly Mesterházy, who helped me locate all the relevant documents.

52 Entirely by chance, archaeologist Péter Árkus visited the Archaeological Institute in Summer 2004, and during our conversation I asked him whether he knew, by any chance, the address of Korek's mother-in-law in Hódmezôvásárhely because I would like to contact the family. He did not know anything about them, but he knew one of Korek's daughters, Mrs Lajos Hangya, who then acted as the president of the Human Policy Committee of the Gyomaendröd local council. I telephoned her and she kindly informed me that they she and her sister had returned everything to the museum after her father's death, keeping only a few books and offprints between them. I would here like to thank her for her helpfulness and kindness.

${ }^{53}$ SzFM Archives, inv. no. 2234-87 (inventoried in March 1987).

54 The photos were inventoried under nos 31-62, 66-76, 79-93, 99 $104-119,125-138,145-147,151-161,168-176,191-198,200-276$, $321-324,373-377,395-513,549-610,646-729,800-871,1067-1072$, 1079-1201, 1214-1229, 1304-1339, 1375-1376, 1381-1392, 1415-1428, $1437-1447$ and $1480-1517$.

55 The negatives inventoried under nos 277-287 (Graves 100 and 114-115), 301-320 (Graves 116-118 and 121), 325-372 (Graves 132, 134-160), 378-394 (Graves 164-173), 1073-1075, 1078 (Graves 338 and 340) are missing.
} 


\section{THE CEMETERY PLAN}

I have been unable to locate the combined plan of the cemetery used by Lengyel, which had most probably been drawn by Korek for his planned monograph. Neither was I able to locate any survey plans or geodesic maps.

While Soproni's reports describe the trenches he had opened, none appear on the cemetery plans made at the end of each season showing the burials uncovered that year. Aside from the 1953 and 1954 reports, the surviving documentation contains no references as to the location of the trenches relative to each other or their dimensions. Soproni meticulously described each burial, but did not record the position of the graves relative to each other, the distances between them or their location in a particular trench. He photographed each burial, taking care that only one grave should appear on each photo (the only exceptions being the photos of Graves 8-12, 20-21, 28-29, 94, 101, 243-246 and 243-245).

The most difficult task was the reconstruction of the combined plan of the cemetery. A separate plan was made for the areas investigated in the 1952, 1954, 1955 and 1956 seasons, as well as for the excavations between 1957 and 1960. There was no cemetery plan for the 1953 season. In addition to these, I also had the cemetery plan used by Lengyel, on which he marked the grave groups he had distinguished through the serological analyses. After covering his circles and ellipses using simple white correction fluid, I had before me the combined cemetery plan, on which I had to check whether each grave was marked and whether the grave numbering was correct.

The digitised version of Soproni's original grave plans drawn on graph paper (without a north point indicating orientation) was prepared by Zsolt Bényei. The re-drawing of the grave plans according to a uniform and consistent scale, the correction of the occasionally uncertain or faint lines was undertaken by Csaba Peterdi of the Archaeological Institute. The north point was added subsequently by György Szabó (Pytheas Studio), based on the description of the graves and the cemetery plan. He also digitised the cemetery plans of each excavation season and systematically compared the graves shown on the plans with the individual grave plans, checking their placement and orientation. I too checked each and every burial. In the end, only a few problems remained to be solved: Grave 112 was marked twice, as was Grave 136. We managed to determine, which of the two was Grave 112 and which was Grave 212; as it turned out, one of the burials marked as Grave 136 was in fact Grave 139, which did not appear on Lengyel's cemetery plan. Grave 393 too was marked twice, but one was Grave 341. We managed to determine the location of Graves $172,212,387$ and 425, which were not shown on the plan. The location of Graves 238 and 239, as well as of Graves 293 and 295 had been mixed up and needed to be corrected. We finally managed to create a combined plan from which only Graves 196 and 211 were missing. The latter was eventually identified with an unnumbered burial. Finally, a co-ordinate system was projected onto this map for easing the overview of the cemetery and enabling the precise determination of each grave's location within the cemetery. The letter/numeral combination appearing in the Catalogue reflects this system (Fig. 8).

\section{THE MODERN RE-ASSESSMENT AND INTERPRETATION OF THE FINDS}

I loaned the finds for the evaluation from the Ferenczy Museum in April 2002. After going through the boxes, I was delighted to find that the condition of the artefacts was not as poor as I had originally anticipated. The finds were all inventoried, the small finds were carefully packed and all lay in the original match boxes or small bags. ${ }^{56}$

Armed with the photocopies of the inventory books and the documentation containing the descriptions of the burials, I began to systematically review the finds. I first checked whether all the finds were available and found that quite a few were missing. Some of these were intact vessels, tools and bead strands which had probably been displayed as part of an exhibition and were either not returned to the museum or were mislaid. Many lithic implements were also missing: these had been loaned by Éva Cs. Balogh when she was writing her doctoral thesis. Although she returned the finds, these were in a separate box which can no longer be found in the museum. Some of the copper artefacts were no longer to be found and there is no record of whether the stones and boulders of the stone-packed burials had originally been deposited in the museum.

There were a few mix-ups during the original inventorying of the finds: although some grave goods had been inventoried as stray finds, these could be easily identified with the artefacts described precisely by Soproni in his field diary. His descriptions of the graves and their finds are extremely precise, virtually enabling the artefacts to be drawn from his words. He conscientiously recorded the dimensions of the grave pottery, enabling the identification of grave vessels which had been inventoried as stray finds (for example in the case of the vessels from Graves 2, 39, 145 and 430). The artefacts originally part of different grave assemblages which had become mixed up during inventorying could likewise be identified from Sop-

\footnotetext{
56 I would here like to thank László Simon, the then director of the museum, for kindly permitting me to loan the material from the museum and take it to the Archaeological Institute for study. Thanks are due to archaeologist Tamás Repiszky for assisting me in the practical issues of the loan and in selecting the relevant documents in the Archives of the Ferenczy Museum. I am also indebted to Éva Maróti, who generously contributed much of her time to sifting through the material in Archives in the search for possible documents.
} 
roni's accurate descriptions (e.g. in the case of Graves 403, 404, 412, 430, 427 and 437).

Parallel to the assessment of the grave goods, the finds were systematically photographed: a black and white photo was made of every single artefact (for deposition in the museum archives). Colour diapositives and colour negatives, as well as CDs of the colour diapositives were also made of every single find, with a view to the later illustrations of the planned monograph. The photographs were made by Tibor Kádas of the Archaeological Institute.

A drawing was made of each artefact. These were then scanned, digitised and edited using a computer graphics programme. This task was undertaken by László Gucsi of the Archaeological Institute.

I made every effort to find photos and/or drawings of the artefacts which had either been lost or mislaid, combing through Banner's monograph, Korek's grave sheets, Cs. Balogh's thesis and the photos given to the Ferenczy Museum by Korek. I was thus able to locate a fairly large portion of the now missing artefacts.

It soon became clear that Korek's grave sheets only showed a selection of the grave inventory owing to the lack of space. Korek's main concern was to show the full range of the grave pottery and he chose to present only the most characteristic types of the other articles deposited in the burial. Sadly, he was not altogether consistent in the representation of the grave pottery for in a few cases (e.g. Grave 177; Fig. 6), only a selection of the ceramics is shown. The same inconsistency can be noted in the case of beads too: in some cases, he drew the entire bead strand, while in others he seemed satisfied with simply presenting one of each type. The drawings appearing on his grave sheets were clearly based on the grave photos: this became obvious from a comparison of the duplicate photos in the Archives of the Ferenczy Museum ${ }^{57}$ and the grave sheets.

Following the preparatory work described in the above, I began the evaluation of the cemetery, enabled by two OTKA grants. ${ }^{58}$

In spite of the immense energy and efforts invested by Korek and his colleagues, the monograph on the Budakalász cemetery was not complete. This "now you see it, now you don't" situation regarding the monograph could best be handled by disregarding all that had been done earlier. I did not even attempt to fit the unpublished graves into the format of the earlier publications, but began everything from scratch with my colleagues, as if nothing had been done previously. We began our work without a preconception and only made use of earlier material in the case of lost finds, in the hope that some information could be gleaned from the earlier documentation.

The current study presents a catalogue of the graves, an evaluation of the funerary rites and the grave goods,

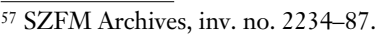

58 OTKA Grants T 37503 and T 62689.
}

the archaeometric analysis of the different materials used for the artefacts found in the graves, and an evaluation of the cemetery's special status and chronology.

Following in the footsteps of Soproni and Korek, and with due respect to their ideas, the Catalogue presents a description of the graves and their finds. Accompanying each grave are the co-ordinates showing the location of the grave on the cemetery plan and the numeral(s) of the plate(s) illustrating the grave and its finds. The grave number appears on the plates too in order to facilitate the identification of a particular grave find (e. g. $8 / 2$, where 8 marks the serial number of the grave and 2 the serial number of the grave good). The same system was used in the studies for quoting a particular artefact. When assembling the illustrations, my main concern was to include a drawing of the grave and of the grave goods. In the case of artefacts which were no longer to be found at the time of the assessment, I used pictograms to indicate that although the find in question had been part of the grave assemblage, no reliable photo or drawing of the find has survived. The grave goods are all shown in a 1:2 scale, while the grave plans in a 1:20 scale..$^{59}$ If a drawing of the grave was not available, but a photo had been made of the burial, I included the latter.

The descriptions of the burials are based on Soproni's meticulous accounts, made with a pathologist's precision, with attention to the smallest detail. He carefully recorded the position of the deceased and of the grave goods (Fig. 7). The metrical data (dimensions and form of the grave pit, the age and sex of the deceased, orientation, placement, anthropological data) are presented in a table.

In the description of the finds, I used the type and raw material determinations of my colleagues, who performed the archaeometric analyses instead of the labels applied by Soproni, while the description of the pottery wares follows my own typological system. I relied on the entries in the inventory books in cases when a particular find was missing. I have in all cases recorded the changes that occurred during the roughly fifty years which have elapsed since the excavation and the inventorying of the finds, and the current evaluation of the cemetery. ${ }^{60}$

I have made every effort to include a photo of each grave in the Catalogue; a drawing of individual burials

\footnotetext{
59 The preparation of the illustrations in a uniform style from the originals made in different formats using different techniques was done by György Szabó (Pytheas Studio).

${ }^{60}$ Changes of this type are especially striking in the case of the beads because the number of the surviving beads available for study often differs significantly from the number recorded in the field diary and the inventory books. Some beads had already been lost by the time the grave assemblages were inventoried, although in some cases the number of beads rose because some of the shell beads had slipped into each other, which was not obvious when the finds from the burial were recorded in the field diary before they were lifted and packed. The number of beads also diminished owing to losses during removal from the museum storeroom for provenance and other archaeometric analyses, this being the reason for the differences between the numbers recorded in the field diary, the inventory books and in Pál Sümegi's study (see pp. 409-435).
} 


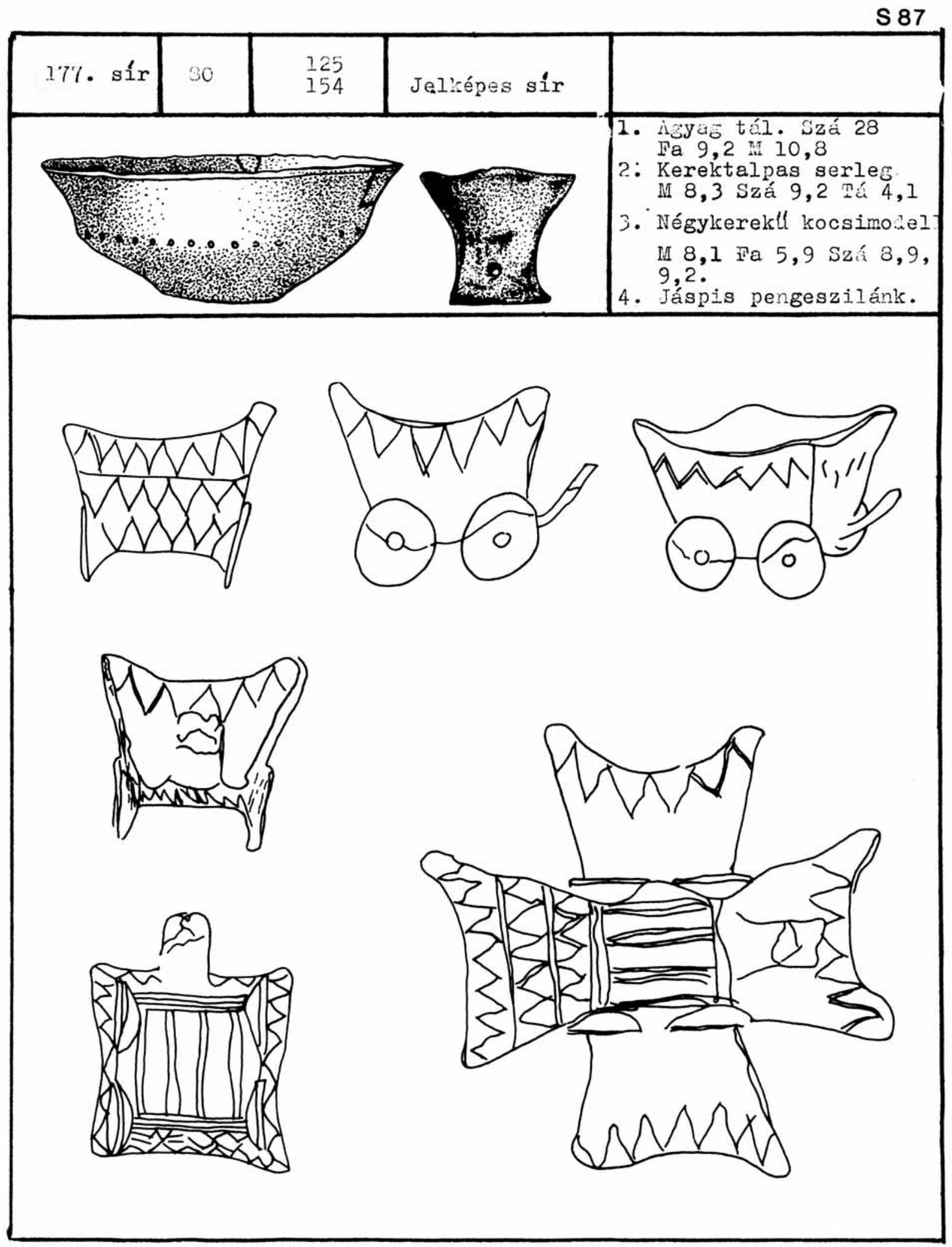

Fig. 6. Grave 177 on fózsef Korek's grave sheet 
1952. $\sqrt{11} .2 . \quad$ nerda.

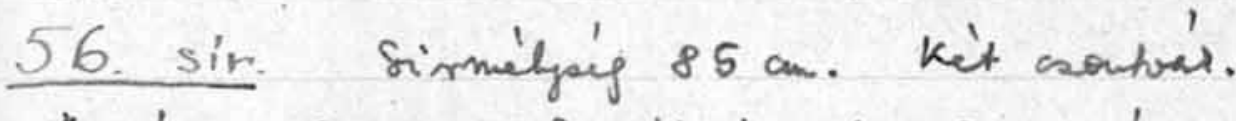

- Av vár felmät mó? Irinjitisa D-K-ÉNy.

hátain fessik, jobthirde a villaig felhirve, falterde ugpanera oldalve a'thajhitor. Fejet a mions mir mybolggattal, edín. tiredilel volter a fij mellet. Rom meytartisú. Ballere a balesipajèn, joht Kere a hastäjion. It sontoir horsa a sintar $85 \mathrm{~cm}$. Letshom $125 \mathrm{~cm}$, nilenép $90 \mathrm{~cm}$

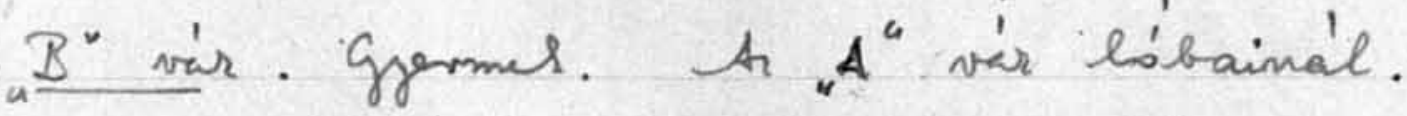
Rom megtartioni, Kogry je is heroskadt. Injitain $N_{y}-k$. hellirlete 5 ggongg. A vis hosm a sirbar ke. $50 \mathrm{~cm}$.

$57 \mathrm{sir} . \quad N_{0}^{\circ}$ ? Jottoldaliosm zougorituc

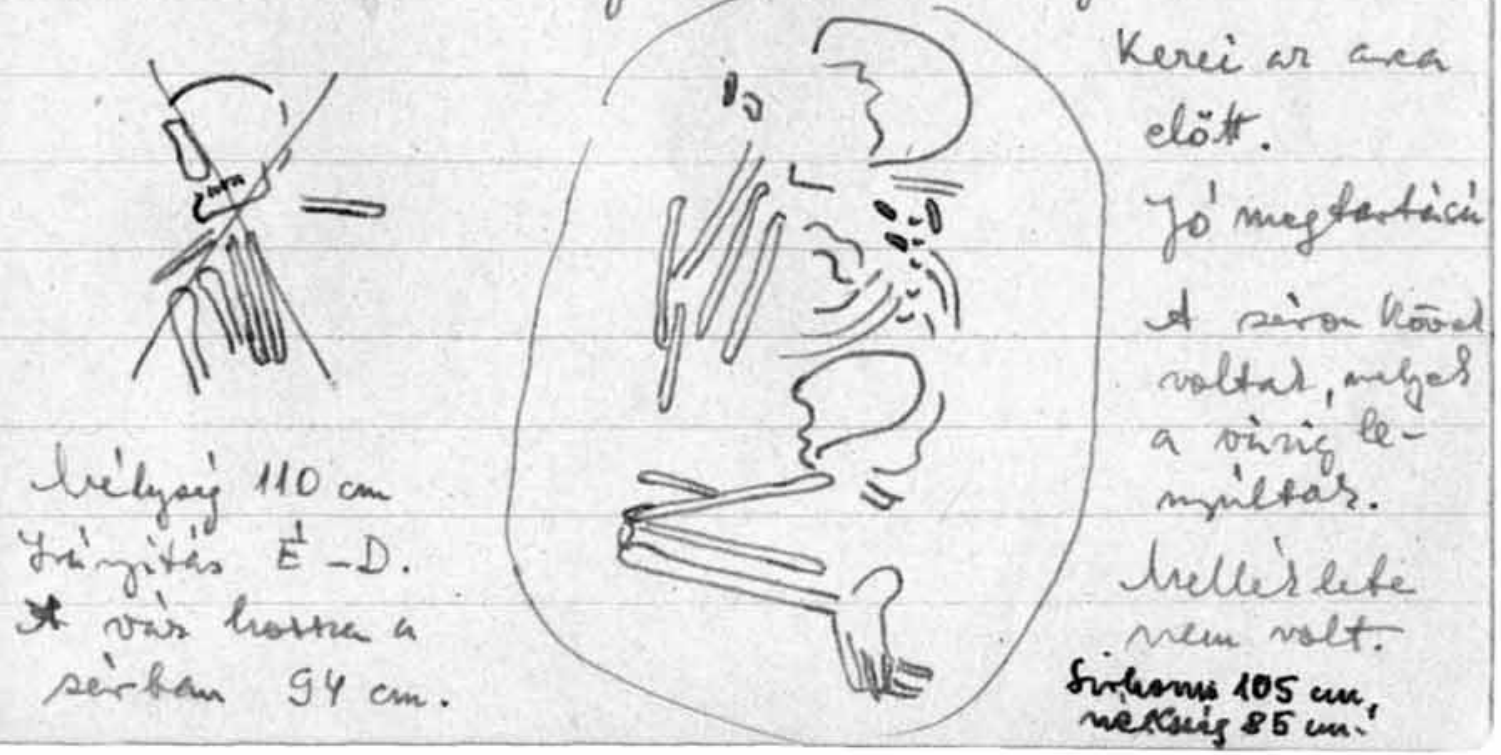

Fig. 7. Description of Graves 56 and 57 in Sándor Soproni's field diary 
has been presented in the Plates. Regrettably, not all the graves were photographed. Only a selection of the grave photos was published in Banner's monograph, suggesting that not all the graves had been photographed during the first excavation season. We know exactly from the documents in the Archives of the Ferenczy Museum which of the graves had been photographed. Unfortunately, even a part of the grave photos filed in the Archives are missing because they were not returned to the museum, and could thus not be included in the present study.

I created a rough typological system while working on the description of the grave pottery. The ceramic finds were made up of a few basic vessel forms (footed goblets, ladles, one-handled cups, dippers, mugs, pitchers, jugs, scooping vessels, pots, amphoras, beakers, bowls and bipartite bowls), with few variations in the main categories. This preliminary typologisation was necessary because I entered each vessel in a database ${ }^{61}$ and needed to employ consistent categories. The statistic analyses of the grave inventories and the secure identification of the finds too called for a consistent terminology. The description of the missing pottery finds was again based on the museum inventory books, whose entries were written by Soproni. A more detailed typological analysis is presented in the chapter on the grave goods.

The lithic artefacts recovered from the burials were analysed by Éva Cs. Balogh in her PhD thesis. Her identification of the raw materials was followed in this volume. ${ }^{62}$ The animal bones were identified and analysed by Erika Gál (Archaeological Institute of the Hungarian Academy of Sciences), aided by László Bartosiewicz (Institute of Archaeological Sciences, Eötvös Loránd University). ${ }^{63}$ The species determination

\footnotetext{
${ }^{61} \mathrm{I}$ assembled a database containing the burials and the grave assemblages. Each entry contains the most important data on a particular burial: grave number, dimensions of the grave pit (depth, length, width), orientation and placement of the deceased, the contracted and total length of the skeleton, condition of the skeletal remains, the primary age/sex data (as recorded in the field diary), the form of the grave pit, any observations made during the excavation and the grave goods. In the case of the latter, I assigned the finds to the one of the main categories (vessel, vessel fragment, bead, shell, bone, copper, miscellaneous finds), which were divided into sub-categories. Vessels were entered according to ceramic types and I made every effort to identify the type in the case of vessel fragments. Jewellery formed a separate category within grave goods: beads (as a general sub-category), shell plaques, shells, snails, neckrings, armrings and copper beads were entered separately. Animal bones, copper artefacts, stone blades and flakes were assigned to the category of miscellaneous finds. A separate field was created for the number of finds (vessels, vessel fragments, beads, shell plaques, shells, copper, miscellaneous finds) for statistical purposes. The missing artefacts complicated the creation of the database; in these cases, I identified the categories from the entries in the inventory books.

I also entered Imre Lengyel's age/sex determinations in a separate field. Lengyel's determinations and the anthropological data in the field diaries often varied. Lengyel prepared an errata list, from which I copied the data. Regrettably, Graves 25-49, 147-169, 196-221 and 407-439 were missing from this list. In these cases, I adopted the descriptions from Korek's grave sheets, assuming that they presented accurate information also regarding the axe/sex of the deceased because they had been intended for publication. However, I did not include the other anthropological information on the grave sheets, such as blood groups, pathological condition, and chemical composition of the skeletal remains or the results of the metallurgical analyses.

62 See pp. $379-408$, in this volume.

${ }^{63}$ See pp. 371-378, in this volume.
}

of the mollusc finds and of the beads was performed by Pál Sümegi (Archaeological Institute, Hungarian Academy of Sciences / Department of Geology and Palaeontology, University of Szeged). His species identification was adopted in the catalogue. ${ }^{64}$ Attila Demény and his colleagues (Institute for Geochemical Research, Hungarian Academy of Sciences) performed the provenancing of the shells and snails using stable isotope analyses, whereby they could determine whether recent or fossil specimens were used by the Budakalász population. ${ }^{65}$

Preliminary research on the human skeletal remains has been briefly described in the above. I felt that the analysis of the skeletal material too should be begun from scratch and I therefore turned to Kitti Köhler (Archaeological Institute, Hungarian Academy of Sciences), requesting her to perform the sexing and age determination of the human remains. The descriptions in the catalogue are based on her work. ${ }^{66}$ Regrettably enough, the Department of Anthropology does not contain the remains from all the burials, ${ }^{67}$ and in the case of missing skeletal material and the cremation graves I used the information contained in the field diaries as the primary source. I could confidently rely on the field diaries because Köhler noted that Soproni's identifications generally agreed with the findings of the anthropological analysis. A list of the preserved skeletal remains (or, conversely, their lack) has been included in the description of the graves in the Catalogue. The age given for the age at death is an estimate. Infant and child remains can rarely be sexed, this being the reason that this is not indicated in the description of infant and child burials. I have also indicated in the tables accompanying the text if the age/sex determination recorded in the field diaries was used by necessity.

Aranka Csősz (Archaeological Institute, Hungarian Academy of Sciences) performed the archaeogenetical evaluation of the anthropological remains. ${ }^{68}$ The primary focus was on determining whether the deceased interred in the double and triple graves were related to each other and whether there was any consanguinity between these graves and the burials in their vicinity. As it turned out, the DNA content of the surviving skeletal remains was insufficient for answering these questions.

The radiocarbon age determination of the burials was co-ordinated by Peter Stadler and performed in the Vienna Environmental Research Accelerator (VERA) in the University of Vienna. When sampling, I concentrated on the richly furnished burials in order to gain secure chronological anchors for the typo-chrono-

\footnotetext{
${ }_{64}$ See pp. 409-436, in this volume.

${ }^{65}$ See pp. 437-448, in this volume.

${ }^{66}$ See pp. 303-364, in this volume.

${ }^{67}$ I am greatly indebted to Ildikó Pap of the Department of Anthropology for allowing the skeletal remains to be transported to the Archaeological Institute for the analyses. I am also grateful to István Matskásy, Director of the Hungarian Natural History Museum, who permitted the archaeogenetical analysis of the multiple burials in the DNA Laboratory of the Archaeological Institute.

${ }^{68}$ See pp. 365-370, in this volume.
} 
logical evaluation of the finds. Unfortunately, the skeletal remains from the graves selected for analysis were not always suitable for sampling and thus the initial sampling strategy was modified on Pál Raczky's suggestion that samples should be collected from each part of the cemetery as far as possible, meaning that sampling was conducted on a "topographical" basis, obviously based on the availability and suitability of the skeletal remains for sampling. The radiocarbon dates thus gained were evaluated by Zsuzsanna Siklósi (Institute of Archaeological Sciences, Eötvös Loránd University), who also performed the seriation and the correspondence analysis of the grave pottery. ${ }^{69}$

A separate chapter is devoted to the historical context of the cemetery, its chronological position, its significance and unique features. ${ }^{70}$ No matter how outstanding the Budakalász cemetery, its finds can hardly solve all the problems surrounding the typology and chronology of the Baden culture because the grave goods recovered from the burials represent but a narrow cross-section of the range of artefacts used by the Baden population. The cemetery was not used over several centuries and thus the finds are unsuitable for identifying typological series reflecting a continuous development. The findings of the archaeological, anthropological and archaeometric analyses have enriched our understanding of how and for how long the cemetery was used by Late Copper Age communities and also provide an answer to why the find material is remarkably homogenous. 

Catalogue of graves 


\section{DESCRIPTION OF THE BURIALS}

\section{Grave 1 (Square J7; Plate I)}

Size of grave pit: L. $125 \mathrm{~cm}, W .100 \mathrm{~cm}$

Depth: $90 \mathrm{~cm}$

Orientation: $\mathrm{W}$ to $\mathrm{E}$, with the head to the west

Position of skeleton: laid on the right side

L. of skeleton (contracted): $95 \mathrm{~cm}$

L. of skeleton (extended): $160 \mathrm{~cm}$

Age at death: $23-30$ years

Sex: male (?)

Condition of skeleton: medium well preserved

Preserved skeletal bones: long bones, pelvic bone, mandible

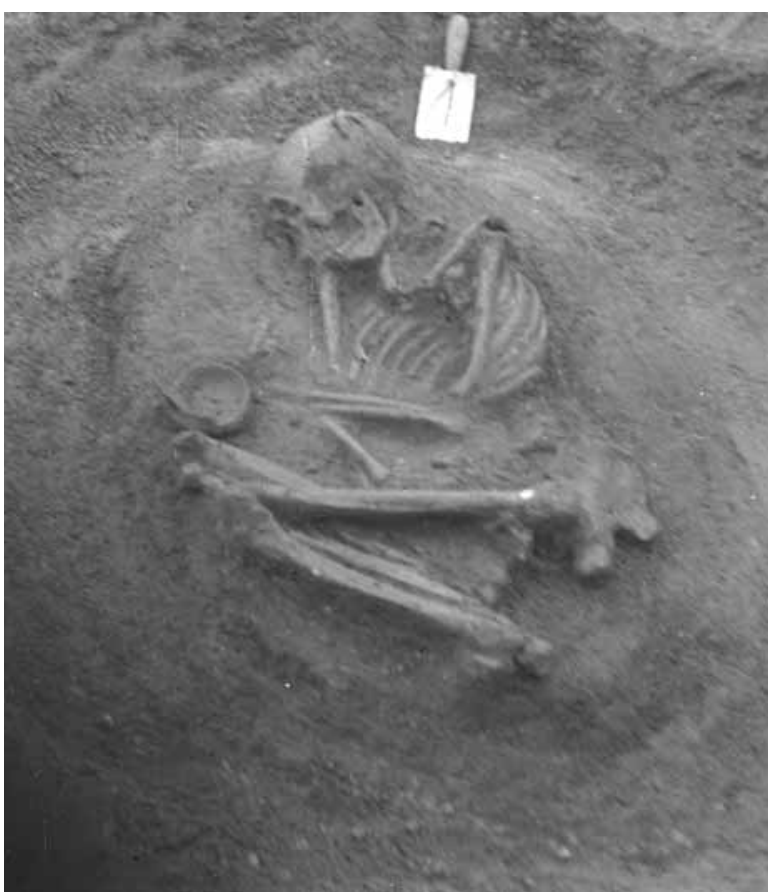

Inhumation burial in an oblong grave pit with rounded corners. The body was laid on the right side in a contracted position with the skull resting on the right temporal bone. The left arm was bent at the elbow, the right one was extended. The thighs were drawn up and the legs were bent back towards the buttocks. The skull had completely disintegrated.

The burial contained the following grave goods: an animal tooth (1) some $4-5 \mathrm{~cm}$ behind the skull; a ladle (2) between the knees and the left arm; another rounded ladle (3) inside the previous vessel.

Grave goods

1. Animal tooth. L. 5 cm. Inv. no. 56.11 .1 .1 (Pl. I. 1/1). ${ }^{1}$

2. Ladle. Reddish-brown, undecorated ladle with two perforations on the handle. The handle is joined. H. $3.2 \mathrm{~cm}$, W. $9.3 \mathrm{~cm}$. Inv. no. 56.11 .1 .2 (Pl. I. 1/2).

3. Ladle. Light brown, undecorated ladle with slightly indrawn rim and rounded base. The handle springing

\footnotetext{
1 According to Erika Gál, the object is not an animal tooth, but a stone.
}

from the rim thickens slightly towards the rim's interior. The handle broke off. $H .3 .6 \mathrm{~cm}$, dM. 10.1 cm. Inv. no. 56.11.1.3 (Pl. I. 1/3).

\section{Grave 2 (Square J7; Plate II)}

Size of grave pit: L. $110 \mathrm{~cm}, W .130 \mathrm{~cm}$

Depth: $95 \mathrm{~cm}$

Orientation: SE to NW, with the head to the SE

Position of skeleton: laid on the left side

L. of skeleton (contracted): $95 \mathrm{~cm}$

L. of skeleton (extended): -

Age at death: 23-30 years

Sex: female

Condition of skeleton: badly preserved

Preserved skeletal bones: skull, long bones

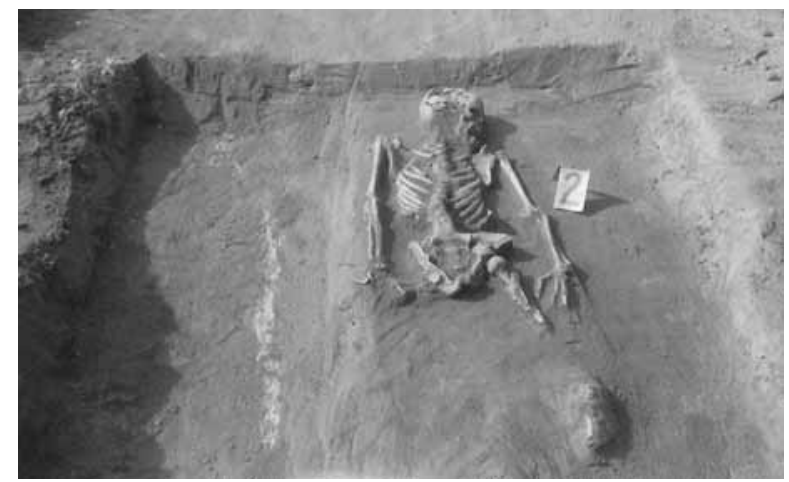

Inhumation burial. The grave was disturbed during earlier earth-moving operations and the fragments of a larger vessel were recovered, which were later collected by Sándor Soproni.

Oblong grave pit containing stones. The body was laid on the left side in a contracted position with the skull resting on the left temporal bone. The right arm was bent and drawn up to the face; the exact position of the left arm could not be established. The thighs were drawn up into a horizontal position, the legs were bent back towards the buttocks.

The burial contained the following grave goods: the broken vessel (1) mentioned above, which had probably been set in front of the face; a dipper (2) between the skull and the right arm; a stone point (3) $c a \cdot 10-15 \mathrm{~cm}$ from the pelvis; a burin (4) and a blade fragment (5) $10-15 \mathrm{~cm}$ away from the pelvis; a necklace of two larger, two smaller and three broken tubular copper beads, nine intact and two broken Dentalium beads, and twenty-three other beads (6) extending from the neck to the pelvis and around the feet (although most beads lay around the pelvis). The copper beads were found inside the Dentalium beads.

\section{Grave goods}

1. Amphora. Although the broken vessel mentioned in the excavation diary was not inventoried among the finds from the burial, it seems likely that the body and handle of a brownish, thick-walled, large amphora listed among the stray finds can be identified with 
the pottery sherds collected by Sándor Soproni. L. 10.2 cm. Inv. no. 56.11 .80 .1 (Pl. II. 2/1).

2. Ladle. Grey ladle decorated with an incised zig-zag pattern under the rim and the inner side of the handle. The handle broke off, the rim is damaged. Joined from its fragments. H. $3 \mathrm{~cm}, \mathrm{~d} M .8 .5 \mathrm{~cm}$. Inv. no. 56.11.2.1 (Pl. II. 2/2).

3. Radiolarite point. Inv. no. 56.11.2.2 (Pl. II. 2/3).

4. Burin made from limnic quartzite. Inv. no. 56.11.2.4 (Pl. II. 2/4).

5. Unretouched blade fragment made from limnic quartzite. Inv. no. 56.11.2.3 (Pl. II. 2/5).

6. Beads. Eleven Dentalium badense beads and twentythree cylindrical limestone beads of varying sizes. Tubular copper beads (two larger, two smaller and three broken pieces) were slipped inside the Dentalium beads. Inv. no. 56.11.2.5 (Pl. II. 2/6).

\section{Grave 3 (Square J8; Pls III-IV)}

Size of grave pit: L. $290-320 \mathrm{~cm}$, W. $125 \mathrm{~cm}$

Depth: $85 \mathrm{~cm}$

Orientation: both burials E-SE to $W-\mathrm{NW}$, with the head to the E-SE

Position of skeleton: A: laid on the left side, B: on the right side L. of skeleton (contracted): A: $75 \mathrm{~cm}, \mathrm{~B}: 100 \mathrm{~cm}$

L. of skeleton (extended): -

Age at death: -

Sex: A: female (?), B: male

Condition of skeleton: both skeletons well preserved

Preserved skeletal bones: ${ }^{2}$ all skeletal remains preserved in situ

Double inhumation burial with a double animal burial. The grave's southern end had been destroyed earlier by earth-moving operations. The grave was undisturbed. According to the excavator, the four burials were contemporaneous.

\section{Burial A}

The body was laid on the left side in a contracted position. The right arm was bent at the elbow and embraced the upper arm of the person interred beside it. The knees rested on the pelvis of Burial B. According to the excavation diary, the extended left hand clasped the left thigh above the knee and the right leg lay on the legs of Burial B. Black tufts, perhaps hair (?), were noted on the skull of Skeleton A.

The burial contained the following grave goods: a red painted, rectangular goblet (1) tilted to one side, $5 \mathrm{~cm}$ west of the pelvis; a stone blade (2) and two flakes (3-4) around the vessel.

\section{Burial B}

The body was laid parallel to Burial A, slightly to its left, in a slightly contracted position on the right side. The head was tilted to the left. The right arm was bent

\footnotetext{
2 The skeletal remains can no longer be found. The anthropological data are quoted from the excavation diary.
}

at the elbow and clasped the left upper arm. The left arm was bent at the elbow and the left hand was drawn up to the chin. The legs were also drawn up.

The burial contained the following grave goods: a copper awl (5) $15 \mathrm{~cm}$ south-east of the knees. ${ }^{3}$

\section{Burial C}

The burial contained the extended skeleton of a young, $8-10$ months old calf, laid $85 \mathrm{~cm}$ south of the left knee of Skeleton B. It was oriented south to north, with the head toward the south. The head and part of the forelegs were destroyed by earth-moving operations. The skeleton was medium well preserved.

\section{Burial D}

A cattle burial deposited parallel to Burial C, directly to its east. The body was extended and oriented south to north, with the head toward the south. The head and part of the forelegs were destroyed by earth-moving operations. The skeleton was medium well preserved.

Grave goods

1. Goblet. Reddish-brown goblet with rectangular upper part set on a triangular foot. The four corners are peaked. The upper part and the foot are decorated with an incised zig-zag pattern. Only small patches remain of the red painting originally covering the entire vessel body. The base has a small perforation. The rim is damaged in some spots. $H .11 \mathrm{~cm}$, dM. 8.3-9 cm, dB. 5.1-6 cm. Inv. no. 56.11.3.1 (Pl. III. 3/1).

2. Unretouched radiolarite blade. Inv. no. 56.11.3.2 (Pl. IV. 3/2).

3. Unretouched radiolarite flake. Inv. no. 56.11.3.3 (Pl. IV. 3/3).

4. Hornstone flake. Inv. no. 56.11.3.4 (Pl. IV. 3/4).4

5. Copper awl with rectangular section. The part fitted to the shaft is round sectioned. L. $6.7 \mathrm{~cm}, T h .0 .44 \mathrm{~cm}$. Inv. no. 56.11.3.5 (Pl. IV. 3/5). ${ }^{5}$

After clearing the burials, the grave was lifted in situ and taken to the Szentendre museum (Fig. 9). According to the museum's acquisitions register, the following vessels were found under Burial A in 1972, when the in situ burials were dismantled:

6. Scooping vessel. Yellowish-red, grey mottled, thinwalled, worn, undecorated semi-spherical scooping vessel. The strap handle rising above the rim spans the rim and the belly. Worn patches of red painting

\footnotetext{
3 According to the excavation diary, the copper awl lay $8 \mathrm{~cm}$ higher than the skeletons.

4 The object has since been lost or mislaid. Its description is quoted from the acquisitions register. The photo is after BANNER 1956, Pl. LXXXIX. 10-13.

5 The object has since been lost or mislaid. Its description is quoted from the acquisitions register. The photo is based on the metallurgical report in the Szentendre museum (SzFM Archives, inv. no. 1170/76, report prepared by Dr. Manfred Schröder). The drawing is based on József Korek's grave sheet.
} 

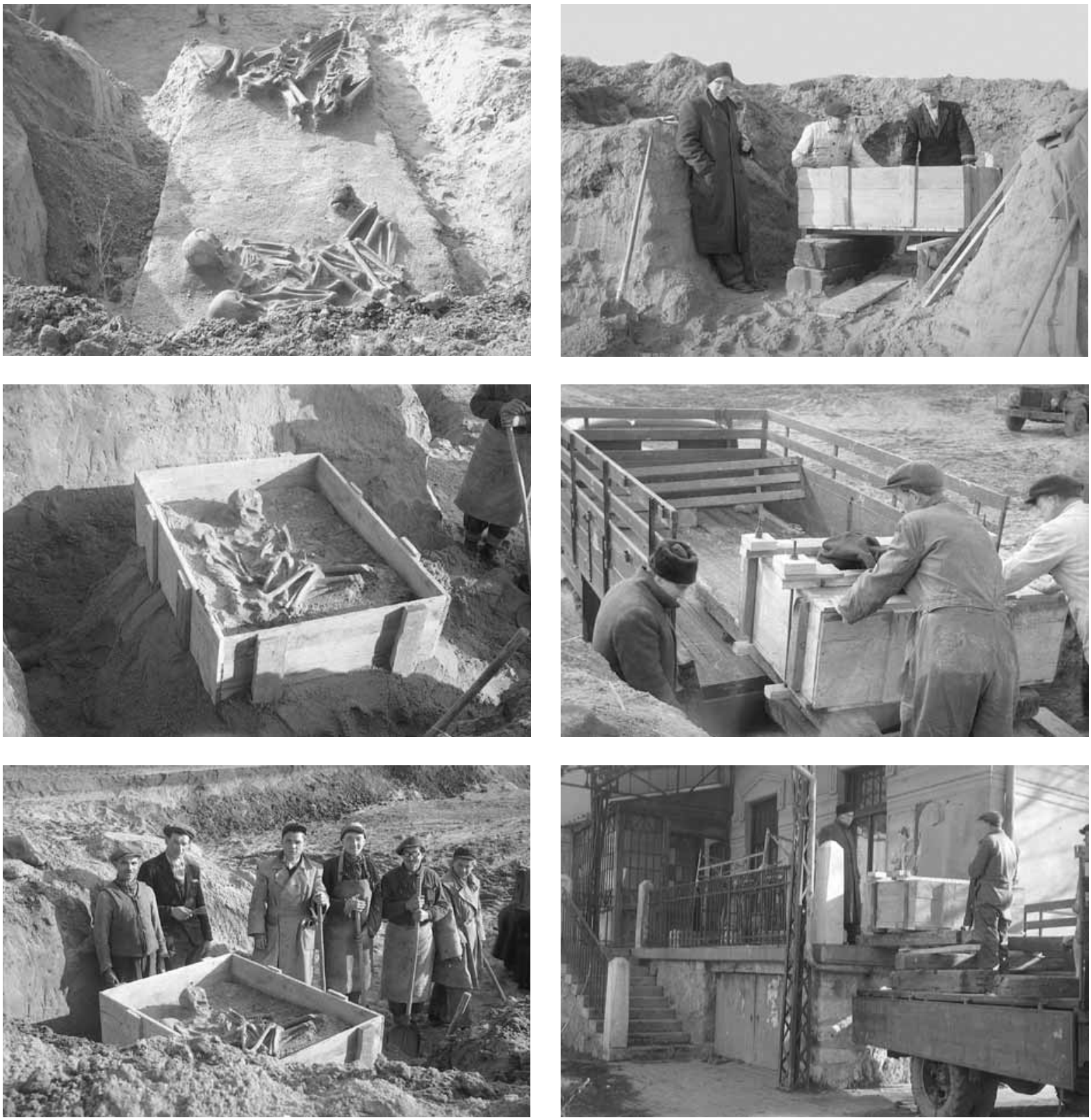

Fig. 9. In situ lifting of Grave 3

can be made out on the vessel body, The vessel is practically intact except for the chipped rim. H. $4.5 \mathrm{~cm}, \mathrm{dM} .11 \mathrm{~cm}, \mathrm{~dB} .8 .5 \mathrm{~cm}$. Inv. no. 72.3 .1 (Pl. IV. 3/6).

7. Goblet. Yellowish-red, grey mottled, worn, undecorated goblet with globular upper part, U shaped stem and oblong base, originally covered with red painting. Assembled from its fragments. H. $10.5 \mathrm{~cm}$, dM. $8.9 \mathrm{~cm}$, dB. $7.1 \mathrm{~cm}$. Inv. no. 72.3 .2 (Pl. IV. 3/7).

Grave 4 (Square J8; Pl. I)

Size of grave pit: L. $105 \mathrm{~cm}, W .90 \mathrm{~cm}$ Depth: $55 \mathrm{~cm}$
Orientation: SE to NW, with the head to the SE

Position of skeleton: laid on the left side

L. of skeleton (contracted): $65 \mathrm{~cm}$

L. of skeleton (extended): -

Age at death: 6-8 years

Sex: child

Condition of skeleton: badly preserved

Preserved skeletal bones: long bones

Inhumation burial in an oblong grave pit with rounded corners containing larger stones. The body was laid on the left side in a contracted position. The arms were bent at the elbows and the hands drawn to the chin.

The burial did not contain any grave goods. 


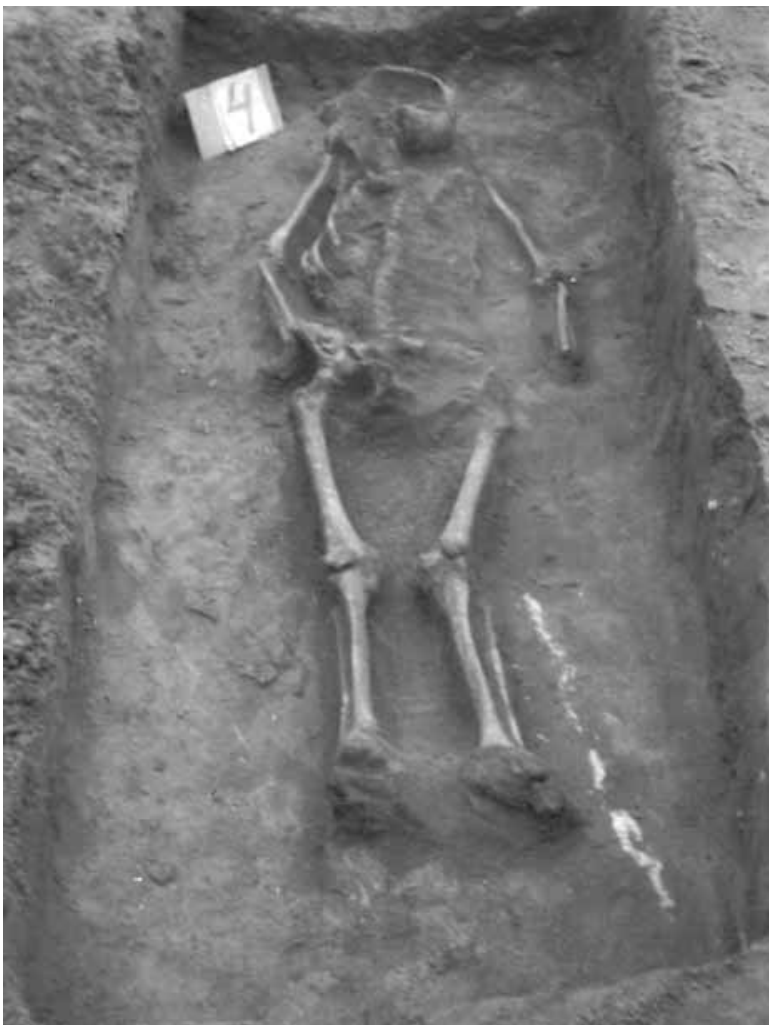

Grave 5 (Square J6; Pl. I)

Size of grave pit: L. $100 \mathrm{~cm}, W .50 \mathrm{~cm}$

Depth: $100 \mathrm{~cm}$

Orientation: $\mathrm{S}$ to $\mathrm{N}$, with the head toward the $\mathrm{S}$

Position of skeleton: laid on the right side

L. of skeleton (contracted): $100 \mathrm{~cm}$

L. of skeleton (extended): $155 \mathrm{~cm}$

Age at death: $40-59$ years

Sex: female

Condition of skeleton: medium well preserved

Preserved skeletal bones: long bones

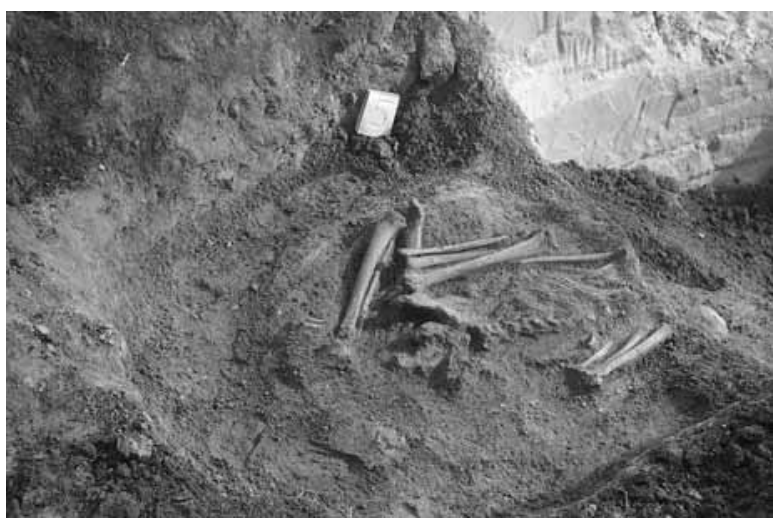

Inhumation burial in a narrow, oblong grave pit with rounded corners. The grave pit contained stones between $-35 \mathrm{~cm}$ and $-70 \mathrm{~cm}$. The skull was partially destroyed during earth-moving operations. The body was laid on the right side in a contracted position. The right and left arms were bent at the elbow and drawn up to the chin. The left thigh was drawn up in front of the body, similarly to the right one.

The burial did not contain any grave goods.

Grave 6 (Square J5; Pl. I)

Size of grave pit: L. $120 \mathrm{~cm} \mathrm{W.} 65 \mathrm{~cm}$

Depth: $55 \mathrm{~cm}$

Orientation: $\mathrm{S}$ to $\mathrm{N}$, with the head toward the $\mathrm{S}$

Position of skeleton: laid on the right side

L. of skeleton (contracted): $85 \mathrm{~cm}$

L. of skeleton (extended): $150 \mathrm{~cm}$

Age at death: $23-\mathrm{x}$ years

Sex: female (?)

Condition of skeleton: badly preserved

Preserved skeletal bones: long bones, skull fragments

Inhumation burial in a narrow, oblong grave pit with rounded corners, containing many stones. The body was laid on the right side in a contracted position. The left arm was bent at the elbow and the hand drawn up to the chin. The left arm was extended beside the body. The thighs were drawn up, the legs were bent back toward the buttocks.

The burial contained the following grave goods: an indistinct pottery sherd (1) lay on the right arm. ${ }^{6}$

\section{Grave 7 (Square J6; Pl. IV)}

Size of grave pit: L. $105 \mathrm{~cm}, W .60 \mathrm{~cm}$

Depth: $70 \mathrm{~cm}$

Orientation: $\mathrm{S}$ to $\mathrm{N}$, with the face toward the $\mathrm{W}$

Position of skeleton: laid on the right side

L. of skeleton (contracted): $70 \mathrm{~cm}$

L. of skeleton (extended): -

Age at death: $13-15$ years

Sex: child

Condition of skeleton: medium well preserved

Preserved skeletal bones: skull, long bones, pelvic bone

Inhumation burial in an oblong grave pit with rounded corners. The body was laid on the right side in a contracted position. The left arm was bent at the elbow and drawn to the chin. The right arm was slightly bent at the elbow and laid toward the pelvis. The thighs were drawn up (the legs were destroyed by earthmoving operations).

The burial contained the following grave goods: a broken pitcher (1) and a broken bowl (2) behind the body.

Grave goods

1. Pitcher. Rim and neck sherd of a greyish-black, undecorated pitcher with cylindrical neck. H. $8.3 \mathrm{~cm}$, dM. $10.1 \mathrm{~cm}$. Inv. no. 56.11.4.2 (Pl. IV. 7/1).

2. Bowl fragment. Body sherd of a greyish-brown, worn, conical bowl with funnel neck and everted

${ }_{6}$ The vessel fragment was not inventoried. None of the pottery sherds among the stray finds inventoried in 1956 can be securely associated with the burial. 
rim, decorated with two parallel rows of punctates, interrupted by the stub of a broken string-hole lug (?). Joined from its fragments. H. $7 \mathrm{~cm}, \mathrm{dM} .10 \mathrm{~cm}$. Inv. no. 56.11.4.1 (Pl. IV. 7/2).

\section{Grave 8 (Square J6; $P l . V$ )}

Size of grave pit: L. $165 \mathrm{~cm}, W .140 \mathrm{~cm}$

Depth: $85 \mathrm{~cm}$

Orientation: W-SW to E-NE, with the head toward the W-SW

Position of skeleton: laid on the right side

L. of skeleton (contracted): $100 \mathrm{~cm}$

L. of skeleton (extended): $165 \mathrm{~cm}$

Age at death: $40-59$ years

Sex: male

Condition of skeleton: well preserved

Preserved skeletal bones: complete skeleton

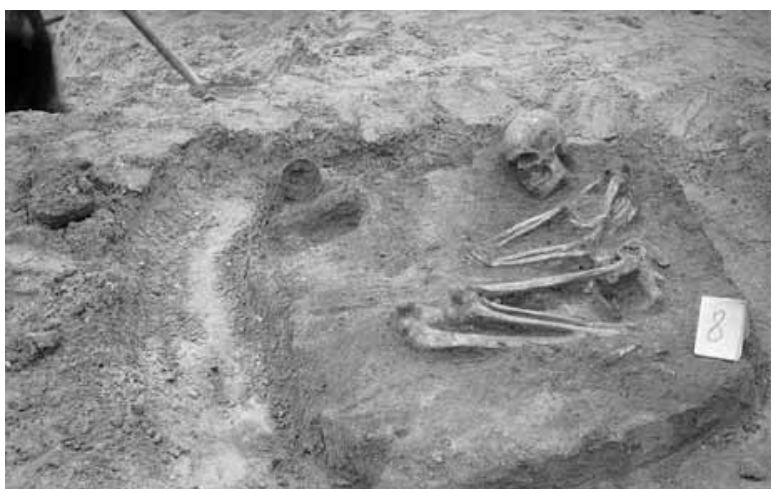

Inhumation burial in an oblong grave pit with rounded corners. The body was laid on the right side in a contracted position. The skull lay tilted to the right. The right and left arms were bent at the elbow, with the right hand holding the left upper arm. The thighs were drawn up, the legs were bent back toward the buttocks.

The burial contained the following grave goods: two necklaces (1-2), the longer one extending to the right forearm (the shells were strung in pairs at this section; ten larger tubular copper beads, twenty fragmentary copper beads, seventy Dentalium beads, four white and seven red beads, eight white beads, eight other beads and seven shells); various stone implements (3-7) $5 \mathrm{~cm}$ east of the pelvis; a round goblet (8) tilted to one side, $50 \mathrm{~cm}$ south of the skull.

Grave goods

1. Beads. Sixty-eight Dentalium badense beads, twentyone limestone beads (Pl. $V .8 / 1 a)$, seven Anadara diluvii shells $(P l . V .8 / 1 b)$, twenty smaller and ten larger copper beads (Pl. V. 8/1c). Inv. no. 56.11.5.1.7

2. Necklace. ${ }^{8}$

3. Unretouched radiolarite blade fragment. Inv. no. 56.11.5.2 (Pl. V. 8/3).

\footnotetext{
7 According to the report on the 1980 revision of the finds, only the copper beads could still to be found. Currently, there are no separate copper beads. Two beads have copper beads inside them. When photographing the finds, we found one white bead, four red beads, seven shells and eighty-four other beads, less than the number mentioned in the excavation diary.
}

4. Unretouched radiolarite flake. Inv. no. 56.11.5.3 (Pl. V. 8/4).

5. Chert trapeze. Inv. no. 56.11.5.4 (Pl. V. 8/5).

6. Chert trapeze. Inv. no. 56.11.5.5 (Pl. $\mathrm{V} .8 / 6)$.

7. Limnic quartzite debitage. Inv. no. 56.11.5.6 (Pl. V. 8/7).

8. Goblet. Two non-joining body fragments of a light brown goblet with rounded cup part and oblong stem. The upper part is plain, the stem is decorated with an incised zig-zag pattern. The upper part and the stem are both joined from their fragments; the base is missing. dM. $10.5 \mathrm{~cm}$. Inv. no. 56.11.5.7 (Pl. V. 8/8).

Grave 9 (Square J6; Pl. VI)

Size of grave pit: L. $105 \mathrm{~cm}, W .60 \mathrm{~cm}$

Depth: $150 \mathrm{~cm}$

Orientation: SE to NW, with the head toward the SE

Position of skeleton: laid on the right side

L. of skeleton (contracted): $100 \mathrm{~cm}$

L. of skeleton (extended): $155 \mathrm{~cm}$

Age at death: $35-45$ years

Sex: male

Condition of skeleton: medium well preserved

Preserved skeletal bones: complete skeleton

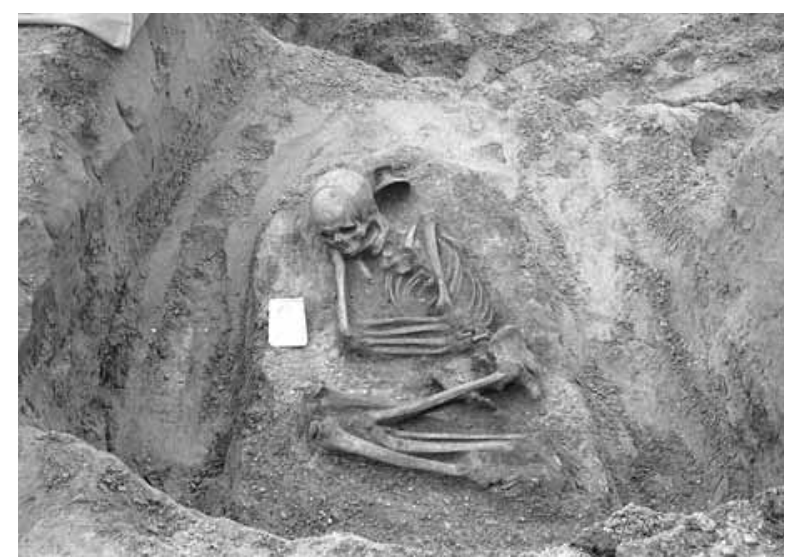

Inhumation burial in an oblong grave pit with rounded corners. The body was laid on the right side in a contracted position. The right and left arms were bent and laid in the lap. The thighs were drawn up into a horizontal position, the legs were bent back toward the buttocks. The left foot lay directly at the edge of the grave pit.

The burial contained the following grave goods: a round goblet (1) tilted to one side to the right of the skull.

Grave goods

1. Goblet. Light brown goblet with rounded cup and round base. The stem has a large round perforation. Originally covered with red painting, of which

8 One single string of beads was inventoried. The stray finds inventoried the same year include another string of beads, which perhaps came from this burial (inv. no. 56.11.74.1, Pl. CLXVI. 4). 
small patches remain. Joined from its fragments. H. $11 \mathrm{~cm}, \mathrm{dM} .11 .1 \mathrm{~cm}, \mathrm{~dB} .6 .1 \mathrm{~cm}$. Inv. no. 56.11 .6 .1 (Pl. VI. 9/1).

\section{Grave 10 (Square J6; $P l . V I)$}

Size of grave pit: L. $105 \mathrm{~cm}, W .55 \mathrm{~cm}$

Depth: $100 \mathrm{~cm}$

Orientation: $\mathrm{S}$ to $\mathrm{N}$, with the head toward the $\mathrm{S}$

Position of skeleton: laid on the right side

L. of skeleton (contracted): $70 \mathrm{~cm}$

L. of skeleton (extended): $110 \mathrm{~cm}$

Age at death: $7-8$ years

Sex: child

Condition of skeleton: medium well preserved

Preserved skeletal bones: skull

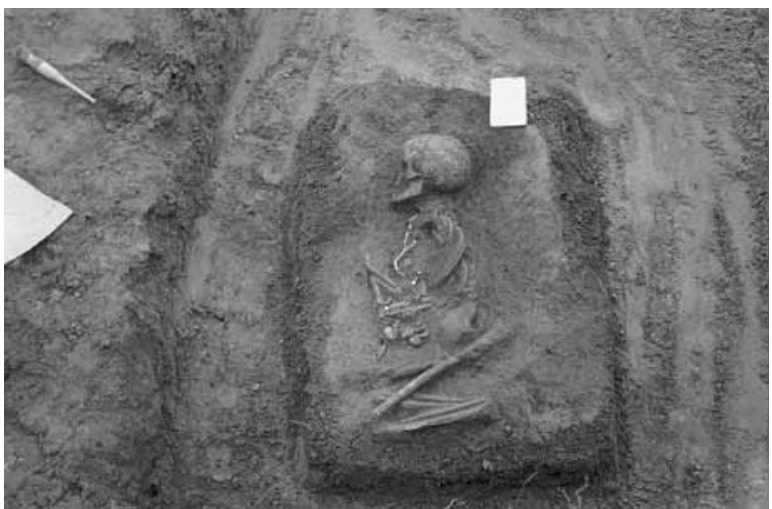

Inhumation burial in an oval grave pit. The body was laid on the right side in a contracted position. The arms were laid across the chest.

The burial contained the following grave goods: a necklace strung of shells and beads (1) around the neck, twisted twice, and extending almost to the pelvis. The shells were strung in pairs on the necklace's lower part. The necklace was strung from eighty-two beads (one broken) and nine shells. Although a few beads were displaced, the overall position of the necklace could be made out.

Grave goods

1. Beads. One Dentalium badense bead, seventy-four cylindrical limestone beads of varying sizes $(P l$. VI. 10/1a) and seven Anadara diluvii shells (Pl. VI. 10/1b). L. of beads $0.6-2.5 \mathrm{~cm}$. Inv. no. 56.11.7.1.9

\section{Grave 11 (Square J6; Pl. VI)}

Size of grave pit: L. $110 \mathrm{~cm}, W .85 \mathrm{~cm}$

Depth: $95 \mathrm{~cm}$

Orientation: E-NE to W-SW, with the head toward the E-NE Position of skeleton: laid on the right side

L. of skeleton (contracted): $80 \mathrm{~cm}$

\footnotetext{
9 The excavation diary lists eighty-two beads and nine shells, of which seventy-six beads and seven shells are entered into the acquisitions register. At present there are seventy-five beads in all.
}

L. of skeleton (extended): $155 \mathrm{~cm}$

Age at death: $40-50$ years

Sex: female

Condition of skeleton: medium well preserved

Preserved skeletal bones: skull, long bones

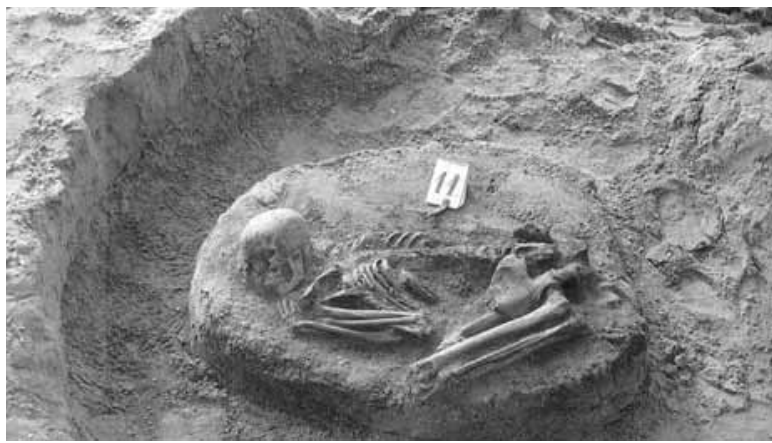

Inhumation burial in an oval grave pit. The body was laid on the right side in a strongly contracted position. The right and left arm were bent at the elbow and drawn up to the chin. The thighs were similarly drawn up in front of the body and the legs bent back toward the buttocks. The right pelvic bone had shifted from its original position owing to the strongly contracted deposition.

The burial did not contain any grave goods.

Grave 12 (Square J6; Pl. VII)

Size of grave pit: L. $105 \mathrm{~cm}, W .100 \mathrm{~cm}$

Depth: $90 \mathrm{~cm}$

Orientation: $\mathrm{E}$ to $\mathrm{W}$, with the head toward the $\mathrm{W}$

Position of skeleton: laid on the right side

L. of skeleton (contracted): $75 \mathrm{~cm}$

L. of skeleton (extended): $145 \mathrm{~cm}$

Age at death: 25-30 years

Sex: female (?)

Condition of skeleton: badly preserved

Preserved skeletal bones: ${ }^{10}$ mandible, long bones and pelvic bone fragment

Inhumation burial in an oval grave pit. The body was laid on the right side in a contracted position. The right and left arm were bent at the elbow and drawn up to the face. The thighs were drawn up in front of the body, the legs were bent back toward the buttocks.

The burial contained the following grave goods: a one-handled pot (1) tilted to one side by the hands (broken during the earth-moving operations); a necklace of seven beads, eight perforated shells and a shell plaque (2) by the left forearm; ${ }^{11}$ a small red stone (3) between the elbows and the thighs.

Grave goods

1. One-handled pot. Brownish-grey pot with slightly everted rim and rounded belly. The handle spans the

\footnotetext{
10 The skeletal remains can no longer be found. The anthropological data are quoted from the excavation diary.
}

11 According to the excavation diary, the shells were strung in pairs. 
rim and the shoulder. The vessel is decorated with two parallel rows of punctates around the belly. Joined from its fragments and restored. $H .11 \mathrm{~cm}, \mathrm{dM} .11 .1 \mathrm{~cm}$, dB. 6.1 cm. Inv. no. 56.11.8.1 (Pl. VII. 12/1).

2. Beads. Eight Anadara diluvii shells, one oblong Unio crassus mussel plaque perforated at both ends $(\mathrm{Pl}$. VII. $12 / 2 b$ ) and seven cylindrical limestone beads of varying sizes (Pl. VII. 12/2a). L. of beads $0.3-1.2 \mathrm{~cm}$. Inv. no. 56.11.8.2.

3. Red stone. ${ }^{12}$

\section{Grave 13 (Square J6; Pl. VIII)}

Size of grave pit: L. $90 \mathrm{~cm}, W .55 \mathrm{~cm}$

Depth: $95 \mathrm{~cm}$

Orientation: both S-SE to N-NW, with the head toward the S-SE Position of skeleton: A: laid on the left side, B: laid on the right side

L. of skeleton (contracted): A: $65 \mathrm{~cm}, \mathrm{~B}: 30-40 \mathrm{~cm}$

L. of skeleton (extended): A: $110 \mathrm{~cm}, \mathrm{~B}:-$

Age at death: A: $10-12$ years, B: infans I

Sex: A: child, B: child

Condition of skeleton: both badly preserved

Preserved skeletal bones: ${ }^{13}$ A: skull, long bones, B:-

Double inhumation burial in an oblong grave pit with rounded corners. The grave pit contained stones and the fragments of two broken vessels: a bowl (1) and a one-handled jug (2).

\section{Burial A}

The body was laid on the left side in a contracted position. The arms were bent at the elbow and drawn up to the face. The thighs were drawn up to a horizontal position, the legs were bent back toward the buttocks.

The burial contained the following grave goods: eighty-four beads (3) around the waist and the pelvis; thirteen oblong shell plaques (4) around the neck.

\section{Burial B}

The body was laid on the right side in a contracted position across the knees and legs of Skeleton A. The exact position of the legs could not be observed.

The burial did not contain any grave goods.

\section{Grave goods}

1. Bowl. Fragment of a greyish-brown conical bowl with cylindrical neck. The neck is smoothed, the belly is coarsened. It is decorated with a row of impressed dots around the belly. Joined from its fragments. H. $6.8 \mathrm{~cm}, \mathrm{dM} .13 \mathrm{~cm}$. Inv. no. 56.11.9.1 (Pl. VIII. 13/1).

2. Jug. Body and base fragments of a worn jug with cylindrical neck and conical body, decorated with horizontal smoothed-in lines around the neck and

\footnotetext{
12 The stone was not inventoried.

13 The skeletal remains of Burial B can no longer be found in the Anthropological Collection. The anthropological data are quoted from the excavation diary.
}

vertical smoothed-in lines on the belly, interrupted by a barely prominent rib with oblique fluting. Joined from its fragments. L. $8.5 \mathrm{~cm}$. Inv. no. 56.11.9.2 (Pl. VIII. 13/2).

3. Beads. Three Dentalium badense beads and eightyone limestone beads of varying sizes. L. of beads 0.6-1.8 cm. Inv. no. 56.11 .9 .3 (Pl. VIII. 13/3).

4. Shell plaques. Oblong Unio crassus mussel plaques with a perforation in each corner. Fourteen pieces, some intact and some broken, of varying sizes. $0.9 \mathrm{~cm} \times 1-1.6 \mathrm{~cm} \times 1 \mathrm{~cm}$. Inv. no. 56.11.9.4 (Pl. VIII. 13/4). ${ }^{14}$

Grave 14 (Square J8; Pl. VII)

Size of grave pit: L. $140 \mathrm{~cm}$, W. $90 \mathrm{~cm}$

Depth: $25 \mathrm{~cm}$

Orientation: S-SW to N-NE, with the head toward the S-SW

Position of skeleton: laid on the left side

L. of skeleton (contracted): $110 \mathrm{~cm}$

L. of skeleton (extended): $150 \mathrm{~cm}$

Age at death: 23-39 years

Sex: male (?)

Condition of skeleton: medium well preserved

Preserved skeletal bones: skull, long bones

Inhumation burial in an oblong grave pit with rounded corners. The body was laid on the left side in a contracted position. The arms were bent at the elbow and drawn up to the face. The left thigh was strongly drawn up, the right one less strongly. The legs were bent back toward the buttocks. The bones were fragmented owing to the frozen soil.

The burial contained the following finds: an indistinct pottery sherd (1) by the right shoulder. ${ }^{15}$

\section{Grave 15 (Square J8; Pl. VII)}

Size of grave pit: surviving L. $50 \mathrm{~cm}, W .65 \mathrm{~cm}$ Depth: $50 \mathrm{~cm}$

Orientation: roughly SE to NW, with the head toward the SE

Position of skeleton: laid on the left side

L. of skeleton (contracted): -

L. of skeleton (extended): -

Age at death: $30-35$ years

Sex: female (?)

Condition of skeleton: well preserved

Preserved skeletal bones: skull fragments, long bones

Inhumation burial in an oval grave pit. A trench dug during the world war destroyed the upper part of the burial between the pelvis and the skull. The body was laid on the left side in a contracted position. The thighs were slightly drawn up, the legs were bent back toward the buttocks.

\footnotetext{
14 The excavation diary lists thirteen shell plaques. We found fourteen plaques, corresponding to the number in the acquisitions register, when photographing the finds.

15 The vessel fragment was not inventoried among the finds from the burial. None of the pottery sherds among the stray finds can be securely associated with this burial.
} 
The burial did not contain any grave goods in the surviving part.

\section{Grave 16 (Square K9; Pl. IX)}

Size of grave pit: L. $130 \mathrm{~cm}, W .90 \mathrm{~cm}$

Depth: $25-30 \mathrm{~cm}$

Orientation: SW to NE, with the head toward the SW

Position of skeleton: laid on the left side

L. of skeleton (contracted): $80 \mathrm{~cm}$

L. of skeleton (extended): $160 \mathrm{~cm}$

Age at death: $40-59$ years

Sex: female

Condition of skeleton: medium well preserved

Preserved skeletal bones: skull, long bones

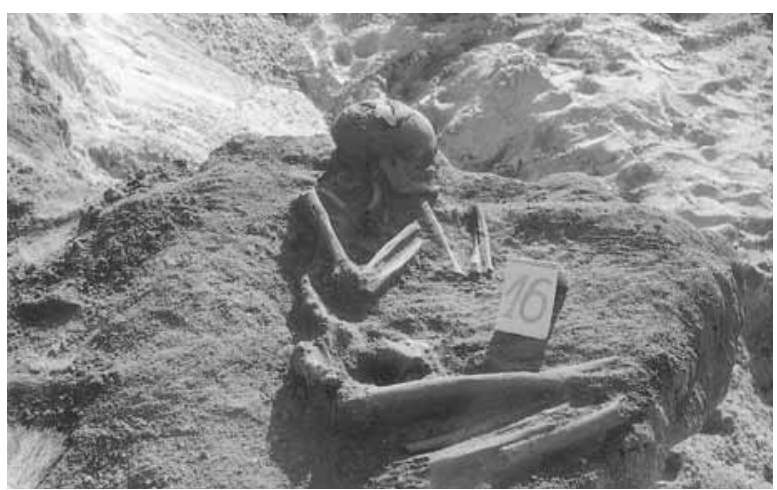

Inhumation burial in an oval grave pit. The body was laid on the left side in a contracted position. The skull was damaged. The arms were bent at the elbow, the hands were drawn up to the face. The thighs were drawn up in a horizontal position, the legs were bent back to the buttocks.

The burial contained the following grave goods: one fragmentary and two intact Dentalium beads (1) around the neck.

\section{Grave goods}

1. Beads. One fragmentary and two intact Dentalium badense beads. Inv. no. 56.11.10.1 (Pl. IX. 16/1).

Grave 17 (Square J6/J7; Pl. IX)

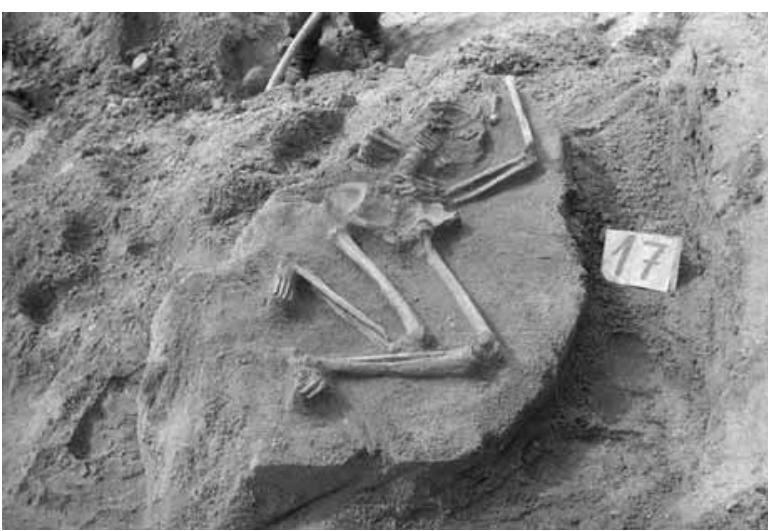

Size of grave pit: L. $110 \mathrm{~cm}, W .80 \mathrm{~cm}$

Depth: $85 \mathrm{~cm}$

Orientation: $\mathrm{E}$ to $\mathrm{W}$, with the head toward the $\mathrm{W}$

Position of skeleton: laid on the left side (?)

L. of skeleton (contracted): $85 \mathrm{~cm}$

L. of skeleton (extended): -

Age at death: $20-30$ years

Sex: female

Condition of skeleton: well preserved

Preserved skeletal bones: skull fragments, long bones

Inhumation burial in an oval grave pit. The skull was displaced and broken during earth-moving operations. The body was laid on the back, the legs were drawn slightly to the left.

The burial did not contain any grave goods.

\section{Grave 18 (Square J8/J9; Pl. IX)}

Size of grave pit: L. $140 \mathrm{~cm}, W .90 \mathrm{~cm}$

Depth: $30 \mathrm{~cm}$

Orientation: S-SW to N-NE, with the head toward the S-SE

Position of skeleton: laid on the right side

L. of skeleton (contracted): $105 \mathrm{~cm}$

L. of skeleton (extended): $165 \mathrm{~cm}$

Age at death: $23-39$ years

Sex: male (?)

Condition of skeleton: badly preserved

Preserved skeletal bones: skull, long bones

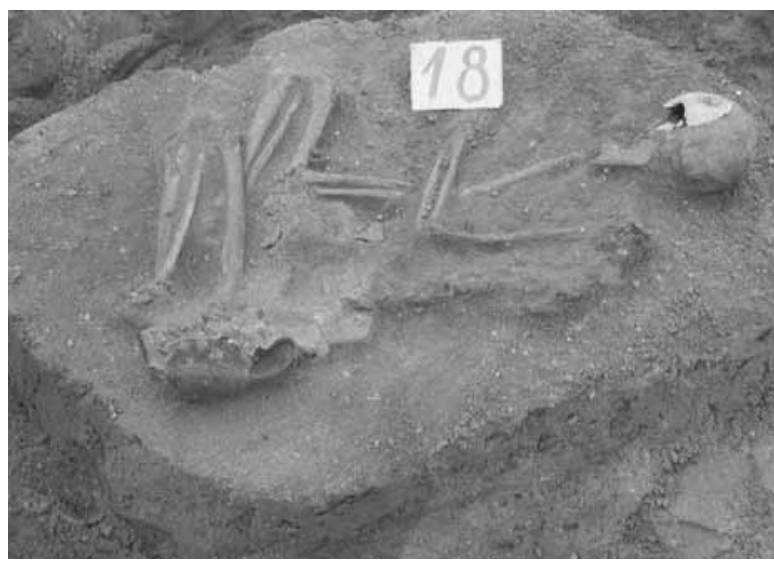

Inhumation burial in an oblong grave pit with rounded corners. The body was laid on the right side in a contracted position. The right arm lay extended beside the body, the left arm was bent at the elbow. The right thigh was drawn up more strongly than the left one. The legs were bent back toward the buttocks.

The burial contained the following grave goods: a scooping vessel (1) tilted to one side behind the pelvis, with its mouth toward the buttocks, and a pot (2) inside it.

\section{Grave goods}

1. Scooping vessel. Greyish-brown scooping vessel with rounded base and a strap handle rising above the everted rim, decorated with a row of impressed dots around the belly. Joined from its fragments and 
restored. H. 6 cm, dM. 14 cm. Inv. no. 56.11.11.1 (Pl. IX. 18/1).16

2. One-handled pot. Brownish-grey, one-handled pot with slightly everted rim. The handle spans the rim and the shoulder; the rim is peaked on either side of the handle. The vessel is decorated with a row of punctates encircling the shoulder and a vertical row of punctates flanking the handle. Joined from its fragments; the handle is broken and restored. H. $10.2 \mathrm{~cm}$, dM. $10.2 \mathrm{~cm}$, dB. $5.7 \mathrm{~cm}$. Inv. no. 56.11.11.2 (Pl. IX. 18/2).

\section{Grave 19 (Square J8; $P l s X-X I$ )}

Size of grave pit: L. $130 \mathrm{~cm}, W .90 \mathrm{~cm}$ Depth: $100 \mathrm{~cm}$

Orientation: S-SE to N-NW, with the head toward the S-SE Position of skeleton: laid on the right side

L. of skeleton (contracted): $80 \mathrm{~cm}$

L. of skeleton (extended): $158 \mathrm{~cm}$

Age at death: $23-59$ years

Sex: male

Condition of skeleton: medium well preserved

Preserved skeletal bones: skull, long bones

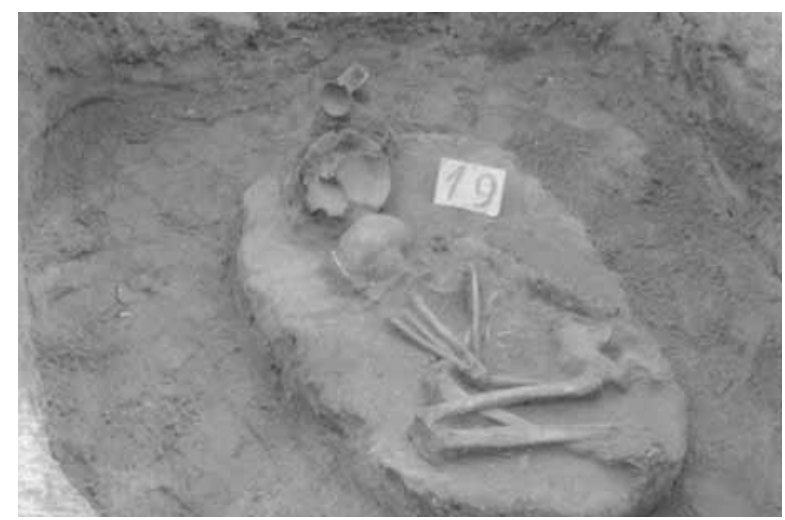

Inhumation burial in a narrow, oval grave pit. The body was laid on the right side in a contracted position. The right arm was bent at the elbow and drawn up in front of the face. The left arm was bent with the hand resting on the shoulder. The thighs were similarly drawn up, the legs were bent back toward the buttocks.

The burial contained the following grave goods: eleven beads (1) on the forehead; a one-handled cup (2), a rectangular goblet (3) and a rounded goblet (4) behind the skull.

\section{Grave goods}

1. Beads. Eleven small limestone beads. Rusty brown patches could be noted on the beads, probably the remains of some pigment. Inv. no. 56.11.12.1 (Pl. X. 19/1).

2. One-handled cup. Greyish-brown, wide-mouthed,

$\overline{16}$ The object has since been lost or mislaid. Its description is quoted from the acquisitions register. The drawing is based on József Korek's grave sheet. large cup with polished patches on the body. The short strap handle rises from the rim to the belly. The rim is peaked on both sides of the handle. The vessel is decorated with a row of impressed dots around the shoulder and a pair of dots at the base of the handle. The cup's interior was decorated with a burnished pattern of oblique lines (now worn and barely discernible). Joined from its fragments; the chipped rim and the vessel body are restored. H. $7 \mathrm{~cm}, \mathrm{dM} .17 .5 \mathrm{~cm}$. Inv. no. 56.11.12.2 (Pl. X. 19/2).

3. Goblet. Yellowish-red, grey mottled goblet with rectangular upper part resting on a rectangular, fenestrated base. The four corners of the upper part are peaked. The entire vessel body is decorated with an incised net pattern and red painting, patches of which also survive on the inner side of the fenestrated base. The vessel interior is plain, except for a few patches of red painting. H. $6.2 \mathrm{~cm}$, dM. $6.2 \mathrm{~cm}, \mathrm{~dB} .2 .7 \mathrm{~cm}$. Inv. no. 56.11.12.3 (Pl. XI. 19/3).

4. Goblet. Yellowish-red, grey mottled goblet with rounded upper part set on two feet. A small stringhole lug is set at the junction of the upper part and the feet. The upper part is decorated with a zig-zag pattern set within an incised band, the feet with a similar incised zig-zag pattern. Patches of red pigment can be noted over the entire vessel body. Joined from its fragments and restored. $H .7 .3 \mathrm{~cm}, \mathrm{dM} .6 .5 \mathrm{~cm}$, dB. 5 cm. Inv. no. 56.11.12.4 (Pl. X. 19/4).

\section{Grave 20 (Square $\mathrm{J} 5 ; \mathrm{Pl} . X I$ )}

Size of grave pit: L. $105 \mathrm{~cm}, W .75 \mathrm{~cm}$

Depth: $105 \mathrm{~cm}$

Orientation: $\mathrm{W}$ to $\mathrm{E}$, with the head toward the $\mathrm{W}$

Position of skeleton: laid on the left side

L. of skeleton (contracted): $75 \mathrm{~cm}$

L. of skeleton (extended): $150 \mathrm{~cm}$

Age at death: $40-50$ years

Sex: male (?)

Condition of skeleton: medium well preserved

Preserved skeletal bones: skull, long bones

Inhumation burial in an oval grave pit. The body was laid on the left side in a contracted position. The arms were bent at the elbow and drawn up to the face. The thighs were drawn up into a horizontal position, the legs were bent back toward the buttocks.

The burial did not contain any grave goods.

\section{Grave 21 (Square J4; Pl. XI)}

Size of grave pit: L. $65 \mathrm{~cm}, W .50 \mathrm{~cm}$

Depth: $120 \mathrm{~cm}$

Orientation: W-SW to E-NE, with the head toward the W-SW

Position of skeleton: laid on the left side

L. of skeleton (contracted): $43 \mathrm{~cm}$

L. of skeleton (extended): $60 \mathrm{~cm}$

Age at death: child 
Sex: -

Condition of skeleton: badly preserved

Preserved skeletal bones: ${ }^{17}$ skull

Inhumation burial in an oval grave pit. The body was laid on the left side in a contracted position. The arms were bent at the elbow and the hands drawn up to the face. The right thigh was drawn up more strongly than the left one, the latter lay in a horizontal position. The legs were bent back toward the buttocks.

The burial contained the following grave goods: a necklace of seventeen beads (1) on the neck and the chest.

\section{Grave goods}

1. Beads. Seventeen limestone beads of varying sizes. Inv. no. 56.11.13.1 (Pl. XI. 21/1).

\section{Grave 22 (Square J4/J5; Pl. XIII)}

Size of grave pit: L. $125 \mathrm{~cm}, W .115 \mathrm{~cm}$

Depth: $110 \mathrm{~cm}$

Orientation: $\mathrm{N}$ to $\mathrm{S}$, with the head toward the $\mathrm{N}$

Position of skeleton: laid on the left side

L. of skeleton (contracted): $115 \mathrm{~cm}$

L. of skeleton (extended): $165 \mathrm{~cm}$

Age at death: 19-21 years

Sex: female (?)

Condition of skeleton: well preserved

Preserved skeletal bones: skull, long bones

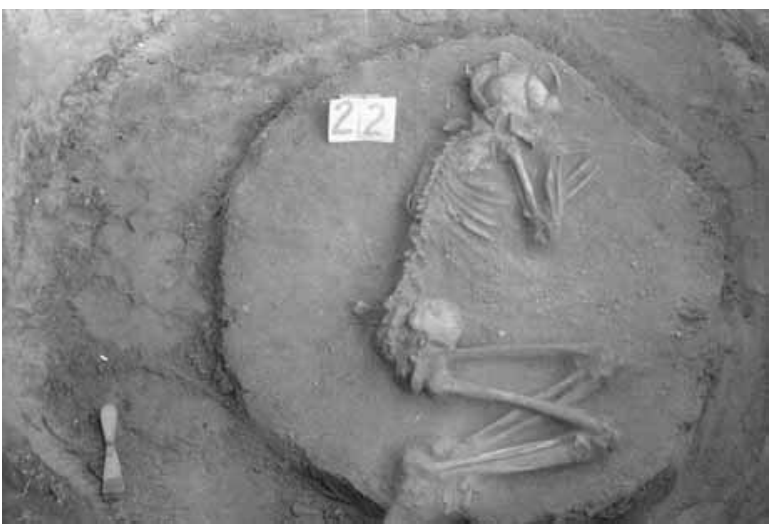

Inhumation burial in a roughly circular grave pit. The grave pit contained stones between -30 and $-70 \mathrm{~cm}$; indistinct pottery sherds lay among the stones. ${ }^{18}$ The body was laid on the left side in a contracted position (the skull was damaged). The arms were bent at the elbow and the hands were drawn up to the face. The thighs were drawn up into a horizontal position, the legs were bent back toward the buttocks.

The burial contained the following grave goods: a stone implement (1) behind the pelvis; five Dentalium beads and a red bead (2) by the neck and on the chest.

\footnotetext{
17 The skeletal remains can no longer be found. The anthropological data are quoted from the excavation diary.

18 No pottery fragments were inventoried among the finds from the burial.
}

Grave goods

1. Hornstone segment. Inv. no. 56.11.14.1 (Pl. XIII. 22/1).

2. Beads. Five Dentalium badense beads, a red Ammonito rosso limestone bead and a white limestone bead. Inv. no. 56.11.14.2 (Pl. XIII. 22/2). ${ }^{19}$

\section{Grave 23 (Square J5; Pl. XII)}

Size of grave pit: L. $90 \mathrm{~cm}, W .60 \mathrm{~cm}$

Depth: $90 \mathrm{~cm}$

Orientation: NW to SE, with the head toward the NW

Position of skeleton: laid on the left side

L. of skeleton (contracted): $70 \mathrm{~cm}$

L. of skeleton (extended): -

Age at death: 18-23 years

Sex: female

Condition of skeleton: badly preserved

Preserved skeletal bones: skull, long bones

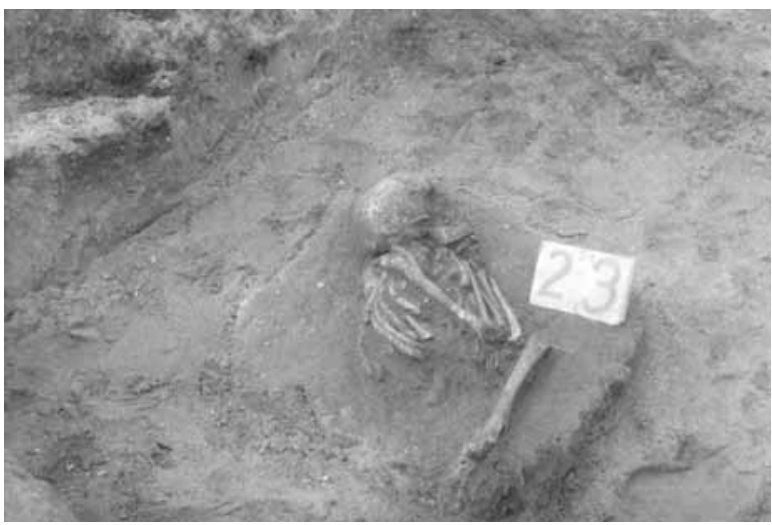

Inhumation burial in an oblong grave pit with rounded corners. The grave pit contained many stones; the fragments of four different vessels were recovered from among the stones: a cup (1), and various fragments (2-4).

The body was laid on the left side in a contracted position. The arms were bent at the elbow and the hands were drawn up to the face. The leg bones were disturbed by an animal burrow: only the right thighbone survived.

The burial contained the following grave goods: a necklace of twenty-six beads (5) around the neck and the waist.

Grave goods

1. One-handled cup. Rim and body fragment of a greyish-brown cup with gently curving neck, decorated with a row of punctates around the neck and vertical and oblique incised lines on the belly. dM. 6 cm. Inv. no. 56.11.15.1 (Pl. XII. 23/1).

2. Bipartite bowl. Rim fragment of a greyish-brown, worn bipartite bowl with indrawn rim, decorated with an incised pattern of bundles of vertical lines flanked by zig-zag motifs under the rim. Joined from

\footnotetext{
${ }_{19}$ The number of beads listed in the acquisitions register is lower by one because the white bead had slipped inside one of the Dentalium shells.
} 
its fragments. H. $4.5 \mathrm{~cm}$, dM. $c a .38 \mathrm{~cm}$. Inv. no. 56.11.15.2 (Pl. XII. 23/2).

3. Bowl. Rim fragment of a greyish-brown, worn bowl with funnel neck, decorated with two parallel rows of punctates set $3.5-4 \mathrm{~cm}$ apart under the rim in the bowl's interior. dM. $12 \mathrm{~cm}$. Inv. no. 56.11.15.3 (Pl. XII. 23/3).

4. Bipartite bowl. Rim fragment of a greyish-brown, worn bipartite bowl with indrawn, peaked rim. The bowl is decorated with vertical incised lines under the rim; the stub of a flat, ornamental knob can be made out. dM. $5.9 \mathrm{~cm}$. Inv. no. 56.11.15.4 (Pl. XII. 23/4).

5. Beads. Twenty-six limestone beads of varying sizes. Inv. no. 56.11.15.7 (Pl. XII. 23/5).

Other finds from the grave pit

6. Pitcher. Neck and shoulder fragment of a greyishblack pitcher with patches of polishing, decorated with barely discernible fluting around the neck. L. 5 cm. Inv. no. 56.11.15.5 (Pl. XII. 23/6).

7. Bipartite bowl. Rim fragment of a greyish-brown, worn bipartite bowl with indrawn rim, decorated with bundles of vertical incised lines flanked by zig-zag motifs under the rim. dM. $4.5 \mathrm{~cm}$. Inv. no. 56.11.15.6 (Pl. XII. 23/7).

\section{Grave 24 (Square J5; Pl. XIV)}

Size of grave pit: L. $130 \mathrm{~cm}, W .90 \mathrm{~cm}$

Depth: $95 \mathrm{~cm}$

Orientation: SW to NE, with the head toward the SW

Position of skeleton: laid on the right side

L. of skeleton (contracted): $95 \mathrm{~cm}$

L. of skeleton (extended): $145 \mathrm{~cm}$

Age at death: $25-35$ years

Sex: female

Condition of skeleton: well preserved

Preserved skeletal bones: skull, long bones and pelvic bone

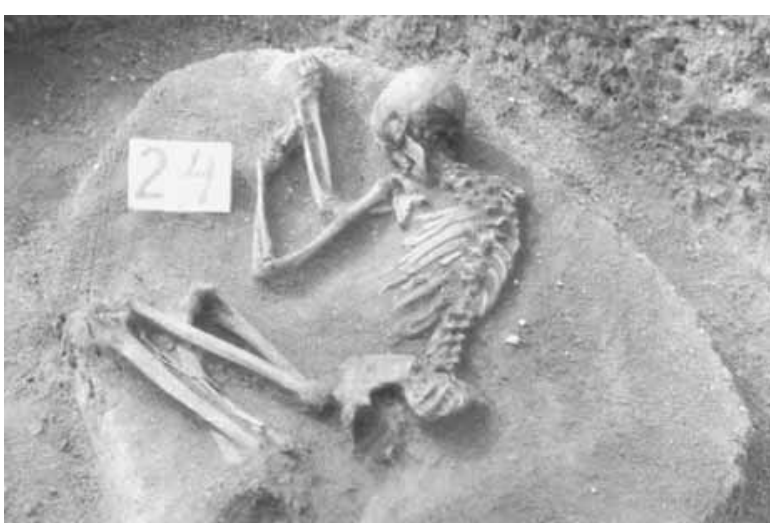

Inhumation burial in an oblong grave pit with rounded corners. The grave pit contained many stones. The body was laid on the right side in a contracted position. The skull lay on the occipital bone. The arms were bent at the elbow and the hands were drawn up in front of the face. The trunk lay prone, the lower part, from the waist downward, lay on the right side. The right thigh was drawn up more strongly than the left one, which lay in a horizontal position. The legs were bent back toward the buttocks.

The burial contained the following grave goods: fourteen beads (1) behind the spine; a stone blade (2) by the knee.

Grave goods

1. Beads. Fourteen limestone beads of varying sizes. Inv. no. 56.11.16.1 (Pl. XIV. 24/1).

2. Unretouched radiolarite blade. Inv. no. 56.11.16.2 (Pl. XIV. 24/2).

\section{Grave 25 (Square I5; Pl. XIII)}

Size of grave pit: L. $115 \mathrm{~cm}, W .90 \mathrm{~cm}$

Depth: $90 \mathrm{~cm}$

Orientation: NW to SE, with the head toward the NW

Position of skeleton: laid on the left side

L. of skeleton (contracted): $85 \mathrm{~cm}$

L. of skeleton (extended): $155 \mathrm{~cm}$

Age at death: $23-40$ years

Sex: female

Condition of skeleton: medium well preserved

Preserved skeletal bones: skull, long bones, pelvic bone

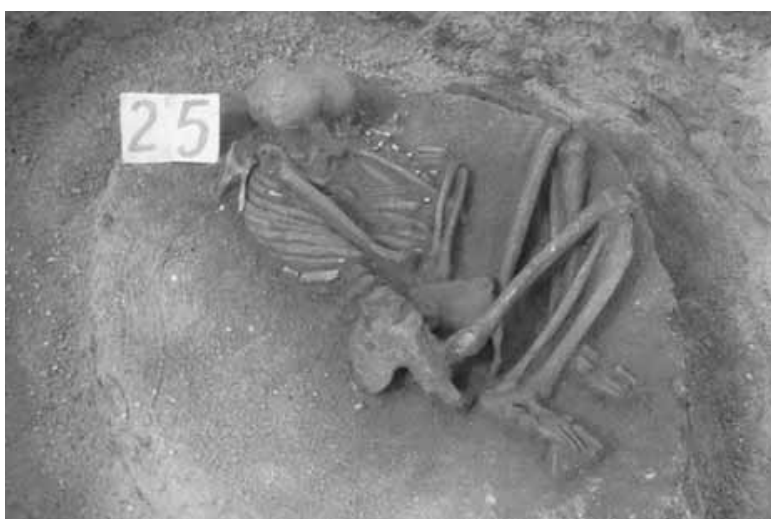

Inhumation burial in an oval grave pit containing many stones. The body was laid on the left side in a contracted position. The right arm was bent at the elbow and the hand was drawn up to the face. The left thigh was strongly drawn up, the right one placed in a horizontal position. The legs were bent back toward the buttocks.

The burial contained the following grave goods: a small red stone (1) on the pelvis; a necklace of thirtyone beads (2) in front of the face and around the arms. ${ }^{20}$

\section{Grave goods}

1. Red stone. Diam. $3.5 \mathrm{~cm}$. Inv. no. 56.11.17.1 (Pl. XIII. 25/1). ${ }^{21}$

\footnotetext{
${ }_{20}$ According to the excavation diary, the "string of beads had fallen apart, but the position of the beads suggested that it had hung around the neck and across the arms."

${ }_{21}$ The object has since been lost or mislaid. Its description is quoted from the acquisitions register. The photo is after BANNER 1956, Pl. XCII. 2.
} 
2. Beads. Thirty-one limestone beads of varying sizes. Patches of red pigment could be noted on the beads. Inv. no. 56.11.17.2 (Pl. XIII. 25/2).

\section{Grave 26 (Square K8)}

Size of grave pit: L. $380 \mathrm{~cm}, W .150 \mathrm{~cm}$

Depth: $90-100 \mathrm{~cm}$

Orientation: $\mathrm{E}$ to $\mathrm{W}$

Position of skeleton: -

L. of skeleton (contracted): -

L. of skeleton (extended): -

Age at death: -

Sex: -

Condition of skeleton:-

Preserved skeletal bones: -

Empty grave pit. A $380 \mathrm{~cm}$ long, $150 \mathrm{~cm}$ wide, roughly east to west oriented discoloured patch (perhaps a burial) was noted west of Grave 16. The depth of the intrusion was $90-100 \mathrm{~cm}$ on the average. It did not yield any finds.

\section{Grave 27 (Square J5; Pl. XIII)}

Size of grave pit: L. $90 \mathrm{~cm}, W .70 \mathrm{~cm}$

Depth: $85 \mathrm{~cm}$

Orientation: $\mathrm{S}$ to $\mathrm{N}$, with the head probably toward the $\mathrm{S}$

Position of skeleton: laid on the left side

L. of skeleton (contracted): -

L. of skeleton (extended): -

Age at death: infans I

Sex: infant

Condition of skeleton: badly preserved

Preserved skeletal bones:22 skull

Inhumation burial in an oval grave pit containing many stones. The body was laid on the left side. Only the skull survived. Two smaller stones lay by the skull.

The burial did not contain any grave good.

\section{Grave 28 (Square I5; Pl. XIV)}

Size of grave pit: L. $135 \mathrm{~cm}$, W. $95 \mathrm{~cm}$

Depth: $95 \mathrm{~cm}$

Orientation: W-NW to E-SE, with the head toward the W-NW Position of skeleton: laid on the right side

L. of skeleton (contracted): $85 \mathrm{~cm}$

L. of skeleton (extended): $150 \mathrm{~cm}$

Age at death: $40-50$ years

Sex: female

Condition of skeleton: medium well preserved

Preserved skeletal bones: skull, long bones, pelvic bone

Inhumation burial in an oval grave pit. The grave pit contained many stones, one of which (measuring $80 \mathrm{~cm}$ by $40-45 \mathrm{~cm}$ by $10-15 \mathrm{~cm}$ ) was set upright by the pelvis. The stone had tilted slightly forward, but even

22 The skeletal remains can no longer be found. The anthropological data are quoted from the excavation diary.

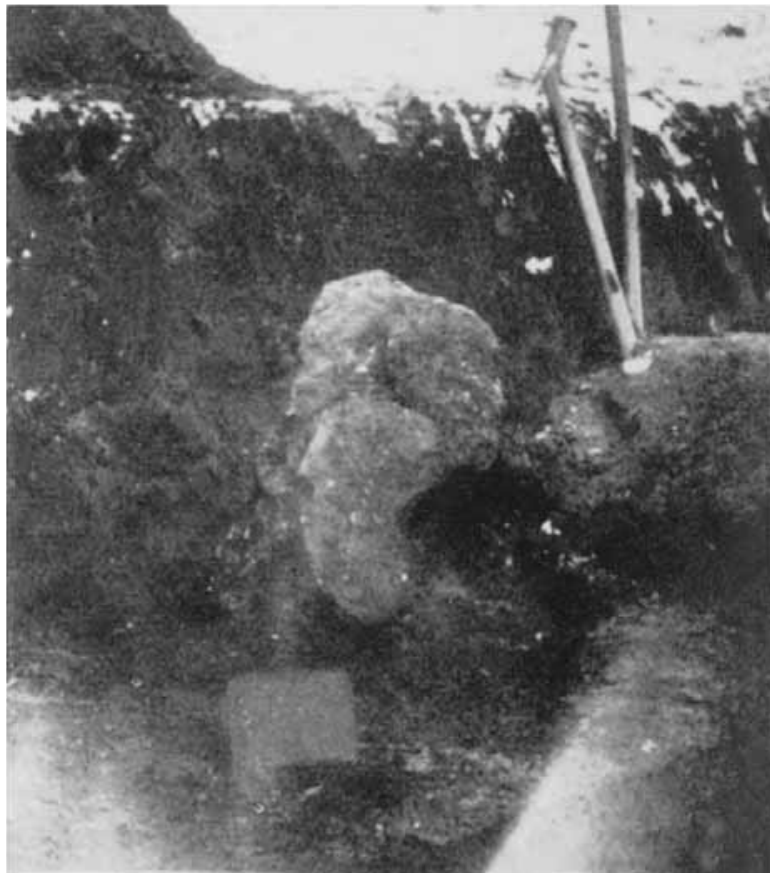

so its tip lay no more than $15-20 \mathrm{~cm}$ under the modern surface.

The body was laid on the right side in a contracted position by the grave pit's northern side. The skull rested on the occipital bone. The arms were bent at the elbow and the hands were drawn up to the face. The thighs were strongly drawn up, the legs were bent back toward the buttocks.

The burial contained the following grave goods: a scooping vessel (1) under the right shoulder; a red stone (2) by the pelvis; a rectangular copper plaque (3) on the left shoulder near the neck.

\section{Grave goods}

1. Scooping vessel. Greyish-brown scooping vessel with a strap handle, decorated with impressed dots and lines in its interior. Joined from its fragments and partly restored. H. $6 \mathrm{~cm}$, dM. $16 \mathrm{~cm}$. Inv. no. 56.11.18.1 (Pl. XIV. 28/1).23

2. Red stone. Diam. $3 \mathrm{~cm}$. Inv. no. 56.11.18.3 (Pl. XIV. 28/2).24

3. Copper plaque. Roughly rectangular copper plaque, bent back at the short end. L. $4.1 \mathrm{~cm}, W .1 .2 \mathrm{~cm}$. Inv. no. 56.11.18.2 (Pl. XIV. 28/3). ${ }^{25}$

23 The object has since been lost or mislaid. Its description is quoted from the acquisitions register. For its photo, cp. BANNER 1956, Pl. XCII. 22.

24 The object has since been lost or mislaid. Its description is quoted from the acquisitions register. The drawing is based on József Korek's grave sheet. For its photo, cp. BANNER 1956, Pl. CXII. 3.

25 The object has since been lost or mislaid. Its description is quoted from the acquisitions register. The photo is based on the metallurgical report in the Szentendre museum (SzFM Archives, inv. no. 1170/76, report prepared by Dr. Manfred Schröder). The drawing is based on József Korek's grave sheet. For its photo, cp. BANNER 1956, Pl. CXII. 4. 
Grave 29 (Square J4/J5; Pl. XIII)

Size of grave pit: L. $95 \mathrm{~cm}, W .75 \mathrm{~cm}$

Depth: $90 \mathrm{~cm}$

Orientation: W-NW to E-SE, with the head toward the W-NW

Position of skeleton: laid on the left side

L. of skeleton (contracted): $75 \mathrm{~cm}$

L. of skeleton (extended): $145 \mathrm{~cm}$

Age at death: maturus

Sex: female

Condition of skeleton: badly preserved

Preserved skeletal bones: ${ }^{26}$ skull

Inhumation burial in an oval grave pit containing stones. The body was laid on the left side in a contracted position. The left arm was extended toward the knees, the right arm was bent at the elbow, with the right hand clasping the left forearm. The thighs were drawn up into a horizontal position, the legs were bent back toward the buttocks.

The burial did not contain any grave goods. However, copper oxide was noted on the right shoulder. The copper artefact causing the stain had completely perished.

\section{Grave 30 (Square J7; Pl. XV)}

Size of grave pit: L. $80 \mathrm{~cm}, W .70 \mathrm{~cm}$

Depth: $90 \mathrm{~cm}$

Orientation: $\mathrm{S}$ to $\mathrm{N}$, with the head toward the $\mathrm{S}$

Position of skeleton: laid on the right side

L. of skeleton (contracted): $65 \mathrm{~cm}$

L. of skeleton (extended): $90 \mathrm{~cm}$

Age at death: 6-7 years

Sex: child

Condition of skeleton: badly preserved

Preserved skeletal bones: skull

Inhumation burial in a circular grave pit. The body was laid on the right side in a contracted position. The arms were bent at the elbow and drawn up in front of the body. The thighs were drawn up into a horizontal position, the legs were bent back toward the buttocks.

The burial contained the following grave goods: a red painted goblet (1) turned upside-down behind the left pelvic bone.

\section{Grave goods}

1. Goblet. Reddish-brown goblet with rounded upper part resting on a solid, cylindrical foot, decorated with red painting on its exterior and interior of which very faint patches remain. Joined from its fragments, the foot partly restored. H. $7.2 \mathrm{~cm}, \mathrm{dM} .10 .2 \mathrm{~cm}$, dB. 4.8 cm. Inv. no. 56.11.19.1 (Pl. XV. 30/1).
Grave 31 (Square J8)

Size of grave pit: L. $60 \mathrm{~cm}, W .50 \mathrm{~cm}$

Depth: $45 \mathrm{~cm}$

Orientation: -

Position of skeleton: -

L. of skeleton (contracted): -

L. of skeleton (extended): -

Age at death: -

Sex: -

Condition of skeleton:-

Preserved skeletal bones: -

Symbolic (?) burial. The grave pit contained many stones, but no skeletal remains or any other finds.

\section{Grave 32 (Square J4; Pl. XV)}

Size of grave pit: L. $115 \mathrm{~cm}$

Depth: $120 \mathrm{~cm}$

Orientation: SE to NW, with the skull lying in the grave pit's SW end

Position of skeleton: disturbed

L. of skeleton (contracted): -

L. of skeleton (extended): -

Age at death: adult

Sex: male

Condition of skeleton: badly preserved

Preserved skeletal bones: ${ }^{27}$ fragments of the skull

Inhumation burial in an oval grave pit. Many stones were found lying at a depth of $-20 \mathrm{~cm}$ from the modern surface. The skeleton had been destroyed by an earlier intrusion. The sides of the grave pit were lined with ten flat stones set on their edge, standing $30-55 \mathrm{~cm}$ high. A large, flat stone was laid on the floor of the grave pit and the body had in part been laid on this stone.

The disturbed burial did not contain any grave goods.

\section{Grave 33 (Square I6; Pl. XV)}

Size of grave pit: L. $155 \mathrm{~cm}, W .80 \mathrm{~cm}$

Depth: $130 \mathrm{~cm}$

Orientation: SE to NW. with the head toward the SE

Position of skeleton: laid on the right side

L. of skeleton (contracted): $105 \mathrm{~cm}$

L. of skeleton (extended): $158 \mathrm{~cm}$

Age at death: $40-50$ years

Sex: male

Condition of skeleton: badly preserved

Preserved skeletal bones: skull, long bones

Inhumation burial in an oblong grave pit with rounded corners. The grave pit contained stones and indistinct pottery sherds among the stones. The body was laid on the right side in a contracted position. The arms were bent at the elbow and placed in the lap. The thighs

\footnotetext{
27 The skeletal remains can no longer be found. The anthropological data are quoted from the excavation diary.

26 The skeletal remains can no longer be found. The anthropological data
are quoted from the excavation diary. 


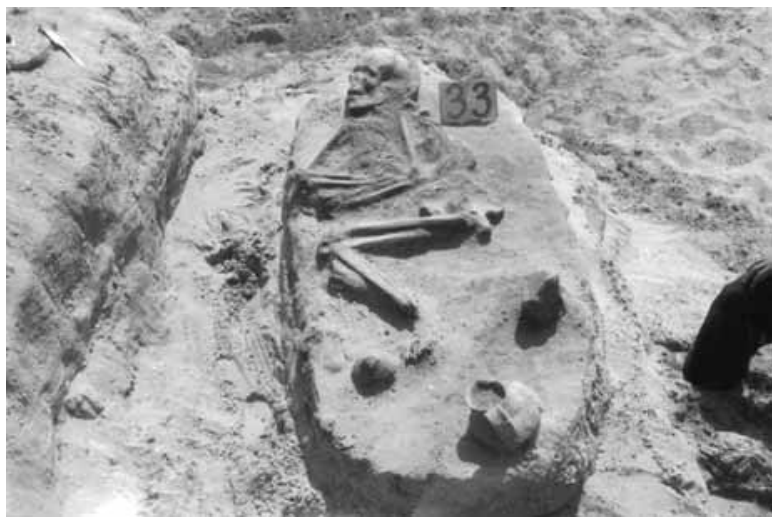

were drawn up into a horizontal position, the legs were bent back toward the buttocks.

The burial contained the following grave goods: a one-handled pitcher (1) north-west of the pelvis; the base fragment of a pot (2) between the previous vessel and the pelvis; a red-painted goblet (3) by the feet; three shells (4) on the waist.

Grave goods

1. Pitcher. Reddish-brown, worn, one-handled pitcher with slightly incurving neck and flattened globular body, decorated with a row of impressed dots around the shoulder and vertical fluting on the belly, interrupted by five vertically set ribs with oblique fluting. The handle spans the rim and the shoulder. The upper part of the handle is decorated with smoothed-in lines. Joined from its fragments and partly restored. H. $11.5 \mathrm{~cm}$, dM. $9.5 \mathrm{~cm}$. Inv. no. 56.11.20.1 (Pl. XV. 33/1).

2. Base fragment of a dark grey, thick-walled pot with a flat base. dB. 10 cm. Inv. no. 56.11.20.2 (Pl. XV. 33/2).

3. Goblet. Reddish-brown goblet with rounded upper part resting on a rectangular foot. The base is missing. It was decorated with red painting, of which faint patches survive on both the exterior and interior. Joined from its fragments. $\mathrm{d} M .9 .5 \mathrm{~cm}$. Inv. no. 56.11.20.3 (Pl. XV. 33/3).

4. Shells. Two intact polished and perforated Anadara diluvii shells and a broken Anadara diluvii shell. Inv. no. 56.11.20.4 (Pl. XV. 33/4).

\section{Grave 34 (Square I7; Pl. XVIII)}

Size of grave pit: -

Depth: $40 \mathrm{~cm}$

Orientation: S-N. with the head toward the S

Position of skeleton: laid on the right side

L. of skeleton (contracted): $45 \mathrm{~cm}$ (without the head)

L. of skeleton (extended): $110 \mathrm{~cm}$ (complete length with the head: $125 \mathrm{~cm})$

Age at death: infans II

Sex: child

Condition of skeleton: badly preserved

Preserved skeletal bones:28 long bone fragments

\footnotetext{
28 The skeletal remains can no longer be found. The anthropological data are quoted from the excavation diary.
}

Inhumation burial. There was no indication of a grave pit. The skull was destroyed during the earth-moving operations. The body was laid on the right side in a contracted position. The arms were slightly bent and placed in the lap. The thighs were drawn up, the legs were bent back toward the buttocks. ${ }^{29}$

The burial did not contain any grave goods.

\section{Grave 35 (Square I7; Pl. XVIII)}

Size of grave pit: L. $75 \mathrm{~cm}$, W. $50 \mathrm{~cm}$

Depth: $105 \mathrm{~cm}$

Orientation: $\mathrm{S}$ to $\mathrm{N}$, with the head toward the $\mathrm{S}$

Position of skeleton: laid on the right side

L. of skeleton (contracted): $50 \mathrm{~cm}$

L. of skeleton (extended): $75 \mathrm{~cm}$

Age at death: $7-14$ years

Sex: child

Condition of skeleton: badly preserved

Preserved skeletal bones: skull, long bones

Inhumation burial in an oval grave pit containing stones. The body was laid on the right side in a contracted position. The arms were bent at the elbow and the hands were drawn up in front of the face. The thighs were drawn up into a horizontal position, the legs were slightly bent back toward the buttocks.

The burial contained the following grave goods: six intact and three broken shells (1) around the waist. ${ }^{30}$

Grave goods

1. Seven polished and perforated Anadara diluvii shells and a broken shell. Inv. no. 56.11.21.1 (Pl. XVIII. 35/1).

\section{Grave 36 (Square I7; Pls XVI-XVII)}

Size of grave pit: L. $135 \mathrm{~cm}, W .112 \mathrm{~cm}$

Depth: $105 \mathrm{~cm}$

Orientation: W-NW to E-SE, with the head toward the W-NW Position of skeleton: laid on the left side

L. of skeleton (contracted): $85 \mathrm{~cm}$

L. of skeleton (extended): $162 \mathrm{~cm}$

Age at death: $40-50$ years

Sex: female

Condition of skeleton: medium well preserved

Preserved skeletal bones: skull, long bones, pelvic bone

Inhumation burial in a circular grave pit. The grave pit extended under Grave 34, meaning that the latter postdated it. The body was laid on the left side in a contracted position. The right arm was bent at the elbow and the right hand rested on the left forearm. The left arm was bent and placed under the head. The thighs were drawn up into a horizontal position, the legs were bent back toward the buttocks.

The burial contained the following grave goods: a pitcher (1) tilted to one side on the knees; a painted

\footnotetext{
${ }_{29}$ The plan of the grave shows the body lying extended and only the legs turned sideways.

${ }^{30}$ Only tow fragmentary shells survived by the time they were inventoried.
} 
three-footed goblet (2) tilted to one side between the knees and the arms at a depth of $10 \mathrm{~cm}$; three oxidised copper beads, thirty-seven intact and broken beads, five white marble beads (3) between the neck and the arms. Grave goods

1. Pitcher. Greyish-brown pitcher with slightly everted rim, flattened globular body and ansa lunata handle with patches of polishing on the body. It is decorated with parallel rows of smoothed-in lines encircling the neck and vertical smoothed-in lines running down the belly. Joined from its fragments, partly restored. H. $14.5 \mathrm{~cm}, \mathrm{~d}$ M. $9.3 \mathrm{~cm}, \mathrm{~dB} .7 .6 \mathrm{~cm}$. Inv. no. 56.11.22.1 (Pl. XVI. 36/1).

2. Goblet. Rectangular, greyish-brown goblet with peaked rim set on three feet on a round base. The vessel body, the feet and the base are decorated with incised zig-zag lines and red and white painting inbetween. Restored. H. $11.5 \mathrm{~cm}$, dM. $9.8 \mathrm{~cm}$, dB. 6 cm. Inv. no. 61.2.181 (Pl. XVII. 36/2). ${ }^{31}$

3. Beads. Forty limestone beads, one Dentalium badense bead (Pl. XVI. 36/3a), two intact and one broken copper beads (Pl. XVI. 36/3b). Inv. no. 56.11.22.2.32

\section{Grave 37 (Square K9; Pl. XVIII)}

Size of grave pit: -

Depth: $40 \mathrm{~cm}$

Orientation: $\mathrm{S}$ to $\mathrm{N}$, with the head toward the $\mathrm{S}$

Position of skeleton: laid on the left side

L. of skeleton (contracted): $85 \mathrm{~cm}$

L. of skeleton (extended): $168 \mathrm{~cm}$

Age at death: $23-40 \mathrm{~cm}$

Sex: male (?)

Condition of skeleton: medium well preserved

Preserved skeletal bones: skull, long bones

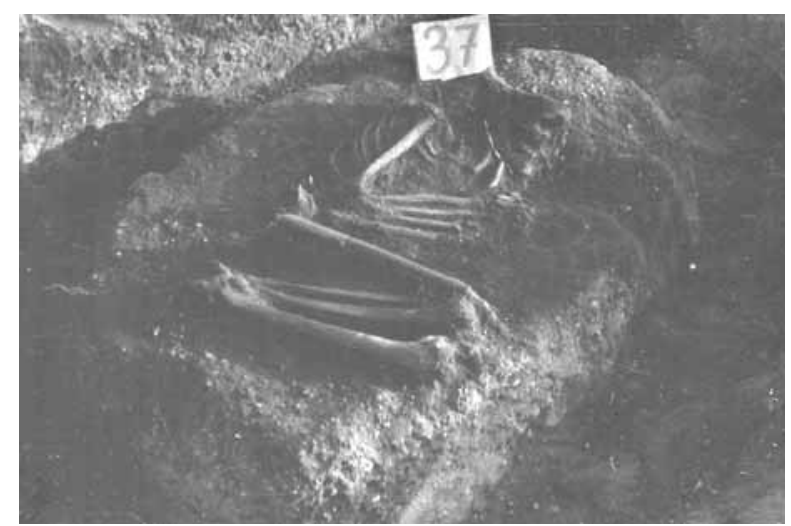

31 László Gucsi noted that the sequence of how the paint was applied to the vessel can be accurately reconstructed: the potter first applied the red paint and added the white paint later, explaining why the red paint extends beyond the incised pattern in some spots. The sequence of the different pigments over each other also allows the reconstruction of how the incised pattern was made.

32 Fewer beads were inventoried than the number listed in the excavation diary: forty beads were registered at the time the finds were inventoried. The inventoried finds do not include marble beads: the marble beads were in fact limestone beads.
Inhumation burial. There was no indication of a grave pit. The body was laid on the left side in a contracted position. The arms were bent at the elbow and the hands were drawn up in front of the face. The thighs were drawn up into a horizontal position, the legs were bent back toward the buttocks.

The burial contained the following grave goods: a necklace of eleven intact and two sliced Dentalium beads (1) around the neck.

\section{Grave goods}

1. Beads. Eleven intact and two sliced Dentalium badense beads. Inv. no. 56.11.23.1 (Pl. XVIII. 37/1).

\section{Grave 38 (Square I5; Pl. XVIII)}

Size of grave pit: L. $105 \mathrm{~cm}, W .85 \mathrm{~cm}$

Depth: $105 \mathrm{~cm}$

Orientation: W-NW to E-SE, with the head toward the W-NW Position of skeleton: laid on the right side

L. of skeleton (contracted): $85 \mathrm{~cm}$

L. of skeleton (extended): $148 \mathrm{~cm}$

Age at death: $40-x$ years

Sex: female

Condition of skeleton: medium well preserved

Preserved skeletal bones: skull, long bones

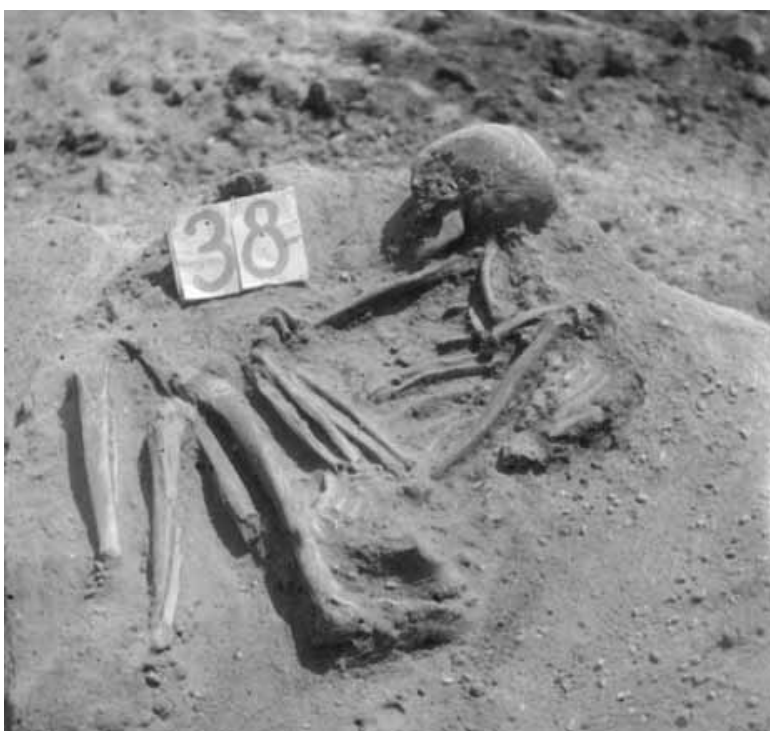

Inhumation burial in an oval grave pit. The body was laid on the right side in a contracted position. The arms were bent at the elbow and laid in the lap. The thighs were drawn up in front of the body, the legs were bent back toward the buttocks.

The burial contained the following grave goods: Two copper beads (1) on the chest.

\section{Grave goods}

1. Copper beads. Two fragmentary, strongly burnt, tubular copper beads. Inv. no. 56.11.24.1 (Pl. XVIII. 38/1).33

\footnotetext{
33 The drawing is based on József Korek's grave sheet.
} 
Grave 39 (Square I7; Pl. XIX)

Size of grave pit: L. $180 \mathrm{~cm}, W .55 \mathrm{~cm}$

Depth: $65 \mathrm{~cm}$

Orientation: N-NW to S-SE, with the head toward the N-NW

Position of skeleton: laid extended on the back

L. of skeleton (contracted): -

L. of skeleton (extended): $162 \mathrm{~cm}$

Age at death: $35-44$ years

Sex: male

Condition of skeleton: medium well preserved

Preserved skeletal bones: skull, long bones, pelvic bone

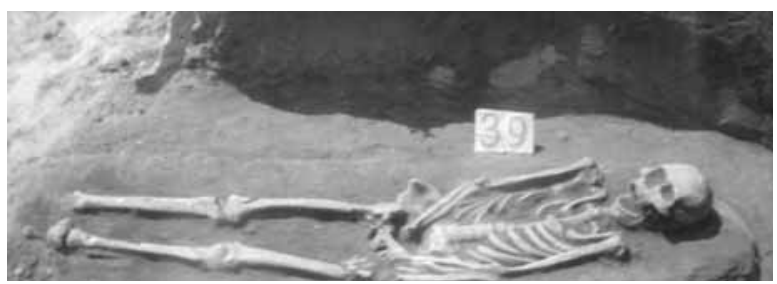

Inhumation burial in an oblong grave pit with rounded corners. The body was laid on the back in an extended position. The head was slightly raised. The right arm was slightly bent at the elbow, with the hand resting on the pelvis. The left arm was extended beside the body and the hand laid on the left thigh.

The date of this burial is uncertain since it did not contain any grave goods. The find circumstances (depth, condition and colour of the skeletal remains) suggest that it was contemporary with the other burials. A small indistinct pottery sherd was found some $20 \mathrm{~cm}$ above the skeleton and another one (1) lay by the right pelvic bone.

According to the excavation diary, a goblet (2) was found at a depth of $-35-40 \mathrm{~cm} c a .40 \mathrm{~cm}$ north of Grave 39. ${ }^{34}$

Finds from the grave pit and its area

1. Indistinct pottery sherd. ${ }^{35}$

2. Goblet. Reddish-brown, worn goblet with rounded upper part set on a cylindrical foot with round base. The vessel is decorated with two parallel rows of zigzags under the rim. Patches of red painting survive on the vessel body. The foot is perforated. The rim is chipped. The upper part is joined from its fragments. H. $8 \mathrm{~cm}, W .9 .4 \mathrm{~cm}, \mathrm{~dB} .4 \mathrm{~cm}$. Inv. no. 56.11.75.1 (Pl. XIX. 39/2).

\section{Grave 40 (Square I7; Pl. XVIII)}

Size of grave pit: L. $90 \mathrm{~cm}, W .50 \mathrm{~cm}$

Depth: $86 \mathrm{~cm}$

Orientation: head toward the S-SW

Position of skeleton: -

\footnotetext{
34 The vessel was inventoried as a stray find. The acquisitions register does not mention its find spot. It could be identified on the basis of the description (including its dimensions) in the excavation diary. It seems likely that the vessel was one of the grave goods of this burial in view of the fact that it lay very close to burial $(40 \mathrm{~cm})$, even though the excavation diary does not mention it among the grave goods.

35 The sherd was not inventoried.
}

L. of skeleton (contracted): -

L. of skeleton (extended): -

Age at death: infans I

Sex: child

Condition of skeleton: badly preserved

Preserved skeletal bones: ${ }^{36}$

Inhumation burial in an oval grave pit. Very few skeletal remains survived. The body had perhaps been laid on the right side.

The burial did not contain any grave goods.

\section{Grave 41 (Square I7; Pl. XIX)}

Size of grave pit: L. $95 \mathrm{~cm}, W .57 \mathrm{~cm}$

Depth: $110 \mathrm{~cm}$

Orientation: S-SW to N-NE, with the head toward the S-SW

Position of skeleton: laid on the left side

L. of skeleton (contracted): $65 \mathrm{~cm}$

L. of skeleton (extended): $92 \mathrm{~cm}$

Age at death: infans II

Sex: child

Condition of skeleton: badly preserved

Preserved skeletal bones: ${ }^{37}$ skull, long bones

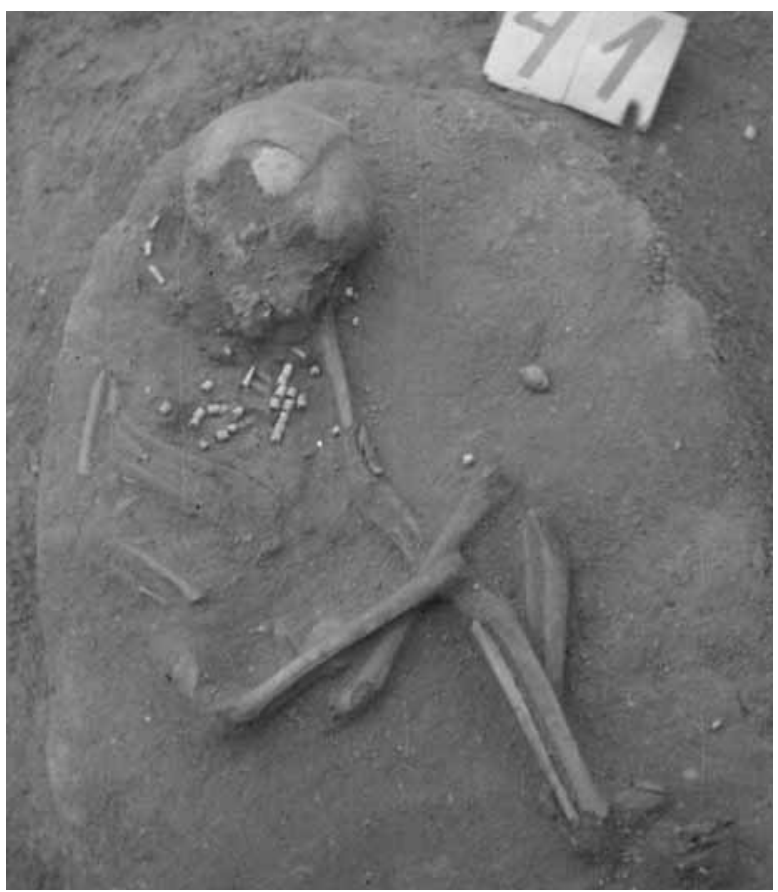

Inhumation burial in an oblong grave pit with rounded corners. The body was laid on the left side in a contracted position. The right arm was slightly bent at the elbow, with the hand resting on the pelvis. The left arm was extended and laid under the knees. The thighs were drawn up into a horizontal position, the legs were slightly bent back toward the buttocks.

The burial contained the following grave goods: a

\footnotetext{
36 The skeletal remains can no longer be found. The anthropological data are quoted from the excavation diary.

37 The skeletal remains can no longer be found. The anthropological data are quoted from the excavation diary.
} 
necklace of twenty-one Dentalium beads, one sliced Dentalium bead, fifty-eight other beads, two red beads, two copper beads (one of them crumbled to dust), and three white beads (1). Copper stains were observed on one of the neck vertebrae, suggesting that the necklace had perhaps been fitted with a copper clasp. A red stone (2) lay $8 \mathrm{~cm}$ south-west of the knees.

\section{Grave goods}

1. Beads. Twenty-two Dentalium badense beads, fiftyseven intact and one broken limestone beads, three crystalline limestone beads and two red clay beads. Inv. no. 56.11.25.1 (Pl. XIX. 41/1). ${ }^{38}$

2. Red stone. Inv. no. 56.11.25.2.39

\section{Grave 42 (Square I6; Pl. XX)}

\author{
Size of grave pit: L. $80 \mathrm{~cm}, W .45 \mathrm{~cm}$ \\ Depth: 90 \\ Orientation: SE to NW, with the head toward the SE \\ Position of skeleton: laid on the left side \\ L. of skeleton (contracted): - \\ L. of skeleton (extended): - \\ Age at death: infans I \\ Sex: child \\ Condition of skeleton: badly preserved \\ Preserved skeletal bones: 40
}

Inhumation burial in a rounded grave pit containing stones. ${ }^{41}$ The body was laid on the left side in a contracted position. Only the position of the skull and the legs could be observed.

The burial contained the following grave goods: six beads (1) around the knees.

Grave goods

1. Beads. Six sliced limestone beads. Inv. no. 56.11.26.1 (Pl. XX. 42/1).

\section{Grave 43 (Square I5; Pl. XXI)}

Size of grave pit: L. $162 \mathrm{~cm}$, W. $110 \mathrm{~cm}$

Depth: $95 \mathrm{~cm}$

Orientation: NW to SE, with the head toward the NW

Position of skeleton: laid on the left side

L. of skeleton (contracted): $97 \mathrm{~cm}$

L. of skeleton (extended): $155 \mathrm{~cm}$

Age at death: $40-59$ years

Sex: male

Condition of skeleton: medium well preserved

Preserved skeletal bones: skull, long bones, pelvic bone

\footnotetext{
38 The four disintegrated copper beads described in the excavation diary are not even mentioned in the acquisitions register.

39 The object has since been lost or mislaid. Its description is quoted from the acquisitions register.

40 No skeletal remains were preserved from the burial.

41 According to the excavation diary, many pottery sherds lay between -25 and $-40 \mathrm{~cm}$ above the burial, but these were not inventoried among the finds from the burial. Lying underneath the pottery fragments were stones (including a large, flat stone). The pottery fragments inventoried among the stray finds from the area of the cemetery could not be associated with a particular grave.
}

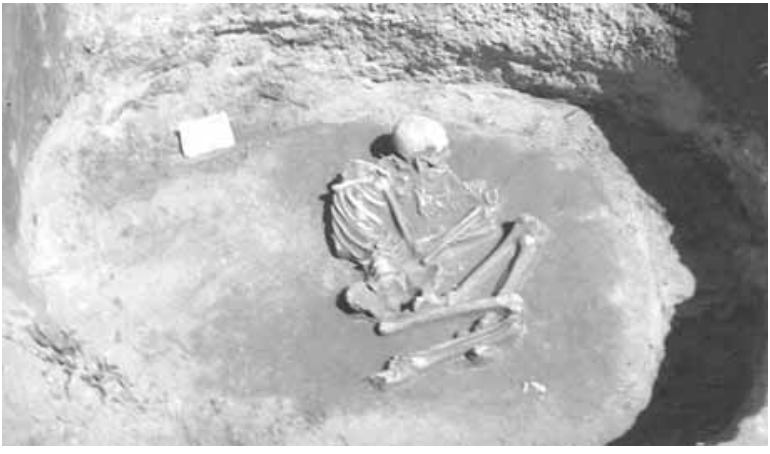

Inhumation burial in an oblong grave pit with rounded corners containing stones down to a depth of -25 to $-65 \mathrm{~cm}$. Many stones were recovered from the grave pit, amounting to $c a .0 .4 \mathrm{~m}^{3}$. The body was laid on the left side in a contracted position. The arms were bent at the elbow, the hands were laid in the lap. The left thigh was strongly drawn up, the right thigh was placed in a horizontal position, the legs were bent back.

The burial contained the following grave goods: a necklace of three Dentalium beads, one sliced Dentalium bead and twenty-seven other beads (1) extending from the neck to the chest, and two shells (2) in the same area.

\section{Grave goods}

1-2. Beads. Three intact and one sliced Dentalium badense beads, twenty-seven limestone beads $(P l$. XXI. 43/1a) and two Anadara diluvii shells (Pl. $X X I .43 / 1 b$ ). Green stains, perhaps the remains of a copper bead, were noted inside one of the Dentalium beads. Inv. no. 56.11.27.1.

\section{Grave 44 (Square I7; Pl. XXI)}

\author{
Size of grave pit: surviving L. $100 \mathrm{~cm}, W .60 \mathrm{~cm}$ \\ Depth: $115 \mathrm{~cm}$ \\ Orientation: SW to NE, with the head toward the SW \\ Position of skeleton: laid on the left side \\ L. of skeleton (contracted): $72 \mathrm{~cm}$ (surviving section) \\ L. of skeleton (extended): $150 \mathrm{~cm}$ \\ Age at death: $23-\mathrm{x}$ years \\ Sex: female (?) \\ Condition of skeleton: badly preserved \\ Preserved skeletal bones: long bones
}

Inhumation burial in an oblong grave pit with rounded corners. The grave pit extended under Grave 40. The skull was destroyed during earth-moving operations and only the skeletal parts from the neck vertebrae and the clavicle downward survived. The body was laid on the left side in a contracted position. The right arm was bent at the elbow, with the hand resting under the left arm-pit. The left arm was bent at the elbow and drawn up to the left shoulder. The thighs were moderately drawn up, the legs were bent back toward the buttocks.

The burial contained the following grave goods: a suspension vessel (1) tilted toward the body on the feet; 
a side-scraper (2) inside the vessel; a red stone (3) by the right foot.

Grave goods

1. Suspension vessel with cylindrical neck, flat base and two stringhole lugs on the belly. The vessel is decorated with incised lines filled with red pigment around the shoulder and on the belly. H. $20.2 \mathrm{~cm}$, dM. $9 \mathrm{~cm}$, dB. $9.1 \mathrm{~cm}$. Inv. no. 56.11.28.1 (Pl. XXI. 44/1). ${ }^{42}$

2. Radiolarite side-scraper. Inv. no. 56.11.28.2 (Pl. XXI. 44/2).

3. Red stone, with one side polished. Inv. no. 56.11.28.3 (Pl. XXI. 44/3). ${ }^{43}$

\section{Grave 45 (Square I6; Pl. XX)}

Size of grave pit: L. $100 \mathrm{~cm}, W .75 \mathrm{~cm}$

Depth: $105 \mathrm{~cm}$

Orientation: SW to NE, with the head toward the SW

Position of skeleton: laid on the left side

L. of skeleton (contracted): $82 \mathrm{~cm}$

L. of skeleton (extended): $140 \mathrm{~cm}$

Age at death: $23-\mathrm{x}$ years

Sex: -

Condition of skeleton: medium well preserved

Preserved skeletal bones: skull, long bones

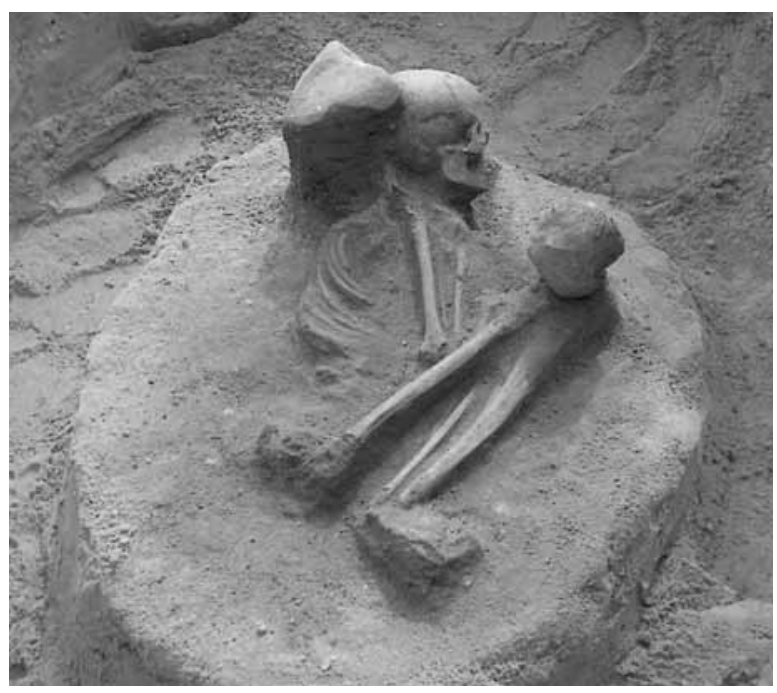

Inhumation burial in an oval grave pit containing stones. The body was laid on the left side in a contracted position. The arms were bent at the elbow and the hands were drawn up in front of the chin. The thighs were drawn up in front of the body, the legs were bent back toward the buttocks. A stone was set on the skull and on the knees.

The burial did not contain any grave goods.

\footnotetext{
42 According to the checklist drawn up in 1979, the vessel was exhibited in Case 1 of the museum's exhibition. The object has since been lost or mislaid. Its description is quoted from the acquisitions register. The drawing is based on József Korek's grave sheet.

43 The object has since been lost or mislaid. Its description is quoted from the acquisitions register. The drawing is based on József Korek's grave sheet.
}

Grave 46 (Square I5; $P l . X X)$

Size of grave pit: L- $120 \mathrm{~cm}, W .85 \mathrm{~cm}$

Depth: $90 \mathrm{~cm}$

Orientation: S-SE to N-NW, with the head toward the S-SE

Position of skeleton: laid on the left side

L. of skeleton (contracted): $100 \mathrm{~cm}$

L. of skeleton (extended): $172 \mathrm{~cm}$

Age at death: 20-30 years

Sex: female

Condition of skeleton: medium well preserved

Preserved skeletal bones: skull, long bones, pelvic bone, ribs, vertebrae

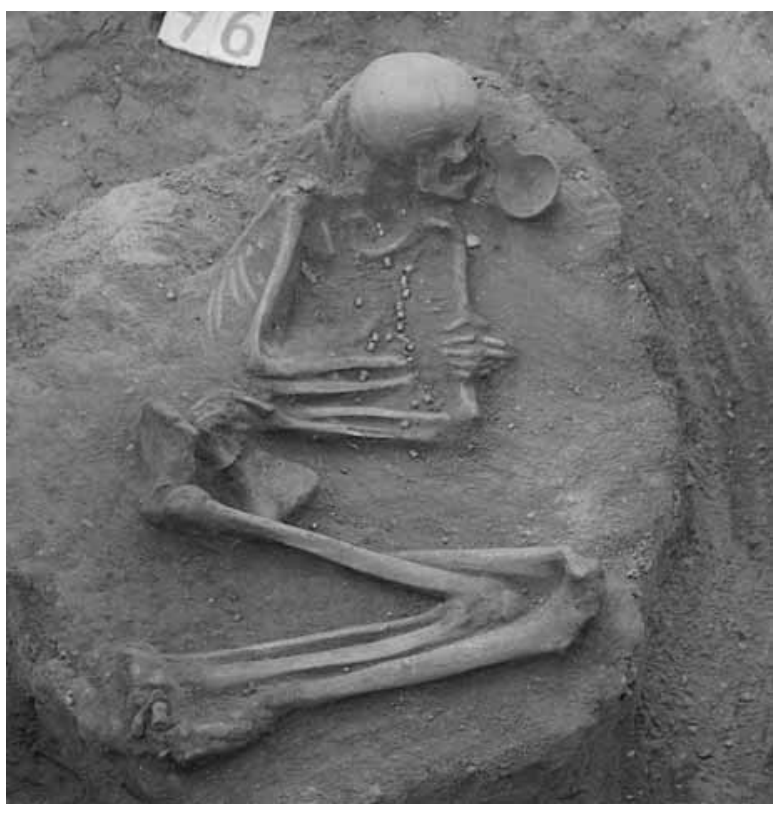

Inhumation burial in an oval grave pit containing stones and indistinct pottery sherds among the stones. ${ }^{44}$ The body was laid on the left side in a contracted position. The right arm was bent at the elbow and drawn up to the left upper arm. The left arm was bent at the elbow and drawn up, with the hand resting on the sacrum. The thighs were drawn up into a horizontal position, the legs were bent back toward the buttocks.

The burial contained the following grave goods: a ladle (1) tilted to one side in front of the face; two intact and six broken shells (2) by the left upper arm; a necklace of four Dentalium beads, two sliced Dentalium beads, fifty-two beads, one white and two red beads (3); a stone tool (4) $5 \mathrm{~cm}$ east of the pelvis.

\section{Grave goods}

1. Ladle. Reddish-brown ladle with two perforations on the handle. Patches of red painting can be noted on the exterior and interior. H. $3 \mathrm{~cm}, \mathrm{dM} .9 .5 \mathrm{~cm}$. Inv. no. 56.11.29.1 (Pl. XX. 46/1).

2. Shells. Seven intact, perforated Anadara diluvii shells and a broken Anadara diluvii shell. A green stain was noted inside one of the shells. Inv. no. 56.11.29.2 (Pl. XX. 46/2).

44 Pottery fragments were not inventoried among the finds from the burial. 
3. A Dentalium badense bead. Inv. no. 56.11.29.3 (Pl. XX. 46/3). 45

4. Trapeze made from limnic quartzite. Inv. no. 56.11.29.4 (Pl. XX. 46/4). ${ }^{46}$

\section{Grave 47 (Square I5; Pl. XXII)}

Size of grave pit: L. $105 \mathrm{~cm}, W .85 \mathrm{~cm}$

Depth: $75 \mathrm{~cm}$, burial C: $85 \mathrm{~cm}$

Orientation: A: SW to NE, with the head toward the SW, B: SW to NE, with the head toward the SW, C: SW to NE, with the head toward the SW

Position of skeleton: A: laid on the right side, B: laid on the right side, C: laid on the right side

L. of skeleton (contracted): A: $42 \mathrm{~cm}, \mathrm{~B}: 40 \mathrm{~cm}, \mathrm{C}: 100 \mathrm{~cm}$ L. of skeleton (extended): A: $65-70 \mathrm{~cm}, \mathrm{~B}:-$, C: $c a .163 \mathrm{~cm}$ Age at death: A: infans II, B: infans I, C: $30-40$ years Sex: A: child, B: child, C: male

Condition of skeleton: A: badly preserved, B: badly preserved, C: medium well preserved

Preserved skeletal bones: ${ }^{47}$ A: skull fragments, B: skull fragments, C: complete skeleton

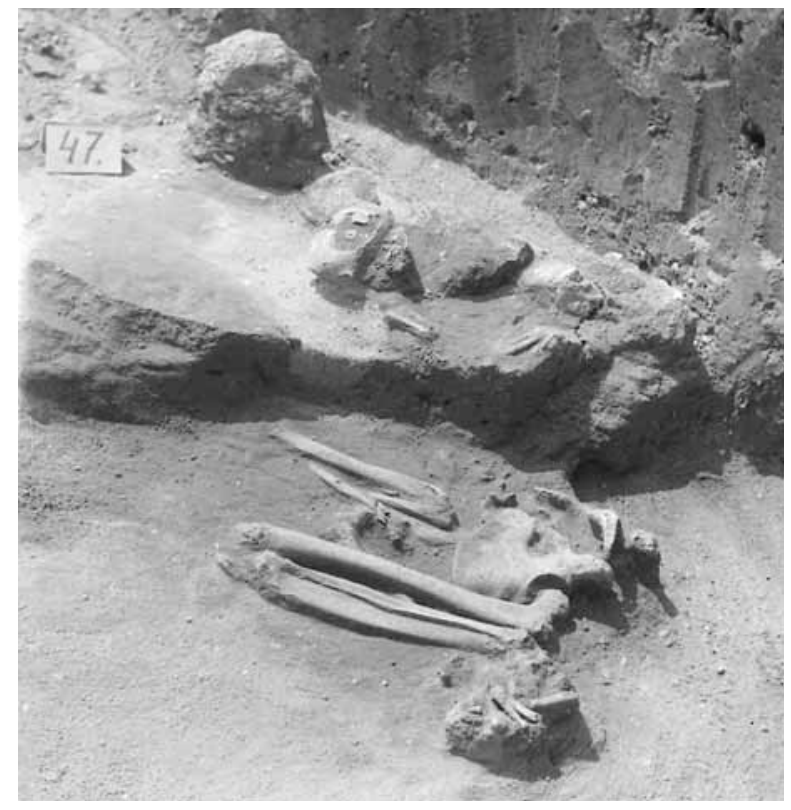

Triple burial of two children and one adult in an oval grave pit. Eight to ten flat stone set upright were found along burials $\mathrm{A}$ and $\mathrm{B}$.

\section{Burial A}

The body was laid on the right side in a contracted position. The arms were bent at the elbow and drawn up in front of the face. The thighs were drawn up in front of the body, the legs were bent back toward the buttocks.

The burial did not contain any grave goods.

\footnotetext{
45 The acquisitions register mentions a single bead from the burial. The beads inventoried under no. 56.11.74.1 perhaps came from this burial or Grave 8 (for its description cp. the section on the stray finds, no. 4, Pl. CLXVI. 4)

46 The object has since been lost or mislaid.

47 The skeletal remains of Burials A and B can no longer be found. The anthropological data are quoted from the excavation diary.
}

Burial B

The body was deposited parallel to Burial A, with the body laid on the right side in a contracted position. The arms were bent at the elbow and drawn up in front of the face. The thighs were drawn up into a horizontal position. The skull was destroyed by an animal burrow.

The burial contained the following grave goods: indistinct pottery sherds by the foot..$^{48}$

\section{Burial C}

The body was deposited between Burials A and B, but lay some $5-10 \mathrm{~cm}$ deeper than the other two burials. The body was laid on the right side in a contracted position. The skull rested on the right side. The trunk was laid prone, the lower part on the right side from the waist downward. The left arm was bent at the elbow and drawn up, with the hand resting on the left shoulder. The right arm was bent at the elbow. The thighs were drawn up in front of the body, the legs were bent back toward the buttocks.

The burial did not contain any grave goods.

The three burials were contemporaneous since no signs of disturbance could be noted in the case of Burial C, even though the depth difference was slight $(5-10 \mathrm{~cm})$. The orientation of the three burials was identical, again suggesting that the bodies had been deposited at the same time.

\section{Grave 48 (Square I6; Pl. XXII)}

Size of grave pit: L. $105 \mathrm{~cm}$, W. $145 \mathrm{~cm}$

Depth: $100 \mathrm{~cm}$

Orientation: A: S-SE to N-NW, B: S-SE to N-NE

Position of skeleton: A: laid on the left side, B: laid on the left side L. of skeleton (contracted): A: $86 \mathrm{~cm}, \mathrm{~B}: 85 \mathrm{~cm}$

L. of skeleton (extended): A: $c a .148 \mathrm{~cm}, \mathrm{~B}: c a .144 \mathrm{~cm}$

Age at death: A: $10-12$ years, B: $14-16$ years

Sex: A: child, B: female

Condition of skeleton: A-B: medium well preserved

Preserved skeletal bones: A: skull, long bones, pelvis, B: complete skeleton

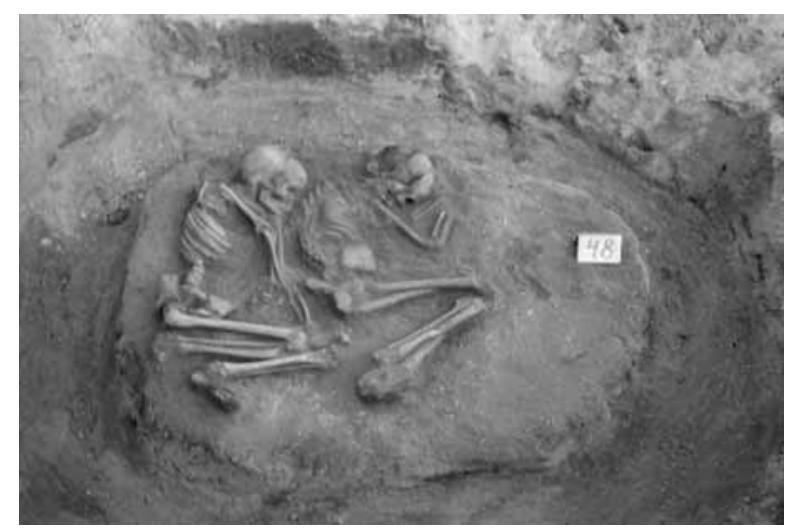

Double inhumation burial in an oval grave pit.

48 The finds were not inventoried. 


\section{Burial A}

The body was laid on the left side in a contracted position. The skull was crushed. The arms were bent at the elbow and drawn up in front of the forehead. The thighs were drawn up into a horizontal position, the legs were bent back toward the buttocks.

The burial contained the following grave goods: a necklace of five intact and five fragmentary copper beads, two Dentalium beads (slipped inside the copper beads), eighteen other beads, three intact and four broken shells (1) around the neck; ten stone implements (2-11) slightly north of the right foot.

\section{Burial B}

The body was deposited next to Burial A. The body was laid on the left side in a contracted position. The skull was crushed. The arms were extended beside the body, with the right arm lying by the pelvis and the left arm by the left knee. The thighs were drawn up into a horizontal position, the legs were bent back toward the buttocks.

The burial did not contain any grave goods.

\section{Grave goods}

1. Beads. Eighteen limestone beads (Pl. XXII. 48/1a), three intact and one broken Anadara diluvii shells (Pl. XXII. 48/1b), three intact and five fragmentary tubular copper beads (Pl. XXII. 48/1c). Inv. no. 56.11.30.1.49

2. Trapeze made from limnic quartzite. Inv. no. 56.11.30.2 (Pl. XXII. 48/2).

3. Trapeze made from radiolarite. Inv. no. 56.11.30.3 (Pl. XXII. 48/3).

4. Trapeze made from limnic quartzite. Inv. no. 56.11.30.4 (Pl. XXII. 48/4).

5. Trapeze made from limnic quartzite. Inv. no. 56.11.30.5 (Pl. XXII. 48/5).

6. Trapeze made from limnic quartzite. Inv. no. 56.11.30.6 (Pl. XXII. 48/6).

7. Trapeze made from limnic quartzite. Inv. no. 56.11.30.7 (Pl. XXII. 48/7).

8. Trapeze made from limnic quartzite. Inv. no. 56.11.30.8 (Pl. XXII. 48/8).

9. Trapeze made from limnic quartzite. Inv. no. 56.11.30.9 (Pl. XXII. 48/9).

10. Trapeze made from limnic quartzite. Inv. no. 56.11.30.10 (Pl. XXII. 48/10).

11. Chert trapeze. Inv. no. 56.11.30.11 (Pl. XXII. 48/11).

\section{Grave 49 (Square I6; Pl. XXII)}

Size of grave pit: L. $100 \mathrm{~cm}, W .70 \mathrm{~cm}$

Depth: $110 \mathrm{~cm}$

Orientation: S-SE to N-NW, with the head toward the S-SE

Position of skeleton: laid on the right side

L. of skeleton (contracted): $80 \mathrm{~cm}$

49 The three fragmentary shells and the two copper beads mentioned in the excavation diary were not inventoried.
L. of skeleton (extended): $c a .145 \mathrm{~cm}$

Age at death: $30-35$ years

Sex: female

Condition of skeleton: badly preserved

Preserved skeletal bones: ${ }^{50}$ skull, long bones

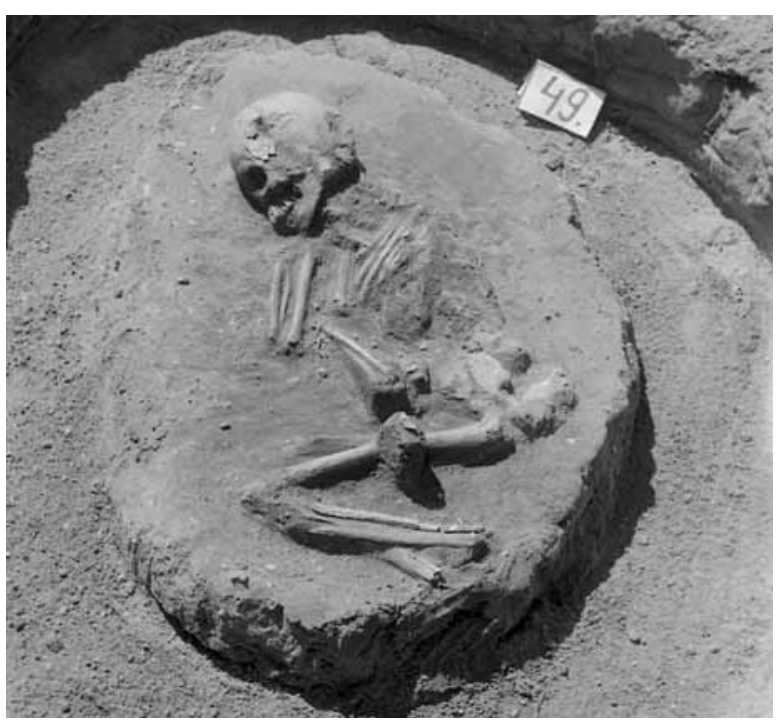

Inhumation burial in an oval grave pit. The body was laid on the right side in a contracted position. The left arm was bent at the elbow and drawn up to the face. The right arm was extended, with the hand turned toward the pelvis. The thighs were drawn up into a horizontal position, the legs were slightly bent back toward the buttocks.

The burial contained the following grave goods: a pebble (1) $5 \mathrm{~cm}$ above the left thigh.

Grave goods

1. Unworked radiolarite pebble. Inv. no. 56.11.31.1 (Pl. XXII. 49/1).

\section{Grave 50 (Square I6; Pl. XXIII)}

Size of grave pit: -

Depth: $55 \mathrm{~cm}$

Orientation: E-SE-W-NW, with the head toward the E-SE

Position of skeleton: laid on the left side

L. of skeleton (contracted): $70 \mathrm{~cm}$

L. of skeleton (extended): -

Age at death: juvenis

Sex: -

Condition of skeleton: badly preserved

Preserved skeletal bones: ${ }^{51}$ skull

Inhumation burial. There was no indication of a grave pit. The body was laid on the left side in a contracted position (the facial bones were missing). The spine was disturbed. The left arm was extended toward the knees,

\footnotetext{
${ }^{5}$ The skeletal remains can no longer be found. The anthropological data are quoted from the excavation diary.

51 The skeletal remains can no longer be found. The anthropological data are quoted from the excavation diary.
} 


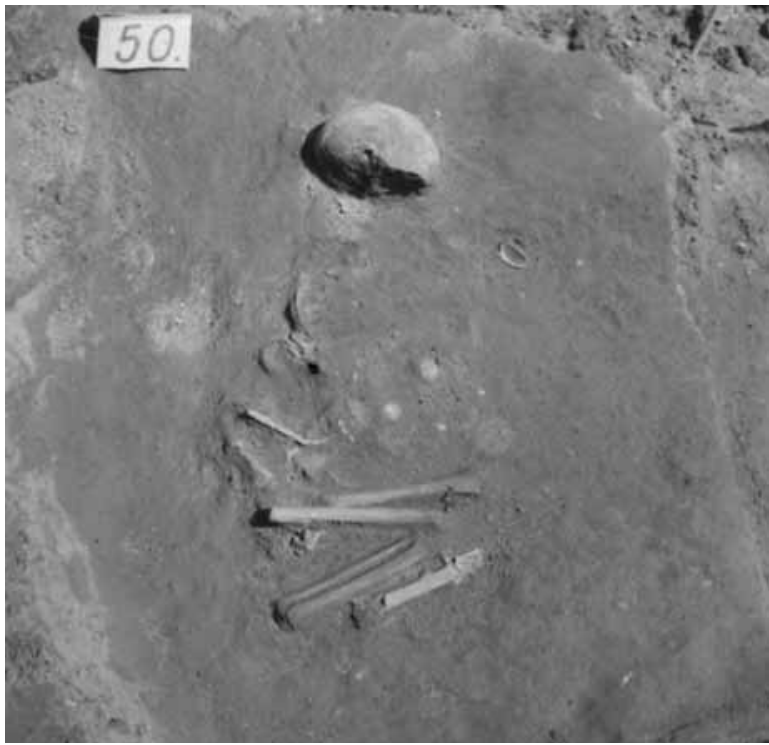

the right arm was also extended. The thighs were drawn up into a horizontal position, the legs were bent back toward the buttocks. The feet were missing owing to the disturbance.

The burial contained the following grave goods: eight shells on the chest (1); a necklace of twenty-nine beads (one containing the remains of a copper bead), a fragmentary copper bead, a red and a white bead (2) on the chest; eleven intact and six broken shell plaques (3) on the left wrist; various pottery fragments (4-6) found scattered in the grave.

Grave goods

1. Shells. Seven Anadara diluvii shells and one perforated Anadara camea shell. One shell had green stains inside it, another one had green and reddish stains inside. Eight pieces. Inv. no. 56.11.32.1 (Pl. XXIII. 50/1).

2. Beads. Twenty-four limestone beads, one red and one white bead (Pl. XXIII. 50/2a), and one fragmentary tubular copper bead (Pl. XXIII. 50/2b). Inv. no. 56.11.32.2.52

3. Shell plaques. Rectangular Unio crassus shell plaques with a pair of perforations along the shorter sides. Eleven more or less intact pieces and six small fragments..$^{53}$ Inv. no. 56.11.32.3 (Pl. XXIII. 50/3).

4. Bowl. Body sherd of a greyish bowl, decorated with four impressed dots and an incised line on the belly. L. 3.6 cm. Inv. no. 56.11.32.4 (Pl. XXIII. 50/4).

5. Bowl. Body sherd of a greyish bowl, decorated with incised lines. L. $4.3 \mathrm{~cm}$. Inv. no. 56.11.32.5 (Pl. XXIII. 50/5).

6. Bowl. Body sherd of a greyish bowl, decorated with incised lines. L. $3.8 \mathrm{~cm}$ Inv. no. 56.11.32.6 (Pl. XXIII. 50/6).

\footnotetext{
52 Twenty-four beads were inventoried. The red and the white bead, as well as the fragmentary copper bead can no longer be found.

${ }^{53}$ Some shell plaques were joined, actually are fifteen pieces.
}

Grave 51 (Square I6; Pl. XXIII)

Size of grave pit: L. $105 \mathrm{~cm}, W .75 \mathrm{~cm}$

Depth: $130 \mathrm{~cm}$

Orientation: S-SW to N-NE, with the head toward the S-SW

Position of skeleton: laid on the left side

L. of skeleton (contracted): $90 \mathrm{~cm}$

L. of skeleton (extended): $c a .130 \mathrm{~cm}$

Age at death: $30-40$ years

Sex: female

Condition of skeleton: well preserved

Preserved skeletal bones: complete skeleton

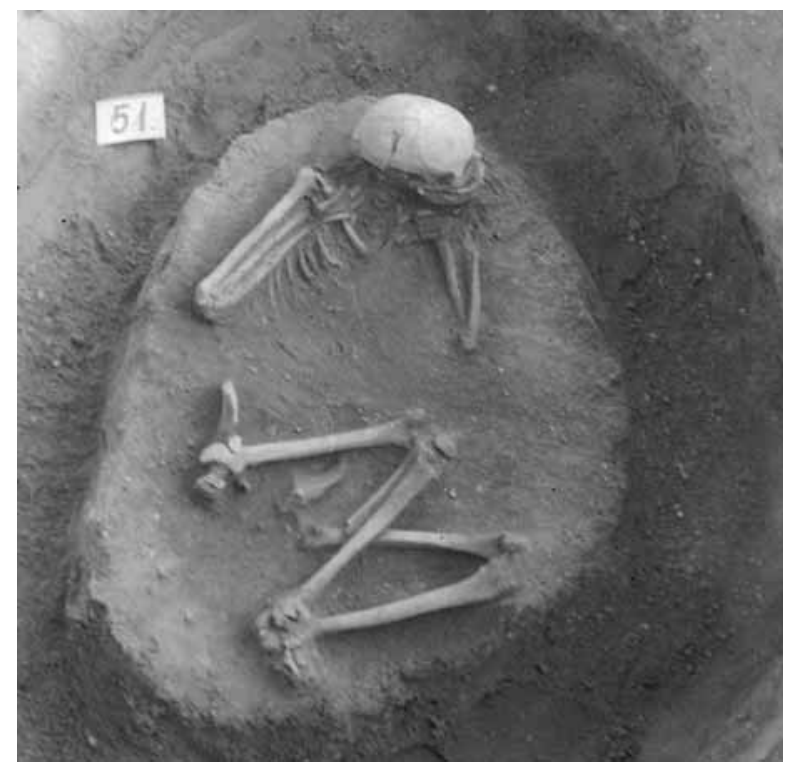

Inhumation burial in an oval grave pit. The grave pit extended under Grave 50. The body was laid on the left side in a contracted position. The skull rested on the occipital bone. The right arm was bent at the elbow and drawn up, with the hand resting on the shoulder. The left arm was bent at the elbow and drawn up, with the hand laid under the skull. The thighs were drawn up into a horizontal position, the legs were bent back toward the buttocks.

The burial contained the following grave goods: fragments of a scooping vessel (1) around the skull; fragments of a pitcher (2), also around the skull.

\section{Grave goods}

1. Scooping vessel. Grey, originally polished scooping vessel with slightly everted rim and flat base, decorated with a row of impressed dots encircling the shoulder and rows of dots running toward the base on either side of the handle. The strap handle spans the rim and the shoulder. The vessel interior is decorated with fine, smoothed-in lines. Joined from its fragments. H. $4.3 \mathrm{~cm}, \mathrm{dM} .15 .3 \mathrm{~cm}$. Inv. no. 56.11.33.1 (Pl. XXIII. 51/1).

2. Pitcher. Body and base fragments of a greyish-black pitcher decorated with fluting on the belly. Five non-joining pieces. Inv. no. 56.11.33.2 (Pl. XXIII. 51/2). 
Grave 52 (Square I7; Pl. XXIV)

Size of grave pit: -

Depth: $70 \mathrm{~cm}$

Orientation: $\mathrm{S}$ to $\mathrm{N}$. with the head toward the $\mathrm{S}$

Position of skeleton: laid on the right side

L. of skeleton (contracted): $108 \mathrm{~cm}$

L. of skeleton (extended): $171 \mathrm{~cm}$

Age at death: $30-40$ years

Sex: male

Condition of skeleton: badly preserved

Preserved skeletal bones: skull, long bones

Inhumation burial. There was no indication of a grave pit. The body was laid on the right side in a contracted position. The arms were bent at the elbow and drawn up, with the hands resting under the chin. The thighs were drawn up into a horizontal position, the legs were bent back toward the buttocks. The facial bones were destroyed by an animal burrow. A pyramid shaped stone was set in front of the face.

The burial did not contain any grave goods.

\section{Grave 53 (Square I6; Pl. XXIV)}

Size of grave pit: L. $97 \mathrm{~cm}, W .62 \mathrm{~cm}$

Depth: $135 \mathrm{~cm}$

Orientation: SE to NW, with the head toward the SE

Position of skeleton: laid on the right side

L. of skeleton (contracted): $53 \mathrm{~cm}$

L. of skeleton (extended): $106 \mathrm{~cm}$

Age at death: $1-14$ years

Sex: child

Condition of skeleton: badly preserved, the skull was crushed

Preserved skeletal bones: skull and long bone fragments

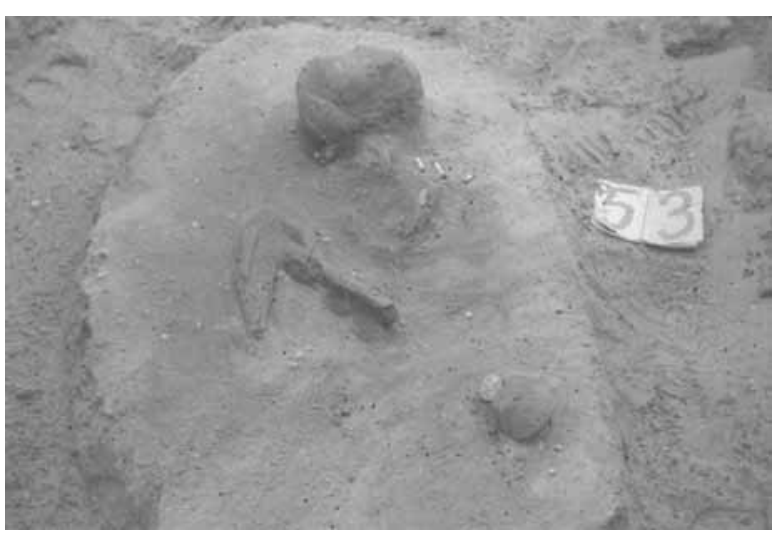

Inhumation burial in an oblong grave pit with rounded corners. The body was laid on the right side in a contracted position. The arms did not survive. The left thigh was drawn up into a horizontal position, the right one slightly higher, the legs were bent back toward the buttocks.

The burial contained the following grave goods: three Dentalium beads (1) above the left shoulder; a small vessel (2) turned upside-down, $15 \mathrm{~cm}$ behind the pelvis; an oval side-scraper (3) beside the vessel.
Grave goods

1. Beads. Three large, red painted Dentalium badense beads. Inv. no. 56.11.34.1 (Pl. XXIV. 53/1).

2. Scooping vessel. Greyish-brown, somewhat squat, plain scooping vessel with conical body. The rim is strongly worn owing to use-wear. The strap handle rises above the rim and springs to the base. The handle is joined from its fragments. H. $3.9 \mathrm{~cm}, \mathrm{~d} M .7 .3 \mathrm{~cm}$, dB. 3.5 cm. Inv. no. 56.11.34.2 (Pl. XXIV. 53/2).

3. Radiolarite side-scraper. Inv. no. 56.11.34.3 (Pl. XXIV. 53/3).

\section{Grave 54 (Square I6; Pl. XXIV)}

Size of grave pit: L. $83 \mathrm{~cm}, W .52 \mathrm{~cm}$

Depth: $110 \mathrm{~cm}$

Orientation: $\mathrm{S}$ to $\mathrm{N}$, with the head toward the $\mathrm{S}$

Position of skeleton: laid on the left side

L. of skeleton (contracted): $40 \mathrm{~cm}$

L. of skeleton (extended): -

Age at death: infans I

Sex: child

Condition of skeleton: badly preserved

Preserved skeletal bones: ${ }^{54}$ small bone fragments

Inhumation burial in an oval grave pit with rounded corners. The body was laid on the left side in a contracted position. Only the position of the skull and the thigh-bone could be recorded.

The burial did not contain any grave goods.

\section{Grave 55 (Square I5/I6; Pl. XXV)}

Size of grave pit: L. $95 \mathrm{~cm}, W .75 \mathrm{~cm}$

Depth: $100 \mathrm{~cm}$

Orientation: A: S to $\mathrm{N}$, with the head toward the $\mathrm{S}, \mathrm{B}: \mathrm{S}$ to $\mathrm{N}$, with the head toward the $\mathrm{S}$

Position of skeleton: A: laid on the right side, B: laid on the left side

L. of skeleton (contracted): A: $50 \mathrm{~cm}, \mathrm{~B}: c a .35 \mathrm{~cm}$

L. of skeleton (extended): A: $82 \mathrm{~cm}, \mathrm{~B}:-$

Age at death: A: infans I, B: infant

Sex: A: child, B: infant

Condition of skeleton: A-B: badly preserved

Preserved skeletal bones: ${ }^{55} \mathrm{~A}$ : skull fragments and long bones

Double burial in a grave pit with rounded corners.

\section{Burial A}

The body was laid on the right side in a contracted position. The arms were extended and laid on the knees. The thighs were drawn up into a horizontal position, the legs were bent back toward the buttocks.

The burial contained the following grave goods: a scooping vessel (1) set upright in front of the knees; a red stone (2) under the previous vessel; twenty-one beads (3) around the neck.

\footnotetext{
${ }^{54}$ The skeletal remains can no longer be found. The anthropological data are quoted from the excavation diary.

${ }_{55}$ The skeletal remains can no longer be found. The anthropological data are quoted from the excavation diary.
} 
Burial B

The body was deposited parallel to Burial A, but about $5-8 \mathrm{~cm}$ higher. It was probably laid on the left side in a contracted position.

The burial did not contain any grave goods.

Grave goods

1. Scooping vessel. Greyish-black, plain vessel with slightly everted rim. The high strap handle spans the rim and the base. H. $4.3 \mathrm{~cm}$, dM. $8.7 \mathrm{~cm}$. Inv. no. 56.11.35.1 (Pl. XXV. 55/1).

2. Triangular red stone. Diam. $4.5 \mathrm{~cm}$. Inv. no. 56.11.35.2 (Pl. XXV. 55/2). ${ }^{56}$

3. Beads. Twenty-one limestone beads of varying sizes. Inv. no. 56.11.35.3 (Pl. XXV. 55/3).

The following finds were also inventoried as coming from this grave: ${ }^{57}$

4. Pot. Body sherd of a reddish-brown, thick-walled, worn pot. L. $12 \mathrm{~cm}$. Joined from its fragments. Inv. no. 56.11.35.4 (Pl. XXV. 55/4).

5. Bowl. Rim and body sherd of a small, greyishbrown, semi-spherical bowl. dM. $5.5 \mathrm{~cm}$. Inv. no. 56.11.35.5 (Pl. XXV. 55/5).

6. Pitcher. Body sherd of a greyish, worn pitcher decorated with fluting. L. $4.2 \mathrm{~cm}$. Inv. no. 56.11.35.6 (Pl. XXV. 55/6).

7. Bowl. Body and base fragment of a greyish-brown bowl. L. $4.5 \mathrm{~cm}$. Inv. no. 56.11.35.7 (Pl. XXV. 55/7).

8. Pitcher handle. Fragment of a brownish, narrow, strap handle. L. $3.5 \mathrm{~cm}, W .1 .9 \mathrm{~cm}$. Inv. no. 56.11.35.8 (Pl. XXV. 55/8).

\section{Grave 56 (Square I7; Pl. XXIV)}

Size of grave pit: L. $115 \mathrm{~cm}, W .90 \mathrm{~cm}$

Depth: $85 \mathrm{~cm}$

Orientation: A: S-SW to N-NE, with the head toward the S-SW, B: $\mathrm{E}$ to $\mathrm{W}$, with the head toward the $\mathrm{W}$

Position of skeleton: A: laid on the right side, B: laid on the right side

L. of skeleton (contracted): A: $85 \mathrm{~cm}, \mathrm{~B}: 50 \mathrm{~cm}$

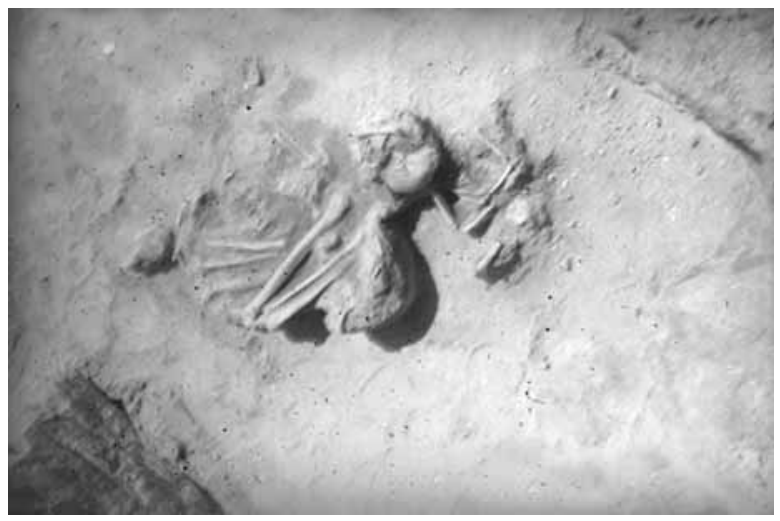

$\overline{56}$ The object has since been lost or mislaid. The drawing is based on József Korek's grave sheet.

57 It is uncertain whether these finds had indeed been recovered from this grave since the excavation diary does not mention pottery sherds.
L. of skeleton (extended): -

Age at death: A: $23-x$ years, B: child

Sex: A: female (?), B: -

Condition of skeleton: A: badly preserved, B: badly preserved

Preserved skeletal bones: ${ }^{58} \mathrm{~A}$ : skull, long bones

Double inhumation burial in an oval grave pit.

\section{Burial A}

The upper part of the body was laid on the back, with the left arm extended and placed on the pelvis, the right arm extended and placed on the belly. The right thigh was drawn up almost to the right shoulder, the left thigh into a horizontal position. The legs were bent back toward the buttocks.

The burial did not contain any grave goods.

\section{Burial B}

The body was deposited crosswise at the feet of Burial A. The body was laid on the right side in a contracted position. Its exact position could not be recorded.

The burial contained the following grave goods: five beads (1) around the neck.

Grave goods

1. Beads. Five small limestone beads. Inv. no. 56.11.36.1 (Pl. XXIV. 56/1).

\section{Grave 57 (Square H5; Pl. XXVI)}

Size of grave pit: L. $105 \mathrm{~cm}, W .85 \mathrm{~cm}$ Depth: $110 \mathrm{~cm}$

Orientation: $\mathrm{N}$ to $\mathrm{S}$, with the head toward the $\mathrm{N}$

Position of skeleton: laid on the right side

L. of skeleton (contracted): $94 \mathrm{~cm}$

L. of skeleton (extended): -

Age at death: $40-x$ years

Sex: male

Condition of skeleton: well preserved

Preserved skeletal bones: skull, long bones

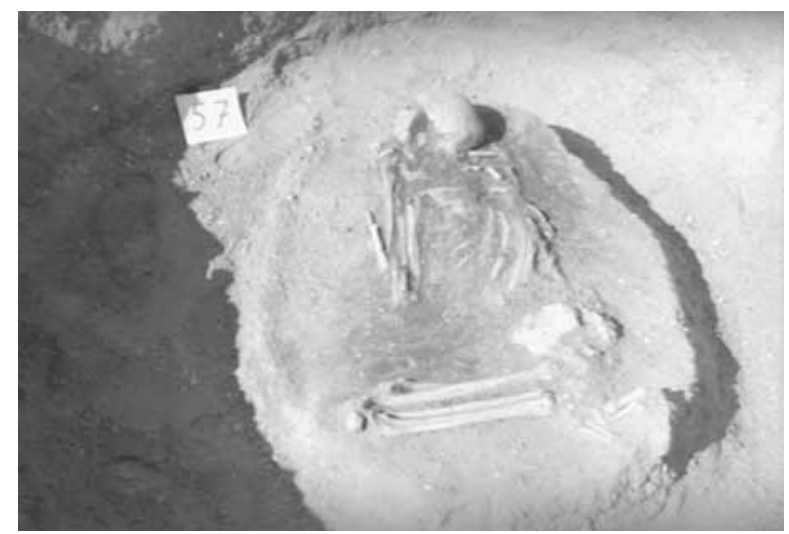

Inhumation burial in an oval grave pit containing stones, which had been heaped over the body. The body was laid on the right side in a contracted position.

\footnotetext{
58 The skeletal remains of Burial B can no longer be found. The anthropological data are quoted from the excavation diary.
} 
The arms were bent at the elbow and drawn up in front of the face. The thighs were drawn up into a horizontal position, the legs were bent back toward the buttocks.

The burial did not contain any grave goods.

\section{Grave 58 (Square I7; Pl. XXVI)}

Size of grave pit: L. $110 \mathrm{~cm}, W .85 \mathrm{~cm}$

Depth: $115 \mathrm{~cm}$

Orientation: $\mathrm{S}$ to $\mathrm{N}$, with the head toward the $\mathrm{S}$

Position of skeleton: laid on the right side

L. of skeleton (contracted): $90 \mathrm{~cm}$

L. of skeleton (extended): $155 \mathrm{~cm}$

Age at death: $40-95$ years

Sex: female

Condition of skeleton: medium well preserved

Preserved skeletal bones: skull, long bones

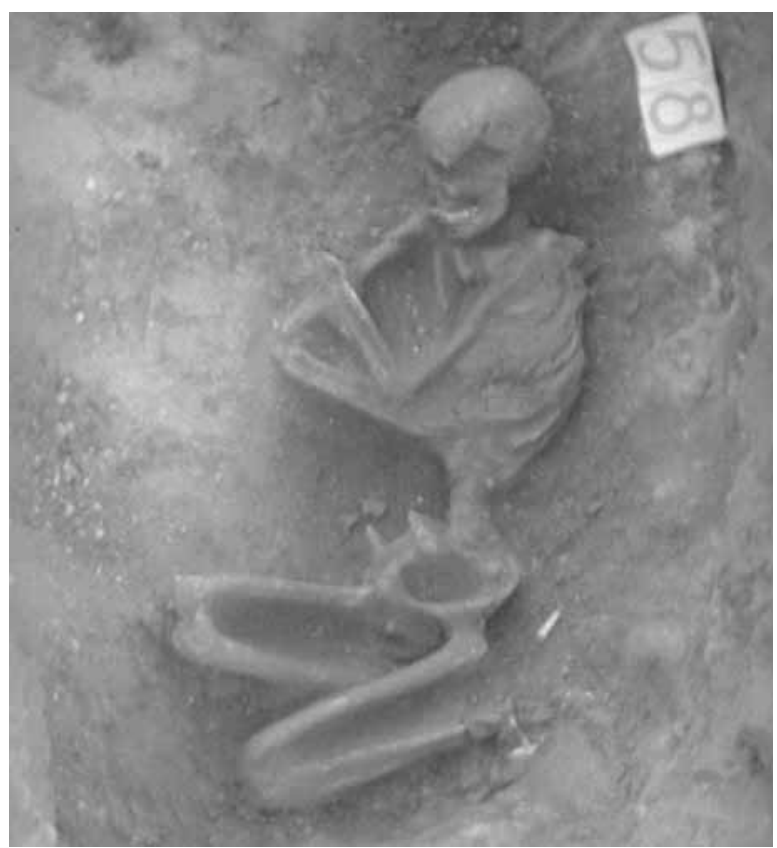

Inhumation burial in a grave pit with rounded corners containing stones between $-30 \mathrm{~cm}$ and $-90 \mathrm{~cm}$. The body was laid on the right side in a contracted position. The arms were bent at the elbow and crossed over the chest. The thighs were drawn up into a horizontal position, the legs were bent back toward the buttocks.

The burial contained the following grave goods: ten beads (1) around the neck and under the skull.

Grave goods

1. Beads. Ten limestone beads of varying sizes. Inv. no. 56.11.37.1 (Pl. XXVI. 58/1).

\section{Grave 59 (Square I4/J4; Pl. XXVII)}

Size of grave pit: -

Depth: $110 \mathrm{~cm}$

Orientation: -

Position of skeleton: -
L. of skeleton (contracted): -

L. of skeleton (extended): -

Age at death: -

Sex: -

Condition of skeleton: -

Preserved skeletal bones: -

The burial was destroyed during earth-moving operations. The grave contained four broken vessels: a bowl (1), a one-handled mug (2), a pitcher (3) and a cup (4).

Grave goods

1. Bowl. Brownish-grey, undecorated, conical bowl with short, cylindrical neck and a small handle on the belly (which broke off). Joined from its fragments and restored. H. $9 \mathrm{~cm}, W .18 .5 \mathrm{~cm}, \mathrm{~dB} .6 .3 \mathrm{~cm}$. Inv. no. 56.11.38.1 (Pl. XXVII. 59/1).

2. Mug. Grey, worn mug with cylindrical neck and flattened globular body. The high-drawn handle spans the rim and the belly. The belly is covered with fluting, now worn. Joined from its fragments and restored. H. $6.5 \mathrm{~cm}$, dM. $4.4 \mathrm{~cm}$. Inv. no. 56.11.38.2 (Pl. XXVII. 59/2).

3. Pitcher. Body and base fragments of a brownishgrey, worn pitcher decorated with vertical fluting on the belly. Three non-joining pieces. Inv. no. 56.11.38.3 (Pl. XXVII. 59/3).

4. Cup. Fragment of a greyish-brown, conical cup with slightly everted rim and a small strap handle springing from the rim to the belly. The body is decorated with a row of punctates around the shoulder and two vertical rows of punctates on either side of the handle. Patches of white encrustation survive in the punctates. Joined from its fragments. H. $4.5 \mathrm{~cm}, \mathrm{~d} M$. $7.6 \mathrm{~cm}$. Inv. no. 56.11.38.4 (Pl. XXVII. 59/4).

\section{Grave 60 (Square J4; Pl. XXVI)}

Size of grave pit: L. $95 \mathrm{~cm}, W .60 \mathrm{~cm}$ Depth: $85 \mathrm{~cm}$

Orientation: SE to NW, with the head toward the SE

Position of skeleton: laid on the left side

L. of skeleton (contracted): $73 \mathrm{~cm}$

L. of skeleton (extended): -

Age at death: $13-14$ years

Sex: child

Condition of skeleton: medium well preserved

Preserved skeletal bones: skull, long bones

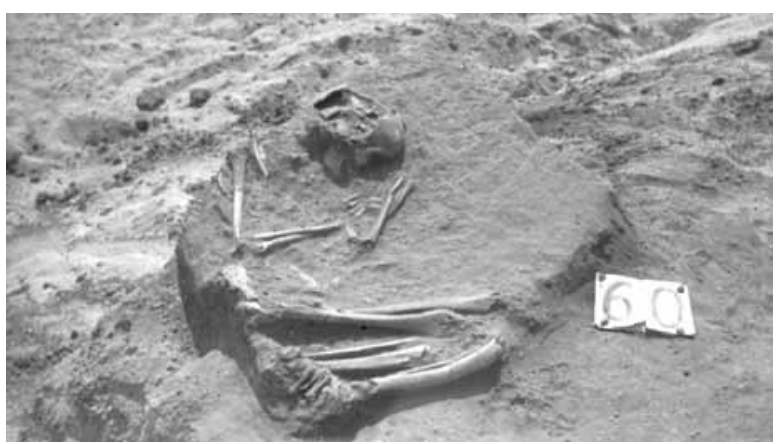


Inhumation burial in an oblong grave pit with rounded corners. The body was laid on the left side in a contracted position. The right arm was bent at the elbow and the hand clasped the left upper arm. The left arm was bent at the elbow and drawn up in front of the face. The thighs were drawn up into a horizontal position, the legs were bent back toward the buttocks.

The burial contained the following grave goods: six Dentalium beads (1), five around the neck and one by the left elbow; a bone implement (2) $35 \mathrm{~cm}$ north-west of the ankle.

Grave goods

1. Beads. Six Dentalium beads. Inv. no. 56.11.39.1 (Pl. XXVI. 60/1). ${ }^{59}$

2. Fragment of a bone implement carved from the long bone of a large sized mammal. Two other similar fragments probably came from bone implements too. Inv. no. 56.11.39.2 (Pl. XXVI. 60/2).

\section{Grave 61 (Square I4; Pl. XXVII)}

Size of grave pit: L. $115 \mathrm{~cm}, W .85 \mathrm{~cm}$ Depth: $110 \mathrm{~cm}$

Orientation: S-SW to N-NE, with the head toward the S-SW

Position of skeleton: laid on the left side

L. of skeleton (contracted): $80 \mathrm{~cm}$

L. of skeleton (extended): $115 \mathrm{~cm}$

Age at death: 6-8 years

Sex: child

Condition of skeleton: medium well preserved

Preserved skeletal bones: skull, long bones

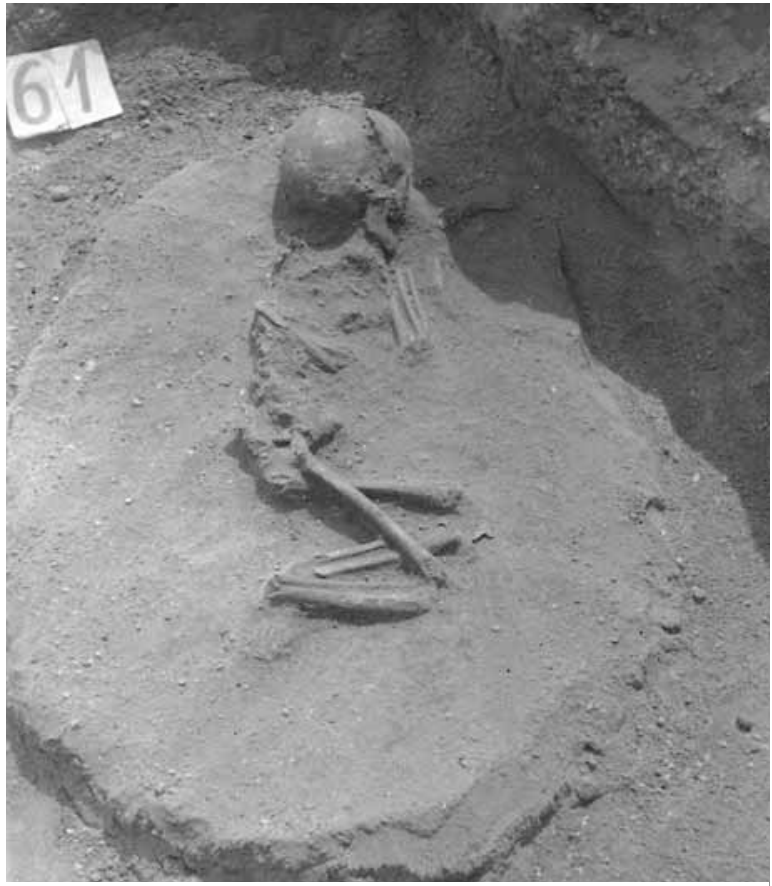

59 Even though the excavation diary mentions six beads, only five are recorded in the acquisitions register, probably because one of the beads slipped into another one. László Gucsi examined all the beads when preparing the drawings and found the sixth bead, which had slipped into another one.
Inhumation burial in a rounded grave pit containing stones. The body was laid on the left side in a contracted position. The arms were bent at the elbow, with the hands placed under the chin. The left thigh was drawn up into a horizontal position, the right thigh was slightly drawn up, the legs were bent back toward the buttocks.

The burial contained the following grave goods: a red-painted goblet (1) in front of the face; a limestone blade (2) behind the head.

\section{Grave goods}

1. Goblet. Fragment of a goblet with red exterior, yellow interior and rounded upper part set on a solid, cylindrical foot with round base. The vessel body was painted red. Joined from its fragments. H. 9 cm, dB. 5.3 cm. Inv. no. 56.11.40.1 (Pl. XXVII. 61/1).

2. Limestone blade. Inv. no. 56.11.40.2 (Pl. XXVII. 61/2).

\section{Grave 62 (Square I5; Pl. XXVI)}

Size of grave pit: L. $70 \mathrm{~cm}, W .48 \mathrm{~cm}$

Depth: $80 \mathrm{~cm}$

Orientation: $W$ to $E$. with the head toward the $W$

Position of skeleton: laid on the left side

L. of skeleton (contracted): $70 \mathrm{~cm}$

L. of skeleton (extended): -

Age at death: $7-8$ years

Sex: child

Condition of skeleton: badly preserved

Preserved skeletal bones: skull, long bone fragments

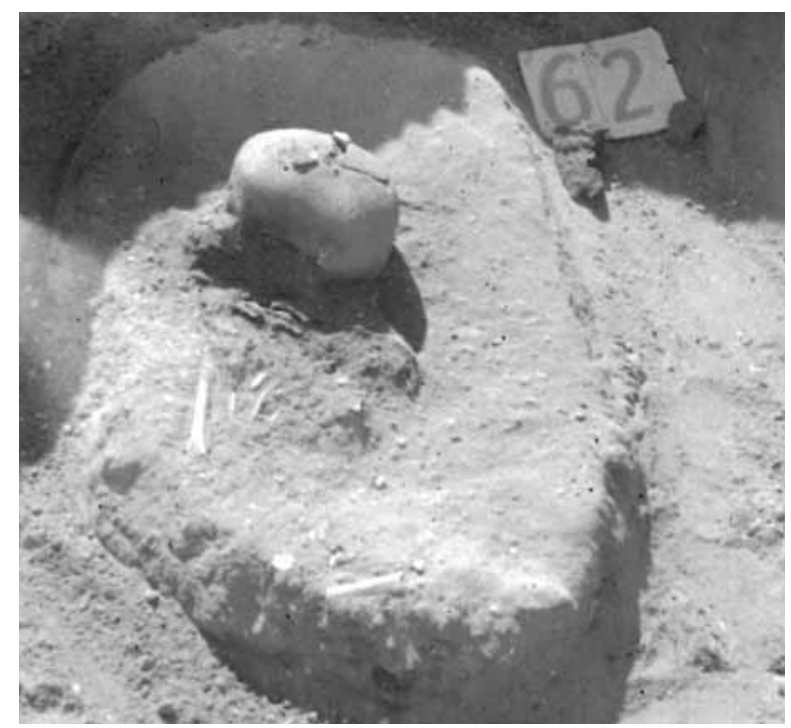

Inhumation burial in a rounded grave pit containing stones. The body was laid on the left side in a contracted position. The thighs were drawn up into a horizontal position. The position of the arms and the legs could not be established.

The burial did not contain any grave goods. 
Grave 63 (Square J4; Pl. XXVIII)

Size of grave pit: L. $100 \mathrm{~cm}, W .90 \mathrm{~cm}$

Depth: $85 \mathrm{~cm}$

Orientation: S-SW to N-NE. with the head toward the S-SW

Position of skeleton: laid on the left side

L. of skeleton (contracted): $72 \mathrm{~cm}$

L. of skeleton (extended): $126 \mathrm{~cm}$

Age at death: $13-15$ years

Sex: child

Condition of skeleton: medium well preserved

Preserved skeletal bones: skull, long bones

Inhumation burial in an oval grave pit. The body was laid on the left side in a contracted position. The skull rested on the left temporal bone. The arms were bent at the elbow and drawn up in front of the face. The right thigh was drawn up into a horizontal position, the leg was bent back toward the buttocks. The left thigh was drawn up in front of the body, with the knee by the left wrist, the leg was bent back toward the buttock with the foot resting under the right ankle.

The burial contained the following grave goods: two shell plaques (1) on the left temple; a copper needle (2) between the fingers; a necklace of thirty-six beads and one Dentalium bead (3) around the neck and on the chest; seven beads (4) around the right leg.

Grave goods

1. Shell plaques. Rectangular Unio crassus shell plaques with a pair of perforation along the short sides. Two broken pieces. Inv. no. 56.11.41.1 (Pl. XXVIII. $63 / 1)^{60}$

2. Copper needle L. $3.5 \mathrm{~cm}$. Inv. no. 56.11.41.2 (Pl. XXVIII. 63/2).61

3. Beads. Thirty-six limestone beads of varying sizes and one broken Dentalium bead. Inv. no. 56.11.41.3 (Pl. XXVIII. 63/3).62

4. Beads. Seven limestone beads. Inv. no. 56.11.41.4 (Pl. XXVIII. 63/4).

\section{Grave 64 (Square I4; Pl. XXVIII)}

Size of grave pit: L. $100 \mathrm{~cm}, W .85 \mathrm{~cm}$

Depth: $75 \mathrm{~cm}$

Orientation: $\mathrm{E}$ to $\mathrm{W}$, with the head toward the $\mathrm{E}$

Position of skeleton: laid on the left side

L. of skeleton (contracted): $85 \mathrm{~cm}$

L. of skeleton (extended): -

Age at death: $40-59$ years

Sex: male

Condition of skeleton: badly preserved

Preserved skeletal bones: skull, long bones

Inhumation burial in an oblong grave pit with rounded corners containing stones, which had been thrown onto

\footnotetext{
$\overline{60}$ Three pieces are shown on the drawing because one of the shell plaques broke in two.

${ }^{61}$ The copper needle still existed according to the checklist drawn up in 1980 , but could no longer be found when the finds were re-examined for this publication. The drawing is based on József Korek's grave sheet.

62 The Dentalium bead has since been lost or mislaid.
}

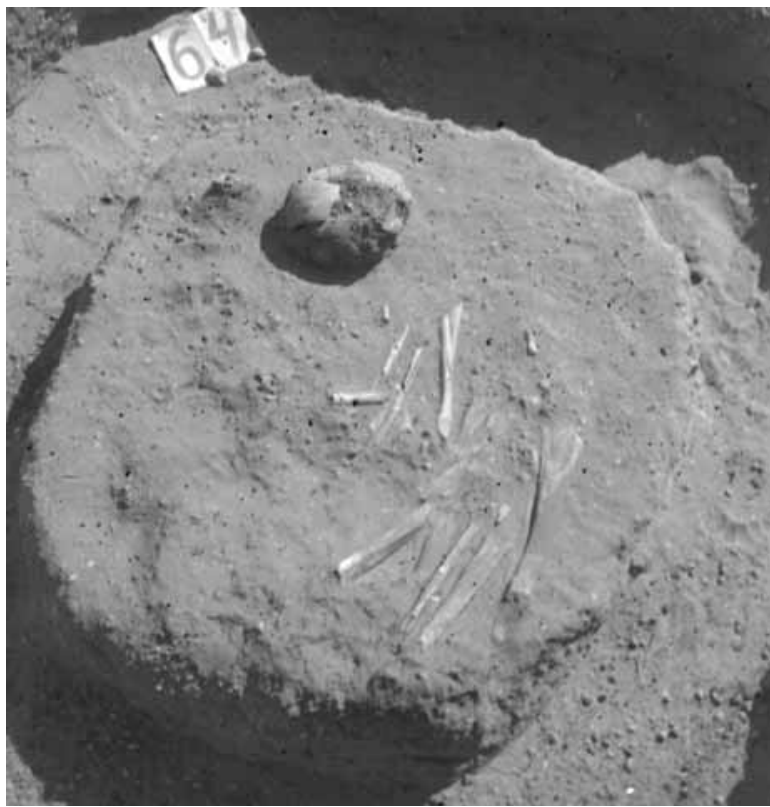

the body. The stones lay between -25 and $-70 \mathrm{~cm}$. The bones were broken. The body was laid on the left side in a strongly contracted position. The right temporal bone was crushed and most of the facial bones were missing (some fragments lay behind the skull). Very little survived of the body's upper part. The arms were bent at the elbow and the hands were drawn up in front of the face. The thighs were drawn up in front of the body, the legs were bent back toward the buttocks.

The burial contained the following grave goods: two stone blades (1-2) behind the skull.

Grave goods

1. Unretouched blade fragment made from limnic quartzite. Inv. no. 56.11.42.1 (Pl. XXVIII. 64/1).

2. Chert blade. ${ }^{63}$

\section{Grave 65 (Square I4; Pl. XXVIII)}

Size of grave pit: L. $110 \mathrm{~cm}, W .80 \mathrm{~cm}$

Depth: $80 \mathrm{~cm}$

Orientation: E-SE to W-NW, with the head toward the E-SE

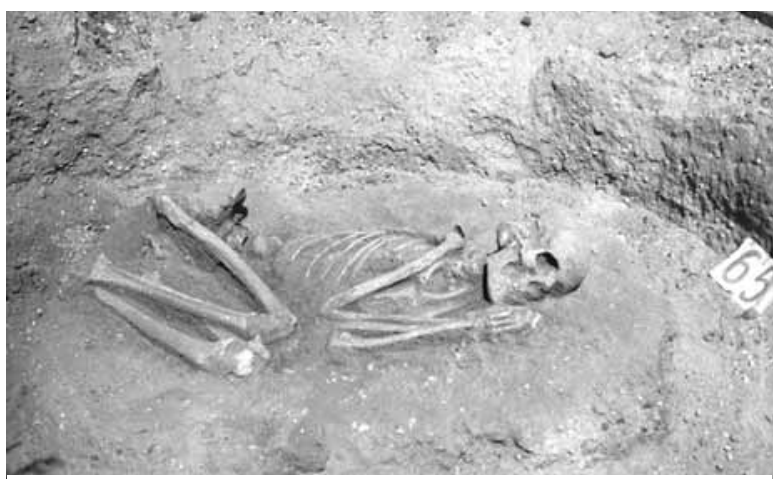

63 The object has since been lost or mislaid. One blade was inventoried as coming from the burial. Even though the stray finds include several stone blades, none of them can be securely associated with this burial. 
Position of skeleton: laid on the left side

L. of skeleton (contracted): $92 \mathrm{~cm}$

L. of skeleton (extended): $163 \mathrm{~cm}$

Age at death: $40-x$ years

Sex: female

Condition of skeleton: well preserved

Preserved skeletal bones: skull, long bones

Inhumation burial in an oval grave pit. The body was laid on the left side in a contracted position. The arms were bent at the elbow and drawn up in front of the face. The skull rested on the left temporal bone. The thighs were drawn up in front of the body, with the right knee almost touching the right elbow, the legs were bent back toward the buttocks.

The burial contained the following grave goods: fragment of a bowl (1) behind the skull.

\section{Grave goods}

1. Bipartite bowl. Rim and body sherd of a greyish, worn, bipartite bowl, decorated with a row of impressed dots under the rim from which descend a vertical row of impressed dots combined with incised lines. L. 5 cm. Inv. no. 56.11.43.1 (Pl. XXVIII. 65/1).

2. Pitcher handle. Fragment of a strap handle rising above the rim of a brownish-grey, polished pitcher. L. $5 \mathrm{~cm}$. Inv. no. 56.11.43.2.64

\section{Grave 66 (Square J4; Pl. XXIX)}

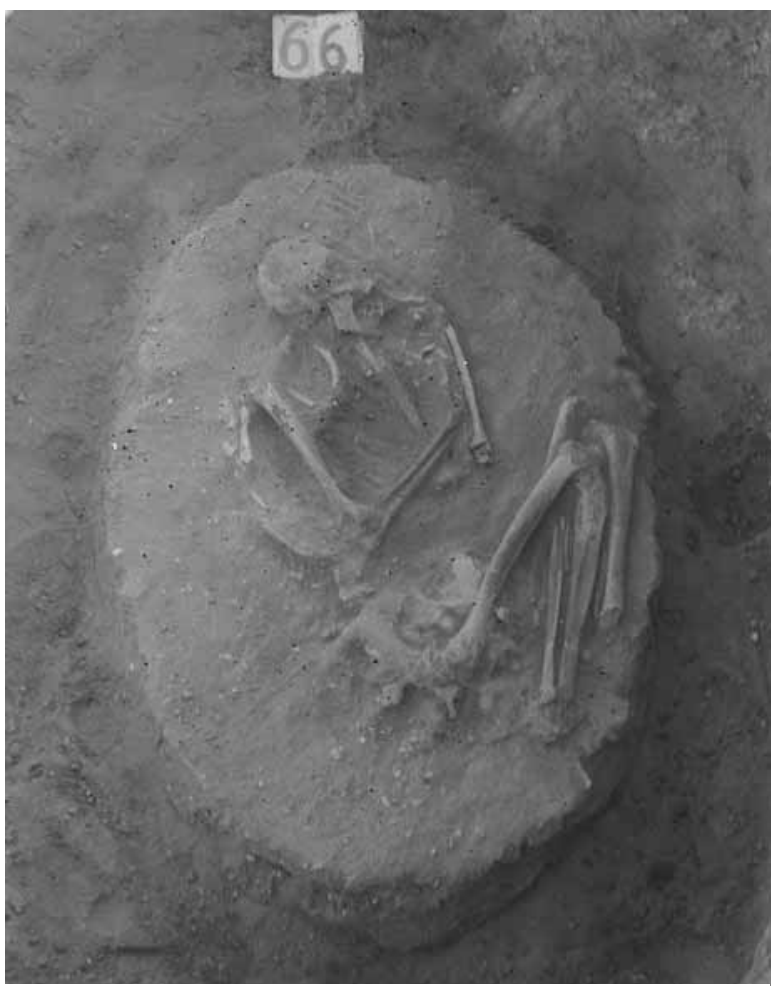

64 Although the excavation diary does not mention this handle fragment, an entry in the acquisitions register describes it as originating from this burial. It seems likely that this vessel fragment was found when the grave goods and skeletal remains were lifted or when the finds were cleaned. The sherd is very worn and it has not been illustrated.
Size of grave pit: L. $110 \mathrm{~cm}, W .80 \mathrm{~cm}$

Depth: $95 \mathrm{~cm}$

Orientation: A: SW to NE, with the head toward the SW, B: NW to SE, with the head toward the NW

Position of skeleton: A: laid on the left side, B: laid on the left side L. of skeleton (contracted): A: $23 \mathrm{~cm}, \mathrm{~B}: 95 \mathrm{~cm}$

L. of skeleton (extended): A: -, B: $165 \mathrm{~cm}$

Age at death: A: $0-1$ years, B: $40-59$ years

Sex: A: infant, B: male

Condition of skeleton: A: badly preserved, B: medium well preserved

Preserved skeletal bones: A: various fragments, B: skull, long bones

Double inhumation burial in an oval grave pit. The grave pit was filled with stones from the modern surface down to the burials.

\section{Burial A}

An infant burial, with the body laid on a flat stone on the chest of the body in Burial B. The body was laid on the left side, probably in a contracted position. The left arm was slightly bent at the elbow, the right arm lay extended beside the body. The skeletal bones were missing from the waist downward.

The burial contained the following grave goods: a broken shell plaque (1) by the waist.

\section{Burial B}

The body was laid on the left side in a strongly contracted position. The arms were bent at the elbow and drawn up, with the hands resting in front of the face. The thighs were drawn up in front of the body, the legs were bent back toward the buttocks. The pelvic bone had shifted from its original position, the skull was heavily damaged by the stones.

The burial contained the following grave goods: a necklace of five Dentalium and eighteen other beads (2) around the neck.

Grave goods

1. Shell plaque. Rectangular, broken Unio crassus shell plaque. Joined from two fragments. Inv. no. 56.11.44.1 (Pl. XXIX. 66/1).

2. Beads. Eighteen limestone beads of varying sizes, four intact and one broken Dentalium badense beads. Traces of polishing can be noted on several beads. Inv. no. 56.11.44.2 (Pl. XXIX. 66/2).

\section{Grave 67 (Square I4; Pl. XXIX)}

\author{
Size of grave pit: L. $135 \mathrm{~cm}, W .105 \mathrm{~cm}$ \\ Depth: $110 \mathrm{~cm}$ \\ Orientation: $W$ to $E$, with the head toward the $W$ \\ Position of skeleton: laid on the left side \\ L. of skeleton (contracted): $90 \mathrm{~cm}$ \\ L. of skeleton (extended): $168 \mathrm{~cm}$ \\ Age at death: $40-50$ years \\ Sex: male \\ Condition of skeleton: medium well preserved \\ Preserved skeletal bones: skull, long bones
}




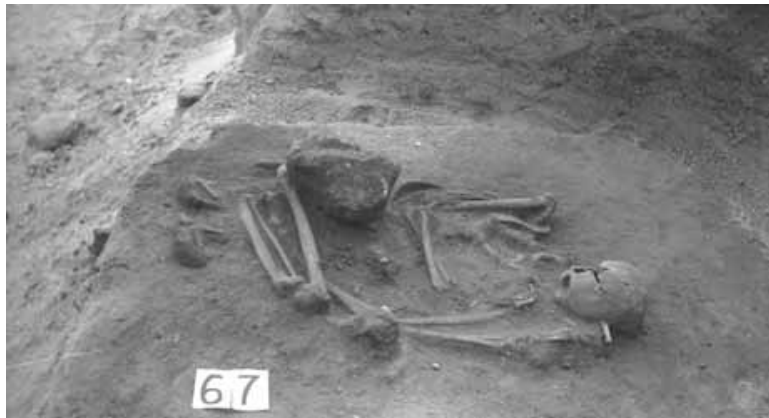

Inhumation burial in an oblong grave pit with rounded corners containing a high number of stones. (The highest number of stones was recovered from this burial.) The body was laid on the left side in a contracted position. The skull lay tilted to the left side. The right arm was bent at the elbow and drawn up, with the hand resting in front of the face. The left thigh was drawn up in front of the body, the right thigh into a horizontal position, the legs were bent back toward the buttocks. The upper part of the body was laid on the back, the lower part was laid on the left side from the waist down.

The burial contained the following grave goods: indistinct pottery sherds (1-2) scattered in the grave pit; thirty-six beads, seven intact and five broken shells (3) along the spine.

Grave goods

1. Body sherd of a grey, worn vessel. L. $4 \mathrm{~cm}$. Inv. no. 56.11.45.1.

2. Bowl. Rim and body sherd of a grey, polished bowl decorated with a row of impressed dots around the shoulder. L. 4.5 cm. Inv. no. 56.11.45.2 (Pl. XXIX. 67/2).

3. Beads. Twenty-nine limestone beads (Pl. XXIX. 67/3a), six intact and five broken Anadara diluvii shells (Pl. XXIX. 67/3b). Inv. no. 56.11.45.3.65

\section{Grave 68 (Square I4; $P l . X X X$ )}

Size of grave pit: L. $80 \mathrm{~cm}, W .65 \mathrm{~cm}$

Depth: $110 \mathrm{~cm}$

Orientation: SE to NW, with the head toward the SE

Position of skeleton: -

L. of skeleton (contracted): -

L. of skeleton (extended): -

Age at death: $1-7$ years

Sex: child

Condition of skeleton: badly preserved

Preserved skeletal bones: skull fragments

Inhumation burial in an oblong grave pit with rounded corners. The body was not laid on the floor of the grave pit, but $20 \mathrm{~cm}$ above it, in the south-western corner of

65 One of the shells is joined from two fragments. Three smaller fragment have not been illustrated. The excavation diary mentions thirty-six beads and twelve shells, but this is higher than the number of inventoried finds.

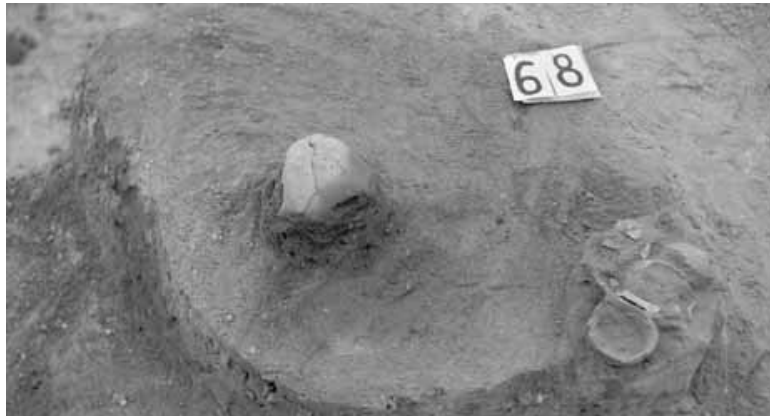

the grave pit. The skull was smashed and only the bones around the skull survived.

The burial contained the following grave goods: a broken cup (1) by the skull; a jug fragment (2) some $30 \mathrm{~cm}$ north-east of the previous vessel in the middle part of the grave pit.

\section{Grave goods}

1. One-handled cup. Fragment of reddish-brown, semi-spherical, one-handled cup, decorated with a row of impressed dots around the shoulder. The rim is fragmentary, the handle has broken off. Joined from its fragments. H. 4 cm, dM. $c a .8 \mathrm{~cm}$. Inv. no. 56.11.46.1 (Pl. XXX. 68/1).

2. Jug. Neck, body and base fragment of a brownish, worn, undecorated jug with cylindrical neck. Joined from its fragments. H. $11.3 \mathrm{~cm}, \mathrm{~dB} .6 \mathrm{~cm}$. Inv. no. 56.11.46.2 (Pl. XXX. 68/2).

\section{Grave 69 (Square I5)}

Size of grave pit: -

Depth: $130 \mathrm{~cm}$

Orientation:-

Position of skeleton: -

L. of skeleton (contracted): -

L. of skeleton (extended): -

Age at death: $23-x$ years

Sex: female (?)

Condition of skeleton: -

Preserved skeletal bones: -

Inhumation burial in a destroyed grave. The grave pit contained stones. The grave lay in the side of the sandpit and was destroyed by a heavy torrent of rain; only the section around the pelvis survived.

The burial did not contain any grave goods.

\section{Grave 70 (Square H5; Pl. XXXI)}

Size of grave pit: -

Depth: -

Orientation: -

Position of skeleton: -

L. of skeleton (contracted): -

L. of skeleton (extended): -

Age at death: $40-59$ years

Sex: female (?)

Condition of skeleton: -

Preserved skeletal bones: skull fragments 
Inhumation burial. It was destroyed by a heavy torrent of rain, similarly to Grave 69.

The burial contained the following grave goods: three broken vessels (1-3).

\section{Grave goods}

1. Goblet. Two non-joining fragments of a brown goblet with rounded upper part set on a solid, rectangular foot with rectangular base. The upper part is decorated with three incised, parallel zig-zag lines, the foot with incised zig-zag motifs and a lattice pattern on two opposing sides. The base is incised with three pairs of intersecting lines. Patches of red painting survive on the vessel body. The base is glued to the upper part. H. $9.1 \mathrm{~cm}, \mathrm{~dB} .3 .7 \times 3.3$ cm. Inv. no. 56.11.47.1 (Pl. XXXI. 70/1).

2. Mug. Greyish mug with cylindrical neck and flattened globular body. The high-flung strap handle spans the rim and the shoulder. The belly is decorated with fluting. Joined from its fragments. H. $6.8 \mathrm{~cm}, \mathrm{dM} .4 .5 \mathrm{~cm}$. Inv. no. 56.11.47.2 (Pl. XXXI. 70/2).

3. Amphora. Rim, neck, body and base fragments of a grey, worn amphora with cylindrical neck and biconical body. Two small, flat handles are set on the shoulder. An incised bundle of lines encircles the neck; the belly is decorated with vertical fluting. H. $13.4 \mathrm{~cm}$, dM. $8 \mathrm{~cm}$, dB. $6.8 \mathrm{~cm}$. Inv. no. 56.11.47.3 (Pl. XXXI. 70/3).

\section{Grave 71 (Square H5; Pl. XXX)}

Size of grave pit: L. $95 \mathrm{~cm}, W .80 \mathrm{~cm}$

Depth: $80 \mathrm{~cm}$

Orientation: A: E-SE to W-NW. with the head toward the E-SE, $\mathrm{B}$ : E-SE to W-NW, with the head toward the E-SE

Position of skeleton: A: laid on the left side, B: laid on the right side (?)

L. of skeleton (contracted): A: $46 \mathrm{~cm}, \mathrm{~B}: 47 \mathrm{~cm}$

L. of skeleton (extended): -

Age at death: A: $0-1$ years, B: $0-1$ years

Sex: A: infant, B: infant

Condition of skeleton: A: badly preserved, B: badly preserved

Preserved skeletal bones: A-B: various fragments

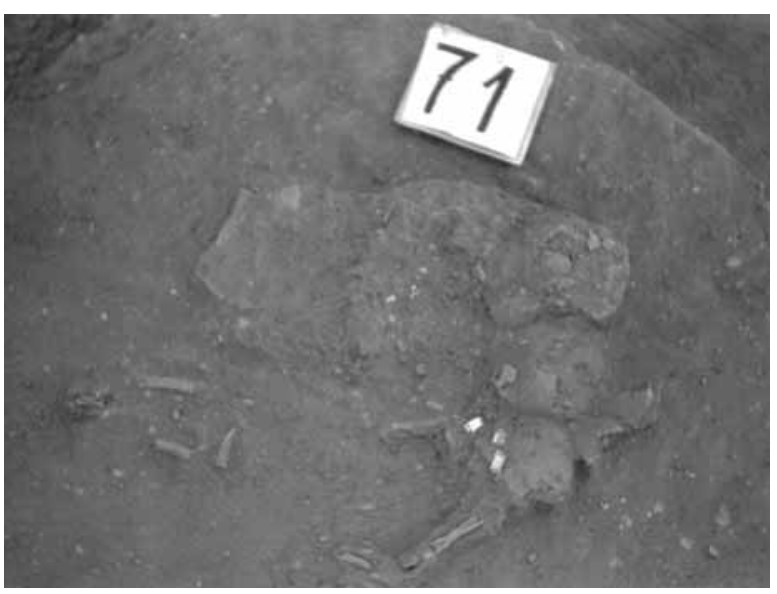

Double inhumation burial in a rounded grave pit containing stones. Two infants of the same age were buried in this grave.

Burial A

The body was laid on the left side in a contracted position. The thighs were drawn up into a horizontal position, the legs were bent back toward the buttocks.

The burial contained the following grave goods: a necklace of thirty-one beads and shell plaques (1) around the neck and on the chest.

\section{Burial B}

The body lay parallel to Burial A, directly beside it. The body was probably laid on the right side in a contracted position.

The burial contained the following grave goods: twelve shell plaques (2) on the forehead. Indistinct pottery sherds (3) were found behind the two skulls. ${ }^{66}$

\section{Grave goods}

1. Beads. Thirty-one limestone beads of varying sizes. Inv. no. 56.11.48.1 (Pl. XXX. 71/1). ${ }^{67}$

2. Shell plaques. Rectangular, broken Unio crassus shell plaques, with a pair of perforations along the shorter side. Twelve pieces. Inv. no. 56.11.48.2 (Pl. XXX. 71/2). ${ }^{68}$

3. Pot. Indistinct body sherd of a reddish-brown pot. L. 5.4 cm. Inv. no. 56.11 .48 .3 .

\section{Grave 72 (Square H5; Pl. XXIX)}

Size of grave pit: L. $120 \mathrm{~cm}, W .75 \mathrm{~cm}$ Depth: $90 \mathrm{~cm}$

Orientation: NW to SE, with the head toward the NW

Position of skeleton: -

L. of skeleton (contracted): -

L. of skeleton (extended): -

Age at death: infans I

Sex: child

Condition of skeleton: badly preserved

Preserved skeletal bones: ${ }^{69}$ various fragments

Inhumation burial in a rounded grave pit containing stones. The body was deposited in the north-western part of the grave pit. Only fragments of the skull and a few ribs survived.

The burial contained the following grave goods: a perforated animal tooth (1) between the ribs.

\footnotetext{
66 Only one sherd was inventoried.

67 When preparing the drawings, László Gucsi noted that several beads were damaged and showed signs of repair: the bead-maker the fractures had been repaired by polishing. Traces of rough polishing could be made out on several beads. Green patina stains can be seen on several beads. ${ }_{68}$ Twelve shell plaques are mentioned in the acquisitions register. The two broken shell plaques from Burial A were not inventoried. Fifteen shell plaques were photographed and illustrated because some of the shell plaques broke.

69 The skeletal remains can no longer be found. The anthropological data are quoted from the excavation diary.
} 
Grave goods

1. Animal tooth. Broken and perforated at one end. L. 2.5 cm. Inv. no. 56.11.49.1 (Pl. XXIX. 72/1).

\section{Grave 73 (Square I4; Pl. XXXII)}

Size of grave pit: L. $135 \mathrm{~cm}, W .85 \mathrm{~cm}$ Depth: $150 \mathrm{~cm}$

Orientation: $\mathrm{E}$ to $\mathrm{W}$, with the head toward the $\mathrm{E}$

Position of skeleton: laid on the left side

L. of skeleton (contracted): $96 \mathrm{~cm}$

L. of skeleton (extended): $152 \mathrm{~cm}$

Age at death: $44-55$ years

Sex: female

Condition of skeleton: well preserved

Preserved skeletal bones: complete skeleton

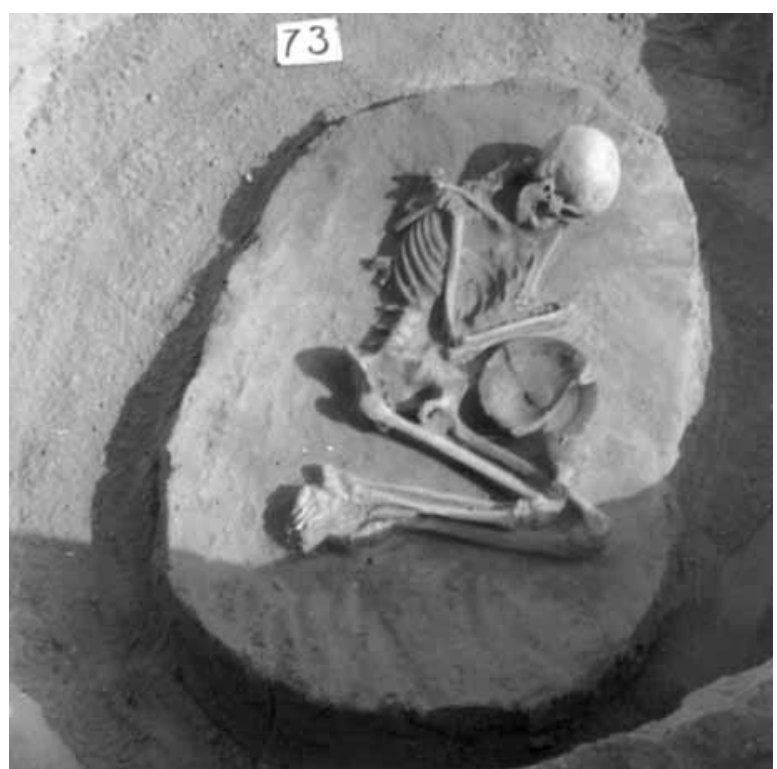

Inhumation burial in an oval grave pit. The body was laid on the left side in a contracted position. The right arm was bent at the elbow, the left arm was extended toward the knee. The thighs were drawn up into a horizontal position, the legs were bent back toward the buttocks.

The burial contained the following grave goods: a goblet (1) tilted to one side $c a .10 \mathrm{~cm}$ from the knees; a crushed bowl (2) between the left thigh and the right forearm; a bone awl (3) beside the goblet; a bone implement (4) behind the ribs; ninety-three intact and six broken beads (5) by the spine.

\section{Grave goods}

1. Goblet. Reddish-brown goblet with rounded upper part set on a cylindrical foot with a round base. The upper part is incised with three zig-zag lines. The foot and the base are plain. The foot is pierced by a round perforation. The vessel body bears patches of red painting on the exterior and interior. The upper part is glued to the foot. H. $8.5 \mathrm{~cm}, \mathrm{~d} M .10 .3 \mathrm{~cm}$, dB. 4.7 cm. Inv. no. 56.11.50.1 (Pl. XXXII. 73/1).
2. One-handled bowl. Grey, worn bowl decorated with a row of punctates encircling the shoulder. The short strap handle spans the rim and the shoulder. Joined from its fragments. H. $8 \mathrm{~cm}, \mathrm{dM} .16 \mathrm{~cm}$, dB. 5.5 cm. Inv. no. 56.11.50.2 (Pl. XXXII. 73/2).

3. Bone fragment. Triangular bone fragment, the tip is broken. L. 3-5 cm. Inv. no. 56.11 .50 .3 (Pl. XXXII. 73/3).

4. Bone implement. Fragments of a round sectioned bone implement (perhaps a haft). L. $3.2 \mathrm{~cm}$. Broken in five pieces. Inv. no. 56.11.50.4 (Pl. XXXII. 73/4).

5. Beads. Ninety-two intact and six broken limestone beads and one stone bead. Inv. no. 56.11.50.5 (Pl. XXXII. 73/5).

\section{Grave 74 (Square I7; Pl. XXXIII)}

\author{
Size of grave pit: L. $105 \mathrm{~cm}$, W. $55 \mathrm{~cm}$ \\ Depth: $80 \mathrm{~cm}$ \\ Orientation: $W$ to $E$, with the head toward the $W$ \\ Position of skeleton: laid on the right side \\ L. of skeleton (contracted): $95 \mathrm{~cm}$ \\ L. of skeleton (extended): - \\ Age at death: $14-16$ years \\ Sex: juvenis \\ Condition of skeleton: medium well preserved \\ Preserved skeletal bones: skull, long bones
}

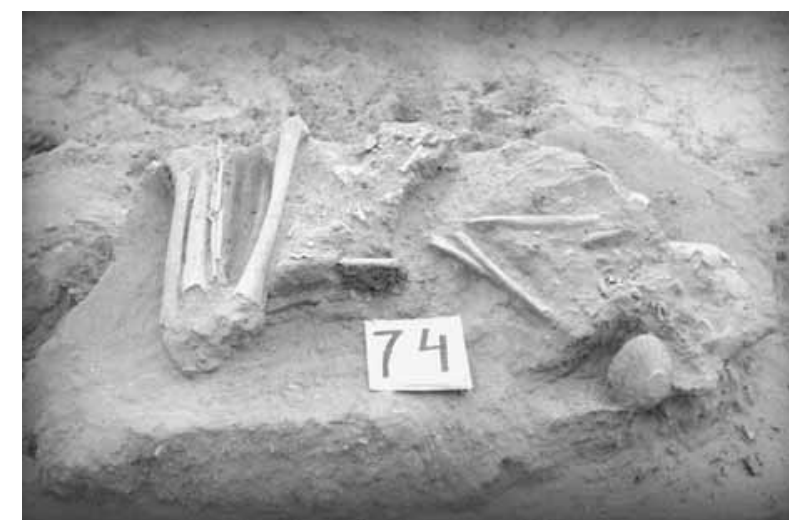

Inhumation burial in an oval grave pit. The grave pit at the edge of the sand-pit collapsed and the block of earth with the burial's lower part lay above the upper one. Since the block of earth was too heavy to be turned over, this section of the burial was excavated first. (The description of the skeletal remains and the finds follows their original position.)

The body was laid on the right side in a contracted position. The right arm was bent at the elbow and drawn up, with the hand resting in front of the face. The left arm was extended beside the body. The thighs were drawn up into a horizontal position, the legs were bent back toward the buttocks.

The burial contained the following grave goods: a necklace of eighty-five beads and thirteen shells (1) by the neck and on the chest; a second necklace of thirty shell beads (2) around the neck; a ladle (3) in front of the face. 
Grave goods

1. Beads. Eighty-five limestone beads of varying sizes (Pl. XXXIII. 74/1b) and thirteen Anadara diluvii shells (Pl. XXXIII. 74/1a). Inv. no. 56.11.51.1.70

2. Beads. Twenty-nine intact and one broken Dentalium badense beads of varying sizes. Inv. no. 56.11.51.2 (Pl. XXXIII. 74/2).

3. Ladle. Grey, worn ladle decorated with three rows of incised zig-zag lines on the body and on the handle. There are two perforations near the tip of the ansa lunata handle, which is joined to the vessel body. H. 4 cm, dM. 10.4 cm, dB. $3.1 \mathrm{~cm}$. Inv. no. 56.11.51.3 (Pl. XXIII. 74/3).

\section{Grave 75 (Square I8; Pls XXXIV-XXXV)}

Size of grave pit: L. $120 \mathrm{~cm}, W .65 \mathrm{~cm}$

Depth: $80 \mathrm{~cm}$

Orientation: S-SW to N-NE, with the head toward the S-SW

Position of skeleton: laid on the left side

L. of skeleton (contracted): $95 \mathrm{~cm}$

L. of skeleton (extended): $145 \mathrm{~cm}$

Age at death: $10-12$ years

Sex: child

Condition of skeleton: badly preserved

Preserved skeletal bones: skull, long bones

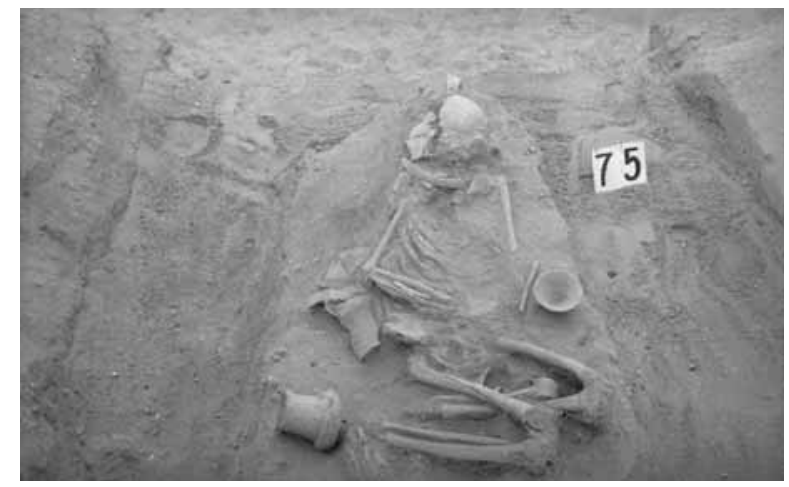

Inhumation burial in an oval grave pit. The body was laid on the left side in a contracted position. The body was more or less extended and only slightly tilted to the left side down to the pelvis, The right arm was bent at the elbow, with the hand resting on the pelvis, the left arm was extended toward the left thigh. The thighs were drawn up into an almost horizontal position, as were the legs, which were bent back toward the buttocks.

The burial contained the following grave goods: a one-handled, broken jug (1) behind the pelvis; a redpainted goblet (2) beside the left forearm; a pitcher (3) by the feet; a broken scooping vessel (4), a broken goblet (5), two fragments of a pitcher (6) and the fragment of another goblet (7) under the right thigh and the left leg; a red-painted, three-footed goblet (8) under the right pelvic bone; oblong antler plaques (9)

$\overline{70}$ Only eighty of the eighty-five inventoried beads could be found when the finds were photographed. Green patina stains can be noted on some beads. around the neck; various stone tools (10-14) between vessel no. 3 and the right foot.

Grave goods

1. Jug. Grey, polished jug with cylindrical neck, biconical body and rounded base, The high-flung handle springs from the rim to the shoulder. The neck is encircled by an incised bundle of lines, the shoulder and the belly are decorated with delicate fluting, as is the handle. Joined from its fragments and restored. H. $16.9 \mathrm{~cm}, \mathrm{dM} .10 \mathrm{~cm}, \mathrm{~dB} .7 .5 \mathrm{~cm}$. Inv. no. 56.11.52.1 (Pl. XXXIV. 75/1).

2. Goblet. Red goblet with rounded upper part set on a cylindrical foot with rounded base. The body and the foot are decorated with a three incised zig-zag lines. The foot is perforated above the base. The vessel body was painted red both on the exterior and interior, but only patches of this red painting survive in the vessel's interior. H. $7.2 \mathrm{~cm}, \mathrm{dM} .9 .1 \mathrm{~cm}$, dB. $4.3 \mathrm{~cm}$. Inv. no. 56.11.52.2 (Pl. XXXIV. 75/2).

3. Pitcher. Grey, worn pitcher with cylindrical neck and flattened globular body. The handle spans the rim and the shoulder. The belly is decorated with vertical fluting. The handle is missing, the rim is damaged. H. $11 \mathrm{~cm}$, dM. $7.5 \mathrm{~cm}$, dB. $5.5 \mathrm{~cm}$. Inv. no. 56.11.52.3 (Pl. XXXIV. 75/3).

4. Scooping vessel. Fragment of a grey, worn, semispherical, one-handled scooping vessel. The highdrawn handle springs from the rim to the base. Six impressed dots decorate the vessel body under the handle. Joined from its fragments. H. $5.5 \mathrm{~cm}$. Inv. no. 56.11.52.4 (Pl. XXXV. 75/4).

5. Goblet. Fragment of a grey, worn goblet with rounded upper part and rounded foot with a round base. Patches of red painting survive on the body. The foot is perforated. Joined from its fragments. dB. $5.6 \mathrm{~cm}$. Inv. no. 56.11.52.5 (Pl. XXXIV. 75/5).

6. Pitcher. Body and base fragment of a grey, worn pitcher. Joined from its fragments. dB. $9 \mathrm{~cm}$. Inv. no. 56.11.52.15 (Pl. XXXV. 75/6).

7. Goblet. Fragments of a reddish-brown goblet with rectangular upper part, perforated, rectangular foot and rectangular base. The body is decorated with zigzag motifs and red painting. Nine non-joining pieces. dB. 3.2 cm. Inv. no. 56.11.52.7 (Pl. XXXV. 75/7).

8. Goblet. Greyish goblet with rounded upper part set on three asymmetric feet, decorated with red painting on the exterior and interior. Joined from its fragments and restored. H. $9 \mathrm{~cm}, \mathrm{dM} .12 .1 \mathrm{~cm}$, dB. 5.5 cm. Inv. no. 56.11.52.8 (Pl. XXXV. 75/8).

9. Eight oblong antler plaques. L. $24 \mathrm{~cm}, W .2 \mathrm{~cm}$. Inv. no. 56.11.52.9 (Pl. XXXV. 75/9). ${ }^{71}$

10. Trapeze made from limnic quartzite. Inv. no. 56.11.52.10 (Pl. XXXV. 75/10).

11. Radiolarite trapeze. Inv. no. 56.11.52.11 (Pl. XXXV. 75/11). 
12. Unretouched radiolarite blade fragment. Inv. no. 56.11.52.12 (Pl. XXXV. 75/12).

13. Retouched radiolarite blade fragment. Inv. no. 56.11.52.13 (Pl. XXXV. 75/13).

14. Trapeze made from limnic quartzite. Inv. no. 56.11.52.14 (Pl. XXXV. 75/14).

Finds from the grave pit:

15. One-handled bowl. Rim, body and base fragment of a brownish, worn conical bowl with cylindrical neck. The shoulder and the belly are encircled by two rows of impressed dots and incised hatched triangles with their tip pointing downward. Joined from its fragments. Ten pieces. dM. $9 \mathrm{~cm}$. Inv. no. 56.11.52.6 (Pl. XXXV. 75/15). ${ }^{72}$

\section{Grave 76 (Square J4; Pl. XXXVI)}

Size of grave pit: L. $95 \mathrm{~cm}, W .75 \mathrm{~cm}$

Depth: $70 \mathrm{~cm}$

Orientation: SW to NE, with the head toward the SW

Position of skeleton: laid on the left side

L. of skeleton (contracted): $75 \mathrm{~cm}$

L. of skeleton (extended): -

Age at death: $40-50$ years

Sex: female

Condition of skeleton: badly preserved

Preserved skeletal bones: skull, long bones

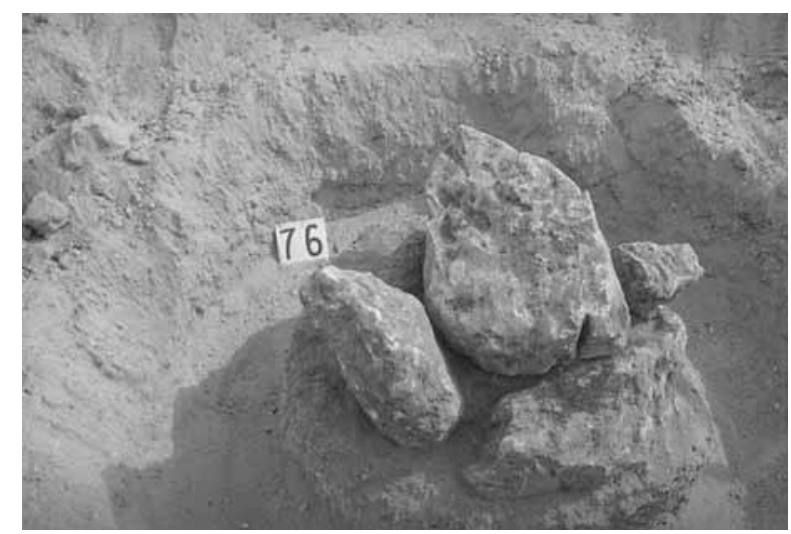

Inhumation burial in an oval grave pit containing stones, which had been thrown over the body. The body was laid on the left side in a contracted position. A large, flat stone lay on the skull. The right arm was bent at the elbow, with the hand clasping the left upper arm. The left elbow was placed under the knee, the hand was drawn up in front of the face. The thighs were drawn up in front of the body, the legs were bent back toward the buttocks.

The burial did not contain any grave goods.

\footnotetext{
72 A wide strap handle fragment with two perforations is mentioned in the same entry. It seems likely that these fragments were among the fragments of vessel 4 and that the pieces belonging different vessels could only be identified when the finds were restored.
}

Grave 77 (Square H5; Pl. XXXVI)

Size of grave pit: L. $60 \mathrm{~cm}, W .45 \mathrm{~cm}$

Depth: $50 \mathrm{~cm}$

Orientation: SW to NE, with the head toward the SW

Position of skeleton: -

L. of skeleton (contracted): $c a .25 \mathrm{~cm}$

L. of skeleton (extended): -

Age at death: infans I

Sex: child

Condition of skeleton: badly preserved

Preserved skeletal bones: ${ }^{73}$ various fragments

Inhumation burial in a rounded grave pit containing a few stones. The skeletal remains could be noted over a roughly $25 \mathrm{~cm}$ section of the grave pit. The position of the body could not be established.

The burial did not contain any grave goods.

\section{Grave 78 (Square H4; Pl. XXXVI)}

Size of grave pit: L. $95 \mathrm{~cm}, W .75 \mathrm{~cm}$

Depth: $85 \mathrm{~cm}$

Orientation: A: S-SE to N-NW, with the head toward the S-SE, B: -

Position of skeleton: A: laid on the right side, B: laid on the left side

L. of skeleton (contracted): A: $60 \mathrm{~cm}, \mathrm{~B}:-$

L. of skeleton (extended): -

Age at death: A: $0.5-1.5$ years, B: 4-6 years

Sex: A: child, B: child

Condition of skeleton: A: badly preserved, B: badly preserved

Preserved skeletal bones: A: skull, long bones, B: skull

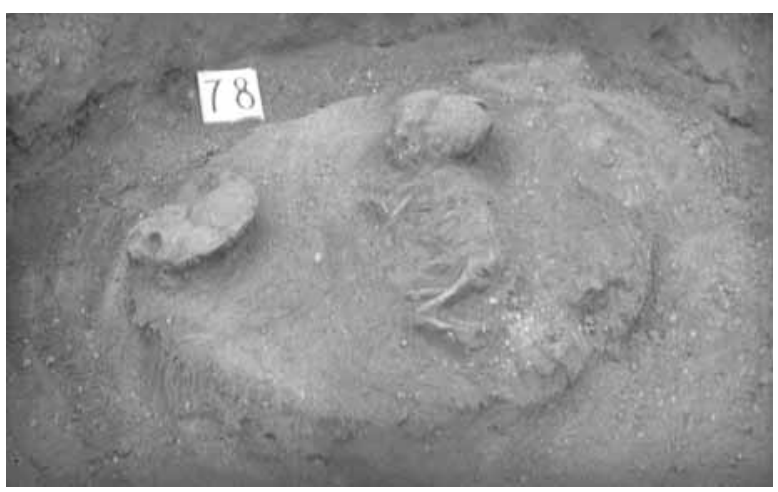

Double inhumation burial in an oval grave pit containing stones. Vessel fragments, including the rim fragment of a goblet (1) lay among the stones.

\section{Burial A}

The body was laid on the right side in a contracted position. The left arm was bent at the elbow and the hand was drawn up in front of the face. The right arm was extended toward the knees. The right thigh was drawn up into a horizontal position, the left thigh to a lesser extent, the legs were bent back toward the buttocks.

The burial did not contain any grave goods.

\footnotetext{
73 The skeletal remains can no longer be found. The anthropological data are quoted from the excavation diary.
} 
Burial B

The body was deposited east of Burial A. A child's crushed skull and a few neck vertebrae by the edge of the grave pit are all that survived. The body was laid on the left side in a contracted position. The occipital bone lay toward the grave pit's edge.

The burial contained the following grave goods: a small copper fragment (2) under the skull.

Grave goods

1. Rim fragment of a goblet. ${ }^{74}$

2. Copper fragment. ${ }^{75}$

\section{Grave 79 (Square I8; Pl. XXXVI)}

Size of grave pit: L. $110 \mathrm{~cm}, W .130 \mathrm{~cm}$ Depth: $20-45 \mathrm{~cm}$

Orientation: A: $\mathrm{S}$ to $\mathrm{N}$, with the head toward the S, B: SE to NW, with the head toward the SE

Position of skeleton: A: laid on the left side, B: laid on the right side

L. of skeleton (contracted): A: $80 \mathrm{~cm}, \mathrm{~B}: 95 \mathrm{~cm}$

L. of skeleton (extended): A: $155 \mathrm{~cm}, \mathrm{~B}: 160 \mathrm{~cm}$

Age at death: A: $25-35$ years, B: $35-45$ years

Sex: A: male, B: female (?)

Condition of skeleton: A: medium well preserved, B: medium well preserved

Preserved skeletal bones: A: skull, long bones, B: skull, long bones

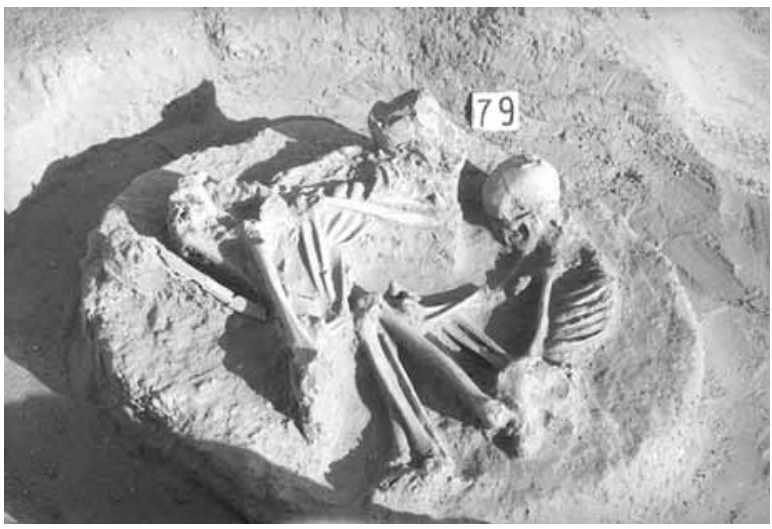

Double inhumation burial in a roughly circular grave pit.

Burial A

The body was laid on the left side in a contracted position. The top of the skull and the right leg was destroyed by ploughing. The skull lay on the occipital bone. The trunk was deposited in a prone position, the pelvic bones had shifted from their original position. The arms were bent at the elbow and the hands were clasped in front of the left knee. The right thigh was drawn up into a horizontal position, with right ankle resting on the left one. The left thigh was drawn higher, the leg was bent back toward the buttocks.

The burial did not contain any grave goods.

\footnotetext{
74 Vessel fragments were not inventoried among the finds from the burial. 75 Copper fragments were not inventoried among the finds from the burial.
}

Burial B

The body was deposited facing Burial A, with the two skulls lying beside each other. The skull of Burial B lay some $15 \mathrm{~cm}$ deeper. The body was laid on the right side in a strongly contracted position. The right arm was extended, with the hand clasping the right thigh. The left arm was bent at the elbow and the hand was clenched under the right forearm. The thighs were drawn up in front of the body, the legs were bent back toward the buttocks.

The burial did not contain any grave goods.

\section{Grave 80 (Square H4/H5; Pl. XXXVII)}

Size of grave pit: L. $90 \mathrm{~cm}, W .100 \mathrm{~cm}$

Depth: $78 \mathrm{~cm}$

Orientation: A: SE to NW, with the head toward the SE, B: -

Position of skeleton: A: laid on the left side, B: -

L. of skeleton (contracted): A: $55 \mathrm{~cm}, \mathrm{~B}:-$

L. of skeleton (extended): -

Age at death: A: 2-3 years, B: infant

Sex: A: child, B: infant

Condition of skeleton: A: badly preserved, B: badly preserved

Preserved skeletal bones: ${ }^{76}$ A: skull, long bones, B: skull fragments

Double inhumation burial in a round grave pit containing stones. Various vessel fragments lay under the stones: a cup (1) and a pitcher (2).

\section{Burial A}

The body was laid on the left side in a contracted position. The arms were bent at the elbow and the hands were drawn up in front of the chin. The thighs were drawn up into a horizontal position, the legs were bent back toward the buttocks.

The burial contained the following grave goods: a broken scooping vessel (3) above the upper arms; an animal bone (4) above the skull.

\section{Burial B}

The body was deposited south-west of Burial A, the two skulls lay beside each other. Although the exact position of the skeletal remains could not be established, it seems likely that the body was deposited parallel to Burial A.

The burial contained the following grave goods: a necklace of four Dentalium beads and four other beads (5) under the chin, and one fragmentary and two intact shells in the same area.

\section{Grave goods}

1. Cup. Fragments of a greyish, worn, semi-spherical cup. The stub of the handle can be seen on one fragment. Two non-joining pieces. L. $6.2 \mathrm{~cm}, 4 \mathrm{~cm}$. Inv. no. 56.11.54.1 (Pl. XXXVII. 80/1).

2. Pitcher. Body and base fragment of a greyish, worn pitcher. dB. $6.2 \mathrm{~cm}$. Inv. no. 56.11.54.3 (Pl. XXXVII. 80/2).

\footnotetext{
76 The skeletal remains from Burial B can no longer be found. The anthropological data are quoted from the excavation diary.
} 
3. Scooping vessel. Fragment of a brownish, polished scooping vessel with flat base, decorated with a row of impressed dots around the shoulder. The strap handle spans the rim and the belly. Joined from its fragments. dM. $10.5 \mathrm{~cm}$. Inv. no. 56.11.54.5 (Pl. XXXVII. 80/3). ${ }^{77}$

4. Animal bone. ${ }^{78}$

5. Beads. Four limestone beads, four Dentalium badense beads (Pl. XXXVII. 80/5b), two intact and one broken Unio crassus mussels (Pl. XXXVII. 80/5a). Inv. no. 56.11.54.7.79

The following finds were also inventoried as coming from this grave: ${ }^{80}$

6. Pot. Base fragment of a brownish, thick-walled pot. L. $6.5 \mathrm{~cm}$. Inv. no. 56.11.53.2.

7. Pot. Rim fragments of a greyish, worn pot with an S profile, decorated with a finger impressed rib under the rim. Two pieces, both joined from smaller fragments. dM. $10 \mathrm{~cm}, 11.5 \mathrm{~cm}$. Inv. no. 56.11 .54 .2 (Pl. XXXVII. 80/8).

8. Bowl. Body sherds from a grey, polished bowl decorated with a row of punctates around the belly. Joined from its fragments. L. $3.4 \mathrm{~cm}$. Inv. no. 56.11.54.4 (Pl. XXXVII. 80/6).

9. Pitcher. Body sherd of a grey, much worn pitcher with fluting on the body. L. $7.5 \mathrm{~cm}$. Inv. no. 56.11.54.6 (Pl. XXXVII. 80/7).

\section{Grave 81 (Square I4; Pl. XXXVI)}

Size of grave pit: L. $105 \mathrm{~cm}, W .60 \mathrm{~cm}$

Depth: $55 \mathrm{~cm}$

Orientation: E-SE to $W$-NW, with the head toward the E-SE

Position of skeleton: laid on the right side (?)

L. of skeleton (contracted): $70 \mathrm{~cm}$ (?)

L. of skeleton (extended): -

Age at death: -

Sex: male (?)

Condition of skeleton: badly preserved

Preserved skeletal bones: ${ }^{81}$ skull, long bone fragments

Disturbed inhumation burial in an oval grave pit. The area above the body and the feet was filled with stones. The skeletal remains could be observed over a $70 \mathrm{~cm}$ long area. The body was probably laid on the right side.

The burial did not contain any grave goods.
Grave 82 (Square I7; Pl. XXXVIII)

Size of grave pit: L. $100 \mathrm{~cm}, W .80 \mathrm{~cm}$

Depth: $50 \mathrm{~cm}$

Orientation: S-SE to N-NW, with the head toward the S-SE

Position of skeleton: laid on the right side

L. of skeleton (contracted): $75 \mathrm{~cm}$

L. of skeleton (extended): $112 \mathrm{~cm}$

Age at death: $9-11$ years

Sex: child

Condition of skeleton: badly preserved

Preserved skeletal bones: skull, long bones

Inhumation burial in a round grave pit containing stones. The body was laid on the right side in a contracted position. The right arm was bent at the elbow and drawn up, with the hand resting under the neck. The left arm was bent at the elbow and drawn up, with the hand laid by the right elbow. The thighs were drawn up in front of the body, the legs were bent back toward the buttocks.

The burial contained the following grave goods: a necklace of Dentalium and other beads (1) around the neck and on the chest.

\section{Grave goods}

1. Beads. Five intact and one broken Dentalium badense beads, twenty-eight limestone beads and one red clay bead. Inv. no. 56.11.55.1 (Pl. XXXVIII. 82/1).

\section{Grave 83 (Square H5; Pl. XXXVI)}

Size of grave pit: L. $120 \mathrm{~cm}, W .75 \mathrm{~cm}$

Depth: $100 \mathrm{~cm}$

Orientation: S-SE to N-NW, with the head toward the S-SE Position of skeleton: laid on the left side

L. of skeleton (contracted): $100 \mathrm{~cm}$

L. of skeleton (extended): $157 \mathrm{~cm}$

Age at death: $45-55$ years

Sex: male

Condition of skeleton: medium well preserved

Preserved skeletal bones: skull, long bones

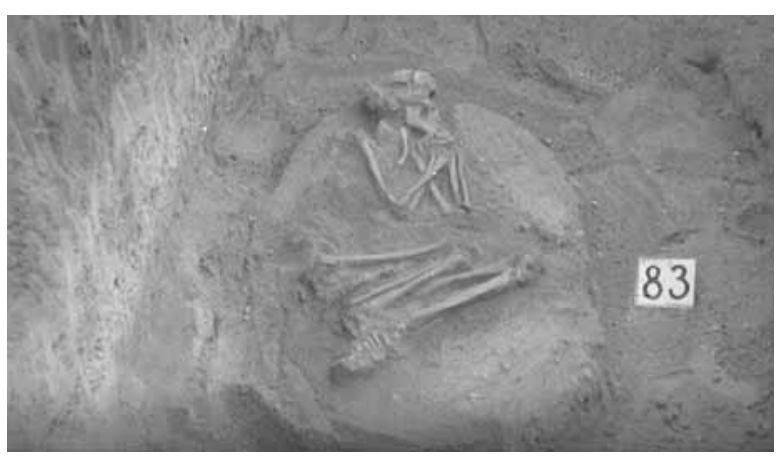

Inhumation burial in an oval grave pit. The body was laid on the left side in a contracted position. The arms were bent at the elbow and drawn up, the hands were clasped in front of the face. The thighs were drawn up in front of the body, the legs were bent back toward the buttocks.

The burial did not contain any grave goods.

\footnotetext{
77 Another fragment of this vessel was inventoried under no. 56.11.53.11 78 Animal bones were not inventoried among the finds from the burial. ${ }^{79}$ The number of beads and shells in the box containing the finds from thi burial is higher than the actual number registered in the acquisition register. There are five limestone beads, four Dentalium badense beads, one broken and three intact Unio crassus mussels and two Anadara diluvii shells ${ }^{80} \mathrm{It}$ is unclear whether these pottery fragments were identified when the finds were cleaned or whether they were accidentally lumped together with the finds from this burial when the finds were inventoried.

81 The skeletal remains can no longer be found. The anthropological data are quoted from the excavation diary.
} 
Grave 84 (Square I6; Pl. XXXVIII)

Size of grave pit: L. $85 \mathrm{~cm}, W .70 \mathrm{~cm}$

Depth: $85 \mathrm{~cm}$

Orientation: $\mathrm{S}$ to $\mathrm{N}$, with the head toward the $\mathrm{S}$

Position of skeleton: laid on the right side

L. of skeleton (contracted): $60 \mathrm{~cm}$

L. of skeleton (extended): $c a .90 \mathrm{~cm}$

Age at death: 6-7 years

Sex: child

Condition of skeleton: badly preserved

Preserved skeletal bones: skull, long bones

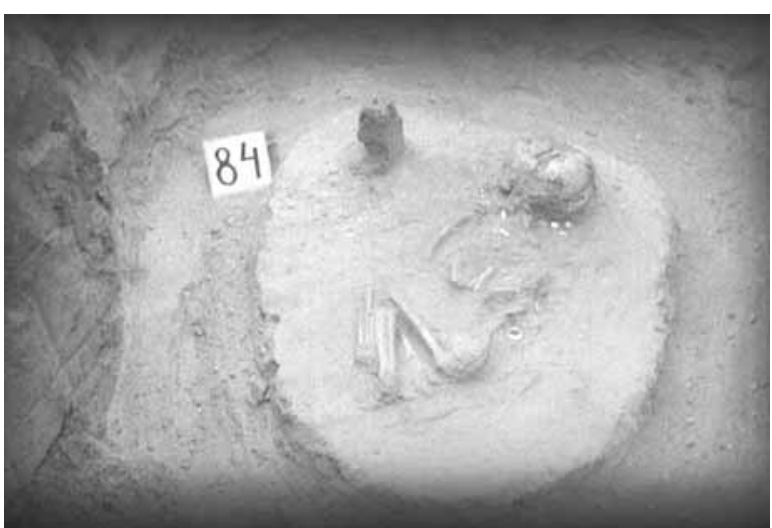

Inhumation burial in an oblong grave pit with rounded corners containing stones. The body was laid on the right side in a contracted position. The skull rested on the occipital bone. The arms were bent at the elbow and drawn up, with the hands resting under the chin. The thighs were drawn up in front of the body, the legs were bent back toward the buttocks.

The burial contained the following grave goods: a stone point (1) set on its edge and standing ca. $15 \mathrm{~cm}$ high $25 \mathrm{~cm}$ east of the face; a blade fragment (2) in front of the face; a necklace of thirty-nine Dentalium beads, two sliced Dentalium beads, one copper bead, one red bead and one shell (3) around the neck and the body; twelve shell plaques (4) around the neck.

Grave goods

1. Radiolarite point. Inv. no. 56.11.56.1 (Pl. XXXVIII. 84/1).

2. Unretouched radiolarite blade fragment. Inv. no. 56.11.56.2 (Pl. XXXVIII. 84/2).

3. Beads. Forty-one Dentalium badense beads, one red bead, three Anadara diluvii shells (Pl. XXXVIII. $84 / 3 a$ ) and one fragmentary tubular copper bead (Pl. XXXVIII. 84/3b). Inv. no. 56.11.56.3.82

4. Shell plaques. Rectangular, broken Unio crassus shell plaques with a pair of perforations along the short sides. Fourteen pieces, one joined from two fragments. Inv. no. 56.11.56.4 (Pl. XXXVIII. 84/4). ${ }^{83}$

\footnotetext{
82 The red bead has since been lost or mislaid. Forty of the forty-one Dentalium beads mentioned in the acquisitions register can still be found. 83 Some of the thin shell plaques broke, this being the reason for the fourteen inventoried pieces.
}

Grave 85 (Square I4; Pl. XXXIX)

Size of grave pit: L. $85 \mathrm{~cm}, W .70 \mathrm{~cm}$

Depth: $70 \mathrm{~cm}$

Orientation: NW to SE, with the head toward the NW

Position of skeleton: laid on the right side

L. of skeleton (contracted): $45 \mathrm{~cm}$

L. of skeleton (extended): -

Age at death: infans II

Sex: child

Condition of skeleton: badly preserved

Preserved skeletal bones: ${ }^{84}$ skull, long bone fragments

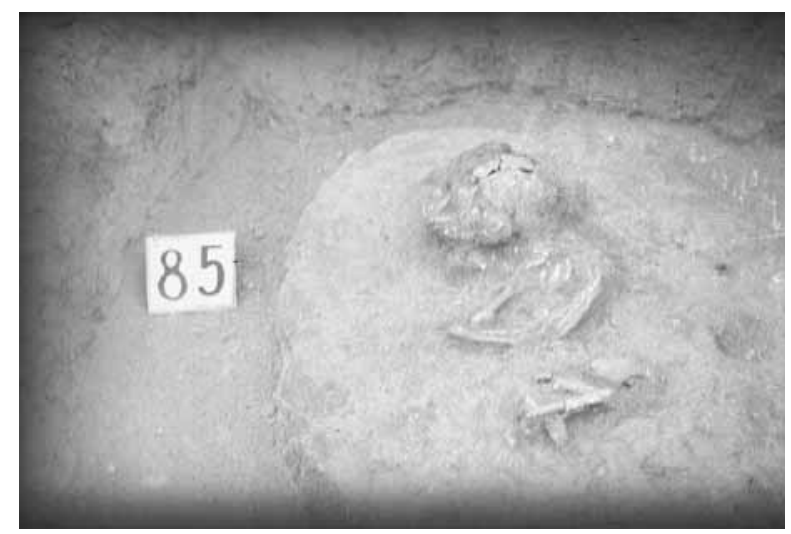

Inhumation burial in a round grave pit containing stones. The body was laid on the right side in a contracted position. The right arm was bent at the elbow, with the hand toward the waist. The left thigh was drawn up into a horizontal position, the right one in front of the body, the legs were bent back toward the buttock.

The burial did not contain any grave goods.

\section{Grave 86 (Square I4; Pl. XXXIX)}

Size of grave pit: L. $85 \mathrm{~cm}, W .65 \mathrm{~cm}$

Depth: $75 \mathrm{~cm}$

Orientation: $\mathrm{N}$ to $\mathrm{S}$, with the head toward the $\mathrm{N}$

Position of skeleton: -

L. of skeleton (contracted): -

L. of skeleton (extended): -

Age at death: infans I

Sex: child

Condition of skeleton: badly preserved

Preserved skeletal bones: ${ }^{85}$ various fragments

Inhumation burial in a round grave pit containing stones. Very little survived of the skeletal remains.

The burial did not contain any grave goods.

\section{Grave 87 (Grave I4; Pl. XXXIX)}

Size of grave pit: L. $60 \mathrm{~cm}, W .50 \mathrm{~cm}$

Depth: $70 \mathrm{~cm}$

Orientation: $\mathrm{N}$ to $\mathrm{S}$, with the head toward the $\mathrm{N}$

\footnotetext{
${ }^{84}$ The skeletal remains can no longer be found. The anthropological data are quoted from the excavation diary.

85 The skeletal remains can no longer be found. The anthropological data are quoted from the excavation diary.
} 
Position of skeleton: laid on the left side

L. of skeleton (contracted): -

L. of skeleton (extended): -

Age at death: infans I

Sex: child

Condition of skeleton: badly preserved

Preserved skeletal bones: ${ }^{86}$ various fragments

Inhumation burial in a round grave pit containing stones. The body was laid on the left side in a contracted position. Only the position of the skull could be recorded.

The burial contained the following grave goods: a dipper (1) tilted to one side among the stones above the skull.

\section{Grave goods}

1. Dipper. Grey, polished dipper with conical body. The high-flung strap handle is decorated with incised lines and springs from the rim to the middle of the vessel body. The rim is restored. $H .8 .8 \mathrm{~cm}, \mathrm{dM} .5 \mathrm{~cm}$, dB. 1.9 cm. Inv. no. 56.11.57.1 (Pl. XXXIX. 87/1).

\section{Grave 88 (Square H5; Pl. XXXIX)}

Size of grave pit: L. $60 \mathrm{~cm}, W .55 \mathrm{~cm}$

Depth: $90 \mathrm{~cm}$

Orientation: $W$ to $E$, with the head toward the $W$

Position of skeleton: laid on the left side

L. of skeleton (contracted): $48 \mathrm{~cm}$

L. of skeleton (extended): -

Age at death: 5-6 years

Sex: child

Condition of skeleton: badly preserved

Preserved skeletal bones: skull, long bones

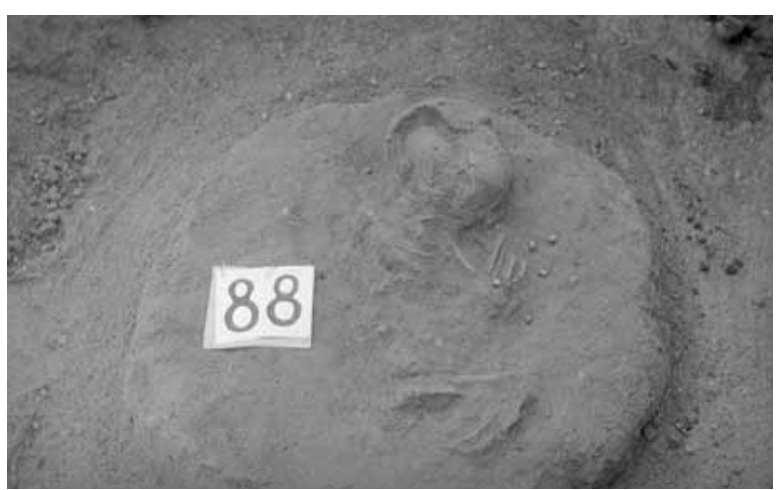

Inhumation burial in a round grave pit containing stones. The fragments of a bowl (1) lay among the stones. The body was laid on the left side in a contracted position. The arms were bent at the elbow, drawn up, and crossed in front of the face. The thighs were drawn up into a horizontal position, the legs were bent back toward the buttocks.

The burial contained the following grave goods: ten beads (2) around the forearms.
Grave goods

1. Bowl. Rim, body and base fragment of a brownish, worn bowl with a small horizontal stringhole lug on the shoulder. Joined from its fragments. H. $12 \mathrm{~cm}$. Inv. no. 56.11.58.1 (Pl. XXXIX. 88/1).

2. Beads. Ten limestone beads of varying sizes. Inv. no. 56.11.58.2 (Pl. XXXIX. 88/2).

\section{Grave 89 (Square I6; Pl. XXXIX)}

Size of grave pit: L. $105 \mathrm{~cm}$, W. $70 \mathrm{~cm}$

Depth: $100 \mathrm{~cm}$

Orientation: S to N, with the head toward the S

Position of skeleton: laid on the left side

L. of skeleton (contracted): $88 \mathrm{~cm}$

L. of skeleton (extended): $155 \mathrm{~cm}$

Age at death: $25-35$ years

Sex: female

Condition of skeleton: medium well preserved

Preserved skeletal bones: skull, long bones

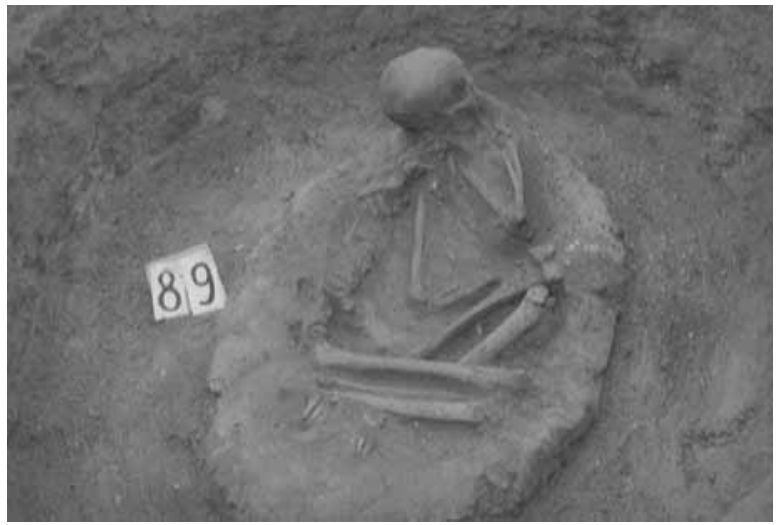

Inhumation burial in an oval grave pit. The body was laid on the left side in a contracted position. The skull rested on the occipital bone. The right arm was bent at the elbow and drawn up, with the hand resting in front of the face. The right thigh was drawn up into a horizontal position, the left one in front of the body, the legs were bent back toward the buttocks.

The burial did not contain any grave goods.

\section{Grave 90 (Square H4; Pl. XL)}

Size of grave pit: L. $70 \mathrm{~cm}, W .60 \mathrm{~cm}$ Depth: $90 \mathrm{~cm}$

Orientation: SE to NW, with the head toward the SE

Position of skeleton: laid on the left side

L. of skeleton (contracted): $62 \mathrm{~cm}$

L. of skeleton (extended): $82 \mathrm{~cm}$

Age at death: infans II

Sex: child

Condition of skeleton: badly preserved

Preserved skeletal bones: ${ }^{87}$ skull, long bones

\footnotetext{
87 The skeletal remains can no longer be found. The anthropological data are quoted from the excavation diary.

86 The skeletal remains can no longer be found. The anthropological data are quoted from the excavation diary. 


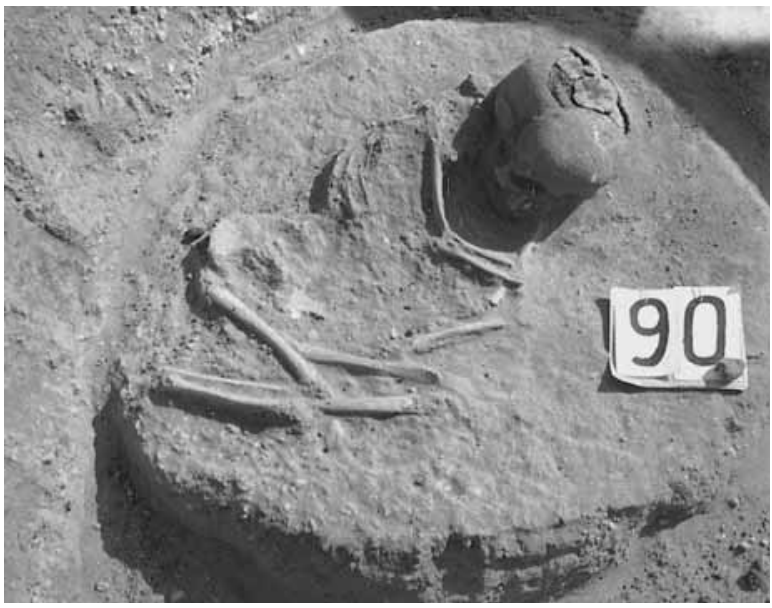

Inhumation burial in an oval grave pit containing one larger stone. The body was laid on the left side in a contracted position. The arms were bent at the elbow and laid in the lap. The right thigh was drawn up into a horizontal position, the left one in front of the body, and the legs were bent back toward the buttocks. The left foot lay under the right knee.

The burial contained the following grave goods: a necklace of six beads (1) around the neck.

Grave goods

1. Beads. Six limestone beads of varying sizes. Inv. no. 56.11.59.1 (Pl. XL. 90/1).

\section{Grave 91 (Square H5; Pls XLI-XLIII)}

Size of grave pit: L. $180 \mathrm{~cm}, W .110 \mathrm{~cm}$

Depth: $105 \mathrm{~cm}$

Orientation: S-SE to N-NW, with the head toward the S-SE

Position of skeleton: laid on the right side

L. of skeleton (contracted): $85 \mathrm{~cm}$

L. of skeleton (extended): $175 \mathrm{~cm}$

Age at death: $45-55$ years

Sex: male (?)

Condition of skeleton: medium well preserved

Preserved skeletal bones: skull, long bones, pelvic bone

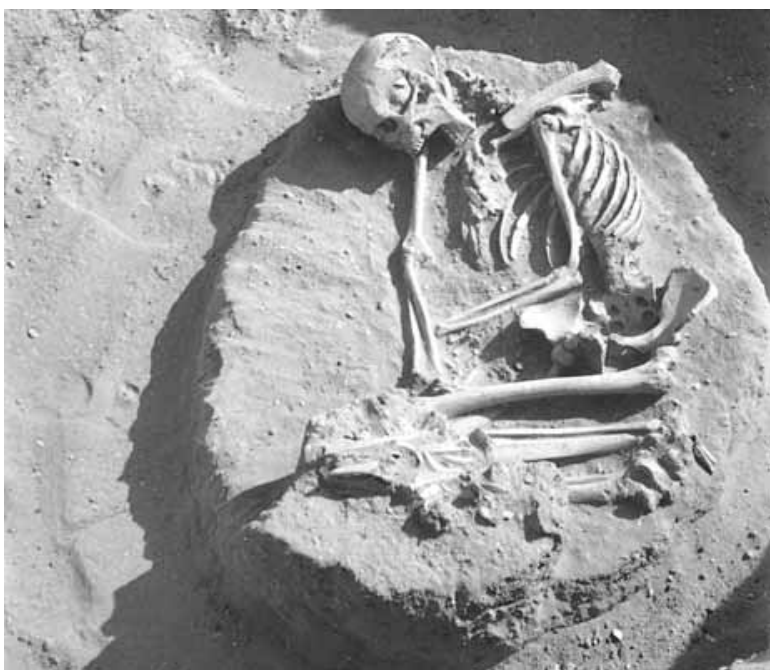

Inhumation burial in an oval grave pit. The body was laid on the right side in a contracted position. The skull lay on the right temporal bone. The right arm was extended, with the hand laid by the left knee, the left arm was bent at the elbow, with the hand resting under the right forearm. The left thigh was drawn up into a horizontal position, the right one to a lesser extent, the legs were bent back toward the buttocks. One part of the right leg-bone was missing and a black stain was noted on the fracture.

The burial contained the following grave goods: an antler axe (1) on the left shoulder-blade, laid perpendicular to the body with its point toward the body; a stone chip (2-3) in each hand; a small lump of chalk (4) on the right pelvic bone; a stone implement (5) and a quartz chip (6) by and partly under the right pelvic bone. Lying on an $8-15 \mathrm{~cm}$ high earthen bank above the legs and the knees were two small serpentinite axes (7-8), sixteen boar canines (9-22, 24-25), a bone awl (23), a piece of haematite (26), six small red stones (27-32), a large stone blade (33), a chert blade (34), an atypical blade (35), two microliths (36-37), four microlithic blades (38-41), an obsidian blade (42), a chert blade (43), seven broken blades (44-50), two obsidian chips (51-52) forty-nine flakes (53-101) and red deer and Caprinae tibia (102-103).

\section{Grave goods ${ }^{88}$}

1. Antler axe. Fragmentary axe with rounded end carved from antler. L. $23.3 \mathrm{~cm}$. Joined from its fragments. Inv. no. 56.11.60.87 (Pl. XLI. 91/1).89

2. Unretouched radiolarite flake. Inv. no. 56.11.60.1 (Pl. XLI. 91/2).90

3. Debitage. Radiolarite chip. Inv. no. 56.11.60.2 (Pl. XLI. 91/3).

4. Chalk-stone fragment. Inv. no. 56.11.60.3.

5. Unretouched hornstone flake. Inv. no. 56.11.60.4 (Pl. XLI. 91/5).

6. End-scraper on a retouched chert blade. Inv. no. 56.11.60.5 (Pl. XLI. 91/6).

7. Stone axe. Damaged trapezoidal stone axe made from serpentinite. L. $5.6 \mathrm{~cm}, W .4 .1 \mathrm{~cm}$. Inv. no. 56.11.60.6 (Pl. XLI. 91/7).

8. Stone axe. Damaged trapezoidal stone axe made from serpentinite. L. $4.5 \mathrm{~cm}, W .4 .3 \mathrm{~cm}$. Inv. no. 56.11.60.7 (Pl. XLI. 91/8).

9. Boar canine fragment. L. $7 \mathrm{~cm}$. Inv. no. 56.11.60.88 (Pl. XLI. 91/9).

10. Boar canine fragment. L. $5 \mathrm{~cm}$. Inv. no. 56.11.60.89 (Pl. XLI. 91/10).

\footnotetext{
88 The description of the finds follows the order of the grave description, which is not identical with the order in which they were inventoried. 89 The object has since been lost or mislaid. The drawing is based on József Korek's grave sheet. The box containing the finds contains uninventoried animal bones (sheep/goat/roe-deer and boar bones).

90 The objects described under nos 2-6 and 26-101 have since been lost or mislaid; their description is quoted from acquisitions register, while the photos are taken from BANNER 1956, the drawings from Cs. BALOGH 1999.
} 
11. Boar canine fragment. L. $4.9 \mathrm{~cm}$. Inv. no. 56.11.60.90 (Pl. XLI. 91/11).

12. Boar canine fragment. Joined from two pieces. L. $4.8 \times 5.6 \mathrm{~cm}$. Inv. no. 56.11.60.91 and 56.11.60.98 (Pl. XLI. 91/12).

13. Boar canine fragment. L. $4 \mathrm{~cm}$. Inv. no. 56.11.60.92 (Pl. XLI. 91/13).

14. Boar canine fragment. L. $3.8 \mathrm{~cm}$. Inv. no. 56.11.60.93 (Pl. XLI. 91/14).

15. Boar canine fragment. L. $7 \mathrm{~cm}$. Inv. no. 56.11.60.94 (Pl. XLI. 91/15).

16. Boar canine fragment. L. $5.1 \mathrm{~cm}$. Inv. no. 56.11.60.95 (Pl. XLI. 91/16).

17. Boar canine fragment. L. $5.5 \mathrm{~cm}$. Inv. no. 56.11.60.96 (Pl. XLI. 91/17).

18. Boar canine fragment. Joined from two pieces. L. $5.5 \times 3.5 \mathrm{~cm}$. Inv. no. 56.11.60.97, 56.11.60.102 (Pl. XLI. 91/18).

19. Boar canine fragment. L. $4.3 \mathrm{~cm}$. Inv. no. 56.11.60.99 (Pl. XLI. 91/19).

20. Boar canine fragment. L. $3.5 \times 2.4 \mathrm{~cm}$. Inv. no. 56.11.60.100, 56.11.60.104 (Pl. XLI. 91/20).

21. Boar canine fragment. L. $4.1 \mathrm{~cm}$. Inv. no. 56.11.60.101 (Pl. XLI. 91/21).

22. Boar canine fragment. L. $2.9 \mathrm{~cm}$. Inv. no. 56.11.60.103 (Pl. XLI. 91/22).

23. Awl carved from a deer metatarsal. The tip is broken. L. $12.5 \mathrm{~cm}$. Inv. no. 56.11.60.8 and 56.11.60.10 (Pl. XLI. 91/23).

24. Boar canine. Spoon shaped bone implement polished to a bright lustre on the convex side. L. 4 cm. Inv. no. 56.11.60.9 (Pl. XLI. 91/24).

25. Boar canine awl. L. $3.3 \mathrm{~cm}$. Inv. no. 56.11.60.105 (Pl. XLI. 91/25).

26. Piece of haematite. Irregular triangular in shape. Diam. 4 cm. Inv. no. 56.11.60.11 (Pl. XLI. 91/26).

27. Red stone. Oblong in shape. L. $3.6 \mathrm{~cm}$. Inv. no. 56.11.60.12 (Pl. XLI. 91/27).

28. Red stone. Irregular rectangular in shape. Diam. $2.1 \mathrm{~cm}$. Inv. no. 56.11.60.13 (Pl. XLI. 91/28).

29. Red stone. Irregular in shape. Diam. $3.1 \mathrm{~cm}$. Inv. no. 56.11.60.14 (Pl. XLI. 91/29).

30. Purple stone. Irregular in shape. Diam. $3.8 \mathrm{~cm}$. Inv. no. 56.11.60.15 (Pl. XLI. 91/30).

31. Red stone. Irregular in shape. Diam. $1.8 \mathrm{~cm}$. Inv. no. 56.11.60.16 (Pl. XLII. 91/31).

32. Red stone. Irregular in shape. Diam. $1.3 \mathrm{~cm}$. Inv. no. 56.11.60.17 (Pl. XLII. 91/32).

33. Unretouched chert blade. Inv. no. 56.11.60.18 (Pl. XLII. 91/33).

34. Truncated chert blade. Inv. no. 56.11.60.19 (Pl. XLII. 91/34).

35. Truncated flint blade. Inv. no. 56.11.60.21 (Pl. XLII. 91/35).

36. Radiolarite segment. Inv. no. 56.11.60.27 (Pl. XLII. 91/36).

37. Radiolarite burin. Inv. no. 56.11.60.28 (Pl. XLII. 91/37).
38. Segment made from limnic quartzite. Inv. no. 56.11.60.26 (Pl. XLII. 91/42).

39. Flint segment. Inv. no. 56.11.60.23 (Pl. XLII. 91/39).

40. Segment made from limnic quartzite. Inv. no. 56.11.60.24 (Pl. XLII. 91/40).

41. Hornstone segment. Inv. no. 56.11.60.25 (Pl. XLII. 91/41).

42. Obsidian segment. Inv. no. 56.11.60.22 (Pl. XLII. 91/38).

43. Unretouched flake made from limnic quartzite. Inv. no. 56.11.60.86.

44. Radiolarite trapeze. Inv. no. 56.11.60.31 (Pl. XLII. 91/44).

45. Unretouched radiolarite blade fragment. Inv. no. 56.11.60.32 (Pl. XLII. 91/45).

46. Unretouched radiolarite blade fragment. Inv. no. 56.11.60.33.

47. Unretouched radiolarite blade. Inv. no. 56.11.60.34 (Pl. XLII. 91/47).

48. Radiolarite debitage. Inv. no. 56.11.60.35.

49. Unretouched chert blade fragment. Inv. no. 56.11.60.36 (Pl. XLII. 91/49).

50. Unretouched chert blade fragment. Inv. no. 56.11.60.29 (Pl. XLII. 91/50).

51. Unretouched obsidian blade fragment. Inv. no. 56.11.60.37 (Pl. XLII. 91/51).

52. Obsidian debitage. Inv. no. 56.11.60.38 (Pl. XLII. 91/52).

53. Unretouched flake. Radiolarite. Inv. no. 56.11.60.30 (Pl. XLII. 91/53).

54. Unretouched flake. Flint. Inv. no. 56.11.60.20 (Pl. XLII. 91/54).

55. Retouched blade tip. Limnic quartzite. Inv. no. 56.11.60.39 (Pl. XLII. 91/55).

56. Debitage. Limnic quartzite. Inv. no. 56.11.60.40 (Pl. XLII. 91/56).

57. Unretouched flake. Flint. Inv. no. 56.11.60.41 (Pl. XLII. 91/57).

58. Unretouched blade fragment. Limnic quartzite. Inv. no. 56.11.60.42 (Pl. XLII. 91/58).

59. Unretouched blade fragment. Limnic quartzite Inv. no. 56.11.60.43 (Pl. XLII. 91/59).

60. Unretouched flake. Limnic quartzite. Inv. no. 56.11.60.44 (Pl. XLII. 91/60).

61. Unretouched flake. Limnic quartzite. Inv. no. 56.11.60.45 (Pl. XLII. 91/61).

62. Unretouched flake. Limnic quartzite. Inv. no. 56.11.60.46 (Pl. XLII. 91/62).

63. Unretouched flake. Chert. Inv. no. 56.11.60.47 (Pl. XLII. 91/63).

64. Debitage. Limnic quartzite. Inv. no. 56.11.60.48 (Pl. XLII. 91/64).

65. Unretouched flake. Limnic quartzite. Inv. no. 56.11.60.49 (Pl. XLII. 91/65).

66. Chert trapeze. Inv. no. 56.11.60.50 (Pl. XLII. 91/66).

67. Chert debitage. Inv. no. 56.11.60.51 (Pl. XLII. 91/67).

68. Unretouched flake. Limnic quartzite. Inv. no. 56.11.60.52 (Pl. XLII. 91/68). 
69. Limnic quartzite trapeze. Inv. no. 56.11.60.53 (Pl. XLII. 91/69).

70. Triangle. Limnic quartzite. Inv. no. 56.11.60.54 (Pl. XLII. 91/70).

71. Radiolarite debitage. Inv. no. 56.11.60.55 (Pl. XLII. 91/71).

72. Unretouched limnic quartzite flake. Inv. no. 56.11.60.56 (Pl. XLII. 91/72).

73. Radiolarite trapeze. Inv. no. 56.11.60.57 (Pl. XLII. 91/73).

74. Unretouched radiolarite flake. Inv. no. 56.11.60.58 (Pl. XLII. 91/74).

75. Debitage. Radiolarite. Inv. no. 56.11.60.59 (Pl. XLII. 91/75).

76. Unretouched limnic quartzite flake. Inv. no. 56.11.60.60 (Pl. XLII. 91/76).

77. Unretouched radiolarite flake. Inv. no. 56.11.60.61 (Pl. XLII. 91/77).

78. Burin. Radiolarite. Inv. no. 56.11.60.62 (Pl. XLII. 91/78).

79. Unretouched radiolarite flake. Inv. no. 56.11.60.63.

80. Radiolarite debitage. Inv. no. 56.11.60.64.

81. Radiolarite debitage. Inv. no. 56.11.60.65.

82. Limnic quartzite debitage. Inv. no. 56.11.60.66.

83. Limnic quartzite debitage. Inv. no. 56.11.60.67.

84. Limnic quartzite debitage. Inv. no. 56.11.60.68.

85. Unretouched radiolarite flake. Inv. no. 56.11.60.69.

86. Unretouched limnic quartzite blade fragment. Inv. no. 56.11.60.70 (Pl. XLIII. 91/86).

87. Unretouched limnic quartzite flake. Inv. no. 56.11.60.71.

88. Limnic quartzite debitage. Inv. no. 56.11.60.72.

89. Jasper flake. Inv. no. 56.11.60.73.

90. Limnic quartzite debitage. Inv. no. 56.11.60.74.

91. Limnic quartzite debitage. Inv. no. 56.11.60.75.

92. Limnic quartzite debitage. Inv. no. 56.11.60.76.

93. Radiolarite debitage. Inv. no. 56.11.60.77.

94. Unretouched hornstone flake. Inv. no. 56.11.60.78.

95. Truncated flake-end-scraper combination. Limnic quartzite. $13.5 \mathrm{~mm} \times 14 \mathrm{~mm} \times 4 \mathrm{~mm}$. Inv. no. 56.11.60.79 (Pl. XLIII. 91/95).

96. Trapeze. Limnic quartzite. Inv. no. 56.11.60.80 (Pl. XLIII. 91/96).

97. Unretouched blade. Limnic quartzite. Inv. no. 56.11.60.81 (Pl. XLIII. 91/97).

98. Unretouched blade fragment. Limnic quartzite. Inv. no. 56.11.60.82 (Pl. XLIII. 91/98).

99. Unretouched blade fragment. Chert. Inv. no. 56.11.60.83 (Pl. XLIII. 91/99).

100. Unretouched radiolarite flake. Inv. no. 56.11.60.84 (Pl. XLIII. 91/100).

101. Unretouched radiolarite blade. Inv. no. 56.11.60.85 (Pl. XLIII. 91/101).

102. Sheep or goat tibia fragment. L. $12.5 \mathrm{~cm}$. Inv. no. 56.11.60.106 (Pl. XLIII. 91/102).

103. Roe deer tibia fragment. L. $10.8+6.6 \mathrm{~cm}$. Inv. no. 56.11.60.107 and 56.11.60.109 (Pl. XLIII. 91/103).
Other finds from the burial: ${ }^{91}$

104. Roe deer tibia fragment. L. $7.2 \mathrm{~cm}$. Inv. no. 56.11.60.108 (Pl. XLIII. 91/104).

105. Sheep or goat tibia fragment. L. $5.8 \mathrm{~cm}$. Inv. no. 56.11.60.110 (Pl. XLIII. 91/105).

106. Small ruminant tibia fragment. L. $4.9 \mathrm{~cm}$. Inv. no. 56.11.60.111.

107. Small ruminant tibia fragment. L. $6.4 \mathrm{~cm}$. Inv. no. 56.11.60.112.

\section{Grave 92 (Square I6/H6; Pl. XL)}

Size of grave pit: L. $85 \mathrm{~cm}, W .90 \mathrm{~cm}$

Depth: $60 \mathrm{~cm}$

Orientation: S-SW to N-NE, with the head toward the S-SW

Position of skeleton: laid on the right side

L. of skeleton (contracted): $52 \mathrm{~cm}$

L. of skeleton (extended): -

Age at death: $1-7$ years

Sex: child

Condition of skeleton: badly preserved

Preserved skeletal bones: skull fragments

Inhumation burial in a round grave pit. The body was laid on the right side in a contracted position. Only the position of the skull and the thigh bones could be recorded.

The burial did not contain any grave goods.

Grave 93 (Square I6; Pl. XL)

Size of grave pit: L. $75 \mathrm{~cm}, W .70 \mathrm{~cm}$

Depth: $70 \mathrm{~cm}$

Orientation: S-SE to N-NW, with the head toward the S-SE

Position of skeleton: laid on the right side

L. of skeleton (contracted): $57 \mathrm{~cm}$

L. of skeleton (extended): -

Age at death: 5-6 years

Sex: child

Condition of skeleton: badly preserved

Preserved skeletal bones: skull fragments

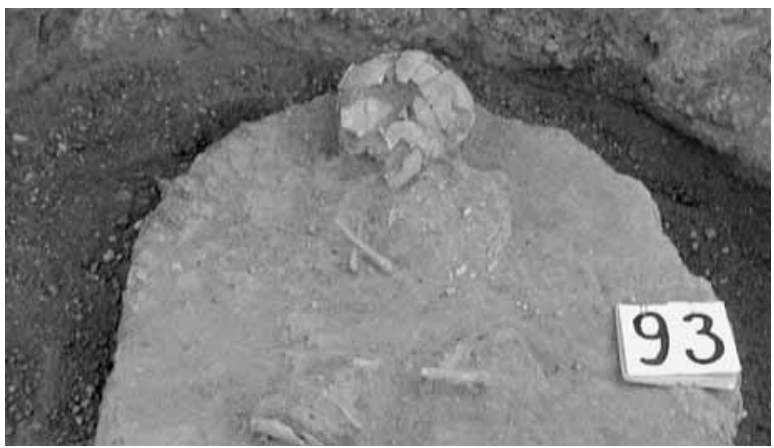

Inhumation burial in a round grave pit containing stones. The stones lay on the skeleton and crushed the skull. The body was laid on the right side in a

91 These bones are probably fragments of the ones described under nos 9-22 and 104-107. I would here like to thank Erika Gál for the species determination. 
contracted position. The arms were bent at the elbow and crossed in front of the chin. The thighs were drawn up into a horizontal position, the legs were bent back toward the buttocks. An animal burrow was noted along the length of the grave pit.

The burial did not contain any grave goods.

\section{Grave 94 (Square I4/H4; Pl. XL)}

Size of grave pit: L. $130 \mathrm{~cm}, W .90 \mathrm{~cm}$ Depth: $100 \mathrm{~cm}$

Orientation: E-SE to W-NW. with the head toward the E-SE Position of skeleton: laid on the left side

L. of skeleton (contracted): $110 \mathrm{~cm}$

L. of skeleton (extended): $162 \mathrm{~cm}$

Age at death: 20-23 years

Sex: male

Condition of skeleton: well preserved

Preserved skeletal bones: skull, long bones, pelvic bone

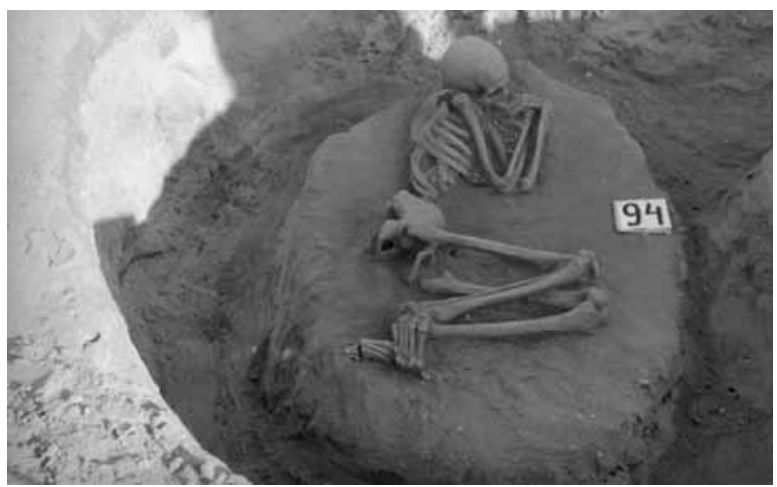

Inhumation burial in an oval grave pit containing stones. The body was laid on the left side in a contracted position. The arms were bent at the elbow and drawn up, with the hands placed in front of the face. The thighs were drawn up into a horizontal position, the legs were bent back toward the buttocks.

The burial contained the following grave goods: a necklace of five Dentalium beads, forty-three other beads (1), and four intact and two broken shells (2) around the neck.

Grave goods

1. Beads. Thirty-nine limestone beads, four Dentalium badense beads (Pl. XL. 94/1a) and three Unio crassus mussels (Pl. XL. 94/1b). Inv. no. 61.2.180.92

2. Beads. Three broken Unio crassus mussels and one Dentalium badense bead. Inv. no. 56.11.61.1 (Pl. XL. 94/2).93

\footnotetext{
92 The beads from Grave 94 were inventoried as two necklaces strung of forty-eight beads (the excavation diary mentions forty-five beads). Thirtynine beads survived from the necklace described under no. 1 , and five of the six shells mentioned in the excavation diary and in the acquisitions register.

While drawing the finds. László Gucsi noted that most of the limestone beads were broken and that the breakages were repaired by re-polishing the beads, where by the beads became somewhat smaller. The edges of the shells were strongly worn, probably from their use as ornaments.

93 Only two shells can now be found.
}

Grave 95 (Square I8; Pl. XLIII)

Size of grave pit: L. $115 \mathrm{~cm}, W .85 \mathrm{~cm}$

Depth: $110 \mathrm{~cm}$

Orientation: S to N, with the head toward the S

Position of skeleton: laid on the left side

L. of skeleton (contracted): $103 \mathrm{~cm}$

L. of skeleton (extended): $155 \mathrm{~cm}$

Age at death: $35-40$ years

Sex: female

Condition of skeleton: medium well preserved

Preserved skeletal bones: skull, long bones

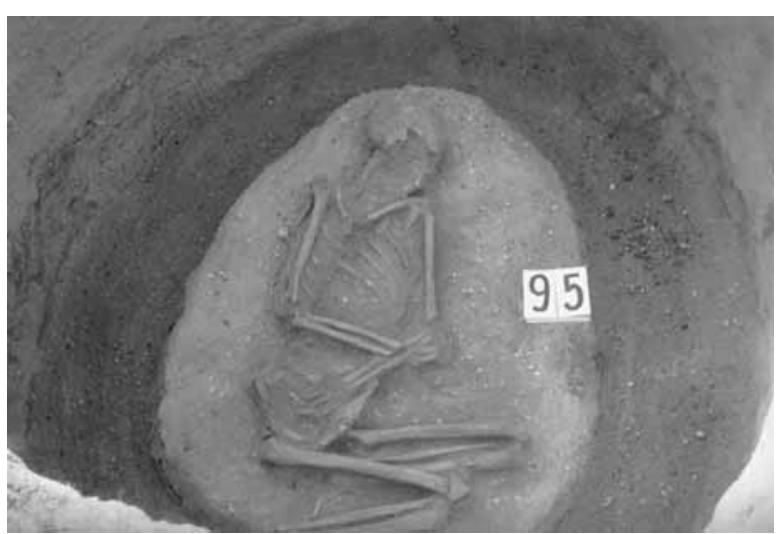

Inhumation burial in an oval grave pit. The body was laid on the left side in a contracted position. The skull rested on the left temporal bone. The left arm, slightly bent at the elbow, was extended beside the body, with the hand resting on the sacrum. The right arm was bent at the elbow and drawn up, with the hand clasping the left elbow. The thighs were drawn up into a horizontal position, the legs were bent back toward the buttocks.

The burial contained the following grave goods: a triangular red stone (1) on the right knee; a stone flake (2) on the upper third of the left tibia; a necklace of a hundred and thirteen beads (3) behind and under the spine; eight intact and four broken shells (4) behind the spine.

Grave goods

1. Triangular red stone. Diam. $4.3 \mathrm{~cm}$. Inv. no. 56.11.62.1 (Pl. XLIII. 95/1).94

2. Unretouched radiolarite flake. Inv. no. 56.11.62.2 (Pl. XLIII. 95/2).

3. Beads. A hundred and seven limestone beads and one Unio crassus mussel. Some of the beads bear patches of ochre. Inv. no. 56.11.62.3 (Pl. XLIII. 95/3). .5

4. Shells. Nine intact and four broken Anadara diluvii shells. Inv. no. 56.11.62.4 (Pl. XLIII. 95/4). ${ }^{96}$

94 The object has since been lost or mislaid. The drawing is based on József Korek's grave sheet.

95 The number of beads was lower than the one specified in the excavation diary by the time the finds were inventoried.

96 Eleven shell fragments were inventoried. The number of shell fragments increased by one because one of the fragments broke in two. 
Grave 96 (Square H5; Pl. XLIV)

Size of grave pit: L. $85 \mathrm{~cm}, W .60 \mathrm{~cm}$

Depth: $110 \mathrm{~cm}$

Orientation: $\mathrm{S}$ to $\mathrm{N}$, with the head toward the $\mathrm{S}$

Position of skeleton: laid on the left side

L. of skeleton (contracted): $62 \mathrm{~cm}$

L. of skeleton (extended): -

Age at death: $3-4$ years

Sex: child

Condition of skeleton: badly preserved

Preserved skeletal bones: skull, long bones

Inhumation burial in an oval grave pit containing stones. The body was laid on the left side in a contracted position. The right arm was bent at the elbow and drawn up, with the hand clasping the left elbow. The left arm was bent at the elbow and drawn up in front of the face. The thighs were drawn up into a horizontal position, the legs were bent back toward the buttocks.

The burial contained the following grave goods: a broken shell (1) on the neck.

Grave goods

1. Shell. Fragment of an Anadara diluvii shell. Inv. no. 56.11.63.1 (Pl. XLIV. 96/1).

\section{Grave 97 (Square I7/I8; Pl. XLIV)}

Size of grave pit: L. $135 \mathrm{~cm}, W .90 \mathrm{~cm}$

Depth: $70 \mathrm{~cm}$

Orientation: N-NE to S-SW, with the head toward the N-NE Position of skeleton: laid on the left side

L. of skeleton (contracted): $100 \mathrm{~cm}$

L. of skeleton (extended): -

Age at death: $12-14$ years

Sex: child

Condition of skeleton: badly preserved

Preserved skeletal bones: skull, long bone fragments

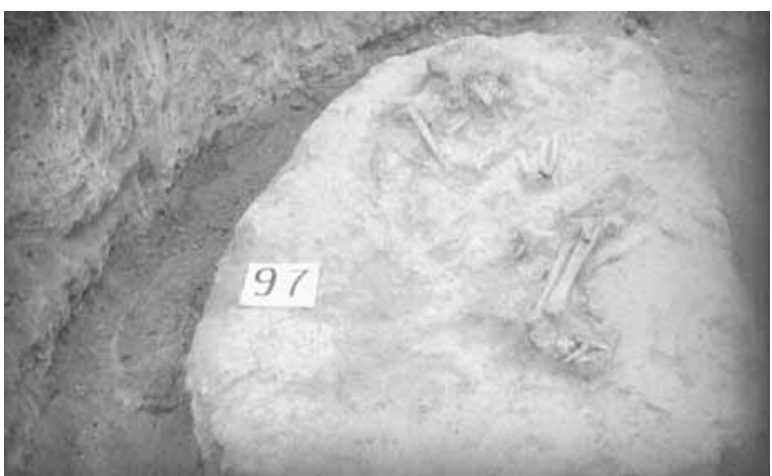

Inhumation burial in an oval grave pit containing stones. The stones were thrown on the body and broke most of the bones. The body was laid on the left side in a contracted position. The arms were bent at the elbow and drawn up, with the hands resting in front of the face. The thighs were drawn up in front of the body, the legs were bent back toward the buttocks.

The burial did not contain any grave goods.
Grave 98 (Square I8; Pl. XLIV).

Size of grave pit: L. $95 \mathrm{~cm}, W .60 \mathrm{~cm}$

Depth: $85 \mathrm{~cm}$

Orientation: $\mathrm{S}$ to $\mathrm{N}$, with the head toward the $\mathrm{S}$

Position of skeleton: laid on the right side

L. of skeleton (contracted): $75 \mathrm{~cm}$

L. of skeleton (extended): $115 \mathrm{~cm}$

Age at death: infans II

Sex: child

Condition of skeleton: badly preserved

Preserved skeletal bones: ${ }^{97}$ skull, long bones

Inhumation burial in an oval grave pit. The grave pit extended under Grave 97. There was no trace of any disturbance. The body was laid on the right side in a contracted position. The left arm was bent at the elbow and drawn up, with the hand resting under the chin. The right arm was extended, with the hand laid on the knee. The right thigh was drawn up into a horizontal position, the left one slightly higher, the legs were bent back toward the buttocks.

The burial contained the following grave goods: a shell (1) in front of the chin.

Grave goods

1. Polished and perforated Anadara diluvii shell. Inv. no. 56.11.64.1 (Pl. XLIV. 98/1).

\section{Grave 99 (Square I4; Pl. XL)}

Size of grave pit: L. $70 \mathrm{~cm}, W .65 \mathrm{~cm}$

Depth: $70 \mathrm{~cm}$

Orientation: NW to SE, with the head toward the NW

Position of skeleton: laid on the right side

L. of skeleton (contracted): $25 \mathrm{~cm}$ (surviving L.)

L. of skeleton (extended): -

Age at death: infans I

Sex: child

Condition of skeleton: badly preserved

Preserved skeletal bones: ${ }^{98}$

Inhumation burial in a round grave pit. Only the position of the left arm, the thigh and the leg could be recorded. The skull was missing. The body was laid on the right side in a contracted position. The left arm was extended toward the knees. The thighs were slightly drawn up, the legs were bent back toward the buttocks.

The burial did not contain any grave goods.

\section{Grave 100 (Square H6; Pl. XLV)}

Size of grave pit: L. $160 \mathrm{~cm}, W .205 \mathrm{~cm}$

Depth: $70 \mathrm{~cm}$

Orientation: A: E-SE to $\mathrm{W}-\mathrm{NW}$, with the head toward the E-SE, $\mathrm{B}$ : E-SE to W-NW, with the head toward the E-SE

\footnotetext{
97 The skeletal remains can no longer be found. The anthropological data are quoted from the excavation diary.

98 The skeletal remains can no longer be found. The anthropological data are quoted from the excavation diary.
} 
Position of skeleton: A: laid on the left side, B: laid on the right side

L. of skeleton (contracted): A: $120 \mathrm{~cm}, \mathrm{~B}: 90 \mathrm{~cm}$

L. of skeleton (extended): A: -, B: -

Age at death: A: adult, B: adult

Sex: A: male, B: female

Condition of skeleton: A: badly preserved, B: burnt

Preserved skeletal bones: ${ }^{99}$ lifted in situ

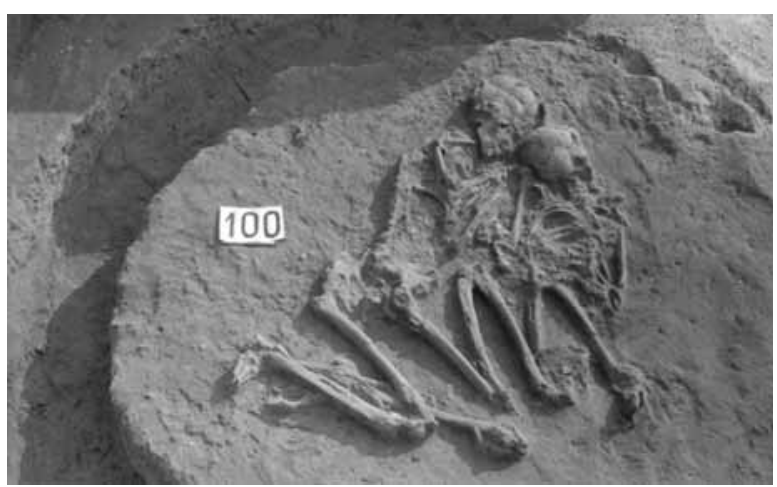

Double inhumation burial in an irregular, oval grave pit, containing the burnt remains of two adults.

\section{Burial A}

The body was laid on the left side in a moderately contracted position. The skull was crushed and lay tilted on the left temporal bone. The arms were bent at the elbow and drawn up, with the hands clasped in front of the face. The pelvis lay extended. The thighs were slightly drawn up, the legs were bent back toward the buttocks.

The burial did not contain any grave goods (1). ${ }^{100}$

\section{Burial B}

The body was deposited beside Burial A and laid prone. The crushed skull lay beside the skull of Burial A, slightly to its south. The arms were bent at elbow and drawn up toward the face. The left thigh was drawn up, with the knee resting beside the pelvis of Burial A and the ankle under the left knee of Burial A.

The burial contained the following grave goods: a necklace of Dentalium beads (1), Dentalium and other beads (2) and shells (3) on the chest and the back.

Both skeletons were burnt, suggesting that a fire had been kindled on the interred bodies. The bones of Burial B were black and brittle, reflecting strong burning. The centre of the fire apparently lay on the body in Burial B. The facial bones of the skull and the chest of the body in Burial A were also quite strongly burnt. The spine was burnt to a bright red colour. The legs were unaffected by the fire. Both skeletons lay in an $8-10 \mathrm{~cm}$ thick layer of black ash. Red ash was noted around the skull of Burial B. Burnt specks lay in the ash,

\footnotetext{
99 The skeletal remains can no longer be found. The anthropological data are quoted from the excavation diary.

100 Beads and shells were found under the skeletal remains after the grave, which was lifted in situ, was dismantled. These finds were not visible at the time the burial was excavated. Some of the beads were strongly burnt.
}

but no charcoal fragments were identified by the excavator. Both burials were lifted in situ and taken to the Szentendre museum on October 7, 1952.

Grave goods

1. Beads. Ninety-two intact limestone beads. Most of the beads had a greyish-black, burnt surface. Inv. no. 72.3.3a (Pl. XLV. 100/1). ${ }^{101}$

2. Beads. Twenty-one burnt Dentalium badense beads. Inv. no. 72.3.3c (Pl. XLV. 100/2). ${ }^{102}$

3. Shells. Fifteen Anadara diluvii shells, ten intact and perforated, one broken and unperforated. Inv. no. 72.3.3b (Pl. XLV. 100/3). ${ }^{103}$

\section{Grave 101 (SquareI4; Pl. XLIV)}

Size of grave pit: L. $85 \mathrm{~cm}, W .75 \mathrm{~cm}$

Depth: $90 \mathrm{~cm}$

Orientation: A: S-SE to N-NW, with the head toward the S-SE, B: S-SE to N-NW, with the head toward the S-SE

Position of skeleton: A: laid on the left side, B: laid on the right side

L. of skeleton (contracted): A: $75 \mathrm{~cm}, \mathrm{~B}: 60 \mathrm{~cm}$

L. of skeleton (extended): A: $115 \mathrm{~cm}, \mathrm{~B}:-$

Age at death: A: $9-10$ years, B: 1-2 years

Sex: A: child, B: child

Condition of skeleton: A: medium well preserved, B: badly preserved

Preserved skeletal bones: A and B: skull, long bones

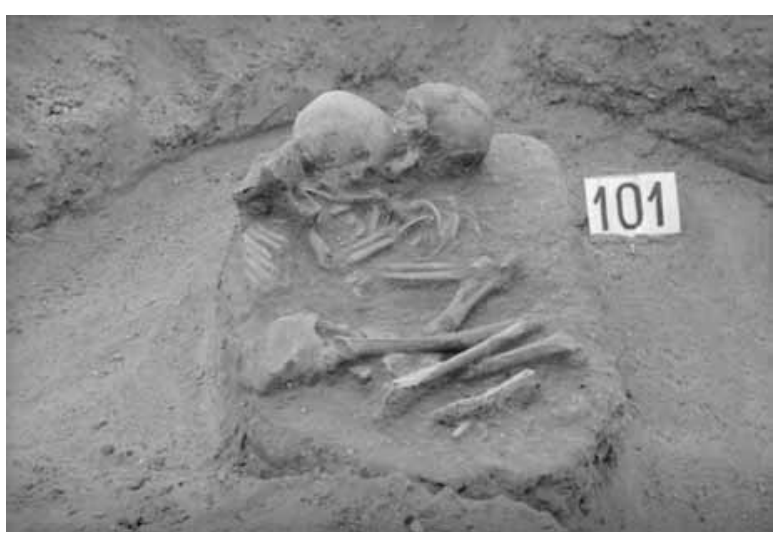

Double inhumation burial in an oval grave pit.

\section{Burial A}

The body was laid on the left side in a contracted position. The right arm was bent at the elbow and drawn up, with the hand resting by the chin. The left arm was turned outward at the elbow, with the hand resting under the body in Burial B. The left thigh was drawn up

\footnotetext{
101 According to the entry in the acquisitions register, the finds inventoried under no. 72.3.3a-c were found on the back and chest of Burial A on November 1, 1972, when the burial lifted in situ was dismantled. There were ninety-one intact and one broken beads. One bead has since been lost. 102 Nine more or less intact and eight fragmentary shell beads were inventoried. Some of the beads broke and there are now twenty-one instead of the original seventeen.

103 There were fifteen intact and broken shells when the finds were drawn, as well as two crumbling fragments.
} 
into a horizontal position, the right one to a lesser extent, the legs were bent back toward the buttocks.

The burial contained the following grave goods: a goblet (1) tilted to one side, with the mouth facing the edge of the grave pit, on the right upper arm.

\section{Burial B}

The body was deposited directly beside Burial A and parallel to it. The body was laid on the right side in a contracted position. The position of the arms could not be recorded. The thighs were moderately drawn up, the left leg was extended, the right one was bent back toward the buttocks.

The burial did not contain any grave goods.

\section{Grave goods}

1. Goblet. Greyish-black, coarsely made goblet with rectangular upper part and peaked rim at the corners resting on two feet with a rectangular base. ${ }^{104}$

\section{Grave 102 (Square H6; Pl. XLV)}

Size of grave pit: L. $70 \mathrm{~cm}, W .60 \mathrm{~cm}$

Depth: $50 \mathrm{~cm}$

Orientation: $W$ to $E$ (?), with the head toward the $W$

Position of skeleton: -

L. of skeleton (contracted): $42 \mathrm{~cm}$ (surviving L.)

L. of skeleton (extended): -

Age at death: $1-7$ years

Sex: child

Condition of skeleton: badly preserved

Preserved skeletal bones: skull

Disturbed inhumation burial in an oval grave pit. Only the skull and a few long bones survived.

The burial did not contain any grave goods.

\section{Grave 103 (Square H5; Pl. XLVI)}

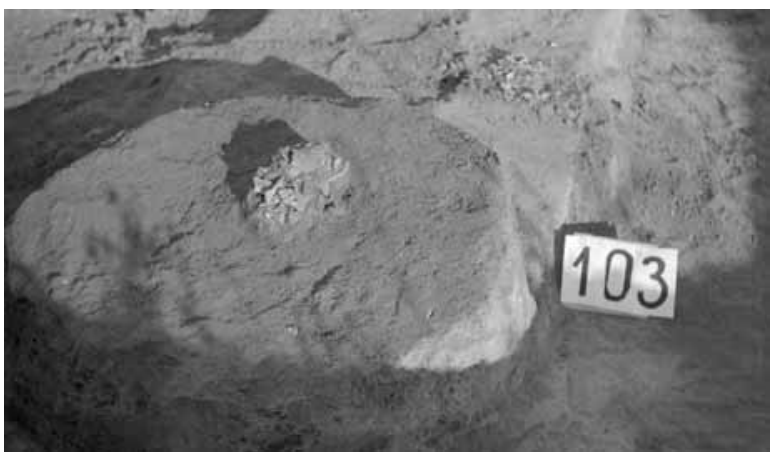

Size of grave pit: diam. $50 \mathrm{~cm}$

Depth: $38 \mathrm{~cm}$

Orientation: -

Position of skeleton: -

104 The vessel perished after the excavation, its description is quoted from the excavation diary.
L. of skeleton (contracted): -

L. of skeleton (extended): -

Age at death: adult

Sex: -

Condition of skeleton:-

Preserved skeletal bones: ${ }^{105}$

Scattered cremation burial in an oval grave pit.

The burial contained the following grave goods: fragments of a cup (1) lying among calcinated bone remains.

\section{Grave goods}

1. One-handled cup. Rim and body sherds of a greyishbrown, polished, thin-walled cup with cylindrical neck made from finely levigated clay, The belly is decorated with fine fluting. The stub of the handle has survived on one fragment. Some fragments joined from smaller ones. Seventeen pieces. Inv. no. 56.11.65.1 (Pl. XLVI. 103/1).

Grave 104 (Square H5; Pl. XLVI)

Size of grave pit: L. $150 \mathrm{~cm}, W .100 \mathrm{~cm}$

Depth: $140 \mathrm{~cm}$

Orientation: S-SE to N-NW, with the head toward the S-SE

Position of skeleton: laid on the left side

L. of skeleton (contracted): $114 \mathrm{~cm}$

L. of skeleton (extended): $153 \mathrm{~cm}$

Age at death: $30-40$ years

Sex: female

Condition of skeleton: medium well preserved

Preserved skeletal bones: skull, long bones

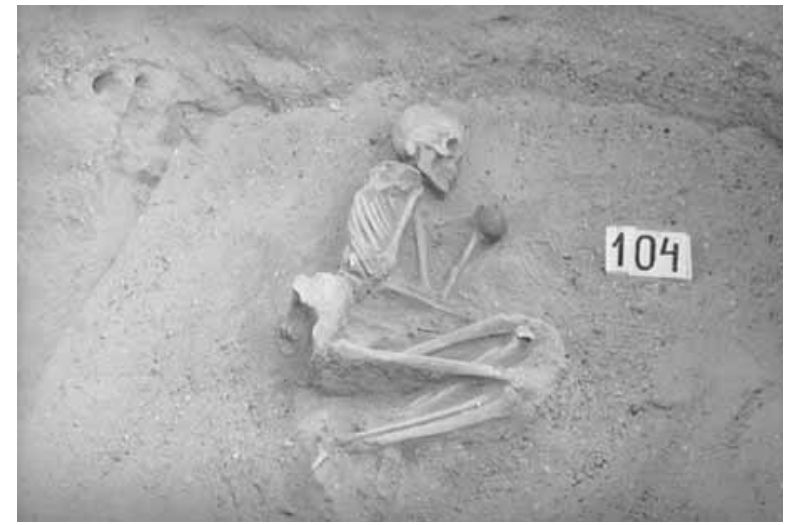

Inhumation burial in an oval grave pit. The body was laid on the left side in a contracted position. The skull rested on the left temporal bone. The left arm was bent at the elbow, with the hand resting in front of the face. The right arm was bent at the elbow, with the hand bent toward the pelvis. The right thigh was drawn up into a horizontal position, the left thigh slightly higher, the legs were bent back toward the buttocks.

The burial contained the following grave goods: a pot (1) tilted to one side by the left wrist.

$\overline{105}$ The skeletal remains can no longer be found in the Anthropological Collection. 
Grave goods

1. One-handled pot. Greyish, worn, squat biconical pot decorated with light fluting on the body, The strap handle has broken off, the rim is restored. H. $6.8 \mathrm{~cm}$, dM. $7.8 \mathrm{~cm}$, dB. $4.2 \mathrm{~cm}$. Inv. no. 56.11.66.1 (Pl. XLVI. 104/1).

\section{Grave 105 (Square I7; Pl. XLVII)}

Size of grave pit: L. $125 \mathrm{~cm}, W .105 \mathrm{~cm}$ Depth: $60 \mathrm{~cm}$

Orientation: E-SE to W-NW, with the head toward the E-SE Position of skeleton: laid on the left side

L. of skeleton (contracted): $104 \mathrm{~cm}$

L. of skeleton (extended): $148 \mathrm{~cm}$

Age at death: $40-x$ years

Sex: male (?)

Condition of skeleton: badly preserved

Preserved skeletal bones: skull, long bones

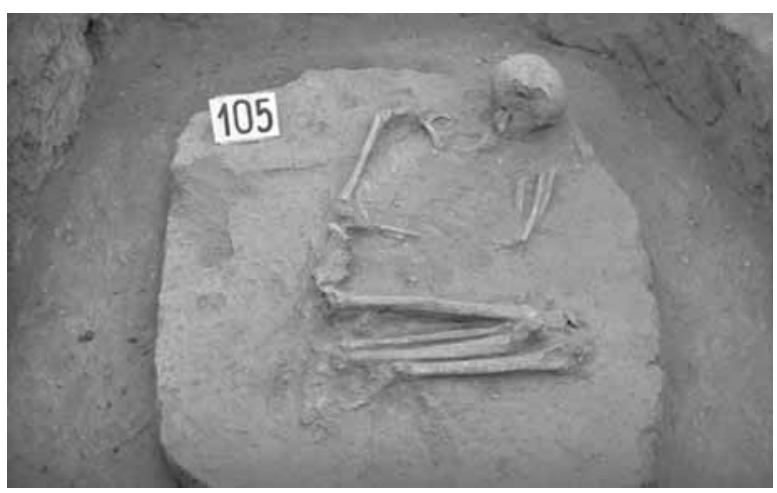

Inhumation burial in an oblong grave pit with rounded corners containing stones. The body was laid on the left side in a contracted position. The skull rested on the occipital bone. The right arm was bent at the elbow, with the hand placed by the left elbow. The left arm was bent at the elbow and drawn up, with the hand laid in front of the face. The thighs were drawn up into a horizontal position, the legs were bent back toward the buttocks. The burial was disturbed by animal burrows, which damaged the skull, the ribs, the right forearm and the left shoulder.

The burial did not contain any grave goods.

\section{Grave 106 (Square H5; Pl. XLVI)}

Size of grave pit: L. $120 \mathrm{~cm}$, W. $95 \mathrm{~cm}$

Depth: $70 \mathrm{~cm}$

Orientation: A: S-SW to N-NE, with the head toward the S-SW, B: S-SW to N-NE, with the head toward the S-SW

Position of skeleton: A: laid on the left side, B: laid on the right side L. of skeleton (contracted): A: 65, B: $94 \mathrm{~cm}$

L. of skeleton (extended): A: $100 \mathrm{~cm}, \mathrm{~B}: 138 \mathrm{~cm}$

Age at death: A: infans II, B: 9-11 years

Sex: A: child, B: child

Condition of skeleton: A: badly preserved, B: medium well preserved Preserved skeletal bones: ${ }^{106} \mathrm{~A}-\mathrm{B}$ : skull, long bones

106 The skeletal remains from Burial A can no longer be found. The anthropological data are quoted from the excavation diary.

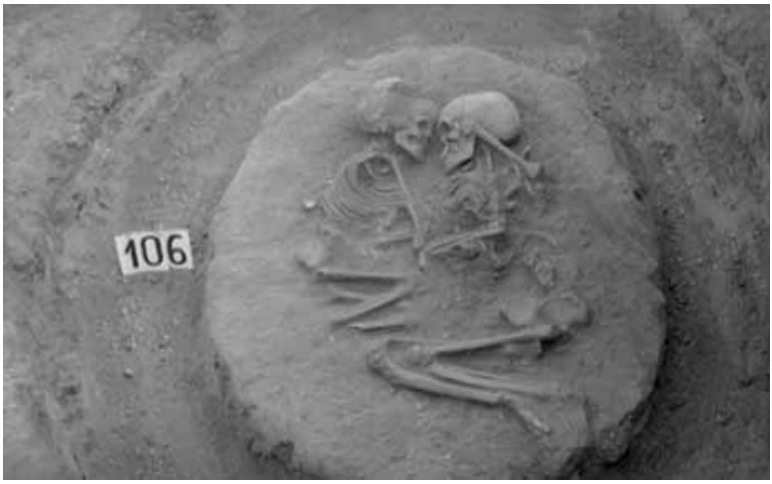

Double inhumation burial in an oval grave pit containing stones.

\section{Burial A}

The body was laid on the left side in a contracted position. The skull rested on the left temporal bone. The right arm was extended toward the knee. The left arm was bent at the elbow and extended toward Burial B. The thighs were drawn up into a horizontal position, the legs were bent back toward the buttocks.

The burial contained the following grave goods: four shells (1) behind the body.

\section{Burial B}

The body was laid on the right side in a contracted position opposite Burial A; the two skulls touched. The skull rested on the right temporal bone. The left arm was bent at the elbow and drawn up, with the hand lying by the right forearm of Burial A. The right arm was bent at the elbow and drawn up, with the hand placed by the chin. The thighs were drawn up into a horizontal position, the legs were bent back toward the buttocks.

The burial did not contain any grave goods.

Grave goods

1. Shells. Three perforated and one broken Anadara diluvii shells. Inv. no. 56.11.67.1 (Pl. XLVI. 106/1).

Grave 107 (Square I7; Pl. XLV)

Size of grave pit: L. $120 \mathrm{~cm}, W .90 \mathrm{~cm}$ Depth: $95 \mathrm{~cm}$

Orientation: $\mathrm{S}$ to $\mathrm{N}$, with the head toward the $\mathrm{S}$

Position of skeleton: laid on the right side

L. of skeleton (contracted): $89 \mathrm{~cm}$

L. of skeleton (extended): $145 \mathrm{~cm}$

Age at death: $35-45$ years

Sex: male (?)

Condition of skeleton: medium well preserved

Preserved skeletal bones: skull, long bones

Inhumation burial in an oval grave pit containing stones. The body was laid on the right side in a contracted position. The skull rested on the right temporal bone. The arms were bent at the elbow and 


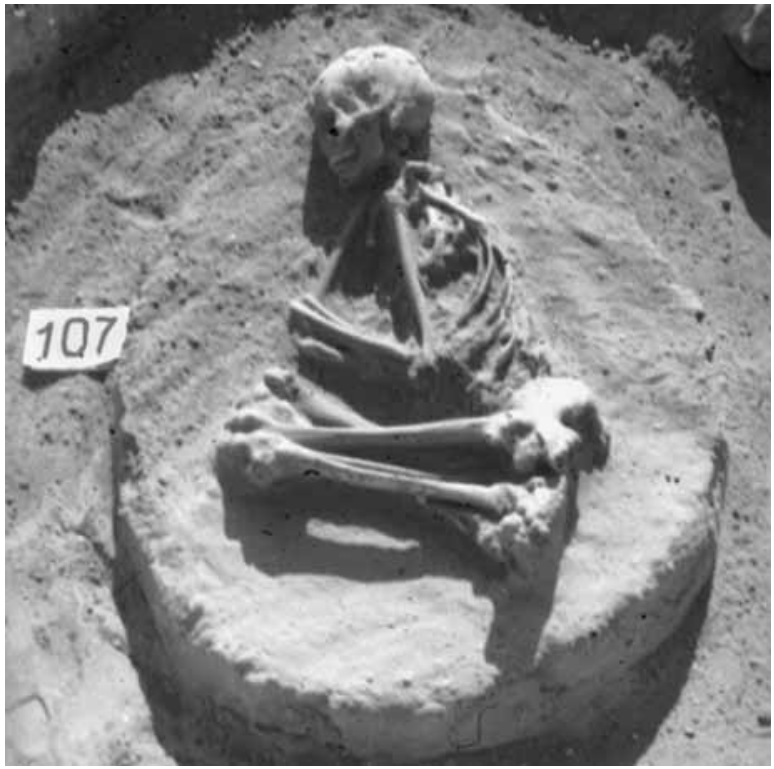

crossed in front of the chest. The left thigh was drawn up into a horizontal position, the right one slightly higher, the legs were bent back toward the buttocks.

The burial did not contain any grave goods.

\section{Grave 108 (Square H6; Pl. XLVII)}

Size of grave pit: L. $110 \mathrm{~cm}, W .90 \mathrm{~cm}$

Depth: $100 \mathrm{~cm}$

Orientation: A: SE to NW, with the head toward the SE, B: S to $\mathrm{N}$, with the head toward the $\mathrm{S}$

Position of skeleton: A: laid on the right side, B: laid on the left side L. of skeleton (contracted): A: $80 \mathrm{~cm}, \mathrm{~B}: 60 \mathrm{~cm}$

L. of skeleton (extended): A: $130 \mathrm{~cm}, \mathrm{~B}: 115 \mathrm{~cm}$

Age at death: A: 9-10 years, B: 7-14 years

Sex: A: child, B: child

Condition of skeleton: A: badly preserved, B: badly preserved

Preserved skeletal bones: A-B: skull, long bones

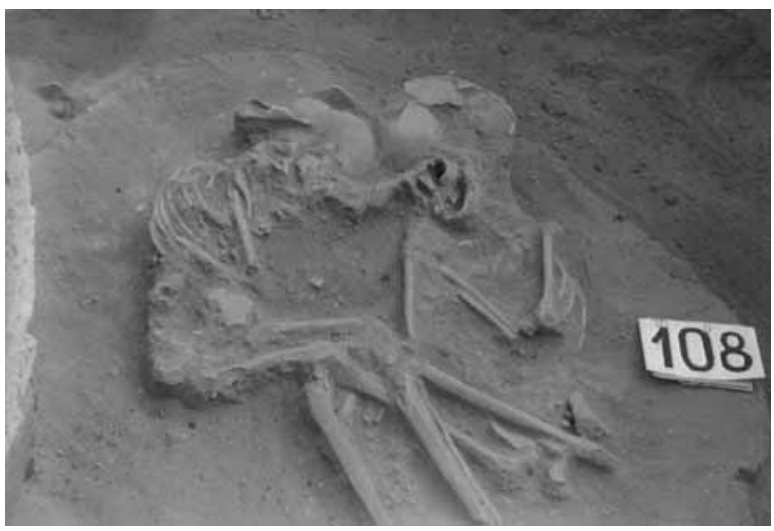

Inhumation burial in a round grave pit.

Burial A

The body was laid on the right side in a strongly contracted position. The left arm was bent at the elbow and drawn up, with the hand resting on the right shoulder. The right arm was extended toward the knees. The thighs were drawn up in front of the body, the legs were bent back toward the buttocks.

The burial did not contain any grave goods.

\section{Burial B}

The body was laid facing Burial A, with the two skulls touching. The body was laid on the left side in a contracted position. The skull was crushed. The position of the arms could not be established. The thighs were drawn up into a horizontal position, with the knees lying under the right hand and left knee of Burial A. The legs were bent back toward the buttocks.

The burial contained the following grave goods: a broken bone awl (1) on the skull.

\section{Grave goods}

1. Bone awl made from a small ruminant tibia. The shaft is broken. Joined from its fragments. L. $9.1 \mathrm{~cm}$. Inv. no. 56.11.68.1 (Pl. XLVII. 108/1).

\section{Grave 109 (Square H7/I7; Pl. XLVII)}

Size of grave pit: L. $105 \mathrm{~cm}, W .80 \mathrm{~cm}$

Depth: $100 \mathrm{~cm}$

Orientation: S-SE to N-NW, with the head toward the S-SE

Position of skeleton: laid on the right side

L. of skeleton (contracted): $60 \mathrm{~cm}$

L. of skeleton (extended): $95 \mathrm{~cm}$

Age at death: infans II

Sex: child

Condition of skeleton: badly preserved

Preserved skeletal bones: ${ }^{107}$ skull

Inhumation burial in an oval grave pit. The body was laid on the right side in a moderately contracted position. The skull was crushed. The arms were bent at the elbow and drawn up, with the hands laid in front of the chin. The thighs were moderately drawn up, the legs were bent back toward the buttocks.

The burial did not contain any grave goods.

\section{Grave 110 (Square H6; Pl. XLVII)}

\author{
Size of grave pit: L. $80 \mathrm{~cm}, W .60 \mathrm{~cm}$ \\ Depth: $50 \mathrm{~cm}$ \\ Orientation: $\mathrm{S}$ to $\mathrm{N}$, with the head toward the $\mathrm{S}$ \\ Position of skeleton: laid on the left side \\ L. of skeleton (contracted): $c a .50 \mathrm{~cm}$ \\ L. of skeleton (extended): - \\ Age at death: infans I \\ Sex: child \\ Condition of skeleton: badly preserved \\ Preserved skeletal bones: ${ }^{108}$ skull fragments
}

\footnotetext{
107 The skeletal remains can no longer be found. The anthropological data are quoted from the excavation diary.

108 The skeletal remains can no longer be found. The anthropological data are quoted from the excavation diary.
} 
Inhumation burial in an oval grave pit. The body was laid on the left side in a contracted position.

The burial did not contain any grave goods.

\section{Grave 111 (Square H7/I7; Pl. XLVIII)}

Size of grave pit: L. $55 \mathrm{~cm}, W .35 \mathrm{~cm}$

Depth: $100 \mathrm{~cm}$

Orientation: $\mathrm{S}$ to $\mathrm{N}$, with the head toward the $\mathrm{S}$

Position of skeleton: laid on the left side

Age at death: $c a .6$ months

Sex: infant

L. of skeleton (contracted): $40 \mathrm{~cm}$

L. of skeleton (extended): -

Condition of skeleton: badly preserved

Preserved skeletal bones: skull fragments

Inhumation burial in an oval grave pit. The body was laid on the left side in a contracted position. The right arm was bent at the elbow. The thighs were drawn up into a horizontal position, the legs were bent back toward the buttocks.

The burial contained the following grave goods: one Dentalium bead and two other beads (1) on the chest; ten shells (2) and two red stones (3-4) also on the chest; a shell (5) on the skull.

Grave goods

1. Beads. One Dentalium badense bead (with copper stains on one end) and two limestone beads. Inv. no. 56.11.69.1 (Pl. XLVIII. 111/1).

2. Shells. Ten perforated Anadara diluvii shells. Inv. no. 56.11.69.2 (Pl. XLVIII. 111/2). ${ }^{109}$

3. Red stone of irregular shape. Diam. $3.5 \mathrm{~cm}$. Inv. no. 56.11.69.3 (Pl. XLVIII. 111/3). ${ }^{110}$

4. Red stone, roughly triangular in shape. Diam. $2.2 \mathrm{~cm}$. Inv. no. 56.11.69.4 (Pl. XLVIII. 111/4). ${ }^{111}$

5. Large, broken Pecten shell, perforated at both ends. L. 5.5 cm. Inv. no. 56.11.69.5 (Pl. XLVIII. 111/5).

\section{Grave 112 (Square H6; Pl. XLIX)}

Size of grave pit: L. $150 \mathrm{~cm}, W .85 \mathrm{~cm}$

Depth: $105 \mathrm{~cm}$

Orientation: $\mathrm{N}$ to $\mathrm{S}$, with the head toward the $\mathrm{N}$

Position of skeleton: laid on the left side

L. of skeleton (contracted): $120 \mathrm{~cm}$

L. of skeleton (extended): $160 \mathrm{~cm}$

Age at death: $30-40$ years

Sex: male

Condition of skeleton: medium well preserved

Preserved skeletal bones: skull, long bones, pelvic bone

Inhumation burial in an oval grave pit. Smaller stones overlay the skull. The body was laid on the left side in a

\footnotetext{
109 Ten shells were inventoried. One has since been lost or mislaid and there are now only nine.

110 The object has since been lost or mislaid. Its description is quoted from the acquisitions register.

111 The object has since been lost or mislaid. Its description is quoted from the acquisitions register.
}

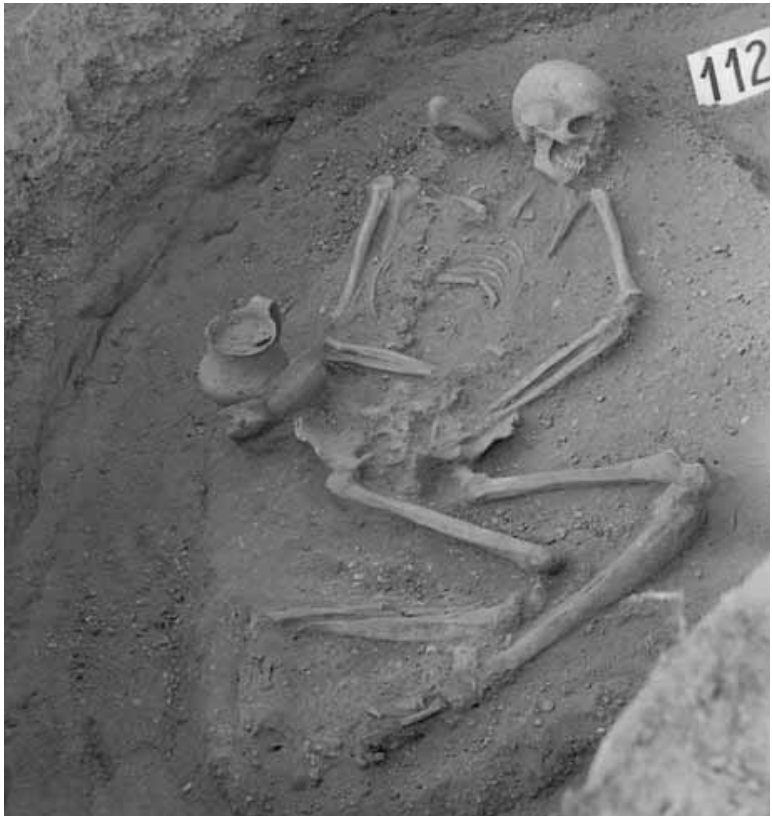

moderately contracted position. The skull rested on the left temporal bone. The body was deposited with the trunk and the pelvis lying extended on the back and tilted slightly to the left. The right arm was bent at the elbow, with the hand resting on the sacrum, the left arm was slightly bent and the hand laid on the pelvis. The left thigh was drawn up into a horizontal position, the right one more moderately, the legs were bent back toward the buttocks. The left foot was drawn back owing to the narrow grave pit.

The burial contained the following grave goods: a scooping vessel (1) by the right pelvic bone; a cup (2) with a pot (3) set on it beside the previous vessel; a stone blade fragment (4) under vessel 2; a stone blade (5) set on its edge by the right forearm; an antler axe (6) with the tip pointing toward the skull behind the skull, $10 \mathrm{~cm}$ north of the right shoulder.

\section{Grave goods}

1. Scooping vessel. Brownish, worn, small scooping vessel with slightly cylindrical neck and conical body, decorated with a row of impressed dots encircling the belly. The high-flung handle spans the rim and the vessel base. Joined from its fragments. H. $4.2 \mathrm{~cm}, \mathrm{dM} .8 .6 \mathrm{~cm}, \mathrm{~dB} .5 .5 \mathrm{~cm}$. Inv. no. 56.11.70.1 (Pl. XLIX. 112/1).

2. Cup. Brownish, worn, one-handled cup with slightly cylindrical neck and conical body, decorated with a row of impressed dots around the belly and impressed dots under the handle. The high-flung handle springs from the rim to the belly. Joined from its fragments, the rim is restored. H. $6 \mathrm{~cm}$, dM. 13.1 cm. Inv. no. 56.11.70.2 (Pl. XLIX. 112/2).

3. One-handled pot. Greyish-brown, polished vessel with cylindrical neck and conical body. The strap handle spans the rim and the belly. Two rows of impressed dots encircle the shoulder and the belly, 
interrupted by three vertical rows of dots under the handle. Incised under the dots are hanging triangles hatched with alternating oblique lines. Cracked. H. 13 cm, dM. 10.1 cm, dB. 6 cm. Inv. no. 56.11.70.3 (Pl. XLIX. 112/3).

4. Unretouched radiolarite blade. Inv. no. 56.11.70.4 (Pl. XLIX. 112/4).

5. Combination of a retouched blade and a déjeté burin. Radiolarite. Inv. no. 56.11.70.5 (Pl. XLIX. 112/5).

6. Antler axe. Fragment of an axe made from a shed red deer antler. L. $12.5 \mathrm{~cm}$. Inv. no. 56.11.70.6 (Pl. $X L I X .112 / 6)$.

\section{Grave 113 (Square I6/H6; Pl. XLVIII)}

Size of grave pit: L. $125 \mathrm{~cm}$, W. $110 \mathrm{~cm}$

Depth: $135 \mathrm{~cm}$

Orientation: A: E-SE to W-NW, with the head toward the E-SE, B: S-SW to N-NE, with the head toward the S-SW

Position of skeleton: A: laid on the left side, B: laid on the left side L. of skeleton (contracted): A: $70 \mathrm{~cm}$, B: $50 \mathrm{~cm}$

L. of skeleton (extended): -

Age at death: A: $9-10$ years, B: infans II

Sex: A: child, B: child

Condition of skeleton: A: badly preserved, B: badly preserved

Preserved skeletal bones: ${ }^{12} \mathrm{~A}-\mathrm{B}$ : complete skeletons

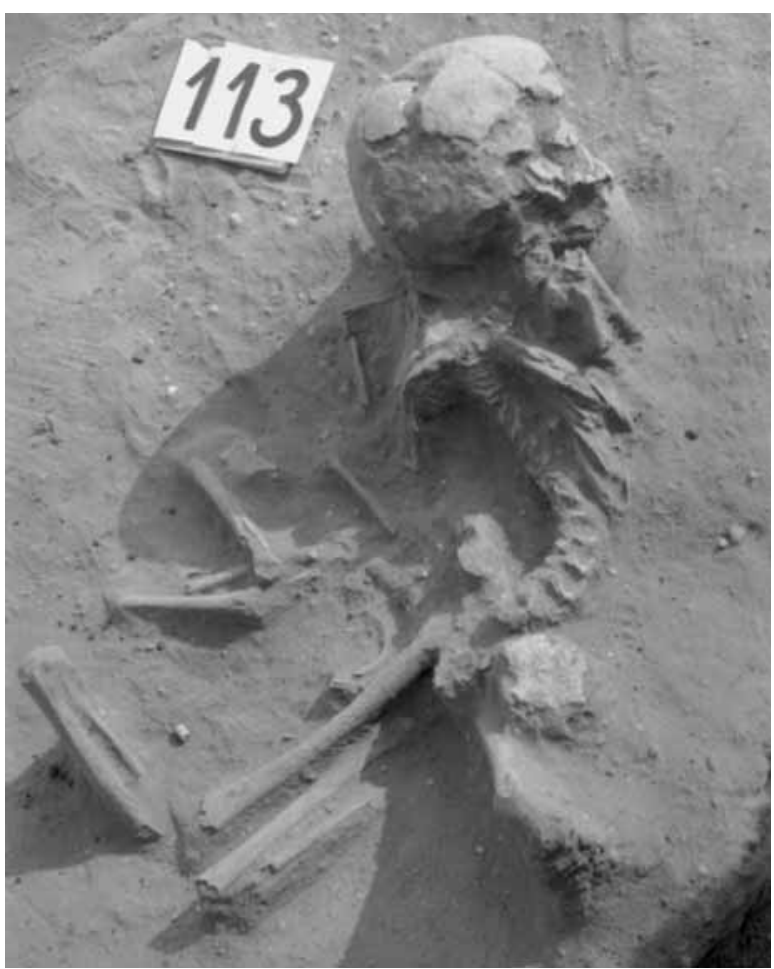

Double inhumation burial in an oval grave pit containing the burnt skeletons of two children. Traces of burning could be noted on the upper part of both skeletons and on the leg bones in Burial A. An 8-10 cm

112 The skeletal remains from Burial B can no longer be found. The anthropological data are quoted from the excavation diary. thick layer of fine ash covered the upper part of both skeletons. The two bodies had apparently been burned in the same manner as the bodies in Grave 100, with the fire kindled on the bodies.

\section{Burial A}

The body was deposited in a contracted position. The skull lay tilted on the left temporal bone with the face toward the south. The trunk was laid prone in a slightly contorted position. The pelvis had shifted from its original position. The left thigh was contorted and laid perpendicular to the body, the leg was extended and in line with the body. The right thigh was extended, the leg was drawn up into a horizontal position. The right arm was bent at the elbow and drawn up in front of the face. The left arm was bent at the elbow toward the chin.

The burial contained the following grave goods: four Dentalium beads, two sliced Dentalium beads, thirteen other beads, one marble bead (1) beside the body; one intact and one fragmentary tubular copper bead (2) by the neck.

\section{Burial B}

The body was laid on the left side in a contracted position beside Burial A. The two bodies were laid parallel to each other, the two skulls lay one over the other. The skull rested on the occipital bone. The arms were bent at the elbow, with the hands laid on the chest. The thighs were drawn up into a horizontal position, the legs were bent back toward the buttocks.

The burial contained the following grave goods: three Dentalium beads with tubular copper beads slipped over them and four fragmentary copper beads (3) around the neck.

\section{Grave goods}

1. Beads. Seven Dentalium badense beads, twelve limestone beads and one marble bead. ${ }^{113}$ Patches of reddish-brown ochre and green stains were noted on two beads. Inv. no. 56.11.71.1 (Pl. XLVIII. 113/1).

2. Copper beads. Two crumbling copper beads. Inv. no. 56.11.71.2 (Pl. XLVIII. 113/2).

3. Beads. Three Dentalium badense beads and four tubular copper beads. Copper beads were slipped over two Dentalium beads and one copper bead was slipped inside one of the Dentalium beads. Inv. no. 56.11.71.3 (Pl. XLVIII. 113/3).

\section{Grave 114 (Square H6; Pl. L)}

Size of grave pit: L. $95 \mathrm{~cm}, W .80 \mathrm{~cm}$

Depth: $105 \mathrm{~cm}$

Orientation: $\mathrm{S}$ to $\mathrm{N}$, with the head toward the $\mathrm{S}$

Position of skeleton: laid on the right side

L. of skeleton (contracted): $46 \mathrm{~cm}$

L. of skeleton (extended): -

$\overline{113}$ No marble beads were found among the finds. 
Age at death: $0.5-1$ years

Sex: child

Condition of skeleton: badly preserved

Preserved skeletal bones: skull, long bone fragments

Inhumation burial in an oval grave pit containing stones. The body was laid on the right side in a contracted position. The skull was crushed and lay on the occipital bone. The left arm was bent at the elbow, with the hand laid by the right elbow. The right arm was bent at the elbow and drawn up, with the hand resting in front of the face. The left thigh was drawn up into a horizontal position, the right one slightly higher, the legs were bent back toward the buttocks.

The burial contained the following grave goods: two tubular copper beads (1) on the forehead.

\section{Grave goods}

1. Copper beads. One long, tubular, well preserved copper bead resembling a Dentalium shell and one fragmentary, burnt (?) copper bead. Inv. no. 56.11.72.1 (Pl. L. 114/1).

\section{Grave 115 (Square H6; Pl. L)}

Size of grave pit: L. $135 \mathrm{~cm}$, W. $90 \mathrm{~cm}$ Depth: $105 \mathrm{~cm}$

Orientation: E-SE to W-NW, with the head toward the E-SE Position of skeleton: laid on the right side

L. of skeleton (contracted): $113 \mathrm{~cm}$

L. of skeleton (extended): $158 \mathrm{~cm}$

Age at death: $30-40$ years

Sex: female

Condition of skeleton: well preserved

Preserved skeletal bones: skull, long bones

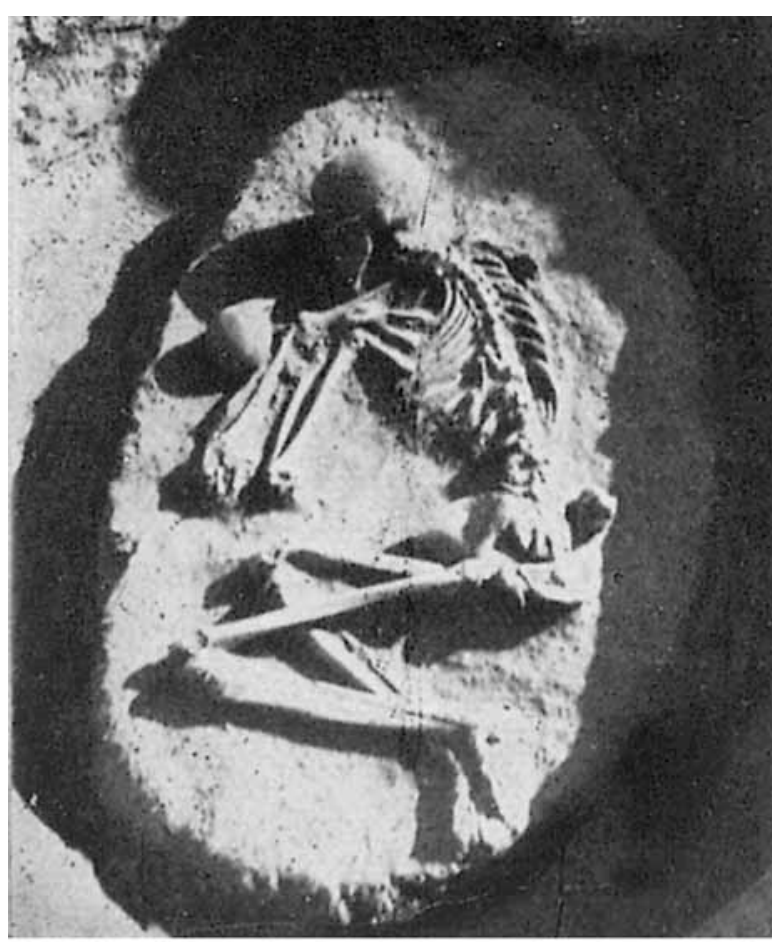

Inhumation burial in an oval grave pit. The body was laid on the right side in a contracted position. The skull rested on the right temporal bone. The trunk and the pelvis were laid prone, slightly tilted to the right. The right upper arm was laid under the neck, the elbow in front of the mouth, the forearm was slightly bent. The left arm was bent and drawn up toward the face, with the hand placed under the left shoulder. The right thigh was drawn up into a horizontal position, the left thigh to a lesser extent, the legs were bent back toward the buttocks.

The burial contained the following grave goods: a ladle (1) by the right elbow and forearm; a side-scraper (2) between the right and the left forearm.

\section{Grave goods}

1. Ladle. Light brown, thin-walled ladle with two perforations on the handle. Barely visible patches of red painting survive on the base. Joined from its fragments. H. $4.2 \mathrm{~cm}, \mathrm{~d} M .10 .6 \mathrm{~cm}$. Inv. no. 56.11.73.1 (Pl. L. 115/1).

2. Radiolarite side-scraper. Inv. no. 56.11.73.2 (Pl. L. 115/2).

Grave 116 (Square H6; Pl. LI)

Size of grave pit: L. $105 \mathrm{~cm}, W .65 \mathrm{~cm}$

Depth: $155 \mathrm{~cm}$

Orientation: NE to SW, with the head toward the NE

Position of skeleton: laid on the right side

L. of skeleton (contracted): $90 \mathrm{~cm}$

L. of skeleton (extended): $138 \mathrm{~cm}$

Age at death: $40-50$ years

Sex: female

Condition of skeleton: medium well preserved

Preserved skeletal bones: skull, long bones

Inhumation burial in an oval grave pit. The body was laid on the right side in a contracted position. The skull lay on the occipital bone. The right arm was bent at the elbow, with the forearm resting on the abdomen. The left arm was bent at the elbow and drawn up, with the hand placed in front of the face. The thighs were drawn up into a horizontal position, the legs were bent back toward the buttocks.

The burial contained the following grave goods: a one-handled pitcher (1) tilted to one side with the mouth toward the edge of the grave pit, $18 \mathrm{~cm}$ from the skull; a rim fragment (2) lying at a depth of $-40 \mathrm{~cm}$.

\section{Grave goods}

1. Pitcher. Dark grey, polished pitcher with slightly everted rim and conical body. The high-flung strap handle spans the rim and the belly. The belly is decorated with fluting, now rather worn. Joined from its fragments and restored. H. $12 \mathrm{~cm}, \mathrm{dM} .8 .5 \mathrm{~cm}$, dB. 6.5 cm. Inv. no. 61.2.1.1 (Pl. LI. 116/1).

2. Pot. Rim fragment of a brownish pot, decorated with a finger impressed rib under the rim. L. $6.3 \mathrm{~cm}$. Inv. no. 61.2.1.2 (Pl. LI. 116/2). 
Grave 117 (Square H7; Pl. L)

Size of grave pit: L. $125 \mathrm{~cm}, W .88 \mathrm{~cm}$

Depth: $75 \mathrm{~cm}$

Orientation: SW to NE, with the head toward the SW

Position of skeleton: laid on the right side

L. of skeleton (contracted): $94 \mathrm{~cm}$

L. of skeleton (extended): $152 \mathrm{~cm}$

Age at death: $30-40$ years

Sex: male (?)

Condition of skeleton: medium well preserved

Preserved skeletal bones: skull, long bones

Inhumation burial in an oval grave pit. The body was laid on the right side in a contracted position. The skull rested on the right side. The right arm was extended beside the body, with the hand laid by the lower third of the right thigh. The left arm was bent at the elbow and drawn up, with the hand placed under the shoulder. The thighs were drawn up into a horizontal position, the legs were bent back toward the buttocks.

The burial contained the following grave goods: a chert rectangle (1) by the right side of the back; a flake (2) in front of the mouth; a broken shell plaque (3) lying at a depth of $-55 \mathrm{~cm}$ in the grave pit.

Grave goods

1. Chert rectangle. Inv. no. 61.2.2.1 (Pl. L. 117/1).

2. Unretouched radiolarite flake. Diam. $2.1 \mathrm{~cm}$. Inv. no. 61.2.2.2 (Pl. L. 117/2).

3. Shell plaque. Rectangular, broken Unio crassus mussel plaque with two pairs of round perforations along the short sides. L. $1.3 \mathrm{~cm}, W .0 .9 \mathrm{~cm}$. Inv. no. 61.2.2.3 (Pl. L. 117/3).

\section{Grave 118 (Square G5/H5; Pl. LII)}

\author{
Size of grave pit: L. $110 \mathrm{~cm}, W .75 \mathrm{~cm}$ \\ Depth: $115 \mathrm{~cm}$ \\ Orientation: $\mathrm{S}$ to $\mathrm{N}$, with the head toward the $\mathrm{S}$ \\ Position of skeleton: laid on the right side \\ L. of skeleton (contracted): $92 \mathrm{~cm}$ \\ L. of skeleton (extended): $153 \mathrm{~cm}$ \\ Age at death: $35-45$ years \\ Sex: female \\ Condition of skeleton: medium well preserved \\ Preserved skeletal bones: skull, long bones
}

Inhumation burial in an oval grave pit containing stones. The body was laid on the right side in a contracted position. The right arm was extended toward the left knee with the hand laid between the right and the left knee. The left arm was bent at the elbow, with the hand placed under the left knee. The thighs were drawn up in front of the body, the legs were bent back toward the buttocks. The ankles rested one over the other.

The burial contained the following grave goods: a goblet (1) behind the left pelvic bone, tilted to one side, and lying on another, slightly damaged goblet (2).
Grave goods

1. Goblet. Reddish-brown, grey mottled goblet with rounded upper part set on a solid rectangular foot with rectangular base. The upper part is incised with three parallel zig-zag lines. The foot is perforated near the base. Joined from its fragments and restored. H. $8.6 \mathrm{~cm}, \mathrm{~d} M .9 .2 \mathrm{~cm}, \mathrm{~dB} .4 .4 \mathrm{~cm} \times 4 \mathrm{~cm}$. Inv. no. 61.2.3.1 (Pl. LII. 118/1).

2. Goblet. Reddish-brown, grey mottled goblet with rounded upper part resting on two rectangular feet. The corners of the upper part are peaked. The sides are trapezoidal. The feet are broken. Patches of red painting survive on the vessel body. Joined from its fragments and restored. H. $7.2 \mathrm{~cm}, \mathrm{dM} .8 .6-8.8 \mathrm{~cm}$. Inv. no. 61.2.3.2 (Pl. LII. 118/2). ${ }^{114}$

\section{Grave 119 (Square H7/H8; Pl. LII)}

Size of grave pit: L. $118 \mathrm{~cm}, W .80 \mathrm{~cm}$

Depth: $54 \mathrm{~cm}$

Orientation: SE to NW, with the head toward the SE

Position of skeleton: laid on the right side

L. of skeleton (contracted): $68 \mathrm{~cm}$

L. of skeleton (extended): $145 \mathrm{~cm}$

Age at death: $8-10$ years

Sex: child

Condition of skeleton: badly preserved

Preserved skeletal bones: skull, long bone fragments

Inhumation burial in an oval grave pit containing stones. The stones lay directly on the body, the bones were badly fragmented. The body was laid on the right side in a contracted position. The skull rested on the occipital bone. The arms were bent at the elbow and drawn up, with the hands pointing toward the face. The thighs were drawn up into a horizontal position, the legs were bent back toward the buttocks.

The burial did not contain any grave goods.

\section{Grave 120 (Square I8/H8)}

Size of grave pit: diam. $28 \mathrm{~cm}$

Depth: $25 \mathrm{~cm}$

Orientation: -

Position of skeleton: -

L. of skeleton (contracted): -

L. of skeleton (extended): -

Age at death: 23-59 years

Sex: female (?)

Condition of skeleton: -

Preserved skeletal bones: various fragments

Scattered cremation burial. There was no indication of a grave pit. Calcinated bone fragments were found over an area with a diameter of $28 \mathrm{~cm}$.

The burial did not contain any grave goods. 114 In his publication of the wagon model from Grave 177, Sándor Soproni
listed the vessels resembling wagon models, including the undecorated goblet from Grave 118 (SOPRONI 1954, 30, Pl. VI. 6). 
Grave 121 (Square H5; Pl. LI).

Size of grave pit: L. $105 \mathrm{~cm}, W .70 \mathrm{~cm}$

Depth: $65 \mathrm{~cm}$

Orientation: S-SE to N-NW, with the head toward the S-SE

Position of skeleton: laid on the left side

L. of skeleton (contracted): $58 \mathrm{~cm}$

L. of skeleton (extended): $c a .110 \mathrm{~cm}$

Age at death: $9-10$ years

Sex: child

Condition of skeleton: badly preserved

Preserved skeletal bones: skull, long bone fragments

Inhumation burial in an oval grave pit. The body was laid on the left side in a contracted position. The left arm was bent at the elbow, the hand rested on the body. The left arm was also bent at the elbow. The thighs were drawn up into a horizontal position, the legs were bent back toward the buttocks.

The burial did not contain any grave goods.

\section{Grave 122 (Square H8; Pl. LI)}

Size of grave pit: L. $65 \mathrm{~cm}, W .85 \mathrm{~cm}$

Depth: $54 \mathrm{~cm}$

Orientation: S-SE to N-NW, with the head toward the S-SE

Position of skeleton: laid on the right side

L. of skeleton (contracted): $52 \mathrm{~cm}$

L. of skeleton (extended): -

Age at death: 2-2.5 years

Sex: child

Condition of skeleton: badly preserved

Preserved skeletal bones: various fragments

Inhumation burial in an oval grave pit containing stones. The body was laid on the right side in a contracted position. The position of the arms could not be observed. The thighs were probably drawn up into a horizontal position, the legs were bent back toward the buttocks.

The burial did not contain any grave goods.

\section{Grave 123 (Square H6; Pl. LIII)}

Size of grave pit: L. $125 \mathrm{~cm}$, W. $88 \mathrm{~cm}$

Depth: $85 \mathrm{~cm}$

Orientation: A: S-SW to N-NE, with the head toward the S-SW, B: $S$ to $N$, with the head toward the $S$

Position of skeleton: A: laid on the left side, B: laid on the right side

L. of skeleton (contracted): A: 112, B: $51 \mathrm{~cm}$

L. of skeleton (extended): A: 155, B: -

Age at death: A: $40-50$ years, B: $1-2$ years

Sex: A: female, B: child

Condition of skeleton: A: medium well preserved, B: badly preserved Preserved skeletal bones: A: skull, long bones, B: various fragments

Double inhumation burial in an oval pit.

\section{Burial A}

The body was laid on the left side in a contracted position. The skull rested on the occipital bone, tilted slightly forward. The trunk was laid prone from the pelvis upward. The right arm was placed under the neck, the forearm was bent back toward the neck with the hand resting on the shoulder. The right arm was bent at the elbow and drawn up, with the hand placed on the shoulder.

The burial contained the following grave goods: a necklace of forty beads (1) extending from the neck to the chest.

\section{Burial B}

The body was deposited directly beside Burial A. The two skulls touched. The body was laid on the right side in a contracted position. The skull was crushed. The left arm was bent at the elbow. The thighs were drawn up into a horizontal position. The position of the legs could not be observed.

The burial did not contain any grave goods.

Grave goods

1. Beads. forty cylindrical and sliced limestone beads of varying sizes and one Dentalium badense bead. Inv. no. 61.2.4.1 (Pl. LIII. 123/1).115

\section{Grave 124 (Square H8; Pl. LIII)}

Size of grave pit: L. $115 \mathrm{~cm}$, W. $98 \mathrm{~cm}$

Depth: $95 \mathrm{~cm}$

Orientation: E-SE to W-NW, with the head toward the E-SE

Position of skeleton: laid on the right side

L. of skeleton (contracted): $89 \mathrm{~cm}$

L. of skeleton (extended): $152 \mathrm{~cm}$

Age at death: $40-x$ years

Sex: male

Condition of skeleton: medium well preserved

Preserved skeletal bones: skull, long bones

Inhumation burial in an almost round grave pit containing stones. The body was laid on the right side in a strongly contracted position. The skull lay on the occipital bone. The right arm was placed under the neck, the upper arm in front of the skull, with the hand in front of the mouth. The left arm was bent at the elbow and drawn up, with the hand toward the face. The thighs were drawn up in front of the body, the legs were bent back toward the buttocks.

The burial contained the following grave goods: a crushed ladle (1) under the left upper arm and the left knee.

Grave goods

1. Ladle. Light brown, worn ladle with two perforations on the handle. Patches of red painting survive in some spots on the body. Joined from several smaller fragments and restored. H. $3.5 \mathrm{~cm}, \mathrm{dM} .11 .3 \mathrm{~cm}, W$. of handle $3.7 \mathrm{~cm}$, L. of handle $5 \mathrm{~cm}$. Inv. no. 61.2.5.1 (Pl. LIII. 124/1).

115 The Dentalium bead is not mentioned in the excavation diary. The number of inventoried beads is thus higher by one. László Gucsi found forty-one beads when drawing the finds; it seems likely that the Dentalium bead had slipped inside another bead. 
Grave 125 (Square H6; Pl. LII)

Size of grave pit: L. $45, W .60 \mathrm{~cm}$

Depth: $68 \mathrm{~cm}$

Orientation: roughly $\mathrm{S}$ to $\mathrm{N}$, with the head toward the $\mathrm{S}$

Position of skeleton: laid on the left side

L. of skeleton (contracted): -

L. of skeleton (extended): -

Age at death: $23-x$ years

Sex: female (?)

Condition of skeleton: badly preserved

Preserved skeletal bones: long bone fragments

Inhumation burial. The burial was disturbed by an animal burrow; only the section below the pelvis survived. The body was laid on the left side in a contracted position. The thighs were drawn up into a horizontal position, the legs were bent back toward the buttocks.

The burial did not contain any grave goods.

\section{Grave 126 (Square H6; Pl. LIV)}

Size of grave pit: L. $145 \mathrm{~cm}, W .100 \mathrm{~cm}$

Depth: $95 \mathrm{~cm}$

Orientation: A: S to N, with the head toward the S, B: N-NW to S-SE, with the head toward the N-NW

Position of skeleton: A: laid on the left side, B: laid on the right side

L. of skeleton (contracted): A: $122 \mathrm{~cm}, \mathrm{~B}: 82 \mathrm{~cm}$

L. of skeleton (extended): A: $158 \mathrm{~cm}, \mathrm{~B}: c a .110 \mathrm{~cm}$

Age at death: A: $30-40$ years, B: $12-14$ years

Sex: A: female, B: child

Condition of skeleton: A: medium well preserved, B: medium well preserved

Preserved skeletal bones: A-B: skull, long bones

Double inhumation burial in an oval grave pit.

Burial A

The body was laid on the left side in a contracted position. The arms were bent at the elbow and drawn up, with the hands placed in front of the face. The right thigh was drawn up into a horizontal position, the left thigh to a lesser extent, the legs were slightly bent back toward the buttocks.

The burial did not contain any grave goods.

\section{Burial B}

The body was deposited a little west of Burial A, and laid in the opposite direction. The body was laid on the right side in a contracted position. The skull was crushed. The arms were bent at the elbow and drawn up, with the hands placed in front of the face. The right thigh was drawn up in front of the body, the left thigh into a horizontal position, the legs were slightly bent back toward the buttocks.

The burial did not contain any grave goods.

\section{Grave 127 (Square H6; Pl. LV)}

Size of grave pit: L. $122 \mathrm{~cm}, W .75 \mathrm{~cm}$ Depth: $105 \mathrm{~cm}$
Orientation: $\mathrm{S}$ to $\mathrm{N}$, with the head toward the $\mathrm{S}$

Position of skeleton: laid on the right side

L. of skeleton (contracted): $108 \mathrm{~cm}$

L. of skeleton (extended): $146 \mathrm{~cm}$

Age at death: $23-30$ years

Sex: female

Condition of skeleton: medium well preserved

Preserved skeletal bones: skull, long bones

Inhumation burial in an oval grave pit containing stones. The stones were deposited in two layers: the lower one was made up of a few stones only, followed by a $20 \mathrm{~cm}$ thick layer of earth, under which lay the body. The body was laid on the right side in a contracted position. The skull was tilted to the right side. The trunk was laid prone, tilted slightly to the right. The arms were bent at the elbow and drawn up, with the hands placed in front of the face. The right thigh was drawn up into a horizontal position, the left one to a lesser extent, the legs were bent back toward the buttocks.

The burial contained the following grave goods: twenty-two rectangular shell plaques (1) around the neck; a two-strand necklace of thirty-six intact and twenty-two sliced Dentalium beads, nine assorted beads of various colour, and six copper beads (2) extending from the right shoulder to the waist and the pelvis (the copper beads, the small white beads and the red beads lay around the neck); thirty-four beads and three shells (3) in a small heap, $5 \mathrm{~cm}$ north of the left elbow.

\section{Grave goods}

1. Shell plaques. Ten intact and twelve broken rectangular Unio crassus shell plaques with a pair of perforations along the short side. Twenty-two pieces. L. $2.2 \mathrm{~cm}, W .0 .8 \mathrm{~cm}$. Inv. no. 61.2.6.1 (Pl. LV. 127/1). ${ }^{116}$

2. Beads. Fifty-seven Dentalium badense beads, four red clay beads, two longish and two round limestone beads. Green stains were noted on one Dentalium bead. Inv. no. 61.2.6.2 (Pl. LV. 127/2). ${ }^{117}$

3. Beads. Thirty-three limestone beads, one clay bead, two Dentalium badense beads (Pl. LV. 127/3a) and three perforated Anadara diluvii shells (Pl. LV. 127/3b). Inv. no. 61.2.6.3.

\section{Grave 128 (Square H6; Pl. LVI)}

Size of grave pit: L. $115 \mathrm{~cm}, W .70 \mathrm{~cm}$

Depth: $93 \mathrm{~cm}$

Orientation: $\mathrm{S}$ to $\mathrm{N}$, with the head toward the $\mathrm{S}$

Position of skeleton: laid on the left side

L. of skeleton (contracted): $87 \mathrm{~cm}$

L. of skeleton (extended): $c a .130 \mathrm{~cm}$

\footnotetext{
116 Twenty-two shell plaques were inventoried, of which twenty were still to be found when the finds were re-examined for this publication.

117 Fewer beads were inventoried (fifty-seven Dentalium beads, four white and four red beads) than the number mentioned in the excavation diary. The copper beads had been lost by the time the grave goods were inventoried and even fewer were found when the finds were re-examined for this publication.
} 
Age at death: $12-13$ years

Sex: child

Condition of skeleton: badly preserved

Preserved skeletal bones: skull, long bone fragments

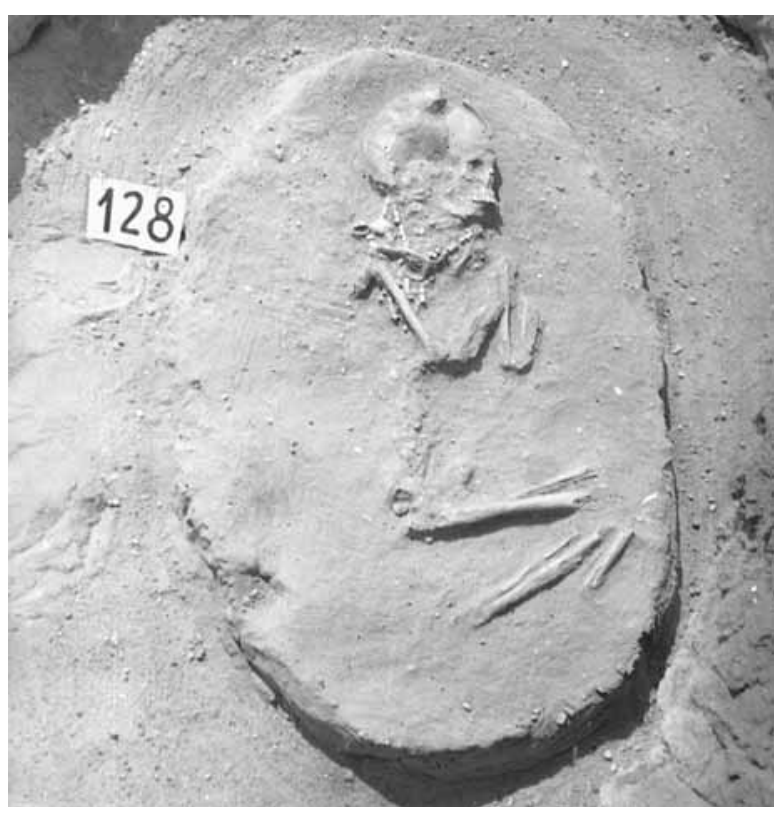

Inhumation burial in an oval grave pit. The body was laid on the left side in a contracted position. The crushed skull rested on the left temporal bone. The arms were bent at the elbow and drawn up, with the hands placed in front of the chin. The thighs were drawn up into a horizontal position, the legs were bent back toward the buttocks.

The burial contained the following grave goods: a two-strand necklace of eighteen shells and a hundred and forty-eight beads (1) around the neck, extending to the upper arm below the right shoulder; a stone chip (2) above the right shoulder.

Grave goods

1. Beads. A hundred and forty-two limestone beads (Pl. LVI. 128/1a) and twelve perforated Anadara diluvii shells (Pl. LVI. 128/1b). Inv. no. 61.2.7.1.118

2. Radiolarite debitage. Inv. no. 61.2.7.2.

\section{Grave 129 (Square H6; Pl. LVII)}

Size of grave pit: L. $55 \mathrm{~cm}, W .60 \mathrm{~cm}$

Depth: $70 \mathrm{~cm}$

Orientation: SE to NW, with the head toward the SE

Position of skeleton: laid on the left side

L. of skeleton (contracted): -

L. of skeleton (extended): -

Age at death: $7-14$ years

Sex: child

Condition of skeleton: badly preserved

Preserved skeletal bones: skull fragments, long bone fragments

$\overline{118 \text { Sixteen shells }}$ were inventoried, of which twelve could be found when the finds were drawn. According to László Gucsi, about one-half of the beads were barrel shaped, rather than cylindrical.
Inhumation burial in an oval grave pit. The greater part of the grave pit lying by the edge of the sand mine collapsed; the skull, the upper part of the body and the arms perished. The body was laid on the left side in a contracted position. The thighs were drawn up into a horizontal position, the legs were bent back toward the buttocks.

The burial contained the following grave goods in the surviving part of the grave: three shells and three beads (1) in front of the chest; a vessel fragment (2) in the grave pit.

\section{Grave goods}

1. Beads. Three limestone beads and three perforated Anadara diluvii shells. Inv. no. 61.2.8.1 (Pl. LVII. 129/1).

2. Bowl. Body sherd of a grey, thick-walled bowl with a string-hole lug. A pattern made up of a horizontal row of impressed dots combined with incised lines and two vertical rows of impressed dots flanking the lug can be made out on the vessel fragment. L. $9 \mathrm{~cm}$. Inv. no. 61.2.8.2 (Pl. LVII. 129/2).

\section{Grave 130 (Square H6/H7; Pl. LIV)}

Size of grave pit: -

Depth: $45 \mathrm{~cm}$

Orientation: -

Position of skeleton: -

L. of skeleton (contracted): -

L. of skeleton (extended): -

Age at death: -

Sex: -

Condition of skeleton: -

Preserved skeletal bones: -

Scattered cremation burial. ${ }^{119}$ There was no indication of a grave pit.

The burial contained the following grave goods: a beaker (1), five beads (2), a piece of sheet copper (3), perhaps a bead fragment. Calcinated bone fragments lay around the vessel over an area with a diameter of $30-35 \mathrm{~cm}$. The copper fragment and the beads lay around the bone fragments.

\section{Grave goods}

1. Beaker. Greyish-brown, one-handled beaker with slightly incurving neck and conical body. The handle rises above the rim and springs to the vessel belly. Joined from its fragments, the handle is restored. H. $7.4 \mathrm{~cm}, \mathrm{dM} .7 .2 \mathrm{~cm}, \mathrm{~dB} .5 .1 \mathrm{~cm}$. Inv. no. 61.2.9.1 (Pl. LIV. 130/1).

2. Beads. Five cylindrical limestone beads. Inv. no. 61.2.9.2 (Pl. LIV. 130/2).

3. Copper fragment. Fragments of rectangular, poorly preserved copper sheet with inward curling edges.

\footnotetext{
$\overline{119}$ The ashes can no longer be found.
} 
Two pieces. L. $2.5 \mathrm{~cm}, 2.6 \mathrm{~cm}, W .0 .8 \mathrm{~cm}, 1 \mathrm{~cm}$. Inv. no. 61.2.9.3 (Pl. LIV. 130/3).120

\section{Grave 131 (Square H7; Pl. LVIII)}

\author{
Size of grave pit: - \\ Depth: $30-45 \mathrm{~cm}$ \\ Orientation: - \\ Position of skeleton: - \\ L. of skeleton (contracted): - \\ L. of skeleton (extended): - \\ Age at death: - \\ Sex: - \\ Condition of skeleton:- \\ Preserved skeletal bones: ${ }^{121}$ -
}

Double burial: a scattered cremation and an inurned burial. There was no indication of a grave pit. Calcinated bones were found in a medium sized, strongly damaged bowl (1) at a depth of $-30 \mathrm{~cm}$, beside which lay a small mug (2). Calcinated bones lay around the two vessels. Other calcinated bones were found under a few centimetres thick layer of earth under the vessels. The bone remains perhaps came from two bodies. The calcinated bones were found over an area with a diameter of $30 \mathrm{~cm}$.

\section{Grave goods}

1. Bowl. Body and base fragments of a reddish-brown, worn bowl with rounded shoulder and conical body. Joined from four fragments. Inv. no. 61.2.10.1 (Pl. LVIII. 131/1).

2. Mug. Grey, worn, thin-walled mug with cylindrical neck and flattened globular body. The high-flung handle spans the rim and the shoulder. The belly is decorated with fluting. Joined from its fragments and restored. H. $5.2 \mathrm{~cm}, \mathrm{dM} .7 .4 \mathrm{~cm}$. Inv. no. 61.2.10.2 (Pl. LVIII. 131/2).

Other finds from the burial

3. Mug. Rim fragment of a brownish, thin-walled mug. Joined from its fragments. L. $4.2 \mathrm{~cm}$. Inv. no. 61.2.10.3 (Pl. LVIII. 131/3).

4. Goblet. Two rim fragments of a light brownishgrey, worn, thin-walled, large goblet decorated with an incised zig-zag pattern under the rim. Both fragments joined from smaller ones. L. $7.3 \mathrm{~cm}, 4.5 \mathrm{~cm}$, dM. 15 cm. Inv. no. 61.2.10.4 (Pl. LVIII. 131/4).

\section{Grave 132 (Square H8; Pl. LIX)}

Size of grave pit: L. $138 \mathrm{~cm}, W .88 \mathrm{~cm}$

Depth: $43 \mathrm{~cm}$

Orientation: $\mathrm{S}$ to $\mathrm{N}$, with the head toward the $\mathrm{S}$

Position of skeleton: laid on the left side

L. of skeleton (contracted): $95 \mathrm{~cm}$

L. of skeleton (extended): $c a .155 \mathrm{~cm}$

120 The copper fragment broke into three pieces.

121 The calcinated bone fragments can no longer be found in the Anthropological Collection.
Age at death: $23-30$ years

Sex: male

Condition of skeleton: badly preserved

Preserved skeletal bones: skull fragments, long bones

Inhumation burial in an oval grave pit. The body was laid on the left side in a contracted position. The skull, the chest, the pelvis and the right foot were disturbed by an animal burrow in the grave pit's eastern half. Only a mandible fragment remained in its original position. The arms were bent at the elbow and drawn up, with the hands placed in front of the face. The right thigh was drawn up into a horizontal position, the left one slightly higher in front of the body, the legs were bent back toward the buttocks.

The burial contained the following grave goods: a crushed ladle (1) $5 \mathrm{~cm}$ west of the right upper arm; a small, damaged scooping vessel (2) inside the previous vessel.

Grave goods

1. Ladle. Reddish-brown, grey mottled ladle with flat base decorated with an incised zig-zag line under the rim. The inner side of the handle has a pattern of four zig-zag lines and two small perforations near the top. Joined from its fragments and restored. H. $3.6 \mathrm{~cm}, \mathrm{dM} .12 .2 \mathrm{~cm}, W$. of handle $4.1 \mathrm{~cm}$. Inv. no. 61.2.11.1 (Pl. LIX. 132/1).

2. Scooping vessel. Greyish scooping vessel with conical body and flat base. The handle springs from the rim to the base. Joined from its fragments and restored. H. $3.9 \mathrm{~cm}$, dM. $10.7 \mathrm{~cm}$. Inv. no. 61.2.11.2 (Pl. LIX. 132/2).

\section{Grave 133 (Square H8)}

Size of grave pit: L. $42 \mathrm{~cm}, W .48 \mathrm{~cm}$

Depth: $65 \mathrm{~cm}$

Orientation: $\mathrm{S}$ to $\mathrm{N}$ (?), with the head toward the $\mathrm{S}$

Position of skeleton: -

L. of skeleton (contracted): -

L. of skeleton (extended): -

Age at death: -

Sex: -

Condition of skeleton: badly preserved

Preserved skeletal bones: ${ }^{122}$ various fragments

Inhumation burial. The grave lay at the edge of the sand-pit and collapsed. Only a part of the leg survived.

The burial did not contain any grave goods in the surviving part.

\section{Grave 134 (Square H8; Pl. LIV)}

Size of grave pit: L. $120 \mathrm{~cm}, W .75 \mathrm{~cm}$

Depth: $53 \mathrm{~cm}$

Orientation: A: $\mathrm{S}$ to $\mathrm{N}$, with the head toward the $\mathrm{S}, \mathrm{B}$ : -

\footnotetext{
122 The skeletal remains can no longer be found. The anthropological data are quoted from the excavation diary.
} 
Position of skeleton: A: laid on the left side, B: laid on the right side L. of skeleton (contracted): A: $70 \mathrm{~cm}, \mathrm{~B}:-$

L. of skeleton (extended): -

Age at death: A: 15-19 years, B: 23-x years

Sex: A: juvenis, B: -

Condition of skeleton: A: badly preserved, B: badly preserved

Preserved skeletal bones: long bones

Double inhumation burial. The grave pit was partly destroyed. Only the skeletal parts from the neck downward survived of Burial A, and only the pelvis and the legs of Burial B.

\section{Burial A}

The body was laid on the left side in a contracted position. The right arm was bent at the elbow and drawn up, with the hand placed in front of the face. The left thigh was drawn up into a horizontal position, the right thigh more moderately, the legs were bent back toward the buttocks. The feet lay one over the other. The waist region was destroyed by an animal burrow.

The burial contained the following grave goods: a burin (1) between the right and the left thigh.

\section{Burial B}

The body was deposited parallel to Burial A. The body was laid on the right side in a contracted position. The right thigh was drawn up into a horizontal position, the left one in front of the body, the legs were bent back toward the buttocks. The feet rested one over the other.

The burial did not contain any grave goods in the surviving part.

Grave goods

1. Radiolarite burin. Inv. no. 61.2.12.1 (Pl. LIV. 134/1).

\section{Grave 135 (Square G5; Pl. LIX)}

Size of grave pit: L. $115 \mathrm{~cm}, W .88 \mathrm{~cm}$

Depth: $60 \mathrm{~cm}$

Orientation: S-SW to N-NE, with the head toward the S-SW

Position of skeleton: laid on the left side

L. of skeleton (contracted): $86 \mathrm{~cm}$

L. of skeleton (extended): $c a .125 \mathrm{~cm}$

Age at death: $15-23$ years

Sex: juvenis

Condition of skeleton: badly preserved

Preserved skeletal bones: skull, long bone fragments

Inhumation burial in an oval grave pit containing stones. The fragments of various thick-walled vessels (1) lay among the stones. The stones lay directly on the body, the skull and the skeletal bones were strongly fractured. The body was laid on the left side in a contracted position. The arms were placed in the lap. The thighs were drawn up in front of the body, the legs were bent back toward the buttocks. A stone set on its edge was found behind the spine.

The burial did not contain any grave goods.
Finds from the grave pit

1. Pot and amphora fragments. Rim, body and base sherd of a dark grey, thick-walled pot (Pl. LIX. 135/1c); one fragment decorated with a knob (Pl. LIX. 135/1b); one amphora fragment has a small stringhole lug (Pl. LIX. 135/1a). Nineteen nonjoining pieces. Inv. no. 61.2.13.

\section{Grave 136 (Square G6; Pl. LX)}

\author{
Size of grave pit: L. $132 \mathrm{~cm}, W .100 \mathrm{~cm}$ \\ Depth: $112 \mathrm{~cm}$ \\ Orientation: S-SW to N-NE, with the head toward the S-SW \\ Position of skeleton: laid on the right side \\ L. of skeleton (contracted): $92 \mathrm{~cm}$ \\ L. of skeleton (extended): $144 \mathrm{~cm}$ \\ Age at death: $23-30$ years \\ Sex: female (?) \\ Condition of skeleton: medium well preserved \\ Preserved skeletal bones: skull, long bones
}

Inhumation burial in an oval grave pit. The body was laid on the right side in a contracted position. The body was deposited diagonally across the grave pit. The crushed skull rested on the right temporal bone. The arms were bent at the elbow and laid in the lap, with the right hand resting on the pelvis, the left hand by the right elbow. The thighs were drawn up in front of the body, the legs were bent back toward the buttocks.

The burial contained the following grave goods: a pitcher (1) tilted to one side, $5 \mathrm{~cm}$ under the knees; six small lumps of ochre (2) beside the vessel; four intact and one broken beads (3) by the left upper arm.

\section{Grave goods}

1. Pitcher. Greyish-black, one handled pitcher with flat base. The belly is decorated with vertical smoothed-in lines. The wide strap handle spans the rim and the belly. The rim is restored. H. $12 \mathrm{~cm}$, dM. $9 \mathrm{~cm}$, dB. $5.7 \mathrm{~cm}$. Inv. no. 61.2.14.1 (Pl. LX. 136/1). ${ }^{123}$

2. Ochre. Small lumps of red ochre, the largest with a polished surface. Six pieces. Inv. no. 61.2.14.2 (Pl. LX. 136/2).

3. Beads. Four limestone beads. Inv. no. 61.2.14.3 (Pl. LX. 136/3). ${ }^{124}$

\section{Grave 137 (Square H8; Pl. LIV)}

Size of grave pit: L. $110 \mathrm{~cm}, W .76 \mathrm{~cm}$

Depth: $92 \mathrm{~cm}$

Orientation: S-SW to N-NE, with the head toward the S-SW

Position of skeleton: laid on the left side

L. of skeleton (contracted): $92 \mathrm{~cm}$

L. of skeleton (extended): $153 \mathrm{~cm}$

Age at death: $14-16$ years

Sex: juvenis

Condition of skeleton: medium well preserved

Preserved skeletal bones: skull, long bones 123 The object has since been lost or mislaid. The drawing is based on
József Korek's grave sheet.

124 There were no broken beads when the finds were drawn. 
Inhumation burial in a narrow, oval grave pit containing many stones. The stones lay on the body, the skull was crushed. The body was laid on the left side in a contracted position with the skull on the left side. The upper part of the body and the pelvis were extended on the back, tilted slightly to the left. The right arm was slightly bent at the elbow, with the hand placed on the sacrum. The left arm was extended, with the hand resting on the pelvis. The right thigh was drawn up into a horizontal position, the left one more strongly, the legs were bent back toward the buttocks.

The burial contained the following grave goods: a Dentalium bead and a tiny white bead (1) on the right shoulder.

Grave goods

1. Beads. One Dentalium badense bead and a tiny limestone bead. Inv. no. 61.2.15 (Pl. LIV. 137/1).

\section{Grave 138 (Square G5; Pl. LX)}

\author{
Size of grave pit: - \\ Depth: $35 \mathrm{~cm}$ \\ Orientation: - \\ Position of skeleton: - \\ L. of skeleton (contracted): - \\ L. of skeleton (extended): - \\ Age at death: $23-x$ years \\ Sex: - \\ Condition of skeleton: - \\ Preserved skeletal bones: -
}

Scattered cremation burial. There was no indication of a grave pit. Calcinated bones lay around a goblet over an area with a diameter of $30 \mathrm{~cm}$.

The burial contained the following grave goods: a goblet (1) and a strand of fifteen beads and five shells (2).

The grave goods were not burnt, suggesting that the beads had been strung into a necklace and placed among the calcinated bones.

\section{Grave goods}

1. Goblet. Brownish-grey, thin-walled, worn goblet with round upper part set on a rectangular foot with a rectangular base. The foot is perforated just above the base. The entire vessel body is decorated with an incised zig-zag pattern, Joined from its fragments; the rim, the foot and the base are restored. $d M .9 .3 \mathrm{~cm}$, H. 8.7 cm. Inv. no. 61.2.16.1 (Pl. LX. 138/1).

2. Beads. Fifteen limestone beads (Pl. LX. 138/2a), four perforated Anadara diluvii shells (Pl. LX. 138/2b), and one fossil Spondylus shell, the latter perforated in at least three spots (Pl. LX. 138/2c). Inv. no. 61.2.16.2.

\section{Grave 139 (Square G7; Pl. LVII)}

Size of grave pit: L. $55 \mathrm{~cm}, W .50 \mathrm{~cm}$

Depth: $55 \mathrm{~cm}$

Orientation: S-SE to N-NW, with the head toward the S-SE
Position of skeleton: laid on the right side

L. of skeleton (contracted): $32 \mathrm{~cm}$

L. of skeleton (extended): $95 \mathrm{~cm}$

Age at death: $7-8$ years

Sex: child

Condition of skeleton: medium well preserved

Preserved skeletal bones: skull, long bones

Inhumation burial in a round grave pit. The body was laid on the right side in a contracted position. The skull rested on the occipital bone with the face toward the north-north-west. The arms were bent at the elbow and drawn up toward the face. The thighs were drawn up in front of the body with the knees places almost by the head, the legs were bent back toward the buttocks.

The burial contained the following grave goods: a large mussel (1) under the head.

\section{Grave goods}

1. Mussel. Large, well preserved, broken Unio crassus mussel. L. $6.3 \mathrm{~cm}, \mathrm{~W} .3 .6 \mathrm{~cm}$. Inv. no. 61.2 .17 (Pl. LVII. 139/1).

\section{Grave 140 (Square H7; Pl. LVIII)}

Size of grave pit: L. $115 \mathrm{~cm}, W .70 \mathrm{~cm}$

Depth: $50 \mathrm{~cm}$

Orientation: S-SE to N-NW, with the head toward the S-SE Position of skeleton: laid on the right side

L. of skeleton (contracted): $90 \mathrm{~cm}$

L. of skeleton (extended): $130 \mathrm{~cm}$

Age at death: $12-14$ years

Sex: child

Condition of skeleton: badly preserved

Preserved skeletal bones: various fragments

Inhumation burial in an oval grave pit containing stones. The stones lay on the body and crushed the skull and the bones. The body sherd of a clay vessel (1) was found under the stones. The body was laid on the right side in a contracted position. The right arm was extended beside the body, the left arm was bent at the elbow. The thighs were drawn up into an almost horizontal position, the legs were bent back toward the buttocks.

The burial did not contain any grave goods.

Finds from the grave pit

1. Bowl. Body sherd of a grey, polished, large bowl decorated with a row of impressed dots encircling the belly. L. $7.2 \mathrm{~cm}$. Inv. no. 61.2 .18 (Pl. LVIII. 140/1).

\section{Grave 141 (Square K9)}

Size of grave pit: -

Depth: $50 \mathrm{~cm}$

Orientation: roughly $W$ to $E$, with the head toward the $W$

Position of skeleton: laid on the right side

L. of skeleton (contracted): -

L. of skeleton (extended): -

Age at death: 23-39 years 
Sex: female (?)

Condition of skeleton: badly preserved

Preserved skeletal bones: long bones

Inhumation burial. There was no indication of a grave pit. The grave lying at the edge of the sand-pit collapsed and only the section from the pelvis downward survived. The position of the legs suggested that the body was laid on the right side in a contracted position. A few stones lay by the knees.

The burial did not contain any grave goods in the surviving part.

\section{Grave 142 (Square G6/H6; Pl. LXI)}

Size of grave pit: L. $155 \mathrm{~cm}, W .130 \mathrm{~cm}$

Depth: $92 \mathrm{~cm}$

Orientation: A: E-NE to W-SW, with the head toward the E-NE, B: S-SW to N-NE, with the head toward the S-SW

Position of skeleton: A: laid on the right side, B: laid on the right side L. of skeleton (contracted): A: $40 \mathrm{~cm}, \mathrm{~B}: 98 \mathrm{~cm}$

L. of skeleton (extended): A: -, B: $157 \mathrm{~cm}$

Age at death: A: $2.5-3.5$ years, B: 23-39 years

Sex: A: child, B: male

Condition of skeleton: A: badly preserved, B: medium well preserved

Preserved skeletal bones: A: various fragments, B: skull, long bones

Double inhumation burial in an oval grave pit.

\section{Burial A}

The burial of an infant lay some $10-15 \mathrm{~cm}$ above Burial $\mathrm{B}$, a little south-east of the skull, the right elbow and the right knee in that burial. The body was laid on the right side in a contracted position. Only the skull, the legs, a few ribs and the upper arm survived. The thighs were drawn up in front of the body.

The burial did not contain any grave goods.

\section{Burial B}

The body was laid on the right side in a contracted position. The skull lay on the occipital bone, tilted slightly to the right. The left arm was bent at the elbow and drawn up, with the forearm placed parallel to the thighs. The right arm was bent at the elbow, with the hand resting on the chest. The thighs were drawn up in front of the body, the legs were bent back toward the buttocks. The feet lay one over the other.

The burial contained the following grave goods: a goblet (1) tilted to one side with the mouth toward the buttocks, $40 \mathrm{~cm}$ north of the pelvis; a cup (2) near the previous vessel, a little to its north-east; a one-handled jug (3) tilted to one side with the mouth facing the skull under the right upper arm and the skull.

Grave goods

1. Goblet. Reddish-brown, thin-walled goblet with rounded upper part set on a flattened cylindrical foot with a round base. The foot is perforated immediately above the base. A dense zig-zag pattern is incised under the rim, under which the vessel body is covered with less closely spaced zig-zag lines down to the base. The rim and the base are partially restored. H. $9.7 \mathrm{~cm}$, dM. $10 \mathrm{~cm}, \mathrm{~dB} .4 \mathrm{~cm}$. Inv. no. 61.2.19.1 (Pl. LXI. 142/1). ${ }^{125}$

2. One-handled cup. Body and base fragment of a grey, worn, thick-walled cup with the stub of the handle. The vessel is decorated with a row of impressed dots around the belly. Joined from smaller fragments. H. 6 cm. Inv. no. 61.2.19.2 (Pl. LXI. 142/2).

3. Jug. Grey, one-handled jug with curved neck and strongly indrawn flat base. The belly is decorated with smoothed-in vertical lines. The strap handle is joined from its fragments. H. $19.7 \mathrm{~cm}$, dM. $9.9 \mathrm{~cm}$, dB. 6 cm. Inv. no. 61.2.19.3 (Pl. LXI. 142/3).126

\section{Grave 143 (Square G5; Pl. LX)}

\author{
Size of grave pit: L. $115 \mathrm{~cm}, W .112 \mathrm{~cm}$ \\ Depth: $132 \mathrm{~cm}$ \\ Orientation: $\mathrm{S}$ to $\mathrm{N}$, with the head toward the $\mathrm{S}$ \\ Position of skeleton: laid on the right side \\ L. of skeleton (contracted): $98 \mathrm{~cm}$ \\ L. of skeleton (extended): $144 \mathrm{~cm}$ \\ Age at death: $30-40$ years \\ Sex: female \\ Condition of skeleton: medium well preserved \\ Preserved skeletal bones: skull, long bones
}

Inhumation burial in a round grave pit. The grave pit lay under Grave 139. There was no sign of disturbance. The body was laid on the right side in a contracted position. The right arm was bent at the elbow and drawn up, with the hand toward the neck. The left arm was bent at the elbow and drawn up, with the hand placed by the right elbow. The left thigh was drawn up into a horizontal position, the right one to a lesser extent, the legs were bent back toward the buttocks. The ankles and the feet lay one over the other.

The burial contained the following grave goods: a broken scooping vessel (1) at the edge of the grave pit, $20 \mathrm{~cm}$ west of the right knee; a small red stone (2) inside the bowl.

\section{Grave goods}

1. Scooping vessel. Brownish, squat, plain scooping vessel with conical body. The strap handle rises above the rim and springs to the base. The rim is restored, the handle is joined from its fragments. $\mathrm{H}$. 5 cm, dM. 10.4 cm. Inv. no. 61.2.20.1 (Pl. LX. 143/1).

2. Stone. Red stone with trapezoidal section, polished smooth on one side. L. $3.5 \mathrm{~cm}, W .3 .1 \mathrm{~cm}$. Inv. no. 61.2.20.2 (Pl. LX. 143/2).

\footnotetext{
125 László Gucsi reconstructed the sequence of the vessel's decoration. The potter first incised a zig-zag pattern on the goblet (this can be seen on the foot and the cup), then smoothed the design and drew a lattice pattern (or something similar) on the vessel.

126 The object has since been lost or mislaid. The drawing is based on József Korek's grave sheet.
} 
Grave 144 (Square H7)

Size of grave pit: L. $60 \mathrm{~cm}, W .50 \mathrm{~cm}$

Depth: $63 \mathrm{~cm}$

Orientation: probably laid with the head toward the S

Position of skeleton: -

L. of skeleton (contracted): -

L. of skeleton (extended): -

Age at death: infant

Sex: child

Condition of skeleton: badly preserved

Preserved skeletal bones: ${ }^{127}$

Inhumation burial in a round pit. Very little of the skeleton survived. An oxidised copper artefact lay beside the head. ${ }^{128}$

\section{Grave 145 (Square G5; Pl. LXII)}

Size of grave pit: L. $93 \mathrm{~cm}, W .75 \mathrm{~cm}$

Depth: $85 \mathrm{~cm}$

Orientation: E-NE to W-SW, with the head toward the E-NE

Position of skeleton: laid on the right side

L. of skeleton (contracted): $60 \mathrm{~cm}$

L. of skeleton (extended): $98 \mathrm{~cm}$

Age at death: 3-4 years

Sex: child

Condition of skeleton: badly preserved

Preserved skeletal bones: skull, long bones

Inhumation burial in an oval grave pit containing stones among which lay vessel fragments (3). The body was laid on the right side in a contracted position. The skull lay on the right side. Both arms were bent at the elbow and drawn up. The thighs were drawn up into a horizontal position, the legs were bent back toward the buttocks.

The burial contained the following grave goods: a scooping vessel (1) behind the skull, lying $8 \mathrm{~cm}$ higher; a necklace of twenty beads (2) around the neck and in front of the face; some beads were dislodged from their original position.

Grave goods

1. Scooping vessel. Grey, thick-walled scooping vessel, decorated with notching around the belly. The highflung handle spanned the rim and the base. The handle is missing. Some portions restored. H. $5.5 \mathrm{~cm}$, dM. 10.3 cm. Inv. no. 61.2.192 (Pl. LXII. 145/1).129

2. Beads. Twenty large limestone stone beads of varying sizes. Inv. no. 61.2.21 (Pl. LXII. 145/2).

3. Vessel fragments. ${ }^{130}$

\footnotetext{
127 The skeletal remains can no longer be found. The anthropological data are quoted from the excavation diary.

128 Copper finds were not inventoried from the burial.

129 Beads were the only grave goods inventoried from this burial. The vessel inventoried under no. 61.2.192 from the stray finds of the 1953 campaign can be identified with a vessel from this burial on the basis of its description and dimensions as recorded in the excavation diary.

130 Vessel fragments were not inventoried among the finds from the burial.
}

Grave 146 (Square G5/H5; Pl. LXII)

Size of grave pit: L. $137 \mathrm{~cm}, W .104 \mathrm{~cm}$

Depth: $80 \mathrm{~cm}$

Orientation: $\mathrm{E}$ to $\mathrm{W}$, with the head toward the $\mathrm{E}$

Position of skeleton: laid on the right side

L. of skeleton (contracted): $84 \mathrm{~cm}$

L. of skeleton (extended): $144 \mathrm{~cm}$

Age at death: $40-50$ years

Sex: female

Condition of skeleton: medium well preserved

Preserved skeletal bones: skull, long bones

Inhumation burial in an oval grave pit containing stones. Indistinct pottery sherds (1) were found among the stones. The body was laid on the right side in a contracted position. The skull lay tilted to the right side, the right arm was bent at the elbow and drawn up, with the hand resting under the chin. The left arm was bent at the elbow and drawn up, with the hand laid by the right shoulder. The thighs were drawn up into a horizontal position, the legs were bent back toward the buttocks. The feet and the ankles rested one over the other. A larger stone was found behind the head.

Finds from the grave pit

1. Pot. Body sherds of a greyish-red, worn pot. Three non-joining pieces. L. $5.7 \mathrm{~cm}, 4.3 \mathrm{~cm}, 3 \mathrm{~cm}$. Inv. no. 61.2.22.131

\section{Grave 147 (Square H6)}

Size of grave pit: -

Depth: $60 \mathrm{~cm}$

Orientation: with the head toward the $S$

Position of skeleton: laid on the left side

L. of skeleton (contracted): -

L. of skeleton (extended): -

Age at death: 1-4 years

Sex: child

Condition of skeleton: badly preserved

Preserved skeletal bones: various fragments

Inhumation burial. There was no indication of a grave pit. The body was laid on the left side in a contracted position. Very little survived of the skeletal remains.

The burial did not contain any grave goods.

\section{Grave 148 (Square G5; Pl. LXIII)}

Size of grave pit: L. $75 \mathrm{~cm}, W .60 \mathrm{~cm}$

Depth: $95 \mathrm{~cm}$

Orientation: SW to NE, with the head toward the SW

Position of skeleton: laid on the right side

L. of skeleton (contracted): $56 \mathrm{~cm}$

L. of skeleton (extended): -

Age at death: $1-7$ years

131 The excavation diary mentions a single pottery sherd. However, three sherds were inventoried. 
Sex: child

Condition of skeleton: badly preserved

Preserved skeletal bones: various fragments

Inhumation burial in a rounded grave pit containing stones, among which lay the fragments of a bipartite bowl (1). The body was laid on the left side in a contracted position. The skull was crushed. Both arms were slight bent and laid beside the body. The thighs were drawn up into a horizontal position, the legs were bent back toward the buttocks.

The burial contained the following grave goods: twenty-seven beads and eight shell plaques $(2-3)$ in front of the face.

\section{Grave goods}

1. Bipartite bowl. Greyish-brown, elaborately ornamented, worn bipartite bowl. A flat ornamental knob with a row of punctates around the edge and an $\mathrm{X}$ motif of two intersecting incised lines in the centre was set on the rim at either end of the inner dividing wall. A row of punctates combined with bundles of four vertically incised lines runs under the rim. Similar bundles of lines flank the two stringhole lugs. A barely prominent rib decorated with punctates runs under the two ornamental knobs. The potter took care that the vertical lines on the vessel body and the $\mathrm{X}$ motif on the knobs should start from the punctates. The top of the inner dividing wall bears groups of punctates. (The restored vessel part has a pair of stringhole lugs decorated with two rows of punctates opposite the dividing wall based on the mistaken assumption that the pattern was symmetrical.) Joined from its fragments, one half restored. Several sherds from the vessel were not inventoried. H. $10 \mathrm{~cm}, \mathrm{~d} M .17 .2 \mathrm{~cm}$, dB. 6.5 cm. Inv. no. 61.2.23.1 (Pl. LXIII. 148/1).

2. Beads. Twenty-six limestone beads of varying sizes. Inv. no. 61.2.23.2 (Pl. LXIII. 148/2).132

3. Shell plaques. Rectangular, broken Unio crassus mussel plaques with a pair of perforations on the short side. Eight pieces. L. $1.5 \mathrm{~cm}$, W. $09 \mathrm{~cm}$. Inv. no. 61.2.23.3 (Pl. LXIII. 148/3).

Other finds from the burial

4. Bowl. Base fragment of a greyish-brown, small bowl decorated with an incised line under the belly. (The fragment was inventoried together with the fragments of the bipartite bowl.) Inv. no. 61.2.23.1.

\section{Grave 149 (Square H7; Pl. LXII)}

Size of grave pit: L. $122 \mathrm{~cm}$, W. $97 \mathrm{~cm}$

Depth: $68 \mathrm{~cm}$

Orientation: A: SE to NW, with the head toward the SE, B: SE to $\mathrm{NW}$, with the head toward the SE

\footnotetext{
132 The excavation diary mentions twenty-seven beads, but only twenty-six
} were inventoried.
Position of skeleton: A: laid on the left side, B: laid on the right side L. of skeleton (contracted): A: 92, B: $74 \mathrm{~cm}$

L. of skeleton (extended): A: $130 \mathrm{~cm}, \mathrm{~B}:-$

Age at death: A: $13-15$ years, B: 5-6 years

Sex: A: child, B: child

Condition of skeleton: A: badly preserved, B: badly preserved

Preserved skeletal bones: A: skull, long bones, B: skull, long bone fragments

Double inhumation burial in an oval grave pit.

\section{Burial A}

The body was laid on the left side in a contracted position. The crushed skull lay on the left side. The arms were bent at the elbow and drawn up, with the hands placed in front of the face. The right thigh was drawn up into a horizontal position, the left one in front of the body, the legs were bent back toward the buttocks. The knees rested on the pelvis and chest of Burial B.

The burial did not contain any grave goods.

\section{Burial B}

The body was laid on the right side in a contracted position next to and parallel to Burial A. The skull was crushed and lay on the right side. The arms were bent at the elbow, the legs were bent back toward the buttocks. An animal burrow destroyed the left leg of Burial A and the thighbones of Burial B.

The burial contained the following grave goods: a stone blade fragment (1) by the middle of the left upper arm.

\section{Grave goods}

1. Unretouched blade fragment. Limnic quartzite. Inv. no. 61.2.24.1 (Pl. LXII. 149/1).

\section{Grave 150 (Square G4; Pl. LXII)}

Size of grave pit: L. $125 \mathrm{~cm}, W .100 \mathrm{~cm}$

Depth: $105 \mathrm{~cm}$

Orientation: SW to NE, with the head toward the SW

Position of skeleton: laid on the left side

L. of skeleton (contracted): $90 \mathrm{~cm}$

L. of skeleton (extended): $142 \mathrm{~cm}$

Age at death: $30-50$ years

Sex: female

Condition of skeleton: medium well preserved

Preserved skeletal bones: skull, long bones

Inhumation burial in an oval grave pit containing many stones. The body was laid on the left side in a contracted position. The skull rested on the left side, Both arms were bent at the elbow and drawn up, with the hands laid over each other in front of the head. The thighs were drawn up in front of the body, the legs were bent back toward the buttocks. The feet rested one over the other.

The burial did not contain any grave goods. 
Grave 151 (Square H7; Pl. LVII)

Size of grave pit: L. $95 \mathrm{~cm}, W .70 \mathrm{~cm}$

Depth: $66 \mathrm{~cm}$

Orientation: $\mathrm{S}$ to $\mathrm{N}$, with the head toward the $\mathrm{S}$

Position of skeleton: laid on the left side

L. of skeleton (contracted): $67 \mathrm{~cm}$

L. of skeleton (extended): $c a .90 \mathrm{~cm}$

Age at death: $5-7$ years

Sex: child

Condition of skeleton: badly preserved

Preserved skeletal bones: various fragments

Inhumation burial in an oval grave pit. The body was laid on the left side in a contracted position. The skull was crushed. The right arm was bent at the elbow, the left arm was also bent and drawn up in front of the chin. The thighs were drawn up into a horizontal position, the legs were bent back toward the buttocks.

The burial did not contain any grave goods.

\section{Grave 152 (Square G4/G5; Pl. LXIV)}

Size of grave pit: L. $135 \mathrm{~cm}, W .90 \mathrm{~cm}$

Depth: $115 \mathrm{~cm}$

Orientation: $\mathrm{E}$ to $\mathrm{W}$, with the head toward the $\mathrm{E}$

Position of skeleton: laid on the right side

L. of skeleton (contracted): $92 \mathrm{~cm}$

L. of skeleton (extended): $158 \mathrm{~cm}$

Age at death: $23-30$ years

Sex: female (?)

Condition of skeleton: medium well preserved

Preserved skeletal bones: skull, long bones

Inhumation burial in an oval grave pit containing stones, which lay on the skeleton. The body was laid on the right side in a contracted position. The skull lay on the right side. The arms were bent at the elbow and drawn up, with the hands resting in front of the chin. The thighs were drawn up in front of the body, the legs were bent back toward the buttocks.

The burial did not contain any grave goods.

\section{Grave 153 (Square G4/G5; Pl. LXIV)}

Size of grave pit: L. $142 \mathrm{~cm}, W .138 \mathrm{~cm}$

Depth: $108 \mathrm{~cm}$

Orientation: A: E-SE to W-NW, with the head toward the E-SE, B: E-SE to W-NW, with the head toward the E-SE

Position of skeleton: A: laid on the right side, B: laid on the right side

L. of skeleton (contracted): A: $116 \mathrm{~cm}, \mathrm{~B}: 110 \mathrm{~cm}$

L. of skeleton (extended): A: $155 \mathrm{~cm}, \mathrm{~B}: 158 \mathrm{~cm}$

Age at death: A: $40-x$ years, B: $40-59$ years

Sex: A: male, B: male (?)

Condition of skeleton: A: medium well preserved, B: medium well preserved

Preserved skeletal bones: A-B: skull, long bones

Double inhumation burial in a round grave pit containing a few stones.
Burial A

The body was laid on the right side in a contracted position. The skull lay on the right side. The right arm was bent at the elbow and drawn up to the chin, the left arm was bent at the elbow and drawn up, with the hand laid under the chin. The trunk was laid prone, the pelvis was dislodged from its original position. The right thigh was drawn up into a horizontal position, the left thigh to a lesser extent, the legs were bent back toward the buttocks. The ankles were placed one over the other.

The burial did not contain any grave goods.

\section{Burial B}

The body was laid on the right side in a contracted position parallel to and behind Burial A. The skull lay on the right side. The arms were bent at the elbow and drawn up, with the hands resting under the chin. The thighs were drawn up into a horizontal position, the left leg was bent back toward the buttocks, the right one to a lesser extent.

The burial did not contain any grave goods.

\section{Grave 154 (Square G7)}

Size of grave pit: -

Depth: $48 \mathrm{~cm}$

Orientation: $W$ to $E$, with the head toward the $W$

Position of skeleton: laid on the right side (?)

L. of skeleton (contracted): $38 \mathrm{~cm}$

L. of skeleton (extended): -

Age at death: 1-2 years

Sex: child

Condition of skeleton: badly preserved

Preserved skeletal bones: various fragments

Inhumation burial. There was no indication of a grave pit. The body was probably laid on the right side in a contracted position. The thighs were drawn up. Only the position of the skull and one of the thigh bones could be recorded.

The burial did not contain any grave goods.

\section{Grave 155 (Square H7; Pl. LXV)}

Size of grave pit: L. $130 \mathrm{~cm}, W .140 \mathrm{~cm}$

Depth: $58 \mathrm{~cm}$

Orientation: A: SW-NE, with the head toward the SW, B: -

Position of skeleton: A: laid on the right side, B: -

L. of skeleton (contracted): A: $60 \mathrm{~cm}, \mathrm{~B}:-$

L. of skeleton (extended): A: $c a .90 \mathrm{~cm}, \mathrm{~B}:-$

Age at death: A: $4-5$ years, B: -

Sex: A: child, B: -

Condition of skeleton: A: badly preserved. B: -

Preserved skeletal bones: ${ }^{133}$ A: skull fragments, B: various fragments

\footnotetext{
133 The skeletal remains of Burial B can no longer be found. The anthropological data are quoted from the excavation diary.
} 
Double burial containing one inhumation and one cremation burial. The grave pit was covered with stones, among which lay vessel fragments (1).

Burial A

Inhumation burial. The body was laid on the right side in a contracted position. The skull rested on the right side. The arms were bent at the elbow and drawn up, with the hands laid in front of the face. The thighs were drawn up, the right one into a horizontal position, the left one in front of the body, the legs were bent back toward the buttocks.

The burial contained the following grave goods: a perforated boar tusk (2) and a wild boar canine (3) by the neck; a necklace of ten beads (4) around the neck.

\section{Burial B}

Cremation burial. Calcinated bones lay by the skull of Burial A (in front of the face). The two burials were either contemporaneous or the cremation burial was earlier than the inhumation one, but it can hardly be later than the inhumation burial. The stone packing covering the grave was undisturbed and cremation burials were not deposited in such a large grave pit.

The burial did not contain any grave goods.

\section{Grave goods}

1. Vessel fragments. Rim, body and base fragments of a brownish-grey, thick-walled, worn pot; body sherd and handle of a grey, worn jug decorated with channelling. Eleven non-joining pieces. Inv. no. 61.2.25.1 (Pl. LXV. 155/1).134

2. Boar tusk pendant perforated at either end. L. $15.5 \mathrm{~cm}$. Inv. no. 61.2.25.2 (Pl. LXV. 155/2). ${ }^{135}$

3. Wild boar canine. Seven pieces. Inv. no. 61.2.25.3 (Pl. LXV. 155/3).

4. Beads. Ten small Dentalium badense beads. Inv. no. 61.2.25.4 (Pl. LXV. 155/4).

\section{Grave 156 (Square G4; Pl. LXVIII)}

Size of grave pit: L. $100 \mathrm{~cm}, W .85 \mathrm{~cm}$

Depth: $64 \mathrm{~cm}$

Orientation: $\mathrm{W}$ to $\mathrm{E}$, with the head toward the $\mathrm{W}$

Position of skeleton: laid on the right side

L. of skeleton (contracted): $48 \mathrm{~cm}$

L. of skeleton (extended): $c a .85 \mathrm{~cm}$

Age at death: 7-8 years

Sex: child

Condition of skeleton: badly preserved

Preserved skeletal bones: skull, long bones

\footnotetext{
134 The fragments of different vessels were entered into the acquisitions register under the same number.

135 The object has since been lost or mislaid. The drawing is based on József Korek's grave sheet.
}

Inhumation burial in an oval grave pit containing stones, among which lay vessel fragments (1). The body was laid on the right side in a strongly contracted position. A stone lay on the skull. The arms were bent at the elbow and drawn up, with the hands resting under the chin. The thighs were drawn up in front of the body. the legs were bent back toward the buttocks.

Finds from the grave pit

1. Vessel fragments. Body sherds of a grey, worn pitcher with fluted decoration (Pl. LXVIII. 156/1); rim fragments of greyish, worn bowls, one with a row of punctates under the rim (Pl. LXVIII. 156/2-3); body and base sherd of a grey, worn, larger pitcher (Pl. LXVIII. 156/5); fragment of a wide strap handle (Pl. LXVIII. 156/4). Fifteen pieces. Inv. no. 61.2.26.1.136

\section{Grave 157 (Square H7; Pl. LXIV)}

Size of grave pit: -

Depth: $50 \mathrm{~cm}$

Orientation: W-SW to E-NE, with the head toward the W-SW

Position of skeleton: laid on the left side

L. of skeleton (contracted): $72 \mathrm{~cm}$

L. of skeleton (extended): $132 \mathrm{~cm}$

Age at death: $40-x$ years

Sex: female

Condition of skeleton: badly preserved

Preserved skeletal bones: skull, long bones

Inhumation burial. There was no indication of a grave pit. The body was laid on the left side in a strongly contracted position. The skull lay on the left side, with the face tilted forward. The right arm was bent at the elbow and drawn up, with the hand resting on the shoulder, the left arm was bent at the elbow and drawn up, with the hand placed under the chin. The thighs were drawn up in front of the body and almost touched the right elbow, the legs were bent back toward the buttocks.

The burial did not contain any grave goods.

\section{Grave 158 (Square G4; Pls $L X V I-L X V I I$ )}

Size of grave pit: L. $125 \mathrm{~cm}, W .125 \mathrm{~cm}$

Depth: $143 \mathrm{~cm}$

Orientation: $\mathrm{W}$ to $\mathrm{E}$, with the head toward the $\mathrm{W}$ Position of skeleton: laid on the right side

L. of skeleton (contracted): $88 \mathrm{~cm}$

L. of skeleton (extended): $156 \mathrm{~cm}$

Age at death: $40-x$ years

Sex: female

Condition of skeleton: medium well preserved

Preserved skeletal bones: skull, long bones, pelvic bone

136 The fragments of different vessels were entered into the acquisitions register under the same number. 
Inhumation burial in a round grave pit. The body was laid on the right side in a contracted position. The skull lay on the right side. The arms were placed in the lap in front of the body, with the hands clasping the elbows. The thighs were drawn up in front of the body, the legs were bent back toward the buttocks. The ankles rested one over the other,

The burial contained the following grave goods: a pitcher (1) tilted to one side in front of the forehead and the face, with the mouth facing the nose; a wagon model (2) beside the previous vessel; a goblet (3) tilted to one side by the buttocks, with the mouth toward the buttocks; a two-strand necklace of thirty-four intact and one broken beads (4) on the chest; a stone flake (5) by vessel no. 2 and the left hand.

\section{Grave goods}

1. Pitcher. Greyish, polished, asymmetric jug with high, cylindrical neck and flattened globular body decorated with fluting on the body. The high-flung strap handle is also fluted, as is the inner side of the handle where it joins the vessel. The handle is joined from its fragments. H. $11.8 \mathrm{~cm}, \mathrm{dM} .7 \mathrm{~cm}$. Inv. no. 61.2.27.1 (Pl. LXVI. 158/1).

2. Wagon model. Red, worn, rectangular vessel with a strap handle spanning the rim and the base. The rim is peaked at the four corners. The vessel is set on four tiny knobs. Red painting covers the vessel's exterior and interior. H. $5.5 \mathrm{~cm}, \mathrm{~d} M .9 .3 \mathrm{~cm}$, dB. 5.5 cm. Inv. no. 61.2.27.2 (Pl. LXVI. 158/2). ${ }^{137}$

3. Goblet. Reddish, worn, thin-walled goblet with round upper part set on a rounded foot with a round base. The foot is perforated. The vessel body bears a symmetrical design of three incised chevrons dividing the surface into four fields, two of which are filled with a diamond pattern and two with an irregular zig-zag pattern. The foot is decorated with a diamond motif above the perforation. The vessel is painted red on the exterior and interior. H. $9.4 \mathrm{~cm}, \mathrm{dM} .11 .5 \mathrm{~cm}$, dB. 4.7 cm. Inv. no. 61.2.27.3 (Pl. LXVII. 158/3).

4. Beads. Thirty-four intact and one broken limestone beads of varying sizes. Patches of red ochre can be noted on the beads. Inv. no. 61.2.27.4 (Pl. LXVI. 158/4).

5. Unretouched radiolarite flake. Inv. no. 61.2.27.5 (Pl. LXVI. 158/5).

\section{Grave 159 (Square G6)}

\author{
Size of grave pit: - \\ Depth: $38 \mathrm{~cm}$ \\ Orientation: - \\ Position of skeleton: - \\ L. of skeleton (contracted): - \\ L. of skeleton (extended): - \\ Age at death: $23-x$ years \\ Sex: female (?)
}

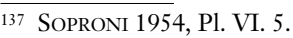

Condition of skeleton:-

Preserved skeletal bones: various fragments

Scattered cremation burial. There was no indication of a grave pit. Calcinated bones lay scattered over an area with a diameter of $15 \mathrm{~cm}$.

The burial did not contain any grave goods.

\section{Grave 160 (Square H8; Pl. LXVII)}

Size of grave pit: L. $65 \mathrm{~cm}, W .55 \mathrm{~cm}$

Depth: $65 \mathrm{~cm}$

Orientation: -

Position of skeleton: -

L. of skeleton (contracted): -

L. of skeleton (extended): -

Age at death: -

Sex: -

Condition of skeleton: -

Preserved skeletal bones: -

Symbolic burial in an oval grave pit. No skeletal remains were found. A scooping vessel (1) lay in the grave pit's southern half, a necklace of thirty-nine beads (2) and ten rectangular shell plaques (3) lay under and among the beads.

Grave goods

1. Scooping vessel. Brownish, squat, conical scooping vessel. The strap handle rising above the rim springs to the base. Smoothed-in decoration can be made out at the junction of the handle and the rim. Joined from its fragments and partially restored. H. $4.5 \mathrm{~cm}$, dM. $10.4 \mathrm{~cm}, \mathrm{~dB} .6 .3 \mathrm{~cm}$. Inv. no. 61.2.28.1 (Pl. LXVII. 160/1).

2. Beads. Thirty-nine limestone beads of varying sizes. Inv. no. 61.2.28.2 (Pl. LXVII. 160/2).

3. Shell plaques. Ten rectangular Unio crassus shell plaques, each with a pair of perforations on the short sides. Most are broken, one is joined from two fragments. L. $2.9 \mathrm{~cm}$, W. $0.8 \mathrm{~cm}$. Inv. no. 61.2.28.3 (Pl. LXVII. 160/3).

Grave 161 (Square H8; Pl. LXIV)

Size of grave pit: L. $135 \mathrm{~cm}, W .96 \mathrm{~cm}$

Depth: $75 \mathrm{~cm}$

Orientation: SE to NW, with the head toward the SE

Position of skeleton: laid on the left side

L. of skeleton (contracted): $102 \mathrm{~cm}$

L. of skeleton (extended): $147 \mathrm{~cm}$

Age at death: $30-40$ years

Sex: male

Condition of skeleton: badly preserved

Preserved skeletal bones: skull, long bones

Inhumation burial in an oval grave pit. The body was laid on the left side in a contracted position. The skull rested on the occipital bone with the face toward the south-west. The left arm was extended beside the body, 


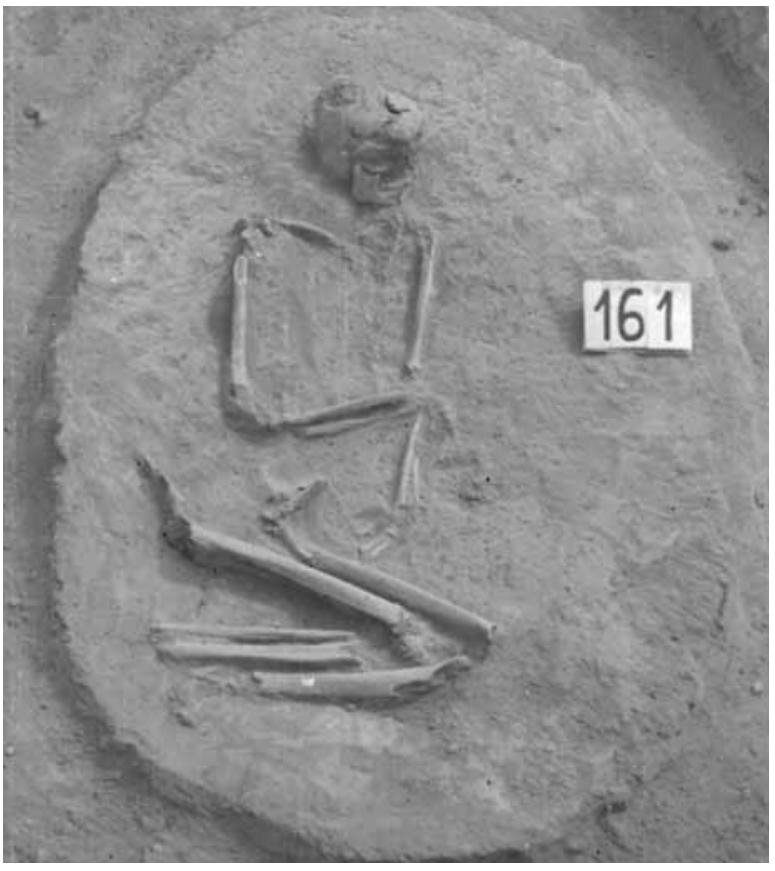

with the hand turned toward the pelvis. The right arm was bent at the elbow and drawn up, with the hand clasping the left elbow. The thighs were drawn up into an almost horizontal position, the legs were bent back toward the buttocks.

The burial did not contain any grave goods.

\section{Grave 162 (Square J9; Pl. LXVIII)}

Size of grave pit:-

Depth: $22 \mathrm{~cm}$

Orientation: SW to NE, with the head toward the SW

Position of skeleton: laid on the left side

L. of skeleton (contracted): $80 \mathrm{~cm}$

L. of skeleton (extended): $c \boldsymbol{c} .140 \mathrm{~cm}$

Age at death: $23-x$ years

Sex: -

Condition of skeleton: badly preserved

Preserved skeletal bones: various fragments

Inhumation burial. There was no indication of a grave pit. The skull and the skeletal remains were damaged by ploughing. The body was laid on the left side in a contracted position. The right arm was bent at the elbow and drawn up, with the hand resting in front of the face. The left arm was slightly bent at the elbow, with the hand laid by the left knee. The thighs were drawn up into a horizontal position, the legs were bent back toward the buttocks.

The burial did not contain any grave goods.

Grave 163 (Square H8; Pl. LXIX)

Size of grave pit: L. $135 \mathrm{~cm}$, W. $125 \mathrm{~cm}$ Depth: $88 \mathrm{~cm}$

Orientation: $\mathrm{S}$ to $\mathrm{N}$, with the head toward the $\mathrm{S}$

Position of skeleton: laid on the right side
L. of skeleton (contracted): -

L. of skeleton (extended): -

Age at death: $35-45$ years

Sex: female

Condition of skeleton: medium well preserved

Preserved skeletal bones: skull, long bones

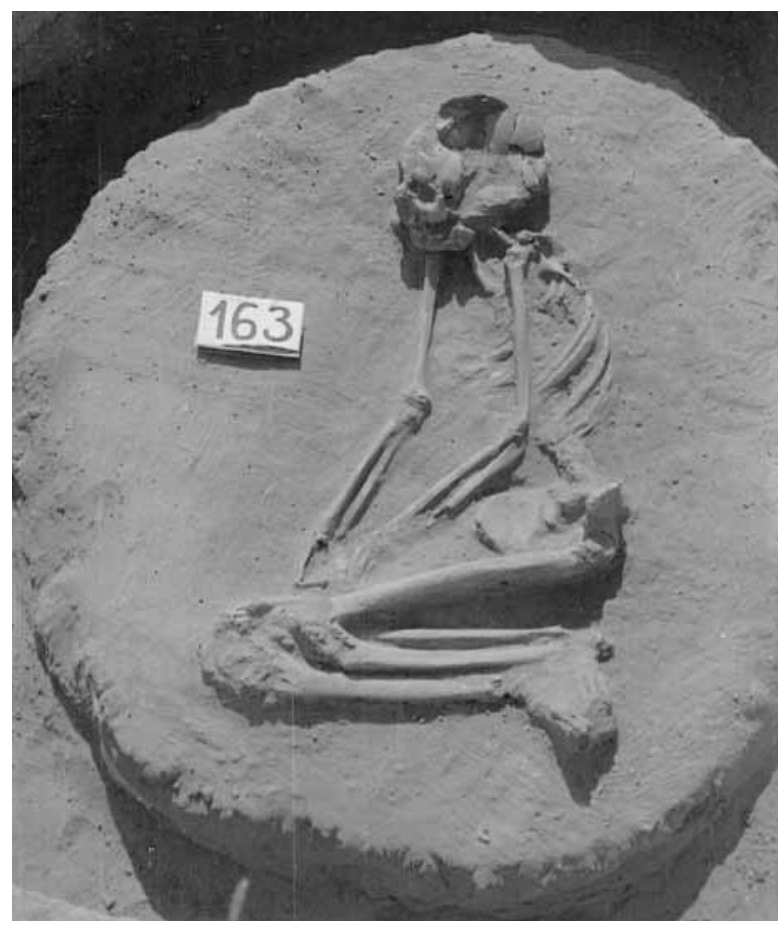

Inhumation burial in a round grave pit containing stones, among which lay the fragments of a bipartite bowl (1). Some of the stones lay on the skeleton and crushed the skull. The body was laid on the right side in a contracted position. The arms were extended beside the body, with the clasped hands placed by the knees. The thighs were drawn up into a horizontal position, the legs were bent back toward the buttocks.

The burial did not contain any grave goods.

Finds from the grave pit

1. Bipartite bowl. Base fragment of a grey, thick-walled, large bipartite bowl with a section of the inner dividing wall. L. $10 \mathrm{~cm}$. Inv. no. 61.2 .29 (Pl. LXIX. 163/1).

\section{Grave 164 (Square H4; Pls $L X X-L X X I$ )}

Size of grave pit: L. $155 \mathrm{~cm}$, W. $116 \mathrm{~cm}$

Depth: $94 \mathrm{~cm}$

Orientation: $\mathrm{W}$ to $\mathrm{E}$, with the head toward the $\mathrm{W}$ Position of skeleton: laid on the right side

L. of skeleton (contracted): $97 \mathrm{~cm}$

L. of skeleton (extended): $163 \mathrm{~cm}$

Age at death: 23-30 years

Sex: male

Condition of skeleton: well preserved

Preserved skeletal bones: long bones, pelvic bone 


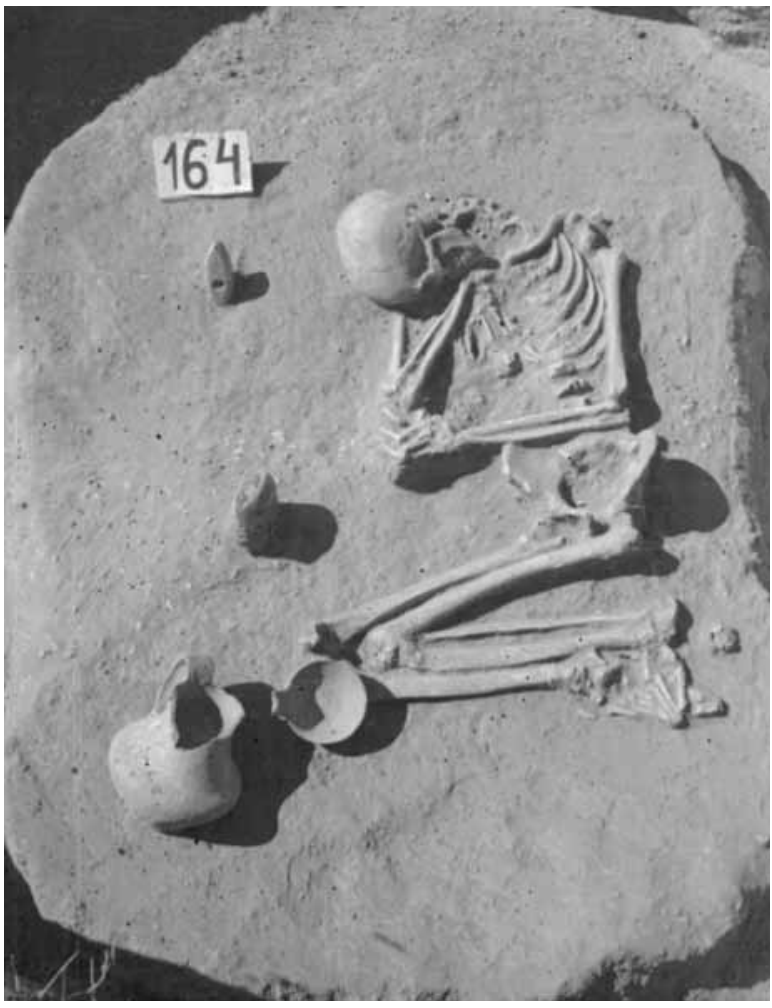

Inhumation burial in an oblong grave pit with rounded corners containing stones, among which lay indistinct pottery sherds (1). The body was laid on the right side in a contracted position. The skull lay tilted to the left side. The neck was strongly bent and the face lay toward the body. The left arm was bent at the elbow, with the hand clasping the right elbow. The right arm was bent at the elbow and drawn up, with the hand resting in front of the chin. The thighs were drawn up into a horizontal position, the legs were bent back toward the buttocks. The upper part of the body practically lay on the back, tilted slightly to the right.

The burial contained the following grave goods: a stone axe (2) with the cutting edge pointing upward, $15 \mathrm{~cm}$ south of the skull; another stone axe (3) tilted to one side with the shaft-hole upward, $17 \mathrm{~cm}$ south-east of the right hand; a ladle (4) on the right knee; a onehandled jug (5) with the mouth facing the knee, $15 \mathrm{~cm}$ south-east of the left knee; four stone implements (6-9) between the left foot and the right ankle; three stone implements (10-12) $5 \mathrm{~cm}$ north of the right foot; a necklace of four intact and two sliced beads, and a tubular copper bead (13) around the neck.

\section{Grave goods}

1. Pottery sherds. Body sherd of a reddish, thick-walled pot, and rim and handle fragment of a grey, worn, one-handled jug (Pl. LXXI. 164/1a-1b). Inv. no. 61.2.30.13.138

2. Stone axe. Boat shaped shaft-hole axe made from

\footnotetext{
138 The fragments of different vessels were entered into the acquisitions register under the same number.
}

serpentinite. L. $10.9 \mathrm{~cm}$, W. $4.2 \mathrm{~cm}$. Inv. no. 61.2.30.1 (Pl. LXX. 164/2). ${ }^{139}$

3. Stone axe. Boat shaped shaft-hole axe made from serpentinite. L. $9.1 \mathrm{~cm}, W .4 .3 \mathrm{~cm}$. Inv. no. 61.2.30.2.

4. Ladle. Reddish, thin-walled, worn ladle. The handle rising above the rim is peaked, with two small perforations under the peaks. An incised zigzag line runs under the rim. Patches of the red painting covering the exterior and interior can be noted on the body. Cracked, the rim is chipped. H. $4.5 \mathrm{~cm}, \mathrm{dM}$. $11.7 \mathrm{~cm}$. Inv. no. 61.2.30.3 (Pl. LXXI. 164/4). The technique of the incised decoration can be reconstructed as follows: the potter first incised the lines inclined to the left, after which the lines running in the opposite direction were added, with the latter intersecting the initially incised lines in several places.

5. Jug. Grey, polished jug with slightly curved cylindrical neck, biconical body and slightly flattened belly. The wide strap handle spans the rim and the shoulder. The handle and the belly are decorated with fluting. Joined from its fragments and restored. H. $19.8 \mathrm{~cm}, \mathrm{dM} .10 .2 \mathrm{~cm}$, DB. $7.7 \mathrm{~cm}$. Inv. no. 61.2.30.4 (Pl. LXX. 164/5).

6. Unretouched chert flake. Inv. no. 61.2.30.5.

7. Chert triangle. Inv. no. 61.2.30.6 (Pl. LXXI. 164/7).

8. Unretouched chert flake. Inv. no. 61.2.30.7.

9. Limnic quartzite point. Inv. no. 61.2.30.8 (Pl. LXXI. 164/9).

10. Limnic quartzite trapeze. Inv. no. 61.2.30.9 (Pl. LXXI. 164/10).

11. Radiolarite trapeze. Inv. no. 61.2.30.10 (Pl. LXXI. 164/11).

12. Retouched limnic quartzite flake. Inv. no. 61.2.30.11.

13. Beads. Four stone beads, two sliced Dentalium badense beads, and one tubular copper bead. Inv. no. 61.2.30.12 (Pl. LXX. 164/13).

\section{Grave 165 (Square H8; Pl. LXVIII)}

Size of grave pit: L. $116 \mathrm{~cm}, W .85 \mathrm{~cm}$

Depth: $25 \mathrm{~cm}$

Orientation: $\mathrm{E}$ to $\mathrm{W}$, with the head toward the $\mathrm{E}$

Position of skeleton: laid on the right side

L. of skeleton (contracted): $93 \mathrm{~cm}$

L. of skeleton (extended): $c a .160 \mathrm{~cm}$

Age at death: $40-59$ years

Sex: male (?)

Condition of skeleton: badly preserved

Preserved skeletal bones: various fragments

Inhumation burial in an oval grave pit. The body was laid on the right side in a contracted position. The skull, lying slightly higher than the body, was destroyed by ploughing. The right arm was bent at the elbow and

139 The object has since been lost or mislaid. Its description is quoted from the acquisitions register. The drawing of the stone axes described under nos 2-3 is based on József Korek's grave sheet. 
drawn up, with the hand placed in front of the face. The left arm was bent at the elbow and drawn up, with the hand facing the chin. The forearm and the hand were partially destroyed by an animal burrow. The thighs were drawn up in front of the body, the legs were bent back toward the buttocks.

The burial did not contain any grave goods.

\section{Grave 166 (Square H8; Pl. LXXI).}

Size of grave pit: L. $105 \mathrm{~cm}, W .80 \mathrm{~cm}$

Depth: $65 \mathrm{~cm}$

Orientation: $\mathrm{S}$ to $\mathrm{N}$, with the head toward the $\mathrm{S}$

Position of skeleton: laid on the left side

L. of skeleton (contracted): $85 \mathrm{~cm}$

L. of skeleton (extended): $c a .135 \mathrm{~cm}$

Age at death: $23-30$ years

Sex: female

Condition of skeleton: badly preserved

Preserved skeletal bones: skull, long bones

Inhumation burial in an oval grave pit. The body was laid on the left side in a contracted position. The skull rested on the occipital bone. The trunk was laid prone from the pelvis upward. The arms were bent at the elbow and drawn up, with the hands pointing toward the skull. The thighs were drawn up into a horizontal position, the legs were bent back toward the buttocks.

The burial did not contain any grave goods.

\section{Grave 167 (Square H8; Pl. LXIX)}

Size of grave pit: L. $115 \mathrm{~cm}, W .80 \mathrm{~cm}$

Depth: $96 \mathrm{~cm}$

Orientation: A: $\mathrm{E}$ to $\mathrm{W}$, with the head toward the $\mathrm{E}, \mathrm{B}$ : $\mathrm{E}$ to $\mathrm{W}$, with the head toward the $\mathrm{E}$

Position of skeleton: A: laid on the left side, B: laid on the left side L. of skeleton (contracted): A: $73 \mathrm{~cm}, \mathrm{~B}: 62 \mathrm{~cm}$

L. of skeleton (extended): A: $125 \mathrm{~cm}, \mathrm{~B}: 92 \mathrm{~cm}$

Age at death: A: $15-17$ years, B: 4-6 years

Sex: A: juvenis, B: child

Condition of skeleton: A: medium well preserved, B: medium well preserved

Preserved skeletal bones: A-B: skull, long bones

Double inhumation burial in an oval grave pit. The grave pit lay under Grave 165. A larger stone was found at a depth of $-50 \mathrm{~cm}$ in the grave pit.

Burial A

A child burial. The body was laid on the left side in a strongly contracted position. The skull was tilted forward toward Burial B. The arms were bent at the elbow and drawn up, with the hands placed in front of the face. The thighs were drawn up in front of the body, the legs were bent back toward the buttocks.

The burial did not contain any grave goods.

Burial B

A child burial. The body was laid on the left side in a contracted position in front of and parallel to Burial A.
The skull rested on the occipital bone with the face toward the south. The right arm was bent at the elbow, with the hand by the left elbow. The left arm was bent at the elbow and drawn up, with the hand resting by the face. The thighs were drawn up in front of the body, the legs were bent back toward the buttocks.

The burial did not contain any grave goods.

An interesting feature must here be noted: even though the humus layer in the area around the grave was no more than $15 \mathrm{~cm}$ thick, the fill of the $96 \mathrm{~cm}$ deep grave pit was made up of humus, suggesting that the humus layer had probably been thicker in this area (i.e. the northern part of the cemetery nearer to the Danube) at the time the grave was dug. The present surface slopes towards the river. It seems likely that the area was later eroded by the Danube's floods.

\section{Grave 168 (Square I4)}

Size of grave pit: -

Depth: $30 \mathrm{~cm}$

Orientation: -

Position of skeleton: -

L. of skeleton (contracted): -

L. of skeleton (extended): -

Age at death: $23-x$ years

Sex: male (?)

Condition of skeleton: -

Preserved skeletal bones: various fragments

Scattered cremation burial. There was no indication of a grave pit. Calcinated bones were found over an area with a diameter of $25 \mathrm{~cm}$.

The burial did not contain any grave goods.

\section{Grave 169 (Square H8; Pl. LXXI)}

Size of grave pit: L. $142 \mathrm{~cm}$, W. $98 \mathrm{~cm}$

Depth: $20 \mathrm{~cm}$

Orientation: A: SW to NE, with the head toward the SW, B: SW to NE, with the head toward the SW

Position of skeleton: A: laid on the right side, B: laid on the right side L. of skeleton (contracted): A: $100 \mathrm{~cm}, \mathrm{~B}: 98 \mathrm{~cm}$

L. of skeleton (extended): A: $c a .150 \mathrm{~cm}, \mathrm{~B}: c a .145 \mathrm{~cm}$

Age at death: A: $35-55$ years, B: $50-70$ years

Sex: A: male (?), B: female (?)

Condition of skeleton: A: badly preserved, B: badly preserved

Preserved skeletal bones: A-B: long bones

Double inhumation burial in an oval grave pit. The skulls of both burials were destroyed by ploughing.

\section{Burial A}

The body was laid on the right side in a contracted position. The left arm was bent at the elbow, with the hand placed by the right elbow. The right arm was extended beside the body with the hand laid between the thighs. The thighs were drawn up into a horizontal position, the legs were bent back toward the buttocks.

The burial did not contain any grave goods. 
Burial B

The body was laid on the right side in a contracted position in front of and parallel to Burial A. Both arms were bent at the elbow and drawn up, with the hands placed in front of the face. The pelvis and a part of the trunk lay under the legs of Burial A. The thighs were drawn up in front of the body, the legs were bent back toward the buttocks. The right knee of Burial A and the knees of Burial B lay beside each other.

The burial did not contain any grave goods.

\section{Grave 170 (Square H3/H4; Pl. LXXII)}

Size of grave pit: L. $125 \mathrm{~cm}$, W. $97 \mathrm{~cm}$

Depth: $76 \mathrm{~cm}$

Orientation: S-SE to N-NW, with the head toward the S-SE

Position of skeleton: laid on the right side

L. of skeleton (contracted): $107 \mathrm{~cm}$

L. of skeleton (extended): $145 \mathrm{~cm}$

Age at death: $30-40$ years

Sex: male

Condition of skeleton: well preserved

Preserved skeletal bones: skull, long bones

Inhumation burial in an oval grave pit. The body was laid on the right side in a contracted position. The skull rested on the occipital bone with the face toward the north. the right arm was bent at the elbow and drawn up, with the hand placed in front of the chin. The left arm was bent at the elbow, with the hand clasping the right elbow. The right thigh was drawn up into a horizontal position, the left one in front of the body, the legs were bent back toward the buttocks.

The burial contained the following grave goods: a trapeze (1) by the right heel; a red bead (2) on the neck.

Grave goods

1. Jasper trapeze. Inv. no. 61.2.31.1 (Pl. LXXII. 170/1).

2. Bead. Red clay bead. L. $0.4 \mathrm{~cm}, W .0 .5 \mathrm{~cm}$. Inv. no. 61.2.31.2 (Pl. LXXII. 170/2).

\section{Grave 171 (Square G4/H4; Pl. LXXII)}

Size of grave pit: L. $120 \mathrm{~cm}, W .110 \mathrm{~cm}$

Depth: $75 \mathrm{~cm}$

Orientation: SW to NE, with the head toward the SW

Position of skeleton: laid on the left side

L. of skeleton (contracted): $82 \mathrm{~cm}$

L. of skeleton (extended): -

Age at death: $40-\mathrm{x}$ years

Sex: male (?)

Condition of skeleton: badly preserved

Preserved skeletal bones: skull, long bones

Inhumation burial in an oval grave pit containing many stones, which lay on the body. The skull and the other skeletal remains were strongly fragmented. The body was laid on the left side in a contracted position, the trunk was laid prone from the pelvis upward. The arms were bent at the elbow and drawn up toward the head.
The thighs were drawn up in front of the body, almost to the shoulders, the legs were bent back toward the buttocks.

The burial contained the following grave goods: indistinct pottery sherds (1), lying among the stones; a large river mussel (2) under the head.

\section{Grave goods}

1. Pottery sherds. Rim and body fragments of a grey, worn bowl decorated with rows of punctates $(P l$. LXXII. 171/1); body sherd of a grey, worn pitcher decorated with vertical fluting and a small, barely prominent rib with oblique fluting on the belly. Six non-joining pieces, one joined from smaller fragments. Inv. no. 61.2.32.1.140

2. Mussel. Large, well preserved right valve of an Unio crassus mussel. L. 7 cm. Inv. no. 61.2.32.2 (Pl. LXXII. 171/2).

\section{Grave 172 (Square H4)}

Size of grave pit: L. $80 \mathrm{~cm}, W .75 \mathrm{~cm}$

Depth: $85 \mathrm{~cm}$

Orientation: $\mathrm{S}$ to $\mathrm{N}$, with the head toward the $\mathrm{S}$

Position of skeleton: laid on the right side

L. of skeleton (contracted): $50 \mathrm{~cm}$

L. of skeleton (extended): -

Age at death: $0-1$ years

Sex: child

Condition of skeleton: badly preserved

Preserved skeletal bones: various fragments

Inhumation burial in a round grave pit containing stones, which lay on the body. The fragments of a large vessel were found among the stones. The body was laid on the right side in a contracted position. The position of the arms could not be established, The right thigh was drawn up into a horizontal position, the left one to a lesser extent.

Finds from the grave pit

1. Fragments of a thick-walled vessel. ${ }^{141}$

\section{Grave 173 (Square H3; Pl. LXIX)}

Size of grave pit: L. $100 \mathrm{~cm}, W .88 \mathrm{~cm}$

Depth: $100 \mathrm{~cm}$

Orientation: NW to SE, with the head toward the NW

Position of skeleton: laid on the right side

L. of skeleton (contracted): $84 \mathrm{~cm}$

L. of skeleton (extended): $161 \mathrm{~cm}$

Age at death: $35-45$ years

Sex: male

Condition of skeleton: medium well preserved

Preserved skeletal bones: skull, long bones

\footnotetext{
140 The fragments of different vessels were entered into the acquisitions register under the same number.

141 The vessel fragments lying among the stones were not inventoried.
} 
Inhumation burial in an oval grave pit. The body was laid on the right side in a contracted position. The skull rested on the occipital bone. The left arm was bent at the elbow and drawn up, with the hand placed on the right shoulder in front of the face. The right arm was bent at the elbow and drawn up, with the hand resting on the right shoulder. The thighs were drawn up in front of the body, the legs were bent back toward the buttocks.

The burial did not contain any grave goods.

\section{Grave 174 (Square H4; Pl. LXXIII)}

Size of grave pit: L. $162 \mathrm{~cm}, W .130 \mathrm{~cm}$

Depth: $94 \mathrm{~cm}$

Orientation: E-NE to W-SW, with the head toward the E-SE

Position of skeleton: laid on the left side

L. of skeleton (contracted): $78 \mathrm{~cm}$

L. of skeleton (extended): $143 \mathrm{~cm}$

Age at death: $14-16$ years

Sex: female

Condition of skeleton: medium well preserved

Preserved skeletal bones: skull, long bones

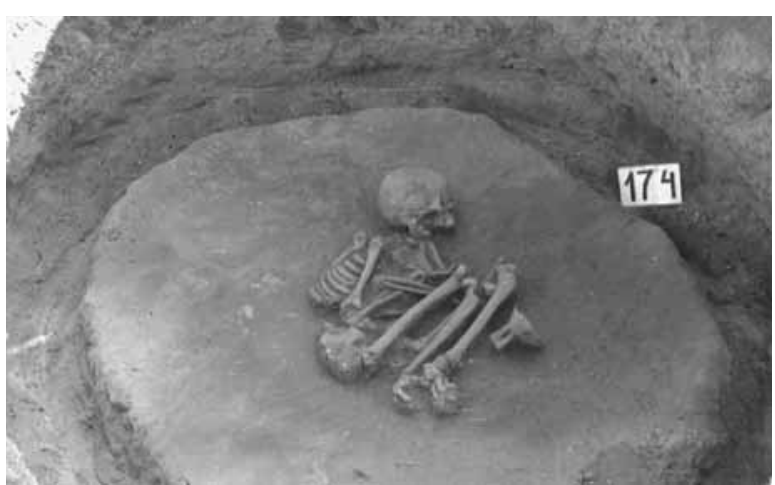

Inhumation burial in an oval grave pit. The body was laid on the left side in a contracted position. The skull lay on the left side. The arms were bent at the elbow and crossed over the chest, with the right hand resting on the left upper arm and the left hand turned toward the right elbow. The thighs were drawn up in front of the body, the legs were bent back toward the buttocks.

The burial contained the following grave goods: a broken scooping vessel (1) and pottery sherds (2) $c a$. 20-25 cm above the body; a goblet (3) tilted to one side with the mouth toward the grave pit's wall, $4 \mathrm{~cm}$ from the left leg; a necklace of fourteen beads and three intact and four broken copper beads (4-5) on the neck and the chest; three stone flakes (6-8) by the right pelvic bone; three stone blades (9-11) by the upper end of the thigh (9-11); a broken bone implement (12) $25 \mathrm{~cm}$ south of the left foot.

\section{Grave goods}

1. Scooping vessel. Grey, poorly fired, worn scooping vessel with flat base. The handle rises above the rim and springs to the shoulder. H. $5.7 \mathrm{~cm}, \mathrm{dM}$.
$13.8 \mathrm{~cm}, \mathrm{~dB} .5 .1 \mathrm{~cm}$. Joined from its fragments and restored. Inv. no. 61.2.33.1 (Pl. LXXIII. 174/1).

2. Pot. Body and base fragment of a larger, greyishbrown pot. Joined from its fragments. dB. $10.1 \mathrm{~cm}$. Inv. no. 61.2.33.2 (Pl. LXXIII. 174/2).

3. Goblet. Reddish-brown goblet with rounded upper part set on a rectangular, perforated foot with a rectangular base. Patches of red painting can be made out on the vessel body. The rim is restored. H. $9.7 \mathrm{~cm}$, dM. $10.7 \mathrm{~cm}, \mathrm{~dB} .4 .5 \mathrm{~cm}$, 3.6 cm. Inv. no. 61.2.33.3 (Pl. LXXIII. 174/3).

4. Beads. Fourteen Dentalium badense beads, one limestone bead and five broken tubular copper beads. Inv. no. 61.2.33.4 (Pl. LXXIII. 174/4).142

5. Beads. One Dentalium badense bead and a tubular copper bead slipped inside the former. Inv. no. 61.2.33.5 (Pl. LXXIII. 174/5).

6. Unretouched radiolarite flake. Inv. no. 61.2.33.6 (Pl. LXXIII. 174/6).

7. Unretouched limnic quartzite flake. Inv. no. 61.2.33.7 (Pl. LXXIII. 174/7).

8. Chert trapeze. Inv. no. 61.2.33.8 (Pl. LXXIII. 174/8).

9. Chert trapeze. Inv. no. 61.2.33.9 (Pl. LXXIII. 174/9).

10. Truncated-retouched radiolarite blade. Inv. no. 61.2.33.10 (Pl. LXXIII. 174/10).

11. Chert trapeze. Inv. no. 61.2.33.11 (Pl. LXXIII. 174/11).

12. Bone implement. Fragment of a bone implement with pointed tip made from an ungulate bone. Broken in two. L. $4.5 \mathrm{~cm}$, W. $0.9 \mathrm{~cm}$. Inv. no. 61.2.33.12 (Pl. LXXIII. 174/12).

Other finds from the burial

13. Bone implement. Fragment of a bone implement with pointed tip made from an ungulate bone. Broken in three. L. $4.4 \mathrm{~cm}, W .1 \mathrm{~cm}$. Inv. no. 61.2.33.13 (Pl. LXXIII. 174/13).143

\section{Grave 175 (Square H4; Pl. LXXII)}

Size of grave pit: L. $102 \mathrm{~cm}$, W. $90 \mathrm{~cm}$

Depth: $97 \mathrm{~cm}$

Orientation: NE to SW, with the head toward the NE

Position of skeleton: laid on the left side

L. of skeleton (contracted): $81 \mathrm{~cm}$

L. of skeleton (extended): $132 \mathrm{~cm}$

Age at death: $13-15$ years

Sex: juvenis

Condition of skeleton: badly preserved

Preserved skeletal bones: skull, long bones

Inhumation burial in an oval grave pit containing many stones. Larger stones were found between -20 and

142 It was strung together with the Dentalium bead described under. no. 5 The beads inventoried under different numbers were strung together when preparing the illustrations.

143 The excavation diary mentions a single bone tool fragment. It can no longer be established whether the fragments inventoried under different numbers had been recovered from the burial or whether the finds were mixed up later. 


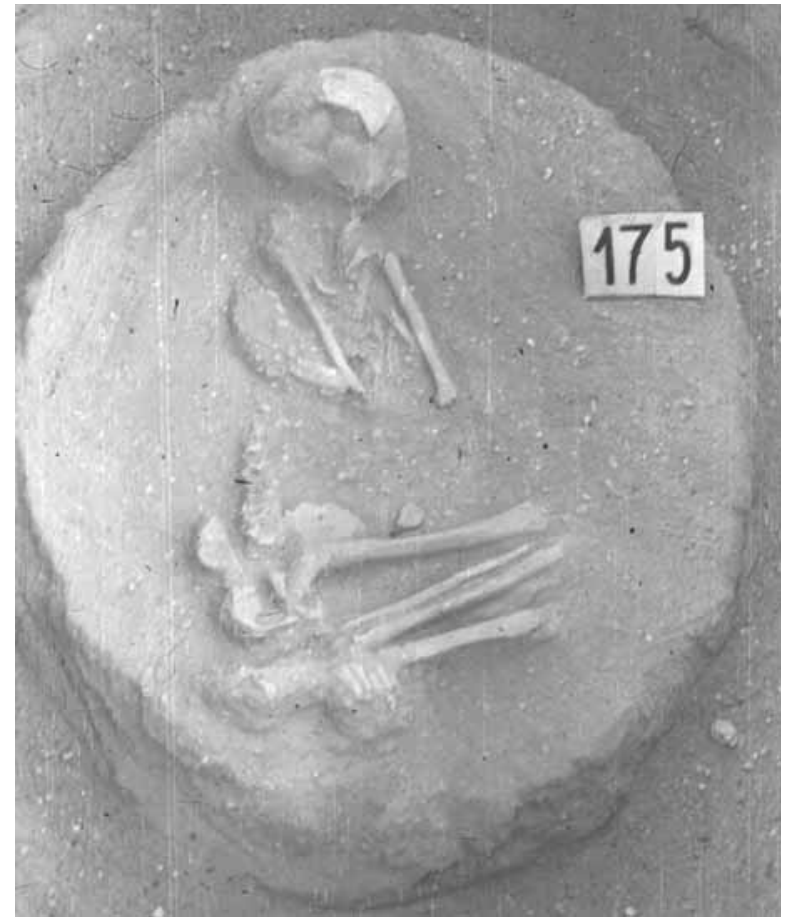

$-60 \mathrm{~cm}$, followed by a layer of earth between -60 and $-70 \mathrm{~cm}$, followed by smaller stones, some of which lay on the body, between -70 and $-90 \mathrm{~cm}$. The body was laid on the left side in a contracted position. The skull was crushed. the body was laid prone from the pelvis upward. The arms were bent at the elbow and drawn up, with the hands toward the chin. The thighs were drawn up into a horizontal position, the legs were bent back toward the buttocks.

The burial contained the following grave goods: an indistinct vessel fragment (1) by the right thigh; an obsidian core (2) by the left elbow.

\section{Grave goods}

1. Pottery sherd. Body sherd of a pot (?) with brown exterior and black interior L. $3.4 \mathrm{~cm}$. Inv. no. 61.2.34.1 (Pl. LXXII. 175/1).

2. An obsidian core fragment. Inv. no. 61.2.34.2 (Pl. LXXII. 175/2).

\section{Grave 176 (Square H4; Pl. LXXIV)}

Size of grave pit: L. $120 \mathrm{~cm}, W .90 \mathrm{~cm}$

Depth: $74 \mathrm{~cm}$

Orientation: $\mathrm{S}$ to $\mathrm{N}$, with the head toward the $\mathrm{S}$

Position of skeleton: laid on the left side

L. of skeleton (contracted): $100 \mathrm{~cm}$

L. of skeleton (extended): $143 \mathrm{~cm}$

Age at death: $30-40$ years

Sex: female

Condition of skeleton: medium well preserved

Preserved skeletal bones: skull, long bones

Inhumation burial in an oval grave pit. The body was laid on the left side in a contracted position. The arms were bent at the elbow and drawn up, with the left hand placed

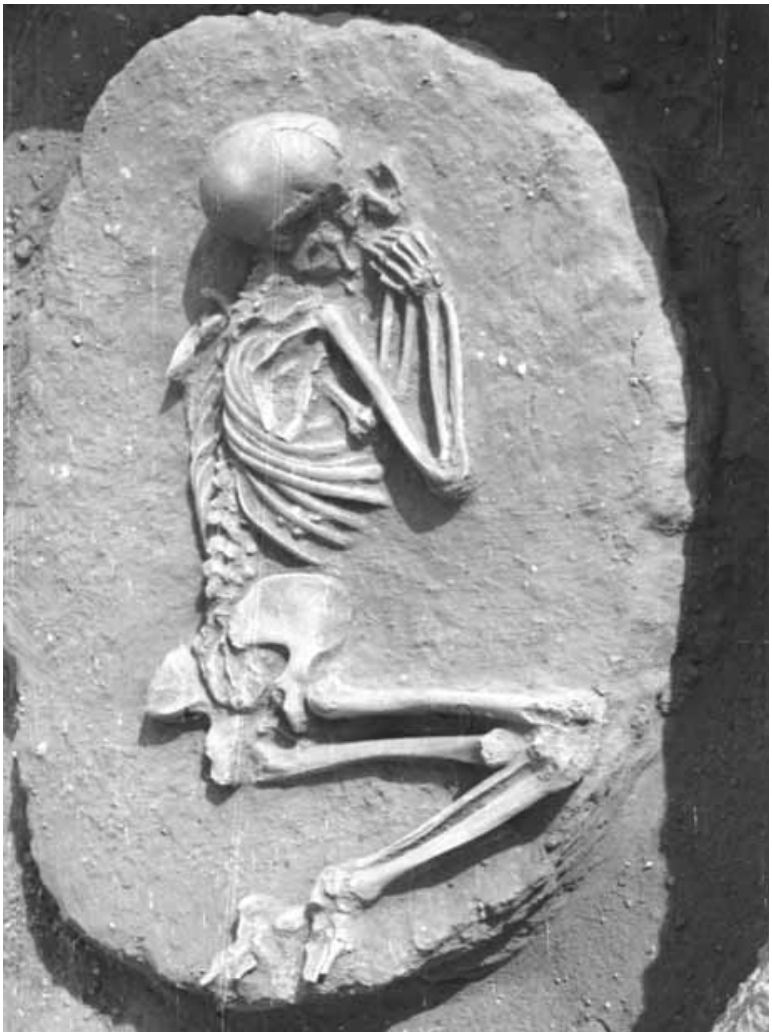

in front of the face and the right one resting on the left wrist. The body was laid prone from the pelvis upward. The thighs were drawn up into a horizontal position, the legs were bent back toward the buttocks with the feet set slightly higher toward the edge of the grave pit.

The burial did not contain any grave goods.

\section{Grave 177 (Square H4; Pls LXXVIII-LXXIX)}

Size of grave pit: L. $154 \mathrm{~cm}, W .125 \mathrm{~cm}$

Depth: $80 \mathrm{~cm}$

Orientation: -

Position of skeleton: -

L. of skeleton (contracted): -

L. of skeleton (extended): -

Age at death: -

Sex: -

Condition of skeleton: -

Preserved skeletal bones: -

Symbolic burial in an oval grave pit. No skeletal remains were found in the grave pit. ${ }^{144}$

The burial contained the following grave goods: a bowl (1) lying upside-down at a depth of $-80 \mathrm{~cm}$; a goblet (2) under the bowl; a wagon model (3) beside the previous vessel; a stone point (4) and a pebble (5) between vessels no. 3 and no. 4 .

\section{Grave goods}

1. Bowl. Greyish-brown, conical, worn bowl with funnel neck and flat base. A row of impressed dots

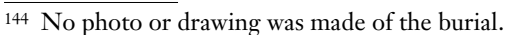


ornaments the rim. A similar row of impressed dots encircles the shoulder. A stringhole lug with two oblique grooves is set on the belly. Joined from its fragments and restored. H. $10.6 \mathrm{~cm}, \mathrm{dM} .28 .1 \mathrm{~cm}$, dB. 10 cm. Inv. no. 61.2.35.1 (Pl. LXXVIII. 177/1).

2. Goblet. Light brown goblet with oval upper part set on a flat, perforated foot with oval base. Patches of red painting can be made out on the vessel exterior and interior. The rim is damaged, the foot is joined from its fragments. H. $8.4 \mathrm{~cm}, \mathrm{dM} .9 .4-8.8 \mathrm{~cm}, \mathrm{~dB}$. 6.3-4 cm. Inv. no. 61.2.35.2 (Pl. LXXVIII. 177/2).

3. Wagon model. "Rectangular scooping vessel modelled in the shape of a four-wheeled wagon. The rim is peaked at the four corners. The vessel body narrows toward the base. Two pairs of solid wheels are set on two opposite sides; the hubs are represented by a flat, round knob with a diameter of $0.65 \mathrm{~cm}$. The wheels are $3.9 \mathrm{~cm}$ high and $3.4 \mathrm{~cm}$ wide. The wheels thin toward the edges. Only the lower part of the fluted handle has survived. Each pair of wheels is connected by two pairs of incised lines indicating the axles on the vessel base. The four pairs of incised lines perpendicular to the two axles on the vessel base symbolise the planks from which the wagon was constructed. Two incised lines on the sides opposite the handle divide the vessel body into three panels, each filled with a zig-zag line. The other two sides are decorated with an incised zig-zag line under the rim. The vessel is painted red both on its exterior and interior; the painting is strongly worn. The vessel was made from finely levigated clay and fired to a black colour. The peaked corners are damaged; two wheels are joined from their fragments, one is partially restored." H. $8.1 \mathrm{~cm}$, dB. $5.9 \mathrm{~cm}$, dM. $9.2 \mathrm{~cm} \times 8.9 \mathrm{~cm}$. Inv. no. 61.2.35.5 (Pl. LXXIX. 177/3).145

4. Radiolarite point. L. $3.1 \mathrm{~cm}, W .1 .8 \mathrm{~cm}$. Inv. no. 61.2.35.3.

5. Unworked radiolarite pebble. Inv. no. 61.2.35.4 (Pl. LXXVIII. 177/5).

\section{Grave 178 (Square H4)}

Size of grave pit: L. $45 \mathrm{~cm}, W .28 \mathrm{~cm}$

Depth: $40 \mathrm{~cm}$

Orientation: -

Position of skeleton: -

L. of skeleton (contracted): -

L. of skeleton (extended): -

Age at death: $15-59$ years

Sex: female (?)

Condition of skeleton: -

Preserved skeletal bones: various fragments

\footnotetext{
145 The acquisitions register does not contain a description of the wagon model. The description given here is quoted from Sándor Soproni's publication (SOPRONI 1954, 29). The wagon model is currently exhibited in the Hungarian National Museum.
}

Scattered cremation burial in an oval grave pit containing stones. The stones lay between a depth of -15 and $-30 \mathrm{~cm}$, the calcinated bones lay under the stones between -35 and $-40 \mathrm{~cm}$.

The burial did not contain any grave goods.

\section{Grave 179 (Square H4; Pl. LXXVIII)}

Size of grave pit: L. $60 \mathrm{~cm}, W .40 \mathrm{~cm}$

Depth: $50 \mathrm{~cm}$

Orientation: $S$ to $N$ (?), with the head toward the $S$

Position of skeleton: -

L. of skeleton (contracted): -

L. of skeleton (extended): -

Age at death: $12-14$ years

Sex: child

Condition of skeleton: badly preserved

Preserved skeletal bones: skull fragments

Inhumation burial in an oval grave pit. The skeletal remains did not survive except for a few skull fragments. The skull lay in the south-western corner of the grave pit, suggesting that the burial had been south to north oriented.

The burial contained the following grave goods: a broken dipper (1) by the southern side of the skull.

\section{Grave goods}

1. Dipper. Dark grey, conical dipper with flat base. The handle broke off, the upper part is damaged and joined from its fragments. H. $6.5 \mathrm{~cm}, \mathrm{~dB} .2 .2 \mathrm{~cm}$. Inv. no. 61.2.36.1 (Pl. LXXVIII. 179/1).

\section{Grave 180 (Square H4; Pl. LXXIV)}

Size of grave pit: L. $130 \mathrm{~cm}, W .110 \mathrm{~cm}$

Depth: $76 \mathrm{~cm}$

Orientation: SW to NE, with the head toward the SW

Position of skeleton: laid on the left side

L. of skeleton (contracted): $92 \mathrm{~cm}$

L. of skeleton (extended): $160 \mathrm{~cm}$

Age at death: $16-18$ years

Sex: female

Condition of skeleton: medium well preserved

Preserved skeletal bones: skull, long bones

Inhumation burial in an oval grave pit. The body was laid on the left side in a contracted position. The skull lay on the left side. The arms were bent at the elbow and drawn up, with the hands resting in front of the chin. The right thigh was drawn up into a horizontal position, the left one in front of the body, the legs were bent back toward the buttocks.

The burial contained the following grave goods: a broken mussel (1) behind the right shoulder.

Grave goods

1. Musssel. A broken, perforated Unio crassus mussel. L. 4 cm. Inv. no. 61.2.37.1 (Pl. LXXIV. 180/1). 
Grave 181 (Square G5; Pl. LXXV)

Size of grave pit: L. $46 \mathrm{~cm}, W .46 \mathrm{~cm}$

Depth: $78 \mathrm{~cm}$

Orientation: -

Position of skeleton: -

L. of skeleton (contracted): -

L. of skeleton (extended): -

Age at death: $23-59$ years

Sex: male (?)

Condition of skeleton: -

Preserved skeletal bones: various fragments

Scattered cremation burial in an oval grave pit containing stones between -25 and $-50 \mathrm{~cm}$, among which lay vessel fragments (1). A few calcinated bones and seven beads (2) were found at a depth of $-50 \mathrm{~cm}$, under which lay calcinated bones. It is possible that the bones also included animal bones.

Grave goods

1. Pot fragments. Body sherds of a reddish, thickwalled pot, two with small, round knobs. Five nonjoining pieces. Inv. no. 61.2.38.2 (Pl. LXXV. 181/1).

2. Beads. Six sliced Dentalium badense beads and one limestone bead. Inv. no. 61.2.38.1 (Pl. LXXV. 181/2).

\section{Grave 182 (Square H4; Pl. LXXVI)}

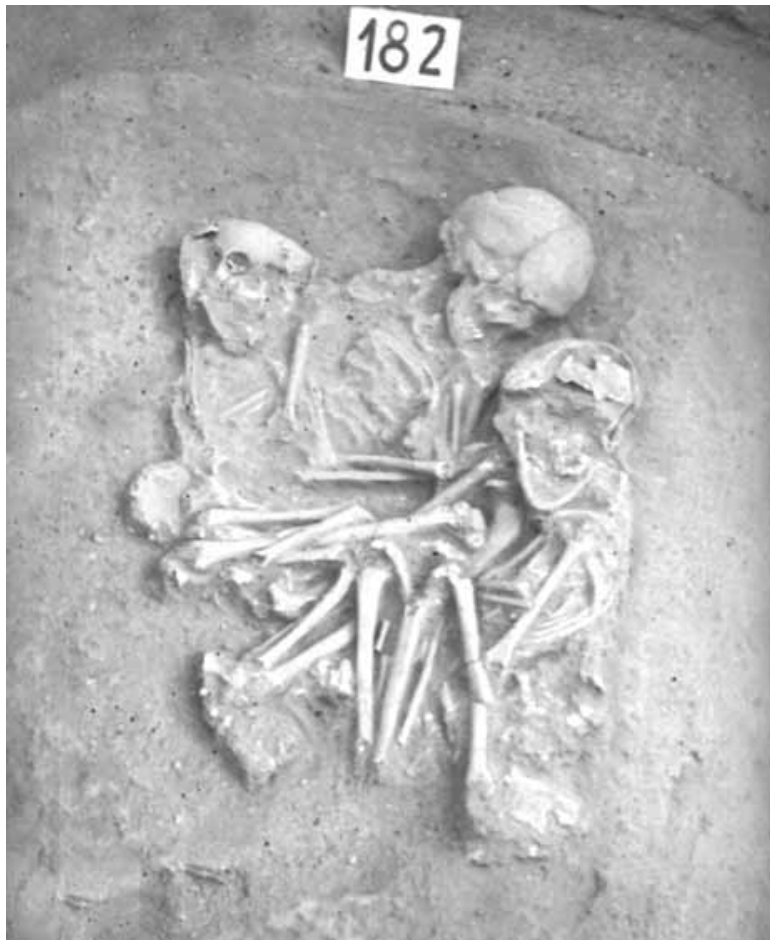

Size of grave pit: L. $138 \mathrm{~cm}, W .137 \mathrm{~cm}$

Depth: $95 \mathrm{~cm}$

Orientation: A: $\mathrm{E}$ to $\mathrm{W}$, with the head toward the $\mathrm{E}, \mathrm{B}$ : E-SE to W-NW, with the head toward the E-SE, C: E to W, with the head toward the $\mathrm{E}$

Position of skeleton: A: laid on the right side, B: laid on the left side, C: laid on the left side
L. of skeleton (contracted): A: $58 \mathrm{~cm}$, B: $87 \mathrm{~cm}$, C: $65 \mathrm{~cm}$ L. of skeleton (extended): A: $102 \mathrm{~cm}, \mathrm{~B}: 141 \mathrm{~cm}, \mathrm{C}: c a .80 \mathrm{~cm}$ Age at death: A: 8-9 years, B: $14-15$ years, C: 5-6 years Sex: A: child, B: juvenis, C: child

Condition of skeleton: A: badly preserved, B: badly preserved, C: badly preserved

Preserved skeletal bones: A-B-C: skull, long bones

Triple burial in an oblong grave pit with rounded corners containing stones between -15 and $-55 \mathrm{~cm}$, among which lay the fragments of a bipartite bowl (1), a ladle (2), a bipartite bowl fragment (3), a scooping vessel (4), a cup fragment (5) and indistinct pottery sherds (6).

\section{Burial A}

The burial of a child (perhaps a girl). The body was laid on the right side in a contracted position. The skull of this burial, tilted slightly forward to the right, lay the highest. The right arm was bent at the elbow and drawn up, with the hand resting on the upper arm. The left arm was bent at the elbow and drawn up. The thighs were drawn up in front of the body, the legs were bent back toward the buttocks. The left knee rested on the left leg of Burial $\mathrm{B}$, the right knee by the left knee of Burial C.

The burial did not contain any grave goods.

\section{Burial B}

The body was laid on the left side in a contracted position between Burials A and C. The skull lay on the left side and was tilted forward. The right arm was bent at the elbow, with the hand resting on the forearm. The left arm was bent at the elbow and drawn up toward the chin. The trunk lay under the trunk of Burial C, the two pelvic bones lay one over the other. The right thigh was drawn up into a horizontal position, the left thigh slightly higher. The left knee rested under the face of Burial A, the legs under the knees of Burial A. The legs were bent back toward the buttocks.

The burial contained the following grave goods: a chert blade (7) under the skull.

\section{Burial C}

A child burial. The body was laid on the left side in a contracted position north of Burial B. The crushed skull lay on the nape. The trunk was laid on the back. The right arm was bent at the elbow and drawn up, with the hand placed by the left shoulder, the left arm was bent at the elbow and drawn up toward the face. The pelvis lay above the pelvis of Burial $\mathrm{B}$, the left shoulder under the right upper arm of Burial B. The thighs were drawn up into a horizontal position, the legs were bent back toward the buttocks. The legs rested on the thighs of Burial $\mathrm{B}$, the right foot on the thigh of Burial B, the left foot by the left foot of Burial B.

The burial did not contain any grave goods.

The sequence of the three burials can be reconstructed as follows. Burial B was the first, followed by the 
deposition of the bodies in Burials A and C. The left shoulder of Burial $C$ lay under the right upper arm of Burial B after deposition since the body in Burial B was laid on the left side and may have "turned back" toward Burial C. The three bodies were probably interred at the same time since there was no indication of any disturbance.

\section{Grave goods}

1. Bipartite bowl. Body sherd of a grey, bipartite bowl with the stub of the inner dividing wall. The body is decorated with incised bundles of lines flanked by a row of punctates. L. $9.7 \mathrm{~cm}$. Inv. no. 61.2.39.2 (Pl. LXXVI. 182/1).

2. Ladle. Handle fragment of a reddish-brown, thinwalled ladle. The handle terminates in four peaks with a perforation under the two outer peaks. It is decorated with an incised zig-zag motif on the exterior. L. $4.2 \mathrm{~cm}$. Inv. no. 61.2.39.3 (Pl. LXXVI. 182/2).

3. Pitcher and bipartite bowl. Body sherd of a greyish, worn pitcher decorated with incised lines on the belly (Pl. LXXVI. 182/3), and body sherds of a worn, bipartite bowl ornamented with a combination of incised lines set between rows of punctates, probably from the vessel described under no. 1 . Three pieces. Inv. no. 61.2.39.4.

4. Scooping vessel. Body and base fragment of a grey, thick-walled scooping vessel with the stub of the handle. Joined from its fragments. L. $9 \mathrm{~cm}$. Inv. no. 61.2.39.5 (Pl. LXXVI. 182/4).

5. Mug. Rim and neck fragment of a grey, thin-walled, worn mug. L. $4.5 \mathrm{~cm}$. Inv. no. 61.2.39.6 (Pl. LXXVI. 182/5-6).

6. Mug (?). Rim and neck fragment of a grey, thinwalled, worn mug. L. $3.4 \mathrm{~cm}$. Inv. no. 61.2.39.7.

7. Retouched chert blade. Inv. no. 61.2.39.1 (Pl. LXXVI. 182/7)

\section{Grave 183 (Square G5; Pl. LXXVII)}

Size of grave pit: L. $118 \mathrm{~cm}$, W. $100 \mathrm{~cm}$

Depth: $104 \mathrm{~cm}$

Orientation: S-SW to N-NE, with the head toward the S-SW

Position of skeleton: laid on the left side

L. of skeleton (contracted): $96 \mathrm{~cm}$

L. of skeleton (extended): $148 \mathrm{~cm}$

Age at death: $30-40$ years

Sex: female

Condition of skeleton: badly preserved

Preserved skeletal bones: skull, long bones

Inhumation burial in an oval grave pit containing stones from a depth of $-70 \mathrm{~cm}$ downward, which lay on the body. The body was laid on the left side in a contracted position. The skull was crushed. The right arm was bent at the elbow and drawn up, with the hand by the left forearm. The left elbow was bent at the elbow and drawn up, with the elbow resting by the right knee and

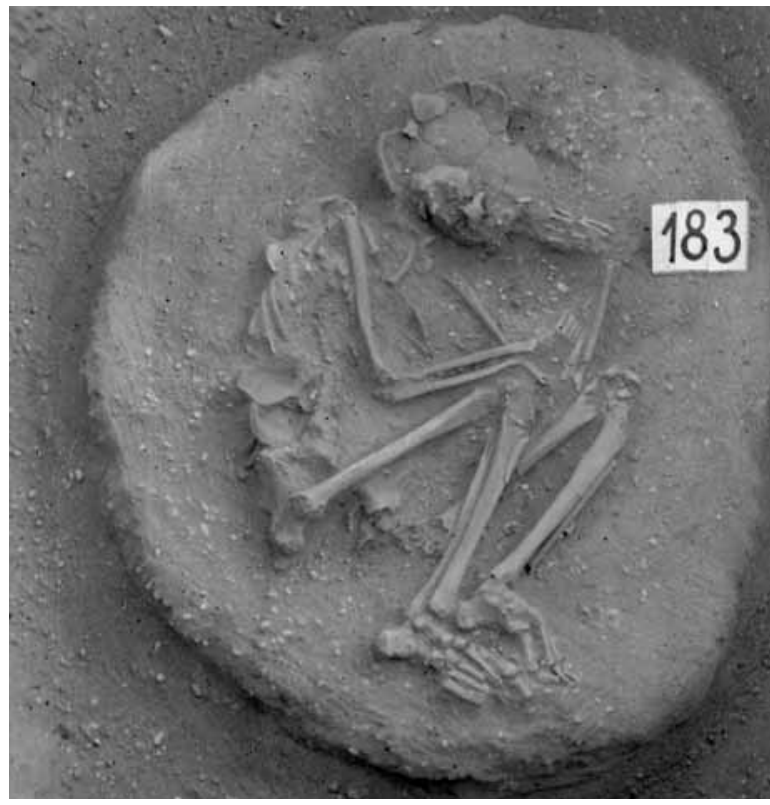

the hand laid by the face. The thighs were drawn up in front of the body, the legs were bent back toward the buttocks. The ankles were placed next to each other.

The burial contained the following grave goods: a scooping vessel (1) behind and under the dorsal vertebrae; eleven beads and two broken shell plaques (2) under the shoulders.

\section{Grave goods}

1. Scooping vessel. Brownish, polished scooping vessel with flat base ornamented with a row of impressed dots around the shoulder and bundles of smoothedin lines forming a cross on the base. The short strap handle spans the rim and the base. The strap handle is also decorated with smoothed-in lines. Traces of use-wear can be noted on the rim. Joined from its fragments. H. $3.5 \mathrm{~cm}, \mathrm{~d} M .11 .7 \mathrm{~cm}$. Inv. no. 61.2.40.1 (Pl. LXXVII. 183/1).

2. Beads. Eleven limestone beads of varying sizes $(P l$. LXXVII. 183/2a) and two broken, rectangular Unio crassus mussel plaques (Pl. LXXVII. 183/2b). Inv. no. 61.2.40.2.

\section{Grave 184 (Square H4)}

\author{
Size of grave pit: L. $75 \mathrm{~cm}, W .50 \mathrm{~cm}$ \\ Depth: $85 \mathrm{~cm}$ \\ Orientation: S-SW to N-NE, with the head toward the S-SW \\ Position of skeleton: laid on the right side \\ L. of skeleton (contracted): $48 \mathrm{~cm}$ \\ L. of skeleton (extended): - \\ Age at death: $3-3.5$ years \\ Sex: child \\ Condition of skeleton: badly preserved \\ Preserved skeletal bones: skull, long bone fragments
}

Inhumation burial in an oval grave pit. The body was laid on the right side in a contracted position. The skull lay on the occipital bone. The position of the arms 
could not be established. The thighs were drawn up into a horizontal position, the legs were bent back toward the buttocks.

The burial did not contain any grave goods.

\section{Grave 185 (Square G4; Pl. LXXIV)}

Size of grave pit: L. $120 \mathrm{~cm}, W .70 \mathrm{~cm}$

Depth: $95 \mathrm{~cm}$

Orientation: $\mathrm{S}$ to $\mathrm{N}$, with the head toward the $\mathrm{S}$

Position of skeleton: laid on the left side

L. of skeleton (contracted): $98 \mathrm{~cm}$

L. of skeleton (extended): $145 \mathrm{~cm}$

Age at death: $35-45$ years

Sex: male

Condition of skeleton: medium well preserved

Preserved skeletal bones: skull, long bones

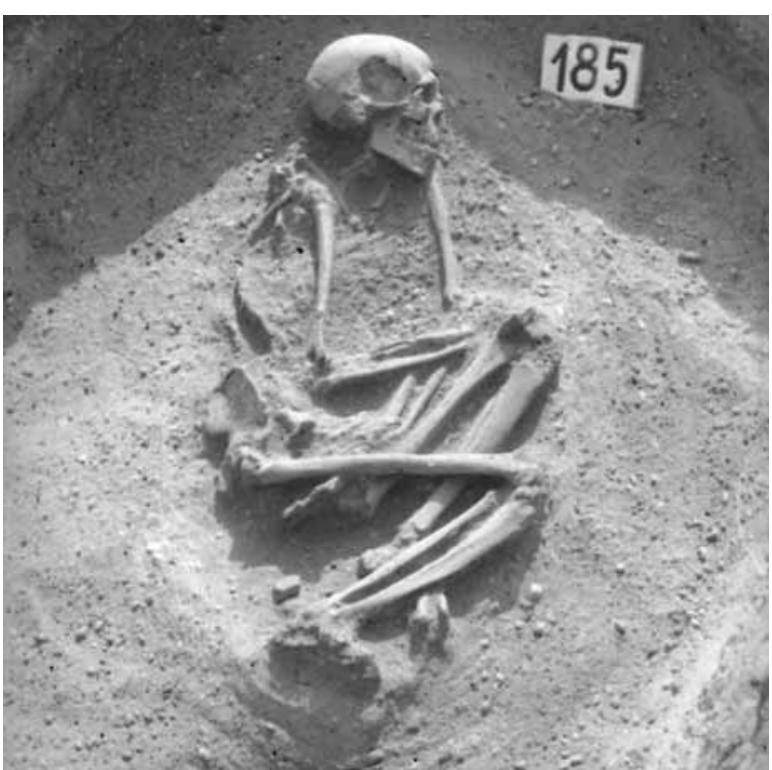

Inhumation burial in an oval grave pit. The body was laid on the left side in a contracted position. The skull lay on the left temporal bone. The right arm was bent at the elbow, with the hand laid under the left knee. The left arm was bent at the elbow, with the hand placed by the left pelvic bone. The right thigh was drawn up into a horizontal position, the left one in front of the body, the legs were bent back toward the buttocks.

The burial contained the following grave goods: a red stone (1) $8 \mathrm{~cm}$ north of the right temporal bone.

\section{Grave goods}

1. Red stone. Rectangular red stone with one side polished smooth. L. $3.7 \mathrm{~cm}, W .2 .3 \mathrm{~cm}$, Th. $1.2 \mathrm{~cm}$. Inv. no. 61.2.41 (Pl. LXXIV. 185/1).146

\footnotetext{
146 The object has since been lost or mislaid. Its description is quoted from
} the excavation diary.
Grave 186 (Square H8; Pl. LXXIV)

Size of grave pit: -

Depth: $40 \mathrm{~cm}$

Orientation: $\mathrm{S}$ to $\mathrm{N}$, with the head toward the $\mathrm{S}$

Position of skeleton: laid on the left side

L. of skeleton (contracted): -

L. of skeleton (extended): $81 \mathrm{~cm}$

Age at death: $40-x$ years

Sex: male

Condition of skeleton: badly preserved

Preserved skeletal bones: skull, long bones

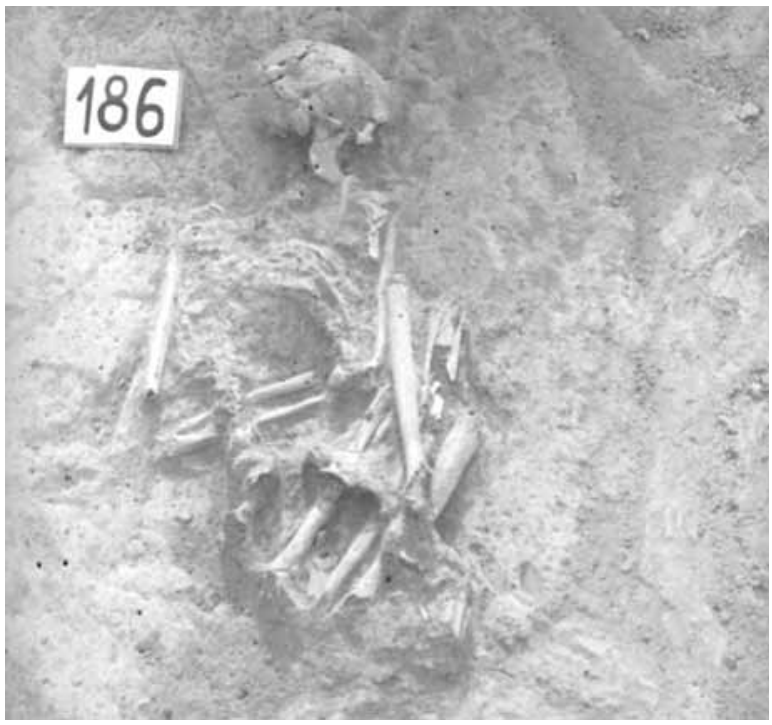

Inhumation burial. There was no indication of a grave pit. The body was laid on the left side in a contracted position. The skull rested on the left temporal bone. The left arm was bent at the elbow, with the forearm resting under the body and the hand by the right elbow. The right arm was bent at the elbow and drawn up, with the hand placed under the chin. The thighs were drawn up in front of the body, the legs were bent back toward the buttocks.

The burial did not contain any grave goods.

\section{Grave 187 (Square H9)}

Size of grave pit: -

Depth: $10-15 \mathrm{~cm}$

Orientation: SW to NE, with the head toward the SW

Position of skeleton: laid on the left side

L. of skeleton (contracted): $95 \mathrm{~cm}$

L. of skeleton (extended): -

Age at death: adult

Sex: -

Condition of skeleton: badly preserved

Preserved skeletal bones: various fragments

Inhumation burial. There was no indication of a grave pit. The skeletal remains were disturbed owing to the shallow depth. The body was laid on the left side in a contracted position.

The burial did not contain any grave goods. 


\section{Grave 188 (Square G4; Pl. LXXV)}

Size of grave pit: L. $120 \mathrm{~cm}, W .103 \mathrm{~cm}$

Depth: $71 \mathrm{~cm}$

Orientation: SE to NW, with the head toward the SE

Position of skeleton: laid on the right side

L. of skeleton (contracted): $97 \mathrm{~cm}$

L. of skeleton (extended): -

Age at death: $40-50$ years

Sex: female

Condition of skeleton: medium well preserved

Preserved skeletal bones: skull, long bones

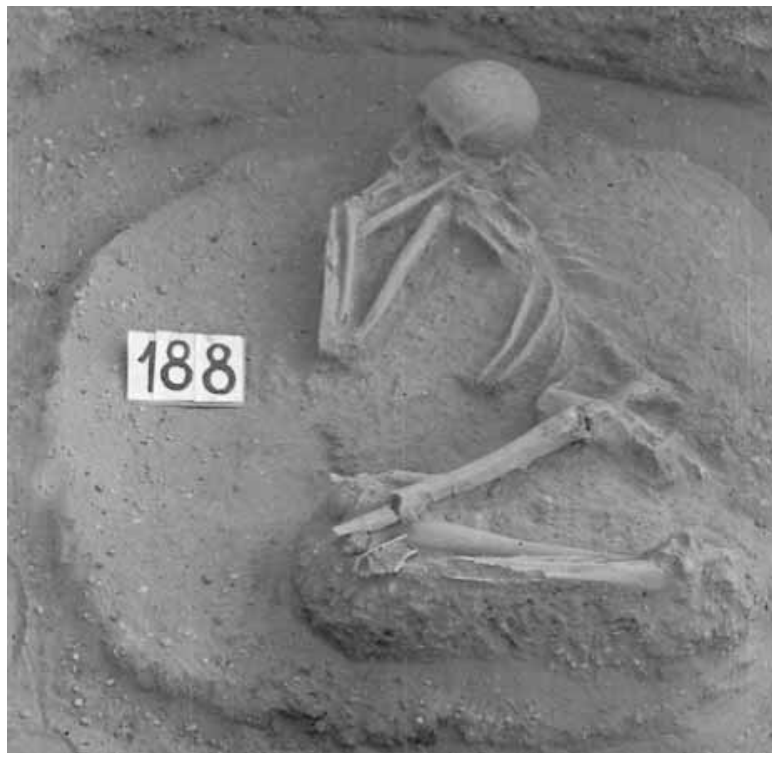

Inhumation burial in a round grave pit. The body was laid on the right side in a contracted position. The skull rested on the occipital bone. The arms were bent at the elbow and drawn up, with the hands placed in front of the face. The right thigh was drawn up into a horizontal position, the left one slightly higher, the legs were bent back toward the buttocks.

The burial did not contain any grave goods.

\section{Grave 189 (Square G4; Pl. $L X X X)$}

Size of grave pit: L. $125 \mathrm{~cm}, W .100 \mathrm{~cm}$

Depth: $117 \mathrm{~cm}$

Orientation: $\mathrm{E}$ to $\mathrm{W}$, with the head toward the $\mathrm{E}$

Position of skeleton: laid on the left side

L. of skeleton (contracted): $116 \mathrm{~cm}$

L. of skeleton (extended): $154 \mathrm{~cm}$

Age at death: $30-40$ years

Sex: female

Condition of skeleton: medium well preserved

Preserved skeletal bones: skull, long bones and the remains of an embryo

Inhumation burial in an oval grave pit. The body was laid on the left side in a moderately contracted position. The crushed skull lay on the left side. The body was placed prone from the pelvis upward and lay slightly tilted to the left. The arms were bent at the elbow and

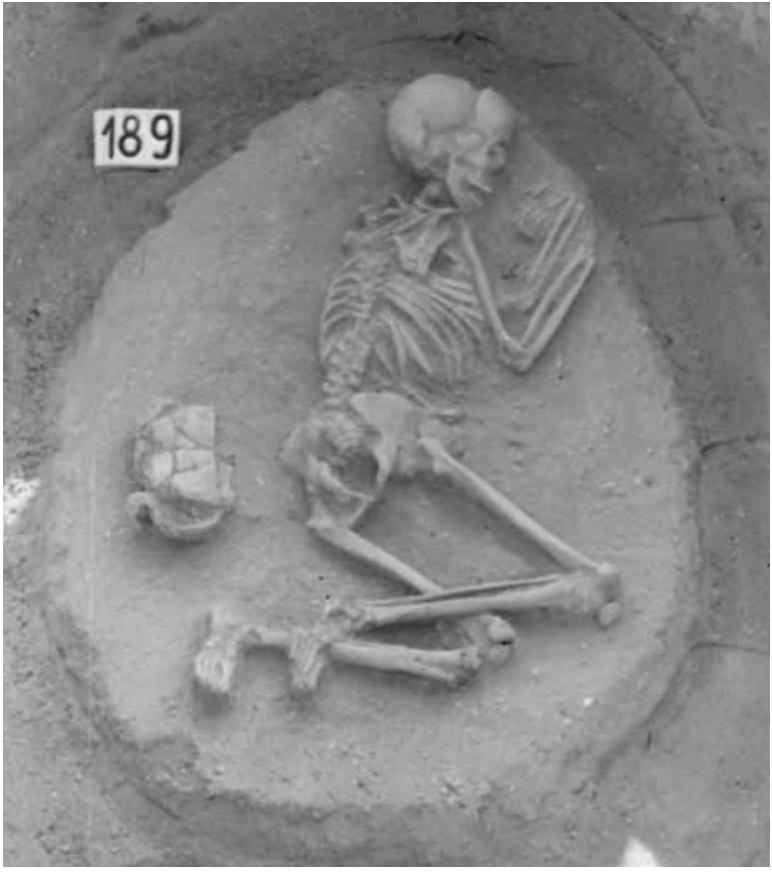

drawn up, with the clenched hands resting in front of the face. The thighs were drawn up into a horizontal position, the legs were bent back toward the buttocks.

The grave contained the burial of a pregnant woman; the skeletal remains of the embryo lay around the pelvis.

The burial contained the following grave goods: a small vessel (1) with the mouth upward, $10 \mathrm{~cm}$ east of the pelvis; a crushed pot (2) tilted to one side with the mouth facing the pelvis on top of the previous vessel; a onehandled cup (3) slightly north of vessel 2 with the mouth facing the pot; a stone chip (4) between vessel 2 and the pelvis; a small red stone (5) under vessel 2.

\section{Grave goods}

1. Scooping vessel. Grey, polished scooping vessel with flat base. The strap handle springs from the rim to the base. Joined from its fragments; the handle is restored. H. $4.6 \mathrm{~cm}, \mathrm{~d} M .12 .3 \mathrm{~cm}, \mathrm{~dB} .5 .3 \mathrm{~cm}$. Inv. no. 61.2.42.1 (Pl. LXXX. 189/1).

2. Pot. Brownish-grey, coarsely made, worn pot with an elongated $\mathrm{S}$ profile. Three small pointed knobs are set under the rim. Joined from its fragments and restored. H. ca. $10 \mathrm{~cm}, \mathrm{~dB} .7 \mathrm{~cm}$. Inv. no. 61.2 .42 .5 (Pl. LXXX. 189/2).

3. One-handled gup. Greyish-brown, poorly fired, worn, shallow cup. The handle rises above the rim and springs to the shoulder. Joined from its fragments. H. $4.5 \mathrm{~cm}, \mathrm{dM} .9 \mathrm{~cm}$. Inv. no. 61.2.42.2 (Pl. LXXX. 189/3).

4. Debitage. Inv. no. 61.2.42.3 (Pl. LXXX. 189/4).

5. Red stone. Broken red stone, with one side polished smooth. L. $3.5 \mathrm{~cm}$, W. $2.2 \mathrm{~cm}$. Inv. no. 61.2.42.4 (Pl. LXXX. 189/5). 
Grave 190 (Square G4; Pl. LXXX)

Size of grave pit: L. $45 \mathrm{~cm}, W .45 \mathrm{~cm}$

Depth: $60 \mathrm{~cm}$

Orientation: -

Position of skeleton: -

L. of skeleton (contracted): -

L. of skeleton (extended): -

Age at death: infant (?)

Sex: child

Condition of skeleton: -

Preserved skeletal bones: ${ }^{147}$

Scattered cremation burial in a round grave pit containing stones to a depth of $-50 \mathrm{~cm}$. Tiny calcinated bone fragments, perhaps the remains of an infant, lay under the stones.

The burial contained the following grave goods: five intact and one broken shell plaques (1). ${ }^{148}$

Grave goods

1. Shell plaques. Rectangular Unio crassus mussel plaques with a pair of perforations on the short sides. All are broken, one joined from two fragments. L. $1.7 \mathrm{~cm}, W .0 .8 \mathrm{~cm}$. Seven pieces. Inv. no. 61.2 .43 (Pl. LXXX. 190/1).

\section{Grave 191 (Square G8; Pl. LXXX)}

Size of grave pit: L. $70 \mathrm{~cm}, W .60 \mathrm{~cm}$

Depth: $70 \mathrm{~cm}$

Orientation: face toward the E-NE

Position of skeleton: laid on the left side

L. of skeleton (contracted): -

L. of skeleton (extended): -

Age at death: $13-15$ years

Sex: female

Condition of skeleton: -

Preserved skeletal bones: -

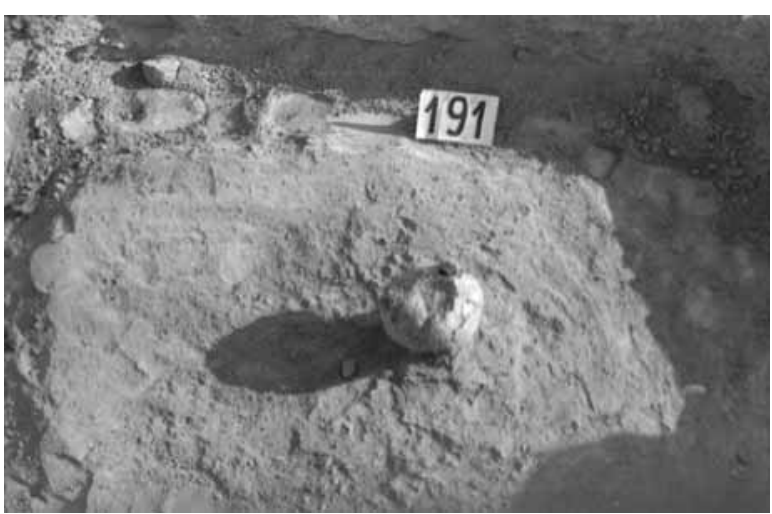

Skull burial. The skull lay in the centre of the grave pit. The skull lay on the parietal bone, tilted slightly to the

\footnotetext{
147 The skeletal remains can no longer be found. The anthropological data are quoted from the excavation diary.

148 The shell plaques were broken by the time they were inventoried. While the excavation diary lists six plaques, seven plaques were inventoried. However, two of these could be joined, meaning that there had been six shell plaques in the burial.
}

left. A few teeth were found in the eastern half of the grave pit. The grave pit contained one stone.

The burial contained the following grave goods: an indistinct pottery sherd (1) in front of the face.

Grave goods

1. Rim fragment of a brown vessel with uneven wall thickness. L. $2.6 \mathrm{~cm}$. Inv. no. 61.2.44.

\section{Grave 192 (Square G4; Pl. LXXV)}

Size of grave pit: L. $102 \mathrm{~cm}, W .80 \mathrm{~cm}$

Depth: $87 \mathrm{~cm}$

Orientation: SW to NE, with the head toward the SW

Position of skeleton: laid on the left side

L. of skeleton (contracted): $87 \mathrm{~cm}$

L. of skeleton (extended): $145 \mathrm{~cm}$

Age at death: 23-30 years

Sex: female

Condition of skeleton: badly preserved

Preserved skeletal bones: skull, long bones

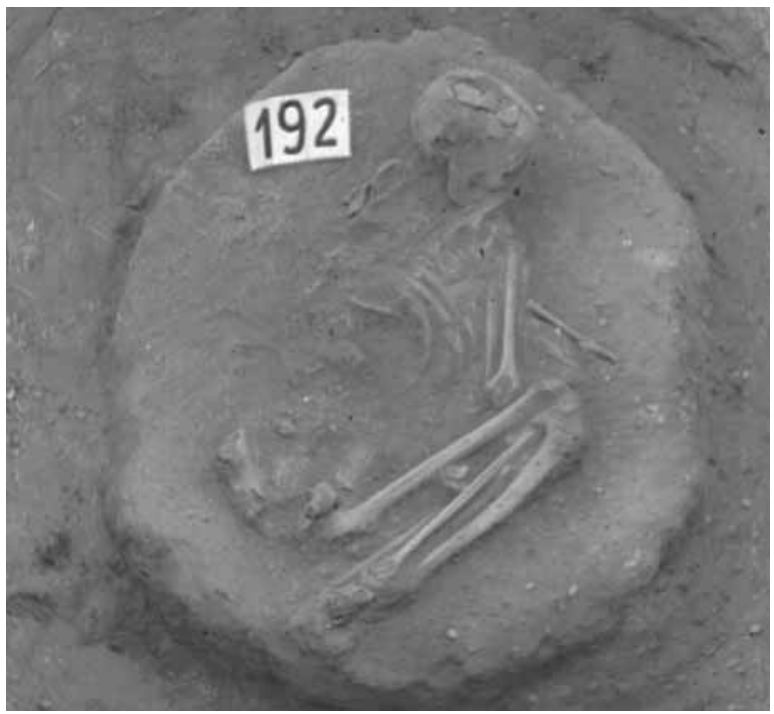

Inhumation burial in an oval grave pit containing stones, which lay on the skeletal remains. The body was laid on the left side in a strongly contracted position. The crushed skull rested on the occipital bone, tilted slightly to the left. The right arm was bent at the elbow and drawn up, with the hand laid under the shoulder. The left arm was extended in front of the body, with the hand laid by the knees. The thighs were drawn up in front of the body, the legs were bent back toward the buttocks. The knees lay by the right elbow.

The burial did not contain any grave goods.

\section{Grave 193 (Square G8; Pl. LXXXII)}

\section{Size of grave pit: -}

Depth: $48 \mathrm{~cm}$

Orientation:-

Position of skeleton: - 
L. of skeleton (contracted): -

L. of skeleton (extended): -

Age at death: $23-x$ years

Sex: -

Condition of skeleton: -

Preserved skeletal bones: calcinated bone fragments

Scattered cremation burial. There was no indication of a grave pit. The calcinated bones were found over an area with a diameter of $35 \mathrm{~cm}$ between -40 and $-48 \mathrm{~cm}$.

The burial contained the following grave goods: a broken vessel (1) $15 \mathrm{~cm}$ north-east of the calcinated bones.

\section{Grave goods}

1. Pitcher. Neck, body and base fragments of a greyish, worn, biconical pitcher with incurving neck and rounded carination. Joined from its fragments. H. 14 cm, dB. 5.6 cm. Inv. no. 61.2 .45 (Pl. LXXXII. 193/1).

\section{Grave 194 (Square H8; Pl. LXXXI)}

Size of grave pit: L. $140 \mathrm{~cm}, W .116 \mathrm{~cm}$

Depth: $88 \mathrm{~cm}$

Orientation: SE to NW, with the head toward the SE

Position of skeleton: laid on the left side

L. of skeleton (contracted): $110 \mathrm{~cm}$

L. of skeleton (extended): $162 \mathrm{~cm}$

Age at death: $30-40$ years

Sex: male (?)

Condition of skeleton: medium well preserved

Preserved skeletal bones: skull, long bones

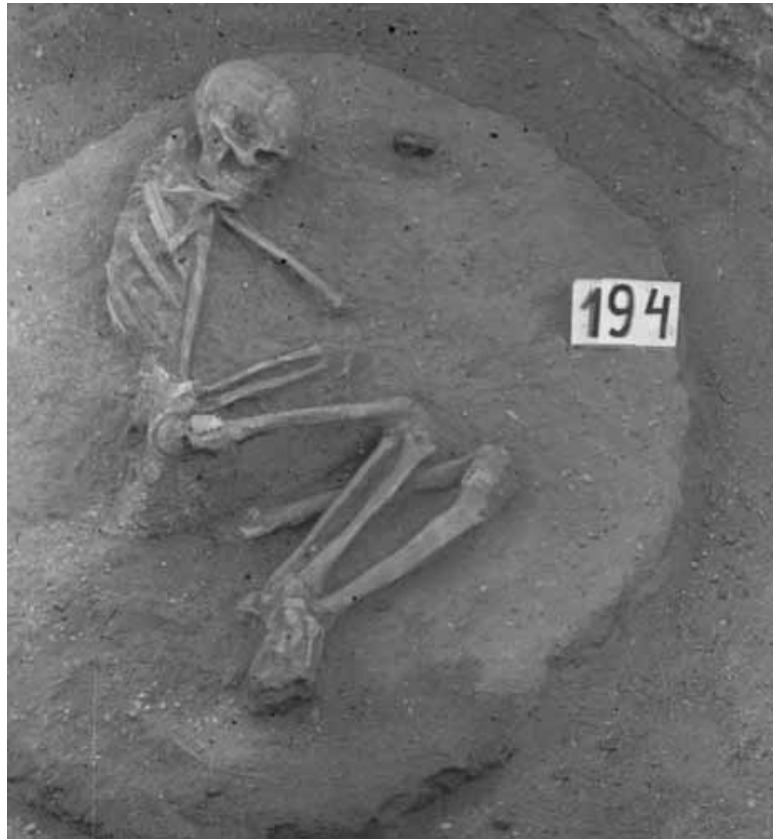

Inhumation burial in an oval grave pit containing stones lying in two layers between -15 and $-60 \mathrm{~cm}$. Various vessel fragments lay among the stones (1-4). The body was laid on the left side in a contracted position. The skull lay on the occipital bone, tilted slightly to the left. The left arm was bent at the elbow and drawn up, with the hand resting under the neck. The right arm was bent at the elbow and drawn up, with the hand placed beside the left elbow. The left thigh was drawn up into a horizontal position, the right one in front of the body, the legs were bent back toward the buttocks. The ankles rested one over the other.

The burial contained the following grave goods: a stone shaft-hole axe (5) tilted to one side with the butt pointing toward the skull, $16 \mathrm{~cm}$ south-west of the skull; a bead (6) on the chest; four Dentalium beads and another bead (7) under the neck.

\section{Grave goods}

1. Bowl. Rim and body fragments of a greyish-brown bowl with funnel neck, decorated with two rows of impressed dots. Four non-joining pieces. Inv. no. 61.2.46.4 (Pl. LXXXI. 194/1).

2. Pitcher. Handle fragment of a grey, worn pitcher. L. $3.9 \mathrm{~cm}$. Inv. no. 61.2.46.5.

3. Pot. Rim fragment of a grey, thin-walled, much worn, small pot with the stub of a knob. L. $3 \mathrm{~cm}$. Inv. no. 61.2.46.6 (Pl. LXXXI. 194/3).

4. Pot (?). Body and base fragment of a greyish, worn pot with patches of red painting on the exterior and interior. L. $8.7 \mathrm{~cm}$. Inv. no. 61.2.46.7 (Pl. LXXXI. 194/4).

5. Stone axe. Boat shaped shaft-hole axe made from serpentinite. L. $6.7 \mathrm{~cm}, W .3 .5 \mathrm{~cm}$. Inv. no. 61.2.46.1 (Pl. LXXXI. 194/5). ${ }^{149}$

6. Bead. Small, cylindrical limestone bead. Inv. no. 61.2.46.2 (Pl. LXXXI. 194/6).

7. Beads. Four Dentalium badense shells and one limestone bead. Inv. no. 61.2.46.3 (Pl. LXXXI. 194/7).

\section{Grave 195 (Square G4; Pl. LXXXII)}

Size of grave pit: L. $122 \mathrm{~cm}, W .105 \mathrm{~cm}$

Depth: $70 \mathrm{~cm}$

Orientation: $\mathrm{A}: \mathrm{W}$ to $\mathrm{E}$, with the head toward the $\mathrm{W}, \mathrm{B}$ : $\mathrm{W}-\mathrm{NW}$ to E-SE, with the head toward the W-NW

Position of skeleton: A: laid on the left side, B: laid on the left side L. of skeleton (contracted): A: $101 \mathrm{~cm}, \mathrm{~B}: 97 \mathrm{~cm}$

L. of skeleton (extended): A-, B: -

Age at death: A: 40-50 years, B: 23-x years

Sex: A: female, B: male (?)

Condition of skeleton: A: badly preserved, B: badly preserved

Preserved skeletal bones: A-B: skull, long bones

Double inhumation burial in an oval grave pit containing stones from $-25 \mathrm{~cm}$ downward, which lay on the bodies.

\section{Burial A}

The body was deposited with the trunk in an extended position and the legs in a contracted position. The

\footnotetext{
149 The object has since been lost or mislaid. Its description is quoted from the acquisitions register. The drawing is based on József Korek's grave sheet.
} 


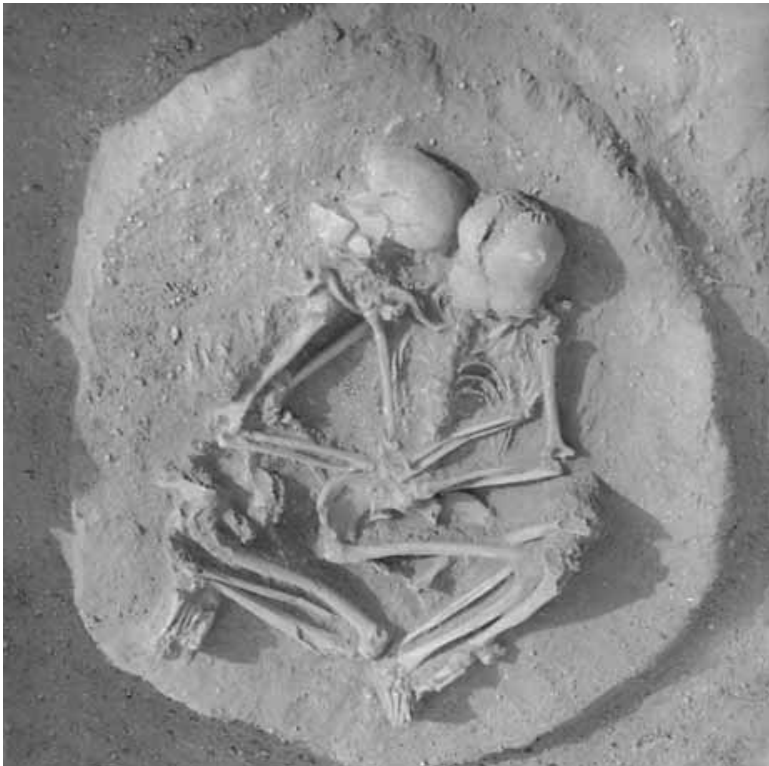

crushed skull lay on the occipital bone. The arms were placed across the chest, with the right hand by the left shoulder and the left hand on the sacrum. The right thigh was drawn up into a horizontal position, the left one in front of the body, the legs were bent back toward the buttocks. The left knee lay higher, almost touching the left elbow.

The burial did not contain any grave goods.

Burial B

The body was laid on the left side in a contracted position parallel to and a little south of Burial A. The skull lay on the left side, beside the skull of Burial A. The right arm was bent at the elbow, with the hand resting by the right elbow and the left hand of Burial A. The left arm was bent at the elbow, with the hand placed by the buttocks of Burial A. The thighs were drawn up into a horizontal position, the legs were bent back toward the buttocks. The knees lay by the ankles of Burial A.

The burial contained the following grave goods: a pebble (1) on the chest.

\section{Grave goods}

1. Broken radiolarite pebble. L. $1.1 \mathrm{~cm}, W .1 \mathrm{~cm}$. Inv. no. 61.2.47.1 (Pl. LXXXII. 195/1).

\section{Grave 196 (Pl. LXXXII)}

Size of grave pit: L. $122 \mathrm{~cm}, W .115 \mathrm{~cm}$

Depth: $107 \mathrm{~cm}$

Orientation: S-SE to N-NW, with the head toward the S-SE

Position of skeleton: laid on the right side

L. of skeleton (contracted): $102 \mathrm{~cm}$

L. of skeleton (extended): $166 \mathrm{~cm}$

Age at death: $35-45$ years

Sex: male

Condition of skeleton: medium well preserved

Preserved skeletal bones: skull, long bones

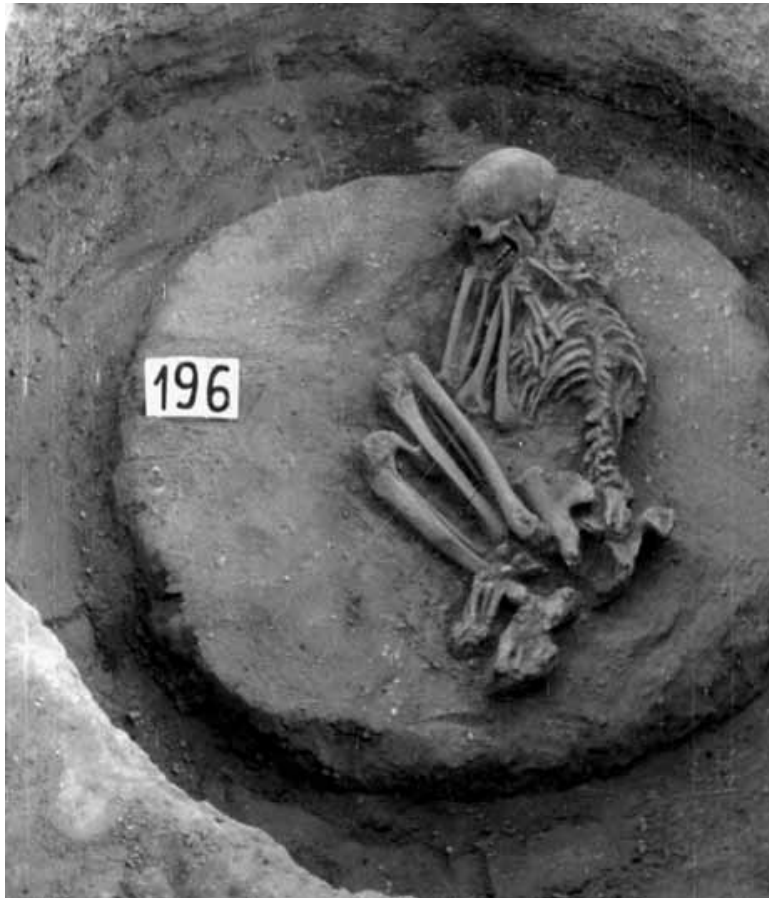

Inhumation burial in a round grave pit containing stones between -35 and $-55 \mathrm{~cm}$, among which lay a pitcher fragment (1). The body was laid on the right side in a strongly contracted position. The skull lay on the right side, tilted forward. The arms were bent at the elbow and drawn up, with the left hand resting under the chin, the right one on the ribs. The trunk was laid slightly prone. The thighs were drawn up in front of the body, the legs were bent back toward the buttocks. A human thighbone lay $8-10 \mathrm{~cm}$ above the left shoulder, perhaps carried there through an animal burrow.

Finds from the grave pit

1. Pitcher. Neck fragment of a brownish pitcher with cylindrical neck. L. 9 cm. Inv. no. 61.2.48.1 (Pl. LXXXII. 196/1).

\section{Grave 197 (Square G5; Pls LXXXIII-LXXXIV).}

Size of grave pit: L. $127 \mathrm{~cm}$, W. $112 \mathrm{~cm}$

Depth: $83 \mathrm{~cm}$

Orientation: SW to NE, with the head toward the SW

Position of skeleton: laid on the right side

L. of skeleton (contracted): $93 \mathrm{~cm}$

L. of skeleton (extended): $158 \mathrm{~cm}$

Age at death: $35-45$ years

Sex: female

Condition of skeleton: medium well preserved

Preserved skeletal bones: skull, long bones

Inhumation burial in an oval grave pit containing stones between -25 and $-30 \mathrm{~cm}$. The body was laid on the right side in a contracted position. The skull lay on the right side. The trunk was placed slightly prone. 


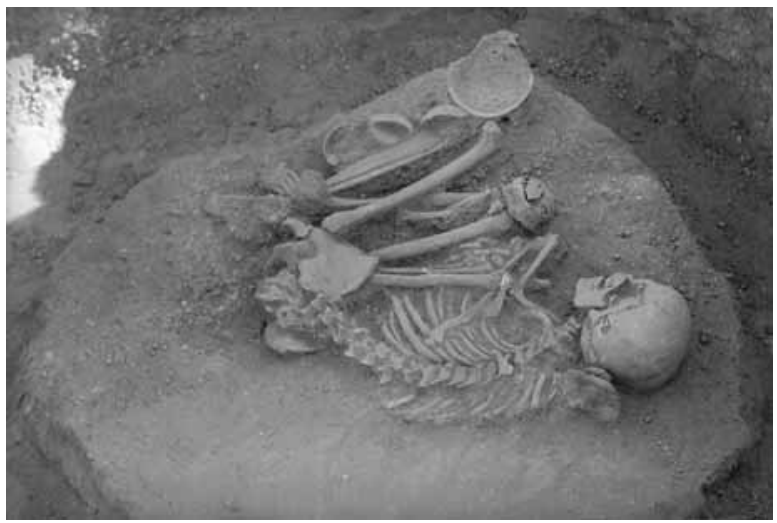

The left arm was bent at the elbow, with the hand resting between the right wrist and the right knee. The right arm was bent at the elbow, with the hand placed by the right knee. The left thigh was drawn up into a horizontal position, the right one in front of the body, the legs were bent back toward the buttocks. The ankles rested one over the other.

The burial contained the following grave goods: a small cup (1) over the right knee; a bowl (2) by the left knee, with the handle pointing toward the edge of the grave pit; a goblet (3) beside the previous vessel, by the leg-bone; a broken pitcher (4) by the left leg-bone; a flake (5) on the right foot; nine stone implements (6-14) by the left ankle; a flake (15) inside vessel 2 .

\section{Grave goods}

1. One-handled cup. Greyish, polished, conical, onehandled cup with slightly curved neck. A row of impressed dots encircles the shoulder and two rows of impressed dots run from the handle to the base. The strap handle spans the rim and base. Joined from its fragments. H. $6 \mathrm{~cm}, \mathrm{dM} .9 .5 \mathrm{~cm}$. Inv. no. 61.2.49.1 (Pl. LXXXIII. 197/1).

2. Bowl. Grey, polished, conical bowl with funnel neck. The ansa lunata handle springs from the rim to the shoulder. The vessel body is decorated with two rows of impressed dots. The two edges of the handle are ornamented with punctates. Joined from its fragments and partially restored. $H .7 \mathrm{~cm}$, dM. $16.5 \mathrm{~cm}, \mathrm{~dB} .5 .6 \mathrm{~cm}$. Inv. no. 61.2.49.2 (Pl. LXXXIV. 197/2).

3. Goblet. Fragments of a light brown, worn goblet with round upper part set on a rectangular foot with a rectangular base. The upper part is ornamented with four vertical ribs rising above the rim, making the upper part slightly angular. The vessel body is ornamented with incised zig-zag lines, which also extend across the ribs. There was a perforation at the junction of the foot and the base. Joined from its fragments. Surviving H. $7.7 \mathrm{~cm}$, dM. $10.5 \mathrm{~cm}$. Inv. no. 61.2.49.3 (Pl. LXXXIII. 197/3).

4. Pitcher. Brownish, biconical pitcher with slightly constricted neck and rounded carination, decorated with vertical fluting on the shoulder and belly. The handle rising above the rim springs to the shoulder. Joined from its fragments and partially restored. H. $11.1 \mathrm{~cm}, \mathrm{dM} .7 \mathrm{~cm}, \mathrm{~dB} .6 .1 \mathrm{~cm}$. Inv. no. 61.2.49.4 (Pl. LXXXIV. 197/4).

5. Unretouched radiolarite flake. L. $1.7 \mathrm{~cm}, W .1 .7 \mathrm{~cm}$. Inv. no. 61.2.49.5.

6. Retouched radiolarite flake. L. $1.4 \mathrm{~cm}, W .1 \mathrm{~cm}$. Inv. no. 61.2.49.6.

7. Radiolarite trapeze. Inv. no. 61.2.49.7 (Pl. LXXXIII. 197/7).

8. Unretouched blade fragment. Limnic quartzite. L. $2.3 \mathrm{~cm}, W .1 .1 \mathrm{~cm}$. Inv. no. 61.2 .49 .8 .

9. Limnic quartzite trapeze. L. $2.2 \mathrm{~cm}, W .1 .1 \mathrm{~cm}$. Inv. no. 61.2.49.9.

10. Chert point. Inv. no. 61.2.49.10 (Pl. LXXXIII. 197/10).

11. Unretouched chert flake. L. $1.5 \mathrm{~cm}, W .1 .3 \mathrm{~cm}$. Inv. no. 61.2.49.11.

12. Chert trapeze. Inv. no. 61.2.49.12 (Pl. LXXXIV. 197/12).

13. Chert trapeze. Inv. no. 61.2.49.13.

14. Obsidian trapeze. Inv. no. 61.2.49.14 (Pl. LXXXIV. 197/14).

15. Unretouched radiolarite flake. L. $2.3 \mathrm{~cm}, W .1 .4 \mathrm{~cm}$. Inv. no. 61.2.49.15.

\section{Grave 198 (Square F4/G4; Pl. LXXXIV)}

Size of grave pit: -

Depth: $35 \mathrm{~cm}$

Orientation: S-SW to N-NE, with the head toward the S-SW

Position of skeleton: laid on the left side

L. of skeleton (contracted): $40 \mathrm{~cm}$

L. of skeleton (extended): -

Age at death: $4-5$ years

Sex: child

Condition of skeleton: badly preserved

Preserved skeletal bones: various fragments

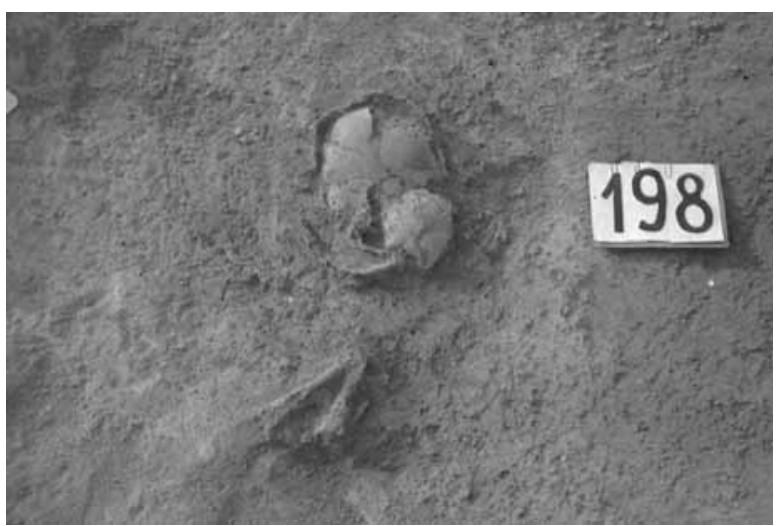

Inhumation burial. There was no indication of a grave pit. A few stones lay above the body. The body was laid on the left side in a strongly contracted position. A stone lay over the crushed skull. The right arm was bent at the elbow and drawn up, with the hand placed in front of the face. The left arm was also bent at the 
elbow. The thighs were drawn up in front of the body, the legs were bent back toward the buttocks. Nothing survived of the trunk.

The burial did not contain any grave goods.

\section{Grave 199 (Square G4; Pl. LXXXIV)}

Size of grave pit: -

Depth: $54 \mathrm{~cm}$

Orientation: S-SE to N-NW, with the head toward the S-SE

Position of skeleton: laid on the left side

L. of skeleton (contracted): $55 \mathrm{~cm}$

L. of skeleton (extended): $97 \mathrm{~cm}$

Age at death: $6-8$ years

Sex: child

Condition of skeleton: badly preserved

Preserved skeletal bones: skull, long bones

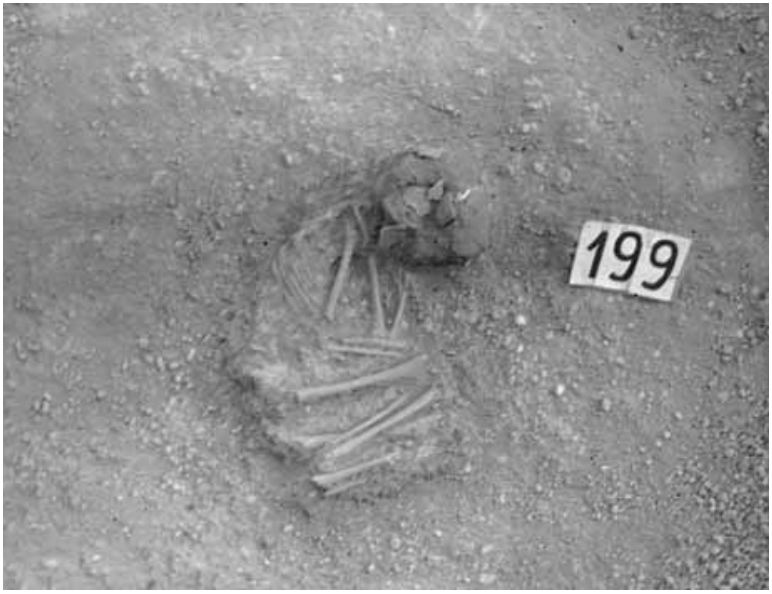

Inhumation burial. There was no indication of a grave pit. The body was laid on the left side in a contracted position. The skull lay on the left side and was tilted forward. The right arm was bent at the elbow, with the hand placed by the right knee. The left arm was bent at the elbow and drawn up, with the hand resting in front of the face. The thighs were drawn up into a horizontal position, the legs were bent back toward the buttocks.

The burial did not contain any grave goods.

\section{Grave 200 (Square G6; Pl. LXXXIV)}

Size of grave pit: L. $85 \mathrm{~cm}, W .65 \mathrm{~cm}$

Depth: $80 \mathrm{~cm}$

Orientation: E-SE to $\mathrm{W}-\mathrm{NW}$, with the head toward the E-SE

Position of skeleton: laid on the left side

L. of skeleton (contracted): $57 \mathrm{~cm}$

L. of skeleton (extended): $123 \mathrm{~cm}$

Age at death: $11-13$ years

Sex: child

Condition of skeleton: badly preserved

Preserved skeletal bones: skull, long bones

Inhumation burial in an oval grave pit containing two larger stones. The body was laid on the left side in a contracted position. The slightly crushed skull lay on

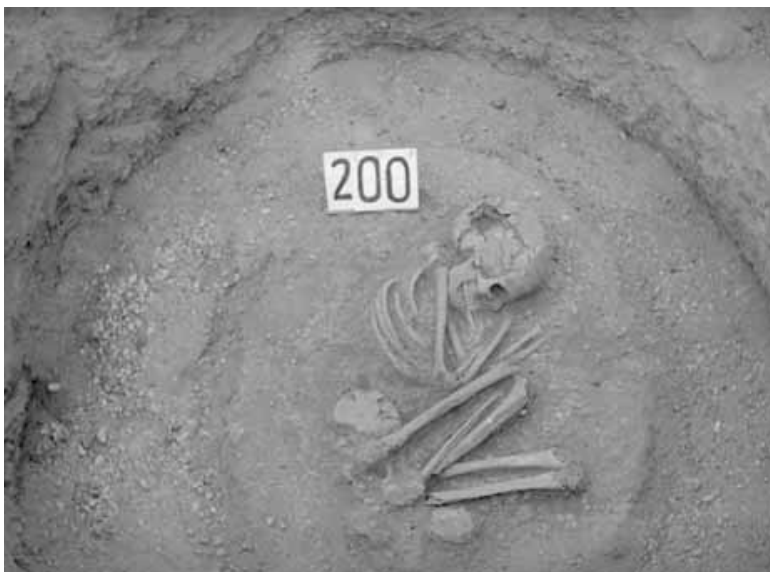

the left side. The arms were bent at the elbow and drawn up, with the hands placed in front of the face. The left thigh was drawn up into a horizontal position, the right one slightly higher, the legs were bent back toward the buttocks. The ankles rested one over the other.

The burial did not contain any grave goods.

\section{Grave 201 (Square G6; Pl. LXXXIV)}

Size of grave pit: L. $95 \mathrm{~cm}, W .83 \mathrm{~cm}$

Depth: $78 \mathrm{~cm}$

Orientation: S-SW to N-NE, with the head toward the S-SW

Position of skeleton: laid on the left side

L. of skeleton (contracted): $70 \mathrm{~cm}$

L. of skeleton (extended): $127 \mathrm{~cm}$

Age at death: $13-14$ years

Sex: child

Condition of skeleton: badly preserved

Preserved skeletal bones: skull, long bones

Inhumation burial in an oval grave pit. The body was laid on the left side in a contracted position. The skull lay on the left side and was partly destroyed by an animal burrow. The arms were bent at the elbow and laid in the lap. The thighs were drawn up in front of the body, the legs were bent back toward the buttocks. The ankles rested one over the other.

The burial did not contain any grave goods.

\section{Grave 202 (Square G4; Pl. LXXXV)}

Size of grave pit: L. $118 \mathrm{~cm}, W .95 \mathrm{~cm}$

Depth: $55 \mathrm{~cm}$

Orientation: S-SE to N-NW, with the head toward the S-SE

Position of skeleton: laid on the left side

L. of skeleton (contracted): $70 \mathrm{~cm}$

L. of skeleton (extended): $102 \mathrm{~cm}$

Age at death: 11-13 years

Sex: child

Condition of skeleton: badly preserved

Preserved skeletal bones: skull, long bones

Inhumation burial in an oval grave pit. The body was laid on the left side in a contracted position. The skull 


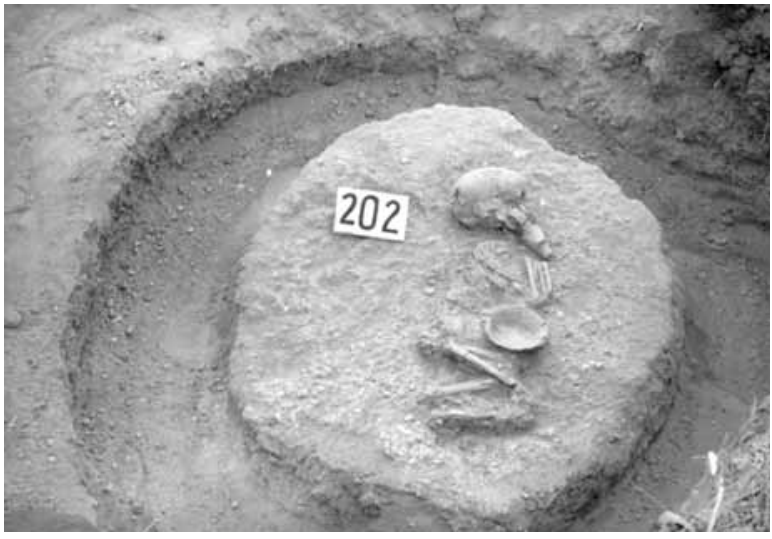

rested on the left side. The arms were bent at the elbow and drawn up, with the hands placed in front of the face. The thighs were drawn up into a horizontal position, the legs were bent back toward the buttocks.

The burial contained the following grave goods: a broken scooping vessel (1) in front of the abdomen; a dipper (2) with the mouth facing the skull between the hands and the mouth; a small flake (3) $10 \mathrm{~cm}$ west of vessel no. 1; a broken shell plaque (4) on the neck.

\section{Grave goods}

1. Scooping vessel. Grey scooping vessel with indrawn, rounded base. The handle spans the rim and the base. Joined from its fragments and restored. H. $4.6 \mathrm{~cm}$, dM. $12.8 \mathrm{~cm}$. Inv. no. 61.2.50.1 (Pl. $L X X X V$. 202/1).150

2. Dipper. Grey dipper with high-flung strap handle. Joined from its fragments and restored. H. $7.7 \mathrm{~cm}$, dM. $5.3 \mathrm{~cm}$, dB. $1.9 \mathrm{~cm}$. Inv. no. 61.2.50.2 (Pl. LXXXV. 202/2). ${ }^{151}$

3. Unretouched radiolarite flake. Inv. no. 61.2.50.3 (Pl. LXXXV. 202/3).

4. Shell plaque. Broken rectangular shell plaque with a pair of holes along the short sides. L. $1.7 \mathrm{~cm}, W .0 .5 \mathrm{~cm}$. Inv. no. 61.2.50.4. ${ }^{152}$

\section{Grave 203 (Square G6; Pl. LXXXVI)}

\author{
Size of grave pit: L. $145 \mathrm{~cm}$, W. $95 \mathrm{~cm}$ \\ Depth: $124 \mathrm{~cm}$ \\ Orientation: S-SE to N-NW, with the head toward the S-SE \\ Position of skeleton: laid on the right side \\ L. of skeleton (contracted): $112 \mathrm{~cm}$ \\ L. of skeleton (extended): $162 \mathrm{~cm}$ \\ Age at death: $48-56$ years \\ Sex: male \\ Condition of skeleton: well preserved \\ Preserved skeletal bones: skull, long bones
}

\footnotetext{
150 The object had been lost or mislaid by the time of the checklist drawn up in 1979. Its description is quoted from the acquisitions register. The drawing is based on József Korek's grave sheet.

151 The object has since been lost or mislaid. Its description is quoted from the acquisitions register. The drawing is based on József Korek's grave sheet.

152 The object has since been lost or mislaid. Its description is quoted from the acquisitions register.
}

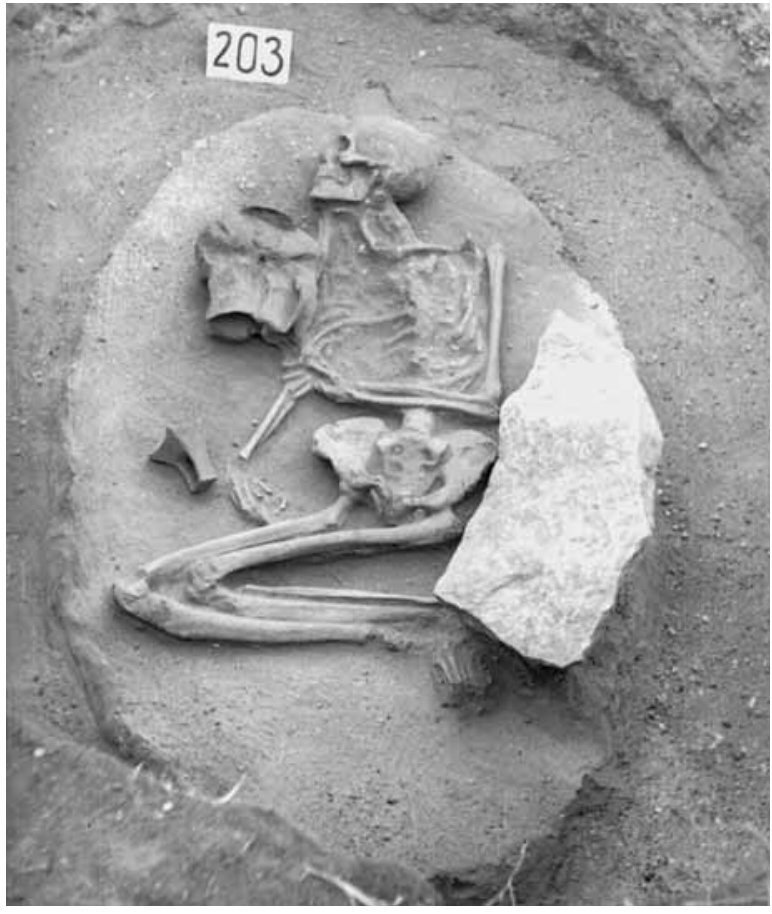

Inhumation burial in an oval grave pit. The body was laid on the right side in a contracted position. The skull lay on the right side. The trunk was placed on the back. The right arm was extended, with the hand placed by the thigh. The left arm was bent at the elbow and drawn up, with the hand clasping the right elbow. The thighs were moderately drawn up, the legs were bent back toward the buttocks. A large, longish block of limestone lay by the left side, near the edge of the grave pit.

The burial contained the following grave goods: a goblet (1) tilted to one side with the mouth facing the edge of the grave pit by the right wrist; a jug (2) by the right upper arm with the mouth facing the knees.

\section{Grave goods}

1. Goblet. Ochre coloured goblet with rectangular upper part and peaked corners set on a rectangular foot. The vessel body and the foot have an incised pattern of two parallel zig-zag lines. Patches of red painting survive in the interior. Cracked. $H .10 .6 \mathrm{~cm}$, dM. 7.9-8.5 cm, dB. 3.2-4 cm. Inv. no. 61.2.51.1 (Pl. LXXXVI. 203/1).153

2. Jug. Greyish jug with curving neck and flat, indrawn base, decorated with a smoothed-in design of oblique lines set between bundles of vertical lines on the belly. The ansa lunata handle springs from the rim to the shoulder. Joined from its fragments and restored. H. $20.3 \mathrm{~cm}$, dM. $11.3 \mathrm{~cm}, \mathrm{~dB} .9 \mathrm{~cm}$. Inv. no. 61.2.51.2 (Pl. LXXXVI. 203/2).

153 The two vessels described under nos 1-2 have since been lost or mislaid. Their description is quoted from the acquisitions register. Their drawing is based on József Korek's grave sheet. 
Grave 204 (Square G6; Pl. LXXXV)

Size of grave pit: L. $125 \mathrm{~cm}$, W. $112 \mathrm{~cm}$

Depth: $87 \mathrm{~cm}$

Orientation: S-SE to N-NW, with the head toward the S-SE

Position of skeleton: laid on the right side

L. of skeleton (contracted): $107 \mathrm{~cm}$

L. of skeleton (extended): $148 \mathrm{~cm}$

Age at death: $35-45$ years

Sex: female

Condition of skeleton: medium well preserved

Preserved skeletal bones: skull, long bones

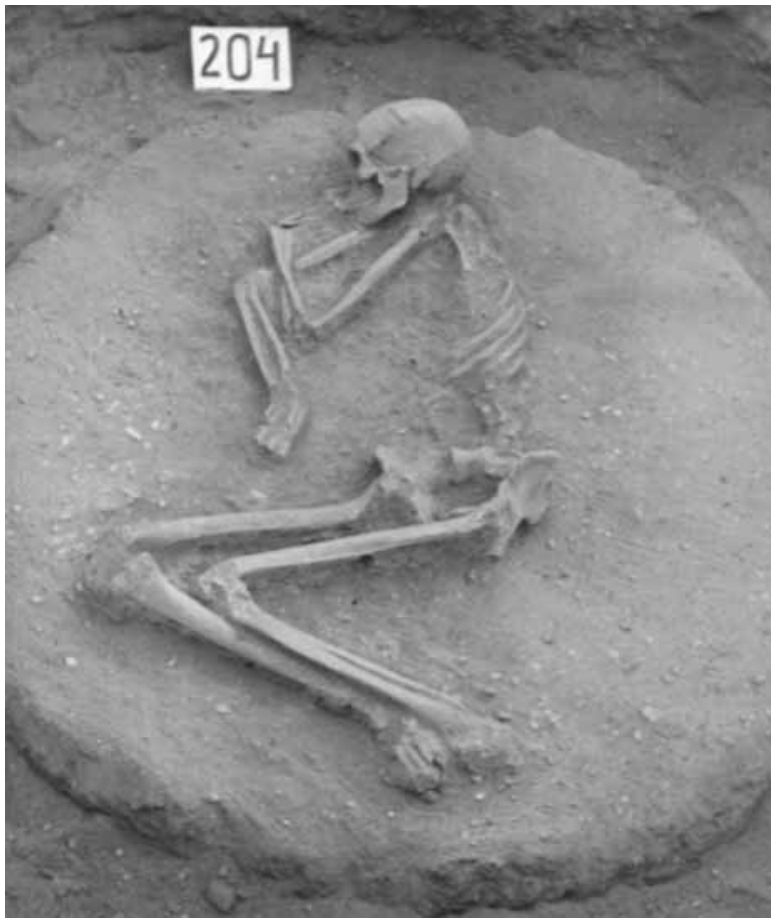

Inhumation burial in an oval grave pit. The body was laid on the right side in a contracted position. The skull lay on the right side. The left arm was bent at the elbow and drawn up, with the hand resting in front of the face. The left arm was turned outward at the elbow and extended toward the knee. The thighs were drawn up into a horizontal position, the legs were bent back toward the buttocks.

The burial did not contain any grave goods.

\section{Grave 205 (Square G4; Pl. LXXXV)}

Size of grave pit: L. $78 \mathrm{~cm}, W .56 \mathrm{~cm}$

Depth: $55 \mathrm{~cm}$

Orientation: -

Position of skeleton: -

L. of skeleton (contracted): -

L. of skeleton (extended): -

Age at death: -

Sex: -

Condition of skeleton: -

Preserved skeletal bones: -
Symbolic (?) burial in an oval grave pit. Two separate layers of stones were found between -15 and $-55 \mathrm{~cm}$. There were no skeletal remains or grave goods under the stones.

\section{Grave 206 (Square H3; Pl. LXXXV)}

Size of grave pit: -

Depth: $38 \mathrm{~cm}$

Orientation: with the head toward the SW (?)

Position of skeleton: laid on the left side

L. of skeleton (contracted): -

L. of skeleton (extended): -

Age at death: 1-7 years

Sex: child

Condition of skeleton: badly preserved

Preserved skeletal bones: skull fragments

Inhumation burial. There was no indication of a grave pit. A child's crushed skull lying on the left side was found at a depth of $-38 \mathrm{~cm}$. The cranium was oriented to the south-west. An animal burrow and a souslik den lay north-east of the skull. The skeletal remains were probably destroyed by this animal burrow.

The burial contained the following grave goods: seven rectangular shell plaques (1) by the occipital bone and in the animal den.

\section{Grave goods}

1. Shell plaques. Rectangular Unio crassus mussel plaques with a pair of perforations along the short sides. Four intact and three broken pieces. L. $1.7 \mathrm{~cm}$, W. $0.7 \mathrm{~cm}$. Inv. no. 61.2.52.154

\section{Grave 207 (Square G3/G4; Pl. LXXXVII)}

Size of grave pit: L. $122 \mathrm{~cm}, W .135 \mathrm{~cm}$

Depth: $85 \mathrm{~cm}$

Orientation: E-SE to W-NW, with the head toward the E-SE

Position of skeleton: laid on the left side

L. of skeleton (contracted): -

L. of skeleton (extended): -

Age at death: $30-40$ years

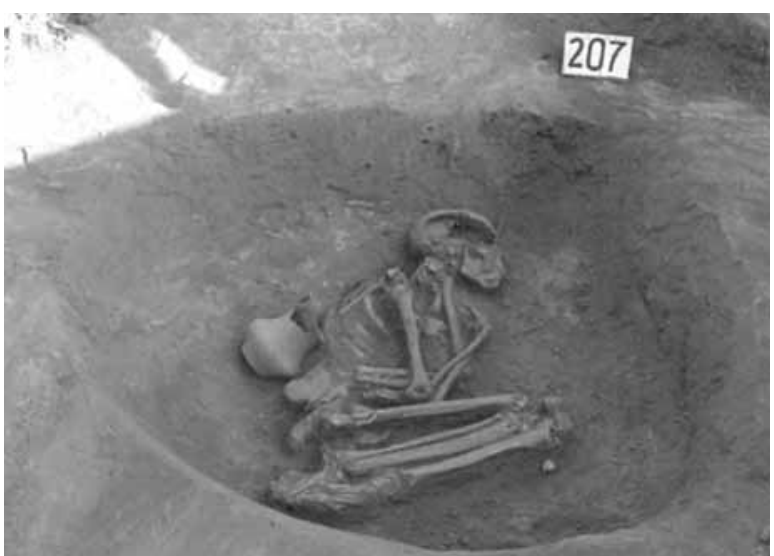

154 The shell plaques have since been lost or mislaid. Their description is quoted from the acquisitions register. 
Sex: male

Condition of skeleton: badly preserved

Preserved skeletal bones: skull, long bones

Inhumation burial in an oval grave pit. The skeleton was overlain by a $5-10 \mathrm{~cm}$ thick layer of earth, above which lay an 8-10 cm thick layer of reddish-black fine ash. The ash layer was only observed in the grave pit's southern half and thickened from the grave pit's centre toward its southern end. The ash layer did not contain any charcoal. The body was laid on the left side in a contracted position. The skull, destroyed by an animal burrow, lay on the left side. The right arm was bent at the elbow and drawn up, with the hand resting under the chin. The left arm was bent at the elbow and drawn up, with the forearm placed under the right arm and the hand turned toward the pelvis. The thighs were drawn up into a horizontal position, the legs were bent back toward the buttocks.

The burial contained the following grave goods: five stone implements (1-5) by the toes; a pitcher (6) tilted to one side with the mouth facing the body behind the waist; a broken shell bead (7) on the chest.

Grave goods

1. Hornstone end-scraper. Inv. no. 61.2.53.1 (Pl. LXXXVII. 207/1).

2. Unretouched radiolarite flake. Inv. no. 61.2.53.2 (Pl. LXXXVII. 207/2).

3. Jasper rectangle. Inv. no. 61.2.53.3 (Pl. LXXXVII. 207/3).

4. Unretouched radiolarite flake. Inv. no. 61.2.53.4 (Pl. LXXXVII. 207/4).

5. Hornstone debitage. Inv. no. 61.2.53.5 (Pl. LXXXVII. 207/5).

6. Pitcher. Grey, biconical pitcher with cylindrical neck, rounded carination and flat base. The vessel body has polished patches. The strap handle rising above the rim springs to the shoulder. The shoulder is decorated with delicate fluting, the belly with a design of vertical and horizontal fluting forming alternating fields. The handle is joined from smaller fragments, the rim is restored. H. $14.9 \mathrm{~cm}, \mathrm{dM} .9 .6 \mathrm{~cm}, \mathrm{~dB}$. 8.5 cm. Inv. no. 61.2.53.6 (Pl. LXXXVII. 207/6).

7. Bead. A broken sliced shell bead. L. $0.7 \mathrm{~cm}$. Inv. no. 61.2.53.7.155

\section{Grave 208 (Square H4; Pl. LXXXVIII)}

Size of grave pit: L. $98 \mathrm{~cm}, W .68 \mathrm{~cm}$

Depth: $91 \mathrm{~cm}$

Orientation: N-NW to S-SE, with the head toward the N-NW Position of skeleton: laid on the left side

L. of skeleton (contracted): $95 \mathrm{~cm}$

L. of skeleton (extended): $146 \mathrm{~cm}$

Age at death: 23-30 years

$\overline{155}$ The object has since been lost or mislaid. Its description is quoted from the acquisitions register.
Sex: female

Condition of skeleton: medium well preserved

Preserved skeletal bones: skull, long bones

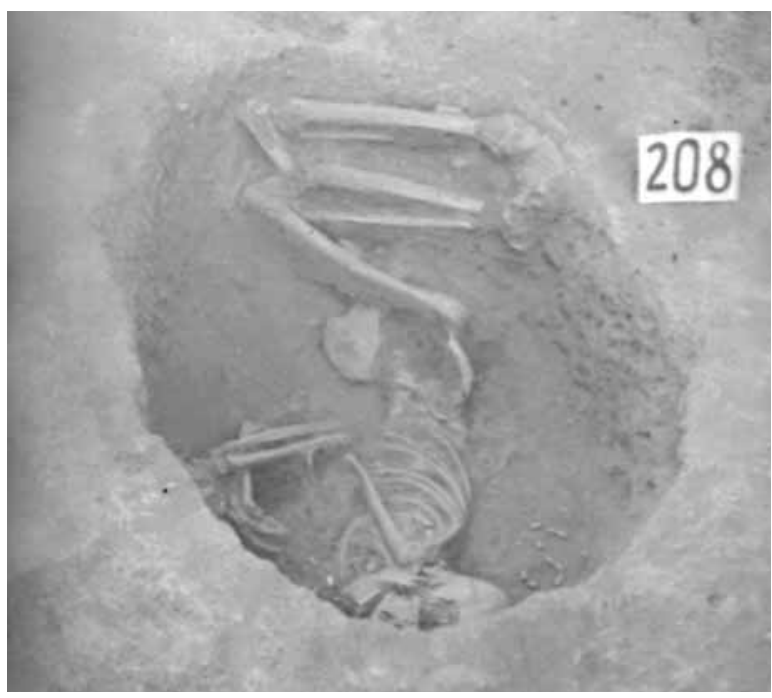

Inhumation burial in a narrow, oval grave pit containing stones between -20 and $-60 \mathrm{~cm}$. A one-handled mug (1) lay among the stones. The body was laid on the left side in a contracted position. The skull rested on the left side. The area of the right eye was disturbed by an animal burrow. The right arm was bent at the elbow and drawn up, with the hand placed by the edge of the grave pit, The left arm was bent at the elbow and drawn up, with the hand turned toward the chin. The thighs were moderately drawn up, the legs were bent back toward the buttocks. The feet were slightly raised and the right sole leaned against the wall of the grave pit.

The burial contained the following grave goods: eleven beads (2) behind the shoulder; forty-eight intact and twelve broken shell plaques (3) around the neck; calcinated bones (4) $10 \mathrm{~cm}$ above the right shoulder; two sliced Dentalium beads, a shell bead and a small white bead (5) on the neck; two boar tusk bracelets (6-7) under the left wrist.

\section{Grave goods}

1. One-handled mug. Greyish-brown mug with indrawn, rounded base. The strap handle springs from the rim to the belly. The handle is joined from its fragments. H. 7.8 cm, dM. 8 cm. Inv. no. 61.2 .54 .7 (Pl. LXXXVIII. 208/1). 156

2. Beads. Ten sliced shell beads and a sliced Dentalium bead. Inv. no. 61.2.54.1.

3. Shell plaques. Rectangular shell plaques with a pair of perforations along the short side. Most are broken. Fifty-one pieces. L. $2.3 \mathrm{~cm}$, W. $0.8 \mathrm{~cm}$. Inv. no. 61.2.54.2.

156 The objects described under nos 1-7 have since been lost or mislaid. Their description is quoted from the acquisitions register. Their drawing of the mug is based on József Korek's grave sheet. 
4. Calcinated bone fragments. Diam. $2.5 \mathrm{~cm}, 1.5 \mathrm{~cm}$. Two pieces. Inv. no. 61.2.54.3.

5. Beads. Two sliced shell beads, a sliced Dentalium bead and a sliced shell bead. Inv. no. 61.2.54.4.

6. Bracelet. Bracelet made from boar tusk, perforated at one end. Broken. L. 4.9 cm. Inv. no. 61.2.54.5.

7. Bracelet. Bracelet made from boar tusk, perforated at one end. L. $5.1 \mathrm{~cm}$. Broken. Inv. no. 61.2.54.6.

\section{Grave 209 (Square H5; Pl. LXXXVII)}

Size of grave pit: L. $108 \mathrm{~cm}, W .80 \mathrm{~cm}$

Depth: $98 \mathrm{~cm}$

Orientation: S-SE to N-NW, with the head toward the S-SE

Position of skeleton: laid on the left side

L. of skeleton (contracted): $82 \mathrm{~cm}$

L. of skeleton (extended): -

Age at death: $45-55$ years

Sex: female

Condition of skeleton: medium well preserved

Preserved skeletal bones: skull, long bones

Inhumation burial in an oval grave pit. The body was laid on the left side in a contracted position. The skull lay on the left side. The left arm was bent at the elbow and drawn up, with the hand resting in front of the face. The right arm was slightly bent at the elbow, with the hand turned toward the knee. The thighs were drawn up into a horizontal position, the legs were bent back toward the buttocks.

The burial contained the following grave goods: seven beads (1) around the neck.

Grave goods

1 Beads. Seven broken shell beads. Inv. no. 61.2.55.1.157

\section{Grave 210 (Square H9; Pls XC-XCI)}

\author{
Size of grave pit: L. $117 \mathrm{~cm}, W .103 \mathrm{~cm}$ \\ Depth: $52 \mathrm{~cm}$ \\ Orientation: S-SE to N-NW, with the head toward the S-SE \\ Position of skeleton: laid on the left side \\ L. of skeleton (contracted): $91 \mathrm{~cm}$ \\ L. of skeleton (extended): $147 \mathrm{~cm}$ \\ Age at death: $30-35$ years \\ Sex: female \\ Condition of skeleton: medium well preserved \\ Preserved skeletal bones: skull, long bones
}

Inhumation burial in an oblong grave pit with rounded corners. The body was laid on the left side in a contracted position. The skull lay on the left side. The trunk lay on the back from the pelvis upward. The arms were laid in the lap with the right hand clasping the left elbow and the left hand resting on the sacrum. The thighs were drawn up into a horizontal position, the legs were bent back toward the buttocks.

\footnotetext{
157 The object has since been lost or mislaid. Its description is quoted from the acquisitions register.
}

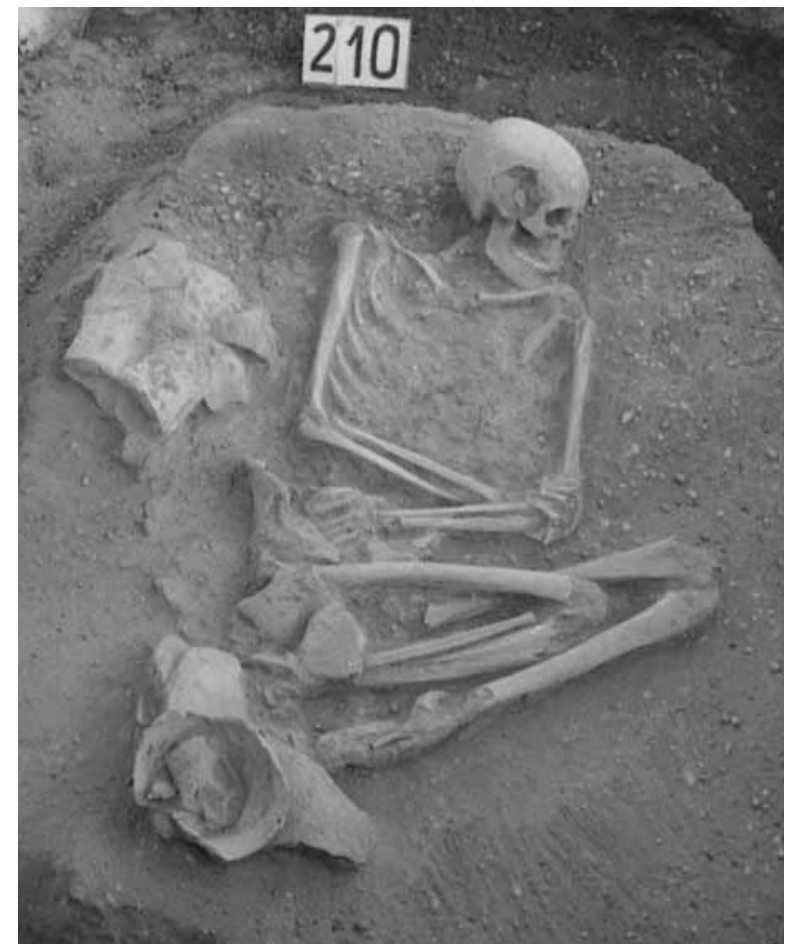

The burial contained the following grave goods: a crushed, one-handled jug (1) with its mouth toward the north by the right upper arm; a broken round bowl (2) by the feet; fragments of a thick-walled pot (3) under vessel 2 by the feet; fragments of various pots (4) by the feet.

\section{Grave goods}

1. Jug. Grey jug with cylindrical neck and flat base. The strap handle springs from the rim to the shoulder. Three small knobs are set on the carination. Joined from its fragments and restored. H. $17.8 \mathrm{~cm}$, dM. $9.3 \mathrm{~cm}, \mathrm{~dB} .4 .5 \mathrm{~cm}$. Inv. no. 61.2.56.1 (Pl. XC. 210/1). 158

2. Bowl. One-half of a greyish-brown, worn, conical bowl with funnel neck, decorated with two rows of impressed dots around the belly. A stringhole lug is set on the belly. Joined from its fragments; the rim is broken. H. $6.5 \mathrm{~cm}, \mathrm{dM} .15 .8 \mathrm{~cm}, \mathrm{~dB} .5 .5 \mathrm{~cm}$. Inv. no. 61.2.56.2 (Pl. XC. 210/2).

3. Pot. Body and base fragment of a thick-walled, slightly coarsened pot with reddish-brown exterior and grey interior. Joined from its fragments. $H .20 \mathrm{~cm}$. Inv. no. 61.2.56.3 (Pl. XCI. 210/3-210/4).

4. Pots. Rim, body and base fragments of slightly coarsened, thick-walled pots with reddish-brown exterior and grey interior. Eight non-joining pieces. Inv. no. 61.2.56.4 (Pl. XC. 210/4).159

\footnotetext{
158 The object has since been lost or mislaid. Its description is quoted from the acquisitions register. The drawing is based on József Korek's grave sheet.

159 Two rim fragments with pointed knobs and other rim fragment probably came from the pot inventoried under no. 61.2.56.3.
} 
Grave 211 (Square G9)

Size of grave pit: -

Depth: $15-20 \mathrm{~cm}$

Orientation: -

Position of skeleton: -

L. of skeleton (contracted): -

L. of skeleton (extended): -

Age at death: $23-x$ years

Sex: -

Condition of skeleton: -

Preserved skeletal bones: calcinated bones

Scattered cremation burial. There was no indication of a grave pit. Calcinated bone remains lay in area with a diameter of $15-20 \mathrm{~cm}$ at a depth of $-15-20 \mathrm{~cm}$.

The burial did not contain any grave goods.

\section{Grave 212 (Square H8; Pl. LXXXIX)}

Size of grave pit: -

Depth: $38 \mathrm{~cm}$

Orientation: SE to NW, with the head toward the SE

Position of skeleton: laid on the right side

L. of skeleton (contracted): $32 \mathrm{~cm}$

L. of skeleton (extended): -

Age at death: $0-1$ years

Sex: child

Condition of skeleton: badly preserved

Preserved skeletal bones: various fragments

Inhumation burial. There was no indication of a grave pit. A larger stone lay under three smaller ones on the body. The body was laid on the right side in a contracted position. The skull was almost destroyed. The right arm was bent at the elbow and drawn up, with the hand placed in front of the face. The left arm was bent at the elbow. The thighs were drawn up into a horizontal position, the legs were bent back toward the buttocks.

The burial did not contain any grave goods.

\section{Grave 213 (Square H9)}

Size of grave pit: -

Depth: $33 \mathrm{~cm}$

Orientation: with the face toward the $\mathrm{N}$

Position of skeleton: laid on the left side

L. of skeleton (contracted): -

L. of skeleton (extended): -

Age at death: 1-4 years

Sex: child

Condition of skeleton: badly preserved

Preserved skeletal bones: various fragments

Inhumation burial. There was no indication of a grave pit. A child's fragmentary skull was found at a depth of $-33 \mathrm{~cm}$, The skull lay on the left side with the cranium toward the west and the face toward the north. A few bone fragments lay east of the skull, but there were no other larger skeletal remains.

The burial did not contain any grave goods.
Grave 214 (Square G9; Pl. LXXXVII)

Size of grave pit: L. $94 \mathrm{~cm}, W .78 \mathrm{~cm}$

Depth: $50 \mathrm{~cm}$

Orientation: $\mathrm{S}$ to $\mathrm{N}$, with the head toward the $\mathrm{S}$

Position of skeleton: laid on the left side

L. of skeleton (contracted): $72 \mathrm{~cm}$

L. of skeleton (extended): -

Age at death: 3-4 years

Sex: child

Condition of skeleton: badly preserved

Preserved skeletal bones: skull, long bone fragments

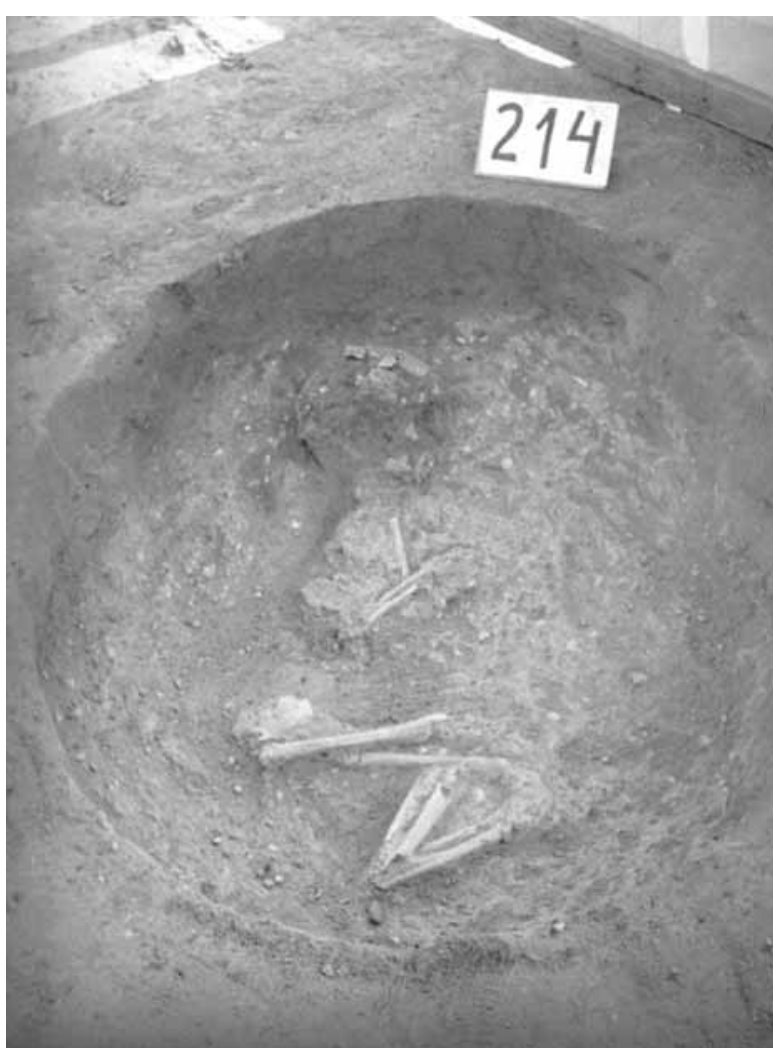

Inhumation burial in an oval grave pit containing stones between -15 and $-40 \mathrm{~cm}$. The body was laid on the left side in a contracted position. The skull lay on the left side. The right arm was bent at the elbow and drawn up, with the hand toward the chin. The position of the upper arm and the left forearm could not be recorded. The thighs were drawn up into a horizontal position, the legs were bent back toward the buttocks.

The burial did not contain any grave goods.

\section{Grave 215 (Square G9; Pl. LXXXVIII)}

Size of grave pit: L. $128 \mathrm{~cm}$, W. $100 \mathrm{~cm}$

Depth: $78 \mathrm{~cm}$

Orientation: A: S-SW to N-NE, with the head toward the S-SW, B: NE to SW (?), C: SW to NE, with the head toward the SW

Position of skeleton: A: laid on the right side, B: laid on the right side; C: laid on the left side

L. of skeleton (contracted): A: $97 \mathrm{~cm}, \mathrm{~B}:-, \mathrm{C}: 95 \mathrm{~cm}$

L. of skeleton (extended): A-B:,- C: $149 \mathrm{~cm}$ 
Age at death: A: $40-50$ years, B: $30-40$ years, C: $30-35$ years Sex: A: male (?), B: female (?), C: female

Condition of skeleton: A: badly preserved, B: badly preserved, C: medium well preserved

Preserved skeletal bones: A: various fragments, B: skull fragments, C: skull, long bone fragments

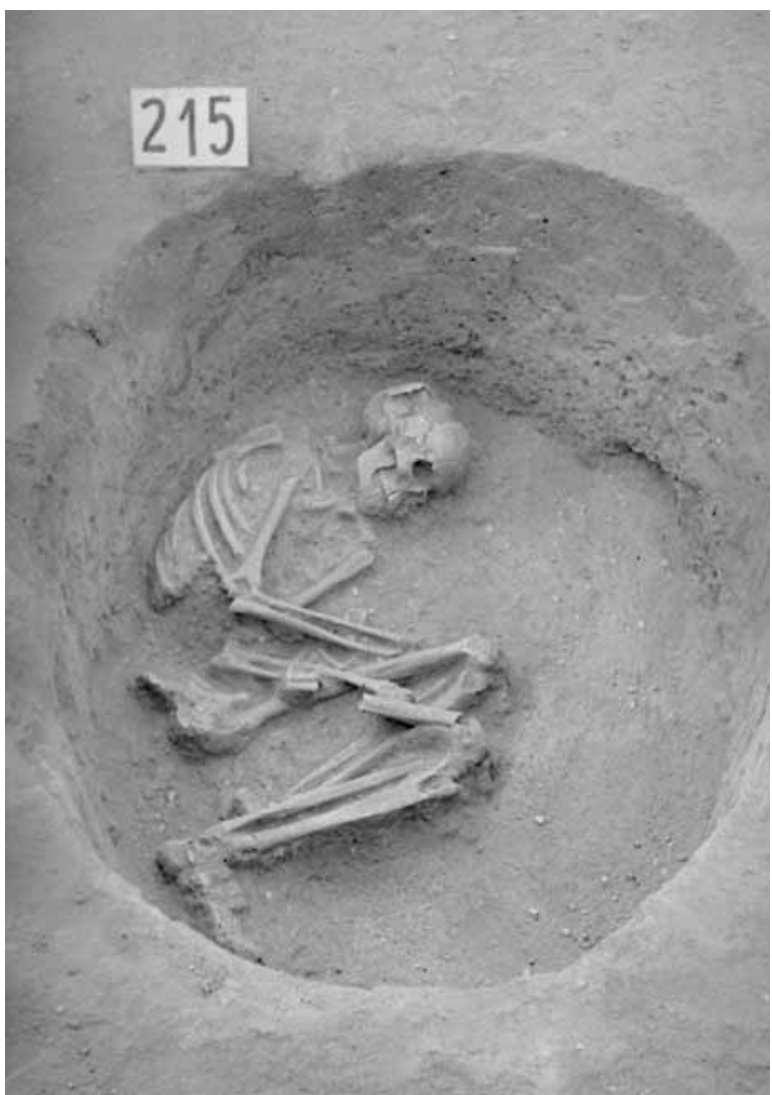

Triple inhumation burial in an oval grave pit containing stones, which lay on Burial A.

Burial A

The body was deposited at a depth of $-37 \mathrm{~cm}$. The body was laid on the right side in a contracted position. The left arm was bent at the elbow and drawn up, with the hand placed in front of the face. The left thigh was drawn up into a horizontal position, the right one to a lesser extent, the legs were bent back toward the buttocks. The skeletal remains were fragmented. The trunk perished.

The burial did not contain any grave goods.

\section{Burial B}

The body was deposited at a depth of $-50 \mathrm{~cm}$. The were stones under Burial A and this burial lay under the stones. The body was laid on the right side in a contracted position. The burial was disturbed during the deposition of the body in Burial A. The skull was crushed. The thighbone was dislodged. The exact position of the skeletal remains could not be established.

The burial contained the following finds: an indistinct pottery sherd (1) beside the skull.
Burial C

There were stones under Burial B; Burial C lay under the stones at a depth of $-78 \mathrm{~cm}$. The stones lay on the body. The skull was crushed by one of the stones lying on it. The body was laid on the left side in a contracted position. The skull lay on the left side. The right arm was bent at the elbow, with the wrist lying by the left knee and the hand bent backward. The left arm was bent at the elbow, with the wrist near the right knee and the hand bent backward. The right thigh was drawn up into a horizontal position, the left one slightly higher, the legs were bent back toward the buttocks. The right thigh and a part of the right forearm were destroyed by an animal burrow.

The burial did not contain any grave goods.

Burials A and B were secondary burials, Burial B was greatly disturbed when Burial A was deposited. The grave pit was not enlarged during the successive burials. The bodies were separated from each other by a stone packing.

Finds from the grave pit

1. Pot. Indistinct body sherd of a brownish-grey, thickwalled pot. L. $5.1 \mathrm{~cm}$. Inv. no. 61.2.57.1.

2. Bowl. Rim fragment of a greyish-brown, thin-walled, small bowl with funnel neck. L. $3.3 \mathrm{~cm}$. Inv. no. 61.2.57.2.160

Grave 216 (Square G8; Pl. XCII)

Size of grave pit: L. $140 \mathrm{~cm}, W .125 \mathrm{~cm}$

Depth: $66 \mathrm{~cm}$

Orientation: S-SE to N-NW, with the head toward the S-SE Position of skeleton: laid on the left side

L. of skeleton (contracted): $86 \mathrm{~cm}$

L. of skeleton (extended): $145 \mathrm{~cm}$

Age at death: $23-30$ years

Sex: female

Condition of skeleton: badly preserved

Preserved skeletal bones: skull, long bones

Inhumation burial in an oval grave pit. The body was laid on the left side in a contracted position. The skull lay on the occipital bone. The right arm was bent at the elbow and drawn up, with the hand placed by the left elbow. The left arm was extended beside the body, with the hand resting by the right knee. The thighs were drawn up into a horizontal position, the legs were bent back toward the buttocks. A healed break could be noted on the right forearm.

The burial contained the following grave goods: a ladle (1) $10 \mathrm{~cm}$ behind the trunk; another ladle (2) inside the previous vessel; three sliced Dentalium beads, eight stone beads, a broken copper bead and three tubular copper beads (3) between the right elbow and

${ }_{160}$ The excavation diary mentions a single vessel fragment. It is uncertain whether the other rim fragment was found during the clearing of the burial or whether the finds became mixed up at some later date. 


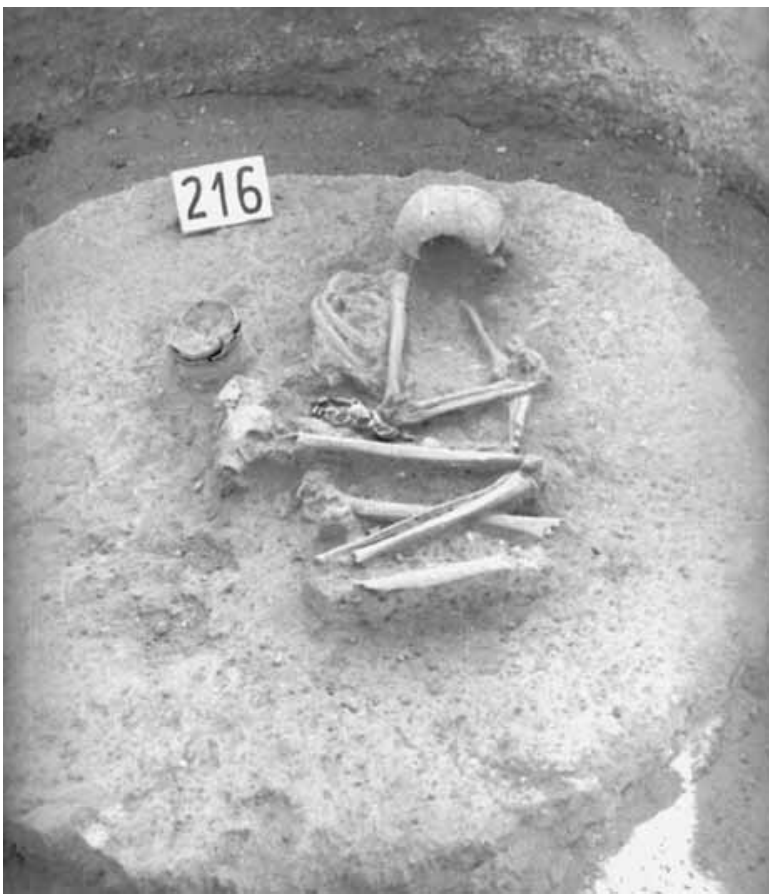

the left pelvic bone; four Dentalium beads and a broken copper bead (4) on the neck; a broken copper bead (5) under the right forearm.

\section{Grave goods}

1. Ladle. Ladle with grey exterior and light brown interior covered with red painting on both sides. The handle broke off, only its stub survived in the bowl's interior. Joined from its fragments; the handle is restored. H. $3.5 \mathrm{~cm}$, dM. $11 \mathrm{~cm}$. Inv. no. 61.2.58.1 (Pl. XCII. 216/1).

2. Ladle. Greyish-brown, worn ladle. Joined from several smaller fragments; the rim is damaged, the handle is restored. H. $3.5 \mathrm{~cm}, \mathrm{dM} .11 .3 \mathrm{~cm}$. Inv. no. 61.2.58.2 (Pl. XCII. 216/2).

3. Beads. Eight limestone beads of varying sizes, three Dentalium badense beads, one tubular copper bead (slipped inside one of the shell beads) and four fragmentary copper beads. Inv. no. 61.2.58.3 (Pl. XCII. 216/3). 161

4. Beads. Four sliced Dentalium badense beads, one with a tiny green copper oxide stain. Inv. no. 61.2.58.4 (Pl. XCII. 216/4).

5. Bead. Fragment of a tubular bead made from sheet copper. L. 2.4 cm. Inv. no. 61.2 .58 .5 (Pl. XCII. 216/5).

\section{Grave 217 (Square G7; Pl. LXXXIX)}

Size of grave pit: L. $125 \mathrm{~cm}$, W. $87 \mathrm{~cm}$ Depth: $106 \mathrm{~cm}$

Orientation: S-SW to N-NE, with the head toward the S-SW Position of skeleton: laid on the left side

161 The copper beads were very fragmented and their original number can no longer be determined.
L. of skeleton (contracted): $92 \mathrm{~cm}$

L. of skeleton (extended): $146 \mathrm{~cm}$

Age at death: 20-23 years

Sex: female

Condition of skeleton: medium well preserved

Preserved skeletal bones: skull, long bones

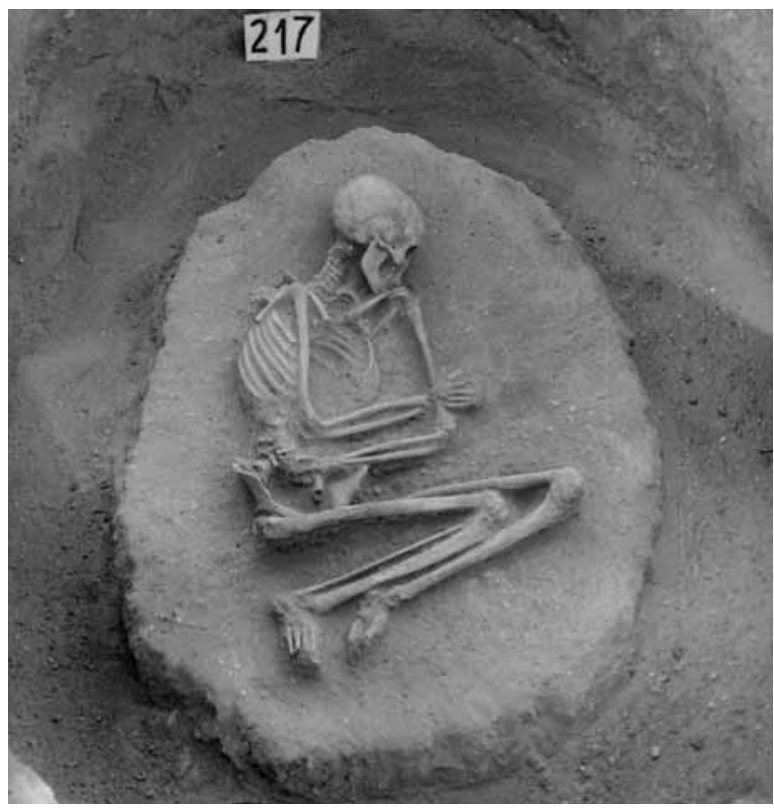

Inhumation burial in an oval grave pit. Two stones lay on the pelvis and the legs. The body was laid on the left side in a contracted position. The skull lay on the left side, tilted slightly forward. The arms were bent at the elbow and placed in the lap, with the left hand resting on the sacrum. The thighs were drawn up in front of the body, the legs were bent back toward the buttocks.

The burial did not contain any grave goods.

\section{Grave 218 (Square G8; Pl. LXXXIX)}

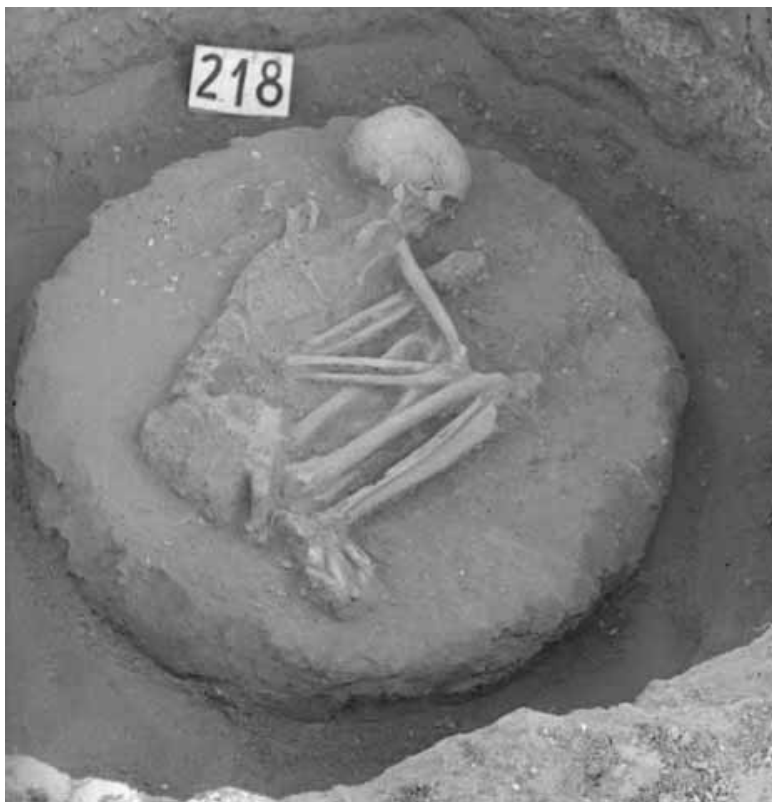


Size of grave pit: L. $98 \mathrm{~cm}, W .86 \mathrm{~cm}$

Depth: $82 \mathrm{~cm}$

Orientation: SE to NW, with the head toward the SE

Position of skeleton: laid on the left side

L. of skeleton (contracted): $85 \mathrm{~cm}$

L. of skeleton (extended): $144 \mathrm{~cm}$

Age at death: $50-59$ years

Sex: female

Condition of skeleton: badly preserved

Preserved skeletal bones: skull, long bones

Inhumation burial in a round grave pit. The body was laid on the left side in a contracted position. The skull lay on the left side, tilted slightly forward. The body was deposited almost prone from the pelvis upward. The left arm was bent at the elbow under the trunk, with the forearm under the right upper arm and the hand placed in front of the face. The right arm was bent at the elbow, with the elbow by the right knee and the hand by the hip. The thighs were drawn up in front of the body, the legs were bent back toward the buttocks.

The burial contained the following grave goods: a broken copper needle (1) on the neck.

\section{Grave goods}

1. Needle. Tip of a copper needle in a strongly crumbled state. L. 0.9 cm. Inv. no. 61.2.59.1 (Pl. LXXXIX. 218/1)

\section{Grave 219 (Square G8)}

Size of grave pit: -

Depth: $35 \mathrm{~cm}$

Orientation:-

Position of skeleton: -

L. of skeleton (contracted): -

L. of skeleton (extended): -

Age at death: $23-x$ years

Sex: -

Condition of skeleton: -

Preserved skeletal bones: calcinated bones

Scattered cremation burial. There was no indication of a grave pit. Calcinated bone remains were found over an area with a diameter of $30 \mathrm{~cm}$ at a depth of $-35 \mathrm{~cm}$.

The burial did not contain any grave goods.

\section{Grave 220 (Square G8; Pl. LXXXIX)}

\author{
Size of grave pit: - \\ Depth: $50 \mathrm{~cm}$ \\ Orientation: $\mathrm{S}$ to $\mathrm{N}$, with the head toward the $\mathrm{S}$ \\ Position of skeleton: laid on the right side \\ L. of skeleton (contracted): $95 \mathrm{~cm}$ \\ L. of skeleton (extended): - \\ Age at death: $23-\mathrm{x}$ years \\ Sex: male (?) \\ Condition of skeleton: badly preserved \\ Preserved skeletal bones: skull, long bone fragments
}

Inhumation burial. There was no indication of a grave pit. The body was laid on the right side in a contracted

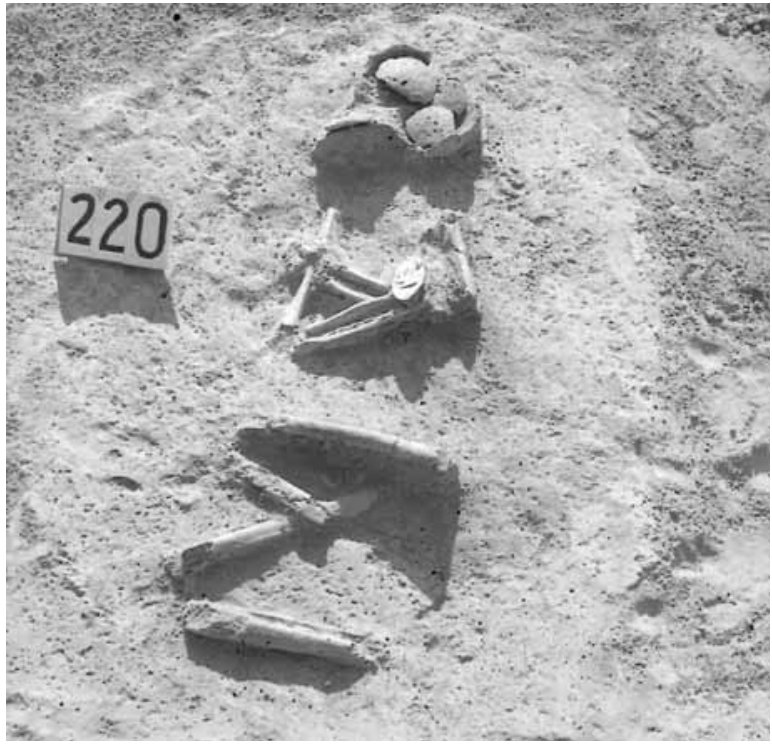

position. The crushed skull lay on the right side. The arms were crossed over the chest. The left thigh was drawn up into a horizontal position, the right one more moderately, the legs were bent back toward the buttocks. Only the skull and the long bones survived.

The burial contained the following grave goods: a large river mussel (1) on the left wrist.

\section{Grave goods}

1. Mussel. Large, broken Anodonta sp. mussel in a bad state of preservation. Diam. 3.7 cm. Inv. no. 61.2.60.1 (Pl. LXXXIX. 220/1).

\section{Grave 221 (Square G7; Pl. XCIII)}

Size of grave pit: L. $112 \mathrm{~cm}, W .80 \mathrm{~cm}$

Depth: $122 \mathrm{~cm}$

Orientation: S-SE to N-NW, with the head toward the S-SE

Position of skeleton: laid on the right side

L. of skeleton (contracted): $61 \mathrm{~cm}$

L. of skeleton (extended): -

Age at death: $2-2.5$ years

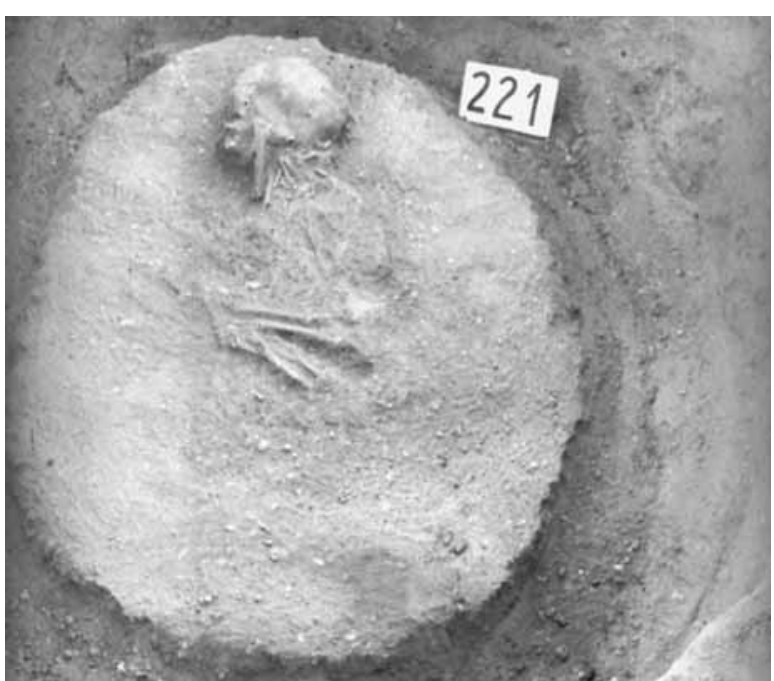


Sex: child

Condition of skeleton: badly preserved

Preserved skeletal bones: skull, long bone fragments

Inhumation burial in an oval grave pit. The body was laid on the right side in a contracted position. The crushed skull lay on the right side. The right arm was bent at the elbow and drawn up, with the hand placed in front of the face. The left arm was bent at the elbow and the hand was turned toward the knee. The thighs were drawn up in front of the body, the legs were bent back toward the buttocks.

The burial contained the following grave goods: a stone blade (1) by the left hand; a bone awl (2) on the mandible; a necklace of thirty-three Dentalium beads, two small red beads and ten copper beads (3) around the neck and on the chest; a stone chip (4) under the left elbow.

\section{Grave goods}

1. Unretouched blade fragment. Limnic quartzite. Inv. no. 61.2.61.1 (Pl. XCIII. 221/1).

2. Bone awl. Bone awl made from a sheep or goat metatarsal. Broken into seven fragments. L. $11 \mathrm{~cm}$. Inv. no. 61.2.61.2 (Pl. XCIII. 221/2).

3. Beads. Twenty-nine Dentalium badense beads of varying sizes and nine tubular copper beads. Inv. no. 61.2.61.3 (Pl. XCIII. 221/3). ${ }^{162}$

4. Debitage. Chert. Inv. no. 61.2.61.4 (Pl. XCIII. 221/4). ${ }^{163}$

\section{Grave 222 (Square G5; Pl. XCIV)}

Size of grave pit: -

Depth: $30 \mathrm{~cm}$

Orientation: -

Position of skeleton: -

L. of skeleton (contracted): -

L. of skeleton (extended): -

Age at death: $40-x$ years

Sex: female (?)

Condition of skeleton: -

Preserved skeletal bones: -

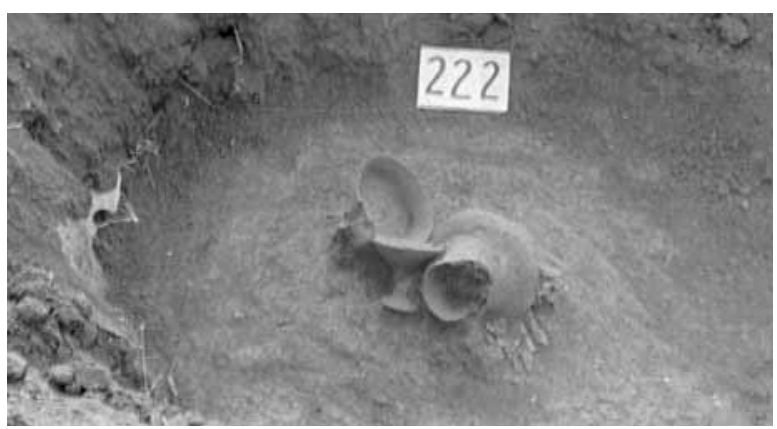

162 The fragments of six copper beads are all that remain. The number of shell beads is also lower than the one recorded in the excavation diary. A photo of the copper beads can be found in the metallurgical report in the Szentendre museum (SzFM Archives, inv. no. 1170/76, report prepared by Dr. Manfred Schröder).

163 A photo of this object was found among the photos made by József Korek in the Archives of the Szentendre museum.
Scattered cremation burial. There was no indication of a grave pit.

The burial contained the following grave goods scattered over an area with a diameter of $45 \mathrm{~cm}$ : a jug (1) tilted to one side; a scooping vessel (2) beside the previous vessel; a goblet (3) set upright between vessels 1 and 2; a small mug (4) inside vessel 1; calcinated bone remains under the vessels.

Grave goods

1. Jug. Greyish-brown jug with slightly everted rim, incurving neck and flat base. Joined from its fragments, the rim partially restored. H. $23 \mathrm{~cm}$, dM. 9 cm, dB. 9.5 cm. Inv. no. 61.2.62.1 (Pl. XCIV. 222/1). 164

2. Scooping vessel. Grey, worn, conical scooping vessel with funnel neck and high-flung strap handle. The belly is decorated with a row of impressed dots. The rim is damaged, the vessel body and the handle are joined from their fragments and restored. $H .6 \mathrm{~cm}$, dM. 15.7 cm, dB. 4.8 cm. Inv. no. 61.2.62.2 (Pl. XCIV. 222/2).

3. Goblet. Greyish-brown goblet with round upper part and round base, with a perforation on the foot above the base. Patches of red painting survive on the vessel exterior and interior. Joined from its fragments. H. $9.9 \mathrm{~cm}$, dM. $11.2 \mathrm{~cm}$, dB. $5.8 \mathrm{~cm}$. Inv. no. 61.2.62.3 (Pl. XCIV. 222/3).

4. Mug. Greyish mug with cylindrical neck and flattened globular body made from poorly levigated clay. The handle rises above the rim and springs to the belly. The handle is missing, the rim and the neck are broken, the body is cracked. Joined from its fragments and restored. H. $6.5 \mathrm{~cm}$. Inv. no. 61.2.62.4 (Pl. XCIV. 222/4).

Grave 223 (Square F6; Pl. XCI)

Size of grave pit: L. $83 \mathrm{~cm}, W .82 \mathrm{~cm}$ Depth: $73 \mathrm{~cm}$

Orientation: S-SW to N-NE, with the head toward the S-SW Position of skeleton: laid on the right side L. of skeleton (contracted): $56 \mathrm{~cm}$

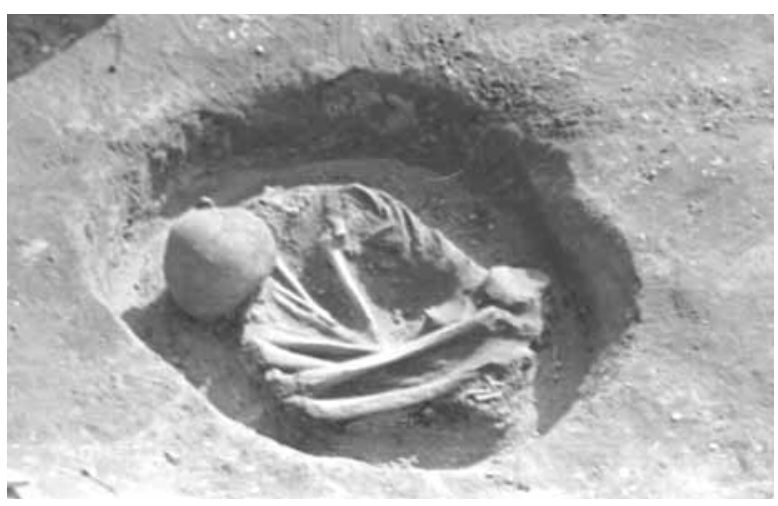

$\overline{164}$ The object has since been lost or mislaid. Its description is quoted from the acquisitions register. 
L. of skeleton (extended): $126 \mathrm{~cm}$

Age at death: -

Sex: female

Condition of skeleton: medium well preserved

Preserved skeletal bones: ${ }^{165}$ skull, long bones

Inhumation burial in a round, narrow grave pit containing stones between -35 and $-50 \mathrm{~cm}$ above the body. Fragments of a jug (1) lay among the stones. The body was laid on the right side in a contracted position with the face tilted forward and the nape on top. The arms were bent at the elbow and drawn up, with the hands resting in front of the face. The thighs were drawn up in front of the body, reaching almost to the shoulders, the legs were bent back toward the buttocks.

The burial did not contain any grave goods aside from the above vessel fragments.

Grave goods

1. Jug. Body and base fragments of a reddish-brown, thick-walled, flowerpot shaped jug. Eleven nonjoining pieces. Inv. no. 61.2 .63 (Pl. XCI. 223/1).

\section{Grave 224 (Square F7; Pl. XCIII)}

Size of grave pit: -

Depth: $27 \mathrm{~cm}$

Orientation: -

Position of skeleton: -

L. of skeleton (contracted): -

L. of skeleton (extended): -

Age at death: $23-x$ years

Sex: -

Condition of skeleton:-

Preserved skeletal bones: -

Scattered cremation burial. There was no indication of a grave pit. Calcinated bone remains were found over an area with a diameter of $25 \mathrm{~cm}$ at a depth of $-27 \mathrm{~cm}$. Fragments of a small mug (1) and of a thick-walled vessel (2) lay on the bone remains.

\section{Grave goods}

1. Mug. Fragments of a grey, thin-walled mug. The narrow strap handle rises above the rim and springs to the belly. Joined from its fragments. Eight pieces. Inv. no. 61.2.64.1 (Pl. XCIII. 224/1).

2. Pot. Body and base fragments of a pot with reddishbrown exterior and grey interior. L. $7 \mathrm{~cm}$. Inv. no. 61.2.64.2 (Pl. XCIII. 224/2).

\section{Grave 225 (Square F4/F5; Pl. XCIII)}

Size of grave pit: -

Depth: $52 \mathrm{~cm}$

Orientation: S-SW to N-NE, with the head toward the S-SW

Position of skeleton: laid on the right side

\footnotetext{
165 The skeletal remains can no longer be found. The anthropological data are quoted from the excavation diary.
}

L. of skeleton (contracted): $46 \mathrm{~cm}$

L. of skeleton (extended):-

Age at death: 3-4 years

Sex: child

Condition of skeleton: badly preserved

Preserved skeletal bones: skull and long bone fragments

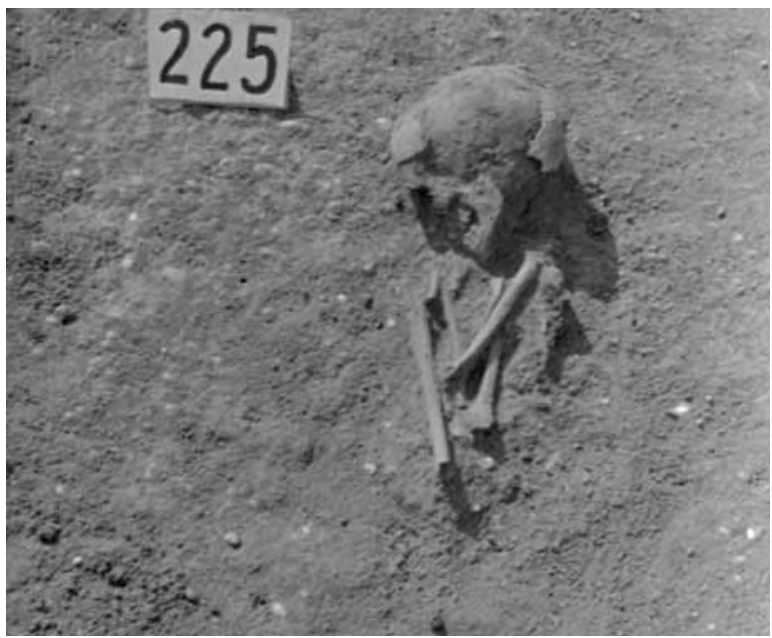

Inhumation burial. There was no indication of a grave pit. The body was laid on the right side in a strongly contracted position. The crushed skull lay on the right side. The arms were bent at the elbow and drawn up, with the hands resting in front of the face. The left thigh was drawn up almost to the chin. The legs were destroyed by an animal burrow.

The burial did not contain any grave goods.

\section{Grave 226 (Square F4; Pl. XCVIII)}

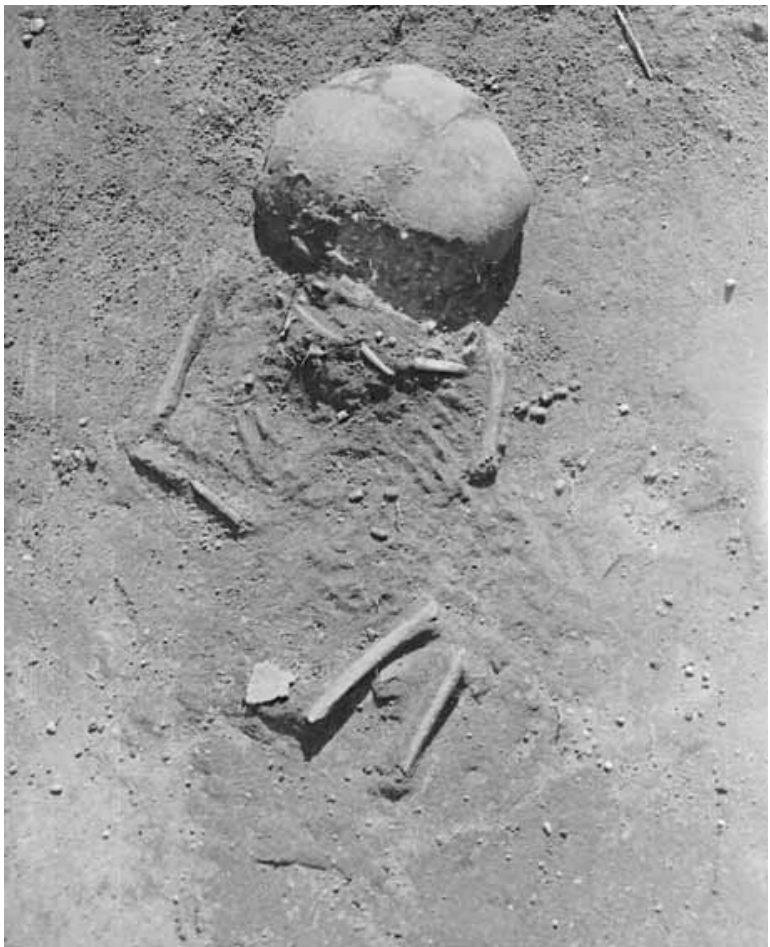


Size of grave pit: L. $118 \mathrm{~cm}, W .99 \mathrm{~cm}$

Depth: $72 \mathrm{~cm}$

Orientation: W-SW to E-NE, with the head toward the W-SW

Position of skeleton: laid on the left side

L. of skeleton (contracted): $51 \mathrm{~cm}$

L. of skeleton (extended): $c a .75 \mathrm{~cm}$

Age at death: $2.5-3$ years

Sex: child

Condition of skeleton: badly preserved

Preserved skeletal bones: skull and long bone fragments

Inhumation burial in an oval grave pit. The body was laid on the left side in a contracted position. The skull lay on the left side. The facial bones were destroyed by an animal burrow. The right arm was bent at the elbow. The position of the left forearm could not be recorded. The right thigh was drawn up in front of the body, the leg was bent back toward the buttocks.

The burial contained the following grave goods: a necklace of Dentalium, clay and assorted other beads, as well as a fragmentary copper bead (1) on the neck and the chest.

Grave goods

1. Beads. Eight Dentalium badense beads, eight clay beads, eight limestone beads, and one fragmentary copper bead. One of the clay beads was slipped inside one of the Dentalium beads. Inv. no. 61.2.65 (Pl. XCVIII. 226/1). ${ }^{166}$

\section{Grave 227 (Square F4; Pls XCV-XCVII)}

Size of grave pit: L. $110 \mathrm{~cm}, W .100 \mathrm{~cm}$

Depth: $80 \mathrm{~cm}$

Orientation: S-SW to N-NE, with the head toward the S-SW

Position of skeleton: laid on the right side

L. of skeleton (contracted): $90 \mathrm{~cm}$

L. of skeleton (extended): $170 \mathrm{~cm}$

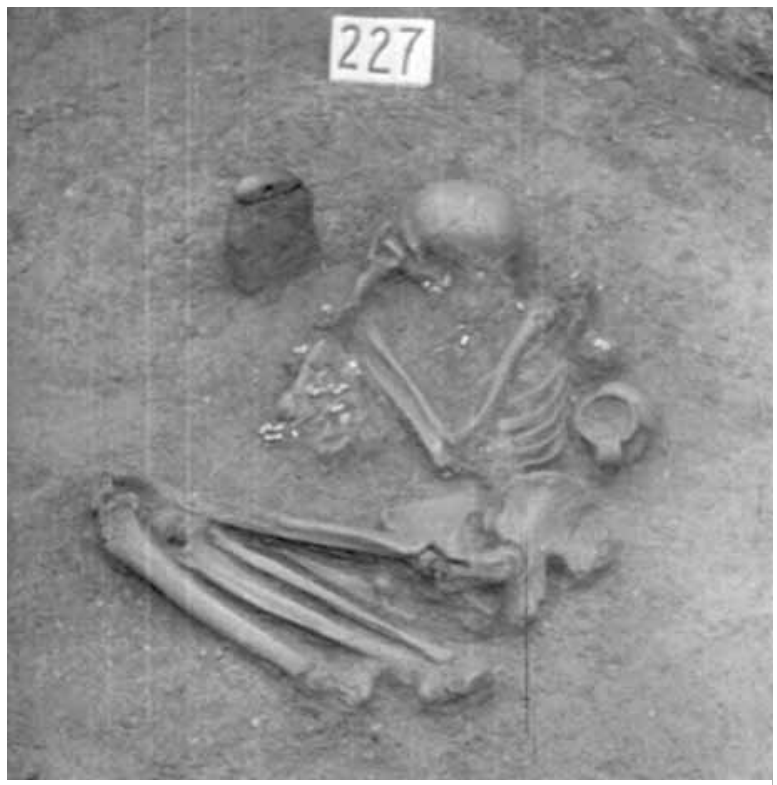

166 The number of beads is lower by one than at the time when they were inventoried.
Age at death: $35-45$ years

Sex: male

Condition of skeleton: medium well preserved

Preserved skeletal bones: skull, long bones, pelvis

Inhumation burial in an almost round grave pit. The body was laid on the right side in a contracted position. The skull lay on the occipital bone with the face toward the south. The right arm was bent at the elbow and drawn up, the left arm was bent at the elbow and the hand placed under the armpit. The thighs were drawn up into a horizontal position, the legs were bent back toward the buttocks. Samples were taken from the patch of burnt earth behind the buttocks.

The burial contained the following grave goods: a bowl (1), pot fragments (2), a ladle (3), a dipper (4), a pitcher (5), indistinct pottery sherds (6-12), burnt animal bones (13) all lying in a heap at a depth of $-60-65 \mathrm{~cm}$ above the body; a mug (14) set upright by the spine; a ladle (15); five stone blades (16-20) $8 \mathrm{~cm}$ from the previous vessels and $10 \mathrm{~cm}$ higher than their bases; a Dentalium shell (21) by the left shoulder; a bracelet of eighteen shell plaques (22) around the middle of the upper arm; seventy-nine beads and eight shells (23) around the right wrist; a copper chisel (24), also by the right wrist; a necklace of Dentalium, red clay and stone beads and six fragmentary tubular copper beads (25) around the mandible and the neck (copper and Dentalium shell beads lay under the mandible, shell beads and the red beads around the neck); a shaft-hole stone axe (26) with the cutting edge pointing toward the head, $15 \mathrm{~cm}$ south of the right upper arm.

\section{Grave goods}

1. Bowl. Reddish-brown bowl with indrawn rim, decorated with a row of punctates encircling the rim and the shoulder. A vertical stringhole lug is set on the shoulder. Two bundles of smoothed-in vertical lines run from the punctates under the rim to the base on the opposite sides of the vessel and two bundles of lines flank the stringhole lug. Joined from its fragments and restored. H. $13.5 \mathrm{~cm}, \mathrm{dM} .24 \mathrm{~cm}$, dB. 8.6 cm. Inv. no. 61.2.66.1 (Pl. XCVI. 227/1).

2. Pot. Body and base fragment of a reddish-brown, thick-walled pot. H. $8 \mathrm{~cm}$. Inv. no. 61.2.66.2 (Pl. $X C V .227 / 2)$.

3. Ladle (?). Fragment of a reddish-brown, worn ladle. H. $3.4 \mathrm{~cm}$, dM. 8.9 cm. Inv. no. 61.2.66.3 (Pl. XCVI. 227/3).

4. Dipper. Greyish, conical dipper decorated with a wavy row of punctates. The high-flung strap handle is missing. Cracked, joined from its fragments and restored. H. $7.5 \mathrm{~cm}, \mathrm{dM} .6 .2 \mathrm{~cm}$, dB. $3.1 \mathrm{~cm}$. Inv. no. 61.2.66.4 (Pl. XCVI. 227/4).

5. Pitcher. Reddish-brown, worn, one-handled pitcher with cylindrical neck, flattened globular body and flat base. The fluted handle rises above the rim and springs to the shoulder. A row of punctates encircles the shoulder and five ribs with oblique grooving are 
set on the belly. The areas between the ribs are filled with vertical fluting. The rim is damaged. Joined from its fragments and partially restored. $H .11 .6 \mathrm{~cm}$, dM. 8.3 cm. Inv. no. 61.2.66.5 (Pl. XCVI. 227/5).

6. Pitcher. Handle fragment of a light brown pitcher. L. $4.8 \mathrm{~cm}$. Inv. no. 61.2.66.6 (Pl. XCVI. 227/6, 9). ${ }^{167}$

7. Bowl. Rim fragment of a brownish, thin-walled bowl with peaked rim. $5.2 \times 4.6 \mathrm{~cm}$ Inv. no. 61.2.66.7 (Pl. XCVII. 227/7).

8. Bowl. Body and base fragment of a greyish bowl. Joined from its fragments. L. $6 \mathrm{~cm}$. Inv. no. 61.2.66.8 (Pl. XCVI. 227/8).

9. Pitcher. Handle fragment of a light brown pitcher. L. 5 cm. Inv. no. 61.2.66.9 (Pl. XCVI. 227/6, 9).168

10. Pitcher. Handle fragment of a brownish pitcher. L. $4.6 \mathrm{~cm}$. Inv. no. 61.2.66.10.

11. Pitcher. Rim and neck fragment of a grey, thinwalled pitcher. Joined from smaller fragments. L. $4.3 \mathrm{~cm}$. Inv. no. 61.2.66.11.

12. Pot. Body sherd of a pot with light brown exterior and greyish-brown interior. L. $8.2 \mathrm{~cm}$. Inv. no. 61.2.66.12.

13. Animal bones. Burnt tibia fragments of a large ungulate. Four pieces. Inv. no. 61.2.66.13 (Pl. XCV. 227/13).

14. Mug. Greyish-brown, worn, one-handled mug with cylindrical neck, flattened globular body and flat base. The fluted handle rises above the rim and springs to the shoulder. A row of punctates encircles the shoulder and five narrow ribs ornamented with impressed dots are set on the belly. The areas between the ribs are filled with vertical fluting. The rim is damaged. Joined from its fragments and partially restored. H. $8.5 \mathrm{~cm}$, dM. 8 cm. Inv. no. 61.2.66.14 (Pl. XCVII. 227/14).

15. Ladle. Reddish-brown ladle with notched rim decorated with zig-zag lines on the handle. Patches of red painting can be made out in its interior. Joined from its fragments, the ladle is restored. H. $4 \mathrm{~cm}$, dM. $8.9 \mathrm{~cm}$. Inv. no. 61.2.66.15 (Pl. XCV. 227/15).

16. Chert blade fragment. L. $1.6 \mathrm{~cm}, W .1 .4 \mathrm{~cm}$. Inv. no. 61.2.66.16. ${ }^{169}$

17. Limnic quartzite trapeze. Inv. no. 61.2.66.17 (Pl. XCV. 227/17).

18. Limnic quartzite trapeze. Inv. no. 61.2.66.18.

19. Unretouched chert flake. Inv. no. 61.2.66.19.

20. Chert blade fragment. Inv. no. 61.2.66.20 (Pl. XCV. 227/20). ${ }^{170}$

21. Bead. A Dentalium badense bead. L. $2.9 \mathrm{~cm}$. Inv. no. 61.2.66.21 (Pl. XCV. 227/21).

22. Shell plaques. Rectangular Unio crassus mussel plaques with a pair of perforations on the short

\footnotetext{
167 Joined with the fragment inventoried under no. 61.2.66.9. 168 Joined with the fragment inventoried under no. 61.2.66.6.

169 The object has since been lost or mislaid. Its description is quoted from the acquisitions register.

170 The object has since been lost or mislaid. Its description is quoted from the acquisitions register.
}

sides. One intact and seventeen broken pieces. Inv. no. 61.2.66.22 (Pl. XCV. 227/22). ${ }^{171}$

23. Beads. Seven intact and one broken perforated Anadara diluvii shells (Pl. XCVII. 227/23a), and seventy-nine limestone beads of varying sizes $(\mathrm{Pl}$. XCVII. 227/23b). Inv. no. 61.2.66.23.

24. Copper chisel with rectangular section. The cutting edge is hammered flat. The end fitted into the shaft tapers. L. $5 \mathrm{~cm}$. Inv. no. 61.2.66.24 (Pl. CCVII. 227/24). ${ }^{172}$

25. Beads. Thirty-two Dentalium badense beads, ten red clay beads, two smaller and forty-one larger limestone beads (Pl. XCV.227/25a), and a broken tubular copper bead (Pl. XCV.227/25b). Inv. no. 61.2.66.25. ${ }^{173}$

26. Stone axe. Boat shaped shaft-hole axe polished to a bright lustre made from basalt (?). L. $10.5 \mathrm{~cm}$, W. $4.2 \mathrm{~cm}$, Th. $3.3 \mathrm{~cm}$. Inv. no. 61.2.66.26 (Pl. XCVII. 227/26).

\section{Grave 228 (Square F4; Pl. XCVIII)}

Size of grave pit: -

Depth: $48 \mathrm{~cm}$

Orientation: N-NW to S-SE, with the head toward the N-NW Position of skeleton: laid on the left side

L. of skeleton (contracted): $52 \mathrm{~cm}$

L. of skeleton (extended): -

Age at death: infans

Sex: child

Condition of skeleton: badly preserved

Preserved skeletal bones: ${ }^{174}$ skull, long bone fragments

Inhumation burial. There was no indication of a grave pit. The body was laid on the left side in a contracted position. The skull was crushed. The left arm was bent at the elbow and drawn up, with the hand resting in front of the face. The right arm was bent at the elbow, with the hand placed by the left elbow. The thighs were drawn up in front of the body, the legs were bent back toward the buttocks.

The burial did not contain any grave goods.

\section{Grave 229 (Square F4; Pl. XCVIII)}

Size of grave pit: L. $98 \mathrm{~cm}, W .91 \mathrm{~cm}$

Depth: $78 \mathrm{~cm}$

Orientation: S-SW to N-NE, with the head toward the S-SW

Position of skeleton: laid on the left side

L. of skeleton (contracted): $70 \mathrm{~cm}$

L. of skeleton (extended): $c a .85 \mathrm{~cm}$

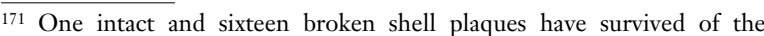
original eighteen.

172 The object has since been lost or mislaid. Its description is quoted from the acquisitions register. The drawing is based on József Korek's grave sheet, the photo on the metallurgical report in the Szentendre museum (SzFM Archives, inv. no. 1170/76, report prepared by Dr. Manfred Schröder).

173 The number of surviving beads is lower than the number inventoried, and nothing remains of the copper beads, whose photo was taken from the metallurgical report in the Szentendre museum (SzFM Archives, inv. no. 1170/76, report prepared by Dr. Manfred Schröder).

174 The skeletal remains can no longer be found. The anthropological data are quoted from the excavation diary. 
Age at death: 3-4 years

Sex: child

Condition of skeleton: badly preserved

Preserved skeletal bones: skull, long bone fragments

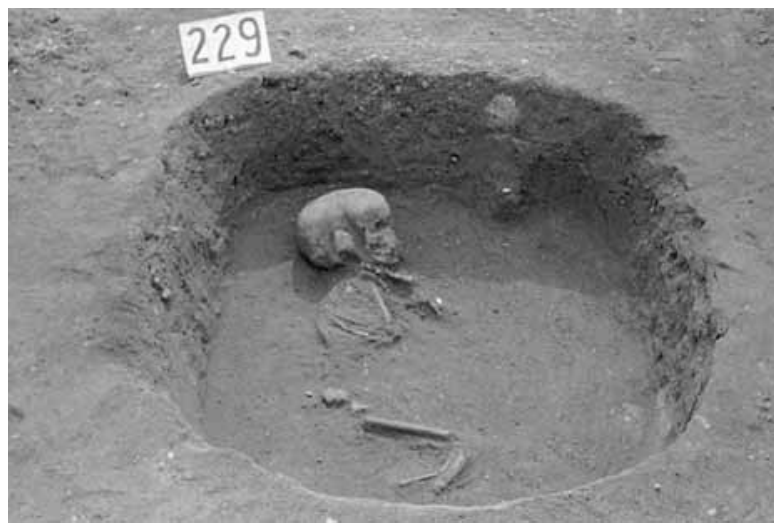

Inhumation burial in an oblong grave pit with rounded corners containing stones between -25 and $-45 \mathrm{~cm}$. The body was laid on the left side in a contracted position. The crushed skull lay on the left side. The position of the right forearm could not be recorded. The left arm was bent at the elbow and drawn up, with the hand placed in front of the chin. The thighs were drawn up into an almost horizontal position, the legs were slightly bent back toward the buttocks.

The burial contained the following grave goods: a necklace of shell and clay beads and five broken tubular copper beads (two clay beads were slipped inside a copper bead) (1) around the neck.

\section{Grave goods}

1. Beads. One Dentalium badense bead, five red clay beads, one animal canine (Pl. XCVIII. 229/1a), three intact and two fragmentary tubular copper beads (Pl. XCVIII. 229/1b). Inv. no. 61.2.67.175

\section{Grave 230 (Square G8; Pl. XCVIII)}

Size of grave pit: -

Depth: $56 \mathrm{~cm}$

Orientation: S-SW to N-NE, with the head toward the S-SW

Position of skeleton: laid on the right side

L. of skeleton (contracted): -

L. of skeleton (extended): $156 \mathrm{~cm}$

Age at death: $40-x$ years

Sex: male

Condition of skeleton: badly preserved

Preserved skeletal bones: skull, long bones

Inhumation burial. There was no indication of a grave pit. The body was laid on the right side in an extended position. The skull lay on the right side. The right arm

175 The number of beads mentioned in the excavation diary (twenty-three beads and five copper beads) and the number of beads listed in the acquisitions register (twelve beads and five copper beads) differs. The number of currently existing beads is lower than the number specified in the acquisitions register.

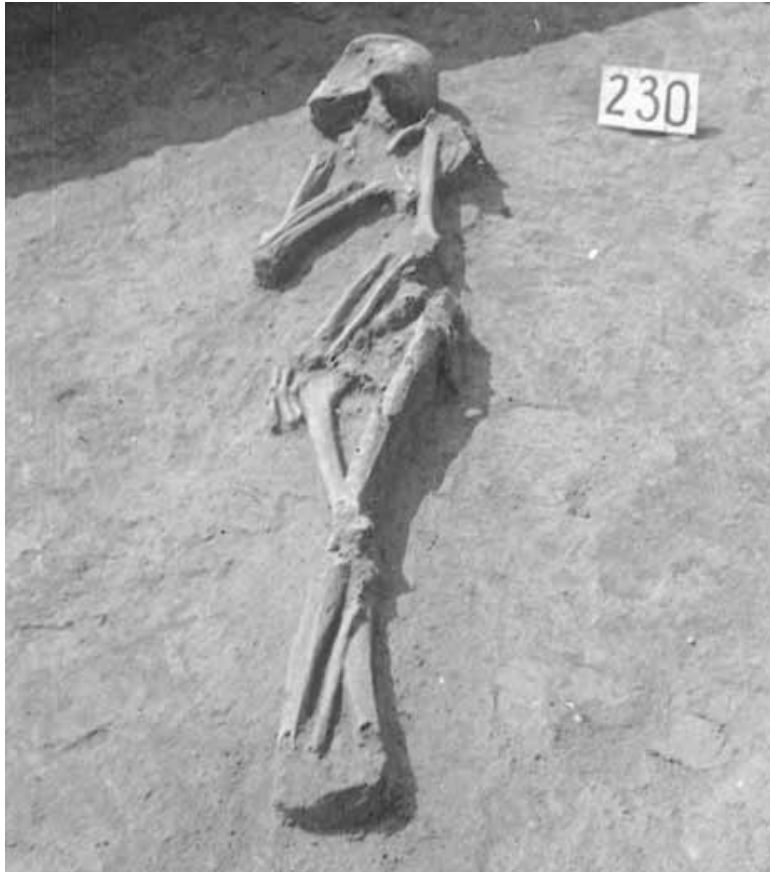

was bent at the elbow and drawn up, with the hand placed by the middle of the left upper arm. The left arm lay extended beside the body, with the hand resting by the upper end of the right thighbone. The legs were extended and crossed. The feet perished.

The burial contained the following grave goods: a stone blade (1) by the left forearm.

Grave goods

1. Retouched radiolarite blade fragment. Inv. no. 61.2.68 (Pl. XCVIII. 230/1).

Grave 231 (Square G8; Pl. XCVIII)

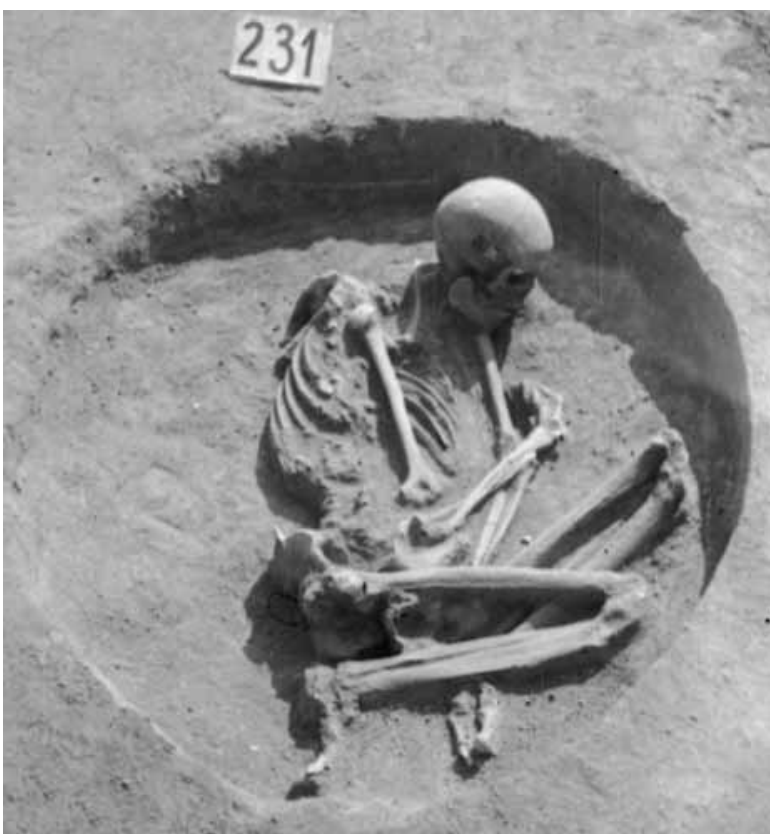


Size of grave pit: L. $112 \mathrm{~cm}$, W. $98 \mathrm{~cm}$

Depth: $61 \mathrm{~cm}$

Orientation: $\mathrm{S}$ to $\mathrm{N}$, with the head toward the $\mathrm{S}$

Position of skeleton: laid on the left side

L. of skeleton (contracted): $99 \mathrm{~cm}$

L. of skeleton (extended): $162 \mathrm{~cm}$

Age at death: $50-x$ years

Sex: male

Condition of skeleton: medium well preserved

Preserved skeletal bones: skull, long bones

Inhumation burial in an oval grave pit. The body was laid on the left side in a contracted position. The skull virtually lay on the occipital bone and was tilted slightly forward. The right arm was bent at the elbow and drawn up, with the forearm resting on the left elbow and the hand by the left upper arm, The left arm was slightly bent at the elbow, with the hand placed between the thighs. The thighs were drawn up in front of the body, the left one more so than the right one, the legs were bent back toward the buttocks.

The burial did not contain any grave goods.

\section{Grave 232 (Square G9; Pl. XCIX)}

Size of grave pit: -

Depth: $35 \mathrm{~cm}$

Orientation: S-SW to N-NE, with the head toward the S-SW Position of skeleton: laid on the right side

L. of skeleton (contracted): $51 \mathrm{~cm}$

L. of skeleton (extended): -

Age at death: $1-7$ years

Sex: child

Condition of skeleton: badly preserved

Preserved skeletal bones: various fragments

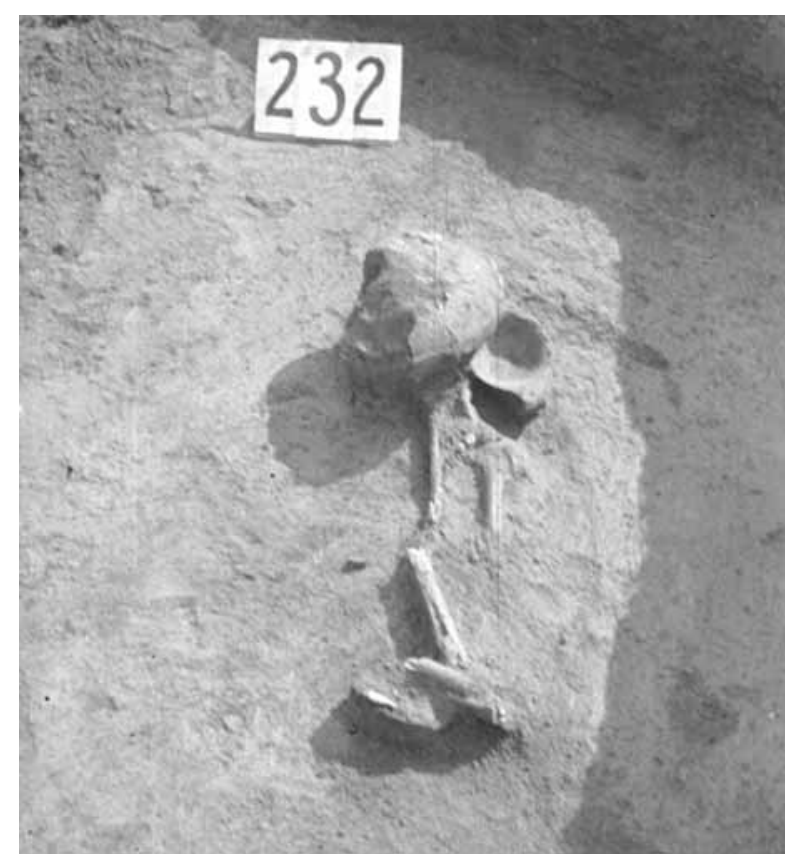

Inhumation burial. There was no indication of a grave pit. The body was laid on the right side in a contracted position. The crushed skull lay on the right side. The right thigh was drawn up in front of the body, the legs were bent back toward the buttocks.

The burial contained the following grave goods: a small scooping vessel (1) set upright under the nape.

Grave goods

1. Scooping vessel. Grey, worn, flat, plain scooping vessel. The short strap handle springs from the rim to the base. The rim is damaged. H. $4.4 \mathrm{~cm}, \mathrm{dM} .8 .7 \mathrm{~cm}$, dB. 3.8 cm. Inv. no. 61.2.69 (Pl. XCIX. 232/1).

\section{Grave 233 (Square F6)}

Size of grave pit: -

Depth: $52 \mathrm{~cm}$

Orientation: -

Position of skeleton: -

L. of skeleton (contracted): -

L. of skeleton (extended): -

Age at death: $15-39$ years

Sex: -

Condition of skeleton:-

Preserved skeletal bones: various fragments

Scattered cremation burial. Calcinated bone fragments lay over an area with a diameter of $38 \mathrm{~cm}$.

The burial did not contain any grave goods.

\section{Grave 234 (Square F6)}

Size of grave pit: -

Depth: $35 \mathrm{~cm}$

Orientation: -

Position of skeleton: -

L. of skeleton (contracted): -

L. of skeleton (extended): -

Age at death: $18-23$ years

Sex: -

Condition of skeleton: -

Preserved skeletal bones: various fragments

Scattered cremation burial. A few calcinated bone fragments lay over an area with a diameter of $15 \mathrm{~cm}$.

The burial did not contain any grave goods.

Grave 235 (Square F6; Pl. XCIX)

An Early Bronze Age burial.

Grave 236 (Square F6)

Size of grave pit: -

Depth: $62 \mathrm{~cm}$

Orientation: -

Position of skeleton:-

L. of skeleton (contracted): -

L. of skeleton (extended): -

Age at death: -

Sex: - 
Condition of skeleton: -

Preserved skeletal bones: ${ }^{176}$ various fragments

Scattered cremation burial. Calcinated bone fragments lay over an area with a diameter of $35 \mathrm{~cm}$.

The burial did not contain any grave goods.

\section{Grave 237 (Square F4; Pl. XCIX)}

Size of grave pit: L. $110 \mathrm{~cm}, W .95 \mathrm{~cm}$

Depth: $70 \mathrm{~cm}$

Orientation: S-SW to N-NE, with the head toward the S-SW

Position of skeleton: laid on the left side

L. of skeleton (contracted): $65 \mathrm{~cm}$

L. of skeleton (extended): -

Age at death: 6- 8 years

Sex: child

Condition of skeleton: badly preserved

Preserved skeletal bones: skull, long bone fragments

Inhumation burial. The body was laid on the left side in a contracted position. The crushed skull lay on the left side. The position of the arms could not be recorded. The right thigh was drawn up into a horizontal position, the left one slightly higher, the legs were bent back toward the buttocks.

The burial contained the following grave goods: eight beads (1) around the neck.

Grave goods

1. Beads. Eight small limestone beads. Inv. no. 61.2.71

(Pl. XCIX. 237/1).177

\section{Grave 238 (Square F5; Pl. C)}

Size of grave pit: L. $30 \mathrm{~cm}, W .30 \mathrm{~cm}$

Depth: $58 \mathrm{~cm}$

Orientation: -

Position of skeleton: -

L. of skeleton (contracted): -

L. of skeleton (extended): -

Age at death: adult

Sex: -

Condition of skeleton: -

Preserved skeletal bones: ${ }^{178}$ calcinated bone fragments

Scattered cremation burial. Calcinated bone fragments lay over an area with a diameter of $30 \mathrm{~cm}$.

The burial contained the following grave goods: a perforated fossil snail (1) among the bones; a broken goblet (2) on the bone remains; a red stone (3) among the bone remains.

Grave goods

1. Fragment of a strongly burnt, perforated, small fossil snail or shell. Inv. no. 61.2.72.1 (Pl. C. 238/1).

\footnotetext{
176 The skeletal remains can no longer be found. The anthropological data are quoted from the excavation diary.

177 The acquisitions register mentions a broken bead, which has since been lost or mislaid.

178 The skeletal remains can no longer be found. The anthropological data are quoted from the excavation diary.
}

2. Goblet. Body and base fragments of an ochre coloured goblet with rounded upper part set on a triangular foot, decorated with smoothed-in zig-zag lines on the upper part and chevrons on the foot. Sixteen pieces, most of them joined. L. $6 \mathrm{~cm}$. Inv. no. 61.2.72.2 (Pl. C. 238/2).

3. Stone. Irregularly shaped, roughly triangular mauvish stone fragment with two sides polished smooth. L. 4 cm, W. 2.8 cm. Inv. no. 61.2.72.3 (Pl. C. 238/3).

\section{Grave 239 (Square F5)}

Size of grave pit: -

Depth: $45 \mathrm{~cm}$

Orientation: -

Position of skeleton: -

L. of skeleton (contracted): -

L. of skeleton (extended): -

Age at death: $15-\mathrm{x}$ years

Sex: female (?)

Condition of skeleton: -

Preserved skeletal bones: various fragments

Scattered cremation burial. Calcinated bone fragments lay over an area with a diameter of $20 \mathrm{~cm}$.

The burial did not contain any grave goods.

\section{Grave 240 (Square F8)}

Size of grave pit: -

Depth: $42 \mathrm{~cm}$

Orientation: -

Position of skeleton: -

L. of skeleton (contracted): -

L. of skeleton (extended): -

Age at death: adult

Sex: -

Condition of skeleton: -

Preserved skeletal bones: ${ }^{179}$ various fragments

Scattered cremation burial. Calcinated bone fragments lay over an area with a diameter of $28 \mathrm{~cm}$. The long bone fragments survived in a fairly good state of preservation.

The burial did not contain any grave goods.

\section{Grave 241 (Square F4/F5; Pl. XCIX)}

Size of grave pit: -

Depth: $53 \mathrm{~cm}$

Orientation:-

Position of skeleton: -

L. of skeleton (contracted): -

L. of skeleton (extended): -

Age at death: adult

Sex: -

Condition of skeleton:-

Preserved skeletal bones: ${ }^{180}$ various fragments

179 The skeletal remains can no longer be found. The anthropological data are quoted from the excavation diary.

180 The skeletal remains can no longer be found. The anthropological data are quoted from the excavation diary. 
Scattered cremation burial. Calcinated bone fragments lay over an area with a diameter of $30 \mathrm{~cm}$.

The burial contained the following grave goods: four beads and two broken, perforated shells (1) among the bone fragments.

Grave goods

1. Beads. Four limestone beads (Pl. XCIX. 241/1a) and two broken, perforated Anadara diluvii shells (Pl. XCIX. 241/1b). Inv. no. 61.2.73.

\section{Grave 242 (Square F8)}

Size of grave pit: -

Depth: $48 \mathrm{~cm}$

Orientation: -

Position of skeleton: -

L. of skeleton (contracted): -

L. of skeleton (extended): -

Age at death: -

Sex: -

Condition of skeleton:-

Preserved skeletal bones: ${ }^{181}$ various fragments

Scattered cremation burial. Calcinated bone fragments formed a $5 \mathrm{~cm}$ thick layer over an area with a diameter of $25 \mathrm{~cm}$.

The burial did not contain any grave goods.

Grave 243 (Square F7; Pl. C)

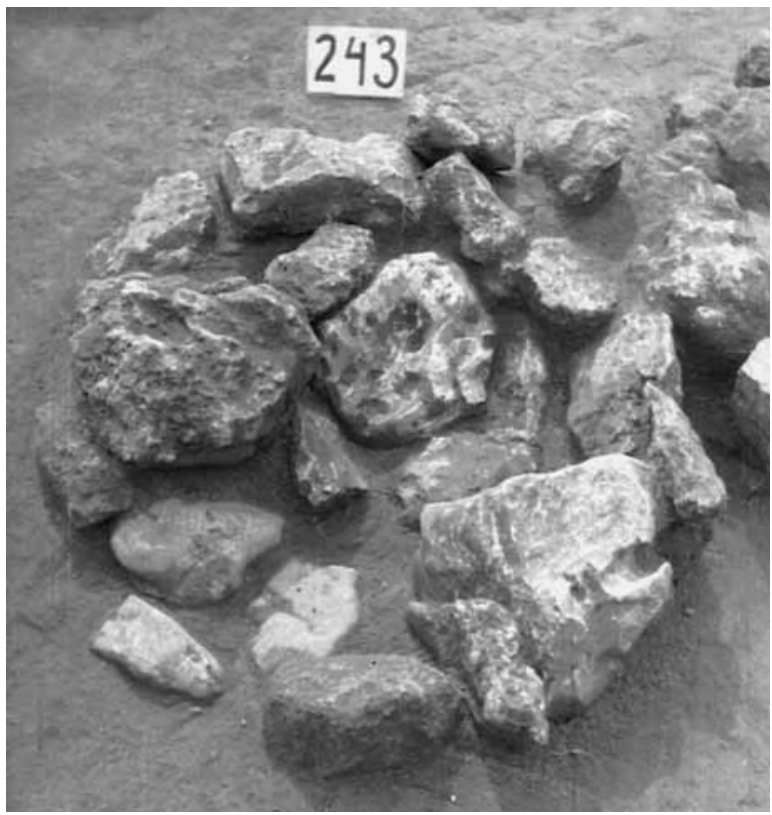

Size of grave pit: L. $70 \mathrm{~cm}, W .70 \mathrm{~cm}$

Depth: $60 \mathrm{~cm}$

Orientation: -

Position of skeleton: -

$\overline{181}$ The skeletal remains can no longer be found. The anthropological data are quoted from the excavation diary.
L. of skeleton (contracted): -

L. of skeleton (extended):-

Age at death: -

Sex: -

Condition of skeleton:-

Preserved skeletal bones: -

Symbolic (?) burial in a round grave pit containing stones between -18 and $-60 \mathrm{~cm}$. No skeletal remains were found under the stones.

The burial did not contain any grave goods.

Grave 244 (Square F7; Pl. C)

Size of grave pit: L. $80 \mathrm{~cm}, W .80 \mathrm{~cm}$

Depth: $60 \mathrm{~cm}$

Orientation: with the head toward the SW

Position of skeleton: -

L. of skeleton (contracted): -

L. of skeleton (extended): -

Age at death: $1-7$ years

Sex: child

Condition of skeleton: -

Preserved skeletal bones: -

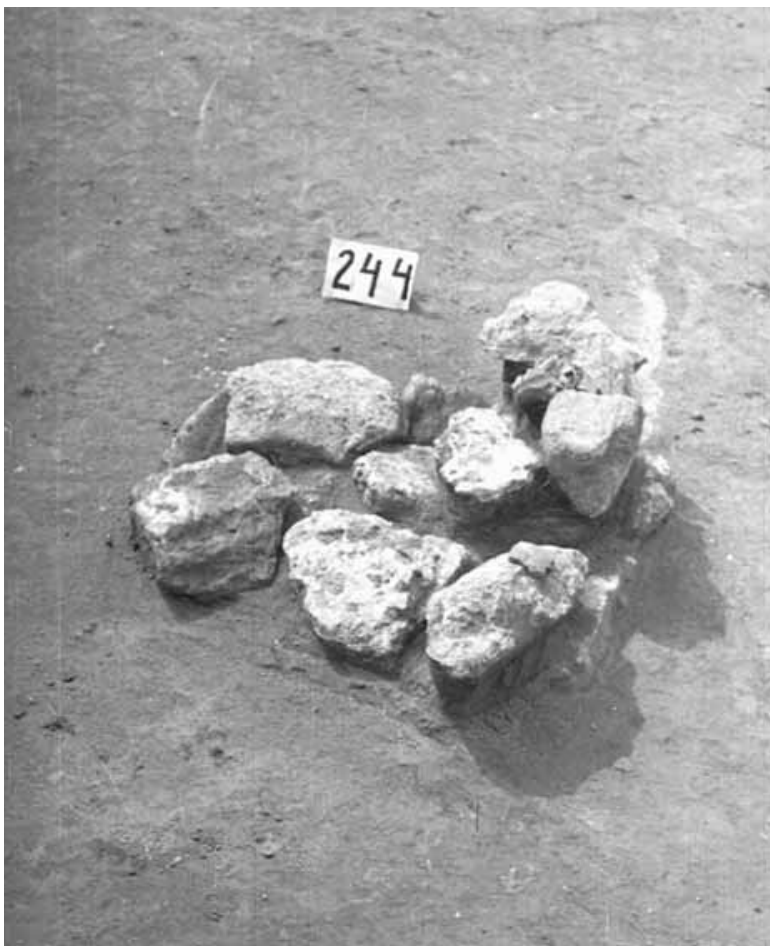

Inhumation burial in a round grave pit containing stones between -20 and $-55 \mathrm{~cm}$. The skeletal remains perished almost completely; only a few remains survived, which suggested that the deceased had been interred with the head toward the south-west. A broken dipper (1) lay among the stones.

Finds from the grave pit

1. Dipper. Fragments of a dark grey, thin-walled dipper, one fragment with the stub of the handle. Three nonjoining pieces. Inv. no. 61.2.74 (Pl. C. 244/1). 
Grave 245 (Square F7; Pl. CI)

Size of grave pit: L. $73 \mathrm{~cm}, W .86 \mathrm{~cm}$

Depth: $102 \mathrm{~cm}$

Orientation: S-SE to N-NW, with the head toward the S-SE Position of skeleton: laid on the left side

L. of skeleton (contracted): $65 \mathrm{~cm}$

L. of skeleton (extended): $104 \mathrm{~cm}$

Age at death: 5-7 years

Sex: child

Condition of skeleton: medium well preserved

Preserved skeletal bones: skull, long bones

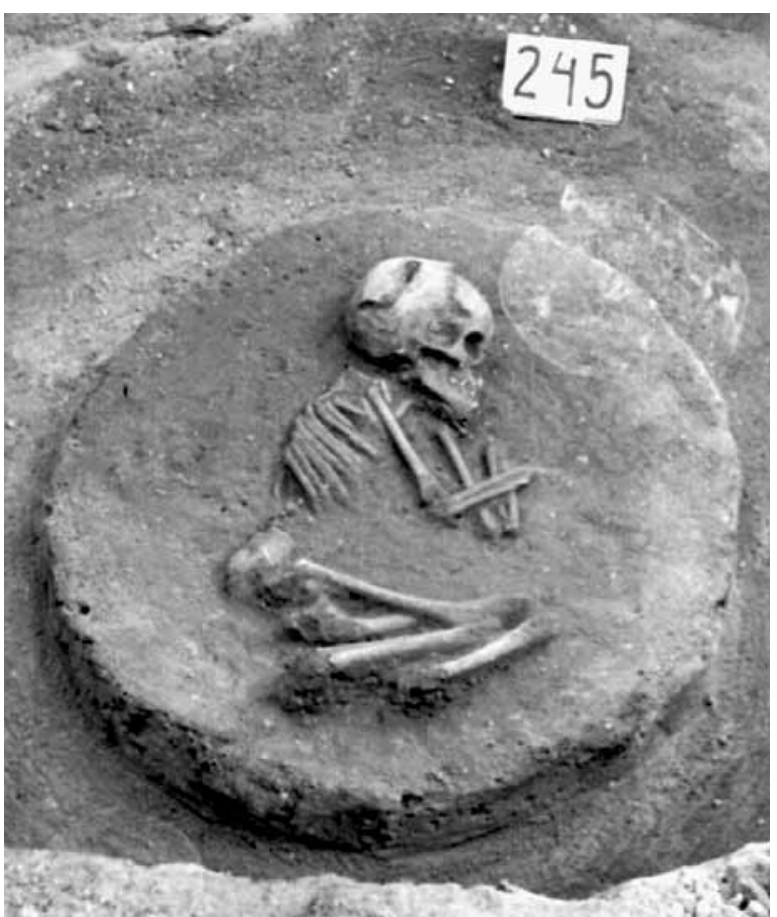

Inhumation burial in an oval grave pit containing many stones between -20 and $-70 \mathrm{~cm}$. The body was laid on the left side in a contracted position. The slightly crushed skull lay on the left side. The left arm was bent at the elbow and drawn up, with the hand placed in front of the chin. The right arm was bent at the elbow and drawn up, with the hand resting in front of the face. The right thigh was drawn up into a horizontal position, the left one slightly higher, the legs were bent back toward the buttocks.

The burial contained the following grave goods: a necklace of Dentalium beads, various other beads and copper beads around the neck (1). Most copper beads had become oxidised.

Grave goods

1. Beads. Seven Dentalium badense shells, eight limestone

\footnotetext{
182 According to the entry in the acquisitions register, one of the broken copper beads survived as a separate piece, while another was slipped inside a Dentalium bead. A photo of one bead can be found in the metallurgical report in the Szentendre museum (SzFM Archives, inv. no. 1170/76, report prepared by Dr. Manfred Schröder). I did not find a single copper bead when the finds were re-examined for this publication.
}

beads, five Anadara diluvii shells and four broken tubular copper beads. Inv. no. 61.2 .75 (Pl. CI. 245/1). ${ }^{182}$

Grave 246 (Square F7; Pl. C)

Size of grave pit: L. $70 \mathrm{~cm}, W .70 \mathrm{~cm}$

Depth: $58 \mathrm{~cm}$

Orientation: -

Position of skeleton: -

L. of skeleton (contracted): -

L. of skeleton (extended): -

Age at death: -

Sex: -

Condition of skeleton: -

Preserved skeletal bones: -

Symbolic (?) burial in a round grave pit containing stones. No skeletal remains were found under the stones.

The burial did not contain any grave goods.

Grave 247 (Square F7; Pl. CI)

Size of grave pit: -

Depth: $52 \mathrm{~cm}$

Orientation: -

Position of skeleton: -

L. of skeleton (contracted): -

L. of skeleton (extended): -

Age at death: $1-7$ years

Sex: child

Condition of skeleton: -

Preserved skeletal bones: various fragments

Scattered cremation burial. The calcinated bone fragments of a child lay over an area with a diameter of $30 \mathrm{~cm}$.

The burial contained the following grave goods: five perforated shells, five intact and one broken Dentalium beads, four intact and two sliced Dentalium beads and seven assorted beads (1) lay among the bone remains.

Grave goods

1. Beads. Seven sliced Dentalium badense beads, eight limestone beads (Pl. CI. 247/1a) and five Anadara diluvii shells (Pl. CI. 247/1b). Inv. no. 61.2.76.183

\section{Grave 248 (Square F7; Pl. CI)}

Size of grave pit: -

Depth: $45 \mathrm{~cm}$

Orientation: -

Position of skeleton: -

L. of skeleton (contracted): -

L. of skeleton (extended): -

Age at death: 23-59 years

Sex: -

Condition of skeleton: -

Preserved skeletal bones: various fragments

183 The number of beads differs in the excavation diary and in the acquisitions register, the latter is also at variance with the current number of beads. 
Scattered cremation burial. Three stones were found $c a .50 \mathrm{~cm}$ from each other: two lay one over the other. The calcinated bone fragments lay among and under the stones.

The burial contained the following grave goods: a broken mug (1) under the two stones lying over each other; a bowl (2) lying up-side down between the stones, but nearer to the third stone.

\section{Grave goods}

1. Mugs. Rim and body fragments of grey, thin-walled mugs. The stub of a handle can be seen on two sherds. Five non-joining pieces. Inv. no. 61.2.77.1 (Pl. CI. 248/1).184

2. Bowl. Plain bowl with slightly indrawn rim. the exterior is brownish with grey mottling, the interior is dark grey. The rim is damaged. $\mathrm{H} .7 \mathrm{~cm}, \mathrm{dM}$. $15.1 \mathrm{~cm}, \mathrm{~dB} .5 .6 \mathrm{~cm}$. Inv. no. 61.2.77.2 (Pl. CI. 248/2).

Other finds from the burial

3. Bowl. Body and base fragment of a brownish-grey, thick-walled bowl. Diam. $9 \mathrm{~cm}$. Inv. no. 61.2.77.3 (Pl. CI. 248/3).185

4. Bipartite bowl. Inner dividing wall fragment of a dark grey, bipartite bowl. Diam. $4.4 \mathrm{~cm}$. Inv. no. 61.2.77.4 (Pl. CI. 248/4).

\section{Grave 249 (Square F7)}

\author{
Size of grave pit: - \\ Depth: $64 \mathrm{~cm}$ \\ Orientation: - \\ Position of skeleton: - \\ L. of skeleton (contracted): - \\ L. of skeleton (extended): - \\ Age at death: adult \\ Sex: - \\ Condition of skeleton: - \\ Preserved skeletal bones: ${ }^{186}$ various fragments
}

Scattered cremation burial. Calcinated bone fragments lay over an area with a diameter of $28 \mathrm{~cm}$ between -60 and $-64 \mathrm{~cm}$.

The burial did not contain any grave goods.

\section{Grave 250 (Square F7)}

Size of grave pit: -

Depth: $38 \mathrm{~cm}$

Orientation: -

Position of skeleton: -

L. of skeleton (contracted): -

L. of skeleton (extended): -

\footnotetext{
184 Although the excavation diary mentions a single mug, the examination of the finds revealed that the sherds came from two separate vessels.

185 The excavation diary does not mention another bowl. The vesse fragments were separated after they were cleaned or other finds became mixed up with the grave goods later.

186 The skeletal remains can no longer be found. The anthropological data are quoted from the excavation diary.
}

Age at death: $15-39$ years

Sex: female (?)

Condition of skeleton: -

Preserved skeletal bones: various fragments

Scattered cremation burial. Calcinated bone fragments lay over an area with a diameter of $25 \mathrm{~cm}$.

The burial did not contain any grave goods.

\section{Grave 251 (Square F7; Pl. CII)}

\author{
Size of grave pit: - \\ Depth: $54 \mathrm{~cm}$ \\ Orientation: - \\ Position of skeleton: - \\ L. of skeleton (contracted): - \\ L. of skeleton (extended): - \\ Age at death: - \\ Sex: - \\ Condition of skeleton: - \\ Preserved skeletal bones: ${ }^{187}$ various fragments
}

Inurned burial. Calcinated bones were found over an area with a diameter of $20 \mathrm{~cm}$ under a broken vessel (1).

\section{Grave goods}

1. Pot fragments. Indistinct fragments of a greyishbrown, thick-walled pot. Four non-joining pieces. Inv. no. 61.2.78.

\section{Grave 252 (Square F6; Pl. CII)}

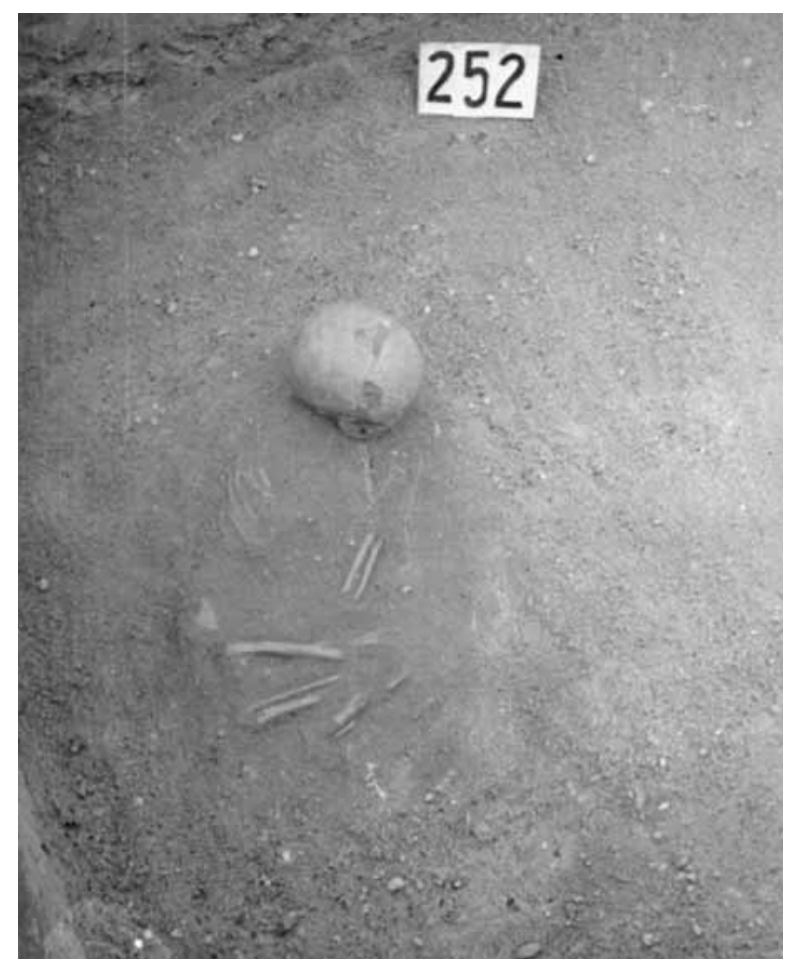

$\overline{187}$ The skeletal remains were unsuitable for anthropological determinations. 
Size of grave pit: L. $65 \mathrm{~cm}, W .46 \mathrm{~cm}$

Depth: $102 \mathrm{~cm}$

Orientation: SE to NW, with the head toward the SE

Position of skeleton: laid on the left side

L. of skeleton (contracted): $52 \mathrm{~cm}$

L. of skeleton (extended): $c a .95 \mathrm{~cm}$

Age at death: $2.5-3.5$ years

Sex: child

Condition of skeleton: medium well preserved

Preserved skeletal bones: skull, long bones

Inhumation burial in an oval grave pit. The fragments of two vessels (1) were found between -40 and $-50 \mathrm{~cm}$. The body was laid on the left side in a contracted position. The skull lay on the occipital bone with the face toward the south-west. The left arm was extended toward the thighs. The position of the right arm could not be established. The thighs were drawn up into a horizontal position, the legs were bent back toward the buttocks.

Finds from the grave pit

1. Bowl and amphora. Non-joining fragments of a greyish, worn bowl with a stringhole lug and worn smoothed-in lines resembling fluting in its interior (Pl. CII. 252/1), and fragments of a worn amphora with a stringhole lug on the shoulder (Pl. CII. 252/2). Seven pieces, two joined. Inv. no. 61.2.79.188

Grave 253 (Square F6; Pl. CIII)

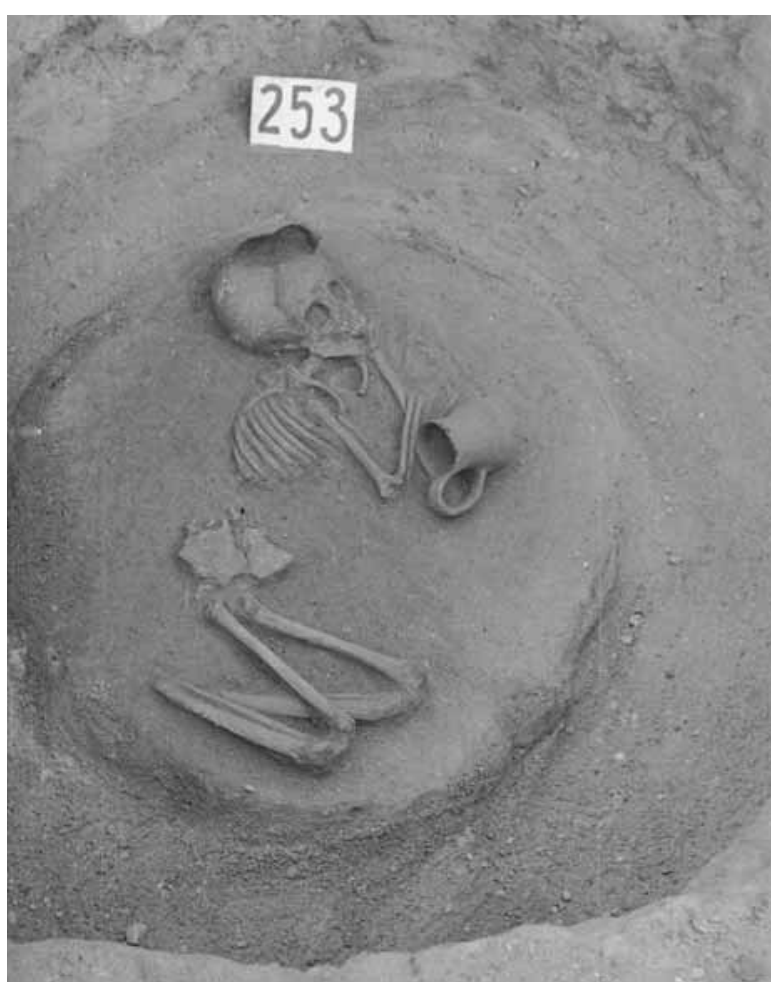

188 As it turned out, the vessel fragment initially identified as coming from a pitcher was in fact the fragment of a bowl and amphora. This probably became clear after the finds were cleaned (although it is possible that the finds became mixed up).
Size of grave pit: L. $67 \mathrm{~cm}, W .75 \mathrm{~cm}$

Depth: $92 \mathrm{~cm}$

Orientation: S-SE to N-NW, with the head toward the S-SE

Position of skeleton: laid on the left side

L. of skeleton (contracted): $76 \mathrm{~cm}$

L. of skeleton (extended): $112 \mathrm{~cm}$

Age at death: $8-9$ years

Sex: child

Condition of skeleton: medium well preserved

Preserved skeletal bones: skull, long bones

Inhumation burial in an oval grave pit. The body was laid on the left side in a contracted position. The skull was crushed and lay with the face upward. The arms were bent at the elbow and drawn up, with the hands placed in front of the face. The left thigh was drawn up into a horizontal position, the right one to a lesser extent, the legs were bent back toward the buttocks.

The burial contained the following grave goods: a pitcher (1) with the mouth facing the pelvis by the elbows.

Grave goods

1. Pitcher. Brownish, grey mottled, worn pitcher with cylindrical neck, flattened globular body and flat base. The handle rising above the rim springs to the shoulder. The neck is encircled by horizontal fluting, the belly with vertical fluting. Cracked, the rim is damaged in some spots. H. $11.7 \mathrm{~cm}$, dM. $7.9 \mathrm{~cm}$, dB. 5.5 cm. Inv. no. 61.2 .80 (Pl. CIII. 253/1).

\section{Grave 254 (Square F6; Pl. CII)}

Size of grave pit: -

Depth: $32 \mathrm{~cm}$

Orientation: -

Position of skeleton: -

L. of skeleton (contracted): -

L. of skeleton (extended): -

Age at death: $1-14$ years

Sex: child

Condition of skeleton: -

Preserved skeletal bones: various fragments

Scattered cremation burial. There was no indication of a grave pit. Calcinated bone fragments lay over an area with a diameter of $15 \mathrm{~cm}$. Indistinct pottery sherds (1) lay among the bone fragments.

Finds from the burial

1. Bowl (?). Indistinct body sherds of a reddish-brown, worn bowl (?). L. 6 cm. Inv. no. 61.2.81.189

\section{Grave 255 (Square F8; Pl. CII)}

Size of grave pit: -

Depth: $20 \mathrm{~cm}$

Orientation: -

Position of skeleton: -

189 The excavation diary mentions several vessel fragments, but only one of these was inventoried. None of the pottery sherds inventoried among the stray finds can be securely associated with this burial. 
L. of skeleton (contracted): -

L. of skeleton (extended): -

Age at death: $3-4$ years

Sex: child

Condition of skeleton: badly preserved

Preserved skeletal bones: skull fragments

Skull burial. There was no indication of a grave pit. A child's skull, destroyed by ploughing, lay at a depth of $-20 \mathrm{~cm}$. The position and orientation of the burial could not be established.

The burial did not contain any grave goods.

\section{Grave 256 (Square F6; Pl. CIII)}

Size of grave pit: L. $112 \mathrm{~cm}, W .83 \mathrm{~cm}$

Depth: $85 \mathrm{~cm}$

Orientation: $\mathrm{W}$ to $\mathrm{E}$, with the head toward the $\mathrm{W}$

Position of skeleton: laid on the right side

L. of skeleton (contracted): $50 \mathrm{~cm}$

L. of skeleton (extended): -

Age at death: $1-7$ years

Sex: child

Condition of skeleton: badly preserved

Preserved skeletal bones: various fragments

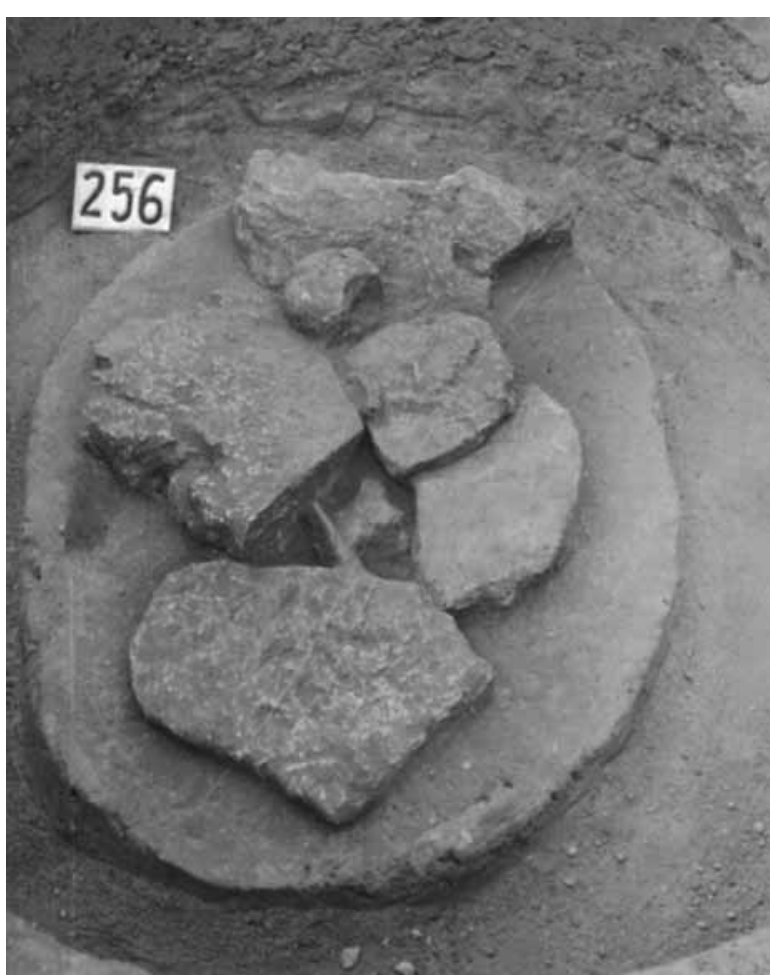

Inhumation burial in an oval grave pit containing stones between -20 and $-50 \mathrm{~cm}$. The body was laid on six more-or-less flat stones. The body was laid on the right side in a contracted position. The completely crushed skull lay on the right side. Only the position of the left upper arm and one of the thighbones could be recorded. The thighs were drawn up in front of the body.

The burial did not contain any grave goods.
Grave 257 (Square J3; Pl. CII)

Size of grave pit: -

Depth: $60 \mathrm{~cm}$

Orientation: -

Position of skeleton: -

L. of skeleton (contracted): -

L. of skeleton (extended): -

Age at death: -

Sex: -

Condition of skeleton: -

Preserved skeletal bones: -

Inhumation burial. An inhumation burial was destroyed in July, 1954, when a military trench was dug as part of a military exercise in the sand-pit southwestern part, which was still uninvestigated at the time. The burial was destroyed, the skeletal remains and the grave goods were taken away by the soldiers. According to their report, the burial contained a goblet. The position of the grave was subsequently recorded. ${ }^{190}$

1. Goblet. ${ }^{191}$

\section{Grave 258 (Square F6)}

Size of grave pit: -

Depth: $35 \mathrm{~cm}$

Orientation: -

Position of skeleton: -

L. of skeleton (contracted): -

L. of skeleton (extended): -

Age at death: -

Sex: -

Condition of skeleton: -

Preserved skeletal bones: ${ }^{192}$ various fragments

Scattered cremation burial. There was no indication of a grave pit. Calcinated bone fragments lay over an area with a diameter of $20 \mathrm{~cm}$.

The burial did not contain any grave goods.

\section{Grave 259 (Square F6; Pl. CIII)}

\author{
Size of grave pit: - \\ Depth: $33 \mathrm{~cm}$ \\ Orientation: - \\ Position of skeleton:- \\ L. of skeleton (contracted): - \\ L. of skeleton (extended): - \\ Age at death: $23-\mathrm{x}$ years \\ Sex: - \\ Condition of skeleton: -
}

Preserved skeletal bones: various fragments

Scattered cremation burial. There was no indication of a grave pit. Calcinated bone fragments lay over an area with a diameter of $45 \mathrm{~cm}$ between -25 and $-30 \mathrm{~cm}$.

190 For the destroyed burial, cp. the reports by Gyula Gazdapusztai (July 17, 1954) and Sándor Soproni (August 27, 1954) in the Archives of the Hungarian National Museum.

191 This vessel did not reach the museum.

192 The skeletal remains can no longer be found. The anthropological data are quoted from the excavation diary. 
The burial contained the following grave goods: a cup and a pot (1-2), both broken, among and under the bone fragments.

Grave goods

1. Pot. Body sherds of a grey, thick-walled, worn pot. Six non-joining pieces. Inv. no. 61.2.82.1 (Pl. CIII. 259/1).

2. Beaker. Light brown, one handled beaker with slightly everted rim. The handle rises above the rim and springs to the belly. The handle broke off. Joined from its fragments and restored. H. $9.1 \mathrm{~cm}, \mathrm{~d} M .10 .5 \mathrm{~cm}$, dB. 6.6 cm. Inv. no. 61.2.82.2 (Pl. CIII. 259/2).

\section{Grave 260 (Square F6; Pl. CIV)}

\author{
Size of grave pit: - \\ Depth: $35 \mathrm{~cm}$ \\ Orientation: - \\ Position of skeleton: - \\ L. of skeleton (contracted): - \\ L. of skeleton (extended): - \\ Age at death: 23-59 years \\ Sex: - \\ Condition of skeleton: - \\ Preserved skeletal bones: various fragments
}

Scattered cremation burial. There was no indication of a grave pit. Calcinated bone fragments lay over an area with a diameter of $30 \mathrm{~cm}$. An indistinct pottery sherd ${ }^{193}$ was found among the bone fragments.

The burial did not contain any grave goods.

\section{Grave 261 (Square E6; Pl. CV)}

Size of grave pit: L. $114 \mathrm{~cm}, W .88 \mathrm{~cm}$

Depth: $138 \mathrm{~cm}$

Orientation: E-SE to W-NW, with the head toward the E-SE

Position of skeleton: laid on the left side

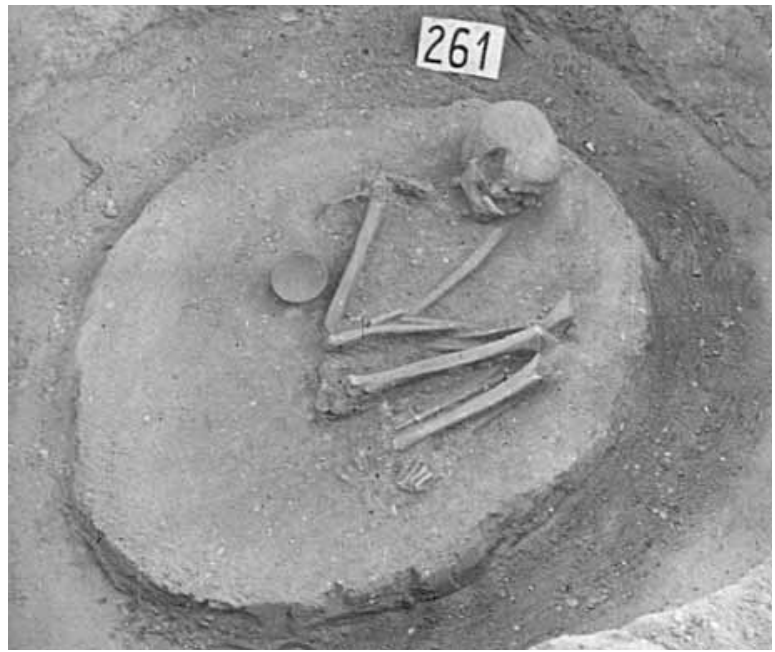

193 The vessel fragment was not inventoried. None of the pottery finds inventoried among the stray finds can be associated with this burial.
L. of skeleton (contracted): $79 \mathrm{~cm}$

L. of skeleton (extended): $c a .145 \mathrm{~cm}$

Age at death: $40-x$ years

Sex: male

Condition of skeleton: badly preserved

Preserved skeletal bones: skull, long bones

Inhumation burial in an oval grave pit. Fragments of two vessels (1-2) lay at a depth of $-35 \mathrm{~cm}$. The body was laid on the left side in a contracted position. The crushed skull lay tilted to the left side on the occipital bone. The arms were bent at the elbow and drawn up, with the hands resting by the knees. The thighs were drawn up in front of the body, the legs were bent back toward the buttocks.

The burial contained the following grave goods: a goblet (3) set upright behind the right upper arm.

Grave goods

1. Pitchers. Rim, body and handle fragments of grey pitchers. One had a cylindrical neck and was a larger vessel, the other had a smoothed neck and was decorated with fluting on the shoulder and the belly. Six non-joining pieces. Inv. no. 61.2.83.1 (Pl. CV. 261/1).

2. Amphora. Body fragments of a reddish-brown, thick-walled, large amphora, one fragment bearing vertical and oblique smoothed-in lines. Five nonjoining pieces. Inv. no. 61.2.83.2 (Pl. CV. 261/2).

3. Goblet. Light brown goblet with round upper part and a round base. The foot and a part of the base are restored. H. $8.8 \mathrm{~cm}$, dM. $9.6 \mathrm{~cm}$. Inv. no. 61.2.83.4 (Pl. CV. 261/3).

Other finds from the burial

4. Stone, Reddish-brown irregular stone with one side polished smooth. Diam. $6.7 \mathrm{~cm}$, Th. $1.5 \mathrm{~cm}$. Inv. no. 61.2.83.3.194

Grave 262 (Square E5; Pl. CIV)

Size of grave pit: -

Depth: $42 \mathrm{~cm}$

Orientation: -

Position of skeleton: -

L. of skeleton (contracted): -

L. of skeleton (extended): -

Age at death: $0-5$ years

Sex: child

Condition of skeleton: badly preserved

Preserved skeletal bones: skull fragments

Skull burial. There was no indication of a grave pit. A child's crushed skull lay at a depth of $-42 \mathrm{~cm}$. Its orientation could not be established.

The burial contained the following grave goods: pottery sherds (1-2), a ladle handle (3) and various indistinct pottery fragments around the skull.

194 The excavation diary makes no mention of a stone among the grave goods. The object has since been lost or mislaid. Its description is quoted from the acquisitions register. 
Grave goods

1. Pitcher (?). Base fragment of a large grey pitcher (?).

L. 5.9 cm. Inv. no. 61.2.84 (Pl. CIV. 262/1).

2. Vessel fragments. ${ }^{195}$

3. Ladle. ${ }^{196}$

Grave 263 (Square E5; Pl. CVI)

Size of grave pit: L. $132 \mathrm{~cm}, W .90 \mathrm{~cm}$

Depth: $73 \mathrm{~cm}$

Orientation: A: S-SE to N-NW, with the head toward the S-SE, B: $S$ to $N$, with the head toward the $S$

Position of skeleton: A: laid on the right side, B: laid on the left side

L. of skeleton (contracted): A: $105 \mathrm{~cm}, \mathrm{~B}: 98 \mathrm{~cm}$

L. of skeleton (extended): A: $163 \mathrm{~cm}, \mathrm{~B}: 157 \mathrm{~cm}$

Age at death: A: 35-59 years, B: 40-49 years

Sex: A: male (?), B: female

Condition of skeleton: A: medium well preserved, B: medium well preserved

Preserved skeletal bones: A-B: skull, long bones

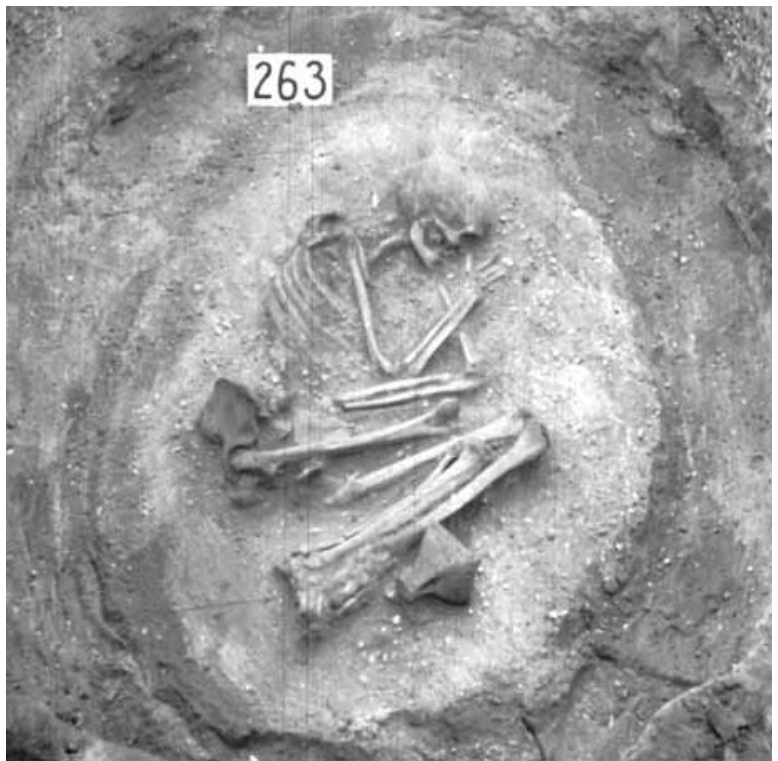

Double inhumation burial in an oval grave pit. Three stones lay above the skulls at a depth of $-35 \mathrm{~cm}$. The two bodies were deposited one over the other. The two burials were contemporaneous since there was no sign of disturbance.

\section{Burial A}

The body was laid on the right side in a contracted position with the trunk laid prone. The arms were placed under the body. The right arm was bent at the elbow and drawn up, with the hand resting by the left elbow under the knee. The left arm was bent at the elbow and drawn up, with the hand placed under the neck. The thighs were drawn up in front of the body, the legs were bent back toward the buttocks. The ankles lay one over the other. The knees rested on the waist of Burial B, the buttocks on the thighs of Burial B.

The burial contained the following grave goods: two rectangular shell plaques and twenty-five beads (1) on the upper arm, above the elbow,

\section{Burial B}

The body was laid on the left side in a contracted position immediately under Burial A. The two skulls rested one over the other. The right arm was bent at the elbow and drawn up, with the hand resting in front of the face. The left arm was bent at the elbow and the hand placed by the pelvis. The thighs were drawn up in front of the body, the legs were bent back toward the buttocks.

The burial contained the following grave goods: a goblet (2) tilted to one side by the foot (near the buttocks of Burial A); two stone implements (3-4) between the two skulls; five beads (5) around the neck; eleven beads (6) around the waist.

Grave goods

1. Beads. Twenty limestone beads of varying sizes (Pl. CVI. 263/1a) and two broken rectangular shell plaques (Pl. CVI. 263/1b). Inv. no. 61.2.85.4. ${ }^{197}$

2. Goblet. Ochre brown goblet with rounded upper part set on two feet on an oval base. The four corners are peaked. The upper part and the feet are covered with an incised zig-zag pattern. Patches of red painting survive on the body. Joined from its fragments; the rim and the base are partially restored. H. $10 \mathrm{~cm}, \mathrm{dM} .10 \mathrm{~cm}, 10.6 \mathrm{~cm}$. Inv. no. 61.2.85.1 (Pl. CVI. 263/2)

3. Radiolarite blade fragment. Inv. no. 61.2.85.2 (Pl. CVI. 263/3).

4. Retouched radiolarite flake Inv. no. 61.2.85.3.

5. Beads. Five sliced limestone beads. Inv. no. 61.2.85.5 (Pl. CVI. 263/5).

6. Beads. Eleven sliced limestone beads of varying sizes. Inv. no. 61.2.85.6 (Pl. CVI. 263/6).

\section{Grave 264 (Square E5; Pl. CIV)}

Size of grave pit: L. $138 \mathrm{~cm}$, W. $95 \mathrm{~cm}$ Depth: $74 \mathrm{~cm}$

Orientation: SE to NW, with the head toward the SE

Position of skeleton: laid on the left side

L. of skeleton (contracted): $94 \mathrm{~cm}$

L. of skeleton (extended): $157 \mathrm{~cm}$

Age at death: $25-35$ years

Sex: male (?)

Condition of skeleton: badly preserved

Preserved skeletal bones: skull, long bones

\footnotetext{
195 Vessel fragments were not inventoried among the finds from the burial. 196 No such vessel was inventoried among the finds from the burial.
}

197 The number of beads was lower by the time they were inventoried. The shell plaques can no longer be found. 


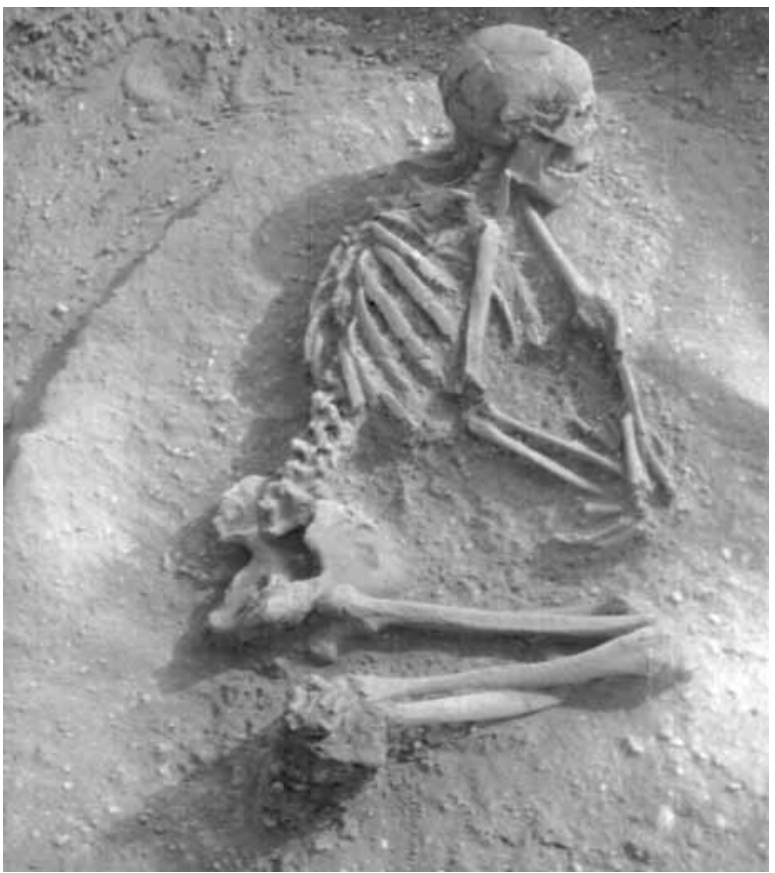

Inhumation burial in an oval grave pit. The body was laid on the left side in a contracted position. The skull lay on the left side, slightly higher than the body. The left arm was extended beside the body toward the knee, the right arm was slightly bent at the elbow, the two hands were clasped. The thighs were drawn up into a horizontal position, the legs were bent back toward the buttocks. The feet lay slightly higher, the ankles rested one over the other.

The burial did not contain any grave goods.

\section{Grave 265 (Square E5; Pl. CVII)}

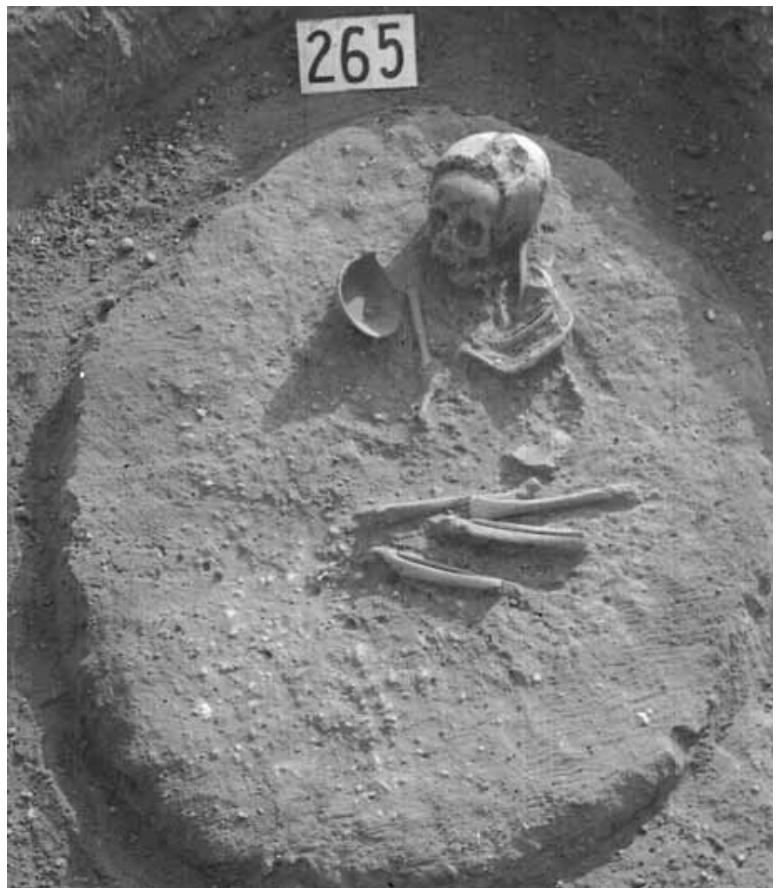

Size of grave pit: L. $108 \mathrm{~cm}, W .83 \mathrm{~cm}$

Depth: $78 \mathrm{~cm}$

Orientation: $\mathrm{S}$ to $\mathrm{N}$, with the head toward the $\mathrm{S}$

Position of skeleton: laid on the right side

L. of skeleton (contracted): $66 \mathrm{~cm}$

L. of skeleton (extended): $c a .93 \mathrm{~cm}$

Age at death: 4-4.5 years

Sex: child

Condition of skeleton: badly preserved

Preserved skeletal bones: skull, long bones

Inhumation burial in an oval grave pit containing stones between -35 and $-50 \mathrm{~cm}$. Various vessel fragments (1-3) lay among the stones. The body was laid on the right side in a contracted position. The skull rested on the occipital bone. The right arm was extended toward the knee. The left arm was bent at the elbow and drawn up toward the face. The thighs were drawn up into a horizontal position, the legs were bent back toward the buttocks.

The burial contained the following grave goods: a small scooping vessel (4) tilted to one side with the mouth toward the edge of the grave pit by the right upper arm.

\section{Grave goods}

1. Ladle. Handle fragment of a grey ladle. The handle is peaked with two small perforations underneath. Patches of red painting survive on the inner side. A tiny section of an incised linear pattern survives at the junction of the handle and the ladle bowl. Inv. no. 61.2.86.1 (Pl. CVII. 265/1).

2. Pots. Rim and body fragments of various reddish pots. Some fragments have a notched rib under the rim, Nine non-joining pieces. Inv. no. 61.2.86.2 (Pl. CVII. 265/2-3).

3. Pot. Body sherds of a grey, worn pot. Two nonjoining pieces. Inv. no. 61.2.86.3.

4. Scooping vessel. Light brown, worn scooping vessel decorated with a row of punctates under the rim and around the base. The short strap handle spans the rim and the base. Cracked, joined from its fragments. H. $3.3 \mathrm{~cm}$, dM. $11.1 \mathrm{~cm}, \mathrm{~dB} .6 .1 \mathrm{~cm}$. Inv. no. 61.2.86.4 (Pl. CVII. 265/4).

\section{Grave 266 (Square F9; Pl. CIV)}

Size of grave pit: -

Depth: $25 \mathrm{~cm}$

Orientation: -

Position of skeleton: -

L. of skeleton (contracted): -

L. of skeleton (extended): -

Age at death: $15-39$ years

Sex: female (?)

Condition of skeleton:-

Preserved skeletal bones: various fragments

Inurned burial. There was no indication of a grave pit. Calcinated bone fragments lay over an area with a diameter of $30 \mathrm{~cm}$. 
The burial contained the following grave goods: a broken pot (1) on the bone fragments; a stone (2) beside the previous vessel; a river mussel (3) among the bone fragments.

\section{Grave goods}

1. Pot. Body and base fragments of a reddish, poorly fired pot. Three pieces. Inv. no. 61.2.87.1.

2. Stone. Irregularly shaped, reddish-brown stone. L. $5.2 \mathrm{~cm}$. Inv. no. 61.2.87.3. ${ }^{198}$

3. Mussel. Left valve of an Unio crassus mussel. L. $5 \mathrm{~cm}$, W. 3.3 cm. Inv. no. 61.2.87.2 (Pl. CIV. 266/3).

\section{Grave 267 (Square E5; Pl. CIV)}

Size of grave pit: L. $75 \mathrm{~cm}, W .50 \mathrm{~cm}$

Depth: $82 \mathrm{~cm}$

Orientation: $\mathrm{S}$ to $\mathrm{N}$ (?), with the head toward the $\mathrm{S}$

Position of skeleton: -

L. of skeleton (contracted): -

L. of skeleton (extended): -

Age at death: $0-5$ years

Sex: child

Condition of skeleton: badly preserved

Preserved skeletal bones: skull fragments

Inhumation burial in an oval grave pit containing five smaller stones at a depth of $-40 \mathrm{~cm}$. Fragments of a dipper (1) lay among the stones. The skeletal remains of the body perished, only the skull fragments survived in the grave pit's southern end.

The burial contained the following grave goods: four beads (2) around the skull.

\section{Grave goods}

1. Dipper. Base and handle fragment of a greyish, thick-walled, conical dipper. Two pieces. $\mathrm{dB} .1 .8 \mathrm{~cm}$. Inv. no. 61.2.88.1 (Pl. CIV. 267/1).

2. Beads. One Turritella badense bead, three Dentalium badense beads and two limestone beads. Inv. no. 61.2.88.2 (Pl. CIV. 267/2). ${ }^{199}$

\section{Grave 268 (Square E5)}

\author{
Size of grave pit: - \\ Depth: $32 \mathrm{~cm}$ \\ Orientation: - \\ Position of skeleton: - \\ L. of skeleton (contracted): - \\ L. of skeleton (extended): - \\ Age at death: $23-x$ years \\ Sex: female (?) \\ Condition of skeleton: - \\ Preserved skeletal bones: various fragments
}

\footnotetext{
198 The object has since been lost or mislaid. Its description is quoted from the acquisitions register.

199 The number of beads differs in the excavation diary and in the acquisitions register; the latter is also at variance with the current number
} of beads.
Scattered cremation burial. There was no indication of a grave pit. Calcinated bone fragments lay over an area with a diameter of $25 \mathrm{~cm}$.

The burial did not contain any grave goods.

\section{Grave 269 (Square E5)}

Size of grave pit:-

Depth: $35 \mathrm{~cm}$

Orientation:-

Position of skeleton: -

L. of skeleton (contracted): -

L. of skeleton (extended): -

Age at death: $23-x$ years

Sex: -

Condition of skeleton: -

Preserved skeletal bones: various fragments

Scattered cremation burial. There was no indication of a grave pit. Calcinated bone fragments lay over an area with a diameter of $15 \mathrm{~cm}$.

The burial did not contain any grave goods.

\section{Grave 270 (Square E5; Pl. CVIII)}

Size of grave pit: L. $155 \mathrm{~cm}, W .115 \mathrm{~cm}$

Depth: $97 \mathrm{~cm}$

Orientation: $\mathrm{W}$ to $\mathrm{E}$, with the head toward the $\mathrm{W}$

Position of skeleton: laid on the left side

L. of skeleton (contracted): $114 \mathrm{~cm}$

L. of skeleton (extended): $165 \mathrm{~cm}$

Age at death: $30-40$ years

Sex: male

Condition of skeleton: medium well preserved

Preserved skeletal bones: skull, long bones

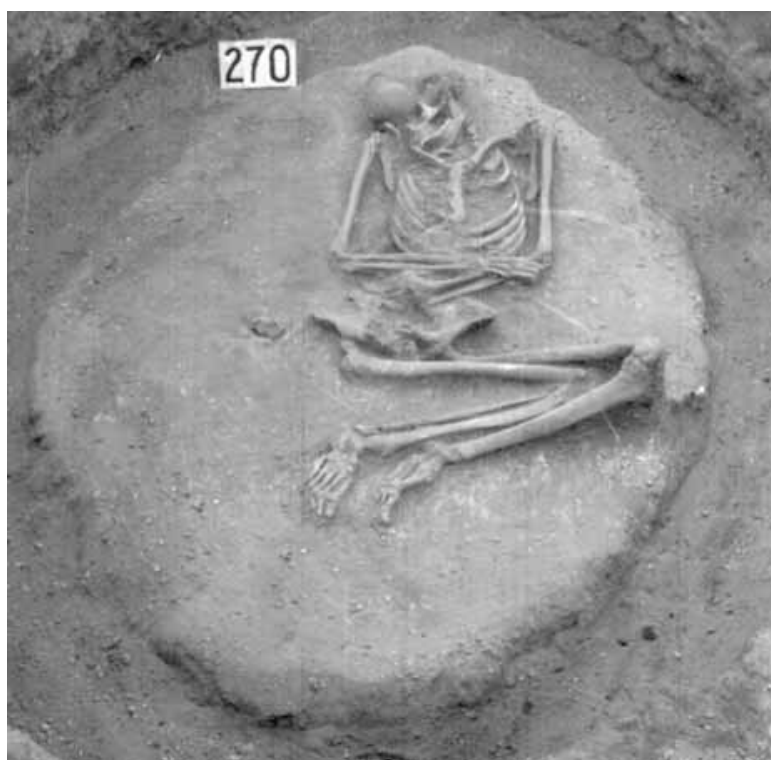

Inhumation burial in an oval grave pit. The body was laid on the left side in a contracted position. The crushed skull lay tilted to the right side with the face toward the south-east. The trunk and the pelvis were 
laid in an extended position on the back. The right arm was bent at the elbow and drawn up, with the wrist placed by the left elbow and the hand clasping the left forearm. The left arm was bent at the elbow and drawn up, with the hand resting on the abdomen. The thighs were drawn up into a horizontal position, the legs were bent back toward the buttocks.

The burial did not contain any grave goods.

\section{Grave 271 (Square E5; Pl. CVIII)}

Size of grave pit: L. $130 \mathrm{~cm}, W .116 \mathrm{~cm}$

Depth: $62 \mathrm{~cm}$

Orientation: E-SE to W-NW, with the head toward the E-SE

Position of skeleton: laid on the right side

L. of skeleton (contracted): $88 \mathrm{~cm}$

L. of skeleton (extended): $138 \mathrm{~cm}$

Age at death: $40-x$ years

Sex: female

Condition of skeleton: badly preserved

Preserved skeletal bones: skull, long bones

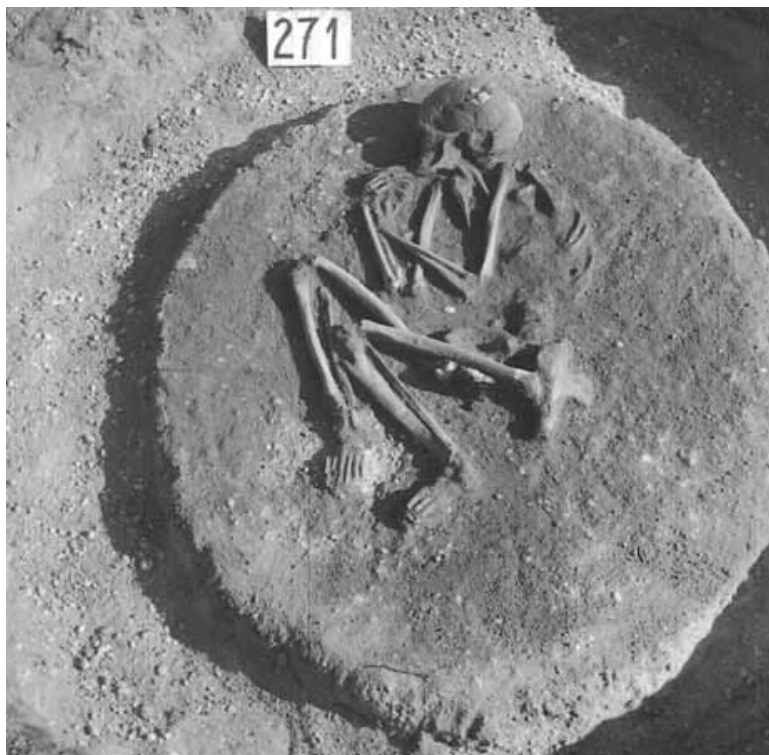

Inhumation burial in an oval grave pit. The body was laid on the right side in a contracted position. The skull lay on the right side with the face toward the north. The arms were bent at the elbow and drawn up, with the clasped hands placed in front of the face. The thighs were drawn up in front of the body, the right one higher than the left one, the legs were bent back toward the buttocks.

The burial did not contain any grave goods.

\section{Grave 272 (Square F8)}

Size of grave pit: -

Depth: $24 \mathrm{~cm}$

Orientation: E-SE to $\mathrm{W}-\mathrm{NW}$, with the head toward the E-SE

Position of skeleton: laid on the right side

L. of skeleton (contracted): $73 \mathrm{~cm}$
L. of skeleton (extended): -

Age at death: 4-6 years

Sex: child

Condition of skeleton: badly preserved

Preserved skeletal bones: various fragments

Inhumation burial. There was no indication of a grave pit. The skeletal remains were almost completely destroyed by ploughing. The surviving long bone fragments suggest that the body had been laid on the right side in a contracted position. The skull lay on the right side.

The burial did not contain any grave goods.

\section{Grave 273 (Square F8; Pls $C X-C X I$ )}

Size of grave pit: diam. $55 \mathrm{~cm}$

Depth: $60 \mathrm{~cm}$

Orientation: -

Position of skeleton: -

L. of skeleton (contracted): -

L. of skeleton (extended): -

Age at death: -

Sex: -

Condition of skeleton: -

Preserved skeletal bones: ${ }^{200}$ various fragments

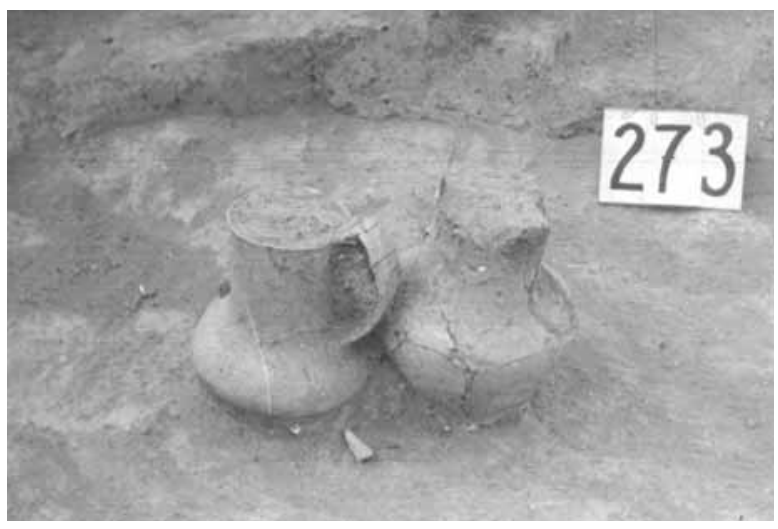

Scattered cremation burial in a round grave pit containing a high amount of calcinated bone fragments.

The burial contained the following grave goods: an amphora (1) set upright, a jug (2) also set upright beside the previous vessel, a red stone (3) under vessel 2, six snails (4) among the bone fragments; a mug (5) in vessel 2.

\section{Grave goods}

1. Amphora (?). Rim, body and base fragments of a grey, thick-walled, worn vessel. Nine non-joining pieces. Inv. no. 61.2.89.1 (Pl. CX. 273/1). ${ }^{201}$

2. Jug. Grey, polished, one-handled jug with cylindrical neck and flattened globular body. The handle rising above the rim springs to the shoulder. Fluted

\footnotetext{
200 The skeletal remains can no longer be found. The anthropological data are quoted from the excavation diary.

201 Sándor Soproni recorded the dimensions of the jug in the excavation diary: dM. $11.1 \mathrm{~cm}, H .21 \mathrm{~cm}$. The vessel had probably fallen apart by the time it was inventoried and some fragments were lost, this being the probable reason that it was not restored.
} 
decoration encircles the neck, the belly is decorated with three slender, impressed ribs. The area between the ribs is filled with vertical fluting. Joined from its fragments and partially restored. H. $17.9 \mathrm{~cm}, \mathrm{dM}$. $9.7 \mathrm{~cm}, \mathrm{~dB} .6 .2 \mathrm{~cm}$. Inv. no. 61.2.89.2 (Pl. CXI. 273/2).

3. Stone. Irregularly shaped red stone, one side polished smooth. L. 4 cm. Inv. no. 61.2.89.3.202

4. Three Turritella badense and two Turritella sp. snails. Inv. no. 61.2.89.4 (Pl. CX. 273/4).203

5. Mug. Grey, worn mug with cylindrical neck and flattened globular body. The handle rises above the rim and springs to the shoulder. The belly is decorated with fluting. Patches of red painting survive on the handle and on the belly under the handle. H. $6.5 \mathrm{~cm}, \mathrm{dM}$. $4.9 \mathrm{~cm}$. Inv. no. 61.2.89.7 (Pl. CXI. 273/5).

Other finds from the burial

6. Pot. Rim and body fragments of a reddish-brown, thick-walled pot decorated with finger impressions under the rim. Four non-joining pieces. Inv. no. 61.2.89.5 (Pl. CXI. 273/6).204

7. Pitcher. Rim fragment of a grey, polished pitcher decorated with impressions along the rim. $\mathrm{dM} .4 .5 \mathrm{~cm}$. Inv. no. 61.2.89.6 (Pl. CXI. 273/7). ${ }^{205}$

\section{Grave 274 (Square F8; Pl. CVIII)}

\author{
Size of grave pit: - \\ Depth: $35 \mathrm{~cm}$ \\ Orientation: - \\ Position of skeleton: - \\ L. of skeleton (contracted): - \\ L. of skeleton (extended): - \\ Age at death: $1-14$ years \\ Sex: child \\ Condition of skeleton: - \\ Preserved skeletal bones: various fragments
}

Scattered cremation burial. There was no indication of a grave pit. Calcinated bone fragments lay over an area with a diameter of $35 \mathrm{~cm}$.

The burial contained the following grave goods: a crushed vessel (1) above the bone fragments; a broken bipartite bowl (2) among the sherds of the previous vessel.

\section{Grave goods}

1. Amphora (?). Rim and body fragments of a grey, worn, undecorated amphora. Eight non-joining pieces. Inv. no. 61.2 .90 (Pl. CVIII. 274/1).

2. Bipartite bowl. Inner dividing wall and base fragment of a bipartite bowl. 206

\footnotetext{
202 The object has since been lost or mislaid. Its description is quoted from the acquisitions register.

203 The number of snails is lower by one in the acquisitions register than in the excavation diary.

204 The excavation diary does not mention a vessel fragment of this type. 205 The excavation diary does not mention a vessel fragment of this type. 206 An inner dividing wall fragment from a bipartite bowl was not inventoried among the finds from the burial. The stray finds do not include a bowl fragment of this type, which can be securely associated with this burial.
}

Grave 275 (Square F8)

Size of grave pit: -

Depth: $38 \mathrm{~cm}$

Orientation: -

Position of skeleton: -

L. of skeleton (contracted): -

L. of skeleton (extended): -

Age at death: child

Sex: -

Condition of skeleton: -

Preserved skeletal bones: ${ }^{207}$ various fragments

Scattered cremation burial. There was no indication of a grave pit. Calcinated bone fragments lay over an area with a diameter of $20 \mathrm{~cm}$.

The burial did not contain any grave goods.

\section{Grave 276 (Square F8; Pl. CXI)}

Size of grave pit: -

Depth: $42 \mathrm{~cm}$

Orientation: -

Position of skeleton: -

L. of skeleton (contracted): -

L. of skeleton (extended): -

Age at death: adult

Sex: -

Condition of skeleton:-

Preserved skeletal bones: ${ }^{208}$ various fragments

Scattered cremation burial. There was no indication of a grave pit. Calcinated bone fragments lay over an area with a diameter of $28 \mathrm{~cm}$.

The burial contained the following grave goods: a broken pitcher (1) originally set upright on the bone fragments.

Grave goods

1. Pitcher. Body, base and handle fragments of a greyish, worn pitcher. Five non-joining pieces. Inv. no. 61.2.91 (Pl. CXI. 276/1).

\section{Grave 277 (Square E6; Pl. CIX)}

Size of grave pit: L. $120 \mathrm{~cm}, W .100 \mathrm{~cm}$

Depth: $94 \mathrm{~cm}$

Orientation: E-SE to W-NW, with the head toward the E-SE Position of skeleton: laid on the right side

L. of skeleton (contracted): $94 \mathrm{~cm}$

L. of skeleton (extended): $160 \mathrm{~cm}$

Age at death: $30-35$ years

Sex: male

Condition of skeleton: medium well preserved

Preserved skeletal bones: skull, long bones

Inhumation burial in an oval grave pit. The body was laid on the right side in a contracted position. The

\footnotetext{
207 The skeletal remains are unsuitable for an anthropological determination

208 The skeletal remains can no longer be found. The anthropological data are quoted from the excavation diary.
} 
crushed skull lay on the right side. The arms were bent at the elbow and drawn up, with the clasped hand placed by the upper third of the thigh. The thighs were drawn up in front of the body, the legs were bent back toward the buttocks.

The burial contained the following grave goods: a small scooping vessel (1) set upright in front of the face.

\section{Grave goods}

1. Scooping vessel. Greyish-brown, polished scooping vessel with flat base. A row of impressed dots encircles the shoulder. The handle spans the rim and the shoulder. Damaged in one spot; joined from its fragments. H. $5.7 \mathrm{~cm}$, dM. $11.5 \mathrm{~cm}$. Inv. no. 61.2 .92 (Pl. CIX. 277/1).

\section{Grave 278 (Square E6; Pl. CVIII)}

Size of grave pit: L. $68 \mathrm{~cm}, W .50 \mathrm{~cm}$

Depth: $58 \mathrm{~cm}$

Orientation: N-NE to S-SW, with the head toward the N-NE

Position of skeleton: laid on the left side

L. of skeleton (contracted): $45 \mathrm{~cm}$

L. of skeleton (extended): -

Age at death: $0-0.5$ years

Sex: child

Condition of skeleton: badly preserved

Preserved skeletal bones: skull, long bones fragments

Inhumation burial in an oval grave pit. The body was laid on the left side in a contracted position. The crushed skull lay on the left side. The right arm was bent at the elbow. The thighs were drawn up into a horizontal position, the legs were bent back toward the buttocks.

The burial did not contain any grave goods.

\section{Grave 279 (Square E7; Pl. CXII)}

Size of grave pit: L. $120 \mathrm{~cm}, W .94 \mathrm{~cm}$

Depth: $68 \mathrm{~cm}$

Orientation: $\mathrm{S}$ to $\mathrm{N}$, with the head toward the $\mathrm{S}$

Position of skeleton: laid on the left side

L. of skeleton (contracted): $97 \mathrm{~cm}$

L. of skeleton (extended): $158 \mathrm{~cm}$

Age at death: $30-50$ years

Sex: male

Condition of skeleton: medium well preserved

Preserved skeletal bones: skull, long bones

Inhumation burial in an oval grave pit. The body was laid on the left side in a contracted position. The skull lay on the occipital bone with the face toward the west. The mandible was fragmented. The right arm was bent at the elbow and drawn up, with the hand placed under the left forearm. The left arm was drawn up to the left shoulder and the hand laid on the shoulder. The pelvic bone was dislodged and lay prone. The thighs were drawn up into a horizontal position, the legs were bent back toward the buttocks. There was an animal burrow by the feet.

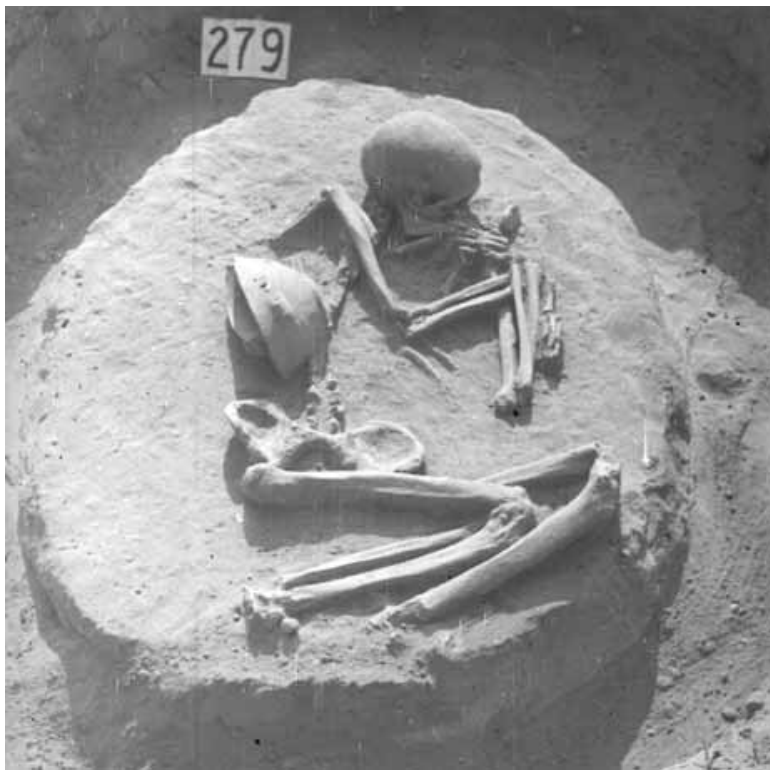

The burial contained the following grave goods: a bowl (1) tilted to one side with the mouth facing the edge of the grave pit by the spine; a stone axe (2) set on its edge in front of the face; a core (3) $c a .2-3 \mathrm{~cm}$ above the axe; a stone blade (4) under nos 2-3.

\section{Grave goods}

1. Bowl. Reddish brown, grey mottled, thin-walled conical bowl with funnel neck. A small stringhole lug is set on the shoulder. The rim is damaged. Joined from its fragments and restored. H. $10.2 \mathrm{~cm}, \mathrm{~d} M$. $21.2 \mathrm{~cm}$, dB. 7 cm. Inv. no. 61.2.93.1 (Pl. CXII. 279/1).

2. Stone axe. Broken yellowish-grey, flat, rectangular stone axe made from serpentinite. L. $4.5 \mathrm{~cm}$, W. 3.4 cm. Inv. no. 61.2.93.2 (Pl. CXII. 279/2).

3. Core. Yellowish-grey hornstone core. L. $6.5 \mathrm{~cm}$. Inv. no. 61.2.93.3 (Pl. CXII. 279/3).

4. Unretouched blade fragment. Limnic quartzite. Inv. no. 61.2.93.4 (Pl. CXII. 279/4).

\section{Grave 280 (Square F7)}

Size of grave pit:-

Depth: $25 \mathrm{~cm}$

Orientation: -

Position of skeleton: -

L. of skeleton (contracted): -

L. of skeleton (extended): -

Age at death: -

Sex: -

Condition of skeleton: -

Preserved skeletal bones: ${ }^{209}$ various fragments

Scattered cremation burial. There was no indication of a grave pit. Calcinated bone fragments lay over an area with a diameter of $15 \mathrm{~cm}$.

The burial did not contain any grave goods.

209 The skeletal remains are unsuitable for an anthropological determination. 
Grave 281 (Square F8)

Size of grave pit: -

Depth: $43 \mathrm{~cm}$

Orientation: SE to NW, with the head toward the SE

Position of skeleton: extended

L. of skeleton: $76 \mathrm{~cm}$

Age at death: $1-3$ years

Sex: child

Condition of skeleton: badly preserved

Preserved skeletal bones: various fragments

Inhumation burial. There was no indication of a grave pit. The body was laid extended. The arms were extended beside the body. The skull was fragmented, the skeletal remains had decayed. Grave 282, a cremation burial lying under this grave, was disturbed when this burial was dug.

The burial did not contain any grave goods.

\section{Grave 282 (Square E8)}

Size of grave pit: -

Depth: $48 \mathrm{~cm}$

Orientation: -

Position of skeleton: -

L. of skeleton (contracted): -

L. of skeleton (extended): -

Age at death: -

Sex: -

Condition of skeleton: -

Preserved skeletal bones: various fragments

Scattered cremation burial. There was no indication of a grave pit. The calcinated bone fragments lay under the thighs and knees of the inhumation burial in Grave 281. This burial was disturbed when Grave 281 was dug and a part of the calcinated bone fragments became scattered.

The burial did not contain any grave goods.

\section{Grave 283 (Square E6; Pl. CIX)}

Size of grave pit: L. $115 \mathrm{~cm}, W .87 \mathrm{~cm}$ Depth: $90 \mathrm{~cm}$

Orientation: S-SE to N-NW, with the head toward the S-SE

Position of skeleton: laid on the right side

L. of skeleton (contracted): $92 \mathrm{~cm}$

L. of skeleton (extended): $142 \mathrm{~cm}$

Age at death: 23-59 years

Sex: female

Condition of skeleton: medium well preserved

Preserved skeletal bones: skull, long bones

Inhumation burial in an oval grave pit containing stones between -40 and $-50 \mathrm{~cm}$. The body was laid on the right side in a contracted position. The skull lay on the right side. The body lay prone, tilted slightly to the right from the pelvis upward. The right arm was bent at the elbow under the body and drawn up, with the hand resting in front of the face. The left arm was bent at the elbow and drawn up, with the hand placed by the

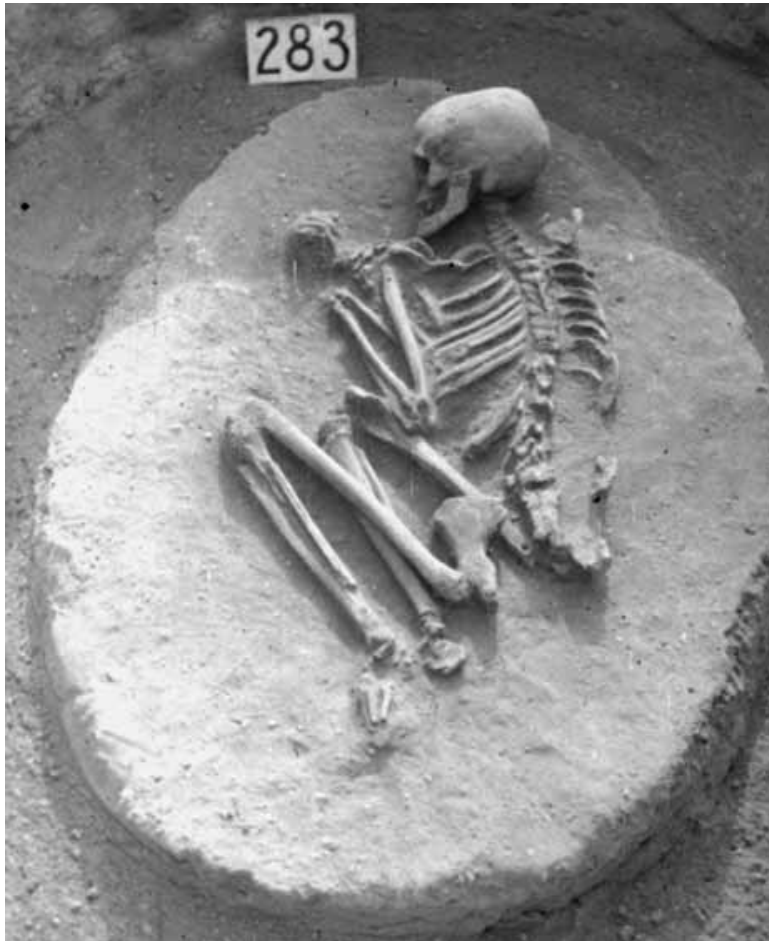

shoulder. The thighs were drawn up in front of the body, the legs were bent back toward the buttocks.

The burial did not contain any grave goods.

\section{Grave $284(\mathrm{H} 9 ;$ Pl. CXIII)}

Size of grave pit: L. $115 \mathrm{~cm}$, W. $95 \mathrm{~cm}$

Depth: $18 \mathrm{~cm}$

Orientation: $\mathrm{E}$ to $\mathrm{W}$, with the head toward the SE

Position of skeleton: laid on the left side

L. of skeleton (contracted): $85 \mathrm{~cm}$

L. of skeleton (extended): $c a .152 \mathrm{~cm}$

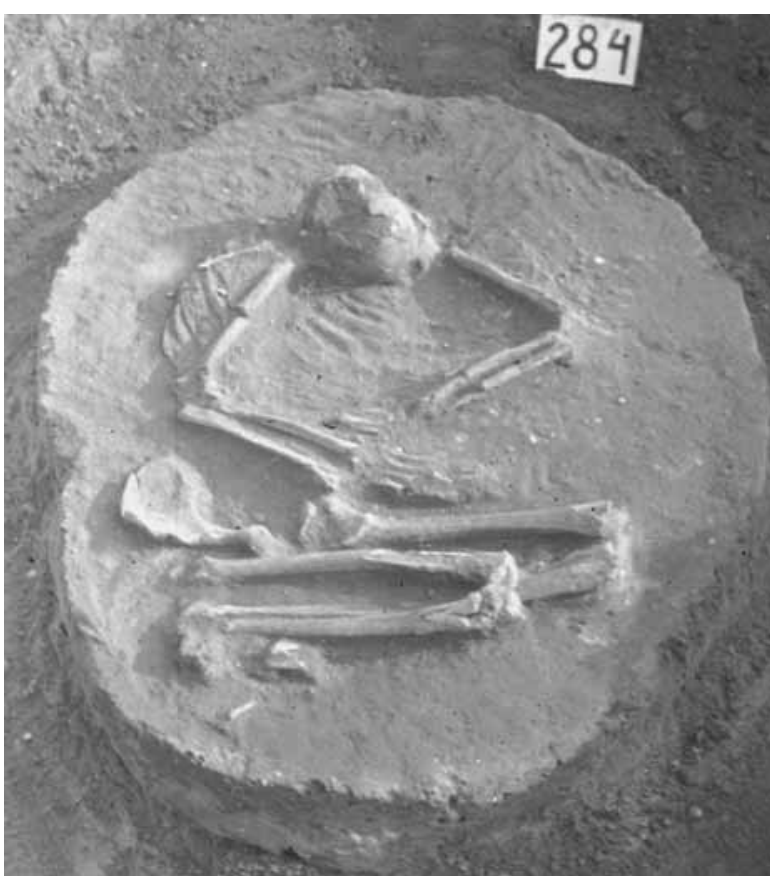


Age at death: $30-40$ years

Sex: female

Condition of skeleton: badly preserved

Preserved skeletal bones: skull, long bone fragments

Inhumation burial in an oval grave pit. The body was laid on the left side in a contracted position. The skull lay on the occipital bone with the face toward the west. The upper part of the skull was destroyed by ploughing. The right arm was bent at the elbow and the hand placed by the left thigh. The left arm was bent at the elbow, with the hand laid by the right wrist. The thighs were drawn up into a horizontal position, the legs were bent back toward the buttocks.

The burial contained the following grave goods: a necklace (1) of thirty-two Dentalium beads and sixtythree assorted beads around the neck, along the spine and on the chest. A copper bead had also been strung among the shells, but it had crumbled away.

Grave goods

1. Beads. Twenty-three Dentalium badense beads and fifty-one limestone beads of varying sizes. Inv. no. 61.2.94 (Pl. CXIII. 284/1). ${ }^{210}$

\section{Grave 285 (Square E6; Pl. CXII)}

Size of grave pit: L. $73 \mathrm{~cm}, W .68 \mathrm{~cm}$ Depth: $68 \mathrm{~cm}$

Orientation: SW to NE, with the head toward the SW

Position of skeleton: laid on the left side

L. of skeleton (contracted): $54 \mathrm{~cm}$

L. of skeleton (extended): -

Age at death: $2-3$ years

Sex: child

Condition of skeleton: badly preserved

Preserved skeletal bones: skull, long bone fragments

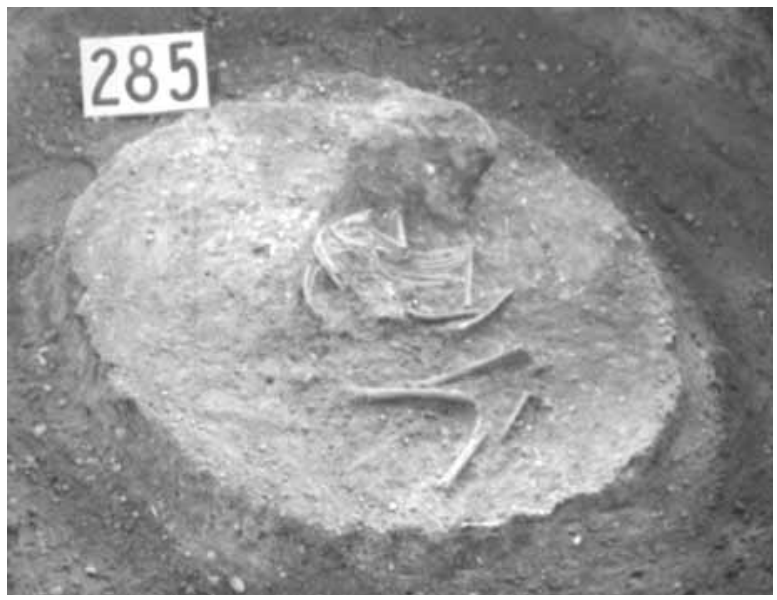

Inhumation burial in a round grave pit containing stones between -40 and $-50 \mathrm{~cm}$. The body was laid on the left side in a contracted position. The skull lay on

210 The number of inventoried beads is lower than the number specified in the excavation diary. the left side. The arms were bent at the elbow and placed in the lap. The thighs were drawn up into a horizontal position, the legs were bent back toward the buttocks.

The burial did not contain any grave goods.

\section{Grave 286 (Square E6; Pl. CXIII)}

Size of grave pit: L. $110 \mathrm{~cm}, W .78 \mathrm{~cm}$

Depth: $85 \mathrm{~cm}$

Orientation: $\mathrm{S}$ to $\mathrm{N}$, with the head toward the $\mathrm{S}$

Position of skeleton: laid on the left side

L. of skeleton (contracted): $50 \mathrm{~cm}$

L. of skeleton (extended): -

Age at death: $1.5-2$ years

Sex: child

Condition of skeleton: badly preserved

Preserved skeletal bones: various fragments

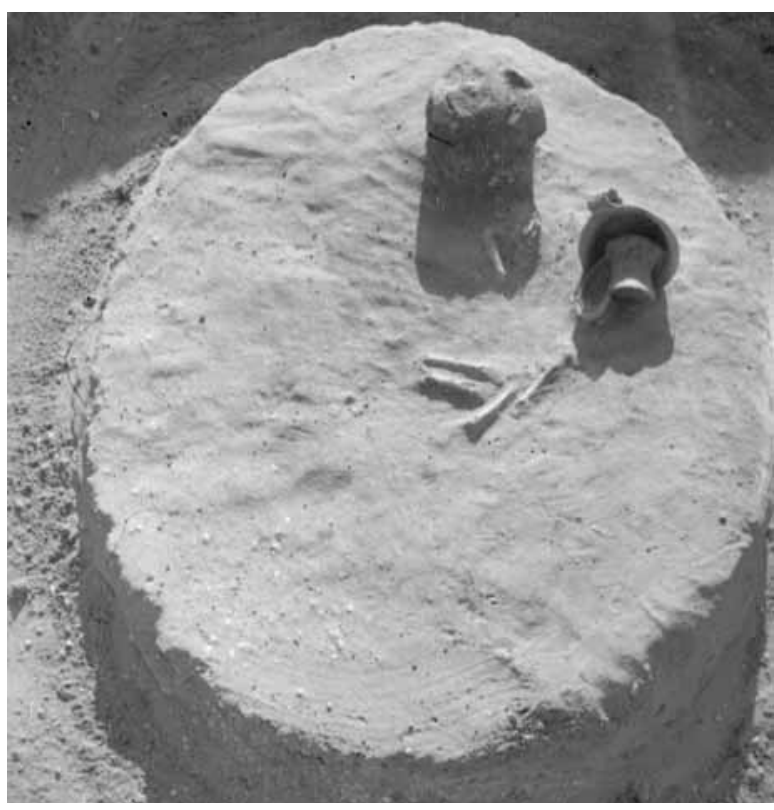

Inhumation burial in an oval grave pit. The body was laid on the left side in a contracted position. The skull was crushed. The right arm was bent at the elbow and drawn up, with the hand placed in front of the face. The thighs were drawn up into a horizontal position, the legs were bent back toward the buttocks.

The burial contained the following grave goods: a small scooping vessel (1) tilted slightly to one side in front of the trunk; a small mug (2) with the mouth facing the knees inside the previous vessel.

\section{Grave goods}

1. Scooping vessel. Brown, polished scooping vessel with flat base. The short strap handle springs from the rim to the shoulder. A row of impressed dots encircles the shoulder and three rows of dots run from the base of the handle to the base. The handle is missing. Joined from its fragments. H. $5.4 \mathrm{~cm}$, dM. 11.8 cm. Inv. no. 61.2.95.1 (Pl. CXIII. 286/1). 
2. Mug. Grey, polished mug with funnel neck and flattened globular body. The handle rises above the rim and springs to the shoulder. The belly was decorated with fluting, now worn. The handle is broken. Joined from its fragments and partially restored. H. $7.5 \mathrm{~cm}$, dM. $5.3 \mathrm{~cm}$. Inv. no. 61.2.95.2 (Pl. CXIII. 286/2).

\section{Grave 287 (Square E6; Pl. CIX)}

Size of grave pit: L. $122 \mathrm{~cm}, W .81 \mathrm{~cm}$ Depth: $130 \mathrm{~cm}$

Orientation: $\mathrm{S}$ to $\mathrm{N}$, with the head toward the $\mathrm{S}$

Position of skeleton: extended on the back

L. of skeleton (contracted): $104 \mathrm{~cm}$

L. of skeleton (extended): $138 \mathrm{~cm}$

Age at death: 23-30 years

Sex: female (?)

Condition of skeleton: badly preserved

Preserved skeletal bones: skull, long bones

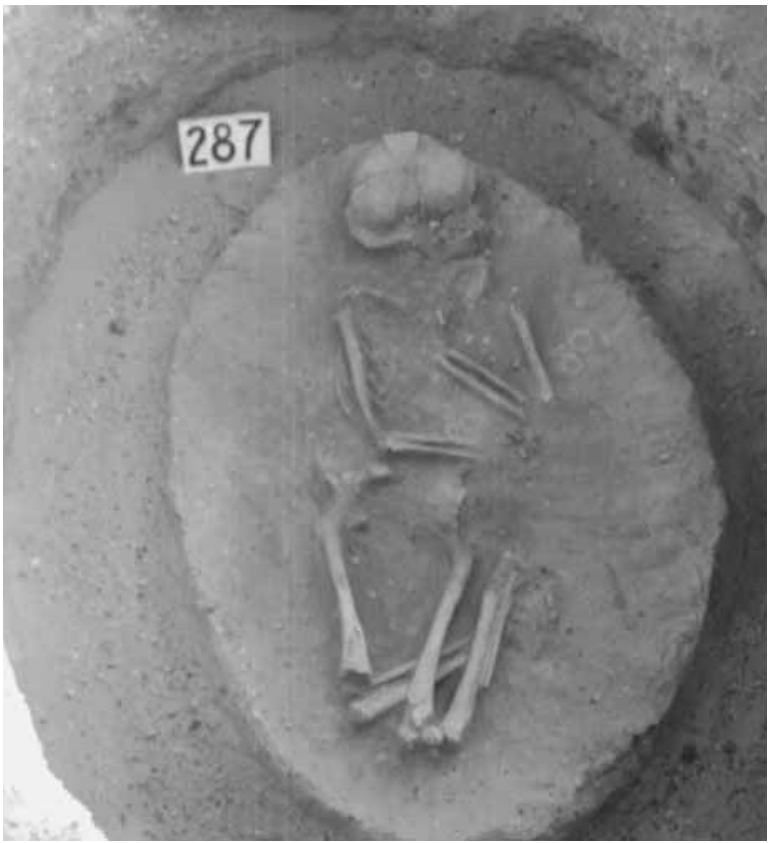

Inhumation burial in an oval grave pit containing two smaller stones lying above the feet between -35 and $-40 \mathrm{~cm}$. The body was deposited in an extended position down to the knees. The skull lay tilted to the left side. The right arm was bent at the elbow, with the hand placed by the left elbow. The left arm was bent at the elbow and the hand laid on the chest. The left leg was bent back with the ankle lying by the upper end of the thigh. The right leg was bent back under the left thigh and the left leg was drawn slightly to the left.

The burial contained the following grave goods: a stone implement (1) $4 \mathrm{~cm}$ south-west of the right elbow.

Grave goods

1. Rectangle. Limnic quartzite. Inv. no. 61.2 .96 (Pl. CIX. 287/1).
Grave 288 (Square E6; Pl. CXII)

Size of grave pit: L. $75 \mathrm{~cm}, W .70 \mathrm{~cm}$

Depth: $100 \mathrm{~cm}$

Orientation: SE to NW, with the head toward the SE

Position of skeleton: laid on the right side

L. of skeleton (contracted): $52 \mathrm{~cm}$

L. of skeleton (extended): $c a .85 \mathrm{~cm}$

Age at death: 2-3 years

Sex: child

Condition of skeleton: badly preserved

Preserved skeletal bones: skull, long bones

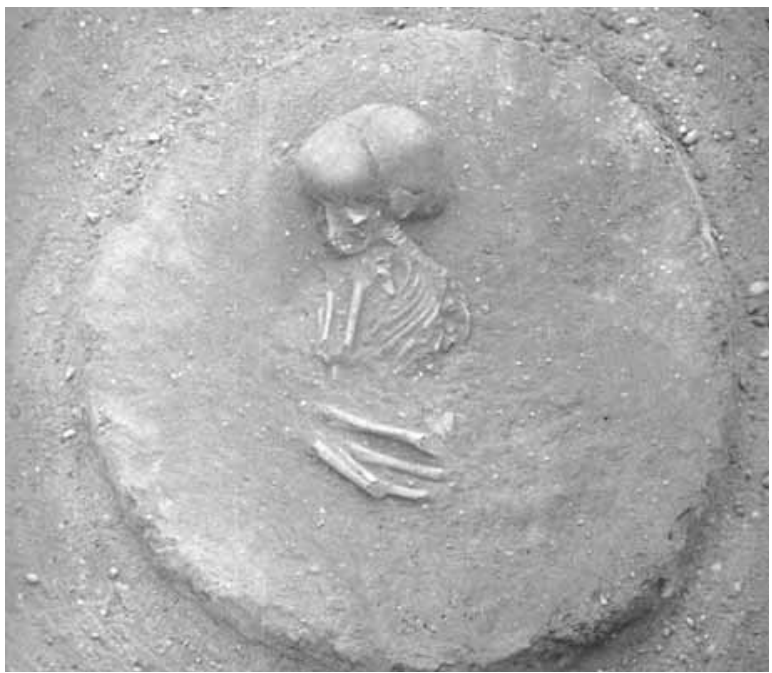

Inhumation burial in a round grave pit containing stones between -40 and $-50 \mathrm{~cm}$. The body was laid on the right side in a contracted position. The crushed skull lay on the right side. The arms were bent at the elbow and drawn up, with the hands placed in front of the face. The thighs were drawn up into a horizontal position, the legs were bent back toward the buttocks.

The burial did not contain any grave goods.

\section{Grave 289 (Square E6; Pl. CXIV)}

Size of grave pit: L. $142 \mathrm{~cm}, W .120 \mathrm{~cm}$ Depth: $80 \mathrm{~cm}$

Orientation: W-SW to E-NE, with the head toward the W-SW Position of skeleton: laid on the right side

L. of skeleton (contracted): $120 \mathrm{~cm}$

L. of skeleton (extended): $152 \mathrm{~cm}$

Age at death: $23-30$ years

Sex: female

Condition of skeleton: well preserved

Preserved skeletal bones: skull, long bones

Inhumation burial in an oval grave pit containing many stones between -10 and $-55 \mathrm{~cm}$. Two smaller areas, each measuring $c a .20-25 \mathrm{~cm}$ in diameter, were devoid of stones (perhaps used for depositing food offerings). Lying among the stones was a broken one-handled mug (1). The body was laid on the right side in a contracted position. The skull was tilted to the right side. The right arm was bent at the elbow and drawn 


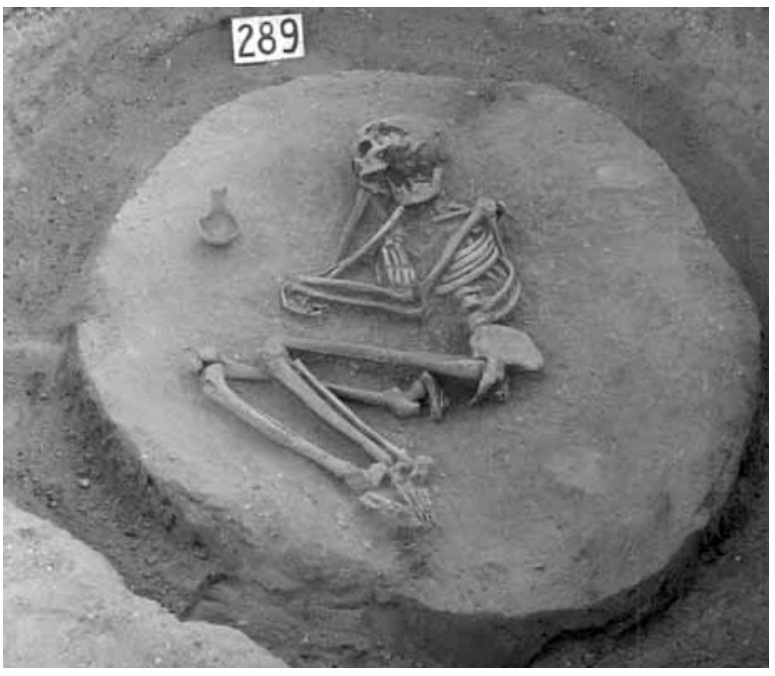

up, with the wrist lying in front of the chin and the hand by the left elbow. The left arm was bent at the elbow, with the wrist placed by the right elbow and the hand bent back. The thighs were drawn up into a horizontal position, the legs were bent back toward the buttocks.

The burial contained the following grave goods: a broken ladle (2) $18 \mathrm{~cm}$ south of the left wrist; the bones of a small ruminant (3) between the mug and the wrist. There was no trace of an animal burrow in this area. The area, which perhaps served for depositing food offerings among the stones, lay above the left shoulder and in the area between the pelvis and the feet.

\section{Grave goods}

1. Mug. Light grey, thin-walled, worn mug with cylindrical neck, flattened globular body and flat base. The handle rises above the rim and springs to the belly a little above the base. Joined from its fragments and restored. H. $5.4 \mathrm{~cm}, \mathrm{dM} .4 .6 \mathrm{~cm}$, dB. 4.5 cm. Inv. no. 61.2.97.1 (Pl. CXIV. 289/1).

2. Ladle. Greyish-brown, worn ladle with two small perforations under the handle's curved terminal. Joined from its fragments and restored. H. $3.5 \mathrm{~cm}$, dM. $7.5 \mathrm{~cm}$, L. of handle $4.7 \mathrm{~cm}, W .3 .2 \mathrm{~cm}$. Inv. no. 61.2.97.3 (Pl. CXIV. 289/2).

3. Animal bones. Bones of a small ruminant. Fourteen pieces. Inv. no. 61.2.97.4 (Pl. CXIV. 289/3).

Other finds from the burial

4. Pot. Indistinct body and base fragments of a reddish, thick-walled pot. L. $6.6 \mathrm{~cm}$. Inv. no. 61.2.97.2.211

\section{Grave 290 (Square G3; Pl. CXIV)}

Size of grave pit: L. $130 \mathrm{~cm}, W .85 \mathrm{~cm}$

Depth: $100 \mathrm{~cm}$

Orientation: A:,$- \mathrm{B}$ : $\mathrm{W}$ to $\mathrm{E}$, with the head toward the $\mathrm{W}$
Position of skeleton: A: -, B: laid on the left side

L. of skeleton (contracted): A:,- B: $88 \mathrm{~cm}$

L. of skeleton (extended): A: -, B: $162 \mathrm{~cm}$

Age at death: A: adult, B: 40-x years

Sex: A: male, B: male

Condition of skeleton: A: badly preserved, B: medium well preserved Preserved skeletal bones: ${ }^{212}$ A: skull , B: skull, long bones

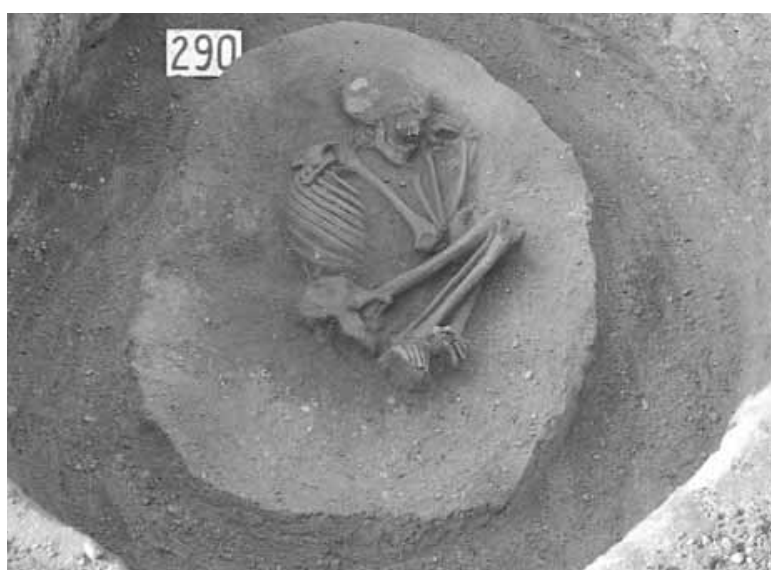

Double inhumation burial in an oval grave pit containing stones from $-60 \mathrm{~cm}$ downward to the bodies. One of the burials was a skull burial.

\section{Burial A}

An adult's crushed skull lay in the grave pit's eastern end at a depth of $-55 \mathrm{~cm}$. The skull lay on the occipital bone.

The burial did not contain any grave goods.

\section{Burial B}

The body was laid on the left side in a contracted position. The skull was completely crushed by the stones; it had probably lain on the left side. The arms were bent at the elbow and drawn up, with the hands placed in front of the chin. The thighs were drawn up in front of the body, the legs were bent back toward the buttocks. The ankles were placed one over the other (they had perhaps been tied together).

The burial contained the following grave goods: five beads (1) around the neck.

Grave goods

1. Beads. Five limestone beads. Inv. no. 61.2.98 (Pl. CXIV. 290/1)

\section{Grave 291 (Square G3/H3; Pl. CXIV)}

Size of grave pit: L. $70 \mathrm{~cm}, W .70 \mathrm{~cm}$

Depth: $45 \mathrm{~cm}$

Orientation: SE to NW, with the head toward the SE

Position of skeleton: laid on the right side

L. of skeleton (contracted): $55 \mathrm{~cm}$

L. of skeleton (extended): anthropological data are quoted from the excavation diary. 
Age at death: $1-7$ years

Sex: child

Condition of skeleton: badly preserved

Preserved skeletal bones: various fragments

Inhumation burial in a round grave pit containing stones from $-20 \mathrm{~cm}$ downward. The stones lay on the body. The body was laid on the right side in a contracted position. Little survived of the skeletal remains. The arms were probably drawn up in front of the face. The thighs were drawn up in front of the body, the legs were bent back toward the buttocks.

The burial contained the following grave goods: two Dentalium beads and one other bead (1) around the waist; a tubular copper bead (2) on the neck; a stone blade (3) under the head.

Grave goods

1. Beads. Two Dentalium badense beads and snail bead. Inv. no. 61.2.99.1 (Pl. CXIV. 291/1).

2. Bead. Tubular copper bead. L. $2.9 \mathrm{~cm}$. Inv. no. 61.2.99.2.213

3. Unretouched radiolarite blade. Inv. no. 61.2.99.3.

\section{Grave 292 (Square E5; Pl. CXV)}

Size of grave pit: L. $120 \mathrm{~cm}, W .113 \mathrm{~cm}$ Depth: $97 \mathrm{~cm}$

Orientation: E-SE to W-NW, with the head toward the E-SE

Position of skeleton: laid on the left side

L. of skeleton (contracted): $109 \mathrm{~cm}$

L. of skeleton (extended): $152 \mathrm{~cm}$

Age at death: $30-50$ years

Sex: female

Condition of skeleton: medium well preserved

Preserved skeletal bones: complete skeleton

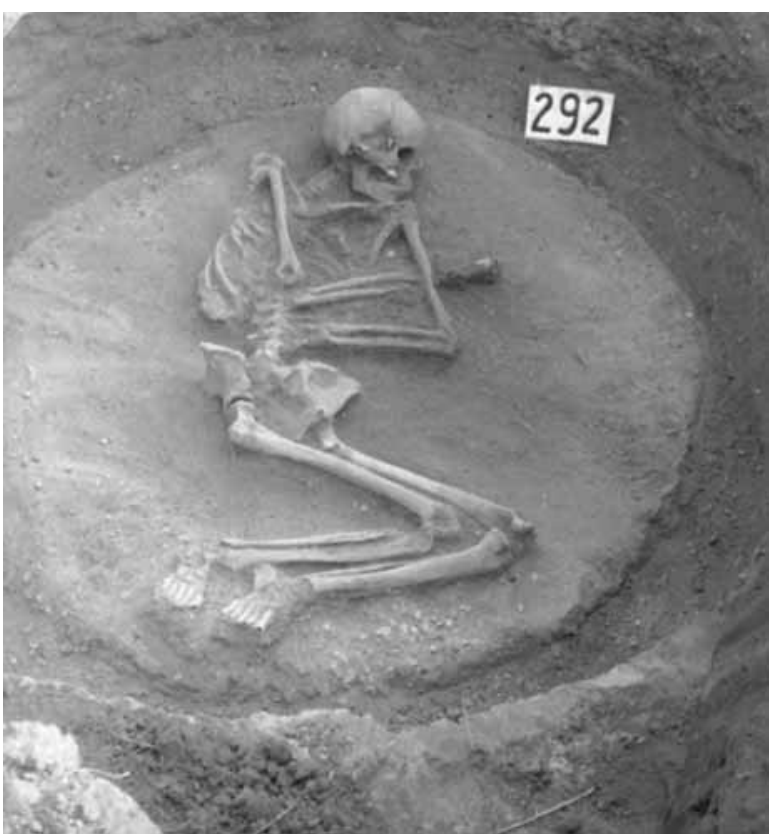

$\overline{213}$ The object has since been lost or mislaid. Its description is quoted from the acquisitions register.
Inhumation burial in a rounded grave pit. The body was laid on the left side in a contracted position. The skull lay on the left side. The arms were bent at the elbow and crossed over the chest. The thighs were moderately drawn up, the legs were bent back toward the buttocks.

The burial did not contain any grave goods.

\section{Grave 293 (Square G3)}

Size of grave pit: L. $65 \mathrm{~cm}, W .65 \mathrm{~cm}$

Depth: $68 \mathrm{~cm}$

Orientation: $\mathrm{S}$ to $\mathrm{N}$, with the head toward the $\mathrm{S}$

Position of skeleton: laid on the right side

L. of skeleton (contracted): -

L. of skeleton (extended): -

Age at death: $0-1$ years

Sex: child

Condition of skeleton: badly preserved

Preserved skeletal bones: various fragments

Inhumation burial in a round grave pit containing stones from $-30 \mathrm{~cm}$ downward. The stones lay on the body. Only the position of the skull and a few fragments could be recorded. The skull lay on the right side. The body was laid on the right side in a contracted position.

The burial did not contain any grave goods.

Grave 294 (Square E5; Pl. CXV)

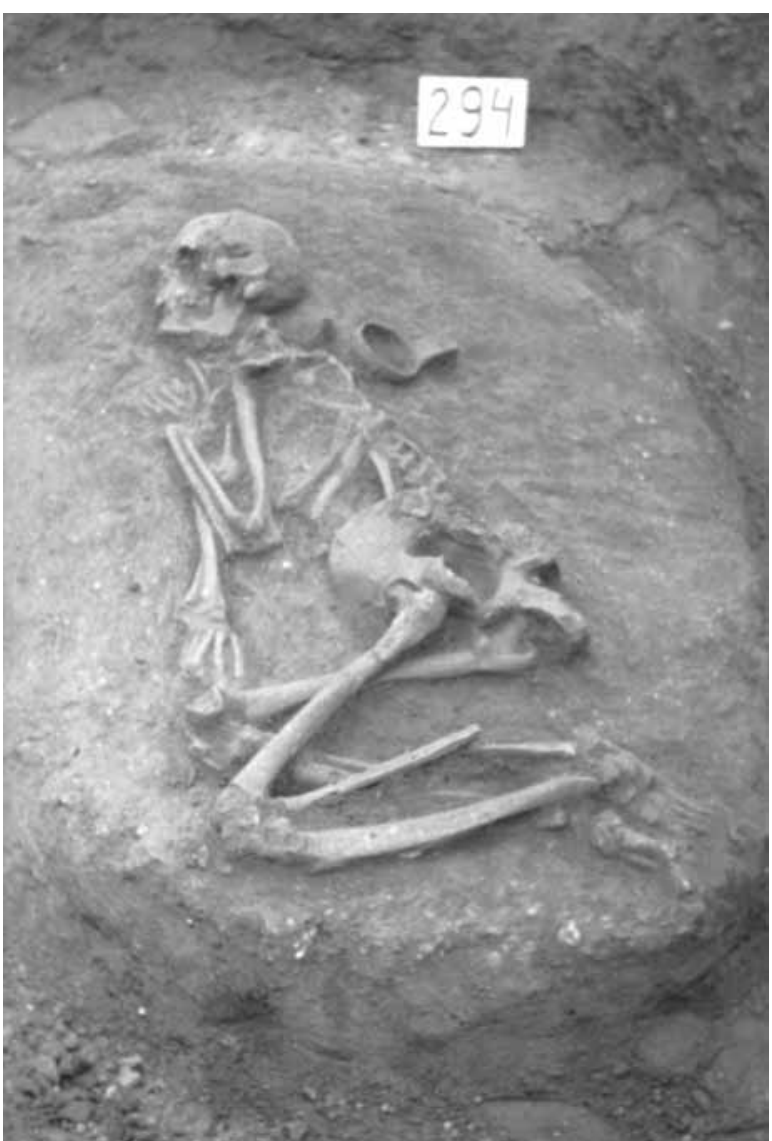


Size of grave pit: L. $135 \mathrm{~cm}$, W. $90 \mathrm{~cm}$

Depth: $65 \mathrm{~cm}$

Orientation: SW to NE, with the head toward the SW

Position of skeleton: laid on the right side

L. of skeleton (contracted): $111 \mathrm{~cm}$

L. of skeleton (extended): $157 \mathrm{~cm}$

Age at death: $25-35$ years

Sex: male

Condition of skeleton: medium well preserved

Preserved skeletal bones: complete skeleton

Inhumation burial in an oval grave pit. The body was laid on the right side in a contracted position. The skull lay on the right side. The left arm was bent at the elbow and drawn up, with the hand placed in front of the chin. The right arm was extended and the hand laid by the right knee. The right thigh was drawn up into a horizontal position, the left one more moderately, the legs were bent back toward the buttocks. The ankles rested one over the other.

The burial contained the following grave goods: a ladle (1) with the handle lying toward the edge of the grave pit behind the shoulders.

\section{Grave goods}

1. Ladle. Brown, worn, plain ladle with two small holes under the curved upper end of the handle. The handle is joined from smaller fragments. $H .3 .5 \mathrm{~cm}$, dM. $9.5 \mathrm{~cm}$, L. of handle $5.5 \mathrm{~cm}, W$. of handle $3.6 \mathrm{~cm}$. Inv. no. 61.2.100 (Pl. CXV. 294/1).

\section{Grave 295 (Square G3; Pl. CXV)}

Size of grave pit: L. $102 \mathrm{~cm}, W .86 \mathrm{~cm}$ Depth: $102 \mathrm{~cm}$

Orientation: $\mathrm{S}$ to $\mathrm{N}$, with the head toward the $\mathrm{S}$

Position of skeleton: laid on the left side

L. of skeleton (contracted): $86 \mathrm{~cm}$

L. of skeleton (extended): $153 \mathrm{~cm}$

Age at death: $40-x$ years

Sex: female

Condition of skeleton: medium well preserved

Preserved skeletal bones: complete skeleton

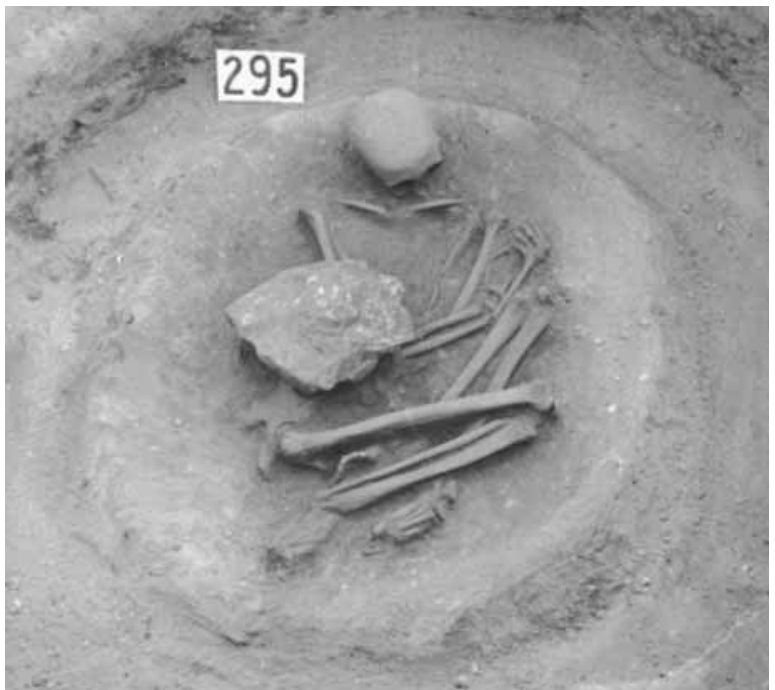

Inhumation burial in an oval grave pit containing stones between -25 and $-100 \mathrm{~cm}$. The stones lay on the skeleton. A broken vessel (1) lay among the stones in the grave pit's western part. The body was laid on the left side in a contracted position. The skull lay on the occipital bone with the face toward the north-west. The trunk lay tilted to one side. The left arm was bent at the elbow and drawn up, with the hand resting by the shoulder. The right arm was bent at the elbow and drawn up, with the hand placed between the left forearm and the upper arm. The thighs were drawn up in front of the body, the left one lying higher, the legs were bent back toward the buttocks. Patches of burnt earth were noted by the right shoulder and around the trunk.

The burial contained no other finds beside the vessel mentioned above.

Finds from the grave pit

1. Scooping vessel. Brownish, conical, thick-walled, plain scooping vessel. The handle rises above the rim and springs to the base. The handle is broken. Joined from its fragments and restored. H. $5.6 \mathrm{~cm}$, dM. 11.8 cm, dB. 6.4 cm. Inv. no. 61.2.101 (Pl. CXV. 295/1).

\section{Grave 296 (Square H3)}

Size of grave pit: diam. $50 \mathrm{~cm}$

Depth: $43 \mathrm{~cm}$

Orientation: -

Position of skeleton: -

L. of skeleton (contracted): -

L. of skeleton (extended): -

Age at death: $23-x$ years

Sex: -

Condition of skeleton: -

Preserved skeletal bones: various fragments

Scattered cremation burial in a round grave pit containing stones from $-20 \mathrm{~cm}$ downward. The calcinated bone fragments were placed under a large flat stone on the grave pit's floor.

The burial did not contain any grave goods.

\section{Grave 297 (Square D6; Pl. CXVI)}

Size of grave pit: L. $52 \mathrm{~cm}$, W. 60

Depth: $55 \mathrm{~cm}$

Orientation: SW to NE, with the head toward the SW

Position of skeleton: laid on the right side

L. of skeleton (contracted): $40 \mathrm{~cm}$

L. of skeleton (extended): -

Age at death: -

Sex: child

Condition of skeleton: badly preserved

Preserved skeletal bones: ${ }^{214}$ skull, long bone fragments

$\overline{214}$ The skeletal remains can no longer be found. The anthropological data are quoted from the excavation diary. 
Inhumation burial in a round grave pit containing stones from $-20 \mathrm{~cm}$ downward. The stones lay on the body. The body was laid on the right side in a strongly contracted position. The crushed skull lay on the occipital bone. The right arm was bent at the elbow and drawn up, with the hand placed in front of the chin. The left arm was extended toward the thigh. The thighs were drawn up in front of the body, the legs were bent back toward the buttocks.

The burial did not contain any grave goods.

\section{Grave 298 (Square D6; Pl. CXVI)}

Size of grave pit: -

Depth: $42 \mathrm{~cm}$

Orientation: -

Position of skeleton: -

L. of skeleton (contracted): -

L. of skeleton (extended): -

Age at death: -

Sex: child

Condition of skeleton: -

Preserved skeletal bones: ${ }^{215}$ various fragments

Scattered cremation burial. There was no indication of a grave pit. Calcinated bone fragments lay over an area with a diameter of $50 \mathrm{~cm}$. Some of the bone fragments were displaced by an animal burrow. Indistinct pottery sherds (1) lay among the bone fragments.

Finds from the burial

1. Pot. Fragments of a reddish-brown pot. Five nonjoining pieces. Inv. no. 61.2.102 (Pl. CXVI. 298/1).

\section{Grave 299 (Square E6; Pl. CXVI)}

Size of grave pit: L. $56 \mathrm{~cm}, W .40 \mathrm{~cm}$

Depth: $65 \mathrm{~cm}$

Orientation: NE to SW, with the head toward the NE

Position of skeleton: laid on the left side

L. of skeleton (contracted): $35 \mathrm{~cm}$

L. of skeleton (extended): -

Age at death: infans I

Sex: child

Condition of skeleton: badly preserved

Preserved skeletal bones: ${ }^{216}$ various fragments

Inhumation burial in an oval grave pit. The body was laid on the left side in a contracted position. Only the position of the fragmented skull and the feet could be recorded. The thighs were drawn up into a horizontal position, the legs were bent back toward the buttocks. The burial lay under Grave 297.

The burial did not contain any grave goods.

\footnotetext{
215 The skeletal remains can no longer be found. The anthropological data are quoted from the excavation diary.

216 The skeletal remains can no longer be found. The anthropological data are quoted from the excavation diary.
}

Grave 300 (Square D6; Pl. CXVI)

Size of grave pit: L. $85 \mathrm{~cm}, W .70 \mathrm{~cm}$

Depth: $86 \mathrm{~cm}$

Orientation: $\mathrm{S}$ to $\mathrm{N}$, with the head toward the $\mathrm{S}$

Position of skeleton: laid on the right side

L. of skeleton (contracted): $57 \mathrm{~cm}$

L. of skeleton (extended): -

Age at death: 3-4 years

Sex: child

Condition of skeleton: medium well preserved

Preserved skeletal bones: complete skeleton

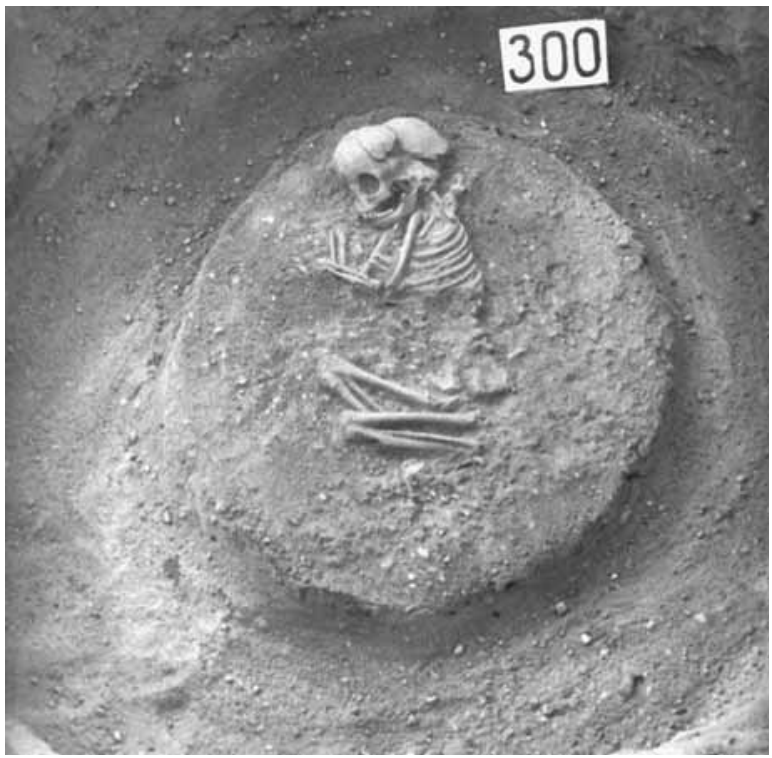

Inhumation burial in a roughly round grave pit. The grave pit lay under Grave 298 (a cremation burial). The body was laid on the right side in a contracted position. The crushed skull lay on the right side. The right arm was bent at the elbow and drawn up, with the hand placed in front of the face. The left arm was bent at the elbow. The right thigh was drawn up in front of the body, the left one into a horizontal position, the legs were bent back toward the buttocks.

The burial did not contain any grave goods.

\section{Grave 301 (Square D6; Pl. CXVI)}

Size of grave pit: L. $77 \mathrm{~cm}$, W. 77

Depth: $80 \mathrm{~cm}$

Orientation: SE to NW, with the head toward the SE

Position of skeleton: laid on the right side

L. of skeleton (contracted): $53 \mathrm{~cm}$

L. of skeleton (extended): -

Age at death: $0-0.5$ years

Sex: child

Condition of skeleton: badly preserved

Preserved skeletal bones: various fragments

Inhumation burial in a round grave pit. The body was laid on the right side in a contracted position. The crushed skull lay on the right side. The left arm was bent at the elbow and drawn up, with the hand placed 


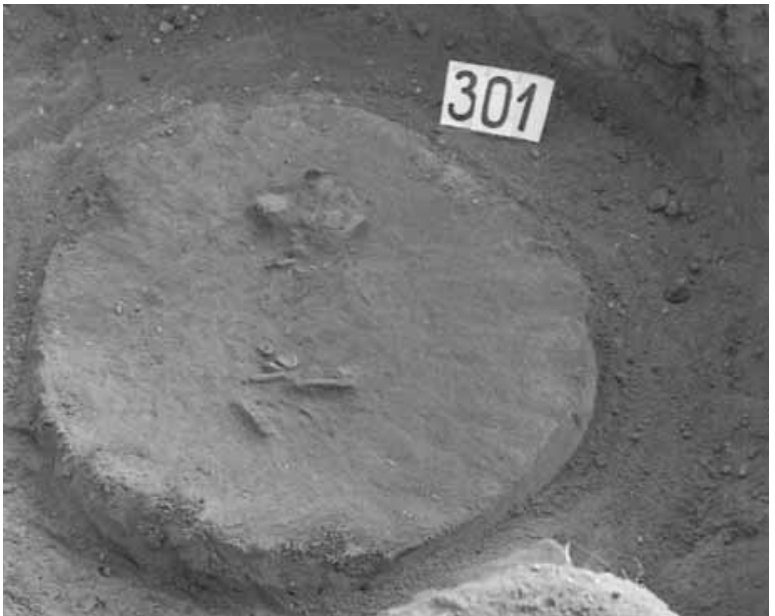

in front of the chin. The thighs were drawn up into a horizontal position, the legs were bent back toward the buttocks.

The burial contained the following grave goods: three shells (1) by the right thigh; six shell beads and five broken tubular copper beads (2) on the neck. The copper beads were slipped inside the shell beads.

Grave goods

1. Shells. Three perforated Anadara diluvii shells. Inv. no. 61.2.103.1 (Pl. CXVI. 301/1).217

2. Beads. Six Dentalium badense beads and five tubular beads of sheet copper. The copper beads were slipped inside the Dentalium beads. Copper oxide stains can be noted on the ends of the Dentalium beads. Inv. no. 61.2.103.2 (Pl. CXVI. 301/2).218

\section{Grave 302 (Square D6; Pl. CXVI)}

Size of grave pit: L. $60 \mathrm{~cm}, W .60 \mathrm{~cm}$

Depth: $80 \mathrm{~cm}$

Orientation: S-SE to N-NW, with the head toward the S-SE Position of skeleton: extended on the back (?)

L. of skeleton (contracted): $40 \mathrm{~cm}$ (surviving section)

L. of skeleton (extended): -

Age at death: $0-1$ years

Sex: child

Condition of skeleton: badly preserved

Preserved skeletal bones: various fragments

Disturbed inhumation burial in a round grave pit containing a stone at a depth of $-50 \mathrm{~cm}$. The body was probably laid extended on the back. The area of the buttocks lay slightly lower than the other skeletal remains. The legs were placed apart. Only the position of a few fragmentary bones could be recorded.

The burial did not contain any grave goods.

\footnotetext{
217 Four shells were inventoried because one of them broke in two. The two fragments were joined before the grave goods were drawn.

218 According to the entry in the acquisitions register, a thread of plant fibre survived in one of the copper beads. The photo is based on the metallurgical report in the Szentendre museum (SzFM Archives, inv. no. 1170/76, report prepared by Dr. Manfred Schröder).
}

Grave 303 (Square D5/D6; Pl. CXVII)

Size of grave pit: L. $120 \mathrm{~cm}, W .100 \mathrm{~cm}$

Depth: $95 \mathrm{~cm}$

Orientation: S to N, with the head toward the S

Position of skeleton: laid on the left side

L. of skeleton (contracted): $92 \mathrm{~cm}$

L. of skeleton (extended): $138 \mathrm{~cm}$

Age at death: $17-20$ years

Sex: female

Condition of skeleton: medium well preserved

Preserved skeletal bones: complete skeleton

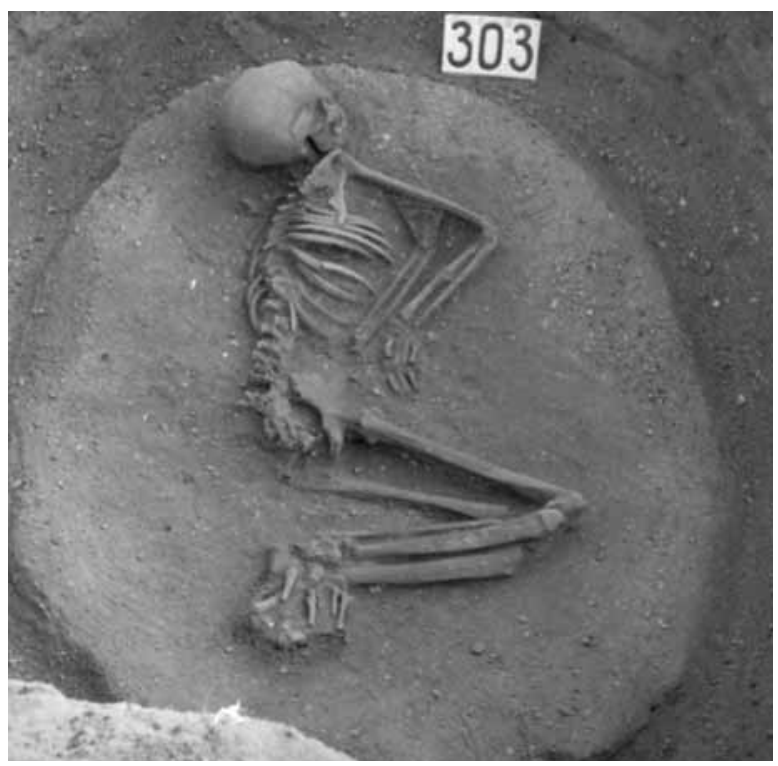

Inhumation burial in an oval grave pit containing stones at a depth of -40 to $-50 \mathrm{~cm}$ and a single stone directly above the feet. The body was laid on the left side in a contracted position. The skull lay on the occipital bone tilted slightly to one side, with the face toward the south-west. The left arm was bent at the elbow and drawn up, with the hand placed under the right armpit. The right arm was bent inward at the elbow, with the hand resting palm upward. The thighs were moderately drawn up, the legs were bent back toward the buttocks. The ankles were laid one over the other.

Finds from the grave pit

1. Mug. Body and handle fragments of a brownish, worn mug with flattened globular body decorated with barely visible fluting. Three non-joining pieces. Inv. no. 61.2.104 (Pl. CXVII. 303/1).

\section{Grave 304 (Square E6)}

Size of grave pit: W. $24 \mathrm{~cm}$ Depth: $45 \mathrm{~cm}$

Orientation: -

Position of skeleton: -

L. of skeleton (contracted): -

L. of skeleton (extended): -

Age at death: 23-39 years

Sex: male (?) 
Condition of skeleton:-

Preserved skeletal bones: calcinated bone fragments

Scattered cremation burial. Calcinated bone fragments lay over an area with a diameter of $24 \mathrm{~cm}$.

The burial did not contain any grave goods.

\section{Grave 305 (Square E7)}

Size of grave pit: L. $51 \mathrm{~cm}, W .43 \mathrm{~cm}$

Depth: $64 \mathrm{~cm}$

Orientation: SE to NW, with the head toward the SE

Position of skeleton: laid on the right side (?)

L. of skeleton (contracted): $33 \mathrm{~cm}$

L. of skeleton (extended): -

Age at death: $0-1$ years

Sex: infant

Condition of skeleton: badly preserved

Preserved skeletal bones: various fragments

Inhumation burial in an almost round grave pit. The body of the newborn infant was probably laid on the right side. The thighs were drawn up. Only very small bone fragments survived.

The burial did not contain any grave goods.

\section{Grave 306 (Square E7; Pl. CXVII)}

Size of grave pit: L. $58 \mathrm{~cm}, W .48 \mathrm{~cm}$

Depth: $56 \mathrm{~cm}$

Orientation: E-SE to W-NW, with the head toward the E-SE

Position of skeleton: laid on the left side

L. of skeleton (contracted): $35 \mathrm{~cm}$

L. of skeleton (extended): -

Age at death: $0-1$ years

Sex: child

Condition of skeleton: badly preserved

Preserved skeletal bones: various fragments

Inhumation burial in an oval grave pit. The body was laid on the left side in a contracted position. The skull, the upper arms and one of the thighbones are all that survived of the skeletal remains.

The burial contained the following grave goods: a pot (1) tilted to one side at a depth of $-48 \mathrm{~cm}$ in the area above the skull; a small mug (2) tilted to one side under the previous vessel.

Grave goods

1. Pot. Reddish-brown, worn, plain pot with an elongated $S$ profile decorated with three small knobs under the rim. H. $14 \mathrm{~cm}, \mathrm{dM} .14 \mathrm{~cm}, \mathrm{~dB} .6 .5 \mathrm{~cm}$. Inv. no. 61.2.105.1 (Pl. CXVII. 306/1).

2. Mug. Fragments of a dark grey, worn mug with cylindrical neck and flattened globular body. The handles rises above the rim and springs to the shoulder. The body and the handle are decorated with fluting. Joined from its fragments. H. $6.2 \mathrm{~cm}$, dM. 4.1 cm. Inv. no. 61.2.105.2 (Pl. CXVII. 306/2).
Grave 307 (Square E7)

Size of grave pit: diam. $30 \mathrm{~cm}$

Depth: $45 \mathrm{~cm}$

Orientation:-

Position of skeleton: -

L. of skeleton (contracted): -

L. of skeleton (extended): -

Age at death: $15-59$ years

Sex: female (?)

Condition of skeleton: -

Preserved skeletal bones: various fragments

Scattered cremation burial. Calcinated bone fragments lay over an area with a diameter of $30 \mathrm{~cm}$.

The burial did not contain any grave goods.

\section{Grave 308 (Square E8; Pl. CXVII)}

Size of grave pit: L. $141 \mathrm{~cm}, W .162 \mathrm{~cm}$

Depth: $78 \mathrm{~cm}$

Orientation: E-SE to W-NW, with the head toward the E-SE

Position of skeleton: laid on the left side

L. of skeleton (contracted): $95 \mathrm{~cm}$

L. of skeleton (extended): $158 \mathrm{~cm}$

Age at death: $23-30$ years

Sex: male

Condition of skeleton: well preserved

Preserved skeletal bones: complete skeleton

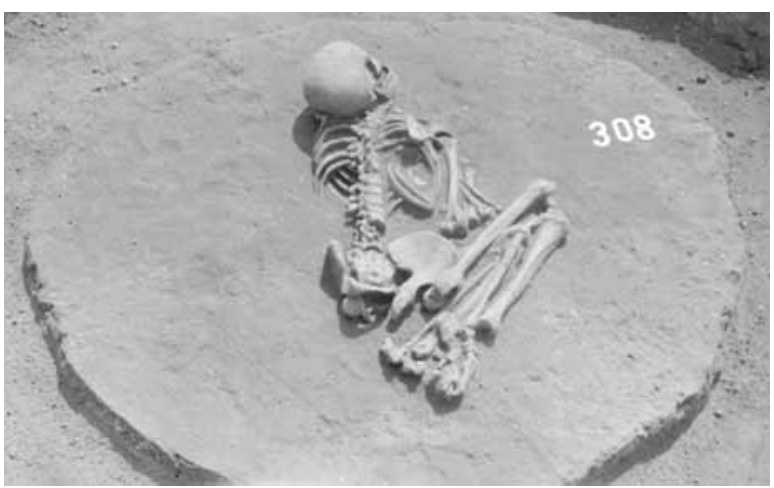

Inhumation burial in a roughly round grave pit. The body was laid on the left side in a contracted position. The skull rested on the occipital bone with the face toward the south-south-east. The trunk was laid prone. The arms were bent at the elbow and drawn up, with the hands placed under the shoulders. The thighs were drawn up in front of the body, the legs were bent back toward the buttocks. The feet were placed on over the other. The trunk probably turned over after the deposition of the body.

The burial did not contain any grave goods.

\section{Grave 309 (Square F9; Pl. CXVIII)}

Size of grave pit: L. $113 \mathrm{~cm}, W .87 \mathrm{~cm}$

Depth: $128 \mathrm{~cm}$

Orientation: S-SW to N-NE, with the head toward the S-SW

Position of skeleton: laid on the left side 
L. of skeleton (contracted): $93 \mathrm{~cm}$

L. of skeleton (extended): $151 \mathrm{~cm}$

Age at death: $35-45$ years

Sex: female

Condition of skeleton: badly preserved

Preserved skeletal bones: skull, long bones

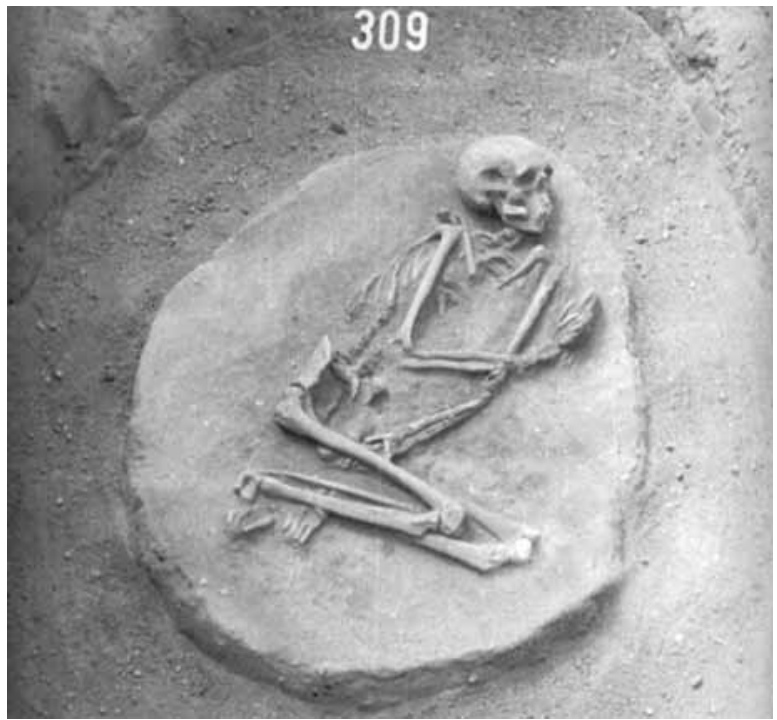

Inhumation burial in an oval grave pit. The body was laid on the left side in a contracted position. The skull lay on the left side. The left arm was slightly bent at the elbow, with the hand resting on the pelvis and between the two thighs. The right arm was bent at the elbow and placed on the left upper arm. The thighs were drawn up into a horizontal position, the legs were bent back toward the buttocks.

The burial contained the following grave goods: a rectangular red stone (1) on the right side of the mandible; animal ribs (2) in and above the right hand, which lay in anatomical order, suggesting that a chunk of meat had been placed in the grave; nine broken snail beads (3) by the mid-section of the left forearm, either dress ornaments or the remains of a bracelet.

Grave goods

1. Stone. Rectangular red stone with one side polished smooth. L. $4.2 \mathrm{~cm}, W .1 .7 \mathrm{~cm}$, Th. $1.3 \mathrm{~cm}$. Inv. no. 61.2.106.1 (Pl. CXVIII. 309/1).219

2. Animal bones. ${ }^{220}$

3. Nine small Lithoglyphus naticoides snails, now broken. Inv. no. 61.2.106.2 (Pl. CXVIII. 309/3).

\section{Grave 310 (Square E9; Pls $C X X-C X X I$ )}

Size of grave pit: L. $73 \mathrm{~cm}, W .55 \mathrm{~cm}$

Depth: $102 \mathrm{~cm}$

Orientation: $W-\mathrm{NW}$ to E-SE, with the head toward the $\mathrm{W}-\mathrm{NW}$ Position of skeleton: laid on the right side (?)

\footnotetext{
219 The object has since been lost or mislaid. Its description is quoted from the acquisitions register. A photo of this object was found among the photos made by József Korek in the Archives of the Szentendre museum. 220 The animal bones were not inventoried.
}

L. of skeleton (contracted): $33 \mathrm{~cm}$

L. of skeleton (extended): -

Age at death: $40-59$ years

Sex: female

Condition of skeleton: badly preserved

Preserved skeletal bones: various fragments

Inhumation burial in an oval grave pit. The body had probably been laid on the right side in a contracted position. The trunk is all that survived, the legs decayed.

The burial contained the following grave goods: fragments of a bipartite bowl (1); vessel fragments (2-3) lying between -30 and $-50 \mathrm{~cm}$; a scooping vessel (4) tilted to one side with the mouth toward the skull $5 \mathrm{~cm}$ south-east of the pelvis.

Grave goods

1. Bipartite bowl. Fragment of the inner dividing wall and base of a dark grey, thick-walled bipartite bowl, decorated with two rows of impressed dots. L. $9.5 \mathrm{~cm}$, $6.1 \mathrm{~cm}$. Inv. no. 61.2.107.1 (Pl. CXX. 310/1).

2. Pot. Body and base fragments of a greyish-red, thick-walled pot. One fragment has a knob on it. Six non-joining pieces, one joined from two smaller fragments. Inv. no. 61.2.107.2 (Pl. CXXI. 310/2).

3. Pitcher. Non-joining rim, neck and body fragments of a greyish-brown, strongly worn pitcher. Five pieces. Inv. no. 61.2.107.3 (Pl. CXX. 310/3).

4. Scooping vessel. Brownish, worn scooping vessel with flate base. The exterior is plain, the interior bears a design of bundles of smoothed-in lines forming a cross. The short strap handle spans the rim and the belly. Joined from its fragments and restored. H. $5 \mathrm{~cm}$, dM. $12.9 \mathrm{~cm}, \mathrm{~dB} .6 .5 \mathrm{~cm}$. Inv. no. 61.2.107.4 (Pl. CXX. 310/4).

\section{Grave 311 (Square F9; Pl. CXVIII)}

Size of grave pit: L. $96 \mathrm{~cm}, W .68 \mathrm{~cm}$

Depth: $95 \mathrm{~cm}$

Orientation of grave pit: S-SE to N-NW.

Position of skeleton: -

L. of skeleton (contracted): -

L. of skeleton (extended): -

Age at death: -

Sex:-

Condition of skeleton: -

Preserved skeletal bones:-

Symbolic burial in an oval grave pit. No skeletal remains were found in the grave pit.

The burial contained the following grave goods: pot fragments (1) at a depth of $-40 \mathrm{~cm}$; a mug (2) with the mouth toward the south-south-east in the grave pit's south-south-eastern end at a depth of $-95 \mathrm{~cm}$; a pitcher fragment (3) beside the previous vessel.

\section{Grave goods}

1. Pot. Body and base sherd of a reddish, thick-walled pot. L. 5 cm. Inv. no. 61.2.108.1 (Pl. CXVIII. 311/1). 
2. Mug. Grey, worn mug with cylindrical neck and flattened globular body. The handle rises above the rim and springs to the shoulder. The base of the handle is decorated with four incised lines. The rim is damaged. H. $7.4 \mathrm{~cm}, \mathrm{dM} .5 .1 \mathrm{~cm}$. Inv. no. 61.2.108.2 (Pl. CXVIII. 311/2).

3. Pitcher. Neck fragment of a grey, thin-walled, polished pitcher decorated with alternating oblique fluting. L. $5.6 \mathrm{~cm}$. Inv. no. 61.2.108.3 (Pl. CXVIII. 311/3)

\section{Grave 312 (Square E9; Pls CXXII-CXXIII)}

Size of grave pit: L. $118 \mathrm{~cm}, W .95 \mathrm{~cm}$

Depth: $125 \mathrm{~cm}$

Orientation: S-SE to N-NW, with the head toward the S-SE

Position of skeleton: laid on the left side

L. of skeleton (contracted): $60 \mathrm{~cm}$

L. of skeleton (extended): -

Age at death: $1-7$ years

Sex: child

Condition of skeleton: badly preserved

Preserved skeletal bones: various fragments

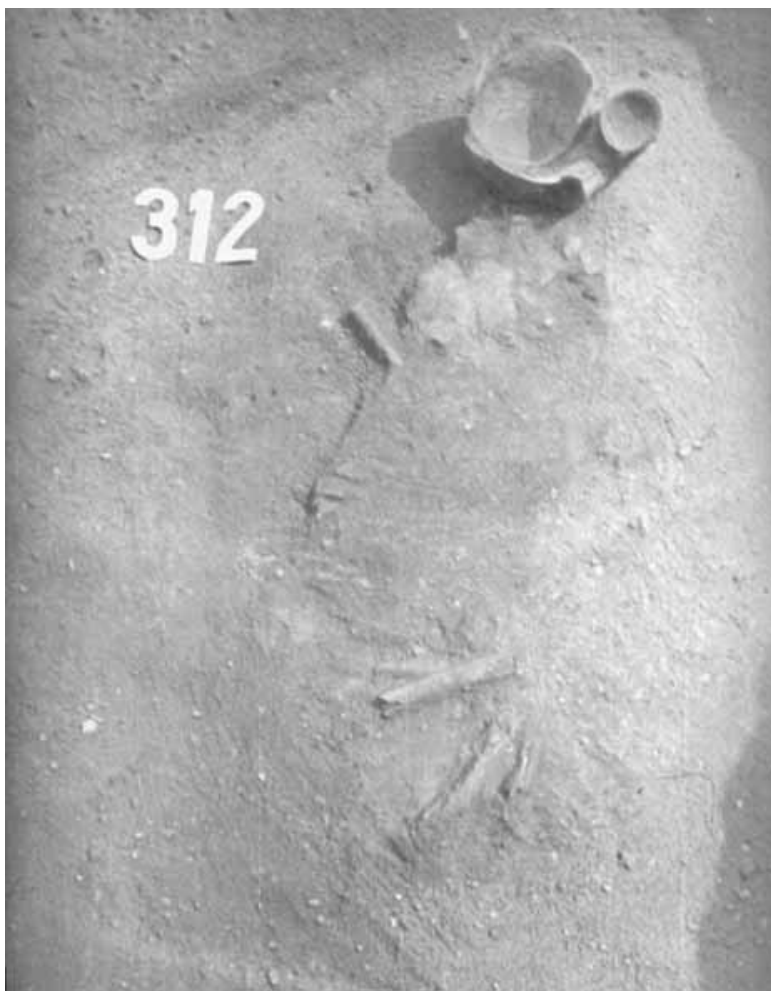

Inhumation burial in an oval grave pit containing stones between -30 and $-50 \mathrm{~cm}$. The body was laid on the left side in a contracted position. The skull was crushed, the skeletal remains were strongly decayed. The right arm was bent at the elbow and drawn up, with the hand placed in front of the mouth. The left arm was extended beside the body. The left thigh was drawn up into a horizontal position, the right one slightly higher, the legs were bent back toward the buttocks.
The burial contained the following grave goods: a jug (1), a bowl fragment (2), pot fragment (3) and a broken quernstone or whetstone (4) among the stones; a cup (5) in the grave pit's south-eastern end at a depth of $-75 \mathrm{~cm}$; vessel fragments (6) at a depth of $-85 \mathrm{~cm}$; a mug (7) set upright and tilted slightly to one side; a broken pot (8) set upright, beside the previous vessel; a bone awl (9) on the base of vessel no. 8, behind and slightly above the skull in the grave pit's south-eastern end.

Grave goods

1. Jug. Neck and body fragment of a grey, thin-walled, worn jug with faint traces of fluting and a thin vertical rib. L. 8 cm. Inv. no. 61.2.109.1 (Pl. CXXII. 312/1).

2. Bowl. Rim and body fragment of a brownish-grey, worn, conical bowl with funnel neck decorated with two rows of impressed dots. L. $9.3 \mathrm{~cm}$. Inv. no. 61.2.109.2 (Pl. CXXII. 312/2, 312/6). ${ }^{221}$

3. Pot. Body and base fragment of a reddish-brown, thick-walled pot. L. $4.3 \mathrm{~cm}$. Inv. no. 61.2.109.3.

4. Quernstone. Fragment of a quernstone with one side polished smooth made from andesite. L. $9 \mathrm{~cm}$, W. $5.6 \mathrm{~cm}$, Th. $2.6 \mathrm{~cm}$. Inv. no. 61.2.109.4 (Pl. CXXIII. 312/4).

5. One-handled cup. Grey, worn, one-handled cup. The belly is encircled by a row of impressed dots and a few dots arranged into a vertical line (spoilt pattern) under the handle, which spans the rim and the belly. Restored. H. $5.6 \mathrm{~cm}, \mathrm{dM} .10 .1 \mathrm{~cm}$. Inv. no. 61.2.109.5 (Pl. CXXIII. 312/5).

6. Bowl. Rim and body sherds of a reddish-brown, thin-walled, worn bowl. One rim fragment has a vertical row of impressed dots. Eleven non-joining pieces. Inv. no. 61.2.109.6 (Pl. CXXII. 312/2, 312/6). ${ }^{222}$

7. Mug. Grey, polished, worn mug with funnel neck and flattened globular body. The handle rises above the rim and springs to the shoulder. The handle and the belly are decorated with fluting. The handle is joined from smaller fragments. H. $8.1 \mathrm{~cm}, \mathrm{~d} M$. $5.6 \mathrm{~cm}$. Inv. no. 61.2.109.7 (Pl. CXXIII. 312/7).

8. One-handled pot. Brownish-grey, polished, onehandled pot decorated with grooving around the belly. The handle rises above the rim and springs to the belly. Joined from its fragments and restored. H. $9.9 \mathrm{~cm}$, dM. $11.3 \mathrm{~cm}$, dB. $5.1 \mathrm{~cm}$. Inv. no. 61.2.109.8 (Pl. CXXIII. 312/8).

9. Bone awl. Awl carved from a small ruminant tibia with traces of sawing on two fragments. Broken in several pieces. Inv. no. 61.2.109.9 (Pl. CXXIII. 312/9).

\section{Grave 313 (Square K2/K3)}

An Early Iron Age inurned burial.

\footnotetext{
221 The pottery fragments inventoried under nos. 61.2.109.2 and 61.2.109.6 came from the same bowl.

222 Currently there are only nine fragments. The pottery fragments inventoried under nos. 61.2.109.2 and 61.2.109.6 came from the same bowl.
} 
Grave 314 (Square E9; Pl. CXXI)

Size of grave pit: -

Depth: $20 \mathrm{~cm}$

Orientation: -

Position of skeleton: -

L. of skeleton (contracted): -

L. of skeleton (extended): -

Age at death: -

Sex: -

Condition of skeleton: -

Preserved skeletal bones: ${ }^{223}$

Scattered cremation burial disturbed by ploughing. A few calcinated bone fragments and six indistinct pottery sherds (1) were found in the burial.

Finds from the grave pit

1. Pottery fragments. Body fragments of a reddish, thin-walled, worn pot. Six non-joining pieces. Inv. no. 61.2.111.

\section{Grave 315 (Square E8)}

Size of grave pit: diam. $25 \mathrm{~cm}$

Depth: $42 \mathrm{~cm}$

Orientation: -

Position of skeleton: -

L. of skeleton (contracted): -

L. of skeleton (extended): -

Age at death: 23-x years

Sex: female (?)

Condition of skeleton: -

Preserved skeletal bones: various fragments

Scattered cremation burial. Calcinated bone fragments lay over an area with a diameter of $25 \mathrm{~cm}$.

The burial did not contain any grave goods.

\section{Grave 316 (Square E8; Pl. CXVIII)}

Size of grave pit: L. $140 \mathrm{~cm}, W .138 \mathrm{~cm}$

Depth: $114 \mathrm{~cm}$

Orientation: S-SE to N-NW, with the head toward the S-SE

Position of skeleton: laid on the right side

L. of skeleton (contracted): $114 \mathrm{~cm}$

L. of skeleton (extended): $149 \mathrm{~cm}$

Age at death: $30-40$ years

Sex: female

Condition of skeleton: badly preserved

Preserved skeletal bones: skull, long bones and various skeletal parts

Inhumation burial in a round grave pit. A larger stone lay in the grave pit's north-western end between -30 and $-60 \mathrm{~cm}$. The body was laid on the right side in a contracted position. The skull lay on the right side. The shoulders lay prone. The right arm was extended, with the hand resting on the right thigh. The left arm

223 The skeletal remains can no longer be found. The anthropological data are quoted from the excavation diary.

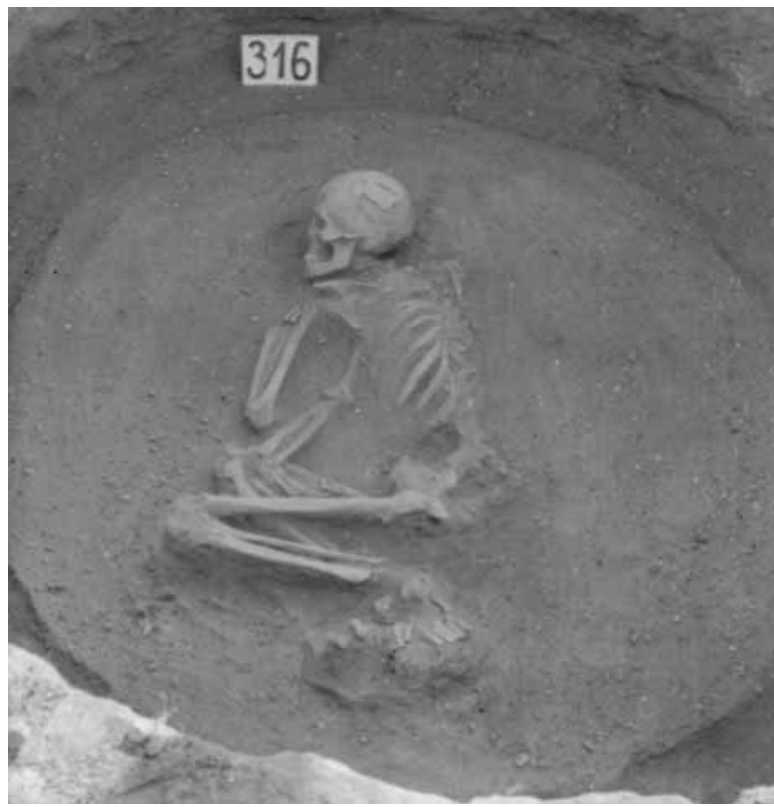

was bent at the elbow and drawn up, with the hand placed in front of the chin. The left thigh was drawn up into a horizontal position, the right one slightly higher, the legs were bent back toward the buttocks. The ankles were placed one over the other.

The burial did not contain any grave goods.

\section{Grave 317 (Square F10; Pl. CXIX)}

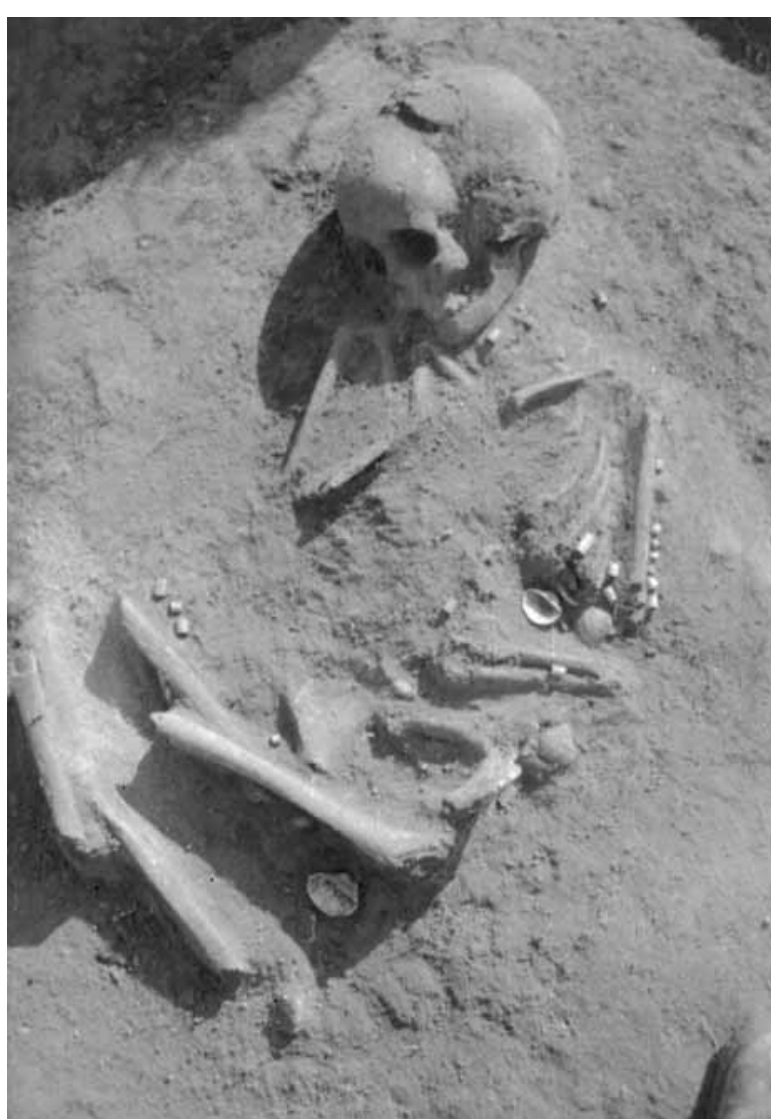


Size of grave pit: L. $126 \mathrm{~cm}, W .98 \mathrm{~cm}$

Depth: $62 \mathrm{~cm}$

Orientation: E-SE to W-NW, with the head toward the E-SE

Position of skeleton: laid on the right side

L. of skeleton (contracted): $72 \mathrm{~cm}$

L. of skeleton (extended): $c a$. $120-130 \mathrm{~cm}$

Age at death: 8-9 years

Sex: child

Condition of skeleton: badly preserved

Preserved skeletal bones: skull, long bone fragments

Inhumation burial in an oval grave pit containing stones from $-25 \mathrm{~cm}$ downward. A larger stone lay in the grave pit's middle on the legs. The body was laid on the right side in a contracted position. The crushed skull lay on the right side. The right arm was bent at the elbow and drawn up, with the hand placed by the neck. The left arm was bent at the elbow. The left thigh was drawn up into a horizontal position, the right one slightly higher, the legs were bent back toward the buttocks.

The burial contained the following grave goods: a jasper blade (1) between the buttocks and the right ankle; three mussels, twenty-two beads and two perforated snails (2) by the left elbow; six beads (3) on the neck; three beads on the neck (4); two shells and three shell beads (5) around the pelvis; three unperforated snails (6) in the same area (these were probably not part of the grave furniture).

Grave goods

1. Stone blade. Jasper blade with retouch along the curved edge. L. $2.5 \mathrm{~cm}, W .1 .3 \mathrm{~cm}$. Inv. no. 61.2.112.1 (Pl. CXIX. 317/1). ${ }^{224}$

2. Three perforated Anadara diluvii shells (Pl. CXIX. $317 / 2 b$ ), three perforated Lithoglyphus naticoides shells (Pl. CXIX. 317/2c), six Dentalium badense beads and sixteen limestone beads (Pl. CXIX. 317/2a). Inv. no. 61.2.112.2.225

3. Beads. Six limestone beads of varying sizes. Inv. no. 61.2.112.3 (Pl. CXIX. 317/3).

4. Beads. Three limestone beads of varying sizes. Inv. no. 61.2.112.4 (Pl. CXIX. 317/4).

5. Two perforated Anadara diluvii shells (Pl. CXIX. 317/5b) and three limestone beads (Pl. CXIX. 317/5a). Inv. no. 61.2.112.5.

6. Snails. Three small snails. Inv. no. 61.2.112.6.226

\section{Grave 318 (Square E8)}

Size of grave pit: L. $95 \mathrm{~cm}, W .95 \mathrm{~cm}$

Depth: $83 \mathrm{~cm}$

Orientation: NW to SE, with the head toward the NW

Position of skeleton: laid on the right side

L. of skeleton (contracted): $45 \mathrm{~cm}$

224 The object has since been lost or mislaid. Its description is quoted from the acquisitions register. A photo of this object was found among the photos made by József Korek in the Archives of the Szentendre museum. 225 The number of snails is lower by one in the excavation diary.

226 Pál Sümegi identified the snails as Cepea vindobonensis and pointed out that they were embedded during a period post-dating the Copper Age. They are thus not part of the grave inventory.
L. of skeleton (extended): -

Age at death: $1-14$ years

Sex: child

Condition of skeleton: badly preserved

Preserved skeletal bones: various fragments

Inhumation burial in a round grave pit. The body was laid on the right side in a contracted position. The skull and one of the thighbones are all that survived of the skeletal remains. The crushed skull lay on the right side with the face toward the south.

The burial did not contain any grave goods.

\section{Grave 319 (Square E8; Pl. CXXIV)}

Size of grave pit: L. $182 \mathrm{~cm}, W .156 \mathrm{~cm}$

Depth: $97 \mathrm{~cm}$

Orientation: S-SE to N-NW, with the head toward the S-SE

Position of skeleton: laid on the left side

L. of skeleton (contracted): $98 \mathrm{~cm}$

L. of skeleton (extended): $171 \mathrm{~cm}$

Age at death: $40-50$ years

Sex: male

Condition of skeleton: well preserved

Preserved skeletal bones: complete skeleton

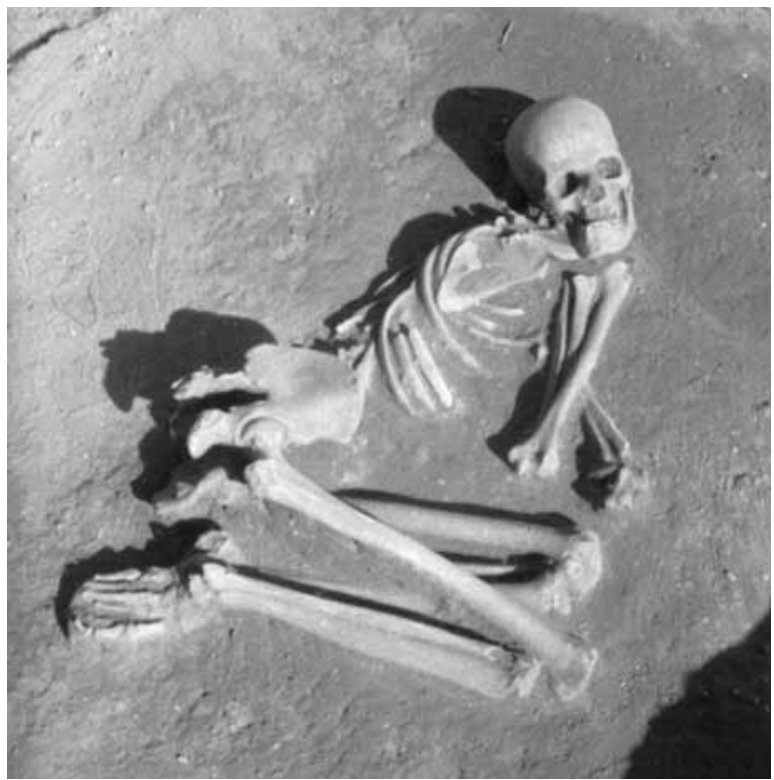

Inhumation burial in an oval grave pit containing a few stones in the middle of the grave pit between -40 and $-60 \mathrm{~cm}$. The body was laid on the left side in a contracted position. The skull rested on the occipital bone with the face toward the east. The right arm was bent at the elbow and drawn up, with the hand placed under the chin. The left arm was extended under the body, with the bent hand resting by the right elbow. The right thigh was drawn up into a horizontal position, the left one slightly higher, the legs were bent back toward the buttocks. The ankles were placed one over the other.

The burial contained the following grave goods: a ladle (1) set upright above the knees at a depth of $-53 \mathrm{~cm}$; a copper chisel (2) $20 \mathrm{~cm}$ north-east of the skull. 
Grave goods

1. Ladle. Brownish, worn, plain ladle. The handle terminal is curved and has two small round perforations. Cracked. H. $3.8 \mathrm{~cm}$, dM. $9.6 \mathrm{~cm}$, L. of handle $4.4 \mathrm{~cm}, W$. of handle $3.7 \mathrm{~cm}$. Inv. no. 61.2.113.1 (Pl. CXXIV. 319/1).

2. Copper chisel. Copper chisel with rectangular section. The end fitted into the haft tapers. The cutting edge is hammered flat. L. $5 \mathrm{~cm}$. Inv. no. 61.2.113.2 (Pl. CXXIV. 319/2).227

\section{Grave 320 (Square E7; Pl. CXXI)}

Size of grave pit: L. $125 \mathrm{~cm}$, W. $107 \mathrm{~cm}$

Depth: $80 \mathrm{~cm}$

Orientation: NE to SW, with the head toward the NE

Position of skeleton: laid on the right side

L. of skeleton (contracted): $97 \mathrm{~cm}$

L. of skeleton (extended): $163 \mathrm{~cm}$

Age at death: 23-39 years

Sex: male (?)

Condition of skeleton: badly preserved

Preserved skeletal bones: skull, long bones

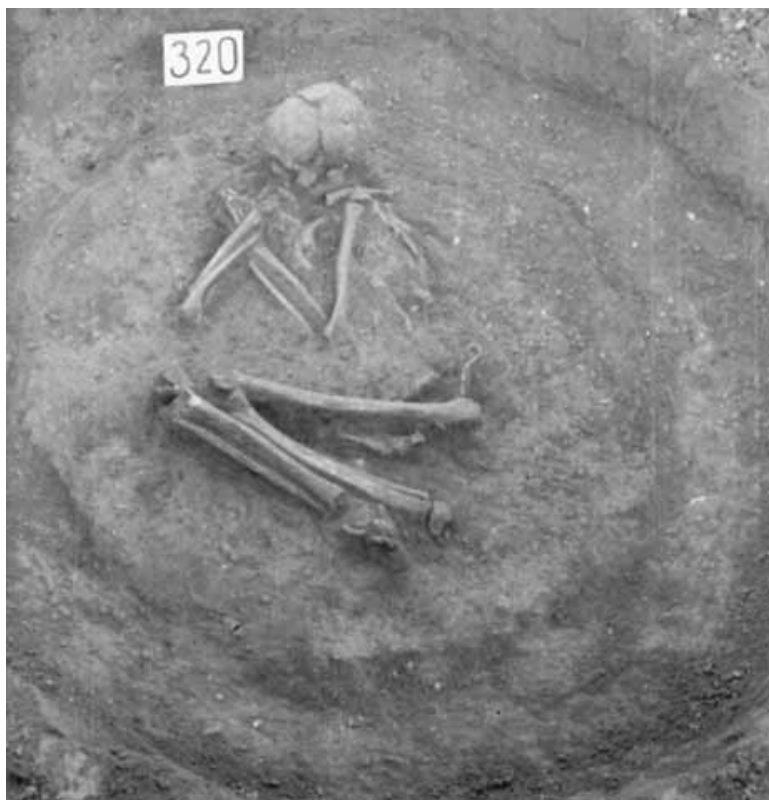

Inhumation burial in an oval grave pit containing flat stones between -25 and $-35 \mathrm{~cm}$. The body was laid on the right side in a contracted position. The skull rested on the occipital bone with the face toward the northwest. The arms were bent at the elbow and drawn up, with the clasped hands placed in front of the face. The thighs were drawn up into a horizontal position, the legs were bent back toward the buttocks.

The burial did not contain any grave goods.

227 The object has since been lost or mislaid. Its description is quoted from the acquisitions register. The drawing is based József Korek's grave sheet.
Grave 321 (Square G10)

Size of grave pit: -

Depth: $15 \mathrm{~cm}$

Orientation: probably $\mathrm{N}$ to $\mathrm{S}$, with the head toward the $\mathrm{N}$

Position of skeleton: -

L. of skeleton (contracted): -

L. of skeleton (extended): -

Age at death: 23-39 years

Sex: -

Condition of skeleton: badly preserved

Preserved skeletal bones: various fragments

Inhumation burial. There was no indication of a grave pit. The burial and the skeletal remains were destroyed by ploughing. The skull and one of the thighbones are all that the survived. The position of the latter suggested that the body had been deposited in a contracted position.

The burial did not contain any grave goods.

Grave 322 (Square D7; Pl. CXXI)

Size of grave pit: L. $83 \mathrm{~cm}, W .80 \mathrm{~cm}$

Depth: $52 \mathrm{~cm}$

Orientation: SE to NW, with the head toward the SE

Position of skeleton: laid on the right side

L. of skeleton (contracted): $68 \mathrm{~cm}$

L. of skeleton (extended): $117 \mathrm{~cm}$

Age at death: $10-11$ years

Sex: child

Condition of skeleton: badly preserved

Preserved skeletal bones: skull, long bones

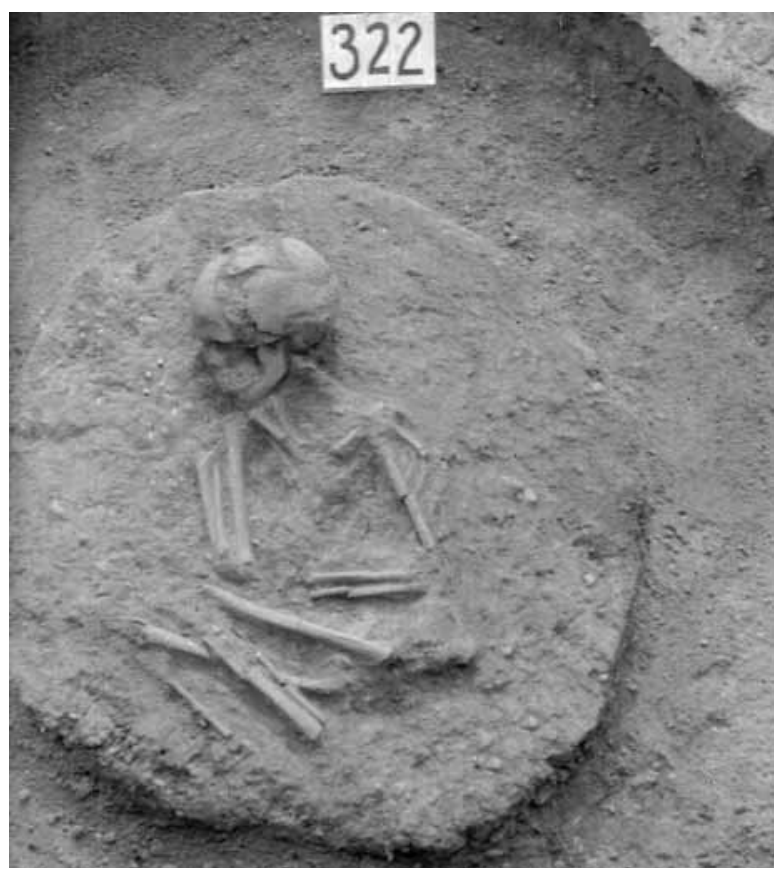

Inhumation burial in a round grave pit containing a few stones at a depth of $-30 \mathrm{~cm}$. The body was laid on the right side in a contracted position. The crushed skull lay on the right side. The right arm was bent at the elbow and drawn up, with the hand resting by the 
shoulder in front of the chin. The left arm was bent at the elbow, with the hand placed by the right elbow. The thighs were drawn up in front of the body, the legs were bent back toward the buttocks.

The burial contained the following grave goods: four beads (1) in front of the face.

Grave goods

1. Beads. Four limestone beads. Inv. no. 61.2.114 (Pl. CXXII. 322/1).

\section{Grave 323 (Square E7)}

Size of grave pit: diam. $52 \mathrm{~cm}$

Depth: $66 \mathrm{~cm}$

Orientation: -

Position of skeleton: -

L. of skeleton (contracted): -

L. of skeleton (extended): -

Age at death: $23-59$ years

Sex: male (?)

Condition of skeleton: badly preserved

Preserved skeletal bones: calcinated fragments

Scattered cremation burial. The grave pit contained stones from $-25 \mathrm{~cm}$ downward and the calcinated bone remains. The bone fragments formed a $13 \mathrm{~cm}$ thick layer. The body had not been completely burned, many bones survived quite intact. There was no apparent pattern in the deposition of the bone remains: the skull fragments lay mixed up with the other bone fragments.

The burial did not contain any grave goods.

\section{Grave 324 (Square F10; Pl. CXXV)}

Size of grave pit: L. $131 \mathrm{~cm}, W .108 \mathrm{~cm}$

Depth: $78 \mathrm{~cm}$

Orientation: SE to NW, with the head toward the SE

Position of skeleton: laid on the left side

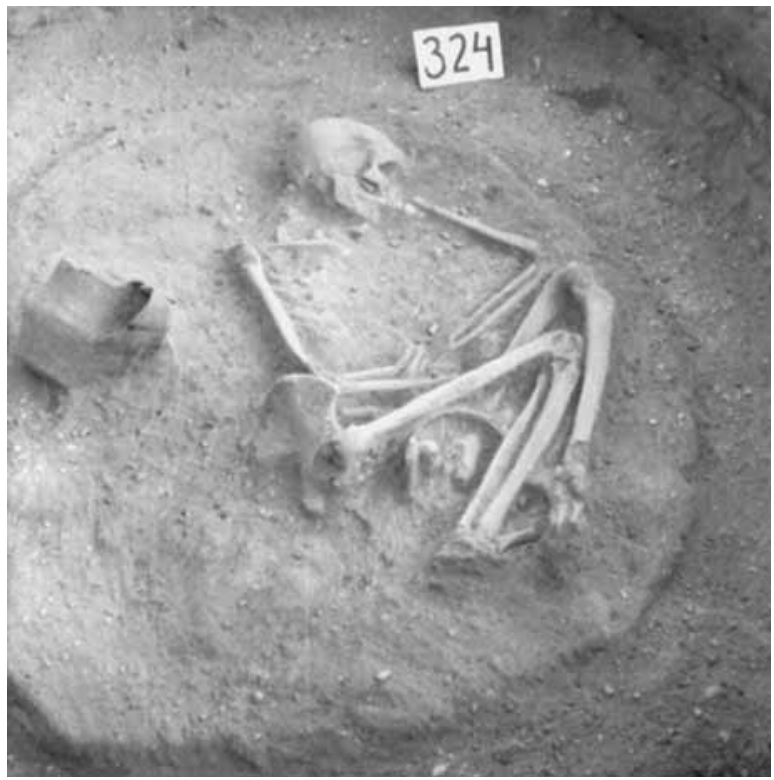

L. of skeleton (contracted): $95 \mathrm{~cm}$

L. of skeleton (extended): $162 \mathrm{~cm}$

Age at death: $30-40$ years

Sex: female

Condition of skeleton: badly preserved

Preserved skeletal bones: skull, long bones

Inhumation burial in an oval grave pit. The body was laid on the left side in a contracted position. The crushed skull lay tilted to one side. The arms were bent at the elbow and laid in the lap with the right hand clasping the left forearm and the left hand the right forearm. The right thigh was drawn up into a horizontal position, the left one slightly higher, the legs were bent back toward the buttocks.

The burial contained the following grave goods: a one-handled pot (1) tilted to one side with the mouth toward the skull, $17 \mathrm{~cm}$ from the spine; three shells and twelve beads (2) on the left upper arm.

Grave goods

1. Pot. Greyish-brown one-handled pot with cylindrical neck and conical body. The handle rises above the rim and springs to the belly. A row of impressed dots encircles the belly. Joined from its fragments and partially restored. H. $15.1 \mathrm{~cm}, \mathrm{~d} M .13 .8 \mathrm{~cm}, \mathrm{~dB}$. $8.8 \mathrm{~cm}$. Inv. no. 61.2.115.1 (Pl. CXXV. 324/1).

2. Beads. Twelve limestone beads ( $P l$. CXXV. 324/2a) and three perforated Anadara diluvii shells (Pl. CXXV. 324/2b). Inv. no. 61.2.115.2.

\section{Grave 325 (Square D7; Pl. CXXIV)}

Size of grave pit: L. $160 \mathrm{~cm}, W .137 \mathrm{~cm}$

Depth: $103 \mathrm{~cm}$

Orientation: NW to SE, with the head toward the NW Position of skeleton: laid on the right side

L. of skeleton (contracted): $104 \mathrm{~cm}$

L. of skeleton (extended): $179 \mathrm{~cm}$

Age at death: 30-40 years

Sex: male

Condition of skeleton: medium well preserved

Preserved skeletal bones: complete skeleton

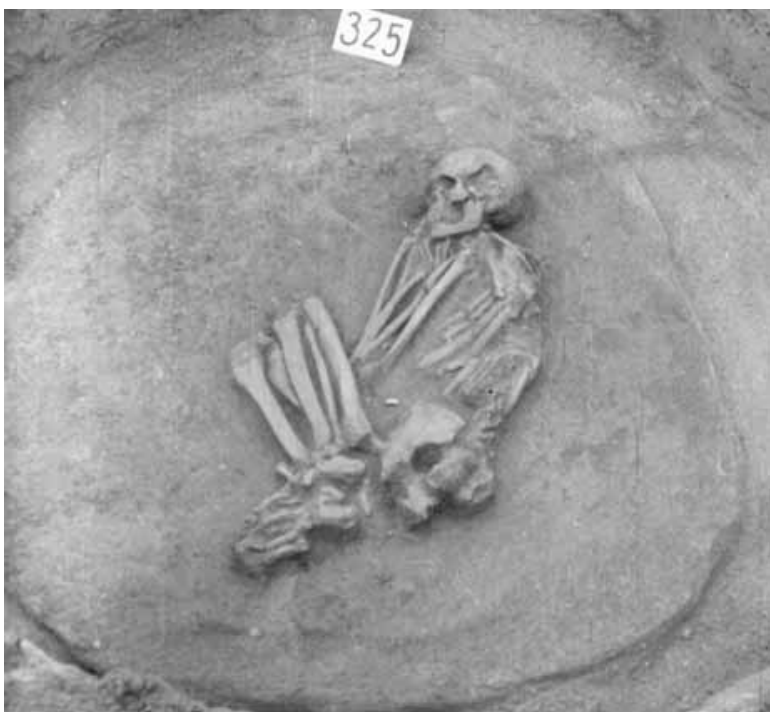


Inhumation burial in a roughly oval grave pit. The body was laid on the right side in a strongly contracted position. The skull lay on the right side. The arms were bent at the elbow and drawn up, with the hands resting under the chin. The thighs were drawn up in front of the body, the legs were bent back toward the buttocks.

The burial contained the following grave goods: a pebble (1) in front of the belly, between the ribs and the thighs.

\section{Grave goods}

1. Unworked chert pebble. L. $2.2 \mathrm{~cm}, W .1 \mathrm{~cm}$. Inv. no. 61.2.116 (Pl. CXXIV. 325/1).228

\section{Grave 326 (Square G3; Pl. CXXI)}

Size of grave pit: L. $80 \mathrm{~cm}, W .78 \mathrm{~cm}$

Depth: $84 \mathrm{~cm}$

Orientation: S-SW to N-NE, with the head toward the S-SW

Position of skeleton: laid on the left side

L. of skeleton (contracted): $42 \mathrm{~cm}$

L. of skeleton (extended): -

Age at death: $4-5$ years

Sex: child

Condition of skeleton: badly preserved

Preserved skeletal bones: various fragments

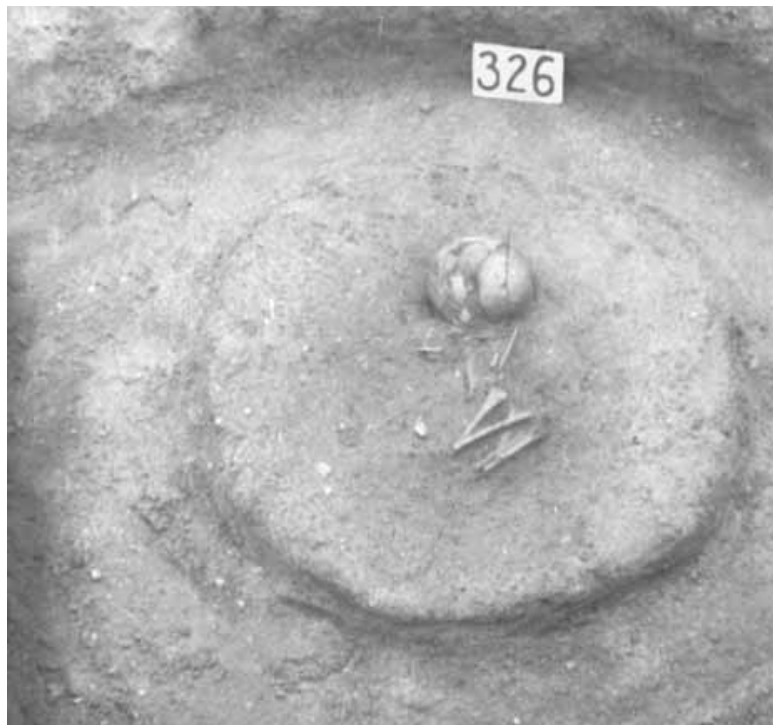

Inhumation burial in a round grave pit containing many stones between -20 and $-70 \mathrm{~cm}$. The body was laid on the left side in a contracted position. The crushed skull lay on the occipital bone with the face toward the west. The arms were bent at the elbow and drawn up, with the hands placed in front of the face. The thighs were drawn up in front of the body, the legs were bent back toward the buttocks.

The burial did not contain any grave goods.

228 A photo of this object was found among the photos made by József Korek in the Archives of the Szentendre museum.
Grave 327 (Square J2)

Early Iron Age inurned burial.

\section{Grave 328 (Square G3)}

Size of grave pit: diam. $28 \mathrm{~cm}$

Depth: $28 \mathrm{~cm}$

Orientation: -

Position of skeleton: -

L. of skeleton (contracted): -

L. of skeleton (extended): -

Age at death: $23-59$ years

Sex: female (?)

Condition of skeleton: -

Preserved skeletal bones: various fragments

Scattered cremation burial. Calcinated bone fragments lay over an area with a diameter of $28 \mathrm{~cm}$ forming a $5-8 \mathrm{~cm}$ thick layer.

The burial did not contain any grave goods.

\section{Grave 329 (Square F10; Pl. CXXIV)}

Size of grave pit: L. $115 \mathrm{~cm}$, W. $87 \mathrm{~cm}$ Depth: $90 \mathrm{~cm}$

Orientation: NW to SE with the head toward the NW Position of skeleton: laid on the right side

L. of skeleton (contracted): $102 \mathrm{~cm}$

L. of skeleton (extended): $164 \mathrm{~cm}$

Age at death: $40-x$ years

Sex: female

Condition of skeleton: badly preserved

Preserved skeletal bones: complete skeleton

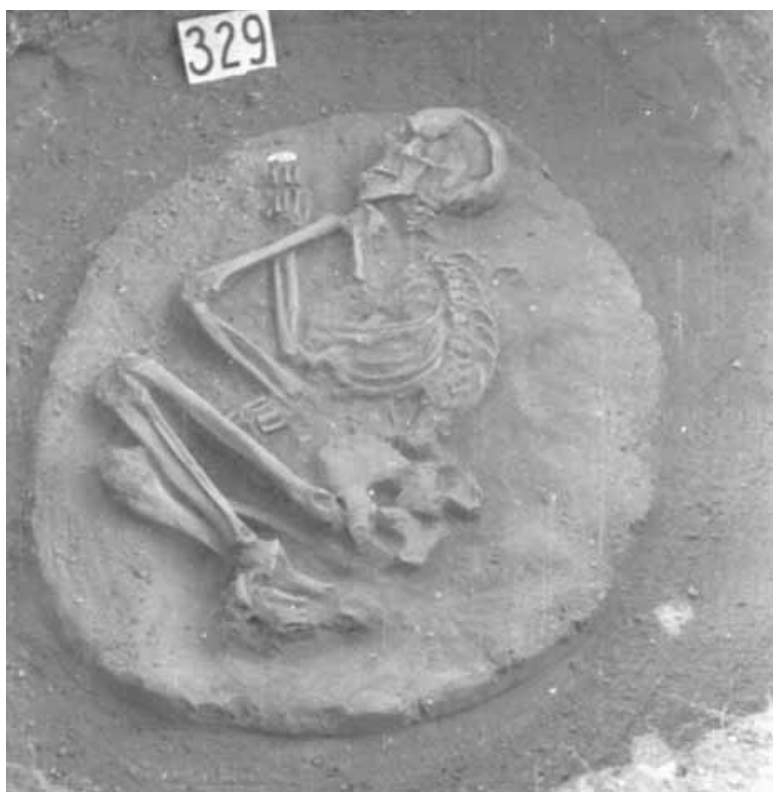

Inhumation burial in an oval grave pit. The body was laid on the right side in a contracted position. The crushed skull lay on the right side. The right arm was bent at the elbow and drawn up, with the hand placed 
in front of the face. The left arm was bent inward at the elbow, with the hand extending under the left thigh. The right thigh was drawn up into a horizontal position, the left one slightly higher, the legs were bent back toward the buttocks.

The burial contained the following grave goods: a broken, crumbled mussel (1) by the left hand.

\section{Grave goods}

1. Broken Anodonta sp. mussel. L. $4.1 \mathrm{~cm}, W .2 .3 \mathrm{~cm}$. Inv. no. 61.2.118 (Pl. CXXIV. 329/1).

\section{Grave 330 (Square D6; Pls CXXVI-CXXVII)}

Size of grave pit: L. $165 \mathrm{~cm}, W .120 \mathrm{~cm}$

Depth: $120 \mathrm{~cm}$

Orientation: SE to NW, with the head toward the SE Position of skeleton: laid on the left side

L. of skeleton (contracted): $102 \mathrm{~cm}$

L. of skeleton (extended): $151 \mathrm{~cm}$

Age at death: $23-25$ years

Sex: female

Condition of skeleton: medium well preserved

Preserved skeletal bones: complete skeleton

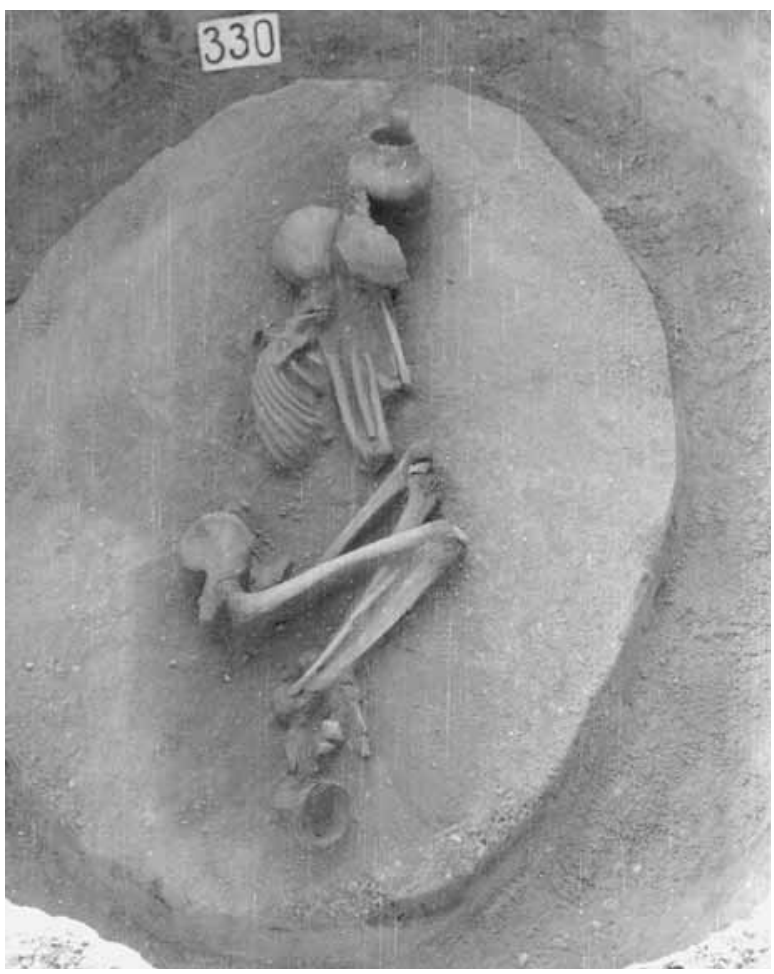

Inhumation burial in an oval grave pit. The body was laid on the left side in a strongly contracted position. The skull lay on the left side. The arms were bent at the elbow and drawn up, with the hands resting in front of the face. The thighs were drawn up in front of the body, the legs were bent back toward the buttocks. Brown stains were noted on the arm bones in the middle (perhaps an indication that the arms had been bound together).

The burial contained the following grave goods: a red stone (1) and a side-scraper (2) between the feet; a goblet (3) tilted to one side with the mouth facing the side of the grave pit beside the feet; a jug (4) tilted to one side with the mouth facing the edge of the grave pit in front of the face; a one-handled pitcher (5) beside the previous vessel, $15 \mathrm{~cm}$ above the skull.

\section{Grave goods}

1. Stone. Irregularly shaped mauve stone with three sides polished smooth. L. $3.2 \mathrm{~cm}, W .2 .6 \mathrm{~cm}$. Inv. no. 61.2.119.1 (Pl. CXXVI. 330/1).

2. Radiolarite side-scraper. Inv. no. 61.2.119.2 (Pl. CXXVI. 330/2).

3. Goblet. Reddish-grey goblet with rounded upper part set on a rectangular foot with rectangular base. The foot has two round perforations near the base, one of which pierces the clay, the other was spoilt. The upper part is decorated with two incised zig-zag lines, the foot bears a design of three horizontal and two vertical zig-zag lines on alternate sides of the foot. Patches of red paining survive on the exterior and exterior, as well as on the vessel base. The sequence of how the pattern was incised can be reconstructed as follows: the lines inclined to the left were incised first, followed by the lines inclined in the opposite direction. H. $10.1 \mathrm{~cm}$, dM. $9.5 \mathrm{~cm}$, dB. $3.6 \mathrm{~cm}$. Inv. no. 61.2.119.3 (Pl. CXXVI. 330/3).

4. Bowl. Greyish-brown, worn bowl with funnel neck and conical body. A row of impressed dots encircles the shoulder under which lie impressed dots arranged into hanging triangles. There was no indication of a handle on the surviving fragments. The rim is damaged. Joined from its fragments and partially restored. H. $8.5 \mathrm{~cm}$, dM. $18.5 \mathrm{~cm}, \mathrm{~dB} .6 .5 \mathrm{~cm}$. Inv. no. 61.2.119.4 (Pl. CXXVI. 330/4).

5. Pitcher. Reddish-brown, polished, one-handled, slightly asymmetrical pitcher with low, cylindrical neck, flattened globular body and flat base. The handle rises above the rim and springs to the shoulder. The vessel is decorated with fluting around the neck and vertical fluting on the body interrupted by five narrow ribs with oblique fluting. The handle is similarly fluted. The rim is partially restored. H. $11.9 \mathrm{~cm}$, dM. $8.8 \mathrm{~cm}$. Inv. no. 61.2 .119 .5 (Pl. CXXVII. 330/5).

\section{Grave 331 (Square E9)}

Size of grave pit: diam. $30 \mathrm{~cm}$

Depth: $30 \mathrm{~cm}$

Orientation: -

Position of skeleton: -

L. of skeleton (contracted): -

L. of skeleton (extended): -

Age at death: 23-59 years

Sex: male (?)

Condition of skeleton: -

Preserved skeletal bones: various fragments 
Scattered cremation burial. Calcinated bone fragments forming a $5 \mathrm{~cm}$ thick layer were found over an area with a diameter of $30 \mathrm{~cm}$.

The burial did not contain any grave goods.

\section{Grave 332 (Square F3; Pl. CXXVII)}

Size of grave pit: L. $105 \mathrm{~cm}, W .95 \mathrm{~cm}$

Depth: $80 \mathrm{~cm}$

Orientation: $\mathrm{S}$ to $\mathrm{N}$, with the head toward the $\mathrm{S}$

Position of skeleton: laid on the left side

L. of skeleton (contracted): $73 \mathrm{~cm}$

L. of skeleton (extended): $142 \mathrm{~cm}$

Age at death: $40-x$ years

Sex: female

Condition of skeleton: medium well preserved

Preserved skeletal bones: complete skeleton

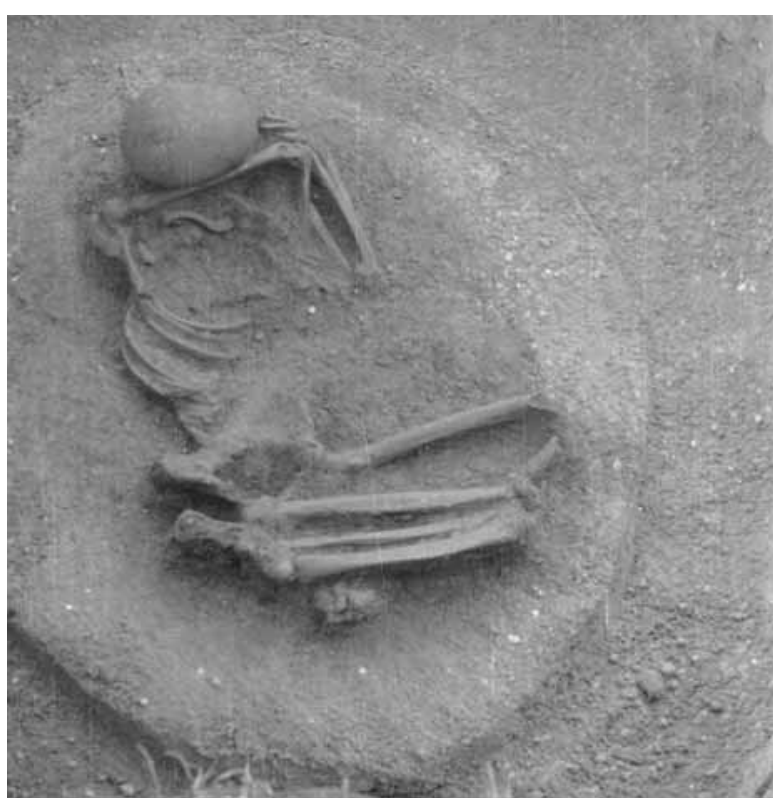

Inhumation burial in a round grave pit containing stones between -25 and $-50 \mathrm{~cm}$. The body was laid on the left side in a contracted position. The skull lay on the occipital bone with the face toward the west. The right arm was drawn up to the neck, with the bent elbow in front of the face and the hand laid toward the belly. The left arm was bent at the elbow and drawn up, with the hand resting in front of the face. The thighs were drawn up into a horizontal position, the legs were bent back toward the buttocks.

The burial did not contain any grave goods.

\section{Grave 333 (Square D6/F6)}

Size of grave pit: diam. $35 \mathrm{~cm}$

Depth: $28 \mathrm{~cm}$

Orientation: -

Position of skeleton: -

L. of skeleton (contracted): -

L. of skeleton (extended): -

Age at death: $15-\mathrm{x}$ years
Sex: female (?)

Condition of skeleton: -

Preserved skeletal bones: various fragments

Scattered cremation burial. Calcinated bone fragments lay over an area with a diameter of $35 \mathrm{~cm}$.

The burial did not contain any grave goods.

\section{Grave 334 (Square D6; Pl. CXXVIII)}

Size of grave pit: L. $82 \mathrm{~cm}, W .68 \mathrm{~cm}$

Depth: $102 \mathrm{~cm}$

Orientation: A: $\mathrm{W}$ to $\mathrm{E}$, with the head toward the $\mathrm{W}-\mathrm{SW}, \mathrm{B}$ : $\mathrm{W}$ to E, with the head toward the W-SW

Position of skeleton: A: laid on the left side, B: laid on the left side

L. of skeleton (contracted): A: $50 \mathrm{~cm}$, B: $25 \mathrm{~cm}$

L. of skeleton (extended): A:,- B: -

Age at death: A: $1.5-2$ years, B: $0-0.5$ years

Sex: A: child, B: child

Condition of skeleton: A: badly preserved, B: badly preserved

Preserved skeletal bones: A: complete skeleton, B: fragments

Double inhumation burial in an oval grave pit. Fragments of a pot (1) lay at a depth of $-55 \mathrm{~cm}$.

\section{Burial A}

The body was laid on the left side in a contracted position. The skull lay on the occipital bone. The arms were extended beside the body. The thighs were drawn up into an almost horizontal position, the legs were bent back toward the buttocks.

The burial did not contain any grave goods.

\section{Burial B}

Very little survived of the skeletal remains. The skull lay adjacent to Burial A, a little to its south. The surviving bone fragments suggested that the body was deposited parallel to Burial A.

The burial did not contain any grave goods.

Finds from the grave pit

1. Pot. Body fragments of a thick-walled pot with reddish exterior and dark grey interior. Three nonjoining pieces, one with a knob. Inv. no. 61.2.120 (Pl. CXXVIII. 334/1).

\section{Grave 335 (Square D6; Pl. CXXVIII)}

Size of grave pit: L. $140 \mathrm{~cm}, W .85 \mathrm{~cm}$

Depth: $115 \mathrm{~cm}$

Orientation: S-SE to N-NW, with the head toward the S-SE

Position of skeleton: laid on the right side

L. of skeleton (contracted): $101 \mathrm{~cm}$

L. of skeleton (extended): $166 \mathrm{~cm}$

Age at death: $30-40$ years

Sex: female (?)

Condition of skeleton: badly preserved

Preserved skeletal bones: skull, long bones

Inhumation burial in an oval grave pit. The body was laid on the right side in a strongly contracted position. 


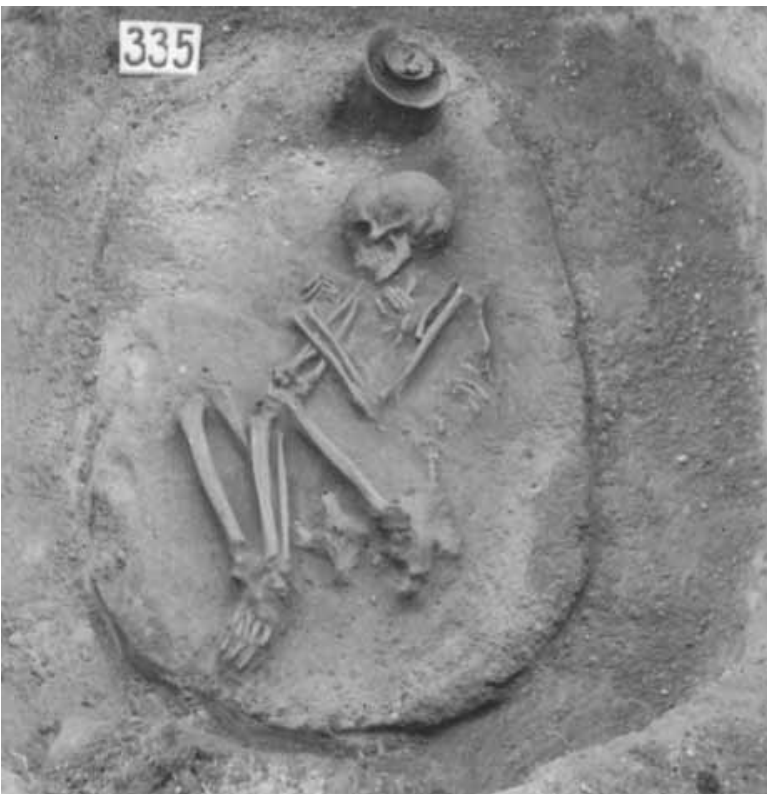

The skull was crushed. The right arm was bent at the elbow and drawn up, with the hand resting in front of the face. The left arm was bent at the elbow and drawn up, with the hand resting on the neck. The thighs were drawn up in front of the body, the legs were bent back toward the buttocks.

The burial contained the following grave goods: a bowl (1) $8 \mathrm{~cm}$ south-south-east of the skull; a goblet (2) in the previous vessel; two stone chips (3-4) under the vessels; a red stone (5) on the eastern side of the vessels.

\section{Grave goods}

1. Bowl. Grey, polished conical bowl with funnel neck. The vessel body is decorated with two irregular rows of impressed dots interrupted by a stringhole lug. Joined from its fragments; the rim is restored in several spots. H. $9 \mathrm{~cm}$, dM. $18 \mathrm{~cm}$, dB. $7.2 \mathrm{~cm}$. Inv. no. 61.2.121.1 (Pl. CXXVIII. 335/1).

2. Goblet. Reddish, worn goblet with rounded upper part set on a low, cylindrical foot with a round base. The upper part of the foot is perforated. Patches of red painting survive on the exterior and interior. The imprint of a cereal grain can be seen on the base. Joined from its fragments; the rim is damaged. H. $6.6 \mathrm{~cm}, \mathrm{dM}$. $9.6 \mathrm{~cm}, \mathrm{~dB} .4 .5 \mathrm{~cm}$. Inv. no. 61.2 .121 .2 (Pl. CXXVIII. 335/2).

3. Debitage. Limnic quartzite. Inv. no. 61.2.121.3 (Pl. CXXVIII. 335/3).229

4. Debitage. Limnic quartzite. Inv. no. 61.2.121.4 (Pl. CXXVIII. 335/4).

5. Red stone. Irregularly shaped red stone. Diam. $5.5 \mathrm{~cm}$. Inv. no. 61.2.121.5.230

\footnotetext{
${ }^{229}$ The drawing of the lithics under nos 3-4 are based on József Korek's grave sheet.

${ }_{230}$ The object has since been lost or mislaid. Its description is quoted from the acquisitions register.
}

Grave 336 (Square D8; Pl. CXXVII)

Size of grave pit: L. $116 \mathrm{~cm}, W .94 \mathrm{~cm}$

Depth: $57 \mathrm{~cm}$

Orientation: SE to NW, with the head toward the S-SE

Position of skeleton: laid on the left side

L. of skeleton (contracted): $90 \mathrm{~cm}$

L. of skeleton (extended): $c a .165 \mathrm{~cm}$

Age at death: 23-x years

Sex: -

Condition of skeleton: badly preserved

Preserved skeletal bones: skull, long bones

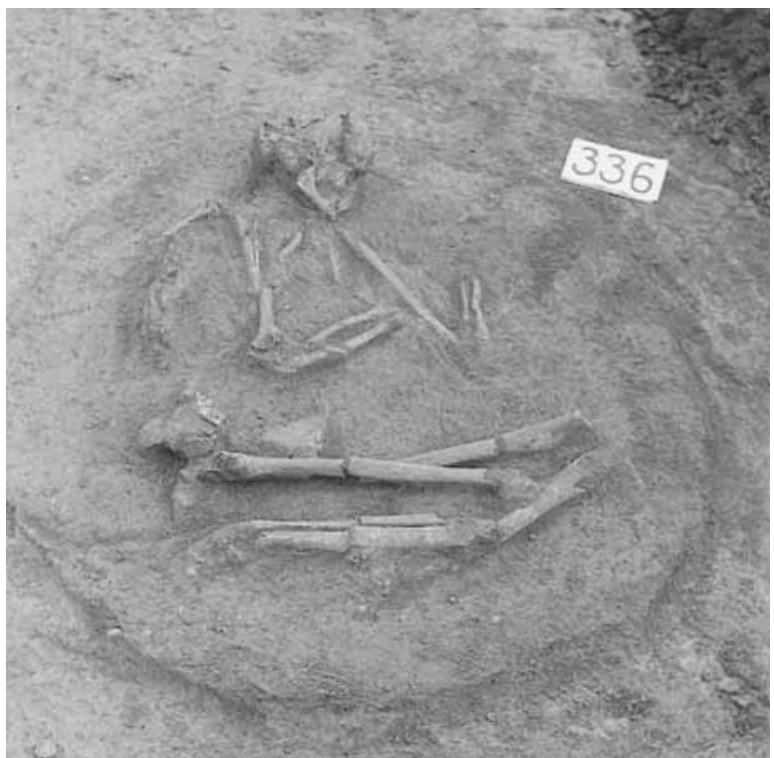

Inhumation burial in an oval grave pit containing stones from $-40 \mathrm{~cm}$ downward. The stones lay on the body, the skeletal remains were strongly fragmented. The body was laid on the left side in a contracted position. The skull lay on the left side. The right arm was bent at the elbow and drawn up, with the hand placed by the lower third of the left upper arm. The left arm was bent at the elbow and drawn up, with the hand resting in front of the face. The right thigh was drawn up into a horizontal position, the left one slightly higher, the legs were bent back toward the buttocks.

The burial did not contain any grave goods.

\section{Grave 337 (Square D7; Pl. CXXIX)}

Size of grave pit: L. $118 \mathrm{~cm}, W .105 \mathrm{~cm}$ Depth: $75 \mathrm{~cm}$

Orientation: E-SE to W-NW, with the head toward the E-SE Position of skeleton: laid on the right side

L. of skeleton (contracted): $95 \mathrm{~cm}$

L. of skeleton (extended): $162 \mathrm{~cm}$

Age at death: $40-59$ years

Sex: male

Condition of skeleton: badly preserved

Preserved skeletal bones: skull, long bones

Inhumation burial in an almost round grave pit. The body was laid on the right side in a contracted position. 


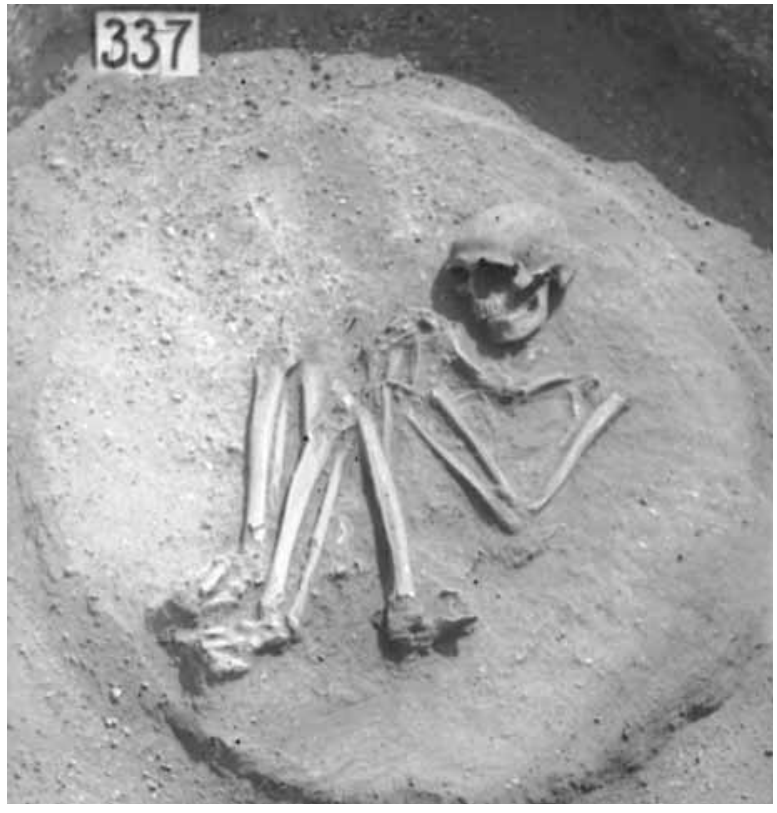

The skull was tilted slightly to the right with the face toward the north. The trunk lay extended on the back. The right arm was bent at the elbow and drawn up, with the hand resting on the right upper arm and the left knee. The left arm was bent at the elbow and drawn up, with the hand placed on the shoulder. The thighs were drawn up in front of the body, almost reaching the right shoulder, the legs were bent back toward the buttocks. The facial part of the skull was destroyed by an animal burrow.

The burial did not contain any grave goods.

\section{Grave 338 (Square D9/E9; Pl. CXXIX)}

Size of grave pit: L. $115 \mathrm{~cm}$, W. $82 \mathrm{~cm}$

Depth: $77 \mathrm{~cm}$

Orientation: S-SE to N-NW, with the head toward the S-SE

Position of skeleton: laid on the right side

L. of skeleton (contracted): $43 \mathrm{~cm}$

L. of skeleton (extended): -

Age at death: $c a$. 1 year

Sex: child

Condition of skeleton: badly preserved

Preserved skeletal bones: skull, long bones

Inhumation burial in an oval grave pit. The body was laid on the right side in a contracted position. The skull lay on the right side. The left arm was extended toward the knee, the right arm was bent at the elbow. The thighs were drawn up into a horizontal position, the legs were bent back toward the buttocks.

The burial contained the following grave goods: a bone awl (1) thrust into the ground, $10 \mathrm{~cm}$ west-southwest of the skull.

\section{Grave goods}

1. Bone awl. Awl with pointed tip made from the tibia of a small ruminant. L. $13.1 \mathrm{~cm}$. Inv. no. 61.2 .122 (Pl. CXXIX. 338/1).
Grave 339 (Square D6; Pl. CXXX)

Size of grave pit: diam. $35 \mathrm{~cm}$

Depth: $32 \mathrm{~cm}$

Orientation: -

Position of skeleton: -

L. of skeleton (contracted): -

L. of skeleton (extended): -

Age at death: $23-x$ years

Sex: female (?)

Condition of skeleton: -

Preserved skeletal bones: various fragments

Disturbed scattered cremation burial. Calcinated bone fragments lay over an area with a diameter of $35 \mathrm{~cm}$. Lying above the bone fragments were sherds from vessels destroyed by ploughing: a bowl (1), another bowl (2) and a small mug (3).

\section{Grave goods}

1. Bowl. Rim and body fragments of a light brown, worn bowl with the stub of the handle on the rim. The body is decorated with a row of impressed dots. Joined from its fragments. L. $14 \mathrm{~cm}$. Inv. no. 61.2.123.1 (Pl. CXXX. 339/1).

2. Bowl. One-half of a light-brown, much worn, thinwalled conical bowl with funnel neck. The body is decorated with a design of three rows of impressed dots around the belly and an incised zig-zag pattern underneath. Joined from its fragments. Surviving H. $5.6 \mathrm{~cm}$, dB. 3 cm. Inv. no. 61.2.123.2 (Pl. CXXX. 339/2).

3. Mug. Non-joining handle, neck and body fragments of a grey, polished mug with fluting on the belly. Three pieces, the handle joined from smaller fragments. Inv. no. 61.2.123.3 (Pl. CXXX. 339/3).

\section{Grave 340 (Square D6; Pl. CXXX).}

Size of grave pit: -

Depth: $30 \mathrm{~cm}$

Orientation: -

Position of skeleton: -

L. of skeleton (contracted): -

L. of skeleton (extended): -

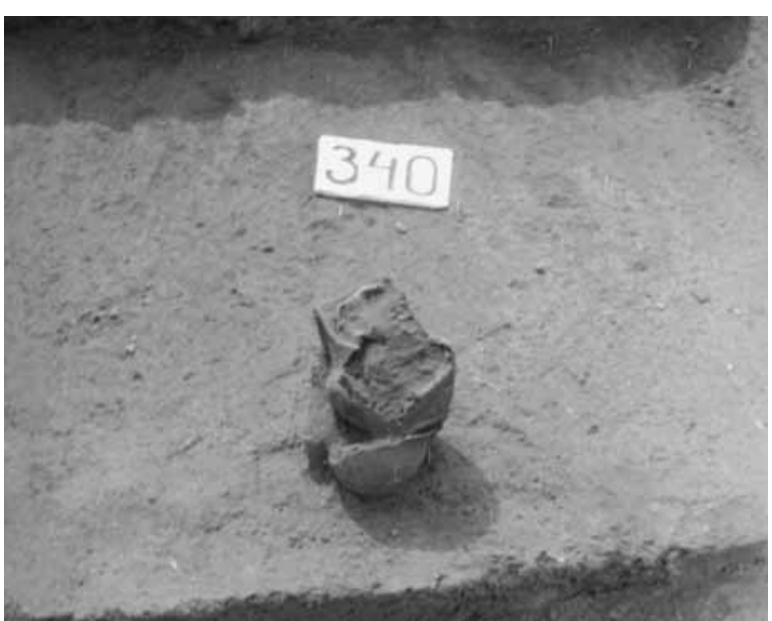


Age at death: $23-79$ years

Sex: female (?)

Condition of skeleton: -

Preserved skeletal bones: various fragments

Disturbed inurned burial. Set on a bowl (1) tilted slightly to one side was a jug (2) also tilted to one side. The jug was damaged by ploughing. The calcinated bones were placed inside the bowl. The vessels lay tilted toward the west and some of the bone fragments spilled out from the vessel.

Grave goods

1. Bowl. Grey, worn, small, plain conical bowl with slightly everted rim. The rim is damaged and restored in some spots. Joined from its fragments. H. $7.5 \mathrm{~cm}$, dM. $11.6 \mathrm{~cm}$, dB. $6.2 \mathrm{~cm}$. Inv. no. 61.2.124.2 (Pl. CXXX. 340/1).

2. Jug. One-half of a light brown biconical jug with cylindrical neck. There is no handle stub on the surviving part. Joined from its fragments and restored. H. $16.6 \mathrm{~cm}, \mathrm{~d} M .9 .3 \mathrm{~cm}, \mathrm{~dB} .7 .6 \mathrm{~cm}$. Inv. no. 61.2.124.1 (Pl. CXXX. 340/2).

\section{Grave 341 (Square E10; Pl. CXXXII)}

Size of grave pit: diam. $30 \mathrm{~cm}$

Depth: $25 \mathrm{~cm}$

Orientation: -

Position of skeleton: -

L. of skeleton (contracted): -

L. of skeleton (extended): -

Age at death: $0-5$ years

Sex: child

Condition of skeleton: -

Preserved skeletal bones: calcinated fragments

Scattered cremation burial. Calcinated bone fragments lay over an area with a diameter of $30 \mathrm{~cm}$. Lying above the bone fragments was the fragment of a thick-walled vessel (1) disturbed and destroyed by ploughing.

Grave goods

1. Pot. Fragment of a reddish, thick-walled pot with rusticated surface bearing the remains of an incised design, Joined from smaller fragments. L. $13.2 \mathrm{~cm}$. Inv. no. 61.2.125 (Pl. CXXXII. 341/1).

\section{Grave 342 (Square E10; Pl. CXXIX)}

Size of grave pit: L. $132 \mathrm{~cm}, W .112 \mathrm{~cm}$

Depth: $45 \mathrm{~cm}$

Orientation: S-SE to N-NW, with the head toward the S-SE

Position of skeleton: laid on the right side

L. of skeleton (contracted): $105 \mathrm{~cm}$

L. of skeleton (extended): $172 \mathrm{~cm}$

Age at death: $30-40$ years

Sex: male

Condition of skeleton: medium well preserved

Preserved skeletal bones: skull, long bones

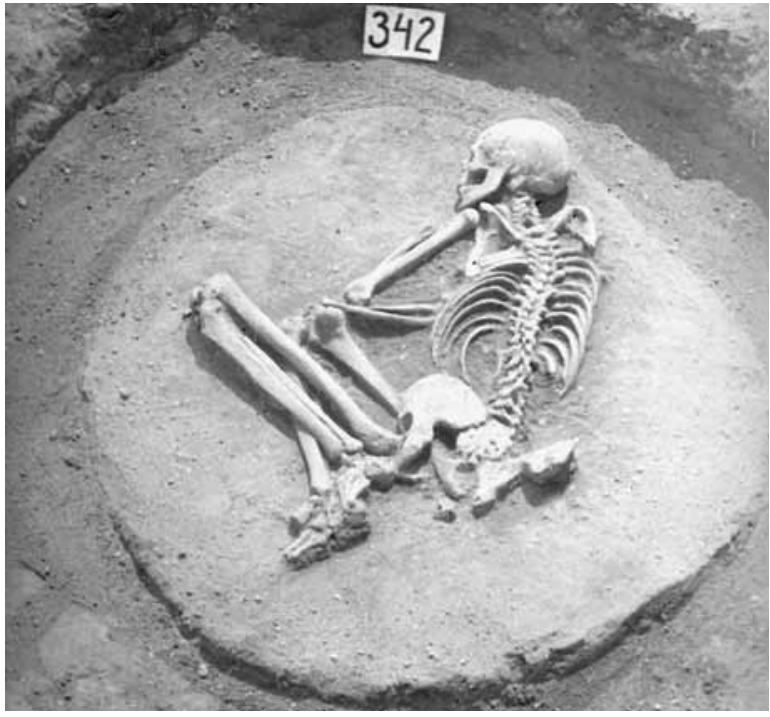

Inhumation burial in an oval grave pit. The body was laid on the right side in a strongly contracted position. The skull lay on the right side. The trunk and the pelvis lay extended on the back. The left arm was bent at the elbow and drawn up, with the hand placed under the left shoulder. The right arm was extended under the body with the hand resting under the right knee. The thighs were drawn up in front of the body, the legs were bent back toward the buttocks.

The burial did not contain any grave goods.

\section{Grave 343 (Square D7)}

Size of grave pit: diam. $45 \mathrm{~cm}$

Depth: $54 \mathrm{~cm}$

Orientation:-

Position of skeleton: -

L. of skeleton (contracted): -

L. of skeleton (extended): -

Age at death: $23-\mathrm{x}$ years

Sex: male (?)

Condition of skeleton: -

Preserved skeletal bones: calcinated bone fragments

Scattered cremation burial. Calcinated bone fragments forming a $5 \mathrm{~cm}$ thick layer were found over an area with a diameter of $45 \mathrm{~cm}$.

The burial did not contain any grave goods.

\section{Grave 344 (Square E10/F11; Pl. CXXXI)}

Size of grave pit: L. $132 \mathrm{~cm}$, W. $94 \mathrm{~cm}$

Depth: $77 \mathrm{~cm}$

Orientation: SE to NW, with the head toward the SE

Position of skeleton: laid on the right side

L. of skeleton (contracted): $97 \mathrm{~cm}$

L. of skeleton (extended): $147 \mathrm{~cm}$

Age at death: $30-50$ years

Sex: female

Condition of skeleton: badly preserved

Preserved skeletal bones: skull, long bones 


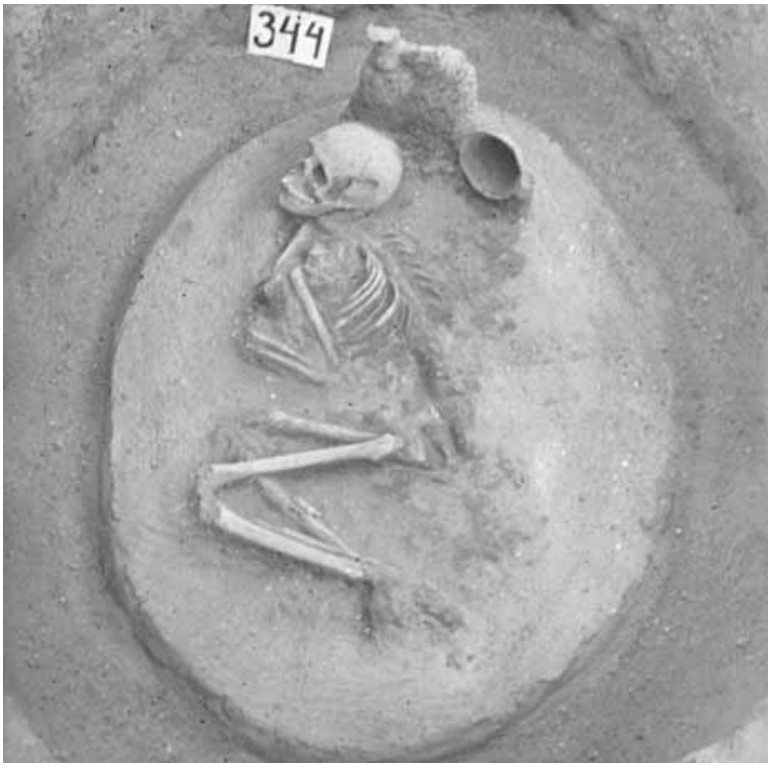

Inhumation burial in an oval grave pit. The body was laid on the right side in a strongly contracted position. The skull lay on the occipital bone, tilted slightly backward. The trunk lay prone. The left arm was bent at the elbow. The left thigh was drawn up into a horizontal position, the right one slightly higher, the legs were bent back toward the buttocks.

The burial contained the following grave goods: a red stone (1) under the left clavicle; a scooping vessel (2) tilted to one side with the mouth toward the edge of the grave pit behind the skull, $15 \mathrm{~cm}$ west-south-west of it; a small mug (3) set upright, $25 \mathrm{~cm}$ behind the skull; a broken pitcher (4) tilted to one side beside the previous vessel, with the mouth facing it.

\section{Grave goods}

1. Stone. irregularly shaped red stone with one side polished smooth. Diam. $4.5 \mathrm{~cm}$. Inv. no. 61.2.126.1.231

2. Scooping vessel. Greyish-brown, polished scooping vessel with flat base. The shoulder is encircled by a row of impressed dots. The short strap handle spans the rim and the shoulder. The rim is damaged, the vessel body is cracked. H. $13.2 \mathrm{~cm}$, dM. $6 \mathrm{~cm}$. Inv. no. 61.2.126.2 (Pl. CXXXI. 344/2).

3. Mug. Greyish-brown, polished mug with constricted neck and flattened globular body, decorated with fine fluting on the neck and belly. The three narrow, vertical ribs on the belly are obliquely fluted. The strap handle rises above the rim and springs to the shoulder. Joined from its fragments and restored. H. $7.6 \mathrm{~cm}$, dM. 5.3 cm. Inv. no. 61.2.126.3 (Pl. CXXXI. 344/3).

4. Pitcher. Dark grey pitcher with cylindrical neck and flattened globular body. The handle rises above the rim and springs to the shoulder. Joined from its fragments. H. $7.5 \mathrm{~cm}, \mathrm{~d} M .5 .5 \mathrm{~cm}$. Inv. no. 61.2.126.4 (Pl. CXXXI. 344/4).

231 The object has since been lost or mislaid. Its description is quoted from the acquisitions register.
Grave 345 (Square D9; Pl. CXXXII)

Size of grave pit: L. $117 \mathrm{~cm}, W .88 \mathrm{~cm}$

Depth: $82 \mathrm{~cm}$

Orientation: S-SE to N-NW, with the head toward the S-SE

Position of skeleton: laid on the right side (?)

L. of skeleton (contracted): $40 \mathrm{~cm}$

L. of skeleton (extended): -

Age at death: infans I

Sex: child

Condition of skeleton: badly preserved

Preserved skeletal bones:232 various fragments

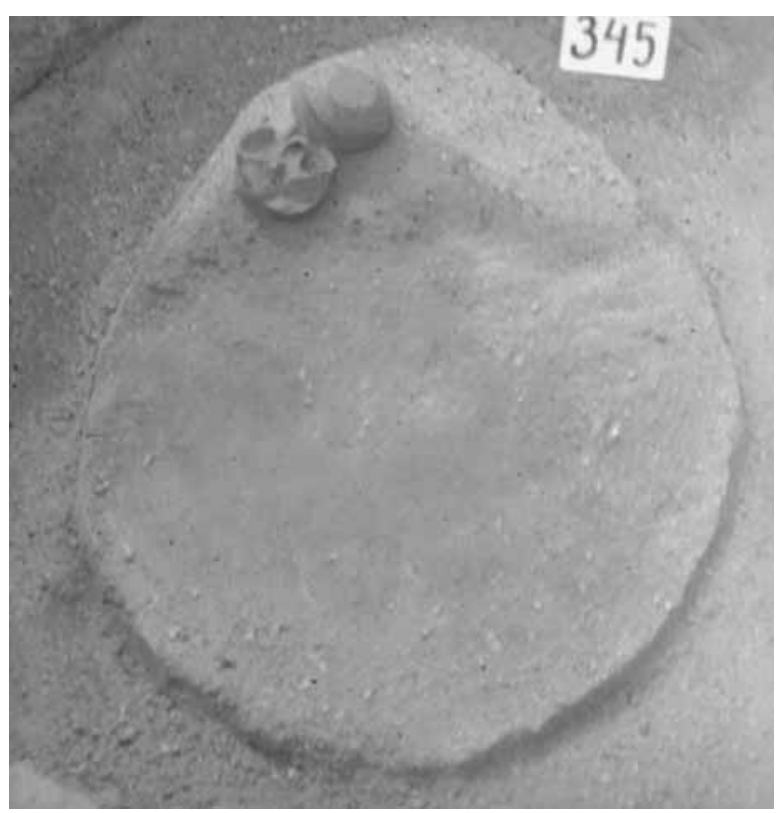

Inhumation burial in an oval grave pit. The skeletal remains had completely disintegrated, the skull and a few bones were all that survived of the skeleton. The body had probably been laid on the right side in a contracted position.

The burial contained the following grave goods: a bowl (1) set upside-down north-north-east of the skull; a broken mug (2) beside the previous vessel; two shells (3) on the chest.

\section{Grave goods}

1. Bowl. Greyish-brown, worn conical bowl with funnel neck. Two rows of impressed dots encircle the body. An unperforated lug is set on the shoulder. The rim is damaged. The vessel body is cracked. H. $6.8 \mathrm{~cm}$, dM. 15 cm. Inv. no. 61.2.127.1 (Pl. CXXXII. 345/1).

2. Mug. Brownish, worn mug. The handle rises above the rim and springs to the shoulder. Joined from its fragments. L. $6.1 \mathrm{~cm}$. Inv. no. 61.2.127.2 (Pl. CXXXII. 345/2).

3. Shells. Two Anadara diluvii shells. Inv. no. 61.2.127.3 (Pl. CXXXII. 345/3).

232 The skeletal remains can no longer be found. The anthropological data are quoted from the excavation diary. 
Grave 346 (Square F10; Pl. CXXX)

Size of grave pit: -

Depth: $44 \mathrm{~cm}$

Orientation: S-SE to N-NW, with the head toward the S-SE

Position of skeleton: laid on the left side

L. of skeleton (contracted): $87 \mathrm{~cm}$

L. of skeleton (extended): -

Age at death: $40-x$ years

Sex: male

Condition of skeleton: badly preserved

Preserved skeletal bones: various fragments

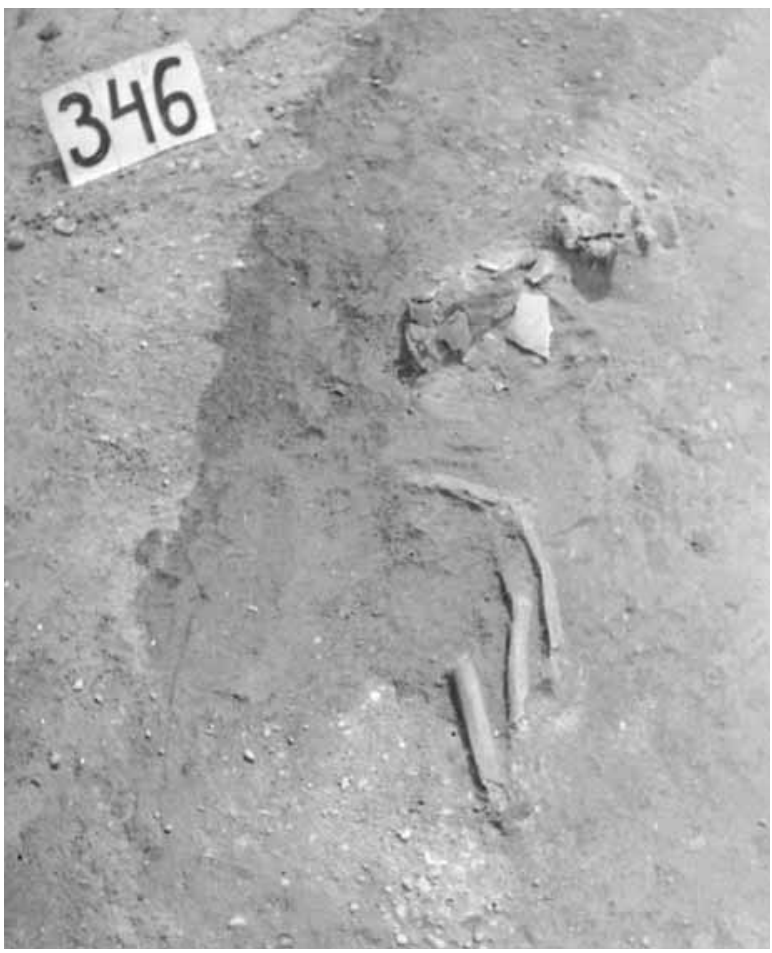

Disturbed inhumation burial. There was no indication of a grave pit. The burial was disturbed and partly destroyed during earth-scraping operations. The body was laid on the left side in a contracted position. The skull was crushed. The right arm was bent at the elbow. The left arm was destroyed. The thighs were drawn up in front of the body. Very little remained of the legs.

The burial did not contain any grave goods in the surviving section.

\section{Grave 347 (Square F11; Pls $C X X X I V-C X X X V)$}

\author{
Size of grave pit: L. $135 \mathrm{~cm}, W .90 \mathrm{~cm}$ \\ Depth: $110 \mathrm{~cm}$ \\ Orientation: NW to SE, with the head toward the NW \\ Position of skeleton: laid on the right side \\ L. of skeleton (contracted): $95 \mathrm{~cm}$ \\ L. of skeleton (extended): $149 \mathrm{~cm}$ \\ Age at death: $30-40$ years \\ Sex: female \\ Condition of skeleton: medium well preserved \\ Preserved skeletal bones: skull, long bones
}

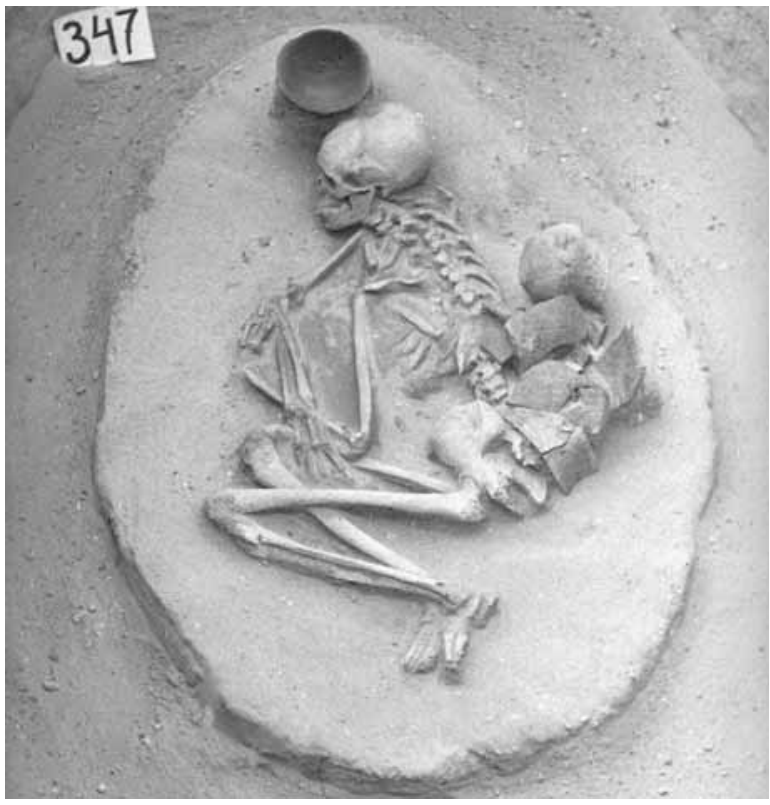

Inhumation burial in an oval grave pit. The body was laid on the right side in a contracted position. The skull rested on the occipital bone, tilted slightly to the right. The right arm was bent at the elbow, with the hand resting on the left forearm and the right thigh. The left arm was bent at the elbow, with the hand placed by the right elbow. The left thigh was drawn up into a horizontal position, the right one slightly higher, the legs were bent back toward the buttocks. The ankles were placed one over the other.

The burial contained the following grave goods: a bowl (1) tilted to one side with the mouth toward the centre of the grave pit behind the skull, but $14 \mathrm{~cm}$ higher; a pitcher (2) tilted to one side with the mouth toward the edge of the grave pit behind the spine; a broken bowl (3) on the spine and pelvis; a core (4) and a flake (5) in front of the face, $10 \mathrm{~cm}$ north-west of the right elbow.

\section{Grave goods}

1. Bowl. Brownish-grey, polished conical bowl with funnel neck. A small stringhole lug is set on the shoulder. A line of three impressed dots, the start of an unfinished row of impressed dots, runs on the left side of the lug. The rim is damaged and restored, the vessel body is cracked. H. $6.3 \mathrm{~cm}, \mathrm{dM} .15 \mathrm{~cm}, \mathrm{~dB}$. 6.5 cm. Inv. no. 61.2.128.1 (Pl. CXXXIV. 347/1).

2. Pitcher. Brownish, red mottled pitcher with constricted neck, flattened globular body and flat base. The handle rises above the rim and springs to the shoulder. The belly is decorated with vertical fluting alternating with obliquely fluted pseudo-ribs on the body. The rim is damaged. H. $12.7 \mathrm{~cm}, \mathrm{dM}$. $7.7 \mathrm{~cm}$. Inv. no. 61.2.128.2 (Pl. CXXXIV. 347/2).

3. Bowl. Fragments of a greyish-brown, polished, semi-spherical bowl with slightly indrawn rim. The rim is decorated with impressed dots, The rim is peaked (resembling an ansa lunata) in one spot above 
a stringhole lug. The interior is decorated with bundles of smoothed-in lines arranged in a cross pattern. The design cannot be precisely reconstructed from the non-joining fragments. Joined from twelve fragments. dM. $20 \mathrm{~cm}$, H. $7.5 \mathrm{~cm}$. Inv. no. 61.2.128.3 (Pl. CXXXV. 347/3).

4. Radiolarite core. Inv. no. 61.2.128.4 (Pl. CXXXIV. 347/4). ${ }^{233}$

5. Radiolarite debitage. Inv. no. 61.2.128.5 (Pl. CXXXIV. 347/5).

\section{Grave 348 (Square D6; Pl. CXXIX)}

Size of grave pit: L. $124 \mathrm{~cm}, W .105 \mathrm{~cm}$

Depth: $75 \mathrm{~cm}$

Orientation: S-SW to N-NE, with the head toward the S-SW

Position of skeleton: laid on the right side

L. of skeleton (contracted): $101 \mathrm{~cm}$

L. of skeleton (extended): $158 \mathrm{~cm}$

Age at death: $40-\mathrm{x}$ years

Sex: female

Condition of skeleton: medium well preserved

Preserved skeletal bones: skull, long bones

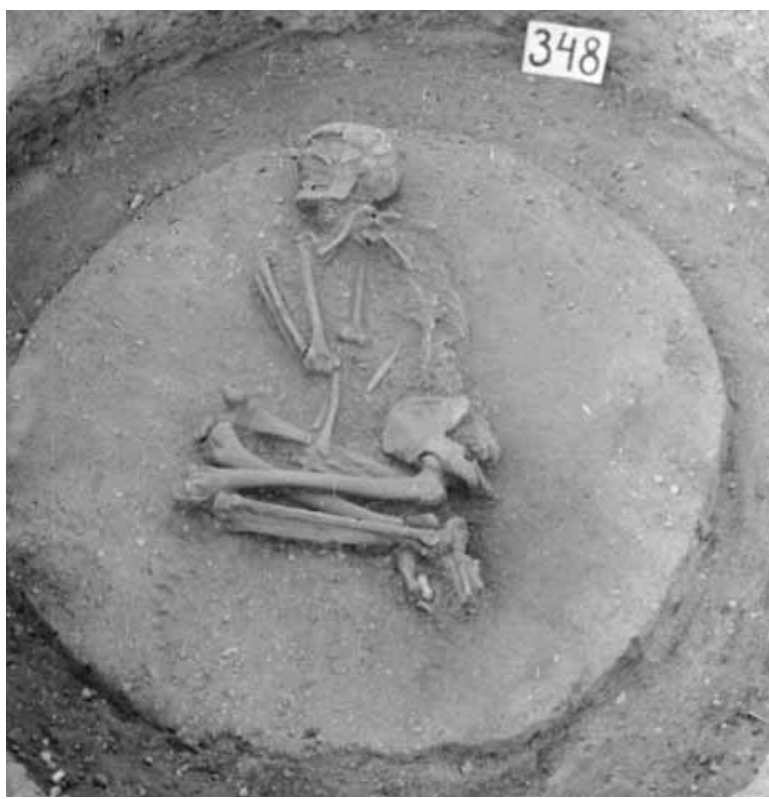

Inhumation burial in an oval grave pit containing a smaller flat stone in the middle at a depth of $-45 \mathrm{~cm}$. The body was laid on the right side in a contracted position. The crushed skull lay on the right side. The right arm was extended, with the hand resting between the two thighs. The left arm was bent at the elbow and drawn up, with the hand placed by the shoulder. The left thigh was drawn up into a horizontal position, the right one slightly higher, the legs were bent back toward the buttocks. The ankles were placed one over the other.

The burial did not contain any grave goods.

233 A photo of nos 3-4 was found among the photos made by József Korek in the Archives of the Szentendre museum.

\section{Grave 349 (Pl. C6; Pl. CXXXIII)}

Size of grave pit: L. $140 \mathrm{~cm}, W .105 \mathrm{~cm}$

Depth: $68 \mathrm{~cm}$

Orientation: -

Position of skeleton: -

L. of skeleton (contracted): -

L. of skeleton (extended): -

Age at death: -

Sex: -

Condition of skeleton: -

Preserved skeletal bones: -

Symbolic burial in an oval grave pit. The grave pit was south-west to north-east oriented. A stone lay in the grave pit's south-western half at a depth of $-50 \mathrm{~cm}$. An animal bone (1) was found in the middle of the grave pit at a depth of $-60 \mathrm{~cm}$. No human skeletal remains were found.

Grave goods

1. Animal bone. Fragment of a deer metatarsal. L. $14 \mathrm{~cm}$. Inv. no. 61.2.129.

\section{Grave $350(\mathrm{Pl} . \mathrm{C} 6 ; \mathrm{Pl}$. CXXXIII $)$}

Size of grave pit: L. $152 \mathrm{~cm}, W .117 \mathrm{~cm}$

Depth: $104 \mathrm{~cm}$

Orientation: $\mathrm{S}$ to $\mathrm{N}$, with the head toward the $\mathrm{S}$ and the face toward the E-SE

Position of skeleton: laid on the right side

L. of skeleton (contracted): $118 \mathrm{~cm}$

L. of skeleton (extended): $151 \mathrm{~cm}$

Age at death: 23-39 years

Sex: female

Condition of skeleton: medium well preserved

Preserved skeletal bones: skull, long bones

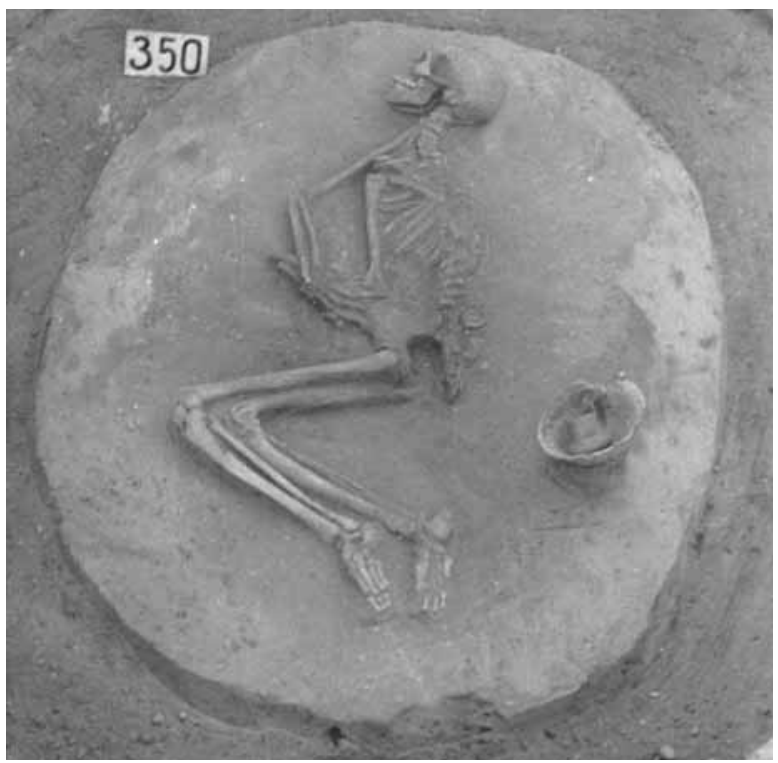

Inhumation burial in an oval grave pit. The body was laid on the right side in a moderately contracted position. The crushed skull lay on the right side. The right arm was bent at the elbow and drawn up, with the 
hand resting by the left elbow. The left arm was bent at the elbow. The thighs were drawn up into a horizontal position, the legs were bent back toward the buttocks. The position of the body and the ribs suggest that deceased had been a pregnant woman.

The burial contained the following grave goods: a broken bowl (1) tilted to one side behind the buttocks, $18 \mathrm{~cm}$ to their north-west; a small mug (2) inside the previous vessel.

Grave goods

1. Bowl. Brownish, grey mottled, polished, conical bowl with funnel neck, A horizontal stringhole lug is set on the shoulder. Joined from its fragments and restored. H. $8.4 \mathrm{~cm}, \mathrm{dM} .16 .6 \mathrm{~cm}, \mathrm{~dB} .6 .5 \mathrm{~cm}$. Inv. no. 61.2.130.1 (Pl. CXXXIII. 350/1).

2. Mug. Light brown, polished mug with cylindrical neck, flattened globular body and an omphalos base. The handle rises above the rim and springs to the shoulder. The shoulder and the belly are decorated with vertical fluting. H. $7.4 \mathrm{~cm}$, dM. $5.4 \mathrm{~cm}$. Inv. no. 61.2.130.2 (Pl. CXXXIII. 350/2).

\section{Grave 351 (Square E10; Pl. CXXXIII)}

Size of grave pit: L. $98 \mathrm{~cm}, W .79 \mathrm{~cm}$

Depth: $c a .25 \mathrm{~cm}$

Orientation: S-SE to N-NW, with the head toward the S-SE

Position of skeleton: laid on the right side

L. of skeleton (contracted): $65 \mathrm{~cm}$

L. of skeleton (extended): -

Age at death: $40-x$ years

Sex: female (?)

Condition of skeleton: badly preserved

Preserved skeletal bones: skull, long bone fragments

Inhumation burial in an oval grave pit containing stones. The presence of stones could be traced from the modern surface down to the burial. Most lay on the body. The body was laid on the right side in a strongly contracted position. The skull was crushed. The position of the arms could not be established. The thighs were drawn up in front of the body, the legs were bent back toward the buttocks.

The burial did not contain any grave goods.

\section{Grave 352 (Pl. C6; Pl. CXXXIII)}

Size of grave pit: L. $117 \mathrm{~cm}$, W. $88 \mathrm{~cm}$

Depth: $84 \mathrm{~cm}$

Orientation: S-SE to N-NW, with the head toward the S-SE

Position of skeleton: laid on the left side

L. of skeleton (contracted): $55 \mathrm{~cm}$

L. of skeleton (extended): $c a .90 \mathrm{~cm}$

Age at death: 4-6 years

Sex: child

Condition of skeleton: badly preserved

Preserved skeletal bones: skull, long bones

Inhumation burial in an oval grave pit. The body was

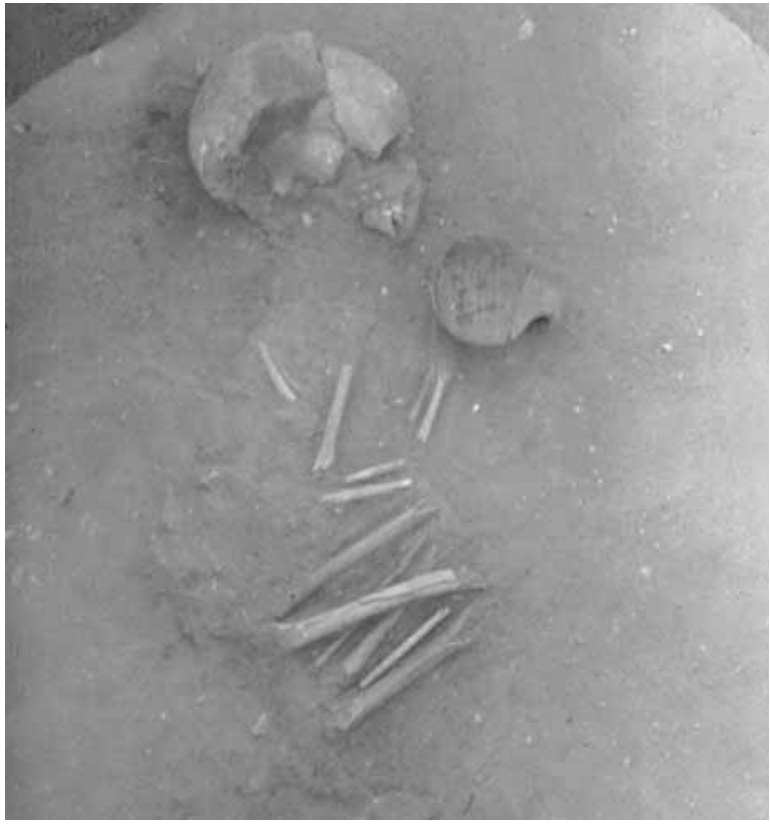

laid on the left side in a contracted position. The crushed skull lay on the left side. The left arm was bent at the elbow, with the hand laid toward the face. The right arm was bent at the elbow. The thighs were drawn up in front of the body, the legs were bent back toward the buttocks.

The burial contained the following grave goods: a small scooping vessel (1) with the handle toward the edge of the grave pit in front of the face; a stone flake (2) on the vessel's northern side.

\section{Grave goods}

1. Scooping vessel. Grey, polished scooping vessel with flat base. The short strap handle spans the rim and the base. Joined from its fragments and partially restored. Inv. no. 61.2.209 (Pl. CXXXIII. 352/1).234 2. Retouched radiolarite flake. Inv. no. $61.2 .188 .{ }^{235}$

\section{Grave 353 (Pl. C6; Pl. CXXXVI)}

Size of grave pit: L. $132 \mathrm{~cm}$, W. $102 \mathrm{~cm}$

Depth: $74 \mathrm{~cm}$

Orientation: SE to NW, with the head toward the SE Position of skeleton: laid on the left side

L. of skeleton (contracted): $100 \mathrm{~cm}$

L. of skeleton (extended): $170 \mathrm{~cm}$

Age at death: $25-35$ years

Sex: male

Condition of skeleton: medium well preserved

Preserved skeletal bones: skull, long bones

Inhumation burial in an oval grave pit containing stones between -30 and $-50 \mathrm{~cm}$. Various vessel fragments (1-2) lay among the stones. The body was

${ }^{234}$ It was found among the material inventoried as stray finds. The number 352 was inscribed on the base (barely legible by now).

235 The flake was not inventoried among the finds from the burial. A flake among the stray finds (inv. no. 61.2.188) perhaps came from this burial. 


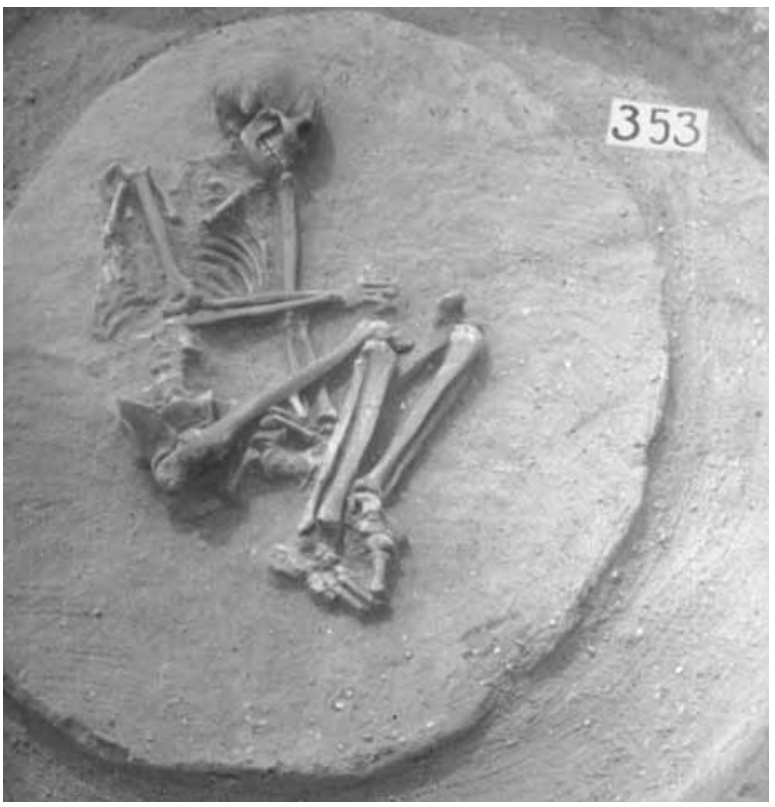

laid on the left side in a strongly contracted position. The skull lay on the left side. The right arm was bent at the elbow, with the hand placed above the knees. The left arm was extended, with the hand resting between the knees. The thighs were drawn up in front of the body, the legs were bent back toward the buttocks.

The burial did not contain any grave goods aside from the vessel fragments among the stones.

\section{Grave goods}

1. Jug. Rim, body and handle fragments of a grey, worn jug. The handle has a pattern of smoothed-in lines. The handle is joined from smaller fragments. Seven pieces. Inv. no. 61.2.131.1 (Pl. CXXXVI. 353/1).

2. Pitcher. Fragments of a grey, worn pitcher. The handle was fitted to the vessel with two pegs set into holes on the vessel body. Five non-joining pieces; the handle is joined from smaller fragments. Inv. no. 61.2.131.2 (Pl. CXXXVI. 353/2).

\section{Grave 354 (Square E4; Pls CXXXVI-CXXXVII)}

Size of grave pit: L. $158 \mathrm{~cm}, W .128 \mathrm{~cm}$

Depth: $78 \mathrm{~cm}$

Orientation: SW to NE, with the head toward the SW

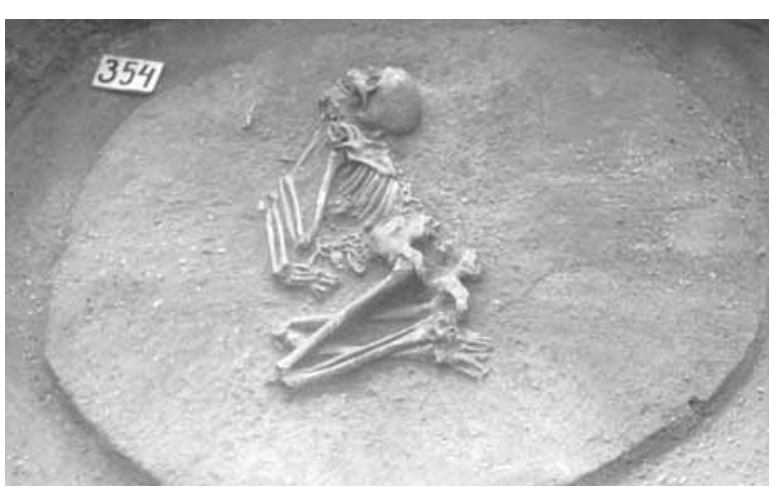

Position of skeleton: laid on the right side

L. of skeleton (contracted): $86 \mathrm{~cm}$

L. of skeleton (extended): $152 \mathrm{~cm}$

Age at death: $23-30$ years

Sex: female

Condition of skeleton: medium well preserved

Preserved skeletal bones: skull, long bones

Inhumation burial in an oval grave pit. There were smaller stones in the grave pit's north-eastern part between -25 and $-43 \mathrm{~cm}$. The body was laid across the grave pit on the right side in a contracted position. The skull rested on the occipital bone and was tilted slightly backward. The right arm was extended, with the hand resting by the left elbow. The right arm was bent at the elbow, with the wrist placed by the lower part of the upper arm. The left thigh was drawn up into a horizontal position, the right one slightly higher, the legs were bent back toward the buttocks. The ankles were placed one over the other.

The burial contained the following grave goods: a stone blade (1) by the right elbow; one intact and fifteen broken shell plaques (2) around the neck; a necklace of eight shells, one red bead, a hundred and forty-one other beads and ninety-one Dentalium beads (3) on the chest, in the lap and behind the spine. The Dentalium beads lay by the neck, the shells in the lap. The necklace was made up of two strands, which extended to the abdomen.

\section{Grave goods}

1. Unretouched limnic quartzite blade fragment. Inv. no. 61.2.132.1 (Pl. CXXXVI. 354/1).

2. Shell plaques. Broken, rectangular shell plaques with a pair of perforations along the short sides. Sixteen pieces. Inv. no. 61.2.132.2 (Pl. CXXXVII. 354/2).

3. Beads. Twenty-five Anadara diluvii shells (Pl. CXXXVII. 354/36), six intact Dentalium badense beads and a hundred and eighty limestone beads (Pl. CXXXVII. 354/3a). Patches of yellow pigment can be noted on most beads. Inv. no. 61.2.132.3.236

\section{Grave 355 (Square E4; Pl. CXXXVIII)}

Size of grave pit: L. $126 \mathrm{~cm}, W .102 \mathrm{~cm}$

Depth: $97 \mathrm{~cm}$

Orientation: S-SW to N-NE, with the head toward the S-SW

Position of skeleton: laid on the left side

L. of skeleton (contracted): $105 \mathrm{~cm}$

L. of skeleton (extended): $163 \mathrm{~cm}$

Age at death: $23-30$ years

Sex: male

Condition of skeleton: medium well preserved

Preserved skeletal bones: skull, long bones

Inhumation burial in an oval grave pit containing stones between -20 and $-40 \mathrm{~cm}$, among which lay

\footnotetext{
236 The number of beads was lower (a hundred and eighty-eight), the number of shells higher (twenty-six) when the finds were inventoried than the number specified in the excavation diary. The number of shells was lower again when the finds were re-examined for this publication.
} 


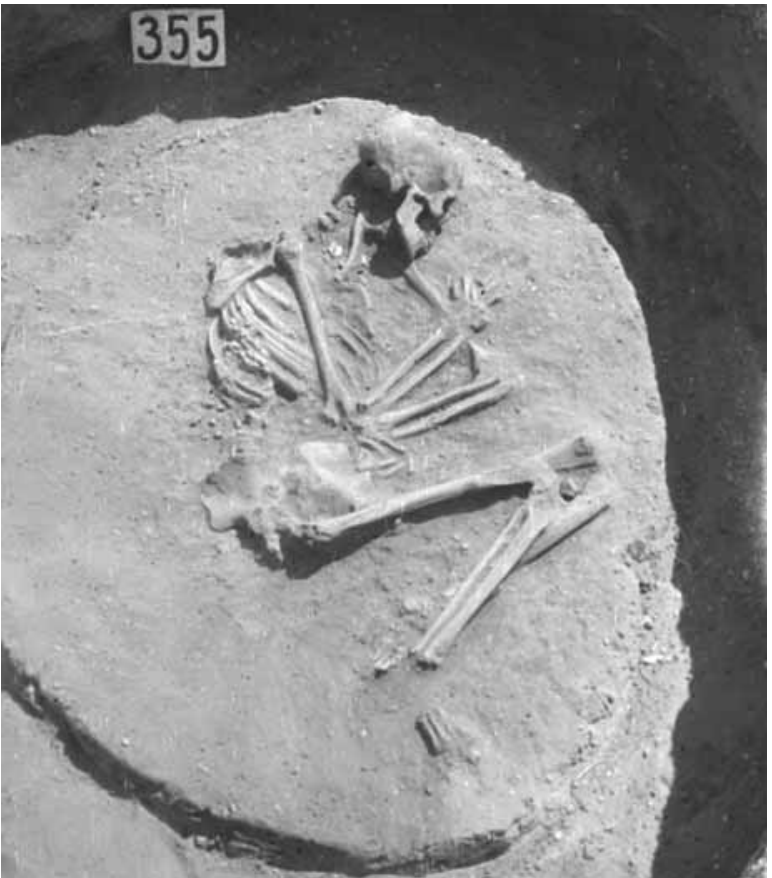

vessel fragments (1). The body was laid on the left side in a contracted position. The skull lay on the left side. The arms were bent at the elbow and folded across the chest. The thighs were drawn up into a horizontal position, the legs were bent back toward the buttocks.

The burial contained the following grave goods: a necklace of fourteen shell plaques, one Dentalium bead and nine other beads (2) around the neck (copper stains were noted on the ribs and on the clavicle, as well as on one of the shells, suggesting that one of the copper beads had been slipped over it); fifty-four beads (3) lying in four rows on the ribs and vertebrae down to the pelvis.

Grave goods

1. Bowl. Base fragment of a grey, polished bowl with flat base. L. $8.8 \mathrm{~cm}$. Inv. no. 61.2.133.3 (Pl. CXXXVIII. 355/1).

2. Beads. Ten sliced Dentalium badense beads and one broken copper bead. Inv. no. 61.2.133.1 (Pl. CXXXVIII. 355/2).237

3. Beads. Fifty-four limestone beads of varying sizes. Inv. no. 61.2.133.2 (Pl. CXXXVIII. 355/3).

\section{Grave 356 (Square D5; Pl. CXXXVIII)}

Size of grave pit: diam. $20 \mathrm{~cm}$

Depth: $35 \mathrm{~cm}$

Orientation: -

Position of skeleton: -

L. of skeleton (contracted): -

L. of skeleton (extended): -

Age at death: $23-59$ years

237 A tiny green patina stain on one of the shell beads is all that survives of the copper bead. The shell plaques mentioned in the excavation diary were not inventoried.
Sex: male (?)

Condition of skeleton: -

Preserved skeletal bones: various fragments

Scattered cremation burial. Calcinated bone fragments lay over an area with a diameter of $20 \mathrm{~cm}$.

The burial contained the following grave goods: a jug (1) south-west of the bone remains, its rim destroyed by ploughing; a bowl (2) beside the previous vessel; a red stone (3) among the bone fragments.

Grave goods

1. Jug. Grey, thick-walled, worn jug with constricted neck and conical body. If it had a handle, it sprang to the missing neck section. The rim is broken, the neck is restored. H. $17.7 \mathrm{~cm}, \mathrm{~dB} .8 .5 \mathrm{~cm}$. Inv. no. 61.2.134.1 (Pl. CXXXVIII. 356/1).

2. Bowl. Bowl with indrawn rim, flat base and a stringhole lug on the body. ${ }^{238}$

3. Stone. Irregularly shaped red stone with three sides polished smooth. L. $3 \mathrm{~cm}$. Inv. no. 61.2.134.2. ${ }^{239}$

\section{Grave 357 (Square E11; Pl. CXXXIV)}

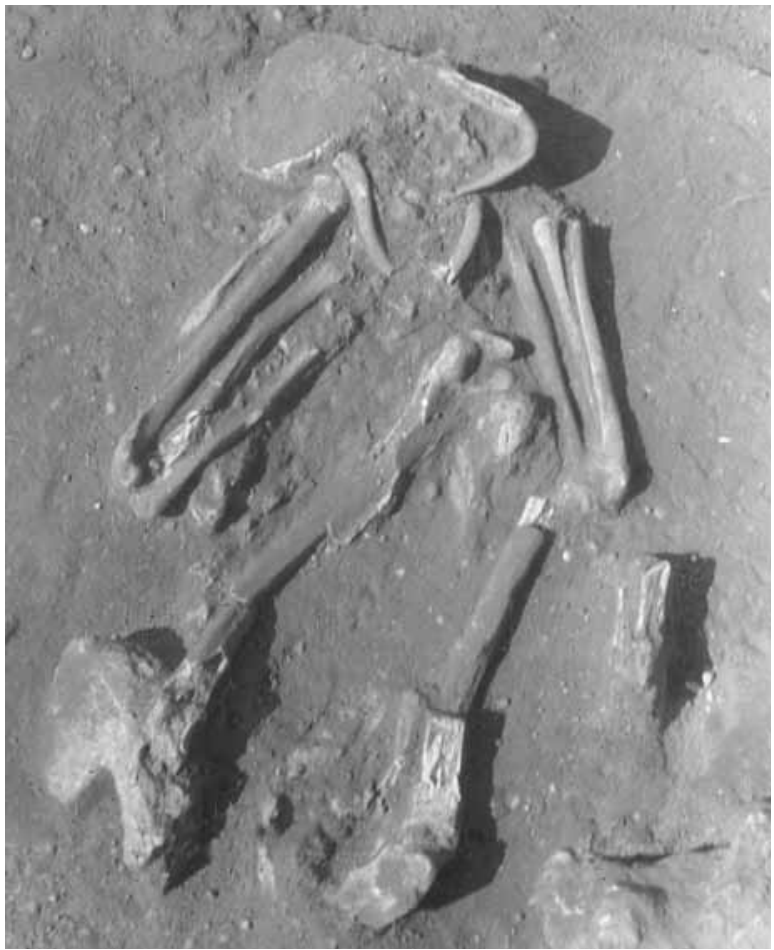

Size of grave pit: L. $118 \mathrm{~cm}, W .97 \mathrm{~cm}$

Depth: $30 \mathrm{~cm}$

Orientation: $\mathrm{S}$ to $\mathrm{N}$, with the head toward the $\mathrm{S}$

Position of skeleton: laid on the left side

L. of skeleton (contracted): $68 \mathrm{~cm}$

L. of skeleton (extended): -

238 The bowl was not inventoried among the finds from the burial. None of the vessels or pottery sherds among the stray finds inventoried in 1956 can be securely associated with the burial.

239 The object has since been lost or mislaid. Its description is quoted from the acquisitions register. 
Age at death: $25-35$ years

Sex: female

Condition of skeleton: badly preserved

Preserved skeletal bones: various fragments

Inhumation burial in an oval grave pit. The body was deposited across the grave pit. The body was covered with stones, some of which were removed in the course of earth scraping operations, which also destroyed a part of the skeletal remains (skull, legs). The body was laid on the left side in a strongly contracted position. The position of the parietal bone suggested that the skull had rested on the occipital bone. The right arm was bent at the elbow and drawn up, with the hand placed by the neck. The left arm was bent at the elbow and drawn up, with the hand resting in front of the face. The thighs were drawn up in front of the body with the knees laid in front of the shoulders, the legs were bent back toward the buttocks.

The burial did not contain any grave goods.

\section{Grave 358 (Square E11; Pl. CXXXIV)}

Size of grave pit: L. $110 \mathrm{~cm}, W .88 \mathrm{~cm}$

Depth: $102 \mathrm{~cm}$

Orientation: SE to NW, with the head toward the SE

Position of skeleton: laid on the right side

L. of skeleton (contracted): $72 \mathrm{~cm}$

L. of skeleton (extended): $173 \mathrm{~cm}$

Age at death: $40-\mathrm{x}$ years

Sex: male

Condition of skeleton: well preserved

Preserved skeletal bones: skull, long bones

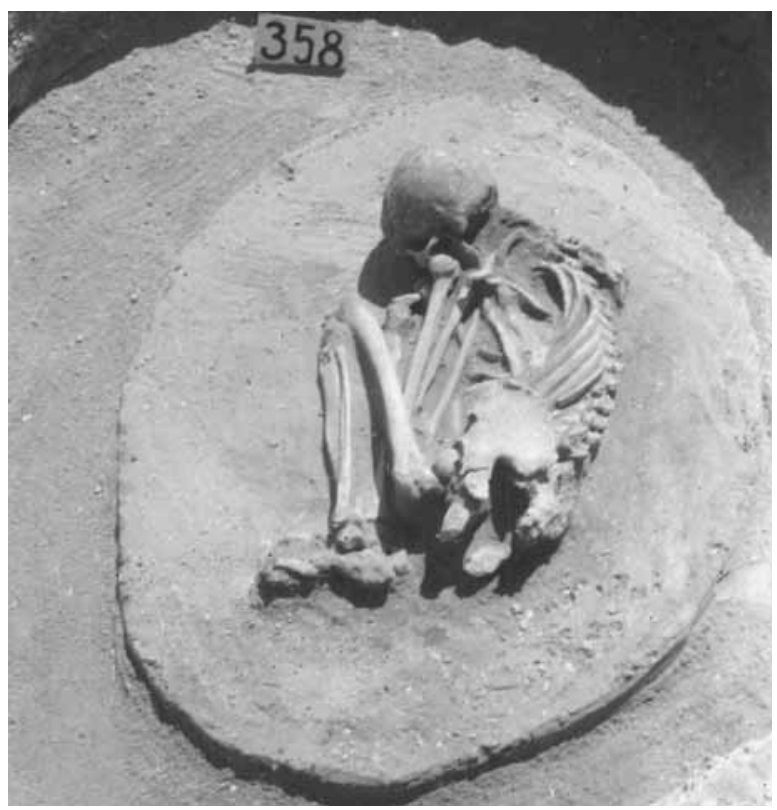

Inhumation burial in an oval grave pit. The grave lay underneath Grave 357. The body was laid on the right side in a strongly contracted position. The skull was tilted forward with the face downward. The left arm was bent at the elbow and drawn up, with the hand placed under the shoulder. The right arm was bent at the elbow and drawn up, with the hand resting under the neck. The thighs were drawn up in front of the face, the legs were bent back toward the buttocks. The ankles were placed one over the other. There was no sign of disturbance in the grave pit.

The burial did not contain any grave goods.

\section{Grave 359 (Square E4; Pls CXL-CXLI)}

Size of grave pit: L. $109 \mathrm{~cm}$, W. $95 \mathrm{~cm}$

Depth: $102 \mathrm{~cm}$

Orientation: S to N, with the head toward the S

Position of skeleton: laid on the left side

L. of skeleton (contracted): $88 \mathrm{~cm}$

L. of skeleton (extended): $145 \mathrm{~cm}$

Age at death: $25-35$ years

Sex: female

Condition of skeleton: medium well preserved

Preserved skeletal bones: skull, long bones

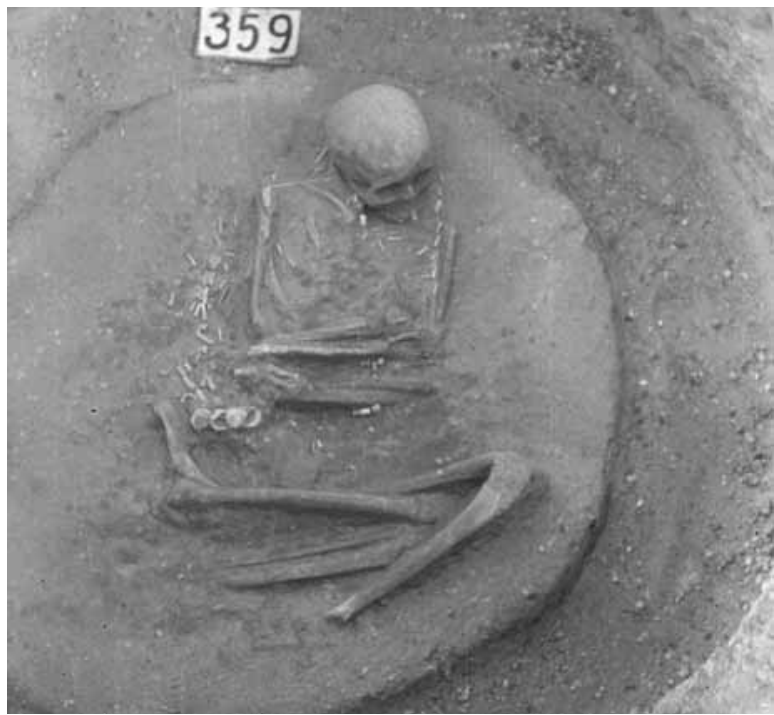

Inhumation burial in an oval grave pit containing many stones between -25 and $-70 \mathrm{~cm}$. The body was laid on the left side in a contracted position. The skull rested on the occipital bone. The arms were laid in the lap. The thighs were drawn up into a horizontal position, the legs were bent back toward the buttocks. The trunk was placed on the back tilted slightly to the left.

The burial contained the following grave goods: five broken shell plaques, thirty-eight beads and a fragmentary copper bead (1), the remains of a necklace around the neck; eighty-six shell beads (mostly sliced) (2) arranged in three rows behind the spine; seven shells and forty-six beads (3) around the waist and on the abdomen; sixteen shell beads (4) on the inner side of the left upper arm; nine beads (5) between the two forearms.

\section{Grave goods}

1. Beads. Forty Dentalium badense beads and two broken clay beads (Pl. CXL. 359/1a), six broken rectangular 
Unio crassus shell plaques, each with a pair of perforations on the short sides (Pl. CXL. 359/1b), probably strung into a necklace. Inv. no. 61.2.135.1.240

2. Beads. Eighty-four Dentalium badense beads (some intact, some broken) and one clay bead. Inv. no. 61.2.135.2 (Pl. CXLI. 359/2).241

3. Beads. Seven perforated Anadara diluvii shells (Pl. CXL. 359/3b), three Dentalium badense beads and forty-three limestone beads of varying sizes (Pl. CXL. 359/3a). Inv. no. 61.2.135.3.

4. Beads. Sixteen Dentalium badense beads. Inv. no. 61.2.135.4 (Pl. CXLI. 359/4).

5. Beads. Nine limestone beads of varying sizes. Inv. no. 61.2.135.5 (Pl. CXLI. 359/5).

\section{Grave 360 (Square C6; Pls CXLII-CXLIII)}

Size of grave pit: L. $140 \mathrm{~cm}, W .98 \mathrm{~cm}$

Depth: $123 \mathrm{~cm}$

Orientation: $\mathrm{E}$ to $\mathrm{W}$, with the head toward the $\mathrm{E}$

Position of skeleton: laid on the left side

L. of skeleton (contracted): $96 \mathrm{~cm}$

L. of skeleton (extended): $130 \mathrm{~cm}$

Age at death: $10-12$ years

Sex: child

Condition of skeleton: badly preserved

Preserved skeletal bones: skull, long bones

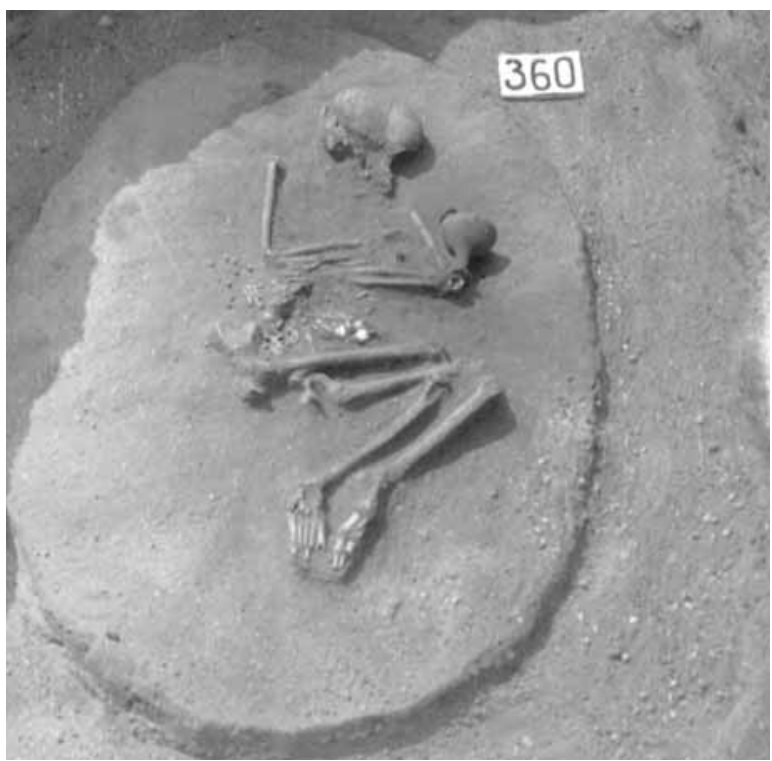

Inhumation burial in an oval grave pit. The body was laid on the left side in a contracted position. The trunk lay extended on the back. The crushed skull lay on the left side. The arms were bent at the elbow and placed in the lap. The thighs were drawn up into a horizontal

\footnotetext{
$\overline{240}$ The number of beads mentioned in the excavation diary and the number of inventoried beads differs. Five of the shell plaques were suitable for drawing.

241 The acquisitions register mentions eighty-two beads, some of which slipped into each other. Eighty-five beads were identified when the finds were re-examined for this publication.
}

position, the legs were bent back toward the buttocks.

The burial contained the following grave goods: a goblet (1) tilted to one side with the mouth toward the skull by the left elbow; a second goblet (2) inside the previous vessel; twenty-six beads and three shells (3) around the waist; a hundred and seventy-four beads and twenty-one shells (4) arranged in three strands immediately above the abdomen, with strands of shells hanging from the bead belt in front and in the back.

\section{Grave goods}

1. Goblet. Light brown goblet with rounded upper part set on a cylindrical foot with a round base. Patches of red paint survive on the exterior and interior. The rim is damaged, the foot is cracked. H. $11 \mathrm{~cm}, \mathrm{dM} .8 .8 \mathrm{~cm}, \mathrm{~dB} .4 .2 \mathrm{~cm}$. Inv. no. 61.2.136.1 (Pl. CXLIII. 360/1).

2. Goblet. Greyish-brown goblet with round upper part set on a cylindrical foot with a round base. The rim is decorated with oblique notching. The body bears a design of incised chevrons on two sides. The foot is perforated above the base. Patches of the red paint covering the entire vessel survive on the exterior and interior. H. $6.8 \mathrm{~cm}, \mathrm{dM} .6 .8 \mathrm{~cm}, \mathrm{~dB} .3 .5 \mathrm{~cm}$. Inv. no. 61.2.136.2 (Pl. CXLIII. 360/2).

3. Beads. Twenty-six limestone beads of varying sizes (Pl. CXLII. 360/3b) and three broken Anadara diluvii shells (Pl. CXLII. 360/3a). Inv. no. 61.2.136.3.

4. Beads. One Dentalium badense bead, one hundred and twenty-four limestone beads of varying sizes ( $P l$. CXLII. 360/4a) and thirteen perforated Anadara diluvii shells, some broken (Pl. CXLII. 360/4b). Inv. no. 61.2.136.4.

\section{Grave 361 (Square E4; Pl. CXXXIX)}

Size of grave pit: L. $112 \mathrm{~cm}$, W. $94 \mathrm{~cm}$

Depth: $85 \mathrm{~cm}$

Orientation: SE to NW, with the head toward the SE

Position of skeleton: laid on the left side

L. of skeleton (contracted): $70 \mathrm{~cm}$

L. of skeleton (extended): $141 \mathrm{~cm}$

Age at death: 11-12 years

Sex: child

Condition of skeleton: medium well preserved

Preserved skeletal bones: skull, long bones

Inhumation burial in an oval grave pit. The body was laid on the left side in a contracted position. The skull lay tilted to the right. The arms were bent at the elbow and drawn up, with the hands resting in front of the face. The right thigh was drawn up into a horizontal position, the left one slightly higher, the legs were bent back toward the buttocks. The ankles were laid one over the other.

The burial contained the following grave goods: a suspension vessel (1) with the mouth toward the face in front of the face; a stone trapeze (2) by the hands between the previous vessel and the face; ten shell 


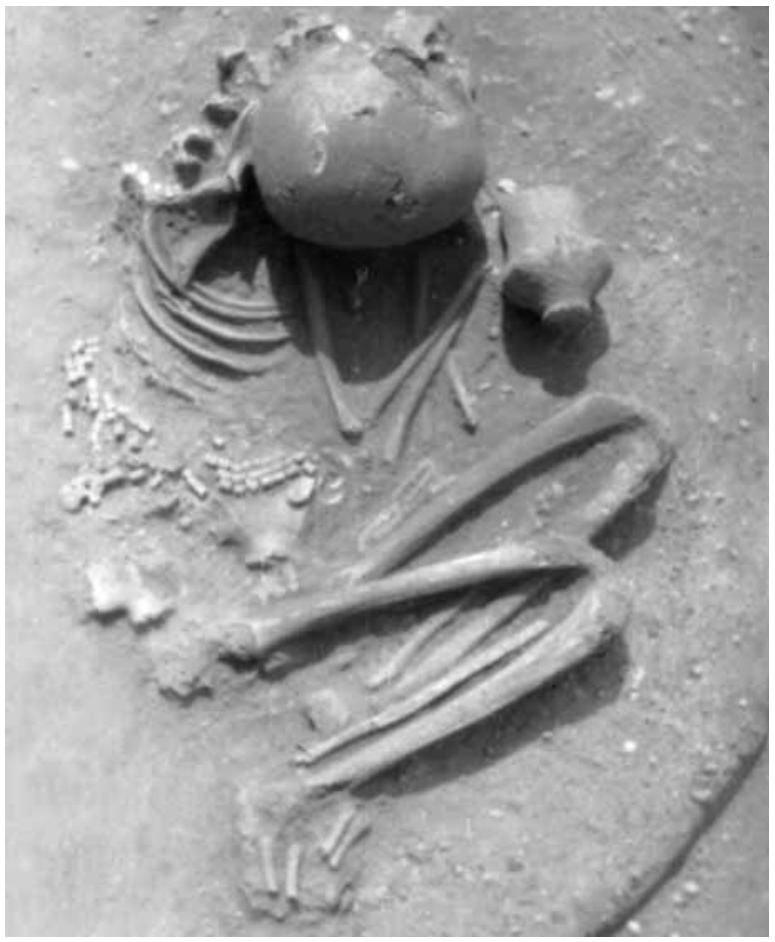

plaques (3) around the neck; beads (4) arranged into three strands around the waist with shells hanging in front and behind (six shells, seventy-three beads and four broken tubular copper beads).

Grave goods

1. Suspension vessel. Greyish-brown, worn footed vessel with cylindrical neck and flattened, angular belly. The base is perforated. The small lugs are set slightly obliquely on the opposite sides of the belly. Traces of wear can be noted between the lugs and the perforations on the base. One lug has broken off. H. $10.5 \mathrm{~cm}, \mathrm{dM} .6 .1 \mathrm{~cm}, \mathrm{~dB} .3 .5 \mathrm{~cm}$. Inv. no. 61.2.137.1 (Pl. CXXXIX. 361/1).

2. Trapeze. Limnic quartzite. L. $16 \times 12.5 \times 3 \mathrm{~mm}$. Inv. no. 61.2.137.2 (Pl. CXXXIX. 361/2).

3. Shell plaques. Rectangular Unio crassus mussel plaques with a pair of perforations on the short sides. Ten pieces, all broken. L. $2.5 \mathrm{~cm}, W .1 .3 \mathrm{~cm}$. Inv. no. 61.2.137.3 (Pl. CXXXIX. 361/3).

4. Beads. Seventy-two limestone beads of varying sizes, one Dentalium badense bead (Pl. CXXXIX. 361/4a), six Anadara diluvii shells (Pl. CXXXIX. 361/4b) and four fragmentary tubular copper beads (Pl. CXXXIX. 361/4c). Inv. no. 61.2.137.4.242

\section{Grave 362 (Square E4/E5; Pl. CXLI)}

Size of grave pit: L. $113 \mathrm{~cm}, W .85 \mathrm{~cm}$ Depth: $48 \mathrm{~cm}$

Orientation: $\mathrm{S}$ to $\mathrm{N}$, with the head toward the $\mathrm{S}$

242 The photo of one of the copper beads is based on the metallurgical report in the Szentendre museum (SzFM Archives, inv. no. 1170/76, report prepared by Dr. Manfred Schröder).
Position of skeleton: laid on the left side

L. of skeleton (contracted): $77 \mathrm{~cm}$

L. of skeleton (extended): -

Age at death: adult

Sex: male

Condition of skeleton: badly preserved

Preserved skeletal bones: ${ }^{243}$ skull, long bones

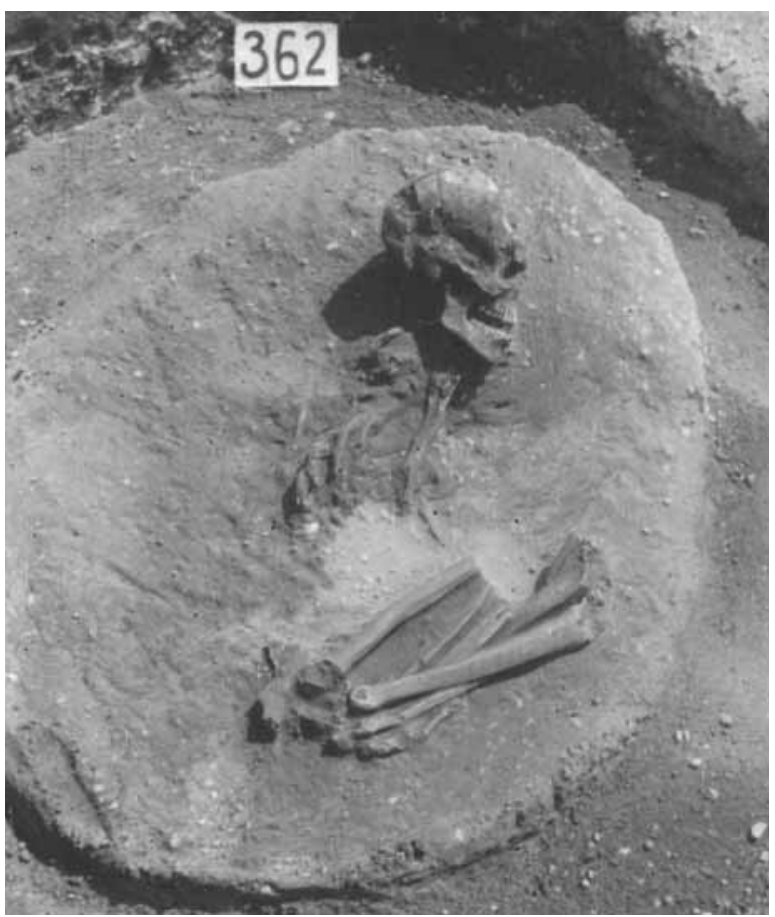

Inhumation burial in an oval grave pit containing stones between -4 and $-40 \mathrm{~cm}$. The stones lay on the body with a larger stone on the skull. The body was laid on the left side in a strongly contracted position. The crushed skull lay on the left side. The left arm was bent at the elbow and the forearm laid under the thighs. The right forearm was destroyed by an animal burrow. The thighs were drawn up in front of the body, the legs were bent back toward the buttocks. The ankles were placed one over the other.

The burial did not contain any grave goods.

\section{Grave 363 (Square E5; Pl. CXLI)}

Size of grave pit: L. $93 \mathrm{~cm}, W .81 \mathrm{~cm}$

Depth: $82 \mathrm{~cm}$

Orientation: SW to NE, with the head toward the S-SW

Position of skeleton: laid on the left side

L. of skeleton (contracted): $69 \mathrm{~cm}$

L. of skeleton (extended): -

Age at death: $12-14$ years

Sex: child

Condition of skeleton: medium well preserved

Preserved skeletal bones: skull, long bones

243 The surviving skeletal remains are unsuitable for an anthropological determination. 


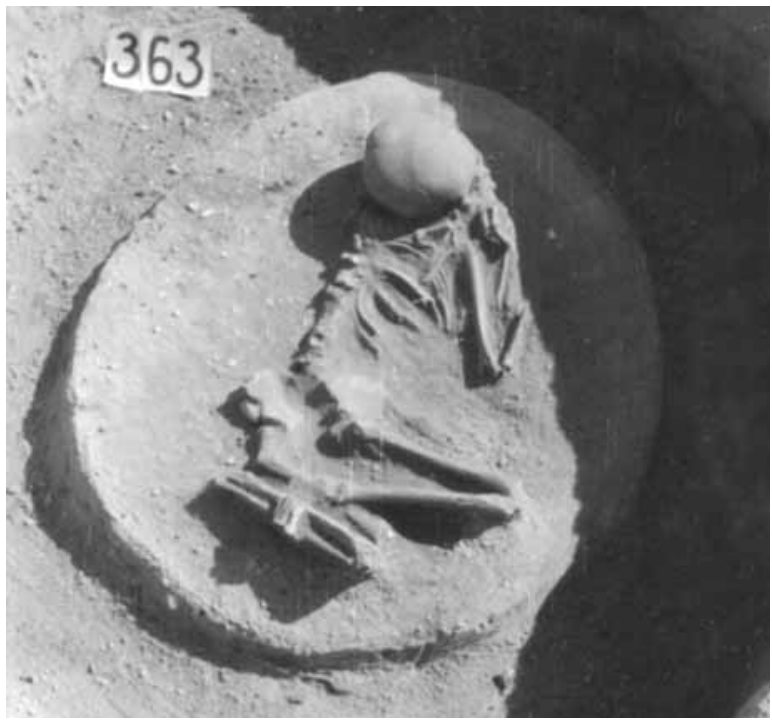

Inhumation burial in a rounded grave pit. The grave lay under Grave 362. The body was laid on the left side in a contracted position. The skull rested on the occipital bone. The trunk was laid prone, tilted slightly to the left. The arms were bent at the elbow and drawn up, with the hands placed in front of the face. The thighs were drawn up into a horizontal position, the legs were bent back toward the buttocks.

The burial contained the following grave goods: a river mussel (1) by the left pelvic bone.

Grave goods

1. River mussel. Left valve of an Unio crassus mussel. L. 4 cm. Inv. no. 61.2 .138 (Pl. CXLI. 363/1).

\section{Grave 364 (Pl. C5; Pl. CXLIII)}

Size of grave pit: L. $86 \mathrm{~cm}, W .84 \mathrm{~cm}$

Depth: $80 \mathrm{~cm}$

Orientation: NW to SE, with the head toward the NW

Position of skeleton: laid on the right side

L. of skeleton (contracted): $36 \mathrm{~cm}$

L. of skeleton (extended): -

Age at death: $0-1$ years

Sex: child

Condition of skeleton: badly preserved

Preserved skeletal bones: various fragments

Inhumation burial in a round grave pit containing stones between -25 and $-40 \mathrm{~cm}$. The body was laid on the right side in a contracted position. The crushed skull and the thighbones are all that survived of the skeletal remains.

The burial contained the following grave goods: a scooping vessel (1) with the mouth toward the skull by the edge of the grave pit.

\section{Grave goods}

1. Scooping vessel. Greyish-brown, conical, plain scooping vessel. The handle rises above the rim and springs to the base. The rim and the handle are damaged. Restored. H. $4.8 \mathrm{~cm}$, dM. 9 cm, dB. $4.6 \mathrm{~cm}$. Inv. no. 61.2.139 (Pl. CXLIII) 364/1).

\section{Grave 365 (Square E4; Pl. CXLIII)}

\section{Size of grave pit:-}

Depth: $41 \mathrm{~cm}$

Orientation: SE to NW, with the head toward the SE

Position of skeleton: laid on the right side

L. of skeleton (contracted): $82 \mathrm{~cm}$

L. of skeleton (extended): -

Age at death: $40-x$ years

Sex: male

Condition of skeleton: badly preserved

Preserved skeletal bones: skull, long bones

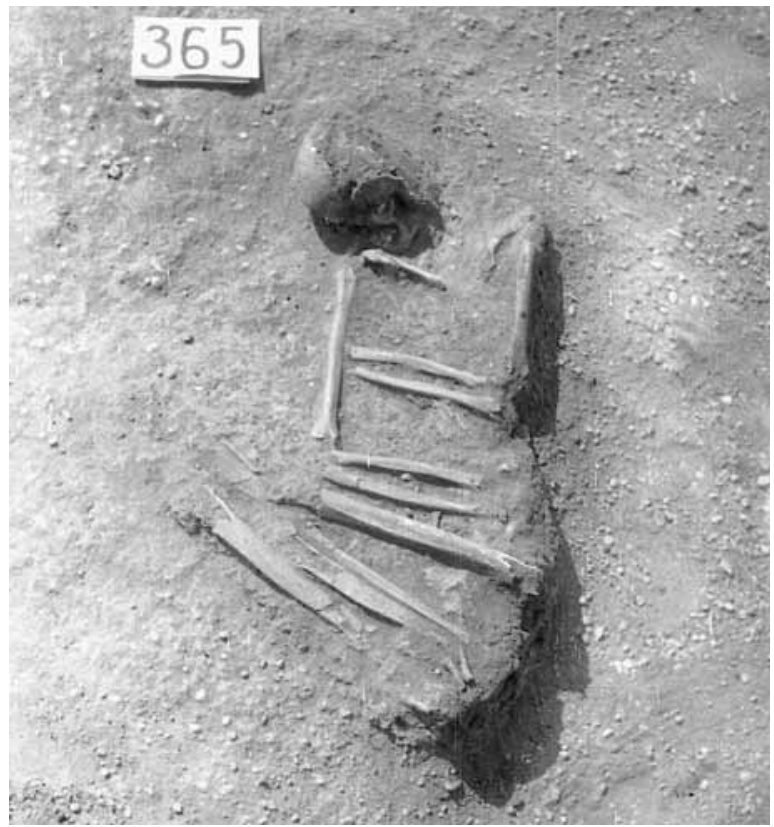

Inhumation burial. There was no indication of a grave pit. The body was laid on the right side in a contracted position. The skull was tilted forward. The arms were bent at the elbow. The thighs were drawn up into a horizontal position, the legs were bent back toward the buttocks.

The burial did not contain any grave goods.

\section{Grave 366 (Square D6; Pl. CXLIV)}

Size of grave pit: L. $168 \mathrm{~cm}$, W. $157 \mathrm{~cm}$

Depth: $112 \mathrm{~cm}$

Orientation: A: SE to NW, with the head toward the SE, B: SE to NW, with the head toward the SE

Position of skeleton: A: laid on the left side, B: laid on the left side L. of skeleton (contracted): A: $99 \mathrm{~cm}, \mathrm{~B}: 100 \mathrm{~cm}$ L. of skeleton (extended): A: $152 \mathrm{~cm}, \mathrm{~B}: 168 \mathrm{~cm}$ Age at death: A: $21-23$ years, B: $40-59$ years Sex: A: female, B: male

Condition of skeleton: A: medium well preserved, B: medium well preserved

Preserved skeletal bones: A-B: skull, long bones 


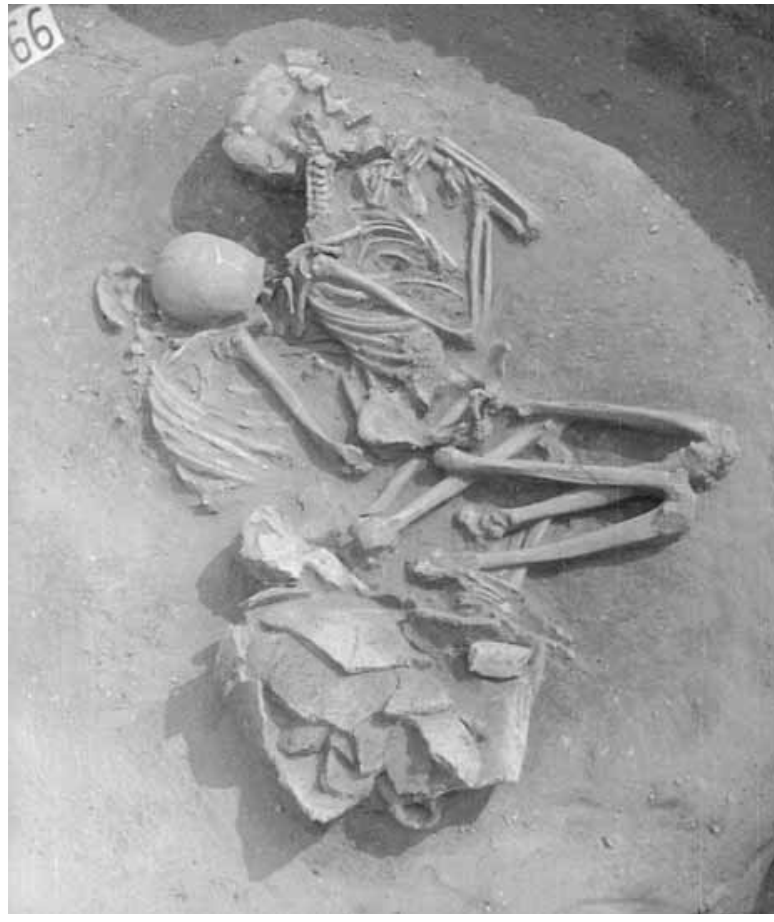

Double inhumation burial in a rounded grave pit. The two bodies were interred at the same time.

\section{Burial A}

The body was laid on the left side in a moderately contracted position with the trunk almost extended. The crushed skull lay on the left side. The right arm was bent at the elbow and drawn up to between the left upper arm and forearm. The left arm was bent at the elbow and drawn up, with the hand placed on the shoulder. The thighs were slightly drawn up, the legs were bent back toward the buttocks.

The burial contained the following grave goods: a piece of charred wood (1) under the right thigh; arrowhead-like antler implements (2-7) under the upper part of the left thigh.

\section{Burial B}

The body was laid on the left side in a contracted position behind and partly under Burial A. The skull rested on the occipital bone. The arms were bent at the elbow and drawn up, with the hands placed in front of the face. The thighs were drawn up into a horizontal position, the legs were bent back toward the buttocks. The thighs lay under Burial A, the feet under the feet of Burial A.

The burial contained the following grave goods: a large, broken pot (8) by the feet with the mouth toward the edge of the grave pit; a red stone (9) by the left knee and under the upper part of the left thigh of Burial A.

Grave goods

1. Piece of charcoal (?). L. $2.4 \mathrm{~cm}$. Inv. no. 61.2.140.3.244

244 The objects listed under nos 1-7 and 9 have since been lost or mislaid. Their description is quoted from the acquisitions register.
2. Antler arrowhead (?). Fragment of a broken antler implement with tapering end. L. $2.9 \mathrm{~cm}, W .0 .8 \mathrm{~cm}$. Inv. no. 61.2.140.4

3. Antler arrowhead (?). Fragment of a broken antler implement with tapering end. L. $4.2 \mathrm{~cm}, W .1 .1 \mathrm{~cm}$. Inv. no. 61.2.140.5.

4. Antler arrowhead (?). Fragment of a broken antler implement with tapering end. L. $4.1 \mathrm{~cm}, W .1 .1 \mathrm{~cm}$. Inv. no. 61.2.140.6.

5. Antler arrowhead (?). Fragment of a broken antler implement with tapering end. L. $5.1 \mathrm{~cm}, W .1 .9 \mathrm{~cm}$. Inv. no. 61.2.140.7.

6. Antler arrowhead (?). Fragment of a broken antler implement with tapering end. L. $3.6 \mathrm{~cm}, W .0 .9 \mathrm{~cm}$. Inv. no. 61.2.140.8.

7. Antler arrowhead (?). Fragment of an arrowheadlike, broken antler implement with tapering end. L. $5.6 \mathrm{~cm}, W .1 .4 \mathrm{~cm}$. Inv. no. 61.2.140.9.

8. Pot. Large, reddish-grey, thick-walled pot with a wide loop handle on the belly. Joined from its fragments and restored. H. $35 \mathrm{~cm}, \mathrm{~d} M .25 .5 \mathrm{~cm}, \mathrm{~dB}$. 13.7 cm. Inv. no. 61.2.140.1 (Pl. CXLIV. 366/8).

9. Stone. Irregularly shaped red stone with one side polished smooth. L. $3.5 \mathrm{~cm}$. Inv. no. 61.2.140.2.

\section{Grave 367 (Square F11; Pls CXLVI-CXLVII)}

Size of grave pit: L. $132 \mathrm{~cm}, W .104 \mathrm{~cm}$

Depth: $58 \mathrm{~cm}$

Orientation: SE to NW, with the head toward the SE

Position of skeleton: laid on the left side

L. of skeleton (contracted): $83 \mathrm{~cm}$

L. of skeleton (extended): $158 \mathrm{~cm}$

Age at death: $40-50$ years

Sex: female

Condition of skeleton: badly preserved

Preserved skeletal bones: skull, long bones

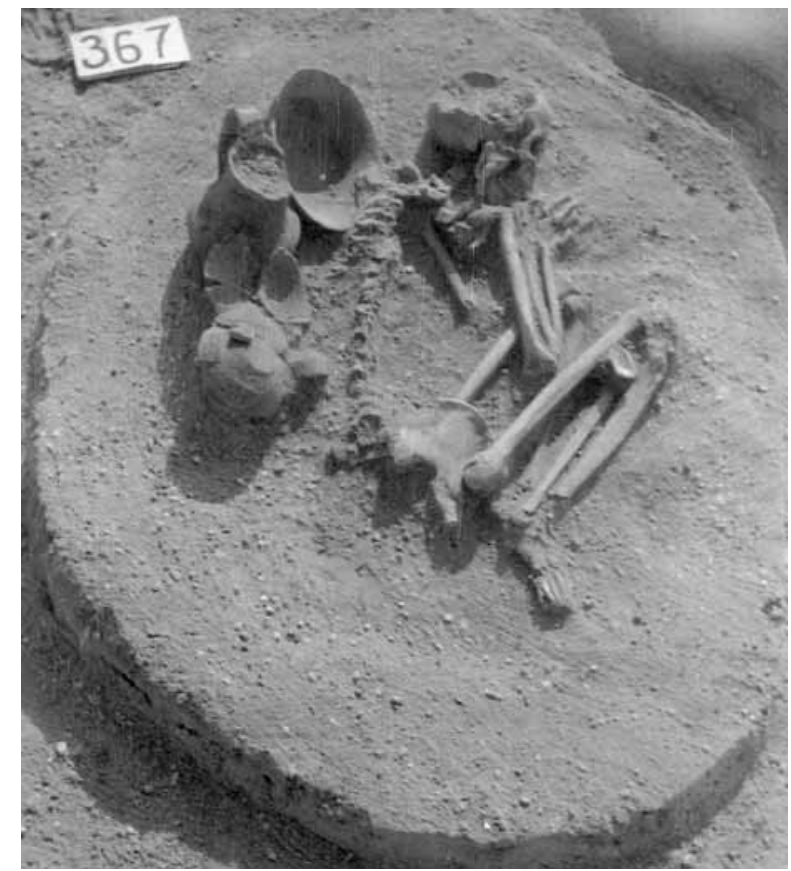


Inhumation burial in an oval grave pit. The body was laid on the left side in a strongly contracted position. The arms were bent at the elbow and drawn up, with the hands placed in front of the face. The thighs were drawn up in front of the body, the legs were bent back toward the buttocks. The ankles rested one over the other. The skull and the vessel rims were damaged by a modern intrusion.

The burial contained the following grave goods: a bowl (1) tilted to one side with the mouth toward the body behind the shoulders; a jug (2) behind the spine, beside the previous vessel; two scooping vessels, one tilted to one side (3), the other set upside down (4) beside the previous vessel; a red stone (5) on vessel 4; a mussel (6) by the right knee, on the calf-bone.

\section{Grave goods}

1. Bowl. Grey bowl with everted rim and constricted, flat base. The rim is decorated with impressed dots. Two rows of impressed dots encircle the vessel body, interrupted by a stringhole lug. H. $9.2 \mathrm{~cm}, \mathrm{dM} .23 \mathrm{~cm}$, dB. 8.5 cm. Inv. no. 61.2.141.1 (Pl. CXLVI. 367/1).245

2. Jug. Grey, polished, worn jug with cylindrical neck and flattened globular body. The handle rises above the rim and springs to the shoulder. The neck is encircled by fluting. Five barely prominent, obliquely fluted ribs are set on the belly; the areas between the ribs are filled with vertical fluting. The handle is similarly ornamented with fluting. Joined from its fragments; the rim is restored. H. $17.3 \mathrm{~cm}, \mathrm{dM}$. $9.1 \mathrm{~cm}, \mathrm{~dB} .7 .5 \mathrm{~cm}$. Inv. no. 61.2.141.2 (Pl. CXLVI. 367/2).

3. Scooping vessel. Dark grey, polished, shallow scooping vessel with flat base. The handle spans the rim and the shoulder. Joined from its fragments. H. $4.5 \mathrm{~cm}, \mathrm{~d} M .12 .8 \mathrm{~cm}, \mathrm{~dB} .5 .1 \mathrm{~cm}$. Inv. no. 61.2.141.3 (Pl. CXLVI. 367/4).

4. Scooping vessel. Grey, polished scooping vessel with rounded base. The short strap handle springs from the rim to the shoulder. Joined from its fragments. H. $4.5 \mathrm{~cm}$, dM. $12.3 \mathrm{~cm}, \mathrm{~dB} .5 \mathrm{~cm}$. Inv. no. 61.2.141.4 (Pl. CXLVII. 367/3).

5. Stone. Rectangular, flat, red stone. L. $3 \mathrm{~cm}, W .2 .6 \mathrm{~cm}$. Inv. no. 61.2.141.5.246

6. Mussel. Broken right valve of an Unio crassus mussel. L. 5 cm. Inv. no. 61.2.141.6 (Pl. CXLVI. 367/6).

\section{Grave 368 (Square D11; Pl. CXLV)}

Size of grave pit: L. $106 \mathrm{~cm}, W .83 \mathrm{~cm}$

Depth: $25 \mathrm{~cm}$

Orientation: $\mathrm{W}$ to $\mathrm{E}$, with the head toward the $\mathrm{W}$

Position of skeleton: laid on the right side

L. of skeleton (contracted): $67 \mathrm{~cm}$

L. of skeleton (extended): -

245 The object has since been lost. Its description is quoted from the acquisitions register. The drawing is based on József Korek's grave sheet. 246 The object has since been lost or mislaid. Its description is quoted from the acquisitions register.
Age at death: 6-7 years

Sex: child

Condition of skeleton: badly preserved

Preserved skeletal bones: skull, long bones

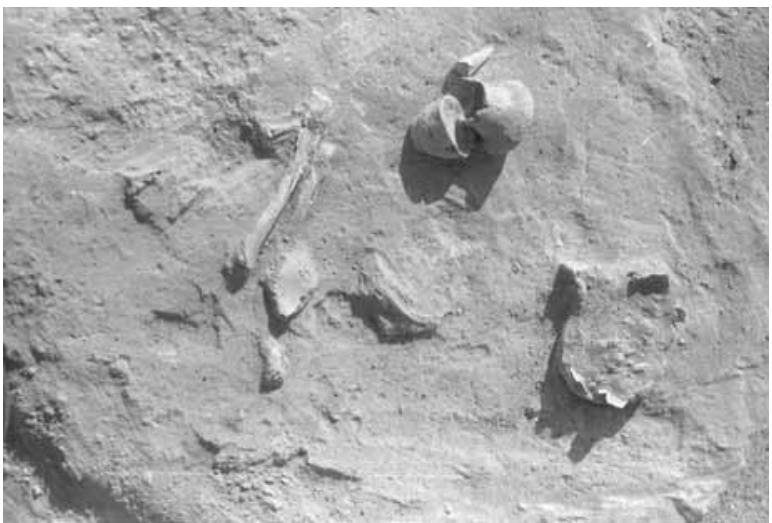

Inhumation burial in an oval grave pit. The body was laid on the right side in a contracted position. The skull lay on the right side. The thighs were drawn up slightly higher than a horizontal position, the legs were bent back toward the buttocks. The earth-scraper cut through the skull and dislodged some of the skeletal remains from their original position.

The burial contained the following grave goods: a broken mug (1) tilted to one side in front of the trunk; a bone or antler chisel (2) with the tip downward beside the vessel; a beaker (3) tilted to one side with the mouth toward the west beside and partly under vessel 1 ; a small red stone (4) under vessel 1.

\section{Grave goods}

1. Mug. Light grey, worn mug with cylindrical neck and flattened globular body decorated with fluting on the belly. The handle broke off, the rim is damaged. Joined from its fragments. $H .7 .5 \mathrm{~cm}, \mathrm{dM}$. $5 \mathrm{~cm}, \mathrm{~dB}$. ca. $4.3 \mathrm{~cm}$. Inv. no. 61.2.142.1 (Pl. CXL. 368/1).

2. Bone chisel. Fragment of a bone or antler chisel. L. 6.2 cm. Inv. no. 61.2.142.2 (Pl. CXLV. 368/2).

3. Beaker. Brownish-grey, flowerpot shaped beaker. Two small knobs are set on opposite sides under the rim. Joined from its fragments and restored. $H .5 .5 \mathrm{~cm}$, dM. $7.1 \mathrm{~cm}, \mathrm{~dB} .4 \mathrm{~cm}$. Inv. no. 61.2.142.3 (Pl. CXLV. 368/3).

4. Stone. Irregularly shaped, small red stone. Diam. $1.6 \mathrm{~cm}$. Inv. no. 61.2.142.4. ${ }^{247}$

\section{Grave 369 (Square D11; Pl. CXLV)}

Size of grave pit: L. $130 \mathrm{~cm}, W .104 \mathrm{~cm}$

Depth: $30 \mathrm{~cm}$

Orientation: $\mathrm{S}$ to $\mathrm{N}$, with the head toward the $\mathrm{S}$

Position of skeleton: extended

${ }_{247}$ The object has since been lost or mislaid. Its description is quoted from the acquisitions register. 
L. of skeleton (contracted): $101 \mathrm{~cm}$

L. of skeleton (extended): -

Age at death: 21-23 years

Sex: female

Condition of skeleton: badly preserved

Preserved skeletal bones: skull, long bones

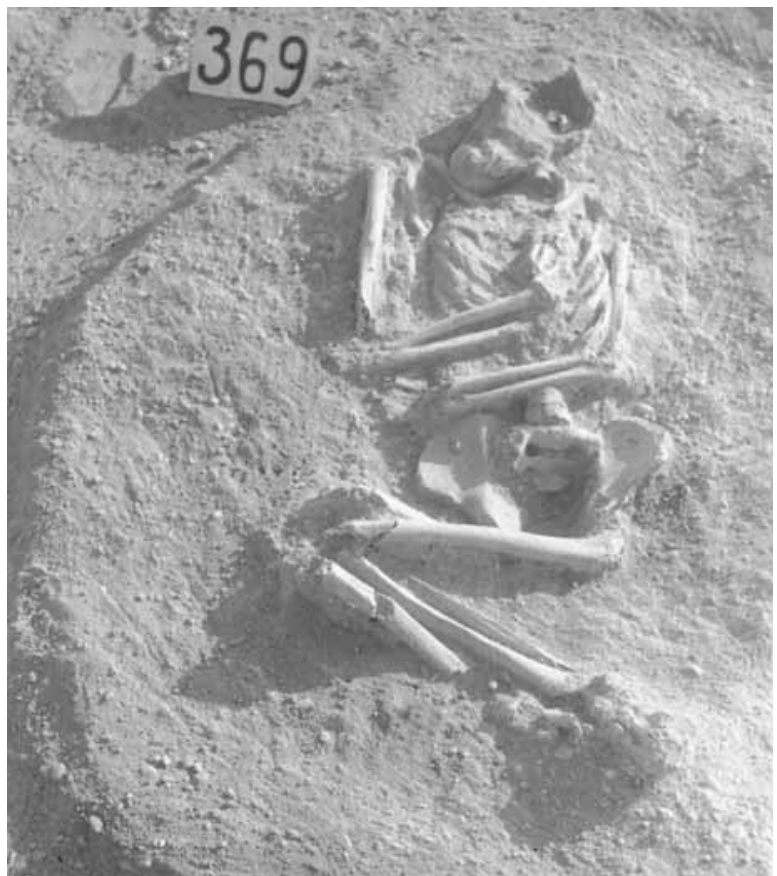

Inhumation burial in an oval grave pit. The body was laid on the right side in a contracted position with the trunk extended on the back. The skull rested on the occipital bone. The arms were bent at the elbow and folded across the chest. The pelvis was dislodged. The thighs were drawn up into a horizontal position, the legs were bent back toward the buttocks. The parietal bone and the knees were destroyed by the earthscraper.

The burial did not contain any grave goods.

\section{Grave 370 (Square F11; Pl. CXLV)}

Size of grave pit: L. $115 \mathrm{~cm}, W .97 \mathrm{~cm}$

Depth: $38 \mathrm{~cm}$

Orientation: S-SE to N-NW, with the head toward the S-SE

Position of skeleton: laid on the left side

L. of skeleton (contracted): $65 \mathrm{~cm}$

L. of skeleton (extended): -

Age at death: $30-40$ years

Sex: female

Condition of skeleton: badly preserved

Preserved skeletal bones: various fragments

Inhumation burial in an oval grave pit. A part of the burial was destroyed by a modern intrusion. The body was laid on the left side in a contracted position. The skull rested on the occipital bone. The left arm was drawn up and placed under the head (the forearm was destroyed by the intrusion). The right arm was bent at

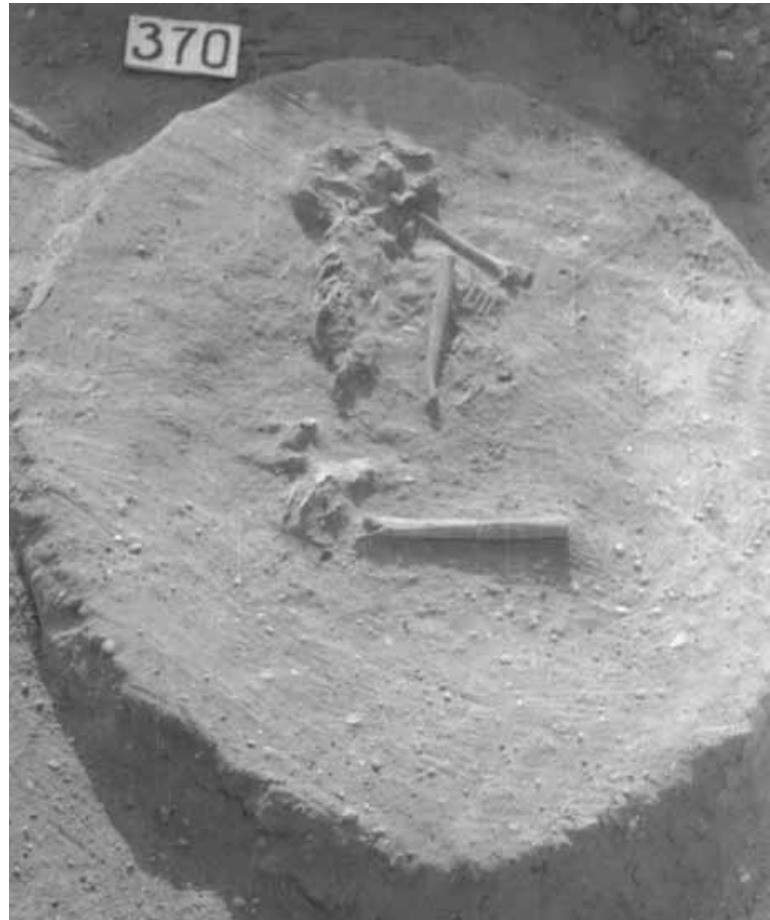

the elbow. The left thigh was drawn up into a horizontal position (the right thigh and the legs were destroyed).

The burial contained the following grave goods: a burin (1) by the right forearm.

Grave goods

1. Radiolarite burin. Inv. no. 61.2.143 (Pl. CXLV. 370/1).

\section{Grave 371 (Square D11; Pl. CXLV)}

Size of grave pit: L. $81 \mathrm{~cm}, W .71 \mathrm{~cm}$ Depth: $45 \mathrm{~cm}$

Orientation: $\mathrm{W}$ to $\mathrm{E}$, with the head toward the $\mathrm{W}$

Position of skeleton: laid on the right side

L. of skeleton (contracted): $55 \mathrm{~cm}$

L. of skeleton (extended): $c a .84 \mathrm{~cm}$

Age at death: 4-6 years

Sex: child

Condition of skeleton: badly preserved

Preserved skeletal bones: skull, long bones

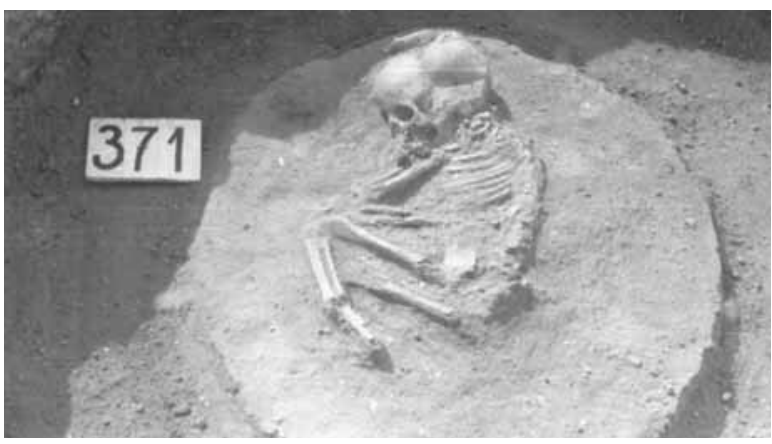

Inhumation burial in an oval grave pit. The body was laid on the right side in a contracted position. The left 
arm was bent at the elbow and drawn up, with the hand placed in front of the chin. The right arm was laid under the trunk and slightly bent at the elbow. The thighs were drawn up in front of the body, the legs were bent back toward the buttocks.

The burial contained the following grave goods: a red stone (1) in front of the chin; a necklace of thirtyeight beads (2) around the neck.

Grave goods

1. Stone. Irregularly shaped red stone with one side polished smooth. L. $3.6 \mathrm{~cm}$. Inv. no. 61.2.144.1 (Pl. CXLV. 371/1).248

2. Beads. Thirty-eight cylindrical limestone beads of varying sizes. L. $0.4-1.5 \mathrm{~cm}$. Inv. no. 61.2.144.2 (Pl. CXLV. 371/2).

\section{Grave 372 (Square D11; Pl. CXLVII)}

Size of grave pit: L. $133 \mathrm{~cm}, W .86 \mathrm{~cm}$

Depth: $48 \mathrm{~cm}$

Orientation: $\mathrm{S}$ to $\mathrm{N}$, with the head toward the $\mathrm{S}$

Position of skeleton: laid on the left side

L. of skeleton (contracted): $46 \mathrm{~cm}$ (surviving section)

L. of skeleton (extended): -

Age at death: $30-x$ years

Sex: female (?)

Condition of skeleton: badly preserved

Preserved skeletal bones: skull and various fragments

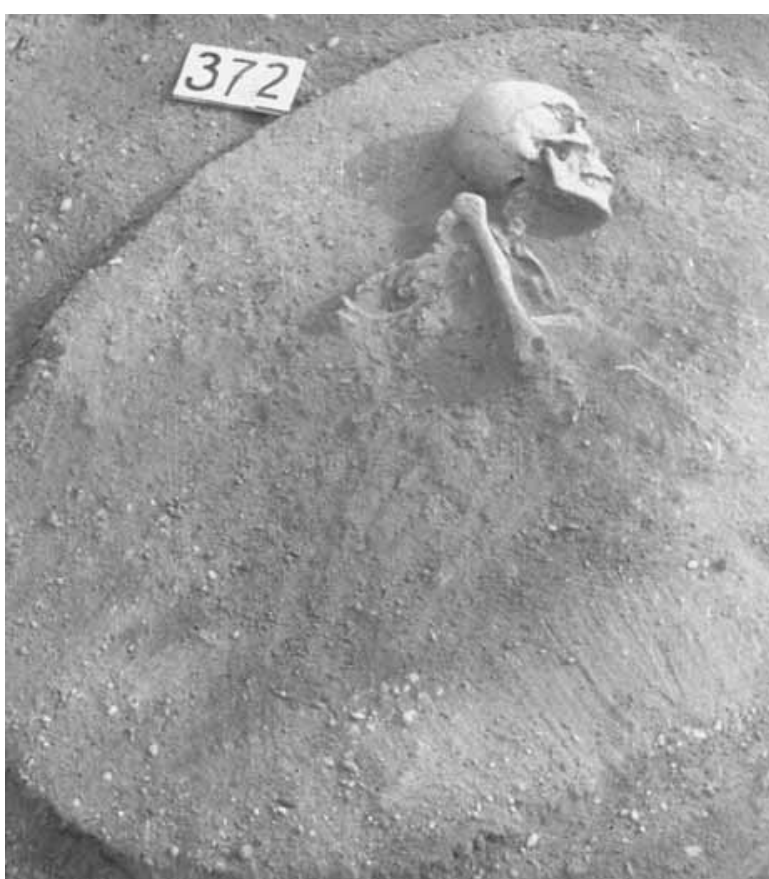

Disturbed inhumation burial in an oval grave pit. The burial was probably disturbed while the cemetery was still in use. The right arm and a few ribs are all that

248 The object has since been lost or mislaid. Its description is quoted from the acquisitions register. The drawing is based on József Korek's grave sheet. survived of the body. The body was laid on the left side in a contracted position. The skull lay on the left side. The right upper arm lay beside the trunk.

The burial did not contain any grave goods.

\section{Grave 373 (Square D11; Pl. CXLVII)}

Size of grave pit: L. $84 \mathrm{~cm}, W .67 \mathrm{~cm}$

Depth: $25 \mathrm{~cm}$

Orientation: $\mathrm{S}$ to $\mathrm{N}$, with the head toward the $\mathrm{S}$

Position of skeleton: laid on the left side

L. of skeleton (contracted): $62 \mathrm{~cm}$

L. of skeleton (extended): $c a .90 \mathrm{~cm}$

Age at death: $4-5$ years

Sex: child

Condition of skeleton: badly preserved

Preserved skeletal bones: various fragments

Inhumation burial in an oval grave pit. The body was laid on the left side in a contracted position. The skull lay on the left side. The earth-scraper damaged a part of the skull. The arms were bent at the elbow and drawn up, with the hands placed in front of the face. The thighs were drawn up into a horizontal position, the legs were bent back toward the buttocks.

The burial did not contain any grave goods.

\section{Grave 374 (Square F11; Pl. CXLVIII)}

Size of grave pit: -

Depth: $26 \mathrm{~cm}$

Orientation: -

Position of skeleton: laid on the left side

L. of skeleton (contracted): -

L. of skeleton (extended): -

Age at death: $23-\mathrm{x}$ years

Sex: male

Condition of skeleton: badly preserved

Preserved skeletal bones: various fragments

Inhumation burial. There was no indication of a grave pit. The burial was almost completely destroyed by an intrusion, only the pelvis and left thigh-bone survived. The position of the surviving skeletal remains suggested that the body had been laid on the left side in a contracted position.

The burial did not contain any grave goods in the surviving section.

\section{Grave 375 (Square E11; Pl. CXLVIII)}

Size of grave pit: L. $131 \mathrm{~cm}, W .102 \mathrm{~cm}$

Depth: $20 \mathrm{~cm}$

Orientation: $\mathrm{S}$ to $\mathrm{N}$, with the head toward the $\mathrm{S}$

Position of skeleton: laid on the left side

L. of skeleton (contracted): $94 \mathrm{~cm}$

L. of skeleton (extended): $c a .170 \mathrm{~cm}$

Age at death: $30-40$ years

Sex: male

Condition of skeleton: badly preserved

Preserved skeletal bones: skull fragments, long bones 


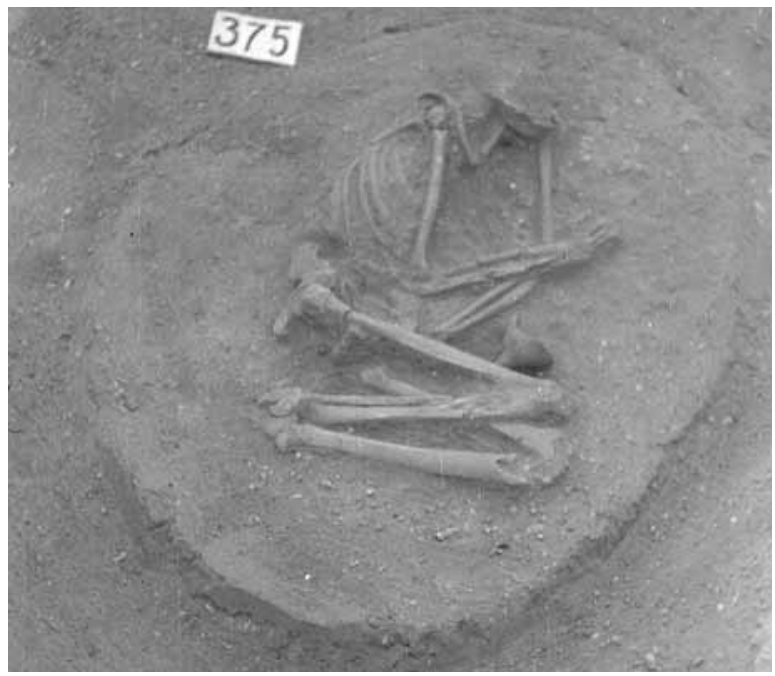

Inhumation burial in an oval grave pit. The body was laid on the left side in a contracted position. The skull was destroyed by ploughing; the position of the mandible suggested that the skull had rested on the occipital bone. The right arm was bent at the elbow and drawn up, the right hand was clenched. The left arm was turned slightly inward, with the hand placed under the right thigh. The thighs were drawn up into a horizontal position, the legs were bent back toward the buttocks. The ankles lay one over the other.

The burial contained the following grave goods: a goblet (1) tilted to one side with the mouth toward the south beside and partly under the right thigh; three blade fragments (2-4) between the vessel and the thighbone.

Grave goods

1. Goblet. Light brown, grey mottled goblet with round upper part set on a cylindrical foot with oval base. There are two perforations on the rim on opposite sides; the perforation on the foot probably served for suspension. The vessel body is decorated with parallel rows of zig-zag lines. Patches of red paint survive on the exterior. The rim is damaged. Joined from its fragments. H. $10.5 \mathrm{~cm}, \mathrm{dM} .10 \mathrm{~cm}$, dB. 3.5 cm. Inv. no. 61.2.145.1 (Pl. CXLVIII. 375/1).

2. Unretouched radiolarite blade fragment. Inv. no. 61.2.145.2 (Pl. CXLVIII. 375/2).

3. Unretouched radiolarite blade fragment Inv. no. 61.2.145.3 (Pl. CXLVIII. 375/3).

4. Unretouched radiolarite blade fragment. Inv. no. 61.2.145.4 (Pl. CXLVIII. 375/4).

\section{Grave 376 (Square D9/D10; Pl. CXLVII)}

Size of grave pit: L. $72 \mathrm{~cm}, W .70 \mathrm{~cm}$

Depth: $53 \mathrm{~cm}$

Orientation: W-SW to E-NE, with the head toward the W-SW

Position of skeleton: laid on the right side

L. of skeleton (contracted): $39 \mathrm{~cm}$

L. of skeleton (extended): -
Age at death: $0-1$ years

Sex: child

Condition of skeleton: badly preserved

Preserved skeletal bones: various fragments

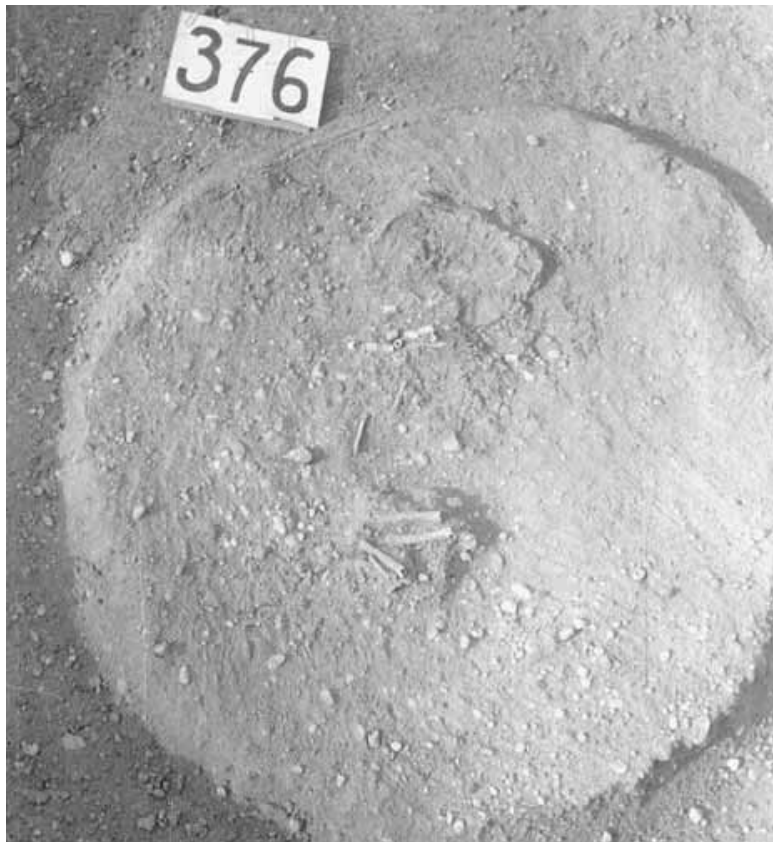

Inhumation burial in a round grave pit. A pitcher fragment (1) lay at a depth of $-40 \mathrm{~cm}$. The body was laid on the right side in a contracted position. The crushed skull lay on the right side. Only the upper arms survived. The thighs were drawn up into a horizontal position, the legs were bent back toward the buttocks.

The burial contained the following grave goods: a necklace of thirteen beads (2) around the neck; a pebble (3) in front of the body.

\section{Grave goods}

1. Pitcher. Neck fragment of a dark grey, polished pitcher with cylindrical neck and flattened globular body. Worn fluting survives on the shoulder and the belly. L. 7 cm. Inv. no. 61.2.146.3 (Pl. CXLVII. 376/1).

2. Beads. Thirteen limestone beads of varying sizes bearing patches of red ochre. L. $0.6-1.3 \mathrm{~cm}$. Inv. no. 61.2.146.1 (Pl. CXLVII. 376/2).

3. Pebble. Unworked radiolarite pebble. Diam. $3 \mathrm{~cm}$. Inv. no. 61.2.146.2.

\section{Grave 377 (Square D9; Pl. CXLIX)}

Size of grave pit: L. $136 \mathrm{~cm}, W .122 \mathrm{~cm}$

Depth: $78 \mathrm{~cm}$

Orientation: SW to NE, with the head toward the SW

Position of skeleton: laid on the right side

L. of skeleton (contracted): $80 \mathrm{~cm}$

L. of skeleton (extended): $119 \mathrm{~cm}$

Age at death: $7-8$ years

Sex: child

Condition of skeleton: medium well preserved

Preserved skeletal bones: complete skeleton 


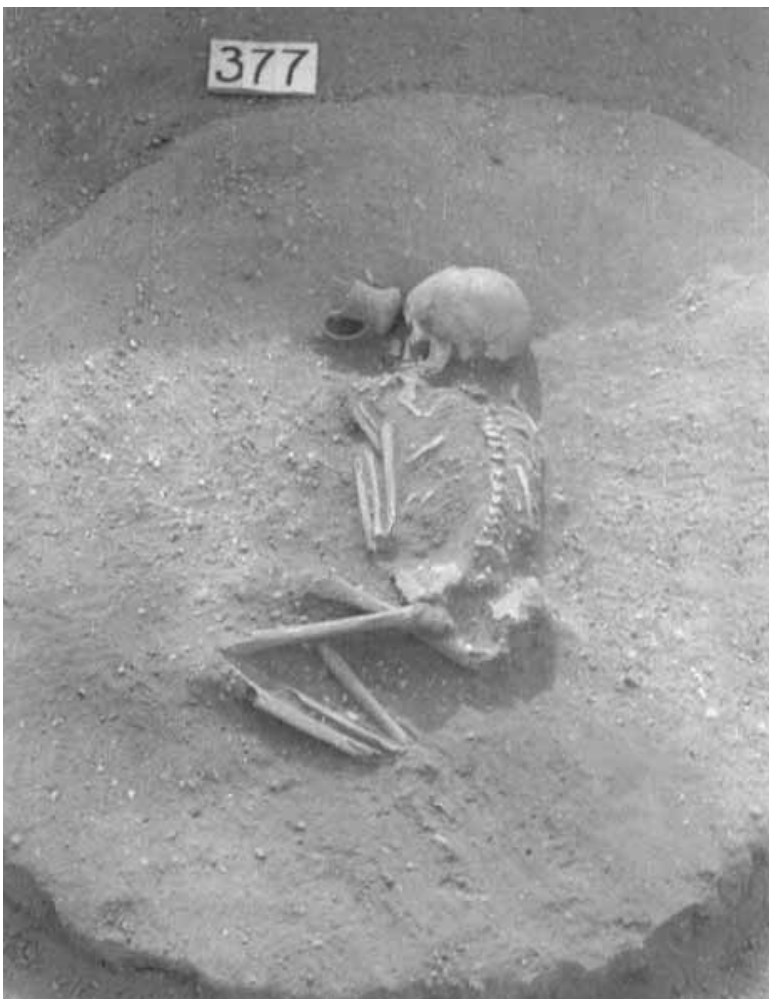

Inhumation burial in an oval grave pit. The body was laid on the right side in a contracted position. The skull lay on the right side. The arms were bent at the elbow and drawn up, with the hands resting by the left shoulder. The right thigh was drawn up into a horizontal position, the left one slightly lower, the legs were bent back toward the buttocks. The ankles were laid one over the other.

The burial contained the following grave goods: a small mug (1) tilted to one side with the base toward the head by the forehead; a stone blade (2) between the vessel and the skull.

\section{Grave goods}

1. Mug. Dark grey, polished, plain mug with cylindrical neck and flattened globular body. The strap handle rises above the rim and springs to the shoulder. The rim is damaged. H. $7.3 \mathrm{~cm}, \mathrm{dM} .5 .3 \mathrm{~cm}$. Inv. no. 61.2.147.1 (Pl. CXLIX. 377/1).

2. Burin on a retouched blade. Hornstone. Inv. no. 61.2.147.2 (Pl. CXLIX. 377/2).

\section{Grave 378 (Square D9; Pl. CL)}

\author{
Size of grave pit: L. $122 \mathrm{~cm}$, W. $102 \mathrm{~cm}$ \\ Depth: $78 \mathrm{~cm}$ \\ Orientation: SE to NW, with the head toward the SE \\ Position of skeleton: laid on the right side \\ L. of skeleton (contracted): $83 \mathrm{~cm}$ \\ L. of skeleton (extended): $126 \mathrm{~cm}$ \\ Age at death: $10-11$ years \\ Sex: child \\ Condition of skeleton: medium well preserved \\ Preserved skeletal bones: complete skeleton
}

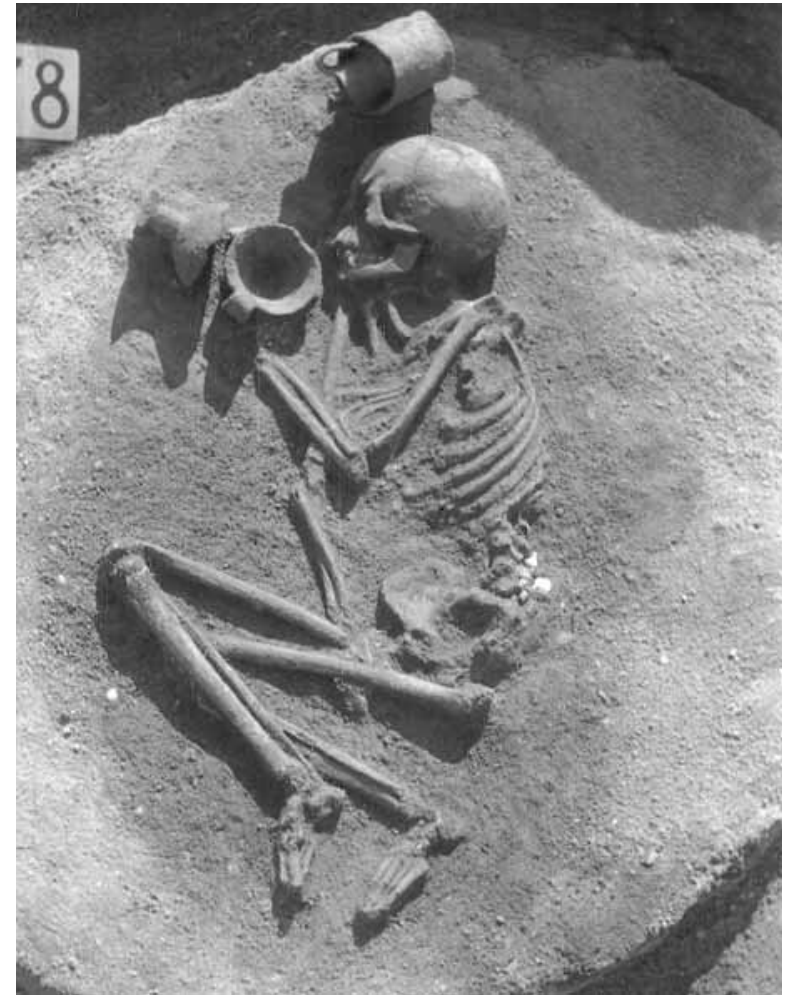

Inhumation burial in an oval grave pit. The body was laid on the right side in a contracted position. The skull lay on the right side. The left arm was bent at the elbow and drawn up, with the hand resting by vessel 3 . The right arm was extended, with the hands placed between the thighs. The thighs were drawn up into a horizontal position, the legs were bent back toward the buttocks.

The burial contained the following grave goods: a beaker (1) tilted to one side behind the forehead; a small mug (2) inside the previous vessel; a small scooping vessel (3) set upright with the handle toward the knee between the chin and the right upper arm; a goblet (4) tilted to one side with the foot toward the edge of the grave pit beside vessel 3; a black pebble (5) between vessels 3 and 4; thirteen shells and ten beads (6) around the waist above the pelvis.

\section{Grave goods}

1. Beaker. Reddish-brown, grey mottled, plain, flowerpot shaped beaker. The body is cracked, the rim is damaged. Partially restored. H. $10 \mathrm{~cm}, W .10 .3 \mathrm{~cm}$, dB. 8.1 cm. Inv. no. 61.2.148.1 (Pl. CL. 378/1).

2. Mug. Dark grey, polished mug with cylindrical neck and flattened globular body. The strap handle rises above the rim and springs to the shoulder. The belly and the handle are fluted. The rim is damaged. H. 6.9 cm, dM. 5.3 cm. Inv. no. 61.2.148.2 (Pl. CL. 378/2).

3. Scooping vessel, Brownish, grey mottled, worn scooping vessel with flat base. The short strap handle spans the rim and the shoulder. The rim is damaged, the handle is joined from smaller fragments. H. $5.5 \mathrm{~cm}$, dM. $10.2 \mathrm{~cm}$, dB. $4.2 \mathrm{~cm}$. Inv. no. 61.2.148.3 (Pl. CL. 378/3). 
4. Goblet. Light brown, grey mottled goblet with a rounded cup set on an oval base. The foot is perforated, Patches of red painting survive on the exterior and interior. The rim and the foot are damaged. H. $8.1 \mathrm{~cm}$, dM. $9.8 \mathrm{~cm}$, dB. $5.4 \mathrm{~cm}$. Inv. no. 61.2.148.4 (Pl. CL. 378/4).

5. Unworked lydite pebble. Diam. $2.5 \mathrm{~cm}$. Inv. no. 61.2.148.5.

6. Beads. Ten cylindrical limestone beads of varying sizes (Pl. CL. 378/6a), one Neogastropod, two Turritella, and nine Anadara diluvii shells (Pl. CL. 378/6b). Inv. no. $61.2 .148 .6 .^{249}$

\section{Grave 379 (Square D4; Pl. CXLVIII)}

Size of grave pit: -

Depth: $27 \mathrm{~cm}$

Orientation: S-SW to N-NE, with the head toward the S-SW

Position of skeleton: laid on the left side

L. of skeleton (contracted): $43 \mathrm{~cm}$

L. of skeleton (extended): -

Age at death: $4-5$ years

Sex: child

Condition of skeleton: badly preserved

Preserved skeletal bones: various fragments

Inhumation burial. There was no indication of a grave pit. The body was laid on the left side in a strongly contracted position. The skull rested on the occipital bone. The right arm was bent at the elbow and drawn up, with the hand resting in front of the chin. The thighs were drawn up in front of the body, the legs were bent back toward the buttocks. The parietal bone was destroyed by ploughing.

The burial did not contain any grave goods.

\section{Grave 380 (Square D4; $P l$. CXLIX)}

Size of grave pit: -

Depth: $22 \mathrm{~cm}$

Orientation: $\mathrm{S}$ to $\mathrm{N}$, with the head toward the $\mathrm{S}$

Position of skeleton: laid on the left side

L. of skeleton (contracted): $38 \mathrm{~cm}$

L. of skeleton (extended): -

Age at death: $1-7$ years

Sex: child

Condition of skeleton: badly preserved

Preserved skeletal bones: various fragments

Inhumation burial. There was no indication of a grave pit. The body was laid on the left side in a contracted position. The skull was almost completely destroyed and very little survived of the skeletal remains.

The burial contained the following grave goods: a core (1) behind the left shoulder.

Grave goods

1. Chert core. Inv. no. 61.2.149.

\footnotetext{
249 The number of shells in the acquisitions register is lower by one than the number listed in the excavation diary.
}

Grave 381 (Square D4; Pl. CXLIX)

Size of grave pit: L. $134 \mathrm{~cm}, W .115 \mathrm{~cm}$

Depth: $103 \mathrm{~cm}$

Orientation: S to N, with the head toward the S

Position of skeleton: laid on the left side

L. of skeleton (contracted): $107 \mathrm{~cm}$

L. of skeleton (extended): $154 \mathrm{~cm}$

Age at death: 21-23 years

Sex: female

Condition of skeleton: medium well preserved

Preserved skeletal bones: complete skeleton

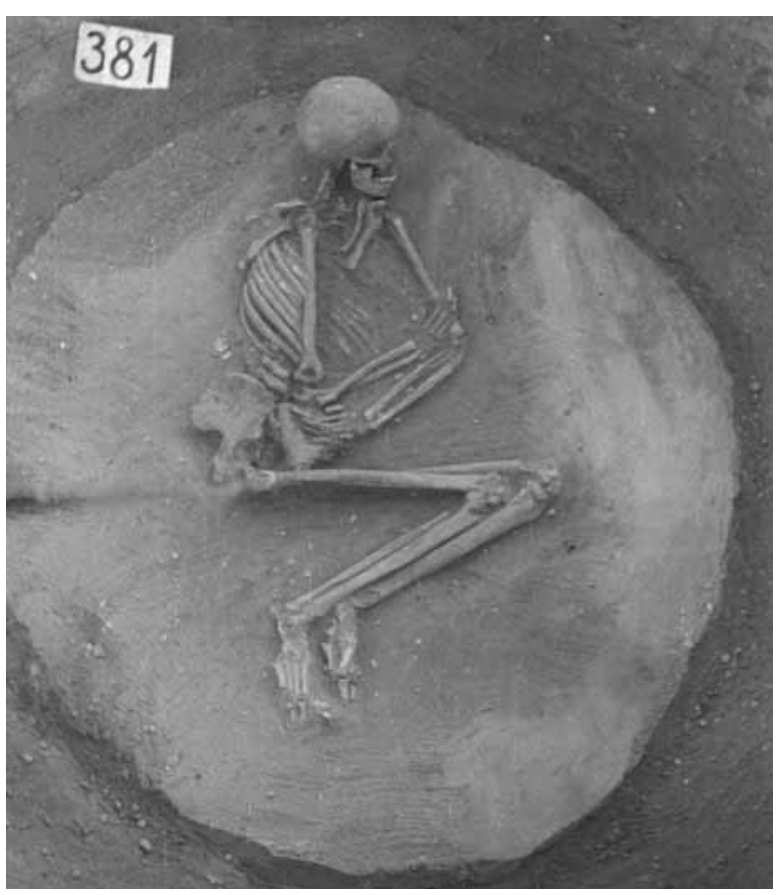

Inhumation burial in an oval grave pit. The body was laid on the left side in a contracted position. The skull rested on the occipital bone, tilted slightly to one side. The arms were bent at the elbow and folded across the chest. The thighs were drawn up into a horizontal position, the legs were bent back toward the buttocks.

The burial contained the following grave goods: three shells and one bead (1) behind the third lumbar vertebra; three beads (2) by the neck.

\section{Grave goods}

1. Beads. Two broken Anadara diluvii shells and one limestone bead. Inv. no. 61.2.150.1 (Pl. CXLIX. 381/1).250

2. Beads. Three cylindrical limestone beads. Inv. no. 61.2.150.2 (Pl. CXLIX. 381/2).

\section{Grave 382 (Square D5; Pl. CLI)}

Size of grave pit: L. $108 \mathrm{~cm}, W .84 \mathrm{~cm}$

Depth: $51 \mathrm{~cm}$

Orientation: E-NE to W-SW, with the head toward the E-NE

250 The number of shells in the acquisitions register is lower by one than the number listed in the excavation diary. 
Position of skeleton: laid on the right side

L. of skeleton (contracted): $89 \mathrm{~cm}$

L. of skeleton (extended): $153 \mathrm{~cm}$

Age at death: $30-40$ years

Sex: female

Condition of skeleton: badly preserved

Preserved skeletal bones: complete skeleton

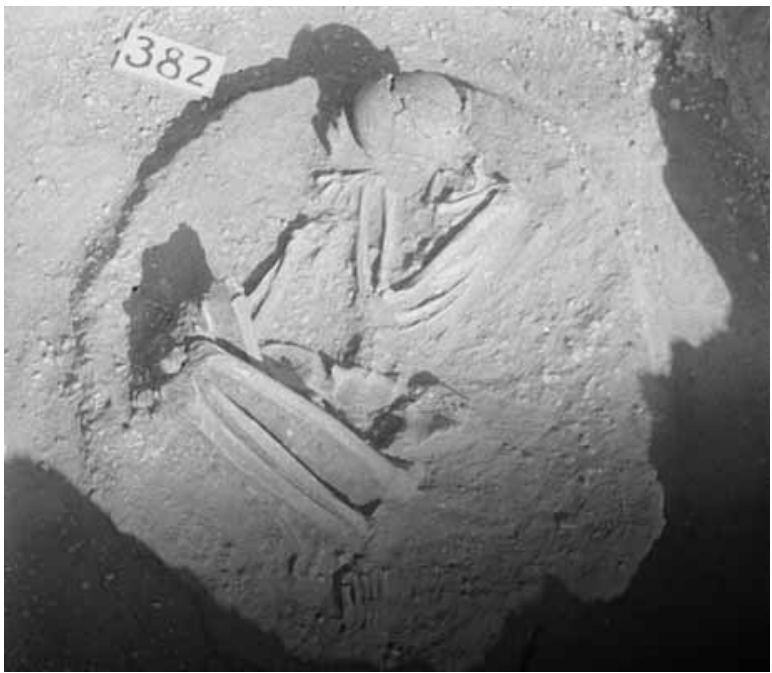

Inhumation burial in a narrow, oval grave pit. The body was laid on the right side in a contracted position. The skull rested on the occipital bone. The left arm was bent at the elbow and drawn up, with the hand placed in front of the face. The right arm was extended, with the hand under the thighs. The thighs were drawn up into a horizontal position, the legs were bent back toward the buttocks.

The burial contained the following grave goods: four broken animal ribs (1) in front of the nose.

\section{Grave goods}

1. Animal bones. Broken ribs. Four pieces. Inv. no. 61.2.151 (Pl. CLI. 382/1).

\section{Grave 383 (Square D5; Pl. CLII)}

Size of grave pit: L. $103 \mathrm{~cm}, W .77 \mathrm{~cm}$

Depth: $72 \mathrm{~cm}$

Orientation: $\mathrm{W}$ to $\mathrm{E}$, with the head toward the $\mathrm{W}$

Position of skeleton: laid on the left side

L. of skeleton (contracted): $72 \mathrm{~cm}$

L. of skeleton (extended): $132 \mathrm{~cm}$

Age at death: $10-12$ years

Sex: child

Condition of skeleton: medium well preserved

Preserved skeletal bones: complete skeleton

Inhumation burial in an oval grave pit. The body was laid on the left side in a contracted position. The crushed skull lay on the left side. The left arm was bent at the elbow and drawn up, with the hand placed under the chin. The right arm was extended toward the thighs with the hand laid under the vessels. The left thigh was drawn up into a horizontal position, the right one slightly lower, the legs were bent back toward the buttocks.

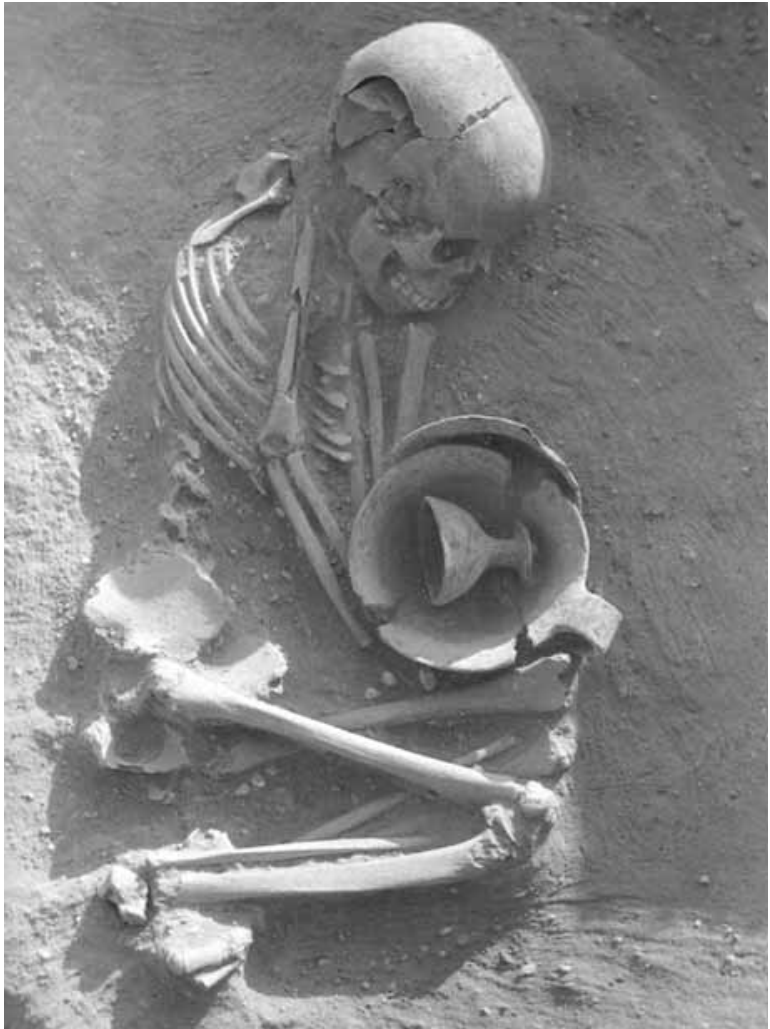

The burial contained the following grave goods: a bowl (1) by the left elbow and the right hand, between the face and the knees; a scooping vessel (2) inside the previous vessel; a small goblet (3) tilted to one side inside vessel 2 .

\section{Grave goods}

1. Bowl. Grey, polished conical bowl with funnel neck. The belly is encircled by a row of impressed dots. The rim and the belly are damaged. H. $7.5 \mathrm{~cm}, \mathrm{~dB}$. 6.5 cm. Inv. no. 61.2.152.1 (Pl. CLII. 383/1).

2. Scooping vessel. Brownish, grey mottled, polished, conical scooping vessel with funnel neck and flat base. The belly is decorated with a row of impressed dots. The handle springs from the rim to the belly. Joined from its fragments and restored. H. $6.9 \mathrm{~cm}$, dM. 15 cm, dB. 7.1 cm. Inv. no. 61.2.152.2 (Pl. CLII. 383/2).

3. Goblet. Light brown, plain goblet with round cup. The interior is grey. The foot has a round perforation. The rim and the base are damaged. Joined from its fragments. H. $7.5 \mathrm{~cm}, \mathrm{dM} .8 \mathrm{~cm}, \mathrm{~dB}$. 4.2 cm. Inv. no. 61.2.152.3 (Pl. CLII. 383/3).

\section{Grave 384 (Square D5; Pl. CLI)}

Size of grave pit: -

Depth: $44 \mathrm{~cm}$

Orientation: $W$ to $E$, with the head toward the $W$

Position of skeleton: laid on the left side

L. of skeleton (contracted): $87 \mathrm{~cm}$

L. of skeleton (extended): - 
Age at death: $23-39$ years

Sex: female

Condition of skeleton: badly preserved

Preserved skeletal bones: various fragments

Inhumation burial. There was no indication of a grave pit. The body was laid on the left side in a contracted position. The skull lay on the left side. The arms were bent at the elbow and drawn up, with the hands placed in front of the chin. The thighs were drawn up into a horizontal position, the legs were bent back toward the buttocks.

The burial contained the following grave goods: an indistinct pottery sherd (1) $8 \mathrm{~cm}$ above the skeletal remains; a broken shell plaque (2) on the neck.

Grave goods

1. Bowl. Non-joining body fragments of a grey bowl. Four pieces. Inv. no. 61.2.153.1.

2. Shell plaque. Broken rectangular, perforated Unio crassus mussel plaque. L. $1 \mathrm{~cm}$. Inv. no. 61.2.153.2 (Pl. CLI. 384/2).

\section{Grave 385 (Square D5; Pl. CXLIX)}

Size of grave pit: L. $88 \mathrm{~cm}, W .67 \mathrm{~cm}$

Depth: $82 \mathrm{~cm}$

Orientation: $\mathrm{S}$ to $\mathrm{N}$, with the head toward the $\mathrm{S}$, the face toward the $\mathrm{E}$

Position of skeleton: laid on the right side

L. of skeleton (contracted): $50 \mathrm{~cm}$

L. of skeleton (extended): -

Age at death: $0.5-1$ years

Sex: child

Condition of skeleton: badly preserved

Preserved skeletal bones: complete skeleton

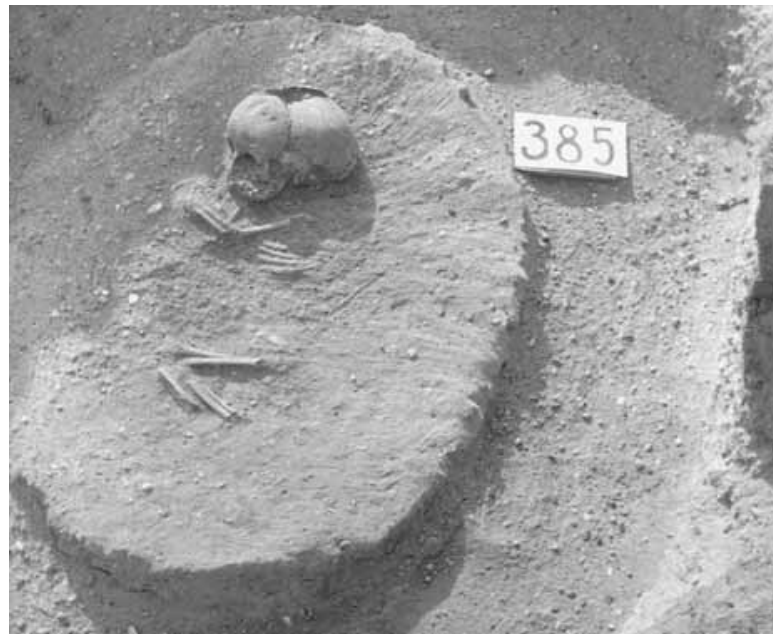

Inhumation burial in an oval grave pit. The body was laid on the right side in a contracted position. The crushed skull lay on the right side. The right upper arm was extended; the position of the forearm could not be documented. The right arm was slightly bent at the elbow toward the face. The thighs were drawn up into a horizontal position, the legs were bent back toward the buttocks.

The burial did not contain any grave goods.

\section{Grave 386 (Square C7)}

Size of grave pit: diam. $45 \mathrm{~cm}$

Depth: $30 \mathrm{~cm}$

Orientation: -

Position of skeleton: -

L. of skeleton (contracted): -

L. of skeleton (extended): -

Age at death: -

Sex: -

Condition of skeleton: -

Preserved skeletal bones: ${ }^{251}$ calcinated fragments

Scattered cremation burial. Calcinated bone fragments lay over an area with a diameter of $45 \mathrm{~cm}$.

The burial did not contain any grave goods.

\section{Grave 387 (Square C6)}

Size of grave pit: diam. $25 \mathrm{~cm}$

Depth: $35 \mathrm{~cm}$

Orientation: -

Position of skeleton: -

L. of skeleton (contracted): -

L. of skeleton (extended): -

Age at death: $23-x$ years

Sex: -

Condition of skeleton: -

Preserved skeletal bones: various fragments

Scattered cremation burial. Calcinated bone fragments lay over an area with a diameter of $25 \mathrm{~cm}$.

The burial did not contain any grave goods.

\section{Grave 388 (Square C5; Pl. CLI)}

Size of grave pit: L. $140 \mathrm{~cm}, W .163 \mathrm{~cm}$

Depth: $63 \mathrm{~cm}$

Orientation: A: S-SW to N-NE, with the head toward the S-SW, B: S-SW to N-NE, with the head toward the S-SW

Position of skeleton: A: laid on the left side, B: laid on the right side L. of skeleton (contracted): A: $98 \mathrm{~cm}, \mathrm{~B}: 92 \mathrm{~cm}$

L. of skeleton (extended): A: $153 \mathrm{~cm}, \mathrm{~B}: 142 \mathrm{~cm}$

Age at death: A: $30-50$ years, B: $40-59$ years

Sex: A: male, B: female

Condition of skeleton: A: badly preserved, B: badly preserved

Preserved skeletal bones: A-B: skull, long bones

Double inhumation burial in an oval grave pit. The two burials were contemporary; there was no indication of disturbance. The grave pit contained a few smaller stones between -35 and $-40 \mathrm{~cm}$. Fragments of a pitcher (1) and same other pottery sherds (2) lay among the stones.

\footnotetext{
$\overline{251}$ The surviving skeletal remains are unsuitable for an anthropological
} determination. 


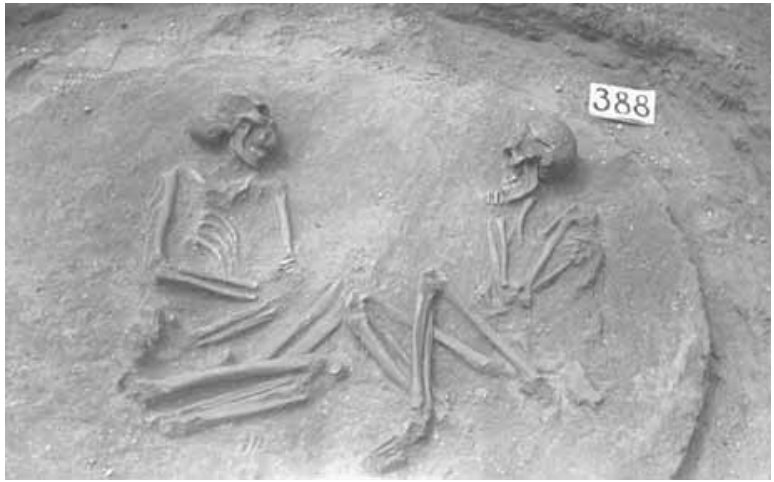

Burial A

The body was laid on the left side in a contracted position. The skull was tilted to the left. The right arm was bent at the elbow, with the hand resting by the left elbow. The left arm was bent at the elbow, with the hand placed by the pelvis. The right thigh was drawn up into a horizontal position, the left one slightly higher, the legs were bent back toward the buttocks. The right foot was missing.

The burial did not contain any grave goods.

\section{Burial B}

The body was deposited parallel to and facing Burial A, although slightly higher. The body was laid on the right side in a contracted position. The skull lay on the right side. The arms were bent at the elbow and drawn up, with the left hand resting in front of the chin, the right hand under the left armpit. The right thigh was drawn up into a horizontal position, the right one slightly higher, the legs were bent back toward the buttocks. The right knee rested on the left knee of Burial A, meaning that Burial A was deposited first.

The burial did not contain any grave goods.

Finds from the grave pit

1. Pitcher. Body fragments of a grey, worn pitcher, with the stub of the handle on one fragment. Eight non-joining pieces. Inv. no. 61.2.154 (Pl. CLI. 388/1).

2. Indistinct pottery sherds. ${ }^{252}$

\section{Grave 389 (Square D4; Pl. CLIII)}

Size of grave pit: L. $115 \mathrm{~cm}, W .103 \mathrm{~cm}$

Depth: $57 \mathrm{~cm}$

Orientation: A: E-SE to W-NW, with the head toward the E-SE, $\mathrm{B}$ : E-SE to W-NW, with the head toward the E-SE

Position of skeleton: A: laid on the right side, B: laid on the right side

L. of skeleton (contracted): A: $97 \mathrm{~cm}, \mathrm{~B}: 75 \mathrm{~cm}$

L. of skeleton (extended): A: $c a .151 \mathrm{~cm}, \mathrm{~B}: c a .121 \mathrm{~cm}$

Age at death: A: $40-59$ years, B: 13-14 years

Sex: A: female, B: child

Condition of skeleton: A: badly preserved, B: badly preserved

Preserved skeletal bones: A-B: skull, long bones

252 No other finds were inventoried among the finds from the burial. None of the vessel fragments among the stray finds can be securely associated with this burial.

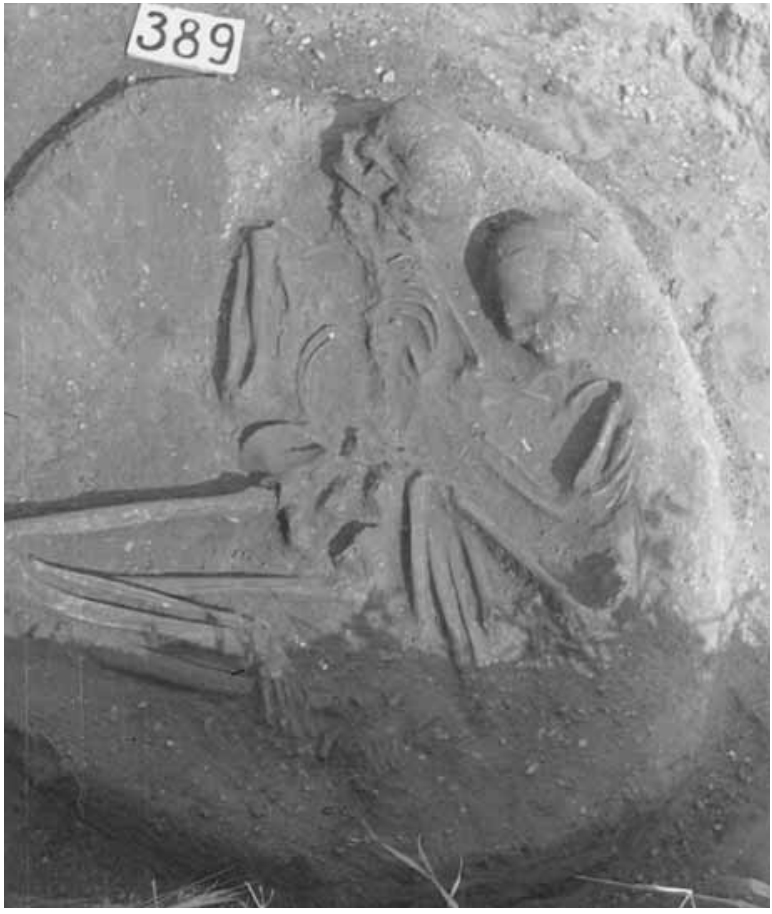

Double inhumation burial in an oval grave pit. The two burials were contemporaneous.

\section{Burial A}

The body was laid on the right side in a contracted position. The skull rested on the occipital bone. The trunk was laid prone. The right arm was bent at the elbow, with the forearm laid under the abdomen. The left arm was bent at the elbow and drawn up, with the hand resting by the shoulder. The thighs were drawn up into a horizontal position, the legs were bent back toward the buttocks.

The burial did not contain any grave goods.

\section{Burial B}

The body was laid on the right side in a contracted position parallel to and behind Burial A. The skull was crushed. The left arm was bent at the elbow, the right arm was extended beside the body. The thighs were drawn up in front of the body, the legs were bent back toward the buttocks.

The burial did not contain any grave goods.

\section{Grave 390 (Square C5; Pl. CLIII)}

Size of grave pit: diam. $33 \mathrm{~cm}$

Depth: $48 \mathrm{~cm}$

Orientation: -

Position of skeleton: -

L. of skeleton (contracted): -

L. of skeleton (extended): -

Age at death: $15-23$ years

Sex: -

Condition of skeleton: badly preserved

Preserved skeletal bones: various fragments 
Scattered cremation burial. Calcinated bone fragments lay over an area with a diameter of $33 \mathrm{~cm}$. The bone fragments formed a $10 \mathrm{~cm}$ thick layer. Two pottery sherds (1) lay among the bone fragments

Grave goods

1. Pot. Indistinct body sherds of a grey pot. Two nonjoining pieces. Inv. no. 61.2.155.

\section{Grave 391 (Square D5; Pl. CLIII)}

Size of grave pit: L. $89 \mathrm{~cm}, W .136 \mathrm{~cm}$

Depth: $64 \mathrm{~cm}$

Orientation: A: E-SE to W-NW, with the head toward the E-SE, $\mathrm{B}$ : SE to NW, with the head toward the SE, C: E-SE to W-NW, with the head toward the E-SE

Position of skeleton: A: laid on the left side, B: laid on the left side, C: laid on the right side

L. of skeleton (contracted): A: $60 \mathrm{~cm}, \mathrm{~B}: 38 \mathrm{~cm}, \mathrm{C}: 43 \mathrm{~cm}$

L. of skeleton (extended): -

Age at death: A: $2-3$ years, B: $0.5-1$ years, C: $5-6$ years

Sex: A: child, B: child, C: child

Condition of skeleton: A: badly preserved, B: badly preserved, C: badly preserved

Preserved skeletal bones: A-C: various fragments

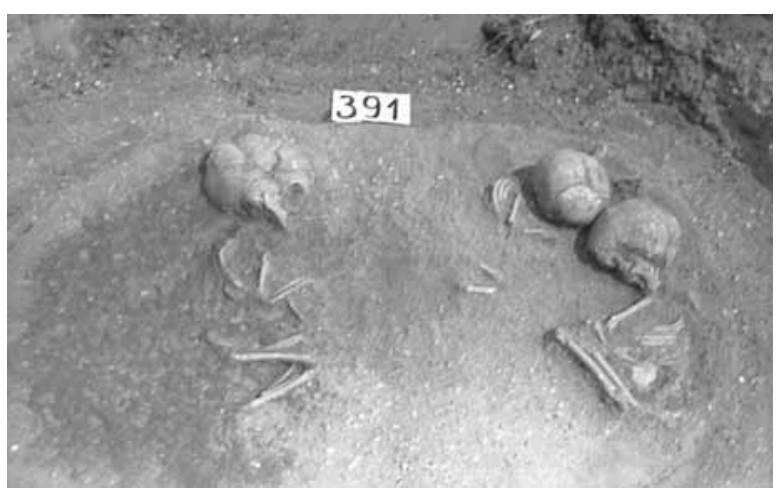

Triple inhumation burial in an oval grave pit.

\section{Burial A}

The body was laid on the left side in a contracted position. The crushed skull was tilted to the left side. The right arm was bent at the elbow, the left arm was extended. The thighs were drawn up into a horizontal position, the legs were bent back toward the buttocks.

The burial did not contain any grave goods.

\section{Burial B}

The body was laid on the left side in a contracted position a little south of Burial A. The skull rested on the occipital bone. The arms were bent at the elbow and drawn up, with the hands in front of the forehead. The thighs were drawn up into a horizontal position, the legs were bent back toward the buttocks.

The burial contained the following grave goods: a goblet (1) set upright beside the skull, between the skull and the edge of the grave pit.
Burial C

The body was laid on the right side in a contracted position adjacent to Burial $\mathrm{B}$, slightly to its south-west. The skull lay on the right side. The arms were bent at the elbow and placed in the lap. The thighs were drawn up into a horizontal position; the position of the legs could not be established.

The burial did not contain any grave goods.

Grave goods

1. Goblet. Fragment of a brownish goblet with round cup set on a rectangular foot with a round base. The foot is decorated with an incised zig-zag line and has a round perforation. Patches of red painting survive on its exterior and interior. The upper part is missing, the foot is damaged. $H .5 .4 \mathrm{~cm}, \mathrm{~dB} .4 .9 \mathrm{~cm}$. Inv. no. 61.2.156 (Pl. CLIII. 391/1).

\section{Grave 392 (Square D5)}

Size of grave pit: -

Depth:-

Orientation: -

Position of skeleton: -

L. of skeleton (contracted): -

L. of skeleton (extended): -

Age at death: $23-\mathrm{x}$ years

Sex: -

Condition of skeleton:-

Preserved skeletal bones: various fragments

Scattered cremation burial. The burial was disturbed when Grave 393 was dug; some of the calcinated bone fragments lay in the grave pit of Grave 393, others were thrown back when the pit of Grave 393 was backfilled.

The burial did not contain any grave goods.

\section{Grave 393 (Square D5; Pl. CLIV)}

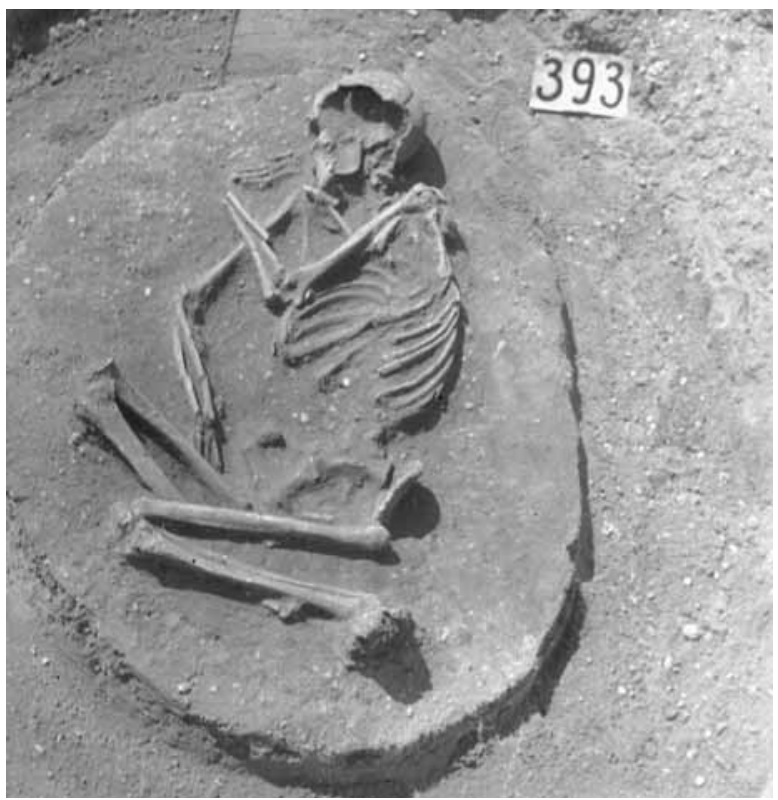


Size of grave pit: L. $117 \mathrm{~cm}, W .82 \mathrm{~cm}$

Depth: $72 \mathrm{~cm}$

Orientation: S-SW to N-NE, with the head toward the S-SW

Position of skeleton: laid on the right side

L. of skeleton (contracted): $100 \mathrm{~cm}$

L. of skeleton (extended): $164 \mathrm{~cm}$

Age at death: $30-40$ years

Sex: female

Condition of skeleton: badly preserved

Preserved skeletal bones: skull, long bones

Inhumation burial in an oval grave pit. The body was laid on the right side in a strongly contracted position. The crushed skull lay on the right side. The trunk lay extended, tilted slightly to the right. The left arm was bent at the elbow and drawn up, with the hand placed in front of the face. The right arm was slightly bent at the elbow, with the hand resting on the right thigh. The left thigh was drawn up into a horizontal position, the right one slightly higher, the legs were bent back toward the buttocks.

The burial did not contain any grave goods. Grave 392 , a scattered cremation burial, was disturbed when this grave was dug.

\section{Grave 394 (Square C5; Pl. CLIV)}

Size of grave pit: L. $73 \mathrm{~cm}, W .51 \mathrm{~cm}$

Depth: $104 \mathrm{~cm}$

Orientation: -

Position of skeleton: extended

L. of skeleton (contracted): -

L. of skeleton (extended): -

Age at death: $0.5-1$ years

Sex: child

Condition of skeleton: badly preserved

Preserved skeletal bones: complete skeleton

Inhumation burial in an oval grave pit. The body was deposited in an extended position. The skull was crushed. The position of the arms could not be established.

The burial contained the following grave goods: a perforated shell (1) on the neck.

\section{Grave goods}

1. Shell. An Anadara diluvii shell cut in two and perforated on its upper third. Inv. no. 61.2.157 (Pl. CLIV. 394/1).

\section{Grave 395 (Square D5)}

Size of grave pit: -

Depth: $45 \mathrm{~cm}$

Orientation: NW to SE, with the head toward the NW

Position of skeleton: -

L. of skeleton (contracted): -

L. of skeleton (extended): -

Age at death: 4-5 years

Sex: child

Condition of skeleton: badly preserved

Preserved skeletal bones: skull
Skull burial. There was no indication of a grave pit. The strongly fragmented, decayed skull lay on the occipital bone.

The burial did not contain any grave goods.

Grave $396(\mathrm{C} 5 ; \mathrm{Pl}$. CLIV)

Size of grave pit: L. $156 \mathrm{~cm}, W .120 \mathrm{~cm}$

Depth: $78 \mathrm{~cm}$

Orientation: A: S-SE to N-NW, with the head toward the S-SE, B: S-SE to N-NW, with the head toward the S-SE

Position of skeleton: A: laid on the left side. B: laid on the right side.

L. of skeleton (contracted): A: $98 \mathrm{~cm}$, B: $95 \mathrm{~cm}$

L. of skeleton (extended): A: $163 \mathrm{~cm}, \mathrm{~B}: c a .158 \mathrm{~cm}$

Age at death: A: $40-x$ years, B: $40-x$ years

Sex: A: female (?), B: male

Condition of skeleton: A: medium well preserved, B: medium well preserved

Preserved skeletal bones: A-B: skull, long bones

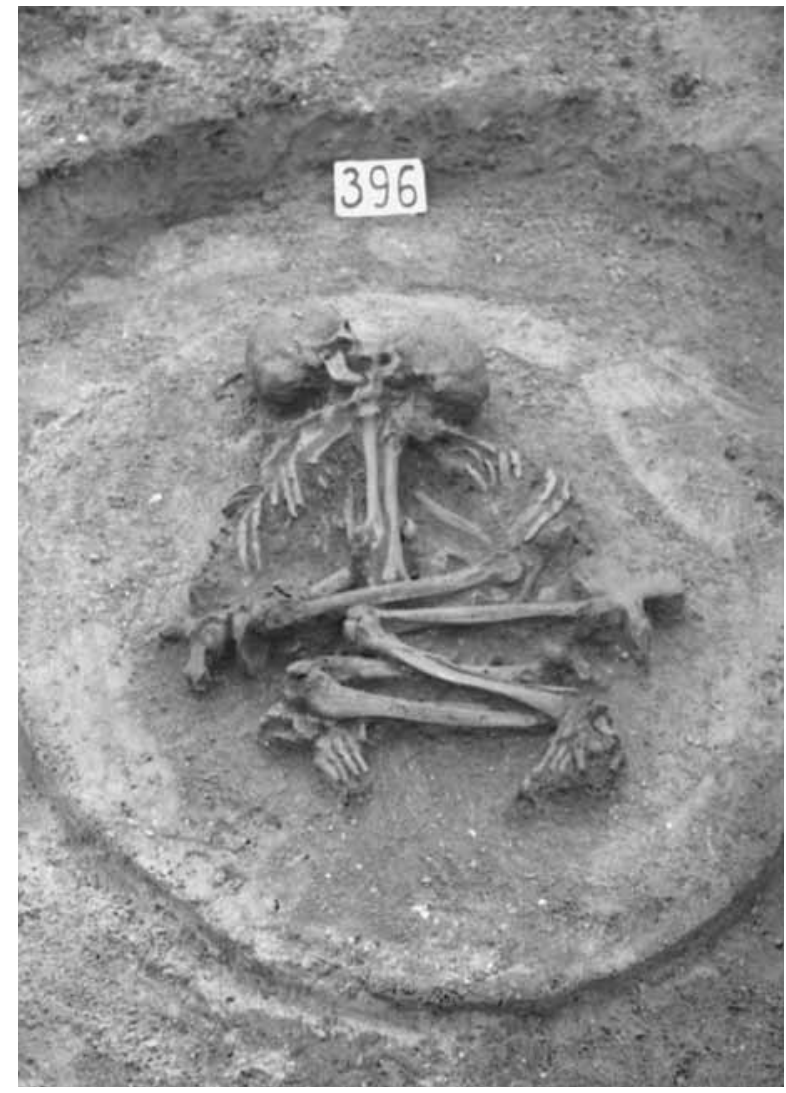

Double inhumation burial in an oval grave pit.

Burial A

The body was laid on the left side in a contracted position. The skull lay on the left side. The arms were bent at the elbow and drawn up toward the skull. The trunk had shifted slightly. The thighs were drawn up in front of the body, the legs were bent back toward the buttocks. The ankles rested one on the other.

The burial did not contain any grave goods. 


\section{Burial B}

The body was laid on the right side in a contracted position adjacent to and facing Burial A. The two skulls lay beside each other. The skull lay on the right side. The left arm was bent at the elbow, the right arm was extended under the thighs. The thighs were drawn up into a horizontal position, the legs were bent back toward the buttocks. The ankles rested one on the other. The left knee lay on the ankle of Burial A.

The burial did not contain any grave goods.

\section{Grave 397 (Square C5; Pl. CLIII)}

Size of grave pit: L. $63 \mathrm{~cm}, W .51 \mathrm{~cm}$

Depth: $56 \mathrm{~cm}$

Orientation: S-SE to N-NW, with the head toward the S-SE

Position of skeleton: laid on the right side

L. of skeleton (contracted): $48 \mathrm{~cm}$

L. of skeleton (extended): -

Age at death: $2.5-3$ years

Sex: child

Condition of skeleton: badly preserved

Preserved skeletal bones: various fragments

Inhumation burial in an oval grave pit containing stones between -35 and $-56 \mathrm{~cm}$. The stones crushed the bones. The body was laid on the right side in a contracted position. The crushed skull lay on the right side. One arm was bent at the elbow and drawn up toward the head. The thighs were drawn up in front of the body, the legs were bent back toward the buttocks.

The burial did not contain any grave goods.

\section{Grave 398 (Square C5; Pl. CLV)}

Size of grave pit: diam. $45 \mathrm{~cm}$

Depth: $48 \mathrm{~cm}$

Orientation: -

Position of skeleton: -

L. of skeleton (contracted): -

L. of skeleton (extended): -

Age at death: -

Sex: -

Condition of skeleton: -

Preserved skeletal bones: ${ }^{253}$ various fragments

Inurned burial. The grave pit contained stones over an area with a diameter of $45 \mathrm{~cm}$ between -22 and $-40 \mathrm{~cm}$. The stones lay on a broken bowl (1), under which lay a few calcinated bone fragments.

\section{Grave goods}

1. Bipartite bowl. Body sherds of a grey bipartite bowl with the stub of the inner dividing wall on one fragment. Five non-joining pieces. Inv. no. 61.2.158 (Pl. CLV. 398/1).

\footnotetext{
253 The surviving skeletal remains are unsuitable for an anthropological
} determination.
Grave 399 (Square C5; Pl. CLIV)

Size of grave pit: L. $134 \mathrm{~cm}, W .96 \mathrm{~cm}$

Depth: $81 \mathrm{~cm}$

Orientation: A: $\mathrm{S}$ to $\mathrm{N}$, with the head toward the $\mathrm{S}, \mathrm{B}$ : -

Position of skeleton: A: laid on the left side, B: -

L. of skeleton (contracted): A: 96, B: -

L. of skeleton (extended): A: 150, B: -

Age at death: A: $30-40$ years, B: $0-1$ years

Sex: A: female, B: child

Condition of skeleton: A: medium well preserved, B: badly preserved

Preserved skeletal bones: A: skull, long bones, B: various fragments

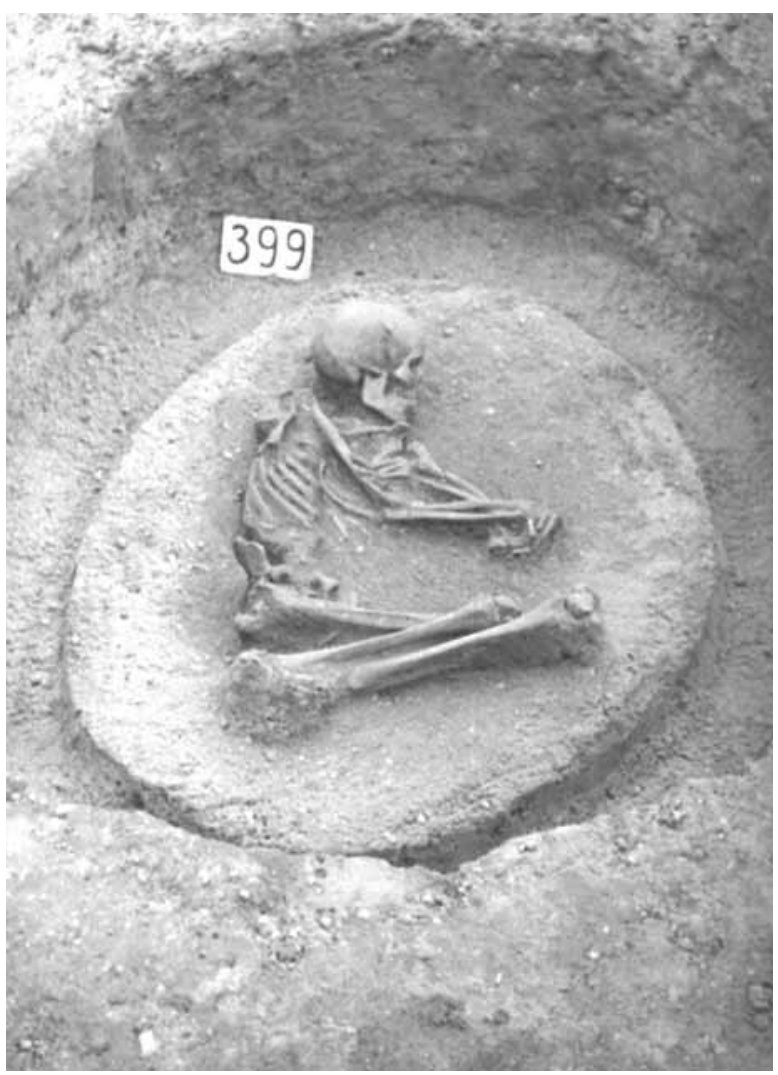

Double inhumation burial in an oval grave pit containing a few stones between -25 and $-40 \mathrm{~cm}$ in the area above the skull. A few calcinated bone fragments lay under the stones.

\section{Burial A}

The body was laid on the left side in a contracted position. The skull lay on the left side. The right arm was slightly bent at the shoulder, with the hand clasping the right upper arm. The thighs were drawn up into a horizontal position, the legs were bent back toward the buttocks.

The burial contained the following grave goods: a snail shell (1) on the chest.

\section{Burial B}

Tiny fragments of a skull lay next to the skull of Burial $\mathrm{A}$ and small bones above the shoulder of Burial A. 
The burial did not contain any grave goods.

Grave goods

1. Snail shell. A broken Turritella snail shell with a round perforation under its edge. L. $3.3 \mathrm{~cm}$. Inv. no. 61.2.159 (Pl. CLIV. 399/1).

\section{Grave 400 (Square C5; Pl. CLV)}

Size of grave pit: L. $122 \mathrm{~cm}$, W. $108 \mathrm{~cm}$ Depth: $91 \mathrm{~cm}$

Orientation: $\mathrm{N}$ to $\mathrm{S}$, with the head toward the $\mathrm{N}$

Position of skeleton: laid on the left side

L. of skeleton (contracted): $114 \mathrm{~cm}$

L. of skeleton (extended): -

Age at death: $30-40$ years

Sex: female

Condition of skeleton: badly preserved

Preserved skeletal bones: skull, long bones

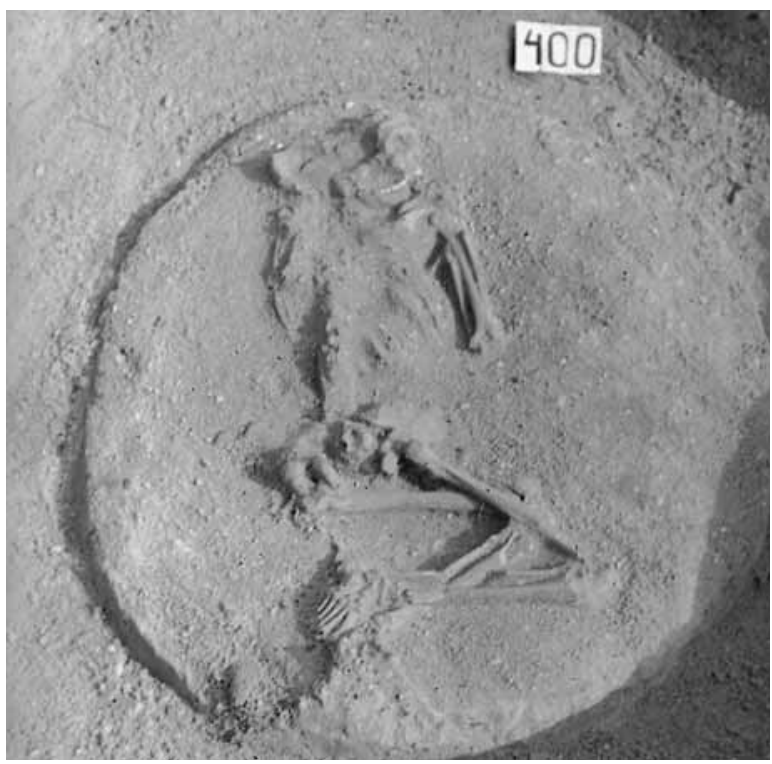

Inhumation burial in an oval grave pit containing many stones from $-30 \mathrm{~cm}$ downward. The stones lay on the body and crushed the skull. The body was laid on the left side in a contracted position. The crushed skull lay on the left side. The trunk had shifted into a prone position. The arms were bent at the elbow and drawn up, with the hands placed in front of the chin. The pelvis too had shifted into a prone position. The left thigh was drawn up into a horizontal position, the right one to a lesser extent, the legs were bent back toward the buttocks.

The burial did not contain any grave goods.

\section{Grave 401 (Square C5; Pl. CLV)}

Size of grave pit: L. $132 \mathrm{~cm}, W .119 \mathrm{~cm}$

Depth: $78 \mathrm{~cm}$

Orientation: S-SE to N-NW, with the head toward the S-SE

Position of skeleton: laid on the left side
L. of skeleton (contracted): $99 \mathrm{~cm}$

L. of skeleton (extended): $162 \mathrm{~cm}$

Age at death: $40-50$ years

Sex: male

Condition of skeleton: badly preserved

Preserved skeletal bones: skull, long bones

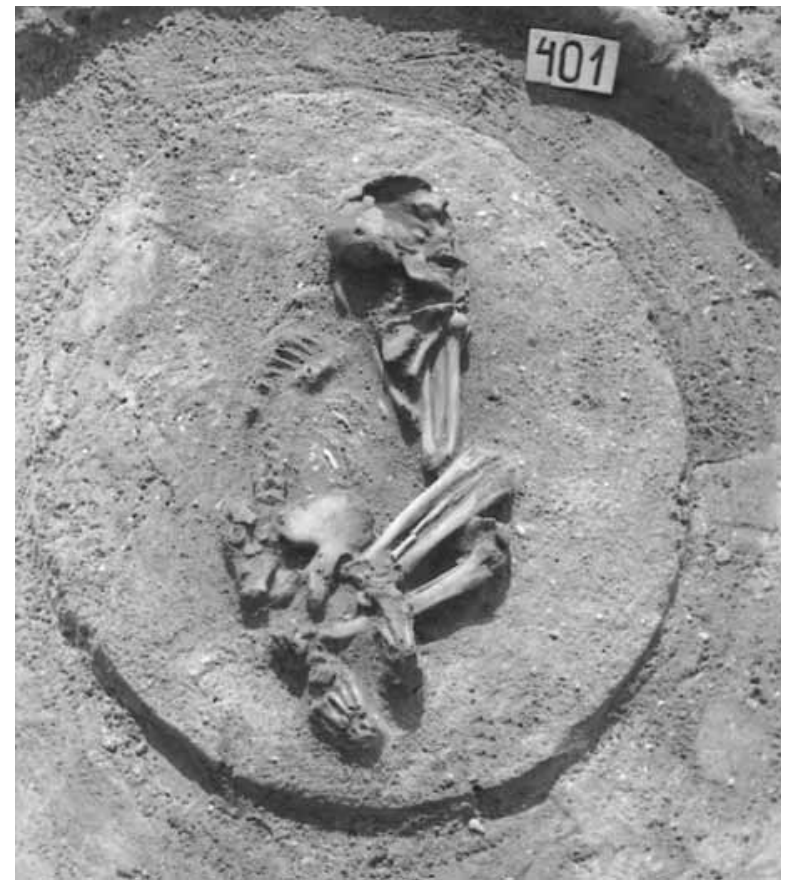

Inhumation burial in an oval grave pit containing stones from $-25 \mathrm{~cm}$ downward. The stones lay on the body. The body was laid on the left side in a strongly contracted position. The crushed skull lay on the left side. The arms were bent at the elbow and drawn up, with the hands placed in front of the mouth. The trunk had shifted into a slightly prone position. The right thigh was drawn to the left elbow, the left one slightly higher than a horizontal position in front of the body, the legs were bent back toward the buttocks.

The burial did not contain any grave goods.

\section{Grave 402 (Square C5; Pl. CLVI)}

Size of grave pit: L. $92 \mathrm{~cm}$, W. $119 \mathrm{~cm}$

Depth: $79 \mathrm{~cm}$

Orientation: S-SW to N-NE, with the head toward the S-SW Position of skeleton: extended on the back

L. of skeleton (contracted): $102 \mathrm{~cm}$

L. of skeleton (extended): $160 \mathrm{~cm}$

Age at death: $35-45$ years

Sex: female

Condition of skeleton: medium well preserved

Preserved skeletal bones: skull, long bones

Inhumation burial in an oval grave pit containing stones from $-45 \mathrm{~cm}$ downward. The stones lay on the body. The trunk was extended on the back, the legs were drawn up. The skull lay tilted to the left side. The arms were bent at the elbow and drawn up, with the 


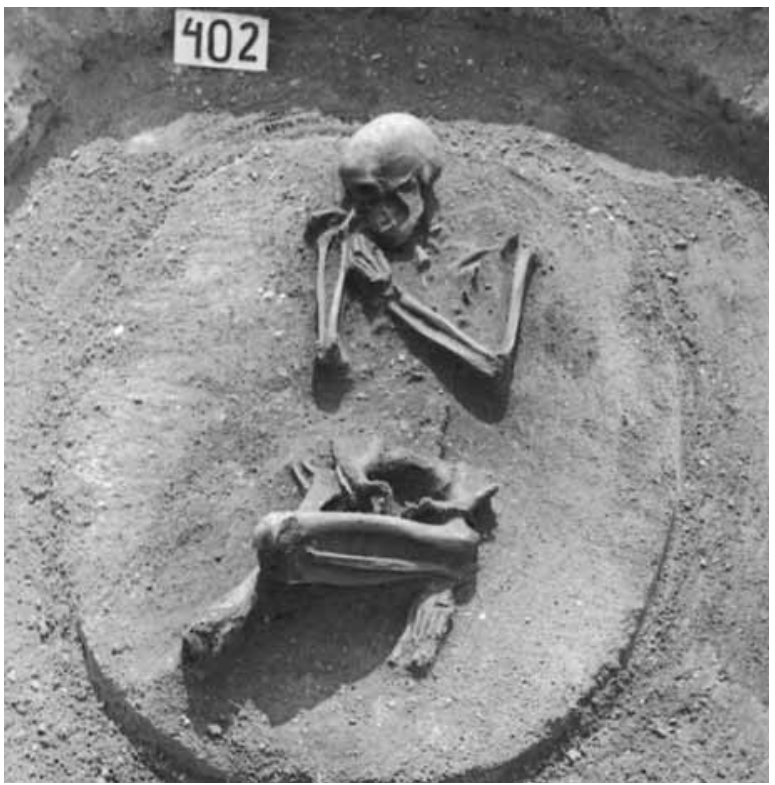

right hand placed in front of the face, the left one in front of the chin. The legs were bent back at the knee, the feet rested under the buttocks.

The burial did not contain any grave goods.

\section{Grave 403 (Square E3; Pl. CLVI)}

Size of grave pit: L. $145 \mathrm{~cm}, W .140 \mathrm{~cm}$

Depth: $71 \mathrm{~cm}$

Orientation: E-SE to W-NW, with the head toward the E-SE

Position of skeleton: laid on the left side

L. of skeleton (contracted): $103 \mathrm{~cm}$

L. of skeleton (extended): $158 \mathrm{~cm}$

Age at death: $40-x$ years

Sex: female

Condition of skeleton: badly preserved

Preserved skeletal bones: skull, long bones

Inhumation burial in a round grave pit containing stones between -20 and $-50 \mathrm{~cm}$. Various vessel fragments (1) lay among the stones. The body was laid on the left side in a contracted position. The skull lay on the left side, but tilted slightly forward. The arms were bent at the elbow and drawn up, with the hands placed in front of the face. The thighs were drawn up into a horizontal position, the legs were bent back toward the buttocks.

The burial contained the following grave goods: a necklace of six beads (2) around the neck, with an animal tooth among the beads; four intact and one broken spool shaped clay artefacts (3-7) lying in one heap in front of the face between the shoulders and the hands.

Grave goods 254

1. Vessel fragments. Non-joining, red and grey coloured vessel fragments. Five pieces. Inv. no. 61.2.160.1.

254 The grave goods from this burial were mistakenly inventoried as coming from Grave 404.

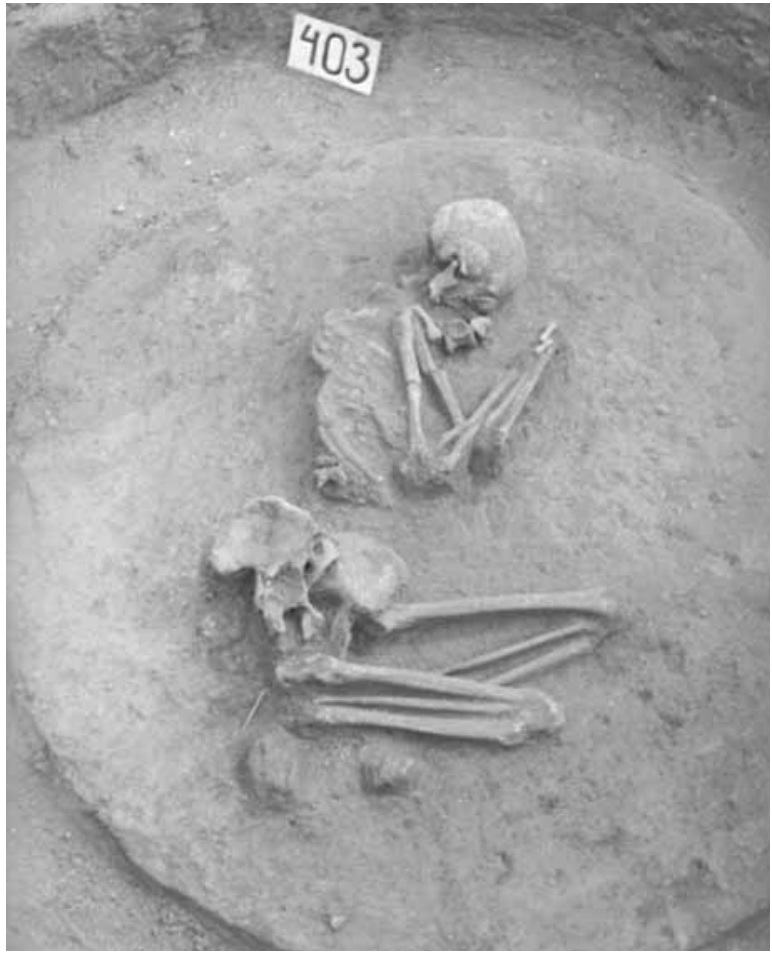

2. Beads. Six cylindrical limestone beads of varying sizes. Inv. no. 61.2.160.2 (Pl. CLVI. 403/2).

3-7. Spool shaped clay artefacts. Reddish-brown, cylindrical, spool shaped artefacts with widening terminals. L. $4 \mathrm{~cm}, 4.3 \mathrm{~cm}$, diam. $3.1 \mathrm{~cm}, 3.2 \mathrm{~cm}$. Inv. no. 61.2.160.3 (Pl. CLVI. 403/3-7).255

Grave 404 (Square F3; Pl. CLVI)

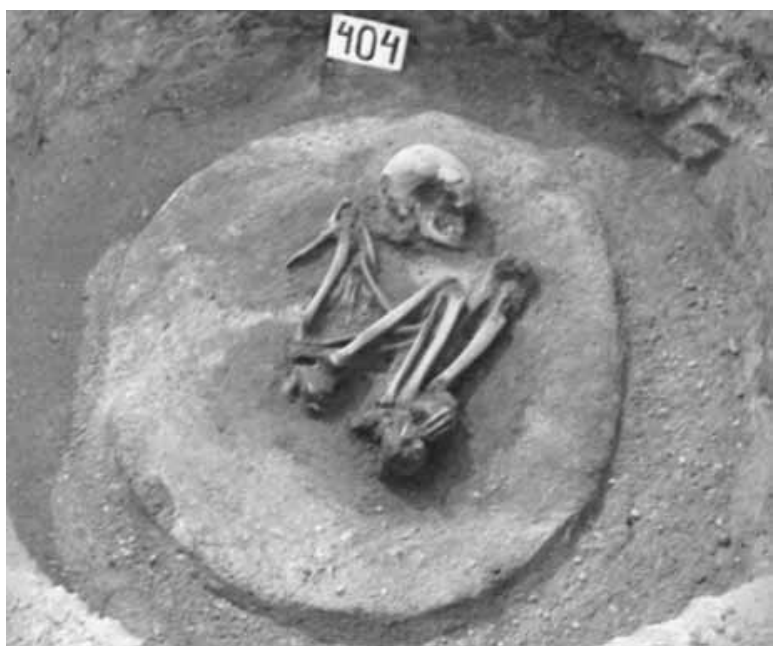

Size of grave pit: L. $118 \mathrm{~cm}$, W. $95 \mathrm{~cm}$ Depth: $88 \mathrm{~cm}$

Orientation: $\mathrm{W}$ to $\mathrm{E}$, with the head toward the $\mathrm{W}$ Position of skeleton: laid on the left side L. of skeleton (contracted): $75 \mathrm{~cm}$

255 Only two of the spool-like clay artefacts were inventoried. The stray finds do not include any similar artefacts. 
L. of skeleton (extended): $c a .160 \mathrm{~cm}$

Age at death: $23-x$ years

Sex: male (?)

Condition of skeleton: badly preserved

Preserved skeletal bones: skull, long bones

Inhumation burial in an oval grave pit containing stones between -25 and $-60 \mathrm{~cm}$. The body was laid on the left side in a contracted position. The skull lay on the left side. The skull was partly destroyed by an animal burrow. The right arm was bent at the elbow and drawn up, with the hand resting under the upper part of the right leg. The left arm was bent at the elbow and drawn up, with the hand resting by the inner side of the right upper arm. The thighs were drawn up in front of the body as high as the skull, the legs were bent back toward the buttocks.

The burial did not contain any grave goods. ${ }^{256}$

\section{Grave 405 (Square F3/G3; Pl. CLVII)}

Size of grave pit: L. $151 \mathrm{~cm}, W .132 \mathrm{~cm}$

Depth: $72 \mathrm{~cm}$

Orientation: A: W-SW to E-NE, with the head toward the $W$ SW, B: W-SW to E-NE, with the head toward the W-SW

Position of skeleton: A: laid on the left side, B: laid on the right side

L. of skeleton (contracted): A: $92 \mathrm{~cm}, \mathrm{~B}: 85 \mathrm{~cm}$

L. of skeleton (extended): A: $156 \mathrm{~cm}, \mathrm{~B}: 173 \mathrm{~cm}$

Age at death: A: $35-45$ years, B: $30-40$ years

Sex: A: male, B: female

Condition of skeleton: A: well preserved , B: well preserved

Preserved skeletal bones: A-B: skull, long bones

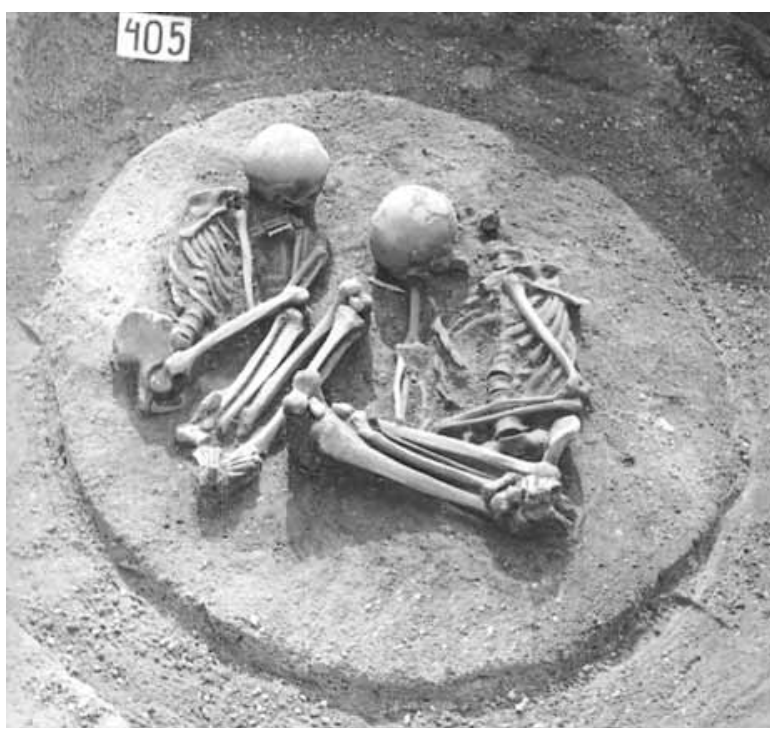

Double inhumation burial in an oval grave pit.

Burial A

The body was laid on the left side in a contracted position. The skull rested on the occipital bone. The

256 The finds inventoried as coming from this burial were actually the grave good of Grave 403. arms were bent at the elbow and drawn up, with the hands placed in front of the face. The thighs were drawn up in front of the body, the legs were bent back toward the buttocks.

The burial did not contain any grave goods.

\section{Burial B}

The body was laid on the right side in a contracted position adjacent to and facing Burial A. The skull was tilted forward, dislodged from its original position. The right arm was extended, with the hand resting by the upper part of the right thigh. The left arm was bent at the elbow, with the hand placed by the right wrist. The thighs were drawn up into a horizontal position, the legs were bent back toward the buttocks. The ankles were laid one over the other.

The burial contained the following grave goods: a bone awl (1) with the tip pointing toward the right upper arm in front of the face.

Grave goods

1. Bone awl. Two fragments of a bone awl carved from the long bone of a small ruminant. L. $4.3 \mathrm{~cm}, 3.1 \mathrm{~cm}$. Inv. no. 61.2.161 (Pl. CLVII. 405/1).

\section{Grave 406 (Square G3)}

Size of grave pit: -

Depth: $22 \mathrm{~cm}$

Orientation: -

Position of skeleton: -

L. of skeleton (contracted): -

L. of skeleton (extended): -

Age at death: $7-14$ years

Sex: child

Condition of skeleton: badly preserved

Preserved skeletal bones: various fragments

Skull burial. There was no indication of a grave pit. The fragments of a completely decayed skull were found at a depth of $22 \mathrm{~cm}$.

The burial did not contain any grave goods.

\section{Grave 407 (Square D4; Pl. CLVII)}

Size of grave pit: L. $101 \mathrm{~cm}$, W. $42 \mathrm{~cm}$

Depth: $85 \mathrm{~cm}$

Orientation: SE to NW, with the head toward the SE

Position of skeleton: laid on the left side

L. of skeleton (contracted): $72 \mathrm{~cm}$

L. of skeleton (extended): -

Age at death: $20-23$ years

Sex: juvenis

Condition of skeleton: badly preserved

Preserved skeletal bones: various fragments

Inhumation burial. A probably modern intrusion destroyed the eastern half of the burial; only a part of the skull, the left forearm, the shoulder, the hands and the knees survived. The body was laid on the left side in 
a contracted position. The skull rested on the occipital bone. The left arm was bent at the elbow and drawn up, with the hand placed on the shoulder, in front of the chin. The position of the knees suggested that the thighs had been drawn up into a horizontal position and the legs had been bent back toward the buttocks.

The burial did not contain any grave goods in the surviving part.

\section{Grave 408 (Square G2; Pl. CLVII)}

Size of grave pit: L. $98 \mathrm{~cm}, W .79 \mathrm{~cm}$

Depth: $68 \mathrm{~cm}$

Orientation: E-NE to $\mathrm{W}$-SW, with the head to the E-NE

Position of skeleton: laid on the left side

L. of skeleton (contracted): $70 \mathrm{~cm}$

L. of skeleton (extended): -

Age at death: $8-9$ years

Sex: child

Condition of skeleton: badly preserved

Preserved skeletal bones: skull, long bones

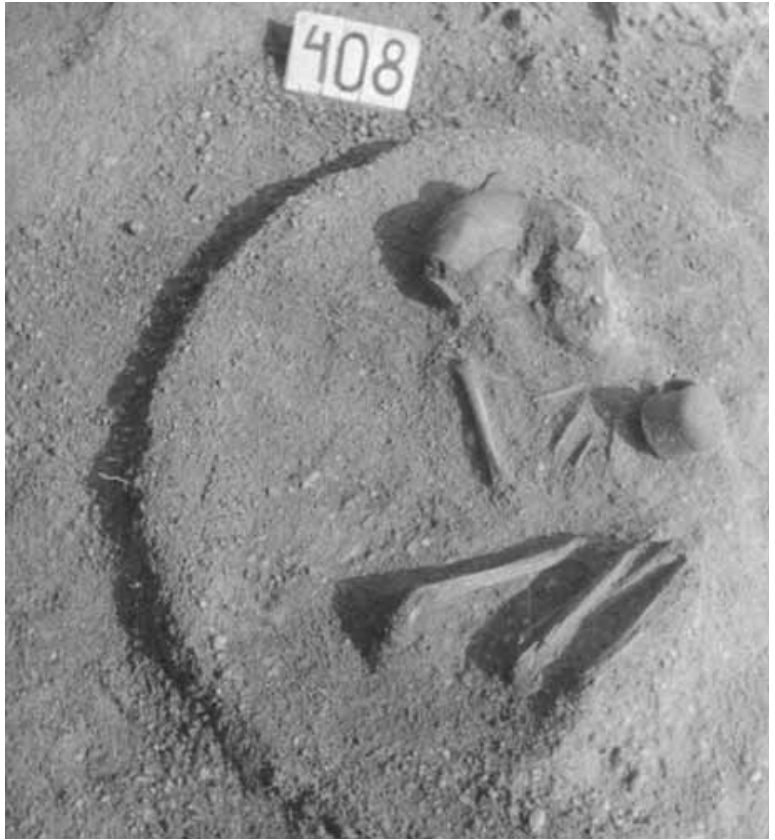

Inhumation burial in an oval grave pit. The body was laid on the left side in a strongly contracted position. The crushed skull lay on the left side. The skull and the long bones are all that survived of the skeletal remains. The arms were bent at the elbow and drawn up in front of the chin. The thighs were drawn up in front of the body, the legs were bent back toward the buttocks.

The burial contained the following grave goods: a mug (1) tilted to one side with the mouth toward the hands in front of the hands.

\section{Grave goods}

1. Mug. One-handled grey mug with cylindrical neck and flattened globular body. A row of impressed dots encircles the belly. The handle rises above the rim and springs to the belly. Cracked. H. $7 \mathrm{~cm}$, dM. 7.3 cm. Inv. no. 61.2.162 (Pl. CLVII. 408/1).

\section{Grave 409 (Square G2; Pl. CLVIII)}

Size of grave pit: L. $106 \mathrm{~cm}, W .91 \mathrm{~cm}$ Depth: $84 \mathrm{~cm}$

Orientation: S-SW to N-NE, with the head toward the S-SW

Position of skeleton: laid on the left side

L. of skeleton (contracted): $72 \mathrm{~cm}$

L. of skeleton (extended): -

Age at death: $13-15$ years

Sex: child

Condition of skeleton: badly preserved

Preserved skeletal bones: skull, long bones

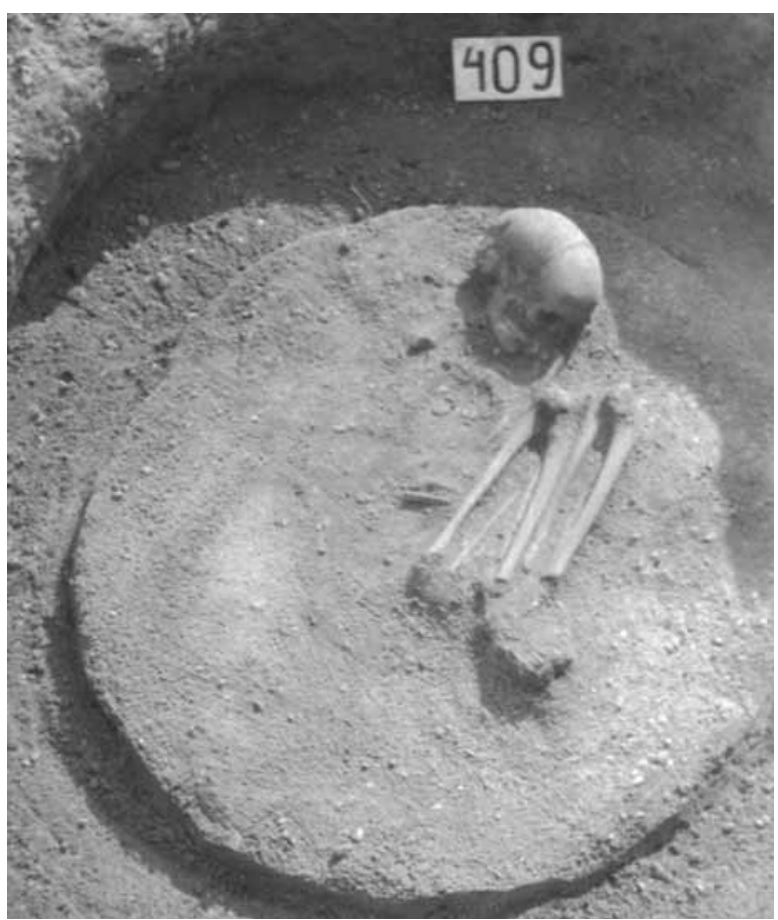

Inhumation burial in an oval grave pit. The body was laid on the left side in a contracted position. The position of the right upper arm could not be established; the right forearm was slightly bent toward the thigh. The left arm was extended, with the hand placed between the thighs. The thighs were drawn up in front of the body, the legs were bent back toward the buttocks.

The burial did not contain any grave goods.

\section{Grave 410 (Square G2; Pl. CLVIII)}

Size of grave pit: L. $118 \mathrm{~cm}, W .90 \mathrm{~cm}$

Depth: $54 \mathrm{~cm}$

Orientation: S-SW to N-NE, with the head toward the S-SW

Position of skeleton: laid on the left side

L. of skeleton (contracted): $78 \mathrm{~cm}$

L. of skeleton (extended): -

Age at death: $40-\mathrm{x}$ years

Sex: male

Condition of skeleton: badly preserved

Preserved skeletal bones: skull, long bones 


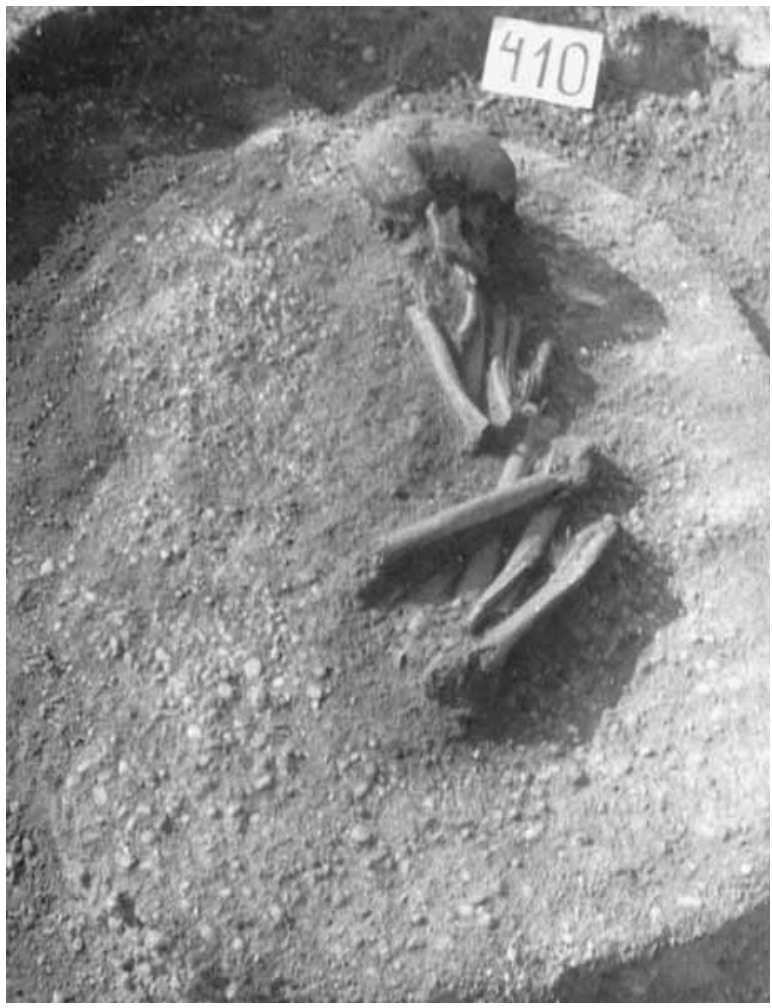

Inhumation burial in an oval grave pit containing stones from $-20 \mathrm{~cm}$ downward. There were upright stones along the edge of the grave pit and stones laid flat in the middle of the grave pit covering the body. One of the stones was placed directly on the head and crushed the skull. The body was laid on the left side in a strongly contracted position. The arms were bent at the elbow and drawn up, with the hands resting in front of the face. The thighs were drawn up in front of the body, the legs were bent back toward the buttocks.

The burial did not contain any grave goods.

\section{Grave 411 (Square F2/F3; Pl. CLVIII)}

Size of grave pit: L. $162 \mathrm{~cm}$, W. $143 \mathrm{~cm}$

Depth: $82 \mathrm{~cm}$

Orientation: W-SW to E-NE, with the head toward the W-SW

Position of skeleton: laid on the right side

L. of skeleton (contracted): $105 \mathrm{~cm}$

L. of skeleton (extended): $178 \mathrm{~cm}$

Age at death: $40-50$ years

Sex: male

Condition of skeleton: medium well preserved

Preserved skeletal bones: complete skeleton

Inhumation burial in an oval grave pit. The body was laid on the right side in a contracted position. The skull rested on the occipital bone. The extended right arm was slightly bent at the elbow and the hand placed beside the right thigh. The left arm was bent at the elbow and drawn up, with the hand placed by the right elbow. The left thigh was drawn up into a horizontal position, the right one slightly higher, the legs were bent back toward the buttocks. The ankles were placed one over the other, the left foot was placed under the thigh.

The burial contained the following grave goods: three stone blades (1-3) in a heap between the left ankle and the left pelvic bone (two jasper blades and a chalcedony blade).

Grave goods 257

1. Stone blade.

2. Stone blade.

3. Stone blade.

\section{Grave 412 (Square F3; Pl. CLIX)}

Size of grave pit: L. $156 \mathrm{~cm}, W .137 \mathrm{~cm}$

Depth: $75 \mathrm{~cm}$

Orientation: $\mathrm{E}$ to $\mathrm{W}$, with the head toward the $\mathrm{E}$ Position of skeleton: laid on the right side

L. of skeleton (contracted): $95 \mathrm{~cm}$

L. of skeleton (extended): $168 \mathrm{~cm}$

Age at death: $35-45$ years

Sex: male

Condition of skeleton: medium well preserved

Preserved skeletal bones: skull, long bones

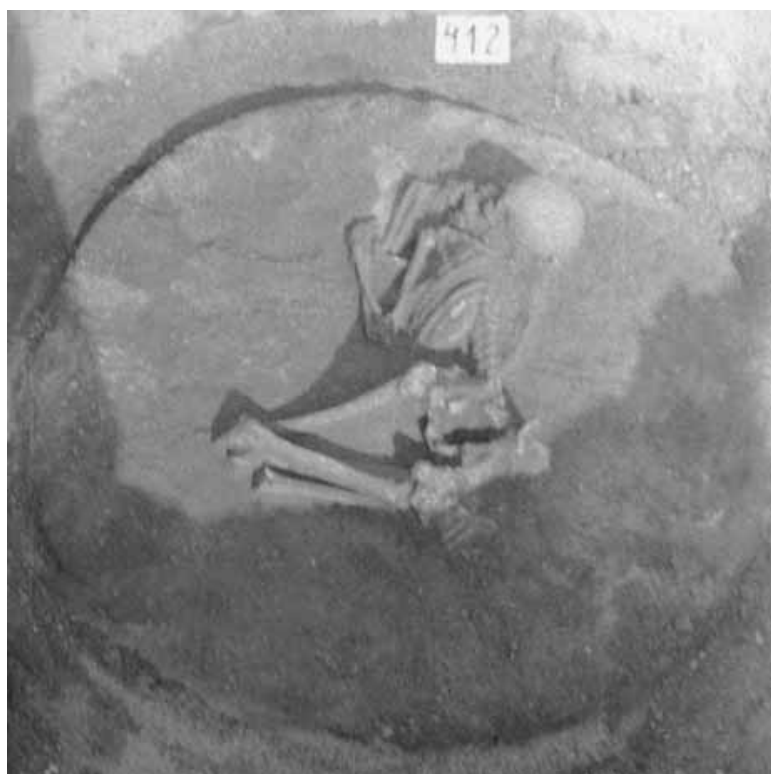

Inhumation burial in a round grave pit containing stones between -15 and $-35 \mathrm{~cm}$. Lying among the stones were a dipper (1) and a broken vessel (2). The body was laid on the right side in a contracted position with the trunk placed prone. The arms were bent at the elbow and drawn up, with the left hand placed by the chin, the right one by the left forearm. The thighs were drawn up into a horizontal position, the legs were bent back toward the buttocks. The ankles were laid one over the other. The floor of the grave pit lay $15 \mathrm{~cm}$ deeper than the body.

$\overline{257}$ No finds were inventoried from this burial. 
The burial contained the following grave goods: a red stone (3) by the right pelvic bone; a necklace of twenty-two Dentalium beads and sliced Dentalium beads (4) around the neck.

\section{Grave goods}

1. Dipper. Grey, conical, plain dipper with pointed base. The handle rises above the rim and springs to the upper third of the vessel body. The rim is damaged. Joined from its fragments. H. $7 \mathrm{~cm}$. Inv. no. 61.2.173.1 (Pl. CLIX. 412/1).258

2. Pitcher. Body fragment of a grey, thin-walled pitcher decorated with smoothed-in lines on the belly. L. $8 \mathrm{~cm}$. Inv. no. 61.2.163.1 (Pl. CLIX. 412/2).

3. Red stone. Irregularly shaped red stone with one smooth side. Diam. $5.1 \mathrm{~cm}$. Inv. no. 61.2.163.2.259

4. Beads. Fifteen intact and sliced Dentalium badense beads and one limestone bead. The remains of a copper bead were found inside one of the Dentalium beads. Inv. no. 61.2.163.3 (Pl. CLIX. 412/4).260

\section{Grave 413 (Square F3; Pl. CLVIII)}

Size of grave pit: L. $82 \mathrm{~cm}, W .73 \mathrm{~cm}$

Depth: $75 \mathrm{~cm}$

Orientation:-

Position of skeleton: -

L. of skeleton (contracted): -

L. of skeleton (extended): -

Age at death: $1-7$ years

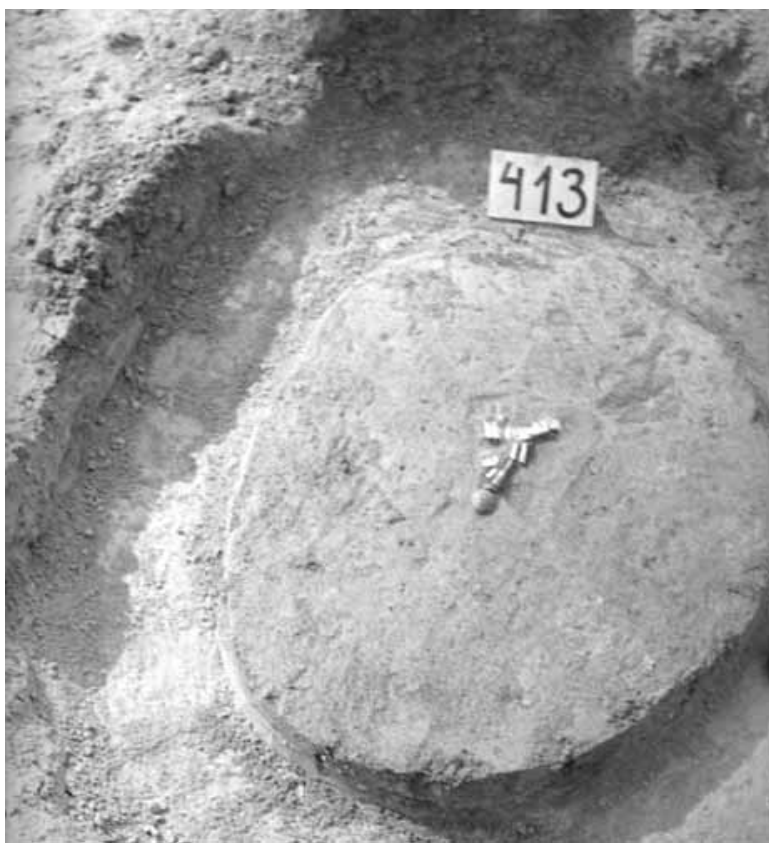

258 A dipper was not inventoried among the finds from the burial. The dimensions in the excavation diary $(H .7 .2 \mathrm{~cm}, \mathrm{~dB} .11 \mathrm{~cm})$ suggest that the dipper inventoried among the finds from Grave 430 (whose grave goods did not include a vessel of this type) actually originated from Grave 412 .

259 The object has since been lost or mislaid. Its description is quoted from the cquisitions register.

260 The excavation diary mentions twenty-three beads, but only sixteen were inventoried.
Sex: child

Condition of skeleton: badly preserved

Preserved skeletal bones: tiny fragments

Inhumation burial in an oval grave pit. The grave pit was south-south-west to north-north-east oriented. The grave pit contained stones between -20 and $-35 \mathrm{~cm}$. A small vessel fragment (1) lay among the stones. The skeletal remains had almost completely disintegrated, a few skull fragments were all that survived in the grave pit's south-south-western half.

The burial contained the following grave goods: a necklace of rectangular shell plaques from which were hung two strands of Dentalium beads and other shells, twenty-two shell plaques, nine beads and three perforated shells (2) around the neck.

\section{Grave goods}

1. Indistinct body sherd of a reddish, thick-walled vessel.

L. $5 \mathrm{~cm}$. Inv. no. 61.2.164.2.

2. Beads. Three perforated shells, eight sliced Dentalium badense beads and twenty-four rectangular Unio crassus mussel plaques perforated along the short sides (some broken). Inv. no. 61.2.164.1 (Pl. CLVIII. 413/2).261

\section{Grave 414 (Square E3; Pl. CLIX)}

Size of grave pit: L. $112 \mathrm{~cm}$, W. $85 \mathrm{~cm}$ Depth: $54 \mathrm{~cm}$

Orientation: S-SW to N-NE, with the head toward the S-SW Position of skeleton: laid on the left side

L. of skeleton (contracted): $82 \mathrm{~cm}$

L. of skeleton (extended): -

Age at death: $30-40$ years

Sex: female

Condition of skeleton: badly preserved

Preserved skeletal bones: skull, long bones

Inhumation burial in an oval grave pit containing stones from $-30 \mathrm{~cm}$ downward. The stones lay on the body. A pitcher fragment (1) lay among the stones. The body was laid on the left side in a contracted position. The crushed skull lay on the left side. A larger stone lay on the skull. The right upper arm is all that survived of the arm bones. The right thigh was drawn up into a horizontal position, the left one slightly higher, the legs were bent back toward the buttocks.

The burial did not contain any grave goods.

Finds from the grave pit

1. Pitchers. Neck and body sherd of a greyish, worn pitcher with cylindrical neck decorated with vertical smoothed-in lines on the belly; body fragment of a similar pitcher with fluted decoration. Two pieces. Inv. no. 61.2.165 (Pl. CLIX. 414/1).

\footnotetext{
261 The shell plaques were all that remained when the finds were reexamined for drawing. We found twenty-four fragments instead of the twenty-two mentioned in the excavation diary and the acquisitions register (the plaques became further fragmented).
} 
Grave 415 (Square E3; Pl. CLVIII)

Size of grave pit: L. $108 \mathrm{~cm}, W .78 \mathrm{~cm}$

Depth: $65 \mathrm{~cm}$

Orientation: S-SW to N-NE, with the head toward the S-SW

Position of skeleton: laid on the left side

L. of skeleton (contracted): $85 \mathrm{~cm}$

L. of skeleton (extended): $178 \mathrm{~cm}$

Age at death: $40-59$ years

Sex: male

Condition of skeleton: badly preserved

Preserved skeletal bones: skull, long bones

Inhumation burial in a narrow, oval grave pit containing stones from $-35 \mathrm{~cm}$ downward. The stones lay above and partly on the body. The body was laid on the left side in a strongly contracted position. The skull, crushed by a stone on it, lay on the left side. The right arm was bent at the elbow, with the hand placed under the thighs. The left arm was bent at the elbow and drawn up, with the hand resting under the chin. The thighs were drawn up in front of the body, the legs were bent back toward the buttocks. The feet lay slightly higher.

The burial did not contain any grave goods.

\section{Grave 416 (Square E3; Pl. CLX)}

Size of grave pit: L. $152 \mathrm{~cm}$, W. $134 \mathrm{~cm}$

Depth: $87 \mathrm{~cm}$

Orientation: E-SE to W-NW, with the head toward the E-SE

Position of skeleton: laid on the left side

L. of skeleton (contracted): $101 \mathrm{~cm}$

L. of skeleton (extended): $168 \mathrm{~cm}$

Age at death: 21-23 years

Sex: female

Condition of skeleton: well preserved

Preserved skeletal bones: complete skeleton

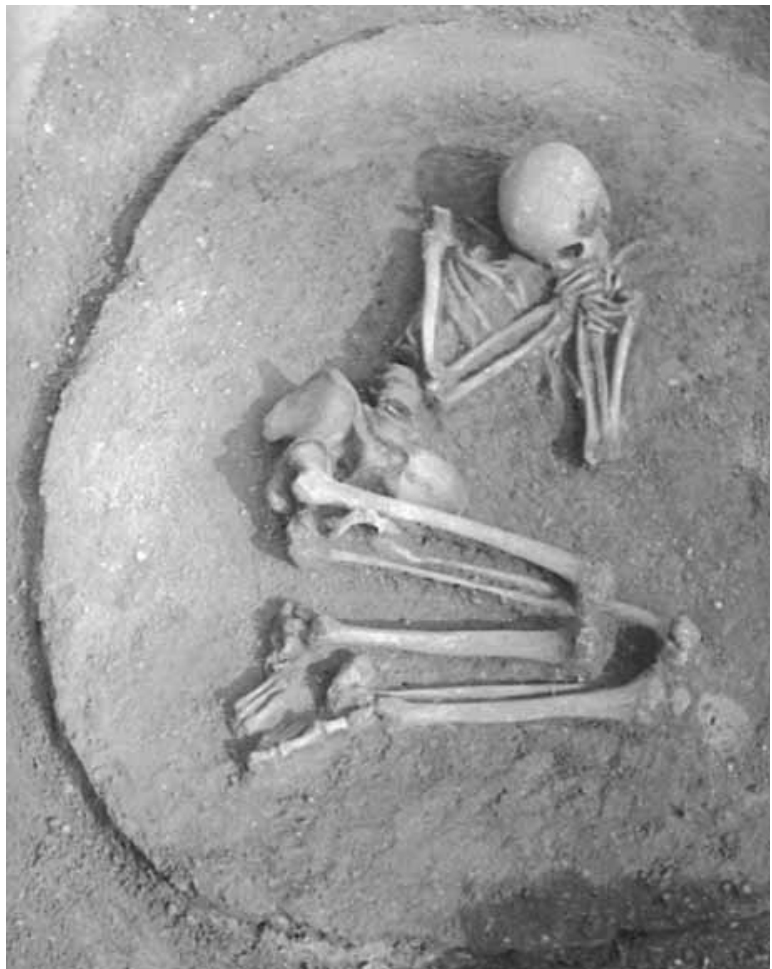

Inhumation burial in an oval grave pit. The body was laid on the left side in a contracted position. The skull rested on the occipital bone and was tilted slightly to the right. The arms were bent at the elbow and drawn up, with the clasped hands placed in front of the face. The thighs were drawn up into a horizontal position, the legs were bent back toward the buttocks.

The burial contained the following grave goods: a necklace of fourteen beads and three tubular copper beads (1) around the neck.

\section{Grave goods}

1. Beads. Five limestone beads, eleven Dentalium badense beads and one tubular copper bead. Inv. no. 61.2.166 (Pl. CLX. 416/1).262

\section{Grave 417 (Square A6; Pl. CLX)}

Size of grave pit: L. $87 \mathrm{~cm}, W .82 \mathrm{~cm}$

Depth: $98 \mathrm{~cm}$

Orientation: E-SE to W-NW, with the head toward the E-SE

Position of skeleton: laid on the right side

L. of skeleton (contracted): $53 \mathrm{~cm}$

L. of skeleton (extended): $91 \mathrm{~cm}$

Age at death: $3-4$ years

Sex: child

Condition of skeleton: medium well preserved

Preserved skeletal bones: complete skeleton

Inhumation burial in a round grave pit. The body was laid on the right side in a contracted position. The skull lay on the right side. The arms were bent at the elbow and laid across the chest, with the hands by the elbows. The thighs were drawn up in front of the body, the legs were bent back toward the buttocks.

The burial did not contain any grave goods.

\section{Grave 418 (Square E3; Pl. CLX)}

Size of grave pit: L. $110 \mathrm{~cm}, W .97 \mathrm{~cm}$

Depth: $37 \mathrm{~cm}$

Orientation: S-SE to N-NW, with the head toward the S-SE

Position of skeleton: laid on the right side

L. of skeleton (contracted): $71 \mathrm{~cm}$

L. of skeleton (extended): -

Age at death: $14-16$ years

Sex: juvenis

Condition of skeleton: badly preserved

Preserved skeletal bones: various fragments

Inhumation burial in a rounded, slightly oval grave pit. The parietal bone was destroyed by ploughing. The body was laid on the right side in a contracted position. The skull lay with the face upward. The right arm was bent at the elbow and placed under the trunk. The left arm was bent at the elbow and drawn up, with the hand

${ }^{262}$ In addition to the copper bead, there were sixteen other beads (the excavation diary mentions fourteen beads, but fifteen beads were inventoried). Nothing survived of the copper bead, except for green patina stains on two Dentalium beads. 
resting in front of the chin. The thighs were pushed back toward the trunk, the legs were bent back toward the buttocks. The knees lay slightly higher.

The burial did not contain any grave goods.

\section{Grave 419 (Square E3; Pl. CLXI)}

Size of grave pit: L. $127 \mathrm{~cm}, W .98 \mathrm{~cm}$

Depth: $110 \mathrm{~cm}$

Orientation: $\mathrm{S}$ to $\mathrm{N}$, with the head toward the $\mathrm{S}$

Position of skeleton: laid on the left side

L. of skeleton (contracted): $84 \mathrm{~cm}$

L. of skeleton (extended): $148 \mathrm{~cm}$

Age at death: $15-16$ years

Sex: juvenis

Condition of skeleton: well preserved

Preserved skeletal bones: complete skeleton

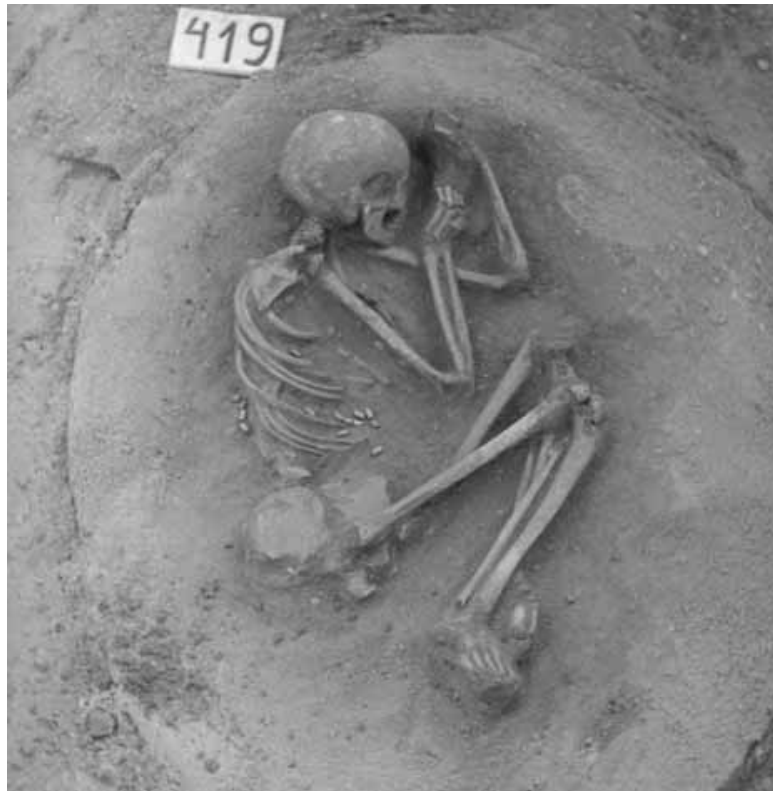

Inhumation burial in an oval grave pit containing stones between -23 and $-40 \mathrm{~cm}$. The body was laid on the left side in a strongly contracted position. The skull lay on the left side, tilted slightly forward. The arms were bent at the elbow and drawn up, with the hands placed in front of the face. The thighs were drawn up in front of the body, the legs were bent back toward the buttocks.

The burial contained the following grave goods: six shell plaques (1) on the forehead; a belt of twenty-nine beads (2) around the waist.

\section{Grave goods}

1. Shell plaques. Six rectangular, broken Unio crassus mussel plaques with a pair of perforations on the short sides. Inv. no. 61.2.167.1 (Pl. CLXI. 419/1).

2. Beads. Seventeen limestone beads, one clay bead, one sliced Dentalium badense bead and ten limestone beads. Inv. no. 61.2.167.2 (Pl. CLXI. 419/2).263
Grave 420 (Square E2; Pl. CLXI)

Size of grave pit: L. $105 \mathrm{~cm}$, W. $141 \mathrm{~cm}$

Depth: $76 \mathrm{~cm}$

Orientation: S-SW to N-NE, with the head toward the S-SW

Position of skeleton: laid on the left side

L. of skeleton (contracted): $105 \mathrm{~cm}$

L. of skeleton (extended): $161 \mathrm{~cm}$

Age at death: $50-\mathrm{x}$ years

Sex: male

Condition of skeleton: medium well preserved

Preserved skeletal bones: complete skeleton

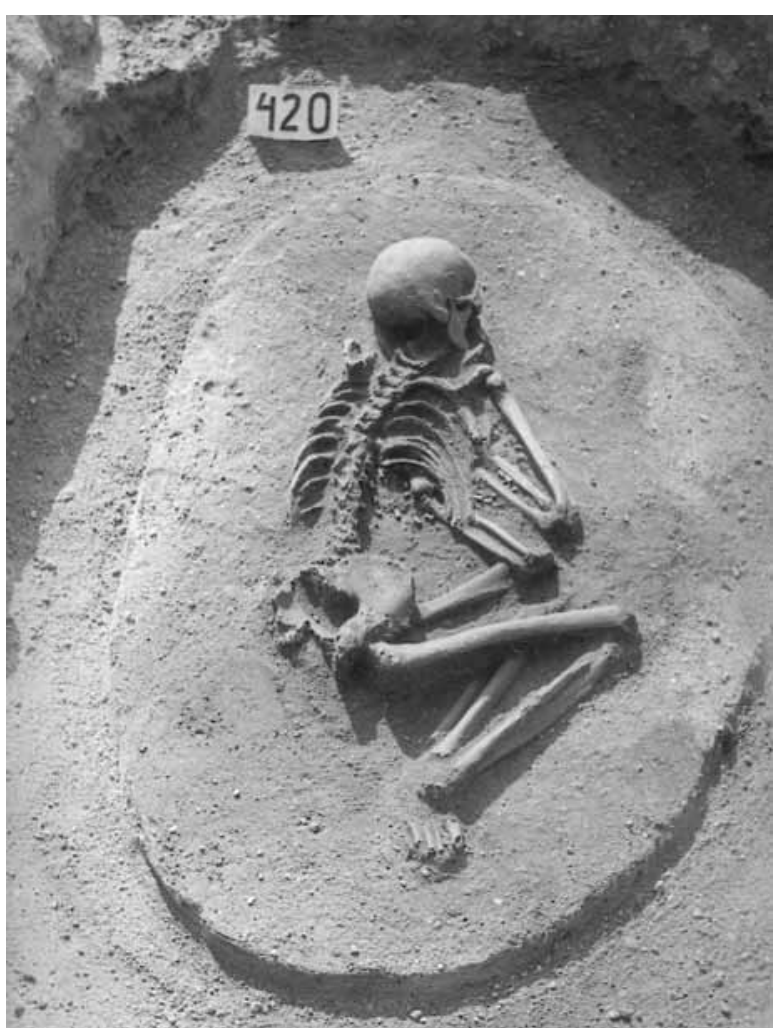

Inhumation burial in an oval grave pit. The body was laid on the left side in a strongly contracted position. The skull lay on the left side, tilted slightly forward. The trunk was placed prone. The right arm was bent at the elbow and laid under the trunk. The left arm was extended under the trunk, with the wrist resting on the left knee. The thighs were drawn up in front of the body, the legs were bent back toward the buttocks. The ankles were placed one over the other.

The burial contained the following grave goods: sixty-nine beads (1) on the chest.

\section{Grave goods}

1. Beads. One Dentalium badense bead and fifty-nine cylindrical limestone beads of varying sizes. Inv. no. 61.2.168 (Pl. CLXI. 420/1).264

264 The excavation diary mentions sixty-nine beads, but only sixty-two were inventoried. Currently there are sixty beads strung into two strands. 
Grave 421 (Square E2; Pl. CLXII)

Size of grave pit: L. $115 \mathrm{~cm}, W .91 \mathrm{~cm}$

Depth: $102 \mathrm{~cm}$

Orientation: N-NE to S-SW, with the head toward the N-NE

Position of skeleton: laid on the right side

L. of skeleton (contracted): $66 \mathrm{~cm}$

L. of skeleton (extended): -

Age at death: 2-3 years

Sex: child

Condition of skeleton: badly preserved

Preserved skeletal bones: skull, long bone fragments

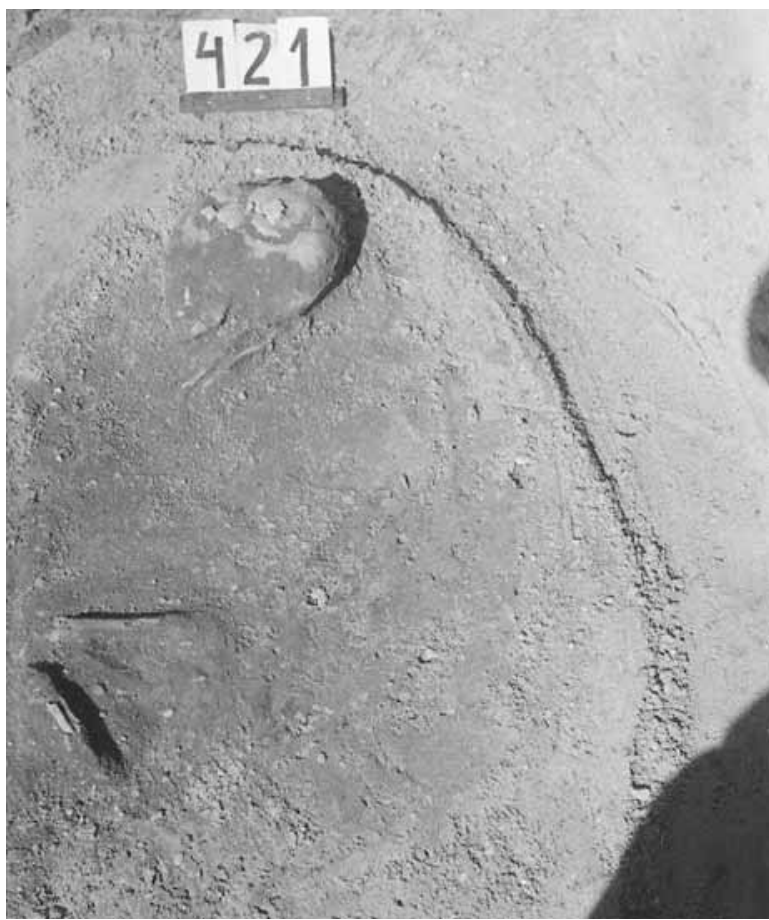

Inhumation burial in an oval grave pit containing many stones between $-20 \mathrm{~cm}$ and $-75 \mathrm{~cm}$. Vessel fragments (1-4) lay on top of the stones. The body was laid on the right side in a contracted position. The skull lay on the right side. The upper arm bone, the thigh bone and the legs are all that survived of the skeletal remains. The thighs were drawn up into a horizontal position, the legs were bent back toward the buttocks.

The burial did not contain any grave goods.

Finds from the grave pit

1. Amphora. Body sherd of a reddish-brown amphora with a small loop handle. L. $7.5 \mathrm{~cm}$. Inv. no. 61.2.169.1 (Pl. CLXII. 421/1).

2. Amphora. Body sherd of a grey amphora with a small loop handle. L. $8.5 \mathrm{~cm}$. Inv. no. 61.2.169.2 (Pl. CLXII. 421/2).

3. Bipartite bowl. Body sherd of a greyish, bipartite bowl with the stub of the inner dividing wall. L. $8 \mathrm{~cm}$. Inv. no. 61.2.169.3 (Pl. CLXII. 421/3).

4. Pitcher. Body sherds of a greyish, worn pitcher decorated with wide fluting. Four non-joining pieces. Inv. no. 61.2.169.4.
Grave 422 (Square E2; Pl. CLXII)

Size of grave pit: L. $124 \mathrm{~cm}$, W. $83 \mathrm{~cm}$

Depth: $45 \mathrm{~cm}$

Orientation: SE to NW, with the head toward the SE

Position of skeleton: laid on the right side

L. of skeleton (contracted): $109 \mathrm{~cm}$

L. of skeleton (extended): $171 \mathrm{~cm}$

Age at death: 19-21 years

Sex: male

Condition of skeleton: badly preserved

Preserved skeletal bones: skull, long bones

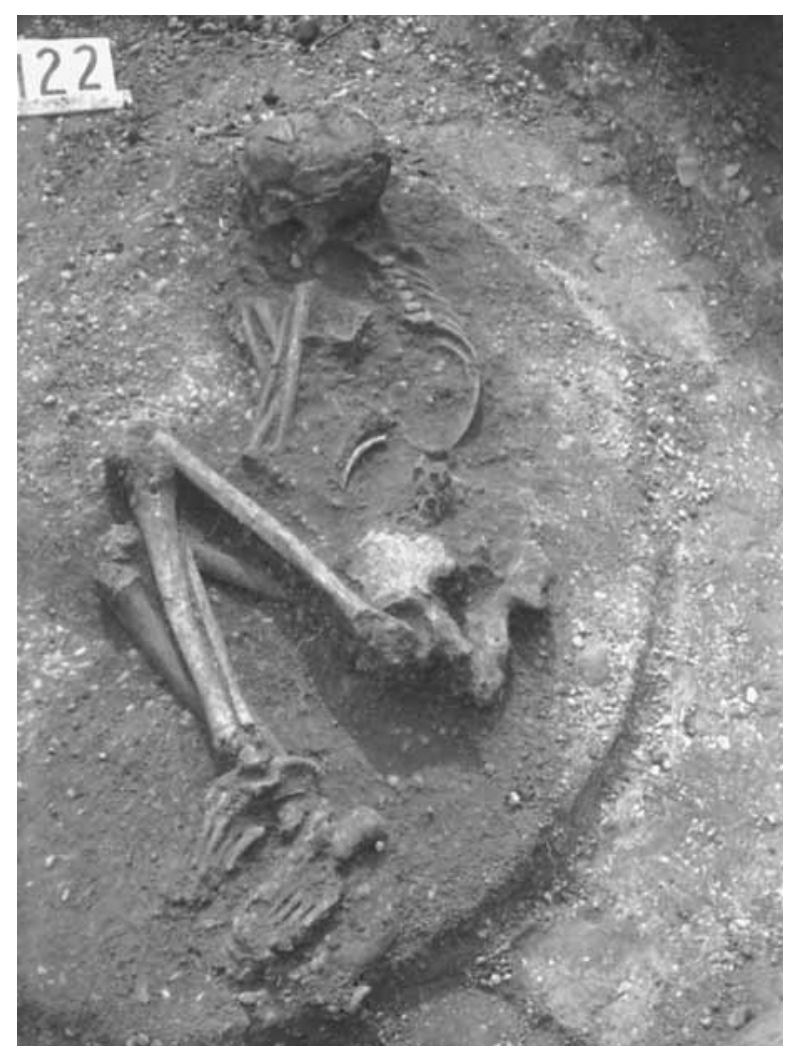

Inhumation burial in an oval grave pit containing a few stones between -20 and $-30 \mathrm{~cm}$. The body was laid on the right side in a strongly contracted position. The crushed skull lay on the right side. The arms were bent at the elbow and drawn up, with the hands resting by the chin. The thighs were drawn up in front of the body, the legs were bent back toward the buttocks. The ankles lay beside each other.

The burial contained the following grave goods: a pebble (1) by the mandible; a vessel fragment (2) under the right femur.

Grave goods

1. Unworked radiolarite pebble. L. $2 \mathrm{~cm}$. Inv. no. 61.2.170.1.

2. Bowl. Body fragment of a dark grey bowl. L. $3.2 \mathrm{~cm}$. Inv. no. 61.2.170.2. 
Grave 423 (Square E3)

Size of grave pit: L. $50 \mathrm{~cm}, W .52 \mathrm{~cm}$

Depth: $48 \mathrm{~cm}$

Orientation: -

Position of skeleton: -

L. of skeleton (contracted): -

L. of skeleton (extended): -

Age at death: -

Sex: -

Condition of skeleton: badly preserved

Preserved skeletal bones: ${ }^{265}$ calcinated bone fragments

Scattered cremation burial in a round grave pit containing stones between -20 and $-40 \mathrm{~cm}$. Calcinated bone fragments lay under the stones. A small bone fragment was found in an animal burrow cutting across the grave pit.

The burial did not contain any grave goods.

\section{Grave 424 (Square E2; Pl. CLXII)}

Size of grave pit: L. $108 \mathrm{~cm}, W .86 \mathrm{~cm}$

Depth: $48 \mathrm{~cm}$

Orientation: S-SE to N-NW, with the head toward the S-SE

Position of skeleton: laid on the right side

L. of skeleton (contracted): $85 \mathrm{~cm}$

L. of skeleton (extended): $160 \mathrm{~cm}$

Age at death: $30-40$ years

Sex: female

Condition of skeleton: badly preserved

Preserved skeletal bones: complete skeleton

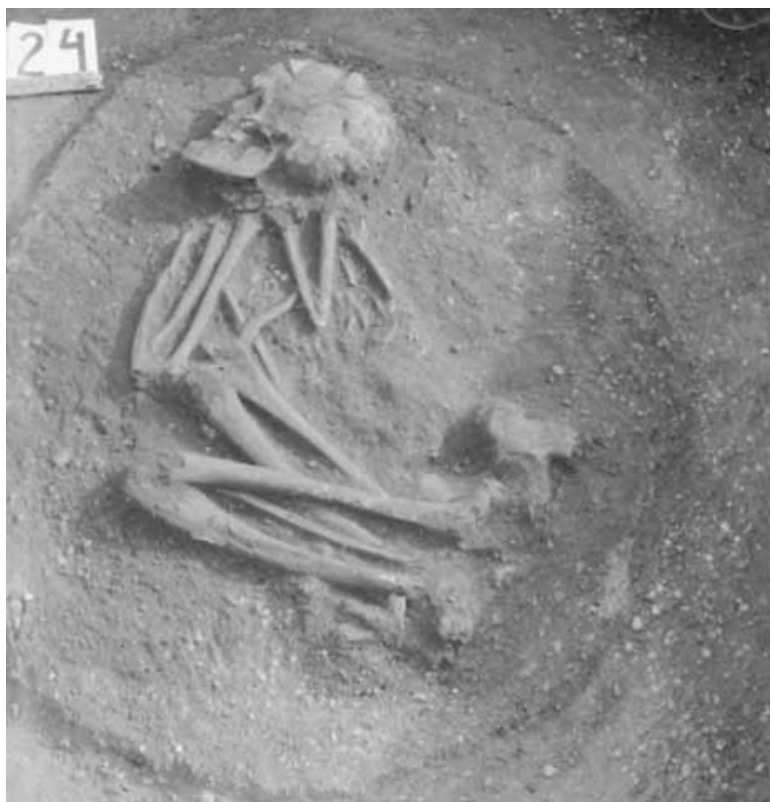

Inhumation burial in an oval grave pit containing stones from $-30 \mathrm{~cm}$ downward. The stones lay on the body and a large flat stone was placed on the head. The body was laid on the right side in a contracted position.

$\overline{265}$ The surviving skeletal remains are unsuitable for an anthropological determination.
The crushed skull lay on the right side. The arms were bent at the elbow and drawn up, with the hands resting in front of the chin. The thighs were drawn up in front of the body, the right thigh higher than the other one, the legs were bent back toward the buttocks. The ankles lay one over the other.

The burial did not contain any grave goods.

\section{Grave 425 (Square E3; Pl. CLXIII)}

Size of grave pit: -

Depth: $42 \mathrm{~cm}$

Orientation: $\mathrm{E}$ to $\mathrm{W}$, with the face toward the $\mathrm{E}$

Position of skeleton: -

L. of skeleton (contracted): -

L. of skeleton (extended): -

Age at death: $10-11$ years

Sex: child

Condition of skeleton: badly preserved

Preserved skeletal bones: skull fragment

Skull burial. There was no indication of a grave pit. A skull lying on the occipital bone with the face toward the east was found at a depth of $-42 \mathrm{~cm}$. A part of the skull was destroyed during its excavation.

The burial contained the following grave goods: a vessel fragment (1) above the skull; a small pebble (2) on the skull's left side.

Grave goods

1. Bowl. Body sherd of a reddish-grey, thick-walled bowl decorated with a barley visible row of impressed dots. L. 6 cm. Inv. no. 61.2.171.1.

2. Unworked radiolarite pebble. L. $2.2 \mathrm{~cm}$. Inv. no. 61.2.171.2.

\section{Grave 426 (Square F2; Pl. CLXIII)}

Size of grave pit: L. $89 \mathrm{~cm}, W .72 \mathrm{~cm}$ Depth: $54 \mathrm{~cm}$

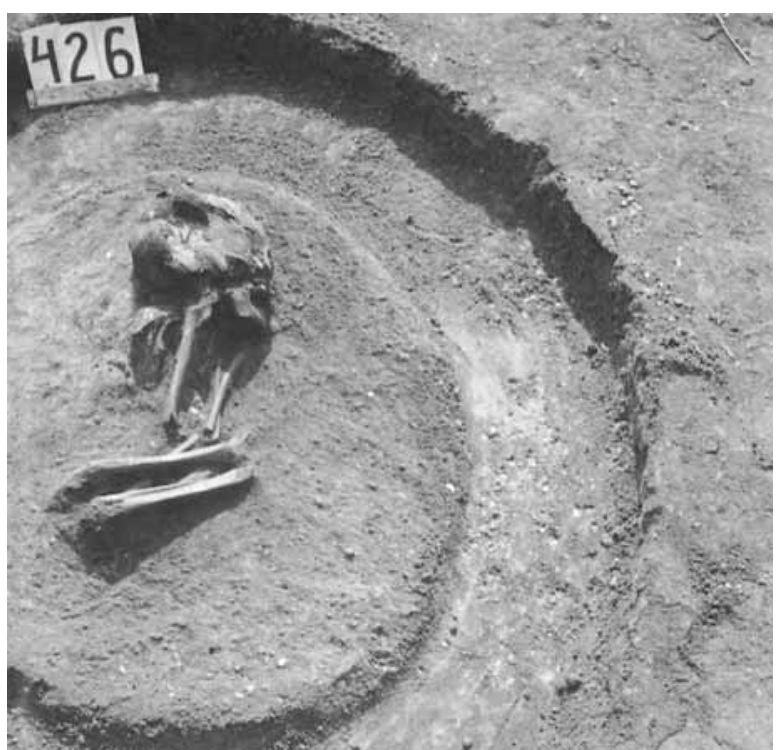


Orientation: S-SE to N-NW, with the head toward the S-SE Position of skeleton: laid on the left side

L. of skeleton (contracted): $55 \mathrm{~cm}$

L. of skeleton (extended): -

Age at death: $8-10$ years

Sex: child

Condition of skeleton: badly preserved

Preserved skeletal bones: complete skeleton

Inhumation burial in an oval grave pit containing stones from $-18 \mathrm{~cm}$ downward. A large flat stone almost covered the entire body. The body was laid on the left side in a contracted position. The crushed skull lay on the left side and was tilted slightly forward. The right arm was bent at the elbow and drawn up, with the hand placed under the chin. The position of the left forearm could not be established. The thighs were drawn up in front of the body, the legs were bent back toward the buttocks. The skeletal remains of the trunk perished.

The burial did not contain any grave goods.

\section{Grave 427 (Square E2; Pl. CLXIII)}

Size of grave pit: L. $96 \mathrm{~cm}, W .77 \mathrm{~cm}$

Depth: $78 \mathrm{~cm}$

Orientation: E-SE to $\mathrm{W}-\mathrm{NW}$, with the head toward the E-SE Position of skeleton: laid on the left side

L. of skeleton (contracted): $58 \mathrm{~cm}$

L. of skeleton (extended): $c a .100 \mathrm{~cm}$

Age at death: $9-10$ years

Sex: child

Condition of skeleton: badly preserved

Preserved skeletal bones: complete skeleton

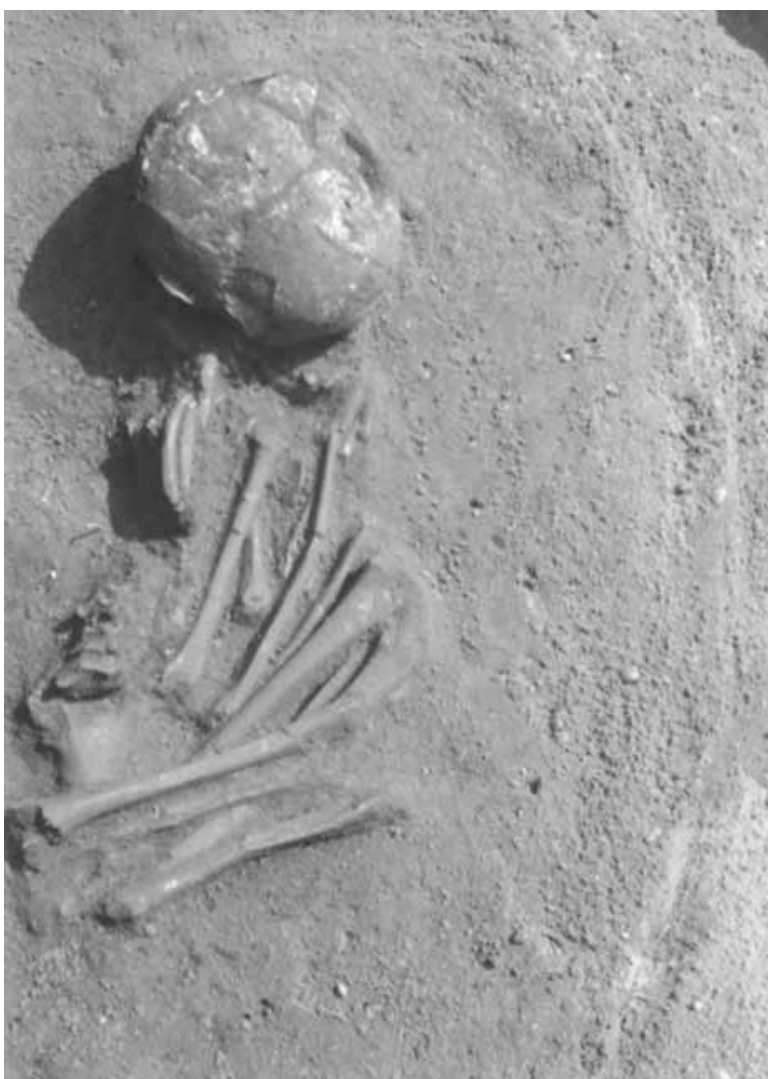

Inhumation burial in an oval grave pit. The body was laid on the left side in a strongly contracted position. The skull rested on the occipital bone and was tilted slightly to the left. The arms were bent at the elbow and drawn up, with the hands placed in front of the chin. The thighs were drawn up in front of the body, the left one higher than the right one, the legs were bent back toward the buttocks.

The burial contained the following grave goods: two shell plaques on the chest and shell plaques by the neck (1).

Grave goods

1. Shell plaques. Twelve rectangular, broken Unio crassus mussel plaques with a pair of perforations along the short sides. Inv. no. 61.2.172 (Pl. CLXIII. 427/1).266

\section{Grave 428 (Square E2/E3; Pl. CLXIII)}

Size of grave pit: L. $94 \mathrm{~cm}, W .71 \mathrm{~cm}$ Depth: $58 \mathrm{~cm}$

Orientation: $\mathrm{E}$ to $\mathrm{W}$, with the head toward the $\mathrm{E}$ Position of skeleton: laid on the right side

L. of skeleton (contracted): $76 \mathrm{~cm}$

L. of skeleton (extended): $c a .160 \mathrm{~cm}$

Age at death: $40-x$ years

Sex: female

Condition of skeleton: medium well preserved

Preserved skeletal bones: complete skeleton

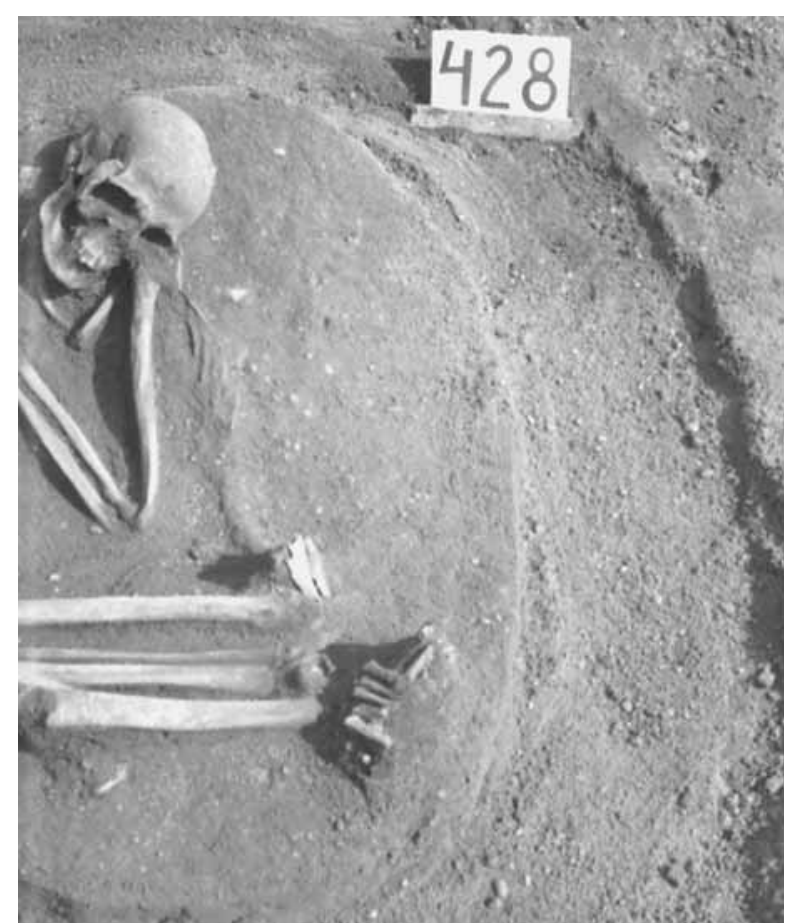

266 According to the acquisitions register, there were nine sliced shell beads, two Vermetus shells and twelve rectangular shell plaques. The excavation diary does not list shell beads among the finds, only shell plaques. It seems likely that the beads inventoried as part of the grave goods from this burial actually originate from the grave furniture of Grave 437. Cp. Pl. CLXV. 437/1 for their drawing. 
Inhumation burial in a narrow, oval grave pit. The body was laid on the right side in a contracted position. The skull lay on the left side. The arms were bent at the elbow and drawn up, with the hands placed in front of the chin. The thighs were drawn up into a horizontal position, the legs were bent back toward the buttocks. The feet were placed one over the other. The right knee, the right wrist and the feet lay slightly higher.

The burial did not contain any grave goods.

\section{Grave 429 (Square E2; Pl. CLXIII)}

Size of grave pit: L. $90 \mathrm{~cm}, W .75 \mathrm{~cm}$

Depth: $45 \mathrm{~cm}$

Orientation: S-SE to N-NW

Position of skeleton: -

L. of skeleton (contracted): -

L. of skeleton (extended): -

Age at death: -

Sex: -

Condition of skeleton: badly preserved

Preserved skeletal bones: ${ }^{267}$ calcinated bone fragments

Scattered cremation burial in an oval grave pit containing stones from $-20 \mathrm{~cm}$ downward. Calcinated bone fragments lay under the stones. A few stones lay west of the grave pit, but these were not associated with the burial.

The burial did not contain any grave goods.

\section{Grave 430 (Square E2; Pl. CLXIV)}

Size of grave pit: -

Depth: $25 \mathrm{~cm}$

Orientation: -

Position of skeleton: -

L. of skeleton (contracted): -

L. of skeleton (extended): -

Age at death: -

Sex: -

Condition of skeleton: badly preserved

Preserved skeletal bones: ${ }^{268}$ calcinated bone fragments

Inurned burial. There was no indication of a grave pit. Calcinated bone fragments lay in a cracked and broken scooping vessel (1) at a depth of $-25 \mathrm{~cm}$.

The burial did not contain any grave goods.

Finds from the burial ${ }^{269}$

1. Scooping vessel. Grey, polished, undecorated scooping vessel. The handle spans the rim and the base. Joined from its fragments and restored. $H .4 .4 \mathrm{~cm}, \mathrm{dM} .12 \mathrm{~cm}$. Inv. no. 61.2.208 (Pl. CLXIV. 430/1).

\footnotetext{
$\overline{267}$ The surviving skeletal remains are unsuitable for an anthropological determination.

268 The surviving skeletal remains are unsuitable for an anthropological determination.

269 The single find inventoried from this burial is a dipper (inv. no. 61.1.173.1). However, the grave goods did not include a dipper since the excavation diary specifies a one-handled bowl. The dipper inventoried as coming from this burial probably originates from Grave 412. The stray finds include a one-handled bowl (inv. no. 61.2.208), which probably came from Grave 430.
}

\section{Grave 431 (Square E2)}

Size of grave pit: diam. $25 \mathrm{~cm}$

Depth: $35 \mathrm{~cm}$

Orientation: -

Position of skeleton: -

L. of skeleton (contracted): -

L. of skeleton (extended): -

Age at death: $23-x$ years

Sex: -

Condition of skeleton: badly preserved

Preserved skeletal bones: calcinated bone fragments

Scattered cremation burial in a round grave pit. Calcinated bone fragments forming a $10 \mathrm{~cm}$ thick layer were found over an area with a diameter of $25 \mathrm{~cm}$ under a smaller, flat stone.

The burial did not contain any grave goods.

\section{Grave 432 (Square E2; Pl. CLXIII)}

Size of grave pit: diam. $28 \mathrm{~cm}$

Depth: $58 \mathrm{~cm}$

Orientation: -

Position of skeleton: -

L. of skeleton (contracted): -

L. of skeleton (extended): -

Age at death: -

Sex: -

Condition of skeleton: badly preserved

Preserved skeletal bones: ${ }^{270}$ calcinated bone fragments

Scattered cremation burial in a round grave pit. Calcinated bone fragments lay over an area with a diameter of $28 \mathrm{~cm}$ under a flat stone at a depth of $-45 \mathrm{~cm}$.

The burial contained the following grave goods: a broken red clay bead (1) under the calcinated bone fragments.

Grave goods

1. Bead. Broken tubular clay bead imitating a Dentalium shell, fired to a red colour. L. $1.2 \mathrm{~cm}$. Inv. no. 61.2.174 (Pl. CLXIII. 432/1).

\section{Grave 433 (Square E2; Pl. CLXV)}

Size of grave pit: L. $52 \mathrm{~cm}, W .36 \mathrm{~cm}$

Depth: $58 \mathrm{~cm}$

Orientation: -

Position of skeleton: -

L. of skeleton (contracted): -

L. of skeleton (extended): -

Age at death: -

Sex: -

Condition of skeleton: badly preserved

Preserved skeletal bones: ${ }^{271}$ calcinated bone fragments

\footnotetext{
${ }^{270}$ The surviving skeletal remains are unsuitable for an anthropological determination.

271 The surviving skeletal remains are unsuitable for an anthropological determination.
} 
Scattered cremation burial in an oval grave pit. The grave pit was west-south-west to east-north-east oriented. The grave pit was covered with smaller stones from $-37 \mathrm{~cm}$ downward. Pottery fragments (1) lay above the stones, under which lay the calcinated bone fragments. A base fragment (2) was found among the bones.

Grave goods

1. Vessel fragments. Body fragment of greyish bipartite bowl with a section of the inner dividing wall and the shoulder fragment of an amphora with oblique fluting and the stub of a knob. Inv. no. 61.2.175 (Pl. CLXV. 433/1).

2. Base fragment of a vessel. 272

\section{Grave 434 (Square F2; Pl. CLXIV)}

Size of grave pit: diam. $30 \mathrm{~cm}$

Depth: $35 \mathrm{~cm}$

Orientation: -

Position of skeleton: -

L. of skeleton (contracted): -

L. of skeleton (extended): -

Age at death: $23-\mathrm{x}$ years

Sex: -

Condition of skeleton: badly preserved

Preserved skeletal bones: calcinated bone fragments

Scattered cremation burial in a round pit. Calcinated bone fragments of an adult lay over an area with a diameter of $30 \mathrm{~cm}$ at a depth of $-35 \mathrm{~cm}$. Various vessel fragments (1) lay among the bone fragments.

Finds from the grave pit

1. Bowls. A greyish, worn, conical bowl with funnel neck decorated with a row of punctates around the shoulder (Pl. CLXIV. 434/1); non-joining body sherds of a grey, worn, thin-walled bowl with funnel neck decorated with punctates arranged into a wavy line (Pl. CLXIV. 434/2); rim fragment of a grey, worn bipartite bowl with indrawn rim, decorated with a row of impressed dots and incised lines running toward the base under the rim (Pl. CLXIV. 434/3); base fragment of a grey, worn bowl (Pl. CLXIV. 434/4). Fourteen pieces, some joined from smaller fragments. Inv. no. 61.2.176. ${ }^{273}$

\section{Grave 435 (Square E2; Pl. CLXV)}

\author{
Size of grave pit: L. $56 \mathrm{~cm}, W .38 \mathrm{~cm}$ \\ Depth: $37 \mathrm{~cm}$ \\ Orientation: N-NW to S-SE \\ Position of skeleton: - \\ L. of skeleton (contracted): - \\ L. of skeleton (extended): - \\ Age at death: -
}

\footnotetext{
272 A base fragment was not inventoried among the finds from the burial. 273 The heap of pottery sherds was made up of the fragments of four different bowls.
}

Sex: -

Condition of skeleton: badly preserved

Preserved skeletal bones: ${ }^{274}$ calcinated bone fragments

Scattered cremation burial in an oval grave pit containing three stones at a depth of $-25 \mathrm{~cm}$. The calcinated bone fragments lay under the stones.

The burial did not contain any grave goods.

\section{Grave 436 (Square D2; Pl. CLXIII)}

Size of grave pit: diam. $35 \mathrm{~cm}$

Depth: $52 \mathrm{~cm}$

Orientation: -

Position of skeleton: -

L. of skeleton (contracted): -

L. of skeleton (extended): -

Age at death: $23-59$ years

Sex: female (?)

Condition of skeleton: badly preserved

Preserved skeletal bones: calcinated bone fragments

Scattered cremation burial in a round grave pit. Calcinated bone fragments forming a $10 \mathrm{~cm}$ thick layer were deposited over an area with a diameter of $35 \mathrm{~cm}$. The bones were relatively lightly burnt. There was no apparent regularity in the deposition of the bones, e.g. the skull fragments were mixed up with the other skeletal remains.

The burial contained the following grave goods: a snail shell (1) and a stone chip (2) among the bone fragments.

Grave goods

1. A broken Turritella snail Inv. no. 61.2.177.1 (Pl. CLXIII. 436/1).

2. Debitage. Chert. Inv. no. 61.2.177.2.

\section{Grave 437 (Square D2; Pl. CLXV)}

Size of grave pit: L. $112 \mathrm{~cm}, W .76 \mathrm{~cm}$

Depth: $102 \mathrm{~cm}$

Orientation: $\mathrm{E}$ to $\mathrm{W}$, with the head toward the $\mathrm{E}$

Position of skeleton: laid on the left side

L. of skeleton (contracted): $88 \mathrm{~cm}$

L. of skeleton (extended): $138 \mathrm{~cm}$

Age at death: $10-12$ years

Sex: child

Condition of skeleton: badly preserved

Preserved skeletal bones: complete skeleton

Inhumation burial in an oval grave pit containing stones from $-65 \mathrm{~cm}$ downward. The stones were arranged in two layers, of which the lower one lay on the body. A larger flat stone in the lower row almost covered the entire body. The body was laid on the left side in a contracted position. The crushed skull lay on the left side. The right arm was bent at the elbow. The left arm was

$\overline{274}$ The surviving skeletal remains are unsuitable for an anthropological determination. 


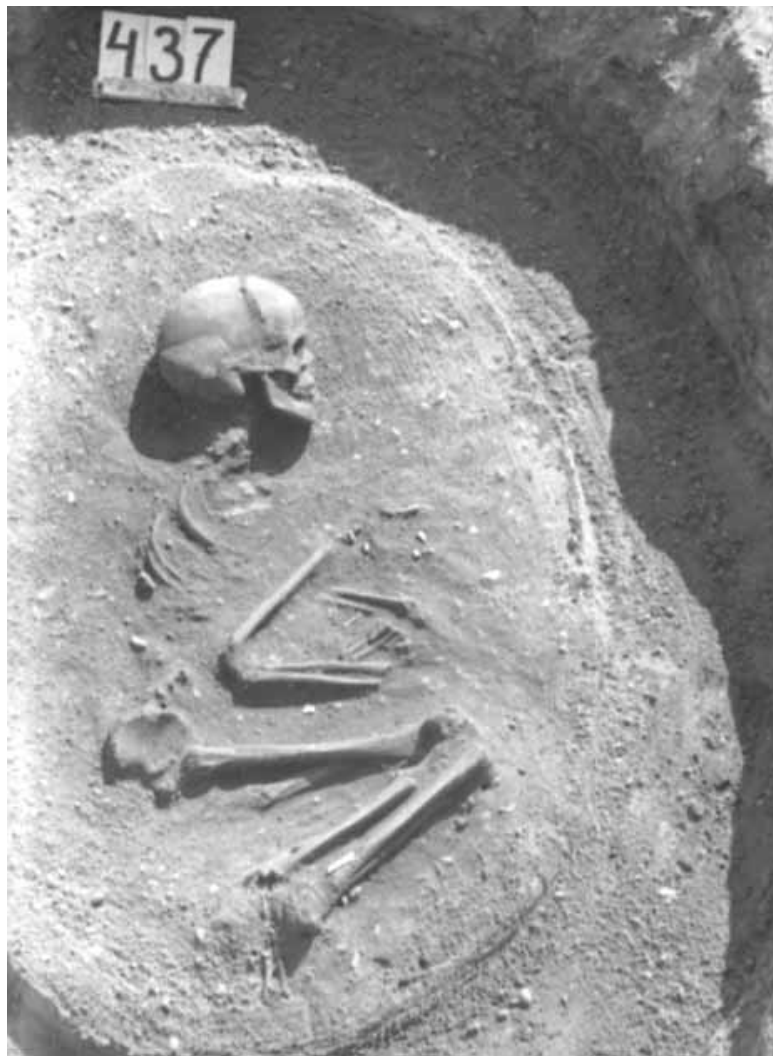

slightly bent. The hands were placed beside each other. The right arm was pressed down in front of the trunk by a stone. The thighs were drawn up into a horizontal position, the legs were bent back toward the buttocks.

The burial contained the following grave goods: beads (1) by the right shoulder; a triangular clay plaque (2) among the beads; a shell plaque (3) between the right forearm and the right femur.

Grave goods

1. Beads. Nine limestone beads. Inv. no. 61.2.172 (Pl. $C L X V .437 / 1) .275$

2. A triangular, perforated clay plaque. ${ }^{276}$

3. Shell plaque. Broken, rectangular, perforated Unio crassus mussel plaque. Inv. no. 61.2.178 (Pl. CLXV. 437/3).

\section{Grave 438 (Square D2; Pl. CLXV)}

Size of grave pit: L. $120 \mathrm{~cm}$, W. $92 \mathrm{~cm}$

Depth: $118 \mathrm{~cm}$

Orientation: $\mathrm{S}$ to $\mathrm{N}$, with the head toward the $\mathrm{S}$

Position of skeleton: laid on the left side

L. of skeleton (contracted): $91 \mathrm{~cm}$

L. of skeleton (extended): $158 \mathrm{~cm}$

Age at death: $30-40$ years

Sex: female

275 Beads were not inventoried among the finds from the burial. It seems likely that the beads from this burial were mistakenly inventoried among the finds from Grave 427. The two Vermetus shells listed in the acquisitions register have been lost or mislaid.

276 This object was not inventoried among the finds from the burial.
Condition of skeleton: medium well preserved

Preserved skeletal bones: complete skeleton

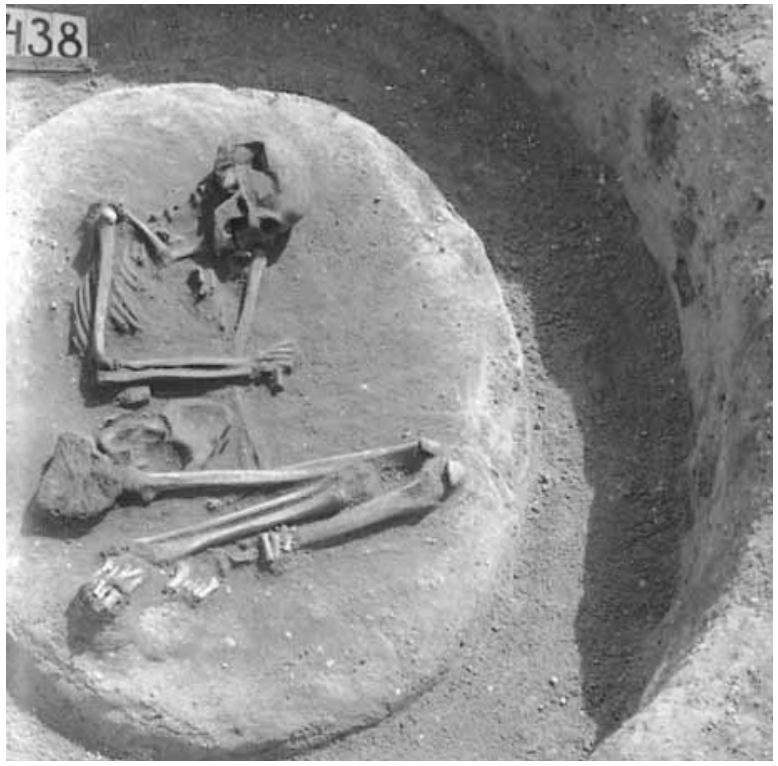

Inhumation burial in an oval grave pit containing stones between -25 and $-108 \mathrm{~cm}$. A rectangular, pointed stone with the pointed end downward lay directly on the skull; its pointed end crushed the skull. The body was laid on the left side in a contracted position. The skull lay on the left side. The left arm was extended between the thighs and the leg bones, with the hand clasping the left leg. The right arm was bent at the elbow, with the wrist laid on the left elbow and the hand flexed. The thighs were drawn up into a horizontal position, the legs were bent back toward the buttocks. A triangular piece of charred wood (1) by the right pelvis and the upper end of the thigh.

Finds from the grave pit

1. Charred wood. A triangular piece of charred wood of unknown function. $14 \mathrm{~cm} \times 14 \mathrm{~cm} \times 12 \mathrm{~cm}$.

\section{Grave 439 (Square D2; Pl. CLXV)}

Size of grave pit: L. $114 \mathrm{~cm}$, W. $107 \mathrm{~cm}$

Depth: $110 \mathrm{~cm}$

Orientation: SE to NW, with the head toward the SE

Position of skeleton: laid on the right side

L. of skeleton (contracted): $81 \mathrm{~cm}$

L. of skeleton (extended): $150 \mathrm{~cm}$

Age at death: $35-45$ years

Sex: female?

Condition of skeleton: medium well preserved

Preserved skeletal bones: complete skeleton

Inhumation burial in a round, slightly oval grave pit. The body was laid on the right side in a contracted position. The skull rested on the occipital bone, the arms were bent at the elbow and drawn up, with the hands placed by the chin. The thighs were drawn up in front of the body, the legs were bent back toward the buttocks. The 


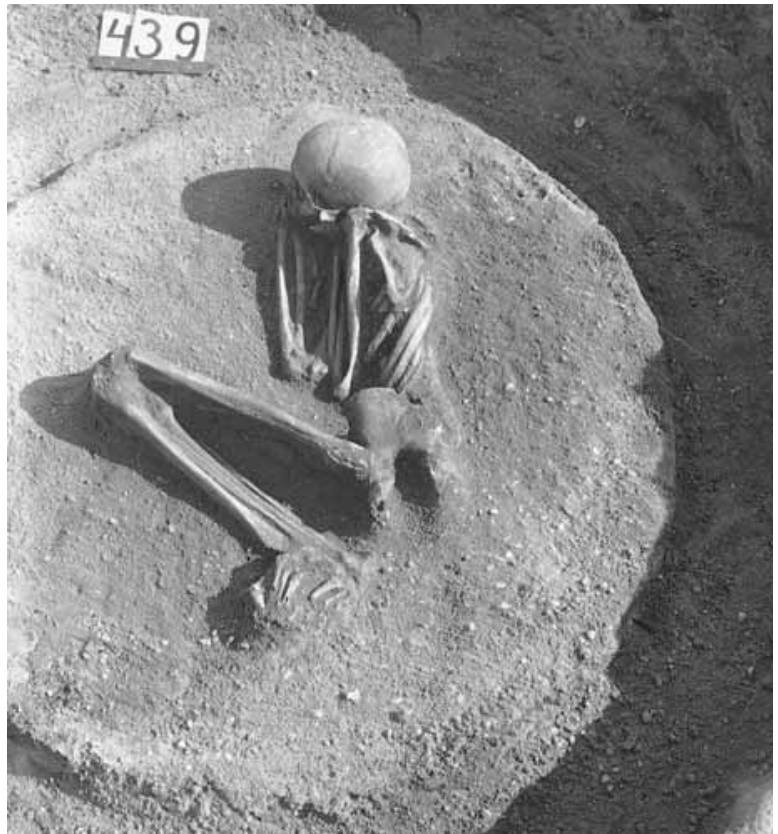

ankles were laid one over the other. Calcinated bones (1) lay between the pelvis and the elbows.

Finds from the burial

1. Animal bones. Small, calcinated bone fragments. Eleven pieces. Inv. no. 61.2.179.

\section{STRAY FINDS FROM THE AREA OF THE CEMETERY}

Relatively few finds from the cemetery's excavated area were inventoried as stray finds. The finds from the 1952 campaign were inventoried in 1956 (inv. nos 56.74.156.80.1); the grave goods from the burials uncovered in 1953 were inventoried in 1956 together with the finds from the campaigns between 1954 and 1960. The stray finds were entered into the acquisitions register under numbers 61.2.182 to 61.2.211. The 1954 excavation diary does not mention stray finds (only two entries in the acquisitions register describe stray finds). Few stray finds were inventoried between 1955 and 1959. Some of the stray finds could be identified as the grave goods of a specific burial: these are not described here because they are listed among the grave goods of the burial in question.

\section{Stray finds collected before the commencement of the excavation in 1952}

1. Dipper. Body and base fragment of a brownishgrey, conical dipper with the stub of the handle. dB. 1.7 cm. Inv. no. 56.11.77.1 (Pl. CLXVI. 1).

2. Scooping vessel. Grey, conical, one-handled scooping vessel. The handle is missing. Joined from its fragments and restored. H. $4.7 \mathrm{~cm}, \mathrm{dM} .9$ cm. Inv. no. 56.11.76.1 (Pl. CLXVI. 2).
3. Cup. Fragment of a light brown, polished cup with cylindrical neck and flattened globular body. The handle is missing, only its stub survived. Joined from its fragments. dM. $4 \mathrm{~cm}$, surviving height (according to the excavation diary) $5.7 \mathrm{~cm}$ Inv. no. 56.11.78.1 (Pl. CLXVI. 3).277

Stray finds without an indication of their findspot or possible burial context

4. Beads. One clay bead, two small Unio shell beads, five Dentalium badense beads and thirty-three limestone beads. Inv. no. 56.11.74.1 (Pl. CLXVI. 4).278

5. Pitcher handle. Body sherd with an ansa lunata handle from a large grey pitcher L. $7.7 \mathrm{~cm}$. Inv. no. 56.11.79.1 (Pl. CLXVI. 5).

$5 \mathrm{a}$. The dimensions of the goblet inventoried under no. 56.11.75.1 suggest that it probably came from Grave 39 (for its description cp, the finds from the burial; Pl. XIX. 39/2).

5 b. The amphora fragment inventoried under no. 56.11.80.1 probably came from Grave 2 (for its description cp. the finds from the burial; Pl. II. 2/1).

\section{Stray finds from the 1953 campaign}

The excavation diary contains few references to these finds.

6. Pot. Squat, brownish pot with an elongated S profile and rusticated belly, decorated with a finger-impressed rib under the rim. Restored. $H .11 .5 \mathrm{~cm}, \mathrm{~d} M .11 \mathrm{~cm}$, dB. 7.5 cm. Inv. no. 61.2 .182 (Pl. CLXVII. 6).

7. Handled cup. Grey cup with cylindrical neck and flattened globular body. The high handle springs to the belly. The rim is restored. H. $7 \mathrm{~cm}, \mathrm{dM} .8 \mathrm{~cm}$. Inv. no. 61.2.183 (Pl. CLXVII. 7).

8. Bowl. Grey bowl with everted, notched rim and flat base. The body is decorated with a row of impressed dots and hatched hanging triangles. Fragmentary. H. $8 \mathrm{~cm}$. Inv. no. 61.2 .184 (Pl. CLXVII. 8).

9. Cup. Brown cup with slightly everted rim, cylindrical neck and flattened globular body. The high handle spans the rim and the belly. Three incised lines decorate the body under the handle. The handle is missing. There is a unfinished perforation under the handle. Joined from its fragments and restored. H. $6.9 \mathrm{~cm}, \mathrm{dM}$. $5.1 \mathrm{~cm}$. Inv. no. 61.2.185 (Pl. CLXVIII. 9).

10. Bipartite bowl. Non-joining rim, body and inner dividing wall fragments of brown bipartite bowls. One is thin-walled and has a row of punctates on the

277 According to the acquisitions register, the finds inventoried under nos 56.11.76.1-56.11.78.1 were found in 1952, before the start of the excavation

278 Even though the number of inventoried beads is lower than the number of beads from Grave 8 and Grave 46, it seems likely that the beads came from one of these burials. 
rim. Its neck bears a design of bundles of incised lines flanked by a vertical row of impressed dots. One fragment has a peaked handle rising above the rim between the incised decoration. The top of the inner dividing wall is also decorated with punctates. The flat knobs set on the inner dividing wall are very worn and it is therefore uncertain whether they were decorated. Inv. no. 61.2.189.1 (Pl. CLXVIII. 10).279

11. Bipartite bowl. Fragment of a brown, thick-walled, coarse bipartite bowl decorated with incised lines on the shoulder. The flat knob set on top of the inner dividing wall has broken off. Inv. no. 61.2.189.1 (Pl. CLXIX. 11). ${ }^{280}$

12. Pot. Rim and body fragments of a large, greyish, thick-walled pot. One fragment has the stub of the handle. Nineteen non-joining pieces. Inv. no. 61.2.189.2 (Pl. CLXIX. 12).

13. Bowl. Grey, polished bowl with funnel neck. The rim is decorated with punctates, the belly with two parallel rows of impressed dots under which lie hatched triangles. A stringhole lug is set on the belly. A cross motif of fluted lines adorns the bowl's interior. Joined from its fragments and restored. H. $13 \mathrm{~cm}$, dM. $28.5 \mathrm{~cm}, \mathrm{~dB} .9 .7 \mathrm{~cm}$. Inv. no. 61.2.186 (Pl. CLXIX. 13).281

13a. Various vessels. Rim, body and base fragments of various vessels (pitchers, bowls, pots). Twenty-two pieces. Inv. no. 61.2.187.282

14. Radiolarite flake. Probably from Grave 352. Inv. no. 61.2.188 (Pl. CLXIX. 14).283

15. Bipartite bowl. Rim and body fragment of a grey, bipartite bowl with one of the flat, decorative knobs. The knob is decorated with a cross motif of punctates, the rim with punctates and vertically incised lines. Two pieces. Inv. no. 61.2.190.1 (Pl. CLXX. 15).284

15a. Pot. Body and base fragments of a reddish, thickwalled pot. Ten non-joining pieces. Inv. no. 61.2.190.2.

16. Pitcher. Fragments of a greyish-brown, polished pitcher with cylindrical neck and flattened globular body. The handle rises above the rim and springs to the shoulder. The belly is decorated with fine fluting. The handle is broken. Four pieces. dB. 6.2 cm. Inv. no. 61.2.191 (Pl. CLXX. 16).285

\footnotetext{
279 According to the excavation diary, nos 10-12 came to light $260 \mathrm{~cm}$ south-east of Grave 151 and lay scattered over an area with a diameter of $130 \mathrm{~cm}$ between -35 and $-40 \mathrm{~cm}$.

280 Eleven fragments of the two vessels were inventoried.

281 The excavation diary mentions that the bowl lay under three stones between -30 and $-40 \mathrm{~cm}$ somewhere near Grave 151 .

282 The excavation diary mentions that the thick-walled and thin-walled vessel fragments came to light between -30 and $-35 \mathrm{~cm}$ in an area with a diameter of $40-50 \mathrm{~cm}$.

283 The excavation diary mentions that the stone blade came to light $220 \mathrm{~cm}$ south-west of Grave of 221 at a depth of $-35 \mathrm{~cm}$.

284 The excavation diary mentions that nos 15 and 15 a came to light at a depth of $-35 \mathrm{~cm}$ in an area with a diameter of $50 \mathrm{~cm}$.

285 The excavation diary mentions that the pitcher fragments came to light $50 \mathrm{~cm}$ south of Grave 153 at a depth of $-40 \mathrm{~cm}$.
}

17. Non-joining rim and body sherds of various pitchers. One fragment has the stub of a handle. Inv. no. 61.2.193.1 (Pl. CLXX. 17).286

18. Non-joining rim and body sherds of various pitchers. One fragment has the stub of a handle. Inv. no. 61.2.193.1 (Pl. CLXX. 18).

19. Bipartite bowl. A flat, decorative knob from a bipartite bowl, decorated with a pattern of impressed dots. Diam. 4.1 cm. Inv. no. 61.2.193.2 (Pl. CLXX. 19).

20. Non-joining rim and body sherds of various bowls. Inv. no. 61.2.193.1 (Pl. CLXX. 20).

21. Non-joining rim and body sherds of various bowls. Inv. no. 61.2.193.1 (Pl. CLXX. 21).

22. Pitchers. Rim and body fragments of grey pitchers, one with the stub of a handle. Inv. no. 61.2.194 (Pl. CLXXI. 22). ${ }^{287}$

23. Pitchers. Rim and body fragments of grey pitchers, one with the stub of a handle. Inv. no. 61.2.194 (Pl. CLXXI. 23).

24. Amphora. Body fragment of a small, worn, reddish, handled amphora. Inv. no. 61.2.195 (Pl. CLXXI. 24). 288

25. Bowl. Rim and body sherd of a brownish, thinwalled bowl with funnel neck, decorated with a row of impressed dots around the shoulder. Inv. no. 61.2.195 (Pl. CLXXI. 25).

26. Pot. Base fragment of a large, grey pot. Inv. no. 61.2.195 (Pl. CLXXI. 26).

27. Ladle. Brownish-grey ladle. The tip of the long handle has broken off at the point, where there were two perforations. The inner side is decorated with incised chevrons. Joined from its fragments and restored. H. $4 \mathrm{~cm}, \mathrm{dM} .11 .3 \mathrm{~cm}$, W. of handle 4.5 cm. Inv. no. 61.2 .196 (Pl. CLXXI. 27).289

28. Bowl. Brown, thin-walled bowl with funnel neck decorated with a row of impressed dots around the belly and a small stringhole lug. Inv. no. 61.2.197 (Pl. CLXXII. 28).290

29. Jug. Handle fragment of a brownish jug, decorated with a combination of incised vertical and zig-zag lines (now worn). Inv. no. 61.2.197 (Pl. CLXXII. 29).

30. Amphora. Fragment of a brown, thin-walled, polished amphora with wide fluting on the belly. Inv. no. 61.2.197 (Pl. CLXXII. 30).

31. Pitcher. Body fragments of a large, brown pitcher decorated with a row of impressed dots around the belly. Inv. no. 61.2.197 (Pl. CLXXII. 31).

\footnotetext{
286 The excavation diary mentions that nos $17-21$ came to light $150 \mathrm{~cm}$ north-west of Grave 160 at a depth of $-45 \mathrm{~cm}$.

287 The excavation diary mentions that nos $22-23$ came to light $50 \mathrm{~cm}$ north of Grave 180 at a depth of $-30 \mathrm{~cm}$.

288 The excavation diary mentions that nos $24-26$ came to light $150 \mathrm{~cm}$ east of Grave 181 at a depth of $-30 \mathrm{~cm}$.

289 The excavation diary mentions that the ladle came to light $120 \mathrm{~cm}$ west of Grave 188 at a depth of $-40 \mathrm{~cm}$.

290 The excavation diary mentions that three vessels lay beside each other $150 \mathrm{~cm}$ north-west of Grave 198 at a depth of $-35 \mathrm{~cm}$.
} 
32. Amphora. Fragments of a dark grey, thin-walled, worn amphora decorated with lines around the neck and fluting on the belly. A small handle is set on the shoulder. Inv. no. 61.2.197 (Pl. CLXXII. 32).

33. Cup. Grey, polished cup with cylindrical neck and flattened globular body decorated with fluting on the belly. The handle rises above the rim and springs to the shoulder. The rim is damaged. H. $5.5 \mathrm{~cm}$, dM. 5.5 cm. Inv. no. 61.2 .198 (Pl. CLXXIII 33). ${ }^{291}$

\section{Stray finds from 1954}

The 1954 excavation diary does not mention stray finds. The acquisitions register has the following entries:

34. Cup. Greyish, polished cup with cylindrical neck and flattened globular body. The belly is decorated with fine fluting. The high handle spans the rim and the shoulder. Impressed dots adorn the body under the handle, which is missing. H. $7.9 \mathrm{~cm}, \mathrm{dM}$. 5.4 cm. Inv. no. 61.2.199 (Pl. CLXXIII. 34). Inventoried as one lot under no. 1954/IV.

35. Stone axe. Trapezoidal stone axe made from serpentinite. Stray find from the eastern part of the cemetery. W. $4.5 \mathrm{~cm}$, L. $5 \mathrm{~cm}$. Inv. no. 61.2 .200 (Pl. CLXXIII. 35).

\section{Stray finds found between 1952 and 1960}

36. Beads. Fourteen limestone beads. Inv. no. 61.2.202 (Pl. CLXXIII. 36).

37. Beads. Six Dentalium badense beads (one containing a piece of sheet copper) and two limestone beads. Inv. no. 61.2.203 (Pl. CLXXIII. 37).

38. Beads. Five tubular copper beads. Inv. no. 61.2.204.292

39. Pot. Grey, worn, one-handled conical pot with cylindrical neck. The strap handle springs from the rim to the shoulder. A row of impressed dots encircles the shoulder. Joined from its fragments and restored. H. $11.9 \mathrm{~cm}, \mathrm{dM} .12 .2 \mathrm{~cm}, \mathrm{~dB} .7 \mathrm{~cm}$. Inv. no. 61.2.206 (Pl. CLXXIII. 39).

40. Bowl. Body sherd of a reddish, thick-walled bowl. A row of impressed dots encircles the shoulder with hatched triangles underneath. The design was carelessly made in several spots for the hatching extends beyond the triangles. H. $10 \mathrm{~cm}$. Inv. no. 61.2.207 (Pl. CLXXIII. 40).

40a. Pot. Large, reddish-brown, thick-walled pot with slightly everted rim and flat base. A handle is set on the body under the rim. H. $29.4 \mathrm{~cm}, \mathrm{dM} .30 .2 \mathrm{~cm}$,

\footnotetext{
291 The excavation diary mentions that the cup came to light $160 \mathrm{~cm}$ southeast of Grave 217 at a depth of $-40 \mathrm{~cm}$.

292 Although the beads are mentioned in the checklist drawn up in 1979, they could no longer be found when the finds were re-examined for this publication.
}

dB. $13 \mathrm{~cm}$. Joined from its fragments and restored. Inv. no. 61.2.210.293

\section{Stray finds from $1957^{294}$}

41. Pounder. Fragment of an axe shaped, polished pounder. L. 6 cm. Inv. no. 61.2.211.1 (Pl. CLXXIV. 41).

41a. Pot. Body fragment of a brown pot. L. $6.5 \mathrm{~cm}$. Inv. no. 61.2.211.2.

42. Limestone. Pitted limestone with traces of burning on one side. L. $9.5 \mathrm{~cm}$. Inv. no. 61.2.211.3 (Pl. CLXXIV. 42).

42a. Daub fragment (?). Irregularly shaped burnt daub fragment burnt to a pink colour. L. $2.7 \mathrm{~cm}$. Inv. no. 61.2.211.4.

43. Bipartite bowl. Body fragment of a large, grey, worn bipartite bowl with the stub of the inner dividing wall and the decorative flat knob. A row of impressed dots runs under the knob. Inv. no. 61.2.201 (Pl. CLXXIV. 43). ${ }^{295}$

44. Bipartite bowl. Rim and body fragments of a grey, worn bipartite bowl decorated with a row of impressed dots under the rim and a design of alternating empty and hatched panels underneath. Inv. no. 61.2.201 (Pl. CLXXIV. 44).

45. Bowl. Fragments of a brown, worn bowl with cylindrical neck decorated with a row of impressed dots around the belly and rows of impressed dots underneath. Inv. no. 61.2.201 (Pl. CLXXV. 45).

\section{Other stray finds}

46. Cup. Brown, worn cup with cylindrical neck and flattened globular body. the high-drawn handle springs from the rim to the belly. Joined from its fragments and restored. Inv. no. 77.44.1 (Pl. CLXXV. 46).

47. Cup. Brown, worn cup with cylindrical neck and flattened globular body. The high-drawn strap handle springs from the rim to the belly. Joined from its fragments and restored. Inv. no. 77.44.2 (Pl. CLXXV. 47).

48. Bipartite bowl. Body fragment of a grey, worn bipartite bowl with a part of the inner dividing wall. Inv. no. 77.44 .3 (Pl. CLXXV. 48).

49. Bipartite bowl. Body fragment of a grey, worn bipartite bowl with a flat decorative knob and a part of the inner dividing wall. Inv. no. 77.44.4 (Pl. CLXXV. 49).

\footnotetext{
293 The object has since been lost or mislaid. Its description is quoted from the acquisitions register.

294 The excavation diary describes Feature $1957 / \mathrm{I}$ as a $75 \mathrm{~cm}$ deep round intrusion with a diameter of $66 \mathrm{~cm}$. Its fill was black. The finds were calcinated bones, burnt daub fragments, an indistinct vessel fragment, a smaller stone and a broken pounder.

295 The excavation diary mentions that vessel fragments (nos 40 and 41) were found scattered among smaller stones $330 \mathrm{~cm}$ west of Grave 423 over an area with a diameter of $80 \mathrm{~cm}$ at a depth of $-40 \mathrm{~cm}$.
} 
Funerary rites in the Budakalász cemetery 
Death and mortuary rites were important elements of community life in prehistory. The chasm between life and death was not as profound as in later civilisations. In spite of all its mysteriousness and incomprehensibility, death was a natural and rather frequent event in prehistoric life, an event which commanded respect and had to be dissociated from life with various rituals. In view of the average life expectancy, the incidence of death did not mean as immense an emotional shock as the loss of a loved one in our days; at the same time, the fears caused by the unfathomable causes of death and the desire to win the benevolence of supernatural powers were important elements underlying funerary rites.

One of the principal Leitmotifs in the evaluation of the Late Copper Age cemetery at Budakalász was the reconstruction of the burial rite and its various phases through the analysis of the available evidence.

Being one of the major rites of passage in prehistoric societies, burial can be seen as an event performed according to specific rites, whose starting point is the moment of death. The first step in the preparation for the funeral is when the community or its appointed members decide whether the deceased will be cremated or inhumed, how many and what kind of grave goods will be deposited in the grave, whether the costume accessories and tools used in life will be placed in the grave, whether the community will offer any funerary gifts, where the grave will be dug, how the community will bid its final farewell and whether the grave will be marked for posterity.

These issues were not so much questions, as practical issues for prehistoric communities. What survives in the archaeological record, however, is not always sufficient for reconstructing the one-time perceptions of death and each phase of the burial rite.

One of my main concerns was to identify the observable traces of funerary activities, such as the preparations for the funeral. I examined the archaeological evidence for the process of cremation, the sequence of interment, the deposition of the grave goods and the various modes of marking the grave, the last in the series of actions constituting the funerary rite.

I studied and analysed the various artefacts placed in the burials and the possible conclusions which can be drawn from them. I have sought to establish whether there is any correlation between orientation and placement on the right or the left side, whether any clear patterning can be recognised between age/sex and grave goods in order to determine what kind of grave goods were accorded to the deceased members of the Budakalász community. I explored whether there were spatial patterns in the location of the burials provided with grave goods and the graves which lacked grave goods. I also examined the chronological relation between inhumation and cremation burials. While reconstructing the various phases of the funerary sequence, I drew extensively from Sándor Soproni's field notes and the documentation of the excavations.
The preparation for the funeral essentially begins at the moment of the death. The preparation of the body, its clothing, its possible physical separation from the living, the vigil beside the deceased, the acquisition, manufacture, preparation and assembly of the paraphernalia of the funeral (a funerary shroud, a mat, a coffin or any facility serving as such, the vessels, ornaments, implements, etc. placed into the grave), the selection of the grave location, the erection of the funerary pyre in the case of cremation burials, the digging and orientation of the grave pit, its preparation for the burial, are all important elements of the funerary sequence. Another important factor is whether the deceased was accorded grave goods, and if so, how many and what kind. It remained to established whether the number and type of grave goods, and the inclusion of rare and unusual prestige items were a reflection of the deceased's rank, wealth and position in the community.

We know next to nothing about the events immediately following death, for there is no evidence whatsoever concerning how the body of the deceased was prepared for the funeral in the archaeological record from Budakalász. The individuals buried according to the inhumation rite do not appear to have been wrapped in a funerary shroud; if they had, this was performed before the onset of the rigor mortis. While Soproni occasionally noted that the ankles or wrists had perhaps been bound, the skeletal remains lay in a loose anatomical order and there was nothing to indicate that the deceased had been tightly wrapped in a shroud, which is perhaps also precluded by their contracted position.

There is evidence for various preparations in the cemetery (the selection of the grave location, the digging and orientation of the grave pit, the special preparation of a few graves) and the collection or acquisition and manufacture of the objects necessary for the funeral in advance (pottery, jewellery articles, tools and implements, etc.).

One important element of the preliminaries to the funeral was the selection of the grave location, which could be influenced by several considerations (the kinsmen of the deceased, social standing, possible exclusion from the community). The plan of the cemetery reveals that each grave location was selected consciously and that care was taken not to disturb or destroy earlier burials. There are no overlaps between the graves: neither the cremation burials, nor the inhumation burials cut through each other, suggesting that the graves were marked with a wooden marker, a stone, perhaps a bush or tree planted over the grave either as part of the funeral ceremony or after it, and that the time interval between successive burials was not too long because these grave markers were still visible at the time of the next funeral. The selection of the grave locations in this manner also means that the Budakalász cemetery could hardly have been used for several centuries because the grave markers could still be seen.

Another important phase of the funeral ceremony 
was the deposition of grave goods, which have survived in the archaeological record and can therefore be studied, even if the entire range of their possible meaning(s) is not always clear. The grave goods include all the articles (pottery, various tools and implements, costume ornaments, weapons, etc.) found in a particular burial, which were placed beside the deceased for one reason or another. The articles deposited in the grave were placed there intentionally as part of the funeral rite, which played a prominent role in the community's life.

The grave goods can be distinguished according to the deceased's costume and its elements (various accessories, costume ornaments, jewellery items) and artefacts presented to the deceased by the living (pottery, tools and implements, weapons, ornaments, etc.). It is difficult to establish whether the ornaments, tools and other articles deposited in a burial had been the personal possessions of the deceased, which were not to be used by others after their owner's death, or whether these items were received after death as gifts from the family and/or the community, or whether they were offerings made to ease the journey to the otherworld in accordance with the funerary rite.

The vessels placed in the grave too had to be manufactured and prepared as a prelude to the funeral, the mussels and snails strung into necklaces or girdles, and other ornaments had to be collected, as did the raw material for the lithics; the copper beads and the various bone and other tools too had to be made if the latter were not one of the tools used in daily life. ${ }^{1}$ Some mussels, snails and lithics were acquired from more distant regions and their provenance provides valuable information on the period's trade network.

It seems likely that the deposition of intact vessels in the grave had some meaning and significance in the funeral rite. If only fragments were placed beside the deceased, it might be taken to indicate that a particular vessel type played no role in the funerary rite or, conversely, that its absence was a reflection of attitudes toward the funeral itself or the persona of the deceased. Seeing that intact vessels and pottery fragments have both been recovered from the burials (from inhumation and cremation graves alike), it seems unlikely that the presence of fragments was accidental and they have therefore been included among the grave goods.

The gifts presented to the deceased, the deposition of the food and drink necessary for the journey to the otherworld, the burial of the deceased's costume, weapons, tools and implements, and of all the other attributes associated with the deceased were meant to ensure a comfortable life in the otherworld and peace for the living.

The grave goods from burials are often used as a basis for the reconstruction of the deceased's social status and

\footnotetext{
The various raw materials and fossil shells were probably acquired on one occasion and stored someplace. It is quite unlikely that a few members of the Budakalász community would have set off to collect these items each time a member of the community passed away.
}

the community's social organisation. This analytical procedure can only yield meaningful results if the graves in question are broadly contemporaneous and if the sample represented by the burials is sufficiently large for a statistical evaluation. I have been cautious in drawing far-reaching conclusions from the statistical analyses and have concentrated on identifying elements and patterns, which can be clearly established from the grouping of the graves according to various criteria.

The next important phase of the funeral rite was the interment of the deceased in the grave. In the case of inhumation burials, this meant the digging of the grave pit and its preparation (e.g. surrounding or lining the pit with stones, the ritual firing of the grave pit), after which interment took place. The grave pits were generally large enough to accommodate the deceased. The deceased were always deposited with great care (disregarding now the changes in the body's position owing to post-depositional processes). The grave pits were not too deep and it was thus possible to arrange the hands and feet in the desired position, to orient the head toward the preferred direction and to arrange the grave goods (if any were accorded) after the body had been lowered into the grave pit. The grave was then filled with earth and/or stones and its location was marked.

It would appear that in the case of certain individuals the head had to be crushed or covered with stones. The most obvious example of this practice comes from Grave 438, which contained a large amount of stones. A rectangular stone with a jagged point lay on the skull, which was smashed by the stone's point. This element of the rite reflects a rather cruel ceremony, which may have been motivated by fear of the deceased and the prevention of the deceased's return by any means.

There is no numerical data on the number of stones deposited in or on the graves. Soproni did not record the number or the weight of the stones found in the graves. The excavation photos reveal that most stones were fairly small and round, and they do not appear to have been too heavy. If the skull was smashed, it could hardly have been crushed by the stones, but was the result of drastic action during the funeral rite involving the pelting of the body in the grave with stones. ${ }^{2}$

In the case of cremation burials, the ashes had to be collected and taken to the grave from the pyre erected beyond the area of the cemetery. This was probably the most solemn phase of this funerary rite. It seems that a rather shallow pit was dug for the ashes and that they were covered with a vessel made from organic material in order to protect the remains from wind and rain. ${ }^{3}$

\footnotetext{
${ }^{2}$ Nándor Kalicz, who read and commented on the draught version of this chapter, does not agree with this interpretation. In his view, the bones could have been broken by the earth thrown in the grave pit when the grave was backfilled, or they could have been crushed by the weight of the stones placed on them.

3 It seems likely that the ashes covered with a wooden or woven basket could survive the centuries in one heap because the vessel covering them provided protection and cohesion during the chemical processes in the soil and prevented the ashes from being blown away or washed away by rain.
} 


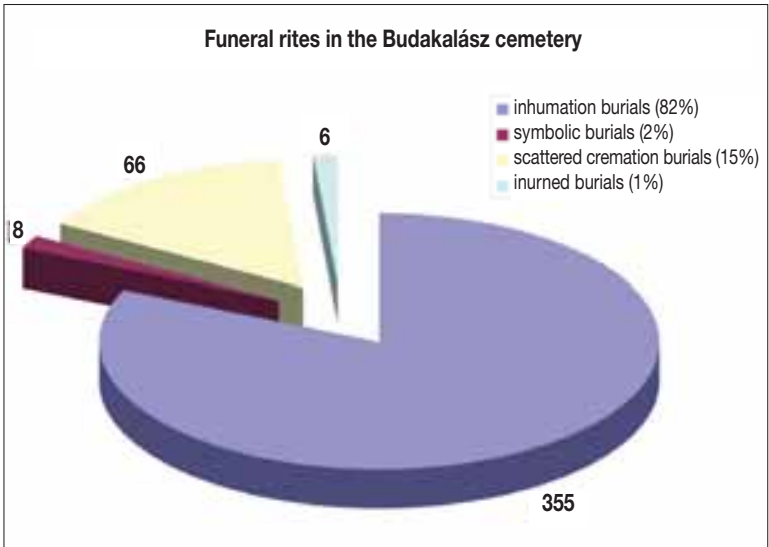

Fig. 10. Funeral rites in the Budakalász cemetery

Various offerings (pots, ornaments, implements) were also deposited in some of the cremation burials.

The departure from the grave and various postinterment actions made up the concluding phase of the funeral rite. Little is known about these and of whether the covering of the burial with stones was part of the funeral proper attended by the community or whether this was performed by a few persons actually completing the burial. It seems likely that this was part of the funeral rite because in many cases the deceased was pelted with stones, which were sometimes thrown with such force as to smash the skull.

The disturbance of the grave too can be regarded as a post-interment event. The identification of Late Copper Age disturbances are important in this respect, even though the reasons for the disturbance remain unknown. Grave robbing as a potential motivation can be excluded in view of the rather poor grave goods. It would appear that the graves disturbed during the Late Copper Age had either not been marked or that the grave marker had perished by the time of the later burial.

The distribution of graves according to burial rite is shown in Fig. 10.

\section{INHUMATION BURIALS}

Of the 436 burials uncovered in the Budakalász cemetery, 355 were inhumation graves containing one or more burials (including the skull burials). 312 graves contained a single burial, 33 graves contained two burials and 4 graves contained three burials. Six single burials and one double burial can be classified as skull burials. Grave 155 contained one inhumation and one scattered cremation burial. ${ }^{4}$

The distribution of the inhumation graves is as follows (Fig. 11. and Fig. 12):

\footnotetext{
4 This grave was only considered once in the statistical calculations. It was not inlcuded among the inhumation burials, but was taken into consideration when calculating the number of interred individuals.
}

(1) Single inhumation graves with grave goods: Graves 1-2, 6-10, 12, 14, 16, 18-19, 21-25, 28, 30, 33, 35-44, 46, 49-51, 53, 58-61, 63-65, 67-68, 70, 72-75, $82,84,87-88,90-91,94-96,98,104,111-112,114-118$, $124,127-129,132,135-137,139-140,143-146,148$, $156,158,163-164,170-172,174-175,179-180,183$, 185, 189, 194, 196-197, 202-203, 206-210, 216, 218, 220-221, 223, 226-227, 229-230, 232, 237, 244-245, $252-253,257,261,265,267,277,279,284,286-287$, 289, 291, 294-295, 301, 303, 306, 309-310, 312, 317, $319,322,324-325,329-330,335,338,344-345,347$, $350,352-355,359-361,363-364,367-368,370-371$, 375-378, 380-384, 394, 403, 408, 411-413, 416, 419-422, 427, 437, 439 (188 graves in all).

(2) Single inhumation graves without grave goods: Graves 4-5, 11, 15, 17, 20, 27, 29, 32, 34, 40, 45, 52, 54, 57, 62, 69 (destroyed burial), 76-77, 81, 83, 85-86, 89, 92-93, 97, 99, 102, 105, 107, 109-110, 119, 121-122, 125, 133 (destroyed burial), 141, 147, 150-152, 154, 157, 161-162, 165-166, 173, 176, 184, 186-188, 192, 198-201, 204, 212-214, 217, 225, 228, 231, 256, 264, 270-272, 278, 281, 283, 285, 288, 292-293, 297, 299-300, 302, 305, 308, 316, 318, 320, 321 (destroyed burial), 326, 332, 336-337, 342, 346, 348, 351, $357-358,362,365,369,372-374,379,385,393,397$, 400-402, 404, 407, 409-410, 415, 417-418, 424, 426, 428,438 (124 graves in all).

(3) Double inhumation graves: Graves 3, 13, 48, 55-56, 66, 71, 78-80, 100-101, 106, 108, 113, 123, 126, $134,142,149,153,167,169,195,263,290,334,366$, 388-389, 396, 399, 405 (66 burials in 33 graves, and Grave 155, containing one inhumation and one cremation burial, i.e. 67 burials in all).

(3a) Double inhumation graves with both burials containing grave goods: Graves 3, 66, 71, 80, 100, 113, 263, 366.

(3b) Double inhumation graves with one burial containing grave goods: Graves 13/A, 48/A, 55/A, 56/B, 78/B, 101/A, 106/A, 108/B, 123/A, 134/A, 142/B, 149/B, 195/B, 290/B, 399/A, 405/B; in the case of Graves 334 and 388, the grave goods lay among the stones and it is therefore unclear to which burial they had belonged.

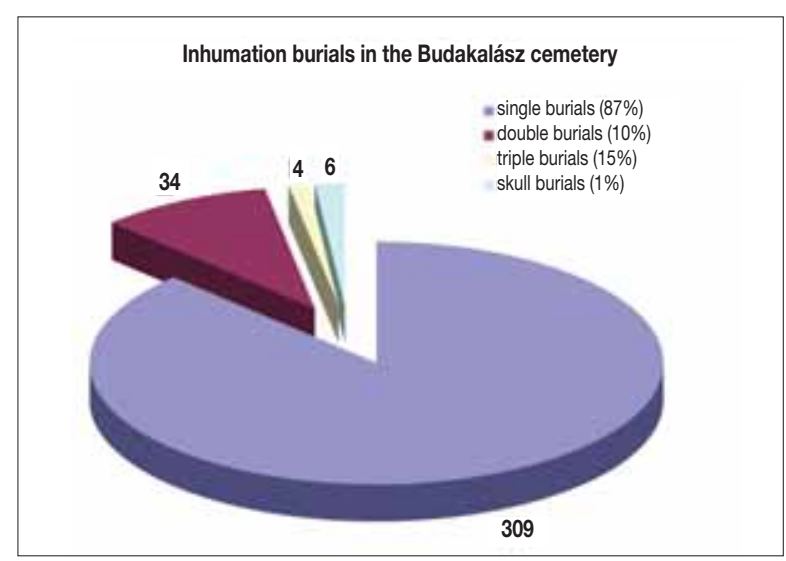

Fig. 11. Inhumation burials in the Budakalász cemetery 
(3c) Double inhumation burials without any grave goods in either burial: Graves 79, 126, 153, 167, 169, 389, 396.

(4) Triple inhumation burials: Graves 47, 182, 215, 391. Only one of the burials in these graves contained grave goods (Grave 47/B, Grave 182/B, Grave 215/B, Grave 391/B), the other two lacked any offerings.

(5) Skull burials: Graves 191, 255, 266, 395, 406, 425 (single burials) and Grave 290/A (double burial).

\section{SINGLE INHUMATION BURIALS WITH GRAVE GOODS}

Grave goods were deposited in 188 of the single burials among the 355 inhumation graves uncovered at Budakalász, accounting for over one-half of the inhumation burials (53 per cent).

\section{Preparation for the funeral}

The selection of the grave location is one of the most easily identifiable events in the case of inhumation burials containing grave goods. A glance at the cemetery map reveals that inhumation and cremation burials usually lie close to each other and that existing graves were rarely disturbed or destroyed by new burials. This would suggest that the graves were marked at the end of the funeral.
Selection of the grave location

Inhumation burials with grave goods (and ones without any grave goods) can be found over the entire territory of the burial ground in looser or denser scatters. No particular clusters of inhumation graves can be made out on the cemetery map and any grouping would be highly arbitrary.

It was observed during the excavations that some graves were dug over earlier ones, meaning that at the time the grave location was selected, the place of the earlier burial was no longer visible. Grave 34 lay over Grave 36, Grave 44 over Grave 40, Grave 51 over Grave 50, Grave 98 over Grave 97, Grave 139 over Grave 143, and Grave 362 over Grave 363.

\section{Orientation}

Table 1 shows the orientation of the burials, together with the data on age, sex and placement on the right or left side. Most frequent was an orientation toward the south. The head was placed toward the south or with a slight deviation to the south-east or south-west in the case of 126 burials (accounting for 67 per cent of the burials). In the case of eleven graves (6 per cent), the head was placed toward the north or with a slight deviation to the north-east or north-west. Twenty burials (11 per cent) were aligned west to east with a few minor deviations, while twenty-five burials (13 per cent) were oriented east to west. The orientation of six burials ( 3 per cent) could not determined.

Table 1. Inbumation graves containing a single burial with grave goods: orientation, deposition, sex and age at death of the deceased*

\begin{tabular}{|c|c|c|c|c|}
\hline Grave & Deposition & Age at death & Sex & Orientation \\
\hline 1 & right side & $23-30$ years & male (?) & $W$ to E, with the head to the $W$ \\
\hline 2 & left side & $23-30$ years & female & SE to NW, with the head to the SE \\
\hline 6 & right side & $23-\mathrm{x}$ years & female (?) & $\mathrm{S}$ to $\mathrm{N}$, with the head to the $\mathrm{S}$ \\
\hline 7 & right side & $13-15$ years & child & SW to NE, with the head to the SW \\
\hline 8 & right side & $40-59$ years & male & SW to NE, with the head to the SW \\
\hline 9 & right side & $35-45$ years & male & SE to NW, with the head to the SE \\
\hline 10 & right side & $7-8$ years & child & $\mathrm{S}$ to $\mathrm{N}$, with the head to the $\mathrm{S}$ \\
\hline 12 & right side & $(25-30$ years $)$ & (female?) & E to $W$, with the head to the $W$ \\
\hline 14 & left side & $23-39$ years & male (?) & S-SW to N-NE, with the head to the S-SW \\
\hline 16 & left side & $40-59$ years & female & SW to NE, with the head to the SW \\
\hline 18 & right side & $23-39$ years & male (?) & S-SW to N-NE, with the head to the S-SW \\
\hline 19 & right side & $23-59$ years & male & S-SE to N-NW, with the head to the S-SE \\
\hline 21 & left side & (child) & (child) & W-SW to E-NE, with the head to the W-SW \\
\hline 22 & left side & 19-21 years & female (?) & W-SW to E-NE, with the head to the E-NE \\
\hline 23 & left side & $18-23$ years & female & NW-SE, with the head to the NW \\
\hline 24 & right side & $25-35$ years & female & SW to NE, with the head to the SW \\
\hline 25 & left side & $23-40$ years & female & NW-SE, with the head to the NW \\
\hline 28 & right side & $40-50$ years & female & W-SW to E-NE, with the head to the W-SW \\
\hline 30 & right side & 6-7 years & child & S-SE to N-NW, with the head to the S-SE \\
\hline 33 & right side & $40-50$ years & male & SE to NW, with the head to the SE \\
\hline 35 & right side & $7-14$ years & child & S-SE to N-NW, with the head to the S-SE \\
\hline 36 & left side & $40-50$ years & female & $\mathrm{W}-\mathrm{NW}$ to E-SE, with the head to the W-NW \\
\hline 37 & left side & $23-40$ years & male (?) & SW to NE, with the head to the SW \\
\hline
\end{tabular}

* The data in parentheses indicate the age/sex determinations quoted from the excavation diary 
Table 1 (cont'd)

\begin{tabular}{|c|c|c|c|c|}
\hline Grave & Deposition & Age at death & Sex & Orientation \\
\hline 38 & right side & $40-x$ years & female & S-SE to N-NW, with the head to the S-SE \\
\hline 39 & $\begin{array}{l}\text { extended } \\
\text { on the back }\end{array}$ & $35-45$ years & male & $\mathrm{N}-\mathrm{NW}$ to $\mathrm{S}-\mathrm{SE}$, with the head toward the $\mathrm{N}-\mathrm{NW}$ \\
\hline 41 & left side & (child) & (child) & S-SW to N-NE, with the head to the S-SW \\
\hline 42 & left side & (child) & (child) & SE to NW, with the head to the SE \\
\hline 43 & left side & $40-59$ years & male & E-NE to W-SW, with the head E-NE \\
\hline 44 & left side & $23-\mathrm{x}$ years & female (?) & SW to NE, with the head to the SW \\
\hline 46 & left side & $20-30$ years & female & S-SE to N-NW, with the head to the S-SE \\
\hline 49 & right side & (30-35 years) & (female) & S-SE to N-NW, with the head to the S-SE \\
\hline 50 & left side & (juvenis) & $(?)$ & E-SE to $W-N W$, with the head to the E-SE \\
\hline 51 & left side & $30-40$ years & female & S-SW to N-NE, with the head to the S-SW \\
\hline 53 & right side & $1-14$ years & child & SE to NW, with the head to the SE \\
\hline 58 & right side & $40-59$ years & female & $\mathrm{S}$ to $\mathrm{N}$, with the head to the $\mathrm{S}$ \\
\hline 59 & - & $(-)$ & $(-)$ & - \\
\hline 60 & left side & $13-14$ years & child & SE to NW, with the head to the SE \\
\hline 61 & left side & $6-8$ years & child & S-SW to N-NE, with the head to the S-SW \\
\hline 63 & left side & $13-15$ years & child & S-SW to N-NE, with the head to the S-SW \\
\hline 64 & left side & $40-59$ years & male & $\mathrm{E}-\mathrm{W}$, with the head to the $\mathrm{E}$ \\
\hline 65 & left side & $40-x$ years & female & S-SE to W-NW, with the head to the SE \\
\hline 67 & left side & $40-50$ years & male & $\mathrm{W}$ to $\mathrm{E}$, with the head to the $\mathrm{W}$ \\
\hline 68 & - & $1-7$ years & child & SE to NW, with the head to the SE \\
\hline 70 & - & $40-59$ years & female (?) & - \\
\hline 72 & - & (child) & (child) & SE to NW, with the head to the SE \\
\hline 73 & left side & $45-55$ years & female & E-W, with the head to the $\mathrm{E}$ \\
\hline 74 & right side & $14-16$ years & juvenis & $W$ to $E$, with the head to the $W$ \\
\hline 75 & left side & $10-12$ years & child & S-SW to N-NE, with the head to the S-SW \\
\hline 82 & right side & $9-11$ years & child & S-SE to N-NW, with the head to the S-SE \\
\hline 84 & right side & $6-7$ years & child & $\mathrm{S}$ to $\mathrm{N}$, with the head to the $\mathrm{S}$ \\
\hline 87 & left side & (child) & (child) & $\mathrm{N}$ to $\mathrm{S}$, with the head to the $\mathrm{S}$ \\
\hline 88 & left side & $5-6$ years & child & W to E, with the head to the west \\
\hline 90 & left side & (child) & (child) & SE to NW, with the head to the SE \\
\hline 91 & right side & $45-55$ years & male (?) & SE to NW, with the head to the SE \\
\hline 94 & left side & $20-23$ years & male & E-SE to $W-N W$, with the head to the E-SE \\
\hline 95 & left side & $35-40$ years & female & $\mathrm{S}$ to $\mathrm{N}$, with the head to the $\mathrm{S}$ \\
\hline 96 & left side & $3-4$ years & child & $\mathrm{S}$ to $\mathrm{N}$, with the head to the $\mathrm{S}$ \\
\hline 98 & right side & (child) & (child) & $\mathrm{S}$ to $\mathrm{N}$, with the head to the $\mathrm{S}$ \\
\hline 104 & left side & $30-40$ years & female & $\mathrm{S}$ to $\mathrm{N}$, with the head to the $\mathrm{S}$ \\
\hline 111 & left side & ca. 6 months & child & $\mathrm{S}$ to $\mathrm{N}$, with the head to the $\mathrm{S}$ \\
\hline 112 & left side & $30-40$ years & male & $\mathrm{N}$ to $\mathrm{S}$, with the head to the $\mathrm{S}$ \\
\hline 114 & right side & $0.5-1$ years & infant & $\mathrm{S}$ to $\mathrm{N}$, with the head to the $\mathrm{S}$ \\
\hline 115 & right side & $30-40$ years & female & E-SE to $W-N W$, with the head to the E-SE \\
\hline 116 & right side & $40-50$ years & female & NE to SW, with the head to the NE \\
\hline 117 & right side & $30-40$ years & male (?) & NE to SW, with the head to the NE \\
\hline 118 & right side & $35-45$ years & female & $\mathrm{S}$ to $\mathrm{N}$, with the head to the $\mathrm{S}$ \\
\hline 124 & right side & $40-\mathrm{x}$ years & male & E-SE to $W-N W$, with the head to the E-SE \\
\hline 127 & right side & $23-30$ years & female & S to $\mathrm{N}$, with the head to the $\mathrm{S}$ \\
\hline 128 & left side & $12-13$ years & child & $\mathrm{S}$ to $\mathrm{N}$, with the head to the $\mathrm{S}$ \\
\hline 129 & left side & $7-14$ years & child & SE to NW, with the head to the SE \\
\hline 132 & left side & $23-30$ years & male & $\mathrm{S}$ to $\mathrm{N}$, with the head to the $\mathrm{S}$ \\
\hline 135 & left side & $15-23$ years & $?$ & S-SW to N-NE, with the head to the S-SW \\
\hline 136 & right side & $23-30$ years & female (?) & S-SW to N-NE, with the head to the S-SW \\
\hline 137 & left side & $14-16$ years & $?$ & $\mathrm{~S}$ to $\mathrm{N}$, with the head to the $\mathrm{S}$ \\
\hline 139 & right side & $7-8$ years & child & S-SE to N-NW, with the head to the S-SE \\
\hline 140 & right side & $12-14$ years & child & S-SE to N-NW, with the head to the S-SE \\
\hline 143 & right side & $30-40$ years & female & $\mathrm{N}-\mathrm{NW}$ to $\mathrm{S}-\mathrm{SE}$, with the head to the N-NW \\
\hline 144 & - & (infant) & (infant) & - \\
\hline 145 & right side & $3-4$ years & child & E-NE to $W-S W$, with the head to the E-NE \\
\hline
\end{tabular}


Table 1 (cont'd)

\begin{tabular}{|c|c|c|c|c|}
\hline Grave & Deposition & Age at death & Sex & Orientation \\
\hline 146 & right side & $40-50$ years & female & $\mathrm{N}-\mathrm{NE}$ to $\mathrm{S}-\mathrm{SW}$, with the head to the $\mathrm{N}-\mathrm{NE}$ \\
\hline 148 & right side & $1-7$ years & child & SW to NE, with the head to the SW \\
\hline 156 & right side & $7-8$ years & child & $\mathrm{W}$ to $\mathrm{E}$, with the head to the west \\
\hline 158 & right side & $40-\mathrm{x}$ year & female (?) & $\mathrm{W}-\mathrm{SW}$ to E-NE, with the head to the $\mathrm{W}-\mathrm{SW}$ \\
\hline 163 & right side & $35-45$ years & female & $\mathrm{S}$ to $\mathrm{N}$, with the head to the $\mathrm{S}$ \\
\hline 164 & right side & $23-30$ years & male & $W$ to E, with the head to the west \\
\hline 170 & right side & $30-40$ years & male (?) & S-SE to N-NW, with the head to the S-SE \\
\hline 171 & left side & $40-x$ years & male (?) & SW to NE, with the head to the SW \\
\hline 172 & right side & $0-1$ years & child & $\mathrm{S}$ to $\mathrm{N}$, with the head to the $\mathrm{S}$ \\
\hline 174 & left side & $14-16$ years & female & E-SE to $W-N W$, with the head to the E-SE \\
\hline 175 & left side & $13-15$ years & child & E-NE to W-SW, with the head to the E-NE \\
\hline 179 & - & $12-14$ years & child & $\mathrm{S}$ to $\mathrm{N}$, with the head to the $\mathrm{S}$ \\
\hline 180 & left side & $16-18$ years & female & S-SW to E-NE with the head to the S-SW \\
\hline 183 & left side & $30-40$ years & female & S-SW to N-NE, with the head to the S-SW \\
\hline 185 & left side & $35-45$ years & male & $\mathrm{S}$ to $\mathrm{N}$, with the head to the $\mathrm{S}$ \\
\hline 189 & left side & $30-40$ years & female & S-SW to N-NE, with the head to the S-SW \\
\hline 194 & left side & $30-40$ years & male (?) & SE to NW, with the head to the SE \\
\hline 196 & right side & $35-45$ years & male & S-SE to N-NW, with the head to the S-SE \\
\hline 197 & right side & $35-45$ years & female & SW to NE, with the head to the SW \\
\hline 202 & left side & $11-13$ years & child & S-SE to N-NW, with the head to the S-SE \\
\hline 203 & right side & $45-55$ years & male & S-SE to N-NW, with the head to the S-SE \\
\hline 206 & - & $1-7$ years & child & - \\
\hline 207 & left side & $30-40$ years & male & E-SE to W-NW, with the head to the E-SE \\
\hline 208 & left side & $23-30$ years & female & W-SW to N-NE, with the ehad to the $\mathrm{W}-\mathrm{NW}$ \\
\hline 209 & right side & $45-55$ years & female & S-SE to N-NW, with the head to the S-SE \\
\hline 210 & left side & $30-35$ years & female & S-SE to N-NW, with the head to the S-SE \\
\hline 216 & left side & $23-30$ years & female & S-SE to N-NW, with the head to the S-SE \\
\hline 218 & left side & $50-59$ years & female & SE to NW, with the head to the SE \\
\hline 220 & right side & $23-\mathrm{x}$ years & male (?) & $\mathrm{S}$ to $\mathrm{N}$, with the head to the $\mathrm{S}$ \\
\hline 221 & right side & $2-2.5$ years & child & S-SE to N-NW, with the head to the S-SE \\
\hline 223 & right side & $(?)$ & (female) & E-SE to $W-N W$, with the head to the E-SE \\
\hline 226 & left side & $2.5-3$ years & child & SW to NE, with the head to the SW \\
\hline 227 & right side & $35-45$ years & male & S-SW to N-NE, with the head to the S-SW \\
\hline 229 & left side & $3-4$ years & child & S-SW to N-NE, with the head to the S-SW \\
\hline 230 & right side & $40-\mathrm{x}$ years & male & S-SW to N-NE, with the head to the S-SW \\
\hline 232 & right side & $1-7$ years & child & $\mathrm{S}$ to $\mathrm{N}$, with the head to the $\mathrm{S}$ \\
\hline 237 & left side & $6-8$ years & child & S-SW to N-NE, with the head to the S-SW \\
\hline 244 & - & $1-7$ years & child & with the head toward the SW \\
\hline 245 & left side & $5-7$ years & child & S-SE to N-NW, with the head to the S-SE \\
\hline 252 & left side & $2.5-3.5$ years & child & SE to NW, with the head to the SE \\
\hline 253 & left side & $8-9$ years & child & S-SE to N-NW, with the head to the S-SE \\
\hline 257 & - & $(-)$ & $(-)$ & - \\
\hline 261 & left side & $40-x$ years & male & S-SE to N-NW, with the head to the S-SE \\
\hline 265 & right side & $4-4.5$ years & child & $\mathrm{S}$ to $\mathrm{N}$, with the head to the $\mathrm{S}$ \\
\hline 267 & - & $0-5$ years & child & $\mathrm{S}$ to $\mathrm{N}$, with the head to the $\mathrm{S}$ \\
\hline 277 & right side & $30-35$ years & male (?) & S-SE to N-NW, with the head to the S-SE \\
\hline 279 & left side & $30-50$ years & male & $\mathrm{S}$ to $\mathrm{N}$, with the head to the $\mathrm{S}$ \\
\hline 284 & left side & $30-40$ years & female & SE to NW, with the head to the SE \\
\hline 286 & left side & $1.5-2$ years & child & $\mathrm{S}$ to $\mathrm{N}$, with the head to the $\mathrm{S}$ \\
\hline 287 & extended & $23-30$ years & female (?) & $\mathrm{S}$ to $\mathrm{N}$, with the head to the $\mathrm{S}$ \\
\hline 289 & right side & $23-30$ years & female & W-SW to E-NE, with the head to the W-SW \\
\hline 291 & right side & $1-7$ years & child & SE to NW, with the head to the SE \\
\hline 294 & right side & $25-35$ years & male (?) & SW to NE, with the head to the SW \\
\hline 295 & left side & $40-\mathrm{x}$ years & female & $\mathrm{S}$ to $\mathrm{N}$, with the head to the $\mathrm{S}$ \\
\hline 301 & right side & $0-0.5$ years & child & SE to NW, with the head to the SE \\
\hline 303 & left side & $17-20$ years & female & $\mathrm{S}$ to $\mathrm{N}$, with the head to the $\mathrm{S}$ \\
\hline 306 & left side & $0-1$ years & child & E-SE to $\mathrm{W}-\mathrm{NW}$, with the head to the E-SE \\
\hline
\end{tabular}


Table 1 (cont'd)

\begin{tabular}{|c|c|c|c|c|}
\hline Grave & Deposition & Age at death & Sex & Orientation \\
\hline 309 & left side & $35-45$ years & female & S-SW to N-NE, with the head to the S-SW \\
\hline 310 & right side & $40-59$ years & female & $\mathrm{W}-\mathrm{NW}$ to E-SE, with the head to the $\mathrm{W}-\mathrm{NW}$ \\
\hline 312 & left side & $1-7$ years & child & S-SE to N-NW, with the head to the S-SE \\
\hline 317 & right side & $8-9$ years & child & E-SE to $W-N W$, with the head to the E-SE \\
\hline 319 & left side & $40-50$ years & male & $\mathrm{E}-\mathrm{W}$, with the head to the $\mathrm{E}$ \\
\hline 322 & right side & $10-11$ years & child & SE to NW, with the head to the SE \\
\hline 324 & left side & $30-40$ years & female & SE to NW, with the head to the SE \\
\hline 325 & right side & $30-40$ years & male & $\mathrm{W}-\mathrm{NW}$ to E-SE, with the head to the $\mathrm{W}-\mathrm{NW}$ \\
\hline 329 & right side & $40-x$ years & female & S-SE to N-NW, with the head to the S-SE \\
\hline 330 & left side & $23-25$ years & female & S-SE to N-NW, with the head to the S-SE \\
\hline 335 & right side & $30-40$ years & female (?) & S-SE to N-NW, with the head to the S-SE \\
\hline 338 & right side & $c a .1$ year & child & S-SE to N-NW, with the head to the S-SE \\
\hline 344 & right side & $30-50$ years & female & E-SE to $W-N W$, with the head to the E-SE \\
\hline 345 & right side (?) & (child) & (child) & S-SE to N-NW, with the head to the S-SE \\
\hline 347 & right side & $30-40$ years & female & NW-SE, with the head to the NW \\
\hline 350 & right side & $23-39$ years & female & $\mathrm{S}$ to $\mathrm{N}$, with the head to the $\mathrm{S}$ \\
\hline 352 & left side & 4-6 years & child & W to E, with the head to the west \\
\hline 353 & left side & $25-35$ years & male (?) & SE to NW, with the head to the SE \\
\hline 354 & right side & $23-30$ years & female & SW to NE, with the head to the SW \\
\hline 355 & left side & $23-30$ years & male & S-SW to N-NE, with the head to the S-SW \\
\hline 359 & left side & $25-35$ years & female & $\mathrm{S}$ to $\mathrm{N}$, with the head to the $\mathrm{S}$ \\
\hline 360 & left side & $10-12$ years & child & S-SW to N-NE, with the head to the S-SW \\
\hline 361 & left side & $11-12$ years & child & SE to NW, with the head to the SE \\
\hline 363 & left side & $12-14$ years & child & S-SW to N-NE, with the head to the S-SW \\
\hline 364 & right side & $0-1$ years & child & SE to NW, with the head to the SE \\
\hline 367 & left side & $40-50$ years & female & SE to NW, with the head to the SE \\
\hline 368 & right side & $6-7$ years & child & $\mathrm{W}$ to $\mathrm{E}$, with the head to the west \\
\hline 370 & left side & $30-40$ years & female & S-SE to N-NW, with the head to the S-SE \\
\hline 371 & right side & 4-6 years & child & S-SW to N-NE, with the head to the S-SW \\
\hline 375 & left side & $30-40$ years & male & $\mathrm{S}$ to $\mathrm{N}$, with the head to the $\mathrm{S}$ \\
\hline 376 & right side & $0-1$ years & child & $\mathrm{W}-\mathrm{SW}$ to E-NE, with the head to the $\mathrm{W}-\mathrm{SW}$ \\
\hline 377 & right side & $7-8$ years & child & SW to NE, with the head to the SW \\
\hline 378 & right side & $10-11$ years & child & SE to NW, with the head to the SE \\
\hline 380 & left side & $1-7$ years & child & $\mathrm{S}$ to $\mathrm{N}$, with the head to the $\mathrm{S}$ \\
\hline 381 & left side & $21-23$ years & female & $\mathrm{S}$ to $\mathrm{N}$, with the head to the $\mathrm{S}$ \\
\hline 382 & right side & $30-40$ years & female & E-NE to W-SW, with the head to the E-NE \\
\hline 383 & left side & $10-12$ years & child & SW to NE, with the head to the SW \\
\hline 384 & left side & $23-39$ years & female (?) & W to E, with the head to the west \\
\hline 394 & extended & $0.5-1$ years & child & - \\
\hline 403 & left side & $40-\mathrm{x}$ years & female & E-SE to $W-N W$, with the head to the E-SE \\
\hline 408 & left side & $8-9$ years & child & E-NE to W-SW, with the head to the E-NE \\
\hline 411 & right side & $40-50$ years & male & W-SW to E-NE, with the head to the W-SW \\
\hline 412 & right side & $35-45$ years & male & E-W, with the head to the E \\
\hline 413 & - & $1-7$ years & child & - \\
\hline 416 & left side & $21-23$ years & female & E-SE to $W-N W$, with the head to the E-SE \\
\hline 419 & left side & $15-16$ years & female & $\mathrm{S}$ to $\mathrm{N}$, with the head to the $\mathrm{S}$ \\
\hline 420 & left side & $50-\mathrm{x}$ years & male & S-SW to N-NE, with the head to the S-SW \\
\hline 421 & right side & $2-3$ years & child & $\mathrm{N}-\mathrm{NE}$ to $\mathrm{S}-\mathrm{SW}$, with the head to the N-NE \\
\hline 422 & right side & 19-21 years & male & SE to NW, with the head to the SE \\
\hline 427 & left side & $9-10$ years & child & E-SE to $W-N W$, with the head to the E-SE \\
\hline 437 & left side & $10-12$ years & child & $\mathrm{E}-\mathrm{W}$, with the head to the $\mathrm{E}$ \\
\hline 439 & right side & $35-45$ years & female & SE to NW, with the head to the SE \\
\hline
\end{tabular}


There was no apparent correlation between orientation/placement and age/sex. In contrast to earlier periods, the funeral rite did not call for a strictly observed placement on one particular side or orientation linked to age and/or sex.

\section{Digging of the grave pit}

The grave pit was probably dug after the occurrence of death, shortly before the funeral. The deceased was carefully placed in the grave.

The dimensions of the grave pits recorded during the excavation must be treated with caution since we know that Soproni measured the depth from the modern, ploughed-up surface in the sand-pit. Very often, the patch of discoloured earth marking the burial could not be observed and the location and size of the grave pit could only be recorded after the skeletal remains had been found. The dimensions recorded in the excavation diary thus do not correspond to the onetime (Copper Age) dimensions, but indicate what remained of the grave pit after soil erosion and farming activities, and they can thus only be regarded as approximate sizes.

Table 2 shows the depth, length, width and form variations of the grave pits.

Table 2. Inhumation graves containing a single burial with grave goods: size and form of the grave pits

\begin{tabular}{|c|c|c|c|c|}
\hline Grave & $\begin{array}{l}\text { Depth } \\
\text { (cm) }\end{array}$ & $\begin{array}{l}\text { Length } \\
\text { (cm) }\end{array}$ & $\begin{array}{l}\text { Width } \\
\text { (cm) }\end{array}$ & Form \\
\hline 1 & 90 & 125 & 100 & oblong grave pit with rounded corners \\
\hline 2 & 95 & 110 & 130 & oblong grave pit with rounded corners \\
\hline 6 & 55 & 120 & 65 & narrow, oblong grave pit with rounded corners \\
\hline 7 & 70 & 105 & 60 & oblong grave pit with rounded corners \\
\hline 8 & 85 & 165 & 140 & grave pit with rounded corners \\
\hline 9 & 150 & 105 & 60 & narrow grave pit with rounded corners \\
\hline 10 & 100 & 105 & 55 & oval grave pit with rounded corners \\
\hline 12 & 90 & 105 & 100 & oval grave pit with rounded corners \\
\hline 14 & 25 & 140 & 90 & oval grave pit \\
\hline 16 & $25-30$ & 130 & 90 & oval grave pit \\
\hline 18 & 30 & 140 & 90 & oval grave pit \\
\hline 19 & 100 & 130 & 90 & oval, narrow grave pit \\
\hline 21 & 120 & 65 & 50 & oval grave pit \\
\hline 22 & 110 & 125 & 115 & roughly round grave pit \\
\hline 23 & 90 & 90 & 60 & oblong grave pit with rounded corners \\
\hline 24 & 95 & 130 & 90 & grave pit with rounded corners \\
\hline 25 & 90 & 115 & 90 & oval grave pit \\
\hline 28 & 95 & 135 & 95 & oval grave pit \\
\hline 30 & 90 & 80 & 70 & round grave pit \\
\hline 33 & 130 & 155 & 80 & grave pit with rounded corners \\
\hline 35 & 105 & 75 & 50 & oval grave pit \\
\hline 36 & 105 & 135 & 112 & grave pit with rounded corners \\
\hline 37 & 40 & - & - & no indication of a grave pit \\
\hline 38 & 105 & 105 & 85 & oval grave pit \\
\hline 39 & 65 & 180 & 55 & oblong grave pit with rounded corners \\
\hline 41 & 110 & 95 & 57 & oval grave pit \\
\hline 42 & 90 & 80 & 45 & grave pit with rounded corners \\
\hline 43 & 95 & 162 & 110 & grave pit with rounded corners \\
\hline 44 & 115 & 100 & 60 & $\begin{array}{l}\text { oval grave pit } \\
\end{array}$ \\
\hline 46 & 90 & 120 & 85 & oval grave pit \\
\hline 49 & 110 & 100 & 70 & oval grave pit \\
\hline 50 & 55 & - & - & no indication of a grave pit \\
\hline 51 & 130 & 105 & 75 & oval grave pit \\
\hline 53 & 135 & 97 & 62 & grave pit with rounded corners \\
\hline 58 & 115 & 110 & 85 & grave pit with rounded corners \\
\hline 59 & 110 & - & - & - \\
\hline 60 & 85 & 95 & 60 & grave pit with rounded corners \\
\hline 61 & 110 & 115 & 85 & grave pit with rounded corners \\
\hline 63 & 85 & 100 & 90 & oval grave pit \\
\hline
\end{tabular}


Table 2 (cont'd)

\begin{tabular}{|c|c|c|c|c|}
\hline Grave & $\begin{array}{l}\text { Depth } \\
\text { (cm) }\end{array}$ & $\begin{array}{l}\text { Length } \\
\text { (cm) }\end{array}$ & $\begin{array}{l}\text { Width } \\
\text { (cm) }\end{array}$ & Form \\
\hline 64 & 75 & 100 & 85 & grave pit with rounded corners \\
\hline 65 & 80 & 110 & 80 & oval grave pit \\
\hline 67 & 110 & 135 & 105 & oblong grave pit with rounded corners \\
\hline 68 & 110 & 80 & 65 & oblong grave pit with rounded corners \\
\hline 70 & - & - & - & - \\
\hline 72 & 90 & 120 & 75 & grave pit with rounded corners \\
\hline 73 & 150 & 135 & 85 & oval grave pit \\
\hline 74 & 80 & 105 & 55 & oval grave pit \\
\hline 75 & 80 & 120 & 65 & oval grave pit \\
\hline 82 & 50 & 100 & 80 & round grave pit \\
\hline 84 & 85 & 85 & 70 & oval grave pit with rounded corners \\
\hline 87 & 70 & 60 & 50 & round grave pit \\
\hline 88 & 90 & 60 & 55 & round grave pit \\
\hline 90 & 90 & 70 & 60 & oval grave pit \\
\hline 91 & 105 & 180 & 110 & oval grave pit \\
\hline 94 & 100 & 130 & 90 & oval grave pit \\
\hline 95 & 110 & 115 & 85 & oval grave pit \\
\hline 96 & 110 & 85 & 60 & oval grave pit \\
\hline 98 & 85 & 95 & 60 & oval grave pit \\
\hline 104 & 140 & 150 & 100 & oval grave pit \\
\hline 111 & 100 & 55 & 35 & oval grave pit \\
\hline 112 & 105 & 150 & 85 & oval grave pit \\
\hline 114 & 105 & 95 & 80 & oval grave pit \\
\hline 115 & 105 & 135 & 90 & oval grave pit \\
\hline 116 & 155 & 105 & 65 & oval grave pit \\
\hline 117 & 75 & 125 & 88 & oval grave pit \\
\hline 118 & 115 & 110 & 75 & oval grave pit \\
\hline 124 & 95 & 115 & 98 & round grave pit \\
\hline 127 & 105 & 122 & 75 & oval grave pit \\
\hline 128 & 93 & 115 & 70 & oval grave pit \\
\hline 129 & 70 & 55 & 60 & oval grave pit \\
\hline 132 & 43 & 138 & 88 & oval grave pit \\
\hline 135 & 60 & 115 & 88 & oval grave pit \\
\hline 136 & 112 & 132 & 100 & oval grave pit \\
\hline 137 & 92 & 110 & 76 & oval, narrow grave pit \\
\hline 139 & 55 & 55 & 50 & round grave pit \\
\hline 140 & 50 & 115 & 70 & oval grave pit \\
\hline 143 & 132 & 115 & 112 & round grave pit \\
\hline 144 & 63 & 60 & 50 & round grave pit \\
\hline 145 & 85 & 93 & 75 & oval grave pit \\
\hline 146 & 80 & 137 & 104 & oval grave pit \\
\hline 148 & 95 & 75 & 60 & round grave pit \\
\hline 156 & 64 & 100 & 85 & oval grave pit \\
\hline 158 & 143 & 125 & 125 & round grave pit \\
\hline 163 & 88 & 135 & 125 & round grave pit \\
\hline 164 & 94 & 155 & 116 & oblong grave pit with rounded corners \\
\hline 170 & 76 & 125 & 97 & oval grave pit \\
\hline 171 & 75 & 120 & 110 & round grave pit \\
\hline 172 & 85 & 80 & 75 & round grave pit \\
\hline 174 & 94 & 162 & 130 & oval grave pit \\
\hline 175 & 97 & 102 & 90 & oval grave pit \\
\hline 179 & 50 & 60 & 40 & oval grave pit \\
\hline 180 & 76 & 130 & 110 & oval grave pit \\
\hline 183 & 104 & 118 & 100 & oval grave pit \\
\hline 185 & 95 & 120 & 70 & oval grave pit \\
\hline 189 & 117 & 125 & 100 & oval grave pit \\
\hline
\end{tabular}


Table 2 (cont'd)

\begin{tabular}{|c|c|c|c|c|}
\hline Grave & $\begin{array}{l}\text { Depth } \\
\text { (cm) }\end{array}$ & $\begin{array}{l}\text { Length } \\
\text { (cm) }\end{array}$ & $\begin{array}{l}\text { Width } \\
\text { (cm) }\end{array}$ & Form \\
\hline 194 & 88 & 140 & 116 & oval grave pit \\
\hline 196 & 107 & 122 & 115 & round grave pit \\
\hline 197 & 83 & 127 & 112 & oval grave pit \\
\hline 202 & 55 & 118 & 95 & oval grave pit \\
\hline 203 & 124 & 145 & 95 & oval grave pit \\
\hline 206 & 38 & - & - & no indication of a grave pit \\
\hline 207 & 85 & 135 & 122 & oval grave pit \\
\hline 208 & 91 & 98 & 68 & oval, narrow grave pit \\
\hline 209 & 98 & 108 & 80 & oval grave pit \\
\hline 210 & 52 & 117 & 103 & oblong grave pit with rounded corners \\
\hline 216 & 66 & 140 & 125 & oval grave pit \\
\hline 218 & 82 & 98 & 86 & round grave pit \\
\hline 220 & 50 & $?$ & $?$ & no indication of a grave pit \\
\hline 221 & 122 & 112 & 80 & oval grave pit \\
\hline 223 & 73 & 83 & 82 & round, narrow grave pit \\
\hline 226 & 72 & 118 & 99 & oval grave pit \\
\hline 227 & 80 & 110 & 100 & round grave pit \\
\hline 229 & 78 & 98 & 91 & oblong grave pit with rounded corners \\
\hline 230 & 56 & - & - & no indication of a grave pit \\
\hline 232 & 35 & - & - & no indication of a grave pit \\
\hline 237 & 70 & 110 & 95 & - \\
\hline 244 & 60 & 80 & 80 & round grave pit \\
\hline 245 & 102 & 73 & 86 & oval grave pit \\
\hline 252 & 102 & 65 & 46 & oval grave pit \\
\hline 253 & 92 & 67 & 75 & oval grave pit \\
\hline 257 & 60 & - & - & - \\
\hline 261 & 138 & 114 & 88 & oval grave pit \\
\hline 265 & 78 & 108 & 83 & oval grave pit \\
\hline 267 & 82 & 75 & 50 & oval grave pit \\
\hline 277 & 94 & 120 & 100 & oval grave pit \\
\hline 279 & 68 & 120 & 94 & oval grave pit \\
\hline 284 & 18 & 115 & 95 & oval grave pit \\
\hline 286 & 85 & 110 & 78 & oval grave pit \\
\hline 287 & 130 & 122 & 81 & oval grave pit \\
\hline 289 & 80 & 142 & 120 & oval grave pit \\
\hline 291 & 45 & 70 & 70 & round grave pit \\
\hline 294 & 65 & 135 & 90 & oval grave pit \\
\hline 295 & 102 & 102 & 86 & oval grave pit \\
\hline 301 & 80 & 77 & 77 & round grave pit \\
\hline 303 & 95 & 120 & 100 & oval grave pit \\
\hline 306 & 56 & 58 & 48 & oval grave pit \\
\hline 309 & 128 & 113 & 87 & oval grave pit \\
\hline 310 & 102 & 73 & 55 & oval grave pit \\
\hline 312 & 125 & 118 & 95 & oval grave pit \\
\hline 317 & 62 & 126 & 98 & oval grave pit \\
\hline 319 & 97 & 182 & 156 & oval grave pit \\
\hline 322 & 52 & 83 & 80 & round grave pit \\
\hline 324 & 78 & 131 & 108 & oval grave pit \\
\hline 325 & 103 & 160 & 137 & oval grave pit \\
\hline 329 & 90 & 115 & 87 & oval grave pit \\
\hline 330 & 120 & 165 & 120 & oval grave pit \\
\hline 335 & 115 & 140 & 85 & oval grave pit \\
\hline 338 & 77 & 115 & 82 & oval grave pit \\
\hline 344 & 77 & 132 & 94 & oval grave pit \\
\hline 345 & 82 & 117 & 88 & oval grave pit \\
\hline 347 & 110 & 135 & 90 & oval grave pit \\
\hline
\end{tabular}


Table 2 (cont'd)

\begin{tabular}{|c|c|c|c|c|}
\hline Grave & $\begin{array}{c}\text { Depth } \\
\text { (cm) }\end{array}$ & $\begin{array}{l}\text { Length } \\
\text { (cm) }\end{array}$ & $\begin{array}{c}\text { Width } \\
\text { (cm) }\end{array}$ & Form \\
\hline 350 & 104 & 152 & 117 & oval grave pit \\
\hline 352 & 84 & 117 & 88 & oval grave pit \\
\hline 353 & 74 & 132 & 102 & oval grave pit \\
\hline 354 & 78 & 158 & 128 & oval grave pit \\
\hline 355 & 97 & 126 & 102 & oval grave pit \\
\hline 359 & 102 & 109 & 95 & oval grave pit \\
\hline 360 & 123 & 140 & 98 & oval grave pit \\
\hline 361 & 85 & 112 & 94 & oval grave pit \\
\hline 363 & 82 & 93 & 81 & round grave pit \\
\hline 364 & 80 & 86 & 84 & round grave pit \\
\hline 367 & 58 & 132 & 104 & oval grave pit \\
\hline 368 & 25 & 106 & 83 & oval grave pit \\
\hline 370 & 38 & 115 & 97 & oval grave pit \\
\hline 371 & 45 & 81 & 71 & oval grave pit \\
\hline 375 & 20 & 131 & 102 & oval grave pit \\
\hline 376 & 53 & 72 & 70 & round grave pit \\
\hline 377 & 78 & 136 & 122 & oval grave pit \\
\hline 378 & 78 & 122 & 102 & oval grave pit \\
\hline 380 & 22 & - & - & no indication of a grave pit \\
\hline 381 & 103 & 134 & 115 & oval grave pit \\
\hline 382 & 51 & 108 & 84 & oval, narrow grave pit \\
\hline 383 & 72 & 103 & 77 & oval grave pit \\
\hline 384 & 44 & - & - & no indication of a grave pit \\
\hline 394 & 104 & 73 & 51 & oval grave pit \\
\hline 403 & 71 & 145 & 140 & round grave pit \\
\hline 408 & 68 & 98 & 79 & oval grave pit \\
\hline 411 & 82 & 162 & 143 & oval grave pit \\
\hline 412 & 75 & 156 & 137 & round grave pit \\
\hline 413 & 75 & 82 & 73 & oval grave pit \\
\hline 416 & 87 & 152 & 134 & oval grave pit \\
\hline 419 & 110 & 127 & 98 & oval grave pit \\
\hline 420 & 76 & 105 & 141 & oval grave pit \\
\hline 421 & 102 & 115 & 91 & oval grave pit \\
\hline 422 & 45 & 124 & 83 & oval grave pit \\
\hline 427 & 78 & 96 & 77 & oval grave pit \\
\hline 437 & 102 & 112 & 76 & oval grave pit \\
\hline 439 & 110 & 114 & 107 & round, slightly oval grave pit \\
\hline
\end{tabular}

The depth of the grave pits varied between 18 and $155 \mathrm{~cm}$, with the average grave depth being around $86 \mathrm{~cm}$. These data can be regarded as approximate values since the datum point from where grave depths were measured, is not known. Until the late 1950s, depth data were not recorded using instruments and thus data of this kind are rather arbitrary, regardless of how carefully and meticulously they were recorded. In view of the above, it would be a rather pointless exercise to search for possible groupings according to the depth data.

The length of the grave pits varied between 55 and $182 \mathrm{~cm}$, the average being $118 \mathrm{~cm}$. The length of the grave pits was determined by practice and it is therefore unlikely that there was any pattern in the size of the grave pits. I have therefore desisted from trying to fit grave pit sizes into an arbitrary pattern.

The width of the grave pits varied between 35 and
$156 \mathrm{~cm}$, the average being $95 \mathrm{~cm}$. Similarly to the length, the width too was determined by practice and no patterning can be discerned in theis respect.

The form of the grave pit was usually oval (124 graves; 66 per cent). There were 28 round grave pits (15 per cent), 24 oblong ones (13 per cent). The patch of the grave pit could not be observed in eight cases (4 per cent) and neither could its form be determined after the clearing of the burial. The form of the grave pit is not known in four cases (2 per cent).

There was no apparent correlation between the size and form of the grave pit and the deceased.

\section{Preparation of the grave pit for the funeral}

We know nothing about the preparations immediately prior to the funeral. Since soil samples were not collected from the graves, we do not know whether 
organic materials (leather, woven mats, plants, textiles, etc.) had been placed into the grave. Soproni's field notes do not include any remarks that the grave pit had perhaps been cleansed by fire before the burial.

\section{Deposition of the body in the grave}

The preparation of the grave pit was followed by the ceremony of burying the deceased. Most bodies were deposited carefully in the so-called embryonic (or perhaps sleeping), or contracted posture. Three bodies were laid on the back. ${ }^{5}$ The placement of the body could not be determined in eleven cases. ${ }^{6}$

Placement on the left side was slightly more frequent than on the right side (91 burials accounting for 48 per cent $v s .83$ burials representing 44 per cent). ${ }^{7}$ However, no apparent correlation could be noted between placement and age/sex (cp. Table 1). Although a few clusters can be identified, where burials with the body laid on one particular side lie next to or close to each other forming groups outlining a variety of shapes, these do not reflect any obvious trend and thus any farreaching conclusions in this respect would be arbitrary.

\section{Grave goods}

Altogether 188 (53 per cent) of the 355 single inhumation burials contained grave goods, meaning that every second deceased was accorded various articles for the journey to the otherworld or was laid to rest with his/her personal (?) belongings.

The graves contained a wide range of grave goods in the following combinations (cp. Table 3):

- vessels

- vessel fragments

- vessels and vessel fragments

- vessels, vessel fragments and jewellery articles

- jewellery articles

- stone artefacts or stones

- vessels and/or vessel fragments and stone artefacts or stones

- jewellery articles and stone artefacts or stones

- jewellery articles and tools

- tools

- vessels and/or vessel fragments and tools

- animal bones

- vessels and/or vessel fragments, jewellery articles and stone blades/stones

\footnotetext{
Graves 39, 287, 394.

${ }^{6}$ Graves 59, 68, 70, 72, 144, 179, 206, 244, 257, 267, 413

7 The deceased was laid on the left side in Graves 2, 14, 16, 21, 22, 23, 25 $36,37,41,42,43,44,46,50,51,60,61,63,64,65,67,73,75,87,88,90$ $94,95,96,104,111,112,128,129,132,135,137,171,174,175,180,183$ $185,189,194,202,207,208,210,216,218,226,229,237,245,252,253$, $261,279,284,286,295,303,306,309,312,319,324,330,352,353,355$, $359,360,361,363,367,370,375,380,381,383,384,403,408,416,419$ $420,427,437$.

The deceased was laid on the right side in Graves $1,6,7,8,9,10,12,18$, $19,24,28,30,33,35,38,49,53,58,74,82,84,91,98,114,115,116,117$ $118,124,127,136,139,140,143,145,146,148,156,158,163,164,170$ $172,196,197,203,209,220,221,223,227,230,232,265,277,289,291$, $294,301,310,317,322,325,329,335,338,344,345,347,350,354,364$, $368,371,376,377,378,382,411,412,421,422,439$.
}

- vessels and/or vessel fragments, jewellery articles and tools

- vessels and/or vessel fragments and animal bones

Table 3 shows the distribution of the grave goods and their combinations. I examined whether there were any correlations between grave good types and sex, or between the position of the grave good(s) in the grave and sex.

Jewellery articles were recovered from 101 burials among the single inhumation burials with grave goods (54 per cent), meaning that every second burial with grave goods contained one or more articles of this type. Table 3 shows the distribution of jewellery articles according to the sex of the deceased and their combination with other grave goods.

Thirty-eight burials (20 per cent of the graves with grave goods; five male, twelve female, twenty child burials and one indeterminable burial) contained exclusively jewellery articles. Beads, medal type ornaments and shell plaques can be distinguished among the jewellery articles. Bone ornaments form a separate category.

Most jewellery items lay on or in the region of the neck, meaning that they were worn around the neck. Soproni found long-stranded necklaces extending to the waist in two burials (Graves 10 and 127). Beads and shells were also found on or around the waist in some burials, ${ }^{8}$ suggesting that these had been applied onto belts or sashes, or were strands simply wound around the waist.

Two copper beads were found by the head of the infant interred in Grave 114 (Pl. L. 114/1). Shell plaques lay on the forehead of the woman in Grave 419, perhaps the remains of a headband or some other headdress (Pl. CLXI. 419/1).

Another combination is made up of jewellery and stone blades/stones. Fourteen burials among the inhumation burials with grave goods had this combination (7 per cent). This combination occurred most frequently in child burials: seven graves were child burials, five were female burials and two were probably male burials. The jewellery articles were generally found by the neck or, less rarely, by the waist, while the stone blades or stones lay by the knee or the ankles in five graves 9 and by the upper body in the other graves. ${ }^{10}$

Three graves yielded a combination of jewellery and tools. All three were child burials. A bone implement (Pl. XXVI. 60/2) was found by the ankle of the child interred in Grave 60, a copper needle (Pl. XXVIII. 63/2) lay between the fingers of the child in Grave 63, while the child in Grave 221 had a stone blade $(\mathrm{Pl}$. XCIII. 221/1) by the left hand, a bone awl (Pl. XCIII. 221/4) by the mandible, and a stone blades/stone $(\mathrm{Pl}$. XCIII. 221/4) under the left elbow. The jewellery articles lay around the neck. The two shell plaques in

\footnotetext{
$\overline{8 \text { Graves 35, 359 }}, 363,381,419,437$.

9 Graves 24, 41, 95, 170, 317.

${ }_{10}$ Graves 25, 84, 111, 117, 128, 291, 309, 354, 371.
} 
Table 3. Distribution of jewellery articles and their combination with other grave goods in the single inhumation burials

\begin{tabular}{|c|c|c|c|c|c|}
\hline Grave good & Male burials & Female burials & Child burials & Indet. sex & Total \\
\hline Jewellery & $\begin{array}{c}5 \\
\text { (Graves 37, 53, } \\
94,220,420\end{array}$ & $\begin{array}{c}12 \\
\text { (Graves 16, 38, 58, } \\
127,180,209,284, \\
329,359,381,416, \\
419)\end{array}$ & $\begin{array}{c}20 \\
\text { (Graves 21, 35, 82, } \\
90,96,98,114, \\
139,206,226,229 \\
237,245,301,322, \\
363,394,427,437)\end{array}$ & $\begin{array}{c}1 \\
\text { (Grave 137) }\end{array}$ & 38 \\
\hline Jewellery, stone blade/stone & $\begin{array}{c}2 \\
\text { (Graves 117, 170) }\end{array}$ & $\begin{array}{c}5 \\
\text { (Graves 24, 25, } \\
95,309,354) \\
\end{array}$ & $\begin{array}{c}7 \\
\text { (Graves 41, 84, 111, } \\
128,291,317,371)\end{array}$ & - & 14 \\
\hline Jewellery and tool & - & - & $\begin{array}{c}3 \\
\text { (Graves 60, 63, 221) }\end{array}$ & & 3 \\
\hline $\begin{array}{l}\text { Vessel/vessel fragment } \\
\text { and jewellery }\end{array}$ & $\begin{array}{c}5 \\
(\text { Graves 19,33, } \\
67,171,355)\end{array}$ & $\begin{array}{c}7 \\
\text { (Graves 23, 36, 183, } \\
208,216,324,384)\end{array}$ & $\begin{array}{c}10 \\
\text { (Graves 42, 74, 88, } \\
129,145,148,267, \\
345,360,413)\end{array}$ & $\begin{array}{c}1 \\
\text { (Grave 50) }\end{array}$ & 23 \\
\hline $\begin{array}{l}\text { Vessel/vessel fragment, } \\
\text { jewellery and stone blade/stone }\end{array}$ & $\begin{array}{c}4 \\
\text { (Graves 8, 207, } \\
227,412)\end{array}$ & $\begin{array}{c}8 \\
(\text { Graves 2, 12, 22, } \\
28,46,136,158,367)\end{array}$ & $\begin{array}{c}6 \\
\text { (Graves 53, 75, 202, } \\
361,376,378)\end{array}$ & - & 18 \\
\hline $\begin{array}{l}\text { Vessel/vessel fragment, } \\
\text { jewellery and tools }\end{array}$ & $\begin{array}{c}2 \\
\text { (Graves } 164,194)\end{array}$ & $\begin{array}{c}3 \\
(\text { Graves } 73,174,403)\end{array}$ & - & - & 5 \\
\hline Total & 18 & 35 & 46 & 2 & 101 \\
\hline
\end{tabular}

Grave 63 (Pl. XXVIII. 63/1) were found on the left temple.

Jewellery and vessels/vessel fragments were found in twenty-three graves. Five of these were male burials, ${ }^{11}$ seven were female burials, ${ }^{12}$ nine were child burials ${ }^{13}$ and two could not be sexed. ${ }^{14}$ The jewellery articles were usually found around the neck or by the trunk. In addition to a necklace strung of shell, limestone and copper beads and shell plaques, the woman interred in Grave 208 had a bracelet made from perforated boar tusks on her left wrist. ${ }^{15}$ Most of the vessels in these graves were bowls or drinking vessels (cups, goblets ladles, dippers, mugs, scooping vessels). The same holds true for the burials containing stone blades/stones or tools in addition to the jewellery and vessels. The vessels in these burials too were predominantly drinking vessels.

There was no apparent correlation between the sex of the deceased and the deposition of jewellery articles. Children were very often laid to rest with a single shell only. ${ }^{16}$

Table 4 shows the distribution of tools and implements according to the sex of the deceased and their combination with other grave goods.

\footnotetext{
11 Graves 19, 33, 67, 171, 355.

12 Graves 23, 36, 183, 208, 216, 324, 384

13 Graves 42, 88, 129, 145, 148, 267, 345, 360, 413.

14 Graves 50, 74

15 The finds from this burial have been lost or mislaid, and are known only from the description in the acquisitions register.

16 Graves 96, 98, 139, 363, 394.
}

Tools and/or red stones were found in seventy-four burials of the single inhumation burials with grave goods, accounting for almost 40 per cent (i.e. every third burial with grave goods contained a stone blade, a core, a bone or copper tool). Most of these finds were stone blades or cores. Graves 2 and 84 yielded an arrowhead (Pl. II. 2/3, Pl. XXXVIII. 84/1), Graves 63 and 218 contained a copper needle (Pl. XXVIII. 63/2, Pl. LXXXIX. 218/1), Graves 73 and 174 had bone tools (Pl. XXXII. 73/3-4, Pl. LXXIII. 174/12-13). A bone awl was deposited in Graves 221 and 338 (Pl. XCIII. 221/2, Pl. CXXIX. 338/1), two stone axes in Grave 164 (Pl. $L X X$. 164/2-3), a copper chisel and a stone axe in Grave 227 (Pl. XCVII. 227/24, 227/26), while Grave 403 contained spool shaped artefacts (Pl. CLVI. 403/3-7). Grave 91 was the most lavishly furnished burial in this category, yielding countless blades and cores, as well as an antler axe, stone axes and various bone implements ( $\mathrm{Pls} X L I-X L I I I)$.

There was no apparent correlation between the deposition of stone blades and other tools and implements and the sex and/or age of the deceased. The joint occurrence of jewellery articles and tools can only be noted in child burials; stone blades were more frequently placed in female and child burials (twentytwo and seventeen graves resp.) than in male burials (nine graves).

Vessels and/or vessel fragments are among the most common grave goods. Table 5 shows the distribution of vessels and their combination with other grave goods. 
Table 4. Distribution of tools and implements and their combination with other grave goods in the single inhumation burials

\begin{tabular}{|c|c|c|c|c|}
\hline Grave good & Male burials & Female burials & Child burials & Total \\
\hline Tool & $\begin{array}{c}1 \\
\text { (Grave 91) }\end{array}$ & $\begin{array}{c}1 \\
\text { (Grave 218) }\end{array}$ & $\begin{array}{c}2 \\
\text { (Graves 144, 338) }\end{array}$ & 4 \\
\hline Stone tool/stone & $\begin{array}{c}5 \\
\text { (Graves 64, 185, 230, } \\
325,411)\end{array}$ & $\begin{array}{c}3 \\
\text { (Graves 49, 287, 370) }\end{array}$ & $\begin{array}{c}1 \\
\text { (Grave 380) }\end{array}$ & 9 \\
\hline $\begin{array}{l}\text { Jewellery and stone } \\
\text { blade/stone }\end{array}$ & $\begin{array}{c}2 \\
\text { (Graves 117, 170) }\end{array}$ & $\begin{array}{c}5 \\
\text { (Graves 24, 25, 95, } \\
309,354)\end{array}$ & $\begin{array}{c}7 \\
\text { (Graves 41, 84, 111, } \\
128,291,317,371)\end{array}$ & 14 \\
\hline Jewellery and tool & - & - & $\begin{array}{c}3 \\
\text { (Graves 60, 63, 221) } \\
\end{array}$ & 3 \\
\hline $\begin{array}{l}\text { Vessel/vessel fragments, } \\
\text { jewellery and stone } \\
\text { blade/stone }\end{array}$ & $\begin{array}{c}4 \\
\text { (Graves 8, 207, } \\
\text { 227, 412) }\end{array}$ & $\begin{array}{c}8 \\
\text { (Graves 2, 12, 22, } \\
28,46,136,158,367)\end{array}$ & $\begin{array}{c}6 \\
\begin{array}{c}\text { (Graves 53, 75, 202, } \\
361,376,378)\end{array}\end{array}$ & 18 \\
\hline $\begin{array}{l}\text { Vessel/vessel fragments, } \\
\text { jewellery and tool }\end{array}$ & $\begin{array}{c}2 \\
\text { (Graves 164, 194) }\end{array}$ & $\begin{array}{c}3 \\
\text { (Graves } 73,174,403)\end{array}$ & - & 5 \\
\hline $\begin{array}{l}\text { Vessels/vessel fragments } \\
\text { and stone blade/stone }\end{array}$ & $\begin{array}{c}3 \\
\text { (Graves 1, 375, 422) }\end{array}$ & $\begin{array}{c}9 \\
\text { (Graves 44, 115, 143, } \\
\text { 189, 197, 330, 335, } \\
344,347)\end{array}$ & $\begin{array}{c}4 \\
\text { (Graves 61, 175, } \\
352,377)\end{array}$ & 16 \\
\hline $\begin{array}{l}\text { Vessel/vessel fragments } \\
\text { and tool }\end{array}$ & $\begin{array}{c}3 \\
\text { (Graves 112, 279, 319) }\end{array}$ & - & $\begin{array}{c}2 \\
\text { (Graves 312, 368) }\end{array}$ & 5 \\
\hline Total & 20 & 29 & 25 & 74 \\
\hline
\end{tabular}

Of the single inhumation burials with grave goods, altogether 115 burials (61 per cent) contained vessels or vessel fragments, often together with other articles (jewellery, tools, etc.), i.e. one or more vessels were placed in every sixth grave.

Most of these burials contained one or two vessels, although sometimes three or four vessels were deposited. The child interred in Grave 75 was given eight vessels, a conspicuously high number.

Most burials yielded one ${ }^{17}$ or more ${ }^{18}$ drinking vessels or liquid containers (cups, jugs, pitchers, scooping vessels, goblets, dippers), the dominant type among the ceramics placed in graves (seventy-four graves, accounting for 64 per cent). Scooping vessels were most frequently deposited (twenty-three graves), followed by goblets (twenty-two graves), cups (thirteen graves), pitchers (twelve graves), ladles (eleven graves), handled cups (eight graves), jugs and dippers (five graves each) and handled mugs (two graves). Bowls were found in eleven graves, an intact bipartite bowl in one grave; handled pots were deposited in five graves, simple pots without handles in three graves. Suspension vessels were recovered from two graves and one burial contained a vessel in the shape of a wagon. Curiously enough, not one single intact or near-

17 Graves 2, 8, 9, $18,28,30,39,46,51,53,59,61,68,74,87,115,116,118$, $124,136,143,145,179,183,207,208,210,216,232,253,261,265,267$ $277,294,295,310,319,347,350,352,360,364,375,377,408,412$.

18 Graves $1,19,33,36,70,73,75,112,132,158,164,174,189,197,202$, $203,227,286,289,312,330,335,344,367,368,378,383$. intact amphora was recovered from the burials; this vessel type is represented by fragments only.

These numbers are obviously higher if the vessel fragments found in fifty-four burials indicating additional vessels are also considered. The selective deposition of intact and broken vessels was not mere chance, although the reason for this practice remains obscure. The burials containing vessel fragments only generally yielded undecorated body sherds. The pottery fragments which could be securely assigned to a specific vessel type represent the same types as the intact vessels placed in the grave, suggesting that the same vessel types were used, although probably with a different symbolic meaning.

\section{Post-interment activities}

Soproni's field notes contain little information on the burial mode. He recorded that stones had been heaped over the body in a few graves, after which a layer of earth was added, followed by stones again (Graves 127, 175, 194). He noted a similar phenomenon in Grave 437, the only difference being that instead of a lower layer of stones, the body was covered with a single large, flat stone.

Soproni mentions a layer of ash and burnt earth in two graves. In Grave 207, an 8-10 cm thick layer of fine, reddish-black ash was found above the $5-10 \mathrm{~cm}$ thick layer of earth covering the body. This ash layer was noted in the southern end of the grave pit only and thickened from the centre of the pit toward the end. A 
Table 5. Distribution of vessels/vessel fragments and their combination with other grave goods in the single inbumation burials

\begin{tabular}{|c|c|c|c|c|c|}
\hline Grave good & Male burials & Female burials & Child burials & Indet. sex & Total \\
\hline Vessels & $\begin{array}{c}7 \\
\text { (Graves 9, 18, } \\
\text { 124, 132, 203, } \\
277,294) \\
\end{array}$ & $\begin{array}{c}4 \\
(\text { Graves 104, 118, } \\
295,350)\end{array}$ & $\begin{array}{c}8 \\
\text { (Graves 30, 87, 179, } \\
232,253,286, \\
364,408)\end{array}$ & - & 19 \\
\hline Vessel fragments & $\begin{array}{c}3 \\
(\text { Graves 14, 196, } \\
353)\end{array}$ & $\begin{array}{c}6 \\
\text { (Graves 6, 65, 146, } \\
163,223,303)\end{array}$ & $\begin{array}{c}6 \\
\text { (Graves 7, 140, 172, } \\
244,252,421) \\
\end{array}$ & $\begin{array}{c}1 \\
(\text { Grave 135) }\end{array}$ & 16 \\
\hline Vessels and vessel fragments & $\begin{array}{c}2 \\
(\text { Graves 39, 261) }\end{array}$ & $\begin{array}{c}5 \\
\text { (Graves 51, 70, } \\
116,210,310) \\
\end{array}$ & $\begin{array}{c}4 \\
\text { (Graves 68, 265, } \\
\text { 306, 383) } \\
\end{array}$ & $\begin{array}{c}1 \\
(\text { Grave 59) }\end{array}$ & 12 \\
\hline $\begin{array}{l}\text { Vessels/vessel fragments } \\
\text { and jewellery }\end{array}$ & $\begin{array}{c}5 \\
(\text { Graves 19,33 } \\
67,171,355)\end{array}$ & $\begin{array}{c}7 \\
\text { (Graves 23, 36, 183, } \\
208,216,324,384)\end{array}$ & $\begin{array}{c}10 \\
\text { (Graves 42, 74, 88, } \\
129,145,148,267, \\
345,360,413)\end{array}$ & $\begin{array}{c}1 \\
(\text { Grave 50) }\end{array}$ & 23 \\
\hline $\begin{array}{l}\text { Vessels/vessel fragments, } \\
\text { jewellery and stone blade/stone }\end{array}$ & $\begin{array}{c}4 \\
\text { (Graves 8, 207, } \\
227,412)\end{array}$ & $\begin{array}{c}8 \\
(\text { Graves 2, 12, 22, 28, } \\
46,136,158,367)\end{array}$ & $\begin{array}{c}6 \\
\text { (Graves 53, 75, 202, } \\
361,376,378) \\
\end{array}$ & - & 18 \\
\hline $\begin{array}{l}\text { Vessels/vessel fragments, } \\
\text { jewellery and tool }\end{array}$ & $\begin{array}{c}2 \\
\text { (Graves 164, 194) } \\
\end{array}$ & $\begin{array}{c}3 \\
(\text { Graves } 73,174,403)\end{array}$ & - & - & 5 \\
\hline $\begin{array}{l}\text { Vessels/vessel fragments } \\
\text { and stone blade/stone }\end{array}$ & $\begin{array}{c}3 \\
\text { (Graves 1, 375, } \\
422)\end{array}$ & $\begin{array}{c}9 \\
\text { (Graves 44, 115, 143, } \\
189,197,330 \\
335,344,347) \\
\end{array}$ & $\begin{array}{c}4 \\
\text { (Graves 61, 175, } \\
352,377)\end{array}$ & - & 16 \\
\hline $\begin{array}{l}\text { Vessels/vessel fragments } \\
\text { and tool }\end{array}$ & $\begin{array}{c}3 \\
\text { (Graves 112, 279, } \\
319) \\
\end{array}$ & - & $\begin{array}{c}2 \\
(\text { Graves 312, 368) }\end{array}$ & - & 5 \\
\hline $\begin{array}{l}\text { Vessels/vessel fragments } \\
\text { and animal bone }\end{array}$ & $\begin{array}{l}- \\
- \\
\end{array}$ & $\begin{array}{c}1 \\
(\text { Grave 289) }\end{array}$ & - & - & 1 \\
\hline Total & 29 & 43 & 40 & 3 & 115 \\
\hline
\end{tabular}

patch of burnt earth was observed behind the deceased's buttocks in Grave 227. Lying some 60-65 cm above the body was a pile of vessels in the centre of the pit.

Soproni made an interesting observation during the excavation of Grave 289, which contained many large stones between -10 and $-55 \mathrm{~cm}$. Two roughly 20-25 cm large round areas were devoid of stones, which in Sopron's interpretation perhaps served for depositing food. Grave 28 too contained many stones, one of which was set upright by the pelvis. It is often unclear from Soproni's field notes whether the stones found in the grave pits had lain over or beside the body. In many cases, he simply noted that the grave pit "contained stones"19 or "contained many stones".20 Grave 90 contained a single large stone. Sometimes, the depths at which the stones lay are recorded, suggesting that there was a layer of stones. However, it remains unknown whether the stones were placed in the grave before or after the deposition of the body. It

\footnotetext{
19 Graves 7, 25, 33 , 35, 42, 46, 61, 72, 82, 84, 87, 88, 94, 96, 114, 118, 128, $145,146,148,156,164$.

20 Graves 6, 23, 24
}

seems more likely that the stones were placed on the body after its deposition, although we cannot exclude the possibility that the area designated for the body was first outlined with stones. In the lack of detailed grave plans and photos, this cannot be established for each grave. There are twenty-two burials (12 per cent) among the single inhumation burials with grave goods in whose case it is unclear when the stones were placed in the pit. The stones were placed in the grave after the deposition of the body in the case of twenty-nine burials (15 per cent).

Fifty-one burials (27 per cent) of the single inhumation burials with grave goods contained stones, meaning that practically each third funeral was concluded by the deposition of stones. The damages to the skull indicate that the mourners did not take care to place the stones carefully on the body. As a matter of fact, it seems more likely that the stones were thrown into the grave pit with the intention of crushing the deceased's skull. ${ }^{21}$

\footnotetext{
${ }^{21}$ Nándor Kalicz does not accept this interpretation. In his view, the skull could have been broken by the earth thrown in the grave pit when the grave was backfilled or could they could have been crushed by the weight of the stones placed on them.
} 
There is little evidence for the concluding part of the burial ceremony, namely the marking of the grave or the erection of a grave marker. The cemetery plan nonetheless suggests that the graves were marked in some way.

\section{Disturbed burials}

A few burials were disturbed during the Late Copper Age, when new graves were dug over earlier ones. ${ }^{22}$ Even though it could be clearly established during the excavation which of the graves was earlier, these superimposed burials offer few typochronological anchors either because they contained no grave goods, ${ }^{23}$ or because the few grave goods in them ${ }^{24}$ are insufficient for typological and chronological comparisons.

The number of destroyed or disturbed burials is low compared to the overall number of graves in this category (188). Copper Age intrusions disturbed six burials (3 per cent), while modern ones affected eighteen burials ${ }^{25}$ ( $c a .10$ per cent).

\section{SINGLE INHUMATION BURIALS WITHOUT GRAVE GOODS}

Burials containing no grave goods whatsoever either on the body of the deceased or in the grave pit are assigned to this category. Altogether 124 single inhumation burials of the 355 inhumation graves in the Budakalász cemetery did not contain any grave goods or archaeologically visible costume accessories. These burials account for over one-third ( 35 per cent) of the graves.

\section{Preparation for the funeral}

One important phase of the funeral rite - the preparation, acquisition and manufacture of the funerary gifts - cannot be discussed since these burials did not contain any grave goods. What can be examined are the selection of the grave location, orientation, the digging of the grave pit and its preparation for the funeral.

\section{Selection of the grave location}

A glance at the cemetery map reveals that the single inhumation burials without any grave goods occur over the entire cemetery in a random distribution. Although certain "clusters" can be noted, it would appear that there was no conscious pattern in the selection of the grave locations (even though the location of the

\footnotetext{
$\overline{22}$ Graves 36 and 34; Graves 44 and 40; Graves 50 and 51; Graves 97 and 98; Graves 143 and 139; Graves 363 and 362.

23 Graves 34, 40, 97, 362.

24 Graves 98, 139 and 363 contained one mussel each.

25 Graves 2, 59, 70, 74, 129, 132, 179, 196, 206, 216, 226, 244, 257, 284, $367,368,370,375$.
}

inhumation burials in which the deceased were not given any grave goods was a conscious choice). New graves rarely destroyed earlier ones, indicating that the graves were marked. The overall lack of disturbed burials and the distribution of the graves within the cemetery indicate that the graves were marked and that the time elapsed between two successive burials was not so great as to be measured in several decades because the grave markers were still visible. The later burials did not disturb the resting place of the community members interred earlier.

\section{Orientation}

The digging and orientation of the grave pit was part of the preparation for the funeral. Table 6 shows the orientation, together with the placement and the age and sex of the deceased.

Fourteen different orientations can be noted among these burials. An orientation toward the south was the most frequent. The head of the deceased was aligned toward the south ${ }^{26}$ or slightly to the south-east ${ }^{27}$ or south-west ${ }^{28}$ in the case of eighty-eight graves (71 per cent). Twenty bodies were deposited with the head toward the north, ${ }^{29}$ or slightly deviating to the northeast ${ }^{30}$ or north-west. ${ }^{31}$ Twelve burials were west to east oriented, ${ }^{32}$ four were east to west oriented, ${ }^{33}$ while ten burials were aligned east-north-east or east-southeast. ${ }^{34}$ The orientation could not be determined in the case of five burials. ${ }^{35}$

Bodies were more often laid on the left side (64 burials, 52 per cent) than on the right (50 burials, 40 percent). There was no apparent correlation between orientation and placement on the right or the left side. Neither was there any patterning as regards orientation, placement and age or sex. In contrast to earlier periods, the burial rite did not call for a strict placement on the right or the left side according to sex and/or age, or orientation by the Baden period.

\section{Digging of the grave pit}

The grave pit was dug after the onset of death, but before the funeral itself. The bodies were placed into the grave carefully and care was taken to arrange the head, the hands and the feet.

\footnotetext{
26 Graves 5, 27, 34, 52, 54, 89, 107, 110, 122, 125, 133, 151, 166, 176, 201, $214,231,293,300,332,362,369,372,373,385,402,438$.

27 South-east to north-west: Graves 4, 15, 32, 119, 121, 161, 188, 212, 264 $281,305,358,365,407$; south-south-east to north-north-west: Graves 83 , $93,109,204,283,292,302,316,336,342,346,351,397,401,418,424$, 426 .

28 South-west to north-east: Graves 76, 77, 150, 186, 187, 192, 285, 297 , 357; south-south-west to north-north-east: Graves 92, 184, 198, 217, 225 , $326,348,379,393,409,410,415$; west-south-west to north-north-east Graves 45, 157, 162 .

29 North to south: Graves 57, 86, 321, 400 .

30 North-east to south-west: Graves 299, 320; north-north-east to south-south-west: Graves 97, 278.

31 North-west to south-east: Graves 85, 99, 318.

32 Graves 20, 29, 62, 102, 141, 154, 173, 228, 256, 270, 288, 404.

33 Graves 17, 152, 165, 428

34 East-north-east to west-south-west: Gave 11; east-south-east to north-north-west: Graves 81, 105, 199, 200, 271, 272, 308, 337, 417 .
}

35 Graves 40, 69, 147, 213, 374. 
Table 6. Inhumation graves containing a single burial without grave goods: orientation, deposition, sex and age at death of the deceased *

\begin{tabular}{|c|c|c|c|c|}
\hline Grave & Deposition & Age at death & Sex & Orientation \\
\hline 4 & left side & $6-8$ years & child & SE to NW, with the head to the SE \\
\hline 5 & right side & $40-59$ years & female & $\mathrm{S}$ to $\mathrm{N}$, with the head to the $\mathrm{S}$ \\
\hline 11 & right side & $40-50$ years & female & E-NE to W-SW, with the head to the E-NE \\
\hline 15 & left side & $30-50$ years & female (?) & SE to NW, with the head to the SE \\
\hline 17 & left side & $20-30$ years & female & E to $W$, with the head to the $W$ \\
\hline 20 & left side & $40-50$ years & male (?) & $W$ to $E$, with the head to the west \\
\hline 27 & left side (?) & (child) & (child) & $\mathrm{S}$ to $\mathrm{N}$, with the head to the $\mathrm{S}$ \\
\hline 29 & left side & (female) & (female) & W-NW to E-SE, with the head to the W-NW \\
\hline 32 & - & (male) & (male) & SE to NW, with the skull lying in the grave pit's $S W$ end \\
\hline 34 & right side & (child) & (child) & S to N, with the head to the $\mathrm{S}$ \\
\hline 40 & right side (?) & (child) & (child) & head to the S-SW \\
\hline 45 & left side & $23-x$ years & ? & W-SW to E-NE, with the head to the W-SW \\
\hline 52 & right side & $30-40$ years & male & S to $\mathrm{N}$, with the head to the $\mathrm{S}$ \\
\hline 54 & left side & child & child & $\mathrm{S}$ to $\mathrm{N}$, with the head to the $\mathrm{S}$ \\
\hline 57 & right side & $40-\mathrm{x}$ years & male & $\mathrm{N}$ to $\mathrm{S}$, with the head to the $\mathrm{S}$ \\
\hline 62 & left side & $7-8$ years & child & $W$ to $E$, with the head to the west \\
\hline 69 & - & - & female (?) & - \\
\hline 76 & left side & $40-50$ years & female & SW to NE, with the head to the SW \\
\hline 77 & - & child & child & SW to NE, with the head to the NE \\
\hline 81 & right side (?) & ? & male (?) & E-SE to W-NW, with the head to the E-SE \\
\hline 83 & left side & $45-55$ years & male & S-SE to N-NW, with the head to the S-SE \\
\hline 85 & right side & child & child & NW-SE, with the head to the NW \\
\hline 86 & - & child & child & $\mathrm{N}$ to $\mathrm{S}$, with the head to the $\mathrm{S}$ \\
\hline 89 & left side & $25-35$ years & female & $\mathrm{S}$ to $\mathrm{N}$, with the head to the $\mathrm{S}$ \\
\hline 92 & right side & $1-7$ years & child & S-SW to N-NE, with the head to the S-SW \\
\hline 93 & right side & $5-6$ years & child & S-SE to N-NW, with the head to the S-SE \\
\hline 97 & left side & $12-14$ years & child & $\mathrm{N}-\mathrm{NE}$ to $\mathrm{S}-\mathrm{SW}$, with the head to the N-NE \\
\hline 99 & right side & infans I & child & NW-SE, with the head to the NW \\
\hline 102 & - & $1-7$ years & child & W-E, with the head to the $W$ \\
\hline 105 & left side & $40-x$ years & male (?) & E-SE to W-NW, with the head to the E-SE \\
\hline 107 & right side & $35-45$ years & male (?) & $\mathrm{S}$ to $\mathrm{N}$, with the head to the $\mathrm{S}$ \\
\hline 109 & right side & (child) & (child) & S-SE to N-NW, with the head to the S-SE \\
\hline 110 & left side & (child) & (child) & $\mathrm{S}$ to $\mathrm{N}$, with the head to the $\mathrm{S}$ \\
\hline 119 & right side & $8-10$ years & child & SE to NW, with the head to the SE \\
\hline 121 & left side & $9-10$ years & child & SE to NW, with the head to the SE \\
\hline 122 & right side & $2-2.5$ years & child & $\mathrm{S}$ to $\mathrm{N}$, with the head to the $\mathrm{S}$ \\
\hline 125 & left side & $23-\mathrm{x}$ years & female (?) & $\mathrm{S}$ to $\mathrm{N}$, with the head to the $\mathrm{S}$ \\
\hline 133 & - & (?) & (?) & $\mathrm{S}$ to $\mathrm{N}$, with the head to the $\mathrm{S}$ \\
\hline 141 & right side & $23-39$ years & female (?) & W to E, with the head to the west \\
\hline 147 & - & $1-4$ years & child & - \\
\hline 150 & left side & $30-50$ years & female & SW to NE, with the head to the SW \\
\hline 151 & left side & $5-7$ years & child & $\mathrm{S}$ to $\mathrm{N}$, with the head to the $\mathrm{S}$ \\
\hline 152 & right side & $23-30$ years & female (?) & E-W, with the head to the $\mathrm{E}$ \\
\hline 154 & right side (?) & $1-2$ years & child & $W$ to $E$, with the head to the west \\
\hline 157 & left side & $40-x$ years & female & W-SW to E-NE, with the head to the W-SW \\
\hline 161 & left side & $30-40$ years & male & SE to NW, with the head to the SE \\
\hline 162 & left side & $23-x$ years & ? & W-SW to E-NE, with the head to the W-SW \\
\hline 165 & right side & $40-59$ years & male (?) & E-W, with the head to the $\mathrm{E}$ \\
\hline 166 & left side & $23-30$ years & female & $\mathrm{S}$ to $\mathrm{N}$, with the head to the $\mathrm{S}$ \\
\hline 173 & right side & $35-45$ years & male & W to E, with the head to the west \\
\hline 176 & left side & $30-40$ years & female & $\mathrm{S}$ to $\mathrm{N}$, with the head to the $\mathrm{S}$ \\
\hline 184 & right side & $3-3.5$ years & child & S-SW to N-NE, with the head to the S-SW \\
\hline 186 & left side & $40-\mathrm{x}$ years & male & SW to NE, with the head to the SW \\
\hline 187 & left side & $?$ & $?$ & SW to NE, with the head to the $S W$ \\
\hline
\end{tabular}

* The data in parentheses indicate the age/sex determinations quoted from the excavation diary 
Table 6 (cont'd)

\begin{tabular}{|c|c|c|c|c|}
\hline Grave & Deposition & Age at death & Sex & Orientation \\
\hline 188 & right side & $40-50$ years & female & SE to NW, with the head to the SE \\
\hline 192 & left side & $23-30$ years & female & SW to NE, with the head to the SW \\
\hline 198 & left side & 4-5 years & child & S-SW to N-NE, with the head to the S-SW \\
\hline 199 & left side & $6-8$ years & child & E-SE to W-NW, with the head to the E-SE \\
\hline 200 & left side & $11-13$ years & child & E-SE to $W-N W$, with the head to the E-SE \\
\hline 201 & left side & $13-14$ years & child & $\mathrm{S}$ to $\mathrm{N}$, with the head to the $\mathrm{S}$ \\
\hline 204 & right side & $35-45$ years & female & S-SE to N-NW, with the head to the S-SE \\
\hline 212 & left side & $0-1$ years & child & SE to NW, with the head to the SE \\
\hline 213 & left side & $1-4$ years & child & - \\
\hline 214 & left side & $3-4$ years & child & $\mathrm{S}$ to $\mathrm{N}$, with the head to the $\mathrm{S}$ \\
\hline 217 & left side & $20-23$ years & female & S-SW to N-NE, with the head to the S-SW \\
\hline 225 & right side & $3-4$ years & child & S-SW to N-NE, with the head to the S-SW \\
\hline 228 & left side & (child) & (child) & W-NW to E-SE, with the head to the W-NW \\
\hline 231 & left side & $50-x$ years & male & $\mathrm{S}$ to $\mathrm{N}$, with the head to the $\mathrm{S}$ \\
\hline 256 & right side & $1-7$ years & child & $W$ to E, with the head to the west \\
\hline 264 & left side & $25-35$ years & male (?) & SE to NW, with the head to the SE \\
\hline 270 & left side & $30-40$ years & male & $\mathrm{W}$ to $\mathrm{E}$, with the head to the west \\
\hline 271 & right side & $40-\mathrm{x}$ years & female & E-SE to $W-N W$, with the head to the E-SE \\
\hline 272 & right side (?) & $4-6$ years & child & $\mathrm{E}-\mathrm{SE}$ to $\mathrm{W}-\mathrm{NW}$, with the head to the E-SE \\
\hline 278 & left side & $0-0.5$ years & child & $\mathrm{N}-\mathrm{NE}$ to $\mathrm{S}-\mathrm{SW}$, with the head to the N-NE \\
\hline 281 & extended & $1-3$ years & child & SE to NW, with the head to the SE \\
\hline 283 & right side & $23-59$ years & female & S-SE to N-NW, with the head to the S-SE \\
\hline 285 & left side & $2-3$ years & child & SW to NE, with the head to the SW \\
\hline 288 & right side & $2-3$ years & child & $W$ to E, with the head to the west \\
\hline 292 & left side & $30-50$ years & female & S-SE to N-NW, with the head to the S-SE \\
\hline 293 & right side & $0-1$ years & child & $\mathrm{S}$ to $\mathrm{N}$, with the head to the $\mathrm{S}$ \\
\hline 297 & right side & $(-)$ & (child) & SW to NE, with the head to the SW \\
\hline 299 & left side & (child) & (child) & NE to SW, with the head to the NE \\
\hline 300 & right side & $3-4$ years & child & $\mathrm{S}$ to $\mathrm{N}$, with the head to the $\mathrm{S}$ \\
\hline 302 & - & $0-0.5$ years & child & S-SE to N-NW, with the head to the S-SE \\
\hline 305 & right side (?) & $0-1$ years & child & SE to NW, with the head to the SE \\
\hline 308 & left side & $23-30$ years & male & E-SE to $W-N W$, with the head to the E-SE \\
\hline 316 & right side & $30-40$ years & female & S-SE to N-NW, with the head to the S-SE \\
\hline 318 & right side & $1-14$ years & child & NW-SE, with the head to the NW \\
\hline 320 & right side & $23-39$ years & male (?) & NE to SW, with the head to the NE \\
\hline 321 & - & $23-39$ years & $?$ & $\mathrm{~N}$ to $\mathrm{S}$, with the head to the $\mathrm{S}$ \\
\hline 326 & left side & $4-5$ years & child & S-SW to N-NE, with the head to the S-SW \\
\hline 332 & left side & $40-\mathrm{x}$ years & female & $\mathrm{S}$ to $\mathrm{N}$, with the head to the $\mathrm{S}$ \\
\hline 336 & left side & $23-\mathrm{x}$ years & $?$ & S-SE to N-NW, with the head to the S-SE \\
\hline 337 & right side & $40-59$ years & male & E-SE to W-NW, with the head to the E-SE \\
\hline 342 & right side & $30-40$ years & male & S-SE to N-NW, with the head to the S-SE \\
\hline 346 & left side & $40-\mathrm{x}$ years & male & S-SE to N-NW, with the head to the S-SE \\
\hline 348 & right side & $40-x$ years & female (?) & S-SW to N-NE, with the head to the S-SW \\
\hline 351 & right side & $40-x$ years & female (?) & S-SE to N-NW, with the head to the S-SE \\
\hline 357 & left side & $25-35$ years & female & SW to NE, with the head to the SW \\
\hline 358 & right side & $40-\mathrm{x}$ years & male & SE to NW, with the head to the SE \\
\hline 362 & left side & ? & $?$ & $\mathrm{~S}$ to $\mathrm{N}$, with the head to the $\mathrm{S}$ \\
\hline 365 & right side & $40-\mathrm{x}$ years & male & SE to NW, with the head to the SE \\
\hline 369 & right side & $21-23$ years & female & $\mathrm{S}$ to $\mathrm{N}$, with the head to the $\mathrm{S}$ \\
\hline 372 & left side & $30-x$ years & female (?) & $\mathrm{S}$ to $\mathrm{N}$, with the head to the $\mathrm{S}$ \\
\hline 373 & left side & $4-5$ years & child & $\mathrm{S}$ to $\mathrm{N}$, with the head to the $\mathrm{S}$ \\
\hline 374 & left side (?) & $23-\mathrm{x}$ years & male & - \\
\hline 379 & left side & $4-5$ years & child & S-SW to N-NE, with the head to the S-SW \\
\hline 385 & right side & $0.5-1$ years & child & $\mathrm{S}$ to $\mathrm{N}$, with the head to the $\mathrm{S}$ \\
\hline 393 & right side & $30-40$ years & female & S-SW to N-NE, with the head to the S-SW \\
\hline 397 & right side & $25-3$ years & child & S-SE to N-NW, with the head to the S-SE \\
\hline 400 & left side & $30-40$ years & female & $\mathrm{N}$ to $\mathrm{S}$, with the head to the $\mathrm{S}$ \\
\hline
\end{tabular}


Table 6 (cont'd)

\begin{tabular}{|c|c|c|c|c|}
\hline Grave & Deposition & Age at death & Sex & Orientation \\
\hline 401 & left side & $40-50$ years & male & S-SE to N-NW, with the head to the S-SE \\
\hline 402 & left side & $35-45$ years & female & S to N, with the head to the S \\
\hline 404 & left side & $23-$ x years & male (?) & SE to E, with the head to the west \\
\hline 407 & left side & $20-23$ years & ? & child the head to the SE \\
\hline 409 & left side & $13-15$ years & male & S-SW to N-NE, with the head to the S-SW \\
\hline 410 & left side & $40-x$ years & male & S-SW to N-NE, with the head to the S-SW \\
\hline 415 & left side & $40-59$ years & child & E-SE to W-NW, with the head to the E-SE \\
\hline 417 & right side & $3-4$ years & female & S-SE to N-NW, with the head to the S-SE \\
\hline 418 & right side & $14-16$ years & female & S-SE to N-NW, with the head to the S-SE \\
\hline 424 & right side & $30-40$ years & child & S-SE to N-NW, with the head to the S-SE \\
\hline 426 & left side & $8-10$ years & female & E-W, with the head to the E \\
\hline 428 & right side & $40-x$ years & female & S to N, with the head to the S \\
\hline 438 & left side & $30-40$ years & &
\end{tabular}

Table 7 shows the depth, length, width and form variations of the grave pits.

The depth of the grave pits ranged between 10 and $130 \mathrm{~cm}$, the average being around $70 \mathrm{~cm}$. The depth of the grave pits is approximate at the most because we do not know the level from which Soproni measured the depths. I have nonetheless distinguished three arbitrary groups: graves whose depth was less than $50 \mathrm{~cm}$, graves

Table 7. Inhumation graves containing a single burial without grave goods: size and form of the grave pits

\begin{tabular}{|c|c|c|c|c|}
\hline Grave & $\begin{array}{c}\text { Depth } \\
\text { (cm) }\end{array}$ & $\begin{array}{l}\text { Lenght } \\
\text { (cm) }\end{array}$ & $\begin{array}{l}\text { Width } \\
\text { (cm) }\end{array}$ & Form \\
\hline 4 & 55 & 105 & 90 & oblong grave pit with rounded corners \\
\hline 5 & 100 & 100 & 50 & narrow, oblong grave pit with rounded corners \\
\hline 11 & 95 & 110 & 85 & oval grave pit \\
\hline 15 & 30 & 50 & 65 & oval grave pit \\
\hline 17 & 85 & 110 & 80 & oval grave pit \\
\hline 20 & 105 & 105 & 75 & oval grave pit \\
\hline 27 & 85 & 90 & 70 & oval grave pit \\
\hline 29 & 90 & 95 & 75 & oval grave pit \\
\hline 32 & 120 & 115 & 95 & oval grave pit \\
\hline 34 & 40 & - & - & no indication of a grave pit \\
\hline 40 & 86 & 90 & 50 & oval grave pit \\
\hline 45 & 105 & 100 & 75 & oval grave pit \\
\hline 52 & 70 & - & - & no indication of a grave pit \\
\hline 54 & 110 & 83 & 52 & oblong grave pit with rounded corners \\
\hline 57 & 110 & 105 & 85 & oval grave pit \\
\hline 62 & 80 & 70 & 48 & oblong grave pit with rounded corners \\
\hline 69 & 130 & - & - & destroyed grave \\
\hline 76 & 70 & 95 & 75 & oval grave pit \\
\hline 77 & 50 & 60 & 45 & rounded grave pit \\
\hline 81 & 55 & 105 & 60 & oval grave pit \\
\hline 83 & 100 & 120 & 75 & oval grave pit \\
\hline 85 & 70 & 85 & 70 & rounded grave pit \\
\hline 86 & 75 & 85 & 65 & rounded grave pit \\
\hline 89 & 100 & 105 & 70 & oval grave pit \\
\hline 92 & 60 & 85 & 90 & rounded grave pit \\
\hline 93 & 70 & 75 & 70 & rounded grave pit \\
\hline 97 & 70 & 135 & 90 & oval grave pit \\
\hline 99 & 70 & 70 & 65 & rounded grave pit \\
\hline 102 & 50 & 70 & 60 & oval grave pit \\
\hline 105 & 60 & 125 & 105 & oblong grave pit with rounded corners \\
\hline
\end{tabular}


Table 7 (cont'd)

\begin{tabular}{|c|c|c|c|c|}
\hline Grave & $\begin{array}{l}\text { Depth } \\
\text { (cm) }\end{array}$ & $\begin{array}{l}\text { Lenght } \\
\text { (cm) }\end{array}$ & $\begin{array}{l}\text { Width } \\
\text { (cm) }\end{array}$ & Form \\
\hline 107 & 95 & 120 & 90 & oval grave pit \\
\hline 109 & 100 & 105 & 80 & oval grave pit \\
\hline 110 & 50 & 80 & 60 & oval grave pit \\
\hline 119 & 54 & 118 & 80 & oval grave pit \\
\hline 121 & 65 & 105 & 70 & oval grave pit \\
\hline 122 & 54 & 65 & 85 & oval grave pit \\
\hline 125 & 68 & 45 & 60 & disturbed \\
\hline 133 & 65 & 42 & 48 & destroyed grave \\
\hline 141 & 50 & - & - & no indication of a grave pit \\
\hline 147 & 60 & - & - & no indication of a grave pit \\
\hline 150 & 105 & 125 & 100 & oval grave pit \\
\hline 151 & 66 & 95 & 70 & oval grave pit \\
\hline 152 & 115 & 135 & 90 & oval grave pit \\
\hline 154 & 48 & - & - & no indication of a grave pit \\
\hline 157 & 50 & - & - & no indication of a grave pit \\
\hline 161 & 75 & 135 & 96 & oval grave pit \\
\hline 162 & 22 & - & - & no indication of a grave pit \\
\hline 165 & 25 & 116 & 85 & oval grave pit \\
\hline 166 & 65 & 105 & 80 & oval grave pit \\
\hline 173 & 100 & 100 & 88 & oval grave pit \\
\hline 176 & 74 & 120 & 90 & oval grave pit \\
\hline 184 & 85 & 75 & 50 & oval grave pit \\
\hline 186 & 40 & - & - & no indication of a grave pit \\
\hline 187 & $10-15$ & - & - & no indication of a grave pit \\
\hline 188 & 71 & 120 & 103 & round grave pit \\
\hline 192 & 87 & 102 & 80 & oval grave pit \\
\hline 198 & 35 & - & - & no indication of a grave pit \\
\hline 199 & 54 & - & - & no indication of a grave pit \\
\hline 200 & 80 & 85 & 65 & oval grave pit \\
\hline 201 & 78 & 95 & 83 & oval grave pit \\
\hline 204 & 87 & 125 & 112 & oval grave pit \\
\hline 212 & 38 & - & - & no indication of a grave pit \\
\hline 213 & 33 & - & - & no indication of a grave pit \\
\hline 214 & 50 & 94 & 78 & oval grave pit \\
\hline 217 & 106 & 125 & 87 & oval grave pit \\
\hline 225 & 52 & - & - & no indication of a grave pit \\
\hline 228 & 48 & - & - & no indication of a grave pit \\
\hline 231 & 61 & 112 & 98 & oval grave pit \\
\hline 256 & 85 & 112 & 83 & oval grave pit \\
\hline 264 & 74 & 138 & 95 & oval grave pit \\
\hline 270 & 97 & 155 & 115 & oval grave pit \\
\hline 271 & 62 & 130 & 116 & oval grave pit \\
\hline 272 & 24 & - & - & no indication of a grave pit \\
\hline 278 & 58 & 68 & 50 & oval grave pit \\
\hline 281 & 43 & - & - & no indication of a grave pit \\
\hline 283 & 90 & 115 & 87 & oval grave pit \\
\hline 285 & 68 & 73 & 68 & round grave pit \\
\hline 288 & 100 & 75 & 70 & round grave pit \\
\hline 292 & 97 & 120 & 113 & round grave pit \\
\hline 293 & 68 & 65 & 65 & round grave pit \\
\hline 297 & 55 & 52 & 60 & round grave pit \\
\hline 299 & 65 & 56 & 40 & oval grave pit \\
\hline 300 & 86 & 85 & 70 & round grave pit \\
\hline 302 & 80 & 60 & 60 & round grave pit \\
\hline 305 & 64 & 51 & 43 & round grave pit \\
\hline 308 & 78 & 141 & 162 & round grave pit \\
\hline
\end{tabular}




\section{Table 7 (cont'd)}

\begin{tabular}{|c|c|c|c|c|}
\hline Grave & $\begin{array}{c}\text { Depth } \\
\text { (cm) }\end{array}$ & $\begin{array}{l}\text { Lenght } \\
\text { (cm) }\end{array}$ & $\begin{array}{l}\text { Width } \\
\text { (cm) }\end{array}$ & Form \\
\hline 316 & 114 & 140 & 138 & round grave pit \\
\hline 318 & 83 & 95 & 95 & round grave pit \\
\hline 320 & 80 & 125 & 107 & oval grave pit \\
\hline 321 & 15 & - & - & destroyed grave \\
\hline 326 & 84 & 80 & 78 & round grave pit \\
\hline 332 & 80 & 105 & 95 & round grave pit \\
\hline 336 & 57 & 116 & 94 & oval grave pit \\
\hline 337 & 75 & 118 & 105 & round grave pit \\
\hline 342 & 45 & 132 & 112 & oval grave pit \\
\hline 346 & 44 & - & - & no indication of a grave pit \\
\hline 348 & 75 & 124 & 105 & oval grave pit \\
\hline 351 & ca. 25 & 98 & 79 & oval grave pit \\
\hline 357 & 30 & 118 & 97 & oval grave pit \\
\hline 358 & 102 & 110 & 88 & oval grave pit \\
\hline 362 & 48 & 113 & 85 & oval grave pit \\
\hline 365 & 41 & - & - & no indication of a grave pit \\
\hline 369 & 30 & 130 & 104 & oval grave pit \\
\hline 372 & 48 & 133 & 86 & oval grave pit \\
\hline 373 & 25 & 84 & 67 & oval grave pit \\
\hline 374 & 26 & - & - & no indication of a grave pit \\
\hline 379 & 27 & - & - & no indication of a grave pit \\
\hline 385 & 82 & 88 & 67 & oval grave pit \\
\hline 393 & 72 & 117 & 82 & oval grave pit \\
\hline 397 & 56 & 63 & 51 & oval grave pit \\
\hline 400 & 91 & 122 & 108 & oval grave pit \\
\hline 401 & 78 & 132 & 192 & oval grave pit \\
\hline 402 & 79 & 92 & 119 & oval grave pit \\
\hline 404 & 88 & 118 & 95 & oval grave pit \\
\hline 407 & 85 & 101 & 42 & the eastern half of the grave pit was destroyed \\
\hline 409 & 84 & 106 & 91 & oval grave pit \\
\hline 410 & 54 & 118 & 90 & oval grave pit \\
\hline 415 & 65 & 108 & 78 & narrow, oval grave pit \\
\hline 417 & 98 & 87 & 82 & round grave pit \\
\hline 418 & 37 & 110 & 97 & rounded, slightly oval grave pit \\
\hline 424 & 48 & 108 & 86 & oval grave pit \\
\hline 426 & 54 & 89 & 72 & oval grave pit \\
\hline 428 & 58 & 94 & 71 & narrow oval grave pit \\
\hline 438 & 118 & 120 & 92 & oval grave pit \\
\hline
\end{tabular}

whose depth ranged between 50 and $100 \mathrm{~cm}$, and graves whose depth exceeded $100 \mathrm{~cm}$. Twenty-seven graves can be assigned to the first group, ${ }^{36}$ seventy-nine to the second, ${ }^{37}$ and eighteen to the third. ${ }^{38}$ There was no apparent correlation between the grave depths and the orientation, age/sex or the placement of the deceased.

The length of the grave pits varied between 42 and $155 \mathrm{~cm}$, the average being $98 \mathrm{~cm}$. Forty-three burials had a grave pit whose length ranged between 42 and

36 Graves 15, 34, 154, 162, 165, 186, 187, 198, 212, 213, 228, 272, 281, 321, $342,346,351,357,362,365,369,372,373,374,379,418,424$.

37 Graves $4,11,17,27,29,40,52,62,76,77,81,85,86,92,93,97,99,102$, $105,107,110,119,121,122,125,133,141,147,151,157,161,166,176,184$, $188,192,199,200,201,204,214,225,231,256,264,270,271,278,283,285$, $292,293,297,299,300,302,305,308,318,320,326,332,336,337,348,385$, $393,397,400,401,402,404,407,409,410,415,417,426,428$.

38 Graves 5, 20, 32, 45, 54, 57, 69, 83, 89, 109, 150, 152, 173, 217, 288, 316, 358,438 .
$98 \mathrm{~cm},{ }^{39}$ while fifty-nine burials lay in grave pits whose length exceeded $100 \mathrm{~cm} .{ }^{40}$ The patch of discoloured earth marking the grave could not be observed in several cases. Some graves were not very deep and the presence of a burial was indicated by the discovery of the skeletal remains. In these cases, Soproni could only determine the depth of the grave. Only partial data are available for twenty-two graves.

The width of the grave varied between 40 and $192 \mathrm{~cm}$,

39 Graves $15,27,29,40,54,62,76,77,85,86,92,93,99,102,110,122$, $125,133,151,184,200,201,214,278,285,288,293,297,299,300,302$, $305,318,326,351,373,385,397,402,417,426,428$.

40 Graves $4,5,11,17,20,32,45,57,81,83,89,97,105,107,109,119,121$, $150,152,161,165,166,173,176,188,192,204,217,231,256,264,270$ $271,283,292,308,316,320,332,336,337,342,348,357,358,362,369$, $372,393,400,401,404,407,409,410,415,418,424,438$.

41 Graves 34, 52, 69, 141, 147, 154, 157, 162, 186, 187, 198, 199, 212, 213, $225,228,272,281,321,346,365,374,379$. 
the average being $116 \mathrm{~cm}$. Eighty-four burials had a width between 40 and $98 \mathrm{~cm},{ }^{42}$ seventeen burials a width between 100 and $192 \mathrm{~cm} .{ }^{43}$ The width of sixteen graves, whose presence was not indicated by a patch of discoloured earth, could not be determined.

It is unclear why some single inhumation burials had a larger than average grave pit. Some of these burials contained stones, ${ }^{44}$ which would perhaps explain their larger size, although some of these larger burials did not have any stones in them..$^{45}$

Most grave pits were oval (seventy burials, 56 per cent), others were round (twenty-three burials, 18.5 per cent) or oblong in form (six burials, 5 per cent). The form of the grave pit could not be reconstructed in twenty-one cases (17 per cent) because the patch of discoloured earth indicating the presence of a burial could not be observed. There is no data on the form of the grave pit for four burials ( 3 per cent). There was no apparent correlation between the size and the form of the grave pit and the orientation, sex or age of the deceased.

\section{Preparation of the grave pit for the funeral}

Soproni mentions in his field notes that he uncovered a small, triangular piece of charred wood of unknown function by the right pelvis in Grave 438 .

There is no evidence that any of the grave pits had been cleansed by fire prior to the deposition of the body. In some cases, stones were placed inside the grave pit as part of the preparations before the actual interment of the body. This phenomenon was observed in inhumation graves both containing or devoid of grave goods, and in the triple burials. The sides of Grave 32 were lined with ten flat stones set upright and a large flat stone was laid on the floor of the grave pit too. The body had been in part laid on this stone. Grave 410 was similarly lined with stones set upright. The number of the stones in this grave was not recorded. A similar phenomenon was observed in Grave 47, a triple inhumation burial, in which eight to ten flat stones set upright were found beside Burials A and B.

Soproni noted that in some graves, the body had been laid on a flat stone (unfortunately, the size of these stones was not recorded). This practice could be noted in the inhumation burials and in one of the symbolic graves. Grave 32 was lined with stones and the deceased was in part laid on a large flat stone placed on the floor of the grave pit. In Grave 256, the body was carefully laid on six flat stones. Soproni mentions that a

\footnotetext{
$\overline{42 \text { Graves 4, 5, 11 }}, 15,17,20,27,29,32,40,45,54,57,62,76,77,81,83$, $85,86,89,92,93,97,99,102,107,109,110,119,121,122,125,133,151$, $152,161,165,166,173,176,184,192,200,201,214,217,231,256,264$ $278,283,285,288,293,297,299,300,302,305,318,326,332,336,351$, $357,358,362,372,373,385,393,397,404,407,409,410,415,417,418$, $424,426,428,438$

43 Graves 105, 150, 188, 204, 270, 271, 292, 308, 316, 320, 337, 342, 348, $369,400,401,402$

44 Graves 105, 150, 316, 320, 400. 401, 402.

45 E.g. Graves 270, 271, 308, 342, 369
}

smaller flat stone was found at a depth of $-45 \mathrm{~cm}$ in Grave 348, but he did not record whether the body had lain on this stone. The infant buried in Grave 66, a double inhumation burial, was placed on a flat stone laid on the chest of Burial B. Grave 349, a symbolic burial, had a stone in the grave pit's south-western half at a depth of $-50 \mathrm{~cm}$.

I examined whether the grave goods in the burials containing stones set upright perhaps included other articles which had been set upright. It seems likely that objects set upright had some special meaning. Both the graves with and without grave goods contained objects of this kind. Aside from Graves 32, 47 and 410, a number of other burials too contained object set upright. Grave 52 contained a pyramid shaped stone set upright in front of the face. One of the grave goods, a stone point, was set on its edge and placed $25 \mathrm{~cm}$ east of the deceased's face in Grave 84, while in Grave 112 a stone blade was set on its edge and placed by the right forearm. An upright stone was set behind the spine of the deceased in Grave 135. The stone axe deposited in Grave 279 was set upright in front of the face.

\section{Deposition of the body in the grave}

Most of the deceased were interred in a contracted position. Sixty-four burials contained bodies laid on the left side (52 per cent), ${ }^{46}$ forty-five burials had the deceased laid on the right side (40 per cent), ${ }^{47}$ and one person was laid extended on the back ( 0.8 per cent). ${ }^{48}$ The placement of the body could not be determined owing to disturbance or the bad preservation of the skeletal remains in nine burials (10 per cent). ${ }^{49}$ In some cases, the body was dislodged from its original position or had turned over as a result of post-depositional processes.

Table 6 shows the orientation and placement, together with the age and sex of the deceased. No matter how the data in the table was grouped, no correlation could be established between placement and sex, i.e. men, women and children were laid to rest both on their right and left side. Fourteen men, nineteen women and twenty-four infants/children were laid on the left side, eleven men, sixteen women and twenty-three infants/children were laid on the right side and in nine cases the placement could not be determined.

\footnotetext{
$\overline{46}$ Graves 4, 15, 17, 20, 29, 45, 54, 62, 76, 83, 89, 97, 105, 110, 121, 125, $150,151,157,161,162,166,176,186,187,192,198,199,200,201,212$ $213,214,217,228,231,264,270,278,285,292,299,308,326,332,336$ $346,357,362,372,373,379,400,401,402,404,407,409,410,415,426$ 438. The deceased in Graves 27 and 374 had probably also been laid on the left side.

47 Graves 5, 11, 34, 52, 57, 85, 92, 93, 99, 107, 109, 119, 122, 141, 152, 165 , $173,184,188,204,225,256,271,283,288,293,297,300,316,318,320$ $337,342,348,351,358,365,369,385,393,397,417,418,424,428$. The deceased interred in Graves 40, 81, 154, 272 and 305 had probably also been laid on the right side.

48 Grave 281

49 Graves 32, 69, 77, 86, 102, 133, 147, 302, 321 .
} 


\section{Post-interment activities}

In the case of burials devoid of grave goods, we can only document how the grave was left behind. Soproni recorded that in many cases stones were placed or thrown on the body and that the skull was broken in several burials. This custom is usually explained by a fear of the return of the deceased and the prevention of their return. Fifty-four burials (44 per cent) contained one or more stones. It is unclear when the stones were deposited in the grave in about one-half of these burials because Soproni did not record this for twenty-seven graves. ${ }^{50}$ The stones were placed in the grave (along the sides and on the floor of the pit) as part of the preparation for the funeral in the case of Grave 32; similarly, six flat stones were placed on the floor of the grave pit in Grave 256 and the deceased was laid on these stones, after which the burial was covered with stones. In twenty-seven burials (about one-half of the burials with stones), the stones were placed in the grave after the funeral. ${ }^{51}$ The stones lay on the body in Graves 152, 192, 293, 357, 401 and 402. The stones were not put in the grave with any particular care since in many cases the longbones were broken as a result of pelting the body with stones, ${ }^{52}$ and sometimes even the skull was smashed. ${ }^{53}$ In other cases, the stones were placed in the grave with greater care and were used for covering the head ${ }^{54}$ or the body..$^{55}$

\section{Disturbed burials}

Twenty-eight of the inhumation burials without grave goods were disturbed (22 per cent). ${ }^{56}$ These burials were disturbed at different times, and a distinction must be drawn between burials disturbed in the Copper Age and graves disturbed by modern intrusions. It is not known why burials without grave goods were disturbed for in these cases looting could hardly have been a motivation. Soproni noted that Grave 327 was probably disturbed while the cemetery was still in use, although he did not elaborate this point. It is unclear whether Graves 32, 102, 302 and 374 were disturbed during the Copper Age or as a result of later intrusions. ${ }^{57}$ Little survived of the skeletal remains in Graves 40, 54, 81, 86, 92,147, 187 and 213, either as a result of disturbances or of chemical (disintegration) processes in the soil.

\footnotetext{
50 Graves $4,5,27,29,45,57,62,69,77,85,86,105,107,122,150,200$ $214,283,285,288,302,316,320,326,332,348,404$.

51 Graves 32, 76, 81, 93, 97, 119, 152, 192, 198, 212, 217, 256, 293, 297, 336, 351, 357, 362, 397, 400, 401, 402, 410, 415, 424, 426, 438.

52 Graves 97, 119, 336, 351, 397

53 Graves 93, 297, 400, 410, 415, 426 .

54 Graves 76, 198, 362, 424.

55 Graves 81, 212, 217, 426

56 Graves 5, 15, 17, 32, 34, 40, 54, 69, 81, 86, 102, 125, 133, 141, 147, 162 , $165,187,272,302,321,346,357,372,373,374,407,418$.

57 Graves 5, 15, 17, 34, 69, 76, 77, 125, 133, 141, 154, 162, 165, 272, 321, $346,357,373,374,407,418$
}

\section{MULTIPLE BURIALS}

The practice of depositing two or more bodies in the same grave pit can be noted throughout prehistory. Only one of the graves in the Budakalász cemetery contained burials according to different rites: Grave 155 contained an inhumation and a scattered cremation burial. Grave 131 contained a scattered cremation and an inurned burial. The other multiple graves were all inhumation burials. One of these contained the remains of two humans and two cattle (Grave 3).

One important issue as regards multiple burials in the same grave is whether the deceased were interred at the same time, as part of the same funeral, or whether some time elapsed between the interments. In the latter case, the question arises whether the funeral was concluded according to the community's funeral rites (e.g. by covering the graves with stones) or whether the grave pit was left open. A few observations made during the excavation of the cemetery offer some guidance in this respect. With the exception of the disturbed burials, the skeletal remains lay in anatomical order in the multiple burials too (similarly to the single inhumation burials), indicating that scavenger animals did not have access to the body and could not disturb the remains. We may therefore exclude the possibility that the grave pit was left open. It also follows from the above that the time elapsed between the deposition of the bodies in the multiple burials was not too long and that the burials in these multiple graves are virtually contemporaneous.

It seems likely that in a large cemetery separate from the settlement, as the one at Budakalász, everything had a special meaning and that double burials were hardly the work of chance. The bond between the individuals buried in these graves was probably so strong that it survived death and continued to bind the two persons: if one died, the other followed him/her even in death. The proportion of infants/children in the double burials is strikingly high, which might suggest that these double burials contain women who died during childbirth. This is not the case, however, since these burials contain one woman buried with another, one man buried with another, women with children, men with children, men with women, and children with children, meaning that there is no correlation between double burials and childbirth.

We may assume that the deceased was buried with his/her close relative, although in this case the community had to perform a cruel, irrational murder in order to ensure the simultaneous burial of the two (or three) persons. These murders were probably ritual in nature.

The number of double burials in the Budakalász cemetery is quite high. Ten per cent of the 355 inhumation burials were uncovered in double graves ${ }^{58}$

\footnotetext{
58 Graves 3, 13, 48, 55, 56, 66, 71, 78, 79, 80, 100, 101, 106, 108, 113, 123 , $126,134,142,149,153,167,169,195,263,290,334,366,388,389,396$ 399,405 , i.e. sixty-six individuals interred in thirty-three graves. Grave 155 , containing one inhumation and one cremation burial, can also be assigned here, giving a total of sixty-seven individuals.
} 
and only 1 per cent in a triple grave..$^{59}$ Compared to the overall number of burials, double burials account for 7.6 per cent and triple burials for less than 1 per cent.

\section{DOUBLE INHUMATION BURIALS}

\section{Preparation for the funeral}

Double inhumation graves can be examined from several perspectives in order to shed light on the archaeologically visible canonised elements of the funerary rite. As has been mentioned in the above, one of the most important elements of the preparation for the funeral was the selection of the grave location. It is clear from the cemetery map that the graves were somehow marked after the funeral (with stones, plants planted over the grave, etc.) and that new burials disturbed earlier ones only if these markers were no longer visible. The digging of the grave pit, its orientation, and the preparation or acquisition of the various articles deposited beside the body (vessels, jewellery, tools and implements, etc.) were similarly important elements of the burial ceremony.

\section{Selection of the grave location}

The plan of the cemetery indicates that double burials occur in greater number in the southern half of the cemetery. Most of these burials lie fairly close to each other in a rather wide zone (twenty-seven graves). ${ }^{60}$ Double burials often lie beside or in close proximity to each other. ${ }^{61}$ Graves 123, 142 and 153 almost formed a line. Only seven double graves were found in the northern part of the cemetery; ${ }^{62}$ of these, Graves 388, 396 and 399 lay close to each other, as did Graves 334 and 366. Lying between the northern and southern part of the cemetery was an area which was devoid of double burials.

\section{Orientation}

Table 8 shows the placement of the body, the orientation, and the sex and age of the deceased.

Table 8. Double inhumation graves: orientation, deposition, sex and age at death of the deceased*

\begin{tabular}{|c|c|c|c|c|}
\hline Grave & Deposition & Age at death & Sex & Orientation \\
\hline $3 / \mathrm{A}$ & left side & (?) & (female ?) & E-SE to W-NW, with the head to the E-SE \\
\hline $3 / \mathrm{B}$ & right side & (?) & (male) & E-SE to W-NW, with the head to the E-SE \\
\hline 13/A & left side & $10-12$ years & child & S-SE to N-NW, with the head to the S-SE \\
\hline 13/B & right side & (child) & (child) & $\mathrm{S}-\mathrm{SE}$ to $\mathrm{N}-\mathrm{NW}$, with the head to the S-SE \\
\hline 48/A & left side & $10-12$ years & child & $\mathrm{S}$ to $\mathrm{N}$, with the head to the $\mathrm{S}$ \\
\hline 48/B & left side & $14-16$ years & female & $\mathrm{S}$ to $\mathrm{N}$, with the head to the $\mathrm{S}$ \\
\hline $55 / \mathrm{A}$ & right side & (child) & (child) & $\mathrm{S}$ to $\mathrm{N}$, with the head to the $\mathrm{S}$ \\
\hline $55 / \mathrm{B}$ & left side (?) & (infant) & (infant) & $\mathrm{S}$ to $\mathrm{N}$, with the head to the $\mathrm{S}$ \\
\hline $56 / \mathrm{A}$ & right side & $23-x$ years & female (?) & E-W, with the head to the E \\
\hline $56 / \mathrm{B}$ & right side & (child) & (?) & SE to NW, with the head to the SE \\
\hline 66/A & left side & $0-0.5$ years & infant & SW to NE, with the head to the SW \\
\hline $66 / \mathrm{B}$ & left side & $40-59$ years & male & NW to SE, with the head to the SE \\
\hline 71/A & left side & $0-1$ years & child & E-SE to W-NW, with the head to the E-SE \\
\hline $71 / \mathrm{B}$ & right side & $0-1$ years & child & E-SE to W-NW, with the head to the E-SE \\
\hline 78/A & right side & $0.5-1.5$ years & child & S-SE to N-NW, with the head to the S-SE \\
\hline 78/B & left side & $4-6$ years & child & - \\
\hline 79/A & left side & $25-35$ years & male & $\mathrm{S}$ to $\mathrm{N}$, with the head to the $\mathrm{S}$ \\
\hline $79 / \mathrm{B}$ & right side & $35-45$ years & female (?) & SE to NW, with the head to the SE \\
\hline 80/A & left side & $2-3$ years & child & SE to NW, with the head to the SE \\
\hline $80 / \mathrm{B}$ & left side & (child) & (child) & - \\
\hline 100/A & left side & (male) & (male) & E-SE to W-NW, with the head to the E-SE \\
\hline $100 / \mathrm{B}$ & ? & (female) & (female) & - \\
\hline 101/A & left side & $9-10$ years & child & $\mathrm{S}-\mathrm{SE}$ to $\mathrm{N}-\mathrm{NW}$, with the head to the S-SE \\
\hline 101/B & right side & $1-2$ years & child & S-SE to N-NW, with the head to the S-SE \\
\hline 106/A & left side & (child) & (child) & S-SW to N-NE, with the head to the S-SW \\
\hline $106 / \mathrm{B}$ & right side & $9-11$ years & child & $\mathrm{S}$ to $\mathrm{N}$, with the head to the $\mathrm{S}$ \\
\hline 108/A & left side & $9-10$ years & child & SE to NW, with the head to the SE \\
\hline
\end{tabular}

* The data in parentheses indicate the age/sex determinations quoted from the excavation diary

59 Graves 47, 182, 215, 391, i.e. twelve individuals in four graves. 60 Graves 3, 13, 48, 55, 56, 66, 71, 78, 79, 80, 100, 101, 106, 108, 113, 123, $126,134,142,149,153,155,167,169,195,290,405$.
${ }_{61}$ Graves 13, 48, 56 and 101 form a cluster, as do Graves 134, 167 and 169, Graves 100, 108,113, 126 and 149, and Graves 55, 71, 78, 80 and 106

62 Graves 263, 334, 366, 388, 389, 396, 399. 
Table 8 (cont'd)

\begin{tabular}{|c|c|c|c|c|}
\hline Grave & Deposition & Age at death & Sex & Orientation \\
\hline 108/B & left side & $7-14$ years & child & $\mathrm{S}$ to $\mathrm{N}$, with the head to the $\mathrm{S}$ \\
\hline 113/A & left side & $9-10$ years & child & $\mathrm{E}-\mathrm{SE}$ to $\mathrm{W}-\mathrm{NW}$, with the head to the E-SE \\
\hline 113/B & left side & (child) & (child) & S-SW to N-NE, with the head to S-SW \\
\hline $123 / \mathrm{A}$ & left side & $40-50$ years & female & S-SW to N-NE, with the head to the S-SW \\
\hline 123/B & right side & $1-2$ years & child & $\mathrm{S}$ to $\mathrm{N}$, with the head to the $\mathrm{S}$ \\
\hline $126 / \mathrm{A}$ & left side & $30-40$ years & female & $\mathrm{S}$ to $\mathrm{N}$, with the head to the $\mathrm{S}$ \\
\hline $126 / \mathrm{B}$ & right side & $12-14$ years & child & $\mathrm{N}-\mathrm{NW}$ to $\mathrm{S}-\mathrm{SE}$, with the head to the N-NW \\
\hline 134/A & left side & $15-19$ years & $?$ & $\mathrm{~S}$ to $\mathrm{N}$, with the head to the $\mathrm{S}$ \\
\hline 134/B & right side & $23-\mathrm{x}$ years & $?$ & $\mathrm{~S}$ to $\mathrm{N}$, with the head to the $\mathrm{S}$ \\
\hline 142/A & right side & $2.5-3.5$ years & child & E-NE to W-SW, with the head to the E-NE \\
\hline 142/B & right side & $23-39$ years & male & S-SW to N-NE, with the head to the S-SW \\
\hline 149/A & left side & $13-15$ years & child & SE to NW, with the head to the SE \\
\hline 149/B & right side & $5-6$ years & child & SE to NW, with the head to the SE \\
\hline $153 / \mathrm{A}$ & right side & $40-x$ years & male & SE to NW-with the head to the SE \\
\hline 153/B & right side & $40-59$ years & male (?) & E-SE to W-NW, with the head to the E-SE \\
\hline $167 / \mathrm{A}$ & left side & $15-17$ years & female & $\mathrm{E}-\mathrm{W}$, with the head to the $\mathrm{E}$ \\
\hline $167 / \mathrm{B}$ & left side & 4-6 years & child & $\mathrm{E}-\mathrm{W}$, with the head to the $\mathrm{E}$ \\
\hline 169/A & right side & $35-55$ years & male (?) & SW to NE, with the head to the SW \\
\hline 169/B & right side & $50-70$ years & female (?) & S-SW to N-NE, with the head to the S-SW \\
\hline 195/A & left side & $40-50$ years & female & $W$ to E, with the head to the west \\
\hline 195/B & left side & $23-\mathrm{x}$ years & male (?) & $\mathrm{W}-\mathrm{NW}$ to $\mathrm{E}-\mathrm{SE}$, with the head to the $\mathrm{W}-\mathrm{NW}$ \\
\hline 263/A & right side & $35-59$ years & male (?) & S-SE to N-NW, with the head to the S-SE \\
\hline $263 / \mathrm{B}$ & left side & $40-49$ years & female & $\mathrm{S}$ to $\mathrm{N}$, with the head to the $\mathrm{S}$ \\
\hline 290/A & $?$ & (male) & (male) & - \\
\hline 290/B & left side & $40-x$ years & male & $W$ to $E$, with the head to the $W$ \\
\hline $334 / \mathrm{A}$ & left side & $1.5-2$ years & child & W-SW to E-NE, with the head to the W-SW \\
\hline 334/B & left side & $0-0.5$ years & child & W-SW to E-NE, with the head to the W-SW \\
\hline 366/A & left side & $21-23$ years & female & SE to NW, with the head to the SE \\
\hline $366 / \mathrm{B}$ & left side & $40-59$ years & male & SE to NW, with the head to the SE \\
\hline 388/A & left side & $30-50$ years & male & S-SW to N-NE, with the head to the S-SW \\
\hline 388/B & right side & $40-59$ years & female & S-SW to N-NE, with the head to the S-SW \\
\hline 389/A & right side & $40-59$ years & female & E-SE to $W-N W$, with the head to the E-SE \\
\hline 389/B & right side & $13-14$ years & child & E-SE to $W-N W$, with the head to the E-SE \\
\hline 396/A & left side & $40-\mathrm{x}$ years & female (?) & S-SW to N-NE, with the head to the S-SW \\
\hline 396/B & right side & $40-x$ years & male & SE to NW, with the head to the SE \\
\hline 399/A & left side & $30-40$ years & female & $\mathrm{S}$ to $\mathrm{N}$, with the head to the $\mathrm{S}$ \\
\hline 399/B & $?$ & $0.5-1$ years & child & - \\
\hline 405/A & left side & $35-45$ years & male & $W$ to E, with the head to the west \\
\hline $405 / \mathrm{B}$ & right side & $30-40$ years & female & $\mathrm{W}-\mathrm{SW}$ to E-NE, with the head to the $\mathrm{W}-\mathrm{SW}$ \\
\hline
\end{tabular}

Orientation shows a wide variability. I examined whether any patterns could be discerned in the orientation of burials with grave goods and those without any grave goods. Tables $9-11$ shows the orientations of the burials in these graves.

Most of the deceased were interred with the head toward the south or with a slight divergence to the south-east, the south-south-east or the east-south-east (thirteen burials). One burial was oriented to the northwest and the orientation could not be determined in the case of two burials.

Placement on the left side (twelve burials) was more frequent than on the right side (three burials). The deceased were laid to rest either facing each other ${ }^{63}$ or

$\overline{63 \text { Graves 66, 100 }}, 113,263$. parallel to each other. ${ }^{64}$ No other patterns could be discerned between orientation and placement on the right or left side.

Most burials were oriented to the south or with a slight divergence to the south-east, the south-southeast or the east-south-east (twenty-four burials). Seven were aligned to the west or roughly to the west, while one burial had an east to west orientation and another one an east-north-east to west-south-west alignment. The orientation of three burials could not be determined.

Placement on the left side (twenty burials) was again more frequent than on the right side (fourteen burials). The deceased were laid to rest either facing each

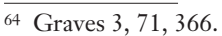


Table 9. Orientation of double burials with grave goods in both burials

\begin{tabular}{|c|c|c|c|c|}
\hline Orientation & Burials & $\begin{array}{l}\text { Laid on the } \\
\text { left side }\end{array}$ & $\begin{array}{l}\text { Laid on the } \\
\text { right side }\end{array}$ & Indet. \\
\hline SW to NE & $\begin{array}{c}1 \\
\text { (Grave 66/A) }\end{array}$ & 1 & - & - \\
\hline E-SE to W-NW & $\begin{array}{c}6 \\
\text { (Graves 3/A, 3/B, 71/A, 71/B, 100/A, 113/A) }\end{array}$ & 4 & 2 & - \\
\hline S-SW to N-NE & $\begin{array}{c}1 \\
(\text { Grave } 113 / \mathrm{B})\end{array}$ & 1 & - & - \\
\hline SE to NW & $\begin{array}{c}4 \\
\text { (Graves 66/B, 80/A, 366/A, 366/B) }\end{array}$ & 4 & - & - \\
\hline S-SE to N-NW & $\begin{array}{c}1 \\
(\text { Grave 263/A) }\end{array}$ & - & 1 & - \\
\hline $\mathrm{S}$ to $\mathrm{N}$ & $\begin{array}{c}1 \\
\text { (Grave 263/B) }\end{array}$ & 1 & - & - \\
\hline Indet. & $\begin{array}{c}2 \\
\text { (Graves } 80 / \mathrm{B}, 100 / \mathrm{B})\end{array}$ & 1 & - & 1 \\
\hline Total & 16 & 12 & 3 & 1 \\
\hline
\end{tabular}

Table 10. Orientation of double burials with grave goods in one of the two burials

\begin{tabular}{|c|c|c|c|c|}
\hline Orientation & Burials & $\begin{array}{l}\text { Laid on the } \\
\text { left side }\end{array}$ & $\begin{array}{l}\text { Laid on the } \\
\text { right side }\end{array}$ & Indet. \\
\hline W-NW to E-SE & $\begin{array}{c}1 \\
\text { (Grave 195/B) }\end{array}$ & 1 & - & - \\
\hline N-NE to W-SW & $\begin{array}{c}1 \\
\text { (Grave 142/A) }\end{array}$ & - & 1 & - \\
\hline E to $W$ & $\begin{array}{c}1 \\
\text { (Grave } 56 / \mathrm{A})\end{array}$ & - & 1 & - \\
\hline $\mathrm{W}$ to $\mathrm{E}$ & $\begin{array}{c}2 \\
\text { (Graves 195/A, 405/a) }\end{array}$ & 2 & - & - \\
\hline W-SW to E-NE & $\begin{array}{c}4 \\
\text { (Graves 290/B, 334/A, 334/B 405/B) }\end{array}$ & 3 & 1 & - \\
\hline S-SW to N-NE & $\begin{array}{c}5 \\
\text { (Graves 106/A, 123/A, 142/B, 388/A, 388/B) }\end{array}$ & 3 & 2 & - \\
\hline SE to NW & $\begin{array}{c}4 \\
\text { (Graves 56/B, 108/A, 149/A, 149/B) }\end{array}$ & 2 & 2 & - \\
\hline S-SE to N-NW & $\begin{array}{c}5 \\
\text { (Graves 13/A, 13/B, 78/A, 101/A, 1001/B) }\end{array}$ & 2 & 3 & - \\
\hline $\mathrm{S}$ to $\mathrm{N}$ & $\begin{array}{c}10 \\
\text { (Graves 48/A, 48/B, 55/A, 55/B, 106/B } \\
\text { 108/B, 123/B, 134/A, 134/B, 399/A) }\end{array}$ & 6 & 4 & - \\
\hline Indet. & $\begin{array}{c}3 \\
\text { (Graves 78/B, 290/A, 399/B) }\end{array}$ & 1 & - & 2 \\
\hline Total & 36 & 20 & 14 & 2 \\
\hline
\end{tabular}

other ${ }^{65}$ or parallel to each other. ${ }^{66}$ No other patterns could be discerned between orientation and placement on the right or left side.

Most burials were again oriented to the south, with

\footnotetext{
$\overline{65}$ Graves 13, 55 , 78, 101, 106, 123, 134, 149, 388, 405.

66 Graves 56, 108, 142, 334, 388.
}

the head of the deceased aligned to the south or with a slight divergence to the south-east, the south-southwest or the east-south-east (ten burials). Two were aligned to the east, while one burial was oriented to the north-north-east and another to the west-north-west.

Placement on the right side (nine burials) was more frequent than on the left side (five burials). The 
Table 11. Orientation of double burials with no grave goods in either burial

\begin{tabular}{|c|c|c|c|}
\hline Orientation & Burials & Laid on the left side & Laid on the right side \\
\hline N-NW to S-SE & $\begin{array}{c}1 \\
\text { (Grave 126/B) }\end{array}$ & - & 1 \\
\hline E to $W$ & $\begin{array}{c}2 \\
\text { (Graves 167/A, 167/B) }\end{array}$ & 2 & - \\
\hline SW to NE & $\begin{array}{c}1 \\
\text { (Grave 169/A) }\end{array}$ & - & 1 \\
\hline E-SE to W-NW & $\begin{array}{c}3 \\
\text { (Graves 153/B, 389/A, 389/B) }\end{array}$ & - & 3 \\
\hline S-SW to N-NE & $\begin{array}{c}2 \\
\text { (Graves 169/B, 396/A) }\end{array}$ & 1 & 1 \\
\hline $\mathrm{SE}$ to $\mathrm{NW}$ & $\begin{array}{c}3 \\
\text { (Graves 79/B, 153/A, 396/B) }\end{array}$ & - & 3 \\
\hline $\mathrm{S}$ to $\mathrm{N}$ & $\begin{array}{c}2 \\
\text { (Graves 79/A, 126/A) }\end{array}$ & 2 & - \\
\hline Total & 14 & 5 & 9 \\
\hline
\end{tabular}

deceased were laid to rest either facing each other ${ }^{67}$ or parallel to each other. ${ }^{68}$ No other patterns could be discerned between orientation and placement on the right or left side.

There was no apparent correlation between orientation and placement, and the age or sex of the deceased or the presence of grave goods. In contrast to earlier periods, the burial rite did not prescribe a strict placement on the right or the left side according to sex and/or age, or orientation by the Baden period.

\section{Digging of the grave pit}

The depth of double inhumation burials varied between 20 and $135 \mathrm{~cm}$, the average being around $80 \mathrm{~cm}$ (Table 12).

Their length ranged between 82 and $290 \mathrm{~cm}$, their width between 55 and $163 \mathrm{~cm}$. Graves 13, 55, 71, 78, 101 and 334, containing child burials, were fairly small, while the unusually large grave pit of Grave 3 accommodated the burials of two adults and two cattle. The size of this grave pit and the presence of cattle burials have led some scholars to believe that the grave had also contained a genuine wagon, but there is nothing in Soproni's field notes to warrant an interpretation along these lines.

Most grave pits were oval. Similarly to the single inhumation burials, there was no correlation between the size of the grave pit and the age or sex of the deceased.

Preparation of the grave pit for the funeral

There is no archaeological evidence for any additional preparation of the grave pit or for the deposition of flat

\footnotetext{
$\overline{67}$ Graves 79, 126, 396.

68 Graves 153, 167, 169, 389.
}

stones on the grave floor. Soproni does not describe the double inhumation burials in as great detail as the single burials; he appers to have been more concerned with determining the sequence of the burials and their possible contemporaneity. His field notes contain no references to flat stones on the floor of the grave pit on which the bodies had been laid, suggesting that there is no relation between double inhumation graves and single inhumation burials, in which the deceased had been placed on stones.

\section{Deposition of the body in the grave}

The deceased laid to rest in double inhumation graves were interred in a contracted position. The double inhumation graves included two graves in which only a skull was placed beside the other body. Burial A in Grave 290 was made up of an adult's skull, without any other skeletal remains, while Burial B contained a complete skeleton, whose skull had been crushed by the stones in the grave. Both were male burials. Burial A in Grave 399 contained the complete skeleton of a woman, while no more than small skull fragments and a few tiny bones remained of Burial $\mathrm{B}$, an infant.

Table 13 shows the orientation and the placement of the deceased. The deceased was laid on the left side in thirty-six burials and on the left side in twenty-seven burials. The placement could not be determined in the case of three burials.

Fig. 13 reveals that the deceased were predominantly oriented to the south or that they diverged but slightly from this direction (49 burials, 74 per cent). An east to west or west to east orientation and their variants could be noted in the double graves, in which only one of the burials was provided with grave goods ( 9 burials, 14 per cent). The double grave in which neither burial had any grave goods (Grave 167) was oriented east to west. The 
Table 12. Double inhumation graves: size and form of the grave pits

\begin{tabular}{|c|c|c|c|c|}
\hline Grave & $\begin{array}{l}\text { Depth } \\
\text { (cm) }\end{array}$ & $\begin{array}{l}\text { Lenght } \\
\text { (cm) }\end{array}$ & $\begin{array}{l}\text { Width } \\
\text { (cm) }\end{array}$ & Form \\
\hline 3 & 85 & $290-320$ & 125 & - \\
\hline 13 & 95 & 90 & 55 & oblong grave pit with rounded corners \\
\hline 48 & 100 & 105 & 145 & oval grave pit \\
\hline 55 & 100 & 95 & 75 & oval grave pit \\
\hline 56 & 85 & 115 & 90 & oval grave pit \\
\hline 66 & 95 & 110 & 80 & oval grave pit \\
\hline 71 & 80 & 95 & 80 & rounded grave pit \\
\hline 78 & 85 & 95 & 75 & oval grave pit \\
\hline 79 & $20-45$ & 110 & 130 & round grave pit \\
\hline 80 & 78 & 90 & 100 & round grave pit \\
\hline 100 & 70 & 160 & 205 & irregular, oval grave pit \\
\hline 101 & 90 & 85 & 75 & oval grave pit \\
\hline 106 & 70 & 120 & 95 & oval grave pit \\
\hline 108 & 100 & 110 & 90 & round grave pit \\
\hline 113 & 135 & 125 & 110 & oval grave pit \\
\hline 123 & 85 & 125 & 88 & oval grave pit \\
\hline 126 & 95 & 145 & 100 & oval grave pit \\
\hline 134 & 53 & 120 & 75 & grave pit partly destroyed \\
\hline 142 & 92 & 155 & 130 & oval grave pit \\
\hline 149 & 68 & 122 & 97 & oval grave pit \\
\hline 153 & 108 & 142 & 138 & round grave pit \\
\hline 167 & 96 & 115 & 80 & oval grave pit \\
\hline 169 & 20 & 142 & 98 & oval grave pit \\
\hline 195 & 70 & 122 & 105 & oval grave pit \\
\hline 263 & 73 & 90 & 132 & oval grave pit \\
\hline 290 & 100 & 130 & 85 & oval grave pit \\
\hline 334 & 102 & 82 & 68 & oval grave pit \\
\hline 366 & 112 & 168 & 157 & round grave pit \\
\hline 388 & 63 & 140 & 163 & oval grave pit \\
\hline 389 & 57 & 115 & 103 & oval grave pit \\
\hline 396 & 78 & 156 & 120 & oval grave pit \\
\hline 399 & 81 & 134 & 96 & oval grave pit \\
\hline 405 & 72 & 151 & 132 & oval grave pit \\
\hline
\end{tabular}

single burial aligned north-north-west to south-southeast had no grave goods either (Grave 126/A).

Soproni interpreted Graves 263, 366, 388 and 389 as contemporaneous burials. Grave 263 was not disturbed, the bodies lay one over the other, and there were three stones in the region above the skulls. Neither was there any apparent disturbance in Grave 388. Form the position of the bodies, Soproni concluded that Burial A was the earlier one and that Burial B was deposited next. The field notes offer no explanation of why Soproni regarded the burials in Graves 366 and 389 as being contemporaneous. As regards the former grave, Burial B lay in part behind and in part under Burial A, suggesting that the former was deposited first and the latter was laid partly over it later.

Soproni recorded two interesting features in the case of Graves 100 and 113, both of which yielded evidence of burning. The skeletal remains in Grave 100 were

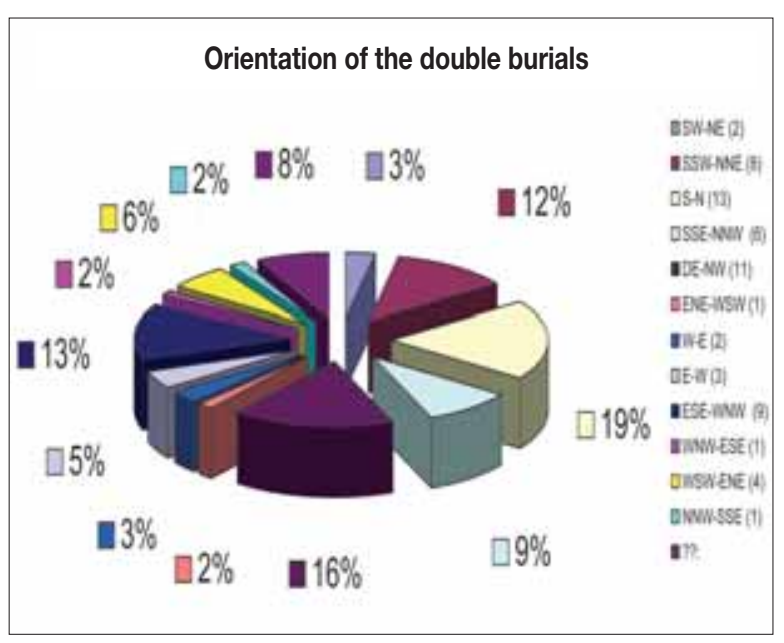

Fig. 13. Orientation of the double burials 
Table 13. Orientation and placement of the deceased in double inbumation burials

\begin{tabular}{|c|c|c|c|c|c|}
\hline Orientation & Burials & $\begin{array}{l}\% \text { of all } \\
\text { double } \\
\text { burials }\end{array}$ & $\begin{array}{l}\text { Laid on } \\
\text { left side }\end{array}$ & $\begin{array}{l}\text { Laid on } \\
\text { right side }\end{array}$ & Indet. \\
\hline SW to NE & $\begin{array}{c}2 \\
\text { (Graves 66/A, 169/A) }\end{array}$ & 3 & 1 & 1 & - \\
\hline E-SE to W-NW & $\begin{array}{c}9 \\
\text { (Graves 3/A, 3/B, 71/A, 71/B, 100/A, 113/A, } \\
\text { 153/B, 389/A, 389/B) }\end{array}$ & 13 & 4 & 5 & - \\
\hline S-SW to N-NE & $\begin{array}{c}8 \\
\text { (Graves 106/A, 113/B, 123/A, 142/B, 169/B, 388/A } \\
\text { 388/B, 396/A) }\end{array}$ & 12 & 4 & 4 & - \\
\hline SE to NW & $\begin{array}{c}11 \\
(\text { Graves 56/B, 66/B, 79/B, 80/A, 108/A, 149/A, 149/B } \\
\text { 153/A, 366/A, 366/B, 396/B) }\end{array}$ & 16 & 6 & 5 & - \\
\hline S-SE to N-NW & $\begin{array}{c}6 \\
\text { (Graves 13/A, 13/B, 78/A, 101/A, 1001/B, 263/A) }\end{array}$ & 9 & 2 & 4 & - \\
\hline S to $\mathrm{N}$ & $\begin{array}{c}13 \\
\text { (Graves 48/A, 48/B, 55/A, 55/B, 79/A, 106/B, 108/B } \\
\text { 123/B, 126/A 134/A, 134/B, 263/B, 399/A) }\end{array}$ & 19 & 9 & 4 & - \\
\hline $\mathrm{W}-\mathrm{NW}$ to $\mathrm{E}-\mathrm{SE}$ & $\begin{array}{c}1 \\
(\text { Grave 195/B) } \\
\end{array}$ & 2 & 1 & - & - \\
\hline E-NE to $W-S W$ & $\begin{array}{c}1 \\
\text { (Grave 142/A) }\end{array}$ & 2 & - & 1 & - \\
\hline E to $W$ & $\begin{array}{c}3 \\
\text { (Graves 56/A, 167/A, 167/B) }\end{array}$ & 5 & 2 & 1 & - \\
\hline $\mathrm{W}$ to $\mathrm{E}$ & $\begin{array}{c}2 \\
\text { (Graves 195/A, 405/A) }\end{array}$ & 3 & 2 & - & - \\
\hline W-SW to E-NE & $\begin{array}{c}4 \\
\text { (Graves 290/B, 334/A, 334/B 405/B) }\end{array}$ & 6 & 3 & 1 & - \\
\hline N-NW to S-SE & $\begin{array}{c}1 \\
(\text { Grave 126/B) }\end{array}$ & 2 & - & 1 & - \\
\hline Indet. & $\begin{array}{c}5 \\
\text { (Graves 78/B, 80/B, 100/B, 290/A, 399/B) }\end{array}$ & 7 & 2 & - & 3 \\
\hline Total & 66 & & 36 & 27 & 3 \\
\hline
\end{tabular}

burnt, suggesting that a fire had been lit on the interred bodies. The bones of Burial B were black and brittle, reflecting strong burning. The centre of the fire apparently lay on the body in Burial B. The facial bones of the skull and the chest of the body in Burial A were also quite strongly burnt. The spine was burnt to a bright red colour. The legs were unaffected by the fire. Both skeletons lay in an $8-10 \mathrm{~cm}$ thick layer of black ash. Red ash was noted around the skull of Burial B. Burnt specks lay in the ash, but no charcoal fragments were found. The deceased were laid in the grave wearing jewellery as shown by the strongly burnt beads found after the grave was cleared: both burials had been lifted in situ and taken to the Szentendre museum. Grave 113 contained two child burials. Traces of burning could be noted on the upper part of both skeletons and on the leg bones in Burial A. An 8-10 cm thick layer of fine ash covered the upper part of both skeletons. The two bodies had apparently been burned in the same manner as the bodies in Grave 100, with the fire kindled on the bodies. Soproni noted a thick ash layer in both graves, suggesting that wood and various plants had been heaped over the bodies for the fire.

The reasons for burning the deceased or for lighting a fire over the bodies are not known. Soproni does not mention the remains of a pyre or a wooden structure in his field notes, suggesting that combustible organic matter had been thrown over the deceased and set on fire. ${ }^{69}$ It seems likely that the aim was not total cremation and that this burning had some other meaning (the techniques for total cremation were well known, as were the materials needed for attaining the necessary temperature, as shown by the contemporaneous inhumation and cremation burials in Grave 155).

69 A similar phenomenon was noted at Sitzenberg (NEUGEbauerMaresch-Teschler-Nicola 1984, 129, 132-133). 
Table 14. Distribution of grave goods according to type in the double graves with grave goods in both burials

\begin{tabular}{|c|c|c|c|c|c|c|}
\hline Grave & Sex & Vessels & Jewellery & Metal & Stone & Other \\
\hline $3 / \mathrm{A}$ & female (?) & $\begin{array}{l}\text { two goblets and } \\
\text { scooping vessel }\end{array}$ & - & & $\begin{array}{l}\text { blade and } \\
\text { two flakes }\end{array}$ & \\
\hline $3 / \mathrm{B}$ & male & - & - & copper awl & - & - \\
\hline 66/A & infant & - & shell plaque & - & - & - \\
\hline 66/B & male & - & bead necklace & - & - & - \\
\hline $71 / \mathrm{A}$ & child & - & $\begin{array}{l}\text { bead necklace } \\
\text { and two } \\
\text { shell plaques }\end{array}$ & - & - & - \\
\hline $71 / \mathrm{B}$ & child & pot fragments & shell plaques & - & - & - \\
\hline 80/A & child & $\begin{array}{l}\text { scooping vessel } \\
\text { and pottery } \\
\text { fragments }\end{array}$ & - & - & - & animal bone \\
\hline $80 / \mathrm{B}$ & child & - & $\begin{array}{c}\text { necklace around } \\
\text { the neck }\end{array}$ & - & - & - \\
\hline 100/A & male & - & bead strand & - & - & - \\
\hline 100/B & female & - & bead strand & - & - & - \\
\hline $113 / \mathrm{A}$ & child & - & beads & $\begin{array}{c}\text { broken } \\
\text { copper bead }\end{array}$ & - & - \\
\hline 113/B & child & - & necklace & copper beads & - & - \\
\hline $263 / \mathrm{A}$ & male (?) & - & $\begin{array}{c}\text { two shell plaques } \\
\text { and beads }\end{array}$ & - & - & - \\
\hline 263/B & female & goblet & beads & - & $\begin{array}{c}\text { blade fragment } \\
\text { and flake }\end{array}$ & - \\
\hline $366 / \mathrm{A}$ & female & - & - & - & - & $\begin{array}{c}\text { arrowhead-like } \\
\text { antler } \\
\text { implements }\end{array}$ \\
\hline $366 / \mathrm{B}$ & male & broken pot & & & & red stone \\
\hline
\end{tabular}

\section{Grave goods}

Bidding the final farewell to the deceased was an important part of the funeral rite. The grave goods, food and drink were placed in or beside the grave during this phase. Grave goods often expressed differences in the social standing of the deceased. The grave goods from the burials ranged from jewellery and tools to vessels and intentionally broken pottery. It is unclear whether the deceased were buried in full costume or with a minimal clothing and jewellery as is customary among aboriginal peoples. There is no conclusive evidence for clothing; the jewellery articles found on the wrist, the waist or by the upper arm may have been ornaments sewn onto the costume or decorative items sewn onto leather straps wound around the arms, or a leather or textile belt around the waist. The beads and shell plaques lying around the neck may have been parts of a necklace or ornaments adorning the costume, The shell plaques on the forehead were probably the decorative elements of a scarf, a headband or a more elaborate headdress.

(a) Double graves with grave goods in both burials (Table 14) Four burials among the double graves with grave goods in both burials had solely jewellery articles (Graves 66,
$71,100,113)$. Jewellery occurred with vessels and/or vessel fragments in three graves (Graves 80, 263, 366).

Bead necklaces or strands of beads were mostly deposited in child burials (Grave 71/A, Pl. XXX. 71/1; Grave 80/B, Pl. XXXVII. 80/5a-b; Grave 113/A, Pl. XLVIII. 113/1; Grave 113/B, Pl. XLVIII. 113/3), although women (Grave 100/B, Pl. XLV. 100/2-3; Grave 263/B, Pl. CVI. 263/5-6) and men (Grave 66/B, Pl. XXIX. 66/2; Grave 100/A, Pl. XLV. 100/1; Grave 263/A, Pl. CVI. 263/1a-b) too were sometimes given jewellery of this type. The necklaces were strung from limestone beads, sliced Dentalium badense shells (Grave 66/A, Pl. XXIX. 66/2; Grave 80/B, Pl. XXXVII. 80/5b; Grave 100/B, Pl. XLV. 100/2), and shells (Grave 80/B, Pl. XXXVII. 80/5a; Grave 100/B, Pl. XLV. 100/2). The single "marble" bead was found in the strand of beads placed beside the child interred in Grave 113/A.70 Copper beads were strung among the other beads in the necklaces deposited in the two child burials of Grave 113 (Pl. XLVIII. 113/2). Shell plaques were found in an infant burial (Grave 66/A, Pl. XXIX. 66/1), in child burials (Graves 71/A-B, Pl. XXX. 71/2) and in what was probably a male burial (Grave 263/A, Pl. CVI. 263/1b).

\footnotetext{
$\overline{70}$ The surviving finds from the burial do not include a marble bead.
} 
The most common vessels in these burials are goblets and scooping vessels. Pottery sherds were sometimes thrown into the grave together with the stones. The graves in this group did not include burials into which only pottery had been deposited. Female burials were furnished with footed goblets (Grave 3, Pl. III. 3/1, 7; Grave 263, Pl. CVI. 263/2) and stone implements (Grave 3/A, Pl. IV. 3/2-4; Grave 263/B, Pl. CVI. 263/3-4). Scooping vessels were found in a female (?) burial (Grave 3/A, Pl. IV. 3/6) and a child burial (Grave 80/A, Pl. XXXVII. 80/3). A broken pot was recovered from the male burial in Grave 366/B ( $P l$. CXLIV. 366/8).

Most of the tools/implements were found in female burials. Stone implements were recovered from Graves 3/A and 263/B, both of which contained a goblet. Six arrowhead-like antler objects were uncovered in Grave 366/A, another female burial. ${ }^{71}$ A copper awl lay in Grave 3/B, probably a male burial (Pl. IV. 3/5).

There was no apparent correlation between the grave goods, and the orientation, placement, sex or age of the deceased in the burials of the double graves in which each burial had grave goods.

(b) Double graves with grave goods in one burial (Table 15) Necklaces or bead strands were deposited in five graves, most of which were child burials (Grave 13/A, Pl. VIII. 13/3; Grave 48/A, Pl. XXII. 48/1a-c; Grave 55/A, Pl. XXV. 55/3; Grave 106/A, Pl. XLVI. 106/1), although beads were found in female burials (Grave 123/A, Pl. LIII. 123/1) and male burials too (Grave 290/B, Pl. CXIV. 290/1). The strands were most often strung from limestone beads (Graves 13/A, 48/A, 55/A, 56/B, 123/A, 290/B), sliced Dentalium badense shells (Graves 13/A, 123/A), and shells (Graves 48/A, 106/A). Grave 399/A, a female burial, yielded a broken Turitella shell (Pl. CLIV. 399/1), a rare shell type in the cemetery.

Shell plaques were found around the neck in Grave 13/A, a child burial (Pl. VIII. 13/4). The necklace in Grave 48/A, another child burial, included tubular copper beads (Pl. XXII. 48/1c).

Six graves contained solely implements. Three were child burials (Graves 48/A, 108/B, 149/B), one was probably a male burial (Grave 195/B), one was a female burial (Grave 405/B), and one could not be determined (Grave 134/A). ${ }^{72}$ Ten trapezes lay by the ankles of the child interred in Grave 48/A (Pl. XXII. 48/2-11). A sharp bone awl was placed on the skull of the child in Grave 108/B (Pl. XLVII. 108/1; there were no apparent signs of injury on the fragmentary skull bones) and a bone awl was set in front of the woman interred in Grave 405/B (Pl. CLVII. 405/1). In his field notes, Soproni mentions that a copper fragment lay under the

\footnotetext{
71 These finds have since been lost and are known only from their description in the acquisitions register.

72 The skeletal remains from this burial were not preserved.
}

skull of the child laid to rest in Grave 78/B. Nothing else is known about this oxidised artefact and thus it can no longer be established whether the fragment came from a tool or an ornament.

The vessels deposited in the burials of this group were principally goblets and scooping vessels. Vessel fragments were sometimes thrown into the grave or onto the stones covering the burial. The grave goods from one child burial (Grave 101/A) and one male burial (Grave 142/B) were made up of vessels only. The former yielded a goblet with rectangular upper part resting on two feet, which disintegrated after it was lifted. Grave 142/B, a male burial, had a relatively rich array of vessels: a finely ornamented goblet (Pl. LXI. 142/1), a one-handled cup decorated with impressed dots (Pl. LXI. 142/2) and a large jug (Pl. LXI. 142/3). Goblets were only placed in child burials (Graves 78/B, 101/A) and a male burial (Grave 142/B) among the burials in this group (unfortunately, none of the goblets from the child burials reached the museum). A scooping vessel lay in another child burial (Grave 55/A: Pl. XXV. 55/1).

It is unclear whether the vessel fragments found among the stones in Graves 334 and 388 had been grave offerings or whether they had been thrown onto the stones at the end of the funeral.

\section{Post-interment activities}

Following the deposition of the deceased and the grave goods, stones were sometimes placed into the grave. ${ }^{73}$ It is not always clear during which phase of the burial ceremony the stones were actually put in the grave: in the preparatory phase or after the conclusion of the funeral.

As has already been mentioned in the above, the grave was marked after the funeral, either by a planting a bush or a tree, by erecting a grave marker, or by covering the grave with stones. The stones in Graves $66,80,195$ and 263 were placed in the grave after the deposition of the body. According to the field diary, the bodies in Grave 66 were densely covered with stones, meaning that they had been placed there at the end of the funeral ceremony, as in Grave 195, in which the bodies were similarly covered with stones. Three stones lay on the head of the deceased in Grave 263 and stones were found around the head in Grave 399 too, apparently placed there toward the end of the ceremony in both cases. Pottery fragments were found under the stones in Grave 80, the implication again being that the stones were put in the grave after the placement of the bodies.

It is also unclear whether the pottery fragments found among the stones were grave offerings placed in the grave before the stones were placed in the grave or whether the vessel fragments were placed among or

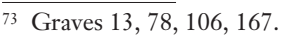


Table 15. Distribution of grave goods according to type in the double graves with grave goods in one burial

\begin{tabular}{|c|c|c|c|c|c|c|}
\hline Grave & Sex & Vessels & Jewellery & Metal & Stone & Other \\
\hline 13/A & child & $\begin{array}{l}\text { broken bowl } \\
\text { and jug }\end{array}$ & beads & - & - & - \\
\hline 13/B & child & - & - & - & - & - \\
\hline 48/A & child & - & $\begin{array}{l}\text { necklace of shells } \\
\text { and copper beads }\end{array}$ & - & $\begin{array}{l}\text { ten stone } \\
\text { implements }\end{array}$ & - \\
\hline 48/B & female & - & - & - & - & - \\
\hline 55/A & child & scooping vessel & necklace & - & - & red stone \\
\hline $55 / \mathrm{B}$ & infant & - & - & - & - & - \\
\hline 56/A & female & - & - & - & - & - \\
\hline $56 / \mathrm{B}$ & indet. & - & necklace & - & - & - \\
\hline $78 / \mathrm{A}$ & child & - & - & - & - & - \\
\hline $78 / \mathrm{B}$ & child & $\begin{array}{l}\text { rim fragment } \\
\text { of a goblet }\end{array}$ & - & $\begin{array}{c}\text { copper } \\
\text { fragment }\end{array}$ & - & - \\
\hline 101/A & child & goblet & - & - & - & - \\
\hline 101/B & child & - & - & - & - & - \\
\hline 106/A & child & - & strand of shells & - & - & - \\
\hline 106/B & child & - & - & - & - & - \\
\hline 108/A & child & - & - & - & - & - \\
\hline 108/B & child & - & - & - & - & bone awl \\
\hline $123 / \mathrm{A}$ & female & - & necklace & - & - & - \\
\hline $123 / \mathrm{B}$ & child & - & - & - & - & - \\
\hline 134/A & indet. & - & - & - & burin & - \\
\hline 134/B & indet. & - & - & - & - & - \\
\hline 142/A & child & - & - & - & - & - \\
\hline $142 / \mathrm{B}$ & male & $\begin{array}{c}\text { goblet, } \\
\text { broken cup, jug }\end{array}$ & - & - & - & - \\
\hline 149/A & child & - & - & - & - & - \\
\hline 149/B & child & - & - & - & blade fragment & - \\
\hline 195/A & female & - & - & - & - & - \\
\hline 195/B & male (?) & - & - & - & blade & - \\
\hline 290/A & male (?) & - & - & - & - & - \\
\hline 290/B & male & - & beads & - & - & - \\
\hline 334/A & child & vessel fragments & - & - & - & - \\
\hline $334 / \mathrm{B}$ & child & ? & - & - & - & - \\
\hline 388/A & male & ? & - & - & - & - \\
\hline 388/B & female & vessel fragments & - & - & - & - \\
\hline 399/A & female & - & shell & - & - & - \\
\hline 399/B & child & - & - & - & - & - \\
\hline 405/A & male & - & - & - & - & - \\
\hline $405 / \mathrm{B}$ & female & - & - & - & - & bone awl \\
\hline
\end{tabular}

thrown onto the stones during the conclusion of the ceremony. ${ }^{74}$

\section{Disturbed burials}

The disturbance of the burials occurred after the funeral. ${ }^{75}$ There is no evidence for the disturbance of the double inhumation burials in prehistory.

\footnotetext{
74 Graves 13, 78, 155, 388.

75 Graves 134, 149, 169.
}

\section{Chronology of the double graves}

The double burials did not exhibit any singular typological traits, which would conclusively prove that they were contemporaneous. Superimposed burials can be of help in determining the relative chronology of the burials. The single superimposed burial among the double graves was noted in the case of Grave 167, which was overlain by a single inhumation burial (Grave 165), meaning that the double grave was the earlier of the two. The single burial, however, did not contain any grave goods, and thus these two 
Table 16. Dimension and form of the triple inhumation burials

\begin{tabular}{|c|c|c|c|c|}
\hline Grave & $\begin{array}{c}\text { Depth } \\
\text { (cm) }\end{array}$ & $\begin{array}{c}\text { Lenght } \\
\text { (cm) }\end{array}$ & $\begin{array}{c}\text { Width } \\
\text { (cm) }\end{array}$ & Form of grave pit \\
\hline 47 & $75-85$ & 105 & 85 & oval \\
\hline 182 & 95 & 138 & 137 & rectangular \\
\hline 215 & 78 & 100 & 128 & oval \\
\hline 391 & 64 & 89 & 136 & oval \\
\hline
\end{tabular}

superimposed graves offer no anchors for an internal chronology.

A rather bold assumption in this respect is that the graves containing one particular snail species (Turitella sp.) among the grave goods were perhaps broadly contemporaneous if one assumes that the Turitella snails were collected at the same time. ${ }^{76}$

\section{TRIPLE INHUMATION BURIALS}

The Budakalász cemetery contained four triple inhumation burials (Graves 47, 182, 215, 391), accounting for less than 1 per cent of the graves.

\section{Preparation for the funeral}

\section{Selection of the grave location}

The cemetery map shows that three of the triple burials (Graves 47, 182, 215) lie in the cemetery's southern half, while the fourth (Grave 391) in the northern half. Lying between the two parts is an area which did not have triple burials. The graves lie far from each other.

There was no other burial near Grave 47. A few inhumation and cremation burials can be found near Graves 182 and 215, while Grave 391 lay among inhumation and cremation burials, and there was also a double burial in its vicinity (Grave 389).

\section{Orientation}

The orientation of the burials in these graves was not particularly varied: south-west to north-east in Graves 47 and 215, east to west in Grave 182, and south-east to north-west in Grave 391.

\section{Digging of the grave pit (Table 16)}

The average depth of the grave pits was $78 \mathrm{~cm}$. Grave 47 , which was relatively small, contained an adult and two infant burials; Grave 391, another rather small grave, contained three child burials. Interestingly enough, the largest grave pit (Grave 182) also contained three child burials.

\footnotetext{
76 Graves 273 and 436 (scattered cremation burials), Graves 263 and 378 (inhumation burials) and Grave 399/A (double inhumation burial) contained a Turitella snail. If the assumption that these burials were broadly contemporaneous is correct, it provides further proof that inhumation and cremation was practiced side by side.
}

\section{Deposition of the body in the grave}

The bodies were placed carefully in the grave, and were laid to rest in a contracted position in the triple burials too. All three bodies were laid on the right side in Grave 47. In Graves 182 and 391, two bodies were laid on the left side (Burials 182/B, 182/C, 391/A, 391/B) and one on the right side (Burials 182/A, 391/C), while in Grave 215, two bodies were laid on the right side (Burials 215/A, 215/B) and one on the left side (Burial 215/C). Seven of the twelve persons buried in the triple graves were laid on the right side and five on the left side.

Soproni interpreted Grave 47 as containing contemporaneous burials: Burial B lay some $5-10 \mathrm{~cm}$ deeper than Burials A and C, between the two. The orientation of the three burials was identical. The burials in Grave 182 were likewise contemporaneous and Soproni reconstructed their sequence as follows: Burial B was first, followed by the deposition of the bodies in Burial A and C. The left shoulder of Burial C lay under the right upper arm of Burial B after deposition since the body in Burial B was laid on the left side and may have "turned back" toward Burial C. The three bodies were probably interred at the same time since there was no indication of any disturbance. It seems likely that some time elapsed between the deposition of the bodies in Grave 215 since the bodies were separated by a stone packing. Burial B, covered with stones, lay above the stones covering Burial C. Burial A was the last burial in the grave, and Burial B was disturbed when the body of Burial A was deposited in the grave. It seems likely that the earlier burial was disturbed by the weight of the newly deposited body.

\section{Grave goods (Table 17)}

The burials in the triple graves were not among the richly furnished burials. Only one of the deceased was given any offerings, the other two were interred without any grave goods. Burials 47/B and 215/B contained indistinct vessel fragments, while a broken goblet was placed in Burial 391/B and a stone blade in Burial $182 / B$. None of the burials contained any jewellery articles. 
Table 17. Distribution of grave goods according to type in the triple inbumation burials

\begin{tabular}{|l|c|c|c|c|c|c|}
\hline Grave & Sex & Vessels & Jewellery & Metal & Stone & Other \\
\hline 47/A & child & - & - & - & - & - \\
\hline 47/B & child & vessel sherds & - & - & - & - \\
\hline 47/C & male & - & - & - & - & - \\
\hline 182/A & child & - & - & - & blade & - \\
\hline 182/B & child & - & - & - & - & - \\
\hline 182/C & child & - & - & - & - & - \\
\hline 215/A & male (?) & - & - & - & - & - \\
\hline 215/B & female (?) & vessel sherds & - & - & - & - \\
\hline 215/C & female & - & - & - & - & - \\
\hline 391/A & child & - & - & - & - & - \\
\hline 391/B & child & broken goblet & - & - & - & - \\
\hline 391/C & child & - & - & - & - & - \\
\hline
\end{tabular}

\section{Post-interment activities}

Three of the triple graves contained stones. There were eight to ten flat stones set upright along the side of the grave pit in Grave 47, whilst the burials in Grave 215 were separated by layers of stones. There was no particular pattern in the position of the stones in Grave 182. Lying among the stones were the fragments of bipartite bowls (Pl. LXXVI. 182/1), a ladle (Pl. LXXVI. 182/2), a scooping vessel (Pl. LXXVI. 182/4), a pitcher (Pl. LXXVI. 182/3) and a cup (Pl. LXXVI. 182/5-6). The single ladle with an incised zig-zag pattern was found in this grave. It is unclear whether the vessel fragments were placed in the grave during the funeral or at its end, after the stones had been deposited in the grave.

\section{Chronology of the triple graves}

The poor furnishings of the triple graves offers no typological anchors for determining whether the triple grave were contemporary or not with any other burials in the cemetery.

\section{SKULL BURIALS}

Skull burials are virtually co-eval with humankind. The symbolic nature and ritual significance of the human head can be noted in most human cultures. Being the repository of the mind and mental abilities, as well as of an individual's wisdom and spiritual essence, the skull was in itself a metaphor for man and a symbolic bodily organ in both life and death.

The study of the ritual role and cult of the skull figures prominently in several disciplines (ethnography, archaeology, cultural anthropology, medicine, psychology, philosophy, literature, art history, etc.), and it is hardly possible to review the vast literature on this subject. Instead, I shall briefly quote the well-known data used in the interpretation of skull burials.
In some cultures, there is evidence for the practice of a skull cult from early childhood. Bandaging a child's head results in an artificially deformed, elongated head, which sets the individual apart from the community's other members.

The separation of head and body had a special meaning in several cultures. The decapitation of a still living human being, beheading as a mode of execution, was a particularly cruel means of destroying the enemy or killing offenders. In some cultures, severing the head from the body was a symbolic act of banishing the individual from the community and of robbing him of his previous status. There is evidence that certain bodily parts, including the skull, were believed to have magical healing properties, and the belief that the apotropaic powers of the severed heads brought back as trophies from battle would protect the victor from various illnesses was fairly widespread. Skulls were important accessories in various rituals too.

The scalping of the slain foe was likewise a symbol of victory, an expression of defeating the enemy and of absorbing his might and power, as well as of seizing the enemy's protective spirit.

The removal of the head from the body after death can be interpreted as a metaphoric expression of ritual, purification and regeneration.

Skull burial was practiced in many cultures. Communities engaged in this practice generally exhumed the body one or two years after the burial and then reburied the skull in another location.

The practice of using human bodily parts as amulets or utilitarian artefacts (such as the drinking vessels fashioned from skulls) is a reflection of the reinterpretation of the role of these bodily parts and their vestment with a new meaning. Skulls played an important role in mythology and art: the perfect mechanism co-ordinating and driving the human body has been immortalised in countless poems, paintings and statues.

The unique dialectics of the skull cult can be seen as an expression of the unity of life and death; the strength 
of the slain enemy is imparted to the vanquisher and protects the community from malevolent spirits. The wisdom and experience of the deceased man passed on to the living and thus lived on.

The poor preservation of the skeletal remains in the Budakalász cemetery might suggest that the graves in which Soproni found nothing but a skull had originally contained other skeletal remains too, which had disintegrated, and that these burials had also been regular inhumation burials. This possibility is contradicted by several factors.

(a) If the other skeletal remains had been destroyed by the chemical properties of the soil, this would also have affected the skull.

(b) One incontestable proof for skull burials in the Budakalász cemetery is Grave 290, containing the burial of an adult male (whose skeleton survived in full) and a skull (probably of another male).

(c) Skull burials have been documented on other Baden sites too, even if infrequently. Examples include the skull burial in a settlement feature at Esztergom-Szentkirály-Duna-dúlő, ${ }^{77}$ as well as in graves at $\mathrm{Nitra}^{78}$ and Szentes-Nagyhegy, ${ }^{79}$ indicating that this rite was practiced in the Baden culture. It is therefore quite likely that skull burials can be regarded as one of the funeral rites in the Budakalász cemetery.

Skull burials were found in six single burials (Graves $191,255,262,395,406,425)$ and in one double burial (Grave 290, Burial A). With the exception of the latter, containing a probably male skull, the other burials contained children's skull and, in one case, the skull of an adolescent girl (Grave 191).

The selection of the grave location for the skull burials can be traced on the cemetery map. The skull burials lie along an arc in the cemetery, formed by Grave 395 at the northern tip of an imaginary north-south axis, three burials on the western side (Graves 290, 406, 425), and another three burials on the eastern side (Graves 191, 262, 255). It is unclear whether the location of these burials was random or reflects some cognitive pattern. The cemetery map also reveals that the skull burials usually lie near double and triple inhumation burials and symbolic graves.

In the case of skull burials, the grave pits of these burials can be examined as regards the preparation for the funeral. The dimensions of the grave pits were recorded for Grave 191 and the double burial, but only the depths are known for the other burials.

Soproni recorded the orientation of the burials in three cases: the face was turned toward the east-northeast in Grave 191 and toward the east in Grave 425. In Grave 395, the head was aligned toward the northwest.

Four of these burials did not contain any grave goods. Three burials contained indistinct pottery

\footnotetext{
77 KÖVECSES-VARGA 1991, 12

78 Pavúk 1972, 8-9; NeVIZÁNSKY 1985, 268-269.

79 BANNER 1956, 89-90.
}

sherds (jug, bowl and pot fragments), the handle fragment of a ladle, ${ }^{80}$ and an unworked pebble. The poor grave goods were placed in the middle of the grave pit in Grave 191 and around the skull in Grave 262. The pebble lay on the left side of the skull in Grave 425 , the indistinct body sherd of a thick-walled bowl was found above the skull (Table 18).

With two exceptions, the skull burials at Budakalász contained children's severed heads. There is no way of telling whether the head was severed after death or whether they were beheaded while still alive. What is quite certain is that these skulls hardly represent war trophies, and it seems unlikely that this rite was intended to absorb a slain enemy's might.

\section{CREMATION BURIALS}

There are two basic variants of cremation burials: scattered cremation and inurned burials. Both variants occur at Budakalász, although the number of inurned burials is virtually negligible compared to scattered cremation burials (Fig. 15 and Fig. 16).

Seventy-two burials of the 436 Late Copper Age graves were cremation burials (16.5 per cent). The overwhelming majority of the cremation graves were scattered cremation burials ( 90 per cent), about onehalf of which contained grave goods and/or costume articles (29 graves, 44 per cent), ${ }^{81}$ The other cremation burials did not contain any grave goods (56 per cent). ${ }^{82}$ The ashes were deposited in an urn in six cases (accounting for 8 per cent of the cremation burials and 1.3 per cent of all the burials). ${ }^{83}$ One grave contained a scattered and inurned cremation burial (Grave 131), another an inhumation and a cremation burial (Grave $155)$.

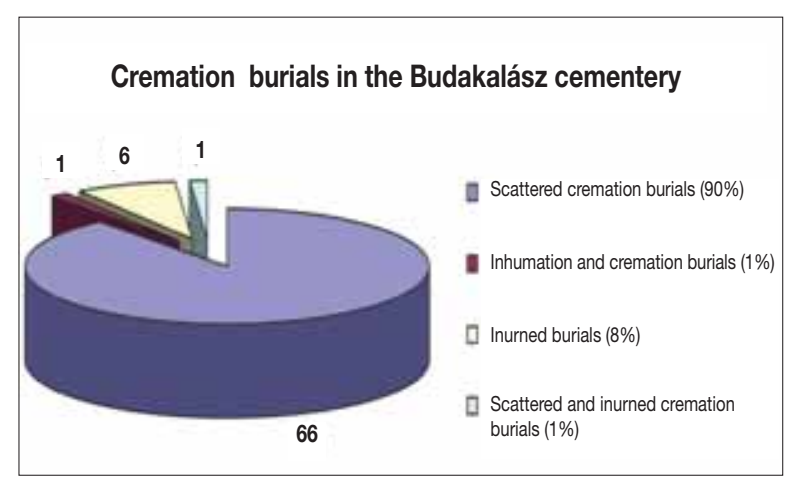

Fig. 15. Cremation burials in the Budakalász cemetery

\footnotetext{
80 The pottery fragments were lost or mislaid; they were not inventoried with the other finds from the burial.

${ }_{81}$ Graves 103, 130, 131, 138, 181, 190, 193, 222, 224, 238, 241, 247, 248, $254,259,260,273,274,276,298,314,339,341,356,390,432,433,434$, 436.

${ }^{82}$ Graves 120, 155/B, 159, 168, 178, 211, 219, 233, 234, 236, 239, 240 $242,249,250,258,268,269,275,280,282,296,304,307,315,323,328$, $331,333,343,386,387,392,423,429,431,435$.

83 Graves 131, 251, 266, 340, 398, 430 .
} 
Table 18. Distribution of grave goods in skull burials

\begin{tabular}{|l|c|c|c|}
\hline Grave & Sex & Age & Grave goods \\
\hline 191 & female & $13-15$ & vessel fragments \\
\hline 255 & child & $3-4$ & - \\
\hline 266 & child & $0-5$ & vessel fragments \\
\hline $290 /$ A & male (?) & adult & - \\
\hline 395 & child & $4-5$ & - \\
\hline 406 & child & $7-14$ & vessel fragments, an unworked pebble \\
\hline 425 & child & $10-11$ & \\
\hline
\end{tabular}

\section{SCATTERED CREMATION BURIALS}

\section{Preparation for the funeral}

An important phase in the preparation for the funeral was the selection of the grave location. The cemetery map indicates that the grave locations were chosen carefully and care was taken not to disturb earlier burials. The cremation burials lie in the cemetery's central, northern and north-western part (Fig. 16). The cremation burials do not cut through each other or the inhumation graves, suggesting that the graves were marked at the end of the funeral and that the time elapsed between two burials was not particularly long because the grave markers were still visible.

A patch of discoloured earth marking the grave was rarely observed in the case of cremation burials. The burial was indicated by the heap of calcinated bones. It seems likely that the grave pit dug for these burials was shallow and that the pit dug into the prehistoric humus level did not penetrate the subsoil, leaving an indication of its presence. ${ }^{84}$

Only in a few cases, mostly the graves containing grave goods, was Soproni able to identify the grave pit and note that the ashes and the grave offerings were deposited in a grave pit, usually round. ${ }^{55}$ The depth of the grave pits varied between $35-40 \mathrm{~cm},{ }^{86} 52-60 \mathrm{~cm}^{87}$ and $60-78 \mathrm{~cm} .{ }^{88}$

\section{Cremation and the deposition of the ashes}

The field notes and the documentation contain no reference whatsoever to the possible location of the funerary pyres. Soproni would undoubtedly have mentioned the remains of pyres, had these been located in the area of the cemetery. The lack of references suggests that the bodies had been cremated outside the cemetery. It is therefore quite certain that the location where the deceased were cremated on a pyre and the

\footnotetext{
${ }_{84}$ It is also possible that the calcinated bones were not placed in a pit dug beforehand, but were simply placed on the ground and covered with a wooden or woven basket.

85 Graves 103, 131, 181, 273, 432, 433, 434, 436.

86 Graves 103, 131, 434

87 Graves 273, 432, 433, 436.

88 Grave 181.
}

grave location differ. Only in two inhumation burials were there traces of kindling a fire on the deposited bodies, ${ }^{89}$ but the reason for these fires was obviously different.

The remains in the scattered cremation burials indicate that the temperature of the pyre was not high enough for completely cremating the body. The low heat generated on the pyre on which the deceased was cremated could be documented in three cases, ${ }^{90}$ when large bones survived almost intact after incineration. The large bones in Grave 436 did not lie in anatomical order, again suggesting that the body had been cremated on a pyre outside the cemetery, after which the remains were collected and taken to the grave, where they were deposited according to the burial rite by placing the remains in a designated area.

Soproni's field notes indicate that there was some regularity in the size of the round area where the ashes were concentrated, both in the cremation burials with and without grave goods.

(a) Cremation burials without grave goods: the diameter of the round area over which the ashes were scattered ranged between 15 and $45 \mathrm{~cm} .{ }^{91}$ Soproni did not record the size of the area over which the ashes had been scattered in the case of ten graves, ${ }^{92}$ and neither were drawings made of these burials. Photographs survive of two (Graves 429 and 435), but the size of the area over which the ashes were scattered can no longer be determined.

(b) Cremation burials with grave goods: the diameter of the round area over which the ashes were scattered ranged between 15 and $50 \mathrm{~cm}$. Soproni did not record the size of the area over which the ashes had been scattered in the case of nine graves, ${ }^{93}$ and neither were drawings made of these burials. Photographs survive of some of these burials, ${ }^{94}$ but the size of the

\footnotetext{
89 Graves 100, 103

90 Graves 240, 323, 436.

91 Sándor Soproni usually recorded the diameter of the area over which the ashes were placed. In many cases, there is no more than a few centimetres difference in the diameter of the small heap of calcinated bones. While too great a significance can hardly be attached to these differences of a few centimetres, they do indicate that Soproni was meticulous in documenting the graves.

92 Graves 155/B, 178, 249, 282, 296, 323, 392, 423, 429, 435.

93 Graves 103, 130, 181, 190, 248, 273, 314, 339, 433 .

94 Graves 103, 181, 248, 273, 433.
} 
area over which the ashes were scattered can no longer be determined.

One intriguing issue is the roughly identical size of the area over which the ashes were scattered and how the ashes could survive in a small heap even if they were not covered with a vessel or a stone. One possible explanation is that the ashes and remains collected from the funeral pyre were taken to the grave in a funerary vessel made from some organic material. The contents of the vessel were then spilled on the ground by turning the vessel upside down and the vessel was placed over the remains. The funerary vessel disintegrated after some time, but the ashes remained in a heap owing to the humidity of the soil and the chemical processes during the disintegration. This would explain why the ashes were not blown away or washed away by rain after the funeral even if they were not covered with stones. This is merely an assumption and there is nothing in the archaeological record to confirm this, but it does offer a potential explanation for this phenomenon..$^{95} \mathrm{It}$ is also possible that one variant of urn burials, when the ashes placed on the ground were covered with a clay vessel, developed from this custom.

Soproni recorded the thickness of the ash layer, which ranged between 5 and $13 \mathrm{~cm}$ in the case of six cremation burials without grave goods. ${ }^{96}$ The thickness of the ash layer was recorded in the case of two burials with grave goods. ${ }^{97}$ Soproni mentions that he found a high amount of ashes in Grave 273, which had a previously dug grave pit and contained several vessels.

\section{Grave goods}

Various grave goods (vessels, vessel fragments, implements, etc.) were deposited in twenty-nine of the sixty-six cremation burials. The grave finds included also jewellery articles, most of which were probably the deceased's personal belongings. No grave goods were found in thirty-seven burials. The reason for this distinction is not known. The burials with and without grave goods often lie beside each other and thus the lack of grave goods was not a reflection of exclusion from the community or a sign of negative discrimination.

In the case of the various articles among the ashes, it is often difficult to determine whether the ashes were deposited first and the grave goods were added subsequently or whether the grave goods (jewellery items, vessel fragments) were placed in the ceremonial vessel into which the ashes were gathered after the cremation on the pyre and then spilled into the grave together. The intentionally broken vessels can probably be linked to the cremation itself (funerary feast, mourning) or the funeral.

It seems quite certain that additional vessels were placed in the grave after the ashes had been deposited

\footnotetext{
95 Nándor Kalicz rejects this interpretation. In his view, the ashes were simply strewn on the ground.

96 Graves 242, 323, 328, 331, 343, 431 .

97 Graves 390 and 436.
}

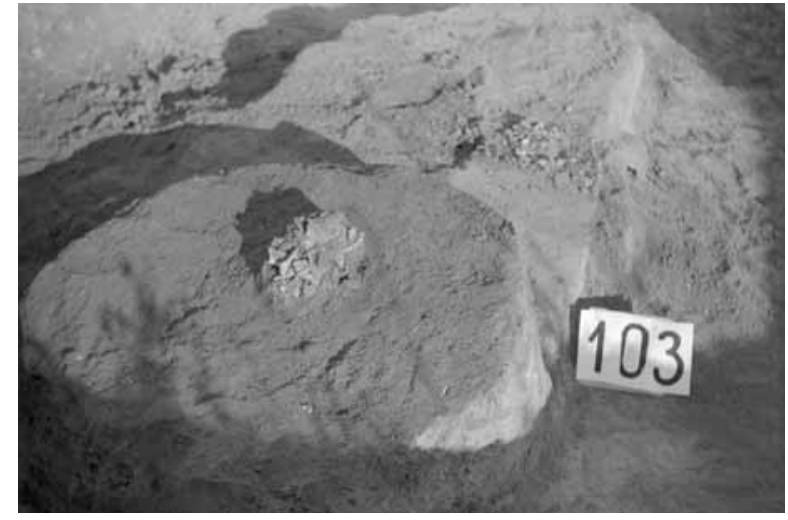

Fig. 17. Vessel fragments in Grave 103

in Graves 222, 276 and 339. The costume ornaments were never placed on the pyre, but were deposited in the grave or on top of the ashes separately.

Various combinations can be noted among the grave goods. Vessels and/or vessel fragments were recovered from twenty-four burials, nineteen of which contained no other grave goods (Graves 103, 131, 193, 222, 224, 248, 254, 259, 260, 274, 276, 298, 314, 339, 341, 356, $390,433,434)$, three burials also contained jewellery articles in addition to the pottery (Graves 130, 138, 181), while three burials contained pottery, jewellery and some other artefact too (Graves 238, 273, 436).

Jug fragments were recovered from Graves 103 and 193 (Fig. 17; Pl. XLVI. 103/1, Pl. LXXXII. 193/1), both adult burials. The goblet and cup fragments inventoried among the finds from Grave 131, containing an inurned (131/A) and a scattered cremation burial (131/B), were probably the grave goods of the latter, found when the ashes were lifted from the grave (they are not mentioned in the excavation diary). Four vessels were placed in Grave 222, a female (?) burial, during the funeral (Fig. 18): a jug (Pl. XCIV. 222/1), a scooping vessel (Pl. XCIV. 222/2), a small mug (Pl. XCIV. 222/4) and a goblet $(P l . X C I V .222 / 3)$. These vessel all lay above the calcinated remains, suggesting that they had been placed in the grave after the deposition of the ashes. Grave 224, the burial of a young adult, yielded

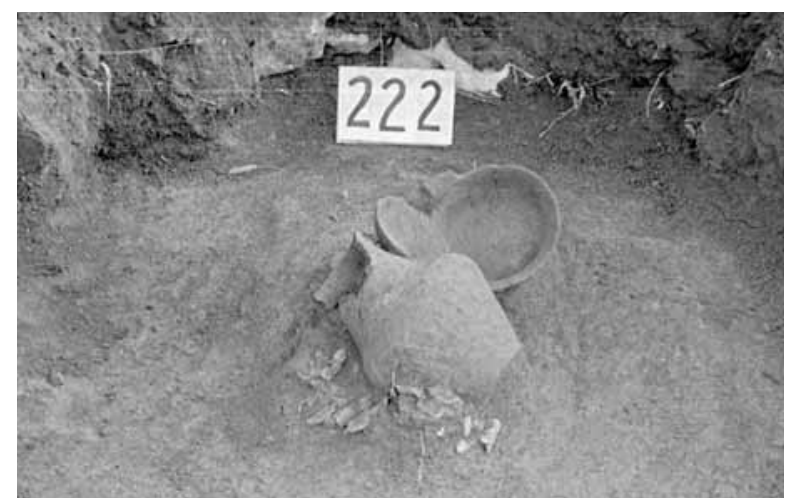

Fig. 18. Grave 222 


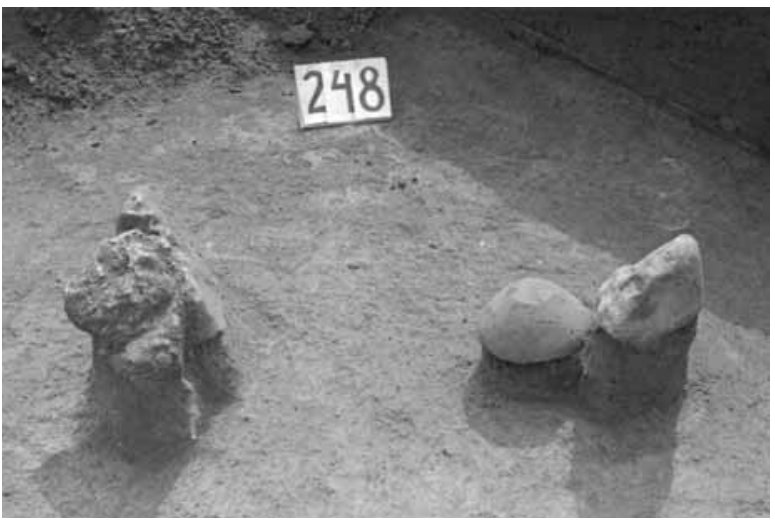

Fig. 19. Grave 248

mug (Pl. XCIII. 224/1) and pot fragments (Pl. XCIII. 224/2), while Grave 248, an adult burial (Fig. 19), contained a plain bowl (Pl. CI. 248/2), mug fragments (Pl. CI. 248/1), a bowl fragment (Pl. CI. 248/3), and the fragment of a bipartite bowl (Pl. CI. 248/4). Grave 254, a child burial, yielded the worn fragments of a bowl or pot. Fragments of a one-handled cup (Pl. CIII. 259/2) and a pot (Pl. CIII. 259/1) lay in Grave 259, an adult burial. One single pottery sherd was found in Grave 260, an adult burial. ${ }^{98}$ Grave 274, a child burial, contained the fragments of an amphora (Pl. CVIII. 274/1) and a bipartite bowl; Grave 276, an adult burial, yielded pitcher fragments (Pl. CXI. 276/1), Grave 298, perhaps a child burial, the non-joining pieces of a pot (Pl. CXVI. 298/1). The fragments of a small pot or bowl were deposited in Grave 314. Two intact bowls $(\mathrm{Pl}$. CXXX. 339/1-2) and a broken mug (Pl. CXXX. 339/3) were found in Grave 339 beside the ashes of a young woman. Grave 341, a child burial, contained pot fragments (Pl. CXXXII. 341/1), as did Grave 390, the burial of a young adult. A jug (Pl. CXXXVIII. 356/1) and a bowl with a stringhole lug, ${ }^{99}$ as well as a red stone were placed in Grave 356, the burial of an adult man. Grave 433 yielded the fragments of a bipartite bowl and an amphora (Pl. CLXV. 433/1 and Fig. 20; a base fragment was also found, but this sherd was not inventoried among the grave goods). The fragments of four different bowls (Pl. CLXIV. 434/1-4) were found beside the ashes of the young adult buried in Grave 434.

Four burials contained solely jewellery articles (Graves 190, 241, 247, 432). Grave 190 contained one broken and five intact shell plaques (Pl. LXXX. 190/1). A strand made up of two broken, perforated shells $(\mathrm{Pl}$. XCIX. 241/1b) and four limestone beads (Pl. XCIX. 241/1a) was placed among the calcinated bones of the adult in Grave 241. The finds were not burnt, suggesting that they been deposited in or on the grave after the cremation. A strand strung of a few beads $(P l$. CI. 247/1a) and five perforated shells (Pl. CI. 247/1b)

\footnotetext{
98 This sherd was not inventoried and thus nothing is known about it. 99 The bowl had been lost or mislaid by the time the finds were inventoried. Although the stone was inventoried, it was later lost and was unavailable by the time of this publication.
}

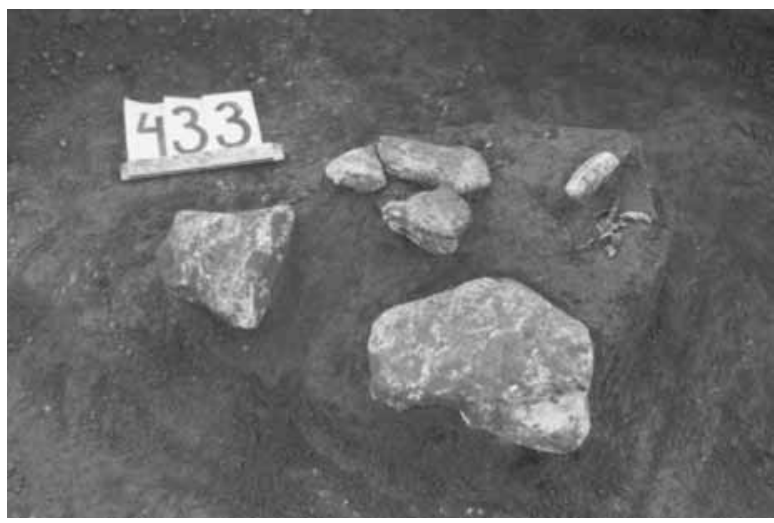

Fig. 20. Grave 433

was found in Grave 247, a child burial. No traces of burning could be observed on the finds, indicating that they had not been worn at the time of the cremation. The fragment of a red clay bead (Pl. CLXIII. 432/1) lay among the ashes in Grave 432.

Pottery/pottery fragments and jewellery articles were found in three burials (Graves130, 138, 181). Grave 130 yielded a broken one-handled cup (Pl. LIV. 130/1), five limestone beads (Pl. LIV. 130/2) and a rectangular copper plaque (Pl. LIV. 130/3), the latter probably the fragment of a copper bead. A goblet (Pl. LX. 138/1) and a strand of limestone beads (Pl. LX. 138/2a) and shells (Pl. LX. 138/2b) was found beside the ashes of the young adult interred in Grave 138. The strand was placed in the grave after cremation seeing that the beads were not burnt. The grave goods placed beside the ashes of the adult man in Grave 181 were the fragments of a thickwalled pot $(P l . L X X V .181 / 1)$ and a strand made up of a few beads (Pl. LXXV. 181/2), again placed in the grave after the cremation of the body.

The grave goods from three burials (Graves 238, $273,436)$ included other articles too in addition to pottery and/or jewellery. Grave 238, an adult burial, yielded a broken goblet (Pl. C. 238/2), a burnt, fossil snail or shell (Pl. C. 238/1) and a mauvish stone $\mathrm{Pl}$. C. 238/3). A mug (Pl. CXI. 273/5) and a jug (Pl. CXI. 273/2) were placed in Grave 273 (Fig. 21). The

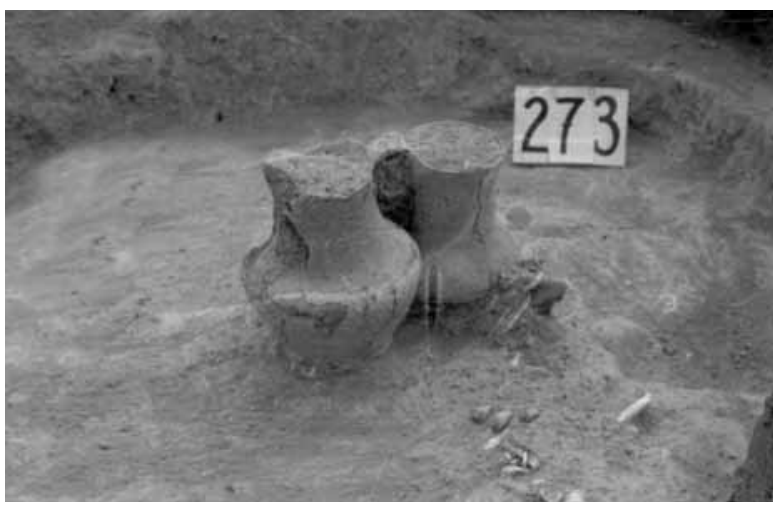

Fig. 21. Grave 273 
fragments of another jug or amphora (Pl. CX. 273/1) were thrown into the grave. The grave goods from this burial included also a strand of five snails ( Pl. CX. 273/4) and an irregularly shaped red stone. Deposited beside the ashes of an adult female (?) in Grave 436 were a snail (Pl. CLXIII. 436/1) and a stone chip.

Vessels

The number of vessels deposited in the burials varied. Twelve burials contained one vessel or the fragments of one vessel (Graves 103, 130, 138, 181, 193, 238, 254, $276,298,314,341,390)$, accounting for 41 per cent of the burials with grave goods; six burials contained two vessels or the fragments thereof (Graves 131/B, 224, $259,274,356,433)$, accounting for 20 per cent; one burial contained three vessels or fragments thereof (Grave 339), accounting for 3 per cent of the burials; two burials contained four vessels or fragments thereof (Graves 224, 434), accounting for $c a .7$ per cent; another two burials had five vessels or fragments thereof (Graves 248, 273), accounting for $c a .7$ per cent. The most frequent vessel types placed in the burials were various drinking vessels (cp. Fig. 26).

Drinking vessels and/or their fragments (mugs, jugs, pitchers, handled cups, goblets, scooping vessels) were deposited in fourteen burials. ${ }^{100}$ Six graves contained one or more bowls or bowl fragments, four burials a bipartite bowl, three burials amphora fragments and nine burials pot fragments. The vessels recovered from burials containing also jewellery items were likewise dominated by drinking vessels. ${ }^{101}$

Interestingly enough, not one single ladle or dipper was deposited in the scattered cremation burials, even though these occur among the drinking vessels in other burials.

\section{Fewellery (Table 19)}

Ten cremation burials contained jewellery items, ${ }^{102}$ most often Dentalium, limestone, clay or copper beads, shells, mussels, and snails, which were collected in various places and then processed (sliced, perforated, polished) before being strung into necklaces or strands, or sewn onto the costume.

Grave 130 yielded five beads (Pl. LIV. 130/2) and a copper fragment (Pl. LIV. 130/3), the latter probably from a copper bead. The grave goods from Grave 138 included fifteen limestone beads (Pl. LX. 138/2a), four perforated Anadara diluvii shells (Pl. LX. 138/2b) and a fossil Spondylus shell perforated in three spots $(P l$. LX. $138 / 2 c$ ), i.e. fifteen beads and five shells. Grave 181 contained six sliced Dentalium badense beads and one limestone bead (Pl. LXXV. 181/2). The child buried in Grave 190 was accorded five intact and one broken shell plaques (Pl. LXXX. 190/1). A strongly burnt, perforated fossil snail or shell was placed in Grave $238 \mathrm{Pl}$. C.

\footnotetext{
100 Graves 103, 130, 131/B, 138, 193, 222, 224, 238, 248, 259, 273, 276 , $339,356$.

101 Graves 130, 138, 238, 273

102 Graves 130, 138, 181, 190, 238, 241, 247, 273, 432, 436
}

238/1), while Grave 241 yielded two broken, perforated Anadara diluvii shells (Pl. XCIX. 241/1b) and four limestone beads (Pl. XCIX. 241/1a). Five Anadara diluvii shells (Pl. CI. 247/1b) and fifteen beads (Pl. CI. 247/1a) were placed beside the ashes of the child interred in Grave 247. Grave 273 contained a strand of five Turitella snails (Pl. CX. 273/4), ${ }^{103}$ and a fragmentary Turitella snail was found also in Grave 436 (Pl. CLXIII. 436/1). Grave 432 yielded a tubular clay bead (Pl. CLXIII. 432/1).

Beads

The beads from the scattered cremation burials included limestone beads (Pl. LIV. 130/2, Pl. LX. 138/2a, Pl. LXXV. 181/2, Pl. XCIX. 241/1a, Pl. CI. 247/1a), fired clay beads (Pl. CLXIII. 432/1), sliced Dentalium badense beads of various sizes (Pl. LXXV. 181/2, Pl. CI. 247/1a), and a fragmentary copper bead $(P l . L I V .130 / 3) .104$

\section{Medal type jewellery}

The finds assigned to this category are the larger Anadara diluvii (Pl. LX. 138/2b, Pl. XCIX. 241/1b, Pl. CI. 247/1b) and Spondylus shells (Pl. LX. 138/2c), as well as the Turitella badense and Turitella sp. snails (Pl. C. 238/1, Pl. CX. 273/4, Pl. CLXIII. 436/1) strung among the other beads. Finds of this type were recovered from six graves. ${ }^{105}$

Turitella snails appear to have been among the more unusual commodities for they occur in very few burials. A snail of this type was the single grave good in one burial. It is possible that these snails were gathered at the same time, perhaps for the funeral of several persons, and we may therefore perhaps assume that the scattered cremation graves containing this snail species are broadly contemporaneous (Graves 273, 436). One of the double inhumation burials (Grave 399; Pl. CLIV. 399/1) too contained a Turitella snail and the two cremation graves were thus perhaps also contemporaneous with this inhumation burial.

The single Spondylus shell from the cemetery (Pl. LX. $138 / 2 b$ ) was strung among the beads from a scattered cremation burial. It seems likely that Spondylus, one of the most valuable prestige commodities up to the Late Neolithic, had lost its significance by the Baden period, explaining its absence from the Budakalász cemetery. 106

\section{Shell plaques}

The rectangular plaques perforated at the four corners polished from Unio crassus, a freshwater mussel, were either worn strung among other beads or were sewn onto the costume, or leather or textile bands. This ornament occurs more frequently in inhumation burials; only one single specimen was found in the scattered cremation burials (Grave 190, Pl. LXXX. 190/1).

\footnotetext{
103 The number of snails is fewer by one in the acquisitions register than in the excavation diary.

104 Graves 130, 138, 181, 238, 241, 247, 432 .

105 Graves 138, 238, 241, 247, 273, 436 .

106 In his comments on the draught version of the manuscript, Nándor Kalicz noted that the Spondylus shell had probably gotten into this grave secondarily from a Middle or Late Neolithic grave because the trade in Spondylus shells in the Carpathian Basin had ceased by the Baden period.
} 
Table 19. Distribution of jewellery types in the scattered cremation burials

\begin{tabular}{|l|c|c|c|c|c|c|c|c|c|}
\hline Grave & $\begin{array}{c}\text { Limestone } \\
\text { bead }\end{array}$ & $\begin{array}{c}\text { Copper } \\
\text { bead }\end{array}$ & $\begin{array}{c}\text { Dentalium } \\
\text { badense bead }\end{array}$ & $\begin{array}{c}\text { Fired } \\
\text { clay bead }\end{array}$ & $\begin{array}{c}\text { Anadara } \\
\text { diluvii shell }\end{array}$ & Spondylus & $\begin{array}{c}\text { Turitella } \\
\text { sp. snail }\end{array}$ & $\begin{array}{c}\text { Turitella } \\
\text { badense snail }\end{array}$ & $\begin{array}{c}\text { Unio crassus } \\
\text { shell plaque }\end{array}$ \\
\hline 130 & $\mathrm{x}$ & $\mathrm{x}$ & & & & & & & \\
\hline 138 & $\mathrm{x}$ & & & & $\mathrm{x}$ & $\mathrm{x}$ & & & \\
\hline 181 & $\mathrm{x}$ & & $\mathrm{x}$ & & & & & & \\
\hline 190 & & & & & & & & & $\mathrm{x}$ \\
\hline 238 & & & & & & & & $\mathrm{x}$ & \\
\hline 241 & $\mathrm{x}$ & & & & $\mathrm{x}$ & & & & \\
\hline 247 & $\mathrm{x}$ & & $\mathrm{x}$ & & $\mathrm{x}$ & & & & \\
\hline 273 & & & & & & & $\mathrm{x}$ & $\mathrm{x}$ & \\
\hline 432 & & & & $\mathrm{x}$ & & & & & \\
\hline 436 & & & & & & & $\mathrm{x}$ & & \\
\hline Total & $\mathbf{5}$ & $\mathbf{1}$ & $\mathbf{2}$ & $\mathbf{1}$ & $\mathbf{3}$ & $\mathbf{1}$ & $\mathbf{2}$ & $\mathbf{2}$ & $\mathbf{1}$ \\
\hline
\end{tabular}

The number of scattered cremation burials from which the remains could be submitted to anthropological analyses was very low ${ }^{107}$ and thus no conclusions can be drawn concerning possible correlations between the deposition of jewellery articles and the age/sex of the deceased.

\section{Other grave goods}

Three scattered cremation burials (Graves 238, 273, 436) contained other objects too in addition to pottery and jewellery articles. Graves 238 and 273 yielded a red stone (Pl. C. 238/3), while Grave 436 a chert fragment identified as debitage.

\section{Correlation between the age/sex of the deceased and the grave goods}

Unfortunately, the surviving bone fragments from some burials were insufficient for anthropological analyses, ${ }^{108}$ It must also be borne in mind that the determination of age and sex is more uncertain in the case of cremation burials, causing difficulties in identifying possible patterns.

There were probably three female burials among the scattered cremation burials with grave goods. ${ }^{109}$ All three contained the remains of women, who died over 23 years of age. Their grave goods were dominated by drinking vessels, such as goblets $(\mathrm{Pl}$. XCIV. 222/3), jugs (Pl. XCIV . 222/1), mugs (Pl. XCIV. 222/4, Pl. CXXX. 339/3), scooping vessels (Pl. XCIV. 222/2) and bowls (Pl. CXXX. 339/3); other grave goods included a snail (Pl. CLXIII. 436/1) and chert debitage (Grave 436). The absence of beads and shells, and of copper and bone artefacts from these burials is quite striking.

\footnotetext{
107 The ashes from Graves 130, 190, 238, 241, 273 were not preserved. 108 The remains from Graves 234, 269, 280, 386, 423, 429, and 432 were insufficient for anthropological analyses. The remains from several cremation burials were not taken to or can no longer be found in the Anthropological Department of the Hungarian Natural History Museum (Graves 103, 130, 131, 190, 236, 238, 240, 241, 242, 249, 258, 273, 276, 298, 314).

109 Graves 222, 339, 436
}

One of the two probably adult male burials yielded pot fragments (Pl. LXXV. 181/1) and beads (Pl. LXXV. 181/2), the other a jug (Pl. CXXXVIII. 356/1), a bowl with a stringhole lug and a red stone (Grave 356).

One of the four child burials contained a pot $(\mathrm{Pl}$. CXXXII. 341/1), another one a bipartite bowl and an amphora (Pl. CVIII. 274/1), a third the fragments of what was probably a bowl (Grave 254), while the fourth a strand of beads (Pl. CI. 247/1a-b).

The age and/or sex of the deceased could not be determined in the case of eighteen graves. ${ }^{110}$ Many of these burials contained drinking vessels, such as goblets (Pl. LX. 138/1, Pl. C. 238/2), jugs (Pl. CXI. 273/2), pitchers (Pl. LXXXII. 193/1, Pl. CXI. 273/7, Pl. CXI. 276/1), mugs (Pl. XLVI. 103/1, Pl. XCIII. 224/1, Pl. CI. 248/1, Pl. CXI. 273/5), handled cups (Pl. LIV. 130/1, Pl. CIII. 259/2), pots (Pl. XCIII. 224/2, Pl. CIII. 259/1, Pl. CXI. 273/6 and the vessel in Grave 390), amphorae (Pl. CX. 273/1, Pl. CLXV. 433/1), bipartite bowls (Pl. CI. 248/4, Pl. CLXIV. 434/3, and the vessel in Grave 433), bowls (Pl. CI. 248/2, Pl. CLXIV. 434/1-2, 4), beads (Pl. LIV. 130/2, Pl. LX. 138/1, Pl. XCIX. 241/1a-b, Pl. CLXIII. 432/1) and snails (Pl. C. 238/1, Pl. CX. 273/4). One burial yielded shell plaques (Pl. LXXX. 190/1).

There are too many uncertainties as regards the age and sex determination of the human remains from these scattered cremation burials and it would be unwise to infer the sex of the deceased in the uncertain burials from the grave goods found in the less uncertain ones; in other words, these burials are unsuitable for statistical evaluations.

The distribution of the various grave goods suggests that there was no strict correlation between the type of grave good accorded to the deceased and age/sex in the case of scattered cremation burials. Neither is there any apparent pattern in terms of age/sex among the thirtyseven burials without any grave goods (accounting for 56 per cent of these burials).

\footnotetext{
110 Graves 103, 130, 138, 190, 193, 224, 238, 241, 248, 259, 260, 273, 276, $298,390,432,433,434$.
} 


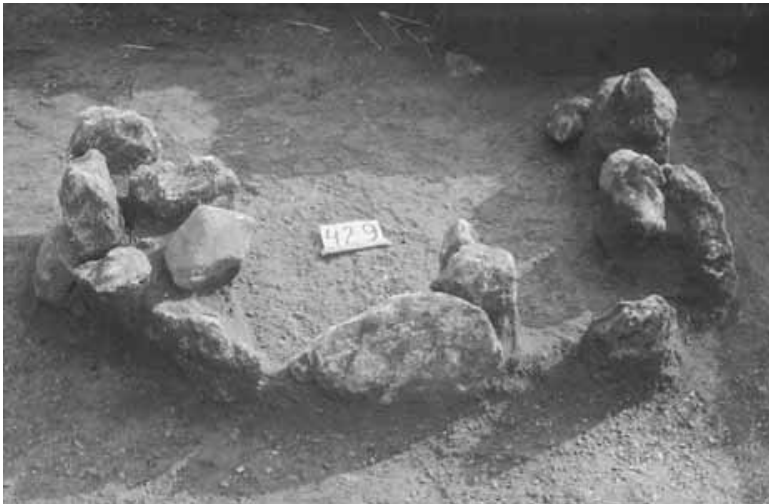

Fig. 22. Grave 429

Even though there is no obvious correlation between age/sex and the grave goods, it is quite evident that the grave goods deposited in cremation burials differ from the ones in the inhumation graves, or better said, certain artefact types are lacking from the former. These include ladles, dippers, suspension vessels, decorated handled pots, handled cups, wagon models, stone axes, quernstones, arrowheads, various copper implements (awls, chisels, pins), bone articles (implements and neckrings), as well as certain shells (Ostrea, Anodonta sp.) and snails (Columbella, Lithoglyphus, Neogastropoda). Scooping vessels were placed more frequently in inhumation burials, as were bowls and bipartite bowls, which are rare finds from cremation burials. Shell plaques, a common grave offering in inhumation burials, occur in one single cremation burial. In contrast, the single Spondylus shell ornament was found in a cremation burial (Pl. LX. 138/2c). One particular variant of pitchers and jugs occurs predominantly in cremation burials.

\section{Post-interment activities}

The funeral did not end with the deposition of the ashes and the grave goods in the grave pit. It seems quite certain that the graves were marked in some manner as part of the funeral ceremony. The cremation

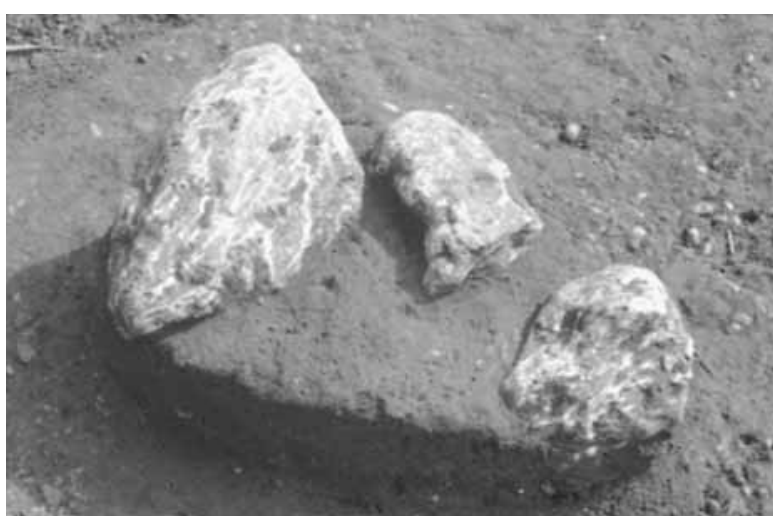

Fig. 23. Grave 435 burials with and without grave goods did not cut each other, but lay near each other, often in close proximity, suggesting that the location of earlier graves was known, explaining why the earlier interred deceased were not disturbed. It also seems likely that the time elapsed between the burials was not too long if the grave markers were still visible.

One practical means of permanently marking burials is to surround or cover the grave with stones. Wooden grave markers were probably also used. The field notes do not specify the exact number of stones found in or around these graves and it is therefore impossible to tell the number and size of the stones from the phrase "many stones" recurring in the description of the graves. The stones from the burials were not preserved or analysed, and their provenance thus remains unknown. It seems likely that the stones were acquired from the nearby mountains for the funerals.

Stones were deposited in seven burials without grave goods. ${ }^{111}$ A shallow grave pit was dug first, after which the ashes were deposited on the floor and the grave was covered with stones. Unfortunately, no photographs or drawings were made of these burials, and thus we know next to nothing about the stones and neither do we know whether only a few stones were used to mark the grave or whether a stone packing was placed over the burial.

The ashes of the 15-59 years old woman (?) in Grave 178 were overlain by stones. In Grave 296, the ashes of a woman (?) older than 23 years were placed on a flat stone and then covered with stones. The imperfectly cremated ashes of a 23-59 years old man lay under the stones in Grave 323. Grave 423 contained stones between -30 and $-40 \mathrm{~cm}$, but it is unclear whether the grave was covered with a stone packing or only a few stones were placed in the grave (the remains were insufficient for determining the age and sex of the deceased). The photograph of Grave 429 shows that the ashes were surrounded with stones (Fig. 22). It seems likely that they were covered with earth and a few more stones were then placed over the burial, some of which later fell among the ashes (the remains were insufficient for determining the age and sex of the deceased in this case too). The ashes of the young adult in Grave 431 were covered with a small, flat stone, while in Grave 435, three stones were laid over the ashes (Fig. 23).

Four of the scattered cremation burials with grave goods contained one or more stones. ${ }^{112}$ The number of stones is not known in most cases and photos were made of two graves only. The stones lay between -25 and $-50 \mathrm{~cm}$ in Grave 181. Found among the stones were the fragments of a thick-walled pot, as well as a few calcinated bone fragments and a few beads at a depth of $-50 \mathrm{~cm}$, under which lay the calcinated bone fragments of a 23-59 years old man (?) (Fig. 24). Grave

\footnotetext{
111 Graves 178, 296, 323, 423, 429, 431, 435

112 Graves 181, 248, 432, 433.
} 
248 contained three stones, two of which lay one over the other, the third about $50 \mathrm{~cm}$ from the other two. A broken mug was found under the two stones lying on each other, and a bowl placed upside-down near the third stone. The calcinated bones of a 23-59 years old adult were found between and under the stones. The calcinated bone fragments lay at a depth of $-45 \mathrm{~cm}$ under a flat stone in Grave 432 (the fragments were insufficient for determining the age and sex of the deceased). Smaller stones lay over the burial from a depth of $-37 \mathrm{~cm}$ downward in Grave 433. Pottery fragments were found above the stones, under which lay the calcinated bone fragments. The base fragment of a vessel was found among the bone remains.

It would appear that there was no correlation between the age/sex of the deceased and the deposition of one or more stones in the burial or the surroundal of the burial with stones.

\section{Disturbed burials}

The disturbance or destroyal of burials not long after the burial (e.g. grave looting) can also be assigned to the category of post-interment activities. Disturbance occurring in later ages (e.g. modern intrusions, disturbance by modern ploughing) do not fall into this category since the disturbance of the burial was not intentional. ${ }^{113}$

Two of the scattered cremation burials were disturbed during the Late Copper Age: Graves 282 and 392 were disturbed when the grave pits of later burials were dug. The calcinated bone fragments of Grave 282 lay under the thighs and knees of the inhumation burial in Grave 281. The cremation burial was disturbed when the Grave 281 was dug and a part of the calcinated bone fragments became scattered. Grave 392 was destroyed when Grave 393 (an inhumation burial) was dug. Some of the calcinated bone fragments lay scattered in Grave 393, other were thrown back when the pit of Grave 393 was backfilled.

It seems likely that there were no visible indications of Graves 282 and 392 when the grave pits for the two later burials were dug. The two cremation burials were earlier than the two inhumation ones; however, none of the four burials contained any grave goods and thus they offer no chronological anchors for the typological study of the finds from the cemetery.

\section{INURNED BURIALS}

Another variant of cremation burials is the deposition of the ashes in a vessel (urn) or the covering of the ashes placed on the ground with a clay vessel. The burials in which pottery fragments were found among the ashes

\footnotetext{
${ }_{113}$ Graves 314, 339.

114 Graves 131, 251, 266, 340, 398, 430.

115 Grave 398.
}

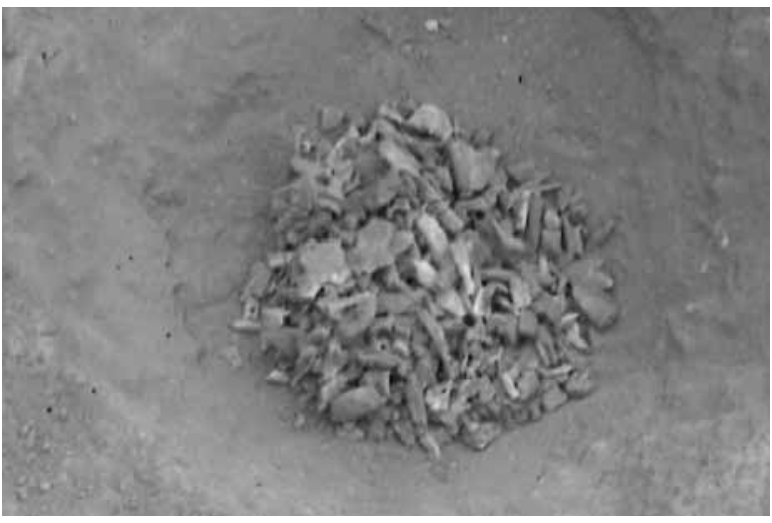

Fig. 24. Grave 181

cannot be regarded as inurned burials because these fragments were not the pieces of a broken urn, but were pottery sherds placed in the grave as part of the funeral rite. Many graves of the Budakalász cemetery (both inhumation and cremation burials) contained a single pottery sherd only, meaning that these were not fragments from vessels destroyed by modern ploughing.

Six burials can be securely identified as inurned burials. ${ }^{114}$ With the exception of Grave 340 (Fig. 25), these burials were not photographed or drawn, and thus the descriptions in the excavation diary are the only source of information about the position of the vessels in these burials and other features.

\section{Preparation for the funeral}

The urn burials lie in the cemetery's northern part, relatively far from each other. Lying beside them were other cremation graves (both burials with and without grave goods). Most graves lie beside each other (but without cutting through each other), suggesting that the time elapsed between two funerals was not too long and that the location of the earlier graves was known, this being the reason that they were not disturbed.

The field notes mention that in one case a grave pit was dug prior to the funeral. ${ }^{115}$ The existence of a grave pit is uncertain in the case of Grave 251, although the

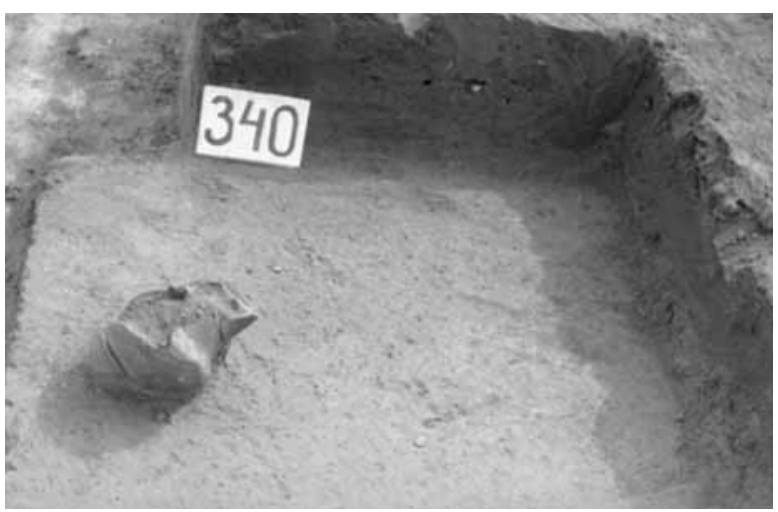

Fig. 25. Grave 340 
depth of the burial certainly suggests that the remains were placed in a pit. Grave 340 was disturbed by ploughing and it is therefore uncertain whether there was a grave pit. Soproni notes that a patch of discoloured earth indicating a grave pit could not be observed in the case of the other burials, ${ }^{116}$ meaning that a very shallow depression was made.

\section{Cremation and the deposition of the ashes}

Inurned burials without grave goods

Grave 430 lay at a depth of $25 \mathrm{~cm}$. There was no discoloured patch of earth indicating a grave pit. The ashes were placed in a scooping vessel set upright $(\mathrm{Pl}$. CLXIV. 430/1). Grave 398 lay at a depth of $-48 \mathrm{~cm}$. The ashes were scattered over an area with a diameter of $45 \mathrm{~cm}$ and partly covered with a bipartite bowl (Pl. $C L V$. 398/1). Grave 251 lay at a depth of $54 \mathrm{~cm}$. The calcinated bone fragments were found over an area with a diameter of $20 \mathrm{~cm}$ under a broken pot.

\section{Inurned burials with grave goods}

Grave 131 contained a scattered cremation and an inurned burial. There was no indication of a grave pit. The calcinated bone fragments were found in and beside a medium sized bowl (Pl. LVIII. 131/1) at a depth of $30 \mathrm{~cm}$, beside which lay a small mug (Pl. LVIII. 131/2). Grave 266 lay at a depth of $26 \mathrm{~cm}$. There was no indication of a grave pit. The calcinated bone fragments lay over an area with a diameter of $30 \mathrm{~cm}$ and formed a $15 \mathrm{~cm}$ thick layer. The imperfectly burnt bones were covered with a larger pot. Grave 340 lay at a depth of $30 \mathrm{~cm}$. The calcinated bones were placed in a bowl (Pl. CXXX. 340/1), on which a jug was set (Pl. $C X X X$. 340/2). Both vessels lay tilted toward the west.

The low number of inurned burials does not allow the identification of any patterns and neither can any general conclusions be drawn from the six burials. I have instead tried to identify the unusual or singular traits of these burials.

Two burials (Graves 251 and 398) lay deeper than the others. The ashes were placed in a vessel before deposition in three cases (Graves 131/A, 340, 430); in the other three burials, the ashes placed on the ground were covered with a vessel (Graves $251,266,398) .{ }^{117}$

\section{Grave goods}

The vessels used as urns for the ashes cannot be regarded as grave goods since they were not gifts for the deceased, but funerary vessels. Disregarding these vessels, the low number of vessels in these burials is quite remarkable.

Three of the six inurned burials contained grave goods: a mug in Grave 131/A, a river mussel and an irregularly shaped stone in Grave 266, a jug in Grave

\footnotetext{
116 Graves 131, 266, 430.

117 Nándor Kalicz rejected the interpretation of these three graves as urn burials.
}

340. Graves 251, 398 and 430 did not contain any grave goods.

The low number of inurned burials and the fact that only three contained any grave goods does not allow the identification of possible patterns in the combination of grave goods. Neither can any funerary precept be reconstructed from these burials. Similarly to the scattered cremation burials, drinking vessels occurred more frequently among the grave goods: two of the three burials with grave goods contained pottery of this type (Graves 131/A and 340).

The inurned burials contained even fewer grave goods than the scattered cremation ones. Some of the articles placed in the latter (goblets, pitchers, handled cups, amphoras, beads, snails, marine shells) were not deposited in inurned burials. However, the lack of these finds in the inurned burials at Budakalász can hardly be generalised for it seems likely that a cemetery with a higher number of inurned burials would yield a different pattern.

Vessels

The mug in Grave 131/A was of the variant with fluted belly and high-flung handle (Pl. LVIII. 131/2), which occurs in both scattered cremation and inhumation burials. Grave 340 yielded the fragment of a worn, biconical jug with cylindrical neck, but without a handle stub (Pl. CXXX. 340/2). This jug type occurs exclusively in cremation burials (Graves 193, 340, 356).

\section{Vessels used as urns}

The ashes were placed in a bowl in Graves 131/A and 340. The bowl from Grave 131/A has a short neck and globular body (Pl. LVIII. 131/1), recalling the upper part of an amphora or jug. It is a unique piece among the pottery finds. The bowl type with cylindrical neck from Grave 340 ( $P l$. CXXX. 340/1) is known from other burials too. Decorated variants are known from two inhumation burials (Graves 80 and 140; Pl. XXXVII. 80/6, Pl. LVIII. 140/1) and a scattered cremation burial (Grave 339; Pl. CXXX. 339/2).

A plain scooping vessel was used as an urn for the ashes deposited in Grave 430 (Pl. CLXIV. 430/1). This vessel type was quite frequent in inhumation burials and a decorated piece was recovered from a scattered cremation burial (Grave 222; Pl. XCIV. 222/2).

The ashes in Graves 251 and 266 were covered with a pot in Graves 251 and 266. Unfortunately, the indistinct body and base fragments do not enable the reconstruction of the vessel form.

A large, deep bipartite bowl was placed over the calcinated bone remains in Grave 398 (Pl. CLV. 398/1). Fragments of bipartite bowls were found in four scattered cremation burials (Grave 248, 274, 433, 434), representing a smaller sized, more carefully made variant. Bowls of this type were also deposited in inhumation burials.

The bowls and other vessels used as urns and the vessels used for covering the urns were both undecorated. 
Other grave goods

An irregularly shaped stone (since lost) and an Unio crassus mussel (Pl. CIV. 266/3) were deposited in Grave 266.

\section{Post-interment activities}

Very little is known about post-interment activities in the case of inurned burials. Soproni recorded that there were stones above the bowl covering the ashes between -20 and $-40 \mathrm{~cm}$ in Grave 398. Nothing else is known about the stones and it is therefore impossible to say whether the stones represented a stone packing.

\section{Disturbed burials}

There was no indication of the disturbance of the burials during the Late Copper Age.

\section{DOUBLE CREMATION BURIALS}

Similarly to inhumation burials, double burials were also found among the cremation graves. Interestingly enough, these graves contained burials according to different cremation rites.

Grave 131 contained an inurned and a scattered cremation burial. Calcinated bones lay in medium sized, broken bowl at a depth of $-30 \mathrm{~cm}$. A small mug lay beside the bowl and calcinated bone fragments lay around the two vessels over an area with a diameter of $30 \mathrm{~cm}$. Other calcinated bone fragments lay under a few centimetres thick layer of earth under the two vessels. Soproni cautiously concluded that the grave perhaps contained the successive burials of two individuals. In his opinion, Grave 248 too contained the remains of two individuals. Three stones were found $c a .50 \mathrm{~cm}$ from each other, two of which lay one over the other. The calcinated bone fragments lay between and under the stones. Soproni suggested that the third stone was used for separating the remains of the individuals from each other. Although his assumption cannot be rejected out of hand, I do not regard this grave as a double burial.

Grave 155 was a biritual burial with one inhumation and one cremation burial. The round grave pit was covered with stones, among which lay pot and jug fragments (Pl. LXV. 155/1). The uniqueness of this grave is indicated by the fact that the individual interred in the inhumation burial wore a necklace of Dentalium beads (Pl. LXV. 155/4) and two perforated neckrings made from boar's tusk (Pl. LXV. 155/2-3). The calcinated bones lay by the skull of Burial A (in front of the face). Soproni noted that the two burials were either contemporaneous or the cremation burial was earlier than the inhumation one, but it could hardly be later than the inhumation burial since the stone packing covering the grave was undisturbed and cremation burials were not deposited in as large a grave pit as the ones dug for inhumation burials. The cremation burial did not contain any grave goods.

\section{Chronology of the cremation graves}

A glance at the cemetery map reveals that the grave locations were chosen consciously and care was taken not to disturb or destroy earlier burials. The cemetery map (Fig. 16) shows that the cremation burials lie in the cemetery's northern, north-western and central part. There are no overlaps between the graves, the cremation burials do not cut each other or the inhumation graves. This would suggest that the graves were marked as part of the funerary rite or afterwards, and that the time elapsed between burials was not too long because the markers were still visible at the time of the new funerals.

The pottery assemblage from the Budakalász graves is fairly uniform, made up of a few basic types, which offer few anchors for an internal chronology. The few superimposed graves are of little help in this respect for they were mostly burials without any grave goods.

A number of singular typological traits could nonetheless be identified in the ceramic inventory, which indicated that some of the vessels placed in the graves had been made by the same potter, suggesting that these burials were more or less contemporary. The vessels reflecting individual stylistic traits indicating the contemporaneity of some scattered cremation and inhumation burials, as well as of scattered and inurned cremation burials, are certain handled cups (Pl. LIV. 130/1, Pl. CIII. 259/2, Pl. CXLV. 368/3, Pl. CL. 378/1), a unique pitcher variant (Pl. LXXXII. 193/1), jugs (Pl. CXXX. 340/2, Pl. CXXXVIII. 356/1), and goblets (Pl. LX. 138/1, Pl. XXXII. 73/1).

The Budakalász cemetery thus offers incontestable proof that inhumation and cremation was practiced contemporaneously and that cremation was still practiced during the classical Baden period. Grave 155 was a biritual burial with one inhumation and one scattered cremation burial. The bipartite bowls, the goblets, cups, jugs and pitchers and various bowl types are all typical for the classical Baden period.

Various typological traits enabled the determination of the contemporaneity between other burials too. These include Graves 273 and 436 (scattered cremation burials), Graves 130, 259, 368, 378 (scattered cremation and inhumation burials), Graves 73 and 138 (scattered cremation and inhumation burials), and scattered cremation and inurned burials (Graves 193, 340, 356). These burials lie far from each other.

There is little difference between the vessels placed in the inhumation and cremation burials. With a few notable exceptions, most types occur in both burial types. Ladles and dippers, for example, do not occur in the scattered cremation burials. Scooping vessels were predominantly placed in inhumation burials and occur in a single scattered cremation and inurned burial 
Table 20. Dimensions and grave goods of the symbolic burials

\begin{tabular}{|c|c|c|c|c|}
\hline Grave & $\begin{array}{c}\text { Depth } \\
\text { (cm) }\end{array}$ & $\begin{array}{c}\text { Lenght } \\
(\mathbf{c m})\end{array}$ & $\begin{array}{c}\text { Width } \\
(\mathbf{c m})\end{array}$ & Grave goods \\
\hline 31 & 45 & 60 & 50 & none \\
\hline 160 & 65 & 65 & 55 & vessel, beads, shell plaques \\
\hline 177 & 80 & 154 & 125 & nossels, wagon model, stone point, pebble \\
\hline 205 & 55 & 78 & 56 & none \\
\hline 243 & 60 & 70 & 70 & none \\
\hline 246 & 58 & 70 & 70 & vessels \\
\hline 311 & 95 & 96 & 68 & animal bone \\
\hline 349 & 68 & 140 & 105 & \\
\hline
\end{tabular}

(Graves 222 and 430). Shell plaques were placed almost exclusively in inhumation burials (the only exception being Grave 190). Bipartite bowls occur more frequently in inhumation graves, their number being virtually negligible in scattered cremation and inurned burials. Bowls occur in high number among the grave goods deposited in burials. They were predominantly placed in inhumation graves; only six scattered cremation burials yielded intact or broken bowls, and in two cases, plain bowls were used as urns for the ashes of the deceased.

The above again confirm the assumption that there is no significant chronological difference between the inhumation and cremation burials of the Budakalász cemetery and that the two rites were practiced simultaneously.

The vessels placed in the burials are worn and their manufacture is identical with the ceramics from settlements, suggesting that the vessels placed in the graves were chosen from among the pieces used in daily life. The single exceptions are goblets, which were probably made specially for funerals or other ceremonies: many of these vessels, especially the ones from the inhumation burials, appear to have been carelessly made. The incised pattern was sometimes redrawn and the entire vessel was immersed in red paint, suggesting that they were manufactured hastily.

\section{SYMBOLIC BURIALS}

Graves, which in addition to a grave pit, also yielded evidence for other acts of the funerary rite (such as the deposition of grave goods or stones in the grave) can be regarded as symbolic burials. Symbolic burials are generally interpreted as the graves of individuals who died away from the settlement.

The selection of the grave location can be traced on the cemetery map. We have seen that the skull burials lie scattered in the cemetery, but along a large arc and lie both to the west and east of an imaginary north-south axis through this arc. The symbolic burials lie along an imaginary polygon, in whose centre lie two burials without any grave goods close to each other (Graves 243 and 246). Three burials lie along the two edges of the polygon in the cemetery's western half (Graves 177, 205, 349) and eastern half (Graves 31, $160,311)$. Two of the burials on the western side contained grave goods (Graves 177 and 349), and the same can be noted in the case of the three burials on the eastern side, of which two contained grave goods (Graves 160 and 311).

The grave pit and the grave goods (Table 20) are two aspects which can be examined as regards the preparation for the funeral.

In terms of the dimensions and form of the grave pit, Graves 31, 205 and 243 resemble the pits of the scattered cremation burials and perhaps symbolised burials of this type. Grave 246 can perhaps also be assigned to this group. Grave 31 had a round grave pit containing many stones, but no skeletal remains or grave goods. Soproni recorded that he found two separate layers of stones between -15 and $-55 \mathrm{~cm}$ in Grave 205, but no skeletal remains or grave goods among or under the stones. Grave 243 had a round pit in which there lay stones between -18 and $-60 \mathrm{~cm}$, but no skeletal remains. Grave 246 too had a round pit, in which no skeletal remains or grave goods were found.

It has already been mentioned that the symbolic burials seem to outline a polygon. The two burials in the middle of this polygon (Graves 243 and 246) probably represent cremation burials, as do the burials without grave goods on the western and eastern side (Graves 205 and 31). The symbolic burials without grave goods can probably be linked to the cremation rite, while the ones with grave goods to the inhumation rite.

In view of their dimensions and grave goods, Graves $160,177,311$ and 349 probably represent inhumation burials. Grave 349 was perhaps intended as a double burial: the stone in the grave pit's south-western half and the animal bone in the its middle were perhaps grave offerings for two different individuals.

The flat, rather squat, undecorated scooping vessel (Pl. LXVII. 160/1) found in the southern half of Grave 160 can be regarded as a typical grave good of inhumation burials. ${ }^{118} \mathrm{~A}$ strand of thirty-nine limestone beads

118 A scooping vessel was found in one scattered cremation burial (Grave 222 ) and one inurned burial (Grave 430). It was used as the container for the ashes in the latter. 
(Pl. LXVII. 160/2) lay to the vessel's north and ten shell plaques (Pl. LXVII. 160/3) were found under the beads.

The body and base fragment of a thick-walled pot lay at a depth of $-40 \mathrm{~cm}$ in Grave 311 (Pl. CXVIII. 311/1). A cup tilted to one side was found at a depth of $-95 \mathrm{~cm}$ in the grave pit's south-south-eastern end $(\mathrm{Pl}$. CXVIII. 311/2), beside which lay the neck fragment of a pitcher (Pl. CXVIII. 311/3). The cup represents a common type in the Baden culture, its only unique trait being the decoration of four incised lines at the base of the handle. This is the single cup from the cemetery with a decoration of this type. The cups, jugs, pitchers and mugs from the cemetery often have a decorated handle, but this decoration takes the form of smoothed-in lines or fluting. The only other handle with incised decoration comes from Grave 353: the handle fragment of a jug decorated with a combination of vertical smoothed-in lines on the upper part and three horizontal incised lines (Pl. CXXXVI. 353/1).

A stone lay in the south-western half of Grave 349. A deer fibula was found at a depth of $-60 \mathrm{~cm}$.

The perhaps best-known burial of the Budakalász cemetery - and of the Baden culture - is Grave 177 . Unfortunately, no photographs or drawings were made of the grave. In his field diary, Soproni recorded that a bowl was found lying upside-down at a depth of $-80 \mathrm{~cm}$ (Pl. LXXIX. 177/1), under which lay a goblet (Pl. LXXIX. 177/2). Placed beside the goblet was a rectangular wagon model set upright (Pl. LXXVIII. 177/3). A stone point and an unworked pebble (Pl. LXXIX. 177/5) were found between the goblet and the wagon model. The goblet from this grave has an oval upper part set on a flat, perforated foot with oval base. It is a unique piece, without any exact parallels either from the Budakalász cemetery or any other Baden site. The bowl with funnel neck is decorated with a row of impressed dots around the rim and the shoulder. It has a stringhole lug with two oblique grooves on the belly. A bowl with a stringhole lug decorated in the same manner is known from Grave 350, a female inhumation burial. It seems likely that the two vessels had been made by the same potter, which would imply that these burials were broadly contemporaneous. 

Grave goods 


\section{POTTERY}

As mentioned in the chapter on the burial rites, every object recovered from a burial was treated as part of the grave inventory, even if found among the stone packing since these objects were placed in the grave intentionally, as part of the funerary rite. Being the remnants of formerly intact vessels, pottery sherds have also been included in the analysis; if the vessel type could be determined, no difference was made between fragmentary and intact vessels in the typological analysis. A discussion of the role of intact and fragmentary vessels in the burial rite, however, is not part of the typological analysis.

Grave goods were recovered from 248 of the 436 Late Copper Age burials of the Budakalász cemetery. 153 burials contained pottery only; altogether 285 intact vessels and pottery sherds were recovered from the burials.

The pottery deposited in the graves does not represent the entire range of Baden vessels and the finds are thus unsuitable for refining the period's chronology or the existing typological systems. The description of the pottery is therefore restricted to the main ceramic traits and the analogous finds, with the exception of the vessels which were expressly made as grave pottery (goblets and ladles) since the high number of the latter warrants a more detailed discussion of these types.

The pottery of the Budakalász cemetery is rather uniform and hardly any sub-types can be distinguished within the main types, unless one has a predilection for over-typologisation. This chapter does not offer a traditional typological analysis, but rather a selective typology, discussing the most characteristic traits of a particular vessel type (Fig. 26).

Fifteen basic vessel types could be distinguished in the Budakalász cemetery. The pottery is grouped according to form and function, but no sub-categories are set up based on smaller variations in decoration.

Even though the grave pottery, in a sense, represents a random sample of Baden ceramics, making a detailed analysis rather pointless, the individual traits of some vessels enabled the identification of near co-eval graves. Accepting the axiom that vessels bearing unique stylistic traits can, similarly to potters' marks, be regarded as the products of the same potter, the graves containing pottery of this type can be considered as being more or less contemporaneous, meaning that the time elapsed between the funerals cannot have been longer than the potter's life. (There is nothing to indicate that there were potters specialising in the manufacture of grave pottery, whose vessels had been stored over several generations.) The chronological framework in the case of these burials is thus twenty to forty years, a time-span that cannot be documented using traditional archaeological techniques, but offers good anchors for identifying near contemporaneous graves.

Examined in the following will be the most important traits of the pottery (fabric, manufacturing technique, form, decoration, individual stylistic traits), and possible correlations between individual vessel types and the funeral rite, as well as between vessel types and the age and sex of the deceased.

The grave pottery included drinking vessels, liquid containers, serving dishes, storage jars and cooking pots. The pottery was dominated by drinking vessels and liquid containers.

Although the pottery deposited in the graves was generally worn, it was of the same quality as the ceramics found on settlements. It would appear that with the exception of two types, the vessels deposited in the graves were selected from among the household vessels used in daily life. Judging from their differing quality, the complete absence of wear and their more frequent occurrence in cemeteries, goblets and ladles were made for funerary purposes, to be used in the burial rite. Many of these vessels, especially the goblets deposited in inhumation burials, were carelessly made, poorly fired pieces, whose incised pattern was sometimes redrawn. No traces of use-wear could be noted on them, suggesting that they had been hastily made for the burial (cp. Table 21).

\section{GOBLETS}

The highest number of goblets from any one site came to light from the graves of the Budakalász cemetery ${ }^{1}$ and it is therefore instructive to discuss this vessel type at greater length.

Goblets are one of the most distinctive ceramic types of the Baden culture. ${ }^{2}$ Their form, size and decoration (or lack of it) shows a great diversity and each goblet can, in a sense, be regarded as a unique piece since there are no two exactly like pieces. Goblets have been variously described as footed chalices, ${ }^{3}$ footed bowls, ${ }^{4}$ footed cups, ${ }^{5}$ ribbon-footed chalices, ${ }^{6}$ wagon models, ${ }^{7}$ and bowls placed on a stand. ${ }^{8}$

Goblets have been recovered from thirty-five graves of the cemetery, accounting for 8 per cent of all graves and 14 per cent of the graves containing grave goods. ${ }^{9}$ The thirty-five burials yielded forty-three goblets in all because some burials contained more than one vessel of this type. ${ }^{10}$ Two goblets were not taken to the

\footnotetext{
1 BanNer 1956, 147; KaliCZ 1999, 86.

2 BANNER 1956, Pl. CXIV. 1-7 ("Fuss-schale", "Fussbecher", "pedestalled goblet”).

3 KoreK 1983, 73-77; Kalicz 1999, 86.

4 NĚmejcová-Pavúková 1974， 269; NĚMejCovÁ-Pavúková 1981 ,

Obr. 4; ENDRŐDI 1997, 129; ENDRÔDI 2002, 36.

5 SOPRONI 1954.

${ }^{6}$ P. BARNA 2003, 110.

FETTICH 1969, 61.

8 FETTich 1969, 61, based on the vessel from Grave 7 of the Tiszavasvári-Gyepáros site.

9 Graves 3, 8-9, 19, 30, 33, 36, 39, 61, 70, 73, 75, 78, 101, 118, 131, 138, $142,158,174,177,197,203,222,238,257,261,263,330,335,360,375$, $378,383,391$

10 Graves 3, 19, 118 and 360 had contained two goblets each, while Grave 75 yielded four goblets.
} 
Table 21. Distribution of the grave pottery according to burial rite

\begin{tabular}{|l|c|c|c|c|c|c|c|c|c|c|}
\hline \multirow{2}{*}{ Vessel type } & \multicolumn{9}{|c|}{ Inhumation } & \multicolumn{9}{l}{ Cremation } \\
& single & double & triple & skull & $\begin{array}{l}\text { scattered } \\
\text { cremation }\end{array}$ & inurned & double & Symbolic & Stray & Total \\
& & & & & & & & \\
\hline goblet & 24 & 5 & 1 & - & 3 & - & 1 & 1 & - & 15 \\
\hline ladle & 14 & - & 1 & 1 & - & - & - & - & - & 16 \\
\hline dipper & 7 & - & - & - & - & - & - & - & - & 7 \\
\hline suspension vessel & 2 & - & - & - & - & - & - & - & - & 2 \\
\hline mug & 18 & 1 & - & - & 7 & - & - & 1 & - & 27 \\
\hline pitcher & 31 & 3 & 1 & - & 3 & - & - & 1 & - & 39 \\
\hline jug & 8 & 2 & 1 & - & 3 & 1 & - & - & 1 & 15 \\
\hline scooping vessel & 25 & 3 & 1 & - & 1 & 1 & - & 1 & 1 & 32 \\
\hline handled cup & 7 & 1 & - & - & - & - & - & - & - & 8 \\
\hline beaker & 2 & - & - & - & 2 & - & - & - & - & 4 \\
\hline handled pot & 5 & 1 & - & - & - & - & - & - & - & 6 \\
\hline amphora & 6 & - & - & - & 3 & - & - & - & - & 9 \\
\hline bowl & 31 & 2 & 1 & 2 & 5 & 1 & 1 & 1 & - & 44 \\
\hline handled bowl & 3 & - & - & - & 1 & - & - & - & - & 4 \\
\hline bipartite bowl & 6 & - & 1 & - & 4 & 1 & - & - & - & 12 \\
\hline
\end{tabular}

museum. ${ }^{11}$ Goblets were the single grave goods deposited beside the deceased in five graves. ${ }^{12}$

Most of these goblets were recovered from inhumation graves, with only four coming from cremation burials. ${ }^{13}$ Goblets were deposited in the inhumation and symbolic burials containing wagon models. ${ }^{14}$ Five double burials ${ }^{15}$ and a triple burial ${ }^{16}$ too contained goblets.

While the fabric of these vessels does not differ from that of the other pottery wares, they appear to have been much more poorly fired. Most goblets are thinwalled, breaking easily, and while their surface was not smoothed or polished, almost all bear traces of pigment, either simple red painting or white painted bands, or a combination of the two.

Even though there are no two identical pieces, the high number of goblets from the Budakalász cemetery (Figs 27-35) enables the creation of a typological sequence based on the vessel proportions, the form of the chalice-like upper part and the foot, as well as the decoration (or its lack).

Goblets can be divided into three main parts: the upper part, the foot and the base. The upper part is either rounded or angular, the foot is cylindrical or prismatic (either triangular or quadrangular), although some pieces are set on clay coils held together by a smaller lump of clay instead of a solid foot. The base is

\footnotetext{
11 Graves 78 and 101 were both double burials. Nothing was inventoried from Grave 78, while the single grave good from Grave 101, a goblet, perished after the excavation of the grave and its description is known only from the excavation diary.

12 Graves 9, 30, 39, 118 and 391.

13 Graves 131, 138, 222 and 238.

14 Graves 158 and 177 .

15 Graves 3, 78, 101, 142 and 263

16 Grave 391.
}

either rectangular, triangular or round. Goblets come in both decorated and plain varieties. Some were decorated on the upper half or the foot only, and a few pieces have a design covering the entire vessel body.

Occasionally, the vessel became damaged during its manufacture. The rim of the goblet from Grave 378 had become chipped before it was painted, and its foot was similarly damaged (Pl. CL. 378/4). A piece broke off the foot of the decorated goblet from Grave 391 before firing (Pl. CLIII. 391/1), while the piece from Grave 330 has two round perforations, one of which was a spoilt one (Pl. CXXVI. 330/3). The pattern on the goblet from Grave 142 was also hastily drawn: it is quite obvious that the potter first made a design of longer lines and then, apparently changing his mind, smoothed the vessel surface and created a lattice pattern (Pl. LXI. 142/1). It would appear that these flaws, made during the goblets' manufacture, did not influence the vessel's role in the funerary rite and that chipped vessels or pieces with a spoilt design could also be deposited in the grave.

The inhumation graves included nine male burials, which yielded ten goblets in all. One of these, Grave 142 , was a double burial. Seven of the ten goblets are decorated, three are plain. Eight have a rounded and two have an angular cup part, and one burial (Grave 19) contained one of each. Five of these goblets have a cylindrical foot, four a ribbon-like foot and one is set on a prismatic foot. The height of these vessels ranges between 6.2 and $11 \mathrm{~cm}$. A possible correlation was sought between age and the size, form and decoration of the goblet and its association with other finds. I found that goblets had been placed beside men who had died between the age of 23 and 59. Older men (40-59) were generally interred with a larger and richer 


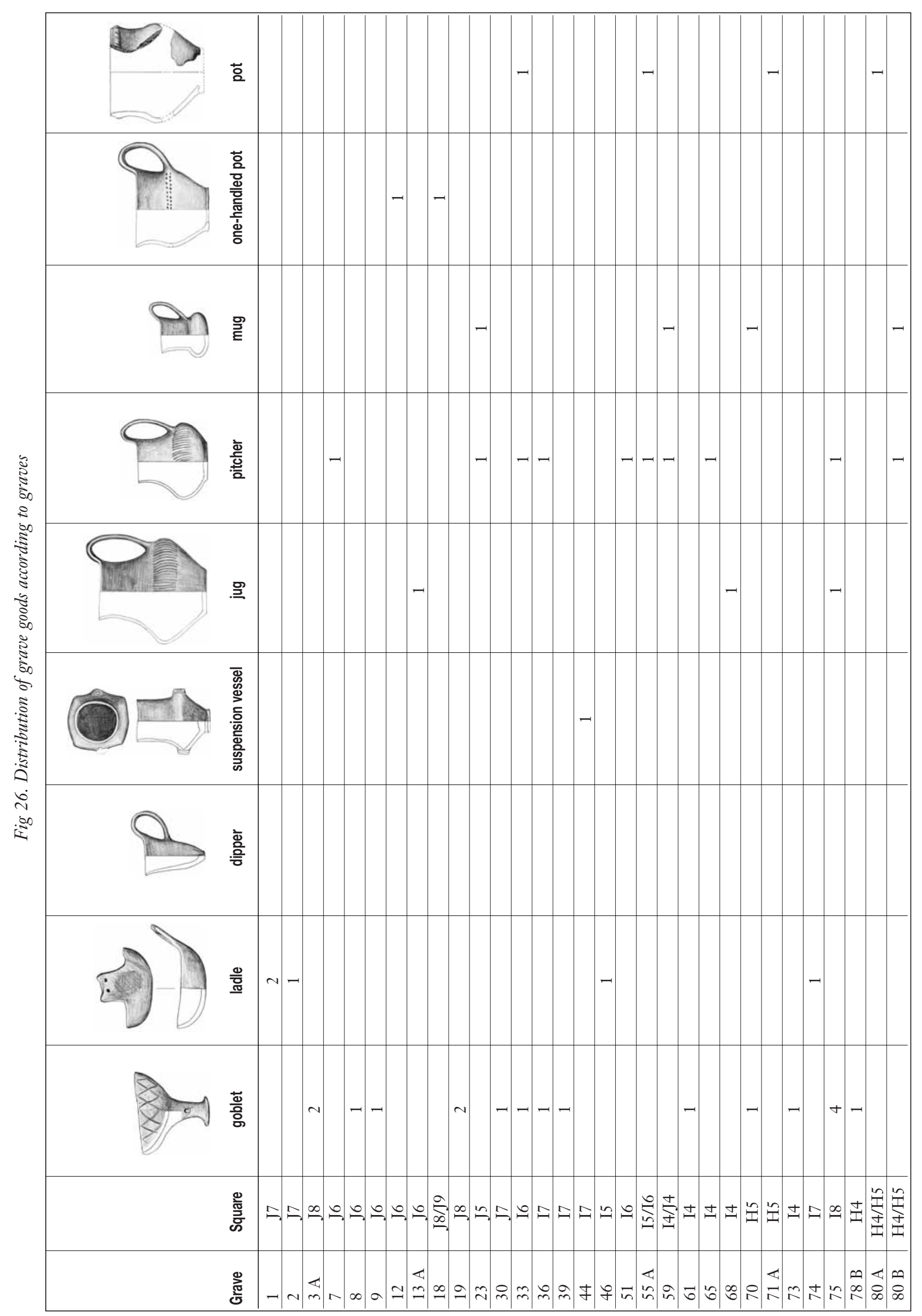




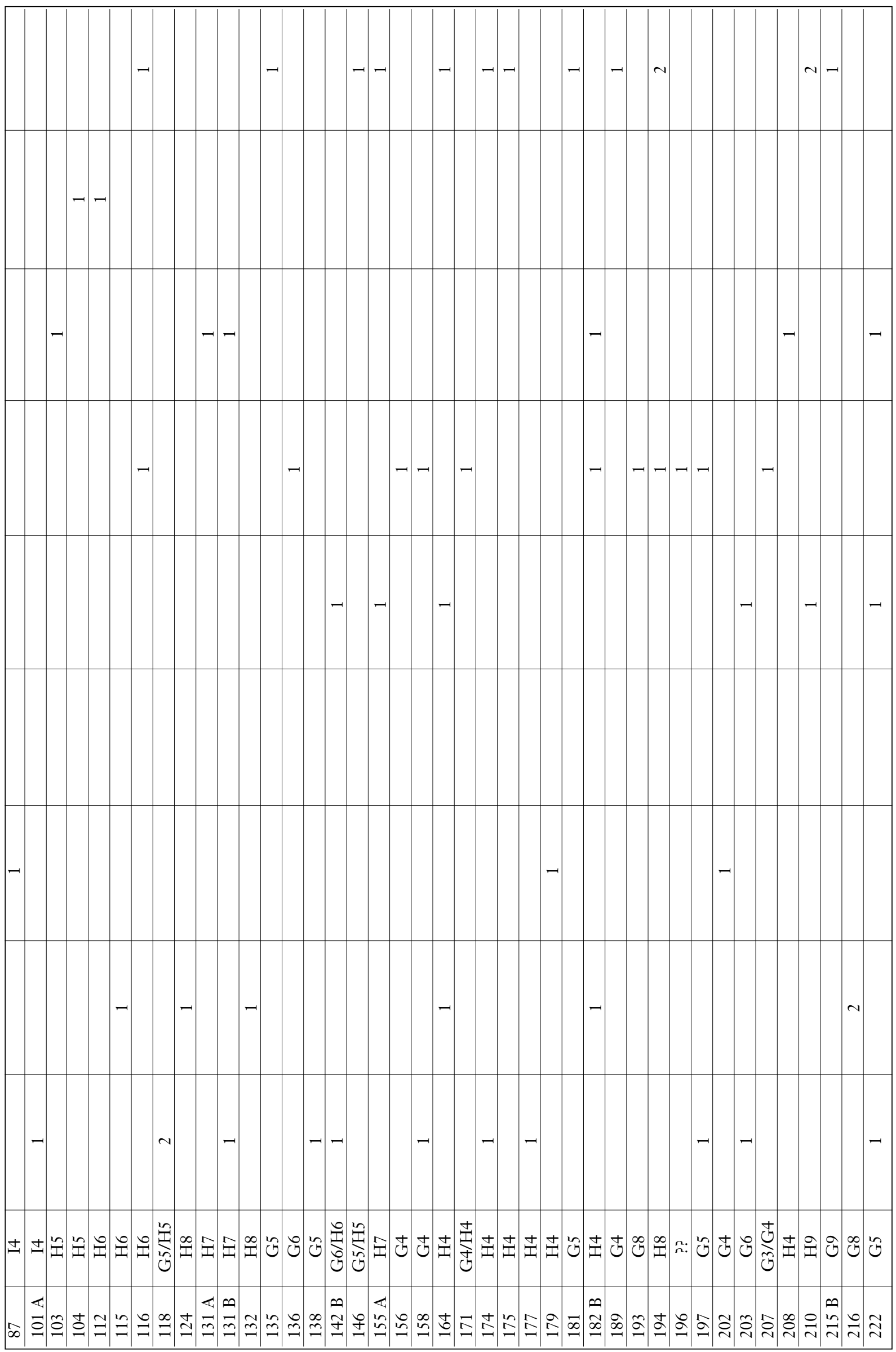




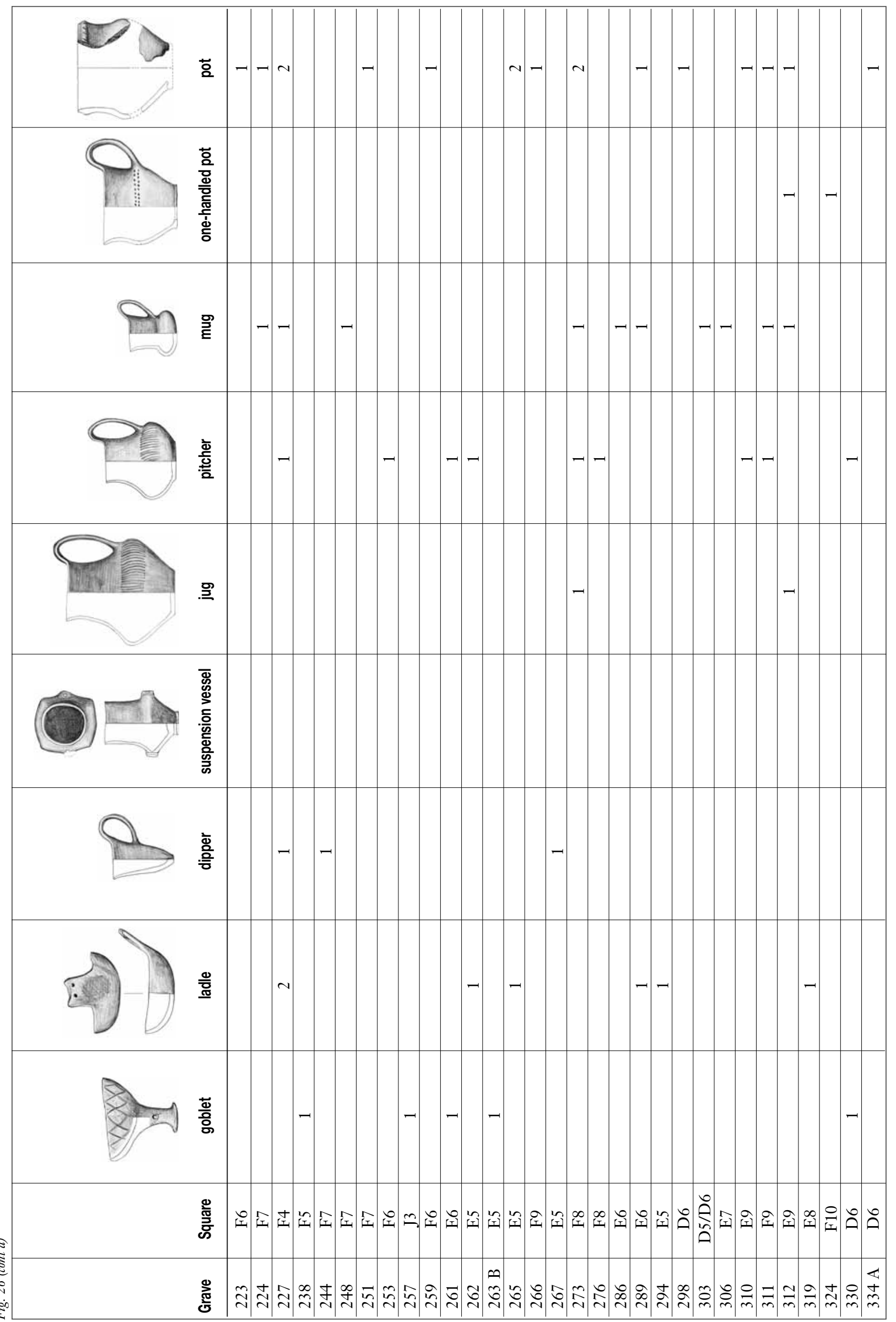




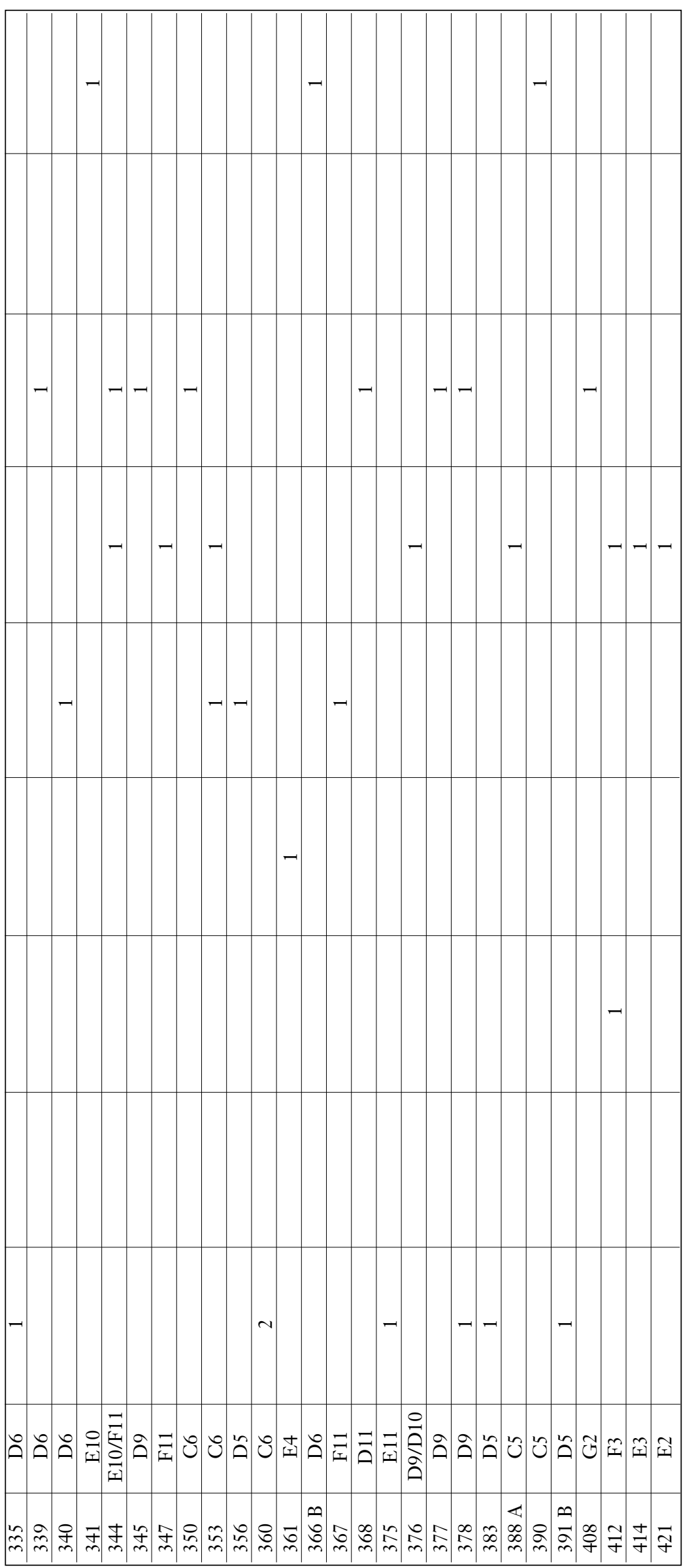




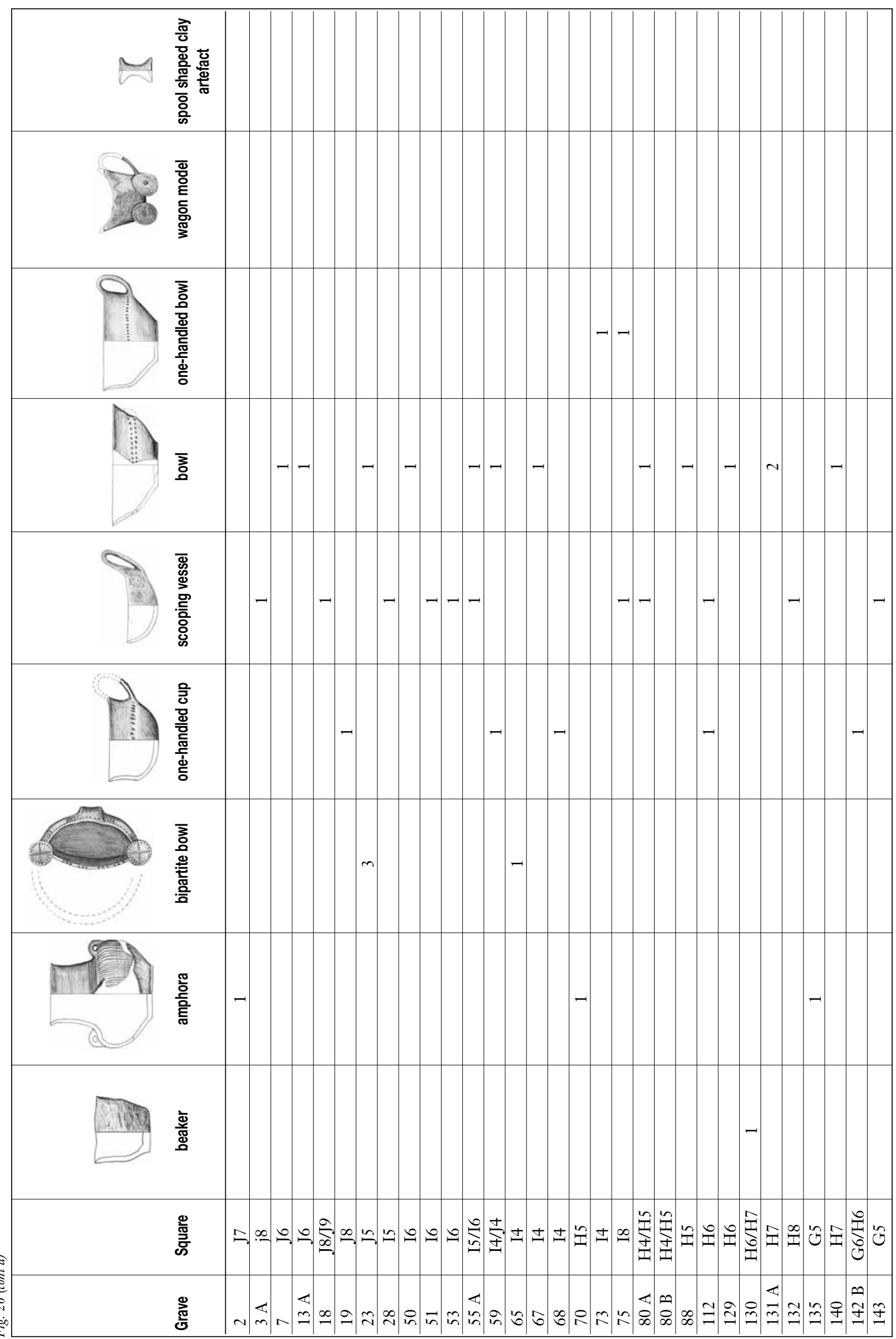




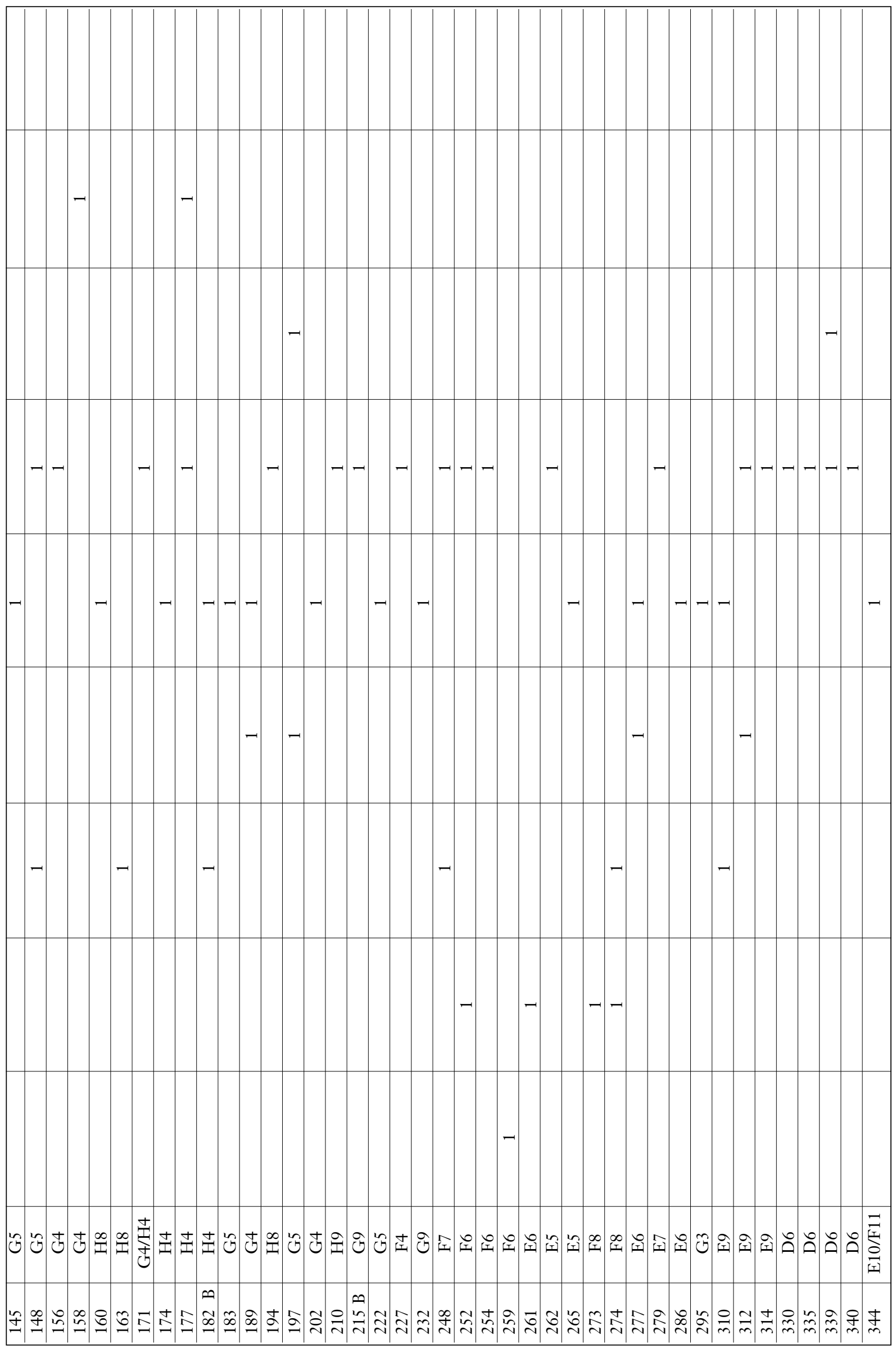




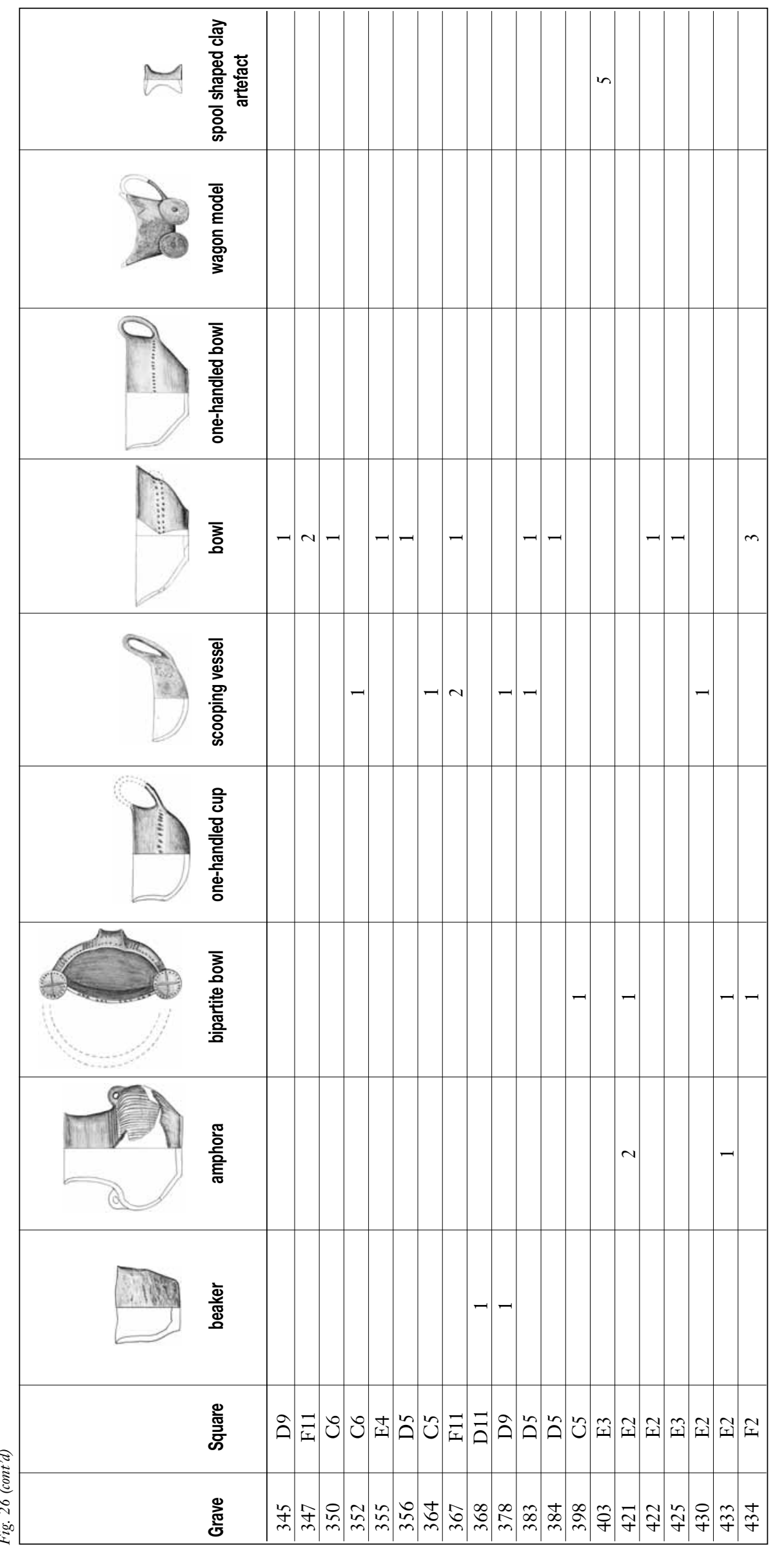




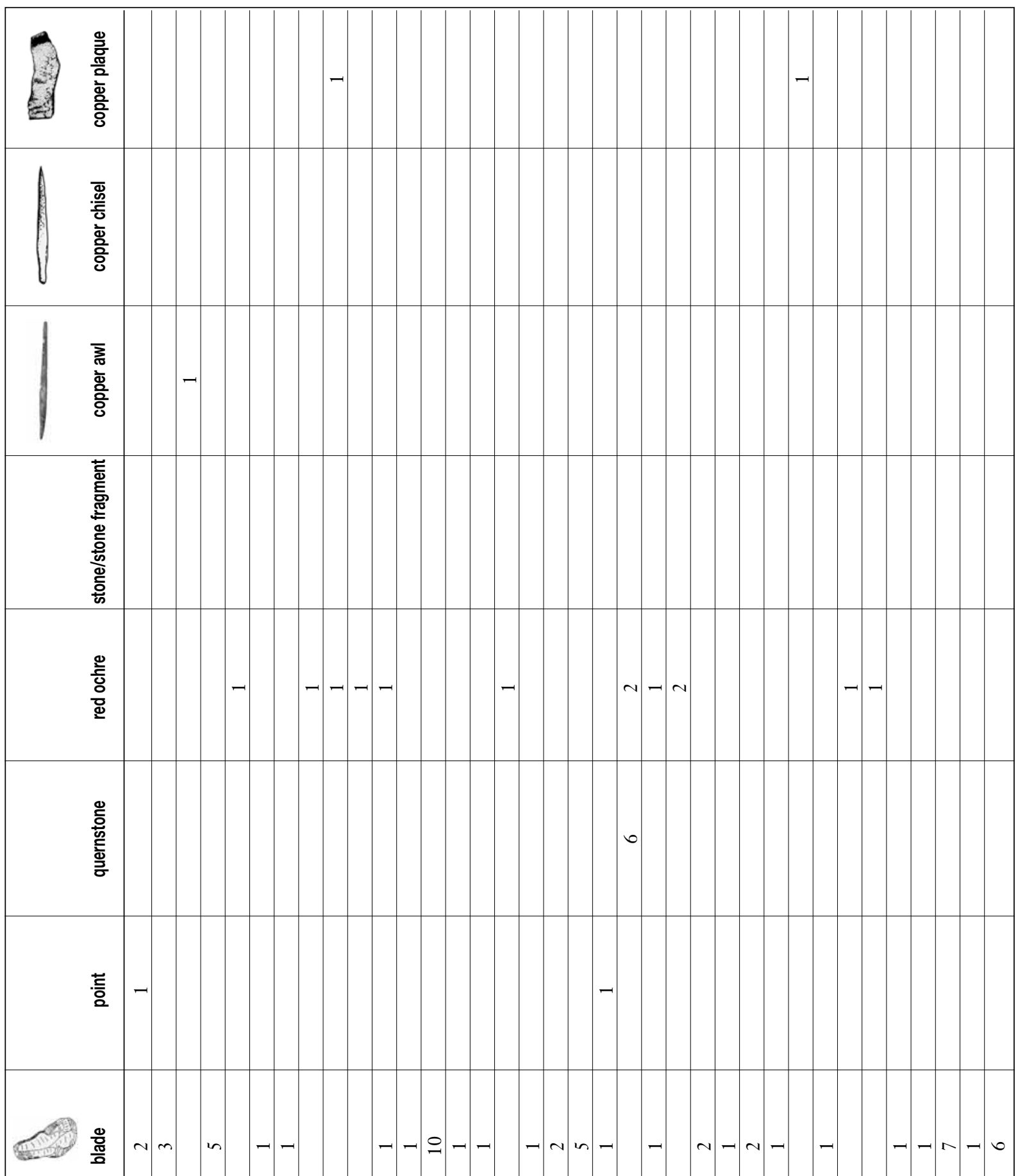

2
2
2
0
के

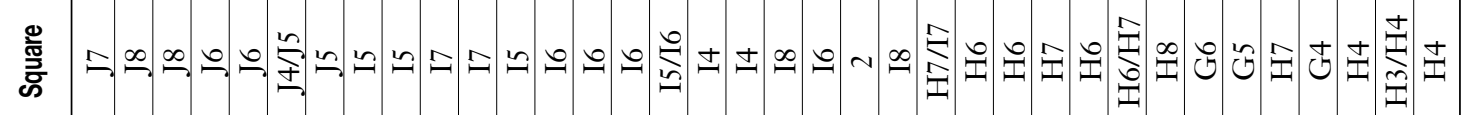

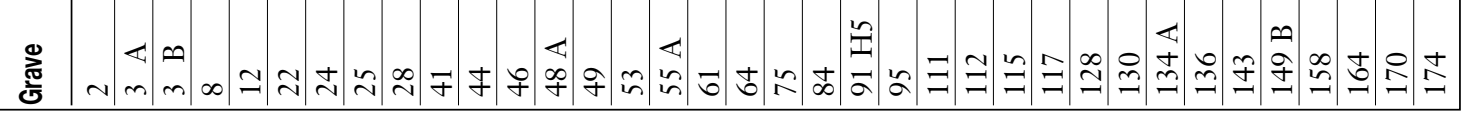




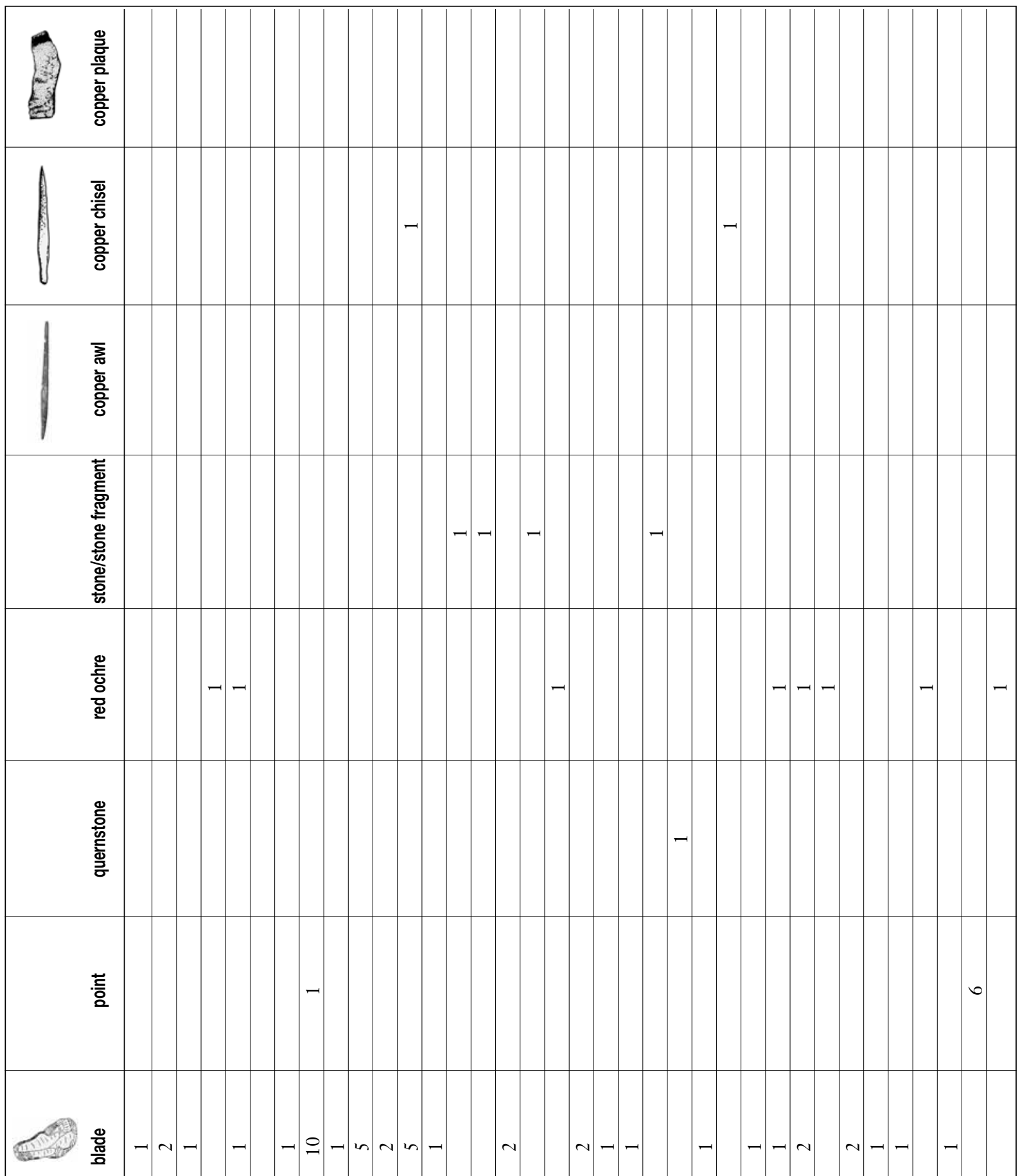

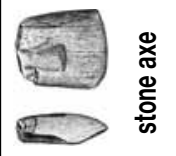

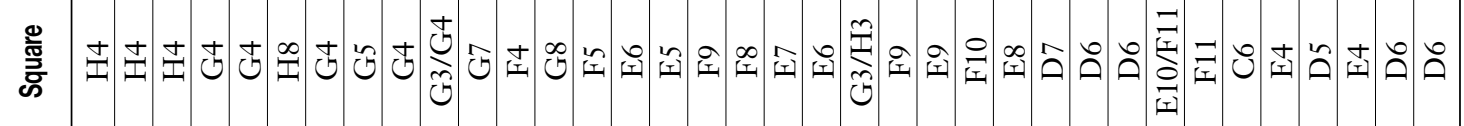

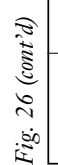

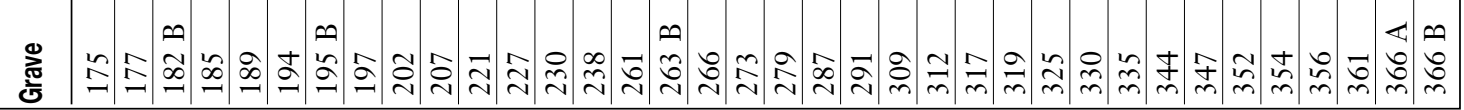




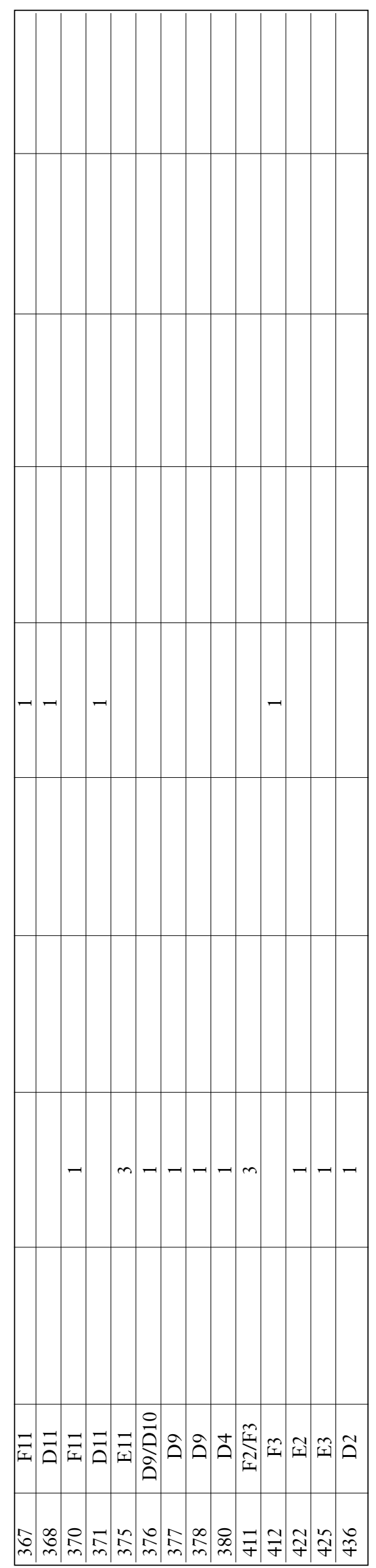


带

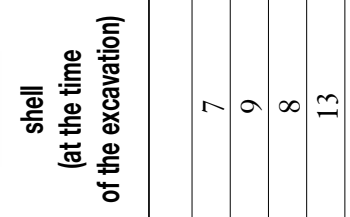

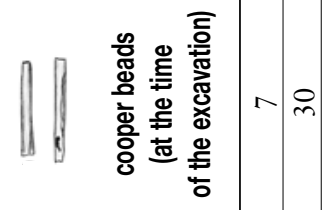

$m \quad \sim \quad$ 는

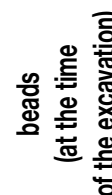

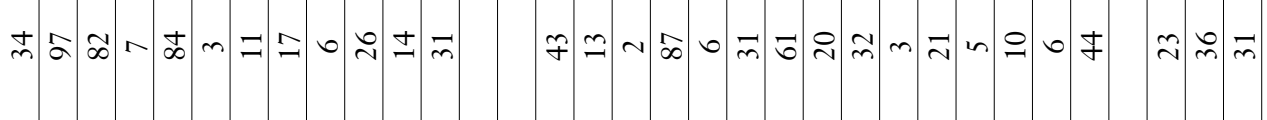

(1)

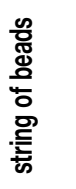

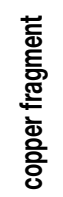

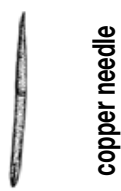

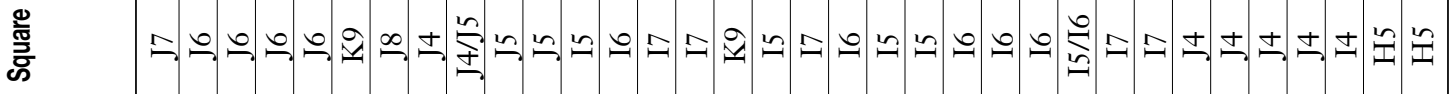

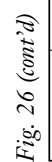

票 


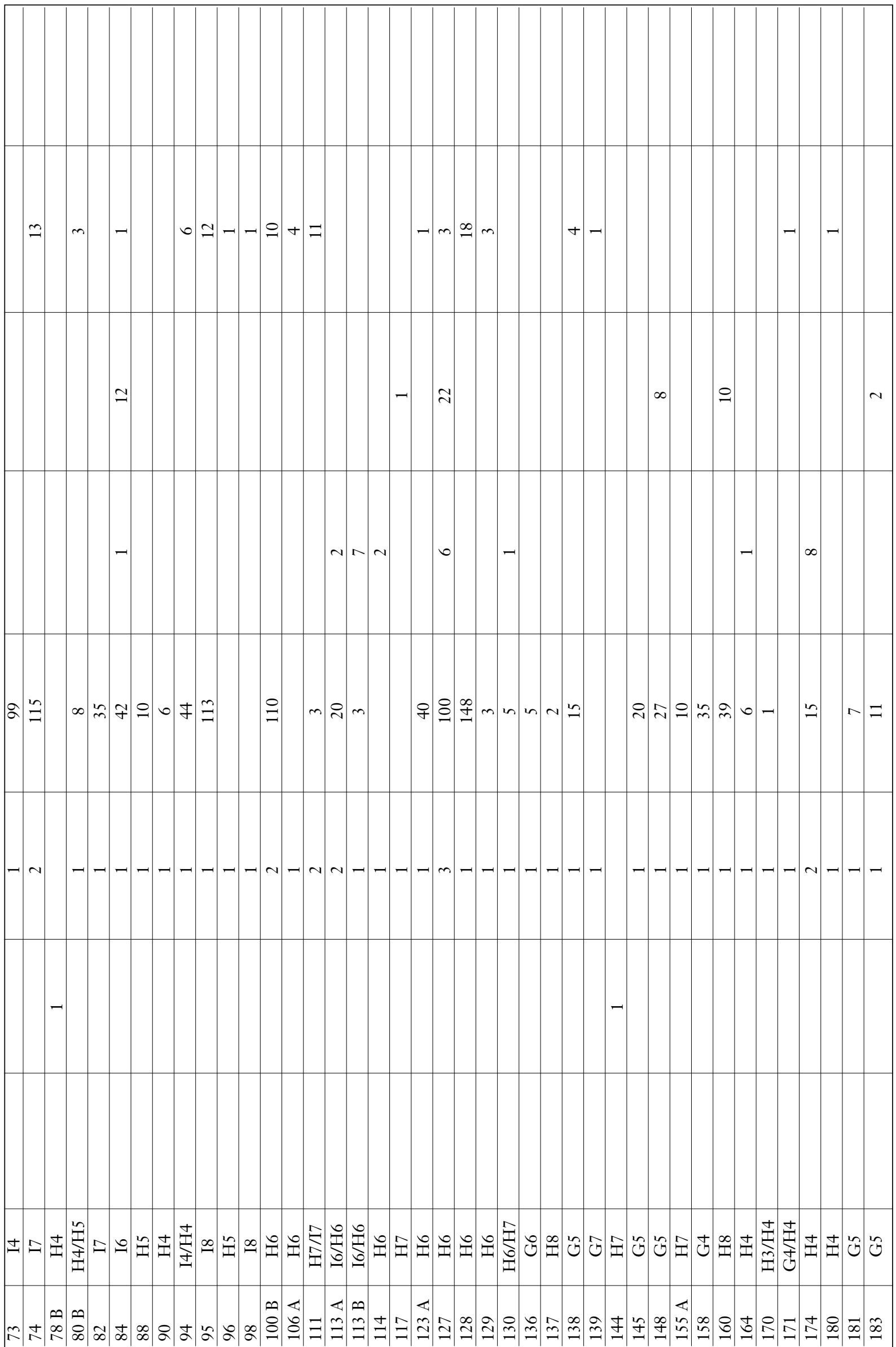




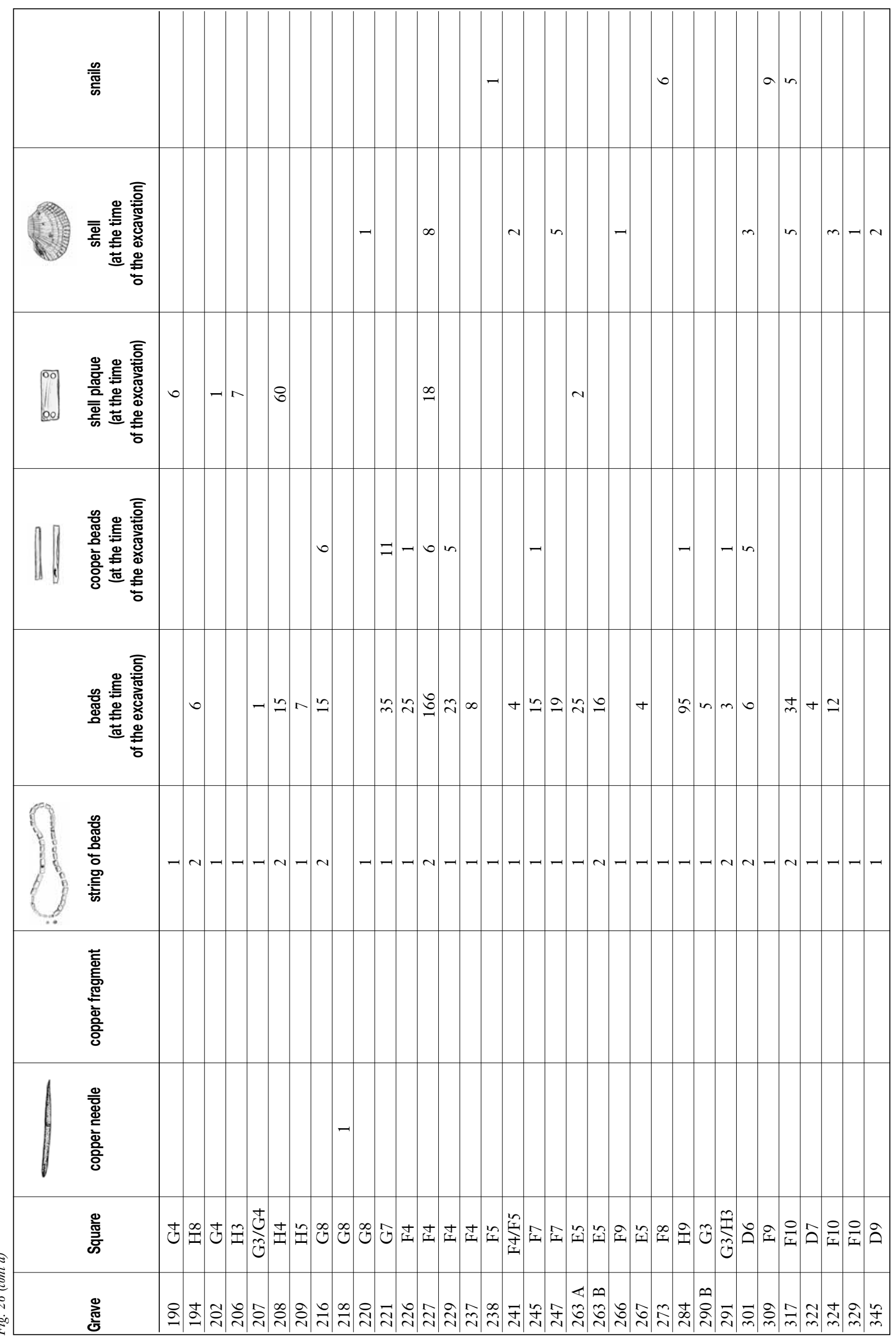




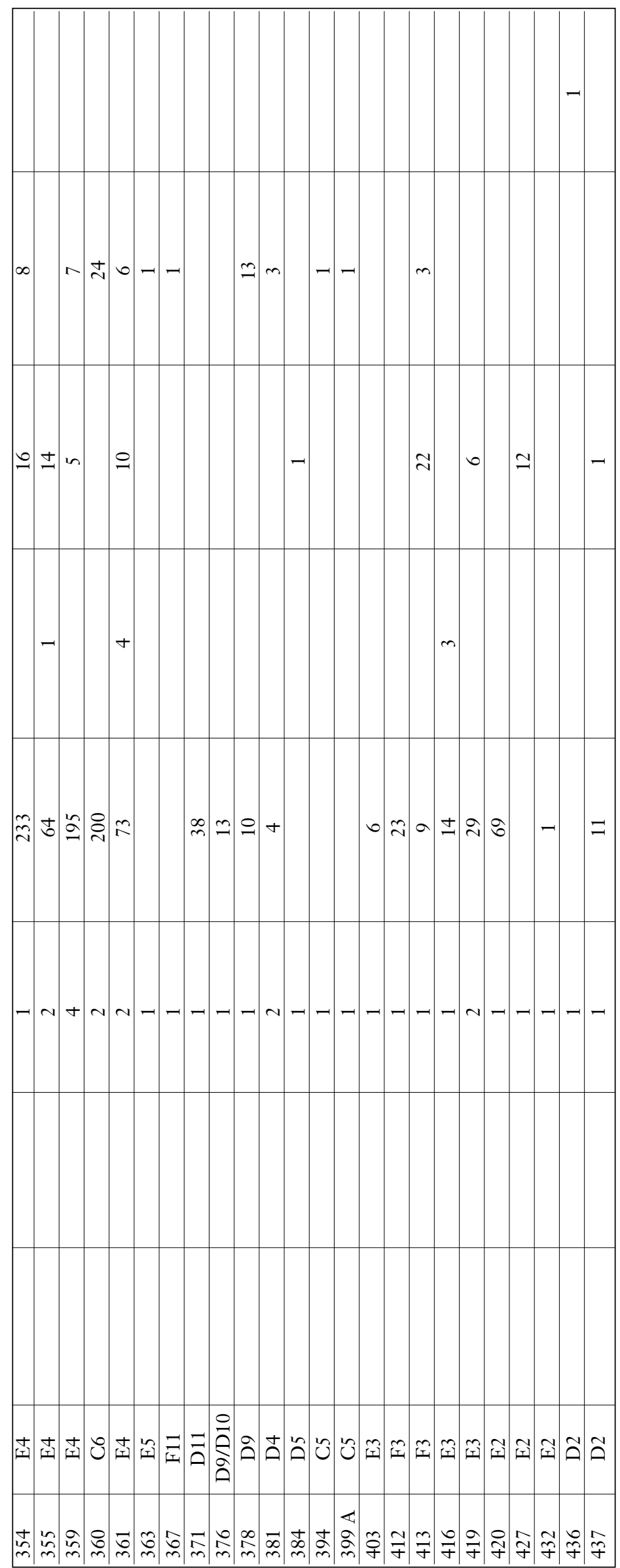



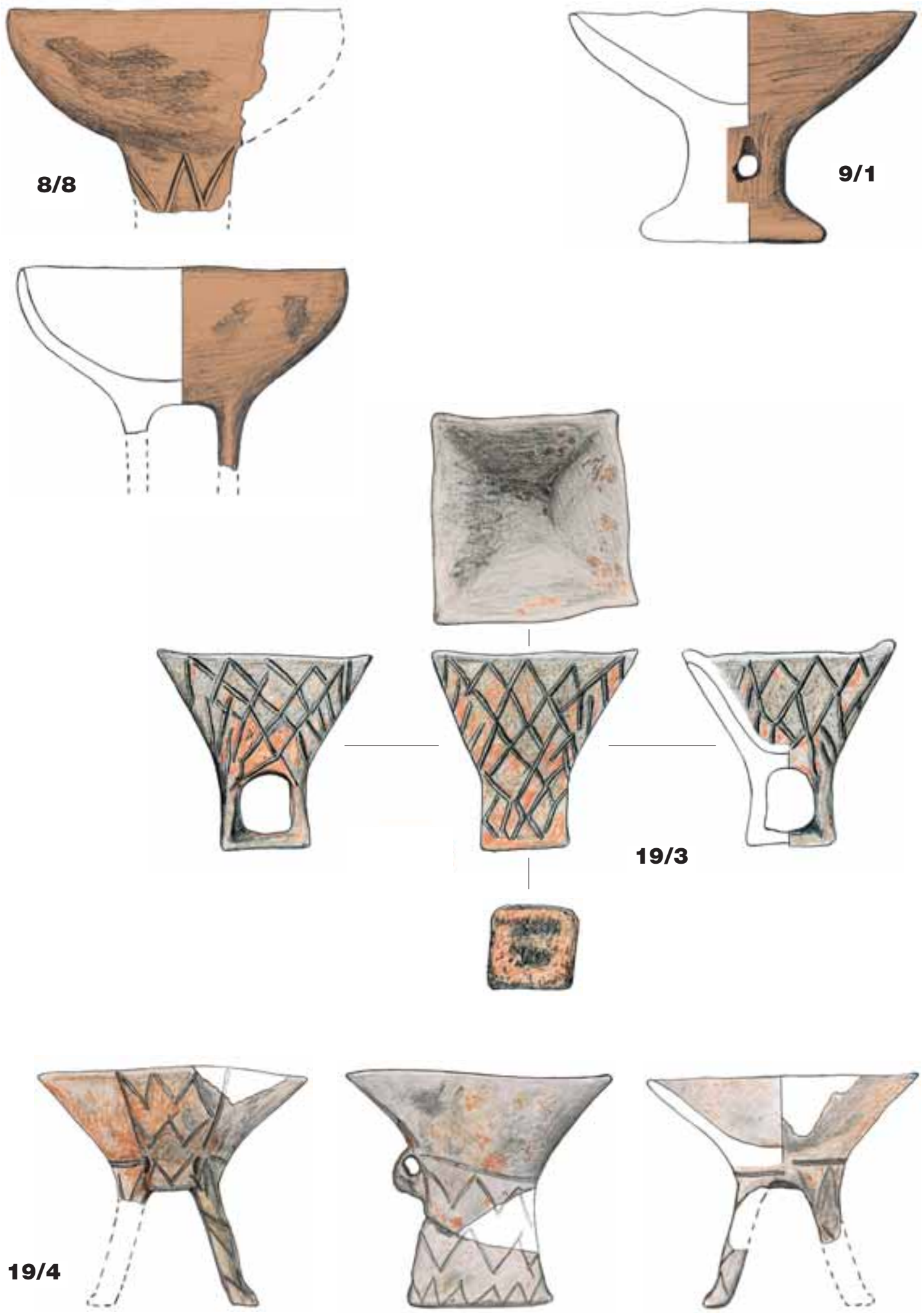

Fig. 27. Goblets from male inhumation burials (Graves 8, 9 and 19) 


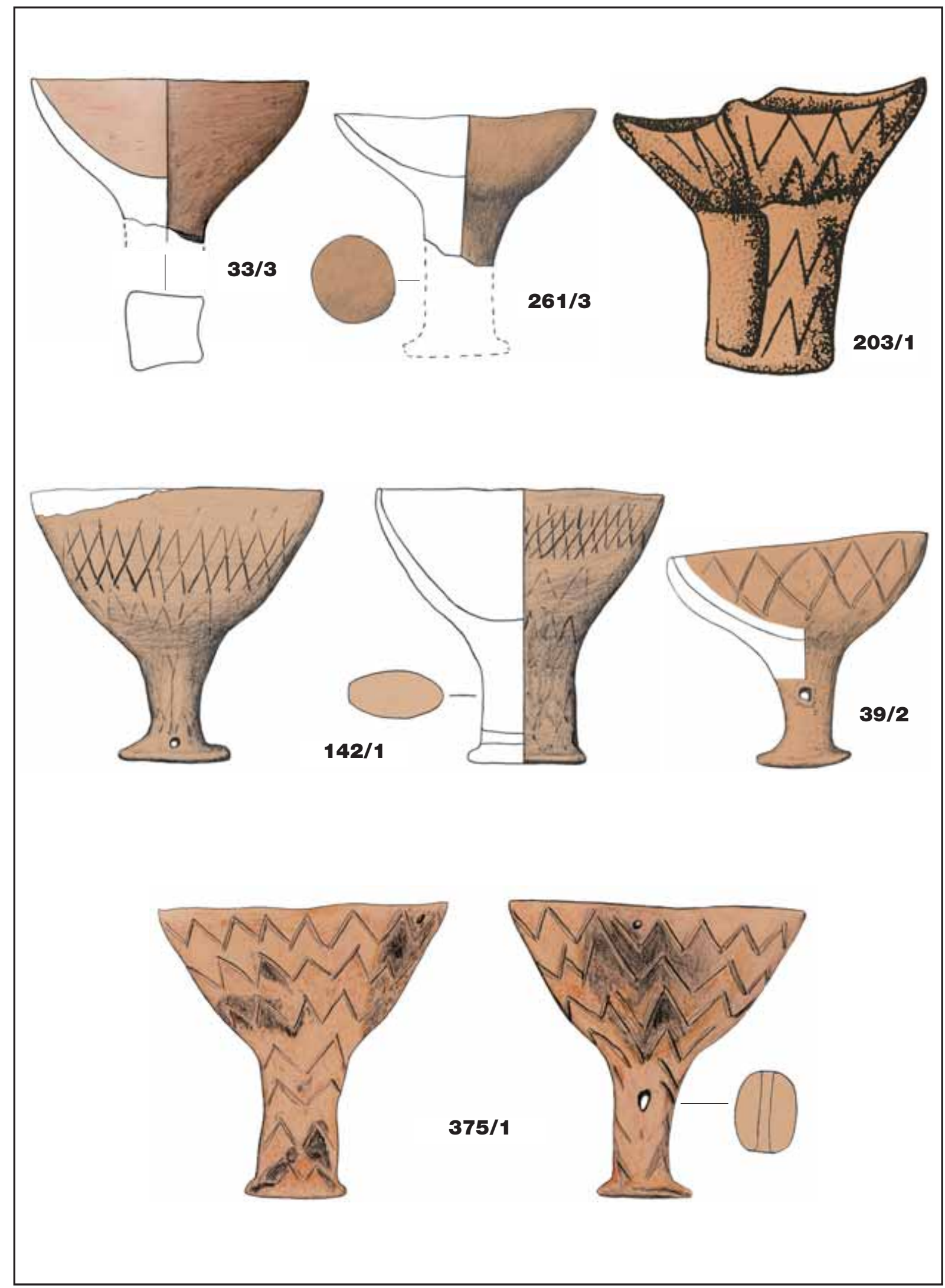

Fig. 28. Goblets from male inhumation burials (Graves 33, 39, 142, 203, 261 and 375) 


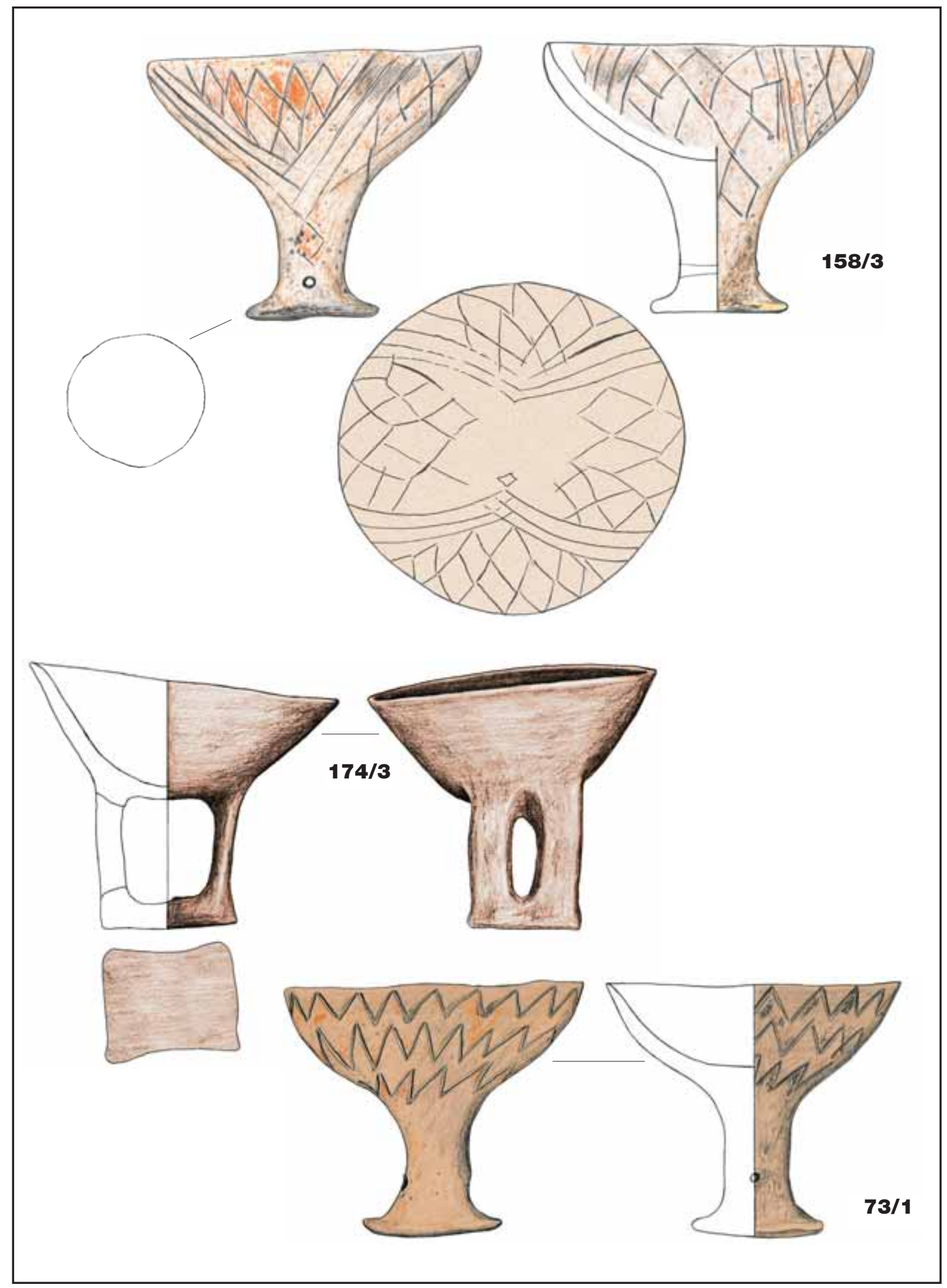

Fig. 29. Goblets from female inhumation burials (Graves 73, 158 and 174) 


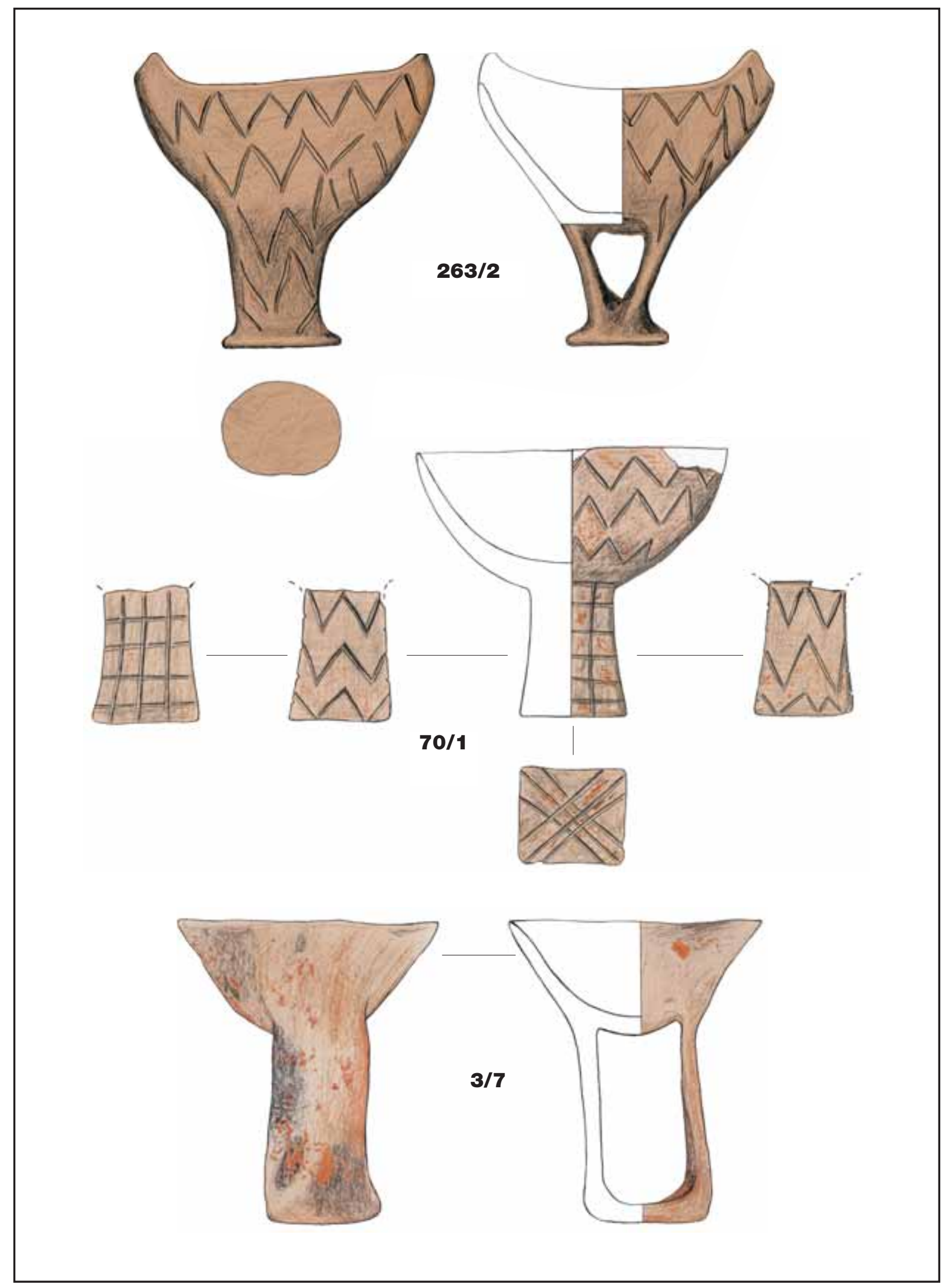

Fig. 30. Goblets from female inbumation burials (Graves 3, 70 and 263) 


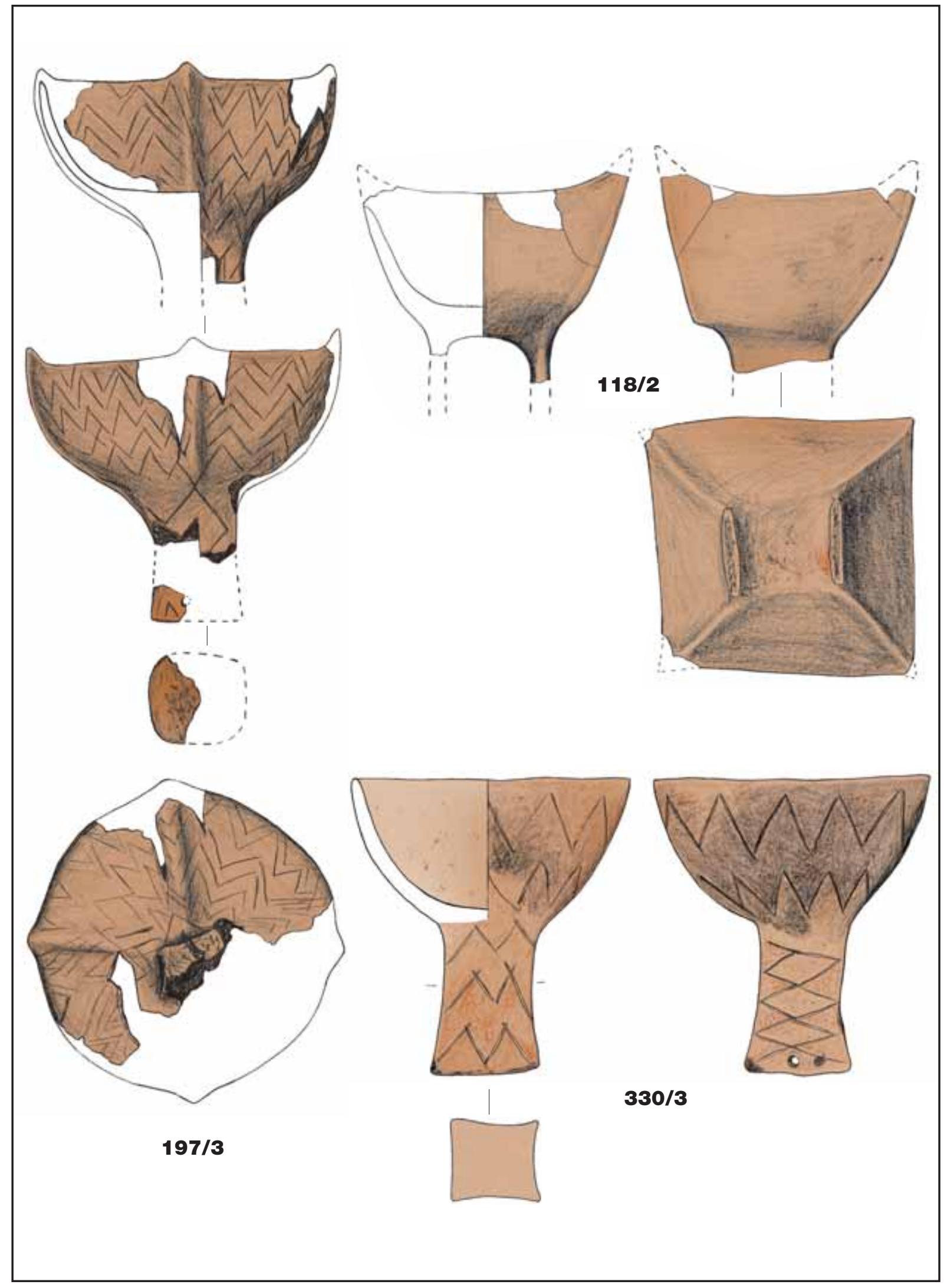

Fig. 31. Goblets from female inhumation burials (Graves 118, 197 and 330) 


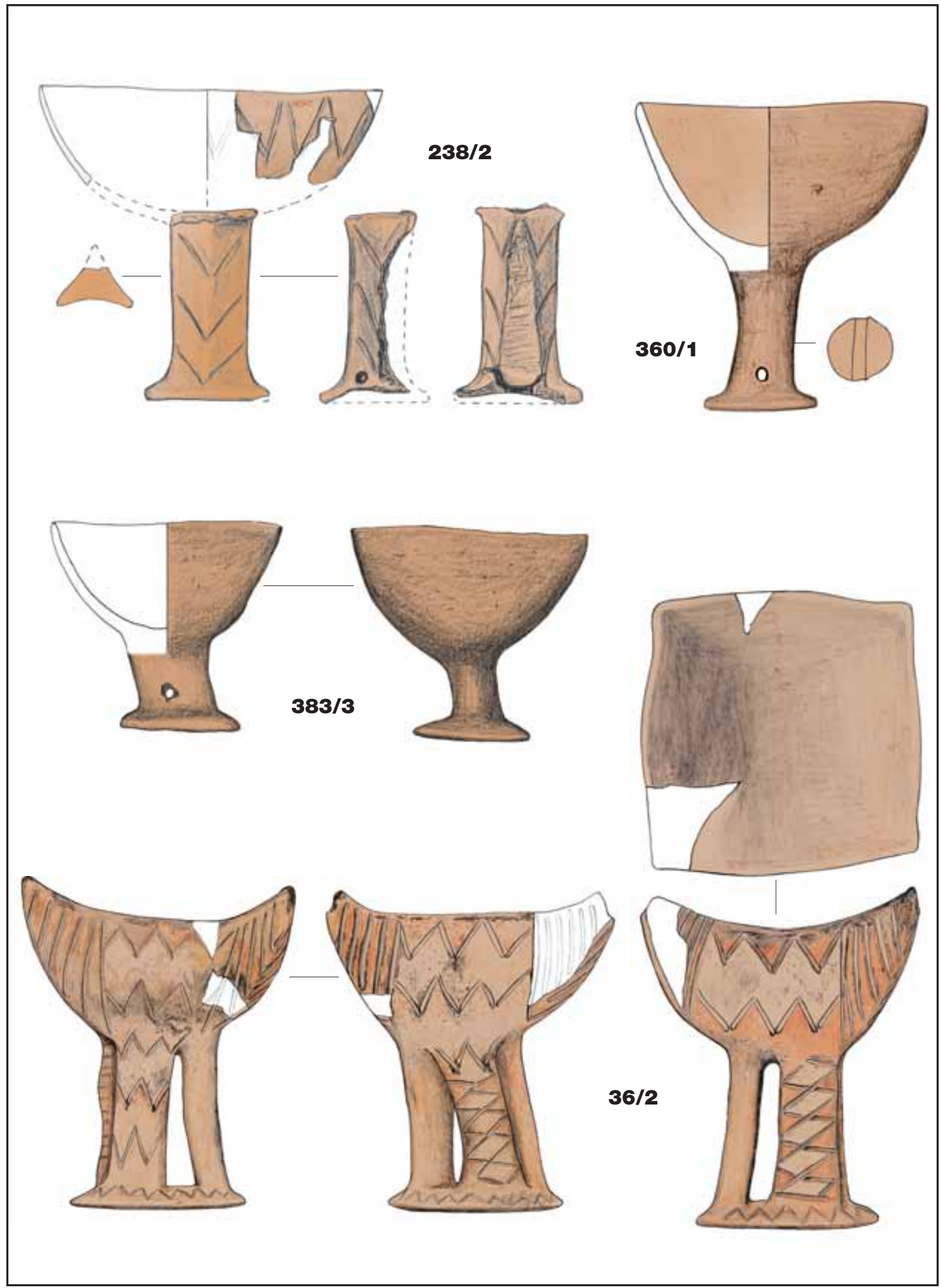

Fig. 32. Goblets from female inbumation burials (Graves 36 and 383), a child inhumation burial (Grave 360) and a cremation burial (Grave 238) 


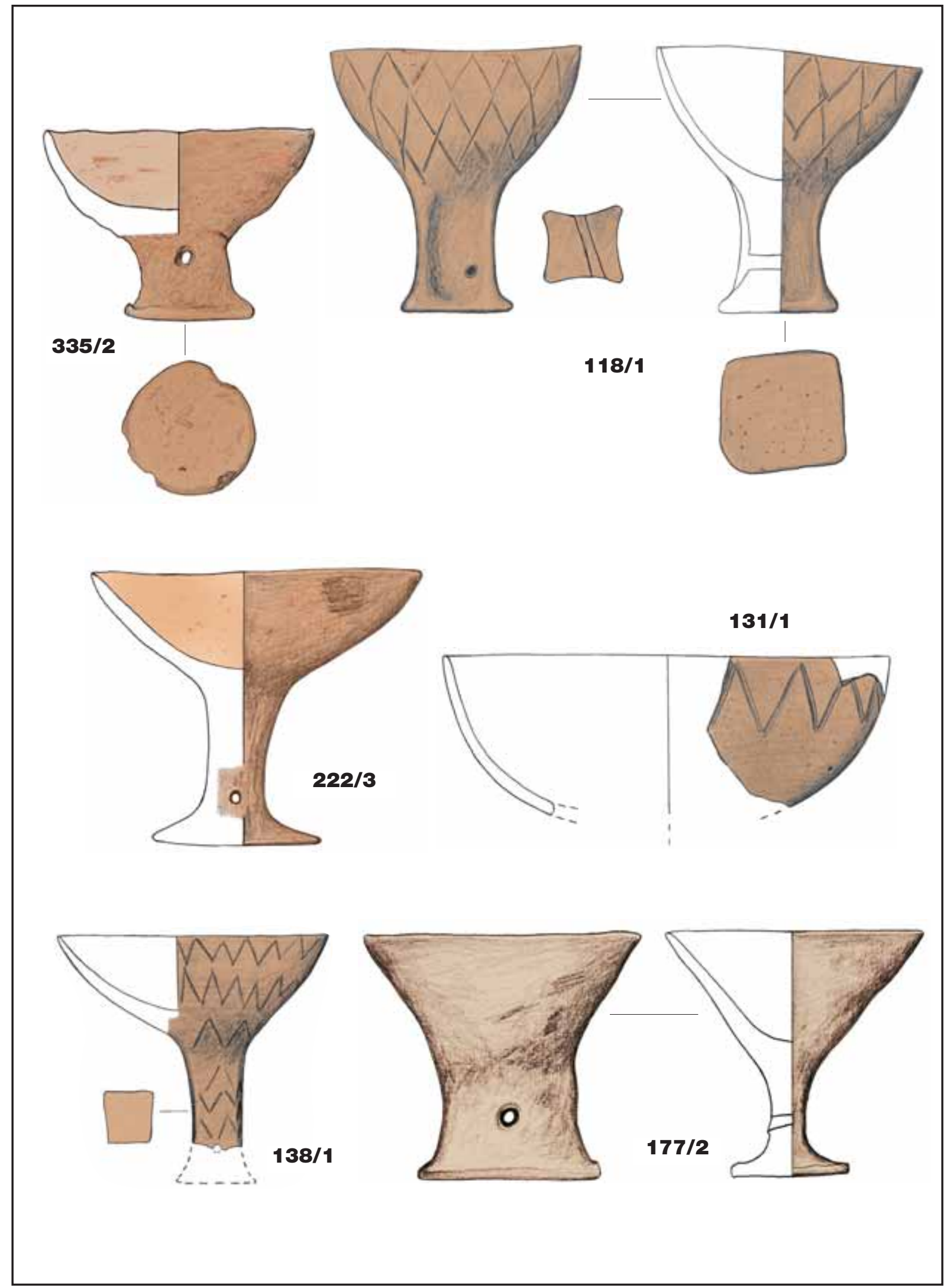

Fig. 33. Goblets from female inhumation burials (Graves 118 and 335), cremation burials (Graves 131, 138 and 222) and a symbolic burial (Grave 177) 


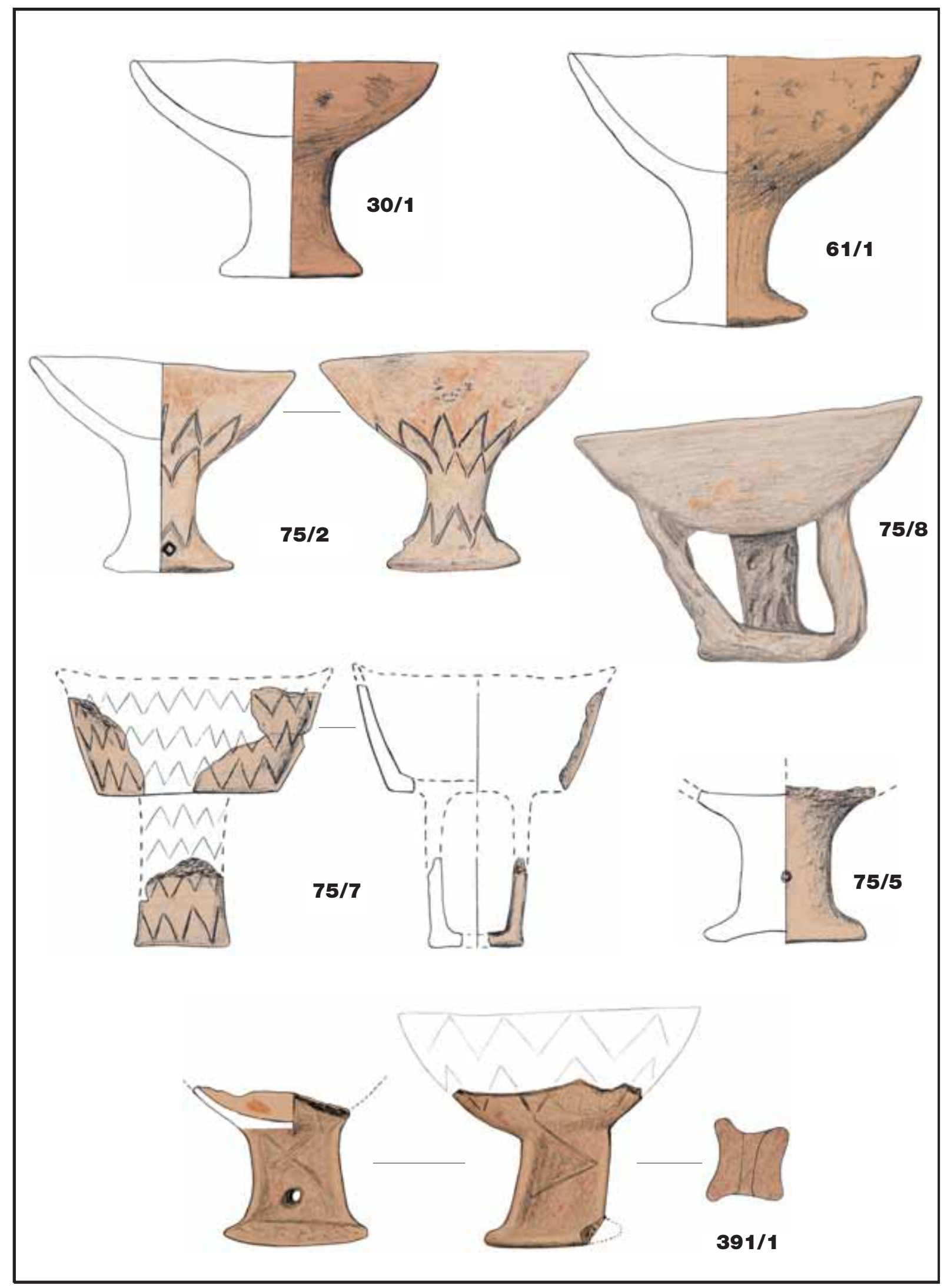

Fig. 34. Goblets from child inhumation burials (Graves 30, 61, 75 and 391) 


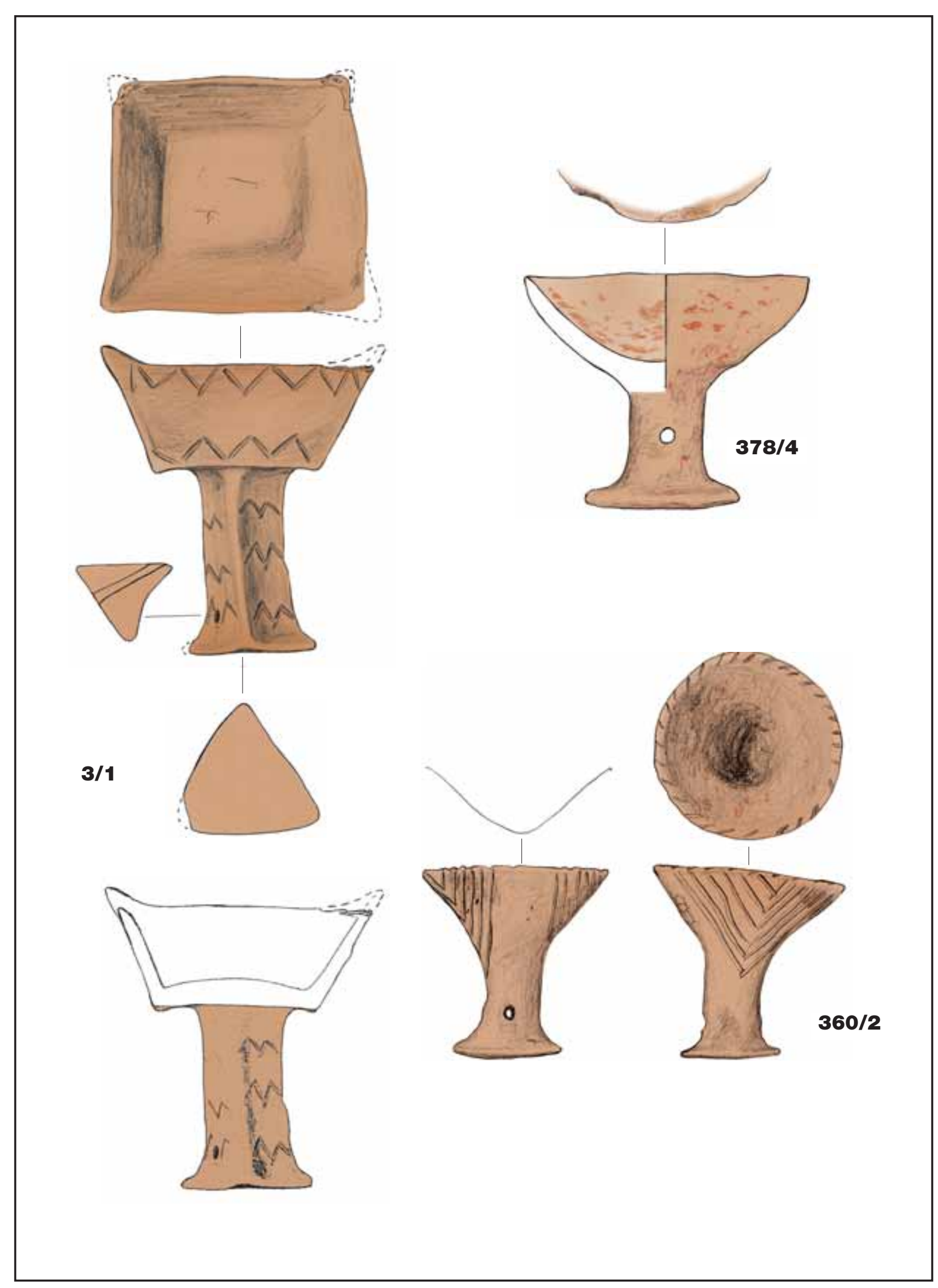

Fig. 35. Goblets from a female inhumation (Grave 3) and child inhumation burials (Graves 360 and 378) 
Table 22. The forme and decoration of the goblets in the female, male and child burials

\begin{tabular}{|l|c|c|c|c|c|c|c|}
\hline & Decorated & Plain & $\begin{array}{c}\text { Ribbon-like } \\
\text { foot }\end{array}$ & $\begin{array}{c}\text { Cylindrical } \\
\text { foot }\end{array}$ & $\begin{array}{c}\text { Prismatic } \\
\text { foot }\end{array}$ & Rounded cup & Angular cup \\
\hline Female burials & 8 & 5 & 5 & 3 & 5 & 9 & 4 \\
\hline Male burials & 7 & 3 & 4 & 5 & 1 & 8 & 2 \\
\hline Child burials & 4 & 9 & 3 & 8 & 1 & 10 & 2 \\
\hline Total & 19 & 17 & 12 & 16 & 7 & 27 & 8 \\
\hline
\end{tabular}

assortment of grave goods. The man laid to rest in Grave 8 wore two bead necklaces, and five stone implements (blades and flakes) had also been placed into the grave in addition to the goblet. The man buried in Grave 33 had three shells on his waist and in addition to the goblet, his grave yielded a pitcher and a base fragment from a pot. Grave 203 contained a pitcher in addition to the goblet, while Grave 261 yielded pitcher and amphora fragments as well. There was no apparent correlation between the form and/or decoration of the goblets and their deposition in a male burial.

Eleven female graves yielded a total of thirteen goblets. Two of these were double burials (Graves 3 and 263). Eight goblets were decorated, five were plain; two burials contained one of each (Graves 3 and 118). Nine goblets had a round, four had an angular cup part; five had a ribbon-like foot, five a prismatic foot and three a cylindrical foot. The height of the goblets ranged between 6.6 and $11.5 \mathrm{~cm}$, roughly corresponding to the pieces in the male burials. Most of the goblets had been deposited in the graves of women who had died between the age of 30 and 59, with the exception of two burials: Grave 174 contained the burial of a 14-16 years old girl, Grave 330 the burial of a 23-25 years old woman. The single goblet with triangular base was recovered from Grave 3, one of the cemetery's more remarkable graves containing a double burial and two animal burials. The unusualness of this grave is reflected also in the unique form of the goblet deposited in the burial. The other grave goods were another goblet, a handled cup and three stone implements. The goblets deposited in the female burials were perhaps the most finely made pieces, elaborately decorated with incised designs and painting.

Nine child graves yielded goblets, two of which were double burials (Graves 78 and 101), while one was a triple burial (Grave 391). The fragment of the goblet from Grave 78 lay among the stones. The goblet from Grave 101 perished and never reached the museum. The nine graves yielded thirteen goblets, four of which were decorated, the rest were plain, with two burials (Graves 75 and 360) containing a pair of decorated and plain goblets. Ten goblets had a rounded and two an angular cup part, with one burial (Grave 75) containing both types. The form of the cup could not be determined in two cases. The child interred in Grave 75 was given four goblets, whose height ranged between 5.4 and $11 \mathrm{~cm}$. Goblets were placed in two infant burials (Graves 78 and 391); the other child graves contained the burials of $6-8$ year olds (Graves 30 and 61) or 9-12 year olds (Graves 75, 101, 360, 378 and 383). 6-8 years old children were given plain goblets with a rounded cup, a cylindrical foot and a round base. A single goblet was the only grave pottery deposited in the burials of children under ten (Graves 30, 78, 101 and 391).

There was no apparent difference between the goblets deposited in male, female and child burials regarding their form, size and decoration, meaning that none of the goblets can be correlated with the sex or age of the deceased. A few tendencies can nonetheless be noted (Table 22).

The most carefully made and elaborately decorated goblets were recovered from female burials, while plain pieces were generally deposited in child burials. The proportion of plain and decorated pieces is roughly the same. Most goblets had a cylindrical foot, the number of goblets with a ribbon-like foot is lower, and both types were predominantly placed in female burials. The single goblet with a triangular base was found in a female inhumation burial. Goblets with a rounded cup were more frequent than ones with an angular cup.

Four of the cemetery's cremation burials contained goblets. Grave 222 yielded an intact goblet (Pl. XCIV. 223/3), while Graves 131, 138 and 238 yielded fragments (Pl. LVIII. 131/4, Pl. LX. 138/1, Pl. C. 238/2). The largest goblet with a rim diameter of $15 \mathrm{~cm}$ was recovered from Grave 131 (Pl. LVIII. 131/4).

Unfortunately, the sex of the deceased could only be determined in the case of Grave 222 since the ashes from Graves 131 and 238 can no longer be found, while the calcinated bone fragments from Grave 138 were only sufficient for determining the age at death (23-79 years).

Even though no obvious correlation could be established between the sex of the deceased and the custom of depositing a goblet in the case of inhumation burials, we may perhaps assume that the deceased of the same sex were given goblets resembling each other, irrespective of whether the person was interred according to the inhumation or cremation rite. If this was indeed the case, Grave 138 was a male burial since the goblet $(P l . L X$. 138/1) resembles the one from Grave 375 (Pl. CXLVIII. 375/1), while Grave 238 may have been a female burial since the goblet from this 
grave has a rounded cup and a triangular base $(\mathrm{Pl}$. C . 238/2) resembling the specimen from Grave 3/A, a female burial (Pl. III. 3/1).

Grave 131 was a double grave with one scattered cremation and one inurned burial. The excavation diary does not mention the remains of the goblet and it is therefore uncertain whether its fragments were found in the bowl containing the ashes or in the earth of the grave.

The other finds from the cremation burials with goblets were shells, stone implements and bead necklaces, which offer few secure anchors for an internal chronology. The other grave ceramics from Graves 131 and 222 can be assigned to the classical Baden period.

As has been mentioned above, the goblets recovered from the burials were in all likelihood made specially for the burial since no traces of wear indicating prior use could be noted on them. ${ }^{17}$ The plain and the decorated pieces both showed a great diversity, and each is practically a unique piece.

The form and size of the plain goblets shows some variation too, ranging from slender, elongated pieces (Pl. CXLIII. 360/1) to squatter ones set on a low foot (Pl. VI. 9/1, Pl. CXXVIII. 335/2, Pl. CLII. 383/3) and pieces with pleasing proportions $(P l . X V .30 / 1, P l . X V$. 33/3, Pl. XXVII. 61/1, Pl. CV. 261/3, Pl. CL. 378/4). The variant with ribbon-like foot comes with a foot created from two or three flattened clay coils $(P l$. IV. 3/7, Pl. XXXV. 75/7, Pl. XXXV. 75/8, Pl. LII. 118/2, Pl. LXXIII. 174/3), two of which are set on oblique feet (Pl. XXXV. 75/8, Pl. LXXIII. 174/3).

Decorated goblets show an even greater diversity, with no two like pieces. Their designs are made up of incised zig-zag lines, lozenges, lattice patterns, hatching and painting. Adding to the great variety are the combinations of the ornamental motifs, the spacing of the various ornamental elements, the lightness or heaviness of the incisions, the careful or careless execution of the decoration and the combination of colours used for painted designs. László Gucsi noted that the incised zig-zag patterns were not drawn continuously, but were created by incising oblique lines, some of which did not join (Pl. XVII. 36/2, Pl. XXXI. 70/1, Pl. LX. 138/1, Pl. LXXXIII. 197/3, Pl. CVI. 263/2, Pl. CXLVIII. 375/1) or extended beyond each other (Pl. CXXVI. 330/3). Incised lattice patterns were created from chevron motifs incised one under the other (Pl. XI. 19/3, Pl. LII. 118/1, Pl. LXI. 142/1, Pl. LXVII. 158/3), resulting in a slight displacement between the zones of the lattice.

Instead of actually painting the vessels, many goblets were dipped in a red paint wash and left to dry, whereby the vessel soaked up the red paint to varying degrees. On some pieces, painting was used for correcting the

\footnotetext{
17 This being one of the possible reasons that their firing and surface treatment was not as careful as that of household vessels intended for longer use.
}

design (in this case, the vessel had not been dipped in the dilute paint wash, as shown by the goblet from Grave 375 (Pl. CXLVIII. 375/1), on which the painting diverges from the incised pattern). According to Gucsi's observation made during the drawing of the cemetery's finds, the goblets were first painted with red and the white painted bands were added afterwards. This procedure can best be noted on the goblet from Grave 36 (Pl. XVII. 36/2).

Most goblets have a perforated or fenestrated foot, except for the ribbon-footed pieces, on which the areas between the flattened coils would have enabled the attachment of the vessel in an upside-down position. A tiny lug at the junction of the foot and the cup of the goblet from Grave 19 (Pl. X. 19/4) probably served this function too. Only a few goblets have a solid, unperforated foot (Pl. XV. 30/1, Pl. XXVII. 61/1, Pl. XXXI. 70/1).

For the correspondence analysis I prepared a detailed typological classification of the goblets:

Type Ia1: 3/7, 9/1, 30/1, 33/3, 61/1, 75/8, 174/3, $222 / 3,261 / 3,335 / 2,360 / 1,378 / 4,383 / 3$

Type Ia2: $177 / 2$

Type Ia3: 70/1, 75/2, 138/1, 158/3, 238/2, 330/3, $375 / 1,391 / 1$

Type Ia4: 39/2, 73/1, 118/1, 131/1, 142/1, 360/2

Type Ia $5: 8 / 8,19 / 4$

Type Ib: 3/1, 19/3, 75/7, 203/1

Type Ic1: 36/2, 197/3, 263/2

Type Ic2: 118/2

Type Id: $75 / 5,78 / 1,101 / 1,257 / 1$

In most cases, these vessels were expressly made for the burial ceremony, for use in the otherworld. There was no apparent pattern in the deposition of the goblets in the grave: they were found in various places in the grave, with some set on the foot, and there was no indication that they had perhaps been costume accessories suspended from the belt. The perforation of the foot therefore served some other purpose.

A glance at the cemetery map reveals that the graves containing goblets occur along the cemetery's northsouth axis and in its south-eastern area, although a few burials lay in the cemetery's north-eastern and southwestern corner (Fig. 36). The cremation burials lay in the centre of this zone.

In addition to examining the grave goods with which these goblets occurred, I also examined whether there were any artefact types with which goblets were never associated. I found that the burials with a goblet never contained ladles, scooping vessels, certain pitcher types, bipartite bowls, suspension vessels, certain bowl types, copper implements (chisels, awls or needles) or Unio shells (or plaques made from this shell). Put more simply, copper artefacts, shell plaques and other drinking vessels or liquid containers were not deposited in burials into which a goblet was placed.

Graves 158 and 177, which yielded the wagon models, both contained a goblet too, indicating the differing function of these vessels. The single Spondylus 
shell was found in a burial into which a goblet had also been deposited.

None of the forty burials in the Alsónémedi cemetery contained any goblets, ${ }^{18}$ suggesting that the deposition of this vessel in a burial was not a requisite element of the burial rite.

János Banner listed several goblets from various sites in his monograph on the Baden culture: Békásmegyer (Grave 2), ${ }^{19}$ Budapest-Andor Street, ${ }^{20}$ Köveskál, ${ }^{21}$ Vörs, ${ }^{22}$ Tihany-Újlak,, ${ }^{23}$ Üllő, ${ }^{24}$ Szikra, ${ }^{25}$ Szentes-Nagyhegy, ${ }^{26}$ and Ózd-Center. ${ }^{27}$ In a recent discussion of goblets, Nándor Kalicz noted that these vessels have been recovered almost exclusively from burials and that in view of their unusual incised patterns and firing technique, they can be regarded as ritual paraphernalia. ${ }^{28}$ He published two goblets from Mezôcsát-Hörcsögös ${ }^{29}$ and Tiszavasvári-Gyepáros-halom ${ }^{30}$ (one representing the type with fenestrated cylindrical foot, the other is ribbon-footed). Yet another goblet came to light from the child burial uncovered at Budapest-Békásmegyer, ${ }^{31}$ and a few pieces have also been reported from the settlements at Nagykanizsa-Billa, ${ }^{32}$ Balatonszemes-Szemesi Berek, ${ }^{33}$ Balatonószöd-Temetói dúloo, ${ }^{34}$ and Budapest. $^{35}$ A plain piece, probably a stray find from Aparhant, is part of a private collection. ${ }^{36}$ Comparable goblets can be quoted from various sites in Yugoslavia, ${ }^{37}$ Slovakia, ${ }^{38}$ and Romania. ${ }^{39}$

There are few similarities between the goblets listed above; each can practically be regarded as a unique piece. There are few pieces bearing a closer resemblance to the ones from the Budakalász cemetery. One of the goblets from Grave 360 (Pl. CXLIII. 360/2) is matched by a vessel from Svodin/Szôgyén, ${ }^{40}$ one of the two goblets known from Slovakia, which has been dated to the Baden IIb period by Viera NěmejcováPavúková. ${ }^{41}$ The goblet from Budakalász differs from

\footnotetext{
18 KOREK 1951; KoREK 1951a.

19 BanNer 1956, Taf. XXXVIII. 23.

20 BANNer 1956, Taf. XXXIV. 38; ENDRôDI 1997, Fig. 6.1 (from a burial at the Tress Factory), Fig. 19. 4, Fig. 28. 1, Fig. 43. 5 (from settlements) 21 BANNER 1956, Taf. VII. 3. In my view, this goblet originates from a burial. Cp. BONDÁR 1987, 48

22 BANNER 1956, Abb. 7. 1-2

23 BANNer 1956, Abb. 2. 19.

24 BANNER 1956, Taf. XXXIII. 7.

25 BanNer 1956, Taf. XXIX. 7.

26 BANNER 1956, Taf. LIX. 10

KEMENCZEI 1966, Fig. 3

28 KALICZ 1999, 86-87.

29 KalicZ 1999, Fig. 11.

30 FetTich 1969, Pl. XIV. 1-3; Kalicz 1999, Fig. 17.

31 ENDRŐDI 2002, Fig. 2. 5.

32 P. BARNA 2003, Fig. 19. 1.

33 BONDÁR-HONTI-KISS 2000, Pl. VIII. 4.

34 Horváth 2004, Fig. 34.

35 Budapest-Tabán (NAGY 1973), and Budapest-Andor Street (ENDRŐDI 2004, Fig. 45).

36 BONDÁR 2000, Fig. 23. 7, for a piece in the collection of Antal Csiszér. 37 Beli Monastir: VINSKI-GASPARINI 1956, Pl. XVII. 90; TASIĆ 1995, Pl. 18. 8.

38 Svodin: NĚMEjCovÁ-Pavúková 1974, Pl. 70. 5; Stránska: NeviZánSKY 1999, Obr. 15.4

39 Sanda 1998, Pl. I. 7 (shown upside down); Piscolţ: Roman-Németi 1978, Pl. 35. 5, Pl. 39. 4.

40 NĚmejcová-PavúKová 1974, Pl. 70. 5.

41 NĚmejCová-Pavúková 1981, Obr. 4, Type M1.
}

the other vessels of this type by its form, size and decoration. The goblets from Graves 73 and 375 (Pl. XXXII. 73/1, Pl. CXLVIII. 375/1) are best matched by the piece from Budapest-Tress Factory ${ }^{42}$ although the latter is squatter than the ones from Budakalász. Several analogies can be quoted to one of the goblets from Grave 75 (Pl. XXXV. 75/7): comparable pieces decorated with similar motifs are known from Szikra, ${ }^{43}$ Tihany-Újlak, ${ }^{44}$ Vörs, ${ }^{45}$ Beli Manastir, ${ }^{46}$ Tiszavasvári, ${ }^{47}$ and Nagykanizsa-Billa. ${ }^{48}$ The goblet from Grave 203 (Pl. LXXXVI. 203/1) has its counterpart in a similar vessel from Tiszavasvári. ${ }^{49}$ Analogies to a few plain specimens (Pl. VI. 9/1, Pl. XV. 30/1, Pl. XV. 33/3, Pl. XXVII. 61/1, Pl. XCIV. 222/3, Pl. CV. 261/3, Pl. CXXVIII. 335/2, Pl. CXLIII. 360/1, Pl. CL. 378/4, Pl. CLII. 383/3) can be quoted from Budapest. ${ }^{50}$

The quoted analogies reveal that while a few pieces have been found on settlements, ${ }^{51}$ most were recovered from burials. One explanation for the few goblets found on settlements is that they were obviously manufactured there and that if one broke, it became unsuitable for deposition in the grave and was simply discarded. While a simple flaw, such as a chipped rim, a hastily drawn, spoilt design, or the perforation of the foot did not necessitate the creation of a new goblet, a new one was made if the vessel intended for the grave broke during its manufacture.

Goblets made their appearance in NěmejcováPavúková's Baden IIb period and were used throughout the Baden III period, corresponding to the culture's early classical and classical phase..$^{52}$ This vessel type was assigned to the Baden III period by Anna Endrốdi. ${ }^{53}$ In her publication of the finds from the Baden settlement at Nagykanizsa-Billa, Judit P. Barna dated goblets to phase D1 of Neustupnýs periodisation. ${ }^{54}$ Pedestalled bowls set on a lower or higher pedestal were current both in the cultures preceding and succeeding the Baden period. The goblets from the burials of the Budakalász cemetery can be assigned to the classical Baden period, with the exception of the piece from Grave 360, which dates from an earlier horizon.

\footnotetext{
42 ENDRŐDI 1997, Fig. 6. 1.

43 BANNER 1956, Taf. XXIX. 7

44 BANNER 1956, Abb. 2.

45 BANNER 1956, Abb. 7.

46 VINSKI-GaSParini 1956, Fig. 90.

47 Kalicz 1999, Fig. 17. 3.

48 P.BARNA 2003, Fig. 19. 1

49 KaliCZ 1999, Fig. 17. 2.

50 ENDRŐDI 1997, Fig. 19. 4, Fig. 28. 1, Fig. 43. 5; ENDRődi 2002, Fig. 2. 5.

51 P. BARNA 2003, 110, according to whom the goblet from Nagykanizsa is the first piece from a secure settlement context. The goblets from Balatonszemes and Balatonószöd too originate from settlements.

52 The goblet from Svodin was assigned to the Baden IIb period (NĚMEJCOVÁ-PavúkOvá 1974, Pl. 70. 5), while other pieces to the Baden III period (NĚMejCOVÁ-PavúKOVÁ 1981, Obr. 5, Type M).

53 ENDRŐdI 1997, Fig. 4.
} 
Table 23. The decoration of the ladles in the female, male and child burials

\begin{tabular}{|l|c|c|}
\hline & Plain & Decorated \\
\hline Female burial & Graves 46, 115,216,289 & Grave 2 \\
\hline Male burial & Graves 1, 124, 227, 294,319 & Graves 132, 164, 227 \\
\hline Child burial & & Grave 74, 182, 262, 265 \\
\hline Stray find & & Pl. CLXXI. 27 \\
\hline
\end{tabular}

\section{LADLES}

Ladles are typical, although not particularly numerous finds of the Baden culture, recovered from both cemeteries and settlements. ${ }^{55}$ Their fabric generally resembles that of the other ceramic wares, although (similarly to goblets) they were more poorly fired than household vessels. Plain ladles and decorated pieces both occur.

Altogether nineteen ladles were deposited in sixteen burials of the Budakalász cemetery, ${ }^{56}$ accounting for 4 per cent of all the graves and 6 per cent of the graves containing grave goods. The graves with ladles were all inhumation burials. Three graves contained two ladles (Graves 1, 216 and 227), while the rest, including a triple burial (Grave 182), contained a single piece only. A plain ladle was the single grave good in Graves 124 and 294, both male burials.

Ladles are made up of two parts: a semi-spherical bowl and a handle attached to the former's outer side. The handle is set perpendicularly (Pl. I. 1/2, Pl. I. 1/3, Pl. II. 2/2, Pl. CXV. 294/1, Pl. CXXIV. 319/1) or at an angle (Pl. XX. 46/1, Pl. XXXIII. 74/3, Pl. L. 115/1, Pl. LIII. 124/1, Pl. LIX. 132/1, Pl. LXXI. 164/4, Pl. XCII. 216/1, Pl. XCII. 216/2, Pl. XCVI. 227/3, Pl. CXIV. 289/2, Pl. CXV. 294/1), and its terminal is either straight, rounded or notched. The handle of the ladles from Graves 74 and 216 was slightly thickened at the point of attachment (Pl. XXXIII. 74/3, Pl. XCII. 216/1).

The ladles from Budakalász are more or less the same size: their height ranges between 3 and $4.5 \mathrm{~cm}$, their rim diameter between 8.5 and $11.7 \mathrm{~cm}$. Plain and decorated pieces both occur, sometimes together, as in Grave 227. Graves 1 and 216 contained a pair of plain ladles. There is no apparent correlation between the deposition of ladles and the sex of the deceased since ladles were recovered from female, male and child burials alike (Table 23).

The most common decoration was the incised zigzag pattern, which occurs both on the bowl ${ }^{57}$ and the handle. ${ }^{58}$ The length of the latter varies, ranging from a short projection ${ }^{59}$ to a long handle. ${ }^{60}$ Many ladles are

\footnotetext{
$\overline{54}$ P. Barna 2003, 114; NeUSTUPNÝ 1973.

55 BANNER 1956. Taf. CXIII. 18-21, variously called handled scooping vessel, "Schöpschale" and "Ossarn plate".

56 Graves 1-2, 46, 74, 115, 124, 132, 164, 182B, 216, 227, 262, 265, 289, 294, 319.

57 Graves 2, 74, 132, 164.

58 Graves 2, 74, 132, 182, 227.

59 Graves 46 and 164.

60 Graves 1, 74, 115, 124, 294
}

covered with red paint both on the exterior and interior, which was achieved by dipping the fired pieces into a red paint wash.

The most finely decorated pieces were recovered from child burials (Pl. XXXIII. 74/3, Pl. LXXVI. 182/2) and male graves (Pl. LIX. 132/1, Pl. XCV. 227/15). Eleven of the nineteen ladles (58 per cent) are undecorated; five of these were recovered from four female burials ( 45 per cent), six from five male burials (55 per cent). Eight ladles bore some sort of decoration: three were found in child burials (38 percent), three in male burials ( 38 per cent), one in a female burial (12 per cent), and one was a stray find (12 per cent).

The ladles include three rather unusual pieces. The richly ornamented piece from Grave 74 (Pl. XXXIII. $74 / 3$ ) and the ladle with notched rim from Grave 227 (Pl. XCV. 227/15) are unique pieces, as is the decorated ladle with peaked handle from Grave 182, a triple burial (Pl. LXXVI. 182/2). A stray ladle find has a decoration of incised multiple chevrons on the handle (Pl. CLXXI. 27), a pattern which does not occur on the other pieces.

Most ladles have two perforations on the handle, ${ }^{61}$ and it seems likely that the pieces with a broken handle too had perforations. ${ }^{62}$ The function of these perforations remains unknown, and we may at the most assume that they served for suspension (e.g. from a belt). However, in view of the fact that this ceramic ware was probably made exclusively for deposition in a burial, it seems unlikely that ladles had been worn suspended from the belt, and thus these perforations served some other purpose.

For the correspondence analysis I prepared a detailed typological classification of the ladles:

Type IIa: 1/2 , 1/3, 46/1, 115/1, 124/1, 216/1, 216/2, $227 / 3,289 / 2,294 / 1,319 / 1$

Type IIb1: 2/2, 164/4, 265/1

Type IIb2: 132/1

Type IIb3: 182/2 and 1953/XV, a stray find

Type IIb4: 74/3

Type IIb5: 227/15

The distribution of graves with ladles in the cemetery (Fig. 37) reveals that these burials lie dispersed along an imaginary sinuous line in the cemetery's central part.

Ladles have few analogies and remained neglected pieces even after the publication of the specimens from

\footnotetext{
61 Graves 1, 46, 74, 115, 124, 132, 164, 265, 289, 294, 319.

62 Graves 1, 182, 216, 227.
} 
Ossarn. ${ }^{63}$ For a very long time, the two ladles from the Alsónémedi cemetery were the single indication that this ware occurs in the Baden material from Hungary. ${ }^{64}$ In his publication of the Alsónémedi cemetery, József Korek discussed the origins of this ceramic type and suggested that it could perhaps be derived from wooden ladles. ${ }^{65}$ Based on the two ladles from Alsónémedi, ${ }^{66}$ a piece from the settlement at Ózd ${ }^{67}$ and the specimens found at Budakalász, Banner too believed that ladles were modelled on wooden pieces and he too quoted similar wares from the earlier Copper Age cultures as possible forerunners. He noted their similarity to the "Ossarn plates" as described by Josef Bayer and suggested that ladles had spread westward from Hungary, together with suspension vessels and bipartite bowls. ${ }^{6}$

In his monograph on the Alsónémedi cemetery, Korek claimed that the number of ladles had hardly increased, ${ }^{69}$ and that the single new pieces came from the late Baden-Kostolac settlement at Szigetcsép. These ladles, however, differed markedly from the other ones. ${ }^{70}$ Korek was apparently unaware that comparable ladles had been found at Nevidzany and Červený Hrádok in Slovakia. ${ }^{71}$

Most ladles were found together with bead necklaces, ${ }^{72}$ although in several graves they occurred in combination with stone implements, ${ }^{73}$ and in one with a copper chisel. ${ }^{74}$ The grave pottery from these graves included a dipper, ${ }^{75}$ a jug, ${ }^{76}$ pitchers, a dipper and a bowl, ${ }^{77}$ a handled cup and a pot, ${ }^{78}$ a mug and a pot, ${ }^{79}$ and indistinct vessel fragments. ${ }^{80}$

It would appear that similarly to goblets, ladles too were vessels which played a role in the burial rite. The few pieces found on settlements represent specimens which for some reason were unsuitable for deposition in a grave and were therefore discarded.

Němejcová-Pavúková assigned ladles to her Baden III period. ${ }^{81}$ This use of this vessel type is documented before and after the Baden period, the latter indicated by the finds from the late Baden-Kostolac settlement at Szigetcsép. ${ }^{82}$

\footnotetext{
63 BAYER 1928.

64 KoreK 1951, Pl. XI. 7, Pl. XII. 5.

65 KoreK 1951, 55-56.

66 BanNER 1956, Taf. XLV. 7, Taf. XLVI. 5.

67 BANNER 1956, Taf. LXIX. 7.

68 BANNER 1956, 148 .

69 KorfK 1980, 22-23.

70 KOREK 1984, Fig. 9. 7, Fig. 13. 1-5.

71 NĚMejcová-Pavúková 1974, Abb. 4. 1-2 (Nevidzany), Abb. 4. 3, Abb. 38/11 (Červený Hrádok).

72 Graves 2, 46, 74, 164, 216, 227

73 Graves 1-2, 46, 115, 164, 227.

74 Grave 319

75 Grave 132

76 Grave 164

77 Grave 227

78 Grave 265.

79 Grave 289

80 Graves 2, 46, 262.

81 NĚMEJCOVÁ-PavúKová 1981, Obr. 5. E/1

82 KOREK 1984, 22-23.
}

\section{DIPPERS}

Dippers represent one of the distinctive Baden pottery wares, which have been recovered both from cemeteries and settlements, although they occur more frequently in ceramic assemblages from settlements. Dippers are usually carefully made, good quality vessels. ${ }^{83}$

Seven graves of the Budakalász cemetery yielded dippers; ${ }^{84}$ all were inhumation burials. These burials account for 2 per cent of all the graves and 3 per cent of the graves containing grave goods. Five of the seven graves were child burials ${ }^{85}$ two contained the burial of a 35-45 years old man. ${ }^{86}$ The stray finds from the cemetery too include a dipper (Pl. CLXVI. 1).

The dippers all have a conical body and a high-drawn handle, which is attached to the vessel body about halfway down its length $(P l$. XXXIX. 87/1, Pl. LXXIX. 179/1, Pl. LXXXV. 202/2, Pl. XCVI. 227/4, Pl. C. 244/1, Pl. CIV. 267/1, Pl. CLIX. 412/1, Pl. CLXVI. 1). Their height ranges between 6.5 and $8.8 \mathrm{~cm}$, their rim diameter between 5 and $6.2 \mathrm{~cm}$, their base diameter between 1.9 and $3.1 \mathrm{~cm}$.

For the correspondence analysis I prepared a detailed typological classification of the vessels. The dipper is Type III.

Graves with dippers lay in the cemetery's central part at a more or less even distance from each other (Fig. 37), the only exception being Grave 246, which lay farther from the other burials.

While Banner distinguished seventeen different dipper types, ${ }^{87}$ most can be assigned to one of three main variants: the first is a conical vessel with a flat base and a high-flung handle springing from the rim to halfway down the body, the second is a conical vessel with a pointed base and the handle spanning the rim and the middle of the vessel body, while the third is a cylindrical vessel with a flat base and the handle spanning the rim and the base. There are chronological differences between the three types: the first variant was popular during the early classical and classical Baden period, while the other two were used during the late Baden period. ${ }^{88}$

Dippers are rare finds among grave goods; only one was found at Alsónémedi, ${ }^{89}$ seven at Budakalász, and none at Mezốcsát-Hörcsögös. ${ }^{90}$ They are more frequently found

\footnotetext{
83 BANNER 1956, Pl. CXIII. 22-23, 25, 31 (described as scooping vessels), and Pl. CXIII. 32-39 (described as a cup shaped scooping vessel). 84 Graves 87, 179, 202, 227, 244, 267, 412.

85 Graves 87, 179, 202, 244, 267.

86 Graves 227 and 412 .

87 BANNER 1956, Taf. CXIII, Types 32-47 (described as "Schöpfgefässe mit flachem Boden" or "Schöpfkellen").

88 BONDÁR 1982, 36; NĚMEJCOVÁ-PAvúKOVÁ 1991, 77-78. NěmejcováPavúková distinguished three main variants and noted that dippers were characteristic ceramic wares of the Early Helladic II period in the western Aegean. Dippers with a wide base appeared in the Carpathian Basin during the Baden III period and were supplanted by variants with a pointed base typical for the Bošáca and Kostolac groups during the Baden IV period. 89 KoreK 1951, Pl. X. 6.

90 KaLICZ described the wide-mouthed, shallow vessels found at this site as dippers (Kalicz 1999, Fig. 14. 2, Fig. 15. 2). Even though the function of the two vessel types was more or less similar, this vessel type cannot be categorised as a dipper; I assigned vessels of this type from the Budakalász cemetery to the category of scooping vessels.
} 
on settlements. There are no differences between the pieces recovered from burials and the ones brought to light on settlements regarding fabric and quality, suggesting that this ceramic type was a common household vessel and was not made specifically for the burial.

Deposits of dippers have also been found on settlements. A heap of twenty-one dippers with highdrawn handle was discovered at Csincse, ${ }^{91}$ and a similar, although smaller deposit lay beside two pits at Esztergom-Szentkirály-Duna-dúlő. ${ }^{92}$ A similar deposit of several dippers, originally strung together through their handle, was found in a pit at Zók-Várhegy. ${ }^{93}$ The reason for these deposits is not known; it is possible that the dippers were collected for some community event and then stored in a certain place. It is equally uncertain whether any association might be assumed between the individuals buried with a dipper and these deposits.

Most of the known dippers are plain. One of the dippers from Budakalász, found in Grave 227, a burial with a remarkable grave inventory, bears a row of punctates arranged in a wavy line (Pl. XCVI. 227/4). Dippers decorated with punctates were generally used during the late Baden period, as shown by the pieces from Bošáca sites ${ }^{94}$ and the ones from Szigetcsép, a settlement inhabited jointly by a Baden and Kostolac community. ${ }^{95}$ The dipper from Budakalász was recovered from a burial whose grave goods included a semi-spherical bowl which can be dated to the classical Baden period, indicating that dippers decorated with punctates came into use before the Bošáca-Kostolac horizon.

Together with ladles, Němejcová-Pavúková assigned the dippers of the type found at Budakalász to her Baden III horizon. ${ }^{96}$ In her study on the Aegean connections of the Baden culture, she noted that dippers appeared during the Baden III period in the Carpathian Basin, becoming more common during the Baden IV period. ${ }^{97}$

\section{SUSPENSION VESSELS}

Coming in various sizes, suspension vessels can be regarded as a variant of amphoras with vertically pierced handles and often a perforated foot-ring, which were suspended by threading a thong through the handles and the foot-ring. ${ }^{98}$ The fabric and quality of these vessels corresponds to that of the Baden culture's other household vessels.

Suspensions vessels were recovered from two inhumation burials. A $20 \mathrm{~cm}$ high globular vessel with cylindrical neck, decorated with incised lines and red

\footnotetext{
91 Mária Wolf's excavation; cp. RégFüz I. 49 (1997) 62.

92 Etelka Kövecses Varga's excavation; cp. RégFüz I. 42 (1991) 11.

93 ECSEDY 1982, 67

94 Pavelćík 1974, Obr. 13. 12; Novotná 1961, Tab. IX. 1-9, Tab. X. 5-7.

95 KoreK 1984, Fig. 3. 2.

96 NĚMejCová-Pavúková 1981, Obr. 5. F.

97 NĚmEJCOVÁ-PAVÚKOVÁ 1991, 77.

98 BanNer 1956, Taf. CXIII, Types 5-9 (described as "Ossarner Hängeurne" and,"Hängegefässe").
}

painting was placed by the feet of the young woman interred in Grave 44 (Pl. XXI. 44/1). ${ }^{99}$ Another vessel of this type with ovoid body standing $10 \mathrm{~cm}$ high was recovered from Grave 361, a child burial, where it was set in front of the face (Pl. CXXXIX. 361/1). The vessel base was perforated to make its suspension easier. The two graves lie quite far from each other in the cemetery's middle part along an imaginary north-west to south-east axis (Fig. 37).

For the correspondence analysis I prepared a detailed typological classification of the vessels. The suspension vessel is Type IV.

The suspension vessels from Budakalász are best matched by the specimens from Szombathely 100 and Köveskál.101

Banner devoted a lengthy discussion to suspension vessels, together with a map showing their distribution. ${ }^{102}$ He quoted similar vessels from Szombathely, ${ }^{103}$ Zalaszántó-Tátika, ${ }^{104}$ Köveskál, ${ }^{105}$ Iregszemcse, ${ }^{106}$ Sárszentloórinc, ${ }^{107}$ Piliny, ${ }^{108}$ Kiskunhalas, ${ }^{109}$ Hódmezôvásárhely-Bodzáspart, ${ }^{110}$ the Szentes area ${ }^{111}$ and Oros, ${ }^{112}$ and mentioned the suspension vessels known from Austria. Banner concluded that each piece was different, noting that the forerunners of this vessel type, known and used since the Early Neolithic, were probably the suspension vessels of the Bodrogkeresztúr culture.

In his study on the Anatolian contacts of the Baden culture, Kalicz too devoted a separate section to these vessels. ${ }^{113} \mathrm{He}$ distinguished two main types, one with horizontally set, vertically pierced handles (often with a foot-ring), and the other with two vertically set, tube-like handles. More recent finds of suspension vessels are known from Segesd-Alsóbogátpuszta ${ }^{114}$ and Balatonôszöd, ${ }^{115}$ from Bajč ${ }^{16}$ and Rúban ${ }^{117}$ in Slovakia, and Reichersdorf in Austria. ${ }^{118}$ Suspension vessels were also used by the Coţofeni ${ }^{119}$ and Kostolac cultures. ${ }^{120}$ Although resembling similar pieces of the Baden culture, the piece from Vučedol is a relic of the Vučedol culture. ${ }^{121}$

\footnotetext{
99 The vessel can no longer be found. The information on this vessel comes from Korek's grave sheet and the description in the acquisitions register. 100 BANNER 1956, Abb. 1 (stray find).

101 BANNER 1956, Taf. VII. 4-5 (stray finds).

102 BANNER 1956, 143-146, Abb. 43.

103 BANNER 1956, Abb. 1 (stray find)

104 BANNER 1956, Taf. IV. 17-19, 22 (stray find).

105 BANNER 1956, Taf. VII. 4-5 (stray finds). Similarly to the vessel from

Bogátpuszta, this vessel may likewise have originated from a burial. Cp. BONDÁR 1987, 48.

106 BANNER 1956, Taf. XXI. 31-33 (from a cremation burial).

107 BANNER 1956, Taf. XXIII. 31.

108 BANNER 1956, Taf. XXVII.45 (from a settlement)

109 BANNER 1956, Taf. XXX. 23 (stray find).

110 BANNER 1956, Abb. 14. 7.

111 BANNER 1956, Taf. LVIII. 18.

112 BANNER 1956, Taf. LXXVIII. 2.

113 KALICZ 1963, 32-35.

114 DraveCZKY 1964, Fig. 1.

115 HoRváth 2006, 103

116 NEVIZÁNSKY 1987, 646. Obr. 3

117 NĚMEjCOVÁ-PAVÚKOVÁ 1991, Abb. 12. 2

118 Neugebauer-Gattringer 1986, 74; Hahnel 1992, 84

119 Roman 1977, Taf. 43. 11.

120 Gomolava 2002, 215, 286.

121 Durman 1988, Cat. no. 73
} 
Němejcová-Pavúková discussed suspension vessels in her study on the Aegean connections of the Baden culture and added more recent finds of this type to the pieces published by Kalicz. She concluded that several Aegean vessel types, such as ovoid pitchers, dippers with a pointed base, sauce-boats and suspension vessels, whose counterparts occur among the ceramics of the Baden culture, can be assigned to the same chronological horizon. Vessels of this type appeared in two successive waves in the Carpathian Basin during the Baden period: pitchers, sauce-boats and suspension vessels appeared during the Baden II period, while dippers made an appearance during the Baden III period. ${ }^{122}$ Němejcová-Pavúková regarded anthropomorphic suspension vessels as a separate category.

Suspension vessels were a ceramic type used since the Neolithic, which survived into the Copper Age and the Bronze Age. The number of these vessels is quite low in the Baden inventory and their function remains enigmatic. Owing to their rarity, a ritual function has sometimes been ascribed to these vessels.

\section{MUGS}

Mugs, pitchers and jugs can be distinguished by their size ${ }^{123}$ and perhaps their function, based on the type of liquid they had contained.

Altogether twenty-eight mugs were recovered from twenty-seven burials, accounting for 6 per cent of all burials and 11 per cent of the burials with grave goods. Mugs were found in cremation, ${ }^{124}$ inhumation ${ }^{125}$ and symbolic burials ${ }^{126}$ alike (Fig. 37). There were no striking differences between the vessels used in the different burial rituals: decorated and plain variants occurred in all three grave types.

The mugs with cylindrical neck, ovoid body and high-drawn handle spanning the rim and the shoulder, some decorated with fluting, placed in inhumation burials differ little from the pieces deposited in cremation graves. Some mugs have a more flattened body ${ }^{127}$ or are more rounded. ${ }^{128}$ The mug with flat base from Grave 289 (Pl. CXIV. 289/1) resembles a cylindrical dipper. The mug from Grave 345 (Pl. CXXXII. 345/2) was fitted with a rather lopsided handle.

Most of the mugs recovered from inhumation burials are decorated with vertical fluting $(\mathrm{Pl}$. XXVII. 59/2, Pl. XXXI. 70/2, Pl. CXI. 273/5, Pl. CXIII. 286/2, Pl. CXVII. 303/1, Pl. CXVII. 306/2, Pl. CXXIII. 312/7, Pl. CXXXI. 344/3, Pl. CXXXIII. 350/2, Pl. CXLV.

\footnotetext{
122 NĚMEjCOVÁ-PaVúKOVÁ 1991, 78-79.

123 Vessels with a height of $5-9 \mathrm{~cm}$ are here categorised as mugs; vessels with a height of $10-15 \mathrm{~cm}$ as pitchers, and vessels standing higher than $16 \mathrm{~cm}$ as jugs.

124 Graves 103, 131, 222, 224, 248, 273, 339.

125 Graves 23, 59, 70, 80, 182, 208, 227, 286, 289, 303, 306, 312, 344, 345, $350,368,377,378,408$.

126 Grave 311.

127 Graves 70, 303, 306, 311, 312, 368, 378.

128 Graves 222, 224, 227, 248, 345, 408.

129 Graves 80, 286, 306, 312, 345, 368, 377, 378, 408
}

368/1, Pl. CL. 378/2). Fewer plain mugs were deposited (Pl. XCIV. 222/4, Pl. XCIII. 224/1, Pl. CXIV. 289/1, Pl. CXXXII. 345/2). The mug from Grave 227, a lavishly equipped burial, is a unique piece with its wide mouth and flattened body decorated with a row of punctates around the shoulder and five ribs with impressed dots with vertical fluting in-between the ribs (Pl. XCVII. 227/14). A similar mug without ribs was found in Grave 23 (Pl. XII. 23/1). A wide-mouthed mug whose mouth diameter is roughly identical with the carination diameter has a row of punctates encircling the belly ( $\mathrm{Pl}$. CLVII. 408/1).

Most mugs were recovered from child burials; altogether nine graves contained vessels of this type. ${ }^{129}$ One male ${ }^{130}$ and six female ${ }^{131}$ burials too contained mugs, as well as a burial, which could not be sexed. ${ }^{132}$ The graves include a double ${ }^{133}$ and a triple burial: ${ }^{134}$ the mugs from these graves were of roughly the same size and all were plain (Pl. XXXVII. 80/1, Pl. LXXVI. 182/5-6).

The mugs recovered from scattered cremation burials include both decorated (Pl. XLVI. 103/1, Pl. CXI. 273/5, Pl. CXXX. 339/3) and plain pieces (Pl. XCIV. 222/4, Pl. XCIII. 224/1, Pl. CI. 248/1).

The mug placed in Burial A of Grave 131, the inurned burial of the double burial, represents a general mug type with high-drawn handle decorated with fluting on the belly (Pl. LVIII. 131/2) known from scattered cremation and inhumation burials. The mug from the other burial in the grave was too fragmented to establish whether it had originally been decorated (Pl. LVIII. 131/3).

With the exception of two mugs, the handles join the vessel body under the shoulder (Pl. XLVI. 103/1, Pl. XCIII. 224/1, Pl. CI. 248/1, Pl. CXXX. 339/3). The rather squat piece from Grave 222 (Pl. XCIV. 222/4) has the handle rising above the rim and springing to the belly, similarly to the fluted mug from Grave 273 (Pl. CXI. 273/5). The position of the handle on the mug fragment from Burial B of Grave 131 cannot be determined. The mugs are roughly the same size: two mugs stand $6.5 \mathrm{~cm}$ high (Graves 227 and 273), while in the case of the third, the drawn reconstruction suggests a similar size.

For the correspondence analysis I prepared a detailed typological classification of the mugs:

Type Va: 80/1, 131/3, 182/5-6, 208/1, 222/4, 224/1, $248 / 1,289 / 1,311 / 2,344 / 4,345 / 2$

Type Vb:59/2, 70/2, 103/1, 131/2, 273/5, 286/2, $303 / 1,306 / 2,339 / 3,350 / 2,368 / 1,377 / 1$, $378 / 2$

Type Vc: $312 / 7$

Type Vd: $344 / 3$

Type Ve: $227 / 14$

Type Vf: 23/1

Type Vg: 408/1

\footnotetext{
130 Grave 227.

131 Graves 70, 208, 289, 303, 344, 350 .

132 Grave 59.

133 Grave 80

134 Grave 182
} 
The mug from Grave 311, a symbolic burial, conforms to the general Baden type, its only unique feature being the decoration of the handle. This is the single mug from the cemetery whose handle is decorated with incised lines at the base (Pl. CXVIII. 311/2). While strap handles on jugs, pitchers and mugs are often adorned with smoothed-in lines or fluting, incised lines only occur on this mug and on the handle of the jug from Grave 353, decorated with a combination of incised lines arranged in three zones and vertical smoothed-in lines on the upper part of the handle springing from the rim (Pl. CXXXVI. 353/1). It seems likely that the two vessels had been made by the same potter and that the two burials can be regarded as more or less contemporaneous.

The mugs of the Baden culture have a wide range of variants. Banner distinguished twenty-three different types. ${ }^{135}$ They were used throughout the Baden sequence, although their proportions and the form of the handle varied. Mugs have been reported from virtually all Baden sites and thus I will refrain from listing the analogous pieces. The type most common at Budakalász is assigned to the Baden III period in Němejcová-Pavúková's typology. ${ }^{136}$

The mugs deposited in the burials of the Budakalász cemetery were household vessels used in daily life and not pieces made especially for the funeral.

\section{PITCHERS}

Most pitchers have a cylindrical neck and ovoid body with a handle rising above the rim. The belly is generally decorated with fluting. Their height ranges between 10 and $15 \mathrm{~cm}$. The fabric and overall quality of the pitchers recovered from the burials is more or less identical with that of similar vessels found on settlements, suggesting that the pieces placed in the graves were household wares used in daily life rather than vessels made specifically for the funeral.

Thirty-nine graves yielded pitchers, accounting for 9 per cent of all burials and 16 per cent of the burials with grave goods (Fig. 38). Most were found in inhumation burials ( 90 per cent), ${ }^{137}$ three of which were double burials ${ }^{138}$ and one a triple burial. ${ }^{139}$ Three cremation burials $^{140}$ and one symbolic grave ${ }^{141}$ too yielded a pitcher, and this vessel type also occurs among the stray finds. ${ }^{142}$

The pitchers from the Budakalász cemetery can be divided into seven sub-variants.

\footnotetext{
135 BANNER 1956, Taf. CXIV. 8-30.

136 NĚMejCovÁ-Pavúková 1981, Obr. 5. G1-2

137 Graves 7, 23, 33, 36, 51, 59, 65, 75, 76, 116, 136, 156, 158, 171, 194, 196, 197, 207, 227, 253, 261, 262, 310, 330, 344, 347, 353, 376, 412, 414, 421.

138 Graves 55, 80, 388.

139 Grave 182 .

140 Graves 193, 273, 276

141 Grave 311.

142 Pl. CLXVI. 5, Pl. CLXX. 16, Pl. CLXXI. 20-23, Pl. CLXXII. 31 and the piece inventoried under no. 61.2.187.
}

(1) Pitchers decorated with a row of punctates around the shoulder, fluting on the belly and grooved ribs (Type VIa, $P l$. XCVI. 227/5). A mug ornamented in the same style was also found in Grave 227 (Pl. XCVII. 227/14), suggesting that the two vessels had been made by the same potter. The wide-mouthed, wide-bellied pitcher from Grave 33 (Pl. XV. 33/1) decorated with a row of impressed dots around the shoulder and vertical fluting interrupted by fluted ribs on the belly resembles the mug and pitcher from the previous burial. The pitcher from Grave 330 (Pl. CXXVII. 330/5) can be assigned to this group too, the single difference being that the curve of the handle is narrower than on the other pieces. A similar pitcher can be quoted from Óbuda. ${ }^{143}$

(2) Pitchers with a decoration dividing the vessel body into panels (Type VIb), such as the specimens from Grave 164 (Pl. LXX. 164/5) and Grave 197 (Pl. LXXXIV. 197/4). Aside from their size, these two vessels resemble each other to the extent that even their fluting is identical at the point where the handle is attached to vessel body, suggesting that the two pieces had been made by the same potter (implying that the two burials were contemporaneous). A comparable pitcher was found at Budapest-Andor Street. ${ }^{144}$

(3) Pitchers with flattened globular body decorated with fluting (Type VIc) were found in two burials: Grave 75, a lavishly furnished burial (Pl. XXXIV. 75/3) and Grave 158, which contained one of the wagon models (Pl. LXVI. 158/1). Similar pieces are known from Nevidzany ${ }^{145}$ and Celldömölk-Sághegy. ${ }^{146}$ A mug with a similar, flattened globular body was recovered from Grave 306 (Pl. CXVII. 306/2).

(4) Squat pitchers with plain neck and handle, decorated with fluting on the belly (Type VId, Pl. LI. 116/1, Pl. LX. 136/1, Pl. CXXXIV. 347/2).

(5) Pitchers decorated with a bundle of smoothed-in lines on the handle and fluting on the belly (Type VIe, Pl. XVI. 36/1, Pl. CIII. 253/1). The handle type on the pitcher from Grave 36 first appeared in the Baden IIb period, ${ }^{147}$ and survived into the Baden III period, although in a slightly modified form. ${ }^{148}$ These pitchers compare well with the pieces from Bracovce, ${ }^{149}$ the Keszthely area, ${ }^{150}$ Budapest-Békásmegyer, ${ }^{151}$ BudapestZugló-Egressy Road,152 Nyíregyháza-Morgó ${ }^{153}$ and Zebegény. ${ }^{154}$

(6) Plain pitchers (Type VIf), such as the one recon-

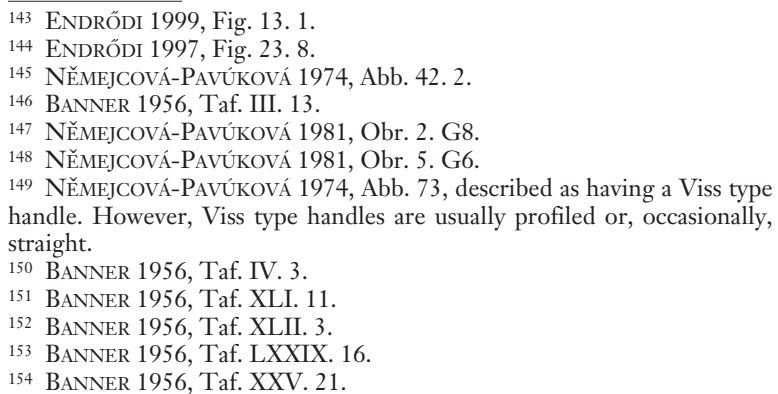


structible from the fragments found in Grave $276(\mathrm{Pl}$. CXI. 276/1).

(7) A transitional form between pitchers/jugs and amphoras: a vessel with narrow neck, which has no indication of a handle on the surviving part (Type VIg). The smaller variants can be assigned to pitchers $(\mathrm{Pl}$. LXXXII. 193/1), the larger ones to jugs. A larger variant was recovered from Grave 356, a cremation burial (Pl. CXXXVIII. 356/1), and a similar piece was found in Grave 340, an inurned burial (Pl. CXXX. 340/2), which had perhaps been made by the same potter (the implication being that these two burials were contemporaneous). This variant has only been found in cremation burials.

The pitcher fragments include pieces, which cannot be assigned to a specific variant (Type VI, $P l$. IV. 7/1, Pl. XII. 23/6, Pl. XXIII. 51/2, Pl. XXVII. 59/3, Pl. XXXV. 75/6, Pl. XXXVII. 80/2, Pl. XXXVII. 80/7, Pl. LXXVI. 182/3, Pl. LXXXII. 196/1, Pl. XCVI. 227/6, Pl. XCVI. 227/9, Pl. CV. 261/1, Pl. CXI. 273/7, Pl. CXX. 310/3, Pl. СХVIII. 311/3, Pl. СХХХVI. 353/2, Pl. CXLVII. 376/1, Pl. CLI. 388/1, Pl. CLIX. 412/2, Pl. CLIX. 414/1). Graves with pitchers are scattered across the entire territory of the cemetery, without any apparent pattern. Němejcová-Pavúková assigned the pitchers of the type found at Budakalász to her Baden IIb-Baden III period. ${ }^{155}$

\section{JUGS}

The jugs found at Budakalász are of the variety with cylindrical neck and flattened globular body, fitted with a handle rising above the rim and attached to the vessel body at the shoulder (the junction of the neck and the belly). Handles are generally decorated with smoothedin lines or fluting. ${ }^{156}$ The height of these vessels ranges between 16.9 and $23 \mathrm{~cm}$, their rim diameter between 9 and $11.3 \mathrm{~cm}$, their base diameter between 6 and $9.5 \mathrm{~cm}$. Plain and decorated pieces both occur.

Jugs were recovered from fifteen graves, accounting for 3.4 per cent of all burials and 6 per cent of the burials with grave goods (Fig. 39).157 Ten graves were inhumation burials (two of which were double burials), one was a double grave with an inhumation and a cremation burial, three were scattered cremations and one was an inurned burial. Their was no apparent pattern in their deposition: jugs were found in male, female and child burials alike. The fabric and overall quality of these vessels does not differ from the household pieces used in daily life, suggesting that the jugs placed in the burials had not been specially made for the funeral.

\footnotetext{
155 NĚMEJCOVÁ-Pavúková 1981

156 The single exception is the handle on the jug from Grave $353(\mathrm{Pl}$. CXXXVI. 353/1), which is decorated with horizontal bundles of incised lines.

157 Graves 13, 68, 75, 142, 155, 164, 203, 210, 222, 273, 312, 340, 353, 356 367, and a stray find (Pl. CLXXII. 29).
}

Five sub-variants can be distinguished among the jugs from Budakalász.

(1) Jugs with smoothed neck decorated with fluting or smoothed-in lines on the belly (Type VIIa), found alike in male (Pl. LXI. 142/3, Pl. LXX. 164/5), female (Pl. CXLVI. 367/2) and child burials (Pl. XXXIV. 75/1).

(2) Similar to the previous type, decorated with smoothed-in lines and slender, impressed ribs on the belly (Type VIIb). One specimen comes from a cremation burial (Pl. CXI. 273/2), another one from a child inhumation burial (Pl. CXXII. 312/1).

(3) Jugs decorated with alternating panels filled with oblique and vertical fluting on the belly (Type VIIc). One piece was brought to light from a child burial in a double inhumation burial (Pl. VIII. 13/2), another one from the burial of an older man (Pl. LXXXVI. 203/2).

(4) The fourth sub-variant is represented by plain jugs (Type VIId), such as the pieces from a child burial (Pl. XXX. 68/2) and a female cremation burial (Pl. XCIV. 222/1).

(5) Coarser vessels with a constricted mouth, which were not fitted with a handle (Type VIIe), represent a separate variant among the plain jugs. Occuring in smaller (Pl. LXXXII. 193/1) and larger sizes (Pl. CXXX. 340/2, Pl. CXXXVIII. 356/1), these vessels represent a transitional type between pitchers/jugs and amphoras. This variant has only been found in cremation burials.

Some of the jugs bear stylistic traits which enable the identification of pieces made by the same potter. The jug from Grave 203, decorated with a pattern arranged in panels (Pl. LXXXVI. 203/2), has its counterpart in the pitcher from Grave 207 (Pl. LXXXVII. 207/6), suggesting that they were fashioned by the same potter, which in turn implies that the two burials were more or less contemporaneous. The same holds true for the jug from Grave 164 (Pl. LXX. 164/5) and the pitcher from Grave 197 (Pl. LXXXIV. 197/4), whose form and decoration are identical down to the fluting at the base of the handle, the only difference between the two vessels being one of size. The two vessels were probably made by the same potter, again implying that the two burials were contemporaneous.

The jugs from Budakalász have countless analogies, not only among similar vessels from other sites, but also among mugs and pitchers from which they differ only in size. Instead of a detailed list of comparable finds, suffice it here to mention a few good parallels from Vörs, ${ }^{158}$ Budapest-Andor Street, ${ }^{159}$ Alsónémedi, ${ }^{160}$ Csépa, ${ }^{161}$ and Uny. ${ }^{162}$

Banner described jugs as "larger pitchers" and devoted a lengthy discussion to their typological traits. ${ }^{163}$

The distribution of burials containing jugs (Fig. 39) shows a concentration in the cemetery's southern half,

\footnotetext{
$\overline{158}$ BANNER 1956, Taf. IX. 4.

159 BANNER 1956, Taf. XXXIV. 39.

160 BANNER 1956, Taf. XLV. 5.

161 BANNER 1956, Taf. LXI. 7.

162 Banner 1956, Taf. XV. 1, 5, Taf. XVII. 4.

163 BANNER 1956, CXIV, Types 33-51 (described as "grössere Krïgen").
} 
with the fifteen graves lying along an imaginary double arc (Graves 164, 68, 13, 75, 210, 367 along one, and Graves 142, 155, 273 and 312 along the other), while the three graves in the cemetery's northern part lie near each other (Graves 353, 340, 356).

Pitchers and jugs are not treated separately in Němejcová-Pavúková's typological scheme for the Baden IIb period, ${ }^{164}$ but are discussed as separate types in the Baden III period. ${ }^{165}$ Jugs survived into the Baden IV period in Endrôdi's typological scheme. ${ }^{166}$ This vessel enjoyed a long popularity in the Baden culture. ${ }^{167}$

\section{SCOOPING VESSELS}

Scooping vessels represent a specific type of drinking vessels, ${ }^{168}$ variously described as handled cups, handled bowls and spherical dippers. ${ }^{169}$ Most are conical with a loop handle rising above the rim and joining the vessel body at the base or slightly above it. The handle was slightly pinched above the rim. Although resembling handled cups and shallow handled bowls, it can be regarded as an individual type owing to its distinctive flattened handle. Its fabric and quality differs little from the other wares of the Baden culture. Decorated and plain varieties of scooping vessels both occur, as do finely made and coarser variants. Their size shows little variation, with the rim diameter ranging between 7.3 and $15.7 \mathrm{~cm}$, and the height between 3.3 and $6.9 \mathrm{~cm}$.

Altogether thirty-four scooping vessels were found in thirty-two graves, ${ }^{170}$ accounting for 7 per cent of all the burials and 13 per cent of the burials with grave goods. Most were deposited in inhumation burials, occurring in double ${ }^{171}$ and triple graves as well. ${ }^{172}$ One was found in a symbolic burial,173 while two were recovered from cremation burials. ${ }^{174}$

Four scooping vessels show a high degree of resemblance, suggesting that they were made by the same potter. The pieces from Graves 277 and 344 are virtually identical (Pl. CIX. 277/1, Pl. CXXXI. 344/2), and were probably fashioned by the same hand, meaning that the two graves are contemporaneous. The same holds true for the scooping vessels from Graves 51 and 183 (Pl. XXIII. 51/1, Pl. LXXVII. 183/1), meaning that these two burials can likewise be regarded as contemporaneous.

A few unique pieces also occur among scooping vessels. With its angular body and decoration of

\footnotetext{
164 NĚMejCová-Pavúková 1981, Obr. 2. G10.

165 NĚMEjCOVÁ-PavúKOVÁ 1981, Obr. 5 . O3.

166 ENDRŐDI 1997, D7.

167 Cp. BONDÁR 2002, 10, for an overview of the chronology of the Úny group.

168 BANNER 1956, Pl. CXIII, Types 22-23.

169 KaLiCZ 1999, 87.

170 Graves 3, 18, 28, 51, 53, 55, 75, 80, 112, 132, 143, 145, 160, 174, 182, $183,189,202,222,232,265,277,286,295,310,344,352,364,367,378$, 383,430 .

171 Graves 3, 55, 80 .

172 Grave 182.

173 Grave 160.

174 Graves 222, 430
}

punctates around the rim and the base, the specimen from Grave 265 (Pl. CVII. 265/4) is unmatched. The pieces from Graves 28, 51 and 310 are decorated with smoothed-in bundles of lines arranged in a cross motif in their interior (Pl. XIV. 28/1, Pl. XXIII. 51/1, Pl. CXX. 310/4). A similar pattern adorns the body of the scooping vessel from Grave 183 (Pl. LXXVII. 183/1).

The vessels from Graves 75 and 286 bear a pattern of impressed dots under the handle (Pl. XXXV. 75/4, Pl. CXIII. 286/1). The piece from Grave 183 is the single specimen with fluting on the handle (Pl. LXXVII. 183/1). A similar piece with decorated handle rising above the rim is known from Obuda, which is likewise decorated with two rows of impressed dots. ${ }^{175}$

One scooping vessels served as a container for the ashes in one of the inurned burials (Pl. CLXIV. 430/1), and as a simple grave good in one of the scattered cremation burials.

For the correspondence analysis I prepared a detailed typological classification of the scooping vessels:

Type VIIIa1: 265/4

Type VIIIa2: 18/1, 80/3

Type VIIIa3: 112/1，145/1，222/2，277/1，344/1， $383 / 2$

Type VIIIa4: 75/4, 286/1

Type VIIIa5: 51/1, 183/1

Type VIIIa6: 28/1, 310/4

Type VIIIb1: 53/2, 55/1, 132/2, 143/1, 160/1, 174/1, $232 / 1,295 / 1,364 / 1,367 / 4,378 / 3$

Type VIIIb2: 3/6, 182/4, 189/1, 202/1, 367/3, 430/1

There is no apparent pattern in the distribution of graves with scooping vessels in the Budakalász cemetery (Fig. 39): these burials can be found across the entire cemetery. This vessel does not appear in Němejcová-Pavúková's typological scheme. Similar vessels can be found among the types assigned to the Baden III and Baden IVa period by Endrődi. ${ }^{176}$

\section{HANDLED CUPS}

The handled cups recovered from the burials have a short cylindrical neck and rounded base, a handle rising above the rim and a decoration of one or two rows of punctates around the shoulder. Their rim diameter ranges between 6 and $17.5 \mathrm{~cm}$, their height between 4 and $7 \mathrm{~cm}$. It is often difficult to distinguish cups from scooping vessels and shallow handled bowls. Cups appear together with dippers in Banner's typological chart. ${ }^{177}$ Although a seemingly widespread form in the Baden culture, few pieces are known from the culture's distribution. Altogether eight handled cups were found in the Budakalász cemetery (Type IX), accounting for 2

\footnotetext{
175 ENDRŐDI 1991, Fig. 10. 4.

176 ENDRŐDI 1997, Fig. 4. A scooping vessel is known from the late Baden settlement at Salgótarján-Pécskő (PATAY 1999, Fig. 2. 2).

177 Banner 1956, Pl. CXIII, Types 27, 29.
} 
per cent of all the graves and 3 per cent of the burials with grave goods. They were recovered exclusively from inhumation burials, ${ }^{178}$ including one double burial. ${ }^{179}$

Two handled cups are decorated with punctates on either side of the handle or below it (Pl. XXVII. 59/4, Pl. XLIX. 112/2). A similar pattern can be noted on a handled pot found at Budapest-Békásmegyer. ${ }^{180}$ The rim of the cup from Grave 19 is peaked on both sides of the handle (Pl. X. 19/2), resembling a vessel found at Budapest-Medve Street. ${ }^{181}$ The cup from Grave 189 (Pl. LXXX. 189/3) represents a plain variant. Handled cups of this type have been reported from several sites in Hungary, ${ }^{182}$ as well as from Cervený Hrádok ${ }^{183}$ and Stránska in Slovakia. ${ }^{184}$

The distribution of burials with handled cups shows a scatter in the cemetery's southern half (Fig. 40).

Cups of this type first appeared in NěmejcováPavúková's Baden IIb ${ }^{185}$ and survived into her Baden III. ${ }^{186}$ They appear among the wares of the Baden III period in Endrốdi's typology. 187

\section{BEAKERS}

Most beakers are thick-walled, coarse vessels with a conical body, sometimes described as flowerpot shaped vessels. It is possible that several pottery fragments can be assigned to this type from the Baden material, which were initially identified as pot or storage jar sherds owing to their indistinct nature. Beakers of this type come in plain and decorated, and handled and handleless varieties.

Four such vessels came to light at Budakalász: two were recovered from inhumation graves and two from cremation burials. The two cremation burials (Graves 130 and 259) and the two inhumation burials (Graves 368 and 378) lie near each other, along an imaginary line (Fig. 40).

The handled beakers from Graves 130 and 259 (Type Xa; Pl. LIV. 130/1, Pl. CIII. 259/2) were almost certainly made by the same potter. The form and quality of these two vessels differ from the pottery generally assigned to the fine wares. The two beakers resemble only each other and the handle-less variant of this beaker type found in Graves 368 and 378 (Type Xb; Pl. CXLV. 368/3, Pl. CL. 378/1), both child burials.

\footnotetext{
$\overline{178 \text { Graves 19, 59 }}$, 68, 112, 142, 189, 197, 312.

179 Grave 142 .

180 ENDRŐDI 2002, Fig. 2. 7.

181 ENDRŐDI 2004, Cat. no. 32

182 Budapest-Vitéz Street (ENDrổi 2004, Cat. no. 36), Budapest-Csabai Road (ENDRÓDI 2004, Cat. no. 119), Budapest-Medve Street (ENDRŐDI 2004, Cat. no. 32).

183 NĚmejCOVÁ-Pavúková 1974, Abb. 20. 5. Two rows of punctates encircle the shoulder.

184 NEVIZÁNSKY 1999, Obr. 15. 5 (this vessel too has two rows of punctates encircling the base)

185 NĚMEjCOVÁ-PavúKová 1981, Obr. 4. C1

186 NĚMEjCOVÁ-PavúKová 1981, Obr. 5. C1, C2.

187 ENDRŐDI 1997, Fig. 4. A2.
}

The typological similarities between the four vessels suggest that these four burials were near-contemporaneous.

This vessel does not appear in the typological charts assembled by Banner and Němejcová-Pavúková. In contrast, Endrődi distinguished three variants of this vessel type in her publication of the find assemblages from various sites in the Budapest area. She dated them to the Baden IVa period. ${ }^{188}$ Nevizánsky dated the type to an earlier period: a flowerpot shaped decorated vessel with a tiny handle appears in his typological chart of Boleráz pottery. ${ }^{189}$ Other pieces were found on the Baden site at Nagyút-Göbölyjárás, ${ }^{190}$ which can be dated to Němejcová-Pavúková's Baden Ic-IIa period. It would appear that this vessel type was used continuously during the Baden period, including the culture's classical phase.

\section{HANDLED POTS}

The vessels assigned to this category resemble beakers ${ }^{191}$ as regards their form, but are usually more carefully made, thin-walled, decorated wares. The handled pots from the cemetery have a short neck, a conical body and a strap handle rising above the rim (Type XI). Their size show little variation, having a rim diameter of $6.8-15.1 \mathrm{~cm}$ and a height of $7.8-13.8 \mathrm{~cm}$.

At Budakalász, handled pots were found in six inhumation graves, ${ }^{192}$ accounting for 1 per cent of all graves and 2 per cent of the burials with grave goods. A stray vessel (Pl. CLXXIII. 39) can also be assigned here. Vessels of this type were placed in male, female and child burials alike (Fig. 41).

Two handled pots are decorated with punctates arranged in a wavy line encircling the shoulder $(P l$. IX. 18/2, Pl. CXXV. 324/1). This motif is not a unique trait reflecting the style of one particular potter or a style particular to the Budakalász community. Punctates forming a wavy line adorn a dipper (Pl. XCVI. 227/4) and a bowl (Pl. CLXIV. 434/2) too. Similar motifs have been found on vessels from the Baden cemetery at Balatonlelle-Felsô-Gamász, ${ }^{193}$ as well as among the stray finds from Budapest-Andor Street ${ }^{194}$ and at Óbuda. ${ }^{195}$ The fact that punctates arranged in a wavy line occur on vessels from other sites too suggests that this motif possibly had a special meaning, which can perhaps be associated with the funerary rite.

Analogies to handled pots can be quoted from various other sites, such as Budapest-Tress Factory, 196

\footnotetext{
188 ENDRŐDI 1997, Fig. 24. 7, Fig. 38. 5-6.

189 NevizáNSKY 2005, Obr. 15. 10.

190 BONDÁR 2005.

191 Most scholars categorise this vessel as a pitcher.

192 Graves 12, 18, 104, 112, 312, 324 and a stray find (Pl. CLXXIII. 39).

193 András Sófalvi's excavation. I would here like to thank Borbála Nagy, who will publish the finds, for informing me about this find.

194 ENDRŐDI 1997, Fig. 35. 6, 8

195 ENDRŐDI 1999, Fig. 10. 3.

196 ENDRŐDI 1997, Fig. 6. 6 (= ENDRŐDI 2004, Cat. no. 21).
} 
Békásmegyer-Kollár fields, ${ }^{197}$ Békásmegyer-Municipal Waterworks Resort, ${ }^{198}$ Békásmegyer-BUVÁTI resort, ${ }^{199}$ which were described as pitchers by Endrödi. Comparable pots have been found at Kajdacs ${ }^{200}$ and Röszke, ${ }^{201}$ as well as at Kamenín in Slovakia. ${ }^{202}$

Banner distinguished three variants of this vessel. ${ }^{203}$ In contrast, Němejcová-Pavúková has no similar vessels in her typological charts, while Endrôdi assigned the pots from Budapest-Andor Street to her Baden IIb. ${ }^{204}$ Nevizánsky dated the Kamenín settlement to the Baden IV period. ${ }^{205}$

\section{POTS}

Most pots are coarse vessels with an elongated S profile, decorated with a rib or knob under the rim. This vessel can be regarded as a general type throughout prehistory, whose form changed little owing to its function.

Altogether thirty-six burials yielded pots, accounting for eight per cent of all graves and 14 per cent of the graves with grave goods. Pots were deposited into inhumation burials ${ }^{206}$ (including double ${ }^{207}$ and triple burials ${ }^{208}$ ), cremation graves, ${ }^{209}$ a grave containing an inhumation and a cremation burial, 210 and symbolic burials (Fig. 41). ${ }^{211}$ They could generally be reconstructed from their fragments, although a part of the base fragments were too small to allow the determination of the vessel type they came from and neither could the one-time size of the vessels be reconstructed either.

The pots from Budakalász are often decorated with a finger impressed rib (Pl. XXXVII. 80/8, Pl. LI. 116/2, Pl. CVII. 265/2-3, Pl. CXI. 273/6) or small round knobs (Pl. LXXX. 189/2, Pl. LXXXI. 194/3, Pl. XC. 210/4, Pl. $C X V I I .306 / 1)$ under the rim, although plain pieces also occur (Pl. XCI. 210/3-4).

For the correspondence analysis I prepared a detailed typological classification of the pots:

Type XII: 33/2, 164/1, 174/2, 194/4, 210/4, 223/1, $224 / 2,227 / 2,227 / 8,259 / 1,311 / 1$

Type XIIa: 80/8, 116/2, 265/2-3, 273/6

Type XIIb: 135/1b, 181/1, 189/2, 194/3, 210/4, $306 / 1,310 / 2,334 / 1,341 / 1$

Type XIIc: $210 / 3-4$

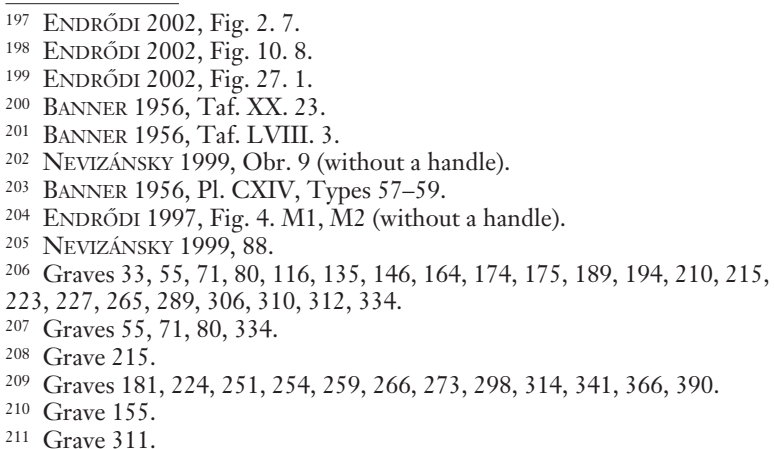

Němejcová-Pavúková assigned the earliest pots of this type to her Baden IIb, noting that they survived into the Baden III period. ${ }^{212}$ These vessels are unsuitable for a finer dating and it is therefore pointless to list the many similar vessels.

\section{AMPHORAS}

Amphoras with cylindrical neck and rounded belly fitted with a pair of handles on the shoulder or the belly come in various sizes. The neck is generally smoothed and undecorated, the vessel body is often fluted. ${ }^{213}$

Nine graves yielded amphora fragments, accounting for 2 per cent of all graves and almost 4 per cent of the burials with grave goods. Three of these were cremation burials, ${ }^{214}$ the rest were inhumation burials, ${ }^{215}$ and fragments of this vessel type could also be identified among the stray finds (Fig. 41). The size of the vessels could not always be reconstructed from the fragments.

Three sub-variants could be distinguished:

(1) Amphora with long neck and rounded belly, decorated with an incised bundle of lines around the neck and fluting on the belly. The handles are set at the junction of the shoulder and the belly (Type XIIIa, $P l$. XXXI. 70/3).

(2) A similar amphora with wider mouth and belly. The handle terminates in two slender ribs (Type XIIIb, Pl. CII. 252/2).

(3) The third variant is represented by a tall amphora with narrow neck and globular body, which was probably undecorated (Type XIIIc, Pl. CX. 273/1).

Since most of the amphoras from the Budakalász cemetery were represented by body and handle fragments, it is difficult to identify their exact analogies among the known finds. Their formal counterparts do not appear in Němejcová-Pavúková's typological charts. Amphoras with comparable proportions appear in her Baden IIb, ${ }^{216}$ surviving into the Baden III. ${ }^{217}$ Endrődi has similar vessels in her Baden II, which disappear in her Baden III and re-appear in her Baden IV.218 Nevizánsky recently devoted a lengthy study to the amphoras of the Baden culture. ${ }^{219} \mathrm{He}$ examined fifty-three vessels and distinguished ten types based on their typological traits (form, decoration, handles) in the Baden sequence. The different types have a dating value: Types I-II and VIII-X fall into the Boleráz period, while Types IV-VII represent the classical Baden period. 220

\footnotetext{
212 NĚmejcová-Pavúková 1981, Obr. 5. P3; Cheben 1984, Obr. 2. P5.

213 BanNer 1956. Pl. CXVII, Types 1-13.

214 Graves 273, 274, 433.

215 Graves 2, 70, 135, 252, 261, 421.

216 NĚmejCová-Pavúková 1981, Obr. 4. N1; Cheben 1984, Obr. 2. N1, N2.

217 NĚMejCovÁ-PavúKová 1981, Obr. 5. N1.

218 ENDRŐDI 1997, Fig. 4. J1-2 and Fig. 4. J3.

219 NEVIZÁNSKY 2004.

220 NEVIZÁNSKY 2004, 72
} 


\section{BOWLS}

Bowl are the most common wares after pots in the pottery of the Baden culture. Decorated with seemingly endless combinations of ornamental elements and coming in many varieties, bowls remained popular during the entire Baden sequence. In spite of appearing highly similar or downright identical at first glance, bowls differ significantly from each other. In terms of minor details, such as the many variations and combinations of incised, impressed and appliqué ornaments depending on the skill, style and creativity of the potter, virtually every bowl can be regarded as an individual piece to some extent, this being the reason that matching pieces are rare even in the material from one settlement or burial site. In spite of these minor variations, several sub-variants can be distinguished.

Bowls occur more frequently on settlements than in cemeteries, suggesting that the bowls deposited in graves were part of household vessel sets, which were then used during the funeral ceremony.

Altogether fifty-seven bowls were brought to light from forty-four burials, accounting for 10 per cent of all graves and 18 per cent of the burials with grave goods (Fig. 42). Some burials contained several bowls. Intact or broken bowls were predominantly deposited in inhumation burials, ${ }^{221}$ including two double burials, ${ }^{222}$ one triple burial, ${ }^{223}$ and two skull burials. ${ }^{224}$ Five were recovered from scattered cremation burials, 225 one from a double cremation grave containing an inurned and a scattered cremation burial 226 and one from an inurned burial. 227 Grave 177, a symbolic burial and one of the cemetery's best-known graves, too contained a bowl.

For the correspondence analysis I prepared a detailed typological classification of the bowls. Two main types can be distinguished: semi-spherical and conical bowls with funnel neck.

\section{Semi-spherical bowls}

\section{Decorated bowls}

Decorated semi-spherical vessels with slightly indrawn mouth and rounded shoulders, fitted with stringhole lugs. Two bowls of this type were found at Budakalász (Type XIVa1, Pl. XCVI. 227/1, Pl. CXXXV. 347/3), both in inhumation burials. The two bowls were each fragmentary and thus their decoration cannot be reconstructed in its entirety. Both were adorned with a pattern of vertical bundles of lines and stringhole lugs.

\footnotetext{
221 Graves 7, 13 $, 23,50,55,59,67,80,88,129,140,148,156,171,194$ $210,215,227,252,262,279,312,330,335,345,347,350,355,367,383$ $384,422,425$.

222 Graves 13, 80.

223 Grave 215

224 Graves 262, 425.

$225248,254,314,339,434$

226 Grave 131.

227 Grave 340
}

The specimen from Grave 227 has a fluted design in its interior, probably forming an $\mathrm{X}$ motif. Comparable bowls, although more coarsely manufactured and with a different decoration, are known from BudapestAndor Street 228 and Mezốcsát-Hörcsögös. 229

This rather rare bowl type appears in the Baden III period in Němejcová-Pavúková's typological scheme ${ }^{230}$ Endrődi assigned it to her Baden IIb and III period.231

Plain bowls

A plain, more coarsely made variant came to light in Grave 248, a cremation burial (Type XIVa2, Pl. CI. 248/2).

\section{Conical bowls}

Conical bowls decorated with one to three rows of punctates and hanging triangles represent the most popular bowl type of the Baden culture. Some bowls have a row of punctates under the rim, while others are adorned with fluting on the rim interior. Most of these vessels have a horizontal stringhole lug on the belly. Plain variants of this type have also been found. Even though this bowl type is by far the most common ware of the Baden culture, there are few analogies to the Budakalász specimens in the published assemblages, in spite of the fact that all variants of the bowl type occur among the grave goods.

The following sub-variants could be distinguished:

(1) Conical bowls decorated with a row of impressed dots with or without a stringhole lug on the belly or the shoulder (Type XIVb11). Owing to their often fragmentary state, it is sometimes impossible to determine whether a particular bowl had originally been fitted with a stringhole lug, and it therefore seemed pointless to set up separate groups for pieces on which the lug had been preserved and the ones on which it had not.

Bowls with stringhole lugs were recovered from inhumation burials (Pl. XC. 210/2) and from Grave 177, the renowned symbolic burial (Pl. LXXIX. 177/1). Only the stub of the rib-like stringhole lug was preserved on the bowl from Grave 347 (PL. CXXXIV. 347/1), which bears three impressed dots, the start of an unfinished row of impressed dots. Bowls fitted with similar lugs bearing impressions were recovered from Graves 347 and 350, and an analogous stringhole lug can be quoted from Červený Hrádok. ${ }^{232}$ Good parallels to bowls with stringhole lugs decorated with a row of impressed dots are known from Balatonboglár ${ }^{233}$ and various sites in the Budapest area, ${ }^{234}$ as well as from Nevidzany. 235

\footnotetext{
228 ENDRŐDI 1997, Fig. 26. 2-3, Fig. 38. 2, Fig. 39. 5-7, Fig. 40. 5

229 KaliCZ 1999, Fig. 12. 5.

230 NĚmejCová-Pavúková 1981, Obr. 5. H1-4.

231 ENDRŐDI 1997, Fig. 4.

232 NĚMfJCOVÁ-PavúkOVÁ 1974, Abb. 18. 8, Abb. 30. 12

233 HoNTI 1981, Pl. III. 1

234 ENDRŐDI 2004, Cat. nos. 20-22, 24.

235 NĚMEJCOVÁ-Pavúková 1974, Abb. 43. 3.
} 
(2) Conical bowls decorated with a row of impressed dots on the belly or the shoulder combined with hatched hanging triangles (Type XIVb12). The bowl with stringhole lug from Grave 129 is decorated with a row of impressed dots combined with hatched hanging triangles (Pl. LVII. 129/2). Similar pieces have been reported from Budapest ${ }^{236}$ and Mezőcsát-Hörcsögös. ${ }^{237}$

(3) Conical bowls decorated with a row of impressed dots on the belly or the shoulder combined with hatched hanging triangles and a stringhole lug (Type $\mathrm{XIVb13).} \mathrm{It} \mathrm{is} \mathrm{uncertain} \mathrm{whether} \mathrm{a} \mathrm{few} \mathrm{bowls} \mathrm{decorated}$ with a row of impressed dots, which could only be reconstructed from their fragments, had originally been fitted with a stringhole lug (Pl. VIII. 13/1, Pl. XXXVII. 80/6, Pl. LVIII. 140/1, Pl. CLII. 383/1, Pl. $C L X I V .434 / 1)$. A similar bowl without a lug has been published from Mező́csát-Hörcsögös. ${ }^{238}$

(4) Conical bowls decorated with two rows of impressed dots on the belly or shoulder and a stringhole lug (Type XIVb2). The bowls of this type were all recovered from inhumation burials $(\mathrm{Pl}$. IV. $7 / 2, \mathrm{Pl}$. CXXII. 312/2, 6, Pl. CXXVIII. 335/1, Pl. CXXXII. 345/1, Pl. CXLVI. 367/1). A fragment from Grave 252, decorated with two vertical rows of impressed dots flanking the stringhole lug, can probably be assigned to this type ( $P l$. CII. 252/1). Bowls with a similar decoration have been found at Alsónémedi, ${ }^{239}$ Balatonboglár, ${ }^{240}$ Budapest, ${ }^{241}$ Mezốcsát-Hörcsögös ${ }^{242}$ and Nagykanizsa-Billa, ${ }^{243}$ as well as Nevidzany.244

(5) Conical bowls decorated with three rows of impressed dots on the belly (Type XIVb3). The single bowl fragment of this type, decorated with a design of three rows of impressed dots around the belly and an incised zig-zag pattern underneath, was recovered from Grave 339, a disturbed cremation burial (Pl. CXXX. 339/2). A comparable bowl is known from Nagykanizsa-Bille. ${ }^{245}$

(6) Conical bowls with a row of impressed dots under the rim (Type XIVb4). Two bowls of this type were found in the cemetery. Grave 23, an inhumation burials, contained a bowl decorated with two rows of punctates under the rim in the bowl's interior $(\mathrm{Pl}$. XII. 23/3), while Grave 434, a cremation burial, contained a thin-walled bowl adorned with one row of impressed dots (Pl. CLXIV. 434/2). The other elements of the design covering the bowl could not be reconstructed from the surviving fragments. A more coarsely made bowl similarly decorated with two rows of punctates under the rim in the vessel interior is known from Mezôcsát-Hörcsögös. ${ }^{246}$

\footnotetext{
236 ENDRŐdI 2004, Cat. no. 144

237 KaLICZ 1999, Fig. 14. 4

238 KALICZ 1999, Fig. 16. 1

239 KoreK 1951, Pl. X. 23.

240 HoNTI 1981, Pl. II. 1.

241 ENDRŐDI 2002, Fig. 2. 3, Fig. 29. 15 (without a stringhole lug), Fig. 30.

5; ENDRŐDI 2004, Kat. 25.

242 KaLiCZ 1999, Fig. 12. 2

243 P. BARNA 2003, Fig. 19.2

244 NĚmejCová-PavúKová 1974, Abb. 10. 2, Abb. 43. 1, Abb. 46.24

245 P. BARNA 2003, Fig. 15. 4.

246 KaliCZ 1999, Fig. 12. 1a.
}

(7) Plain conical bowls with or without a stringhole lug (Type XIVb5). Plain bowls with a stringhole lug can be reconstructed from the fragments found in four inhumation burials (Pl. XXVII. 59/1, Pl. XXXIX. 88/1, Pl. CXII. 279/1, Pl. CXXXIII. 350/1). The lug on the bowl from Grave 350 bears a series of impressions resembling the lug on the bowl from Grave 347. Similar plain bowls with a stringhole lug have been found at Budapest, ${ }^{247}$ Nagykanizsa-Billa ${ }^{248}$ and Nevidzany. ${ }^{249}$

(8) Plain conical bowls (Type XIVc). Two bowls, differing from the previous ones, were recovered from two inurned burials. The bowls placed in Graves 131/A and 340 served as containers for the ashes. The bowl from Grave 131, containing an inurned and a scattered cremation burial, is a wide vessel with a very short neck, resembling an amphora or a pitcher whose neck had been removed (Pl. LVIII. 131/1). It is a unique form without any known analogies. The somewhat deeper bowl with funnel neck from Grave 340 (Pl. CXXX. 340/1) is a common form, although it is uncertain whether it had been fitted with a stringhole lug. A comparable bowl is known from Budapest-Andor Street. 250

The two main bowl types were current from the early Baden period onward ${ }^{251}$ and remained in use throughout the culture's life with smaller modifications. A detailed discussion of the typology of these bowls and the diversity and changes in their form and decoration can be found in Němejcová-Pavúková's studies. ${ }^{252}$

\section{HANDLED BOWLS}

Bowls with a strap handle are fairly rare among the published finds of the Baden culture, the reason being that these vessels are generally discussed together with cups. While it is often indeed difficult to determine whether a handled vessel should be described as a cup or a bowl, a distinction could be made in the case of the Budakalász cemetery. Low vessels with a smaller rim diameter than bowls are here treated as cups; to put it more simply, larger, deeper cups were assigned to bowls.

The handled bowls in this category have a funnel neck and a slightly everted rim. They are fitted with a slender, high-flung handle rising above the rim, attached to the vessel body on the belly. Their rim diameter is around $16 \mathrm{~cm}$, their height ranges between 6 and $8 \mathrm{~cm}$.

Four bowls can be definitely assigned to this

\footnotetext{
247 ENDRỔDI 2004, Cat. no. 26.

248 P. BARNA 2003, Fig. 15. 2.

249 NĚMejCOVÁ-PavúKOVÁ 1974, Abb. 40. 17.

250 ENDRŐDI 1997, Fig. 7. 3, Fig. 8. 9.

251 NĚMejCOVÁ-Pavúková 1981, Obr. 1. H1-2, J1-2 (Baden Ia), Obr. 2. H1-2, J1-2 (Baden Ib); NĚMEJCOVÁ-PavúKOVÁ 1984, Obr. 33. H1-3, J1-5 (Baden Ic); NĚMEJCOVÁ-PavúKová 1981, Obr. 4. H1, J1 (Baden IIb), Obr. 5. H1-3, J1-4 (Baden III).

252 NĚMEJCOVÁ-PavúKová 1968, 396-408; NĚMEjCOVÁ-PavúKOVÁ 1974, 259-271; NĚMEJCOVÁ-PAVÚKOVÁ 1984, 142.

253 Graves 73, 75, 197 (inhumation burials) and 339 (scattered cremation burial).
} 
category, 253 and while it seems likely that other bowl fragments too came from similar vessels, their categorisation is uncertain owing to the lack of the handle on the surviving fragments. The handled cups from Budakalász have a plain neck. Some specimens have a row of punctates encircling the belly (Pl. XXXII. 73/2, Pl. CXXX. 339/1), others have a design of two rows of punctates (Pl. LXXXIV. 197/2). One bowl is decorated with a combination of punctates and hatched hanging triangles (Pl. XXXV. 75/15).

One bowl has impressed dots around the rim, the belly and along the edges of the strap handle (Pl. LXXXIV. 197/2). The impressed dots are arranged in wavy lines, a motif perhaps having some special meaning since it occurs on ceramic wares from various other sites too.

For the correspondence analysis I prepared a detailed typological classification of the handled bowls:

Type XV: 50/5，50/6，67/2，156/2，156/3，171/1, $194 / 1,355 / 1$

Type XVa: 73/2, 339/1

Type XVb: 50/4, 171/1

Type XVc: $75 / 15$

Type XVd: $197 / 2$

There are no exact analogies to the handled cups from the Budakalász cemetery. A few similar vessels can be quoted from Červený Hrádok ${ }^{254}$, Bíňa/Bény ${ }^{255}$, Balatonboglár ${ }^{256}$ and Budapest-Medve Street. ${ }^{257}$

Three of the handled bowls described above were found in female burials, ${ }^{258}$ while one came from a child burial,259 suggesting that this vessel type was not deposited in male burials. The three inhumation burials can be assigned to the more richly furnished graves, and it seems likely that this bowl type was a prestige item. All three were found together with one or more goblets and various stone and bone artefacts.

There is no apparent pattern in the distribution of the graves with handled bowls, which lay quite far from each other (Fig. 43). The three inhumation burials lie in the cemetery's southern half, while the cremation grave in the northern half.

Handled bowls appeared in the Baden IIa period in Němejcová-Pavúková's typological scheme, ${ }^{260}$ while her next period only has bowls with stringhole lugs, although vessels with a similar form, but different proportions appear among the cups.

\section{BIPARTITE BOWLS}

Bipartite bowls can be regarded as a ceramic ware with a special form and function. The most striking trait of this

\footnotetext{
${ }^{254}$ NĚMEjCOVÁ-PavúKovÁ 1974, Abb. 10. 1 (a handled bowl with fluting in its interior).

255 CHEBEN 1984, Obr.8. 21.

256 HONTI 1981, Pl. I. 5.

257 ENDRŐDI 1991, Fig. 7. 3, described as a cup (the vessel's dimensions are not specified).

258 Graves 73, 197, 339

259 Grave 75

260 NĚMejCová-PavúKová 1981, Obr. 4. J2, J4.
}

fine ware is the dividing wall, dividing the vessel interior in a roughly $1 / 3: 2 / 3$ proportion. ${ }^{261}$ Its function remains enigmatic; most scholar ascribe a ritual role to this vessel.

Most bipartite bowls are well made, richly adorned vessels fitted with ornamental knobs and handles. They are generally decorated with a design combining incised lines and impressed dots, and sometimes also encrusted with lime (or painted white as on the pieces from the Nyírség region). Bowls of this type have been found on settlements and in cemeteries alike.

Twelve burials yielded intact or fragmentary bipartite bowls, accounting for 3 per cent of all burials and 4 per cent of the burials with grave goods. Seven were inhumation graves, ${ }^{262}$ including one triple burial, ${ }^{263}$ four were scattered cremation burials ${ }^{264}$ and one was an inurned burial (Fig. 43).265

Fragments of a finely decorated bowl came to light from Grave 148, a child burial (Pl. LXIII. 148/1), which also contained a bead strand and shell plaques. Grave 23 contained the fragments of three different bipartite bowls (Pl. XII. 23/2, 4, 7). Fragments of the plain dividing wall (Pl. CI. 248/4) and a rim fragment (Pl. CLXIV. 434/3) were found in the cremation burials, which are insufficient for reconstructing the exact vessel form. The stray finds included seven fragments from bipartite bowls (Pl. CLXIX. 12, Pl. CLXX. 15, 19, Pl. CLXXIV. 43-44, Pl. CLXXV. 48-49).

For the correspondence analysis I prepared a detailed typological classification of the bipartite bowls:

Type XVI: 42/3, 163/1, 248/4

Type XVIa: 148/1, 65/1?, 182/1?, 434/3?

Type XVIb: 310/1

Type XVIc: 23/2, 23/4, 23/7

Type XVId: 398/1

Most of the bipartite bowls were deposited in child burials. The distribution of the graves with bipartite bowls shows a patterning of four groups, roughly corresponding to the four cardinal directions. Grave 398 was the single grave with a bipartite bowl in the north; Graves 421, 433 and 434 lying close to each other form the western group, Graves 310, 248, 274 and 163 the eastern group, and Graves 148, 63 and 23 lying near Grave 182, a triple burial, make up the southern group.

Bipartite bowls decorated in a manner resembling the pieces from Budakalász are known from Békásmegyer and Pünkösdfürdô in the Budapest area, ${ }^{266}$ and from Kamenín/Kéménd in Slovakia. ${ }^{267}$

The first bipartite bowl was found at Pécel. It was exhibited at the international prehistoric congress held

\footnotetext{
261 The single exception is a bipartite vessel divided into roughly equal halves from Kiskunfélegyháza (BANNER 1956, 64). Cp. also BANNER 1956 Pl. CXIII. 1-4.

262 Graves 23, 65, 148, 163, 310, 421.

263 Grave 182

264 Graves 248, 274, 433, 434

265 Grave 398.

266 ENDRŐ́DI 2002, Fig. 3. 5-6, Fig. 4. 15, Fig. 12. 4.

267 NeVIZÁNSKY 1999, Obr. 7, Obr. 8.1, 3, 10a.
} 
in Budapest in 1876.268 In his monograph on the Baden culture, Banner published bowls of this type and their fragments from forty-two different sites. He noted that even though this bowl type had been known in Hungary since 1876 , this ware first attracted scholarly interest after the publication of the finds from Ossarn. ${ }^{269} \mathrm{He}$ also discussed the possible antecedents of bipartite bowls, suggesting that they can perhaps be derived from the Tiszapolgár and Bodrogkeresztúr bowls. ${ }^{270}$ Banner devoted a detailed discussion to the ornamental elements of these bowl (decorative knobs, dividing walls, decoration and form of the handles, encrusted patterns). Examining the distribution of bipartite bowls, ${ }^{271}$ he found that most sites were concentrated in the plainland of the Middle Danube Basin, suggesting that these bowls had probably evolved in this region. ${ }^{272}$ Banner also claimed that bipartite bowls had been predominantly deposited in male burials, ${ }^{273}$ which was uncritically accepted by prehistoric research.

In his publication of the Alsónémedi cemetery, Korek too reviewed bipartite bowls. Two burials yielded bowls of this type. Korek assumed that with the exception of the piece from Budapest-Lágymányos, the intact bipartite bowls from Pécel, Szigetújfalu, Pusztaistvánháza, Szombathely, and Szerbkeresztúr known at the time had originated from burials. He noted that fragments of such bowls had also been found on settlements. Korek suggested that these bowls had been sacrificial vessels. Even though the two bowls from Alsónémedi were found in male burials, he rejected the claim that bipartite bowls had been exclusively deposited in male burials. ${ }^{274}$ Korek derived bipartite bowls from wooden prototypes. He interpreted them as ritual vessels, in which two different types of sacrifices had been presented. He noted that one cemetery generally contained one or two bipartite bowls at the most, which seemed to confirm their ritual role. ${ }^{275}$ Korek again briefly discussed bipartite bowls in his doctoral thesis, focusing on their origins and the chronological position of the sites yielding finds of this type. ${ }^{276}$

Němejcová-Pavúková dated the appearance of this bowl type to her Baden III period. 277

Nevizánsky published a lengthy study on the typology of bipartite bowls. ${ }^{278} \mathrm{He}$ distinguished different styles based on the form, the decorative knobs, the size and ornamentation of handles, and the decorative patterns on intact or near intact specimens, and mapped the distribution of these styles. ${ }^{279}$ Bipartite bowls and their fragments have been found on over fifty sites in

\footnotetext{
${ }_{268}$ Its drawing was published by József Hampel in 1886: HAMPEL 1886, Taf. LXXVIII. 1.

269 BANNER 1942, 73

270 BANNER 1942, 83, 87.

271 BANNER 1956, Abb. 41

272 BANNER 1956, 141-142.

273 BANNER 1956, 194.

274 KoreK 1951, 54. Misunderstanding Korek's remark Banner claimed that bipartite bowls were only deposited in male burials.

275 KOREK 1980, 23.

276 KoreK 1983, 79-82.

277 NĚMEjCOVÁ-Pavúková 1981, Obr. 5. L1.

278 NEVIZÁNSKY 2001
}

Slovakia, recovered from a variety of contexts: settlement pits, burials, vessel deposits, and from pits containing skeletons. ${ }^{280} \mathrm{He}$ noted that bipartite bowls first appeared in the Nevidzany-Viss horizon. ${ }^{281}$ Their use was uninterrupted on the upland and mountain sites, but were lacking in the Bošáca group, as well as in the Kostolac and Cotofoni cultures. ${ }^{282}$

Nevizánsky's map showing the distribution of intact bipartite bowls indicates that one major concentration of these vessels lies in the area extending from the Danube Bend to Csepel Island, essentially corresponding to the distribution of amphoras. ${ }^{283}$ This distribution, however, shows an entirely different picture if the fragments of bipartite bowls are also considered. Fragments of these vessels have been found on some 120 sites in Hungary alone; 284 taken together with the intact pieces and the fragments known from the entire Baden distribution, an entirely different distribution pattern is outlined.

Most of the currently known bipartite bowls were found on settlements, with only a few coming from burials, ${ }^{285}$ suggesting that these bowls were not part of the paraphernalia used in funerary rituals. If the bowls had indeed functioned as vessels used in various rituals, they were used in rituals practiced on settlements.

The overwhelming majority of bipartite bowls can be dated to the classical and late Baden period, ${ }^{286}$ from the Baden IIb to the Baden IV horizon. Evidence for a slightly earlier use comes from two sites: one is Bíňa/Bény, a settlement dated to the Baden IIa period, 287 the other is Battonya, a site dating from the Baden Ia period on the testimony of the finds. ${ }^{288}$ The use of bipartite bowls thus spans a fairly long period of the Baden sequence.

\section{OTHER CERAMIC FINDS}

\section{CLAY SPOOLS}

Grave 403 of the Budakalász cemetery yielded four intact and one broken cylindrical spool shaped artefacts (Pl. CLVI. 403/3-7).289 The function of these cylindrical artefacts terminating in two flat discs is enigmatic:

\footnotetext{
279 NevizáNSKY 2001, Map 1.

280 NEVIZÁNSKY 2001, 311-312.

281 NEVIZÁNSKY 2001, 317.

282 The German version of this study has not been published yet. I would here like to thank Gábor Nevizánsky for sending me a digest of his study. 283 NeviZÁNSKY 2001, Map 1; NEVIZÁNSKY 2004, Karte 1.

284 Based on a study of bipartite bowls funded by a generous grant from the National Research Fund (OTKA grant no. 37503). A detailed discussion of these vessels and their possible function will be published in a separate study by the present author.

285 Ảlsónémedi, Budakalász, Budapest-Andor Street, Debrecen-Ohat, Felsôvadász-Várdomb, Kiskunfélegyháza, Moha-Homokbánya, Szigetszentmárton.

286 NĚMEJCOVÁ-PavúKOVÁ 1981, 269; BONDÁR 1982, 35; ENDRŐDI 1997, 125.

287 Cheben 1984, Abb. 5. 2. Seven other fragments, all stray finds, also came from bipartite bowls

288 BONDÁR-MATUZ-SZABÓ 1998, Fig. 5. 2, and note 2 on p. 10.

289 According to the excavation diary, Grave 403 contained one broken and four intact spools; however, only two of these were later inventoried.
} 
they are variously described as spools, spindle-whorls or simply as cylindrical artefacts. Although occurring over an extensive area from the Late Copper Age to the Late Bronze Age, very few have been recovered from well-documented contexts.

Most of these small ceramic artefacts came to light on settlements. Finds of this type have been reported from Bulgaria, ${ }^{290}$ Romania, ${ }^{291}$ the former Yugoslavia, ${ }^{292}$ Austria, ${ }^{293}$ Slovakia, ${ }^{294}$ Moravia, ${ }^{295}$ and Bohemia, ${ }^{296}$ as well as from several Hungarian sites, ${ }^{297}$ from the Aegean, Anatolia and Mesopotamia. ${ }^{298}$

Very few comparable finds are known from the Baden distribution, and it is quite possible that some were not published owing to their seeming insignificance. Artefacts of this type, known mainly from settlements and cemeteries of the early Baden period from the culture's entire distribution, are generally interpreted as spindle whorls, i.e. as accessories of spinning and weaving.

However, an alternative interpretation is also possible. While studying the wagon model from Szigetszentmárton, on which the axle and the wheel are combined in one, it occurred to me that these small objects had perhaps been parts of similar wagon models. ${ }^{299}$ Assuming that the axle was not fixed through the wagon box, several rectangular objects, which can perhaps be interpreted as wagon boxes, can be added to the corpus of currently known Late Copper Age wagon models. ${ }^{300}$ In this case, the combination of the axle and the wheels meant the creation of rollers onto which the rectangular wagon box was placed. While a technical solution of this kind would hardly have been too practical in the case of real-life wagons, it may have been used in the case of their clay replicas. Most scholars agree that wagon models were part of the paraphernalia of rituals and in this context, a separate wagon box placed on top of an axle-with-wheels element

\footnotetext{
Nothing is known about what happened to the other pieces and similar objects do not appear among the stray finds either.

290 Slatino: CoCHADZIEv 1986, Abb. 2. XI, cylindrical artefacts decorated with black, red or white encrustation from the Early Copper Age.

291 Cilnik: Roman 1977, Pl. 52. 27 and Roman 1977a, Taf. 39. 10; Bocşa Montană: Roman 1977, Pl. 52. 30; Dubova-Cuina-Turcului: Roman 1977, Pl. 52. 36, all finds of the Cotofeni culture.

292 Brza Vrba: Medović 1976, Taf. 5. 19, Taf. 11. 14 and Medović 1976a Taf. VI. 5, finds of the Cernavoda culture; Sarvaš: BALEN 2006, Tab. 58 220-222, from the Copper Age.

293 Mödling-Jennyberg: RUTTKAY 1995, Abb. 16. 8; Pleissing: RUTTKAY 2000, Taf. 6. 66; Schwechat: RutTKAY 1971, Taf. A. 11, all finds of the Boleráz group.

294 Malá nad Hronom: NĚMEjCOVÁ-Pavúková 1974, Abb. 54. 22-23; Nevidzany: NĚMEJCOVÁ-PavúKová 1974, Abb. 42. 22; Bratislava: BAXÁKaminská 1984, Tab. 2. 2; Mužla: KuZma 1995, Obr. 80. 2; Nizný Žipov: DANO-JuHAS-Musil 1994, Obr. 20. 3, all finds of the Boleráz group and the Baden culture.

295 Finds from Layers $\mathrm{C}, \mathrm{C} 1$ and $\mathrm{C} 2$ of the Jevišovice settlement: Medunová-Beneśová 1981, Taf. 48. 1, 3, Taf. 49. 9, 11-13, Taf. 113. 6-7, Taf. 146. 7-9. Layer C1 is contemporaneous with the Baden period. 296 Cimburk: ZápOTOCKÝ 2000, Taf. 4. 20.

297 Pilismarót-Basaharc (István Torma, pers. comm.); Nagykanizsa-Billa: P. BARNA 2003, Fig. 23. 13; Nagyút-Göbölyjárás: BONDÁR 2001, Fig. 6. 3; Balatonôszöd-Temetôi dúló: HoRváTH 2006, 105, note 38 and Fig. 12, all sites of the Boleráz group and the Baden culture.

298 RAHMSTORF 2006, 73-81. Abb. 11, Anhang 5.

299 BONDÁR 2004, 15-16, Fig. 1. 3b.

300 Bondár 2004, Fig. 2. 1-3, Fig. 3, Fig. 4. 1-2.
}

would have been a simple and ingenious combination.

One case in point is the wagon model from Szigetszentmárton, ${ }^{301}$ which instead of individual solid wheels, clearly has two rollers on a longish axle on which the rectangular wagon box was placed. ${ }^{302}$ Similar wheels can be seen on a Mesopotamian wagon model too, ${ }^{303}$ which has a covered wagon box placed on a clay axle with two wheels, and on a bronze model from Anatolia, which has the wagon box likewise placed on the axles fitted with a pair of wheels. ${ }^{304}$ The underside of another bronze wagon model from Anatolia provides an excellent illustration of this technical solution. ${ }^{305}$ The creation of wagon models from their two main components (a separate wagon box and the wheels fixed to it together with axles) would explain why the axles are not marked on the vessel-like, rectangular wagon models without wheels. It would also provide an explanation for the enigmatic spool-like artefacts coming in various sizes found on Boleráz sites, which have generally been regarded as a relic of household crafts (spinning and weaving). Accepting the above interpretation of the wagon models from Szigetszentmárton and Anatolia, the possible function of these hitherto neglected spools can be set in a new perspective. Obviously, the currently known spool finds must be rigorously examined in order to determine whether they had indeed functioned as roller-like wheels based on their form, size and traces of use-wear.

Spool-like artefacts of this type have been found together with wagon models on the Baden sites at Pilismarót-Basaharc and Budakalász. The finds from Mödling-Jennyberg too include both spools and a wagon model, again providing additional evidence in favour of the interpretation proposed in the above.

The grooved cylinders on house models from Anatolia and Mesopotamia ${ }^{306}$ suggest another possible function, namely a decorative use as gable ornaments on houses of the Late Copper Age. Spool-like decorative elements of this type occur on various depictions from the Ancient Near East, for example on house shaped urns. ${ }^{307}$ Several buildings of the Late Uruk period in Mesopotamia, contemporaneous with the Baden period, were decorated with colourful mosaics created from black, red and white painted stone cones driven into the wall of temples, distinguishing thereby sacred buildings from profane ones. ${ }^{308}$ Temples of this type are called stone-cone temples.

Another possible function is illustrated by a clay figurine found in Gilat, dating from 4500-3800 BC, portraying a woman sitting on a biconical stool, holding a two-handled vessel resembling the pans of the Baden culture under her right arm and a spool-like

\footnotetext{
301 KALICZ 1976, Fig. 2

302 BONDÁR 2004, Fig. 1. 3b.

303 BONDÁR 2004, Fig. 13. 4.

304 BONDÁR 2004, Fig. 14. 2b.

305 BONDÁR 2004, Fig. 14. 3b.

306 Perrot 1979, Fig. 73.

307 Land der Bibel, Cat. no. 31.

308 Von Babylon bis Jerusalem, Cat. nos 239-240.
} 
object under her left. ${ }^{309}$ However, the possible symbolic meaning of the joint occurrence of these two artefacts remains elusive.

In his discussion of the distribution of various commodities and innovations of the Early Bronze Age (depas amphikypellon, Syrian flasks, decorated bone cylinders, cylinder seals, weights, spools, scales, etc.), Lorenz Rahmstorf noted that the wares and innovations of Mesopotamia and Anatolia rapidly spread to the eastern Aegean at the time of the socalled second urban revolution. He suggested that the rapid spread of these commodities could be attributed to the fact that the Aegean communities had reached a similar level of civilisation and were therefore ready to absorb new consumer goods. Spools represented one of the many new innovations: one particular variant of spools perhaps functioned as scale weights, reflecting an advanced mathematical knowledge. ${ }^{310}$ Spools made from marble and Spondylus were probably prestige items. Discussing the possible function of spools, Rahmstorf raised the possibility that they were used as pestles or rubbing stones, or that they functioned as polishers used by metalsmiths, or as the headrest of Cycladic figurines. ${ }^{311}$

Quoting comparable finds from Germany and their reconstruction, Tünde Horváth recently proposed another possible interpretation of these spool-like objects, suggesting that these small artefacts, made from either clay or stone, had been used as pestles for crushing salt. ${ }^{312}$ In a more recent study, she suggested six possible functions for these artefacts. She quotes evidence that they may have been thread spools used in spinning and weaving, ${ }^{313}$ or stands for vessels during cooking or pottery firing. ${ }^{314}$ In her view, these cylindrical artefacts may equally well have been used as hair braid clamps, ${ }^{315}$ or as back-rests and head-rests. ${ }^{316}$ It seems to me that of the possible uses suggested by Horváth, spools could hardly have been suitable for crushing salt or for use as back-rests owing to their size and fragility.

While spools and spool-like objects appear to be artefacts occurring over an extensive area and during many periods, the number of published finds is surprisingly low. It is possible that these seemingly insignificant objects were not published or, alternately, that their number is indeed low. In the latter case, they could hardly have been used for everyday activities since in that case considerably more pieces would be known. If the number of these finds is indeed as low as it appears to be, it confirms their rare, unusual function. While the function of these small ceramic objects continues to elude us, the above overview of

\footnotetext{
309 Land der Bibel, Cat. no. 19.

310 RaHMSTORF 2006, 76

311 RAHMSTORF 2006, 74

312 Horváth 2006, 105, note 38 and Fig. 12.

313 HoRváth 2008, Fig. 5.

314 Horváth 2008, Fig. 4

315 Horváth 2008, Fig. 6

316 HoRváth 2008, Fig. 7.
}

their possible uses will perhaps stimulate interest in these objects.

The examples quoted above tend to belie the everyday utilitarian use of these artefacts. The Anatolian and Mesopotamian examples would rather reflect a special usage, perhaps as a symbolic artefact expressing prestige or as a ritual object. While the actual meaning attached to these artefacts remains enigmatic, the contexts in which these spools have been found (wagon model and spools, ${ }^{317}$ vessel modelled in the shape of a female body and spools, ${ }^{318}$ Bratislava type bowl and spools, ${ }^{319}$ etc.) certainly support an interpretation as a ritual object. It is certainly noteworthy that spools were deposited in several graves of the PilismarótBasaharc and Budakalász cemeteries. ${ }^{320}$ At Balatonôszöd, one of the most remarkable sites of the Baden culture, the features containing spools yielded a number of other less than common finds: a mask, a stamp, a goblet, a bipartite bowl and the wheel of a wagon model, ${ }^{321}$ It therefore seems likely that these artefacts had a non-domestic, unusual meaning during the Late Copper Age.

\section{WAGON MODEL}

Graves 158 and 177 of the cemetery each yielded a wagon model, both of which were first published by Sándor Soproni. ${ }^{322}$ Interestingly enough, the wagon model from Grave 177 acquired instant fame, appearing in many scholarly publications and articles written about prehistoric transportation, while the handled wagon model from Grave 158 is barely mentioned. 323

The first overview of wagon models and wheels was written by Gordon Childe, whose studies are rightly the classics of prehistoric research. ${ }^{324}$ The discovery of the Budakalász wagon model, the first of its kind from the Carpathian Basin, ${ }^{325}$ after the known wagon depictions from the Ancient Near East, gave a fresh impetus to studies in this field and modified the earlier dating of the use of wheeled transportation. In his publication of the Budakalász models, Soproni discussed the possible steppean origins of these wagons since no comparable finds were known from the Balkans, providing a possible link between the Carpathian Basin and the Ancient Near East.

The next major overview of wagon models and wheels was published by István Bóna, who was primarily concerned with the Bonze Age finds. ${ }^{326}$ Intact or fragmentary wagon models had come to light on nine of

\footnotetext{
317 Pleissing, Pilismarót-Basaharc, Budakalász.

318 Balatonőszöd, Bratislava, Brza Vbra, Jevišovice, Pilismarót-Basaharc.

319 Bratislava, Brza Vbra, Jevišovice.

320 Pilismarót-Basaharc: six spools from Grave 401 and four spools from

Grave 411; Budakalász: one broken and four intact spools from Grave 403.

321 Horváth 2008, Table 1a.

322 SOPRONI 1954, Pl. 6. 5.

323 Foltiny 1959; BÓNA 1960; FetTich 1969; KoreK 1973.

324 CHILde 1951; ChILde 1954.

325 SOPRONI 1954.

326 BÓNA 1960
} 
the seventy-three sites yielding finds of this type, while only wheel models were reported form the other sites. 327 In his evaluation of the finds, spanning the period from the Late Copper Age to the Early Iron Age, Bóna discussed the origins of wagons and their appearance in the Carpathian Basin, and he also proposed a typological sequence for them. ${ }^{328} \mathrm{He}$ regarded clay wheel models, which he interpreted as wagon fixtures, as major proof for the widespread use of wagons in the Carpathian Basin. ${ }^{329}$ Bóna believed that wagons had first appeared in the ancient civilisations of Mesopotamia, Syria and Anatolia, spreading northward to Crete and the Caucasus at the turn of the 3rd-2nd millennia BC. He suggested that wagons reached the Carpathian Basin from the Balkans along the route leading through the Marica and Morava valleys, and along the route from the Pontic and the Lower Danube region. 330

Following the seminal studies by Childe, Soproni and Bóna, countless articles appeared describing new finds (chiefly from the Bronze Age) and discussing various aspects of these wagon models. I shall not review the prolific studies written on wagon models and the various theories on the emergence of wagons or the theories advanced on the possible ritual role of wagon models, ${ }^{331}$ but shall concentrate on the two pieces from the Budakalász cemetery.

The two graves yielding wagon models lay close to each other in the Budakalász cemetery, in Squares G4 and $\mathrm{H} 4$ (Fig. 44).

Grave 158 contained the inhumation burial of a $c a$. 40 years old woman, while Grave 177 was a symbolic burial without any human remains. In addition to the wagon model, both graves contained a goblet and a stone implement. Grave 158 also yielded a necklace of limestone beads and a pitcher with ovoid body, while Grave 177 contained also a funnel necked bowl with stringhole lugs. The goblets from these graves are both unique pieces, as are the bowl and the pitcher, none of which offer typological or chronological anchors for a closer dating. A comparison with the pieces published from other sites suggests that the two wagon models can be dated to the classical Baden period since their modelling and execution differ markedly from the pieces found in Boleráz contexts.

Several theories have been advanced on why wagon models were deposited in burials. Soproni associated the wagon model from Grave 177, containing the symbolic burial, with the cult of the dead, suggesting that they represented the forerunners of later burials

\footnotetext{
327 BóNA 1960, 92, 104, Fig. 7.

328 BÓNA 1960, 87-89, Fig. 3.

329 Miniature wheels were for a long time interpreted as spindle whorls, sun discs or covers for oil-lamps.

330 BÓNa 1960, 110.

331 Suffice it here to quote the perhaps most important monographs (Piggott 1983; Piggott 1992; Vosteen 1999; Rad und Wagen 2004), the most recent Hungarian studies in this field (BONDÁR 2004; BONDÁR 2006; KováCs 2006) and the collection of studies in a recent conference volume (PÉTREQUIN et al. 2006), all of which offer an excellent overview of earlier studies in this field, together with an exhaustive literature.
}

containing genuine wagons. ${ }^{332}$ Bóna suggested that the wagon model, originally a cult object, had acquired a secondary role, becoming an unused object by the time it was deposited in the grave. ${ }^{333}$ János Makkay interpreted the wagon models as votive objects, which had been used for presenting offerings to the Goddess. 334 Nándor Fettich believed that wagon models represented the funerary wagons which transported the deceased to the goddess presiding over the netherworld. ${ }^{335}$ Kalicz too regarded wagon models as part of the ritual paraphernalia. Quoting parallels from Mesopotamia, he suggested that these objects had been used for storing the sacred ointment used in various rituals. 336

In their discussion of the wagon models from Hungary, Soproni and Banner both touched upon the issue of whether the cattle burials in Grave 3 of the Budakalász cemetery and Graves 3 and 28 of the Alsónémedi cemetery should be interpreted as the remains of genuine wagon burials. ${ }^{337}$ József Csalog was firmly convinced that the couple interred in Grave 3 had been placed on a funeral wagon drawn by a pair of cattle. ${ }^{338}$ He interpreted the discoloured patches visible on the photograph of Grave 28 of the Alsónémedi cemetery as representing the remains of the wagon. 339 Taking note of the above opinions, Korek nonetheless maintained his view advanced in his publication of the Alsónémedi cemetery that the cattle burials should not be interpreted as wagon burials, but as sacrificial animals deposited in chieftain graves ${ }^{340}$ since the graves did not contain any discoloured patches indicating the deposition of a wooden wagon. Another counterargument was that the animal bones represented the remains of a cow and a calf: the former, a dairy animal, was too valuable for the community to be used as a draught animal, while the latter was unsuited to this task, being a young animal. ${ }^{341}$

Yet another issue must be briefly discussed. Fettich believed that Grave 118 too had contained a wagon model, resembling the piece from Grave 158.342 A closer look at the vessel set on four tiny knobs clearly shows that it is not a wagon model, but the fragment of a goblet with an angular upper part. ${ }^{343}$ Genuine wagon models and goblets can be clearly distinguished among the finds from the Budakalász cemetery. Graves containing both vessel types indicate that the two had entirely different functions - in other words, the goblets from these graves can hardly be interpreted as wagon models.

\footnotetext{
332 SOPRONI 1954, 35.

333 BÓNA 1960, 109.

334 MaKKaY 1963; MaKKaY 1965.

335 FeTtich 1969, 51.

336 KALICZ 1976a, 117.

337 SOPRONI 1954, 35; BanNer 1956, 207

338 CSALOG 1961, 7-12.

339 Csalog 1961, 10

340 KOREK 1980, 22.

341 KoreK 1980, 22.

342 FETTICH 1969, 51, 61

343 Luckily, this erroneous interpretation did not gain wider acceptance among prehistorians.
} 


\section{JEWELLERY}

Possible correlations between the deposition of various ornaments (beads, shells, shell plaques, bone ornaments) and the burial rite, as well as the age and/or sex of the deceased have been discussed in the chapter covering the funerary rites, together with possible patterns in the combination of the grave goods deposited in the burials. This chapter will focus on the aspects which have not been discussed in the foregoing.

Beads, shells, shell plaques, snails, and neckrings and bracelets made of bone are generally interpreted as jewellery items worn as part of the costume. Their presence in the grave is usually taken as an indication of the fact that the deceased was interred in some sort of clothing together with the jewellery articles and adornments worn in life. However, the possibility must also be considered that some of these articles were placed in the grave as part of the funeral rite and had never belonged to the deceased, but were a gift from the community. Ethnographic analogies suggest that in some cases, jewellery items were not costume adornments, but were vested with a symbolic meaning in the community's beliefs: the ornaments placed in the grave as the community's gift expressed the one-time status of the deceased and the beliefs or attitudes associated with that status, most of which elude us.

We know that shells were part of an elaborate set of symbols. Among aboriginal peoples, shells were a symbol of the rebirth of the dead, the virginity of young girls, and of the search for a suitable spouse; ${ }^{344}$ shells were often deposited in the grave of young girls for a ritual purpose, in order to ensure that she would find a spouse in the otherworld. Shells often played an important role in initiation rites. ${ }^{345}$ According to some beliefs, shells played a role in the rebirth of the dead. ${ }^{346}$ There is also evidence that shells were part of the paraphernalia of the funerary ritual. ${ }^{347}$

I examined the jewellery items from the Budakalász cemetery from the perspective of whether they had been part of the costume worn in life or whether they had been deposited in the grave for some other reason. Altogether 130 burials had some sort of jewellery or ornaments placed in them (Fig. 45). These graves predominantly contained inhumation burials; only ten were cremation burials. It would appear that the custom of depositing jewellery items in the grave was principally associated with the inhumation rite. The position of the ornaments and the sequence of individual elements in inhumation burials can contribute much to the reconstruction of the one-time costume or the funeral shroud.

Most of the jewellery articles deposited in inhumation burials lay in the region of the forehead, the neck,

\footnotetext{
344 Eliade 1997, 172; Eliade 1998, 17; Eliade 2002, 49.

345 ELIADE 1997, 172

346 ELIADE 1977,175

347 ELIADE 2002, 48
}

the chest, the upper arm, the wrist, and the waist (Fig. 46). ${ }^{348}$ These may equally well have been ornaments sewn onto the costume, or worn as ornaments or apotropaic amulets sewn onto leather straps worn around the arm or wrist, or the accessories of a cloth or a leather belt. The beads and shell plaques lying around the neck may have been necklaces or small ornaments trimming the neckline of a dress. The beads and shell plaques lying on the forehead most likely adorned a headdress or a shawl. However, little is known about clothing, the usual costume worn by members of the community, or the funerary shroud, ${ }^{349}$ and neither do we know whether the deceased had worn the jewellery and ornaments found in the grave in life.

It is also possible that the deceased were only partially dressed and that the jewellery items and various adornments were an important part of the incomplete costume, similarly to the practice observed among some aboriginal peoples.

In the case of cremation burials, the jewellery was in all cases placed on top of the ashes or in the grave after the cremation of the corpse. They were not cremated together with the deceased, ${ }^{350}$ meaning that they were not part of the costume, but had some other significance. It seems likely that the jewellery items placed in cremation burials were gifts received at the funeral.

Soproni found the burnt beads of a necklace in Grave 100, a double inhumation burial. Since the skeletons were also burnt, Soproni concluded that a fire had been kindled on the interred bodies, explaining why the beads were also burnt.

There was no apparent correlation between the funeral rite and the type of jewellery deposited in inhumation and cremations burials, although a few minor variations could be observed. None of the triple inhumation burials contained any jewellery. Shells were more often deposited in child burials ${ }^{351}$ than in adult graves. Shell plaques were generally placed in inhumation burials, although Grave 190, a scattered cremation burial, also contained ornaments of this type. The single ornament made from Spondylus (Pl. LX. $138 / 2$ c) was recovered from a cremation burial. Turritella snails were more often placed in cremation burials; only one piece was recovered from an inhumation burial (Grave 399, a double inhumation burial).

The jewellery from the graves of the Budakalász cemetery were fashioned from stone (most often limestone), fired clay, shells (Anadara diluvii, Spondylus and Unio crassus), snails (Dentalium badense and

\footnotetext{
348 In view of possible post-depositional changes, it can at best only be assumed that the jewellery articles found in the region of various bodily parts had been actually worn there during life (neck, wrist, arm, waist, etc.). Some ornaments may have become dislodged from their original position: for example, ornaments originally worn around the neck may have slipped down to the arm or waist. In some cases, beads were found around the feet, which most likely slipped there from the waist.

349 The position of the Dentalium beads in Grave 609 of the Copper Age cemetery at Durankulak in Bulgaria suggested that they had been used to embroider a funerary shroud. AVRAMOVA 2002, Abb. 236

350 Graves 138, 181, 241, 247.

351 Graves 96, 98, 139, 363, 394
} 

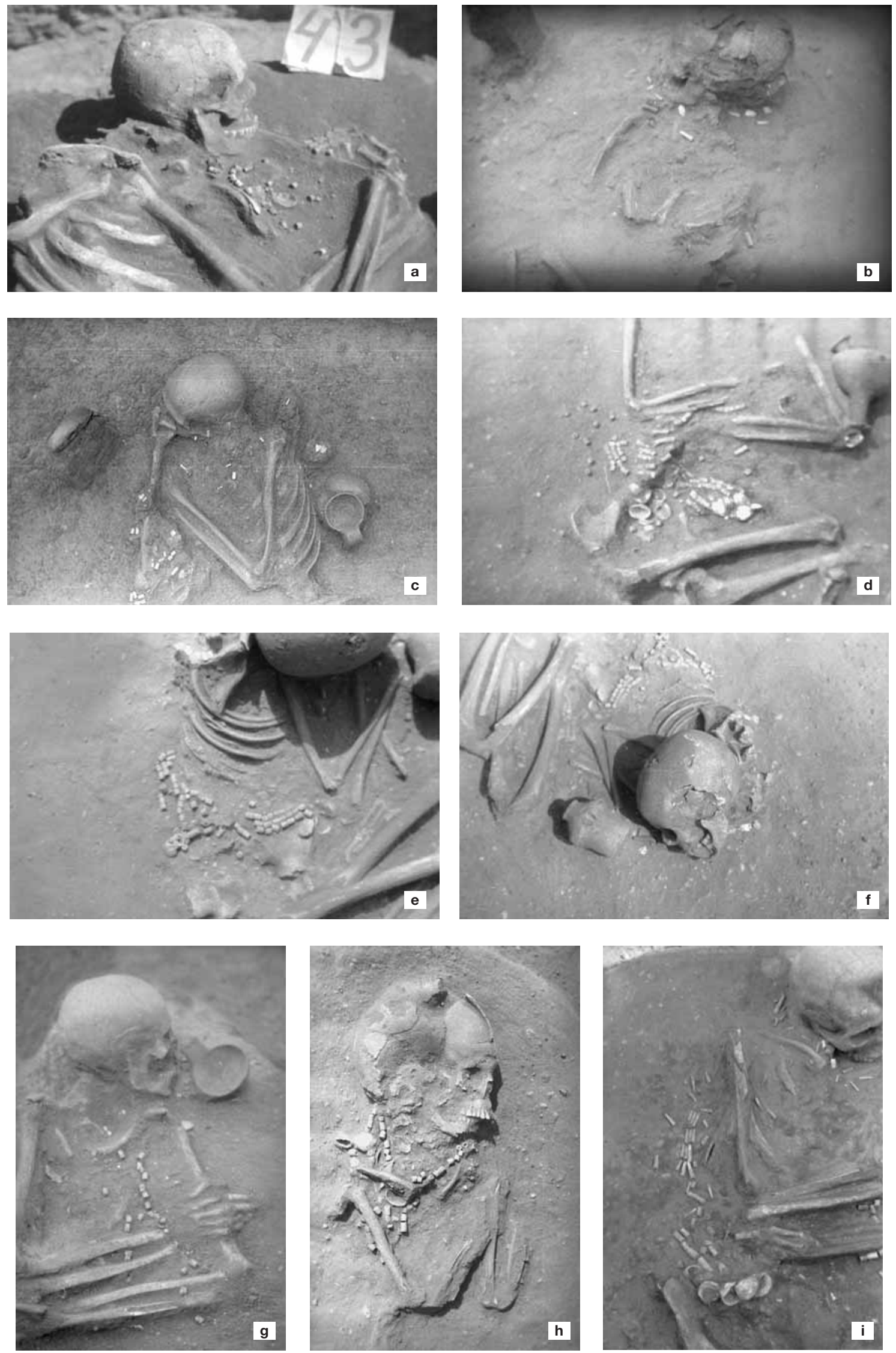

Fig. 46. Position of jewellery finds in the graves of the Budakalasz cemetery

a: Grave 43; b: Grave 84; c: Grave 227; d: Grave 360; e-f: Grave 361; g: Grave 46; b: Grave 128; i: Grave 359 
Turritella) and, more rarely, from bone and copper. The different elements of necklaces and other bead strands were grouped according to the following categories: beads, medal-like ornaments and plaquelike ornaments.

The jewellery and ornaments recovered from the burials comprised 3518 beads, 126 copper beads, 279 shells, 271 shell plaques and 22 snails (cp. Fig. 26).

\section{BEAD STRANDS}

The description of the jewellery found in Grave 413 (Pl. CLVIII. 413/2) in the excavation diary faithfully records the original position of the beads and ornaments strung into necklaces and bead strands: "a necklace around the neck of the skeleton. Rectangular shell plaques lay on top around the neck, from which were hung two strands of Dentalium shells combined with other shells at their end. 22 rectangular shell plaques, 9 beads and 3 perforated shells." Unfortunately, neither a close-up photo, nor a drawing was made showing these artefacts.

\section{Beads}

Beads were strung into strands ranging from simple neck ornaments of one or two beads ${ }^{352}$ to elaborate multi-strand necklaces of over a hundred beads, sometimes reaching down to the waist. ${ }^{353}$ Bead strands were found in 130 graves. Beads lying far from each other beside different bodily parts were regarded as coming from different strands. In this sense, twentyone burials contained two strands of beads, ${ }^{354}$ while Grave 127 contained three strands, and Grave 359 contained four strands. Beads were made from shells, snails, limestone, clay and hammered strips of sheet copper.

In his excavation diary, Soproni identified the beads from the burials as Dentalium, stone, shell, marble and Vermetus beads. The re-examination of the finds revealed that most beads had been made from Dentalium badense, limestone of differing colour and fired clay. ${ }^{355}$ The stone beads, shell beads and marble beads in Soproni's descriptions had in fact been fashioned from limestone, while the Vermetus beads turned out to be Dentalium or clay beads. ${ }^{356}$

Dentalium was the most popular raw material for the manufacture of beads. The cylindrical Dentalium shell was first sliced up into the desired lengths and then

\footnotetext{
352 Graves 32, 170, 207, 432.

353 Graves 10 and 127 .

${ }^{354}$ Graves 8, 46, 63, 74, 100/B, 111, 113/A, 174, 194, 208, 216, 227, 263/B, $291,301,317,355,360,361,381,419$.

355 The material of the beads was analysed and identified by Pál Sümegi. Stable isotope analyses were performed on the beads by Attila Demény and his colleagues in order to determine whether the beads were made from recent or fossil Mollusca species and to identify their possible provenance. Cp. pp. 409-436 and 437-448, in this volume.

356 Vermetus is a marine gastropod with spiral shell: the shell has a regular spiral form at first, which become irregular later in life. BREHM 2000.
}

polished. The beads were then strung into necklaces or bead strands together with other articles such as shells, animal teeth and the like. Dentalium beads can easily be mistaken for limestone beads. Soproni described Dentalium beads as sliced shell beads in his excavation diary.

The overwhelming majority of stone beads was made from Quaternary freshwater limestone, deposits of which occur in the broader area of the Budakalász cemetery and farther afield. Red limestone can be found in the Gerecse Mountains, lying fairly close to the site, and crystalline limestone could also be collected among the pebbles lying on the Danube bank. However, the stable isotope analyses performed on some beads suggested that the freshwater limestone used for the manufacture of these beads was not procured in the Buda and/or Gerecse Mountains, but from some other location. ${ }^{357}$

Sümegi suggested that the raw material for the reddish clay beads was probably obtained locally in the Budakalász area. ${ }^{358}$ The stable isotope analyses revealed that one of the beads from Grave 227 was a speleothem bead. ${ }^{359}$

Twenty-six graves yielded copper beads, ${ }^{360}$ while copper plaques were recovered from two burials. ${ }^{361}$ One burial yielded a copper fragment, ${ }^{362}$ and copper oxide was noted in three burials. ${ }^{363}$ None of the necklaces were made up exclusively of copper beads; these beads were always strung together with other jewellery items (other beads, shells and shell plaques). The necklaces from nine graves each contained a copper bead. ${ }^{364}$ The highest number of copper beads was recovered from Grave 8 (thirty copper beads altogether).

Only a few copper beads were submitted to archaeometric analyses. The results of Manfred Schröder's trace analyses, probably performed in 1962, are known. The composition of the copper beads from Graves 221, 227, 245, 301 and 361 analysed in Stuttgart as part of the Studien zu den Anfängen der Metallurgie project were the following: ${ }^{365}$

The archaeometric analyses revealed that the copper beads and copper plaques from Budakalász contained silver and traces of nickel, iron and lead, and also that there were hardly any differences in their trace element composition, i.e. they were virtually identical.

Beads rolled from strips of poor quality, hammered

\footnotetext{
357 Cp. pp. 439-440, in this volume.

${ }_{358}$ Cp. p. 426 , in this volume.

${ }^{359}$ Cp. pp. $442-443$, in this volume.

${ }^{360}$ Graves 2, 8, 36, 38, 48/A, 50, 84, 113/A, 113/B, 114, 127, 130, 164, 174, $216,221,226,227,229,245,284,291,301,355,361,416$.

361 Graves 28 and 130

362 Grave 78.

363 Graves 29, 111, 144

364 Graves 50, 84, 130, 164, 226, 245, 284, 291, 355.

365 Cp. Table 24. "Zur gefl. Beachtung: Kupfer stellt bei allen Analysen die Hauptmenge dar. Seine Grösse ergibt sich mit hinreichender Genauigkeit, wenn man die Somme der 11 angegebenen hauptsächlichen Beimengungen von 100 subtrahiert. Die Elemente sind quantitativ bestimmt und die Werte in Prozent angegeben. Nur Gold (Au) und Eisen (Fe) werden, sofern vorhanden, mit +, ++, gekennzeichnet." SzFM Archives, inv. no. 1170/76. $S p$ is an abbreviation for "Spur", meaning insufficient amount.
} 
Table 24. Composition of the copper beads from Budakalász

\begin{tabular}{|l|c|c|c|c|c|c|c|c|c|c|c|}
\hline Grave & Sn & $\mathbf{P b}$ & As & Sb & Ag & $\mathbf{N i}$ & $\mathbf{B i}$ & $\mathbf{A u}$ & $\mathbf{Z i}$ & $\mathbf{C o}$ & $\mathbf{F e}$ \\
\hline 28 & 0 & 0 & 00 & 0.03 & 0 & 00 & 0 & 0 & 0 & 0 & $\mathrm{Sp}$ \\
\hline 221 & 0 & 0 & 0 & 0 & $\mathrm{~N} 0.01$ & 0 & 0 & 0 & 0 & 0 & 0 \\
\hline 227 & 0 & $\mathrm{Sp}$ & 0 & 0 & 0.03 & $\mathrm{Sp}$ & 0 & 0 & 0 & 0 & + \\
\hline 245 & - & - & - & 0 & - & - & - & - & - & - & - \\
\hline 301 & 0 & 0 & 0 & - & $\mathrm{N} 0.01$ & 0 & 0 & 0 & 0 & 0 & $\mathrm{Sp}$ \\
\hline 361 & 0 & $\mathrm{Sp}$ & 0 & 0 & 0.03 & $\mathrm{Sp}$ & 0 & 0 & 0 & 0 & + \\
\hline
\end{tabular}

sheet copper imitating Dentalium beads were often strung among the other beads of the necklaces. The copper bead was sometimes crimped around the Dentalium bead, resulting in a longish, rolled bead such as the one from Grave 113 (Fig. 46). The copper beads had often disintegrated and no more than a few crumbs of copper or a green patina stain on the Dentalium bead were all that remained. The finds described as copper plaques found in some burials were probably strips of hammered sheet copper used for making the beads which had not been used for some reason or other.

Clay and copper imitation of Dentalium beads were often strung among the latter. The reason for this practice is unclear, seeing that Dentalium was abundantly available. Neither do we know whether there was a pattern in the type of beads strung into one necklace - we may, at the most, assume that the number and type of beads did have some significance, as did the number of beads for the simple reason that there is an obvious visual difference between "one" and "many", and that this distinction had a significance even before the evolution of complex conceptual thought. ${ }^{366}$

\section{Medallion type jewellery}

Drilled shells and snails strung onto some cord of organic material are categorised as medallion type jewellery. Fifty graves contained shells either singly or together with other jewellery elements. Four graves contained only shells. ${ }^{367}$ Shell strands were recovered from three burials. ${ }^{368}$ Eight graves contained over ten shells; ${ }^{369}$ the highest number of shells, twenty-four pieces in all, was recovered from Grave 360, in which two strands had been placed.

The single freshwater species among the shells and snails was Unio crassus, which was readily available in the Danube. The recent individuals of other species thrive in seas, which might be taken to indicate trade contacts with distant regions. However, Sümegi's comparative analyses and Demény's stable isotope analyses indicated

\footnotetext{
366 Even without assuming an advanced mathematical knowledge or a numerological system, it seems likely that there was a difference in the meaning conveyed by one and the multiple of even numbers of incidences. 367 Graves 33, 35, 106/A, 345.

368 Graves 33, 35, 106/A.

${ }^{369}$ Graves $67,74,95,111,128,360,378$
}

that the overwhelming majority of the shells and snails found at Budakalász were fossil individuals originating from Miocene marine sediments, which also occur in Hungary, and thus these finds do not provide evidence for trade contacts with far-away regions such as the Mediterranean. Fossil shells and snails occur abundantly in the Cserhát, Börzsöny, Buda and Gerecse Mountains, all within a $50 \mathrm{~km}$ radius from Budakalász, and could thus easily be collected during the Copper Age. It is uncertain whether the single Spondylus fragment ${ }^{370}$ came from a recent individual (i.e. from the Copper Age) or from a fossil (Miocene) shell.

\section{Plaque jewellery}

The rectangular shell plaques with perforated corners assigned to this category generally lay in the neck region, ${ }^{371}$ suggesting that they had been sewn onto some sort of cloth or leather band or strung onto cord threaded through the perforations. The few pieces found lying on the forehead ${ }^{372}$ had perhaps adorned a headdress. Some plaques lay by the wrist ${ }^{373}$ or the upper arm, ${ }^{374}$ perhaps the adornments of dress sleeves or of bracelets and armlets created by sewing them on textile or leather bands, or simply stringing a cord through the plaques. (The plaques found on the chest $^{375}$ or the thighs ${ }^{376}$ probably slipped there from the arm and are therefore not regarded as a separate element of the costume.) The exact position of the shell plaques within the burial was not recorded in one case. ${ }^{377}$

Shell plaques were recovered from twenty-seven burials. This jewellery article was occasionally the single adornment deposited in a burial. Four graves contained a single shell plaque, ${ }^{378}$ ten graves yielded over ten plaques, ${ }^{379}$ while the highest number, sixty pieces, was recovered from Grave 208.

The roughly identical plaques perforated at the four corners were all made from Unio crassus shells. Unio was a living species during the Copper Age. Its meat was

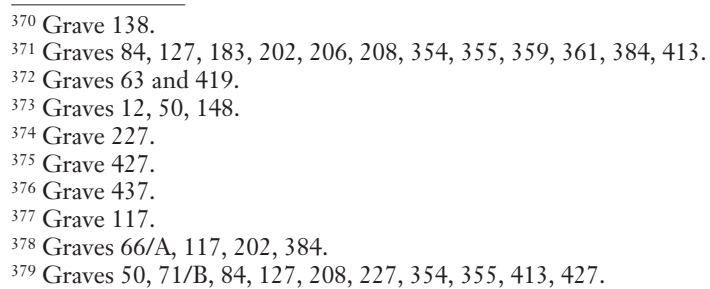


consumed, while the shell was utilised as a raw material for jewellery. Unio was abundantly available in the broader area of Budakalász; however, the stable isotope analyses indicated that the material of the shell plaques bore a greater resemblance to similar shells from the River Tisza in eastern Hungary.

\section{BONE JEWELLERY}

Very few bone artefacts (tools, implements, jewellery) came to light in the Budakalász cemetery. No more than five bone ornaments were found.

Neckrings of boar tusks perforated at both ends were recovered from Graves 75 and 155, while Grave 208 yielded two small bracelets. One neckring ( $P l$. XXXV. 75/9) came from the burial of a 10-12 years old child interred with a rich array of grave goods. Another grave, the burial of a 4-5 years old child, yielded two neckrings. The finds from Grave 155, a double inhumation burial, included a perforated boar tusk neckring (Pl. LXV. 155/2) and the fragments of a boar canine $(P l . L X V .155 / 3)$ by the neck. It is unclear whether the grave inventory of the two burials differed because of differences in age or social status. While Grave 75 contained nine different vessels and five stone implements, Grave 155 only yielded a bead strand and the neckrings.

The boar tusk bracelets lay by the left wrist of the young, 23-30 years old woman interred in Grave 208. Only one end of the tusks was perforated, suggesting that they had been suspended from a cord. This burial yielded the highest number of shell plaques, sixty in all, in the entire cemetery; the plaques lay around the neck according to the excavation diary. ${ }^{380}$

Neckrings and bracelets were probably special jewellery articles, at least judging from the fact that only three burials contained articles of this type. It is not known whether the three individuals were related or not, and neither do we know whether they enjoyed a similar status in the community. We can, at the most, note that they were interred with an unusual, rare article.

$$
* * *
$$

Surprisingly enough, bead strands made up of various elements are rare finds in the cemeteries of the Baden culture. The jewellery items from the Alsónémedi cemetery were made from shells, snails and copper. Dentalium was the most popular bead type, occurring in eight graves, ${ }^{381}$ while copper beads were recovered from five burials. ${ }^{382}$ The Dentalium beads in the Alsónémedi cemetery were made from fossil shell, the copper beads from native copper. The Vörs burial, renowned for the copper diadem found in it, also contained thirteen bone beads. ${ }^{383}$ A cylindrical shell bead was brought to light

\footnotetext{
380 Unfortunately, the finds were lost, and they could not be examined more closely.

381 KOREK 1951, 57 (Graves 4, 14, 19, 20, 25, 32, 43, 53).

382 KoreK 1951, 57 (Graves 3, 4, 20, 34, 36).

383 BANNER 1956, 111, Taf. LXXXVII. 6.
}

from a cremation burial uncovered at Kajdacs. ${ }^{384}$ Dentalium beads were found in several burials of the cemetery containing ten graves investigated at Szentes-Nagyhegy. ${ }^{385}$ The mass grave uncovered at Balatonlelle, containing the remains of twelve individuals, yielded two bead strands made up of limestone beads, spiral copper beads rolled from strips of sheet copper and small Lithoglyphus snails. ${ }^{386}$ The limestone was identified as originating from the Bakony Mountains. A small family graveyard was excavated at Balatonmagyaród-Hídvégpuszta during the salvage operations preceding the construction of the Little Balaton reservoirs. One of the double Baden burials yielded a bead strand strung of twenty-six snails and 137 white limestone beads of varying sizes and red chert. ${ }^{387}$ This bead strand did not include copper beads, although greenish stains, perhaps the remains of copper were noted. The bead strand found at Köveskál was made up of eighty-eight beads and eleven small copper tubes, ${ }^{388}$ while the bead strand from Grave 7, an inhumation burial of the Mezôcsát cemetery, was strung of seventytwo drilled snails and a copper bead. ${ }^{389}$ The grave containing the wagon model in the Szigetszentmárton cemetery also yielded an Unio shell. ${ }^{390}$ A Copper Age crouched inhumation burial containing beads was uncovered during the salvage excavations preceding the construction of the Road 61 Bypass at Kaposvár. 391 Eighteen of the twenty-two burials excavated at Balatonlelle-Felső-Gamász contained grave goods, amongst them copper and limestone beads. ${ }^{392}$

Evidence for human burials is known from 110 of the over 1800 sites of the Baden culture in Hungary. ${ }^{393}$ The archaeological evidence points towards a population interring its dead according to different rites and in cemeteries of different size. ${ }^{394}$ Most of the burials are still unpublished; according to the brief preliminary excavation reports, twelve of these sites yielded bead strands or various elements of bead strands. The grave goods, and especially the jewellery articles, would suggest that there were major differences between the cemeteries of the Baden culture, at least judging from the known burials, despite the fact that there are few completely excavated burial grounds and that the sites where no more than a handful of burials were uncovered may be part of a larger cemetery.

\footnotetext{
384 BANNER 1956, 48.

${ }^{385}$ BANNER 1956, 89-90, Taf. LIX. 1-5.

386 HoNTI 1981, 29, Fig. 4. 1-5.

387 BONDÁR 1987, 47-48, Fig. 6 . The snails were identified as belonging to the Errato genus by Margit Havas Mrs Péter Bohn (Geological Institute of Hungary).

388 Hampel 1895, 43; Bondár 1987, 48, Figs 10-11.

389 KALICZ 1999, 65, Fig. 13. 5.

390 KALICZ 1976, 190.

391 SOMOGYI 1999, 213. The laconic excavation report did not contain any additional information.

392 Sófalvi-NagY-SKRiba 2007, 155-156.

393 BONDÁR 2002, 13-14.

394 BONDÁR 1987, 48-49; BONDÁR 2002, 13-14.
} 


\section{TOOLS AND IMPLEMENTS}

Possible correlations between the deposition of various artefacts and the burial rite, as well as the age and sex of the deceased have been discussed in the chapter covering the funerary rite, together with possible patterns in the combination of grave goods from the burials. This chapter will focus on the aspects which have not been discussed in the foregoing.

Various tools and implements of stone, bone, clay and copper were recovered from 103 burials of the Budakalász cemetery. While their overwhelming majority (scrapers, stone axes, copper pins and copper chisels) can be linked to a particular craft, the finds also include bone and chipped stone arrowheads, quernstones and clay plaques.

\section{STONE TOOLS}

Chipped stone implements were recovered from fiftynine burials: 395 blades, flakes, cores and debitage. In addition to the other grave goods, one to three lithic implements were sometimes placed in the grave, except for Graves 46 and 197, which contained ten stone implements, and Grave 91, which contained seventyeight implements. ${ }^{396}$

Five graves contained seven polished stone axes; ${ }^{397}$ two burials had two axes each. ${ }^{398}$ The $45-55$ years old man laid to rest in Grave 91 was interred exclusively with stone and bone tools and implements. The grave goods included two stone axes (Pl. XLI. 91/7-8). The greater part of the grave goods was placed on a small earthen bank in the grave. Korek interpreted the grave as the burial of a knapper in the light of the grave goods. ${ }^{399}$ The $23-30$ years old man buried in Grave 164 was given vessels, various chipped stone implements and two stone axes (Pl. LXX. 164/2). Vessels, a bead strand and a stone axe (Pl. LXXXI. 194/5) were deposited beside the 30-40 years old man interred in Grave 194, while the 35-45 years old man laid to rest in Grave 227 was given vessels, a bead strand, chipped stone implements, a stone axe (Pl. XCVII. 227/26) and a copper chisel. Grave 279, the burial of a $30-50$ years old man, contained a plain bowl, a core, a stone blade and a stone axe (Pl. CXII. 279/2). Stone axes were deposited exclusively in male inhumation burials.

Chipped stone arrowheads were deposited in Graves 2, 84 and 197 (Pl. II. 2/3, Pl. XXXVIII. 84/1, Pl. LXXXIII. 197/10). Six arrowhead-like objects made

\footnotetext{
$\overline{395 \text { Graves 2, 3/A }, 8,22, ~ 24, ~ 44, ~ 46, ~ 48 / A, ~ 49, ~ 53, ~ 61, ~ 64, ~ 75, ~ 84, ~ 91, ~ 95, ~ 112, ~}$ $115,117,128,134 / \mathrm{A}, 149 / \mathrm{B}, 158,164,170,174,175,177,182 / \mathrm{B}, 189$ 195/B, 197, 202, 207, 221, 227, 230, 263/B, 279, 287, 291, 317,325, 330 $335,347,352,354,361,370,375,376,377,378,380,411,422,425,436$ 396 The lithic artefacts were analysed and evaluated by Éva Cs. Balogh (pp. $379-408$, in this volume).

397 Graves 91, 164, 194, 227, 279.

398 Graves 91 and 164

399 KOREK 1986.
}

from antler were found in Grave 366/A. ${ }^{400}$ Although arrowheads are usually associated with hunting activities pursued by men, the pieces from the Budakalász cemetery came to light from female and child burials.

The red stone and ochre lumps placed in twentythree burials undoubtedly had a ritual significance. ${ }^{401}$ The irregularly shaped mauvish stones found in some burials were also grave goods. ${ }^{402}$ (These are not identical with the larger sandstones and the stone packing between burials.)

The single quernstone (Pl. CXXIII. 312/4) was found in Grave 312, the burial of a 1-7 years old child. It seems likely that its deposition was ritual in nature, rather than a reflection of the implement's daily use.

\section{BONE AND ANTLER TOOLS AND IMPLEMENTS}

Bone tools and implements were deposited in eleven burials. ${ }^{403}$ A bone awl was placed in Graves 91, 108, 221, 312, 338 and 405 (Pl. XLI. 91/23, 91/25, Pl. XLVII. 108/1, Pl. XCIII. 221/2, Pl. CXXIII. 312/9, Pl. CXXIX. 338/1, Pl. CLVII. 405/1). Grave 91 was the burial of an older male, the other graves contained child burials. The pieces recovered from child burials could hardly have been tools used by these children in life. The awls were thrust into the ground near the skull in Graves 108, 221 and 338, while the piece from Grave 312 lay on a broken vessel base.

The single bone chisel came to light from Grave 368, a child burial (Pl. CXLV. 368/2). Similarly to some of the awls, it was thrust into the ground.

An antler axe was deposited in Graves 91 and 112, both male burials (Pl. XLI. 91/1, Pl. XLIX. 112/6).

Fragments of undeterminable tools and implements were recovered from several other graves.

Soproni found various animal bones in eleven graves. ${ }^{404}$ Most were broken and it is therefore uncertain whether they represent food remains or a broken tool or implement. One is a perforated animal tooth, perhaps intended to be worn as jewellery. The animal bones in Grave 309 lay in anatomical order, suggesting that they were the remains of a meat offering. 405

\section{COPPER TOOLS AND IMPLEMENTS}

Five burials (Fig. 44) yielded copper tools and implements. The man interred in Grave 3/B was buried with a copper awl (Pl. IV. 3/5). Graves 227 and 319, both male burials, yielded a copper chisel (Pl. XCVII.

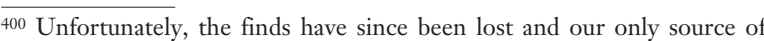
information is the excavation diary.

401 Graves 12, 25, 28, 41, 44, 55/A, 91, 95, 111, 136, 143, 185, 189, 273, 330 , $335,344,356,366 / \mathrm{B}, 367,368,371,412$

402 Graves 91, 238, 261, 266, 309.

403 Graves 60, 73, 91, 108/B, 112, 174, 221, 312, 338, 368, 405/B.

404 Graves 72, 73, 80/A, 91, 208, 227, 289, 309, 349, 382, 439.

405 The animal bones were analysed and evaluated by Erika Gál (pp. $371-378$, in this volume).
} 
Table 25. The composition of copper tools and implements

\begin{tabular}{|c|c|c|c|c|c|c|c|c|c|c|c|}
\hline Grave & Sn & Pb & As & Sb & Ag & Ni & Bi & Au & Zn & Co & Fe \\
\hline 3 & 0 & 0 & 0 & 0 & N0.01 & 0 & 0 & 0 & 0 & 0 & 0 \\
\hline 227 & 0 & 0 & 0 & 0 & $<0.01$ & 0 & 0 & 0 & 0 & 0 & 0 \\
\hline 319 & 0 & 0 & 0 & 0 & 0.02 & Sp & 0 & 0 & 0 & 0 & 0 \\
\hline
\end{tabular}

227/24, Pl. CXXIV. 319/2), while copper needles were recovered from Grave 63, a child burial (Pl. XXVIII. 63/2) and Grave 218, a female burial (Pl. LXXXIX. 218/1).

In 1962, Korek sent the copper artefacts from three graves to Stuttgart to be analysed as part of the Studien zu den Anfängen der Metallurgie project in Suttgart. For the results of the analyses, see cp. Table 25.406

The analytical results indicate that the copper artefacts in question contained silver and traces of nickel, and that their composition was virtually identical.

\section{CLAY ARTEFACTS}

Grave 437 contained the burial of a 10-12 years old child wearing a necklace around the neck. According to the excavation diary, there was a small triangular clay plaque among the beads. This plaque was not inventoried among the grave goods and can no longer be found. I have no knowledge of any remotely similar ornament from this period.

Clay spools (Pl. CLVI. 403/3-7) are generally regarded as artefacts used in daily life. I have suggested a different interpretation for the possible function of these artefacts, this being the reason that they are discussed in the previous section, among the miscellaneous clay artefacts. It seems to me that the spools deposited in burial had a sacral meaning, even if their one-time function can only be guessed at from their possible uses.

The tools and implements deposited in the graves were not a reflection of the ordinary, domestic use of these artefacts (in the case of quernstones, bone awls and spools, for example), but had another meaning. The assumption that the tools and implements deposited in the burials had been used in life by the deceased and were the attributes of a specific activity reflects our own, essentially western attitudes to what is placed in the grave today. It is hardly conceivable that grinding would have been the task of a child seven years old at the most, and that the quernstone in the grave symbolised this activity. Another important circumstance is that pointed implements such as bone awls and chisels, copper awls and chisels, and stone axes were deposited with the point thrust into the ground. This

\footnotetext{
406 SzFM Archives, inv. no. 1170/76
}

deposition mode could hardly have been motivated by practical considerations; it seems more likely that its meaning was similar to that of stones driven into the ground in the case of the stones place into the grave pit.

The preliminary reports on the cemeteries of the Baden culture, most of which are still unpublished, mention few tools and implements among the grave goods. This would support my assumption that the apparently domestic implements were not artefacts symbolising an occupation or a craft, but served to express some other idea or belief.

Seven of the fifty-eight graves uncovered at Alsónémedi contained stone tools. Triangular arrowheads were recovered from Graves 19 and 30, ${ }^{407}$ while Graves 28 and 46 contained worked stone blades, ${ }^{408}$ and Graves 4, 5, 19 and 42 yielded unworked blades. ${ }^{409}$ Three stone blades lay in the grave containing the cattle burial at Baja-233 Dózsa György Road.410 Arrowheads were also brought to light from Grave 4 of the cemetery at Szentes-Nagyhegy, containing ten burials ${ }^{411}$ and from Grave 5, a child burial, of the Balatonmagyaród cemetery. ${ }^{412}$ Two burials of the cemetery investigated at Balatonlelle-Felsô-Gamász yielded flint arrowheads: one contained seven, the other eight specimens. ${ }^{413} \mathrm{~A}$ finely polished bone arrowhead was found in Grave 407.414

Stone axes are rare in the culture's cemeteries. A broken stone axe lay in Grave 3, a cremation burial, of the Fonyód-Bézsenypuszta cemetery; ${ }^{415}$ the grave goods of the burial uncovered at Köveskál also included a stone axe. ${ }^{416}$

Quernstones are similarly infrequent among the grave goods. Several burials of the cemetery at Balatonlelle-Felsô-Gamász contained quernstones, usually deposited in pairs. ${ }^{417}$ Quernstones were deposited in two burials at Mezốcsát. ${ }^{418}$

Copper tools and implements were rarely placed in burials. A copper awl was found in Grave 25 of the Alsónémedi cemetery. ${ }^{419} \mathrm{~A}$ copper needle, a copper awl

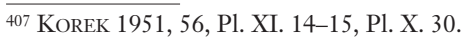

408 KoreK 1951, 56, Pl. XI. 3, Pl. XIII. 7.

409 KoreK 1951, 56.

${ }^{410}$ Mihály Kóhegyi's excavation in 1960. RégFüz I. 14 (1961) 52.

411 BANNER 1956, Taf. LIX. 6-7.

412 BONDÁR 1987, 47.

413 Sófalvi-NagY-SKriBa 2007, 156

414 Sófalvi-Nagy 2007, 164.

415 BANNER 1956, 29.

416 BONDÁR 1987, Fig. 11. 2

417 Sófalvi-NagY-Skriba 2007, 156; Sófalvi-Nagy 2007, 163.

418 Kalicz 1999, 59, 66, Fig. 16. 5 (Grave 2), Fig. 16. 4 (Grave 9).

419 KoreK 1951, 57, Pl. X. 25.
} 
and a copper dagger were recovered from various burials at Balatonlelle-Felsô-Gamász. ${ }^{420}$ The culture's other few known copper artefacts came to light on settlements. The list of copper tools and implements has not grown substantially during the ten years since the publication of Zsuzsa Virág's study discussing the period's copper finds, ${ }^{421}$ supporting the generally accepted view that copper production declined compared to the abundance of metalwork of the preceding periods. The reason for this decline is not known: it has been variously suggested that it can perhaps be attributed to the exhaustion of the surface ore deposits and to the lack of more sophisticated ore mining techniques. The latter can hardly be proven since little is known about Copper Age mines and mining tools. In his broad overview of the metallurgy of the Copper Age and the Early Bronze Age,422 Rüdiger Krause noted that the metal artefacts from Budakalász could not be fitted into the currently accepted chronological framework of the Baden culture.

$$
\text { *** }
$$

The analysis of the grave goods from the Budakalász cemetery indicated that there was no correlation between the deposition of a particular artefact type and the age or sex of the deceased. Whilst a few patterns can be discerned in the provisioning of the deceased with various artefacts, these can hardly be generalised because the culture's other cemeteries are only partially excavated and very few have been published.

We may rightly assume that the artefacts placed in the grave were not deposited by chance. The community's traditions, the lineage of the deceased and his/her status in the community undoubtedly played a role in the type and number of artefacts placed in the grave, this being the reason that only a single bead was placed in some burials, while others were furnished with several vessels, bead strands and various tools and implements, and that some graves were entirely devoid of grave goods, or at least of archaeologically visible artefacts. Any conclusions based on the reconstruction of the one-time social hierarchy as reflected in the number of artefacts placed in a grave based on modern attitudes to death would be grossly misleading. It must be repeatedly emphasised that the incidence of bead strands and various tools and implements, generally regarded as artefacts of everyday life, is much less frequent than one might think, and the same holds true for the other Late Copper Age cemeteries, the implication being that the cemetery had entirely different social dimensions, which cannot be compared with the setting of daily life, and that the patterns noted on settlements can hardly be projected onto burial grounds. Life and death were part of distinct spheres, not only in the physical, but also in the ritual and cognitive realm: they were part of different worlds in which the most important elements were the individual's role in the community, his social status and the associated prestige.

The main goal of the cemetery's analysis was not an overview of each reference to the Budakalász burial ground in the archaeological literature and a detailed history of the cemetery's research or an overview of the unresolved issues in the research of the Baden culture. There seemed no point in listing all the possible analogies to the grave finds, and especially to the pottery. The main focus in the cemetery's analysis was the reconstruction of the funerary practices (death, preparations for the burial, burial rites and postinternment activities) and of the cemetery's significance in the sacral sphere, as well as the identification of meaningful patterns reflecting the practices and beliefs of the prehistoric community using the cemetery through the analysis of the available evidence. As a result of this work, it proved possible to challenge former conclusions based on the earlier published burials. It is quite obvious from the above that the even the full evaluation of the Budakalász cemetery could hardly hope to solve major issues in Late Copper Age archaeology because the use-life of the cemetery did not span the entire Baden sequence, and neither do the grave goods represent the entire range of the culture's artefacts. The grave goods do not comprise import wares or artefacts reflecting long-distance trade connections. The cemetery is a cross-section of a relatively short period of time, preserving the artefacts and rituals associated with the sacral sphere, many elements of which still need to be deciphered. 


\section{References}

AVRAMOVA 2002

BALEN 2006

Cs. Balogh 1993

BANNER 1942

BANNER 1956

P. BARNA 2003

BAYER 1928

BaXÁ-KaMINSKá 1984

BÓNA 1960

BONDÁR 1982

BONDÁR 1987

BONDÁR 1990

BONDÁR 2000

BONDÁR 2001

BONDÁR 2002

BONDÁR 2004

BONDÁR 2005

BONDÁR 2006

BONDÁR-HONTI-KISS 2000

BONDÁR-MATUZ-SZABÓ 1998

BREHM 2000

Cheben 1984

ChILDE 1951

CHILde 1954

ČOCHADŽIEV 1986

Csalog 1961
Avramova, Maja: Der Schmuck aus den Gräbern von Durankulak. In: Durankulak. Die prähistorischen Gräberfelder. Band II. Ed. by Todorova, Henrieta. Berlin 2002, 191-206.

Balen, Jacqueline: Sarvaš - neolitičko i eneolitičko naselje. Sarvaš - Neolithic and Eneolithic settlement. Zagreb 2006. (Catalogues and monographs of the Archaeological Museum in Zagreb. vol. 2) Cs. Balogh, Éva: Rézkori és bronzkori pattintott kőeszközök Pest megyében és a Dunától keletre eső területeken. Tipológiai és statisztikai feldolgozás [Copper and Bronze Age chipped stone implements in County Pest and the regions east of the Danube]. Univ. PhD thesis. Budapest 1993.

Banner, János: Adatok a kétosztású badeni tálak elterjedéséhez [Angaben zur Verbreitung der zweiteiligen Badener Schüsseln]. ArchÉrt új f. 3 (1942) 73-87.

Banner, János: Die Péceler Kultur. Budapest 1956. (ArchHung 35)

P. Barna, Judit: Késő rézkori település Nagykanizsa-Billa lelóhelyen [Late Copper Age Settlement in Nagykanizsa-Billa]. ZalaiMúz 12 (2003) 97-142.

Bayer, Josef: Die Ossarner Kultur, eine äneolithische Mishkultur im östlichen Mitteleuropa. Eiszeit und Urgeschichte 5 (1928) 60-91.

Baxá, Peter-Kaminská, Lubomira: Nové nálezy bolerázskej skupiny z Bratislavy [Neufunde der Boleráz-Gruppe aus Bratislava]. SlovArch 32 (1964) 179-194.

Bóna, István: Clay Models of Bronze Age Wagons and Wheels in the Middle Danube Basin. ActaArchHung 12 (1960) 83-111.

Bondár, Mária: Spätkupferzeitliche Siedlung in Pécs-Vasas. MittArchInst 10-11 (1980-1981) [1982] 25-44, 341-348.

Bondár, Mária: Újabb adatok a badeni kultúra temetkezéseihez [Neuere Beiträge zu Bestattungen der Badener Kultur]. ZalaiMúz 1 (1987) 47-58.

Bondár, Mária: Das frühbronzezeitliche Wagenmodell von Börzönce. CommArchHung 1990, 77-91. Bondár, Mária: A badeni kultúra telepmaradványa Aparhant-Felsố legelő lelóhelyen [The settlement fragment of the Baden Culture on the site Aparhant-Felsố pasture]. WMMÉ 22 (2000) 39-74.

Bondár, Mária: L'état des recherches sur la culture de Baden en Hongrie (Les découvertes récentes concernant la période ancienne). In: Cernavodă III-Boleráz. Ein vorgeschichtliches Phänoman zwischen dem Oberrhein und unteren Donau. Symposium Mangalia/Neptun 18.-24. Oktober 1999. Ed. by Roman, Petre-Diamandi, Saviana) Bucureşti 2001 [2002], 437-458. (Studia Danubiana, Series Symposia 2)

Bondár, Mária: A badeni kultúra kutatási helyzete Magyarországon (Vázlat) [Der Forschungsstand der Badener Kultur in Ungarn (Abriss)]. MFME-StudArch 8 (2002) 7-30.

Bondár, Mária: A kocsi a késő rézkori Európában [Der Wagen im spätkupferzeitlichen Europa]. ArchÉrt 129 (2004) 5-34.

Bondár, Mária: Rézkori település az M3 autópálya mellett (Nagyút-Göbölyjárás II) [Copper Age settlement near at the highway M3 (Nagyút-Göbölyjárás II)]. Manuscript. Budapest 2005.

Bondár, Mária: Le chariot en Europe au Chalcolithique récent. In: Premiers chariots, Premiers araires. La diffusion de la traction animale en Europe pendant les IVè et III ̀̀ millénaires avant notre ère. (Sous la direction de Pierre Pétrequin, Rose-Marie Arbogast, Anne-Marie Pétrequin, Samuel van Willigen et Maxence Bailly). Paris 2006, 225-237. (Collection de Recherches Archéologiques. Monographies 29)

Bondár, Mária-Honti, Szilvia-Kiss, Viktória: A tervezett M7-es autópálya Somogy megyei szakaszának megelőzố régészeti feltárása (1992-1999). Elôzetes jelentés I [The preceding archeological excavation of the planing M7 highway in County Somogy (1992-1999)]. Preliminary report I. SMK 14 (2000) 91-114.

Bondár, Mária-D. Matuz, Edit-Szabó, J. József: Rézkori és bronzkori településnyomok Battonya határában [Kupfer- und bronzezeitliche Siedlungsspuren in der Gemarkung von Battonya]. MFMÉ StudArch 4 (1998) 7-53.

Brehm, Alfred: Thierleben. Vols I-XIX. 1863-1869. CD-ROM, Arcanum, Budapest 2000

Cheben, Ivan: Sídlisko badenskej kultúry v Bíni [Siedlung der Badener Kultur in Bíña]. SlovArch 32 (1984) 147-177.

Childe, Gordon: The First Waggons and Carts from the Tigris to the Severn. PPS 17 (1951) 177-194. Childe, Gordon: The Diffusion of Wheeled Vehicles. EAF 2 (1954) 1-17.

Čochadžiev, Stefan: Frühneolihische Keramik aus der prähistorischen Siedlung bei Slatino, Bezirk Kjustendil. StudPraehist 8 (1986) 185-202.

Csalog, József: Adatok a bádeni (péceli) nép kocsitemetkezéseihez és életformájának kérdéséhez [Data to the Waggon burials and the ways of life of the Baden (Pécel) Folk]. ArchÉrt 88 (1961) 7-22. 
DAŇO-JUHÁS-MUSIL 1994

DraveCZKY 1964

DURMAN 1988

ECSEDY 1982

ELIADE 1997

ELIADE 1998

ELIADE 2002

ENDRŐDI 1991

ENDRŐDI 1997

ENDRŐDI 1999

ENDRŐDI 2002

ENDRŐDI 2004

FetTich 1969

FODOR 1995

FoLTINY 1959

GOMOLAVA 2002

HAHNEL 1992

HAMPEL 1886

HAMPEL 1895

HONTI 1981

HoRvÁTH 2004

HORVÁTH 2006

HoRVÁTH 2007

HORVÁTH 2008

KaLICZ 1963

KaLICZ 1976

KALICZ 1976a

KaLICZ 1999

KeMeNCZeI 1966

KoREK 1951

KOREK 1951a

KOREK 1973
Daňo, Róbert-Juhás, Bohumil-Musil, Viktor: Prieskumy a záchranné výskumy na trase Plynovodu [Begehungen und Rettungsgrabungen auf der Gasleitungstrasse]. AVANS 1994 (1996) 202.

Draveczky, Balázs: A bogátpusztai függeszthetô edény [The suspension vessel at Bogátpuszta]. JPMÉ (1964) 141-142.

Durman, Alexandar: The Vučedol Culture. In: Vučedol. Three thousand years b.c. Catalogue of the exposition 21. 07-31. 08.1988. Ed. by Durman, Alexandar. Zagreb 1988.

Ecsedy, István: Ásatások Zók-Várhegyxen (1977-1982). Elôzetes jelentés [Excavations at Zók-Várhegy (1977-1982). Preliminary Report]. JPMÉ 27 (1982) 59-105

Eliade, Mircea: Képek és jelképek [Images et symbols]. Budapest 1997.

Eliade, Mircea: Az örök visszatérés mítosza [Le mythe de l'éternel retour]. Budapest 1998.

Eliade, Mircea: Okkultizmus, boszorkányság és kulturális divatok [Occultism, Witchraft and Cultural Fashions]. Budapest 2002.

Endrődi, Anna: Újabb adatok a bádeni kultúra megtelepedéséhez Budapest területén [Neuere Beiträge zur Niederlassung der Badener Kultur auf dem Gebiet von Budapest]. BudRég 28 (1991) 59-82.

Endrődi, Anna: A késő rézkori bádeni kultúra Budapest, Andor utcai telepanyaga a kulturális kapcsolatok tükrében [Die Siedlungsmaterialen der spätkupferzeitlichen Badener Kultur aus der Andorstrasse im Spiegel der kulturellen Verbindungen]. BudRég 31 (1997) 121-175.

Endrődi, Anna: Késô rézkori leletek Óbudáról [Late Copper Age Finds from Óbuda]. BudRég 32 (1999) 105-122.

Endrôdi, Anna: Adatok Békásmegyer ôskori településtörténetéhez: a késô rézkori bádeni kultúra települései és temetkezései [Facts concerning the prehistoric settlement history of Békásmegyer: settlements and burial-places of the Baden Culture from the Late Copper Age]. BudRég 35 (2002) 35-75.

Endrődi, Anna: Késô rézkor Budapest területén - a Baden- kultúra népe [Late Copper Age in the territory of Budapest - The people of the Baden Culture]. In: Hétköznapok és vallásos élet a rézkor végén. A Baden-kultúra 5000 éves emlékei Budapesten [Everyday life and spirituality at the end of the Copper Age]. Ed. by Endrődi, Anna. Budapest 2004, 11-20.

Fettich, Nándor: Újabb adatok az ôskori kocsihoz a Kárpát-medencében [Neue Beiträge zum prähistorischen Wagen im Karpatenbecken]. Ethnográfia 80 (1969) 30-69.

Fodor, István.: Dr. Korek József (1920-1992). FolArch 44 (1995) 9-22.

Foltiny, Stephan: The Oldest Representations of Wheeled Vehicles in Central and Southeastern Europe. AJA 63 (1959) 53-58.

Petrović, Jelka-Jovanović, Borislav: Gomolava. Naselja kasnog eneolita [Gomolava. Settlements of the Late Neolithic]. Novi Sad - Beograd 2002.

Hahnel, Bernhard: Spätneolithische Gräber in Österreich. FÖ 31 (1992) 79.

Hampel, Joseph: Trouvailles de l'Âge du bronze en Hongrie [A bronzkor emlékei Magyarhonban]. Budapest 1886.

Hampel, József: Nouvelles études de l'Âge du Cuivre. Budapest 1895.

Honti, Szilvia: Rézkori temetkezés Balatonbogláron [Ein Grab aus der Kupferzeit von Boglárlelle (sic!)]. SMK 4 (1981) 25-42.

Horváth, Tünde: Emberi vázakat tartalmazó objektumok Balatonôszöd-Temetôi dúló badeni településéról [Human skeletons from Balatonőszöd]. SMK 16 (2004) 71-109.

Horváth, Tünde: A badeni kultúráról rendhagyó módon [About Baden Culture - an irregular approach]. NyJAMÉ 48 (2006) 89-133.

Horváth, Tünde: Állattemetkezések Balatonôszöd-Temetői dúlő badeni lelőhelyen [Animal burials in the Late Copper Age Baden Site: Balatonôszöd-Temetôi dúló]. SMK 17 (2006) [2007] 107-152.

Horváth, Tünde: „Spulni”: egy ismeretlen funkciójú tárgytípus a Badeni kultúrában (Variációk egy témára) [Spools: an artefact type of unknown function in the Baden culture (Variations on a theme)]. SMK 18 (2008) 157-166.

Kalicz, Nándor: Die Péceler (Badener) Kultur und Anatolien. Budapest 1963. (StudArch 2)

Kalicz, Nándor: Ein neues kupferzeitliches Wagenmodell aus der Umgebung von Budapest. In: Festschrift für Richard Pittioni zum Siebzigsten Geburtstag. Ed. by Mitscha-Märheim, Herbert-Friesinger, Hervig-Kerchler, Helga. ArchAustriaca Beiheft 13 (1976), 188-202.

Kalicz, Nándor: Novaja nahodka modeli povozki epohi eneolita iz okrestnoctej Budapesta [Découverte d'un modèle de chariot énéolithique dans les environs de Budapest]. SA 1976, 106-117. Kalicz, Nándor: A késố rézkori Báden kultúra temetője Mezôcsát-Hörcsögösön és TiszavasváriGyepároson [Das Gräberfeld der spätkupferzeitlichen Badener Kultur in Mezőcsát-Hörcsögös und in Tiszavasvári-Gyepáros]. HOMÉ 37 (1999) 57-101.

Kemenczei, Tibor: A péceli kultúra újabb emberalakú urnalelete Centeren [A new human urn of the Pécel culture from Center]. HOMK 6 (1966) 10-13.

Korek, József: A badeni kultúra temetóje Alsónémedin [The cemetery of the Baden culture at Alsónémedi]. MTA II. Osztályának Közleményei 1 (1951) 41-66.

Korek, József: Ein Gräberfeld der Badener Kultur bei Alsónémedi. ActaArchHung 1 (1951) 35-54. Korek, József: Der älteste Wagenfund Europas. Helms-Museum. Hamburgische Museum für Vorund Frühgeschichte 1973. 
KOREK 1980

KOREK 1983

KoREK 1984

KoReK 1986

KOREK 1986a

KovÁCs 2006

KÖVECSES-VARGA 1991

KraUSE 2003

KUZMA 1995

Land der Bibel

LENGYEL 1983

MAKKAY 1963

MAKKAY 1965

Medović 1976

Medović 1976a

MedunOVÁ-Benešová 1981

MEZNERICS 1951

MRT 7

NAGY 1973

NĚMEJCOVÁ-PavúKOVÁ 1968

NĚMEJCOVÁ-Pavúková 1974

NĚMEJCOVÁ-PAVÚKOVÁ 1981

NĚMEJCOVÁ-PavÚKOVÁ 1984

NĚMEJCOVÁ-PavúKovÁ 1991

NEMESKÉRI 1956
Korek, József: Alsónémedi történetének régészeti forrásai a honfoglalás koráig [The archaeologica sources of the history of Alsónémedi until the Conquest period]. In: Alsónémedi története és néprajza. Ed. by Balassa, Iván. Alsónémedi 1980, 9-47.

Korek, József: Közép-Kelet-Európa a rézkor végén [Central-Eastern Europe on the end of the Copper Age]. Budapest 1983. Dissertation of DSc, manuscript.

Korek, József: Ásatások Szigetcsép-Tangazdaság lelôhelyen I. A késôrézkori település [Ausgrabungen auf dem Fundort Szigetcsép-Tangazdaság I. Funde der spätkupferzeitlichen Siedlung]. CommArchHung 1984, 5-30.

Korek, József: Budakalász. In: MRT 7, 45-47.

Korek, József: The Grave of an Artisan in the Copper Age at Budakalász. In: International conference on prehistoric flint mining and lithic raw material identification in the Carpathian Basin. Ed. by T. Bíró, Katalin. Budapest-Sümeg 1986, 317-322.

Kovács, Tibor: Bisher unbekannte kupfer- und bronzezeitliche Wagenmodelle aus Ungarn. Acta ArchHung 57 (2006) 35-45.

Kövecses-Varga, Etelka: Grubenhäuser mit verschmiertem Boden in einer Siedlung der Badener (Péceler) Kultur. In: Die Ergebnisse der archäologischen Ausgrabung beim Aufbau des Kraftwerksystems Gabčikovo-Nagymaros. Ed. by Chropovský, Bohuslav. Nitra 1990 [1991] 11-15.

Krause, Rüdiger: Studien zur kupfer- und frühbronzezeitlichen Metallurgie zwischen Karpatenbecken und Ostsee. Leidorf 2003. (Vorgeschichtliche Forschungen Bd. 24)

Kuzma, Ivan: Pohrebisko z obdobia avarského kaganátu a objekty badenskej kultúry v Mužli-Jurskom chlme [Gräberfeld aus der Zeit des awarischen Kaganats und Objekte der Badener Kultur in Mužla-Jurský chlm]. AVANS 1995 (1997) 117-118.

Land der Bibel. Schätze aus dem Israel Museum Jerusalem. Ed. by Seipel, Wilfried. Katalog zur Ausstellung der Kunsthistorischen Museums Wien. Wien, Künstlerhaus, 22 September 1997 bis 18. Jänner 1998. Milano-Wien-Jerusalem 1997.

Lengyel, Imre: Nem, életkor, vércsoport értékelése a budakalászi bádeni temetóben [Sex, age and blood groups in the Baden cemetery at Budakalász]. Budapest 1983. (Régészeti Továbbképző Füzetek 2)

Makkay, János: Adatok a péceli (badeni) kultúra vallásos elképzeléseihez [Data to the religious Beliefs of the Pécel (Baden) Culture]. ArchÉrt 90 (1963) 1-14.

Makkay, János: What was the Copper Age Clay Wagon model of Budakalász. Alba Regia 4-5 (1963-1964) [1965] 11-15.

Medović, Predrag: Eneolitsko naselje „Brza Vrba” kod Kovina [The aeneolithic Settlement „Brza Vrba” near Kovin]. Grada 6-7 (1976) 5-18.

Medović, Predrag: Die Cernavoda III-Kultur im jugoslawischen Donaugebiet. Istraživanja 5 (1976) $105-110$.

Medunová-Benešová, Anna: Jevišovice-Starý Zámek. Schicht C2, C1, C. Katalog der Funde. Brno 1981. Meznerics, Ilona: Az alsónémedi dentáliumok vizsgálata [Untersuchung der Dentalien aus Alsónémedi]. In: KOREK 1951, 102-104.

Dinnyés, István-Kővári, Klára-Lovag, Zsuzsa-Tettamanti, Sarolta-Topál, Judit-Torma, István: Pest megye régészeti topográfiája. A budai és szentendrei járás. Ed. by Torma, István. Budapest 1986. (Magyarország régészeti topográfiája 7)

Nagy Tibor: Budapest története az ôskortól a honfoglalásig [History of Budapest from the Prehistory to the Conquest period]. In: Budapest története I/1. Ed. by Gerevich, László. Budapest 1973, 39-216. Němejcová-Pavúková, Viera: Äneolithische Siedlung und Stratigraphie in Iža. SlovArch 16 (1968), 354-433.

Němejcová-Pavúková, Viera: Beitrag zum Kennen der Postboleráz-Entwicklung der Badener Kultur. SlovArch 22 (1974) 237-360.

Němejcová-Pavúková, Viera: Načrt periodizácie badenskej kultúrý a jej chronologických vztahov k juhovýchodnej Európe [An outline of the periodical system of Baden Culture and its chronological relations to Southeast Europe]. SlovArch 29 (1981) 261-296.

Němejcová-Pavúková, Viera: K problematike trvania a konča bolerázskej skupiny na Slovensku [Zur Problematik von Dauer und Ende der Boleráz-Gruppe in der Slowakei]. SlovArch 32 (1984) 75-146.

Němejcová-Pavúková, Viera: Typologische Fragen der relativen und absoluten Chronologie der Badener Kultur. SlovArch 39 (1991) 59-90.

Nemeskéri, János: Anthropologische Übersicht des Volkes der Péceler Kultur. In: BanNer 1956, $295-311$.

Neugebauer-Maresch-Teschler-Nikola 1984 Neugebauer-Maresch, Christine-Teschler-Nikola, Maria: Eine spätneolithische Doppelbrandbestattung aus Sitzenberg, VB Tulln, NÖ. FÖ 23 (1984) 129-141.

Neugebauer-Gattringer 1986 Neugebauer, Johannes Wolfgang-Gattringer, Alois: Rettungsgrabungen im Unteren Traisental in den Jahren 1985/86. Fünfter Vorbericht über die Aktivitäten der Abt. f. Bodendenkmale des Bundesdenkmalamtes im Raum St. Pölten-Traismauer. FÖ 24/25 (1985/86) [1986] 71-77.

NeUsTUPNÝ 1973 Neustupný, Evžen: Die Badener Kultur. In: Symposium über die Entstehung und Chronologie der Badener Kultur. Ed. by Chropovský, Bohuslav. Bratislava 1973, 317-352.

Nevizánsky, Gabriel: Grabfunde und Überbauerscheinungen der Träger der Badener Kultur im Zentralen Gebiet des Karpatenbeckens. SlovArch 33 (1985) 249-272. 
NEVIZÁNSKY 1987

NEviZÁNSKY 1999

NEVIZÁNSKY 2001

NEVIZÁNSKY 2004

NEVIZÁNSKY 2005

\section{NovotNÁ 1961}

Patay 1999

PAVELČíK 1974

Pavúk 1972

Perrot 1979

PÉTREQUiN et al. 2006

PigGOTt 1983

PIgGOTt 1992

Rad und Wagen 2004

RAHMSTORF 2006

ROMAN 1977

ROMAN 1977a

ROMAN-NÉMETI 1978

RUTTKAY 1971

RUTTKAY 1995

RUTTKAY 2000

SANDA 1998

SóFALVI-NAGY-SKRIBa 2007

SóFALVI-NAGY 2007

SoMOgYI 1999

SOPRONI 1954

SOPRONI 1956

SOPRONI 1956a

TASIĆ 1995
Nevizánsky, Gabriel: K počiatkom domestikácie koňa v karpatskej kotline [Zu den Anfängen der Domestikation des Pferdes im Karpatenbecken]. ArchRozh 39 (1987) 644-654.

Nevizánsky, Gabriel: Novšie výskumy sídlisk l'uudu badenskej kultúry na južnom Slovensku [Neuere Ausgrabungen von Siedlungen der Träger der Badener Kultur in der Südslowakei]. SlovArch 47 (1999) 67-89.

Nevizánsky, Gabriel: Delené misy badenskej kultúry [Zweiteilige Schüsseln der Badener Kultur]. Pravěk 8 (2001) 311-324.

Nevizánsky, Gabriel: Amphoren der Badener Kultur. In: Einflüsse und Kontakte alteuropäischer Kulturen. Festschrift für Jozef Vladár zum 70. Geburstag. Ed. by Bátora, Jozef-Furmánek, Václav-Veliačik, Ladislav. Nitra 2004, 57-74.

Nevizánsky, Gábriel: Nové poznatky o bolerázskej skupine na západnom Slovensku [Neuere Erkenntnisse über bie Boleráz-Gruppen in der Slovakei]. Otázky a eneolitu našich krajín 2004. Nitra 2005, 241-276.

Novotná, Mária: Bošácko-kostolacký horizont na strednom Považi [Der Horiziont Bošáca-Kostolac im mittleren Waagtal]. Musaica 12 (1961) 21-35.

Patay, Pál: A badeni kultúra Ózd-pilinyi csoportjának magaslati telepei [Höhensiedleungen der spätbadener Ózd-Pilinyer Gruppe]. HOMÉ 37 (1999) 45-56.

Pavelčík, Jiři: Eneolitická sídliště Uherský Brod/Kyčkov a Havřice/cihelna [Die äneolithischen Siedlungen in Uherský Brod/Kyčkov und Havřice/Ziegelwerk]. Studie Archeologického Ústavu Československé Akademie věd v Brne. Brno 1974, 3-79.

Pavúk, Juraj: Neolitisches Gräberfeld in Nitra. SlovArch 20 (1972) 5-105.

Perrot, Jean: Syrien-Palästina. München 1979. Die grossen Kulturen der Welt. (Archaeologia Mundi) Premiers chariots, Premiers araires. La diffusion de la traction animale en Europe pendant les IVè et III ${ }^{2}$ millénaires avant notre ère. (Sous la direction de Pierre Pétrequin, Rose-Marie Arbogast, AnneMarie Pétrequin, Samuel van Willigen et Maxence Bailly). Paris 2006. (Collection de Recherches Archéologiques. Monographies 29)

Piggott, Stuart: The Earliest Wheeled Transport. From the Atlantic Coast to the Caspian Sea. London 1983.

Piggott, Stuart: Wagon, Chariot und Carriage. London 1992.

Rad und Wagen. Der Ursprung einer Innovation: Wagen im Vorderen Orient und Europa. Ed. by Burmeister, Stefan-Fansa, Mamoun. Mainz am Rhein 2004. (Beiheft der archäologische Mitteilungen aus Nordwestdeutschland 40)

Rahmstorf, Lorenz: Zur Ausbreitung vorderasiatischer Innovationen in der frühbronzezeitliche Ägäis. PZ 81 (2006) 49-96.

Roman, Petre: The Late Copper Age Coţofeni Culture of South-East Europe. Oxford 1977. (BAR Supplementary Series 32)

Roman, Petre: Die Coţofeni-Kultur. PZ 52 (1977) 189-198.

Roman, Petre-Németi, Ioan: Cultura Baden în România. Bucureşti 1978. (Bibliotheca de Archeologie 31)

Ruttkay, Elisabeth: Neolithische und bronzezeitliche Siedlungsreste in Schwechat, p. B. WienUmgebung, NÖ. ArchAustriaca 50 (1971) 21-63.

Ruttkay, Elisabeth: Boleráz-Gruppe. In: Lenneis, Eva-Neugebauer-Maresch, Christine-Ruttkay, Elisabeth: Jungsteinzeit im Osten Österreichs. St. Pölten-Wien 1995, 145-160. (Forschungsberichte zur Ur- und Frühgeschichte 17).

Ruttkay, Elisabeth: Siedlungsfunde der Boleráz-Gruppe aus Wien und dem norddanubischen Niederösterreich. FÖ 38 (1999) [2000] 609-622.

Sanda, Crişan: Câteva observaţii privind procesele de interferenţâ între culturile Baden şi Coţofeni în vestul României [Some observations about the relations between cultures of Baden and Coţofeni in the west of Romania]. Ziridava 21 (1998) 3-13.

Sófalvi, András-Nagy, Borbála-Skriba, Péter: Balatonlelle-Országúti dúlő és Balatonlelle-Felsô-Gamász. In: Gördülő idô. Régészeti feltárások az M7-es autópálya Somogy megyei szakaszán Zamárdi és Ordacsehi között. Rolling Time. Excavations on the Motorway in Country Somogy between Zamárdi and Ordacsehi. Ed. by Belényesy, Károly-Honti, Szilvia-Kiss, Viktória. Budapest 2007, 151-162.

Sófalvi, András-Nagy, Borbála: A badeni kultúra temetkezése Balatonlellén. In: Gördülő idő. Régészeti feltárások az M7-es autópálya Somogy megyei szakaszán Zamárdi és Ordacsehi között. Rolling Time. Excavations on the Motorway in Country Somogy between Zamárdi and Ordacsehi. Eds, by Belényesy, Károly-Honti, Szilvia-Kiss, Viktória) Budapest 2007, 162-166.

Somogyi, Krisztina: Kaposvár, 61-es út elkerülő szakasz, 1. számú lelóhely [Kaposvár, Bypass Road 61, Site1]. In: Régészeti kutatások Magyarországon 1999. - Archeological investigations in Hungary. Ed. by Marton, Erzsébet. Budapest 2002.

Soproni, Sándor: A budakalászi kocsi [Der Wagen in Budakalász]. FolArch 6 (1954) 29-36.

Soproni, Sándor: A négyezeréves agyagszekér [A four thousand years old clay wagon]. Budapest 1956. (A MNM Történeti Múzeum népszerúsítő kiadványai)

Soproni, Sándor: Budakalász, Luppa csárda. In: BANNER 1956, 111-128.

Tasić, Nikola: Eneolithic Cultures of Central and West Balkans. Beograd 1995. 
VINSKI-GASPARINI 1956

M. VIRÁG 1999

Von Babylon bis Jerusalem

VOSTEEN 1999

ZÁPOTOCKÝ 2000
Vinski-Gasparini, Ksenija: Iskapanje prethistorijskog naselja u Belom Manastiru [Ausgrabung prähistorischer Siedlungsgruben in Beli Manastir]. Osjecki Zbornik 5 (1956) 5-38.

M. Virág, Zsuzsa: A badeni kultúra rézleletei Sármellék-Égenföldön [Die Kupferfunde der Badener Kultur in Sármellék-Égenföld]. ZalaiMúz 9 (1999) 13-54.

Von Babylon bis Jerusalem. Die Welt der altorientalischen Königsstädte. I-III Ed. by Seipel, Wilfried-Wieczorek, Alfried. Milano 1999.

Vosteen, Markus Uwe: Urgeschichtliche Wagen in Mitteleuropa. Eine archäologische und religionswissenschaftliche Untersuchung neolithischer bis hallstattzeitlicher Befunde. Leidorf 1999. (Freiburger archäologische Studien Bd. 3)

Zápotocký, Milan: Cimburk und die Höhensiedlungen des frühen und älteren Äneolithikums in Böhmen. Prague 2000. (PamArch Suppl. 12) 


\section{THE ANTHROPOLOGICAL REMAINS FROM THE BUDAKALÁSZ CEMETERY}

Kitti Köhler 


\section{INTRODUCTION}

The currently known largest cemetery of the Late Copper Age Baden culture was excavated at Budakalász-Luppa-csárda by Sándor Soproni between 1952 and 1960. A total of 439 burials (436 of which date from the Late Copper Age) were uncovered during the successive excavation seasons. The burial ground was not excavated completely: an estimated 85 to 90 per cent of the burials were uncovered. The human skeletal remains from the burials were taken to the Department of Anthropology of the Hungarian Natural History Museum. ${ }^{1}$

The burials of the first excavation season were published by Sándor Soproni, ${ }^{2}$ who then asked József Korek to evaluate the remaining burials and their finds. Korek asked specialists from other disciplines to participate in the examination and evaluation to ensure the complex, interdisciplinary analysis of the finds. $\mathrm{He}$ wrote his doctoral thesis on this cemetery, but the thesis was not published in a book format owing to his death in 1992. Work on the finds too suffered a setback. A team was recently formed with the aim of fully evaluating the finds. The archaeological finds were evaluated by Mária Bondár and Pál Raczky, while the anthropological material was analysed by the present author.

The evaluation of the skeletal finds too had a promising start since it was begun by Mihály Malán while the excavations were still underway. The analysis of the skeletal finds was continued by János Nemeskéri, who outlined the taxonomy of the Budakalász cemetery (based on the skeletal remains from 110 burials) and of the Baden population in general. ${ }^{3}$ Unfortunately, Nemeskéri did not complete the classical anthropological evaluation of the cemetery owing to his interest in living human populations. Luckily, Imre Lengyel's chemical analyses of the skeletal remains from the entire cemetery were completed. His serological method, based on 10-20 gr samples taken from spongy bone areas (principally vertebrae), is a useful technique in the case of assemblages which cannot be evaluated using the traditional analytical procedures of anthropology. The samples taken from the skeletal remains of 401 burials enabled a reconstruction of the cemetery's demography and of "family groups" based on the blood group of the deceased. His findings remained largely unpublished due to his death and only a few preliminary reports are available. ${ }^{4}$

The anthropological significance of the Budakalász cemetery lies in the fact that the high number of skeletal remains provides a large series for a detailed anthropolo-

\footnotetext{
1 I would here like to thank Dr. Ildikó Pap, Director of the Department of Anthropology of the Hungarian Natural History Museum for kindly granting me permission to study the finds. The skeletal remains from the Budakalász cemetery were inventoried under the following numbers: 7539-7607, 9842-9996, 10667-10754, 10832-10866, 11921-11973.

2 SOPRONI 1956

3 NEMESKÉRI 1956

4 LeNGYel 1975; LeNGYel 1983.
}

gical analysis of the Baden population. One indication of the cemetery's importance is that the detailed publication of the archaeological and anthropological finds has since long been awaited by scholars of both disciplines. This study intends to redeem the many decades' long debt of historical anthropology by presenting the findings of the cemetery's anthropological analysis using the discipline's traditional analytical methods. ${ }^{5}$

\section{PREVIOUS RESEARCH ON THE ANTHROPOLOGY OF THE BADEN POPULATION}

The anthropology of the Baden populations settling in the Carpathian Basin during the Late Copper Age was for a long time based on the skeletal remains from the Alsónémedi cemetery. ${ }^{6}$ The traditional anthropological evaluation of the Budakalász cemetery, the Baden culture's largest burial ground, was not completed owing to the circumstances described above. For a very long time, the culture's new anthropological finds came from sites yielding no more than a few graves or skull burials only (e.g. Palotabozsok, Szentes-Nagyhegy, Budapest-Andor Street, Budapest-Káposztásmegyer). ${ }^{7}$

More recently, the archaeological excavations preceding the construction of the M7 motorway along the southern shoreline of Lake Balaton have brought to light many Late Copper Age burials of the Baden, Boleráz and Kostolác period (e.g. Balatonôszöd-Temetôi-dúloo, Balatonlelle-Országúti-dúloo, BalatonlelleFelső-Gamász), which have enriched the skeletal remains representing this population. Together with the full evaluation of the Budakalász material, it is now possible to describe the anthropology of the Baden population based on several mortuary sites.

Before proceeding with the overview of previous anthropological research, a brief detour on the main archaeological models of the culture's origins seems in order. Conforming to the so-called short chronological framework, the Baden culture was for a long time derived from the south. Nándor Kalicz believed that the culture's ultimate homeland lay in Anatolia and that the Baden population could be identified with groups fleeing that region after the destruction of Troy V. ${ }^{8}$ He emphasized the sharp break between the preceding Bodrogkeresztur culture and the Baden culture, and pointed out the many strands linking the latter to the southern Balkans. ${ }^{9}$ István Ecsedy called attention to the role of the steppean Pitgrave groups in the Baden culture's ethnic make-up, although he too accepted the existence of central

\footnotetext{
5 I am most grateful to Mária Bondár for asking me to analyse and evaluate the anthropological material. I am greatly indebted to Zsuzsanna K. Zoffmann and Balázs Gusztáv Mende for their valuable insights and comments. The photographs were made by Róbert Fenyvesi, the plates by Zsolt Réti and Csaba Peterdi, whom I both thank for their conscientious work.

6 NeMESKÉRI 1951a; NeMESKÉRI1951b.

NEMESKÉRI 1956; ZOFFMANN 1987-1988; ZOFFMANN 1998

8 KaLICZ 1963

9 KalicZ 1973
} 


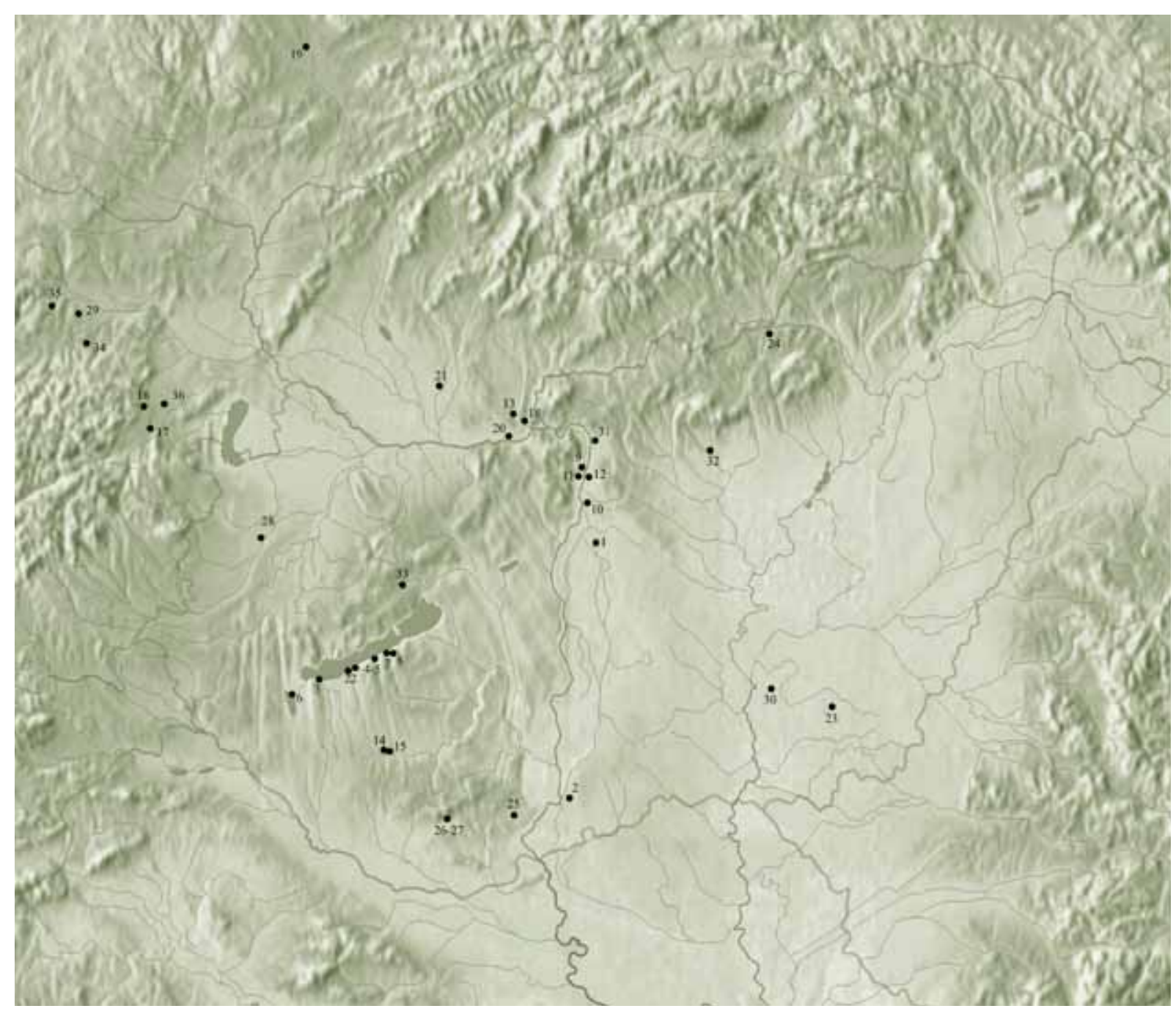

Fig. 1. Sites yielding skeletal remains of the Baden (and Boleráz) culture in the Carpatbian Basin

Balkanic elements in the Baden population. ${ }^{10}$ The theories concerning the origins and the chronology of the Baden culture have been revised in several respects during the past decades. The available radiocarbon dates suggest that the culture emerged at a much earlier date and thus the link with Troy $\mathrm{V}$ has been rejected, as has the culture's southern homeland. It has more recently been argued that the culture's origins should be sought in Central Europe, whence it spread to the south-east. ${ }^{11}$

The Late Copper Age Boleráz and Baden population is represented by 669 skeletons from 36 sites (172 males, 204 females, 225 children and 68 undetermined adults). Table 1 and Fig. 1 show the sites from which anthropological material has been analysed and/or published.

The anthropology of the Baden culture was first discussed by Nemeskéri in the 1950s, based on the skeletal remains from the Alsónémedi cemetery. His study provided the foundations for the culture's

\footnotetext{
10 ECSEDY 1981.

11 MARAN 1998; WILD et al. 2001; BONDÁR 2002.
}

anthropological characterisation for a very long time. Nemeskéri distinguished three main groups according to the traditional typology: (a) a meso-hypsicranic group with Mediterranean variants and some Negroid and brachymorph elements arriving from the southwest, (b) a meso-dolicho-hypsicranic, Mediterranean+ proto-European (Cro-Magnoid) groups arriving from the north-west, from the Linear Pottery and Corded Ware distribution, and (c) a brachy-hypsicranic, AlpineDinaric group reflecting eastern and western ethnic impacts. ${ }^{12}$

The two child burials uncovered at BudapestBékásmegyer were analysed at roughly the same time. ${ }^{13}$ Together with these finds and the human remains from Budapest-Andor Street, Palotabozsok, Szentes-Nagyhegy and the already analysed 110 burials from Budakalász, Nemeskéri again attempted a characterisation of the culture's population. ${ }^{14}$ The mean sizes and mean indices of the forty-seven skulls available for study

\footnotetext{
12 NeMESKÉRI 1951a; NeMESKÉRI $1951 \mathrm{~b}$

13 Nemeskéri, quoted by Korek 1951.

14 NeMeskérI 1956.
} 
Table 1. Sites yielding skeletal remains of the Baden (and Boleráz) culture in the Carpathian Basin

\begin{tabular}{|c|c|c|c|c|c|}
\hline Sites and references & Children & Males & Females & $?$ & Total \\
\hline 1. Alsónémedi (NEMESKÉRI 1951a, 1951b) & 14 & 16 & 8 & 6 & 44 \\
\hline 2. Baja, 233 Dózsa Gy. Street (FARKAs 1975) & - & 1 & - & - & 1 \\
\hline 3. Balatonkeresztúr, Réti-dúlő (KöHLER, unpublished) & - & 7 & 6 & 3 & 16 \\
\hline 4. Balatonlelle-Felső-Gamász, M7/S-17 (ZOFFMANN 2006) & 4 & 11 & 6 & - & 21 \\
\hline 5. Balatonlelle-Országúti-dúlő, M7/S-16 (ZOFFMANN, unpublished) & 2 & - & 2 & - & 4 \\
\hline 6. Balatonmagyaród-Hídvégpuszta-Déli rév (PAP, cit. BONDÁR 1987) & 1 & 1 & 3 & - & 5 \\
\hline 7. Balatonszemes-Szemesi berek, M7/S-13 (ZOFFMANN, unpublished) & 1 & 1 & - & - & 2 \\
\hline 8. Balatonőszöd-Temetói-dúlő, M7/S-10 (ZoFFMANN 2004a) & 21 & 8 & 14 & 2 & 45 \\
\hline 9. Budakalász-Luppa csárda (KÖHLER, present study) & 142 & 89 & 127 & 50 & 408 \\
\hline 10. Budapest-Andor Street (NEMESKÉRI 1956) & - & 1 & - & - & 1 \\
\hline 11. Budapest-Békásmegyer (KoREK 1951) & 2 & - & - & - & 2 \\
\hline 12. Budapest-Káposztásmegyer (ZOFFMANN 1987-1988) & - & 1 & 1 & - & 2 \\
\hline 13. Kamenin-Kiskukoricás (JАKAB 1980) & 1 & - & 1 & - & 2 \\
\hline 14. Kaposújlak-Várdomb, Road 61 Bypass, Site 29 (ZoFFMANN, unpublished) & 9 & 6 & 5 & 1 & 21 \\
\hline 15. Kaposvár, Road 61 Bypass, Site 1 (ZOFFMANN, unpublished) & - & - & 1 & - & 1 \\
\hline 16. Leobersdorf (TESCHLER-NICOLA-SCHULTZ 1984) & 3 & 1 & 1 & - & 5 \\
\hline 17. Lichtenwörth (TESCHLER-NICOLA-SCHULTZ 1984) & 3 & 6 & 2 & 2 & 13 \\
\hline 18. Malá nad Hronom (NEviZÁNSKY et al. 1995-1996) & 2 & - & 1 & 1 & 4 \\
\hline 19. Moravičany (STLOUKAL 1982) & - & - & 1 & - & 1 \\
\hline 20. Mužla-Cenkov-Vilmakert (VONDRÁKOVÁ 1985) & - & - & 1 & - & 1 \\
\hline 21. Nitriansky Hrádok (VLČEK 1953) & 2 & 5 & 5 & - & 12 \\
\hline 22. Ordacsehi-Bugaszeg, M7/S-29 (ZOFFMANN, unpublished) & 1 & - & 1 & - & 2 \\
\hline 23. Orosháza-Vöröscsillag TSZ (FARKAS 1975) & 1 & - & - & - & 1 \\
\hline 24. Ózd-Center (NEMESKÉRI, cit. KALICZ 1963) & 4 & 1 & 1 & - & 6 \\
\hline 25. Palotabozsok (NEMESKÉRI 1956) & - & - & 1 & - & 1 \\
\hline 26. Pécs-Hőerómú (ZOFFMANN 1998) & 2 & 4 & 3 & - & 9 \\
\hline 27. Pécs-Vasas-Homokbánya (ZOFFMANN, unpublished) & - & - & 1 & - & 1 \\
\hline 28. Sárvár, Bypass, Site 25 (TóTH, unpublished) & - & 1 & - & - & 1 \\
\hline 29. Sitzenberg (NEUGEBAUER-MARESCH-TESCHLER-NICOLA 1986) & - & 1 & 1 & - & 2 \\
\hline 30. Szentes-Nagyhegy (NEMESKÉRI 1956) & - & 3 & 1 & - & 4 \\
\hline 31. Vác-17 Liliom Street (ZoFFMANN, unpublished) & - & - & - & 1 & 1 \\
\hline 32. Vámosgyörök-Motorhajtóanyag-tároló (MHAT) (MARCSIK, cit. FARKAS 2004) & 7 & 4 & 9 & - & 20 \\
\hline 33. Veszprém, Jutasi Road (KÖHLER, unpublished) & 2 & - & 1 & 1 & 4 \\
\hline 34. Wolfersdorf (RUTTKAY-TESCHLER-NICOLA 1984) & - & 2 & - & 1 & 3 \\
\hline 35. Wagram an der Traisen (RUTTKAY-TESCHLER-NICOLA 1984) & 1 & 1 & - & - & 2 \\
\hline 36. Zillingtal (KRITSCHER 1985) & - & 1 & - & - & 1 \\
\hline Total & 225 & 172 & 204 & 68 & 669 \\
\hline
\end{tabular}

suggested that in addition to the three components distinguished at Alsónémedi (the meso-dolichohypsicranic Mediterranean and the brachy-hypsicranic Alpine element, as well as the meso-hypsicranic element reflecting a local population mix between the two), a fourth, dolicho-hypsicranic group could be identified at Budakalász. Nemeskéri linked this latter to the Atlanto-Mediterranean type. In his view, the culture's population was dominated by gracile and classical Mediterranean types, which could in part be derived from the local Neolithic Tisza population and in part from new immigrants from the south-east. Regarding the brachycephalic component, he derived the so-called eastern Alpine type with planoccipital nape profile from the east and the so-called western
Alpine type with curvoccipital nape profile from the west. ${ }^{15}$

Nemeskéri published one other study on the anthropology of the Baden population, in which he emphasized that in addition to the dominance of dolichomorphic elements, the proportion of brachymorphic elements was quite significant compared to the preceding Bodrogkeresztúr period. In his view, the striking presence of brachycephalic components (estimated at 30 to 35 per cent) reflected a change in the anthropological spectrum during the Late Copper Age. ${ }^{16}$

In the meantime, the anthropological description of the inurned burials from Ózd-Center became avail-

\footnotetext{
15 NeMESKÉRI 1956.
}

16 NEMESKÉRI 1961. 
able, ${ }^{17}$ together with the demographic analysis of the Alsónémedi cemetery, ${ }^{18}$ and the skeletal remains from Baja-233 Dózsa György Street and Orosháza-Vöröscsillag TSZ.19 The palaeoserological analysis of the Alsónémedi and Budakalász cemeteries were also completed. The great degree of correspondence between the distributions of the $\mathrm{ABO}$ blood groups of the two communities suggested that the two populations resembled each other. ${ }^{20}$ In his preliminary report on the serological analysis of the Budakalász cemetery, Lengyel described the distribution of sex, age at death and blood groups, on the basis of which he reconstructed "family groups" in the burial ground. The $\mathrm{ABO}$ phenotype frequencies of the cemetery's male and female population indicated a high degree of resemblance, suggesting the uniform ethnic make-up of the community which had interred its dead there. At the same time, the large serogenetic distances between the $\mathrm{ABO}$ phenotype frequencies of individuals who could be assigned to a family group and the ones who could not, did not preclude the possibility that the Budakalász cemetery had been used by two different ethnic groups. ${ }^{21}$

Besides the traditional typological analyses, the first comparative bio-statistical analyses based on metric data also appeared. The Penrose distance analysis of the male skulls from the Alsónémedi cemetery was performed by Ilse Schwidetzky and her colleagues. They found that the skull series from Alsónémedi had rather diverse contacts. Significant affinities could be detected with the regionally closer Starčevo, Hamangia and Gumelniţa cultures, the Neolithic series from Bulgaria and the Sarata Monteoru series of the Bronze Age. At the same time, there were links with more distant prehistoric cultures in western Europe and northern Africa. ${ }^{22}$ Unfortunately, it is difficult to place these results in a historical context since they ranged between rather broad chronological and geographical boundaries owing to the rather high significance level of 5 per cent used during the analysis, which does not offer reliable results.

Tibor Tóth discussed the relation between the Baden population and other contemporary groups in Europe in several studies. His analyses were essentially based on the series from Alsónémedi, complemented with a few smaller assemblages. In contrast to Nemeskéri, he found that the male series of the Baden culture was closer to the Beaker population of Bohemia than to the local Neolithic population. ${ }^{23} \mathrm{He}$ also found a morphological similarity between the male series of the Baden culture and the Gumelniţa group of the Ruse cemetery and the Rinaldone group in Tuscany. ${ }^{24}$

Zsuzsanna K. Zoffmann too employed the Penrose

\footnotetext{
17 Nemeskéri, quoted by KaLICZ 1963.

18 ACSÁDI-NEMESKÉRI 1970.

9 FARKAS 1975.

20 LENGYEL 1975.

21 LENGYEL 1983.

22 SCHWIDETZKY 1967.

23 Tóth 1977.

24 То́тн 1980
}

distance analysis in her bio-statistical comparison of the Baden culture with other Neolithic and Copper Age populations of the Carpathian Basin. ${ }^{25}$ The Baden series continued to be based on the community using the Alsónémedi cemetery, complemented by the anthropological finds from a handful of smaller sites (Baja233 Dózsa György Street, Budapest-Andor Street, Budapest-Káposztásmegyer-Farkaserdô, Szentes-Nagyhegy). She drew the significance level at 0.1 and 0.5 per cent and thus her analyses gave far more detailed and reliable data. She found that the Baden population could be linked to the so-called south-eastern group, which included Anatolian (Troy I-V), Greek (Neolithic and Early Helladic) and Bulgarian (Ruse) series. In contrast, she found no Penrose similarities with the Neolithic and Copper Age series from the Carpathian Basin. Zoffmann concluded that there was a direct link between the Baden population and the south-eastern region, which apparently confirmed the then current archaeological theory of the culture's south-eastern origins and the suggestion that the Baden groups had migrated to the Carpathian Basin from the southeast. ${ }^{26}$

Zoffmann also applied the metric traits of the categories as defined by Valery P. Alekseyev and Georgy F. Debetz for describing various prehistoric populations. She distinguished type variants based on facial height ranges, considered to be the least affected by the local tendency toward gracilisation (types A-D, each with sub-variants). The disappearance of the earlier continuously present high-leptomorphic variant characterised by a constant gracilisation (B3) and the low-eurymorphic variant $(\mathrm{C} 4)$ from the Baden population, and the appearance of robust variants of the highleptomorphic type (B1-B2), which had no apparent forerunners, suggested a major population change. The low leptomorphic variant (D1-D2) and the robust variant $(\mathrm{C} 1-\mathrm{C} 2)$ of the low eurymorphic type, which could be linked to the Pit-grave population, nonetheless reflect some degree of continuity with the Middle Copper Age. ${ }^{27}$

More recently, several Late Copper Age sites have been identified and investigated during the excavations preceding the construction of the M7 motorway. Some sites, such as Balatonszemes-Szemesi berek yielded a few burials only, while elsewhere regular cemeteries were found, as at Balatonlelle-Felsó-Gamász; in some cases, the burials lay among settlement features, as at Balatonôszöd-Temetôi-dúlố, Kaposújlak-Várdomb, and Kaposvár, Road 61 Bypass. The analysis of the anthropological finds was undertaken by Zoffmann, and the results will be published as part of the monographs evaluating a particular site and its finds. The skeletal finds from the Boleráz/Baden burials

\footnotetext{
25 ZOFFMANN 1987-1988; ZOFFMANN 1992.

26 ZOFFMANN 1987-1988; ZoFFMANN 1992.

27 ZOFFMANN 1992.
} 
uncovered at Balatonôszöd-Temetôi-dúlố and Balatonlelle-Felsô-Gamász have already been published. ${ }^{28}$

The welcome increase in the Late Copper Age anthropological material enabled a new Penrose distance analysis using three Boleráz/Baden series based on samples from the Budapest area, the Balaton region, and various other areas. The results of this analysis confirmed earlier findings, according to which the Baden groups differed markedly from other Neolithic and Copper Age series in the Carpathian Basin and exhibited a significant relationship with the early populations of Anatolia, Greece and the eastern Balkans. This again suggested that the Baden population had migrated to the Carpathian Basin from the south-east. Zoffmann hypothesised that this migration occurred in several waves and that there was no large-scale mixing between the immigrants and the local population. ${ }^{29}$

Anthropological finds from the north-western fringes of the Carpathian Basin are known from Lichtenwörth and Leobersdorf, 30 Wolfersdorf and Wagram an der Traisen, ${ }^{31}$ as well as Sitzenberg ${ }^{32}$ in Lower Austria. The skull from Zillingtal, dating from the Boleráz period, was noteworthy on account of its trepanation. ${ }^{33}$ Emanuel Vlček assigned the anthropological finds from Nitriansky Hrádok (Slovakia) to the proto-Mediterranean-Dinaric type and noted that this population had much in common with the Alsónémedi community. ${ }^{34}$ The well-preserved female skeleton from Moravičany (Boleráz period) was described as representing the gracile leptodolichomorphic type on the basis of the skull's metric and morphological characteristics. ${ }^{35}$ The other anthropological finds from Slovakia include the burials uncovered at Mužla-Cenkov-Vilmakert, ${ }^{36}$ Kamenin-Kiskukoricás, ${ }^{37}$ and Malá nad Hronom, ${ }^{38}$ the latter dating from the Boleráz period.

\section{MATERIALS AND METHOD}

A total of 436 Late Copper Age graves were uncovered in the Budakalász cemetery, which included inhumation burials with the body deposited in a contracted position, inurned and scattered cremation burials, as well as skull burials, and a few symbolic graves. The dominant funerary rite was inhumation (cremation burials accounted for 16 per cent of the burials). A spatial and chronological patterning could be clearly identified among the burials performed according to

\footnotetext{
8 ZOFFMANN 2004a; ZOFFMANN 2005; ZOFFMANN 2006.

29 ZOFFMANN 2004b.

30 Teschler-Nicola-Schultz 1984

31 Ruttkay-Teschler-Nicola 1984

32 Neugebauer-Maresch-Teschler-Nicola 1986

33 KRITSCHER 1985

34 VLČEK 1953

35 STLOUKAL 1982

36 VONDRÁKOVA 1985.

37 JAKAB 1980.

8 NeviZANSKY et al. 1995-1996.
}

different rites, as shown for example by the burials overlying the cremation graves. The single grave with multiple burials performed according to different rites was Grave 155.

The cemetery contained 356 inhumation graves, 318 of which contained a single burial only. The skeletal remains from thirty of these burials could not be examined (Graves 12, 21, 27, 29, 32, 34, 40, 41, 42, $49,50,54,72,77,81,85,86,87,90,98,99,109,110$, 133, 144, 223, 228, 297, 299, 345). Thirty-four graves contained double burials (sixty-eight individuals), of which twelve were not available for study (Burials 3/AB, 13/B, 55/A-B, 56/B, 80/B, 100/A-B, 106/A, 113/B, 290/A). Four graves contained triple burials: the skeletal remains from two of these burials (Burials 47/A-B) are missing. The 356 inhumation graves yielded the skeletal remains of 398 individuals, of which 354 were available for study.

Seventy-one cremation graves were uncovered. One of these (Grave 131) was a double burial containing a scattered cremation and an inurned burial, while another one (Grave 155) contained an inhumation and a scattered cremation burial. The anthropological finds from fifteen cremation burials were missing (Graves 103, 130, 131, 190, 236, 238, 240, 241, 242, 249, 258, 273, 276, 298, 314).

According to the excavation documentation, eleven graves did not contain any skeletal remains. Nine of these can be regarded as symbolic burials (Graves 26, $31,160,177,205,243,246,311,349)$, while two burials (Graves 59 and 257) were destroyed by sand mining operations.

During the evaluation of the anthropological material, we double-checked the skeletal remains by comparing them with the excavation photos, the excavation diary, and the grave sheets compiled by Korek. The latter contained a drawing of the burial and the grave goods together with their brief description, the size and orientation of the burials, as well as the information provided by Lengyel on sex and age, the chemical composition of the bones and the diseases indicated by the serological analyses. We also had an "errata list" assembled by Lengyel after he had gone over his data with Korek and corrected a few errors arising from mix-ups during sampling. ${ }^{39}$ This list, however, did not contain data on Graves 25-49, $147-169$, and 407-439. It must here be noted that the demographic data in the excavation diary and in Lengyel's list are often at variance with each other.

The qualitative and quantitative representation value of the anthropological material is rather unsatisfactory. Nemeskéri had noted in one of his studies that the skeletal remains from Budakalász were very poorly preserved and very often not even the age could be determined. ${ }^{40}$ In many cases, the fragmentary neurocranium is all that survived of the skull, with the

\footnotetext{
39 Archives of the Hungarian National Museum, inv. no. VII.61/1984. 40 NeMESKÉRI 1956.
} 
splanchnocranium missing in most cases. Even though some of the fragmentary or missing splanchnocraniums were occasionally reconstructed during earlier anthropological analyses, these were unsuitable for computing metric data. The post-cranial bones were likewise badly preserved. Usually only the long bones survived, most of which lacked the epiphyses, and thus even the basic metric data for calculating stature were rarely available. Other bones of the post-cranial skeleton (pelvis, vertebrae, ribs, etc.) were seldom preserved, meaning that the number of individuals, whose sex could be determined was rather low and that pathological deformations and anatomical variations could not be systematically studied either.

Sexing was performed according to the traditional procedure based on the metric and morphological variables of the skull and post-cranial bones. ${ }^{41}$ If these features were unsuitable for sexing, we determined the sex from the general morphological features of the skeleton (gracility/robustness, degree of muscle markings).

The determination of the age at death was based on the development and eruption sequence of milk and permanent teeth in the case of children ( $0-14$ years) ${ }^{42}$ and on the length of the long bones. ${ }^{43}$ We used the tables detailing the epiphyseal union in the case of juveniles (15-23 years). ${ }^{44}$ Adults' age was estimated from the stage of cranial suture closure, ${ }^{45}$ the changes of the symphyseal face of the pubic bone and the extent of dental attrition. ${ }^{46}$ Other procedures, such as the one based on the changes of the sternal end of ribs, ${ }^{47}$ could seldom be applied owing to the fragmentary and incomplete state of the skeletal remains. The extent of dental attrition, however, is influenced not only by age, but also by dietary habits, such as the types of food consumed and the preparation of food (e.g., ground cereals). Cultural practices and tasks performed using teeth can also influence the extent of abrasion. In other words, if age determination was based on teeth alone, the age at death was estimated within rather broad age brackets, according to the major age groups.

The measurements and indices of the skull and postcranial bones were determined according to the procedure elaborated by Rudolf Martin and Karl Saller ${ }^{48}$ while the values thus gained were assigned to categories as defined by Alekseyev and Debetz. ${ }^{49} \mathrm{We}$ examined nine traits in the morphological description of the skulls..$^{50}$ Stature was estimated using Torstein

\footnotetext{
41 ÉRY et al. 1963.

42 SChOur-Massler 1941; Ubelaker 1989.

43 StLloukal-Hanáková 1978.

44 SCHINZ et al. 1952; FEREMBACH et al. 1979

45 NeMESKÉRI et al. 1960; MEINDL-LOVEJOY 1985

46 TodD 1920, 1921; Miles 1963; Perizonius 1981. We did not apply the determination method traditionally used in Hungary based on the internal structual changes of the proximal epiphysis of the humerus and femur (NEMESKÉRI et al. 1960).

47 ISSCAN et al. 1984; ISSCAN et al. 1985.

48 Martin-Saller 1957.

49 AleKseyev-Debetz 1964

50 Martin-Saller 1957.
}

Sjøvold's formulae, applicable to all population types. ${ }^{51}$ The results were then compared with Kinga Éry's data on the stature of the peoples of the Carpathian Basin. ${ }^{52}$

We took note of the pathological cases which could be identified macroscopically ${ }^{53}$ and of the hereditary epigenetic traits and anatomical variations. ${ }^{54}$

In the case of cremation burials, we first determined whether the remains had belonged to one or more individuals based on anatomical formulas. Sex and age at death were determined using the same techniques as in the case of non-cremated remains. ${ }^{55}$ Very often, however, the state of the preservation of the cremated bones did not enable sexing, and age estimates were in most cases restricted to the separation of adult/child age groups.

\section{DEMOGRAPHIC ANALYSIS}

\section{Age distribution of the deceased}

Table 2 presents the individual demographic data of 354 individuals from inhumation burials and 56 individuals from cremation burials determined with the methods described above. Tables 3-4 show the age and sex distribution of the individuals from the inhumation and cremation burials, while Table 5 and Fig. 2 shows the breakdown of sex and age groups across the entire cemetery. Sex could not be determined for 11 per cent of the skeletal remains, while age at death for 3.7 per cent of the sample.

The age distribution of the Budakalász population was compared with other prehistoric series (Table 6). The adult/child ratio (individuals over $15-16$ years were assigned to the adult group) was 252:142 (64:36 per cent). The number and proportion of children more or less corresponded to the expected values, although in a breakdown according to individual age groups, this percentage differed from the expected values. The very low proportion (4.9 per cent) of neonates $(0-1$ year) is noteworthy since the mortality rate was generally highest around birth in all archaeological periods. The data in Table 7 seem to contradict this since the same low proportion can be noted among the Baden burials from Balatonôszöd (4.4 per cent) and the Late Neolithic burials uncovered at Mórágy (6.1 per cent); in contrast, this age group is entirely lacking in two Linear Pottery series from Germany. The ratio of neonates is slightly higher, although still below the expected values in the Baden cemetery at Alsónémedi (13.1 per cent). It has been suggested that the lack or low proportion of neonate and infant burials can perhaps be explained by mortuary practices (they were interred elsewhere),

\footnotetext{
$\overline{51 \text { SJøVOLD } 1990 .}$

52 ÉRY 1998.

53 STEInbock 1976; Ortner-Putschar 1981; MANCHESTER 1983.

54 Hauser-De Stefano 1989.

55 NEMESKÉRI-HARSÁNYI 1968
} 
Table 2. Individual data of the sex and age of the Budakalász findings

\begin{tabular}{|c|c|c|c|c|c|}
\hline Grave & Sex & $\begin{array}{c}\text { Value of } \\
\text { sexualisation }\end{array}$ & $\begin{array}{c}\text { Number of } \\
\text { examined features }\end{array}$ & $\begin{array}{l}\text { Estimated age } \\
\text { (years) }\end{array}$ & Criteria of age estimation \\
\hline 1 & male? & $+0,20$ & 5 & $23-30$ & tooth wear \\
\hline 2 & female & $-0,92$ & 12 & $23-30$ & tooth wear, cranial sutures \\
\hline 4 & $?$ & - & - & $6-8$ & dentition \\
\hline 5 & female & $-1,00$ & 5 & $40-59$ & tooth wear \\
\hline 6 & female? & $-1,50$ & 2 & $23-x$ & estimation \\
\hline 7 & $?$ & - & - & $13-15$ & dentition, length of bones \\
\hline 8 & male & $+1,00$ & 15 & $40-59$ & tooth wear, cranial sutures \\
\hline 9 & male & $+0,42$ & 14 & $35-45$ & tooth wear, cranial sutures \\
\hline 10 & $?$ & - & - & $7-8$ & dentition, length of bones \\
\hline 11 & female & $-1,00$ & 7 & $40-50$ & tooth wear \\
\hline 13/A & $?$ & - & - & $10-12$ & dentition, length of bones \\
\hline 14 & male? & $+0,37$ & 8 & $23-39$ & tooth wear, cranial sutures \\
\hline 15 & female? & $+0,25$ & 4 & $30-50$ & cranial sutures \\
\hline 16 & female & $-0,75$ & 8 & $40-59$ & estimation \\
\hline 17 & female & $-1,75$ & 4 & $20-30$ & estimation \\
\hline 18 & male? & $+0,22$ & 7 & $23-39$ & tooth wear, cranial sutures \\
\hline 19 & male & $+1,00$ & 4 & $23-59$ & estimation \\
\hline 20 & male? & $+0,20$ & 10 & $40-50$ & tooth wear, cranial sutures \\
\hline 22 & female? & $-0,31$ & 13 & $19-21$ & epiphyseal union, tooth wear \\
\hline 23 & female & $-1,00$ & 8 & $18-23$ & dentition \\
\hline 24 & female & $-1,63$ & 8 & $25-35$ & tooth wear, cranial sutures \\
\hline 25 & female & $-0,75$ & 8 & $23-40$ & tooth wear, cranial sutures \\
\hline 28 & female & $-0,50$ & 6 & $40-50$ & tooth wear, cranial sutures \\
\hline 30 & $?$ & - & - & $6-7$ & dentition \\
\hline 33 & male & $+0,43$ & 7 & $40-50$ & tooth wear \\
\hline 35 & $?$ & - & - & $7-14$ & estimation \\
\hline 36 & female & $-1,60$ & 10 & $40-50$ & tooth wear, cranial sutures \\
\hline 37 & male? & $+0,22$ & 9 & $23-40$ & tooth wear, cranial sutures \\
\hline 38 & female & $-1,44$ & 9 & $40-x$ & tooth wear, cranial sutures \\
\hline 39 & male & $+1,00$ & 15 & $35-45$ & tooth wear, pubic symphysis \\
\hline 43 & male & $+0,50$ & 14 & $40-59$ & tooth wear, pubic symphysis \\
\hline 44 & female? & $-1,00$ & 1 & $23-x$ & estimation \\
\hline 45 & $?$ & - & - & $23-x$ & estimation \\
\hline 46 & female & $-0,93$ & 14 & $20-30$ & tooth wear, epiphyseal union \\
\hline $47 / \mathrm{C}$ & male & $+0,80$ & 10 & $30-40$ & tooth wear, cranial sutures \\
\hline 48/A & $?$ & - & - & $10-12$ & dentition \\
\hline 48/B & female & $-1,33$ & 6 & $14-16$ & epiphyseal union \\
\hline 51 & female & $-1,00$ & 10 & $30-40$ & tooth wear, cranial sutures \\
\hline 52 & male & $+0,43$ & 7 & $30-40$ & estimation \\
\hline 53 & $?$ & - & - & $1-14$ & estimation \\
\hline $56 / \mathrm{A}$ & female? & $\pm 0,00$ & 2 & $23-x$ & estimation \\
\hline 57 & male & $+0,42$ & 12 & $40-x$ & tooth wear, cranial sutures \\
\hline 58 & female & $-1,23$ & 13 & $40-59$ & tooth wear, cranial sutures \\
\hline 60 & $?$ & - & - & $13-14$ & dentition, length of bones \\
\hline 61 & $?$ & - & - & $6-8$ & dentition \\
\hline 62 & $?$ & - & - & $7-8$ & dentition \\
\hline 63 & $?$ & - & - & $13-15$ & dentition \\
\hline 64 & male & $+0,57$ & 7 & $40-59$ & estimation \\
\hline 65 & female & $-0,62$ & 14 & $40-\mathrm{x}$ & tooth wear, cranial sutures \\
\hline 66/A & $?$ & - & - & $0-0.5$ & estimation \\
\hline $66 / \mathrm{B}$ & male & $+0,67$ & 12 & $40-59$ & tooth wear, cranial sutures \\
\hline 67 & male & $+0,43$ & 15 & $40-50$ & tooth wear, cranial sutures \\
\hline 68 & $?$ & - & - & $1-7$ & estimation \\
\hline 69 & female? & $-2,00$ & 2 & $23-x$ & estimation \\
\hline
\end{tabular}




\begin{tabular}{|c|c|c|c|c|c|}
\hline Grave & Sex & $\begin{array}{c}\text { Value of } \\
\text { sexualisation }\end{array}$ & $\begin{array}{c}\text { Number of } \\
\text { examined features }\end{array}$ & $\begin{array}{c}\text { Estimated age } \\
\text { (years) }\end{array}$ & Criteria of age estimation \\
\hline 70 & female? & $-0,33$ & 3 & $40-59$ & tooth wear, cranial sutures \\
\hline 71 & ? & - & - & $0-1$ & estimation \\
\hline $71 / \mathrm{A}$ & $?$ & - & - & $0-1$ & estimation \\
\hline 73 & female & $-0,93$ & 15 & $45-55$ & $\begin{array}{l}\text { tooth wear, pubic symphysis, } \\
\text { cranial sutures }\end{array}$ \\
\hline 74 & juvenis & - & - & $14-16$ & epiphyseal union, dentition \\
\hline 75 & $?$ & - & - & $10-12$ & dentition, length of bones \\
\hline 76 & female & $-1,40$ & 5 & $40-50$ & cranial sutures \\
\hline $78 / \mathrm{A}$ & $?$ & - & - & $0.5-1.5$ & dentition \\
\hline $78 / \mathrm{B}$ & $?$ & - & - & $4-6$ & dentition \\
\hline 79/A & male & $+0,66$ & 6 & $25-35$ & tooth wear, cranial sutures \\
\hline 79/B & female? & $-0,22$ & 9 & $35-45$ & tooth wear, cranial sutures \\
\hline 80 & ? & - & - & $2-3$ & dentition \\
\hline 82 & $?$ & - & - & $9-11$ & dentition \\
\hline 83 & male & $+0,57$ & 7 & $45-55$ & tooth wear, cranial sutures \\
\hline 84 & $?$ & - & - & $6-7$ & dentition \\
\hline 88 & $?$ & - & - & $5-6$ & dentition \\
\hline 89 & female & $-1,28$ & 14 & $25-35$ & tooth wear, cranial sutures \\
\hline 91 & male? & $+1,00$ & 4 & $45-55$ & $\begin{array}{l}\text { pubic symphysis, } \\
\text { humerus prox. epiph. }\end{array}$ \\
\hline 92 & $?$ & - & - & $1-7$ & estimation \\
\hline 93 & $?$ & - & - & $5-6$ & dentition \\
\hline 94 & male & $+0,62$ & 16 & $20-23$ & epiphyseal union \\
\hline 95 & female & $-0,86$ & 7 & $35-40$ & tooth wear, cranial sutures \\
\hline 96 & $?$ & - & - & $3-4$ & dentition \\
\hline 97 & $?$ & - & - & $12-14$ & length of bones \\
\hline 101/A & $?$ & - & - & $9-10$ & dentition \\
\hline 101/B & $?$ & - & - & $1-2$ & estimation \\
\hline 102 & $?$ & - & - & $1-7$ & estimation \\
\hline 104 & female & $-1,00$ & 16 & $30-40$ & tooth wear, cranial sutures \\
\hline 105 & male? & $+0,67$ & 3 & $40-\mathrm{x}$ & estimation \\
\hline 106/B & $?$ & - & - & $9-11$ & dentition \\
\hline 107 & male? & $-0,10$ & 11 & $35-45$ & tooth wear, cranial sutures \\
\hline 108/A & $?$ & - & - & $9-10$ & length of bones \\
\hline 108/B & $?$ & - & - & $7-14$ & estimation \\
\hline 111 & $?$ & - & - & ca. 6 months & estimation \\
\hline 112 & male & $+0,46$ & 13 & $30-40$ & tooth wear, cranial sutures \\
\hline 113/A & $?$ & - & - & $9-10$ & dentition \\
\hline 114 & $?$ & - & - & $0.5-1$ & dentition \\
\hline 115 & female & $-1,10$ & 14 & $30-40$ & tooth wear, cranial sutures \\
\hline 116 & female & $-1,17$ & 6 & $40-50$ & tooth wear, cranial sutures \\
\hline 117 & male? & $+0,36$ & 14 & $30-40$ & tooth wear, cranial sutures \\
\hline 118 & female & $-0,67$ & 12 & $35-45$ & tooth wear, cranial sutures \\
\hline 119 & $?$ & - & - & $8-10$ & length of bones \\
\hline 120 & female? & - & - & $23-59$ & estimation \\
\hline 121 & $?$ & - & - & $9-10$ & dentition \\
\hline 122 & $?$ & - & - & $2-2,5$ & dentition \\
\hline $123 / \mathrm{A}$ & female & $-1,00$ & 9 & $40-50$ & tooth wear, cranial sutures \\
\hline $123 / \mathrm{B}$ & $?$ & - & - & $1-2$ & dentition \\
\hline 124 & male & $+0,55$ & 10 & $40-x$ & tooth wear, cranial sutures \\
\hline 125 & female? & - & - & $23-x$ & estimation \\
\hline $126 / \mathrm{A}$ & female & $-1,00$ & 10 & $30-40$ & tooth wear, cranial sutures \\
\hline $126 / \mathrm{B}$ & $?$ & - & - & $12-14$ & dentition \\
\hline 127 & female & $-1,50$ & 12 & $23-30$ & tooth wear, cranial sutures \\
\hline 128 & $?$ & - & - & $12-13$ & dentition \\
\hline
\end{tabular}


Table 2 (cont'd)

\begin{tabular}{|c|c|c|c|c|c|}
\hline Grave & Sex & $\begin{array}{c}\text { Value of } \\
\text { sexualisation }\end{array}$ & $\begin{array}{c}\text { Number of } \\
\text { examined features }\end{array}$ & $\begin{array}{c}\text { Estimated age } \\
\text { (years) }\end{array}$ & Criteria of age estimation \\
\hline 129 & $?$ & - & - & $7-14$ & estimation \\
\hline 132 & male & $+0,83$ & 6 & $23-30$ & tooth wear \\
\hline $134 / \mathrm{A}$ & juvenis & - & - & $15-19$ & epiphyseal union \\
\hline 134/B & ? & - & - & $23-x$ & estimation \\
\hline 135 & juvenis & $-1,75$ & 4 & $15-23$ & estimation \\
\hline 136 & female? & $-1,00$ & 4 & $23-30$ & tooth wear \\
\hline 137 & juvenis & - & - & $14-16$ & epiphyseal union \\
\hline 138 & ? & - & - & $23-x$ & estimation \\
\hline 139 & $?$ & - & - & $7-8$ & dentition \\
\hline 140 & ? & - & - & $12-14$ & dentition \\
\hline 141 & female? & $-1,00$ & 1 & $23-39$ & estimation \\
\hline 142/A & ? & - & - & $2.5-3.5$ & dentition \\
\hline $142 / \mathrm{B}$ & male? & $+0,33$ & 12 & $23-39$ & tooth wear, cranial sutures \\
\hline 143 & female & $-0,73$ & 11 & $30-40$ & tooth wear, cranial sutures \\
\hline 145 & $?$ & - & - & $3-4$ & dentition, length of bones \\
\hline 146 & female & $-0,80$ & 10 & $40-50$ & tooth wear, cranial sutures \\
\hline 147 & ? & - & - & $1-4$ & estimation \\
\hline 148 & $?$ & - & - & $1-7$ & estimation \\
\hline 149/A & $?$ & - & - & $13-15$ & dentition \\
\hline 149/B & ? & - & - & $5-6$ & dentition \\
\hline 150 & female & $-1,00$ & 8 & $30-50$ & tooth wear, cranial sutures \\
\hline 151 & ? & - & - & $5-7$ & dentition \\
\hline 152 & female? & $-0,33$ & 9 & $23-30$ & tooth wear, cranial sutures \\
\hline $153 / \mathrm{A}$ & male & $+0,86$ & 14 & $40-x$ & pubic symphysis, tooth wear \\
\hline $153 / \mathrm{B}$ & male? & $+0,33$ & 15 & $40-59$ & tooth wear, cranial sutures \\
\hline 154 & $?$ & - & - & $1-2$ & dentition \\
\hline $155 / \mathrm{A}$ & $?$ & - & - & $4-5$ & dentition \\
\hline $155 / \mathrm{B}$ & $?$ & - & - & $?$ & - \\
\hline 156 & $?$ & - & - & $7-8$ & dentition \\
\hline 157 & female & $-0,43$ & 7 & $40-x$ & estimation \\
\hline 158 & female? & $-0,27$ & 11 & $40-x$ & tooth wear, cranial sutures \\
\hline 159 & female? & - & - & $23-x$ & estimation \\
\hline 161 & male & $+0,43$ & 7 & $30-40$ & tooth wear \\
\hline 162 & ? & - & - & $23-x$ & estimation \\
\hline 163 & female & $-0,50$ & 8 & $35-45$ & tooth wear, cranial sutures \\
\hline 164 & male & $+0,36$ & 14 & $23-30$ & tooth wear, cranial sutures \\
\hline 165 & male? & $+2,00$ & 2 & $40-59$ & tooth wear \\
\hline 166 & female & $-1,12$ & 8 & $23-30$ & tooth wear, cranial sutures \\
\hline $167 / \mathrm{A}$ & juvenis & $-1,33$ & 6 & $15-17$ & epiphyseal union \\
\hline $167 / \mathrm{B}$ & ? & - & - & $4-6$ & dentition, length of bones \\
\hline 168 & male? & - & - & $23-x$ & estimation \\
\hline 169/A & male? & $\pm 0,00$ & 2 & $35-55$ & femur prox. epiphysis \\
\hline 169/B & female? & $-1,50$ & 2 & $50-70$ & estimation \\
\hline 170 & male & $+0,43$ & 14 & $30-40$ & tooth wear, cranial sutures \\
\hline 171 & male? & $+0,33$ & 9 & $40-x$ & tooth wear, cranial sutures \\
\hline 172 & $?$ & - & - & $0-1$ & estimation \\
\hline 173 & male? & $+0,10$ & 12 & $35-45$ & tooth wear, cranial sutures \\
\hline 174 & juvenis & $-0,60$ & 5 & $14-16$ & epiphyseal union \\
\hline 175 & juvenis & - & - & $13-15$ & epiphyseal union \\
\hline 176 & female & $-1,38$ & 13 & $30-40$ & tooth wear \\
\hline 178 & female? & - & - & $15-59$ & estimation \\
\hline 179 & ? & - & - & $12-14$ & length of bones \\
\hline 180 & female & $-0,54$ & 10 & $16-18$ & epiphyseal union \\
\hline 181 & male? & $+1,50$ & 2 & $23-59$ & estimation \\
\hline $182 / \mathrm{A}$ & $?$ & - & - & 8-9 & dentition, length of bones \\
\hline 182/B & juvenis & - & - & $14-15$ & dentition, length of bones \\
\hline
\end{tabular}


Table 2 (cont'd)

\begin{tabular}{|c|c|c|c|c|c|}
\hline Grave & Sex & $\begin{array}{c}\text { Value of } \\
\text { sexualisation }\end{array}$ & $\begin{array}{c}\text { Number of } \\
\text { examined features }\end{array}$ & $\begin{array}{l}\text { Estimated age } \\
\text { (years) }\end{array}$ & Criteria of age estimation \\
\hline $182 / \mathrm{C}$ & $?$ & - & - & $5-6$ & dentition, length of bones \\
\hline 183 & female & $-1,00$ & 9 & $30-40$ & tooth wear, cranial sutures \\
\hline 184 & $?$ & - & - & $3-3.5$ & dentition \\
\hline 185 & male & $+0,44$ & 9 & $35-45$ & tooth wear, cranial sutures \\
\hline 186 & male & $+0,62$ & 8 & $40-x$ & tooth wear, cranial sutures \\
\hline 187 & $?$ & - & - & $?$ & - \\
\hline 188 & female & $-1,00$ & 11 & $40-50$ & tooth wear, cranial sutures \\
\hline 189 & female & $-0,85$ & 13 & $30-40$ & tooth wear, cranial sutures \\
\hline 191 & juvenis & $-1,11$ & 9 & $13-15$ & dentition \\
\hline 192 & female & $-1,12$ & 8 & $23-30$ & tooth wear, cranial sutures \\
\hline 193 & $?$ & - & - & $23-x$ & estimation \\
\hline 194 & male? & $+0,20$ & 10 & $30-40$ & tooth wear, cranial sutures \\
\hline 195/A & female & $-0,83$ & 6 & $40-50$ & tooth wear, cranial sutures \\
\hline 195/B & male? & $+1,00$ & 2 & $23-\mathrm{x}$ & estimation \\
\hline 196 & male & $+0,45$ & 11 & $35-45$ & tooth wear, cranial sutures \\
\hline 197 & female & $-0,77$ & 13 & $35-45$ & tooth wear, cranial sutures \\
\hline 198 & $?$ & - & - & $4-5$ & dentition \\
\hline 199 & $?$ & - & - & $6-8$ & dentition, length of bones \\
\hline 200 & $?$ & - & - & $11-13$ & dentition, length of bones \\
\hline 201 & $?$ & - & - & $13-14$ & dentition \\
\hline 202 & $?$ & - & - & $11-13$ & dentition \\
\hline 203 & male & $+0,71$ & 14 & $45-55$ & $\begin{array}{l}\text { tooth wear, cranial sutures, } \\
\text { pubic symphysis }\end{array}$ \\
\hline 204 & female & $-0,92$ & 12 & $35-45$ & tooth wear, cranial sutures \\
\hline 206 & $?$ & - & - & $1-7$ & estimation \\
\hline 207 & male & $+0,66$ & 12 & $30-40$ & tooth wear, cranial sutures \\
\hline 208 & female & $-0,83$ & 6 & $23-30$ & tooth wear, cranial sutures \\
\hline 209 & female & $-1,10$ & 10 & $45-55$ & tooth wear, cranial sutures \\
\hline 210 & female & $-1,00$ & 11 & $30-35$ & tooth wear, cranial sutures \\
\hline 211 & $?$ & - & - & $23-x$ & estimation \\
\hline 212 & $?$ & - & - & $0-1$ & estimation \\
\hline 213 & $?$ & - & - & $1-4$ & estimation \\
\hline 214 & $?$ & - & - & $3-4$ & dentition \\
\hline 215/A & male? & $+0,50$ & 2 & $40-50$ & tooth wear \\
\hline $215 / \mathrm{B}$ & female? & $-0,28$ & 7 & $30-40$ & tooth wear \\
\hline $215 / \mathrm{C}$ & female & $-0,85$ & 13 & $30-35$ & tooth wear, cranial sutures \\
\hline 216 & female & $-1,33$ & 6 & $23-30$ & tooth wear \\
\hline 217 & female & $-0,84$ & 14 & $20-23$ & epiphyseal union \\
\hline 218 & female & $-1,12$ & 8 & $50-59$ & tooth wear, cranial sutures \\
\hline 219 & $?$ & - & - & $23-x$ & estimation \\
\hline 220 & male? & $+0,66$ & 3 & $23-x$ & estimation \\
\hline 221 & $?$ & - & - & $2-2.5$ & dentition \\
\hline 222 & female? & - & - & $40-x$ & estimation \\
\hline 224 & ? & - & - & $23-x$ & estimation \\
\hline 225 & $?$ & - & - & $3-4$ & dentition, length of bones \\
\hline 226 & $?$ & - & - & $2,5-3$ & dentition \\
\hline 227 & male & $+0,45$ & 11 & $35-45$ & tooth wear, cranial sutures \\
\hline 229 & $?$ & - & - & $3-4$ & dentition \\
\hline 230 & male & $+0,71$ & 7 & $40-x$ & estimation \\
\hline 231 & male & $+0,64$ & 11 & $50-x$ & tooth wear, cranial sutures \\
\hline 232 & $?$ & - & - & $1-7$ & estimation \\
\hline 233 & $?$ & - & - & $15-39$ & estimation \\
\hline 234 & $?$ & - & - & $8-23$ & estimation \\
\hline 237 & $?$ & - & - & $6-8$ & dentition \\
\hline 239 & female? & - & - & $15-\mathrm{x}$ & estimation \\
\hline 244 & $?$ & - & - & $1-7$ & estimation \\
\hline
\end{tabular}


Table 2 (cont'd)

\begin{tabular}{|c|c|c|c|c|c|}
\hline Grave & Sex & $\begin{array}{c}\text { Value of } \\
\text { sexualisation }\end{array}$ & $\begin{array}{c}\text { Number of } \\
\text { examined features }\end{array}$ & $\begin{array}{l}\text { Estimated age } \\
\text { (years) }\end{array}$ & Criteria of age estimation \\
\hline 245 & $?$ & - & - & $5-7$ & dentition \\
\hline 247 & $?$ & - & - & $1-7$ & dentition \\
\hline 248 & ? & - & - & $23-59$ & estimation \\
\hline 250 & female? & - & - & $15-39$ & estimation \\
\hline 251 & ? & - & - & $?$ & - \\
\hline 252 & $?$ & - & - & $2.5-3.5$ & dentition, length of bones \\
\hline 253 & $?$ & - & - & $8-9$ & dentition, length of bones \\
\hline 254 & $?$ & - & - & $1-14$ & estimation \\
\hline 255 & $?$ & - & - & $3-4$ & dentition \\
\hline 256 & $?$ & - & - & $1-7$ & estimation \\
\hline 259 & $?$ & - & - & $23-x$ & estimation \\
\hline 260 & ? & - & - & $23-59$ & estimation \\
\hline 261 & male? & $+0,37$ & 8 & $40-x$ & tooth wear, cranial sutures \\
\hline 262 & $?$ & - & - & $0-5$ & estimation \\
\hline 263/A & male? & $+0,15$ & 13 & $35-45$ & tooth wear, cranial sutures \\
\hline 263/B & female & $-1,08$ & 12 & $40-59$ & $\begin{array}{l}\text { tooth wear, cranial sutures, } \\
\text { pubic symphysis }\end{array}$ \\
\hline 264 & male? & $+0,33$ & 6 & $25-35$ & tooth wear, cranial sutures \\
\hline 265 & $?$ & - & - & $4-4.5$ & dentition \\
\hline 266 & female? & - & - & $15-39$ & estimation \\
\hline 267 & $?$ & - & - & $0-5$ & estimation \\
\hline 268 & female? & - & - & $23-x$ & estimation \\
\hline 269 & ? & - & - & $23-x$ & estimation \\
\hline 270 & male & $+0,40$ & 10 & $30-40$ & tooth wear \\
\hline 271 & female & $-1,22$ & 9 & $40-x$ & tooth wear \\
\hline 272 & $?$ & - & - & $4-6$ & dentition \\
\hline 274 & $?$ & - & - & $1-14$ & estimation \\
\hline 275 & $?$ & - & - & $?$ & - \\
\hline 277 & male? & $+0,37$ & 8 & $30-35$ & tooth wear, cranial sutures \\
\hline 278 & $?$ & - & - & $0-0,5$ & length of bones \\
\hline 279 & male & $+2,00$ & 1 & $30-50$ & estimation \\
\hline 280 & $?$ & - & - & $?$ & - \\
\hline 281 & $?$ & - & - & $1-3$ & estimation \\
\hline 282 & $?$ & - & - & $?$ & - \\
\hline 283 & female & $-1,14$ & 7 & $23-59$ & estimation \\
\hline 284 & female & $-0,86$ & 7 & $30-40$ & estimation \\
\hline 285 & $?$ & - & - & $2-3$ & dentition \\
\hline 286 & $?$ & - & - & $1.5-2$ & dentition \\
\hline 287 & female? & $-1,50$ & 2 & $23-30$ & tooth wear \\
\hline 288 & $?$ & - & - & $2-3$ & dentition \\
\hline 289 & female & $-1,13$ & 15 & $23-30$ & epiphyseal union, tooth wear \\
\hline 290/B & male & $+0,54$ & 11 & $40-x$ & estimation \\
\hline 291 & $?$ & - & - & $1-7$ & estimation \\
\hline 292 & female & $-1,00$ & 3 & $30-50$ & estimation \\
\hline 293 & $?$ & - & - & $0-1$ & dentition \\
\hline 294 & male? & $+0,38$ & 13 & $25-35$ & tooth wear, cranial sutures \\
\hline 295 & female & $-0,42$ & 7 & $40-x$ & tooth wear, cranial sutures \\
\hline 296 & $?$ & - & - & $23-x$ & estimation \\
\hline 300 & $?$ & - & - & $3-4$ & dentition, length of bones \\
\hline 301 & $?$ & - & - & $0-0.5$ & length of bones \\
\hline 302 & $?$ & - & - & $0-0.5$ & estimation \\
\hline 303 & female & $-1,50$ & 8 & $17-20$ & epiphyseal union \\
\hline 304 & male? & - & - & $23-39$ & cranial sutures \\
\hline 305 & $?$ & - & - & $0-1$ & estimation \\
\hline 306 & $?$ & - & - & $0-1$ & estimation \\
\hline 307 & female? & $-1,00$ & 1 & $15-59$ & estimation \\
\hline
\end{tabular}


Table 2 (cont'd)

\begin{tabular}{|c|c|c|c|c|c|}
\hline Grave & Sex & $\begin{array}{c}\text { Value of } \\
\text { sexualisation }\end{array}$ & $\begin{array}{c}\text { Number of } \\
\text { examined features }\end{array}$ & $\begin{array}{c}\text { Estimated age } \\
\text { (years) }\end{array}$ & Criteria of age estimation \\
\hline 308 & male & $+0,73$ & 15 & $23-30$ & tooth wear, cranial sutures \\
\hline 309 & female & $-1,10$ & 10 & $35-45$ & tooth wear, cranial sutures \\
\hline 310 & female & $-1,22$ & 11 & $40-59$ & tooth wear, cranial sutures \\
\hline 312 & ? & - & - & $1-7$ & dentition \\
\hline 315 & female? & $-0,50$ & 1 & $23-x$ & estimation \\
\hline 316 & female & $-0,80$ & 5 & $30-40$ & tooth wear, cranial sutures \\
\hline 317 & $?$ & - & - & $8-9$ & dentition, length of bones \\
\hline 318 & $?$ & - & - & $1-14$ & estimation \\
\hline 319 & male & $+0,87$ & 15 & $40-50$ & $\begin{array}{l}\text { tooth wear, cranial sutures, } \\
\text { pubic symphysis }\end{array}$ \\
\hline 320 & male? & $+0,12$ & 8 & $23-39$ & tooth wear \\
\hline 321 & $?$ & - & - & $23-39$ & tooth wear \\
\hline 322 & $?$ & - & - & $10-11$ & dentition \\
\hline 323 & male? & - & - & $23-59$ & cranial sutures \\
\hline 324 & female & $-1,28$ & 14 & $30-40$ & tooth wear, cranial sutures \\
\hline 325 & male & $+0,62$ & 8 & $30-40$ & tooth wear, cranial sutures \\
\hline 326 & $?$ & - & - & $4-5$ & dentition \\
\hline 328 & female? & $-1,50$ & 3 & $23-59$ & estimation \\
\hline 329 & female? & $-0,33$ & 6 & $40-x$ & tooth wear \\
\hline 330 & female & $-1,75$ & 4 & $23-25$ & epiphyseal union \\
\hline 331 & male? & - & - & $23-59$ & cranial sutures \\
\hline 332 & female & $-1,00$ & 7 & $40-\mathrm{x}$ & tooth wear, cranial sutures \\
\hline 333 & female? & - & - & $15-\mathrm{x}$ & estimation \\
\hline 334/A & $?$ & - & - & $1.5-2$ & dentition \\
\hline 334/B & ? & - & - & $0-0.5$ & dentition \\
\hline 335 & female? & $-0,22$ & 9 & $30-40$ & tooth wear, cranial sutures \\
\hline 336 & $?$ & - & - & $23-x$ & estimation \\
\hline 337 & male & $+0,50$ & 8 & $40-59$ & tooth wear \\
\hline 338 & $?$ & - & - & $c a .1$ & estimation \\
\hline 339 & female? & - & - & $23-x$ & estimation \\
\hline 340 & female? & - & - & $23-x$ & estimation \\
\hline 341 & $?$ & - & - & $0-5$ & estimation \\
\hline 342 & male & $+0,50$ & 10 & $30-40$ & tooth wear \\
\hline 343 & male? & - & - & $23-x$ & estimation \\
\hline 344 & female & $-0,75$ & 4 & $30-50$ & tooth wear \\
\hline 346 & male & $+1,00$ & 4 & $40-\mathrm{x}$ & tooth wear \\
\hline 347 & female & $-1,38$ & 16 & $30-40$ & tooth wear, cranial sutures \\
\hline 348 & female? & $-0,25$ & 8 & $40-\mathrm{x}$ & tooth wear \\
\hline 350 & female & $-0,66$ & 9 & $23-39$ & tooth wear \\
\hline 351 & female? & - & - & $40-\mathrm{x}$ & tooth wear \\
\hline 352 & ? & - & - & $4-6$ & dentition \\
\hline 353 & male? & $+0,25$ & 8 & $25-35$ & tooth wear, cranial sutures \\
\hline 354 & female & $-1,10$ & 12 & $23-30$ & tooth wear, cranial sutures \\
\hline 355 & male & $+0,50$ & 8 & $23-30$ & tooth wear \\
\hline 356 & male? & - & - & $23-59$ & estimation \\
\hline 357 & female & $-0,66$ & 6 & $25-35$ & tooth wear \\
\hline 358 & male & $+0,69$ & 13 & $40-\mathrm{x}$ & tooth wear, cranial sutures \\
\hline 359 & female & $-1,20$ & 11 & $25-35$ & tooth wear, cranial sutures \\
\hline 360 & $?$ & - & - & $10-12$ & dentition, length of bones \\
\hline 361 & $?$ & - & - & $11-12$ & dentition, length of bones \\
\hline 362 & $?$ & - & - & $?$ & - \\
\hline 363 & $?$ & - & - & $12-14$ & dentition, length of bones \\
\hline 364 & $?$ & - & - & $0-1$ & estimation \\
\hline 365 & male & $+0,14$ & 7 & $40-x$ & tooth wear \\
\hline $366 / \mathrm{A}$ & female & $-1,38$ & 8 & $21-23$ & epiphyseal union \\
\hline $366 / \mathrm{B}$ & male & $+0,92$ & 13 & $40-59$ & tooth wear, cranial sutures \\
\hline
\end{tabular}


Table 2 (cont'd)

\begin{tabular}{|c|c|c|c|c|c|}
\hline Grave & Sex & $\begin{array}{c}\text { Value of } \\
\text { sexualisation }\end{array}$ & $\begin{array}{l}\text { Number of } \\
\text { examined features }\end{array}$ & $\begin{array}{l}\text { Estimated age } \\
\text { (years) }\end{array}$ & Criteria of age estimation \\
\hline 367 & female & $-1,14$ & 7 & $40-50$ & tooth wear \\
\hline 368 & ? & - & - & $6-7$ & dentition \\
\hline 369 & female & $-1,00$ & 5 & $21-23$ & epiphyseal union \\
\hline 370 & female & $-0,43$ & 7 & $30-40$ & tooth wear \\
\hline 371 & ? & - & - & $4-6$ & dentition \\
\hline 372 & female? & - & - & $30-x$ & estimation \\
\hline 373 & ? & - & - & $4-5$ & dentition \\
\hline 374 & male & $+1,00$ & 2 & $23-x$ & estimation \\
\hline 375 & male & $+0,75$ & 4 & $30-40$ & tooth wear \\
\hline 376 & $?$ & - & - & $0-1$ & length of bones \\
\hline 377 & $?$ & - & - & $7-8$ & dentition, length of bones \\
\hline 378 & $?$ & - & - & $10-11$ & dentition, length of bones \\
\hline 379 & $?$ & - & - & $4-5$ & dentition \\
\hline 380 & ? & - & - & $1-7$ & estimation \\
\hline 381 & female & $-1,60$ & 10 & $21-23$ & epiphyseal union \\
\hline 382 & female & $-0,55$ & 9 & $30-40$ & tooth wear, cranial sutures \\
\hline 383 & ? & - & - & $10-12$ & dentition, length of bones \\
\hline 384 & female? & $-0,25$ & 4 & $23-39$ & tooth wear \\
\hline 385 & ? & - & - & $0.5-1$ & length of bones \\
\hline 386 & $?$ & - & - & $?$ & - \\
\hline 387 & $?$ & - & - & $23-x$ & estimation \\
\hline 388/A & male & $+0,66$ & 9 & $30-50$ & tooth wear, cranial sutures \\
\hline 388/B & female & $-1,00$ & 11 & $40-59$ & tooth wear, cranial sutures \\
\hline 389/A & female & $-0,92$ & 12 & $40-59$ & tooth wear \\
\hline 389/B & $?$ & - & - & $13-14$ & dentition \\
\hline 390 & $?$ & - & - & $15-23$ & epiphyseal union \\
\hline 391/A & $?$ & - & - & $2-3$ & dentition \\
\hline $391 / \mathrm{B}$ & $?$ & - & - & $0.5-1$ & dentition \\
\hline $391 / \mathrm{C}$ & $?$ & - & - & $5-6$ & dentition \\
\hline 392 & $?$ & - & - & $23-x$ & estimation \\
\hline 393 & female & $-0,77$ & 13 & $30-40$ & tooth wear \\
\hline 394 & $?$ & - & - & $0,5-1$ & dentition, length of bones \\
\hline 395 & ? & - & - & $4-5$ & dentition \\
\hline $396 / \mathrm{A}$ & female? & $-0,16$ & 12 & $40-x$ & tooth wear \\
\hline $396 / \mathrm{B}$ & male & $+0,54$ & 13 & $40-x$ & tooth wear, cranial sutures \\
\hline 397 & $?$ & - & - & $2.5-3$ & dentition \\
\hline 398 & $?$ & - & - & $?$ & - \\
\hline 399/A & female & $-0,54$ & 13 & $30-40$ & tooth wear, cranial sutures \\
\hline 399/B & $?$ & - & - & $0-1$ & estimation \\
\hline 400 & female? & $-0,33$ & 6 & $30-40$ & tooth wear \\
\hline 401 & male? & $+0,20$ & 10 & $40-50$ & tooth wear, cranial sutures \\
\hline 402 & female & $-0,69$ & 13 & $35-45$ & tooth wear, cranial sutures \\
\hline 403 & female & $-1,10$ & 10 & $40-x$ & tooth wear, cranial sutures \\
\hline 404 & male? & $+0,50$ & 2 & $23-x$ & estimation \\
\hline $405 / \mathrm{A}$ & male & $+0,40$ & 15 & $35-45$ & tooth wear, cranial sutures \\
\hline $405 / \mathrm{B}$ & female & $-1,40$ & 5 & $30-40$ & pubic symphysis \\
\hline 406 & $?$ & - & - & $7-14$ & estimation \\
\hline 407 & juvenis & - & - & $20-23$ & epiphyseal union \\
\hline 408 & ? & - & - & 8-9 & dentition \\
\hline 409 & $?$ & - & - & $13-15$ & dentition, length of bones \\
\hline 410 & male & $+0,50$ & 4 & $40-x$ & tooth wear \\
\hline 411 & male & $+0,66$ & 12 & $40-50$ & $\begin{array}{l}\text { tooth wear, cranial sutures, } \\
\text { pubic symphysis }\end{array}$ \\
\hline 412 & male & $+0,42$ & 12 & $35-45$ & tooth wear, cranial sutures \\
\hline 413 & $?$ & - & - & $1-7$ & estimation \\
\hline
\end{tabular}


Table 2 (cont'd)

\begin{tabular}{|c|c|c|c|c|c|}
\hline Grave & Sex & $\begin{array}{c}\text { Value of } \\
\text { sexualisation }\end{array}$ & $\begin{array}{c}\text { Number of } \\
\text { examined features }\end{array}$ & $\begin{array}{c}\text { Estimated age } \\
\text { (years) }\end{array}$ & Criteria of age estimation \\
\hline 414 & female & $-1,42$ & 7 & $30-40$ & estimation \\
\hline 415 & male? & $+0,16$ & 12 & $40-59$ & tooth wear, cranial sutures \\
\hline 416 & female & $-0,71$ & 14 & $21-23$ & epiphyseal union \\
\hline 417 & $?$ & - & - & $3-4$ & dentition, length of bones \\
\hline 418 & juvenis & $-1,40$ & 7 & $14-16$ & dentition, length of bones \\
\hline 419 & juvenis & $-1,36$ & 11 & $15-16$ & dentition, epiphyseal union \\
\hline 420 & male & $+0,91$ & 11 & $50-\mathrm{x}$ & tooth wear, cranial sutures \\
\hline 421 & $?$ & - & - & $2-3$ & dentition \\
\hline 422 & male & $+0,73$ & 11 & $19-21$ & epiphyseal union \\
\hline 423 & $?$ & - & - & $?$ & - \\
\hline 424 & female & $-0,90$ & 10 & $30-40$ & tooth wear, cranial sutures \\
\hline 425 & $?$ & - & - & $10-11$ & dentition \\
\hline 426 & $?$ & - & - & $8-10$ & dentition, length of bones \\
\hline 427 & $?$ & - & - & $9-10$ & dentition \\
\hline 428 & female & $-0,60$ & 10 & $40-\mathrm{x}$ & tooth wear, cranial sutures \\
\hline 429 & $?$ & - & - & $?$ & - \\
\hline 430 & $?$ & - & - & $?$ & - \\
\hline 432 & $?$ & - & - & $?$ & - \\
\hline 433 & $?$ & - & - & $?$ & - \\
\hline 434 & $?$ & - & - & $23-x$ & estimation \\
\hline 431 & $?$ & - & - & $23-x$ & estimation \\
\hline 435 & $?$ & - & - & $?$ & - \\
\hline 436 & female? & $-1,33$ & 3 & $23-59$ & estimation \\
\hline 437 & $?$ & - & - & $10-12$ & dentition, length of bones \\
\hline 438 & female & $-0,50$ & 12 & $30-40$ & tooth wear, cranial sutures \\
\hline 439 & female? & $-0,33$ & 6 & $35-45$ & tooth wear \\
\hline
\end{tabular}

Table 3. Age and sex distribution of the inbumation burials of the Budakalász cemetery

\begin{tabular}{|l|c|c|c|c|}
\hline Age groups & Indet. & Male & Female & Total \\
\hline 0-1 year & 20 & - & - & $20(5.7 \%)$ \\
\hline Infans I (1-7 years) & 69 & - & - & $69(19.5 \%)$ \\
\hline Infans II (7-14 years) & 48 & - & - & $48(13.6 \%)$ \\
\hline Juvenis (15-23 years) & 14 & 2 & 10 & $26(7.4 \%)$ \\
\hline Juvenis-Adultus & - & - & 2 & $2(0.6 \%)$ \\
\hline Adultus (23-39 years) & 1 & 27 & 46 & $74(21.2 \%)$ \\
\hline Adultus-Maturus & - & 14 & 13 & $27(7.6 \%)$ \\
\hline Maturus (40-59 years) & - & 19 & 21 & $40(11.3 \%)$ \\
\hline Maturus-Senilis & - & 16 & 14 & $30(8.5 \%)$ \\
\hline Senilis (60-x years) & - & - & - & - \\
\hline Adultus-Senilis (23-x years) & 4 & 4 & 6 & $14(4 \%)$ \\
\hline Indet. & 2 & - & - & $2(0.6 \%)$ \\
\hline Total & $158(44.9 \%)$ & $82(23.3 \%)$ & $112(31.8 \%)$ & $352(100 \%)$ \\
\hline
\end{tabular}

Table 4. Age and sex distribution of the cremation burials of the Budakalász cemetery

\begin{tabular}{|l|c|c|c|c|}
\hline Age groups & Indet. & Male & Female & Total \\
\hline Infans I-II (0-14 years) & 5 & - & - & $5(8.9 \%)$ \\
\hline Juvenis (15-23 years) & 1 & - & - & $1(1.8 \%)$ \\
\hline Adultus-Senilis (24-79 years) & 15 & 7 & 15 & $37(66.1 \%)$ \\
\hline Indet. & 13 & - & - & $13(23.2 \%)$ \\
\hline Total & $34(60.7 \%)$ & $7(12.5 \%)$ & $15(26.8 \%)$ & $56(100 \%)$ \\
\hline
\end{tabular}


Table 5. Age and sex distribution of the Budakalasz population

\begin{tabular}{|l|c|c|c|c|}
\hline Age groups & Indet. & Male & Female & Total \\
\hline 0-1 year & 20 & - & - & $20(4.9 \%)$ \\
\hline Infans I (1-7 years) & 71 & - & - & $71(17.4 \%)$ \\
\hline Infans II (7-14 years) & 51 & - & - & $51(12.5 \%)$ \\
\hline Juvenis (15-23 years) & 15 & 2 & 11 & $28(6.9 \%)$ \\
\hline Adultus (23-39 years) & 7 & 37 & 61 & $105(25.7 \%)$ \\
\hline Maturus (40-59 years) & 6 & 37 & 42 & $85(20.8 \%)$ \\
\hline Senilis (60-x years) & 7 & 13 & 13 & $33(8.1 \%)$ \\
\hline Indet. & 15 & - & - & $15(3.7 \%)$ \\
\hline Total & $192(47.1 \%)$ & $89(21.8 \%)$ & $127(31.1 \%)$ & $408(100 \%)$ \\
\hline
\end{tabular}

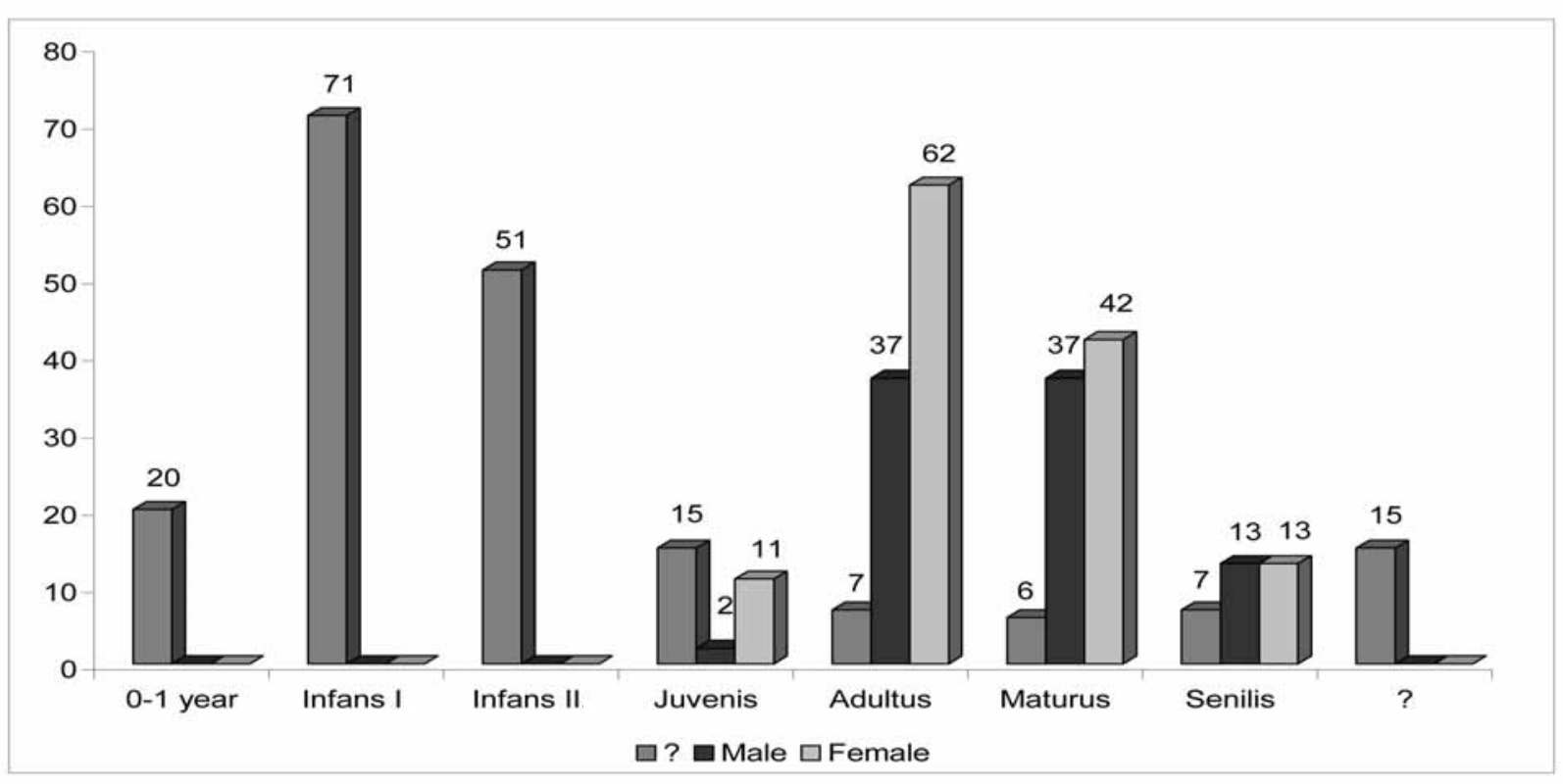

Fig. 2. Age and sex distribution of the Budakalász population

Table 6. Percentage distribution of age groups in the Budakalász population and other prehistoric series

\begin{tabular}{|l|c|c|c|c|c|c|c|c|}
\hline Series & $?$ & Inf. I & Inf. II & Juv. & Ad. & Mat. & Sen. & Literature \\
\hline Bruchstedt (Linear Pottery c.) & - & 14.8 & 18 & 11.5 & 22.9 & 11.5 & 3.3 & BACH 1978 \\
\hline Sondershausen (Linear Pottery c.) & - & 10.6 & 14.9 & 6.4 & 40.5 & 25.5 & 2.1 & BACH 1978 \\
\hline Szegvár-Túzköves (Tisza c.) & 4.8 & 20.6 & 9.5 & 28.6 & 27 & 9.5 & - & FARKAS et al. 1993 \\
\hline Zengóvárkony (Lengyel c.) & - & 4.7 & 1.6 & 5.5 & 24.5 & 48.9 & 14.8 & ZOFFMANN 1969-1970 \\
\hline Mórágy B1 (Lengyel c.) & - & 21.9 & 19.5 & 11 & 11 & 25.6 & 11 & ZOFFMANN 2004d \\
\hline Alsónémedi (Baden c.) & 11.7 & 30.2 & 2.3 & 4.6 & 37.2 & 11.7 & 2.3 & NEMESKÉRI 1951a \\
\hline Balatonószöd (Baden c.) & - & 24.4 & 17.8 & 13.4 & 23.3 & 20 & 1.1 & ZOFFMANN 2004a \\
\hline Budakalász (Baden c.) & 3.7 & 22.3 & 12.5 & 6.9 & 25.7 & 20.8 & 8.1 & present study \\
\hline Budakalász (Baden c.) & - & 21.2 & 11.5 & 15.2 & 32.2 & 15.9 & 4 & LENGYEL 1983 \\
\hline
\end{tabular}

the destruction caused by erosion and later earthmoving operations, later intrusions and/or excavation techniques. ${ }^{56}$ The proportion of the Infans I age group (22.3 per cent) resembles the values from other series. The decreasing mortality rate among the Infans II age

\footnotetext{
56 ÉRY 1967-1968.
}

group (12.5 per cent) is hardly surprising. The mortality of 7-14 years old children decreased in all of the series used in the comparison (Tables 5-6).

The proportion of the juvenile age group (6.9 per cent) shows a decrease compared to the infant age group, a realistic tendency since the lowest mortality rate usually occurs in this group. The mortality rate of 
Table 7. Percentage distribution of neonates in the Budakalász population and other prehistoric series

\begin{tabular}{|l|c|l|}
\hline Series & Frequency & \multicolumn{1}{|c|}{ Literature } \\
\hline Bruchstedt (Linear Pottery c.) & $0 \%$ & BACH 1978 \\
\hline Sondershausen (Linear Pottery c.) & $0 \%$ & BACH 1978 \\
\hline Tiszapolgár-Basatanya (Tiszapolgár c.) & $0 \%$ & KuTZIáN 1963 \\
\hline Tiszapolgár-Basatanya (Bodrogkeresztúr c.) & $0 \%$ & KuTZIáN 1963 \\
\hline Balatonőszöd-Temetói-dúlő (Baden c.) & $4.4 \%$ & ZOFFMANN 2004a \\
\hline Budakalász (Baden c.) & $4.9 \%$ & present study \\
\hline Neolithic series (Great Britain) & $5.4 \%$ & BROTHWELL 1973 \\
\hline Mórágy B1 (Lengyel c.) & $6.1 \%$ & ZOFFMANN 2004d \\
\hline Alsónémedi (Baden c.) & $13.1 \%$ & ACSÁDI-NEMESKÉRI 1970 \\
\hline
\end{tabular}

the adult group too conforms to the pattern noted in other prehistoric series ${ }^{57}$. Mortality rate was highest in the adult group ( 25.7 per cent) and decreased towards the maturus group. The proportion of the maturus group is no more than 20.8 per cent and that of the senilis age group is 8.1 per cent. Mortality rate was higher among females both in the adult and the maturus age group, reflected by their higher proportion among the deceased interred in the cemetery.

We compared the age distribution of the deceased from Budakalász with the series from Alsónémedi and Balatonôszöd, as well as other anthropological samples of the Baden culture (Fig. 3). The expected proportion of children could only be noted in the Balatonôszöd series and was below the expected values in all other cases. The low proportion of the Infans II age group is especially striking in the Alsónémedi series. Mortality was highest among the adult age groups in all series, with a decreasing tendency in the maturus and senilis age groups (except in the Alsónémedi cemetery). The lowest mortality rate could be noted among the juvenis and senilis age group in all the series.

A comparison of the results of the age determination performed using traditional anthropological techniques with those of the serological analyses ${ }^{88}$ indicated that while the proportion of children (Infans I and II) was more or less identical, the proportion of the juvenile age group was twice as high according to Lengyel than the number arrived at using the traditional analytical procedure. Smaller variations can be noted in the mortality rate of the adult age groups too. The serological analyses resulted in a higher adult proportion and lower maturus and senilis ones. The divergence between the two sets of data is not too great. The roughly identical proportion of children confirms the usefulness of both methods, while the variations in the juvenile and adult groups indicate a flaw in one of the analytical procedures. The identification of individuals in the juvenile age group can be performed accurately in the case of well preserved skeletal remains based on

\footnotetext{
57 ACSÁDI-NEMESKÉRI 1970.

58 LENGYEL 1983; Archives of the Hungarian National Museum, inv. no. VII.61/1984.
}

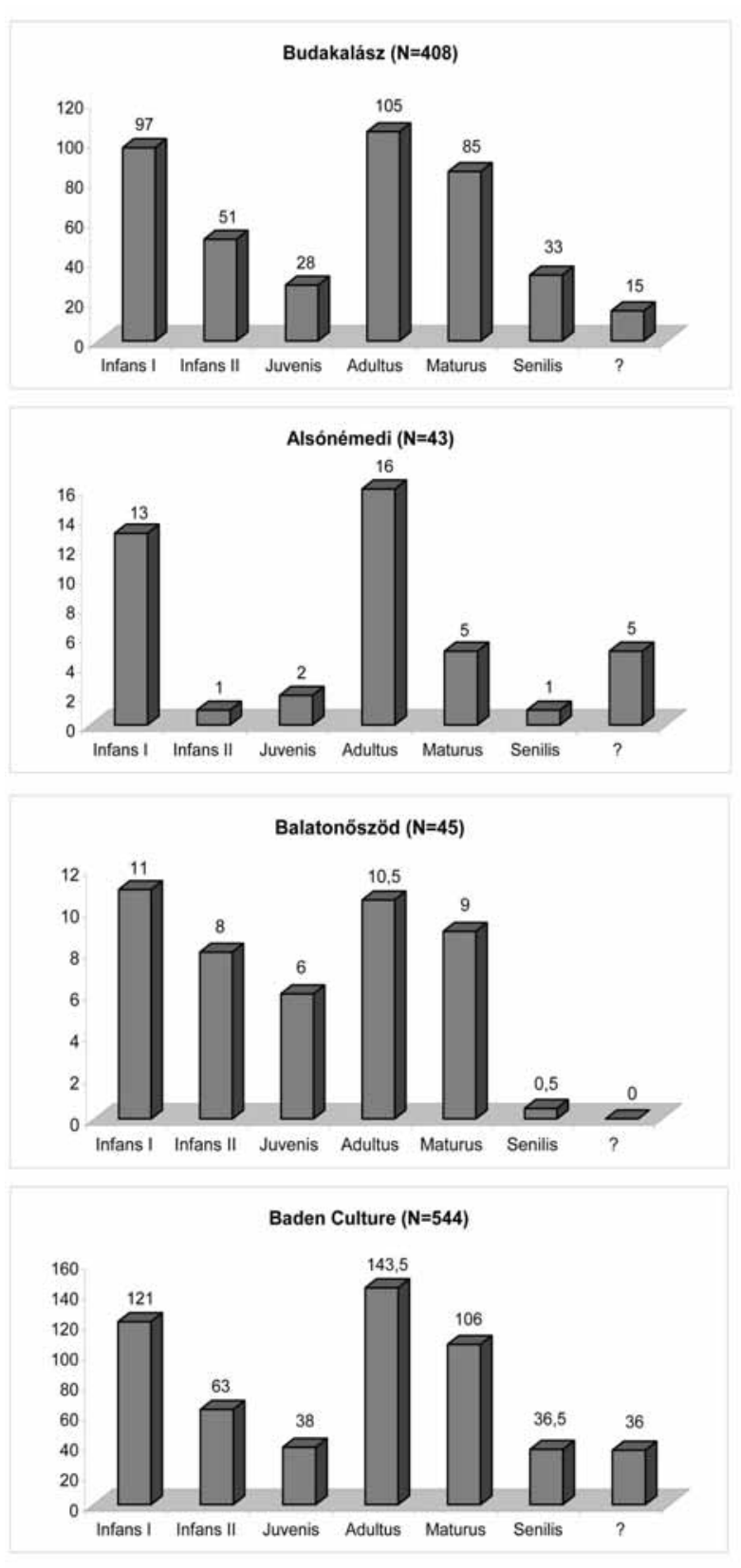

Fig. 3. Age distribution of the Budakalász population and other Baden populations 
Table 8. The male/female proportion and the sexualisation ratio of the Budakalász population and other prehistoric series

\begin{tabular}{|l|c|c|c|c|c|l|}
\hline Series & $?$ & Male & Female & Total & Sex ratio & \multicolumn{1}{l|}{ Literature } \\
\hline Mórágy B1 (Lengyel c.) & 37 & 14 & 31 & 82 & 45,2 & ZOFFMANN 2004d \\
\hline Balatonószöd-Temetói-dúlö (Baden c.) & 23 & 8 & 14 & 45 & 57,1 & ZOFFMANN 2004a \\
\hline Aszód-Papi földek (Lengyel c.) & 78 & 48 & 72 & 204 & 66,7 & ZOFFMANN 1998-1999 \\
\hline Budakalász (Baden c.) & 192 & 89 & 127 & 408 & 70,1 & present study \\
\hline Bruchstedt (Linear Pottery c.) & 10 & 17 & 23 & 61 & 73,9 & BACH 1978 \\
\hline Zengóvárkony (Lengyel c.) & 6 & 25 & 33 & 64 & 75,7 & ZOFFMANN 1969-1970 \\
\hline Sondershausen (Linear Pottery c.) & 12 & 17 & 18 & 47 & 94,4 & BACH 1978 \\
\hline Tiszapolgár-Basatanya (Bodrogkeresztúr c.) & 18 & 37 & 38 & 84 & 97,4 & KUTZIÁN 1963 \\
\hline Szegvár-Túzköves (Tisza c.) & 19 & 29 & 15 & 63 & 193,3 & FARKAS et al. 1993 \\
\hline Alsónémedi (Baden c.) & 19 & 16 & 8 & 43 & 200,0 & NEMESKÉRI 1951a \\
\hline Tiszapolgár-Basatanya (Tiszapolgár c.) & 21 & 25 & 11 & 57 & 227,2 & KUTZIÁN 1963 \\
\hline
\end{tabular}

the epiphyseal union of long bone terminals using the traditional method.

Several graves contained double or triple burials and it therefore seemed instructive to examine the sex and age distribution of these burials separately. The high proportion of children among these burials was obvious according to both the archaeological and anthropological observations. The remains from twenty-three double burials could be examined: in fourteen cases, one of the deceased was a child, who was buried together with another child (Graves 71, 78, 101, 108, 149, 334), a juvenile (Graves 48, 167), an adult woman (Graves 123, $126,389,399)$ or an adult man (Graves 66, 142). The other double burials contained the remains of adults: two men (Grave 153) or a man and a woman (Graves 79, $169,195,263,366,388,396,405)$. The remains from all three burials could only be studied in the case of the three triple burials: one of these contained three child burials (Grave 391), another two children and a juvenile (Grave 182), while the third one the remains of two adult women and one adult man (Grave 215). The ritual pits containing the skeletal remains of several individuals uncovered at Balatonôszöd usually included a child too, suggesting a rite centred on children.59 Any comparison with the Baden series from Balatonôszöd, however, must be treated with caution owing to the ritual nature of the burials uncovered at that site.

In sum, the age distribution of the Budakalász population shows rather balanced age group proportions. The ratio of infants is low, similarly to other prehistoric series. The age group distribution of Infans I and II children and of adults is realistic, conforming to the expected values, according to which mortality was highest among adult age group.

\section{Male-female distribution of the deceased}

The number and proportion of the identifiable males and females interred in the Budakalász cemetery indicates a higher proportion of females both among

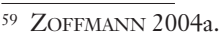

inhumation and cremation burials (127 females, 89 males; Tables 3-5).

Table 8 presents the male/female proportion and the sexualisation ratio $^{60}$ of other prehistoric cemeteries. The higher proportion of females at Budakalász resembles the proportion observed in the Linear Pottery cemetery of Bruchstedt, and the Mórágy and Aszód burials of the Lengyel culture. The male/female proportions vary in the case of the other Baden sites (Fig. 4). A significant lack of males can be noted at Balatonôszöd, 61 while the burials at Alsónémedi included considerably more men. ${ }^{62}$ The overall record for the anthropologically evaluated Late Copper Age burials uncovered in the Carpathian Basin indicated a higher proportion of women.

Several explanations have been proposed for the disproportionate male/female ratios. Even though the Budakalász cemetery has not been completely excavated and it is therefore not known whether the graves beyond the investigated area were male or female burials, it seems unlikely that they had been predominantly male burials. This is also supported by the fact that there were no separate clusters of male or female burials in the excavated area, with the burials of the two sexes occurring side by side. The disproportion may theoretically be caused by flaws in the traditional sexing method. Since, however, the serological analyses too indicated a dominance of women, ${ }^{63}$ it seems likely that this possibility can be excluded. The higher proportion of women may be attributed to the death and burial of several men far from their community, which is usually associated with battles and warfare. The finds of the

\footnotetext{
$\overline{60}$ A sexualisation ratio of $c a .100$ means an equal proportion of males and females. A higher number indicates the dominance of males, a lower one a dominance of females.

61 ZOFFMANN 2004a,

62 NEMESKÉRI 1951a; NEMESKÉRI $1951 \mathrm{~b}$.

63 According to Imre Lengyel, 175 males and 226 females were interred in the Budakalász cemetery. This number includes also children, whose sex he determined (LENGYEL 1975; LENGYEL 1983). The sexing of the skeletal remains using these two methods gave differing results. A correspondence of no more than 68 per cent can be noted in the case of adults, a rather bad ratio. Divergences on a similar scale have been reported in the case of other prehistoric cemeteries too (e.g. Mórágy-Tűzkődomb B1). The reason for these divergences is not known.
} 

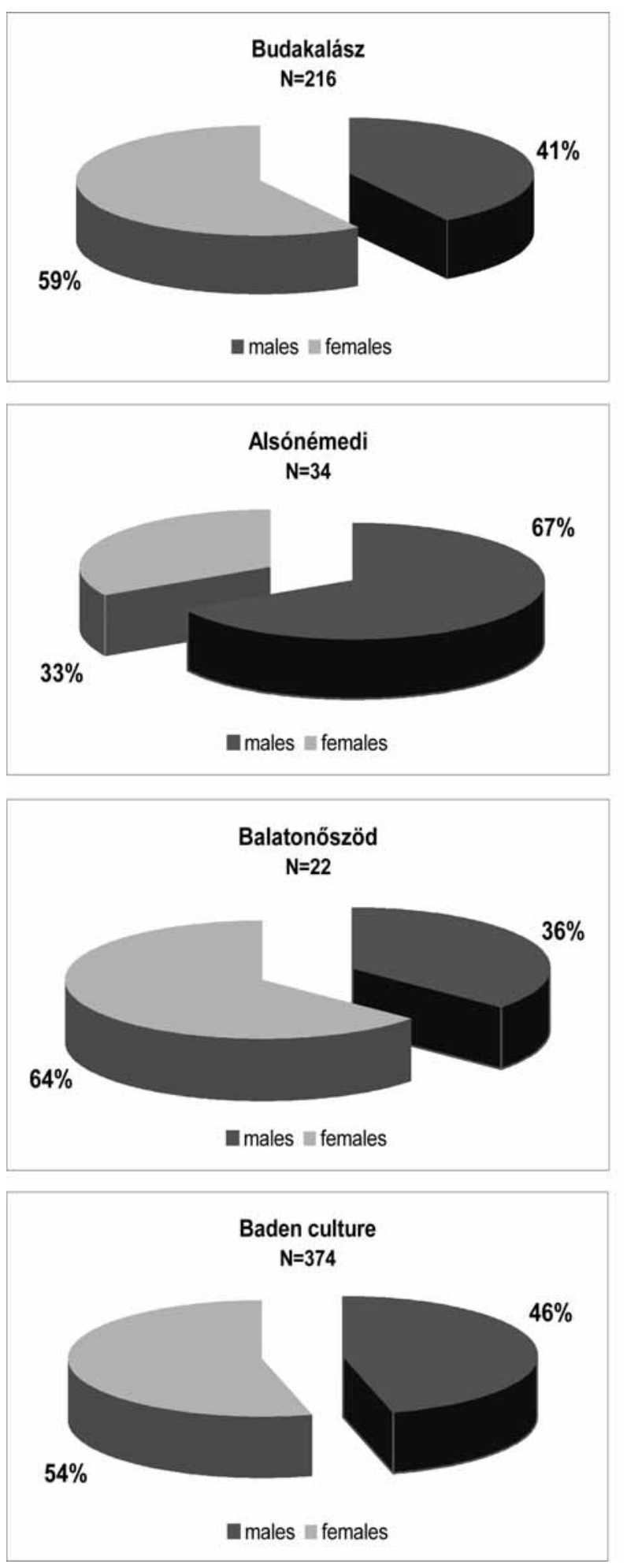

Fig. 4. The male/female proportion of the Budakalász population and other Baden populations

Baden period, however, reflect a long, peaceful development without any indication of major population movements or warfare in the archaeological record. The possible burial of men in a separate location can also be linked to subsistence practices or to mortuary rites, in accordance with which certain men were not interred in the community's burial ground. Neither can the destruction of burials by erosion and modern agricultural cultivation be excluded, although it seems unlikely that these would have primarily destroyed the graves of men, who had stronger and sturdier bones. Polygamy might be another possible reason, supported by ethnographic data, but this can neither be proved, nor disproved using anthropological methods.

In sum, the sex distribution of the deceased in the Budakalász cemetery indicates a higher proportion of females, a not unusual feature compared to other prehistoric cemeteries.

\section{The sexualisation of the Budakalasz population}

Sexing was performed by examining the metric and morphological features of the skull and the post-cranial bones, and then calculating the sexualisation index, the traditional method applied in Hungary. ${ }^{64}$ If the index value fell between +0.40 and -0.40 or if the traits for sexing were non-evaluable, the general morphological features of the bones (gracility/robustness, degree of muscle markings, traces of childbirth on the pelvis) were used for sexing the remains. Owing to their poor state of preservation, the sex of the deceased could often only be determined from the cranial features. The post-cranial bones were for the greater part fragmentary and incomplete, and thus many of the pelvic traits indicating marked sexual dimorphism could not be observed. Of the post-cranial bones, the femur proved to be the most suitable for sexing.

Table 9 and Fig. 5 present the data on the diagnostic sexual features of the Budakalász population. The sexualisation values of males ranges between +1.0 and -0.07 , that of females between -1.45 and -0.33 , both rather broad brackets. The mean sexualisation value is +0.65 for males and -0.99 for females: neither is particularly strong, but they do reflect a definite sexual dimorphism.

The most frequently examinable traits were the glabella, the mastoid processes, the occipital area, the mental eminence, the mandibular angle on the skull, and the caput femoris and the linea aspera on the postcranial bones for both sexes.

Of the individual diagnostic sexing traits, the most masculine ones were the mastoid process $(+0.90)$, the orbita $(+0.77)$, the glabella $(+0.67)$, as well as the zygomatic arch $(+0.67)$ on the skull, while the frontal and the parietal eminence $(-0.07)$ were slightly feminine in nature. The features of the pelvis, the preauricular sulcus $(+1.00)$ and the greater sciatic notch $(+0.73)$, were the most marked in the case of the postcranial bones.

In the case of females, the most diagnostic female characteristics are the external occipital protuberance $(-1.33)$, the squama occipitalis $(-1.03)$, the glabella

\footnotetext{
64 ÉRY et al. 1963.
} 
Table 9. Diagnostic sexual features and their sexualisation index

\begin{tabular}{|c|c|c|c|c|c|}
\hline \multirow[b]{2}{*}{ Sexual traits (Éry et al. 1963) } & \multicolumn{2}{|c|}{ Males } & \multicolumn{2}{|c|}{ Females } & \multirow[t]{2}{*}{ Sex distance } \\
\hline & Mean & $\mathbf{N}$ & Mean & N & \\
\hline \multicolumn{6}{|l|}{ Skull } \\
\hline 1.Tuber frontale et parietale & $-0,07$ & 57 & $-0,71$ & 83 & 0,64 \\
\hline 2. Glabella, arcus superciliaris & $+0,67$ & 66 & $-1,12$ & 92 & 1,79 \\
\hline 3. Processus mastoideus & $+0,90$ & 63 & $-0,61$ & 84 & 1,51 \\
\hline 4. Protuberantia occipitalis externa & $+0,41$ & 66 & $-1,33$ & 89 & 1,74 \\
\hline 5. Planum occipitale & $+0,45$ & 67 & $-1,03$ & 89 & 1,48 \\
\hline 6. Margo supraorbitalis et orbita & $+0,77$ & 31 & $-0,83$ & 24 & 1,60 \\
\hline 7. Arcus zygomaticus & $+0,66$ & 12 & $-0,93$ & 15 & 1,59 \\
\hline 8. Facies zygomaticus & $+0,39$ & 46 & $-0,67$ & 55 & 1,06 \\
\hline 9. Corpus mandibulae & $+0,31$ & 39 & $-0,33$ & 45 & 0,64 \\
\hline 10. Trigonum mentale & $+0,29$ & 62 & $-1,12$ & 74 & 1,41 \\
\hline 11. Angulus mandibulae & $+0,65$ & 57 & $-0,63$ & 67 & 1,28 \\
\hline 12. Caput mandibulae & $+0,39$ & 38 & $-0,46$ & 46 & 0,85 \\
\hline Mean & $+0,48$ & & $-0,81$ & & \\
\hline \multicolumn{6}{|l|}{ Post-cranial bones } \\
\hline 13. Pelvis major & $+2,00$ & 1 & - & - & - \\
\hline 14. Angulus pubis & $+1,00$ & 1 & - & - & - \\
\hline 15. Incisura ischiadica major & $+0,73$ & 22 & $-1,45$ & 29 & 2,18 \\
\hline 16. Sacrum & - & - & $-1,00$ & 2 & - \\
\hline 17. Caput femoris & $+0,62$ & 47 & $-1,35$ & 54 & 1,97 \\
\hline 18. Linea aspera & $+0,55$ & 82 & $-0,96$ & 94 & 1,51 \\
\hline 19. Sulcus praeauricularis & $+1,00$ & 20 & $-1,41$ & 29 & 2,41 \\
\hline Mean & $+0,98$ & & $-1,23$ & & \\
\hline Average sexualization value & $+0,65$ & & $-0,99$ & & 1,64 \\
\hline
\end{tabular}

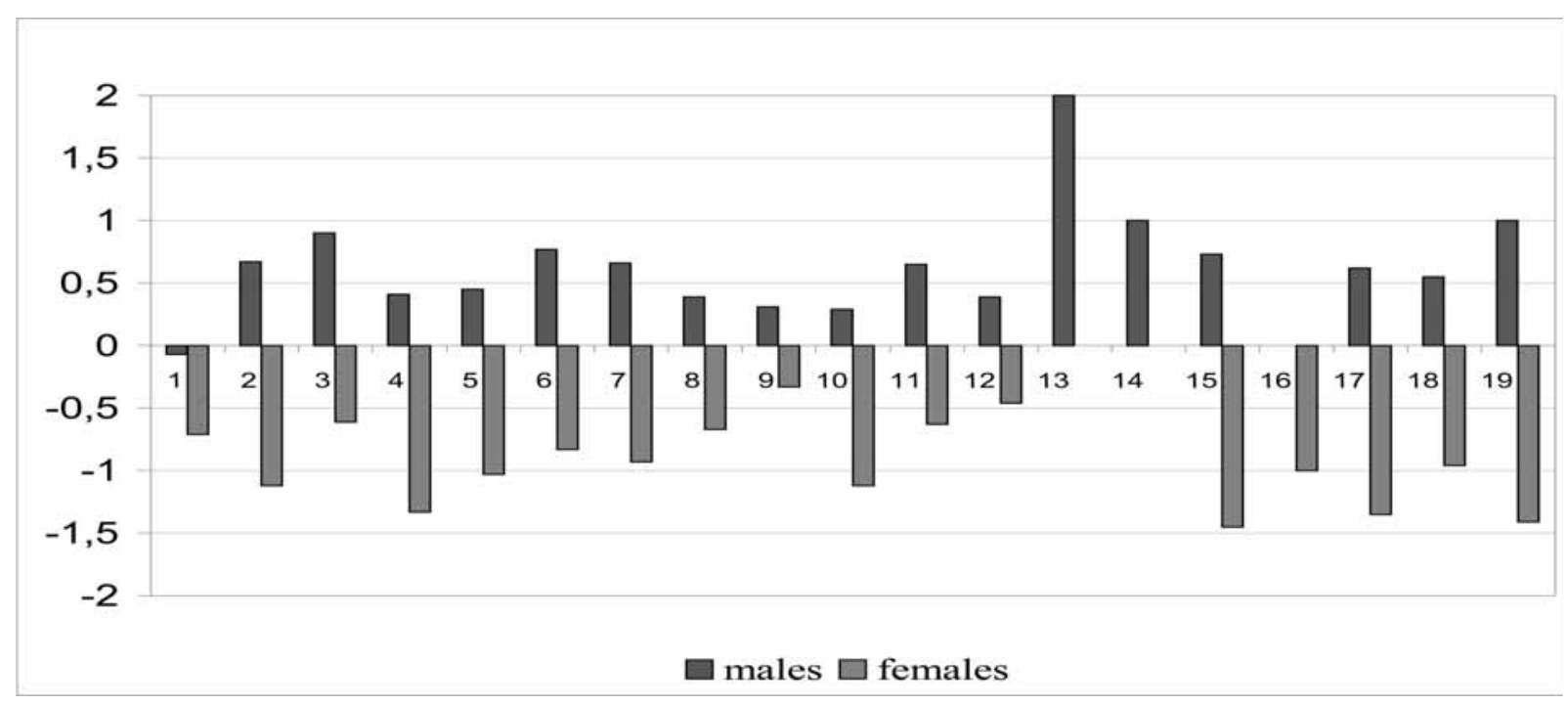

Fig. 5. Diagnostic sexual features of the Budakalasz population

$(-1.12)$, and the body of the mandible $(-1.12)$ on the skull. As regards the post-cranial bones, the female characteristics are best reflected by the pelvic features - the preauricular sulcus $(-1.41)$ and the greater sciatic notch $(-1.45)$ - and the head of the femur $(-1.35)$.

The greatest variation between the two sexes could be noted in the relief of the glabella (1.79) and the external occipital protuberance (1.74) on the skull, and the examinable diagnostic traits of the pelvis - the preauricular sulcus (2.41) and the greater sciatic notch (2.18) - among the post-cranial bones. One single feature of the skull, the frontal and parietal eminence, was feminine for both males and females $(-0.07$ for males and -0.71 for females). The body of the mandible 
was the single feature which gave indifferent values for both sexes ( +0.31 for males and -0.33 for females).

In sum, we may say that the cemetery was characterised by a greater proportion of female diagnostic traits and that the features of the postcranial bones had stronger diagnostic traits both among males and females.

\section{THE METRIC AND MORPHOLOGICAL EVALUATION OF THE FINDS: A TYPOLOGICAL ANALYSIS}

The metric and morphological traits of the skulls and the estimation of the stature enable the typological evaluation of the finds and their comparison, which in turn contributes to the reconstruction of a particular population's taxonomic composition.

Unfortunately, the tabulation of the metric and morphological traits was possible for a smaller portion of the Budakalász skulls owing to their strongly fractured state. Some finds are represented by one or two measurements only. Table 10 presents the individual skull sizes and indices of males and females, Table 11 the parameters of the sizes and indices, Tables 12 and 13 gives the frequency and groupings of the metric data and indices according to Alekseyev and Debetz's classification system. These reveal the following about the Budakalász series.

The values of two most important neurocranium measurements, the greatest length (M1) and the greatest breadth (M8), fall within rather broad ranges; extreme values can be noted among both sexes. Medium long and long neurocraniums are most frequently represented, with some females having an extremely long neurocranium. The greatest skull breadth usually falls into the medium-broad category for both sexes. The length-breadth index calculated from these two measurements $(8: 1)$ generally corresponds to mesocranial values, although the series includes dolicho-hyperdolichocrans and brachycrans too. The two heights (M17 and M20) fall into the medium high and very high values among both males and females. Most fall in the ortho-hypsicranial group in the range indicated by the length-height index values (17:1 to 20:1) and into the metrio-acrocran category as regards the breadth-height index values (17:8 to 20:8). Although the smallest frontal breadth (M9) and the values of the frontoparietal index (9:8) show a broad scatter for both sexes, the dominance of medium broad and metriometopic foreheads is quite clear.

The values of the face breadth (M45) indicate a frequency of narrow and medium narrow types, although individuals with broad faces occur too. The absolute values of the facial and upper facial height (M47 and M48) fall into a broad range, with very low, low and medium sizes having a higher proportion. The facial and the upper facial indexes (47:45 and 48:45) show a strong variation, with values falling between euryprosopic and leptoprosopic types, and hyper- euryene and leptene types. The values of the orbital index (52:51) show a similarly broad scatter, with a higher frequency of chamaeconch and mesoconch types. The values of the nasal index (54:55) indicate that most cases can be assigned to the leptorrhin and mesorrhin category. The palatal index (63:62) could only be determined in two cases owing to the poorly preserved material: these fell into the brachystaphyline and hyperbrachystaphyline category.

The distribution and the frequency of the observed morphological characteristics are presented in Table 14. The form of the brain-case is varied in the vertical view. Ovoid and pentagonoidal forms are the most frequent among both sexes, although the series includes also rhomboid and sphenoid forms typical for the brachyand mesocranic components. Viewed from norma occipitalis, the brain-cases of both sexes are houseshaped and all the skulls are characterised by a curvoccipital nape profile. Variations arising from sexual dimorphism can be noted in the prominence of the glabella and the external occipital protuberance. The glabellar region of males is developed (Broca 3), while those of females is smooth (Broca 1-2). The external occipital protuberance is weakly developed among males (Broca 2), and even less pronounced among females (Broca $0-1$ ).

Owing to the fragmentary state of the facial skeletons, descriptive characteristics could be rarely observed. The orbita of males is angular, while those of females is round. The lower margin of the apertura piriformis has an anthropine form among males and an anthropine form or has a fossa praenasalis among females. The fossa canina of both sexes is usually medium deep or deep. Alveolar prognathism is moderate or does not occur at all.

The individual measurements of the post-cranial bones, the indices and the estimated statures are presented in Table 15. Most long bones were poorly preserved and owing to the lack of the epiphyses, there are very few length data from which the stature of the interred individuals can be calculated using Sjøvold's formula. ${ }^{65}$ Table 16, showing the distribution of stature according to Martin's categories, ${ }^{66}$ revelas that higher and lower statures occur among both males and females. The stature of males shows a proportionate scatter among the different stature categories; in contrast, females included many medium tall and tall individuals. The mean values for both sexes indicate a medium tall stature $(164.2 \mathrm{~cm}$ for males and $156.4 \mathrm{~cm}$ for females).

In his evaluation of the Alsónémedi cemetery, Nemeskéri published the stature data of ten males and two females, calculated according to Hermann Welcker and Léonce Manouvrier's method (although he did not present the data of the long bones). The mean values indicated that both sexes had a small and

\footnotetext{
65 SJøVOLd 1990.

66 Martin-Saller 1957.
} 
Table 10. Individual cranial measurements and indices of males and females

\begin{tabular}{|c|c|c|c|c|c|c|c|c|c|c|}
\hline Grave & $\begin{array}{l}8 \\
0^{7}\end{array}$ & $\begin{array}{l}9 \\
0^{7}\end{array}$ & $\begin{array}{l}20 \\
\sigma^{7}\end{array}$ & $\begin{array}{l}39 \\
\sigma^{7}\end{array}$ & $\begin{array}{l}43 \\
\sigma^{7}\end{array}$ & $\begin{array}{l}52 \\
\sigma^{7}\end{array}$ & $\begin{array}{c}66 / B \\
\sigma^{7}\end{array}$ & $\begin{array}{l}67 \\
\sigma^{7}\end{array}$ & $\begin{array}{c}94 \\
\sigma^{7}\end{array}$ & $\begin{array}{c}112 \\
0^{7}\end{array}$ \\
\hline \multicolumn{11}{|c|}{ Martin No. } \\
\hline 1 & 168 & 194 & 185 & 189 & 181 & 185 & 184 & 185 & 190 & 180 \\
\hline 5 & - & - & - & - & - & - & - & 104 & 106 & - \\
\hline 8 & 144 & (149) & 146 & 146 & 140 & 142 & - & 144 & 150 & 134 \\
\hline 9 & 94 & 100 & 95 & 106 & 94 & 91 & - & 95 & 99 & 98 \\
\hline 10 & 118 & 132 & (124) & 125 & 119 & 123 & - & 122 & 125 & 121 \\
\hline 11 & 133 & - & $(125)$ & 138 & - & - & 115 & 125 & 123 & 115 \\
\hline 12 & 120 & 110 & 114 & 130 & 112 & - & 111 & 82 & (117) & 105 \\
\hline 17 & - & - & - & - & - & - & - & 132 & 145 & - \\
\hline 20 & - & - & - & - & - & - & - & - & 125 & - \\
\hline 23 & 520 & 543 & 530 & 543 & 522 & 522 & - & 533 & 538 & 513 \\
\hline 40 & - & - & - & - & - & - & - & - & 102 & - \\
\hline 43 & 105 & 107 & 102 & 102 & (104) & - & - & - & 109 & 108 \\
\hline 44 & - & - & - & - & - & - & - & - & 98 & - \\
\hline 45 & - & - & - & - & - & - & - & - & (126) & (124) \\
\hline 46 & - & - & - & - & - & - & - & - & 95 & - \\
\hline 47 & - & - & - & - & - & - & - & - & 119 & - \\
\hline 48 & - & - & - & - & - & - & - & - & 68 & - \\
\hline $51 \mathrm{~d}$. & - & - & - & - & - & - & - & - & 39 & - \\
\hline $51 \mathrm{s.}$ & - & - & - & - & - & - & - & - & 40 & - \\
\hline $52 \mathrm{~d}$. & - & - & - & - & - & - & - & - & 31 & - \\
\hline $52 \mathrm{~s}$. & - & - & - & - & - & - & - & - & 31 & - \\
\hline 54 & - & - & - & - & - & - & 24 & - & 22 & - \\
\hline 55 & - & - & - & - & - & - & 55 & - & 51 & - \\
\hline 60 & - & - & - & - & - & - & 59 & - & - & - \\
\hline 61 & - & - & - & - & - & - & 66 & - & 64 & - \\
\hline 62 & - & - & - & - & - & - & 43 & - & - & - \\
\hline 63 & - & - & - & - & - & - & 40 & - & 40 & - \\
\hline 65 & 126 & - & 120 & 132 & - & - & - & 115 & - & 123 \\
\hline 66 & 104 & - & 99 & 112 & - & - & - & 93 & 99 & 103 \\
\hline 68 & 85 & - & 80 & 84 & (74) & - & - & 70 & 78 & 75 \\
\hline 69 & 34 & 35 & 26 & 33 & (28) & - & 31 & 27 & 38 & 29 \\
\hline 70 & 66 & - & 58 & 67 & $(65)$ & - & & 66 & - & 55 \\
\hline 71 & 29 & (33) & 28 & 32 & 26 & - & - & 29 & 35 & $(28)$ \\
\hline 72 & - & - & - & - & - & - & - & - & 94 & - \\
\hline 75 & - & - & - & - & - & - & - & - & - & - \\
\hline $75 / 1$ & - & - & - & - & - & - & - & - & - & - \\
\hline 79 & 115 & - & 120 & 121 & $(120)$ & - & - & 117 & 131 & 130 \\
\hline 38 & - & - & - & - & - & - & - & 1460 & - & - \\
\hline $8: 1$ & 85,7 & 76,8 & 78,9 & 77,2 & 77,3 & 76,8 & - & 77,8 & 78,9 & 74,4 \\
\hline $17: 1$ & - & - & - & - & - & - & - & 71,4 & 76,3 & - \\
\hline $17: 8$ & - & - & - & - & - & - & - & - & 65,8 & - \\
\hline $20: 1$ & - & - & - & - & - & - & - & 91,7 & 96,7 & - \\
\hline $20: 8$ & - & - & - & - & - & - & - & - & 83,3 & - \\
\hline $9: 8$ & 65,3 & 67,1 & 65,1 & 72,6 & 67,1 & 64,1 & - & 66,0 & 66,0 & 73,1 \\
\hline $47: 45$ & - & - & - & - & - & - & - & - & $(94,4)$ & - \\
\hline $48: 45$ & - & - & - & - & - & - & - & - & $(54,0)$ & - \\
\hline $52: 51 \mathrm{~d}$. & - & - & - & - & - & - & - & - & 79,5 & - \\
\hline $52: 51 \mathrm{s.}$ & - & - & - & - & - & - & - & - & 77,5 & - \\
\hline $54: 55$ & - & - & & - & - & - & 43,6 & - & 43,1 & - \\
\hline $61: 60$ & - & - & & - & - & - & 111,9 & - & - & - \\
\hline $63: 62$ & - & - & - & - & - & - & 93,0 & - & - & - \\
\hline
\end{tabular}


Table 10 (cont'd)

\begin{tabular}{|c|c|c|c|c|c|c|c|c|c|c|}
\hline Grave & $\begin{array}{c}117 \\
\sigma^{7}\end{array}$ & $\begin{array}{c}124 \\
\sigma^{7}\end{array}$ & $\begin{array}{c}\text { 142/B } \\
\sigma^{7}\end{array}$ & $\begin{array}{c}\text { 153/A } \\
\sigma^{2}\end{array}$ & $\begin{array}{c}164 \\
\sigma^{7}\end{array}$ & $\begin{array}{c}170 \\
\sigma^{7}\end{array}$ & $\begin{array}{c}173 \\
0^{\prime \prime}\end{array}$ & $\begin{array}{c}203 \\
\sigma^{2}\end{array}$ & $\begin{array}{c}227 \\
\sigma^{7}\end{array}$ & $\begin{array}{c}231 \\
\sigma^{7}\end{array}$ \\
\hline \multicolumn{11}{|c|}{ Martin No. } \\
\hline 1 & 176 & 184 & 178 & 187 & 184 & 184 & 178 & 184 & 185 & 177 \\
\hline 5 & - & - & - & - & - & - & 97 & 112 & 105 & - \\
\hline 8 & 137 & 152 & 135 & 127 & 142 & 144 & 156 & 132 & 143 & 140 \\
\hline 9 & - & 106 & 96 & 95 & (91) & 100 & 93 & 91 & 101 & 95 \\
\hline 10 & - & (128) & $(120)$ & 116 & 118 & 125 & 127 & 115 & 130 & 120 \\
\hline 11 & 114 & 127 & 111 & 105 & - & $(125)$ & 125 & 108 & 118 & - \\
\hline 12 & 113 & 115 & 112 & 108 & 110 & 109 & 114 & 105 & 116 & 117 \\
\hline 17 & - & - & - & - & - & - & - & 145 & 136 & - \\
\hline 20 & - & - & 114 & - & $(122)$ & - & - & - & 118 & - \\
\hline 23 & - & 535 & 505 & 510 & - & 529 & 523 & 508 & 533 & 514 \\
\hline 40 & - & - & - & - & - & - & - & - & 105 & - \\
\hline 43 & - & - & 102 & 100 & - & 106 & 103 & 100 & $(108)$ & - \\
\hline 44 & - & - & - & - & - & - & - & - & $(97)$ & - \\
\hline 45 & - & - & - & - & - & - & - & - & (133) & - \\
\hline 46 & - & - & - & - & 90 & - & - & - & - & - \\
\hline 47 & - & - & - & - & - & - & - & - & $(108)$ & - \\
\hline 48 & - & - & - & - & 72 & - & 80 & - & (66) & - \\
\hline $51 \mathrm{~d}$ & - & - & - & - & - & - & - & - & (39) & - \\
\hline $51 \mathrm{~s}$ & - & - & - & - & - & - & - & - & (40) & - \\
\hline $52 \mathrm{~d}$ & - & - & - & - & - & - & - & - & $(30)$ & - \\
\hline $52 \mathrm{~s}$ & - & - & - & - & - & - & - & - & (30) & - \\
\hline 54 & - & - & - & - & - & - & - & - & $(26)$ & - \\
\hline 55 & - & - & - & - & - & - & - & - & $(45)$ & - \\
\hline 60 & - & - & - & - & - & - & - & - & - & - \\
\hline 61 & - & - & - & - & 61 & - & - & - & - & - \\
\hline 62 & - & - & - & - & - & - & - & - & - & - \\
\hline 63 & - & - & - & - & 36 & - & - & - & - & - \\
\hline 65 & - & - & - & - & - & 119 & - & - & - & - \\
\hline 66 & - & - & - & - & - & 98 & - & 93 & 96 & - \\
\hline 68 & - & - & - & - & - & 71 & - & - & 74 & - \\
\hline 69 & - & - & - & 26 & 34 & 29 & 36 & 33 & 36 & - \\
\hline 70 & - & - & - & - & & 54 & - & - & 59 & - \\
\hline 71 & - & - & - & 28 & 32 & 28 & 34 & 35 & 31 & - \\
\hline 72 & - & - & - & - & - & - & - & - & 97 & - \\
\hline 75 & - & - & - & - & - & - & - & - & 128 & - \\
\hline $75 / 1$ & - & - & - & - & - & - & - & - & & - \\
\hline 79 & - & - & - & - & - & 130 & - & - & 119 & - \\
\hline 38 & - & - & - & - & - & - & - & 1644,8 & 1672,6 & - \\
\hline $8: 1$ & 77,8 & 82,6 & 75,8 & 67,9 & 77,2 & 78,3 & 87,6 & 71,7 & 77,3 & 79,1 \\
\hline $17: 1$ & - & - & - & - & - & - & - & 78,8 & 73,5 & - \\
\hline $17: 8$ & - & - & 64,0 & - & 66,3 & - & - & - & 63,8 & - \\
\hline $20: 1$ & - & - & - & - & - & - & - & 109,8 & 95,1 & - \\
\hline $20: 8$ & - & - & 84,4 & - & 85,9 & - & - & - & 82,5 & - \\
\hline $9: 8$ & - & 69,7 & 71,1 & 74,8 & $(64,1)$ & 69,4 & 59,6 & 68,9 & 70,6 & 67,9 \\
\hline $47: 45$ & - & - & - & - & - & - & - & - & $(81,2)$ & - \\
\hline $48: 45$ & - & - & - & - & - & - & - & - & $(49,6)$ & - \\
\hline $52: 51 \mathrm{~d}$ & - & - & - & - & - & - & - & - & $(76,9)$ & - \\
\hline $52: 51 \mathrm{~s}$ & - & - & - & - & - & - & - & - & $(75,0)$ & - \\
\hline $54: 55$ & - & - & - & - & - & - & - & - & $(57,8)$ & - \\
\hline $61: 60$ & - & - & - & - & - & - & - & - & - & - \\
\hline $63: 62$ & - & - & - & - & - & - & - & - & - & - \\
\hline
\end{tabular}


Table 10 (cont'd)

\begin{tabular}{|c|c|c|c|c|c|c|c|c|c|c|}
\hline Grave & $\begin{array}{c}261 \\
\sigma^{7}\end{array}$ & $\begin{array}{c}263 / \mathrm{A} \\
\sigma^{7}\end{array}$ & $\begin{array}{c}294 \\
\sigma^{7}\end{array}$ & $\begin{array}{c}308 \\
\sigma^{7}\end{array}$ & $\begin{array}{c}319 \\
0^{7}\end{array}$ & $\begin{array}{c}320 \\
0^{\prime \prime}\end{array}$ & $\begin{array}{c}353 \\
\sigma^{7}\end{array}$ & $\begin{array}{c}358 \\
\sigma^{7}\end{array}$ & $\begin{array}{c}366 / B \\
\sigma^{7}\end{array}$ & $\begin{array}{c}388 / A \\
\sigma^{7}\end{array}$ \\
\hline \multicolumn{11}{|c|}{ Martin No. } \\
\hline 1 & 182 & 183 & 177 & 189 & 183 & 188 & 185 & 187 & 182 & 192 \\
\hline 5 & - & - & - & - & - & - & - & - & - & - \\
\hline 8 & $(142)$ & 138 & 140 & 156 & 146 & - & 132 & 142 & 151 & 131 \\
\hline 9 & 97 & 96 & 95 & - & 96 & (97) & 93 & 97 & 96 & - \\
\hline 10 & - & 123 & 121 & (133) & 130 & - & 106 & 125 & 131 & (109) \\
\hline 11 & - & (116) & 120 & - & (120) & - & 117 & 115 & 125 & - \\
\hline 12 & (112) & 108 & 112 & $(122)$ & (112) & 114 & 116 & 114 & 122 & - \\
\hline 17 & - & - & - & - & - & - & - & - & - & - \\
\hline 20 & - & $(117)$ & - & - & 119 & - & - & - & - & - \\
\hline 23 & - & 521 & 510 & $(525)$ & 534 & - & 517 & 538 & 530 & - \\
\hline 40 & - & - & - & - & - & - & - & - & - & - \\
\hline 43 & - & - & 101 & - & 105 & - & - & - & - & - \\
\hline 44 & - & - & (94) & - & 97 & - & - & - & - & - \\
\hline 45 & - & - & - & - & - & - & - & - & - & - \\
\hline 46 & - & - & - & - & 90 & - & - & - & - & - \\
\hline 47 & - & - & $(126)$ & - & (118) & - & - & - & - & - \\
\hline 48 & - & - & - & - & 69 & - & - & - & - & - \\
\hline $51 \mathrm{~d}$. & - & - & - & - & 40 & - & - & - & - & - \\
\hline $51 \mathrm{s.}$ & - & - & (40) & - & 39 & - & - & - & - & - \\
\hline $52 \mathrm{~d}$. & - & - & - & - & 29 & - & - & - & - & - \\
\hline $52 \mathrm{~s}$. & - & - & (33) & - & 29 & - & - & - & - & - \\
\hline 54 & - & - & - & - & 25 & - & - & - & - & - \\
\hline 55 & - & - & - & - & 47 & - & - & - & - & - \\
\hline 60 & - & - & - & - & 60 & - & - & - & - & - \\
\hline 61 & - & - & - & - & 59 & - & - & - & - & - \\
\hline 62 & - & - & - & - & - & - & - & - & - & - \\
\hline 63 & - & - & - & - & 35 & - & - & - & - & - \\
\hline 65 & - & - & - & - & - & - & - & - & - & - \\
\hline 66 & - & - & - & - & - & - & - & - & - & - \\
\hline 68 & - & - & - & - & (79) & - & - & - & - & - \\
\hline 69 & - & - & - & - & 37 & - & - & - & - & - \\
\hline 70 & - & - & - & - & 65 & - & - & - & - & - \\
\hline 71 & - & - & - & - & 32 & - & - & - & - & - \\
\hline 72 & - & - & - & - & - & - & - & - & - & - \\
\hline 75 & - & - & - & - & - & - & - & - & - & - \\
\hline $75 / 1$ & - & - & - & - & - & - & - & - & - & - \\
\hline 79 & - & - & - & - & 125 & - & - & - & - & - \\
\hline 38 & - & - & - & - & - & - & - & - & - & - \\
\hline $8: 1$ & $(78,0)$ & 75,4 & 79,1 & 82,5 & 79,8 & - & 71,4 & 75,9 & 83,0 & 68,2 \\
\hline $17: 1$ & - & - & - & - & - & - & - & - & - & - \\
\hline $17: 8$ & - & $(63,9)$ & - & - & 65,0 & - & - & - & - & - \\
\hline $20: 1$ & - & - & - & - & - & - & - & - & - & - \\
\hline $20: 8$ & - & $(84,8)$ & - & - & 81,5 & - & - & - & - & - \\
\hline $9: 8$ & $(68,3)$ & 69,6 & 67,9 & - & 65,8 & - & 70,5 & 68,3 & 63,6 & - \\
\hline $47: 45$ & - & - & - & - & - & - & - & - & - & - \\
\hline $48: 45$ & - & - & - & - & - & - & - & - & - & - \\
\hline $52: 51 \mathrm{~d}$. & - & & 82,5 & - & 72,5 & - & - & - & - & - \\
\hline $52: 51 \mathrm{~s}$. & - & - & - & - & 74,3 & - & - & - & - & - \\
\hline $54: 55$ & - & & - & - & 53,2 & - & - & - & - & - \\
\hline $61: 60$ & - & - & - & - & 98,3 & - & - & - & - & - \\
\hline $63: 62$ & - & - & - & - & - & - & - & - & - & - \\
\hline
\end{tabular}


Table 10 (cont'd)

\begin{tabular}{|c|c|c|c|c|c|c|c|c|c|c|}
\hline Grave & $\begin{array}{c}396 / B \\
\sigma^{2}\end{array}$ & $\begin{array}{c}411 \\
\sigma^{7}\end{array}$ & $\begin{array}{c}412 \\
0^{7}\end{array}$ & $\begin{array}{c}420 \\
\sigma^{7}\end{array}$ & $\begin{array}{c}422 \\
\sigma^{7}\end{array}$ & $\begin{array}{l}2 \\
\text { Q }\end{array}$ & $\begin{array}{c}23 \\
\bigcirc\end{array}$ & $\begin{array}{c}24 \\
\bigcirc\end{array}$ & $\begin{array}{c}36 \\
\text { Q }\end{array}$ & $\begin{array}{c}46 \\
\bigcirc\end{array}$ \\
\hline \multicolumn{11}{|c|}{ Martin No. } \\
\hline 1 & 188 & 182 & 181 & 186 & 178 & 177 & 165 & 163 & 170 & 177 \\
\hline 5 & - & - & - & - & - & - & - & - & - & - \\
\hline 8 & 142 & 144 & 150 & 142 & 140 & 144 & 137 & 139 & 137 & (142) \\
\hline 9 & 108 & 92 & 96 & 100 & 95 & 95 & - & 90 & - & 99 \\
\hline 10 & 129 & 125 & 102 & 122 & 117 & 121 & (109) & 115 & 122 & 128 \\
\hline 11 & (119) & - & - & 119 & 125 & - & - & - & - & 119 \\
\hline 12 & 114 & 118 & 114 & 114 & 118 & $(115)$ & (103) & - & - & 117 \\
\hline 17 & - & - & - & - & - & - & - & - & - & - \\
\hline 20 & 121 & 122 & 123 & 117 & - & - & - & - & - & - \\
\hline 23 & 541 & 527 & 520 & 531 & 505 & 518 & 477 & 493 & 504 & 515 \\
\hline 40 & - & - & - & - & - & - & - & - & - & - \\
\hline 43 & - & 106 & 101 & 107 & - & - & - & - & - & 103 \\
\hline 44 & - & 98 & 93 & 97 & - & - & - & - & - & - \\
\hline 45 & - & - & $(130)$ & $(124)$ & - & - & - & - & - & - \\
\hline 46 & - & 95 & $(90)$ & $(92)$ & - & - & - & - & - & - \\
\hline 47 & - & - & 113 & (104) & - & - & - & - & - & - \\
\hline 48 & - & 75 & (67) & 63 & - & - & - & - & - & - \\
\hline $51 \mathrm{~d}$. & - & 40 & 39 & 40 & - & - & - & - & - & - \\
\hline $51 \mathrm{s.}$ & - & 40 & 40 & 40 & - & - & - & - & - & - \\
\hline $52 \mathrm{~d}$. & - & 32 & 34 & 28 & - & - & - & - & - & - \\
\hline $52 \mathrm{~s}$. & - & 32 & (35) & 28 & - & - & - & - & - & - \\
\hline 54 & - & 23 & - & 25 & - & - & - & - & - & - \\
\hline 55 & - & 51 & 50 & 51 & - & - & - & - & - & - \\
\hline 60 & - & 61 & - & - & - & - & - & - & - & - \\
\hline 61 & - & - & - & - & - & - & - & - & - & 58 \\
\hline 62 & - & 39 & - & - & - & - & - & - & - & - \\
\hline 63 & - & - & - & - & - & - & - & - & - & 37 \\
\hline 65 & - & - & 121 & - & - & - & - & - & - & - \\
\hline 66 & - & 104 & 104 & - & - & - & - & - & - & 99 \\
\hline 68 & - & - & 76 & - & - & - & - & - & - & 72 \\
\hline 69 & - & 33 & 29 & 25 & - & - & - & - & - & 31 \\
\hline 70 & - & - & 59 & - & - & - & - & - & - & - \\
\hline 71 & - & - & 33 & 31 & - & - & - & - & - & 30 \\
\hline 72 & - & - & - & - & - & - & - & - & - & - \\
\hline 75 & - & - & - & - & - & - & - & - & - & - \\
\hline $75 / 1$ & - & - & - & - & - & - & - & - & - & - \\
\hline 79 & - & - & 122 & - & - & - & - & - & - & 126 \\
\hline 38 & - & - & - & - & - & - & - & - & - & - \\
\hline $8: 1$ & 75,5 & 79,1 & 82,9 & 76,3 & 78,7 & 81,4 & 83,0 & 85,3 & 80,6 & $(80,2)$ \\
\hline $17: 1$ & - & - & - & - & - & - & - & - & - & - \\
\hline $17: 8$ & 64,4 & 67,0 & 68,0 & 62,9 & - & - & - & - & - & - \\
\hline $20: 1$ & - & - & - & - & - & - & - & - & - & - \\
\hline $20: 8$ & 85,2 & 84,7 & 82,0 & 82,4 & - & - & - & - & - & - \\
\hline $9: 8$ & 76,1 & 63,9 & 64,0 & 70,4 & 67,9 & 66,0 & - & 64,7 & - & 69,7 \\
\hline $47: 45$ & - & - & $(86,9)$ & $(83,9)$ & - & - & - & - & - & - \\
\hline $48: 45$ & - & - & $(51,5)$ & $(50,8)$ & - & - & - & - & - & - \\
\hline $52: 51 \mathrm{~d}$. & - & 80,0 & 87,2 & 70,0 & - & - & - & - & - & - \\
\hline $52: 51 \mathrm{~s}$ & - & 80,0 & 87,5 & 70,0 & - & - & - & - & - & - \\
\hline $54: 55$ & - & 45,1 & - & 49,0 & - & - & - & - & - & - \\
\hline $61: 60$ & - & - & - & - & - & - & - & - & - & - \\
\hline $63: 62$ & - & - & - & - & - & - & - & - & - & - \\
\hline
\end{tabular}


Table 10 (cont'd)

\begin{tabular}{|c|c|c|c|c|c|c|c|c|c|c|}
\hline Grave & $\begin{array}{c}58 \\
\text { 운 }\end{array}$ & $\begin{array}{c}65 \\
\text { 운 }\end{array}$ & $\begin{array}{c}73 \\
\text { ㅇ }\end{array}$ & $\begin{array}{c}\text { 79/B } \\
\text { ○ }\end{array}$ & $\begin{array}{c}89 \\
\text { ㅇ }\end{array}$ & $\begin{array}{c}104 \\
\bigcirc\end{array}$ & $\begin{array}{c}115 \\
\bigcirc\end{array}$ & $\begin{array}{c}118 \\
\end{array}$ & $\begin{array}{c}\text { 123/A } \\
\bigcirc\end{array}$ & $\begin{array}{c}126 / A \\
ㅇ\end{array}$ \\
\hline \multicolumn{11}{|c|}{ Martin No. } \\
\hline 1 & 178 & 175 & 172 & 174 & 178 & 172 & 180 & 185 & 176 & 179 \\
\hline 5 & - & - & 95 & - & 95 & 102 & - & - & - & - \\
\hline 8 & (138) & $(140)$ & 133 & 136 & 137 & 137 & 134 & 135 & 141 & 133 \\
\hline 9 & 100 & 93 & 90 & 98 & 87 & 98 & 99 & 98 & 92 & 98 \\
\hline 10 & $(121)$ & 118 & 112 & 122 & 114 & 120 & (119) & 123 & 117 & (114) \\
\hline 11 & - & $(110)$ & $(108)$ & $(116)$ & 113 & 120 & - & 116 & - & $(103)$ \\
\hline 12 & 111 & 109 & 108 & 112 & 104 & 111 & - & 113 & 110 & 104 \\
\hline 17 & - & - & 135 & - & 125 & 139 & - & - & - & - \\
\hline 20 & - & - & - & - & - & 117 & - & 109 & - & - \\
\hline 23 & 513 & 517 & - & 498 & 504 & 498 & - & 520 & 514 & 506 \\
\hline 40 & - & - & 97 & - & 91 & 98 & - & - & - & - \\
\hline 43 & - & 104 & 98 & - & - & 104 & - & 105 & - & - \\
\hline 44 & - & - & - & - & - & 100 & - & 98 & - & - \\
\hline 45 & - & - & - & - & 115 & 127 & - & $(120)$ & - & - \\
\hline 46 & - & - & - & - & 87 & (94) & - & - & - & - \\
\hline 47 & - & - & - & - & - & 118 & - & - & - & - \\
\hline 48 & - & - & - & - & 61 & 70 & - & (69) & - & - \\
\hline $51 \mathrm{~d}$. & - & - & - & - & 38 & 43 & - & 39 & - & - \\
\hline $51 \mathrm{s.}$ & - & - & - & - & - & 42 & - & 40 & - & - \\
\hline $52 \mathrm{~d}$. & - & - & - & - & 34 & 35 & - & 32 & - & - \\
\hline $52 \mathrm{~s}$. & - & - & - & - & - & 35 & - & 32 & - & - \\
\hline 54 & - & - & - & - & 23 & 25 & - & 25 & - & - \\
\hline 55 & - & - & - & - & 47 & 52 & - & (51) & - & - \\
\hline 60 & - & - & - & - & - & 58 & - & - & - & - \\
\hline 61 & - & - & 57 & - & 59 & 63 & - & - & - & - \\
\hline 62 & - & - & - & - & - & 39 & - & - & - & - \\
\hline 63 & - & - & 35 & - & 38 & 40 & - & - & - & - \\
\hline 65 & - & $(113)$ & (97) & - & (106) & 112 & - & - & - & - \\
\hline 66 & 101 & 94 & 82 & - & - & 89 & - & - & - & - \\
\hline 68 & 71 & 76 & 78 & - & - & 81 & - & - & - & - \\
\hline 69 & - & 28 & 37 & - & - & 37 & - & - & - & - \\
\hline 70 & 56 & 55 & 57 & - & - & 55 & - & - & - & - \\
\hline 71 & - & 29 & 34 & - & - & 30 & - & - & - & - \\
\hline 72 & - & - & 95 & - & - & 104 & - & - & - & - \\
\hline 75 & - & - & - & - & - & 122 & - & - & - & - \\
\hline $75 / 1$ & - & - & - & - & - & - & - & - & - & - \\
\hline 79 & - & 117 & 125 & - & - & 130 & - & - & - & - \\
\hline 38 & - & - & 1454,5 & - & 1439,5 & 1524,7 & - & - & - & - \\
\hline $8: 1$ & $(77,5)$ & $(80,0)$ & 77,3 & 78,2 & 77,0 & 79,7 & $74,, 4$ & 73,0 & 80,1 & 74,3 \\
\hline $17: 1$ & - & - & 78,5 & - & 70,2 & 80,8 & - & - & - & - \\
\hline $17: 8$ & - & - & - & - & - & 68,0 & - & 58,9 & - & - \\
\hline $20: 1$ & - & - & 101,5 & - & 91,2 & 101,5 & - & - & - & - \\
\hline $20: 8$ & - & - & - & - & - & 85,4 & - & 80,7 & - & - \\
\hline $9: 8$ & $(72,5)$ & $(66,4)$ & 67,7 & 72,1 & 63,5 & 71,5 & 73,9 & 72,6 & 65,2 & 65,2 \\
\hline $47: 45$ & - & - & - & - & - & 92,9 & - & - & - & - \\
\hline $48: 45$ & - & - & - & - & 53,0 & 55,1 & - & $(57,5)$ & - & - \\
\hline $52: 51 \mathrm{~d}$. & - & - & - & - & 89,5 & 81,4 & - & 82,1 & - & - \\
\hline $52: 51 \mathrm{~s}$. & - & - & - & - & - & 83,3 & - & 80,0 & - & - \\
\hline $54: 55$ & - & - & - & - & 48,9 & 48,1 & - & 49,0 & - & - \\
\hline $61: 60$ & - & - & - & - & - & 108,6 & - & - & - & - \\
\hline $63: 62$ & - & - & - & - & - & 102,6 & - & - & - & - \\
\hline
\end{tabular}


Table 10 (cont'd)

\begin{tabular}{|c|c|c|c|c|c|c|c|c|c|c|}
\hline Grave & $\begin{array}{c}158 \\
\circ\end{array}$ & $\begin{array}{c}188 \\
\bigcirc\end{array}$ & $\begin{array}{c}197 \\
\bigcirc\end{array}$ & $\begin{array}{c}204 \\
\bigcirc\end{array}$ & $\begin{array}{c}209 \\
\text { 인 }\end{array}$ & $\begin{array}{c}215 / \mathrm{C} \\
\circ\end{array}$ & $\begin{array}{c}216 \\
\propto\end{array}$ & $\begin{array}{c}217 \\
\bigcirc\end{array}$ & $\begin{array}{c}\text { 263/B } \\
\circ\end{array}$ & $\begin{array}{c}283 \\
\text { O }\end{array}$ \\
\hline \multicolumn{11}{|c|}{ Martin No. } \\
\hline 1 & 173 & 178 & 190 & 178 & 177 & 179 & 169 & 177 & 184 & 182 \\
\hline 5 & - & - & - & - & - & - & - & - & - & - \\
\hline 8 & 133 & 141 & 134 & 137 & 131 & - & 140 & 130 & 133 & 132 \\
\hline 9 & - & 98 & 91 & 91 & 95 & 94 & - & 92 & 90 & 93 \\
\hline 10 & 121 & (121) & $(116)$ & $(116)$ & 117 & 115 & 123 & 110 & 114 & - \\
\hline 11 & (106) & 117 & - & (114) & 110 & - & 115 & 110 & 104 & - \\
\hline 12 & - & 107 & - & (109) & 107 & $(101)$ & 104 & 108 & 108 & - \\
\hline 17 & - & - & - & - & - & - & - & - & - & - \\
\hline 20 & - & - & - & - & - & - & - & - & - & - \\
\hline 23 & - & 513 & - & 508 & 505 & - & - & 500 & - & - \\
\hline 40 & - & - & - & - & - & - & - & - & - & - \\
\hline 43 & - & 100 & - & - & - & - & - & - & - & - \\
\hline 44 & - & - & - & - & - & - & - & - & - & - \\
\hline 45 & - & - & - & - & - & - & - & - & - & - \\
\hline 46 & - & - & - & - & - & - & - & - & - & - \\
\hline 47 & - & - & - & - & - & - & - & - & - & - \\
\hline 48 & - & - & - & - & - & - & - & - & - & - \\
\hline $51 \mathrm{~d}$. & - & - & - & - & - & - & - & - & - & - \\
\hline $51 \mathrm{s.}$ & - & - & - & - & - & - & - & - & - & - \\
\hline $52 \mathrm{~d}$. & - & - & - & - & - & - & - & - & - & - \\
\hline $52 \mathrm{~s}$. & - & - & - & - & - & - & - & - & - & - \\
\hline 54 & - & - & - & - & - & - & - & - & - & - \\
\hline 55 & - & - & - & - & - & - & - & - & - & - \\
\hline 60 & - & - & - & - & - & - & - & - & - & - \\
\hline 61 & - & - & - & - & - & - & - & - & - & - \\
\hline 62 & - & - & - & - & - & - & - & - & - & - \\
\hline 63 & - & - & - & - & - & - & - & - & - & - \\
\hline 65 & - & 126 & - & - & - & - & - & - & - & - \\
\hline 66 & - & 99 & - & - & - & - & - & - & - & - \\
\hline 68 & - & 74 & - & - & - & - & - & - & - & - \\
\hline 69 & - & $(27)$ & - & - & - & - & - & - & - & - \\
\hline 70 & - & 55 & - & - & - & - & - & - & - & - \\
\hline 71 & - & 31 & - & - & - & - & - & - & - & - \\
\hline 72 & - & - & - & - & - & - & - & - & - & - \\
\hline 75 & - & - & - & - & - & - & - & - & - & - \\
\hline $75 / 1$ & - & - & - & - & - & - & - & - & - & - \\
\hline 79 & - & 132 & - & - & - & - & - & - & - & - \\
\hline 38 & - & - & - & - & - & - & - & - & - & - \\
\hline $8: 1$ & 76,9 & 79,2 & 70,5 & 77,0 & 74,0 & - & 82,8 & 73,4 & 72,3 & 72,5 \\
\hline $17: 1$ & - & - & - & - & - & - & - & - & - & - \\
\hline $17: 8$ & - & - & - & - & - & - & - & - & - & - \\
\hline $20: 1$ & - & - & - & - & - & - & - & - & - & - \\
\hline $20: 8$ & - & - & - & - & - & - & - & - & - & - \\
\hline $9: 8$ & - & 69,5 & 67,9 & 66,4 & 72,5 & - & - & 70,8 & 67,7 & 70,5 \\
\hline $47: 45$ & - & - & - & - & - & - & - & - & - & - \\
\hline $48: 45$ & - & - & - & - & - & - & - & - & - & - \\
\hline $52: 51 \mathrm{~d}$. & - & - & - & - & - & - & - & - & - & - \\
\hline $52: 51 \mathrm{s.}$ & - & - & - & - & - & - & - & - & - & - \\
\hline $54: 55$ & - & - & - & - & - & - & - & - & - & - \\
\hline $61: 60$ & - & - & - & - & - & - & - & - & - & - \\
\hline $63: 62$ & - & - & - & - & - & - & - & - & - & - \\
\hline
\end{tabular}


Table 10 (cont'd)

\begin{tabular}{|c|c|c|c|c|c|c|c|c|c|c|}
\hline Grave & $\begin{array}{c}289 \\
+\end{array}$ & $\begin{array}{c}295 \\
\circ\end{array}$ & $\begin{array}{c}309 \\
+\end{array}$ & $\begin{array}{c}310 \\
\circ\end{array}$ & $\begin{array}{c}316 \\
\circ\end{array}$ & $\begin{array}{c}354 \\
\wp\end{array}$ & $\begin{array}{c}381 \\
\wp\end{array}$ & $\begin{array}{c}382 \\
\circ\end{array}$ & $\begin{array}{c}\text { 396/A? } \\
\text { ㅇ }\end{array}$ & $\begin{array}{c}399 / A \\
\text { ㅇ }\end{array}$ \\
\hline \multicolumn{11}{|c|}{ Martin No. } \\
\hline 1 & 176 & $(182)$ & 178 & 171 & 192 & $(175)$ & 174 & 175 & 184 & 190 \\
\hline 5 & 101 & - & - & - & - & - & - & - & - & - \\
\hline 8 & 129 & 143 & 139 & 137 & $(143)$ & 135 & 131 & 144 & 150 & 138 \\
\hline 9 & $(87)$ & 101 & 92 & 87 & 88 & (94) & 95 & 98 & 102 & 97 \\
\hline 10 & - & 123 & 116 & 118 & - & 119 & $(114)$ & - & 127 & $(116)$ \\
\hline 11 & $(106)$ & 120 & 123 & - & - & 116 & - & - & 131 & - \\
\hline 12 & $(109)$ & 112 & $(109)$ & - & - & 97 & - & - & 120 & (104) \\
\hline 17 & 122 & - & - & - & - & - & - & - & - & - \\
\hline 20 & - & - & 111 & - & - & - & - & - & 125 & - \\
\hline 23 & 497 & 527 & 518 & - & - & - & - & - & - & - \\
\hline 40 & - & - & - & - & - & - & - & - & - & - \\
\hline 43 & - & - & 102 & - & - & - & - & - & - & - \\
\hline 44 & 93 & - & 98 & - & - & - & - & - & - & - \\
\hline 45 & - & - & 130 & - & - & - & - & - & - & - \\
\hline 46 & $(92)$ & - & 91 & - & - & - & - & - & - & - \\
\hline 47 & (111) & - & (108) & - & - & - & - & - & - & - \\
\hline 48 & $(68)$ & - & $(63)$ & - & - & - & - & - & - & - \\
\hline $51 \mathrm{~d}$. & - & - & 40 & - & - & - & - & - & - & - \\
\hline $51 \mathrm{s.}$ & - & - & 39 & - & - & - & - & - & - & - \\
\hline $52 \mathrm{~d}$. & - & - & 32 & - & - & - & - & - & - & - \\
\hline $52 \mathrm{~s}$. & - & - & 32 & - & - & - & - & - & - & - \\
\hline 54 & (24) & - & 22 & - & - & - & - & - & - & - \\
\hline 55 & (53) & - & 47 & - & - & - & - & - & - & - \\
\hline 60 & - & - & - & - & - & - & - & - & - & - \\
\hline 61 & - & - & - & - & - & - & - & - & - & - \\
\hline 62 & - & - & - & - & - & - & - & - & - & - \\
\hline 63 & - & - & - & - & - & - & - & - & - & - \\
\hline 65 & 110 & - & - & - & - & - & - & - & - & - \\
\hline 66 & 90 & - & 88 & - & - & - & - & - & - & - \\
\hline 68 & 73 & - & 73 & - & - & - & - & - & - & - \\
\hline 69 & (27) & - & 29 & - & - & - & - & - & - & - \\
\hline 70 & 50 & - & 56 & - & - & - & & - & - & - \\
\hline 71 & 28 & - & 34 & - & - & - & - & - & - & - \\
\hline 72 & - & - & - & - & - & - & - & - & - & - \\
\hline 75 & - & - & - & - & - & - & - & - & - & - \\
\hline $75 / 1$ & - & - & - & - & - & - & - & - & - & - \\
\hline 79 & 131 & - & 125 & - & - & - & - & - & - & - \\
\hline 38 & 1335,1 & - & - & - & - & - & - & - & - & - \\
\hline $8: 1$ & 73,3 & $(78,6)$ & 78,1 & 80,1 & $(74,5)$ & $(77,1)$ & 75,3 & 82,3 & 81,5 & 72,6 \\
\hline $17: 1$ & 69,3 & - & - & - & - & - & - & - & - & - \\
\hline $17: 8$ & - & - & 62,4 & - & - & - & - & - & 67,9 & - \\
\hline $20: 1$ & 94,6 & - & - & - & - & - & - & - & - & - \\
\hline $20: 8$ & - & - & 79,9 & - & - & - & - & - & 83,3 & - \\
\hline $9: 8$ & $(67,4)$ & 70,6 & 66,2 & 63,5 & $(61,5)$ & $(69,6)$ & 72,5 & 68,1 & 68,0 & 70,3 \\
\hline $47: 45$ & - & - & 83,1 & - & - & - & - & - & - & - \\
\hline $48: 45$ & - & - & 48,5 & - & - & - & - & - & - & - \\
\hline $52: 51 \mathrm{~d}$. & - & - & 80,0 & - & - & - & - & - & - & - \\
\hline $52: 51 \mathrm{s.}$ & - & - & 82,1 & - & - & - & - & - & - & - \\
\hline $54: 55$ & 45,3 & - & 46,8 & - & - & - & - & - & - & - \\
\hline $61: 60$ & - & - & - & - & - & - & - & - & - & - \\
\hline $63: 62$ & - & - & - & - & - & - & - & - & - & - \\
\hline
\end{tabular}


Table 10 (cont'd)

\begin{tabular}{|c|c|c|c|c|}
\hline Grave & $\begin{array}{c}403 \\
\bigcirc\end{array}$ & $\begin{array}{c}416 \\
\bigcirc\end{array}$ & $\begin{array}{c}419 \\
\bigcirc\end{array}$ & $\begin{array}{c}438 \\
\circ\end{array}$ \\
\hline \multicolumn{5}{|c|}{ Martin No. } \\
\hline 1 & 174 & 178 & 172 & 189 \\
\hline 5 & - & 108 & - & - \\
\hline 8 & (134) & 137 & 126 & 132 \\
\hline 9 & $(91)$ & 93 & 94 & 91 \\
\hline 10 & (114) & 120 & 114 & 112 \\
\hline 11 & 115 & 125 & 108 & - \\
\hline 12 & 105 & 107 & 105 & 106 \\
\hline 17 & - & 132 & - & - \\
\hline 20 & 111 & 109 & 110 & - \\
\hline 23 & 498 & 510 & 490 & - \\
\hline 40 & - & 109 & - & - \\
\hline 43 & $(100)$ & 102 & 95 & - \\
\hline 44 & - & 93 & 91 & - \\
\hline 45 & - & 128 & - & - \\
\hline 46 & - & (93) & - & - \\
\hline 47 & - & 106 & - & - \\
\hline 48 & 57 & 58 & - & - \\
\hline $51 \mathrm{~d}$. & - & 39 & 38 & - \\
\hline $51 \mathrm{s.}$ & - & 39 & 38 & - \\
\hline $52 \mathrm{~d}$. & - & 29 & 31 & - \\
\hline $52 \mathrm{~s}$. & - & 28 & 30 & - \\
\hline 54 & 26 & 23 & 20 & - \\
\hline 55 & 46 & 45 & 49 & - \\
\hline 60 & - & - & - & - \\
\hline 61 & - & 61 & - & - \\
\hline 62 & - & - & - & - \\
\hline 63 & - & 34 & - & - \\
\hline 65 & - & - & - & - \\
\hline 66 & - & 95 & - & - \\
\hline 68 & - & 70 & 68 & - \\
\hline 69 & - & $(28)$ & 17 & - \\
\hline 70 & - & 53 & 47 & - \\
\hline 71 & - & 30 & 28 & - \\
\hline 72 & - & - & - & - \\
\hline 75 & - & - & - & - \\
\hline $75 / 1$ & - & - & - & - \\
\hline 79 & - & 123 & 120 & - \\
\hline 38 & - & 1503,5 & - & - \\
\hline $8: 1$ & $(77,0)$ & 77,0 & 73,3 & 69,8 \\
\hline $17: 1$ & - & 74,2 & - & - \\
\hline $17: 8$ & 63,8 & 61,2 & 64,0 & - \\
\hline $20: 1$ & - & 96,4 & - & - \\
\hline $20: 8$ & $(82,8)$ & 79,6 & 87,3 & - \\
\hline $9: 8$ & $(67,9)$ & 67,9 & 74,6 & 68,9 \\
\hline $47: 45$ & - & 82,8 & - & - \\
\hline $48: 45$ & - & 45,3 & - & - \\
\hline $52: 51 \mathrm{~d}$. & - & 74,4 & - & - \\
\hline $52: 51 \mathrm{s.}$ & - & 71,8 & - & - \\
\hline $54: 55$ & 56,5 & 51,1 & - & - \\
\hline $61: 60$ & - & - & - & - \\
\hline $63: 62$ & - & - & - & - \\
\hline
\end{tabular}

medium stature $(162.4 \mathrm{~cm}$ for men and $152.5 \mathrm{~cm}$ for women). ${ }^{67}$ At the same time, he claimed that the stature of the Budakalász population fell into the medium tall category, based on the estimated stature of eight men and seven women (with mean values of $164.7 \mathrm{~cm}$ for men and $153.4 \mathrm{~cm}$ for women). From these two sets of stature data, Nemeskéri characterised the Baden population as being of a medium tall stature. ${ }^{68}$ Zoffmann published the distribution of stature data according to categories of ten men and three women of the Baden-Kostolac-Coţofeni culture: men were dominated by individuals of medium and medium small stature, while women by individuals of medium and medium tall stature. ${ }^{69}$ From her study of the anthropological samples of the Copper Age in the Carpathian Basin (including material from cultures other than the Baden culture), Éry determined the mean stature of men as $165.91 \mathrm{~cm}$ and that of women as $155.49 \mathrm{~cm} .{ }^{70}$ The mean values of the Budakalász population differ little from these data.

The estimated statures, their distribution according to categories and the mean values indicate that the Budakalász population had a medium tall stature on the average. Our findings confirm Nemeskéri's claim that the stature of the Budakalász population was very heterogeneous.

The scatter of the metric and morphological traits too reflects the heterogeneity of the Budakalász series. The fragmentedness of the skeletal remains made the taxonomical analysis of this population rather difficult and a more detailed diagnosis was virtually impossible in most cases. During the examination of the anthropological material, we also had to consider the fact that individual skeletons could rarely be assigned to a particular taxon, the reason for this being the mixing between types from early prehistory onward, which makes taxonomic analysis uncertain. Even so, we could establish that the Budakalász population was dominated by the so-called gracile Mediterranean type characterised by a small or medium small stature, small absolute sizes, a gracile body and a leptodolichocran skull (Pls 1-3). Other types present in the series were the Atlanto-Mediterranean type with a medium tall or tall stature, leptodolichomorphic skull and a moderate cranial relief, and the Alpine type with a medium small stature, a brachymorphic skull and a curvoccipital nape profile (Pls 4-5).

Nemeskéri's supposition that the Baden population is dominated by the dolichocephalic Mediterranean type, the principal type throughout prehistory, seems to be well founded. The proportion of the previously dominant Nordic and Cro-Magnoid component seems to have diminished significantly. In contrast, the proportion of the brachycranial anthropological component increased significantly compared to the preceding Bodrogkeresztúr

\footnotetext{
67 NemESKÉRI $1951 \mathrm{~b}$

68 NEMESKÉRI 1956.

69 ZOFFMANN 1992.

70 ÉRY 1998.
} 
Table 11. Parameters of the cranial measurements and indices

\begin{tabular}{|c|c|c|c|c|c|c|c|c|}
\hline \multirow[b]{2}{*}{ Martin No. } & \multicolumn{4}{|c|}{ Males } & \multicolumn{4}{|c|}{ Females } \\
\hline & N & $V_{\text {min }}-V_{\text {max }}$ & $M$ & s & $\mathrm{N}$ & $V_{\text {min }}-V_{\text {max }}$ & M & s \\
\hline 1 & 35 & $168-194$ & 183,5 & 4,99 & 39 & $163-192$ & 177,4 & 6,31 \\
\hline 5 & 4 & $104-112$ & 106,8 & 3,11 & 5 & $95-108$ & 100,2 & 4,87 \\
\hline 8 & 33 & $127-156$ & 142,4 & 6,8 & 38 & $126-150$ & 136,6 & 4,79 \\
\hline 9 & 31 & $91-108$ & 96,7 & 4,17 & 35 & $87-102$ & 94,0 & 4,10 \\
\hline 10 & 31 & $102-133$ & 122,0 & 7,13 & 35 & $109-128$ & 117,7 & 4,41 \\
\hline 11 & 24 & $105-138$ & 120,1 & 7,33 & 23 & $103-131$ & 114,1 & 6,85 \\
\hline 12 & 33 & $82-130$ & 113,0 & 7,37 & 29 & $97-120$ & 108,1 & 4,70 \\
\hline 17 & 4 & $132-145$ & 139,5 & 5,67 & 5 & $122-139$ & 130,6 & 6,28 \\
\hline 20 & 10 & $114-125$ & 119,8 & 3,18 & 7 & $109-125$ & 113,1 & 5,46 \\
\hline 23 & 29 & $505-543$ & 524,8 & 11,16 & 23 & $477-527$ & 506,2 & 11,21 \\
\hline 40 & - & - & - & - & 4 & $91-109$ & 98,8 & 6,49 \\
\hline 43 & 17 & $100-112$ & 104,9 & 3,33 & 9 & $98-105$ & 102,0 & 2,16 \\
\hline 44 & 7 & $93-98$ & 96,3 & 1,83 & 5 & $93-100$ & 96,4 & 2,87 \\
\hline 45 & 5 & $124-133$ & 127,4 & 3,55 & 5 & $115-130$ & 124,0 & 5,62 \\
\hline 46 & 5 & $90-95$ & 92,4 & 2,24 & 5 & $87-94$ & 91,4 & 2,42 \\
\hline 47 & 6 & $104-126$ & 114,7 & 7,29 & 4 & $106-118$ & 110,8 & 4,54 \\
\hline 48 & 7 & $63-80$ & 69,7 & 5,39 & 7 & $57-70$ & 63,7 & 4,95 \\
\hline 51 & 7 & $39-40$ & 39,6 & 0,49 & 5 & $38-43$ & 39,8 & 1,72 \\
\hline 52 & 7 & $28-34$ & 31,0 & 2,00 & 5 & $29-35$ & 32,4 & 2,06 \\
\hline 54 & 6 & $22-26$ & 24,2 & 1,34 & 7 & $22-26$ & 24,0 & 1,31 \\
\hline 55 & 7 & $45-55$ & 50,0 & 2,98 & 7 & $45-53$ & 48,7 & 2,96 \\
\hline 60 & 3 & 59-61 & 60,0 & 0,82 & - & - & - & - \\
\hline 61 & 4 & 59-66 & 62,5 & 2,69 & 5 & $57-63$ & 59,6 & 2,15 \\
\hline 63 & 4 & $35-40$ & 37,8 & 2,27 & 5 & $34-40$ & 36,8 & 2,13 \\
\hline 65 & 7 & $115-132$ & 122,3 & 5,06 & 6 & $97-126$ & 110,7 & 8,67 \\
\hline 66 & 11 & $93-112$ & 100,5 & 5,38 & 8 & $82-99$ & 92,0 & 5,48 \\
\hline 68 & 11 & $70-85$ & 76,9 & 4,62 & 8 & $70-81$ & 74,6 & 3,31 \\
\hline 69 & 19 & $25-38$ & 31,5 & 3,97 & 8 & $27-37$ & 30,5 & 3,94 \\
\hline 70 & 10 & $54-67$ & 61,4 & 4,67 & 7 & $50-57$ & 54,4 & 2,13 \\
\hline 71 & 17 & $26-35$ & 30,8 & 2,65 & 8 & $28-34$ & 30,8 & 2,05 \\
\hline 72 & 3 & $94-102$ & 97,7 & 3,3 & - & - & - & - \\
\hline 79 & 11 & $115-131$ & 122,7 & 5,25 & 8 & $117-132$ & 126,1 & 4,59 \\
\hline $8: 1$ & 33 & $67,9-87,6$ & 77,7 & 4,16 & 38 & $69,8-85,3$ & 77,1 & 3,69 \\
\hline $17: 1$ & 4 & $71,4-78,8$ & 75,0 & 2,81 & 5 & $69,3-80,8$ & 74,6 & 4,49 \\
\hline $20: 1$ & 10 & $62,9-68,0$ & 65,1 & 1,53 & 7 & $58,9-68,0$ & 63,7 & 3,10 \\
\hline $17: 8$ & 4 & $91,7-110$ & 98,3 & 6,90 & 5 & $91,2-102,0$ & 97,0 & 3,99 \\
\hline $20: 8$ & 10 & $81,5-85,9$ & 83,7 & 1,45 & 7 & $79,6-87,3$ & 82,7 & 2,69 \\
\hline $9: 8$ & 30 & $59,6-76,1$ & 68,0 & 3,56 & 34 & $61,5-74,6$ & 68,9 & 3,18 \\
\hline $47: 45$ & 4 & $81,2-94,4$ & 86,6 & 4,96 & 3 & $82,8-92,9$ & 86,3 & 4,7 \\
\hline $48: 45$ & 4 & $49,6-54,0$ & 51,5 & 1,59 & 5 & $45,3-57,5$ & 51,9 & 4,43 \\
\hline $52: 51$ & 7 & $70,0-87,2$ & 78,4 & 5,41 & 5 & $74,4-89,5$ & 81,5 & 4,84 \\
\hline $54: 55$ & 6 & $43,1-57,8$ & 48,6 & 5,36 & 7 & $45,3-56,5$ & 49,4 & 3,37 \\
\hline
\end{tabular}

period. The proportion of brachycranial individuals was relatively high in the Budakalász cemetery (17 per cent) and even higher at Alsónémedi (25 percent), while it is sporadic in the material from the sites around Lake Balaton (e.g. it was not attested at Balatonószöd). The proportion of this type in the Middle Copper Age was a mere 4 per cent $(\mathrm{N}=28),{ }^{71}$ rising to $15-16$ per cent in the
Baden period $(\mathrm{N}=113) .^{72}$ This suggests a significant change in the Baden culture's anthropological composition or the arrival of a new population to the Carpathian Basin.

The nape profile, showing a curvoccipital or planoccipital form in the lateral view, is an important trait for assigning brachycranial individuals to a particular type. 
Table 12. Frequency and groupings of the cranial metric data according to Alekseyev and Debetz's classification system

\begin{tabular}{|c|c|c|c|c|c|c|c|}
\hline Martin No. & Categories & Males & Females & Males & Females & Total & $\%$ \\
\hline \multirow[t]{6}{*}{1} & very short & $161-171$ & $153-163$ & 1 & 1 & 2 & 2.7 \\
\hline & short & $172-177$ & $164-169$ & 3 & 2 & 5 & 6.7 \\
\hline & medium-long & $178-184$ & $170-175$ & 15 & 12 & 27 & 36.5 \\
\hline & long & $185-190$ & $176-181$ & 14 & 15 & 29 & 39.2 \\
\hline & very long & $191-201$ & $182-192$ & 2 & 9 & 11 & 14.9 \\
\hline & & & Total: & 35 & 39 & 74 & 100 \\
\hline \multirow[t]{6}{*}{8} & very narrow & $125-133$ & $120-128$ & 4 & 1 & 5 & 7 \\
\hline & narrow & $134-138$ & $129-133$ & 4 & 10 & 14 & 19.7 \\
\hline & medium-broad & $139-144$ & $134-139$ & 15 & 17 & 32 & 45.1 \\
\hline & broad & $145-149$ & $140-144$ & 4 & 9 & 13 & 18.3 \\
\hline & very broad & $150-158$ & $145-153$ & 6 & 1 & 7 & 9.9 \\
\hline & & & Total: & 33 & 38 & 71 & 100 \\
\hline \multirow[t]{6}{*}{9} & very narrow & $82-89$ & $79-86$ & - & - & - & - \\
\hline & narrow & $90-93$ & $87-90$ & 6 & 7 & 13 & 19.7 \\
\hline & medium-broad & 94-98 & $91-95$ & 17 & 16 & 33 & 50 \\
\hline & broad & 99-102 & 96-99 & 5 & 9 & 14 & 21.2 \\
\hline & very broad & $103-110$ & $100-107$ & 3 & 3 & 6 & 9.1 \\
\hline & & & Total: & 31 & 35 & 66 & 100 \\
\hline \multirow[t]{6}{*}{17} & very low & $118-126$ & $113-120$ & - & - & - & - \\
\hline & low & $127-131$ & $121-125$ & - & 2 & 2 & 25 \\
\hline & medium-high & $132-136$ & $126-130$ & 2 & - & 2 & 25 \\
\hline & high & $137-141$ & $131-135$ & - & 2 & 2 & 25 \\
\hline & very high & $142-150$ & $136-143$ & 2 & - & 2 & 25 \\
\hline & & & Total: & 4 & 4 & 8 & 100 \\
\hline \multirow[t]{6}{*}{20} & very low & $101-108$ & $97-103$ & - & - & - & - \\
\hline & low & $109-112$ & $104-107$ & - & - & - & - \\
\hline & medium-high & $113-116$ & $108-111$ & 1 & 5 & 6 & 35.3 \\
\hline & high & $117-120$ & $112-115$ & 4 & 1 & 5 & 29.4 \\
\hline & very high & $121-128$ & $116-122$ & 5 & 1 & 6 & 35.3 \\
\hline & & & Total: & 10 & 7 & 17 & 100 \\
\hline \multirow[t]{6}{*}{45} & very narrow & $117-125$ & $109-116$ & 2 & 1 & 3 & 30 \\
\hline & narrow & $126-130$ & $117-121$ & 2 & 1 & 3 & 30 \\
\hline & medium-broad & $131-136$ & $122-127$ & 1 & 1 & 2 & 20 \\
\hline & broad & $137-141$ & $128-132$ & - & 2 & 2 & 20 \\
\hline & very broad & $142-150$ & $133-140$ & - & - & - & - \\
\hline & & & Total: & 5 & 5 & 10 & 100 \\
\hline \multirow[t]{6}{*}{47} & very low & $96-107$ & $88-89-105$ & 1 & - & 1 & 10 \\
\hline & low & $108-114$ & $100-106$ & 2 & 1 & 3 & 30 \\
\hline & medium-high & $115-122$ & $107-113$ & 2 & 2 & 4 & 40 \\
\hline & high & $123-129$ & $114-120$ & 1 & 1 & 2 & 20 \\
\hline & very high & $130-141$ & $121-131$ & - & - & - & - \\
\hline & & & Total: & 6 & 4 & 10 & 100 \\
\hline \multirow[t]{6}{*}{48} & very low & $58-64$ & $54-59$ & 1 & 2 & 3 & 21.4 \\
\hline & low & $65-68$ & $60-63$ & 3 & 2 & 5 & 35.7 \\
\hline & medium-high & $69-73$ & $64-68$ & 1 & 1 & 2 & 14.3 \\
\hline & high & $74-77$ & $69-72$ & 1 & 2 & 3 & 21.4 \\
\hline & very high & $78-84$ & $73-78$ & 1 & - & 1 & 7.2 \\
\hline & & & Total: & 7 & 7 & 14 & 100 \\
\hline \multirow[t]{6}{*}{51} & very narrow & $36-38$ & $34-36$ & - & - & - & - \\
\hline & narrow & $39-40$ & $37-38$ & 7 & 1 & 8 & 66.7 \\
\hline & medium & $41-42$ & $39-40$ & - & 3 & 3 & 25 \\
\hline & broad & $43-44$ & $41-42$ & - & - & - & - \\
\hline & very broad & $45-47$ & $43-45$ & - & 1 & 1 & 8.3 \\
\hline & & & Total: & 7 & 5 & 12 & 100 \\
\hline
\end{tabular}


Table 12 (cont'd)

\begin{tabular}{|l|llc|c|c|c|c|}
\hline Martin No. & Categories & Males & Females & Males & Females & Total & $\%$ \\
\hline 52 & very low & $28-30$ & $28-30$ & 3 & 1 & 4 & 33.3 \\
& low & $31-32$ & $31-32$ & 2 & 2 & 4 & 33.3 \\
& medium & $33-34$ & $33-34$ & 2 & 1 & 3 & 25 \\
& high & $35-36$ & $35-36$ & - & 1 & 1 & 8.4 \\
& very high & $37-39$ & $37-39$ & - & - & - & - \\
\hline & & & Total: & 7 & 5 & 12 & 100 \\
\hline 54 & narrow & $22-23$ & $22-23$ & 2 & 3 & 5 & 38.5 \\
& medium & $24-25$ & $24-25$ & 3 & 3 & 6 & 46.1 \\
& broad & $26-27$ & $26-27$ & 1 & 1 & 2 & 15.4 \\
& very broad & $28-30$ & $28-30$ & - & - & - & - \\
\hline \multirow{2}{*}{55} & & & Total: & 6 & 7 & 13 & 100 \\
& very low & $43-47$ & $40-44$ & 2 & - & 2 & 14.3 \\
& low & $48-50$ & $45-47$ & 1 & 4 & 5 & 35.7 \\
& medium & $51-53$ & $48-50$ & 3 & - & 3 & 21.4 \\
& high & $54-56$ & $51-53$ & 1 & 3 & 4 & 28.6 \\
& very high & $57-61$ & $54-58$ & - & - & - & - \\
\hline & & & Total: & 7 & 7 & 14 & 100 \\
\hline
\end{tabular}

Table 13. Frequency and groupings of the cranial indices according to Alekseyev and Debetz's classification system

\begin{tabular}{|c|c|c|c|c|c|c|c|}
\hline Martin No. & Categories & Males & Females & Males & Females & Total & $\%$ \\
\hline \multirow[t]{6}{*}{$8: 1$} & hyperdolichocran & $67,7-73,2$ & $68,5-74,1$ & 4 & 10 & 14 & 19.7 \\
\hline & dolichocran & $73,3-76,4$ & $74,2-77,3$ & 6 & 11 & 17 & 23.9 \\
\hline & mesocran & $76,5-79,9$ & $77,4-80,8$ & 17 & 11 & 28 & 39.5 \\
\hline & brachycran & $80,0-83,1$ & $80,9-84,0$ & 4 & 5 & 9 & 12.7 \\
\hline & hyperbrachycran & $83,2-88,7$ & $84,1-89,7$ & 2 & 1 & 3 & 4.2 \\
\hline & & & Total: & 33 & 38 & 71 & 100 \\
\hline \multirow[t]{6}{*}{$17: 1$} & hyperchamaecran & $63,8-69,2$ & $63,9-69,4$ & - & 1 & 1 & 11.2 \\
\hline & chamaecran & $69,3-72,3$ & $69,5-72,5$ & 1 & 1 & 2 & 22.2 \\
\hline & orthocran & $72,4-75,6$ & $72,6-75,8$ & 1 & 1 & 2 & 22.2 \\
\hline & hypsicran & $75,7-78,7$ & $75,9-78,9$ & 1 & 1 & 2 & 22.2 \\
\hline & hyperhypsicran & $78,8-84,2$ & $79,0-84,5$ & 1 & 1 & 2 & 22.2 \\
\hline & & & Total: & 4 & 5 & 9 & 100 \\
\hline \multirow[t]{6}{*}{$20: 1$} & hyperchamaecran & $55,0-59,4$ & $55,2-59,6$ & - & 1 & 1 & 5.9 \\
\hline & chamaecran & $59,5-61,8$ & $59,7-62,0$ & - & 1 & 1 & 5.9 \\
\hline & orthocran & $61,9-64,7$ & $62,1-64,9$ & 5 & 3 & 8 & 47.1 \\
\hline & hypsicran & $64,8-67,1$ & $65,0-67,3$ & 4 & - & 4 & 23.5 \\
\hline & hyperhypsicran & $67,2-71,6$ & $67,4-71,8$ & 1 & 2 & 3 & 17.6 \\
\hline & & & Total: & 10 & 7 & 17 & 100 \\
\hline \multirow[t]{7}{*}{$17: 8$} & hypertapeinocran & $80,2-87,9$ & $79,4-87,1$ & - & - & - & - \\
\hline & tapeinocran & $88,0-92,3$ & $87,2-91,4$ & 1 & 1 & 2 & 22.2 \\
\hline & metriocran & $92,4-97,0$ & $91,5-96,1$ & 2 & 1 & 3 & 33.4 \\
\hline & acrocran & $97,1-101,4$ & $96,2-100,4$ & - & 1 & 1 & 11.1 \\
\hline & hyperacrocran & $101,5-109,2$ & $100,5-108,2$ & - & 2 & 2 & 22.2 \\
\hline & h. hyperacrocran & $109,3-\mathrm{x}$ & $108,3-\mathrm{x}$ & 1 & - & 1 & 11.1 \\
\hline & & & Total: & 4 & 5 & 9 & 100 \\
\hline \multirow[t]{6}{*}{$20: 8$} & hypertapeinocran & $70,0-75,8$ & $69,4-75,1$ & - & - & - & - \\
\hline & tapeinocran & $75,9-78,9$ & $75,2-78,2$ & - & - & - & - \\
\hline & metriocran & $79,0-82,8$ & $78,3-82,1$ & 4 & 3 & 7 & 41.2 \\
\hline & acrocran & $82,9-85,9$ & $82,2-85,2$ & 6 & 2 & 8 & 47.1 \\
\hline & hyperacrocran & $79,0-82,8$ & $85,3-91,0$ & - & 2 & 2 & 11.7 \\
\hline & & & Total: & 10 & 7 & 17 & 100 \\
\hline
\end{tabular}


Table 13 (cont'd)

\begin{tabular}{|c|c|c|c|c|c|c|c|}
\hline Martin No. & Categories & Male & Female & Male & Female & Total & $\%$ \\
\hline \multirow[t]{6}{*}{$9: 8$} & hyperstenometop & $57,0-62,7$ & $57,3-63,0$ & 1 & 1 & 2 & 3.1 \\
\hline & stenometop & $62,8-66,0$ & $63,1-66,3$ & 10 & 6 & 16 & 25 \\
\hline & metriometop & $66,1-69,6$ & $66,4-69,9$ & 10 & 14 & 24 & 37.5 \\
\hline & eurymetop & $69,7-72,9$ & $70,0-73,2$ & 6 & 10 & 16 & 25 \\
\hline & hypereurymetop & $73,0-78,7$ & $73,3-79,0$ & 3 & 3 & 6 & 9.4 \\
\hline & & & Total: & 30 & 34 & 64 & 100 \\
\hline \multirow[t]{5}{*}{$47: 45$} & euryprosop & $80,6-85,8$ & $80,2-85,4$ & 2 & 2 & 4 & 57.1 \\
\hline & mesoprosop & $85,9-91,6$ & $85,5-91,1$ & 1 & - & 1 & 14.3 \\
\hline & leptoprosop & $91,7-96,9$ & $91,2-96,4$ & 1 & 1 & 2 & 28.6 \\
\hline & hyperleptoprosop & $97,0-106,2$ & $96,5-105,6$ & - & - & - & - \\
\hline & & & Total: & 4 & 3 & 7 & 100 \\
\hline \multirow[t]{6}{*}{$48: 45$} & hypereuryen & $42,8-48,3$ & $42,6-48,1$ & - & 1 & 1 & 11.1 \\
\hline & euryen & $48,4-51,4$ & $48,2-51,2$ & 2 & 1 & 3 & 33.3 \\
\hline & mesen & $51,5-54,9$ & $51,3-54,7$ & 2 & 1 & 3 & 33.3 \\
\hline & lepten & $55,0-58,0$ & $54,8-57,8$ & - & 2 & 2 & 22.3 \\
\hline & hyperlepten & $58,1-63,6$ & $57,9-63,4$ & - & - & - & - \\
\hline & & & Total: & 4 & 5 & 9 & 100 \\
\hline \multirow[t]{6}{*}{$52: 51$} & hyperchamaeconch & $65,1-73,8$ & $67,4-76,4$ & 2 & 1 & 3 & 25 \\
\hline & chamaeconch & $73,9-78,7$ & $76,5-81,5$ & 1 & 2 & 3 & 25.0 \\
\hline & mesoconch & $78,8-84,3$ & $81,6-87,3$ & 3 & 1 & 4 & 33.3 \\
\hline & hypsiconch & $84,4-89,2$ & $87,4-92,4$ & 1 & 1 & 2 & 16.7 \\
\hline & hyperhypsiconch & $89,3-98,0$ & $92,5-101,5$ & - & - & - & - \\
\hline & & & Total: & 7 & 5 & 12 & 100 \\
\hline \multirow[t]{6}{*}{$54: 55$} & hyperleptorrhin & $35,4-42,5$ & $36,1-43,3$ & - & - & - & - \\
\hline & leptorrhin & $42,6-46,6$ & $43,4-47,5$ & 3 & 2 & 5 & 38.5 \\
\hline & mesorrhin & $46,7-51,1$ & $47,6-52,1$ & 1 & 4 & 5 & 38.5 \\
\hline & chamaerrhin & $51,2-55,2$ & $52,2-56,3$ & 1 & - & 1 & 7.7 \\
\hline & hyperchamaerrhin & $55,3-62,4$ & $56,4-63,6$ & 1 & 1 & 2 & 15.3 \\
\hline & & & Total: & 6 & 7 & 13 & 100 \\
\hline \multirow[t]{5}{*}{$61: 60$} & hyperdolichouranisch & $93,2-105,4$ & $92,6-104,7$ & 1 & - & 1 & 33.3 \\
\hline & dolichouranisch & $105,5-112,7$ & $104,8-112,0$ & 1 & 1 & 2 & 66.7 \\
\hline & mesouranisch & $112,8-120,5$ & $112,1-119,7$ & - & - & - & - \\
\hline & brachyuranisch & $120,6-127,8$ & $119,8-127,0$ & - & - & - & - \\
\hline & & & Total: & 2 & 1 & 3 & 100 \\
\hline \multirow[t]{6}{*}{$63: 62$} & hyperleptostaphylin & $63,4-75,7$ & $63,5-75,8$ & - & - & - & - \\
\hline & leptostaphylin & $75,8-82,6$ & $75,5-82,7$ & - & - & - & - \\
\hline & mesostaphylin & $82,7-90,3$ & $82,8-90,5$ & - & - & - & - \\
\hline & brachystaphylin & $90,4-97,2$ & $90,6-97,4$ & 1 & - & 1 & 50 \\
\hline & hyperbrachystaphylin & $97,3-109,6$ & $97,5-109,8$ & - & 1 & 1 & 50 \\
\hline & & & Total: & 1 & 1 & 2 & 100 \\
\hline
\end{tabular}

Nemeskéri identified four individuals with a planoccipital nape profile at Alsónémedi, but his attribution has been seriously challenged. ${ }^{73}$ The appearance of this type in the Carpathian Basin is generally dated to a later period and associated with the the appearance of the Beaker population in the Early Bronze Age. ${ }^{74}$

In sum, the proportions of the physical anthropological components of the population changed in the Late Copper Age compared to the preceding period,

\footnotetext{
73 Gerhardt 1978; ZoFfmann 1998-1999; ZofFMANN 2001.

74 ZOFFMANN 2001.
}

suggesting the arrival of new population groups to the region.

\section{THE PENROSE DISTANCE ANALYSIS}

In addition to traditional taxonomic analyses, several biostatistical methods are employed to determine the origins of a population and possible relations between various populations. One of these is the Penrose distance analysis, the statistical comparison of the standardised mean size values of skull series. The generalised size and form distance between the analysed skull series is 
Table 14. Distribution and the frequency of the cranial morphological characteristics of the Budakalasz population

\begin{tabular}{|c|c|c|c|c|}
\hline \multicolumn{2}{|l|}{ Morphological traits } & \multirow{2}{*}{$\begin{array}{c}\text { Males } \\
13\end{array}$} & \multirow{2}{*}{$\begin{array}{c}\text { Females } \\
17\end{array}$} & \multirow{2}{*}{$\frac{\text { Total }}{30}$} \\
\hline Norma verticalis & ovoid & & & \\
\hline & pentagonoid & 18 & 24 & 42 \\
\hline & spheroid & 2 & 3 & 5 \\
\hline & sphenoid & 3 & 4 & 7 \\
\hline & ellipsoid & 5 & 2 & 7 \\
\hline & romboid & 3 & 9 & 12 \\
\hline & Total: & 44 & 59 & 103 \\
\hline \multirow[t]{4}{*}{ Norma occipitalis } & bomb shaped & 7 & 11 & 18 \\
\hline & house shaped & 32 & 40 & 72 \\
\hline & tent shaped & 5 & 6 & 11 \\
\hline & Total: & 44 & 57 & 101 \\
\hline \multirow[t]{7}{*}{ Glabella } & Broca 1 & 1 & 25 & 26 \\
\hline & Broca 2 & 9 & 27 & 36 \\
\hline & Broca 3 & 22 & 5 & 27 \\
\hline & Broca 4 & 8 & - & 8 \\
\hline & Broca 5 & 2 & - & 2 \\
\hline & Broca 6 & - & - & - \\
\hline & Total: & 42 & 57 & 99 \\
\hline \multirow{7}{*}{$\begin{array}{l}\text { Protuberantia } \\
\text { occipitalis } \\
\text { externa }\end{array}$} & Broca 0 & 2 & 30 & 32 \\
\hline & Broca 1 & 15 & 25 & 40 \\
\hline & Broca 2 & 22 & 3 & 25 \\
\hline & Broca 3 & 4 & - & 4 \\
\hline & Broca 4 & - & - & - \\
\hline & Broca 5 & - & - & - \\
\hline & Total: & 43 & 58 & 101 \\
\hline \multirow[t]{6}{*}{ Fossa canina } & filled & 1 & - & 1 \\
\hline & shallow & 1 & 3 & 4 \\
\hline & moderate & 8 & 3 & 11 \\
\hline & deep & 5 & 8 & 13 \\
\hline & very deep & 2 & 1 & 3 \\
\hline & Total: & 17 & 15 & 32 \\
\hline \multirow{6}{*}{$\begin{array}{l}\text { Spina nasalis } \\
\text { anterior }\end{array}$} & Broca 1 & - & - & - \\
\hline & Broca 2 & - & 1 & 1 \\
\hline & Broca 3 & 2 & - & 2 \\
\hline & Broca 4 & 2 & 1 & 3 \\
\hline & Broca 5 & - & 1 & 1 \\
\hline & Total: & 4 & 3 & 7 \\
\hline \multirow{4}{*}{$\begin{array}{l}\text { Prognathia } \\
\text { alveolaris }\end{array}$} & absent & 7 & 7 & 14 \\
\hline & mod. prognath & 6 & 6 & 12 \\
\hline & prognath & - & 1 & 1 \\
\hline & Total: & 13 & 14 & 27 \\
\hline \multirow[t]{5}{*}{ Apertura piriformis } & infantil & - & - & - \\
\hline & fossa praenasalis & 5 & 1 & 6 \\
\hline & anthropin & 12 & 13 & 25 \\
\hline & sulcus praenasalis & 2 & 1 & 3 \\
\hline & Total: & 19 & 15 & 34 \\
\hline \multirow[t]{5}{*}{ Profile of occiput } & bathrocran & - & - & - \\
\hline & mod. curvoccipital & 5 & 4 & 9 \\
\hline & curvoccipital & 35 & 51 & 86 \\
\hline & planoccipital & 2 & 1 & 3 \\
\hline & Total: & 42 & 56 & 98 \\
\hline
\end{tabular}


Table 15. Individual measurements of the post-cranial bones, indices and estimated statures of the Budakalász population

\begin{tabular}{|c|c|c|c|c|c|c|c|c|c|c|c|c|c|c|}
\hline \multirow{2}{*}{$\begin{array}{l}\text { Grave } \\
\text { Martin No. }\end{array}$} & \multicolumn{2}{|c|}{$\begin{array}{l}8 \\
0^{7}\end{array}$} & \multicolumn{2}{|c|}{$\begin{array}{l}9 \\
0^{7}\end{array}$} & \multicolumn{2}{|c|}{$\begin{array}{l}67 \\
0^{7}\end{array}$} & \multicolumn{2}{|c|}{$\begin{array}{l}91 \\
0^{7}\end{array}$} & \multicolumn{2}{|c|}{$\begin{array}{l}94 \\
0^{7}\end{array}$} & \multicolumn{2}{|c|}{$\begin{array}{c}153 / \mathrm{A} \\
0^{7}\end{array}$} & \multicolumn{2}{|c|}{$\begin{array}{c}\text { 153/B } \\
\mathrm{O}^{\prime \prime}\end{array}$} \\
\hline & d. & s. & d. & s. & d. & s. & d. & s. & d. & s. & d. & s. & d. & s. \\
\hline \multicolumn{15}{|l|}{ Clavicula: } \\
\hline 1 & (155) & - & - & - & (159) & 160 & - & 145 & - & - & - & - & - & - \\
\hline 6 & 40 & 39 & - & - & 35 & 36 & - & 35 & - & - & - & - & - & - \\
\hline $6: 1$ & $(25,8)$ & - & - & - & $(22,0)$ & 22,5 & - & 24,1 & - & - & - & - & - & - \\
\hline \multicolumn{15}{|l|}{ Humerus: } \\
\hline 1 & - & 296 & 295 & - & - & - & 308 & 305 & - & - & - & - & - & 289 \\
\hline 2 & - & 294 & 291 & - & - & - & 306 & 303 & - & - & - & - & - & 288 \\
\hline 4 & - & 63 & - & 59 & - & 64 & (59) & 59 & 63 & - & - & - & - & 50 \\
\hline 5 & 22 & 21 & 24 & 23 & 21 & 21 & 22 & 21 & 23 & - & - & 21 & - & 21 \\
\hline 6 & 20 & 18 & 18 & 16 & 18 & 18 & 18 & 17 & 20 & - & - & 20 & - & 18 \\
\hline 7 & 65 & 65 & 62 & 60 & 60 & 60 & 61 & 60 & 65 & 66 & - & 60 & - & 61 \\
\hline 10 & - & 44 & - & - & - & - & 45 & 44 & - & - & - & 39 & - & 42 \\
\hline $7: 1$ & - & 22,0 & 21,0 & - & - & - & 19,8 & 19,7 & - & - & - & - & - & 21,1 \\
\hline \multicolumn{15}{|l|}{ Radius: } \\
\hline 1 & - & - & - & - & (236) & - & 239 & (238) & - & - & - & - & - & - \\
\hline 4 & 15 & 17 & 14 & 15 & 15 & - & 16 & 15 & 16 & 16 & - & - & - & - \\
\hline 5 & 11 & 12 & 11 & 12 & 11 & - & 12 & 12 & 11 & 13 & - & - & - & - \\
\hline \multicolumn{15}{|l|}{ Ulna: } \\
\hline 1 & 249 & - & - & - & - & - & - & 262 & - & - & - & - & - & - \\
\hline 11 & 18 & 17 & 17 & 18 & 17 & 18 & 17 & 15 & 15 & 15 & - & - & - & - \\
\hline 12 & 15 & 16 & 16 & 16 & 14 & 14 & 17 & 16 & 18 & 18 & - & - & - & - \\
\hline \multicolumn{15}{|l|}{ Femur: } \\
\hline 1 & - & (440) & - & (426) & (448) & 448 & - & 450 & - & - & 423 & 429 & 404 & 405 \\
\hline 2 & - & (432) & - & (418) & (447) & 447 & - & 442 & - & - & 426 & 427 & 399 & 400 \\
\hline 6 & 27 & 27 & 26 & 26 & 27 & 26 & 30 & 29 & 27 & - & 31 & 30 & 26 & 27 \\
\hline 7 & 25 & 25 & 24 & 25 & 25 & 27 & 28 & 29 & 26 & - & 24 & 25 & 24 & 25 \\
\hline 8 & 85 & 85 & 81 & 83 & 86 & 85 & 90 & 90 & 86 & - & 90 & 87 & 82 & 83 \\
\hline 9 & 32 & 35 & - & 29 & 32 & 34 & 34 & 37 & 33 & 33 & 33 & 33 & 32 & 33 \\
\hline 10 & 23 & 23 & - & 23 & 23 & 23 & 26 & 27 & 24 & 25 & 24 & 25 & 22 & 24 \\
\hline 19 & 46 & - & (43) & (44) & - & 44 & 47 & 47 & 47 & 47 & 45 & (45) & 45 & 44 \\
\hline 21 & - & - & - & - & - & (73) & - & 78 & - & - & - & - & 79 & - \\
\hline $8: 2$ & - & 19,7 & - & 19,9 & $(19,2)$ & 19,0 & - & 20,4 & - & - & 21,1 & 20,4 & 20,6 & 20,8 \\
\hline $6: 7$ & 108,0 & 108,0 & 108,3 & 104,0 & 108,0 & 96,3 & 107,1 & 100,0 & 103,8 & - & 129,2 & 120,0 & 108,3 & 108,0 \\
\hline \multicolumn{15}{|l|}{ Tibia: } \\
\hline 1 & - & 346 & - & - & 358 & 357 & - & - & 374 & 373 & - & - & 342 & 340 \\
\hline $1 \mathrm{~b}$ & - & 348 & - & - & 357 & 356 & - & - & 369 & 372 & - & - & 340 & 338 \\
\hline 3 & - & (71) & - & - & - & 70 & - & (71) & (71) & (71) & - & - & (67) & (68) \\
\hline $8 \mathrm{a}$ & 37 & 35 & - & 36 & 35 & 35 & - & 39 & 35 & 36 & - & 38 & 35 & 36 \\
\hline $9 \mathrm{a}$ & 24 & 22 & - & 25 & 20 & 22 & - & 23 & 24 & 27 & - & 23 & 22 & 21 \\
\hline $10 \mathrm{~b}$ & 75 & 74 & - & - & 75 & 73 & - & 81 & 81 & 82 & - & 72 & 74 & 77 \\
\hline 10b:1 & - & 21,4 & - & - & 20,9 & 20,4 & - & - & 21,7 & 22,0 & - & - & 21,6 & 22,6 \\
\hline \multicolumn{15}{|l|}{ Fibula: } \\
\hline 1. & - & - & - & - & - & - & - & - & - & - & - & - & - & 327 \\
\hline $\begin{array}{l}\text { Stature: } \\
\text { (Sjøvold) }\end{array}$ & \multicolumn{2}{|c|}{160,7} & \multicolumn{2}{|c|}{158,3} & \multicolumn{2}{|c|}{165,7} & \multicolumn{2}{|c|}{163,6} & & & & 1,7 & & 6,7 \\
\hline
\end{tabular}


Table 15 (cont'd)

\begin{tabular}{|c|c|c|c|c|c|c|c|c|c|c|c|c|c|c|}
\hline \multirow{2}{*}{$\begin{array}{l}\text { Grave } \\
\text { Martin No. }\end{array}$} & \multicolumn{2}{|c|}{$\begin{array}{c}194 \\
0^{7}\end{array}$} & \multicolumn{2}{|c|}{$\begin{array}{c}263 / A \\
\sigma^{7}\end{array}$} & \multicolumn{2}{|c|}{$\begin{array}{c}294 \\
\text { రౌ }\end{array}$} & \multicolumn{2}{|c|}{$\begin{array}{c}308 \\
0^{7}\end{array}$} & \multicolumn{2}{|c|}{$\begin{array}{c}319 \\
\text { त̛ }\end{array}$} & \multicolumn{2}{|c|}{$\begin{array}{c}320 \\
\text { तु }\end{array}$} & \multicolumn{2}{|c|}{$\begin{array}{c}325 \\
\sigma^{7}\end{array}$} \\
\hline & d. & s. & d. & S. & d. & S. & d. & s. & d. & s. & d. & s. & d. & s. \\
\hline \multicolumn{15}{|l|}{ Clavicula: } \\
\hline 1 & - & - & - & - & - & - & - & - & - & - & - & - & - & - \\
\hline 6. & - & - & - & - & - & - & - & - & - & - & - & - & - & - \\
\hline $6: 1$ & - & - & - & - & - & - & - & - & - & - & - & - & - & - \\
\hline \multicolumn{15}{|l|}{ Humerus: } \\
\hline 1 & - & 310 & - & - & - & 282 & 325 & - & - & - & - & - & - & - \\
\hline 2 & - & - & - & - & - & 281 & 323 & - & - & - & - & - & - & - \\
\hline 4 & - & - & - & - & 59 & - & 52 & - & - & - & - & - & - & - \\
\hline 5 & 20 & 20 & - & - & 21 & 20 & 21 & 22 & 22 & 22 & 20 & 20 & - & 23 \\
\hline 6 & 16 & 17 & - & - & 19 & 18 & 18 & 18 & 17 & 17 & 16 & 18 & - & 18 \\
\hline 7 & 53 & 55 & - & - & 60 & 56 & 60 & 60 & 65 & 65 & 60 & 61 & - & 65 \\
\hline 10 & - & - & - & - & - & 43 & 44 & - & - & - & - & - & - & - \\
\hline $7: 1$ & - & 17,7 & - & - & - & 19,9 & 18,5 & - & - & - & - & - & - & - \\
\hline \multicolumn{15}{|l|}{ Radius: } \\
\hline 1 & - & - & - & - & - & - & 245 & - & - & - & - & $(242)$ & - & 262 \\
\hline 4 & - & 12 & - & - & - & - & 16 & - & - & - & 15 & 15 & - & 17 \\
\hline 5 & - & 10 & - & - & - & - & 12 & - & - & - & 11 & 12 & - & 13 \\
\hline \multicolumn{15}{|l|}{ Ulna: } \\
\hline 1. & - & - & - & - & - & - & - & - & - & - & $(255)$ & - & - & 285 \\
\hline 11 & - & 14 & - & - & - & - & - & - & - & - & 19 & - & - & 21 \\
\hline 12 & - & 13 & - & - & - & - & - & - & - & - & 17 & - & - & 20 \\
\hline \multicolumn{15}{|l|}{ Femur: } \\
\hline 1 & $(425)$ & 429 & - & 397 & 403 & 405 & 437 & - & 480 & 487 & - & 455 & - & $(489)$ \\
\hline 2 & $(420)$ & 427 & - & 393 & 399 & - & 435 & - & 477 & 482 & - & 448 & - & (489) \\
\hline 6 & 23 & 23 & 25 & 24 & 25 & 25 & 29 & 30 & 29 & 30 & 29 & 27 & 32 & 30 \\
\hline 7 & 28 & 28 & 24 & 24 & 23 & 24 & 28 & 27 & 27 & 27 & 24 & 24 & 31 & 31 \\
\hline 8 & 80 & 82 & 79 & 77 & 77 & 78 & 87 & 90 & 89 & 90 & 84 & 82 & 97 & 95 \\
\hline 9 & 32 & 33 & - & 28 & 28 & 29 & 34 & 35 & 36 & 35 & 32 & 33 & 38 & 40 \\
\hline 10 & 23 & 23 & - & 22 & 22 & 23 & 23 & 24 & 25 & 25 & 22 & 22 & 25 & 24 \\
\hline 19 & 49 & 50 & 44 & 44 & 42 & $(42)$ & 48 & 48 & 49 & 49 & - & $(45)$ & - & 50 \\
\hline 21 & - & - & 71 & 73 & - & - & 81 & 81 & - & $(79)$ & - & - & - & - \\
\hline $8: 2$ & $(19,0)$ & 19,2 & - & 19,6 & 19,3 & - & 20,0 & - & 18,7 & 18,7 & - & 18,3 & - & 19,4 \\
\hline $6: 7$ & 82,1 & 82,1 & 104,2 & 100,0 & 108,7 & 104,2 & 103,6 & 111,1 & 107,4 & 111,1 & 120,8 & 112,5 & 103,2 & 96,8 \\
\hline \multicolumn{15}{|l|}{ Tibia: } \\
\hline 1. & - & - & - & 309 & - & - & 351 & - & - & - & - & - & - & - \\
\hline $1 \mathrm{~b}$ & - & - & - & 300 & - & - & 350 & - & - & - & - & - & - & - \\
\hline 3 & - & - & - & 70 & - & - & 74 & - & - & - & - & - & - & - \\
\hline $8 \mathrm{a}$ & 32 & 32 & - & 34 & - & 33 & 37 & - & - & - & - & - & - & - \\
\hline $9 \mathrm{a}$ & 18 & 17 & - & 21 & - & 22 & 27 & - & - & - & - & - & - & - \\
\hline $10 \mathrm{~b}$ & 71 & 70 & 71 & 70 & - & - & 83 & - & - & - & - & - & - & - \\
\hline 10b: 1 & - & - & - & 22,6 & - & - & 23,6 & - & - & - & - & - & - & - \\
\hline \multicolumn{15}{|l|}{ Fibula: } \\
\hline 1. & - & - & - & - & - & - & - & - & - & - & - & - & - & - \\
\hline $\begin{array}{l}\text { Stature: } \\
\text { (Sjøvold) }\end{array}$ & \multicolumn{2}{|c|}{161,6} & \multicolumn{2}{|c|}{151,2} & \multicolumn{2}{|c|}{153,8} & \multicolumn{2}{|c|}{165,9} & 17 & & & & & \\
\hline
\end{tabular}


Table 15 (cont'd)

\begin{tabular}{|c|c|c|c|c|c|c|c|c|c|c|c|c|c|c|}
\hline \multirow{2}{*}{$\begin{array}{l}\text { Grave } \\
\text { Martin No. }\end{array}$} & \multicolumn{2}{|c|}{$\begin{array}{c}342 \\
0^{7}\end{array}$} & \multicolumn{2}{|c|}{$\begin{array}{c}353 \\
\sigma^{\prime \prime}\end{array}$} & \multicolumn{2}{|c|}{$\begin{array}{c}358 \\
\sigma^{7}\end{array}$} & \multicolumn{2}{|c|}{$\underset{O^{\prime}}{405 / A}$} & \multicolumn{2}{|c|}{$\begin{array}{c}441 \\
0^{7}\end{array}$} & \multicolumn{2}{|c|}{5} & \multicolumn{2}{|c|}{$\begin{array}{l}24 \\
\text { ○ }\end{array}$} \\
\hline & d. & s. & d. & s. & d. & s. & d. & s. & d. & s. & d. & s. & d. & s. \\
\hline \multicolumn{15}{|l|}{ Clavicula: } \\
\hline 1 & - & - & - & - & - & - & - & - & - & - & - & - & - & - \\
\hline 6. & - & - & - & - & - & - & - & - & 40 & 41 & - & - & - & - \\
\hline $6: 1$ & - & - & - & - & - & - & - & - & - & - & - & - & - & - \\
\hline \multicolumn{15}{|l|}{ Humerus: } \\
\hline 1 & - & - & - & - & - & 309 & 326 & - & - & 327 & - & - & - & - \\
\hline 2 & - & - & - & - & - & 305 & 321 & - & - & 325 & - & - & - & - \\
\hline 4 & - & - & - & - & - & - & 54 & 53 & 69 & 68 & 21 & 21 & - & 18 \\
\hline 5 & - & - & - & - & - & 21 & 22 & 22 & 21 & 21 & 16 & 16 & - & 13 \\
\hline 6 & - & - & - & - & - & 17 & 21 & 20 & 17 & 18 & 57 & 57 & - & 48 \\
\hline 7 & - & - & - & - & - & 60 & 62 & 60 & 62 & 61 & - & - & - & - \\
\hline 10 & - & - & - & - & - & (40) & 48 & - & - & 42 & - & - & - & - \\
\hline $7: 1$ & - & - & - & - & - & 19,4 & 19,0 & - & - & 18,7 & - & - & - & - \\
\hline \multicolumn{15}{|l|}{ Radius: } \\
\hline 1 & 248 & - & - & 216 & 250 & - & - & - & $(261)$ & - & - & - & - & (208) \\
\hline 4 & 16 & - & - & 15 & 15 & 14 & 16 & - & 16 & 15 & 13 & - & - & 12 \\
\hline 5 & 12 & - & - & 15 & 12 & 12 & 12 & - & 12 & 12 & 12 & - & - & 9 \\
\hline \multicolumn{15}{|l|}{ Ulna: } \\
\hline 1 & - & - & 227 & - & - & - & - & 270 & $(273)$ & - & - & - & - & - \\
\hline 11 & - & - & 20 & - & 19 & 18 & 16 & 15 & 16 & 16 & - & - & - & 14 \\
\hline 12 & - & - & 15 & - & 16 & 17 & 14 & 13 & 15 & 14 & - & - & - & 12 \\
\hline \multicolumn{15}{|l|}{ Femur: } \\
\hline 1 & - & 457 & - & - & 437 & - & - & 454 & 454 & - & - & 425 & 408 & - \\
\hline 2 & - & 452 & - & - & 434 & - & - & 453 & - & - & - & 423 & 406 & - \\
\hline 6 & 27 & 27 & 26 & 26 & 29 & 28 & 29 & 31 & 28 & 26 & 27 & 26 & 22 & 22 \\
\hline 7 & 25 & 26 & 26 & 26 & 26 & 27 & 28 & 28 & 26 & 26 & 24 & 24 & 21 & 22 \\
\hline 8 & 83 & 85 & 83 & 83 & 97 & 97 & 88 & 92 & 86 & 85 & 80 & 78 & 70 & 70 \\
\hline 9 & 31 & 30 & 34 & 34 & 31 & 30 & 34 & 34 & 31 & 33 & 29 & 31 & 28 & 27 \\
\hline 10 & 25 & 26 & 26 & 25 & 26 & 26 & 27 & 26 & 23 & 24 & 24 & 25 & 18 & 20 \\
\hline 19 & - & 45 & - & - & 45 & - & - & 49 & 47 & 47 & - & (43) & 39 & 39 \\
\hline 21 & 78 & 78 & - & - & - & - & - & 85 & - & - & - & - & 70 & - \\
\hline $8: 2$ & - & 18,8 & - & - & 22,4 & - & - & 20,3 & - & - & - & - & 17,2 & - \\
\hline $6: 7$ & 108,0 & 103,8 & 100,0 & 100,0 & 111,5 & 103,7 & 103,6 & 110,7 & 107,7 & 100,0 & 112,5 & 108,3 & 104,8 & 100,0 \\
\hline \multicolumn{15}{|l|}{ Tibia: } \\
\hline 1 & - & 375 & - & - & - & - & - & - & - & - & - & - & (324) & - \\
\hline $1 \mathrm{~b}$ & - & 371 & - & (321) & - & - & - & - & - & - & - & - & 322 & - \\
\hline 3 & - & 72 & - & - & - & - & - & - & - & - & - & - & - & - \\
\hline $8 a$ & - & 32 & - & 34 & - & - & 37 & 38 & 37 & 37 & 31 & 30 & 29 & 29 \\
\hline $9 \mathrm{a}$ & - & 22 & - & 23 & - & - & 22 & 22 & 20 & 21 & 23 & 23 & 17 & 17 \\
\hline $10 \mathrm{~b}$ & - & 75 & - & 68 & - & - & 73 & 75 & 79 & 79 & 70 & 70 & 62 & 62 \\
\hline 10b:1 & - & 20,0 & - & - & - & - & - & - & - & - & - & - & $(19,1)$ & - \\
\hline \multicolumn{15}{|l|}{ Fibula: } \\
\hline 1. & - & - & - & - & - & - & - & - & - & - & - & - & - & - \\
\hline $\begin{array}{l}\text { Stature: } \\
\text { (Sjфvold) }\end{array}$ & \multicolumn{2}{|c|}{169,3} & \multicolumn{2}{|c|}{156,3} & \multicolumn{2}{|c|}{164,3} & \multicolumn{2}{|c|}{169,3} & & & & 1,0 & & \\
\hline
\end{tabular}


Table 15 (cont'd)

\begin{tabular}{|c|c|c|c|c|c|c|c|c|c|c|c|c|c|c|}
\hline \multirow{2}{*}{$\begin{array}{l}\text { Grave } \\
\text { Martin No. }\end{array}$} & \multicolumn{2}{|c|}{$\begin{array}{l}39 \\
\text { O }\end{array}$} & \multicolumn{2}{|c|}{$\begin{array}{l}46 \\
\text { Q }\end{array}$} & \multicolumn{2}{|c|}{$\begin{array}{c}143 \\
\text { O }\end{array}$} & \multicolumn{2}{|c|}{$\begin{array}{c}197 \\
\text { Ọ }\end{array}$} & \multicolumn{2}{|c|}{$\begin{array}{c}215 / C \\
\stackrel{+}{C}\end{array}$} & \multicolumn{2}{|c|}{ 263/B } & \multicolumn{2}{|c|}{$\begin{array}{c}289 \\
\text { O }\end{array}$} \\
\hline & d. & s. & d. & s. & d. & s. & d. & s. & d. & s. & d. & s. & d. & s. \\
\hline \multicolumn{15}{|l|}{ Clavicula: } \\
\hline 1 & - & - & - & - & - & - & - & - & - & - & - & - & - & - \\
\hline 6 & - & - & - & - & - & - & - & - & - & - & - & - & - & - \\
\hline $6: 1$ & - & - & - & - & - & - & - & - & - & - & - & - & - & - \\
\hline \multicolumn{15}{|l|}{ Humerus: } \\
\hline 1 & 275 & - & - & - & - & - & - & (301) & - & - & - & - & - & 278 \\
\hline 2 & 271 & - & - & - & - & - & - & - & - & - & - & - & - & 275 \\
\hline 4 & - & - & - & - & - & - & - & - & - & - & - & - & - & 52 \\
\hline 5 & 22 & - & - & - & - & - & 20 & 21 & - & - & 20 & - & 21 & 20 \\
\hline 6 & 17 & - & - & - & - & - & 17 & 18 & - & - & 16 & - & 15 & 16 \\
\hline 7 & 62 & - & - & - & - & - & 57 & 58 & - & - & 54 & 53 & 56 & 55 \\
\hline 10 & - & - & - & - & - & - & - & - & - & - & - & - & - & (36) \\
\hline $7: 1$ & 22,5 & - & - & - & - & - & - & - & - & - & - & - & - & 19,8 \\
\hline \multicolumn{15}{|l|}{ Radius: } \\
\hline 1 & - & - & $(221)$ & - & - & - & - & 241 & 230 & - & - & - & - & $(221)$ \\
\hline 4 & - & - & 16 & 14 & - & - & - & 13 & 14 & 14 & - & 14 & - & 14 \\
\hline 5 & - & - & 11 & 10 & - & - & - & 12 & 11 & 11 & - & 10 & - & 11 \\
\hline \multicolumn{15}{|l|}{ Ulna: } \\
\hline 1 & - & - & $(253)$ & - & - & - & 259 & 261 & - & - & - & - & - & (240) \\
\hline 11 & - & - & 17 & - & - & - & 17 & 16 & - & 17 & - & 18 & - & 15 \\
\hline 12 & - & - & 16 & - & - & - & 14 & 12 & - & 16 & - & 13 & - & 13 \\
\hline \multicolumn{15}{|l|}{ Femur: } \\
\hline 1 & 437 & - & 433 & - & - & $(360)$ & $(424)$ & - & - & $(433)$ & 404 & - & 405 & - \\
\hline 2 & 435 & - & 431 & - & - & $(359)$ & $(423)$ & - & - & $(430)$ & 402 & - & $(400)$ & - \\
\hline 6 & 29 & - & 25 & 24 & 25 & 27 & 27 & 28 & - & 25 & 25 & 24 & 25 & 25 \\
\hline 7 & 30 & - & 25 & 25 & 23 & 24 & 27 & 27 & - & 21 & 24 & 25 & 22 & 22 \\
\hline 8 & 92 & - & 80 & 79 & 72 & 78 & 82 & 83 & - & 78 & 76 & 76 & 74 & 74 \\
\hline 9 & 37 & - & 32 & 33 & 27 & 28 & 32 & 32 & - & 27 & 29 & 30 & 26 & 25 \\
\hline 10 & 27 & - & 22 & 23 & 21 & 23 & 23 & 23 & - & 21 & 21 & 21 & 22 & 22 \\
\hline 19 & 48 & - & (44) & 44 & - & - & 43 & 43 & - & (44) & 41 & 41 & 37 & 36 \\
\hline 21 & 81 & - & - & - & - & - & - & - & - & - & - & - & - & - \\
\hline $8: 2$ & 21,1 & - & 18,6 & - & - & $(21,7)$ & 19,4 & - & - & 18,1 & 18,9 & - & $(18,5)$ & - \\
\hline $6: 7$ & 96,7 & - & 100,0 & 96,0 & 108,7 & 112,5 & 100,0 & 103,7 & - & 119,0 & 104,2 & 96,0 & 113,6 & 113,6 \\
\hline \multicolumn{15}{|l|}{ Tibia: } \\
\hline 1 & - & - & - & - & 293 & - & - & & - & - & 345 & - & - & (324) \\
\hline $1 \mathrm{~b}$ & - & - & - & 349 & 294 & - & - & & - & - & 346 & - & - & (326) \\
\hline 3 & - & - & - & - & $(58)$ & - & - & & - & - & - & - & - & - \\
\hline $8 \mathrm{a}$ & - & - & 35 & 35 & 28 & - & - & & 32 & 33 & 31 & 31 & - & 30 \\
\hline $9 \mathrm{a}$ & - & - & 21 & 21 & 17 & - & - & & 22 & 21 & 19 & 19 & - & 21 \\
\hline $10 \mathrm{~b}$ & - & - & 73 & 75 & 62 & - & 73 & & 67 & 63 & 64 & 65 & - & 62 \\
\hline 10b:1 & - & - & - & - & 21,2 & - & - & & - & - & 18,6 & - & - & $(19,1)$ \\
\hline \multicolumn{15}{|l|}{ Fibula: } \\
\hline 1. & - & - & - & - & - & - & - & & - & - & - & - & - & - \\
\hline $\begin{array}{l}\text { Stature: } \\
\text { (Sjøvold) }\end{array}$ & \multicolumn{2}{|c|}{155,2} & \multicolumn{2}{|c|}{160,7} & \multicolumn{2}{|c|}{143,6} & \multicolumn{2}{|c|}{161,3} & & & & & & 4,4 \\
\hline
\end{tabular}


Table 15 (cont'd)

\begin{tabular}{|c|c|c|c|c|c|c|c|c|}
\hline \multirow{2}{*}{$\begin{array}{l}\text { Grave } \\
\text { Martin No. }\end{array}$} & \multicolumn{2}{|c|}{$\begin{array}{c}350 \\
\text { O }\end{array}$} & \multicolumn{2}{|c|}{$\begin{array}{c}\text { 405/B } \\
\text { P }\end{array}$} & \multicolumn{2}{|c|}{$\begin{array}{c}1416 \\
\stackrel{+}{+}\end{array}$} & \multicolumn{2}{|c|}{$\begin{array}{c}439 \\
\text { O }\end{array}$} \\
\hline & d. & s. & d. & s. & d. & s. & d. & s. \\
\hline \multicolumn{9}{|l|}{ Clavicula: } \\
\hline 1 & - & - & - & - & - & $(141)$ & - & - \\
\hline 6 & - & - & - & - & 32 & 32 & 28 & 28 \\
\hline $6: 1$ & - & - & - & - & - & $(22,7)$ & - & - \\
\hline \multicolumn{9}{|l|}{ Humerus: } \\
\hline 1 & - & - & 291 & - & - & - & - & 279 \\
\hline 2 & - & - & 288 & - & - & - & - & 275 \\
\hline 4 & - & - & 53 & - & - & - & - & 58 \\
\hline 5 & - & - & 20 & - & - & 29 & - & 20 \\
\hline 6 & - & - & 15 & - & - & 16 & - & 16 \\
\hline 7 & - & - & 53 & - & - & 53 & - & 53 \\
\hline 10 & - & - & 40 & - & - & - & - & 19,0 \\
\hline $7: 1$ & - & - & 18,2 & - & - & - & - & - \\
\hline \multicolumn{9}{|l|}{ Radius: } \\
\hline 1 & - & - & - & - & $(222)$ & $(222)$ & - & $(215)$ \\
\hline 4 & - & - & - & - & 13 & 12 & - & 14 \\
\hline 5 & - & - & - & - & 10 & 10 & - & 9 \\
\hline \multicolumn{9}{|l|}{ Ulna: } \\
\hline 1 & - & - & - & - & - & $(246)$ & - & - \\
\hline 11 & - & - & - & - & - & 15 & 16 & 15 \\
\hline 12 & - & - & - & - & - & 13 & 13 & 14 \\
\hline \multicolumn{9}{|l|}{ Femur: } \\
\hline 1 & - & 401 & - & 405 & 441 & - & - & - \\
\hline 2 & - & 395 & - & 403 & 440 & - & - & - \\
\hline 6 & - & 25 & 24 & 24 & 24 & 24 & 27 & 25 \\
\hline 7 & - & 24 & 25 & 26 & 24 & 25 & 25 & 25 \\
\hline 8 & - & 75 & 78 & 80 & 73 & 75 & 78 & 76 \\
\hline 9 & 30 & 30 & 30 & 34 & 29 & 30 & 29 & 29 \\
\hline 10 & 23 & 24 & 20 & 21 & 22 & 23 & 21 & 21 \\
\hline 19 & - & 37 & - & 43 & 47 & 47 & - & - \\
\hline 21 & - & - & - & 71 & (78) & - & - & - \\
\hline $8: 2$ & - & 19,0 & - & 19,9 & 16,6 & - & - & - \\
\hline $6: 7$ & - & 104,2 & 96,0 & 92,3 & 100,0 & 96,0 & 108,0 & 100,0 \\
\hline \multicolumn{9}{|l|}{ Tibia: } \\
\hline 1 & $(330)$ & 326 & - & - & - & - & - & - \\
\hline $1 \mathrm{~b}$ & (328) & 325 & - & - & - & - & - & - \\
\hline 3 & - & 65 & - & - & - & - & - & - \\
\hline $8 \mathrm{a}$ & 32 & 31 & - & - & - & - & - & - \\
\hline $9 \mathrm{a}$ & 22 & 19 & - & - & - & - & - & - \\
\hline $10 \mathrm{~b}$ & 67 & 67 & - & - & - & - & - & - \\
\hline 10b:1 & $(20,3)$ & 20,6 & - & - & - & - & - & - \\
\hline \multicolumn{9}{|l|}{ Fibula: } \\
\hline 1. & - & - & - & - & - & - & - & - \\
\hline $\begin{array}{l}\text { Stature: } \\
\text { (Sjøvold) }\end{array}$ & \multicolumn{2}{|c|}{155,2} & \multicolumn{2}{|c|}{154,5} & \multicolumn{2}{|c|}{160,3} & \multicolumn{2}{|c|}{151,9} \\
\hline
\end{tabular}


Table 16. Distribution of stature in the Budakalasz population according to Martin's categories

\begin{tabular}{|l|c|c|c|c|r|r|}
\hline Stature Class Categories & Males & N & $\%$ & Females & N & $\%$ \\
\hline small & $150-159.9$ & 5 & 26.4 & $140-148.9$ & 1 & 7.7 \\
small-medium & $160-163.9$ & 4 & 21.0 & $140-152.9$ & 1 & 7.7 \\
medium & $164-166.9$ & 3 & 15.8 & $150-155.9$ & 5 & 38.5 \\
tall-medium & $167-169.9$ & 3 & 15.8 & $150-158.9$ & 1 & 7.7 \\
tall & $170-179.9$ & 4 & 21 & $150-167.9$ & 5 & 38.5 \\
\hline Total & & 19 & 100 & & 13 & 100 \\
\hline
\end{tabular}

expressed with one number (the so-called $\mathrm{CR}_{\mathrm{R}}{ }^{2}$ value). The smaller this value, the greater the similarity between the series. The analysis can be performed for contemporary series from different regions and for the anthropological series of subsequent cultures in one region. ${ }^{75}$

Earlier statistical comparisons of the mean values of skull series representing the Baden culture were principally based on the Alsónémedi population. Ilse Schwidetzky and her colleagues worked with a high significance level (5\%) and found highly varied relations, whose historical interpretation was difficult; ${ }^{76}$ in contrast, Zoffmann's analysis with a lower significance level (0.1 and $0.5 \%$ ) outlined a Late Copper Age population with southern and south-eastern relations. ${ }^{77}$

As a result of the many large-scale archaeological excavations preceding motorway constructions, there has been a welcome increase in the anthropological samples representing the Baden population and it is now possible to include several Baden skull series (from the Budapest area, from the Balaton region, and from other areas) for testing the earlier results of the Penrose analyses. $^{78}$ The new analyses have confirmed the southern and south-eastern biological relations of the Baden population.

In spite of their fragmentary state, the Budakalász skulls provided a suitable number of cases for calculating mean values needed for the Penrose distance analysis. It was also possible to combine the mean values of male and female skull sizes standardised according to the Alekseyev-Debetz method and thus to compare them to other series. ${ }^{79}$ The analysis was based on the mean values of ten skull sizes as defined by Martin (M1, M8, M9, M17, M45, M48, M51, M52, M54, and M55). The first six were chosen because they characterise the size and form of the skull from several angles, while the last four are suitable for defining the finer facial features. The evaluation of the $\mathrm{C}_{\mathrm{R}}{ }^{2}$ values was performed with a significance level drawn at 0.1 and 0.5 per cent. A similarity or relation between the series of various cultures can be assumed for the series falling below this significance level.

\footnotetext{
5 Penrose 1954; ZofFManN 1984.

6 SCHWIDETZKY 1967; SCHWIDETZKY 1978

7 ZOFFMANN 1987-1988; ZOFFMANN 1992.

78 ZOFFMANN 2004b.

79 Alekseyev-Debetz 1964.
}

Included in the comparison were forty series representing the Neolithic and Copper Age cultures of the Carpathian Basin, Central, Eastern, North-East and South-East Europe, as well as the Ancient Near East, most of which had been part of Zoffmann's analysis (and had in part been assembled by her). In order to make the results of the analysis more reliable, we only used series which contained at least seven cases. There remained several chronological and regional gaps because samples with the necessary number of cases are lacking from larger regions and major periods. In the Carpathian Basin, for example, series representing the Balaton-Lasinja, the Ludanice and the Pit-grave culture are lacking, and neither are there any series from the central and westerly regions of the Balkans. The series presented in Table 17 fulfilled the quantitative criteria of the analysis.

We sought an answer to the following questions using the Penrose analysis: whether there was a connection - and if so, how strong - between the series from Budakalász and the other series of the Baden culture. A significant Penrose identity between these series may be taken to indicate the homogeneous composition of the Baden population. We also examined whether there was any connection between the Budakalász series and the other Neolithic and Copper Age populations of the Carpathian Basin. In this case, a significant Penrose connection would suggest an indigenous origin, while its lack a foreign origin. We also sought an answer to the question of whether there were any Neolithic and Copper Age populations beyond the Carpathian Basin related to the Baden series from Budakalász. A significant Penrose connection would indicate that the Baden population had immigrated to the Carpathian Basin from some other region and would also provide clues as to the homeland of this population.

According to the data presented in Table 18, showing the $\mathrm{C}_{\mathrm{R}}{ }^{2}$ values expressing the generalised distance of size and shape between the series, the Budakalász population has a significant Penrose similarity $(0.1 \%)$ with the three other Baden series only. There was no significant similarity between the Budakalász population and the other Neolithic and Copper Age peoples of the Carpathian Basin, although a link with the Körös/Criş population could be demonstrated at the 1 per cent significance level. 
Table 17. The Neolithic and Copper Age series used in the Penrose distance analysis

\begin{tabular}{|c|c|}
\hline Series & Literature \\
\hline $\begin{array}{l}\text { Carpathian Basin } \\
\text { Baden series from the vicinity of Budapest } \\
\text { Baden series from around Lake Balaton } \\
\text { Baden series of other isolated finds } \\
\text { Lepenski Vir culture } \\
\text { Starčevo culture } \\
\text { Körös/Criş culture } \\
\text { Alföld Linear Pottery culture } \\
\text { Lengyel culture from southern Transdanubia } \\
\text { Lengyel culture from Aszód } \\
\text { Lengyel culture from Mórágy B1 } \\
\text { Tisza culture } \\
\text { Hrtkovci-Gomolava, Vinča culture } \\
\text { Tiszapolgár culture } \\
\text { Bodrogkeresztúr culture }\end{array}$ & $\begin{array}{l}\text { ZOFFMANN 2004b } \\
\text { ZOFFMANN 2004b } \\
\text { ZOFFMANN 2004b } \\
\text { ZOFFMANN 2004b } \\
\text { ZOFFMANN 2004b } \\
\text { ZOFFMANN 2004b } \\
\text { ZOFFMANN 2004b } \\
\text { ZOFFMANN 1984 } \\
\text { ZOFFMANN 2004b } \\
\text { ZOFFMANN 2004d } \\
\text { ZOFFMANN 2004b } \\
\text { ZOFFMANN 1986-1987 } \\
\text { ZOFFMANN 1984 } \\
\text { ZOFFMANN 2004b }\end{array}$ \\
\hline $\begin{array}{l}\text { Central Europe } \\
\text { Central European Linear Pottery culture } \\
\text { Linear Pottery in Bohemia } \\
\text { Corded Ware culture in Bohemia } \\
\text { Bruchstedt, Linear Pottery culture } \\
\text { Sondershausen, Linear Pottery culture } \\
\text { Schönstedt, Walternienburg-Bernburg culture } \\
\text { Corded Ware culture in Germany } \\
\text { Corded Ware culture in Poland } \\
\text { Złota culture in Poland } \\
\text { Brześć Kujawski, Jordanów culture }\end{array}$ & $\begin{array}{l}\text { JELINEK } 1973 \\
\text { ZOFFMANN } 1984 \\
\text { CHOCHOL } 1964 \\
\text { BACH } 1978 \\
\text { BACH } 1978 \\
\text { BACH et al. } 1972 \\
\text { BACH } 1966 \\
\text { WIERCINSKI } 1973 \\
\text { WIERCINSKI } 1973 \\
\text { ŻEJMO-ŻEJMIS } 1938\end{array}$ \\
\hline $\begin{array}{l}\text { North-East and Eastern Europe } \\
\text { Dereivka, Dneper-Donets culture } \\
\text { Vovnigi, Dneper-Donets culture } \\
\text { Volnoje, Dneper-Donets culture } \\
\text { Bilcze Złote, Tripolye culture } \\
\text { Globular Amphora culture in Poland } \\
\text { Funnel Beaker culture in Poland } \\
\text { Fatyanovo culture } \\
\text { Ochre Grave culture in Rumania } \\
\end{array}$ & $\begin{array}{l}\text { ZINEVIČ } 1967 \\
\text { ZINEVIČ } 1967 \\
\text { SURNINA } 1961 \\
\text { WIERCINSKI } 1973 \\
\text { WIERCINSKI } 1973 \\
\text { WIERCINSKI } 1973 \\
\text { DEBETZ } 1973 \\
\text { SCHWIDETZKY } 1978 \\
\end{array}$ \\
\hline $\begin{array}{l}\text { South-East Europe and Anatolia } \\
\text { Cernavodă, Hamangia cultures } \\
\text { Cernica, Boian culture } \\
\text { Ruse, Gumelniţa culture } \\
\text { Neolithic and Early Helladic periods in Greece } \\
\text { Central and East Anatolia, Chalcolithic } \\
\text { Nea Nikomedeia, Neolithic } \\
\text { Tepe Hissar II, Chalcolithic } \\
\text { Al’Ubaid, Neolithic }\end{array}$ & $\begin{array}{l}\text { NECRASOV et al. } 1982 \\
\text { NECRASOV et al. } 1983 \\
\text { BOEV } 1972 \\
\text { ANGEL } 1944 \\
\text { ANGEL } 1951 \\
\text { ANGEL } 1973 \\
\text { KURTH } 1973 \\
\text { KEITH } 1927\end{array}$ \\
\hline
\end{tabular}

Earlier analyses noted that the Baden and the Körös/Criş populations belong to the so-called southeastern population unit, which also included the Anatolian, Greek and south-east Balkanic series, ${ }^{80}$ suggesting that the origins of these two populations lay in the south and the south-east. The link between the Baden and the Körös/Criş populations is indirect and merely reflects an origin from the same region and a broadly identical ethnic background. ${ }^{81}$ In sum, we may say that similarly to earlier analytical results, the local, indigenous origin of the Baden population in the Carpathian Basin cannot be demonstrated using the Penrose analysis.

Table 18 indicates that of the South-East European 
series, the combined Budakalász series shows a closer relationship with the Gumelniţa cemetery at Ruse (with a 0.5 per cent significance). The relation is much looser (1 per cent) with the series representing the Greek Neolithic and the Early Helladic, and the Copper Age of central and eastern Anatolia. Among the peoples of Central and Eastern Europe, a closer Penrose relation can be demonstrated with the Zlota culture of Poland and the Tripolye population of the Bilcze Zlote cemetery $(0.5$ per cent).

Even though the archaeological theory no longer confirms earlier views on the culture's southern origins, the results of the Penrose analysis presented here still indicate that the culture's population included an anthropological component with southern and southeastern affinities, as already noted by earlier research.

The above obviously need to be refined in many respects. Other issues which need to be explored are the Penrose relations spanning extensive geographic regions and chronological periods, which may indicate a geographic or chronological continuity. However, the currently available anthropological record is insufficient for proving a continuity of this type because the known series are not representative of a particular region and/or period. In an ideal situation, there would be several skull series for all prehistoric cultures, enabling the computation of relations between different cultures and, also, of a culture's internal development. However, many population groups of the Balkans and Central Europe are virtually unknown as regards their anthropological composition. The currently available evidence, although continuously enlarged, is merely sufficient for a broad outline of the anthropological contacts and origins of the Baden population.

\section{ANATOMICAL VARIATIONS}

Changes occurring during ossification resulting in size, form or relief differences are grouped under anatomical variations or hereditary epigenetic traits. There is much debate in the field of physical anthropology over whether non-metric traits are genetically controlled, environmentally determined, or due to habitual activity. The identification of these traits, which are often hereditary, can sometimes be of aid in identifying blood relations between the deceased, and are also useful for comparing cemeteries and burial clusters, as well as for determining possible blood relations between individuals interred in multiple burials. ${ }^{82}$ A study of anatomical variations, however, can only be fruitful if all the skeletal remains are examined. The anthropological material from Budakalász was only partially suited to this study. The fragmented state of the skulls meant that the variations on the neurocranium were all that could be identified, while the traits of the splanchnocranium could be examined to a limited extent only. The following

\footnotetext{
82 HaUSer-De S TEFANo 1989.
}

section offers an overview of the most frequent and most distinctive traits noted on adult skulls and postcranial bones (Table 19), as well as a comparison with other prehistoric series (Table 20).

\section{Metopic suture (Sutura metopica)}

The metopic suture dividing the frontal bone usually closes by the end of the second year after birth or by the eighth year at the latest, although in very exceptional cases, it can persist in adult life. The metopic suture could be observed on thirteen of the 140 skulls suitable for study (9.3 per cent). Its frequency varies in the known prehistoric series. It was not observed at Gomolava and Tiszavalk among the series from the Carpathian Basin, while at Mórágy its frequency is slightly higher (12.2 per cent) than at Budakalász, and even more frequent in the combined Neolithic, Copper Age and Bronze Age series from the Great Hungarian Plain. ${ }^{83}$

\section{Epipteric bone (Os epiptericum)}

The observation of the bone at the pterion point could only be observed in fourteen cases owing to the fragmentedness of the skulls and the fusion of the sutures; this trait could be observed in two cases (14.3 per cent). This variation was more frequent at Mórágy (42.1 per cent) and Gomolava (30 per cent); in contrast, values resembling the one from Budakalász have been reported for the combined Neolithic, Copper Age and Bronze Age series of the Great Hungarian Plain and the Neolithic series from Great Britain.

\section{Ossicle at asterion (Os astericum)}

The bone at the asterion point where the lambdoid, the occipitomastoid and the parietomastoid sutures meet could be observed in two cases out of seventy-three (2.7 per cent). There is no reference to its occurrence in other prehistoric series in the anthropological literature.

Lambdoid ossicle (Ossa suturae lambdoidea, Ossa wormiana) The high frequency of bones in the course of the lambdoid suture, observed in fifty-three cases out of 122 (43.4 per cent), is a characteristic trait of other prehistoric series too. It therefore seems likely that this trait is unsuitable for identifying blood relations between individuals. ${ }^{84}$

\section{Ossicle at lambda (Os lambdae)}

The lambdoid bone is an independent bone of varying size and form at the lambda point where the saggital and the lambdoid suture meet. It differs from the Inca bone in that the suture at the distal border of the lambdoid bone always runs well above the asterion. It could be noted in eight of the 131 examinable skulls (6.1 per cent). This suture bone was not registered in several

\footnotetext{
83 The low number of cases and the combination of major archaeological cultures according to archaeological periods can yield grossly misleading results.

84 BRoTHWELL 1973
} 
Table 18. Generalised distance of size and shape between the Budakalász population and other Neolithic and Copper Age series

\begin{tabular}{|c|c|c|c|}
\hline Series & $\mathrm{C}_{\mathrm{R}}^{2}$ & $D_{p^{2}}$ & $\mathbf{P} \%$ \\
\hline Baden series of other isolated finds & 0,054 & 0,705 & $P>99,9$ \\
\hline Baden series from around Lake Balaton & 0,073 & 0,947 & $\mathrm{P}>99,9$ \\
\hline Baden series from the vicinity of Budapest & 0,074 & 0,956 & $\mathrm{P}>99,9$ \\
\hline Bilcze Zlote, Tripolye culture & 0,126 & 1,636 & $99,9>\mathrm{P}>99,5$ \\
\hline Złota culture, Poland & 0,137 & 1,777 & $99,9>\mathrm{P}>99,5$ \\
\hline Ruse, Gumelnița culture & 0,14 & 1,817 & $99,9>\mathrm{P}>99,5$ \\
\hline Körös/Criş culture & 0,176 & 2,284 & $99,5>\mathrm{P}>99,0$ \\
\hline Central and East Anatolia, Chalcolithic & 0,178 & 2,315 & $99,5>\mathrm{P}>99,0$ \\
\hline Neolithic and Early Helladic periods in Greece & 0,194 & 2,517 & $99,5>\mathrm{P}>99,0$ \\
\hline Cernica, Boian culture & 0,203 & 2,638 & $99,0>\mathrm{P}>97,5$ \\
\hline Funnel Beaker culture in Poland & 0,216 & 2,807 & $99,0>\mathrm{P}>97,5$ \\
\hline Sondershausen, Linear Pottery culture & 0,219 & 2,843 & $99,0>\mathrm{P}>97,5$ \\
\hline Al'Ubaid, Neolithic & 0,222 & 2,881 & $99,0>\mathrm{P}>97,5$ \\
\hline Bruchstedt, Linear Pottery culture & 0,226 & 2,931 & $99,0>\mathrm{P}>97,5$ \\
\hline Schönstedt, Walternienburg-Bernburg culture & 0,232 & 3,015 & $99,0>\mathrm{P}>97,5$ \\
\hline Bodrogkeresztúr culture & 0,241 & 3,123 & $99,0>\mathrm{P}>97,5$ \\
\hline Nea Nikomedeia, Neolithic & 0,267 & 3,462 & $97,5>\mathrm{P}>95,0$ \\
\hline Cernavodă, Hamangia cultures & 0,279 & 3,63 & $97,5>\mathrm{P}>95,0$ \\
\hline Lengyel culture in southern Transdanubia & 0,284 & 3,693 & $97,5>\mathrm{P}>95,0$ \\
\hline Starčevo culture & 0,292 & 3,789 & $97,5>\mathrm{P}>95,0$ \\
\hline Corded Ware culture in Poland & 0,299 & 3,879 & $97,5>\mathrm{P}>95,0$ \\
\hline Linear Pottery in Bohemia & 0,348 & 4,521 & $95,0>\mathrm{P}>90,0$ \\
\hline Hrtkovci-Gomolava, Vinča culture & 0,358 & 4,653 & $95,0>\mathrm{P}>90,0$ \\
\hline Tisza culture & 0,363 & 4,716 & $95,0>\mathrm{P}>90,0$ \\
\hline Lengyel culture from Mórágy B1 & 0,364 & 4,728 & $95,0>\mathrm{P}>90,0$ \\
\hline Brześć Kujawski, Jordanów culture & 0,365 & 4,745 & $95,0>\mathrm{P}>90,0$ \\
\hline Tiszapolgár culture & 0,38 & 4,94 & $90,0>\mathrm{P}>70,0$ \\
\hline Alföld Linear Pottery culture & 0,381 & 4,95 & $90,0>\mathrm{P}>70,0$ \\
\hline Central European Linear Pottery culture & 0,408 & 5,298 & $90,0>\mathrm{P}>70,0$ \\
\hline Corded Ware culture in Germany & 0,432 & 5,616 & $90,0>\mathrm{P}>70,0$ \\
\hline Tepe Hissar II, Chalcolithic & 0,435 & 5,647 & $90,0>\mathrm{P}>70,0$ \\
\hline Lengyel culture from Aszód & 0,437 & 5,677 & $90,0>\mathrm{P}>70,0$ \\
\hline Globular Amphora culture in Poland & 0,496 & 6,447 & $90,0>\mathrm{P}>70,0$ \\
\hline Ochre Grave culture in Rumania & 0,513 & 6,656 & $90,0>\mathrm{P}>70,0$ \\
\hline Corded Ware culture in Bohemia & 0,526 & 6,827 & $90,0>\mathrm{P}>70,0$ \\
\hline Fatyanovo culture & 0,545 & 7,081 & $90,0>\mathrm{P}>70,0$ \\
\hline Lepenski Vir culture & 0,684 & 8,884 & $70,0>\mathrm{P}>50,0$ \\
\hline Dereivka, Dneper-Donets culture & 0,897 & 11,651 & $50,0>\mathrm{P}>30,0$ \\
\hline Vovnigi, Dneper-Donets culture & 1,116 & 14,49 & $30,0>\mathrm{P}>10,0$ \\
\hline Volnoje, Dneper-Donets culture & 1,446 & 18,776 & $10,0>\mathrm{P}>5,0$ \\
\hline
\end{tabular}

prehistoric series (the one from Tiszavalk and the combined Neolithic and Copper Age series from the Great Hungarian Plain). Its frequency is low in the combined Bronze Age series from the Great Hungarian Plain, but is strikingly frequent in the series from Mórágy (27.5 per cent) and Gomolava (36.4 per cent).

Inca bone (Os incae)

The division of the squama occipitalis by a tranverse suture could be registered in two cases out of 138 (1.4 per cent), a very low frequency rate. There is no reference to its occurrence in other prehistoric series in the anthropological literature.

\section{Palatine torus (Torus palatinus)}

The bony prominence along the median line of the hard palate is a trait which could rarely be observed owing to the fragmentation of the finds, explaining why few prehistoric incidences are known. It could be observed on three of the twenty-one examinable skulls (14.3 per cent). This trait occurred frequently at Mórágy (41.4 per cent) and Tiszavalk (50 per cent); although its frequency was lower in the Gomolava series (28.6 per cent), the number of incidences was still higher than at Budakalász. 
Table 19. Anatomical variations on the skulls from the Budakalász cemetery

\begin{tabular}{|l|c|c|c|}
\hline Anatomical variations & Number examined & Number with trait & Per cent proportion with trait \\
\hline Metopic suture & 140 & 13 & $9.3 \%$ \\
\hline Ossicle at bregma & 123 & 0 & $0 \%$ \\
\hline Epipteric bone & 14 & 2 & $14.3 \%$ \\
\hline Ossicle at asterion & 73 & 2 & $2.7 \%$ \\
\hline Lambdoid ossicle & 122 & 53 & $43.4 \%$ \\
\hline Ossicle at lambda & 131 & 8 & $6.1 \%$ \\
\hline Inca bone & 138 & 2 & $1.4 \%$ \\
\hline Palatine torus & 21 & 3 & $14.3 \%$ \\
\hline
\end{tabular}

Table 20. Percentage distribution of anatomical variations in the Budakalász cemetery and other prehistoric series

\begin{tabular}{|c|c|c|c|c|c|c|c|c|c|}
\hline Series & 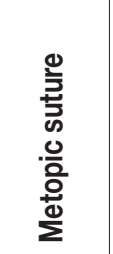 & 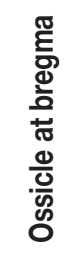 & 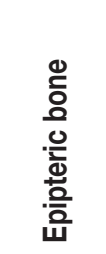 & 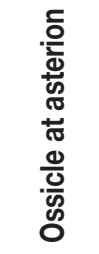 & 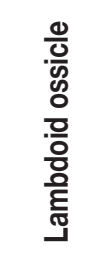 & 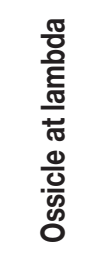 & 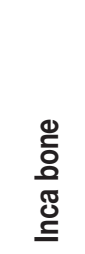 & 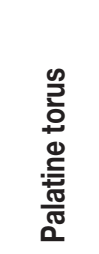 & Literature \\
\hline $\begin{array}{l}\text { Budakalász } \\
\text { (Baden c.) }\end{array}$ & $9.3 \%$ & $0 \%$ & $14.3 \%$ & $27 \%$ & $43.4 \%$ & $6.1 \%$ & $1.4 \%$ & $14.3 \%$ & present study \\
\hline $\begin{array}{l}\text { Mórágy B1 } \\
\text { (Lengyel c.) }\end{array}$ & $12.2 \%$ & ? & $42.1 \%$ & ? & $46.2 \%$ & $27.5 \%$ & ? & $41.4 \%$ & ZOFFMANN 2004d \\
\hline $\begin{array}{l}\text { Hrtkovci-Gomolava } \\
\text { (Vinča c.) }\end{array}$ & $0 \%$ & ? & $30 \%$ & ? & $54.6 \%$ & $36.4 \%$ & ? & $28.6 \%$ & $\begin{array}{l}\text { ZOFFMANN } \\
1986-1987\end{array}$ \\
\hline $\begin{array}{l}\text { Tiszavalk-Tetes } \\
\text { (Bodrogkeresztúr c.) }\end{array}$ & $0 \%$ & $?$ & $?$ & $?$ & $54.6 \%$ & $0 \%$ & $?$ & $50 \%$ & ZOFFMANN 1986 \\
\hline $\begin{array}{l}\text { Neolithic series, } \\
\text { Great Hungarian Plain }\end{array}$ & $25 \%$ & ? & $18.3 \%$ & ? & $16.7 \%$ & $0 \%$ & ? & ? & $\begin{array}{l}\text { FARKAS-MARCSIK } \\
1975\end{array}$ \\
\hline $\begin{array}{l}\text { Copper Age series, } \\
\text { Great Hungarian Plain }\end{array}$ & $27.3 \%$ & ? & $9.1 \%$ & ? & $45.5 \%$ & $0 \%$ & ? & ? & $\begin{array}{l}\text { FARKAS-MARCSIK } \\
1975\end{array}$ \\
\hline $\begin{array}{l}\text { Bronze Age series, } \\
\text { Great Hungarian Plain }\end{array}$ & $19.6 \%$ & $?$ & $7.1 \%$ & $?$ & $37.5 \%$ & $3.6 \%$ & $?$ & $?$ & $\begin{array}{l}\text { FARKAS-MARCSIK } \\
1975\end{array}$ \\
\hline $\begin{array}{l}\text { Neolithic series, } \\
\text { Great Britain }\end{array}$ & $7.5 \%$ & ? & $15 \%$ & ? & ? & ? & ? & $7.4 \%$ & BROTHWELL 1973 \\
\hline
\end{tabular}

Perforation of the olecranon fossa

The perforation of the olecranon fossa at the distal end of the humerus was registered in fifteen of the 55 examinable remains (27.3 per cent), all incidences being females with one exception. This confirms the view that this trait is more common among women. ${ }^{85}$

In sum, we may say that of the morphological traits described above, the proportion of one anatomical variation, the incidence of the lambdoid ossicle, is rather high (over 40 percent and a similarly high proportion has been observed in other prehistoric series too), making it unsuitable for identifying blood/genetic relations among the deceased. In certain cases, the joint occurrence of traits can be noted (most often of the
Lambdoid ossicle in combination with the Ossicle at lambda, the Metopic suture and the Inca bone).

One oft-debated issue in anthropological studies is whether anatomical variations are sex-related or not. ${ }^{86}$ There was no significant difference between the ratio of traits according to sex in the Budakalász cemetery, i.e. most occurred in roughly similar proportion among males and females, the only exception being the perforation of the olecranon fossa, which with one exception was restricted to females.

A glance at the distribution of variations across the cemetery indicated that while the Wormian bones could be noted in all areas, occurrences of the Ossicle at lambda were restricted to the southern and northern part of the cemetery. Relatively few variations could be 
noted among the individuals interred in the cemetery's eastern part. The observed variations did not form clusters - seldom did we find that one particular trait could generally be noted on individuals buried near each other.

\section{PATHOLOGICAL DEFORMATIONS}

A knowledge of the pathological state of a population is a prerequisite to any biological reconstruction and most certainly contributes much to a reconstruction of this kind. Numerous disease leave their mark on bones and thus provide the opportunity to learn about the general health and diseases of different prehistoric populations. Unfortunately, many diseases do not affect the bones, and thus the record remains incomplete. Moreover, the identification of the visible evidence is complicated by the fact that different diseases often leave similar marks on bones.

Owing to the fragmented and incomplete state of the anthropological material, the observation of pathological cases in the Budakalász population ran into difficulties. It seems likely that many more pathological variations could have been recorded, had the skeletal remains been better preserved and had there not been so many skeletal elements - vertebrae, ribs, pelvic bones, finger bones - missing from the material. For example, the observation of the common degenerative change of the spine (spondylosis deformans) is hardly possible in a series which barely contains any vertebrae. It is therefore impossible even to estimate the frequency of diseases in the Budakalász population or to assess the community's general health condition. The following section provides an overview of the macroscopically observed diseases.

\section{Traumatic lesions}

Of the traumatic deformation of bones, very few fractures could be observed in the material. Broken clavicles, which have a high frequency in ancient cemeteries, were identified in two cases (Graves 195/B and 358), one of which involved the overlapping of the fractured ends and the formation of false joints during the healing process. A broken and healed radius was found in two cases (Graves 216 and 365), a broken and healed ulna also in two cases (Graves 51 and 279). The in loco tipico fractures of the ulnae occurred during accidental falls, resulting in a spindle shaped thickening in the distal third. The fractures of the lower arm had in all cases healed without any complications and deformations. A broken and healed humerus can be assumed in the case of the man interred in Grave 279, judging from the thickening in the middle of the bone (Pl. 6. 1-3, 5-6).

A healed skull wound is suggested by the $1 \mathrm{~cm} \times 1 \mathrm{~cm}$ large round, indented area above the external occipital protuberance on the occipital bone of the man from Grave 366/B (Pl. 8. 4a-b). The injury was probably caused by a blow from some tool or weapon. It is also obvious that this injury was not the cause of death since the injury visibly healed.

\section{Degenerative changes}

Arthrosis deformans, spondylosis deformans and spondylarthrosis, accounting for the highest percentage of pathological alterations in the skeletal material from early prehistory onward, are generally classified as degenerative changes. The reason for their varying frequencies can be sought in the life conditions and/or the resistance of a given population to these diseases.

Spondylosis deformans is the most frequent degenerative joint disease of the spine. A heavy strain, monotonous work, trauma and infections all played a role in its aetiology. In most cases, its onset occurred once adulthood had been reached and its severity increased with age. It seems likely that this degenerative disease was frequent in the Budakalász population, but the lack of vertebrae meant that only a few instances could be recorded. Bony growths (osteophytes) extending from the margins of the vertebrae was noted in the case of four males (Graves 264, 358, 405 and 420) and one female (Grave 208) (Pl. 7. 1-3). It probably extended to all three sections of the spine, although this cannot be stated with certainty because the bones were fragmentary and incomplete. In the case of two elderly males (Graves 358 and 420), the osseous union of the vertebrae could also be noted $(\mathrm{Pl}$. 7. 4, 5a-b). This degenerative change is known as block vertebrae, whose causes include spondylosis, spondylitis, and growth disorders.

Similar types of ossification and bony extensions can appear elsewhere on the skeleton with advancing age. However, no traces of this alteration on the auricular surfaces of appendicular joints were visible in the Budakalász sample, even though this disease has been identified in anthropological samples from the Neolithic onward. ${ }^{87}$ The lack of this deformation in the Budakalász series can be attributed to the fragmentedness of the long bone epiphyses and the lack of other post-cranial bones.

\section{Cribra orbitalia}

Cribra orbitalia, causing pitting of the smooth bone on the orbit, the roof of the eye socket, is caused by the primary and secondary diseases of the hematopoietic system. This disease, known from all prehistoric periods and from practically every region, occurs most frequently among women and children. The aetiology of this disease is still debated; it has been attributed to one type of haemolytic anaemia ( $\beta$ thalassemia), as well as to iron and protein deficiency and a one-sided diet. ${ }^{88}$ At Budakalász, the milder, so-called porotic form was more frequent $(P l$. 8. 1a-b). Its occurrence was recorded for twelve children out of forty-one and for thirty-one

\footnotetext{
87 GÁSPÁRDY 1961; REGÖLY-MÉREI 1962. 88 MaRCSIK 1975; FARKAS-MARCSIK 1975.
} 
adults out of eighty-three (one juvenile, twelve males and eighteen females).

\section{Periostitis and osteomyelitis}

The so-called non-specific inflammation of the bones usually starts in the periosteum and the bone marrow. Evidence for this infection consists of irregular bone deposits and porosity. Although trauma and other causes cannot be entirely eliminated, infection seems to be the most likely cause of the alteration.

Periostitis usually occurs on the diaphysis of the long bones, most often on the bones of the lower extremity (on the femur, the tibia and the fibula). It is generally indicated by a plaque-like bony growth on the original cortical surface. Males dominated the individuals with periostitic lesions in the Budakalász series (the males interred in Graves 66/B, 153/B, 186, 375 and 422, the females buried in Graves 382 and $389 / \mathrm{A})$. In most cases, the lesion affected the tibia and was moderately severe.

Osteomyelitis causes an excessive growth of bone, with the bone surface becoming uneven and covered with fistulas resulting from pyosis. Osteomyelitis most often develops on the metaphysis of long bones, from where it spreads to the diaphysis and the epiphysis. An excessive growth of bone, a deformation indicating this disease, was observed on the tibia of the man buried in Grave 112 (Pl. 6. 4a-b).

\section{Enthesopathy}

Even though it cannot be regarded as a pathologic deformation, the occurrence of enthesopathy, a variant of excessive bone growth (hyperostosis) caused by increased strain, must by all means be mentioned. This deformation takes the form of ridges and crests at the attachment of muscles and tendons. It can most often be noted on the heel bone and the kneecap, but also occurs on the femur, the tibia, and the pelvis. It is generally caused by exacting physical work, excess walking, etc., although it can be a side-symptom of other diseases (spondylarthritis, DISH, trauma) too. ${ }^{89}$ At Budakalász, enthesopathy was recorded among males only: on the heel bone in six cases (Graves 8, 57, 91, 263/A, 342, and 411), of which it could be noted also on the kneecap in two cases (Graves 8 and 91). In three other cases, the deformation was noted on the femur (Graves 43, 64, and 153/A).

\section{Other diseases}

Symmetric osteoporosis, a typical old-age disease, was recorded on the skull of the maturus-senilis woman in Grave 38. It was morphologically indicated by the symmetric porosity and thinning of the parietal eminences and the dilatation of the thinned corticalis (Pl. 8. 2a-b). The outer side of the parietal bone on the fragmentary skull of the man buried in Grave 105 was uneven with erosions. The surface of the skulls from

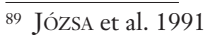

four burials (Graves 33, 46, 57, and 163) was porous and eroded in the area of the supercilliary arch and the glabella (Pl. 8. 3a-b).

In sum, we may say that the pathological deformations recorded at Budakalász are all of the type, which were common in prehistory. Unfortunately, the fragmented and incomplete condition of the skeletal remains do not permit any conclusions concerning the frequency of a particular disease at Budakalász and neither can a comparison be made with other series. Few bone fractures could be observed, even though this has been frequently reported in historical palaeopathological studies, and only in one case was there a deformation suggesting a force-induced injury (a blow). It is striking that not one single incidence of joint diseases indicating arthrosis deformans was found in the Budakalász series, in spite of the frequency of this disease in prehistory. There are also very few cases of spondylosis, the degenerative joint disease of the spine.

\section{DENTAL HEALTH}

The study of the teeth is just as important as the metrical and morphological study of the bones. Since teeth are particularly resistant to decay when buried, they survive much longer in some soils than bones. The general characteristics of a population's dental health enable the reconstruction of dietary customs, oral hygiene, and, to a certain extent, of lifeways. During the examination of the skeletal remains from Budakalász, we recorded the number of the examined teeth, as well as the pre- and post-mortem tooth loss. Teeth affected by caries and the various abscesses/cysts caused by inflammations were evaluated separately. Table 21 shows the number and proportion of the examined teeth, the pre-mortem tooth loss, the carious teeth and the number of abscesses/cysts according to age groups..$^{90}$

Of the 354 excavated skeletons, those of 176 adults were suitable for oral pathological analysis. The number of surviving teeth was 3029 , pre-mortem tooth loss was 189, while post-mortem tooth loss was 398 . The archaeological dental index for this series, showing the percentage of examinable and existing teeth at the time of death, is 56.4, a rather good value since this index is usually lower in the case of prehistoric samples. ${ }^{91}$

\section{Dental caries}

Dental caries is perhaps the best known and most frequent pathologic disease of the teeth. Carious cavities were found in 118 of 3029 permanent teeth, for a frequency of 3.9 per cent (Table 21). Within the subadults, four incidences of milk teeth with dental

\footnotetext{
${ }^{90}$ It must here be noted that the dental health of a part of the Budakalász population (836 teeth of forty-four individuals) has already been analysed (MOLNÁR-MOLNÁR 1985)

91 The higher the ADI index, the more reliable the material
} 
Table 21. Number and proportion of the examined teeth, pre-mortem tooth loss, carious teeth and the abscesses/cysts according to age groups in the Budakalász population

\begin{tabular}{|c|c|c|c|c|}
\hline Age-groups /N/ & Number of & Number of & Number of pre-mortem & Number of \\
\hline Juvenis & 395 & $2(0.5 \%)$ & $(0 \%)$ & $0(0 \%)$ \\
\hline Adultus $/ 80 /$ & 1545 & $38(2.5 \%)$ & $14 \quad(0.9 \%)$ & $5(0.3 \%)$ \\
\hline Maturus /60/ & 968 & 63 (6.5\%) & $101(10.4 \%)$ & $20(2.1 \%)$ \\
\hline Senilis $\quad / 16 /$ & 121 & $15(12.4 \%)$ & $74(61.1 \%)$ & $4 \quad(3.3 \%)$ \\
\hline Total: & 3029 & $118(3.9 \%)$ & $189 \quad(6.2 \%)$ & $29(0.9 \%)$ \\
\hline
\end{tabular}

caries were observed in two cases, and in one instance a permanent tooth was also affected. A comparison with other prehistoric series indicates that the extent of caries was relatively low in the Budakalász population (Table 22). The frequency of this disease shows a proportionate increase with age, with most occurrences recorded among the elderly and the fewest among juveniles. As regards the breakdown according to sex, women tended to have more teeth affected by caries. Carious lesions were slightly more common in mandibular teeth than maxillary teeth. In most cases, caries affected the region of the tooth neck, mostly on molars (Pl. 9. 1). It has been suggested that this was caused by the diet of prehistoric communities causing ulatrophy, the recession of the gum, resulting in the exposure of part of the root. ${ }^{92}$ Occlusal (enamel) caries, more typical for modern man, and caries affecting the anterior teeth were noted in a few cases. The lower incidence of occlusal (enamel) caries is likely due to high fluoride ingestion.

\section{Abscesses/cysts}

Abscesses/cysts can develop in association with general periodontal infection, considerable tooth wear or caries. The abscesses/cysts are caused by bacteria entering the tooth owing to the exposure of the pulp cavity. The two disorders are evaluated jointly because it is not always easy to distinguish between them on archaic skeletal remains. Abscesses/cysts were noted in twenty-nine cases among sixteen adults (Table 21). These inflammations, usually extending to the periosteum, generally occurred on mandibles, which also contained teeth affected by caries (Pl. 9. 2). This tends to confirm the fact that abscesses generally develop in consequence of caries.

\section{Pre-mortem tooth loss}

Pre-mortem tooth loss can be caused by caries, various periodontal diseases, loosening of the teeth, abrasion leading to the opening of the dental cavity and vitamin deficiency. ${ }^{93}$ It is indicated by the absence of a tooth and the lack of remodelling in the associated alveolus. Pre-mortem tooth loss affected 189 teeth among 41 adults (Pl. 9. 3). The frequency of this disease increased with age (Table 21). We found a minimal variation in

\footnotetext{
92 HuSZÁr-SCHRANCZ 1952; SCHRANCZ-HuSZÁr 1962

93 HUSZŹr-SCHRANCZ 1952.
}

frequencies between sexes, although tooth loss was considerably higher among women than men. There were several women, who had lost all their teeth (owing to advanced age or some oral disease; Pl. 9. 4).

A population's dental health can be expressed through the caries intensity, which was calculated using Stloukal's formula. ${ }^{94}$ This value, which also takes into considers pre-mortem tooth loss, was 9.6 for Budakalász, a fairly low value compared to other prehistoric series (Table 23).

\section{Abrasion}

The extent of tooth abrasion was scored according to Huszár's six-degree scale. ${ }^{95}$ Abrasion is influenced not only by age, but also by the composition of the food and how it was prepared, the intensity of chewing and the use of teeth as implements. ${ }^{96}$ György Huszár and Dénes Schranz have suggested that dental wear of the occlusal surfaces of teeth reached a considerable level in the Neolithic and Copper Age in part because more types of tough and hard food were consumed, and in part because particles from the grinding stones became mixed up with flour (and the foodstuffs made from them) in consequence of rudimentary grinding techniques. ${ }^{97}$ Tooth abrasion was not particularly extensive in the Budakalász population, and even though it increased with age, abrasion extending to the tooth neck was observed in few cases only.

\section{Other dental anomalies}

Dental anomalies are most often the result of developmental anomalies. Divergencies of this type can be usually traced to genetic or environmental factors. One common anomaly is the impaction of teeth, which was most often noted on the third molar on three mandibles. We also identified one impacted lower canine (Pl. 9. 5). Dental crowding and rotation could be observed in no more then five cases at Budakalász owing to the high degree of fragmentation (Pl. 9. 6). In contrast, it occurred much more frequently at Mórágy

\footnotetext{
94 STLOUKal 1963

95 HusZár 1976.

96 The extent of tooth abrasion was also used for sexing, although we also took into consideration the fact that the state of dentition varied from individual to individual and cannot be in itself regarded as a reliable indication of age.

97 Huszár-SCHRANCZ 1952.
} 
Table 22. Frequency of caries in the Budakalász population and other prebistoric series

\begin{tabular}{|l|c|l|}
\hline Series & Frequency of Caries & \multicolumn{1}{|c|}{ Literature } \\
\hline Mórágy B1 (Lengyel c.) & $2.3 \%$ & ZOFFMANN 2004d \\
\hline Neolithic series, Great Britain & $3.1 \%$ & BROTHWELL 1973 \\
\hline Corded Ware culture in Germany & $3.7 \%$ & BACH 1978 \\
\hline Hrtkovci-Gomolava (Vinča c.) & $3.8 \%$ & ZOFFMANN 1986-1987 \\
\hline Budakalász (Baden c.). & $3.9 \%$ & present study \\
\hline Linear Pottery in Germany & $7.1 \%$ & BACH 1978 \\
\hline Tiszavalk-Tetes (Bodrogkeresztúr c.) & $8.1 \%$ & ZOFFMANN 1986 \\
\hline
\end{tabular}

Table 23. Caries intensity in the Budakalász population and other prebistoric series

\begin{tabular}{|l|c|l|}
\hline Series & $\begin{array}{c}\text { Caries intensity } \\
\text { (Stloukal) }\end{array}$ & \multicolumn{1}{|c|}{ Literature } \\
\hline Corded Ware culture in Germany & 6 & BACH 1978 \\
\hline Budakalász (Baden c.) & 9.1 & present study \\
\hline Linear Pottery in Germany & 9.6 & BACH 1978 \\
\hline Hrtkovci-Gomolava (Vinča c.) & 20.9 & ZOFFMANN 1986-1987 \\
\hline Tiszavalk-Tetes (Bodrogkeresztúr c.) & 26.7 & ZOFFMANN 1986 \\
\hline Mórágy B1 (Lengyel c.) & 28.9 & ZOFFMANN 2004d \\
\hline
\end{tabular}

(40.7 per cent) and Zengóvárkony (36.8 per cent). ${ }^{98}$ This phenomenon was not observed at Gomolava. ${ }^{99}$

In sum, we may say that the general oral pathological status of the Budakalász population was fairly good. The frequency of dental caries, alveolar abscesses/cysts and pre-mortem tooth loss was relatively low, which can probably be explained by healthy dietary habits, a carbohydrate diet rich in nutrients and an adequate dental hygiene.

\section{SUMMARY}

The currently known largest cemetery of the Baden culture was excavated by Sándor Soproni between 1952 and 1960 at Budakalász-Luppa-csárda. Various funerary rites could be observed: the graves included inhumation burials, inurned and cremation burials, skull burials and symbolic graves. Most of the inhumation graves contained a single body only (in 318 cases), although some contained two or even three bodies (in 34 and 4 cases resp.) The anthropological analysis was based on the skeletal remains from 354 inhumation and 56 cremation burials. The human remains from the cemetery are stored in the Department of Anthropology of the Hungarian Natural History Museum. In spite of the poorly preserved skeletal remains, the anthropological material from Budakalász enables an outline of the cemetery's Late Copper Age population owing to the high number of graves.

\footnotetext{
98 ZOFFMANN 1969-1970; ZOFFMANN 2004d.

99 ZOFFMANN 1986-1987.
}

The age distribution of the deceased was as follows: while the proportion of children (36 per cent) more or less corresponded to the expected values, the number of neonates and infants was low, similarly to other prehistoric series. The reason for this low number, variously attributed to erosion, decomposition, ritual customs, excavation techniques, still needs to be clarified. The proportion of the elderly too corresponded to the expected values. The lowest number of deaths could be demonstrated among the juvenile age group (6.9 per cent) and the highest number among the adult age group (25.7 per cent).

The sex distribution of the adult population indicated a higher proportion of women (the remains of 128 females and 89 males could be securely identified). The mortality rate of females was higher in both the adult and the elderly group, which can be attributed to the overall higher proportion of women in the population.

The identification of hereditary anatomical variations can contribute to the identification of possible blood relations between the deceased and the blood relation between individuals buried in the same grave. Unfortunately, the fragmentary and incomplete state of the remains did not permit a systematic analysis for each skeleton and skull. The occurrence of one trait, the lambdoid ossicle, was very high (over 40 per cent), and it was thus unsuitable for tracing blood relations. No clusters could be observed as regards anatomical variations in the cemetery, i.e. very rarely was one trait observed among individuals interred near other.

Very few pathological alterations could be noted. Considerably more diseases could have been identified had the state of preservation of the skeletal remains 
been better. Fractures, degenerative changes, traces of non-specific diseases caused by traumas and cribra orbitalia caused by nutritional deficiencies observed in other prehistoric and historic cemeteries were rare in the Budakalász cemetery. The incidences of dental caries, pre-mortem tooth loss and abscesses/cysts caused by inflammation were also low compared to other prehistoric cemeteries.

A typological analysis based on metric and morphological traits could be performed in very few cases. The Budakalász population is dominated by the dolichocranial, gracile Mediterranean type, alongside an almost 20 per cent proportion of the brachycranial Alpine element. The latter's frequency in the preceding Middle Copper Age was very low and thus its higher proportion in the Late Copper Age population reflects a change in the anthropological spectrum or perhaps the arrival of a new population to the Carpathian Basin.

Earlier hypotheses on the origins of the Baden culture assumed the arrival of a new population during the Late Copper Age (infiltration/migration), although most prehistorians suggested a migration from the south and south-east, from Anatolia. ${ }^{100}$ More recently, however, a model for the evolution of the Baden culture in Central Europe has been proposed. ${ }^{101}$

The origins of the Baden population are not instantly recognizable from an anthropological perspective. Nemeskéri argued that the meso-dolichocranial (Mediterranean) component in the culture's anthropologic make-up was of local origin, although he did allow for immigration from the south-east. He derived the brachycranial (Alpine and Dinaric) elements in part from the east and in part from the west. ${ }^{102}$ In contrast, Zoffmann found that the results of the Penrose distance analysis clearly suggested an immigration from the south-east. ${ }^{103}$ The findings of the Penrose distance analysis presented in this study do not challenge Zoffmann's findings, suggesting that the population of the Carpathian Basin during the Late Copper Age was not of indigenous, local origin, but one with southern and south-eastern affinities in the biological sense. More precise results can only be expected from the archaeological and anthropological analysis of additional Late Copper Age sites. $\overline{100}$ KaliCZ 1963, KaliCZ 1973; KoreK 1983.

101 Maran 1998; Wild et al. 2001; Bondár 2002.
102 Nemeskéri 1951a; Nemeskéri 1951b; NemeskÉRI 1956. 103 ZOFFMANN 1987-1988; ZOFFMANN 1992; ZOFFMANN 2000; ZOFFMANN 2004b. 


\section{References}

ACSÁDI-NEMESKÉRI 1970

ALEKSEYEV-DebetZ 1964 ANGEL 1944

ANGEL 1951

ANGEL 1973

BACH 1978

BACH-BACH 1972

BACH 1966

BANNER 1956

BoEv 1972

BoEv 1973

BONDÁR 1987

BONDÁR 1996

BONDÁR 2002

BoteZATU et al. 1987

BROTHWELL 1973

Сhochol 1964

DeBetz 1973

ECSEDY 1981

ÉRY 1967-1968

ÉRY et al. 1963

ÉRY 1998

FARKAS 1972

FARKAS 1975

FARKAS et al. 1993

FARKAS-MARCSIK 1975

Ferembach et al. 1979
Acsádi, György-Nemeskéri, János: History of human life span and mortality. Budapest 1970. Alekseyev, Valery P.-Debetz, George F.: Kraniometrija [Craniometry]. Moscow 1964.

Angel, J. Lawrence: A racial analysis of the ancient Greeks: An essay on the use of morphological types. American Journal of Physical Anthropology Vol. 2. N. s. 4. (1944) 329-376.

Angel, J. Lawrence: Troy. The human remains. Cincinnati 1951.

Angel, J. Lawrence: Early Neolithic people of Nea Nikomedia. In: Die Anfänge des Neolithikums vom Orient bis Nordeuropa. Ed. by Schwabedissen, Hermann. Köln 1973, 103-112. (Foundamenta Reihe B, VIIIa, Anthropologie, Teil 1)

Bach, Adelheid: Neolithische Populationen im Mittelelbe-Saale-Gebiet. Zur Anthropologie des Neolithikums unter besonderer Berücksichtigung der Bandkeramiker. Weimar 1978. (Weimarer Monographien zur Ur- und Frühgeschichte 1).

Bach, Adelheid-Bach, Herbert: Anthropologische Analyse des Walternienburg-Bernburger Kollektivgrabes von Schönstedt in Thüringer Becken. Alt-Thüringen 12 (1972) 59-107.

Bach, Herbert: Zur Anthropologie der Schnurkeramiker. Alt-Thüringen 8 (1966) 117-165.

Banner, János: Die Péceler Kultur. Budapest 1956. (ArchHung 35)

Boev, Peter: Die Rassentypen der Balkanhalbinsel und der Ostägäischen Inselwelt und deren Bedeutung für die Herkunft ihrer Bevölkerung. Sofia 1972.

Boev, Peter: Anthropologie des Neolithikums auf der Balkanhalbinsel. In: Die Anfänge des Neolithikums vom Orient bis Nordeuropa. Ed. by Schwabedissen, Hermann. Köln 1973, 113-136. (Fundamenta Reihe B, VIIIa, Anthropologie, Teil 1)

Bondár, Mária: Újabb adatok a badeni kultúra temetkezéseihez [Neuere Beiträge zu Bestattungen der Badener Kultur]. ZalaiMúz 1 (1987) 47-58.

Bondár, Mária: Késô rézkori sírok Balatonbogláron (A kostolaci kultúra leletei Somogy megyében I.) [Late Copper Age Graves at Balatonboglár. Finds of the Kostolac Culture in Somogy County I]. SMK 12 (1996) 3-16.

Bondár, Mária: A badeni kultúra kutatási helyzete Magyarországon (Vázlat) [Der Forschungsstand der Badener Kultur in Ungarn (Abriss)]. MFMÉ-StudArch 8 (2002) 7-30.

Botezatu, D.-Aldea, H.-Ciugudean, H.: Consideraţii asupra unui craniu trepanat descoperit la Livezile (jud. Alba) aparţinând culturii Coţofeni (începutul mileniului II. î.e.n.) [Considérations sur un crâne trépane decouvert à Livezile, dep. d'Alba, appartenant à la civilisation Cotofeni commencement du IIe millénaire n.e.]. Studii şi Communicări de Antropologie 24 (1987) 3-7.

Brothwell, Don R.: The human biology of the neolithic population of Britain. In: Die Anfänge des Neolithikums vom Orient bis Nordeuropa. Ed. by Schwabedissen, Hermann. Köln 1973, 280-299. (Fundamenta Reihe B, VIIIa, Anthropologie, Teil 1)

Chochol, Jaromir: Antropologické materialí z nových výzkumu neolitu a doby bronzové v Cechách. [Anthropological material from new excavations of Neolithic and Bronze Age sites in Czechoslovakia]. Praha 1964. (Crania Bohemica 1).

Debetz, George F.: Die Sowjetunion. In: Anfänge des Neolithikums vom Orient bis Nordeuropa. Ed. by Schwabedissen, Hermann. Köln 1973, 153-169. (Fundamenta Reihe B, VIIIb, Anthropologie, Teil 2)

Ecsedy, István: A keletmagyarországi rézkor fejlődésének fontosabb tényezói [On the factors of the Copper Age development in Eastern Hungary]. JPMÉ 26 (1981) 73-95.

Éry, Kinga: Reconstruction of the tenth century population of Sárbogárd on the basis of archaeological and anthropological data. Alba Regia 8-9 (1967-1968) 93-147.

Éry, Kinga-Kralovánszky, Alán-Nemeskéri, János: Történeti népességek rekonstrukciójának reprezentációja [A representative reconstruction of historic population]. Anthropologiai Közlemények 7 (1963) 41-90. Éry, Kinga: Length of Limb Bones and Stature in Ancient Populations in the Carpathian Basin. Budapest 1998. (Humanbiologia Budapestinensis 26)

Farkas, Gyula: Antropológiai praktikum I. Paleoantropológiai metodikák [Handbook of Anthropology I. Methods in Palaeoanthropology]. Szeged 1972.

Farkas, Gyula: A Délalföld őskorának paleoantropológiája [Palaeoanthropology of prehistoric populations in the southern part of the Great Hungarian Plain]. CSc thesis. Szeged 1975.

Farkas, Gyula-Marcsik, Antónia-Oláh, Sándor: Történeti idők embere Szegváron [Historical peoples at Szegvár]. Anthropologiai közlemények 35 (1993) 7-37.

Farkas, Gyula-Marcsik, Antónia: Anatomical variations and palaeopathological observations in prehistoric series. Acta Biologica Szegediensis 21 (1975) 147-163.

Ferembach, Denise-Schwidetzky, Ilse-Stoukal, Milan: Empfehlungen für die Alters- und Geschlechtsdiagnose am Skelett. Homo 30 (1979) 132. 
FINNEGAN-MARCSIK 1979

GÁSPÁRDY 1961

GÁSPÁRDY-NEMESKÉRI 1960

GERHARDT 1973

Hauser-De STEFano 1989 HRDLIČKA 1932

HUSZÁR 1976

HUSZÁR-SCHRANZ 1952

IşCAN et al. 1984

IşCAN et al. 1985

JAKAB 1980

JELINEK 1973

JóZSA et al. 1991

KALICZ 1963

KALICZ 1973

KaLICZ 1985

KeIтH 1927

KOREK 1951

KoREK 1983

KRITSCHER 1985

KURTH 1973

KuTZIÁN 1963

LENGYEL 1975

LENGYEL 1983

MANCHESTER 1983

MARAN 1998

MARCSIK 1975

Martin-Saller 1957

MEINDL-LOVEJOY 1985

MiLes 1963

MOLNAR-MOLNAR 1985
Finnegan, Michael-Marcsik, Antónia: A non-metric examination of the relationships between osteological remains from Hungary representing populations of Avar Period. Acta Biologica Szegediensis 25 (1979) 97-118.

Gáspárdy, Géza: Paläopathologische Untersuchungen an aeneolitischen Skelettfunden in Ungarn. Ethnographisch Archäologischen Zeitschrift 2 (1961) 1-32.

Gáspárdy, Géza-Nemeskéri, János: Paleopathological Studies on the Copper Age Skeletons Found at Alsónémedi. Acta Morphologica Academiae Scientiarum Hungaricae 9 (1960) 203-219.

Gerhardt, Kurt: Paläoanthropologie der Glockenbecherleute. In: Die Anfänge des Neolithikums vom Orient bis Nordeuropa. Ed. by Schwabedissen, Hermann. Köln 1973, 265-316. (Fundamenta Reihe B, VIIIb, Anthropologie, Teil 2)

Hauser, Gertrud-De Stefano, Gian Franco: Epigenetic Variants of the Human Skull. Stuttgart 1989. Hrdlička, Aleš: The principal dimensions, absolute and relative, of the humerus in the white race. American Journal of Physical Anthropology 16 (1932) 431-450.

Huszár, György: A fogkopás vizsgálatának újabb módszerei és ezek alapján végzett összehasonlító értékelésének eredményei [New methods in the study of tooth abrasion and the results of comparative analyses using these methods]. DSc thesis. Budapest 1976.

Huszár, György-Schranz, Dénes: A fogszuvasodás elterjedése a Dunántúlon az újabb kôkortól az újkókorig [Die Zahnkaries in Transdanubien von der Neolithenzeit bis zur Neuzeit]. Fogorvosi Szemle 6-9 (1952) 3-38.

Işcan, Mehmed Yaşar-Loth, Susan R.-Wright, Ronald K.: Age estimation from the rib by phase analysis: white males. Journal of Forensic Sciences 29 (1984) 1094-1104.

Işcan, Mehmed Yaşar-Loth, Susan R.-Wright, Ronald K.: Age estimation from the rib by phase analysis: white females. Journal of Forensic Sciences 30 (1985) 853-863.

Jakab, Július: Antropologická charakteristika kostier z Kamenína [Anthropologische Charakteristik der Skelette aus Kamenín]. AVANS 1978 (1980) 115-118.

Jelinek, Jan: Die neolithische und bronzezeitliche Besiedlung der heutigen Tschechoslowakei. In: Die Anfänge des Neolithikums vom Orient bis Nordeuropa. Ed. by Schwabedissen, Hermann. Köln 1973, 186-199. (Fundamenta Reihe B, VIIIa, Anthropologie, Teil 1)

Józsa, László-Pap, Ildikó-Fóthi, Erzsébet: Enthesopathies (Insertion tendopathies) as indicators of overuse of tendons and muscles in ancient Hungarian population. Annales Historico-Naturales Musei Nationalis Hungarici 83 (1991) 269-276.

Kalicz, Nándor: Die Péceler (Badener) Kultur und Anatolien. Budapest 1963. (StudArch 2)

Kalicz, Nándor: Die chronologischen Probleme das Spätneolitikums und der Kupferzeit im WestKarpatenbecken. In: Actes du VIII ${ }^{e}$ Congrès international des Sciences préhistoriques et protohistoriques. Beograd 9-15 septembre 1971. Ed. by Garašanin, Milutin-Benać, Alojz-Tasić, Nikola. Beograd 1973, 328-339.

Kalicz, Nándor: On the chronological Problems of the Neolithic and Copper Age in Hungary. MittArchInst 14 (1985) 21-51.

Keith, Arthur: Report on the Human Remains. In: Ur excavations. Ed. by Hall, Harry R. H.Woolley, Leonard. Oxford 1927, 214-240.

Korek, József: Ein Gräberfeld der Badener Kultur bei Alsónémedi. ActaArchHung 1 (1951) 35-51.

Korek, József: Közép-Kelet-Európa a rézkor végén [Central-Eastern Europe on the end of the Copper Age]. DSc thesis. Manuscript. Budapest 1983.

Kritscher, Herbert: Ein Neolithisches Calvarium mit Trepanation aus Zillingtal. Wissenschaftliche Arbeiten aus dem Burgenland 71 (1985) 37-50.

Kurth, Gerhardt: "Neolithische" Menschenreste des Weiteren Nahostraums. In: Die Anfänge des Neolithikums vom Orient bis Nordeuropa. Ed. by Schwabedissen, Hermann. Köln 1973, 87-102. (Fundamenta Reihe B, VIIIa, Anthropologie, Teil 1)

B. Kutzián, Ida: The Copper Age Cemetery of Tiszapolgár-Basatanya. Budapest 1963. (ArchHung 42) Lengyel, Imre: Palaeoserology. Blood typing with the fluorescent antibody method. Budapest 1975. Lengyel, Imre: Nem, életkor, vércsoport értékelése a budakalászi Badeni temetôben [Sex, age and blood groups in the Baden cemetery at Budakalász]. Budapest 1983, 3-14. (Régészeti Továbbképző Füzetek 2) Manchester, Keith: The archaeology of disease. Bradford 1983.

Maran, Joseph: Die Badener Kultur und der ägäisch-anatolische Bereich. Ein Neubewertung eines alten Forschungsproblems. Germania 76: 2 (1998) 497-525.

Marcsik, Antónia: Egy csontelváltozás feltételezett aetológiája [The presumed etiology of a bone change]. Anthropologiai Közlemények 19 (1975) 47-53.

Martin, Rudolf-Saller, Karl: Lehrbuch der Anthropologie III. Stuttgart 1957.

Meindl, Richard S.-Lovejoy, C. Owen: Ectocranial Suture Closure: A Revised Method for the Determination of Skeletal Age at Death Based on the Lateral-anterior Sutures. American Journal of Physical Anthropology 68 (1985) 57-66.

Miles, Albert Edward William: The dentition in the assessment of individual age in skeletal material. In: Dental Anthropology. Ed. by Brothwell, Don R. Oxford 1963, 191-209.

Molnar, Stephen-Molnar, Iva: Observations of dental diseases among prehistoric populations of Hungary. American Journal of Physical Anthropology 67 (1985) 51-63. 
NeCrasov et al. 1982

NeCRASOV et al. 1983

NEMESKÉRI 1951a

NEMESKÉRI $1951 \mathrm{~b}$

NEMESKÉRI 1956

NEMESKÉRI 1961

NEMESKÉRI et al. 1960

NeMESKÉRI-HARSÁNYI 1968

Neugebauer-Maresch-Teschler-Nicola 1986 Neugebauer-Maresch, Christine-Teschler-Nicola, Maria: Eine spätneolithische

NEUSTUPNÝ 1959

NEUSTUPNÝ 1973

NEVIZÁNSKY et al. 1995-1996

ORTNER-PUTSCHAR 1981

PenRose 1954

PERIZONIUS 1981

REGÖLY-MÉREI 1962

RutTKaY-Teschler-Nicola 1984 Ruttkay, Elisabeth-Teschler-Nicola, Maria: Zwei Gräber der Badener Kultur aus dem Verwaltungsbezirk St. Pölten, Niederösterreich. Annalen des Naturhistorischen Museums in Wien 86 (1984) 71-87. Schmidt, Robert Rudolf: Die Burg Vučedol. Zagreb 1945.

SCHMIDT 1945

SCHRANZ-HUSZÁR 1962

SJøVOLD 1990

SCHINZ et al. 1952

SCHOUR -MASSLER 1941

SCHWIDETZKY 1967

SCHWIDETZKY 1973

SOPRONI 1956

STEINBOCK 1976

STLOUKAL 1982

STLOUKAL-HaNÁKOVÁ 1978

SURNINA 1961

SZATHMÁRY 1980

SZATHMÁRY-NEMESKÉRI 1975

TESCHLER-NICOLA-SCHULTZ 1984 Teschler-Nicola, Mar

tz, Michael: Jungneolithische Skelette der Badener Kultur aus

Lichtenwörth und Leobersdorf, Niederösterreich. Annalen des Naturhistorischen Museums in Wien 86 (1984) 111-144.

Necrasov, Olga-Cristescu, Maria-Botezatu, Dan-Miu, Georgeta: Aspects démographiques et carac-

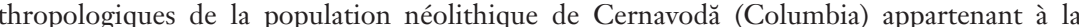
Necrasov, Olga-Cristescu, Maria-Botezatu, Dan-Miu, Georgeta: Sur les caractéristiques anthropologiques de la population Néolithique de Cernica, appartenant à la culture Boian. Annuaire roumain Nemeskéri, János: Anthropologische Untersuchungen der Skelettfunde von Alsónémedi. ActaArchHung (1951) 55-72

[Anthropological examinations of the skeletal remains interred at Alsónémedi]. MTA II. osztályának (1951) 66-89. 295-314.

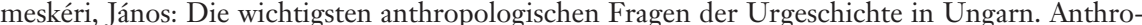

Nemeskéri, János-Harsányi, László-Acsádi, György: Methoden zur Diagnose des Lebensalters von (1960) 70-95.

Doppelbrandbestattung aus Sitzenberg, VB Tulln, NÖ. Fundberichte aus Österreich 23 (1986) 129-137.

Neustupný, Evžen: Zur Entstehung der Kultur mit kannelierter Keramik. SlovArch 7 (1959) 260-284.

Neustupný, Evžen.: Die Badener Kultur. In: Symposium über die Entstehung und Chronologie der

nad Hronom. Saarbrücker Studien und Materialen Zur Altertumskunde 4-5 (1995-1996) 251-272.

Ortner, Donald J.-Putschar, Walter G. J.: Identification of Pathological Conditions in Human Skeletal Remains. Washington, 1981. (Smithsonian Contributions to Anthropology 28)

Penrose, Lionel Sharples: Distance, size and shape. Annals of Eugenics 18 (1954) 337-343. Netherlands. I. Berichten van de Rijksdienst voor het Oudheidkundig Bodemaderzoek 31 (1981) 369-413. Regöly-Mérei, Gyula: Az ôsemberi és késóbbi emberi maradványok rendszeres kórbonctana. PalaeoSchranz, Dénes-Huszár, György: Caries findings on prehistoric human dentitions from Hungary. Zeitschrift für Morphologie und Anthropologie 52 (1962) 141-154.

Sj $\phi$ vold, Torstein: Estimation of stature from long bones utilizing the line of organic correlation. Human Evolution 5 (1990) 431-447.

Schinz, Hans Rudolf-Baensch, Willy Edward-Friedl, E.-Uehlinger, E.: Ossifikationstabelle. In: Lehrbuch der Röntgen-Diagnostik. Ed. Schinz, Hans Rudolf. Stuttgart 1952.

Schour, Isaac-Massler, Maury: The Development of Human Dentition. Journal of the American Dental Association 28 (1941) 1153-1160.

Schwidetzky, Ilse: Vergleichend-statistische Untersuchungen zur Anthropologie des Neolithikums. Homo 18 (1967) 160-174.

Schwidetzky, Ilse: Anthropologie der Schnurkeramik und Streitaxtkulturen. In: Die Anfänge des Neolithikums vom Orient bis Nordeuropa. Ed. by Schwabedissen, Hermann. Köln 1973, 241-264. (Fundamenta Reihe B, VIIIa, Anthropologie, Teil 2)

Soproni, Sándor: Budakalász, Luppa-csárda. In: BANNER 1956, 111-128.

Steinbock, R. Ted: Paleopathological Diagnosis and Interpretation: Bone Diseases in Ancient Human Populations. Springfield, IL 1976.

Stloukal, Milan: Kostra z Obdobi Bolerázského Typu z Moravican, okr. Sumperk [A skeleton of the Boleráz period from Moravicany, the Šmperk distr.]. ArchRozhl 34 (1982) 486-487, 580.

Stloukal, Milan-Hanáková, Hana: Die Lange der Langsknochen altslawischer Bevölkerungen unter besonderer Berücksichtigung von Wachstumsfragen. Homo 29 (1978) 53-69.

Surnina, T. S.: Paleoantropologičeskie materijali iz Volnjenskogo neolitičeskogo mogilnika. Antropologicheskij Sbornik 3 (1961) 1-25.

Szathmáry, László: Autochtonous and immigrated components in the Carpatian Basin Copper Age. Journal of Indo-European Studies 8 (1980) 231-244.

Szathmáry, László-Nemeskéri, János: A Debreceni Déri Múzeum neolit (eneolit) és rézkori csontvázleleteinek vizsgálata [Examination of skeletal finds of the Neolithic (Eneolithic) and Copper Age in Déri Museum]. DMÉ (1975) 121-159. 
ТóтH 1977

Тóтн 1980

UBELAKER 1989

VLČEK 1953

VONDRÁKOVÁ 1985

WIERCIŃSKI 1973

WILD et al. 2001

ŻejMo-ŻEJMIS 1938

ZINEVIČ 1967

ZINEVIČ-KRUC 1968

ZOFFMANN 1969-1970

ZOFFMANN 1972-1973

ZOFFMANN 1984

ZOFFMANN 1986

ZOFFMANN 1986-1987

ZOFFMANN 1987-1988

ZOFFMANN 1992

ZOFFMANN 1998-1999

ZOFFMANN 1998

ZOFFMANN 2000

ZOFFMANN 2001

ZOFFMANN 2004a

ZOFFMANN 2004b

ZOFFMANN 2004c

ZOFFMANN 2004d

ZOFFMANN 2005

ZOFFMANN 2006
Tóth, Tibor: Morfogenetikai trendek az ôskori Közép-Duna medencében [On the morphogenetic trends in the Central Danube Basin during the prehistoric age]. Anthropologiai Közlemények 21 (1977) 34-42. Tóth, Tibor: Some anthropological problems of the Early postglacial and Historic Europide. Annales Historico-Naturales Musei Nationalis Hungarici 72 (1980) 295-307.

Ubelaker, Douglas H.: Human Skeletal Remains. Excavation, Analysis, Interpretation. Washington 1989.

Vlček, Emanuel: Hromadné kostrové pohoby s kanelovanou keramikou v Nitrianském Hrádku na Slovensku [Sépultures collectives à inhumation avec de la céramique canelée, dégaées à Nitriansky Hrádok en Slovaquie]. ArchRozhl 5 (1953) 733-736, 839.

Vondráková, Mária: Kostra z jami Badenskoj kultury z Mužle-Cenkov [Skelett aus einer Grube der Badener Kultur Mužle-Cenkov]. ArchRozhl 37 (1985) 151.

Wierciński, Andrej: Untersuchungen zur Anthropologie des Neolithikums in Polen. In: Die Anfänge des Neolithikums vom Orient bis Nordeuropa. Ed. by Schwabedissen, Hermann. Köln 1973, 170-185. (Fundamenta Reihe B, VIIIa, Anthropologie, Teil 1)

Wild, Eva Maria-Stadler, Peter-Bondár, Mária-Draxler, Susanna-Friesinger, Herwig-Kutschera, Walter-Priller, Alfred-Rom, Werner-Ruttkay, Elisabeth-Steier, Peter: New Chronological Frame for the Young Neolithic Baden Culture in Central Europe (4th Millenium BC). Radiocarbon 43 (2001) $1057-1064$.

Żejmo-Żejmis, Stanisław: Seria czaszek neolitycznych z Brześćia Kujawskiego [Eine neolitische Serie aus Brześć Kujawski]. Wiadomości Archeologiczne 15 (1938) 158-201.

Zinevič, G. P.: Očerki paleoantropologiji Ukrajini [The palaeoanthropology of the Ukraine]. Kijev 1967. Zinevič, G. P-Kruc, S. I.: Antropologiceskaja harakteristika davnoga naseljenija teritoriji Ukrajini [Anthropological characteristics of ancient settlements in the Ukraine]. Kijev 1968.

K. Zoffmann, Zsuzsanna: Anthropological Analysis of the Cemetery at Zengóvárkony and the Neolithic Lengyel Culture in SW Hungary. JPMÉ 14-15 (1969-1970) 53-72.

K. Zoffmann, Zsuzsanna: Die Aufarbeitung des kupferzeitlichen und frühbronzezeitlichen anthropologischen Materials aus Vučedol (Jugoslawien). JPMÉ 17-18 (1972-1973) 51-60.

K. Zoffmann, Zsuzsanna: An attempt to use physical anthropological data in the study of the southeastern connections of Central European Neolithic populations. Alba Regia 21 (1984) 139-146. K. Zoffmann, Zsuzsanna: Das anthropologische Material des kupferzeitlichen Gräberfeldes von Tiszavalk-Tetes. FolArch 37 (1986) 47-74.

K. Zoffmann, Zsuzsanna.: Das anthropologische Material des spätneolotihischen Gräberfeldes von Gomolava-Hrtkovci. Rad Vojvodjanskog Muzeja 30 (1986-1987) 43-39.

K. Zoffmann, Zsuzsanna: A Badeni kultúra embertani leleteinek vizsgálata a Penrose-féle analízis segítségével [Investigation of anthropological finds of the Baden Culture with the help of the Penrose Analysis]. Anthropologiai Közlemények 3 (1987-1988) 121-137.

K. Zoffmann, Zsuzsanna: Kelet Kárpát-medence neolitikus és rézkori népességeinek embertani vázlata [Anthropology of the Neolithic and Copper Age populations of the Carpathian Basin]. CSc thesis. Budapest 1992.

K. Zoffmann, Zsuzsanna: Anthropological data of the Transdanubian Prehistoric populations living in the Neolithic, the Copper, the Bronze and the Iron Ages. Savaria 24: 3 (1998-1999) 33-49.

K. Zoffmann, Zsuzsanna: Embertani leletek a Badeni kultúra Pécs-Hôerômú lelóhelyéról [Anthropological finds from the Baden Culture unearthed at Pécs-Hóerómú]. JPMÉ 43 (1998) 141-146.

K. Zoffmann, Zsuzsanna: Anthropological sketch of the prehistoric population of the Carpatian Basin. Acta Biologica Szegediensis 44 (2000) 75-79.

K. Zoffmann, Zsuzsanna: Anhropological structure of the prehistoric populations living in the Carpatian Basin in the Neolithic, Copper, Bronze and Iron age. ActaArchHung 52 (2001) 49-62.

K. Zoffmann, Zsuzsanna: A Badeni népesség Balatonőszöd lelóhelyról való embertani leleteinek ismertetése [Anthropological Study on the Baden Population of the Balatonőszöd Site]. SMK 16 (2004) 111-125.

K. Zoffmann, Zsuzsanna: Ôslakosok és bevándorlók a neolitikus és rézkori Kárpát-medencében az embertani adatok alapján (A Somogy megyében újonnan feltárt Badeni temetók Penrose-analízise) [Autochtonous population and immigrants in the Carpathian Basin of the Neolithic and the Copper Age after the anthropological data. The Penrose analysis of the recently unearthed Baden cemeteries in Somogy county]. SMK 16 (2004) 127-137.

K. Zoffmann, Zsuzsanna: A késó-rézkori Kostolac-kultúra hamvasztott embertani leletei Balatonboglár-Berekre-dúlő lelóhelyról [The cremated anthropological finds of the Late Copper Age Kostolac culture from the Balatonboglár-Berekre dúlő site]. SMK 16 (2004) 161-163.

K. Zoffmann, Zsuzsanna: A Lengyeli kultúra Mórágy B.1. temetkezési csoportjának embertani ismertetése [Anthropological description of the Mórágy B.1. burial group of the Lengyel culture]. WMMÉ 26 (2004) 137-152.

K. Zoffmann, Zsuzsanna: Prehistoric Anthropological Finds in the Carpathian Basin and the Penrose Connections of the Ethnic Groups they Present. Praehistoria 6 (2005) 103-129.

K. Zoffmann, Zsuzsanna: Balatonlelle környékéról származó késô-rézkori embertani leletek [Late Copper Age anthropological finds from Balatonlelle]. SMK 17 (2006) 97-106. 


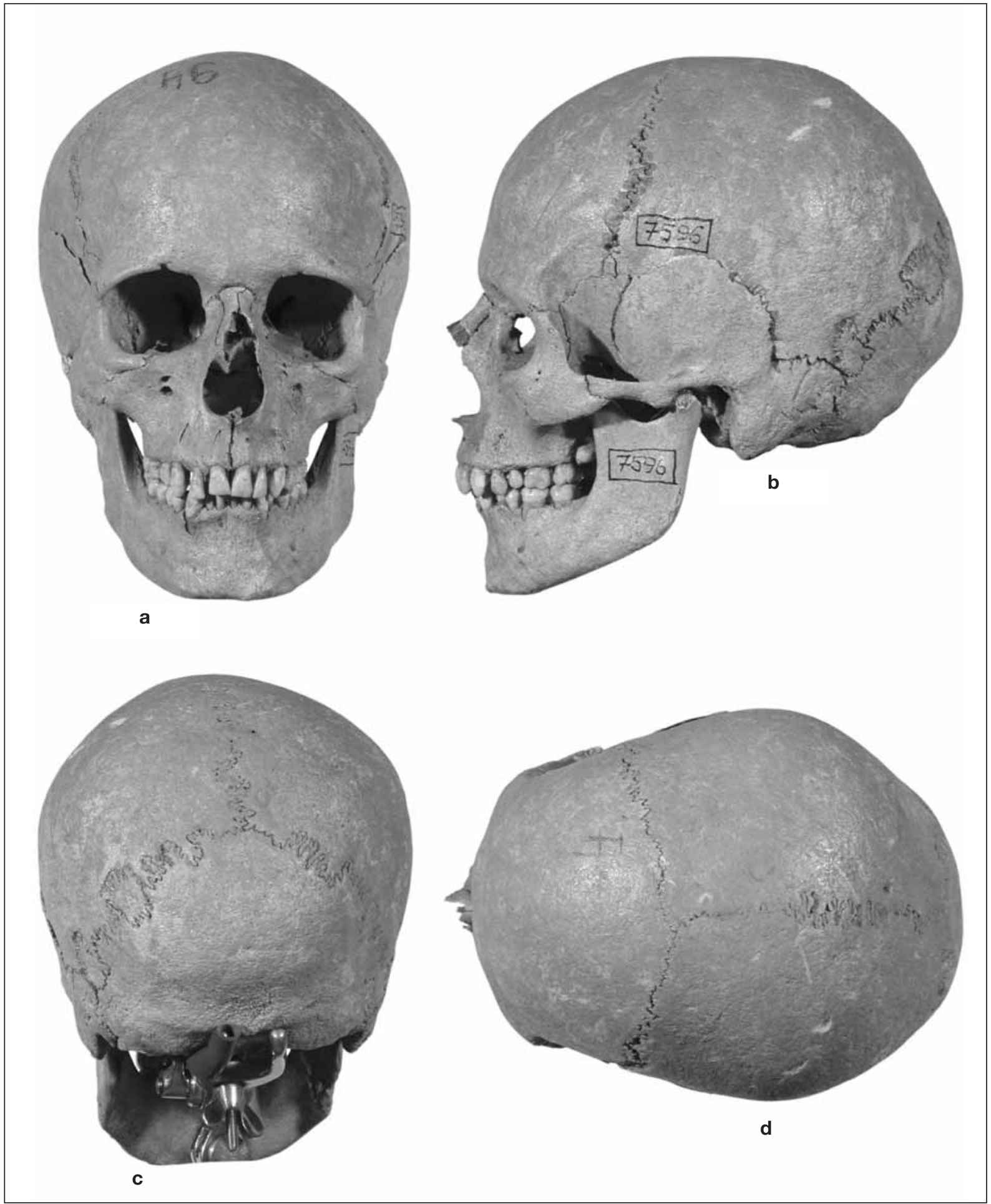

Pl. 1. a-d. Skull of a juvenile male buried in Grave 94. Gracile Mediterranean type 


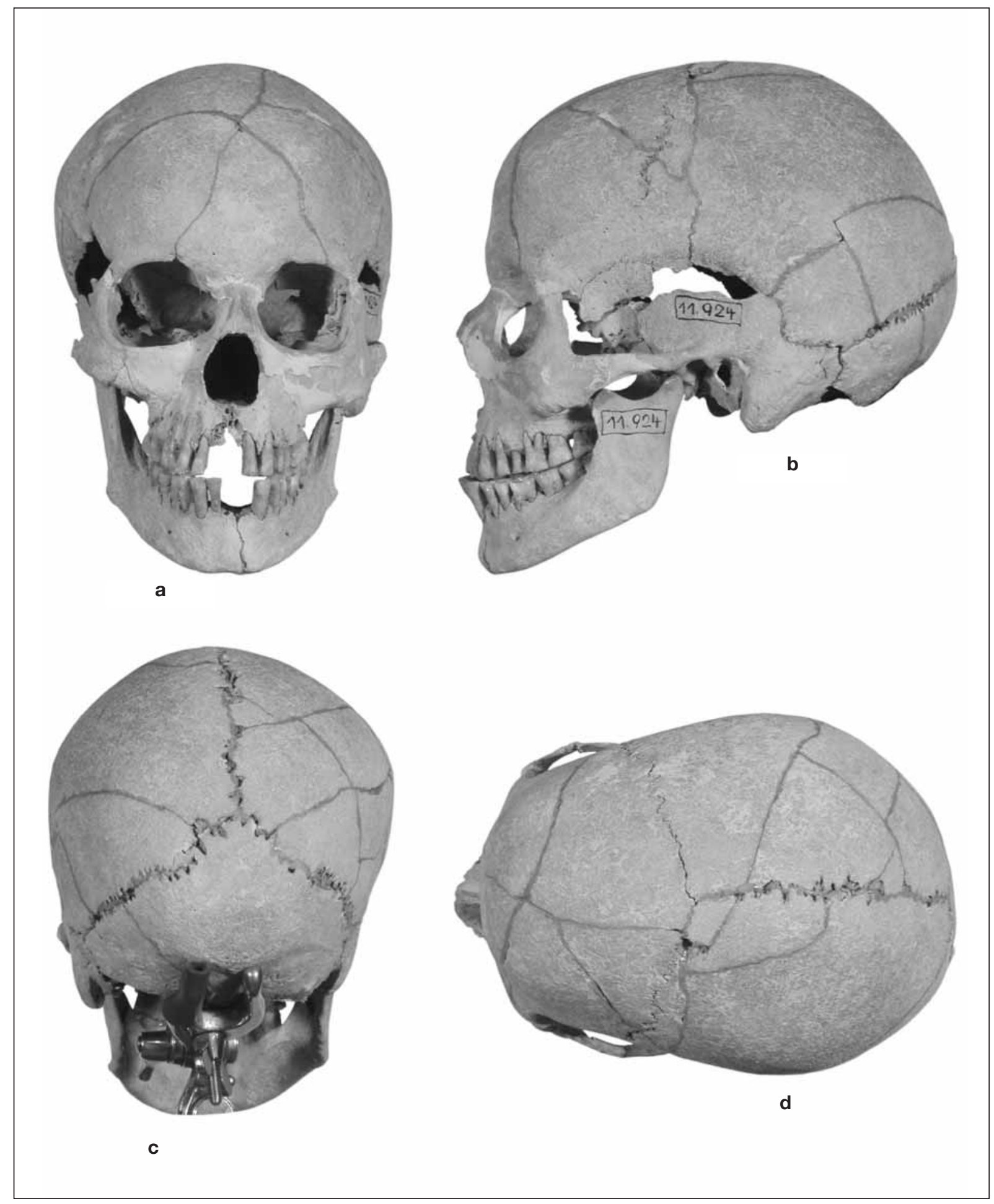

Pl. 2. a-d. Skull of a mature female buried in Grave 389/A. Gracile Mediterranean type 


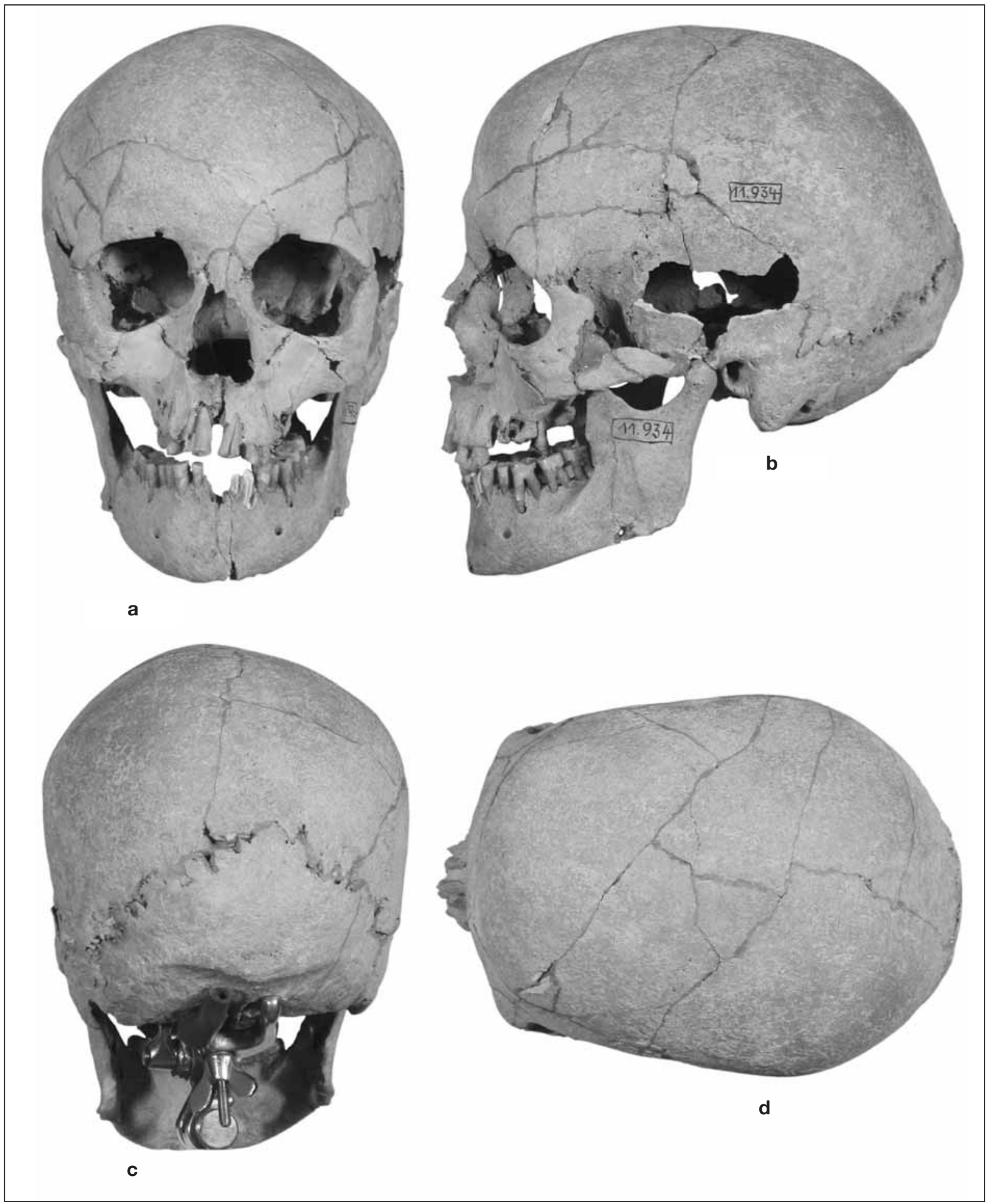

Pl. 3. a-d. Skull of a mature male buried in Grave 396/B. Gracile Mediterranean type 


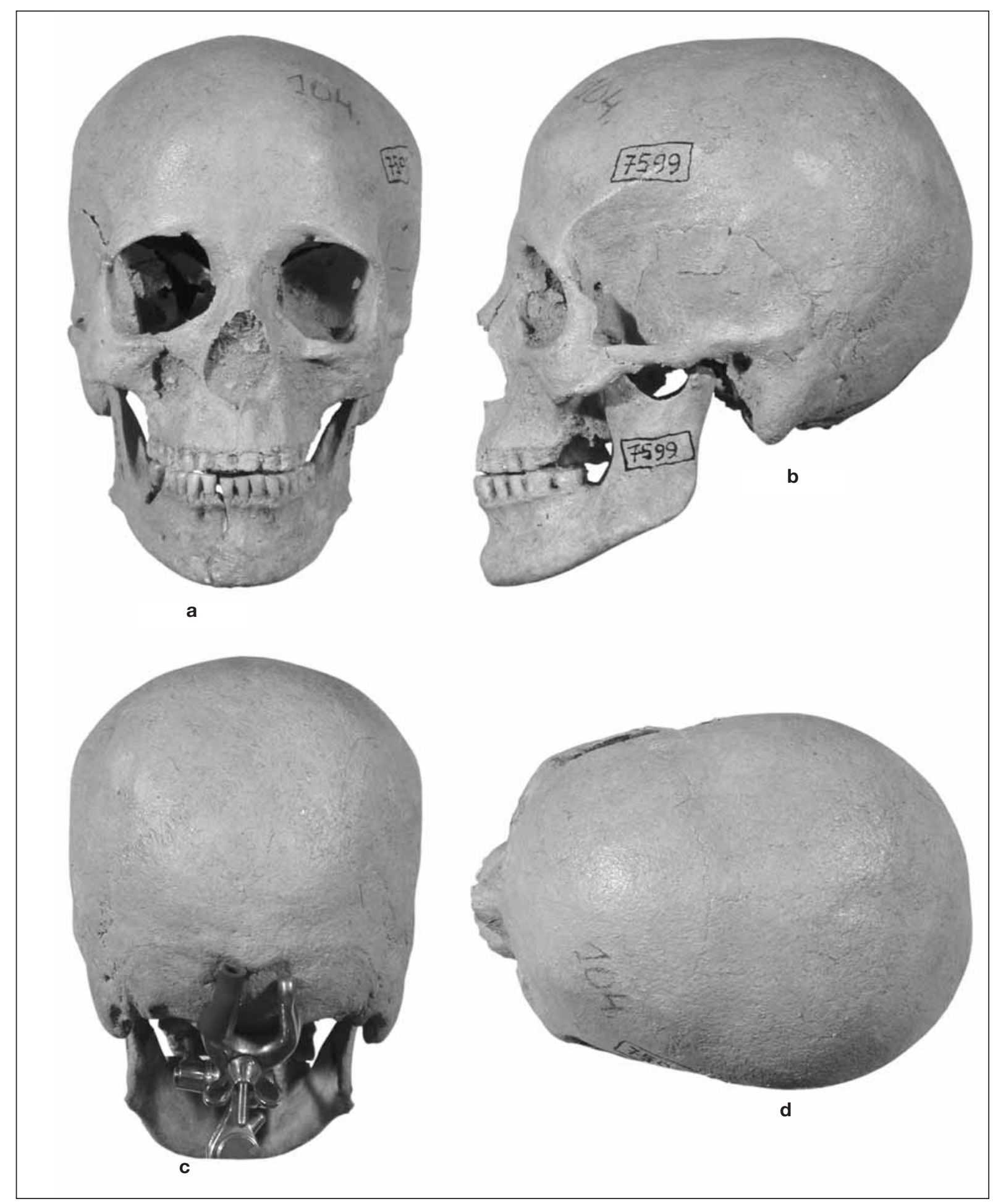

Pl. 4. a-d. Skull of an adult female buried in Grave 104. Atlanto-Mediterranean + Alpine type 

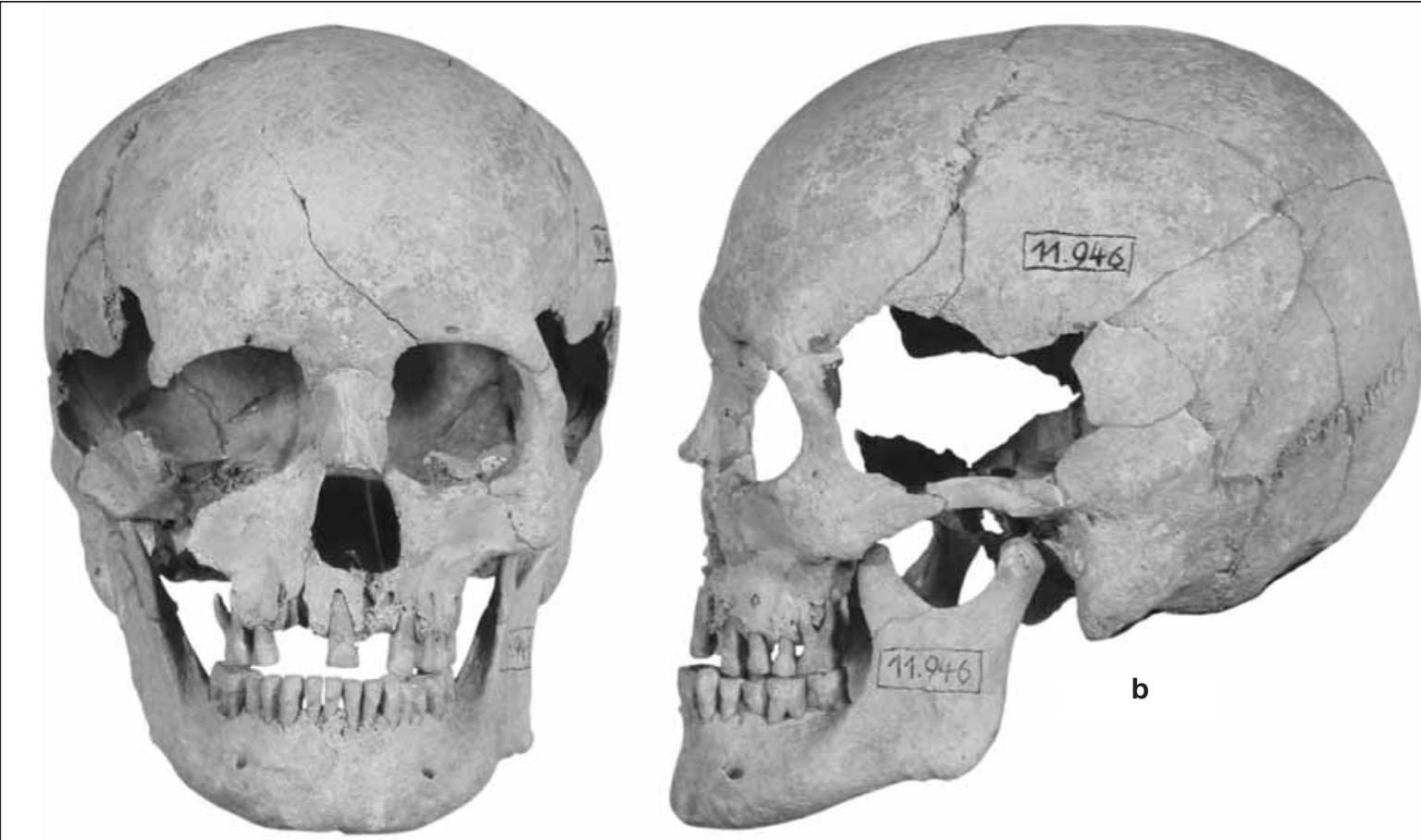

a
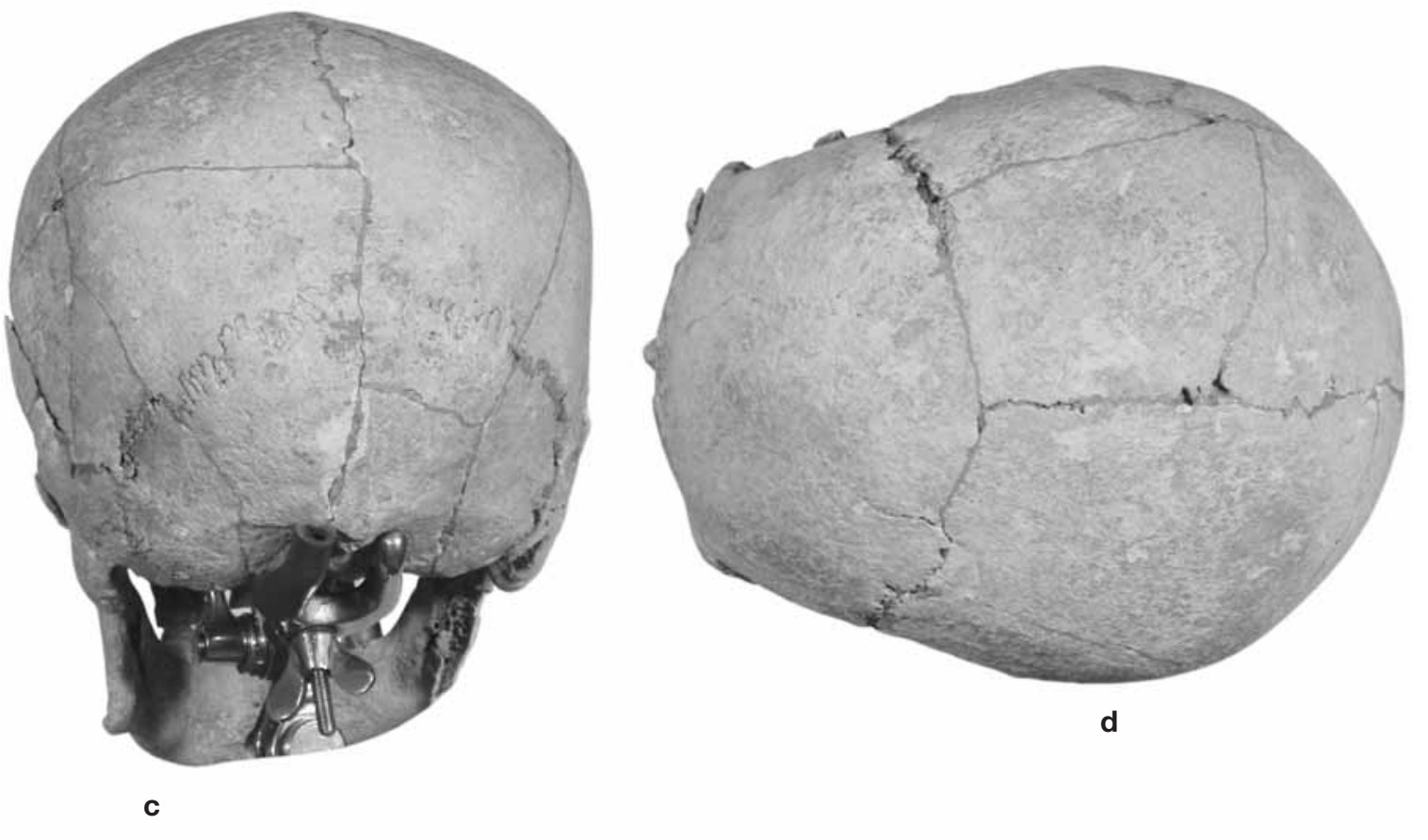

Pl. 5. a-d. Skull of an adult-mature male buried in Grave 412. Alpine type 


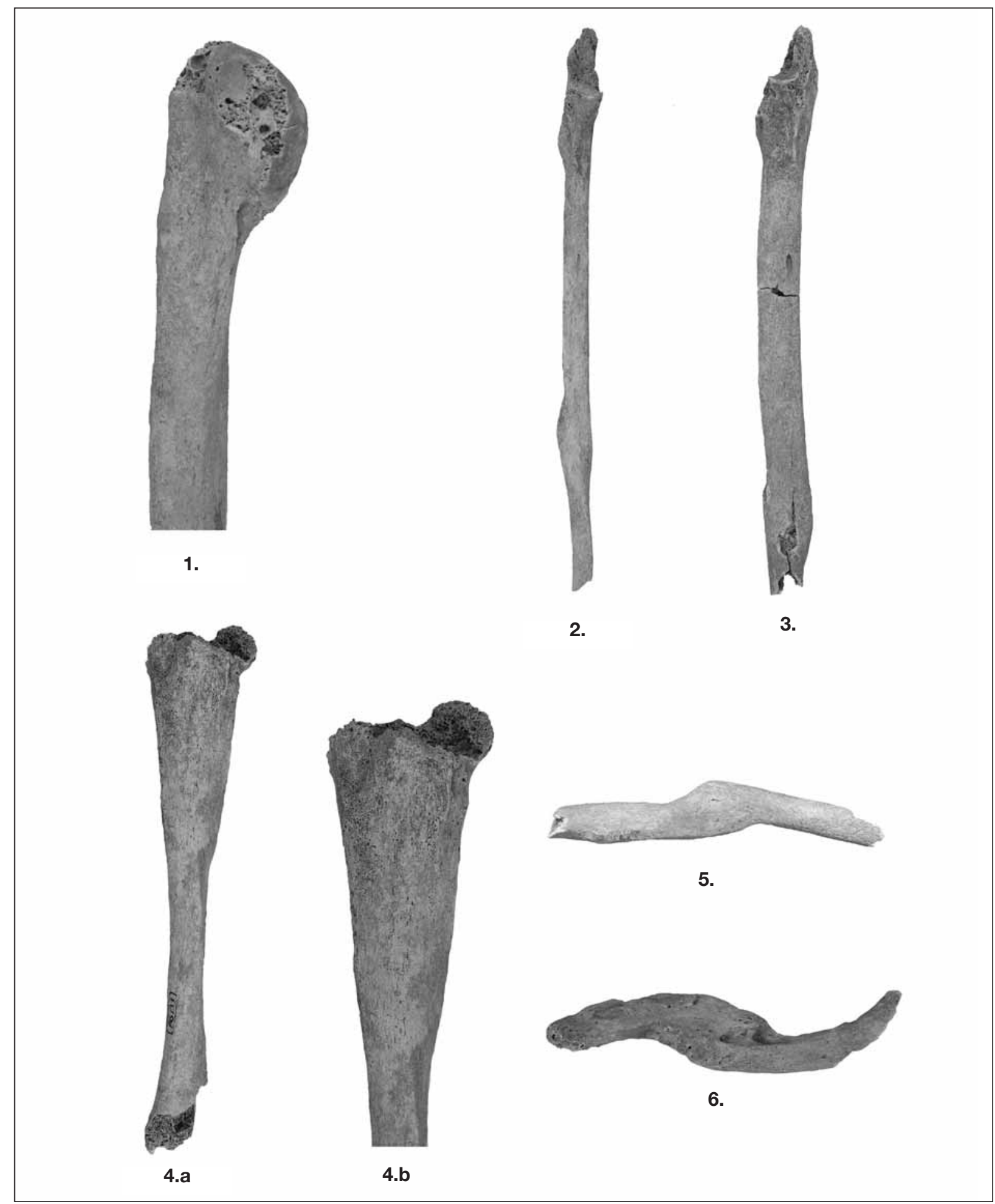

Pl. 6. 1. Healed fracture in bumerus neck (Grave 264), 2. bealed fracture of ulna (Grave 51), 3. healed fracture of ulna (Grave 279), 4. a. osteomyelitis of tibia (Grave 112), 4. b. osteomyelitis of tibia (Grave 112), enlargement, 5. healed fracture of clavicle (Grave 195/B), 6. healded fracture of clavicle (Grave 358) 


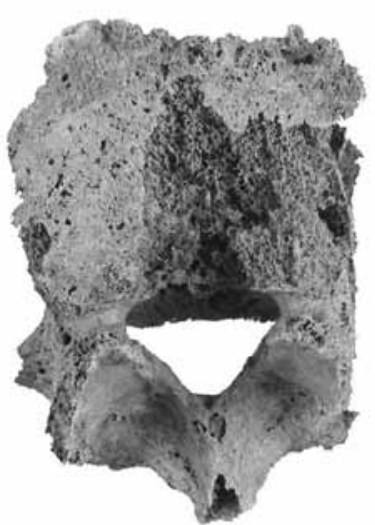

1.

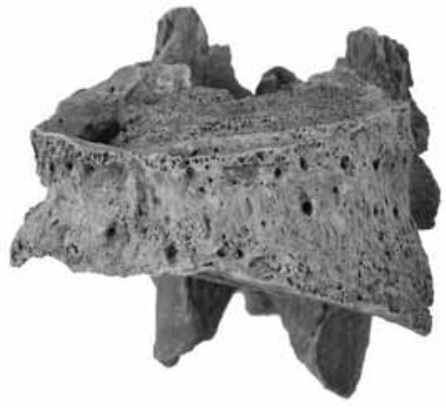

3.

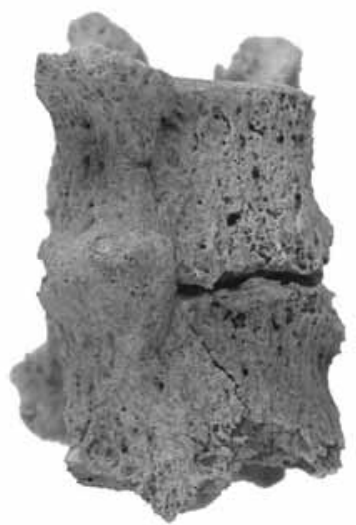

5.a

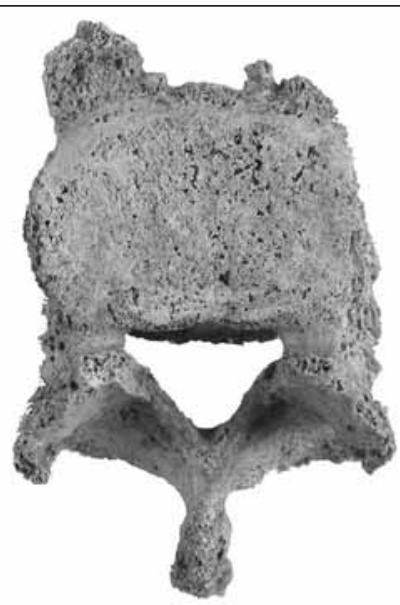

2.

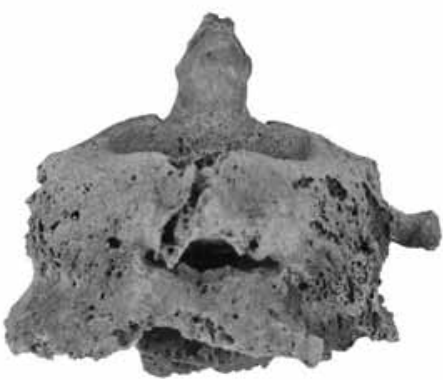

4.

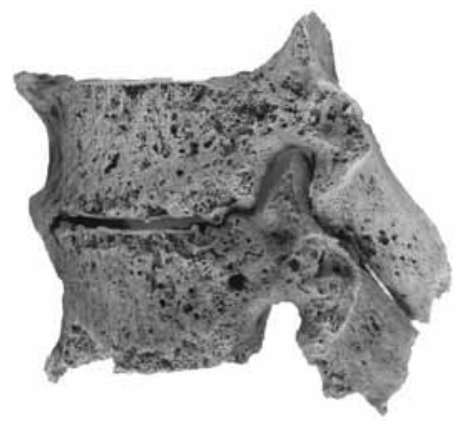

5.b

Pl. 7. 1. Spondylosis deformans on lumbar vertebra (Grave 358), 2. spondylosis deformans on lumbar vertebra (Grave 358), 3. osteophyte development and collapse of a lumbar vertebral body (Grave 405), 4. block cervical vertebrae (Grave 420), 5. a. union of thoracic vertebrae, anterior view (Grave 358), 5. b. union of thoracic vertebrae, lateral view (Grave 358) 


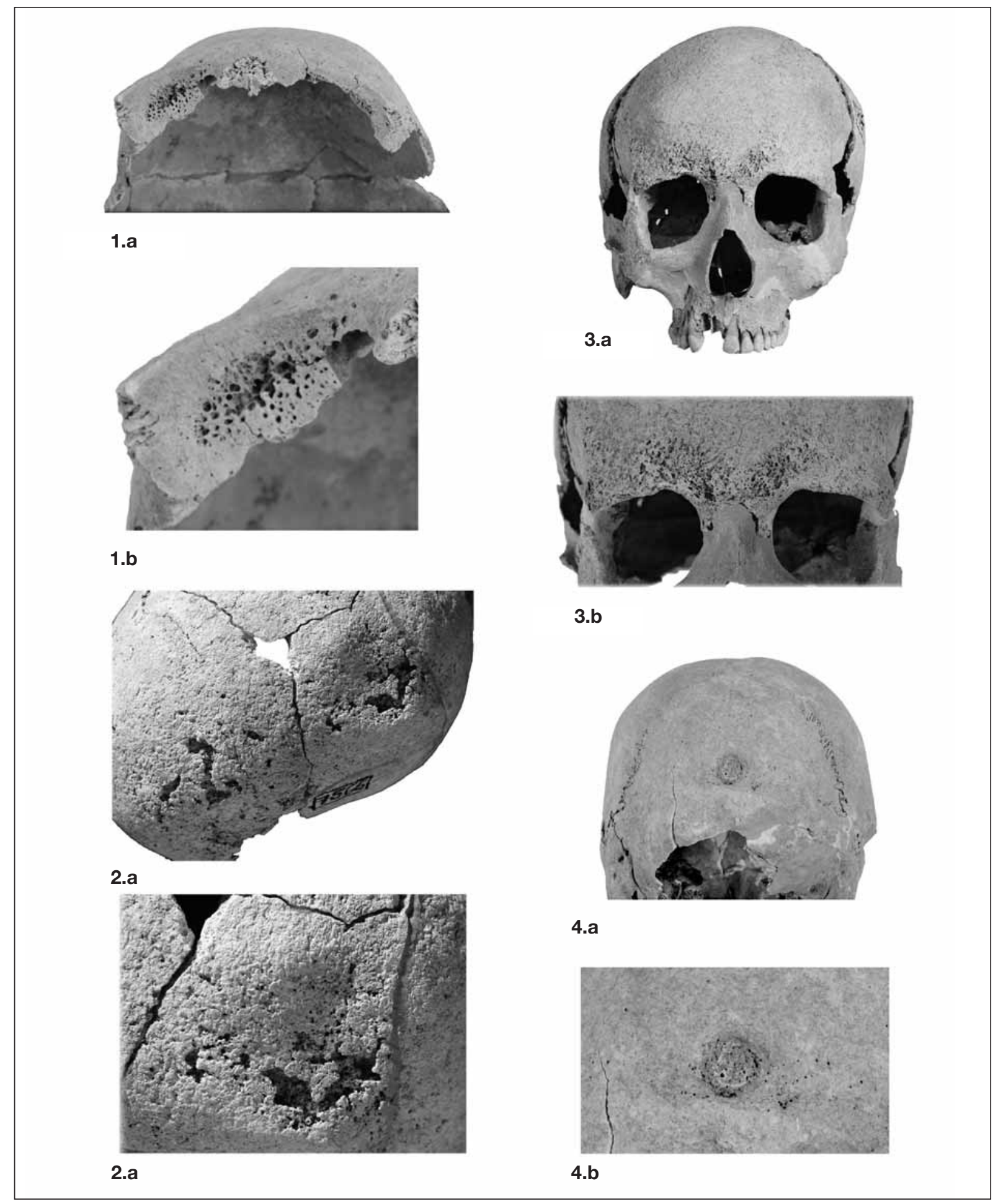

Pl. 8. 1. a. Porotic byperostosis, porotic type (Grave 303), 1. b. porotic byperostosis, porotic type (Grave 303) enlargement, 2. a. symmetric osteoporosis (Grave 38), 2. b. symmetric osteoporosis (Grave 38) enlargement, 3. a. Porous and eroded surface in the area of the supercilliary arch and the glabella of the skull (Grave 46), 3. b. porous and eroded surface in the area of the supercilliary arch and the glabella of the skull (Grave 46) enlargement, 4. a. healed skull wound (Grave 366/B), 4. b. healed skull wound (Grave 366/B) enlargement 


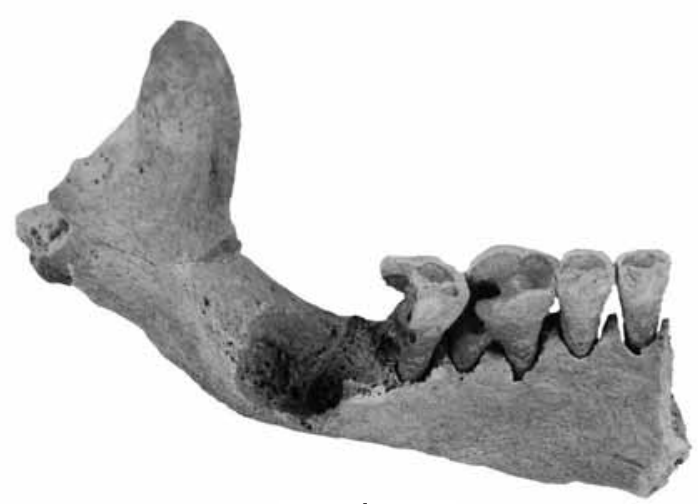

1.

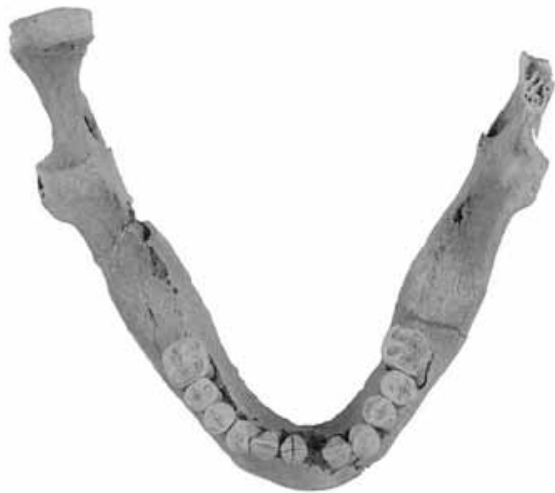

3.

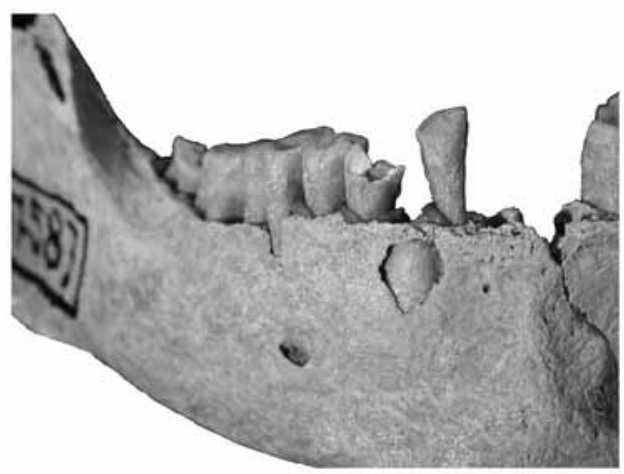

5.

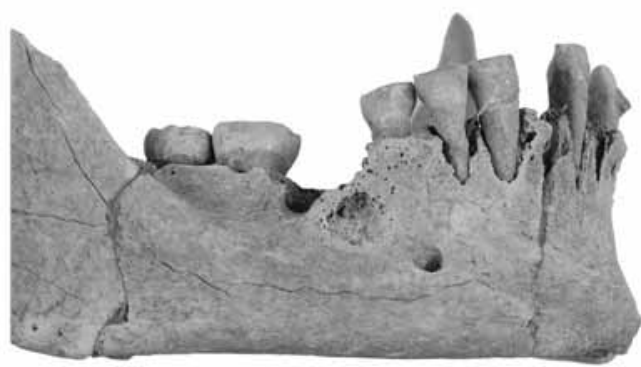

2.

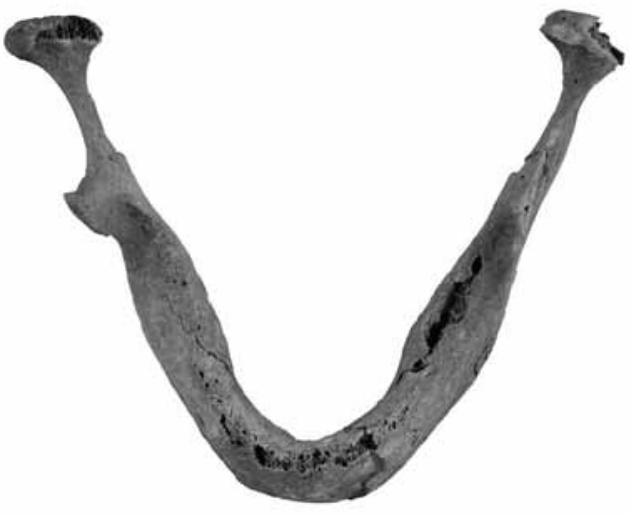

4.

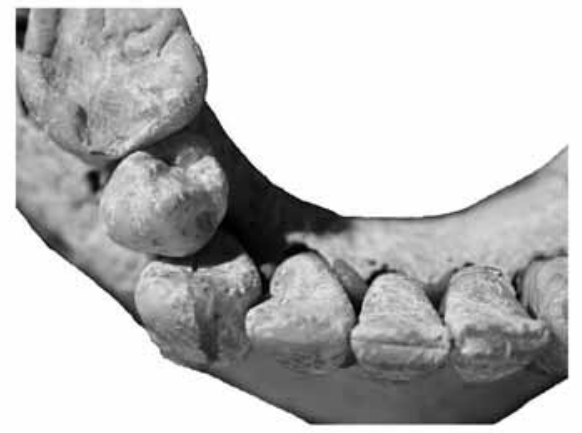

6.

Pl. 9. 1 Mandibular first and second molar with existence cervical caries and cyst/abscess (Grave 195/A), 2. cysts/abscesses on the mandible at the second premolar and first molar (Grave 283), 3. pre-mortem loss of molars on mandible (Grave 188), 4. alveolar resorption on the mandible (Grave 348), 5. impaction of the lower right canine tooth (Grave 66), 6. crowding on the lower right dental arch (Grave 60) 


\section{ARCHAEOGENETIC ANALYSIS OF HUMAN SKELETAL SAMPLES FROM THE BUDAKALÁSZ CEMETERY}

Aranka Csốsz 


\section{INTRODUCTION}

Samples taken from human bone remains of the Late Copper Age cemetery at Budakalász-Luppa csárda were submitted to molecular genetic analyses. The cemetery dates from the Baden culture (3600/3500-3000 BC) meaning that the surviving tissues are approximately 5000 years old. Very few analyses of human remains from such an early period of prehistory are known, ${ }^{1}$ and thus the analysis of the DNA contents of the human skeletal remains from the site are of interest not only to Hungarian archaeogenetic studies.

The main goal of the analysis was to address the question of whether the individuals interred beside each other were directly related to each other. As it turned out, the extremely poor state of the skeletal material's preservation called for a reformulation of the initial research objective, namely whether the samples were suitable for an analysis of this type.

\section{SAMPLING}

The poor state of preservation of the skeletal remains strongly limited sampling and also restricted the nature and number of possible research objectives. Only one of the possible theoretical questions concerning the cemetery's population (such as family relations, maternal or paternal lineage, methodological issues) remained relevant.

The poor state of preservation also made it doubtful whether a sufficient amount of DNA of adequate quality for analytical purposes had survived in the bones. In order to determine this, we performed the analysis of the selected samples with a view to methodological issues using the marker whose extraction offers the greatest chance of meaningful results in the case of archaic remains. By studying a part of the mitochondrial DNA (mtDNA) content, we hoped to obtain information on the state of the DNA surviving in the bones.

One great advantage of mtDNA as a molecular marker in the case of degraded samples is the number of copies. ${ }^{2}$ Owing to its high number (several hundred copies per cell), its extraction is considerably more productive than that of chromosomal DNA, present in no more than one or two copies. mtDNA has several other favourable properties too (maternal inheritance, lack of recombination, ${ }^{3}$ high mutation rate ${ }^{4}$ ), whereby the results can be widely applied, especially in the research of population genetics.

\footnotetext{
${ }^{1}$ HirOKI et al. 2001; HAAK et al. 2006; CHILvERSA et al. 2008; CHANDLER 2005.

2 FORAN 2006.

3 Giles et al. 2006.

${ }^{4}$ RichardS-MaCAULAY 2001.
}

\section{DIFFICULTIES IN THE STUDY OF ANCIENT SAMPLES}

Parallel to the decay of tissues and cells, the amount of DNA in them decreases. The increasingly smaller amounts of DNA present in decaying tissues also leads to their degradation, resulting in the deterioration of both the quality and the amount of DNA. The "active" DNA content of cells suitable for analysis too decreases. The multi-phase degradation process has both intra-cellular and extra-cellular catalysts.

The decay of DNA in the cell is accelerated by endonucleases, whose concentration varies depending on the tissue type. DNA in tissues with a higher nuclease content decays more rapidly than in the cells of tissues with a lower nuclease contents (such as bone and teeth).

In addition to the body's own endonucleases, microbial exonucleases (bacteria, fungi) also participate in the degradation processes. Because one precondition to the appearance and activity of microbes is water, samples exposed to humidity may undergo very rapid decay. A high temperature in a given range also favours the appearance of microbes and the commencement of enzymatic processes; DNA decays most rapidly in a warm and humid environment. In contrast, conditions diminishing the activity of nucleases and preventing the reproduction of microbes are favourable for preserving the condition of DNA. The drying of the finds, their storage in a cold environment and their isolation from air are the main prerequisites for the conservation of their DNA contents.

DNA is also damaged by natural chemical modifications, the most frequent among these being the loss of amino groups. Bases suffering modification too serve as a basis for the creation of new strands in the amplification procedure, meaning that erroneous bases can also become incorporated into the new DNA sequences, resulting in erroneous results. If misincorporation occurs in the first cycle of the PCR (Polymerase Chain Reaction), a false polymorphism occurs. If misincorporation occurs in a later phase of the PCR, the erroneous base does not occur in every PCR product, only in some, although a base differing from the others may occur in each product. ${ }^{5}$

Oxidative free radicals are another source of damage to the bases, causing the oxidation of the bases, which in turn leads to the segmentation of the strands.

The study of ancient remains is sometimes complicated by the fact that various substances from the degradation of the body tissues or from the micro-environment of the burial (e.g. clothing, coffin remains) can contaminate the sample; these substances are purified together with the ancient DNA during its isolation and hinder its selective extraction.

The analysis of remains containing contaminants can yield results similar to samples containing degraded

\footnotetext{
5 Рё̈̈во et al. 2004.
} 
Table 1. The relevant data of the analysed bone samples

\begin{tabular}{|l|c|c|c|c|}
\hline Sample number & Sample type & Grave number & Sex & Age $^{6}$ \\
\hline 34 B & B & 48/A & child & $10-12$ \\
\hline 35 B & B & 48/B & juvenis (female) & $14-16$ \\
\hline 36 B & B & 134/A & juvenis (?) & $15-19$ \\
\hline 37 B & B & 134/B & male & $23-x$ \\
\hline 38 B & B & 153/A & male & $40-x$ \\
\hline 39 B & B & 153/B & male & $35-59$ \\
\hline 41 B & B & 169/A & female & $50-70$ \\
\hline 42 B & B & 263/B & male & $35-45$ \\
\hline 43 B & B & 263/B & female & $40-59$ \\
\hline 44 B & B & 366/A & female & $21-23$ \\
\hline 45 B & B & 366/B & male & $40-59$ \\
\hline
\end{tabular}

*B: bone

or minimal amounts of DNA; in these cases, amplification does not yield a sufficient amount of products.

The DNA of dead tissues/cells suffers natural chemical and physical decay even under normal temperature, under conditions ideal for the preservation of DNA. This process is relatively slow, but the damage is cumulative. In addition to the individual age of the deceased, the archaeological age of the sample is also important. The remains from which the samples were extracted had been exposed to these environmental damages for many thousands of years, and thus the likelihood of extensive damage to the DNA was more than likely.

\section{PREVENTION OF CONTAMINATION}

One of the greatest dangers during the analysis of ancient human samples is contamination by modern DNA. The poor state of preservation of the archaic DNA samples meant that contamination was a potentially high risk and thus increased attention was paid to ensuring sterile circumstances during the analytical procedures. The samples were analysed using sterilised equipment in a wholly sterilised room. The reliability of the procedures was verified by means of negative controls as part of the analytical procedure. A negative control and an isolational negative control sample (taken before pulverisation) were associated with each sample in order to exclude erroneous results from possible contamination.

\section{MATERIALS AND METHODS}

\section{The samples}

The bone remains from six double burials were submitted to analysis. Of the 436 burials excavated at Budakalász, we chose Graves 48, 134, 153, 169, 263 and 366. Each grave contained two individuals. The poor preservation of the skeletons limited the sampling options, as did the fact that child burials were excluded owing to the low amount of cortical bone.

Our initial goal was to extract mtDNA from seven of the twelve skeletons. The samples were in all cases extracted from the proximal end of the femur. A $2.5 \mathrm{~cm}$ long and $1.5 \mathrm{~cm}$ wide section was removed, two-thirds of which was then pulverised to fine powder.

It has been suggested in a series of studies that DNA is better preserved in teeth than in other skeletal remains. One of the difficulties with teeth is that they are often dislodged from the alveolus and are subsequently lost, and it is therefore often difficult to establish which skeleton they had originated from in the case of multiple burials. We chose the best preserved skeletal remains from the cemetery's anthropological material, but even so, the teeth which had fallen out could not always be associated with one or the other skeleton in a particular grave.

\section{DNA extraction}

Previously, we mostly analysed human remains from the Early Middle Ages. The analysis of the material from Budakalász-Luppa csárda therefore meant an exciting challenge from a technological point of view.

We employed isolation techniques which had proven successful in the case of 10th century samples and we also tested new kits, namely two variants of the GENECLEAN® Kit For Ancient DNA (Qbiogene), two variants of the Dneasy® Tissue Kit (QIAGEN), the QIAamp® DNA Micro Kit and the isolation protocol developed by Tibor Kalmár.7 We applied at least two isolation procedures for each sample and attempted the extraction of mtDNA at least twice during each procedure. The tests indicated that the DNA still present in the bones had suffered serious damage.

\footnotetext{
${ }^{6}$ We would like to thank Kitti Köhler for the data.

7 KALMÁR et al. 2000
} 


\section{$m t D N A$ amplification}

The sequence required for the informative categorisation of mtDNA was assembled from two partly overlapping segments. We gained a 400bp (base pair) mtDNA sequence from the HVSI range between 16020-16420. After discounting the primary regions (40 bp) necessary for the amplification procedure, we had a 360 bp segment. The separation of mitochondrial categories (haplogroups/haplotypes) is based on the mutation motifs of this segment, complemented by the analysis of the mutation points in the HVSII and the mtDNA coding region. While this procedure proved successful in the case of well preserved $8^{\text {th }}-10^{\text {th }}$ century samples, it was unsuccessful in the case of the Budakalász samples.

The extracted sequence was divided into four instead of two segments during the PCR. We hoped to obtain the desired region from the joining of a 168, 151, 155 and 160 bp product. The following primers were used: L16040 (5'-TCTGTTCTTTCATGGGGAAG-3') ${ }^{\circ}$ / H16168 (5'-GGGGTTTTGATGTGGATTGG-3') ${ }^{9}$; L16130 (5-'CAGCCACCATGAATATTGTACG-3') 9 / H16239 (5-GTGGCTTTGGAGTT-GCAGTT3`); ${ }^{9}$ L16200 (5`-AACCCCCTCCCCATGCTTA-3`) / H16313 (5-'CTATGTACGGTAAATGGCTTTATG3') ${ }^{9}$; L16280 (5-'CCCTCACCCACTAGGATACC-3') / H16401 (5 -TGATTTCACGGAGGATGGTG-3`). ${ }^{10}$

The primer pairs comprising shorter segments were first validated on bones with well preserved DNA. The tests indicated that all four primer pairs were successful.

PCR

The composition of the amplification mixture in $25 \mathrm{ml}$ volume: 1 x AmpliTaq Gold-Puffer (Applied Biosystems), $25 \mathrm{pmol} / \mathrm{ml}$ for each primer, $800 \mathrm{mM} \Sigma \mathrm{dNTP}$ (Fermentas), $1.5 \mathrm{mM} \mathrm{MgCl}_{2}, 4 \mathrm{mg} / \mathrm{ml} \mathrm{BSA} \mathrm{(Sigma),} 5 \mathrm{ml}$ bone extractum and $2 \mathrm{U}$ AmpliTaq Gold-Polymerase (Applied Biosystems).

The PCR parameters: $95^{\circ} \mathrm{C} 10 \mathrm{~min}$, for 34 cycles: $94^{\circ} \mathrm{C} 30 \mathrm{~s}, 55^{\circ} \mathrm{C} 1 \mathrm{~s}, 72^{\circ} \mathrm{C} 30 \mathrm{~s}$ and the final extension: $72^{\circ} \mathrm{C} 5 \mathrm{~min}$.

$5 \mu \mathrm{l}$ of the PCR product was separated on $8 \%$ Polyacrylamide gel and stained in ethidium bromide.
A positive PCR does not necessarily mean that the analysis was successful. The PCR product extracted from the bone and then amplified is often of poor quality and/or has a mixed DNA content. The usability of the amplified DNA can only be evaluated at the end of the analytical procedure.

\section{Sequencing}

The successful and uncontaminated PCR product was purified in a Microcon Centrifugal Filter (Millipore) and concentrated in $12 \mu \mathrm{l}$ volume. The sequencing reaction was performed with the ABI Prism 310 sequencer (Perkin-Elmer), using the ABI Prism BigDye ${ }^{\circledR}$ Terminator v3.0 Cycle Sequencing Ready Reaction Kit. The primer pairs used for sequencing were identical with the primers used for the PCR.

\section{RESULTS}

Only one of the seven analysed samples proved suitable for amplifying a short segment of the mtDNA content. The mtDNA content was best preserved in the sample from Grave 153/B (Sample 39B): the amplification of the shortest, $151 \mathrm{bp}$ segment yielded evaluable results. The sequence thus gained could only be clearly read for a length of $97 \mathrm{bp}$. The sequence of Sample 39B correspond to the Cambridge reference sequence ${ }^{11}$ for this short segment.

In addition to a 360 bp long HVSI segment, the coding region positions and further control are necessary for determining the maternal lineage. The extracted $97 \mathrm{bp}$ long segment was insufficient for answering any questions by means of $\mathrm{mtDNA}$ analyses. The analysis was not aimed at answering questions of this type; our main goal was to determine whether an adequate volume of DNA suitable for analysis had survived in the bones. We found that the DNA in the skeletal remains uncovered at Budakalász-Luppa csárda had suffered serious damage since the deposition. The quality of the mtDNA extracted from the samples did not yield any evaluable results.

Several sequences were gained from the sample, but all of them were mixed and unevaluable.

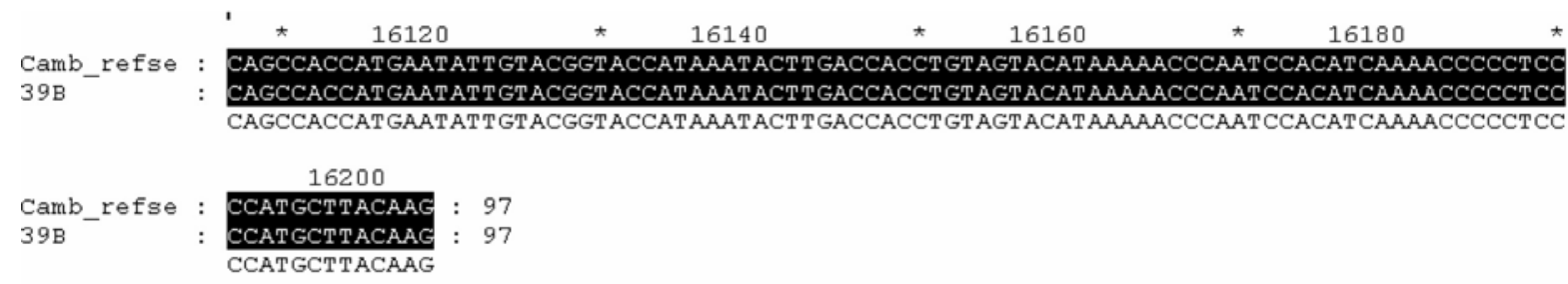

Fig. 1. The base sequence of the sequence extracted from Sample 39B and the Cambridge Reference sequence

\footnotetext{
8 TÖMÖRY et al. 2007

9 The present study
}

${ }_{10}$ Kalmár et al. 2000.

${ }^{11}$ ANDREWs et al. 1999. 


\section{SUMMARY}

Archaeogenetics as an independent discipline is a relatively recent field of research. The first studies were written in the early $1980 \mathrm{~s},{ }^{12}$ followed by several studies reporting the successful genetic analysis of human tissues. The number of studies is relatively low and mostly discuss the difficulties of the procedure and the various factors limiting analysis. This is especially true regarding human remains from prehistory (Neolithic, Copper Age, Bronze Age, Iron Age). ${ }^{13}$

Our main goal was to examine the state of preservation of the DNA in the human skeletal remains from the cemetery at Budakalász-Luppa csárda. Previously, we had only worked with samples from the $9^{\text {th }}-10^{\text {th }}$ centuries $\mathrm{AD}$ and thus the analysis of almost five thousand years old bones represented an exciting challenge.

We analysed the remains from six double burials of the Copper Age cemetery. Sampling was severely restricted by the poor state of preservation of the skeletal material.

We employed both well-established protocols for isolation and tested a newly developed kit. In addition to applying different extraction procedures, we also attempted the amplification of shorter DNA segments in the hope of success.

However, we were unable to extract a sufficient amount of mtDNA of acceptable quality from the selected samples. One must always reckon with the lack of evaluable results in the case of molecular analyses performed on archaeological remains. Insofar as one goal of the analytical procedures is to establish whether DNA can be extracted, even the lack of any results provides important information. The results of the molecular genetic analyses on the human remains from the Copper Age cemetery at Budakalász-Luppa csárda indicate that the DNA contents of the skeletal remains had been degraded to such an extent over the millennia that does not enable the extraction of meaningful information for archaeological studies from the available samples.

$$
\text { *** }
$$

We continued the analyses of the samples after submitting the manuscript for publication. By testing new protocols, we have since succeed in extracting new mtDNA fragments from the available samples. Sample $38 \mathrm{~B}$ was successfully amplified and yielded a $240 \mathrm{bp}$ product, while Sample 40B yieled a 238bp product. We now also have a $360 \mathrm{bp}$ product suitable for identifying haplogroups from Sample 39B, the single sample which had initially yielded evaulable results. The successful extraction of evaulable $\mathrm{mtDA}$ products clearly indicates that even the analysis of seemingly hopeless samples should be pursued because the latest protocols and kits hold out a fair chance of success.

\footnotetext{
12 Wang et al. 1981; HigUCHI et al. 1984; РёÄво 1985.

${ }^{13}$ Chilversa et al. 2008; Fily et al. 1998; Caramelli et al. 2007.
} 


\section{References}

ANDREWs et al. 1999

CARAMELli et al. 2007

Chandler et al. 2005

Chilversa et al. 2008

FILY et al. 1998

FORAN 2006

GILES et al. 1980

HAAK et al. 2006

HigUCHI et al. 1984

HiROKI et al. 2001

KALMÁR et al. 2000

РӒӒво 1985

РёÄво et al. 2004

RiCHARDS-MACAULAY 2001

TÖмÖRY et al. 2007

WANG et al. 1981
Andrews, R. M.-Kubacka, I.-Chinnery, P. F.-Lightowlers, R. N.-Turnbull, D. M.-Howell, N.: Reanalysis and revision of the Cambridge reference sequence for human mitochondrial DNA. Nature Genetics 23 (1999) 147.

Caramelli, D.-Vernesi, C.-Sanna, S.-Sampietro L.-Lari, M.-Castrì L.-Vona, G.-Floris, R.- Francalacci, P.-Tykot, R.-Casoli, A.-Bertranpetit, J.-Lalueza-Fox, C.-Bertorelle, G.-Barbujani. G.: Genetic variation in prehistoric Sardinia. Human Genetics 122 (2007) 327-336.

Chandler, H.-Sykes, B.-Zilhão, J.: Using ancient DNA to examine genetic continuity at the Mesolithic-Neolithic transition in Portugal. In Arias, P.; Ontañón, R.; García-Moncó, C. In: Actas del III Congreso del Neolítico en la Península Ibérica. Santander 5 a 8 de octubre de 2003. Ed. by P. A. Cabal, R. Ontañón Peredo and C. García-Monco Piñeiro. Monografías del Instituto Internacional de Investigaciones Prehistóricas de Cantabria 1. Santander (2005) 781-786.

Chilversa, R. E.-Bouwmana, S. A.-Brown, A. K.-Arnott, G. R.-Prag, N. W. J. A.-Brown, T. A, Ancient DNA in human bones from Neolithic and Bronze Age sites in Greece and Crete. Journal of Archaeological Science 35 (2008) 2707-2714.

Fily, M.-L.-Crubézy, É.-Courtaud, P.-Keyser, C.-Ébrard, D.-Ludes, B.: Analyse paléogénétique des sujets de la grotte sépulcrale d'Elzarreko Karbia (Bronze ancien, Pays Basque) - Paleogenetic analysis of the skeletons from the sepulchral cave of Elzarreko Karbia (Bronze Age, Basque Country). Comptes Rendus de l'Académie des Sciences - Series III - Sciences de la Vie 321 (1998) 79-85.

Foran, D. R.: Relative degradation of nuclaer and mitochondrial DNA: an experimental approach. Journal of Forensic Science 51 (2006) 766-770.

Giles R. E.-Blanc, H.-Cann, H. M.-Wallace D. C.: Maternal inheritance of human mitochondrial DNA. Proceedings of the Natural Academy of Sciences of the United States 77 (1980) 6715-6719.

Haak, W.-Forster, P.-Bramanti, B.-Matsumura, S.-Brandt, G.-Tänzer, M.-Villems, R.-Renfrew, C.-Gronenborn, D.-Alt, K. W.-Burger, J.: Ancient DNA from the first European farmers in 7500year-old Neolithic sites. Science 310 (2006) 964-965.

Higuchi, R.-Bowman, B.-Freiberger, M.-Ryder, O. A.-Wilson, A. C.: DNA sequences from the quagga, an extinct member of the horse family. Nature 312 (1984) 282-284.

Hiroki, O.-Kunihiko, K.-Surin, P.-Takafumi, I.-Shintaroh, U.: Genetic Study of the Paleolithic and Neolithic Southeast Asians. Human Biology 73 (2001) 225-231.

Kalmár, T.-Bachrati, C. Z.-Marcsik, A.-Raskó, I.: A simple and efficient method for PCR amplifiable DNA extraction from ancient bones. Nucleic Acids Research 28 (2000) E67.

Pääbo, S.: Molecular cloning of ancient Egyptian mummy DNA. Nature 314 (1985) 644-645.

Pääbo S.-Poinar, H.-Serre, D.-Jaenicke-Despres, V.-Hebler, J.-Rohland, N.-Kuch, M.-Krause, J.-Vigilant, L. - Hofreiter, M.: Genetic analyses from ancient DNA. Annual Review of Genetics 38 (2004) 645-679.

Richards, M.-Macaulay, V.: The mitochondrial gene tree comes of age. American Journal of Human Genetics 68 (2001) 1315-1320.

Tömöry, G.-Csányi, B.-Bogácsi-Szabó, E.-Kalmár T.-Czibula, A.-Csősz, A.-Priskin, K.- Mende, B.-Langó, P.-Downes, C. S.-Raskó, I.: Comparison of maternal lineage and biogeographic analyses of ancient and modern Hungarian populations. American Journal of Physical Anthropology 134 (2007) 354-368.

Wang, G. H.-Lu, C.-L.: Isolation and identification of nucleic acids of the liver from a corpse from the Changssha Han tomb. Shen Wu Hua Hsueh Yu Sheng Wu Li Chin Chan 17 (1981) 70-75. 


\section{ANIMAL BONE OFFERINGS FROM THE BADEN CEMETERY AT BUDAKALÁSZ}

Erika Gál 


\section{INTRODUCTION}

Animal bone samples from the Copper Age have been studied and analysed since the 1960s in Hungary; ${ }^{1}$ many of these came from Baden contexts. ${ }^{2}$ At the same time, little is known about the animal bone remains from the cemeteries of the Baden period.

The custom of depositing various offerings in burials can be documented from the Neolithic onward in Hungary. ${ }^{3}$ In contrast to Neolithic burials, which contain few grave goods, a wide range of finds have been recovered from Copper Age graves. The Early and Middle Copper Age cemeteries at Tiszapolgár-Basatanya and Tiszavalk-Tetes yielded a wealth of animal related offerings, including food, tools and implements, ornaments and sacrifices. ${ }^{4}$ Compared to the richness of these offerings, the known Baden burials yielded fewer animal remains, ${ }^{5}$ and only in a few cases have these finds been evaluated from an archaeozoological perspective. ${ }^{6}$

The excavations directed by Sándor Soproni at Budakalász-Luppa-csárda in 1952-1960 brought to light over four hundred burials of the Baden culture. A detailed description of the first hundred and fifty burials, together with an illustration of the wide range of grave goods, has already been published. ${ }^{7}$ In addition to lithic, copper and pottery finds, the grave goods included the remains of vertebrate and invertebrate animals. ${ }^{8}$ The evaluation of the vertebrate animal remains presented here is part of the effort to provide the scholarly community with the monographic publication of the site. ${ }^{9}$ I received the animal bone remains several years ago and studied them from a zoological point of view only; the in-depth archaeological and typological analysis of the remains falls beyond the scope of this study.

\section{RESULTS}

Altogether ninety-one bone, tusk and antler remains have been identified from eighteen graves. Although Soproni's initial publication of the burials mentions animal teeth from Graves 1 and 72,10 these turned out to be rim and handle fragments from various pots. The skeletons of an 8-10 months old calf and an adult cattle were found in Grave 3, a double inhumation burial. I

\footnotetext{
1 E.g. BÖKÖNYI 1959; BÖKÖNYI 1974; VÖRÖS 1988; VÖRÖS 2001.

2 E.g. BÖKÖNYI 1968, 60-62; BÖKÖNYI 1974, 345, 361; VÖRÖs 1982; VÖRÖS 1985; BARTOSIEWICZ 2000.

3 DOMBORÓCZKI 1997; KaLICZ-Koós 2000.

4 BOGNÁR-KUTZIÁN 1963, VÖRÖS 1986.

${ }^{5}$ BÖKÖNYI 1974, 344; HoNTI 1981; BONDÁR 1987; KALICZ 1999; HONTI et al. 2004.

6 BÖKÖNYI 1951.

7 SOPRONI 1956

${ }^{8}$ For the mollusc finds, cp. Pál Sümegi, in this volume (pp. 409-436).

${ }^{9}$ I would here like to thank Mária Bondár, editor of the present volume, for inviting me to study the animal bone remains. I am also indebted to her for providing the necessary archaeological background to the finds. László Bartosiewicz kindly revised the manuscript.

${ }^{10}$ Soproni 1956, 113, 121, Pl. LXXXVIII. 1, Pl. XCIX. 13.
}

did not have the opportunity to examine these remains since their location is unknown. Neither could the withers height of cattle be estimated because bone sizes were not published. ${ }^{11}$

The breakdown of the animal remains according to graves can be found in the Appendix. The distribution of the animal finds according to adult (male and female) and child burials is roughly the same, as is the ratio according to male and female burials. In addition to Grave 3, there were four other double inhumation burials (Graves 108, 155, 366 and 405). Grave 349 was interpreted as a symbolic burial since it yielded only animal remains (Table 1).

Most of the animal remains fall into the category of tools and implements and jewellery items, the latter mostly pendants. A smaller proportion represents food offerings. In some cases, the remains were fragmented to the extent that the nature of the find could not be determined. The poor state of preservation of the bone remains sometimes did not enable the identification of animal taxa. Three wild animals - red deer (Cervus elaphus L.), roe deer (Capreolus capreolus L.) and wild boar (Sus scrofa $\mathrm{L}$.) - could be identified to the species level. Two bones have been attributed to Caprinae, but it is uncertain whether they belonged to sheep (Ovis aries L.) or goat (Capra bircus L.). Several remains have been identified as originating from small ruminants. These may have come either from sheep or goat and roe deer. The remains identified as representing a large mammalian species can equally well come from cattle (Bos taurus L.), aurochs (Bos primigenius Boj.) or red deer. However, we shall include cattle in our analyses as a recognized species because its presence has been indicated in the earlier reference. ${ }^{12}$

\section{DISCUSSION}

Only nineteen of the over four hundred graves uncovered in the Baden cemetery of Budakalász included animal remains among the grave goods. This is a rather small proportion, but it must here be noted that human skeletal remains were found in about one-half of the graves. The other graves were cremation burials, in which grave goods were rarely deposited. There are exceptions (Graves 138, 181, 241 and 247) into which the deceased's necklace was placed. ${ }^{13}$ Still, the amount of animal remains is rather poor even taking into account the inhumation graves only.

The graves of the Budakalász cemetery are of varying richness. As regards animal bones, Grave 91 (most probably a male burial) is the richest. The man wore a pendant made from wild boar tusk. Placed in the grave were various implements, such as a large antler axe and two awls made from the metatarsus of red

\footnotetext{
1 SOPRONI 1956,113, Pl. XC. 1,3

12 SOPRONI 1956, 113.

${ }^{13}$ Mária Bondár, personal communication.
} 


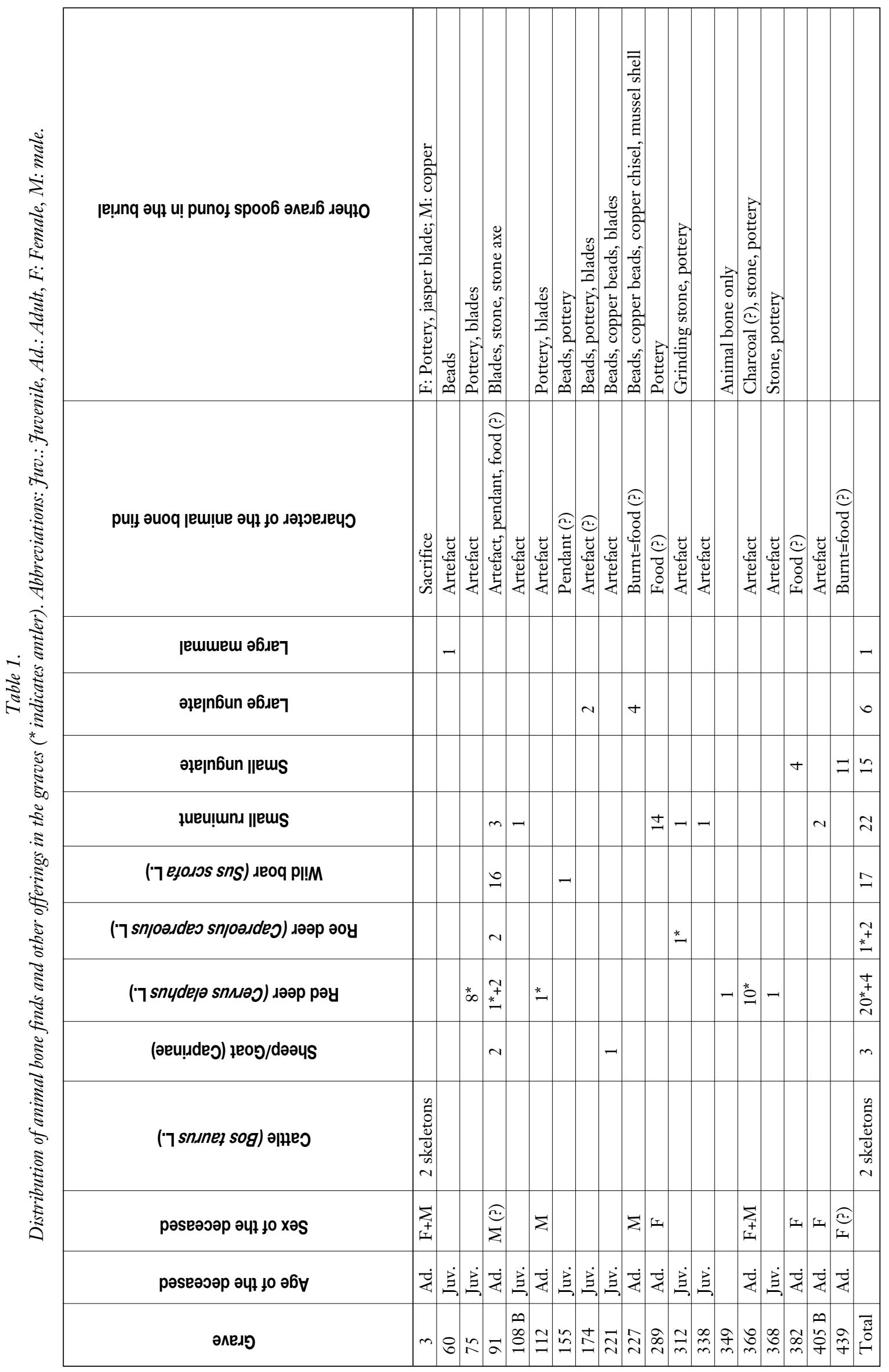


deer. ${ }^{14}$ The red deer and sheep or goat tibia can most likely be regarded as food offerings. The grave goods from this burial included various stone blades and stone axes (Grave 91). Grave 227, a male burial, was lavishly equipped. The grave goods included various copper and stone tools, as well as a copper bracelet and other jewellery articles. The four animal bones recovered from the burial came from a large sized mammal. The bones were burnt, perhaps indicating food refuse. Grave 112 , another male burial, contained fewer grave goods, among them a rather well preserved rose and beam axe made from the shed antler of a red deer (Grave 112/6). ${ }^{15}$

The female burials yielding animal remains (Graves 289, 382 and 439) did not contain tools or implements, but only food remains and, in some cases, pottery. The bone fragments of a small-sized mammal found in Grave 439 were calcinated.

Three of the five double graves yielding animal remains contained the burial of adult couples. In addition to the human burials, Grave 3 contained a calf and cattle, probably sacrificial animals. The finds from Grave 366 included the fragments of an antler artefact. The woman laid to rest in Grave 405 had two awls made from the bones of small ruminants (Grave 405/1).

The number of grave goods varied considerably in the child burials. Some contained nothing but an implement made from animal bone (Graves $108 \mathrm{~B}^{16}$ and 338), but their majority had several grave goods ranging from beads to pottery, stone blades and quernstones in addition to the animal remains. The child laid to rest in Grave 221 appears to have been provided with the richest array of grave goods, which included also copper beads. Most child burials contained one tool or jewellery article, the only exception being Grave 312, which yielded an antler tool as well as an awl made from a sheep or goat tibia (Grave 312/9). It is also noteworthy, that food remains represented by animal bones were not found in the graves of children (Table 2). Consequently, if meat was placed into these graves, it must have been boned and trimmed meat.

Grave 349 has been interpreted as a symbolic burial since only the proximal fragment of a red deer metatarsus was found in it. The epiphysis is not completely preserved, but it was possible to calculate the most important measurements. The proximal width of $34.7 \mathrm{~mm}$ and the proximal depth of $38.6 \mathrm{~mm}$ suggest either a female or a subadult specimen. The age of the animal is unknown since the diagnostic distal end of the bone is missing.

The domestic and wild animal species represented in the animal bone sample are shown Table 1. Cattle, sheep and goat were the most common domestic species providing meat and secondary products for herding communities. The two cattle skeletons in

\footnotetext{
${ }^{14}$ Soproni 1956, Pl. CII. 39-47, Pl. CIII. 26.

15 Soproni 1956, Pl. CIII. 21.

16 SOPRONI 1956, Pl. CIII. 19.
}

Grave 3 and the lack of individual cattle bones would suggest that this species was highly valued at Budakalász. Owing to the bad preservation of the small ruminant remains, it was often impossible to distinguish between sheep and goat, and roe deer bones. Few remains could be identified on the species level from these small ruminants.

Game animals are represented by roe deer, red deer and wild boar. Red deer can generally be recognized by its antlers. In view of the fact that only worked antlers without any attached skull fragments were found, it is uncertain whether red deer were actually killed or only their shed antlers were collected. Knowing that antler is shed in annual cycles after the rutting season, they can be easily collected every year during spring. In contrast, wild boars had to be killed in order to acquire their tusks and since an individual yields one pair of lower tusks only, several had to be hunted in order to acquire the sixteen pendants deposited in Grave 91. It is noteworthy that boar tusk pendants were found in two graves only as opposed to the five burials containing antler objects.

Ornaments made from various mollusc shells represent the articles of animal origins in most Baden cemeteries in Hungary. Perforated shells were recovered from an infant burial in the cemetery at Balatonboglár ${ }^{17}$ and a necklace strung of twenty-six shells was placed in a female burial (Grave 2) in the burial ground uncovered at Balatonmagyaród-Hídvégpuszta. ${ }^{18}$ The necklace found in the scattered cremation burial (Grave 7) at Mező́csát-Hörcsögös was strung from perforated fox (Vulpes vulpes L.) and dog teeth (Canis familiaris L.). The skeleton of a pig deposited in a contracted position was also found at this site. ${ }^{19}$

Of the forty-four burials uncovered at Alsónémedi, Graves 3 and 28 each contained the skeleton of a calf and an adult cattle. The estimated withers height of these animals was $128-132 \mathrm{~cm}$ and $130-133 \mathrm{~cm}$, respectively. Since the animals deposited in the graves were not a female and male cattle, they have been interpreted as sacrifices rather than animals sent to the otherworld for helping their owners to begin a new farming life..$^{20}$ The recently excavated site at Balatonlelle-Országúti-dúlő had two features containing animal remains. The skeleton of a dog accompanying its young owner was discovered in a large storage pit. A number of cut up animal bones, representing food offerings, were found around them. A well with a cattle burial was also uncovered at this site. ${ }^{21}$ A $10-11$ months old goat was sacrificed at the Middle Copper Age sacrificial site of the Ludanice culture at Füzesabony-Szikszópuszta. ${ }^{22}$

\footnotetext{
17 HoNTI 1981.

18 BONDÁR 1987.

${ }^{19}$ KALICZ 1999, 65

${ }^{20}$ BÖKÖNYI 1951.

${ }^{21}$ Honti et al. 2004, 18-21, Pl. VI.

22 VÖRÖS 1998.
} 
Table 2. Distribution of animal bone finds in the graves according to the age and sex of the deceased. Abbreviations: Fuv.: Fuvenile, Ad.: Adult, F: Female, M: male.

\begin{tabular}{|l|c|c|c|c|}
\hline Grave & $\begin{array}{c}\text { Age of the } \\
\text { deceased }\end{array}$ & $\begin{array}{c}\text { Sex of the } \\
\text { deceased }\end{array}$ & Worked skeletal material & Food offering \\
\hline 405 B & Ad. & F & Artefact & Food (?) \\
\hline 289 & Ad. & F & & Food (?) \\
\hline 382 & Ad. & F & & Burnt=food (?) \\
\hline 439 & Ad. & F (?) & & Burnt=food (?) \\
\hline 366 & Ad. & F+M & Artefact & Food (?) \\
\hline 112 & Ad. & M & Artefact & \\
\hline 227 & Ad. & M & Artefact, pendant & \\
\hline 91 & Ad. & M (?) & Artefact & \\
\hline 60 & Juv. & & Artefact & \\
\hline 75 & Juv. & & Artefact & \\
\hline 221 & Juv. & & Artefact & \\
\hline 312 & Juv. & & Artefact & \\
\hline 338 & Juv. & & Artefact & \\
\hline 368 & Juv. & & Artefact & \\
\hline 108 B & Juv. & & Artefact (?) & \\
\hline 174 & Juv. & & Pendant (?) & \\
\hline 155 & Juv. & & &
\end{tabular}

The burials in Early and Middle Copper Age cemeteries contained a much wider range of grave goods by comparison. Most of the graves uncovered in the Tiszapolgár-Basatanya cemetery contained various animal remains. The high number of split pig mandibles deposited according to a particular pattern is noteworthy in this respect for they apparently represent more than simple food offerings. ${ }^{23}$ Sixteen of the twenty-five burials uncovered at Tiszavalk-Tetes were provided with a similarly rich array of grave goods. ${ }^{24}$ Animal bones were recovered from four burials (Graves 8,11, 12 and 13) of the thirteen graves uncovered in the Bodrogkeresztúr cemetery at Hódmezôvásárhely-Kishomok. However, this sample has not been analysed from an archaeozoological perspective. Most of these bones lay near the pottery deposited in the graves and they thus most likely represent food remains. ${ }^{25}$

In terms of raw material, the artefacts from the Budakalász cemetery can be assigned to three main groups: antler artefacts, tusk implements and bone tools. Both red deer and roe deer antlers were used for producing hafted and simple tools, as well as ornaments. The best preserved antler artefact (Grave 112) was made from the rose and beam of a shed antler of red deer. The surviving section of the rose is rounded and heavily worn suggesting the tool's intensive use for beating. The beam of this piece was carved into an edge running parallel to the probably wooden haft (Pl. XLIX. 112/6). ${ }^{26}$ Based on this criterion alone, this form is traditionally called an "axe". ${ }^{27}$

\footnotetext{
23 BOGNÁR-KUTZIÁN 1963.

24 VÖRÖS 1986.

25 BONDÁR-KOREK 1995.

${ }^{26}$ Soproni 1956, Pl. CIII. 21

27 BARTOSIEWICZ 2006, 175.
}

The antler rose and beam implement found on the Baden settlement uncovered at Balatonôszöd-Temetôi-dúlô in south-western Hungary resembles the $\mathrm{Bu}$ dakalász artefact in terms of its raw material, although its form differs since the perforation for the haft was drilled in a medio-lateral direction and the haft of the implement was thus perpendicular to the carved edge of the beam..$^{28}$ This implement type is traditionally labelled a hoe, even though it may have been used for other tasks as well.

The other fragmentary axe was recovered from Grave 91. It was made from a longer antler beam. The haft and edge of the implement are in the same plane (Pl. XLI. 91/1). ${ }^{29}$ The settlement at Balatonôszöd too yielded a similar artefact. ${ }^{30}$

Graves 366 and 368 contained simpler antler tools such as awls and chisels. Finally, the eight oblong antler pieces from Grave 75, carved from the compact tissue of antler, were probably ornaments.

Antler was a popular raw material owing to its toughness and resilience. It is, at the same time, a rather rare raw material, which can be acquired either by killing deer or by the seasonal gathering of shed antlers. These qualities made antler a valuable resource and the artefacts produced from it represent "first class" tools. According to the theoretical work done by Alice M. Choyke on the manufacturing continuum, one may distinguish between Class I and Class II tools by analyzing planned versus opportunistic features of artefacts. Class I tools demonstrate characteristics indicating that they had been planned, starting with the

\footnotetext{
${ }_{28}^{8}$ Gál in print, Fig. 2.

${ }^{29}$ SOPRONI 1956, Pl. CIII. 26.

${ }^{30}$ Gál in print, Fig. 3.
} 
selection of species and skeletal part available. This consciousness is typical throughout the whole process of manufacturing and patterned use of Class I tools. Such ornaments and implements reflect the social and economic value of the task they were used for in relation to the society as a whole; therefore, their uselife often was prolonged by successive curation. On the other hand, less energy and care were invested in the manufacture of Class II tools, which were often abandoned after completing the task for which they were used. This group also includes ad hoc fragments, which were made from a greater variety of skeletal parts and species, and often used only for a single occasion. Studying individual artefacts within the manufacturing continuum defined between these extremes allows us to interpret cultural attitudes towards bone as a raw material. 31

The boar tusk ornaments from Graves 91 and 155 were likewise planned articles. Knowing that the wild boars had to be killed in order to acquire their tusks, they were probably even more valued. These artefacts perhaps symbolised bravery and prowess, qualities which are both needed in hunting dangerous animals. Although the distal ends of the tusks are broken, ${ }^{32}$ we may assume that they had been perforated and worn either as necklaces or costume ornaments. A comparable perforated tusk pendant was found at Balatonôszöd. ${ }^{33}$

The bone tools found at Budakalász are less impressive. Most were carved from the tibia and metapodia of sheep and goat, although long bone diaphyses from large sized mammals were also used as raw material for awls. Most are fragmentary and lack the base, ${ }^{34}$ making their classification more difficult. It must here be noted that Caprinae bones (especially tibia) dominate the worked bone assemblage from the Baden settlements at Balatonôszöd-Temetôi-dúlólo ${ }^{35}$ and Aparthant-Felsố legelö. ${ }^{36}$

The Baden cemetery at Mezôcsát-Hörcsögös yielded a single pendant made from fox and dog teeth. ${ }^{37}$ More numerous Copper Age artefacts were brought to light from the cemeteries at Tiszavalk-Tetes and Polgár-Basatanya. The various bone objects, ranging from bone spoons to awls and pendants, as well as boar tusk and antler implements from the latter site show a much greater variety; the hafted antler axe and the perforated wild boar tusks ${ }^{38}$ share numerous similarities with similar finds from Budakalász. Antler axes and wild boar tusks have been also found at Tiszavalk-Tetes; fine awls made from the long bone diaphyses of Caprinae and roe deer were especially frequent at this site. ${ }^{39}$

\footnotetext{
31 CHOYKe 1997.

32 Soproni 1956, Pl. CII. 40-46.

33 GÁL in print, Fig. 4.

${ }^{34}$ SOPRONI 1956, Pl. CII. 39; Pl. XX. 1-2; Pl. XXXII. 10; Pl. CIII. 19.

${ }^{34}$ Gál in print, Table 1, Fig. 5.

36 BARTOSIEWICZ 2000.

${ }^{37}$ Kalicz 1999, 65.

38 Bognár-KutZián 1963, Pl. LXX. 1, Pl. LIX. 9.

39 PATAY 1978.
}

\section{CONCLUSIONS}

In comparison with other Copper Age cemeteries, the remains of vertebrate animals are rather underrepresented in the Baden graves unearthed at Budakalász-Luppa-csárda. The over one hundred animal bones recovered from nineteen graves in the culture's largest cemetery in Hungary represent sacrificial animals, various bone tools and implements, ornaments and food offerings. Domestic species are represented by cattle and Caprinae, while game species by red deer, roe deer and wild boar. Interestingly, domestic pig was missing from the assemblage. Cattle appears to have been exclusively a sacrificial animal. It is must here be noted that in contrast to the preceding Lengyel culture, for example, and the subsequent Bronze Age cultures, pig bones tend to be underrepresented in animal bone samples from Copper Age settlements. ${ }^{40}$

The finds represent artefacts or ornaments probably owned by the individual buried in the grave for the greater part, although the occasional food offering was also placed in the grave. Most burials contained the remains of one particular species, the only exception being Grave 91. There was no "species combinations" as in the Bodrogkeresztúr cemetery at Tiszavalk-Tetes, where the animal bone sample from the burials was dominated by small ruminants, while cattle was more abundant in the two features containing domestic refuse uncovered at the edge of the cemetery. ${ }^{41}$

The scarcity of food remains in the burials could be taken to indicate that meat was a valuable commodity during the use-life of the Budakalász cemetery. The lack of cattle, the most common meat providing species, and the sacrificial cattle found in Grave 3 seemingly confirms this hypothesis. An alternative explanation is that the deceased were provided with filleted meat and other provisions made from meat, which did not contain bones.

Artefacts were manufactured from all three of the raw material types, namely antler, boar tusk and bone. Even though they were rather fragmented, similarly to the other animal bone remains, they could nonetheless be compared to artefacts from other Early and Middle Copper Age cemeteries, with which they shared numerous similarities. It has been noted that with the exception of Grave 405B, the animal bones from male and child burials were usually fashioned into tools and ornaments, while the bone remains found in female burials generally represent food offerings.

The species composition and the overall nature of the artefacts and animal sacrifice indicate that the animal bone finds recovered from the Budakalász cemetery conform to the pattern of other Copper Age cemeteries from an archaeozoological point of view. However, more animal bone samples from other Baden graves are needed to increase our knowledge of animal-related mortuary practices in this period.

\footnotetext{
${ }^{40}$ Figler et al. 1977, 217-218; BARTOSIEWICZ 2000.

41 VÖRÖS 1986.
} 


\section{References}

BANNER 1956

BARTOSIEWICZ 2000

BARTOSIEWICZ 2006

BOGNÁR-KuTZIÁN 1963

BONDÁR 1987

BONDÁR-KOREK 1995

BÖKÖNYI 1951

BÖKÖNYI 1959

BÖKÖNYI 1968

BÖKÖNYI 1974

CHOYкe 1997

DOMBORÓCZKI 1997

FIGLER et al. 1997

GÁL in print

HONTI 1981

HoNTI et al. 2004

KALICZ 1999

KALICZ-Koós 2000

Patay 1978

SOPRONI 1956

VÖRÖs 1982

VÖRÖs 1985

VÖRÖS 1986

VÖRÖs 1988

VÖRÖs 2001
Banner, János: Die Péceler Kultur. Budapest 1956. (ArchHung 35)

Bartosiewicz, László: A badeni kultúra állatcsontleletei Aparhant-Felsô legelő lelóhelyról [Animal remains from the Baden culture settlement at Aparhant-Felső legelő, Western Hungary]. WMMÉ 22 (2000) 75-88.

Bartosiewicz, László: Régenvolt háziállatok [Domestic animals of yore]. Budapest 2006.

Bognár-Kutzián, Ida: The Copper Age cemetery of Tiszapolgár-Basatanya. Budapest 1963. (ArchHung 42)

Bondár, Mária: Újabb adatok a badeni kultúra temetkezéseihez [Neure Beiträge zu Bestattungen der Badener Kultur]. ZalaiMúz 1 (1987) 47-58.

Bondár, Mária-Korek, József: A Hódmezôvásárhely-Kishomoki rézkori temetố és település [Gräberfeld und Siedlung aus der Kupferzeit in Hódmezôvásárhely-Kishomok]. MFMÉ-StudArch 1(1995) $25-48$.

Bökönyi, Sándor: Untersuchung der Haustierfunde aus dem Gräberfeld von Alsónémedi. ActaArchHung 1 (1951) 72-79.

Bökönyi, Sándor: Die frühalluviale Wirbeltierfauna Ungarns (Vom Neolithicum bis zur La TèneZeit). ActaArchHung 11 (1959) 39-102.

Bökönyi, Sándor: Die Wirbeltierfauna der Siedlung von Salgótarján-Pécskő. ActaArchHung 20 (1968) 59-100.

Bökönyi, Sándor: History of domestic animals in Central and Eastern Europe. Budapest 1974.

Choyke, Alice: The bone manufacturing continuum. Anthropozoologica 25-26 (1997) 65-72.

Domboróczki, László: Füzesabony-Gubakút. Újkôkori falu a Kr. e. VI. évezredból [Neolithic village from the $6^{\text {th }}$ Millenium B.C]. In: Utak a múltba - Paths into the Past Ed. by Raczky, Pál-Kovács, Tibor-Anders, Alexandra. Budapest 1997, 19-27.

Figler, András-Bartosiewicz, László-Füleky, György-Hertelendi, Ede: Copper Age settlement and the Danube water system: a case study from north-western Hungary. In: Landscapes in Flux. Central and Eastern Europe in Antiquity. Ed. by Chapman, John-Dolukhanov, Pavel. Oxford 1997, 209-230. (Colloquia Pontica 3)

Gál, Erika: Tool variety at the Baden culture settlement Balatonôszöd-Temetôi-dúlő in Southwestern Hungary. In: Of People and Bones: The Archaeology of Osseous Artefacts. Ed. by Zidarov, P. Proceedings of the $5^{\text {th }}$ Meeting of the ICAZ Worked Bone Research Group, August 29-September 3, 2005 Veliko Turnovo, Bulgaria. in print

Honti, Szilvia: Rézkori temetkezés Balatonbogláron [Ein Grab aus der Kupferzeit von Boglárlelle]. SMK 4 (1981) 25-42.

Honti, Szilvia-Belényesi, Károly-Fábián, Szilvia-Gallina, Zsolt-Hajdú, Ádám Dávid-Hansel, BalázsHorváth, Tünde-Kiss, Viktória-Koós, István-Marton, Tibor-Németh, Péter Gergely-Oross, Krisztián-Osztás, Anett-Polgár, Péter-P-Szeóke, Judit-Serlegi, Gábor-Siklósi Zsuzsa-Sófalvi, András-Virágos, Gábor: A tervezett M7-es autópálya Somogy megyei szakaszának megelôzô régészeti feltárása (2002-2003). Elôzetes jelentés III. [Preliminary report III. The preceding archaeological excavations [2002-2003] of the M7 highway in Somogy county]. SMK 16 (2004) 3-70.

Kalicz, Nándor: A késô rézkori Baden kultúra temetője Mezôcsát-Hörcsögösön és TiszavasváriGyepároson [Das Gräberfeld der spätkupferzeitlichen Badener Kultur in Mezőcsát-Hörcsögös und in Tiszavasvári-Gyepáros]. HOMÉ 37 (1999) 57-101.

Kalicz, Nándor-Koós, Judit: Település a legkorábbi újkókori sírokkal Északkelet-Magyarországról [Eine Siedlung mit Ältestneolitischen Gräbern in Nordostungarn]. HOMÉ 39 (2000) 45-76.

Patay, Pál: A Tiszavalk-Tetesi rézkori temetô és telep [Kupferzeitliches Gräberfeld und Siedlung von Tiszavalk-Tetes]. FolArch 29 (1978) 21-55.

Soproni, Sándor: Budakalász, Luppa-csárda. In: BANNER 1956, 111-128.

Vörös, István: A boglárlellei késố rézkori gödör állatcsontleletei [The animal bone sample from the Late Copper Age pit at Boglárlelle]. CommArchHung 1982, 27-28.

Vörös, István: Késő rézkori szarvasmarha-áldozat Tahitótfalu-Váci révnél [Spätkupferzeitliches Rinderopfer bei der Überfahrt Tahitótfalu-Vác]. Studia Comitatensia 17 (1985) 15-23.

Vörös, István: Animal remains from the funeral ceremonies in the Middle Copper Age cemetery at Tiszavalk-Tetes. FolArch 37 (1986) 75-97.

Vörös, István: Rézkori sakralis hely állatcsontmaradványai Füzesabony-Szikszópusztán [Überreste von Tierknochen an sacraler Stelle aus der Kupferzeit in der Szikszópuszta bei Füzesabony]. Agria 24 (1988) 51-57.

Vörös, István: A Csongrád-Bokros, Bokrospusztai középsố rézkor végi telep állatcsontleletei [The animal bone sample from the Middle Copper Age settlement at Csongrád-Bokros, Bokrospuszta]. MFMÉ-StudArch 7 (2001) 91-113. 


\section{Appendix: list of animal bone finds}

Grave 3 (double, male and female [?] inhumation burial) Skeletons of an 8-10 months old calf and an adult cattle.

Grave 60 (child inhumation burial)

Worked long bone diaphysis fragment of a large sized mammal (inv. no. 56.11.39.2).

Grave 75 (child inhumation burial)

Eight oblong antler fragments of red deer (inv. no. 56.11.52.9).

Grave 91 (male [?] inhumation burial):

Two awls (with fragmentary tips) made from the metatarsus of red deer (inv. nos 56.11.60.8, 56.11.60.10).

Axe fragment made from red deer antler (inv. no. 56.11.60.87).

Sixteen wild boar tusk fragments (inv. nos 56.11.60.9, 56.11.60.88-105).

Distal fragment of the right tibia of sheep or goat (inv. no. 56.11.60.106).

Two tibia fragments of roe deer (inv. no. 56.11.60.107-108).

Diaphysis of the right tibia of sheep or goat (inv. no. 56.11.60.109).

Proximal fragment of the left tibia of a subadult sheep or goat (inv. no. 56.11.60.110)

Diaphysis of the left tibia of a small ruminant (inv. no. 56.11.60.111).

Proximal fragment of the tibia of a subadult small ruminant (inv. no. 56.11.60.112).

Grave 108 (double child inhumation burial, the animal bones lay in Burial B)

Awl made from the left tibia diaphysis of a small ruminant (inv. no. 56.11.68.1)

Grave 112 (male inhumation burial)

Axe or hammer made from the right antler rose and beam of red deer (inv. no. 56.11.70.6).

Grave 155 (double burial with one child inhumation and one cremation burial; the animal remains lay beside Burial A) Right side lower tusk from wild boar (inv. no. 61.2.25.3).

Grave 174 (female inhumation burial)

Two long bone diaphysis fragments from large ungulate(s), probably parts of artefact(s) (inv. no. 61.2.33.12-13).
Grave 221 (child inhumation burial)

Awl made from the right metatarsus of sheep or goat (inv. no. 61.2.61.2).

Grave 227 (male inhumation burial)

Four calcinated fragments from the tibia diaphysis of a large ungulate (inv. no. 61.2.66.13).

Grave 289 (female inhumation burial)

Fourteen diaphysis fragments from a subadult small ruminant (inv. no. 61.2.97.4)

Grave 312 (child inhumation burial)

Awl made from the tibia diaphysis of a small ruminant; antler from roe deer (inv. no. 61.2.109.9).

Grave 338 (child inhumation burial)

$13.1 \mathrm{~cm}$ long awl made from the left tibia distal fragment of a small ruminant (inv. no. 61.2.122).

Grave 349 (symbolic burial)

Proximal fragment of a left metatarsus of red deer (inv. no. 61.2.129).

Grave 366 (double, male and female inhumation burial; from Burial A [female])

Ten antler fragments from red deer (remains of the same artefact; inv. no. 61.2.140.4-9).

Grave 368 (child inhumation burial)

Chisel made from the antler or bone of a large mammal, possibly red deer (inv. no. 61.2.142.2).

Grave 382 (female inhumation burial)

Four rib fragments of a small ungulate (inv. no. 61.2.151).

Grave 405 (double, male and female inhumation burial; from Burial B [female])

Two fragments of an awl made from the long bone diaphysis of a small ruminant (inv. no. 61.2.161)

Grave 439 (female [?] inhumation burial)

Eleven calcinated bone fragments of a small ungulate (inv. no. 61.2.179). 


\section{THE LITHIC FINDS FROM BUDAKALÁSZ \\ Éva Cs. Balogh}




\section{INTRODUCTION}

The Copper Age and the Early and Middle Bronze Age is characterised by the widespread use of distinctive chipped stone implements. I have published several studies discussing the typology and statistics of chipped stone implements from various prehistoric sites. This research project, begun many years ago and still in progress, has been generously funded by grants from the Hungarian Credit Bank and the Hungarian Scientific Research Fund (OTKA). ${ }^{1}$

The survival of chipped stone implements into the metal ages indicates that similarly to earlier periods, they were still suitable for a particular activity, irrespective of whether that activity was domestic ${ }^{2}$ or ritual $^{3}$ in nature. In addition to local raw materials, tools were also made from lithics acquired from distant sources in order to manufacture artefacts suited to working all natural materials. Chert, for example, has a Mohs hardness of 7 (the steel used for modern tools, by comparison, has a hardness of $5-8.5$ on the same scale). ${ }^{4}$ In addition to quality and durability, the hardness of a particular rock was also an important consideration in the choice of raw material for tool manufacture. The hardness of rocks is measured on the Mohs scale of mineral hardness, while the Brinell scale characterises the indentation hardness. ${ }^{5}$ The typological variability of Copper and Bronze Age chipped stone implements, their manufacturing techniques, the use of local rocks and raw materials imported through long-distance trade reveals much about the technological level of Copper and Bronze Age cultures, about the survival and use of traditional techniques, and the innovative capabilities of a particular society. ${ }^{6}$

I have described the Copper and Bronze Age chipped stone implements according to the accepted typological and statistical system used in prehistoric (Palaeolithic) studies. The form of the tool, the blank, the manufacturing technique and the tool's function can usually be determined in the case of most tools. Function can vary even in the case of one tool or because of subsequent renewal. Together with the statistical data, the overall typological and technological nature of an assemblage allows its categorisation as a typical industry similar to the ones known from the Palaeolithic and several other prehistoric cultures. The terminology used here was elaborated during the many years of studying stone tools (Fig. 11). 7

The need for a uniform terminology was first realised during the study of Palaeolithic tools because

\footnotetext{
${ }^{1}$ OTKA grant T 22941. Cs. Balogh 1993; Cs. Balogh 1998-99, 13-35; Cs. BALOGH 2004.

2 The use of sickle blades with bifacial serration can be noted in the Early and Middle Bronze Age.

${ }^{3}$ E.g. the chipped stone implements deposited in Early and Middle Copper Age burials.

4 Cs. BalOGH 1998-99, 29.

5 T. Dobosi-Homola 1989, 43

${ }^{6}$ Simán 2000.

7 Cs. Balogh 1993; Cs. Balogh 2000, 49-50.
}

stone tools provided the most useful information on the cultural attribution of sites from that period. A wide range of interdisciplinary methods is now available for the study and interpretation of archaeological features and associated phenomena in order to reconstruct a culture's the narrower and broader environment. ${ }^{9}$ Several studies have been devoted to creating a uniform typological terminology and to the discussion of statistical analyses enabling the comparison of find assemblages from the Palaeolithic and the Mesolithic. Still, no matter how objective a typological system, there is need for caution even in the case of roughly contemporaneous assemblages; the nature of a particular lithic industry is also influenced by the spatial distribution of its sites. The typological and technological tendencies indicating similarities between prehistoric lithic industries must by all means be considered in the evaluation and interpretation of cumulative curves and indexes, together with possible local features. ${ }^{10}$

In addition to the typological and statistical evaluation of a lithic assemblage, use-wear studies ${ }^{11}$ too provide valuable insights into how a tool was used. A tool comes into contact with various materials during its use (wood, plants, bone, leather, antler, meat, etc.), all of which leave visible traces. These can be divided into three main categories. Scraping leaves rounded or smoothed edges or small pits, striations reveal the motion of the tool in use, while edge damage is an indication of the hardness of the worked material. ${ }^{12}$

The stone tools recovered from the burials of the Budakalász cemetery ${ }^{12}$ have not been submitted to usewear analyses and thus only the use-wear traces visible to the naked eye are discussed here. Since the entries in the acquisitions register rarely contained detailed information on the lithic finds, ${ }^{13}$ the catalogue presented here includes only the lithic finds, which I could personally examine and evaluate. There is a minimal difference between the number of lithic artefacts, which are listed in the acquisitions register, but can no longer be found, and the number of the pieces I have examined, and thus the roughly two hundred lithic artefacts described and discussed here offer an accurate picture of the industry represented by the finds from Budakalász.

Although the chipped stone implements from the Budakalász cemetery have already been briefly described, ${ }^{14}$ their detailed typological and statistical evaluation is presented here for the first time.

\footnotetext{
${ }^{8}$ In addition to interdisciplinary studies, environmental and experimental archaeology has also contributed much to this field of research.

9 T. Dobosi-Homola 1989, 38-41.

${ }^{10}$ BÁCSKAY 1995.

${ }_{11} \mathrm{Cp}$. the micro-wear studies conducted by Erzsébet Bácskay and the present author: BÁCSKAY 1995; Cs. BALOGH 1997; Cs. BALOGH 1998-99; Cs. Balogh 2000; Cs. Balogh 2004.

12 MRT 7, 45-47.

${ }^{13}$ The description of the lithic finds in the museum's acquisitions register is usually very basic: "stone tool", "stone", "stone fragment", "arrowhead", etc.

14 T. Dobosi 1968; T. Bíró 1984b.
} 
Described in the catalogue is the type, the dimensions and the raw material of each piece, followed by the typological and technological evaluation of the entire assemblage and a discussion of the possible sources of the raw materials used for their manufacture. This complex analysis will hopefully contribute to a better understanding of the tool-kits used by the communities of the Late Copper Age Baden culture, and of the spatial and chronological aspects of the manufacture and use of stone tools (acquisition of raw material; manufacture; use; disposal or discard in the case of tools). ${ }^{15}$ As "material remains of past concepts", the grave goods from the Budakalász cemetery provide a wealth of information ${ }^{16}$ for interpreting the stone implements deposited in burials since the number and type(s) of lithic artefacts placed into a burial may be an indication of the deceased's social status and may in some cases also reflect the individual's daily activity while still alive (e.g. Grave 91).

\section{CATALOGUE OF THE LITHIC FINDS ${ }^{17}$}

\section{Grave 2}

Point

Atypical triangular point made with small, steep, marginal retouch. Radiolarite. $19 \mathrm{~mm} \times 12 \mathrm{~mm} \times 2 \mathrm{~mm}$. Inv. no. 56.52.14 (Fig. 22. 1).

Trapeze-déjeté burin combination

Geometric microlith with a natural fracture at the distal end. Truncated by oblique retouch at the butt. The $2 \mathrm{~mm}$ wide edge on the left side was created by removing burin spalls. Patinated limnic quartzite. $12.5 \mathrm{~mm} \times 8 \mathrm{~mm} \times 2.5 \mathrm{~mm}$. Inv. no. 56.11.2.4 (Fig. 22. 2).

Medial fragment of an unretouched blade

Patinated limnic quartzite. $14 \mathrm{~mm} \times 12 \mathrm{~mm} \times 2 \mathrm{~mm}$. Inv. no. 56.11.2.3

\section{Grave 3}

Unretouched flake

Unretouched flake with traces of preparation. The platform is punctiform, the bulb of percussion was thinned. Radiolarite. $13 \mathrm{~mm} \times 11.5 \mathrm{~mm} \times 3 \mathrm{~mm}$. Inv. no. 56.11.3.3.

Hornstone flake Inv. no. 56.11.3.4.

Unretouched blade fragment The platform is punctiform, the bulb of percussion is flat. Radiolarite. $16 \mathrm{~mm} \times 9 \mathrm{~mm} \times 3 \mathrm{~mm}$. Inv. no. 56.11.3.2.

\section{Grave 8}

Trapeze

Geometric microlith truncated by oblique retouch at the butt on the dorsal surface and at the distal end on the ventral surface. The left edge on the dorsal side is retouched. Patinated bluish-grey chert. $13.5 \mathrm{~mm} \times 14 \mathrm{~mm} \times 4 \mathrm{~mm}$. Inv. no. 56.11.5.4 (Fig. 22. 3). Made from the same raw material as the trapeze from this grave.

Trapeze

Geometric microlith truncated by oblique retouch at the distal

\footnotetext{
${ }^{15}$ RENFREW-BAHN 1999, 50.

16 RENFREW-BAHN 1999, 369-402.

${ }_{17}$ Unfortunately, some of the finds have been mislaid or lost.
}

end on the dorsal side and at the butt on the ventral side. Patinated bluish-grey chert. $16 \mathrm{~mm} \times 12 \mathrm{~mm} \times 3 \mathrm{~mm}$. Inv. no. 56.11.5.5 (Fig. 22. 4)

Unretouched blade fragment

Reddish-brown radiolarite. $19 \mathrm{~mm} \times 7 \mathrm{~mm} \times 2 \mathrm{~mm}$. Inv. no. 56.11.5.2.

Unretouched flake

Rectangular flake with traces of surface working. The platform and the bulb of percussion are missing. Reddishbrown radiolarite. $13 \mathrm{~mm} \times 11 \mathrm{~mm} \times 4 \mathrm{~mm}$. Inv. no. 56.11.5.3.

Debitage

Limnic quartzite. $14 \mathrm{~mm} \times 11.5 \mathrm{~mm} \times 2 \mathrm{~mm}$. Inv. no. 56.11.5.6.

\section{Grave 22}

Segment

Geometric microlith. Medial fragment of a retouched, wide, backed blade. Grey hornstone. $14 \mathrm{~mm} \times 14 \mathrm{~mm} \times 4 \mathrm{~mm}$. Inv. no. 56.11.14.1 (Fig. 22. 5).

\section{Grave 24}

Unretouched blade

Wide, triangular blade. The platform is punctiform, the bulb of percussion is flat. $30.5 \mathrm{~mm} \times 15 \mathrm{~mm} \times 2 \mathrm{~mm}$. Reddishbrown, bluish-white mottled radiolarite. Inv. no. 56.11.16.2 (Fig. 22. 6).

\section{Grave 44}

Side-scraper

Slightly pointed side-scraper retouched along the left edge on the dorsal side and the distal end. Sickle gloss covers the retouched working edge, which was created with parallel, steep, scalar retouch. The platform and the bulb of percussion are both present. Greyish-brown radiolarite, $21 \mathrm{~mm}$ x $30 \mathrm{~mm}$ x 9.5 mm. Inv. no. 56.11.28.2 (Fig. 22. 7).

\section{Grave 46}

Trapeze

Geometric microlith truncated by oblique retouch at both ends on the ventral side of the blade. Patinated limnic quartzite. $16.5 \mathrm{~mm} \times 11 \mathrm{~mm} \times 3 \mathrm{~mm}$. Inv. no. 56.11.29.4 (Fig. 22. 8).

\section{Grave 48}

Trapeze

Geometric microlith truncated by oblique retouch at both ends on the dorsal side. Patinated limnic quartzite. $16 \mathrm{~mm} \times$ $9 \mathrm{~mm} \times 2$ mm. Inv. no. 56.11.30.2 (Fig. 22. 9).

Trapeze

Geometric microlith truncated by oblique retouch at the distal end and the butt. Pink-brown radiolarite. $16.5 \mathrm{~mm} \times 8 \mathrm{~mm} \times$ 2 mm. Inv. no. 56.11 .30 .3 (Fig. 22. 10).

Trapeze

Geometric microlith truncated by oblique retouch at the slightly concave distal end. The butt has a natural fracture. Limnic quartzite. $19.5 \mathrm{~mm} \times 6 \mathrm{~mm} \times 1.5 \mathrm{~mm}$. Inv. no. 56.11.30.4 (Fig. 22. 11).

Trapeze

Geometric microlith truncated by oblique retouch at both ends. Patinated limnic quartzite. $14.5 \mathrm{~mm} \times 11 \mathrm{~mm} \times 4 \mathrm{~mm}$. Inv. no. 56.11.30.5 (Fig. 22. 12)

Trapeze

Geometric microlith truncated by retouch at the concave distal end and oblique, steep retouch at the butt on the ventral side. Limnic quartzite. $19 \mathrm{~mm} \times 10 \mathrm{~mm} \times 2 \mathrm{~mm}$. Inv. no. 56.11.30.6 (Fig. 22. 13).

Trapeze

Geometric microlith. Oblique natural fracture at the butt and steep, rough retouch at the distal end. Patinated limnic 
quartzite. $17 \mathrm{~mm} \times 11.5 \mathrm{~mm} \times 1.5 \mathrm{~mm}$. Inv. no. 56.11 .30 .7 (Fig. 22. 14).

Trapeze

Geometric microlith truncated by linear retouch at both ends on the dorsal side. Patinated limnic quartzite. $15.5 \mathrm{~mm} \times 10 \mathrm{x}$ 3 mm. Inv. no. 56.11 .30 .8 (Fig. 22. 15).

Trapeze

Geometric microlith truncated by oblique retouch at the butt. The distal end has a natural fracture. Limnic quartzite. $18.5 \mathrm{~mm} \times 15.5 \mathrm{~mm} \times 2.5 \mathrm{~mm}$. Inv. no. 56.11.30.9 (Fig. 22. 16).

Trapeze

Geometric microlith truncated by oblique retouch at both ends on the dorsal side. Cream chert. $14.5 \mathrm{~mm} \times 7.5 \mathrm{~mm} \times$ 1.5 mm. Inv. no. 56.11 .30 .10 (Fig. 22. 17).

Trapeze

Geometric microlith. Medial fragment of a wide blade with oblique retouch at the distal end and a natural fracture at the butt. Limnic quartzite. $20 \mathrm{~mm} \times 12 \mathrm{~mm} \times 1.5 \mathrm{~mm}$. Inv. no. 56.11.30.11 (Fig. 22. 18).

\section{Grave 49}

Worked pebble

Yellowish-brown radiolarite. $38 \mathrm{~mm} \times 11 \mathrm{~mm}$. Inv. no. 56.11.31.1.

\section{Grave 53}

Side-scraper

Side-scraper on a convex flake. The working edge was created by steep retouch on the ventral side. Reddish-brown radiolarite. $34.5 \mathrm{~mm} \times 23.5 \mathrm{~mm} \times 7.5 \mathrm{~mm}$. Inv. no. 56.11 .34 .3 (Fig. 22. 19).

\section{Grave 61}

Blade

White blade with smooth edges worked on one side. Limestone. Inv. no. 56.11.40.2.

\section{Grave 64}

Fragment of an unretouched blade

Blade with large platform and bulb of percussion, broken at the distal end. Limnic quartzite. $27 \mathrm{~mm} \times 16 \mathrm{~mm} \times 3 \mathrm{~mm}$. Inv. no. 56.11.42.1 (Fig. 22. 20).

\section{Grave 75}

Trapeze

Geometric microlith truncated by oblique retouch at both ends. Translucent, bluish-grey limnic quartzite. $15.5 \times 10 \times$ $3.5 \mathrm{~mm}$. Inv. no. 56.11. 52.10 (Fig. 23. 1). Made from the same raw material (limnic quartzite) as the trapeze shown in.

Trapeze

Geometric microlith truncated by oblique retouch starting from the ventral side on both ends. Brown radiolarite. $13.5 \mathrm{~mm} \times 8 \mathrm{~mm} \times 2.5 \mathrm{~mm}$. Inv. no. 56.11 .52 .11 (Fig. 23. 2). Trapeze

Geometric microlith truncated by oblique retouch at both ends. Translucent, bluish-grey limnic quartzite. $15 \mathrm{~mm} \times$ $10 \mathrm{~mm} \times 2.5 \mathrm{~mm}$. Inv. no. 56.11 .52 .14 (Fig. 23. 3).

Fragment of a retouched blade

Butt fragment of a blade retouched along the lower third on the dorsal side. The butt was thinned by small marginal retouch on the ventral side. The distal end has a natural fracture. Reddish-brown radiolarite. $17.5 \mathrm{~mm} \times 10 \mathrm{~mm} \times 3 \mathrm{~mm}$. Inv. no. 56.11.52.13 (Fig. 23. 4).

Fragment of an unretouched blade Small, atypical striations at the distal end, probably from usewear. Brown radiolarite. $19 \mathrm{~mm} \times 9 \mathrm{~mm} \times 1.5 \mathrm{~mm}$. Inv. no. 56.11.52.12 (Fig. 23. 5).

\section{Grave 84}

Point

Triangular, truncated, retouched flake. The width suggests that the blank was a flake. All three sides of the dorsal side are retouched. One side is completely retouched, another side is partially retouched on the ventral side. Small, steep, parallel retouch was used during its manufacture. One of the most carefully and finely worked tools in the lithic assemblage. Reddish-brown radiolarite. $18 \mathrm{~mm} \times 20 \mathrm{~mm} \times 4 \mathrm{~mm}$. Inv. no. 56.11.56.1 (Fig. 23. 6).

Fragment of an unretouched blade

The distal end is broken obliquely. The platform and the bulb of percussion were removed. Dark brown radiolarite. $20 \mathrm{~mm} x$ $9.5 \mathrm{~mm} \times 2.5 \mathrm{~mm}$. Inv. no. 56.11 .56 .2 (Fig. 23. 7).

\section{Grave 91}

One of the most interesting lithic assemblages was recovered from this male burial.

Short end-scraper on a retouched blade

Short end-scraper on a blade worked with small, parallel, steep retouch on the right edge on the dorsal side. The scraping edge was made by steep scraper retouch. The butt is truncated by retouch. Bluish-grey brownish patinated flint. $14 \mathrm{~mm} \times$ $14.5 \mathrm{~mm} \times 3.5 \mathrm{~mm}$. Inv. no. 56.11 .60 .5 (Fig. 25. 12).

Truncated flake-end-scraper combination

The distal end of the rectangular flake was truncated by linear, parallel retouch. The platform is large, the bulb of percussion is pronounced. Patinated limnic quartzite. $13.5 \mathrm{~mm} \times 14 \mathrm{~mm} \times$ 4 mm. Inv. no. 56.11.60.79 (Fig. 25. 13).

Retouched blade tip

The distal end of the blade was worked with small, steep, marginal retouch on both edges on the ventral side. The platform and the bulb of percussion are present. Brownishgrey limnic quartzite. $35 \mathrm{~mm} \times 10 \mathrm{~mm} \times 3.5 \mathrm{~mm}$. Inv. no. 56.11.60.39 (Fig. 26. 23).

Truncated blade

Medium sized blade truncated by retouch at both ends. The distal end on the dorsal side was truncated by steep, oblique retouch, and by rough retouch on the ventral side. Chert. $37 \mathrm{~mm} \times 17.5 \mathrm{~mm} \times 6 \mathrm{~mm}$. Inv. no. 56.11 .60 .19 (Fig. 26. 21). Truncated blade

The butt of the wide blade is truncated by rough linear retouch on the ventral side. A burin-like working edge was created by thinning on the dorsal side. Patinated bluish-grey flint. $37 \mathrm{~mm} \times 18 \mathrm{~mm} \times 5 \mathrm{~mm}$. Inv. no. 56.11 .60 .21 (Fig. 26 . 22).

Trapeze

Microlithic blade truncated by oblique retouch at the distal end on the dorsal side. The platform is present, the bulb of percussion is flat. Patinated limnic quartzite. $15 \mathrm{~mm} \times 7.5 \mathrm{~mm} \times$ 2 mm. Inv. no. 56.11 .60 .53 (Fig. 25. 14).

Trapeze

A micro-blade truncated by small, parallel retouch at the distal end. The platform and the bulb of percussion are punctiform. Cream chert. $15 \mathrm{~mm} \times 7 \mathrm{~mm} \times 2 \mathrm{~mm}$. Inv. no. 56.11 .60 .50 (Fig. 25. 15).

Trapeze

The distal end is truncated by small, parallel, steep retouch. Light brown radiolarite. $25 \mathrm{~mm} \times 5 \mathrm{~mm} \times 3.5 \mathrm{~mm}$. Inv. no. 56.11.60.57 (Fig. 25. 17).

Trapeze

A flake truncated by steep retouch. The butt was retouched by parallel, blunting retouch. Limnic quartzite. $115 \mathrm{~mm} \mathrm{x}$ $12.5 \mathrm{~mm} \times 3.5 \mathrm{~mm}$. Inv. no. 56.11 .60 .80 (Fig. 25. 16). Burin

Déjeté micro-burin. Sickle gloss covers the upper two thirds of the left edge on the dorsal side and a small section at the distal end. The platform and the bulb of percussion are 
punctiform. Brown radiolarite. $15 \mathrm{~mm} \times 10 \mathrm{~mm} \times 2.5 \mathrm{~mm}$. Inv. no. 56.11.60.28 (Fig. 25. 20).

Burin

The relatively wide, $3 \mathrm{~mm}$ wide burin was created by the removal of burin spalls on the left edge. Brown radiolarite. $17 \mathrm{~mm} \times 7 \mathrm{~mm} \times 3 \mathrm{~mm}$. Inv. no. 56.11.60.62 (Fig. 25. 21).

Trapeze

Microlithic blade truncated by oblique retouch at both ends. Sickle gloss covers the upper right side of the distal end on the dorsal side. The sickle gloss extends to a part of the retouched truncation, although it mainly covers the tool's unretouched surface. The butt and the bulb of percussion are punctiform. Reddish-brown radiolarite. $16.5 \mathrm{~mm} \times 7 \mathrm{~mm} \times 3 \mathrm{~mm}$. Inv. no. 56.11.60.31 (Fig. 25. 18).

Triangle

Triangular microlithic tool. Two sides of the triangle were worked with small, steep, marginal retouch. The third side has a natural fracture. Patinated limnic quartzite. $15 \mathrm{~mm} \mathrm{x}$ $15 \mathrm{~mm} \times 2$ mm. Inv. no. 56.11 .60 .54 (Fig. 25. 19).

Segment

Microlith. The curved left edge was worked with small, steep retouch on the dorsal side; the other side is straight with a natural edge. Obsidian. $16.5 \mathrm{~mm} \times 8 \mathrm{~mm} \times 4.5 \mathrm{~mm}$. Inv. no. 56.11.60.22 (Fig. 26. 1).

Segment

Microlith. The curved right edge was worked with steep retouch on the dorsal side. The other edge is straight and sharp. The ventral side was thinned with bipolar percussion. The platform and the bulb of percussion are missing. Brownish flint. $15 \mathrm{~mm} \times 11 \mathrm{~mm} \times 4 \mathrm{~mm}$. Inv. no. 56.11.60.23 (Fig. 26. 2). Segment

Microlith. The curved right edge was worked with steep retouch on the dorsal side. The other edge is straight and sharp. Patinated limnic quartzite. $15 \mathrm{~mm} \times 10 \mathrm{~mm} \times 4 \mathrm{~mm}$. Inv. no. 6.11.60.24 (Fig. 26. 3).

Segment

Microlith. The curved right edge was worked with steep retouch on the dorsal side. The other edge is straight and sharp. Sickle gloss covers two-thirds of the unretouched, proximal left edge on the dorsal side. The butt is broken. Hornstone. $13 \mathrm{~mm} \times 9 \mathrm{~mm} \times 3.5 \mathrm{~mm}$. Inv. no. 56.11 .60 .25 ( Fig. 26. 4).

Segment

Microlith. The left edge was worked with steep retouch on the dorsal side. The other edge is straight and sharp. The butt is broken. White limnic quartzite. $13 \mathrm{~mm} \times 10.5 \mathrm{~mm} \times 3 \mathrm{~mm}$. Inv. no. 56.11.60.26 (Fig. 26. 6).

Segment

Microlithic flake with linear retouch. Truncated by small, marginal retouch. The platform and the bulb of percussion are punctiform. Brown radiolarite. $14 \mathrm{~mm} \times 16 \mathrm{~mm} \times 3 \mathrm{~mm}$. Inv. no. 56.11.60.27 (Fig. 26. 5).

Medial fragment of an unretouched blade

Radiolarite. $11 \mathrm{~mm} \times 8.5 \mathrm{~mm} \times 2 \mathrm{~mm}$. Inv. no. 56.11 .60 .32 (Fig. 26. 7).

Medial fragment of an unretouched blade

Bluish-grey chert. $15 \mathrm{~mm} \times 7 \mathrm{~mm} \times 1.5 \mathrm{~mm}$. Inv. no. 56.11.60.36 (Fig. 26. 8).

Medial fragment of an unretouched blade

Patinated limnic quartzite. $13 \mathrm{~mm} \times 12 \mathrm{~mm} \times 2 \mathrm{~mm}$. Inv. no. 56.11.60.42 (Fig. 26. 9).

Unretouched blade fragment

The distal end is broken. The butt and the bulb of percussion are punctiform. Patinated limnic quartzite. $19.5 \mathrm{~mm} \times 7.5 \mathrm{~mm}$ × 4 mm. Inv. no. 56.11 .60 .43 (Fig. 26. 10).

Unretouched blade fragment

The butt is broken. Obsidian with cortex. $15 \mathrm{~mm} \times 6 \mathrm{~mm} \times$ 2 mm. Inv. no. 56.11 .60 .37 (Fig. 26. 11).
Unretouched blade fragment

The distal end is broken. The butt is punctiform, the bulb of percussion is flat. Patinated limnic quartzite. $11.5 \mathrm{~mm} \times$ $7 \mathrm{~mm} \times 1.5 \mathrm{~mm}$. Inv. no. 56.11 .60 .70 (Fig. 26. 12).

Unretouched blade fragment

The distal end is missing. The platform is present, the bulb of percussion was removed. Light yellow limnic quartzite. $14.5 \mathrm{~mm} \times 8 \mathrm{~mm} \times 2.5 \mathrm{~mm}$. Inv. no. 56.11.60.82 (Fig. 26. 13). Unretouched blade

Microlith. The platform and the bulb of percussion are missing. Dark brown radiolarite. $18 \mathrm{~mm} \times 6 \mathrm{~mm} \times 2 \mathrm{~mm}$. Inv. no. 56.11.60.34 (Fig. 26. 14).

Unretouched blade

Microlithic tool. The butt is punctiform, the bulb of percussion is flat. $21 \mathrm{~mm} \times 9 \mathrm{~mm} \times 3 \mathrm{~mm}$. Inv. no. 56.11 .60 .81 (Fig. 26. 15).

Unretouched blade

Micro-blade. The platform is present, the bulb is flat. Pinkbrown radiolarite. $15.5 \mathrm{~mm} \times 7.5 \mathrm{~mm} \times 2 \mathrm{~mm}$. Inv. no. 56.11.60.85 (Fig. 26. 16).

Unretouched blade fragment

The distal end is broken. The platform is present, the bulb of percussion is flat. Chert with cortex. $31 \mathrm{~mm} \times 13.5 \mathrm{~mm} \times 5 \mathrm{~mm}$. Inv. no. 56.11.60.83 (Fig. 26. 17).

Unretouched blade fragment

The distal end is broken. The platform and the bulb of percussion are present. Patinated bluish-grey chert. $29 \mathrm{~mm} \times$ $9 \mathrm{~mm} \times 3.5 \mathrm{~mm}$. Inv. no. 56.11.60.29 (Fig. 26. 18).

Unretouched blade

The platform and the bulb of percussion are missing. White chert. $46 \mathrm{~mm} \times 21 \mathrm{~mm} \times 8 \mathrm{~mm}$. Inv. no. 56.11 .60 .18 (Fig. 26. 19).

Unretouched blade fragment

The distal end is missing. The platform and the bulb of percussion are present. Dark brown radiolarite. $15.5 \mathrm{~mm} \times$ $9 \mathrm{~mm} \times 2.5 \mathrm{~mm}$. Inv. no. 56.11.60.33.

Unretouched flake

Medium sized, wide flake. The platform and the bulb of percussion are missing. Patinated brownish-grey flint. $42 \mathrm{~mm} \times 26 \mathrm{~mm} \times 8 \mathrm{~mm}$. Inv. no. 56.11.60.20 (Fig. 26. 20).

Unretouched flake

Rectangular flake with worked surface. The platform and the bulb of percussion are missing. Patinated bluish-grey flint. $17 \mathrm{~mm} \times 13 \mathrm{~mm} \times 5 \mathrm{~mm}$. Inv. no. 56.11.60.41.

Unretouched flake

The platform is missing, the bulb of percussion is flat. Light brown radiolarite. $14 \mathrm{~mm} \times 12 \mathrm{~mm} \times 2 \mathrm{~mm}$. Inv. no. 56.11.60.1.

Unretouched flake

The platform and the bulb of percussion are punctiform. Reddish-brown radiolarite. $12 \mathrm{~mm} \times 11 \mathrm{~mm} \times 2.5 \mathrm{~mm}$. Inv. no. 56.11.60.30.

Unretouched flake

Triangular flake. The platform and the bulb of percussion are punctiform. Patinated limnic quartzite. $18 \mathrm{~mm} \times 10.5 \mathrm{~mm} \times$ $3.5 \mathrm{~mm}$. Inv. no. 56.11.60.44.

Unretouched flake

Triangular flake. The platform and the bulb of percussion are missing. Patinated limnic quartzite. $15 \mathrm{~mm} \times 11 \mathrm{~mm} \times 2.5 \mathrm{~mm}$. Inv. no. 56.11.60.46.

Unretouched flake

The platform and the bulb of percussion are present. Cream chert. $14 \mathrm{~mm} \times 11.5 \mathrm{~mm} \times 4 \mathrm{~mm}$. Inv. no. 56.11.60.47.

Unretouched flake

The platform is punctiform, the bulb of percussion is pronounced. Patinated limnic quartzite. $11 \mathrm{~mm} \times 12 \mathrm{~mm} \times 2 \mathrm{~mm}$. Inv. no. 56.11.60.49.

Unretouched flake

Unretouched rectangular flake with large platform and bulb of 
percussion. Patinated limnic quartzite. $10 \mathrm{~mm} \times 11.5 \mathrm{~mm} \times$ $2.5 \mathrm{~mm}$. Inv. no. 56.11.60.52.

Unretouched flake

Triangular unretouched blade. The platform is angled, the bulb of percussion is thinned. Limnic quartzite. $15 \mathrm{~mm} \mathrm{x}$ $13 \mathrm{~mm} \times 3 \mathrm{~mm}$. Inv. no. 56.11 .60 .56 .

Unretouched flake

The platform is punctiform, the bulb of percussion is flat. Light brown radiolarite. $15 \mathrm{~mm} \times 11 \mathrm{~mm} \times 3 \mathrm{~mm}$. Inv. no. 56.11.60.61

Unretouched flake

The platform and the bulb of percussion are missing. Hornstone with cortex. $25.5 \mathrm{~mm} \times 17.5 \mathrm{~mm} \times 3.5 \mathrm{~mm}$. Inv. no. 56.11.60.78

Unretouched flake

The bulb of percussion is pronounced, the platform is present. Brown radiolarite. $10 \mathrm{~mm} \times 12 \mathrm{~mm} \times 3 \mathrm{~mm}$. Inv. no. 56.11.60.84.

Unretouched flake

The bulb of percussion is flat, the platform is punctiform. Patinated limnic quartzite. $18 \mathrm{~mm} \times 12 \mathrm{~mm} \times 3 \mathrm{~mm}$. Inv. no. 56.11.60.86

Unretouched flake

Traces of preliminary preparation on the dorsal and the ventral side. Hornstone. $26 \mathrm{~mm} \times 13.5 \mathrm{~mm} \times 4.5 \mathrm{~mm}$. Inv. no. 56.11.60.4

Unretouched flake

The platform and the bulb of percussion are missing. Yellowish-red radiolarite. $15 \mathrm{~mm} \times 8 \mathrm{~mm} \times 3 \mathrm{~mm}$. Inv. no. 56.11 .60 .58

Unretouched flake

The platform and the bulb of percussion are punctiform. Brown radiolarite. $9 \mathrm{~mm} \times 6.5 \mathrm{~mm} \times 1 \mathrm{~mm}$. Inv. no. 56.11.60.69

Unretouched flake

The platform is punctiform, the bulb of percussion is flat. Brown radiolarite. $11.5 \mathrm{~mm} \times 7.5 \mathrm{~mm} \times 2.5 \mathrm{~mm}$. Inv. no. 56.11.60.63.

Unretouched flake

The platform is present, the bulb of percussion is flat. Patinated limnic quartzite. $12 \mathrm{~mm} \times 13 \mathrm{~mm} \times 2 \mathrm{~mm}$. Inv. no. 56.11.60.45.

Unretouched flake

The platform and the bulb are present. Patinated limnic quartzite. $12 \mathrm{~mm} \times 13 \mathrm{~mm} \times 2 \mathrm{~mm}$. Inv. no. 56.11.60.60.

Unretouched flake

The platform is punctiform, the bulb of percussion is pronounced. Yellowish-brown limnic quartzite. $8.5 \mathrm{~mm} \mathrm{x}$ $14 \mathrm{~mm} \times 2.5 \mathrm{~mm}$. Inv. no. 56.11.60.71

Debitage

Yellowish-brown radiolarite. $12.5 \mathrm{~mm} \times 10.5 \mathrm{~mm} \times 4 \mathrm{~mm}$. Inv. no. 56.11 .60 .2

Debitage

Yellowish-brown radiolarite. $13.5 \mathrm{~mm} \times 9 \mathrm{~mm} \times 2.5 \mathrm{~mm}$. Inv. no. 56.11.60.35

Debitage

Obsidian. $16 \mathrm{~mm}$ x $5 \mathrm{~mm} \times 2.5 \mathrm{~mm}$. Inv. no. 56.11 .60 .38 .

Debitage

Limnic quartzite with patination in some spots. $16.5 \mathrm{~mm} \mathrm{x}$ $12.5 \mathrm{~mm} \times 2 \mathrm{~mm}$. Inv. no. 56.11.60.40.

Debitage

Patinated limnic quartzite. $14 \mathrm{~mm} \times 10 \mathrm{~mm} \times 2 \mathrm{~mm}$. Inv. no. 56.11.60.48

Debitage

White chert. $14 \mathrm{~mm} \times 8 \mathrm{~mm} \times 1 \mathrm{~mm}$. Inv. no. 56.11 .60 .51 .

Debitage

Mauvish-brown radiolarite. $27 \mathrm{~mm} \times 14 \mathrm{~mm} \times 1.5 \mathrm{~mm}$. Inv. no. 56.11 .60 .55
Debitage

Brown radiolarite. $19 \mathrm{~mm} \times 12 \mathrm{~mm} \times 4 \mathrm{~mm}$. Inv. no. 56.11.60.59.

Debitage

Patinated limnic quartzite. $10.5 \mathrm{~mm} \times 10 \mathrm{~mm} \times 4 \mathrm{~mm}$. Inv. no. 56.11.60.67.

Debitage

Patinated limnic quartzite. $12 \mathrm{~mm} \times 9 \mathrm{~mm} \times 2 \mathrm{~mm}$. Inv. no. 56.11 .60 .68

Debitage

Brown radiolarite. $12.5 \mathrm{~mm} \times 10 \mathrm{~mm} \times 2 \mathrm{~mm}$. Inv. no. 56.11.60.64.

Debitage

Light brown radiolarite. $14.5 \mathrm{~mm} \times 8 \mathrm{~mm} \times 3.5 \mathrm{~mm}$. Inv. no. 56.11 .60 .65

Debitage

Brown radiolarite. $11 \mathrm{~mm} \times 8 \mathrm{~mm} \times 1.5 \mathrm{~mm}$. Inv. no. 56.11.60.77.

Debitage

Light yellow limnic quartzite. $13 \mathrm{~mm} \times 10 \mathrm{~mm} \times 2.5 \mathrm{~mm}$. Inv. no. 56.11 .60 .76

Debitage

Patinated limnic quartzite. $14 \mathrm{~mm} \times 7 \mathrm{~mm} \times 2 \mathrm{~mm}$. Inv. no. 56.11.60.75.

Debitage

Translucent limnic quartzite. $13 \mathrm{~mm} \times 8 \mathrm{~mm} \times 1 \mathrm{~mm}$. Inv. no. 56.11.60.74

Debitage

Patinated limnic quartzite. $12 \mathrm{~mm} \times 7 \mathrm{~mm} \times 1.5 \mathrm{~mm}$. Inv. no. 56.11.60.72.

Debitage

Patinated limnic quartzite. $12 \mathrm{~mm} \times 8.5 \mathrm{~mm} \times 3 \mathrm{~mm}$. Inv. no. 56.11 .60 .66

\section{Grave 95}

Fragment of an unretouched flake

The platform and the bulb of percussion are missing. Brown radiolarite. $29.5 \mathrm{~mm}$ x $19 \mathrm{~mm}$ x $6 \mathrm{~mm}$. Inv. no. 56.11.62.2.

\section{Grave 112}

Unretouched blade

Blade with a large, wide platform and bulb of percussion. Reddish-brown radiolarite. $29 \mathrm{~mm} \times 13 \mathrm{~mm} \times 3 \mathrm{~mm}$. Inv. no. 56.11.70.4 (Fig. 23. 8).

Combination of a retouched blade and a déjeté burin

The left edge was worked with parallel, steep retouch on the dorsal side. The retouch extends to the upper third on the right side of the ventral side. Sickle gloss can be noted along the entire length of the retouched edge on the dorsal side and to the mid-section of the blade on the ventral side. The distal end has a natural fracture and is covered with thick sickle gloss. The $3 \mathrm{~mm}$ wide burin edge on the right edge of the butt was created by removing two burin spalls. One possible interpretation of the use-wear traces on the working edge is that this technique was designed to ensure the easier hafting of the implement. However, this possibility can only be confirmed by the microscopic examination of the implement. The platform and the bulb of percussion are present. Reddishbrown radiolarite. $35 \mathrm{~mm} \times 15 \mathrm{~mm} \times 4.5 \mathrm{~mm}$. Inv. no. 56.11.70.5 (Fig. 23. 9).

\section{Grave 115}

Side-scraper

Side-scraper with atypical, curved working edge on a flake. The scraping edge was made with scalar, steep retouch. Brown radiolarite. $27 \mathrm{~mm} \times 35 \mathrm{~mm} \times 7.5 \mathrm{~mm}$. Inv. no. 56.11.73.2 (Fig. 23. 10). 


\section{Grave 117}

Unretouched flake

Wide flake with striations reflecting use-wear. The platform and the bulb of percussion are present. Brown radiolarite. $24 \mathrm{~mm} \times 14.5 \mathrm{~mm} \times 2 \mathrm{~mm}$. Inv. no. 61.2.2.2 (Fig. 23. 11).

Rectangle

Rectangular implement with small, steep retouch along two sides of the ventral side. Probably made from the medial fragment of a thin, wide blade. Blue mottled cream chert. $14.5 \mathrm{~mm} \times 15 \mathrm{~mm} \times 3.5 \mathrm{~mm}$. Inv. no. 61.2.2.1 (Fig. 23. 12).

\section{Grave 128}

Debitage

Brown radiolarite. $13 \mathrm{~mm}$ x $6.5 \mathrm{~mm}$. Inv. no. 61.2.7.2.

\section{Grave 134}

Dihedral burin on a retouched blade

The left edge was worked with parallel retouch on the ventral side. The distal end of the wide blade was formed into a burin. The $c a .3 \mathrm{~mm}$ wide burin edge was created by removing several burin spalls. Brown radiolarite. $40 \mathrm{~mm}$ x $18 \mathrm{~mm}$ x 6.5 mm. Inv. no. 61.2.12.1 (Fig. 23. 13).

\section{Grave 149}

Medial fragment of an unretouched blade

Strongly patinated limnic quartzite. $18 \mathrm{~mm} \times 13 \mathrm{~mm} \times 3 \mathrm{~mm}$. Inv. no. 61.2.24 (Fig. 23. 14).

\section{Grave 158}

Unretouched flake

Flake with worked surface. The platform is punctiform, the bulb of percussion is flat. Dark brown radiolarite. $24 \mathrm{~mm} x$ $17 \mathrm{~mm} \times 4 \mathrm{~mm}$. Inv. no. 61.2.27.5.

\section{Grave 164}

Trapeze

Narrow, geometric microlith. The ventral side was truncated by oblique retouch on both ends. The ventral side was notched by small marginal retouch on the right side. Limnic quartzite. $21.5 \mathrm{~mm} \times 13 \mathrm{~mm} \times 4 \mathrm{~mm}$. Inv. no. 61.2.30.9 (Fig. 23. 15).

Trapeze

Narrow, geometric microlith. The dorsal side was truncated by oblique retouch at both ends. The dorsal side was notched by small marginal retouch on the right side. Brown radiolarite. $19 \mathrm{~mm} \times 9 \mathrm{~mm} \times 3 \mathrm{~mm}$. Inv. no. 61.2.30.10 (Fig. 23. 16).

Triangle

Geometric tool truncated obliquely at the distal end. Worked with steep marginal retouch. The platform and the bulb of percussion are missing. Patinated chert with cortex. $15.5 \mathrm{~mm} \mathrm{x}$ $11 \mathrm{~mm} \times 3$ mm. Inv. no. 61.2.30.6 (Fig. 23. 17)

Point

Truncated by slightly oblique, steep retouch at the butt. Retouched from the lower to the mid-section on the left edge on the dorsal side. The distal end has a natural fracture. Limnic quartzite. $14.5 \mathrm{~mm} \times 12 \mathrm{~mm} \times 2 \mathrm{~mm}$. Inv. no. 61.2.30.8 (Fig. 23. 18).

Retouched flake

Flake retouched with small marginal retouch at the butt. The bulb of percussion is present. Limnic quartzite. $17.5 \mathrm{~mm} \times$ $10 \mathrm{~mm} \times 2 \mathrm{~mm}$. Inv. no. 61.2.30.11.

Unretouched flake

Flake with small platform and pronounced bulb of percussion. Patinated white chert. $20 \mathrm{~mm} \times 12 \mathrm{~mm} \times 4.5 \mathrm{~mm}$. Inv. no. 61.2.30.5.

Unretouched flake

The platform and the bulb of percussion are missing. Patinated white chert. $15 \mathrm{~mm} \times 11 \mathrm{~mm} \times 2 \mathrm{~mm}$. Inv. no. 61.2.30.7.

\section{Grave 170}

Trapeze

Geometric microlith truncated by linear, steep retouch starting from the ventral side at the distal end, and with oblique retouch at the butt. Jasper. $17 \mathrm{~mm} \times 11 \mathrm{~mm} \times 2 \mathrm{~mm}$. Inv. no. 61.2.31.1 (Fig. 24. 1).

Trapeze

Geometric microlith. The form was created by truncating the tool with oblique, steep retouch at both ends on the ventral side. White chert. $15 \mathrm{~mm} \times 10 \mathrm{~mm} \times 1.5 \mathrm{~mm}$. Inv. no. 61.2.33.9 (Fig. 24 2).

\section{Grave 174}

Trapeze

Geometric microlith truncated with oblique retouch at the distal end. The butt is slightly convex and truncated by retouch. White chert. $18 \mathrm{~mm} \times 14.5 \mathrm{~mm} \times 3 \mathrm{~mm}$. Inv. no. 61.2.33.8 (Fig. 24. 3).

\section{Trapeze}

Trapeze form with concave butt truncated by retouch. The distal end has a natural fracture. White chert. $18 \mathrm{~mm} \times$ $14 \mathrm{~mm} \times 4 \mathrm{~mm}$. Inv. no. 61.2.33.11 (Fig. 24. 4).

Truncated-retouched blade

The right edge has steep, parallel retouch on the ventral side. The distal end has a natural fracture. The butt has a rough truncation. Brown radiolarite. $18 \mathrm{~mm} \times 9 \mathrm{~mm} \times 3 \mathrm{~mm}$. Inv. no. 61.2.33.10 (Fig. 24. 5).

Unretouched flake

The platform and the bulb of percussion are present. Reddishbrown radiolarite. $14 \mathrm{~mm} \times 11.5 \mathrm{~mm} \times 2 \mathrm{~mm}$. Inv. no. 61.2.33.6.

Unretouched flake

Blade-like flake. The platform was removed by percussion and thinned. Tiny striations can be noted on the butt. The bulb of percussion is present. Limnic quartzite. $19 \mathrm{~mm} \times 11 \mathrm{~mm} \times$ 2 mm. Inv. no. 61.2.33.7 (Fig. 24. 6).

\section{Grave 175}

Core fragment

Amorphous core fragment with flake and blade negative. Obsidian with cortex. $33 \mathrm{~mm} \times 28 \mathrm{~mm}$. Inv. no. 61.2.34.2.

\section{Grave 177}

Point

A point was created by parallel, steep retouch on the left edge on the ventral side. The distal end and the butt have a natural fracture. Radiolarite. $16 \mathrm{~mm} \times 12 \mathrm{~mm} \times 3 \mathrm{~mm}$. Inv. no. 61.2.35.4 (Fig. 24. 7).

Unworked pebble

Brown radiolarite. $31 \mathrm{~mm} \times 17 \mathrm{~mm} \times 10.5 \mathrm{~mm}$. Inv. no. 61.2.35.3.

\section{Grave 182}

Retouched blade

Blade with steep retouch along the upper two-thirds of the right edge on the dorsal and ventral side. Sickle gloss extends to the ridge on the dorsal side. Both ends of the blade are broken. Patinated white mottled chert. $32 \mathrm{~mm} \times 14 \mathrm{~mm} \times$ 6 mm. Inv. no. 61.2.39.1 (Fig. 24. 8).

\section{Grave 189}

Debitage

One piece. Inv. no. 61.2.42.3.

\section{Grave 195}

Quarter pebble fragment

Brown radiolarite. $10.5 \mathrm{~mm} \times 9.5 \mathrm{~mm}$. Inv. no. 61.2.47.1. 


\section{Grave 197}

Trapeze

Atypical tool truncated by linear retouch at the distal end on the dorsal side. The distal end has a natural fracture. The platform and the bulb of percussion are missing. Brown radiolarite. $13 \mathrm{~mm} \times 8 \mathrm{~mm} \times 1.5 \mathrm{~mm}$. Inv. no. 61.2.49.7 (Fig. 24. 9).

Trapeze

Atypical tool truncated by retouch at the distal end. Obsidian. $13 \mathrm{~mm} \times 12 \mathrm{~mm} \times 1 \mathrm{~mm}$. Inv. no. 61.2.49.14 (Fig. 24. 10).

Trapeze

Truncated with oblique retouch on the ventral side. Cream chert. $15.5 \mathrm{~mm} \times 13 \times 4 \mathrm{~mm}$. Inv. no. 61.2.49.13 (Fig. 24. 11).

Trapeze

Microlith truncated with oblique retouch at the distal end on the dorsal side. It was worked with steep retouch. White chert. $11 \mathrm{~mm} \times 12 \mathrm{~mm} \times 2.5 \mathrm{~mm}$. Inv. no. 61.2.49.12.

Trapeze

Truncated with small marginal retouch at both ends on the dorsal side. The platform is punctiform, the bulb of percussion is flat. Reddish-brown limnic quartzite. $23 \mathrm{~mm} \times 10.5 \mathrm{~mm}$ x $1.5 \mathrm{~mm}$. Inv. no. 61.2.49.9.

Point

Triangular, bifacially worked point. The point was worked with surface retouch, there is no indication of marginal retouch. Cream chert. $14 \mathrm{~mm} \times 17 \mathrm{~mm} \times 4 \mathrm{~mm}$. Inv. no. 61.2.49.10 (Fig. 24. 12).

Retouched flake

Flake with occasional retouching on the right edge on the dorsal surface. Radiolarite. $17 \mathrm{~mm} \times 10.5 \mathrm{~mm} \times 2 \mathrm{~mm}$. Inv. no. 61.2.49.6.

Unretouched flake

Flake with traces of working on the surface. The platform and the bulb of percussion are missing. Reddish-brown radiolarite. $14 \mathrm{~mm} \times 18 \mathrm{~mm} \times 2.5 \mathrm{~mm}$. Inv. no. 61.2.49.5.

Unretouched flake

Flake with traces of working on the surface. The platform is punctiform, the bulb of percussion was removed. Radiolarite. $23 \mathrm{~mm} \times 14 \mathrm{~mm} \times 3 \mathrm{~mm}$. Inv. no. 61.2.49.15.

Unretouched flake

Triangular flake. The platform and the bulb of percussion are missing. Cream chert. $15 \mathrm{~mm} \times 12.5 \mathrm{~mm} \times 2 \mathrm{~mm}$. Inv. no. 61.2.49.11.

Unretouched blade fragment

The platform and the bulb of percussion were removed, the distal end is missing. Reddish-brown limnic quartzite. $23 \mathrm{~mm} x$ $12.5 \mathrm{~mm} \times 3 \mathrm{~mm}$. Inv. no. 61.2.49.8

\section{Grave 202}

Unretouched flake

The platform is punctiform, the bulb of percussion was removed. Light brown radiolarite. $16.5 \mathrm{~mm} \times 10.5 \mathrm{~mm} \times 3 \mathrm{~mm}$. Inv. no. 61.2.50.3

\section{Grave 207}

Curved end-scraper on a flake

The distal end of the tool is curved and worked with retouch typical for end-scrapers. Even though the platform and the bulb of percussion are missing, its form indicates that it was made on a flake. Hornstone. $17 \mathrm{~mm} \times 14 \mathrm{~mm} \times 3 \mathrm{~mm}$. Inv. no. 61.2.53.1 (Fig. 24. 13).

Rectangle

The tool is broken at the butt. The right edge of the dorsal side is retouched. It was made from a rectangular micro-endscraper. Brownish-mauve jasper. $11 \mathrm{~mm} \times 14.5 \mathrm{~mm} \times 2.5 \mathrm{~mm}$. Inv. no. 61.2.53.3 (Fig. 24. 14)
Unretouched flake

Traces of preliminary working on the surface. The platform and the bulb of percussion are missing. Reddish-brown radiolarite. $17 \mathrm{~mm} \times 15.5 \mathrm{~mm} \times 2.5 \mathrm{~mm}$. Inv. no. 61.2.53.2.

Unretouched flake

The platform and the bulb of percussion are missing. Reddishbrown radiolarite. $14 \mathrm{~mm} \times 8.5 \mathrm{~mm} \times 2.5 \mathrm{~mm}$. Inv. no. 61.2.53.4.

Debitage

Hornstone with cortex. $17.5 \mathrm{~mm} \times 10 \mathrm{~mm} \times 4.5 \mathrm{~mm}$. Inv. no. 61.2.53.5

\section{Grave 221}

Unretouched blade fragment The distal end is broken. Large platform and bulb of percussion. Translucent limnic quartzite with patination in some spots. $26 \mathrm{~mm} \times 11 \mathrm{~mm} \times 2.5 \mathrm{~mm}$. Inv. no. 61.2.61.1 (Fig. 24. 15).

Debitage

White chert with cortex. $23 \mathrm{~mm} \times 10 \mathrm{~mm}$. Inv. no. 61.2.61.4.

\section{Grave 227}

Trapeze

Geometric microlith. The butt is truncated by oblique, slightly concave, steep retouch. The distal end has a natural oblique fracture. Limnic quartzite with cortex. $16.5 \mathrm{~mm} \mathrm{x}$ $9.5 \mathrm{~mm} \times 2 \mathrm{~mm}$. Inv. no. 61.2.66.17 (Fig. 24./16).

Trapeze

Geometric microlith. Truncated by oblique retouch at both ends. Patinated limnic quartzite. $18 \mathrm{~mm} \times 11 \mathrm{~mm} \times 3 \mathrm{~mm}$. Inv. no. 61.2.66.18 (Fig. 24. 17).

Unretouched flake

The platform and the bulb of percussion are missing. White chert. $16 \mathrm{~mm} \times 12 \mathrm{~mm} \times 3 \mathrm{~mm}$. Inv. no. 61.2.66.19.

\section{Grave 230}

Distal fragment of a retouched blade

Sturdy retouched blade tip. Worked with tiny, steep, parallel retouch on the upper third of the right edge on the dorsal side. The platform and the bulb of percussion are missing. Radiolarite. $32 \mathrm{~mm} \times 8 \mathrm{~mm} \times 7$ mm. Inv. no. 61.2.68 (Fig. 24 . 18).

\section{Grave 263}

Retouched blade tip Blade tip worked with small, parallel, steep retouch on the upper two-thirds of the right edge on the ventral side. Wide blade with punctiform platform and bulb of percussion. The tip is broken. The slightly rounded tip was created at the intersection of the natural fracture and the retouched edge. Brown, black banded radiolarite. $40 \mathrm{~mm} \times 20 \mathrm{~mm} \times 5.5 \mathrm{~mm}$. Inv. no. 61.2.85.2 (Fig. 24. 19).

Retouched flake

Worked with small, parallel retouch on one edge. The platform and the bulb of percussion are missing. Brown-white radiolarite. $27.5 \mathrm{~mm} \times 18 \mathrm{~mm} \times 3 \mathrm{~mm}$. Inv. no. 61.2.85.3.

\section{Grave 279}

Unretouched blade fragment

The distal end is broken. The platform is large, the bulb of percussion is punctiform. Reddish-yellowish-white limnic quartzite. $29 \mathrm{~mm} \times 12 \mathrm{~mm} \times 4 \mathrm{~mm}$. Inv. no. 61.2.93.4 (Fig. 25. 1).

Core

Yellowish-grey hornstone with traces of removal. L. $6.5 \mathrm{~cm}$. Inv. no. 61.2.93.3. 
Grave 287

Rectangle

Medial fragment of an unretouched blade. Although unretouched, it is a good example of how a tool of the required size and form was made by intentional breakage. Several other examples of this tool form in the same size can be quoted; some are occasionally retouched at one end. Greyish-white limnic quartzite. $14 \mathrm{~mm} \times 12.5 \mathrm{~mm} \times 3 \mathrm{~mm}$. Inv. no. 61.2 .96 (Fig. 25. 2).

\section{Grave 291}

Unretouched blade

Wide blade. The platform and the bulb of percussion are missing. Traces of core preparation on the dorsal side. Brown radiolarite. $37 \mathrm{~mm} \times 17 \mathrm{~mm} \times 4 \mathrm{~mm}$. Inv. no. 61.2.99.3.

\section{Grave 325}

Unworked pebble

Pink chert. $22.5 \mathrm{~mm}$ x $11 \mathrm{~mm}$. Inv. no. 61.2.116.

\section{Grave 330}

Side-scraper

Triangular side-scraper worked with parallel steep retouch down the entire length of the left edge on the dorsal side. The retouched edge is covered with sickle gloss. The platform and the bulb of percussion are missing. Judging from its size, it was part of a larger, wide, sturdy blade. Radiolarite. $24 \mathrm{~mm} \times$ $16.5 \mathrm{~mm} \times 5.5 \mathrm{~mm}$. Inv. no. 61.2.119.2 (Fig. 25. 3).

\section{Grave 335}

Debitage

Amorphous fragment. The platform and the bulb of percussion are missing. Patinated limnic quartzite. $26 \mathrm{~mm} \times 21 \mathrm{~mm} \times$ $5 \mathrm{~mm}$. Inv. no. 61.2.121.3.

Debitage

Amorphous fragment. The platform and the bulb of percussion are missing. Patinated grey limnic quartzite. $23.5 \mathrm{~mm} \mathrm{x}$ $16 \mathrm{~mm} \times 7.5 \mathrm{~mm}$. Inv. no. 61.2.121.4.

\section{Grave 347}

Core

Small, amorphous core fragment. Brown radiolarite. $19 \mathrm{~mm} \times$ $19 \mathrm{~mm}$. Inv. no. 61.2.128.4.

Debitage

Amorphous. The platform and the bulb of percussion are missing. Yellowish-brown radiolarite. $19 \mathrm{~mm} \times 12 \mathrm{~mm} \times 6.5 \mathrm{~mm}$. Inv. no. 61.2.128.5.

\section{Grave 354}

Unretouched blade fragment

The distal end is broken. The platform is small, the bulb of percussion was thinned. Translucent limnic quartzite. $31 \mathrm{~mm} x$ $16 \mathrm{~mm} \times 4.5 \mathrm{~mm}$. Inv. no. 61.2.132.1 (Fig. 25. 4).

\section{Grave 361}

Trapeze

Geometric microlith. Truncated by small, oblique retouch at both ends on the dorsal side. Patinated limnic quartzite. $16 \mathrm{~mm} \times$ $12.5 \mathrm{~mm} \times 3 \mathrm{~mm}$. Inv. no. 61.2.137.2 (Fig. 25. 5).

\section{Grave 370}

Déjeté burin on a curved flake truncated by retouch The curved upper end was worked with small marginal retouch on the dorsal side. The upper two-thirds of the left edge were retouched on the ventral side. The $4 \mathrm{~mm}$ wide burin edge was created at the intersection of the retouched edges. The platform is present, the bulb of percussion is flat.
Reddish-brown radiolarite. $19 \mathrm{~mm} \times 18 \mathrm{~mm} \times 5 \mathrm{~mm}$. Inv. no. 61.2.143 (Fig. 25. 6).

\section{Grave 375}

Unretouched blade fragment

The platform and the bulb of percussion are missing. Rust brown radiolarite. $19.5 \mathrm{~mm} \times 8.5 \mathrm{~mm} \times 2 \mathrm{~mm}$. Inv. no. 61.2.145.2 (Fig. 25. 7)

Unretouched blade fragment The distal end is broken. The platform and the bulb of percussion are punctiform. Rust brown radiolarite. $18 \mathrm{~mm} \times$ $8 \mathrm{~mm} \times 2.5 \mathrm{~mm}$. Inv. no. 61.2.145.3 (Fig. 25. 8).

Unretouched flake

Triangular flake with traces of preliminary preparation. The platform is wide, the bulb of percussion is visible. Probably debitage from the trimming of a core. Pink-brown radiolarite. $12 \mathrm{~mm} \times 19 \mathrm{~mm} \times 5 \mathrm{~mm}$. Inv. no. 61.2.145.4 (Fig. 25. 9).

\section{Grave 376}

Unworked pebble

Radiolarite. 28 mm x 14 mm. Inv. no. 61.2.146.2.

\section{Grave 377}

Déjeté burin on a retouched blade

The $c a .5 \mathrm{~mm}$ wide burin edge lies at the intersection of two wide burin planes perpendicular to the tool's axis and the retouched upper section of the right edge on the ventral side. Sickle gloss covers the dorsal section of the retouched edge on the ventral side. Sickle gloss can be made out parallel to the upper third of the left edge on the dorsal side. The platform is broken. Hornstone. $29 \mathrm{~mm} \times 16.5 \mathrm{~mm} \times 6 \mathrm{~mm}$. Inv. no. 61.2.147.2 (Fig. 25. 10).

\section{Grave 378}

Unworked pebble

Lydite. $25 \mathrm{~mm}$ x $19 \mathrm{~mm}$. Inv. no. 61.2.148.5.

\section{Grave 380 \\ Core}

Prism shaped core. Pink-brown chert with cortex. $29 \mathrm{~mm} \times$ $14 \mathrm{~mm}$. Inv. no. 61.2.149.

\section{Grave 422}

Unworked pebble

Yellowish-brown radiolarite. $20 \mathrm{~mm} \times 16 \mathrm{~mm}$. Inv. no. 61.2.170.1.

\section{Grave 425}

Unworked pebble Cracked pebble. The crack is natural. Brown radiolarite. $23 \mathrm{~mm} \times 9 \mathrm{~mm}$. Inv. no. 61.2.171.2.

\section{Grave 436}

Debitage

Amorphous piece without platform and bulb of percussion. Chert. $23.5 \mathrm{~mm} \times 8 \mathrm{~mm} \times 6.5 \mathrm{~mm}$. Inv. no. 61.2.177.2.

\section{Stray finds}

\section{Retouched flake}

The right upper third is worked with small marginal retouch on the dorsal side. The greater part of the wide, medium sized blade-like flake is covered with occasional retouch. The platform is wide and large, the bulb of percussion is pronounced. Mauvish-brown cream radiolarite. $41 \mathrm{~mm} \times$ $27 \mathrm{~mm} \times 11 \mathrm{~mm}$. Inv. no. 61.2.188 (Fig. 25. 11). 


\section{TYPOLOGY AND TECHNOLOGY OF THE LITHIC FINDS}

László Vértes's monograph on the Palaeolithic and Mesolithic finds from Hungary marked a milestone in the study of the most ancient chipped stone implements. ${ }^{18}$ Several studies and monographs have been devoted to the typology and technology of prehistoric chipped stone implements. However, these studies generally focused on the typology of the finds, with little discussion of the tools and implements reflecting the technological characteristics of a particular industry. Exactly forty years after Vértes's study, Katalin Simán published a paper on the production of Palaeolithic chipped stone tools. ${ }^{19}$ She briefly discussed the different phases of tool production, from the acquisition of the necessary raw materials to the discarding of the finished tool. Zsolt Holló, György Lengyel and Zsolt Mester too have described the technological features of chipped stone implements. ${ }^{20}$ These studies have greatly contributed to the re-thinking and renewal of the Hungarian terminology used for the description and discussion of chipped stone implements. ${ }^{21}$

Similarly to the Palaeolithic and the Mesolithic, the manufacture of stone stools was an important activity during later prehistoric periods too. There is abundant evidence for stone tool manufacture and the survival of lithic technologies from the Neolithic to the close of the Late Bronze Age. 22

The preparation of cores was an important phase in the general production process $^{23}$ from the Lower Palaeolithic to the close of the Bronze Age. In her study on the production of Palaeolithic chipped stone implements, Simán discussed the various modes of raw material acquisition and the semi-finished and finished products made from them. ${ }^{24}$ She distinguished several phases in the production process, in part quoting the generally accepted views in this field of research, and in part based on her own experiments with flint knapping.

(1) Preparation. The preparation of the raw material for transportation on the spot of its acquisition (splitting the rock into smaller chunks, removal of the matrix $^{25}$ and decortication $\left.{ }^{26}\right)$. Hammerstones, flakes

\footnotetext{
18 VÉRTES 1960, 68-82; VÉRTES 1965, 235-254.

19 Simán 2000.

${ }^{20}$ Holló et al. 2001; Holló et al. 2002.

${ }^{21}$ Holló et al. 2002, 98. One of the main purposes was to introduce a technological terminology and, in a wider sense, a new approach to the study of lithics modelled on the generally accepted terminology of lithic technology in French scholarship based on both theoretical models and experimental studies.

22 Cs. Balogh 1993; Cs. Balogh 2001, 91-92.

${ }^{23}$ Production process: a process from the procurement of the raw material to the discard of the tool/implement (SIMÁN 2000, 7); Chaîne opératoire: a creative human process in the course of which techniques and procedures for achieving a desired goal are mastered and passed on. In the production of chipped stone implements, the chaine opératoire is the following: 1. raw material procurement, 2. preparation of the raw material, 3. processing, manufacture of semi-finished products, 4. manufacture of finished products, 5. use, 6. discard (HoLLó et al. 2001, 53-54).

24 SiMÁN 2000

${ }^{25}$ Matrix: the sediment under- and overlying the bank of raw material or the rock in which the nodules of raw material are embedded. SIMÁN 2000, note 17 .
}

with cortex and large flakes are usually an indication of this activity.

(2) Core preparation in workshops on permanent or seasonal settlements. The lithic assemblages from workshops of this type are predominantly made up of the debitage from core preparation.

(3) The two main techniques used for working cores were core reduction or flaking, ${ }^{27}$ and shaping. The flakes and blades removed from the core were the blanks for future tools. After some time, the maintenance of the cores, the renewal of the striking platform became necessary. The flakes detached from the core in the course of preparing and rejuvenating the core platform provide evidence for this activity on a site (core rejuvenation flakes, exhausted and discarded cores).

(4) In the course of tool manufacture, the blank is worked with secondary retouch. ${ }^{28}$ The renewal of the worn working edge was accomplished by different types of retouch. Edge and surface retouch was used for creating new tool types, which differed from the originally prepared tool as regards both their form and function (Fig. 1).

The tool production process as described by Mester and his colleagues by and large corresponds to the one described above, although they challenge the expression "production process" suggested by Simán, preferring to describe tool production as an operational sequence (chaîne operatoire) rather than a production process. ${ }^{29}$ In their terminology, this production process was as follows:

(1) Acquisition (raw material, knowledge);

(2) Manufacture (manufacture of products);

(3) Use (the use, transformation, rejuvenation of products);

(4) Discarding (the discarding of no longer utilised or worn products).

It is not my intention in this study to confirm or challenge the various models proposed by prehistorians. However, the original blank (blade/flake) must certainly be distinguished from the form of the actual tool produced from it and the chronological context of a particular tool-kit must also be borne in mind. The mental template of the tool and the end-product might differ in spite of an excellent technological knowledge and its conscious application owing to a flaw in the raw material, accidental breakage, careless percussion technique or subsequent working. The blanks used during the Palaeolithic were blades and flakes, whose subsequently worked and modified forms make up the

\footnotetext{
${ }_{26}$ Decortication is usually unnecessary in the case of pebbles. Simán considers decortication to be the first phase in core reduction (SIMÁN 2000, 8).

${ }^{27}$ Holló et al. 2002, 99, have argued that the expression "flaking" is misleading because this technique was also used for producing flakes.

${ }^{28}$ According to Simán, "retouch is a form of flaking, which is not aimed at the creation of a blank, but at the modification of a tool or implement's edge. One can distinguish between edge retouch, whose purpose is to create a working edge of the required thickness and sharpness, and blunting retouch, whose purpose is to reduce sharpness." SIMÁN 2000, 19; VÉRTES $1965,237-238$.
}

${ }^{29}$ Holló et al. 2002, 99. 
archaeological types on the basis of which the lithics of a particular culture can be statistically evaluated and the relation of typical tool types to each other can be determined (index calculations). Obviously, lithic assemblages include several "ad hoc" tools - implements, which could be immediately used for a certain activity from the moment they were detached from the core. Statistical indexes offer meaningful insights only if a particular assemblage contains a sufficient number of tools and thus the evaluation of other lithic types reflecting technological characteristics should also be included in the evaluation of an industry. In later prehistory, especially during the Early and Middle Copper Age, the main purpose of tool manufacture appears to have been the production of unretouched blades, most of which have been recovered from burials (prestige items).

\section{THE TOOLS AND IMPLEMENTS OF THE BUDAKALÁSZ CEMETERY}

The dorsal surface of a lithic implement is the original core surface on which there are usually one or two ridges. The ventral surface is the side with the bulb of percussion after detachment from the core. The position of the platform and the bulb of percussion determine the orientation of the blank because these enable the identification of the tools manufactured from the blank (products made on flakes or blades). Another important consideration in the determination of stone tools is that in addition to the primary typological function, the tool may have acquired a secondary function following renewal. This is all the more important because the technological features of an industry are indicated by whether the main tendency is the manufacture of flake or blade tools and whether changes in the proportion of flake and blade tools can be attributed to external cultural impacts or a culture's internal development. ${ }^{30}$ The axis of the semi-finished blank, the flake or the blade, does not necessarily coincide with the functional axis of the finished tool. Geometric tools are a case in point. The blank of the tool (the properly oriented flake or blade) and the functional form (as the tool is actually used) does not coincide in the case of geometric tools: the axis shifts by some ninety degrees, with the butt and the distal end forming the tool's right and left edge (Fig. 1).

\section{MICROLITHS}

Although microlithic tools first appeared in the later Upper Palaeolithic, their widespread use began in the Mesolithic. ${ }^{31}$ These tools were made by notching the

\footnotetext{
30 The typological and statistical study of the lithic finds from the two culture layers of the late Upper Palaeolithic site at Ságvár (Cs. BALOGH 1997, 17-46; Cs. BaLOGH 2000b, 339-344) and the Early and Middle Copper Age cemetery at Tiszapolgár-Basatanya (Cs. BALOGH 2004, 19-43) seems to confirm this.

31 VÉRTES 1960, 72; KozlowsKI-KOZlowSKI 1980, 13-20.
}

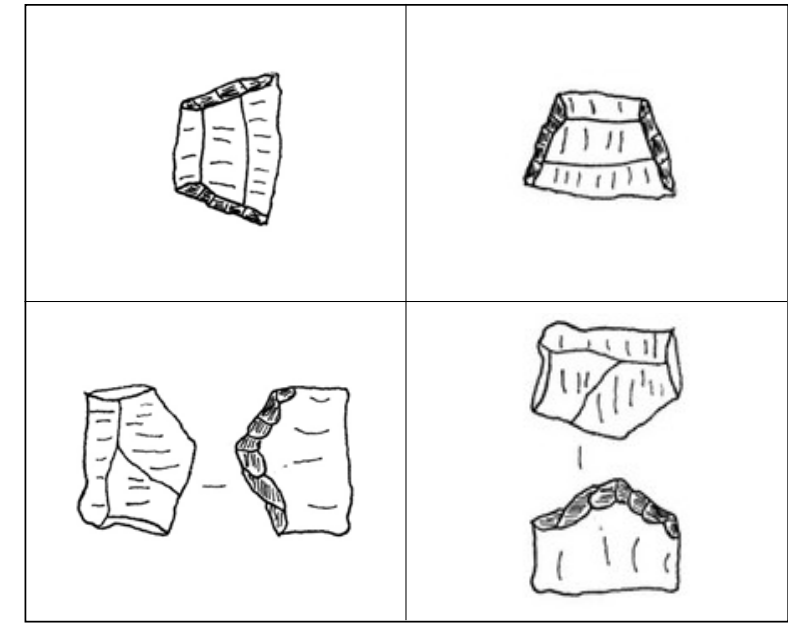

Fig. 1. The original form and the later function of tools

blade and then intentionally breaking the blade obliquely at the notch..$^{32}$ Most have a regular geometric form, although irregular forms also occur. Their size ranges between 3 and $4 \mathrm{~cm}$ or smaller. ${ }^{33}$ Jacques Tixier has noted that the microliths of the North African Epipalaeolithic were usually $12 \mathrm{~mm}$ to $50 \mathrm{~mm}$ long. ${ }^{34}$ These implements were used both with and without retouch and they can be distinguished from accidentally broken artefacts (Fig. 4. 2). At Budakalász, the Late Copper Age microliths (blades and various points) were made by linear, marginal, steep and blunting retouch. The purpose was the creation of hunting implements. However, a few specimens exhibit sickle gloss, indicating that chipped stone implements were put to a variety of uses. Sickle gloss is caused by the abrasive action of silica present in the stem of cereals. $^{35}$

\section{Truncated microlithic blades}

Microlithic tools were principally made by truncating larger blades and flakes. Retouched and unretouched types both occur. Most have one or both ends truncated. Truncation was usually perpendicular to the axis and could be straight, oblique, concave or convex. Microliths are usually described as geometric tools; ${ }^{36}$ this seems to be a rather simplified description since in addition to geometric forms, the artefacts assigned to this category often include a variety of blades and other tools, which were used to perform tasks similar to the ones for which geometric microliths were used.

\section{Triangles (Fig. 2)}

Form: triangular

Blank: blade, flake

\footnotetext{
32 BRÉZILLON 1968, 128. Fig. 27

33 VÉRTES 1960, 68

${ }^{34}$ Holló et al. 2002, 102.

35 Bá́CSKAY E. 1995.

36 BRÉZILLON 1968, 272-273.
} 
The two short edges of the triangle are truncated by retouch, the third, longest edge is usually formed by the natural edge of the triangular blade. Their form ranges from equilateral to isosceles and scalene triangles.

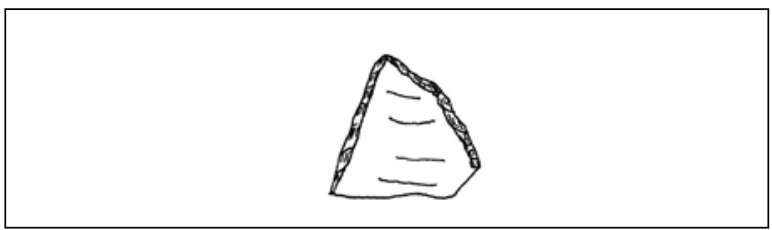

Fig. 2. Truncated microlithic blade: triangle

\section{Geometric rectangles (Figs 3-4)}

Trapeze (Fig. 3)

Form: trapezoidal

Blank: wide or narrow blade

The most widely occurring variant of geometric rectangles. The desired form was made by two symmetrical or asymmetrical truncations perpendicular to the blade's axis. Truncation can be straight, oblique, convex or concave.

Rectangles (Fig. 4)

Form: narrow or wide rectangle

Blank: narrow or wide blade

A widespread variant of geometric rectangles. One edge of the blade is retouched on the ventral side, with the retouch grading into one or two truncations at one or both ends. Two variants were found at Budakalász. It is sometimes difficult to distinguish this type from atypical trapezoidal and rhombical forms.

\section{Segments (Fig. 5)}

Form: crescentic

Blank: flake, blade, bladelet

Retouched by blunting retouch parallel to the axis on one edge at least along one-half of its length. Opposite the retouched edge is the blade's natural edge.

\section{Points (Fig. 6)}

Form: borer-like

Blank: wide or narrow blade

The implement has a borer-like working edge made by retouch on the dorsal or ventral side (the single exception is the bifacially worked point shown in Fig. 6. 4).

\section{Other tools (Fig. 7)}

Although dominated by geometric microliths, the assemblage includes also a few other characteristic tool types, such as burins on retouched blades, sidescrapers, double truncated blades, short end-scrapers, etc. The presence of these tools indicates that the community, which buried its dead in the Budakalász

\begin{tabular}{|c|c|c|}
\hline$=0$ & $\begin{array}{l}=1 \\
-1 \\
-1\end{array}$ & $\begin{array}{l}1 \\
=1 \\
=1\end{array}$ \\
\hline 形期 & 5 & $\begin{array}{l}0=1 \\
6\end{array}$ \\
\hline
\end{tabular}

\begin{tabular}{|l|l|c|}
\hline Type & \multicolumn{1}{|c|}{ Trapeze types } & $\begin{array}{c}\text { No. of } \\
\text { specimens }\end{array}$ \\
\hline 1 & $\begin{array}{l}\text { Truncated by retouch at the butt on the dorsal side and the distal end on the ventral side; one } \\
\text { edge of the dorsal side is retouched }\end{array}$ & 1 \\
\hline 2 & Truncated at the distal end on the dorsal side and at the butt on the ventral side & 2 \\
\hline 3 & Truncated by retouch at both ends on the ventral side & 6 \\
\hline 4 & Truncated by retouch at both ends on the dorsal side & 11 \\
\hline 5 & Truncated by retouch at one end on the dorsal side; the other end has a natural fracture & 2 \\
\hline 6 & Truncated by retouch at one end on the ventral side; the other end has a natural fracture & \\
\hline
\end{tabular}

Fig. 3. Trapeze types 


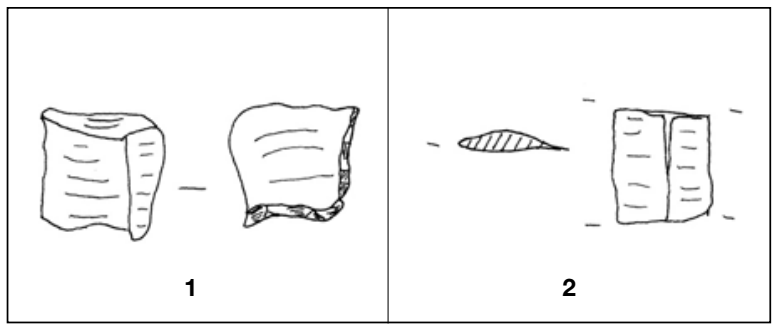

Fig. 4: Rectangle types

1. Medial blade fragment with retouch along the edge and truncated at one end,

2. Medial blade fragment with natural fracture

cemetery, was in command of the necessary technological skills for making these types. In contrast to weapons, which were recovered from both male and female burials, very few of these implements were deposited in the graves, suggesting that being artefacts used in daily life, they were much valued.

\section{Implements with sickle gloss (Fig. 8)}

The implements from the Budakalász burials include pieces with sickle gloss. Most are burins or retouched blades, although a few segments bearing sickle gloss have also been found. Burins are one of the most typical tool types of the Palaeolithic. The piece shown in Fig. 8. 5 suggests that in addition to traditional "household tools", geometric microliths were also used as sickle inserts.

\section{STATISTICAL EVALUATION}

In addition to geometric microlithic tools, the lithic assemblage from Budakalász included several other tools and implements: end-scrapers, side-scrapers, burins, and retouched blades. Most of these can be assigned to the category of microliths in view of their size; very few are slightly larger. Most of the latter occur among the tools made on intact blades and flakes since the tools made from them were subsequently worked. Besides intentional breaking, the most frequent technique was truncation by retouch at one or both ends. The original tool blank can thus only be determined after a thorough technological examination and in many cases, the original form does not always coincide with the tool's later function (Fig. 1). The nature of the raw materials used most certainly contributed to the small and medium size of the tools deposited in the burials, although it must also be borne in mind that microlithisation was a conscious human activity and its application reflects knowledge of ancient technologies (Figs 9-10). We may certainly agree with Simán that "technology is more than an individual, isolated activity or a routine work process; it is rather a reflection of an organised social system and

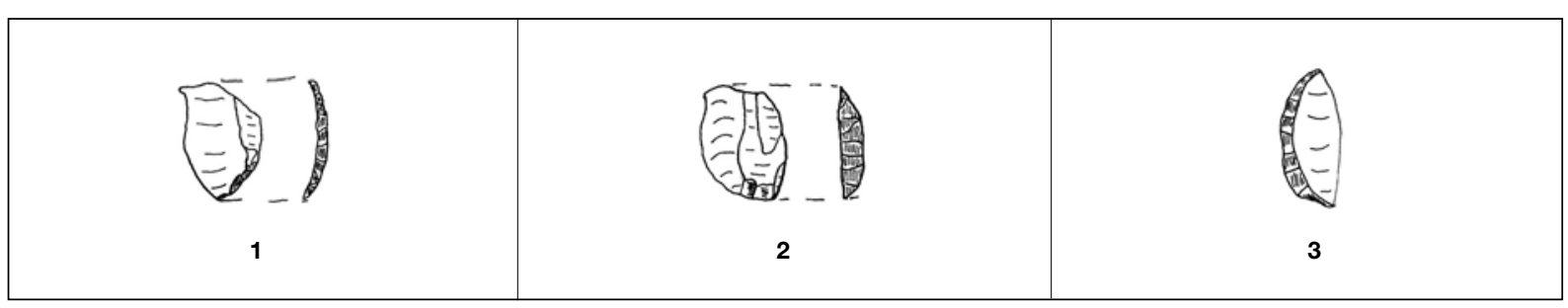

Fig. 5. Segment types

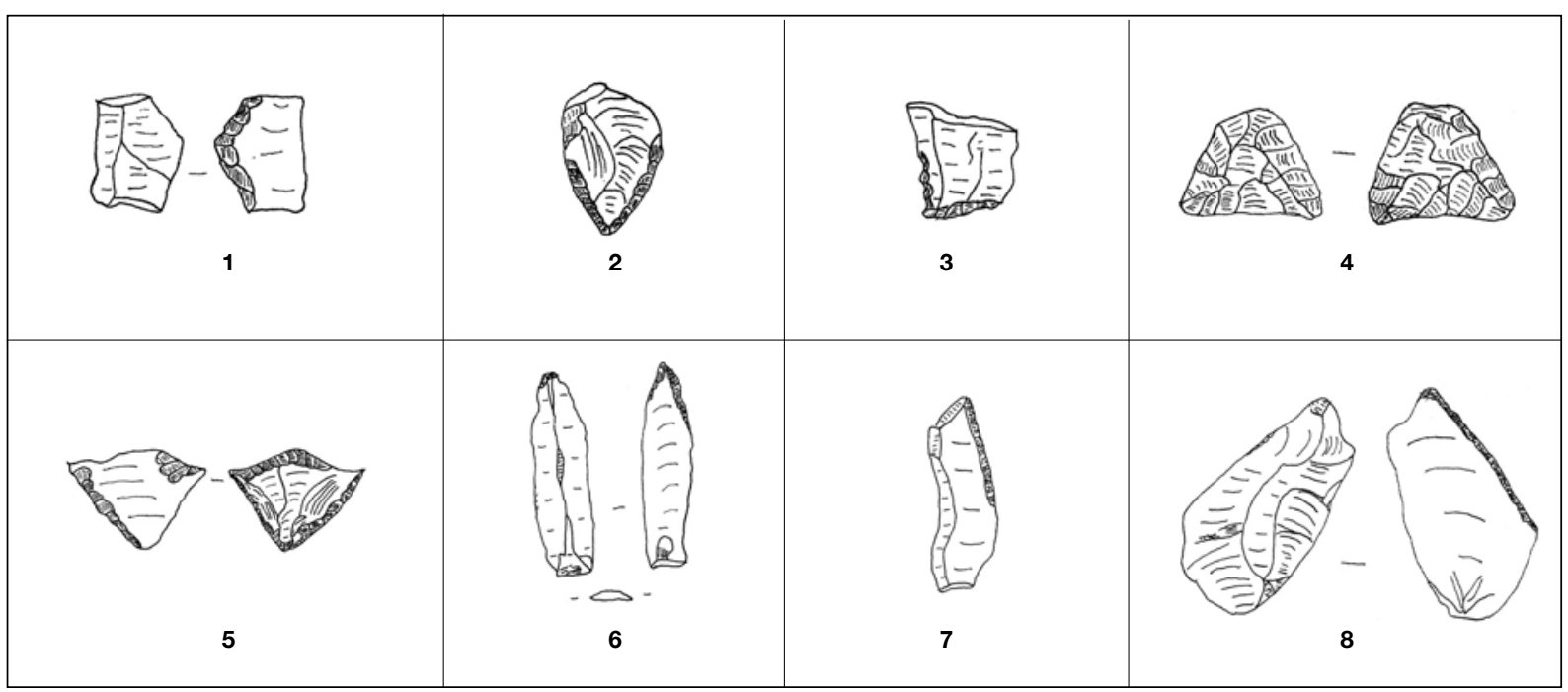

Fig. 6. Point types 


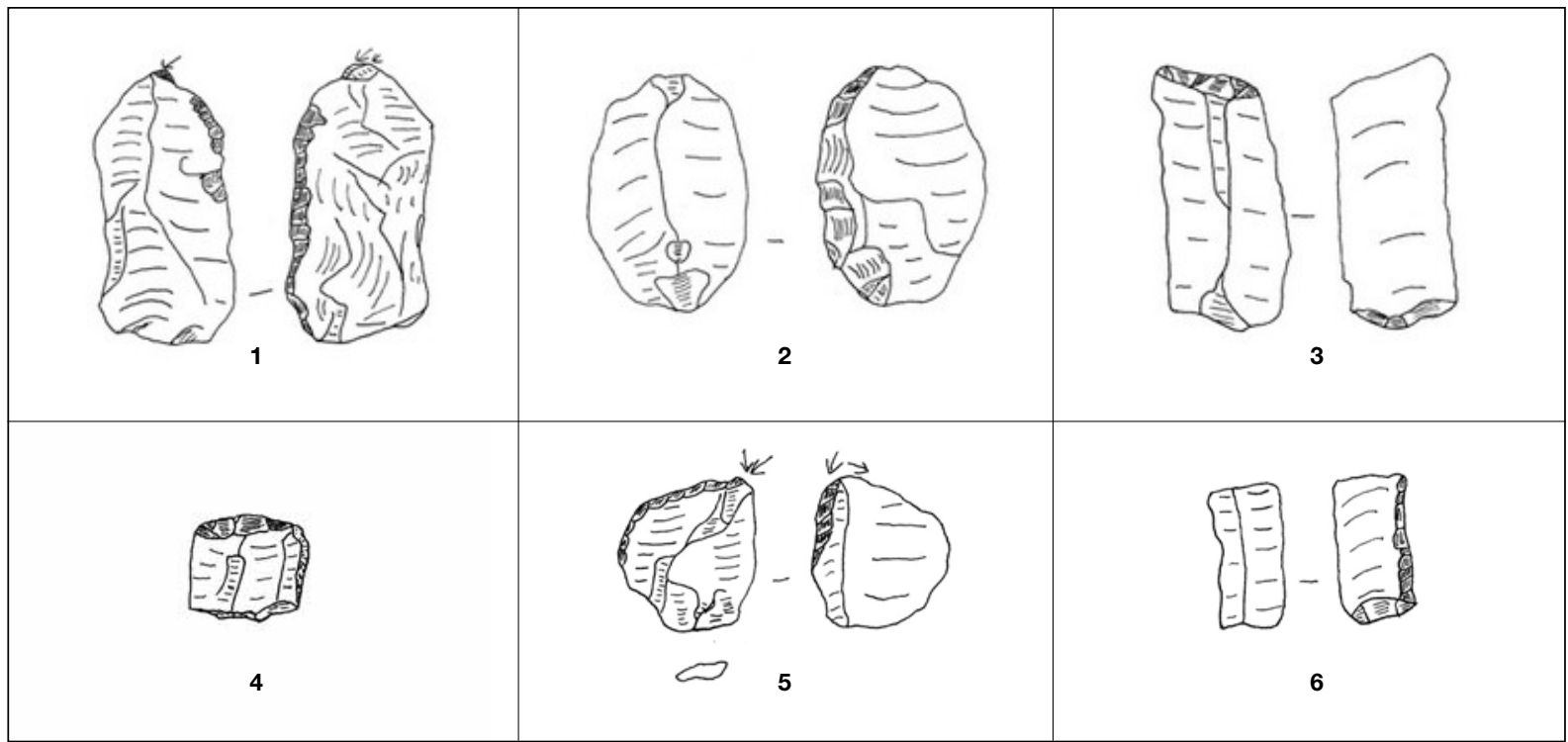

Fig. 7. Other tools

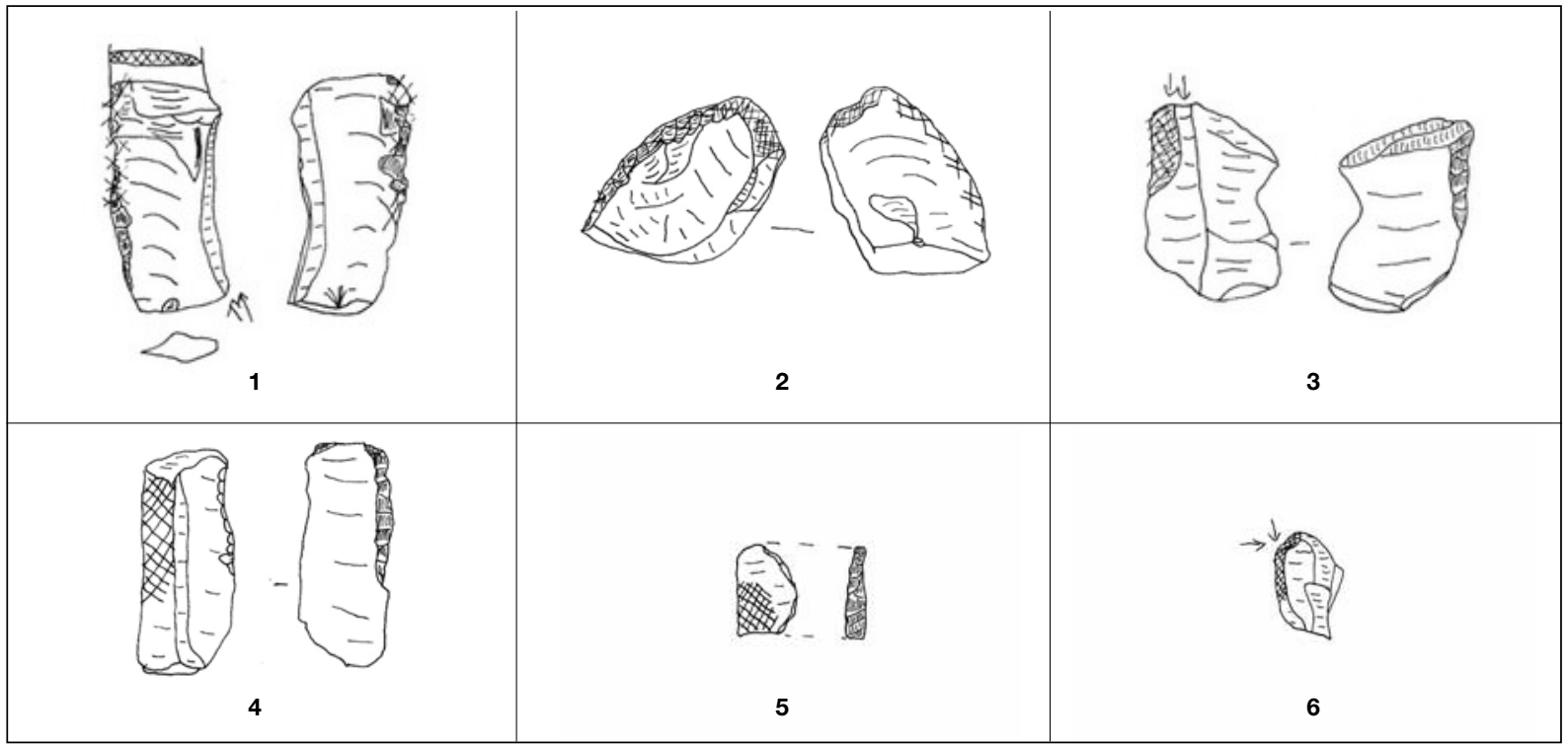

Fig. 8. Implements with sickle gloss

of a society's capabilities for adaptation and innovation." 37

The entries in the acquisitions registers reveal that the number of lithic finds recovered from the burials is higher than the number of finds I have examined personally. I examined a total of 110 blades, flakes, tools and debitage from the graves (excluding the finds from Grave 91; Fig. 11). This lithic assemblage includes a few non-archaeological artefacts (unworked pebbles, fragments), and thus the statistical evaluation is based on 103 lithic artefacts. To which I added the finds from Grave 91 (72 of the 73 artefacts recovered from that burial).

I grouped the artefacts described in detail in the

\footnotetext{
${ }^{37}$ SIMÁN 1995.
}

Catalogue according to my terminology for the statistical evaluation. The lithic artefacts from the graves of the Late Copper Age Budakalász cemetery reflect a microlithic blade industry, which is at the same time characterised by a high percentage of flakes (cp. the finds from Grave 91). The singular nature of this lithic assemblage and its distinctness compared to other lithic assemblages from the same cultural complex ${ }^{38}$ can be plotted if the names of the types described under "A-P" in Fig. 12 are used consistently. Further studies are necessary for determining the reason for variations within the same cultural complex.

The above comparative diagrams clearly show that the assemblage is dominated by microliths (Fig. 13).

\footnotetext{
${ }^{38}$ Alsónémedi: KOREK 1951; KOREK 1980.
} 


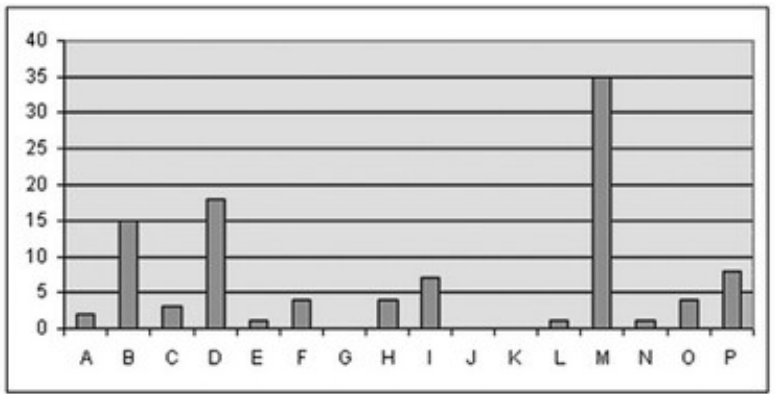

Fig. 9. Graphic representation of tool types (excluding Grave 91)

Their proportion is high among the finds from Grave 91 too, where is most highly represented, which can be regarded as a transition between truncated microliths and geometric forms (Fig. 14). The lithic inventory from Grave 91 is dominated by unretouched flakes and blades, although geometric tools (especially segments) occur in high number too. Unretouched flakes and blades were found in great number throughout the cemetery. Even though the platform and the bulb of percussion are generally missing from unretouched flakes, these artefacts can nonetheless be defined as flakes based on other features typical for the production of lithic implements. The occurrence of other tool types is minimal, the only exception being points, which come in a variety of forms. They are usually worked with marginal retouch for creating the pointed tip.

The presence of sickle gloss can be noted with the naked eye on several artefacts, most of which can be assigned to the category of burins, which were used for working leather and wood. The lithic inventory includes few cores, which is hardly surprising given that the finds are grave goods. Grave 91 yielded a great amount of debitage (amorphous flakes without a platform or a bulb of percussion), which had perhaps been deposited in the deceased man's burial by members of the community as part of the burial rite.

\section{RAW MATERIAL}

The conscious selection of raw materials can be noted from the earliest times in human history. ${ }^{39}$ This consciousness does not preclude improvisation because good quality raw materials were not always available. The ratio of locally available and imported lithics often depended on to what extent the latter could be acquired. Simán has pointed out that some groups collected raw material near their settlement (Tata, Érd), while others used lithics from different regions (Bodrogkeresztúr), and others still used the raw materials brought with them (Esztergom-Gyurgyalag). Some communities used rocks (e.g. the sites in the Pilismarót area) and some used river pebbles (Ságvár). ${ }^{40}$

\footnotetext{
39 T. BíRÓ-PÁLOSI 1986, 407-435. 40 SimÁN 2000, 8.
}

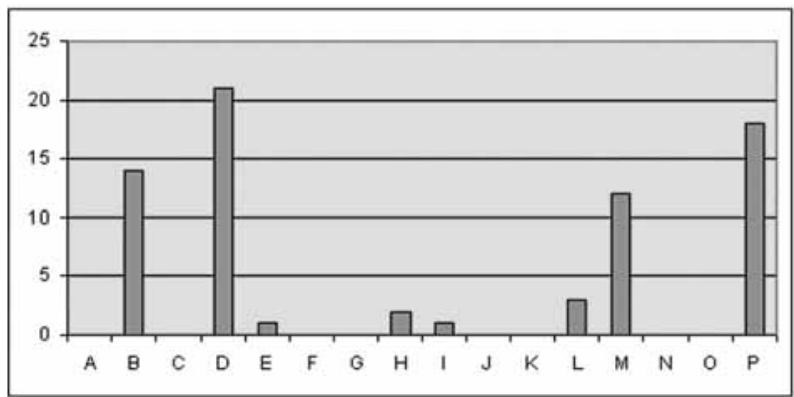

Fig. 10. Graphic representation of tool types of Grave 91

The varying ratio of local and imported raw materials can be noted in later prehistory too, as well as in the Copper Age. Compared to the Early Copper Age Tiszapolgár culture, the use of imported raw materials declined in the Middle Copper Age Bodrogkeresztúr culture. The latter was characterised by a sturdier blade industry owing to the nature of locally available lithic resources. Translucent, greyish-brown chert and blue chert from the Prut region and Volhynia dominated the imported raw materials during the Early Copper Age, while hydroquartzite, limnic quartzite, radiolarite and obsidian were available locally or could be acquired from less distant deposits. Even though the dominance of imported greyish-brown flint can be noted in the Middle Copper Age, there is a definite rise in the proportion of artefacts manufactured from locally available raw materials and from rocks acquired from smaller distances. ${ }^{41}$

The principal raw materials used for the manufacture of the artefacts at Budakalász came from locally collected lithics. Regional raw materials, brought from deposits lying at no more than one or two days' walking distance, were also used. According to Lívia Ravasz Baranyai, the majority of the tools from the Budakalász cemetery were made from Polish flint, while Katalin T. Bíró claimed that the raw material of the ninety-five pieces examined by her was predominantly white, translucent, patined, light coloured limnic quartzite (Fig. 15).42

My own examination indicated that the lithic assemblage from the cemetery is dominated by radiolarite, followed by limnic quartzite. This proportion is inverse in the case of Grave 91, whose lithic assemblage is dominated by limnic quartzite (Figs 16-17). The ratio of other raw materials is negligible - this is valid for the entire lithic assemblage and the finds from Grave 91. Even though T. Bíró noted the dominance of limnic quartzite, this can be attributed to the fact that she analysed 95 artefacts, while I examined 175 lithic finds. ${ }^{43}$

In sum, the lithic assemblage from Budakalász is dominated by local and regional raw materials, the latter acquired from deposits lying at smaller distances,

\footnotetext{
${ }^{41}$ Cs. BalOGH 2004, 31, 34, Fig. 7.

42 T. Bíró 1984b, 76.

43 T. Bíró 1984b, 76, Table 17.
} 


\begin{tabular}{|c|c|c|c|}
\hline \multicolumn{4}{|c|}{ Indexes of the lithic finds (including Grave 91) } \\
\hline & $\begin{array}{l}\text { Length } \\
(\mathrm{mm})\end{array}$ & $\begin{array}{l}\text { Width } \\
(\mathrm{mm})\end{array}$ & $\begin{array}{c}\text { Thickness } \\
(\mathrm{mm})\end{array}$ \\
\hline Average size of the lithic finds & 19 & 12.3 & 2.9 \\
\hline Tools & 19 & 12.6 & 3 \\
\hline Blades & 21 & 11.7 & 2.6 \\
\hline Flakes & 13 & 13 & 3.5 \\
\hline Index of the geometric tools & & 34 & \\
\hline Trapezes & & 83 & \\
\hline Index of unretouched blades and flakes & & 33 & \\
\hline Blades & & 14.6 & \\
\hline Flakes & & 17.5 & \\
\hline other (debitage) & & 7.7 & \\
\hline \multicolumn{4}{|c|}{ Index of lithic finds from Grave 91} \\
\hline & $\begin{array}{c}\text { Length } \\
(\mathrm{mm})\end{array}$ & $\begin{array}{l}\text { Width } \\
\text { (mm) }\end{array}$ & $\begin{array}{c}\text { Thickness } \\
\text { (mm) }\end{array}$ \\
\hline Average size of the finds from Grave 91 & 17.7 & 11.2 & 3 \\
\hline Tools & 19 & 11 & 3.5 \\
\hline Index of geometric tools & & 16.7 & \\
\hline Trapezes & & 42 & \\
\hline Segments & & 50 & \\
\hline Index of unretouched blades and flakes & & 50 & \\
\hline Blades & & 20 & \\
\hline Flakes & & 30 & \\
\hline other (debitage) & & 25.7 & \\
\hline
\end{tabular}

Fig. 11. Statistical indexes of the lithic finds from Budakalaisz

suggesting that the Budakalász community exploited the lithic resources lying nearest to the settlement for manufacturing the artefacts and semi-finished products deposited in the burials. The question arises as to the location of the settlement, where these artefacts were produced. The raw material of the few lithic assemblages from settlements I have examined does not differ from that used for the production of the artefacts recovered from burials. The assemblages from settlements do not include finds reflecting local tool manufacture (high number of flakes, debitage, cores, hammer-stones, anvils, retouchers, etc.).

One might think that in addition to the use of local resources, the importance of imported raw materials rose in later prehistory, especially in the Copper Age. This is certainly true for the Early and Middle Copper Age, although a decline in imported raw materials acquired from more distant regions can be noted during the Middle Copper Age. In the Late Copper Age, one can note the dominance of regional raw materials despite of the appearance of wheeled wagons, which undoubtedly played a role in long-distance trade and which were no doubt also used regionally for the transportation of raw material. In her study on the archaeological evidence for the use wheeled wagons, Mária Bondár noted that in addition to clay wagon models, figurines portraying draught animals and finds of clays wheels, various features and phenomena observed on settlements and in cemeteries all indicated that wagons were known in the Carpathian Basin before the onset of the classical Baden period. ${ }^{44}$

The accurate determination of the raw materials used for the manufacture of the chipped tools is crucial because the sources from where a particular culture procured its raw material reveals much about that culture. Viola T. Dobosi has aptly noted that in spite of the importance of sourcing raw materials, the identification of the material of lithic finds from archaeological sites is performed rather carelessly. ${ }^{45} \mathrm{In}$

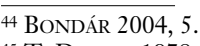

45 T. Dobosi 1978,7
} 


\begin{tabular}{|l|c|c|c|}
\hline Type & \multicolumn{2}{|c|}{ Number } \\
\hline & $\begin{array}{c}\text { Graves } \\
\text { (excluding Grave 91) }\end{array}$ & Grave 91 & Total \\
\hline A Retouched blade & 2 & - & 2 \\
\hline B Unretouched blade & 15 & 14 & 29 \\
\hline C Retouched flake & 3 & - & 39 \\
\hline D Unretouched flake & 18 & 1 & 2 \\
\hline E End-scraper & 1 & - & 4 \\
\hline F Side-scraper & 4 & - & - \\
\hline G Saw & - & 2 & 6 \\
\hline H Burin & 4 & 1 & 8 \\
\hline I Point & 7 & - & - \\
\hline J Borer & - & - & - \\
\hline K Notched blade & - & 3 & 4 \\
\hline L Truncated tool & 1 & 12 & 47 \\
\hline M Geometric tool & 35 & - & 1 \\
\hline N Combined tool & 1 & - & 4 \\
\hline O Core & 4 & 18 & 26 \\
\hline P Other (debitage) & 8 & 72 & 175 \\
\hline Total & 103 & & \\
\hline
\end{tabular}

Fig. 12. The artefact types and their frequencies

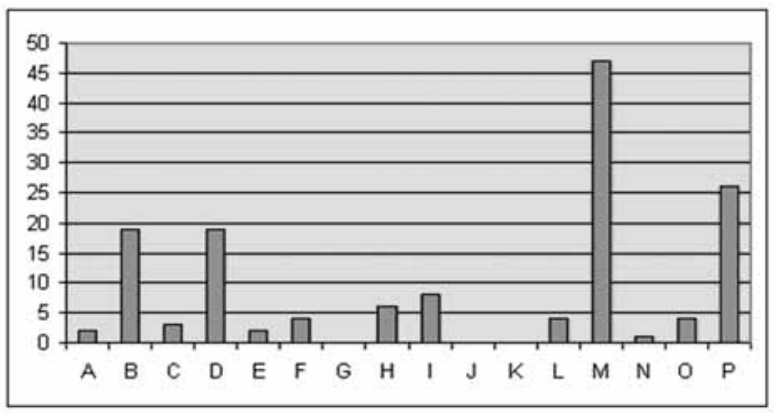

Fig. 13. Overall graphic representation of graves in the Budakalász cemetery

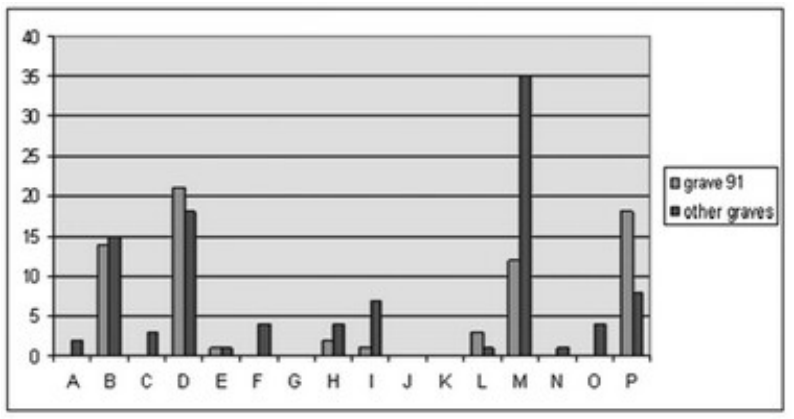

Fig. 14. Comparative graphic representation of Grave 91 and of other graves

\begin{tabular}{|l|c|c|}
\hline \multicolumn{1}{|c|}{ Raw material } & & Number \\
\hline Limnic quartzite & 35 & 43 \\
$\quad$ white, translucent, patinated & 6 & \\
$\quad$ less translucent & 2 & \\
$\quad$ brownish-mauvish shade & & 34 \\
\hline Radiolarite (flint of various shades and a Carpathian variety) & & 6 \\
\hline Chert & & 3 \\
\hline Limestone & & 4 \\
\hline Porcelanite from the Zemplén Mountains & & 4 \\
\hline Obsidian & & 1 \\
\hline Grey hornstone & & \\
\hline
\end{tabular}

Fig. 15. Distribution of the raw material of the ninety-five pieces examined by Katalin T. Biró

her view, the identification of the raw material is fairly easy if the tool was made from an easily recognisable rock. The more difficult task is the refinement of the identification. In spite of many advances in this field of research, the macroscopic identification of raw materials can be a source of controversies, as shown by the differences between Lívia Baranyai Ravaszné and T. Bírós identification of the raw materials used at Budakalász (e.g. limnic quartzite vs. Polish flint imported from the north). 


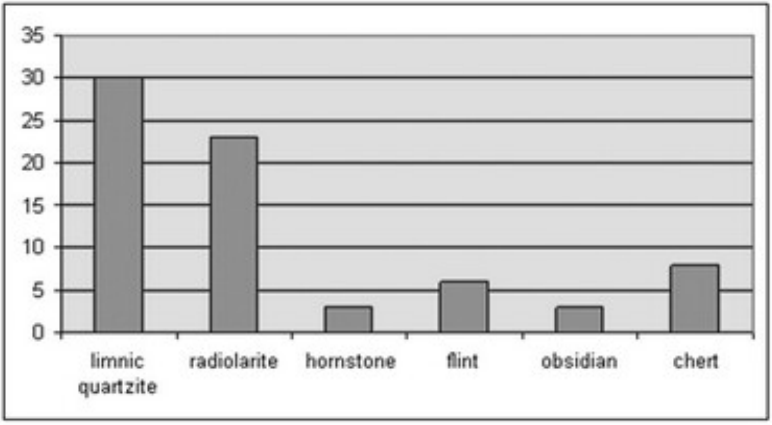

Fig. 16. Raw material distribution of Grave 91

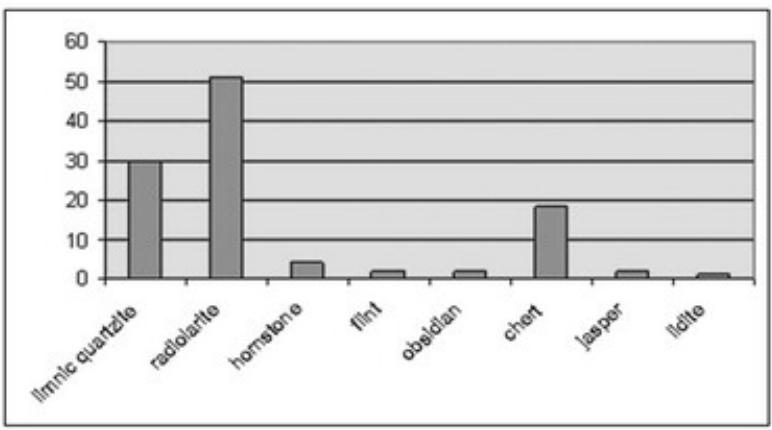

Fig. 17. Raw material distribution of litbics (excluding Grave 91)

The raw materials used at Budakalász were as follows (Fig. 18). ${ }^{46}$

\section{Volcanic rocks}

\section{Limnic quartzite}

Usually translucent white, greyish, yellow or bluish-grey hydrothermal rock deposited in freshwater lakes. It is an easily worked, durable rock. Most of the lithic finds were made from this rock. It is often covered with a cortex or patina. Deposits of this raw material are known from eastern Slovakia, the Velence and Tokaj Mountains, the southern foreland of the Bükk Mountains and the Mátra Mountains. ${ }^{47}$ Limnic quartzite is the second most frequent raw material after radiolarite in the lithic inventory from Budakalász (including blanks and debitage). The varieties used at Budakalász were translucent bluish-grey, brownish, white and reddishbrown. Many pieces were patinated. Cores of this raw material were not recovered from the burials. The lithic finds from Grave 91 were dominated by limnic quartzite.

\section{Obsidian}

A volcanic rock, excellently suited to the manufacture of stone tools. Surface outcrops are known from Tolcsva and Erdóbénye in the Tokaj Mountain (Carpathian 2 variety). The translucent Slovakian variety

\footnotetext{
$\overline{46}$ T. BíRÓ 1984a; T. Bíró 1984b; T. DOBOSI 1978, 10-18

47 T. Bíró 1984a; T. Bíró 1984b.
}

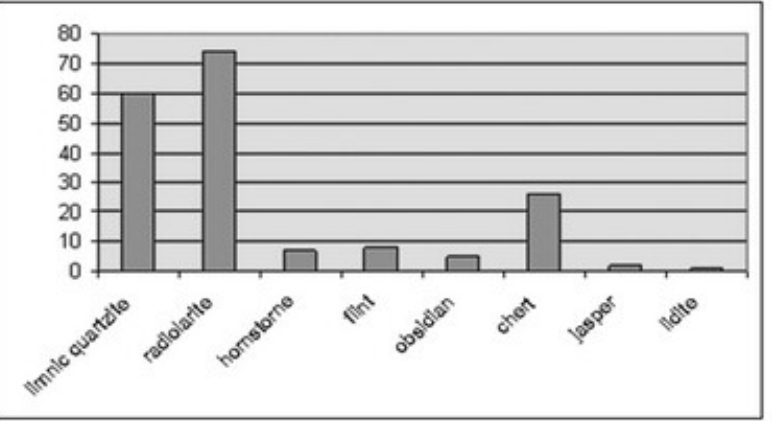

Fig. 18. Overall distribution of the raw material of the lithics found in the Budakalász cemetery

(Carpathian 1) occurs in archaeological assemblages. Few obsidian tools were deposited in the Budakalász burials. One grave yielded a small obsidian core.

\section{Marine sedimentary rocks (quartz variants)}

\section{Flint}

A greyish-yellow rock with conchoidal fracture of organic origin, occurring in the form of nodules and compact lenses. It was widely used for the manufacture of chipped stone implements. Flint deposits are quite frequent in the Transdanubian Mountain Range and in the Mecsek Mountains. In contrast to radiolarite and limnic quartzite, artefacts made from flint were hardly deposited in the Budakalász burials. The variety used at this site was bluish-grey mottled.

\section{Radiolarite}

A Jurassic rock of organic origin. Flints with sponge spicules are known Szentgál, Urkút and Bakonycsernye in the Bakony Mountains. Bakony flints occur frequently in lithic assemblages recovered from archaeological sites. Two frequently exploited types of Bakony radiolarite were the Szentgál variety (a red flint with white inclusions) and the Urkút-Eplény variety (a mustard yellow flint with yellow and black veins). Radiolarite deposits can be found from the Gerecse Mountains to the western Bakony Mountains. Upper Jurassic flints with greenish-blue, grey, greenish-pink, pale pink and brownish-dark red varieties are known also from the Mecsek Mountains. On the basis of their colour, the tools and flakes from Budakalász were made from Jurassic radiolarite from the Gerecse or the Bakony Mountains. The colour spectrum of radiolarite ranges from reddish-brown through brown to yellow and greyish-brown. The lithic finds from archaeological contexts suggest that Bakony radiolarites were the most frequently used raw materials.

\section{Hornstone}

A grey, lustrous, marine sedimentary rock with splintery fracture occurring in nut-size nodules, usually embedded in dolomitic rocks. Hornstone deposits 
occur in the Buda Mountains, the Keszthely Mountains, the Balaton Uplands, the Cserhát Mountains and the Bükk Mountains. The hornstone used for the manufacture of the few Budakalász implements was probably procured from the dolomite in the nearby Buda Mountains.

\section{Chert}

The label "chert" is usually given to artefacts, whose raw material cannot be precisely identified macroscopically.

In the light of the above, the possible sources of the raw materials used for the manufacture of lithic artefacts at Budakalász lay in the Tolcsva, the Mátra and the Bakony Mountains, the Balaton Uplands and the Buda Mountains, i.e. Hungary's central-western, northern and north-eastern regions, and in Slovakia, where the obsidian, marine sedimentary rocks and the hydro- and limnic quartzite deposits were to be found. Most prehistoric chipped stone implements were made from raw materials procured from these regions. ${ }^{48}$ Accepting T. Bírós claim that the Budakalász artefacts were not produced from northern flint (which seems quite likely in spite of the fact that some pieces can be mistaken for northern types as far as their colour is concerned), we may say that the artefacts in the lithic assemblage were made from locally available raw materials and rocks procured from deposits lying no farther than one or two days' walking distance. Radiolarite was probably acquired from the Bakony Mountains, while limnic quartzite and hornstone from the Buda Mountains. Wagons, which had become widespread by this period, no doubt facilitated the transportation of raw materials and reduced transportation time. Given that the Baden distribution extended to southern Poland and Cracow in the north, to central Transylvania in the east, to Sarajevo in Bosnia in the south, and the River Inn and the Czech-Moravian Basin in the west, one might expect a larger quantity of imported raw materials on the culture's sites in Hungary. ${ }^{49}$ However, this was not the case as shown by the raw materials.

T. Bíró's studies have contributed greatly to the identification of the raw materials from which prehistoric chipped stone implements were made. She has demonstrated that certain raw materials, e.g. a few varieties of limnic quartzite, resemble the translucent yellow and yellowish-grey white mottled Jurassic flints containing sponge spicules of the Cracow area and the smoky, greyish-brown, brown translucent Cretaceous chert of the Upper Dniester region, this being the reason that this local raw material is sometimes described as greyish-brown flint or bluish chert imported from the north. ${ }^{50}$

\footnotetext{
${ }_{48}$ T. Bíró 1984a, 43, Fig. 1.

49 ENDRŐDI 1988

50 T. Bíró 1984a, 47, 52; T. Bíró 1984b.
}

\section{DISCUSSION}

One of the most intriguing questions regarding the lithic assemblage from the Budakalász cemetery is where the chipped stone implements deposited in the burials were made. A comparison with the types and number of chipped stone finds from the culture's other cemeteries and settlements can prove instructive in this respect.

The Baden sites in the Budapest area and in County Pest must certainly be considered when searching for the location where the stone implements recovered from the Budakalász cemetery were made. Anna Endrôdi's $\mathrm{PhD}$ thesis contains a list of these sites. ${ }^{51}$ With the exception of Remete Cave, the Baden population established its settlements and burial grounds on the Danube or near the river in the broader Budapest area. Several settlements and cemeteries have been identified and uncovered in Budapest and County Pest. Some cemeteries lay adjacent to the settlement, ${ }^{52}$ others were separate from the settlement.

The chipped stone tools from the small Baden cemetery containing forty, mostly undisturbed burials uncovered by József Korek at Alsónémedi in 1949 must be mentioned here. ${ }^{33}$ Seven stone tools were recovered from the inhumation burials: four unretouched flakes, one side-scraper, one point and one truncated flake. The truncated flake can be assigned to the category of geometric flakes with oblique truncation on the ventral side. Similar pieces are known from Budakalász, suggesting that this type was fairly common. The stone tools from Alsónémedi were made from radiolarite, ${ }^{54}$ and with the exception of a child burial, they were all recovered from male burials. ${ }^{55}$

Baden settlements have been investigated at Pécel, Üllő, Szigetcsép, Solymár, Szentendre-Pannóniatelep and Tököl in the broader Budapest area. The finds from these settlements are dominated by pottery, with a few chipped stone implements only, which hardly allows any conclusions about the production of stone tools. A few Baden pits were uncovered at the multi-period site of Budapest-Medve Street. In addition to pottery, the assemblage included blades and flakes of red Szentgál radiolarite, red jasper, limnic quartzite, hornstone and obsidian. The lithic assemblage of twenty-two pieces was examined by T. Bíró, according to whom the greater part of the lithic artefacts was manufactured from hornstone procured from the Buda Mountains. Other raw materials included Szentgál and Urkut-Eplény radiolarite, red jasper from the regions east of the Danube and obsidian from Slovakia. ${ }^{56}$ Characteristic segment types occur among the lithic finds. In

\footnotetext{
${ }^{51}$ I would here like to thank Anna Endrődi for kindly letting me quote her still unpublished Univ. PhD thesis. ENDRŐDI 1988.

52 ENDRŐDI 1988.

53 KoreK 1951, 35-91; Korek 1980, 9-47.

54 Cs. BalogH 2000, 50-51.

${ }^{55}$ KOREK 1951; KOREK 1980.

56 ENDRŐDI 1988, 62-76.
} 
Endrôdi's interpretation, the site was not a genuine settlement site, but rather a location for mining clay. ${ }^{57}$

Several Baden pits and a burial of the Baden culture were uncovered at Budapest-Káposztásmegyer-Farkaserdô in the early 1980s. The lithic assemblage of thirty-four pieces was examined by T. Bíró. Most pieces were made from hornstone, with a few manufactured from limnic quartzite from the Northern Mountain range, Mecsek radiolarite, and "Lengyel" quartzite. ${ }^{58}$

The number of chipped stone implements from the Baden period is rather low and the lithic finds from more recent excavations are still unpublished. ${ }^{59}$

The stone finds from Gyöngyöshalász-Encspuszta in County Heves date from the pre-Baden Boleráz period. The site on the right bank of the Gyöngyös Stream was discovered during the construction of the M3 Motorway. János J. Szabó uncovered finds of the Boleráz culture during his rescue excavation in 1981.60 The archaeological collection of the Dobó István Castle Museum in Eger includes Late Copper Age stone tools from Gyöngyöshalász-Encspuszta (or Gyöngyöshalász-Encs-tanya according to the entry in the museum's acquisitions register; Fig. 19).

The assemblage contains thirty-two pieces. Most are unretouched blades and flakes (15 pieces), cores (amorphous and prismatic; 5 pieces), and worked or unworked raw material fragments (4 pieces). The two retouched blades are micro-blades worked with marginal retouch. Tools in the strict sense of the word are practically lacking. The assemblage includes two pieces of debitage, a burin spall, and worked and unworked raw material fragments. Similarly to several other Late Copper Age lithic assemblages, the number of finds is too low for a statistical evaluation. The raw materials used at this site were obsidian, hydroquartzite, jasper and limnic quartzite, all locally available raw materials with the exception of obsidian. ${ }^{61}$

The lithic finds from the Late Copper Age settlement at Ózd-Kőaljatetô (County Borsod-AbaújZemplén) are housed in the Herman Ottó Museum in Miskolc. The finds were collected by Márton Rozsnyói and Dezsô Pollák, who presented them to the museum. ${ }^{62}$ In 1950, Korek conducted an excavation on the site, where he uncovered a settlement of the Baden culture (Fig. 20).

One of the retouched blades is retouched with steep retouch on the right edge of the ventral side, the other is the distal fragment of a retouched blade. In spite of the poor material, the tool was very carefully worked with parallel, steep, scalar retouch.

\footnotetext{
$\overline{57}$ ENDRŐDI $1988,78$.

58 ENDRŐDI 1988, 114-116.

59 E.g. the lithic finds from the Balatonszemes-Szemesi berek site, investigated by Szilvia Honti in 1999-2000. The finds are housed in the Kaposvár museum. I would here like to thank Szilvia Honti for allowing the examination and eventual publication of the finds.

${ }^{60}$ Régészeti Füzetek Ser. I (1982) 12

${ }^{61}$ T. Bíró 1984b, 76.

62 BANNER 1956.
}

\begin{tabular}{|l|c|}
\hline Retouched, modified flakes & 2 \\
\hline Unretouched flakes & 7 \\
\hline Retouched blades & 2 \\
\hline Unretouched blades & 8 \\
\hline Flat burin & 1 \\
\hline Cores & 5 \\
\hline Other & 7 \\
\hline Total & 32 \\
\hline
\end{tabular}

Fig. 19. The artefact types from GyöngyöshalászEncspuszta

One of the unretouched blades is triangular and covered with sickle gloss of the type known from the Early and Middle Neolithic. During later periods, sickle gloss generally ran parallel to the axis of the blade or flake. ${ }^{63}$ This piece was made from blue chert. This tool differs from the other unretouched blades as regards both its type and its raw material. It was part of the surface collection. The other unretouched blades were made from lydite and limnic quartzite.

The end-scrapers can be assigned to the atypical nosed type, the carinated type and atypical scraperplane type. The atypical nature of the end-scrapers can be attributed to the pebble raw material from which they were made.

One burin was dihedral, the other was of the déjeté type.

The truncated tools were made up of two straight, truncated blades and two straight truncated flakes. All four had one end modified by retouched truncation.

The cores were conical, rounded and rectangular in shape and had one or multiple planes.

The lithic assemblage from the Ózd-Köaljatetô settlement is made up of forty-eight pieces. The proportion of end-scrapers, burins and truncated tools is roughly the same. The assemblage is not dominated by any one tool type. The finds did not include typical geometric forms; they can be best compared to the trapezes assigned to Type 5 (Fig. 3. 5). The number of cores and debitage is surprising low compared to other settlement assemblages, but their presence does indicate local knapping. The atypical nature of the tools can be attributed to the raw material, the locally available limnic quartzite, hydroquartzite and jasper pebbles.

Another lithic assemblage in the collection of the Herman Ottó Museum is the one brought to light by Korek in 1950 at the Late Copper Age settlement of Szerencs-Hajdúrét. The finds came to light from a pit of the Baden culture (Fig. 21).

The assemblage of twenty-four pieces is rather poor and made up of indistinct specimens manufactured from hydroquartzite and limnic quartzite. This is not surprising in view of the other lithic assemblages from this period. Over three hundred pits yielding solely Baden finds and some fifty pits yielding mixed Baden

\footnotetext{
${ }_{63}$ BÁCSKAY 1977.
} 


\begin{tabular}{|l|c|}
\hline Retouched blades & 2 \\
\hline Unretouched blades & 9 \\
\hline Unretouched flakes & 5 \\
\hline Worked flakes & 3 \\
\hline End-scrapers & 3 \\
\hline Burins & 2 \\
\hline Truncated tools & 4 \\
\hline Shouldered point & 1 \\
\hline Cores & 7 \\
\hline Other (debitage) & 12 \\
\hline Total & 48 \\
\hline
\end{tabular}

Fig. 20. The lithic assemblage from Ózd-Köaljatetö

finds were uncovered at Pilismarót-Szobi rév. The lithic finds are made up of a few typologically indistinct unretouched blades and flakes. ${ }^{64}$

In sum, we may say that the few settlement finds, including the assemblages of the Baden culture, described above do not include geometric microliths. While they do contain the occasional truncated piece, the trapezes and segments so frequent at Budakalász are entirely lacking. A few geometric truncated pieces occur among the lithic finds of the Early Copper Age Tiszapolgár culture, which were mostly made from medial blade fragments. They were probably used in hunting before the appearance and spread of bifacially worked arrowheads in the Middle Copper Age.

When examining the typological and technological features of an industry, one important point in addition to the determination of the general tendencies in stone tool manufacture, is the identification of possible technological features which are characteristic of that culture alone, and the determination of possible related cultural groups in terms of typology. Beside the general technological traits, the contexts from which the stone tools were recovered must also be taken into consideration (e.g. the closed nature of the grave assemblages in the case of the Budakalász cemetery). The wide range of technologies employed in the manufacture of the stone tools reflects the technological knowledge of the Baden population. However, without a knowledge of where the stone tools were actually made and of whether the lithic assemblage from the cemetery represents a unique assemblage within the culture, we can hardly claim to have an overall understanding of the entire spectrum of the Baden culture's stone tool manufacture.

The study of the chaine opératoire during the examination of a community's technological knowledge enables the identification of the different stages in the production of various artefacts. ${ }^{65}$ The chaine opératoire approach has not become widespread in Hungarian prehistoric studies; Holló, Lengyel and Mester are now making concerted efforts to introduce this technological approach, according to which

\footnotetext{
$\overline{64}$ Mária Bondár's kind personal communication.

${ }^{65}$ Holló et al. 2001, 51.
}

\begin{tabular}{|l|c|}
\hline Retouched blades & 1 \\
\hline Unretouched blades & 9 \\
\hline Unretouched flakes & 9 \\
\hline Cores & 7 \\
\hline Other & 5 \\
\hline Total & 31 \\
\hline
\end{tabular}

Fig. 21. The artefact types from Szerencs-Hajdúrét

"technology, as used in prehistoric studies and prehistoric archaeology, is concerned with the study of prehistoric human activities and the overall nature of technological systems used in a particular culture. The focus is on human behaviour, which is inseparable from the socio-economic system and the ecologic environment." Typological classification and statistical evaluations are indispensable to the better understanding of an industry because the typological breakdown reveals the significant traits of a culture. The lithic finds suggests that the Budakalász community had a blade industry used for the production of microlithic, geometric weapons. These geometric microliths have a wide typological range: trapezes and trapezoidal forms dominate the assemblage as a whole, while the finds from Grave 91 are dominated by segments.

The following schematic model has been suggested for creative human activities: starting point (raw material, implements, mental templates) - realisation (technologies, skills) - result (finished product). In the case of the Budakalász cemetery, we know the starting point (the raw materials and the mental templates) and the results (geometric microliths for hunting), while the technologies used for producing various lithic types can be reconstructed from the statistical analysis of the industry. The assemblage from the Budakalász cemetery is made up of closed grave assemblages; the examination of the chipped stone implements from all the burials and of the ones from Grave 91 suggests that the creation of formally distinct types was an important point in the knappers" "decision-making".

When seeking an answer to whether the man laid to rest in Grave 91 was a knapper, an interpretation first suggested by Korek, ${ }^{66}$ the following points must be considered: "The activity of a particular individual is determined by the chaine operatoire, which was created by the community during its history and development." 67 In this sense, the deposition of the high number of chipped stone implements in the burial of the man interred in Grave 91 can be regarded as an expression of the community's social and symbolic behavioural norms. The chipped stone implements deposited in the burials reflect the beliefs of the Baden communities. Seeing that lithic artefacts were deposited in male, female and child burials alike, an interpretation along the lines suggested for the Early

\footnotetext{
66 KOREK 1986.

${ }^{67}$ Holló et al. 2001, 53.
} 
and Middle Copper Age, when lithics were exclusively placed in male burials, seems unlikely. ${ }^{68}$ The tools deposited in Grave 91 of the Budakalász cemetery include few types used in daily life (end-scrapers, sidescrapers, etc.), while the technology employed in their manufacture (geometric microliths) precludes the possibility that they were $a d$ boc artefacts placed in the burial as part of the funeral rite. The grave did not contain any pottery, whereas it yielded a high number of bone implements, suggesting that the man buried in this grave had been a bone worker, rather than a knapper.

The other burials contained many unretouched blades and flakes, as well as a few cores and their remains. The stone tools recovered from the burials indicate a special microlithic blade industry with predominantly geometric tools, unretouched blades and flakes. The tendency towards microlithisation can in part be attributed to the use of locally available pebbles and in part to the fact that these were the types of implements (weapons) needed for daily life and for the burial rites (shown by their deposition regardless of the age and sex of the deceased). The geometric forms were created by intentional breakage and truncation. Although the finds have not been submitted to usewear analyses, most of the microliths show no sign of having been used, suggesting that they functioned as weapons. Geometric implements of this type have been found in contexts which clearly suggested that they had been used as arrowheads for hunting. ${ }^{69}$

The lithic assemblages, and especially the finds from Grave 91, contained many micro-flakes and debitage..$^{70}$ These are usually the by-products of the preparation of the core's striking platform and of flaking. There are few cores in the assemblage, which would confirm this claim. The raw material was prepared in lithic workshops lying farther from the deposits, while the cores from which flakes and blades worked into tools and implements were struck were usually prepared on the settlement.

The tools produced on the settlement were deposited in the burials as part of the funeral rite. Their typological breakdown does not reflect any correlation between age, sex or higher social status. ${ }^{71}$ Grave 177 stands out by the wagon model deposited in it. A similar wagon model without wheels, a rectangular vessel with red-painted exterior and interior, was recovered from Grave 158.72 Both graves contained one stone tool each: an unretouched radiolarite flake was deposited in Grave 158, a radiolarite point in Grave 177. The description of the lithic finds in this catalogue and the one in the museum's acquisitions register differs since the stone finds are simply described as "stone tools" in the latter, with some pieces occasionally described as "arrowheads". The distribution of stone implements according to graves does not show any particular pattern: a richer variety of stone tools can be equally found in male, female and child burials (Grave 48: child burial; Graves 91, 207, 227, 375, 411: male burials; Graves 174, 197: female burials).

The systematic study of the chipped stone assemblages typical for the Baden culture will no doubt contribute to the location of the workshops of this microlithic blade industry and enrich our knowledge of the beliefs of the Baden community at Budakalász.

\footnotetext{
8 Cs. Balogh 2000; Cs. Balogh 2004.

69 VÖRÖS 1987.

70 The label "debitage" was used for the amorphous flake and blade fragments without a platform or bulb of percussion.
}

\footnotetext{
71 Cs. BALOGH 2004, 49-64.

72 BONDÁR 2004, 7-8, Fig. 1. 1-2.
} 


\section{References}

BANNER 1956

BÁCSKAY 1977

BÁCSKAY 1995

Cs. BALOGH 1993

Cs. BALOGH 1997

Cs. BALOGH 1998-99

Cs. BALOGH 2000

Cs. BALOGH 2001

Cs. Balogh 2004

T. BíRÓ-PÁLOSI 1986

T. BíRÓ 1984a

T. BíRÓ 1984b

BONDÁR 2004

BRÉZILLON 1968

T. Dobosi 1968

T. Dobosi 1978

T. Dobosi-Homola 1989

ENDRŐDI 1988

HoLló et al. 2001

HoLLó et al. 2002

KOREK 1951

KOREK 1980

KOREK 1986

KOZŁowSKI-KOZLOWSKI 1980

MRT 7
Banner, János: Die Péceler Kultur. Budapest 1956. (ArchHung 35)

Bácskay, Erzsébet: Early Neolithic chipped stone implements in Hungary. Budapest 1977. (Dissertationes archaeologicae II. 4)

Bácskay, Erzsébet: Kísérleti eredmények kôeszközökön [Experiments on stone implements]. http://www.mek.iif.hu/porta/szint/tarsad/muzeum/bacskay.hun

Cs. Balogh, Éva: Rézkori és bronzkori pattintott kőeszközök Pest megyében és a Dunától keletre eső területeken. Tipológiai és statisztikai feldolgozás [Copper and Bronze Age chipped stone implements in County Pest and the regions east of the Danube]. Univ. PhD thesis. Budapest 1993.

Cs. Balogh, Éva: A ságvári késói felsôpaleolit lelőhely tipológiai és technológiai vizsgálata [Ságvár late upper palaeolithic site. Typological analysis of the tool-kit]. FolArch 46 (1997) 17-46.

Cs. Balogh, Éva: Tipológiai és traszeológiai vizsgálatok rézkori és bronzkori pattintott kőeszközökön [Typological and Microscopic investigations ("Traceologie") on Copper Age and Bronze Age Chipped Stones Tools]. FolArch 47 (1998-1999) 13-41.

Cs. Balogh, Éva: Rézkori pattintott kóeszközök a Magyar Nemzeti Múzeumban [Copper Age Chipped Stone Artifacts from the Hungarian National Museum]. CommArchHung 2000, 49-64.

Cs. Balogh, Éva: Adatok a rézkori, bronzkori pattintott kóeszközök tipológiai értékeléséhez. (JászNagykun-Szolnok megye) [Angaben zur Typologischen Verwertung der Steingeräte aus der Kupferund der Bronzezeit. Komitat Jász-Nagykun-Szolnok]. Tisicum 12 (2001) 91-101.

Cs. Balogh, Éva: Pattintott kốeszközök rézkori sírokban [Chipped stones in the Copper Age graves]. In: $M \Omega M \Omega \Sigma$ III. Öskoros kutatók III. összejövetelének konferenciakötete. Halottkultusz és temetkezés. Ed. by Ilon, Gábor. Szombathely 2004, 19-41.

T. Bíró, Katalin-Pálosi, Márta: A pattintott kôeszközök nyersanyagának forrásai Magyarországon [Sources of the raw material of chipped stone implements in Hungary]. A Magyar Állami Földtani Intézet évi jelentése az 1983 -as évról (1986) 407-435.

T. Bíró, Katalin: Ốskôkori és ôskori pattintott kôeszközeink nyersanyagának forrásai [Raw material of Palaeolithic and prehistoric chipped stone implements in Hungary]. ArchÉrt 111 (1984) 42-52.

T. Bíró, Katalin: Ốskôkori és őskori pattintott kőeszközök nyersanyagai Magyarországon [Raw material of Palaeolithic and prehistoric chipped stone implements in Hungary]. CSc thesis. Budapest 1984.

Bondár, Mária: A kocsi a késô rézkori Európában [Der Wagen im Spätkupferzeitlichen Europa]. ArchÉrt 129 (2004) 5-34.

Brézillon, Michel: La dénomination des objets de pierre taillée. Matériaux pour un vocabulaire des préhistoriens de langue française. Paris 1968.

T. Dobosi, Viola: Kupferzeitliche Silexgeräte aus Ungarn. AAC 10 (1968) 271-285.

T. Dobosi, Viola.: A pattintott kóeszközök nyersanyaga [On the raw material of chipped stone tools]. FolArch 29 (1978) 7-19.

T. Dobosi, Viola-Homola, István: Tipológiai-technológiai megfigyelések kőeszközökön [Typologisch-technische Beobachtungen abgesprenter Steinwerkzeuge]. FolArch 11 (1989) 37-53.

Endrôdi, Anna: A badeni kultúra lelóhelyei Budapest területén [Sites of the Baden culture in Budapest]. PhD thesis. Budapest 1988.

Holló, Zsolt-Lengyel, György-Mester, Zsolt: Egy pattintott kőeszköz életútja. Magyar kifejezések a technológiai vizsgálatokhoz. [The "life" of a Hungarian stone implement. Hungarian terminology for technological analyses]. Ôsrégészeti Levelek 3 (2001) 51-57.

Holló, Zsolt-Lengyel, György-Mester, Zsolt: Egy pattintott kőeszköz elkészítése. Magyar kifejezések a technológiai vizsgálatokhoz 2 [The "life" of a Hungarian stone implement. Hungarian terminology for tecnhnological analysis]. Ösrégészeti Levelek 4 (2002) 98-104.

Korek, József: Ein Gräberfeld der Badener Kultur bei Alsónémedi. ActaArchHung 1 (1951) 35-91.

Korek, József: Alsónémedi történetének régészeti forrásai a honfoglalás koráig [The archaeological sources of the history of Alsónémedi until the Conquest period]. In: Alsónémedi története és néprajza. Ed. by Balassa, Iván. Alsónémedi 1980, 9-47.

Korek, József: The grave of an artisan in the Copper Age Cemetery at Budakalász. In: Papers for the $1^{\text {st }}$ International Conference on Prehistoric Flint Mining and Lithic Raw Material Identification in the Carpathian Basin. Ed. by T. Bíró, Katalin. Budapest 1986, 317-322.

Kozłowski, Janusz Krystof-Kozłowski, Stefan Karol: Multivariate analysis of Upper Palaeolithic and Mesolithic stone assemblages. Warszawa 1980, 16-57.

Dinnyés, István-Kóvári, Klára-Lovag, Zsuzsanna-Tettamanti, Sarolta-Topál, Judit-Torma, István: Pest megye régészeti topográfiája. A budai és szentendrei járás. Ed. by Torma, István. Budapest 1986. (Magyarország Régészeti Topográfiája 7) 
RENFREW-BAHN 1999

SiMÁN 1995

SIMÁN 2000

VÉRTES 1960

VÉRTES 1965

VÖRÖs 1987
Renfrew, Colin-Bahn, Peter: Régészet. Elmélet, módszer, gyakorlat [Archaeology. Theory, Methods and Practice]. Budapest 1999.

Simán, Katalin: Nyersanyag és technológia [Raw material and technology]. http://www.mek.iif.hu/ porta/szint/tarsad/muzeum/siman.hun

Simán, Katalin: Az őskôkori pattintott kóeszköz. Gyártása és szakkifejezései [Manufacture of Palaeolithic stone tools and the technical terms]. FolArch 48 (2000) 7-26.

Vértes, László: Az őskókor és az átmeneti kókor magyar szakkifejezései [Les termes techniques hongrois du paléolithique et de l'énéolithique]. ArchÉrt 87 (1960) 68-83.

Vértes, László: Az őskookor és átmeneti kôkor emlékei Magyarországon [The Palaeolithic and the Mesolithic in Hungary]. Budapest 1965.

Vörös, István: A bow as weapon of hunting in the late neolithic. CommArchHung 1987, 25-30. 


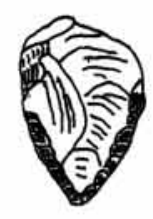

1

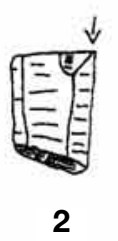

2

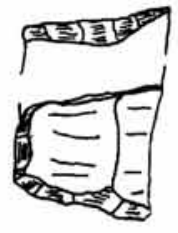

3

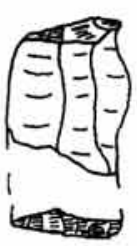

4

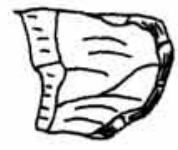

5

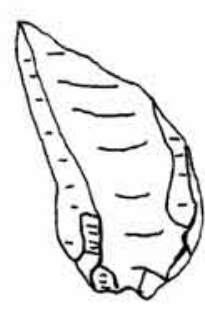

6
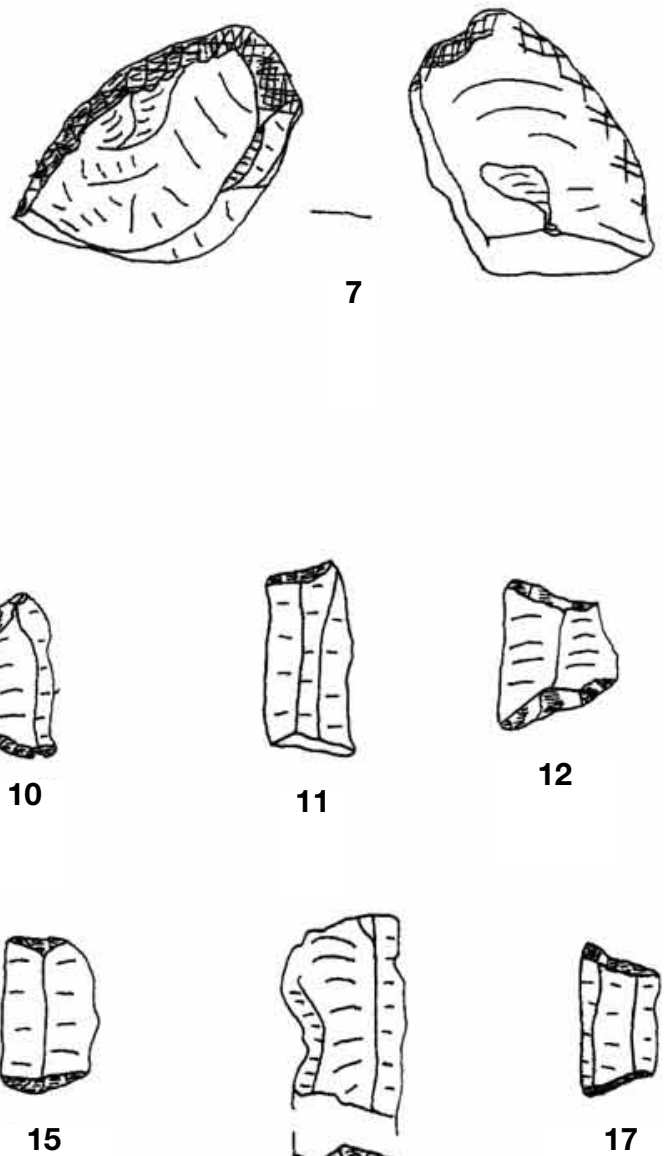

16

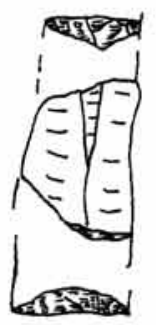

8

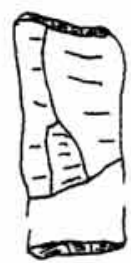

13

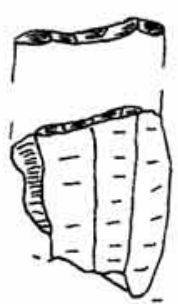

18
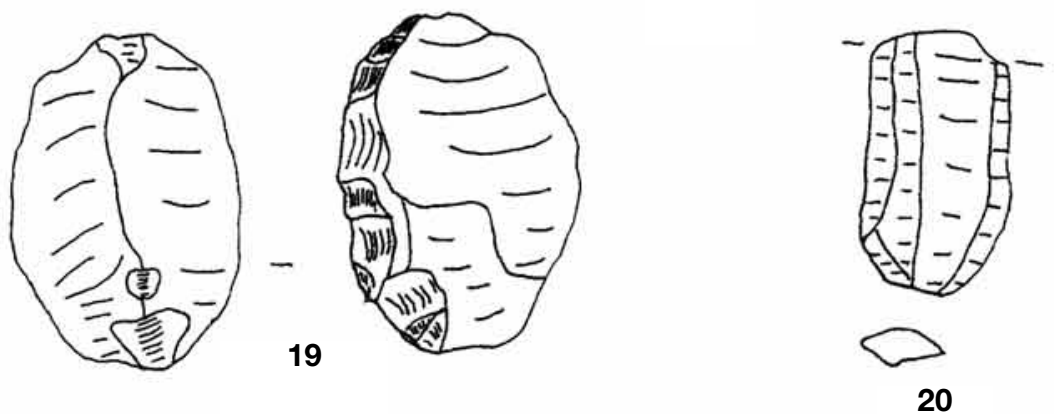

Fig. 22. Chipped stone implements from Budakalász. 1-2. Grave 2, 3-4. Grave 8, 6. Grave 22, 5. Grave 24, 7. Grave 44, 8. Grave 46, 9-18. Grave 48, 19. Grave 53, 20. Grave 64 

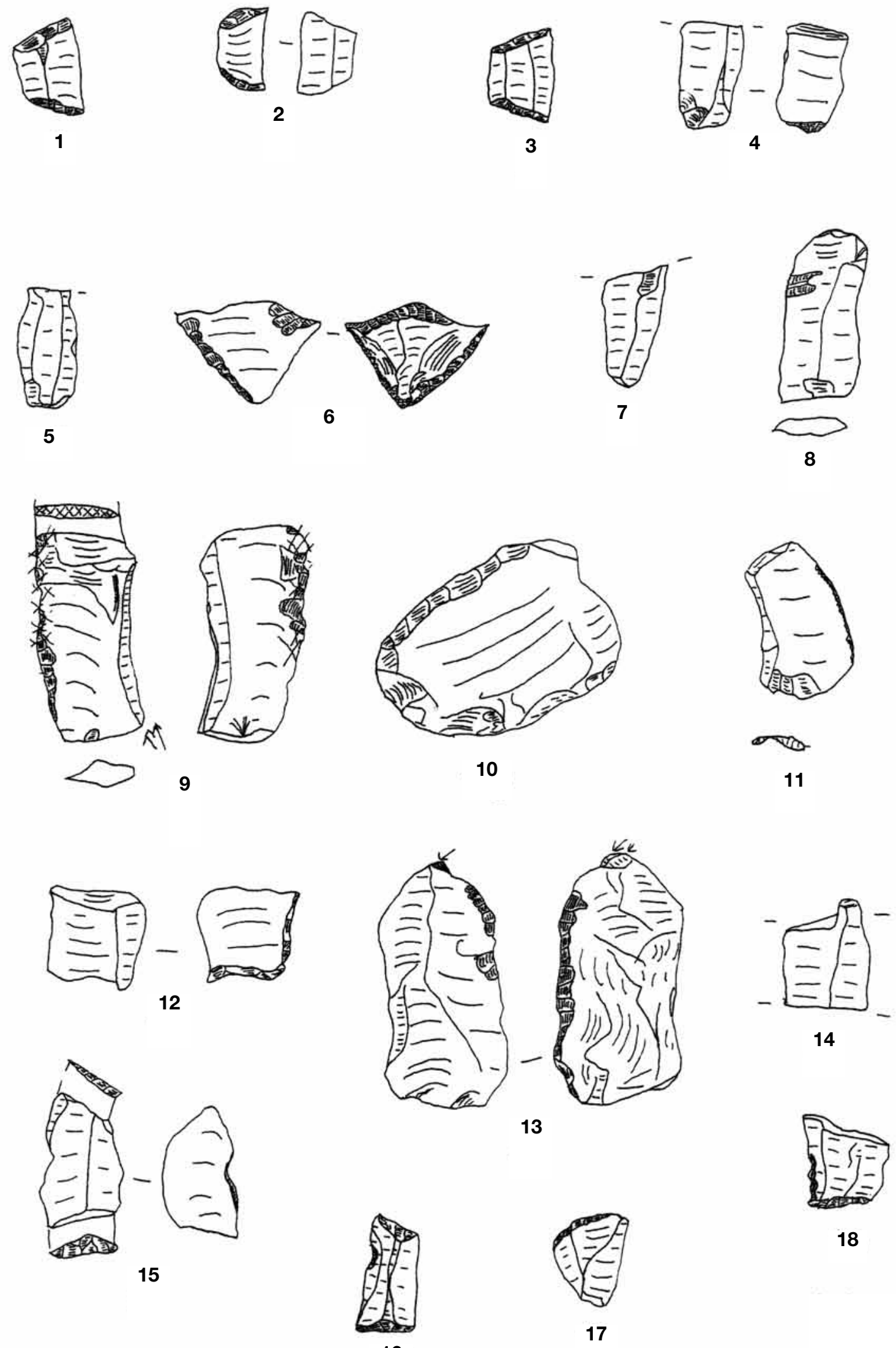

18

Fig. 23. Chipped stone implements from Budakalász. 1-5. Grave 75, 6-7. Grave 84, 8-9. Grave 112, 10. Grave 115, 11-12. Grave 117, 13. Grave 134, 14. Grave 149, 15-18. Grave 164 


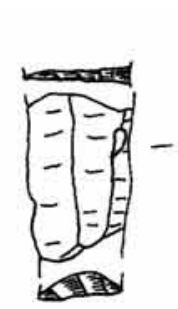

1

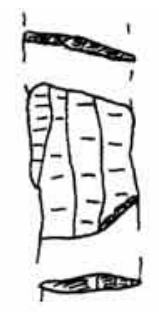

2

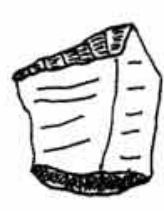

3

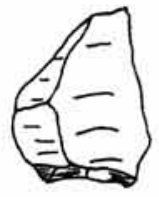

4

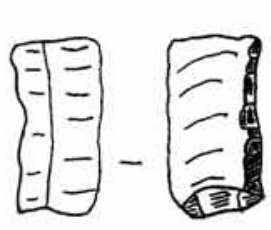

5
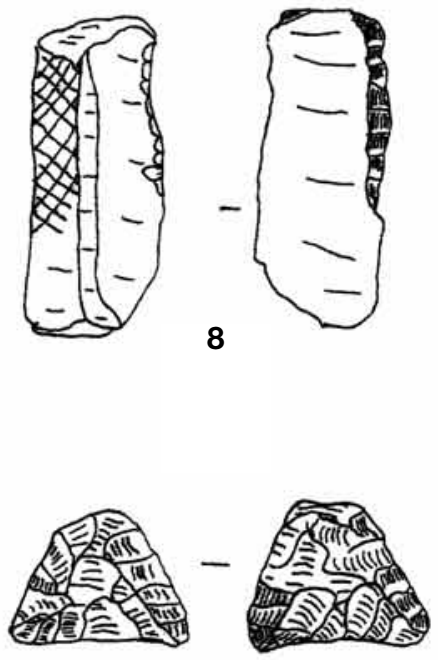

12

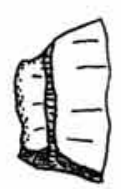

16

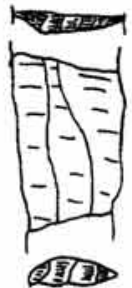

17
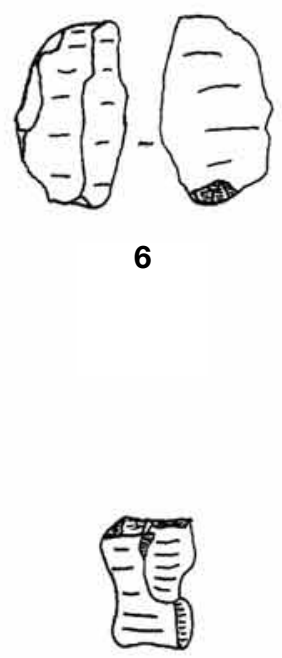

9
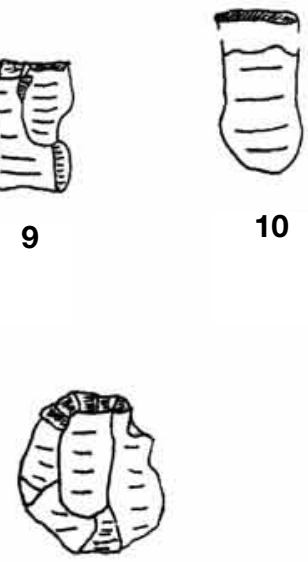

10

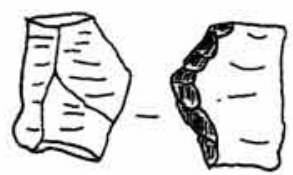

7

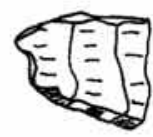

11
13

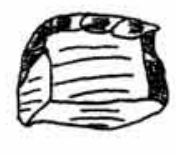

14

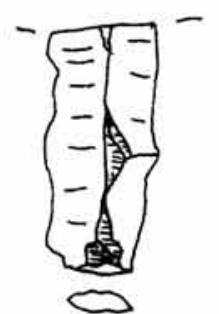

15

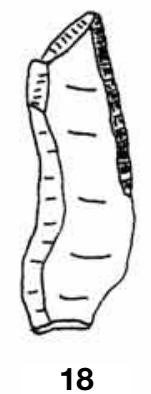

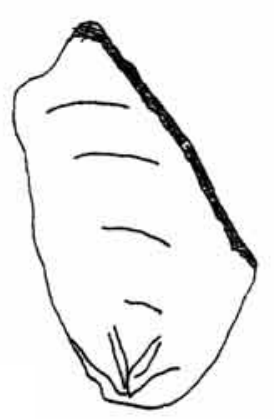

$1: 1$

Fig. 24. Chipped stone implements from Budakalász. 1-2. Grave 170, 3-6. Grave 174, 7. Grave 177, 8. Grave 182, 9-12. Grave 197, 13-14. Grave 207, 15. Grave 221, 16-17. Grave 227, 18. Grave 230, 19. Grave 263 

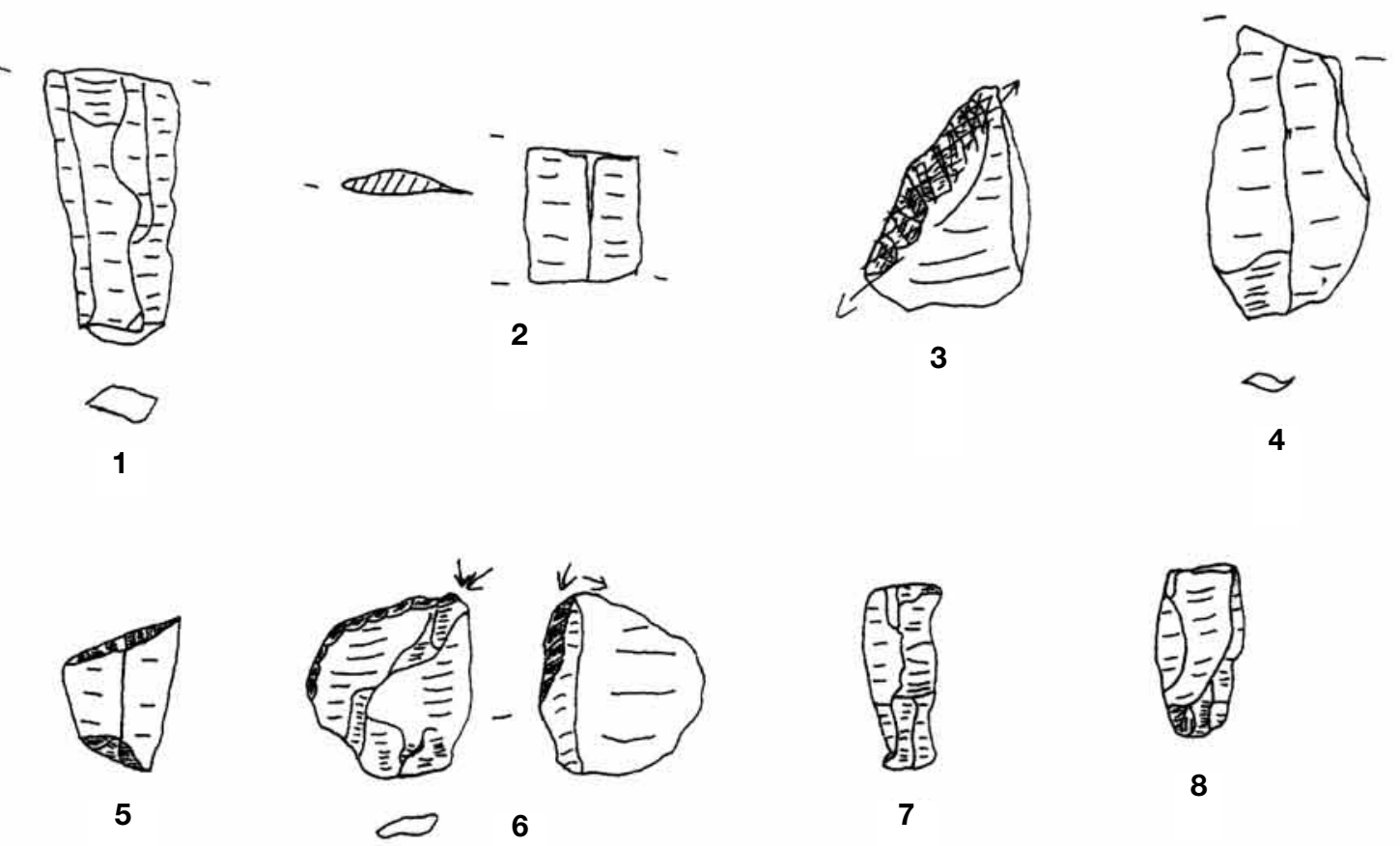

5
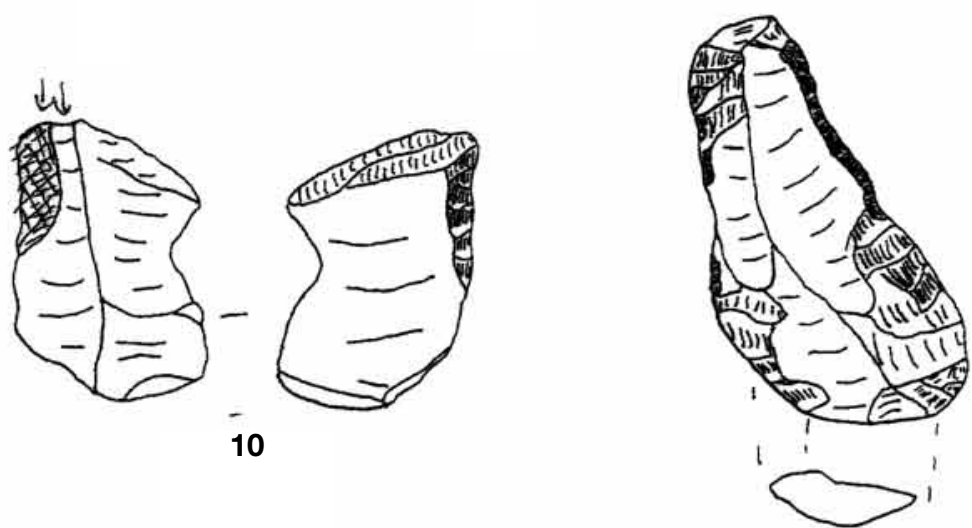

11
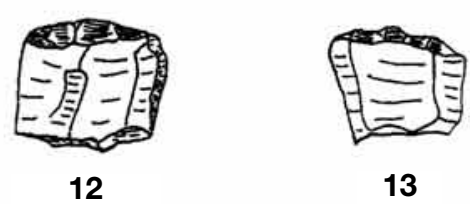

13

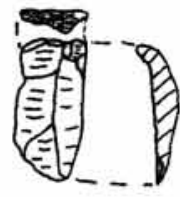

15

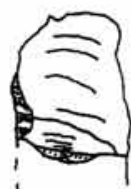

एका

16
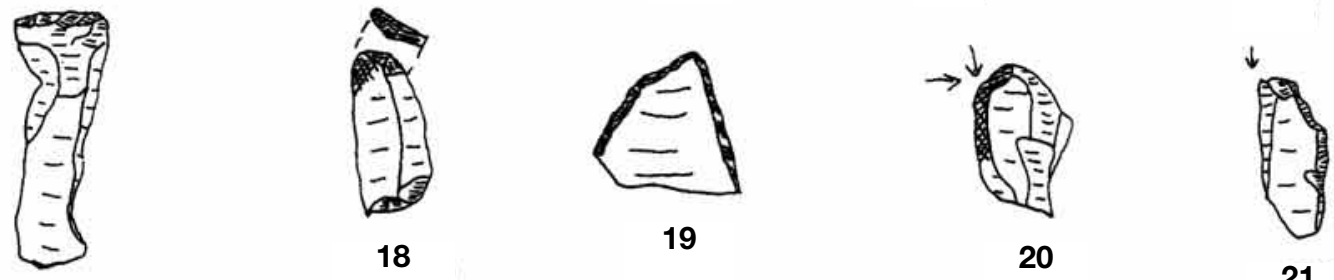

17

Fig. 25. Chipped stone implements from Budakalász. 1. Grave 279, 2. Grave 287, 3. Grave 330, 4. Grave 354, 5. Grave 361, 6. Grave 370, 7-9. Grave 375, 10. Grave 377, 11. stray find, 12-21. Grave 91 


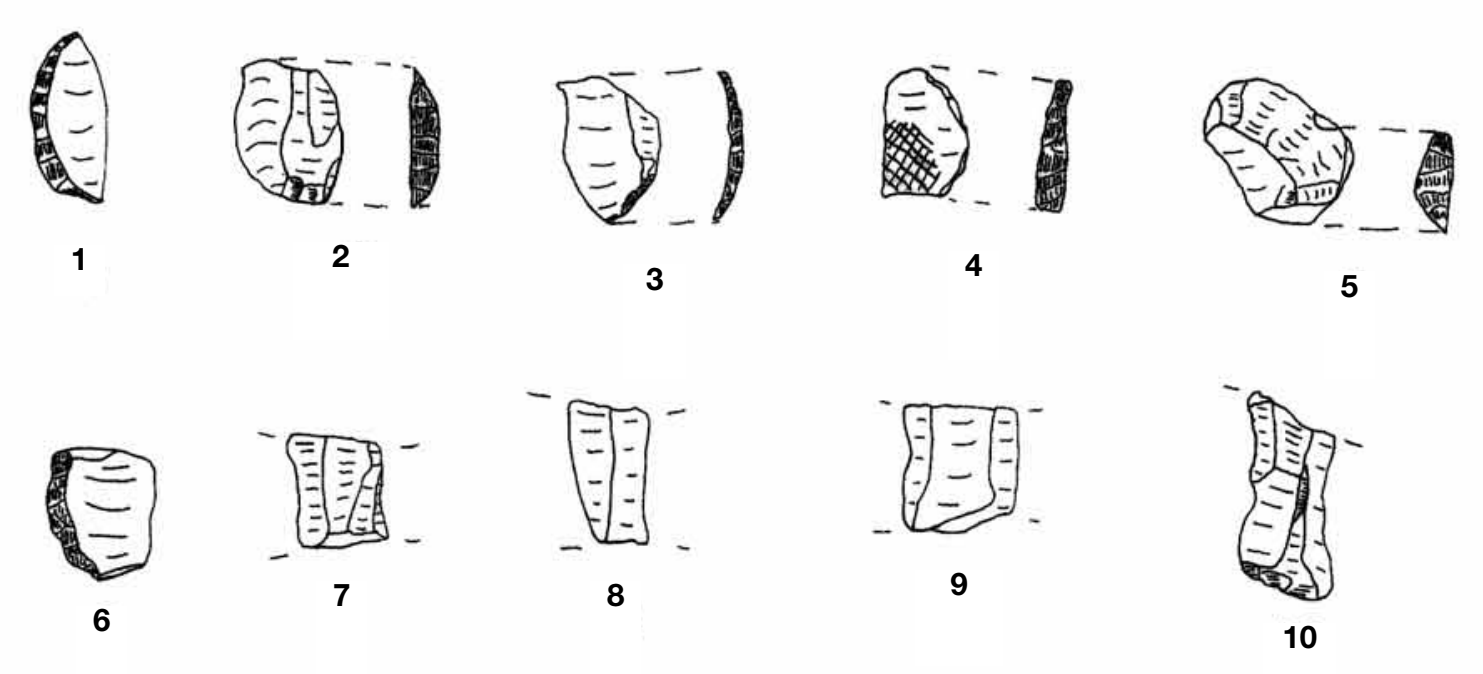

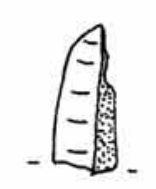

11

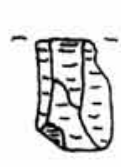

12

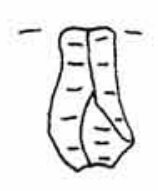

13

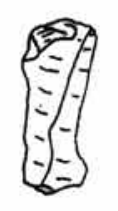

14

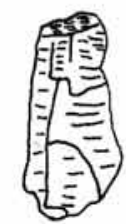

15
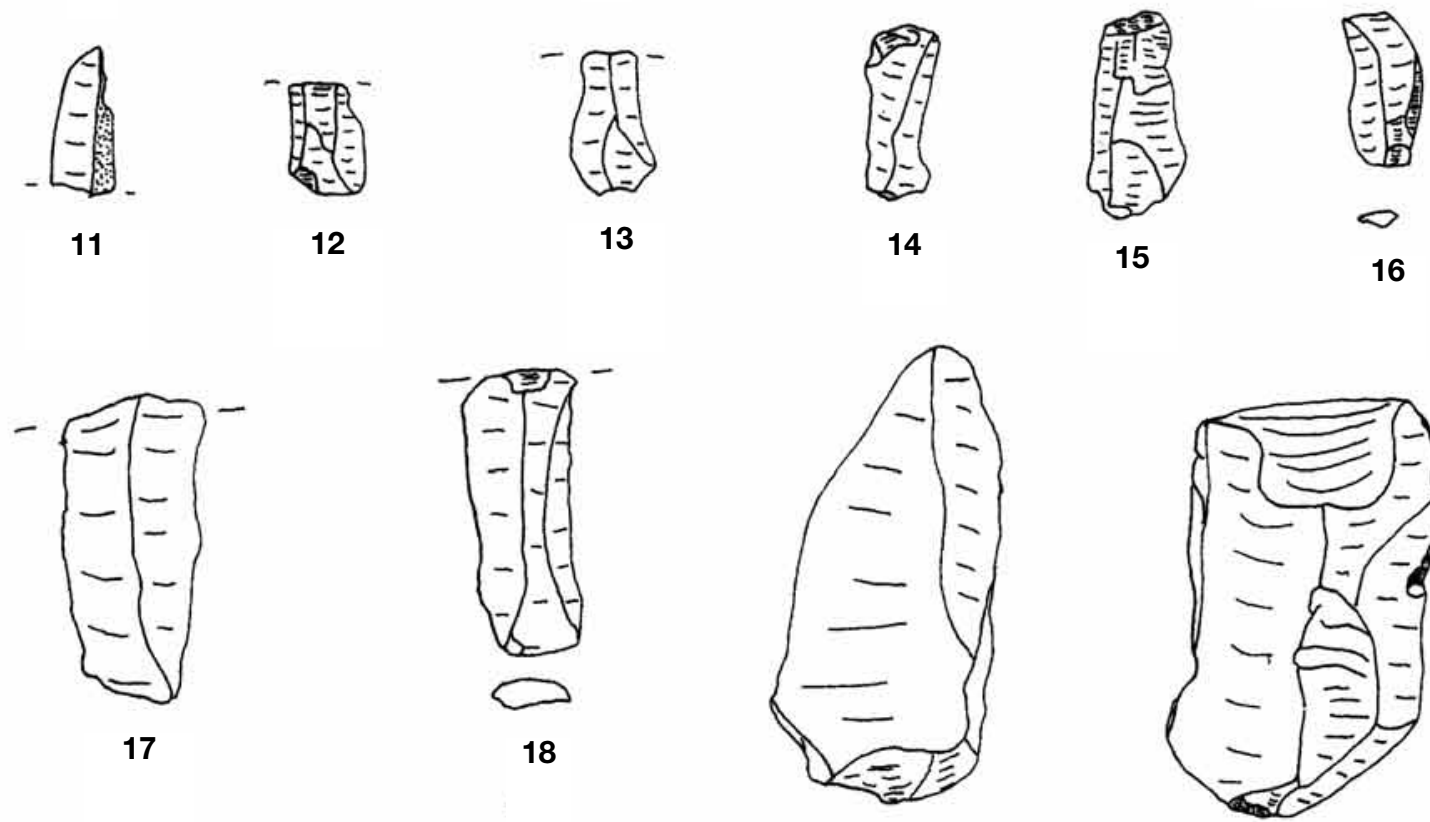

19

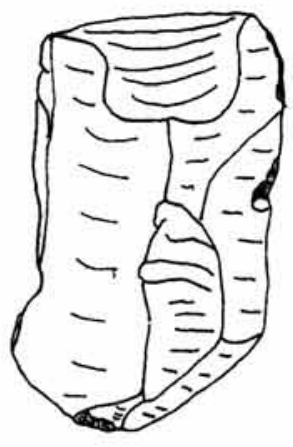

20

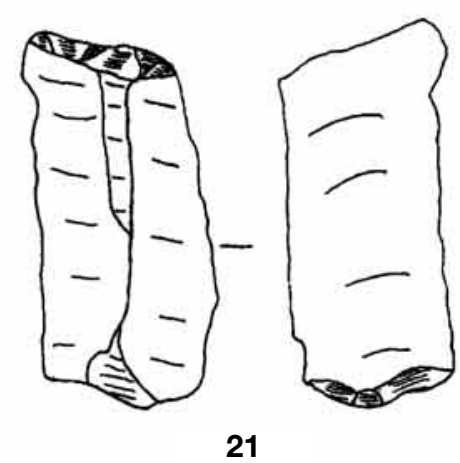

$1: 1$
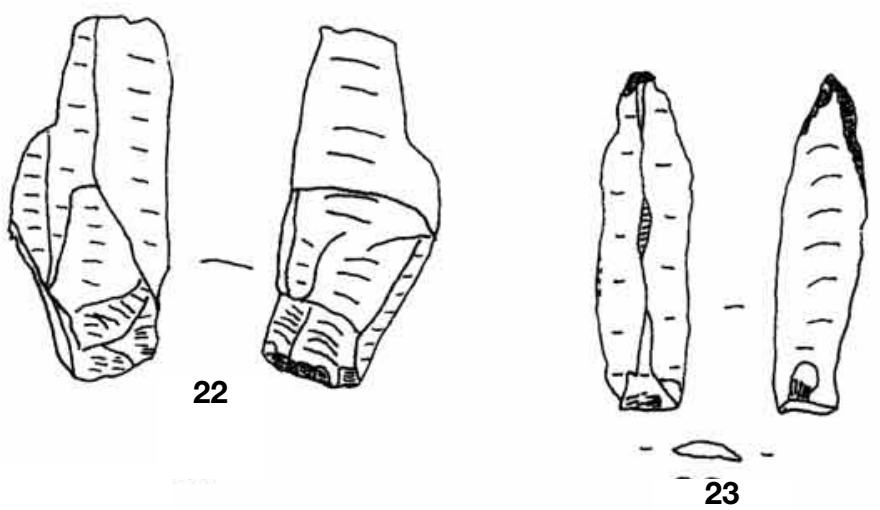

Fig. 26. Chipped stone implements from Budakalász. 1-23. Grave 91 



\section{THE ARCHAEOZOOLOGICAL ANALYSIS OF THE BEADS AND MOLLUSCS FROM THE LATE COPPER AGE BADEN CEMETERY AT BUDAKALÁSZ}

Pál Sümegi 


\section{INTRODUCTION}

One of the best-known Late Copper Age archaeological sites in Hungary is the burial ground of the Baden culture uncovered at Budakalász, where the renowned wagon model was found. ${ }^{1}$ In addition to anthropological remains and the pottery finds, the burials yielded a rich assemblage of molluscs. The archaeological finds from the burial ground are described and discussed by Mária Bondár. The editors of this volume felt that the mollusc finds should also be evaluated in order to provide as full a picture as possible of the finds. I was requested to evaluate the beads, snails, mussels and shells recovered from the burials. It became clear from the examination of the mollusc finds and of the artefacts previously assigned to this category that this material had originally not been described by a malacologist, as shown by the many erroneous entries in the acquisitions register and the first publications (Table 1). For example, countless limestone beads had originally been described as snail and shell beads, and the nomenclature used in the descriptions diverges significantly from the one employed in malacological studies. There were also inconsistencies in the use of Latin and Hungarian names.

The primary goal of this analysis, then, was to accurately determine the mollusc shells recovered from the burials, to distinguish the beads and other jewellery articles made from mussels, snails, scaphopods and limestone from each other (Table 1). The other main goal was to identify the provenance of the molluscs used for making ornaments, to separate the Copper Age species from those that can be regarded as fossils by that period, and to determine whence these commodities were procured. The macroscopic separation of fossil and recent Copper Age molluscs is difficult and often uncertain owing to the postdepositional alterations on the surface and in the material of molluscs buried in the Copper Age, and therefore several beads and molluscs were submitted to isotope geochemical analyses in the Geochemical Research Institute of the Hungarian Academy of Sciences. ${ }^{2}$ The results of these analyses enabled a more reliable determination of the provenance of the molluscs and, also, of the transformations caused by groundwater on the beads and other jewellery articles after their deposition, which in turn enabled the accurate identification of beads made from molluscs and those made from limestone.

\section{ANALYTICAL PROCEDURES}

The examination of the finds extended to the determination of the various rocks and the taxonomical identification of the molluscs, the identification of the human modifications observable on the beads and mollusc shells, as well as the classification of the mechanical, chemical and biogenic damages occurring in the one-time habitat and after deposition (Table 1). We measured the width and height of each mollusc. The main goal of these surface and metric analysis was to determine as accurately as possible the provenance of the molluscs from which the jewellery articles of the Budakalász cemetery had been fashioned and to gain a better knowledge of post-depositional changes. We hoped that the statistical evaluation would also provide an answer to whether the molluscs were consciously selected, or whether they were gathered en masse or randomly. We took digital photos from several angles of every mollusc from the Budakalász cemetery which we then entered into the malacological database created by the Department of Geology and Palaeontology of Szeged University containing the finds from several other malacological samples. ${ }^{3}$ When comparing and evaluating the beads in order to determine the ratio of various types, we only considered the copper jewellery articles found together with limestone beads and molluscs. It must be borne in mind that the number of copper ornaments and their proportion among the grave goods is much higher than would be apparent from this study; however, our goal was not an overall evaluation of the jewellery and other finds from the cemetery, but simply an examination of the mollusc finds and of the items earlier assigned to this category.

\footnotetext{
${ }^{1}$ SOPRONI 1954; BONDÁr 2004.

2 DEMÉNY et al. in this volume (pp. 437-448).
}

\footnotetext{
${ }^{3}$ SüMEGI 2000. Catalogue of the historical and prehistoric ornaments made from the mussel and snail shells. Manuscript. Department of Geology and Palaeontology, University of Szeged, Hungary.
} 


\section{EVALUATION OF THE FINDS}

Table 1. Overview of the beads recovered from the Budakalász cemetery

\begin{tabular}{|c|c|c|c|c|}
\hline Grave & $\begin{array}{l}\text { Description in the } \\
\text { inventory book }\end{array}$ & New description & $\begin{array}{l}\text { Anthropogenic } \\
\text { changes }\end{array}$ & $\begin{array}{c}\text { Traces of mechanical, } \\
\text { chemical and } \\
\text { biological erosion }\end{array}$ \\
\hline $\begin{array}{l}\text { Grave } 2 \\
56.11 .2 .5 \\
\text { Pl. II. } 2 / 6\end{array}$ & $\begin{array}{l}34 \text { beads, shells and } \\
\text { three beads with } \\
\text { pointed terminals }\end{array}$ & $\begin{array}{l}11 \text { Dentalium badense } \\
\text { and } 23 \text { limestone } \\
\text { beads }\end{array}$ & $\begin{array}{l}\text { The ends of the Dentalium } \\
\text { shells were trimmed and } \\
\text { polished; the limestone } \\
\text { beads were perforated with } \\
\text { an awl }\end{array}$ & $\begin{array}{l}\text { Boring sponge traces and } \\
\text { boreholes of a Natica snail } \\
\text { on the Dentalium shells; } \\
\text { post-depositional } \\
\text { groundwater action; } \\
\text { carbonate diagenesis on the } \\
\text { limestone beads }\end{array}$ \\
\hline $\begin{array}{l}\text { Grave } 8 \\
56.11 .5 .1 \\
\text { Pl. V. } 8 / 1 a-1 c\end{array}$ & $\begin{array}{l}83 \text { shell beads, } \\
9 \text { small red and } \\
\text { white beads and } \\
\text { seven shells }\end{array}$ & $\begin{array}{l}68 \text { Dentalium } \\
\text { badense, } 7 \text { Anadara } \\
\text { diluvii and } \\
21 \text { limestone beads }\end{array}$ & $\begin{array}{l}\text { The ends of the Dentalium } \\
\text { shells were trimmed and } \\
\text { polished; the limestone } \\
\text { beads were perforated with } \\
\text { an awl; the umbo of the } \\
\text { Anadara shells was trimmed } \\
\text { and polished }\end{array}$ & $\begin{array}{l}\text { Boring sponge traces on the } \\
\text { Dentalium and Anadara } \\
\text { shells; post-depositional } \\
\text { groundwater action; } \\
\text { carbonate diagenesis on the } \\
\text { limestone beads }\end{array}$ \\
\hline $\begin{array}{l}\text { Grave } 10 \\
56.11 .7 .1 \\
\text { Pl. VI. } 10 / 1 a-1 b\end{array}$ & $\begin{array}{l}76 \text { cylindrical beads } \\
\text { of various sizes and } \\
\text { seven shells }\end{array}$ & $\begin{array}{l}1 \text { Dentalium badense, } \\
7 \text { Anadara diluvii, } \\
\text { and } 74 \text { limestone } \\
\text { beads }\end{array}$ & $\begin{array}{l}\text { The ends of the Dentalium } \\
\text { shells were trimmed and } \\
\text { polished; the limestone } \\
\text { beads were perforated with } \\
\text { an awl; the umbo of the } \\
\text { Anadara shells was trimmed } \\
\text { and polished }\end{array}$ & $\begin{array}{l}\text { Boring sponge traces on the } \\
\text { Dentalium and Anadara } \\
\text { shells; post-depositional } \\
\text { groundwater action; } \\
\text { carbonate diagenesis on the } \\
\text { limestone beads }\end{array}$ \\
\hline $\begin{array}{l}\text { Grave } 12 \\
56.11 .8 .2 \\
\text { Pl. VII. } 12 / 2 a-2 b\end{array}$ & $\begin{array}{l}8 \text { perforated shells, } \\
\text { one oblong shell } \\
\text { plaque perforated at } \\
\text { both ends and } \\
7 \text { cylindrical shell } \\
\text { beads of varying } \\
\text { sizes }\end{array}$ & $\begin{array}{l}1 \text { Unio crassus } \\
\text { plaque, } 8 \text { Anadara } \\
\text { diluvii and } \\
7 \text { limestone beads }\end{array}$ & $\begin{array}{l}\text { The mussel shell was } \\
\text { polished into an oblong } \\
\text { shape resembling a flat } \\
\text { button and the four corners } \\
\text { were perforated with an } \\
\text { awl; the limestone beads } \\
\text { were perforated with an } \\
\text { awl; the umbo of the } \\
\text { Anadara shells was trimmed } \\
\text { and polished }\end{array}$ & $\begin{array}{l}\text { Boring sponge traces on the } \\
\text { surface of the Anadara } \\
\text { clams, caused by wave } \\
\text { action; post-depositional } \\
\text { groundwater action; } \\
\text { carbonate diagenesis on the } \\
\text { limestone beads }\end{array}$ \\
\hline $\begin{array}{l}\text { Grave } 13 \\
56.11 .9 .3 \\
\text { Pl. VIII. } 13 / 3\end{array}$ & $\begin{array}{l}84 \text { cylindrical shell } \\
\text { beads of varying } \\
\text { sizes }\end{array}$ & $\begin{array}{l}3 \text { Dentalium badense } \\
\text { and } 81 \text { limestone } \\
\text { beads }\end{array}$ & $\begin{array}{l}\text { The ends of the Dentalium } \\
\text { shells were trimmed and } \\
\text { polished; the limestone } \\
\text { beads were perforated with } \\
\text { an awl }\end{array}$ & $\begin{array}{l}\text { Post-depositional } \\
\text { groundwater action; } \\
\text { carbonate diagenesis on the } \\
\text { limestone beads }\end{array}$ \\
\hline $\begin{array}{l}\text { Grave } 13 \\
56.11 .9 .4 \\
\text { Pl. VIII. } 13 / 4\end{array}$ & $\begin{array}{l}14 \text { intact and broken } \\
\text { oblong shell plaques } \\
\text { perforated at the } \\
\text { corners of varying } \\
\text { sizes }\end{array}$ & $\begin{array}{l}14 \text { perforated Unio } \\
\text { crassus plaques }\end{array}$ & $\begin{array}{l}\text { The mussel shells were } \\
\text { polished into an oblong } \\
\text { shape resembling a flat } \\
\text { button and the four corners } \\
\text { were perforated with an awl }\end{array}$ & $\begin{array}{l}\text { The corners broke away at } \\
\text { the perforation on some } \\
\text { plaques }\end{array}$ \\
\hline $\begin{array}{l}\text { Grave } 16 \\
56.11 .10 .1 \\
\text { Pl. IX. } 16 / 1\end{array}$ & $\begin{array}{l}1 \text { broken and } \\
2 \text { intact Dentalium } \\
\text { shells }\end{array}$ & $\begin{array}{l}3 \text { Dentalium badense } \\
\text { shells }\end{array}$ & $\begin{array}{l}\text { The ends of the Dentalium } \\
\text { shells were trimmed and } \\
\text { polished }\end{array}$ & $\begin{array}{l}\text { Boring sponge traces and } \\
\text { traces of complex erosion } \\
\text { can be noted on the two } \\
\text { broken Dentalium shells, } \\
\text { and holes drilled by Natica } \\
\text { snails on the third one; } \\
\text { post-depositional } \\
\text { groundwater action; } \\
\text { carbonate precipitation and } \\
\text { chemical alterations on the } \\
\text { shells }\end{array}$ \\
\hline
\end{tabular}


Table 1 (cont'd)

\begin{tabular}{|c|c|c|c|c|}
\hline Grave & $\begin{array}{l}\text { Description in the } \\
\text { inventory book }\end{array}$ & New description & $\begin{array}{l}\text { Anthropogenic } \\
\text { changes }\end{array}$ & $\begin{array}{c}\text { Traces of mechanical, } \\
\text { chemical and } \\
\text { biological erosion }\end{array}$ \\
\hline $\begin{array}{l}\text { Grave } 19 \\
56.11 .12 .1 \\
\text { Pl. X. } 19 / 1\end{array}$ & $\begin{array}{l}11 \text { small shell beads, } \\
\text { some with brownish } \\
\text { stains, probably } \\
\text { patches of pigment }\end{array}$ & 11 limestone beads & $\begin{array}{l}\text { The limestone beads were } \\
\text { polished into a cylindrical } \\
\text { shape and perforated with } \\
\text { an awl }\end{array}$ & $\begin{array}{l}\text { Post-depositional } \\
\text { groundwater action; } \\
\text { carbonate precipitation and } \\
\text { chemical alterations on the } \\
\text { limestone beads }\end{array}$ \\
\hline $\begin{array}{l}\text { Grave } 21 \\
56.11 .13 .1 \\
\text { Pl. XI. } 21 / 1\end{array}$ & $\begin{array}{l}17 \text { shell beads of } \\
\text { varying sizes }\end{array}$ & 17 limestone beads & $\begin{array}{l}\text { The limestone beads were } \\
\text { polished into a cylindrical } \\
\text { shape and perforated with } \\
\text { an awl }\end{array}$ & $\begin{array}{l}\text { Post-depositional } \\
\text { groundwater action; } \\
\text { carbonate precipitation and } \\
\text { chemical alterations on the } \\
\text { surface of the limestone } \\
\text { beads surfaces }\end{array}$ \\
\hline $\begin{array}{l}\text { Grave } 22 \\
56.11 .14 .2 \\
\text { Pl. XIII. } 22 / 2\end{array}$ & $\begin{array}{l}5 \text { Dentalium shells } \\
\text { and } 1 \text { red stone bead }\end{array}$ & $\begin{array}{l}5 \text { Dentalium badense } \\
\text { beads, } 1 \text { white } \\
\text { limestone and } 1 \text { red } \\
\text { limestone bead }\end{array}$ & $\begin{array}{l}\text { The ends of the Dentalium } \\
\text { shells were trimmed and } \\
\text { polished; the limestone } \\
\text { beads were polished into a } \\
\text { cylindrical shape and } \\
\text { perforated with an awl }\end{array}$ & $\begin{array}{l}\text { Post-depositional } \\
\text { groundwater action; } \\
\text { carbonate precipitation and } \\
\text { chemical alterations on the } \\
\text { Dentalium shells and the } \\
\text { limestone beads }\end{array}$ \\
\hline $\begin{array}{l}\text { Grave } 23 \\
56.11 .15 .7 \\
\text { Pl. XII. } 23 / 5\end{array}$ & $\begin{array}{l}26 \text { shell beads of } \\
\text { varying sizes }\end{array}$ & 26 limestone beads & $\begin{array}{l}\text { The limestone beads were } \\
\text { polished into a cylindrical } \\
\text { shape and perforated with } \\
\text { an awl }\end{array}$ & $\begin{array}{l}\text { Post-depositional } \\
\text { groundwater action; } \\
\text { carbonate precipitation and } \\
\text { chemical alterations on the } \\
\text { limestone beads }\end{array}$ \\
\hline $\begin{array}{l}\text { Grave } 24 \\
56.11 .16 .1 \\
\text { Pl. XIV. } 24 / 1\end{array}$ & $\begin{array}{l}14 \text { shell beads of } \\
\text { varying sizes }\end{array}$ & 14 limestone beads & $\begin{array}{l}\text { The limestone beads were } \\
\text { polished into a cylindrical } \\
\text { shape and perforated with } \\
\text { an awl }\end{array}$ & $\begin{array}{l}\text { Carbonate precipitation and } \\
\text { chemical alterations on the } \\
\text { limestone beads }\end{array}$ \\
\hline $\begin{array}{l}\text { Grave } 25 \\
56.11 .17 .2 \\
\text { Pl. XIII. } 25 / 2\end{array}$ & $\begin{array}{l}31 \text { shell beads of } \\
\text { varying sizes }\end{array}$ & 31 limestone beads & $\begin{array}{l}\text { The limestone beads were } \\
\text { polished into a cylindrical } \\
\text { shape and perforated with } \\
\text { an awl }\end{array}$ & $\begin{array}{l}\text { Carbonate precipitation and } \\
\text { chemical alterations on the } \\
\text { limestone beads }\end{array}$ \\
\hline $\begin{array}{l}\text { Grave } 33 \\
56.11 .20 .4 \\
P l . X V .33 / 4\end{array}$ & $\begin{array}{l}1 \text { broken and } \\
2 \text { intact shells }\end{array}$ & $\begin{array}{l}2 \text { Anadara diluvii } \\
\text { clam shells and } \\
1 \text { broken Anadara } \\
\text { diluvii clam shell }\end{array}$ & $\begin{array}{l}\text { The umbo of the Anadara } \\
\text { shells was trimmed and } \\
\text { polished }\end{array}$ & $\begin{array}{l}\text { Carbonate precipitation and } \\
\text { traces of dissolution on the } \\
\text { shells }\end{array}$ \\
\hline $\begin{array}{l}\text { Grave } 35 \\
56.11 .21 .1 \\
\text { Pl. XVIII. } 35 / 1\end{array}$ & $\begin{array}{l}6 \text { intact and } \\
2 \text { broken shells }\end{array}$ & $\begin{array}{l}7 \text { Anadara diluvii } \\
\text { clams and } \\
1 \text { unidentifiable, } \\
\text { broken shell }\end{array}$ & $\begin{array}{l}\text { The umbo of the Anadara } \\
\text { shells was trimmed and } \\
\text { polished }\end{array}$ & $\begin{array}{l}\text { Carbonate precipitation and } \\
\text { traces of dissolution on the } \\
\text { shells }\end{array}$ \\
\hline $\begin{array}{l}\text { Grave } 36 \\
56.11 .22 .2 \\
\text { Pl. XVI. } 36 / 3 a-3 / b\end{array}$ & $\begin{array}{l}1 \text { broken and } \\
39 \text { intact shell beads, } \\
1 \text { broken and two } \\
\text { intact copper beads }\end{array}$ & $\begin{array}{l}40 \text { limestone beads } \\
\text { and } 1 \text { Dentalium } \\
\text { badense bead }\end{array}$ & $\begin{array}{l}\text { The limestone beads were } \\
\text { polished into a cylindrical } \\
\text { shape and perforated with } \\
\text { an awl; the ends of the } \\
\text { Dentalium shells were } \\
\text { trimmed and polished }\end{array}$ & $\begin{array}{l}\text { Post-depositional } \\
\text { groundwater action; } \\
\text { carbonate precipitation and } \\
\text { chemical alterations on the } \\
\text { limestone beads and the } \\
\text { shell }\end{array}$ \\
\hline $\begin{array}{l}\text { Grave } 37 \\
56.11 .23 .1 \\
\text { Pl. XVIII. } 37 / 1\end{array}$ & $\begin{array}{l}11 \text { intact and } \\
2 \text { sliced Dentalium } \\
\text { shells }\end{array}$ & $\begin{array}{l}13 \text { beads polished } \\
\text { from Dentalium } \\
\text { badense shell }\end{array}$ & $\begin{array}{l}\text { The ends of the Dentalium } \\
\text { shells were trimmed and } \\
\text { polished }\end{array}$ & $\begin{array}{l}\text { Post-depositional } \\
\text { groundwater action; } \\
\text { carbonate precipitation and } \\
\text { chemical alterations on the } \\
\text { shell }\end{array}$ \\
\hline $\begin{array}{l}\text { Grave } 41 \\
56.11 .25 .1 \\
\text { Pl. XIX. } 41 / 1\end{array}$ & $\begin{array}{l}1 \text { sliced and } \\
21 \text { intact Dentalium } \\
\text { shells, } 1 \text { broken and } \\
57 \text { intact shell beads, } \\
3 \text { white marble } \\
\text { beads, } 2 \text { red stone } \\
\text { beads }\end{array}$ & $\begin{array}{l}22 \text { Dentalium badense } \\
\text { shells, } 58 \text { limestone } \\
\text { beads, } 3 \text { crystalline } \\
\text { limestone beads and } \\
2 \text { fired clay beads }\end{array}$ & $\begin{array}{l}\text { The ends of the Dentalium } \\
\text { shells were trimmed and } \\
\text { polished; the limestone } \\
\text { beads were polished into a } \\
\text { cylindrical shape and } \\
\text { perforated with an awl }\end{array}$ & $\begin{array}{l}\text { Post-depositional } \\
\text { groundwater action; } \\
\text { carbonate precipitation and } \\
\text { chemical alterations on the } \\
\text { shells and limestone beads }\end{array}$ \\
\hline Grave 42 & 6 shell beads & 6 sliced limestone & The limestone beads were & Carbonate precipitation and \\
\hline
\end{tabular}


Table 1 (cont'd)

\begin{tabular}{|c|c|c|c|c|}
\hline $\begin{array}{l}56.11 .26 .1 \\
P l . X X .42 / 1\end{array}$ & & beads & $\begin{array}{l}\text { polished into a cylindrical } \\
\text { shape and perforated with } \\
\text { an awl }\end{array}$ & $\begin{array}{l}\text { chemical alterations on the } \\
\text { beads }\end{array}$ \\
\hline $\begin{array}{l}\text { Grave } 43 \\
56.11 .27 .1 \\
\text { Pl. XXI. } 43 / 1 a-1 / b\end{array}$ & $\begin{array}{l}27 \text { shell beads, } \\
4 \text { Dentalium beads, } \\
2 \text { shells }\end{array}$ & $\begin{array}{l}27 \text { limestone beads, } \\
4 \text { Dentalium badense } \\
\text { beads and } 2 \text { Anadara } \\
\text { diluvii clam shells }\end{array}$ & $\begin{array}{l}\text { The ends of the Dentalium } \\
\text { shells were trimmed and } \\
\text { polished; the limestone } \\
\text { beads were polished into a } \\
\text { cylindrical shape and } \\
\text { perforated with an awl; the } \\
\text { umbo of the Anadara shells } \\
\text { was trimmed and polished }\end{array}$ & $\begin{array}{l}\text { Post-depositional } \\
\text { groundwater action; } \\
\text { carbonate precipitation and } \\
\text { chemical alterations on the } \\
\text { limestone beads and shells }\end{array}$ \\
\hline $\begin{array}{l}\text { Grave } 46 \\
56.11 .29 .2 \\
P l . X X .46 / 2\end{array}$ & $\begin{array}{l}6 \text { intact and } \\
2 \text { broken shells }\end{array}$ & $\begin{array}{l}8 \text { Anadara diluvii } \\
\text { clam shells }\end{array}$ & $\begin{array}{l}\text { The umbo of } 7 \text { Anadara } \\
\text { shells was trimmed and } \\
\text { polished, } 1 \text { is broken }\end{array}$ & $\begin{array}{l}\text { Carbonate precipitation and } \\
\text { traces of dissolution on the } \\
\text { shells }\end{array}$ \\
\hline $\begin{array}{l}\text { Grave } 46 \\
56.11 .29 .3 \\
P l . X X .46 / 3 \\
\end{array}$ & 1 Dentalium bead & $\begin{array}{l}1 \text { Dentalium badense } \\
\text { bead }\end{array}$ & $\begin{array}{l}\text { The tips of the Dentalium } \\
\text { shells were trimmed and } \\
\text { polished }\end{array}$ & $\begin{array}{l}\text { The Dentalium shell is } \\
\text { intact }\end{array}$ \\
\hline $\begin{array}{l}\text { Grave } 48 \\
56.11 .30 .1 \\
\text { Pl. XXII. } 48 / 1 a-1 c\end{array}$ & $\begin{array}{l}18 \text { shell beads, } 1 \\
\text { broken and } 3 \text { intact } \\
\text { shells, } 3 \text { intact and } \\
5 \text { broken shells }\end{array}$ & $\begin{array}{l}18 \text { limestone beads } \\
\text { and } 4 \text { Anadara } \\
\text { diluvii clam shells }\end{array}$ & $\begin{array}{l}\text { The limestone beads were } \\
\text { polished into a cylindrical } \\
\text { shape and perforated with } \\
\text { an awl; the umbo of the } \\
\text { Anadara shells was trimmed } \\
\text { and polished }\end{array}$ & $\begin{array}{l}\text { Post-depositional } \\
\text { groundwater action; } \\
\text { carbonate precipitation and } \\
\text { chemical alterations on the } \\
\text { limestone beads and shells }\end{array}$ \\
\hline $\begin{array}{l}\text { Grave } 50 \\
56.11 .32 .1 \\
\text { Pl. XXIII. } 50 / 1\end{array}$ & 8 shells & $\begin{array}{l}8 \text { Anadara diluvii } \\
\text { clam shells }\end{array}$ & $\begin{array}{l}\text { The umbo of } 7 \text { Anadara } \\
\text { shells was trimmed and } \\
\text { polished, one perforated in } \\
\text { the "cameo" style }\end{array}$ & $\begin{array}{l}\text { Carbonate precipitation and } \\
\text { traces of dissolution; traces } \\
\text { of a boring sponge on the } \\
\text { shells }\end{array}$ \\
\hline $\begin{array}{l}\text { Grave } 50 \\
56.11 .32 .2 \\
\text { Pl. XXIII. } 50 / 2 a-2 / b\end{array}$ & $\begin{array}{l}24 \text { shell beads, } 1 \text { red } \\
\text { and } 1 \text { white bead, } \\
1 \text { broken copper } \\
\text { bead }\end{array}$ & 4 limestone beads ${ }^{4}$ & $\begin{array}{l}\text { The limestone beads were } \\
\text { polished into a cylindrical } \\
\text { shape and perforated with } \\
\text { an awl }\end{array}$ & $\begin{array}{l}\text { Carbonate precipitation and } \\
\text { chemical alteration on the } \\
\text { limestone beads }\end{array}$ \\
\hline $\begin{array}{l}\text { Grave } 50 \\
56.11 .32 .3 \\
\text { Pl. XXIII. } 50 / 3\end{array}$ & $\begin{array}{l}11 \text { fragmentary and } \\
6 \text { tiny fragments of } \\
\text { oblong shell plaques } \\
\text { with a pair of } \\
\text { perforations along } \\
\text { the short sides }\end{array}$ & $\begin{array}{l}15 \text { Unio crassus } \\
\text { plaques }\end{array}$ & $\begin{array}{l}\text { The mussel shells were } \\
\text { polished into an oblong } \\
\text { shape resembling a flat } \\
\text { button and the four corners } \\
\text { were perforated with an awl }\end{array}$ & $\begin{array}{l}\text { A minimal dissolution on } \\
\text { the surface of the mussel } \\
\text { plaques; the corners broke } \\
\text { away at the perforation on } \\
\text { some plaques; worn, broken } \\
\text { plaques }\end{array}$ \\
\hline $\begin{array}{l}\text { Grave } 53 \\
56.11 .34 .1 \\
P l . X X I V .53 / 1\end{array}$ & $\begin{array}{l}3 \text { large Dentalium } \\
\text { shells }\end{array}$ & $\begin{array}{l}3 \text { Dentalium badense } \\
\text { shells }\end{array}$ & $\begin{array}{l}\text { The ends of the Dentalium } \\
\text { shells were trimmed and } \\
\text { polished; each shell was } \\
\text { painted red }\end{array}$ & $\begin{array}{l}\text { Carbonate precipitation and } \\
\text { traces of dissolution on the } \\
\text { shells }\end{array}$ \\
\hline $\begin{array}{l}\text { Grave } 55 \\
56.11 .35 .3 \\
P l . X X V .55 / 3\end{array}$ & $\begin{array}{l}21 \text { shell beads of } \\
\text { varying sizes }\end{array}$ & 21 limestone beads & $\begin{array}{l}\text { The limestone beads were } \\
\text { polished into a cylindrical } \\
\text { shape and perforated with } \\
\text { an awl }\end{array}$ & $\begin{array}{l}\text { Carbonate precipitation and } \\
\text { chemical alterations on the } \\
\text { beads }\end{array}$ \\
\hline $\begin{array}{l}\text { Grave } 56 \\
56.11 .36 .1 \\
P l . X X I V .56 / 1\end{array}$ & 5 small shell beads & 5 limestone beads & $\begin{array}{l}\text { The limestone beads were } \\
\text { polished into a cylindrical } \\
\text { shape and perforated with } \\
\text { an awl }\end{array}$ & $\begin{array}{l}\text { Carbonate precipitation and } \\
\text { chemical alterations on the } \\
\text { beads }\end{array}$ \\
\hline $\begin{array}{l}\text { Grave } 58 \\
56.11 .37 .1 \\
\text { Pl. XXVI. } 58 / 1\end{array}$ & $\begin{array}{l}10 \text { shell beads of } \\
\text { varying sizes }\end{array}$ & 10 limestone beads & $\begin{array}{l}\text { The limestone beads were } \\
\text { polished into a cylindrical } \\
\text { shape and perforated with } \\
\text { an awl }\end{array}$ & $\begin{array}{l}\text { Carbonate precipitation and } \\
\text { chemical alterations on the } \\
\text { beads }\end{array}$ \\
\hline $\begin{array}{l}\text { Grave } 60 \\
56.11 .39 .1 \\
\text { Pl. XXVI. } 60 / 1\end{array}$ & 5 Dentalium shells & $\begin{array}{l}6(!) \text { Dentalium } \\
\text { badense beads }\end{array}$ & $\begin{array}{l}\text { The ends of the Dentalium } \\
\text { shells were trimmed and } \\
\text { polished }\end{array}$ & $\begin{array}{l}\text { Carbonate precipitation and } \\
\text { traces of dissolution on the } \\
\text { shells }\end{array}$ \\
\hline $\begin{array}{l}\text { Grave } 63 \\
56.11 .41 .1 \\
\text { Pl. XXVIII. } 63 / 1\end{array}$ & $\begin{array}{l}2 \text { fragmentary, } \\
\text { oblong shell plaques } \\
\text { with a pair of }\end{array}$ & $\begin{array}{l}2 \text { Unio crassus } \\
\text { plaques }\end{array}$ & $\begin{array}{l}\text { The mussel shells were } \\
\text { polished into an oblong } \\
\text { shape resembling a flat }\end{array}$ & $\begin{array}{l}\text { A minimal dissolution on } \\
\text { the shell surfaces; the } \\
\text { corners broke away at the }\end{array}$ \\
\hline
\end{tabular}

\footnotetext{
${ }^{4}$ The red and white stone beads and the copper bead can no longer be found.
} 
Table 1 (cont'd)

\begin{tabular}{|c|c|c|c|c|}
\hline Grave & $\begin{array}{l}\text { Description in the } \\
\text { inventory book }\end{array}$ & New description & $\begin{array}{l}\text { Anthropogenic } \\
\text { changes }\end{array}$ & $\begin{array}{c}\text { Traces of mechanical, } \\
\text { chemical and } \\
\text { biological erosion }\end{array}$ \\
\hline & $\begin{array}{l}\text { perforations along } \\
\text { the short sides }\end{array}$ & & $\begin{array}{l}\text { button and the four corners } \\
\text { were perforated with an awl }\end{array}$ & $\begin{array}{l}\text { perforation on some } \\
\text { plaques }\end{array}$ \\
\hline $\begin{array}{l}\text { Grave } 63 \\
56.11 .41 .3 \\
\text { Pl. XXVIII. } 63 / 3\end{array}$ & $\begin{array}{l}36 \text { shell beads of } \\
\text { varying sizes and } \\
1 \text { broken Dentalium } \\
\text { shell }\end{array}$ & 36 limestone beads 5 & $\begin{array}{l}\text { The limestone beads were } \\
\text { polished into a cylindrical } \\
\text { shape and perforated with } \\
\text { an awl }\end{array}$ & $\begin{array}{l}\text { Carbonate precipitation and } \\
\text { chemical alterations on the } \\
\text { beads }\end{array}$ \\
\hline $\begin{array}{l}\text { Grave } 63 \\
56.11 .41 .4 \\
\text { Pl. XXVIII. } 63 / 4\end{array}$ & 7 shell beads & 7 limestone beads & $\begin{array}{l}\text { The limestone beads were } \\
\text { polished into a cylindrical } \\
\text { shape and perforated with } \\
\text { an awl }\end{array}$ & $\begin{array}{l}\text { Carbonate precipitation and } \\
\text { chemical alterations on the } \\
\text { beads }\end{array}$ \\
\hline $\begin{array}{l}\text { Grave } 66 \\
56.11 .44 .1 \\
\text { Pl. XXIX. 66/1 }\end{array}$ & $\begin{array}{l}\text { Broken oblong shell } \\
\text { plaque }\end{array}$ & $\begin{array}{l}\text { Broken oblong } \\
\text { mussel plaque }\end{array}$ & $\begin{array}{l}\text { The mussel shells were } \\
\text { polished into an oblong } \\
\text { shape and the four corners } \\
\text { were perforated with an awl }\end{array}$ & $\begin{array}{l}\text { A minimal dissolution on } \\
\text { the mussel plaques; the } \\
\text { corners broke away at the } \\
\text { perforation on some plaques }\end{array}$ \\
\hline $\begin{array}{l}\text { Grave } 66 \\
56.11 .44 .2 \\
P l . X X I X .66 / 2\end{array}$ & $\begin{array}{l}18 \text { shell beads of } \\
\text { varying sizes, } \\
1 \text { broken and } \\
4 \text { intact Dentalium } \\
\text { shells }\end{array}$ & $\begin{array}{l}18 \text { limestone and } \\
5 \text { Dentalium badense } \\
\text { beads }\end{array}$ & $\begin{array}{l}\text { The ends of the Dentalium } \\
\text { shells were trimmed and } \\
\text { polished; the limestone } \\
\text { beads were polished into a } \\
\text { cylindrical shape and } \\
\text { perforated with an awl }\end{array}$ & $\begin{array}{l}\text { Post-depositional } \\
\text { groundwater action; } \\
\text { carbonate precipitation and } \\
\text { chemical alterations on the } \\
\text { limestone and shell beads }\end{array}$ \\
\hline $\begin{array}{l}\text { Grave } 67 \\
56.11 .45 .3 \\
P l . X X I X . \\
67 / 3 a-3 / b\end{array}$ & $\begin{array}{l}29 \text { shell beads, } \\
6 \text { intact and } \\
5 \text { broken shells }\end{array}$ & $\begin{array}{l}29 \text { limestone beads } \\
\text { and } 11 \text { Anadara } \\
\text { diluvii clam shells }\end{array}$ & $\begin{array}{l}\text { The umbo of the Anadara } \\
\text { shells was trimmed and } \\
\text { polished, two were painted } \\
\text { red; the limestone beads } \\
\text { were polished into a } \\
\text { cylindrical shape and } \\
\text { perforated with an awl, one } \\
\text { bead was painted red }\end{array}$ & $\begin{array}{l}\text { Post-depositional } \\
\text { groundwater action; } \\
\text { carbonate precipitation and } \\
\text { chemical alterations on the } \\
\text { limestone beads and shells }\end{array}$ \\
\hline $\begin{array}{l}\text { Grave } 71 \\
56.11 .48 .1 \\
\text { Pl. } X X X .71 / 1\end{array}$ & $\begin{array}{l}31 \text { shell beads of } \\
\text { varying sizes }\end{array}$ & 31 limestone beads & $\begin{array}{l}\text { The limestone beads were } \\
\text { polished into a cylindrical } \\
\text { shape and perforated with } \\
\text { an awl }\end{array}$ & $\begin{array}{l}\text { Carbonate precipitation and } \\
\text { chemical alterations on the } \\
\text { limestone beads }\end{array}$ \\
\hline $\begin{array}{l}\text { Grave } 71 \\
56.11 .48 .2 \\
\text { Pl. } X X X .71 / 2\end{array}$ & $\begin{array}{l}\text { Broken } 12 \text { shell } \\
\text { plaques }\end{array}$ & $\begin{array}{l}\text { Broken shell } \\
\text { plaques, probably } \\
\text { polished from } \\
2 \text { Unio crassus } \\
\text { mussels }\end{array}$ & $\begin{array}{l}\text { The mussel shells were } \\
\text { polished into an oblong } \\
\text { shape resembling a flat } \\
\text { button and the four corners } \\
\text { were perforated with an awl }\end{array}$ & $\begin{array}{l}\text { A minimal dissolution on } \\
\text { the shell plaques; the } \\
\text { plaques are fragmentary }\end{array}$ \\
\hline $\begin{array}{l}\text { Grave } 73 \\
56.11 .50 .5 \\
\text { Pl. XXXII. } 73 / 5\end{array}$ & $\begin{array}{l}92 \text { intact and } \\
6 \text { broken shell } \\
\text { beads, } 1 \text { stone bead }\end{array}$ & $\begin{array}{l}98 \text { limestone beads } \\
\text { and } 1 \text { stone bead }\end{array}$ & $\begin{array}{l}\text { The limestone beads were } \\
\text { polished into a cylindrical } \\
\text { shape and perforated with } \\
\text { an awl; one bead is disc } \\
\text { shaped }\end{array}$ & $\begin{array}{l}\text { Carbonate precipitation and } \\
\text { chemical alterations on the } \\
\text { limestone beads }\end{array}$ \\
\hline $\begin{array}{l}\text { Grave } 74 \\
56.11 .51 .1 \\
\text { Pl. XXXIII. } \\
74 / 1 a-1 b\end{array}$ & $\begin{array}{l}85 \text { shell beads and } \\
13 \text { shells }\end{array}$ & $\begin{array}{l}80 \text { limestone beads } \\
\text { and } 13 \text { Anadara } \\
\text { diluvii clam shells }\end{array}$ & $\begin{array}{l}\text { The stone beads were } \\
\text { polished into a cylindrical } \\
\text { shape and perforated with } \\
\text { an awl; green patina was } \\
\text { noted on } 3 \text { beads, } \\
\text { suggesting that they had } \\
\text { been strung together with } \\
\text { copper beads; the umbo of } \\
\text { the Anadara shells was } \\
\text { trimmed and polished }\end{array}$ & $\begin{array}{l}\text { Post-depositional } \\
\text { groundwater action; } \\
\text { carbonate precipitation and } \\
\text { chemical alterations on the } \\
\text { limestone beads and shells }\end{array}$ \\
\hline $\begin{array}{l}\text { Grave } 74 \\
56.11 .51 .2 \\
\text { Pl. XXXIII. } 74 / 2\end{array}$ & $\begin{array}{l}29 \text { Vermetus shells of } \\
\text { varying sizes }\end{array}$ & $\begin{array}{l}30 \text { Dentalium badense } \\
\text { shells }\end{array}$ & $\begin{array}{l}\text { The ends of the Dentalium } \\
\text { shells were trimmed and } \\
\text { polished }\end{array}$ & $\begin{array}{l}\text { Post-depositional ground- } \\
\text { water action; carbonate } \\
\text { precipitation and chemical } \\
\text { alterations on the shells }\end{array}$ \\
\hline
\end{tabular}

\footnotetext{
${ }_{5}^{5}$ The Dentalium shell can no longer be found.
} 


\begin{tabular}{|c|c|c|c|c|}
\hline $\begin{array}{l}\text { Grave } 80 \\
56.11 .54 .7 \\
P l . X X X V I I . \\
80 / 5 a-5 b\end{array}$ & $\begin{array}{l}4 \text { shell beads, } \\
4 \text { Dentalium shells, } \\
1 \text { broken and } 2 \text { intact } \\
\text { shells }\end{array}$ & $\begin{array}{l}4 \text { Dentalium badense } \\
\text { and } 5 \text { limestone } \\
\text { beads, } 1 \text { broken and } \\
3 \text { intact Unio crassus } \\
\text { mussels and } \\
2 \text { Anadara diluvii } \\
\text { clam shells }\end{array}$ & $\begin{array}{l}\text { The ends of the Dentalium } \\
\text { shells were trimmed and } \\
\text { polished; the umbo of the } \\
\text { Anadara shells was trimmed } \\
\text { and polished; the mussel } \\
\text { shells were polished into an } \\
\text { oblong shape }\end{array}$ & $\begin{array}{l}\text { Post-depositional } \\
\text { groundwater action; } \\
\text { carbonate precipitation and } \\
\text { chemical alterations on the } \\
\text { beads and shells }\end{array}$ \\
\hline $\begin{array}{l}\text { Grave } 82 \\
56.11 .55 .1 \\
\text { Pl. XXXVIII. } 82 / 1\end{array}$ & $\begin{array}{l}5 \text { Dentalium shells, } \\
1 \text { small, flat red bead } \\
\text { and } 29 \text { shell beads }\end{array}$ & $\begin{array}{l}1 \text { broken and } \\
5 \text { intact Dentalium } \\
\text { badense beads, } \\
28 \text { limestone beads, } \\
\text { and } 1 \text { fired clay bead }\end{array}$ & $\begin{array}{l}\text { The ends of the Dentalium } \\
\text { shells were trimmed and } \\
\text { polished; the limestone } \\
\text { beads were polished into a } \\
\text { cylindrical shape and } \\
\text { perforated with an awl }\end{array}$ & $\begin{array}{l}\text { Post-depositional } \\
\text { groundwater action; } \\
\text { carbonate precipitation and } \\
\text { chemical alterations on the } \\
\text { limestone and shell beads }\end{array}$ \\
\hline $\begin{array}{l}\text { Grave } 84 \\
56.11 .56 .3 \\
\text { Pl. XXXVIII. } \\
84 / 3 a-3 b\end{array}$ & $\begin{array}{l}41 \text { Dentalium shells, } \\
1 \text { red bead, } 1 \text { shell, } \\
1 \text { broken tubular } \\
\text { copper bead }\end{array}$ & $\begin{array}{l}40 \text { Dentalium badense } \\
\text { beads and } 1 \text { Anadara } \\
\text { diluvii clam shell }\end{array}$ & $\begin{array}{l}\text { The ends of the Dentalium } \\
\text { shells were trimmed and } \\
\text { polished; the umbo of the } \\
\text { Anadara shells was trimmed } \\
\text { and polished }\end{array}$ & $\begin{array}{l}\text { Post-depositional } \\
\text { groundwater action; } \\
\text { carbonate precipitation and } \\
\text { chemical alterations on the } \\
\text { shells }\end{array}$ \\
\hline $\begin{array}{l}\text { Grave } 84 \\
56.11 .56 .4 \\
\text { Pl. XXXVIII. } 84 / 4\end{array}$ & $\begin{array}{l}14 \text { broken, oblong } \\
\text { shell plaques with a } \\
\text { pair of perforations } \\
\text { along the short sides }\end{array}$ & $\begin{array}{l}14 \text { Unio crassus } \\
\text { mussel plaques }\end{array}$ & $\begin{array}{l}\text { The mussel shells were } \\
\text { polished into an oblong } \\
\text { shape resembling a button } \\
\text { and the four corners were } \\
\text { perforated with an awl }\end{array}$ & $\begin{array}{l}\text { A minimal dissolution on } \\
\text { the mussel plaques; the } \\
\text { corners broke away at the } \\
\text { perforation on some } \\
\text { plaques; fragmentary } \\
\text { plaques }\end{array}$ \\
\hline $\begin{array}{l}\text { Grave } 88 \\
56.11 .58 .2 \\
\text { Pl. XXXIX. } 88 / 2\end{array}$ & $\begin{array}{l}10 \text { shell beads of } \\
\text { varying sizes }\end{array}$ & 10 limestone beads & $\begin{array}{l}\text { The limestone beads were } \\
\text { polished into a cylindrical } \\
\text { shape and perforated with } \\
\text { an awl }\end{array}$ & $\begin{array}{l}\text { Carbonate precipitation and } \\
\text { chemical alterations on the } \\
\text { beads }\end{array}$ \\
\hline $\begin{array}{l}\text { Grave } 90 \\
56.11 .59 .1 \\
\text { Pl. XL. } 90 / 1\end{array}$ & $\begin{array}{l}6 \text { shell beads of } \\
\text { varying sizes }\end{array}$ & 6 limestone beads & $\begin{array}{l}\text { The limestone beads were } \\
\text { polished into a cylindrical } \\
\text { shape and perforated with } \\
\text { an awl }\end{array}$ & $\begin{array}{l}\text { Carbonate precipitation and } \\
\text { chemical alterations on the } \\
\text { beads }\end{array}$ \\
\hline $\begin{array}{l}\text { Grave } 94 \\
56.11 .61 .1 \\
\text { Pl. XL. } 94 / 2\end{array}$ & $\begin{array}{l}3 \text { broken shells and } \\
1 \text { Dentalium bead }\end{array}$ & $\begin{array}{l}1 \text { Dentalium badense } \\
\text { shell and } 2 \text { Unio } \\
\text { crassus mussel shells }\end{array}$ & $\begin{array}{l}\text { The umbo of the complete } \\
\text { pair and the single right } \\
\text { Unio crassus valves were } \\
\text { perforated; the ends of the } \\
\text { Dentalium shell were } \\
\text { trimmed and polished }\end{array}$ & $\begin{array}{l}\text { Carbonate precipitation and } \\
\text { chemical alterations on the } \\
\text { shells; strong dissolution on } \\
\text { the Unio crassus shells }\end{array}$ \\
\hline $\begin{array}{l}\text { Grave } 94 \\
61.2 .180 \\
\text { Pl. XL. } 94 / 1 a-1 b\end{array}$ & $\begin{array}{l}43 \text { sliced shell beads, } \\
4 \text { Vermetus shells } \\
\text { and } 3 \text { river mussels }\end{array}$ & $\begin{array}{l}3 \text { Unio crassus mussel } \\
\text { shells, } 4 \text { Dentalium } \\
\text { badense shells and } \\
39 \text { limestone beads }\end{array}$ & $\begin{array}{l}\text { The stone beads were } \\
\text { polished into a cylindrical } \\
\text { shape and perforated with } \\
\text { an awl; the ends of the } \\
\text { Dentalium shells were } \\
\text { trimmed and polished; the } \\
\text { umbo of the Unio crassus } \\
\text { valves was perforated }\end{array}$ & $\begin{array}{l}\text { Carbonate precipitation and } \\
\text { chemical alterations on the } \\
\text { limestone beads; boring } \\
\text { sponge traces and the } \\
\text { borehole of a Natica snail on } \\
\text { the Dentalium shells; } \\
\text { "healed" mechanical } \\
\text { damage }\end{array}$ \\
\hline $\begin{array}{l}\text { Grave } 95 \\
56.11 .62 .3 \\
\text { Pl. XLIII. } 95 / 3\end{array}$ & $\begin{array}{l}108 \text { sliced shell } \\
\text { beads of roughly } \\
\text { equal sizes, with } \\
\text { ochre stains on } \\
\text { some beads }\end{array}$ & $\begin{array}{l}107 \text { limestone beads } \\
\text { and } 1 \text { bead polished } \\
\text { from Unio cf. crassus }\end{array}$ & $\begin{array}{l}\text { The limestone beads were } \\
\text { polished into a cylindrical } \\
\text { shape and perforated with } \\
\text { an awl; } 3 \text { beads were } \\
\text { painted red }\end{array}$ & $\begin{array}{l}\text { Carbonate precipitation and } \\
\text { chemical alterations on the } \\
\text { limestone beads }\end{array}$ \\
\hline $\begin{array}{l}\text { Grave } 95 \\
56.11 .62 .4 \\
\text { Pl. XLIII. } 95 / 4 \\
\end{array}$ & $\begin{array}{l}7 \text { intact and } \\
4 \text { broken perforated } \\
\text { shells }\end{array}$ & $\begin{array}{l}9 \text { intact and } \\
3 \text { broken } \text { Anadara } \\
\text { diluvii clam shells }\end{array}$ & $\begin{array}{l}\text { The umbo of } 9 \text { Anadara } \\
\text { diluvii shells was trimmed } \\
\text { and polished }\end{array}$ & $\begin{array}{l}\text { Carbonate precipitation and } \\
\text { chemical alterations on the } \\
\text { shells }\end{array}$ \\
\hline $\begin{array}{l}\text { Grave } 96 \\
56.11 .63 .1 \\
\text { Pl. XLIV. } 96 / 1 \\
\end{array}$ & $\begin{array}{l}1 \text { broken, badly } \\
\text { preserved shell }\end{array}$ & $\begin{array}{l}1 \text { broken Anadara } \\
\text { diluvii clam shell }\end{array}$ & $\begin{array}{l}\text { The Anadara diluvii shell } \\
\text { was perforated }\end{array}$ & $\begin{array}{l}\text { Carbonate precipitation and } \\
\text { chemical alterations on the } \\
\text { shell }\end{array}$ \\
\hline $\begin{array}{l}\text { Grave } 98 \\
56.11 .64 .1 \\
\text { Pl. XLIV. } 98 / 1\end{array}$ & 1 perforated shell & $\begin{array}{l}1 \text { Anadara diluvii } \\
\text { clam shell }\end{array}$ & $\begin{array}{l}\text { The umbo of the Anadara } \\
\text { shell was trimmed and } \\
\text { polished }\end{array}$ & $\begin{array}{l}\text { Carbonate precipitation and } \\
\text { chemical alterations on the } \\
\text { shell }\end{array}$ \\
\hline Grave 100 & 1 broken and & 92 limestone beads & The limestone beads were & Carbonate precipitation and \\
\hline
\end{tabular}


Table 1 (cont'd)

\begin{tabular}{|c|c|c|c|c|}
\hline Grave & $\begin{array}{l}\text { Description in the } \\
\text { inventory book }\end{array}$ & New description & $\begin{array}{l}\text { Anthropogenic } \\
\text { changes }\end{array}$ & $\begin{array}{c}\text { Traces of mechanical, } \\
\text { chemical and } \\
\text { biological erosion }\end{array}$ \\
\hline $\begin{array}{l}\text { 72.3.3a } \\
P l . X L V .100 / 1\end{array}$ & $\begin{array}{l}92 \text { intact Dentalium } \\
\text { beads, most with a } \\
\text { greyish-black burnt } \\
\text { surface }\end{array}$ & & $\begin{array}{l}\text { polished into a cylindrical } \\
\text { shape and perforated with } \\
\text { an awl; the beads were not } \\
\text { burnt, but covered with a } \\
\text { greyish carbonate } \\
\text { precipitation owing to the } \\
\text { groundwater }\end{array}$ & $\begin{array}{l}\text { chemical alterations on the } \\
\text { beads }\end{array}$ \\
\hline $\begin{array}{l}\text { Grave } 100 \\
72.3 .3 \mathrm{~b} \\
P l . X L V .100 / 3\end{array}$ & $\begin{array}{l}1 \text { broken, } \\
\text { unperforated and } \\
9 \text { intact perforated } \\
\text { shells }\end{array}$ & $\begin{array}{l}15 \text { Anadara diluvii } \\
\text { clam shells, } 10 \text { with } \\
\text { the umbo still } \\
\text { visible, the rest } \\
\text { broken }\end{array}$ & $\begin{array}{l}\text { The umbo of ten Anadara } \\
\text { shells was trimmed and } \\
\text { polished }\end{array}$ & - \\
\hline $\begin{array}{l}\text { Grave } 100 \\
72.3 .3 \mathrm{c} \\
P l . X L V .100 / 2\end{array}$ & $\begin{array}{l}9 \text { more or less intact } \\
\text { and } 8 \text { broken shell } \\
\text { beads }\end{array}$ & $\begin{array}{l}21 \text { Dentalium badense } \\
\text { shells with burnt } \\
\text { surface }\end{array}$ & $\begin{array}{l}\text { The ends of the Dentalium } \\
\text { shells were trimmed and } \\
\text { polished; all had a burnt } \\
\text { surface }\end{array}$ & - \\
\hline $\begin{array}{l}\text { Grave } 106 \\
56.11 .67 .1 \\
\text { Pl. XLVI. } 106 / 1\end{array}$ & $\begin{array}{l}4 \text { broken, perforated } \\
\text { shells }\end{array}$ & $\begin{array}{l}\text { 4 Anadara diluvii } \\
\text { clam shells, } 3 \text { with } \\
\text { the umbo still } \\
\text { present, one broken }\end{array}$ & $\begin{array}{l}\text { The umbo of } 3 \text { Anadara } \\
\text { shells was trimmed and } \\
\text { polished }\end{array}$ & - \\
\hline $\begin{array}{l}\text { Grave } 111 \\
56.11 .69 .1 \\
\text { Pl. XLVIII. } 111 / 1\end{array}$ & $\begin{array}{l}1 \text { Dentalium shell } \\
\text { and } 2 \text { shell beads }\end{array}$ & $\begin{array}{l}1 \text { Dentalium badense } \\
\text { and } 2 \text { limestone } \\
\text { beads }\end{array}$ & $\begin{array}{l}\text { Copper patina could be } \\
\text { noted on the end of the } \\
\text { Dentalium badense bead; the } \\
\text { limestone beads were } \\
\text { polished into a cylindrical } \\
\text { shape and perforated with } \\
\text { an awl }\end{array}$ & $\begin{array}{l}\text { Post-depositional } \\
\text { groundwater action; } \\
\text { carbonate precipitation and } \\
\text { chemical alterations on the } \\
\text { limestone and shell beads }\end{array}$ \\
\hline $\begin{array}{l}\text { Grave } 111 \\
56.11 .69 .2 \\
\text { Pl. XLVIII. } 111 / 2 \\
\end{array}$ & $\begin{array}{l}10 \text { perforated shells, } \\
\text { some broken }\end{array}$ & $\begin{array}{l}9 \text { Anadara diluvii } \\
\text { clam shells }\end{array}$ & $\begin{array}{l}\text { The umbo of the Anadara } \\
\text { shells was trimmed and } \\
\text { polished }\end{array}$ & The shells were fragmented \\
\hline $\begin{array}{l}\text { Grave } 111 \\
56.11 .69 .5 \\
\text { Pl. XLVIII. } 111 / 5\end{array}$ & $\begin{array}{l}\text { Large, broken } \\
\text { Ostrea shell with two } \\
\text { perforations at } \\
\text { either end }\end{array}$ & $\begin{array}{l}1 \text { broken, thick- } \\
\text { walled Pecten scallop } \\
\text { shell }\end{array}$ & $\begin{array}{l}\text { The shell was polished and } \\
\text { perforated at both ends }\end{array}$ & The shell was fragmented \\
\hline $\begin{array}{l}\text { Grave } 113 \\
56.11 .71 .1 \\
\text { Pl. XLVIII. } 113 / 1\end{array}$ & $\begin{array}{l}4 \text { intact and } 2 \text { sliced } \\
\text { Dentalium shells, } \\
1 \text { broken and } \\
12 \text { intact shell beads, } \\
\text { and } 1 \text { marble bead }\end{array}$ & $\begin{array}{l}7 \text { Dentalium badense } \\
\text { and } 12 \text { limestone } \\
\text { beads }\end{array}$ & $\begin{array}{l}\text { The ends of the Dentalium } \\
\text { shells were trimmed and } \\
\text { polished; the limestone } \\
\text { beads were polished into a } \\
\text { cylindrical shape and } \\
\text { perforated with an awl }\end{array}$ & $\begin{array}{l}\text { Carbonate precipitation and } \\
\text { chemical alterations on the } \\
\text { limestone and shell beads }\end{array}$ \\
\hline $\begin{array}{l}\text { Grave } 113 \\
56.11 .71 .3 \\
\text { Pl. XL VIII. } 113 / 3\end{array}$ & $\begin{array}{l}3 \text { Dentalium shells } \\
\text { and } 4 \text { long, broken } \\
\text { copper beads }\end{array}$ & $\begin{array}{l}3 \text { Dentalium badense } \\
\text { beads }\end{array}$ & $\begin{array}{l}\text { Two Dentalium beads had } \\
\text { Dentalium shaped tubular } \\
\text { copper beads slipped onto } \\
\text { them, one had a copper } \\
\text { bead slipped inside it }\end{array}$ & - \\
\hline $\begin{array}{l}\text { Grave } 117 \\
61 \cdot 2 \cdot 2 \cdot 3 \\
\text { Pl. L. } 117 / 3\end{array}$ & $\begin{array}{l}\text { Broken oblong shell } \\
\text { plaque with a pair of } \\
\text { tiny round } \\
\text { perforations along } \\
\text { the short sides }\end{array}$ & $\begin{array}{l}1 \text { Unio crassus } \text { mussel } \\
\text { plaque }\end{array}$ & $\begin{array}{l}\text { The mussel shell was } \\
\text { polished into an oblong } \\
\text { shape resembling a flat } \\
\text { button and the four corners } \\
\text { were perforated with an awl }\end{array}$ & - \\
\hline $\begin{array}{l}\text { Grave } 123 \\
61.2 .4 .1 \\
\text { Pl. LIII. } 123 / 1\end{array}$ & $\begin{array}{l}40 \text { cylindrical sliced } \\
\text { shell beads of } \\
\text { varying sizes and } \\
1 \text { Vermetus shell }\end{array}$ & $\begin{array}{l}1 \text { Dentalium badense } \\
\text { and } 40 \text { limestone } \\
\text { beads }\end{array}$ & $\begin{array}{l}\text { The ends of the Dentalium } \\
\text { shell were trimmed and } \\
\text { polished; the limestone } \\
\text { beads were polished into a } \\
\text { cylindrical shape and } \\
\text { perforated with an awl }\end{array}$ & $\begin{array}{l}\text { Carbonate precipitation and } \\
\text { chemical alterations on the } \\
\text { limestone and shell beads }\end{array}$ \\
\hline Grave 127 & 22 broken oblong & 20 Unio crassus & The mussel shells were & A minimal dissolution on \\
\hline
\end{tabular}




\begin{tabular}{|c|c|c|c|c|}
\hline $\begin{array}{l}\text { 61.2.6.1 } \\
\text { Pl. LV. } 127 / 1\end{array}$ & shell plaques & mussel plaques & $\begin{array}{l}\text { polished into an oblong } \\
\text { shape resembling a flat } \\
\text { button and the four corners } \\
\text { were perforated with an awl }\end{array}$ & $\begin{array}{l}\text { the mussel plaques; the } \\
\text { corners broke away at the } \\
\text { perforation on some } \\
\text { plaques; the plaques are } \\
\text { fragmentary }\end{array}$ \\
\hline $\begin{array}{l}\text { Grave } 127 \\
61.2 .6 .2 \\
\text { Pl. LV. } 127 / 2\end{array}$ & $\begin{array}{l}57 \text { Dentalium shells, } \\
4 \text { small white shell } \\
\text { beads and } 4 \text { red clay } \\
\text { beads }\end{array}$ & $\begin{array}{l}56 \text { Dentalium badense } \\
\text { beads, } 4 \text { red, fired } \\
\text { clay beads, } 2 \text { longish } \\
\text { and } 2 \text { round } \\
\text { limestone beads }\end{array}$ & $\begin{array}{l}\text { The ends of the Dentalium } \\
\text { shells were trimmed and } \\
\text { polished; the limestone } \\
\text { beads were polished into a } \\
\text { cylindrical shape and } \\
\text { perforated with an awl }\end{array}$ & $\begin{array}{l}\text { Carbonate precipitation and } \\
\text { chemical alterations on the } \\
\text { limestone and shell beads }\end{array}$ \\
\hline $\begin{array}{l}\text { Grave } 127 \\
61.2 .6 .3 \\
\text { Pl. LV. } 127 / 3 a-3 b\end{array}$ & $\begin{array}{l}33 \text { shell beads, } 1 \text { red } \\
\text { clay bead and } 3 \\
\text { perforated shells }\end{array}$ & $\begin{array}{l}2 \text { Dentalium badense } \\
\text { and } 31 \text { limestone } \\
\text { beads, } 1 \text { clay bead } \\
\text { and } 3 \text { Anadara } \\
\text { diluvii clam shells }\end{array}$ & $\begin{array}{l}\text { The ends of the Dentalium } \\
\text { shells were trimmed and } \\
\text { polished; the limestone } \\
\text { beads were polished into a } \\
\text { cylindrical shape and } \\
\text { perforated with an awl; the } \\
\text { umbo of the Anadara shells } \\
\text { was trimmed and polished }\end{array}$ & $\begin{array}{l}\text { Carbonate precipitation and } \\
\text { chemical alterations on the } \\
\text { limestone beads and the } \\
\text { shells }\end{array}$ \\
\hline $\begin{array}{l}\text { Grave } 128 \\
61.2 .7 .1 \\
\text { Pl. LVI. } 128 / 1 b\end{array}$ & $\begin{array}{l}142 \text { sliced shell } \\
\text { beads and } 16 \\
\text { perforated shells }\end{array}$ & $\begin{array}{l}142 \text { limestone beads } \\
\text { and } 12 \text { Anadara } \\
\text { diluvii clam shells }\end{array}$ & $\begin{array}{l}\text { The limestone beads were } \\
\text { polished into a cylindrical } \\
\text { shape and perforated with } \\
\text { an awl; the umbo of the } \\
\text { Anadara shells was trimmed } \\
\text { and polished }\end{array}$ & $\begin{array}{l}\text { Carbonate precipitation and } \\
\text { chemical alterations on the } \\
\text { limestone beads and the } \\
\text { shells }\end{array}$ \\
\hline $\begin{array}{l}\text { Grave } 129 \\
61.2 .8 .1 \\
\text { Pl. LVII. } 129 / 1\end{array}$ & $\begin{array}{l}3 \text { sliced shell beads } \\
\text { and } 3 \text { perforated } \\
\text { Unio shells }\end{array}$ & $\begin{array}{l}3 \text { stone beads and } \\
3 \text { Anadara diluvii } \\
\text { shells perforated } \\
\text { through the umbo }\end{array}$ & $\begin{array}{l}\text { The limestone beads were } \\
\text { polished into a cylindrical } \\
\text { shape and perforated with } \\
\text { an awl; the umbo of the } \\
\text { Anadara shells was trimmed } \\
\text { and polished }\end{array}$ & $\begin{array}{l}\text { Carbonate precipitation and } \\
\text { chemical alterations on the } \\
\text { limestone beads and the } \\
\text { shells }\end{array}$ \\
\hline $\begin{array}{l}\text { Grave } 130 \\
61.2 \cdot 9.2 \\
\text { Pl. LIV. } 130 / 2\end{array}$ & $\begin{array}{l}5 \text { cylindrical sliced } \\
\text { shell beads }\end{array}$ & 5 limestone beads & $\begin{array}{l}\text { The limestone beads were } \\
\text { polished into a cylindrical } \\
\text { shape and perforated with } \\
\text { an awl }\end{array}$ & $\begin{array}{l}\text { Carbonate precipitation and } \\
\text { chemical alterations on the } \\
\text { beads }\end{array}$ \\
\hline $\begin{array}{l}\text { Grave } 136 \\
61.2 .14 .3 \\
\text { Pl. LX. } 136 / 3\end{array}$ & $\begin{array}{l}1 \text { broken and } \\
4 \text { intact sliced shell } \\
\text { beads }\end{array}$ & 4 limestone beads & $\begin{array}{l}\text { The limestone beads were } \\
\text { polished into a cylindrical } \\
\text { shape and perforated with } \\
\text { an awl }\end{array}$ & $\begin{array}{l}\text { Carbonate precipitation and } \\
\text { chemical alterations on the } \\
\text { beads }\end{array}$ \\
\hline $\begin{array}{l}\text { Grave } 137 \\
61.2 \cdot 15 \\
\text { Pl. LIV. } 137 / 1\end{array}$ & $\begin{array}{l}1 \text { Dentalium shell } \\
\text { and } 1 \text { shell }\end{array}$ & $\begin{array}{l}1 \text { Dentalium badense } \\
\text { shell and } \\
1 \text { limestone bead }\end{array}$ & $\begin{array}{l}\text { The ends of the Dentalium } \\
\text { shells were trimmed and } \\
\text { polished; the limestone bead } \\
\text { was perforated with an awl }\end{array}$ & $\begin{array}{l}\text { Carbonate precipitation and } \\
\text { chemical alterations on the } \\
\text { limestone beads }\end{array}$ \\
\hline $\begin{array}{l}\text { Grave } 138 \\
61.2 \cdot 16.2 \\
\text { Pl. LX. } 138 / 2 a-2 b\end{array}$ & $\begin{array}{l}15 \text { sliced shell beads } \\
\text { and } 5 \text { perforated } \\
\text { shells of varying } \\
\text { sizes }\end{array}$ & $\begin{array}{l}15 \text { limestone beads, } \\
4 \text { Anadara diluvii } \\
\text { shells and } 1 \text { fossil } \\
\text { Spondylus fragment }\end{array}$ & $\begin{array}{l}\text { The limestone beads were } \\
\text { polished into a cylindrical } \\
\text { shape and perforated with } \\
\text { an awl; the umbo of the } \\
\text { Anadara shells was trimmed } \\
\text { and polished; the Spondylus } \\
\text { was polished and perforated } \\
\text { in at least three spots }\end{array}$ & $\begin{array}{l}\text { Carbonate precipitation and } \\
\text { chemical alterations on the } \\
\text { limestone beads; no traces } \\
\text { of chemical or biogenic } \\
\text { erosion on the polished } \\
\text { Spondylus fragment }\end{array}$ \\
\hline $\begin{array}{l}\text { Grave } 139 \\
61.2 .17 \\
\text { Pl. LVII. } 139 / 1 \\
\end{array}$ & 1 river mussel valve & $\begin{array}{l}\text { Left valve of an Unio } \\
\text { crassus mussel }\end{array}$ & A broken mussel shell & $\begin{array}{l}\text { The tip was damaged } \\
\text { during lifting or handling } \\
\text { during storage }\end{array}$ \\
\hline $\begin{array}{l}\text { Grave } 145 \\
61.2 .21 \\
\text { Pl. LXII. } 145 / 2\end{array}$ & $\begin{array}{l}20 \text { large sliced shell } \\
\text { beads of varying } \\
\text { sizes }\end{array}$ & 20 limestone beads & $\begin{array}{l}\text { The limestone beads were } \\
\text { polished into a cylindrical } \\
\text { shape and perforated with } \\
\text { an awl }\end{array}$ & $\begin{array}{l}\text { Carbonate precipitation and } \\
\text { chemical alterations on the } \\
\text { beads }\end{array}$ \\
\hline $\begin{array}{l}\text { Grave } 148 \\
61.2 .23 .2 \\
\text { Pl. LXIII. } 148 / 2\end{array}$ & $\begin{array}{l}26 \text { sliced shell beads } \\
\text { of varying sizes }\end{array}$ & 26 limestone beads & $\begin{array}{l}\text { The limestone beads were } \\
\text { polished into a cylindrical } \\
\text { shape and perforated with } \\
\text { an awl }\end{array}$ & $\begin{array}{l}\text { Carbonate precipitation and } \\
\text { chemical alterations on the } \\
\text { beads }\end{array}$ \\
\hline
\end{tabular}


Table 1 (cont'd)

\begin{tabular}{|c|c|c|c|c|}
\hline Grave & $\begin{array}{l}\text { Description in the } \\
\text { inventory book }\end{array}$ & New description & $\begin{array}{l}\text { Anthropogenic } \\
\text { changes }\end{array}$ & $\begin{array}{c}\text { Traces of mechanical, } \\
\text { chemical and } \\
\text { biological erosion }\end{array}$ \\
\hline $\begin{array}{l}\text { Grave } 148 \\
61.2 .23 .3 \\
\text { Pl. LXIII. } 148 / 3\end{array}$ & $\begin{array}{l}\text { Broken oblong } \\
8 \text { shell plaques }\end{array}$ & $\begin{array}{l}8 \text { Unio crassus mussel } \\
\text { plaques }\end{array}$ & $\begin{array}{l}\text { The mussel shells were } \\
\text { polished into an oblong } \\
\text { shape resembling a flat } \\
\text { button and the four corners } \\
\text { were perforated with an awl }\end{array}$ & $\begin{array}{l}\text { A minimal dissolution on } \\
\text { the mussel plaques; the } \\
\text { corners broke away at the } \\
\text { perforation on some } \\
\text { plaques; the plaques are } \\
\text { fragmentary }\end{array}$ \\
\hline $\begin{array}{l}\text { Grave } 155 \\
61.2 .25 .4 \\
\text { Pl. LXV. } 155 / 4 \\
\end{array}$ & $\begin{array}{l}10 \text { small Vermetus } \\
\text { shells }\end{array}$ & $\begin{array}{l}10 \text { Dentalium badense } \\
\text { beads }\end{array}$ & $\begin{array}{l}\text { The ends of the Dentalium } \\
\text { shells were trimmed and } \\
\text { polished }\end{array}$ & $\begin{array}{l}\text { Carbonate precipitation and } \\
\text { chemical alterations on the } \\
\text { Dentalium beads }\end{array}$ \\
\hline $\begin{array}{l}\text { Grave } 158 \\
61.2 .27 .4 \\
\text { Pl. LXVI. } 158 / 4\end{array}$ & $\begin{array}{l}1 \text { broken and } \\
34 \text { intact sliced shell } \\
\text { beads of varying } \\
\text { sizes }\end{array}$ & 35 limestone beads & $\begin{array}{l}\text { The limestone beads were } \\
\text { polished into a cylindrical } \\
\text { shape and perforated with } \\
\text { an awl }\end{array}$ & $\begin{array}{l}\text { Carbonate precipitation and } \\
\text { chemical alterations on the } \\
\text { beads, ferrous patches from } \\
\text { groundwater on some pieces }\end{array}$ \\
\hline $\begin{array}{l}\text { Grave } 160 \\
61.2 .28 .2 \\
\text { Pl. LXVII. } 160 / 2\end{array}$ & $\begin{array}{l}39 \text { sliced shell beads } \\
\text { of varying sizes }\end{array}$ & 39 limestone beads & $\begin{array}{l}\text { The limestone beads were } \\
\text { polished into a cylindrical } \\
\text { shape and perforated with } \\
\text { an awl }\end{array}$ & $\begin{array}{l}\text { Carbonate precipitation and } \\
\text { chemical alterations on the } \\
\text { beads }\end{array}$ \\
\hline $\begin{array}{l}\text { Grave } 160 \\
(61.2 .28 .3) \\
(\text { Pl. LXVII. 160/3) }\end{array}$ & $\begin{array}{l}10 \text { oblong shell } \\
\text { plaques }\end{array}$ & $\begin{array}{l}10 \text { Unio crassus } \\
\text { mussel plaques }\end{array}$ & $\begin{array}{l}\text { The mussel shells were } \\
\text { polished into an oblong } \\
\text { shape resembling a flat } \\
\text { button and the four corners } \\
\text { were perforated with an awl }\end{array}$ & $\begin{array}{l}\text { A minimal dissolution on } \\
\text { the shell plaques; the } \\
\text { corners broke away at the } \\
\text { perforation on some } \\
\text { plaques; the plaques are } \\
\text { fragmentary }\end{array}$ \\
\hline $\begin{array}{l}\text { Grave } 164 \\
61.2 .30 .12 \\
\text { Pl. } L X X .164 / 13\end{array}$ & $\begin{array}{l}2 \text { Vermetus shells, } \\
2 \text { sliced Dentalium } \\
\text { shells, } 2 \text { sliced shell } \\
\text { beads and } 1 \text { broken } \\
\text { tubular copper bead }\end{array}$ & $\begin{array}{l}2 \text { sliced Dentalium } \\
\text { badense and } \\
4 \text { limestone beads }\end{array}$ & $\begin{array}{l}\text { The ends of the Dentalium } \\
\text { shells were trimmed and } \\
\text { polished; the limestone } \\
\text { beads were perforated with } \\
\text { an awl }\end{array}$ & $\begin{array}{l}\text { Carbonate precipitation and } \\
\text { chemical alterations on the } \\
\text { limestone and shell beads }\end{array}$ \\
\hline $\begin{array}{l}\text { Grave } 170 \\
61.2 .31 .2 \\
\text { Pl. LXXII. } 170 / 2\end{array}$ & Red clay bead & 1 fired clay bead & - & - \\
\hline $\begin{array}{l}\text { Grave } 171 \\
61.2 .32 .2 \\
\text { Pl. LXXII. } 171 / 2\end{array}$ & $\begin{array}{l}\text { Large, well } \\
\text { preserved river } \\
\text { mussel }\end{array}$ & 1 Unio crassus mussel & $\begin{array}{l}\text { The umbo of the intact } \\
\text { right valve of the Unio } \\
\text { crassus mussel was } \\
\text { perforated }\end{array}$ & $\begin{array}{l}\text { Traces of dissolution on the } \\
\text { shell, perhaps owing to an } \\
\text { acidic or thermal water } \\
\text { habitat }\end{array}$ \\
\hline $\begin{array}{l}\text { Grave } 174 \\
61.2 .33 .4 \\
\text { Pl. LXXIII. } 174 / 4\end{array}$ & $\begin{array}{l}14 \text { Dentalium and } \\
\text { Vermetus beads, } \\
5 \text { broken tubular } \\
\text { copper beads }\end{array}$ & $\begin{array}{l}14 \text { Dentalium } \\
\text { badense beads and } \\
1 \text { limestone bead }\end{array}$ & $\begin{array}{l}\text { The ends of the Dentalium } \\
\text { shells were trimmed and } \\
\text { polished }\end{array}$ & $\begin{array}{l}\text { Carbonate precipitation and } \\
\text { chemical alterations on the } \\
\text { Dentalium beads }\end{array}$ \\
\hline $\begin{array}{l}\text { Grave } 174 \\
61.2 .33 .5 \\
\text { Pl. LXXIII. } 174 / 5\end{array}$ & $\begin{array}{l}1 \text { Dentalium shell } \\
\text { and } 1 \text { broken, } \\
\text { tubular copper bead } \\
\text { slipped inside the } \\
\text { Dentalium shell }\end{array}$ & $\begin{array}{l}1 \text { Dentalium badense } \\
\text { shell }\end{array}$ & $\begin{array}{l}\text { The ends of the Dentalium } \\
\text { shell were trimmed and } \\
\text { polished }\end{array}$ & $\begin{array}{l}\text { Carbonate precipitation and } \\
\text { chemical alterations on the } \\
\text { bead }\end{array}$ \\
\hline $\begin{array}{l}\text { Grave } 180 \\
61.2 .37 .1 \\
P l . L X X I V .180 / 1\end{array}$ & 1 river mussel valve & $\begin{array}{l}\text { Left valve of an Unio } \\
\text { crassus mussel }\end{array}$ & $\begin{array}{l}\text { The broken mussel shell } \\
\text { was perforated }\end{array}$ & $\begin{array}{l}\text { Traces of dissolution on the } \\
\text { mussel shell, perhaps owing } \\
\text { to an acidic or thermal } \\
\text { water habitat }\end{array}$ \\
\hline $\begin{array}{l}\text { Grave } 181 \\
61.2 .38 .1 \\
P l . L X X V .181 / 2\end{array}$ & $\begin{array}{l}5 \text { sliced Dentalium } \\
\text { shells and } 2 \text { sliced } \\
\text { shell beads }\end{array}$ & $\begin{array}{l}6 \text { Dentalium badense } \\
\text { beads and } \\
1 \text { limestone bead }\end{array}$ & $\begin{array}{l}\text { The ends of the Dentalium } \\
\text { shells were trimmed and } \\
\text { polished; the limestone } \\
\text { bead was polished into a } \\
\text { cylindrical shape and } \\
\text { perforated with an awl }\end{array}$ & $\begin{array}{l}\text { Carbonate precipitation and } \\
\text { chemical alterations on the } \\
\text { shell and stone beads }\end{array}$ \\
\hline $\begin{array}{l}\text { Grave } 183 \\
61.2 .40 .2 \\
\text { Pl. LXXVII. } 2 a-2 b\end{array}$ & $\begin{array}{l}11 \text { sliced shell beads } \\
\text { of varying sizes and } \\
2 \text { broken oblong }\end{array}$ & $\begin{array}{l}11 \text { limestone beads } \\
\text { and } 2 \text { Unio crassus } \\
\text { mussel plaques }\end{array}$ & $\begin{array}{l}\text { The limestone beads were } \\
\text { polished into a cylindrical } \\
\text { shape and perforated with }\end{array}$ & $\begin{array}{l}\text { Carbonate precipitation and } \\
\text { chemical alterations on the } \\
\text { limestone beads; a minimal }\end{array}$ \\
\hline
\end{tabular}




\begin{tabular}{|c|c|c|c|c|}
\hline & shell plaques & & $\begin{array}{l}\text { an awl; the mussel shells } \\
\text { were polished into an } \\
\text { oblong shape resembling a } \\
\text { flat button and the four } \\
\text { corners were perforated } \\
\text { with an awl }\end{array}$ & $\begin{array}{l}\text { dissolution on the mussel } \\
\text { plaques; the corners broke } \\
\text { away at the perforation on } \\
\text { some plaques; the plaques } \\
\text { are fragmentary }\end{array}$ \\
\hline $\begin{array}{l}\text { Grave } 190 \\
61.2 .43 \\
\text { Pl. LXXX. 190/1 }\end{array}$ & $\begin{array}{l}7 \text { oblong shell } \\
\text { plaques with a pair } \\
\text { of tiny round } \\
\text { perforations along } \\
\text { the short sides }\end{array}$ & $\begin{array}{l}6 \text { Unio crassus mussel } \\
\text { plaques }\end{array}$ & $\begin{array}{l}\text { The mussel shells were } \\
\text { polished into an oblong } \\
\text { shape resembling a flat } \\
\text { button and the four corners } \\
\text { were perforated with an awl }\end{array}$ & $\begin{array}{l}\text { A minimal dissolution on } \\
\text { the mussel plaques; the } \\
\text { corners broke away at the } \\
\text { perforation on the plaques; } \\
\text { all the plaques are broken }\end{array}$ \\
\hline $\begin{array}{l}\text { Grave } 194 \\
61.2 .46 .2 \\
\text { Pl. LXXXI. 194/6 }\end{array}$ & $\begin{array}{l}\text { Short, cylindrical } \\
\text { sliced shell bead }\end{array}$ & 1 limestone bead & $\begin{array}{l}\text { The limestone bead was } \\
\text { polished into a cylindrical } \\
\text { shape and perforated with } \\
\text { an awl }\end{array}$ & $\begin{array}{l}\text { Carbonate precipitation and } \\
\text { chemical alterations on the } \\
\text { bead }\end{array}$ \\
\hline $\begin{array}{l}\text { Grave } 194 \\
61.2 .46 .3 \\
\text { Pl. LXXXI. 194/7 }\end{array}$ & $\begin{array}{l}4 \text { Dentalium shells } \\
\text { and } 1 \text { sliced shell } \\
\text { bead }\end{array}$ & $\begin{array}{l}1 \text { limestone and } \\
4 \text { Dentalium badense } \\
\text { beads }\end{array}$ & $\begin{array}{l}\text { The ends of the Dentalium } \\
\text { shells were trimmed and } \\
\text { polished; the limestone } \\
\text { bead was polished into a } \\
\text { cylindrical shape and } \\
\text { perforated with an awl }\end{array}$ & $\begin{array}{l}\text { Carbonate precipitation and } \\
\text { chemical alterations on the } \\
\text { shell and stone beads }\end{array}$ \\
\hline $\begin{array}{l}\text { Grave } 206 \\
61.2 .52\end{array}$ & $\begin{array}{l}7 \text { oblong shell } \\
\text { plaques }\end{array}$ & $\begin{array}{l}7 \text { broken Unio } \\
\text { crassus mussel } \\
\text { plaques }\end{array}$ & $\begin{array}{l}\text { The corners of the mussel } \\
\text { plaques broke off }\end{array}$ & $\begin{array}{l}\text { Broken, probably damaged } \\
\text { by handling during storage }\end{array}$ \\
\hline $\begin{array}{l}\text { Grave } 216 \\
61.2 .58 .3 \\
\text { Pl. XCII. } 216 / 3\end{array}$ & $\begin{array}{l}8 \text { sliced shell beads } \\
\text { of varying sizes, } \\
1 \text { sliced Dentalium } \\
\text { shell, } 2 \text { sliced } \\
\text { Vermetus shells, } \\
1 \text { broken tubular } \\
\text { copper bead and } 4 \\
\text { broken copper beads }\end{array}$ & $\begin{array}{l}3 \text { Dentalium badense } \\
\text { and } 8 \text { limestone beads }\end{array}$ & $\begin{array}{l}\text { The ends of the Dentalium } \\
\text { shells were trimmed and } \\
\text { polished; the limestone } \\
\text { beads were polished into a } \\
\text { cylindrical shape and } \\
\text { perforated with an awl }\end{array}$ & $\begin{array}{l}\text { Carbonate precipitation and } \\
\text { chemical alterations on the } \\
\text { shell and stone beads }\end{array}$ \\
\hline $\begin{array}{l}\text { Grave } 216 \\
61.2 .58 .4 \\
\text { Pl. XCII. } 216 / 4\end{array}$ & $\begin{array}{l}4 \text { sliced Dentalium } \\
\text { beads }\end{array}$ & $\begin{array}{l}4 \text { sliced Dentalium } \\
\text { badense beads }\end{array}$ & $\begin{array}{l}\text { The ends of the Dentalium } \\
\text { shells were trimmed and } \\
\text { polished }\end{array}$ & $\begin{array}{l}\text { Carbonate precipitation and } \\
\text { chemical alterations on the } \\
\text { Dentalium beads; one has } \\
\text { copper patina inside the } \\
\text { perforation }\end{array}$ \\
\hline $\begin{array}{l}\text { Grave } 220 \\
61.2 .60 .1 \\
\text { Pl. LXXXIX. } \\
220 / 1\end{array}$ & $\begin{array}{l}1 \text { broken river } \\
\text { mussel }\end{array}$ & $\begin{array}{l}\text { Broken Anodonta sp. } \\
\text { clam shell }\end{array}$ & - & $\begin{array}{l}\text { Probably damaged during } \\
\text { lifting or handling during } \\
\text { storage }\end{array}$ \\
\hline $\begin{array}{l}\text { Grave } 221 \\
61.2 .61 .3 \\
\text { Pl. XCIII. } 221 / 3\end{array}$ & $\begin{array}{l}29 \text { Dentalium and } \\
\text { Vermetus shells of } \\
\text { varying sizes and } 9 \\
\text { tubular copper beads }\end{array}$ & $\begin{array}{l}29 \text { Dentalium badense } \\
\text { beads }\end{array}$ & $\begin{array}{l}\text { The ends of the Dentalium } \\
\text { shells were trimmed and } \\
\text { polished }\end{array}$ & $\begin{array}{l}\text { Carbonate precipitation and } \\
\text { chemical alterations on the } \\
\text { Dentalium beads }\end{array}$ \\
\hline $\begin{array}{l}\text { Grave } 226 \\
61.2 .65 \\
\text { Pl. XCVIII. 226/1 }\end{array}$ & $\begin{array}{l}3 \text { intact and } 4 \text { sliced } \\
\text { Dentalium shells, } \\
9 \text { red clay beads, } \\
1 \text { broken and } 8 \text { intact } \\
\text { sliced shell beads } \\
\text { and } 1 \text { broken copper } \\
\text { bead (one of the red } \\
\text { clay beads was } \\
\text { slipped inside one of } \\
\text { the Dentalium shells) }\end{array}$ & $\begin{array}{l}8 \text { Dentalium badense, } \\
8 \text { limestone and } \\
8 \text { fired clay beads }\end{array}$ & $\begin{array}{l}\text { The ends of the Dentalium } \\
\text { shells were trimmed and } \\
\text { polished; the limestone } \\
\text { beads were polished into a } \\
\text { cylindrical shape and } \\
\text { perforated with an awl }\end{array}$ & $\begin{array}{l}\text { Carbonate precipitation and } \\
\text { chemical alterations on the } \\
\text { shell and stone beads }\end{array}$ \\
\hline $\begin{array}{l}\text { Grave } 227 \\
61.2 .66 .22 \\
P l . X C V .227 / 22\end{array}$ & $\begin{array}{l}1 \text { intact and } \\
17 \text { broken oblong } \\
\text { shell plaques }\end{array}$ & $\begin{array}{l}17 \text { Unio crassus } \\
\text { mussel plaques }\end{array}$ & $\begin{array}{l}\text { The mussel shells were } \\
\text { polished into an oblong } \\
\text { shape resembling a flat } \\
\text { button and the four corners } \\
\text { were perforated with an awl }\end{array}$ & $\begin{array}{l}\text { A minimal dissolution on } \\
\text { the mussel plaques; the } \\
\text { corners broke away at the } \\
\text { perforation on some } \\
\text { plaques; the plaques are } \\
\text { fragmentary }\end{array}$ \\
\hline
\end{tabular}


Table 1 (cont'd)

\begin{tabular}{|c|c|c|c|c|}
\hline Grave & $\begin{array}{l}\text { Description in the } \\
\text { inventory book }\end{array}$ & New description & $\begin{array}{l}\text { Anthropogenic } \\
\text { changes }\end{array}$ & $\begin{array}{c}\text { Traces of mechanical, } \\
\text { chemical and } \\
\text { biological erosion }\end{array}$ \\
\hline $\begin{array}{l}\text { Grave } 227 \\
61.2 .66 .23 \\
P l . X C V I I . \\
227 / 23 a-23 b\end{array}$ & $\begin{array}{l}1 \text { broken and } 7 \\
\text { intact Unio shells, } \\
79 \text { sliced shell beads }\end{array}$ & $\begin{array}{l}8 \text { Anadara diluvii } \\
\text { clam shells and } \\
79 \text { limestone beads }\end{array}$ & $\begin{array}{l}\text { The limestone beads were } \\
\text { polished into a cylindrical } \\
\text { shape and perforated with } \\
\text { an awl; the umbo of the } \\
\text { Anadara shells was trimmed } \\
\text { and polished }\end{array}$ & $\begin{array}{l}\text { Carbonate precipitation and } \\
\text { chemical alterations on the } \\
\text { shell and the limestone } \\
\text { beads }\end{array}$ \\
\hline $\begin{array}{l}\text { Grave } 227 \\
61.2 \cdot 66.25 \\
P l . X C V .227 / 25 a- \\
25 b\end{array}$ & $\begin{array}{l}38 \text { sliced shell beads } \\
\text { of varying sizes, } \\
37 \text { Vermetus beads, } \\
10 \text { small red clay } \\
\text { beads, } 2 \text { small white } \\
\text { beads, } 1 \text { broken } \\
\text { tubular copper bead }\end{array}$ & $\begin{array}{l}32 \text { Dentalium badense } \\
\text { beads, } 10 \text { clay beads, } \\
2 \text { small and } 41 \text { large } \\
\text { limestone beads }\end{array}$ & $\begin{array}{l}\text { The ends of the Dentalium } \\
\text { shells were trimmed and } \\
\text { polished; the limestone } \\
\text { beads were polished into a } \\
\text { cylindrical shape and } \\
\text { perforated with an awl }\end{array}$ & $\begin{array}{l}\text { Carbonate precipitation and } \\
\text { chemical alterations on the } \\
\text { shell and stone beads }\end{array}$ \\
\hline $\begin{array}{l}\text { Grave } 229 \\
61.2 .67 \\
\text { Pl. XCVIII. } \\
229 / 1 a-1 b\end{array}$ & $\begin{array}{l}5 \text { sliced shell beads, } \\
2 \text { Dentalium shells, } \\
5 \text { red clay and } 3 \text { tubu- } \\
\text { lar copper beads, and } \\
2 \text { broken tubular } \\
\text { copper beads }\end{array}$ & $\begin{array}{l}1 \text { Dentalium badense } \\
\text { and } 5 \text { red, fired } \\
\text { clayed beads, and } \\
1 \text { animal canine }\end{array}$ & $\begin{array}{l}\text { The ends of the Dentalium } \\
\text { shells were trimmed and } \\
\text { polished; the animal canine } \\
\text { was polished }\end{array}$ & $\begin{array}{l}\text { Carbonate precipitation and } \\
\text { chemical alterations on the } \\
\text { Dentalium bead }\end{array}$ \\
\hline $\begin{array}{l}\text { Grave } 237 \\
61.2 .71 \\
P l . X C I X .237 / 1\end{array}$ & $\begin{array}{l}1 \text { broken and } \\
8 \text { intact small sliced } \\
\text { shell beads }\end{array}$ & 8 limestone beads & $\begin{array}{l}\text { The limestone beads were } \\
\text { polished into a cylindrical } \\
\text { shape and perforated with } \\
\text { an awl }\end{array}$ & $\begin{array}{l}\text { Carbonate precipitation and } \\
\text { chemical alterations on the } \\
\text { beads }\end{array}$ \\
\hline $\begin{array}{l}\text { Grave } 238 \\
61.2 .72 .1 \\
\text { Pl. C. } 238 / 1\end{array}$ & $\begin{array}{l}1 \text { strongly burnt } \\
\text { perforated fossil } \\
\text { shell or snail }\end{array}$ & $\begin{array}{l}\text { A fragment of an } \\
\text { Unio crassus mussel }\end{array}$ & $\begin{array}{l}\text { The fragment of the Unio } \\
\text { crassus mussel was polished } \\
\text { and perforated }\end{array}$ & $\begin{array}{l}\text { The fragment of the Unio } \\
\text { crassus mussel is burnt }\end{array}$ \\
\hline $\begin{array}{l}\text { Grave } 241 \\
61.2 .73 \\
P l . X C I X . \\
241 / 1 a-1 b\end{array}$ & $\begin{array}{l}4 \text { sliced shell beads, } \\
2 \text { broken shells }\end{array}$ & $\begin{array}{l}4 \text { limestone beads } \\
\text { and } 2 \text { Anadara } \\
\text { diluvii clam shells }\end{array}$ & $\begin{array}{l}\text { The limestone beads were } \\
\text { polished into a cylindrical } \\
\text { shape and perforated with } \\
\text { an awl; the umbo of the } \\
\text { Anadara shells was trimmed } \\
\text { and polished }\end{array}$ & $\begin{array}{l}\text { The surface of the Anadara } \\
\text { shells is burnt }\end{array}$ \\
\hline $\begin{array}{l}\text { Grave } 245 \\
61.2 .75 \\
\text { Pl. CI. } 245 / 1\end{array}$ & $\begin{array}{l}9 \text { Dentalium shells, } \\
6 \text { Vermetus shells, } \\
1 \text { small marble bead, } \\
\text { and } 4 \text { broken copper } \\
\text { beads }\end{array}$ & $\begin{array}{l}7 \text { sliced Dentalium } \\
\text { badense and } \\
8 \text { limestone beads, } \\
5 \text { Anadara diluvii } \\
\text { clam shells }\end{array}$ & $\begin{array}{l}\text { The ends of the Dentalium } \\
\text { shells were trimmed and } \\
\text { polished; the limestone } \\
\text { beads were polished into a } \\
\text { cylindrical shape and } \\
\text { perforated with an awl; the } \\
\text { umbo of the Anadara shells } \\
\text { was trimmed and polished }\end{array}$ & $\begin{array}{l}\text { Carbonate precipitation and } \\
\text { chemical alterations on the } \\
\text { beads }\end{array}$ \\
\hline $\begin{array}{l}\text { Grave } 247 \\
(61.2 .76) \\
\text { Pl. CI. } 247 / 1 a-1 b\end{array}$ & $\begin{array}{l}5 \text { intact Dentalium } \\
\text { badense shells, } \\
2 \text { sliced Dentalium } \\
\text { and } 8 \text { sliced shell } \\
\text { beads, and } \\
5 \text { perforated shells }\end{array}$ & $\begin{array}{l}7 \text { sliced Dentalium } \\
\text { badense beads, } \\
8 \text { limestone beads } \\
\text { and } 5 \text { Anadara } \\
\text { diluvii clam shells }\end{array}$ & $\begin{array}{l}\text { The ends of the Dentalium } \\
\text { shells were trimmed and } \\
\text { polished; the limestone } \\
\text { beads were polished into a } \\
\text { cylindrical shape and } \\
\text { perforated with an awl; the } \\
\text { umbo of the Anadara shells } \\
\text { was trimmed and polished }\end{array}$ & $\begin{array}{l}\text { Carbonate precipitation and } \\
\text { chemical alterations on the } \\
\text { beads }\end{array}$ \\
\hline $\begin{array}{l}\text { Grave } 263 \\
61.2 .85 .4 \\
\text { Pl. CVI. } 263 / 1 a-1 b\end{array}$ & $\begin{array}{l}20 \text { sliced shell beads } \\
\text { of varying sizes and } \\
2 \text { broken oblong } \\
\text { shell plaques }\end{array}$ & 20 limestone beads & $\begin{array}{l}\text { The limestone beads were } \\
\text { polished into a cylindrical } \\
\text { shape and perforated with } \\
\text { an awl }\end{array}$ & $\begin{array}{l}\text { Carbonate precipitation and } \\
\text { chemical alterations on the } \\
\text { beads }\end{array}$ \\
\hline $\begin{array}{l}\text { Grave } 263 \\
61.2 .85 .5 \\
\text { Pl. CVI. } 263 / 5\end{array}$ & 5 sliced shell beads & 5 limestone beads & $\begin{array}{l}\text { The limestone beads were } \\
\text { polished into a cylindrical } \\
\text { shape and perforated with } \\
\text { an awl }\end{array}$ & $\begin{array}{l}\text { Carbonate precipitation and } \\
\text { chemical alterations on the } \\
\text { beads }\end{array}$ \\
\hline Grave 263 & 11 sliced shell beads & 11 limestone beads & The limestone beads were & Carbonate precipitation and \\
\hline
\end{tabular}




\begin{tabular}{|c|c|c|c|c|}
\hline $\begin{array}{l}\text { 61.2.85.6 } \\
\text { Pl. CVI. } 263 / 6\end{array}$ & & & $\begin{array}{l}\text { polished into a cylindrical } \\
\text { shape and perforated with } \\
\text { an awl }\end{array}$ & $\begin{array}{l}\text { chemical alterations on the } \\
\text { beads }\end{array}$ \\
\hline $\begin{array}{l}\text { Grave } 266 \\
61.2 .87 \\
\text { Pl. CIV. 266/3 }\end{array}$ & Broken river mussel & $\begin{array}{l}\text { Left valve of an Unio } \\
\text { crassus mussel }\end{array}$ & - & $\begin{array}{l}\text { Traces of strong dissolution } \\
\text { on the valve, perhaps owing } \\
\text { to an acidic habitat; the tip } \\
\text { was damaged during lifting } \\
\text { or handling during storage }\end{array}$ \\
\hline $\begin{array}{l}\text { Grave } 267 \\
61.2 .88 .2 \\
\text { Pl. CIV. } 267 / 2\end{array}$ & $\begin{array}{l}1 \text { sliced Dentalium } \\
\text { shell, } 1 \text { sliced shell } \\
\text { bead, } 2 \text { Vermetus } \\
\text { shells and } 1 \text { long, } \\
\text { conical, fossil snail }\end{array}$ & $\begin{array}{l}1 \text { Turritella badense } \\
\text { snail shell, } \\
3 \text { Dentalium badense } \\
\text { and } 2 \text { limestone } \\
\text { beads }\end{array}$ & $\begin{array}{l}\text { The ends of the Dentalium } \\
\text { shells were trimmed and } \\
\text { polished; the limestone } \\
\text { beads were polished into a } \\
\text { cylindrical shape and } \\
\text { perforated with an awl; the } \\
\text { Turritella shell was polished }\end{array}$ & $\begin{array}{l}\text { Carbonate precipitation and } \\
\text { chemical alterations on the } \\
\text { beads; the umbo of the } \\
\text { Turritella shell broke off; } \\
\text { boreholes left by predatory } \\
\text { snails on the side }\end{array}$ \\
\hline $\begin{array}{l}\text { Grave } 273 \\
61.2 .89 .4 \\
\text { Pl. CX. } 273 / 4\end{array}$ & $\begin{array}{l}5 \text { perforated, conical } \\
\text { fossil shells of } \\
\text { varying types }\end{array}$ & $\begin{array}{l}5 \text { Turritella snail } \\
\text { shells ( } 3 \text { Turritella } \\
\text { badense and } \\
2 \text { Turritella } \mathrm{sp.)}\end{array}$ & $\begin{array}{l}\text { The Turritella snails were } \\
\text { perforated, their umbo was } \\
\text { polished }\end{array}$ & $\begin{array}{l}\text { Carbonate precipitation and } \\
\text { chemical alterations on the } \\
\text { beads; the umbo of the } \\
\text { Turritella shell broke; } \\
\text { damage caused by wave } \\
\text { action on the shell }\end{array}$ \\
\hline $\begin{array}{l}\text { Grave } 284 \\
61.2 .94 \\
\text { Pl. CXIII. 284/1 }\end{array}$ & $\begin{array}{l}52 \text { sliced shell beads } \\
\text { of varying sizes, } \\
3 \text { sliced Dentalium } \\
\text { and } 19 \text { Vermetus } \\
\text { beads }\end{array}$ & $\begin{array}{l}23 \text { Dentalium badense } \\
\text { and } 51 \text { limestone } \\
\text { beads }\end{array}$ & $\begin{array}{l}\text { The ends of the Dentalium } \\
\text { shells were trimmed and } \\
\text { polished; the limestone } \\
\text { beads were polished into a } \\
\text { cylindrical shape and } \\
\text { perforated with an awl }\end{array}$ & $\begin{array}{l}\text { Carbonate precipitation and } \\
\text { physical and chemical } \\
\text { alterations on the beads }\end{array}$ \\
\hline $\begin{array}{l}\text { Grave } 290 \\
61.2 .98 \\
\text { Pl. CXIV. 290/1 }\end{array}$ & 5 sliced shell beads & 5 limestone beads & $\begin{array}{l}\text { The limestone beads were } \\
\text { polished into a cylindrical } \\
\text { shape and perforated with } \\
\text { an awl }\end{array}$ & $\begin{array}{l}\text { Carbonate precipitation and } \\
\text { physical and chemical } \\
\text { alterations on the beads }\end{array}$ \\
\hline $\begin{array}{l}\text { Grave } 291 \\
61.2 .99 .1 \\
\text { Pl. CXIV. 291/1 }\end{array}$ & $\begin{array}{l}2 \text { Dentalium shells } \\
\text { and } 1 \text { fossil snail }\end{array}$ & $\begin{array}{l}1 \text { fired clay bead, } \\
2 \text { Dentalium badense } \\
\text { shells and } 1 \\
\text { Columbella sp. shell }\end{array}$ & $\begin{array}{l}\text { The ends of the Dentalium } \\
\text { shells and the umbo of the } \\
\text { Columbella were trimmed } \\
\text { and polished; the final } \\
\text { whorl of the Columbella } \\
\text { shell was perforated }\end{array}$ & $\begin{array}{l}\text { Carbonate precipitation and } \\
\text { physical and chemical } \\
\text { alterations on the stone } \\
\text { beads }\end{array}$ \\
\hline $\begin{array}{l}\text { Grave } 301 \\
\text { 61.2.103.1 } \\
\text { Pl. CXVI. } 301 / 1\end{array}$ & $\begin{array}{l}4 \text { broken, perforated } \\
\text { Unio shells, some } \\
\text { broken }\end{array}$ & $\begin{array}{l}3 \text { Anadara diluvii } \\
\text { clam shells } \\
\text { perforated through } \\
\text { the umbo }\end{array}$ & $\begin{array}{l}\text { The umbo of the Anadara } \\
\text { clams was trimmed and } \\
\text { polished }\end{array}$ & $\begin{array}{l}\text { Physical alterations caused } \\
\text { by wave action on the shell } \\
\text { surface }\end{array}$ \\
\hline $\begin{array}{l}\text { Grave } 301 \\
61.2 .103 .2 \\
\text { Pl. CXVI. } 301 / 2 \\
\end{array}$ & $\begin{array}{l}6 \text { Vermetus beads } \\
\text { and five broken, } \\
\text { tubular copper beads }\end{array}$ & $\begin{array}{l}6 \text { Dentalium badense } \\
\text { shells }\end{array}$ & $\begin{array}{l}\text { The ends of the Dentalium } \\
\text { shells were trimmed and } \\
\text { polished }\end{array}$ & $\begin{array}{l}\text { Carbonate precipitation and } \\
\text { chemical alterations on the } \\
\text { shell surfaces }\end{array}$ \\
\hline $\begin{array}{l}\text { Grave } 309 \\
61.2 .106 .2 \\
\text { Pl. CXVIII. } 309 / 3\end{array}$ & $\begin{array}{l}9 \text { strongly } \\
\text { fragmented, small } \\
\text { snail beads }\end{array}$ & $\begin{array}{l}9 \text { Lithoglyphus } \\
\text { naticoides snails }\end{array}$ & $\begin{array}{l}\text { The snails were perforated } \\
\text { and strung into a necklace }\end{array}$ & $\begin{array}{l}\text { The shell surfaces are } \\
\text { smooth, but the shells are } \\
\text { fragmentary; mechanical } \\
\text { damage after burial }\end{array}$ \\
\hline $\begin{array}{l}\text { Grave } 317 \\
61.2 .112 .2 \\
\text { Pl. } C X I X . \\
317 / 2 a-2 c\end{array}$ & $\begin{array}{l}3 \text { perforated Unio } \\
\text { mussels, } 3 \text { small } \\
\text { perforated snails, } \\
6 \text { sliced Dentalium } \\
\text { shells and } 16 \text { sliced } \\
\text { shell beads }\end{array}$ & $\begin{array}{l}3 \text { Lithoglyphus } \\
\text { naticoides snails } \\
\text { perforated through } \\
\text { their side, } 3 \text { Anadara } \\
\text { diluvii clam shells, } \\
6 \text { Dentalium badense } \\
\text { and } 16 \text { limestone } \\
\text { beads }\end{array}$ & $\begin{array}{l}\text { The umbo of the Anadara } \\
\text { clams was trimmed and } \\
\text { polished; the Lithoglyphus } \\
\text { naticoides snails were } \\
\text { perforated through their } \\
\text { side; the ends of the } \\
\text { Dentalium shells were } \\
\text { trimmed and polished; the } \\
\text { limestone beads were } \\
\text { polished into a cylindrical } \\
\text { shape and perforated with } \\
\text { an awl }\end{array}$ & $\begin{array}{l}\text { Carbonate precipitation and } \\
\text { physical and chemical } \\
\text { alterations on the beads and } \\
\text { molluscs }\end{array}$ \\
\hline $\begin{array}{l}\text { Grave } 317 \\
61.2 .112 .3 \\
\end{array}$ & $\begin{array}{l}6 \text { sliced shell beads } \\
\text { of varying sizes }\end{array}$ & 6 limestone beads & $\begin{array}{l}\text { The limestone beads were } \\
\text { polished into a cylindrical }\end{array}$ & $\begin{array}{l}\text { Carbonate precipitation and } \\
\text { physical and chemical }\end{array}$ \\
\hline
\end{tabular}


Table 1 (cont'd)

\begin{tabular}{|c|c|c|c|c|}
\hline Grave & $\begin{array}{l}\text { Description in the } \\
\text { inventory book }\end{array}$ & New description & $\begin{array}{l}\text { Anthropogenic } \\
\text { changes }\end{array}$ & $\begin{array}{c}\text { Traces of mechanical, } \\
\text { chemical and } \\
\text { biological erosion }\end{array}$ \\
\hline Pl. CXIX. 317/3 & & & $\begin{array}{l}\text { shape and perforated with } \\
\text { an awl }\end{array}$ & alterations on the beads \\
\hline $\begin{array}{l}\text { Grave } 317 \\
61.2 .112 .4 \\
\text { Pl. CXIX. } 317 / 4\end{array}$ & 3 sliced shell beads & 3 limestone beads & $\begin{array}{l}\text { The limestone beads were } \\
\text { polished into a cylindrical } \\
\text { shape and perforated with } \\
\text { an awl }\end{array}$ & $\begin{array}{l}\text { Carbonate precipitation and } \\
\text { physical and chemical } \\
\text { alterations on the beads }\end{array}$ \\
\hline $\begin{array}{l}\text { Grave } 317 \\
61.2 .112 .5 \\
\text { Pl. CXIX. } 317 / 5 a- \\
5 b\end{array}$ & $\begin{array}{l}2 \text { perforated Unio } \\
\text { shells and } 3 \text { sliced } \\
\text { shell beads }\end{array}$ & $\begin{array}{l}2 \text { Anadara diluvii } \\
\text { clam shells } \\
\text { perforated through } \\
\text { the umbo and } \\
3 \text { limestone beads }\end{array}$ & $\begin{array}{l}\text { The umbo of the Anadara } \\
\text { clams was trimmed and } \\
\text { polished; the limestone } \\
\text { beads were polished into a } \\
\text { cylindrical shape and } \\
\text { perforated with an awl }\end{array}$ & $\begin{array}{l}\text { Carbonate precipitation and } \\
\text { physical and chemical } \\
\text { alterations on the beads and } \\
\text { shells }\end{array}$ \\
\hline $\begin{array}{l}\text { Grave } 317 \\
61.2 .112 .6\end{array}$ & 3 small snails & $\begin{array}{l}\text { Cepaea vindobonensis } \\
\text { snails }\end{array}$ & $\begin{array}{l}\text { The snails probably got } \\
\text { into the grave after the } \\
\text { burial }\end{array}$ & $\begin{array}{l}\text { The snail surfaces are } \\
\text { smooth }\end{array}$ \\
\hline $\begin{array}{l}\text { Grave } 322 \\
61.2 .114 \\
\text { Pl. CXXII. 322/1 }\end{array}$ & 4 sliced shell beads & 4 limestone beads & $\begin{array}{l}\text { The limestone beads were } \\
\text { polished into a cylindrical } \\
\text { shape and perforated with } \\
\text { an awl }\end{array}$ & $\begin{array}{l}\text { Carbonate precipitation and } \\
\text { chemical alterations on the } \\
\text { beads }\end{array}$ \\
\hline $\begin{array}{l}\text { Grave } 324 \\
61.2 .115 .2 \\
P l . C X X V \\
324 / 2 a-2 b\end{array}$ & $\begin{array}{l}3 \text { perforated shells } \\
\text { and } 12 \text { sliced shell } \\
\text { beads }\end{array}$ & $\begin{array}{l}3 \text { Anadara diluvii } \\
\text { clam shells } \\
\text { perforated through } \\
\text { the umbo and } \\
12 \text { limestone beads }\end{array}$ & $\begin{array}{l}\text { The umbo of the Anadara } \\
\text { clams was trimmed and } \\
\text { polished; the limestone } \\
\text { beads were polished into a } \\
\text { cylindrical shape and } \\
\text { perforated with an awl }\end{array}$ & $\begin{array}{l}\text { Carbonate precipitation and } \\
\text { physical and chemical } \\
\text { alterations on the beads and } \\
\text { shells }\end{array}$ \\
\hline $\begin{array}{l}\text { Grave } 329 \\
61.2 .118 \\
\text { Pl. CXXIV. } 329 / 1 \\
\end{array}$ & $\begin{array}{l}\text { Strongly fragmented } \\
\text { river mussel }\end{array}$ & $\begin{array}{l}1 \text { Anodonta sp. } \\
\text { mussel fragment }\end{array}$ & $\begin{array}{l}\text { The mussel broke following } \\
\text { its deposition }\end{array}$ & $\begin{array}{l}\text { The surface of the shell is } \\
\text { smooth }\end{array}$ \\
\hline $\begin{array}{l}\text { Grave } 345 \\
61.2 .127 .3 \\
\text { Pl. CXXXII. } 345 / 3\end{array}$ & $\begin{array}{l}2 \text { perforated Unio } \\
\text { shells }\end{array}$ & $\begin{array}{l}2 \text { perforated } \\
\text { Anadara diluvii clam } \\
\text { shells }\end{array}$ & $\begin{array}{l}\text { The umbo of the Anadara } \\
\text { shells was trimmed and } \\
\text { polished }\end{array}$ & $\begin{array}{l}\text { Carbonate precipitation and } \\
\text { physical and chemical } \\
\text { alterations on the surface of } \\
\text { the shells }\end{array}$ \\
\hline $\begin{array}{l}\text { Grave } 354 \\
61.2 .132 .2 \\
\text { Pl. CXXXVII. } \\
354 / 2\end{array}$ & $\begin{array}{l}16 \text { broken, oblong } \\
\text { shell plaques with a } \\
\text { pair of tiny round } \\
\text { perforations along } \\
\text { the short sides }\end{array}$ & $\begin{array}{l}16 \text { Unio crassus } \\
\text { mussel plaque } \\
\text { fragments }\end{array}$ & $\begin{array}{l}\text { The mussel shells were } \\
\text { polished into an oblong } \\
\text { shape resembling a flat } \\
\text { button and the four corners } \\
\text { were perforated with an awl }\end{array}$ & $\begin{array}{l}\text { Carbonate precipitation and } \\
\text { physical and chemical } \\
\text { alterations on the shells }\end{array}$ \\
\hline $\begin{array}{l}\text { Grave } 354 \\
61.2 .132 .3 \\
\text { Pl. CXXXVII. } \\
354 / 3 a-3 b\end{array}$ & $\begin{array}{l}26 \text { perforated shells, } \\
180 \text { sliced shell } \\
\text { beads of varying } \\
\text { sizes, } 7 \text { Vermetus } \\
\text { Dentalium shells, } 1 \\
\text { broken red clay bead } \\
\text { (patches of a yellow } \\
\text { coating can be noted } \\
\text { on most beads) }\end{array}$ & $\begin{array}{l}25 \text { Anadara diluvii } \\
\text { clam shells } \\
\text { perforated through } \\
\text { the umbo, } 6 \text { intact } \\
\text { Dentalium badense } \\
\text { and } 180 \text { limestone } \\
\text { beads }\end{array}$ & $\begin{array}{l}\text { The umbo of the Anadara } \\
\text { shells was trimmed and } \\
\text { polished; the ends of the } \\
\text { Dentalium shells were } \\
\text { trimmed and polished; the } \\
\text { limestone beads were } \\
\text { polished into a cylindrical } \\
\text { shape and perforated with } \\
\text { an awl }\end{array}$ & $\begin{array}{l}\text { Carbonate precipitation and } \\
\text { chemical alterations on the } \\
\text { beads and shells }\end{array}$ \\
\hline $\begin{array}{l}\text { Grave } 355 \\
61.2 .133 .1 \\
\text { Pl. CXXXVIII. } \\
355 / 2\end{array}$ & $\begin{array}{l}1 \text { Dentalium and } \\
9 \text { Vermetus beads }\end{array}$ & $\begin{array}{l}10 \text { Dentalium badense } \\
\text { beads }\end{array}$ & $\begin{array}{l}\text { The ends of the Dentalium } \\
\text { shells were trimmed and } \\
\text { polished }\end{array}$ & $\begin{array}{l}\text { Carbonate precipitation and } \\
\text { chemical alterations on the } \\
\text { beads }\end{array}$ \\
\hline $\begin{array}{l}\text { Grave } 355 \\
61.2 .133 .2 \\
\text { Pl. CXXXVIII. } \\
355 / 3\end{array}$ & $\begin{array}{l}54 \text { sliced shell beads } \\
\text { of varying sizes }\end{array}$ & 54 limestone beads & $\begin{array}{l}\text { The limestone beads were } \\
\text { polished into a cylindrical } \\
\text { shape and perforated with } \\
\text { an awl }\end{array}$ & $\begin{array}{l}\text { Carbonate precipitation and } \\
\text { physical and chemical } \\
\text { alterations on the beads }\end{array}$ \\
\hline $\begin{array}{l}\text { Grave } 359 \\
61.2 .135 .1 \\
\text { Pl. CXL. } 1 a-1 b\end{array}$ & $\begin{array}{l}42 \text { Dentalium and } \\
\text { Vermetus beads and } \\
6 \text { broken, oblong }\end{array}$ & $\begin{array}{l}40 \text { Dentalium badense } \\
\text { beads (some intact), } \\
6 \text { Unio mussel }\end{array}$ & $\begin{array}{l}\text { The ends of the Dentalium } \\
\text { shells were trimmed and } \\
\text { polished; the mussel shells }\end{array}$ & $\begin{array}{l}\text { Carbonate precipitation and } \\
\text { chemical alterations on the } \\
\text { beads and shells }\end{array}$ \\
\hline
\end{tabular}




\begin{tabular}{|c|c|c|c|c|}
\hline & $\begin{array}{l}\text { shell plaques with a } \\
\text { pair of tiny round } \\
\text { perforations along } \\
\text { the short sides }\end{array}$ & $\begin{array}{l}\text { plaques perforated } \\
\text { at the corners and } \\
2 \text { broken clay beads }\end{array}$ & $\begin{array}{l}\text { were polished into an } \\
\text { oblong shape resembling a } \\
\text { flat button and the four } \\
\text { corners were perforated } \\
\text { with an awl }\end{array}$ & \\
\hline $\begin{array}{l}\text { Grave } 359 \\
61.2 .135 .2 \\
\text { Pl. CXLI. } 359 / 2\end{array}$ & $\begin{array}{l}82 \text { Dentalium and } \\
\text { Vermetus beads }\end{array}$ & $\begin{array}{l}84 \text { Dentalium badense } \\
\text { beads (some intact, } \\
\text { some broken) and } 1 \\
\text { fired clay bead }\end{array}$ & $\begin{array}{l}\text { The ends of the Dentalium } \\
\text { shells were trimmed and } \\
\text { polished }\end{array}$ & $\begin{array}{l}\text { Carbonate precipitation and } \\
\text { physical and chemical } \\
\text { alterations on the beads }\end{array}$ \\
\hline $\begin{array}{l}\text { Grave } 359 \\
61.2 .135 .3 \\
\text { Pl. CXL. } \\
359 / 3 a-3 b\end{array}$ & $\begin{array}{l}7 \text { perforated shells } \\
\text { and } 46 \text { sliced shell } \\
\text { beads of varying } \\
\text { sizes }\end{array}$ & $\begin{array}{l}7 \text { Anadara diluvii } \\
\text { clam shells } \\
\text { perforated through } \\
\text { the umbo, } \\
3 \text { Dentalium badense } \\
\text { and } 43 \text { limestone } \\
\text { beads }\end{array}$ & $\begin{array}{l}\text { The ends of the Dentalium } \\
\text { shells were trimmed and } \\
\text { polished; the umbo of the } \\
\text { Anadara shells was trimmed } \\
\text { and polished }\end{array}$ & $\begin{array}{l}\text { Carbonate precipitation and } \\
\text { chemical alterations on the } \\
\text { beads; physical alterations } \\
\text { caused by wave action on } \\
\text { the shell surface }\end{array}$ \\
\hline $\begin{array}{l}\text { Grave } 359 \\
61.2 .135 .4 \\
\text { Pl. CXLI. } 359 / 4 \\
\end{array}$ & 16 Vermetus beads & $\begin{array}{l}16 \text { Dentalium badense } \\
\text { beads }\end{array}$ & $\begin{array}{l}\text { The ends of the Dentalium } \\
\text { shells were trimmed and } \\
\text { polished }\end{array}$ & $\begin{array}{l}\text { Carbonate precipitation and } \\
\text { physical and chemical } \\
\text { alterations on the beads }\end{array}$ \\
\hline $\begin{array}{l}\text { Grave } 359 \\
61.2 .135 .5 \\
\text { Pl. CXLI. } 359 / 5\end{array}$ & $\begin{array}{l}9 \text { sliced shell beads } \\
\text { of varying sizes }\end{array}$ & 9 limestone beads & $\begin{array}{l}\text { The limestone beads were } \\
\text { polished into a cylindrical } \\
\text { shape and perforated with } \\
\text { an awl }\end{array}$ & $\begin{array}{l}\text { Carbonate precipitation and } \\
\text { chemical alterations on the } \\
\text { beads }\end{array}$ \\
\hline $\begin{array}{l}\text { Grave } 360 \\
61.2 .136 .3 \\
\text { Pl. CXLII. } 360 / 3 a- \\
3 b\end{array}$ & $\begin{array}{l}26 \text { sliced shell beads } \\
\text { of varying sizes and } \\
3 \text { broken, perforated } \\
\text { shells }\end{array}$ & $\begin{array}{l}3 \text { broken Anadara } \\
\text { diluvii clam shells } \\
\text { and } 26 \text { limestone } \\
\text { beads }\end{array}$ & $\begin{array}{l}\text { The umbo of the Anadara } \\
\text { shells was trimmed and } \\
\text { polished; the limestone } \\
\text { beads were polished into a } \\
\text { cylindrical shape and } \\
\text { perforated with an awl }\end{array}$ & $\begin{array}{l}\text { Carbonate precipitation and } \\
\text { physical and chemical } \\
\text { alterations on the beads; } \\
\text { physical alterations caused } \\
\text { by wave action on the shells }\end{array}$ \\
\hline $\begin{array}{l}\text { Grave } 360 \\
61.2 .136 .4 \\
\text { Pl. CXLII. } \\
360 / 4 a-4 b\end{array}$ & $\begin{array}{l}125 \text { sliced shell } \\
\text { beads of varying } \\
\text { sizes and } 13 \\
\text { perforated, well } \\
\text { preserved Unio } \\
\text { shells, some broken }\end{array}$ & $\begin{array}{l}13 \text { broken Anadara } \\
\text { diluvii clam shells } \\
\text { perforated through } \\
\text { the umbo, } \\
1 \text { Dentalium badense } \\
\text { and } 124 \text { limestone } \\
\text { beads }\end{array}$ & $\begin{array}{l}\text { The umbo of the Anadara } \\
\text { shells was trimmed and } \\
\text { polished; the limestone } \\
\text { beads were polished into a } \\
\text { cylindrical shape; the ends } \\
\text { of the Dentalium shells were } \\
\text { trimmed and polished }\end{array}$ & $\begin{array}{l}\text { Carbonate precipitation and } \\
\text { physical and chemical } \\
\text { alterations on the beads }\end{array}$ \\
\hline $\begin{array}{l}\text { Grave } 361 \\
61.2 .137 .3 \\
P l . C X X X I X . \\
361 / 3\end{array}$ & $\begin{array}{l}10 \text { broken oblong } \\
\text { shell plaque with a } \\
\text { pair of tiny round } \\
\text { perforations along } \\
\text { the short sides }\end{array}$ & $\begin{array}{l}10 \text { Unio crassus } \\
\text { mussel plaques } \\
\text { perforated at the } \\
\text { corners }\end{array}$ & $\begin{array}{l}\text { The mussel plaques were } \\
\text { polished into an oblong } \\
\text { shape resembling a flat } \\
\text { button and the four corners } \\
\text { were perforated with an awl }\end{array}$ & $\begin{array}{l}\text { Carbonate precipitation and } \\
\text { physical and chemical } \\
\text { alterations on the shells }\end{array}$ \\
\hline $\begin{array}{l}\text { Grave } 361 \\
61.2 .137 .4 \\
P l . C X X X I X . \\
361 / 4 a-4 c\end{array}$ & $\begin{array}{l}73 \text { sliced shell beads } \\
\text { of varying sizes, } \\
6 \text { Unio shells (some } \\
\text { broken) and } \\
4 \text { broken, tubular } \\
\text { copper beads }\end{array}$ & $\begin{array}{l}6 \text { broken } \text { Anadara } \\
\text { diluvii clam shells, } \\
1 \text { Dentalium badense } \\
\text { and } 72 \text { limestone } \\
\text { beads }\end{array}$ & $\begin{array}{l}\text { The umbo of the Anadara } \\
\text { shells was trimmed and } \\
\text { polished; the ends of the } \\
\text { Dentalium shells were } \\
\text { trimmed and polished; the } \\
\text { limestone beads were } \\
\text { polished into a cylindrical } \\
\text { shape and perforated with } \\
\text { an awl }\end{array}$ & $\begin{array}{l}\text { Carbonate precipitation and } \\
\text { physical and chemical } \\
\text { alterations on the beads }\end{array}$ \\
\hline $\begin{array}{l}\text { Grave } 363 \\
61.2 .138 \\
\text { Pl. CXLI. } 363 / 1\end{array}$ & $\begin{array}{l}1 \text { broken river } \\
\text { mussel }\end{array}$ & $\begin{array}{l}\text { Left valve of an Unio } \\
\text { crassus mussel }\end{array}$ & $\begin{array}{l}\text { The umbo of the valve } \\
\text { broke off }\end{array}$ & $\begin{array}{l}\text { The surface is smooth, } \\
\text { without any mechanical } \\
\text { damage; the umbo was } \\
\text { damaged during lifting from } \\
\text { the grave or handling } \\
\text { during storage }\end{array}$ \\
\hline $\begin{array}{l}\text { Grave } 367 \\
61.2 .141 .6 \\
\text { Pl. CXLVI. } 367 / 6\end{array}$ & $\begin{array}{l}1 \text { broken river } \\
\text { mussel }\end{array}$ & $\begin{array}{l}\text { Right valve of an } \\
\text { Unio crassus mussel }\end{array}$ & $\begin{array}{l}\text { The umbo of the valve } \\
\text { broke off }\end{array}$ & $\begin{array}{l}\text { The surface is smooth, } \\
\text { without any mechanical } \\
\text { damage; the umbo was } \\
\text { damaged during lifting from } \\
\text { the grave or handling } \\
\text { during storage }\end{array}$ \\
\hline
\end{tabular}


Table 1 (cont'd)

\begin{tabular}{|c|c|c|c|c|}
\hline Grave & $\begin{array}{l}\text { Description in the } \\
\text { inventory book }\end{array}$ & New description & $\begin{array}{l}\text { Anthropogenic } \\
\text { changes }\end{array}$ & $\begin{array}{c}\text { Traces of mechanical, } \\
\text { chemical and } \\
\text { biological erosion }\end{array}$ \\
\hline $\begin{array}{l}\text { Grave } 371 \\
61.2 .144 .2 \\
P l . C X L V .371 / 2\end{array}$ & $\begin{array}{l}38 \text { cylindrical shell } \\
\text { beads of varying } \\
\text { sizes }\end{array}$ & 38 limestone beads & $\begin{array}{l}\text { The limestone beads were } \\
\text { polished into a cylindrical } \\
\text { shape and perforated with } \\
\text { an awl }\end{array}$ & $\begin{array}{l}\text { Carbonate precipitation and } \\
\text { chemical alterations on the } \\
\text { beads; the beads were } \\
\text { covered with ochre }\end{array}$ \\
\hline $\begin{array}{l}\text { Grave } 376 \\
61.2 .146 .1 \\
\text { Pl. CXLVII. } 376 / 2\end{array}$ & $\begin{array}{l}13 \text { cylindrical shell } \\
\text { beads of varying } \\
\text { sizes (patches of red } \\
\text { ochre can be noted } \\
\text { on the beads) }\end{array}$ & 13 limestone beads & $\begin{array}{l}\text { The limestone beads were } \\
\text { polished into a cylindrical } \\
\text { shape and perforated with } \\
\text { an awl }\end{array}$ & $\begin{array}{l}\text { Carbonate precipitation and } \\
\text { chemical alterations on the } \\
\text { stone beads; the beads were } \\
\text { covered with ochre }\end{array}$ \\
\hline $\begin{array}{l}\text { Grave } 378 \\
61.2 .148 .6 \\
\text { Pl. CL. } 378 / 6 a-6 b\end{array}$ & $\begin{array}{l}10 \text { cylindrical shell } \\
\text { beads of varying } \\
\text { sizes and } \\
12 \text { perforated fossil } \\
\text { shells of varying } \\
\text { types, some broken }\end{array}$ & $\begin{array}{l}10 \text { limestone beads, } \\
2 \text { Turritella badense } \\
\text { snails, } 9 \text { Anadara } \\
\text { diluvii clam shells, } \\
\text { and the broken, } \\
\text { polished siphon of a } \\
\text { Neogastropod }\end{array}$ & $\begin{array}{l}\text { The limestone beads were } \\
\text { polished into a cylindrical } \\
\text { shape and perforated with } \\
\text { an awl; the umbo of the } \\
\text { Anadara shells was trimmed } \\
\text { and polished; the columella } \\
\text { and the siphon of the } \\
\text { Neogastropod was polished }\end{array}$ & $\begin{array}{l}\text { Carbonate precipitation and } \\
\text { physical and chemical } \\
\text { alterations on the beads }\end{array}$ \\
\hline $\begin{array}{l}\text { Grave } 381 \\
61.2 .150 .1 \\
\text { Pl. CXLIX. 381/1 }\end{array}$ & $\begin{array}{l}2 \text { broken shells and } \\
1 \text { shell bead }\end{array}$ & $\begin{array}{l}2 \text { broken Anadara } \\
\text { diluvii clam shell } \\
\text { and } 1 \text { limestone } \\
\text { bead }\end{array}$ & $\begin{array}{l}\text { The umbo of the Anadara } \\
\text { clams was trimmed and } \\
\text { polished; the limestone } \\
\text { bead was polished into a } \\
\text { cylindrical shape and } \\
\text { perforated with an awl }\end{array}$ & $\begin{array}{l}\text { Carbonate precipitation and } \\
\text { physical and chemical } \\
\text { alterations on the beads }\end{array}$ \\
\hline $\begin{array}{l}\text { Grave } 381 \\
61.2 .150 .2 \\
\text { Pl. CXLIX. 381/2 }\end{array}$ & $\begin{array}{l}3 \text { cylindrical shell } \\
\text { beads }\end{array}$ & 3 limestone beads & $\begin{array}{l}\text { The limestone beads were } \\
\text { polished into a cylindrical } \\
\text { shape and perforated with } \\
\text { an awl }\end{array}$ & $\begin{array}{l}\text { Carbonate precipitation and } \\
\text { physical and chemical } \\
\text { alterations on the beads }\end{array}$ \\
\hline $\begin{array}{l}\text { Grave } 384 \\
61.2 .153 .2 \\
\text { Pl. CLI. } 384 / 2\end{array}$ & $\begin{array}{l}1 \text { broken oblong } \\
\text { shell plaque }\end{array}$ & $\begin{array}{l}1 \text { Unio crassus mussel } \\
\text { plaque }\end{array}$ & $\begin{array}{l}\text { The mussel shell was } \\
\text { polished into an oblong } \\
\text { shape resembling a flat } \\
\text { button and the four corners } \\
\text { were perforated with an awl }\end{array}$ & $\begin{array}{l}\text { Carbonate precipitation and } \\
\text { chemical alterations on the } \\
\text { mussel }\end{array}$ \\
\hline $\begin{array}{l}\text { Grave } 394 \\
61.2 .157 \\
\text { Pl. CLIV. 394/1 }\end{array}$ & Fossil shell & $\begin{array}{l}\text { 1 Anadara diluvii } \\
\text { clam shell }\end{array}$ & $\begin{array}{l}\text { The valve was cut in half } \\
\text { and perforated in the upper } \\
\text { third }\end{array}$ & $\begin{array}{l}\text { Physical alteration caused } \\
\text { by wave action on the shell } \\
\text { surface }\end{array}$ \\
\hline $\begin{array}{l}\text { Grave } 399 \\
61.2 .159 \\
\text { Pl. CLIV. 399/1 } \\
\end{array}$ & $\begin{array}{l}\text { Fossil shell with a } \\
\text { round perforation } \\
\text { along one edge }\end{array}$ & $\begin{array}{l}\text { Turritella sp. snail } \\
\text { shell fragment }\end{array}$ & The shell is perforated & $\begin{array}{l}\text { Physical alteration caused } \\
\text { by wave action on the } \\
\text { surface }\end{array}$ \\
\hline $\begin{array}{l}\text { Grave } 403 \\
61.2 .160 .2 \\
\text { Pl. CLVI. } 403 / 2\end{array}$ & $\begin{array}{l}6 \text { cylindrical shell } \\
\text { beads of varying } \\
\text { sizes }\end{array}$ & 6 limestone beads & $\begin{array}{l}\text { The limestone beads were } \\
\text { polished into a cylindrical } \\
\text { shape and perforated with } \\
\text { an awl }\end{array}$ & $\begin{array}{l}\text { Carbonate precipitation and } \\
\text { physical and chemical } \\
\text { alterations on the beads }\end{array}$ \\
\hline $\begin{array}{l}\text { Grave } 412 \\
61.2 .163 .3 \\
\text { Pl. CLIX. } 412 / 4\end{array}$ & $\begin{array}{l}16 \text { intact and sliced } \\
\text { Dentalium shells }\end{array}$ & $\begin{array}{l}1 \text { limestone and } \\
15 \text { Dentalium badense } \\
\text { beads }\end{array}$ & $\begin{array}{l}\text { The ends of the Dentalium } \\
\text { shells were trimmed and } \\
\text { polished; the limestone } \\
\text { bead was polished into a } \\
\text { cylindrical shape and } \\
\text { perforated with an awl }\end{array}$ & $\begin{array}{l}\text { Carbonate precipitation and } \\
\text { physical and chemical } \\
\text { alterations on the beads }\end{array}$ \\
\hline $\begin{array}{l}\text { Grave } 413 \\
61.2 .164 .1 \\
\text { Pl. CLVIII. } 413 / 2\end{array}$ & $\begin{array}{l}3 \text { perforated fossil } \\
\text { shells, } 8 \text { sliced } \\
\text { Dentalium shells and } \\
22 \text { oblong shell } \\
\text { plaques with a pair } \\
\text { of tiny round } \\
\text { perforations along } \\
\text { the short sides } \\
\text { (some broken) }\end{array}$ & $\begin{array}{l}24 \text { broken Unio } \\
\text { crassus mussel } \\
\text { plaques perforated } \\
\text { at the corners }\end{array}$ & $\begin{array}{l}\text { The mussel shells were } \\
\text { polished into an oblong } \\
\text { shape resembling a flat } \\
\text { button and the four corners } \\
\text { were perforated with an awl }\end{array}$ & $\begin{array}{l}\text { Carbonate precipitation and } \\
\text { physical and chemical } \\
\text { alterations on the beads }\end{array}$ \\
\hline
\end{tabular}




\begin{tabular}{|c|c|c|c|c|}
\hline $\begin{array}{l}\text { Grave } 416 \\
61.2 .166 \\
\text { Pl. CLX. } 416 / 1\end{array}$ & $\begin{array}{l}5 \text { sliced shell beads, } \\
10 \text { Vermetus shells } \\
\text { and } 1 \text { tubular } \\
\text { copper bead }\end{array}$ & $\begin{array}{l}5 \text { limestone and } \\
11 \text { intact Dentalium } \\
\text { badense beads }\end{array}$ & $\begin{array}{l}\text { The ends of the Dentalium } \\
\text { shells were trimmed and } \\
\text { polished; the stone beads } \\
\text { were polished into a } \\
\text { cylindrical shape and } \\
\text { perforated with an awl }\end{array}$ & $\begin{array}{l}\text { Carbonate precipitation and } \\
\text { physical and chemical } \\
\text { alterations on the beads }\end{array}$ \\
\hline $\begin{array}{l}\text { Grave } 419 \\
61.2 .167 .1 \\
\text { Pl. CLXI. } 419 / 1\end{array}$ & $\begin{array}{l}6 \text { broken oblong } \\
\text { shell plaques with a } \\
\text { pair of tiny round } \\
\text { perforations along } \\
\text { the short sides }\end{array}$ & $\begin{array}{l}6 \text { broken Unio } \\
\text { crassus mussel } \\
\text { plaques perforated } \\
\text { at the corners }\end{array}$ & $\begin{array}{l}\text { The mussel shells were } \\
\text { polished into an oblong } \\
\text { shape resembling a flat } \\
\text { button and the four corners } \\
\text { were perforated with an awl }\end{array}$ & $\begin{array}{l}\text { Carbonate precipitation and } \\
\text { physical and chemical } \\
\text { alterations on the beads }\end{array}$ \\
\hline $\begin{array}{l}\text { Grave } 419 \\
61.2 .167 .2 \\
\text { Pl. CLXI. } 419 / 2\end{array}$ & $\begin{array}{l}29 \text { cylindrical, sliced } \\
\text { shell beads of } \\
\text { varying sizes }\end{array}$ & $\begin{array}{l}\text { One string of } 1 \text { clay } \\
\text { and } 17 \text { limestone } \\
\text { beads; a second } \\
\text { string of } 1 \text { sliced Den- } \\
\text { talium badense and } \\
10 \text { limestone beads }\end{array}$ & $\begin{array}{l}\text { The ends of the Dentalium } \\
\text { shells were trimmed and } \\
\text { polished; the limestone } \\
\text { beads were polished into a } \\
\text { cylindrical shape and } \\
\text { perforated with an awl }\end{array}$ & $\begin{array}{l}\text { Carbonate precipitation and } \\
\text { physical and chemical } \\
\text { alterations on the beads }\end{array}$ \\
\hline $\begin{array}{l}\text { Grave } 420 \\
61.2 .168 \\
\text { Pl. CLXI. } 420 / 1\end{array}$ & $\begin{array}{l}62 \text { cylindrical, sliced } \\
\text { shell beads of } \\
\text { varying sizes }\end{array}$ & $\begin{array}{l}1 \text { Dentalium badense } \\
\text { fragment and } \\
59 \text { limestone beads }\end{array}$ & $\begin{array}{l}\text { The ends of the Dentalium } \\
\text { shells were trimmed and } \\
\text { polished; the limestone } \\
\text { beads were polished into a } \\
\text { cylindrical shape and } \\
\text { perforated with an awl }\end{array}$ & $\begin{array}{l}\text { Carbonate precipitation and } \\
\text { physical and chemical } \\
\text { alterations on the beads }\end{array}$ \\
\hline $\begin{array}{l}\text { Grave } 427 \\
61.2 .172 \\
\text { Pl. CLXIII. } 427 / 1\end{array}$ & $\begin{array}{l}12 \text { broken, oblong } \\
\text { shell plaques with a } \\
\text { pair of tiny round } \\
\text { perforations along } \\
\text { the short sides }\end{array}$ & $\begin{array}{l}12 \text { broken Unio } \\
\text { crassus mussel } \\
\text { plaques }\end{array}$ & $\begin{array}{l}\text { The mussel shells were } \\
\text { polished into an oblong } \\
\text { shape resembling a flat } \\
\text { button and the four corners } \\
\text { were perforated with an awl }\end{array}$ & $\begin{array}{l}\text { Carbonate precipitation and } \\
\text { physical and chemical } \\
\text { alterations on the shells; } \\
\text { mechanical damage after } \\
\text { burial or handling during } \\
\text { storage }\end{array}$ \\
\hline $\begin{array}{l}\text { Grave } 432 \\
61.2 .174 \\
\text { Pl. CLXIII. } 432 / 1\end{array}$ & $\begin{array}{l}\text { Longish, red, } \\
\text { broken clay bead }\end{array}$ & $\begin{array}{l}\text { A red clay bead } \\
\text { imitating a } \\
\text { Dentalium shell }\end{array}$ & - & - \\
\hline $\begin{array}{l}\text { Grave } 436 \\
61.2 .177 .1 \\
\text { Pl. CLXIII. } 436 / 1 \\
\end{array}$ & Broken fossil snail & $\begin{array}{l}\text { Turritella sp. } \\
\text { fragment }\end{array}$ & - & $\begin{array}{l}\text { Mechanical damage after } \\
\text { burial or handling during } \\
\text { storage }\end{array}$ \\
\hline $\begin{array}{l}\text { Grave } 437 \\
61.2 .172 \\
\text { Pl. CLXV. } 437 / 1\end{array}$ & $\begin{array}{l}9 \text { sliced shell beads } \\
\text { and } 2 \text { Vermetus } \\
\text { shells }\end{array}$ & 9 limestone beads & $\begin{array}{l}\text { The limestone beads were } \\
\text { polished into a cylindrical } \\
\text { shape and perforated with } \\
\text { an awl }\end{array}$ & $\begin{array}{l}\text { Carbonate precipitation and } \\
\text { physical and chemical } \\
\text { alterations on the beads }\end{array}$ \\
\hline $\begin{array}{l}\text { Grave } 437 \\
61.2 .178 \\
\text { Pl. CLXV. } 437 / 3\end{array}$ & $\begin{array}{l}1 \text { broken oblong } \\
\text { shell plaque }\end{array}$ & $\begin{array}{l}1 \text { broken Unio } \\
\text { crassus plaque }\end{array}$ & $\begin{array}{l}\text { The mussel shell was } \\
\text { polished into an oblong } \\
\text { shape and the four corners } \\
\text { were perforated with an awl } \\
\text { and resembled a flat button }\end{array}$ & $\begin{array}{l}\text { Mechanical damage after } \\
\text { burial or handling during } \\
\text { storage }\end{array}$ \\
\hline $\begin{array}{l}\text { Stray find } \\
61.2 .202 \\
\text { Pl. CLXXIII. } 36\end{array}$ & 14 sliced shell beads & 14 limestone beads & $\begin{array}{l}\text { The limestone beads were } \\
\text { polished into a cylindrical } \\
\text { shape and perforated with } \\
\text { an awl }\end{array}$ & $\begin{array}{l}\text { Carbonate precipitation and } \\
\text { physical and chemical } \\
\text { alterations on the beads }\end{array}$ \\
\hline $\begin{array}{l}\text { Stray find } \\
61.2 .203 \\
\text { Pl. CLXXIII. } 37\end{array}$ & $\begin{array}{l}7 \text { Vermetus and } \\
2 \text { sliced shell beads }\end{array}$ & $\begin{array}{l}6 \text { Dentalium badense } \\
\text { shells, one with a } \\
\text { copper bead slipped } \\
\text { inside it, and } \\
2 \text { limestone beads }\end{array}$ & $\begin{array}{l}\text { The ends of the Dentalium } \\
\text { shells were trimmed and } \\
\text { polished; the limestone } \\
\text { beads were polished into a } \\
\text { cylindrical shape and } \\
\text { perforated with an awl }\end{array}$ & $\begin{array}{l}\text { Carbonate precipitation and } \\
\text { physical and chemical } \\
\text { alterations on the beads }\end{array}$ \\
\hline
\end{tabular}


THE COMPOSITION AND ORIGINS OF THE ANALYSED ORNAMENTS

The re-examination of the finds (cp. Table 1) has revealed that the over 60 per cent of the beads which were originally described as shell beads, had in fact been made from limestone and that only about onethird of the beads had been manufactured from mollusc shells. Some of these molluscs (Dentalium badense, Anadara diluvii, Pecten, Turritella, Columbella) were fossils originating from Miocene marine sediments. The Spondylus shell was polished before being made into ornaments and it was thus impossible to macroscopically determine whether it came from a fossil, Miocene marine sediment or from a living sea in the Copper Age. If it was a recent marine shell in the Copper Age, it probably originated from the Mediterranean. The isotope chemical analyses, however, have demonstrated that the Spondylus shells were procured from Miocene marine sediments. ${ }^{6}$ In addition to ornaments made from Miocene fossil molluscs, the finds included jewellery items created from freshwater mollusc species, such as Lithoglyphus naticoides, Unio crassus and Anodonta, which were recent in the Copper Age (Table 2).

We also strove to determine the origins of the other beads. Fossil marine snails (Turritella badense), shells (Anadara diluvii, Pecten) and scaphopods (Dentalium badense) abound in Hungarian Miocene marine sediments, ${ }^{7}$ and specifically in the Badenian sediments made up of marine and coastal deposits, as well as in sandy deposits containing volcanic tuff and continental materials, and in limestone deposits. ${ }^{8}$ Sediments containing these fauna elements occur in the Cserhát, Börzsöny, Buda and Gerecse Mountains in the broader environs of Budakalász, on the outskirts of Bia, Szob, Letkés, and Budapest-Rákos. ${ }^{9}$ The fossil mollusc shells from the Budakalász cemetery could thus have been easily procured from within a $50 \mathrm{~km}$ radius and it is possible that other deposits too existed in the gullies, stream banks and deposits along the Danube during the Copper Age. The boreholes left by snail predators, the boring sponge traces, the abrasion from wave action and the traces of crab predations on mollusc shells are all traits typical for habitats on Badenian coasts in the Miocene. ${ }^{10}$ The fossil record of bioerosion too confirms the origins of the fossil malacological material.

The stone beads were predominantly made from freshwater limestone. The isotope geochemical analyses clearly revealed that this limestone type underwent significant alterations following the manufacture of the

\footnotetext{
${ }^{6}$ DEMÉNY et al. in this volume (pp. 437-448).

7 CSEPREgHY-MEZERNICS 1956.

8 Báldi-KóKay 1970; Dulai 1995; Dulai 1996; SainT-Martin et al. 2000

9 Csepreghy-Mezernics 1956; Báldi-Kókay 1970; Dulai 1995; Dulai 1996; Dulai 2001; Hámor 1985; VADÁSZ 1906

${ }^{10}$ KowalevsKI et al. 1998; Dudás 2001.
}

Table 2. The material of the beads from the Budakalász. cemetery

\begin{tabular}{|l|c|c|}
\hline Material & Number & Percentage \\
\hline Dentalium badense & 662 & 19.22 \\
\hline Anadara diluvii & 248 & 7.20 \\
\hline Spondylus sp. & 1 & 0.03 \\
\hline Pecten sp. & 1 & 0.03 \\
\hline Turritella badense & 10 & 0.29 \\
\hline Columbella sp. & 1 & 0.03 \\
\hline Lithoglyphus naticoides & 12 & 0.35 \\
\hline Cepaea vindobonensis & 3 & 0.09 \\
\hline Unio crassus & 205 & 5.95 \\
\hline Anodonta & 2 & 0.06 \\
\hline Molluscs (total) & $\mathbf{1 1 4 5}$ & $\mathbf{3 3 . 2 4}$ \\
\hline Freshwater limestone & 2164 & 62.82 \\
\hline Crystalline limestone & 6 & 0.17 \\
\hline Red limestone & 1 & 0.03 \\
\hline Fired clay & 41 & 1.19 \\
\hline Copper & 88 & 2.55 \\
\hline Otber (total) & $\mathbf{2 3 0 0}$ & $\mathbf{6 6 . 7 6}$ \\
\hline Total & $\mathbf{3 4 4 5}$ & $\mathbf{1 0 0}$ \\
\hline
\end{tabular}

beads and after their burial. ${ }^{11}$ The surface of the limestone was transformed by groundwater action, a part of the beads dissolved and carbonate precipitated from the groundwater on its surface. Freshwater limestone formed during the Quaternary abounds in the Buda Mountains and in the broader area of the Budakalász cemetery, as well as on the Danube bank and in various gullies. ${ }^{12}$

The clay beads were probably made from Kiscell clay, while the red limestone beads were most likely manufactured from the Jurassic red limestone in the Gerecse Mountains. Crystalline limestone pebbles of Alpine origin can be found on the bars and islets of the Danube.

Table 2 shows that the beads from the Budakalász cemetery were principally made from locally available raw materials. The Pleistocene freshwater limestone found in the Budakalász area, the red limestone from the Gerecse Mountains, the crystalline limestone found on the Danube bank (also in the form of pebbles), the fossil mollusc shells occurring in the Miocene Badenian sediments of the Buda Mountains and the broader area, the Danubian mussels attested throughout the Holocene and still thriving today, and the clay for the clay beads were all procured locally and not through long-distance trade. The copper ornaments have not been submitted to any analyses and thus they cannot be sourced. However, surface copper deposits are known in the Börzsöny and the Mátra Mountains, not too far from Budakalász. We may therefore conclude that the

\footnotetext{
${ }_{11}$ DEMÉNY et al., in this volume (pp. 437-448).

12 Krolopp 1961; Krolopp 1982; Krolopp 2004; SZENTES 1968.
} 
Table 3. Modifications on the mollusc shells

\begin{tabular}{|l|c|c|c|c|}
\hline \multicolumn{1}{|c|}{ Mollusc } & $\begin{array}{c}\text { Umbo removed, } \\
\text { shell polished } \\
\text { and sliced }\end{array}$ & $\begin{array}{c}\text { Umbo removed, } \\
\text { polished }\end{array}$ & $\begin{array}{c}\text { Button-like plaques } \\
\text { perforated at } \\
\text { the four corners }\end{array}$ & $\begin{array}{c}\text { Fragmentary, } \\
\text { perforated } \\
\text { or unmodified shells }\end{array}$ \\
\hline Dentalium badense & $662(100 \%)$ & - & - & - \\
\hline Anadara diluvii & - & $239(96.37 \%)$ & & $9(4.63 \%)$ \\
\hline Unio crassus & - & - & $197(96.10 \%)$ & $8(3.90 \%)$ \\
\hline Lithoglyphus naticoides & - & $12(100 \%)$ & - & - \\
\hline Turritella badense & $10(100 \%)$ & - & - & - \\
\hline Columbella sp. & - & $1(100 \%)$ & - & - \\
\hline Anodonta sp. & - & - & - & $2(100 \%)$ \\
\hline Pecten sp. & - & - & - & $2(100 \%)$ \\
\hline Spondylus & - & - & - & $1(100 \%)$ \\
\hline
\end{tabular}

artefacts deposited in the burials were made from locally available materials collected in the broader area of the cemetery and not from commodities acquired through long-distance trade from regions beyond the Carpathian Basin.

\section{TECHNICAL ALTERATIONS ON THE ORNAMENTS}

Distinctive ornament making techniques could be noted on the jewellery items recovered from the Budakalász burials. Freshwater limestone was polished into a cylindrical or roughly spherical form and perforated with an awl, while crystalline limestone, red limestone and clay beads were fashioned into sturdy oval rings. These manufacturing techniques are discussed in a separate chapter. ${ }^{13}$ The most frequent modifications noted on the mollusc shells are shown in Table 3.

The mollusc sample is dominated by Dentalium badense, a fossil shell of the Scaphopod class. Dentalium shells were found in various states of preservation and it was initially suggested that some were recent shells in the Copper Age (Fig. 1), which would have indicated the existence of long-distance trade contacts between this region and the Mediterranean, where Dentalium species are to be found. However, the isotope geochemical analyses clearly showed that the well preserved Dentalium shells too came from fossil specimens, although they were probably collected from rocks other than the moderately well preserved specimens (Fig. 2).14 It seems likely that the better preserved specimens were buried under different conditions (deeper groundwater table, a soil with less carbonate content indicated by the minimal carbonate precipitation on the shells). When making ornaments from the moderately well preserved Dentalium shells, the umbo was removed, the shell was polished and fashioned into long, cylindrical beads (Fig. 3) or, alternately, the shell was sliced into smaller pieces and

\footnotetext{
13 GUCSI, in this volume (pp. 449-456).

${ }^{14}$ DEMÉNY et al., in this volume (pp. 437-448).
}

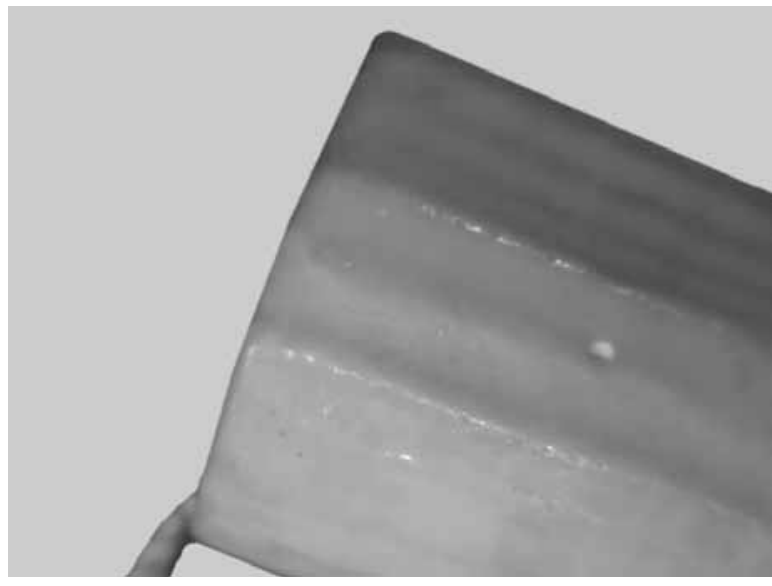

Fig. 1. Well preserved Dentalium badense bead (Grave 46)

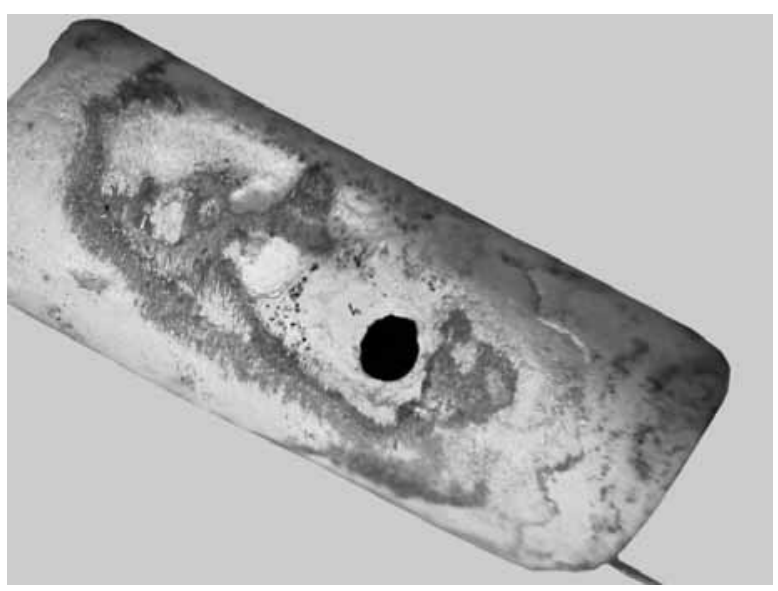

Fig. 2. Medium well preserved Dentalium badense shell (Grave 16)

made into smaller beads (Fig. 4, Fig. 16). The two ends of the beads were carefully polished into trumpet shaped terminals (Fig. 5). In addition to beads of this type, an ornament combined with tubular beads of sheet copper was also quite popular: the tubular copper beads, whose shape resembled the Dentaliums (Fig. 6), were slipped over the shell (Fig. 7). Copper patina stains on the Dentalium shells are a clear indication of the combined 


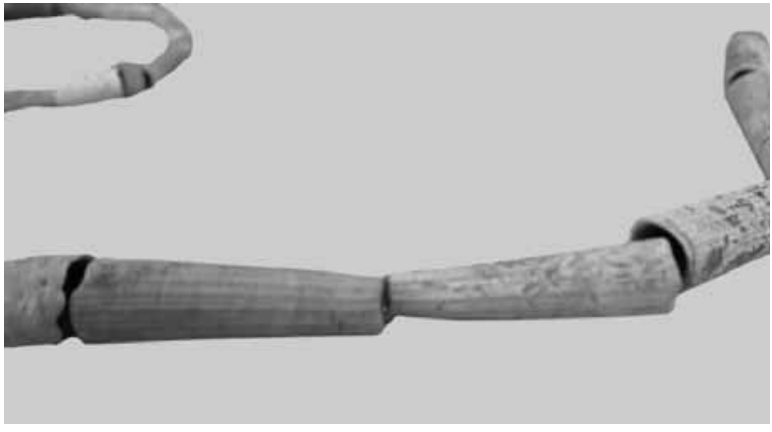

Fig. 3. Dentalium badense shell fashioned into an ornament (Grave 43)

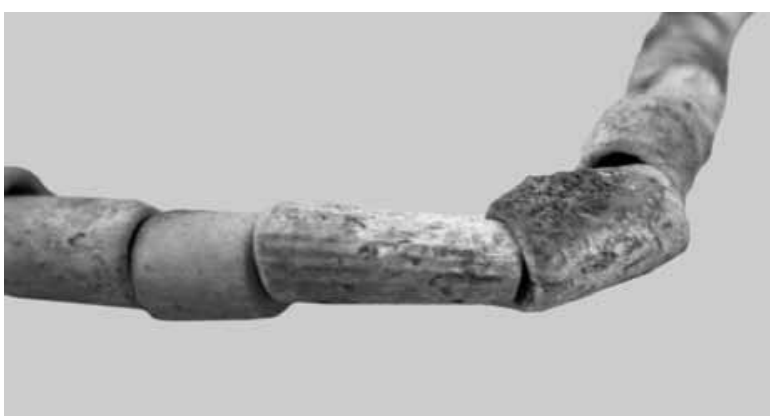

Fig. 4. Sliced Dentalium badense shell (Grave 37)

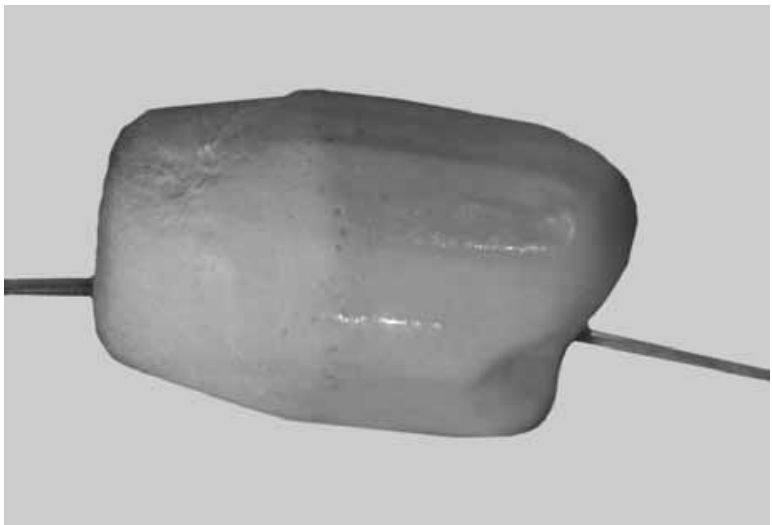

Fig. 5. Sliced Dentalium badense shell with polished ends (Grave 36)

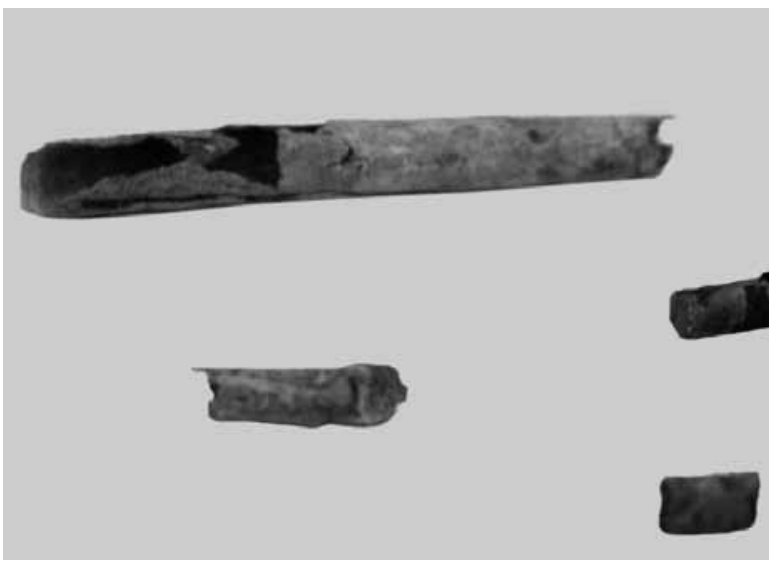

Fig. 6. Dentalim shaped tubular copper beads (Grave 48)

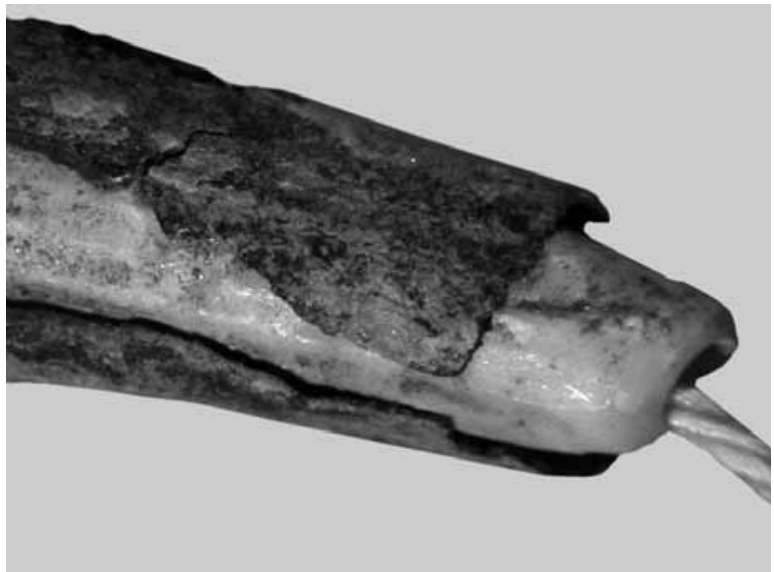

Fig. 7. Dentalim shaped tubular copper beads and Dentalium badense shells (Grave 74)

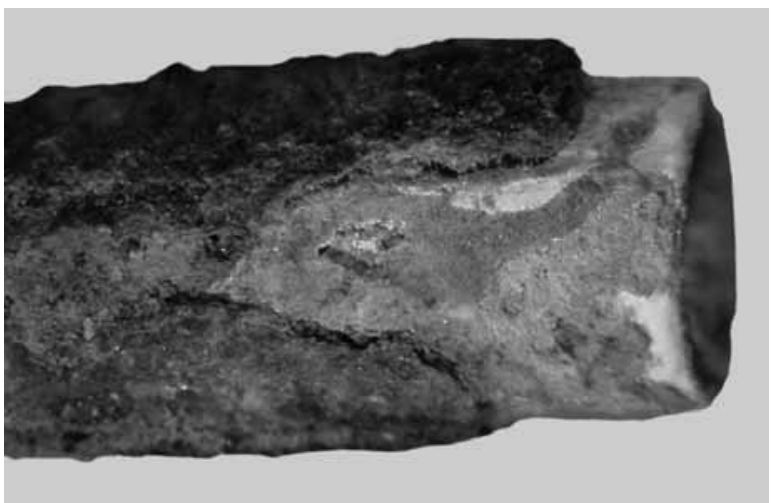

Fig. 8. Copper patina on a Dentalium badense shell (Grave 74)

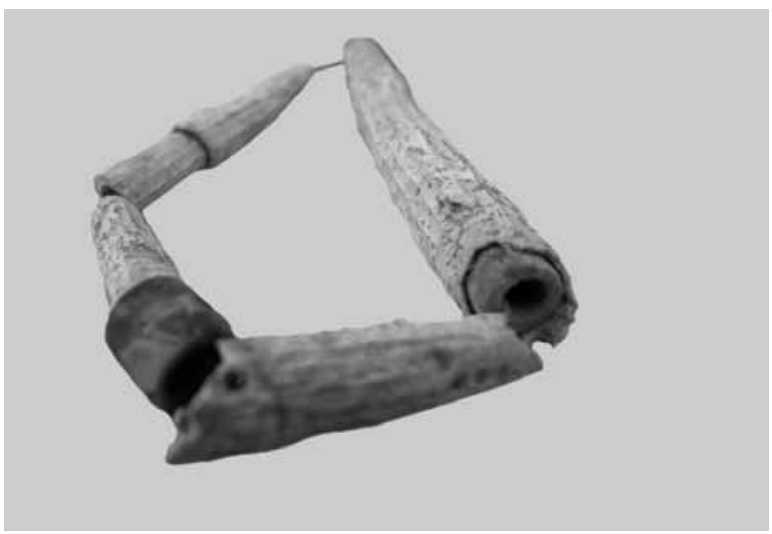

Fig. 9. Ornament made from the combination of a Dentalium badense bead and a limestone (Grave 80).

use of shell and copper for ornament making (Fig. 8). Some of the long, cylindrical Dentalium beads were strung together with round limestone beads (Fig. 9), resembling the bead pendants popular among the Native Americans of North America (Fig. 10).

The ethnographic record and photographic evidence from North America reveals that Dentalium shells were still widely used by Native American tribes 


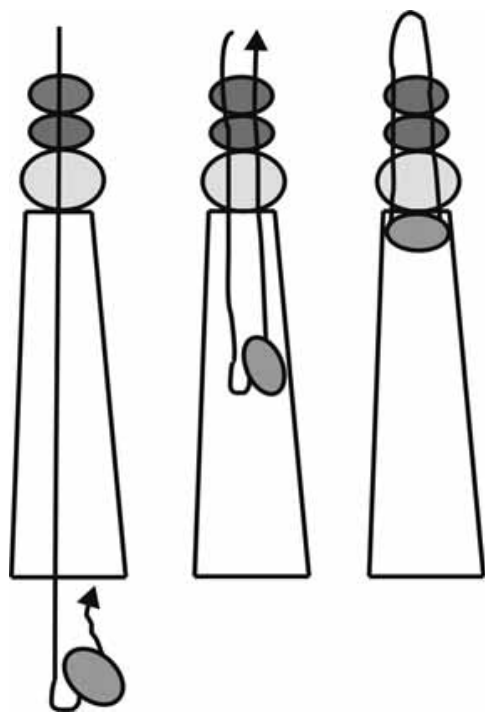

Fig. 10. Dangle ornament made from Dentalium and bead

during the 19th century for making necklaces and bangles, and for embroidering baby papooses and ceremonial shirts. Hopi Indians used Dentalium shells as a standard of monetary exchange, which they kept in elaborate carved elk horn purses. The use of fossil shells for making ornaments can be attested from the Upper Palaeolithic. ${ }^{15}$ Shell ornaments were often placed in burials of the Epipalaeolithic Natufian culture. ${ }^{16}$ Dentalium has been recovered from Neolithic and Copper Age sites too. ${ }^{17}$ This shell was used for making ornaments since the Upper Palaeolithic in Hungary, ${ }^{18}$ and the archaeological record from both Hungary ${ }^{19}$ and other regions of Europe suggests that fossil Dentalium shells gathered in the Miocene outcrops of the Danube Bend had reached sites north of the Alps through long-distance trade. ${ }^{20}$ It would appear that in addition to its pleasing appearance, the form of Dentalium shells too made it a popular raw material for the creation of various implements, prestige items and jewellery articles from the Upper Palaeolithic to the present.

Shells of the Anadara diluvii species were also highly represented. Anadara taxons are widespread in seas and in subtropical and tropical waters, and they also thrive in the Mediterranean. Anadara diluvii still thrives in the Adriatic, lying some 800-900 km from the Budakalász cemetery. ${ }^{21}$ The isotope geochemical analyses suggested that the shells deposited in the Budakalász burials were fossil specimens rather than Holocene ones. ${ }^{22}$

\footnotetext{
15 Callapez 2002; Callapez 2003; Rahle 1981; Rahle 1987; Rahle 1994; SCHMidT 1977; PASDa 1994; Sedlmeier 1988; VANHaEREN et al. 2005.

16 BAR-MEYER 2005.

17 Crewe et al. 2002; Dimitrov-Dimitrov 2004;

18 GÁBORI 1964.

${ }^{19}$ GÁBORI 1964.

${ }^{20}$ HÁMORI 1985.

${ }^{21}$ HrS-BRENKO-LEgAC 1996.

22 DEMÉNY et al. in this volume (pp. 437-448).
}

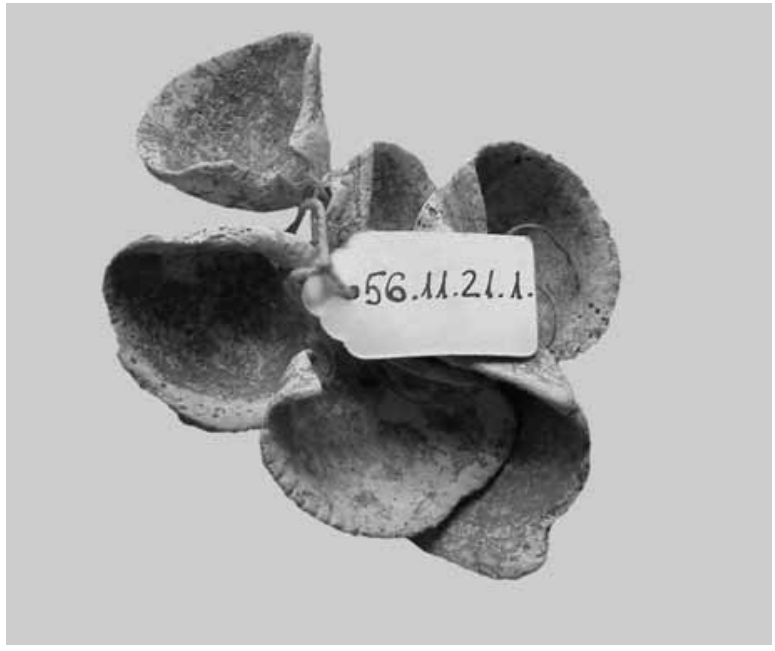

Fig. 11. Anadara diluvii clam shells (Grave 35)

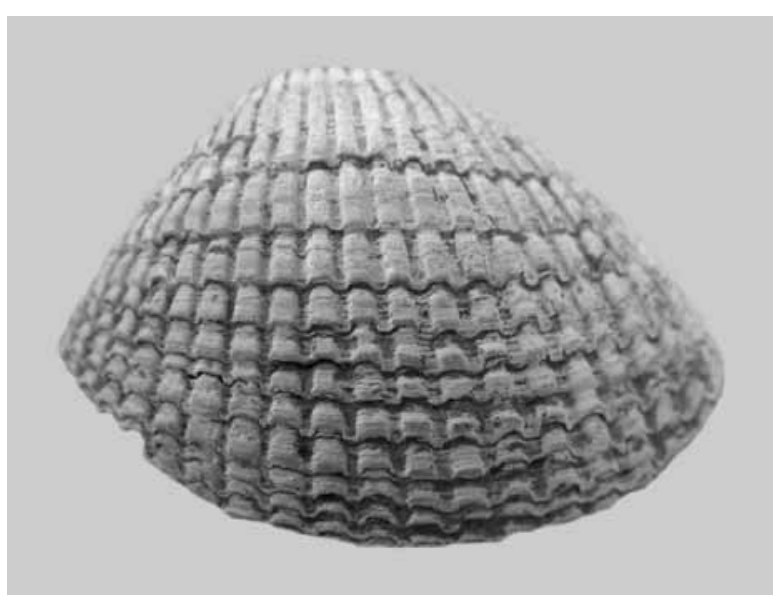

Fig. 12. Anadara diluvii clam shells (Grave 100)

This is also supported by the state of preservation of the shells (Fig. 11). The specimens recovered from the burials were small, lozenge shaped, convex pieces with uneven sides and slightly indented centre. Their width ranged between $3.8-4.7 \mathrm{~cm}$, their height between 2.9-3.9 cm (Fig. 12). Traces of physical, chemical or biological erosion occurring in the one-time habitat could often be noted on the surface of these shells (Figs 13-14).

Anadara diluvii shells of comparable size bearing traces of erosions have been found in the middle Miocene layers at Szob near Budakalász. There is evidence for mass deposits of this species in the marine sediments containing continental and volcanic material in the Cserhát and Börzsöny Mountains (Letkés, Damásdi Stream, etc.), ${ }^{23}$ suggesting that the Anadara diluvii shells used by the Budakalász community had been procured from Miocene sediments.

Various ornament manufacturing techniques can be noted on the Anadara diluvii shells. The umbo was trimmed and polished, whereby a perforation was

\footnotetext{
${ }^{23}$ Csepreghy-MEZernics 1956; Hámor 1998; Dudás 1999.
} 


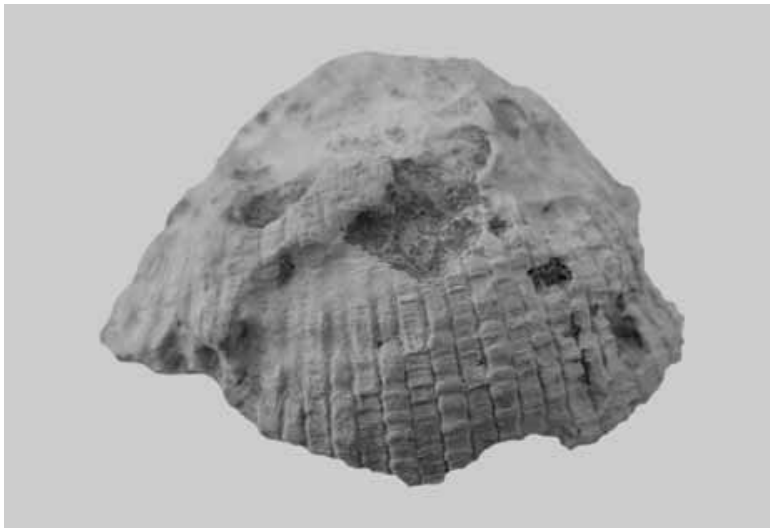

Fig. 13. Anadara diluvii clam shell with traces of syngenetic (Miocene) bioerosion on the surface (Grave 12)

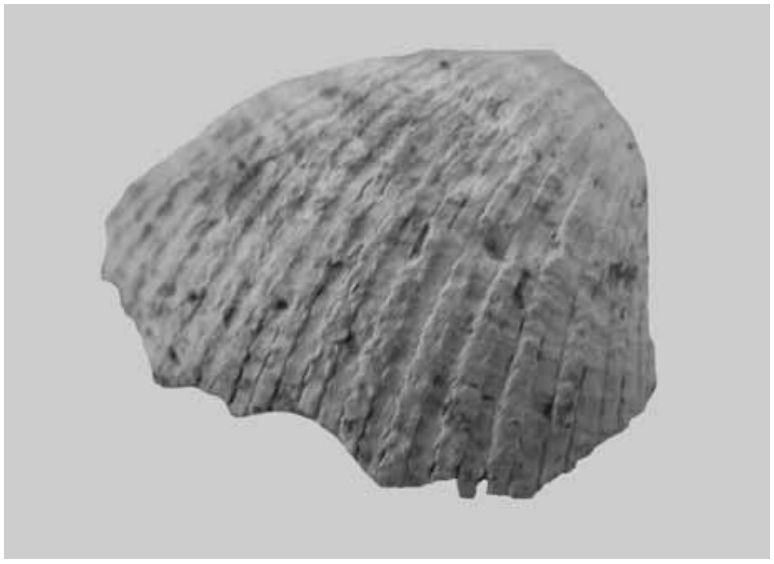

Fig. 14. Anadara diluvii clam shell with traces of syngenetic (Miocene) bioerosion on the surface (Grave 12)

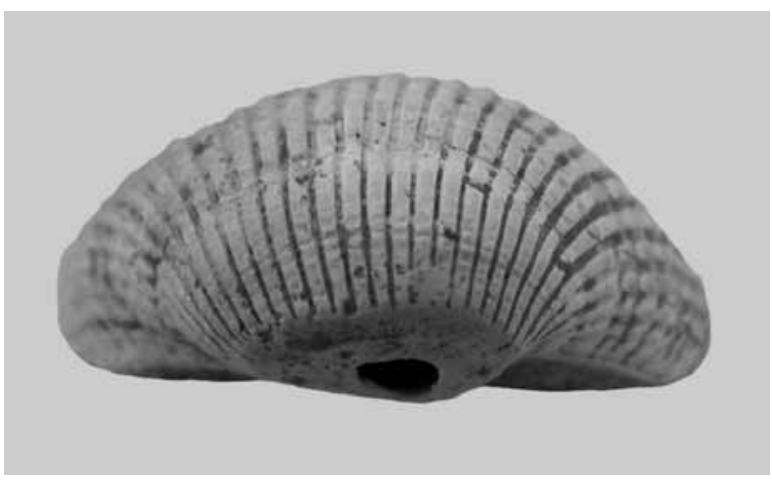

Fig. 15. Anadara diluvii clam shell with polished umbo

(Grave 35)

created under the umbo (Figs 15 and 17). It seems likely that the freshwater limestone beads were used for threading the Anadara shells after they were perforated at the umbo (Fig. 16). A very pretty pendant can be made by placing a limestone bead on either side of the polished and perforated Anadara umbo and threading a cord through them (Fig. 18). A very decorative necklace can be made by threading several shells in this manner. Ornaments made from Anadara diluvii shells apparently

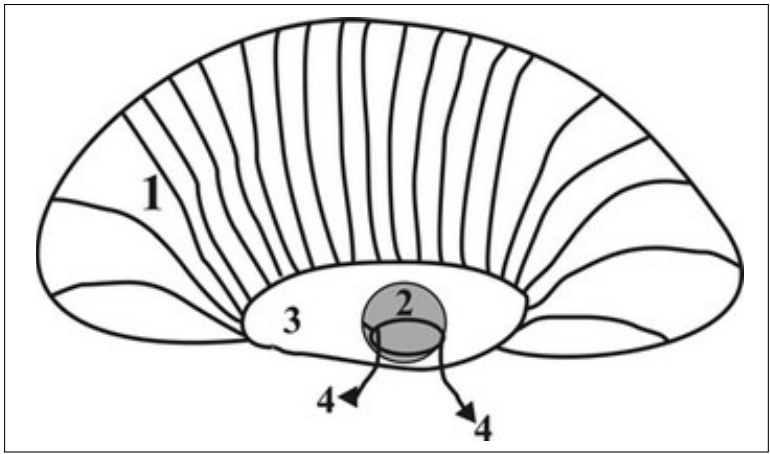

Fig. 16. Ornmament combining an Anadara clam shell with trimmed and polished umbo and perforated freshwater limestone beads. 1. Anadara diluvii clam shell,

2. freshwater limestone bead on the inner side of the trimmed and polished Anadara umbo, 3. trimmed and polished Anadara umbo, 4. cord threaded through the umbo and the limestone bead

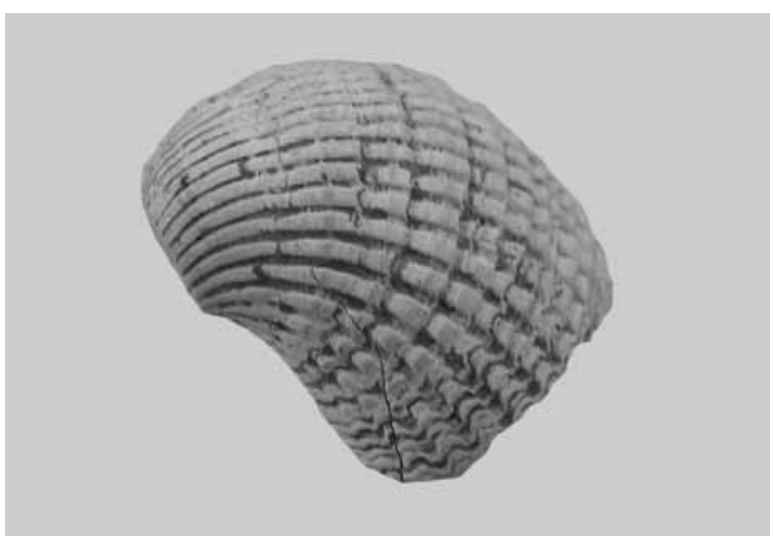

Fig. 17. Anadara diluvii clam shell with polished umbo (Grave 33)

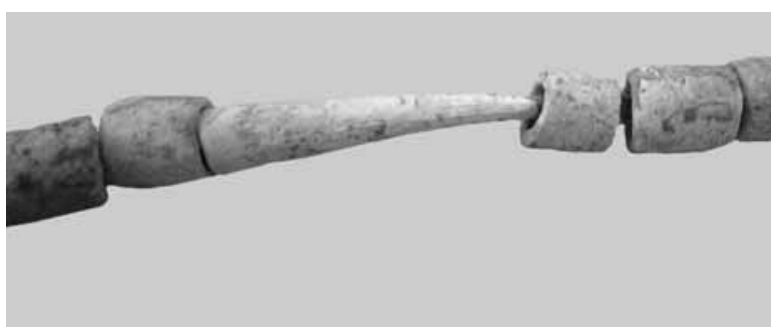

Fig. 18. Freshwater limestone bead perforated at the two ends (Grave 71)

played an important role in Copper Age funerary rites since some shells were painted red with ochre, a symbol of blood and life (Figs 19-20). In addition to Anadara shells strung through the polished and perforated umbo, the finds included a shell which had been perforated in several spots (Figs 21-22), which had probably been threaded more intricately using several cords or sewn onto the dress, although it is also possible that Dentalium and Anadara shells were combined when making ornaments. 


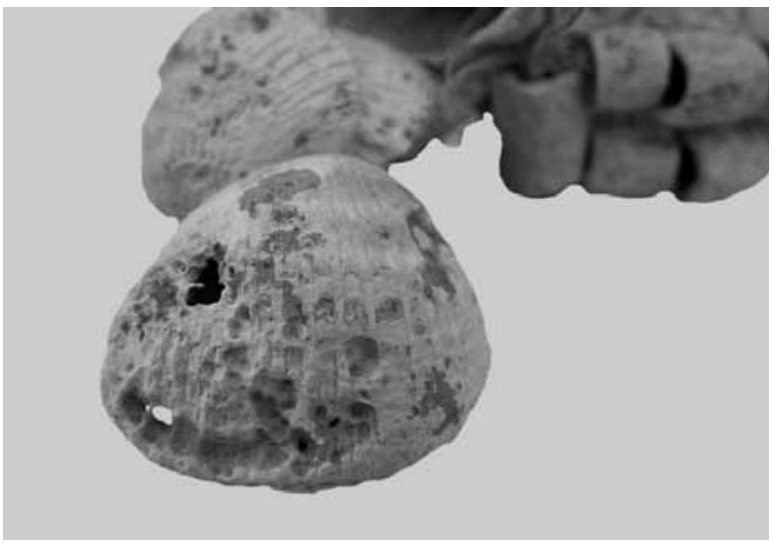

Fig. 19. Anadara diluvii clam shell painted red (Grave 67)

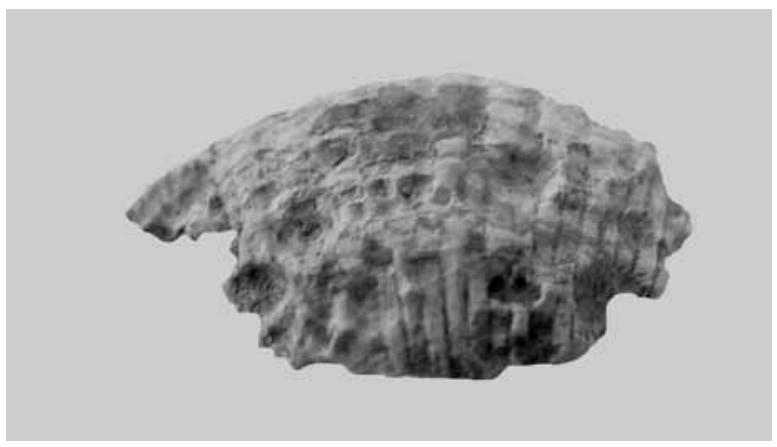

Fig. 20. Anadara diluvii clam shell painted red (Grave 67)

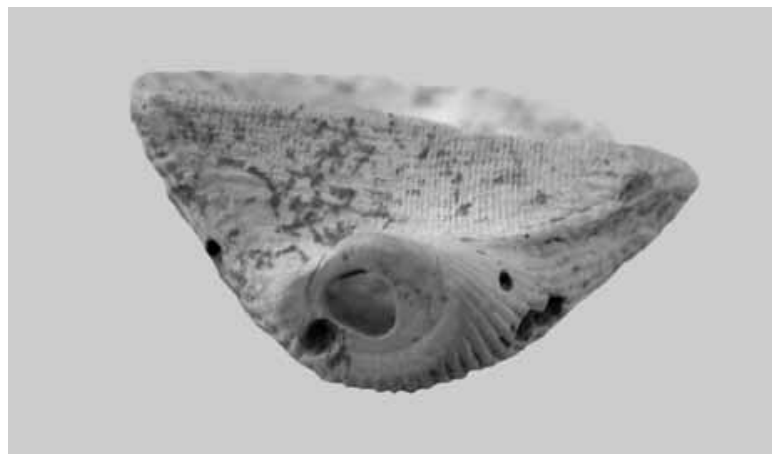

Fig. 21. Anadara diluvii clam shell perforated in several spots for suspension or embroidery (Grave 50)

Anadara shells are known from Middle Palaeolithic coastal sites in Italy and China, ${ }^{24}$ from Upper Palaeolithic sites in Western Europe (predominantly from France and Portugal), ${ }^{25}$ and from Neolithic and Copper Age sites in Portugal. ${ }^{26}$ The use of fossil Anadara shells as ornaments has been chiefly documented on Central European sites. ${ }^{27}$

Alongside Dentalium badense and Anadara diluvii shells, the third most frequently found ornaments were Unio crassus mussel shells (Figs 23-24) and plaques

\footnotetext{
24 Peresani et al. 2001.

25 Callapez 2003; Zilhao 1997; Chauviere 2002.

${ }^{26}$ Callapez 1992.

27 TABORIN 1993.
}

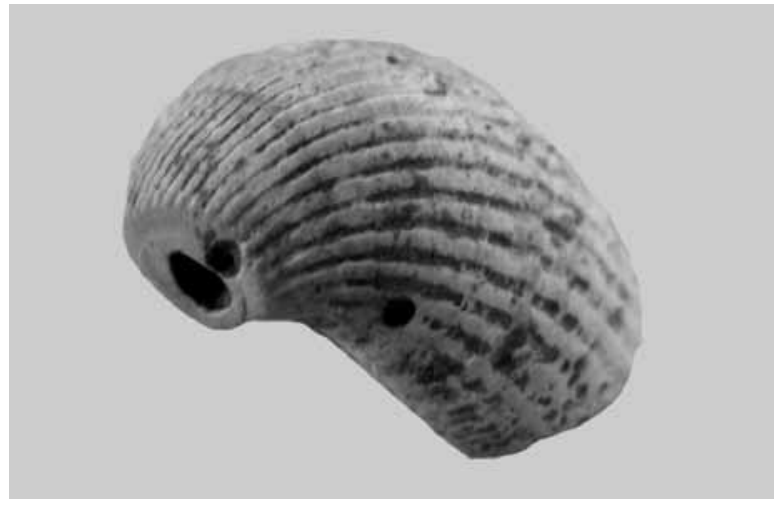

Fig. 22. Anadara diluvii clam shell perforated in several spots for suspension or embroidery (Grave 50)

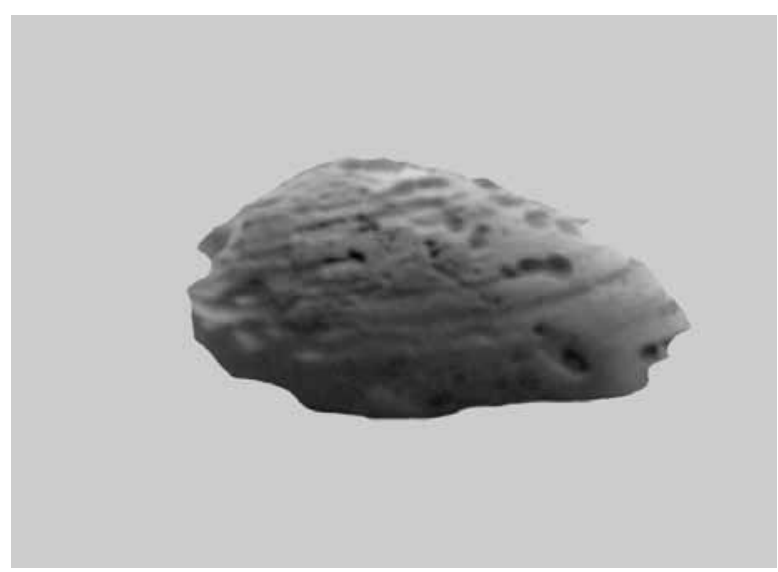

Fig. 23. Fragmentary Unio crassus mussel shell with traces of dissolution on the surface (Grave 180)

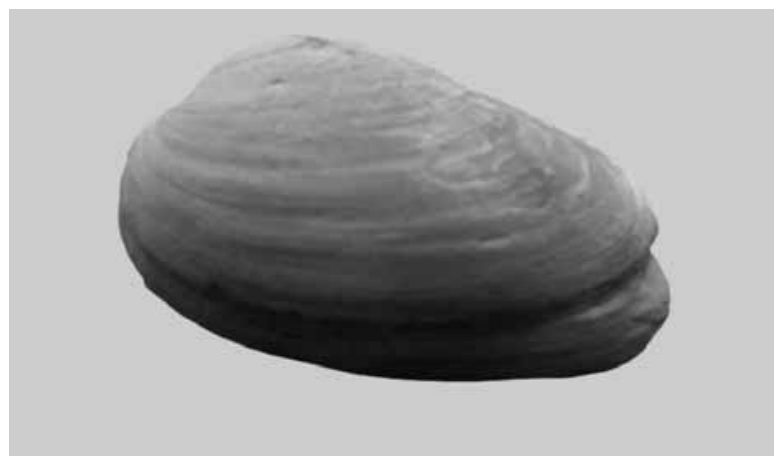

Fig. 24. Unio crassus mussel shell (Grace 190)

perforated at the four corners for attachment made from Unio crassus mussels (Figs 25-26). The recent malacological data indicated that these freshwater Unio crassus mussels of probably Danubian origin dated from the Holocene and thrived in the river during the Copper Age, meaning that the Budakalász community had probably collected the mussels washed ashore by the river. These shells were completely transformed by breaking off $15-20 \mathrm{~mm}$ by $6-11 \mathrm{~mm}$ large pieces, which were carefully polished into small plaques. Tiny 


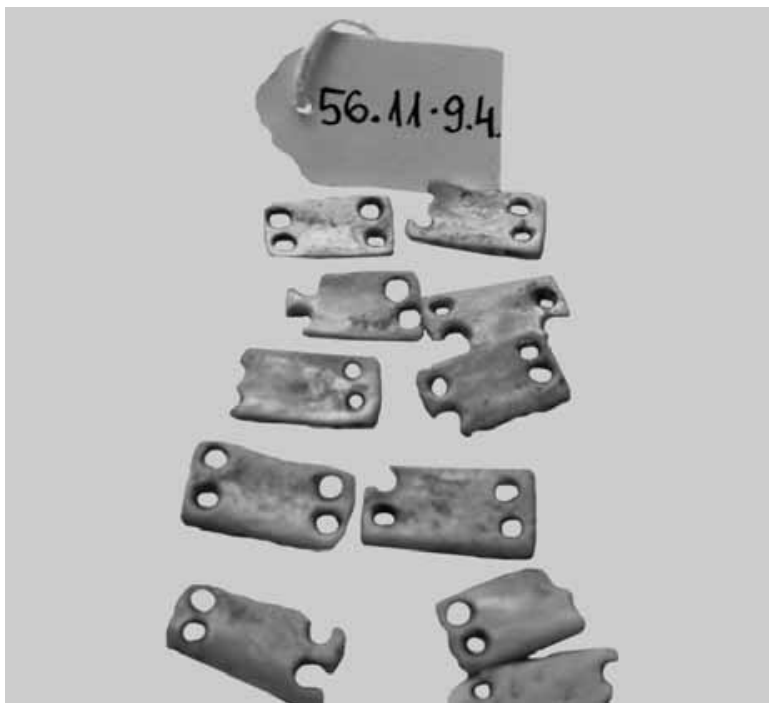

Fig. 25. Button shaped plaques perforated at the four corners polished from Unio crassus mussels (Grave 13)

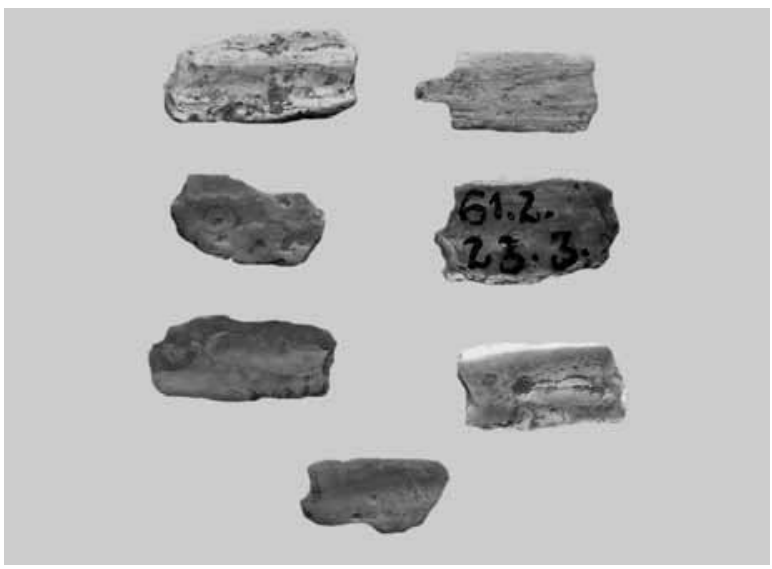

Fig. 26. Button shaped plaques perforated at the four corners (now broken) polished from Unio crassus mussels (Grave 148)

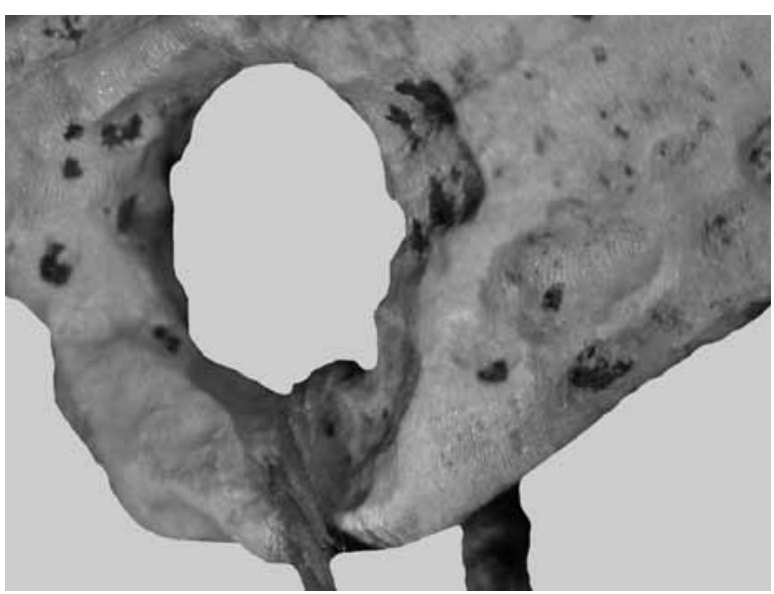

Fig. 27. Shell pendant polished from Miocene fossil Spondylus (Grave 138) holes were bored in the four corners, enabling their attachment to textile or leather. These small plaques resemble buttons, but they could hardly have functioned as such since the plaques were so thin $(0.2-0.6 \mathrm{~mm})$ that any physical pressure would have resulted in their breakage. It seems likely that these shell plaques had been embroidered onto the deceased's clothing. Although the perforated corner broke off on some pieces (Fig. 25), this cannot be automatically attributed to use-wear, because they may have become damaged during or after the funeral, or during the excavation of the grave or afterwards.

Mention must be made of the few Unio crassus shells whose surface bears strong traces of dissolution. These mussels probably lived in waters with an acidic $\mathrm{pH}$ or in locations where thermal springs flowed into the Danube since similar traces of dissolution can be noted on contemporary Danubian mussels in similar habitats.

Unio mussels were regularly collected on a large scale by prehistoric communities for consumption and, to a lesser extent, for vessel decoration from the Neolithic onward. ${ }^{28}$ The archaeological record indicates that these mussels were used for making ornaments since the Upper Palaeolithic. ${ }^{29}$

In addition to the above described shells, fragments of Turritella badense and Columbella snails originating from Miocene deposits, and Pecten and Spondylus shells were also found. The use of Turritella badense snail shells as ornaments can be documented from the Upper Palaeolithic in the Carpathian Basin, ${ }^{30}$ and their widespread use as jewellery can be linked to this period since they were one of the commodities traded among the Upper Palaeolithic communities living in this region. ${ }^{31}$ The same holds true for the Columbella and Pecten fragments. Outstanding among the mollusc remains, represented by a single specimen only, is a polished, fossil Spondylus pendant perforated in several spots (Fig. 27), the first instance of the use of fossil Spondylus as an ornament, since the presence of this shell in the Carpathian Basin during the Neolithic is usually linked to long-distance trade with the Mediterranean, or better said, the Aegean. ${ }^{32}$

The mollusc finds included an Anodonta shell fragment, a species which is quite frequent in various freshwater lakes and rivers in the Carpathian Basin even today. This species has been found on other Mesolithic and Neolithic sites in this region, ${ }^{33}$ although their proportion is low compared to the other mollusc finds, and thus their occurrence in the Copper Age is hardly surprising. It is uncertain what they were used for since their shell becomes very fragile after desiccation and often disintegrates, making them unsuitable for the manufacture of ornaments.

\footnotetext{
28 GULYÁS-SÜMEGI 2004.

${ }^{29}$ Callapez 2003; Zilhao 1997; Chauviere 2002.

${ }^{30}$ GÁBORI 1964.

31 GÁBORI 1964

32 KALICZ-SZÉNÁSZKY 2001; SHACKLETON-ANDEL 1986

33 SÜMEgI 2003.
} 
The re-examination of the over 3400 jewellery items from the Baden cemetery at Budakalász revealed that the beads were dominated by pieces made from freshwater limestone (accounting for about 63 per cent) and not from snails or shells (roughly 33 per cent), as earlier believed. In addition to these two major groups, the finds included copper ornaments (2.6 per cent) and beads made from clay, as well as beads manufactured from Mesozoic and crystalline limestone (the latter accounting for less than 1.5 per cent of the finds).

Freshwater limestone formed by springs active in the Pleistocene and the Holocene can be found in several locations in the cemetery's broader environs. However, the majority of adornments made from mollusc shells came from Miocene marine layers. Aside from fossil mollusc shells, mussels from the Danube were also used for making ornaments (principally Lithoglyphus naticoides and Unio crassus).

The mollusc sample was dominated by Dentalium badense, a Miocene fossil shell used for making beads strung into necklaces or pendants worn as earrings and hair ornaments, or embroidered onto dresses. These shells were sometimes combined with tubular copper beads imitating the form of Dentalium shells. Miocene Anadara diluvii shells were found in substantial number too. After their umbo was trimmed and polished, these shells were combined with limestone beads or, more rarely, with Dentalium shells, to make dangles for necklaces. One Anadara shell was fashioned in a manner as to suggest it had been horizontally attached to some textile or the costume. A similar attachment mode can be noted in the case of cameos, the polished gemstones adorning chokers. It is also possible that this shell medallion had been sewn onto the dress or perhaps the funerary shroud, similarly to the small rectangular plaques made from Unio crassus. The latter were so thin and fragile as to preclude their everyday use which would have led to their breakage, whereas most were found intact. The other mollusc shells in the sample, represented by one or two specimens, were also used as adornments for necklaces (Columbella, Spondylus, Pecten). 


\section{References}

BÁLDY-KÓKAY 1970

BAR-YOSEF 1989

BAR-YOSEF 1991

BONDÁR 2004

Callapez 2002

Callapez 2003

Chauvière 2002

Crewe et al. 2002

CSEPREGHY-MEZERNICS 1956

Dimitrov-Dimitrov 2004

DudÁs 2001

DUlaI 1995

DulaI 1996

DULAI 2001

GÁBORI 1964

GULYÁS-SÜMEGI 2004

HÁMOR 1985

HÁMOR 1988

HRs-BRENKo-Legac 1996

KALICZ-SZÉNÁSZKY 2001

KoWALEWSKI et al 1998

KROLOPP 1961

KROLOPP 1982

KROLOPP 2004

PASDA 1994
Báldy, T.- Kókay, J.: A kismarosi tufit faunája és a börzsönyi andezitvulkánosság kora [Die Tuffitfauna von Kismarton und das Alter des Börzsönyer Andesitvulknismus]. Földtani Közlöny 100 (1970) 274-284.

Bar-Yosef, D. E.: Late Paleolithic and Neolithic Marine shells in the southern Levant as cultural markers. In: Proceedings of the 1986 Shell Bead Conference. Ed. by C. F. Hayes and L. Ceci. Rochester 1989, 169-174.

Bar-Yosef, D. E.: Changes in the selection of marine shells during the transition from the Natufian to the Neolithic. In: The Natufian Culture in the Levant. Ed. by F. Valla and O. Bar-Yosef Ann. Arbor 1991, 629-636. (International Monographs in Prehistory)

Bondár, Mária: A kocsi a késố rézkori Európában [Der Wagen im spätkupferzeitlichen Europa]. ArchÉrt 129 (2004) 5-34.

Callapez, P.: A malacofauna críptica da Gruta do Caldeirûo (Tomar, Portugal) e as faunas de gastrópodes terrestres do Plistocénico superior e Holocénico da Estremadura portuguesa. Revista Portuguesa de Arqueologia 5: 2 (2002) 5-28.

Callapez, P.: Moluscos marinhos e fluviais do Paleolítico superior da Gruta do Caldeirão (Tomar, Portugal): evidencias de ordem sistemática, paleobiológica e paleobiogeográfica. Revista Portuguesa de Arqueología 6: 1 (2003) 5-15.

Chauvière, F.-X.: Industries et parures sur matières dures animales du Paléolithique supérieur de la grotte de Caldeirûo (Tomar, Portugal). Revista Portuguesa de Arqueologia 5: 2 (2002) 5-28.

Crewe, L.-Peltenburg, E.-Spanou, S.: Contexts for cruciforms: figurines of prehistoric Cyprus. Antiquity 76 (2002) 21-22.

Csepreghy-Mezernics, I.: A szobi és a letkési puhatestű fauna [Die Mollusken von Szob und Letkés]. Magyar Állami Földtani Intézet Évkönyve 45 (1956) 361-448.

Dimitrov, P.-Dimitrov, D.: The Black Sea, the flood and the ancient myths. Varna 2004.

Dudás, G.: Naticidae fúrásnyomok középsố-miocén puhatestúek mészvázain (Ipolydamásd, Börzsöny-hegység) [Sign of Naticid predation on the shell of Middle Miocene (Badenian) Molluscs]. Malakológiai Tájékoztató 17 (2001) 21-36.

Dulai, A.: Middle Miocene (Badenian) lunulitiform Bryozoa from Szob (Börzsöny Mts., Hungary). Annales historico-naturalis Musei Naturalis Hungarici 87 (1995) 35-54.

Dulai, A.: Taxonomic composition and paleoecological features of the Early Badenian (Middle Miocene) bivalve fauna of Szob (Börzsöny Mts., Hungary). Annales historico-naturalis Musei Naturalis Hungarici 88 (1996) 31-56.

Dulai, A.: Middle Miocene (Badenian) Polyplacophora (Mollusca) remains from borehole Szokolya-2 (Börzsöny Mts, Hungary, Central Parathetys). Fragmenta Palaeontologica Hungarica 19 (2001) 39-49. Gábori, M. A késói paleolitikum Magyarországon [The Upper Palaeolithic in Hungary]. Budapest 1964. Gulyás, S.-Sümegi, P.: Some aspects of prehistoric shellfishing from the Early Neolithic (Körös) site of Tiszapüspöki, Hungary: methods and findings. Soosiana 32 (2004) 60.

Hámor, G.: A Nógrád-Cserháti kutatási terület földtani viszonyai [Geology of the Nógrád-Cserhát area]. Geologica Hungarica 22 (1985) 1-297.

Hámor, G.: A magyarországi miocén rétegtana [The stratigraphy of the Hungarian Miocene]. In: Magyarország geológiai képződményeinek rétegtana. Ed. by Bérczi, I. and Jámbor, Á. Budapest 1988, $437-453$.

Hrs-Brenko, M.-Legac, M.: A review of bivalve species in Eastern Adriatic Sea. II. Pteromorphia (Arcidae and Noetidae). Natura Croatica 5: 3 (1996) 221-247.

Kalicz, N.-Szénászky, J.: Spondylus-Schmuck im Neolithikum des Komitats Békés, Südostungarn. PZ 76 (2001) 24-54.

Kowalewski, M.-Dulai, A.-Fürsich, F.: A fossil record full of holes: The Phanerozoic history of drilling predation. Geology 26 (1998) 1091-1094

Krolopp, E.: A Buda környéki alsó-pleisztocén mésziszapok csigafaunájának állatföldrajzi és ökológiai vizsgálata [The zoobiogeographic and ecological analyses of the snail fauna from Lower Pleistocene freshwater chalk layers of the Buda Mountain and its environs]. CSc Thesis. Budapest 1961.

Krolopp, E.: Biostratigraphic classification of Pleistocene formations in Hungary on the basis of their mollusc fauna. In: Quaternary Studies in Hungary. Ed. by Pécsi, M. Budapest 1982, 107-111.

Krolopp, E.: Pleisztocén Mollusca-faunánk taxonómiai, faunisztikai, rétegtani és paleoökológiai értékelése [Taxonomical, faunistic, stratigraphic and palaeoecological values of the Quaternary Mollusc faunas in Hungary]. DSc Thesis. Budapest 2004.

Pasda, C.: Das Magdalénien in der Freiburger Bucht. Stuttgart 1994. (Materialhefte zur Archäologie in Baden-Württemberg 25) 
Peresani et al. 2001

RAHLE 1981

RAHLE 1987

RAHLE 1994

SAINT-MARTIN et al. 2000

SCHMIDT 1977

SEDLMEIER 1988

SHACKLETON-ANDEL 1986

SOPRONI 1954

SÜMEGI 2003

SZENTES 1968

TABORIN 1993

VADÁSZ 1906

VANHAEREN et al. 2005

ZILHAO 1997
Peresani, M.-Bertola, S.-Peretto, C.-Thun-Hohenstein, U.: Paleoecological and paleoeconomical aspects of the Middle Palaeolithic site of the Ghiacciaia Cave (Venetian PreAlps). In: Atti del XIII Congresso degli Antropologi Italiani, Roma Sabaudia, Ottobre 1999. Ed. by G. Spedini, G. DestroBisol, and G. Manzi. Roma 2001, 3-7.

Rahle, W.: Schmuckschnecken aus jungpaläolithischen Fundschichten vom Hohlen Fels bei Schelklingen (Alb-Donau-Kreis). Archäologisches Korrespondenzblatt 11 (1981) 179-180.

Rahle, W.: Die Molluskenfaunen der Grabung Felsställe bei Mühlen, Stadt Ehingen, Alb-DonauKreis. In: Das Felsställe. Eine jungpaläolithisch-frühmesolithische Abri- Station bei EhingenMühlen, Alb-Donau-Kreis. Ed. by C.-J. Kind. Stuttgart 1987, 269-274. (Forschungen und Berichte zur Vor- und Frühgeschichte in Baden-Württemberg 23)

Rahle, W.: Neue Funde jungpaläolitischen Schalenschmuckes vom Hohlen Fels bei Schelklingen, Alb und Donau Kreis und vom Petersfels bei Engen, Kreis Konstanz. Fundberichte aus Baden Württemberg 19 (1994) 95-98.

Saint-Martin, J. P.-Müller, P.-Moissette, P.-Dulai, A.: Coral microbialite environment in a middle Miocene reef of Hungary. Palaeogeography, Palaeoclimatology, Palaeoecology 16 (2000) 179-191.

Schmidt, E.: Die Umwelt der Jäger vom Kesslerloch. In: Die Kultur der Eiszeitjäger aus dem Kesslerloch. Ed. by H.-G. Bandi, J. Bürgi, K. Gerhardt, H. Müller-Beck and E. Schmidt. Konztanz 1977, 56-62.

Sedlmeier, J.: Jungpaläolithischer Molluskenschalen-Schmuck aus nordwestschweizerischen Fundstellen als Nachweis für Fernverbindungen. Archäologisches Korrespondenzblatt 18 (1988) 1-6.

Shackleton, J. C.-van Andel, Tj. H.: Prehistoric shore environments, shellfish availability, and shellfish gathering at Franchthi, Greece. International Journal of Geoarchaeology 1 (1986) 127-143. Soproni, S.: A budakalászi kocsi [Der Wagen im Budakalász]. FolArch 6 (1954) 29-36.

Sümegi, P.: Régészeti geológia és történeti ökológia alapjai [Archaeological geology and historical ecology]. Szeged 2003.

Szentes, F.: Magyarázó Magyarország 1:200 000-es földtani térképéhez. L31-I. Tatabánya [The 1:200,000 geological map of Hungary, Section L31-I. Tatabánya]. Budapest 1968.

Taborin, Y.: La parure en coquillage au Paléolithique. Supplement to Gallia Préhistoire 29. Paris 1993. Vadász, M. E.: Budapest-Rákos felsôo mediterránkorú faunája [Über die Obermediterrane Fauna von Budapest-Rákos]. Földtani Közlöny 36 (1906) 256-283.

Vanhaeren M.-Fano Martínez, M. A.-d'Errico, F.-Álvarez Fernández, E.: La parure de la Cueva de El Horno (Ramales, Cantabria). In: Industrie osseuse et parures du Solutréen au Magdalénien en Europe. Table ronde sur le Paléolithique supérieur récent. Angoulême, 28-30 mars 2003. Ed. by V. Dujardin. Mémoire XXXIX de la Société Préhistorique Française. Paris 2005, 197-208.

Zilhao, J.: O Paleolítico Superior da Estremadura portuguesa. Lisboa 1997. 



\section{STABLE ISOTOPE ANALYSIS OF CARBONATIC ORNAMENTS FROM THE LATE COPPER AGE CEMETERY AT BUDAKALÁSZ}

Attila Demény, Bernadett Bajnóczi, Sándor Kele, István Fórizs, Gabriella Barna and Zoltán Siklósy 


\section{WHAT IS STABLE ISOTOPE GEOCHEMISTRY?}

Before discussing the results of the stable isotope analyses, it might be instructive to briefly review what stable isotope data, $\delta$ values and per mil dimension denote. Stable isotope geochemistry deals with the natural distributions of the stable isotopes of five light elements (hydrogen, carbon, nitrogen, oxygen and sulphur), and with the investigation of the governing processes. The studied isotopes of these elements are ${ }^{2} \mathrm{H}$ (or $\mathrm{D}$, deuterium), ${ }^{1} \mathrm{H}$ (protium), ${ }^{13} \mathrm{C},{ }^{12} \mathrm{C}, 15 \mathrm{~N},{ }^{14} \mathrm{~N},{ }^{18} \mathrm{O}$, ${ }^{16} \mathrm{O},{ }^{34} \mathrm{~S}$ and ${ }^{32} \mathrm{~S}$. Discussed in this study are the samples taken from artefacts containing calcium carbonate $\left(\mathrm{CaCO}_{3}\right)$, meaning that the archaeometric analyses focused on carbon and oxygen isotopes. During reaction with phosphoric acid, $\mathrm{CO}_{2}$ is produced from the studied sample; the isotopic ratios of the samples were obtained by the analysis of the $\mathrm{CO}_{2}$ gas led into a mass spectrometer. The measurements were made using the Finnigan MAT delta $S$ and Thermo Finnigan delta plus XP mass spectrometers of the Institute for Geochemical Research. Knowing that the isotope ratio of the gas can even change during measurements, each analysis is performed using a standard whose isotopic composition is well known. This is known as standardisation, meaning that the same treatment is applied to the standard and the sample; the data obtained on the sample is expressed relative to the data of the standard. This is shown by the $\delta$ value used in stable isotope geochemistry:

$$
\delta=\left(\mathrm{R}_{\text {sample }} / \mathrm{R}_{\text {standard }}-1\right) \times 1000,
$$

where $R_{\text {sample }}$ and $R_{\text {standard }}$ are the isotope ratios in the sample and in the standard ${ }^{13} \mathrm{C} /{ }^{12} \mathrm{C}$ and ${ }^{18} \mathrm{O} /{ }^{16} \mathrm{O}$ in this case), respectively. Owing to the small variations usually measured, the $\delta$ value would be inconveniently small and it is therefore multiplied by 1000 . This is expressed by the per mil value (\%), which in this case does not denote concentration. The values are reported relative to an international reference standard: in the case of carbon, it is Pee Dee Belemnite (V-PDB, a marine fossil) and in the case of oxygen, the V-PDB and V-SMOW ("Standard Mean Ocean Water"), where "V" stands for Vienna, where the International Atomic Energy Agency supplying the standards is based. It follows from the formula that the more heavy isotopes a sample contains, the more positive the $\delta$ value, while enrichment in light isotopes gives increasingly negative $\delta$ values.

At the dawn of stable isotope geochemistry, Harold Urey and his colleagues concluded from theoretical calculations and empirical observations on the $\delta^{18} \mathrm{O}$ values of marine carbonates that these isotopic values could be used as a palaeothermometer reflecting the climatic and palaeoenvironmental conditions during the formation of carbonate. Isotope thermometry has become a standard procedure as shown by the proliferation of papers in this field of research. However, the oxygen isotope composition of carbonates is determined not only by temperature, but also by the ${ }^{18} \mathrm{O} /{ }^{16} \mathrm{O}$ ratio of the water from which the carbonate precipitated. Knowing that different water types (seawater, meteoric waters of different climate regimes, lake water, etc.) have different isotopic compositions, the limestones too show major $\delta^{18} \mathrm{O}$ variations. The situation is further complicated by the variations in carbon isotope compositions. Living organisms strive to acquire nutrients at the lowest energy investment and therefore prefer ${ }^{12} \mathrm{C}$ which has a smaller bonding energy than ${ }^{13} \mathrm{C}$. If a carbonate sample contains organic-derived carbon, its $\delta^{13} \mathrm{C}$ values shifts in a negative direction. Rocks of this type include freshwater limestones deposited in an environment rich in organic matter; in contrast, marine limestones show a scatter around $0 \%$ (if the reference sample is a marine carbonate, the VPDB). Moreover, limestones are frequently transported to immense depths during orogeny where they undergo recrystallisation at several hundred ${ }^{\circ} \mathrm{C}$ and form the marbles used by sculptors and architects.

It follows from the above that the limestone samples discussed in the following have widely differing isotopic compositions depending on the formation processes. Knowing that different processes can result in an identical isotope composition, this method is useful for studying formation processes, although the interpretation of individual compositions calls for a careful consideration of the possible factors. ${ }^{1}$

\section{CATHODOLUMINESCENCE: FASCINATING OBSERVATIONS UNDER THE MICROSCOPE}

Cathodoluminescence (CL; fluorescence generated by electrons) is visible light emitted by materials interacting with any electron beam. The light is generated by the imperfections in the crystal structure or impurities in minerals (ions of transition metals such as $\mathrm{Mn}^{2+}$ or $\mathrm{Fe}^{2+}$, and rare earth elements). Different phases or inhomogenities in the studied sample emit light at varying intensities and colour that can be used to observe textural features. Calcium carbonate (limestone rock, and calcite and aragonite minerals) is probably the most frequently studied material in geology by cathodoluminescence microscopy. Fig. 1 presents an excellent example of the detection of different generations in a calcite vein. CL variations are most frequently caused by $\mathrm{Mn}$ substitution in the calcite structure, inducing yellow to orange CL colour in calcite and green CL emission in aragonite. However, a number of factors may affect the intensity of cathodoluminescence, such as the amount of incorporated $\mathrm{Mn}$ and the presence of $\mathrm{Fe}$ substitution in the carbonate structure, the latter weakening or downright prohibiting CL emission. ${ }^{2}$

\section{DISCUSSION}

The main goal of the present work was to determine if the materials used for the manufacture of beads were

\footnotetext{
${ }^{1}$ For good overviews, cp. DEMÉNY 2003 and DEMÉNY 2004.

${ }^{2}$ For a more detailed discussion, cp. BAJNócZI et al. 2005.
} 


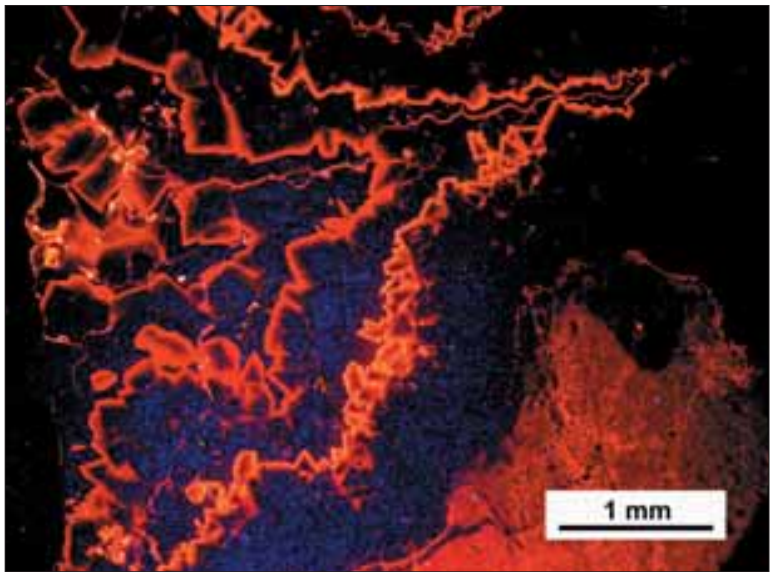

Fig. 1. Cathodoluminescence microscopic image of calcite $(\mathrm{CaCO})_{3}$ crystals formed in a void over several generations

recent marine bivalve shells of the Copper Age. The post-depositional alterations on the samples, visible to the naked eye, challenged the possibility that their age was no more than a few thousand years, although these alterations could have been caused by burial in the soil causing corrosion and secondary carbonate precipitation on the surface of the limestone beads. ${ }^{3}$ The beads in question were submitted to stable isotope analysis, supplemented by optical and cathodoluminescence microscopic examination.

The results of the carbon and oxygen isotope analyses are listed in Table 1 and plotted in Fig. 2. The different morphological types can be distinguished on the basis of their isotope compositions. Limestone beads, Anadara shells, Dentalium beads and mussel shell plaques fall into different $\delta^{13} \mathrm{C}-\delta^{18} \mathrm{O}$ fields without any overlaps. Since these were acquired from different sources, the interpretation of their isotopic composition will be presented separately for each ornament type.

\section{Limestone beads}

Based on the characteristics of their texture, Pál Sümegi identified the material of the limestone beads as travertine (freshwater limestone), with the exception of six pieces of well crystallised limestone beads, and suggested a local source in the Budakalász area. ${ }^{4}$ Fig. 3 shows the isotopic composition of the limestone beads, as well as those of the major travertine deposits in the area. ${ }^{5}$ Only a part of the limestone beads has a similar composition as the travertine deposits in the Buda Mountains, and specifically as the Budakalász travertines within this spectrum. However, about two-thirds of the beads fell into the range with less negative $\delta^{18} \mathrm{O}$ values. This difference can be attributed to subsequent alterations, the presence of rocks of different age and origin, and to possible $\delta^{13} \mathrm{C}-\delta^{18} \mathrm{O}$ variations in the Budakalász deposits that have remained unobserved to date.

\footnotetext{
${ }^{3}$ See pp. 426-432, in this volume.

${ }^{4}$ See p. 426 , in this volume.

${ }^{5}$ KeLE et al. 2003; KeLE et al. 2007.
}

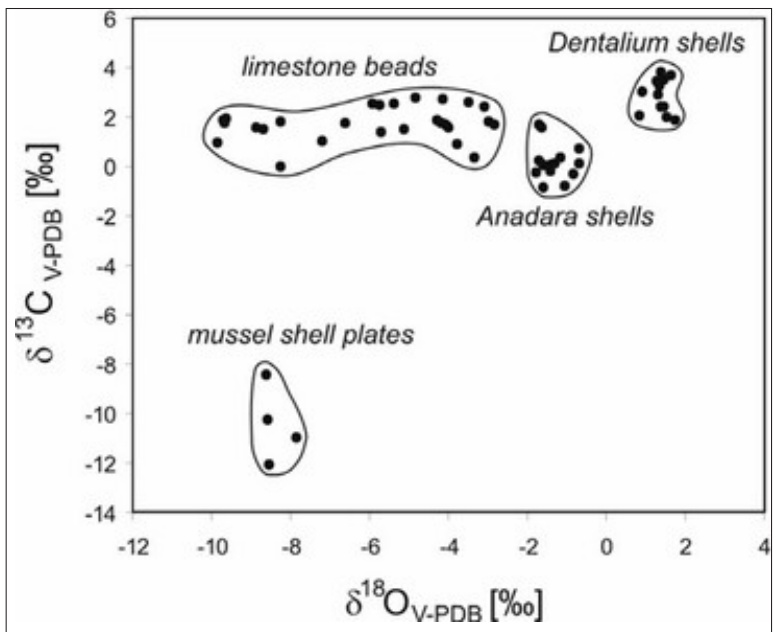

Fig. 2. Stable carbon and oxygen isotope compositions $\left(\delta^{13} \mathrm{C}\right.$ and $\delta^{18} \mathrm{O}$ values in \%o relative to $V-P D B$ standard) of Anadara and Dentalium shells, mussel shell plaques and limestone beads

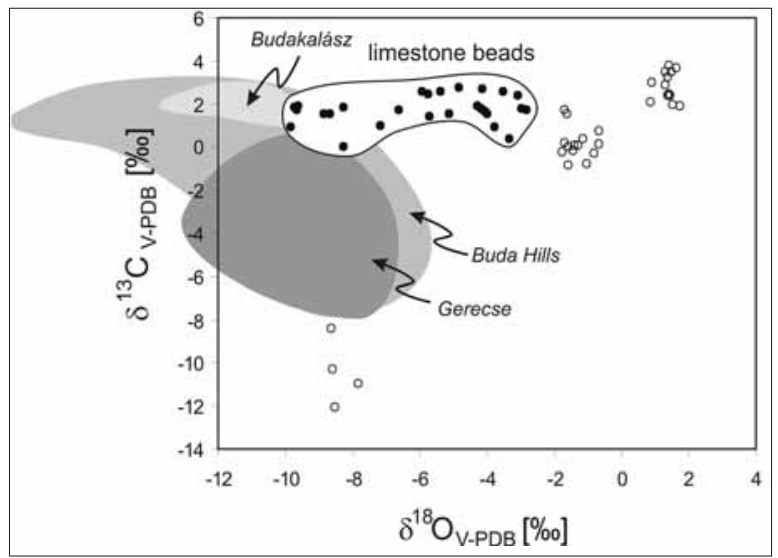

Fig. 3. Stable isotope compositions of the Budakalász samples and of the travertine deposits of the Buda and Gerecse Mountains (after KELE et al. 2003 and 2007).

During the several thousand years of burial in the soil, the beads may have undergone significant alteration causing carbonate recrystallisation and/or secondary precipitation of soil carbonate. In both cases, the alterations resulted in a new isotopic composition reflecting equilibrium with the groundwater. The isotopic composition of altered beads and of specimens without indication of alteration were plotted in Fig. 4 in order to decide this issue; we found that there was no difference between the two types, most likely owing to the fact that the secondary carbonate has an isotopic composition resembling that of the limestone beads, or that the $\delta^{18} \mathrm{O}$ variation was caused by other processes. The macroscopic examination of the beads indicated several textural rock types, and therefore all the beads were examined under a stereo microscope; polished surfaces were produced on some of the beads and submitted to cathodoluminescence microscopic analyses. The following types could be identified from the stereomicroscopic examination: 


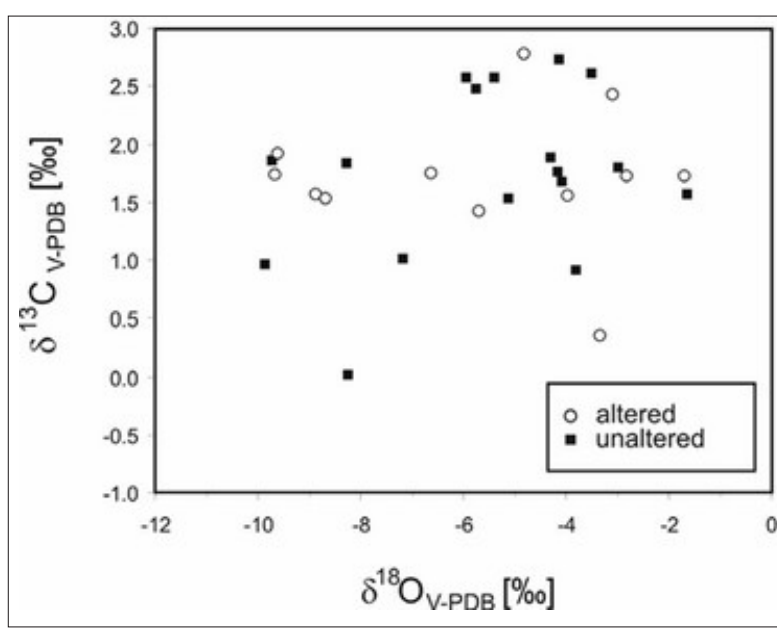

Fig. 4. Stable isotope compositions of limestone beads with and without post-burial alterations

(a) porous, white, rock beads containing calcite veinlets and blebs, the most similar to the Budakalász travertines;

(b) well-crystallised, fine-grained, beige rock beads;

(c) well-crystallised, white beads containing calcite veinlets and, probably, microfossils (inv. nos 56.11.51.1, 61.2.66.23, 61.2.66.25, 61.2.73). The fossils may be foraminifer remnants indicating a marine limestone origin, although a more reliable identification was not possible owing to the small size of the beads;

(d) translucent beads with a fine lamination (inv. no. 61.2.66.23), macroscopically resembling stalagmites.

The limestone beads containing assumed fossils have $\delta^{18} \mathrm{O}$ values ranging between -5.8 and $-3.0 \%$, falling into the less negative end of the $\delta^{18} \mathrm{O}$ range of the limestone beads.

The analysis of the polished beads yielded interesting observations. Significant variations in the extent of alteration could be noted on the beads from Graves 123/A and 164 (inv. nos 61.2.4.1. and 61.2.30.12; Fig. 5). The bead from Grave 164 did not undergo any alterations, its colour resembles that of the Budakalász travertines, although its texture is more fine-grained. The beads from Graves 123/A show strong alteration, with only the innermost parts preserving the original material, which resembles the bead from Grave 164. Even though the secondary carbonate was most probably sampled and analysed for the bead from Grave 123/A, the isotopic compositions of these samples are very close to each other, indicating that alteration did not cause significant isotopic change. At the same time, the cathodoluminescence features of these samples differ from the CL characteristics of the Budakalász travertines (Fig. 5), corresponding to the isotopic differences.

The above observations suggested that the postdepositional alterations of the beads caused by the soil did not lead to significant isotopic changes and thus the scatter of $\delta^{18} \mathrm{O}$ values cannot be exclusively attributed to these alterations and, more significantly, that the beads originated from various rock types, including marine limestones. More reliable identifications could be performed from thin sections, but the preparation of thin sections would lead to the destruction of a part of the selected bead. The overwhelming majority of the examined beads was apparently made from travertine, whose exact source remains unknown in the light of the its textural characteristics and isotopic compositions. These observations can serve as a good starting point for future provenance studies.

\section{Dentalium and Anadara shells}

Sümegi identified these necklace components as Dentalium badense and Anadara diluvii species, and suggested that they originated from Miocene (Badenian) marine sediments. ${ }^{6}$ The most obvious feature is the isotopic difference between the two fossil types (Fig. 6) which can be attributed to the differences between living organism (different organisms incorporate varying amounts of ${ }^{13} \mathrm{C},{ }^{12} \mathrm{C},{ }^{18} \mathrm{O}$ and ${ }^{16} \mathrm{O}$ isotopes from the same environment). Based on earlier studies on similar remains, ${ }^{7}$ there is no significant isotopic difference between scaphopods (including Dentalium) that would exclude "physiological" effects. Another possibility is that the original organisms lived in differing environments. Studies on the $\mathrm{C}$ and $\mathrm{O}$ isotopic compositions of Palaeocene sediments indicated that scaphopods thrive in normal marine environments, while mussels prefer coastal areas with stronger freshwater influx, resulting in lower $\delta^{13} \mathrm{C}$ and $\delta^{18} \mathrm{O}$ values, ${ }^{8}$ corresponding to the values of our samples. However, it must here be noted that the mussels indicated $\delta^{13} \mathrm{C}-\delta^{18} \mathrm{O}$ trends rather than narrow compositional fields.

An alternative explanation can be suggested based on the data appearing in the relevant publications. Fig. 6 presents the compositions of the Budakalász samples and published data on the region's Miocene sediments, ${ }^{9}$ the latter indicating that the Sarmatian and Badenian sediments of the Pannonian Lake were deposited in a normal marine or even highly saline environment caused by strong evaporation in a warm and arid climate, while the $\delta^{13} \mathrm{C}$ and $\delta^{18} \mathrm{O}$ values of younger Miocene sediments indicate increasing an degree of freshwater influx. The differences between the Dentalium and Anadara shells could be attributed to age variations of this type, suggesting that the shells were procured from different sources. The statistically significant isotopic difference and the narrow $\delta^{13} \mathrm{C}-\delta^{18} \mathrm{O}$ ranges would suggest that the Dentalium and Anadara shells originate from Badenian and early Pannonian deposits. An exact answer to this question can be gained from a detailed analysis of Dentalium and Anadara fossils from geological occurrences.

\footnotetext{
${ }^{6}$ See pp. 409-436, in this volume.

7 BuCHARDT 1977; Grossman-Ku 1986; ThiERsteIn et al. 1991.

8 TRIPATI et al. 2001.

${ }^{9}$ Mátyás et al. 1996; LATAL et al. 2004; HarzHauser et al. 2007.
} 

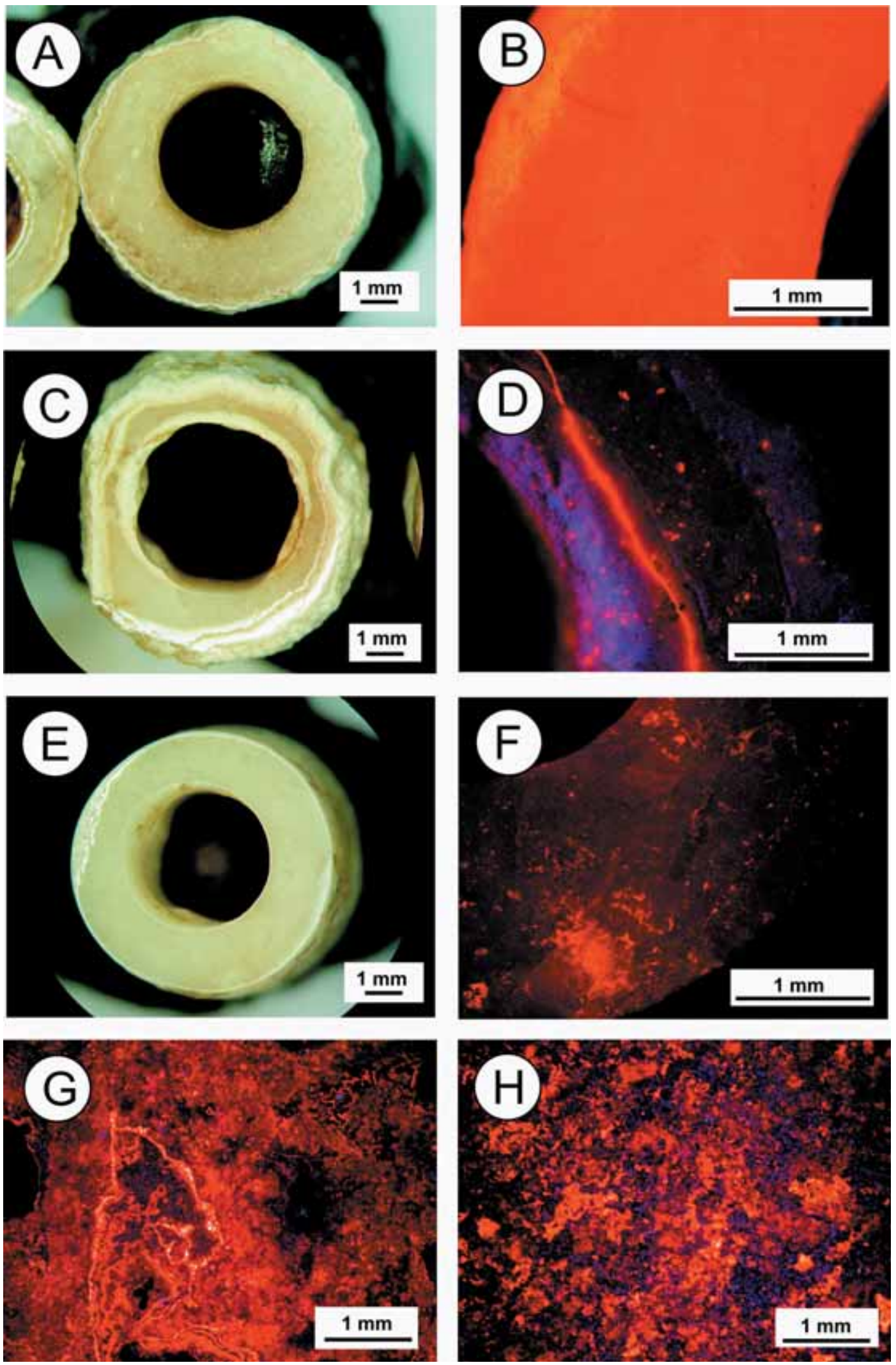

Fig. 5. A. Cut and polished surface of a limestone bead from Grave 2, B. cathodoluminescence microscopic image of the bead from Grave 2, C. cut and polished surface of a limestone bead from Grave 123/A, D. cathodoluminescence microscopic image of the bead from Grave 123/A, E. cut and polished surface of a limestone bead from Grave 164,

F. cathodoluminescence microscopic image of the bead from Grave 164, G-H. cathodoluminescence microscopic images of travertine samples from Budakalász 


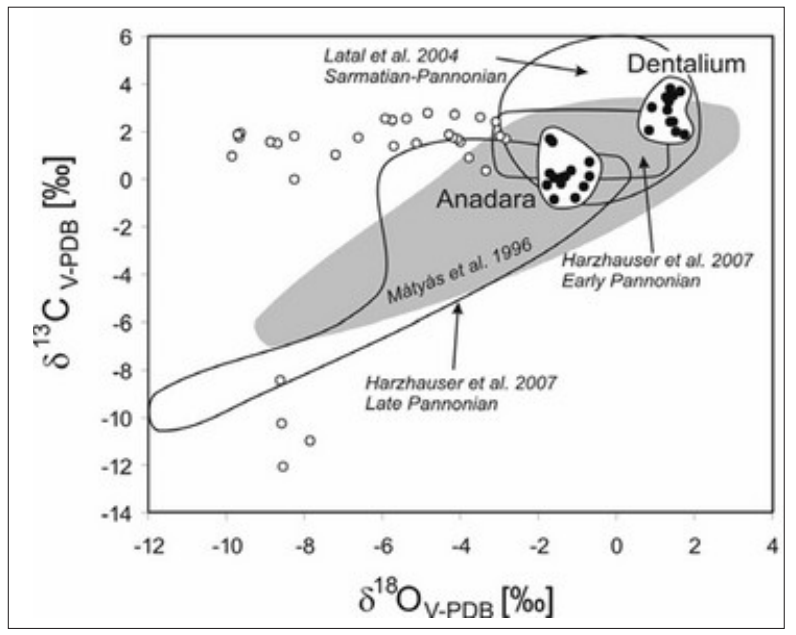

Fig. 6. Stable isotope compositions obtained in this study and those of Miocene rocks of the Carpathian Basin and its surrounding region.

\section{Mussel shell plaques}

These ornaments were undoubtedly made from freshwater mussel (Unio crassus) shells, whose macroscopic appearance differs from that of the Dentalium and Anadara pieces. Not surprisingly, their isotopic compositions too diverge significantly from the former, mainly due to their very low $\delta^{13} \mathrm{C}$ values. The low $\delta^{13} \mathrm{C}$ values can be explained by the higher amount of organicderived $\mathrm{C}$ atoms in the carbonate structure, which can in part be attributed to the mussel's organism ("metabolic carbon"), and in part to the carbon dissolved in water originating from the decomposition of organic matter. Although the data obtained from the Budakalász samples is insufficient for drawing far-reaching conclusions, an overview of the available Unio data from the Carpathian Basin was possible. The data from the Budakalász sample and the isotopic compositions of mussel shells from the Danube, the Tisza and Lake Balaton ${ }^{10}$ presented in Fig. 7 indicate regional differences. The $\delta^{13} \mathrm{C}$ and $\delta^{18} \mathrm{O}$ values of the lake shells are much less negative than those from rivers owing to the strong evaporation of lake water and the related ${ }^{13} \mathrm{C}$ and ${ }^{18} \mathrm{O}$ enrichments. The mussels are in isotopic equilibrium (or at least in exchange) with this water enriched in heavy isotopes, thus, showing less negative isotopic values compared to the shells from rivers. Recent shells from the Danube and Tisza have similar, but slightly different isotopic compositions. The reason for this difference is that the Danube contains meltwater from the Alps with very negative $\delta^{18} \mathrm{O}$ values causing a negative $\delta^{18} \mathrm{O}$ shift in the shell carbonate. However, the shell plaques from Budakalász should be compared to shells of similar age, ${ }^{11}$ i.e. subfossils in the geological sense. There is hardly any data on Danubian mussels for only six shells have been analysed to date from the period between $5800 \mathrm{BC}$ and $166 \mathrm{AD}$. Eighteen subfossil shells have been examined from the

\footnotetext{
${ }^{10}$ FóRIzs 2003, Fórizs-JuHÁsz 2004.

11 FóRIZs 2005
}

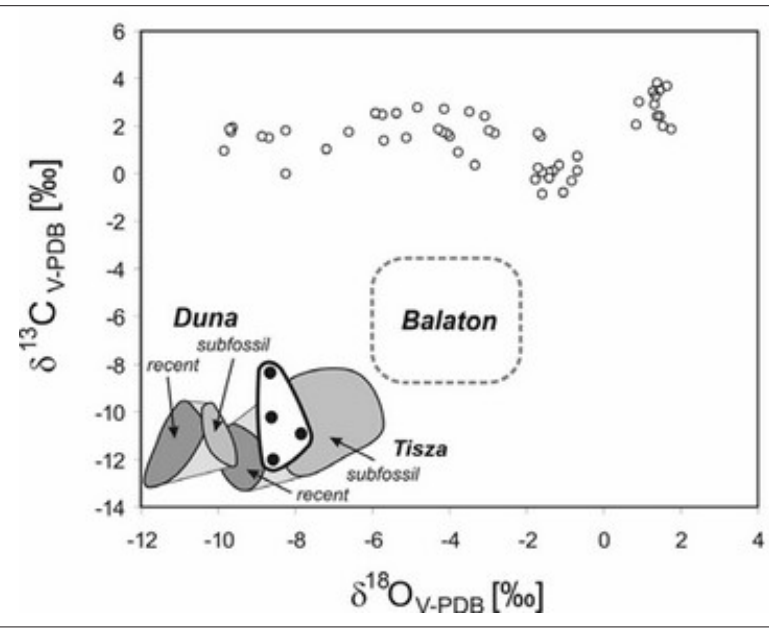

Fig. 7. Stable isotope compositions obtained in this study and those of Unio shells (recent and subfossil) from the Danube, the Tisza and Lake Balaton (István Fórizs, unpublished data).

Tisza region, dating from the period between 5800 and 4000 BC. The available data indicate that the subfossil shells have slightly less negative $\delta^{13} \mathrm{C}$ and $\delta^{18} \mathrm{O}$ values than their recent counterparts, no doubt a reflection of river regulations. Unregulated rivers flow slowly in their meandering beds and undergo strong evaporation during the warm seasons, the living periods of mussels. The data from Lake Balaton cited in the above indicate that evaporation results in $\delta^{13} \mathrm{C}$ and $\delta^{18} \mathrm{O}$ changes, which can be noted in subfossil shells. One interesting aspect of the present data series is that the isotopic composition of the mussel plaques from Budakalász is closer to that of the shells of the Tisza region, suggesting that the shells were either obtained from the Tisza region or from a river with similar isotopic properties. Knowing that the Drava is the single other river of Carpathian Basin draining meltwater from the Alps, all other rivers can be assumed to be isotopically similar to the Tisza. For the time being, however, we can only assume that the studied shells originate from a small river near Budakalász. An alternative explanation is that the Unio mussels, known to thrive in shallow water environments, were obtained from areas in which the Danube received major influxes of meteoric water. In this case, the habitats of the mussels may have been enriched by infiltrating groundwater. Again, further studies are necessary to resolve this issue.

\section{"Speleothem" beads}

The beads of the necklace from Grave 227 (inv. no. 61.2.66.23) have a white, finely laminated $(<1 \mathrm{~mm})$ texture resembling the polished surface of speleothems (speleothems are carbonate precipitations formed in caves known as stalagmites and stalactites). The beads were described as sliced mussel shells in the field diary. ${ }^{12}$ The growth lamination of mussel shells is certainly

\footnotetext{
12 See pp. 119-120, in this volume.
} 

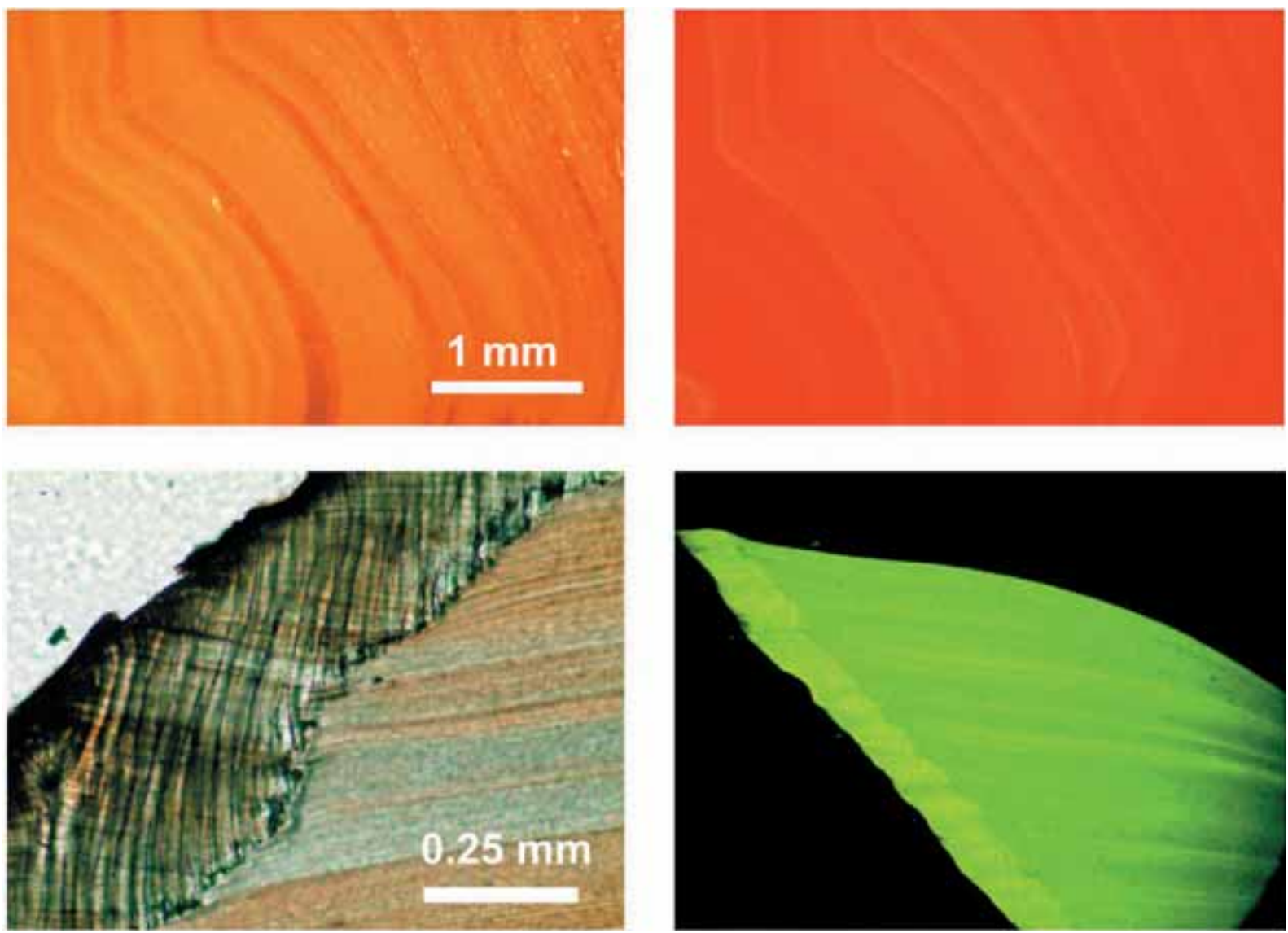

Fig. 8. The "speleothem" bead from Grave 227 in reflected light (A) and under cathodoluminescence microscope (B), optical (C) and cathodoluminescence (D) microscopic pictures of a thin section of an Unio shell from Lake Balaton (collected and analysed by Gabriella Barna)

similar to the texture observed on the beads (cp. Fig. $8 \mathrm{~A}$ and Fig. $8 C$ ) and thus they cannot be distinguished by optical microscopic examination. However, cathodoluminescence (CL) can provide additional information. The bead in question is calcitic with orange CL emission (Fig. 8B); in contrast, the large Unio shells from the area are aragonitic (another $\mathrm{CaCO}_{3}$ structural form) with green luminescence (Fig. 8D). Speleothems usually have dark blue luminescence, but elevated concentrations of manganese and rare earth elements result in a bright yellow to red CL colour. ${ }^{13} \mathrm{We}$ examined stalagmite samples from several localities in Hungary, all of which had a dull blue luminescence. Another possible source for the beads could be the flowstone-like carbonate encrustations in local travertine deposits at Budakalász that also exhibits fine laminations, whose CL colour resembled that of local stalagmites. Knowing that carbonate CL colour is determined by its trace element contents that can vary locally, additional data are needed for settling this issue.

Stable isotope geochemistry is a useful technique for addressing this question. One of the beads was selected and sampled at a resolution of $\sim 0.5 \mathrm{~mm}$ using microdrilling, and was then analysed for carbon and oxygen isotope compositions (cp. Table 1). The results are presented in Fig. 9. Fig. $9 \mathrm{~A}$ and Fig. $9 \mathrm{~B}$ show the data according to the sampling sequence, corresponding to $0.5 \mathrm{~mm}$ steps. Both the $\delta^{13} \mathrm{C}$ and $\delta^{18} \mathrm{O}$ values display $1-1.5 \%$ fluctuations similarly to that observed for stalagmites in the area. The $\delta^{13} \mathrm{C}$ and $\delta^{18} \mathrm{O}$ data show a positive correlation (Fig. 9C) indicating non-equilibrium carbonate precipitation. ${ }^{14}$ Plotting the data against the other data obtained during the study of the analysed samples reflects a good separation between them (Fig. 9D). The $\delta^{13} \mathrm{C}$ data are unusually positive, a trait not found in the region's speleothem carbonates. It is therefore possible that the finely laminated encrustation in the Budakalász travertine may have been the source material. Fig. 9D also shows the compositional field of carbonate samples collected in the travertine quarry of Budakalász. The isotopic composition of this encrustation is typical for carbonates precipitated from meteoric water, and, in view of the large $\delta^{13} \mathrm{C}$ difference, it could hardly have been the source material.

The bead was also submitted to U/Th dating, performed by Zoltán Siklósy at the laboratory of the 
Table 1. Stable carbon and oxygen isotope compositions ( $\delta^{13} C$ and $\delta^{18} \mathrm{O}$ values in $\%$ relative to $V-P D B$ standard) of Anadara and Dentalium shells, mussel shell plaques and limestone beads, and their stereo microscopic description.

\begin{tabular}{|c|c|c|c|c|c|c|c|}
\hline Grave No. & Inv. no. & $\delta^{180}$ & $\delta^{13} \mathrm{C}$ & Grave No. & Inv. no. & $\delta^{180}$ & $\delta^{13} C$ \\
\hline Anadara shell & \multicolumn{7}{|c|}{ Limestone Beads } \\
\hline 8 & 56.11.5.1. & -1.7 & 0.2 & 2 & 56.11.2.5. & -8.9 & 1.6 \\
\hline 12 & 56.11.8.2. & -1.4 & -0.2 & 8 & 56.11.5.1. & -4.1 & 1.7 \\
\hline 43 & 56.11.27.1. & -1.1 & -0.8 & 8 & 56.11.5.1. & -8.3 & 0.0 \\
\hline 48 & 56.11.30.1. & -1.6 & -0.9 & 10 & 56.11.7.1. & -5.4 & 2.6 \\
\hline 50 & 56.11.32.1. & -0.7 & 0.7 & 12 & 56.11 .8 .2 & -7.2 & 1.0 \\
\hline 67 & 56.11.45.3. & -1.6 & 0.0 & 13 & 56.11 .9 .3 & -5.9 & 2.6 \\
\hline 74 & 56.11.51.1. & -1.2 & 0.4 & 23 & 56.11.15.7. & -4.3 & 1.9 \\
\hline 96 & 56.11.63.1. & -1.3 & 0.1 & 24 & 56.11.16.1. & -3.3 & 0.4 \\
\hline 227 & 61.2 .66 .23 & -0.7 & 0.1 & 24 & 56.11.16.1. & -9.9 & 1.0 \\
\hline 241 & 61.2 .73 & -0.8 & -0.3 & 25 & 56.11.17.2. & -9.6 & 1.9 \\
\hline 247 & 61.2 .76 & -1.8 & -0.2 & 43 & 56.11.27.1. & -2.8 & 1.7 \\
\hline 324 & 61.2.115.2. & -1.4 & 0.1 & 48 & 56.11 .30 .1$. & -8.7 & 1.5 \\
\hline \multicolumn{4}{|c|}{ Dentalium shells } & 50 & 56.11.32.2. & $-5,1$ & 1.5 \\
\hline 2 & 56.11.2.5 & 1.8 & 1.9 & 50 & 56.11.32.2. & -9.7 & 1.9 \\
\hline 8 & 56.11.5.1. & 1.3 & 3.5 & 63 & 56.11 .41 .3 . & -9.7 & 1.7 \\
\hline 13 & 56.11.9.3. & 1.5 & 3.5 & 67 & 56.11 .45 .3 . & -3.1 & 2.4 \\
\hline 181 & 61.2.38.1. & 0.9 & 3.0 & 71 & 56.11.48.1. & -5.7 & 1.4 \\
\hline $215 / \mathrm{C}$ & & 0.9 & 2.1 & 73 & 56.11 .50 .5 . & -6.6 & 1.8 \\
\hline 227 & 61.2.66.21. & 1.4 & 3.8 & 74 & 56.11.51.1. & -4.2 & 1.8 \\
\hline 227 & 61.2.66.22.-23. & 1.5 & 2.0 & 74 & 56.11.51.1. & -4.8 & 2.8 \\
\hline 227 & 61.2.66.25. & 1.5 & 2.4 & $123 / \mathrm{A}$ & 61.2 .4 .1 & -4.0 & 1.6 \\
\hline 229 & 61.2 .67 & 1.3 & 2.9 & 164 & 61.2 .30 .12 . & -1.6 & 1.6 \\
\hline 245 & 61.2 .75 & 1.4 & 3.3 & 227 & 61.2 .66 .25 & -4.1 & 2.7 \\
\hline 247 & 61.2 .76 & 1.6 & 3.7 & 227 & 61.2 .66 .23 & -5.7 & 2.5 \\
\hline 403 & 61.2.160.2. & 1.4 & 2.4 & 229 & 61.2 .67 & -3.5 & 2.6 \\
\hline 412 & 61.2.163.3. & 1.4 & 2.4 & 237 & 61.2.71. & -8.3 & 1.8 \\
\hline \multicolumn{4}{|c|}{ Mussel shell plaques } & 241.0 & 61.2 .73 & $-3,0$ & 1.8 \\
\hline 63 & 56.11.41.1. & -7.8 & -10.9 & 247 & 61.2 .76 & -3.8 & 0.9 \\
\hline 208 & - & -8.5 & -12.0 & $123 / \mathrm{A}$ & 61.2.4.1. & -1.7 & 1.7 \\
\hline 227 & 61.2.66.22. & -8.6 & -8.4 & & & & \\
\hline 427 & 61.2 .172 & -8.6 & -10.3 & & & & \\
\hline \multicolumn{8}{|c|}{ "Speleothem beads" (Grave 227, inv. no. 61.2.66.23) } \\
\hline sample point & $\delta^{18} \mathrm{O}$ & $\delta^{13} \mathrm{C}$ & sample point & $\delta^{18} \mathrm{O}$ & $\delta^{13} \mathrm{C}$ & & \\
\hline 1 & -8.3 & 7.8 & 8 & -8.6 & 8.0 & & \\
\hline 2 & -8.2 & 8.0 & 9 & -8.7 & 8.0 & & \\
\hline 3 & -8.2 & 8.3 & 10 & -8.4 & 8.2 & & \\
\hline 4 & -8.5 & 8.0 & 11 & -8.0 & 8.4 & & \\
\hline 5 & -8.7 & 7.9 & 12 & -8.4 & 8.6 & & \\
\hline 6 & -8.8 & 7.8 & 13 & -8.0 & 8.5 & & \\
\hline 7 & -8.4 & 8.1 & 14 & -7.4 & 8.6 & & \\
\hline \multicolumn{8}{|c|}{ Stereo microscopic description } \\
\hline Grave & Inv. no. & \multicolumn{6}{|c|}{ Description } \\
\hline 2 & 56.11 .2 .5 & \multicolumn{6}{|c|}{ White beads with very altered surface. } \\
\hline 8 & 56.11.5.1. & \multicolumn{6}{|c|}{$\begin{array}{l}\text { Well-crystallized, yellow, sometimes with fine lamination. } \\
\text { Soil-related alteration can be excluded. }\end{array}$} \\
\hline 8 & 56.11.5.1. & \multicolumn{6}{|c|}{$\begin{array}{l}\text { Porous, white material, the chance for soil-related alteration is higher, but the } \\
\text { effect of secondary carbonate can be excluded. }\end{array}$} \\
\hline 10 & 56.11.7.1. & \multicolumn{6}{|c|}{ Well-crystallized, packed texture, unaltered type. } \\
\hline 12 & 56.11.8.2. & \multicolumn{6}{|c|}{ Well-crystallized, packed texture, unaltered type. } \\
\hline 13 & 56.11 .9 .3 & \multicolumn{6}{|c|}{ Large sized, well crystallized, unaltered limestone beads. } \\
\hline 23 & 56.11 .15 .7 & \multicolumn{6}{|c|}{$\begin{array}{l}\text { Strongly altered beads with diagenetic calcite blebs, but the sampling surface is good, } \\
\text { showing a well-crystallized, packed texture. }\end{array}$} \\
\hline
\end{tabular}




\begin{tabular}{|c|c|c|}
\hline 24 & 56.11 .16 .1$. & $\begin{array}{l}\text { Strongly altered beads with diagenetic calcite blebs, but the sampling surface is } \\
\text { good, showing a well-crystallized, packed texture. }\end{array}$ \\
\hline 24 & 56.11.16.1. & Well-crystallized, packed texture, slightly altered type with yellowish colour. \\
\hline 25 & 56.11.17.2. & Strongly altered. \\
\hline 43 & 56.11.27.1. & Strongly altered. \\
\hline 48 & 56.11.30.1. & Strongly altered. \\
\hline 50 & 56.11.32.2. & Well-crystallized, packed texture, slightly altered type. Travertine bead. \\
\hline 50 & 56.11.32.2. & $\begin{array}{l}\text { Well-crystallized, packed texture, slightly altered type, but its surface is covered by } \\
\text { secondary carbonate. Travertine bead. }\end{array}$ \\
\hline 63 & 56.11.41.3. & Strongly altered travertine bead. \\
\hline 67 & 56.11.45.3. & Strongly altered, similar to those with shell fragments. \\
\hline 71 & 56.11.48.1. & Strongly altered. \\
\hline 73 & 56.11 .50 .5 . & Strongly altered. \\
\hline 74 & 56.11.51.1. & $\begin{array}{l}\text { Well-crystallized, packed texture, slightly altered type. Small shell fragments, } \\
\text { perhaps foraminifers, on the surface. }\end{array}$ \\
\hline 74 & 56.11.51.1. & Slightly altered. \\
\hline 123/A & 61.2.4.1. & Very strongly altered. The bead interior resembles that of the piece from Grave 164. \\
\hline 164 & 61.2.30.12. & Well-crystallized, packed texture, yellowish, perfectly unaltered type. \\
\hline 227 & 61.2 .66 .25 & $\begin{array}{l}\text { Well-crystallized, packed texture, unaltered type. Small shell fragments (foraminifers?) } \\
\text { on the surface. }\end{array}$ \\
\hline 227 & 61.2 .66 .23 & $\begin{array}{l}\text { Well-crystallized, packed texture, unaltered type. Small shell fragments (foraminifers?) } \\
\text { on the surface. }\end{array}$ \\
\hline 229 & 61.2 .67$. & Well-crystallized, packed texture, white, unaltered type limestone beads. \\
\hline 237 & 61.2.71. & $\begin{array}{l}\text { Well-crystallized, packed texture, white limestone beads with strongly altered } \\
\text { surface. Coverted by secondary carbonate, sampled from the unaltered part. }\end{array}$ \\
\hline 241 & 61.2 .73 & $\begin{array}{l}\text { Well-crystallized, packed texture, unaltered type. Small shell fragments (foraminifers?) } \\
\text { on the surface. }\end{array}$ \\
\hline 247 & 61.2.76. & Well-crystallized, packed texture, perfectly unaltered type. \\
\hline 123/A & 61.2.4.1. & Very strongly altered. The interior of the bead resemles that of the piece from Grave 164 \\
\hline 50 & 56.11.32.2. & $\begin{array}{l}\text { Well-crystallized, packed texture, slightly altered travertine beads covered by secondary } \\
\text { carbonate. }\end{array}$ \\
\hline 63 & 56.11.41.3. & Strongly altered travertine beads. \\
\hline 67 & 56.11 .45 .3 . & Strongly altered, similar to those with shell fragments. \\
\hline 71 & 56.11.48.1. & Strongly altered. \\
\hline 73 & 56.11 .50 .5 . & Strongly altered. \\
\hline 74 & 56.11.51.1. & $\begin{array}{l}\text { Well-crystallized, packed texture, slightly altered type. Small shell fragments, } \\
\text { perhaps foraminifers, on the surface. }\end{array}$ \\
\hline 74 & 56.11.51.1. & Slightly altered. \\
\hline 123/A & 61.2.4.1. & Very strongly altered. The interior of the bead resemles that of the piece from Grave 164 \\
\hline 164 & 61.2.30.12. & Well-crystallized, packed texture, slightly altered type with yellowish colour. \\
\hline 227 & 61.2 .66 .25 & $\begin{array}{l}\text { Well-crystallized, packed texture, unaltered type. Small shell fragments (foraminifers?) } \\
\text { on the surface. }\end{array}$ \\
\hline 227 & 61.2 .66 .23 & $\begin{array}{l}\text { 1) Well crystallized, packed texture, unaltered type. Small shell fragments, } \\
\text { perhaps foraminifers, on the surface. } \\
\text { 2) White, finely laminated }(<1 \mathrm{~mm}) \text { laminated beads resembling stalagmite textures. }\end{array}$ \\
\hline 229 & 61.2 .67$. & Well-crystallized, packed texture, unaltered, white limestone beads. \\
\hline 237 & 61.2.71. & $\begin{array}{l}\text { Well-crystallized, packed texture, unaltered, white limestone beads with altered surface } \\
\text { covered by secondary carbonate, sampled from the unaltered part. }\end{array}$ \\
\hline 241 & 61.2 .73$. & $\begin{array}{l}\text { Well crystallized, packed texture, unaltered type. Small shell fragments, } \\
\text { perhaps foraminifers, on the surface. }\end{array}$ \\
\hline 247 & 61.2 .76$. & Well crystallized, packed texture, unaltered type. \\
\hline $123 / \mathrm{A}$ & 61.2.4.1. & Very strongly altered. The bead interior resembles that of the piece from Grave 164. \\
\hline
\end{tabular}

University of Taiwan. The results gave a date of $364000 \pm 10000 \mathrm{BP}$. The climate of that period was much colder than the current one, although the glacial maximum was not reached. Speleothems of similar age are infrequent in this area, partly because older stalagmites are encrusted by younger ones and large stalagmites are difficult to sample. Nevertheless, it is important to note that the speleothems of Hungary usually have quite negative $\delta^{13} \mathrm{C}$ values (cp. Fig. 9D) owing to the soil cover of the recharge area (supplying 


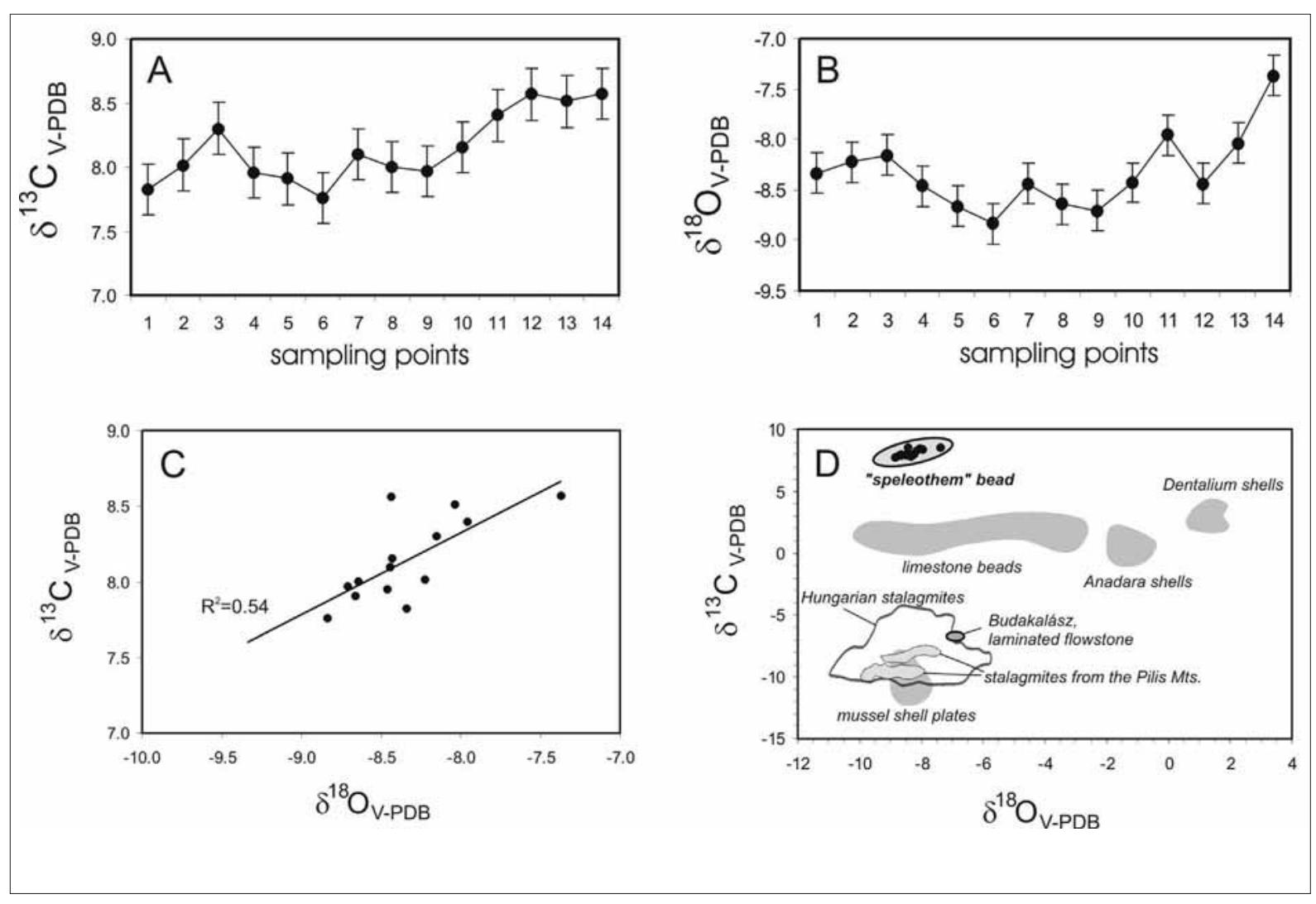

Fig. 9. $A-B . \delta^{13} C$ and $\delta^{18} O$ values of the "speleothem" bead from Grave 227 in the order of analyses points, $C-D . \delta^{13} C$ vs. $\delta^{18} \mathrm{O}$ values of the "speleothem" beads (closed circles) and the other examined samples from Budakalász

dripwater). Soil activity produces organic-derived carbon dissolved in groundwater whose carbon isotope composition is negative. Positive $\delta^{13} \mathrm{C}$ values similar to those observed in the Budakalász sample are found in speleothems formed in high mountain areas of the Alps and the Carpathians, ${ }^{15}$ suggesting an origin in these regions for the "speleothem" beads.

\section{SUMMARY}

The study presents the findings of the stable isotope geochemical analyses performed on carbonate beads and ornaments from which the necklaces and strands deposited in the Budakalász burials were made. The stable isotope data enabled the secure identification of limestone beads, Anadara and Dentalium shells, and mussel shells. The limestone beads were made from several different rock types, most typically from local travertine deposits. However. some of the limestone beads could not be related to deposits in the Buda and the Gerecse Mountains. The cathodoluminescence microscopic analyses and stable isotope compositions provide a firm basis for further provenance studies. Interestingly enough, the Budakalász sample included also marine limestone beads.

The ornaments made from Anadara diluvii and
Dentalium badense shells have isotopic compositions resembling that of Miocene sediments, from which they were probably collected. Significant differences can be noted in the isotopic composition of the two species, suggesting acquisition from deposits of different geological ages. The composition of Dentalium shells resembles that of Badenian-Sarmatian sediments, while the Anadara shells compare well with younger Miocene Pannonian sediments.

The isotopic compositions of mussel shell plaques resemble the isotope values of river mussels, corresponding to the morphological species determination. One interesting observation is that the shells from which the plaques were made were obtained from a small river rather and not the Danube flowing near the site.

The texture, age and isotopic compositions of the finely laminated beads from Grave 227 indicate a speleothem origin, most probably deriving from a high mountain area.

In sum, we may conclude that stable isotope geochemistry can be a useful tool for provenance studies, especially if used in combination with cathodoluminescence microscopy. In the case of the Budakalász samples, the analytical results all pointed towards predominantly local sources for the raw materials of the ornaments.

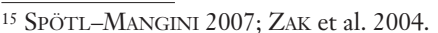




\section{References}

BAJNÓCZI et al. 2005

BUCHARDT 1977

DEMÉNY 2003

DEMÉNY 2004

FóRIZs 2003

FóRIZs 2005

FóRIZS-JUHÁsZ 2004

GROSSMAN-Ku 1986

HARZHAUSER et al. 2007

KELE et al. 2003

KeLE et al. 2007

LATAL et al. 2004

MáTYÁs et al. 1996

MiCKLER et al. 2006

RICHTER et al. 2004

SPÖTL - MANGINI 2007

THIERSTEIN et al. 1991

TRIPATI et al. 2001

ZAK et al. 2004
Bajnóczi, B.-Tóth, M.-Mersdorf, Zs.: Kerámiák vizsgálata katódlumineszcens mikroszkóppal, zalavári - kora középkori - leletek példáján [Petrografic study of early medieval pottery from Zalavár by cathodluminescence]. Archeometriai Múhely 2 (2005) 31-41.

Buchardt, B.: Oxygen isotope ratios from shell material from the Danish Middle Paleocene (Selandian) deposits and their interpretation as paleotemperature indicators. Palaeogeography, Palaeoclimatology, Palaeoecology 22 (1977) 209-230.

Demény, A.: Stabilizotóp-geokémia és termometria: hogyan és mire? [Stable isotope geochemistry and thermometry procedures and applications]. Földtani Közlöny 133 (2003) 263-270.

Demény, A.: Stabilizotóp-geokémia [Stable isotope geochemistry]. Magyar Kémiai Folyóirat 109-110 (2004) 192-198.

Fórizs, I.: Isotopes as natural tracers in the water cycle: Examples from the Carpathian Basin. Studia Universitatis Babeş-Bolyai, Physica, Special Issue 48 (2003) 69-77.

Fórizs, I.: Effect of river regulation on the isotopic characteristics of river water and molluscs. In: UFZ-Report 02/2005. Strauch G.-Weise S. M. ESIR-European Society for Isotope Research, VIII Isotope Workshop, Extended Abstract Volume (June 25-30, 2005, Leipzig, Germany), UFZ Centre for Environmental Research Leipzig-Halle, Leipzig 2005, 156-158.

Fórizs, I.-Juhász, P.: Climate of catchments recorded in isotopic composition of riverine mollusks' shells. Résumés-Abstracts of the International Workshop on the Application of Isotope Techniques in Hydrological and Environmental Studies. UNESCO, Paris, France, September 6-8, 2004, $113-114$.

Grossman, E. L.-Ku, T.-L.: Oxygen and carbon isotope fractionation in biogenic aragonite: Temperature effects. Chemical Geology (Isotope Geoscience Section) 59 (1986) 59-74.

Harzhauser, M.-Latal, Ch.-Piller, W. E.: The stable isotope archive of Lake Pannon as a mirror of Late Miocene climate change. Palaeogeography, Palaeoclimatology, Palaeoecology 249 (2007) $335-350$.

Kele, S.-Vaselli, O.-Szabó, Cs.-Minissale, A.: Stable Isotope Geochemistry of Pleistocene Travertines from Budakalász (Buda Mts., Hungary). Acta Geologica Hungarica 46 (2003) 161-175.

Kele, S.-Demény, A.-Borsody, J.: Stable isotopic investigations on travertines from the Gerecse Mts. (Hungary) - IX ESIR Workshop, Abstract Volume, Studia Universitatis Babeş-Bolyai, Geologia, 52 (2007) 39-40.

Latal, Ch.-Piller, W. E.-Harzhauser, M.: Palaeoenvironmental reconstructions by stable isotopes of Middle Miocene gastropods of the Central Paratethys. Palaeogeography, Palaeoclimatology, Palaeoecology 211 (2004) 157-169.

Mátyás, J.-Burns, S. J.-Müller, P.-Magyar, I.: What can stable isotopes say about salinity? An example from the Late Miocene Pannonian Lake. Palaios 11 (1996) 31-39.

Mickler, P. J.-Stern, L. A.-Banner, J. L.: Large kinetic isotope effects in modern speleothems. GSA Bulletin 118 (2006) 65-81.

Richter, D. K.-Gotte, T.-Niggemann, S.-Wurth, G.: REE3+ and Mn2+ activated cathodoluminescence in lateglacial and Holocene stalagmites of central Europe: evidence for climatic processes? The Holocene 14 (2004) 759-768.

Spötl, C.-Mangini, A.: Speleothems and paleoglaciers. Earth and Planetary Science Letters 254 (2007) 323-331.

Thierstein, H. R.-Macdougal, J. D.-Martin, E. E.-Larsen, B.-Barron, J.-Baldauf, J. G.: Age determinations of Paleogene diamictites from Prydz Bay (Site 739), Antarctica, using Sr isotopes of mollusks and biostratigraphy of microfossils (diatoms and coccoliths). In: Barron, J., Larsen, B., et al., Proceedings Ocean Drilling Project, Scientific Results (1991) 739-745.

Tripati, A.-Zachos, J. C.-Marincovich, L.-Bice, K.: Late Paleocene Arctic coastal climate inferred from molluscan stable and radiogenic isotope ratios. Palaeogeography, Palaeoclimatology, Palaeoecology 70 (2001) 101-113.

Zak, K.-Urban, J.-Cilek, V.-Hercman, H.: Cryogenic cave calcite from several Central European caves: age, carbon and oxygen isotopes and a genetic model. Chemical Geology 206 (2004) 119-136. 



\section{THE MANUFACTURING TECHNIQUES OF THE GRAVE POTTERY FROM BUDAKALÁSZ \\ László Gucsi}


Settlement pottery offers considerably more information on pottery manufacturing techniques than grave pottery. The different potting techniques and breakage patterns can be better observed on vessel fragments recovered from refuse pits and settlement occupation levels. Settlement pottery comprises the entire range of vessels used by a community, enabling the examination of all ceramic types. Vessels are vulnerable to everyday wear and tear during their use in daily life, resulting in their damage (e.g. thermal stress and other mechanic impacts during cooking). Broken pieces of cooking pots, larger storage jars and bowls occur in greater proportion on settlements, where they are part of the average household refuse. Damaged vessels often broke at their weak points, most often as a result of the techniques used in prehistoric pottery manufacture.

In contrast, grave pottery generally comprises intact vessels. Very often, only specific vessel types were deposited in burials, offering fewer opportunities for observations on manufacturing techniques. The identification of technical traits is also hindered by the fact that once the vessels are joined from their fragments and restored, the original breakage surfaces can no longer be examined, nor can the different join modes or the techniques of how handles were applied.

I am familiar with pottery manufacturing techniques because I have made countless clay vessels using prehistoric techniques and have fired these vessels using the same procedures as in prehistory. Thus, I have learnt from my own experience the practical techniques used by prehistoric potters. While preparing the illustrations to this monograph, I systematically studied the vessels in order to identify the tiny details offering insights into manufacturing techniques, possible flaws and possible divergences from the average, the type of information one rarely finds in archaeological studies.

One of the most widespread pottery making techniques in the case of hand-thrown vessels was coiling, involving the building of the vessel body from various elements, most often coils or rolls of clay, and then pressing the coils together and smoothing away the surface. The structure of the finished vessel preserves the surfaces along which the elements were bonded to each other.

The pottery manufacturing techniques are here discussed according to a particular phase or procedure in the manufacturing process. Specific techniques and smaller details are illustrated by specific vessels. I have also made an attempt at determining the skills of the potters making the vessels, a continuation of earlier studies on pottery manufacture during various periods. ${ }^{1}$

\section{MODELLING OF THE BASE}

\section{Flattening rounded bases}

The one-handled cup from Grave 19 originally had a rounded base. The base was created during the drying of the vessel using either a smaller clay coil which was then smoothed or by joining a thin clay disc to the vessel body. The subsequently added base broke off, probably during firing, revealing that the base originally had a rounded form (Pl. X. 19/2).

The jug from Grave 75 too had a rounded base to begin with. The horizontal plane of the base was created by applying a small coil around the base and then shaping it into a rectangular form. The join is clearly visible on the broken vessel. The correction was not perfect because the jug still wobbles owing to its rounded base, suggesting that the original vessel base was not sufficiently malleable at the time the clay coil was added to ensure an adequate bonding and that it also proved impossible to alter the originally rounded form of the base because the clay had probably dried to such an extent that it was no longer possible to model it by pressing it into another shape (Pl. XXXIV. 75/1).

Traces of adding a small clay coil used for creating a flat base can be seen along a roughly $2 \mathrm{~cm}$ long section on the outer side of the base of the scooping vessel from Grave 383. The potter did not smooth the joins along this section and the join is visible to the naked eye even without a breakage (Pl. CLII. 383/2).

The subsequent shaping of the rounded base in the first manufacturing phase results in a set of distinctive traits which can be made out on drawings of the vessel profile. The most conspicuous among these is the unbroken curve of the interior at the base; the centre of the base is the deepest point where the vessel wall is the thinnest.

In the case of the above three vessels, the procedure could be reconstructed from the remains of clay coils added later. However, remains or traces of the small clay coil used for creating a flattened vessel base cannot be identified on all vessels.

Examining the section of the vessels, a similar procedure of transforming an originally rounded base into a flat one can be assumed in the case of a ladle (Pl. XXIII. 74/3), a few scooping vessels (Pl. LXXX. 189/1, Pl. XCIV. 222/2, Pl. CXLVI. 367/4, Pl. CL. 378/3) and a few bowls (Pl. LXXXIV. 197/2, Pl. XC. 210/2, Pl. CLXIX. 13), as well as in the case of a jug (Pl. CXLVI. 367/2) and two pitchers (Pl. XXXIV. 75/3, Pl. CIII. 253/1). The rounded base is created by pressing or squeezing a single lump or ball of clay in the potter's palm for small vessels and in a batt in the case of larger vessels, in which the pot was set during modelling and drying.

\section{Plain disc bases}

An impression of the disc base can be made out on the horizontal breakage surface under the belly of the small 
pot from Grave 265 (Pl. CVII. 265/2-3). The first clay coil of the vessel body was pressed into the disc base, whereby a recumbent $\mathrm{S}$ shaped join and a smaller rim resembling rimmed disc bases were formed. However, because the rim created in this manner was no more than $2 \mathrm{~mm}$ high and the $\mathrm{S}$ shaped joins are identical owing to the smoothing of the coils, this fragment is assigned to the category of plain disc bases. There is no indication that the potter intended to create a more pronounced rim: the rim was simply the deformation of the join where the clay coils of similar hardness were pressed together.

A join can be made out on the base fragment of a pitcher (Pl. CLXXI. 23). Seeing that this join can only be observed along a $3 \mathrm{~mm}$ long section, it is uncertain whether the disc base had a rim.

The impression of the clay coil applied to the disc base can be made out on the fragment of a deep bowl decorated with geometric motifs (Pl. XXXV. 75/15).

\section{Rimmed disc bases}

A $5 \mathrm{~mm}$ high rim encircles the clay disc forming the base on the pot fragment from Grave 210 (Pl. XCI. 210/3-4). The first clay coil of the vessel body was built against this rim from the interior. The vessel later broke along this join. The broken lower half of a large pot from Grave 310 (Pl. CXXI. 310/2) has preserved the imprint of the $1.3 \mathrm{~cm}$ high rim along an $8.5 \mathrm{~cm}$ section on the disc base.

The impression of the clay coil was preserved along a $6 \mathrm{~cm}$ long section on the base fragment of an amphora (Pl. CLXXI. 24). A $6 \mathrm{~mm}$ high rim can be seen along the edge of the disc base.

Similarly to the flattening of rounded bases, the use of disc bases can be noted on several vessels, on which traces of bonding are no longer visible. It is often no longer possible to determine whether the vessel body was built on a rimmed or plain disc. In some cases, however, the section does provide clues for this procedure. Two main types can be distinguished: the first comprises vessels whose disc base has parallel sides as on some scooping vessels (Pl. CVII. 265/4, Pl. CXV. 295/1, Pl. CXLIII 364/1), a mug (Pl. XXVII. 59/2), a few bowls (Pl. XXXII. 73/2, Pl. CI. 248/2, Pl. CXXVIII. 335/1) and jugs (Pl. LXX. 164/5, Pl. CXXXVIII. 356/1), a pitcher (Pl. LXXXVII. 207/6), an amphora (Pl. CLXXII. 32) and a one-handled pot (Pl. CXXIII. 312/8). The second type comprises vessels whose disc base is thickest in the middle and thins towards the edge. The best examples can be quoted from among bowls (Pl. LXXIX. 177/1, Pl. CXII. 279/1, Pl. CXXXIII. 350/1), pitchers (Pl. XVI. 36/1, Pl. LI. 116/1, Pl. LXXXIV. 197/4), jugs (Pl. CXI. 273/2, Pl. CXXX. 340/2), an amphora (Pl. XXXI. 70/3), a beaker (Pl. CIII. 259/2) and pots (Pl. LXXX. 189/2, Pl. CXXV. 324/1, Pl. CLXXIII. 38).

It would appear that certain modelling techniques can be associated with a particular vessel type. Scoop- ing vessels, mugs and goblets (with the exception of angular variants) were usually made with a rounded base, suggesting that these types were not intended to be set upright. The stems on which the goblets were set were either perforated or fenestrated, and a cord could be strung through them. Ladle handles too generally have two perforations, allowing the vessel to be suspended by means of a cord threaded through them. One single mug (Pl. CXXIII. 350/2) has an omphalos base. The omphalos was created by pressing the rounded base inward, from the midline toward the handle, suggesting that the omphalos was modelled lastly. The examples quoted above indicate that the originally round bases were flattened by means of a small clay disc or clay coil enabling the vessel to be set upright on a level surface. Other, larger vessel types such as jugs and bowls were obviously expected to stand upright on a straight, level surface, this being the reason that the vessel body was built on a flat disc base. The jug and bowl types discussed in the foregoing were originally modelled with a rounded base which was then re-modelled in order to create a flat base. This procedure is interesting because the potter obviously had a specific vessel type in mind. In order to produce a functional vessel, the potter had to know what he/she intended to make and select the appropriate modelling procedure. The above examples indicate that the potters of the Baden culture were capable of producing the same vessel types starting from both a rounded and a disc base. The variability was at most limited by the forms themselves: jugs and bowls can also be modelled starting from a rounded base which is subsequently flattened. Scooping vessels and mugs too can be built on disc bases, while pots and amphoras can be exclusively produced using the latter technique.

\section{MODELLING THE VESSEL BODY}

\section{Coils}

Several joins can be seen on the fragment of the bipartite bowl from Grave 182 (Pl. LXXVI. 182/1). A U shaped join can be noted $3.5 \mathrm{~cm}$ from the edge of the rim, the mark of the coil used for modelling the rim. Another $U$ shaped join can be made out on the horizontal breakage surface under the carination. The two joins suggest that $4.5 \mathrm{~cm}$ wide coils were used for building the vessel body. Another, previously unobserved technical detail can also be noted on this fragment: the vertical S shaped join where the ends of the coils were pressed together. This small detail survived because the potter did not smooth together the ends of the coils in the vessel interior and fitted the slab of the dividing wall over the groove-like seam. Although the join of the clay coils was thus concealed, the triple join created here weakened the vessel's structure and the interior dividing wall broke off, revealing the join described above. This fragment is 
eloquent proof for the use of clay coils in building vessels. Until now, we could at the most hypothesise their use based on observations drawn from the joins and the average distance between them. In this case, the vertical join of the two ends of the coil has survived.

The joins of four clay coils can be seen on the base fragments of the amphora from Grave 273 (Pl. CX. 273/1). The following observations could be made proceeding in the order of the modelling, from bottom to top: a flat, slightly incurving join can be seen $1.7 \mathrm{~cm}$ above the base fragment. Although the fragment of the first coil is lacking, it can be reconstructed from the surviving fragments. The distance between the lowermost join and the join above it corresponds to the missing coil which was $2.5 \mathrm{~cm}$ wide. The horizontal join under the carination resembles a recumbent $S$ shape. The next join lies at the greatest circumference of the belly and is $\mathrm{U}$ shaped. The distance between the latter two is $3.2 \mathrm{~cm}$. Proceeding upward, the next join is a recumbent $S$ shaped join; the distance between the two joins indicates the use of a $2.6 \mathrm{~cm}$ wide clay coil. Finally, an incurving $U$ shaped join can be noted at the junction of the neck and the shoulder. The distance between the latter two is $3.2 \mathrm{~cm}$, corresponding to the width of the coil used for the shoulder.

The first horizontal, almost completely smooth join lying $1.7 \mathrm{~cm}$ above the base is noteworthy. There are two possible explanations for the presence of a join at this unusual place. The first, that the potter created a rib around the base by pinching the clay of the base. The thickness of this rib corresponded to the later thickness of the vessel wall and the first coil was laid on the smoothed surface of this rib. The other possibility is that a coil was placed around the base and the vessel was built on this coil. Vessels made using the latter technique are known from the Baden material excavated at Aparhant-Felsô-legelő. ${ }^{2}$

\section{Bipartite bowls}

The join between the vessel interior and the internal dividing wall can be seen on a fragment from Grave 163 (Pl. LXIX. 163/1). The join between the vessel interior and the internal dividing wall can also be observed on the fragment from Grave 310 (Pl. CXX. 310/1). A small clay coil was applied for reinforcement to the outer curve of the inner edge at the junction of the elements. A small fragment of the dividing wall bowl broke off from another bipartite bowl (Pl. CLXX. 19). There is no indication on this small fragment of additional reinforcement by means of smaller clay coils. Traces of the join can be made out on the fragment of the decorative knob from a bipartite bowl (Pl. CLXX. 19). The 5-7 mm thick clay disc made for the knob was not carefully smoothed over the lower part.

\footnotetext{
${ }^{2}$ BONDÁR 2000, 55, Fig. 6. 11; GUCSI 2000, 99, Fig. 4. 3.
}

\section{HANDLES}

\section{Strap bandles}

In many cases, potters attached strap handles by smearing a part of the clay from the handle onto the vessel body. If the amount of clay used for this purpose was not replaced, the parallel edges of the handles narrowed near the point of attachment. This type of handle attachment can be observed on mugs (Pl. CXI. 273/5, Pl. CXVIII. 311/2, Pl. CLVII. 408/1) and scooping vessels (Pl. LXXIII. 174/1, Pl. LXXX. 189/1, Pl. CIX. 277/1), as well as on a pitcher (Pl. LI. 116/1) in the ceramic inventory from the cemetery.

\section{Stringbole lugs}

The perforation through the lug on the belly of the bowl from Grave 177 (Pl. LXXIX. 177/1) was made with a long pointed implement with a slightly conical end. The lug was made by attaching a smaller lump of clay to the vessel body and then perforating it sideways. While lugs of this type were generally perforated from both ends in order to create a regular perforation, in this case the implement was stuck through the clay from one side only.

A closer look at the stringhole lug from Grave 252 (Pl. CII. 252/1) reveals that the lug had been applied onto the smooth vessel body and that it had later broken off along this join.

The pitcher from Grave 261 (Pl. CV. 261/1) had a loop handle with a round section set on the shoulder. The handle broke off along the join with the vessel body. The handle was attached to the rounded, smooth vessel surface without a handle peg.

The attachment of stringhole lugs and loop handles without the use of handle pegs could also be noted on Baden pottery from the culture's other sites.

\section{Handle pegs}

The large strap handle fragment from Grave 2 (Pl. II. 2/1) has a large, oval peg across the entire width of the handle on its lower end, which can be clearly made out on the breakage surface. The potter did not make a separate peg at the end of the handle, but pierced the vessel body with a perforation whose size corresponded to the width of the handle and fitted the handle into the perforation.

A probably round sectioned handle peg was made at the lower end of the handle of the one-handled cup from Grave 68 (Pl. XXX. 68/1). A similar round peg can be noted on the lower end of the handle of the mug from Grave 222 (Pl. XCIV. 222/2). The horizontal breakage surface extends along the peg, revealing the small perforation in the vessel body, the peg of the handle and the gap between the two.

The handle of the mug from Grave 306 (Pl. CXVII. 306/2) was attached to the vessel body by means of a 
peg. The peg is conical from above and is in line with the handle's symmetry axis. Viewed from the side, however, one notes that the peg is located higher than the handle's midline. The reason for this is that the hole for the peg was misplaced by the potter and this mistake had to be corrected after the handle was attached in order to maintain the curve or size of the handle. Fairly great pressure is applied to the handle along its inner curve when the handle is attached to the vessel body and the clay is smoothed. During smoothing, the handle slips slightly from its original position, while the peg at the end remains in the same position.

The wide strap handle of a pitcher from Grave 353 (Pl. CXXXVI. 353/2) was attached by means of oval pegs of roughly the same size as the handle's width on both ends. The pegs indicate that the handle had been attached to a vessel with a wall thickness of 1-1.2 cm.

The $2 \mathrm{~cm}$ by $0.5 \mathrm{~cm}$ large peg from the lower half of the broken handle of a scooping vessel (Pl. CLXVI. 2) broke off into the vessel wall.

\section{Reinforcement of vessel handles}

The clay coil of the high-swung handle of the onehandled cup from Grave 189 (Pl. LXXX. 189/3) became strongly cracked during its modelling. The potter did not smooth away the cracks, still visible on the handle's outer curve and on the left edge. Instead, the potter added a small blob of clay to the inner curve for reinforcement, but did not smooth it, leaving this technical solution visible.

The upper end of the handle of the small pot from Grave 312 (Pl. CXXIII. 312/8) was attached to the rim interior. The potter applied a small blob of clay to the inner curve, but did not bother with smoothing away the small clay blob used for reinforcement. Similar means of reinforcement could be noted among the pottery finds from the Aparhant-Felsô legelô site. ${ }^{3}$

A large jug was recovered from Grave 367 (Pl. CXLVI. 367/2). A roughly $1 \mathrm{~mm}$ thick strip came off along an $8.5 \mathrm{~cm}$ by $1.5 \mathrm{~cm}$ wide section in the interior of the high-drawn handle, probably a similar, but more carefully executed technique for reinforcement.

\section{MISCELLANEOUS OBSERVATIONS ON MANUFACTURING TECHNIQUES}

The stem of the decorated goblet from Grave 73 (Pl. XXXII. 73/1) broke off the base of the cup along a regular breakage. However, little can be said about how the foot was originally attached because the broken vessel was glued together during its restoration.

The $2.4 \mathrm{~cm}$ wide clay strip forming the handle of the ladle from Grave 216 (Pl. XCII. 216/1) was attached to the interior after the modelling of the bowl part. The

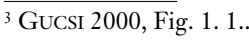

handle later broke off along a $5.5 \mathrm{~cm}$ long section of the join with the vessel interior.

The handle of the ladle from Grave 227 (Pl. XCV. $227 / 15)$ was made from a $3.5 \mathrm{~cm}$ wide clay strip and attached to the bowl interior. The potter drew the rim of the cup slightly upward to provide a better support for the handle. The handle later broke in line with the edge of the rim; the breakage surface shows the join between the vessel wall and the handle. Ladles generally had the handles attached to the interior of the bowl. The perforation at the end of the handle was generally made by piercing outward from the vessel interior.

The triangular stem of the goblet from Grave 238 (Pl. 238/2) was attached to the disc forming the base of the cup by means of a $0.7 \mathrm{~cm}$ high semi-spherical peg with a diameter of $1.3 \mathrm{~cm}$. A relatively large gap remained between the peg and the perforation made for it.

An $\mathrm{S}$ shaped join can be noted along a $4 \mathrm{~cm}$ long section on the upper breakage surface on the belly of the pot from Grave 259 (Pl. CIII. 259/1). There is no indication of a join on the lower, irregularly shaped breakage surface and thus the width of the clay coils used for building the vessel body cannot be reconstructed.

The small bowl from Grave 347 (Pl. CXXXIV. 347/1) is decorated with three impressed dots on the carination, to the left of a stringhole lug. The line of dots does not continue around the body as on other similar vessels. Unfinished patterns of this type and clumsily made designs can often be seen on prehistoric vessels, even on carefully made ceramics with pleasing proportions.

The lower edge of the stem of the goblet from Grave 391 (Pl. CLIII. 391/1) broke off before the vessel was fired. Pre-firing breakages (and the breakages of secondarily burnt pottery) can be recognised by their colour: the breakages are the same colour as the vessel. In contrast, the breakage surfaces on vessels breaking after firing usually consist of layers of different colour.

An unsmoothed join can be seen in line with the carination in the interior of a stray cup (Pl. CLXVI. 3). The vessel body was made from two parts: the flattened semi-spherical lower part and the cylindrical upper part comprising the shoulder, neck and rim.

The high-drawn handle of another stray cup $(\mathrm{Pl}$. CLXVIII. 9) broke off. Two unfinished perforations can be seen under the rim to the left of the handle. The smaller one is $2 \mathrm{~mm}$ large and is barely impressed into the surface. The other one is a $6 \mathrm{~mm}$ large tapering perforation which almost pierces the rim. The cup was unsuitable for a domestic use owing to its damaged condition and was deposited in a burial after it proved impossible to repair it.

\section{POTTERY DECORATION}

The sequence of how the lines for zig-zag and lattice patterns were incised can be observed on several vessels, if the incised lines cross each other. In the case of zig-zag lines, the lines inclined to the left were drawn first and 
the ones to the right subsequently, while lattice patterns were not created from longer lines crossing each other but from zig-zagging lines placed above each other.

The rim and the foot of the goblet from Grave 378 (Pl. 378/4) became chipped along a $2 \mathrm{~cm}$ long section on the cup and a $3 \mathrm{~cm}$ long section on the foot. Red paint covers the breakage in both cases. The rim is chipped in another spot too, but this damage was recent because it is not covered by paint. It would appear that the goblet had been used in daily life before its deposition in the grave and that it was painted with red ochre after it had been damaged.

\section{TRACES OF USE-WEAR}

The four tiny knobs supporting the rectangular wagon model from Grave 158 (Pl. LXVI. 158/2) are strongly worn owing to use. Clear traces of use-wear can be noted along a $9 \mathrm{~cm}$ long section on the rim of the scooping vessel from Grave 183, to the left of the handle (Pl. LXXVII. 183/1). A stray handled cup with globular body (Pl. CLXVII. 7) has a strongly worn rim left of the handle, with about 3-5 $\mathrm{mm}$ missing in that spot.

The traces of use-wear visible on these vessels suggest that they had been used over a longer period of time. The rim of the scooping vessel and the stray cup is so strongly worn as to suggest their use for several years. The owners of these vessels were right-handed because only in this case can the rim section left of the handle be worn, assuming that the vessels were held in the right hand. Use-wear traces of this type only originate from the regular abrasion of the vessels used for scooping against the storage jar from which the liquid, cereals, flour or cooked food was scooped.

The traces of use-wear and the other phenomena described and discussed above (subsequent painting over chips, intentions of repair, etc.) indicate that several vessels were used in daily life for some time before their deposition and that they were not specifically made for the burial.

\section{THE POTTERS}

While drawing the vessels, I noticed that many had been made by individuals who were not particularly experienced in this craft. While prehistoric pottery is often slightly irregular because pots were hand-thrown, most of the vessels made by prehistoric potters are finely made and attractive. The pieces created by novices and advanced learners mastering the art of pottery making techniques can be nonetheless be identified despite these general irregularities. The characteristic traits of vessels made by inexperienced potters can be identified as follows:

- the wall thickness is often the double of the usual wall thickness of similar vessels and the vessels are often quite robust;
- the vessel's proportions differ from the usual proportions typical for the culture's ceramic repertoire;

- the vessel surface is often lumpy and uneven, and the fingerprints remaining after modelling are not or barely smoothed away;

- the graceful, flowing curve of the vessel is interrupted, lending a clumsy appearance to the pot; very often, the vessel is strongly asymmetrical;

- the decoration is carelessly made.

The miniature pots, amphoras, urns and other similar vessels were probably made by novices. The vessels modelled by inexperienced potters can probably be regarded as the work of children in prehistory.

Three main categories could be distinguished in terms of the quality of the ceramics recovered from the Budakalász cemetery.

(1) Novices. The artefacts assigned to this category were made by individuals who were new to the art of the potter. They still had difficulties in handling clay during modelling.

(2) Advanced learners. The artefacts in this group were made by individuals who had mastered the art of modelling malleable clay. However, they were not skilled enough to re-create in their own work the right proportions of the formal repertorie of their material culture (the vessels and artefacts they were supposed to copy, which they encountered and used in their daily life).

(3) Experienced potters. The overwhelming majority of archaeological pottery can be assigned to this category. While even the vessels made by these potters can sometimes be irregular or slightly asymmetrical and the rim is occasionally slightly wavy, the overall design of the vessel is well-proportioned. Their wall thickness is even, the ornamentation is in harmony with the vessel form and accentuates its form. The vessels are proportionate, the curves are graceful and the most outstanding pieces are masterpieces of the potter's craft.

Obviously, there are no sharp boundaries between the three categories since the pots reflect different levels of expertise, the result of a long process of learning.

The ceramic wares recovered from archaeological sites were for the greater part made by experienced potters. When examining the grave pottery from this perspective, I focused on the vessels falling into the first and second category, i.e. the pieces differing from ones made by skilled craftsmen.

The pieces assigned to the category of vessels made by novices include the scooping vessel from Grave 55 (Pl. XXV . 55/1) which has an uneven wall and the curve of the handle is wobbly. The plain goblet set on three feet from Grave 75 (Pl. XXXV. 75/8) has a carefully modelled upper part, while the foot is of visibly inferior quality, suggesting that the two parts were made by two different potters; the foot is obviously the work of a novice. The dipper from Grave 179 (Pl. LXXIX. 179/1), the single grave good, has an uneven wall. The body sherds of a large amphora recovered from Grave 274 (Pl. CVIII. 274/1) include a belly fragment, which 
is very uneven. The quality of the goblet from Grave 335 (Pl. CXXVIII. 335/2) is inferior by far compared to similar pieces: its wall is very uneven and twice as thick as usual for this ware. The small jug from Grave 340 (Pl. CXXX. 340/2) has a strongly uneven, lumpy surface and its wall is disproportionately thick compared to its size. Its asymmetric form too adds to its clumsiness. Another small jug, recovered from Grave 356 (Pl. CXXXVIII. 356/1), resembles the previous one: although its proportions are slightly better, its wall is disproportionately thick. The mug from Grave 345 (Pl. CXXXII. 345/2) has a slanting handle and an unsmoothed modelling flaw left of the handle. A beaker resembling a miniature pot was found in Grave 368 (Pl. CXLIV. 368/3). Vessels of this size, known from virtually all prehistoric cultures, are usually interpreted as toys. It seems likely that many of these vessels had in fact been made by children. The miniature beaker from Grave 378 (Pl. CL. 378/1) has rather uneven walls and its rim is extremely wavy.

The vessels representing the pieces made by advanced learners include the goblet from Grave 9 (Pl. VI. 9/1) with a strongly wavy rim, whose wall thickness is greater than usual for this ware. The vessel is rather robust and the perforation on the stem is larger than the average. The edge of the foot-ring is thick compared to other pieces which have a carefully thinned edge.

The proportions of the pitcher from Grave 75 (Pl. $X X X I V$. 75/3) differ significantly from other similar vessels of the Baden culture. Its belly is low-swung, the inner curve of the shoulder is far too angular, the curve of the rim is uneven in the vessel's upper third and the rim is thickened slightly instead of thinned. The rhythm of the vertical fluting on the belly is interrupted in several spots. The fluting was originally intended to be vertical, but became oblique by the time it encircled the vessel belly.

The scooping vessel from Grave 145 (Pl. LXII. 145/1), the single artefact deposited in the burial, has a disproportionately thick wall and its decoration is also careless. The scooping vessel from Grave 160 (Pl. LXVII. 160/1) has a wavy rim, its wall thickness is double the other vessels of this type, and its handle is askew and has a rib-like edge around the lower part. The rib can perhaps be attributed to the custom of creating a rounded base or was perhaps intended to represent the carination around the belly. The vessel wobbles if set on a level surface.

The small pot from Grave 189 (Pl. LXXX. 189/2) is rather asymmetrical. Knowing that the pot shape is one of the most easily hand-modelled forms, the lack of symmetry in the case of such a simple form can only be explained by the lack of experience. The same grave yielded a small one-handled cup (Pl. LXXX. 189/3) with uneven wall thickness and strongly wavy rim. The curve of the handle is interrupted at the junction with the vessel body. A small, unsmoothed blob of clay applied for reinforcement can be seen on the right side of the handle.

The row of punctates under the rim of the dipper from Grave 227 (Pl. XCVI. 227/4) is both unusual and irregular. The vessel itself is fairly well made, although a comparison with other dippers of this type (such as the pieces from Graves 87 and 412) is quite instructive. A small foot can only be noted on pieces regarded as children's work; the other dippers all have a rounded or conical base.

The decorated pitcher from Grave 253 (Pl. CIII. 253/1) is far too much thinned at the carination and the middle of the base. The vessel lacks the angular shoulder typical for the pitchers of the Baden culture; instead, the vessel has a single dynamic curve from the belly to the neck and the rim. The handle is over-sized, causing the pitcher to tilt owing to its weight, while its width is about two-thirds or half the size of the handles generally attached to pitchers.

The decorated pitcher from Grave 347 (Pl. CXXXIV. 347/2) is strongly asymmetrical and its wall thickness is uneven; the base is heavy, the rim is far too thin, the handle is slightly wider than the average and the fluting was carelessly made.

The scooping vessel from Grave 367 (Pl. CXLVI. 367/4) has a slightly wavy rim and a handle with far too heavy terminals. Although the middle section corresponds to the usual thickness of these handles, its form does not conform to the flowing curve of most Baden handles, the reason probably being that the vessel would have tilted owing to the large handle were it not pressed inward toward the centre of gravity.

Grave 378 yielded a scooping vessel with a similarly modelled handle (Pl. CL. 378/3). Found in the same burial was a goblet (Pl. CL. 378/2) whose wall thickness is almost the double of similar vessels and whose footring is not as carefully thinned around the edge as that of the other pieces.

The mug from Grave 408 (Pl. CLVII. 408/1) has twice as thick walls as the other small mugs of this vessel type. It handle is much heavier and more carelessly made than that of other pieces.

The twenty-three vessels described in the above can be regarded as the work of novices and advanced learners. However, one or another of the traits characterising these vessels also holds true for several other vessels. These were omitted from the discussion because they represent a transition between the works of advanced learners and experienced potters. The find material from the cemetery's burials comprises 252 vessels, disregarding the smaller fragments and the lost pieces. The twenty-three vessels listed above represent 9.1 per cent of the pottery finds. The same ratio for the ceramic assemblage from the Baden settlement at Aparhant-Felsô legeló was 3.4 per cent. The almost triple incidence of novices' and children's work in the cemetery may perhaps be interpreted as a sign of the deceased's personal attachment to the artefacts placed in the grave. An alternative interpretation for the higher proportion of these vessels is that these pieces had a smaller use-value than the pottery used in daily life and this was the reason that they were selected for deposition in the burials. 


\section{References}

BONDÁR 2000

GUCSI 2000

GUCSI 2006
Bondár, Mária: A badeni kultúra telepmaradványa Aparhant-Felsố legelő lelőhelyen [The settlement fragment of the Baden culture on the site Aparhant-Felsố pasture]. WMMÉ 22 (2000) 39-74.

Gucsi, László: Kerámiatechnikai megfigyelések a badeni kultúra leletein [Pottery technical observations on the findings of the Baden culture]. WMMÉ 22 (2000) 89-99.

Gucsi, László: Rézkori és kora bronzkori kerámiákon végzett technikai megfigyelések. [Technical Obsevations on Ceramics of Copper Age and Early Bronze Age]. Ed. by Holló, Andrea SzilviaSzulovszky, János. Az agyagmúvesség évezredei a Kárpát-medencében [Thousands of Years of Pottery in the Carpathian Basin]. Budapest-Veszprém 2006, 7-18. 


\section{ABSOLUTE AND INTERNAL CHRONOLOGY OF THE LATE COPPER AGE CEMETERY AT BUDAKALÁSZ}

Zsuzsanna Siklósi 


\section{RADIOCARBON CHRONOLOGY}

Radiocarbon measurements were made by the Vienna Environmental Research Accelerator (VERA) Laboratory using accelerator mass spectrometry (AMS). The submitted samples were taken from human skeletal remains. ${ }^{1}$ One of the main considerations in sampling was to collect samples from every section of the cemetery in order to identify possible patterns per directions in the cemetery's growth. Another was to select graves which had been richly furnished with pottery for testing/confirming the cemetery's internal chronology based on pottery typology. However, since a considerable time had elapsed since the cemetery's excavation, some skeletal remains were lost or were in a very poor state of preservation, restricting possibilities for sampling. The results of the radiocarbon measurements are shown in Table 1. between Graves 403, 230, 142/B, 182/A, 182/C and 252, and the same holds true for Graves 13/A, 383, 182/B, 19 and 378. Otherwise, the very similar uncalibrated dates suggest that there might only be slight chronological differences between them. Grave 182, a triple burial, confirms this possibility because the calibrated radiocarbon dates for Graves 182/A and 182/C are identical (3330 (68.2\%) 3020 cal BC), while Grave 182/B seems slightly younger (3030 (68.2\%) $2920 \mathrm{cal} \mathrm{BC})$, even though Grave 182/B lay partially under Graves 182/A and 182/C (Figs 5-6, 10). It would appear that the deceased were interred at the same time ${ }^{4}$ and are contemporaneous despite the different radiocarbon dates. This is a major caveat for the burials contemporaneous with Grave 182/B; it seems likely that they are chronologically very close to the group of older graves.

Only Grave 75 falls within a longer, steep phase of the calibration curve, enabling a more precise dating

Table 1. AMS radiocarbon dates for the graves of the Budakalász cemetery

\begin{tabular}{|c|c|c|c|c|}
\hline Sample No. & Grave & $\delta^{13} \mathbf{C}(\%) 1 \sigma$ & ${ }^{14} \mathbf{C}$ age BP & Error \\
\hline VERA-4382 & 403 & $-21.0 \pm 0.6$ & 4510 & 35 \\
\hline VERA-4378 & 230 & $-22.9 \pm 1.2$ & 4465 & 40 \\
\hline VERA-4377 & $142 / \mathrm{b}$ & $-22.3 \pm 0.6$ & 4460 & 40 \\
\hline VERA-3546 & $182 / \mathrm{a}$ & $-20.8 \pm 0.3$ & 4455 & 30 \\
\hline VERA-3548 & $182 / \mathrm{c}$ & $-21.5 \pm 0.4$ & 4445 & 35 \\
\hline VERA-4379 & 252 & $-23.1 \pm 1.2$ & 4440 & 35 \\
\hline VERA-4375 & $13 / \mathrm{a}$ & $-21.6 \pm 1.2$ & 4420 & 40 \\
\hline VERA-4381 & 383 & $-20.5 \pm 0.6$ & 4400 & 35 \\
\hline VERA-3547 & $182 / \mathrm{b}$ & $-18.7 \pm 0.3$ & 4375 & 35 \\
\hline VERA-4376 & 19 & $-20.1 \pm 0.7$ & 4370 & 40 \\
\hline VERA-3549 & 378 & $-19.6 \pm 0.3$ & 4340 & 40 \\
\hline VERA-3543 & 75 & $-19.8 \pm 0.3$ & 4295 & 40 \\
\hline VERA-3545 & 174 & $-21.7 \pm 0.5$ & 4215 & 4170 \\
\hline VERA-3544 & 158 & $-22.6 \pm 0.5$ & & \\
\hline
\end{tabular}

\section{CALIBRATION AND ANALYSIS}

The evaluation and interpretation of the radiocarbon data necessitated their calibration. I used the OxCal v.4.1.3 software and the IntCal04 curve for calibration. ${ }^{2}$

Table 1 and Figs $2-15$ present the individual calibrated dates for the sampled burials, indicating that the graves can be dated between 3350 (68.2\%) $3110 \mathrm{cal} \mathrm{BC}$ and $2880(68.2 \%) 2670 \mathrm{cal} \mathrm{BC}$, or 3360 (95.4\%) $3090 \mathrm{cal} \mathrm{BC}$ and $2890(95.4 \%) 2620 \mathrm{cal} \mathrm{BC}$. There are several long plateaux and wiggles on the calibration curve during the 4th millennium BC. One falls between 3300 and $2900 \mathrm{cal}$ $\mathrm{BC}$, another between 2800 and $2600 \mathrm{cal} \mathrm{BC}$, this being the reason that individual calibrated dates fluctuate within very broad limits. ${ }^{3}$ It is therefore impossible or hardly possible to determine chronological differences

\footnotetext{
${ }^{1}$ I would like here to thank Dr. Eva M. Wild, Dr. Peter Stadler and their colleagues for their work.

2 Bronk Ramsey 1995, 2001, 2008; Reimer et al. 2004

3 BLACKWELL et al. 2006, 411.
}

(Fig. 13). This date (3010 (68.2\%) 2880 cal BC), however, is the last in the compact radiocarbon sequence. Two burials (Graves 174 and 158) seem much younger than the others. These younger dates also lie on a plateau of the calibration curve (Figs 14-15). The date for Grave 75 might be seen as being intermediate between the younger and the older graves, suggesting that there is no reason for assuming that the young date of these samples can be attributed to contamination or that there was a hiatus between the older and younger graves in the cemetery's use. However, an interpretation along these lines is not supported by the typological analysis of the pottery grave goods. In the lack of stable isotope analyses, it cannot be excluded that the seemingly younger age of these two graves can be explained by the reservoir effect.

The individual calibrated dates indicate that the span of the cemetery's use can be estimated at as much

\footnotetext{
$\overline{4}$ See pp. 201, 225 $, 229,230,236$, in this volume
} 


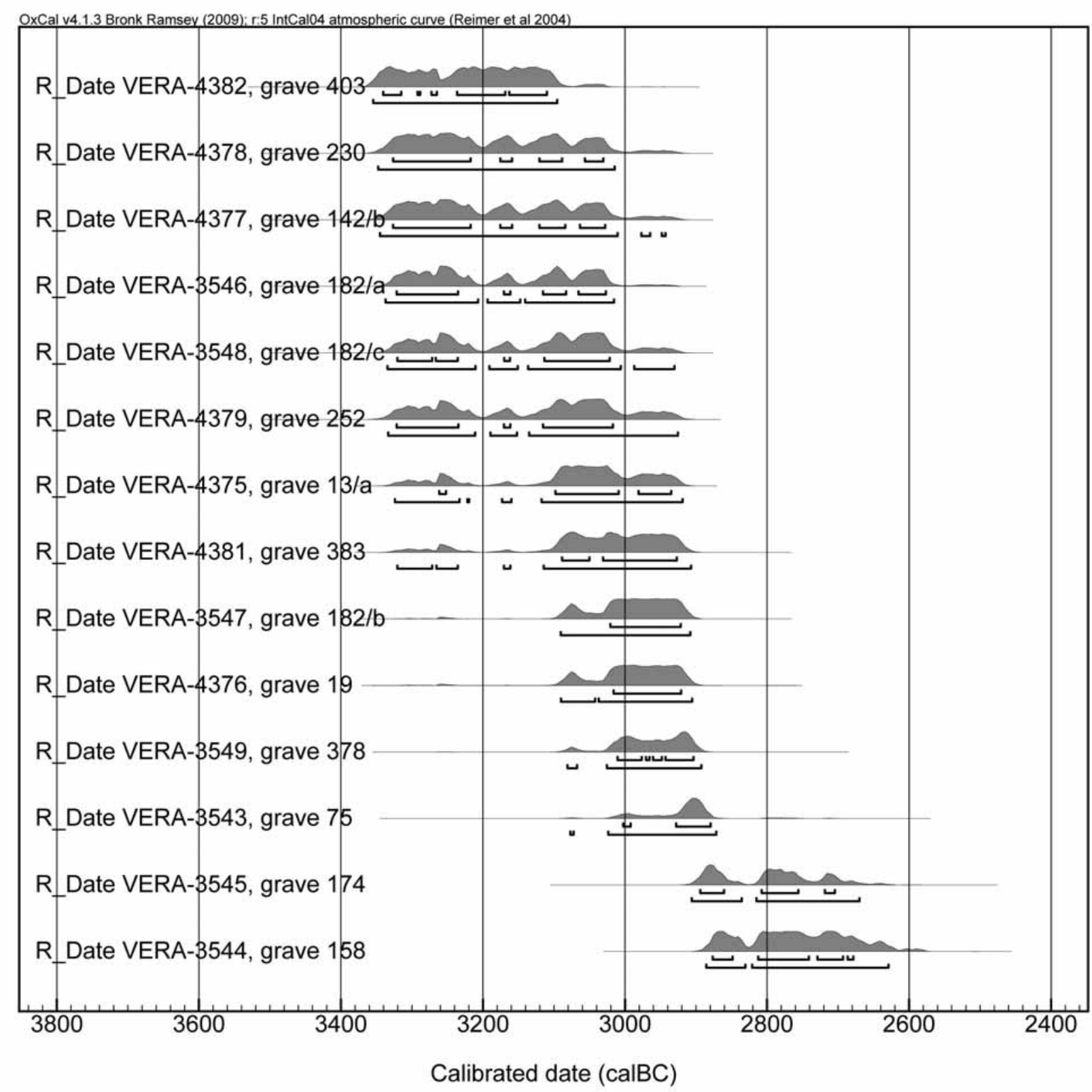

Fig. 1. All individual calibrated radiocarbon dates. The bars under the probability distribution show the $68.2 \%$ and $95.4 \%$ ranges

as $455-470$ years. ${ }^{5}$ However, if the two youngest dates are disregarded, the span was ca. 285-460 years (Fig. 1).

Imprecision caused by the wiggles of the calibration curve can be decreased by the Bayesian method. 6 There are surprisingly few superimposed burials in the cemetery; $;^{7}$ since there are no radiocarbon dates for

\footnotetext{
${ }_{5}^{5}$ On the basis of the means of the oldest and the youngest 1 and $2 \sigma$ dates. ${ }^{6}$ BuCK et al. 1991.

7 Grave 36 lay under Grave 34, Grave 44 under Grave 40, Grave 51 under Grave 50, Grave 78 and 80 were contemporary because vessel fragments recovered from the burials could be joined, Grave 98 lay under Grave 97, Grave 143 under Grave 139, Grave 167 under Grave 165, Grave 282 under Grave 281, Grave 299 under Grave 297, Grave 300 under Grave 298, Grave 358 under Grave 357, and Grave 363 under Grave 362. Grave 393 post-dated Grave 392 because the digging of Grave 393 destroyed Grave 392 and calcinated bones were thrown back.
}

these burials and in the lack of complementary stratigraphic information, the radiocarbon dates were calibrated in one sequence and one phase (Fig. 16). This technique enables the restriction of the rather wide temporal intervals caused by the imprecision of the calibration curve. Every calibrated date had a fairly high, over $80 \%$ agreement index. The dates for Graves 174 and 158 fall into the interval corresponding to the close of the Late Copper Age on other sites in this region. The probability distribution representing the boundary date of the start of cemetery's use is 3230 (68.2\%) $3080 \mathrm{cal} \mathrm{BC}$ and 3360 (95.4\%) $3050 \mathrm{cal} \mathrm{BC}$ (Fig. 17). The probability distribution for the boundary date of the end of the cemetery's use is $2890(68.2 \%)$ $2810 \mathrm{cal} \mathrm{BC}$ and 2890 (95.4\%) $2700 \mathrm{cal} \mathrm{BC} \mathrm{(Fig.} \mathrm{18).}$ 


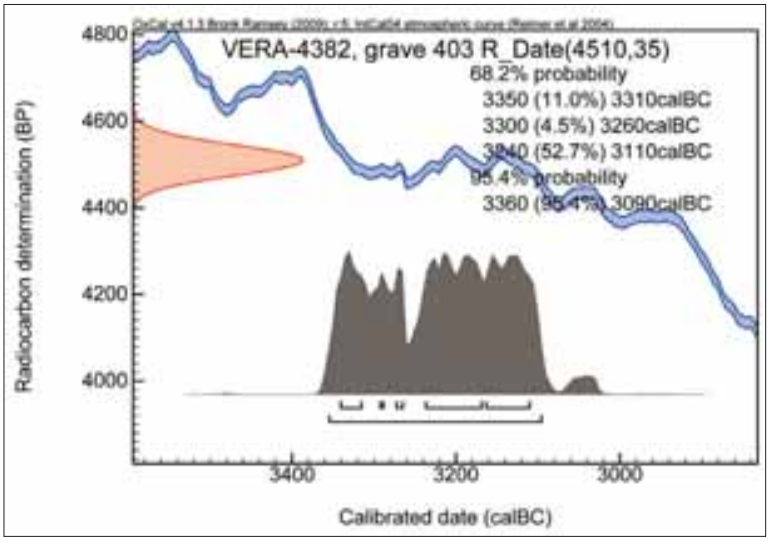

Fig. 2. Individual calibrated radiocarbon date for Grave 403

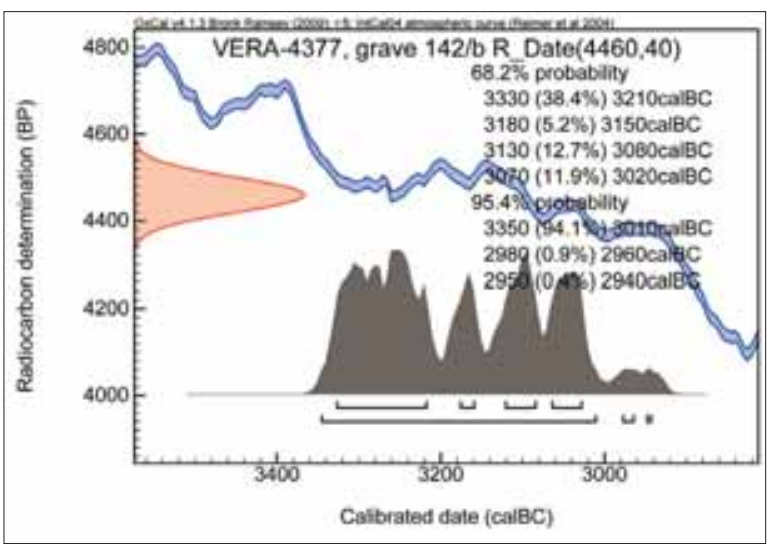

Fig. 4. Individual calibrated radiocarbon date for Grave 142/B

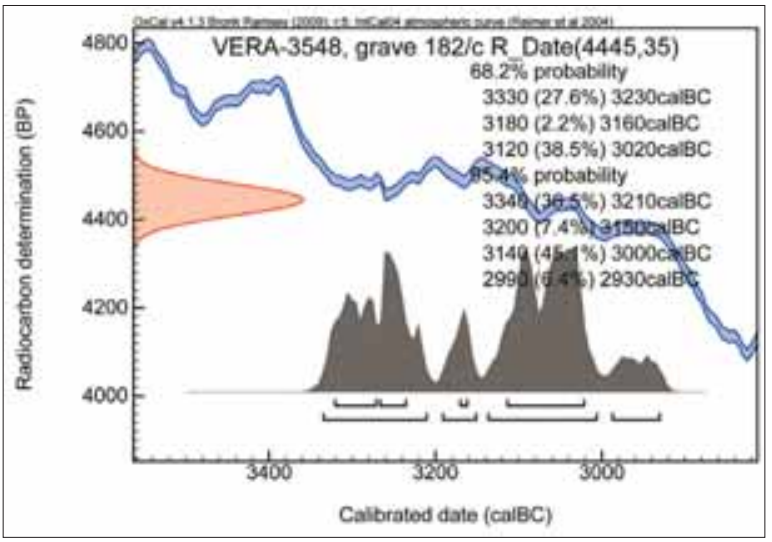

Fig. 6. Individual calibrated radiocarbon date for Grave 182/C

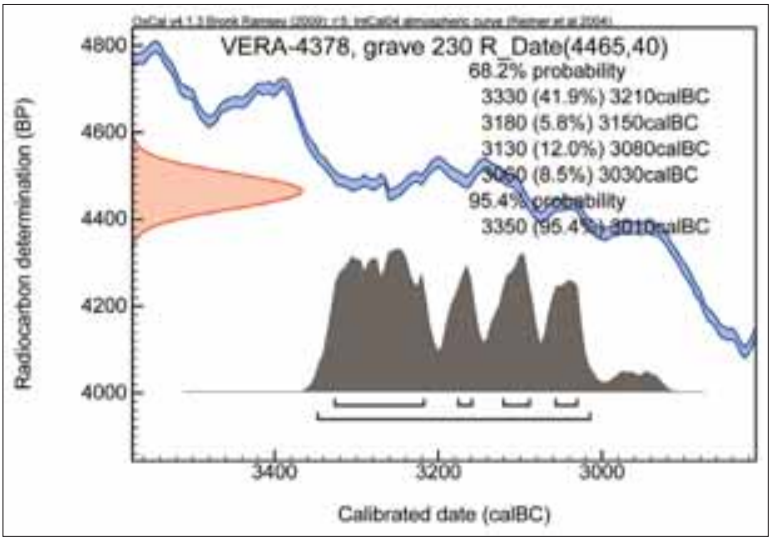

Fig. 3. Individual calibrated radiocarbon date for Grave 230

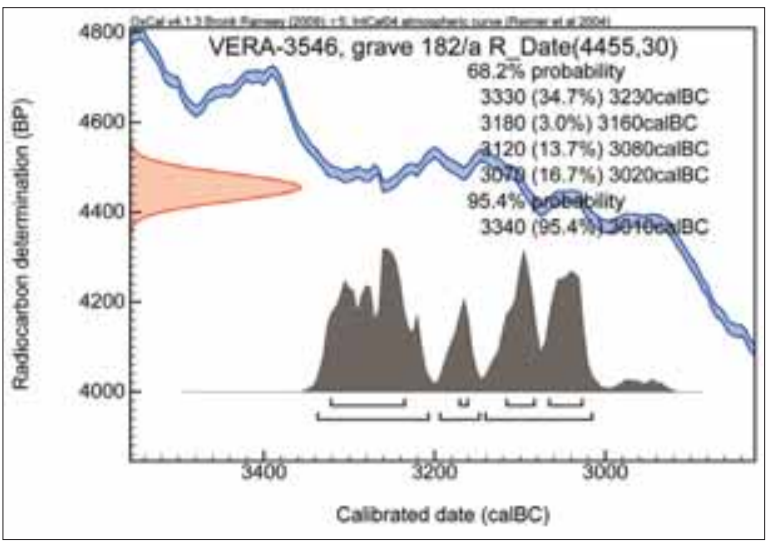

Fig. 5. Individual calibrated radiocarbon date for Grave 182/A

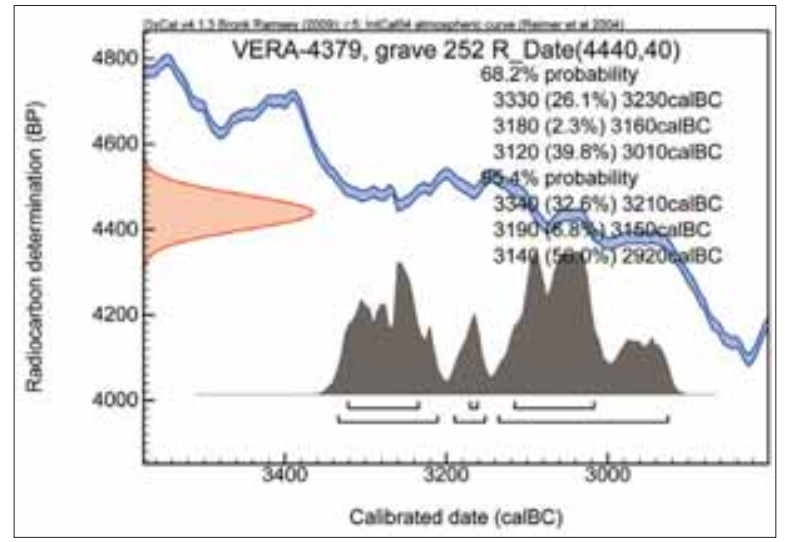

Fig. 7. Individual calibrated radiocarbon date for Grave 252 


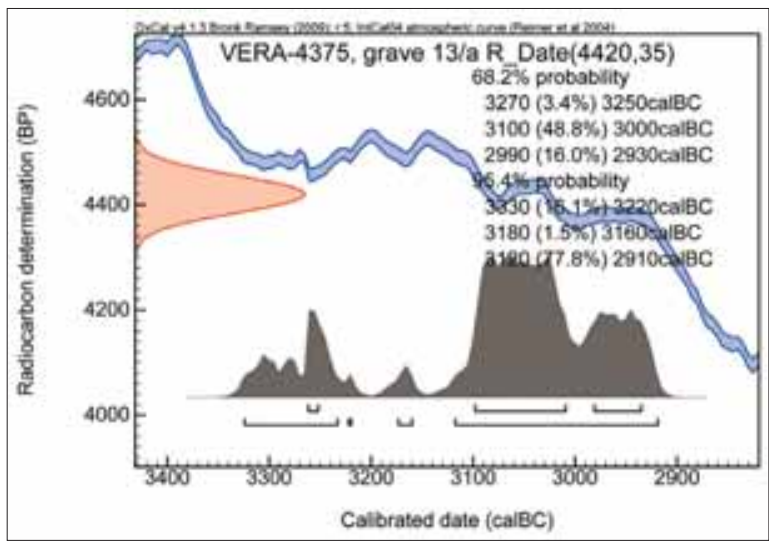

Fig. 8. Individual calibrated radiocarbon date for Grave 13/A

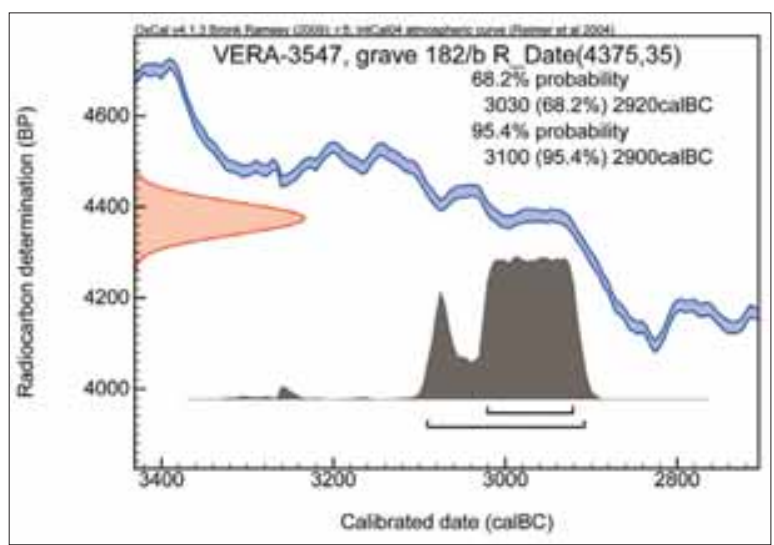

Fig. 10. Individual calibrated radiocarbon date for Grave 182/B

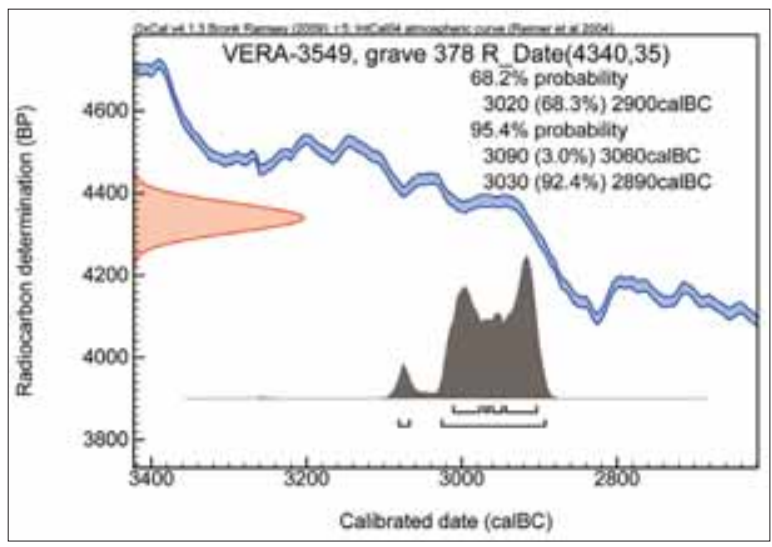

Fig. 12. Individual calibrated radiocarbon date for Grave 378

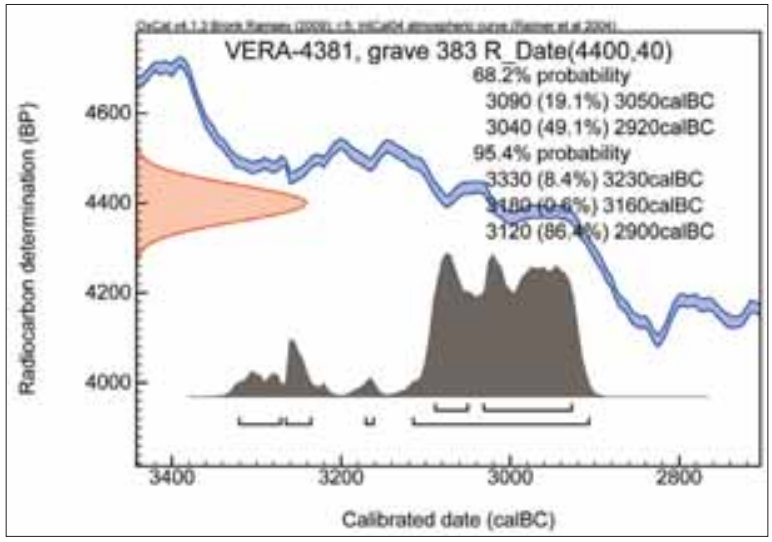

Fig. 9. Individual calibrated radiocarbon date for Grave 383

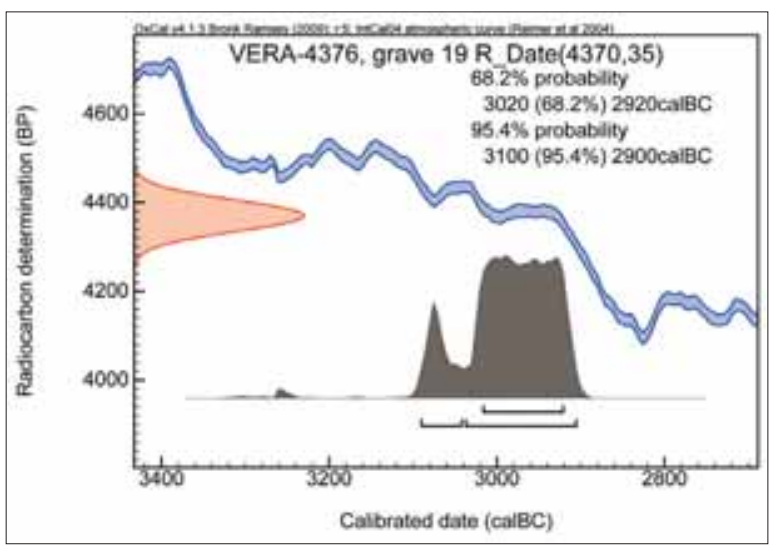

Fig. 11. Individual calibrated radiocarbon date for Grave 19

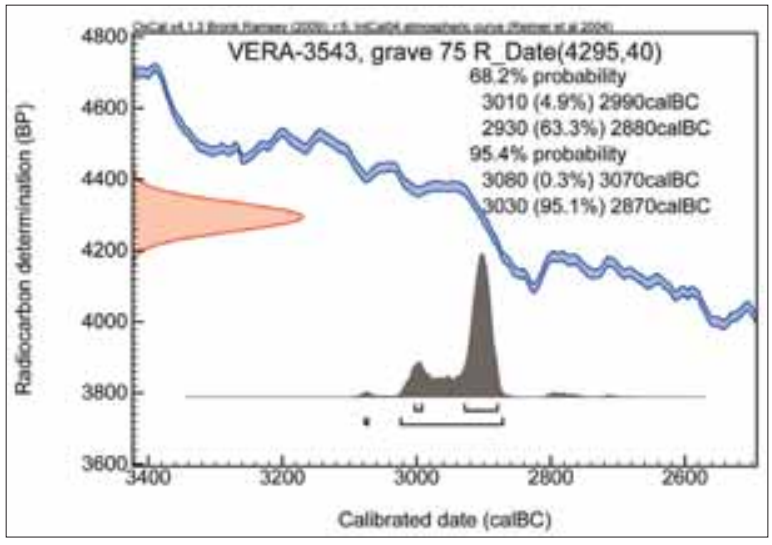

Fig. 13. Individual calibrated radiocarbon date for Grave 75 


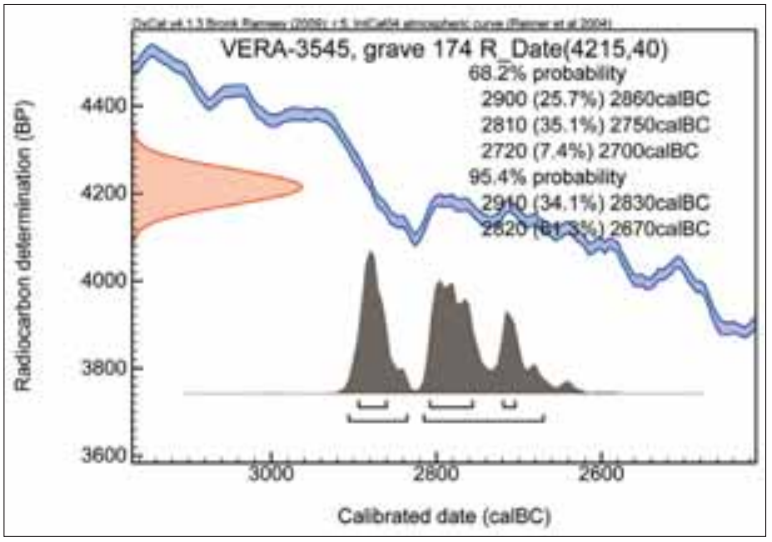

Fig. 14. Individual calibrated radiocarbon date for Grave 174

The probability distribution representing the entire span of the cemetery's use is $200(64.6 \%) 350,370$ (3.6\%) 390, 160 (95.4\%) 510 years, most probably ca. 240 years (Fig. 19).

Rejecting the two youngest dates, the above dates are modified to some extent. In this model, the agreement indices are low: the modelled date of the oldest burial (Grave 403 ) barely exceeds the $60 \%$ limit, while the date of the youngest one has no more than a $44 \%$ agreement index. It would appear that this grave was chronologically closer to Graves 174 and 158. This close relation is supported by the typological analysis of the grave goods. In this case, the probability distribution representing the boundary date for the start of the cemetery's use is 3160 (68.2\%) $3040 \mathrm{cal} \mathrm{BC}$ and 3310 (95.4\%) $3030 \mathrm{cal} \mathrm{BC} \mathrm{(Fig.}$ 20), while the probability distribution representing the boundary date for the end of the cemetery's use is 3020 (68.2\%) $2900 \mathrm{cal} \mathrm{BC}$ and 3080 (95.4\%) $2850 \mathrm{cal}$ BC (95.4\%) (Fig. 21). The probability distribution representing the span of the cemetery's use is $30(68.2 \%) 210$ and 0 (95.4\%) 360 years. The cemetery was most probably used for some 100-150 years (Fig. 22).

\section{CHRONOLOGICAL POSITION OF THE BUDAKALÁSZ CEMETERY IN THE LATE COPPER AGE}

Few new radiocarbon dates have been published ${ }^{8}$ since the last comprehensive analysis of the absolute chronology of the Late Copper Age. ${ }^{9}$ Regarding Hungary, new radiocarbon dates have been published from Györ-Szabadrétdomb and Balatonôszöd; ${ }^{10}$ however, these dates are consistently younger than the currently available dates from other sites. The radiocarbon dates for the

\footnotetext{
${ }^{8}$ FuRHOLT 2008A, 622. He published new radiocarbon dates from the territory of Poland and the Czech Republic.

${ }^{9}$ WILD et al. 2001.

${ }^{10}$ Figler et al. 1997, 212, Tab. 2. The dates for the Boleráz period ranged between $3508(68.2 \%) 2924 \mathrm{cal}$ BC. The radiocarbon dates from Balatonôszöd placed the Boleráz phase between 3325 (68.2\%) $3027 \mathrm{cal} \mathrm{BC}$, the ones for the early classical Baden phase between 3016 (68.2\%) $2687 \mathrm{cal}$ BC; HoRváTH et al. 2008. These dates are roughly 300 years younger than the dates for other sites. These are not AMS dates.
}

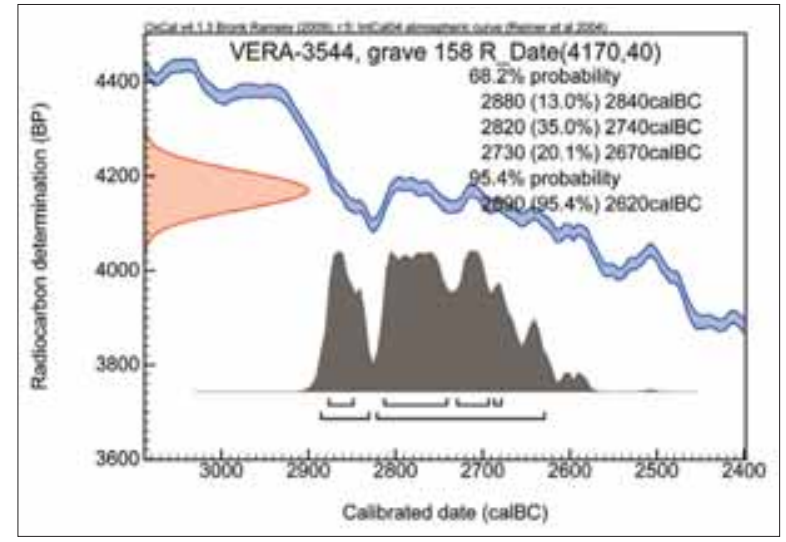

Fig. 15. Individual calibrated radiocarbon date for Grave 158

Budakalász cemetery harmonize well with the formerly known chronological picture.

The onset of the Late Copper Age, marked by the Proto-Boleráz period, can be dated around 3640 (68.2\%) $3370 \mathrm{cal} \mathrm{BC.}{ }^{11}$ The radiocarbon dates for the ensuing Boleráz period fall into exactly the same time interval. ${ }^{12}$ The main reason for this is that there is a long plateau in this phase of the calibration curve, which does not enable a more accurate dating. On the other hand, the dates from Poland, the Czech Republic, Slovakia, Hungary, Austria and Switzerland provided the sample for sum calibration and thus merged possible chronological differences among these regions. Martin Furholt has convincingly demonstrated the rapid expansion of pottery in the Boleráz style and regional differences by separately grouping these radiocarbon dates. ${ }^{13}$ It is possible that the virtual contemporaneity of these two phases or styles can in part be explained by the fact that sum calibrations and few radiocarbon dates conceal the differences in the rhythm of cultural development, as well as the receptiveness toward innovations or a strict adherence to traditions not only between regions, but also between individual sites.

The classical Baden period can be clearly separated from the Proto-Boleráz and Boleráz periods on the basis of the radiocarbon dates; it can be dated between $3350(68.2 \%) 2870$ BC. ${ }^{14}$ The radiocarbon dates for the Budakalász cemetery are virtually identical (3350 (68.2\%) 2880 cal BC). The typologically closest site to Budakalász for which radiocarbon dates are available is Nagykanizsa-Billa, whose finds include artefacts reflecting the traits of the late classical Baden phase. The site illustrates the difficulties of a finer chronological periodisation of the classical Baden period because finds bespeaking characteristic traits of the early and

\footnotetext{
${ }^{11}$ WiLD et al. 2001, 1061-1062; KALICZ 2001, 406. Sum calibration of the published dates with the IntCal04 calibration curve.

12 WILD et al. 2001, 1062.

${ }^{13}$ Furholt 2008A, 2008B.

14 WILD et al. 2001, 1062. The transitional period (represented by five dates) shows a considerable overlap with the preceding periods.
} 


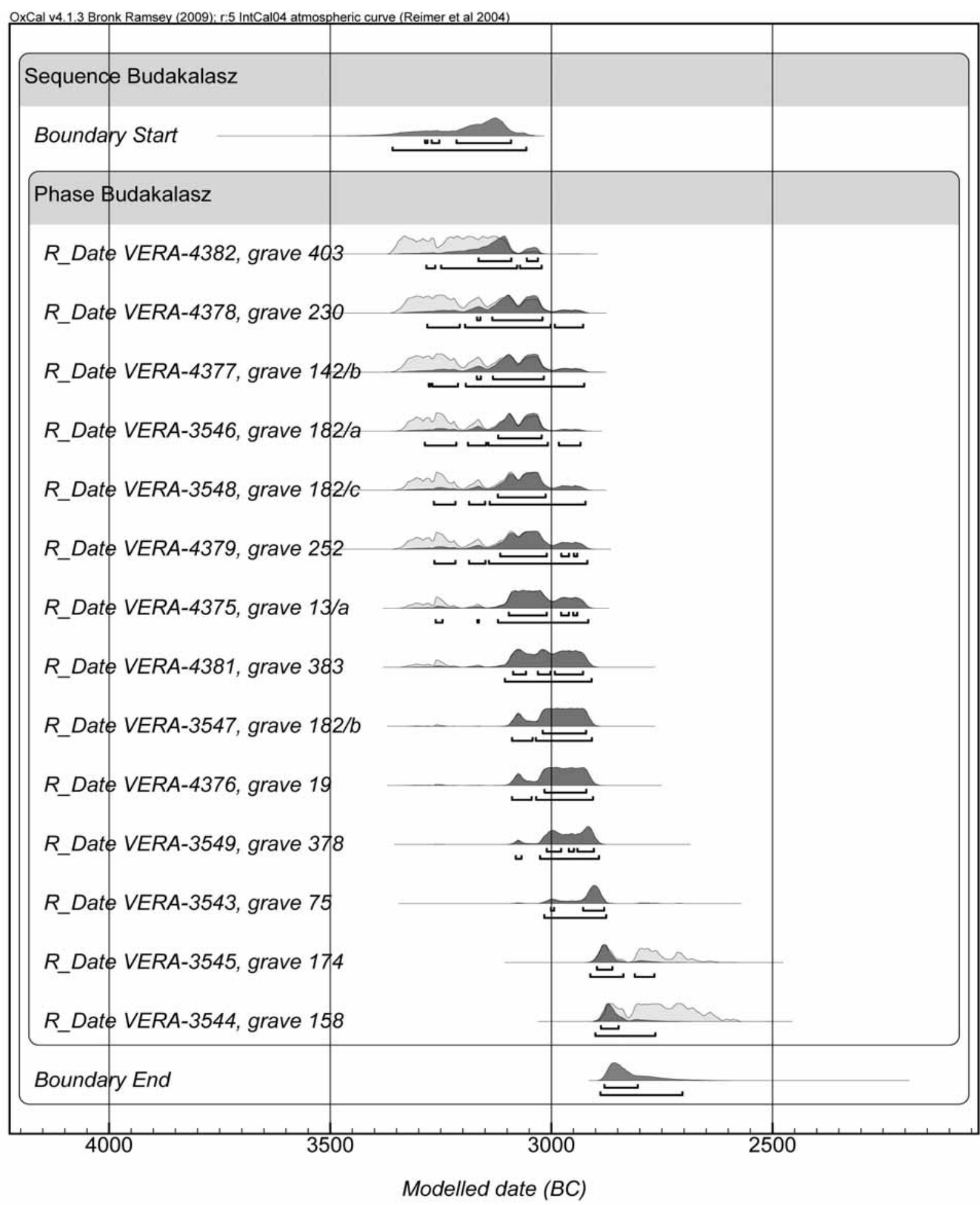

Fig. 16. Analysis of calibrated radiocarbon dates. The light grey probability distributions represent individual calibrated dates. The dark grey probability distributions represent the calibrated dates using the Bayesian method. The bars under the probability distribution show the $68.2 \%$ and $95.4 \%$ ranges 


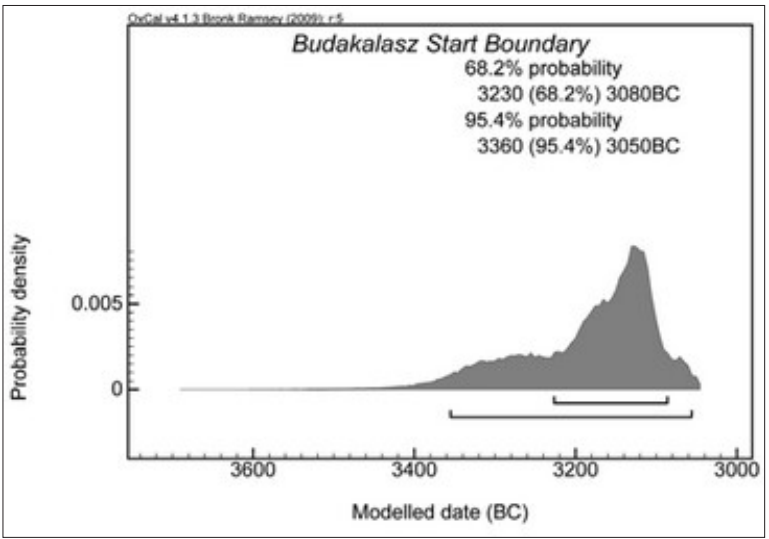

Fig. 17. Probability distribution showing the start boundary of the modelled data shown in Fig. 16

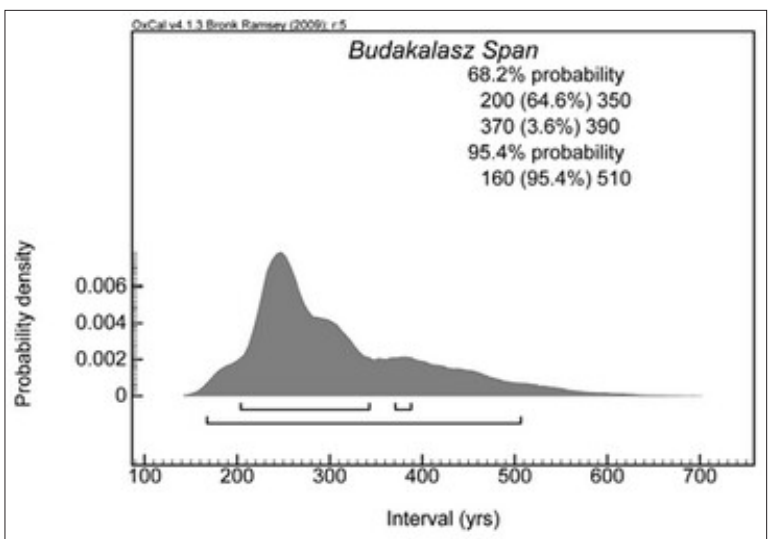

Fig. 19. Probability distribution showing the span of the cemetery's use, based on the modelled data in Fig. 16

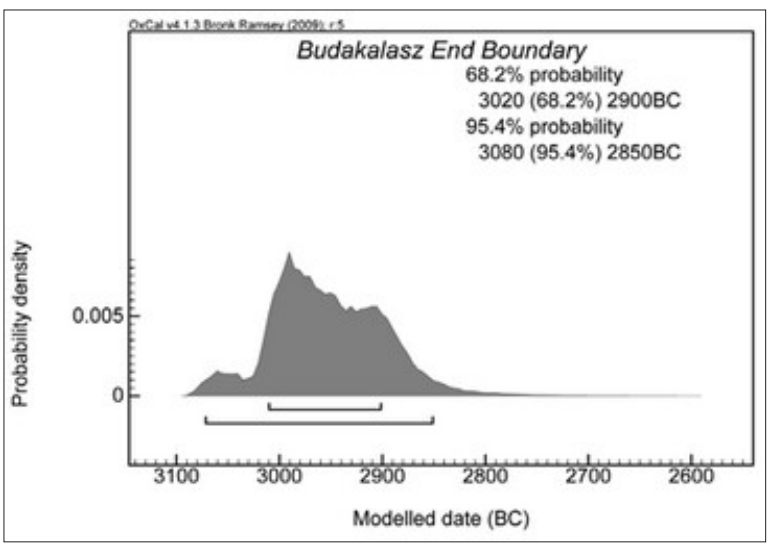

Fig. 21. Probability distribution showing the end boundary of the modelled data in Fig. 16, excluding the dates for Graves 174 and 158

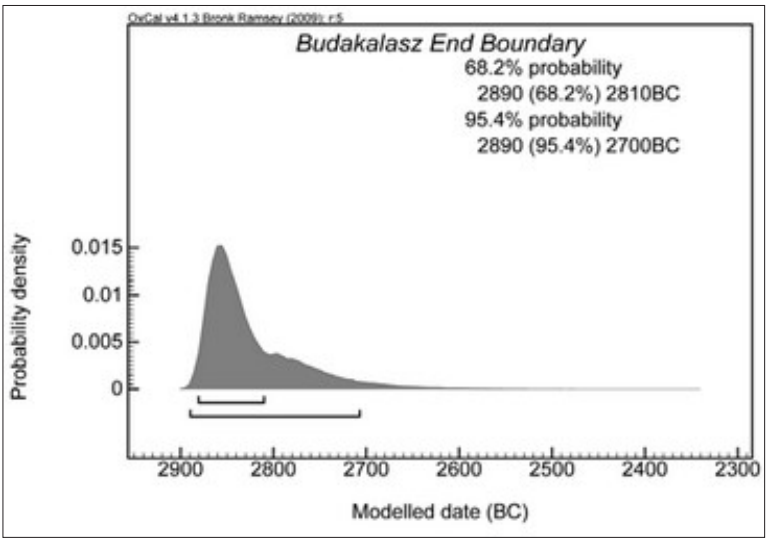

Fig. 18. Probability distribution showing the end boundary of the modelled data shown in Fig. 16

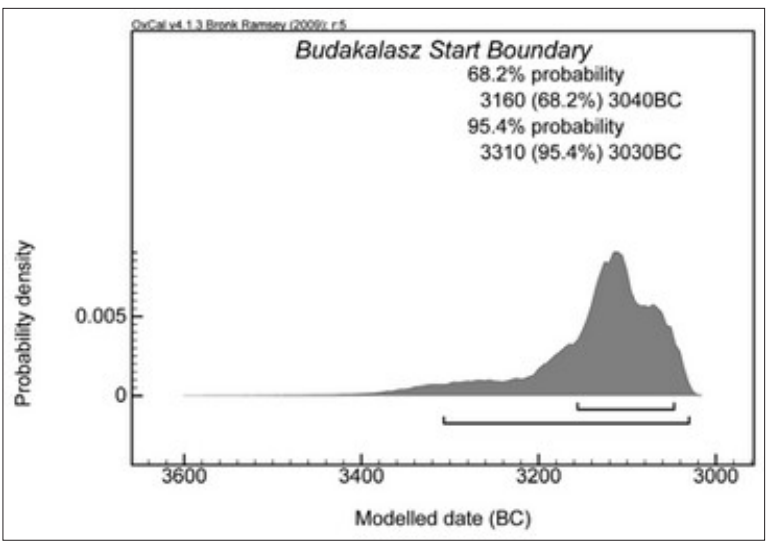

Fig. 20. Probability distribution showing the start boundary of the modelled data in Fig. 16, excluding the dates for Graves 174 and 158

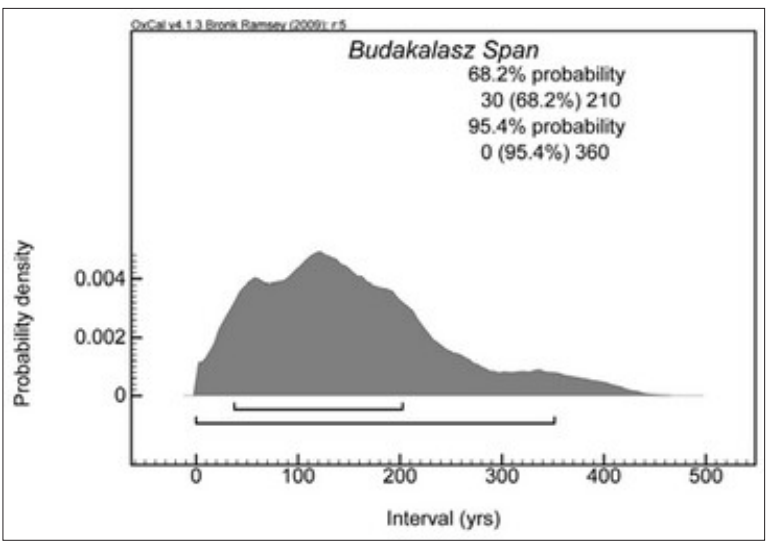

Fig. 22. Probability distribution showing the span of the cemetery's use, excluding the dates for Graves 174 and 158 
late classical Baden period appeared together in the same features. ${ }^{15}$ This site can be dated between 3270 (68.2\%) $2920 \mathrm{cal} \mathrm{BC}$ and 3340 (95.4\%) $2910 \mathrm{cal} \mathrm{BC}$ (95.4\%).16 Good parallels to the Budakalász finds can be quoted from Svodín, dated between $3320(8.1 \%)$ $3230 \mathrm{cal}$ BC and $3110(60.1 \%) 2870$ cal BC, 17 indicating that it is absolutely contemporary with the Budakalász cemetery.

The radiocarbon dates for the end of the cemetery's use seem a bit younger than the other known dates, especially in the light of the fact that characteristic traits of the late classical Baden period are lacking from the Budakalász cemetery. On the basis of the radiocarbon dates, the estimated end of the cemetery was contemporary with the Kostolac and Vučedol cultures. The radiocarbon dates for late Baden sites with Kostolac style pottery (Ószentiván VIII, Szigetcsép-Tangazdaság) fall into the same time interval as the ones from the Kostolac core territory and they uniformly date between 3330 (68.2\%) $2870 \mathrm{cal}$ BC. ${ }^{18} \mathrm{We}$ are again dealing with the imprecisions of the calibration curve because these dates would suggest that the Kostolac culture was contemporaneous with the classical Baden period. It must be borne in mind, however, that only one single radiocarbon date is known from each site, which is obviously insufficient for the more precise dating of the close of the Late Copper Age in the Carpathian Basin. Tell sites with Kostolac occupation layers overlying Baden layers would help to solve this problem. Only one radiocarbon date is known from Gomolava, which is younger than the two Kostolac dates, and thus additional radiocarbon dates would be necessary from this site too. The probability distribution for the boundary date of the start of the Baden occupation at Gomolava using the Bayesian method falls between 3290 (68.2\%) 2930 cal BC, the probability distribution for the Baden/Kostolac transition is $3060(68.2 \%) 2920 \mathrm{cal} \mathrm{BC}$, while the probability distribution for the boundary date of the end of the Kostolac occupation is 2920 (68.2\%) 2820 cal BC. At the Vučedol site, the Kostolac occupation layers overlying the Baden layers were followed by Vučedol layers. This stratigraphic sequence would provide a good basis for the clarification of radiocarbon chronology, but the standard deviation of the available radiocarbon dates is too high $(100-180$ years), ${ }^{20}$ making this impossible. The radiocarbon dates for the typologically early Vučedol finds from Vučedol and Pivnica gave a date of around $3100(60.9 \%) 2860$

\footnotetext{
15 P. BARNA 2003.

16 WILD et al. 2001, 1061. Sum calibration of four samples (VERA-840, $841,843,844)$ with the IntCal04 calibration curve. The fifth sample (VERA-846) was too young, and was therefore omitted.

17 STADLER et. al. 2001, 553. Sum calibration of samples Bln-2169, 2173 , 2174 with the IntCal04 calibration curve.

18 BognáR-KutZián 1972, 211; ForENBAHER 1993, 240.

19 Waterbolk 1988; Forenbaher 1993, 240; Petrović-Jovanović 2002, 82, 303-304, 362, 370-371. Recalibration of samples GrN-7371, $7372,7373,13167,13168,15681$ with the IntCal04 calibration curve.

20 SRDOČ et al. 1987, 136; SRDOČ et al. 1989, 87.
}

and $2810(7.3 \%) 2750 \mathrm{cal} \mathrm{BC}$ for the beginning of the Vučedol culture. ${ }^{21}$ The stratigraphic data provide a good starting point for the relative chronology of these cultures, but they are unsuitable for resolving problems of absolute chronology. The 200-300 years long plateaux and wiggles of the calibration curve could be one reason for the apparent contemporaneity of the classical Baden, the Kostolac and the Vučedol cultures, although an alternative explanation might be sought in regional differences. The Kostolac and Vučedol cultures may have emerged in their core territory at a time when the classical Baden culture was still distributed in Transdanubia.

The radiocarbon date for the Kétegyháza-Törökhalom kurgan is 3020 (45.4\%) 2850, 2820 (17.1\%) 2740 and $2730(5.7 \%) 2690$ cal BC, ${ }^{22}$ reflecting a partial overlap with the second half of the Budakalász cemetery.

The radiocarbon dates from South-East Europe indicate that the Budakalász cemetery was contemporaneous with Ezero XIII-VII and Sitagroi IV. The absolute chronology of Cernavodă I and III is uncertain because the few dates available for the Cernavodă I period fall into an extremely wide time interval which would make it contemporaneous with the entire Boleráz and classical Baden sequence. No radiocarbon dates are available for the Cernavodă III period..$^{23}$

One of the cardinal questions regarding the Budakalász cemetery is the span of its use. The individual calibrated radiocarbon dates suggesting a span of 455-470 years would cover over one-half of the Late Copper Age (ca. $700-800$ years), which is most unlikely in view of the homogeneity of the find material, even assuming that the deceased interred in the cemetery came from a traditionalist community or communities. An estimated span of 100-240 years using the Bayesian method seems more likely.

It is obvious from the limitations of the radiocarbon dating method and the calibration curve that only the early (Proto-Boleráz, Boleráz) and late (classical Baden, Kostolac) phase of the Late Copper Age can be distinguished. The number of radiocarbon dates from the Late Copper Age and the Early Bronze Age is still too low and there are several old, traditional radiocarbon dates among them whose standard deviations are too high to enable a more accurate dating and the separation of individual phases. Regional differences can also be assumed behind the different rhythm in the spread of different ceramic styles. It must also be borne in mind that stylistic change is a continuous process without really sharp boundaries. The typological traits of the grave assemblages and the radiocarbon dates both indicate that the cemetery can be

\footnotetext{
${ }^{21}$ SRDOČ et al. 1987, 136; SRdoČ et al. 1989, 87; DuRMAN-Obelí 1989 , 1004, 1006. Sum calibration of samples Z-1447, 1621, 1637, GrN-8010 with the IntCal04 calibration curve.

22 QuitTA-KoHL 1969; Forenbaher 1993, 241. Sample Bln-609 was recalibrated with the IntCal04 calibration curve.

${ }^{23}$ WiLD et al. 2001, 1062-1063.
} 
dated to the classical Baden period. It cannot be dated more accurately either on typological grounds, or on the basis of the radiocarbon dates.

\section{INTERNAL CHRONOLOGY, SERIATION AND CORRESPONDENCE ANALYSIS OF THE POTTERY GRAVE GOODS}

\section{Statistical methods for the analysis of prebistoric mortuary data}

Statistical methods are based on the assumption that human behaviour can be expressed in numbers. Accepting this axiom, processual archaeology applies methods adopted from the natural and social sciences. These methods are popular among archaeologists because they are considered to be objective. However, a closer look at statistical methods reveals that even these procedures incorporate elements of subjectivity and are not without problems.

The application of statistical methods in archaeology is by all means justified in cases when one is confronted with large sets of data since it would otherwise be extremely difficult or even impossible to evaluate the data. Statistics enable the identification of major patterns and relationships in a sample. However, the sampling procedure itself and ensuring that the sample is representative raises serious methodological problems. Archaeologically excavated graves cannot be considered to form a random sample because the mortuary treatment of the deceased was a series of intentional acts. This is further complicated by the fact that it is usually not known what percentage of the area of the entire cemetery the excavated sections represent, or how large a portion of the population the excavated graves represent. Another problem, even in the case of completely excavated cemeteries, is whether each member of the community was buried there and whether the cemetery was used by one or more communities. The excavated material can therefore hardly be considered a sample in the statistical sense of the word.

Statistical analyses became popular in prehistoric archaeology with spread of New Archaeology. Processual archaeology assumes that the one-time social structure is reflected in the mortuary practices which can be described precisely with quantitative methods and then interpreted. The use of quantitative methods became rarer with the emergence of post-processual archaeology and the emphasis on the ideological aspects of mortuary practices because symbols and ideology are usually regarded as non-quantifiable features. ${ }^{24}$

There is a general consensus among the followers of various theoretical trends that the patterns observed in the mortuary treatment of the dead have some meaning and that they reflect elements of a real, idealistic or ideologically biased social structure, and that they play a role in its manifestation. The statistical analysis of mortuary data is

\footnotetext{
${ }^{24}$ MCHuGH 1999, 62-63.
}

complicated further by the fact that the information provided by burials is made up of the overlapping elements of an intricate social system such as age, sex, social ranking, etc., meaning that units or groups can rarely be clearly separated, especially in view of the fact that much of the information on the past is lost. ${ }^{25}$ Additional elements in this complicated picture are the temporal changes forming a further axis in mortuary analysis.

The information gleaned from excavated graves has to be ordered into a database, i.e. the information must be coded. This procedure in itself involves subjective decisions. One must decide, for example, whether to use nominal, ordinal or scale variables, and one must be aware of the fact that coding considerably influences later results. Unsuitable coding may conceal existing patterns in the data set. For example, the possible meaning of pottery decoration might remain undetected if the statistical analysis of the pottery grave goods focuses on whether a grave contained pottery or not, and how many vessel were deposited in a grave. Or, for example, if the deposition of a vessel in the grave had some significance per se, the over-categorisation of vessels according to smaller details and a too fine typology will again conceal important patterns. It is often very difficult to find a good solution. The interpretation of the results is also rather subjective.

Seriation is a popular, widely applied technique for analysing chronological changes in find assemblages despite its drawbacks. The latter can be eliminated to some extent by using correspondence analysis, a more recent statistical method.

\section{Seriation}

Seriation is based on the assumption that artefacts undergo gradual modification over time. The identification of stylistic changes in grave goods and find assemblages enables their ordering into a relative chronological sequence. Stratigraphic data and seriation complement each other well, but if the results of the two are at variance, it does not necessarily mean that one is wrong. Seriation only provides a statistical probability of the sequence of artefacts and of the graves containing them, while stratigraphy provides the genuine, one-time sequence. For example, if a young individual was buried first with new, "fashionable" artefacts and an elderly individual was interred later with old, "outmoded" artefacts, the real sequence of the burials would be at variance with the general sequence of artefact types. ${ }^{26}$ Contradictions of this type can be easily resolved with radiocarbon dates insofar as sufficient time, reflected in radiocarbon dates, had elapsed between the digging of the two graves.

The main disadvantage of seriation is that it can only be performed on artefact types which occur in at least two graves, and thus unique types are excluded from

\footnotetext{
${ }^{25}$ Either because the artefacts were made of organic material or because certain elements of the social differences reflected in the mortuary ritual are not preserved in the archaeological record (e.g. the length of mourning or who participated at the funeral).

${ }^{26}$ JENSEN-NIELSEN 1997, 37.
} 


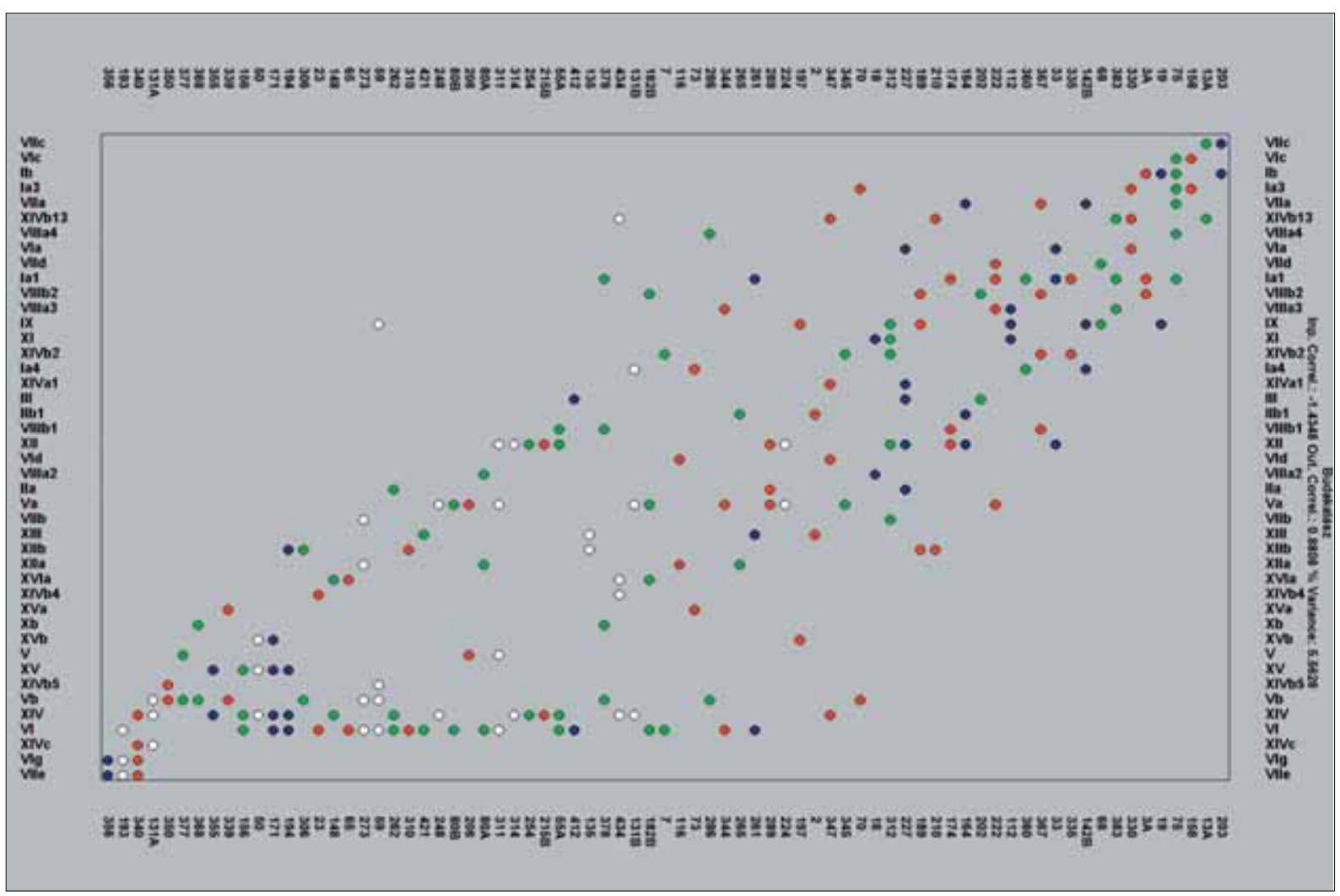

Fig. 23. Seriation of pottery grave goods coloured by age and sex. Red: female, blue: male, green: child

the analysis. Burials representing a homogeneous, short time span too can only be handled with difficulty. At the same time, too common types also cause problems because they dominate and bias seriation, and they must therefore also be omitted from the analysis. Too richly furnished graves cause similar problems because they provide far too many possibilities of linking and their place in seriation can easily vary.

The biggest drawback of seriation is that artefacts are "forced" into a continuous series even if a pattern of this type did not exist in the sample at all. Seriation orders the data along a single axis, namely chronological change. Very often, a closer look at the seriated data revealed that while the seriation itself was apparently successful, the artefacts were separated according to gender. This problem can be resolved by omitting gender-specific artefacts or by separating seriation according to sex. These and similar hidden errors can be identified and eliminated by correspondence analysis. When interpreting the results of seriation, it must be borne in mind that seriation is only suitable for handling continuous data sequences and that it is unsuitable for recognising and handling hidden groups in the data set. Seriation is thus only suitable for identifying gradual chronological changes, but is unsuitable for identifying other patterns influencing mortuary practices and thus seriation in itself is insufficient for mortuary analysis. At the same time, it is an excellent technique for analysing the internal chronology of a cemetery if complemented by absolute chronological dates and stratigraphic data.

\section{Correspondence analysis}

The great advantage of correspondence analysis is that it can be used for binary and abundance variables as well. Correspondence analysis reveals hidden patterns in a data set on the basis of mean similarities among types or units. This method is excellently suited to analysing mortuary data because it reveals the continuity and grouping of data and it can handle them at the same time. In contrast to seriation and cluster analysis, its main advantage is that it also reveals if there are no patterns in a data set. ${ }^{27}$ Because correspondence analysis is able to handle data simultaneously according to several axes or aspects, it is especially suited to examining the relative chronological sequence of graves $^{28}$ and to analysing social structure. ${ }^{29}$ Naturally, it remains the archaeologist's task to interpret the results. The method is exceptionally sensitive for outliers which can bias or conceal general patterns in a data set, ${ }^{30}$ offering good results by eliminating outliers.

\footnotetext{
${ }^{27}$ Cluster analysis orders the data into groups or clusters even if a pattern of clusters had not been present in the data set, while seriation orders data into a continuous series even if there were no such series originally.

28 A perfect seriation takes the form of a parabola in correspondence analysis.

${ }^{29}$ If clusters can be identified in the data set, distinct clusters of points will appear in the plot of the correspondence analysis.

30 MCHugH 1999, 80-84. This problem is encountered in virtually every statistical method because each of these is concerned with identifying patterns and tendencies in large data sets, meaning that they are rarely useful for the interpretation of unique traits or small groups.
} 
Table 2. Typological codes of the pottery grave goods

\begin{tabular}{|c|c|}
\hline Ia1 & Undecorated goblet with rounded cup \\
\hline Ia2 & Undecorated goblet with rounded flat cup \\
\hline Ia3 & Goblet with decorated rounded cup and decorated foot \\
\hline Ia4 & Goblet with decorated rounded cup and undecorated foot \\
\hline Ia5 & Goblet with undecorated rounded cup and decorated foot \\
\hline $\mathrm{Ib}$ & Decorated goblet with rectangular cup \\
\hline Ic1 & Rectangular goblet with peaked rim, decorated cup and foot \\
\hline Ic2 & Rectangular, undecorated goblet with peaked rim \\
\hline Id & Goblet, footed goblet \\
\hline IIIa & Undecorated ladle \\
\hline IIb1 & Ladle decorated under the rim \\
\hline IIIb2 & Ladle decorated under the rim and on the handle \\
\hline $\mathrm{IIb} 3$ & Ladle with decorated handle \\
\hline IIb4 & Ladle with decorated body and handle \\
\hline IIIb5 & Ladle with notched rim \\
\hline III & Dipper \\
\hline IV & Suspension vessel \\
\hline $\mathrm{V}$ & Mug \\
\hline Va & Undecorated mug \\
\hline $\mathrm{Vb}$ & Mug with fluted belly \\
\hline $\mathrm{Vc}$ & Mug with fluted belly and decorated handle \\
\hline $\mathrm{Vd}$ & Mug with fluted belly decorated with ribs \\
\hline $\mathrm{Ve}$ & Mug with fluted belly decorated with ribs and a row of impressed dots \\
\hline $\mathrm{Vf}$ & Mug with fluted belly decorated with a row of impressed dots \\
\hline $\mathrm{Vg}$ & Mug decorated with a row of impressed dots on the belly \\
\hline VI & Pitcher \\
\hline VIa & Pitcher with fluted belly, decorated with grooved ribs and a row of impressed dots around the shoulder \\
\hline VIb & Pitcher with a decoration dividing the vessel body into panels \\
\hline VIc & Strongly flattened globular pitcher with fluted belly \\
\hline VId & Squat, handled pitcher with fluted belly and undecorated neck \\
\hline VIe & Pitcher decorated with a bundle of smoothed-in lines on the neck and fluting on the belly \\
\hline VIf & Undecorated pitcher \\
\hline VIg & Vessel with narrow neck, without indication of a handle \\
\hline VIIa & Jug with smoothed neck decorated with fluting or smoothed-in lines on the belly \\
\hline VIItb & Jug with smoothed neck decorated with rows of impressed dots and ribs on the belly \\
\hline VIIc & Jug decorated with alternating panels filled with oblique and vertical fluting on the belly \\
\hline VIId & Undecorated jug \\
\hline VIIe & Coarse vessel with constricted mouth, without a handle \\
\hline VIIIIa1 & Rectangular scooping vessel decorated with a row of impressed dots \\
\hline VIIIIa2 & Rounded scooping vessel decorated with a row of impressed dots under the rim \\
\hline VIIIIa3 & Rounded scooping vessel decorated with a row of impressed dots encircling the belly \\
\hline VIIIIa 4 & Rounded scooping vessel decorated with impressed dots under the handle \\
\hline VIIIIa 5 & Scooping vessel decorated with smoothed-in lines forming a cross at the base \\
\hline VIIIa6 & Scooping vessel decorated with smoothed-in lines forming a cross in its interior \\
\hline VIIIIb1 & Squat, undecorated scooping vessel \\
\hline VIIIIb2 & Rounded, undecorated scooping vessel \\
\hline IX & Handled cup \\
\hline $\mathrm{Xa}$ & Undecorated handled beaker \\
\hline $\mathrm{Xb}$ & Plain, flowerpot shaped beaker without handle \\
\hline $\mathrm{XI}$ & One-handled pot \\
\hline XII & Atypical pot \\
\hline XIIa & Pot decorated with a notched rib \\
\hline XIIb & Pot decorated with knobs \\
\hline XIIc & Undecorated pot \\
\hline XIII & Amphora \\
\hline XIIIIa & Amphora with long neck and rounded fluted belly \\
\hline
\end{tabular}


Table 2 (cont'd)

\begin{tabular}{|l|l|}
\hline XIIIb & Amphora with wide mouth, rounded belly and a handle terminating in two slender ribs \\
\hline XIIIc & Amphora with narrow neck and globular body \\
\hline XIV & Bowl \\
\hline XIVa1 & Semi-spherical bowl, decorated \\
\hline XIVa2 & Semi-spherical bowl, undecorated \\
\hline XIVb11 & Conical bowl decorated with triangles and a row of impressed dots \\
\hline XIVb12 & Handled conical bowl decorated with triangles and a row of impressed dots \\
\hline XIVb13 & Conical bowl decorated with triangles and a row of impressed dots, perhaps with handle \\
\hline XIVb2 & Conical bowl decorated with two rows of impressed dots \\
\hline XIVb3 & Conical bowl decorated with three rows of impressed dots \\
\hline XIVb4 & Conical bowl decorated with a row of impressed dots under the rim \\
\hline XIVb5 & Undecorated conical bowl \\
\hline XIVc & Undecorated coarse bowl \\
\hline XV & Atypical handled bowl \\
\hline XVa & Handled bowl decorated with a row of impressed dots \\
\hline XVb & Handled bowl decorated with two rows of impressed dots \\
\hline XVc & Handled bowl decroated with two rows of impressed dots and hatched triangles \\
\hline XVd & Handled bowl decorated with several rows of impressed dots \\
\hline XVI & Atypical bipartite bowl \\
\hline XVIa & Bipartite bowl decorated with ornamental knobs, stringhole lugs and a row of impressed dots \\
\hline XVIb & Bipartite bowl decorated with two rows of impressed dots \\
\hline XVIc & Bipartite bowl decorated with incised zig-zag lines \\
\hline XVId & Undecorated bipartite bowl \\
\hline
\end{tabular}

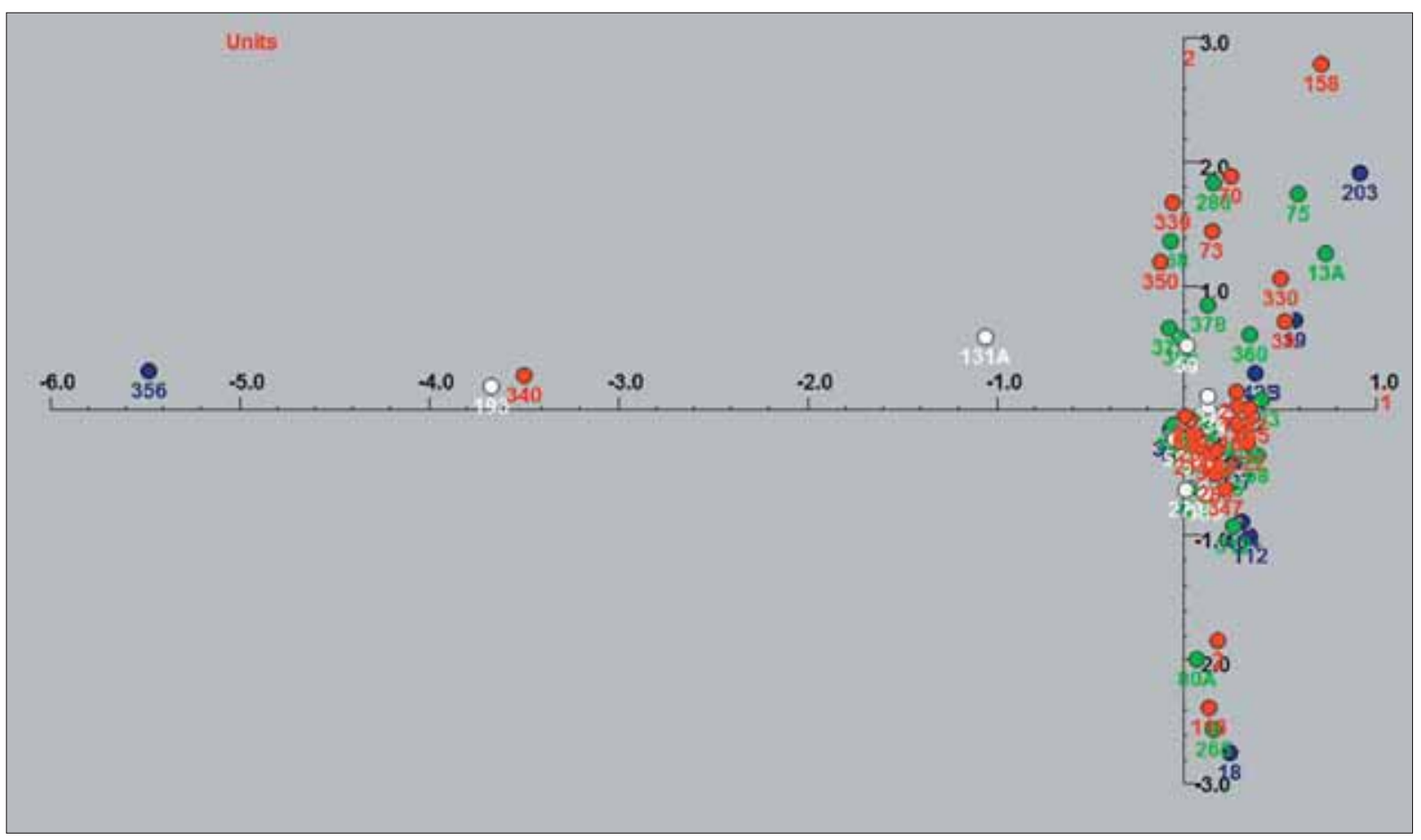

Fig. 24. Correspondence analysis of pottery grave goods coloured by age and sex. Red: female, blue: male, green: child 


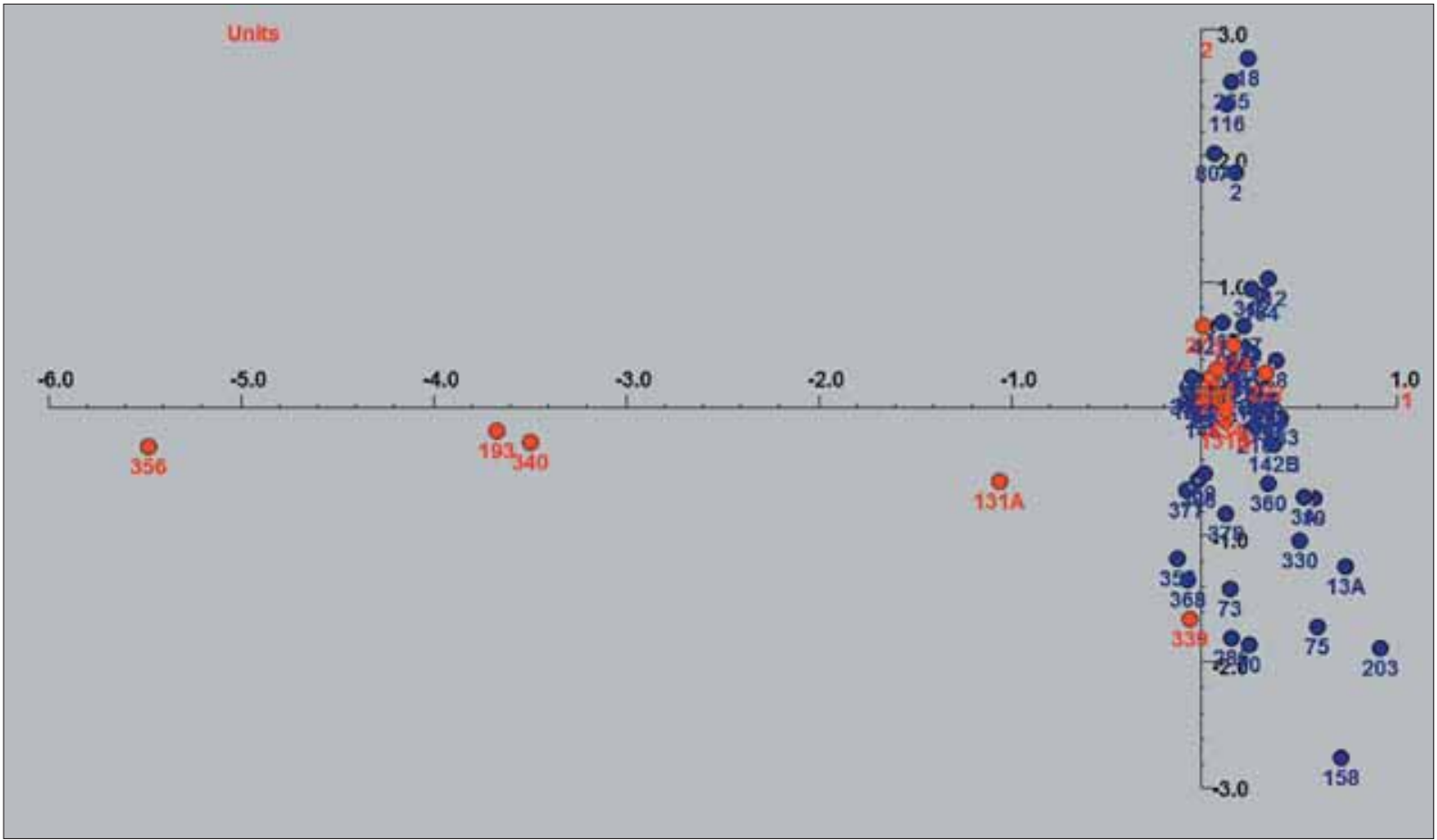

Fig. 25. Correspondence analysis of pottery grave goods coloured by burial rite. Blue: inhumation, red: cremation

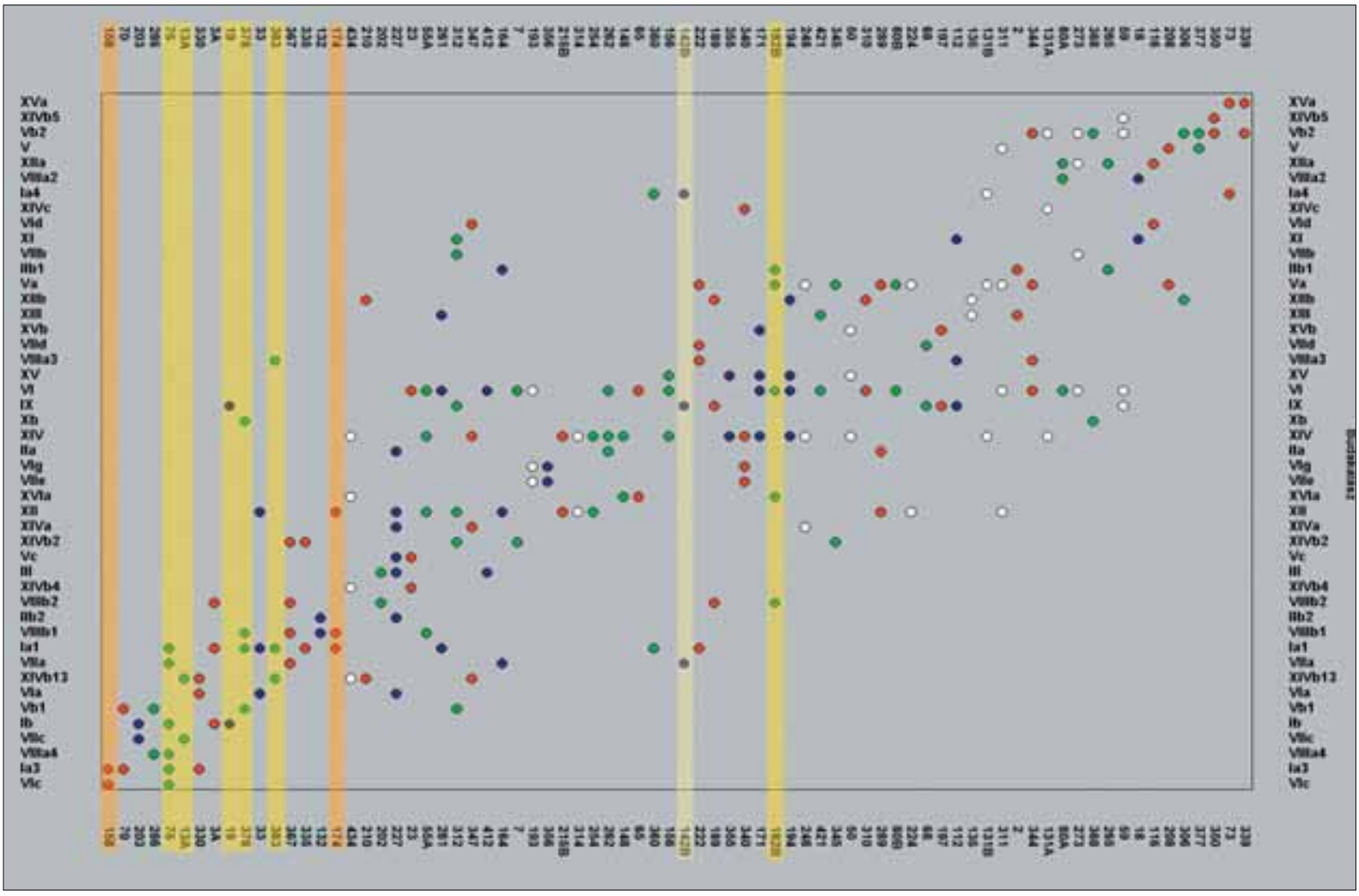

Fig. 26. Seriation of pottery grave goods coloured by age and sex. Red: female, blue: male, green: child. The shaded bands represent the radiocarbon dated graves. Light yellow: the oldest radiocarbon date, yellow: the majority of virtually contemporaneous radiocarbon dates, orange: the youngest radiocarbon dates 


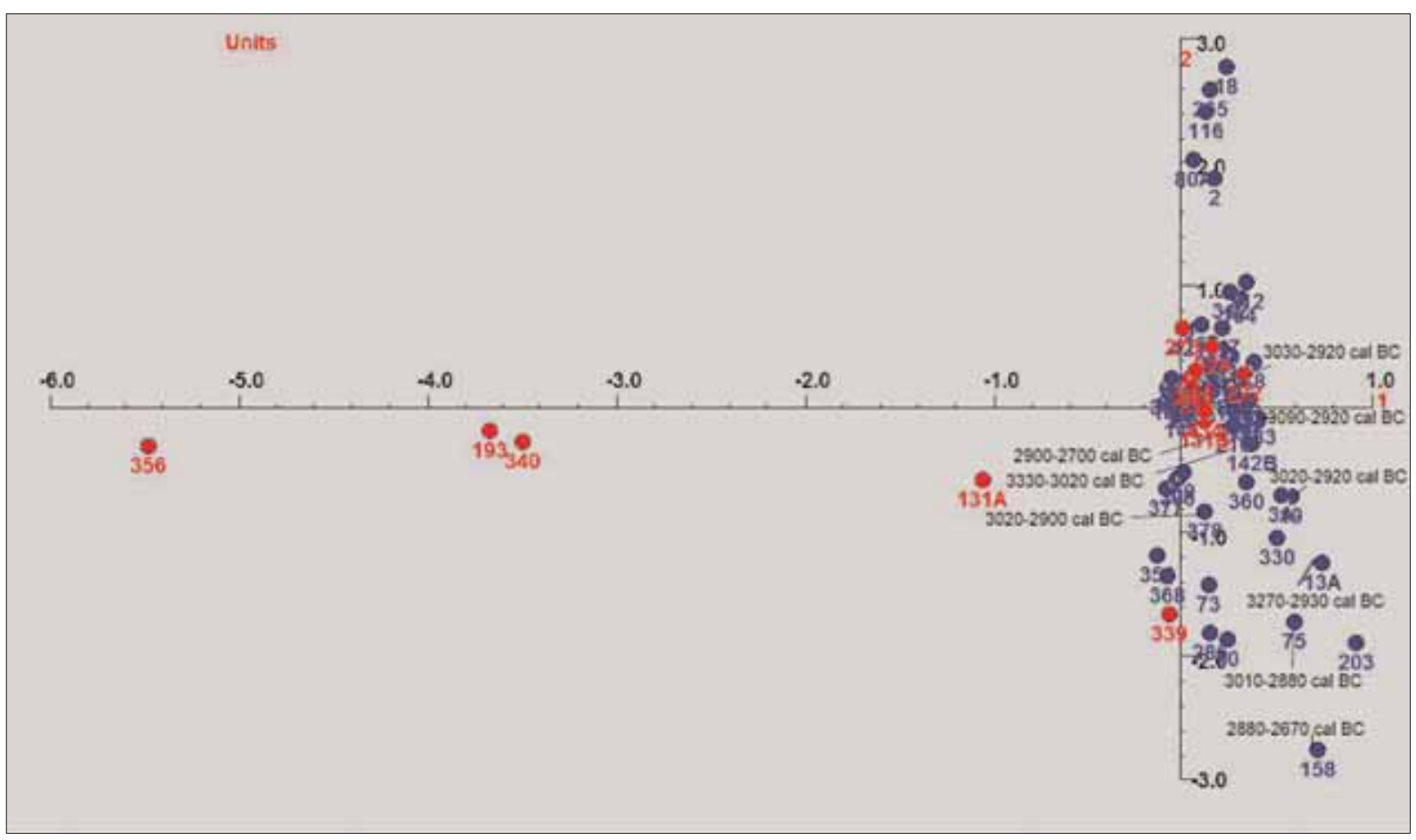

Fig. 27. Position of calibrated radiocarbon dated graves (68.2\%) in the correspondence analysis

\section{ANALYSIS OF THE LATE COPPER AGE CEMETERY}

The Late Copper Age cemetery at Budakalász-Luppacsárda containing 436 graves can be regarded as almost completely excavated. Because chronological differences between the burials could not be demonstrated through traditional typological analysis, I tried to determine the internal chronology of the cemetery through the seriation and correspondence analysis of the pottery grave goods.

Altogether 167 graves contained pottery. The number of unique types (27) and the number of burials containing a single vessel only (67 graves) was so high that only 75 graves were suitable for seriation and correspondence analysis. Both statistical analyses are based on Mária Bondár's pottery typology. ${ }^{31}$ The type codes in the graphs correspond to the ones used in the analysis of the pottery grave goods (Table 2).

First, I depicted seriation coloured by age and sex to determine whether these played a role in the inclusion of pottery among the grave goods and whether seriation could demonstrate genuine chronological differences. Seeing that male, female and child burials are scattered through the whole seriation and correspondence analysis, it would appear that no distinction can be drawn according to this variable. Pitchers (Type VI) and bowls (Type XIV) at the end of the series represent fragments of vessels which could not be assigned to a more specific sub-variant and were highly frequent types dominating seriation, and I therefore diminished their weight to zero. Types VIg

\footnotetext{
31 See pp. $246-286$, in this volume.
}

and VIIe at the very end of the sequence were vessels with narrow neck, unusual in this period, and they were almost entirely separated from the other graves (Fig. 23). This separation is even more visible in the correspondence analysis.

Testing seriation by correspondence analysis revealed that with the exception of graves containing narrow necked vessels, the other graves are very close to each other. The continuous line of graves, which fits well along the middle section of a parabola, confirms the result of the seriation. The diverse associations of vessel types provide an explanation for why the graves lie close to each other on the plot. It is highly probable that they represent only a short time span (Fig. 24).

The question arose whether certain elements of the mortuary practice such as orientation, cremation, etc. had a chronological dimension. It seems that orientation did not, while every outlier was a cremation burial. Other cremations were in the middle part of the sequence (Fig. 25). Narrow necked vessel types are clearly associated with cremation burials. A group of "early" graves characterised by vessels bearing rows of punctates and pots decorated with finger impressed ribs is slightly separated at one end of the seriation and in the correspondence analysis. At the other end of the sequence were the "late" graves, containing cups with channelling and round or angular footed goblets. It can be seen from the plot of the correspondence analysis that the graves form a continuous sequence, indicating that the occurrence and proportions of vessels decorated with rows of punctates and fluted vessels changed continuously, meaning that the two "phases" cannot be sharply separated. 


\section{TESTING INTERNAL CHRONOLOGY AGAINST ABSOLUTE CHRONOLOGY}

I compared the relative chronological sequence based on vessel typology with the radiocarbon data. Two of the fourteen radiocarbon dated burials did not contain grave goods, ${ }^{32}$ and another two did not yield pottery grave goods. The radiocarbon dates indicated that the oldest grave with pottery grave goods (Grave 142/B) was in the middle of the seriation. One of the two youngest graves was the latest in the seriation and correspondence analysis (Grave 158), while the other one (Grave 174) lay in the last quarter of the sequence. The other radiocarbon dated graves were virtually contemporaneous in the light of the radiocarbon dates. The relative chronological sequence harmonizes well with this because each grave in this group was in the last quarter of the sequence (Fig. 26).

\section{EVALUATION}

Two main conclusions can be drawn from the above analyses. Firstly, the radiocarbon dates support the relative chronology based on the statistical evaluation of the pottery grave goods. However, I would like to emphasise that the two statistical methods used for establishing the internal chronology of the cemetery and the calibrated radiocarbon dates can only provide a probability sequence. Still, the fact that three independent methods yielded similar results increases the likelihood that the results are accurate. Secondly, one special consequence of the comparison of radiocarbon dates and the results of the seriation and correspondence analysis is that the radiocarbon dates surprisingly represent only the younger half of the seriation. There could be several reasons for this.

(1) The graves chosen for radiocarbon measurements only represent the younger phase of the cemetery. Accepting the accuracy of both the radiocarbon dates and the seriation, one must assume that the span of the cemetery's use may have been longer than the estimated 100-240 years based on the radiocarbon dates. Assuming a uniform rate of stylistic change and that approximately the same number of graves were dug during the older phase as during the younger one, the span of cemetery's use may have been twice as long.

(2) Another option is to assume that the radiocarbon dates represent the entire span of the cemetery's use. In this case, the contradiction between the two can only be resolved by a correspondence analysis. The chronological "accumulation" of the seriation sequence is reflected also by the fact that approximately onequarter of the seriation sequence appears to be contemporaneous in the light of the radiocarbon dates, without temporal differences between the graves. Correspondence analysis is more suited to the analysis of mortuary practices because it is capable of revealing and simultaneously handling data clusters and continuous data sequences, without forcing the data into a continuous sequence. This advantage is apparent from the fact that the inhumation graves were arranged into a continuous sequence, while the cremation burials were clearly separated. Its other advantage is that the extent of similarity and dissimilarity between the analytical units (in this case, the graves) is clearly expressed. The more similar two graves are to each other, the closer they lie to each other in the plot. It would appear that seriation does indeed demonstrate temporal change, corresponding to the continuous line in the correspondence analysis; at the same time, the cremation burials form a stylistically distinct separate cluster. ${ }^{33}$ The radiocarbon dated graves represent the younger section of the sequence in the correspondence analysis too; at the same time, the extremely tight cluster of highly similar graves in the middle of the sequence is more visible than in the seriation. Radiocarbon dated Grave 182/B lies in the middle of this group, whose dating can be extended to the other burials of this group. Another major difference is that only five graves form the group of "early" graves (Graves 18, 265, 116, 80/A, 2) in the correspondence analysis; the absolute chronological position of these graves remains unknown (Fig. 27).

Both the correspondence analysis and the radiocarbon dates indicate that the Budakalász cemetery had an initial period represented by a few similar graves and that the main phase of its use was characterised by numerous burials furnished with pottery grave goods dug over a relatively short period of time, followed by a period during which the number of graves gradually decreased.

The spatial distribution of the graves based on the probability sequence established through statistical methods indicates that cemetery did not spread from one direction towards another, but contained several smaller, contemporary spatial groups. The spatial distribution of the radiocarbon data supports this result (Fig. 28).
32 These were the three burials of Grave 182; the pottery grave goods lay amongs the stones and Grave 182B contained a chert blade. ${ }^{33}$ It must here be noted that the probability order of the graves was based
solely on the pottery grave goods, and the conclusions are therefore
limited. 


\section{References}

P. BARNA 2003

BLACKWELL et al. 2006

BOGNÁR-KUTZIÁN 1972

BRONK RAMSEY 1995

BRONK RAMSEY 2001

BRONK RAMSEY 2008

BuCK et al. 1991

DuRMAN-OBELIĆ 1989

FIGLER et al. 1997

FORENBAHER 1993

FURHOLT 2008a

FURHOLT 2008b

HorváTH et al. 2008

JENSEN-NIELSEN 1997

KaLICZ 2001

McHugh 1999

QUITTA-KoHL 1969

Petrović-Jovanović 2002

REIMER et al. 2004

SRDOČ et al. 1987

SRDOČ et al. 1989

STADLER et al. 2001
P. Barna, Judit: Késố rézkori település Nagykanizsa-Billa lelőhelyen [Late Copper Age settlement in Nagykanizsa-Billa]. ZalaiMúz 12 (2003) 97-142.

Blackwell, Paul G.-Buck, Caitlin E.-Reimer, Paula J.: Important features of the new radiocarbon calibration curves. Quaternary Science Reviews 25 (2006) 408-413.

Bognár-Kutzián, Ida: The Early Copper Age Tiszapolgár culture in the Carpathian Basin. Budapest 1972. (ArchHung 48)

Bronk Ramsey, Christopher: Radiocarbon calibration and analysis of stratigraphy: The OxCal program. Radiocarbon 37 (1995) 425-430.

Bronk Ramsey, Christopher: Development of the radiocarbon calibration program OxCal. Radiocarbon 43 (2001) 355-363.

Bronk Ramsey, Christopher: Deposition models for chronological records. Quaternary Science Reviews 27 (2008) 42-60.

Buck, Caitlin E.-Kenworthy, James B.-Litton, Cliff D.- Smith, A. F. M. Combining archaeological and radiocarbon information: a Bayesian approach to calibration. Antiquity 65 (1991) 808-821.

Durman, Aleksandar-Obelić, Bogomil: Radiocarbon dating of the Vučedol culture complex. Radiocarbon 31 (1989) 1003-1009.

Figler, András-Bartosiewicz, László-Füleky, György-Hertelendi, Ede: Copper age settlement and the Danube water system: a case study from North Western Hungary. In: Landscapes in Flux. Central and Eastern Europe in Antiquity. Ed. by Chapman, John-Dolukhanov, Pavel. Oxford 1997, 209-230. (Colloquia Pontica 3)

Forenbaher, Stašo: Radiocarbon dates and absolute chronology of the Central European Early Bronze Age. Antiquity 67 (1993) 218-256.

Furholt, Martin: Pottery, cultures, people? The European Baden material re-examined. Antiquity 82 (2008) 617-628.

Furholt, Martin: Culture history beyond cultures: the case of the Baden Complex. In: The Baden Complex and the Outside World. Ed. by Furholt, Martin-Szmyt, Marzena-Zastawny, Albert. Proceedings of the $12^{\text {th }}$ Annual Meeting of the EAA in Cracow 19-24th September 2006. Bonn 2008, 13-24. (Studien zur Archäologie in Ostmitteleuropa 4)

Horváth, Tünde-S. Svingor, Éva-Molnár, Mihály: New radiocarbon dates for the Baden culture. Radiocarbon 53 (2008) 447-458.

Jensen, C. Kjeld-Nielsen, K. Høilund: Burial Data and Correspondence Analysis. In: Burial \& Society. The Chronological and Social Analysis of Archaeological Burial Data. Ed. by Jensen, C. Kjeld-Nielsen, K. Høilund. Aarhus 1997, 29-61.

Kalicz, Nándor: Die Protoboleráz-Phase an der Grenze von zwei Epochen. In: Cernavodă III-Boleráz. Ein vorgeschichtliches Phänomen zwischen dem Oberrhein und der Unteren Donau. Mangalia/Neptun 18.-24. Oktober 1994. Ed. by Roman, Petre-Diamandi, Saviana. București 2001, 385-435. (Studia Danubiana Series Symposia 2)

McHugh, Feldore: Theoretical and Quantitative Approaches to the Study of Mortuary Practice. Oxford 1999. (British Archaeological Reports International Series 785)

Quitta, Hans-Kohl, Günther: Neue Radiocarbondaten zum Neolithikum und zur frühen Bronzezeit Südosteuropas und der Sowjetunion. Zeitschrift für Archäologie 3 (1969) 223-255.

Petrović, Jelka-Jovanović, Borislav: Gomolava. Naselja kasnog eneolita. [Gomolava. Settlements of the Late Eneolithic]. Novi Sad - Beograd 2002.

Reimer, Paula J.-Baillie, Mike G. L.-Bard, Edouard-Bayliss, Alex-Beck, J. Warren-Bertrand, Chanda J.H.-Blackwell, Paul G.-Buck, Caitlin E.-Burr, George S.-Cutler, Kirsten B.-Damon, Paul E.-Edwards, R. Lawrence-Fairbanks, Richard G.-Friedrich, Michael-Guilderson, Thomas P.-Hogg, Alan G.-Hughen, Konrad A.-Kromer, Bernd-McCormac, Gerry-Manning, Stuart-Bronk Ramsey, Christopher-Reimer, Ron W.-Remmele, Sabine-Southon, John R.-Stuiver, Minze-Talamo, Sahra-Taylor, Fred W.-van der Plicht, Johannes-Weyhenmeyer, Constanze E.: IntCal04 terrestrial radiocarbon age calibration, 0-26 cal kyr BP. Radiocarbon 46 (2004) 1029-1058.

Srdoč, Dušan-Obelić, Bogomil-Sliepčević, Adela-Bronić, Ines Krajcar-Horvatinčić, Nada: Rudjer Bošković Institute radiocarbon measurements X. Radiocarbon 29 (1987) 135-147.

Srdoč, Dušan-Obelić, Bogomil-Horvatinčić, Nada-Bronić, Ines Krajcar: Rudjer Bošković Institute radiocarbon measurements XI. Radiocarbon 31 (1989) 85-98.

Stadler, Peter-Draxler, Susanne-Friesinger, Herwig-Kutschera, Walter-Priller, Alfred-Rom, Werner-Steier, Peter-Wild, Eva Maria: Absolute chronology for Early Civilizations in Austria and Central Europe using ${ }^{14} \mathrm{C}$ dating with accelerator mass spactrometry with special results for the absolute chronology of the Baden Culture. In: Cernavodă III-Boleráz. Ein vorgeschichtliches 
WATERBOLK 1988

Phänomen zwischen dem Oberrhein und der Unteren Donau. Mangalia/Neptun 18.-24. Oktober 1994. Ed. by Roman, Petre-Diamandi, Saviana. Bucureşti 2001, 541-562. (Studia Danubiana Series Symposia 2)

Waterbolk, H.: C-14 Datierungen von Gomolava. In: Gomolava, Chronologie und Stratigraphie der vorgeschichtlichen und antiken Kulturen der Donauniederung und Südosteuropas. Ed. by Tasić, Nicola. Novi Sad 1988, 117-121.

WILD et al. 2001

Wild, Eva Maria-Stadler, Peter-Bondár, Mária-Draxler, Susanne-Friesinger, Herwig-Kutschera, Walter-Priller, Alfred-Rom, Werner-Ruttkay, Elisabeth-Steier, Peter: New chronological frame for the young Neolithic Baden culture in Central Europe (4th Millennium BC). Radiocarbon 43 (2001) $1057-1064$. 


\section{HISTORICAL CONTEXT OF THE LATE COPPER AGE CEMETERY AT BUDAKALÁSZ \\ Pál Raczky}


The narrower problems of the Budakalász cemetery were embedded the broader research of the Pécel/Baden culture in the Carpathian Basin, ever since the discovery of the first burials and the publication of the first 115 graves by Sándor Soproni ${ }^{1}$ in a separate chapter of János Banner's seminal monograph on the culture. ${ }^{2}$ Soproni mentioned that the number of burials had in the meantime risen to 332 , for the rescue excavation continued during the preparation of Banner's monograph for publication. ${ }^{3}$ József Korek specified the number of graves as 439 in his doctoral thesis (submitted in 1983), in which he noted that the Budakalász cemetery was the then known largest Late Copper Age cemetery in Europe. ${ }^{4}$ The significance and prominence of the Budakalász cemetery remained unchallenged, despite the proliferation of studies on several other fully or partially excavated burial sites of the Baden culture. 5 The Budakalász cemetery represents a unique concentration of Late Copper Age burials among the Baden cemeteries in the Budapest area, no doubt a reflection of its historical significance during that period. The forty-one graves uncovered at Alsónémedi, ${ }^{6}$ another completely excavated burial ground, suggest that there also existed a smaller cemetery type in the Budapest area comprising the graves of a Late Copper Age population, whose grave assemblages provide a smaller, but nonetheless fairly representative cross-section of Baden types. Compared to Alsónémedi, Budakalász and its 436 graves $^{7}$ bespeak an entirely different category of social representation. It seems to me that the 1:10 ratio of burials in the two cemeteries reflects two levels of community integration as represented by the two burial grounds.

One important advance in the analysis of the cemetery was that in 1983, Korek estimated that the cemetery had been used over a period of some 150 years, roughly between 2250 and 2100 BC, based on the then known historical facts; elsewhere, he suggested $130 \pm 20$ years for the cemetery's use-life. ${ }^{8}$ He believed that the entire Baden sequence spanned the period between 2350 and 2000 BC. ${ }^{9}$

Korek believed that there was a relative chronological difference between the cemetery's inhumation and cremation burials; quoting the cremation burials from Pilismarót-Basaharc assigned to the Boleráz period representing the early phase of the Baden culture, he regarded the seventy-three cremation burials (actually, only seventy-two) as being earlier. ${ }^{10}$

\footnotetext{
SOPRONI 1956, 111-128.

2 BANNER 1956.

BANNER 1956, 187 and note 12.

${ }^{4}$ KOREK 1983, 10

5 NeVIZANSKÝ 1985; BondÁr 2001, 438-439; BondÁr 2002, 13-14; KaLICZ 2004, 178-179; KÖHLER 2008, 95-98.

6 KoreK 1951

The 439 graves of the Budakalász cemetery comprised also an Early Bronze Age burial and two Iron Age burials, meaning that the number of Copper Age burials totalled 436.

${ }^{8}$ KOREK 1983, Table II, and the chronological chart of the Baden culture on p. 136.

9 KOREK 1983, 168-169.

10 TORMA 1973.
}

He assigned the cemetery's cremation graves to the Budakalász I phase. From his analysis of the cemetery plan, Korek reconstructed seven clusters of cremation burials in the cemetery's middle, arranged along imaginary circles and arcs. ${ }^{11}$ In contrast, Banner argued that the inhumation and cremation burials were contemporaneous, both in the Budakalász cemetery and in the other burials grounds of the Pécel/Baden culture. $^{12}$ Korek distinguished three main phases (Budakalász I-III) in the cemetery's use-life ${ }^{13}$ and attempted to identify genetically related groups ("families") based on Imre Lengyel's serological analyses. Korek reconstructed thirty-three "family units" (Fig. 1), based on Lengyel's identification (his Groups I-XXVIII; Fig. 2). ${ }^{14}$ It is quite obvious that these reconstructions can be rejected in the light of modern analyses. Korek's other claim, based on the skeletal remains from the inhumation burials, that the middle section of the Budakalász cemetery (equated with his Budakalász III phase) was used by the same Baden community which buried its dead in the Alsónémedi cemetery, ${ }^{15}$ is also untenable. At the same time, Korek correctly perceived that the cemetery was used simultaneously by several "family" groups, who buried their dead in pre-allocated, well-definable areas. Another important observation made by him was that only a certain part of a single tribe interred its dead in the cemetery. ${ }^{16}$ What is still acceptable from Korek's two points in the light of modern analyses is that the graves of the Budakalász cemetery contained the burials of several social communities, selected according to an intricate set of socio-economic and sacral criteria. Banner correctly noted that there was no apparent patterning according to orientation, age or sex among the initially excavated 115 burials of the cemetery. ${ }^{17}$ Following Alasdair Whittle, ${ }^{18}$ John Chapman too noted that the Budakalász cemetery "is a good example of a cemetery whose spatial order, internal variability and external contacts are guided by fuzzy rules rather than polar opposites in mortuary wealth and diversity." 19 Another important point made by Chapman was that the "overall distribution of age-sex categories indicates a drastic difference from that of the Basatanya cemetery." 20 The internal order of the Budakalász cemetery can thus be seen to have been governed by a paradigmatically different system than the earlier burial grounds of the Copper Age in the Carpathian Basin. The eighteen grave groups/grave lines reconstructed by Chapman ${ }^{21}$ were rather dubious

\footnotetext{
1 KOREK 1983, 21-22.

12 BANNER 1956, 200 and note 46.

${ }^{13}$ KoreK 1983, 21-24.

14 KoreK 1983, 134-152; Lengyel 1983.

${ }^{15}$ KoreK 1983, 23, 152-154.

${ }^{16}$ KoreK $1983,154$.

17 BANNER 1956, 189

18 WHitTLE 1996, 124.

19 Chapman 2000, 160

20 Chapman 2000, 133.

${ }^{21}$ Chapman 2000, 126-133, Fig. 31, Table 34.
} 


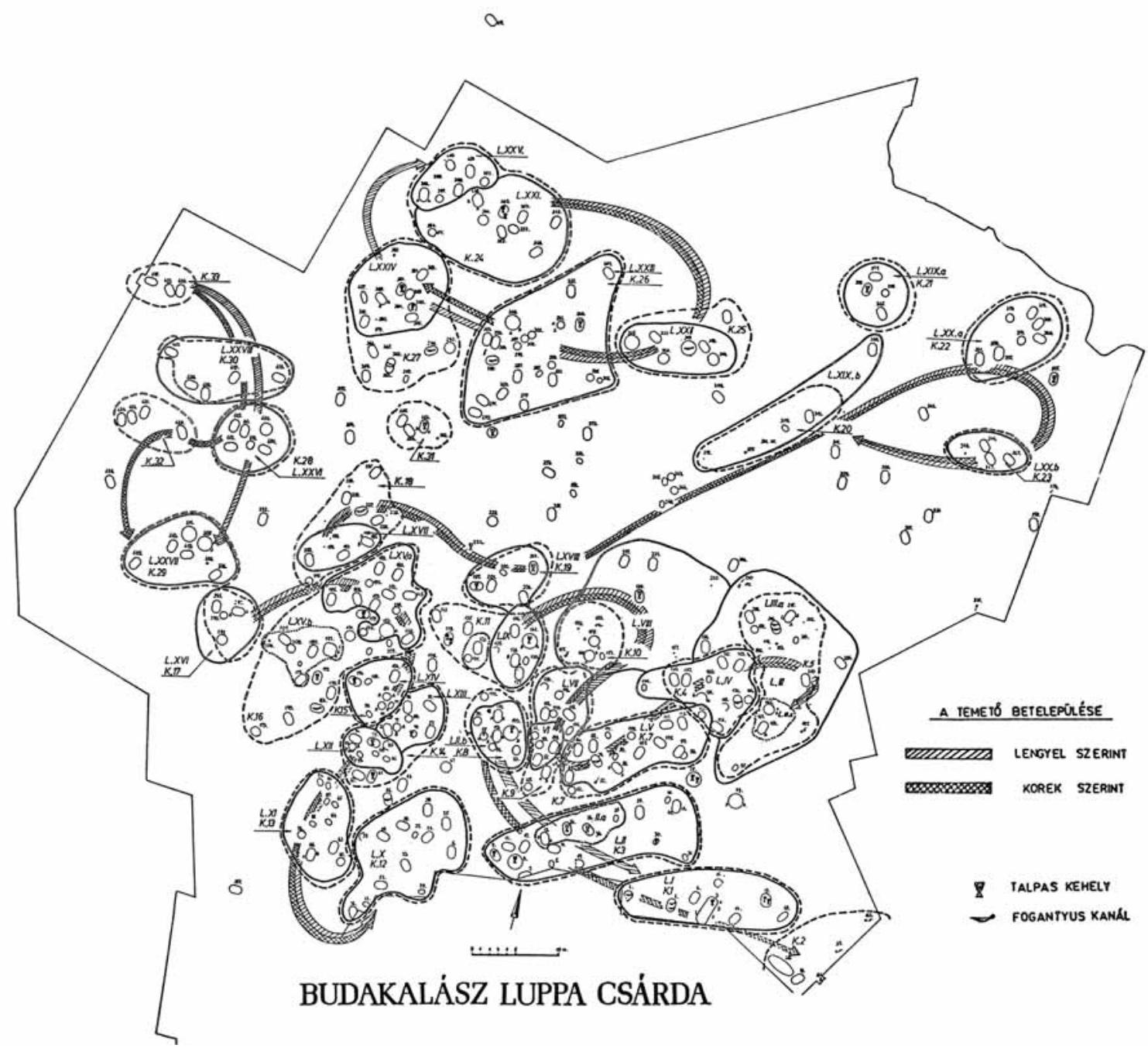

Fig. 1. Grave groups 1-33 and I-XXVIII of the Budakalász cemetery reconstructed by fózsef Korek and Imre Lengyel in 1983 (after Korek 1983)

exactly because of the lack of a clear patterning and of a precise chronological framework. Chapman quoted a range of 3600-2800 cal BC22 which, however, spanned the entire Baden sequence; no radiocarbon dates were available for the cemetery itself at the time..$^{23}$ Opinions were divided regarding the relative chronological position of the Budakalász cemetery, which was variously dated to the later phase of the classical Baden period and the early phase of the culture's classical period, immediately after the Boleráz period. ${ }^{24}$

The calibrated radiocarbon dates indicate that the Baden sequence can most likely be dated between 3650 and $2900 \mathrm{cal} \mathrm{BC} .{ }^{25}$ One of the perhaps most significant advances during the past four decades of research was that as a result of the "radiocarbon revolution", ${ }^{26}$ based in part on research conducted in the Aegean and in the

\footnotetext{
22 ForenbaCHER 1993, 246, Fig, 4.

23 Chapman 2000, 131.

${ }^{24}$ For an excellent overview, cp. KALICZ 2004, 186.

${ }^{25}$ Furholt 2008, 18-19; Furholt 2009, 205-212.

26 NeustupnÝ 1968, 47 and Table 5; RenFrew 1973, 436-439; KalicZ 1985, 34-35.
}

Balkans, ${ }^{27}$ the emergence of the Baden culture was placed before Troy I by 500-600 years and the Baden sequence was synchronised with the later 4th millennium BC. 28 The new dates called for a revision of earlier views on the culture's Anatolian origins and its correlation with the Anatolian Early Bronze Age, ${ }^{29}$ and they also drew attention to the culture's local roots and the cultural milieu of the Carpathian Basin, ${ }^{30}$ leading to the identification of the Proto-Boleráz horizon (called also Baden Ia phase) based on typological considerations, which represented the first instance of a uniform cultural development east and west of the Danube..$^{31}$ (It must be borne in mind, however, that the

\footnotetext{
27 Cp. Renfrew 1986; Sherratt 1986; Maran 1998.

${ }^{28}$ Cp. Maran 1998; Johnson 1999; KaliCz 2004, 194-196; Horváth et al. 2008, 447-448.

29 Kalicz 1963, 77-81; Roman 1979; Roman 1992; NĚMejcová-PavúKOVÁ 1981, 293-296; NĚMEJCOVÁ-PAVÚKOVÁ 1982, 173-176; NĚMEJCOVÁPavúková 1991, 79-81; Parzinger 1993, 323-325.

30 NĚMEJCOVÁ-PavúKOVÁ 1979, 55; KaLICZ 1991.

31 Kalicz 1991, 375-380; Kalicz 2001; NĚMejCová-Pavúková 1981, 293-294; NemejCová-Pavúková 1982, 150-153; NĚMejCová-Pavúková 1999, 45-50.
} 


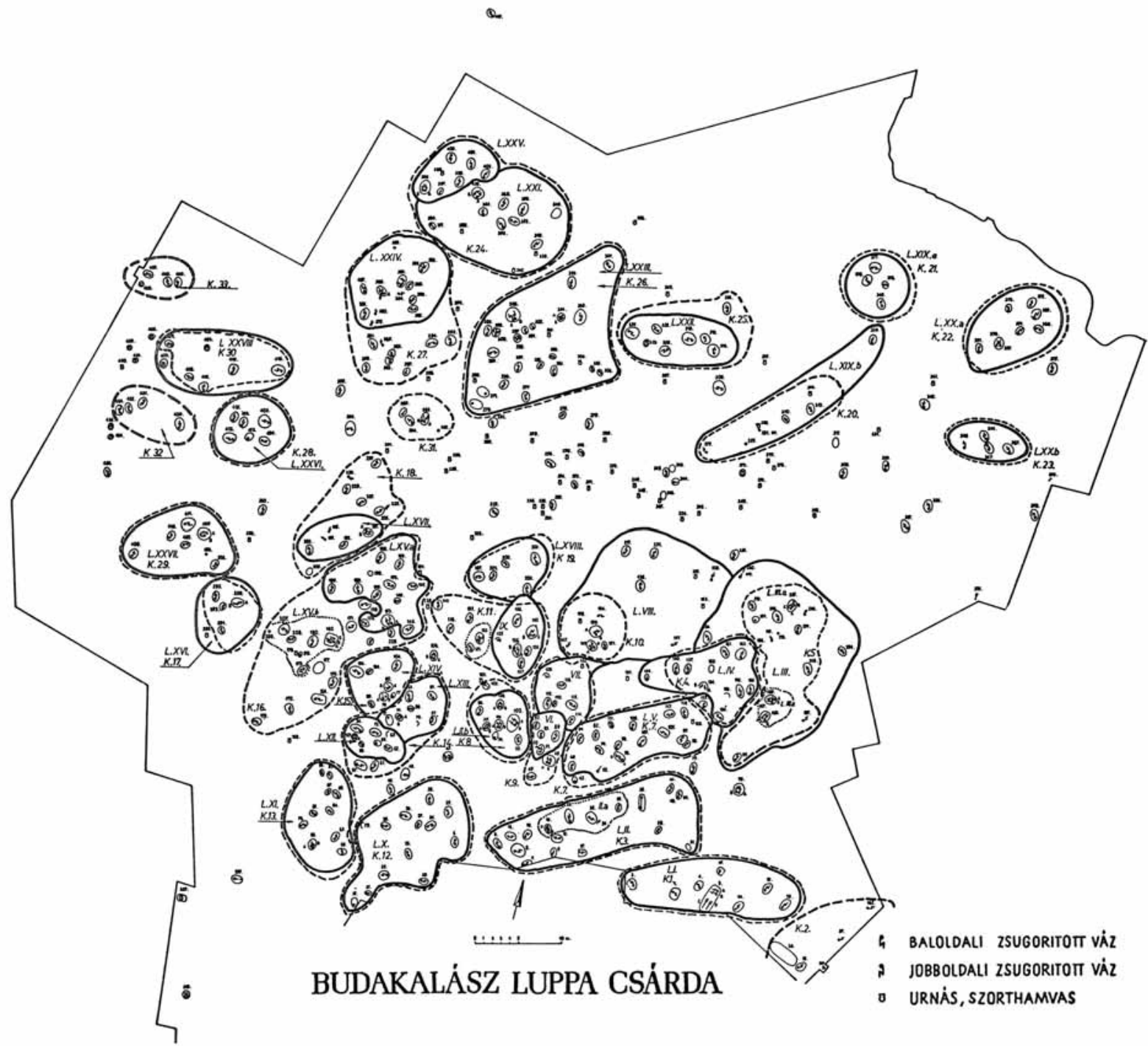

Fig. 2. Grave groups I-XXVIII containing the burials of individuals related by blood in the Budakalasz cemetery as reconstructed by Imre Lengyel (after Korek 1983)

calibrated radiocarbon dates for the Proto-Boleráz and Boleráz sites do not indicate major chronological differences between the horizons outlined by these two find assemblage types. ${ }^{32}$ ) Martin Furholt made a significant point concerning the chronological dimensions of the transformation leading to the emergence of the Baden complex, arguing that the appearance of the Baden cultural complex could be dated to a relatively brief time interval between 3650 and 3500 cal BC. ${ }^{33}$ From their reading of the archaeological record, other prehistorians too regarded the formative Baden phase as a relatively short period, assigning it to the period before $3600 / 3500$ BC. ${ }^{34}$ At the same time, a span of 150 years is far too brief a

32 STADLER et al. 2001, 543; WiLd et al. 2002, 1062.

33 Furholt 2008a, 18; Furholt 2008b, 623, FurHolt 2009, 205-207.

34 KaliCZ 2001, 406; WILD et al. 2001; HorvátH et al. 2008, 453. period for an ethnic homogenisation across the entire Carpathian Basin, the implication being that the homogenisation observable in the material culture can hardly be explained by a large-scale population change and the emergence of an ethnic unit which by and large overlapped with the distribution of Baden traits, the latter extending well beyond the Carpathian Basin. The above called for a fresh approach to the analysis of the seemingly uniform Baden pottery style and a reinterpretation of the different registers of material culture. ${ }^{35}$ It seems relevant in this context that only 167 of the 436 graves in the Budakalász cemetery contained pottery and that 67 of these graves contained a single vessel only. Moreover, the range of ceramic types deposited in the burials was rather limited, suggesting that the social orientation of the Budakalász burials was

\footnotetext{
$\overline{35 \text { Furholt 2008 }}$; Furholt 2008b; FuRHOLT 2009.
} 
not primarily expressed through pottery. Compared to the Middle Copper Age Bodrogkeresztúr culture, pottery appears to have been accorded a "propagandistic role" in the Late Copper Age cultural milieu of the Carpathian Basin and that pottery in the Baden style was meant to symbolise a uniform Baden ideology and a new code of values that transcended the earlier community boundaries of the earlier Middle Copper Age cultural units. In other words, Baden pottery was designed to conceal earlier differences as manifested in material culture. Furholt went even further, claiming that the fine wares of the Baden culture expressed a homogenous supra-regional style extending across Central Europe, while coarse wares continued local traditions and could be ordered into six main groups. ${ }^{36}$ Viewed from this perspective, there is no sense in speaking of a "Baden culture" in the traditional archaeological sense of the word - the label "Baden complex" would be more accurate for Central Europe. ${ }^{37}$ The analysis of the culture's fine and coarse wares indicated the existence of a complex system of supra-regional and local social networks. ${ }^{38}$ David L. Clarke arrived at a similar conclusion in the late 1960s, describing the "Baden culture group" as "a group of affinally related collateral cultures, characterised by assemblages sharing a polythetic range, but differing states, of the same specific multistate artefact types." ${ }^{39}$ Furholt's methodological approach, characterised by a disillusionment regarding the usefulness of the label "archaeological culture", was a well-established view in Anglo-Saxon archaeological studies, perhaps best articulated by Ian Hodder at the time. ${ }^{40}$

The duality of fine and coarse wares is echoed in a remarkably similar form in Christian Strahm's model, according to which the regional cultures of the Early Bronze Age were made up of a Bell Beaker set and local traditional pottery assemblages ("complementary pottery"). ${ }^{41}$ The spread of the "Beaker ideology" and the "Beaker package" across Europe, and the archaeologically visible traits of the latter's occurrences provides an excellent parallel to, as well as an interpretative framework for the earlier Baden complex. ${ }^{42}$ Viewed in this context, one striking similarity between the Baden and Bell Beaker complexes appears to be the rise of a new elite accompanied by what has been described as a "new reality of individualisation". One reflection of this is the social appearance of individuals with a visibly prominent status in the context of large cemeteries and competing codes of new symbols. ${ }^{43}$ It is therefore hardly mere chance that a biritual Early Bronze Age cemetery of the Bell Beaker-Csepel group containing

\footnotetext{
$\overline{36}$ Furholt 2008a, Furholt 2008b, 623-627; Furholt 2009, 204-221. 37 Furholt 2008a, 16-22; Furholt 2008b, 618-627; Furholt 2009, 20-26.

${ }^{38}$ Furholt 2008b, 623-626 and Fig. 7; Furholt 2009, 212-221.

39 Clarke 1968, 300 and Fig. 70.

40 HODDER 1982, 1-12.

${ }^{41}$ STRAHM 2008, 210-211, Fig. 1.

42 Harrison-HeYd 2007, 203-207.

43 Harrison-HeYd 2007, 132-134.
}

some 1100 graves has been found near one of the major Danubian crossing-places over the Danube, not far from the extraordinarily large Baden cemetery at Budakalász. ${ }^{44}$ It must be repeatedly emphasised that the two burial grounds in question eclipse by far the much smaller cemeteries containing between 50 to 100 graves along the $40-50 \mathrm{~km}$ long Danube section in the Budapest area. ${ }^{45}$ It seems likely that the Baden and Beaker cemeteries in the Budapest area were a reflection of an at least two-tier social representation, implying that in addition to Furholt's supra-regional and regional communal systems, there was also a microregional one, at least judging from the cemeteries. This would in turn suggest the existence of a many-tiered social system within a larger geographic region, specifically in the Baden complex in the broader Budakalász area. The above chain of inferences and the conclusions drawn thereof are to some extent confirmed by the archaeological observations made in the Eneolithic cemetery of Varna, all pointing in the direction that Varna was a supra-regional burial ground. The burial ground was used simultaneously by several communities, which buried individuals with a special social status in pre-allocated areas. The graves contained the burials of select individuals from the settlements in the settlement network of a broader geographic region, laid to rest in the community unit of a focal cemetery. Some of the burials among the 294 graves were extraordinarily richly furnished, but even the "poorer" burials and the burials lacking grave goods contained the earthly remains of distinguished individuals, who attained this status simply by being interred in this cemetery. The Varna cemetery thus offered the option of a higher level of community definition and an arena for social competition for a supra-regional elite. Smaller cemeteries with fewer graves are known from the direct environs of the Eneolithic tell settlements of north-eastern Bulgaria and the system can thus be interpreted to reflect a multi-tier community representation within the context of the period's extra-mural cemeteries. ${ }^{46}$

Turning to the archaeological record from the Carpathian Basin, let us now look for further traits that can be of aid in the interpretation of the Budakalász cemetery from a fresh perspective incorporating the advances in European archaeology mentioned in the above.

One of the perhaps most remarkable findings of Zsuzsanna Siklósi's analysis of the radiocarbon dates ${ }^{47}$ is that the use-life of the cemetery can be put between $3160 / 3040$ and 3020/2900 cal BC (these dates do not include the two latest dates, which diverge from the other ones in the series), ${ }^{48}$ suggesting that its use spanned between 30 and 360 years. In the model

\footnotetext{
44 OTTOMÁNYI-CZENE 2006.

45 ENDRŐDi 2004, Fig 3; KALICZ-SChreIBER 2001, Abb. 2.

46 RENFrEW 1986; HigHAM et al. 2007, 647-652.

47 See pp. $457-474$, in this volume.

48 The dates quoted are all cal BC data at the $1 \sigma$ confidence level.
} 
proposed here, the cemetery was used for roughly 140-170 years, a relatively short span of time. The statistical analyses indicated that there was no clear patterning in the sequence of burials; the evidence points towards the simultaneous use of smaller burial clusters. The separateness of the seventy-two cremation burials cannot simply be explained by a chronological difference, suggesting that the different burial rites were used to define diverse social identities and were the reflections of a community dimension differing from that of the inhumation graves. The groups using the Budakalász cemetery thus interred their dead around several focal points within a short period of time, a practice resembling the spatial patterning of the Varna cemetery. It would appear that the Baden cemetery at Budakalász functioned as a larger regional or supra-regional burial ground for prominent individuals with a distinguished social status from several communities. The roughly 1:10 ratio of the number of burials in the Alsónémedi and the Budakalász cemeteries reflects a two-tier community representation in these two Baden burial grounds, both lying in the broader Budapest area. It would appear that a comparable ideological framework, the multi-tier display of social differences on the cemetery level can be assumed in the cultural milieu of the Bell BeakerCsepel group. This raises the question of whether the Danube section in the Budapest area had a exceptional role from the Late Copper Age onward and whether this strategic, socially constructed focus survived into the Early Bronze Age, up to the beginning of the 3rd millennium BC.

One remarkable find from the Budakalász cemetery, again highlighting its unique position, is the clay wagon-cup from Grave 177, a symbolic burial, ${ }^{49}$ presumably a cenotaph without a body. ${ }^{50}$ It is less known that Grave 158, an inhumation burial, contained a rectangular one-handled vessel in the form of a wagon. The vessel was covered with pastose red paint, highlighting its symbolic significance. ${ }^{51}$ Goblets with a rectangular cup can also be assigned to this category, a point noted by the excavator at a fairly early date. ${ }^{52}$

Together with the wagon model from Szigetszentmárton, found among the grave goods of a burial, ${ }^{3}$ these finds point toward the symbolic significance of wagons and their prestige role in the Baden complex. ${ }^{54}$ The same holds true for the double bovid burials in the light of their incidence at Budakalász and Alsónémedi; ${ }^{55}$ more recent investigations have shown that this burial type was quite frequent in the Budapest area. ${ }^{56}$ Aside from the burial of genuine animals, the animal figurines deposited in the Boleráz/early Baden graves

\footnotetext{
49 SOPRONI 1954; Sopront 1956, 128, Abb. 32, Taf. CXX

50 SOPRONI 1954, 29; SHERRATT 1997, 162.

51 Soproni 1954, 30, Pl. VI. 5.

52 SOPRONI 1954, 30.

53 KALICZ 1976

54 Maran 2004a; Bondár 2006; Furholt 2009, 238-240.

${ }_{55}$ KOREK 1983, 121-123; SherRATt 1997, 161.

56 ENDRŐDI 2004, 29, Fig. 46.
}

of the cemetery at Pilismarót-Basaharc reflect the indirect, symbolic significance of this funerary act from the Late Copper Age onward. ${ }^{57}$

The introduction of animal traction and wheeled wagons undoubtedly contributed much to a prospering economy, in addition to accelerating social interaction and extending its geographic scale across Europe. ${ }^{58}$ Irrespective of whether the appearance of wagons can be conceptualised in a unicentral ${ }^{59}$ or polycentral ${ }^{60}$ model, the use of wagons rapidly spread throughout Europe from the mid-4th millennium BC, ${ }^{61}$ suggesting that the exchange of information, ideologies and cultural values occurred within a similarly brief historic period, stimulating the homogenisation of material culture and the appearance of large pottery groups with a similar style. The movement of population groups undoubtedly contributed to this process, even though human movement was not the main force behind the period's cultural dynamism.

It is my belief that the Budakalász cemetery is yet another indication that social roles were expressed in an entirely novel way, through a new code of symbols, which incorporated a new set of cultural values compared to the preceding Middle Copper Age. What was earlier generally described as the "impoverishment" of the Baden graves (at least compared to the abundance of metal artefacts during the Middle Copper Age) should rather be seen as a shift to the use of new raw materials and artefacts for expressing cultural values, in other words, a shift to new material and cultural packages. ${ }^{62}$ Compared to the codes of representation and "propaganda idioms" of the earlier Copper Age cemeteries, the Baden cemetery at Budakalász reflects a change of paradigm and the seminomadic/nomadic values of a mobile lifestyle in the Carpathian Basin.

In addition to the characteristic traits of the extramural cemeteries of the Baden complex, it seems instructive to briefly review the human and animal remains from the period's intramural graves ${ }^{63}$ because they shed additional light on the context and the broader interpretative framework of the Budakalász cemetery. What certainly needs to be mentioned in this respect is the growing number of human remains brought to light from various unusual features on Baden settlements. While human remains are often found together with various animal remains, the latter - and especially sheep/goat and cattle - also occur independently, both in the form of complete and incomplete skeletons. The perhaps best examples come from the Baden settlement investigated at Balatonôszöd-Temetôi-dúlő, ${ }^{64}$ one of the culture's most

\footnotetext{
57 Torma 1972, 24-26, Taf. 30; Torma 1973, 494, Abb. 5:2; KaliczRACZKY 2005, Fig. 21.

58 SHERrATt 1997, 158-198; FANSA-BurmeISTER 2004.

59 Sherratt 2003; Sherratt 2004; Maran 2004b.

${ }^{60}$ HÄUSler 1994; VOSTEEN 2002.

${ }^{61}$ Furholt 2009, 238-240.

62 Kalicz 1992, 10, 13.

${ }^{63}$ SACHSSE 2008, 57-59.

${ }^{64}$ Horváth 2004, 68-72; HoRváth 2008, 73-75, Fig. 4-8.
} 
remarkable settlements excavated during the past decades. Fifty-one complete and incomplete human skeletons were brought to light, indicating that only a certain segment of the one-time Baden population was interred in the culture's territory of cemeteries. The bodies of various individuals or a part of their bodies were deposited in irregularly shaped pits and well-like shafts as part of demonstrably differing funerary rituals than the ones observed in the case of extramural graves. The human remains recovered from deep shafts are particularly intriguing, reflecting a ritual orientation closely bound to the subterranean sphere..$^{65}$ The deposition of a child and a mass of various animal species in a pit and the regularities in the arrangement of their remains provide evidence for a ritual system governed by a set of elaborate codes and a consistent choreography at Balatonôszöd. ${ }^{66}$ While certain similarities can undoubtedly be noted with like phenomena from earlier periods of the Copper Age, specifically with the deep sacrificial pits/wells of the Bodrogkeresztúr culture lying within a well-defined enclosure separate from the culture's settlements, ${ }^{67}$ the striking frequency of pits with unusual deposits on various Baden settlements reflects a major transformation of beliefs and a shift in their orientation across the entire Baden distribution and perhaps the assertion of chthonic community beliefs. This fits in neatly with the transformation of the codes of representation noted in the extramural cemeteries of the Baden culture, and confirms the ideological and cultural transformations permeating all spheres of life during the Late Copper Age.

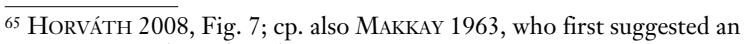
interpretation along these lines.
${ }_{66}$ Horváth 2008, 74.
${ }_{67}$ MaKKaY 2001, 54-56. 


\section{References}

BANNER 1956

BONDÁR 2001

BONDÁR 2002

BONDÁR 2006

CHAPMAN 2000

Clarke 1968

ENDRŐDI 2004

FANSA-BURMEISTER 2004

FORENBAHER 1993

FuRHOLT 2008a

FuRHOLT 2008b

FuRHOLT 2009

HARRISON-HEYD 2007

HäUSLER 1994

Higham et al. 2007

HODDER 1982

HoRVÁTH 2004

HORVÁTH 2008

HoRvÁTH et al. 2008

JOHNSON 1999

KALICZ 1963

KaLICZ 1976

KALICZ 1985

KaLICZ 1991

KaLICZ 1992
Banner, János: Die Péceler Kultur. Budapest 1956. (ArchHung 35)

Bondár, Mária: L'état des recherches sur la culture de Baden en Hongrie (Les découvertes récentes concernant la période ancienne). In: Cernavodă III-Boleráz. Ein vorgeschichtliches Phänomen zwischen dem Oberrhein und der Unteren Donau. Mangalia/Neptun 18.-24. Oktober 1999. Ed. by Roman, Petre-Diamandi, Savina. Bucureşti 2001, 437-458. (Studia Danubiana, Series Symposia 2) Bondár, Mária: A badeni kultúra kutatási helyzete Magyarországon. - (Vázlat) [Der Forschungsstand der Badener Kultur in Ungarn (Abriss)]. MFMÉ-StudArch 8 (2002) 7-30.

Bondár, Mária: Le chariot en Europe au Chalcolithique. In: PÉTREQUIN et al. 2006, 225-237.

Chapman, John: Tension at funerals. Micro-Tradition Analysis in Later Hungarian Prehistory. Budapest. (Archaeolingua Series Minor 14)

Clarke, David L.: Analytical Archaeology. London 1968.

Endrôdi, Anna: Késô rézkor Budapest területén - a Baden-kultúra népe. Late Copper Age in the territory of Budapest - The people of the Baden Culture. In: Hétköznapok és vallásos élet a rézkor végén. A Baden-kultúra 5000 éves emlékei Budapesten. - Everyday life and spirituality at the end of the Copper Age. Ed. by Endrôdi, Anna. Budapest 2004, 11-20.

Rad und Wagen. Der Ursprung einer Innovation. Wagen im Vorderen Orient und Europa. Ed. by Fansa, Mamoun- Burmeister, Stefan Mainz am Rhein 2004.

Forenbaher, Stašo: Radiocarbon dates and absolute chronology of the Central European Early Bronze Age. Antiquity 67 (1993) 218-256.

Furholt, Martin: Culture History Beyond Cultures: The Case of the Baden Complex. In: The Baden Complex and the Outside World. Proceedings of the 12th Annual Meeting of the EAA in Cracow 19-24th September 2006. Ed. by Furholt, Martin-Szmyt, Marzena-Zastawny, Albert. Bonn 2008, 13-24. (Studien zur Archäologie in Ostmitteleuropa 4)

Furholt, Martin: Pottery, cultures, people? The European Baden material re-examined. Antiquity 82 (2008) 617-628.

Furholt, Martin: Die nördlichen Badener Keramikstile im Kontext des mitteleuropäischen Spätneolithikums (3650-2900 v. Chr.). Bonn 2009. (Studien zur Archäologie in Ostmitteleuropa 3)

Harrison, Richard-Heyd, Volker: The Transformation of Europe in the Third Millennium BC: the example of 'Le Petit-Chasseur I + III' (Sion, Valais, Switzerland). PZ 82 (2007) 129-214.

Häusler, Alexander: Archäologische Zeugnisse für Pferd und Wagen in Ost- und Mitteleuropa. In: Die Indogermanen und das Pferd. Festschrift für Bernfried Schlerath. Ed. by Hänsel, Bernhard-Zimmer, Stefan. Budapest 1994, 217-257.

Higham, Tom-Chapman, John-Slavchev, Vladimir-Gaydarska, Bisserka-Honch, Noah-Yordanov, Yordan-Dimitrova, Branimira: New perspectives on the Varna cemetery (Bulgaria) - AMS dates and social implications. Antiquity 81 (2007) 640-654.

Hodder, Ian: Symbols in action. Ethnoarchaeological studies of material culture. Cambridge 1982.

Horváth, Tünde: Late Copper Age settlement in Balatonôszöd, Hungary. AAC 39 (2004) 59-85.

Horváth, Tünde: Balatonőszöd - an Unusual Baden Settlement? In: The Baden Complex and the Outside World. Proceedings of the 12 ${ }^{\text {th }}$ Annual Meeting of the EAA in Cracow 19-24 $4^{\text {th }}$ September 2006. Ed. by Furholt, Martin-Szmyt, Marzena-Zastawny, Albert. Bonn 2008, 71-87. (Studien zur Archäologie in Ostmitteleuropa 4)

Horváth, Tünde-Svingor, Éva S.-Molnár, Mihály: New radiocarbon dates for the Baden Culture. Radiocarbon 50 (2008) 447-458.

Johnson, Mats: Chronology of Greece and South-east Europe in the Final Neolithic and Early Bronze Age. PPS 65 (1999) 319-336.

Kalicz, Nándor: Die Péceler (Badener) Kultur und Anatolien. Budapest 1963. (StudArch 2)

Kalicz, Nándor: Ein neues kupferzeitliches Wagenmodell aus der Umgebung von Budapest. In: Festschrift für Richard Pittioni zum Siebzigsten Geburtstag. Ed. by Mitscha-Mäheim, HerbertFriesinger, Herwig-Kerchler, Helga. Arch Austriaca Beiheft 13 (1976), 188-202.

Kalicz, Nándor: On the Chronological Problems of the Neolithic and Copper Age in Hungary. Mitt ArchInst 14 (1985) 21-51.

Kalicz, Nándor: Beiträge zur Kenntnis der Kupferzeit im ungarischen Transdanubien. In: Die Kupferzeit als historische Epoche. Symposium Saarbrücken und Otzenhausen 1988. Ed. by Lichardus, Jan. Bonn 1991, 347-387. (Saarbrücker Beiträge zur Altertumskunde 55)

Kalicz, Nándor: A legkorábbi fémleletek Délkelet-Európában és a Kárpát-medencében az i. e. 6-5. évezredben [The oldest metal finds in Southeastern Europe and the Carpathian Basin in the $6^{\text {th }}$ to $5^{\text {th }}$ millennia BC]. ArchÉrt 119 (1992) 3-14. 
KALICZ 2001

KALICZ 2002

KALICZ 2004

KALICZ-RACZKY 2005

KALICZ-SCHREIBER 2001

KOREK 1951

KOREK 1983

KÖHLER 2008

LENGYEL 1983

MAKKAY 1963

MAKKAY 2001

MARAN 1998

MARAN 2004a

Maran 2004b

NĚMEJCOVÁ-PAVúKOVÁ 1979

NĚMejCOVÁ-PavúKovÁ 1981

NĚMEJCOVÁ-PavúKOVÁ 1982

NĚMEjCOVÁ-PavúKOVÁ 1991

NĚMEJCOVÁ-PavúKová 1999

NeUSTUPNÝ 1968

NEVIZÁNSKY 1985

OTTOMÁNYI-CZENE 2006

PÉTREQUin et al. 2006

PARZINGER 1993

RENFREW 1976
Kalicz, Nándor: Die Protoboleráz-Phase an der Grenze von zwei Epochen. In: Cernavodă III-Boleráz. Ein vorgeschichtliches Phänomen zwischen dem Oberrhein und der Unteren Donau. Mangalia/Neptun (18.-24. Oktober 1999) Ed. by Roman, Petre-Diamandi, Saviana. Bucureşti 2001, 385-435. (Studia Danubiana, Series Symposia 2)

Kalicz, Nándor: Eigenartige anthropomorphe Plastik der kupferzeitlichen Badener Kultur im Karpatenbecken. BudRég 36 (2002) 11-53.

Kalicz, Nándor: Die kupferzeitliche Badener Kultur in der Auffassung von Viera NěmejcovaPavúková und der ungarischen Forschung. In: Zwischen Karpaten und Ägäis. Neolithikum und ältere Bronzezeit. Ed. by Hänsel, Bernhard-Studeniková, Etela. Rahden/Westf. 2004, 177-205.

Kalicz, Nándor-Raczky, Pál: The Neolithic and the Copper Age (6000-2800 B.C.). In: Between East and West. History of the peoples living in the Hungarian lands 4000,000 B.C.-804. A.D. Guide to the Archaeological Exhibition of the Hungarian National Museum 4000,000 B.C.-804. A.D. Ed. by Kovács, Tibor-Garam, Éva. Budapest 2005, 31-45.

Kalicz, Nándor-Schreiber, Rózsa: Veränderungen der Besiedlungsdichte in der Umgebung von Budapest während des 3. Jahrtausends v. Chr. In: Mensch und Umwelt während des Neolithikums und der Frühbronzezeit in Mitteleuropa. Ergebnisse interdisciplinärer Zusammenarbeit zwischen Archäologie, Klimatologie, Biologie und Medizin. Ed. by Lippert, Andreas-Schultz, Michael-Shennan, Stephen-Teschler-Nicola, Maria. Rahden/Westf. 2001, 165-179. (Internationale Archäologie, Arbeitsgemeinschaft, Symposium, Tagung, Kongress 2)

Korek, József: Ein Gräberfeld der Badener Kultur bei Alsónémedi. ActaArchHung 1 (1951) 35-54.

Korek, József: Közép-Kelet-Európa a rézkor végén [Central-Eastern Europe on the end of the Copper Age]. DSc Thesis. Budapest 1983.

Köhler, Kitti: The Physical Anthropological Characterization of the Population Connected to the Baden Culture in Hungary. In: The Baden Complex and the Outside World. Proceedings of the $12^{\text {th }}$ Annual Meeting of the EAA in Cracow 19-24th September 2006. Eds. by Furholt, Martin-Szmyt, Marzena-Zastawny, Albert. Bonn 2008, 95-110. (Studien zur Archäologie in Ostmitteleuropa 4)

Lengyel, Imre: Nem, életkor, vércsoport értékelése a budakalászi bádeni temetôben [Sex, age and blood groups in the Baden cemetery at Budakalász]. Budapest 1983. (Régészeti Továbbképzó Füzetek 2)

Makkay, János: Adatok a péceli (badeni) kultúra vallásos elképzeléseihez [Data to the religious Beliefs of the Pécel (Baden) Culture]. ArchÉrt 90 (1963) 3-16.

Makkay, János: Die Grabenanlagen im indogermanischen Raum. Budapest 2001.

Maran, Joseph: Die Badener Kultur und der ägaisch-anatolische Bereich. Eine Neubewertung eines alten Forschungsproblems. Germania 76 (1998) 497-525.

Maran, Joseph: Die Badener Kultur und ihre Räderfahrzeuge. In: FANSA-BurmeISTER 2004, 265-282. Maran, Joseph: Kulturkontakte und Wege der Ausbreitung der Wagentechnologie im 4. Jahrtausend v. Chr. In: FANSA-BURMeISTER 2004, 429-442.

Němejcová-Pavúková, Viera: Počiatky bolerázskej skupiny na Slovensku [Die Anfänge der BolerázGruppe in der Slowakei]. SlovArch 27 (1979) 17-55.

Němejcová-Pavúková, Viera: Náčrt periodizácie badenskej kultúry a jej chronologických vzt'ahov k juhovýchodnej Európe [An outline of the periodical system of Baden Culture and its chronological relation to Southwest Europe]. SlovArch 29 (1981) 261-296.

Němejcová-Pavúková, Viera: Periodisierung der Badener Kultur und ihre chronologischen Beziehungen zu Südosteuropa. Thracia Praehistorica = Pulpudeva 3 (1982) 150-176.

Němejcová-Pavúková, Viera: Typologische Fragen der relativen und absoluten Chronologie der Badener Kultur. SlovArch 39 (1991) 59-90.

Němejcová-Pavúková, Viera: Bemerkungen zur Frühbronzezeit in Westbulgarian und Nordostgriechenland im Licht der „Importe” aus dem Karpatenbecken. SlovArch 47 (1999) 42-65.

Neustupný, Evžen: Absolute Chronology of the Neolithic and Aeneolithic Periods in Central and South-Eastern Europe. SlovArch 16 (1968) 19-60.

Nevizánsky, Gabriel: Grabfunde und Überbauerscheinungen der Träger der Badener Kultur im Zentralen Gebiet des Karpatenbeckens. SlovArch 33 (1985) 249-272.

Ottományi, Katalin-Czene, András: Az M0-s autópálya északi szakaszának feltárása, Budakalász. Régészeti kutatások másfél millió négyzetméteren. Autópálya és gyorsforgalmi utak építését megelőzô régészeti feltárások Pest megyében 2001-2006. Ed. by Tari, Edit. Szentendre 2006, 69-73. (Pest Megyei Múzeumi Füzetek 7)

Premiers chariots, premiers araires. La diffusion de la traction animale en Europe pendant les IVe et III ${ }^{\mathrm{e}}$ millénaires avant notre ère. Ed. by Pétrequin, P.-Arbogast, R.-M.-Pétrequin, A.-M.-Willigen, S.-Bailly, M. Paris 2006. (Collection de Recherches Archéologiques. Monographies 29)

Parzinger, Hermann: Studien zur Chronologie und Kulturgeschichte der Jungstein-, Kupfer-, und Frühbronzezeit zwischen Karpaten und mittlerem Taurus. Mainz 1993. (Römisch-germanische Forschungen 52)

Renfrew, Colin: Before Civilisation: The Radiocarbon Revolution and Prehistoric Europe. Harmondsworth 1976. 
RENFREW 1986

ROMAN 1979

ROMAN 1992

SACHSSE 2008

SHERRATT 1986

SHERRATT 1997

SHERRATT 2003

SHERRATT 2004

SOPRONI 1954

SOPRONI 1956

STADLER et al. 2001

STRAHM 2008

TORMA 1972

TORMA 1973

VOSTEEN 2002

WhitTLE 1996

WILD et al. 2001
Renfrew, Colin: Sitagroi in European Prehistory. In: Excavations at Sitagroi. A Prehistoric Village in Northeast Greece. Ed. by Renfrew, Colin-Gimbutas, Marija-Elster, Ernestine. Los Angeles 1986, 477-485. (Monumenta Archaeologica 13)

Roman, Petre: Die südliche Beziehungen der Badener-Kultur. Dacia 23 (1979) 307-311.

Roman, Petre: Das chronologische Verhältnis zwischen Ezero und Troja im Lichte der nordbalkanischen Forschungen. Thraco-Dacica 13 (1992) 25-34

Sachsse, Claudia: Baden Cultural Identities? Late Copper Age Funerals Reviewed. In: The Baden Complex and the Outside World. Proceedings of the 12th Annual Meeting of the EAA in Cracow 19-24th September 2006. Ed. by Furholt, Martin-Szmyt, Marzena-Zastawny, Albert. Bonn 2008, 49-68. (Studien zur Archäologie in Ostmitteleuropa 4)

Sherratt, Andrew: The Pottery of Phases IV and V: The Early Bronze Age. In: Excavations at Sitagroi. A Prehistoric Village in Northeast Greece. Ed. by Renfrew, Colin-Gimbutas, Marija-Elster Ernestine. Los Angeles 1986, 429-476. (Monumenta Archaeologica 13)

Sherratt, Andrew: Economy and Pastoralism: Aspects of the Secondary Products Revolution. In: Economy and Society in Prehistoric Europe. Changing Perspectives. Ed. by Sherratt, Andrew. Princeton 1997, 158-198.

Sherratt, Andrew: The Baden (Pécel) culture and Anatolia: perspectives on a cultural transformation. In: Morgenrot der Kulturen. Frühe Etappen der Menschheitsgeschichte in Mittel- und Südosteuropa. Festschrift für Nándor Kalicz zum 75. Geburtstag. Ed. by Jerem, Erzsébet-Raczky, Pál. Budapest 2003, 415-429.

Sherratt, Andrew: Wage, Pflug, Rind: ihre Ausbreitung und Nutzung - Probleme der Quelleninterpretation. In: FANSA-BURMEISTER 2004, 409-428.

Soproni Sándor: A budakalászi kocsi [Der Wagen in Budakalász]. FolArch 6 (1954) 29-36.

Soproni, Sándor: Budakalász, Luppa csárda. In: BANNER 1956, 111-128.

Stadler, Peter-Draxler, Susanne-Friesinger, Herwig-Kutschera, Walter-Priller, Alfred-Rom, WernerSteier, Peter-Wild, Eva Maria: Absolute Chronology for Early Civilizations in Austria and Central Europe using ${ }^{14} \mathrm{C}$ Dating with Accelerator Mass Spectometry with special Results for the Absolute Chronology of the Baden Culture. In: Cernavodă III-Boleráz. Ein vorgeschichtliches Phänomen zwischen dem Oberrhein und der Unteren Donau. Mangalia/Neptun (18.-24. Oktober 1999) Ed. by Roman, Petre-Diamandi, Saviana. Bucureşti 2001, 541-562. (Studia Danubiana, Series Symposia 2) Strahm, Christian: The Complementary Ware in Bell Beaker everyday life: the Italian model - a theory. In: Bell Beaker in Everyday Life. Ed. by Baioni, M. et al. Firenze 2008, 209-219. (Millenni Studi di Archeologia Prehistorica 6)

Torma, István: Die Tierstatuetten der Boleráz-Gruppe von Pilismarót, Basaharc. In: Idole. Prähistorische Keramiken aus Ungarn. Ed. by Bachmayer, Friedrich. Wien, 1972, 24-26. (Veröffentlichungen des Naturhistorisches Museums N. F. 7)

Torma, István: Die Boleráz-Gruppe in Ungarn. In: Symposium über die Entstehung und Chronologie der Badener Kultur, Bratislava 1969. Ed by. Chropovský, Bohuslav. Bratislava 1973, 483-512. Vosteen, Markus Uwe: Die fünffache Erfindung von Rad und Wagen. In: Schleife, Schlitten, Rad und Wagen. Zur Frage früher Transportmittel nördlich der Alpen Ed. by Köninger, Joachim-Mainberger, Martin-Schlichterle, Helmut-Vosteen, Markus. Gaienhofen-Hemmenhofen 2002, 143-148. (Hemmenhofener Skripte 3)

Whittle, Alasdair: Europe in the Neolithic. The Creation of New Worlds. Cambridge 1996.

Wild, Eva Maria-Stadler, Peter-Bondár, Mária-Draxler, Susanne-Friesinger, Herwig-Kutschera, Walter-Priller, Alfred-Rom, Werner-Ruttkay, Elisabeth-Steier, Peter: New chronological frame for the young Neolithic Baden culture in Central Europe (4th Millennium BC). Radiocarbon 43 (2001) $1057-1064$. 


\section{ABBREVIATIONS}

JOURNALS, PERIODICALS, SERIES

\section{AAC}

AJA

ArchAustriaca

ArchÉrt

ActaArchHung

ArchHung

ArchRozhl

AVANS

BAR

BudRég

CommArchHung

DMÉ

EAF

FolArch

FÖ

HOMÉ

HOMK

JPMÉ

MFMÉ-StudArch

MittArchInst

NyJAMÉ

PamArch

PPS

PZ

SA

SlovArch

SMK

StudArch

StudPraeh

WMMÉ

ZalaiMúz

\section{OTHER}

dM
dB
diam.
H.
HNM
L.
SzFM
W.

Acta Archeologica Carpathica (Kraków)

American Journal of Archeology (New York)

Archaeologia Austriaca (Wien)

Archaeologiai Értesítő (Budapest)

Acta Archaeologica Academiae Scientiarum Hungaricae (Budapest)

Archaeologia Hungarica (Budapest)

Archeologické rozhledy (Praha)

Archologické Výskumy a Nálezy na Slovensku (Nitra)

British Archaeological Reports (Oxford)

Budapest Régiségei (Budapest)

Communicationes Archaeologicae Hungariae (Budapest)

Déri Múzeum Évkönyve (Debrecen)

Ethnographisch-Archäologische Forschungen (Berlin)

Folia Archaeologica (Budapest)

Fundberichte aus Österreich (Wien)

Herman Ottó Múzeum Évkönyve (Miskolc)

Herman Ottó Múzeum Közleményei (Miskolc)

Janus Pannonius Múzeum Évkönyve (Pécs)

Móra Ferenc Múzeum Évkönyve - Studia Archaeologica (Szeged)

Mitteilungen des Archäologischen Instituts der Ungarischen Akademie der Wissenschaften (Budapest)

A Nyíregyházi Jósa András Múzeum Évkönyve (Nyíregyháza)

Památky Archeologické (Praha)

Proceeding of the Prehistoric Society (Cambridge)

Prähistorische Zeitschrift (Berlin)

Sovetskaja Archeologija (Moskva)

Slovenská Archeológia (Bratislava)

Somogy Megyei Múzeumok Közleményei (Kaposvár)

Studia Archaeologica (Budapest)

Studia Praehistorica (Sofia)

A Wosinsky Mór Megyei Múzeum Közleményei (Szekszárd)

Zalai Múzeum (Zalaegerszeg)

\author{
diameter of mouth \\ diameter of base \\ diameter \\ height \\ Hungarian National Museum (Budapest) \\ length \\ Ferenczy Károly Museum (Szentendre) \\ width
}



PLATES 
stone implement

indistinct pottery sherd

bone/bone implement

copper fragment

stone/stone fragment

$\because \cdots$ beads

goblet

stone axe

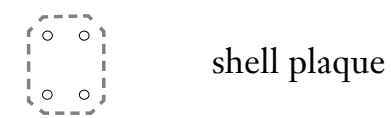

shell bead

bracelet made from boar tusk

pot

ladle

bipartite bowl

bowl

clay plaque

spool

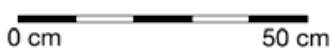

Scale of all grave plans 


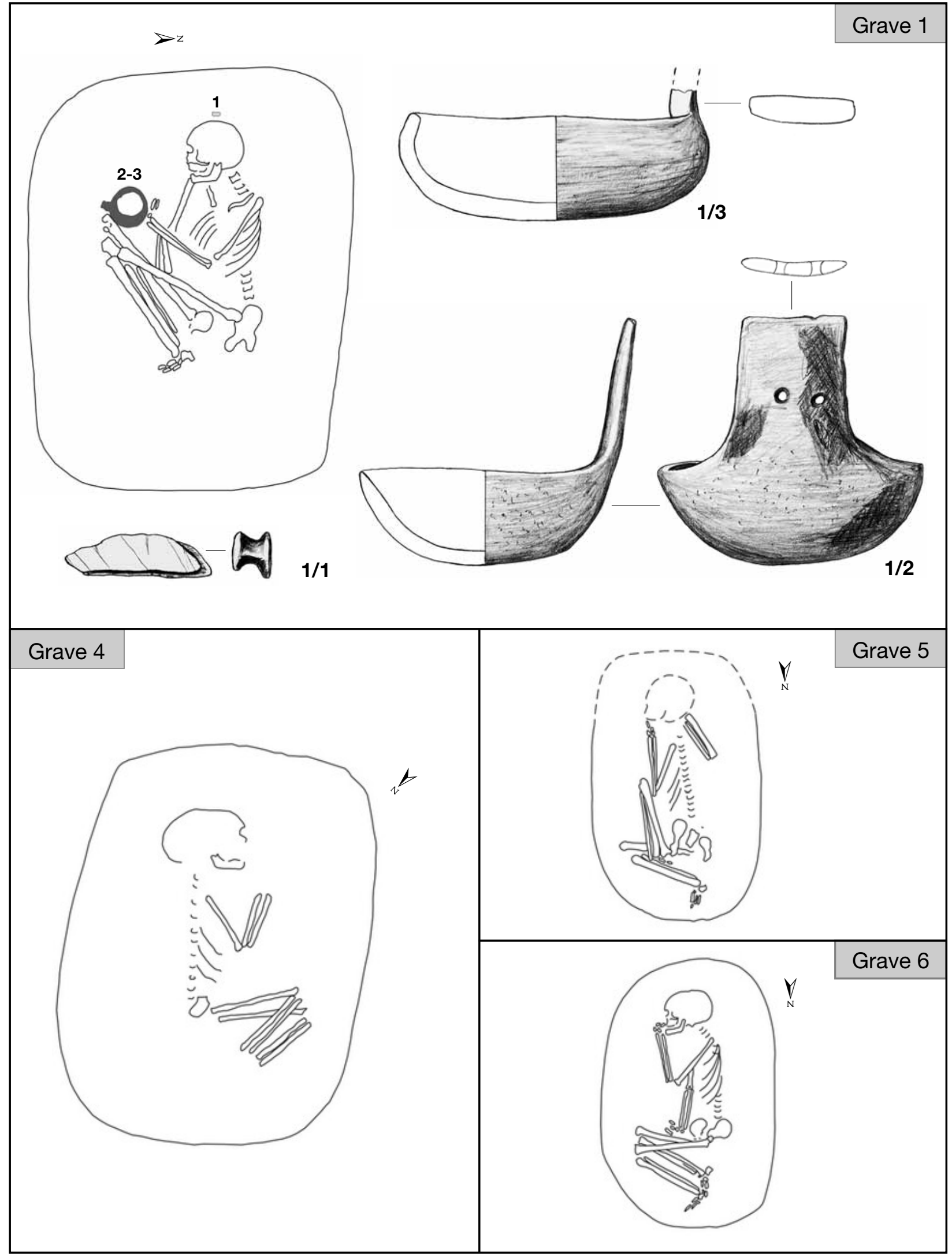

Plate I. Graves 1 and 4-6 


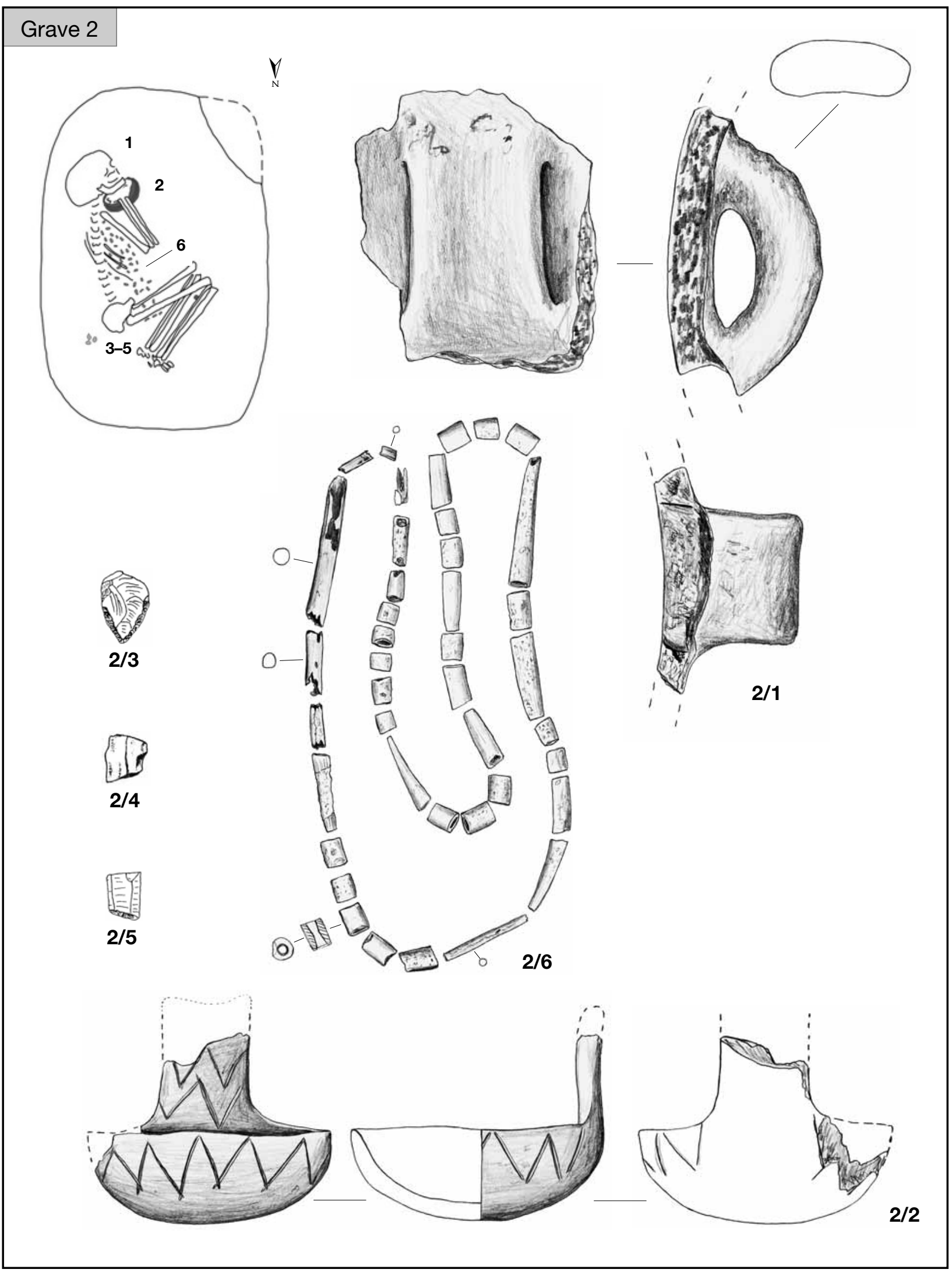

Plate II. Grave 2 (2/3-2/5: after Cs. BALOGH 1993) 

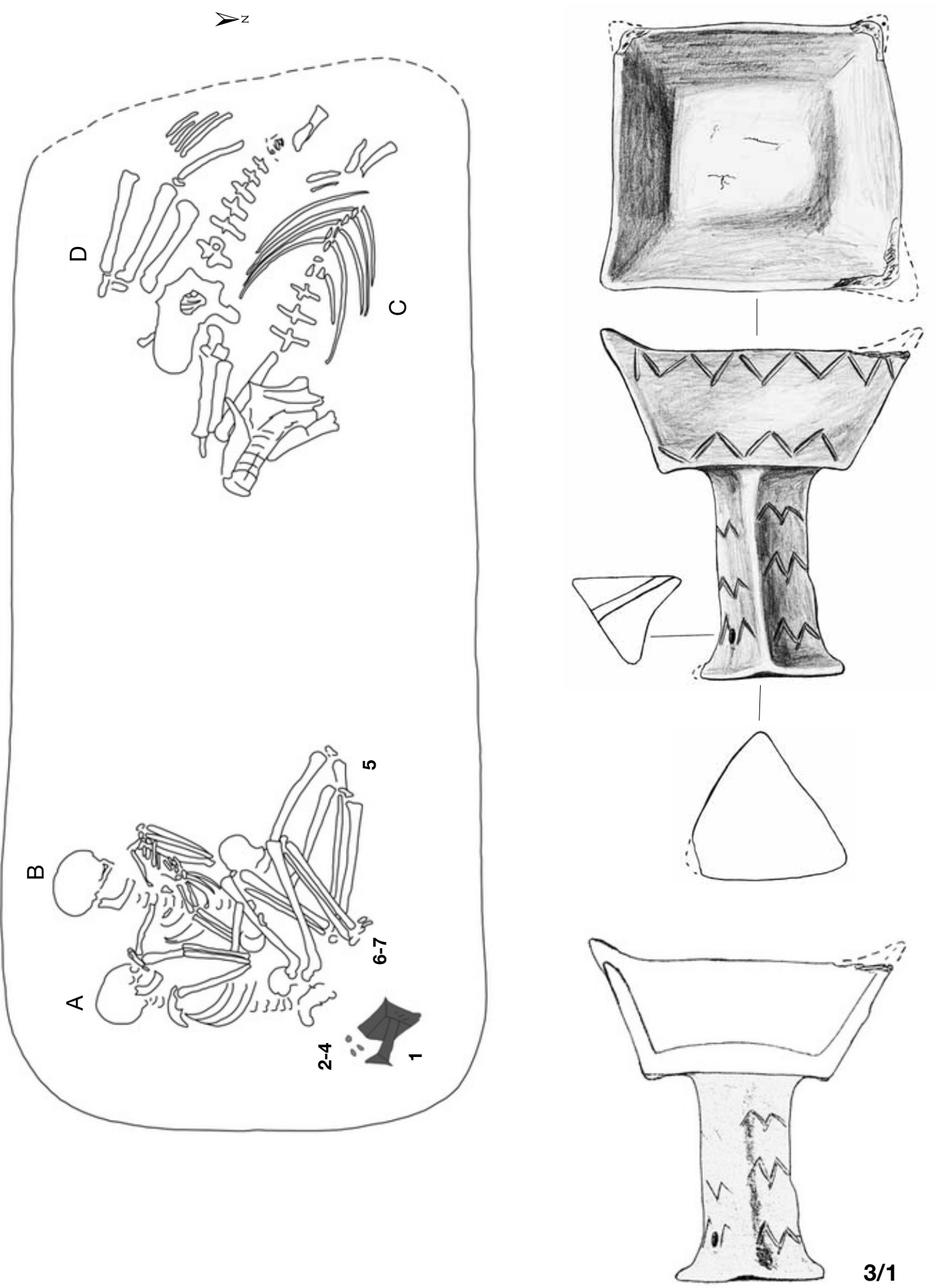

Plate III. Grave 3 


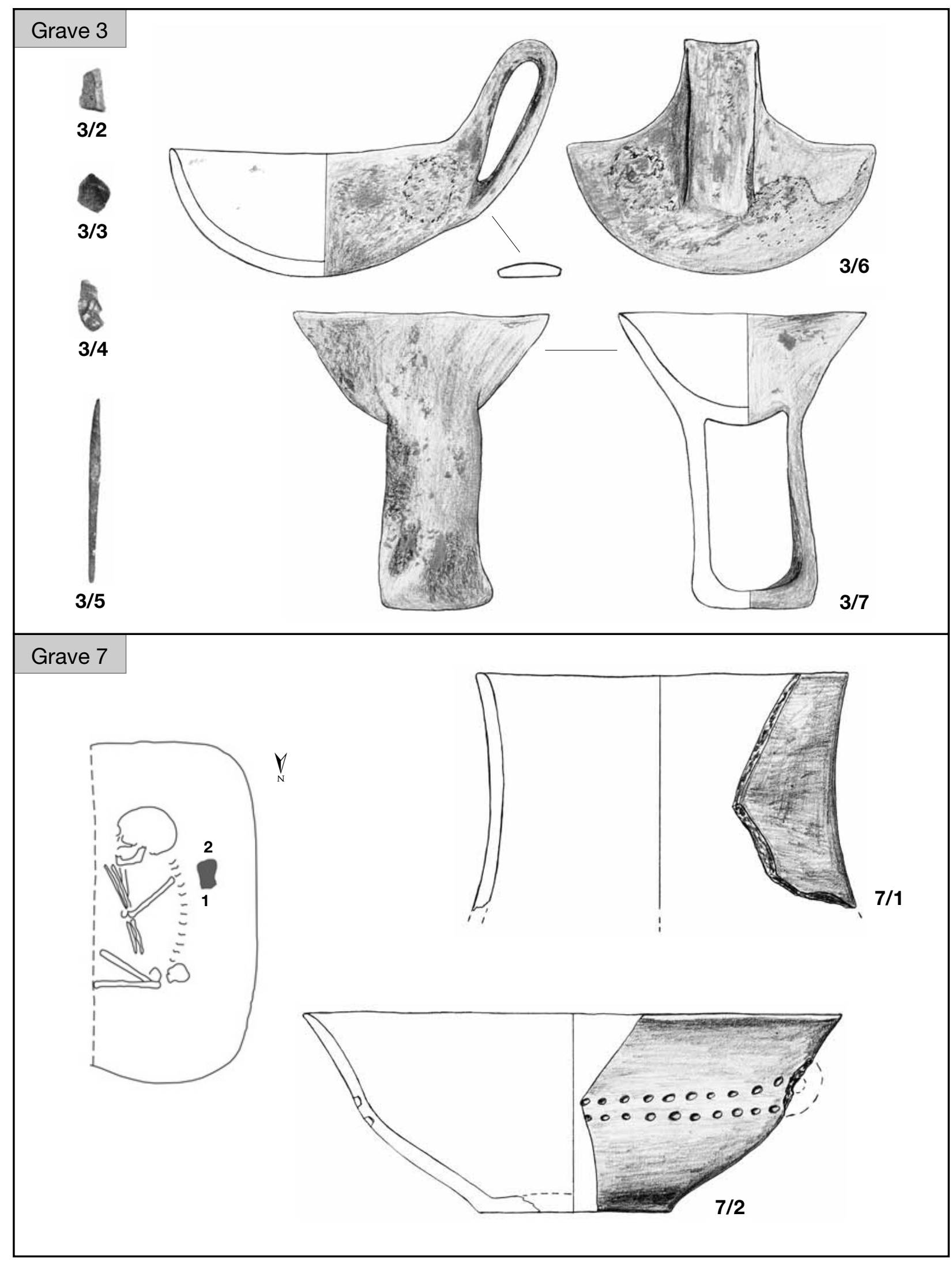

Plate IV. Graves 3 and 7 (3/2-5: after BANNER 1956, Taf. LXXXIX. 10-13) 


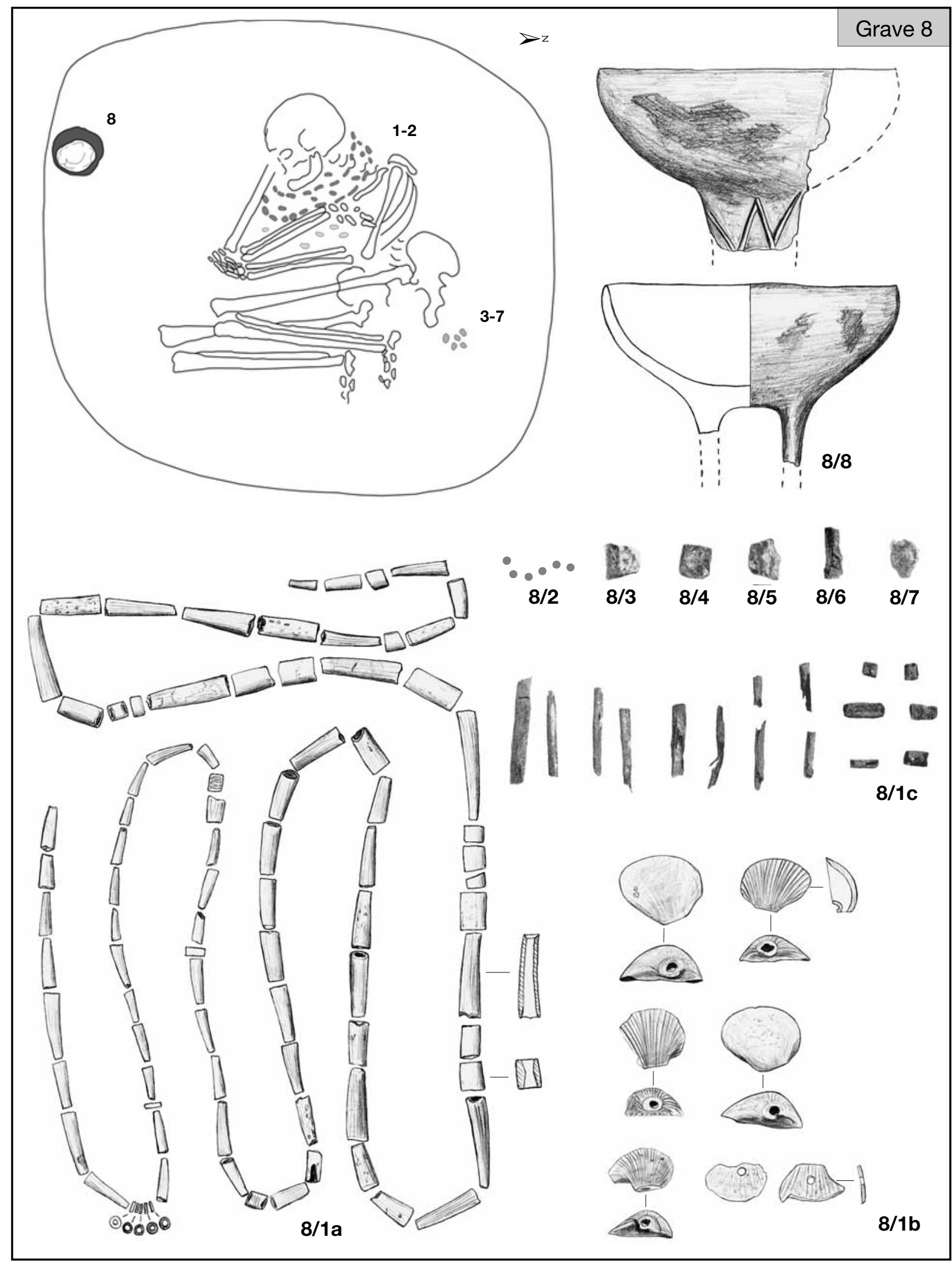

Plate V. Grave 8 (8/3-7: after BANNER 1956, Taf. LXXXIX. 14-18; 8/1c after BANNER 1956, Taf. LXXXIX. 19-34) 


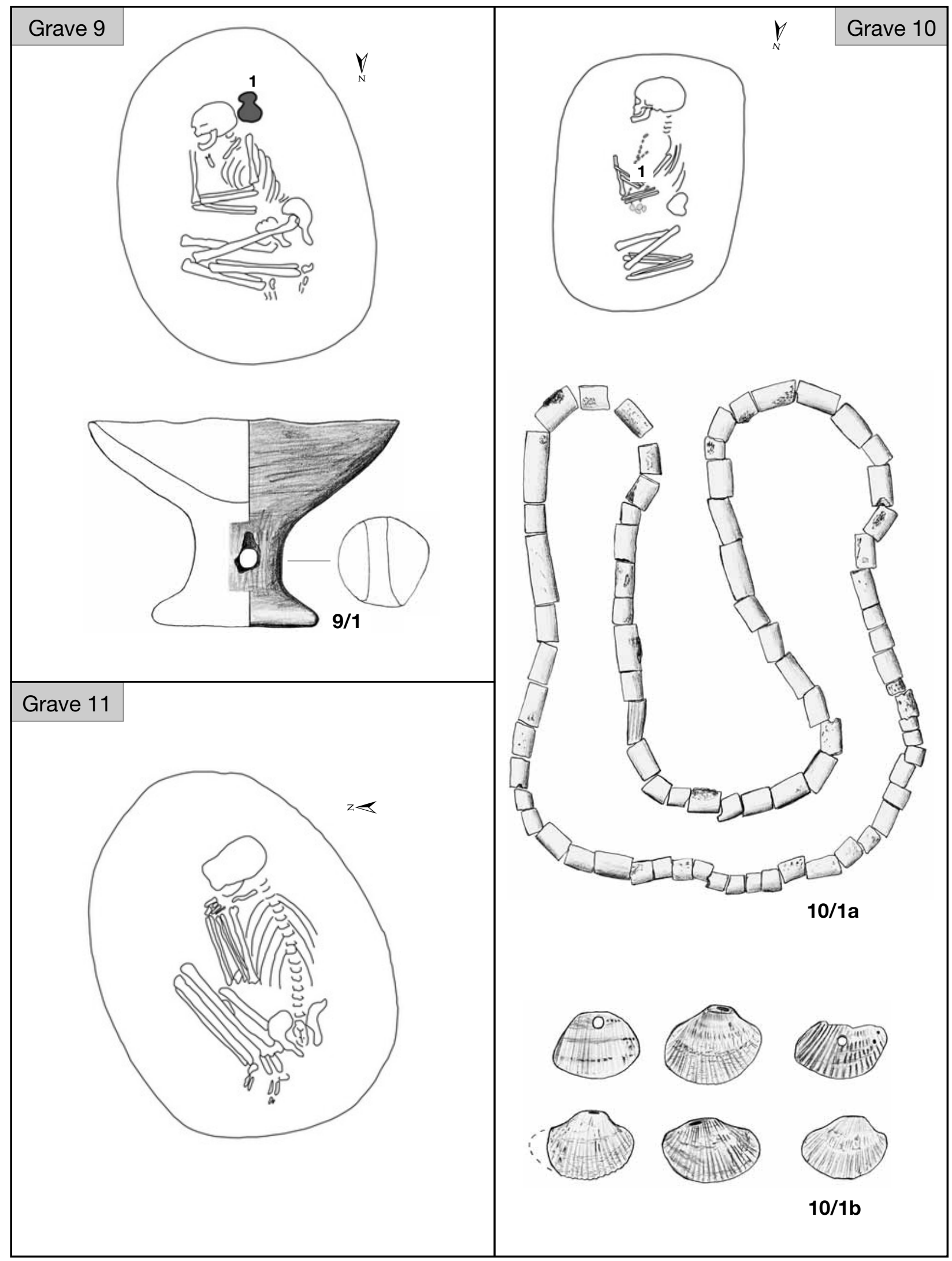

Plate VI. Graves 9-11 


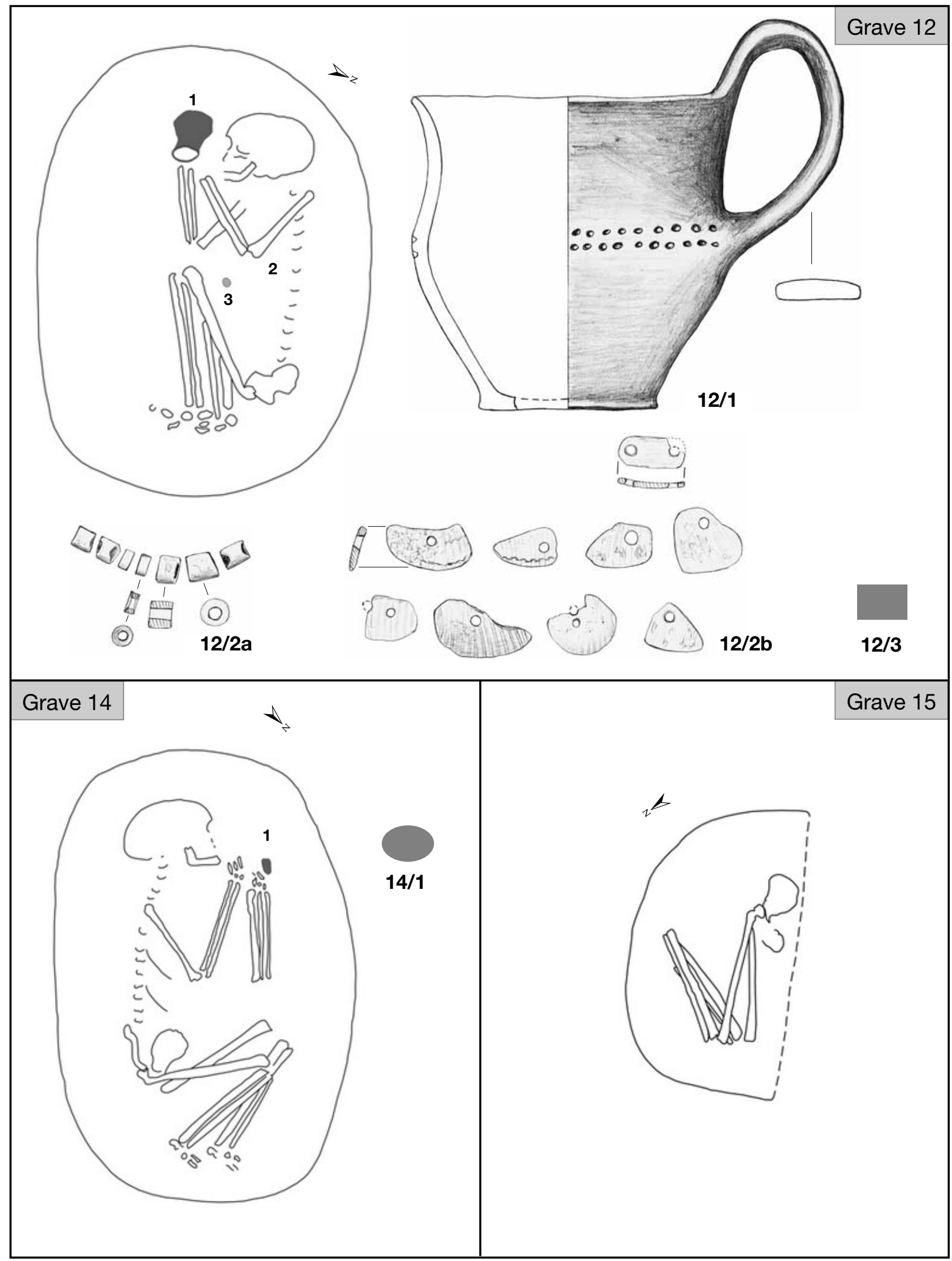

Plate VII. Graves 12 and 14-15 


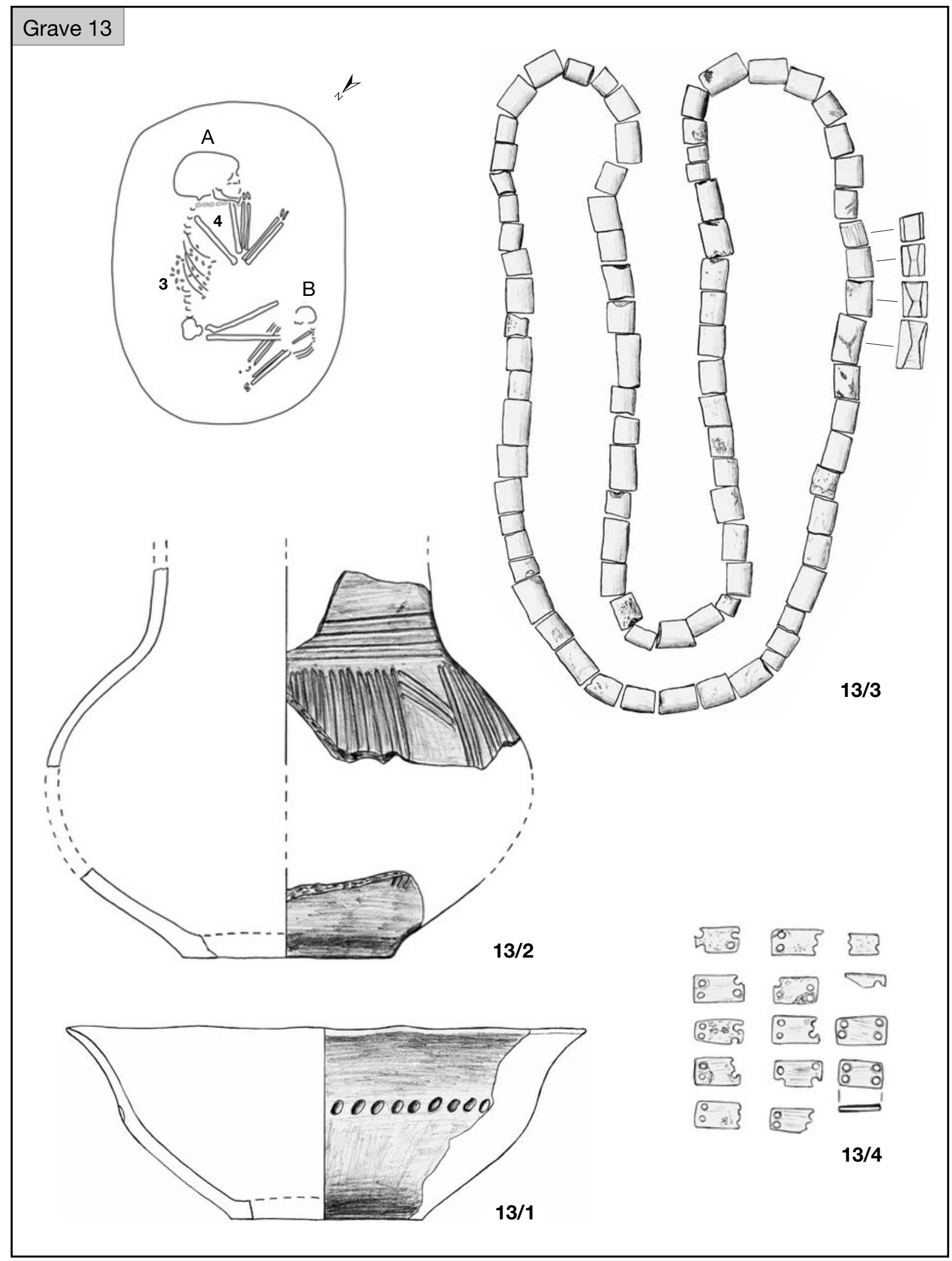

Plate VIII. Grave 13 


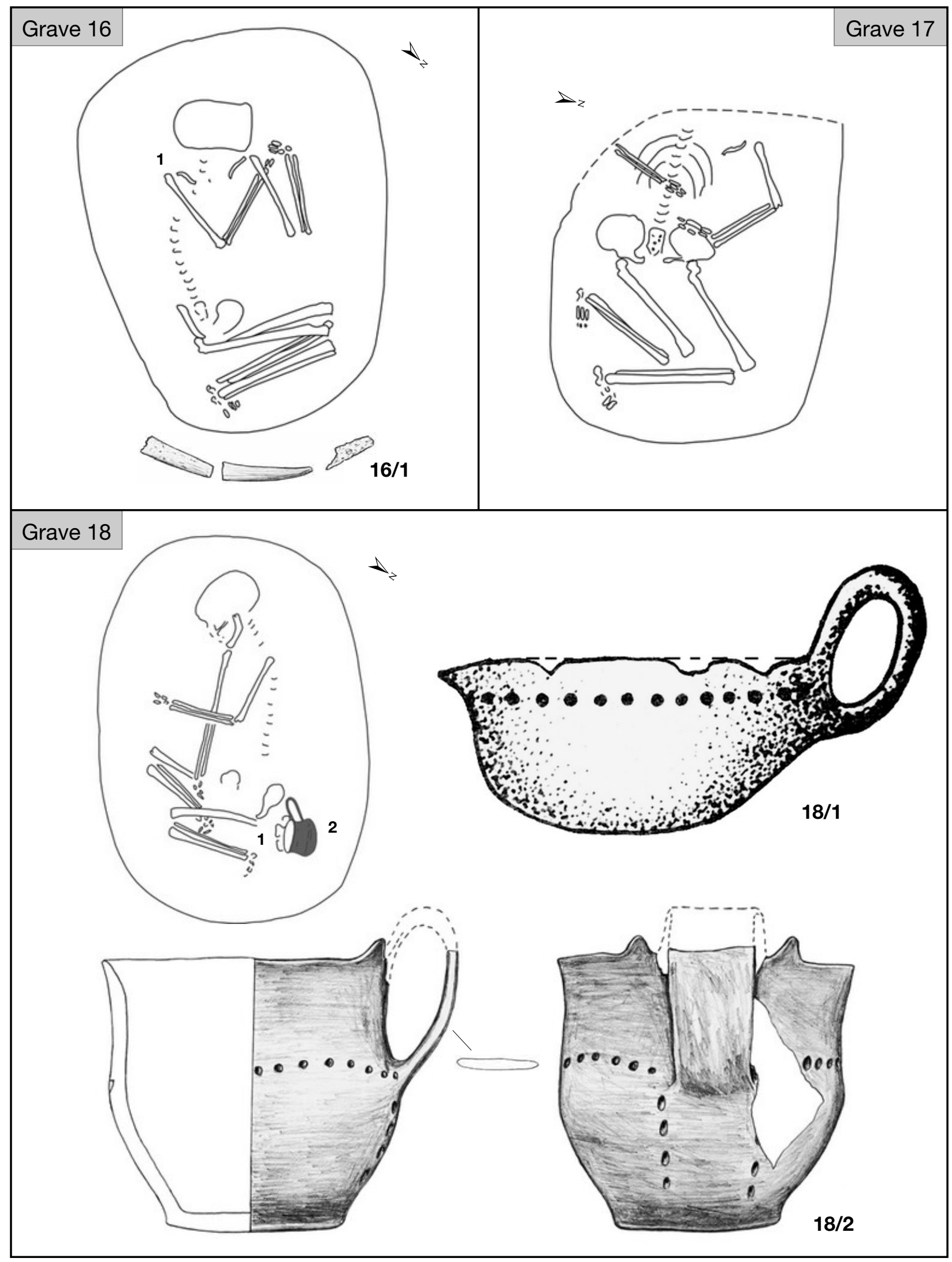

Plate IX. Graves 16-18 (18/1: after JózSEF KoREK's grave sheet) 


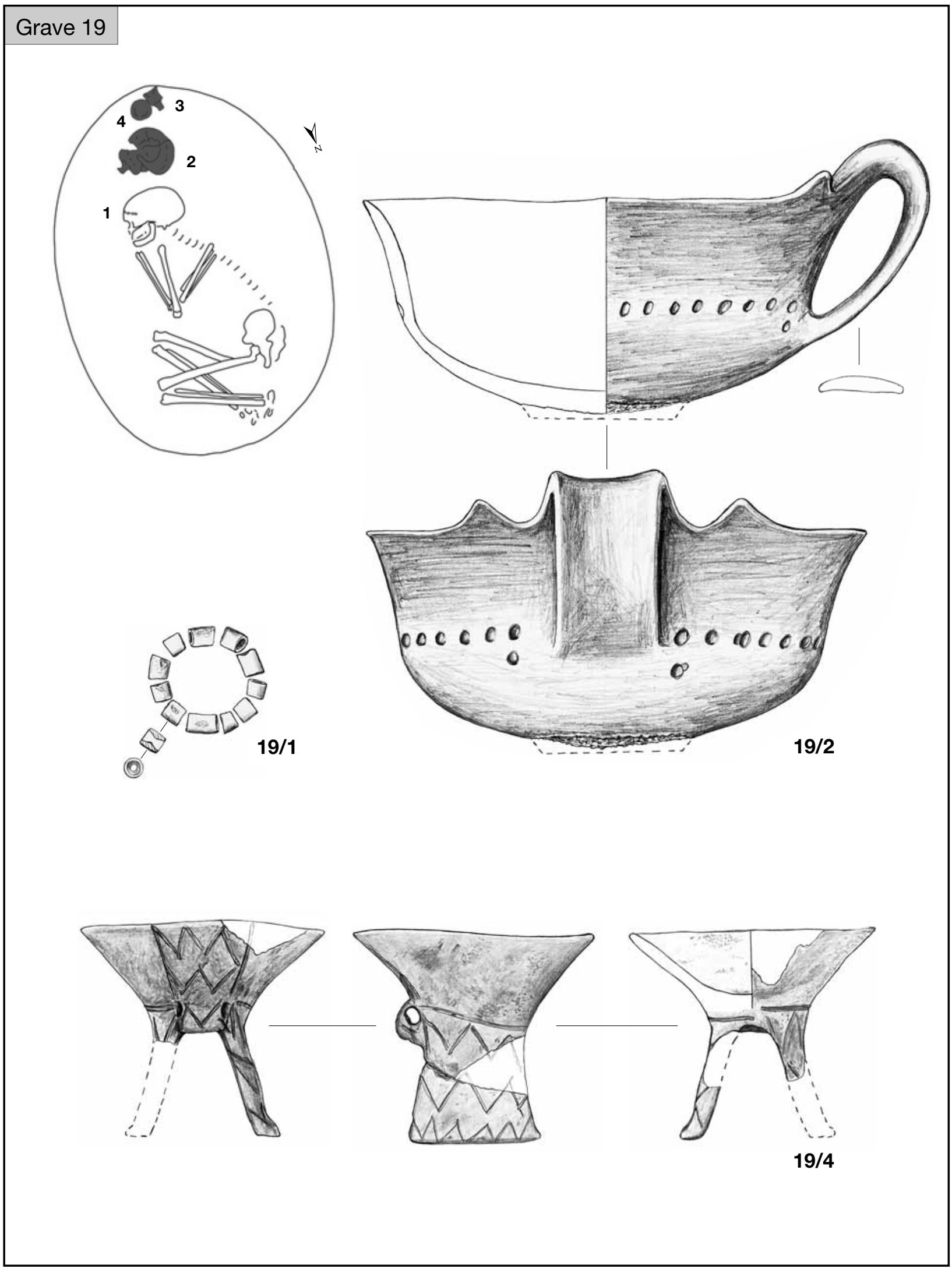

Plate X. Grave 19 


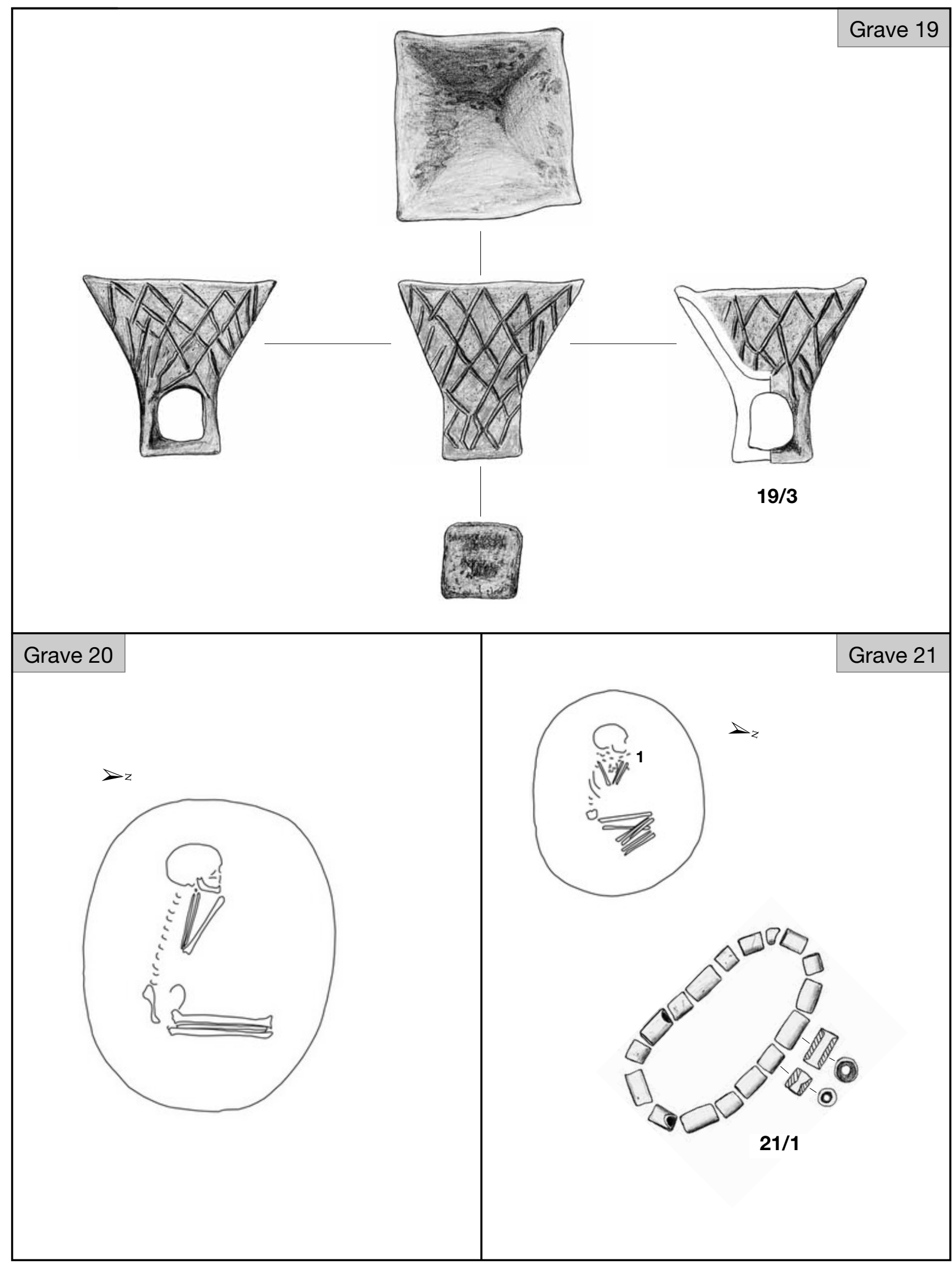

Plate XI. Graves 19-21 


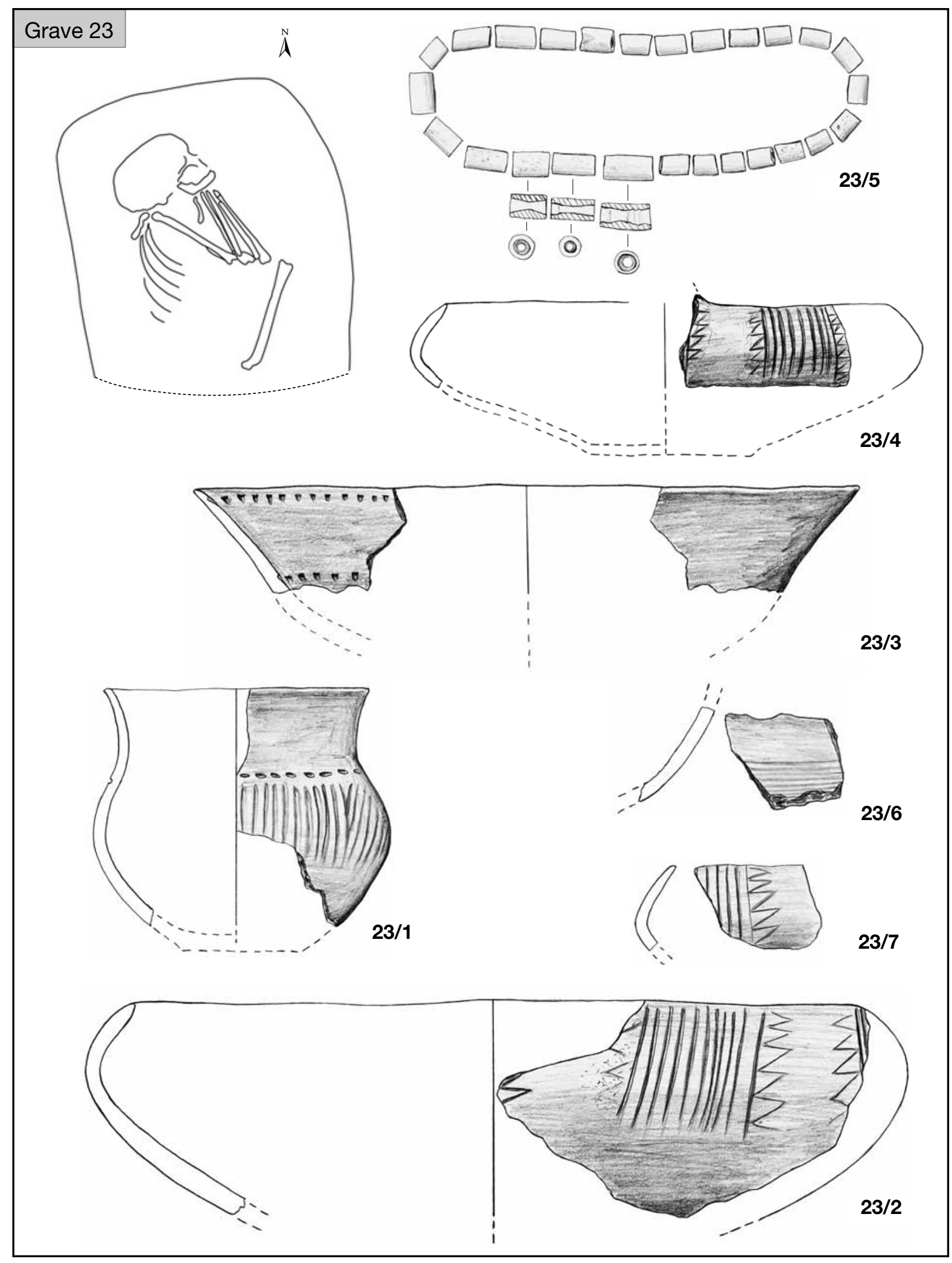

Plate XII. Grave 23 


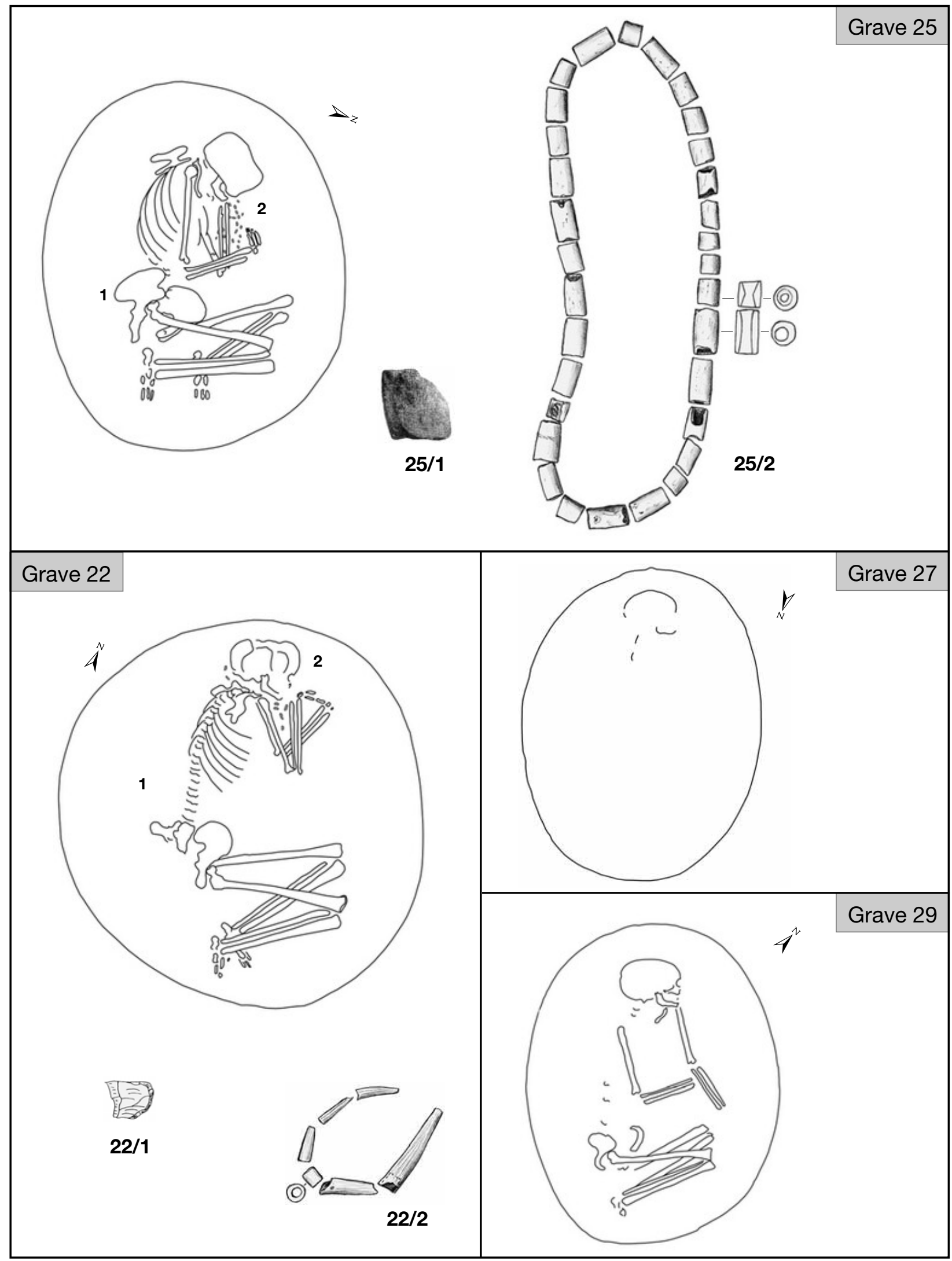

Plate XIII. Graves 22, 25, 27 and 29 (22/1: after Cs. BALOGH 1993; 25/1: after BANNER 1956, Taf. XCII. 2) 


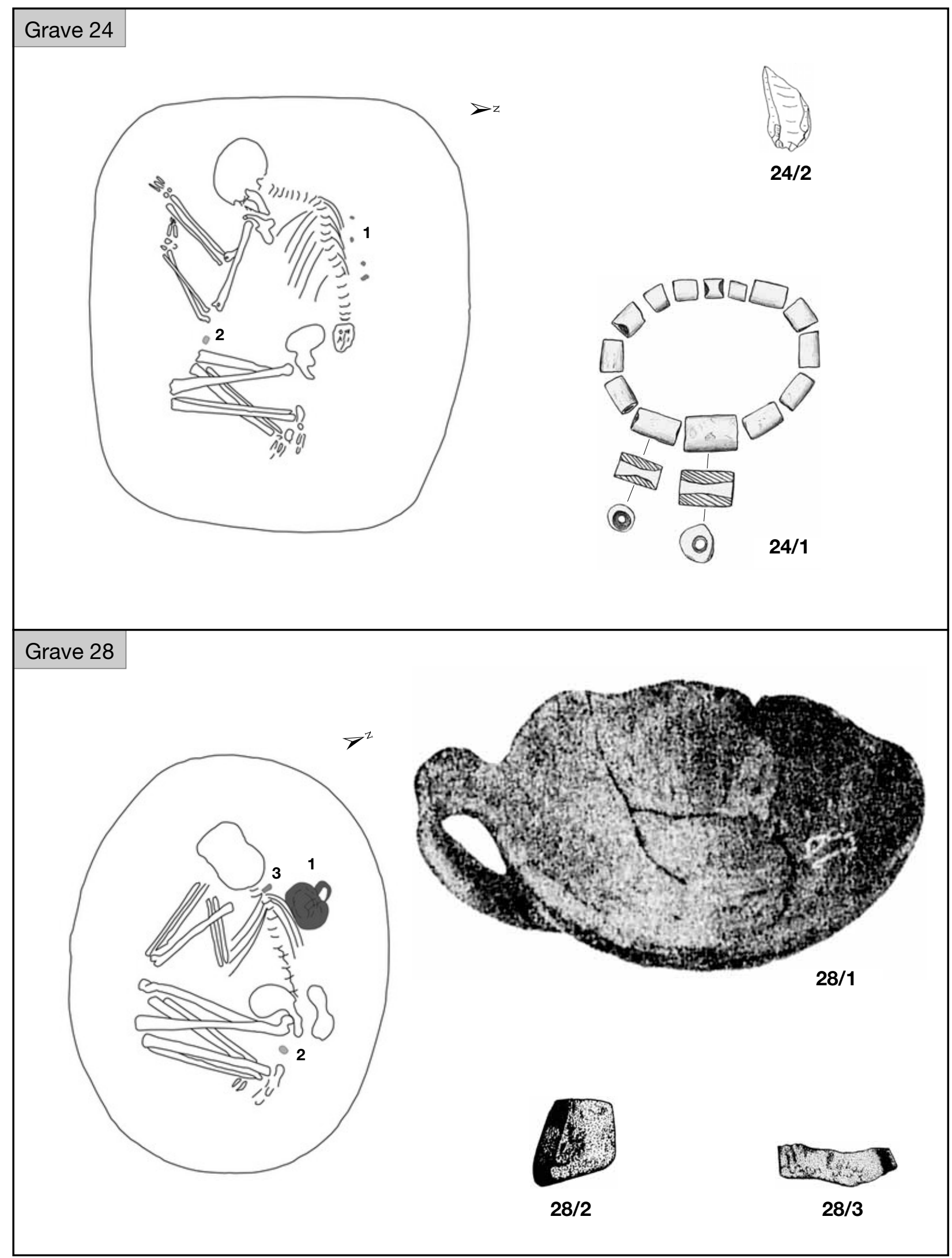

Plate XIV. Graves 24 and 28 (24/2: after Cs. BALOGH 1993; 28/1-3: after BANNER 1956, Taf. XCII. 3-4, 22) 


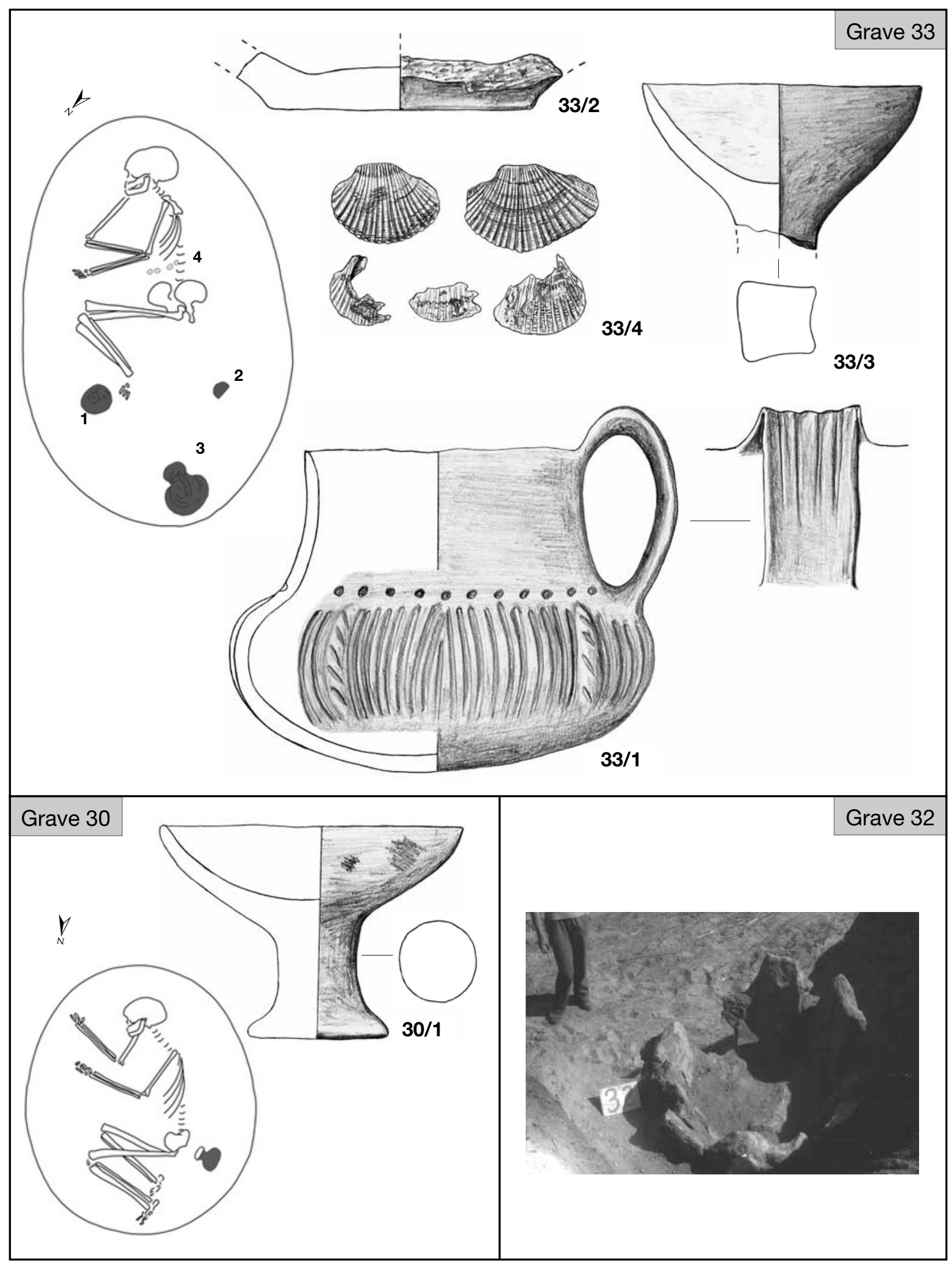

Plate XV. Graves 30 and 32-33 


\section{Grave 36}
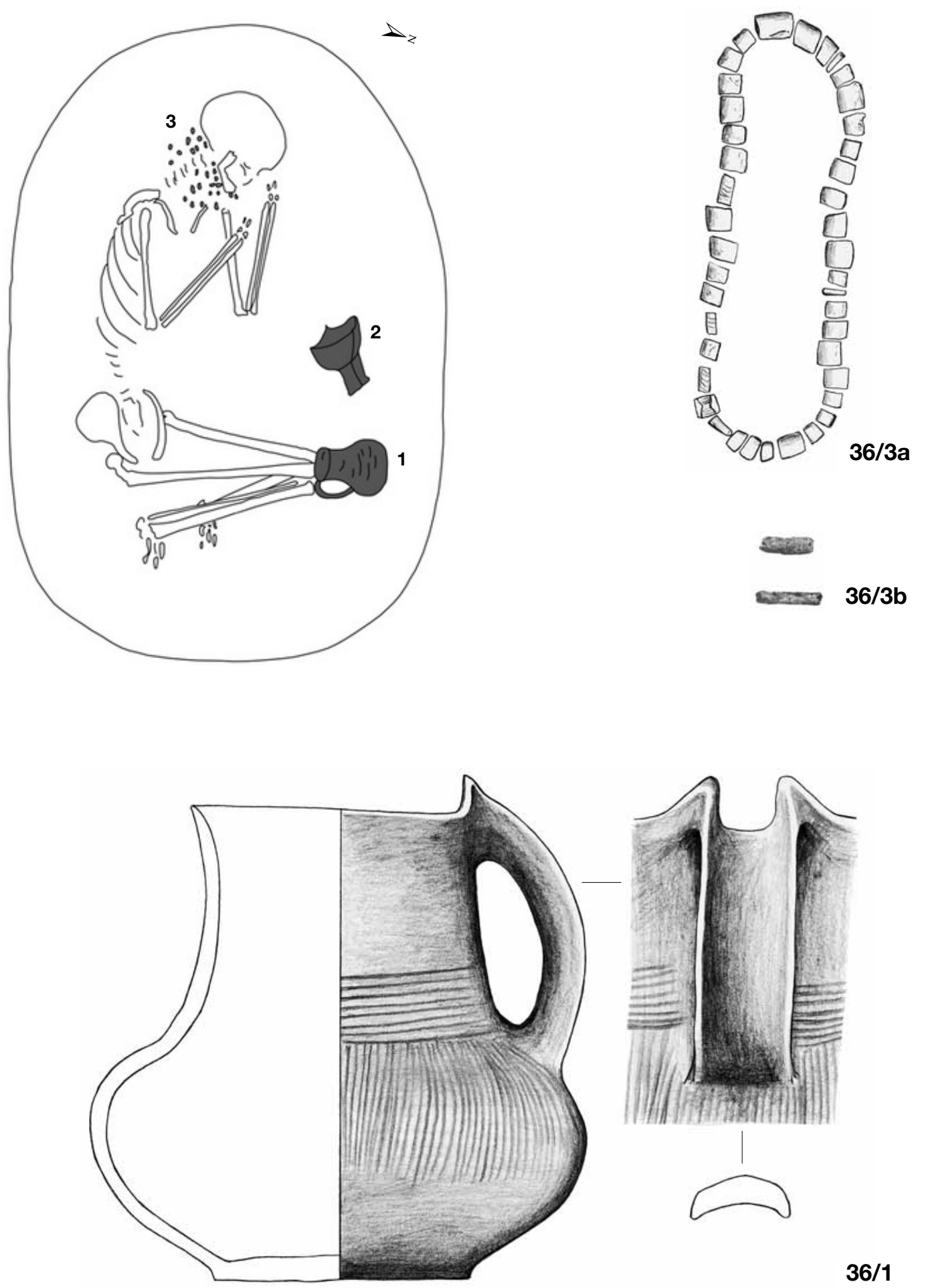

$36 / 1$

Plate XVI. Grave 36 (36/3b: after BANNER 1956, Taf. XCII. 5-6) 


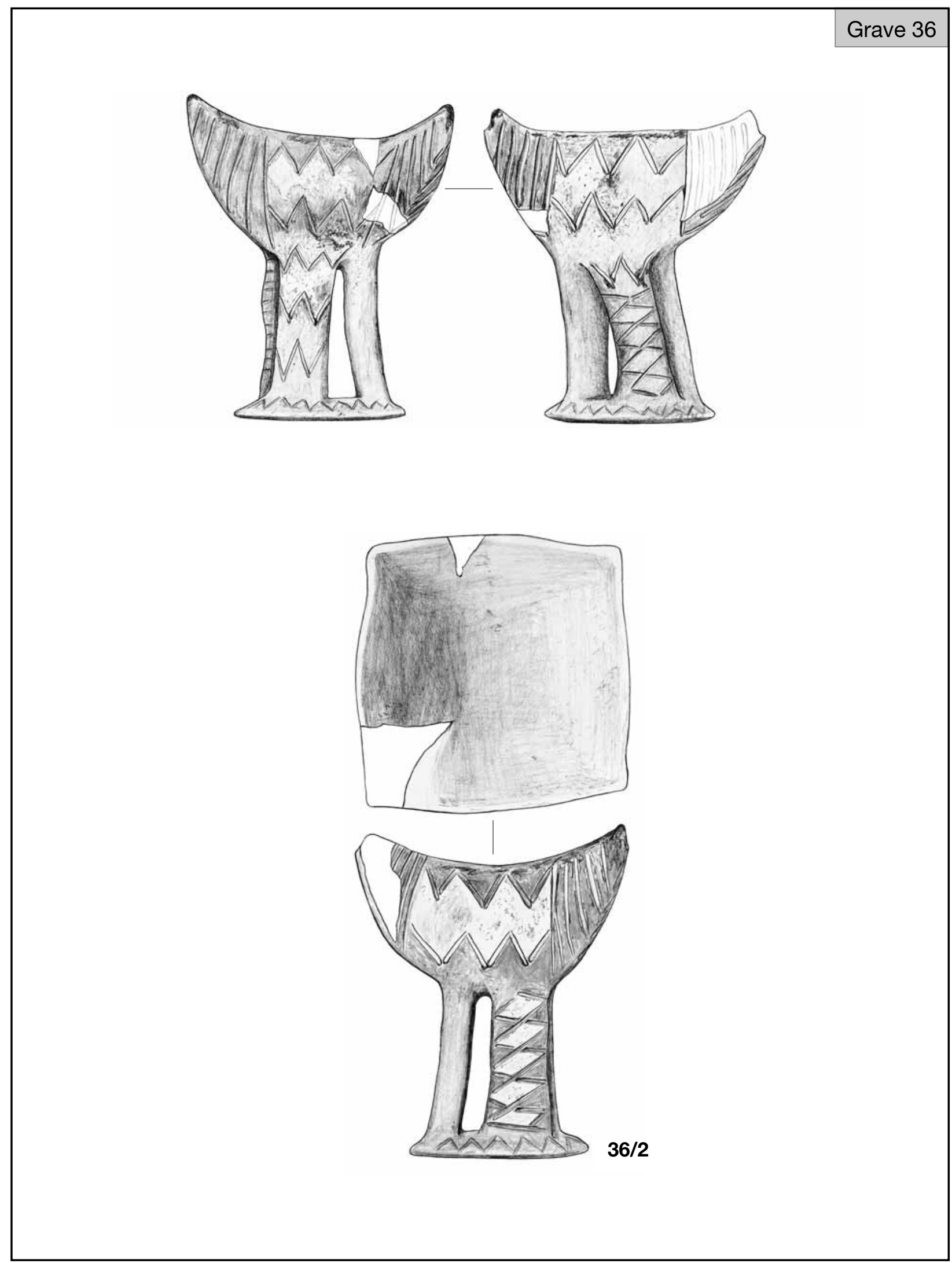

Plate XVII. Grave 36 


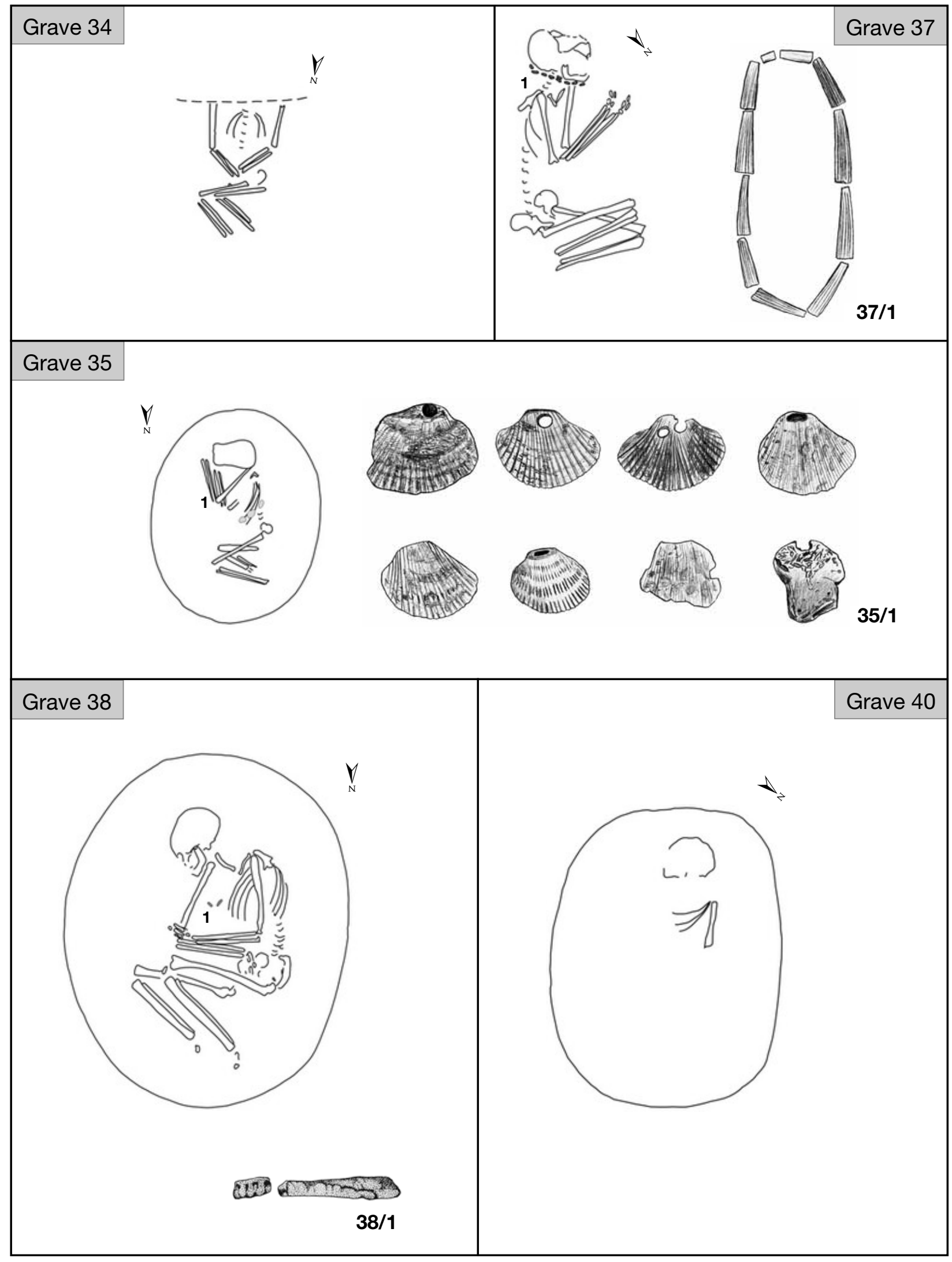

Plate XVIII. Graves 34-35, 37-38 and 40 (38/1: after JÓZSEF KOREK's grave sheet) 


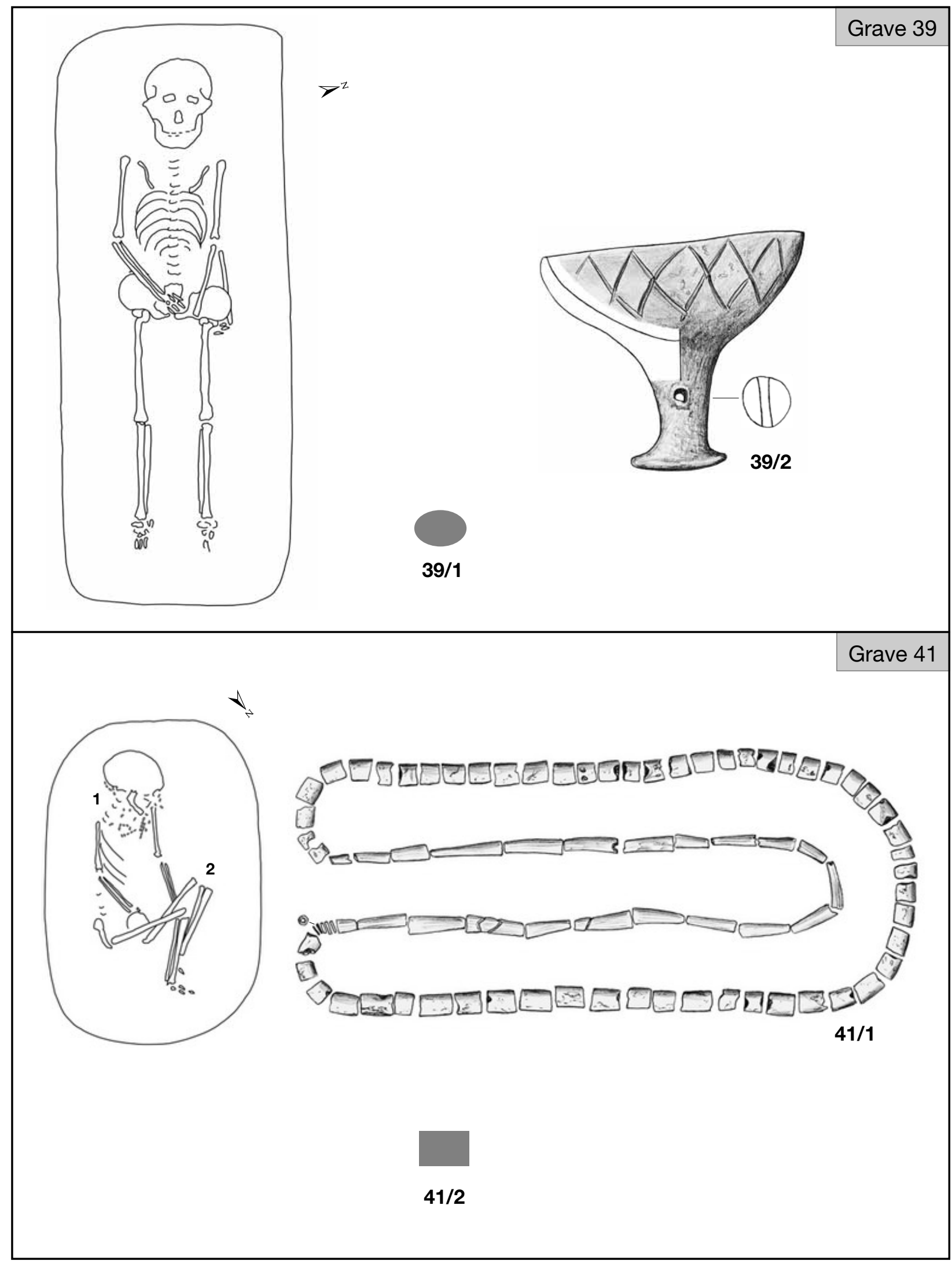

Plate XIX. Graves 39 and 41 


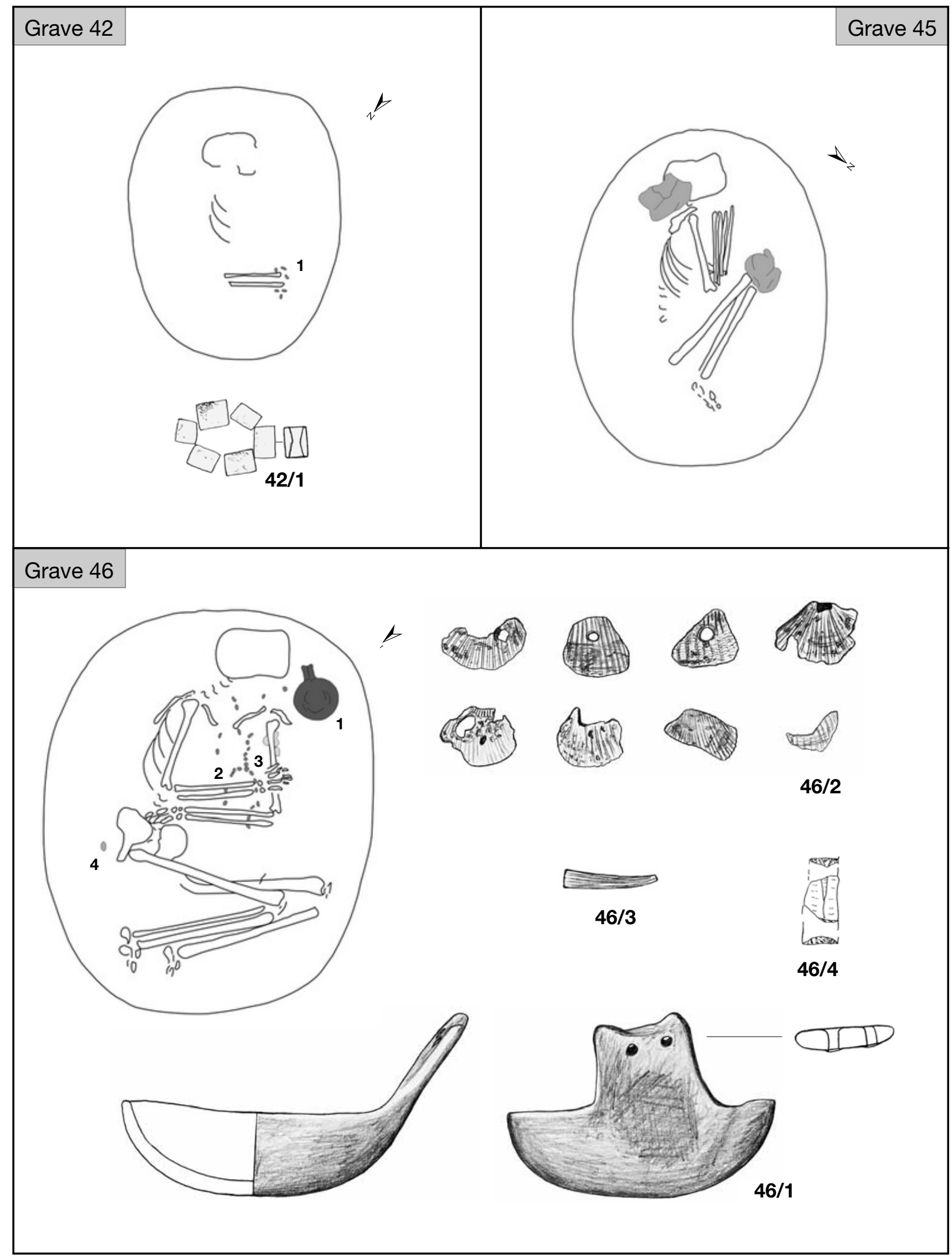

Plate XX. Graves 42 and 45-46 (46/4: after Cs. BALOGH 1993) 


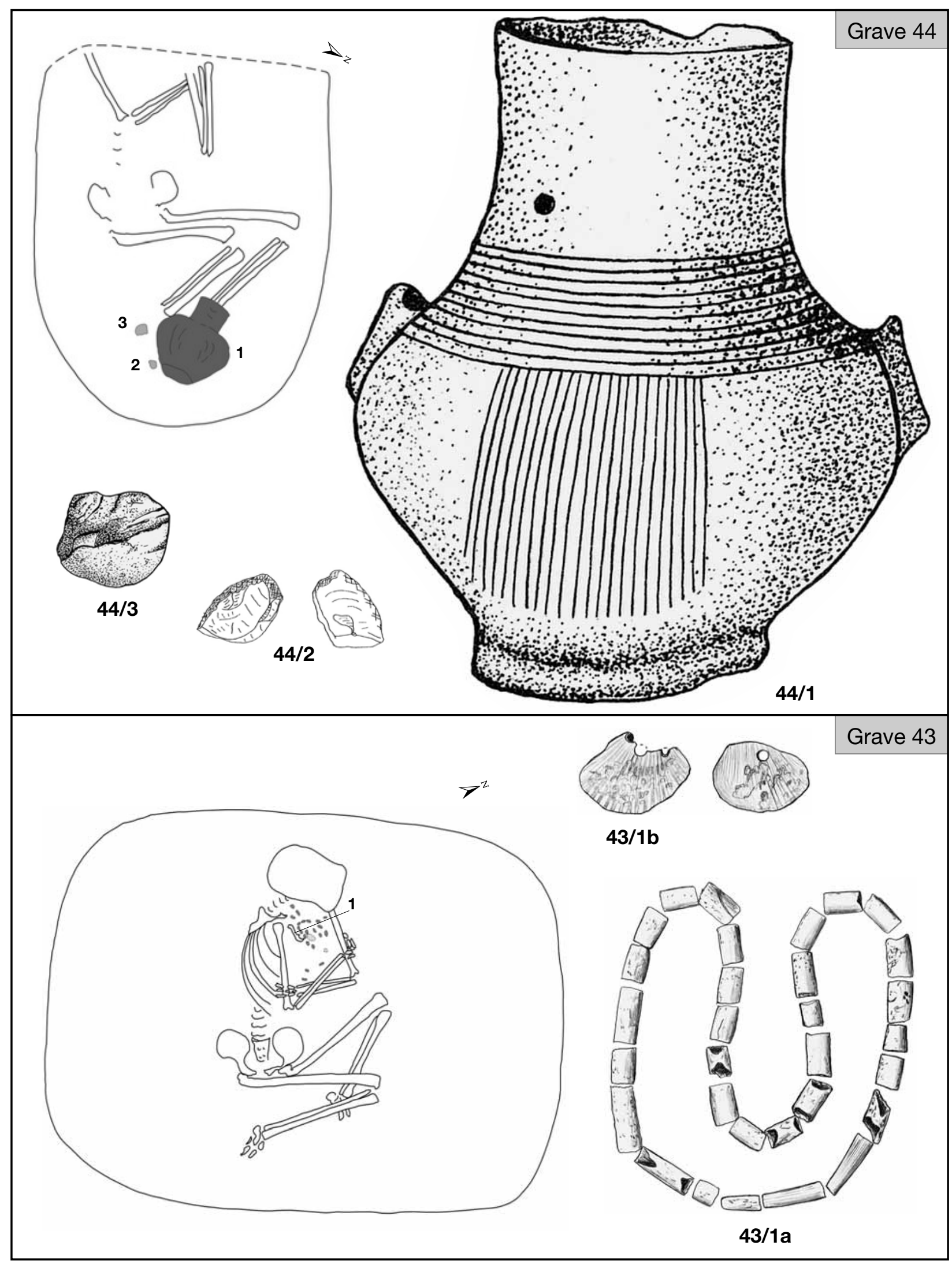

Plate XXI. Graves 43-44 (44/1, 3: after JÓZSEF KOREK’s grave sheet; 44/2: after Cs. BALOGH 1993) 


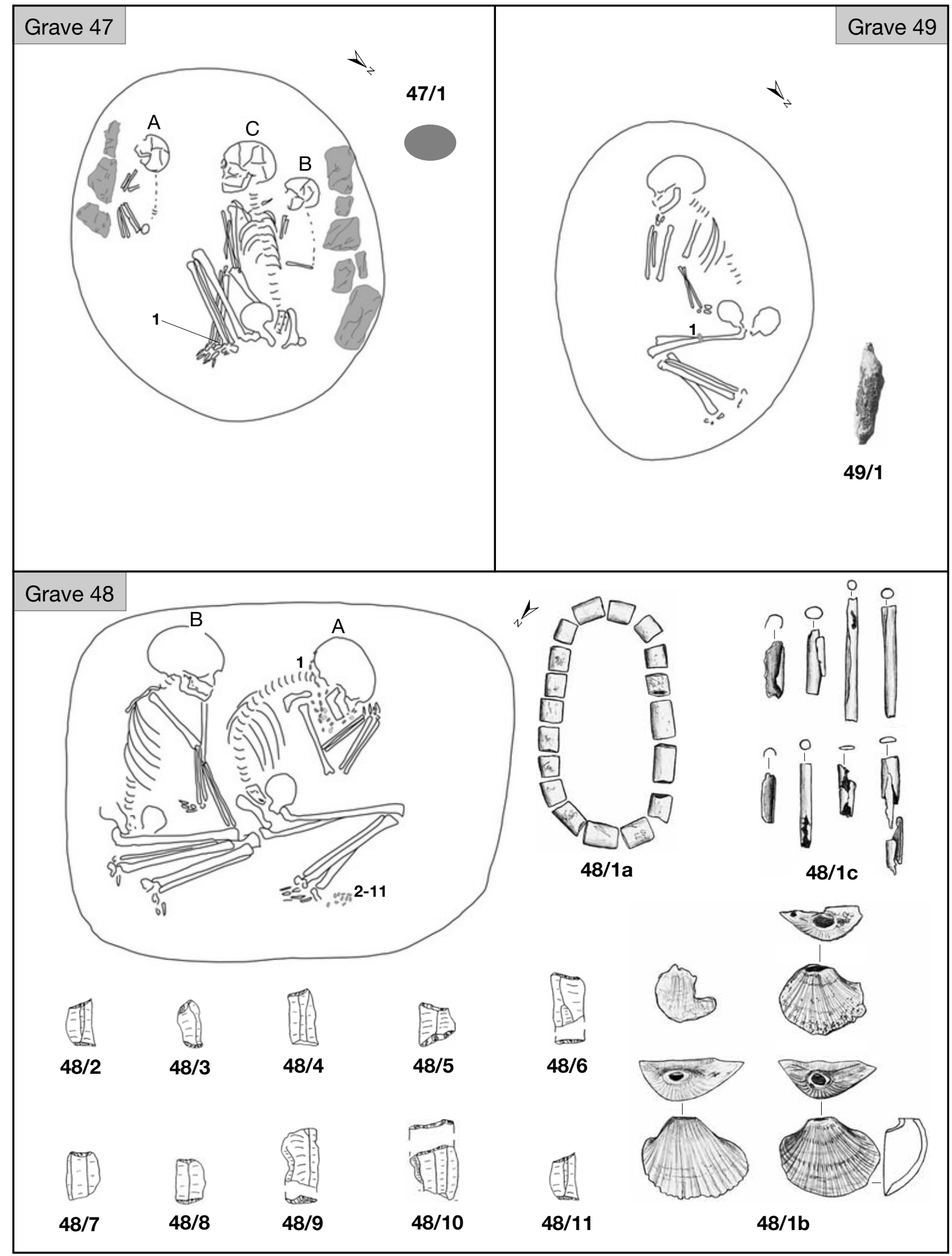

Plate XXII. Graves 47-49 (48/2-11: after Cs. BALOGH 1993; 49/1: after BANNER 1956, Taf. XCV. 19) 


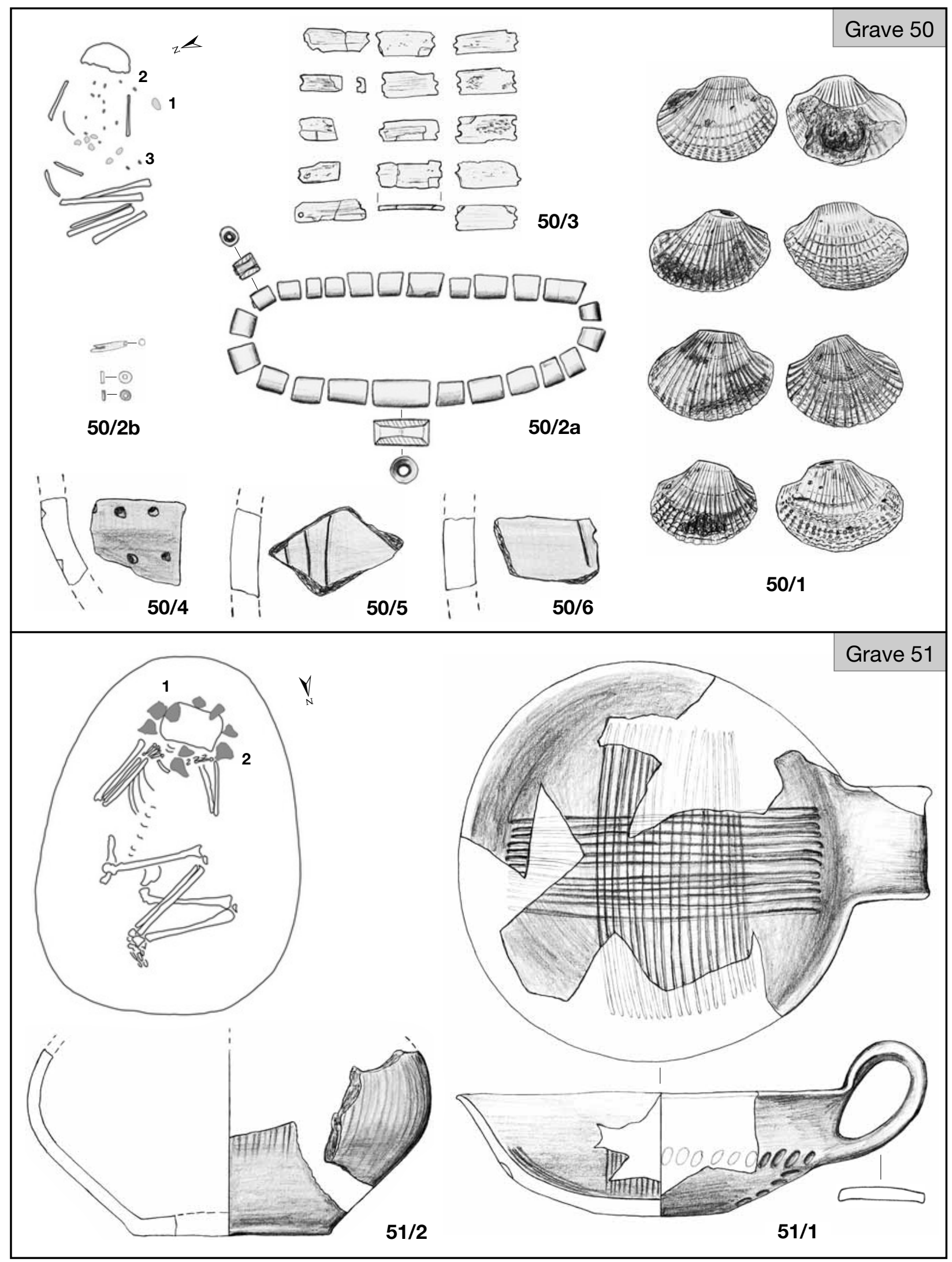

Plate XXIII. Graves 50-51 


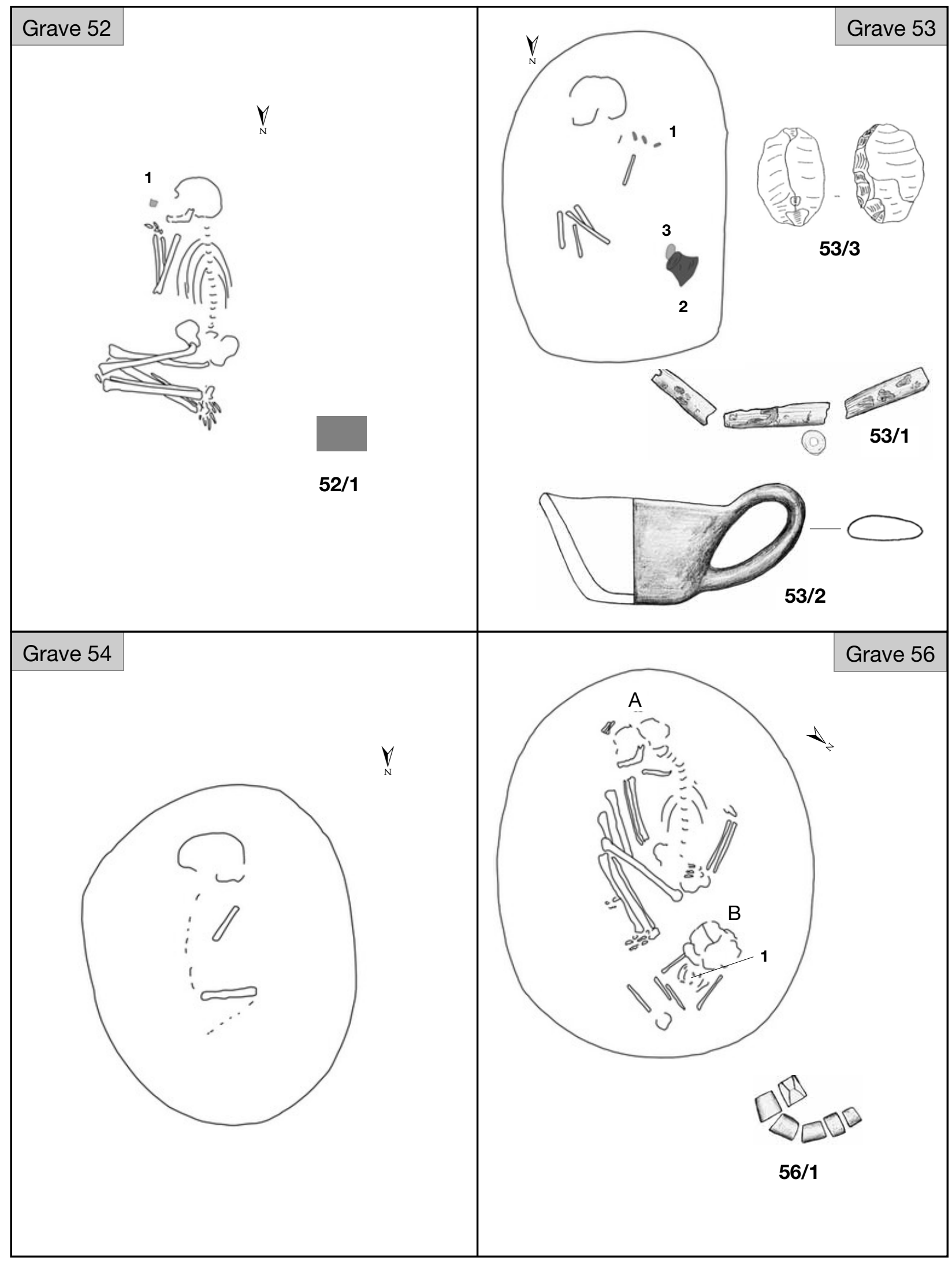

Plate XXIV. Graves 52-54 and 56 (53/3: after Cs. BALOGH 1993) 


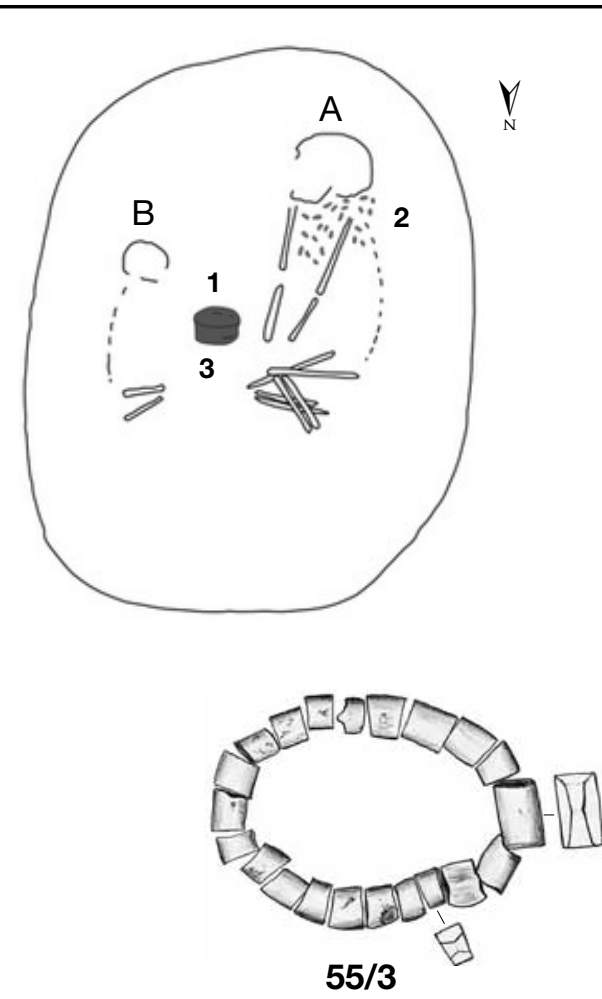

Grave 55
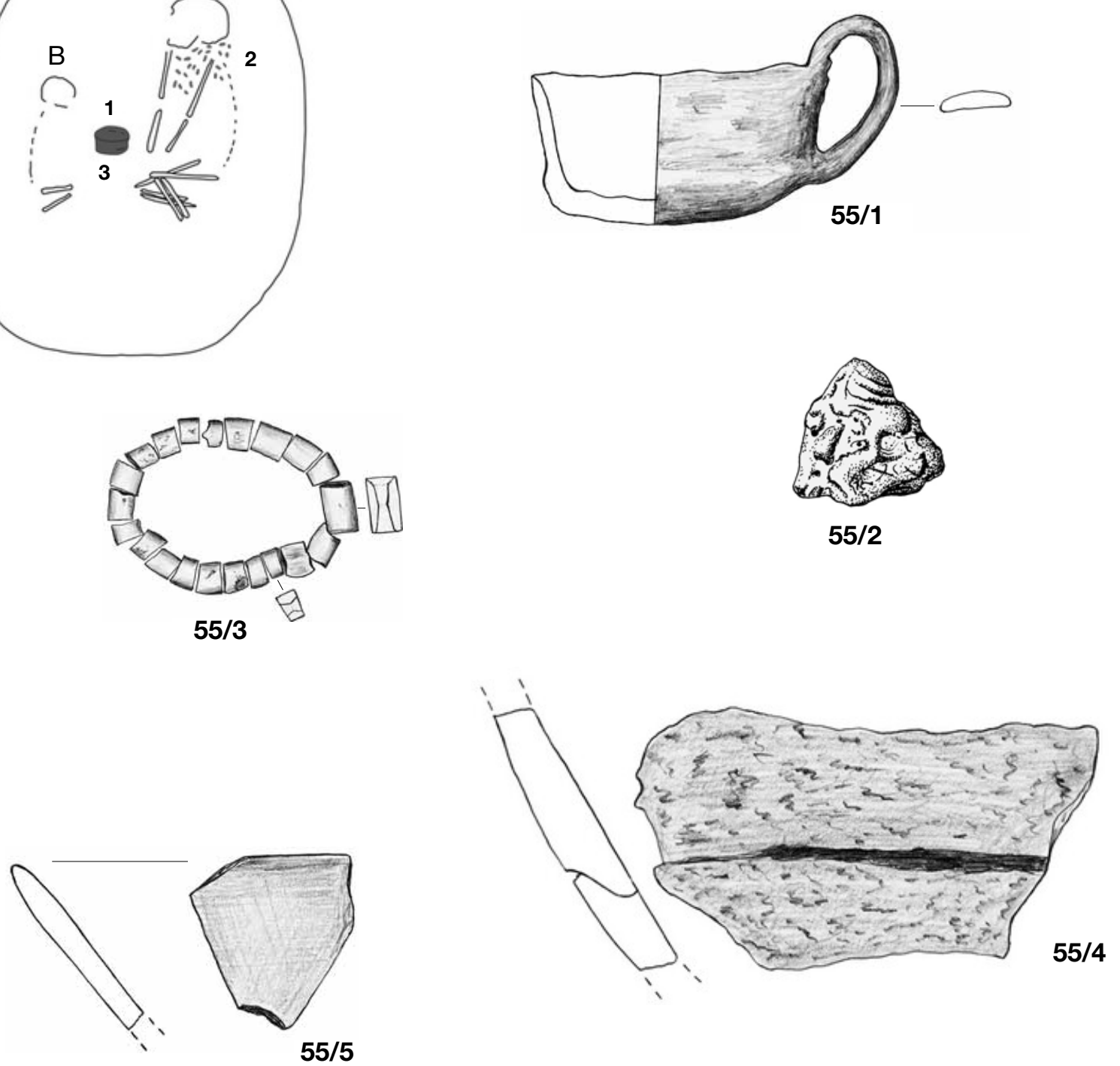

$55 / 5$
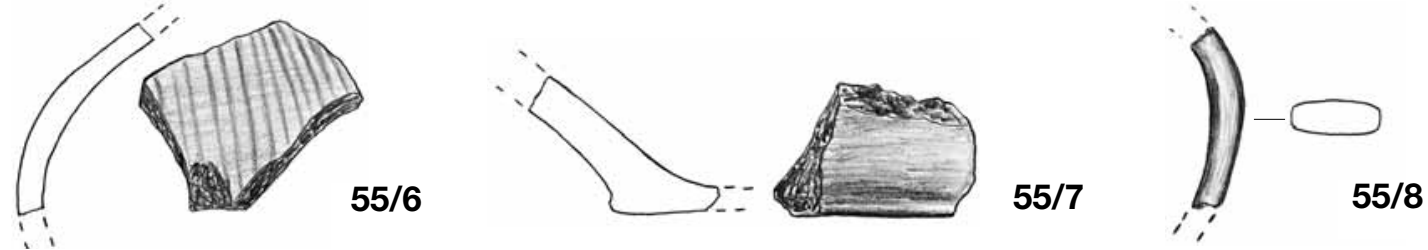

Plate XXV. Grave 55 (55/2: after JóZSEF KOREK's grave sheet) 


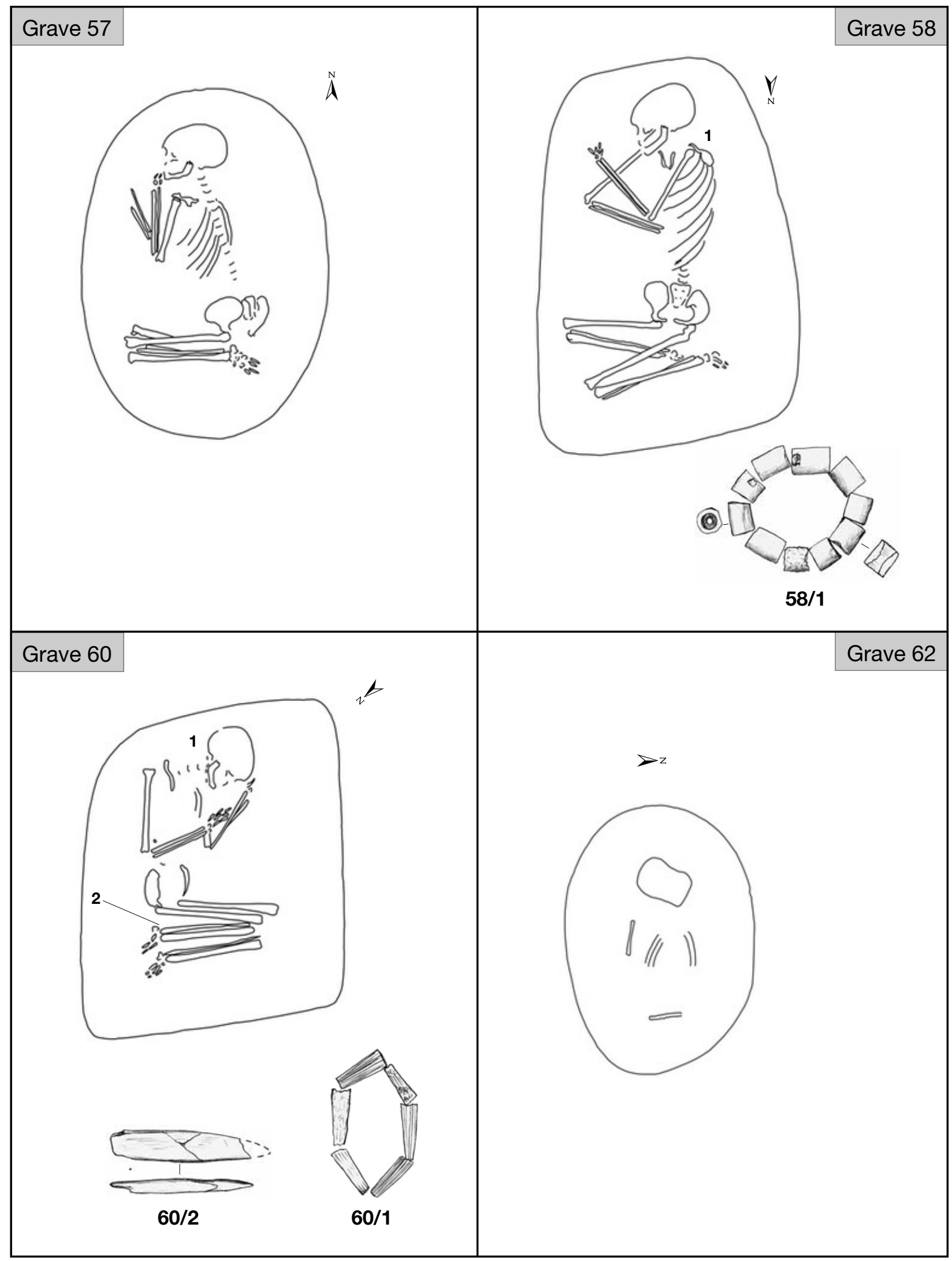

Plate XXVI. Graves 57-58, 60 and 62 


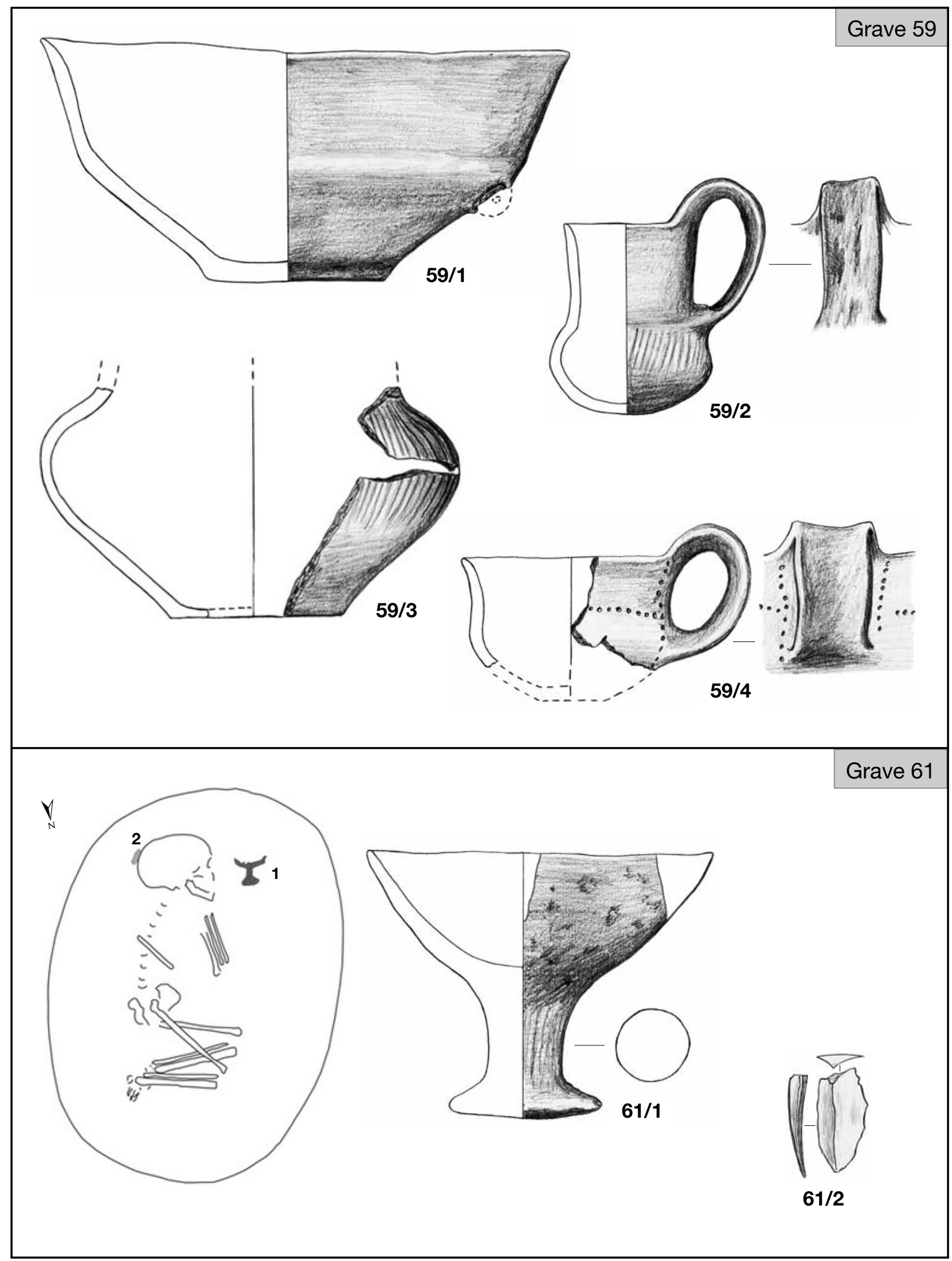

Plate XXVII. Graves 59 and 61 


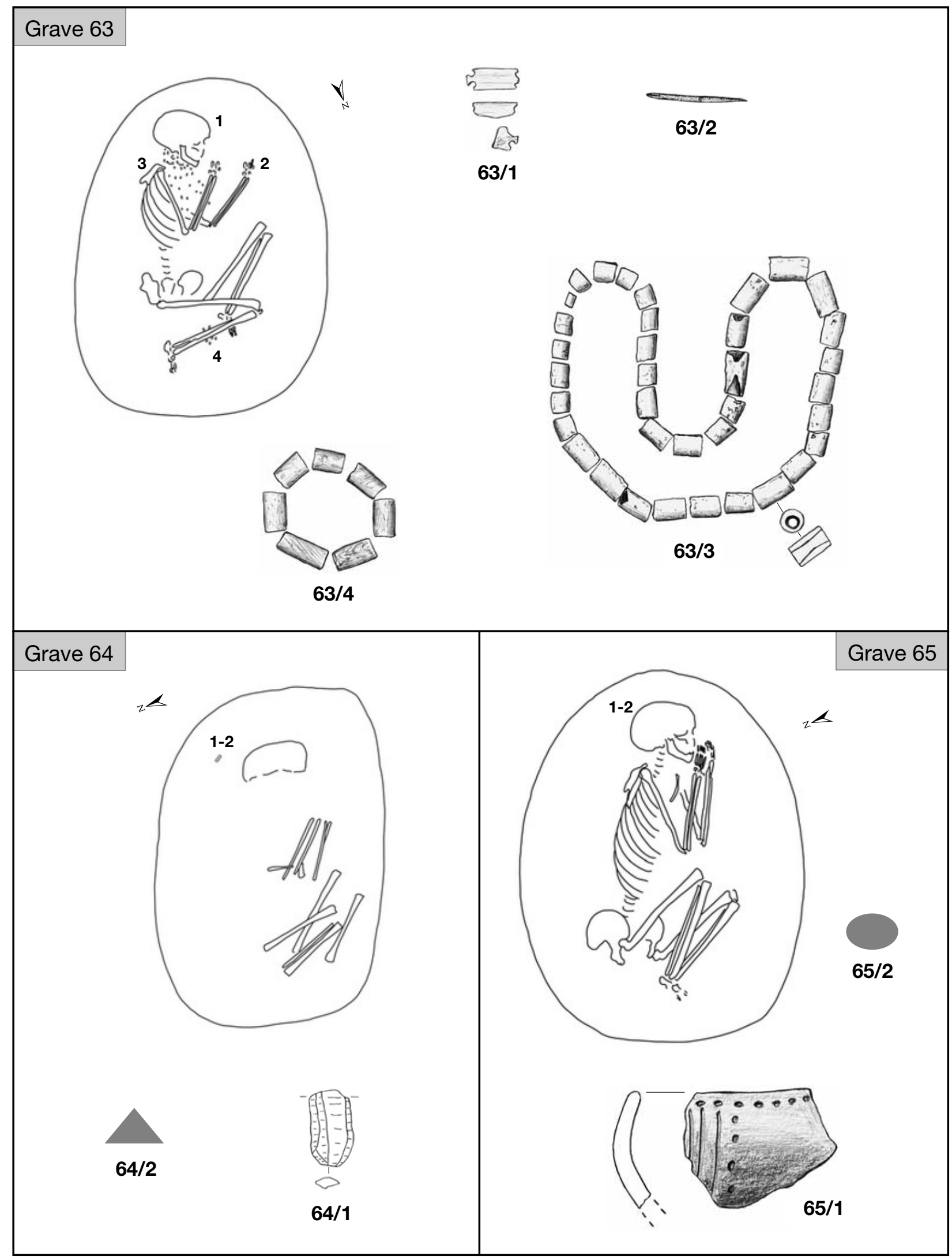

Plate XXVIII. Graves 63-65 (63/2: after JózSEF KoREK’s grave sheet; 64/1: after Cs. BALOGH 1993) 


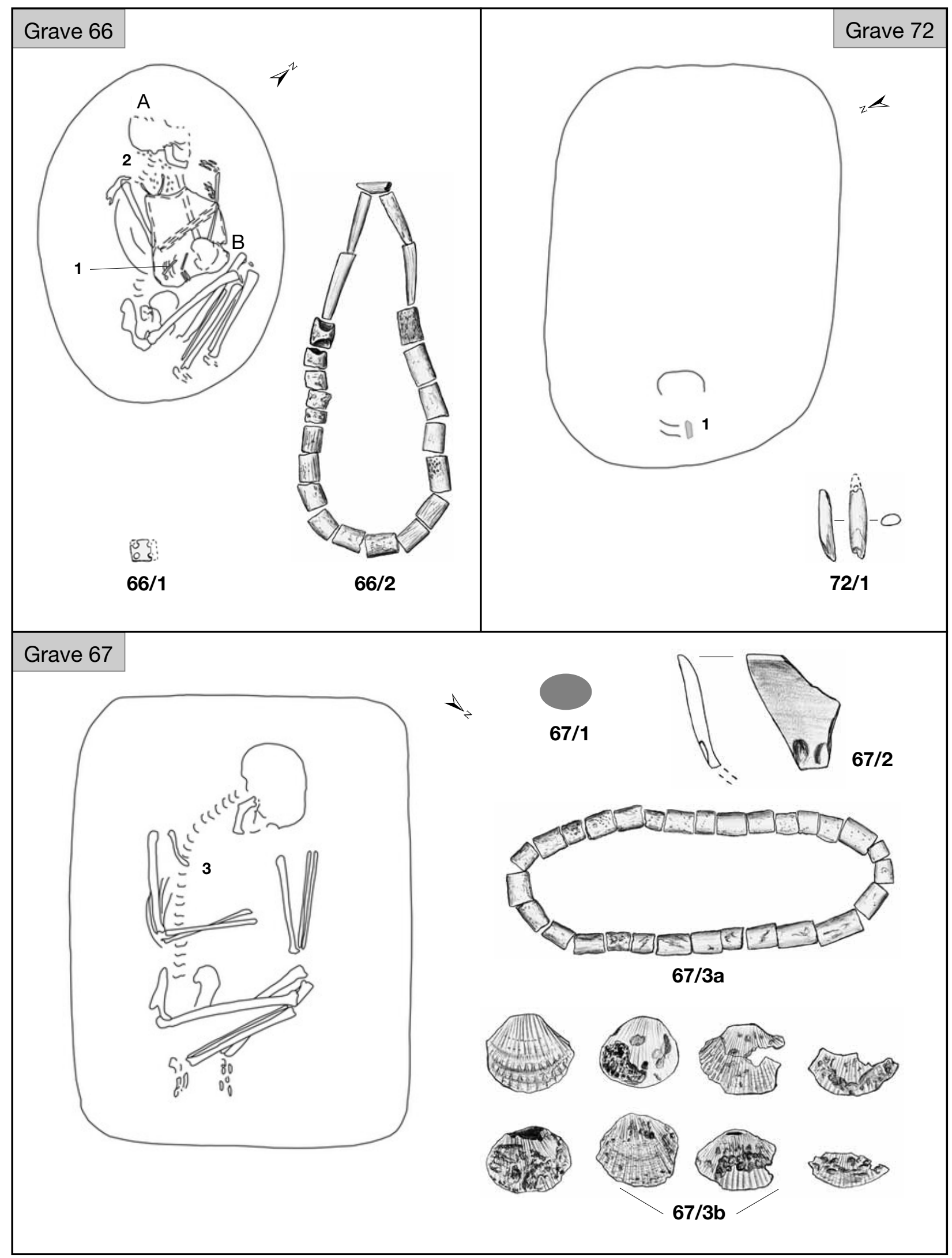

Plate XXIX. Graves 66-67 and 72 


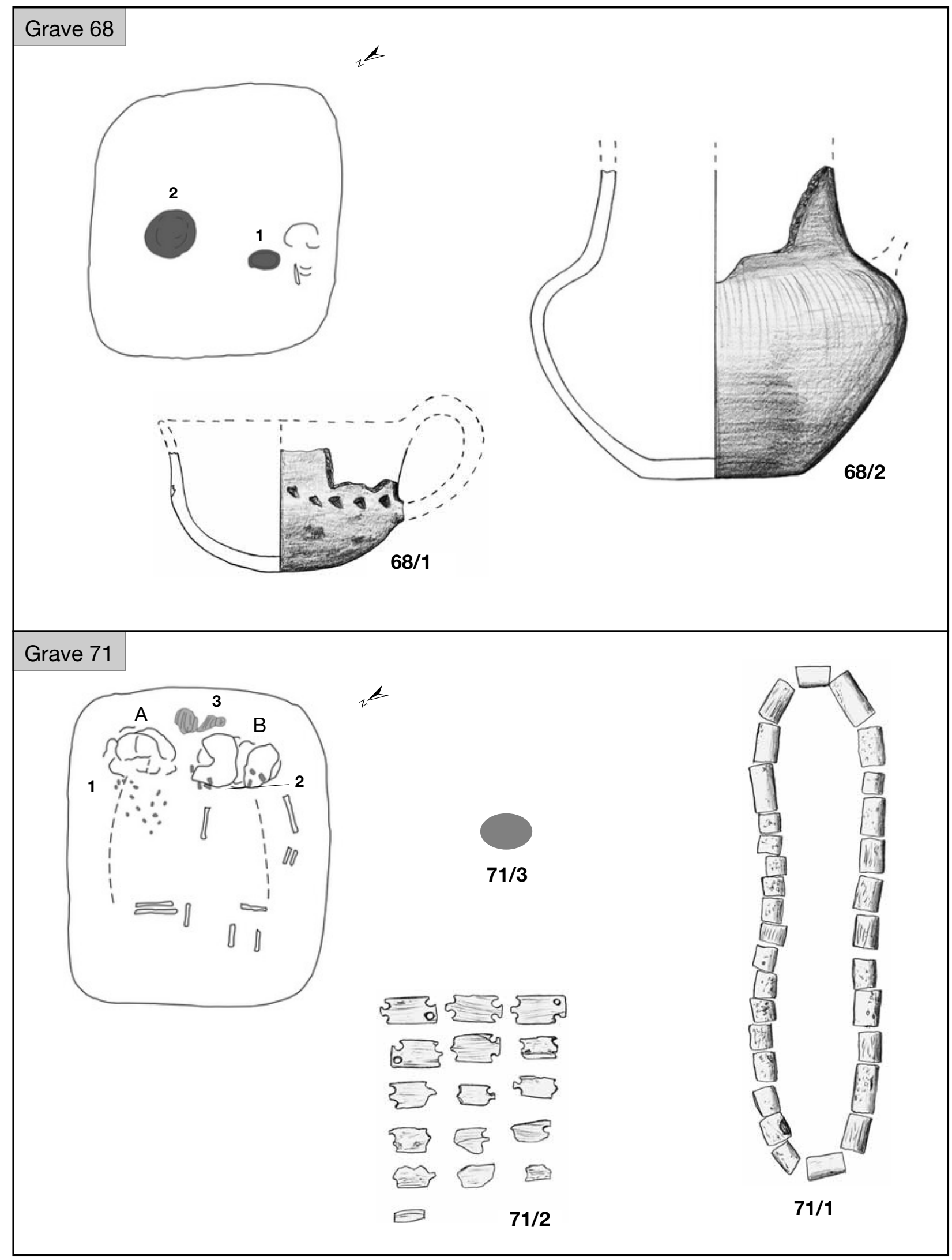

Plate XXX. Graves 68 and 71 

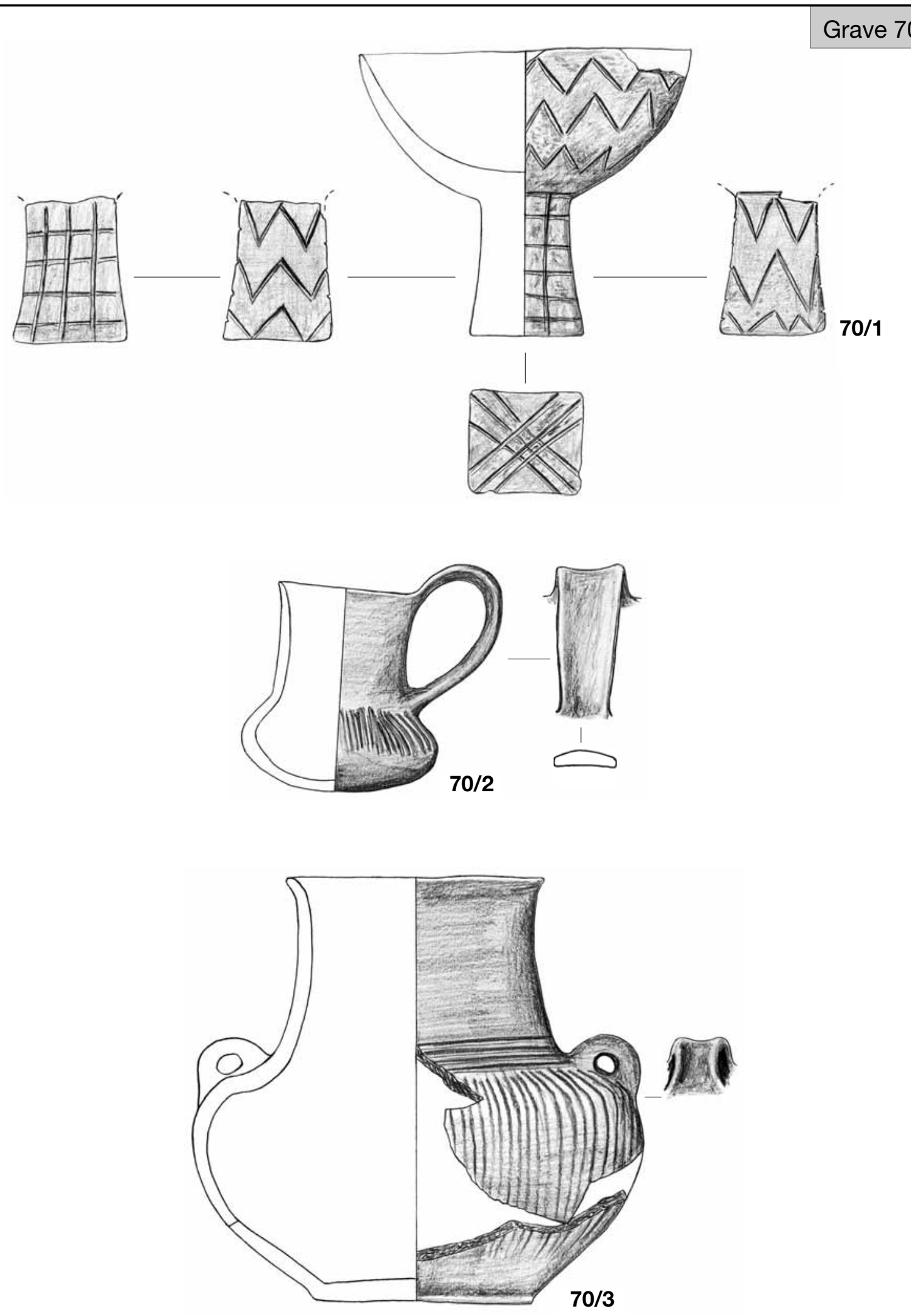

Plate XXXI. Grave 70 


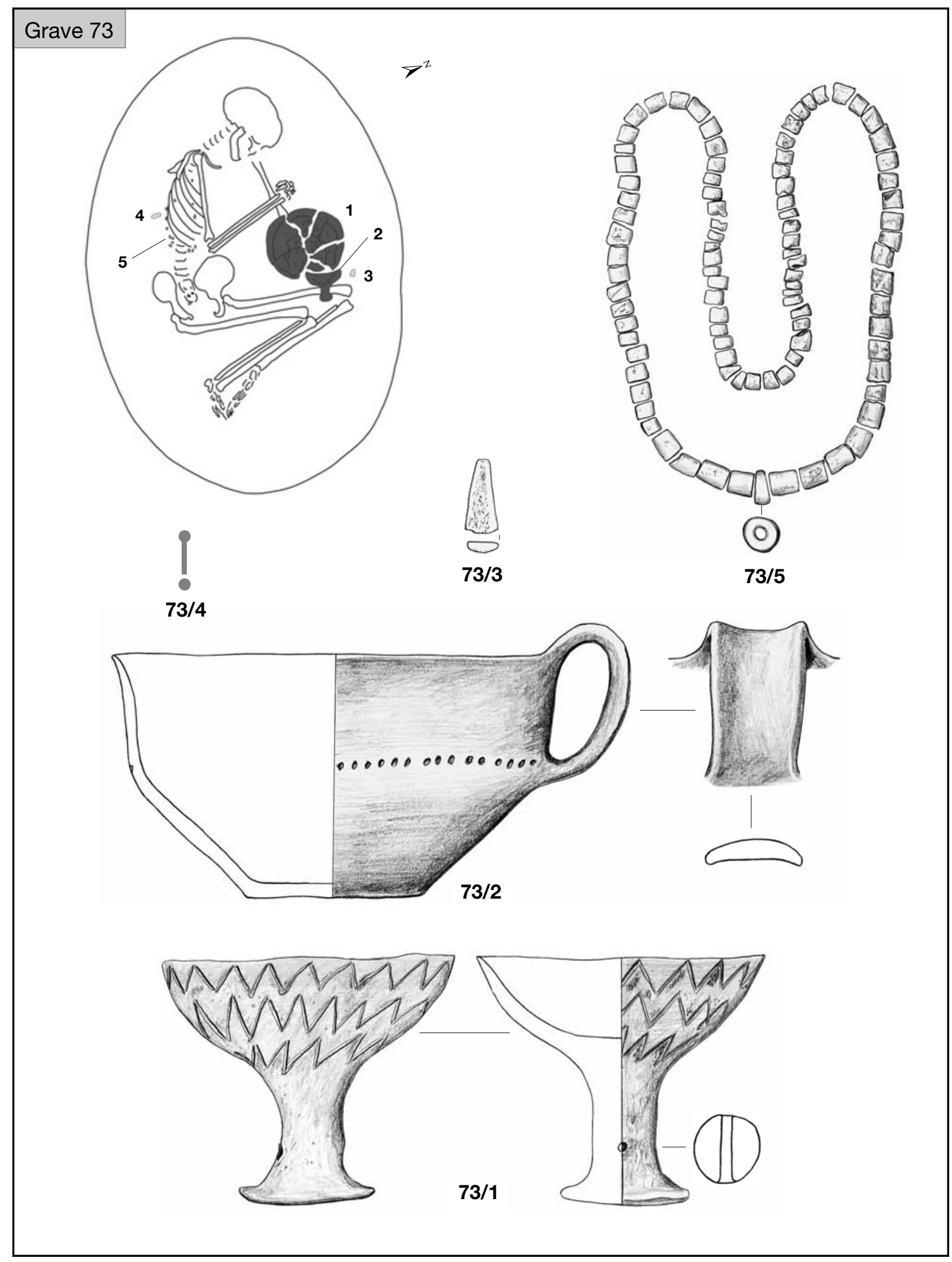

Plate XXXII. Grave 73 


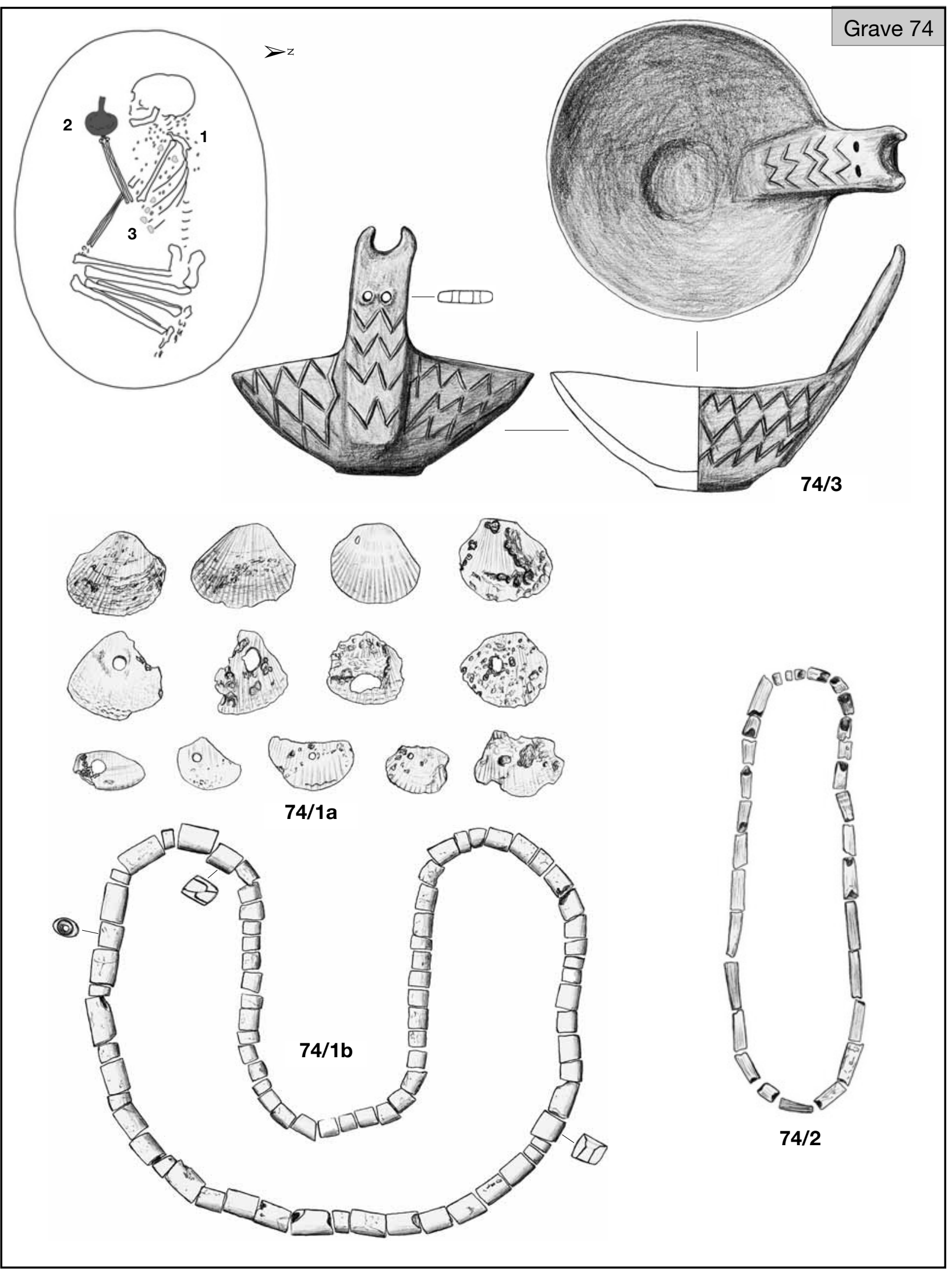

Plate XXXIII. Grave 74 


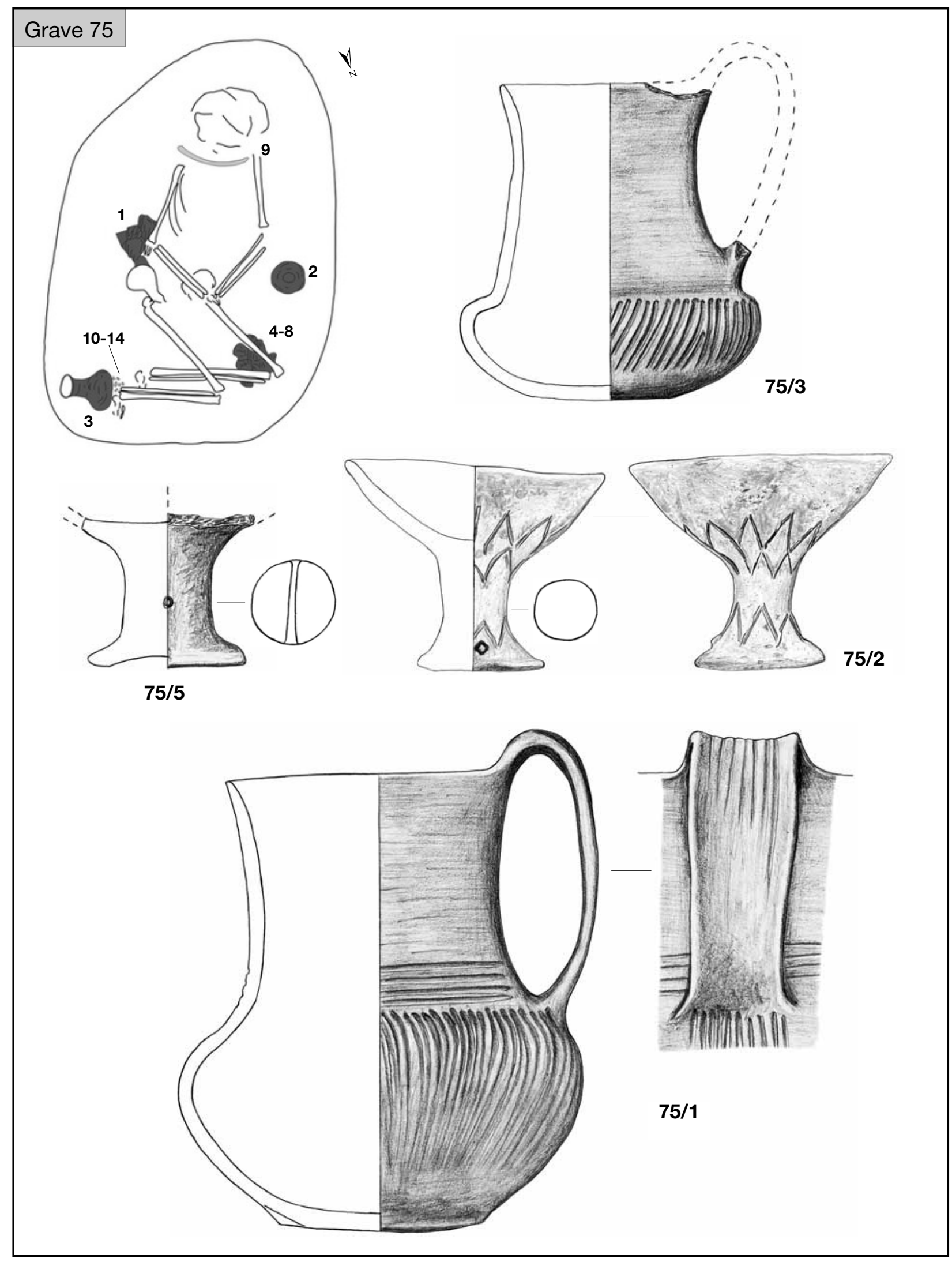

Plate XXXIV. Grave 75 


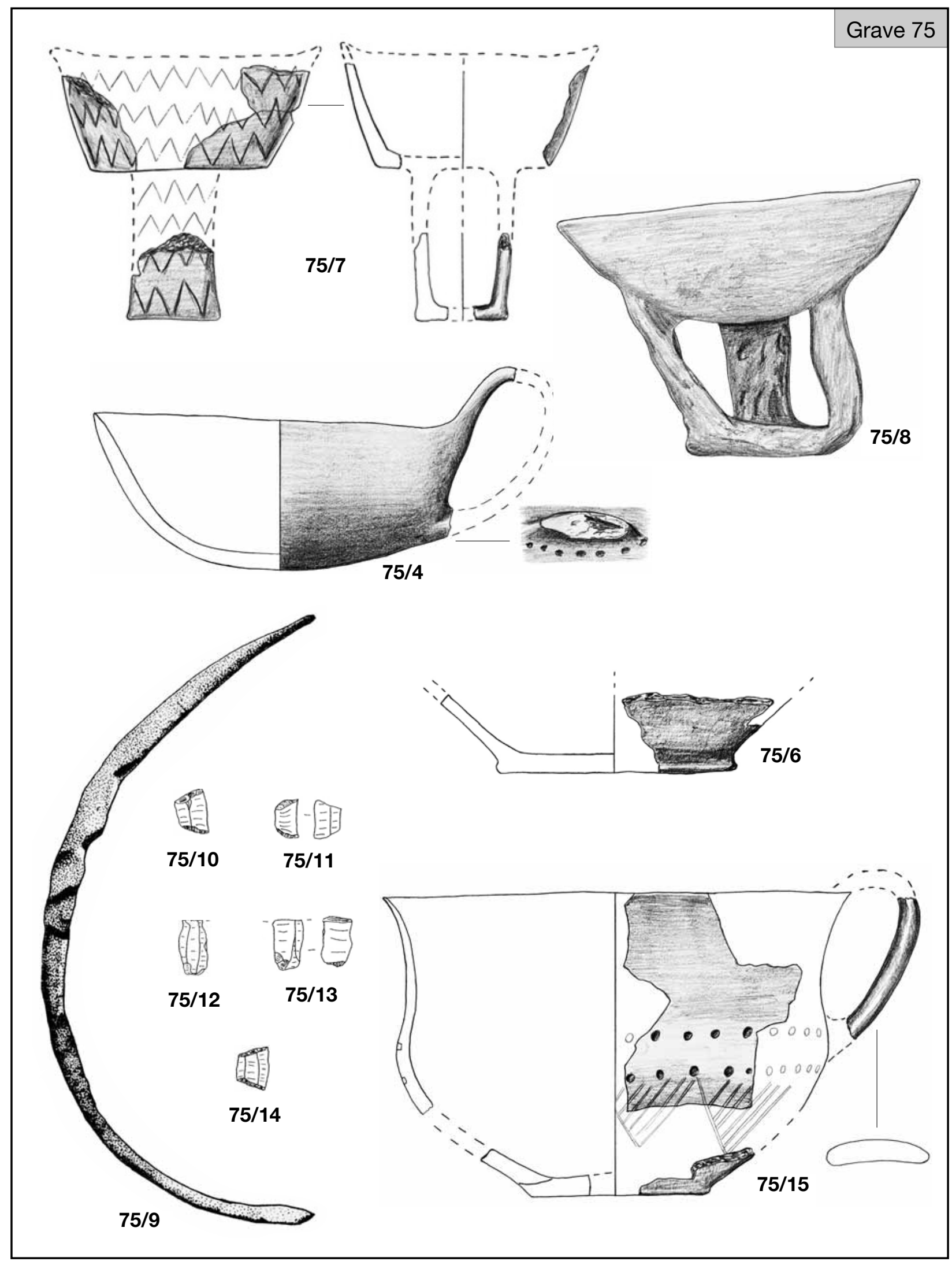

Plate XXXV. Grave 75 (75/9: after JóZSEF KonEK’s grave sheet; 75/10-14: after Cs. BALOGH 1993) 


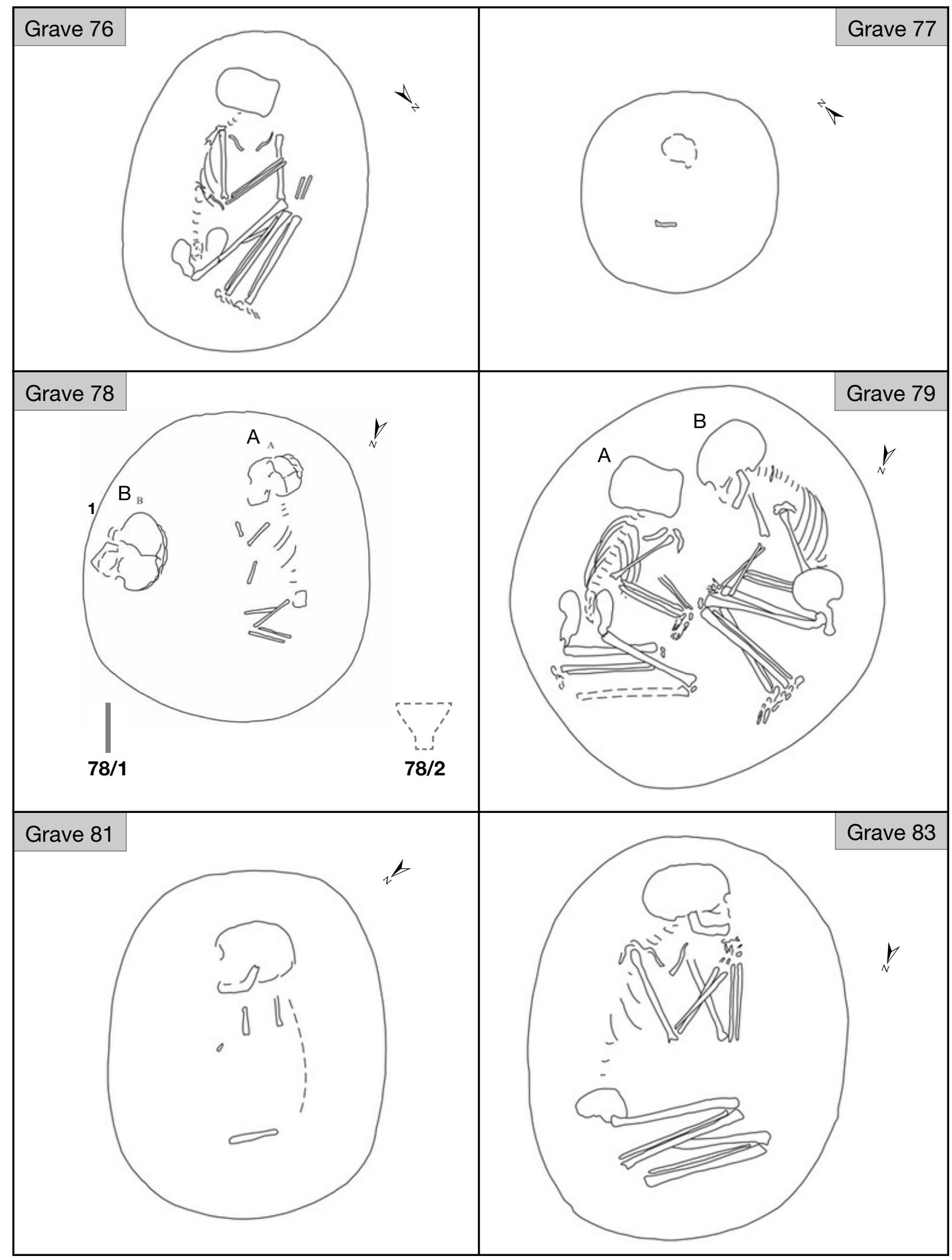

Plate XXXVI. Graves 76-79, 81 and 83 


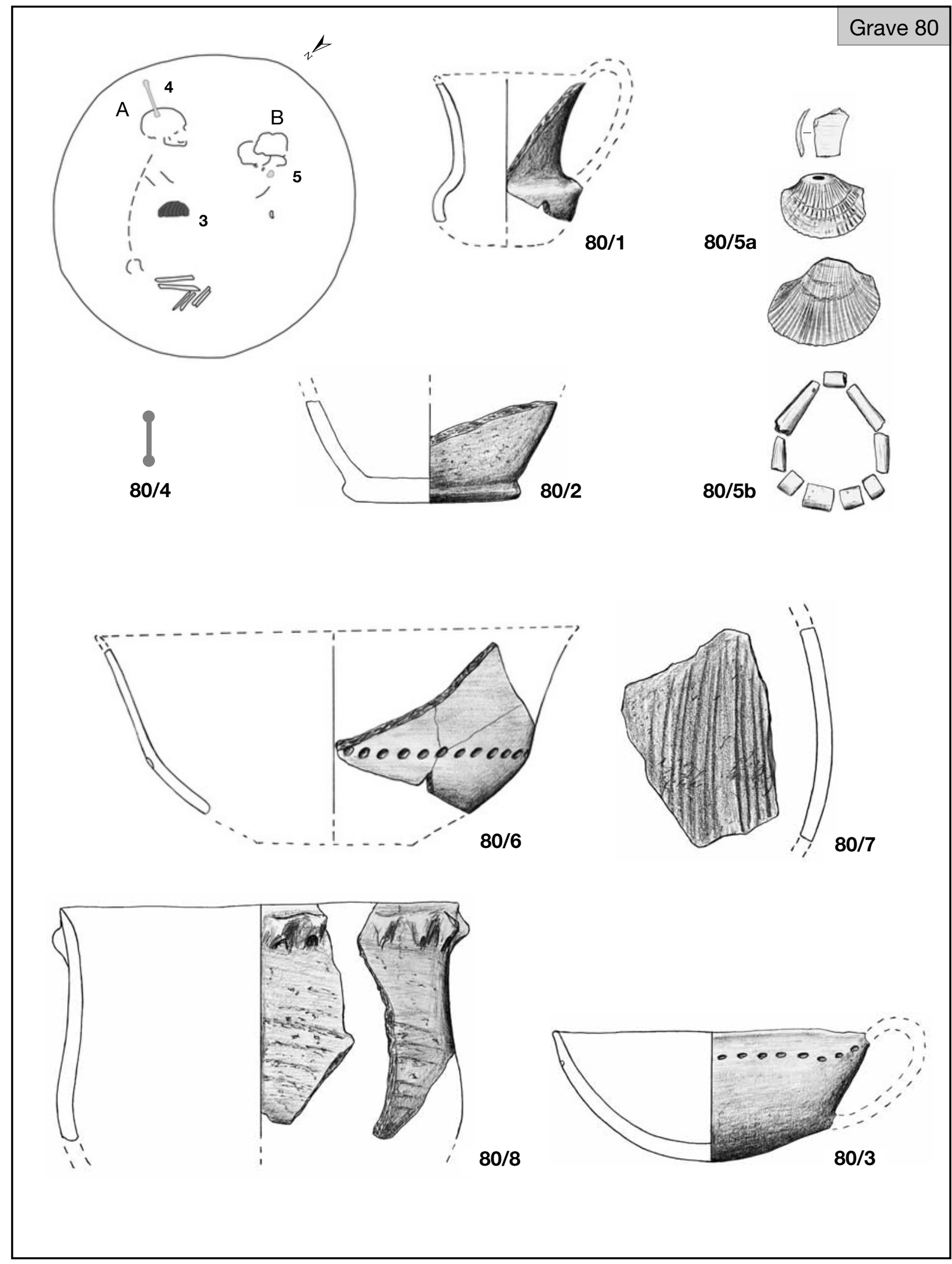

Plate XXXVII. Grave 80 


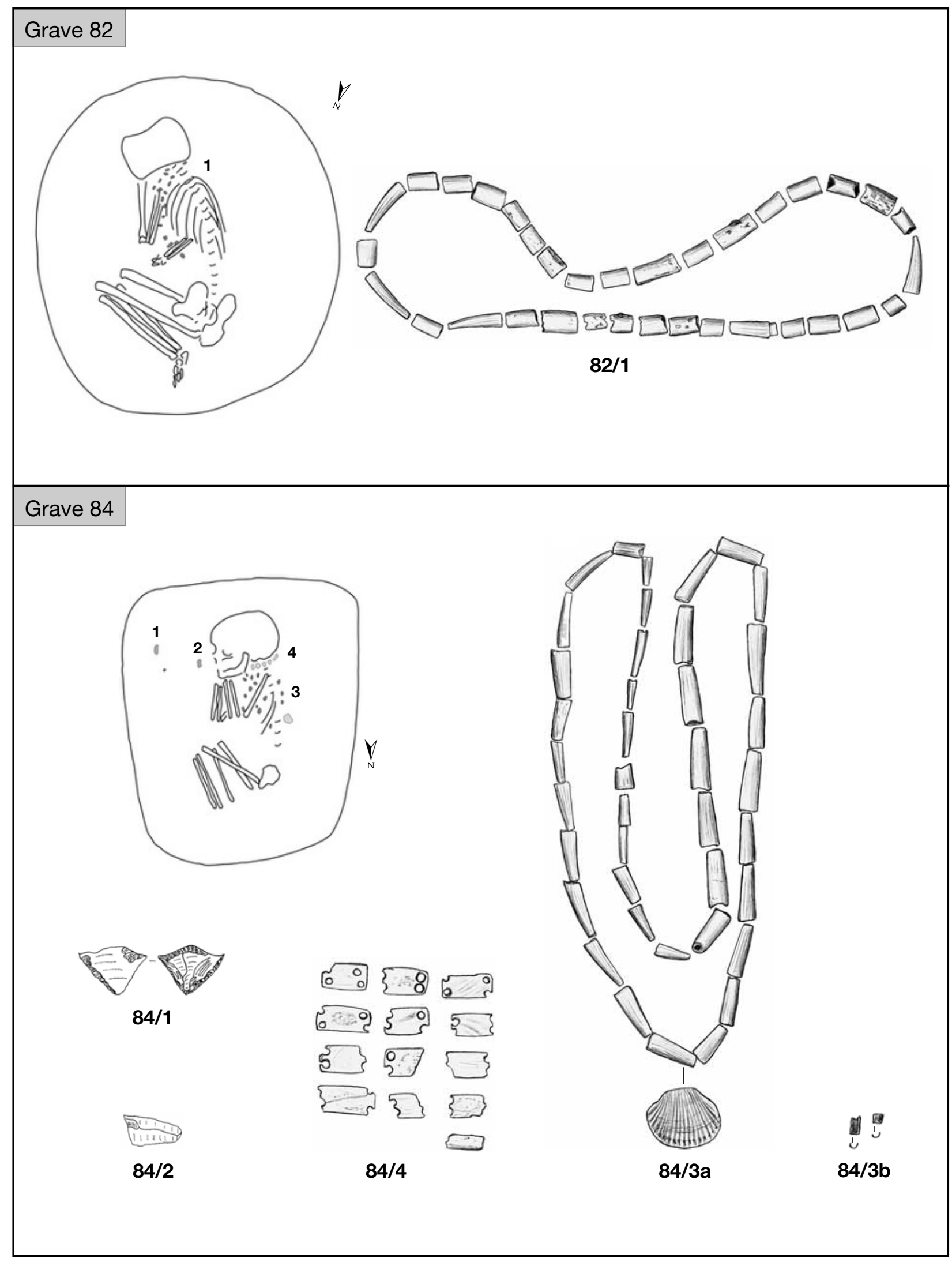

Plate XXXVIII. Graves 82 and 84 (84/1-2: after Cs. BALOGH 1993) 


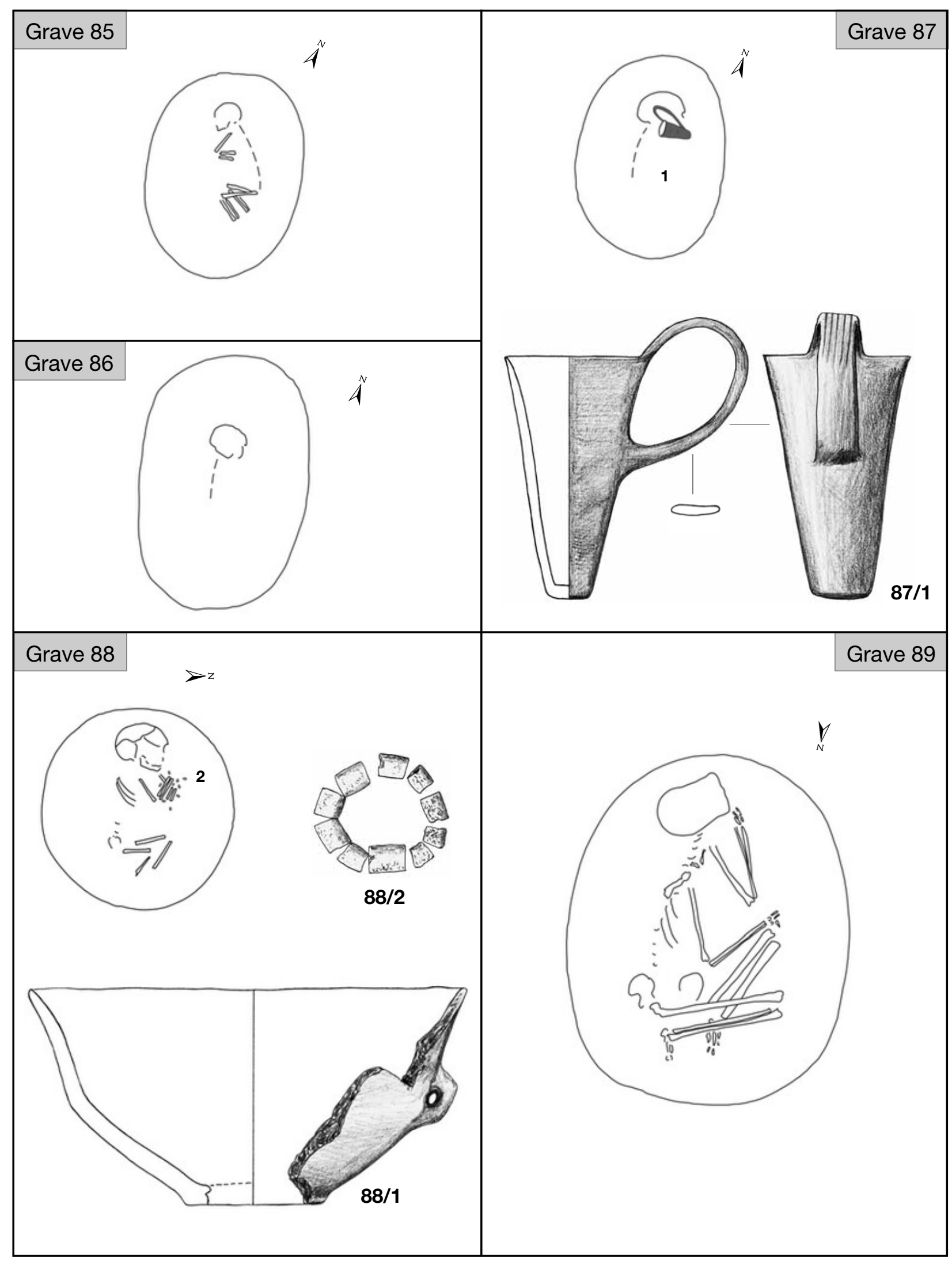

Plate XXXIX. Graves 85-89 


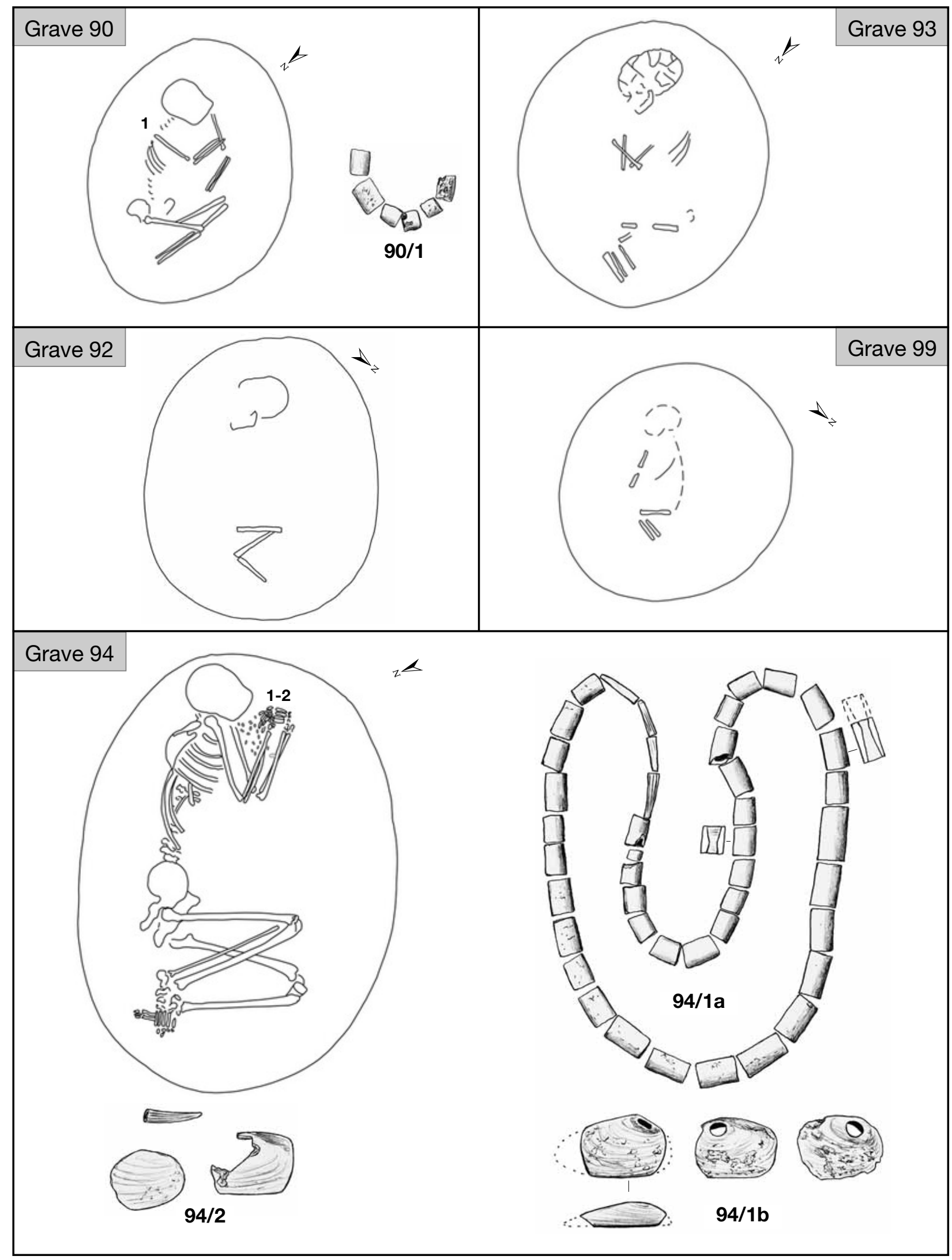

Plate XL. Graves 90, 92-94 and 99 


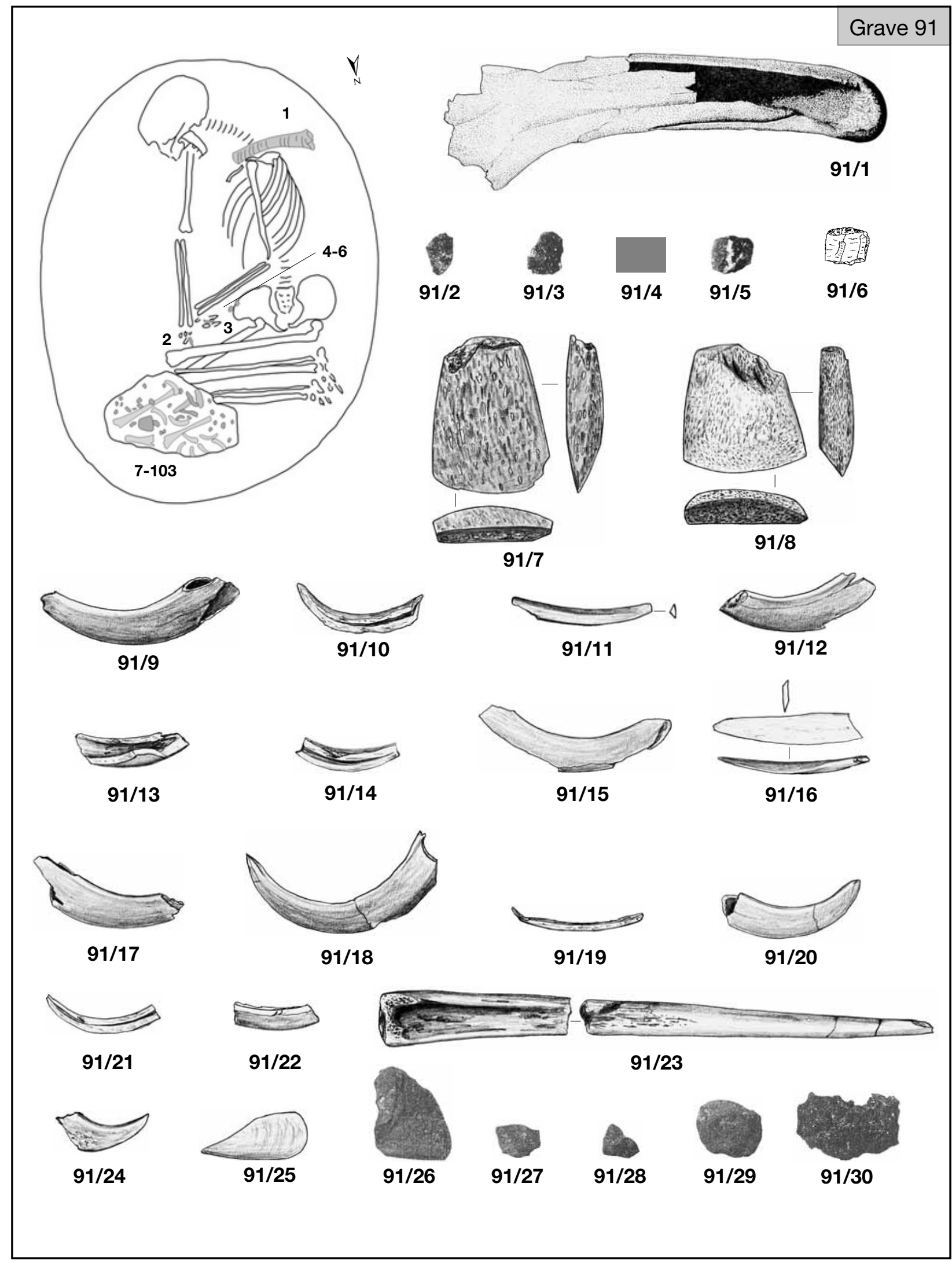

Plate XLI. Grave 91 (91/1: after JózSEF KoreK's grave sheet; 91/2-3, 5: after BANNER 1956, Taf. CII. 25, 35, 37; 91/6: after Cs. BALOGH 1993; 91/26-30: after BANNER 1956, Taf. CII. 3, 28-30 ) 


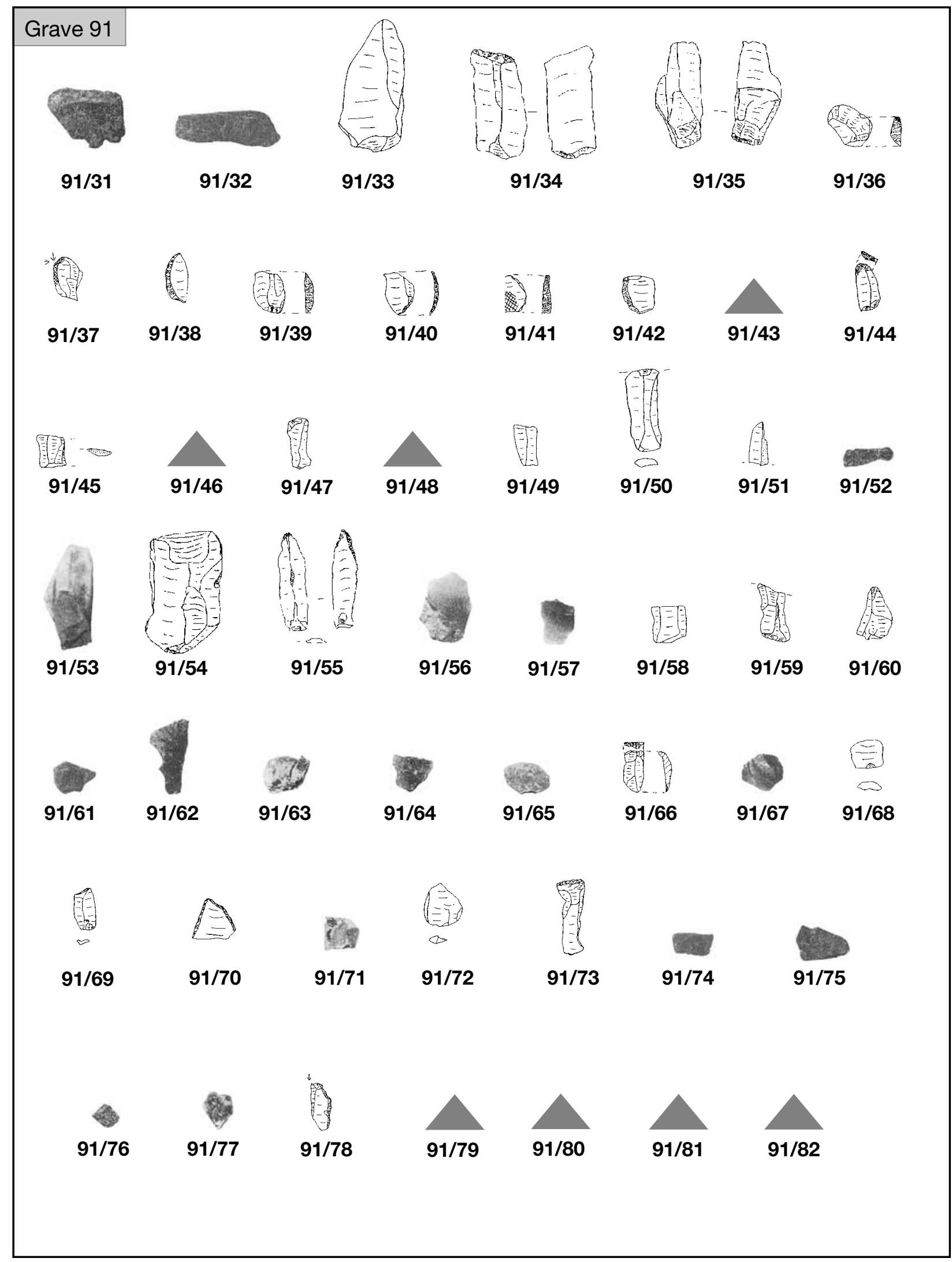

Plate XLII. Grave 91 (91/31-32, 52-53, 56-57, 61-65, 67, 71, 74-77: after BANNER 1956, Taf. CII. 7, 9-10, 11, $13,15,17-20,21,23-24,31-32,34,36$; 91/33-42, 44-45, 47, 49-51, 54-55, 58-60, 69-70, 72-73, 78: after Cs. BALOGH 1993) 


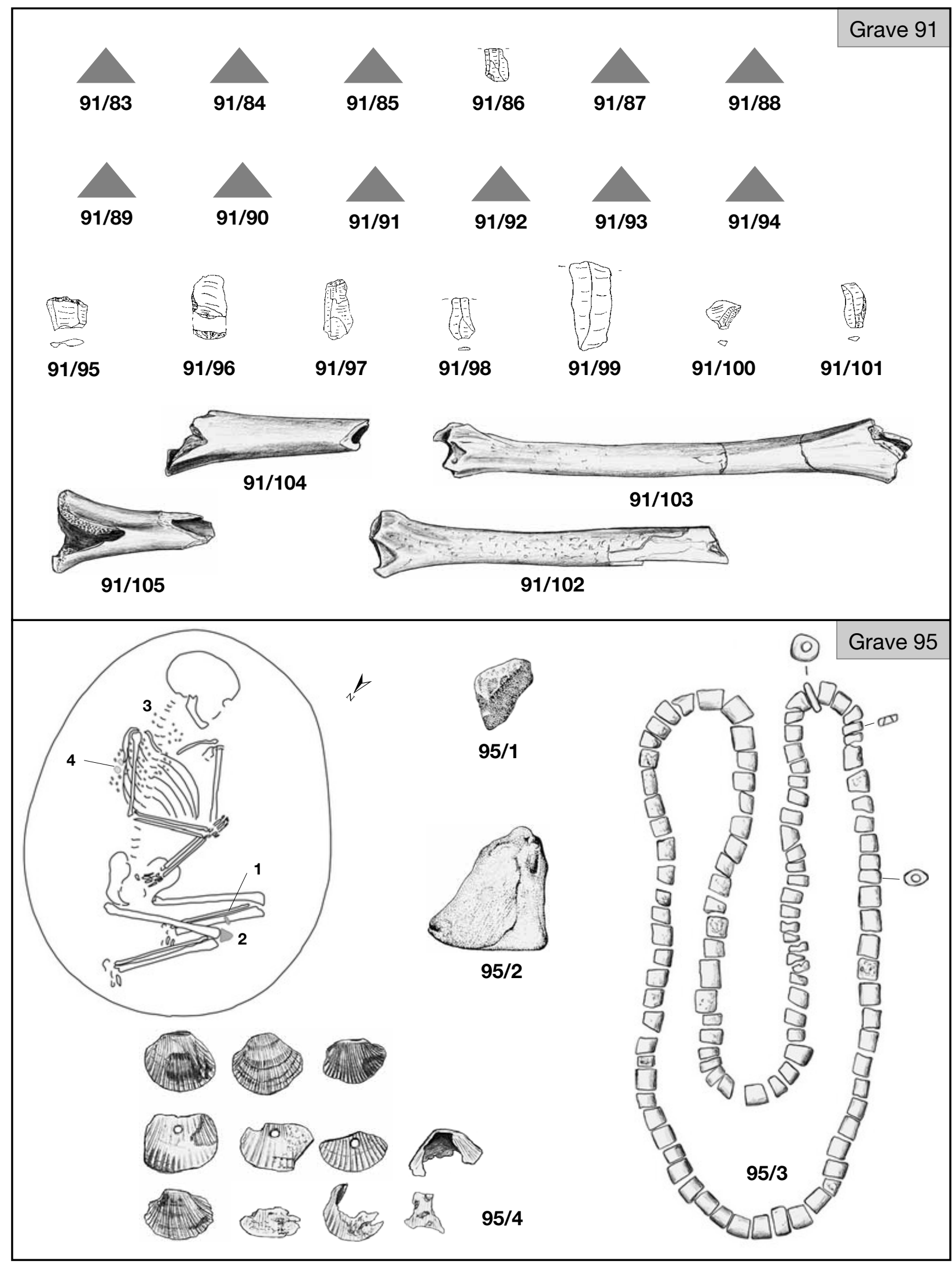

Plate XLIII. Graves 91 and 95 (91/86, 95-100: after Cs. BALOGH 1993; 95/1-2: after JózSEF KoreK’s grave sheet) 


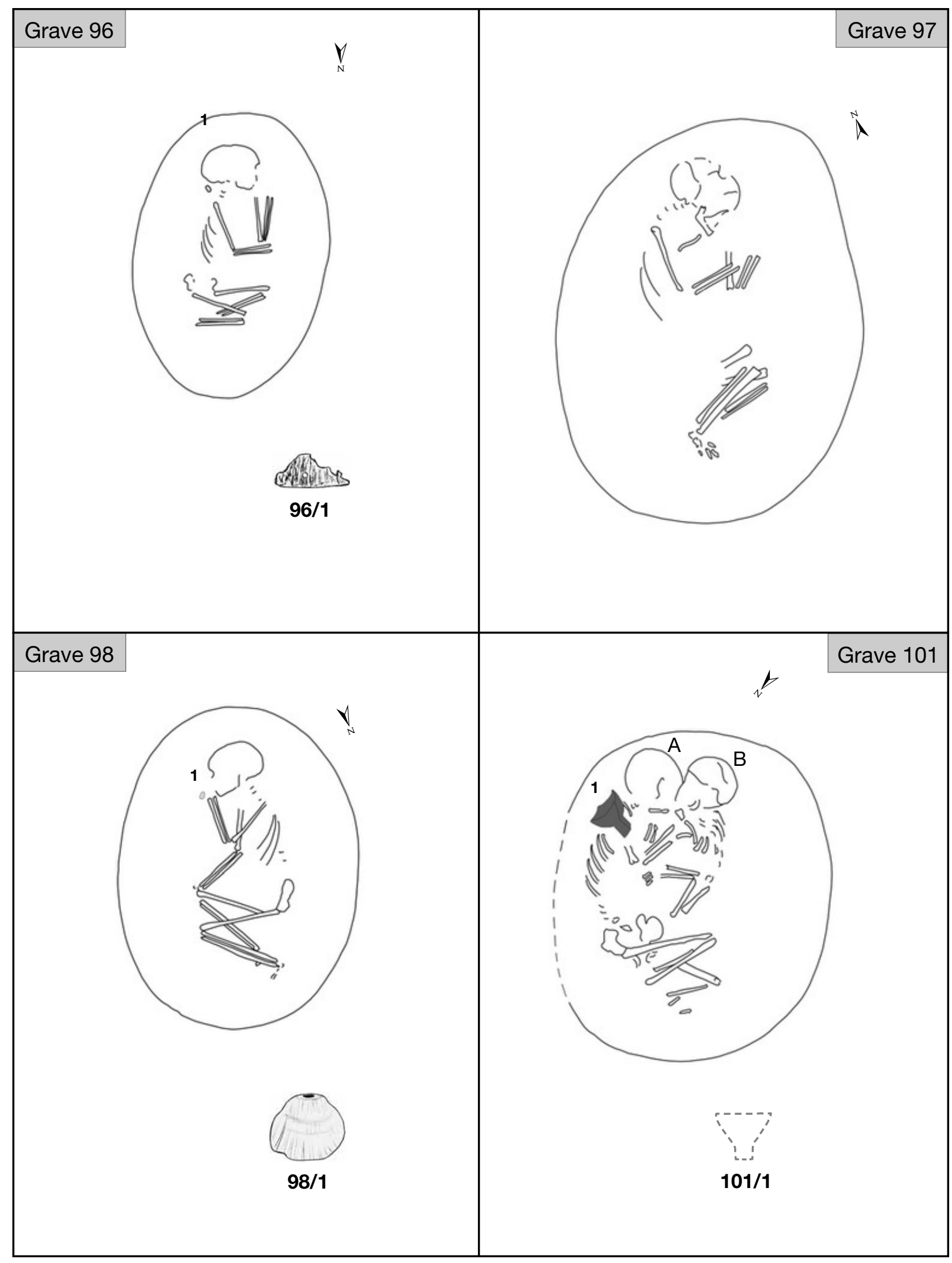

Plate XLIV. Graves 96-98 and 101 


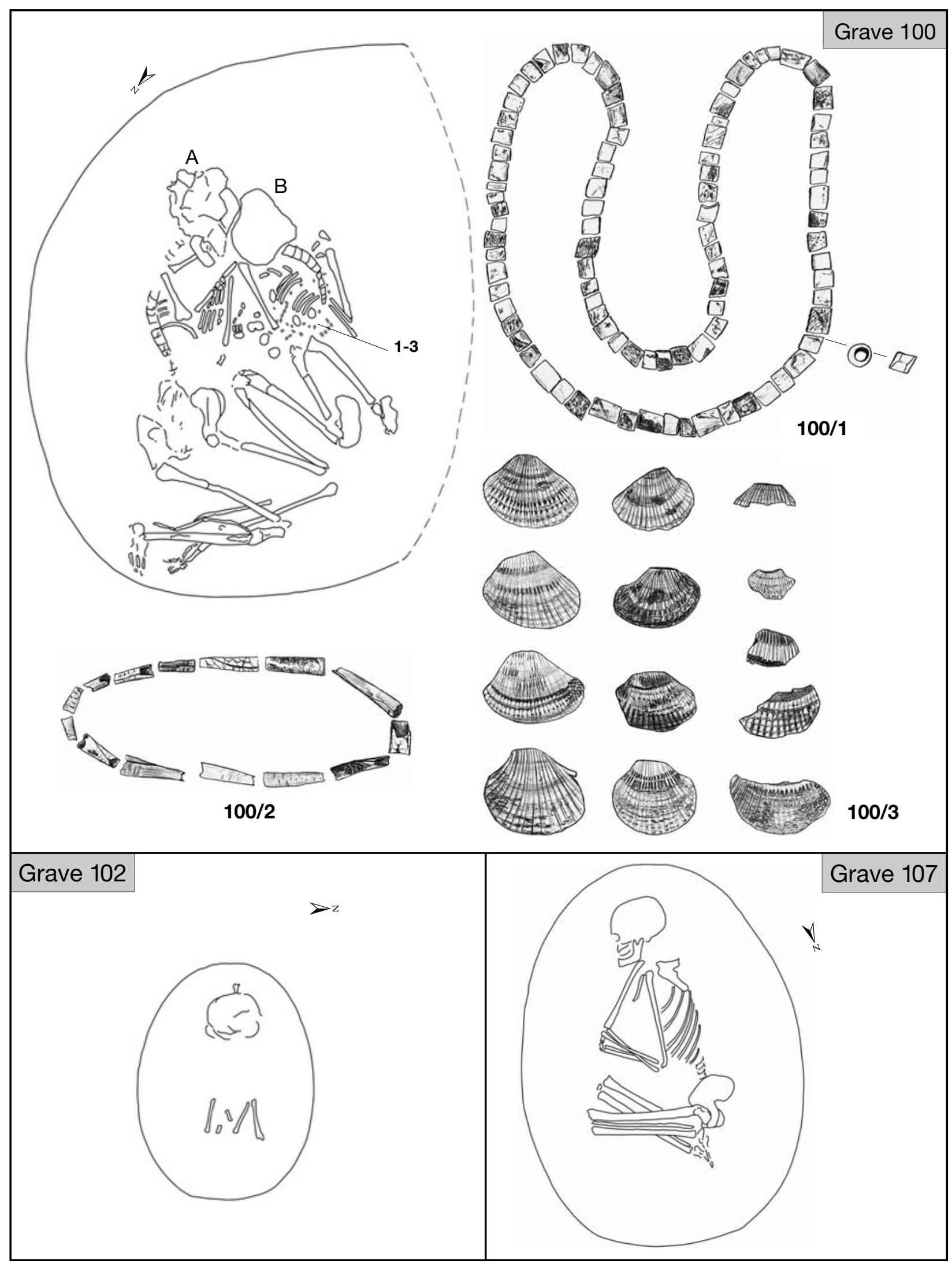

Plate XLV. Graves 100, 102 and 107 


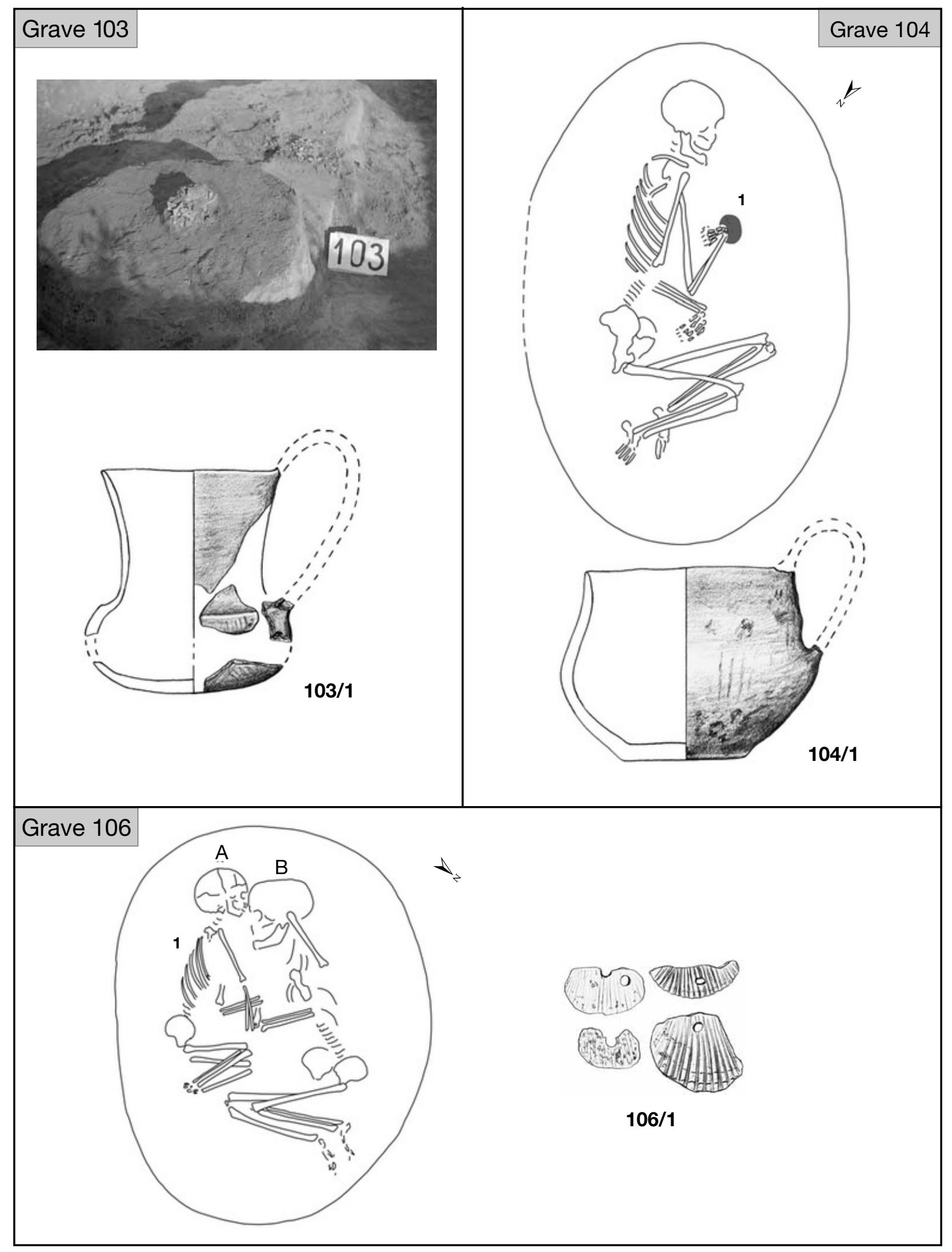

Plate XLVI. Graves 103-104 and 106 


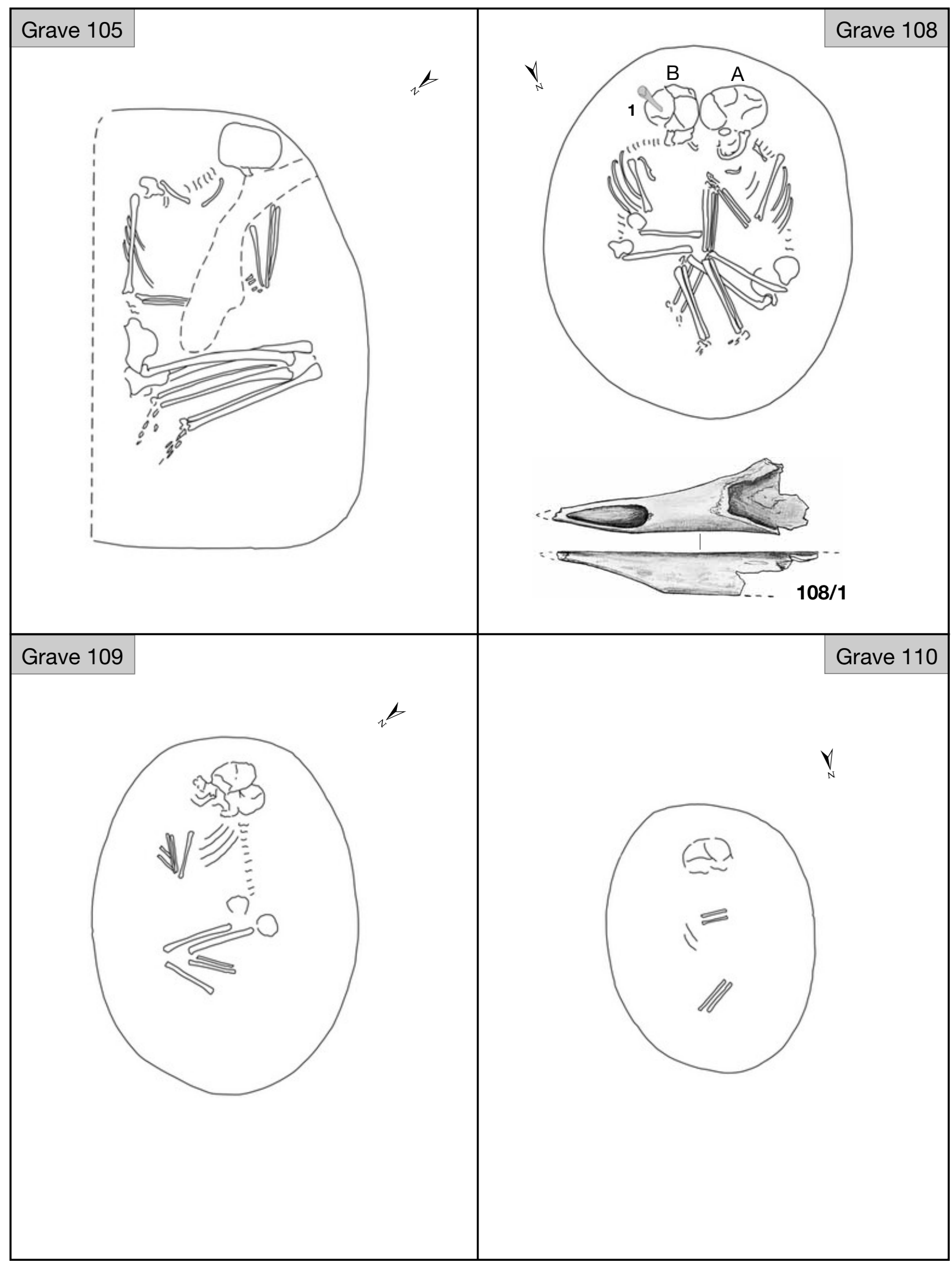

Plate XLVII. Graves 105 and 108-110 


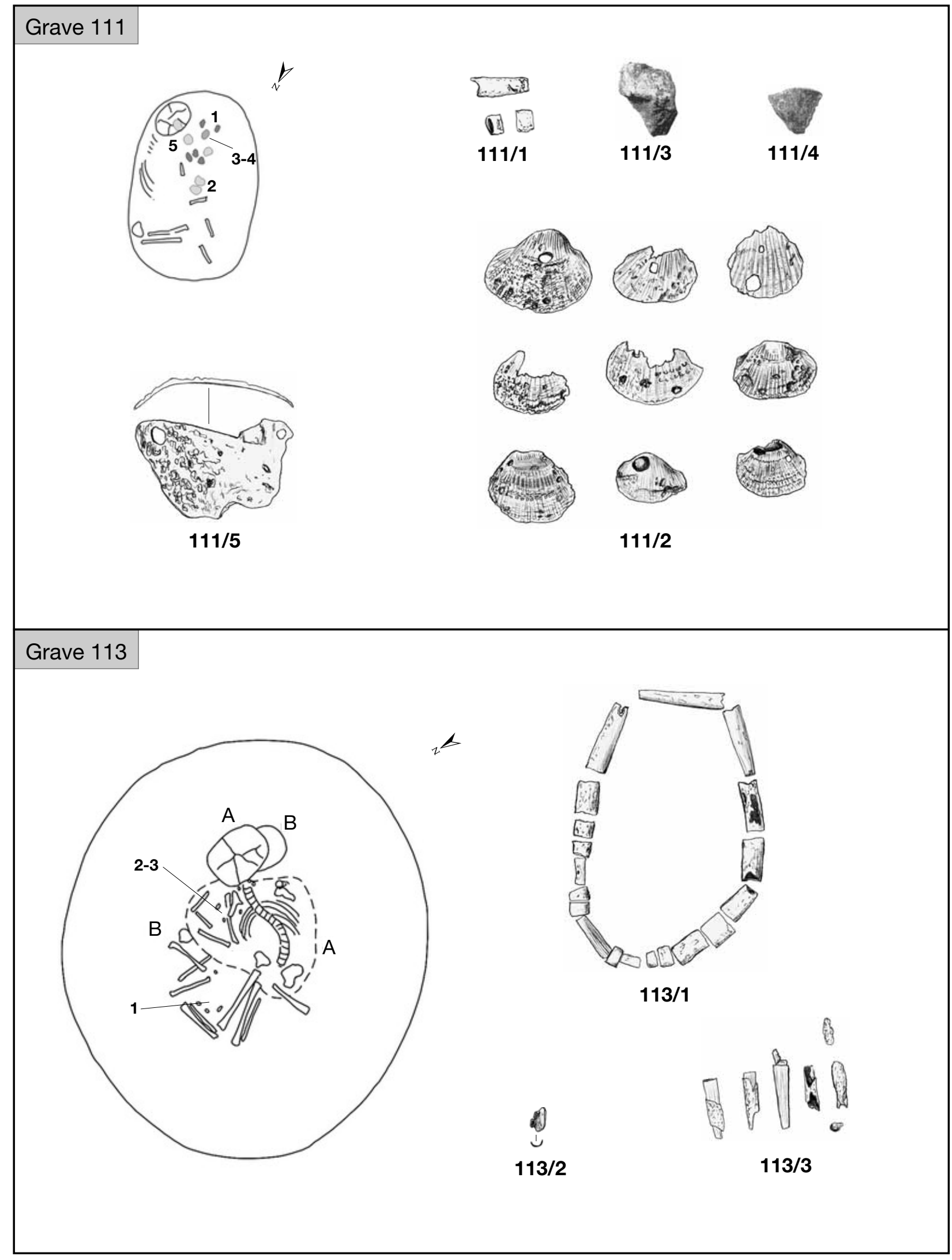

Plate XLVIII. Graves 111 and 113 (111/3-4: after BANNER 1956, Taf. CIII. 6-7) 


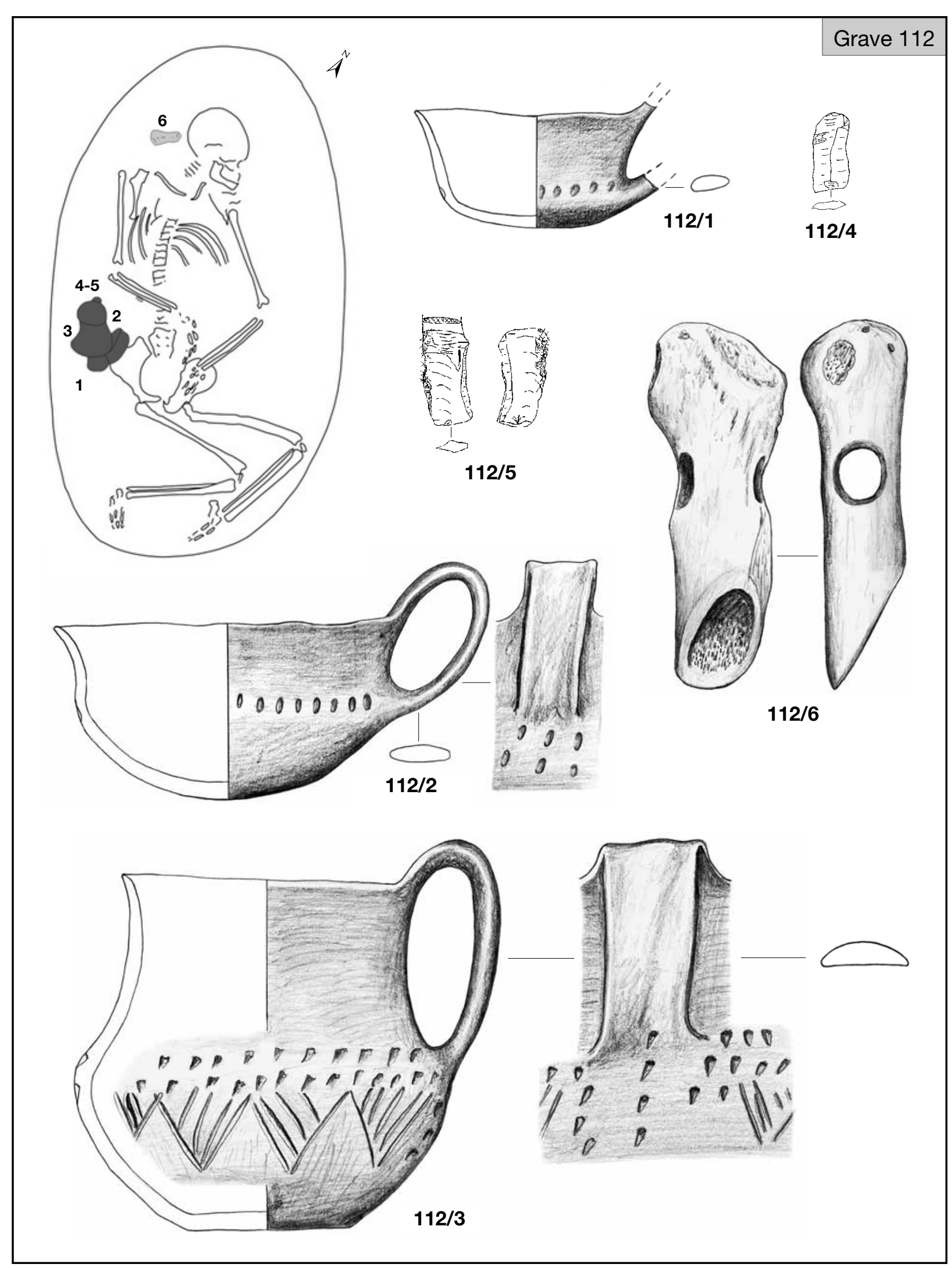

Plate XLIX. Grave 112 (112/4-5: after Cs. BALOGH 1993) 


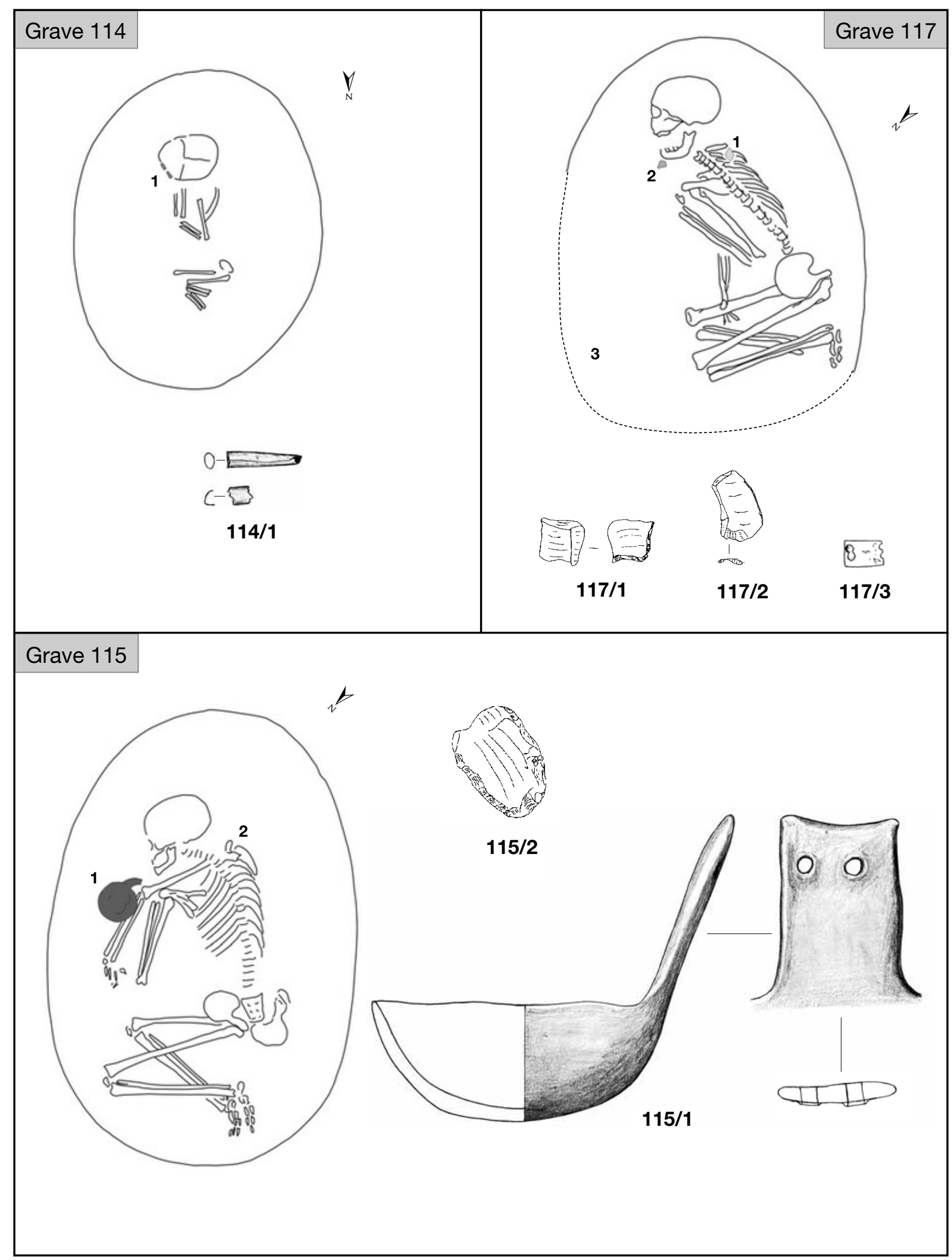

Plate L. Graves 114-115 and 117 (115/2, 117/1-2: after Cs. BALOGH 1993) 


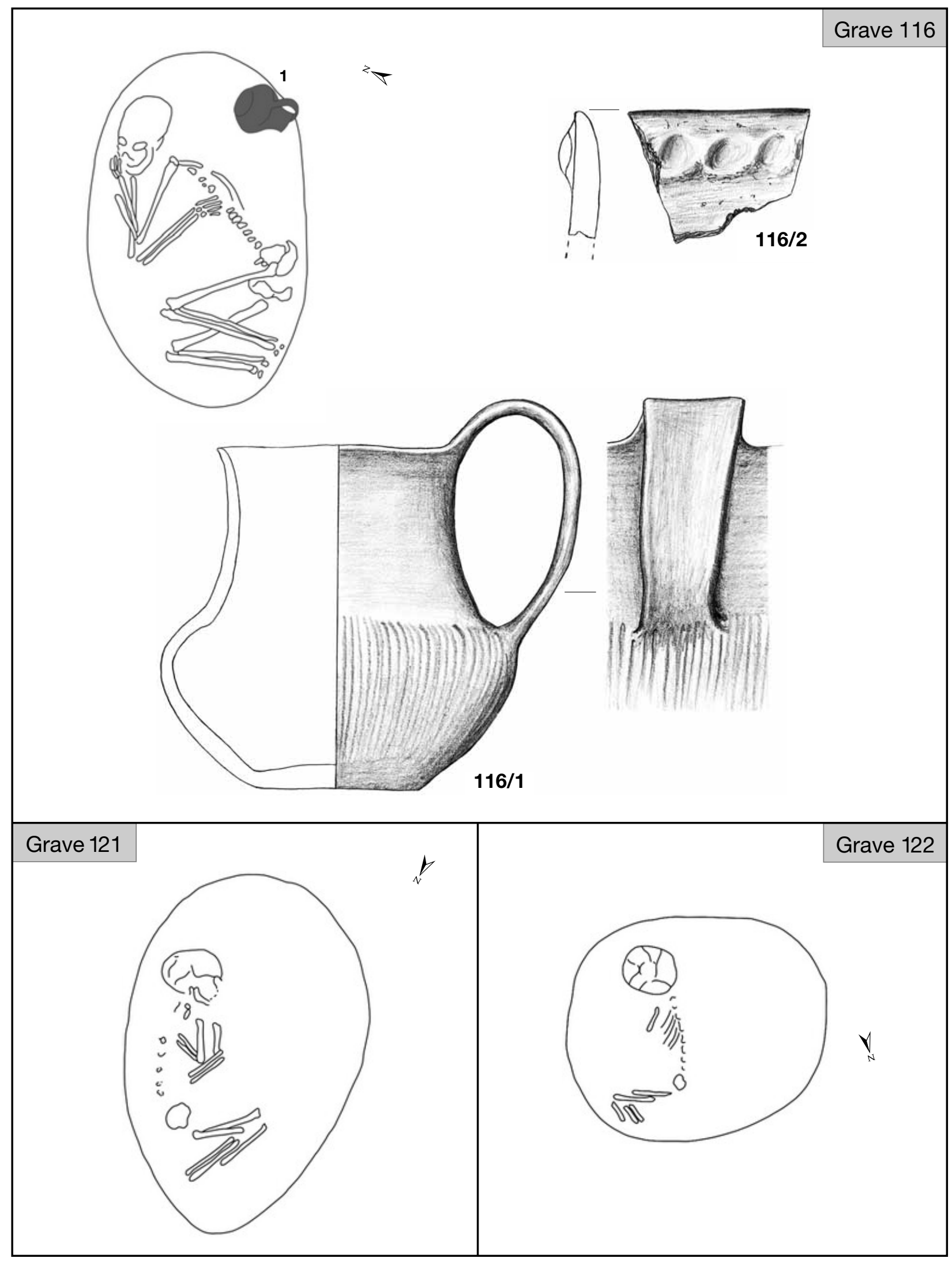

Plate LI. Graves 116 and 121-122 


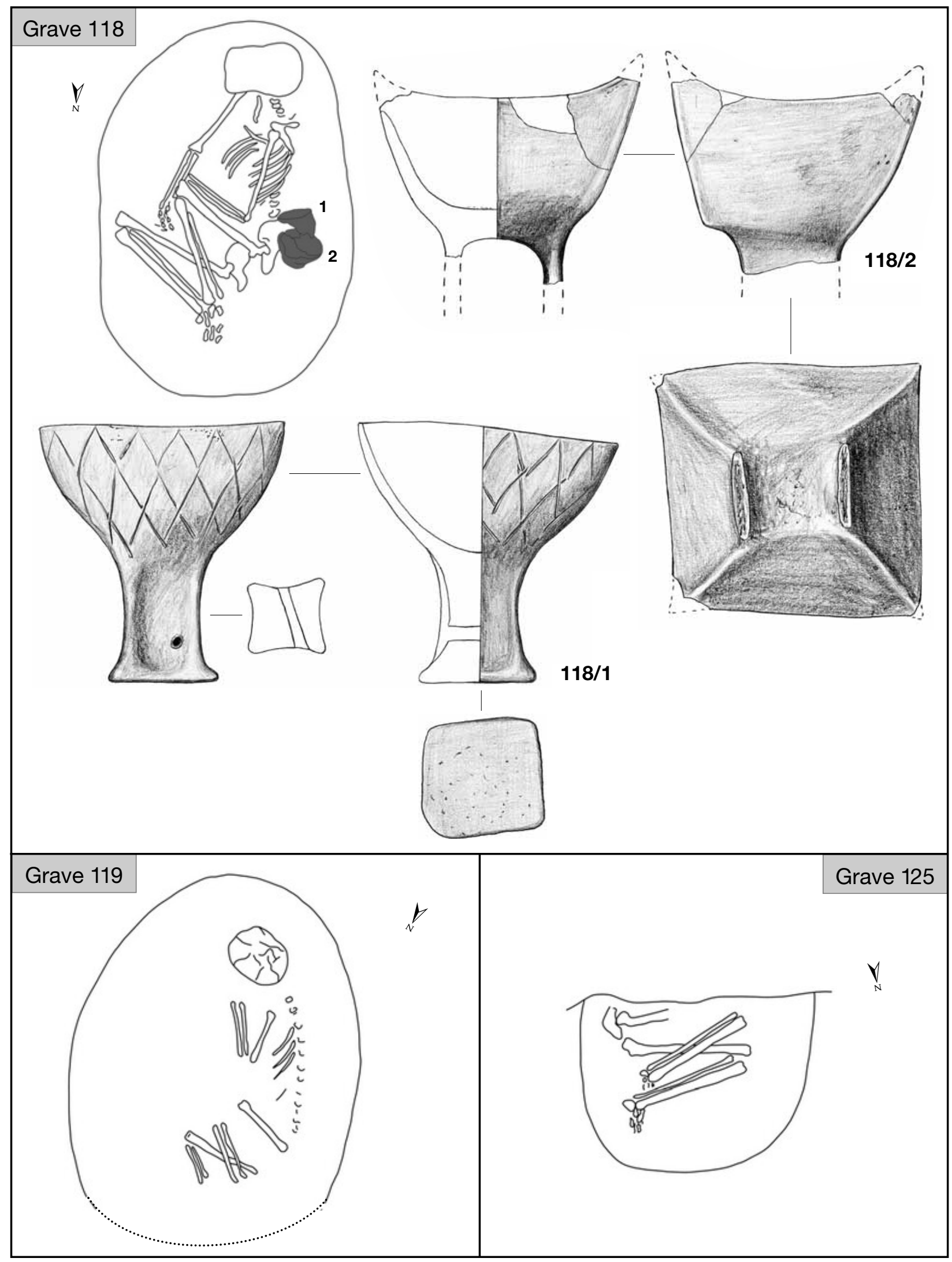

Plate LII. Graves 118-119 and 125 


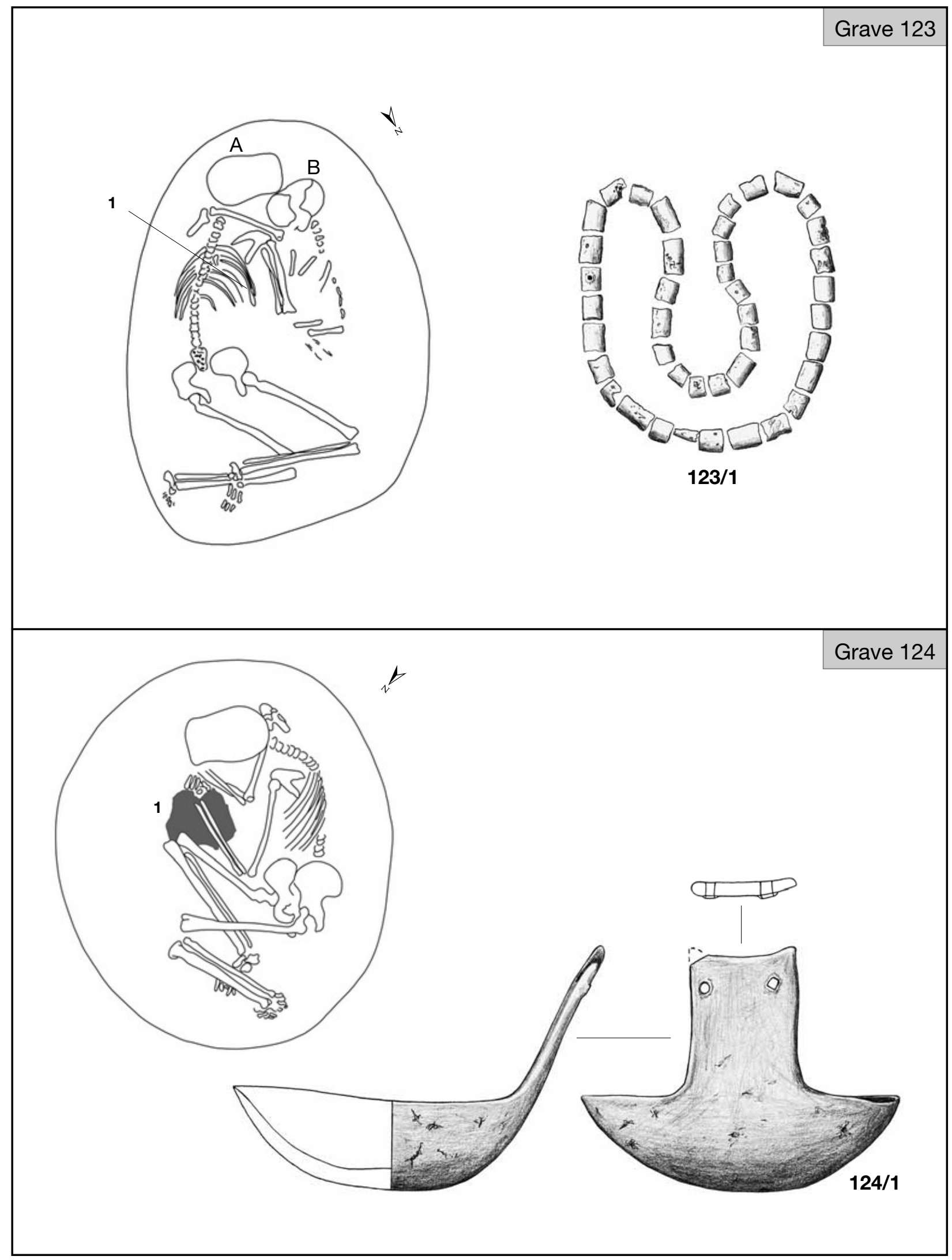

Plate LIII. Graves 123-124 


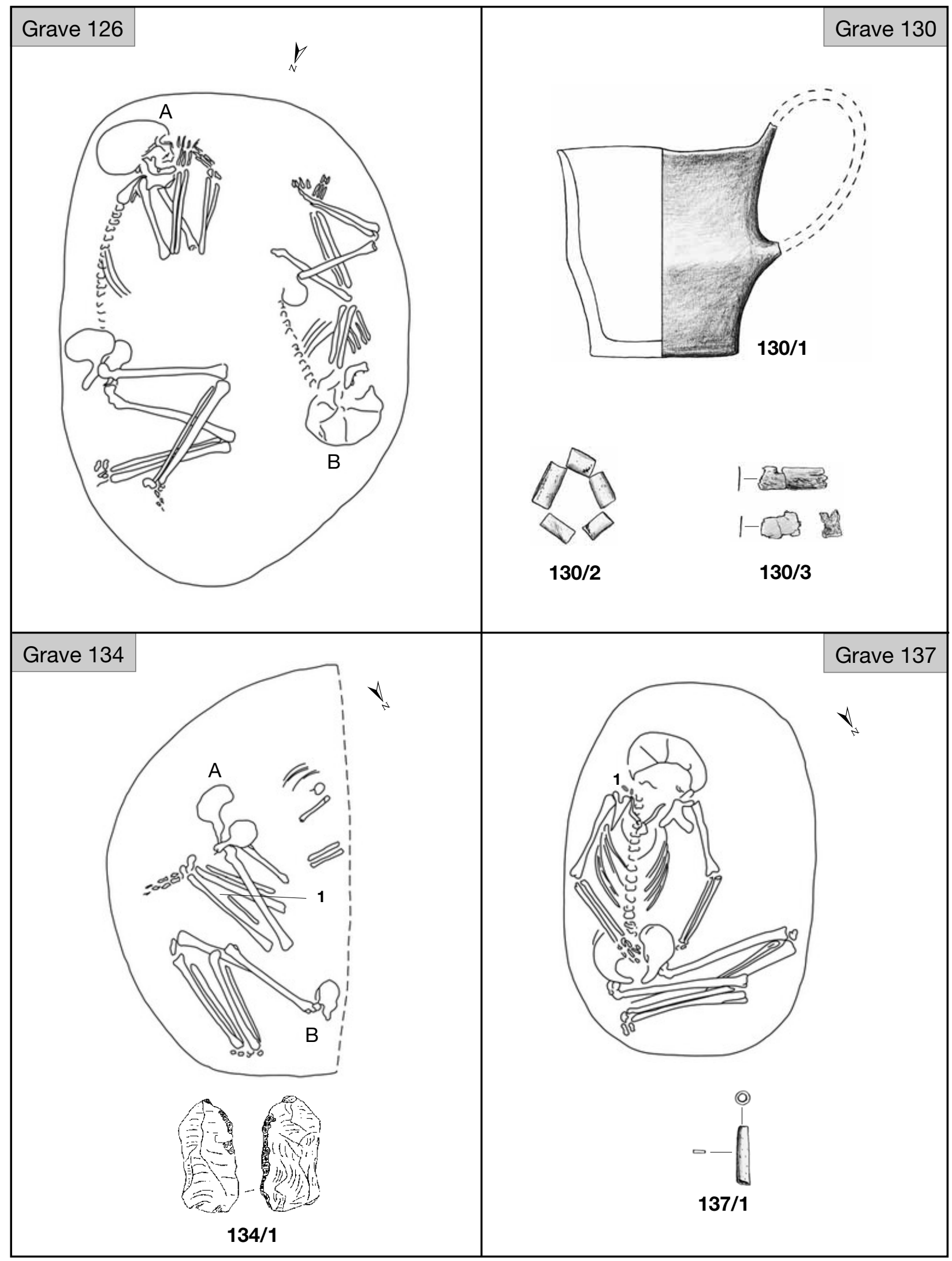

Plate LIV. Graves 126, 130, 134 and 137 (134/1: after Cs. BALOGH 1993) 


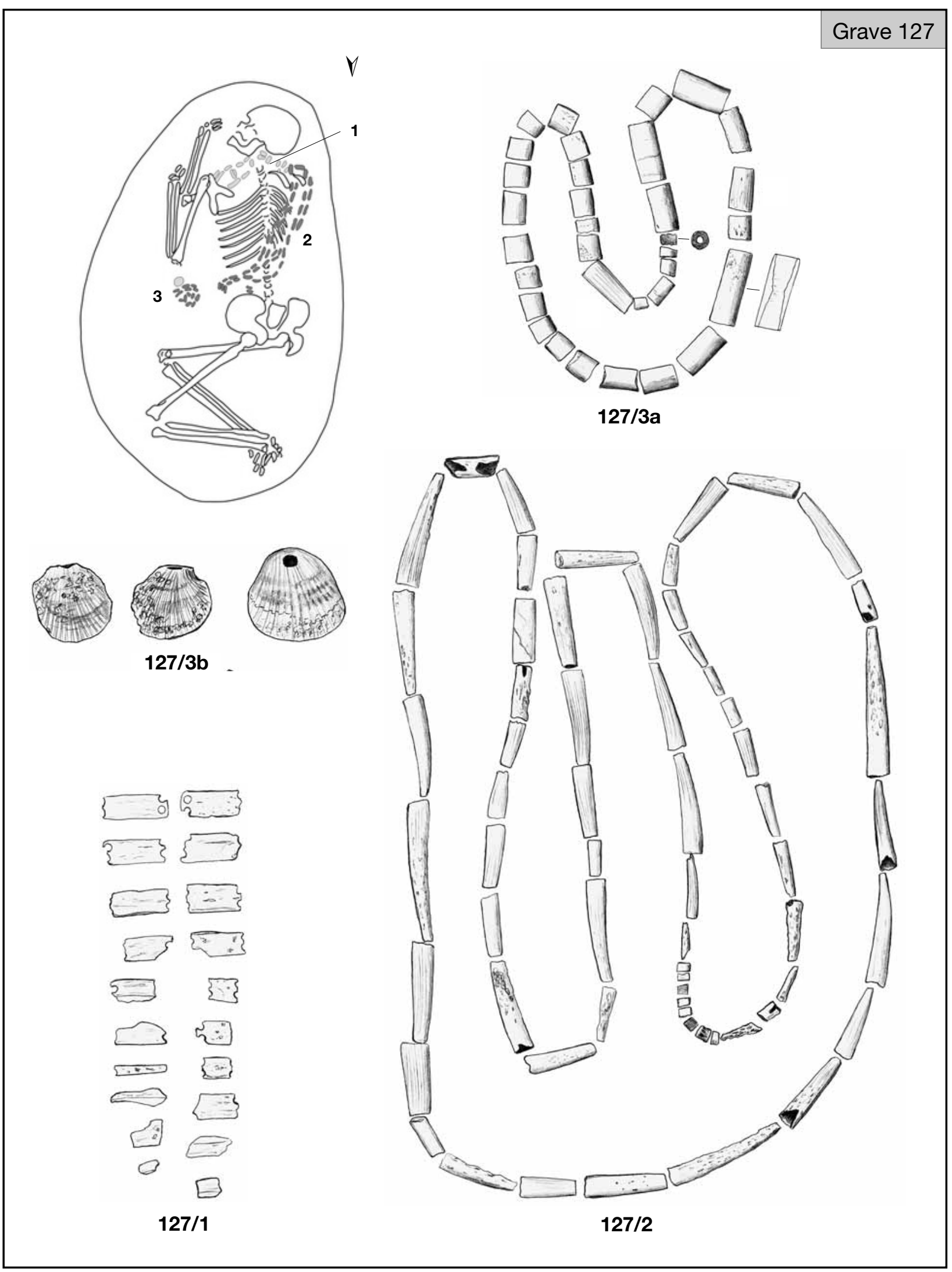

Plate LV. Grave 127 


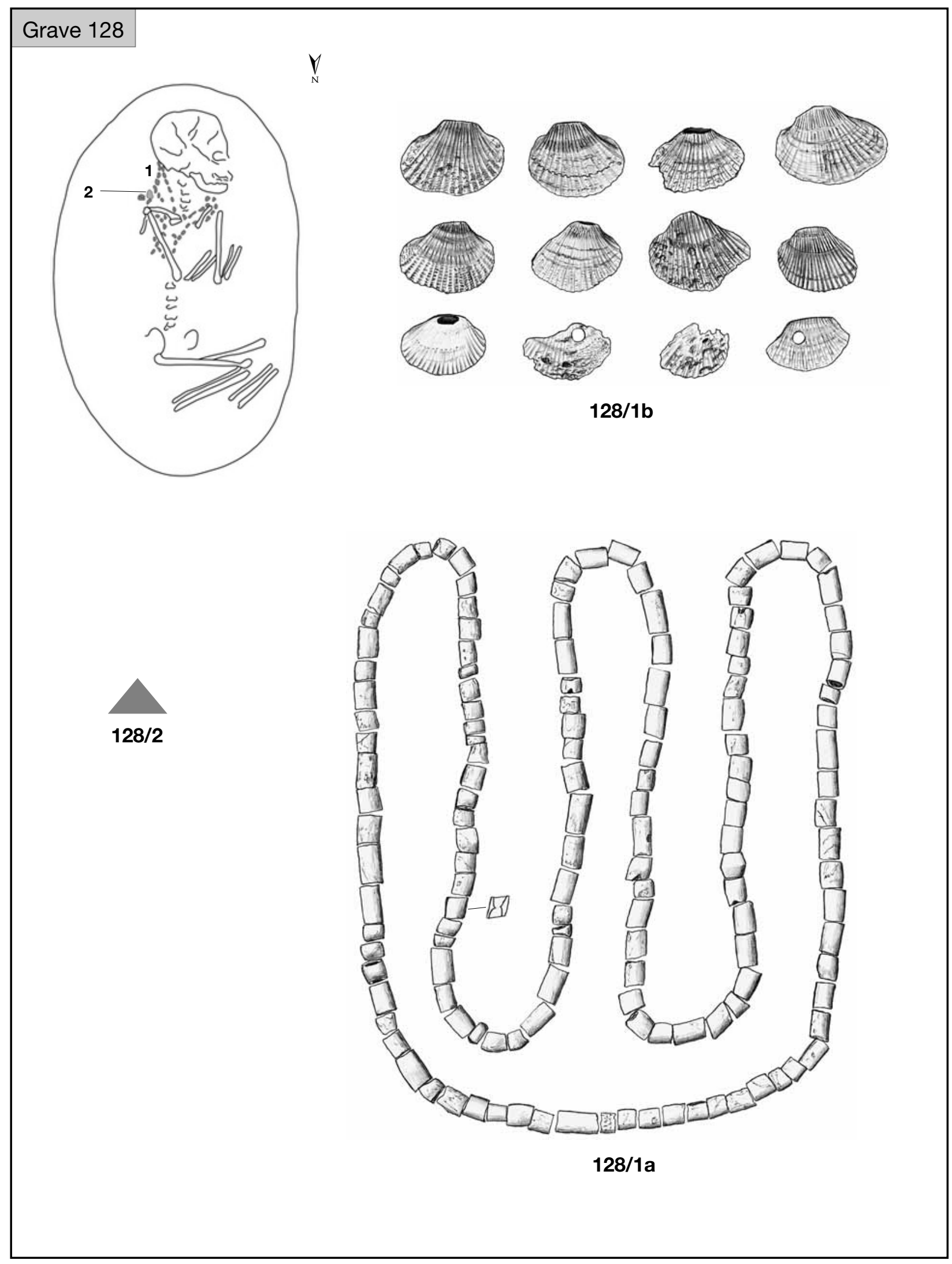

Plate LVI. Grave 128 


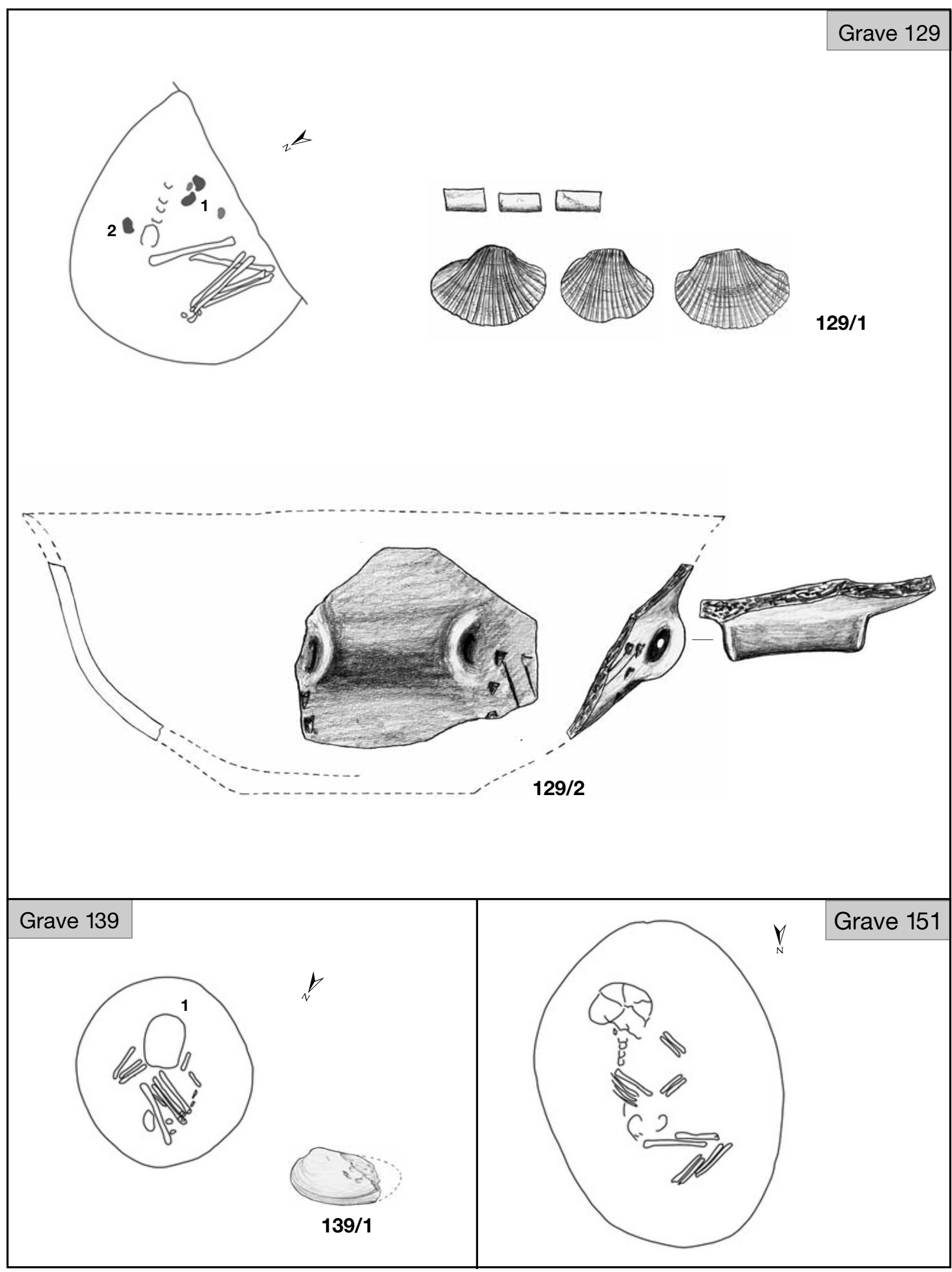

Plate LVII. Graves 129, 139 and 151 


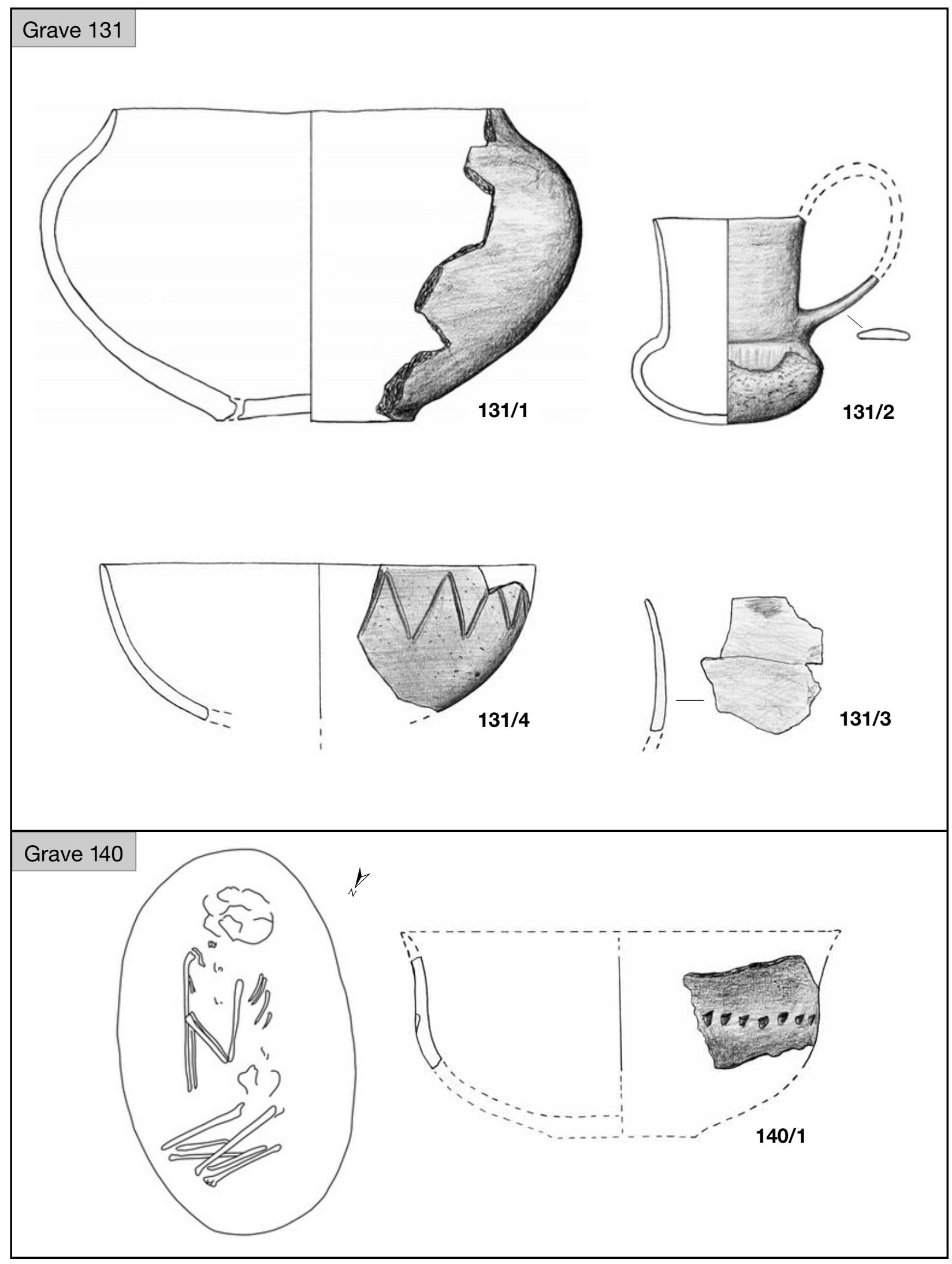

Plate LVIII. Graves 131 and 140 


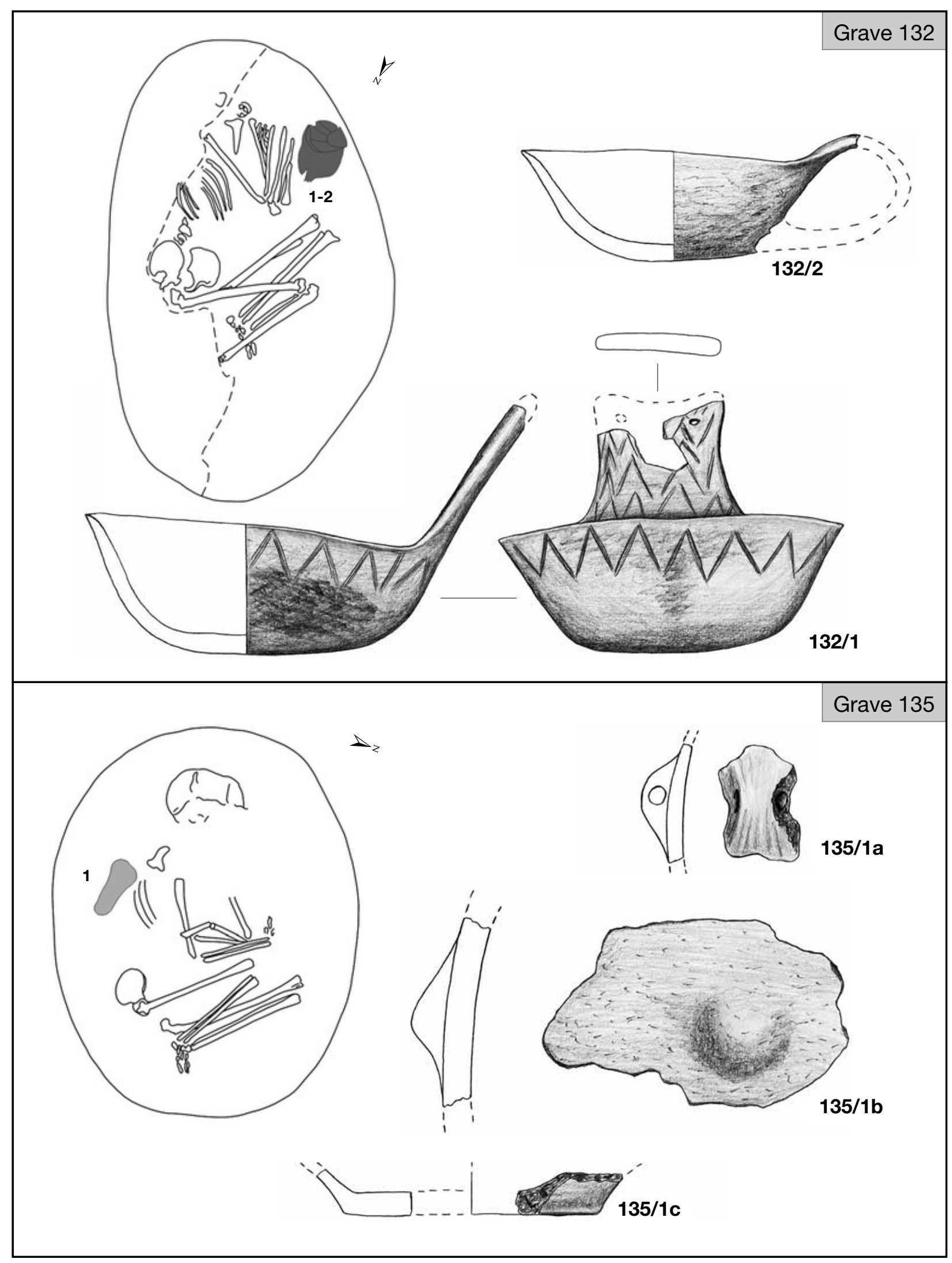

Plate LIX. Graves 132 and 135 


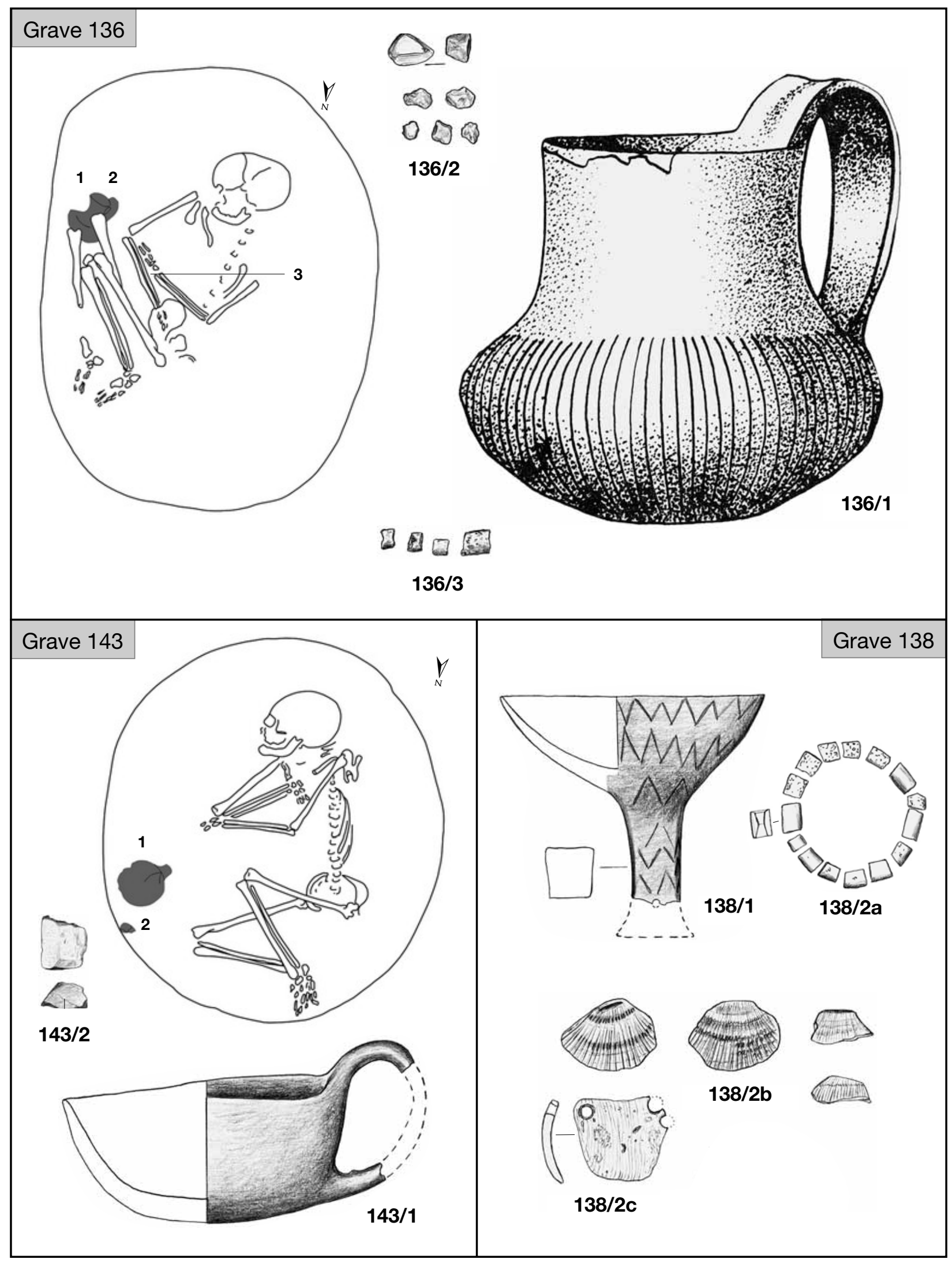

Plate LX. Graves 136, 138 and 143 (136/1: after JózSEF KOREK’s grave sheet) 


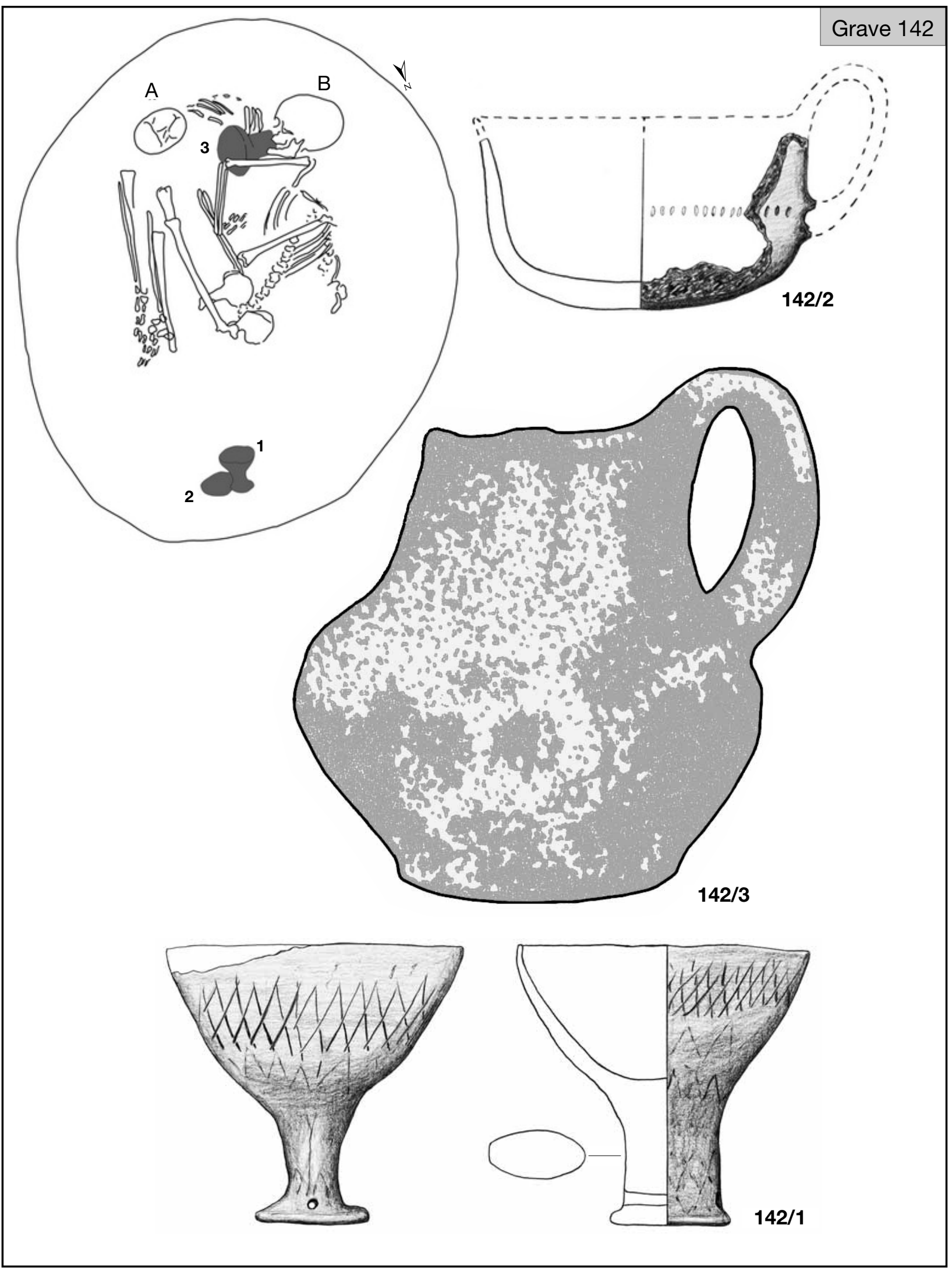

Plate LXI. Grave 142 (142/3: after JÓZSEF KOREK’s grave sheet) 


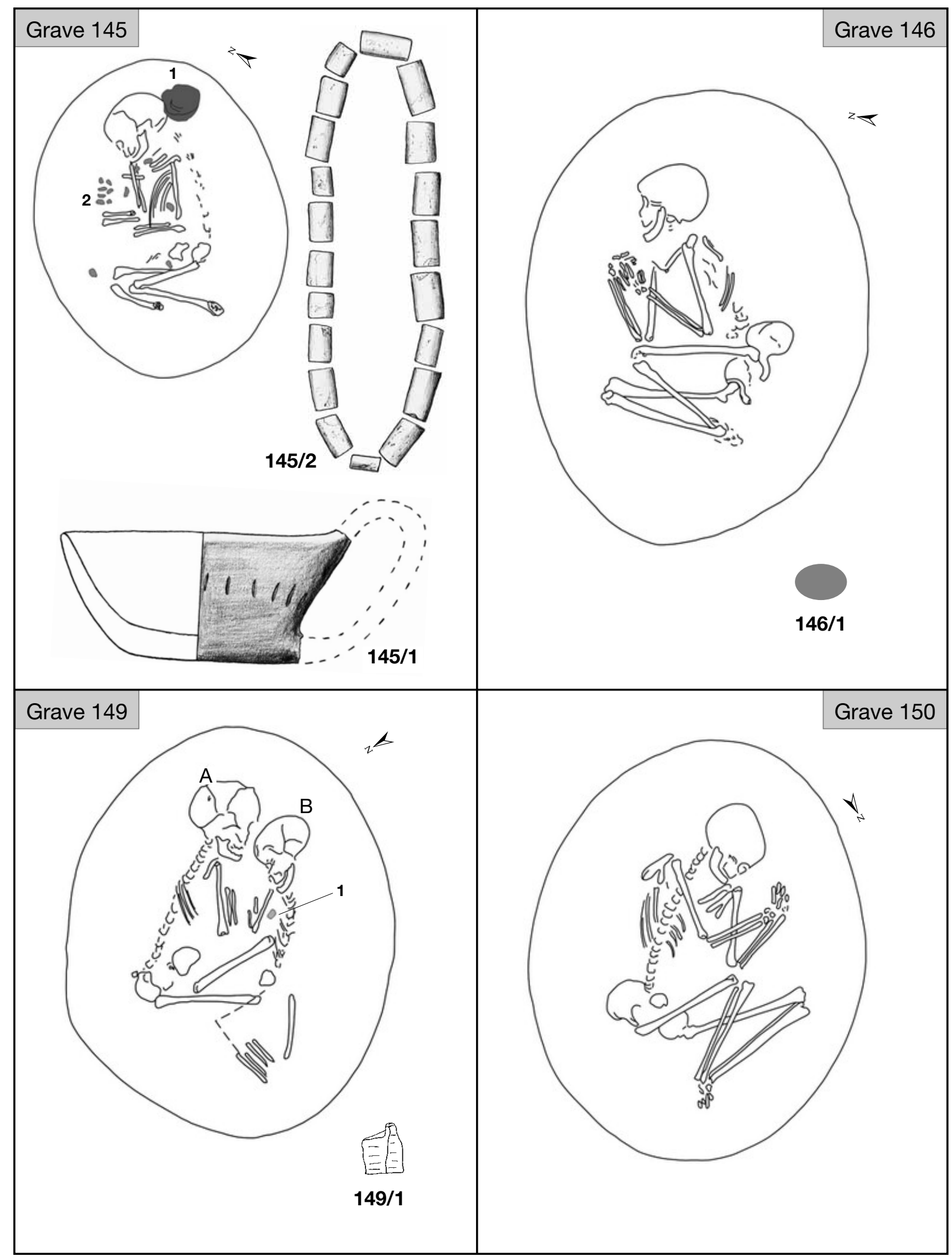

Plate LXII. Graves 145-146 and 149-150 (149/1: after Cs. BALOGH 1993) 


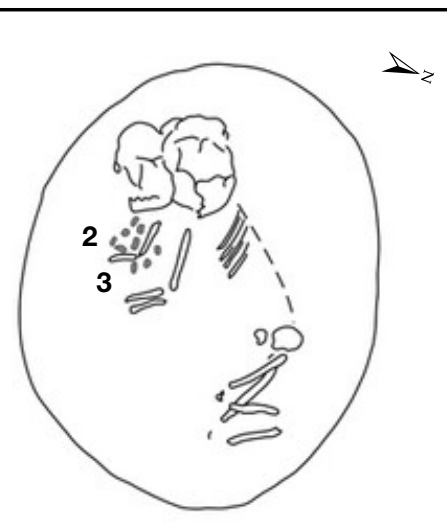

$\square \square$

Grave 148
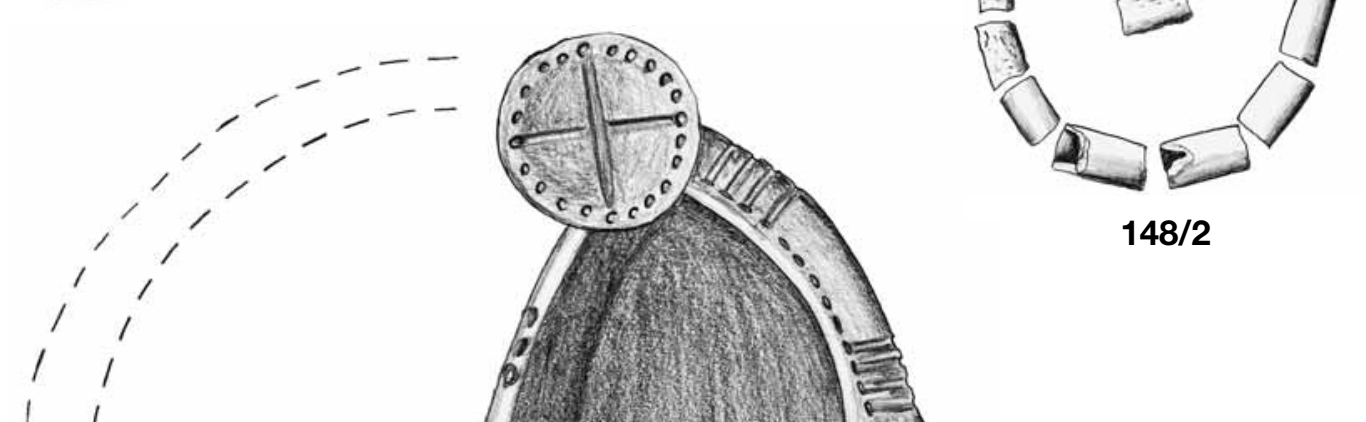

$148 / 3$
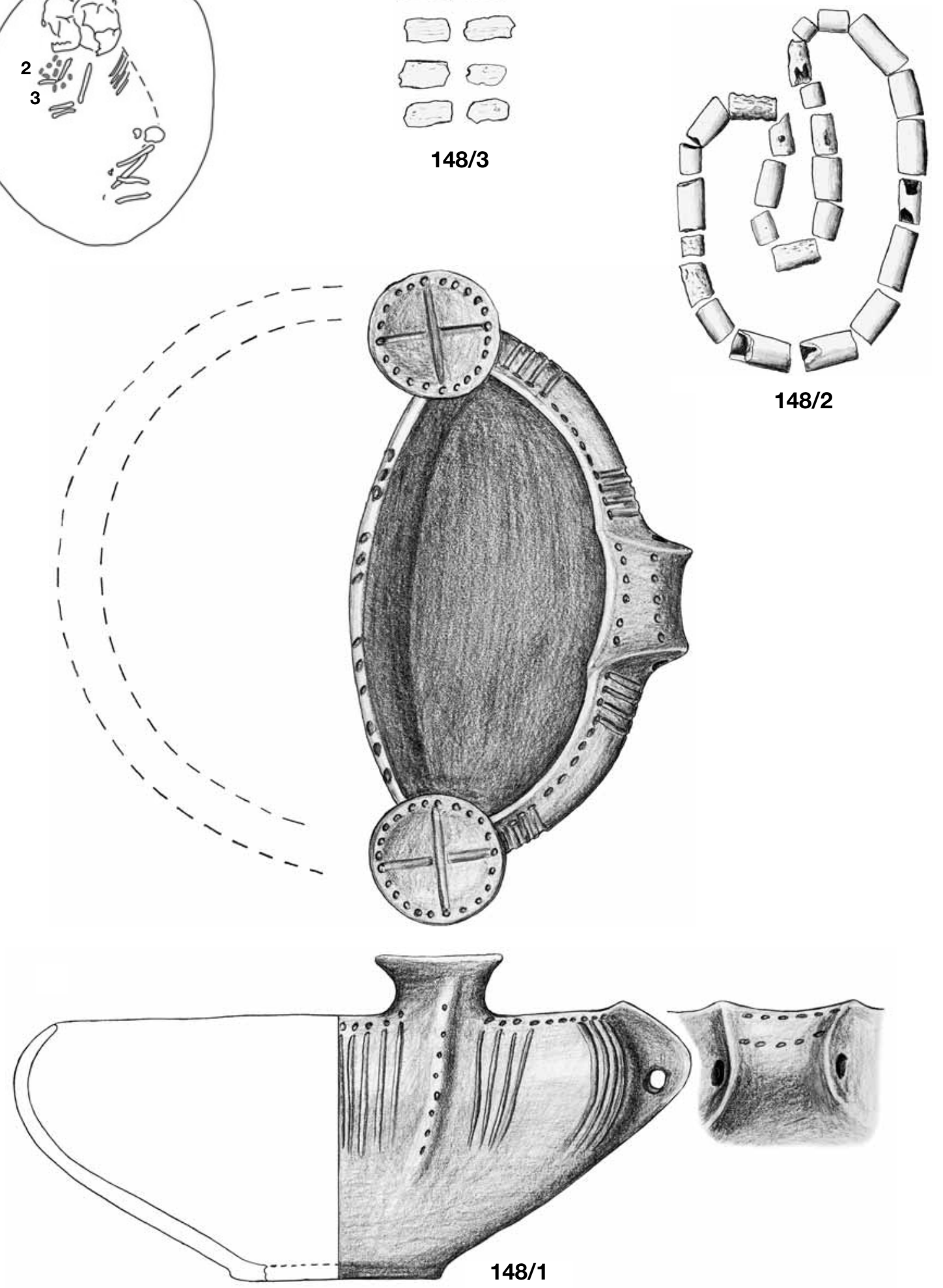

Plate LXIII. Grave 148 


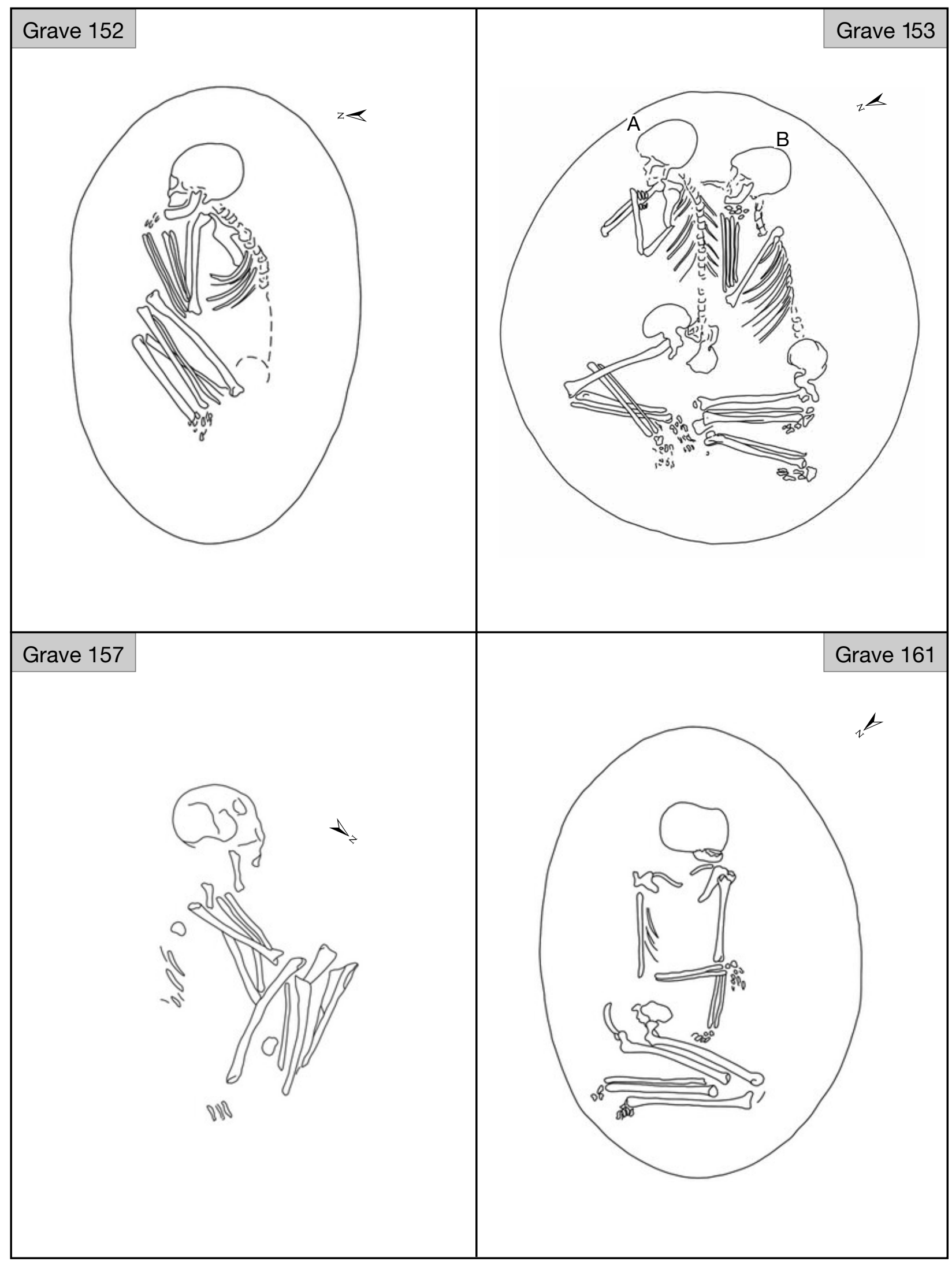

Plate LXIV. Graves 152-153, 157 and 161 


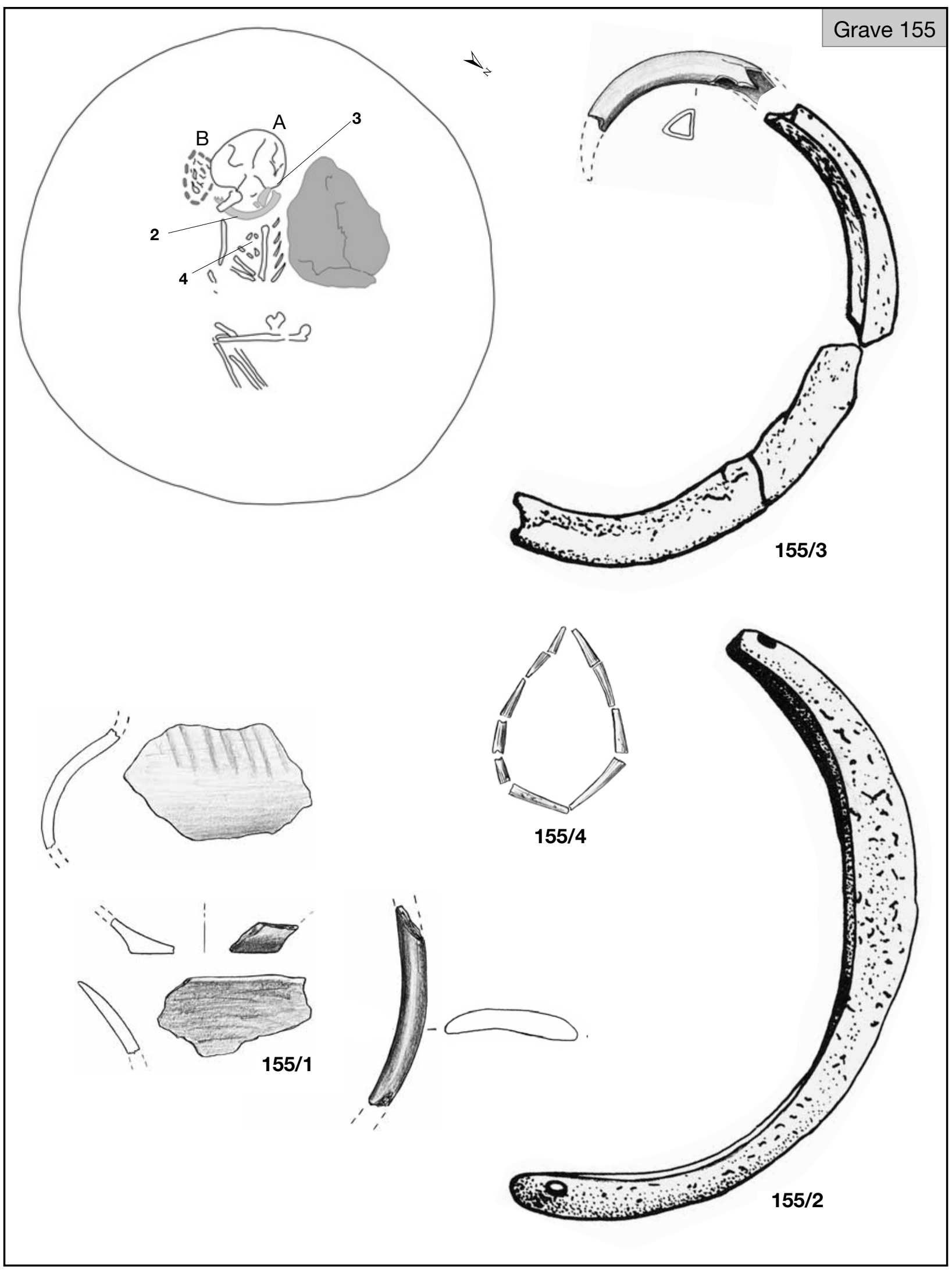

Plate LXV. Grave 155 (155/2-3: after JóZSEF KoREK’s grave sheet) 


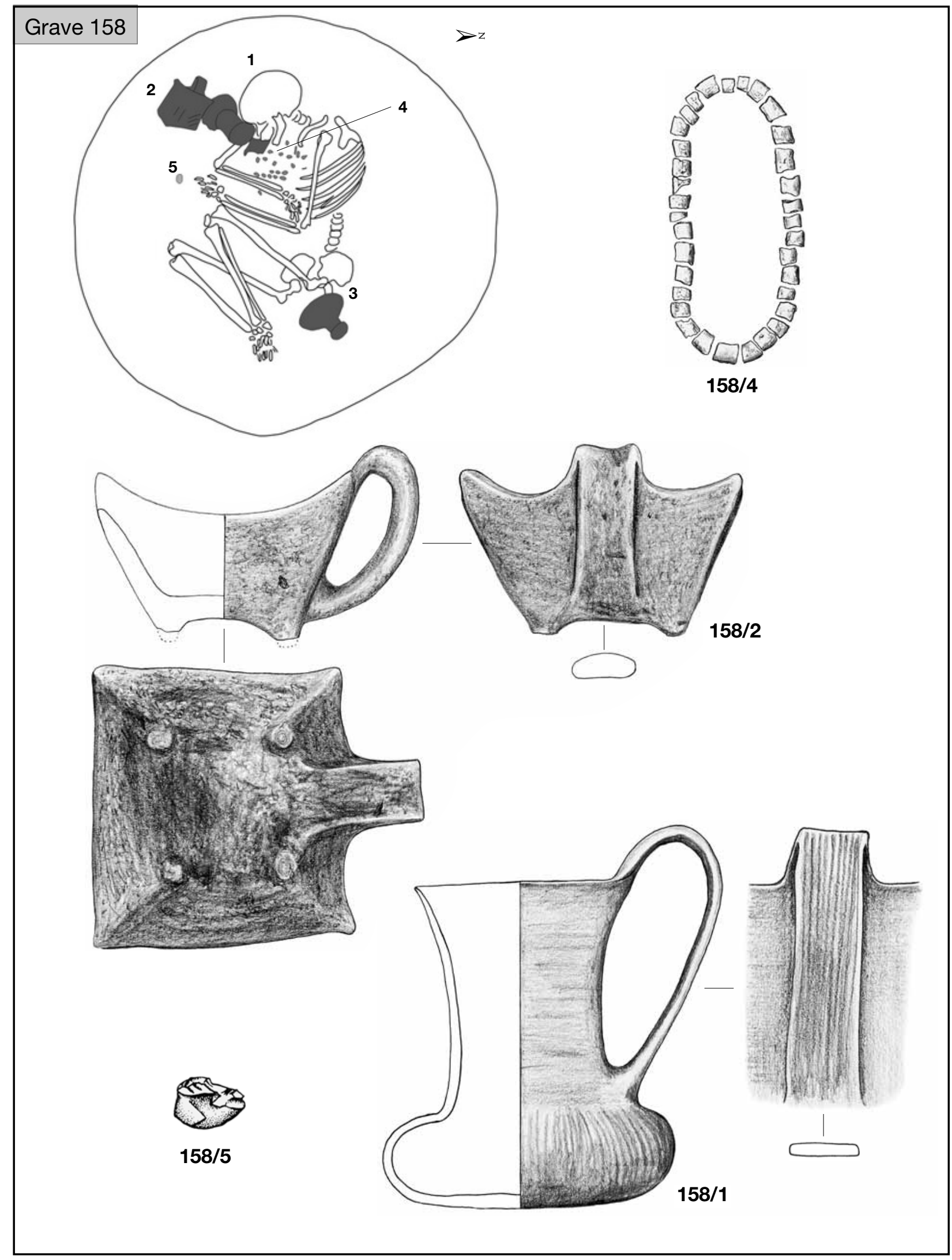

Plate LXVI. Grave 158 (158/5: after JózSEF KOREK’s grave sheet) 


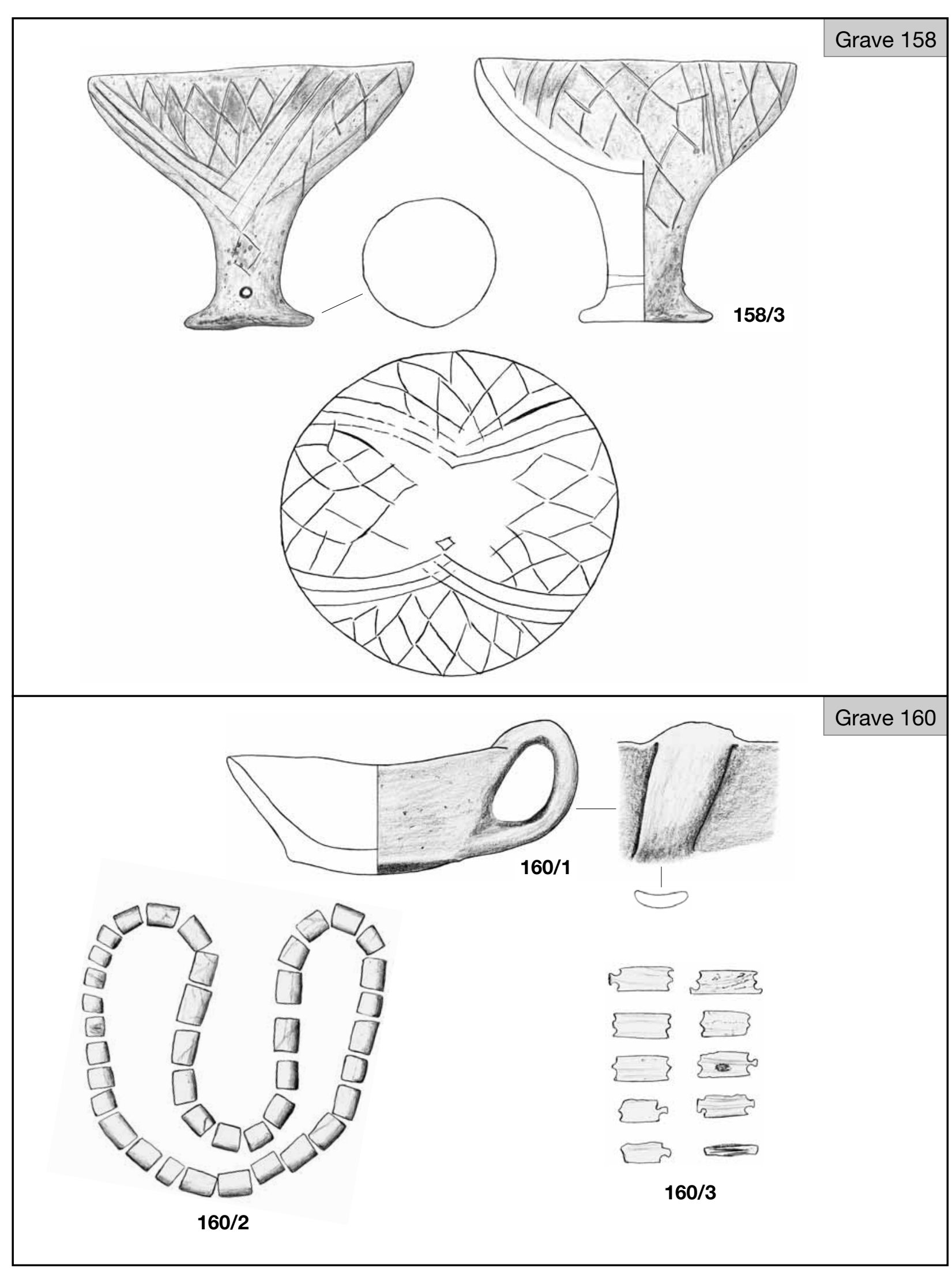

Plate LXVII. Graves 158 and 160 


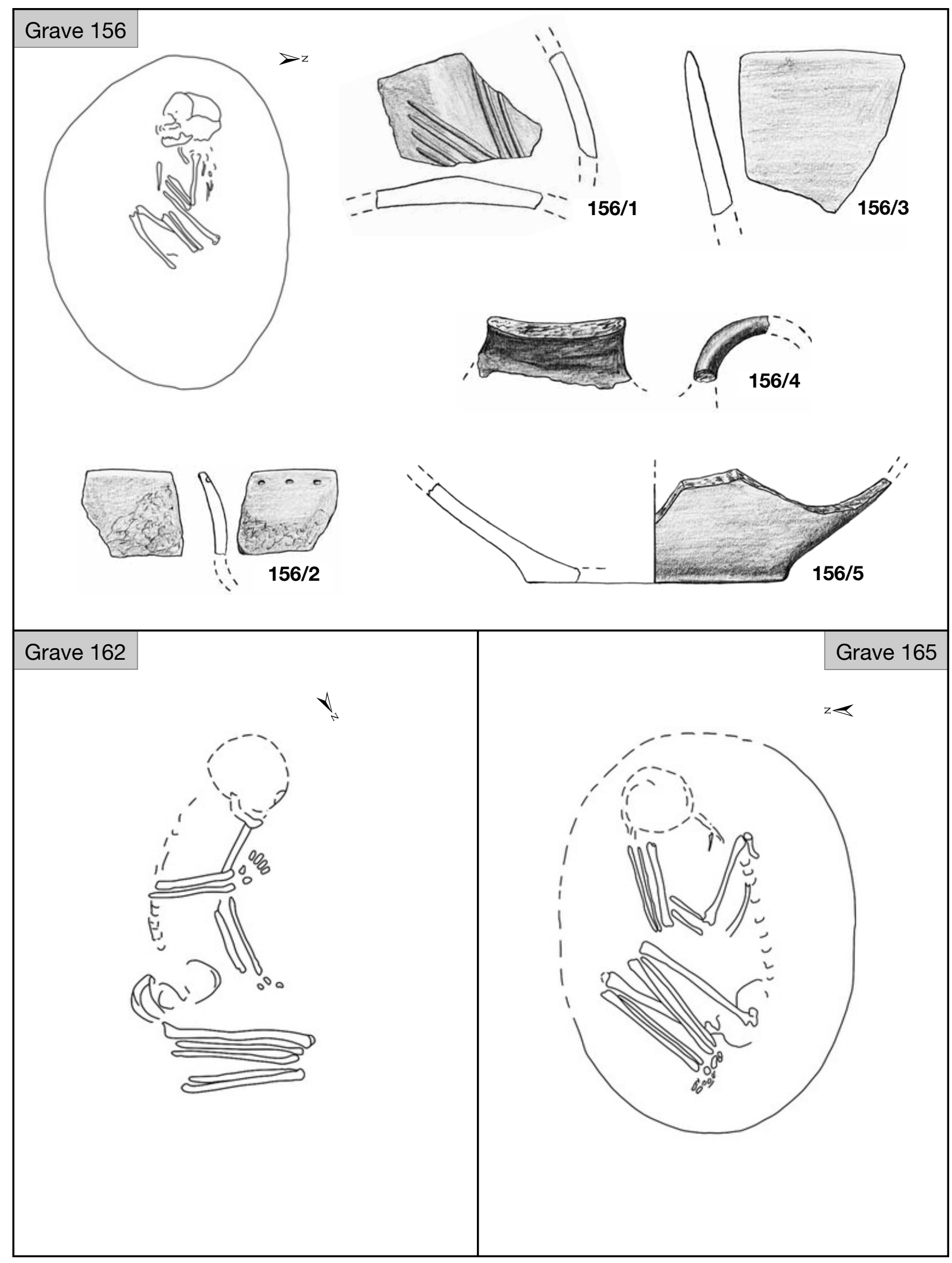

Plate LXVIII. Graves 156, 162 and 165 


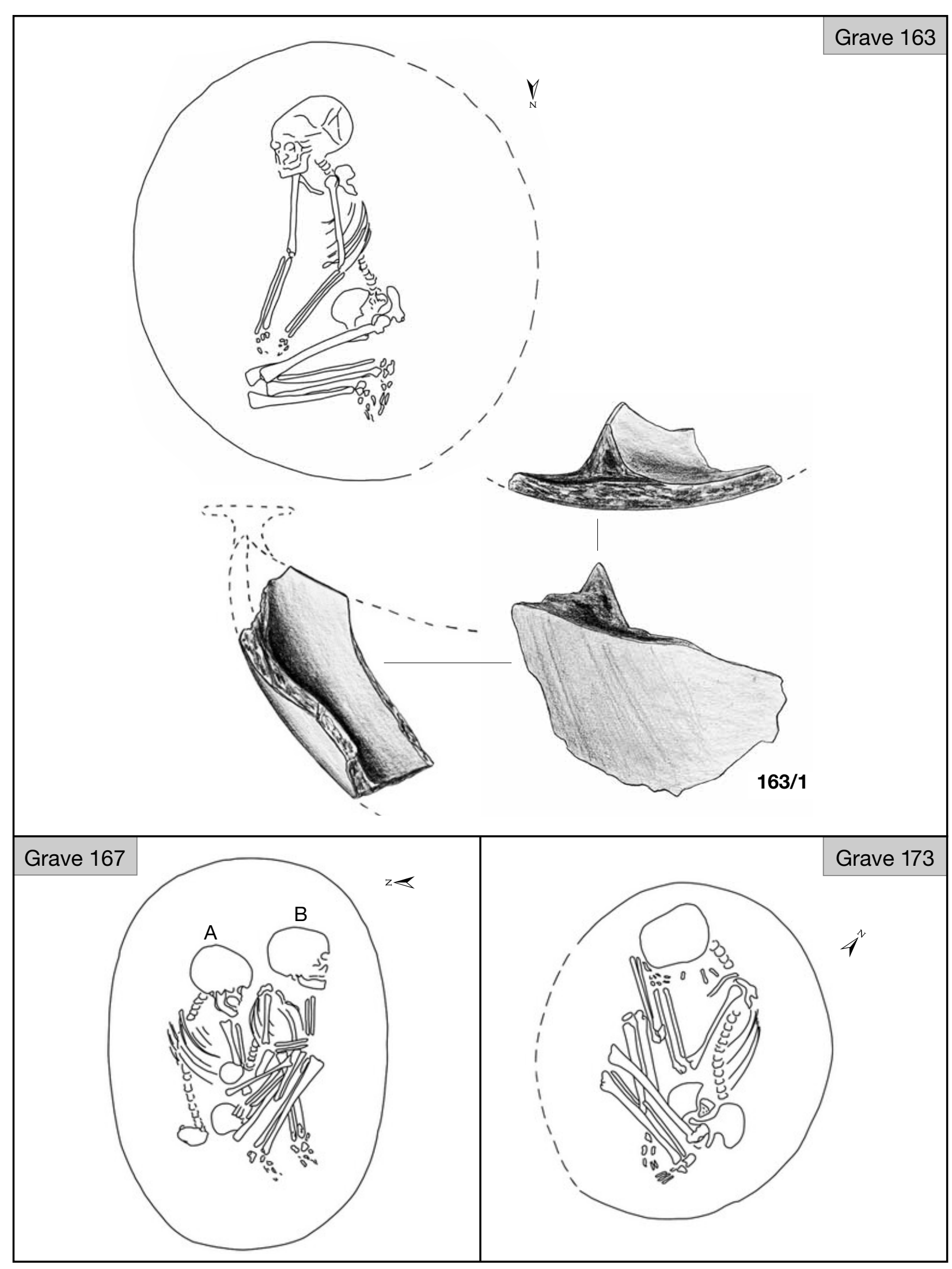

Plate LXIX. Graves 163, 167 and 173 


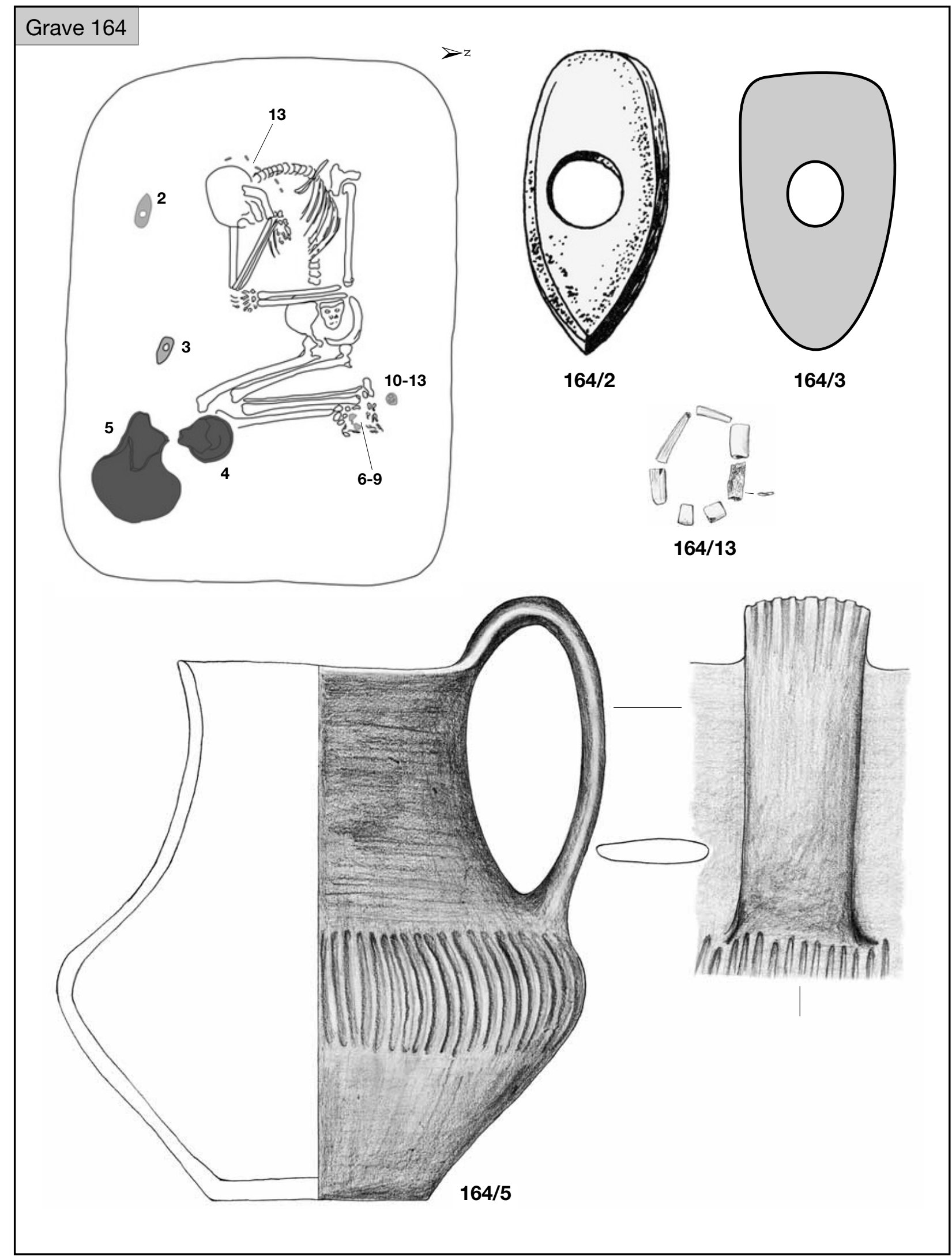

Plate LXX. Grave 164 (164/2: after JózSEF KOREK’s grave sheet) 


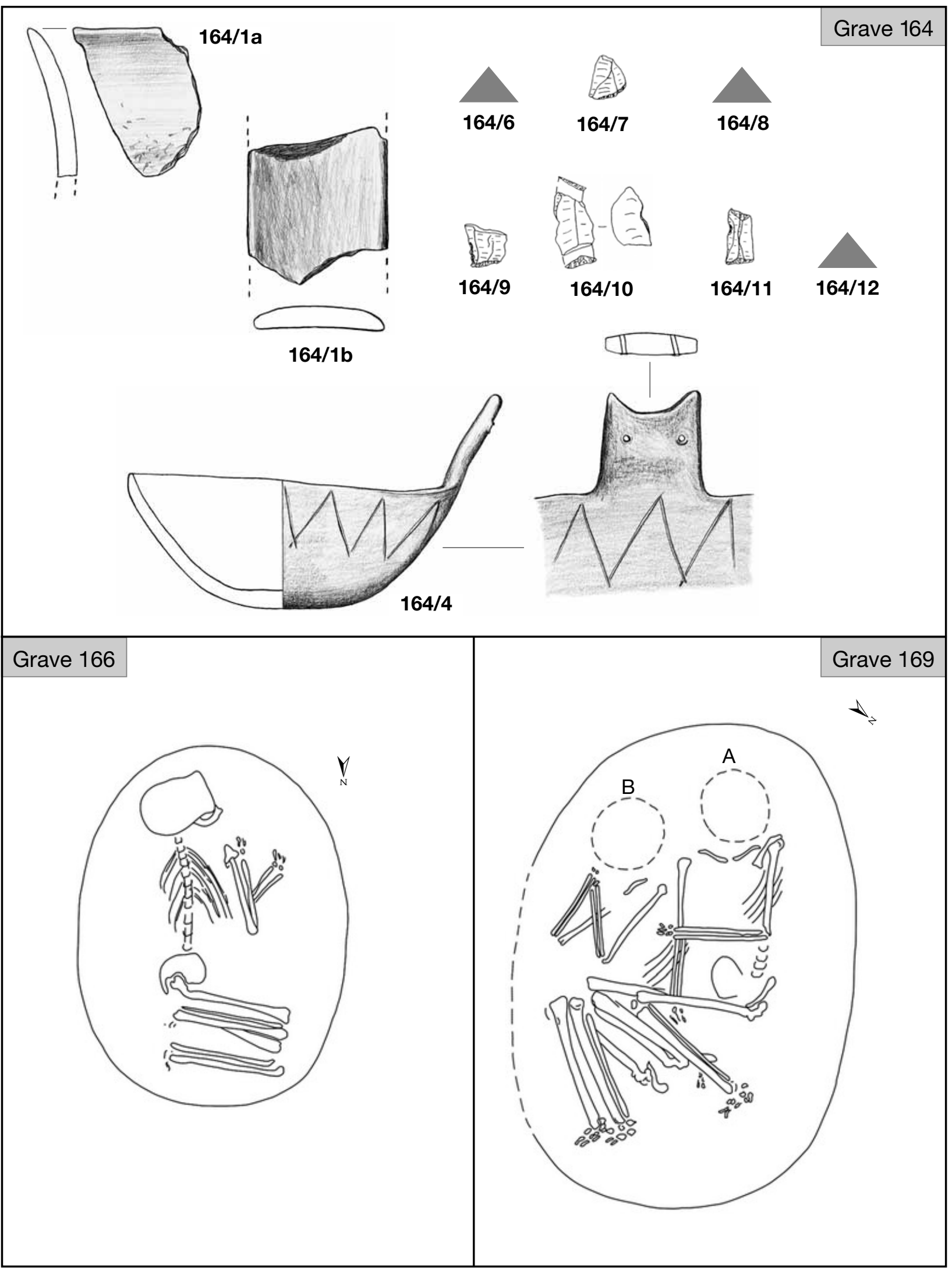

Plate LXXI. Graves 164, 166 and 169 (164/9-11: after Cs. BALOGH 1993) 


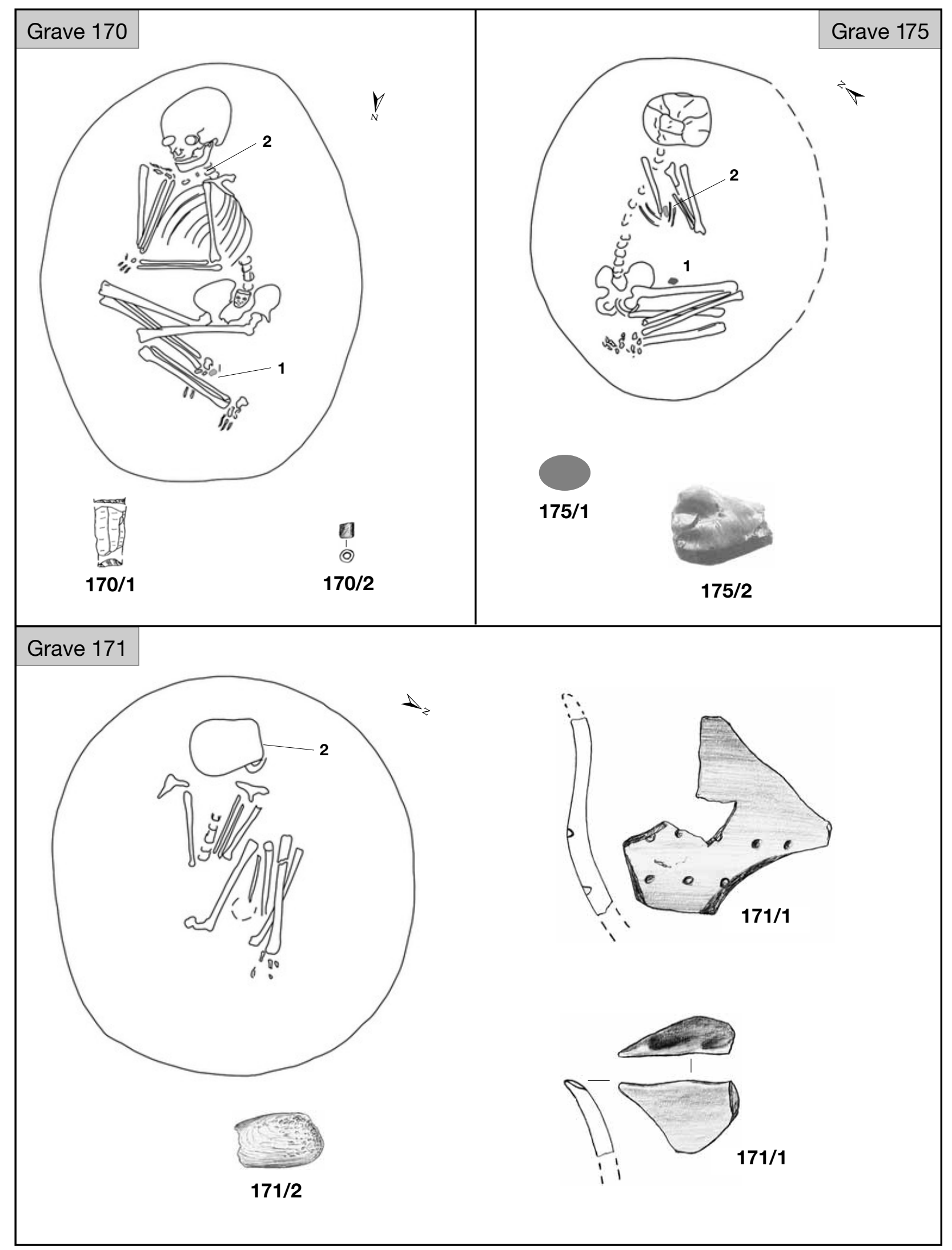

Plate LXXII. Graves 170-171 and 175 (170/1: after Cs. BALOGH 1993; 175/2: after JózSEF KoreK's grave sheet) 


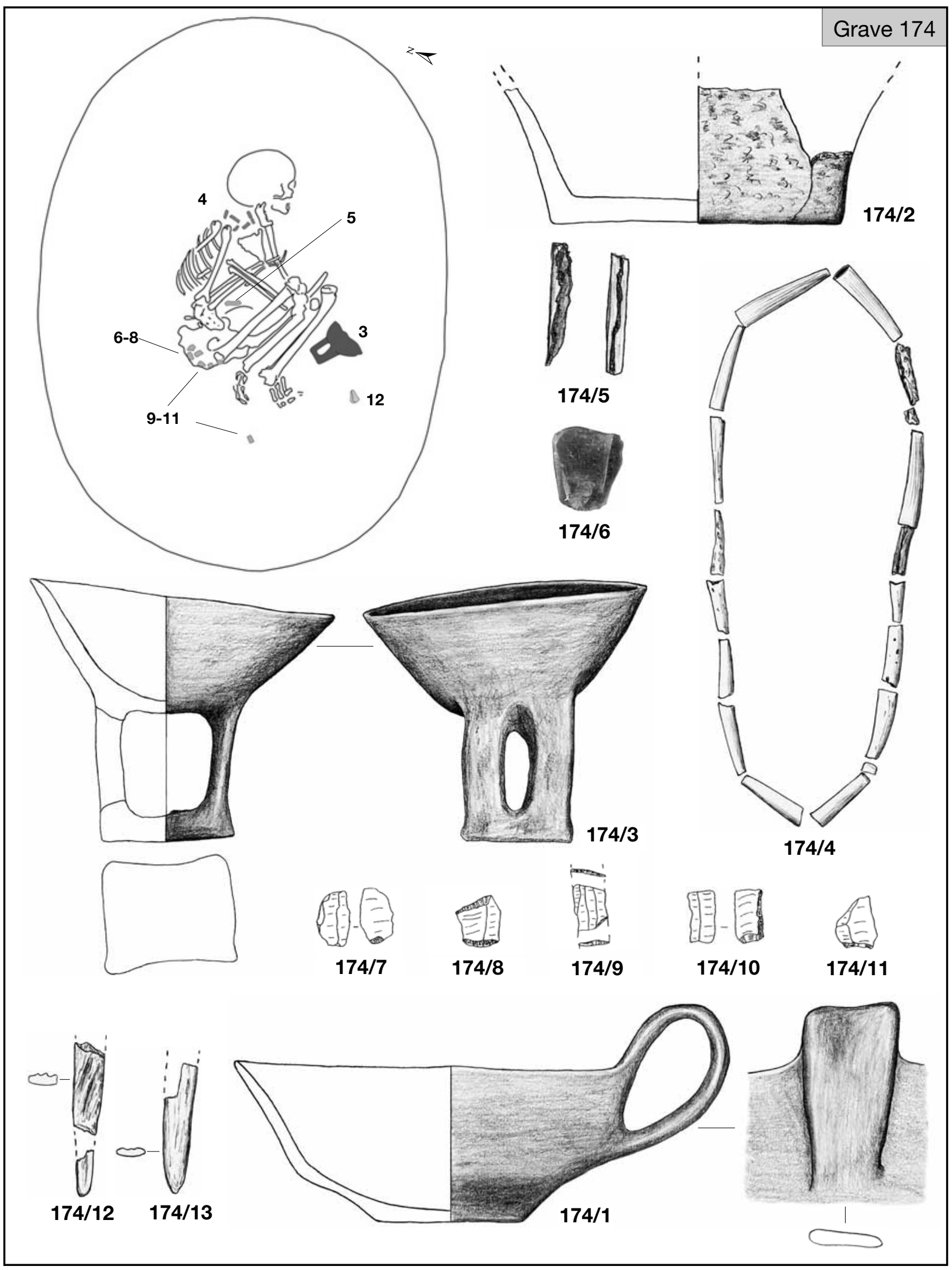

Plate LXXIII. Grave 174 (174/6: after JózSEF KOREK's photo, courtesy of the SzFM Archives; 174/7-11: after Cs. BALOGH 1993) 


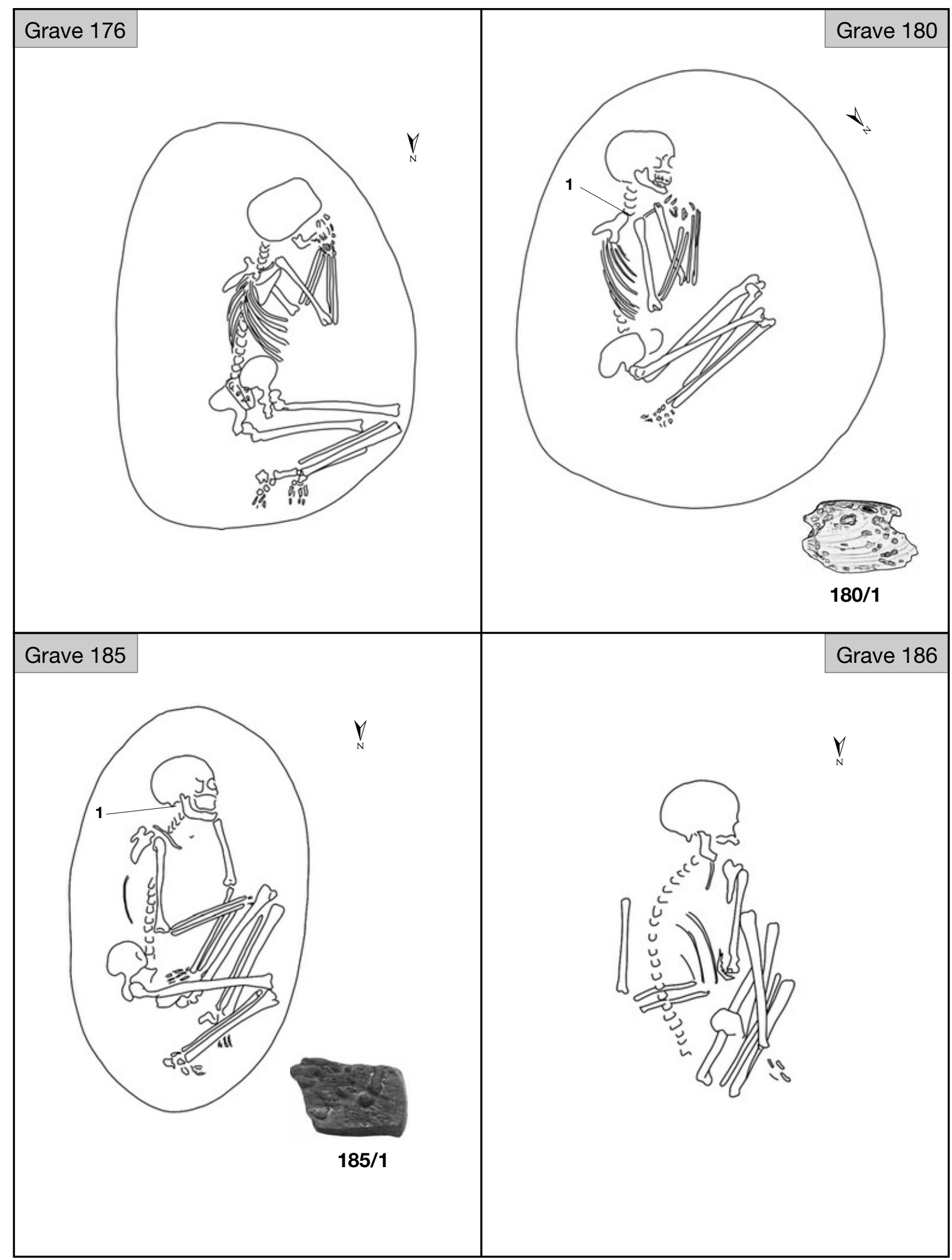

Plate LXXIV. Graves 176, 180 and 185-186 (185/1: after JózSEF KOREK's photo, courtesy of the SzFM Archives) 


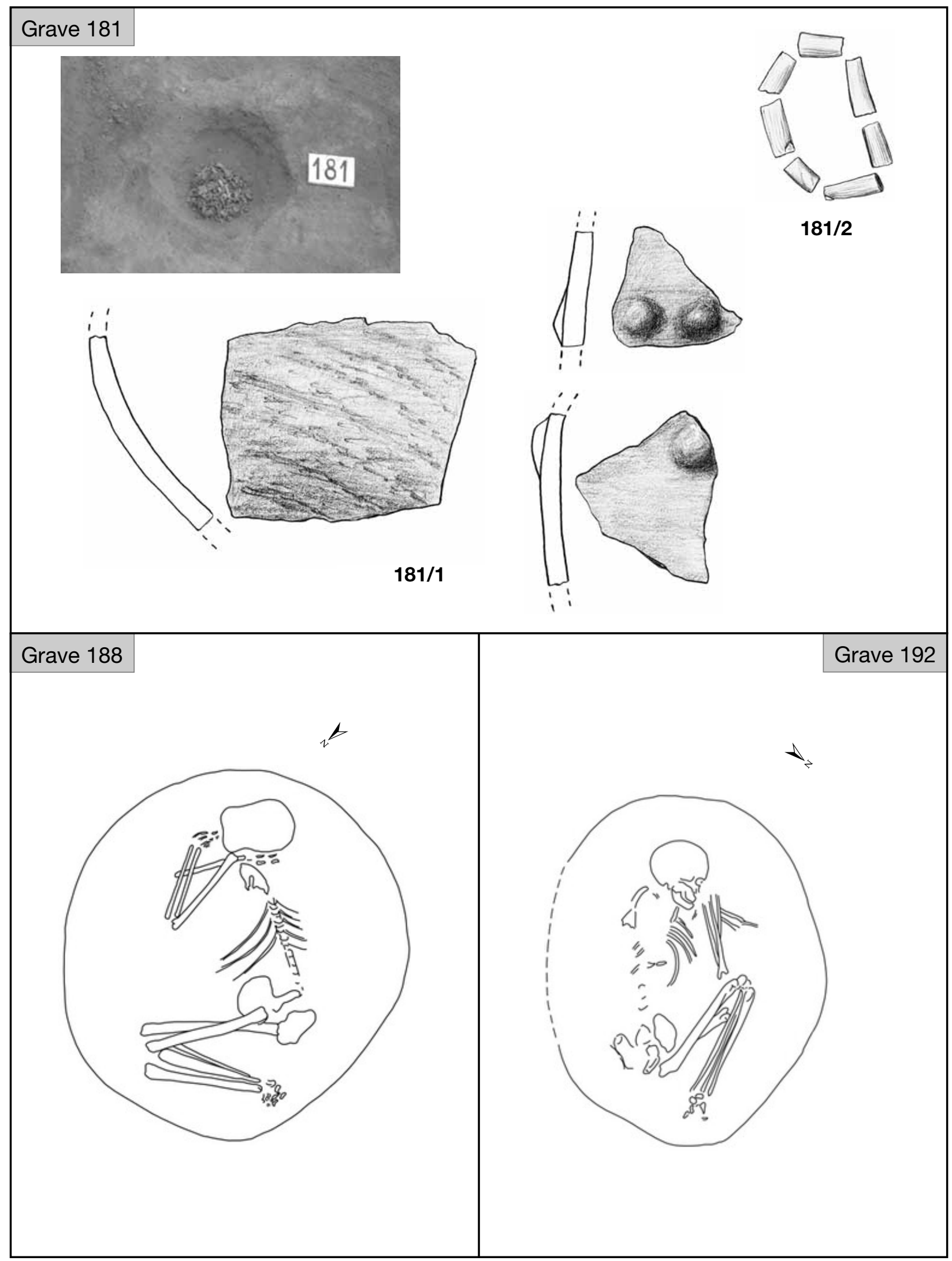

Plate LXXV. Graves 181, 188 and 192 


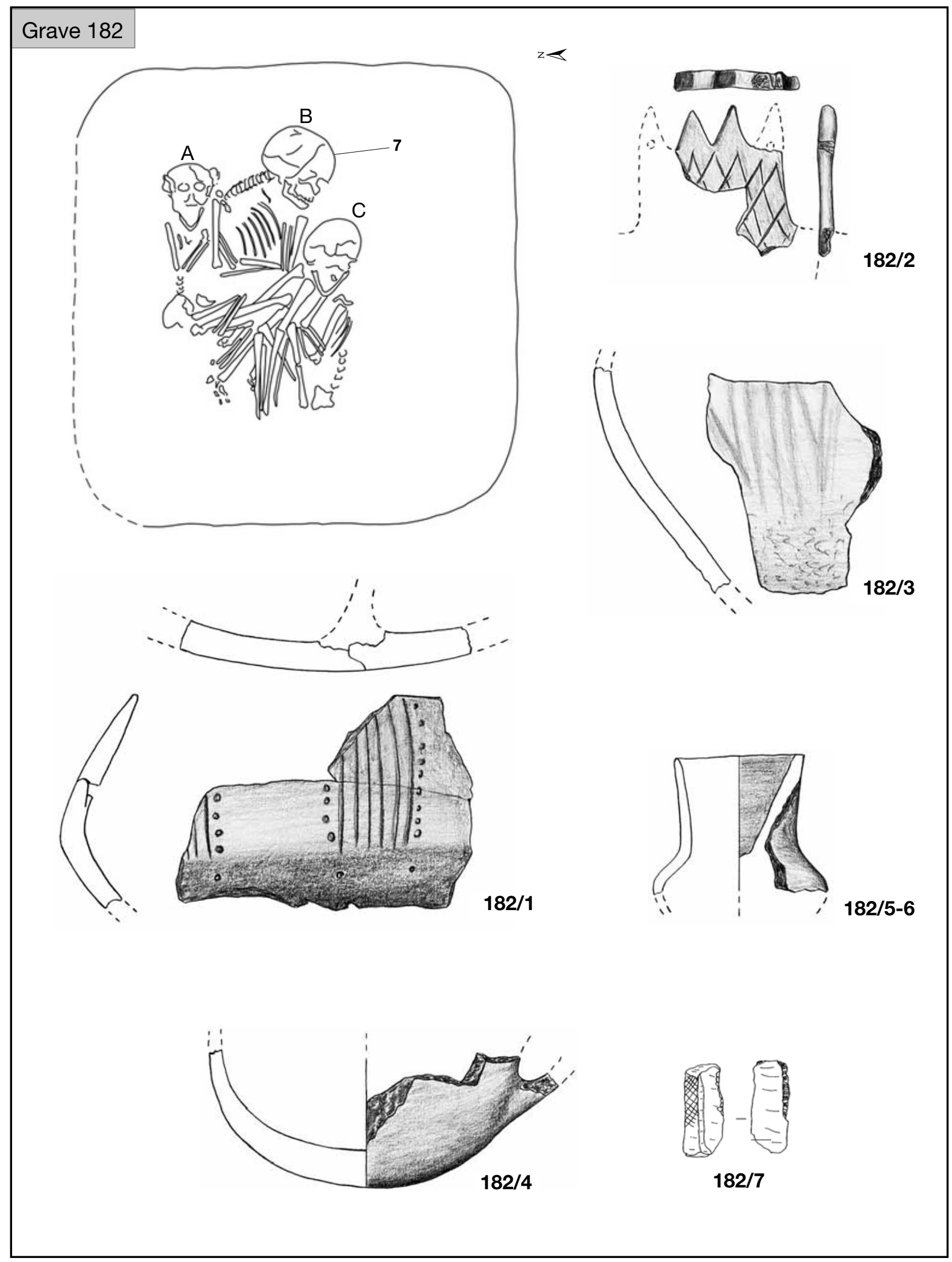

Plate LXXVI. Grave 182 (182/7: after Cs. BALOGH 1993) 


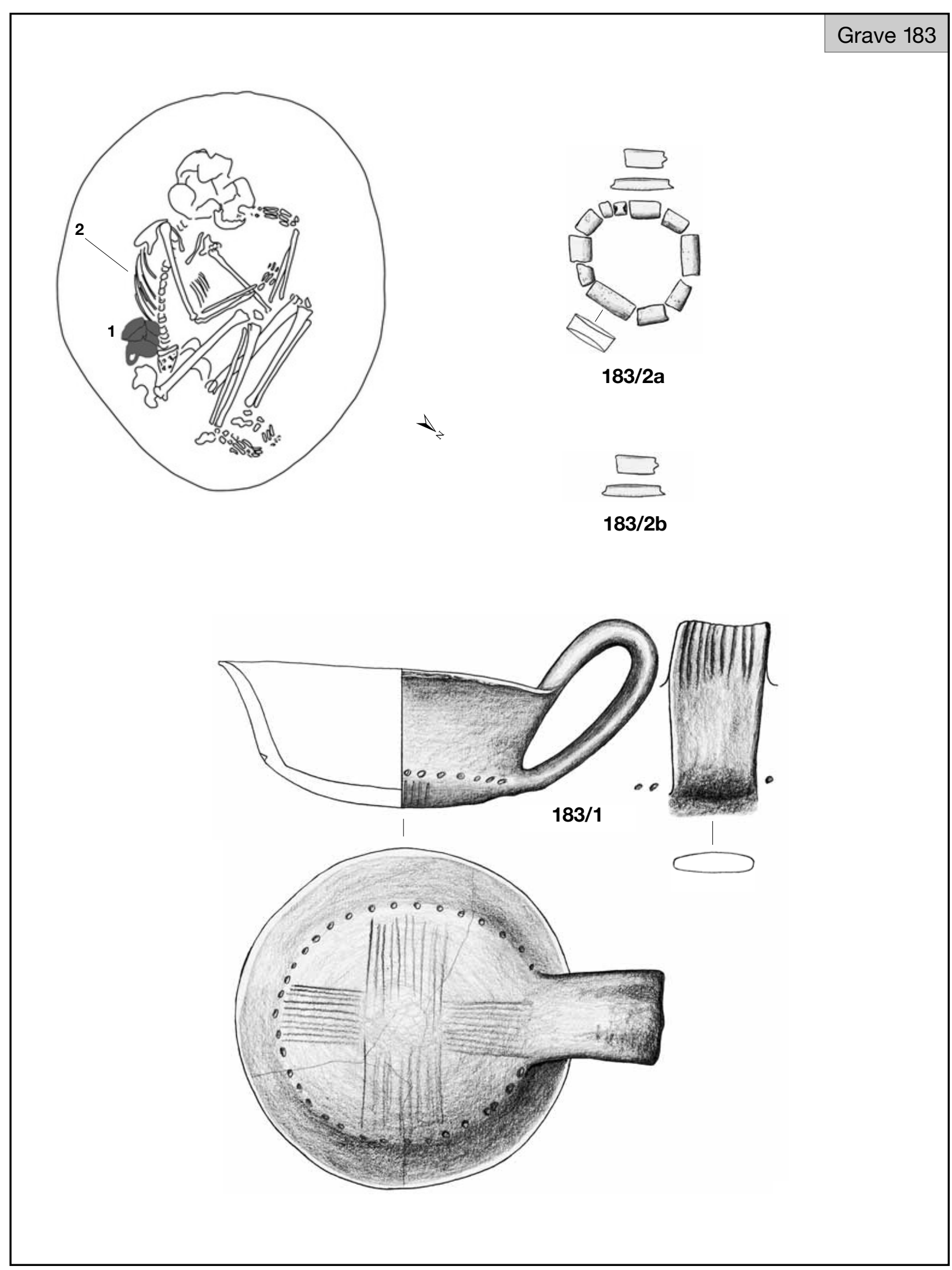

Plate LXXVII. Grave 183 


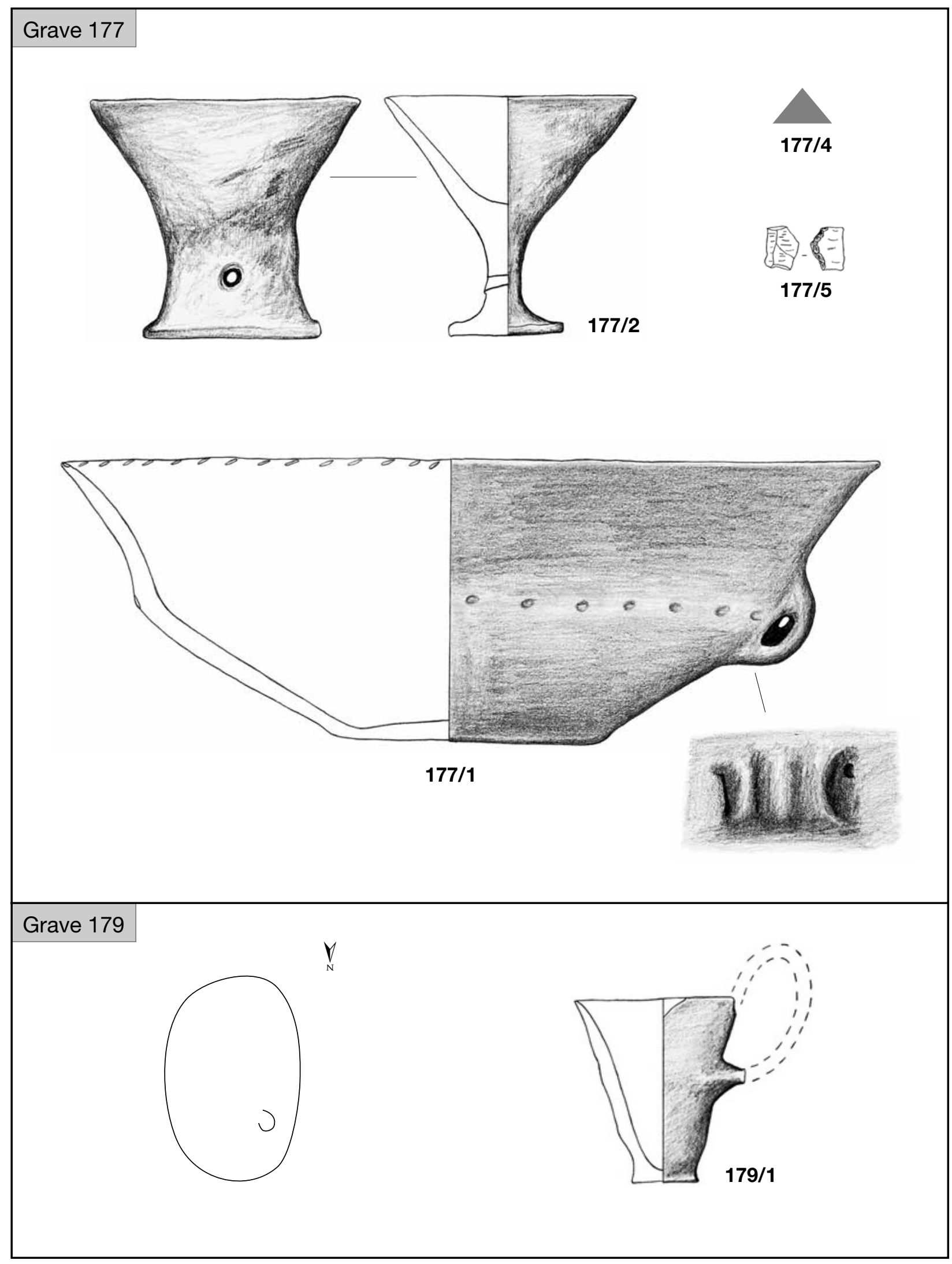

Plate LXXVIII. Graves 177 and 179 (177/5: after Cs. BALOGH 1993) 


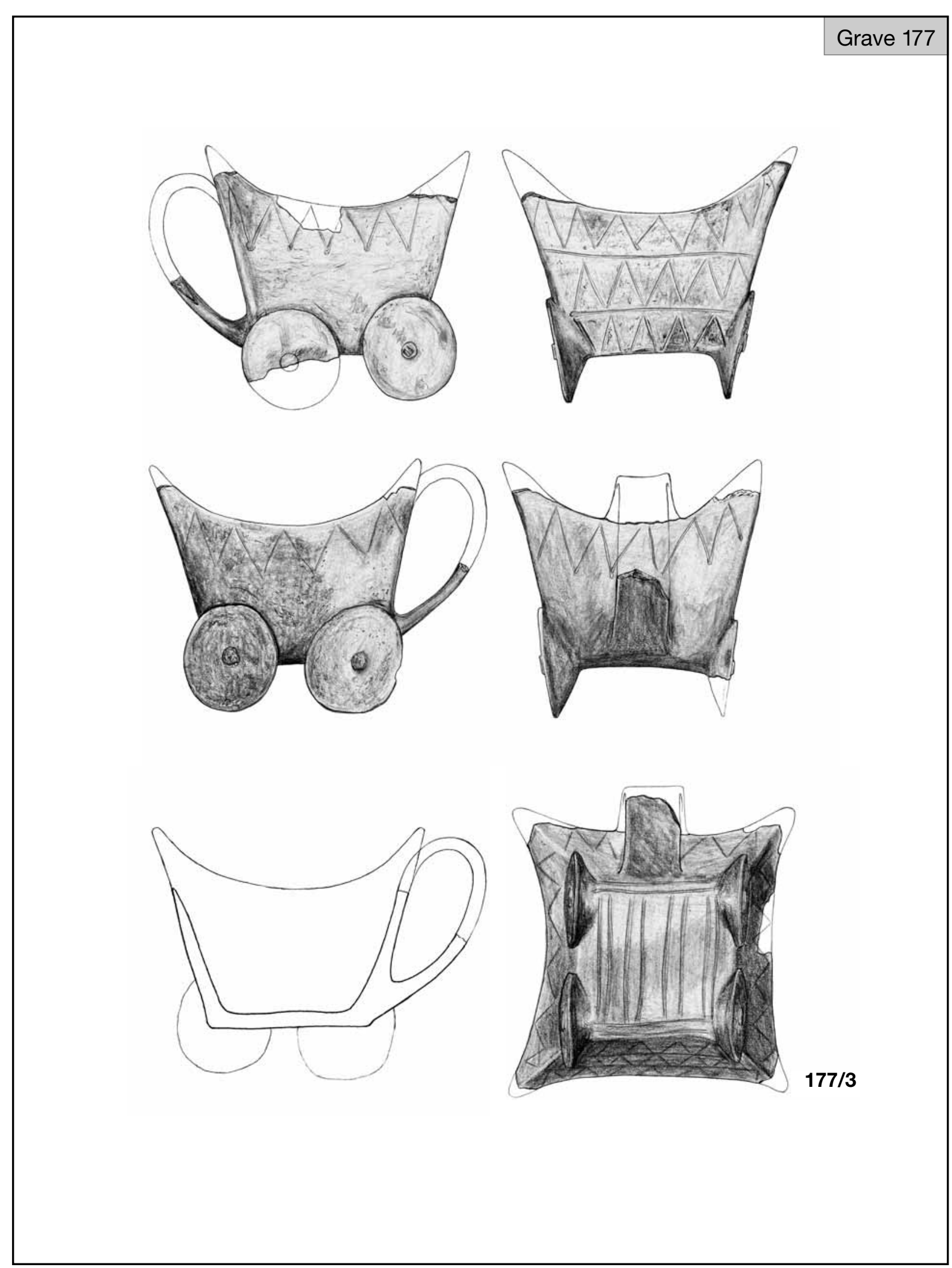

Plate LXXIX. Grave 177 


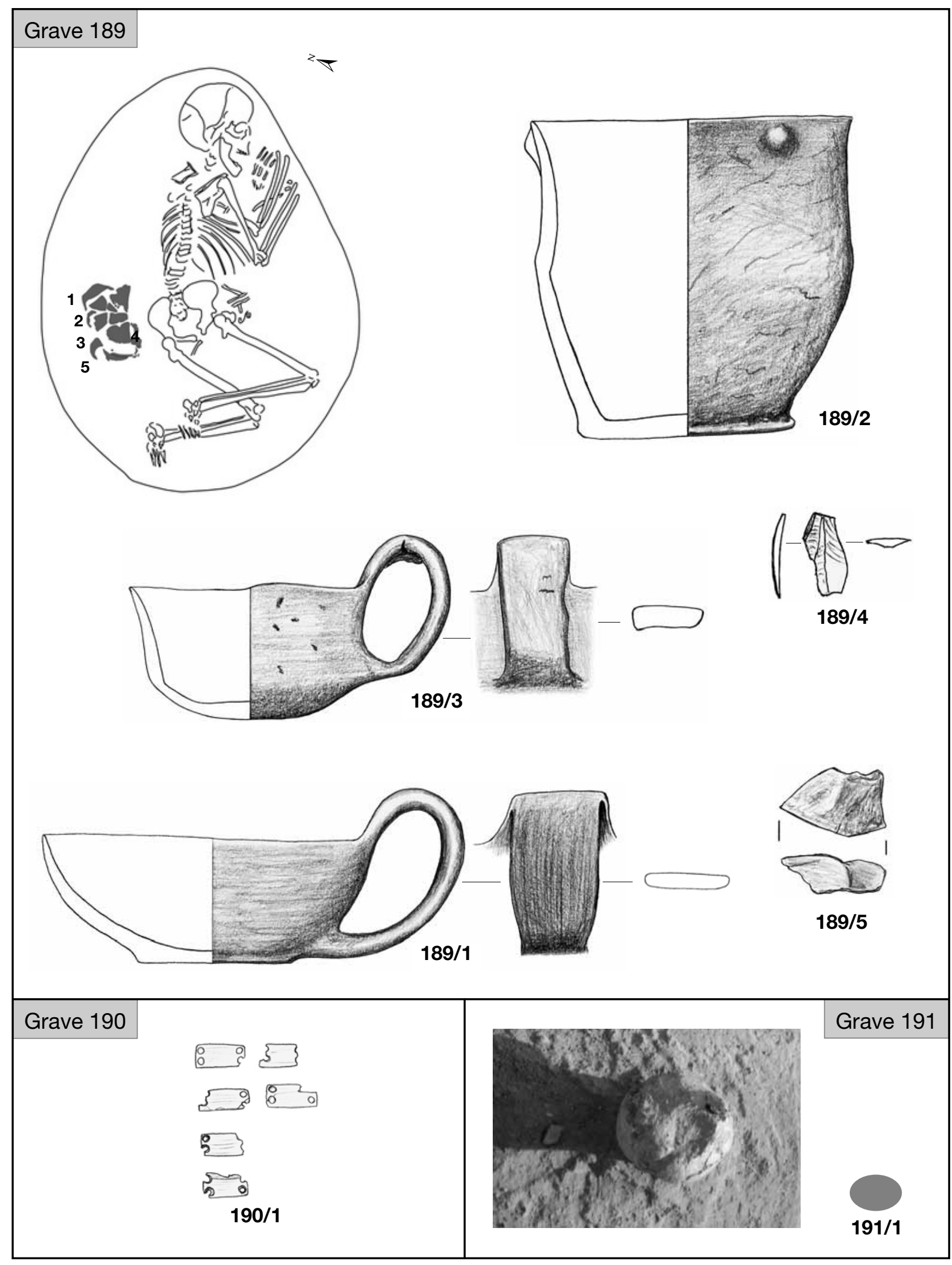

Plate LXXX. Graves 189-191 


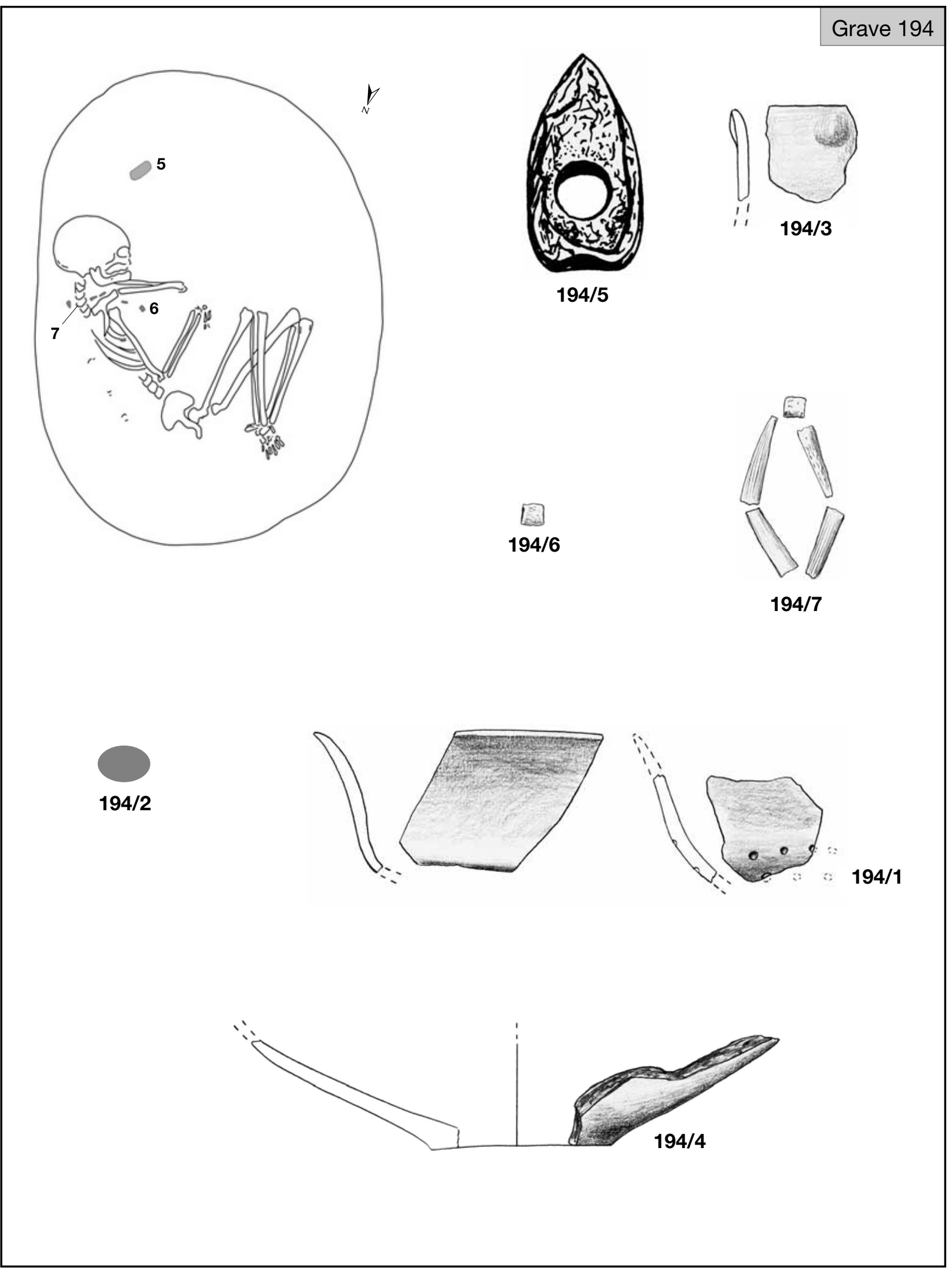

Plate LXXXI. Grave 194 (194/5: after JózSEF KorEK's grave sheet) 


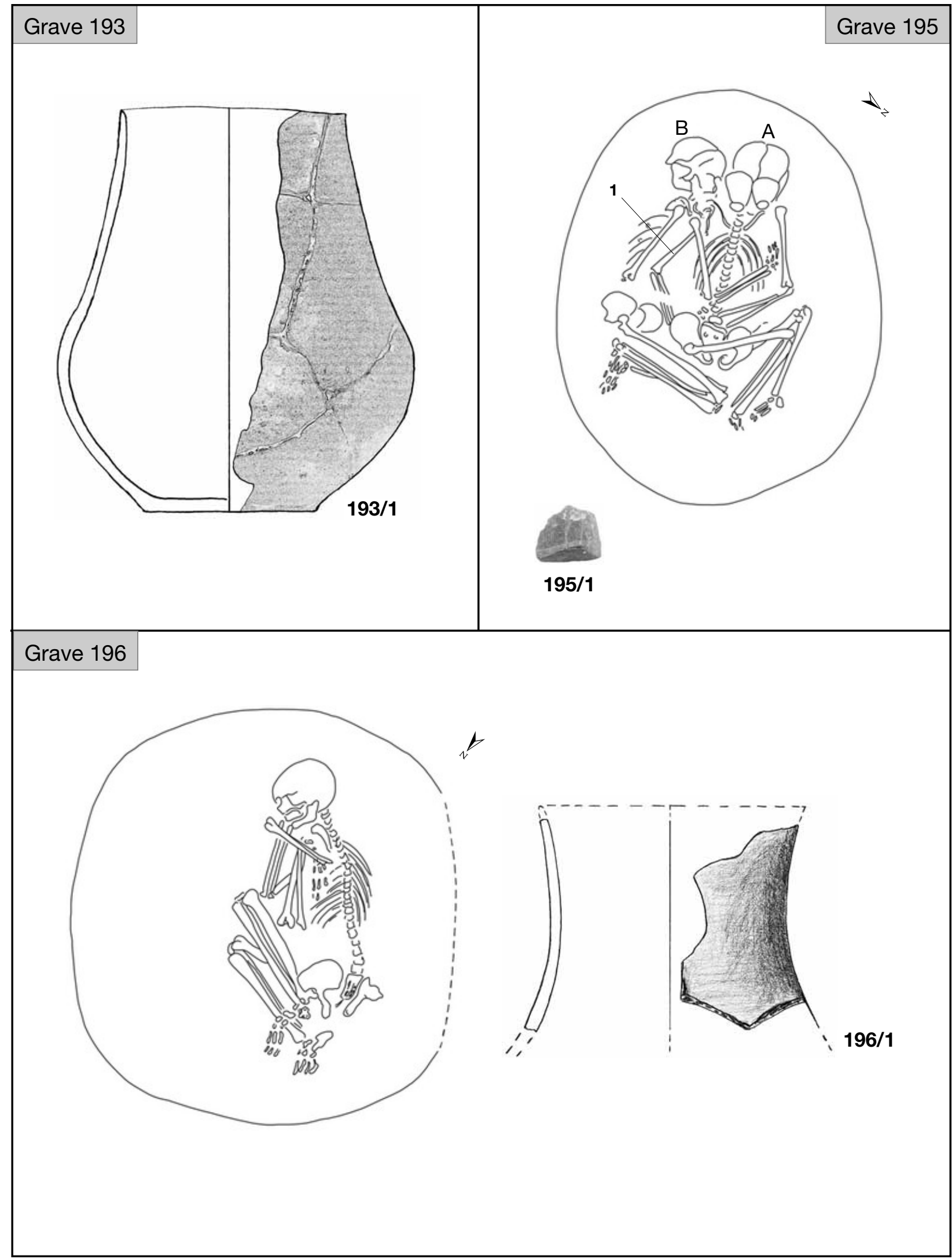

Plate LXXXII. Graves 193 and 195-196 (195/1: after JózSEF KOREK's photo, courtesy of the SzFM Archives) 


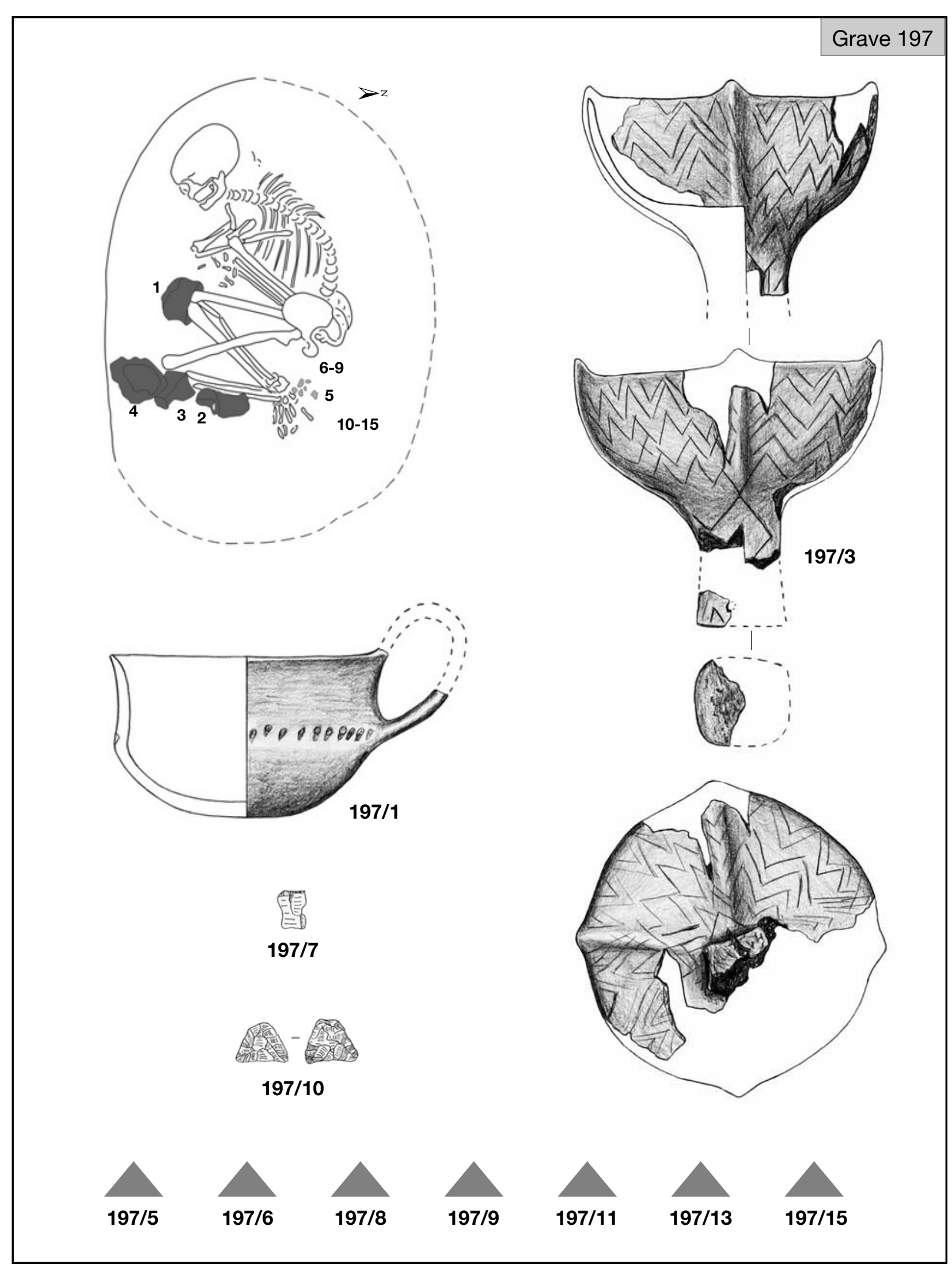

Plate LXXXIII. Grave 197 (197/7, 10: after Cs. BALOGH 1993) 


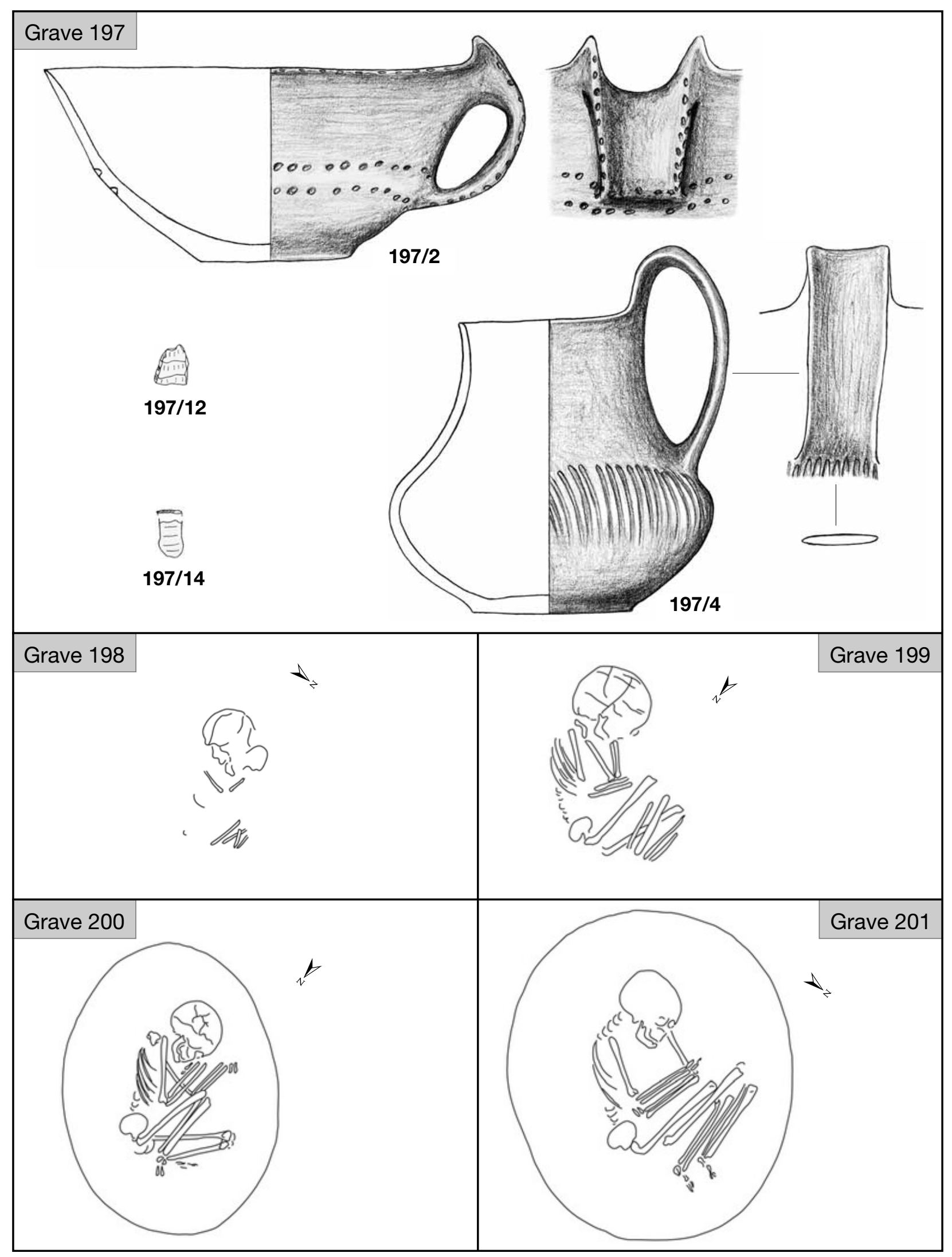

Plate LXXXIV. Graves 197 and 198-201 (197/12, 14: after Cs. BALOGH 1993) 


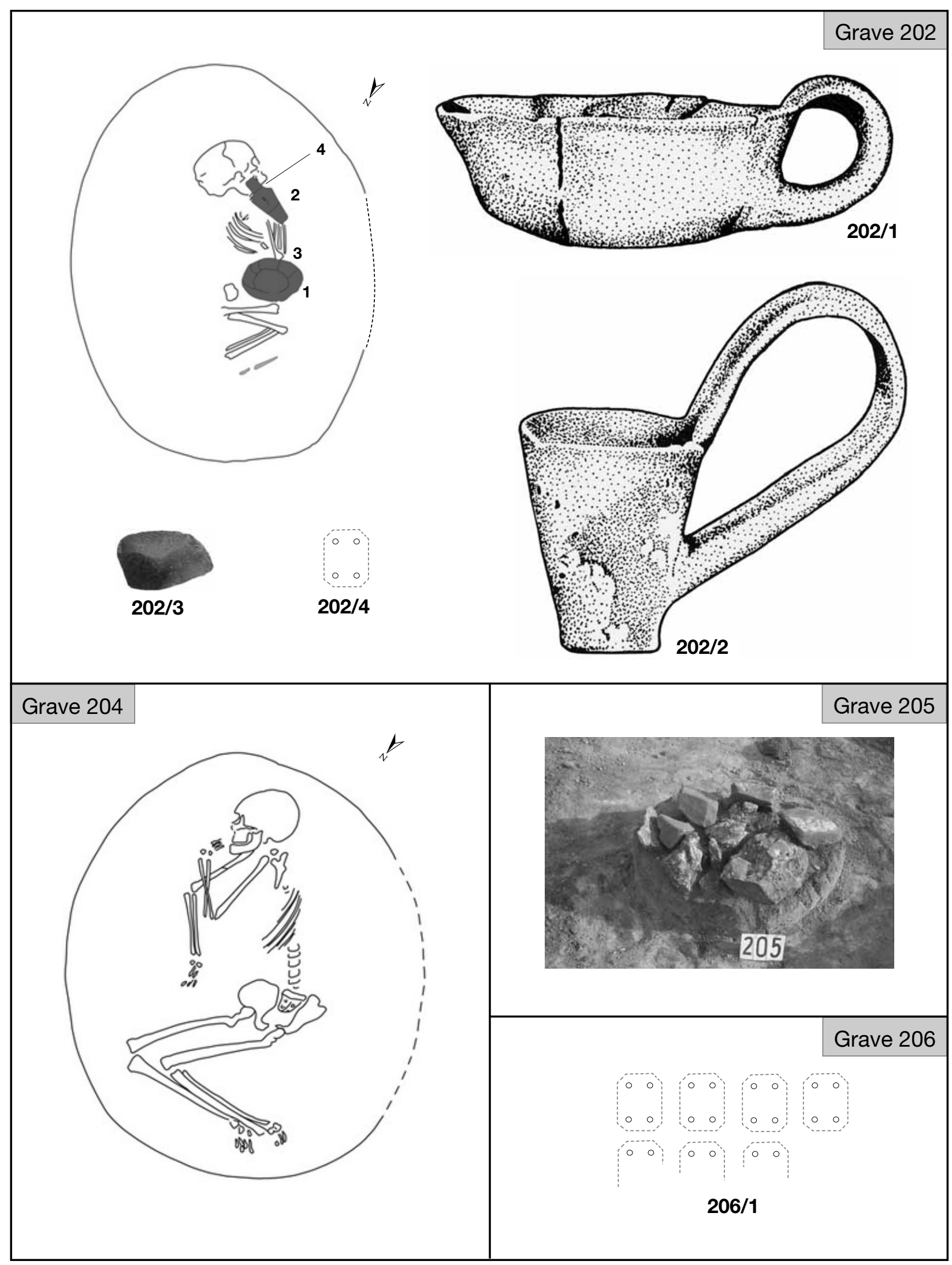

Plate LXXXV. Graves 202 and 204-206 (202/1-2: after JÓZSEF KOREK’s grave sheet; 202/3: after JózSEF KOREK's photo, courtesy of the SzFM Archives) 


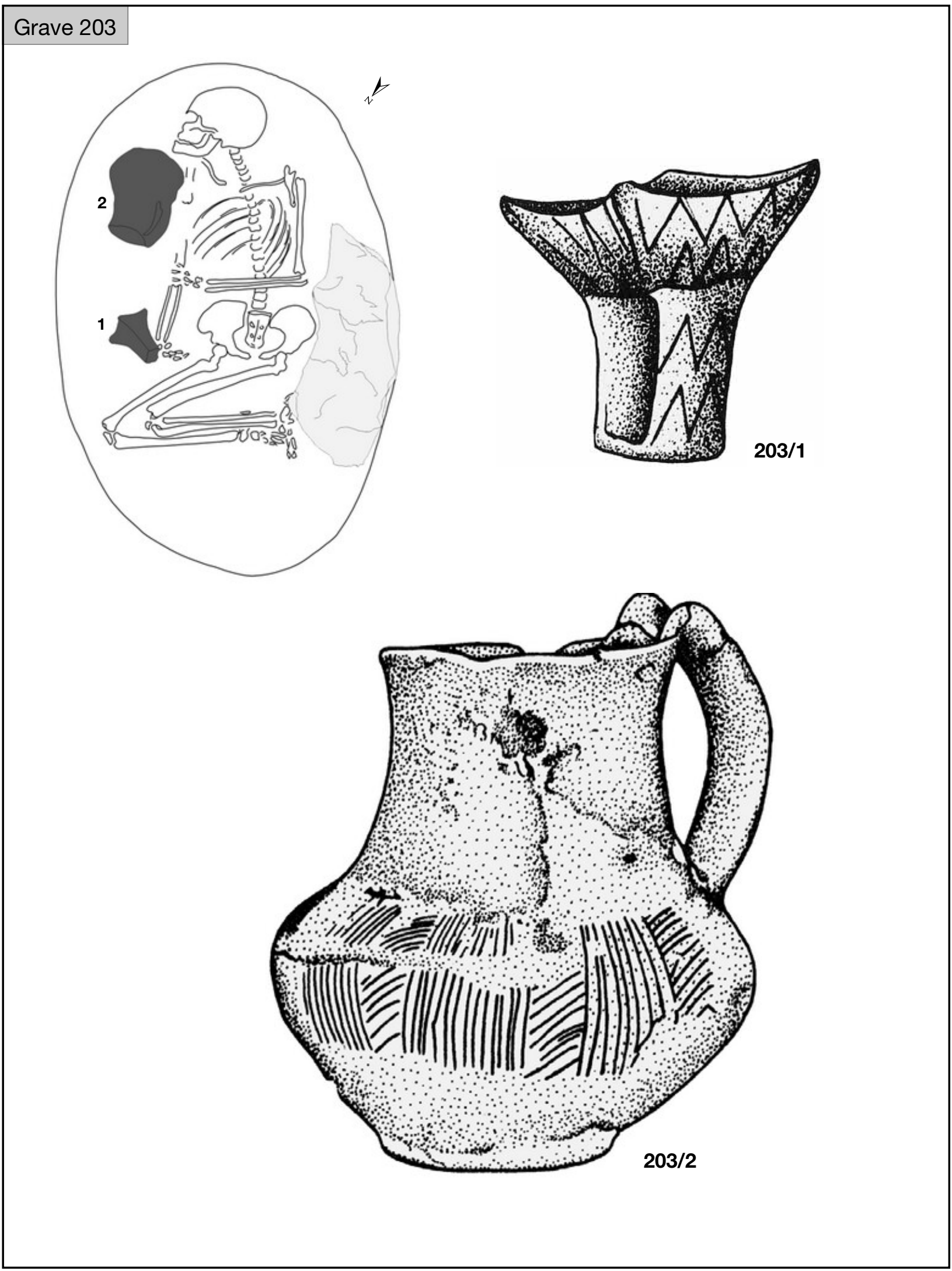

Plate LXXXVI. Grave 203 (203/1-2: after JóZSEF KOREK's grave sheet) 


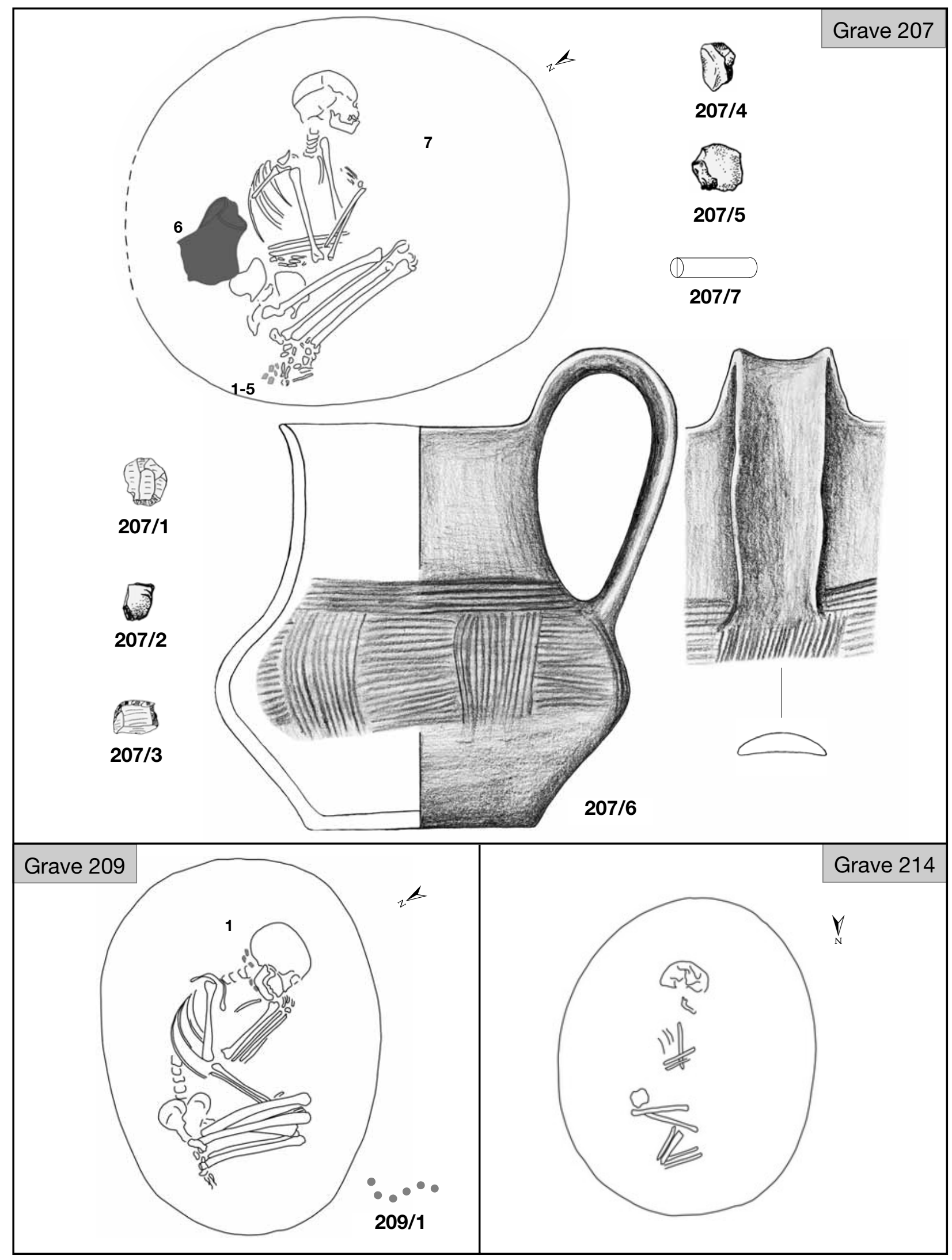

Plate LXXXVII. Graves 207, 209 and 214 (207/2, 4-5: after JózSEF KOREK’s grave sheet) 


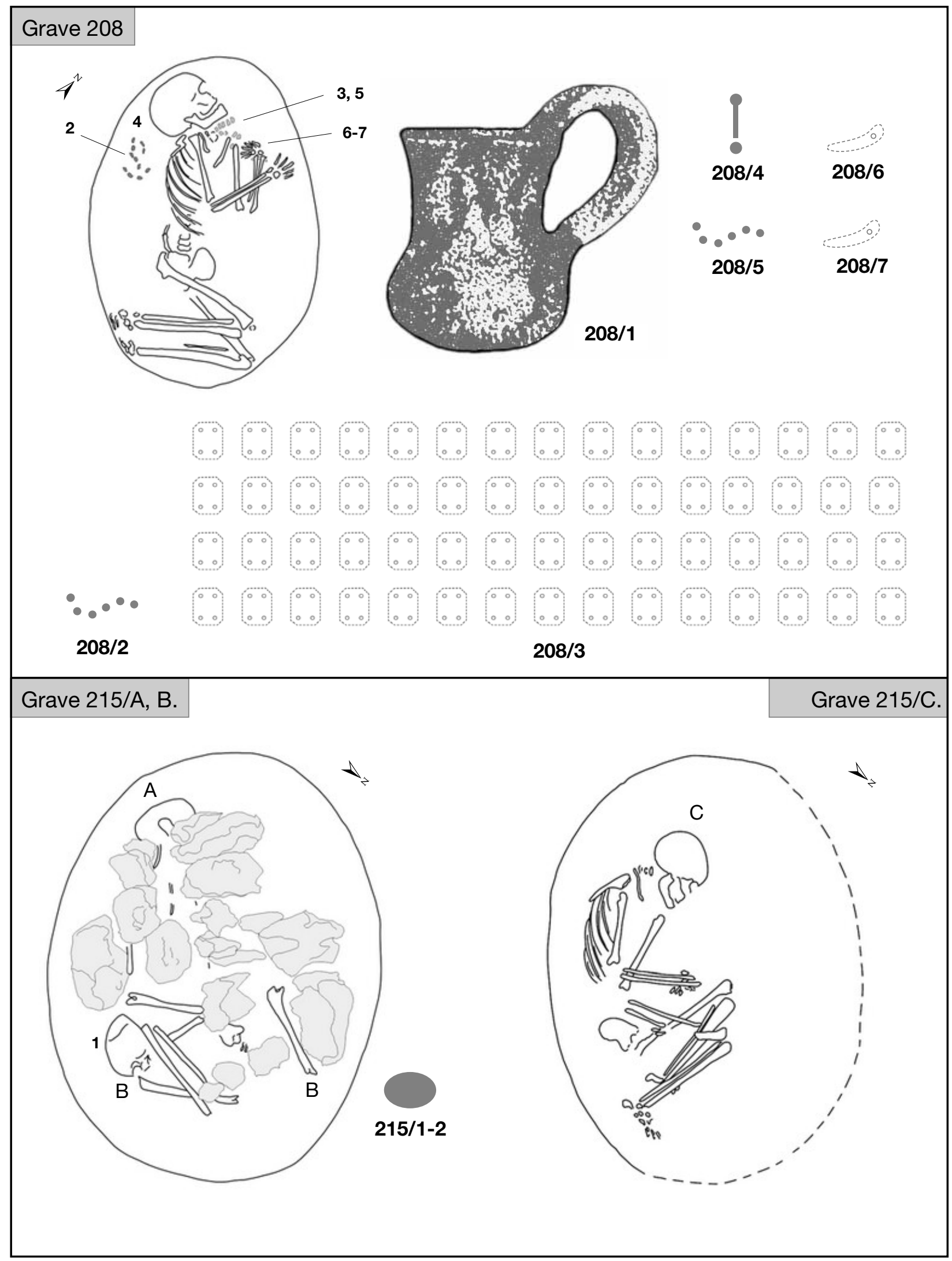

Plate LXXXVIII. Graves 208-209 (208/1: after JóZSEF KoREK’s grave sheet) 


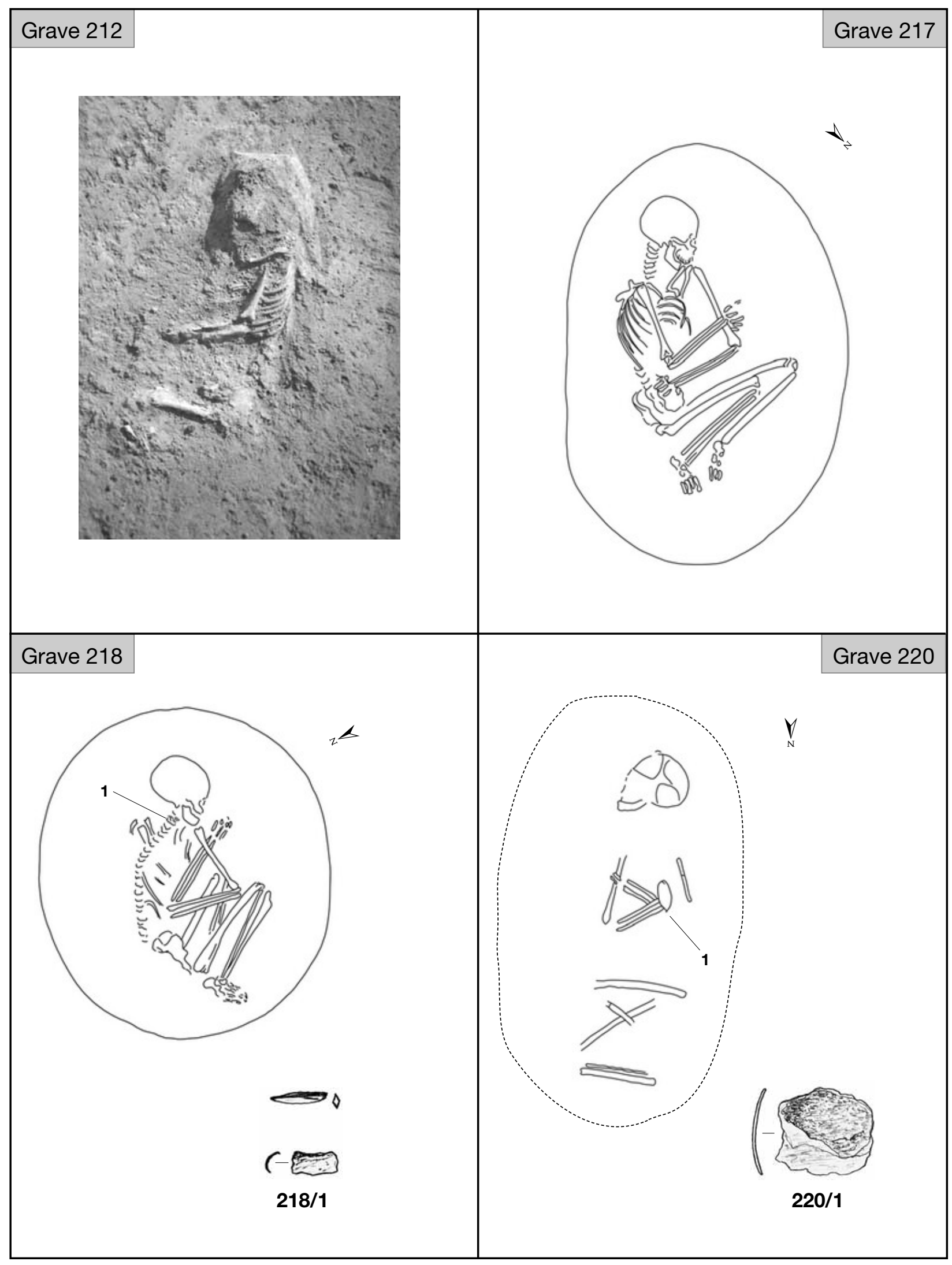

Plate LXXXIX. Graves 212, 217-218 and 220 


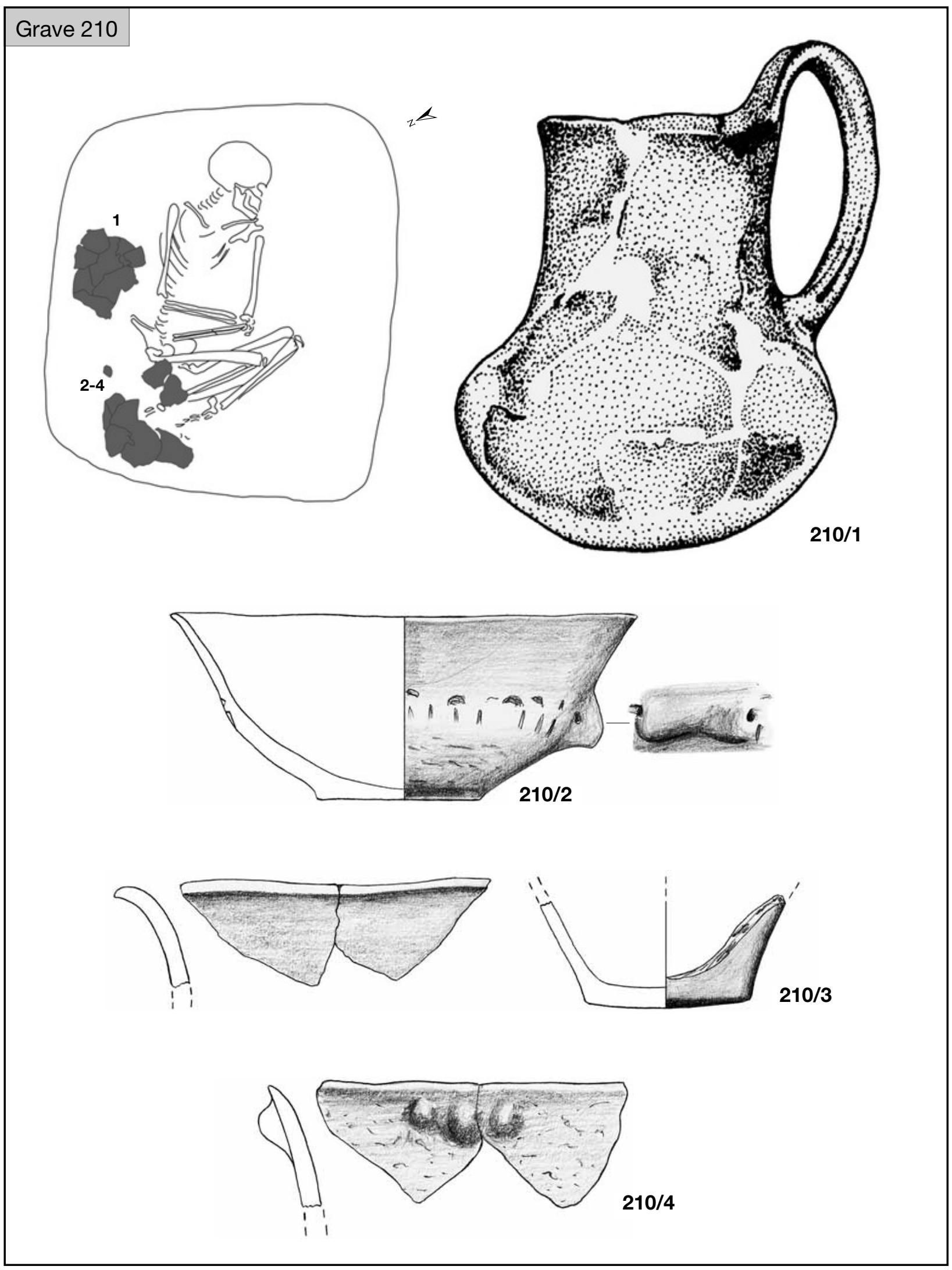

Plate XC. Grave 210 (210/1: after JóZSEF KorEK’s grave sheet) 


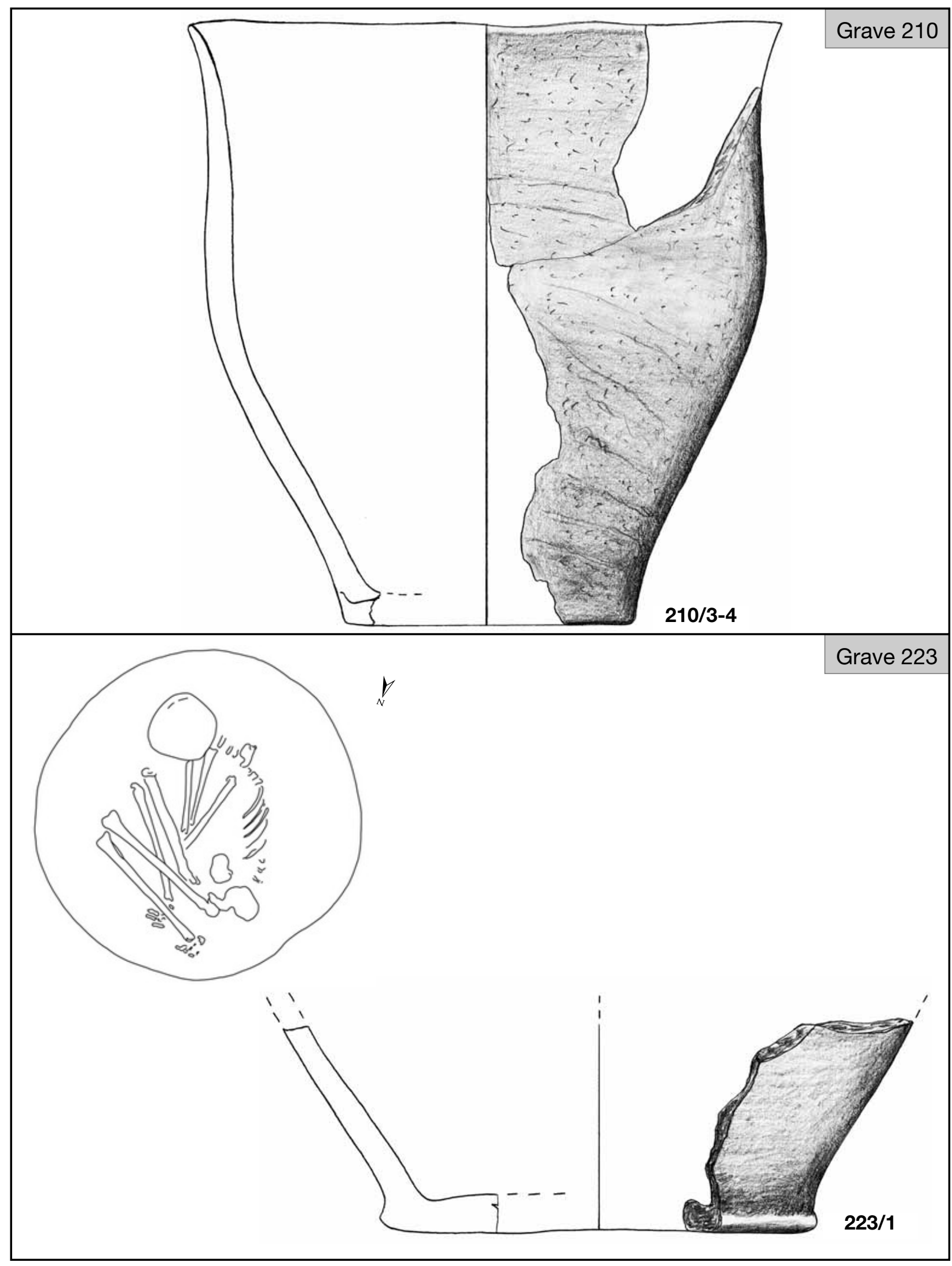

Plate XCI. Graves 210 and 223 


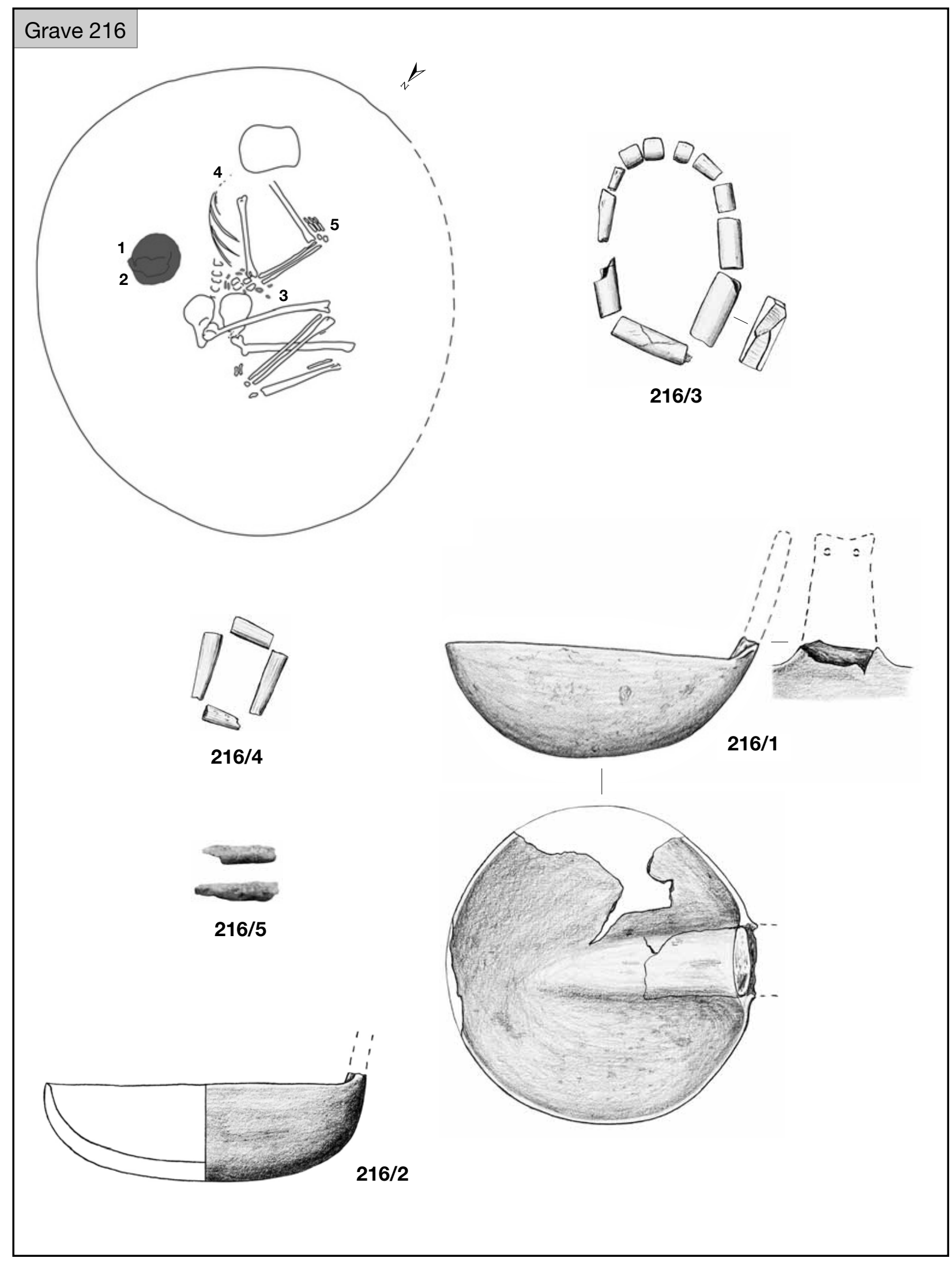

Plate XCII. Grave 216 (216/5: after JózSEF KOREK’s grave sheet) 


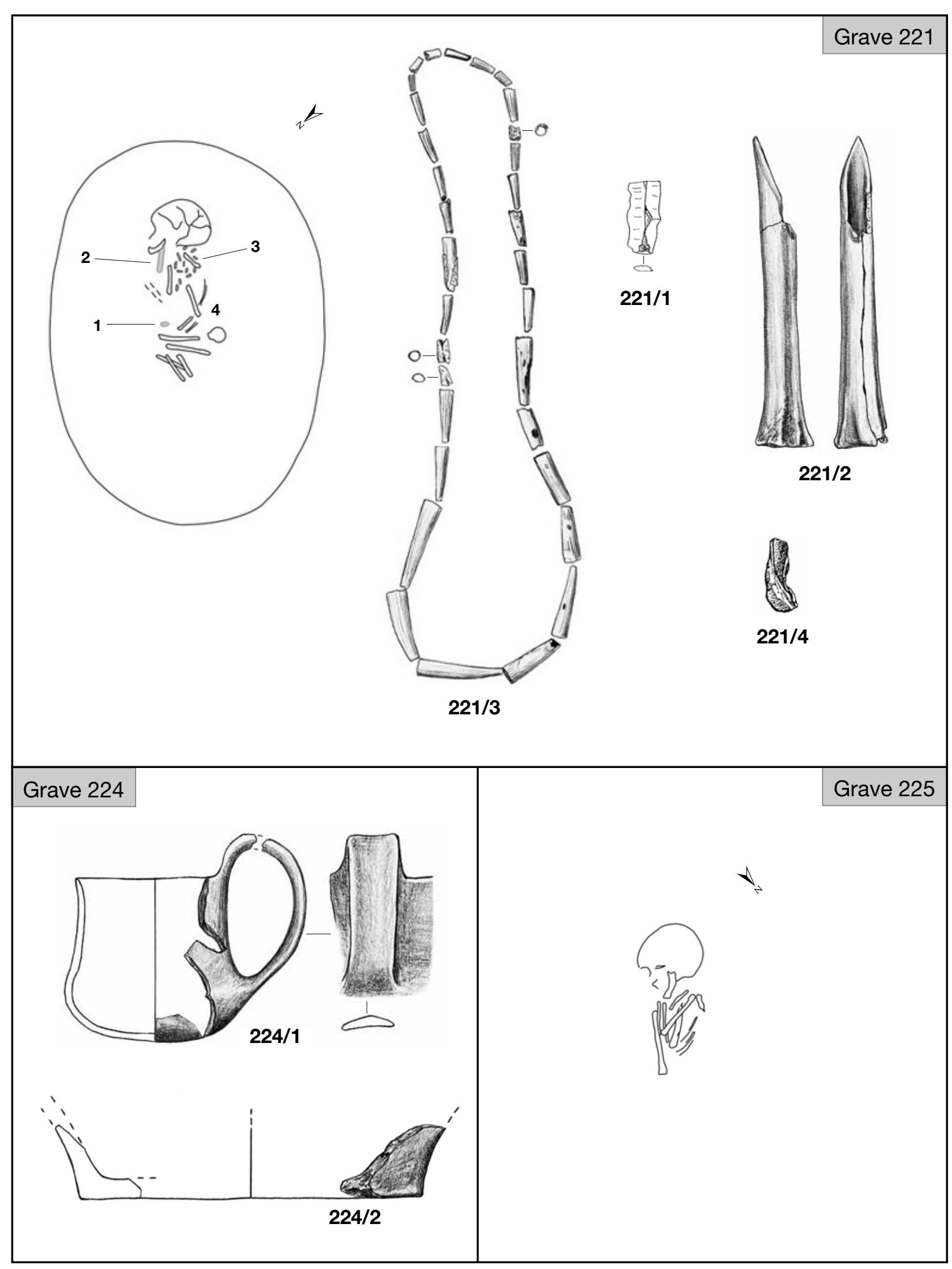

Plate XCIII. Graves 221 and 224-225 (221/1: after Cs. BALOGH 1993; 221/4: after JÓZSEF KOREK’s grave sheet) 


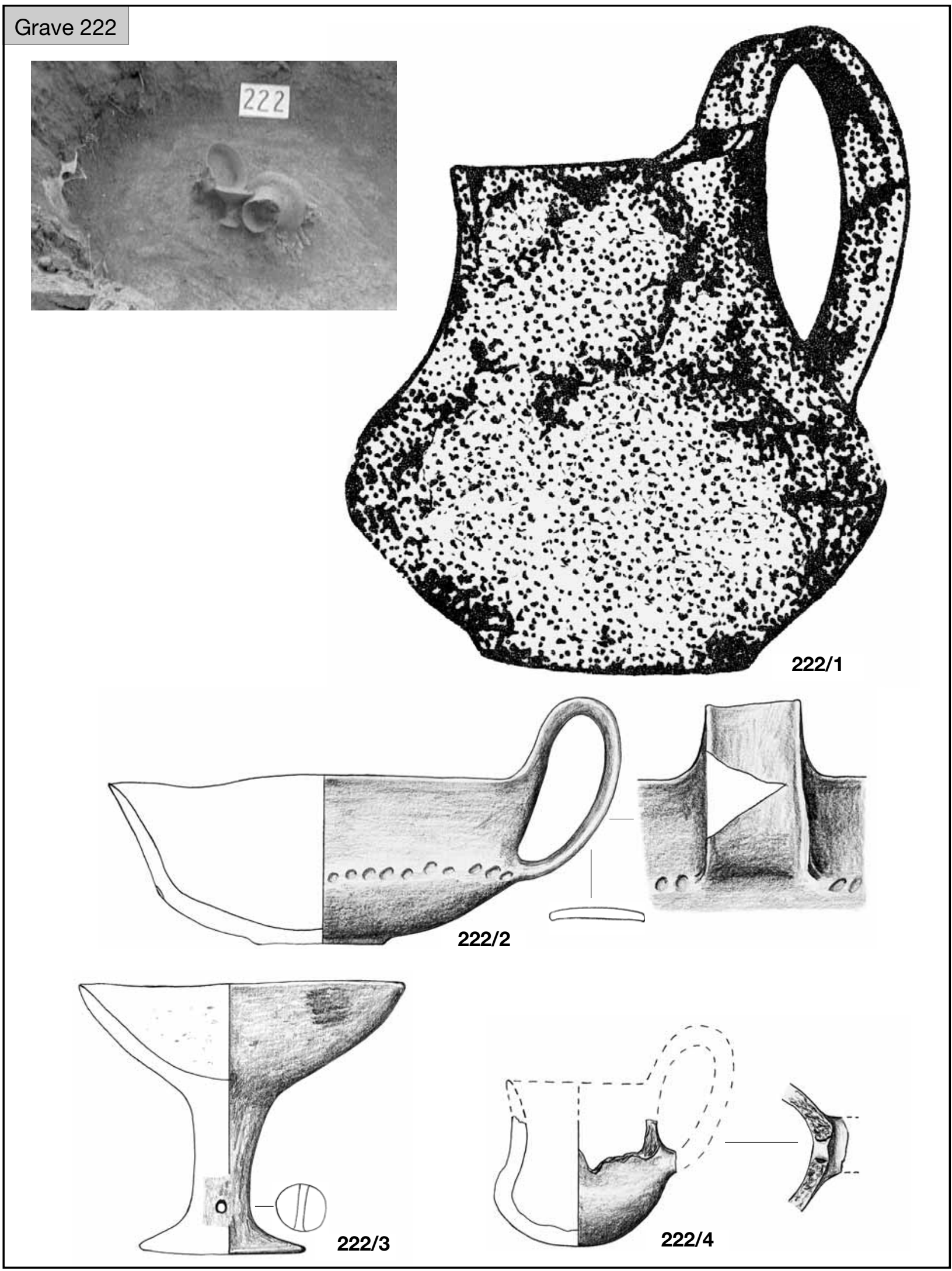

Plate XCIV. Grave 222 (222/1: after JóZSEF KOREK’s grave sheet) 


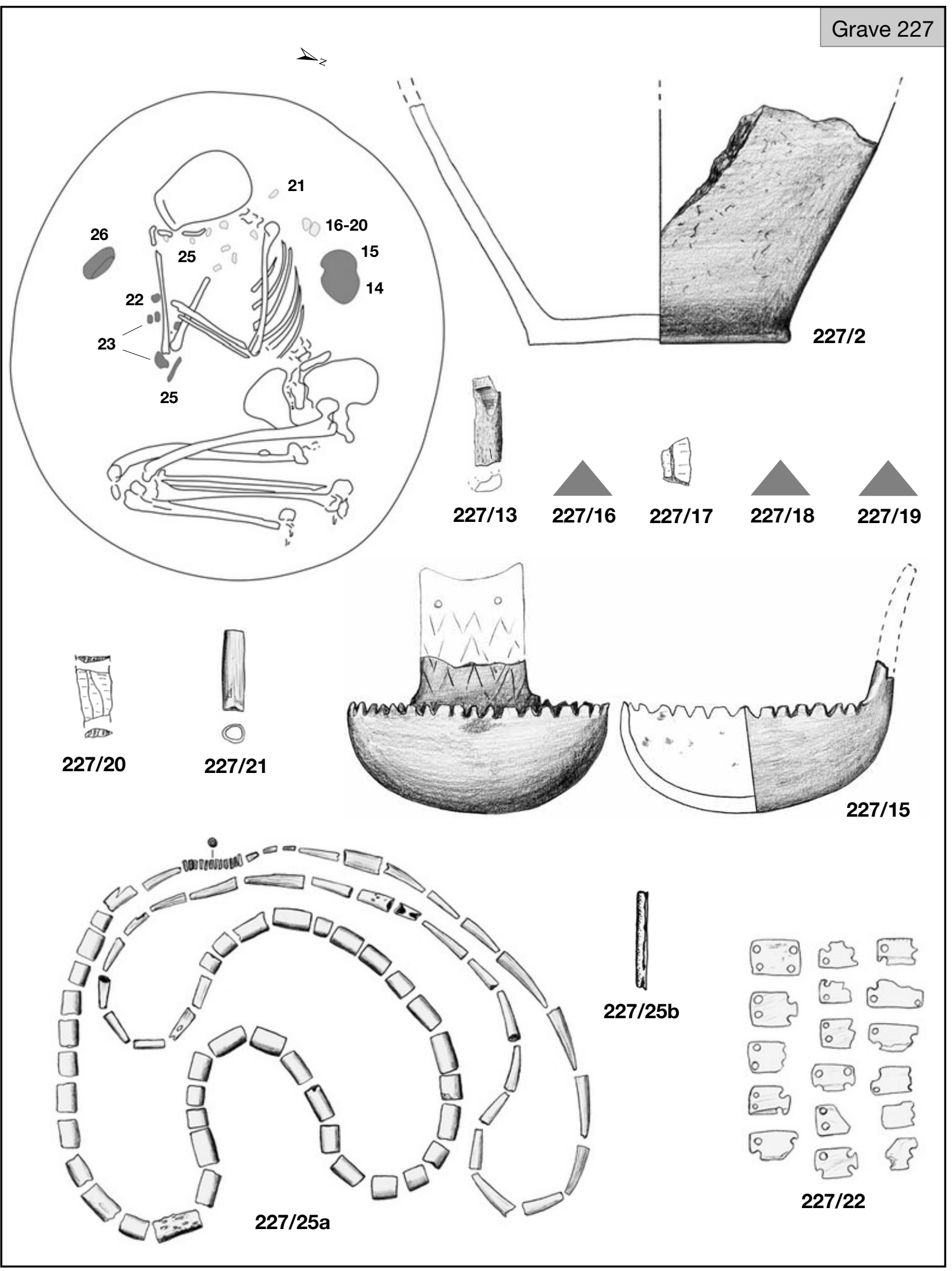

Plate XCV. Grave 227 


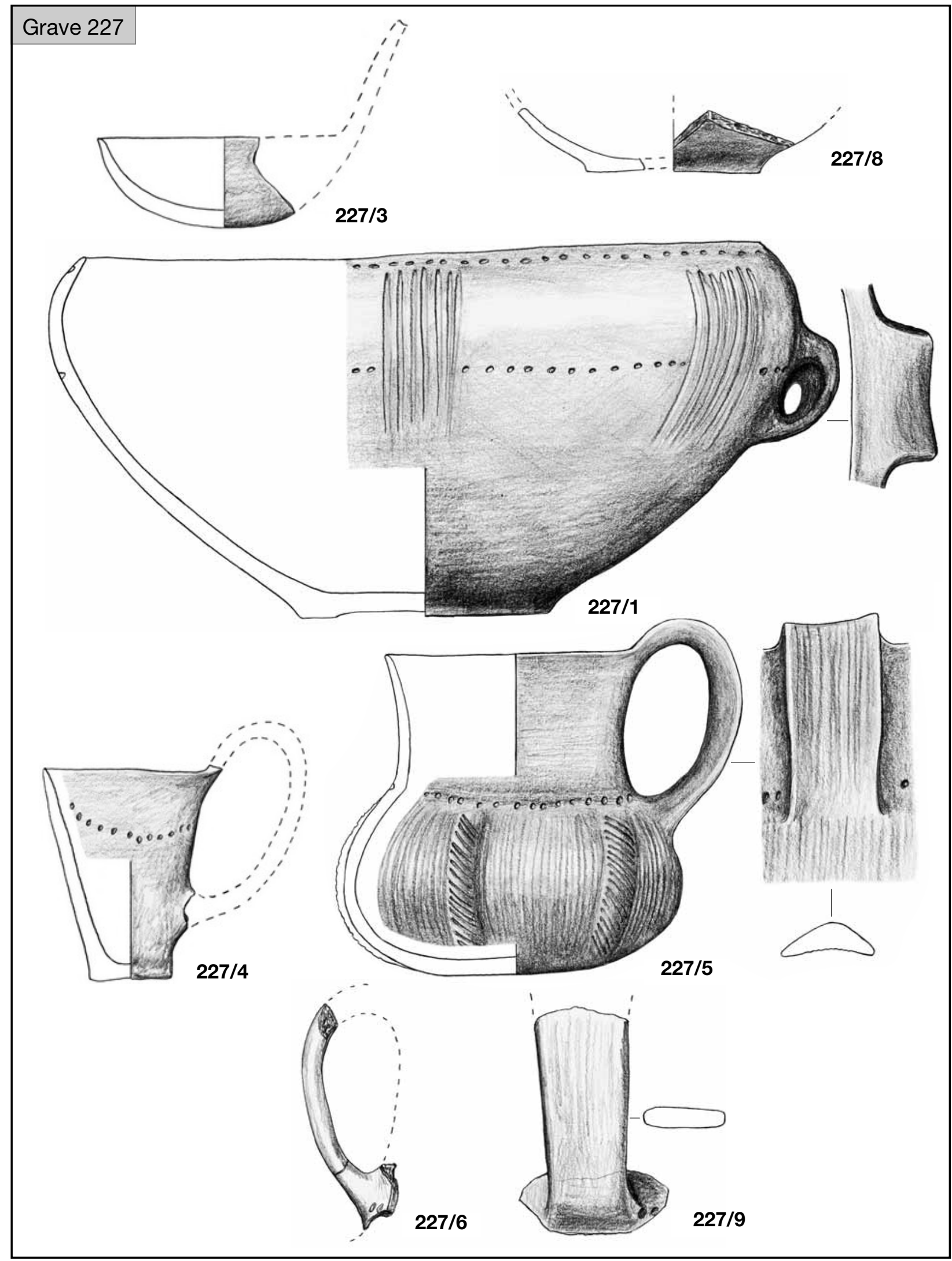

Plate XCVI. Grave 227 


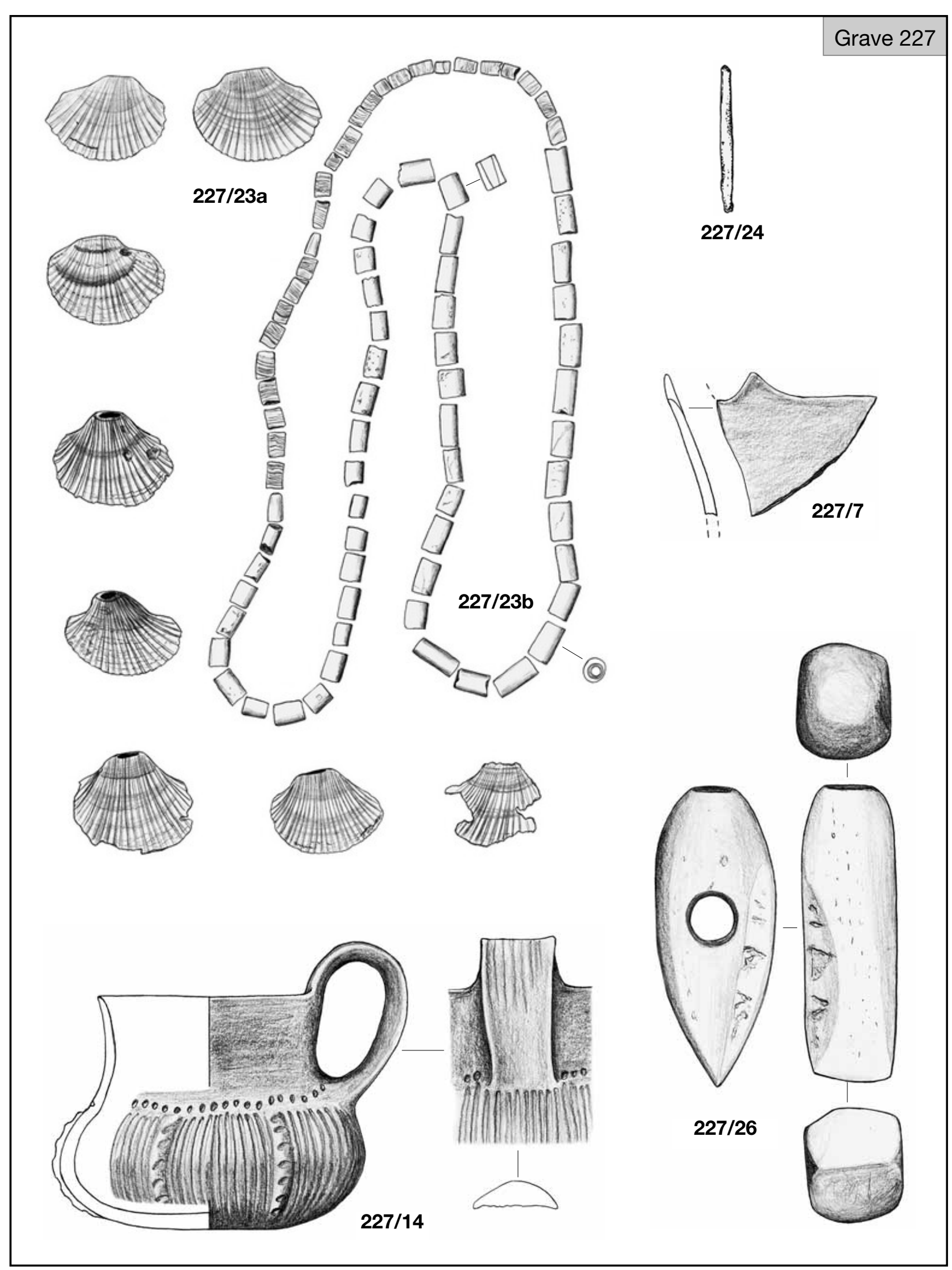

Plate XCVII. Grave 227 (227/24: after JÓZSEF KOREK’s grave sheet) 


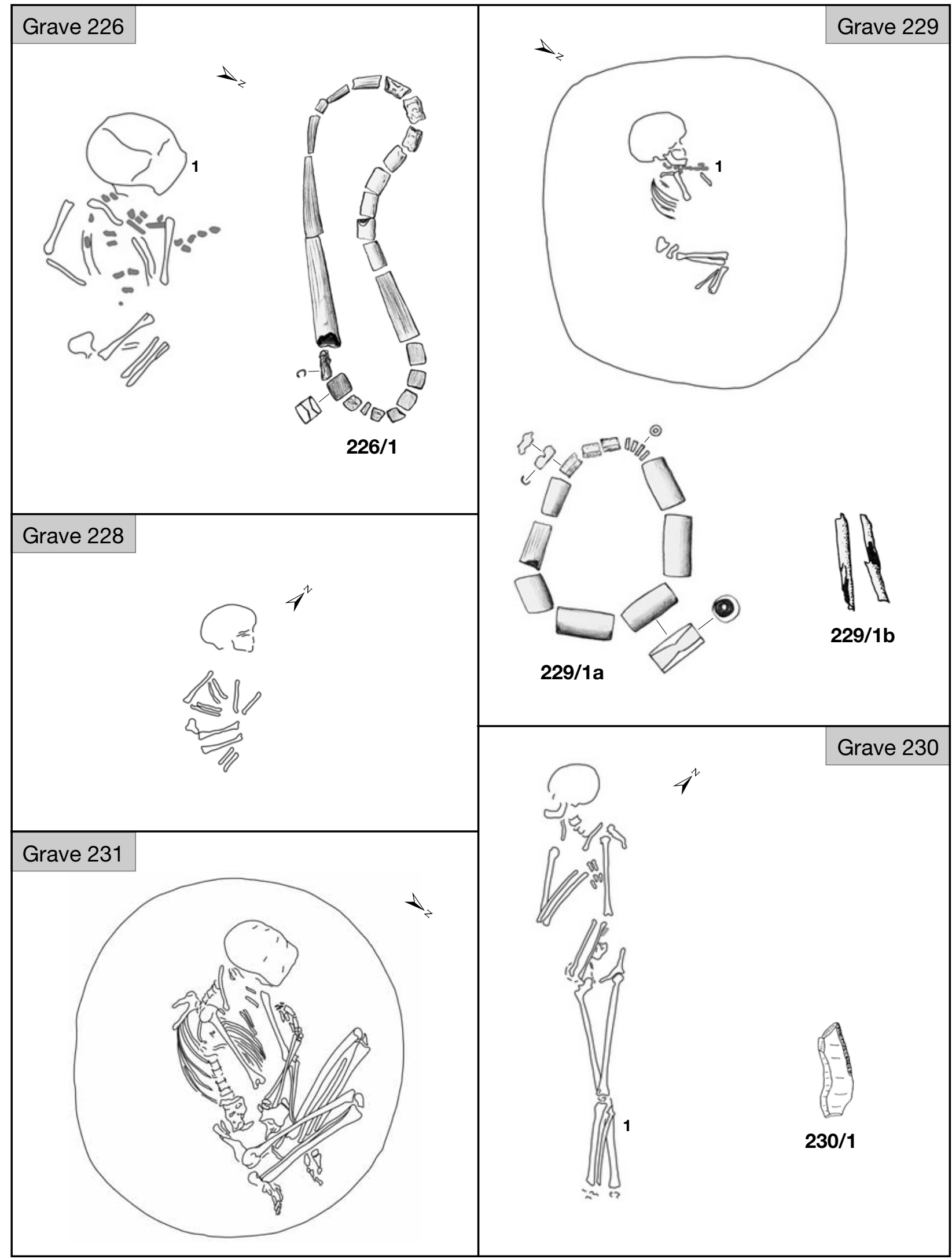

Plate XCVIII. Graves 226 and 228-231 (229/1b: after JóZSEF KonEK’s grave sheet; 230/1: after Cs. BALOGH 1993) 


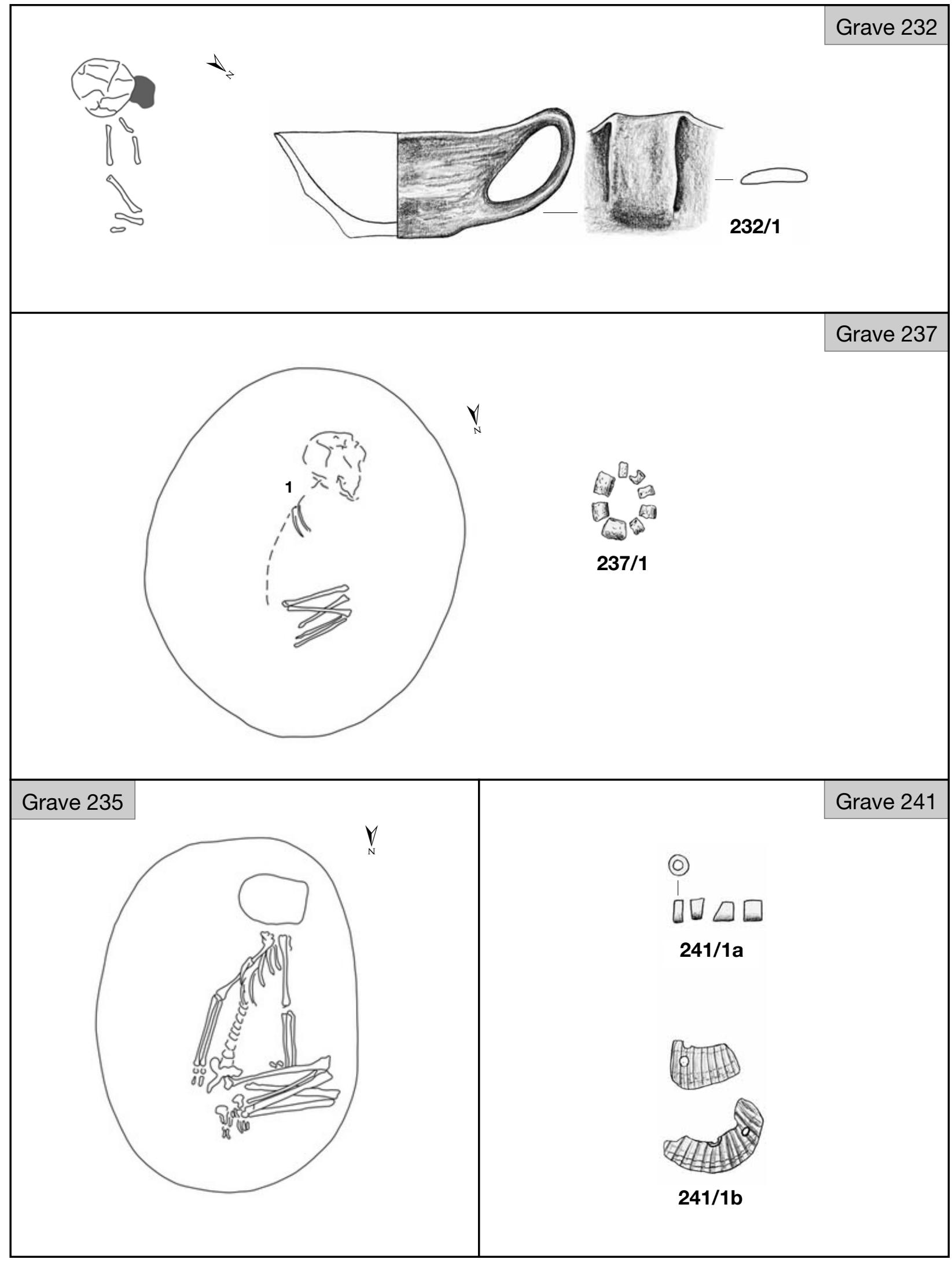

Plate XCIX. Graves 232, 235, 237 and 241 


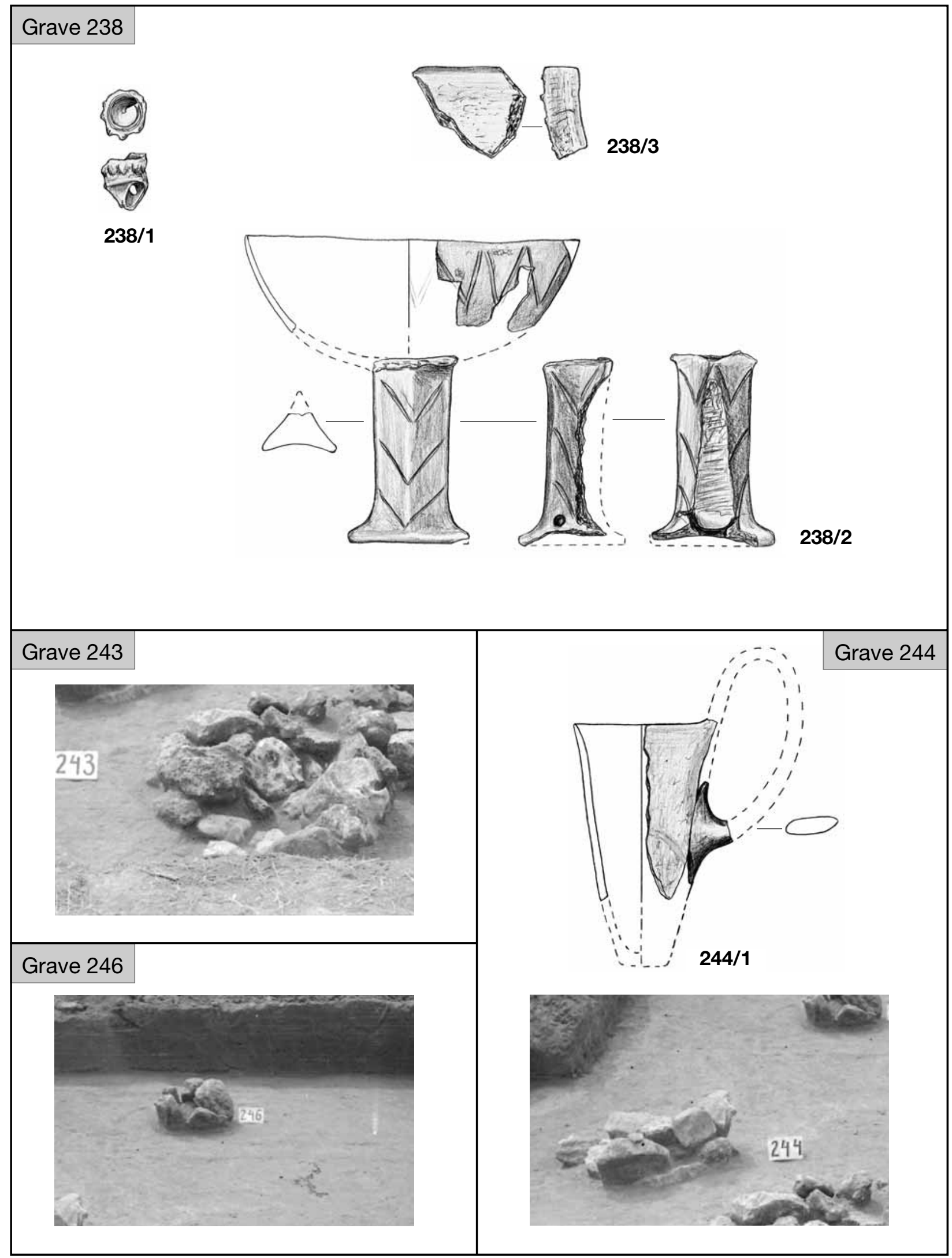

Plate C. Graves 238, 243-244 and 246 


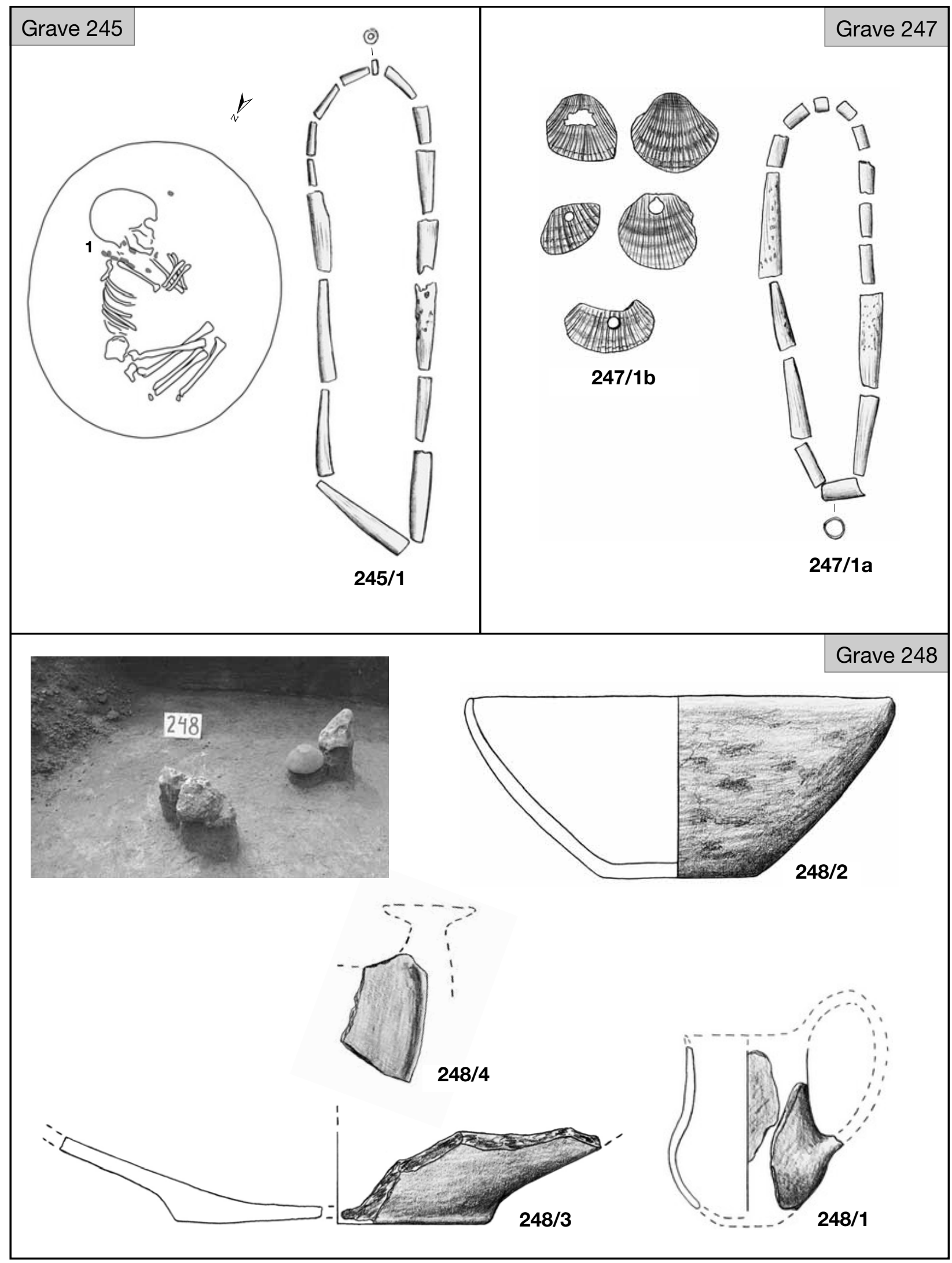

Plate CI. Graves 245 and 247-248 


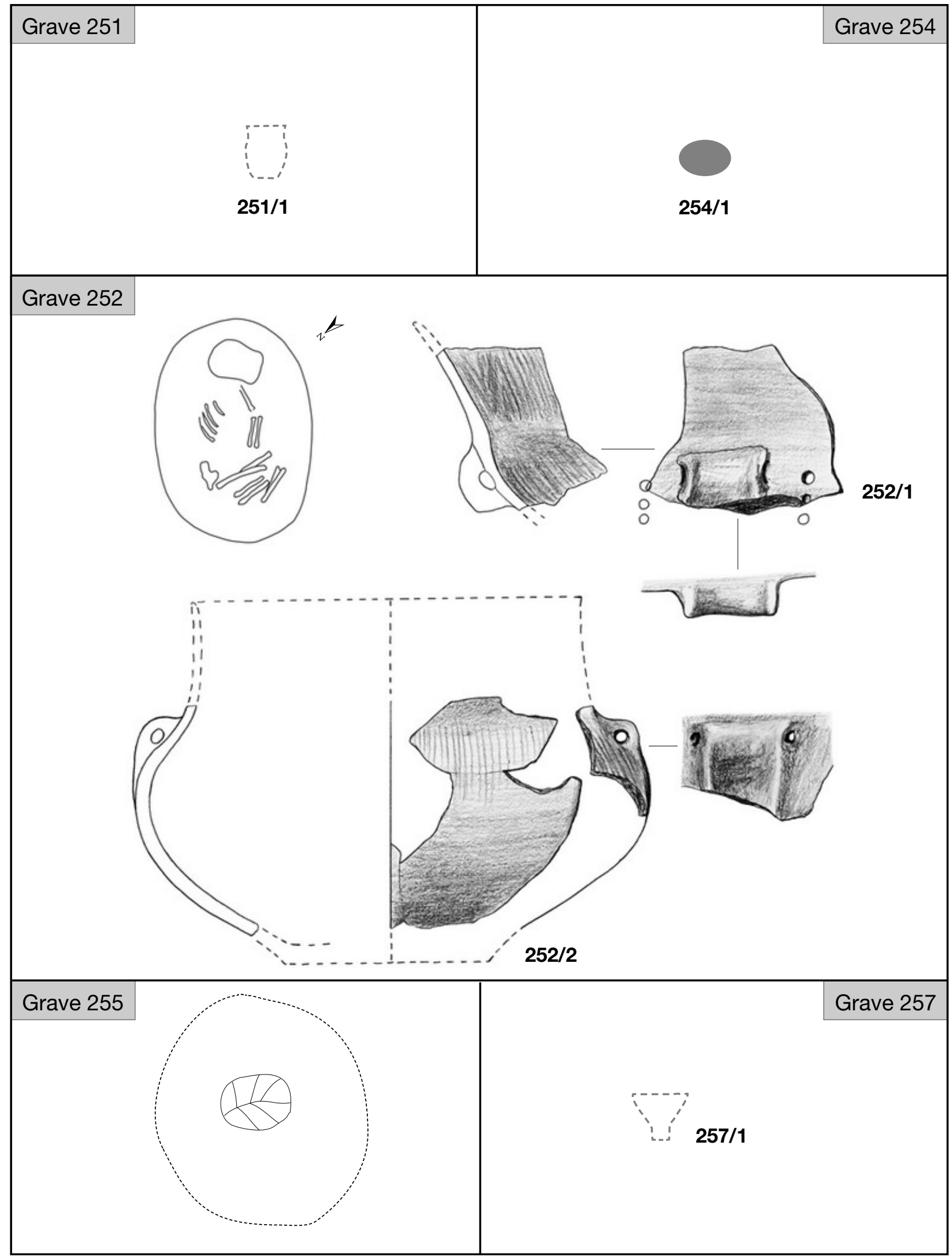

Plate CII. Graves 251-252, 254-255 and 257 


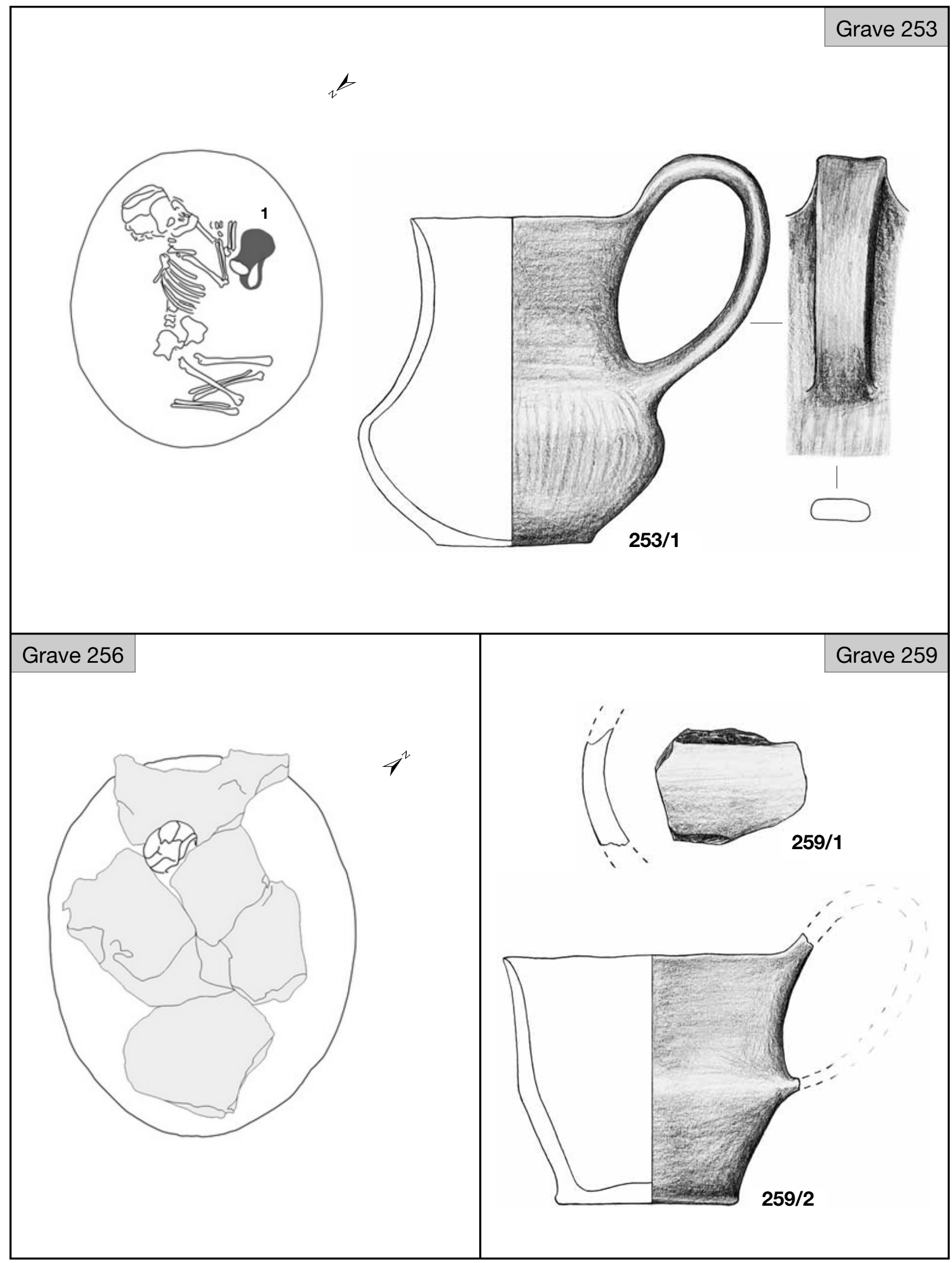

Plate CIII. Graves 253, 256 and 259 


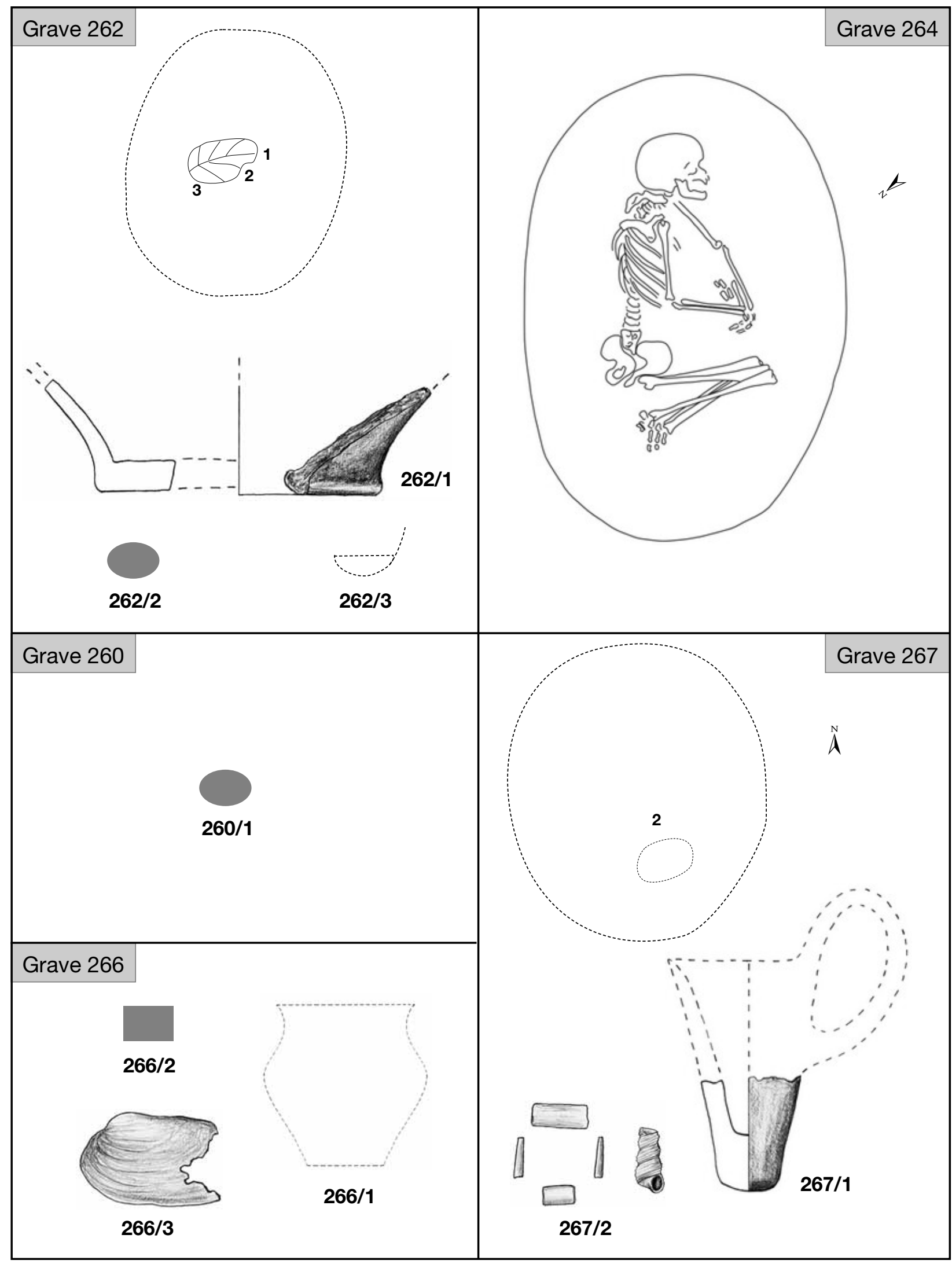

Plate CIV. Graves 260, 262, 264 and 266-267 

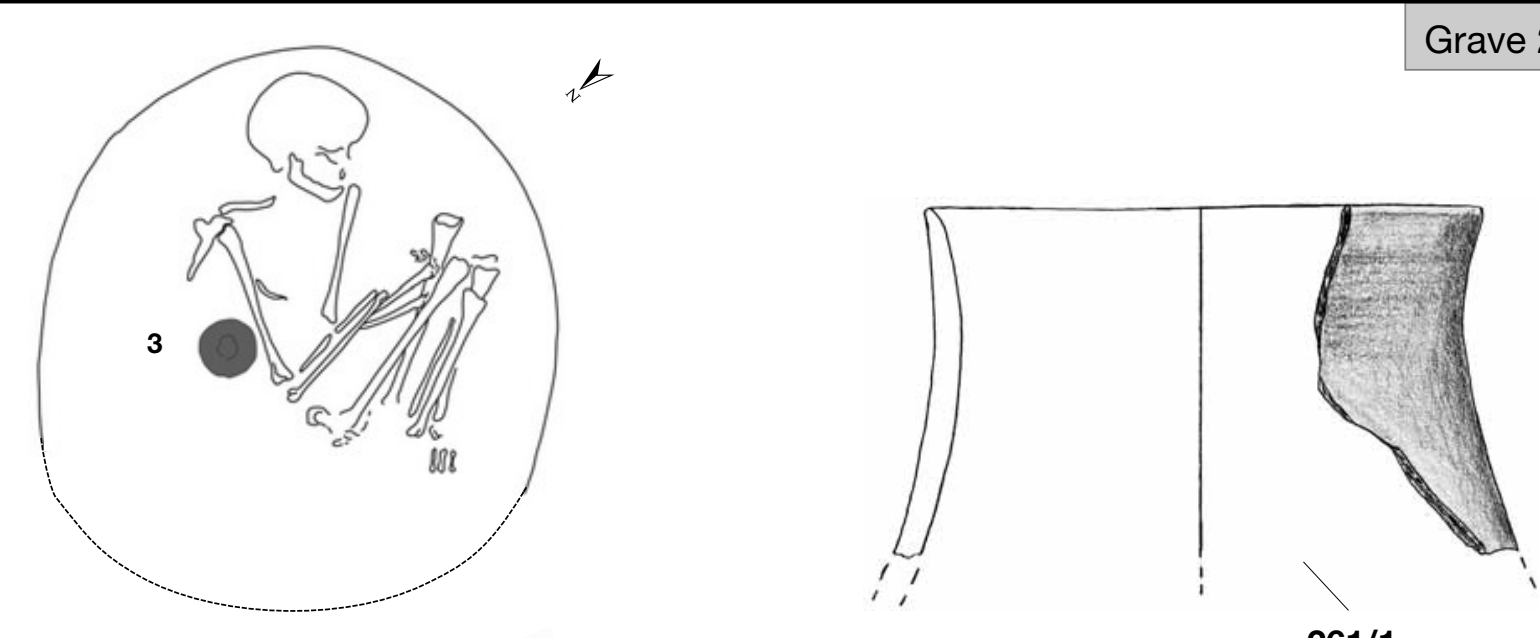

261/1
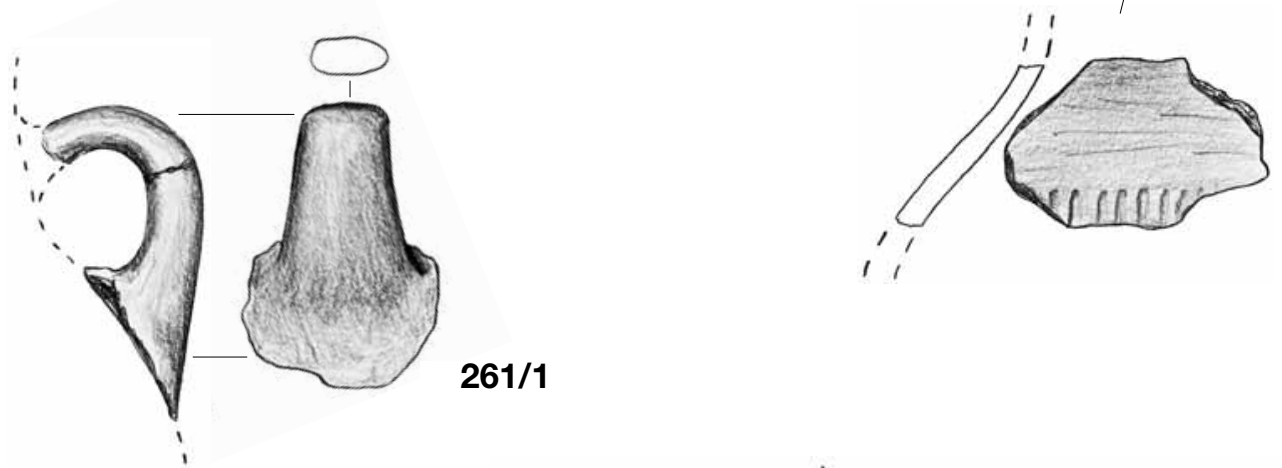

$261 / 1$
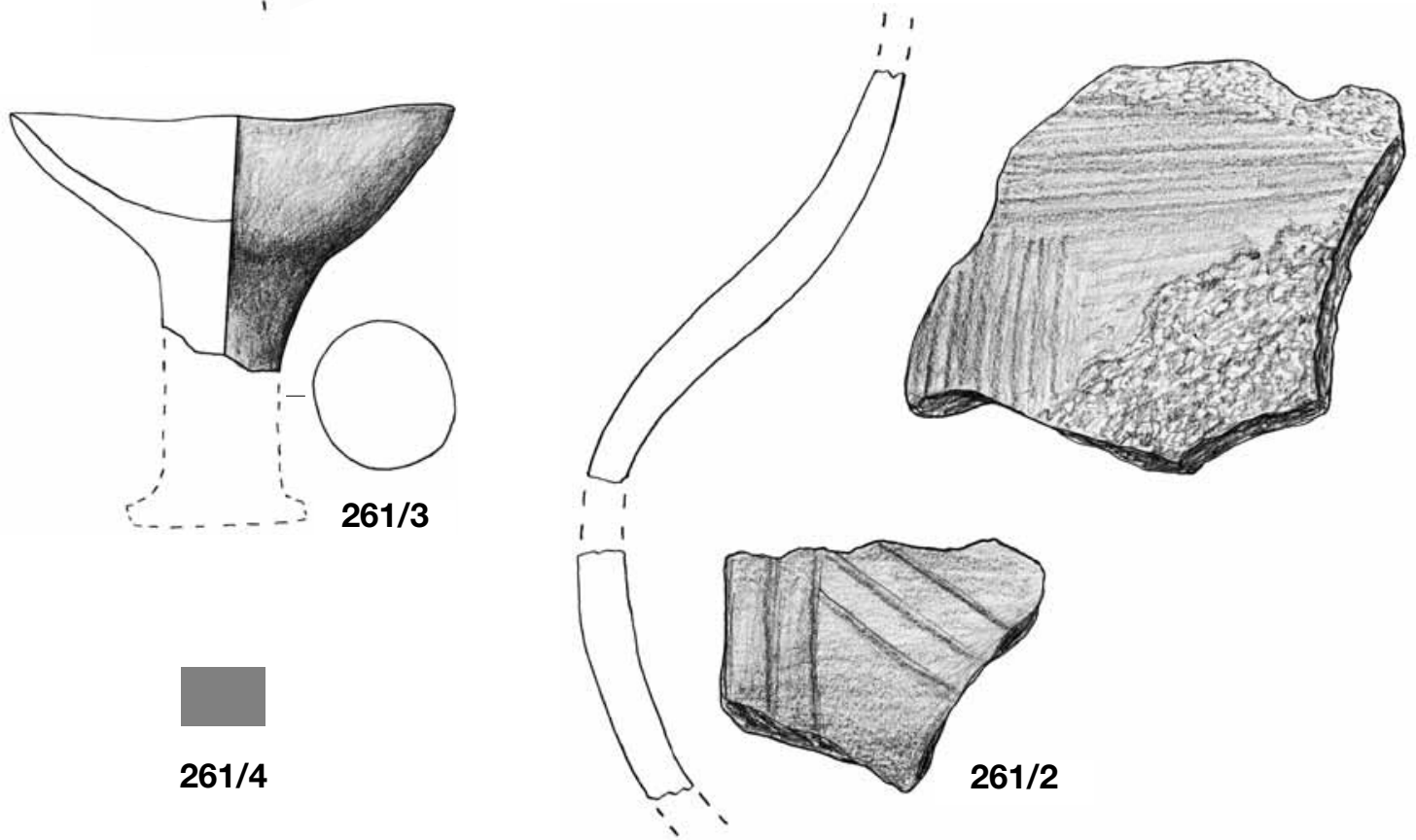

Plate CV. Grave 261 


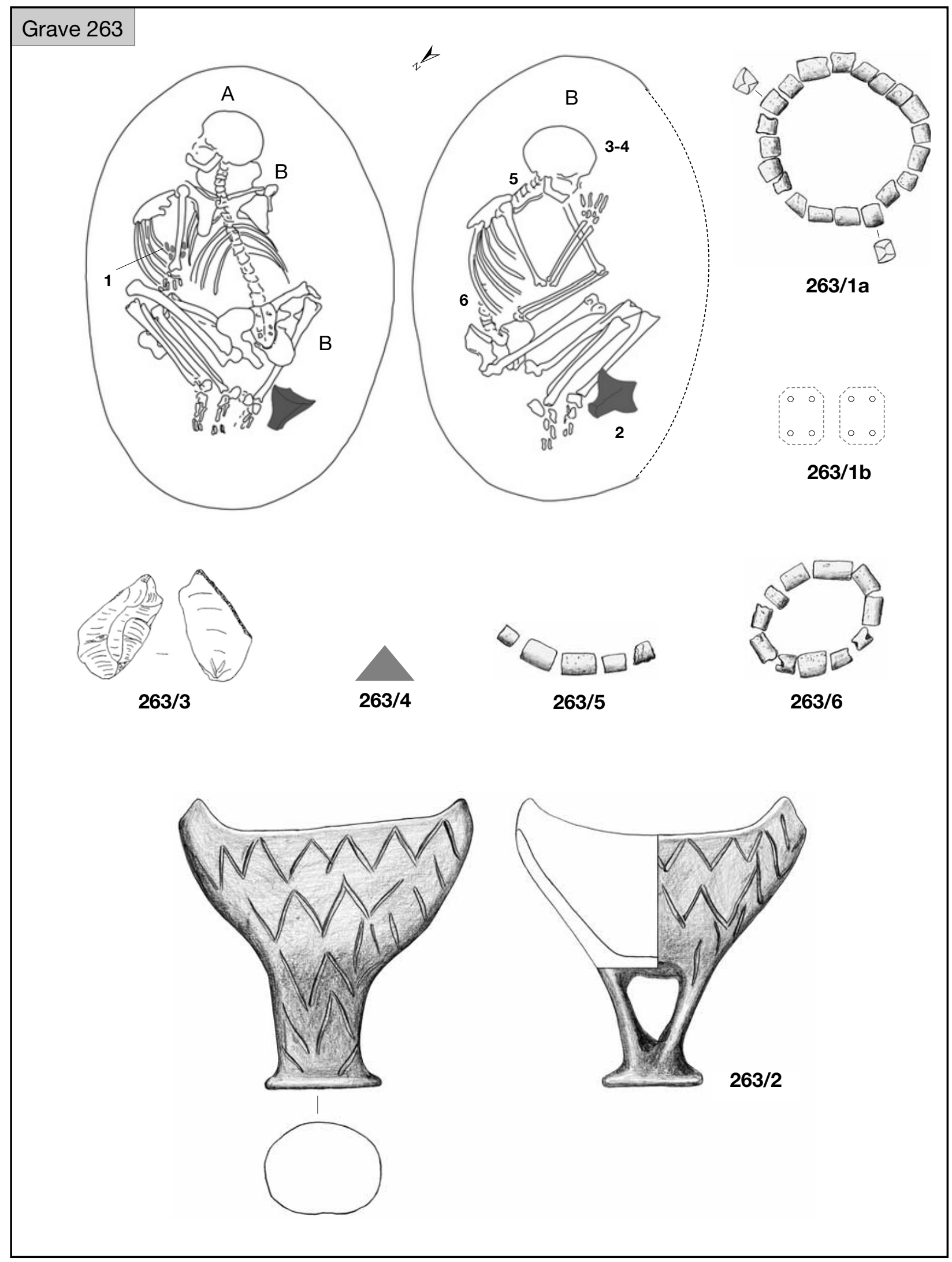

Plate CVI. Grave 263 (263/3: after Cs. BALOGH 1993) 


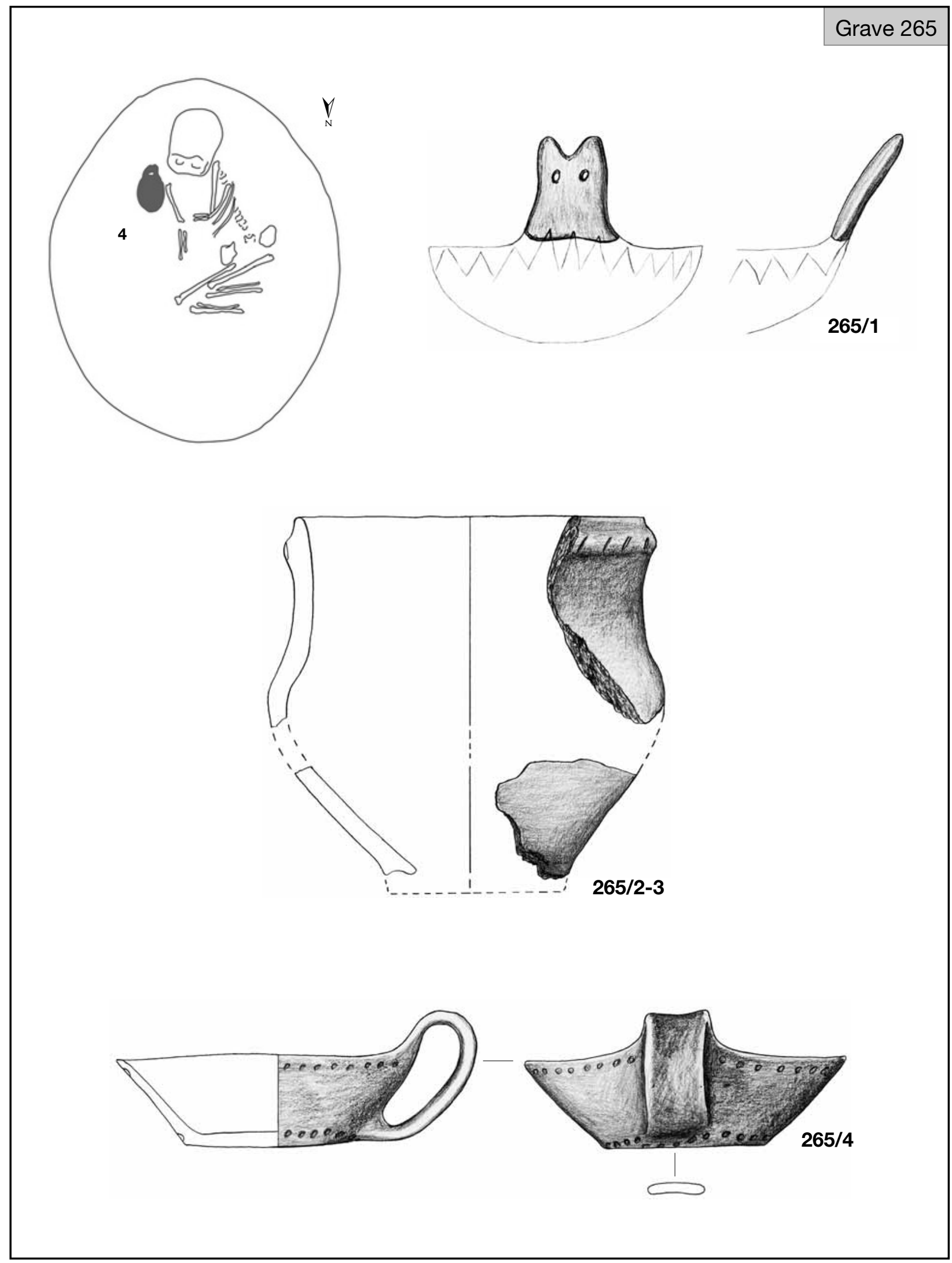

Plate CVII. Grave 265 


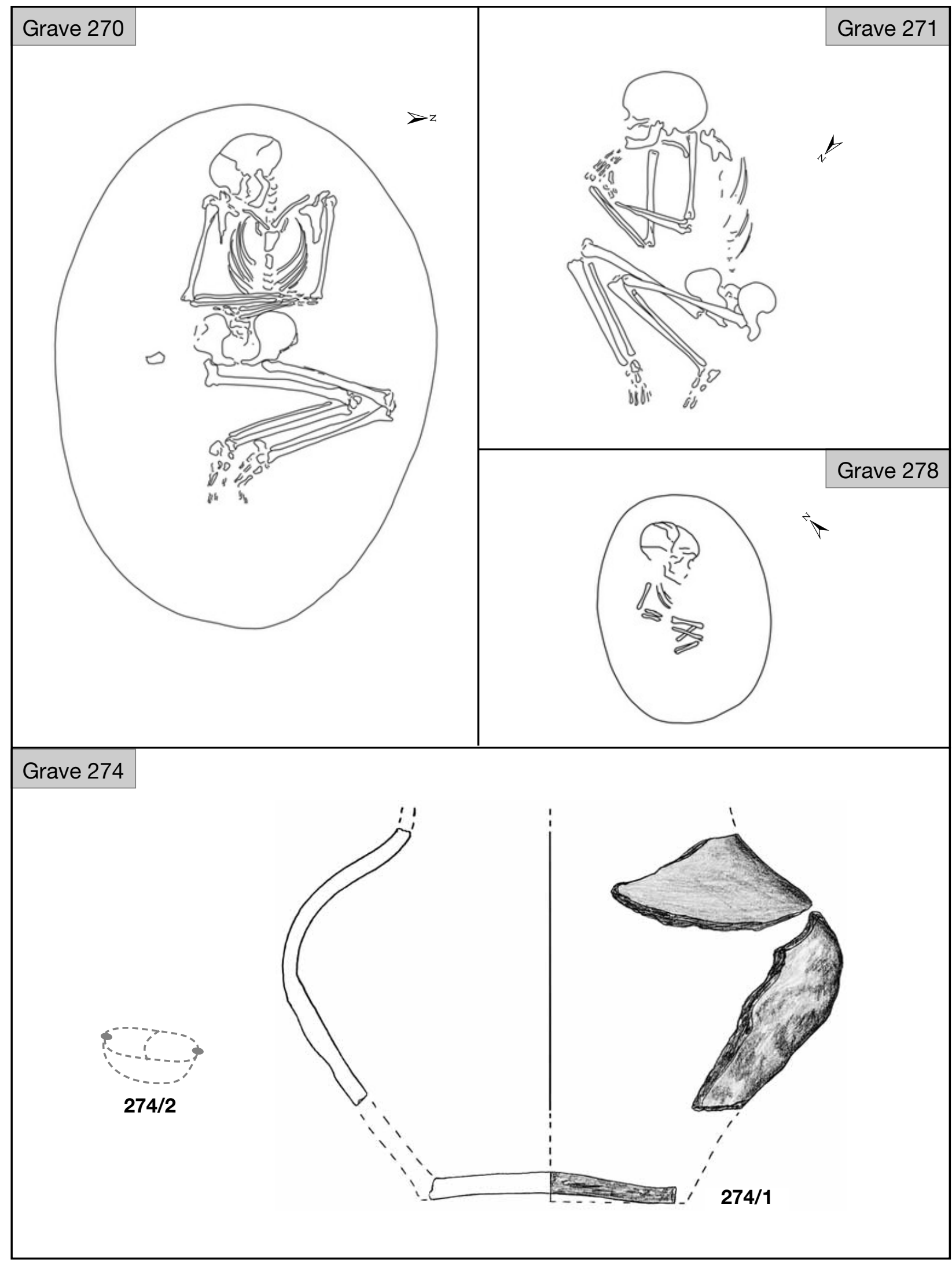

Plate CVIII. Graves 270-271, 274 and 278 


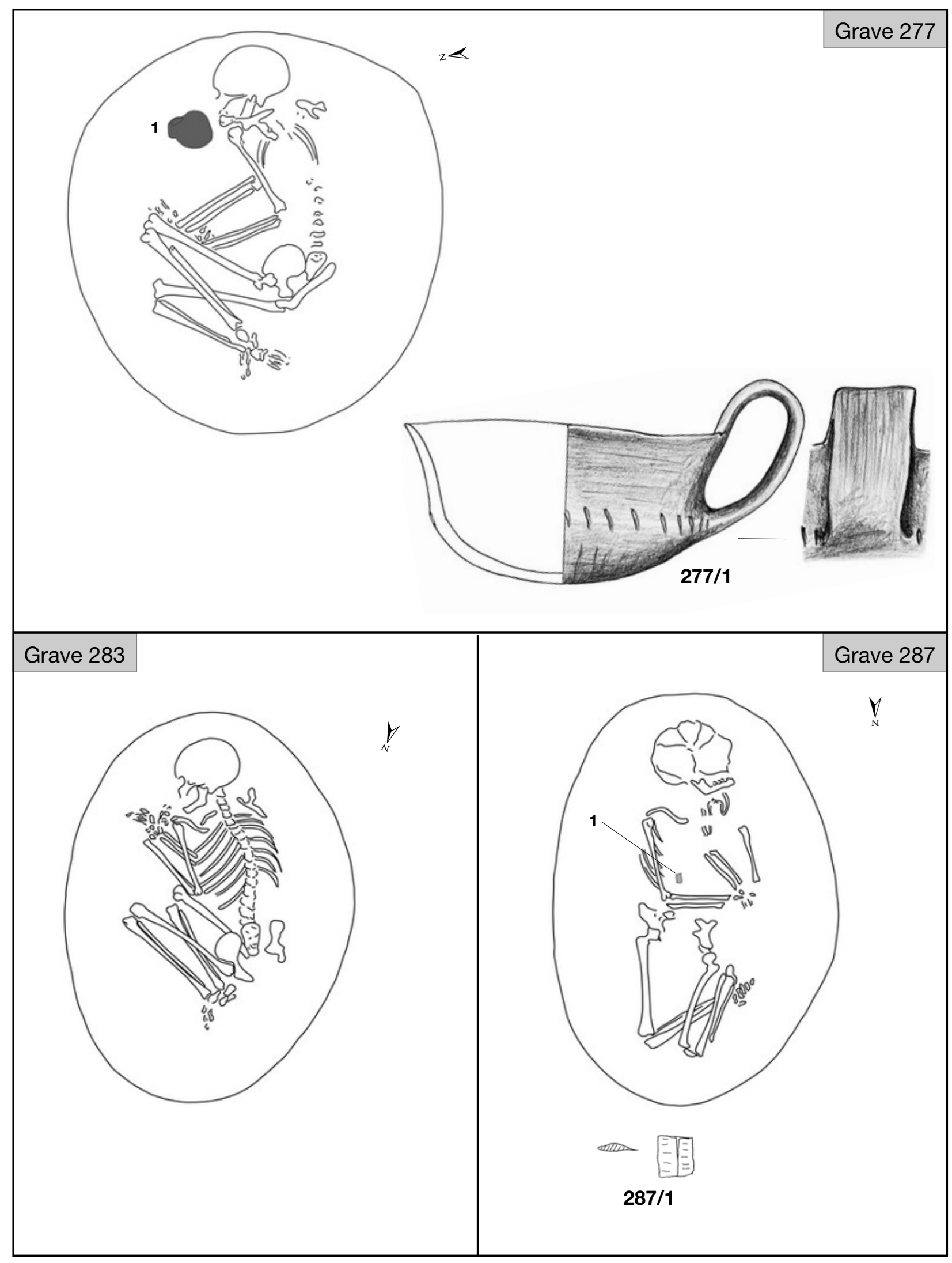

Plate CIX. Graves 277, 283 and 287 (287/1: after Cs. BALOGH 1993) 


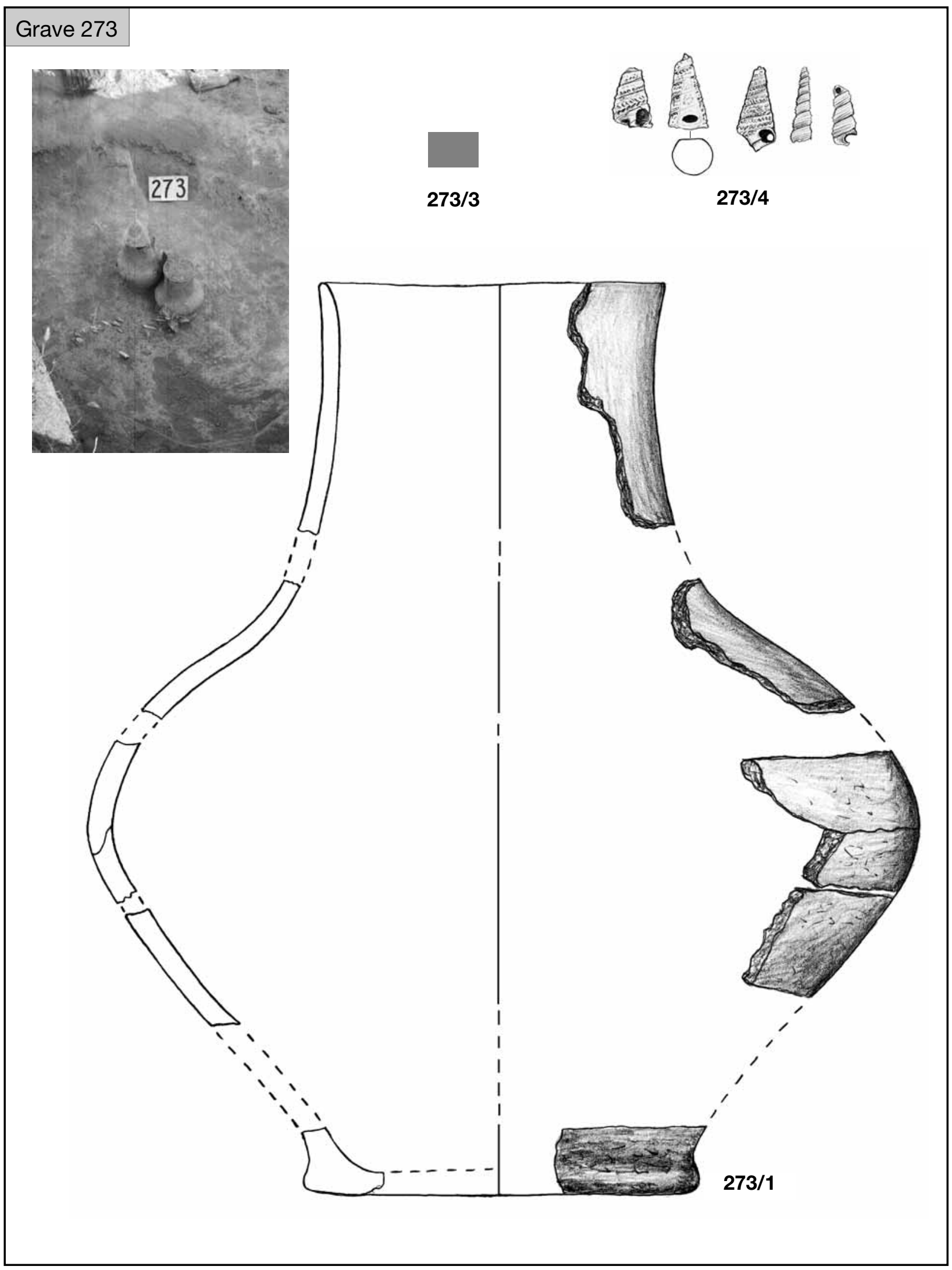

Plate CX. Grave 273 


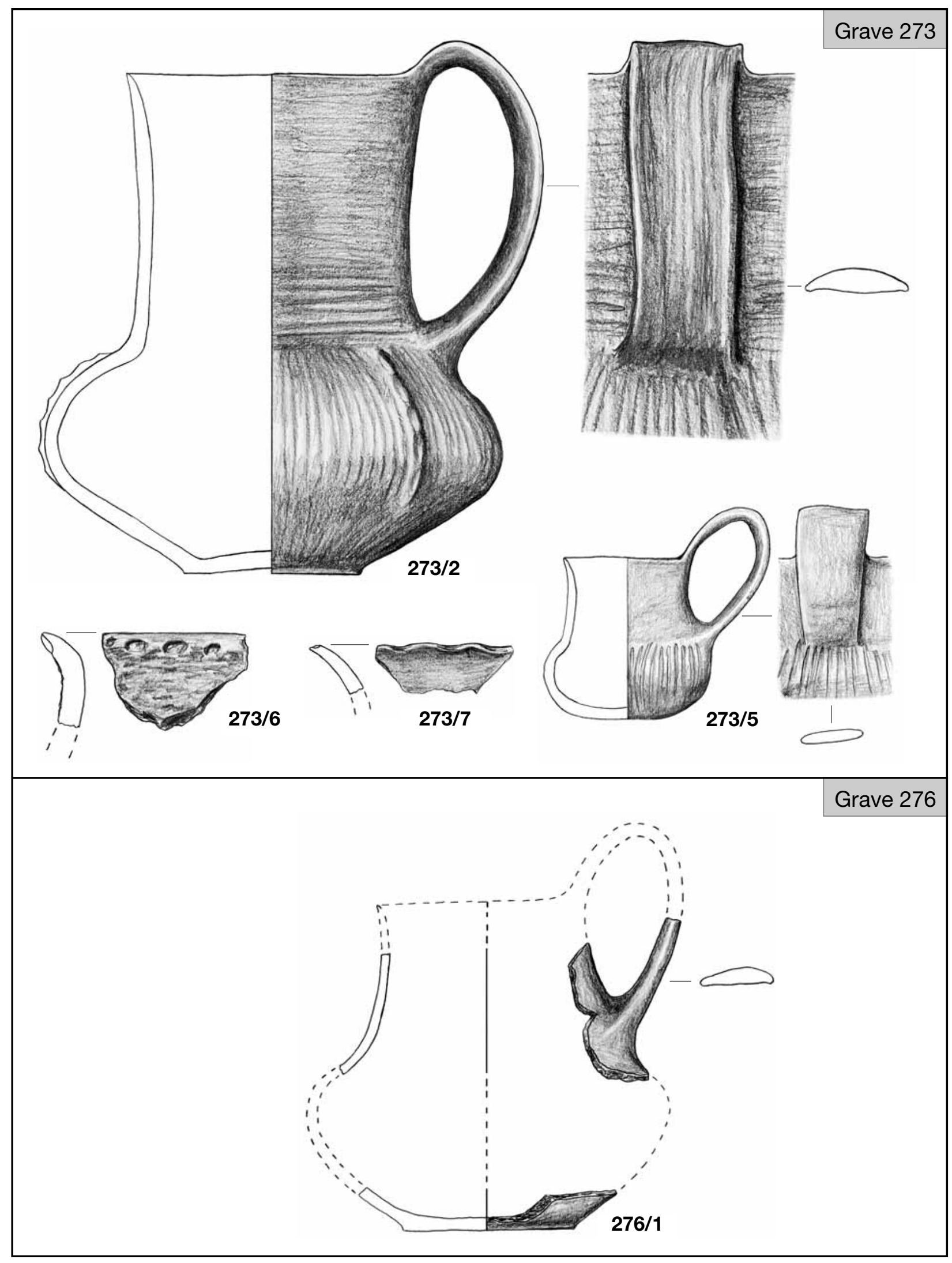

Plate CXI. Graves 273 and 276 


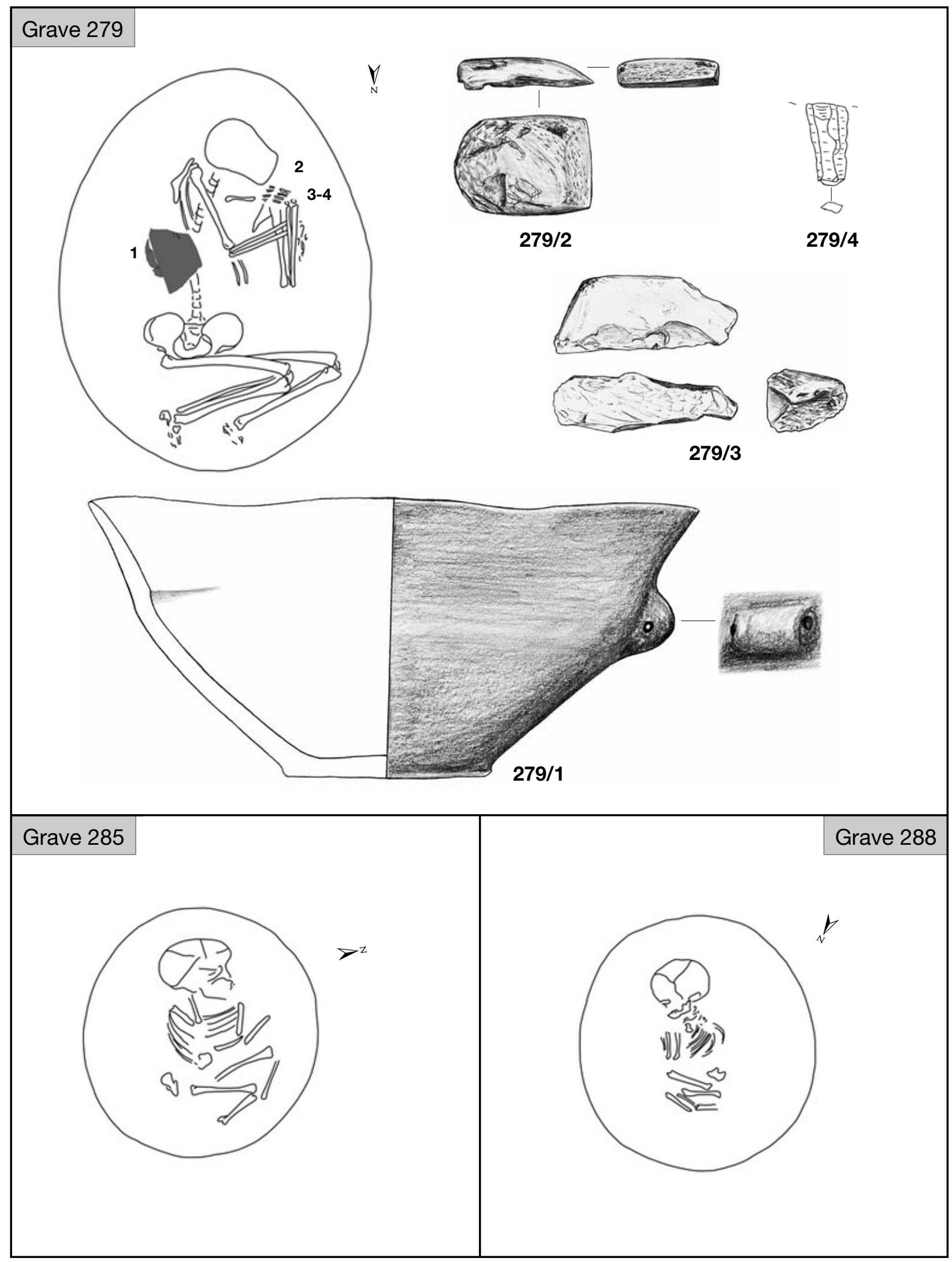

Plate CXII. Graves 279, 285 and 288 (279/4: after Cs. BALOGH 1993) 


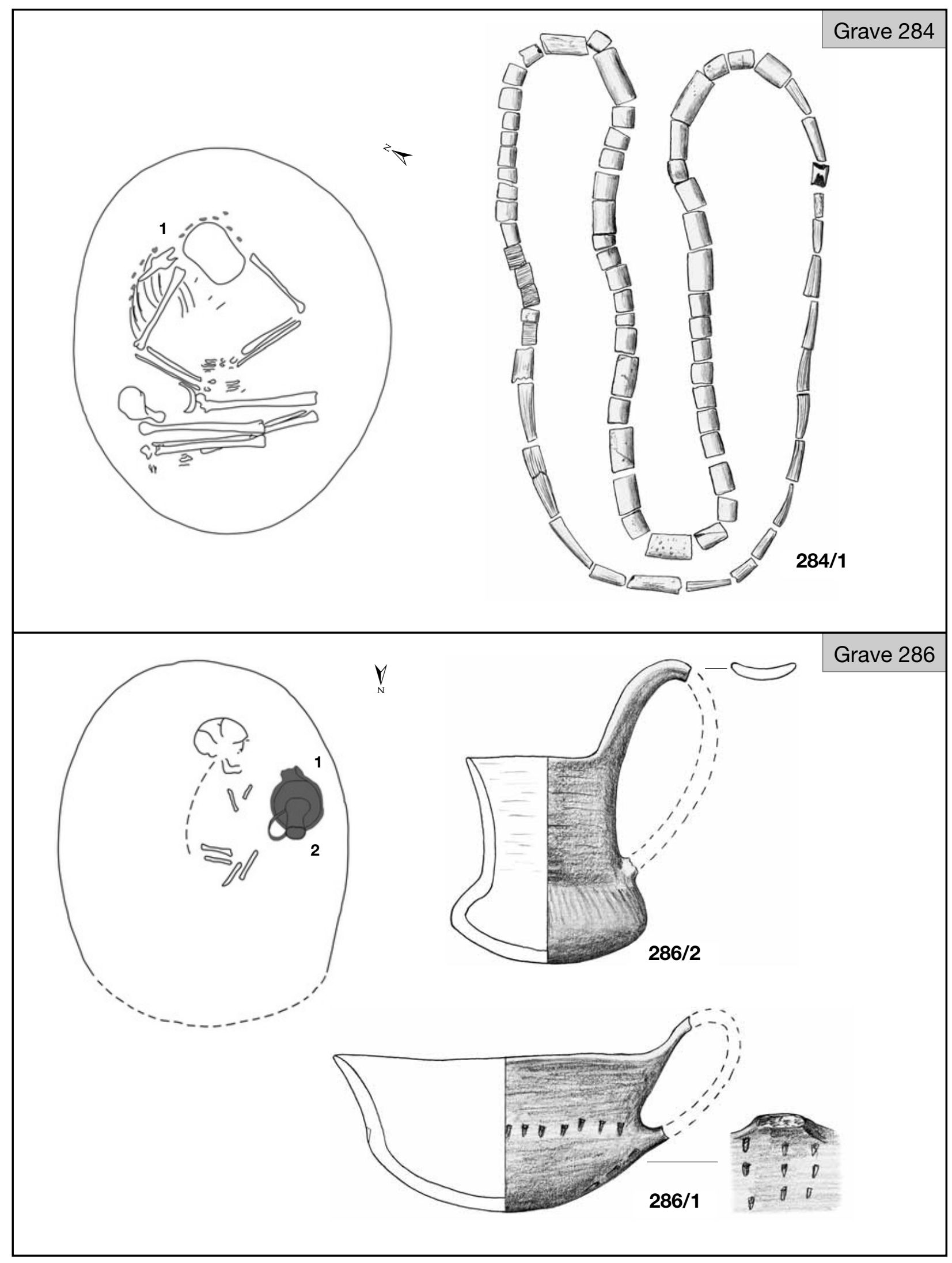

Plate CXIII. Graves 284 and 286 


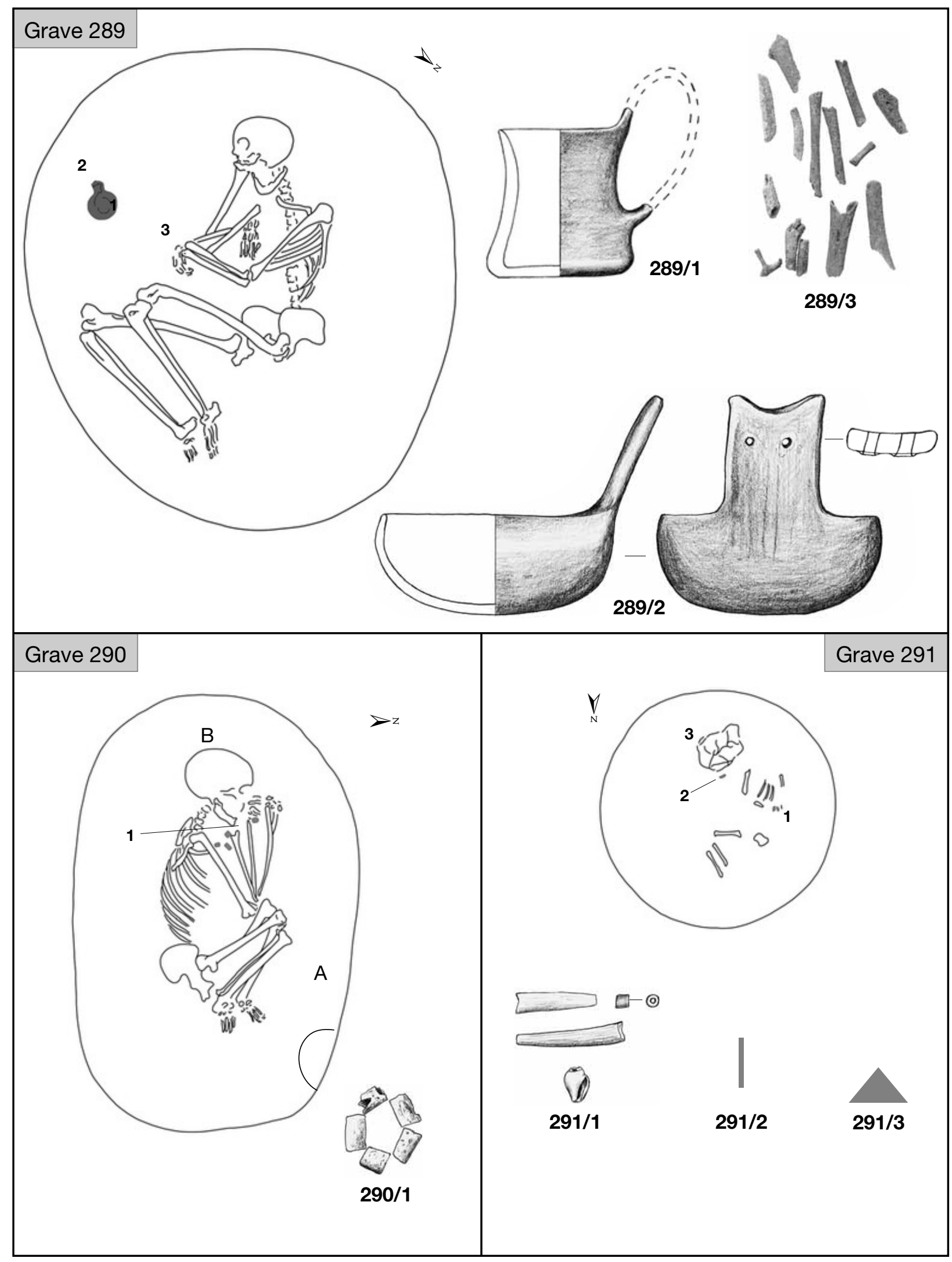

Plate CXIV. Graves 289-291 (291/3: after JózSEF KOREK’s photo, courtesy of the SzFM Archives) 


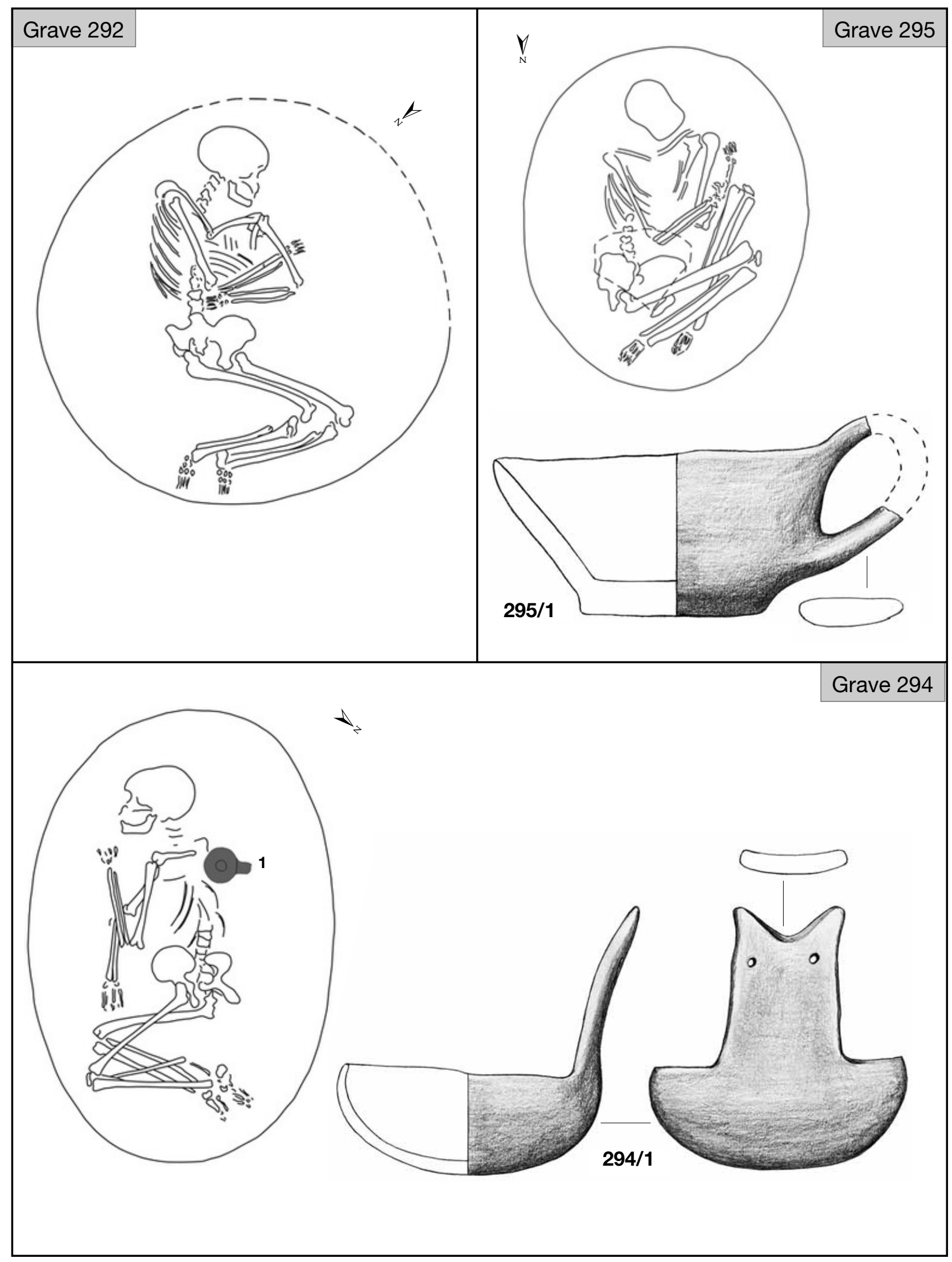

Plate CXV. Graves 292 and 294-295 


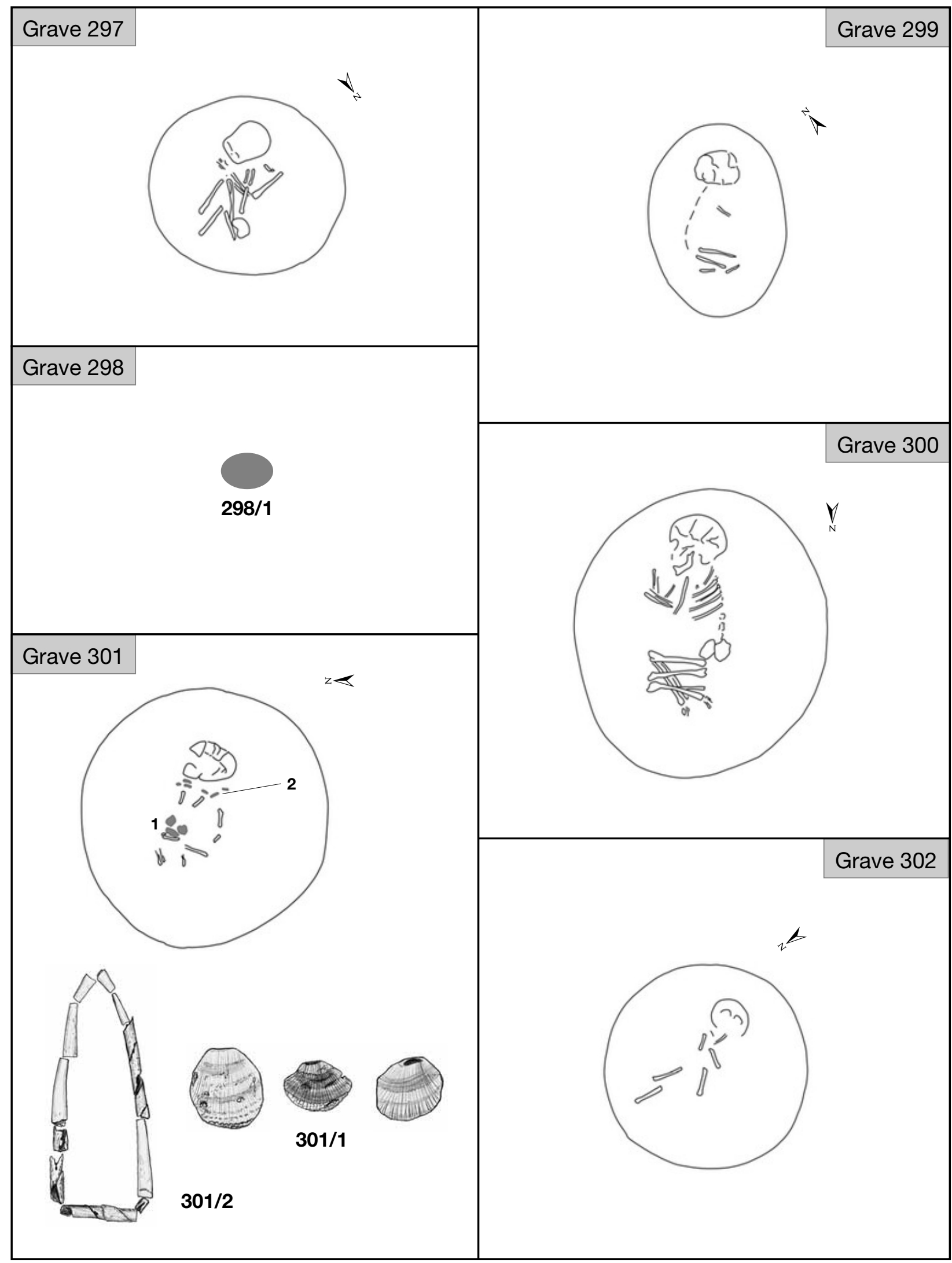

Plate CXVI. Graves 297-302 


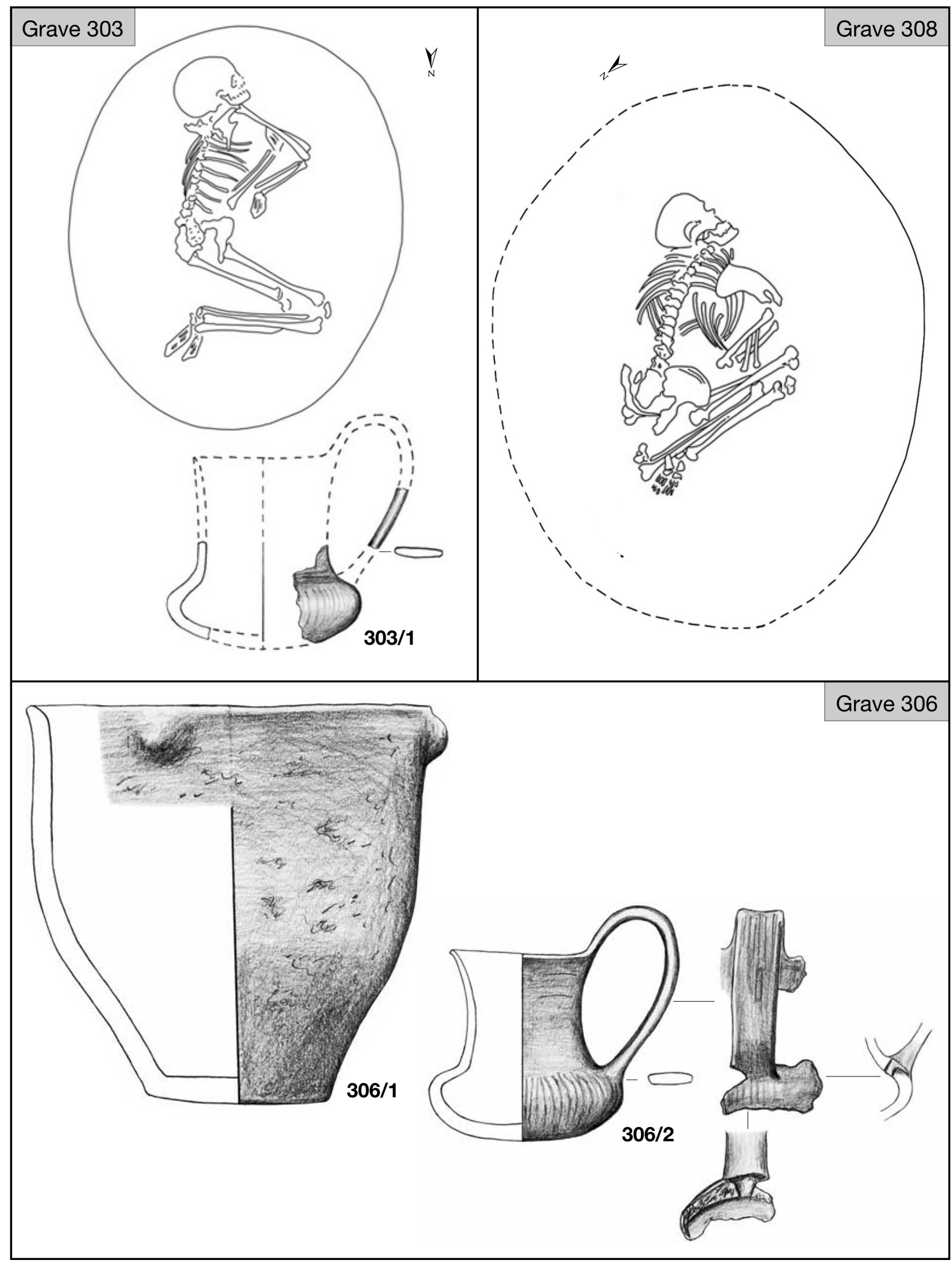

Plate CXVII. Graves 303, 306 and 308 


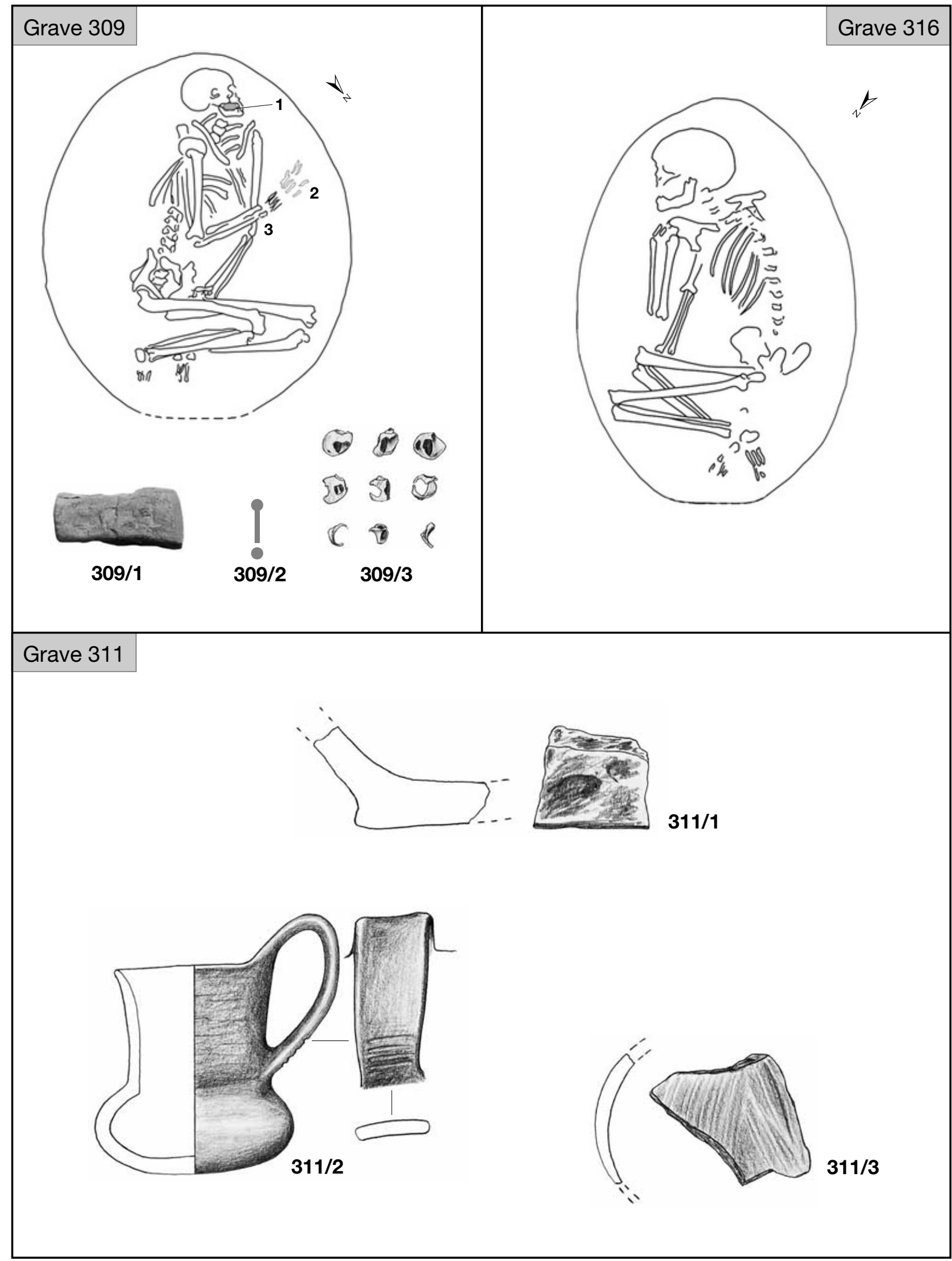

Plate CXVIII. Graves 309, 311 and 316 (309/1: after JózSEF KOREK’s photo, courtesy of the SzFM Archives) 


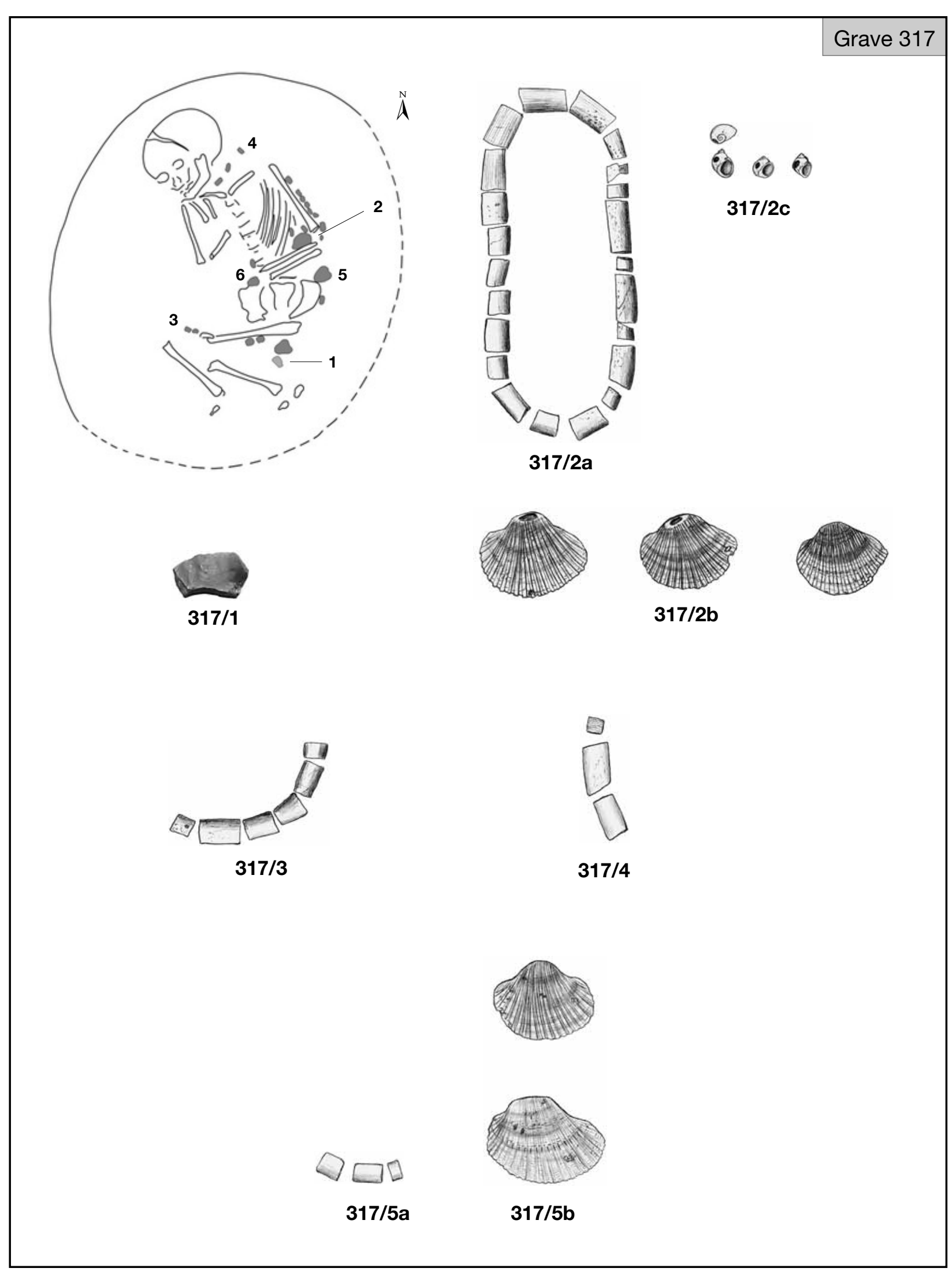

Plate CXIX. Grave 317 (317/1: after JózSEF KOREK's photo, courtesy of the SzFM Archives) 


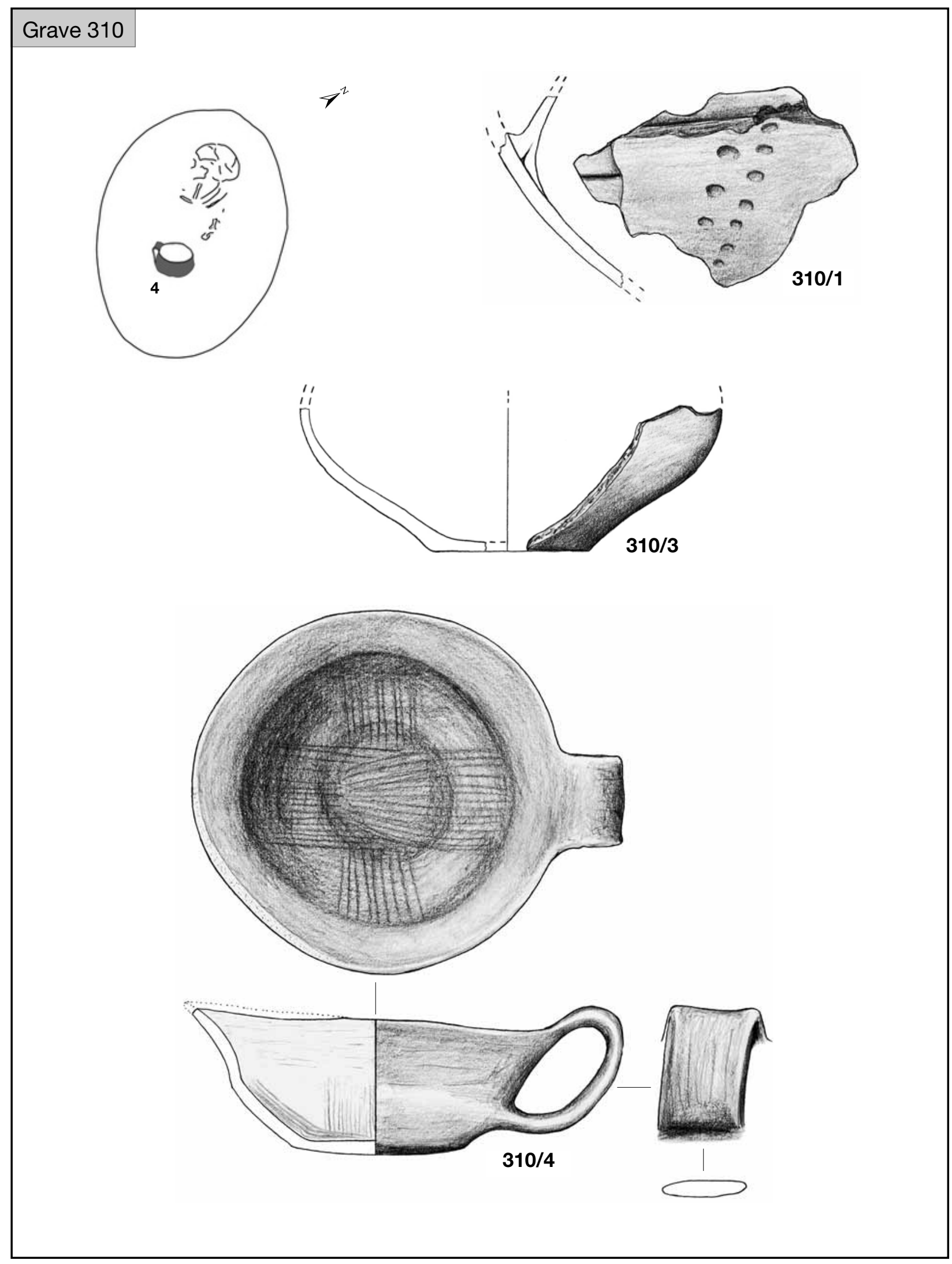

Plate CXX. Grave 310 


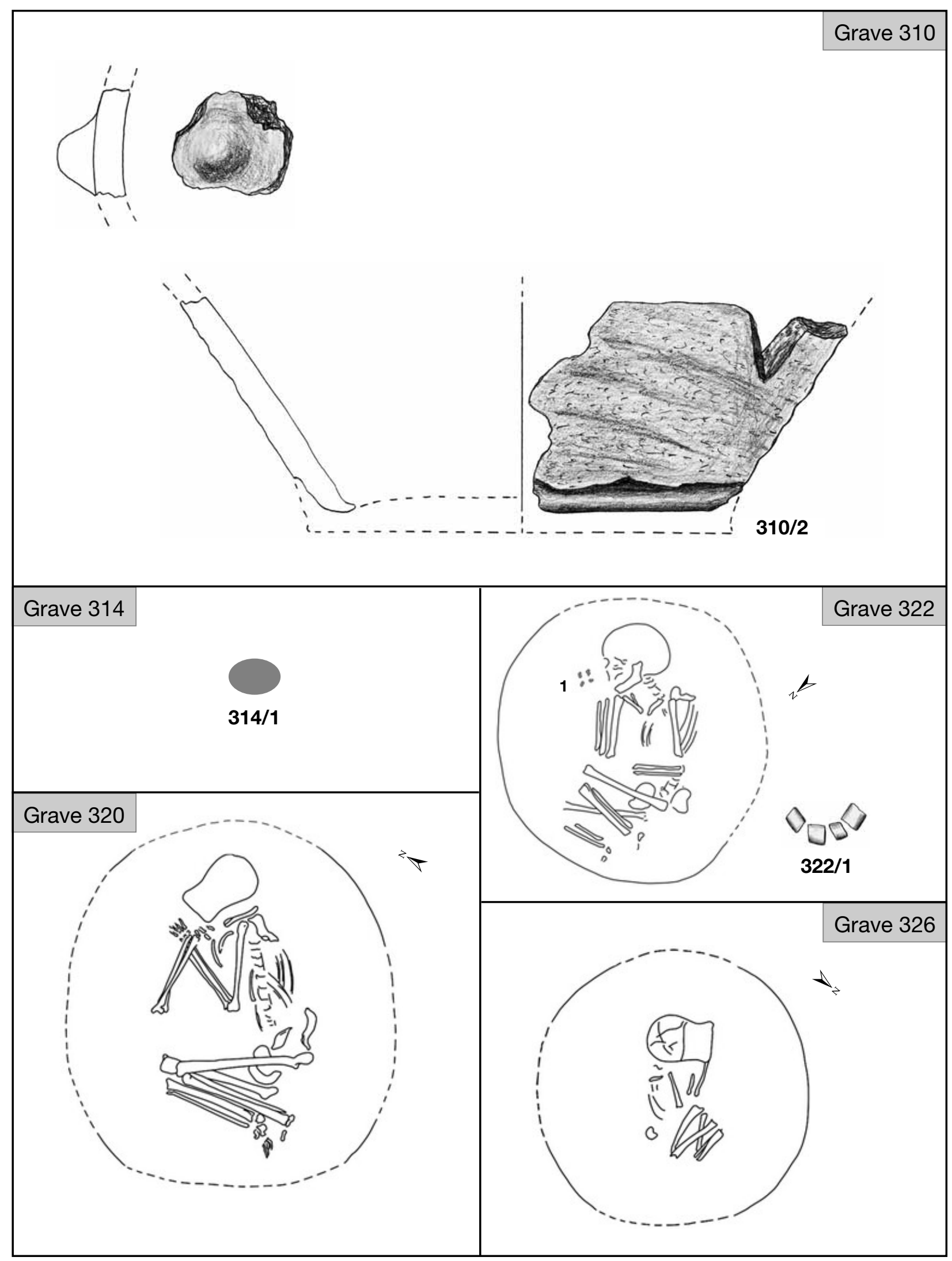

Plate CXXI. Graves 310, 314, 320, 322 and 326 


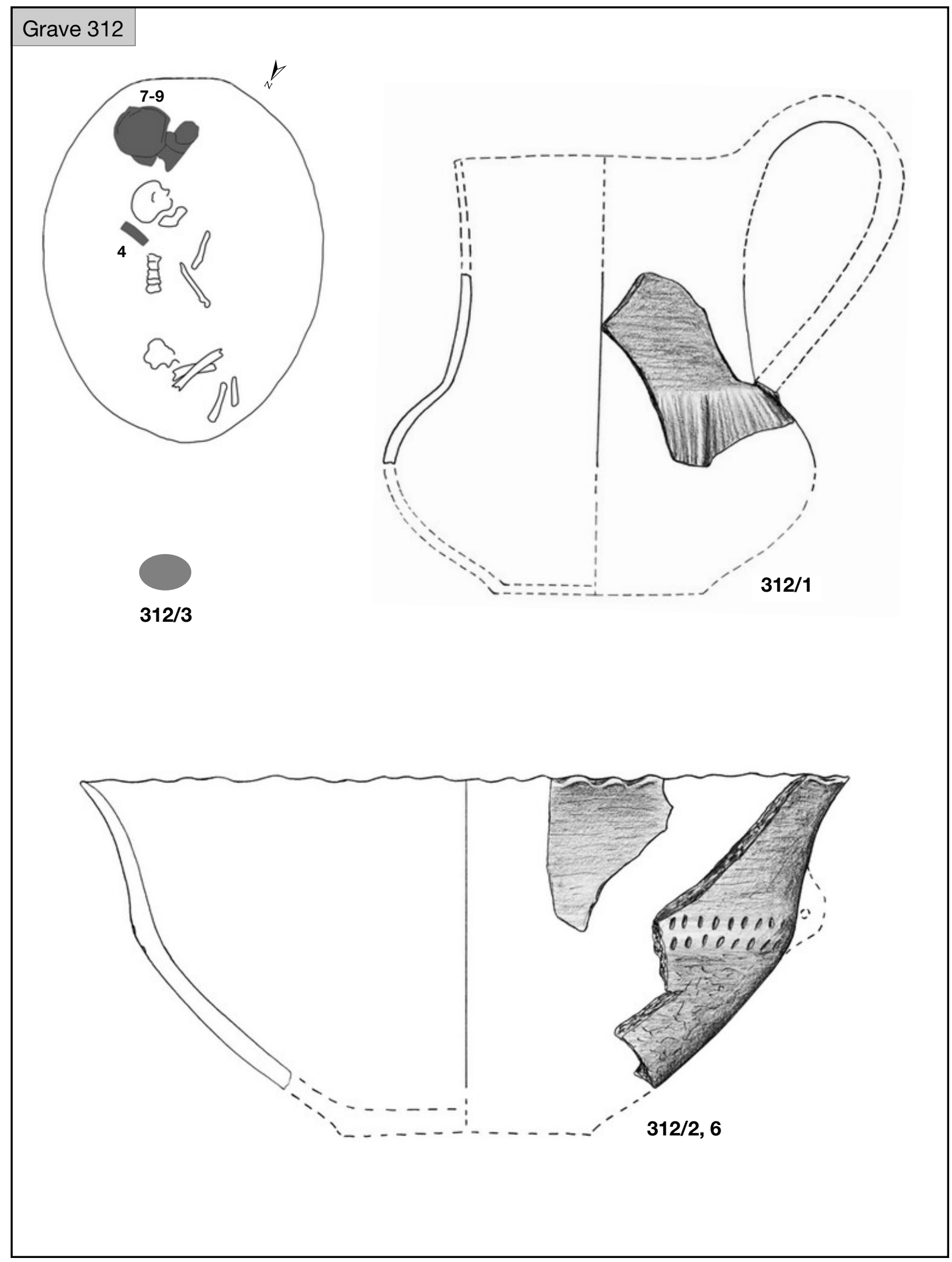

Plate CXXII. Grave 312 


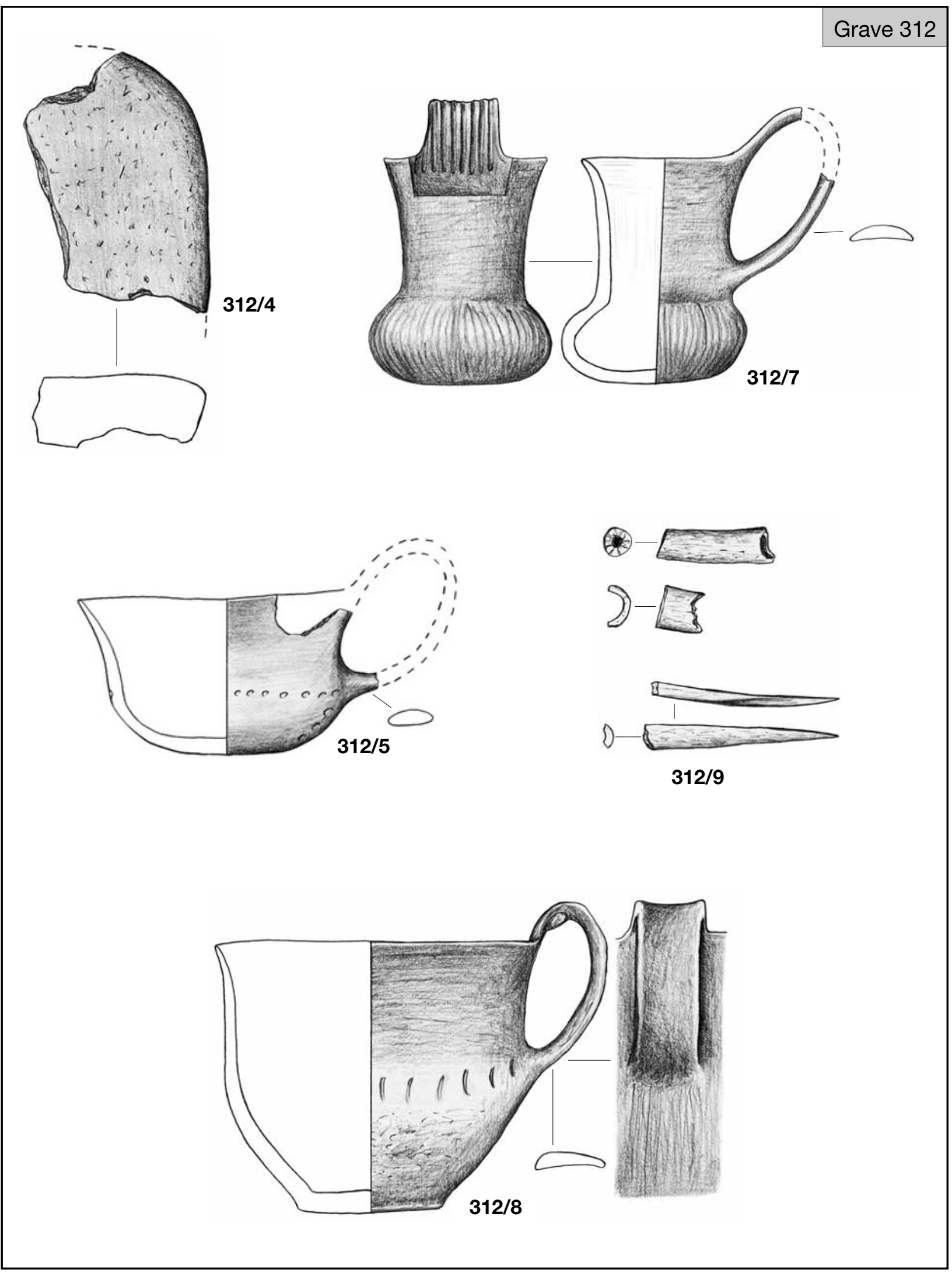

Plate CXXIII. Grave 312 


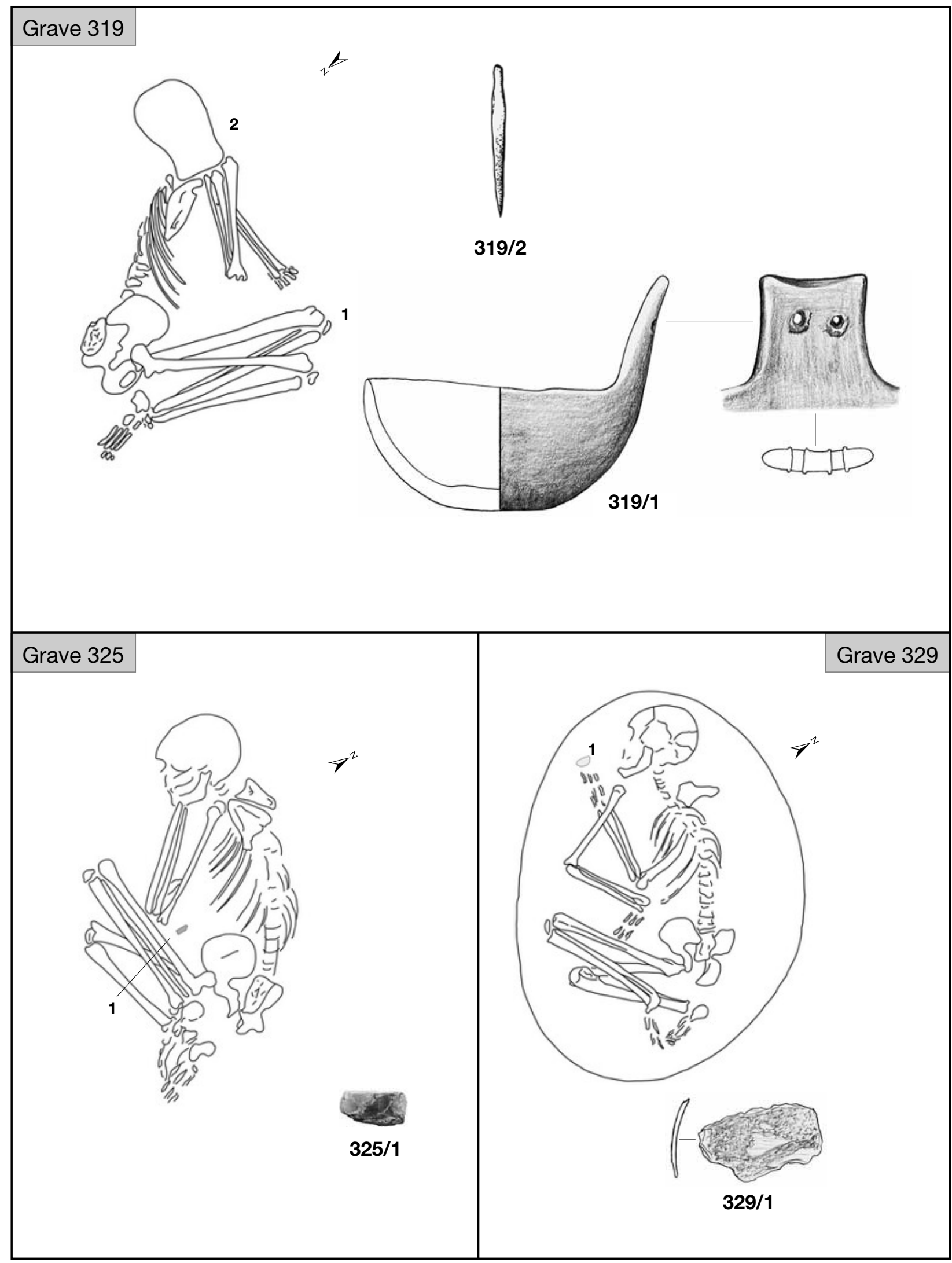

Plate CXXIV. Graves 319, 325 and 329 (319/2, 325/1: after JÓZSEF KOREK’s photo, courtesy of the SzFM Archives) 


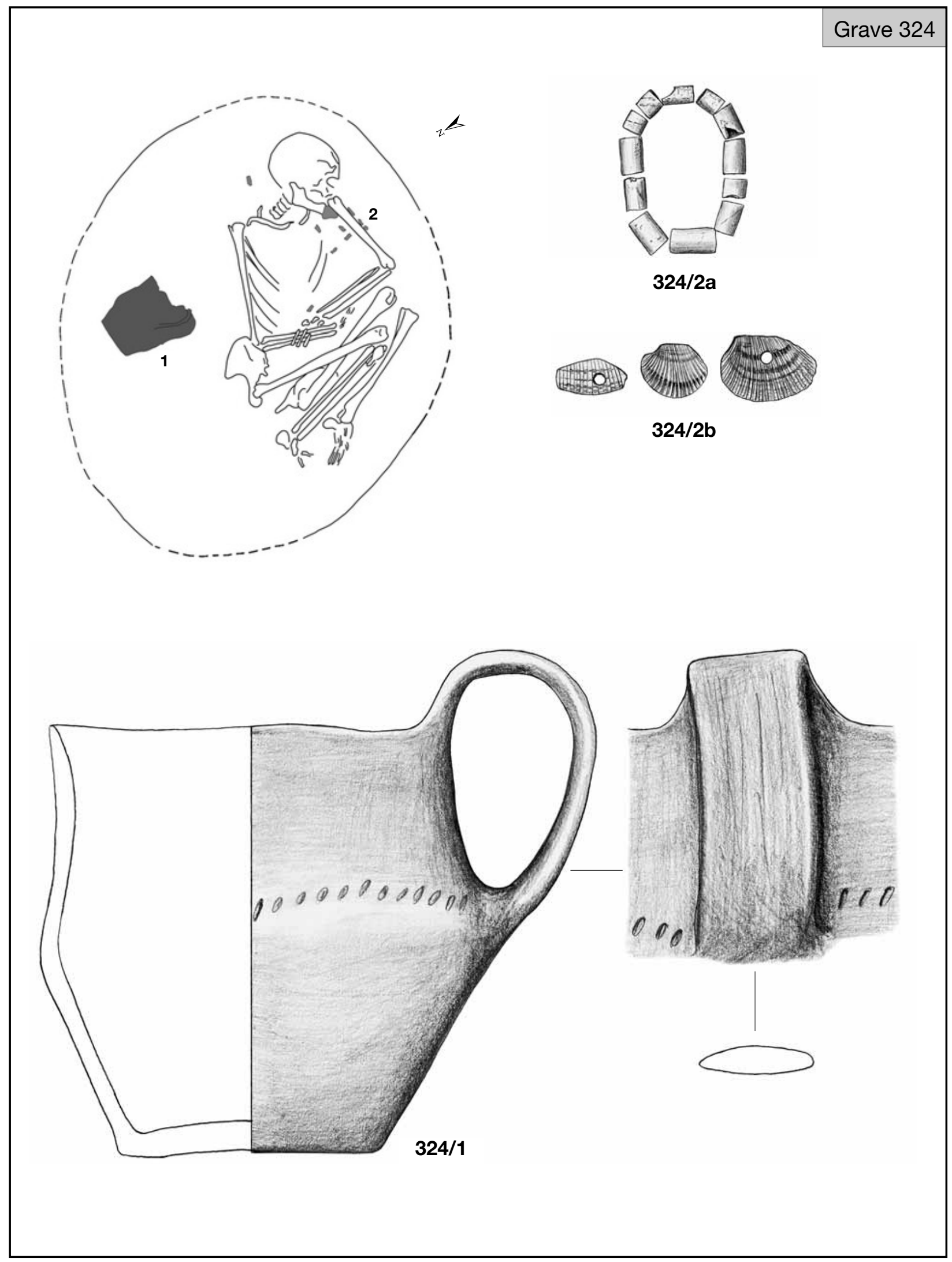

Plate CXXV. Grave 324 


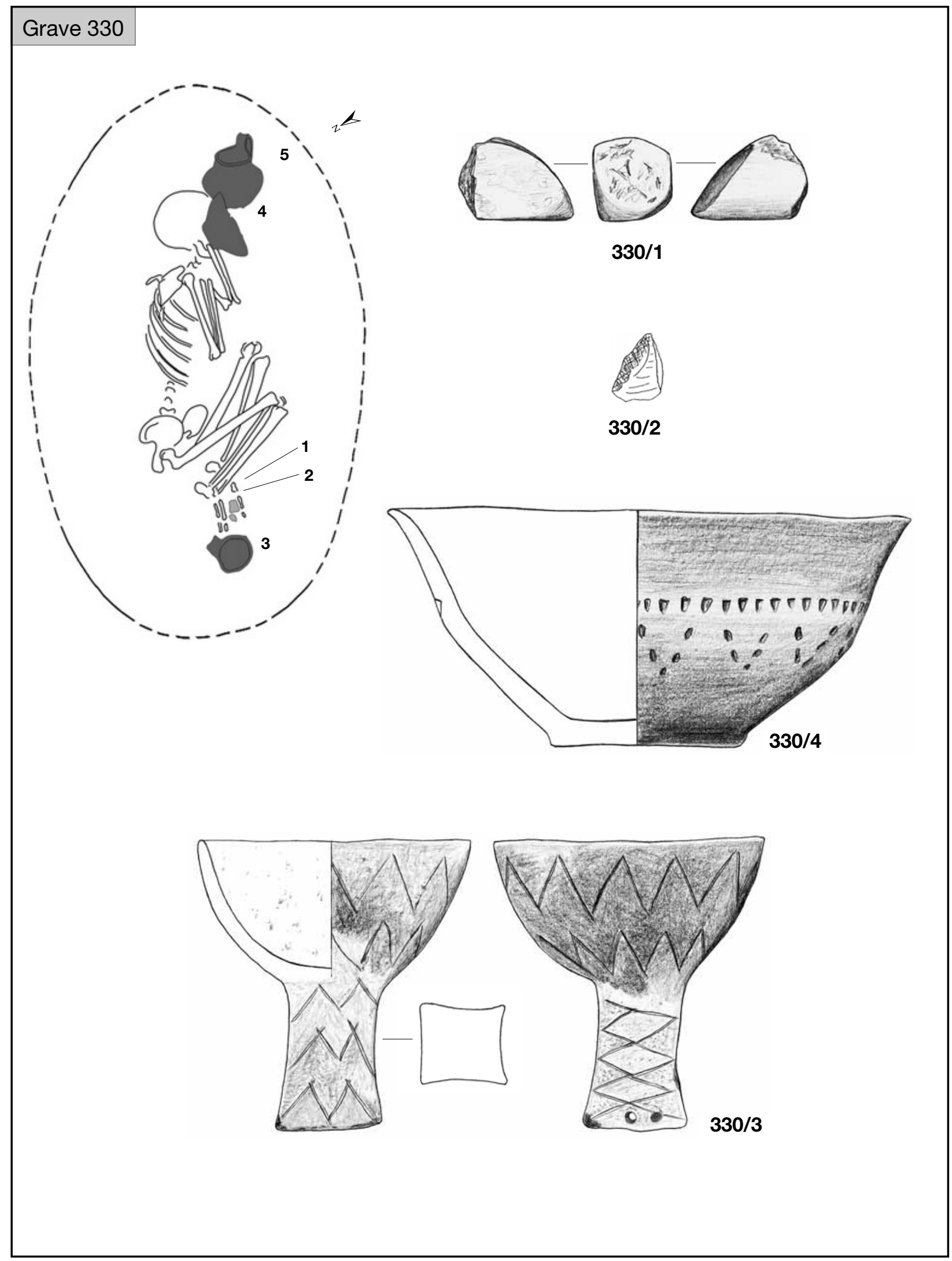

Plate CXXVI. Grave 330 (330/2: after Cs. BALOGH 1993) 


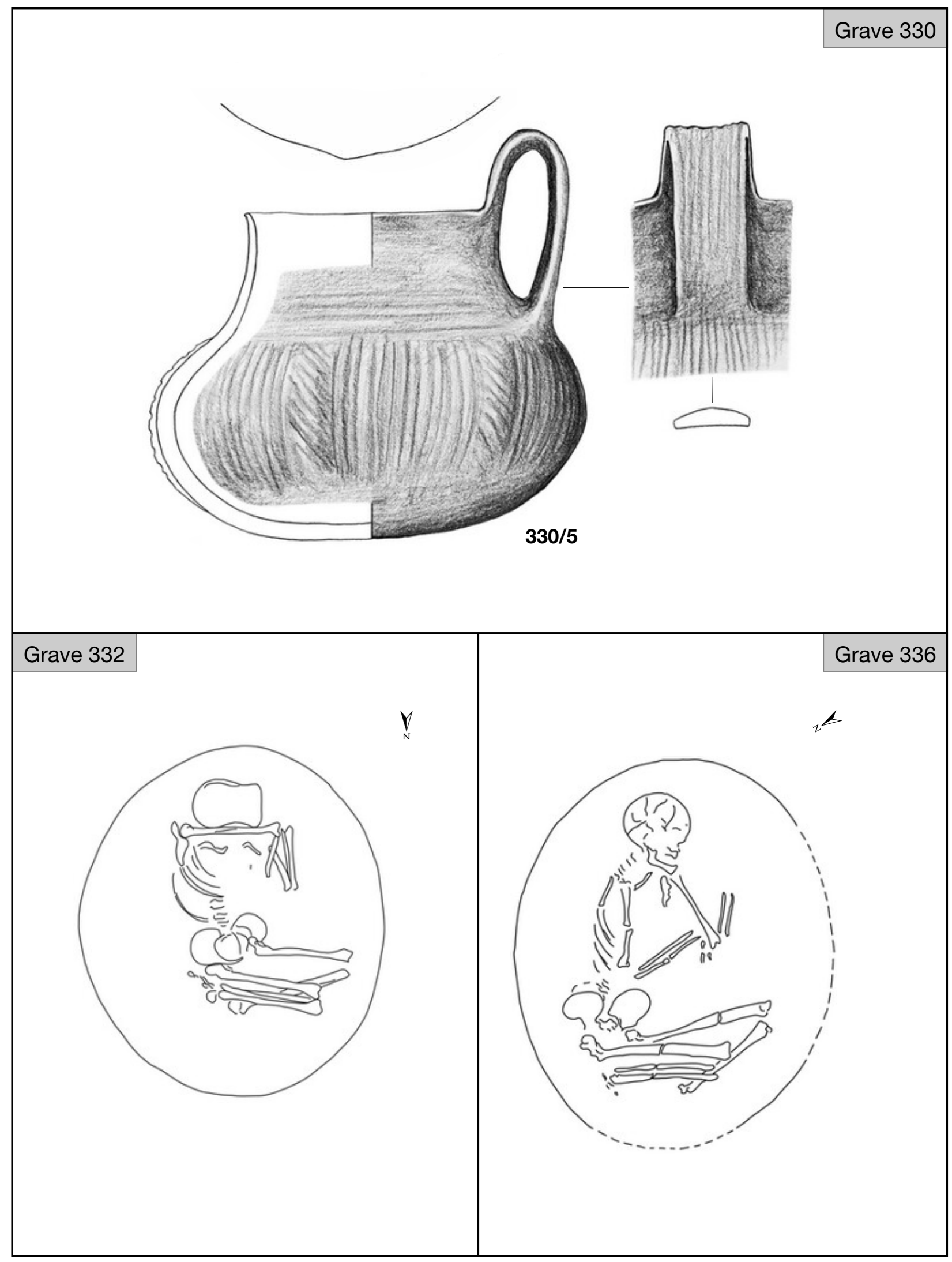

Plate CXXVII. Grave 330, 332 and 336 


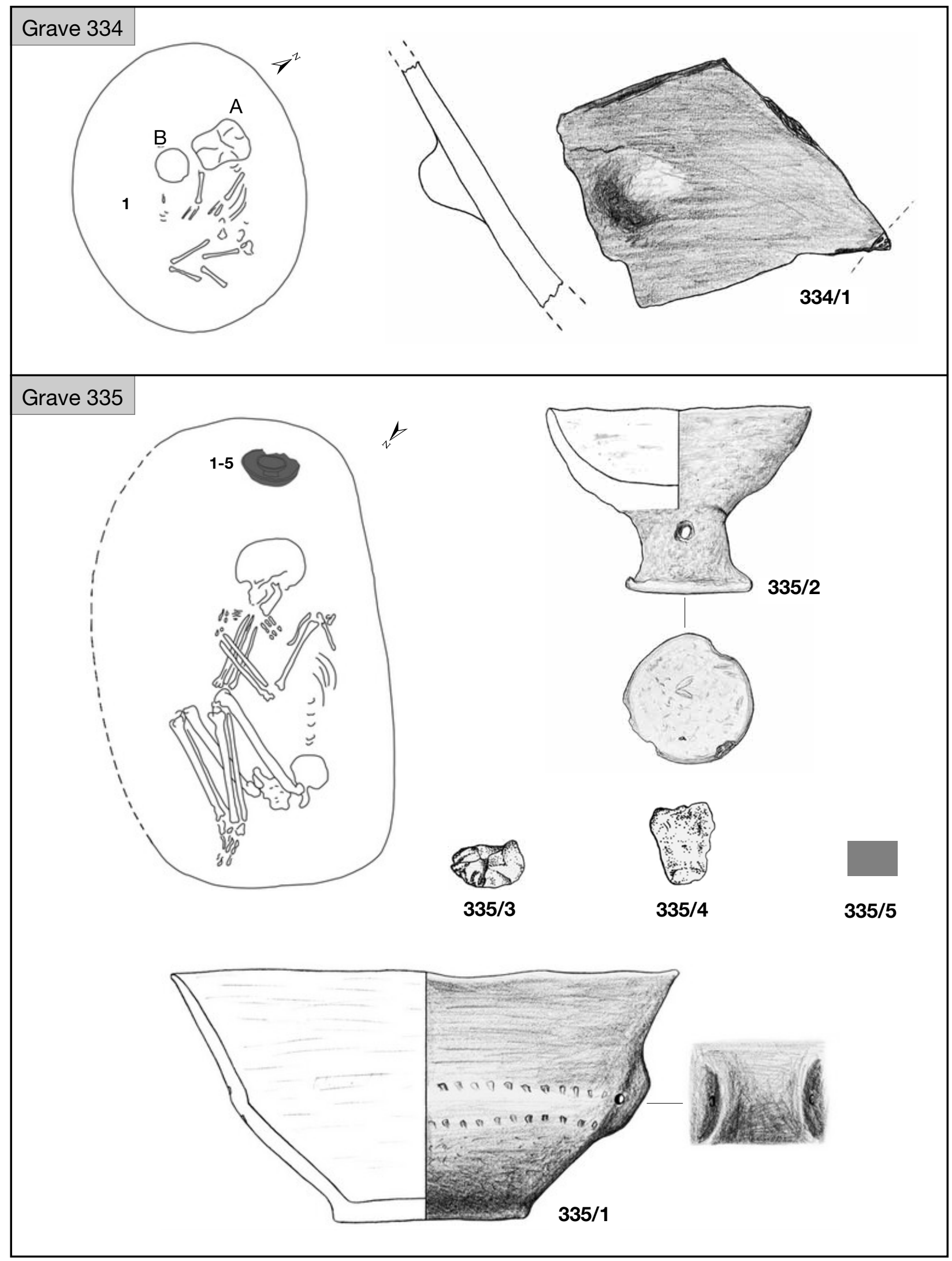

Plate CXXVIII. Graves 334-335 (335/3-4: after JóZSEF KOREK’s grave sheet) 


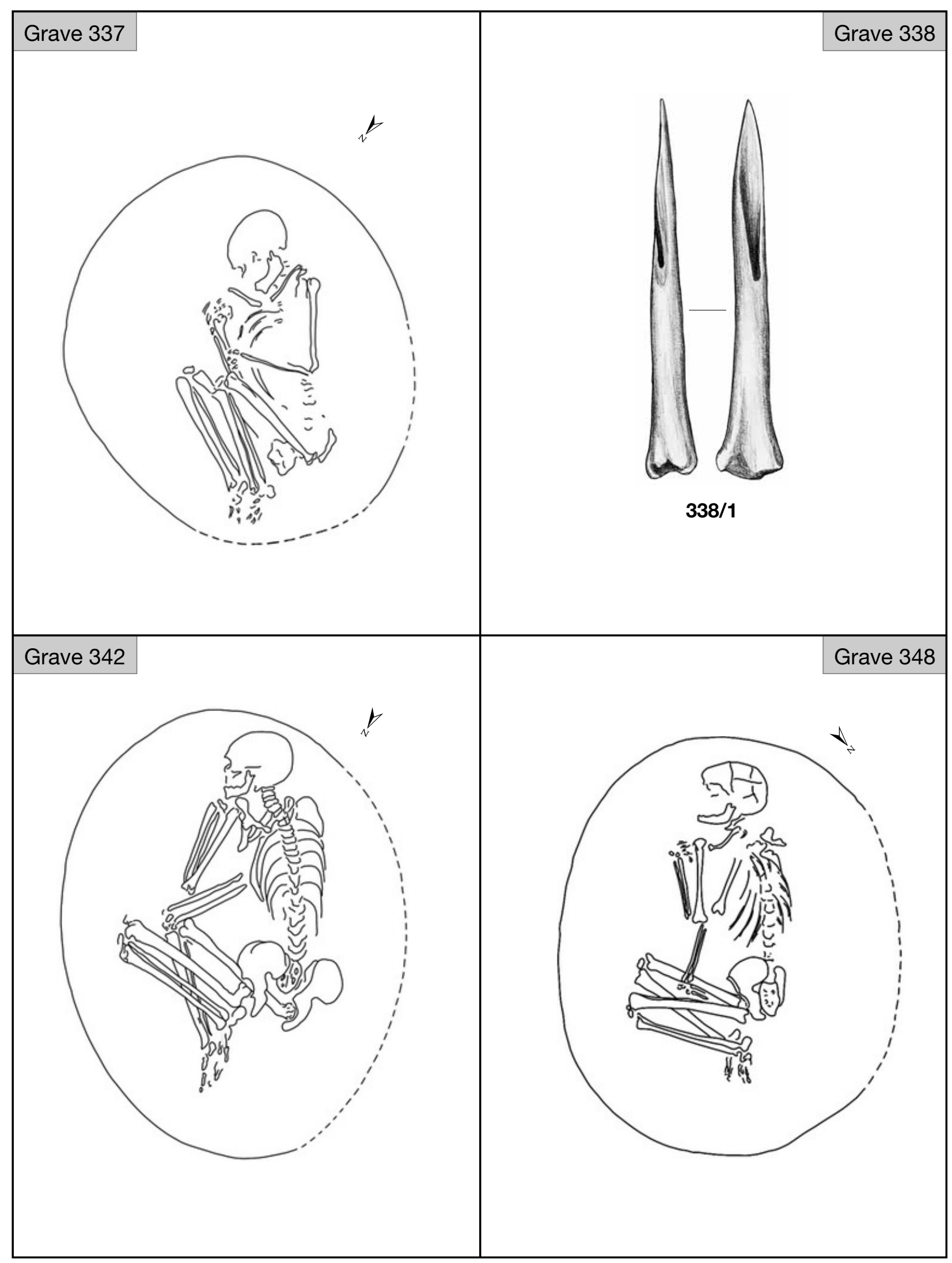

Plate CXXIX. Graves 337-338, 342 and 348 


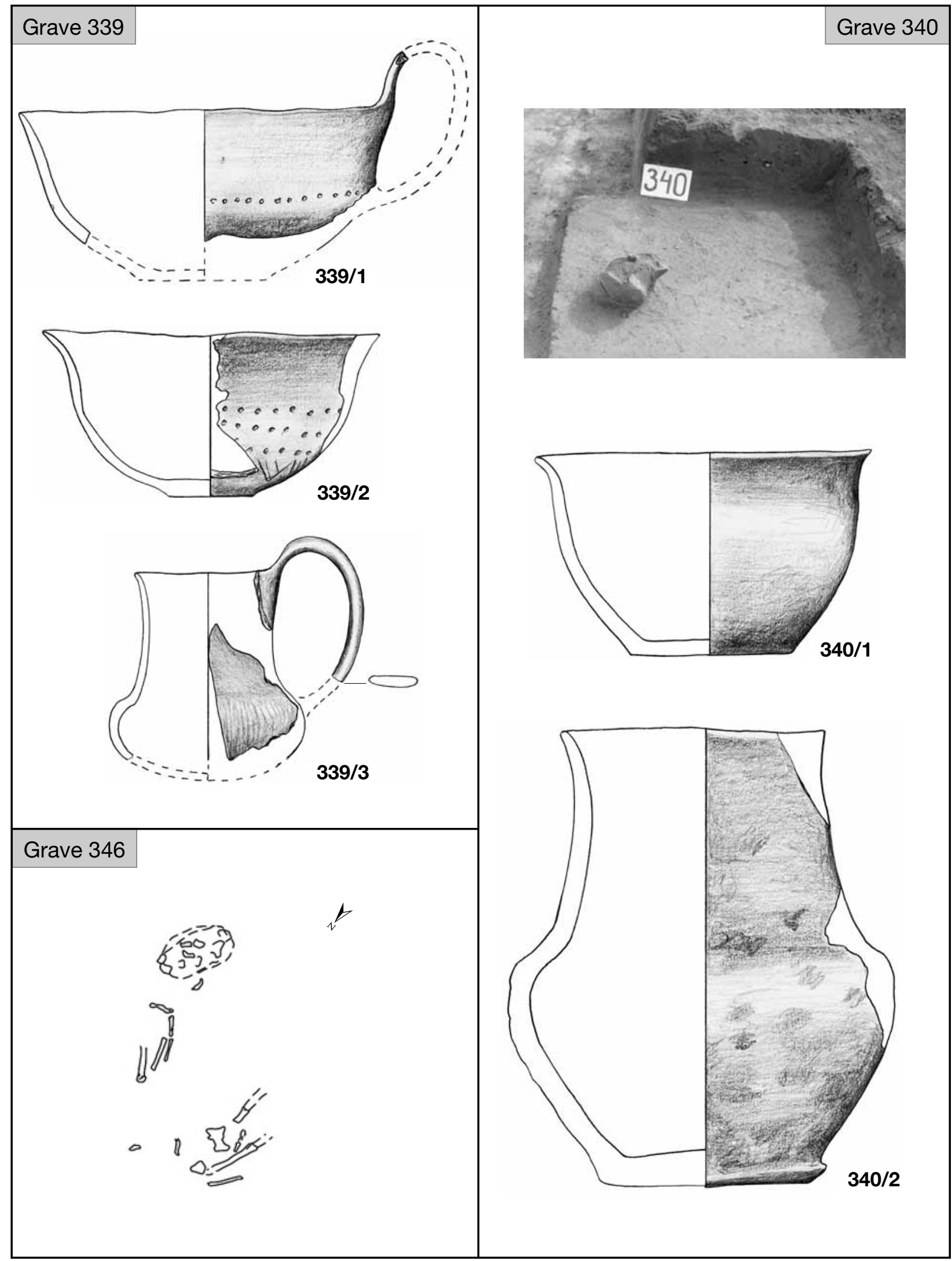

Plate CXXX. Graves 339-340 and 346 


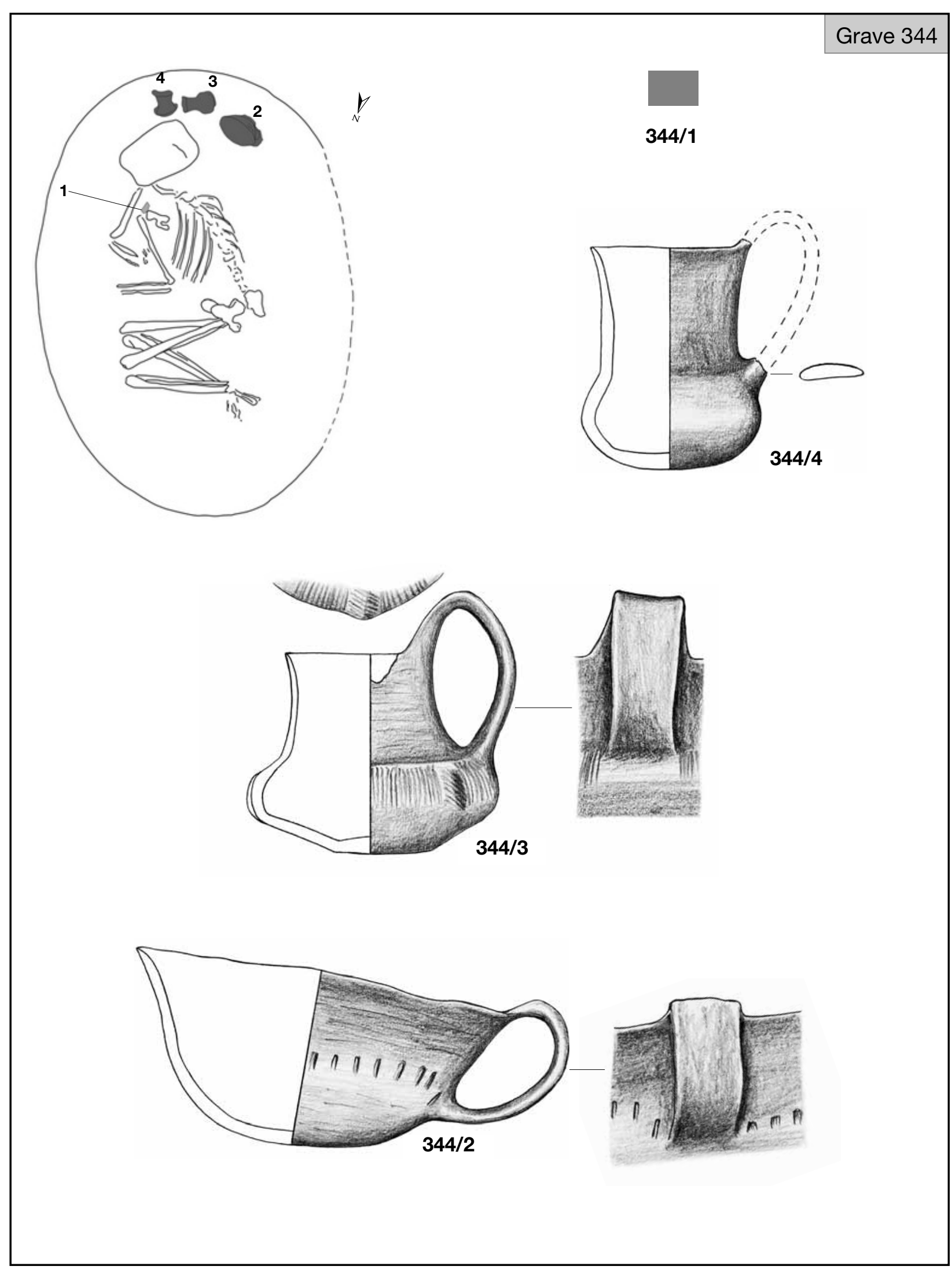

Plate CXXXI. Grave 344 


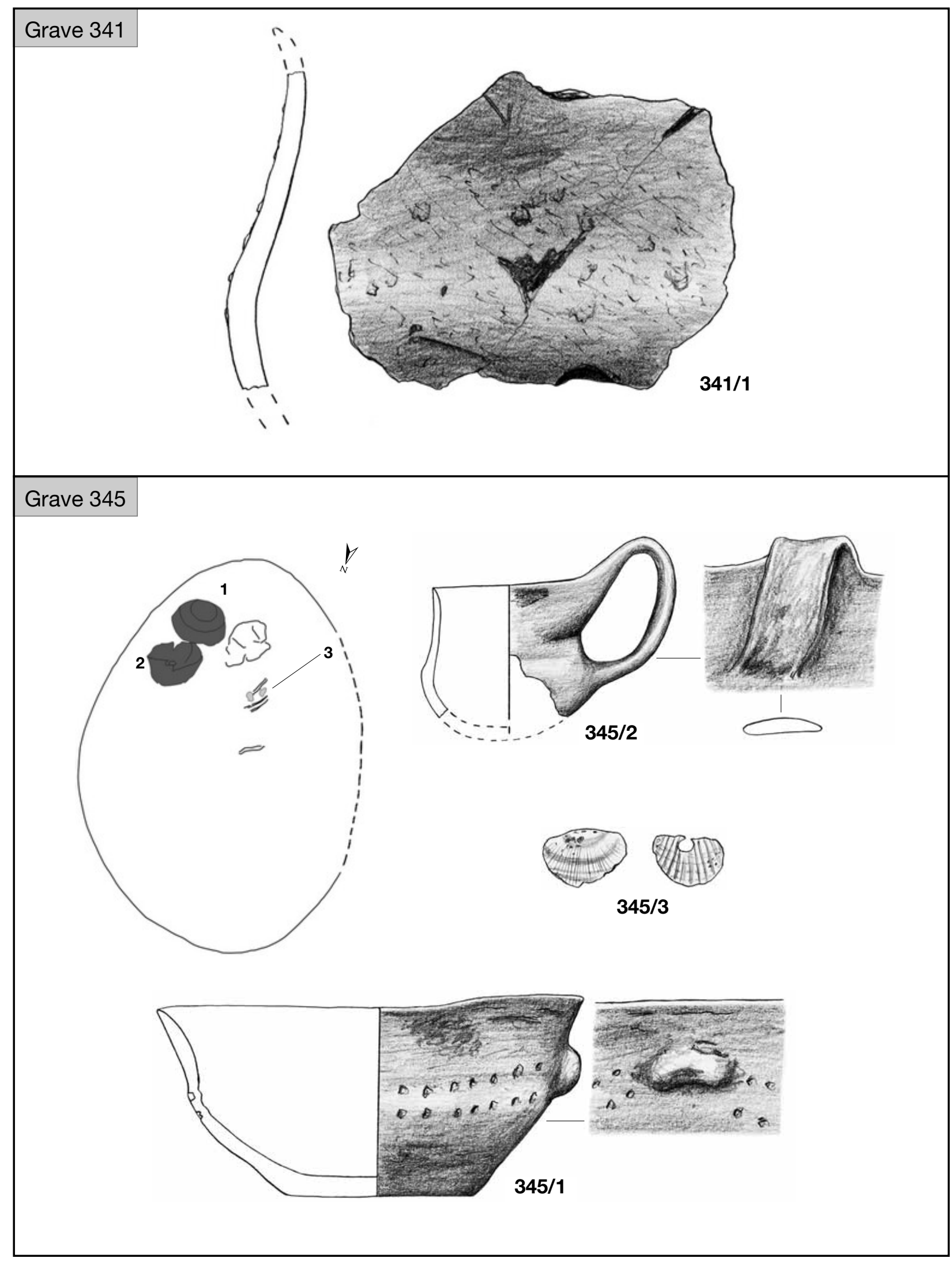

Plate CXXXII. Graves 341 and 345 


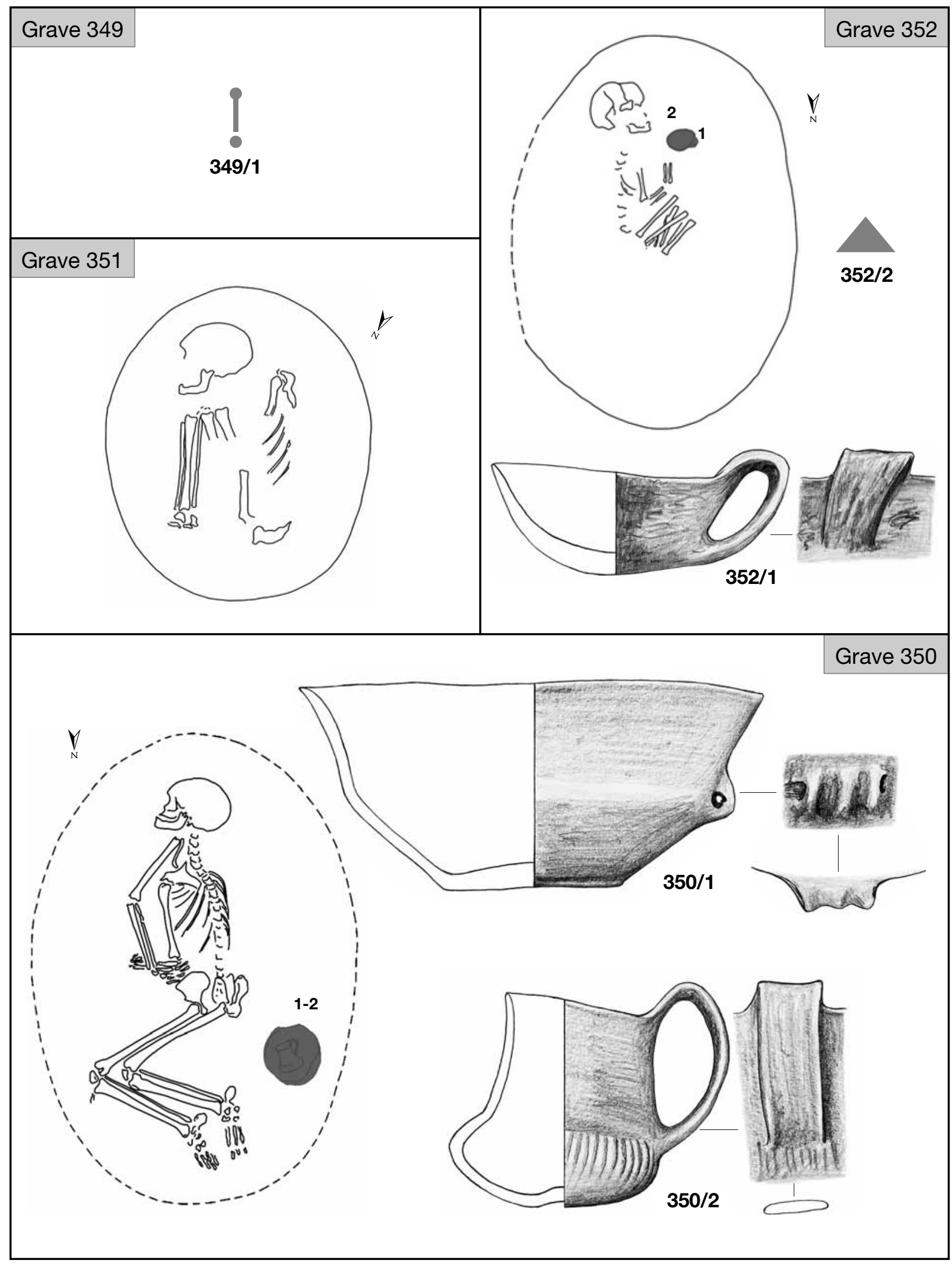

Plate CXXXIII. Graves 349-352 


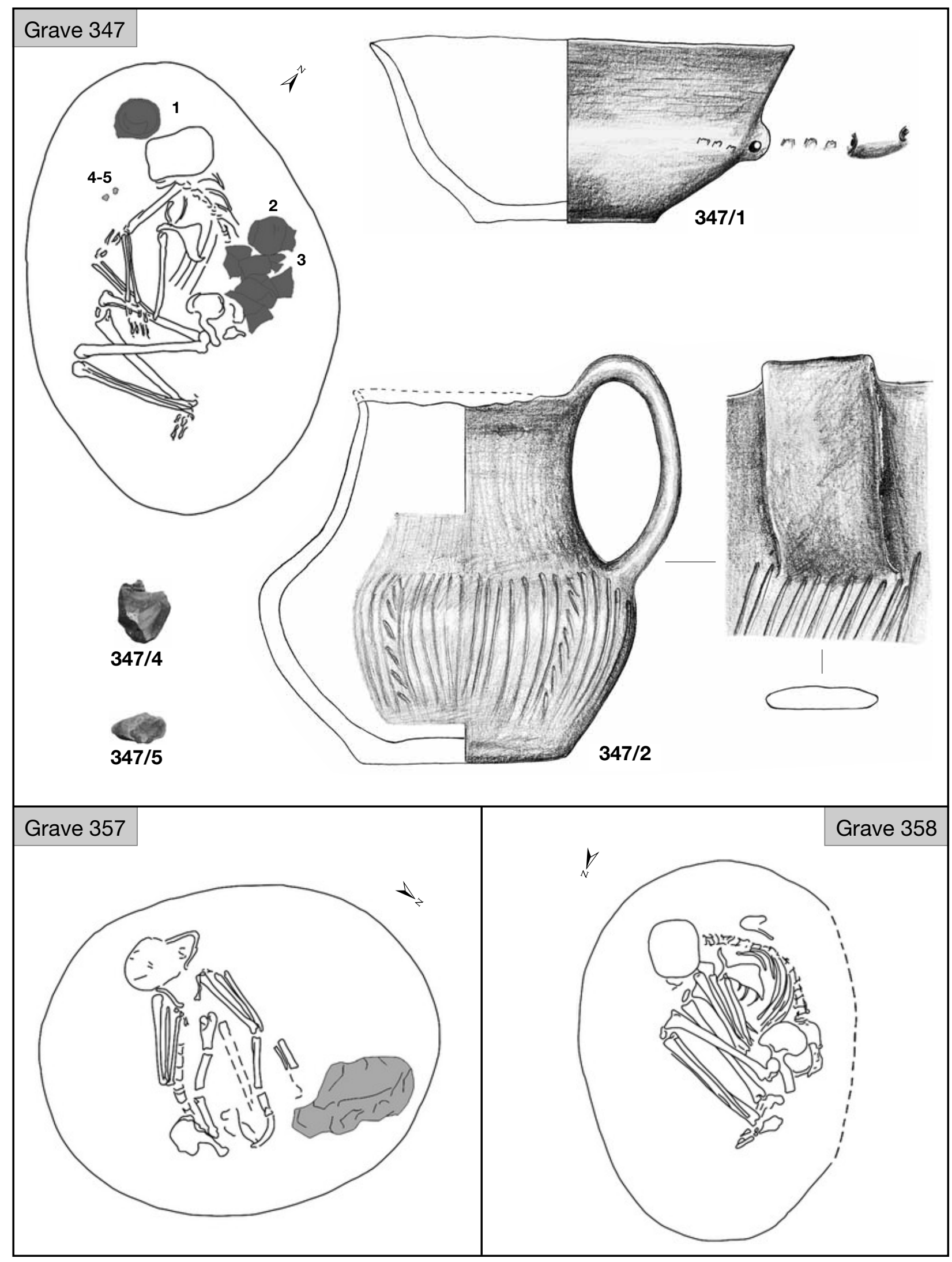

Plate CXXXIV. Graves 347 and 357-358 (347/4-5: after JózSEF KoREK's photo, courtesy of the SzFM Archives) 


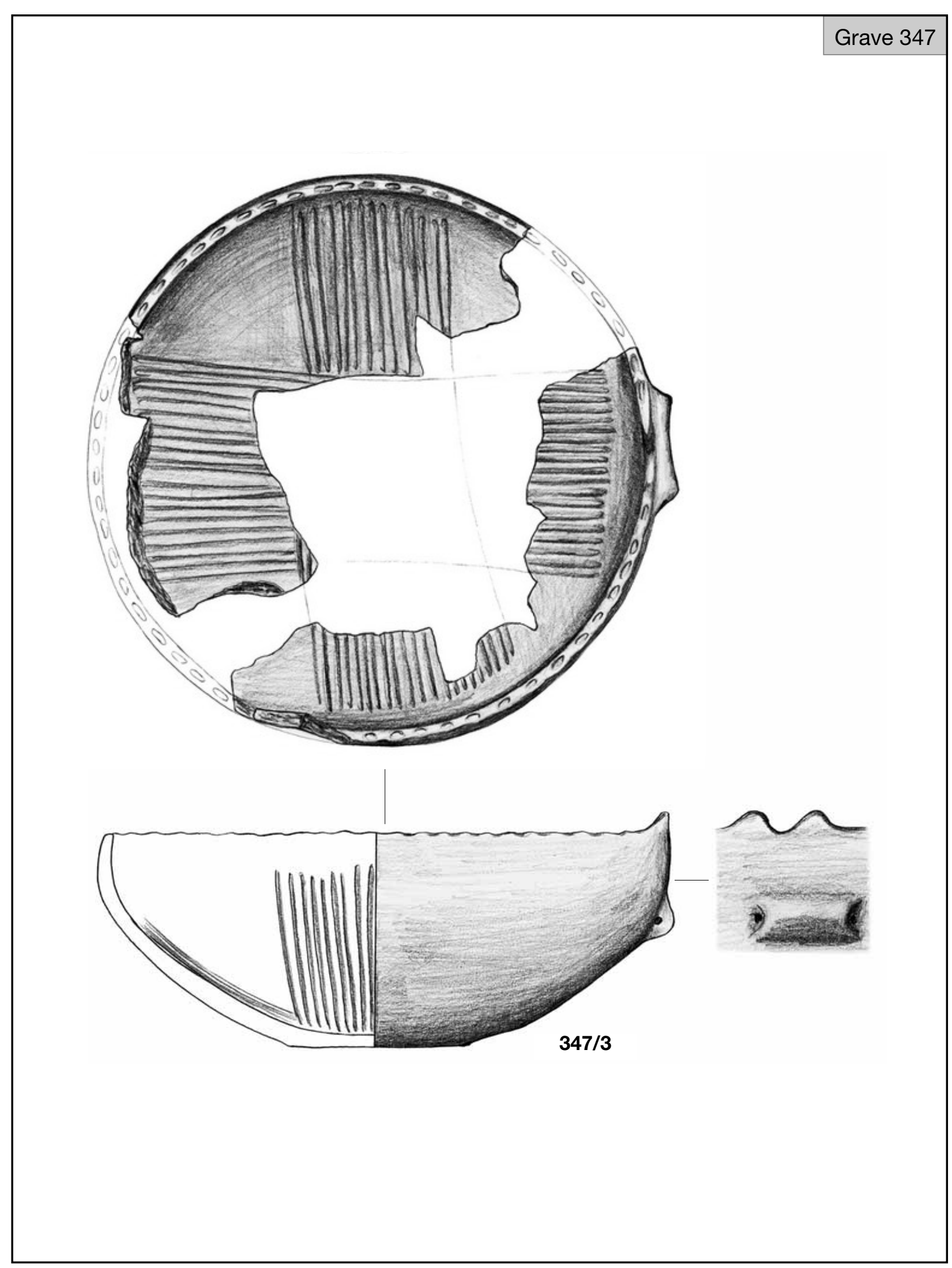

Plate CXXXV. Grave 347 


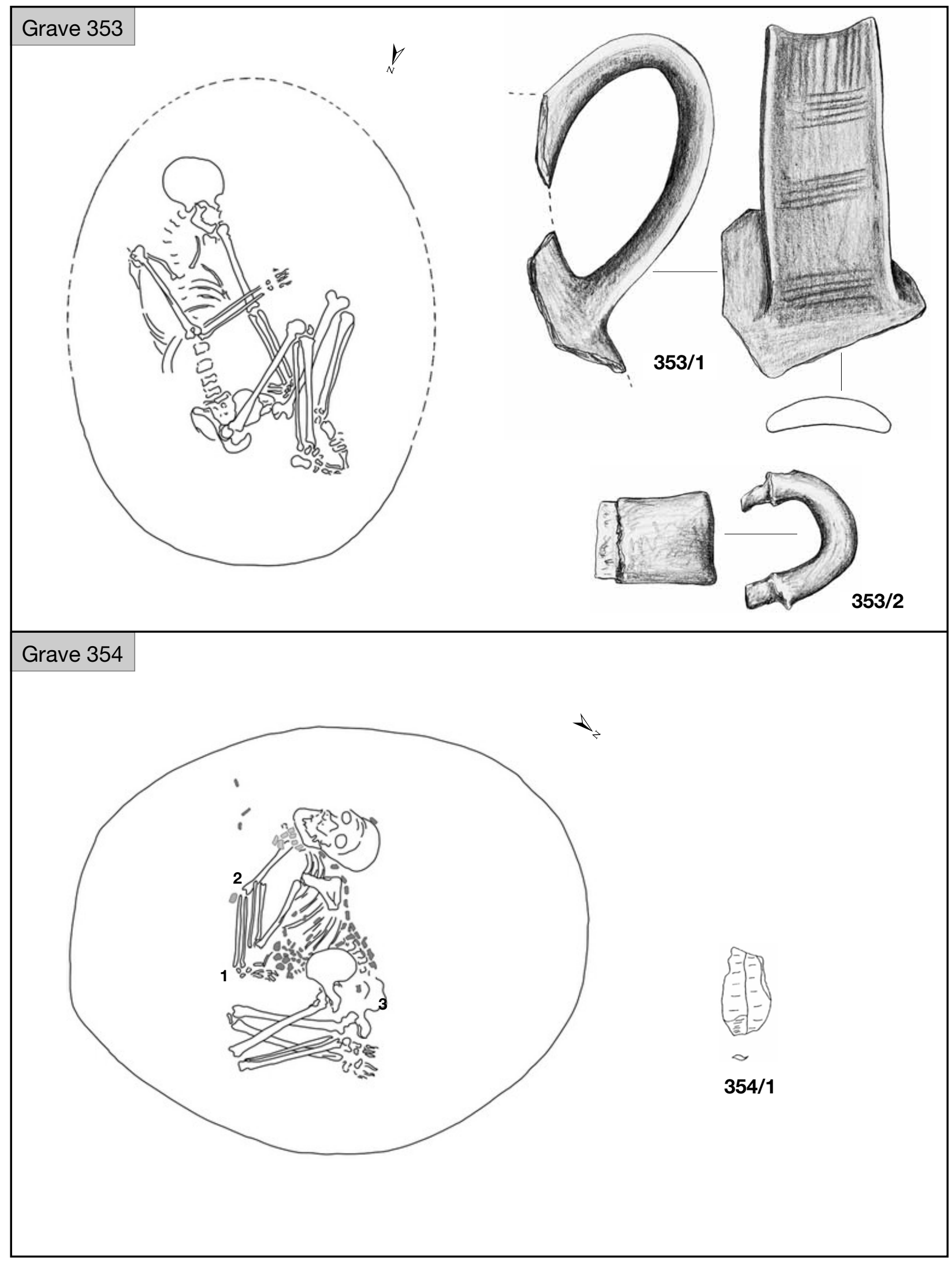

Plate CXXXVI. Graves 353-354 (353/1: after Cs. BALOGH 1993) 


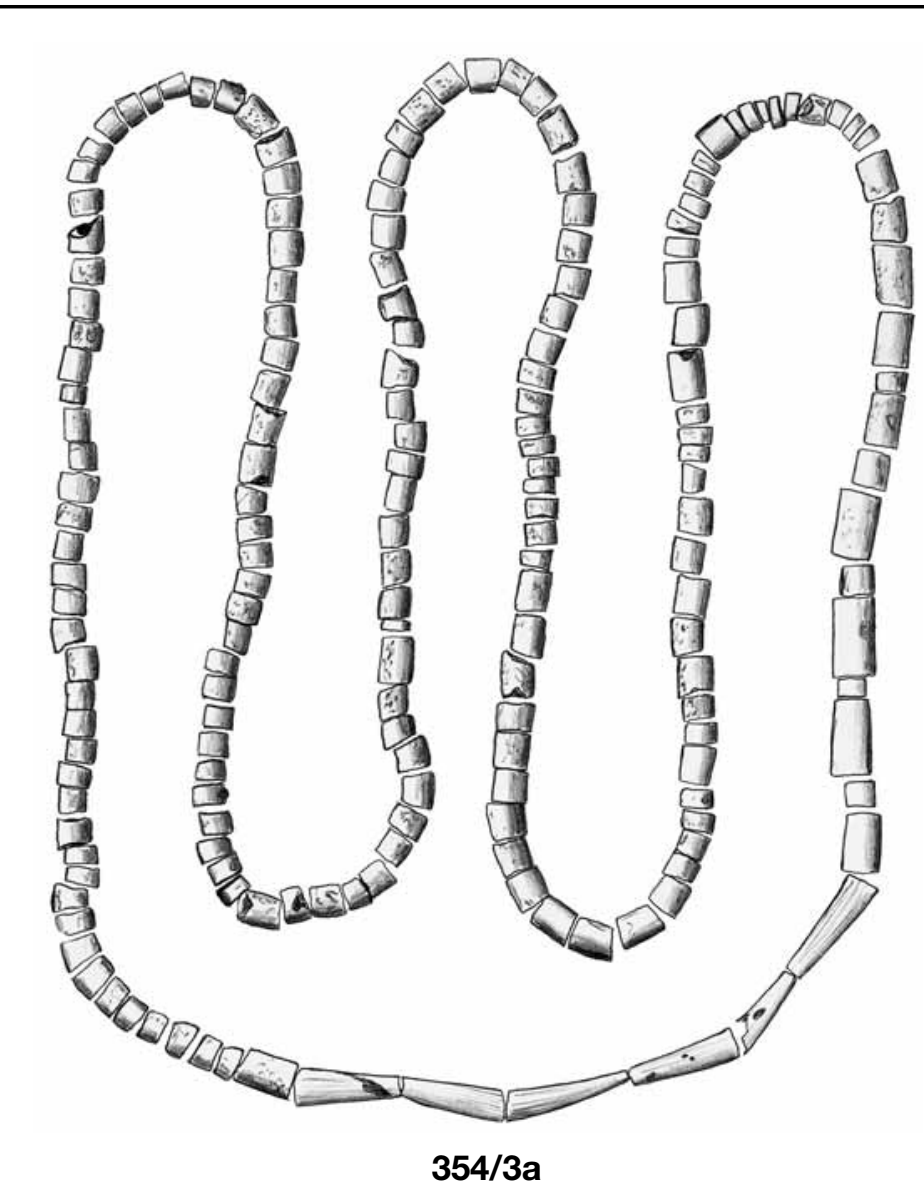

Grave 354
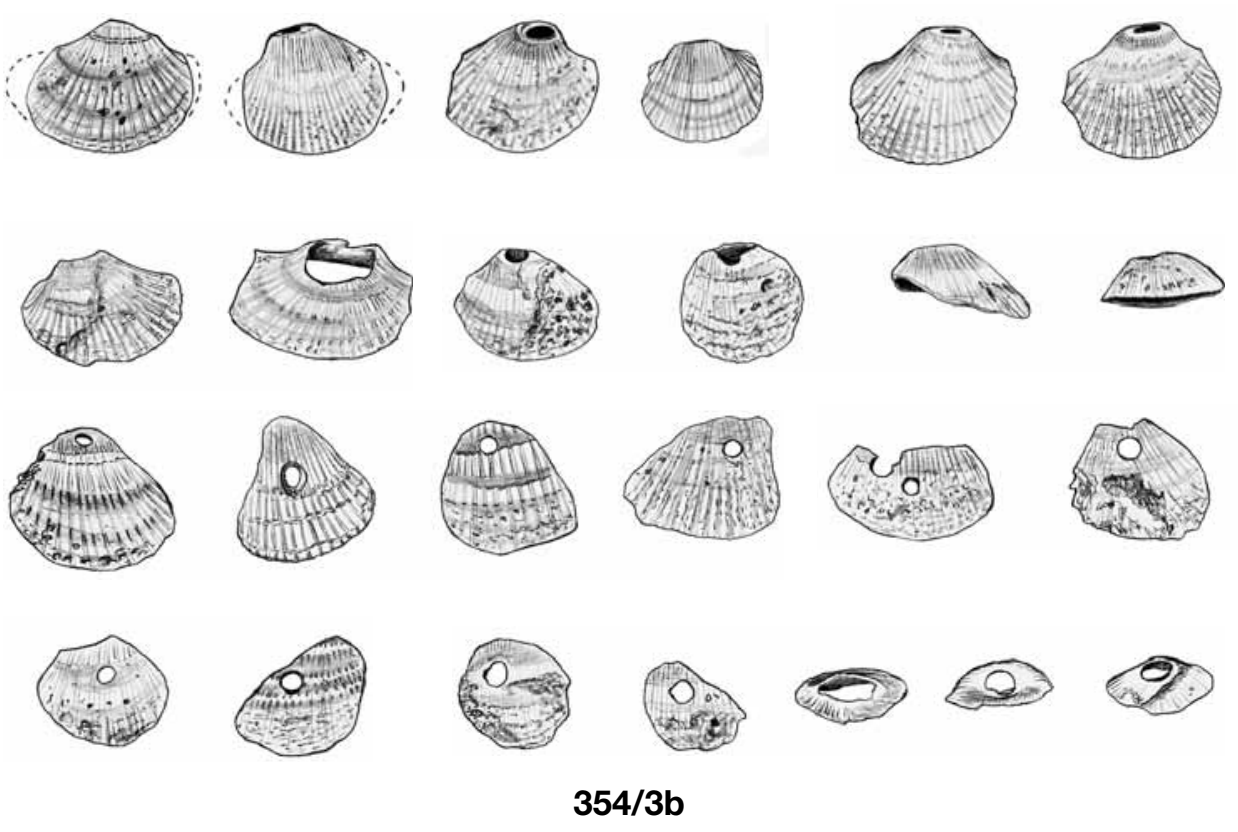

Plate CXXXVII. Grave 354 


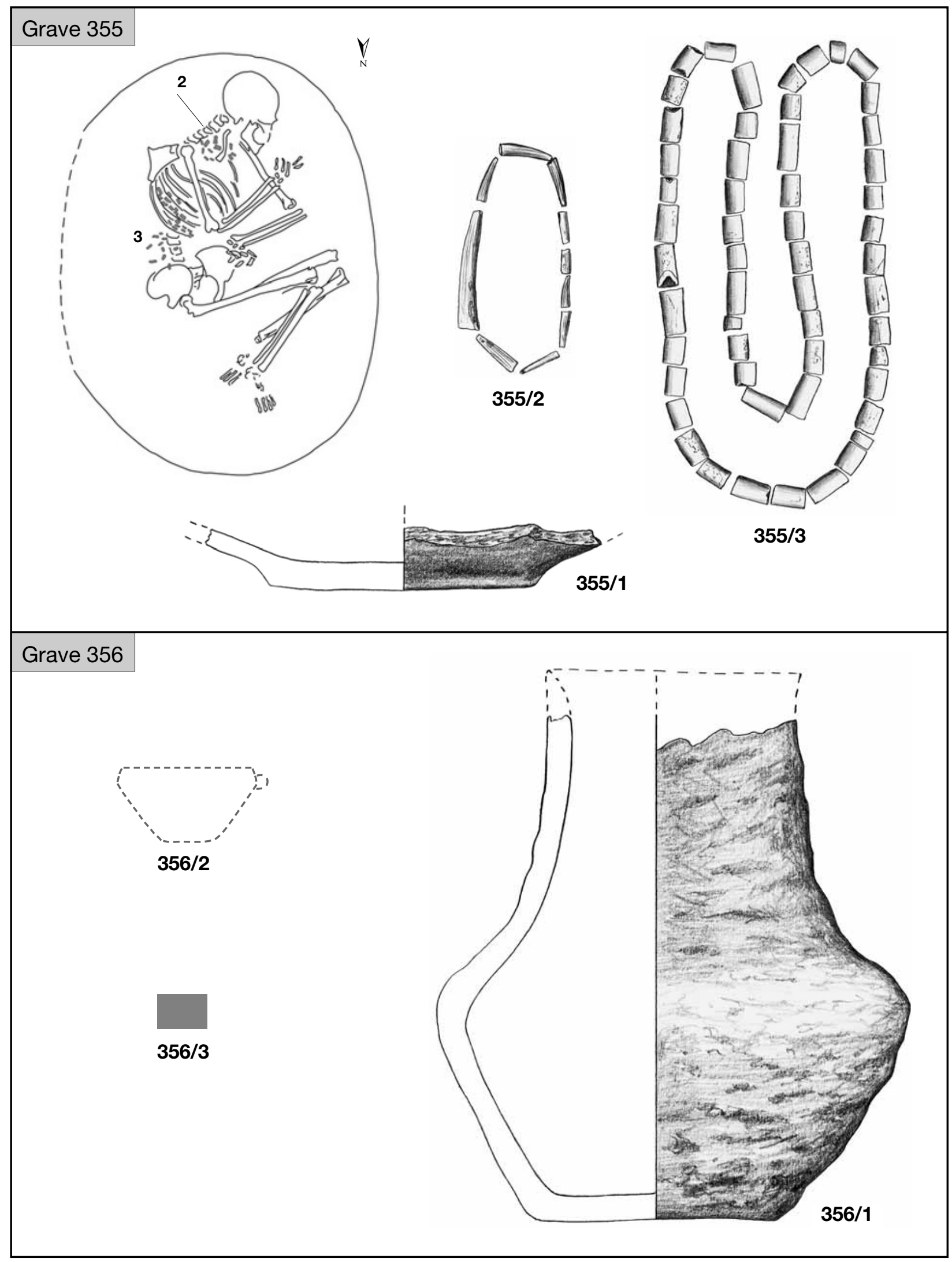

Plate CXXXVIII. Graves 355-356 


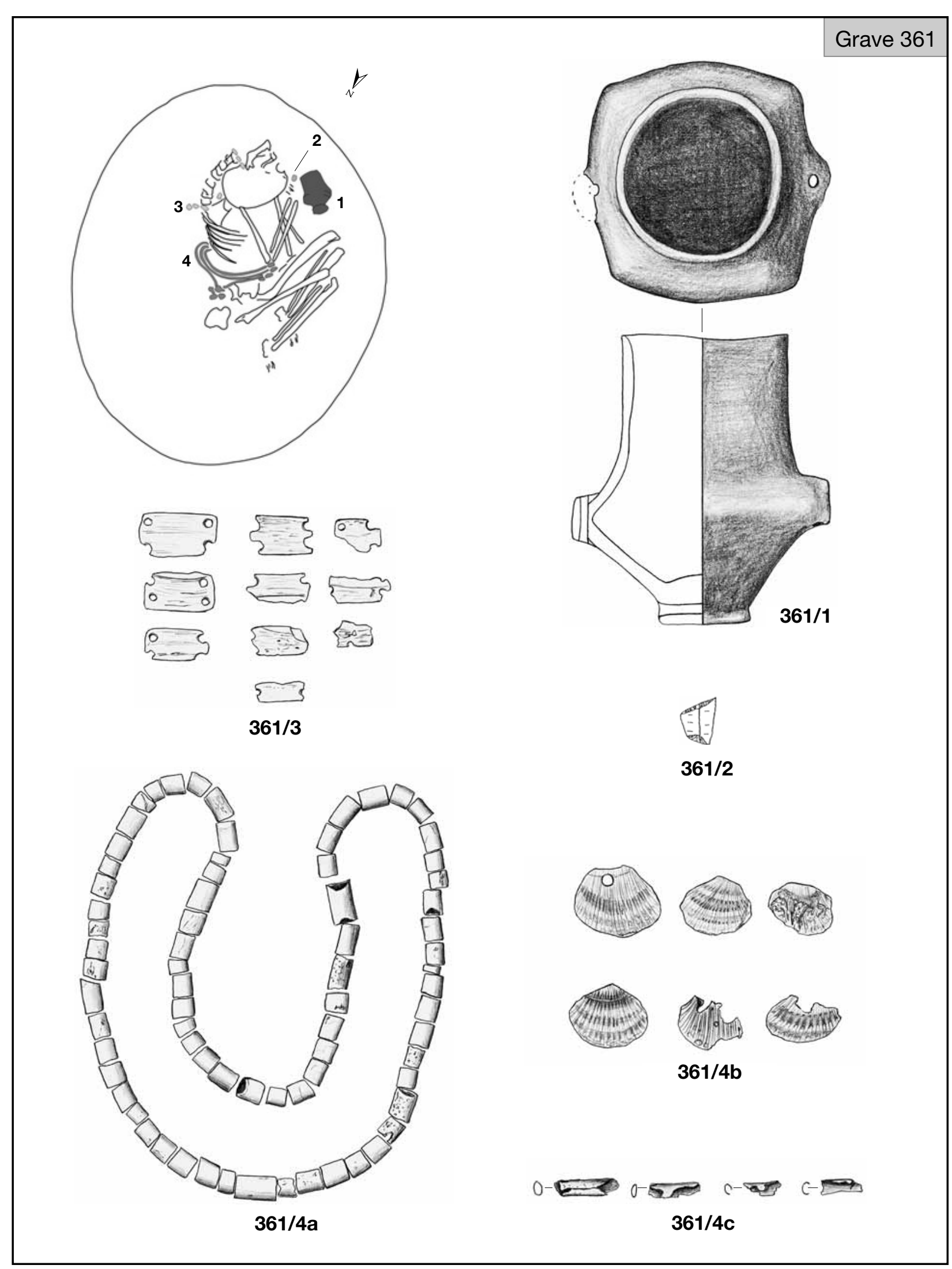

Plate CXXXIX. Grave 361 (361/2: after Cs. BALOGH 1993) 


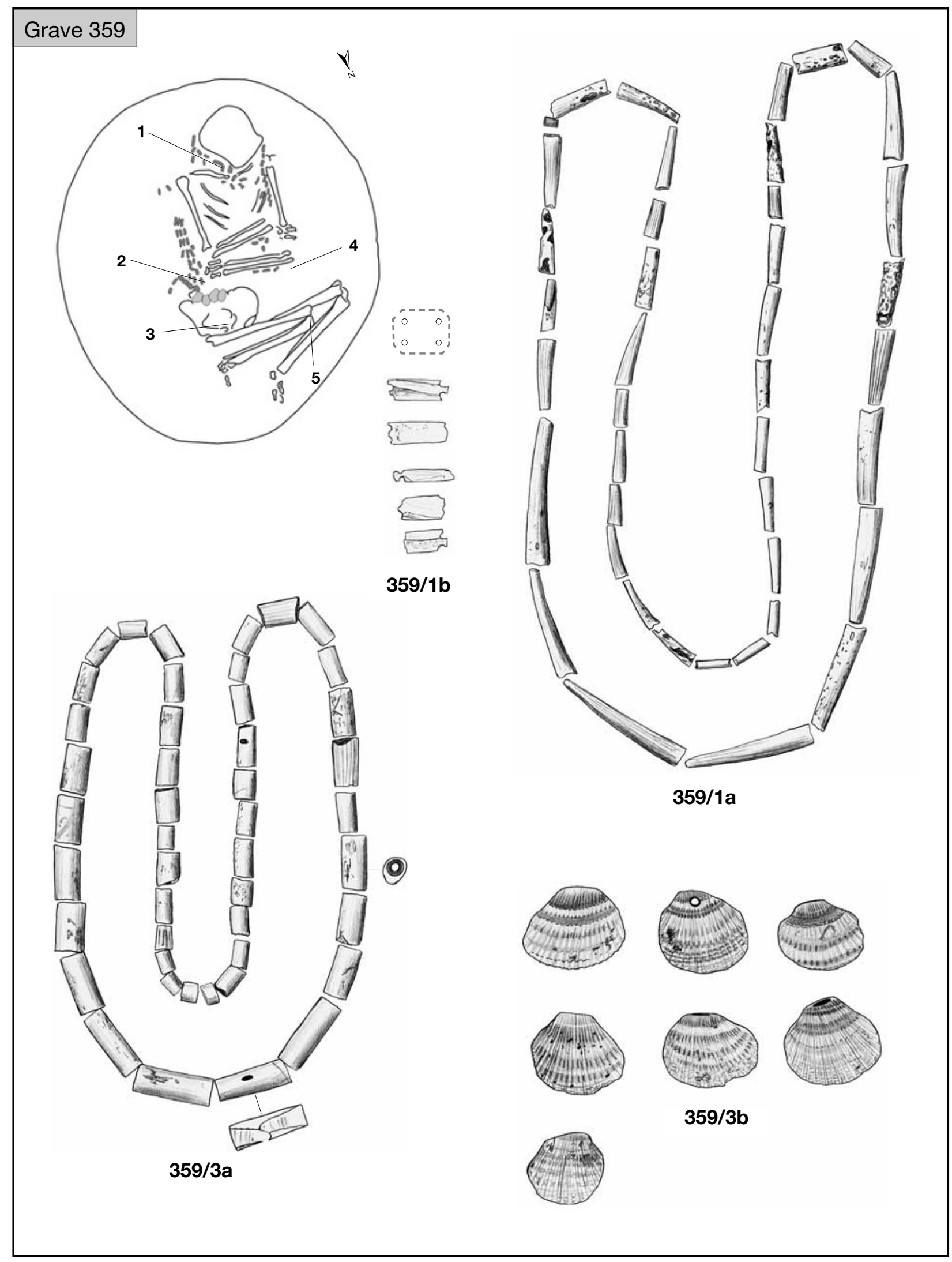

Plate CXL. Grave 359 


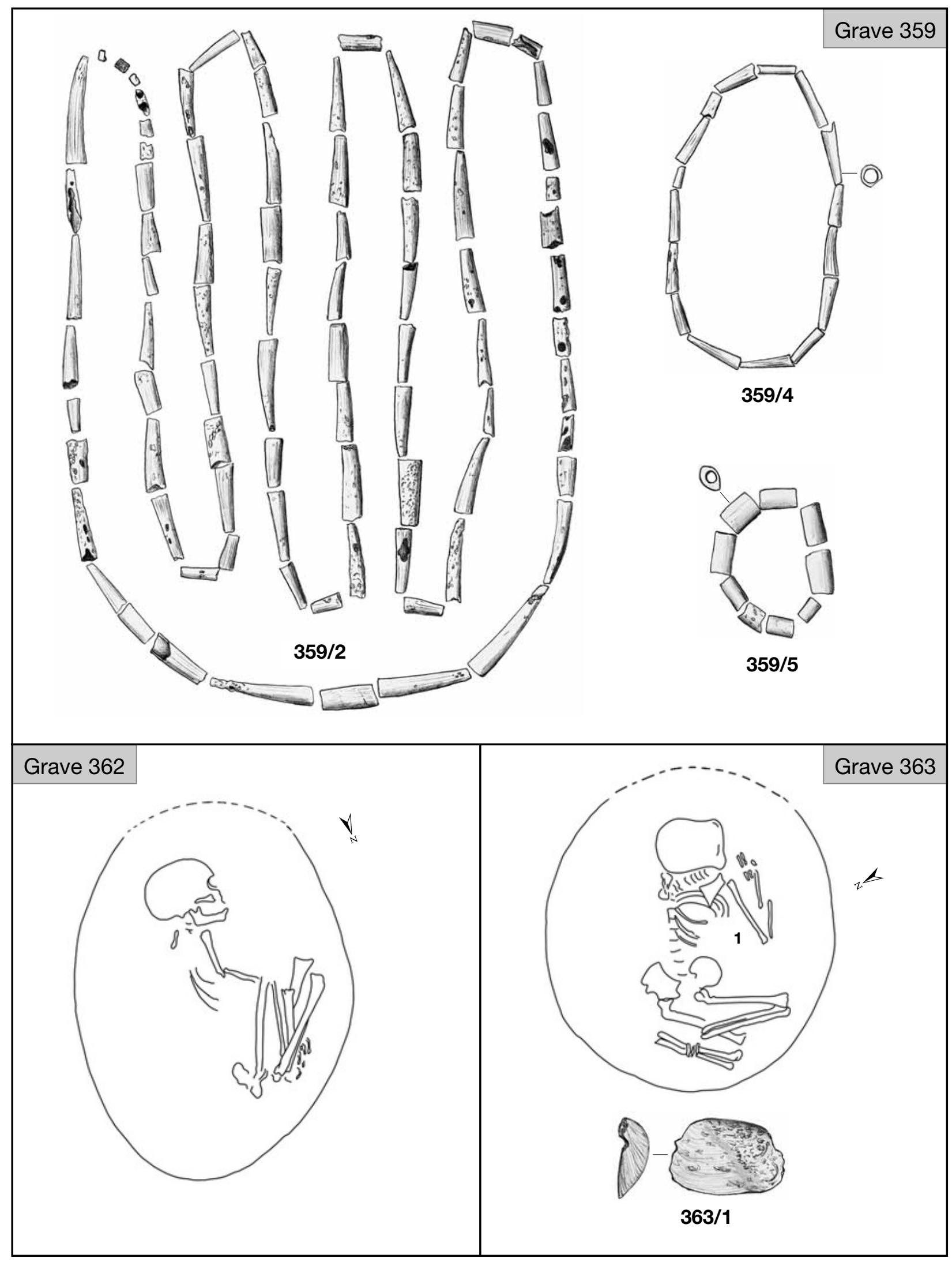

Plate CXLI. Graves 359 and 362-363 


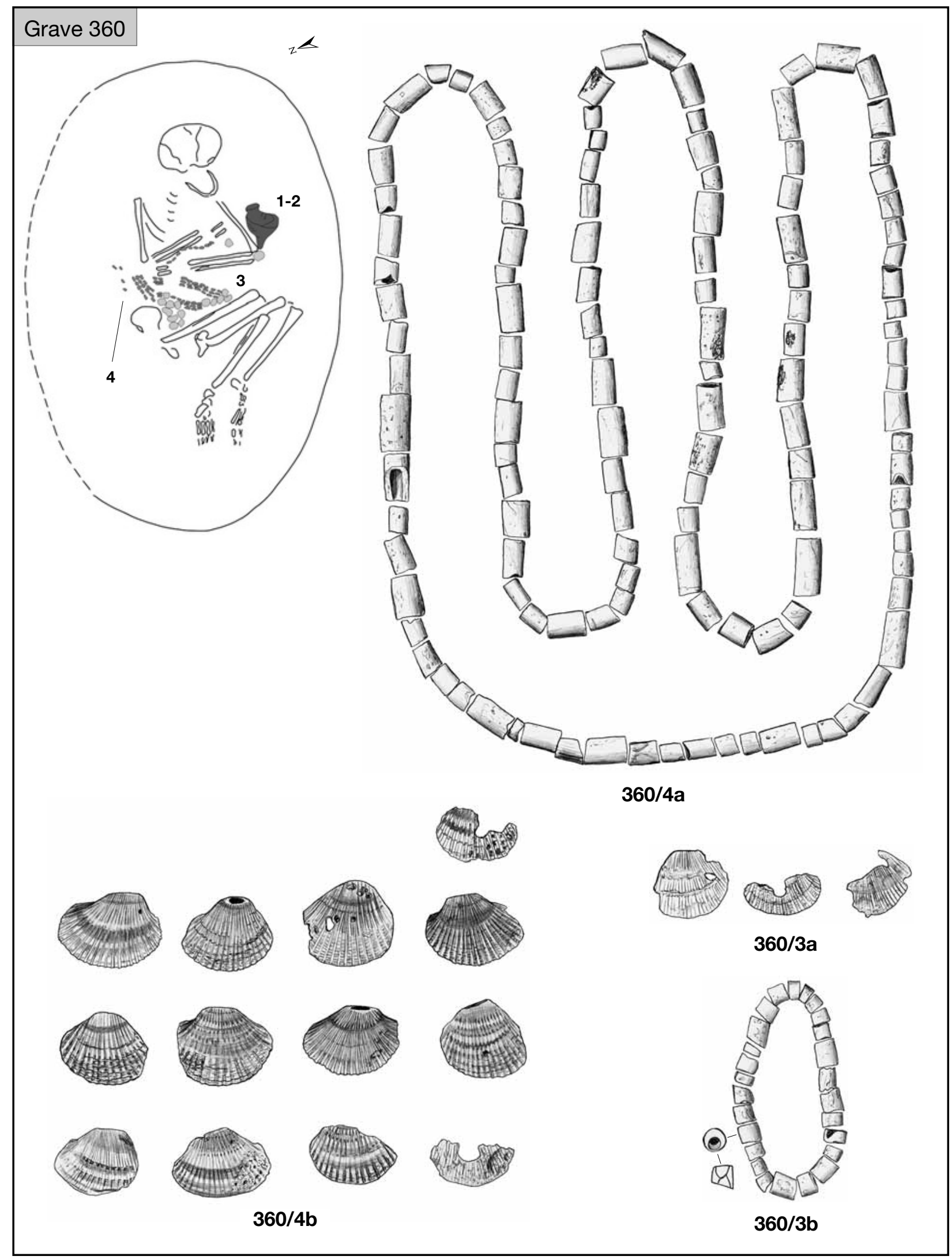

Plate CXLII. Grave 360 


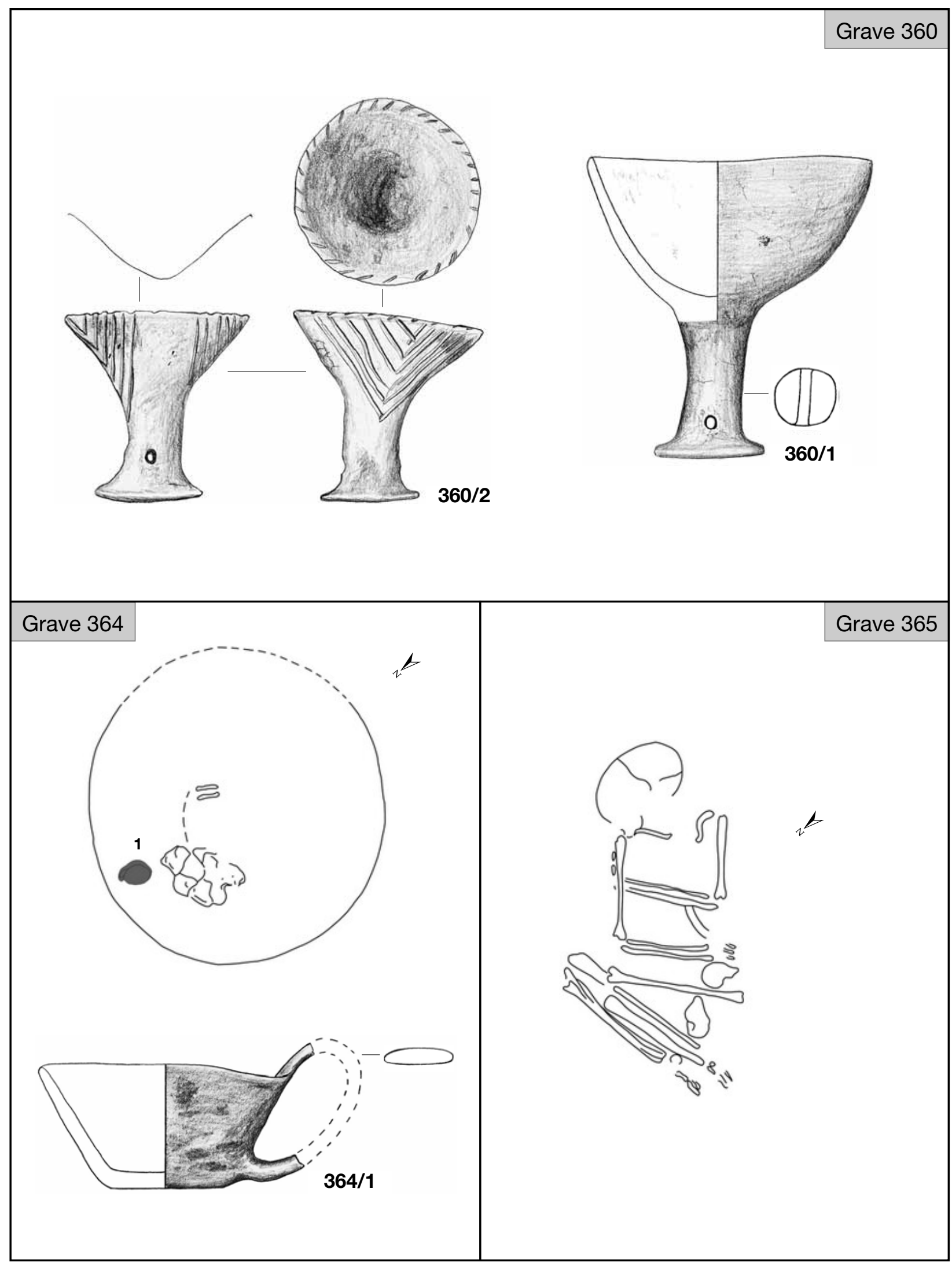

Plate CXLIII. Graves 360 and 364-365 


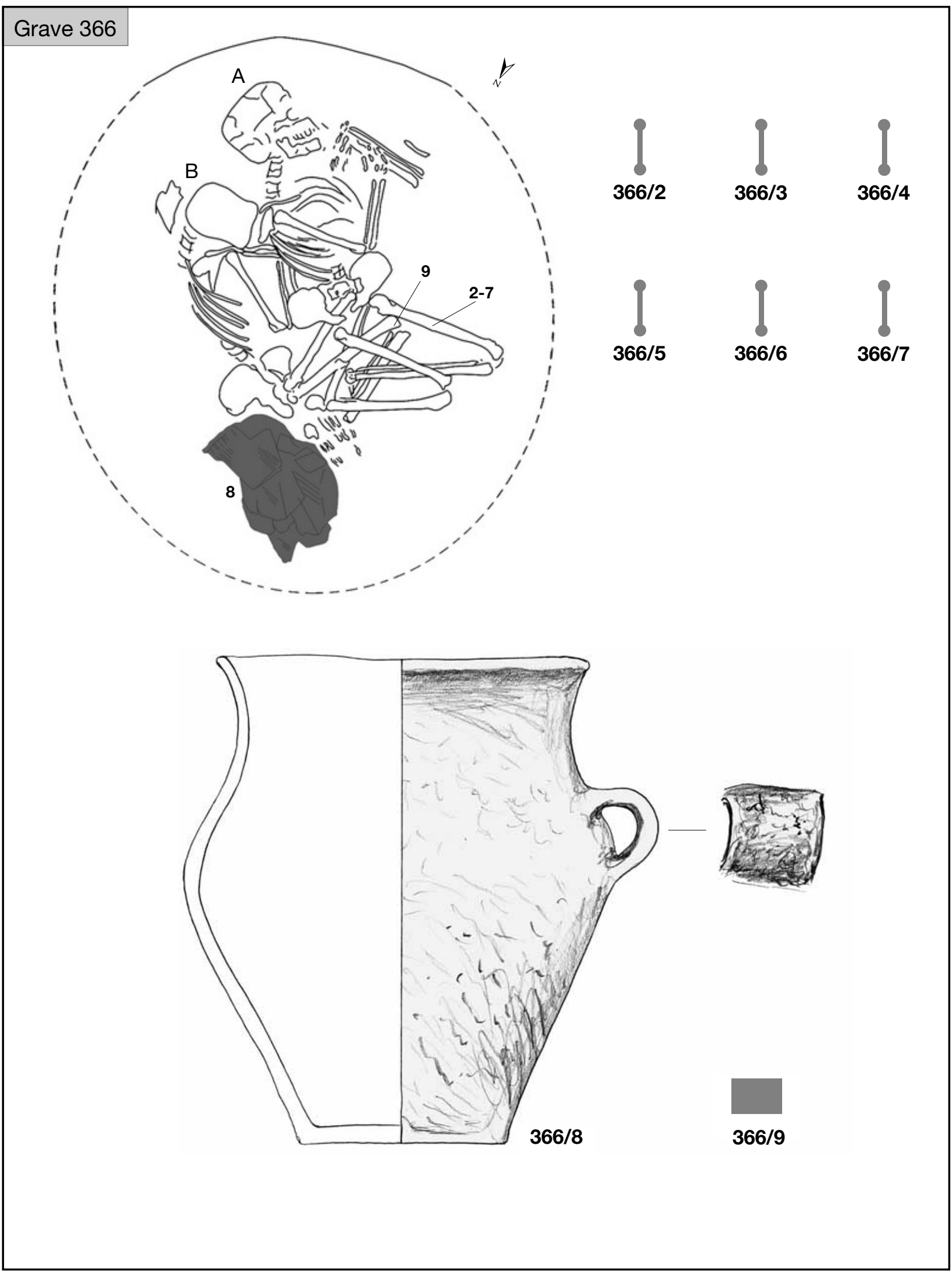

Plate CXLIV. Grave 366 


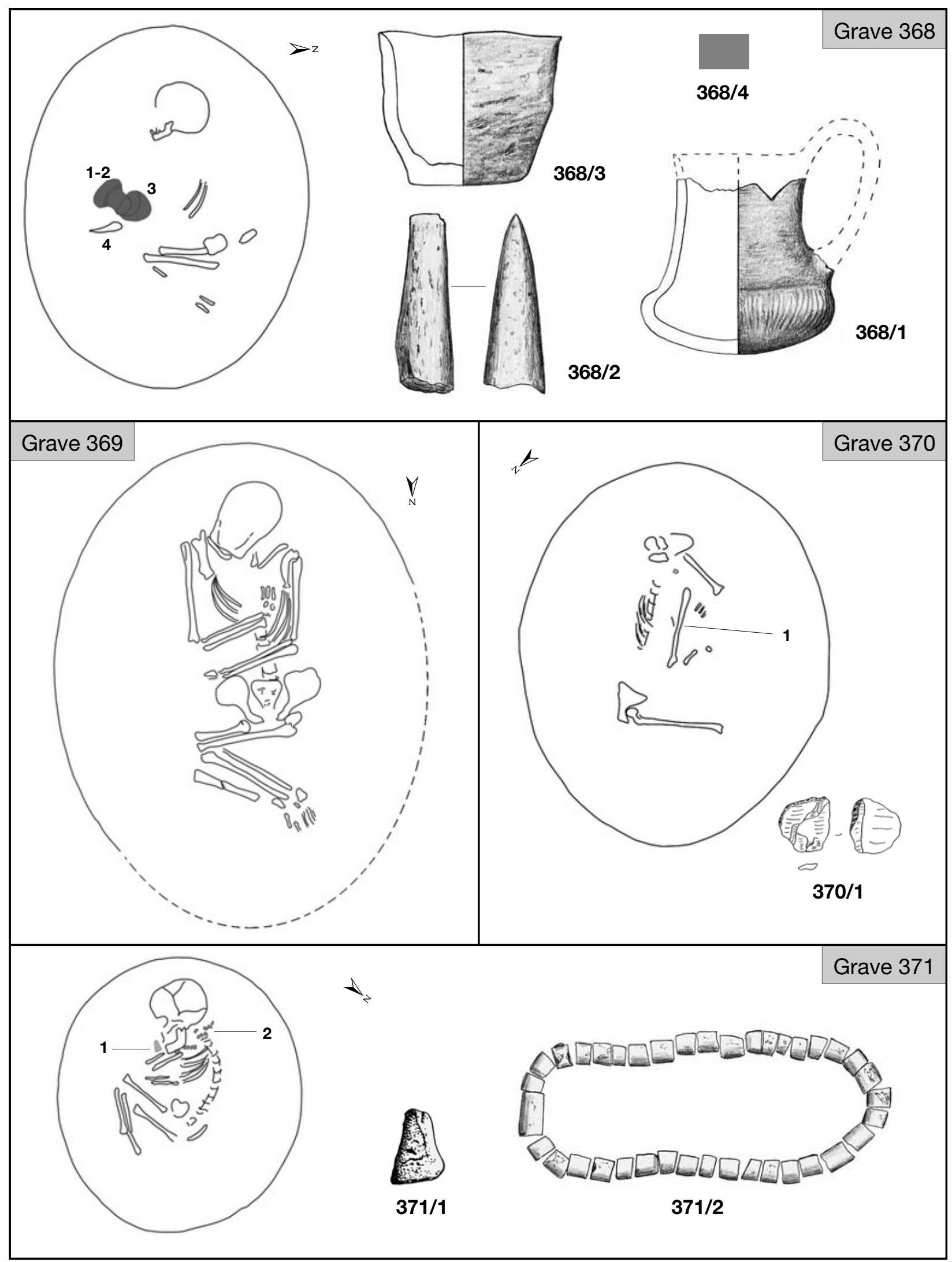

Plate CXLV. Graves 368-371 (371/1: after JózSEF KoREK's grave sheet) 


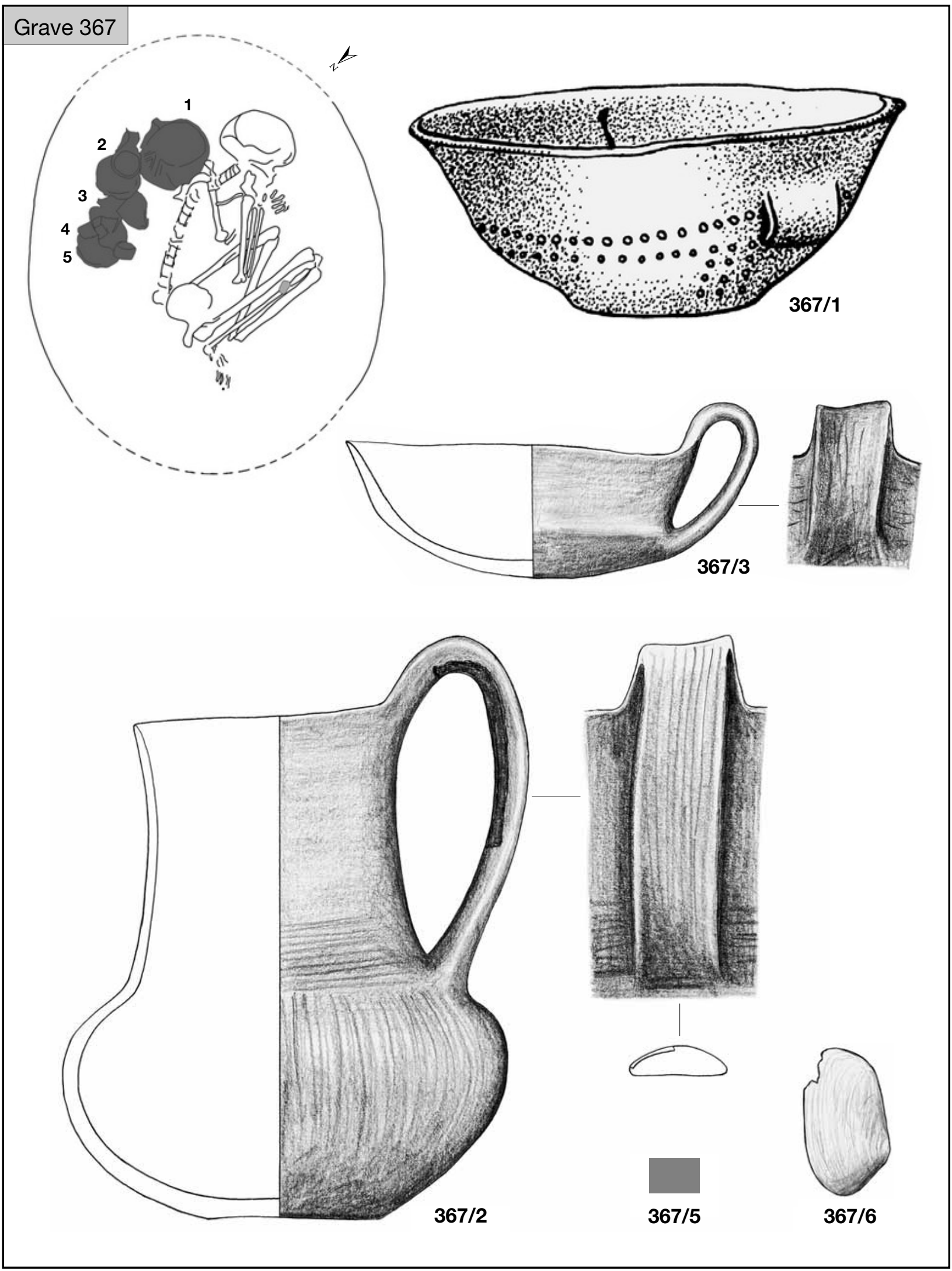

Plate CXLVI. Grave 367 (367/1: after JóZSEF KoREK’s grave sheet) 


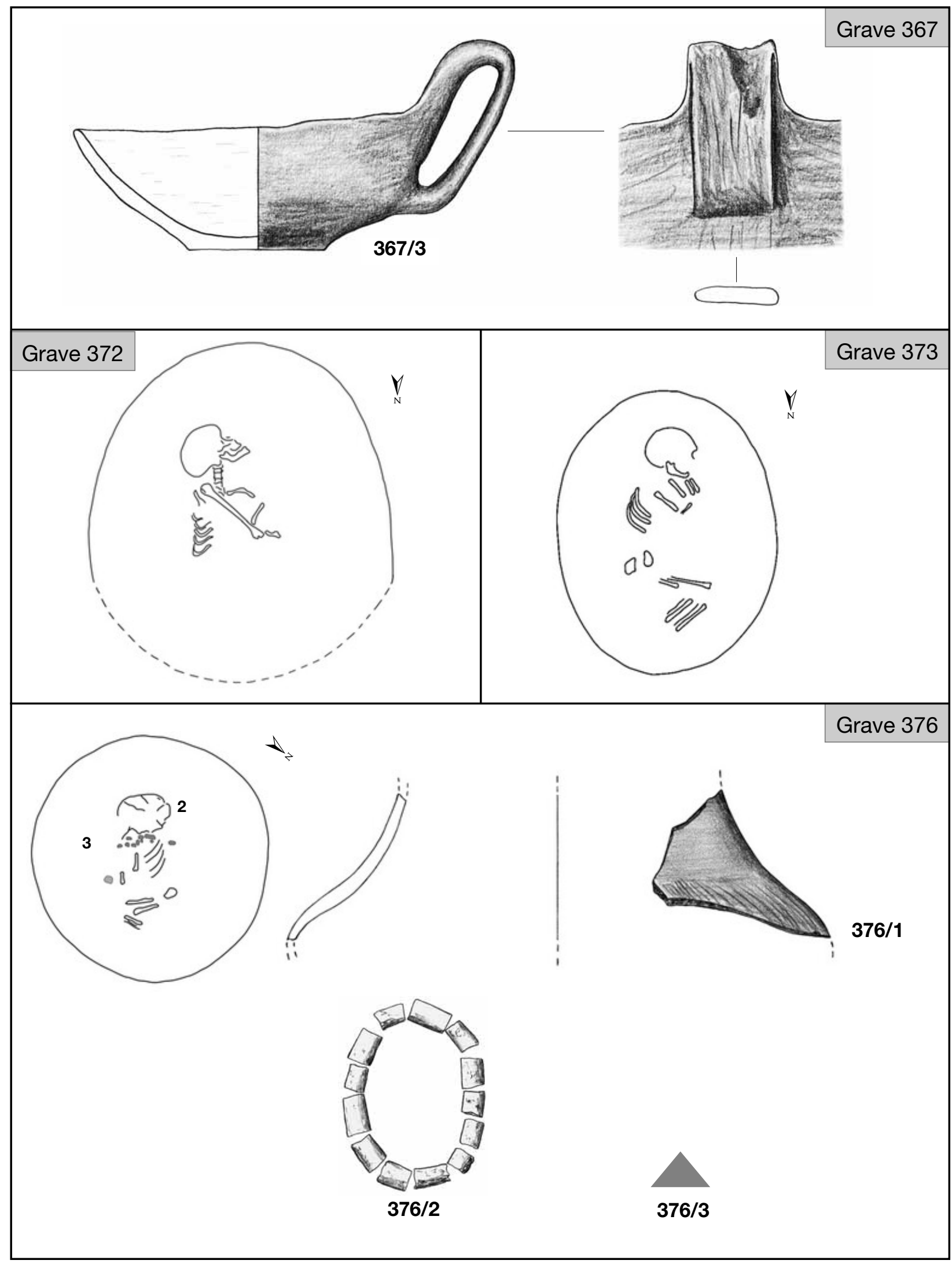

Plate CXLVII. Graves 367, 372-373 and 376 


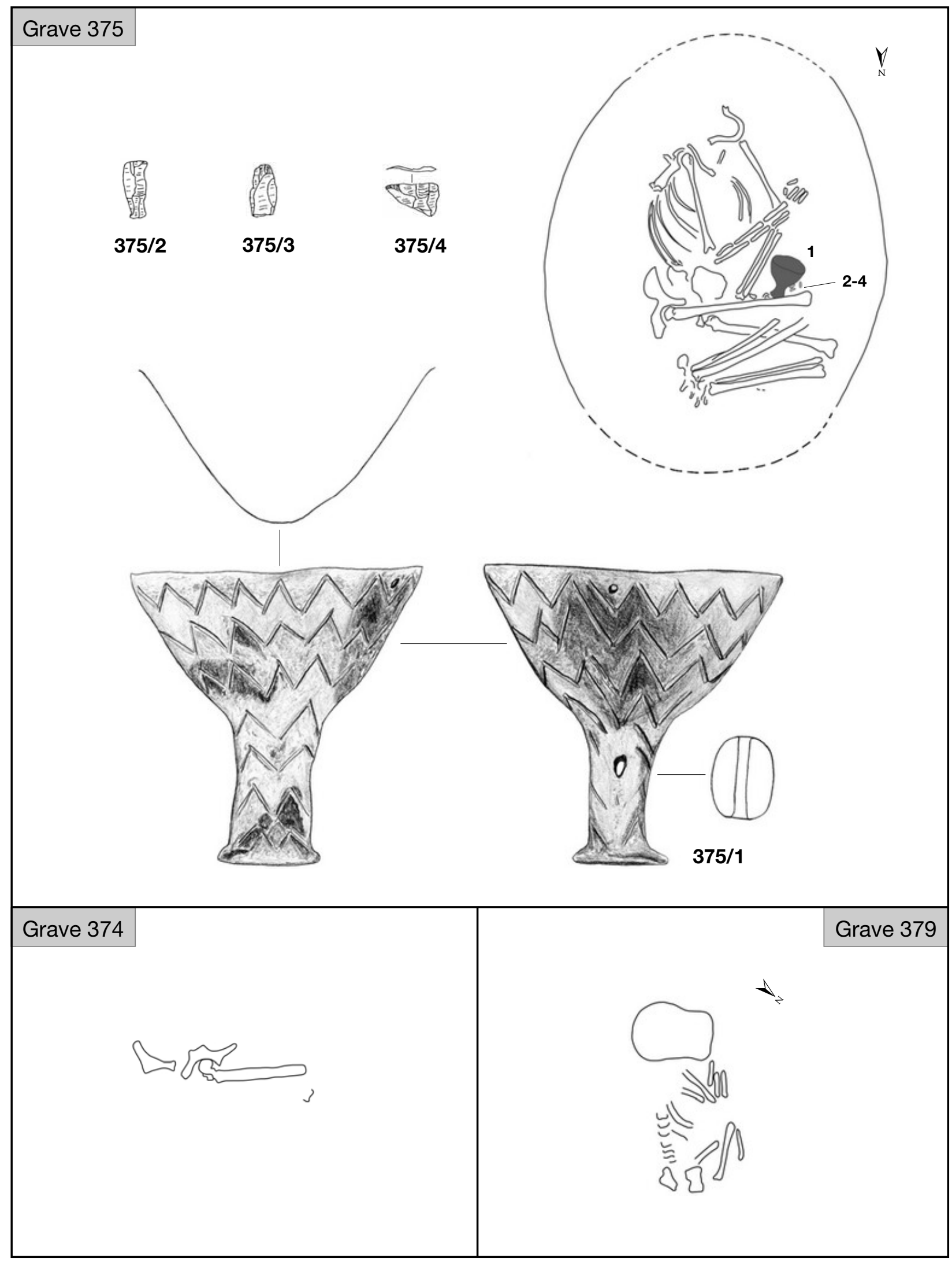

Plate CXLVIII. Graves 374-375 and 379 (375/2-4: after Cs. BALOGH 1993) 


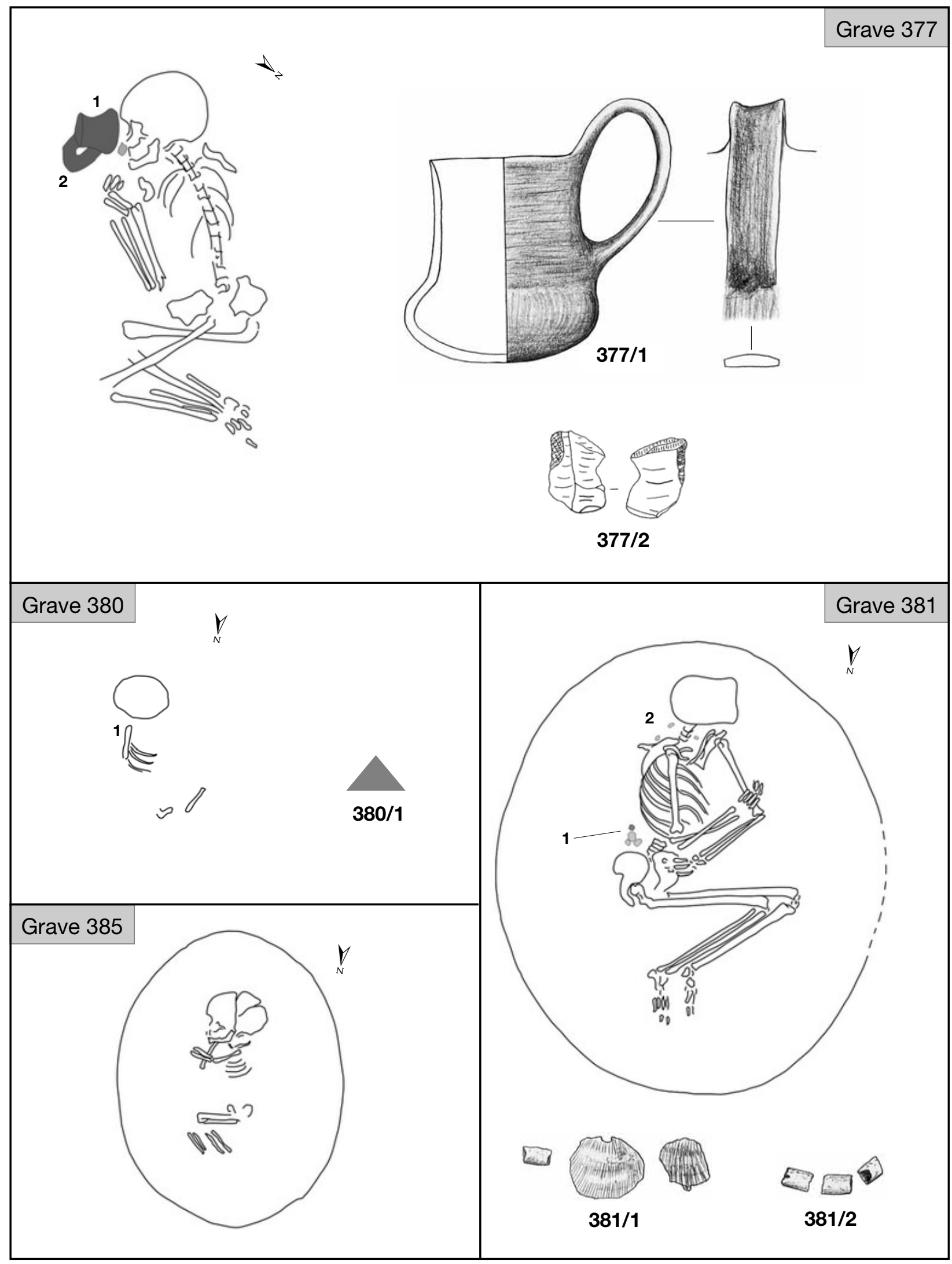

Plate CXLIX. Graves 377, 380-381 and 385 (377/2: after Cs. BALOGH 1993) 


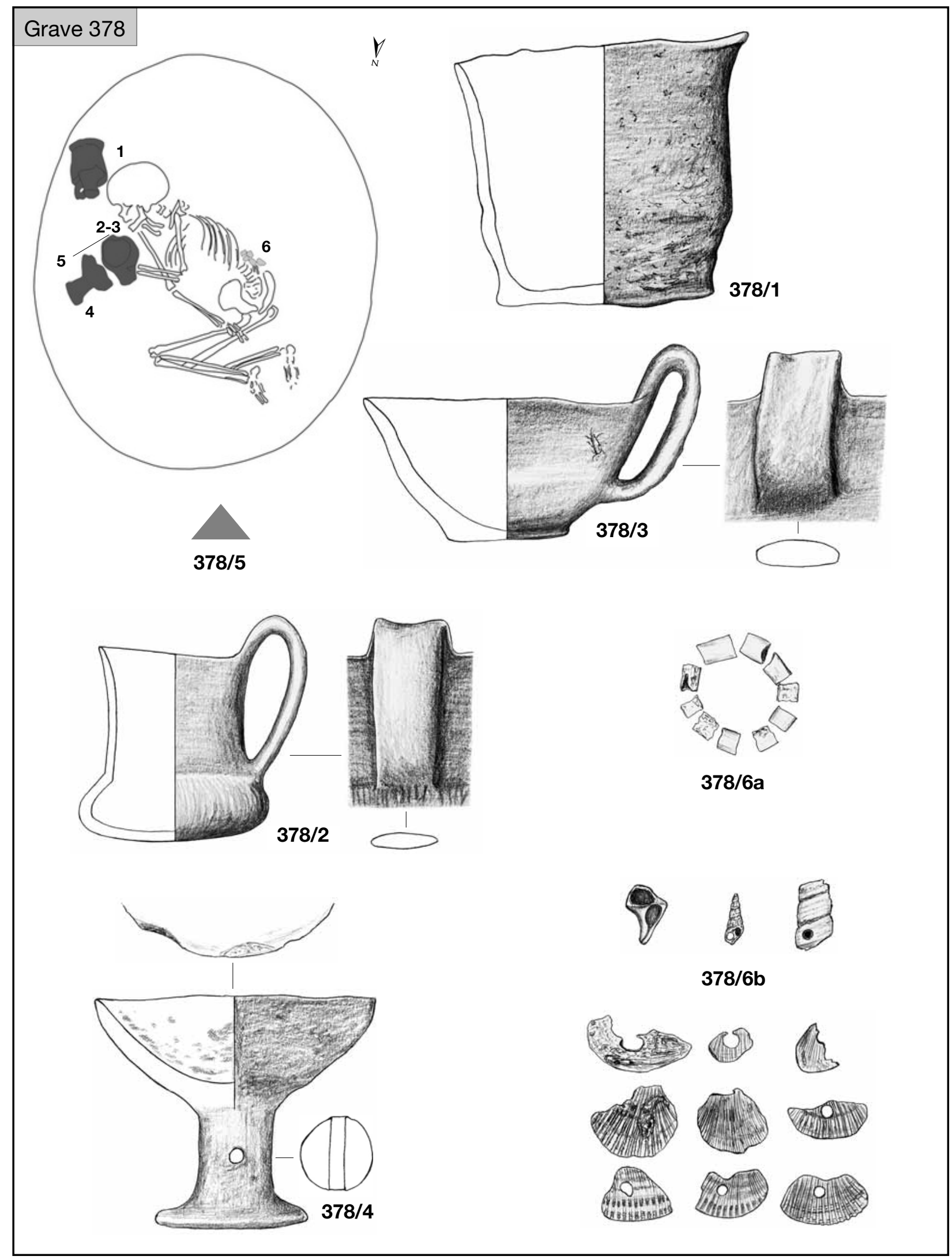

Plate CL. Grave 378 


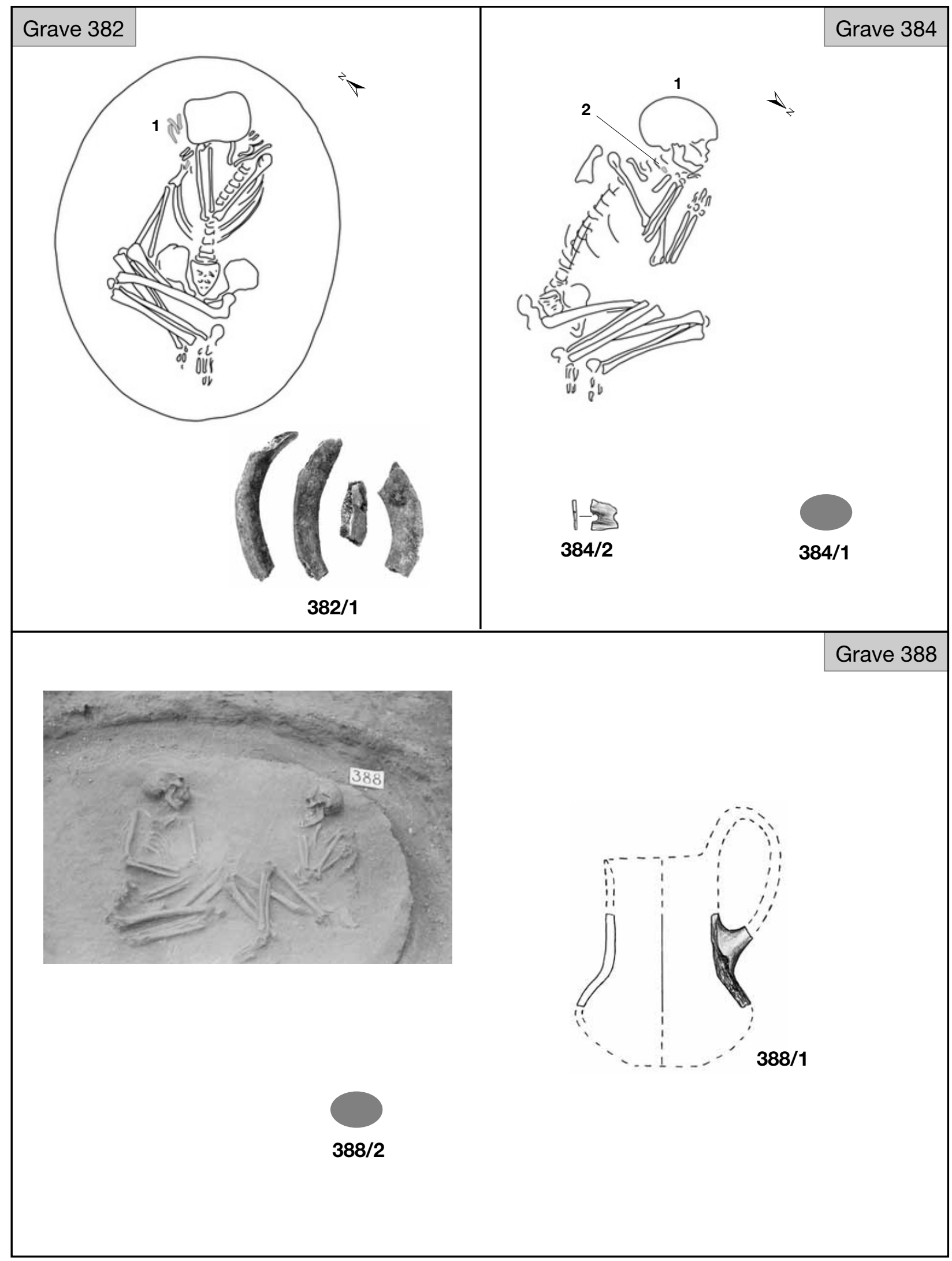

Plate CLI. Graves 382, 384 and 388 


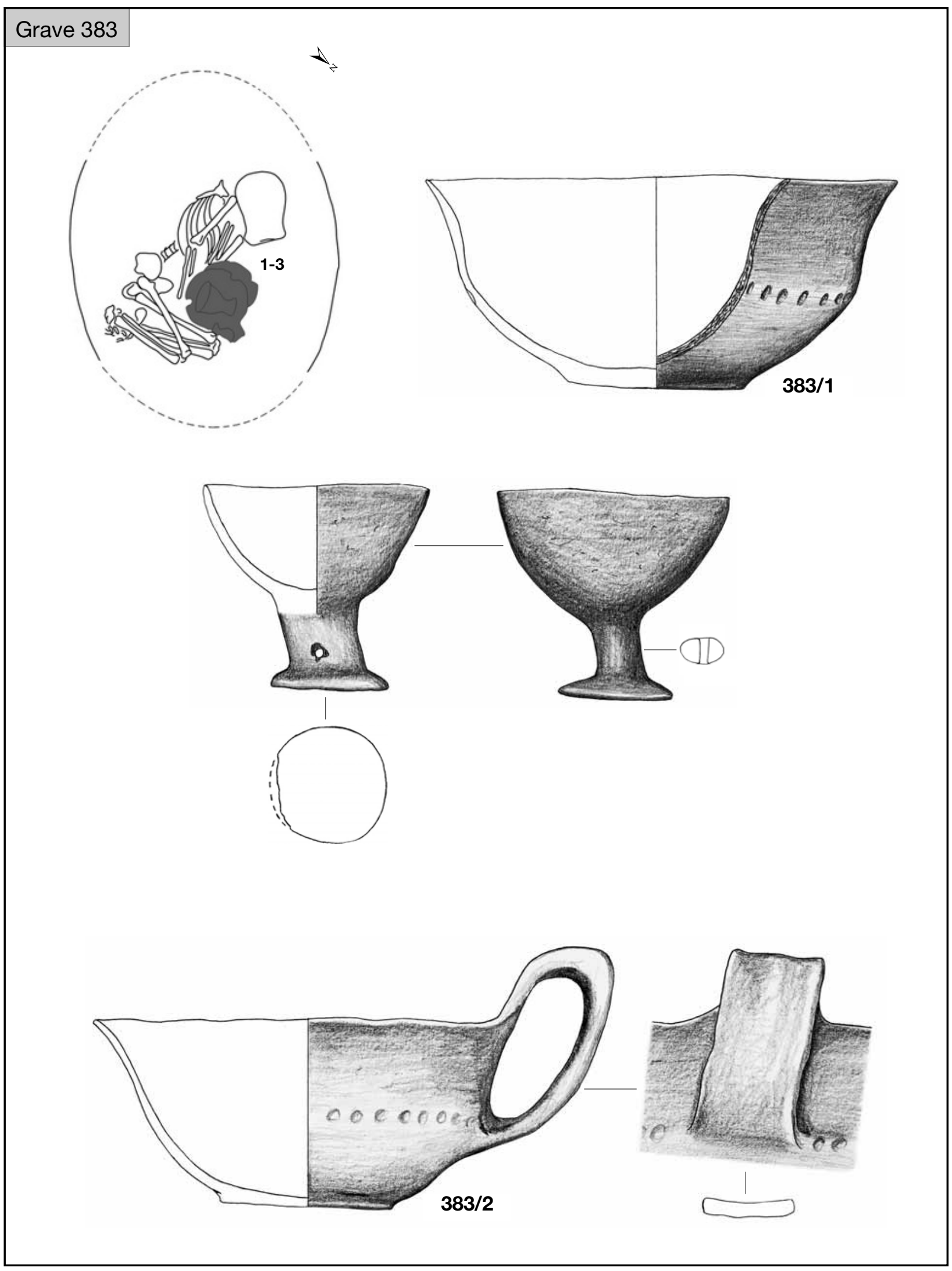

Plate CLII. Grave 383 


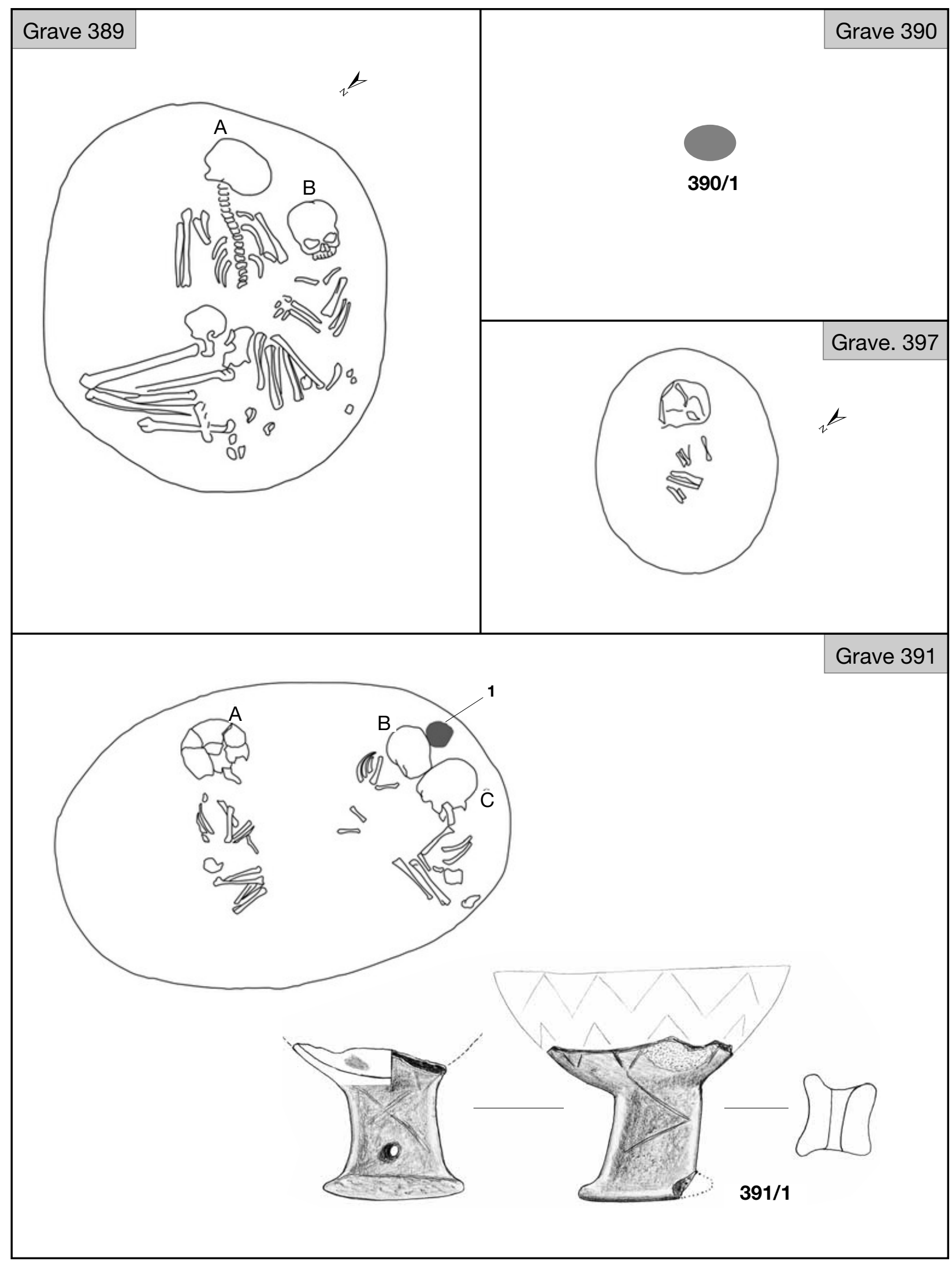

Plate CLIII. Graves 389-391 and 397 


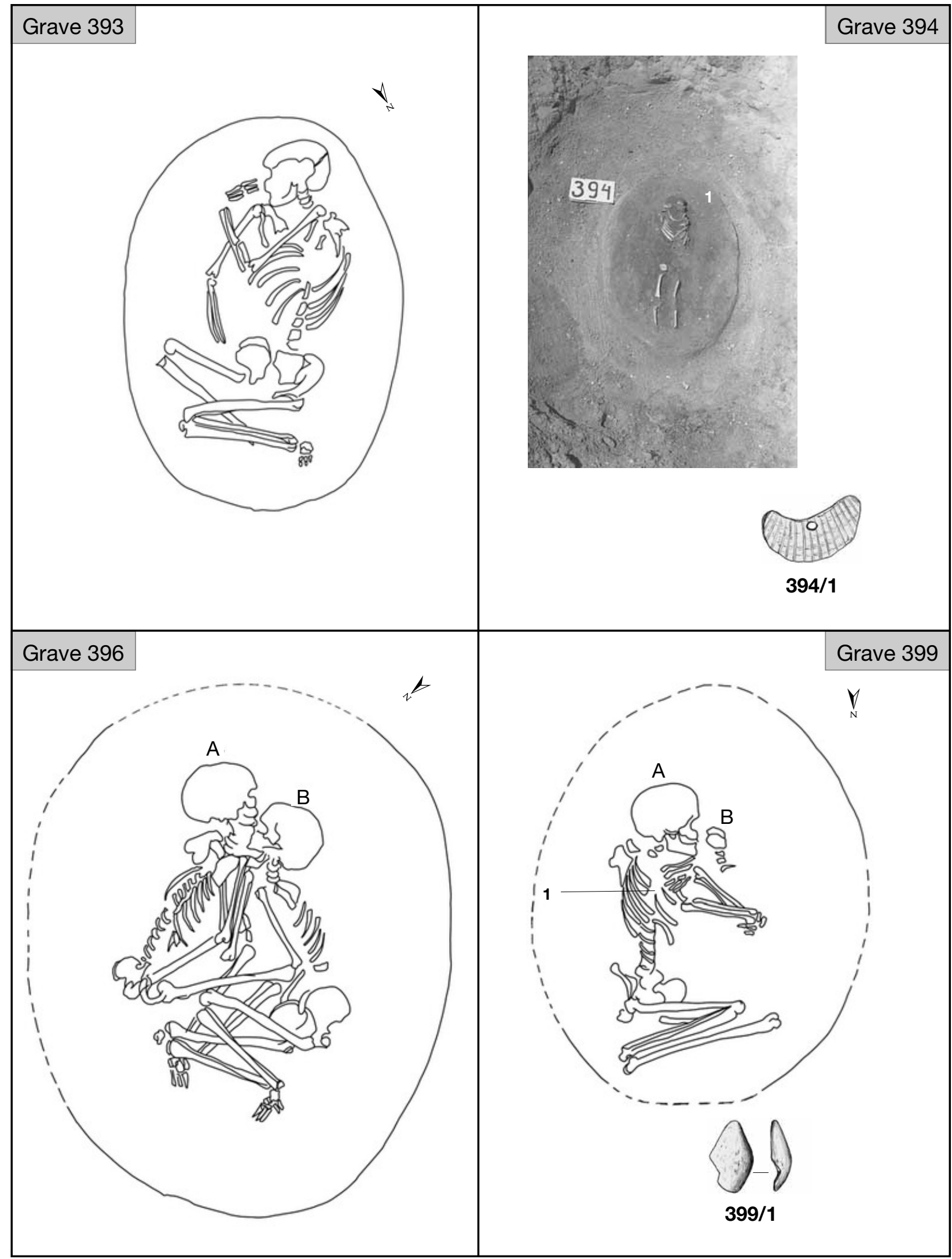

Plate CLIV. Graves 393-394, 396 and 399 


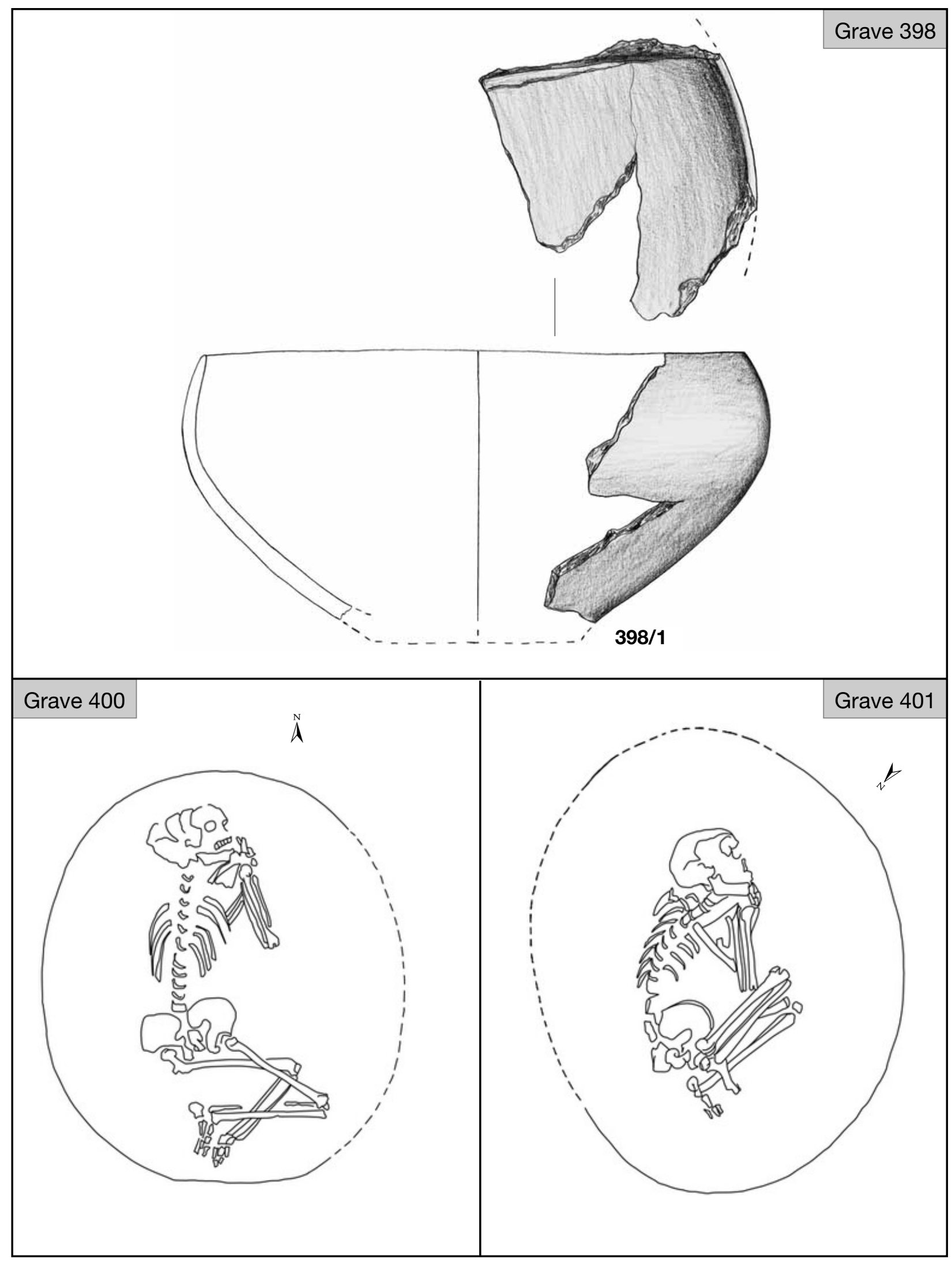

Plate CLV. Graves 398 and 400-401 


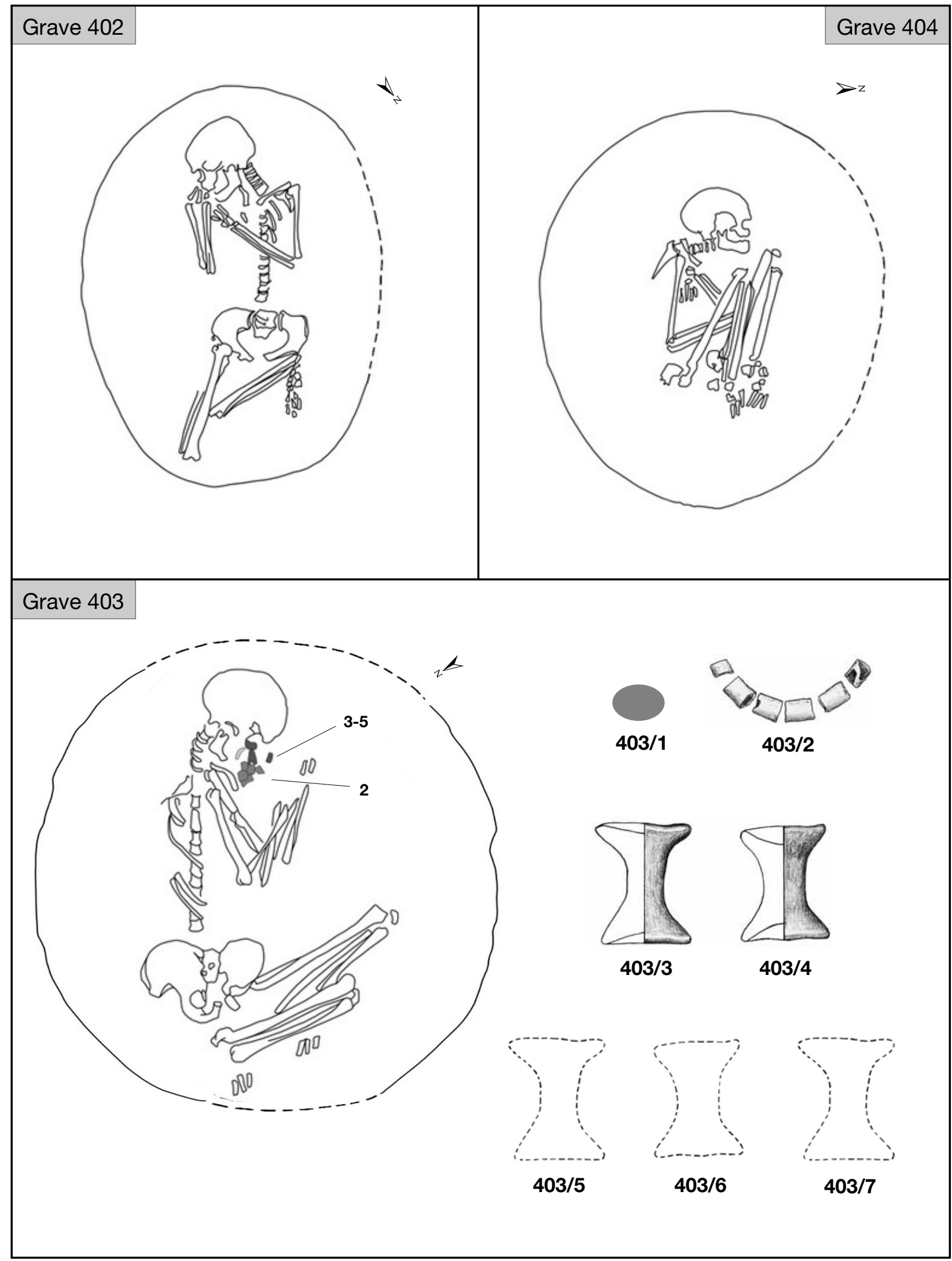

Plate CLVI. Graves 402-404 


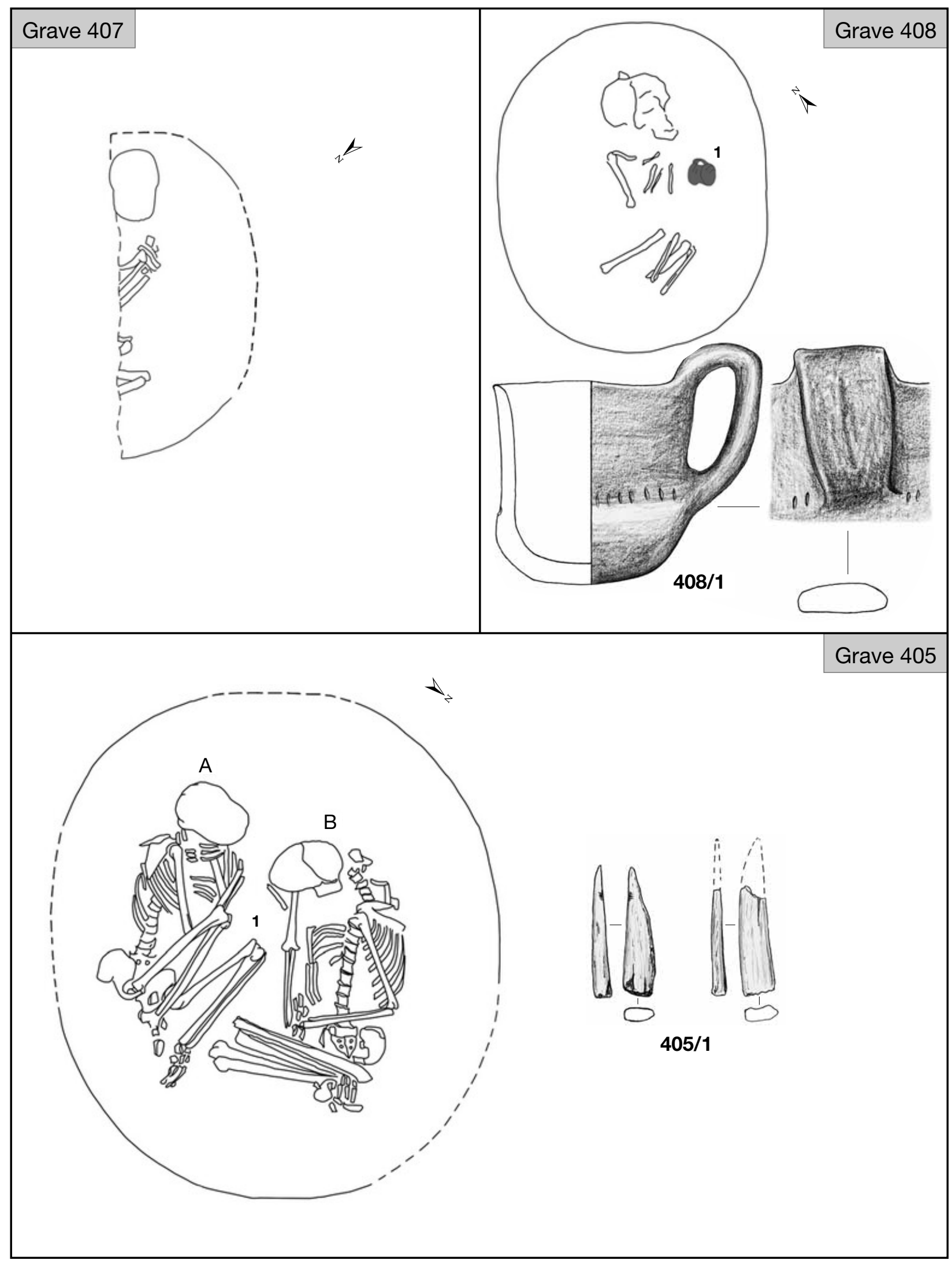

Plate CLVII. Graves 405 and $407-408$ 


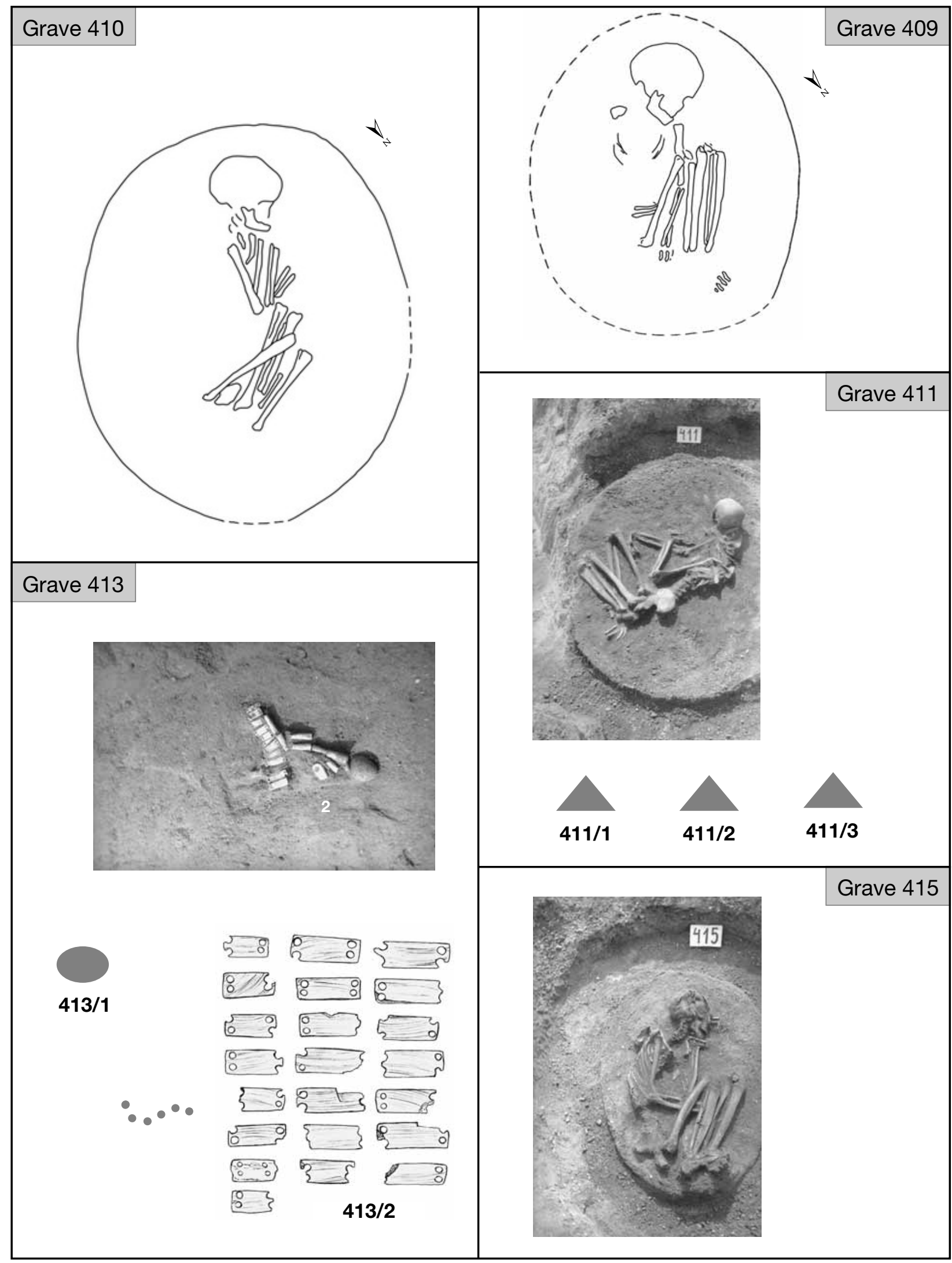

Plate CLVIII. Graves 409-411, 413 and 415 


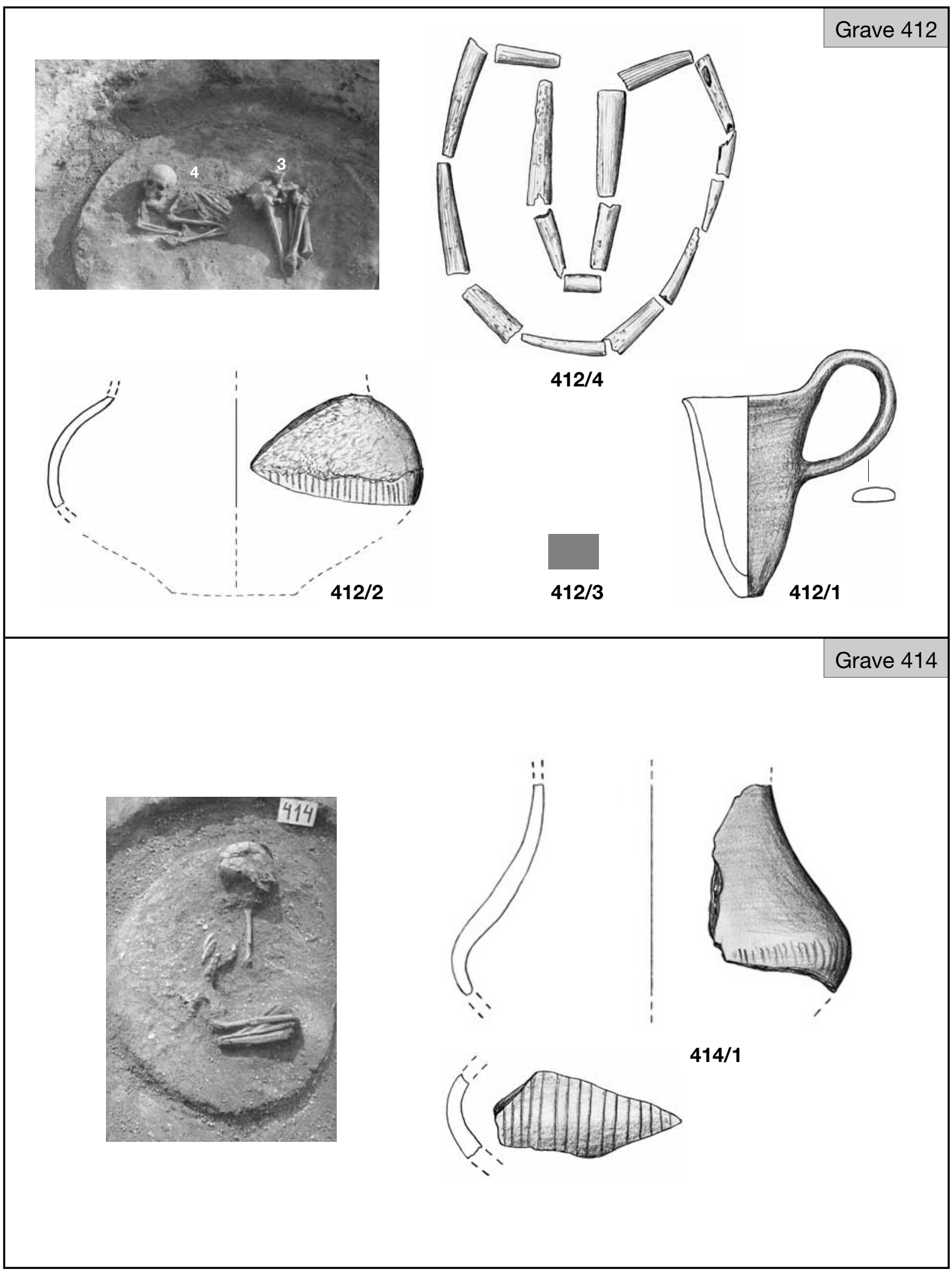

Plate CLIX. Graves 412 and 414 


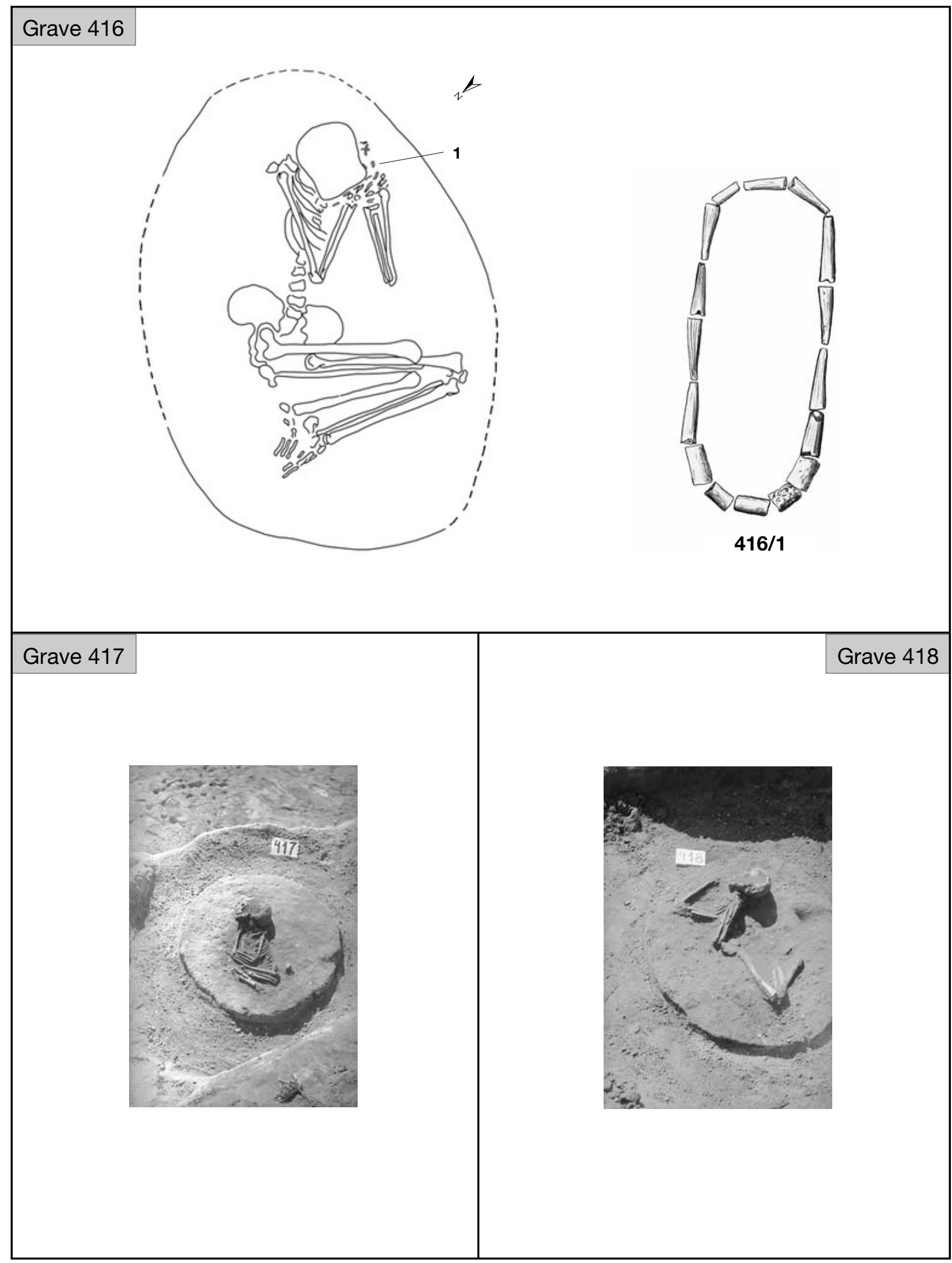

Plate CLX. Graves 416-418 


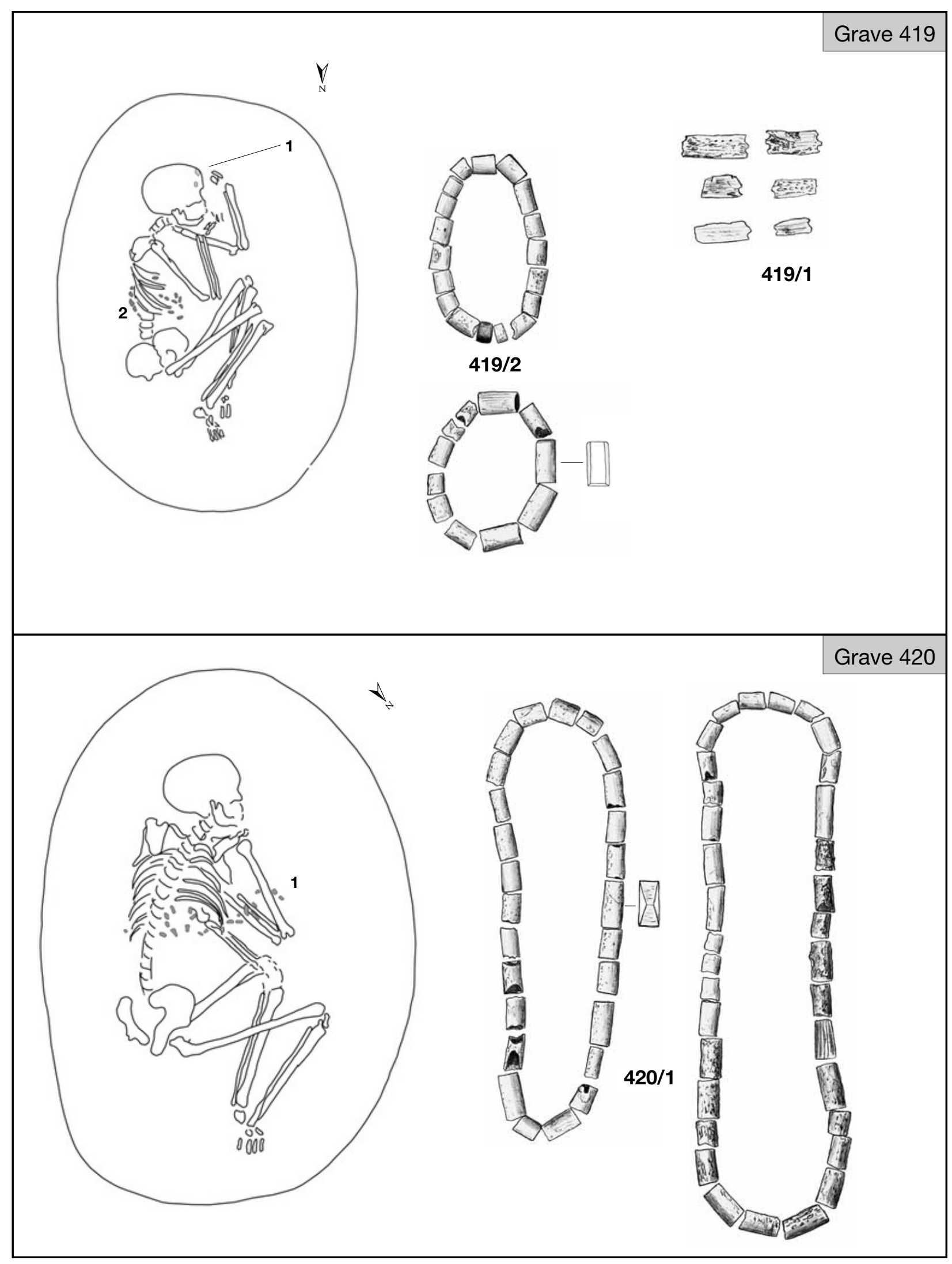

Plate CLXI. Graves 419-420 


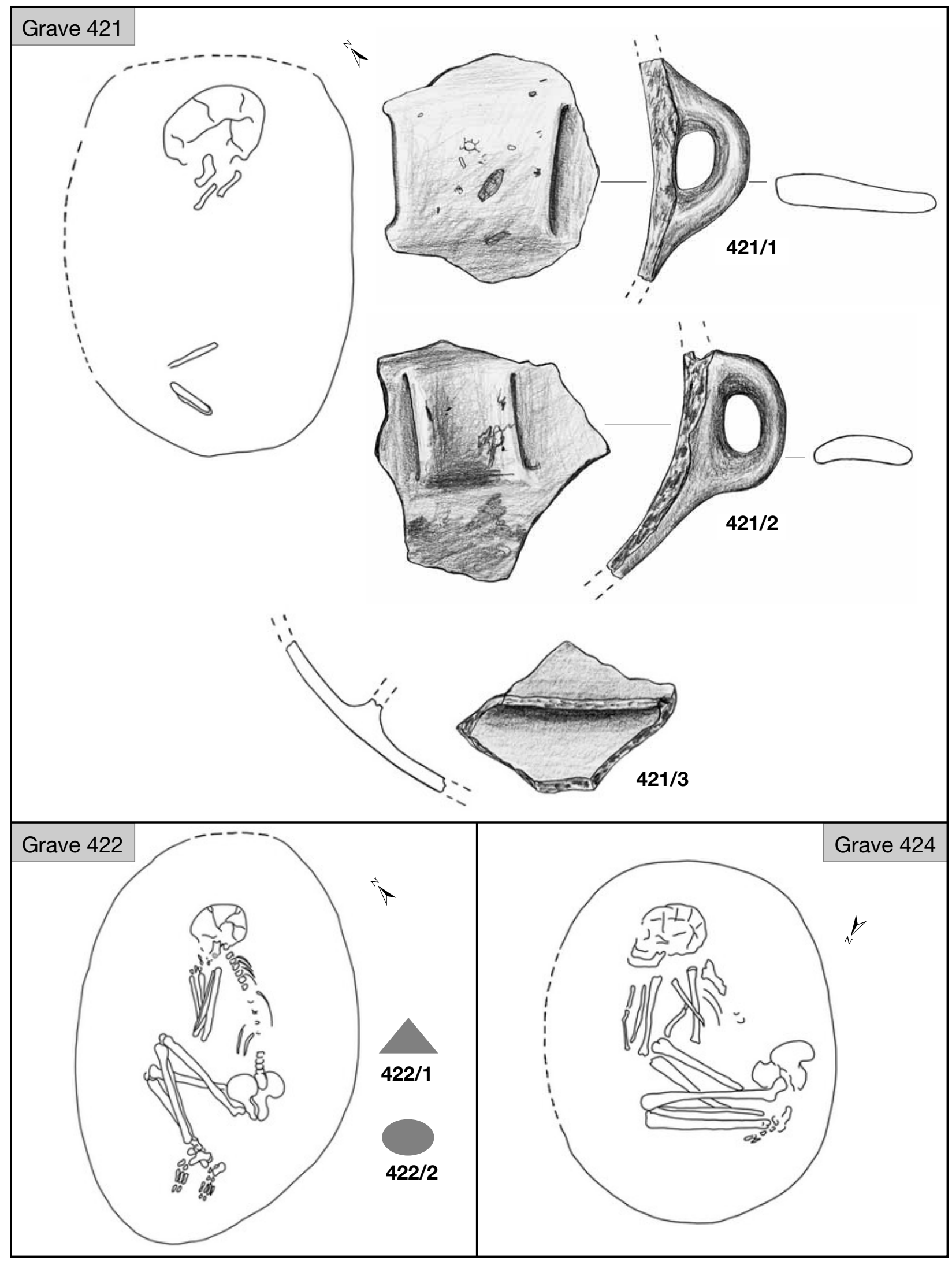

Plate CLXII. Graves 421-422 and 424 


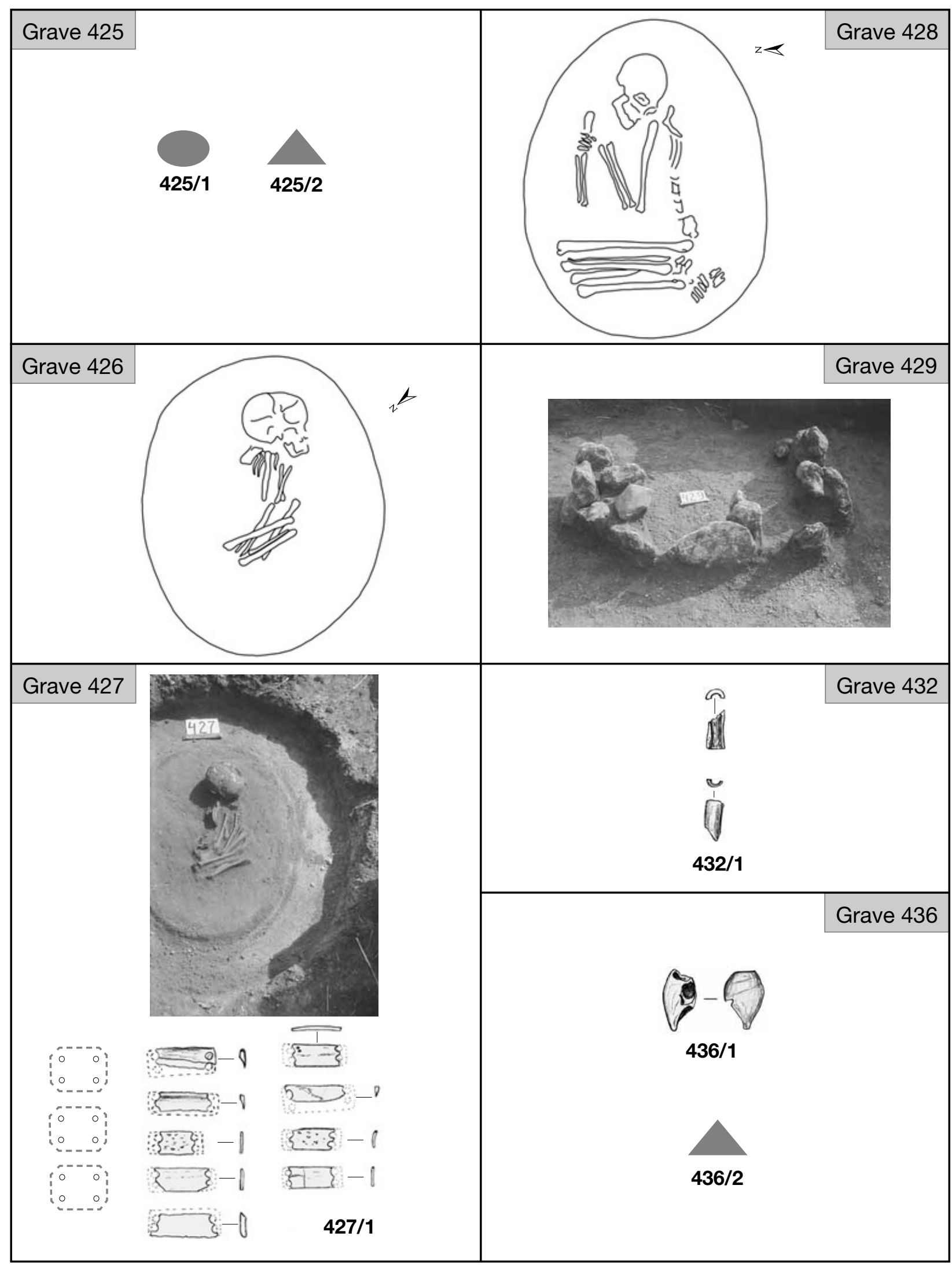

Plate CLXIII. Graves 425-428, 432 and 436 


\section{Grave 430}

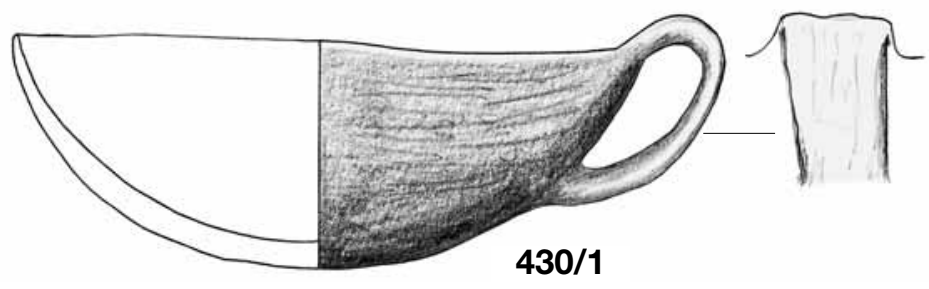

Grave 434
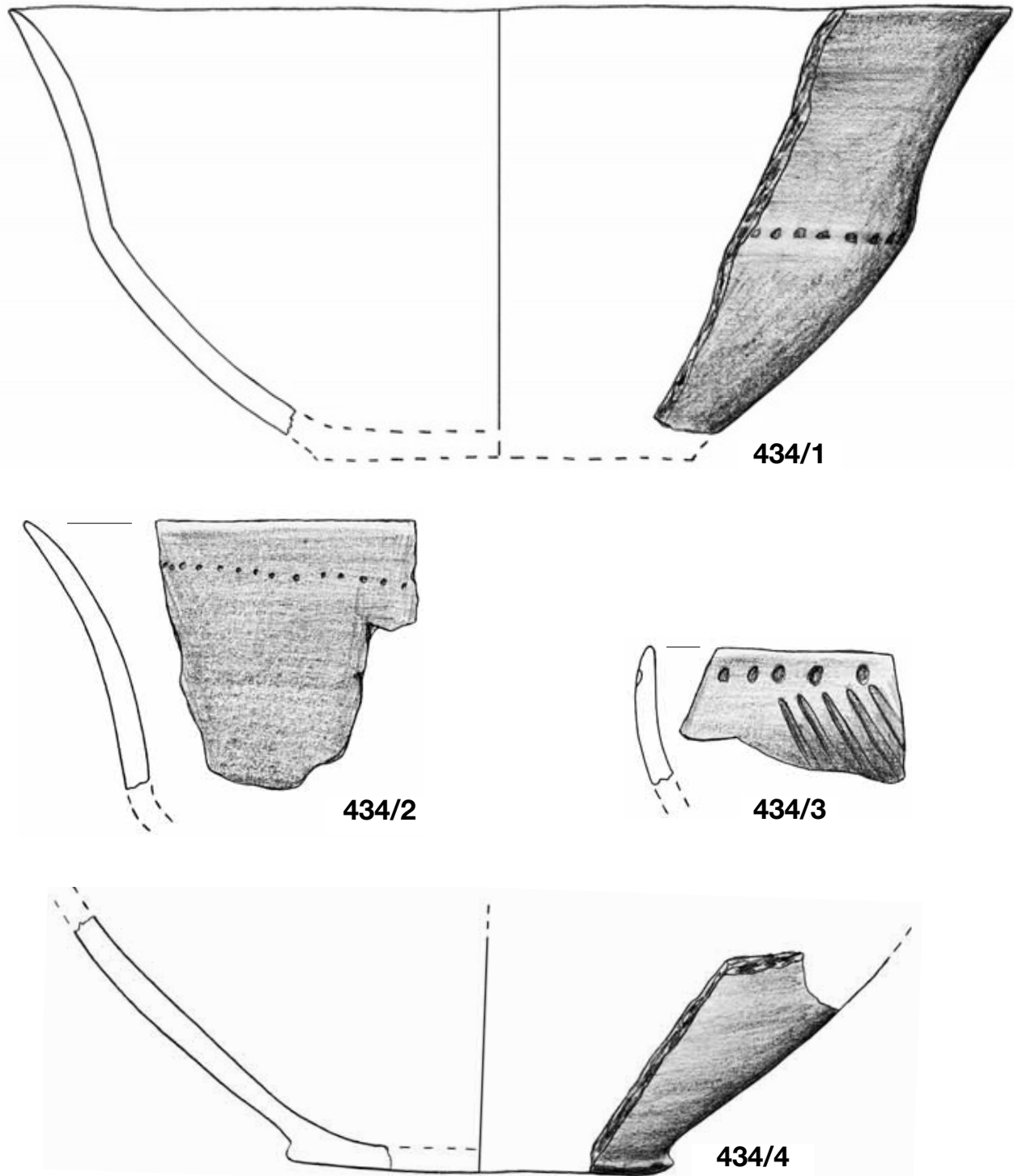

Plate CLXIV. Graves 430 and 434 


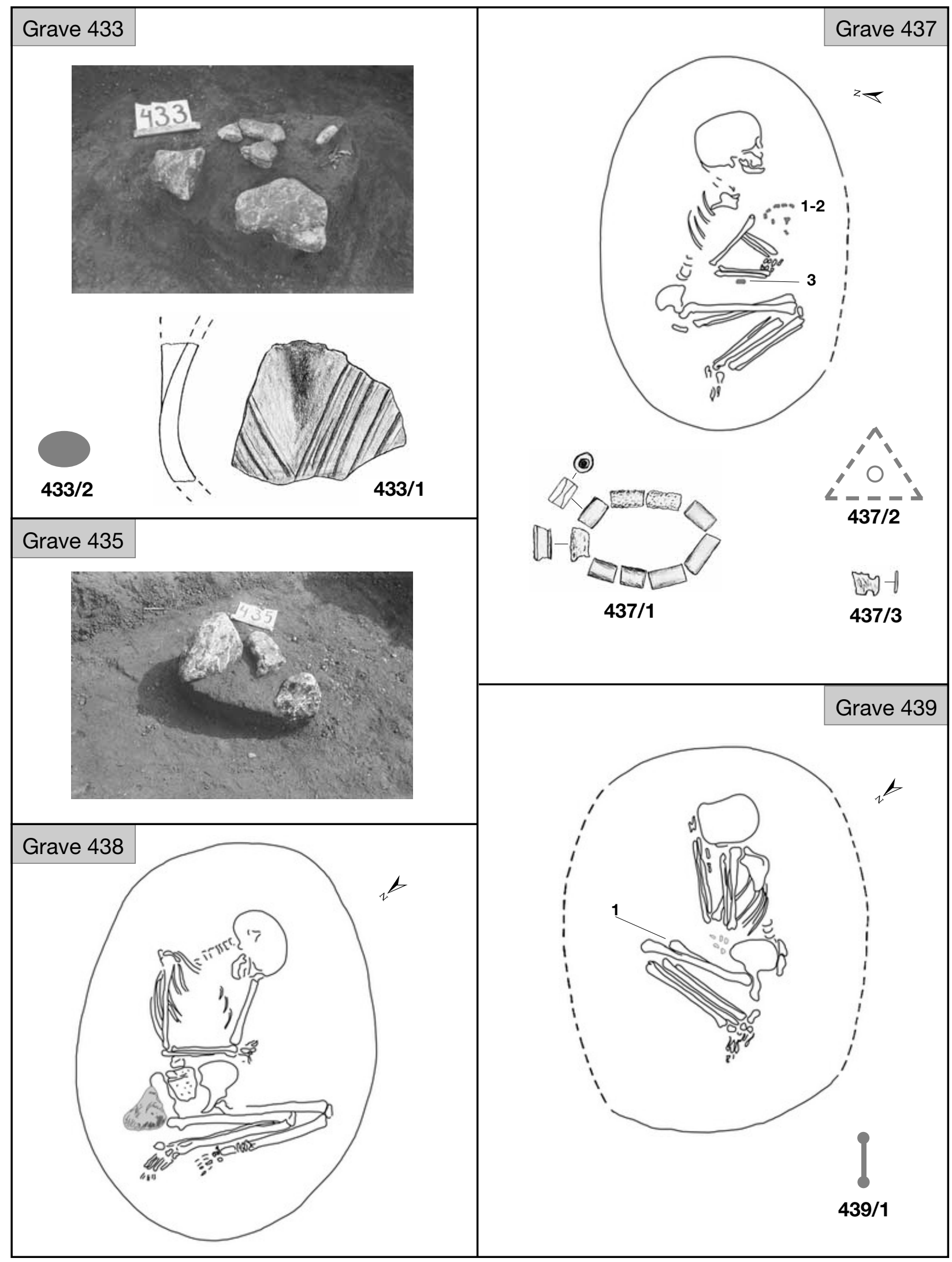

Plate CLXV. Graves 433, 435 and 437-439 


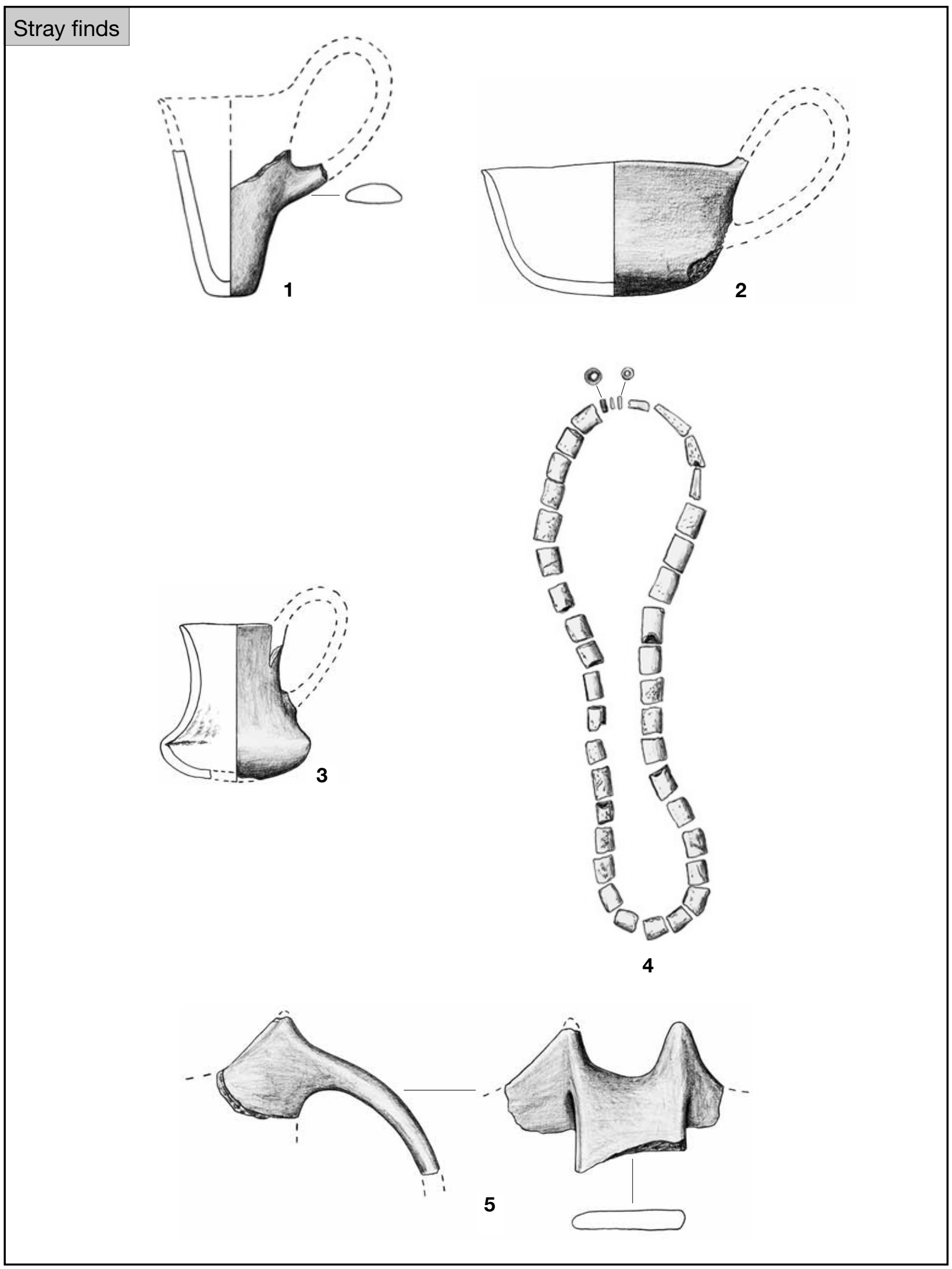

Plate CLXVI. Stray finds from the area of the cemetery 


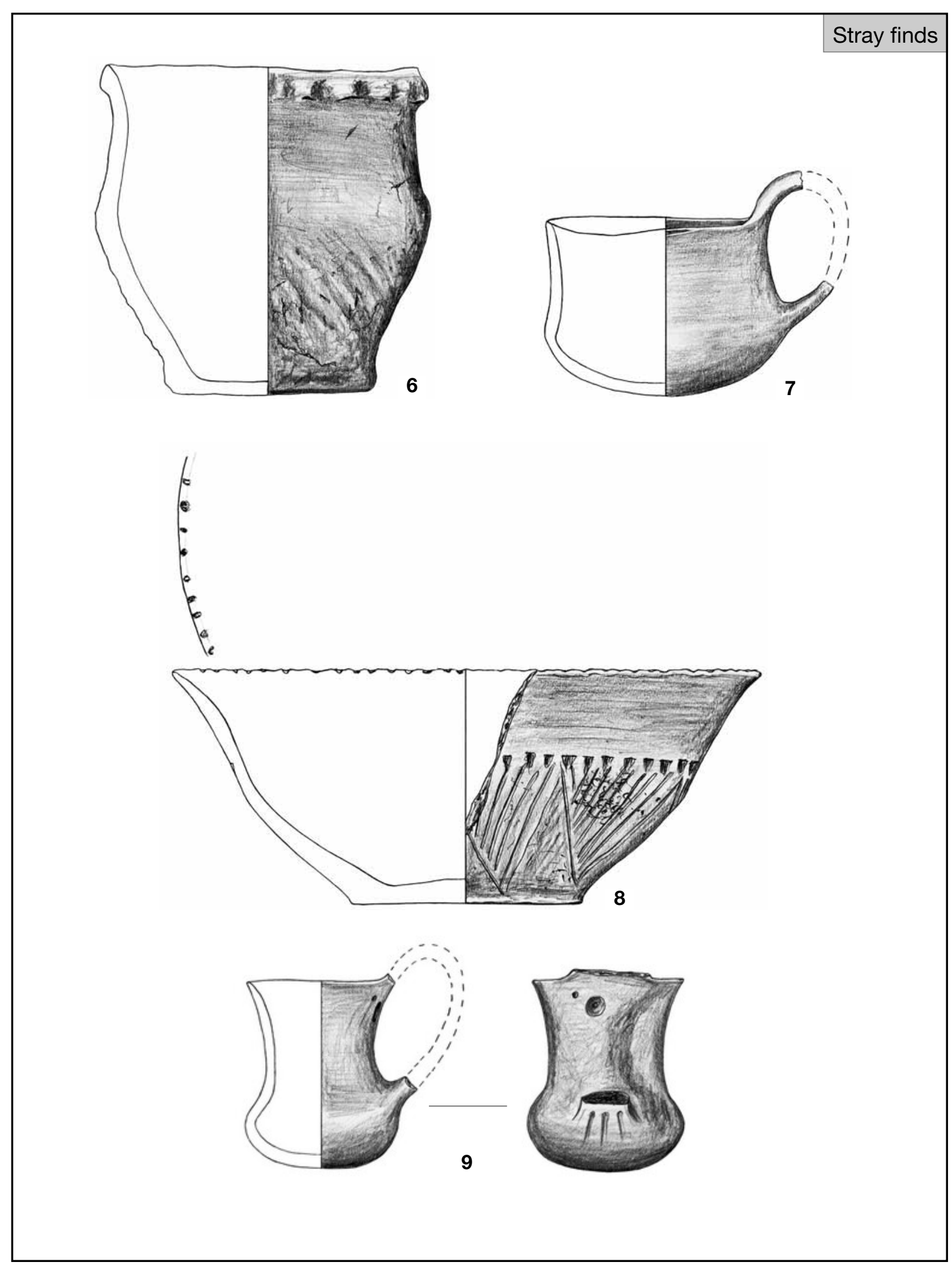

Plate CLXVII. Stray finds from the area of the cemetery 


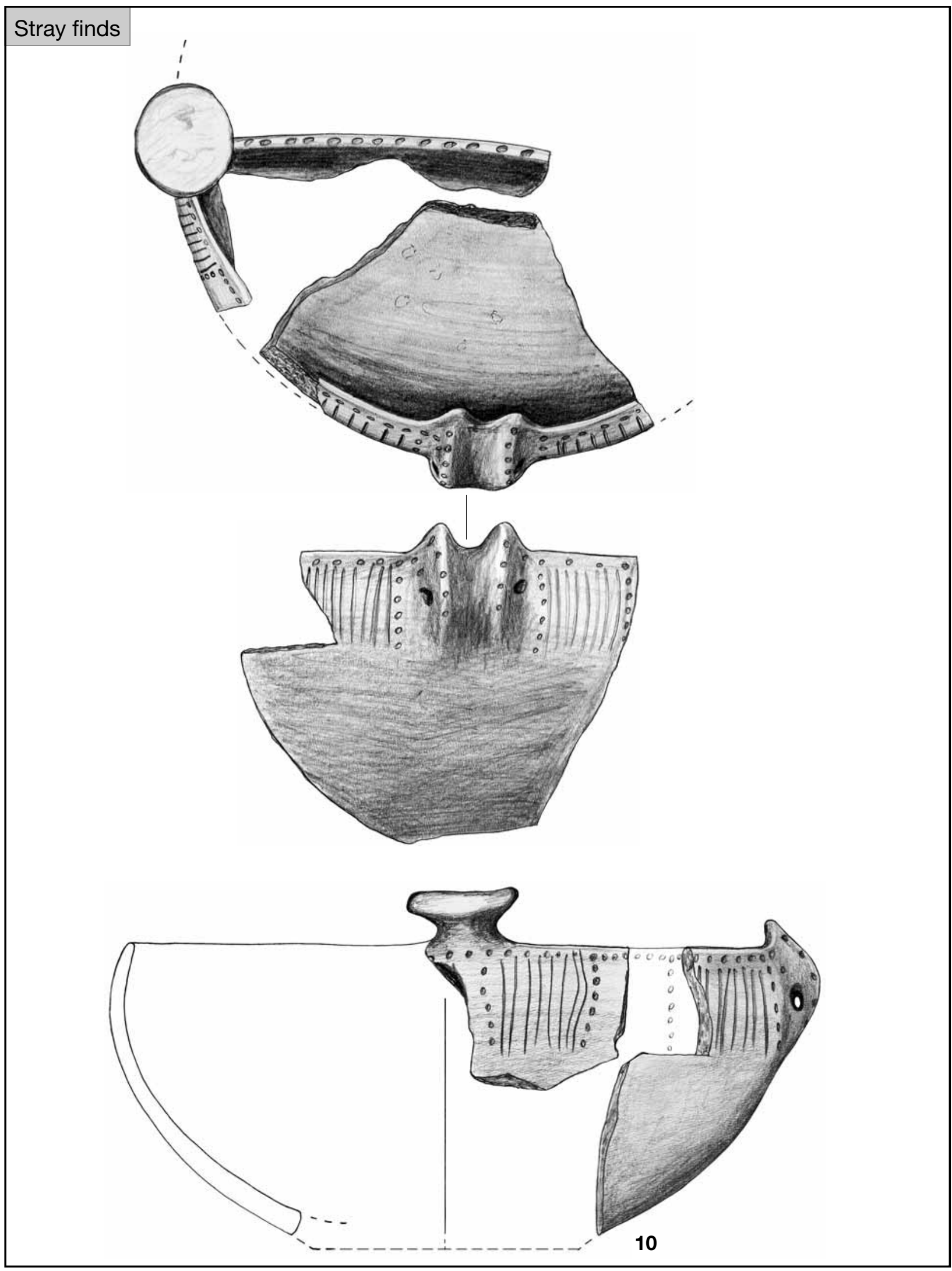

Plate CLXVIII. Stray finds from the area of the cemetery 


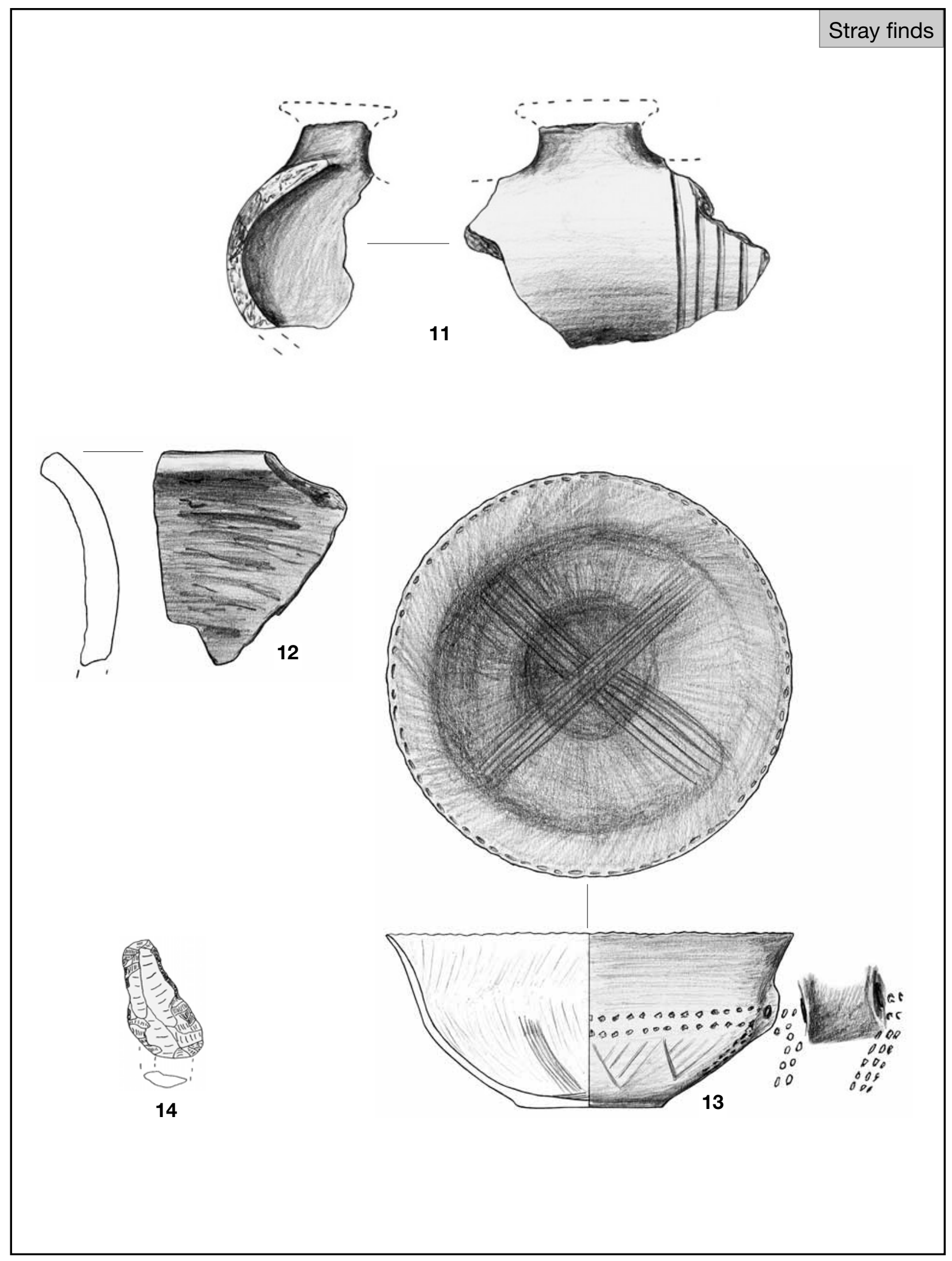

Plate CLXIX. Stray finds from the area of the cemetery 


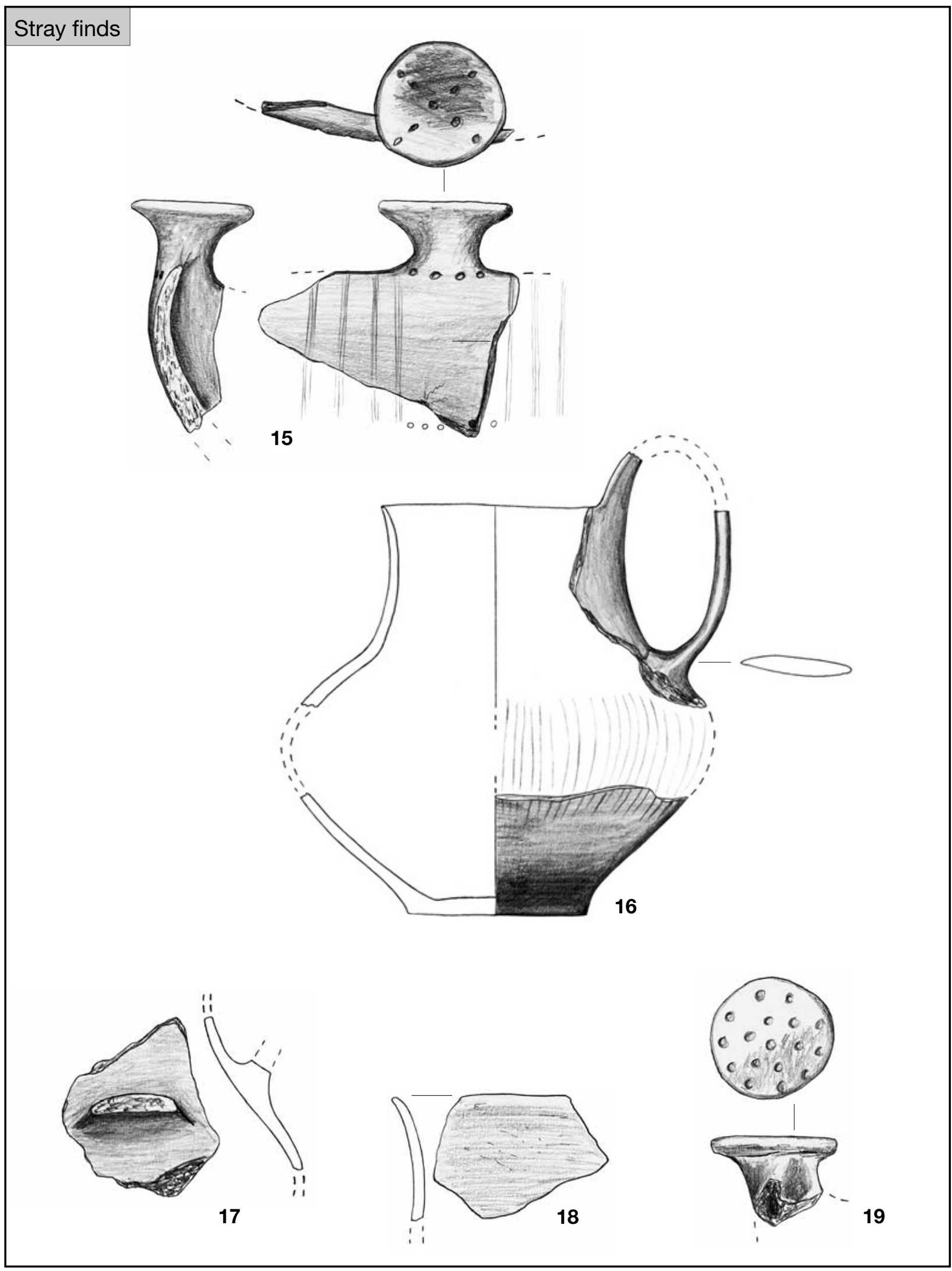

Plate CLXX. Stray finds from the area of the cemetery 


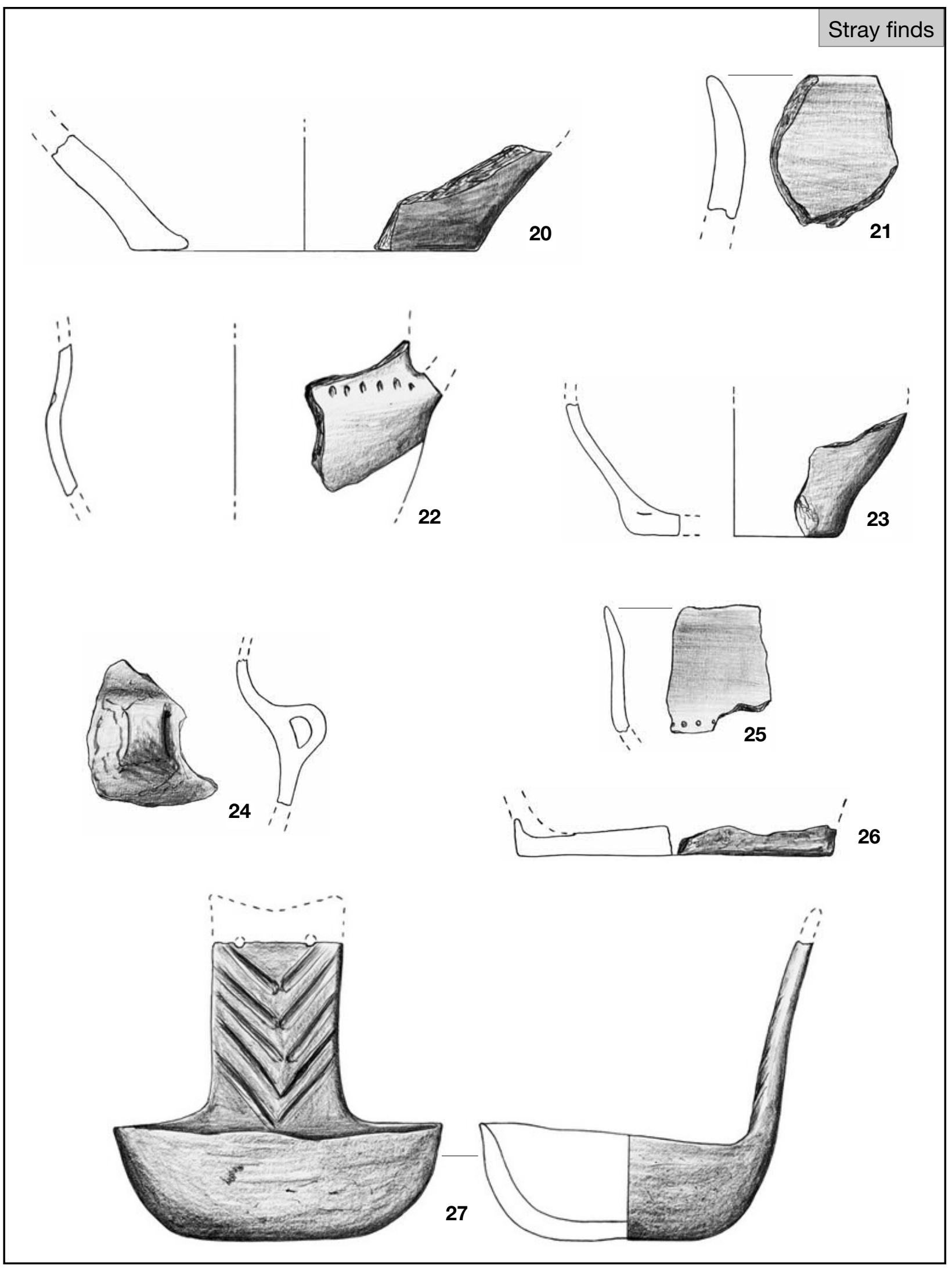

Plate CLXXI. Stray finds from the area of the cemetery 


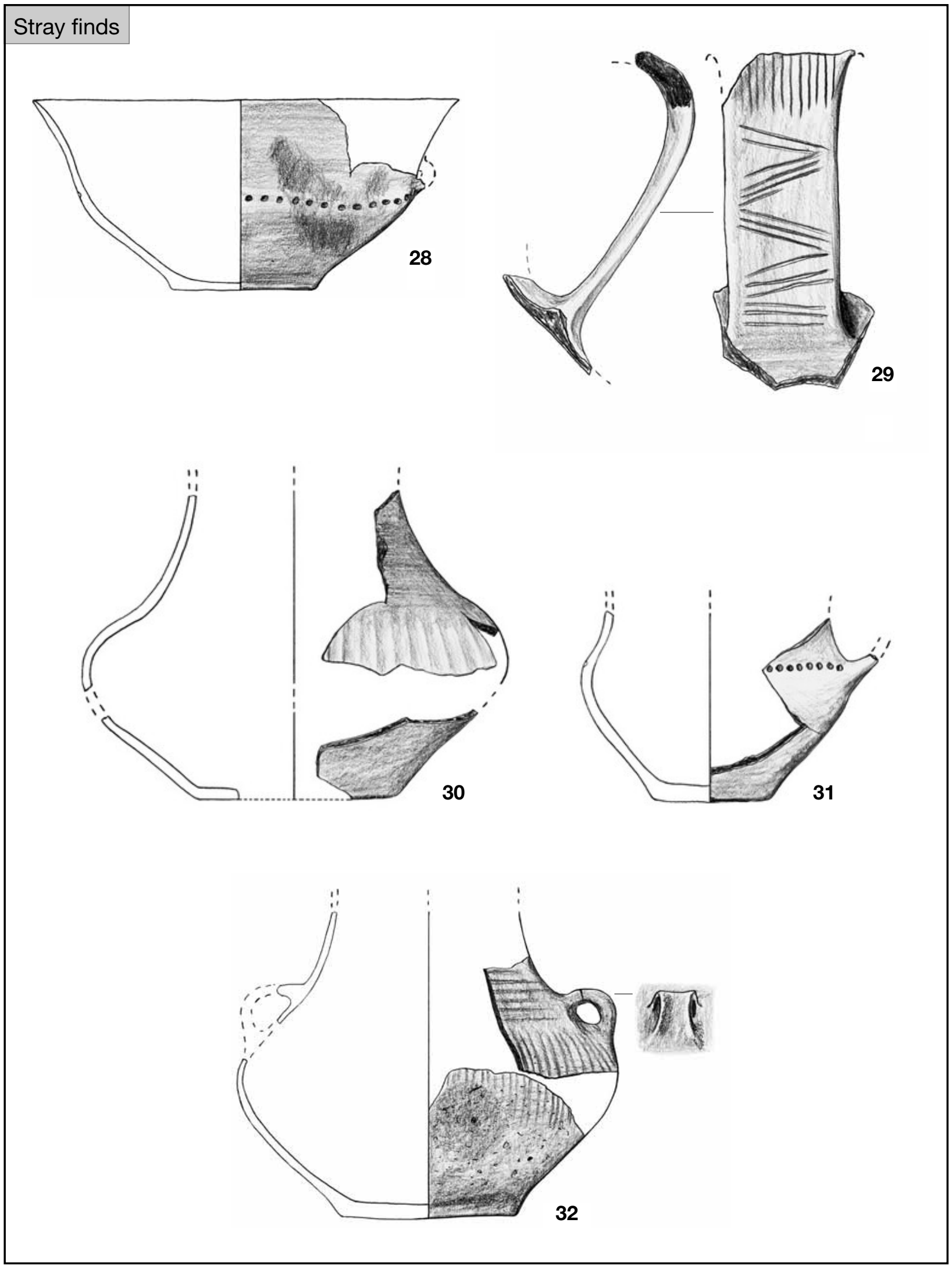

Plate CLXXII. Stray finds from the area of the cemetery 


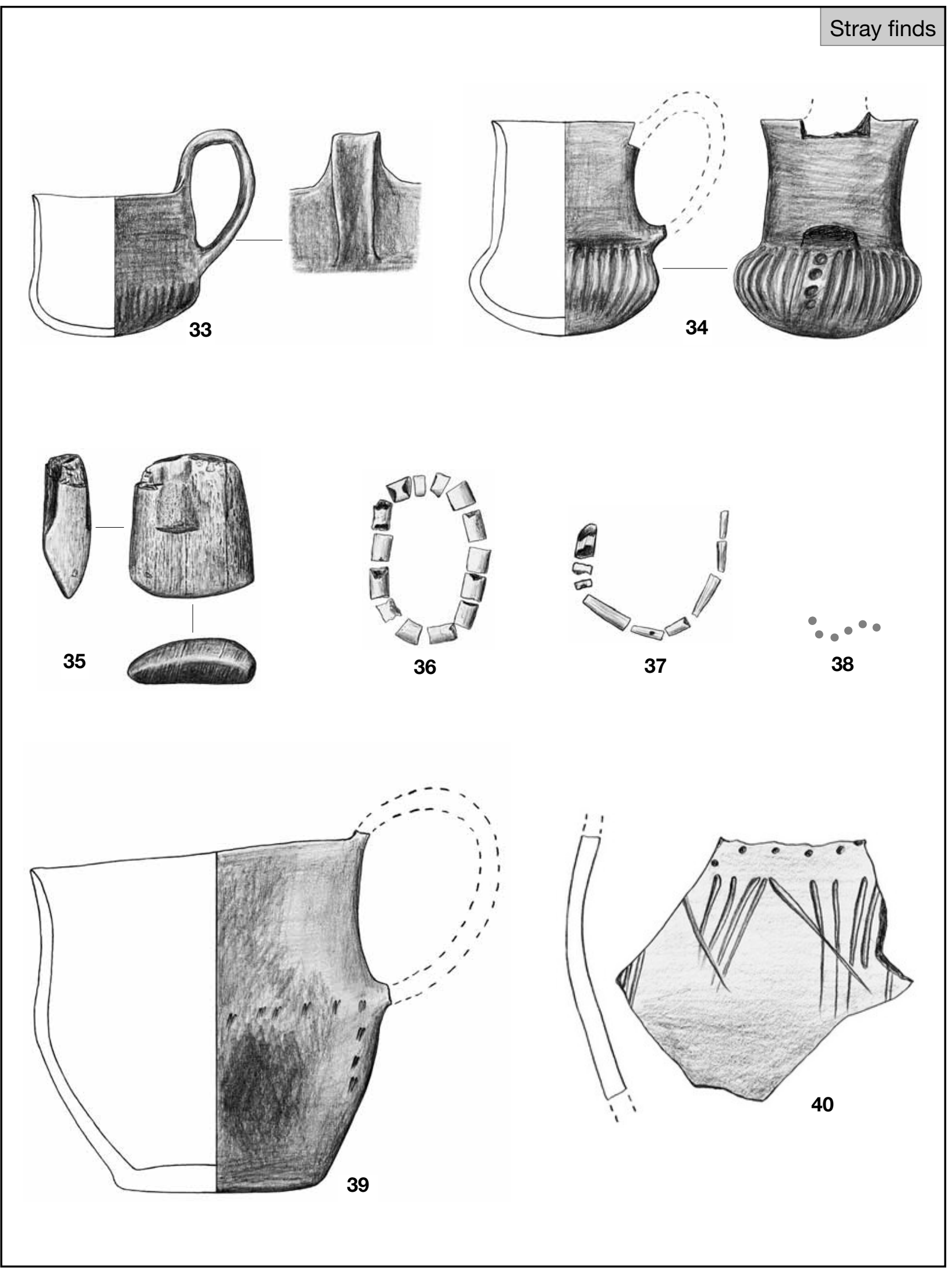

Plate CLXXIII. Stray finds from the area of the cemetery 

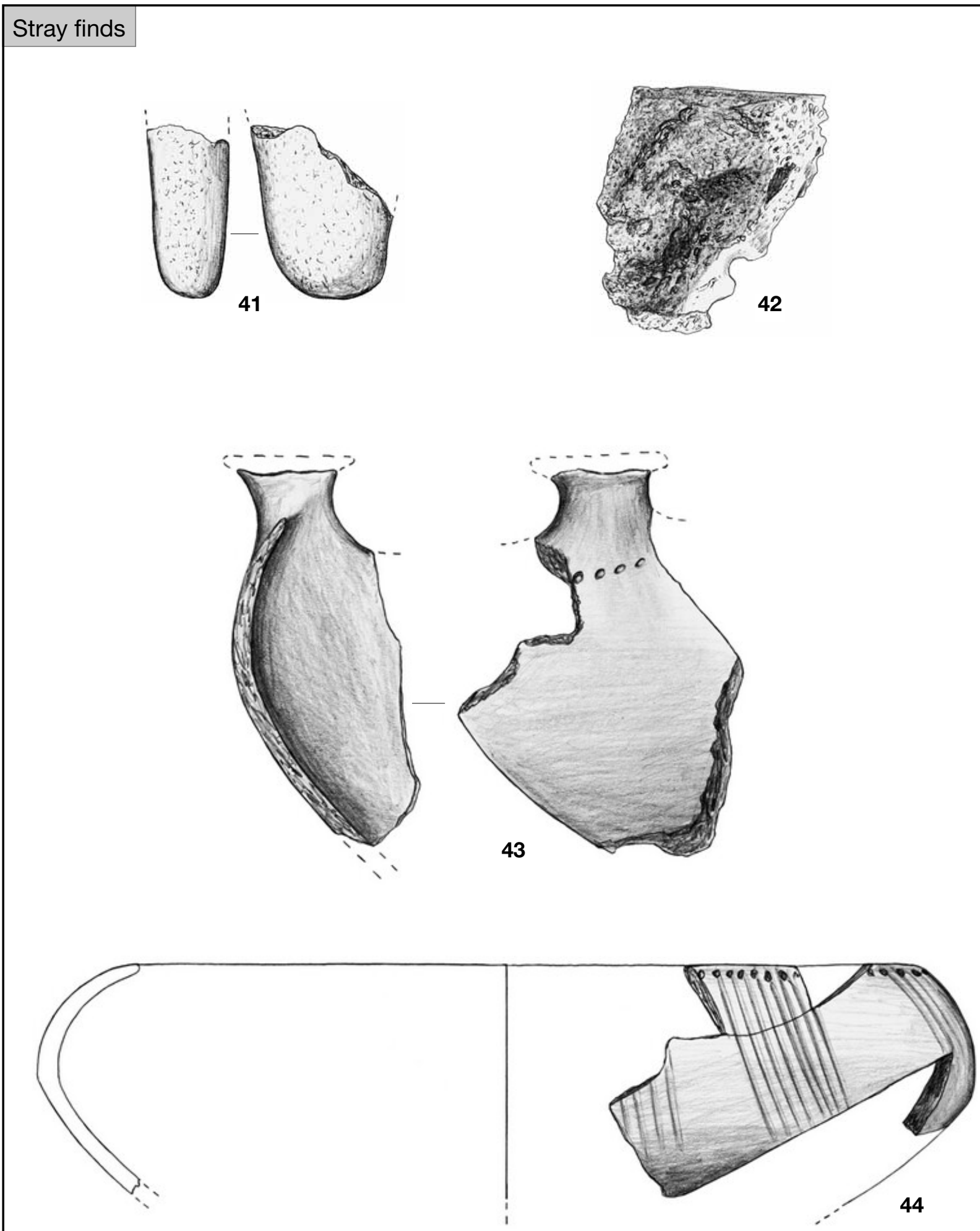

Plate CLXXIV. Stray finds from the area of the cemetery 


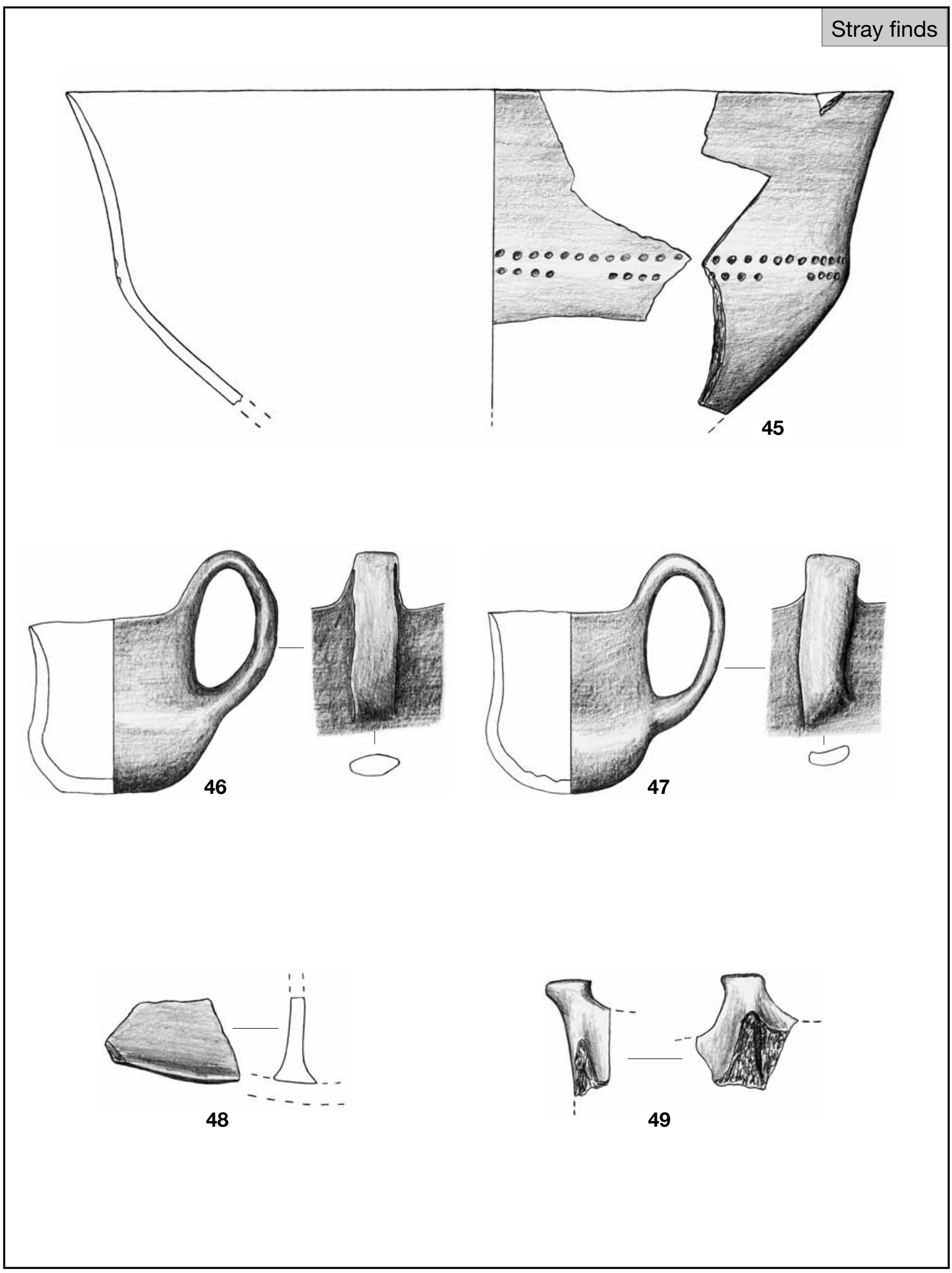

Plate CLXXV. Stray finds from the area of the cemetery 


\section{LIST OF CONTRIBUTORS}

Mária Bondár

Archaeological Institute, Hungarian Academy of Sciences (Budapest)

1014 Budapest, Úri u. 49.

bondar@archeo.mta.hu

Pál Raczky

Institute of Archaeological Sciences, Eötvös Loránd University (Budapest)

1088 Budapest, Múzeum krt. 4/B

raczky@ludens.elte.hu

\section{Bernadett Bajnóczi}

Institute for Geochemical Research, Hungarian

Academy of Sciences

1112 Budapest, Budaörsi út 45.

bajnoczi@geochem.hu

Gabriella Barna

Institute for Geochemical Research, Hungarian

Academy of Sciences

1112 Budapest, Budaörsi út 45.

gbarna@geochem.hu

Éva Cs. Balogh

Matrica Museum, Százhalombatta

spelta@freemail.hu

Aranka Csốsz

Archaeological Institute, Hungarian Academy of

Sciences (Budapest)

1014 Budapest, Úri u. 49.

csosza@archeo.mta.hu

Attila Demény

Institute for Geochemical Research, Hungarian

Academy of Sciences

1112 Budapest, Budaörsi út 45 .

demeny@geochem.hu

István Fórizs

Institute for Geochemical Research, Hungarian

Academy of Sciences

1112 Budapest, Budaörsi út 45.

forizs@geochem.hu
Erika Gál

Archaeological Institute, Hungarian Academy of

Sciences (Budapest)

1014 Budapest, Úri u. 49.

gal@archeo.mta.hu

László Gucsi

Archaeological Institute, Hungarian Academy of Sciences (Budapest)

1014 Budapest, Úri u. 49.

gucsi@vipmail.hu

\section{Sándor Kele}

Institute for Geochemical Research, Hungarian

Academy of Sciences

1112 Budapest, Budaörsi út 45.

keles@geochem.hu

Kitti Köhler

Archaeological Institute, Hungarian Academy of

Sciences (Budapest)

1014 Budapest, Úri u. 49.

kohler@archeo.mta.hu

\section{Zsuzsanna Siklósi}

Institute of Archaeological Sciences, Eötvös Loránd

University (Budapest)

1088 Budapest, Múzeum krt. 4/B

siklosizs@gmail.com

Zoltán Siklósy

Institute for Geochemical Research, Hungarian

Academy of Sciences

1112 Budapest, Budaörsi út 45.

siklosy@geochem.hu

\section{Pál Sümegi}

Department of Geology and Paleontology, University of Szeged

6722 Szeged, Egyetem u. 2-6.

and Archaeological Institute, Hungarian Academy of

Sciences (Budapest)

1014 Budapest, Úri u. 49.

sumegi@geo.u-szeged.hu 


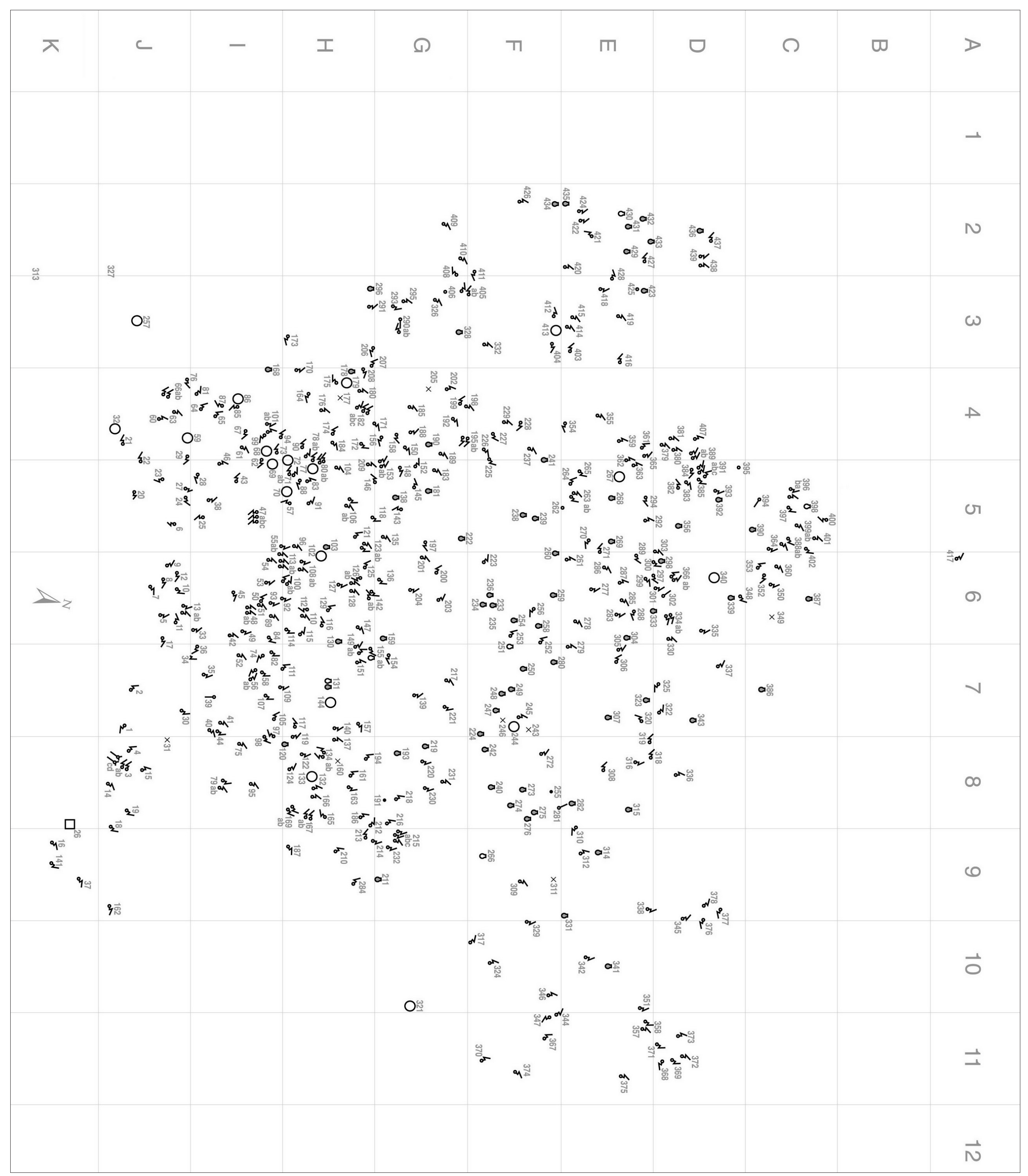



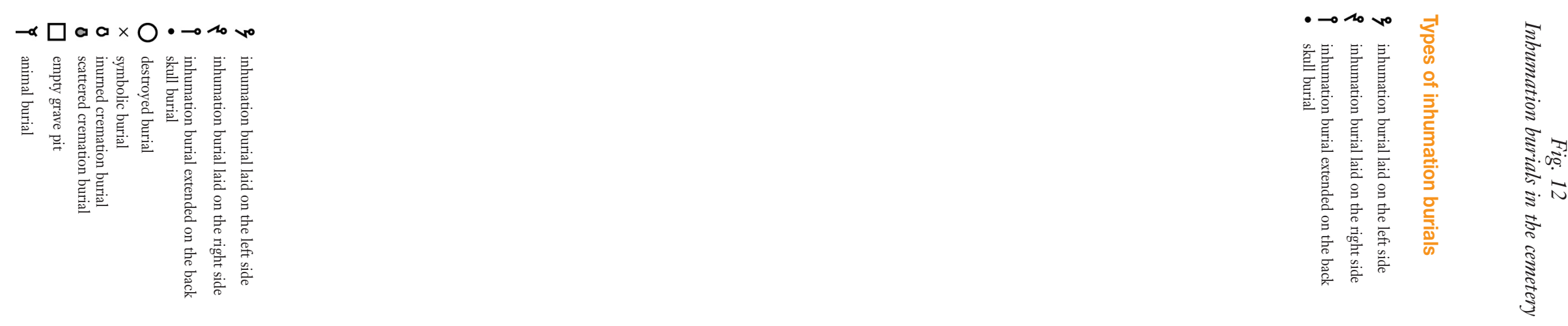

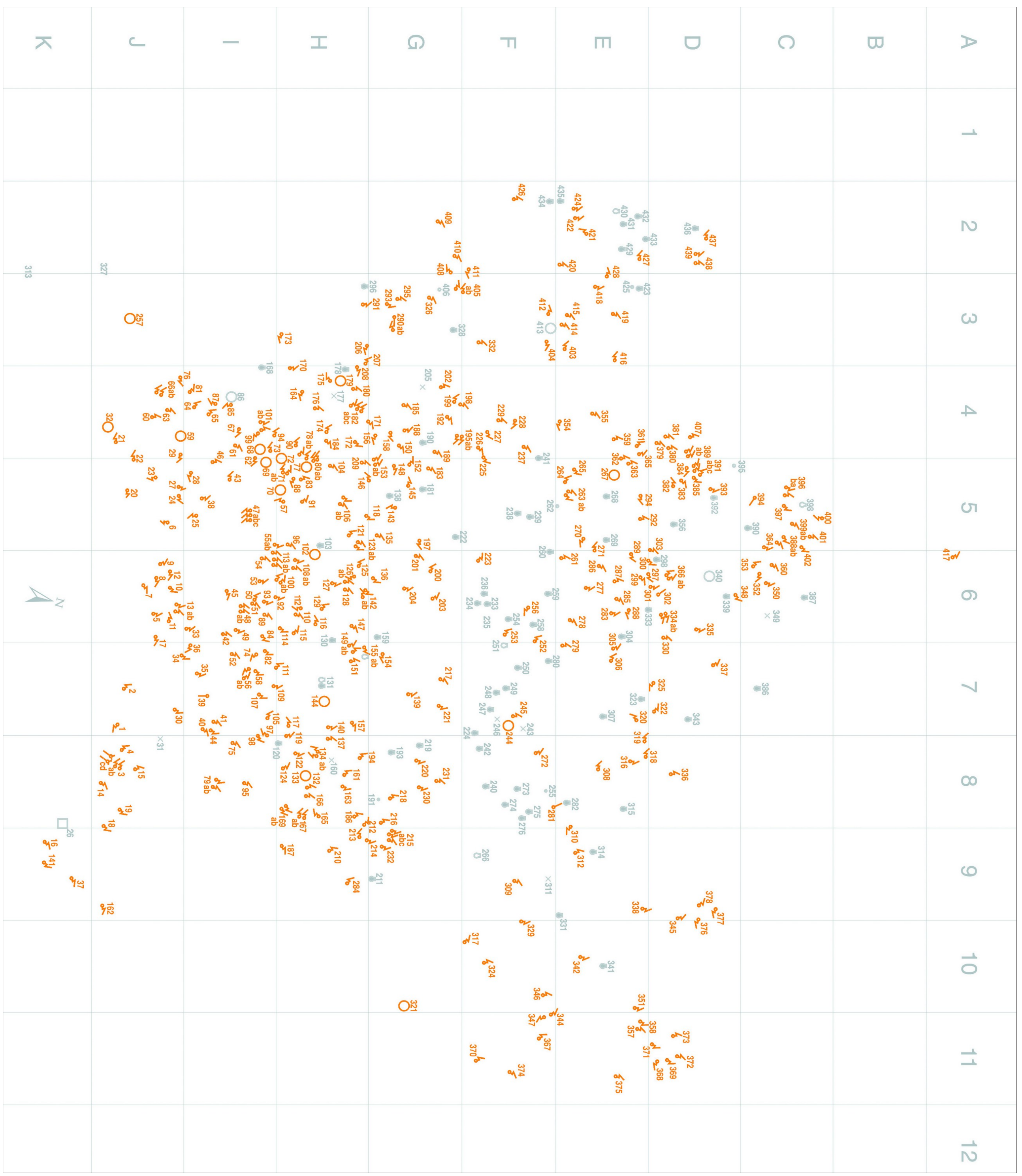




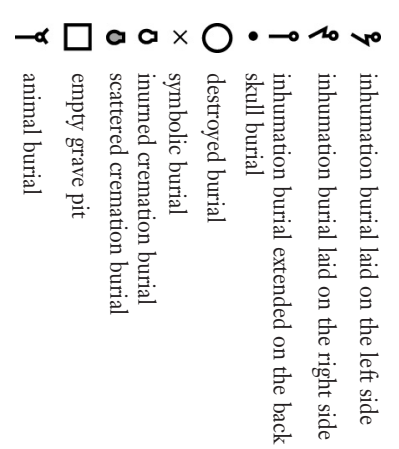

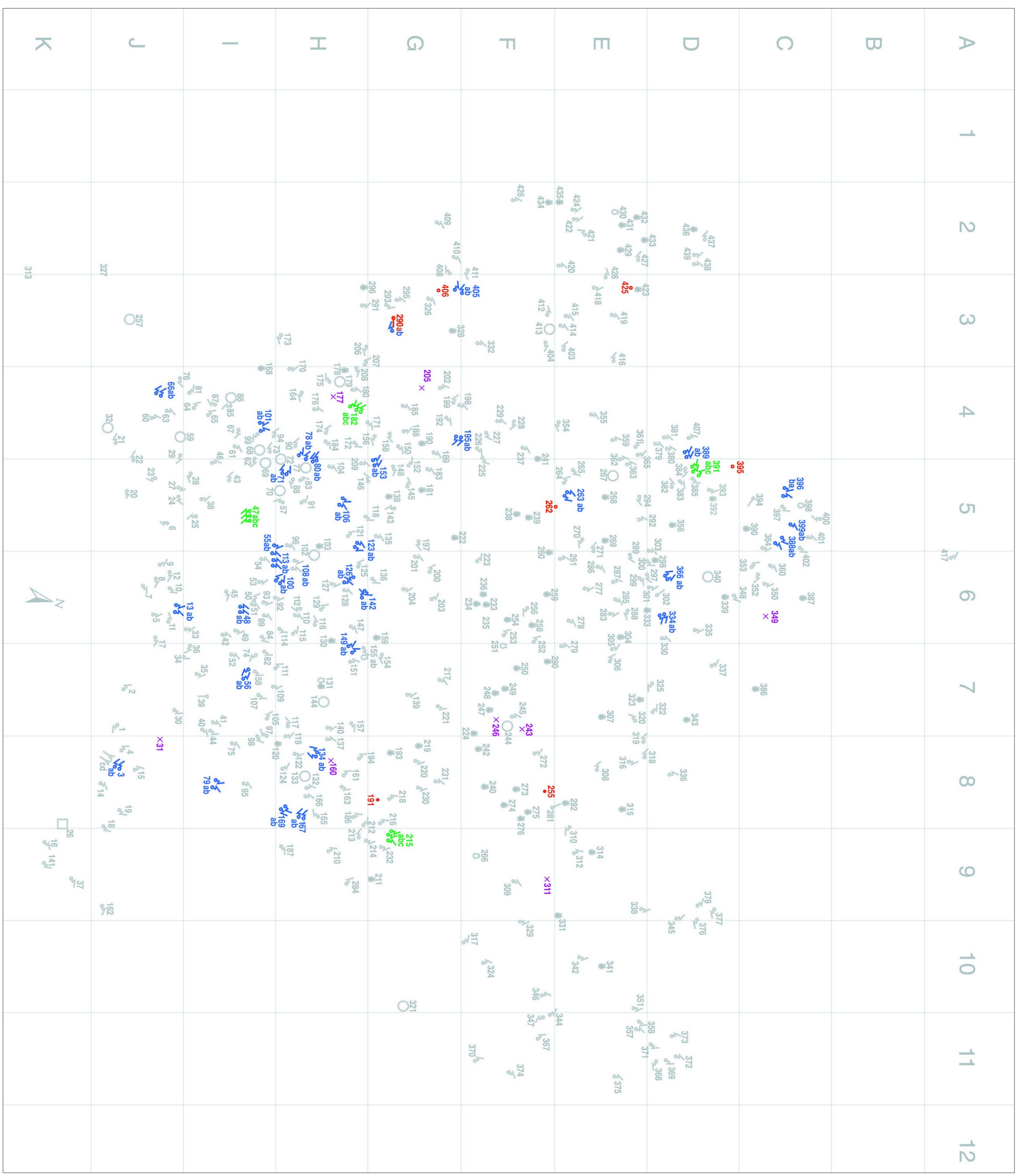



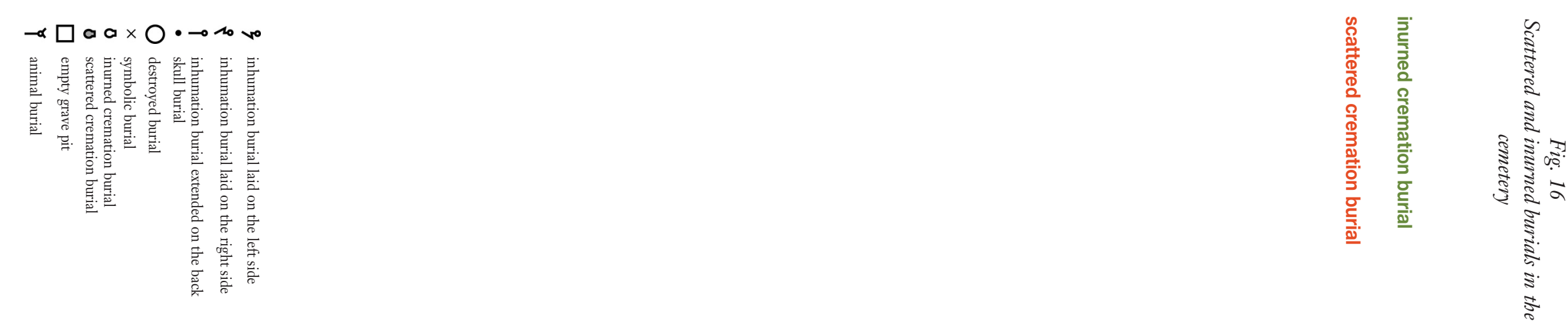

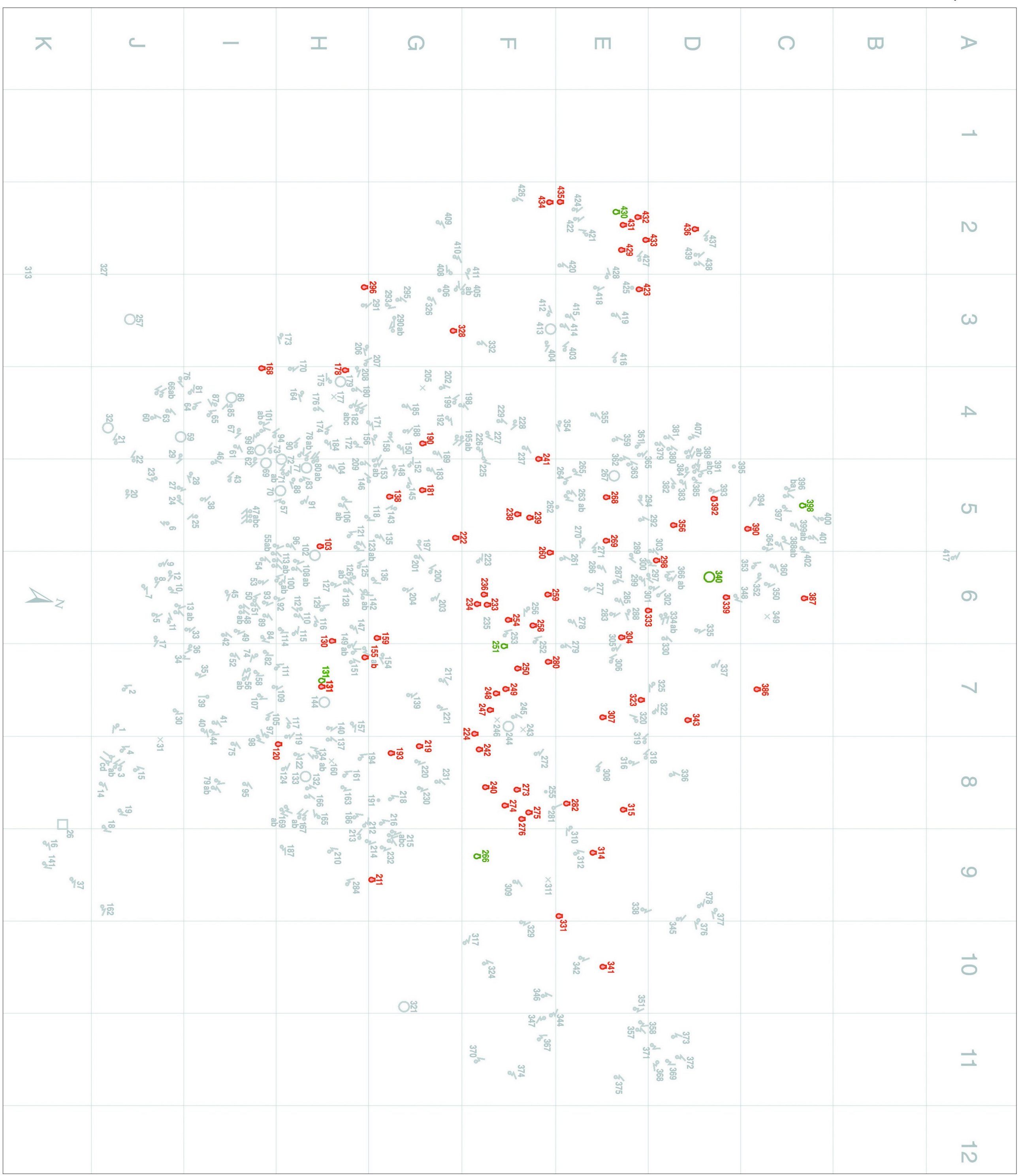




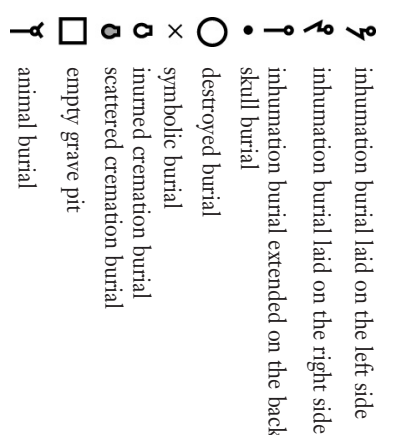

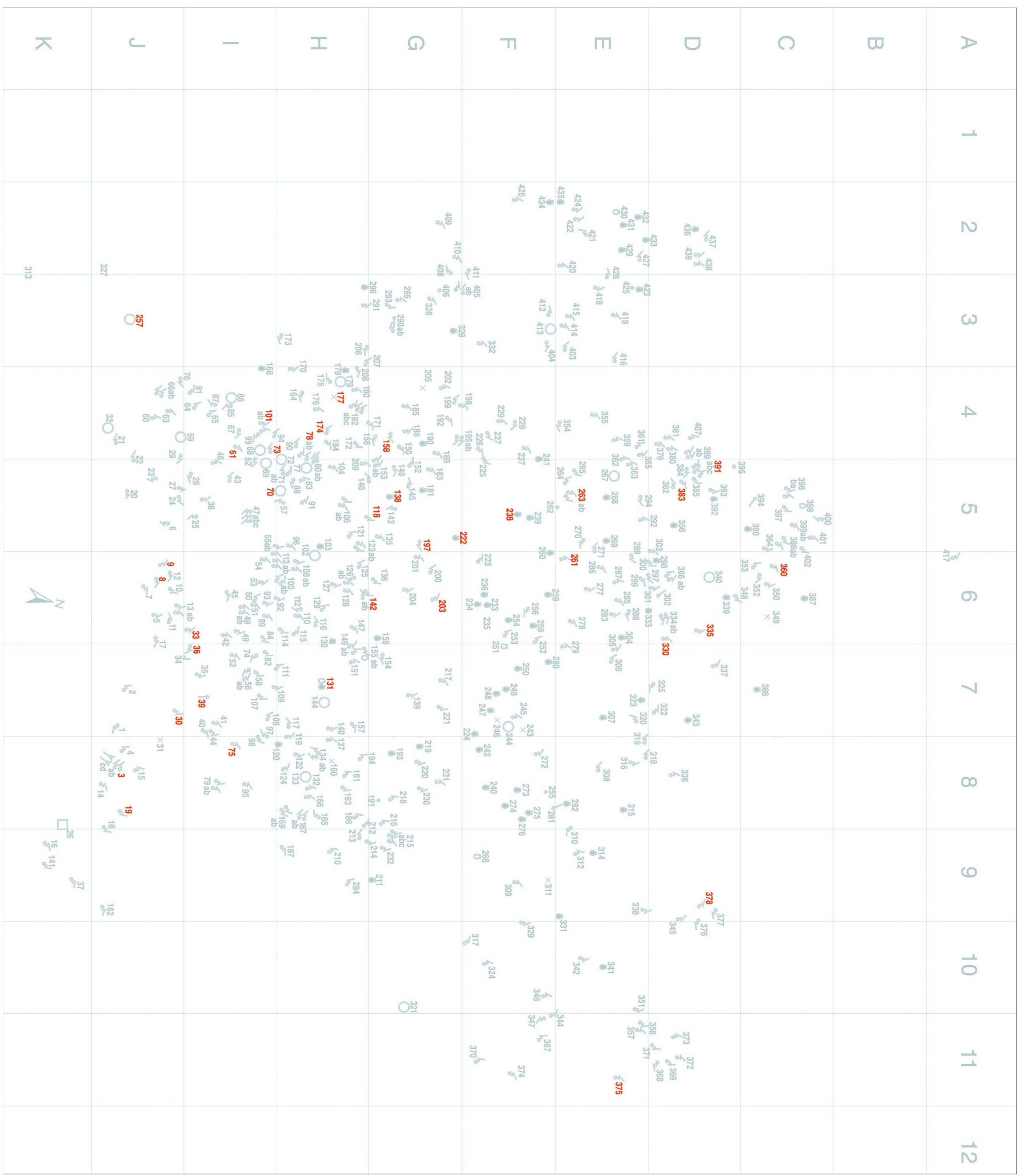




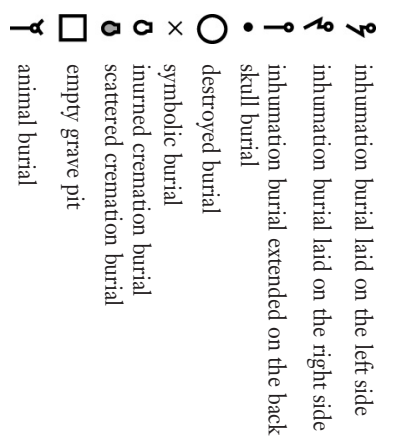


$-\alpha a 0 \times 0 \cdot 1010$

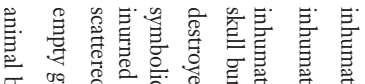

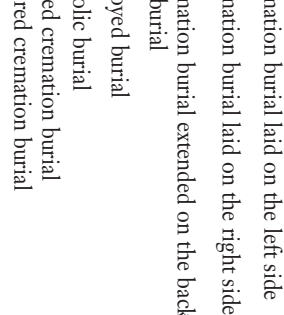

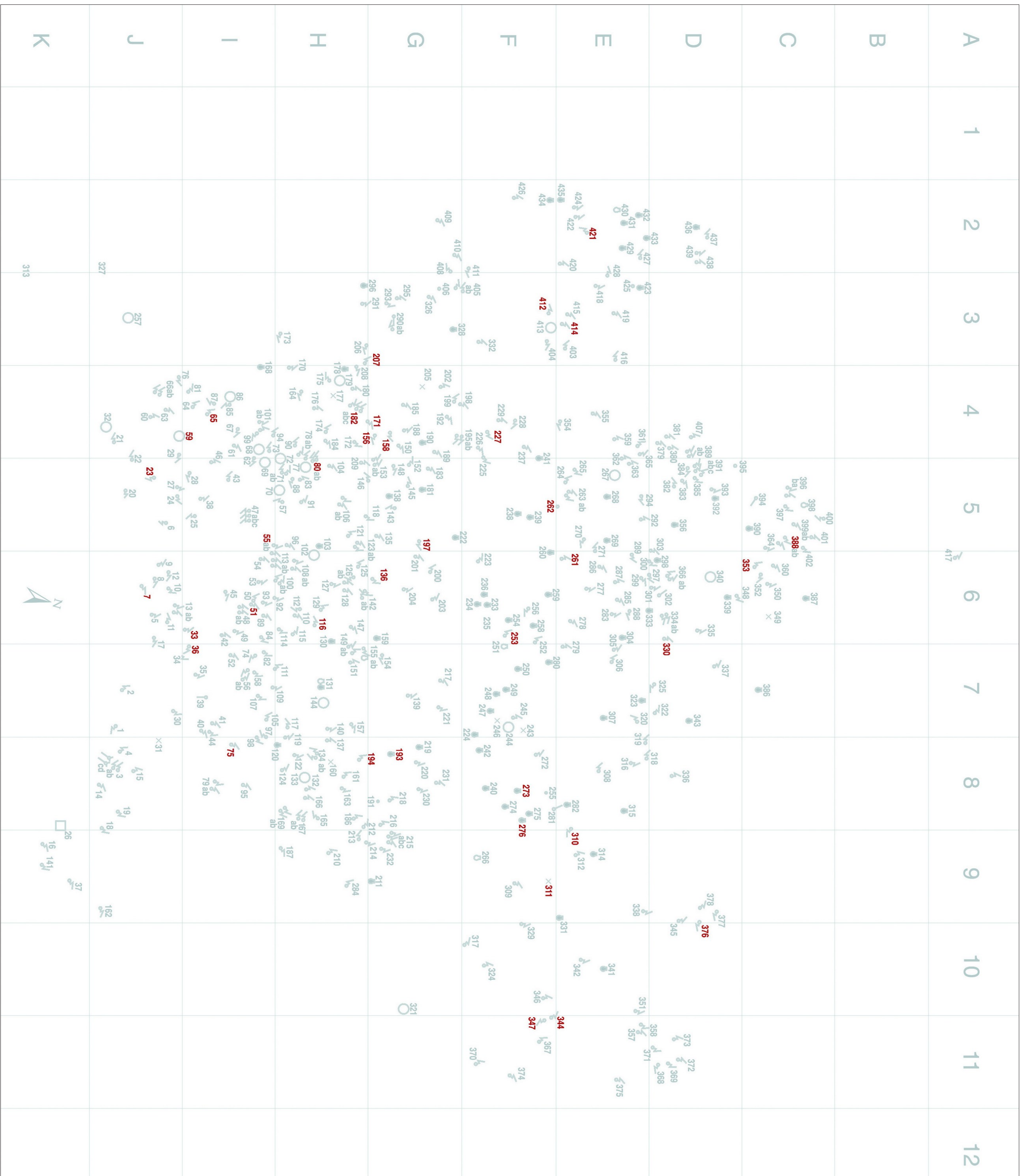




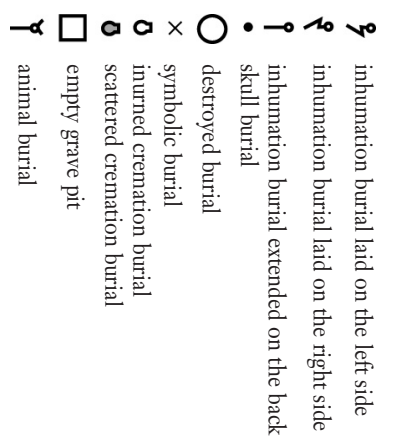

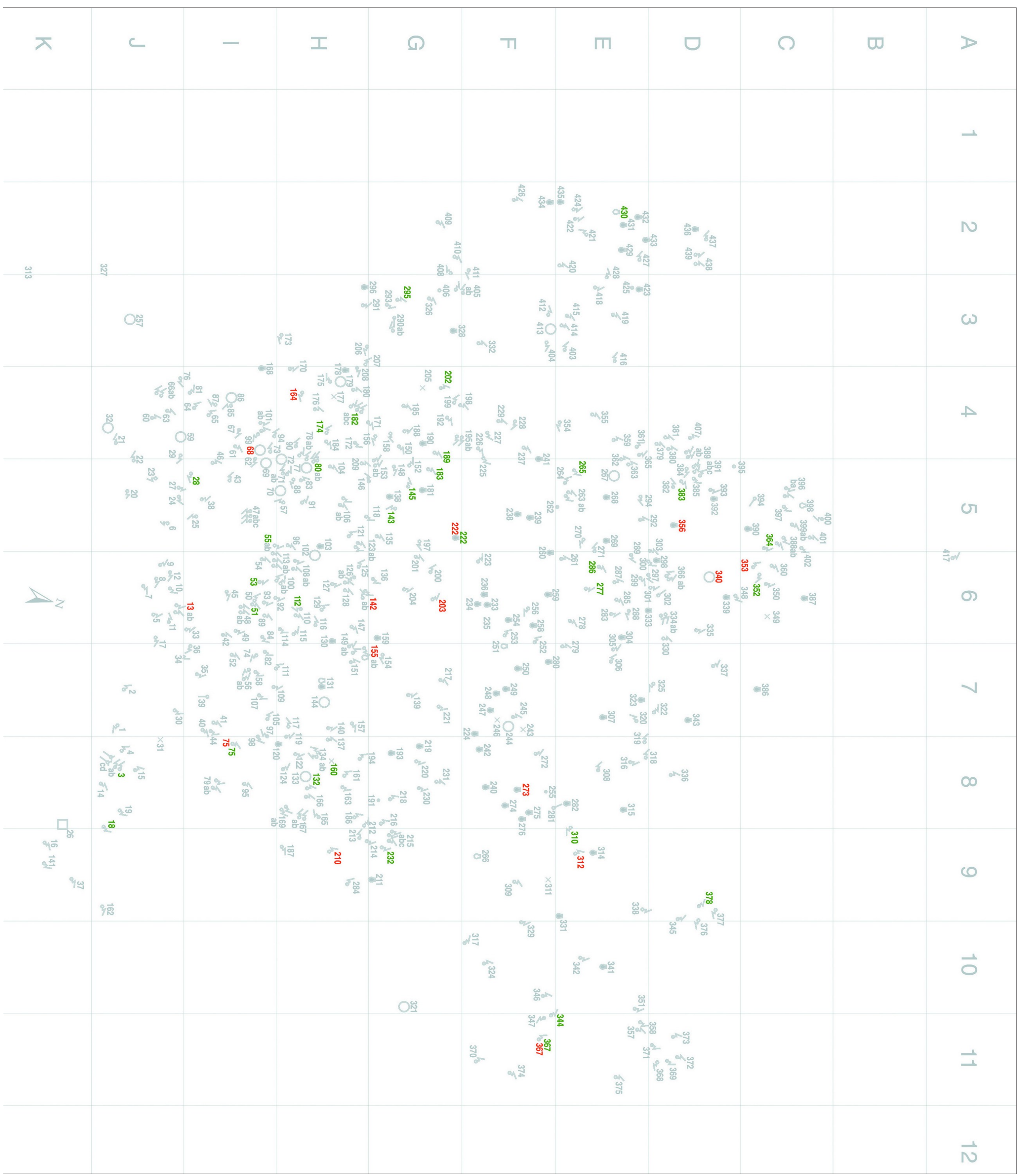



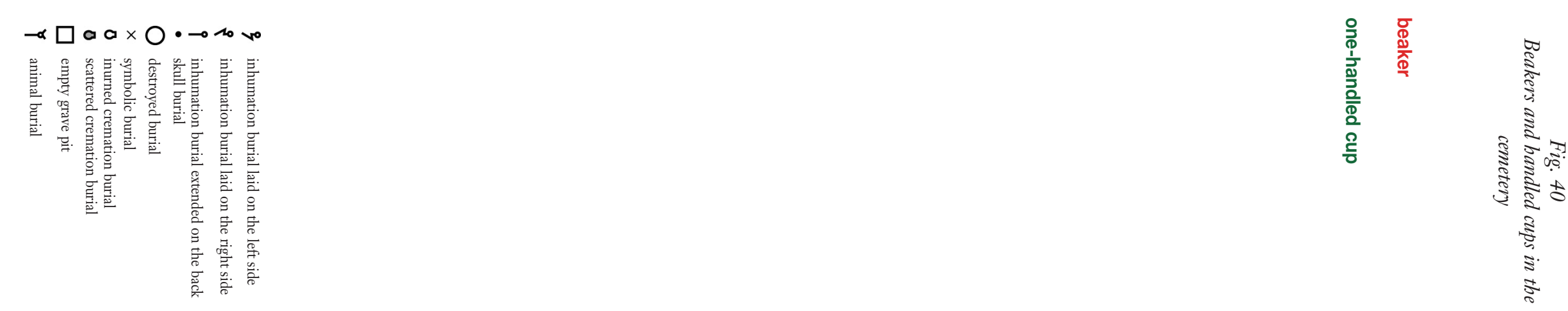

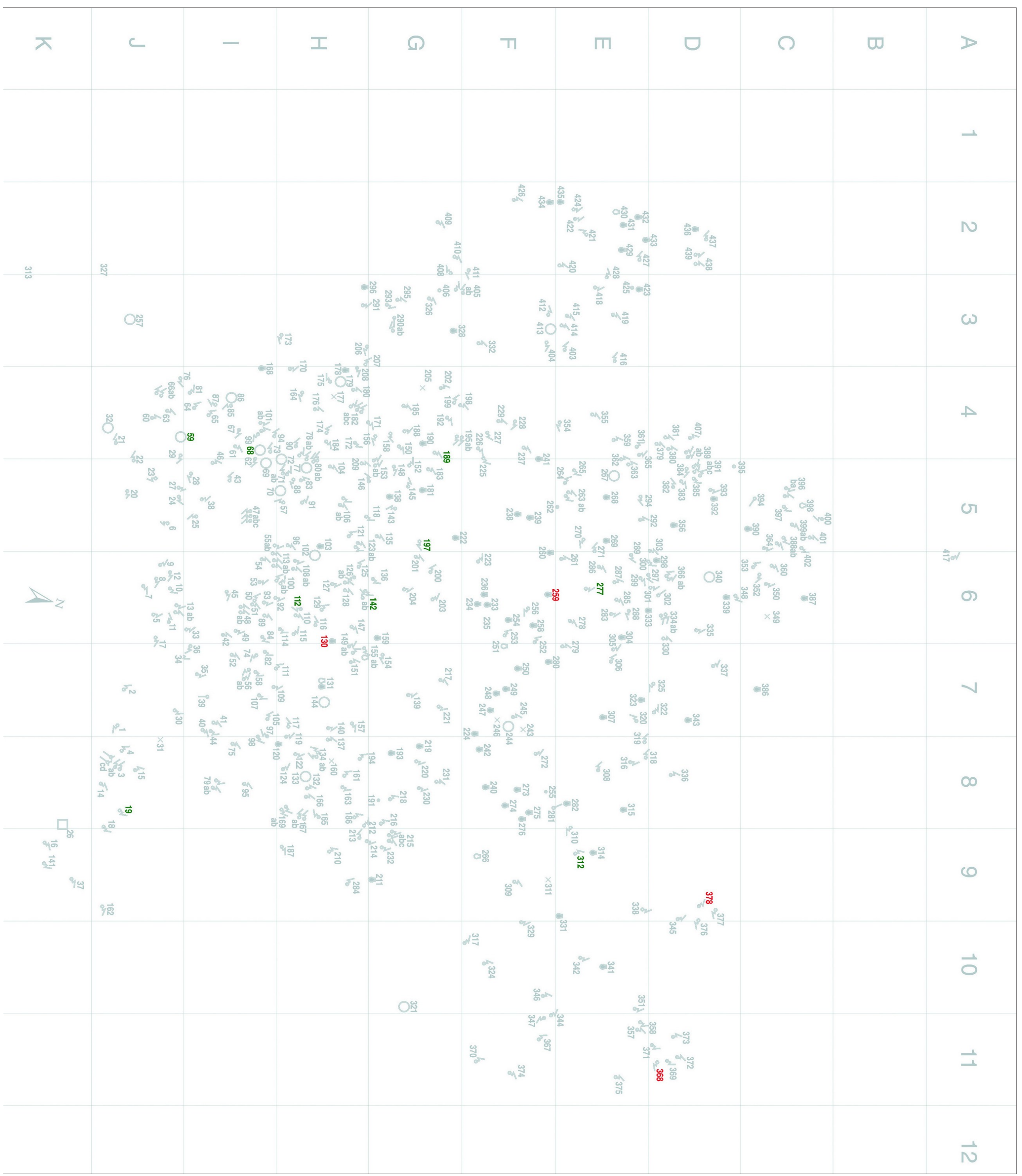



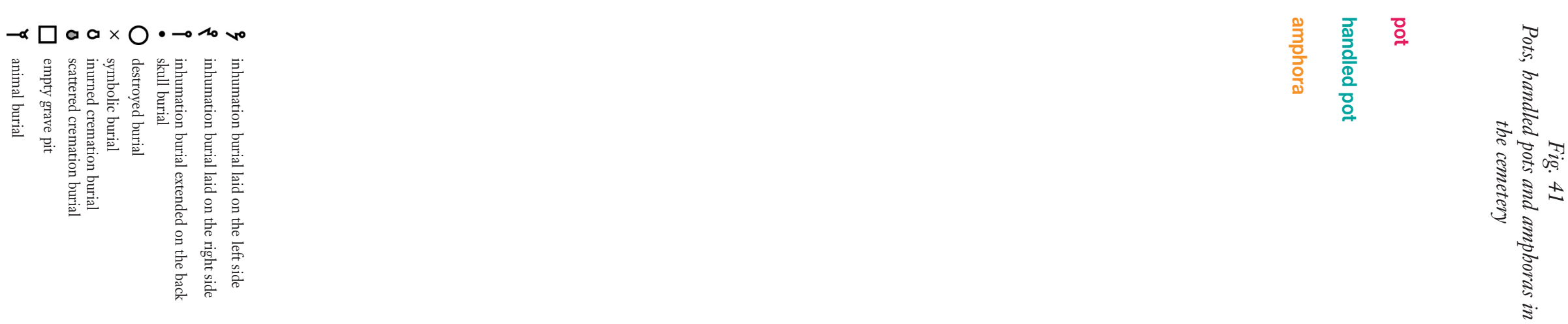

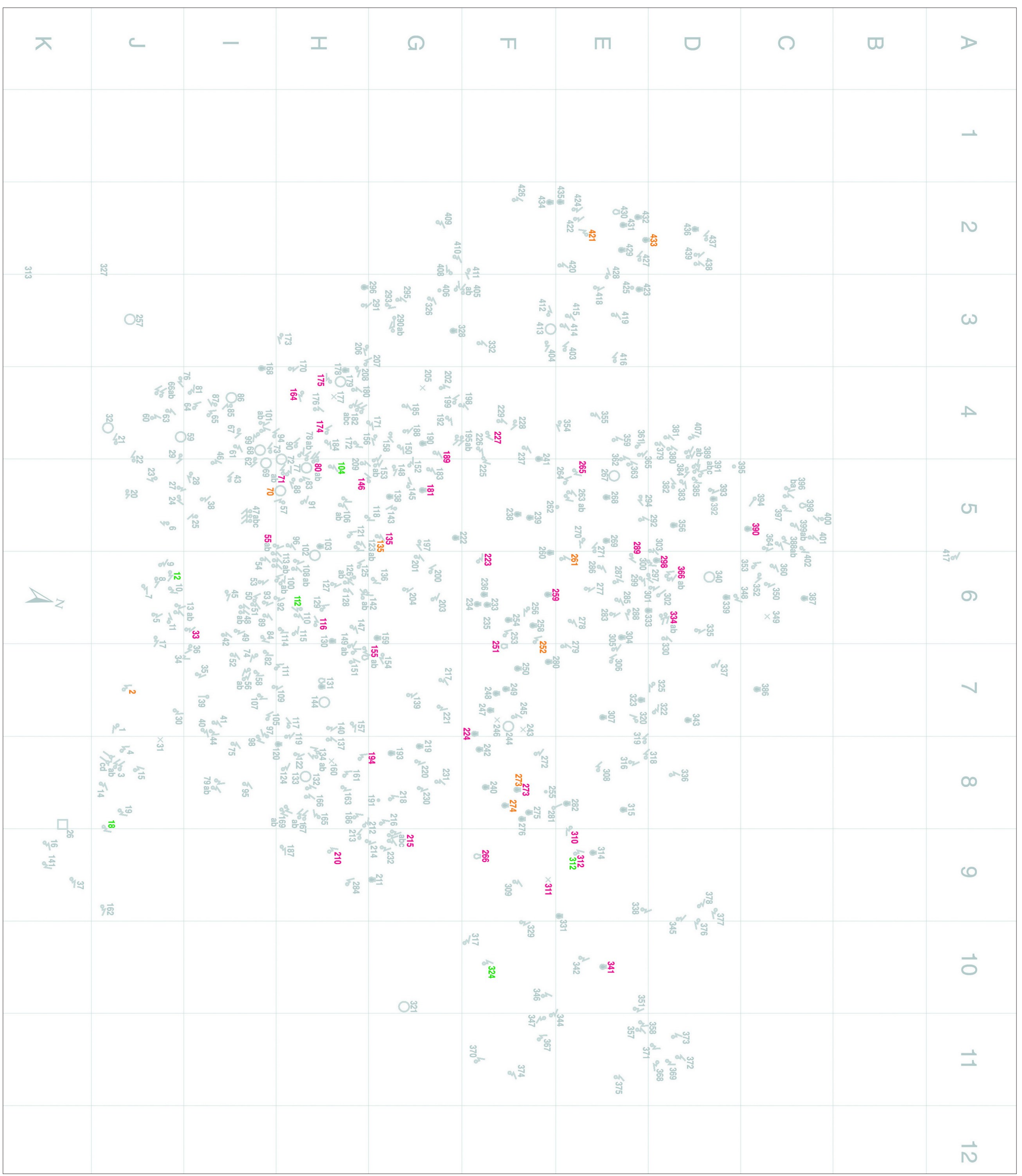




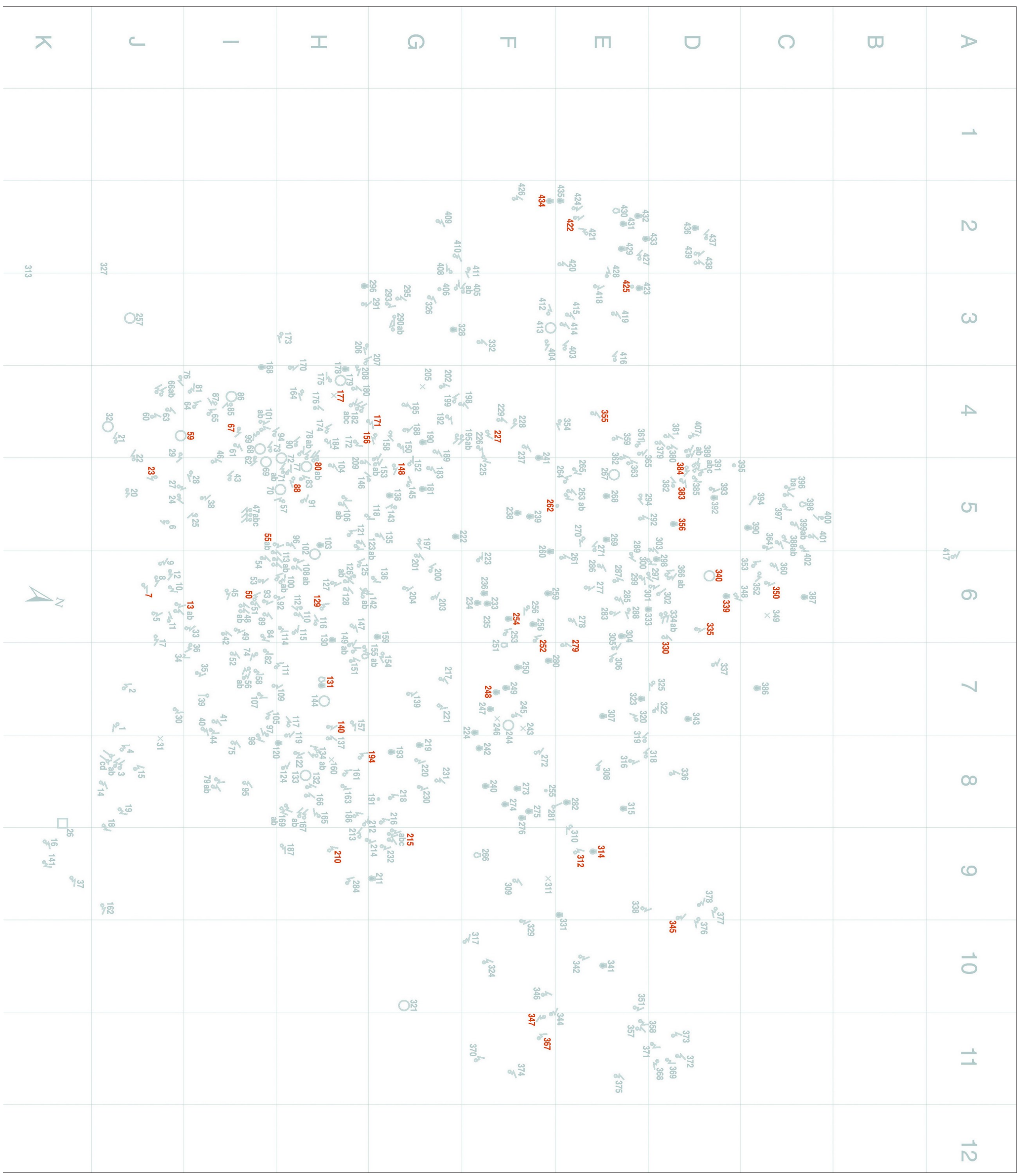



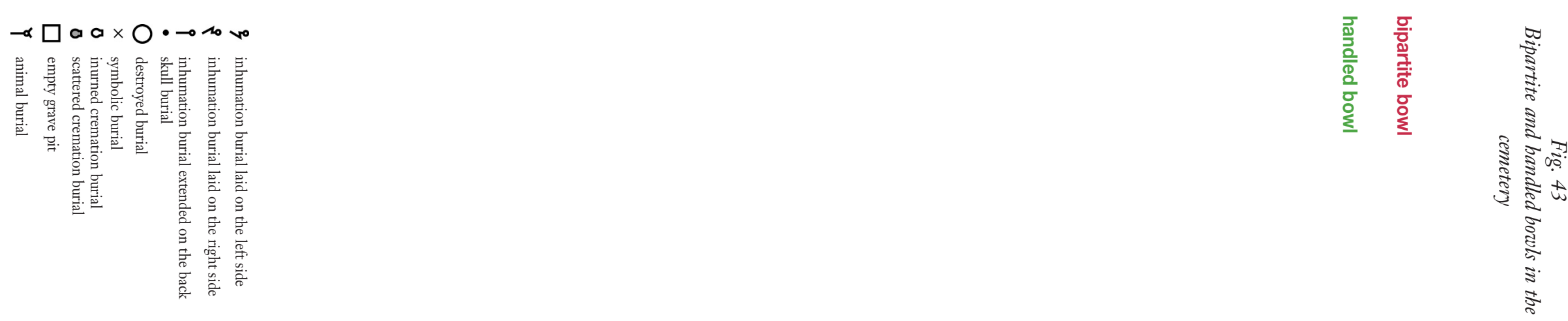

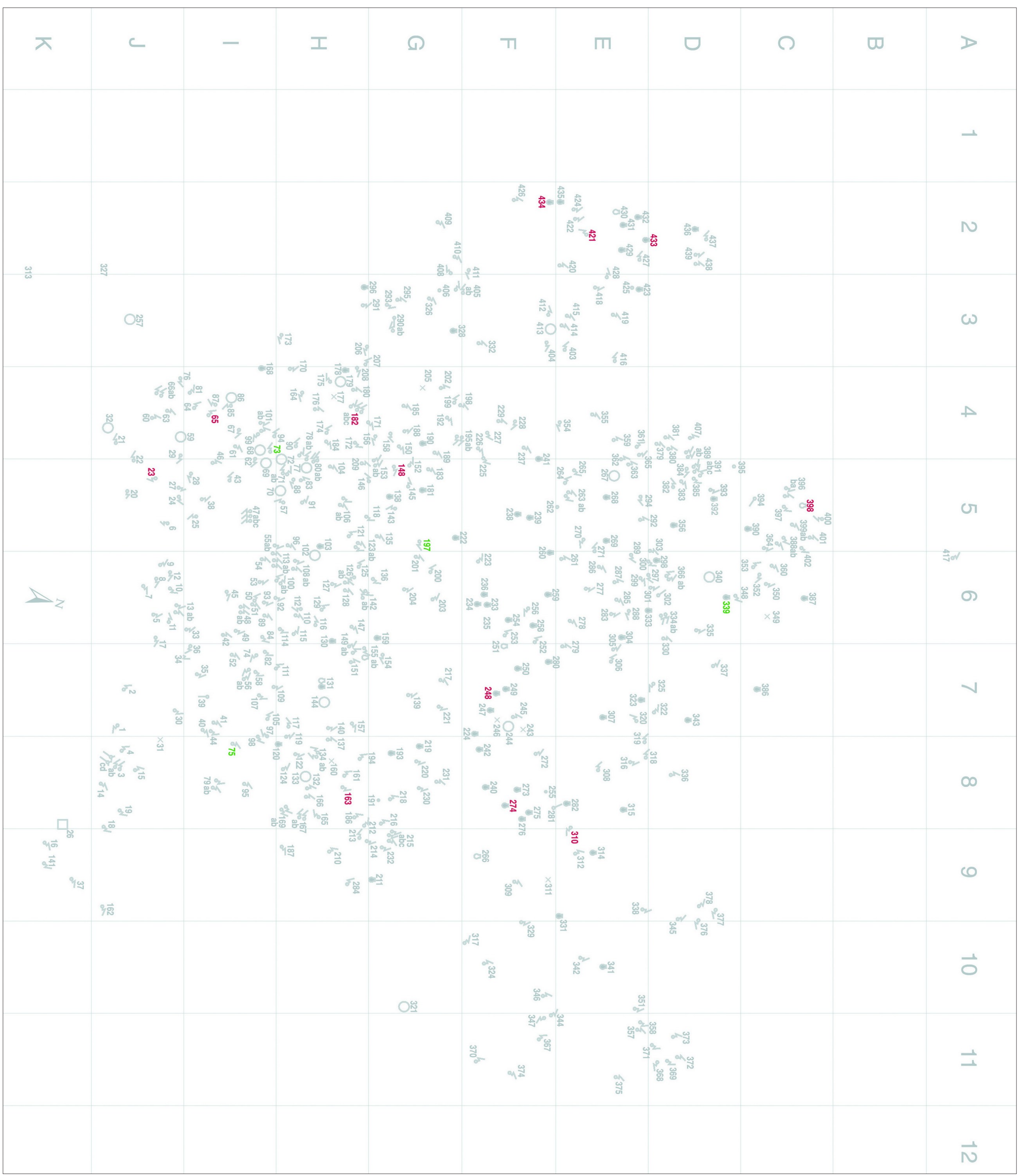



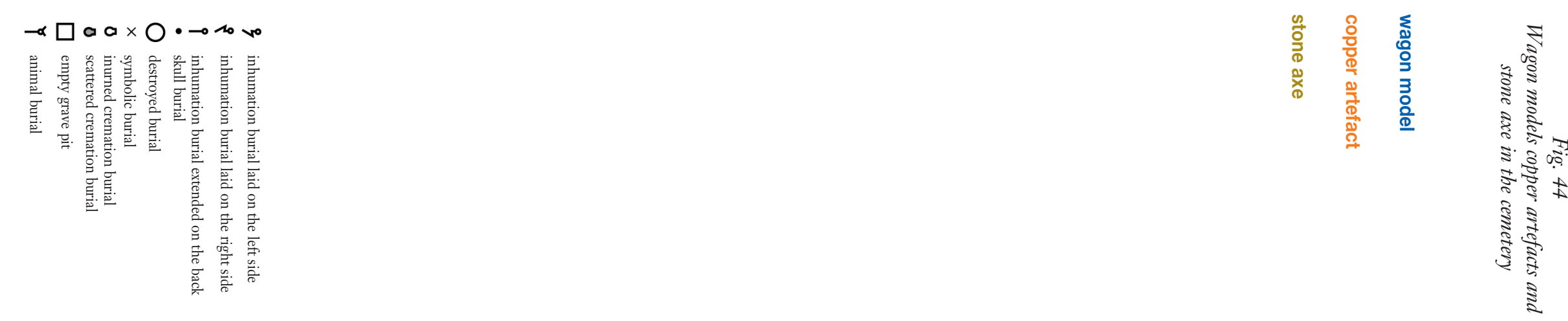

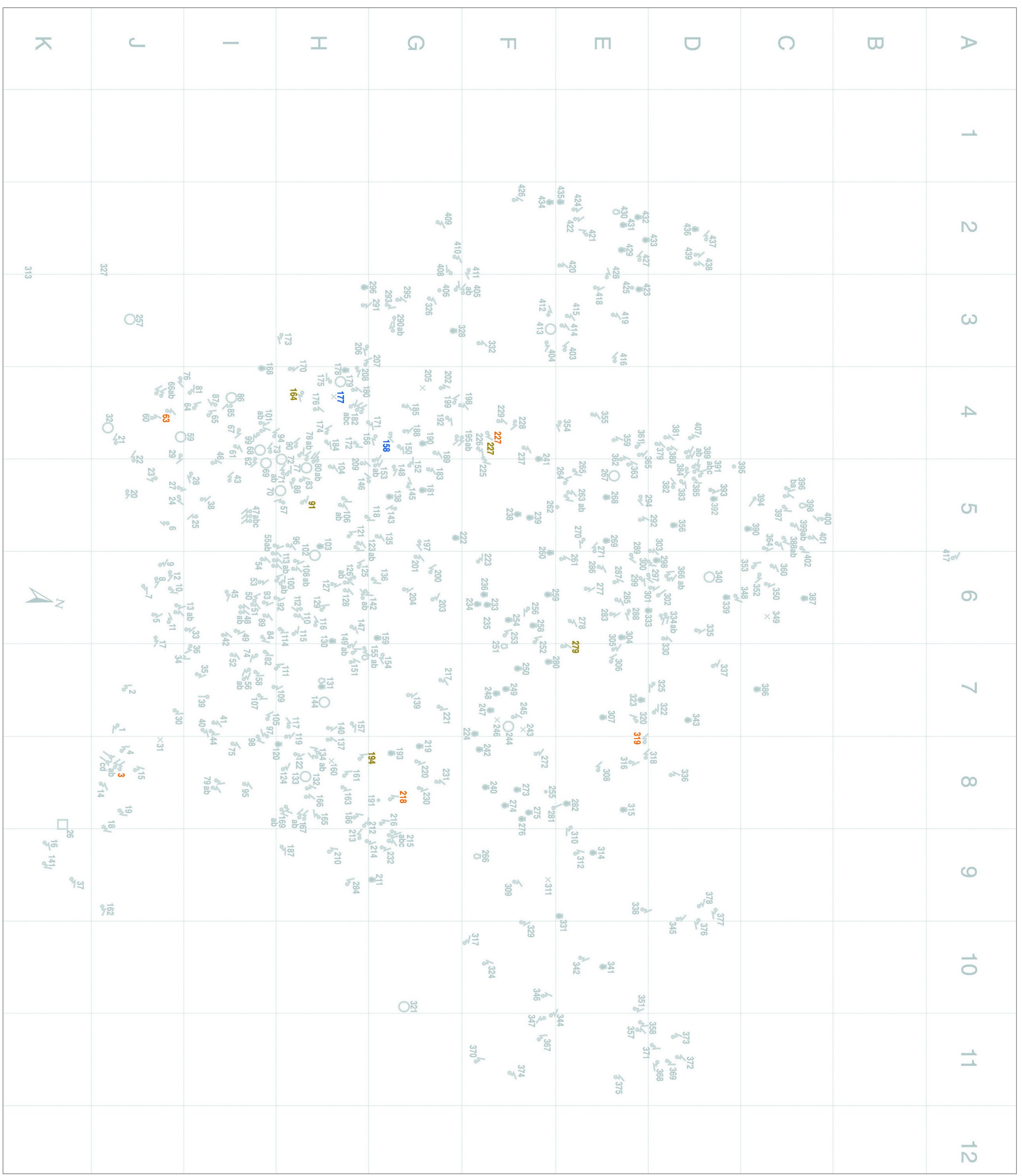



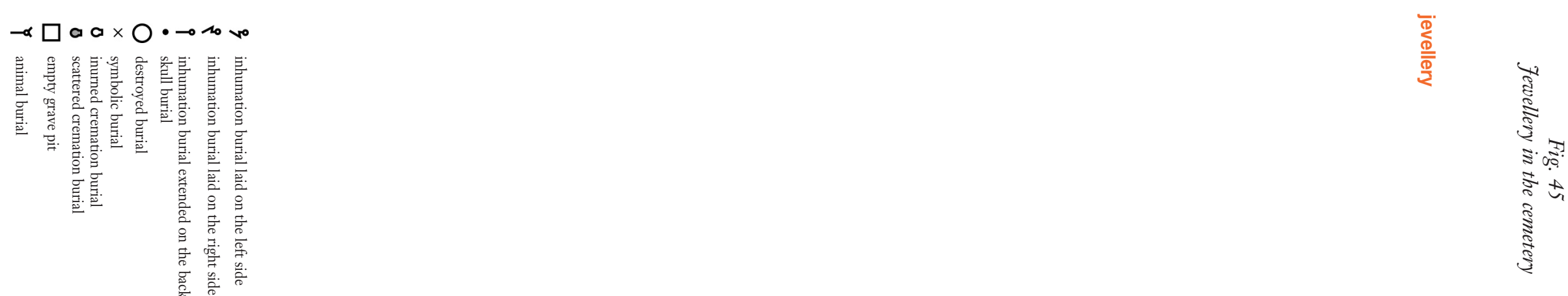

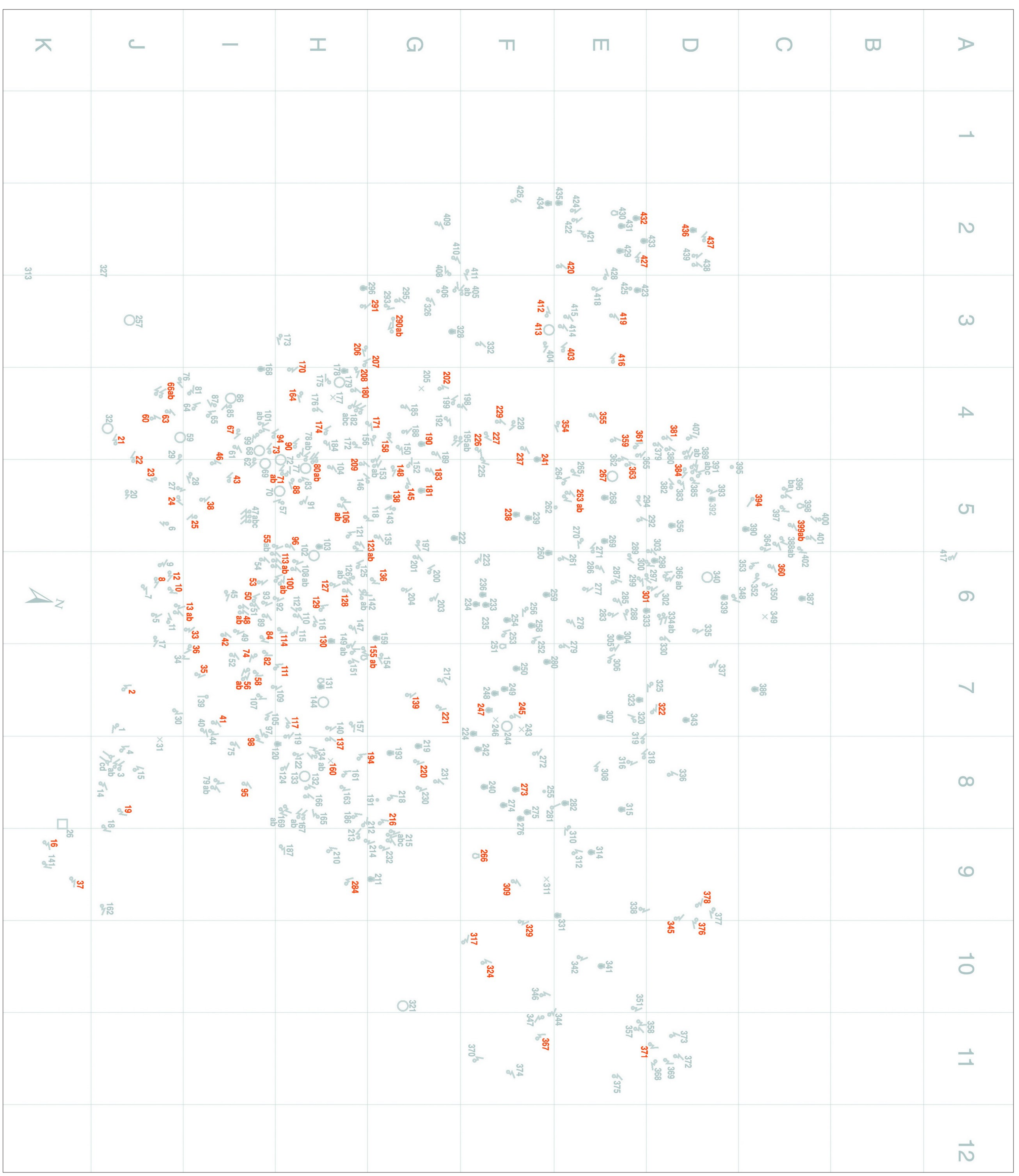


$-a, D a \times 0 . \rightarrow 10$ w

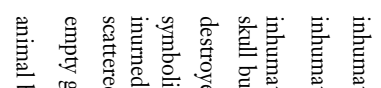

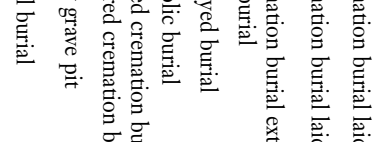

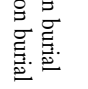
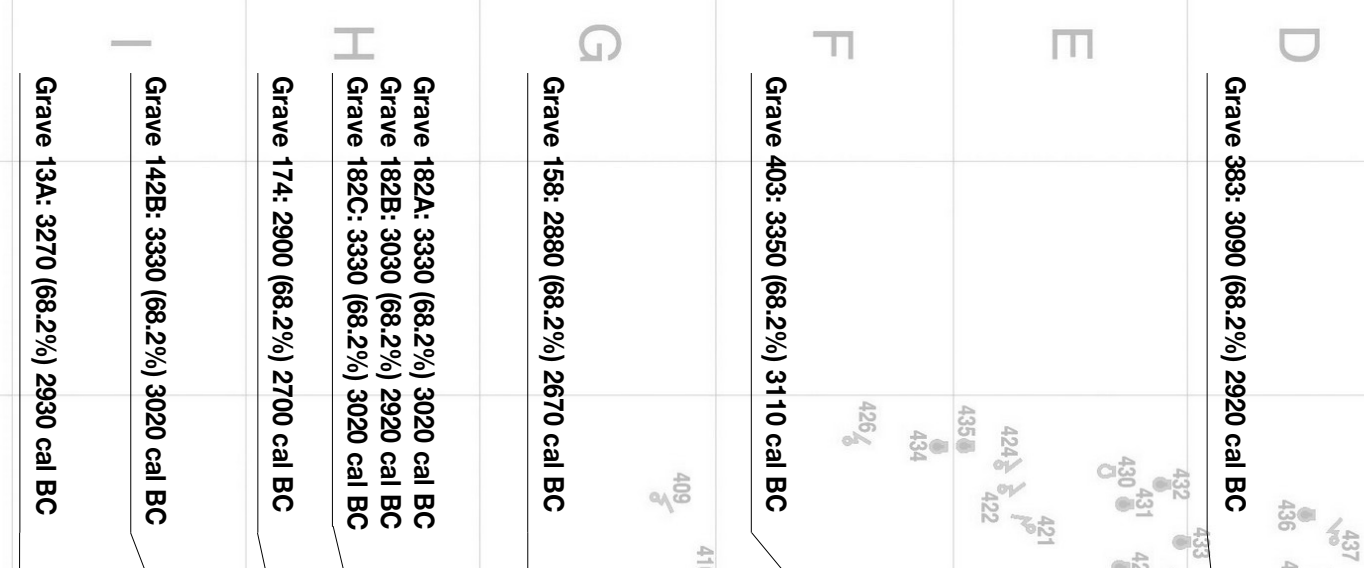

$D$

$\bar{\lambda}$

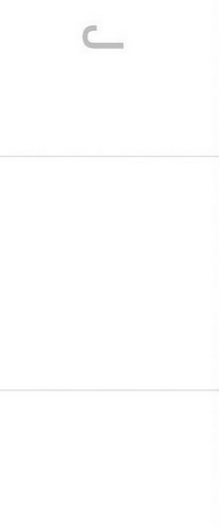

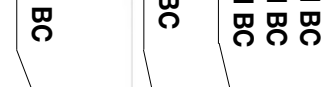

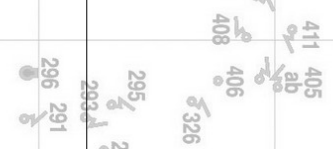

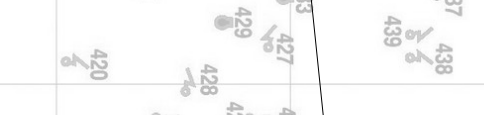

से की

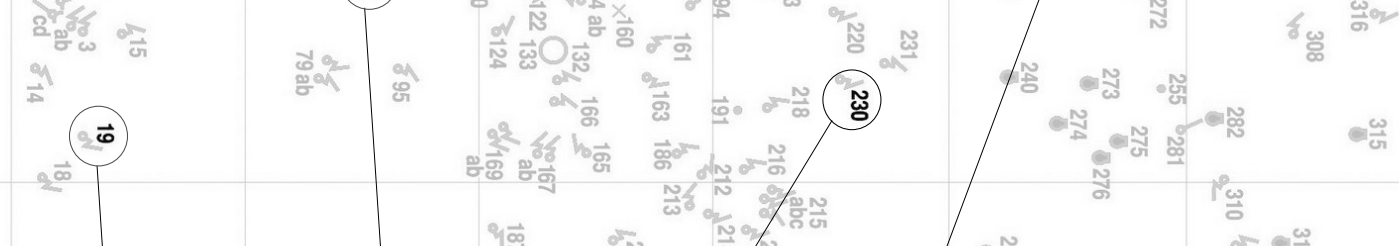
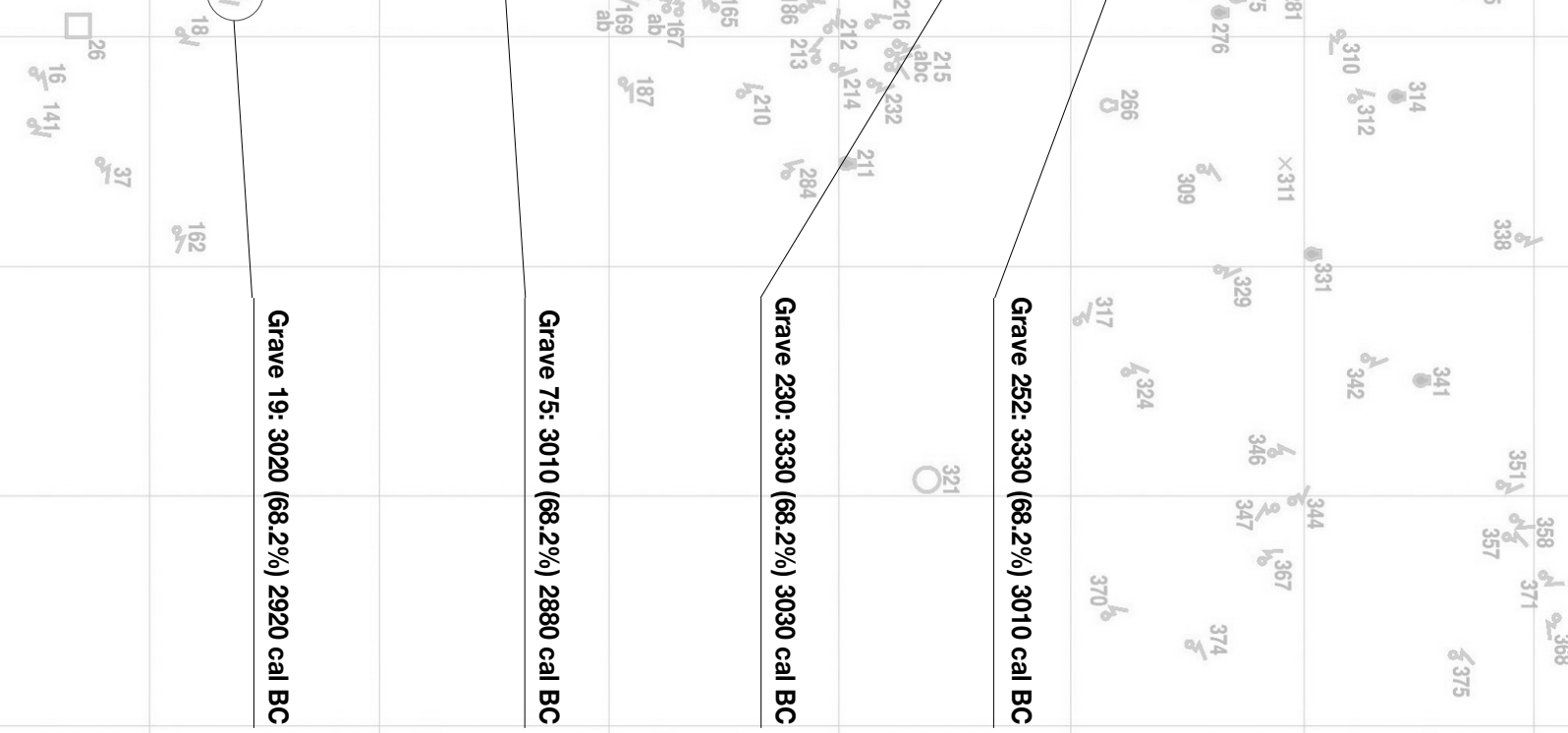

(a) 